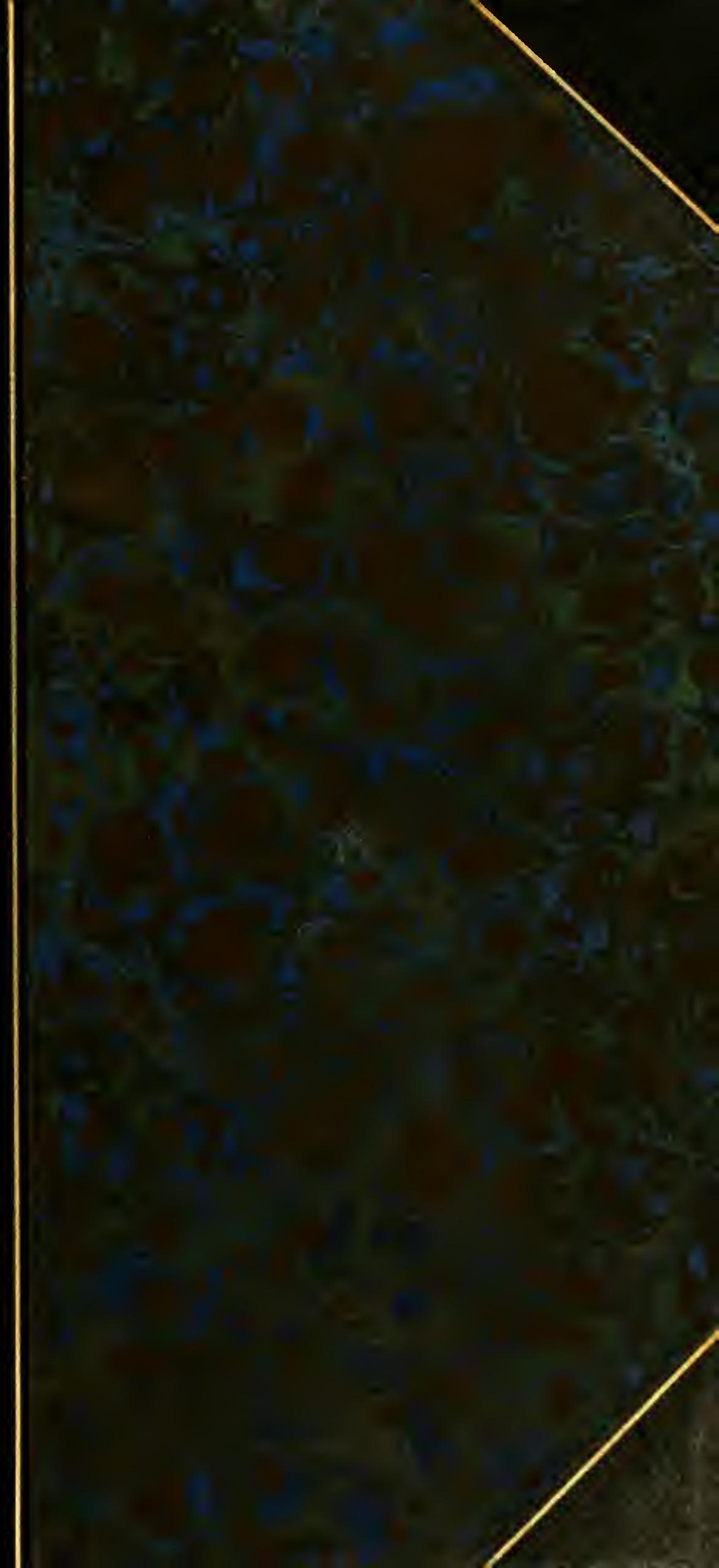







L'EMBRYLOGIE COMPARÉE 
ATRES OUVRAGE DIOACTQUES DU MHE MTEU

Cours de Zoologie générale et médicale, recueilli pal : l'aris-Toulume. Bentuen-Prwat. I88?.

L'Embryologie générale (Bibliolhíque des sciences comem.

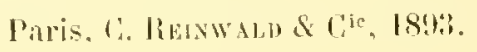





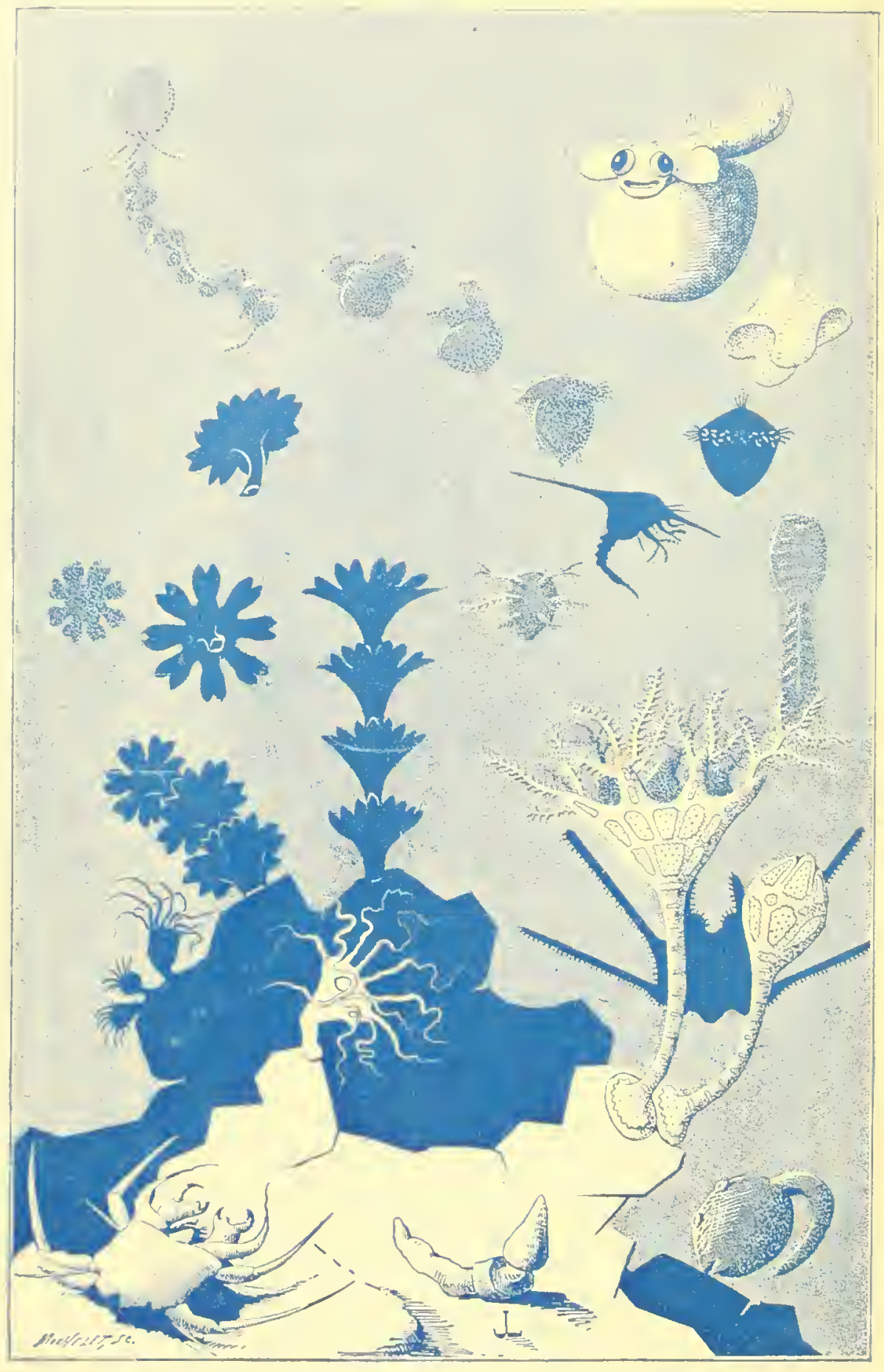

LARVES MARINES 


\section{LES FORMES DES ANIIAUX}

LEUII UEBUT, IEUR SLITE, LEL'R LIAISOX.

L.a nature va du simple au complexe; elle pro-

cede au moven d'une differenciation morpholomule, continue et prosressive, lice a la division du iravail pliysiologique.

(Irincipe fonchamenust.

d'apres 11. MLXE-EDWMGOS.)

\section{l'EUBRTOLOGIE C'0IPARÉE}

PAR

\section{Le $D^{r}$ Louis ROULE}

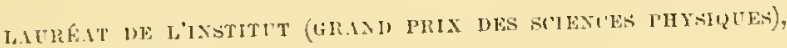

PROFESSEUR A LA FACULTH DLS SCIENCHS DE TOLLOUSE

OTIRAGE ORTE UE IOLA FICLIES IASA LE TEATE

el d'un froulispice en rouleur.

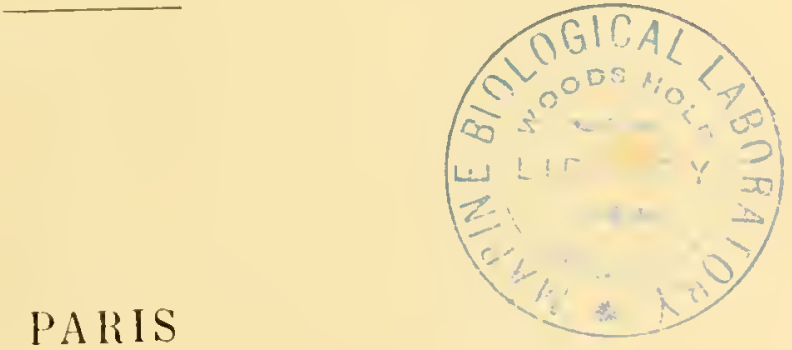

C. REINWALD \& C.F, I.IBRAIRES-FDITEURS

li, WUE WES SAITS-PBHES, 15

1894

Tous droits riserves. 



\section{PREFACE}

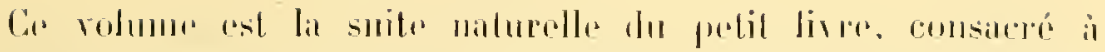

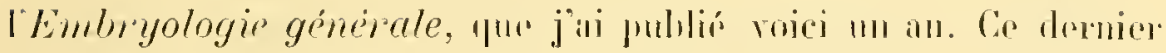
est umr introduction au present omragen. common il en est lit condusion. Diuns un sens. il indigure les phénomines góméraux du développement: daus l'autre, il montre de quelle maniere exs données découlent dos linits partienliers, of romment elles per-

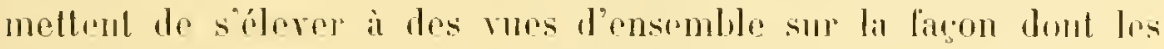
animan arrivent ì édilice lunr organismr.

Anssi était-il inutile d'ierire ì nonveatu des motions purilini-

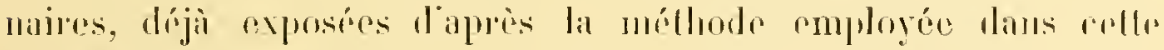
Embryologie rompare. Le chapitre. eonsacré it lit classification. yni termine l'Embryologie gémérale. ast lit base du volume actuel :

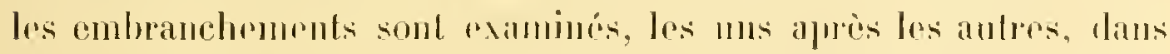
les diverses manifestalions dre lour dévelopjement. Les modres

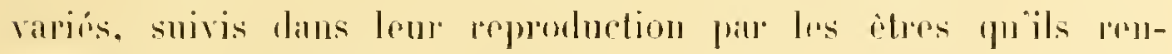
lement; lo faromement de leurs lenillets. pui senls comstitumul

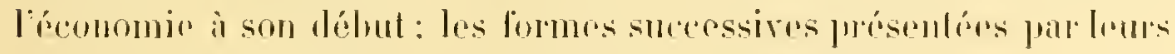

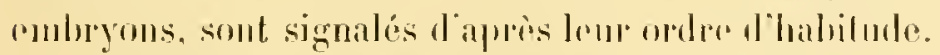

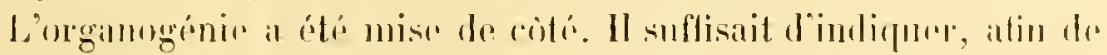

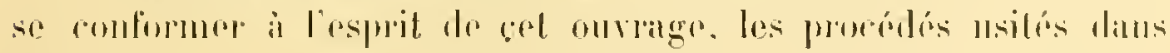

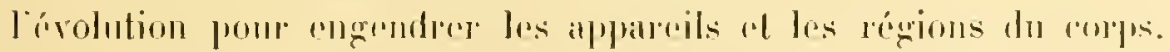

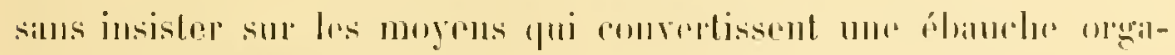

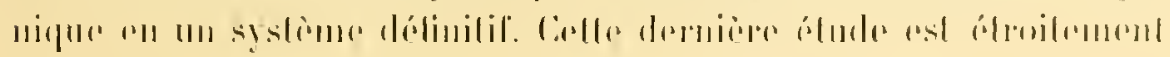




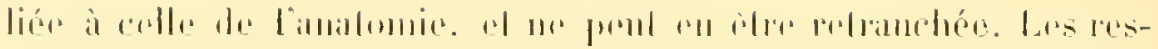

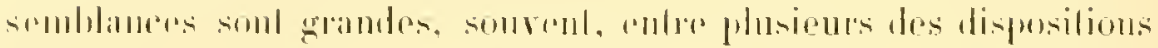

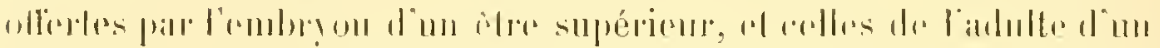

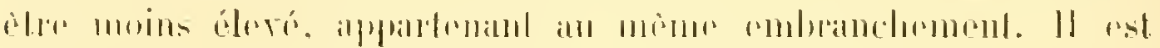

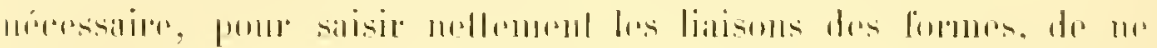

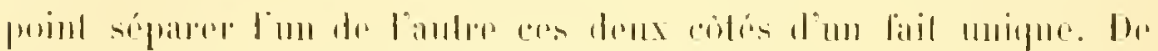

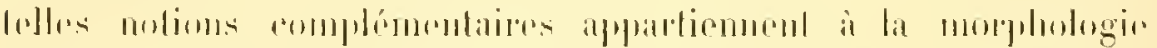

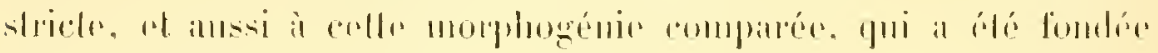

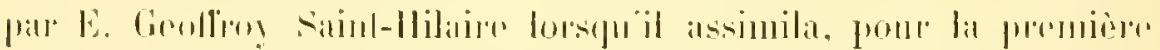

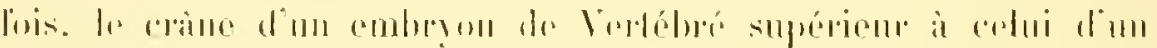

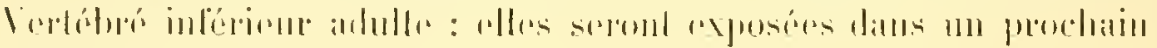
bolumb!

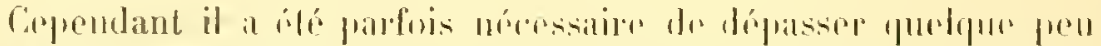

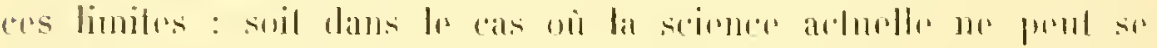

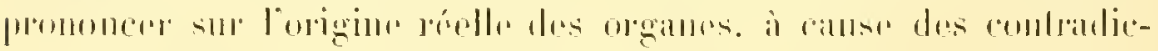

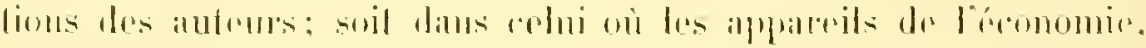

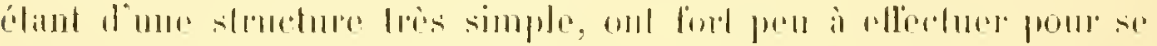

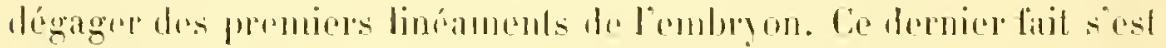

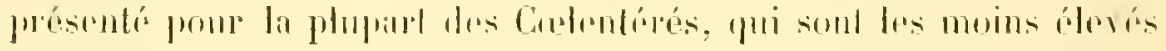

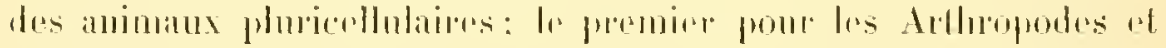

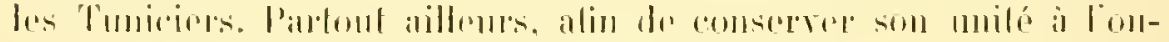

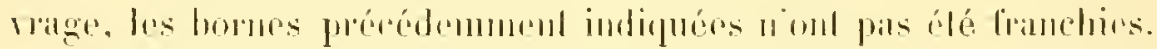

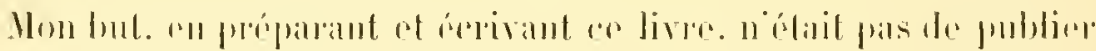

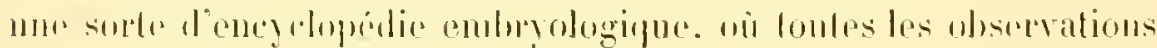

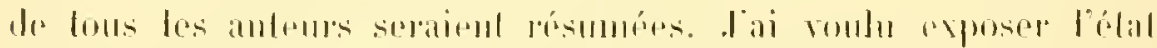

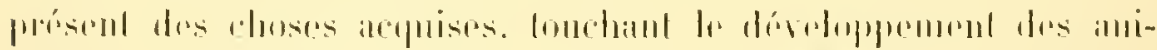

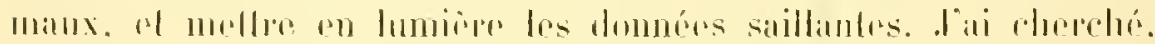

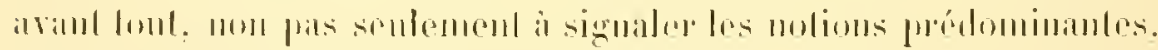

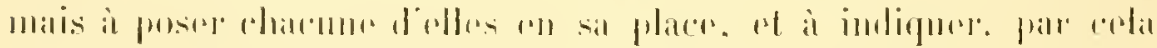

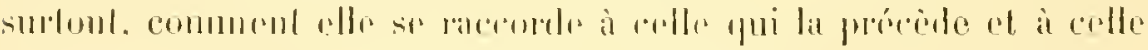

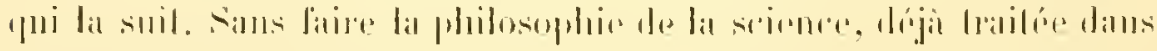

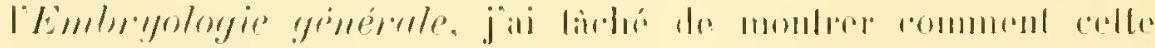

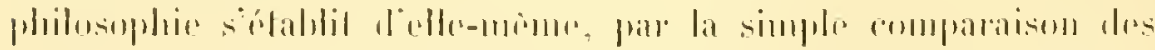

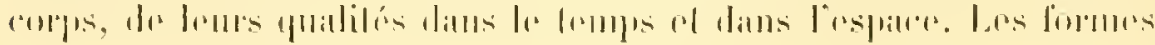




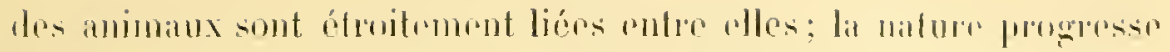

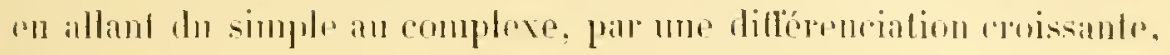

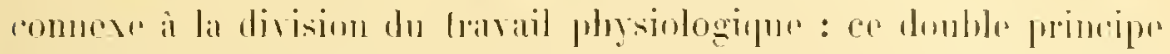

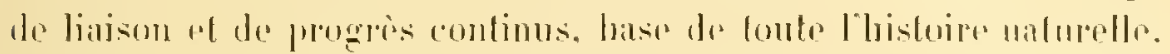

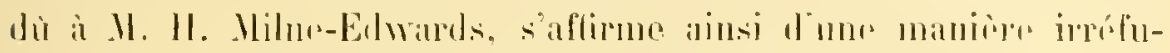

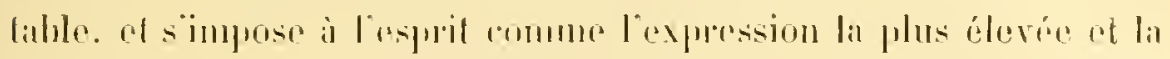
phus romplote de la philosophie des sciences biologiques. Les faits seuls. fols que nous los ronmatssons de nos jours. sullisoul à loéla-

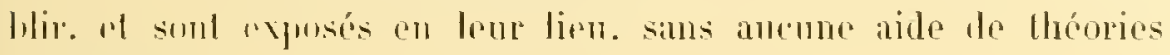
particuliomes.

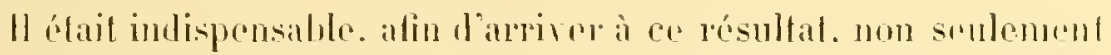

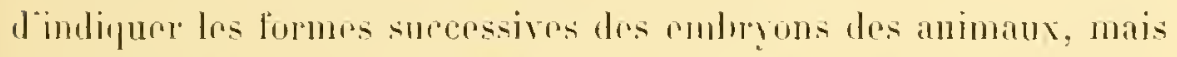

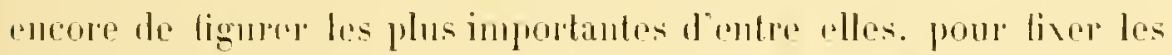

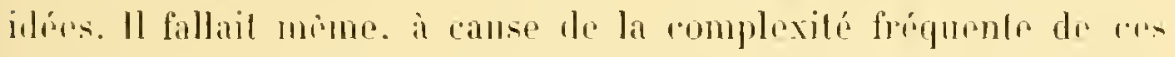

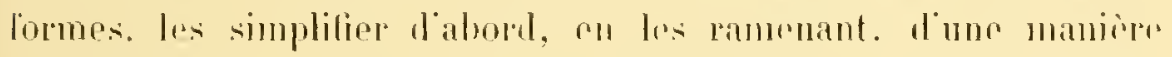
diagrammaliqur. an solides fondamentams. ol los représonlue msuilo dans lour réalití. fellos qu plles evislent aroe lours coulums

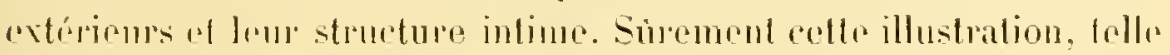

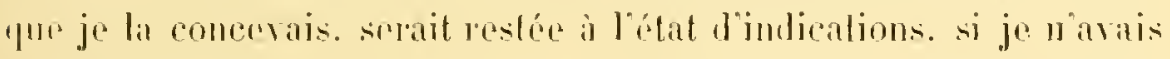

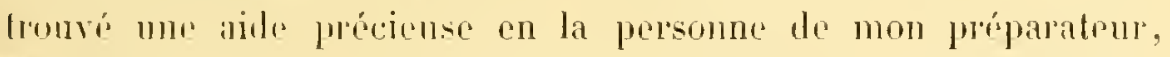

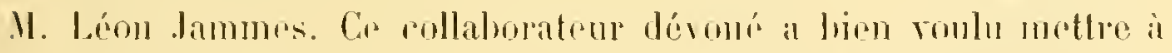

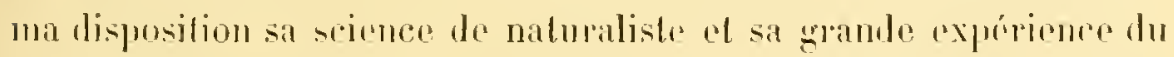

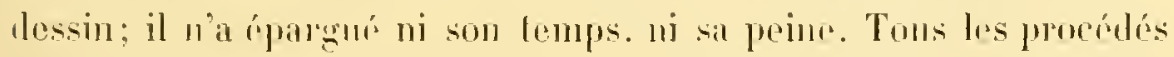

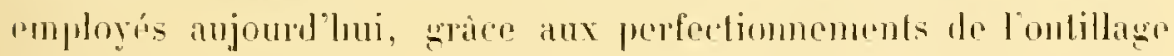
comblomporain, ont étr utilisés, on rherchant paroui les plus simples

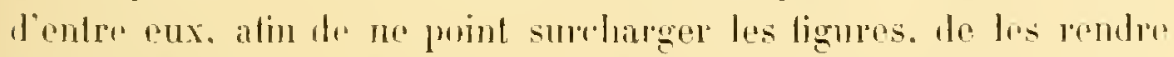

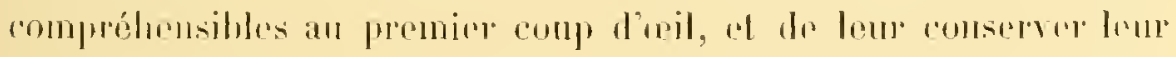

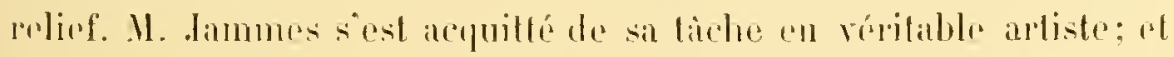

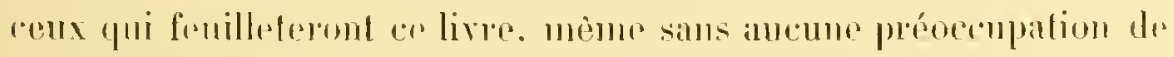

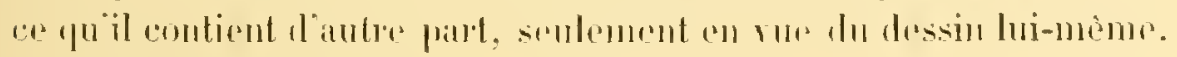
sment do mon avis.

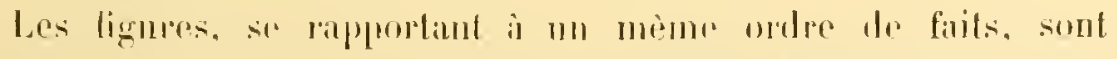

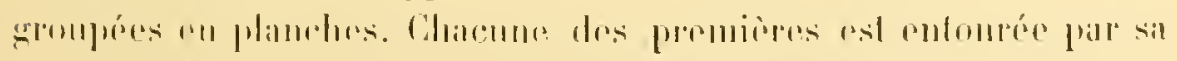

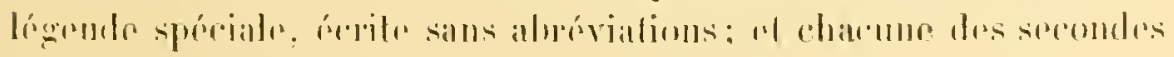

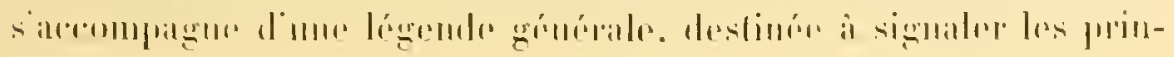


ripales des notions montrons par los dessins. Cefle illustration,

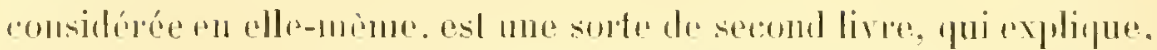
sons unr forme conterith at tris acerssible, les données exposérs dans le texte. De plus, un comt résmó tromine chaque chapitme.

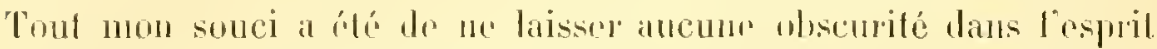

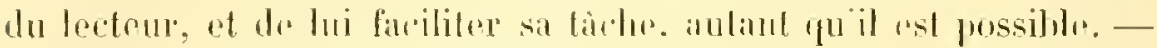
Un tel whume. ansi muni d'annexes anssi importants pour le pisullat à fournir, était llune grande délicatesse de composition. La

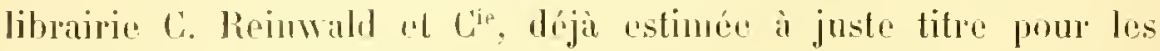

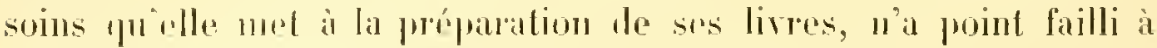
ses fraditions, malgré des difficultés de foutes sortes; je prie mes excellents iditents don accepter nons vits romerciements.

Tel yu’il est, cel onvrage me parait répondre et à l'esprit philosophifur ale la biologie moderne, et à la préoccupation de ceux yui veulent savoir Io romment des choses: étudiants et rurieux de la nahure. Dı moins, je l'ai écrit dans eet esprit, et j’ai consacré à atteindre ce lut tous les eflor's dont je suis capable.

J) Locts liocte.

Fevrier losi. 


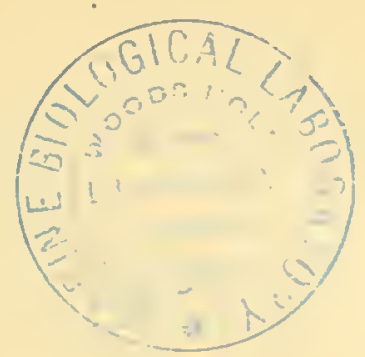

\title{
TIBLE METHOHOOQL DES MATIERES
}

\author{
C.UAPITRE PRE IIER \\ Embryoloyie des Protozuaires Surcolaires.
}

11. Renéralités sur le développement..................................

§ 2. Reproduction yar fissiparite....................................... 4

1. Monériens ....................................................

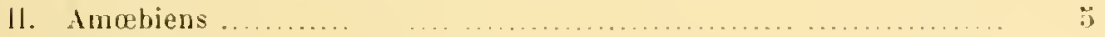

III. Sporozoaires .................................................. 6

IV. Foraninilëres. - Fissiparité complète, on des Ionothalames. - Fis. siparite incomplete, ou des l'olylhalames................... 6

V. Vésieulaires, - Fissiparite complèle. - Fissipalrité incomplete....... 10

v. Flagellates. - Nodollagellés. - Choanollagellés. - Dinollilgellis. Grstollagelles .... $\quad \ldots \quad \ldots \ldots \ldots \ldots \ldots$. 12

$\$$ 3. lieproduclion par gemmiparite................................ 18

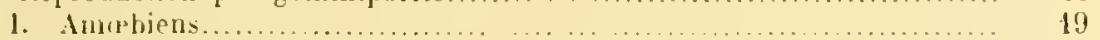

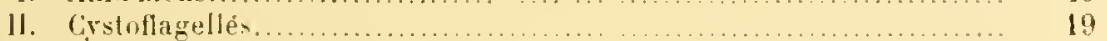

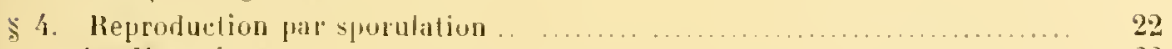

1. Nonérien .. ........ .

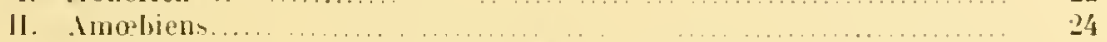

III. Sporozoaires. - Sporulation des Monogeniques. - rpurulation des Amphigrinifues : enkystement el genèse les protospores; irolution des proluspores et genese des dentospnres; évolution des

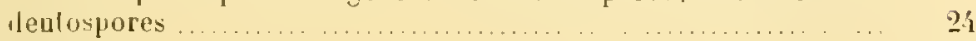

IV. Foraminilères...... . . . ............................. 36

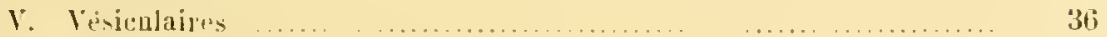

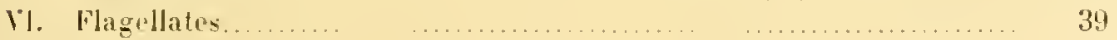

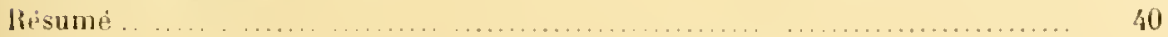

CHAPTRE WEI XIEME

Embryoloyie des protasouires ćiliaires.

\$. Consilerations generales.... . . ............................. 43

1. Caractères................................................... 43

II. Hẻveluppement en genéral .................................. 43

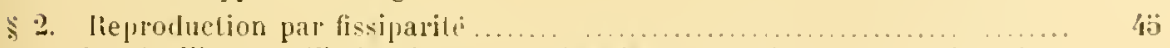

I. Lucilies. - Fissiparite. - Conjugaicon : aceolenent; morlifications nueleaires; séparation des indivilus...................... 45

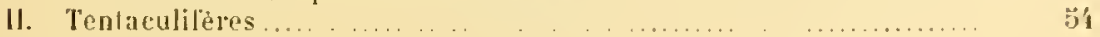




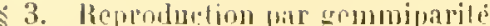

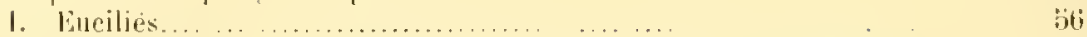

I1. Tentacnlilipes. - Gemmiparite simple; gemmipariti multiple .. 56

$\$$ 4. lieprodurtion par sporulation. . . . ... $\quad . . .60$

I. Vincilies ... ... ....... 61

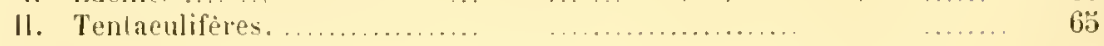

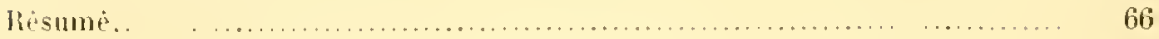

CIIAUTRE TUUISIE ME

liveloppeneml des Mesuzodires.

\$1. Consilération générales................................ 70

I. Caractères el elassification .................................. 70

II. Ginemalitis sur le leveloppement...................... 70

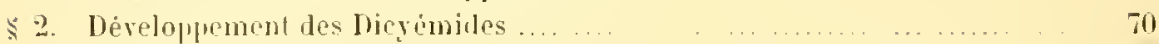

I. Embryons remiformes. ...... .. . . ................... 71

11. Linhryons intusorifomes......... . . . . . . . 72

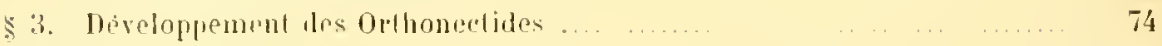

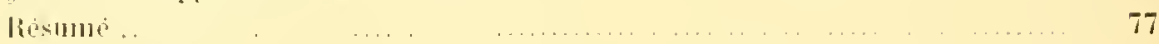

LHA ITISE QUATHIEHE

Embryologie des spongiaires.

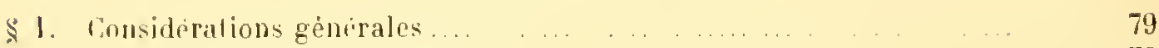

1. Caractères et classification $\quad 79$

11. liéveloppenent en gènemal. ... 79

$\$ 2$. Segmentatiou el feuillets blastorlermípes. . . . . 81

1. Elèments reproducteurs.......... . . . ....... 81

II. Segmentalion et fenillets blastodermiques en géuriral. 83

III. Calcisponges..... .

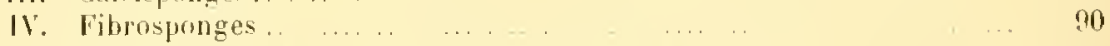

\$3. Fixation des larves; dixeloppement des cavités internes. . . $\$ 4$

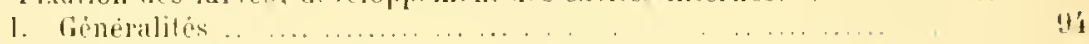

II. leveloppement incurve, on i reploiement. - Calcisponges. Myxosponges. - Couclusion. . .... ... .... . ....... 90

111. Dèveloplement massif ............ . . . . . . . . . . . 10.3

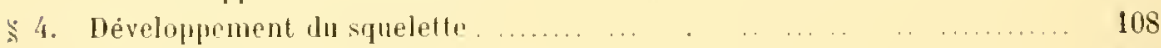

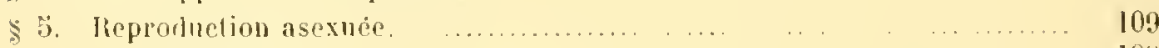

1. Gemmipalé. ... .................................. 104

11. Gemmulation. . ........................................ 111

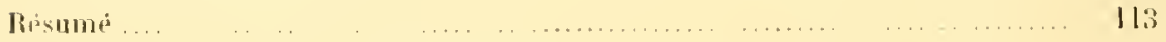

CIIAMTE CINUIIEME

Embryologic des Hylrosuaires.

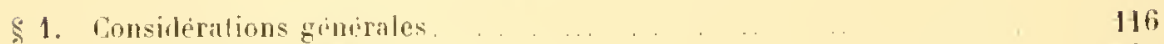

1. Caracléres el rassification ............... 116

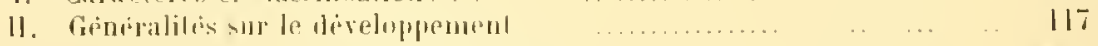

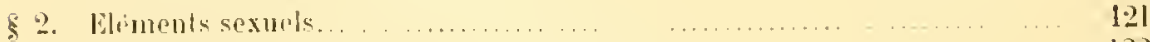

I. Trvelopperment des plements sexuels ..................... 122

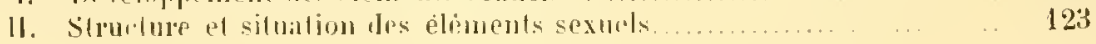


5. Segnentation et developpement les feuillots blastodermigues..

1. Considèrations gẻnẻrales ............................... 126

II. Authydraires el Hịdroméduses diplomorphes................ 1.27

III. Ifydromeduses holomorphes............................... 129

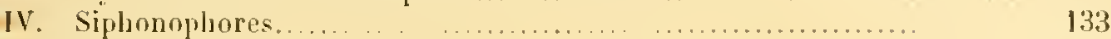

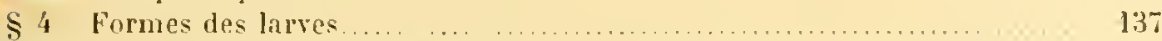

I. Considèrations générales................................. 137

II. Authydraires el Hydromeduses diplomorphes : larve l'rothydrula:

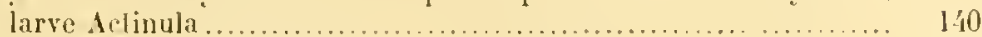

III. Siphonophores : larve Siphomula : larve Jisconula ................ 142

IV. Hydromèdnses holomorphes ................................

$\$ 5$. Keproduction asexuée ............................................. 151

I. Gemmiparitè. - Gemmiparitè des polypes : forme des polypes; marehe du bourgeonnement. - Gemmiparite des méduses ......

II. Fissiparité. - Fissiparité les polypes; lissiparitẻ des méluses ........

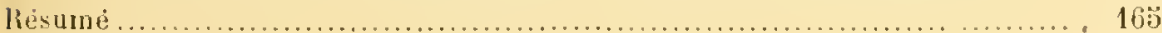

\section{CHAPITRE SIXII:HE}

Embryologie des Scyphozoaires.

$\$ 1$ Considėalions générales............................................ $\quad 170$

I. Caractères ..................................................... 170

II. Strueture générale. - Scyphoméduses. - Anthozoaires. - Cteno-

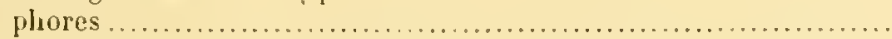

III. Déreloppement en géuéral. - Diveloppements sexués : Seyphomëduses; Inthozoaires : Clẻnophores. - Dèveloppemenls asexués.....

W. Classification des Scrphozoaires. - Scyphomèrluses. - Cténophores. - Anthozouires.

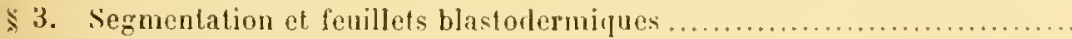

I. Scyphoméduses : dèveloppenents dilalès ; dẻveloppenents condrnsẻs.

II. Clénophores.

III. Anthozoaires : developpements dilatès; dèveloppements rondensés

\$1. Formes embryonnaires.

I. Generalites

II. Scyphoméduses. - Seyphistome. - Eplyye : transformation simple: transformation multiple, ou sirohilisation. - Héduse définilive.

III. Cténophores. - Phise Clenula. - Etat définilif......................

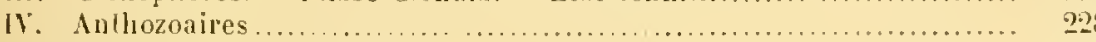

$\$$ :i. Origine Jes organes internes,....................................... $23 \dot{z}$

I. Ectollerme. - Ilèsorlerme. - Systéme nerveux et ol'ganes sensitils.. $23 \%$

II. Endoderme et enteron. - Seyphomeduses. - Cténophores. -

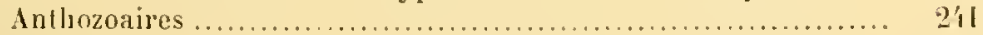

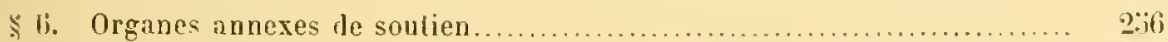

1. Octactiniaires................................................

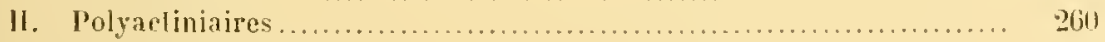

\$. Reproduclion asexuee............................................ $26 t^{*}$

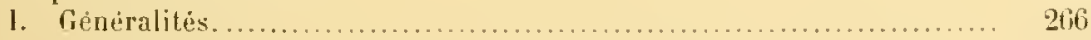

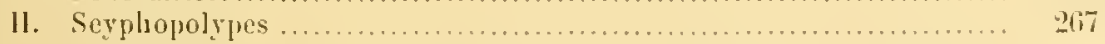

11. Anthozotires oclactiniaires: bourgeonnement slolonial; bourgenne-

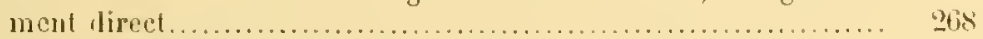

IV. Anthozoaires polyacliniaires. - Fissiparile des Nadréporides. Gemmiparite des Madréporides..................................

ROULE. - EmBryologit: 
§ 8. Gẻnérations alternantes.

I. Seyphomėiluses. .............................................. 276

II. Anthozoaires.................................................. 276

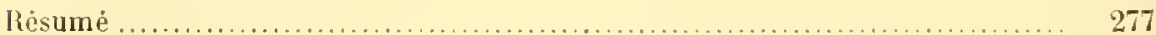

CIIAPITRE SEPTIËME

Développement des Plathelminthes.

$\S 1$. Considérations générales........................................

1. Caractères et classificalion ..................................... 286

1I. Généralités sur le diveloppement ............................. 287

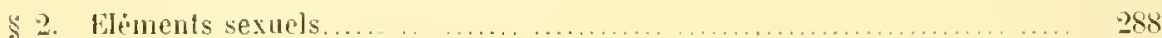

1. Sexualilé en génépal ....................................... 288

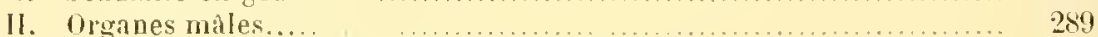

III. Organes femelles............................................... 289

$\$ 3$. Iléveloppement des feuillets blastodemiques ..................... 291

1. OEufs simples. - Nẻmerlines : déveloplements sans amnios: développements avec amnios. - Dendroecles digonopores ..........

II. OEufs composés on cocons. - Turbrlariès. - Tremalodes. - Cestodes....

\$4. Formes embryonmaires ...........................................

I. Généralités ... .............................................. 306

11. Turbellaries et Némertines ...................................... 307

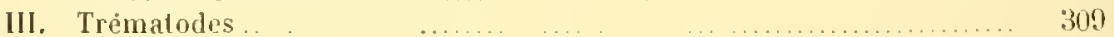

IV. Cestodes ......... .................................... 316

\$. Reprorluetion asexuée, ct. alternance des générations... .. . ... ... 319

1. Etude gènėrale. - Fissiparité. - Gemmipariti. - Gemmulation.... 319

11. Segmentation du corps des Cestorles. ... ....................... 321

$\$ 6$. Migralions embryonnaires ..................................... 32 .

I. Considérations générales.................................... 324

II. Fitude spéciale. - Trématodes, — Cestodes..................... $32: ;$

$\$ 7$. Développement des Myzostomes... ... …................ 329

$\$$ 8. Développement des Acantlociphales. ... .................. . . 330

I. Consilérations générales ................................... 330

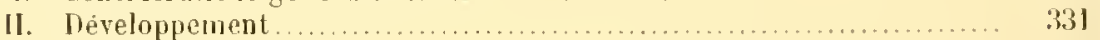

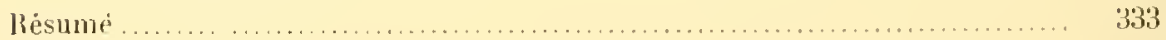

\section{CIIA PITRE IUITIE}

Diveloppement des Némalhelminthes.

\$. Considerations generales

1. Caractères el clissification................................

11. Généralités sur le développement ................................. 3il

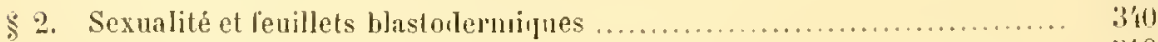

I. Sexualite........................................................ 310

II. Feuillets blastodermiques ...................................... 340

\$. Migrations enloryonnaires : premier groupe; second groupe; trnisiene

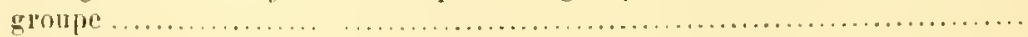

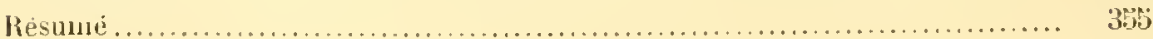




\section{CHAPITRE NEUVIE IE}

$\$ 1$ Considerations générales.

337

$3: i 7$

11. Génèralités sur le díveloppemeut .............................. 360

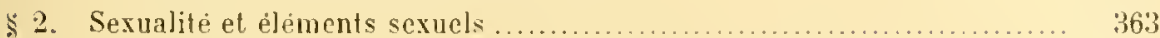

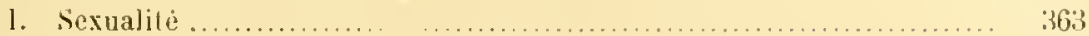

II. Eléments sexuels ............................................. 360

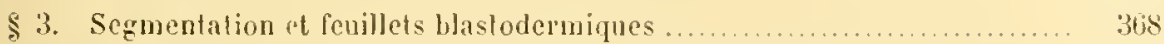

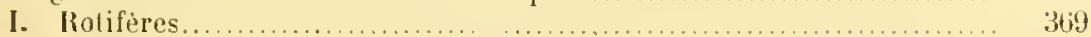

11. Mollusques : gastrulation: planulation indirecie produsant me planule ertulaire; planulation indirecte succedant a me segmentation totale, et produisant une planule lécithique; planulation indirecte succeddant it une segmentation partielle, ef aboutissant at une planule lécithique..

III. Tenlaculifères. - Lirachioporles. - Bryozoaires. - Phoronidiens. -

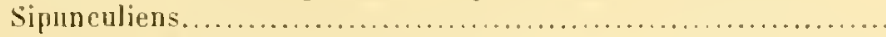

IV. Annèlides : gastrulation des Archiannélides et de plusienrs Polychurtes; plauulation directe de la plupart des Chétopodes; planulation indlirecte des Itirudinces ............................. 391

Y. Pscudannẻlides................................................. 397

\$ i. Formes embryonnaires.......................................... 399

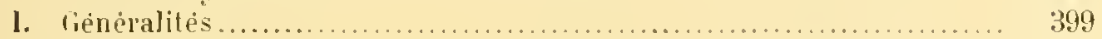

11. liotifères ......................................................

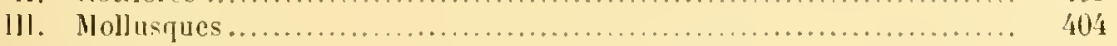

IV. Tentaculilères. - Sipmeuliens. - Phoronicliens. - Bryozoaires. Brachiopodes ......................................... 410

V. Pseudannèlides................................................. 418

1. Annelides.................................................... 419

$\$ \%$ Origine des organes........................................... 422

I. Organes d'origine ectodermirue : centres nerveux et organes des sens; soies: cuticules .................................... 422

11. Organes dorigine endodermique............................... 426

III. Organes d'origine mésoderuinue : disposition gènérale du misolerme; colome el appareil irrigateur; organes exerètenrs; organes sexuels .....

\$ 6. Reploduction asexué, et allernance de gènérations................. i38

1. Fissiparitẻ.....................................................

I1. Cemmiparitè et gemmutation ..................................... 193

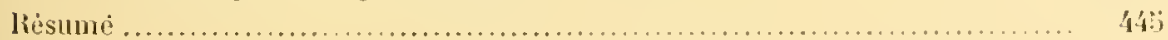

\section{CUAMTRE HXIENE}

Développement des Arltropodes.

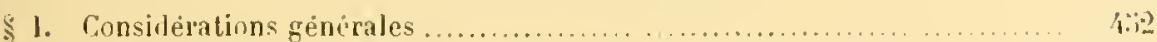

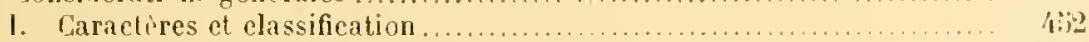

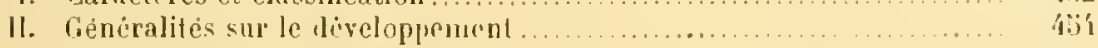

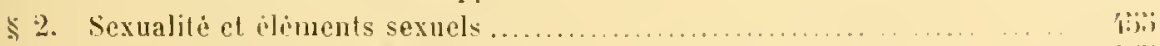

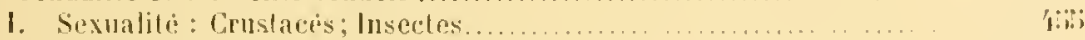

II. Elements sexuels...................

\$3. Segmentation et feuillets blastodermirques...................... 40.0 
I. Segmentation. - Crustacés mulomostracés. - Crustacés malacostracis. - Miroslomatés, Pyenogonides, el Arachnides. - Myriapodes et Insertes

460

II. Déreloppenent des feuillets blastodermiques. - Considérations génerales. - Cruslacés. - Arudinides. - Insectes (amnios) .........

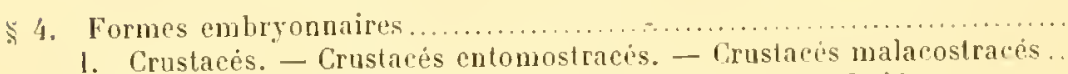

1. Crustacés. - Crustacés entomostracis. - Cruslacis malacostracés..
II. Acères. - Pyenogonides. - Mérostomatés. - Arachnides..........

111. Dicères. - Myriaporles. - lnsectes : métanorphoses embryonnaires dans leur ensemble; types palticuliers des métamorphoses; métamorplıoses des organes embryonnaires (histolyse et histogenèse). .

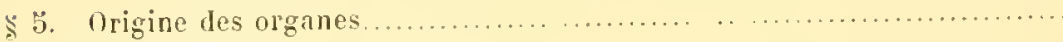

I. Appendices..............

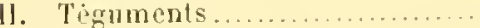

III. Centres nerveux.................

IV. Organes des sens. - Considèrations gẻnérales. - Ocelles. - Yeux composés.

V. Appareil digestif et ses amnexes. - Stomeon et ses annexes. Proeteon et ses annexes. - Enteron et ses ammexes ..............

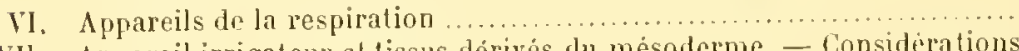

v1l. Appareil irrigateur el tissus dérivés du mésoderme. - Considerations générales. - Tissus musculaires. - $\Lambda$ ppareil irrigateur et cour.

VIlI. Organes sexuels.

§i. Alternances de générations

CII APITIB OXZIE IE

\section{Diveloppement des Chrotoynathes.}

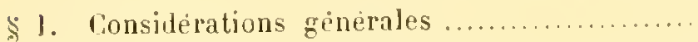

I Caractères

II. leveloppement en gènéral................................... 600

\$2. Segmentation et développement des fenillets.........................

I. Sermentation et genése les lenillets embryonnaires............... 601

IJ. Plases nltiricures du diveloppement ........................... 603

lipsumé.

CHAPIT RE DUUZIËM

liveloppement des Onychophores.

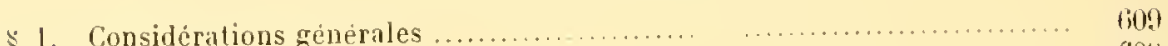

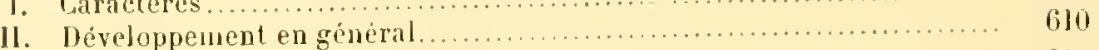

\& Segmentation el développenent des feuillets ........................ 610

I. Pliénomènes cxtérieurs à l'entıryon.......................... 610

II. Whénomènes propres à l'embryon........................... 6]:3

$\$$ 3. Formes embryonnaires et développement parliculier des organes....... 617

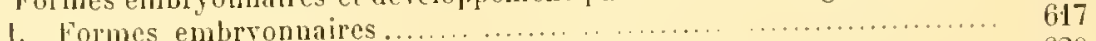

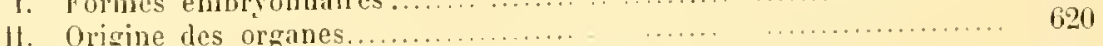

$\$$ 4. Discussion relative aux pluases embryonnaires les P'éripates ............ 62'

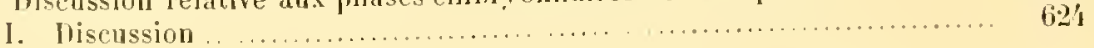




\section{CIIAPITRE TREIZIEME}

leveloppement des Echinodermes.

§. Consideralions generales

I. Caractères el classification. - Caractères. - Classification.

II. Diveloppenent en gènẻral. - Gẻuéralitẻs. - Particularités essentielles du developpement. - Conclusion.

\$2. Sexualiti et developpement des deux feuillets blastodermiques primor-

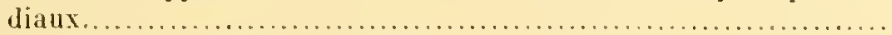

I. Considérations gémérales. - Sexualite. - Généralités sur les leuillets primordiaux.

II. Développements parliculiers des feullets blaslodermiques primorliaux. - Ilololhuriles. - Echinides. - Istérides el Ophiurides. Ginoindes

\$. 3. Développenent les feuillels définitifs, des entérocules et de l'hralrocoele.

I. Consideralions gènẻrales : notions prèliminaires; endoderme détinitif et entèron; mésoderme épilhélial, entérocoles el liydrocule. liésumé et conclusion.

6isis

11. Développements parliculiers des feuilleds blaslodermiques définitifs. - Ilolothurides. - Echinides. - Astérides ol Ophiurides. -Crinoïdes.

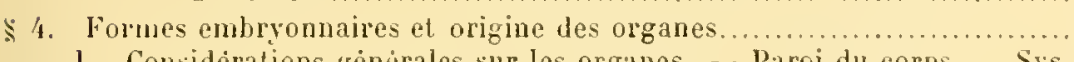

1. Considérations générales sur les organes. - Paroi du corps. - Syslème nerveux. - Tube digestil. - Ip]areil irrigateur. - Appál'ei] exereteur. - Organes sexuels.

II. Considérations générales sur les formes embryomaires : mélamorphoses complètes; mélamorphoses restreintes ou nulles.

III. Developpenent particulier des Ilolothurides : mélamorplıoses complètes ; métamorphoses restreintes ou nulles ; origine des organes.

IV. Developpement particulier des Echinides : genese du Pluteus; diverses formes du Pluleus: genèse de lorganisme delinilil; origine des olganes..

V. lèveloppement parliculier des Astèrides : métamorphoses complètes, genèse de la Bipinnaria el de la Buacliolaria; genèse de l'organisme difinitif; métamorphoses restreinles ou nulles; origine des organes. . . .

IT. Développenent particulier des Ophiurides.

III. Jéveloppement particulier des Crinoides. - Considerations genérales. - J'remière phase libre : ètal anlérieur à l'éclosion, ou préparation de la larve libre; élal de libertí conséculif it l'éclosion. - I'base fixee : élat cyslieléen; état pentalcinoide. Seconde phase libre. - Appendice.

$\$$ :i. Reproulution asexuelle. - Fissiparite. - Gemmiparite............... 
I1. Ciènéralités sur le léveloppement.

\$2. Développement des feuillets, et formes cubryomaires des buteropmeusles

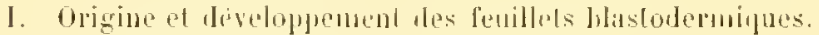

Il. Formes larvires. - Type dired. - Type Tornarien.

III. Origine première des organes

IIIAITRE OUINZIEME

Développement des Tumiciers.

\$. Considérations generales.

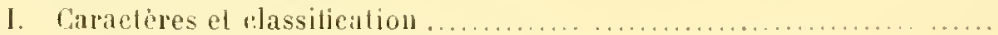

II. Généralités sur le déroloprement.

ร. 2. Sexualiti, et developjement les feuillels blaslodermiques............... $\mathbf{7 7 2}$

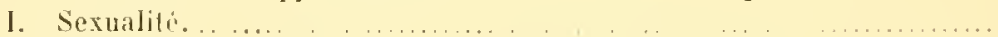

11. Seguentalion et feuillets liaslodermiques primurdiaux. - Blastulation et gastrulation. - Planulation : plannlalion direte; plannlation indirecte.

III. Feuillets blastodermiques definitifs, el urganes primordianx; messoderme, notoeorde, el nellraxe. - Dévelopremenls gastrulaires: changements de forne de la gastrule; genese de la notocorde; genèse du neuraxe; grenẻse du mésoderne; déveloplenenl gèniral des pirties. - léveloppenents planulaires.

$\$ 3$. Formes embryounaires...

1. Consilerations générales.

11. Embryons simples. - Larves urodèles : faronnenenl de la larve uroulèle, jusqu'à l'íclosion; éelosion ont fixalion de la larve urodèle. - Embryons alnoures.

III. Embryons genmipires. - Annexes des embryons gemmipares : annexes reproducteurs; annexes nutrilifs. - Duree Je la vie des embryons gemmipares......

\$. Origgine des organes.

812

I. Consirlérations générales

810

II. Aspeet extrieur el lígunents.

813

III. Centres nervenx ef glande neurate.

IV. Tube digestil et cavilé périlınchiale. - Cavilé peribranchiale. Ehatuche lnanchiale. - Ebaurhe intestinale.

v. Appareit irrigateur. - Aprareil irrgatem proprenent dit. - Crur et péricarde. - I)eutoculome..............................

11. Appareils l'énaux el sexuels.

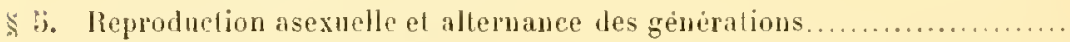

I. Considerations génerales.

11. Développenent des bourgeons. - J'wenance des burrgeons. Nitissance des bourgeons. - Evolution des buurgeons. - Formes coloniales...

III. Marche de la gemmiparite, et gènèrtions alternantes. - Consillerations générales. - Botryllides. - Pyrosomides. - Salpides.

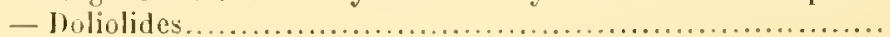




\section{CIIA IT IIE S EIZIE II}

\$ิ Consiléralions génèrales

$8: 59$

I. Caractéres et classification

11. Considérations grènerales sur le déreloppement

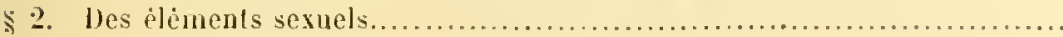

I. De la sexualité. - Du moment de la sexualité. - Nature de la sexualitẻ

II. Des sperumatozoïdes.

III. Des ovules

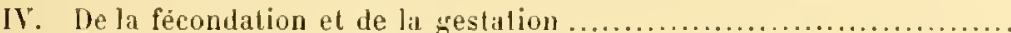

$\$ 3$. Ves leuillets blastodermiques en génèral, et de l'origine première des organes

1. Donnes essentielles du developpement des leuillets blastodermiques. - Cienése des feuillets blastodermiques primordiaux. - Genèse ef léveloppement du mésoderme: genẻse; développement de l'épithẻlio-mésoderme; développement du mésoderne mėsenchymateux. - Neuraxe. - Nolocorde. - Résumè.

11. Modilications introduites, dans le développenent des feuillels blastodermiques, par les condensations embryonnaires. - Feuillets Bastodermiques primordiaux. - Mésoderme. - Neuraxe et Notocorde

\$4. Développement des feuiliets blastodermiques chez les Acraniens

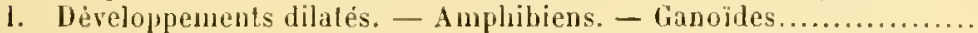

11. Tẻreloppements condensès. - Téléostèens. - Sélaciens ..............

$\$ 7$. Développement des leuillets blastodermiques elez les Sauropidés ........

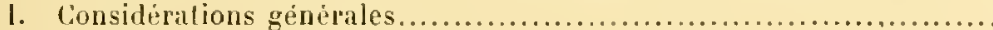

II. Feuillets primordiaux du blastoderme cmbryonnaire..................

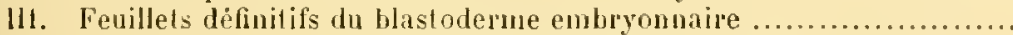

IV. Blastoderne para-embryonnaire ou vitellin

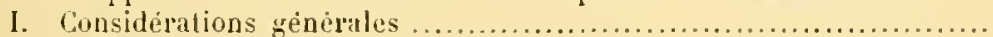

11. Segmentaliou, et genèse de lit cueloplanule.

111. Feuillets définitifs

982

IV. Inversion des feuillets. - Considérations générules. - lıversion chez le Lapin. - tnversion chez le Campangnol, le Rit, et la Souris. Inversion chez le Cobaye .....................................

Risumę...

\section{CHA IPTRE DIX-SEHTIEME}

Les formes et les annexes des embryons des lertébris.

\$1. Considerations générales.

1. Plan de l'organisme embryonnaire.

11. Formes embryounaires des Vertébrés. - Développements larvaires. - Developpements fortaux....

11t. Annexes embryonalires. - Annexes dorigne extra-ovulaire. Annexes dorigine ovulaire. - Annexes d'origine embryounale. Kèsumé 
\$2. Formes embryonnaires des Aeraniens et des Cyclostomes................

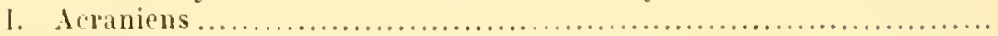

11. Cyclostomes : mélamorphoses de l'embryon avaụt son éclosion : metamorpliose ite l'embryon en Ammocrete; metamorphose de l'Ammoerrte en aululte

\$3. Formes et annexes embryonnaires des felnthyopsilès ....................

1. Imphibiens. - Considerations générales. - Gymmophiones. - Irodéles. - Anoures : développement avanl l'éclosion; métamorphoses postérieures it l'éclosion; diverses lormes de têtarits:

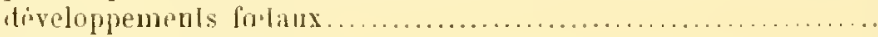

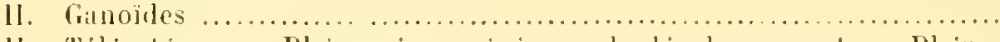

11I. Téléostéens. - Phènomènes gẻnéraux dı développenent. - Plıẻnamènes farticuliers du développement. - Développements vivipares

IV. Sélaciens

\$4. Généralités sur les annexes embryonnaires des dmnioles.............. $10: 38$

1. Considerations générales....................................... 10.38

II. lieveloppement de l'amnios. - Délimitalion de lia zone enbryonnaire. - Dẻveloppement du ecelome externe. - Début de l'amnios. - Achèvement de l'amnios................................

111 Développement de la vésicule allantoïde.......................... $107 \mathrm{j}$

IV. Nature des ammexes embryonnaires des Amniotes................... 1083

\$5. Formes et annexes embryonnaires des Sauropsides .................... 1089

I. Considerations générales ........................................ 1089

11. Plases embryonnaires da Poulet, choisi comme type. - Plases antérieures it l'éelosion. - l'hènomènes de l'éclosion............ 1092

$\$$ 6. Formes el annexes embryonnaires des Mamnifères.................... 1099

1. Considėrations génèrales...................................... 10ng

11. Callutres...................................................... 1]

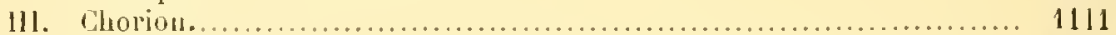

IV. Vésicule vitelline ............................................. 111 ;

I. Culome externe............................................. 1117

V1. Amnios......................................................... 117

VIl. Vésicule allantoïde ......................................... $\quad \mathbb{1} 20$

vill. Cordon ombilieal ........................................... 1121

IT. Llacenta. - theveloppenent dn placenta : période de formation de l'ecloplacenta; périorle de remaniement; periode d'aclıèvement; décollenent du placenta. - Formes placentaires.............. 1122

X. Kèpartition des annexes dans la série des Mammifères.............. $113 !$

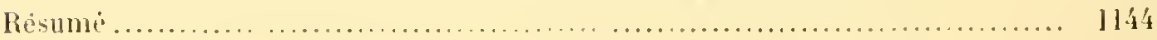




\title{
TABLE DES FIGURES
}

\author{
CONPRISES DANS LE TEXTE
}

C:IIAPITRE P'IEMIER

I'rotozoaires Surcoduires.

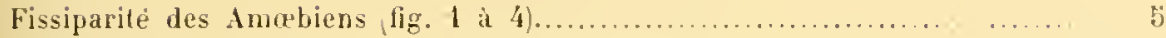

rissiparite des Foraminifẻres fig. 5 à 7 . ................................. 7

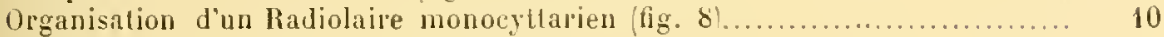

Fissiparité d'un Radiolaire monoeyttarien (fig. 9 í 11 ) .................... 11

Fissiparite des llagellales (fig. 12 a 14 ) .................................. 15

Gemmiparite des Cystollagelles firg. 15 a 17 ) ............................. 20

Phases essentielles de la sporulation des l'rotozoaires sarcodaires fig. 18 at 24$) \quad 23$

Sporulation des Sporozoaires uronogeniques lig. 20 a 30 ..................... $26^{\circ}$

Conjugrison, eukystement, et genèse des protospores chez les Sporozarires amphigeniques (fig 31 à 33 ).

Erolution des protospores el des deutospores des Sporozoaires amphigeniques (fig. 36 a 41 )

\section{CIIAITIE DEUXIEME}

I'rotazanires Ciliuires.

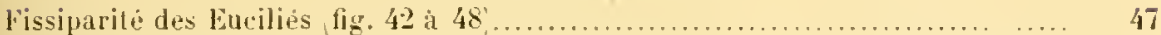

Conjugraison temporaire des Eucilies (fig. 49 a 51 .......................... $\vdots 1$

Tableau diagrammatique exprimant les divisions nucleaires de lat conjugaison

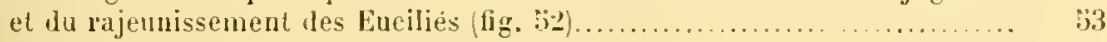

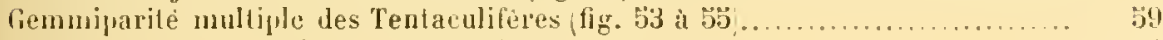

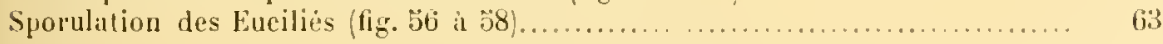

CIIAITLE TROISIEME

Mésozonares.

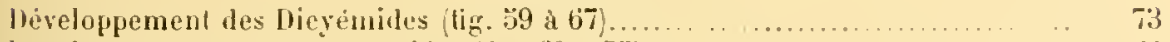

leveloppement des 0 rthonectides (lig. 68 is 77 )...................... 74

\section{A ITRE OUATRIËUE}

Spongiuires.

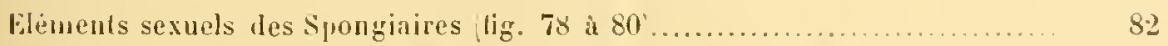

tèveloppement des feuillets hlastodermiques diu Caleisponge tig. 81 it $84, \ldots$. 86 
Diveloppement cytulaire des feuillets embryonnilies des Eponges (ïg. 85 à 87 )

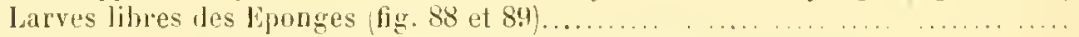
Jhases du developpement incurve des Myxusponges lig. 90 a 92).

Organisalion blastoplanulaire de l'économie res lponges (lig. 93 i 97 ).

Gemmiparifi des sponeriares (fiz. 98 a 100 ).

Gemmales des Spongillides (fig. 101 i 103 ).

\section{CIIAPITE CINOUIEME}

\section{IIydrozouires.}

Jèveloppement génèal des feuilèels embryounaires des llydrozoaires (fig. 104 il 109).

Developpement des leuillets embryonmaires des Iuthydraires et des llydromé-

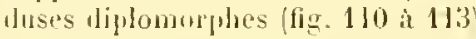

Déselopmement des leuillels embryonnailes des llydromiduses holomorplies lit. 11' i 119).

beveloppenent des leuillets embryonuaires dhez des siphonophores fig. 1:20 i) 123

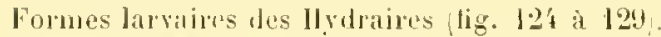

Formes linvaires des Iydraires fig. 130 et 131).

Formes larvaires des Siulnonophores lin. 132 el 13:3

Formes larvaires des Narcoméluses fig. 1:34 il 1:30).

146

formes larvales des Trachymeduses lig. $1: 37$ a $142 \ldots \ldots \ldots \ldots \ldots \ldots \ldots \ldots$

Genmuparite des IIylromiduses diplomorylles [ig. 143)

148

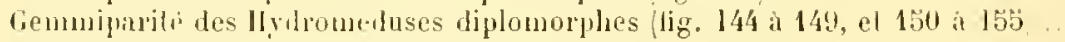

$15 \% 2$

$15 \%$

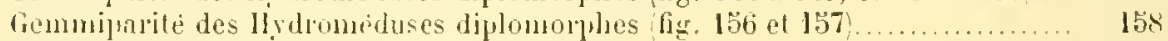

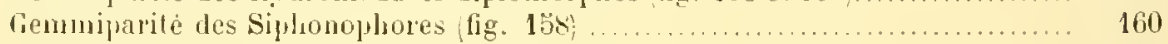

fomminarité des mèduses (fig. 159).

\section{CIIIITRE SIXIEME}

\section{Sicyphozaaires.}

Dispositions des cloisons gastriques chez les principaux grompes des Anthozo:tires polyactiniaires (figr. 160 a 1605 ) ...

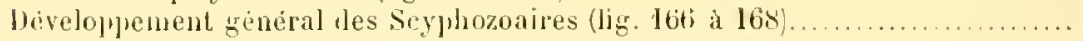

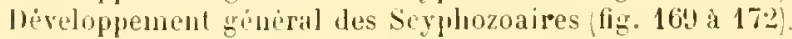

Développement généra] des Seyplozoaires (lig. 173 et 174; suite des précerlutes).

levelopjement condensi des Serphomeduses (fig. 175 a 177).

béveloppement des leuillets blastodermiques chez les Cténophores fig. 17s a 182$)$.

Organisation gènérile d'une lave du type Seyplule (lig. 183 a 185 )........

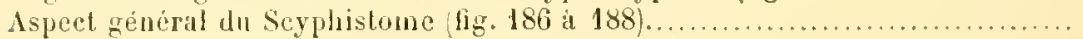

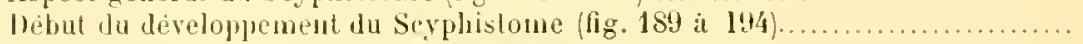

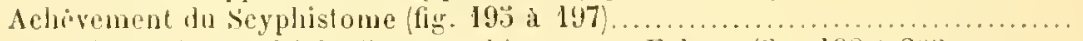

Translormation multiple d'un Seyphistome en Ephyre (lig. 198 ì $203 \ldots \ldots . . . .$.

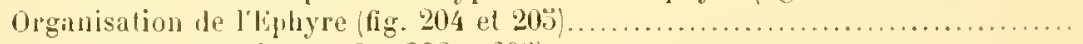

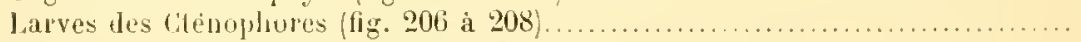

Organisation des larves de liténopluores (figg. 20y à 211).

larves des Intlozoaires (lig. 212 el 213 ).

Formition du mésoderne, et des cloisons, chez les Anthozoaires (fig. 2/4 et 215

beveloppenent ales douze cloisous de la couronne des Zoanthaires (lig. 2ló (1) 219 ). 
Developpement total des eloisons des Zoanthaires (fig. 220 à 225 )

formation du polypier des Madreporides lig. 229 à 231

Formalion du polypier des Madreporides (fig. 232 et 233)

\section{CIIAPITHE SEDTIEME}

Plathelminthes.

OEuf compose des Plathehminthes tig. 244

Développenent génèral des feuillets blastotermiques des Plathelminthes fig. 245 a 249

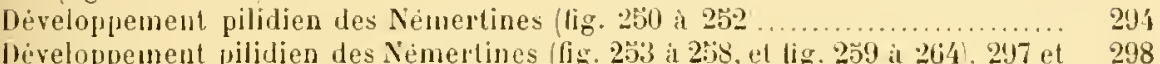

Déreloppenent des Némertines par la lanve le Desor fir. 2tö

300

Dérehppenrent des feuillets blastoderminues abez les bendrocotes trielates (fig. 26 bi is 27 ?

Développement des feuillets blastodemiques ehezles l'rematodes fig. 273 a 280

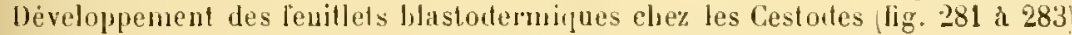
Larves les 'lurbellaries dendrocules fin. 284 et 2800 )

Larres primaires des 'Trematodes endoparasites (ig. 286 à 288)

Larves secondaires des Tremalodes entoparasites (fig. 289 et 290 ).

Evolution Iu Crsticer'jue fig. 291 à $2966^{\prime}$

Types te Cysticerques (fig. 297 et 248 ).

300

304

306

308

311

313

314

318

320

Fissiparite des Turbellariés rhabdocoles (fig. 249 à 304)

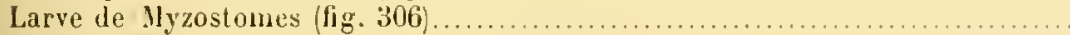

\section{CIIIPITRE IIIITIEME}

\section{Nèmathelminthes.}

Segmentation ovulaire des Nèmatodes (fig. 310 it 315 )

345

bilimitation des feuillets primordiaux chez les Nimatorles (fig. 316 a 318 ) ... 348

Délimitation des feuillets définitifs chez les Nèmatodes lig. 319 it 321$\} \ldots \ldots \ldots .399$

\section{CIIAPITRE NELVIËME}

Trochuzadires.

Organisation generale d'une larve Trochophore (1ig. 322 et 323$\}$...............

premières phases le la genèse du mésolderme chez les larves Trochophores (figr. 32' i : 3330$\}$.

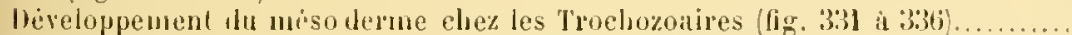

Dẻveloprement des ovules chez les Anueliues oligochutes (lig. 337 i 340 .....

bevelupjement des leuillets blustoderminues chez les Mollusques (fir. 3 il

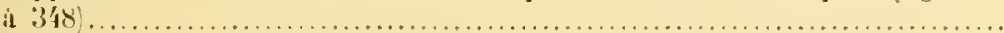

héveloppenent des lenillets blastodermiques chez les Mollusques [lig. 3i!! it $3 \ddot{3} 21$.....

Segmentation ovulaire ef genese des feuillets primondiaux enez les Phoronidiens $\{$ lig. $335:\}$ a $: 366\}$. 
Plarses gastrulaires des Tentaculifères (fig. 367 à :369).

Ciastrulation chez les innélides (1ig. 370 a 373 1..............

Planulation directe ehe\% les Annélides (fig. 374 i 381 )...

Planulation indirecte ehez les Innelides (tig. 382 et 38:3).

393

prosome et mitasume des Trochozoailes (lig. 384 it 388).

396

Rotiferes et Trochophores (fig. 389 à 391 ).

l'rincipaux types de Trochophores (fig. 342 a 395).

Rotifëres et Trochuphores (fig. 396 is 398)

I'rineipaux trpes de Trochophores (fig. 3004 a $\mathbf{4}(12)$

Larves des Hollusinues (fig. 403 a 409 ).

Diveloppenent des Phoronidiens (fig. 410 a 418 )

larves des Trochozonires monomèriques (fir. 419 a 423 )

Larres d'Anuclides fig. 424 it 4297

Larves de l'seudannélides (fig. 430 at 431 )

Origine des centres nerveux des Troeliozoaires (lig. 432 a 434 )

Diveloppement et cloisunnement du mesoderme des Trochuzoaires polymeriques fig. 433 à 444 ).

Développenent des caviles segmentaires, des cloisons, ot des néphridies, chez les Annélides (fig. 445).

Fissiparite des Annèlides lig. 446)

Gemmulation des Bryozoaires fig. 447 et 448 )

398

399

402

405

408

408

412

415

418

421

425

428

434

442

445

\section{CUA ITTRE DIXIENE}

\section{Arlliropoles.}

Segmentalion tolale de l'oruf des Crustacis (fig. 449 et 450).

Segmentalion (utile de f'ouf des Cruslaces (fig. 451 il 4550 )................... 463

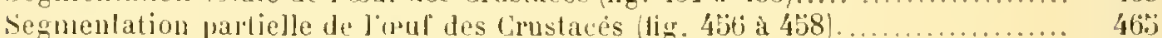

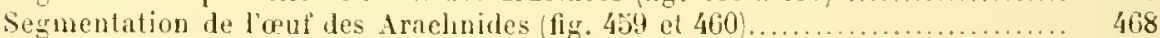

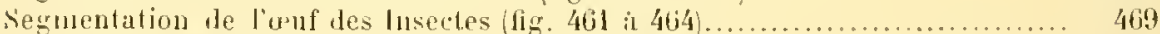

Urganisation essentielle d'un . Irthropode (fig. $46 \%$.......................... 474

Développement gènéral des feuillets du hastoderme chrz les Arthropodes fir. 460 it 470 .

Dévelopjement des feuillets alu blaslorlerme elıez les Crustacés (fig. 471 à 476 )

Déraloppement des lenillets du blastoderme chez les lnseetes (fig. 477 ì 480 ).

Disposition muluelle des trois feuildets chez les jennes embryons des luseetes (fig. 481)

Dèveloppentent general de l'annios des lusectes (fig. 482 i 486 ).

beveloppencent particulier de l'amnios des Insectes (fig. 4si il 493).............

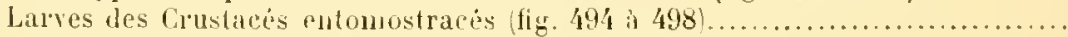

Embryons des Malacostracés edriophthalmes (ig. 499 et 500 ..................

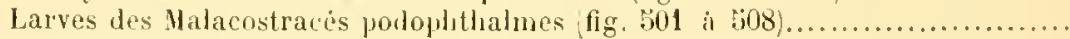

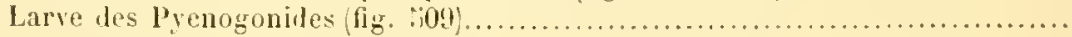

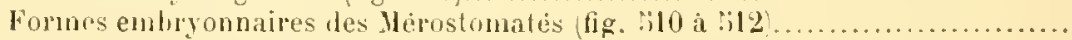

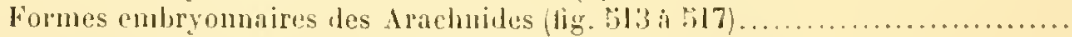

Formes embryonnaires des Lingunlules fig.

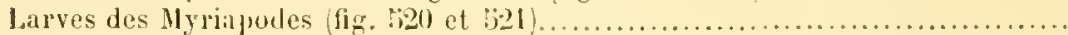

Formos des embryons des Insectes (fig. 522 a 1727 ).

Formes eubryonnaires des Insectes fig. 828 et $; 029$.

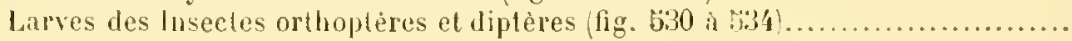

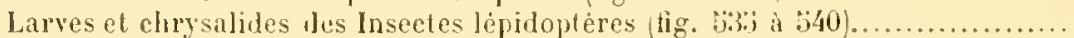

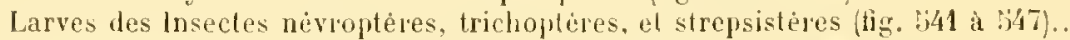

Larves des lnsectes colépitères et hyménoptères fig.

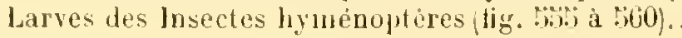


llistolyse et disques imaginaux des pupes d'lnsectes fig, $66 \mathrm{~L}$ it :ifol

structure d'un disque imaginal dinsecte $(\mathrm{fig} .566)$.

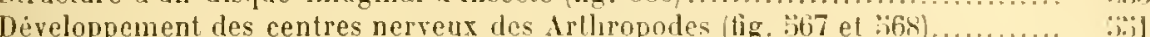

Déreloppement des neelles des Arthropodes (fig. 1609 à $\$ 71$.................. ;ij?

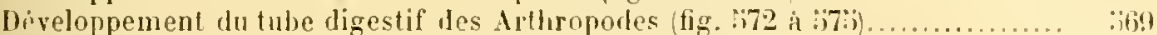

Développement des lissus mésodermirues lig. 576 et 577$) \ldots \ldots \ldots \ldots \ldots \ldots \ldots \ldots .576$

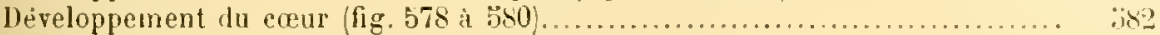

CUAPITR: OXZIË U E

Chotoynathes.

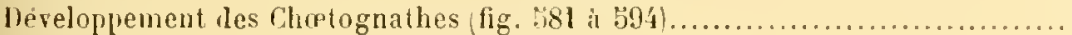

\section{CIIAPITRE DOUZIEIE}

Néphrophares ou Onychophores.

Développement des feuillets blastodermiques firg. 5993 à 602 ?.

Prenières formes embryonnaires des péripates (fig. 603 it 609$\}$................ Structure des premières ébauches organiques (fig. $610 \nmid \ldots \ldots \ldots \ldots \ldots \ldots \ldots \ldots$. Dernières formes embryonnaires des l'éripates (fig. 611 el 612 )................

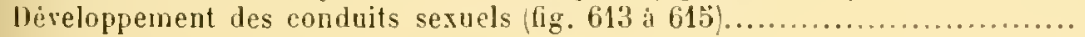

\section{CIIAPITRE TRI:UIEME}

\section{Echinodermes.}

Organisalion générale des larves d'Eelinodermes (fig. 616 à 619$) \ldots \ldots \ldots \ldots \ldots$. . . . Développement général des premières ébauches organiques (fig. 620 à $62: i$ ).... léveloppement gẻnèral des premières èbaurhes organiques (fig. 626 ì 628 )..... Développement général de l'hydrocale et de l'appareil lyydrophore (fig. 629 is 6311 .

Véveloppement général de l'hydroewle el de l'appareil hydrophore fig. 632 a 6.34 ).

Développement général des feuillets primordiaux (fig. 6335 a 638 . . . . . . . . . . Développement particulier des feuillets primordia ux (fig. 639 is 642 ............. Disposition génèrale des fenillets détinitifs et des plemie̊res ébauches orga-

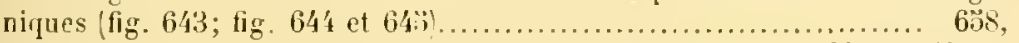
Développeurent des fenillets définitifs elıez les Holoflurirles (lig. 616 i $6: 0$ )... Dẻveloppement des fenillets définitifs des Lehiniles (fig. 65l it 6:ib).

Développement des feuillets définitifs et des prenic̀res ébnuebes organiques

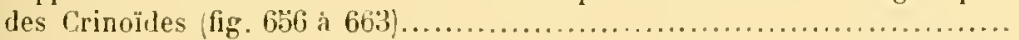

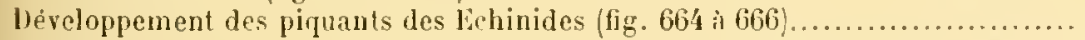
Esquisse générale des métamorphoses larvaires des Echinorlermes (tig. 667 it 674 ).

Mitamorphoses des llolothurides (lig. 675 it 683 )

Achivement des metamorphoses les Ilolothuriles (fig. 684 it 686$) \ldots \ldots . . . . . .$.

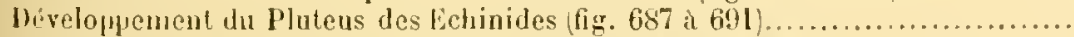

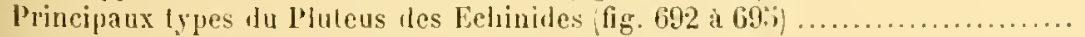

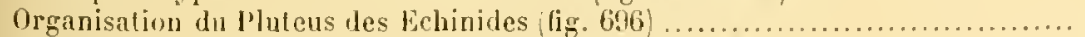

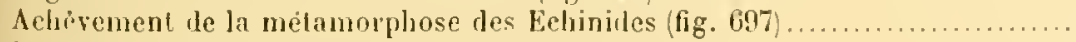

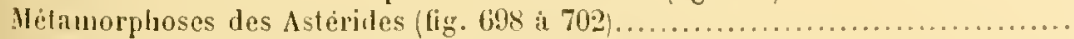

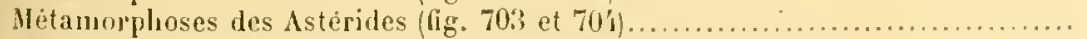

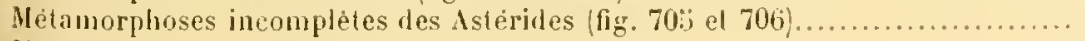

Ifetamorphoses des ophiurides (fig. 707 à 710 ). 
Mẻlamorphoses des Ophiurides fig. 711 in 7131 .

principales dispositions du plan organique des Echinodermes (fig. 714 i 717 ).

\section{(CIIITAE QUTORZIENE}

Entrinopnerestes.

Développement des fenillets hastodemiques des Entiropneustes (fig. 728 a 730 ) Mélamorphoses des Entéropneustes, lans le eas rle développement direct (fig. 731 it $7: 36$ i

Milamorphoses des linteropnenstes dans le cas de developpement Tornarien

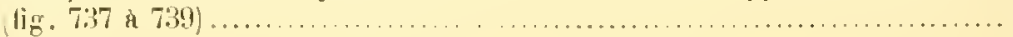

CIIATTRE QUIXIEME.

Tuniciers.

Développenent gẻnéral des feuillets blastotermiques chez les Tuniciers lig. 7'00

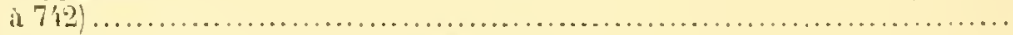

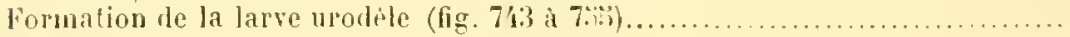

Metamorphose de la larve urodèle (fig. $7: 00$ in 760 )

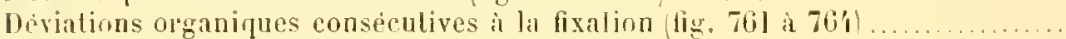

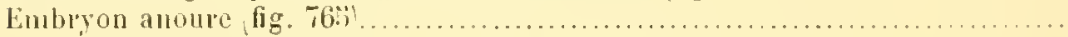

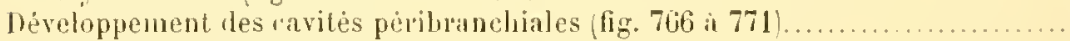
Bomrgeonnement des Botryllides (fig. 772)

Bouryeonnement des Pyrosomides (fig. 773)

lBonlgeonnement des Salpes (fig. 77y it 776 ).

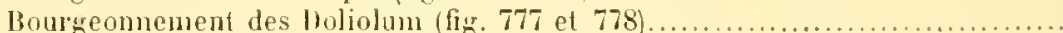

\begin{tabular}{|c|c|c|}
\hline 一 & - & 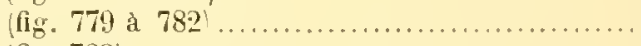 \\
\hline - & - & (fig. 783 ) $\ldots \ldots \ldots$ \\
\hline - & 一 & (fig. 781) ........ \\
\hline - & - & $(f \mathrm{fo} .78,3$ el 786$)$ \\
\hline
\end{tabular}

CIIIPITRE SEIZIËME

Feuillets blastodermiques des fierlébrés.

Amblystome et Axolotl (tig. 787 et. 788). . .

Origine essentielle des fouillets et des organes primordiaux chez les Vertébrès (fig. 789 : 792

origine essentielle des fenillets el des organes primordiaux cliez les Vertébrès (iig. 793 el 794).....

Dispositions esseulielles des fruillels et des organes primordiaux chez les Vertébrès fig. $79 ;$ a 801

$86:$

882

Phases essenlielles du diveloppemenf du misoderme des Vertébrès (fig. 802 a 800 )

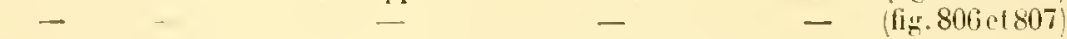

Vilats mivers, snivant la Ienenr de l'ovule en deutolecithe, des feuillets blastodermiques primordiaux des Vertébrés (fig. 808 à 812 )..................

Développement des feuillels blastodermiques primordiaux chez les Aeraniens (figt. 813 is 816 ).

béveloppement des feuillets blastodermiqnues primordiaux chez la pluparl des Cyclostomes, des Ganoules, el des Mmphibiens (fig. 817 i 822 ).

Irveloppenent des lenillets hlastudermiques primordianx elıez les sélaciens et

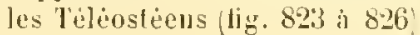


Developpement des fenillets blastodermiques primordianx chez les Samropirles (fig. 8.27 is 8.30

Développement des feuillels blastodermirues primordian chez les Mammifères fig. 831 à $8: 35$ ?.

Elats divers, suivant la tenem de l'ovule en deutolecithe, des fenillels blasto-

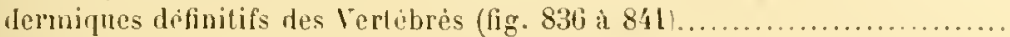

Segmentation el genese des fenillets hlastodermiques chez les Acraniens lig. 812 à 853$)$.

Elements sexuels des Cyclostomes fig. 8 :ii et 8 :ii) .........................

Developpement des feuillets chez les Cyclostomes (fig. 8000 a $8 . i 9)$............

Segmentalion ovulaire chez les ranoides fig. 860 el 861

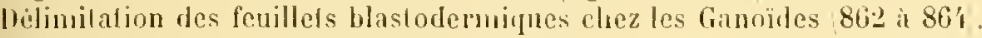

Blastule d'un Amplibien urodèle fig. 8603 .

Blastule d"un Ampluibien anoure fig. $866^{\circ}$

Segmentation ovulaire chez les Sauropsides fig. 867 à 871 ..

helimitation des feuillets chez les embryons des Situropsidés fig. 872 à 883 ..

fig. 881 à 888 ...

Segmentation ovuline et délimilation des feulleds primordiaux chez les Mammilèles fig. 889 à 891

n)?

(13:3

938

(1)

913

!)

96.2

968

Delimitation des fenillels hlastodermiques of des organes primnrdiaux chez les Hammifèles lig. êt? ì S?!

981

984

Phénoménes généranx de l'inversion des feuillels ehez les Mammilides lig. s!̈j a 900 .

Inversion des fenillets blastorlermiques cluez le Lapin lig. 001 à $90:$ i...........

988

19122

$9 ! 16$

Inversion des feuillets blastodermiques chez le Campagnol fig. 910 a $416 \quad \ldots . .1002$

Inversion des feuillels blastodermiques chez le Cobave fig. 917 a $923 \ldots \ldots . . . .1006$

\section{CIAPITRE OIX-SEPTIEM E}

\section{Les formes el les annexes des embryons des lertébris.}

Folmes embryonnaires des Cyclostomes tig. 9124 a 929 .

1030

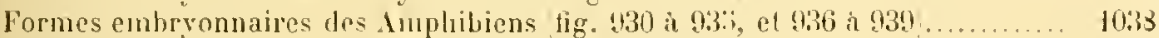

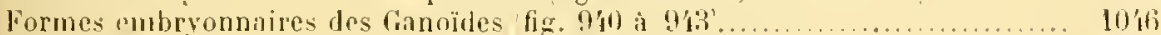

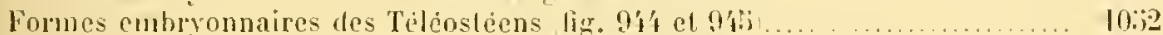

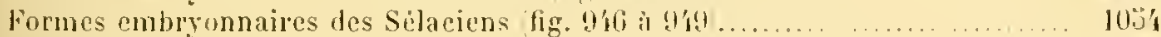

brveloppement géneral des annexes ombryonnaires cliez les Vierlibrés

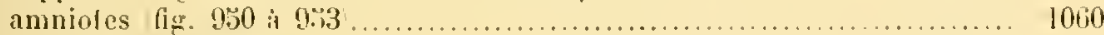

Déreloppement génèral des annexes embryonnaires chez les Vertebrés

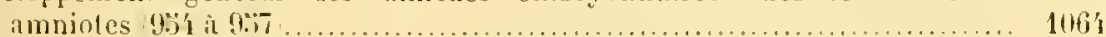

leveloppement général des annexes embryonnaires cluez les Verlibrés

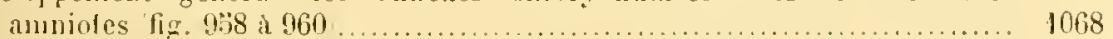

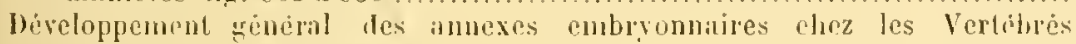

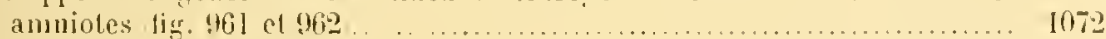

Diveloppenent reneral des annexes cmbryommires choz les Vertibris aminioles $l i$.

beveloppenent genenal des annexes emblyommires chez les Verbires

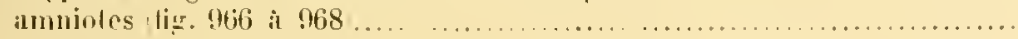

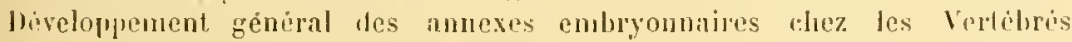

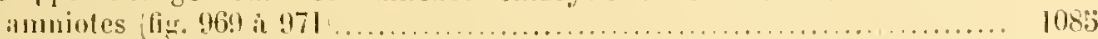

divelofpemenl. general des annexes embryonaimes che\% les lertibres

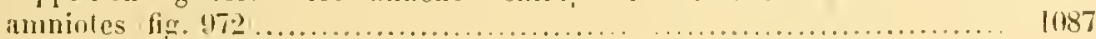

fiomes stecessives des anmexes de lembryon du l'oulet fig. 
Dispositions successives des annexes et des enveloppes de l'embryon du l'oulet fig. 980 et 981

Dispositions successives des annexes of des enveloppes de l'embryon du l'oulet fig. 982 a $98 \%$.

Opposition des Mammiféres vivipares aux Sauropsides en ce qui concerne leurs orules ef leurs annexes embryonnaires fig. 986 à $989 \ldots \ldots \ldots \ldots \ldots \ldots \ldots$. . . . . . .

léreloppencut des annexes embryonnaires des llammilères vivipares fig. 910

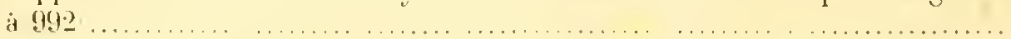

Développement des annexes embrronnaires des Jammifères vivipares fig. 993 el 991

Dèveloppement gèneral du placenta des Mammiferes tig. !g:

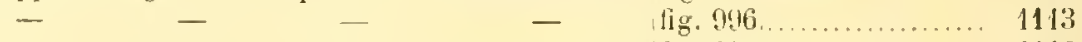

- $\quad$ - $\quad$ - $\quad$ - fig. $997 \ldots \ldots \ldots \ldots \ldots . .1119$

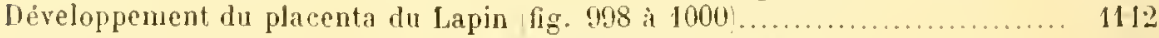

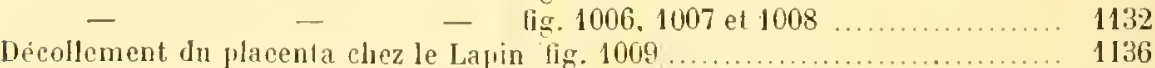

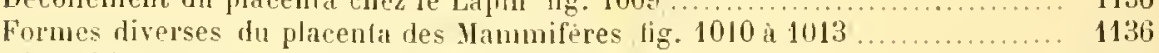

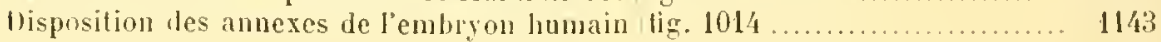




\title{
LMBRANCHEMEN'T \\ DES \\ PROTOZOAIRES SARCODAIRES
}

\author{
- eneros \\ CHAPITRE PREMLR \\ EMBRYOLOGIE DES SARCODAIRES

\section{\$1. - Considérations générales.}

1. - Caractères et classification. - Les Protozouires surcodaires sont des animaux unicellulaires, munis de psendopodes, on de fouets, el déponrvus de cils viluratiles.

L'embranchement se divise en deux sous-embranchements : les Pseudopodaires, et les Flagellaires; ces dernicrs sont encore nommés des Flagellates, on des Hastigophores. - Les Pseudoporlaires sont caraclérisés par le fail de posséder des psendopodes, appendices capalıles de changer constamment de forme. Par contre, les Flagellaires sont munis de fonets, appendices fins et allongés, d'aspect immuable, et sont privés de psendopodes.

A. - Le sons-embranchement des Pseudopodaires contient cinq classes :

$1^{\circ}$ Les Honeriens, privés de noyaux; ces itres correspondent aux Protistes des auteurs.

$2 \circ$ Les Amceliens, pourvus de noyaux, munis de pseudopodes duranl leur vie entière, et privés de carrapaces calcaires comme de squeleltes siliceux. Le nom de la classe est dù à l'un des représentants, le genre Amebre.

$3^{\circ}$ Les Sporozonires, pourvus de noyaux, ne possélant, pour la plupart, des psimtoporles que durant leur jeune igge, privés de carrapaces calcaires comme de squelelles silicenx, el se reproduisant d'habilude au moyen de deux générations do spores. Tous les Sporozoaires sout des parasites d'animaux plus romplexes qu'enx en opranisalion. Cortains d'entre enx n’oltient qu une seule génération despores; it ast permis de les nommer Honogéniques, pour les opposer aux autres, que le terme 
CHAPITRE PHEMIEI

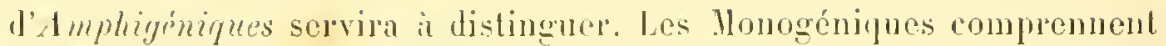
les Microsmoridies el les Myrosporidies; les Impligéniques ronferment fous les aulles Sporozoaires, c'est-itdiro les surcosporidies, les Coccidies

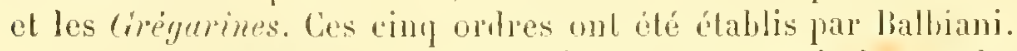

$4^{\circ}$ Los Formmiferes, pourvus de noyau, munis de joseudopodes durant leur vie entière, enveloppés par une carapace, de nahre calcaire, ou faile de débris anglutimés.

¿0 Les lésiculaires, pourvos de noyanx, munis de psemtopodes durant leur vie entiòre, possédant de nombreuses vésicules dans lem eclosarpur, larfois lans lem endosarque, el enveloppés assez souvent par une carapace siliceuse, de forme l’égulièse.

B. - Le sous-em!ranchement des Flagellaires renferme quatre classes :

$6^{\circ}$ Les Nudoflagellès, dont les appendices s'insèrent librement sur le corps, et sont nus, c'est-ì-dire ne présentent ancune enveloppe parliculièe. Co caractère de nudité s’applique seulement aux fouets, aux apprendices locomoteurs, el nullement i lorganisme enticr, qui est entouré, chez cerlains lypes, nommés Thécoflayellès par cela mène, d'une cartpace chitineuse.

$7^{\circ}$ Les Choano/layellés, dont les appendices sont entourés, à leur base, par une expransion en lorme do colleretle.

So Les Dinoflagellés, dontle rorps, muni de deux fonets, est enveloppé par une carapace siliceuse, munie d'un sillon épuatorial, dans lequel se ment en ondulant le plus mince des l'ouets. Les monvements de cel appendice sont tellement rapides, qu'on s'était antrefois trompé à son égard; on almcltail que le sillon équalorial portait une rangée de cils vibratiles, d'vì le terme de Cilio/lagellés souvent cmployé jour désigner ces ètres.

9o Les Cystoflngelles, dont le corps ghobuleux, rempli de nombreuses vésicules, el limilé frar une membrane résistante, olló l'aspect d'un kyste. Les Noctilurues appartiennent à celte classe, qu'elles représentent presifue à elles seules.

11. Généralités sur le développement. - Les phénomìnes de la reproduction sont lies simples chez des ètres aussi pen complexes, doul tont l'organisme est constitué prar une seule cellule; les procédés y sont mème moins élevés que leurs corlespondants des Protozoaires ciliaires. Ces deniners animanx présentent, pour la plupart, du moins daus l'état des faits acquis à la science, une conjugaison accompagnée de rajeunissement; celle conjugaison, lien que temporaine d'habilude, est me circonstance normale de lévolution vitale; elle parait intervenir forcément, dans tous les cas où le protoplasme est épuisé par une série répétéc de livisions lissipares, et clle lútermine un rajennissement de ce protoplasme. Pill conlre, chez les Sareodaires, la conjugitson n'existe sourent pas; ou bien, lorsquion la constale, elle semble etre acciden- 
telle et ne point constituer un phénomène habituel. tes Sarcodaires montrent mème, sous ce rapport, une série asremlante, qu'il est important de signaler. Les Sarcoulaires les plus simples, tels que les Amubiens, se reproduisent saus se conjuguer; parfois diver's individus, "pue le hasarl place còte à còte, se fusionnent les uns arec les autres, majs le nombre de ces individus n est point déterminé, el celte union accidentelle n’entraine point forcément, à sa suite, des phases de segmentalion. La conjugaison semble derenir plus fréłuente chez les Sarcodares supérieurs, les Grégarines et les libgellaires par exemple; elle est souvent de regle lorstue la reproduclion a pour lout de produire un grand uombre de descendants (sporulation). Dans ce dernier cas, la masse protoplasmique, destinée à se diviser, est plus volumineuse, puisqu'elle résulte de l'union de deux indivilus; et cette union parait en outre lonner au protoplasme une grande activité gŕnératrice. Mais la conjugaison n'est pourtant pas encore un fait normal et hahituel; elle est sous la dépendance des milieux extérieurs, en ce sens yue la présence de circonstances défarorables (froid, dessication) la facilite; et le nombre des individus qui parriennent à se conjuguer n'est nullement limité.

Les Sarcadaires présentent trois modes de reproduction : la fissiparité, la gremmiparité, et la sporulation.

A. - Dans la fissiparité, l'individu-mère commence par divises son noyau, lorsqu'il en possède un, puis partage son protoplasme, de mamjère à produire denx lescendants, semblables sous tous les rapports à l'organisme maternel. La tissiparité est complète ou incomplète; elle est complète, lorspue les descendants se séparent entièrement l'un de l'aulre, el vivent isolément; elle est incompléte, lorsque les deux individus-filles restent unis par une portion de leur corps. I)ans ce dernier cas, la divison est parfois inégale; l’undes individus-filles, plus grand que l'autre, parait ètre la persistance directe du générateur. La fissiparité incomplète aboulit à la formalion d'une colonie, dont les zooïles sont des èlres nonocellulaires; la colonie présente souvent une forme fixe et précise, toujours la mème pour les représentants d'une espece déterminée.

IB. - Dans la gemmipurite, on voit d'abord le noyau de l'individumère émetlre des expausions, pui se lirigent rers la périphérie du corp's; ces segments mucléares culrainent avec eux une partie du protoplasme te lorganisme, el forment, par ce moyen, dos cxcroissances, qui sont des bourgeons. Lorganisme maternel supporte ainsi plusieurs petils mamelous, dont clacun est constilué par une masse de protoplasme contenant un noran; les hourgeons se détachent ensuite, et deviennent autant de petits c̀tres semblables à leur générateur.

$C$. - La spomulation est un phénomène assez complexe. tes ageuts extérieurs parajssent avoir sur sil juésence une grande intluence; le lroil et la dessication létermincut frépuenment son apparition. Les Sprozoaires seuls font exception, cal la genese des spores est poul 
eux un fait normal; corollaire probalule le leur adaptation à l'endoparasilisme, qui nécessite mue grande quantité de germes pour assurer la conservation de l'esprico. Ia sporulation est simple on composíc. Elle est simple, lorsqu'un individu déterminé se résout en spores, sans rien emprunter à l'organisme J'autres individus; e'est là un cas assez fréquent chez les Sarcodaires. La sporulation est composée, lorsquelle est précédée d'une conjugaison; le nomlire des individus fusionnés est varialle, mais le plus souvent égal à deux ou a trois; et cetle fusion, mème lorsfu'elle existe, ne paraîl jas être d'une absolne nécessité pour amener la sporulation, puisque la mème espèce renferme des individus, dont les uns se résolvent en spores aprés conjugaison, el dont les autres subissent isolément une évolution identique (chez les Sporozoaires par exemple).

Quels que soient les actes qui précèdent la sporulation, le corps destiné ả se segmenter perd sa forme habituelle, rétracte lous ses appendices locomoteurs, et prend l'aspect d'une sphère; puis il s'entoure l'une cuticule épaisse, parfois encrontée de silice ou de calcaire, el se divise ì l'abri de celte coque protectrice. La coutue recoil le nom de kyste, et l'on nomme enkystement celte opération préalable. La sporulation est donc précédée d'un enkystement; cette épaisse enveloppe protectrice, dile paroi cystique, est imporlante pour préserver le protoplasme de l'action nuisible des agents extérienrs, notamment pour le protéger contre le froid el contre la dessication.

Les phénomènes de la division en spores sont peu counus; d'après les observations acquises, il parait certain qu’ils ressemblent en toul a ceux de la division cellulare ordinaire. Le noyau se divise d'alord en deux parties, el le protoplasme agit de mène; puis chacune des parcelles se partage à son tour en deux autres masses, el ainsi de suile, jusquau moment où le nombre des segments est devenu considérable. Chacun de ceux-ci est donc constitué par du protoplasme et pran un noyan. La sporulation est alor's achevée. Les produits de cette livision s'arrondissent, s'entoment d'une paroi propre plus où moins épaisse, la paroi sporulaire, et revetent ainsi lenr aspect particulier de spores: ils altendent l'iustant où des circonstances farorables leur premettent d'otre mis en liberté, par la rupture de la paroi cystique. Les spores se lébarrassent alors le leur membrane propre, et se développent. Souvent, lors des premieres phases de lenr évolution, chacune d'elles produit un ou deux forrets, qui lenr servent d'appendices locomotemrs, et disparaissent par la suite; en cet état, elles sont diles des zoospores, par comparaison arec leurs similaires des végétaux inférieurs.

\section{\$2. - Reproduction par Fissiparité.}

1. Monériens. - La reprouluction fissipare existe chez tous les Monériens; elle s'effectue sans que le générateur rétracte ses pseudo- 
podes, ni cesse de se mouvoir, et s'exerce en mème temps que les autres fonctions de l'organisme. Lindividu, en roie de division, se partage en deux masses par un étranglement, qui va s'approfondissant de plus en plus, jusqu’à re que la bijartition soit opérée Un seul ètre donne ainsi naissance $\ddot{a}$ deux descendants, plus petits que l'organisme primordial; ceux-ei augmentent ensuite de taille, et se livisent plus tard l'après le mème procédé: les individus de troisième grénération agissent de mème; el l'évolution continue ainsi. Ce morle de développement est le seul trouré jusqu'à présent chez les Gymnomonériens; les Lépomonériens se reproduisent, en outre, par sporulation.

Les observations manquent encore pour savoir comment le protoplasme arrive a se diviser, sans qu’il existe, par suite le l'alisence du noyau, des filanents nucléaires chargés de déterminer, et de diriger, cette division.

Les denx cas secondaires de la reproduction fissipare se présentent chez les Monériens. - Ou bien, et c’est là le morle le plus fréquent, la fissiparilé est complète; les deux descendants se séparent entièrement l’un de l'autre. - Ou bien la fissiparité est incompléte, et les descenlants sont unis les uns aux autres par quelques psendopodes. Comme, lans ce dernier cas, le fait se renouvelle pour toutes les générations successives, il se forme une colonie, composée d'un nombre souvent considérable d’indivilus soulés entre eux jar leurs appendices, et présentant l'aspect d'un réseau protoplasmique : tels sont, par exemple, le Myxodyctinm sociale llackel, et le Monobia confluens Schneider.

11. Amœbiens. - La fissiparité s’ellectue, chez les Amcbiens, de la mc̀me façon que chez les Monériens; avec cette différence pourtant,

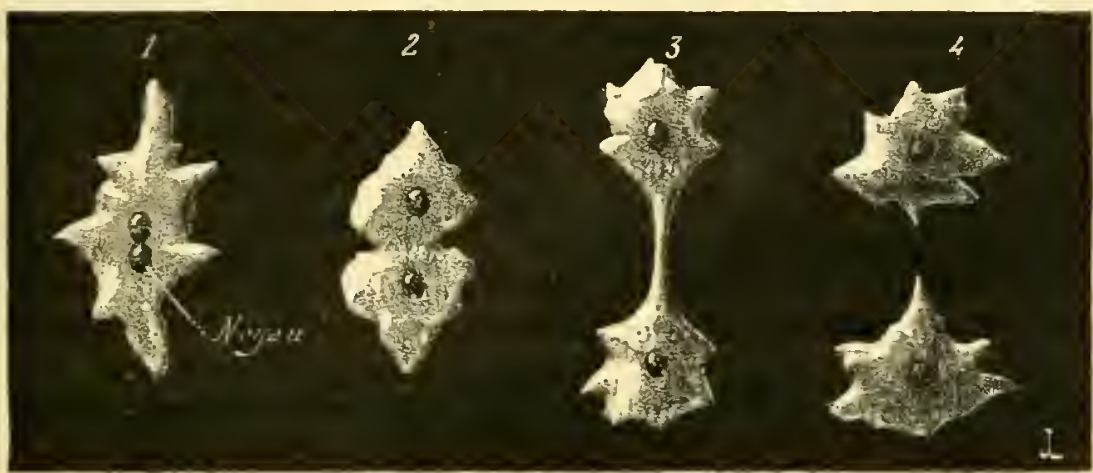

Fig. I a 4. - Fissilarite des IMOEBnis (figures reelles). - En l, generateur commençant à diviser son noyau. - En 2, le protoplasme se scinde a son tour. - En 3, les deux parties s'écartent l'une de l'autre. - En f́, les deux descendants sont séparés.

quo l’individu en roie de division rétracte somvent ses psemloporles arant de procéder à cette opération. Mais la différence principale con- 
siste dans le rôle joné par le noyan; ce dernirr, qui ne manque jamais. se srimle aver le plotoplasme.

[11. Sporozoaires. - le senl mode do reproduction, signalé jusqu'ici chez les Sporozoaires, est la sporulation. Prut-être existe-t-il, el notamment chez les formes inférieures, des phénomènes de fissiparilé semblables à cenx tronvés cho\% les Anobiens; mais ces fails nont pas encorété décrils avec cerlitude. Peut-être aussi cerlains aspects, signalés par les auteurs romme répondant à ha conjugaison de lenx individus l'ahor'cl séparés, s'accorderaient-ils plubôt aver une reproduction fissipare. Les observations effectuées jusqu’ici ne permeltent pas d'élucider cetle question.

IV. Foraminifères. - En revanche, les seuls phénomènes de reproduction, signalés avec certilude chez les Foraminifères, se rapporlent à la fissiparité. Ce dranier mode se présente avec ses deux procédés secondaires : lantôl la fissiparité est complète, ot alors les individus, se séparant les uns des autres, restent toujours simples, on Wonothalames; tantôt la fissiparití est incomplete, el les individus, demenrant accolés, forment une colonie. Dans ce durnier cas, les Foraminifères sont dits l'olythalames. Ces leux modes sont reliés l'un à l'aulre prar loule mne série d'intermédiaires.

Fissiparite complite, ou des Monothalames. - Chez diverses Ciromia, el nolamment la Gromia oviformis (paludosa), lorganisme te lindividu-mère se divise en deux segments, qui se séparnt completement l'un de l’aulre. Ponr cela, le test du généralour se perce d'une ouverture dans la région opposée a la bouche, et le nouvel orifice laisse sortir an tehors une partic đu corps; celle-ci émet des pseudoporles, puis se sépare peu à peu du protoplasme encore enfermé dans la coquille. Lorsine la séparalion est achovée, celie nonvelle masse plasmífue, ainsi parrenue à l'extérienr, s'entoure d'une carapace, el devient un individu parfail.

Des phénomènes semblahles ont élé ohservés chez la Crromia socialis; its présentent cependant nne certaine complexité, qui permet de concevoir le mode de formation des colonies de Polythalanes. Le protoplasme du génératenr se divise en deux parlies égales, rarement en trois (denx pelites of une granle); un senl de ces segments reste dans la cavité de la carapace; l'autre, on les deux autres, sont rejetés au dehor's par la bouche; il ne se crense done point d'orifice secondaire, contrairement à ce qu'il en est chez les Gromia oviformis. T'habitude, le scogment, qui se déplace pour parvenir il l'extérieur, n'est pas celui placé en regard de l'ouverture buceale, mais hien le profond, qui est ainsi ohlige de contournu son similaire pour ailer au dehors. An moment oi il arrivan nivan de la bouche, il rmed des psemblopoles; fuis, en s'étirant et se contractunt alternativement, il finil par sortir lout à fait, et levient libre. 
Deux cas se présentent ensuile. Dans le premier. le segment lihre se détache complètement de l'autre, s'arrondil, el produit deux petits appendices, semblahles a des foutets de Flagellates; it prend ainsi l'aspect d'une zonspore, nagre au moyen de ses fouets, ot s'éloigne lu test ou il a pris naissance; on ignore son érohution ultíricure. Dans le second cas, le segment libre reste toujours uni il l'autre jar quelipues trattus protoplasmiques, et s'enveloppe hativement d'une carapace, pendant que son congénère continue à vivre lans le test du générateur. P'ar suite, la première Gromia a produit deux descendants semblalıles l'un ì l'antre, et réunis par des tractus protoplasmiques. Ces descendants contimuent
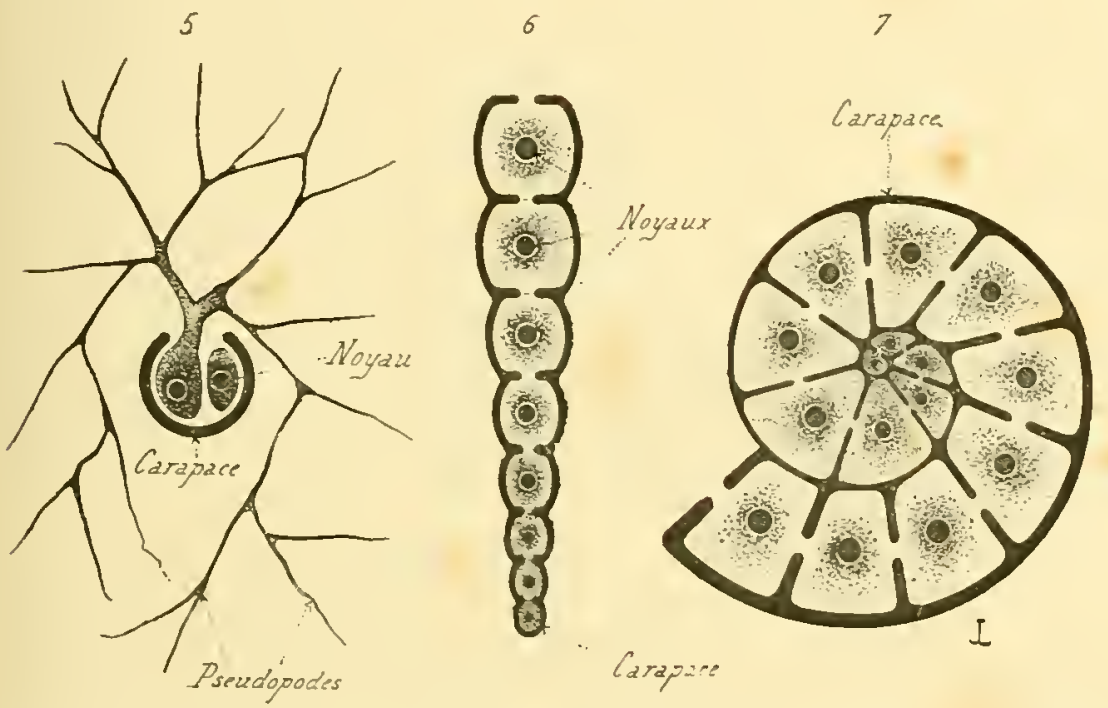

Fig. 5 a 7. - Fissiparité nes Foramisifìres (coupes demi-diagrammaliques), - En 5 , division fissipare d'un Monothalame, la Gromin socialis. - Fn 6, mlonie, produite par fissiparite. d'un Polythalame à carapace droite, le Rheophax nodulosa. - En T, colonie, jroduite par fissiparité, d'un Polythalame a carapace spiralee, du type des Rotalines ct des $\mathbf{A} u m-$ mulitcs. - En 6 et en $\tau$, les loges communiquent entre elles, dans la réalité, par plusicurs pores, dont un seul est représenté.

i se diviser par le mème procété; el il se crée peu à peu une colonie, it nombreux indivilus reliés par tes expansions psembonodiques.

Ce procédé est important i connaitre, car il permet le comprendre la genése des colonies de lolythalames. II suffil, en eftet, He se reprísenter les trarlus mnissints romme devenus fort courts, el d'admeltre, en outre, fue la division, an lien de surve une marehe irréguliere. s'effectue toujours, et daus toutes les générilions, suivant un sens tixe

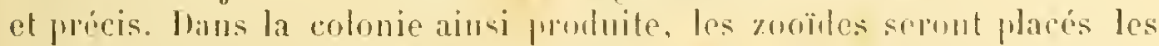

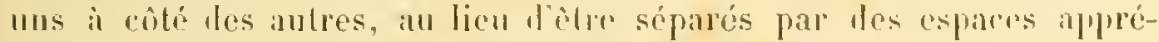

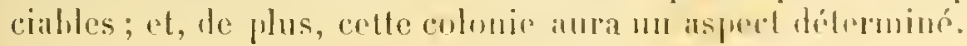


Fissiparité incomplète, ou des Polythalames. - La reproduclion fissipare des foraminiferes polythalames a pour effet damener la formation, aux dépens d'un indivilu monotoculaire primilif, d'une colonic composée par un nombre variable de zowïdes silués les mus à côté des antres. Le procédé génétipue n’a pas encore élé observé directement; mais il est permis de le pressentir, en se basant sur le développement des Cromia socialis, el comparant les colonies engendrées par ces dernières aux colonies les plus simples des l'olythalames, puis celles-ei aux colonies les plus complexes.

A. - Que lon s'adresse aux Imperforés agglutinants, aux Imperforés rulcuires, ou aux I'erfores, les colonies les plus simples des genres polythalames rappeltent des assemblages d'individus monolhalames jlacés bout à bout: tels sont, frar exemple, les Riteophux parmi les Imperforés, les Nodosuria parmi les l'erforés. La production de ces colonies est semblable, sans aucun donte, ì celle díji signalée cluez les Cromia socialis; les rajports, entre ces l'olythalames peu complexes et les llonothalames, sont du mème ordre que cenx existant entre les Gromin socialis el les Gromir oviform is. Lintivilu primitif se divise en deux segments, qui ne se séparent pas complètement l'un de l'autre; l'un d'eux devient lilore, ot demenre relie, par un courl tractus protoplasmique, a celui qui demeure dans le lest; puis, le premier s'entoure it son tour l'une carapace. Il s'est produil ainsi un assemblage te deux individus. Le nème phénomène continue à s'elfecturer, et la colonic s'accroit à mesure.

Ces groupes ì disposilion fort simple, étroitement ratlachés aux colonies de Ciromia socialis, se relient de mème aux assemblages phus complexes, tels que les Cilobigerina, les Nummulites, elc. Les dillérences sout forl pieu importantes; elles se bornent ì rendre plus étroite l'union des individus, en élargissant les régions d'adbérence, el en régularisant l’aspect général.

Il est donc possible d'établir une série ascendante, qui part de la firomia socialis, el va jusquaux Polylualames les plus complexes. If est ógalement prermis de construire une série correspondanle, llestinée ¿ montrer comment les colonies parviennent ì acquérir une forme régulière. Les types inférienrs ne suivent nullement, daus leur division, mue marche bien lélerminée; les zoö̈les sont placés lout à lıoul, snivant une ligne droite, m lien une ligne brisce : el, si parfois ils se disposent en une spirale, cette spirale, fort irriguliere, ne montre jamais l'orlu précis les foraminiferes plus élevés.

13. - Ainsi, parmi les Imperforés agglutinants, les colonies de Sucramina, de lihéplux, sont ronstituées par une série d'individus placés les uns derriere les antres, suivant mne ligne tortueuse, rarement linéaire. Les Troclemmina commencent it oflrir un débul de lisposition sprinalie, qui ne dure pas chez certines espèces ( $T$. linciformis), alors 
que d'autres la présentenl d'une façon constante ( $T$. coronata). Cetle organisation devient un pen plus précise clıez les autres Agrglulinants; les cloisons forment un mème angle avec laxe des loges, les loges augmentent régulièrement de taille depuis la première jusqu'aux dernieres, et le test revèt alors un aspect régulier.

Ine série analogue se relrouve chez les Imperforés calcaires. Les Sifuammulina monoloculaires couduisent à des colonies simples, comme celles des drticulina au lest droit, el des J'ertebratina au lest enroulé d'abord, et droil ensuite. On arrive ainsi à des assemblages plus complexes, donl le test est réguliorement spiralé; telles sont les Orbilolites el les Miliolites (Biloculina, Triloculina, etc.).

Les Foraminifires perfores moutrent, micux encore que les ordres précédents, culte série ascendante. Le point de départ est loujours reprósenté par des lypes Monothalames; mais les diverses transilions vers les Polythalames supérieurs sont plus nombreuses, et de phus, ces derniers parviennent a une complexilé d'aspect, que les plus élevés des Imperforés ne montrent jamais. Les formes monoculaires sond ici les Lagena; des Lagena, on passe à des carapaces droites (Todosaria), on fablement arquées (I)entalina), comparables à des séries d'individus semblaliles à des Lagena, et placés hout à bout. La failile conrbure des Dentalina devient phus prononcée chez l'autres types, dont le test s'enroule sur lui-mème en une sprirale, d'abord confuse (Polymorphina), précise ensuile. Un arrive ainsi aux Ciloligérinides, aux Lotalides, et aux Nummulitides, dont les carapaces comprement de nombremx tours disposés en spirale, et croissant régulièrement depuis le centre jusqu’à la périphérie.

On a souvent disculé, pour savoir si l'organisme des Foraminifores polythatumes correspond à undivilu unique, on à une colonie llindividus. Les sérjes ascendantes, établies dans l'exposé qui précèle, montrent le quelle façon lente et ménagée on passe des Monolholames aux l'olythalames. Chacun de ces derniers peut être assimilé à une colonie ile Cromia, dont les individus seraient très voisins les uns des autres, et soudés par une parlie de leur lest; partant, leur organisme est une colonie dout chaque segment, ou loge, correspond à un seul individu. - Il ne faut pas l'oublier cependant, ces colonies sont conslilućes par l'assemblage d’èlres monocellulaires, parlant lrès plastiques, el susceplihles de se ronfondre les uns arec les autres, pour produire, par leur union, un copps simple en apparence. Une telle union résulte du peu de complexite de leur slruchre; duacun des zoö̈des se compuse l'me masse protoplasmique nullement différenciée, el l'on n’éprouve ancune difficulté a comprentre la coliésion de masses parcilles en un ensemble, qui parait constituer à lui senl un alre simple. los phénomènes semblalles se retronvent che\% des animaux phus élevés en organisation 'fue les Prolozoaires; les colonies des Spongiaries, far cxemple, semblent souvent correspondre it des organismes simples, 
alors qu’en réalité elles sont constituéns par un certain nombre de zooïles fusionnés.

V. Vésiculaires. - La fissiparité, dhez les Vésiculaires. est complite ou incomplite. Thans le premier cas, dle alleint l'inclividu-mère entier, el elle a pour effot de le prarlager en deux descendants distincts. Dans le second cas, la division fissipare se horne à intéresser l'endosarque, avec sa rapsule; aussi l'organisme maternel parait-il ètre in-

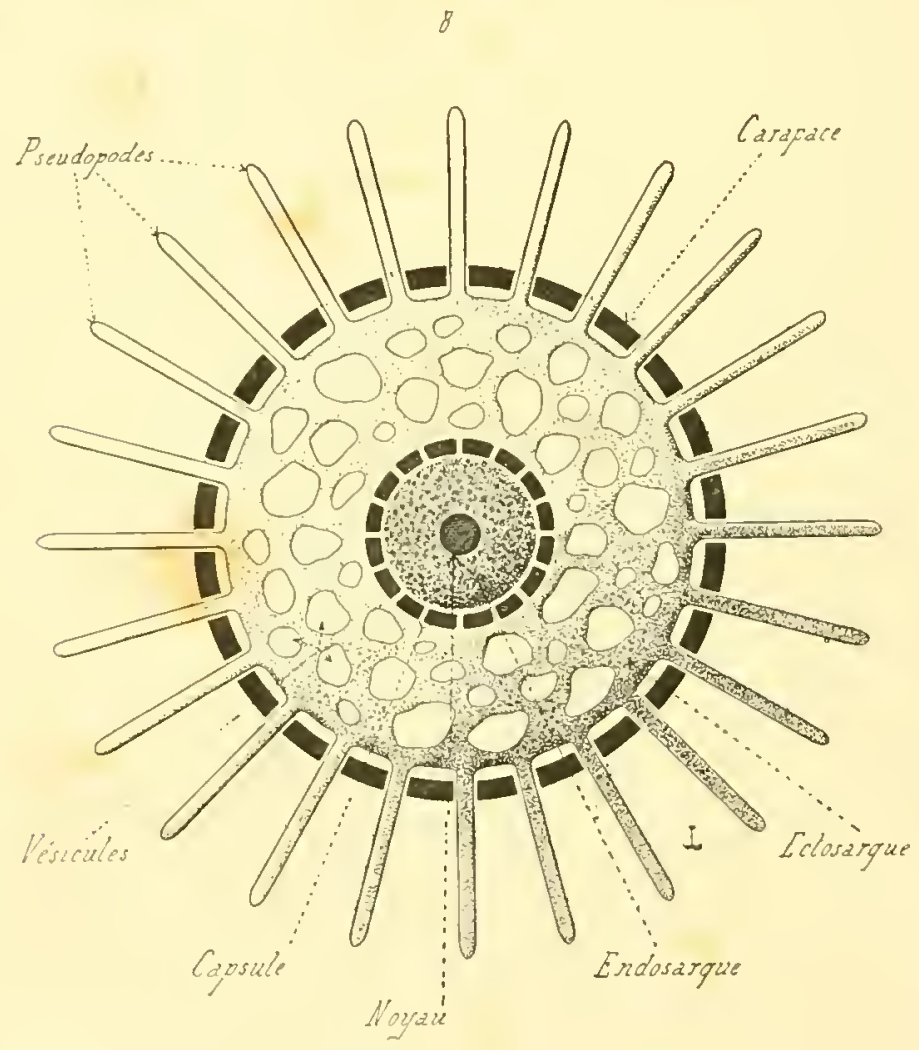

Fig. S. - Orgaxisatiox dex Radolales Moxocyttarien (coupe demi-dia!jrammatique).

divis extérieurement. alors qu'il contient denx on phosieurs masses endosarcales, entourées de leurs capsules respectives. Ce dernier mode existe chez les seuls kadiolaires qui appartiennent à l'ordre des Polycyttariens, ot elle sert ì caractírisou cet ordre.

Fisspante comprotise. - Ce procélé a été trouvé chez un certain nombre d'lléliozoaires (surtont les Ihiliosmires nus), el chez quel pues Rarliolaires monocyltariens, les Aulosphorides par exemple. Lor'squ'm 
Iléliozoaire va se diviser en deux parties, il commenere par perdre les vésicules de son ectosarque; toutes ces enclaves liquiles disparaissent, ot la couche externe se réduil is une minee lande proloplasmique, semblahle en tout ì son lomologue des Amoxhiens. l'uis, les psendopodes se rétractent, tantót entierement, tantò à demi; dans re lenjer cas, ils deviennent courts el massifs, variquenx, de sorte que l'lléliozoaire, en ce moment, ne diffère pas trop d'un Amalien. Les appentices ítant rétractés, le corps se divise en deux segments, égaux d'ordinaire, qui

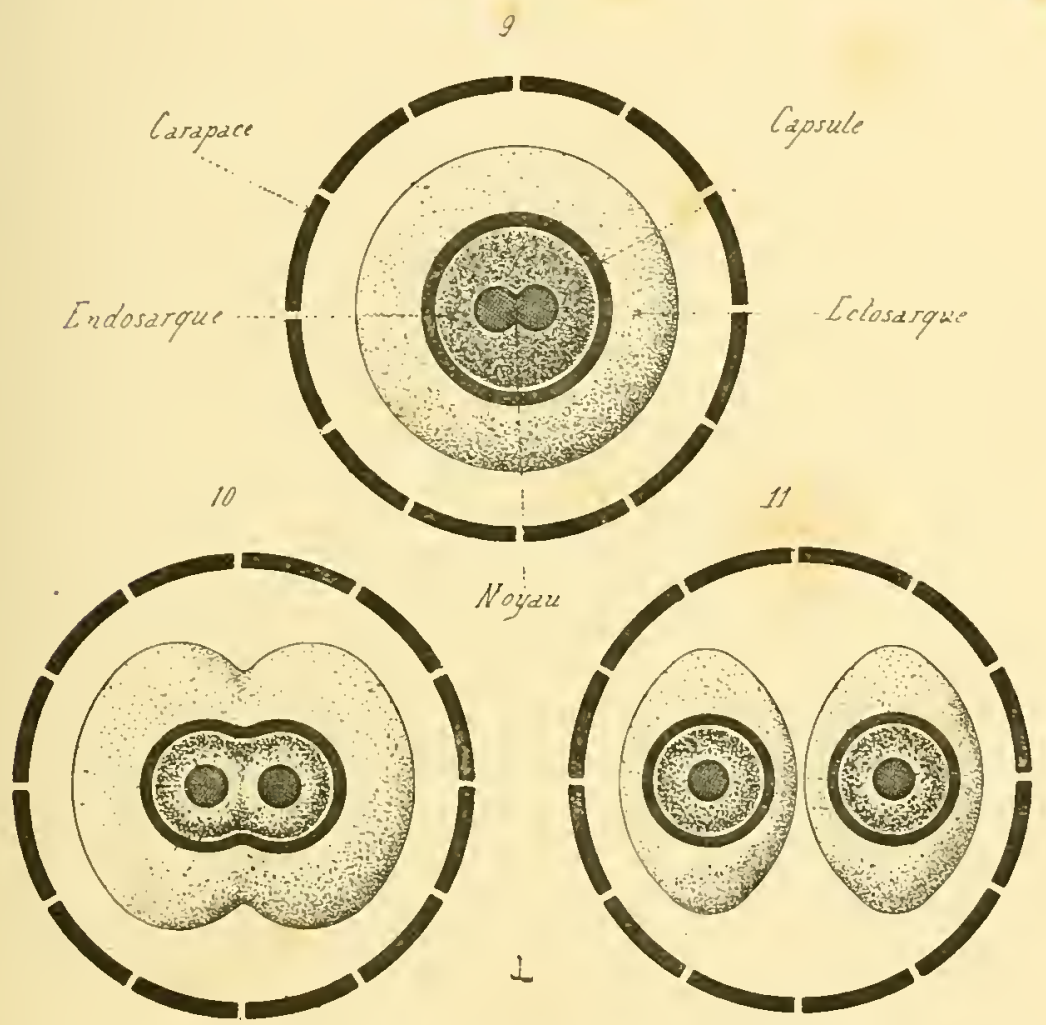

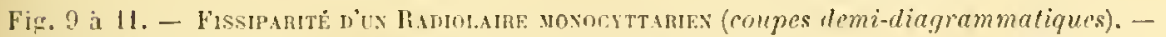
kn ?, générateur contrate, dont les pseudopodes sont rétractes. - lin 10, debut de la division lissipare. - En 11 , lin de la lissiparite : le générateur est divisé en deux descendants.

se séparent l'un de l'aulre. Charun de res segments revôt ensuile l'aspect présenté par l'individu-mère frimordial, arant les modificalions qui ont précédé la fissiparité. Le roble du noyau, dans retle division, n’est pas

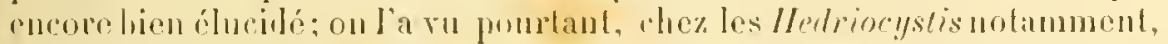
se partager avant le protophisme du corps; mais nn ignore encore romment les choses so passent, Iorsque te noyau prinitif sest fractionné 
en une multitude de parcelles, el c'est là le cas le plus fréquent chez les lléliozoaires.

Les faits sont un pen plus nets pour ce qui a trait anx quelques Radiolaires monocyttariens, chez lesquels on a observé la reproduction fissipare. Le noyan se divise d'abord en denx parties; puis l'endosarque et sa capsule sallongent, sélirent en biscuil, et finissent par se segmenter en deux masses, dont chacune contient l'une des parties du noyan primitif. L'eclosaryue se partage ensuite, suivant le mème plan que l'endosarpue et le noyau. L'individu-mère est ainsi scindé en deux descendants, qui se séparent l'un de l'autre, revètent l'aspect primitif de l'organisme maternel, et mènent une vie indépendante.

Fissmanté ixconulete. - Les phénomènes de la division fissipare n'ont point été constatés direclement chez les Radiolaires polycyttariens, sanf un petit nombre d'olservations éparses, qu'il est impossible de raccorder. Cependant, par analogie arec les faits qui viemnent d'ètre sigmalés, il est permis, sans doute, de considérer l'organisme si remarfuable des P'olycytlariens comme dù à une fissiparilé incomplète; la division, répélée un certain nombre de fois, atleint seulement l'endosarque avec sa capsule, et laisse indemne l'ectosarpue. Anssi ce dernier, parfaitement indivis, entonre-t-il une certaine quantité, souvent consilérable, de masses endosarcales, dont chacune possède sa capsule. Ces dernières se groupent l'habilude arec une certaine régularité, se disposent en couches concentriques, ot se placent ì des distances égales les unes des antres. Cette fissiparité incomplète produil une colonie d'un type particulier, en ce sens que les zooïles sont distincts par lenrs régions profondes seulement, et sont confondus dans leurs zones périphériques.

VI. Flagellates. - La fissiparité semlıle itre le mode de reproduction le plus répandu chez les flagellates: elle se manifeste sourent avec des caractères particuliers, qu’il est necessaire de suive dans chacune des quatre classes.

Nunfugectes. - La reproduction fissipare est lantót complite, tantót incomplete. Dans te prenier cas, Ios descendants sont distincts; elle alıoutit, dans le second, à la genèse d'une colonie.

A. - La plupart des Nudotlagellés, à fissiparite complite, se divisent presqne suivint le mème procédé. Le noyan se partage d’abord en denx portions; le proloplasme du corps se segmente cnsuite, le plan de cette division étant sonvent perallèle is l'axe longitudinal du corps. Ce plan est, en outre, médian; les deux individus-filles sont done sensiblement égaux de taille. Lorsque le généraleur appartiont is un type dont les représentants sont munis d'un seul fonel, comme les Cercomonas par exemple, la division du corjus commence a la lase de ce foute et s'éteml peu à peu ver's l'extrénité opposée; le lonet ne se partageant pas luimème, appartient tont entier à l'un des descentants. l'endant que lit scission s'eflectue, un second fonet prend naissance sur le corps de 
l'autre individu, dans une zone homologue de la région llagellifère du premier. Lorsque, par contre, l'individu-mère jossède plusieurs fouets, ces derniers sont d'luabitude en nombre pair, et le plan de segmentation se dispose de telle maniere, que chacun des descendants porte autant de fouets que son congénère. Les rejetons devenus libres, le nombre de foucts se complète, pour chacun d'eux, de manière à égaler celui de l'organisme primordial. Tel est le cas pour les Hexamita, les Chilomonas, etc.

Le plus souvent, les Nudoflagellés, en voie de fissiparisation, ne perdent aucun de leurs caractères extérieurs, et conservent leur aspect habiluel. Cependant, il n'en est jas ainsi pour plusieurs d'entre enx, el notamment pour les Euglènes. La reproduction fissipare des Euglena viridis, toujours complète, s'effectue suivant deux procédés. Le premier morle ne dillèro en rien de celui qui vient d'être déerit pour les autres Nudoflagellés. Dans le second cas, par contre, l'individu rétracle son fouet, perd sa forme de fusean pour devenir ovalaire, et mème globuleux, puis s'entoure d’une coque épaisse, constituée par une substance chitineuse; en somme, il s'enkyste. L'enkystement des Protozoaires précède ordinairement la sporulation, el comme on le verra plus loin, les Euglénes présentent aussi ce desuier mode de reproduction; mais, dans le cas parliculier, examiné ici, la division ne s'opère qu'une seule fois, el s'arrète dès que le noyan et le protoplasme sont scindés en deux parties. Il s'agit donc l'un véritable phénomène de fissijarité. Les deux descendants brisent la paroi du kyste, se séparent l'un de l'autre, s'allongent, donnent naissance à leur fouet, et deviennent en lout seml, lables à leur générateur.

La fissiparité incomplète el longitudinale existe chez divers Nudoflagellés coloniaux, les Anthophysa par exemple. Le corps d'un individu isolé d'Anthophysa est porté par un pédoncule cylindrique, qu'entoure une fine membrane chilineuse; lorsque cel individu se divise en deux jar fissiparilé, la segmentation s'exerce seulement sur le corps, sals atteindre le pédoncule; il en résulte donc denx individus, portés sur un pied unique. Ces derniers se partagent à leur lour suivant le mème [urocédé, et ainsi de suite; une colonie prend naissance, composéc par un nomlre souvent considérable de roö̈des, quarante ou cinquante, el mème davantage.

Les colonies d'Anthophysa ne se ressemblent pas, car la marche le la segmentation n'est point toujours la mème. Daus un premier cas, la division s'arrète exactement au point de jonction du corps et du pédoncule; un fait analogue se reproduisant pour toutes les générations, il en résulte que la colonie est formée par un certain nombre de zooïdes serrés les uns contre les autres, et montés sur un seul piel, ce dernier grossissant à mesure que s'aceroìt le chillie des indivitus; la colonie entiere présente assez bien l'aspect d'un houquet. Inns un denxieme cas, la division atteint quelque peu le sommet du pédoncule primitif; chacun des 
descendants de seconde génération est lonc supporté par ce pédicule grèle, qui semble che une hanche dn premier. Le mème phénomène se reproduisant pom toutes les générations successives, la colonio entière présente l'aspect d'une grappe, constituée jall un axe primaire répondant au pédoncule primilif, ct prar plusieurs axes sceundares el tertiaires ramifiés eux-mênos, les lranches de deruier ordre portant toutes un individu à leur sommel. Ces deux modes dillérents se combinent, el se mélangent souvent dans une mème colonie : l'où résultent hes aspects rariés offerts par les assemblages d'ththophysu.

Les zooïles ne restent pas loujours adhórents les uns aux autres. Parfois l'un deux se séprare de la masse de ses congénères, el devient, libre; il émet alors un certain nombre d'expansions pseudopodiques, courtes el trapues, et nage au moyen de son fouct. Lorsquil vient à rencontrer un corps étranger, il se fixe sur lui par l'expansion opposéc au fouel; celle-ci s'allonge quelque pen, se recourre d'une membrane cuticulaire, el devient le péloncule d'altache. Les autres appendices se rélractent, el l’individu revêt son aspect délinilif. II se multiplie ensuite par fissiparité, d'après le procédé précédemment lécrit, et devient le point de lépart d'une nouvelle colonic.

$B$. - La fissiparité n'est pas toujours longitudinale chez les Nudoflagellés; elle est parfois trunsversale, car le plan de division est perpendiculaire à l'axe longituliual du corps. Dans ce lernier mode, comme dans le premier, la fissiparilé est cumplète ou incomplète.

La fissiparilć transversale est complete, lorsque les deux descendants se séparont entierement l'mn de l'autre; il ne se produit lonc point de colonie. Telles sont, par exemple, les Brcosaca. L'animal adulte est renfermé dans une loge, aupuel il s'atlache par un pédoncule; l’individu ne remplit pas normalement loute la carité de sa loge. Lorspue le moment de la reproduction approche, cet individu grossit de manière à occuper la cavité entière, puis il se divise transversilement; un des segments conlinue à babiter la loge primilive, le second devient libre. Ce dernier possede le fonet du cénćraleur, et se diplace grâce à lui; il en produil mème un second, qui lui sert pour s'accrocher à un corps élranger. La fixalion élant laite, ce descendant libre acquiert rapidement baspect de l'organisme primitif. Le segment arbérent continue a vive dans la loge du générateur; et toute son évolution se bolne à la genèse du fouct „ui lui manquail, puisłue l'minge appendice de la mere est devenu la propriété du segrment libre.

La fissiparité transrersale est incomplite, lorsque les descendants continuent ì adhérer les uns aux autres par une prortion de leur corps; ce procédé a été observé chez un rertain nombre de Nudoflagellés coloniaux, et notamment chez les llinobryon. Lindividu primitif habite une loge très allongée, cylindro-conique, et lixée par une extrémité effilée; lor'sque la segmentation s'est effechée, cel individu est parlagé en deux segments, dont l'un correspond au segment libre des Lícoseca 
(fissiparité transversale complète), et l'autre au segment adhérent. Ce dernicr se développe comme son correspondant des Bicosøect, et garde la loge du générateur. Le prenier, mnni des fouets de l'urganisme primordial, ne se sépare pas complètement de son homologne, et lui reste uni par une rígion étroite; cette dernière s'étire et s'allonge en un longr pédicule, qui sinsère sur les côtés du segment adhérent, ou sur la paroi interne de la loge entourant celui-ci. Celle évolulion abontit à la genèse d'une colonie, composée de zooïdes allongés et éti-

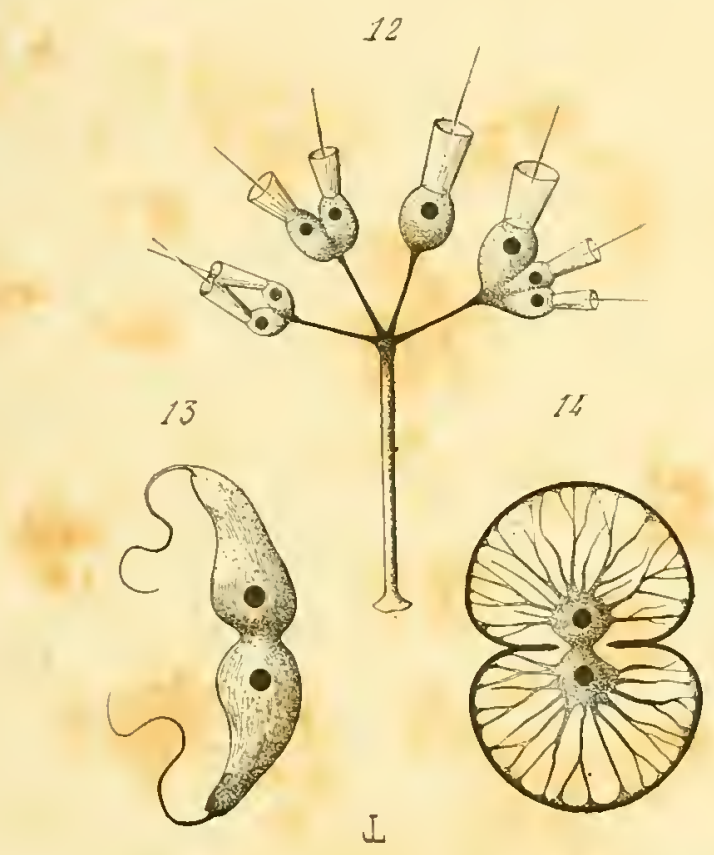

Fig. 12 à 14. - Fissiparité des Flagellates (figures demi-diagrammatiques). - En 12, colonie de Codosiga botrytis, d'après Stein, montrant un type de fissiparite longitudinale et incomplèle. - lin 13, debut de la fissiparite transversale d’un Nudoflagellè. - En 14, debut de la fissiparite d'une Noctiluca, d’apres Ch. liobin.

rés comme l'était l'organisme maternel, el perchés l'un sur l’autre; l'individu inférieur s'attache par la pointe de son pédoncule ì un corps étranger, et l'individu supérienr alhère ì l'inférieur par la région correspondante. Les mèmes faits sé renouvelant un certain nombre de fois, le chiffre des zooïdes coloniaux s'accroit, tous ces ètres étant fixés les uns sur les autres par leur pointe. La colonie n'est pourtant pas linéaire, car certains indivilus se fissiparisent deux uu trois fois te suite, et supportent un nombre corresjondant de congénères; dès lors, la colonie présente un aspect quelque pen ramifié, et non la forme d'éventail ou de bouquet, caractéristipue des tissiparités longitulinales et incomplètes. 
Chonxofageldés. - Certains représentants de cet ordre vivent en colonies montées sur des pérloncules; tels sont les Corlosiga. Aussi, le mode de formation de ces colonies est-il sonvent semblable a celui décrit chez les Anthophysa, et préscnte-t-il les mèmes particularités; parfois, comme chez ces derničes, un zooïde se nétache du gronpe, el mène pendant quelipue tempss une vie libre, pour se fixer ensuite, et derenir la souche l'une nouvelle colonie.

Cependant, tous les Choanoflagellés ne se reproduisent point par une fissiparité semblable à celle des Anthophysa, c'est-à-dire par une fissiparité dans laquelle le plan de division est parallèle à l'axe longitulinal du corps. Un assez grand nombre d'entre eux se partagent transversalement; et il faut encore distinguer deux cas, suivant que la fissiparité est suivie de la séparation complète des indivilus, ou bien de leur accolement en un assemblage colonial. La fissijarité est complete chez les Salpingeca, et, en général, chez tous les Choanoflagellés solitaires. Au moment oi la division va s'effectuer, le corps de lindividumire grossit souvent, au point de remplir la cavits entière de la loge; puis, le noyan se divise, et ensuite le protoplasme, l'après un plan perpendiculaire à l'axe longitulinal du corjs: cetle division est done transversale. Hes denx descemlants ainsi produits, le jus voisin de l'ouverture de la loge se séprare le son similare, devient libre, et nage au moyen de fouets 'qu’il posside seul, prisqu’il est constitué par le segment mmni des fouels dn générateur; il ne larde jas à se fixer, et à se compléter. Le second descendant (segment adhérent) continue à habiter la loge du générateur; il engendre les fouets qui lui manquent, et parvient, de son còté, à l'état parfait.

Ians le cas d’assemblage colonial ales individus prodnits, la fissiparité est également complèle; l'organisme maternel se livise entièrement en deux descendants, qui se partagent de mème, et ainsi de sujte. Senloment, ces lerniers, an lieu de s'écarter les uns des aulres pour mener une rie indépenlante, sunissent à nouveau, et s'acculent en un syneytium. Cet assemblage, qui ditfère par son mode génétique des autres colonies de Flagellates, possede parfois nne forme indéterminée, et aillenrs un aspeet précis suivant les espèces. Les Protospongia appartiennent an Iremier cas; les Phalansterium an second. Les agrégats, lans ce dernier genre, ont un aspect globulenx, les fouets étant tous extérienrs.

IMxofliglis. - Le développement de ces ètres est encore pen conmu. Les observations, effectuées sur un pareil sujet, sont dues à Claparèe et Lacluman, à Stein, ì Pouchet, ct nont pas élucidé la question.

Les Dinotlagellés se reproduisent certainement par tissiparité; le fait a été constaté sur les représentants de livers genres, les Peridinium entre autres. Le corjss de l'adulte est convert par une carapace résistante, constituée par de la cellulose incrustée de silice; le protoplasme, semblable à celui des Cystotlagellés, renferme des vacuoles, qui lui donnent un aspect aréolaire. Ces enclaves liquides disparaissent an mo- 
ment où la fissiparité va s'acromplir, et le protoplasme se rassemble en une masse ovalaire on sphérique; la caraflace, étant donnée sa nature, - ne subit pas une contraction correspondante; un espace assez raste rèste ménagé entre sa paroi interne et le curpss protoplasmique. D'après Stein et Bergh, cel espace se remplit d'unc substance mupuense; un tel procédé ne se produit point, si l'on en juge d'après les observalions récentes de Pouchet.

Quoi yu'il en soil, cette condensation du protoplasme dénole l'existence d'une période d'enkỵstement, car les ajpendices sont rétractés, et le corps se trouve réduit à son plus petit volume; la carapace joue ici le rúle de l'enveloppe du liyste. Dans certains cas, l'enkystement n’est point suivi par la division fissipare; le corps, ainsi réduit, devient libre par' la rupture da test (Peridinium), el s'enveloppe ensuite d'une nouvelle carajace: à moins que cette dernière ne prenne naissance lorsque le test primitif n’est pas encore brisé(Ćlenodinium). Hais, à ce qu'il semble, l'enlisstement précide d'ordinaire la segmentation; les faits ne s'écartent done pas de ceux offerts par certains Nulollagellés, les Euglènes entre autres. - Le plan de segmentation serait transversal d’après Stein, contrairement aux observalions de Pouchet. Le phénomène n’a point iei une bien grande importance, car les appendices sont rétraelés, el le corps se troure réduit a une simple masse protoplasmique. Chacun des deux descendants produits est d'alıord mis en liberté, par la brisure du lest qui enveloplail l'organisme primordial, puis il s'entoure d'une nouvelle carapace semblable au test primitif. Parfois, la lissiparité s'etfectue après la rupture du test maternel, et non avant; le corjs de l'individu-mère est done mis à nu pendant un certain tempss, et c'est durant celte période que la division s'opère (Glenodinium cinctum).

- Certains Amphidinium, et notamment I'Amphidinium operculatum, présentent, d'après Pouchel, un mode de fissiparité analogue à eelıi des Jiatomées. Ce fait, joint à la présence de la cellulose dans la carapace des l'éridiniens, el a la grande ressemblance de plusieurs de ces ¿̀tres avec quelpues Desmidiées, contribue à faire admettre l'existence de liens étroits, entre les Algues unicellulaires appartenant à la classe des Diatomées, el les Protozoaires du groupe des linollagellés.

Tivers Dinollagellés, et notamment les Ceratium, les Dinophysis, les Amphidinium, ele., vivent réunis en chaines; d'habitude, les indivilus d'une mème chaine sont attachés les uns anx autres par les ap'pentices crochus de lenrs carapaces, l'appendice du premier individu se maintenant au rebord du sillon équatorial du second, celui-ci agrissant de mème ponr le troisiene, el ainsi de suite. On ignore si le procédé formatif de ces chaines est une lissiparité incomplète, on hien s'il répond ì un accolenent secondairer l’indiviłns isolés dies l’abord.

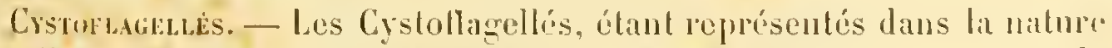
actuelle prar les deux genres Voctiluca el Leptodiscus, les phénonienes de 


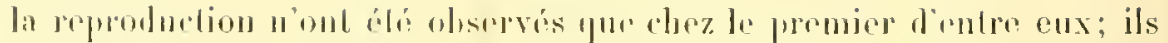
ont été lien éludićs par Ch. linhin.

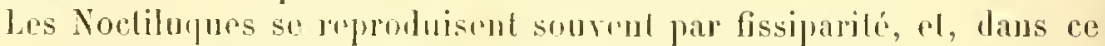

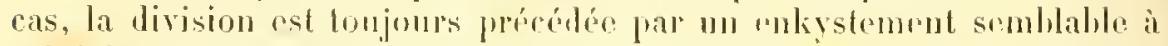

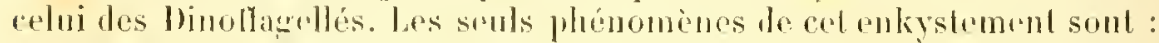
la disparition des appendires, et la persislance de l'envoloppe du copps comme paroi cyslipur. Il Ine se produit done point demveloppe particu-

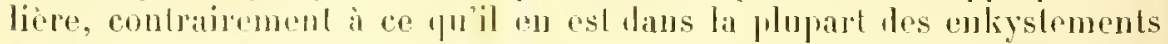

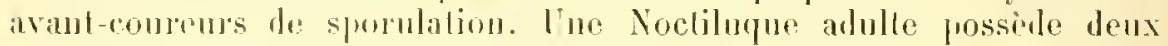

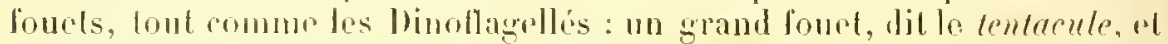
un autre plus petit, mommé le flugellum; ces lemx appendices disparaissont pen avont la tissipariti, el l'imlividu se convertil an une masse ovalaire, fortant encore la lumelar et le sillon dorsal. Les racuoles du frotoplasme, si mombremses ol si crandes dans les Noclihques, persistent durant toule la segmontation.

la phus grande parlio du protoplasme est situce non loin de la bouche, oì elle forme mus mass anx conloms ingeguliess, el contenant le noyan; la division commence en eflu region, délnte par lo noyau, ef inléresse ensuile le poluplasme. Lu pan he segmentalion passe par la louche, qui est divisée ru deux parlices, el s'etend rapidement dans le reste du corps: la síparalion eomplete des leux drscemlants s'effeclue pourlant, en derner lien, dans lo voisinage de la bonche. Cluann de res alemiers possiele ainsi la moitio de l"enveloppe, du protoplasme le la boucle, et du novau de louganisme maleruel; comme la sćparalion se produit pen i fren, par un changloment circulaire devenant de phus en plus profond, l'enveloppe dr. "larpue individu-lille ne présente ancune solulion le comlinuile, si ce n'est an nivin de l'ouverture huccale, tui n'est jamais fermée. les leseondants se lomroul pontros de loules les parlirs pui leur sont nécessuires, siuf les deux loucts. lo grand fouct, le tenta-

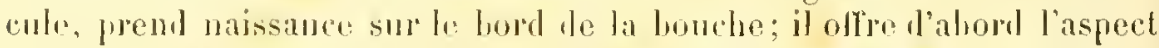
d’un bpaississement proloplasmiqur, pui souleve le legument an-dessus le lai. Colte régin epaissie so peree en son milieu d'une onverture, el pend la folmo l'une anse; l'une les extrémités le l'anse reste adhé-

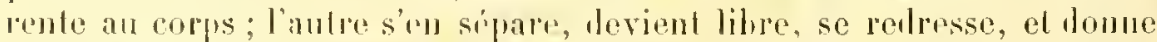

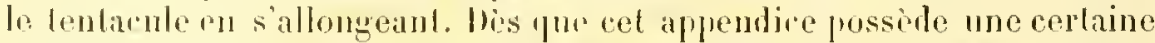
longucur, il se ment cu omlulant, el prósente les slues caracléristipues du tentacnle adulte. Le mode de prodnction du petit fonet n'est pas "rucore connu; selon toutrs les probabilités, et par analogie, il doit se former commo le lontacule, par l'étimenent d'une saillic locale du protoplasine.

\section{\$3. - Gemmiparité.}

La reprouluclion gemmipare est rare chez les Sarcolaires; divers

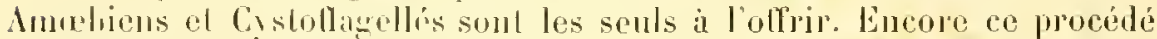
de léreloppement loil-il être considéré, non comme nue gemmiparilé 
virilable, of simblable à celle gue présentent plusieurs l'rotoznaires ci-

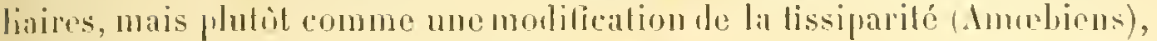
our de la sporulalion (Cystoflagellés).

I. Amœbiens. - La reproduction par hourgenonnment n’a élé ol,-

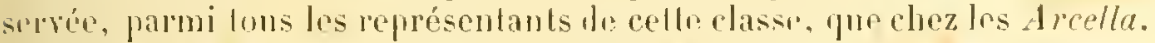

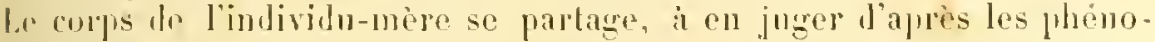
mines ullimes, on deux porlions incigales; la plus grambe reste enfermí dams la carapace, et doit itre romsidécécomme la persistance directe du gémśratem; la plus petilo se divise en un cerlain nombre de segments íganx, on jurespue rganx, dont clacun est destiné à devenio nn nourel organisme. Comme le second de ces phénomènes suit immédiatement le premier, sans que la petite portion ait en le temps de se séparer le la grande, il sensuit que fous les suments sont confomlus far leur hase ave cette demiero, et ressemblent a antant de bourgeons fromluts par elle. La earapace des. l\%elle ayant la forme l'une onbrelle, dont In face inléricure, aplanie, porte lorilipe destiné a laisser sortir les pseurloporles, lous les bourgeons font suillio sur celte face inféricure; ils se séparent bientól de la grande postion, qui conlinue a vive lans le tist maleruel, s̈isolent les uns des autres, deviennent libres, s'entourent lime envelopye, et eonstituent ainsi do nomveamx itres.

Co procédé est somvent disigné sous le nom le grmmiparité, ou de lomgeonnement des Areella; le termo est ract, cal il sagit rainent dume produclion le bourgeons. Mais cette gremmiparite loit ètre considéréc comme une segmentation tissipare rajude, et non comme nu prociolé entièrement nururean.

II. Gystoflagellés. - Si le bourunonnement des Imeliens se rapproche de la lissiparite, cehi des Vortihupues correspoul prespue à une sporntation. En effot, le génératenr peral ses appendices, ferme sa houche, s'enliyste en somme, et produit des zoospores; les sunles dillérences, existant entre celte série de phénomènes et me véritable sporulation, portent sur l'alisence l'une paroi eyslipue, et sur ce fait que le protoplasme de l'individn-mère n'est pas complefenent employé a jroduire des spores. Ces lissemblances mises à part, et eucore la deruiere seule possiole-l-rlle une certaine imprortance, le procédé de repruduclion, désigné sous le nom de gemmiparilé des Nochiluques, doit ètre pris comme une morlifiration du dérelujpement sporulaire.

A. - Les alivers phénoménes un bonrgeonnement des Nombinques ont été décrits par Cienkowsky d’alome, par Rohin ensuite. l’individu, yui ra so reproduire, perle son tenlacule avee son llagellum, ferme sa lomele par ba sombure des lieves, et ellace son pli dorsal; il premd done

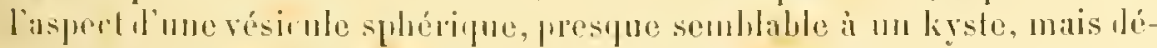

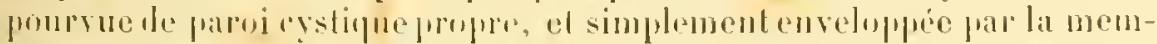
brane cuticulare de l'animal. La's vacuoles ulu protophasme ne disparissent point; le corps garle son aspect aréolaire caractéristique. Chez 
l'individu normal, me grande partic du protoplasme est rassemblée, pres de la bonche, en une matse renlermanl te noyan; cette masse senle donne maissance aux zoospores; les bandes qui limilent les aréoles ne frennent ancume part à cette formation. Le noyan se divise en deux segmunts; l'un d'eux se porte au-dessous de lit cuticule, et, avec le protoplasme gui l'entoure, sonfive cette membrane, en domant me sailie assez rolumineuse; l'autre leste dans lo corps. Co dernicr ne se divise plus ensuite; il conserve la mème place, ct deviendra le noyau détinitif

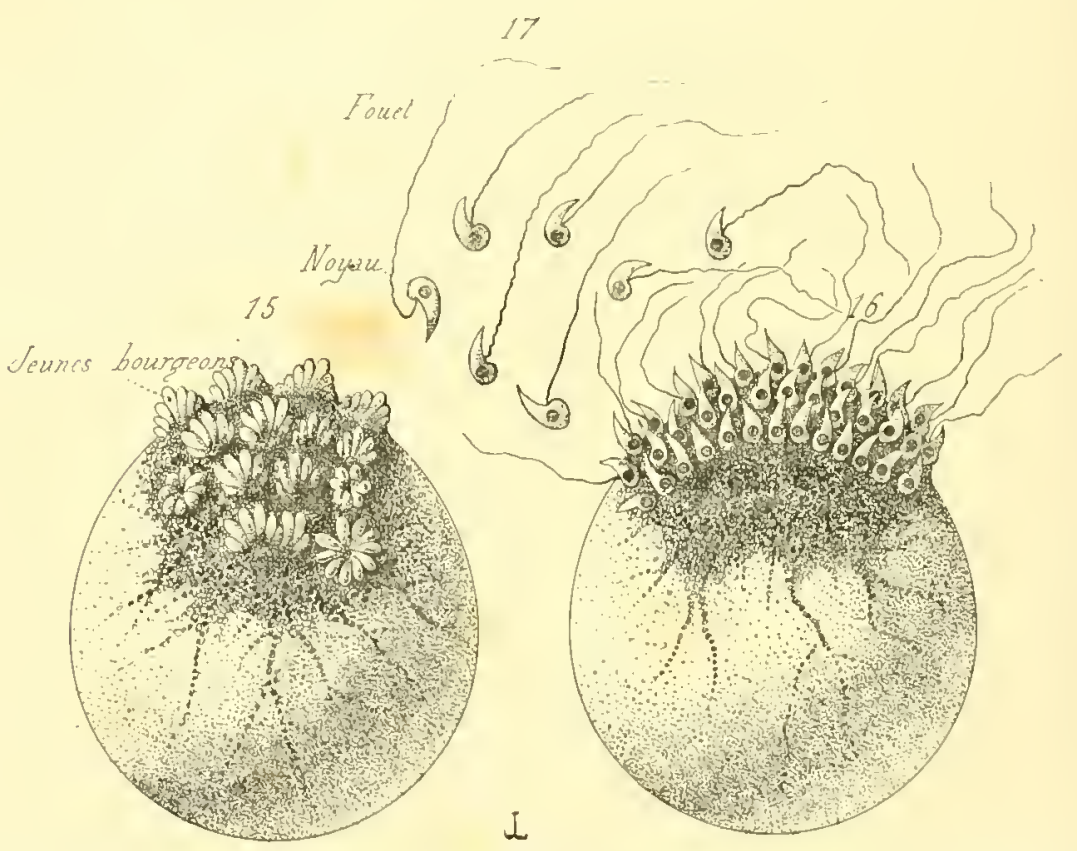

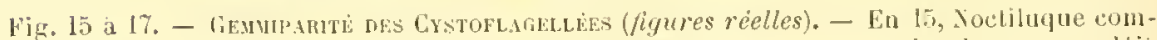
mençant à produire ses buurgeons. - En l6, Yoctiluque portaul des bourgeons dèja mürs. - En 17, bourgeons mûrs, detathes du gineratenr, et devenus libres. - baprès les recherches faites par lih. liobin.

du générateur, lorsque les zoospores auront été engendrées, el détachées de l'organisme de ce dernier.

Il n'en est pas de même pour le premier segment nucléaire. Celui-ci, avec le proloplasme qui l'unveloppe, se seinde d'abord en deux segments, puis en qualre, puis en huit, el ainsi de suite, juspunan chilfre 2ait, et parfois an chiffre 512; 111 grand nombre de petits nodules protoplasmiques, munis de noyaux, prennent ainsi naissance sur la Noctiluque, dans une région relalivement restreinte, et voisine de l'ancienne houche. Ces nodules vont se transformer en zoospores. A mesure qu'ils prement naissance, ils s'écartont purlque peu les uns les autres; ot, au moment où la segmentation est acherće, la région luccale de l'organisme nater- 
uel les porle lous, groupés sur une zone, qui occupe a peu pros le tiers ou le quart dr la surface de cet organisme. Ils ont l'aspent de petitos saillies implantres sur le gónirateur, el miritent donc bien le nom do bourgeons qui leur a été donné.

Ces hourgeons se moditient ensuite, et se changent en zoospores. Pour arriver a ce but, chacun d'eux élire d’abord sa base d’implantalion, et la lransforme en un court el mince pédoncule. Puis, l'extrémité opposćc i la région d’albírence s’allonge en une pointe acérée, et se convertit en un fouet qui, par ses mourements. permet au pelit itre dosciller sur sa base. Ces oscillations ont ponr effet le rompre le pérloncule d'altacho; les hourgeons se séparent alors de l'inclividu qui leur a douné naissance, et se próscntent comme des corps ovoüdes, nucléés, munis de fouets. Ces hourgeons libres sont des zoospores.

La Noctiluque primitive a done produit dewx sortes d'èues. D'un côté, un nombre considérable de zoospores, qui sont loin d'aroir les contours extórieurs ef la structure de l'adulle; de l'autre, un oranisme arrondi et vésiculeux, garlant du générateur la moilié de son novau, la moilié de sa masse protoplasmique buccale, el lout le protoplasme aréolaire. Ce corps ressemble done à une Noctihque prive de fouet. de tentacule, ot de bouche; comme ces trois organes ne tardent point à apparaitre. la structure normale se compliele, et il est permis, en somme, de considérer cet indivilu comme la persistance directe du génćrateur. Ce dernier a rélracté ses appendices pour produire les bourgeons, puis, les lourgeons formés, il engendre de nouveaux appendices pour relrouver son organisation premire.

B. - Les zoospores, après avoir menć mne vie libre pendant un certain temps, se transforment en Noctilurues. Les phases de cette évolulion ne sont pas foutes connues; la description suivante découle des observations effectuces par Ch. Robin. - Tout en nagcant, la zoospore grossil, par l'apparilion dans son intérieur de plusicur's vacuoles. Cas varuoles grandissent; par suite, le profoplasme du petit otre devient. vésiculeux et aréolaire, sauf en une région, où le profoplasme reste assemblé en une masse assez volumineuse, qui conlicul le noyau.

l'endant que cette transformation se produit, le fonel se rotracte, te corps perd sa forme conique. el devient arrondi; une membrane prend naissance sur sa périphérie. La zoospore s'est modifiée en un corps sphírique, dípoury de tout appendice, et dont le protoplasme offre l'aspect aróblare caractóristique de l'adulte; cotle zonspore est déjà une Nocliluque, mais me Yoctiluque privere de louche, le lagrellum, de tentacule, el ciny ou six fois plus petite environ que l'indivilu parfait. Pour parrenir ì ee dernies élat, il lui suffit le grandis, en cxagérant encore son aspect résiculeux, ef do donomer naissance aux ologanes ahsents. La homche apparail la promière: frois on qualpe pelites saillies juxtaposres so lorment sur la rógion qui surmonto loproloplasme nuclóe : 
une dépression so crense entre clles, s’allonger, el pénelpe jusque dans

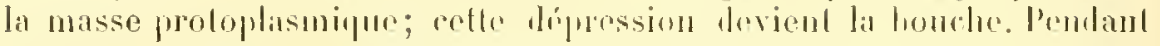

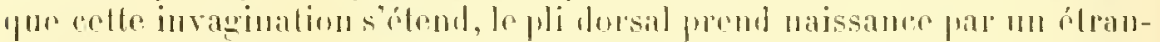

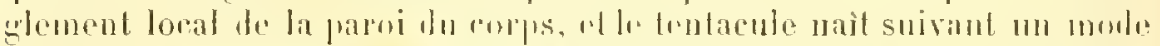

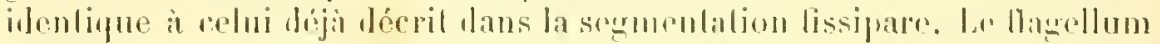

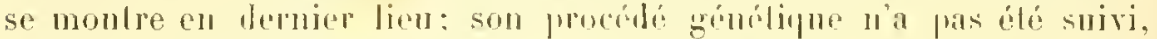

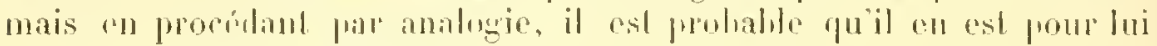
romme pour le lentarule.

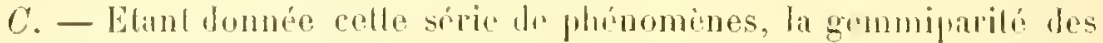
Noctilupues est nu mélange de repuraluction fissipare al de développement sporulaire.

Ia reproduclion lissipare se retrouve daus la division imomplete de l'indivilu primilif en deux farlies, Jont l'une so lansforme en un

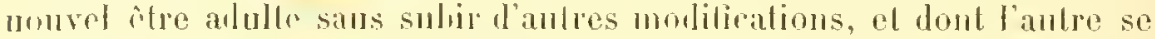
parlage en wn nombre consiberable de segments serombires. Les ressemblances avec la sporulation consistrnt lans la perte des appendices, fa fermelure de la houche, ed dans l'aspret zonsporé des senuents devenus libres; mais res analogies n’atlémuent en rien les vóribbles dillérences, pui portent sur l'alisence d"une paroi cystique projre, et sur la division sformaire d'une seule partie hu protoplasme matormel. lous loule véritable sporulalion de Sarcolaire, el sanl quelyues rares exceptions, le protoplasme entice hu gumeraterr se fragmente en spures; or, tel n'est fias le cas des Necliluques, car ces itres commencent par se tissipariser imrompletemenl, et lin des deux segments fonne seml massance aux zoospores.

Plusicurs antenrs ont signabé l'existence de Nocliluques conjuguées, c'est-it-dire unies deux par denx. Denx individus s'accoleraicut l'un à l'autre par leur houche, rétracteraicul leurs appendicas, puis se fusionneraient peu à pru cu un senl organismr. Comme la séric complete les fhémomienes n'a pas été suivie, il esl permis de se demamder si ces

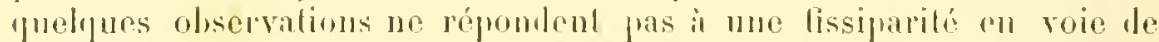

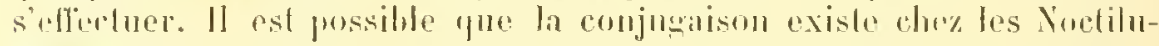

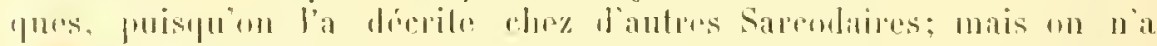

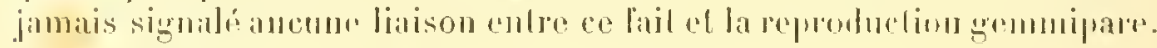

\section{4. - Sporulation.}

Le diveloppenunt par sporulalion a cité olservé dans toules lesclasses lo: l'embranchement

I. Monériens. - La sporulation des Homprions romsiste on edle

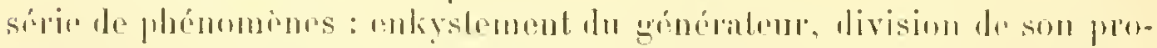

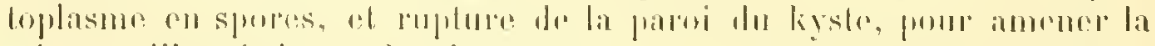

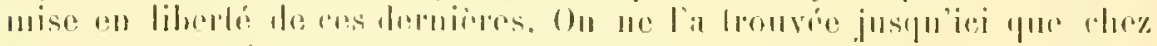

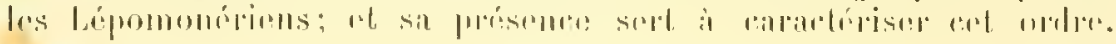


Lorsque la fragmentation va s'effecluer, le génératour rétracte ses pseulopodes, el cesse toutes ses fonctions de mulrition. P'uis son protoplasme laisse exsuder une sulistance chilineuse fort résislanle, dont il s'entoure, el qui devient sonvent très épaisse; cetle enveloppe est la paroi cystiqne. Lorsque la paroi est complete, ou un peu avant ce moment, le proloplasme se divise, prar un procélí encore ineonnu, en sprores, dont le nombre est loujours supérieur à deux. Les I'ampyrella en prodnisent qualre seulement; les autres lépomonériens en montront une plus grande quautité. Les I ampyrella etlectueraient lone, sous le rapport

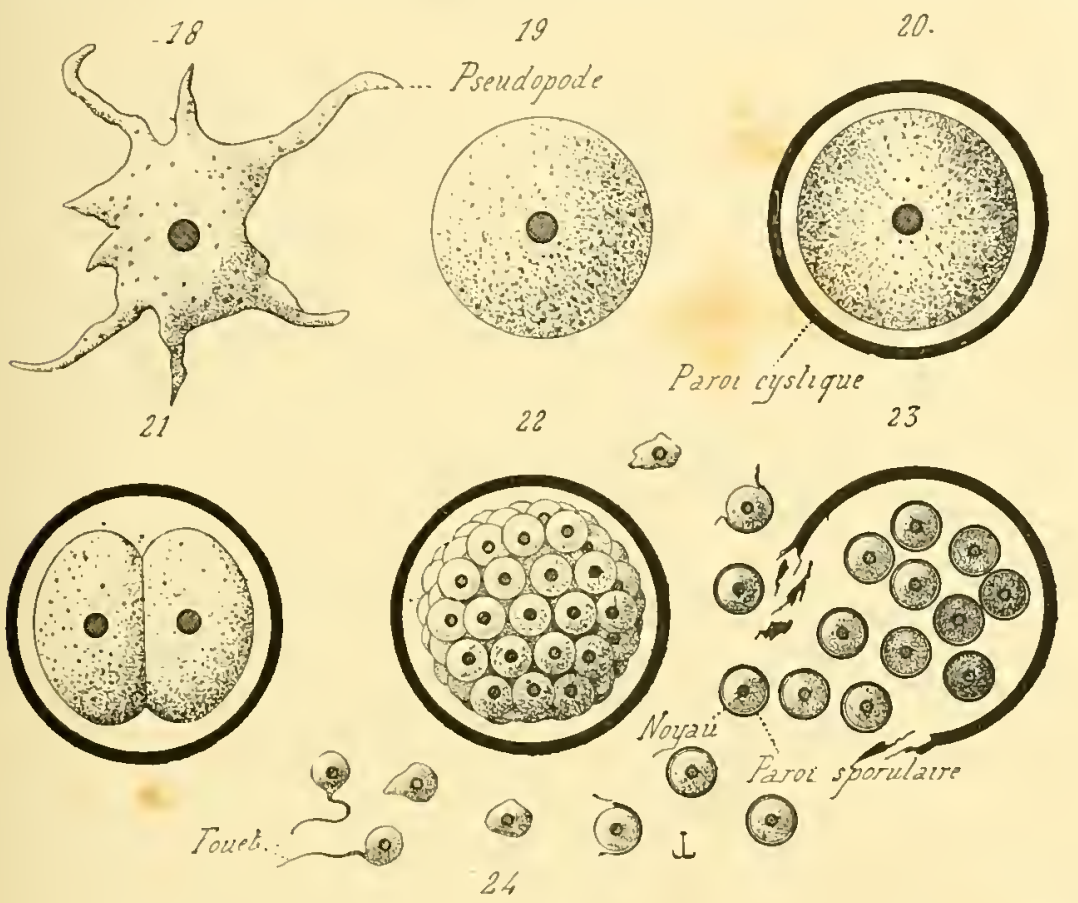

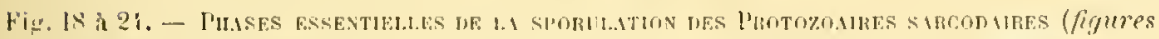

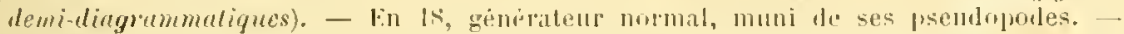

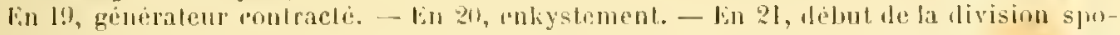
mulaire. - lin 22, fin de la division spomlaire : le protoplasme du greniraleur est eou verli en spores. - lin : s;, germination lu kyste : rupture le la paroi cystipur, "t mise en liberli des sprores. - lin 24, germintion dos spores : rupture de la patoi sporu-

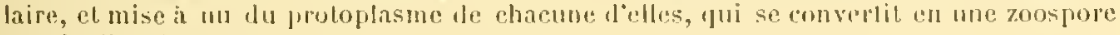
munie d'un fomel.

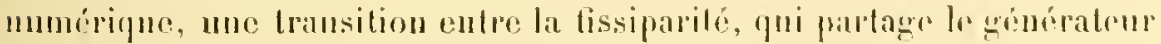
endeux individus de seromde généralion, wh la sporulation de la phupar

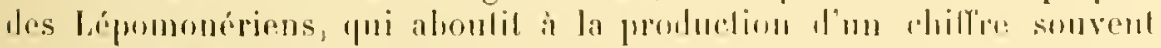
comsideralde de descrmbints.

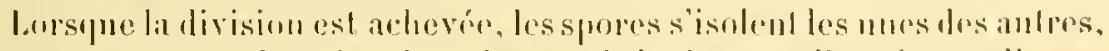

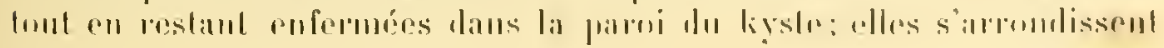


derdinaire, et sentomrent à leur tour d'une membrane sporulaire. Elles

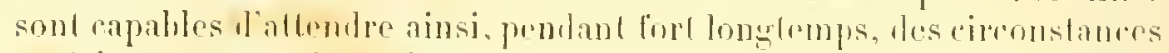
vxtérieures assez favorahtes four permeltre four développement ultérieur. Lorsque ces condilions sont rólisíns, ol la jurmière l'entre elles consiste en l'existence d’une humidité capahle de ramollir la paroi du kyste, cette dernirre se brise; los spores sont alors mises en liberté. Leur protoplasme se délarrasse de la memlirane qui l'enveloppait, et le petit ètre commenee par ponssor un pseutoporle to formo allongée, comprable is un fouel; en eetétat, chacun des descentants est une zoospore. Pruis, de unureaux pseutopotes prennent naissance, el l'individu finit par ressembler ì son génératem.

11. Amœbiens. - les senles olservations prócises, relatives ì la reproduction sporulaire, portent, commecelles ayant trait à la gemmiparití, sur les représentants du genre Areella. De même que chez les Lépomonériens, Yindividu rétracte ses pseuloporles; il contracte ensuile son protoplasme, do façon ì l'arrondir en une masse sphrírique. qui se sépare de la rarapace; puis, il entoure ce protoplasme condensé d'une seconte cuticule épaisse, el de forme ágalement sphripue. Les recherehes effectuées se hornent ì constater cetle série de phénomènes; il est cependant prohahle yu'il s'agit jci l’un enkystement semblable a celui des Lépomonériens, el ayant sans doute la mème signification. En ce cas, le protoplasme enkystí se diviserait en un cerlain nombre de spores.

l'arfois deux on trois de ces ètres se rapprochent les uns des autres, s'accolent par la lace inférieure de leur test, face munie de l'orifice huccal, et missent ensuite leurs corps. Solon toute évidence, ce phruomene est unc conjugaison accilentelle: on ignore si cette fusion précide une reproduction, ou si elle ne possede aucune signification.

III. Sporozoaires. - La reproduction sporulaire est lo seul mode génétique, signalé arec corlitude rhez les Sporozoaires. Cette prósence ronstante de la sporulation, procédé de brancoup suprórienr à la fissiparité quant au nombre des descenlants, est en rapport sans doule avee le parasitisme te ces ètres. Les chances le conservation de l'espèce sont en effet plus grandes, si le chilfre des descentants est plus considérahle.

Les phases de la sporulation offrent une série de caractires communs it tous les Sporozoaires. L'indivitu s'entonre an préalahle d'une paroi chitinense épaisse, el s’enkyste. lienkystement n'est pas tres uot chez les Honogéniques; l'individu se horne a rétractor ses prentdopodres, el sa paroi cyslique ne prarait pas forl épaisse. Il n'on esl plus fout it fait ainsi chez les Amphigéniques, notamment chez les Sarensporilies et les Crógarines, Jont la paroi rystique ost lien déreloppér, el très résistante; relte paroi subit mìme, chez les frógarines des modifications qui ont pour olygut de lui fairr produire tes tubes, les sporodurles, chargés de combire les spores an inhors. 
J'babitude, lenkystement est solitaire. Les Corégariurs soules font expplinn, du moins dans lietat actuel de mos commissances; olles préseutent bien parfois l'enkystemont solitaire. mais d'labilude of pluénomene esl prócédé l'mue conjugaison.

Lévolution des spores cugendrées n'est pas la mème clıez tous les Sporozoaires. Les germes des Monogéniques se borneut i produirr birecrectement des descendants; ceux des Amphiréniques subissent, il leup Inur, une deuxiome segmentation. qui abontit a une gencse de unnvelles spores. Ces spores de seconde grinération sont seules chargios le devenir les organismes définitifs. Les Jlonoginiques présentent lone une semle généution le spores. Les Amplugéniques en offreut deux. qui se succédent régulierement : un indiviłu-mère donne des spores le première gónération, les prolospores; rluacune de ces dernières produit i son tour des spores de seconde génération. les dentospores; el enlin chaque dentospore se transforme en un indivilu, qui grandit. passe à l'élat adulte, et recommence le cycle.

les spores des Monogéniques correspondent probahlement aux protospores des Amphigéniques, et dilièrent de relles-ci en ce quelles restent simples. Le nom le psorospemies leur a élŕ arcorlé autrefois. ct on l’a étendu également aux prolospores les Ampligéniques: ces dernioues sont cependant lésignées, dans certain cas. comme des psendo-navicelles, car elles ressemblent forl à certaines Diatomies'(Navicelles), ct les ileutospores comme des corps falciformes, à cause de leur aspect en croissant, en faux. Il serait plus simple de supprimer ces termes, qui ont seulement nu intírèl historique. et de conscrver le mot spore, tantôt employé senl, tantôt. suivant le cas, précédé les suftixes proto et deuto, clargrís de désignor lordre des générations.

Ios Sporozoaires monogéniques subissent donc unr reprouluction directe, landis que les Amphigéuiques présentent une alternance de gúnéralions.

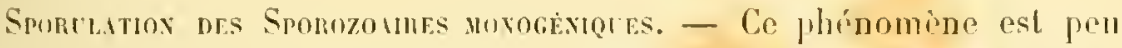
connu: ensomme, les observations, faitrs jusqu'ici, schornent ì monlrer l'apprarilion des spores dans le proloplasme de l'individu-mèe. l'après un rerlain nombre de recherches, dôes principalement il liitsehli et it balliani, il est permis de se reprósmter ainsi la sélie des pluses :

1. - Lindivilu, ì l’instant oì il mait de sa spore, est conslitué par un proloplasmo panrese en granulations; il envoir. lans tous les

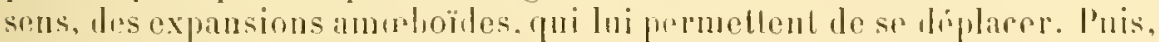

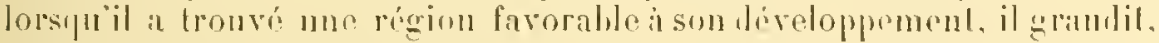
se remplil de gramules, el commence prospue de suilo i problube des sporas; an pelit nombe d'alorol. en plus grambe quantita par la suile,

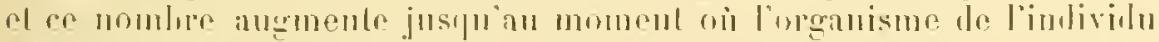

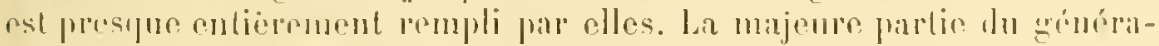
teur est alors comvortio en spores, el seulos les gramblations restent en 
dehors d'else. La fine memlrane, qui entourait l'organisme initial, disprarait pen ì pen, les granulations se dissocient, el les spores sont mises en lilierté an soin des lissus de l'hite. Ces spores germent alors; chacune d'elles produit un numel ithr, qui recommence la mène évoIntion.

Le deus fails ì remarquer sont: lol'alsene presifue complète l'une période d’onliystrmenl, car la memlrane périphérique reste tonjours assez miner: ¿ju la gramde durce le la prériode de reproduction. Celle-ci se manifeste durant lonte la vie de l'animal, ì tel point yue les spores naissent au fur et it mesure de la croissance, jusqu'à uno prérode ullime oì, cettr croissance étant achevée, la spornlation l'est aussi. Il y a donc,

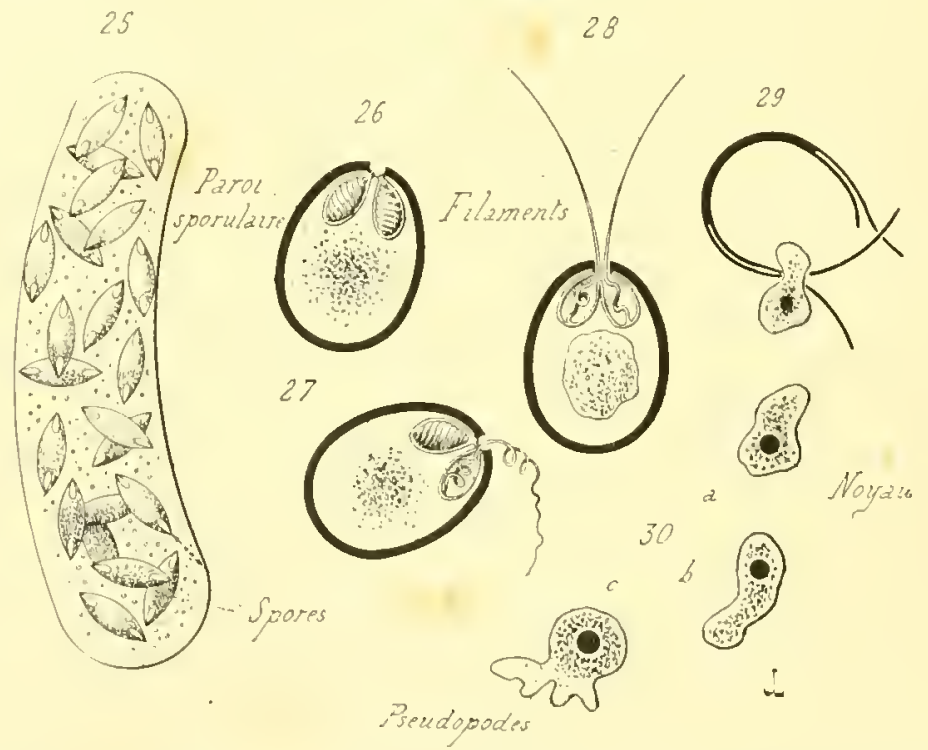

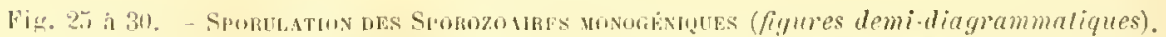

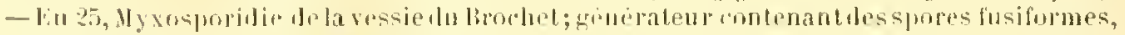

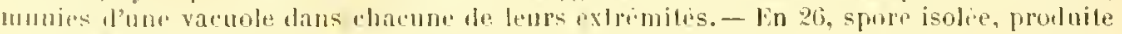

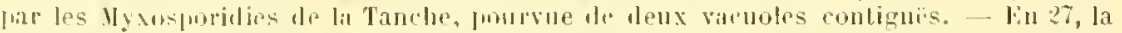

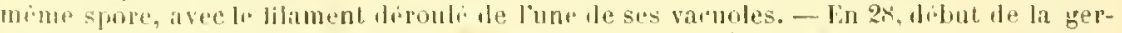

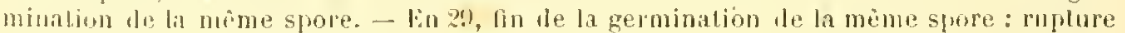

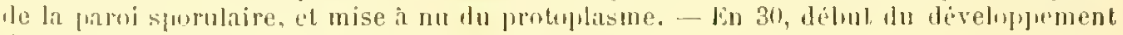
lu proloplasmo sporulaire, conscrulif a la promination; en a et b, premieres phases:

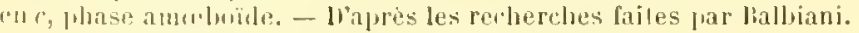

dans l'ábolution vitale des sporrzoatres monogéniques, mélange de la

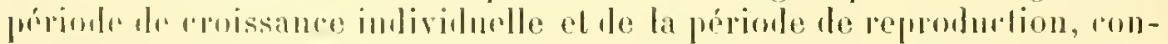

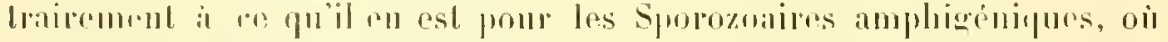
cos derox moments sont distincls l’un de l'antre; tonte l'évolution vitale

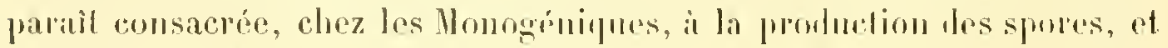

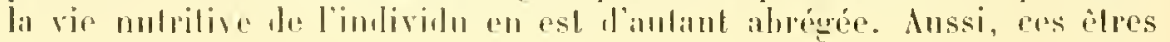


apparaissent-ils comme les masses de protoplasme granuleux, plongées dans les tissus de l'hòte qu'ils babitent, et renfermant un nombre considérable de spures, de prsorospermios.

Les fonclions du noyau daus ces phénomènes sont il peine conunes. IBülschli a vu parfois des parcelles nucléaires se sugmenter, mais n'a pas suivi leur óvolulion. II avance que, lans cerlains cas, ehez les Jrasporilies notamment, chaque spore jeune contient trois noyanx, dont deux se détruisent, el dont un seul persiste; il serail nécessaire d'elfectuer sur ces faits de nouvelles olsservations, alin de juger en connaissance de cause.

I3. - Les spores, ou psorospermies, des Sporozoaires monogéniques, diffèrent l'asprect suivant que l'on s'alresse aux Microsporilies on aux Mrxosporities. - Celles les llierosporidies sont lrìs pelites, de forme ovalaire, et possintent à peine trois it qualre us de longueur, en moyenne; lenr frotoplasme hyalin s'échappe par un petil pore, qui se perce à l'une de lenrs extrémilis, et, devenu libre, il se transforme en m nouvel individu.

Les spores des Myxosporidies, lantòt arrondies, lantôt ovalaires, on mème fusiformes, sont flus grandes, et mesurent en moyenne 10 à 20) \% de longnenr. Lenr paroi, an lien diùre lisse comme celle des spores des Vlicrosporidies, présente, suivant sa longueur, un sillon étroil, qui la fail diviser en denx valves. lorsqu elle s'onvre ponr livrer passage au proloplasme. Ce dernier renferme deux vacuoles, dont chacune contient un lilanent enronté sur lui-mrime, it l'état de repos, el susceptible de se délendre brusijuement frour s’élaler an dehors; ces petils organes, qui paraissent itre des appareils le défense, ressemblent, par lemr forme ot lan disposition, anx lrichocystes des Infusoires ciliés. Ces vacuoles sont dhabilude placées côte à còte dans les spores largement ovalaires, cumme le sont celles de la plupart des Myxosporidies, el localisées vers l'extrémilé la phus étroite. I'ar contre, dans les spores allougées en fuseau, chacuue d'elles est pelégnće en une des extrémilés de ces dernières; les denx varmoles soul alors diamétralenent opjusiós.

La parri des spores le Ilyosporilies, forl épaisse, joue par suile

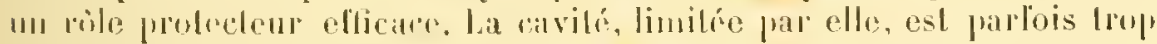

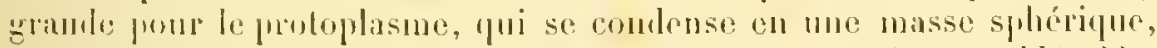
at lasse endre lai et la paroi un espace libre plus ou moins considéralite. the meme que pour los spores de lons las l'roloronares, eetle paroi, bien que produite à l'origine par le protoplasme, sert simplement a le prolinger; el ce dernier s'en débrarrasse lor'sin’il se développre.

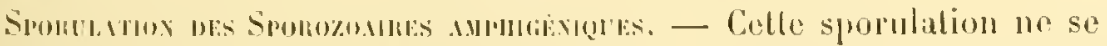

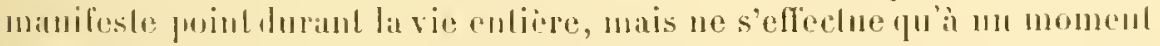

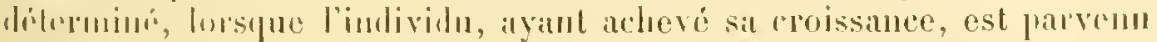

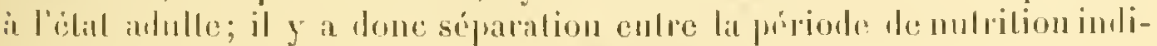
vidurlln. 
próridant tonjours la seronele. La sépie des phases, qui se manilestent

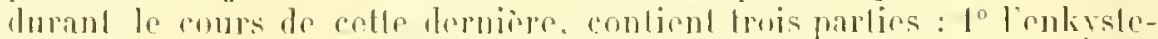

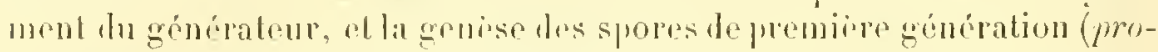
lospores): 2o l'exolution les prolospores, el la genese des spores de seconde gónéralion (denlospores): $3^{\circ}$ l'évolulion des deutospores, qui se transforment en indivilus dáfinilifs.

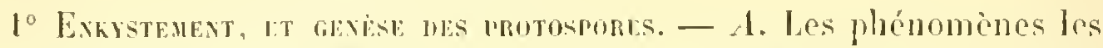
plus simples sont offerts par les Cocedies; lenkystement se réduit it la production. autour du protoplasme, d'une paroi cyslique assez épaisse, et à la condensation assez fríquente du corps en une masse glolulense. plus pelite que la arité limilíe par la paroi du kyste. Lienkystemont, lonjours solitaire, n'est point précédé par une conjugaison prialalule: lindividu, au monent où il va se reprodure, sentoure daborl le la membane reslique, puis subit la conlraction précidemmont indiquée: te protospores prennent ensuite naissance. - Les Sarcospopilies rappellunt les Cocrilies en ce que l'enliyslement est solilaire; la scule difference porle sur la paroi protectrice, somvent très épaisse che\% les Sareosporidies, et peróe dun grand nombre de pelils canaliules radiaux; la présence le ces canalicules rend la paroi trés friable. ot la fail se lísagrioger aveo farilité.

Les Grégarines olfrent une complexité plus grande. lienligslement es frarfois solitairo, mais il est le plus souvent pricédé par la conjugaison de deux individus, rarement de lrois ou de quatre (Aggregata pormidrum, parasite dans l’inlestin des Custacés décapoles). Lrosque deux Houocystidées vont se conjuguer, elles saccolent par une région quelconque do leur copps; lípirve disparail au point de contact, el les deus inlividus se fusionnenl pru à fren en me sente masse. ()uand l'union

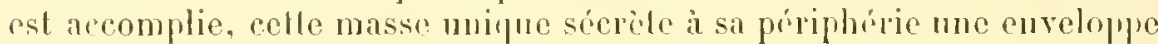
résistante, et l'enkyslement se lrouve acheré. Słil s’agit des Polycystidés, les épimírites les individus en vojo de conjugaison tomlient, s’i an existe; ces individus passent ainsi, de l'ibat de cephalins, à celui do sporadins. Puis ces oreranismes s'unissent, de facon que lextrémilé postérieure du deulomíplo de l'un s’acole à l'extrémilé antérienre du protomérite de l'autre; la fusion s'offretue onsuilo comme dans le cas les dlonocrstidées. Lorsque les individus commengroul a se souder l'un i lautue, ils paraissonl former une colonie, conslibéc par un pelit uomlore te zooliles. Slein avait eonsidéré a tort ce phénomine aceilentel comme un fail permaneut, et avail réé la famille des llilymorphidrs.s. pour les quelques organismes conjugués qüil avait renconlrós. Celle

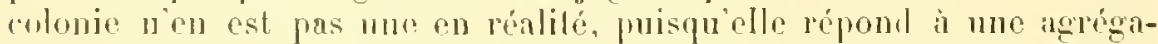

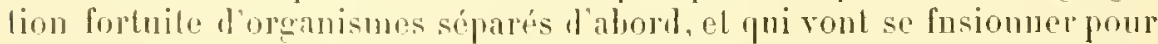
se reprodure. Les modilications sulies par les noyax, dans ces flhomomines, mo sonl fas rommors.

Les formes des kystes rappellent celles des individus dont ils provien- 
nent; aussi, glohuleux on ovö̈les chez les fircyanes et les Cocoilies, présentent-ils l'habitude nn aspect de fuseall che\% les sarcosporidies. Leur épaisse paroi, lisse le plus souvent, ne porte ancune ormenentition.

lj. - Les Coccilies présentent les dispositions les plus élémentaires sous le rapport de la grenèse des protospores, et montrent une scirie pogressive de complexite croissante. Chez les Eimeriu et les Orhospora (Coccidies monosporées), le protoplasme de l'individu produit me seule prolospore; lorsque lenkystement est achevé, le protoplasme se borne à se contracter quelque peu, et devient en entier nue protospore, capable d'engendrer des deutospores par la suite. Les Cyclospor at les Isosporr vont un pen plus loin dans cette voie; leur protoplasme se divise en deux masses, dont chacune se transforme en une protospore; chaque générateur prołuit donc deux protospores (Coccidies disporées). Le nombre de ces dernières s'úlève à quatre chez les Coccidium (Coceidies tétrasporées); enfin, les Klossia el les Benedenia donnent naissance à un nombre considémable de protospores, renfermées dans la cavití que limite la paroi du kyste (Coccidies jolysporées). les caractères, tirés du nombre des protospores, ont été employés, par $\mathrm{A}$. Schneider, pour diviser en trois tribus l'ordre des Coccidies : la tribu des Konosporées; celledes Jligosporées, contenant les Disporées et les Tétrasporées; enfin celle des I'olysporées.

Le cas des Coccidies polysporées est également celui des Sarcosporidies el des Grégarines. La genèse des protospores 11 a pas encore été bien suivie chez les représentants du premier ordre; les observatious faites jusqu'ici se bornent à montrer de tres nombrenses spores daus la cavité du liyste. II n'en est pas de mème pour les Grégarines.

Lorsque les indivilus conjugnés se sont entièrement confondus, le corps résultant de la conjugaison s"entoure d"une ćpaisse membrane, qui est la paroi du kysie; un fait semblable se manifeste aussi dans les cnkystements solitaires. Puis la division du protoplasme en ectosarque et endosarque (ou sarcocyte et endocyte) s'efliace; les granulations de l'endosarque se rassemblent en une masse centrale, et son protoplasme se joint à celui de l'ectosarque. Le corplis enliysté se diflárencie, par ce moyen, en deux zones : l'une centrale, de coulenr sombre; l'antre périplúrique, hyaline et transparente. La zone centrile reste inerte; tout au plus se divise-t-elle parfois en leux on quatre masses. Hlle se lissocic en définitive; ses gramulations deviennent libres dans la cavité du kyste, oì elles se mélangent aux protospores.

La genèse de celles-ci est ellectuée jar la zone périphéripue senle. I mesure pue rette dernicre se sépare de la masse granulense centrialo, elle se divise, far un procédé encore inconnu, en nu grand nombre de petits segurnts sphériques, placés les uns ì coité des autres, et disposés sur mo ou plusieurs roucles, qui entourent la mone centrale. Chat cun de ces pelits segments est nue protospore; som protoplasme s'entoure d'une paroi épaisse, qui l’isole de ses voisines, et lui constitue 
unc enveloppe sporulaire. Ensuite les protospores se siparent, at se louvenl libres dans la cavilé du kisle.

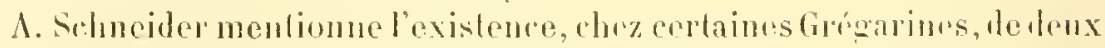
surles de liystes, les uns gros, les aubes phas petits; les promiors dérive-

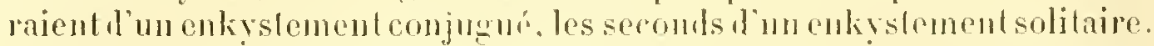
Les spores des arands liysles semient de meme plus volumineuses fun

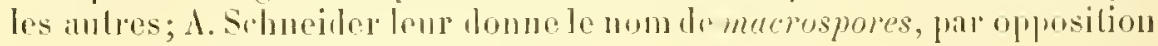
it celui le microspores, 'pu’il accordr à celles placées dans les pelils kysles.

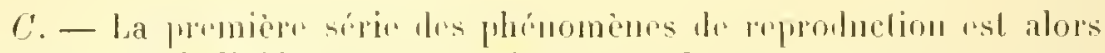

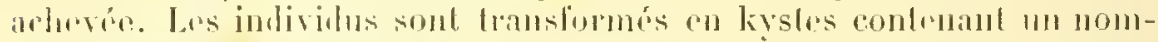

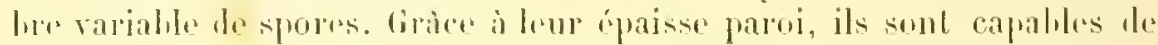

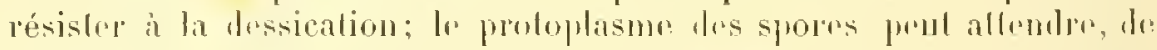

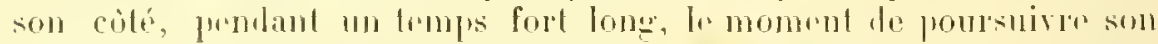

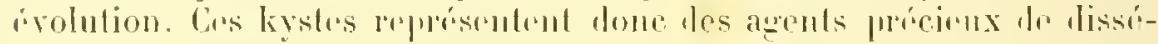

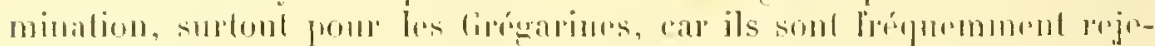

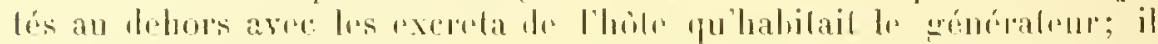

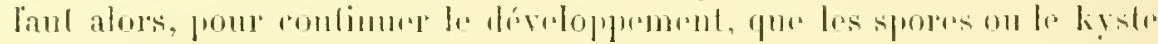

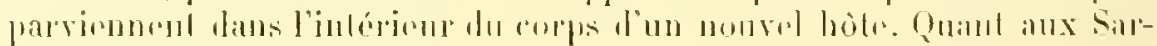

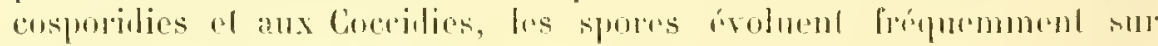
pher, sans parvenio au delusts.

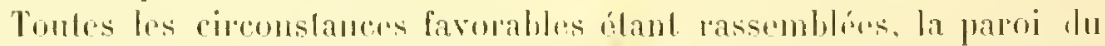

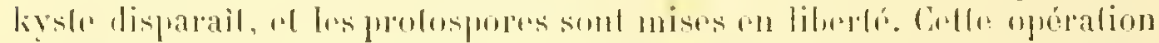

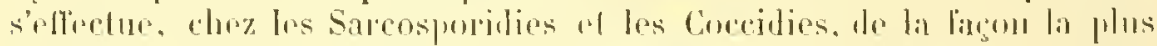

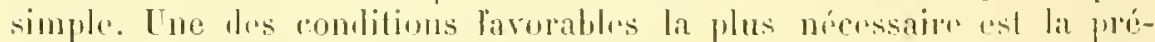

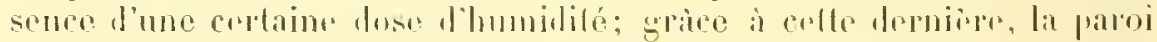

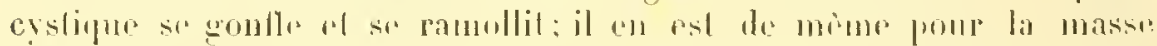

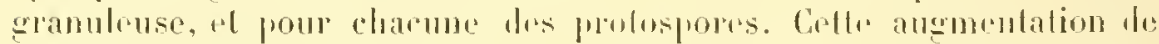

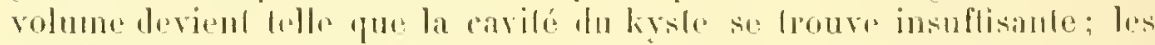

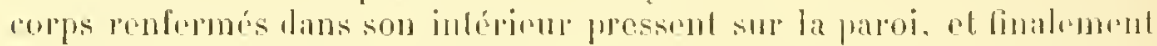

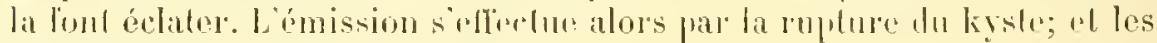
prolospores somb mises an liberli.

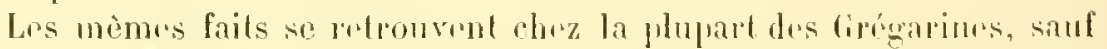

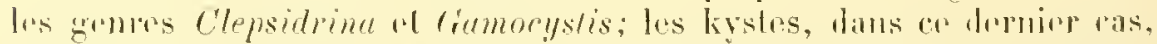
sont mumis do combuls lubulaires. diss sporoductes, qui servol a rom-

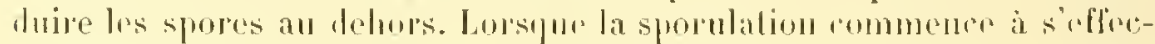

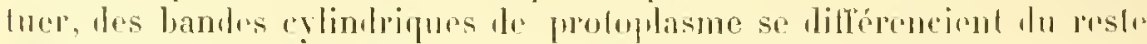

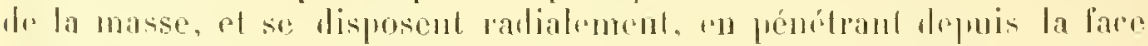

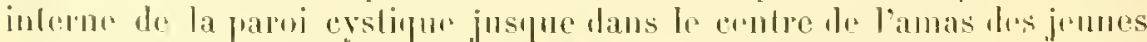

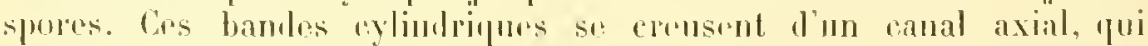

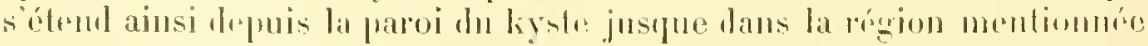

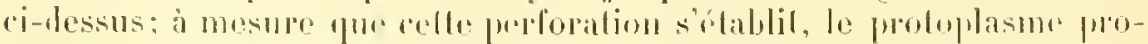

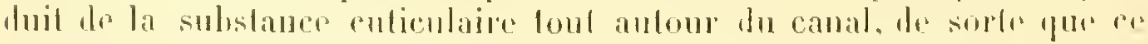

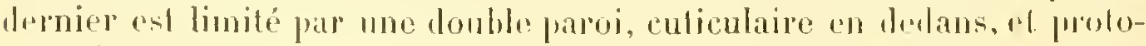
plasmique an dehors. Chacune le ces lıamles est l'ébaucho d'un sporo- 


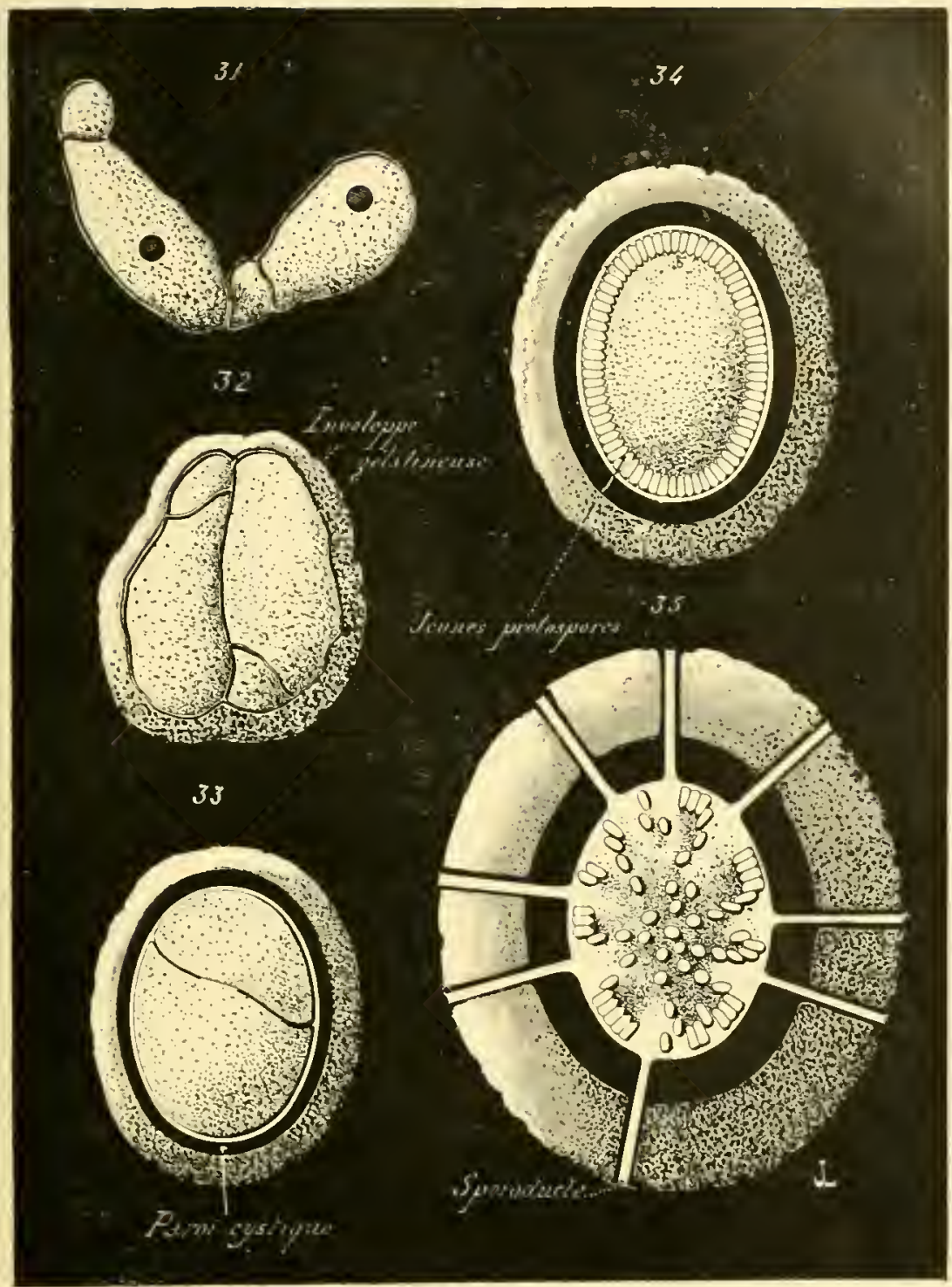

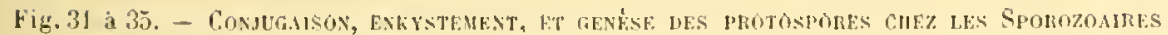

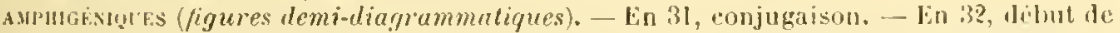
l'enliystement, la conjugaison continuant is s'opérer, et exsudation d'une envelopue gulatinense. - En 33, suite de l'enkystement, el apparition de la paroi tystique sons lonve. loppe gélatineuse. - In 3i, fin de l'unliystement, et genese des protospors; dans la réalité, ces dernières, tout en étant disposẻes de la même facon, sont flus pelitus et plus nombreuses. - lin 35, emission des protospores, au moven do spornductes, yui traversent la paroi cystique el l'enveloppe gélatineuse. - Waprès les recherches faites par Builschli sur la Clepsiurina blallarum. 
ducte; son canal axial ast mowet aux deux bouts, d'un cote dans la

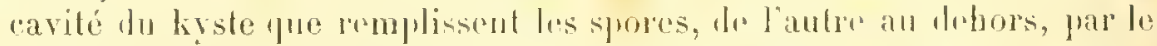
ramollissement el la destruction de la paroi cystique an ce point. - Lorsque l'énission va s'eflectuer, la probi lu kyslo so: gontle, et presse sur les spores, qui réagissent i lene four sur les sporoductes. La pression des spores se dirigeant surtout ilu centro vers la périphérie, l'exténité

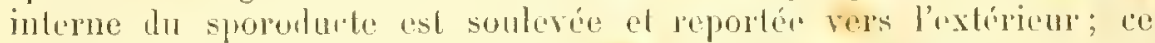

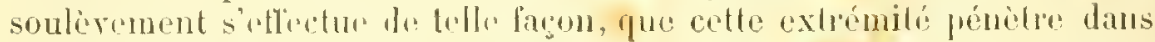
l. canal mene du sporouluch, ut elsemine dans ce canal en allant foujours vers l. duhors; e. phenomine se réduit en somme ì me éraginalion de l'appracil, comparalıle à celle d"un doigl de gant, dont on soulererait jex it peu ho fond pour rondre externe la face interne, et réciproyuement. Los sque co mourenent est achové, le sporoducte est completement rvaginé son "xtrimilé situéo sur la proi du kyste ast reslée rn flace, mais celte plongée lans la caviti du kyste est devenue externe.

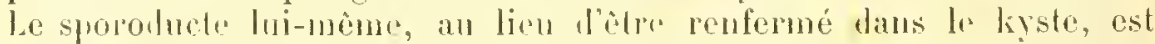
"nlièroment extéricur; il forme comme un haguelte cruse, éterée rn saillie sme la parri du liyste. Les spores s'ongagent alors daus son canal, el parviemont au dehors. Le nombere des sporoducles varic, suivant les especes, de loois a louze par liyste.

Les protuspores les Sporozuares ampligéniqurs, ansi mises cu liberte, ne produisent point directrment de nouveaux indivilus; mais leur direlopipment a pour ohjot de déterminer la genese des spores de serondr gónération, des deutospores.

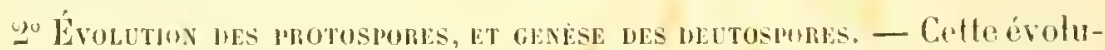
tion se réduit à un segunentalion du protoplasme des prolospores. Dans celle fragmentation, jas plus que dans le développement des protosfrores, on n'a ru les morliticalions subies par le noyau.

Les protospores, parvenues à maturité, sont cunstiluées par me masse protoplasmique mononucléée, souvent hyaline, contenant parlois un petit nombre do lines gramulations; leur piroi sporulaire est assez éprisse, et fort résistantr. Lenr lome est lo plus sonvent sphérique, on ovalaine; parfois, les deux rxlémités dr l'ovale sont quelque preu déprimées. - Lorsyue la proluspore commence à se développer, son probplasme se divise d'aborl endenx parties; puis chacume d'elles se segunente à son lour en leux mutres parties, le plan le segmentation étant loujums parallele a l'axe longituliual de la spore; entiu, chacune lo ces dernieres se partage a son lour an dems autres masses, suivant la mène direction. Cas phrnomines acherés, lo protoplasme osl divisé en huit segments allongés, et placés les uns a côté des autres commo les coltes dim molon. Chacun le es derniers s'enton\% d'une mom-

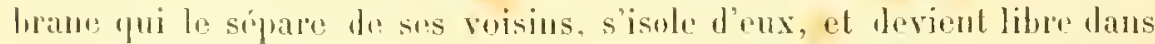
la carilé limitée par la paroi de la protospore; en cel élat, il comslitue une spore de seconde génération, une deutospore. 
Le montre dies leutospores est te phus sourent de huil prar protospore. Chez certains genpers pourtant, appartrnaut pour la plupart it l'ordre des Coccilies, la segmentation s'arrète an chiffre \& (O) rhospore, par exemple); chaque protospore contient quatre dentospores. Les Coccidium montreraicnt mème une évolulion beancoup phrs simple, juisque le protoplasme de la protospore se transforme en une seule deutospore. C'est lit, évidemment, un lyje primilif, rappelant de pres les Sporozoaires monogéniques, puisru’une protospore ne donne naissance qu'ì un indivilu délnitif. tes Coccidium et les Orthospor constituent done une série rattachant, à ce point de vue. les Honogéniques aux Amphigénį̣ues, et permetlant d'arriver a l'évolulion habituelle de ces derniers, dont chaque spore de première génération produit en moyenue huit deutospores.

La segmentation va mème plus foin chez d'autres genres; plusieurs ides huil segments, el mème tous dans certains cas, se partagent à leur tour, et lenombre de deutospores se trouve considérablement augmenté: lels sont les Eimeria el les Isospora parmi les Coccidies. Ce fail est une exagération de l'érolution uormale.

Le proloplasme de la prolospore n'rst pas entierement employé à la formation des deutospores; il reste souvent un pelit amas de granulalions, comparable, loutes proportions gardées, à la masse granulense centrale des liystes. Cet amas a été désigné, par $\Lambda$. Scluneider, sous le mon de noyau de reliquat; il ne faul pass se méprendre sur le sens dine telle expression, car il n'existe rien de nucléaire en lui.

lass deutospores sont des corps allongés en fuseau, et libres dans la cavité dr la protospore, qu'efles remprissent presque en entier. D'ordinaire, elles sont reconrlées en croissant, on en faucille, ce qui leur a valu, de la prart des auteurs, les noms de corpuscules falciformes, ou de corps fulciformes. Charune d'elles préscnte une paroi mince, entourant un frotoplasme hyalin, qui contient un noyau. Ces dentuspores, ainsi constituées, doivent se transformer en indivilus, semblables à cenx qui se sont enkystés pour produire les protospores dont elles dérivent. P'our arriver à ce but, if faut que la paroi de la frolospore lisparaisse; ce phénomène se produit par simple rupture de cette paroi.

30 Ĺvolition nes onutospons. - A. Les deutospores, étant parrenues dans un milien favorable a leur léveloppement, vont a leur tour évoluer jour se translormer en individns parlaits; les diverses plases de cette évolution ont été suivies aree netleté chez les Coccilies. Claque deutospore est constituée par une petite masse de protoplasme, contenant nu noya; cette masse commence par produire des psendopodes lobés, qui servent an jeune organisme ponr se déplacer. Les pseudoporles sont dabord en nombre restreint; puis leur quantité angmente, ol tinalement toute lis surface de la spore en posside; l'aspect filciforme fisparait, car la deulospore virnt de se moditier en un petit Amabe. Cel élat mérite done le nom de phase ameboïde.

ROULE. - EMBRYOLOGIE. 
Les Coccidies rivent, en parasites, daus lr protoplasme de cethules

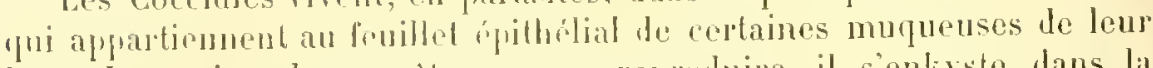
hicte. Lorsfunun de res idres ra se reprodure, il senkyste dans la collule qu'il hahitr, y donmonaissance a dos protospores, et ces dermières engembent survent lens's deutospores sans quitter l'intérienr du kyste. En détinitive, les dentospores sont rojetés à la surface de la muqueuse, par la triple rupture de la paroi des protospores, de la paroi du kyste, el de la mombrane propore de la cellule habitée. Il en résulte que les jennes Cocejdies issues de dentospores, el parrenues à la phase amoboide, rampent sur cette surface, et s'y déplacent a laide de leurs

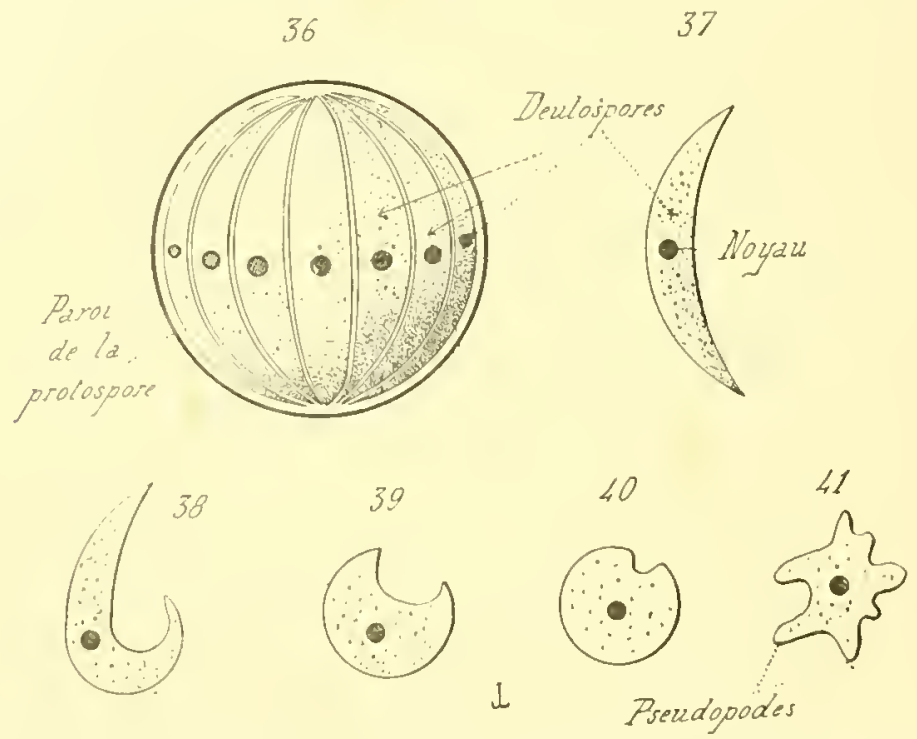

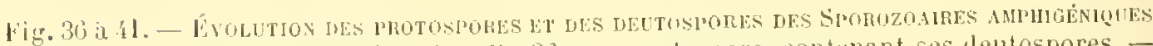
(figures demi-diayrammatiques), - Lin 30, une protospore, contenant ses deutospores. lin 37, une deutosprole devenue libre, el isolée. - lin 38. délut du déreloprement de la deutospre. - Eir 39, 40 el 11, silte de ce developrement, qui convertit la deutospore en 11 urganisme amuboide. - Dapres les recherches faites par limer sur une Coecidie, l'Eimeria fulciformis.

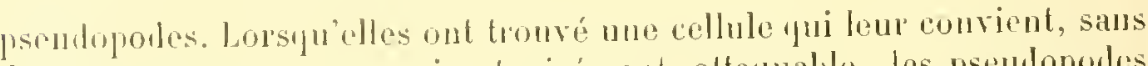
doute en ce que sa firoi rst aiscuent altayuable, les psendopodes perforent eette provi, s’insinnent lans le protoplasme de cet élément,

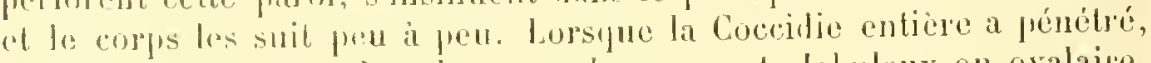
dle rétracte ses psendopodes, frend un aspect ghobuleux on oralaire, passe a l'état adulte, et présente ainsi lous les caracteres que possédait son gronératerr.

L'ívolublion des dentospores des Sareosporidies nest pas emore bien

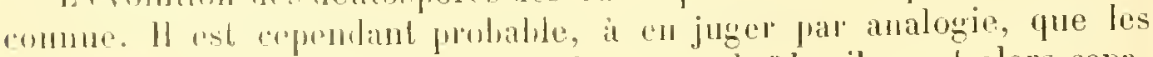
jemes passent de mème par une phase amcboide; ils sont alors capa- 
bles, grâce à leurs psendopodes, de se déplacer, pour aller ì la recherche d'un endroit favorable, ou ils revelent l'aspect do l'adulte.

Le développement des lirégarines lappolle refui dos Cocoilios, mais des observalions completes font enrore défant. A en juger pourtant d'apres les faits recueillis, il est permis dr eonsiderel, comme cerlains, la lransformation de la deulospore en un organisme amoboide, et le changement de ce ternier cu cirégarine adulte, par la rétraction des pseudoporles el par la produclion d’un épjeyte. L'érolution serait done semblable à celle des Coceidies; et même, les jemnes Cirégarines amolıiformes seraient susceptibles de pénétrej lans le protoplasme des cellules de leur hôte, comme les jeunes Coccidies, mais prour lequilter plus tarl. Il y anrait cependant quelques dillérences lo délail. - Les Grégarines vivent, non pas dans les cellules yuj limitent les cavités naturelles de leur hòle, mais dans ces cavitís clles-mèmes, et surtout dans la cavité intestinale; il en résulle jue les judividus enkystés sont fréquemment rejetés au dehors arec los excriments. Or, jour que les deutospores. yni proviennent des protospores renfermés dius ces livstes, puissent germer, il faul qu'elles relournent lans la ravilé intestinale d'un hôte apparlenant au mème type que l'hòle primilil. Il y anrail done ici de véritables migralions, el $110 n$ point un dóveloppenent sur place comme celui des Coccidies, ou celui des Sarcosporidies.

Les différences ne sont pourtant pas tries cunsidérables. Au moment où l'ùtre habilé par des Coreidies et des Sarcosporilies vient à périr, les spores de ces dernières doirent atteudre de nonvelles circonstances farorables pour se développer; il leur faut, paj conséquent, pénétrer dins un organisme presque semblable ì celui de l'hôle primilif. Il y a donc, dans ce cas, migration conne pour les Gregarines. Mais le fail est ici accidentel, tandis qu'il tend ì tre habituel chez les Grégariues; on a cepeudant constaté parfois. en ce qui rogarde les dentospores de ces dernières, des développements sur jlace.

13. - Daprès des olservations faites par Ed. Van Benelen sur les spores de la T'orospora giganter, qui vil cu parasile lans la cavité intesliuale du llomard, il semble que les jemmes Gregarines, parvenues ì la phase amobö̈le, seraient susceptibles le se reproduire frar lissiparité : d’oir genesse d'une lroisiòme généralion dodescondants. Eil. Van Beneden a donnc aux faits qu’il a constales mo importance praliculiere, dont on troure la lace dans les termes quil muploie. Le corps mème du jenue

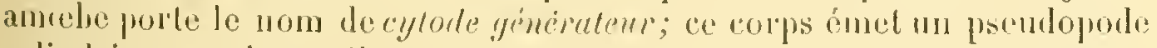
cylimbripue, qui grandit et se délache; it canse de son aspect, semblable i celui d'un rer némalode du grenpe filurir, l'antenr lo désigne par le num

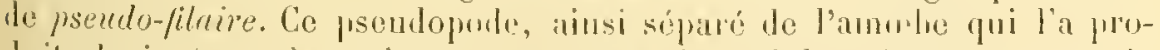

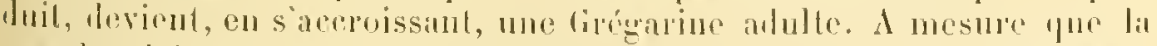

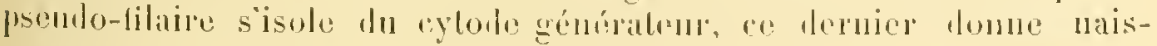
sance a 110 second pseutoporle; celui-ci sanplitic comme le premier, 
mais ne se detache pas du wode, et reste torjours en contact avec lui. Il fait passer peu à peu dans sa masse le protophasme meme du cytode, el augmente ì ses dépens; puis, lorsque lous deux me forment plus qu'un seul corps d'égale épaiscenr, lenr consemble se convertit également en me Grógrine alulto.

Il est hien évident pu'il s'agit iei dephénomènes comparables à ceux signalés chez les Imobiens. La jemne lirgarine, parvenue à sa phase amcboüle, imet des pseudopodes; parfois un te ces psendopodes se sépare de l'être qui l'a produit, pour se transformer en un individu somblable à colui lont il provient, el capahle le poursuirre la mène évolution. Cors fuits sont idenliques à coux montrés par les Imuliens; et, dans les denx cas. on loit leur donner la mime significalion : celle l'mo reproduction tissipare. Quant an développement de la seconde pseudo-filaire, elle se ramine ì la genèse d'un pisemlopode, qui grandit aux déprens du son générateur, et linit par comstituer à lui seul l'organisme entier.

Ilsuffit, enterminant, dementionnerl'existenced'ubservations éparses, nullement lices entre elles, ef tendant à faure croire que les protospores de certaines rirégarines sont susceptibles de produre des individus parfaits, sams engendrer des deutospores au préalable. Ces faits demandent contirmation.

IV. Foraminifères. - La fissiparité est presque l'mnique mode reproducteur commu chez res animan. Les seuls faits comstates, au sujet de la sporulation, fortent sur le nombre considérable de noyaux Louvés prafois dans he protoplasme d'une même loge, el sur la présence le jeunes Foraminiferes compusios d’un, de denx, vu de frois siements, dans lintérienr de colonies plus emplexes. Tolles sont les jennes Triloculimes, issues do l'olylualanes appartenant aux genres Milioln et lotalina; at les individus monoloculaines provenant des colonies de spirillina vivipura.

I. Vésiculaires. - Lil sporulation existe chez les Vésiculaires, et ne liffere pas de celle obsuré chez les antres Sareodaires. Il est necessaire cependant, from lit hioncomprentre, de connaitre l'évolution partivuliere suvie par le noyan de ces clres.

1. - liexistence d'un noyau n’a pas été constatée chez lous les Vésiculares; mais, comme la plupart les fléliozoaires et mu bon nombre de haliolaires en pussident un, il est permis de considirer sa prósence comme générale, car il faut tenir compte des diflicultés d'oliservation.

liévolulion romplète du noyau n’est pas encore élucidée; les faits suivants paraissent senls blre hors de loute. - Les indivilus jemnes portent un noyau dans leur endosirque; cet étiment est constilur par

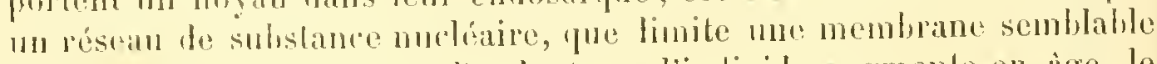
au résean par sa nature. I'endant que l'individu augmente en àge, le 
novau primitif suhit tes défomalions, et des fragmentalious, qui ne se rapporlent en rieu, selon loutes problalilités, à les jhémumines troproduction. Tout d'abord le noyan grambit, et nu nucleole alpparait dans son interieur; l’augmentation the taille nest pas régulière, car le corps nucléaje prend une forme allungée. mamelonnée parfois, an lien de rester simple et sphérique. La membrane se plisse sourent, ef ces plis, vus de face, domment au noyau un faux aspect librillaire; le nucléole offre aussi, dans certains eas, des molificalions semblables. Lnfin. certains des plis de la membrane nucliaire, devenant plus profonds, ront rejoindre d'atutres sillons diamétralement opposis, et, en se soudant, partagent l'unique novan primitif en plusieurs fragments. Ces fragments sont susceplibles ile se liviser de nouvean, toujours par le mème procéłé, qui ne rappelle uullement les pluénomènes de la kariokynise, el auqu l, par suite, on ne doil pas donner la mème signification; cetle scission est une framentation de la sulsstance nucléare, et non jas une segmentation raje, lestinée à entrainer el à ljuiger relle du protoplasme. Ce phénomeno est comparalle à la division uucléare qui se manifeste dans certaines collules en voie de dégénŕrescence: il correspond prohablement a me allération jathologique du novau.

l.es individus adultes contiennent ainsi, lans leur cmdosarque, une crrande quantitó de parenlles nucléajes: ce chiffre est parfois supérieur i cent. On ne connait pas l'arenir de ces fragments; d'apres quelpues olservations dues a R. llertwig, il semble quils sont capables de se fusionner ì noureau, el fle reconstiluer un noyan simple, ou un pelil mombre de noyax. l'eut-èlre aussi la plupart d'entre eux ne possidentils aucun ròle, et correspondont-il i remx yui, froduits par le noyau des Infusoires ciliés, sont rejetés au dehors, lors de la conjugaison.

l. - Les phases le la sporulation nout encore été olservées que che\% certains lléliozaires, quelques Radiolaires monocyllariens, el plusicurs Polycyllariens. En somme, la sporulation n’a guècé été tronvée que chez les lésiculaires déponrvus de squelelte, on lijen dont le squelette est sculement compusé de piquants; il est permis de pruser que les aulres Vésiculaires sonl capables le se reproduire par le méme procélé, mais il faut tenir compte des difficultós délude. C'rest li un olsalacle scirinx, (a) l'on ne peut suivre en délail, au lravers du test, les changrments qui s'effectuent dans l'endosarque.

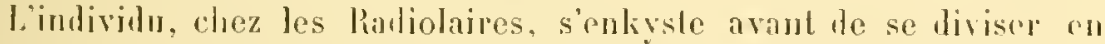
spores. Limliystement est somvent solitaire; il est pourlanl des cas où loux, et meme plusieurs imdivilus, se conjuguent arant de senlisster

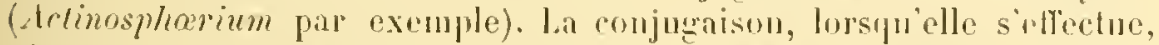

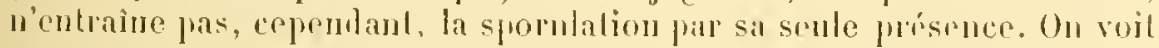
assez somvent, et surtunt clez les fléliozaires, drux indivilus de mème

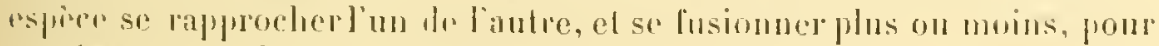
se séparer ensuile, on rester confondus, sans que l'une on l'aulprodrees 
deux issues soit forcément le prélude d'un enkystement suivi de sporulation. La conjugaison, chez les Vésiculaires comme chez la plupart des autres Sarcodaires, n'est pas la condition próalalle el nécessaire de la sporulation.

l'organisme en voie d’onliystrment peral ses vésioules liquiles, et rétracte ses psendopodes, Loui comme dans le cas de fissiparilo; seulement il s'envoloppe en untre, s’il est dépourvu de squelette, d'une membrane clitimuso épisse. Cottr menhrane ne se produil pas, ou se montre à peine lorspur l'imdividu possèle un symoletle: dans ce cas, le ropes diminue le plus possible, son volume se ribacte presque en entire dans la membrane capsulaire, el tombe au fond de l'ean. L'individu est alors enliyste.

Lorspue lenkystement sest affectur, to protoplasme se divise en un nombre variablo Je prarcolles, dont chacune dovient une spore: les phénomines intimes de ceth scission ne sunt pas élncilés. - On voit, chez lit phuparl des Radiolaires studiés jusłunicj, le novan se partager en segments. of le protoplismo rontenu dans la capsule se scimder de la mome facon; puis, pharmu des lenx parties produites so divise à son lour; et ainsi le suito, jusqu"ì re que le protojlasme, renfermé dans la capsule, se soit morectí en mu zrand nombre de petites masses, dont chacune posside 1 frament de noyan primilif. Ces pelites masses sont des spores. Lorsqur loules unl pris naissance, la membrane capsulaire se brise, et elles soml mises an lilurlé. In moment le four ímission,

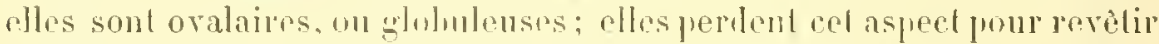
celui de zoospores munies d'un on de drux lomels. Jpris mu sertain

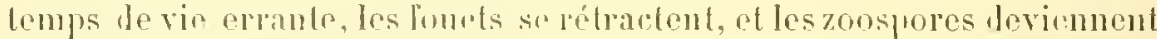
semblables a leur cremiralour.

La série les phónomónes parail dre la mème chez les lléliozaires; elle présente copendant moins de fixité. Linsi, les Chlulhrulima plegans, qui appartiennenl an eroupe des lláliozoaires sumeletifires, tantôt

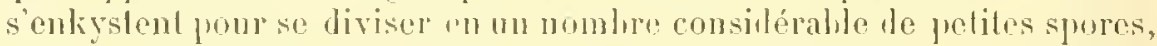
tantot se hornent it se seindup en trois partios, dont denx senfoment revetent l'aspect to spors, la troisiome restant dans la carapace matenchlo jour y devenir un organisme abulte. I'aulpes lléliozonires apparterant i la trihu lus lléliozoaires nus, les Ciliophrys par exemple, offrent encore phus de variche : parlois un individn se segmente en un certain nombre do spors, pui rovolent ensuite l'aspect de zoospores munies do lents fonuts: dans llantrus eas, lindividu, an lien de se segmenter, se transformo tout rntier m une seule zoospore. La spornlation nost fonc pas, cho\% les Vísiculaires les plus simples, un phri-

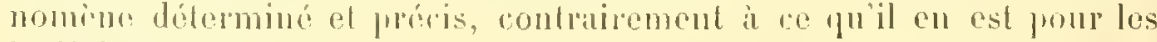
Radiolaires.

Les spores de plusiours theliozoaires, et notamment celles des Actimosplicrim, othent parfois un phenomone remarquable. Elles se fusionnent deux pill doux, dans la cavité du kyste, par me véritale 
conjugaison; le corps résultant de celle conjugaison est la spore définilive, capalile de se transformer en une zoospore, el de parrenir ì l'útal adulte. Ce phénomène rappelle la conjngaison zrgosporée de cerlaines Mlgnes, el celle des Volvocinées.

Vl. Flagellates. - La sporulation des lilagellales est à peine connue; peul-ètre mème ce procédé de reproduction n’existe-t-il pas chez la plupart de ces ètres. Cependant, comme cerlains l'entre enx prisentent une fragmentation sporulaire, il est permis diulmeltre que ce phrinomène se retrouve chez les autres représentants in groupe, mais is de longs intervalles, et d'une façon accidentelle sans doute; linfluence des milieux extérienrs dait joner un granıl röle.

Pour ce qui est des Nuloflagellés et des Choanoflagellís, les Euglena viridis soul les senles à montrer une spornlation; el encore ce phénomène parail-il ètre une exagéralion, quant an nombre des segments produits, de la fissiparité précédée d'enkystement, que présentent ces animaux. La genise du liyste ne semble pas devoir être nécessairement précédée par une conjugaison, bien que l'union de deux individus ait été dfícrite à diverses reprises; l'enkystement est le plus souvent solitaire. L'indivilu se conlracle, perd son fonet, prend une forme ovoüde, et s'entoure de la paroi cyslique. Son noyau grossit. sallonge, el se divise en denx, fuatre, huil petits segments, ou davantage; le protoplasme se parlage comme le noyan; et lorsque cetle série de fragmentalions est achevée, le grénéraleur' s'est converti en un grand nombre de petites spores. La paroi cystipne se brise ensuite; les spores sont mises en lilierlé, et se transforment en zoosporrs munies d'un seul fonel; ces dernio res deviennent plus lard des Ënglines adultes. - On désigue souvent le novau des indivilus enkrstés par le nom de corps embryonnaire; ce lerme est improprer, car il tentrait à faire croire qu'il prouluil senl les jemes spores, ce qui u'est pas.

Comme les luglines, et divers aulres Flagellates, se fissiparisent parfois après s’ètre enkystés, e’est-i-tlire s'entourent d'une praroi cyslique, el se divisent ensuile en deux descendants. il est probable que leur sporulation dérive de leur lissiparité. Il suffit en eflel, les phénomines primorliaux élant les mèmes, que les demx segments se pardagent à leur tour, pour obtenir la sporulation telle qu'elle est décrile ci-dessus.

Ces considéralions sont applicahtes aux Ilinoflagellés, dont la fissiparilé est sonvent frécídín par un enkystemint. Parfois, on a trouvé des kystes de Dinollagellés, renfermant quatre ou huil corps proloplasmiques nuclés; ces corps sont irvilemment des spores, at he gunese de ces spores duil atre prise comme nne exagéralion de li lissiparité habituelle. La forme des kysles liflere parfois de celle ollerte par limlivilu normal; lels sout les r'eridinium, dont l'alulte est ovalaire, el le kyste rerourbé sur Ini-mème en un croissant.

La sporulation des Cystollagellés présente, on l’a vu plus haut, les 
caractires d'une gemmiparili. Il se pourrail cependant que ces bles se reproduisissent aussi par une raje sporulation, car J. Nïller dit avoir

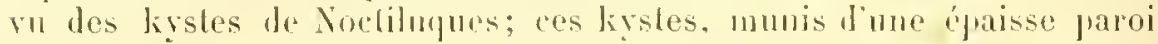
transparente, nout pas éfir suivis dans leur érolution.

\section{RÉSUMÉ}

S 1. - Les Prolozoaires sarcodaires offrent trois modes de reproduction : la tissipariti, la gemmignritr, et la sporulation.

\$. - Fissiparité. La lissiparité est le procédé par lequel un iulividu détermins se partage en dems autres imdividus; elle est complote, lorsque la séparation des denx individus-filles est moliver ello est incomplite. lorspue les leux imlividus-filles restent unis par un prartic de leur corps. Il se prouluit un cotonje dans ce dernier cas, wr le mime phénomène est réfélé daus loules les générations sucressives des descendanls.

Les Honiriems se tissifarisent par étranglement du probojlasme; celle division nesl point prickdre prar celle du noyan, puistue ce dernier manque à ces ètres.

La fissiparite des fmoliens ressemble a celle des Monériens : la seule diftérence porte sur la segmenlation du corjs nucléaire, car les Amoliens possident un noyau.

La lissiparité n'est pas conume oluez les sporosonires: an revanche, alle possede une graude impurtance chez les Foraminifires. La livision est romplete chez les Monothalames: dans ceptaiss ras cependanl, hez les fromia socinlis entre autres. Jus individus restenl unis par leurs peudoporles; ce procidé elfectue mue transition vers la lissiparilá inconplete les I'olylualames. Ces derniers formenl des rolonies, asprectirrégulier chez les typor les plus simples, à disposilion gromintique cluez les lypes superieurs.

Les l'ésicularies offrent de mème la fissiparilé complete el la fissiparié incomplele. Dans l" premier cas, elle ahonlit ì la sáparalion

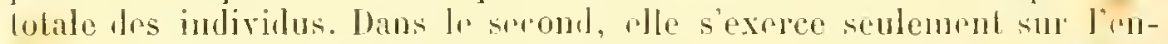
dosarque; la colonie est alors constituée par un erlosarque simple. entomant plusienrs masses endosarcales munies de leur capsulu. Les Radiolaires jolycyltarious sont les seuls a prósenter ca demier procédr.

La reprobuction tissipare est lies rópandue cliez les Flayellates. -

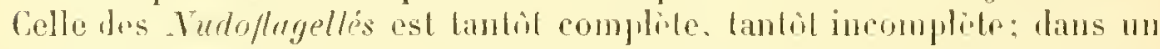
cas comme dans lautre, elte est fanlibl longiludinale, lorsque le plan do

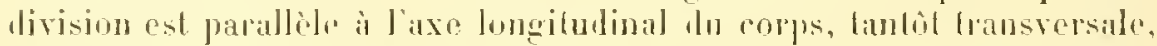

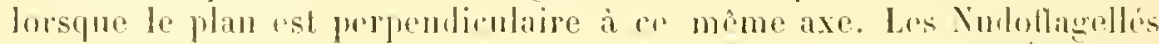
prisontrut donc qualre principans moles de segmentalion fissipare.

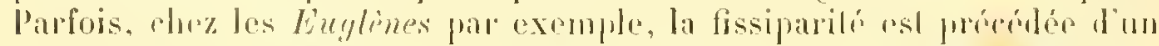

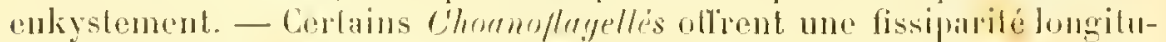

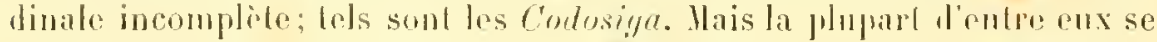


lissiparisent transversalement, la division élant tonjours complite. Sumoment, tankit les individus-tilles se séparent ditinitivement fos ms des antres, at tantöt ils se rassemblent en un ronsorlium pour former me colonie par agrégation. - Les Dinoflagellés se reprodnisent par tissiparité complite, soit dans la cavité de leur carapace, soit hor's de cette cavité: ils s'enkrstent fréquenment jour procéder à cetle opération. It en est le mime pour les Cystoflugellés, qui commencent par pridre leurs apprendices arant de se diviser; puis la séparation des deux desrendants élant effectnce, chacun d'eux prorlnit à nouveau des apremtices, jour revêtir l'aspect normal.

\$3. - Gemmiparité. La gemmipraté est, hez les Surcodaires, une modificalion le la tissiparilé, on de la sporulation. On l’a oliservíe seulement chez les Amobiens et les Cysloflagellés.

Parmi les Imoliens, les Ireella sont les senls il hourgeonner, sur la face inféricure de leur carapace; le protoplasme du générateur émel, par la bouche de cette rarapace, un bourgron, qui se tissijarisr rapidement un certain nombre de fois; les seguments se séparent ensuite les uns des antres, et deviemuent autant de descondants.

La gemmiparité des Cystoflugellés est une altíration dn divelopprement sporulaire. Lindividu perd ses appendices, ferme sa bouche, et senkrste a demi, car il mo possede point de paroi cystique vraie; puis son protoplasme produit, dans la région buccale, un nombre considérable de petits hourgeons, qui se séparent de lui, premnent l'aspect de zonspores, el se transforment en jeunes Noctiluques.

§ 4 . - Sporulation. La sporulation des Sarcodaires est le procédé par lequef nn individu divise son corps en un grand nombe le pelites masses mucléces, les spores, dont chafune est capahle de produre mu nouvel organisme semblable au générateur. Lal sporulation, précílée ou uon d'une conjugaison, déhute normalement par le plénomine lésigué sons le nom i'enliystement; lindivilu-mire rétractr ses appendices, conlrarle son protoplasme, abambne son test, sil en possirle un, el sentoure l"une paroi propre, yui est la paroi cystique. Le noyau et le protoplasue se divisent ensuite en spores; chanue spore posside igalement une paroi propre, la propi spomelnire. Les spores sont mises en liberté frar la rupture de la praroi cystipue; puis lil spore se déluarasse en sus de sal paroi particulirpe. le prolophasme nuclée de la spore, devenu entioment libre, prend l'abord l'aspect d'un Zoospore, puis revet lit forme normale de lorganisme mitternel. - Toules les classes des Sarcolaires présontent ce procédé reproductemr.

Parmi les Homéviens, les Lépononóriens seuls se peproduisent par sporulation, suivant nu mode pui ne sécarte en rien de la marche

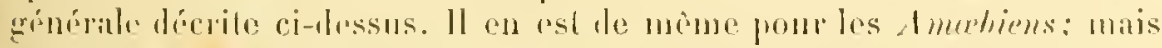

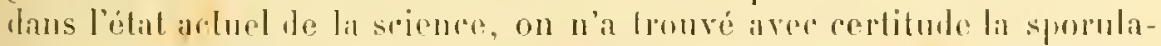

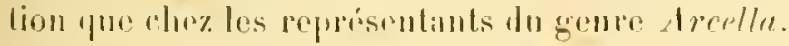


La sporulation prend une grande importance chez les Sporozoaires; ce fait est te corollaire de la vie parasitaire de ces êtres. - La sporulafion des Monogéniques n'est précédéc ni de conjugaison, ni d’enkystement véribble aver paroi cystique; il n'existe qu’une seule génération de spores, nommées sonvent psorospermies. Les spores des Microsporidies sont lios petites, et munies d'un protoplasme compact; celles des Myxosporidies sont phs grandes, et leur protoplasme, entouré par une paroi hiralve, renforme deux vacuoles, qui contiennent un tilamont replié sur luimème. - Ia sporulation des dmpligóniques est sourent précótér d'une conjugaison, parfois accidentelle, normale chez les Grégarines: clle est toujonrs accompagnce l'un enkystement complet. Les Amphigéniques présentent denx généralions de spores : les prolospores, ou piseudo-navicelles, et les deutospores, ou corps falciformes; l'individu enlirsté produit les potospores, qui engendront à leur tour les deutospores; ces dernieres évolurnt pour se trausformer en individus parfaits. Les protospores sont chassées de la cavité lu liyste, soit par ruplure de la paroi cystipue, soit an moyen de sporobluctes; tes dentospores, en so développant, quittent leur paroi propre, el passent par me pluase amoboïle, durant layulle elles se fissiparisent parfois.

La sporulation u'est pas tris connue chez les Foraminifires. Il n'on est pas ainsi pour les lésiculuires, dont le développement sporulaire ue differe pas de la marche générale dúja indiquée; le role du noyau n’est cependant pas liès bien élucilé, car ce corps nucléaire sulit souvent une dégénérescence particulicre, caractériséc par son hypertrophie, et pal" sa division en un gramb nombre de petits fragments.

Parmi tes Flugellates, les Euglénes seutes, et quelques Dinoflagrellés, montrent des phínomenes certains de spornation. Ce procédé reproduclenr dóhule comme mo fissipariló ordinaire; mais les denx segments continnent at se diviser encore un certain nombro le fois, et produisent ainsi les spores. Lévolution ultérieure le res spores n'est pas encore conour. 


\title{
EMBRANCHEMENT
}

\section{DES \\ PROTOZOAIRES CIIIAIRES}

\section{CIAPITRE II}

\author{
EMBRYOLOGIE DES CILIAIRES
}

\section{1. - Considérations générales.}

I. Garactères. - Les Protozoaires riliares sont des animaux unicellulaires, conslamment privés de preuloportes et de foucts, et munis, au moins durant une partie dr lonr vie, de cils vibratiles.

les cils viluatiles sont des appendices locomoteurs, le nalure chilinense, implantés par leur base dans les régions superficiclles de lorgiznisme aupuel ils apparliennent, et semblables a des pelils batonnels l’une exlrême trinuilé.

Le corps des Ciliaires est, dans sa structure, dime plus gramble complexité que celui des Sarcorlaires. Sous re rapuorl, lun des cararteres los plus imporlants consiste en la prisence de drux masses de substance nueliaire, lont l'une est d'halibude plus rolumineuse pue l'autre; la premicre est le noyau, et la seronile le micromoyau. Dans les descriplions des auteurs, te nuyau est frépuemmont désigné par les termes de nucléus, on d'endoplaste, el le micronoyau par ceux de micronucléus, d'endoplastule, ou de paramucléns.

1I. Développement en général. - Les Ciliaires se reproduisunt suivant les lrois moles déja signalés pour les Sarrodaires : la lissipariti., la gemmiparité, el la sporulation. Mais, conlrairement aux Sirreotaires,

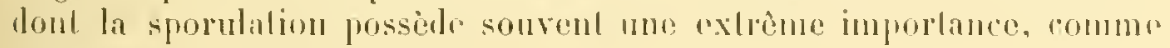
procídi de reproduclion el de consurvation de l'esprice, la fissiparilí jouc ici le phus grand rojle.

La fissiparité étant l'acte par lepuel un individu délorminése parlage.

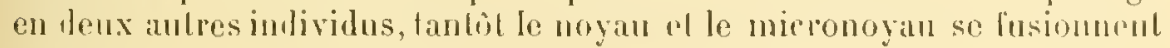
en mu seul anas, qui se livise cu entainanl la segmentalion du proto- 


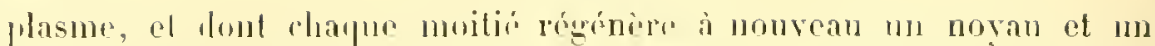

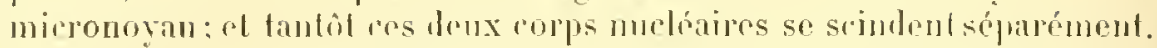
la résultat ultime est le mème dans les drux cas; le genératenr a engendrí deux descendants semblables ì lui, qui se reproduisunt de noureau par le mème moyen. Jusqu'ici, les faits ne diffirent proint de ceux olservés clez les Sareodaires; mais les Ciliares présentent, en suphlus, mne seconde sirie de phrinomenes, abscute ou accibentelle, du moins dans l'étal actuel dr nos commaissances, chez les représentants du premier de ces embranchements, nécessaire ot normale chez ceux du denxirme. Celte seconde séric le phrnomènes est me conjusison, accompragnéc de rajeunissenent.

Lus chérations issues le la lissiparite se succedent en mombre assez. consilfrable: chez les Sarcolaires, cette succession croissante est arrèléc par la sporulation, do moins dans h phos grand nombre des cas: ello l'est par la conjugaison chu\% les Ciliaires. Heux individus s'accolent, perdent leur noyan par atrophie, puss divisent leur micronovan en plusieurs parcelles; ces dermières st bétruisent, sauf deux pal organisme, et chacun de ces ilpes échange une de es parcelles avec son congénère: ensuite, fous denx se séparent. La conjugaison n'aboutit donc pas a l'union compliotr et lofmitive des itres mis en cause, mais simplement à l'échauge le frazments nucléaires provenant du mioronovan de sun assocjé tomporaire: cos ienx corpusemles se fusiomemt, et la masse risultant de eot assemhlage se segmente en deux partics: liune d'elles so transforme en mu micronovan, el laulre en un novau. Lopranisalion premiore siost dome rotrouvión.

Celte conjugajom est un verilable acte de sexualite, comparable, en tant que significatiour, à la reproduction sexuolle des Matazoaires. Lovule de ces derniers ne se dévelopyr quaprès l'mnion de son pronovau femelle avec mo prónoyu mile; ce fait répond done, en définilive, à la jonction de denx parcellrs nucléaires dorigine diffrente. Or, lexposé précident montre qu'il en est de mime dans la conjugaison les Ciliairos.

Celle dernione ne cause pas la sporulation, mais dotermine senlemont f'ichange de particulis nucléaires: apris quod, les individus "onjugues se séparent. Cel cohange est ici nicessaire. La fissiparilé, pripelíc un trop errand nombre de lois, ambne la dégénérescence des imbivibus, et leur rahugrissement; lorsque art echamge a eu lieu, les

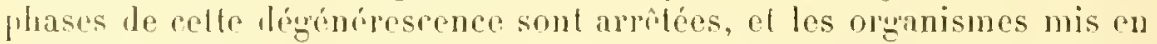
"ause so tromvent rapaliles le fourur un chiflre considipalie de génerations surecessives. Il sest donc manifeste, far l'óchange, un véribble rajounissument de la substance des noyanx, semblable a celui signalé rhez les Nlewes.

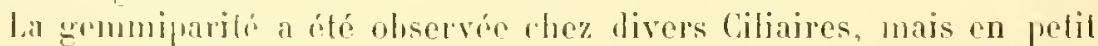
mombre. Le corps de l'imlivilu-mire poduit ass bontereons, pui se

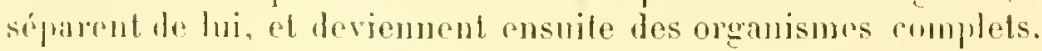


La sporulation est rare chez les Ciliaires; on l'a trouvée jusifu'ici chez diverses especes parasites, et un petit nombre l'espèces libres. Lille est souvent précédée d'enkystement; les spores brisent la paroi du kysie, et se transforment ensuite en nonveanx organismes, sans passer par l'état de zoospores. Aussi la sporulation, à en juger d'apres nos comnaissances, ne semble-t-ejle pas joner un grand loble parmi les procédés de reproduction; la plus haute importance, sous ce rapport, est acpuise à la fissiparité accompaguée de conjugaison.

\section{2. - Reproduction par Fissiparité.}

I. Euciliès. - On a suivi plus haut, dans les consilérations générales, exposées sur le déreloppenent des Ciliaires, la série des phénomènes yui se succèdent dans la reproduction des Euciliés. Ces phénomènes sont rassemblés en deux groupes : la fissiparilé d'ahorl, qui entraine l'augmentation du nombre des individus; la conjugaison ensuite, qui, en rajeunissant la sulsstance nucléaire, permet de fournir sans fatigue à de nouvelles lipartilions.

Fissipanté - A. La segmentation fissipare des Euciliés présente toutes les morlifications secondaires, déjà signalées thez les Sarcodaires flagrellaires; tantòt elle s'exerce suivant un plan parallèle à l'axe longitudinal du corps (fissiparité lonyitudinale), et tantôt suivant un plan fierpendiculaire à ce mème axe (fissiparité transversule); tantòt elle est complete; tantôt, par contre, elle est incomplète, et détermine la lormation de colonies. Elle offre même, parfois, une particularilé que les Sarcodaires ne montrent pas : le dimorphisme des descendants. Le plus souvent, les deux individus-filles sont semblables l'un à l'autre, comme ils le sont ì l'organisme maternel; la fissiparilé, daus ce cas, est egale. Hais, partois, un seul des descendants ressemble an générateur. le second ayant un aspect propre el un rôle particulier; la fissiparité est alor's inégale.

D’ordinaire, la fissiparité transversale est complèto et égale; la fissifarité longitudinale est souvent incomplite, parfois inégale. Dans cerlains cas, fort rares, le plan de segmentation est oblique sur l'axe longitudinal du corps, nais il est permis de rapporter ces faits it la fissiparité tranversale.

Quel que soit le mode cmployé, les phénomines intimes de la fissiparité ne changent pas; ils sont répartis en deux types principaux. bans le premier type, de beancoup le plus fréquent, le noyau ef te micronoyau se segmentent séparément, el leur division détermine celle du protoplasme. Le noyau s'allonge, en se portant vers le milien du corps, el se partage en deux masses égales, on presque égales; le proloplasme se scinle cusnite d'iprès le mème plan que le noyan, et le micronoyau se divise en mène temps; chacune des deux parties, formées ainsi aux 
lépens du générateur, contient done une moilié du noyau, el une moilié du micronoran, de cet individu. - Dans le second type, le noyan et le micronoyau de l'organisme maternel se confontent; la masse résullant de cetle union se partage en deux segments, el le corps de l'Infusoire se divise suivant le meme plan. Chayde descendant conticut donc, fusionnées en un seulcolps, de la sulistance nucléaire el de la substance micronucléaire; ces deux snlostances s̈isolent, lorsipue la segmentation est achevée, et reproduiscut, dans le corps de chacun des rejetons, un novan et un micronoyau.

B. - La fissiparité est complite choz la plupart des IIolotriches, des IJétérotriches. ol des Ilypolriches; dans ce cas, clle est au surplus transversale el égale. La bipartilion n'offre rien de particulier chez les Holotriches; les cils viluratiles étant partout d'égale longueur, le corps se borne à s'etrangler, vers son milieu, suivant une ligne circulaire. L'étranglement devient de plus en plus profond; et, tinalement, il partage l'individu en deux moitiés semblables, qui sont autant de descendants. L’un de ces derniers conserve, de l'organisme maternel, la lonche, et la région buccale arec sa forme particuliere, varial,le suivant les genres; l'autre est obligé le produire i nonvean ces organes, pour revetir l'aspert habituel de l'espece à laquelle il applartient.

Les faits sont plus complexes chez Ies Hypotriches, el surtout chez les Hétérotriches; les cils qui entourent la bouche different des autres par leur laille, el délimitent, antour de celle ouverture, une région nommée le péristome. An moment oì l'un de ces itres va se diviser, et pendant que les ćléments nuclíaires se segmentent, une couronte de cils vibratiles. semblables à ceux du péristome, el disposés de la mème façon, apparait vers la région médiane du corps; la scission du protoplasme s'effectue en arant de celle seconde courome. l'ar lì, si l'un des individus-filles conserve la louche el le préristome de l'organisme maternel, le second possede nu péristome lien développé, au moment mème oin il se sépare du premier, et il lni suffit de creuser une onverture lonceale pour présenter l'aspuect normal. Lorsque le péristome est assoz conrt, conme celuides Bulantidium par exemple, le deuxième péristome prend naissance séparément; par contre, lorsque le péristome, très allongé, sétend sur la majenre partie du corps, chez les Bursuria. les Sprostomm, ete., il se horme il s'étendre davantage, puis à se diviser en deux parties, au niveau du plan suivant lequel s'effectuera la segmenlation.

C. - La fissiparilé des l'éritriches est lantòt complète, lantùt inconplete, et presque loujours longitudinale. Elle est égale dans le cas de tissiparité incomplète; par contre, dans celni de fissiparité complite, ollo est parfois ryale, pt prurois incugale.

Le corps des l'éritrichuses porté par un pédoncule plus on mons long; la division longilutinale s'exerce sur le corps entier, atteint mème, 
dans certains cas, la partie du pédoncule qui touche directement au corps, mais ne s'étend pas jusqu’à sa base. les phénomènes sont semblables, quel que soit le résultat ultime de la segmentation. La rouronne spiralée de cils vibratiles, placée autour de la bunche, et qui encarle le péristome, se contracte quelque peu; les noyaux se divisent les premiers. puis le protoplasme se partage à son tour en deux massus. La scission
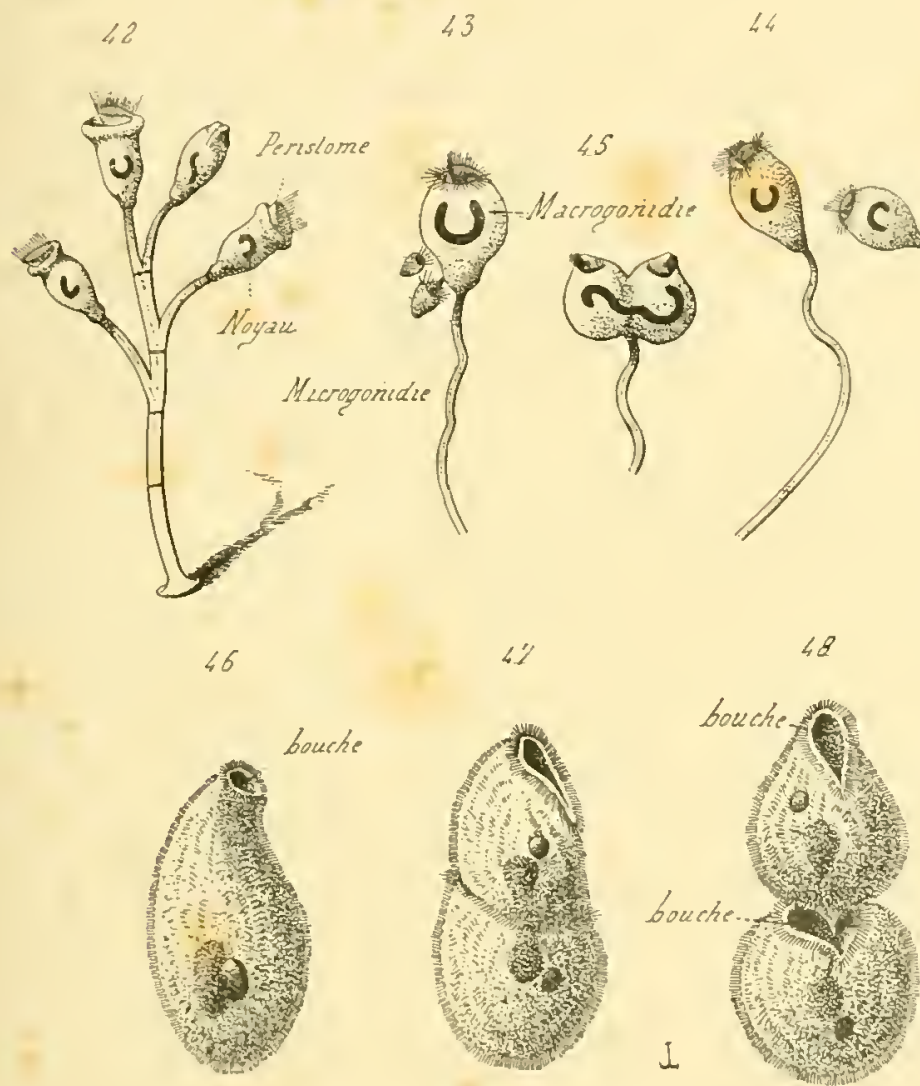

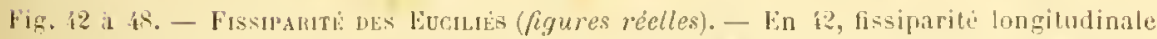
incomplete d'un Peritriche lu genle Carchesium, lonnant une colonie. - Ln i3, if et is, li-siparite lougitudinale complètc d'un l'uritriche lu gente Vorticella (d'apris slein); en 13, fissiparite inegale, donnant des microgonilies el. des macrogonilies; en if, fissi. parjé égale, lonnant des deseembants semblables; en 45 , debut d'une lissiparilè érale. - En if, 6 el 48 , plotses successives de la lissiparite, transversale et complete, l'un lletẻrotriche du genre Balantidium.

délute par la rétrion péristomiale, coupe en deux la houche ef la conronue de cils, puis sétend an rorps entier en sapprochant per à peu le la hase, et finalement atteint le pédoncule. Le corps de l'or'gunisme maternel s'est anısi divisé en deux individus-filles, mmis d'une partie de 
péristome, et n’ayant qưì compléler colle région pour acquérir la slauture normale de ladulte.

Lorsigue la fissiparité est inromplete, plle est au surplus égale, car les deux deseendants se ressemlulent enle enx. La seguentation s'exerce senlement sur une petile partie du pédoncule, voisinu du corps, mais me s'étend pas anx autres régions de cet appendice; il résulte de ce fail nn assemblagr le deux nourcaux ilres, munis d'un petil pédicule, el monlés sur un mème pied, qui rorrespond à la région basilaire du pidoncule materual. Ces denx lnfusoires de seconde génération allonwent prelque peu leur pédicule particulier, se divisent encore al'a rès le mème procélé, et ainsi te suite. Il se produit ainsi une colonie, consliluée par phusienrs zoö̈les, dont les pédicules sont portés par un gros pied inilial, altaché à un corps itranger. Tels sont les Curchesium, les Epistylis, ol plusieurs autres genres.

Dans le cas de sogmentation complice, la fissiparilé est lantôt rónale, tantibl inégale. - Elle est égale lorsque les deux individus-filles sont semblables l'un et l'aulre par la laille, hien que le péristome ne soit pas disposé de la mème façon. La division s’arèle au niveau du point d'union du corpes avec le pédoncule; les deux descendants sont alor's portés par le même pied. P’uis l'un de ces ètres se sépare du pied, tandis "jue l'antre conlinue ì lui rester adhérent; ce dernier conserve, de celte facon, le pédoncule maleruel, el n’a yu’i compléler son péristome pour levenir alulte. Il n'en est pas de mêne pour le promicr. Celui-ci est dépourvu de pédicule; sa couronne de cils vibratiles lui sent pour nager, et se dóplacer librement dans l'ear. Il se tixe ensuite pall une région opposée a la comronne, allonge cetle zone en un pédoncule, et devient semblahle à son congénère.

La fissiparité complele ost inigale, lorsque les deux deseondants diflèrent par teur laille. Loronisme libre est beancoup plus petit que colui resté sur le pédoncule; il a recu las noms de microsoüde el de microgonidie, contrairement i ceus de macrozöide el de macrogonidie lonnés au second. En outre, la division s'efleclue de telle sorte que le pristome entier reste la proprićté du macrozoïle; le petit individu libre produit alors mue compone vibmatile dans la région postérienre de son corps, el s'en sert pour nager. Ies microgonidies paraissent incapables le se fixer pour se compléter à elles seules. Leur rôle est en rapjort avec la conjugaison; ils sont en effel chargés, semble-t-il dapris les rares olsservations faites, de se fusionner arec les macrogonidies, pour déterminer l'enkystement ef lit spormation de ces dernières. - l'arlois, les deux lypes de lissiparité lomgiludinale complete, la segmentalion rgale el la sommenlation inégale, se mélangent l'un avee l'autre; en effel, l'individu lifre formé par division écale, snivant la lescription donnée. ci-dessus, se livise il diverses reprises, el donne naissance a un nomlre variathe le destendants, qui, dans ce cas, sont tous des microgonidies.

Ces faits, observés chez les Vorlicelles, sunt tries remaryuables. Wor- 
dinaire, la tissiparilé des Euciliés aboulit à la genese d’iudivilus semlilables, capables de se srinder it nomvean, el de se conjuguer jour rajeunir leur noyau; apres quoi, les deux organismes conjugrués se stiparent l'un de l'aulre, el recommencent leur évolution fissipare. Les phinomines offerts par los Vorlicelles sont plus complexes, et liennent a un véritable dimopphisme sexuel; juisque cerlains imlivilus, les microgonidies, sont incapables de division fissipare, teur unique rote se hornant i se conjuguel avec l'aulres imdivilus normanx. De plus, celle conjugaison n'est pas temporaire, mais hien permanente; la microgonilie et la macrogronidie se fusionnent compliatement, el restent confondues en un seul corps.

La conjugaison ordinaire des Euciliés peut ètre considéréc comme un acte de sexualití bien faible, ayant pour but le simple rajounissement de la sulıslance nucléaire. La sexualité des Vorticelles est plus complète; senblable, en cela, à celle de certains Sarcodaires, des Grégrines entre autres, elle rappelle presque la sexualité des Métazoaires, puisqu’il existe chèz elles des organismes sexués lifférents, et s'unissant foul enliers sans se séparer jar la sujle. Seulement l'or ranisme d’une Vortirelle, étant coustilué par une seule cellule, comme celui de tons les autres Prolozoaires, n'est point divisé en une parlie somaljune et une partie généralrice, par conlraire ì ce qu’il en est chez les llétazoaires; l'étre tout entier est fonction daus la scxualité, les deux parlies n'étand nullement dislinates l'mue de l'autre.

I). - La fissipariló, répétéc un grand nombre de fois sans ètre accompagnée de conjugaison, entraine, à sa suite, des phénomenes de dégénéresence; les oliservalions, eflectuées par llaupas, sont conchunles i cet ryarl. Les généralions fissipares se succident l'une l'autre pendant un laps de temps souvent fort longe, el avec une rapilité varialile, suirant que les condilions de milieu sont plus ou moins farorables. Le nombre de ces gonéralions successives, qui se suivoul sans être interrompues par la conjuraison, est considérable; 316 enriron from les Sulylonichia pustulata, G60 el davantage chez les Lencophrys patula, ele. les individus, pruluils par les premieres divisions fissipares, sont tous grands, hicu comslitues, el possedenl leurs denx noyanx complets; il r'en est pas ainsi pour ceux des dernières. Leur taille est de licancoup at1-1lessous de la moyenne; celte diminulion va jusqu'i leur domner des dimensions moindres du liers, ou du quarl, des organismes morman. Leur noyau se rapelisse, el se brise fn fragments, qui disparaissent par résorption ou par expulsion; teur micronoyan subil des modifications analognes, et satrophie presque complólenent. En somme, les individus des dernieres grénéralions subissent des phrmomenes certains de dégénérescence sénile; et, si la fissiparilé conlinuail i s'exrocer sans ancume intervention de conjugatison, elle aboulinat soms peu ì la mort des deruicrs ètres engendrés. 
La conjugaison est destinée à empècher cette fin. Par son intermédiaire, les noyaux prennent me nonvelle vigueur, el sont susceptibles de fournir encore à un grand nombre de divisions; lorganisme entier acquiert par elle la vitalité qui lui faisait défaut. La conjugaison détermine donc mu véritable rajeunissement du corps des lulusoires.

Coxuganox. - Les phénomines de la conjugaison, olsservés autrefois par Balbiani, ont été íludiés depuis par plusieurs auteurs, nolamment frar Bülschli el par Maupas. Liessence mème de ces phénomènes consiste en l'accolement de denx individus, suivi de modifications dans le plasma uncléaire. le noyau se désagronge sourent, et disparait; le micronoyau se divise en plusieur's prarcelles, qui s'itrophient également, sauf deux; ces dernicres jouent seules un rile actif dans la conjugaison. P'uis, lorspue les segments du micronoyu ont accompli leurs lonctions, les deux individus se séparent. Le micronoyau pussiale done, seul, une valeur gémétique lans l'organisme des Infusoires: lin noyan n'en a point, el n'exerce sans doute llartion que sur la vie nutritive de l'ètre.

Cette conjugaison est temporaire, ear les individus conjugues ne se fusionnent pas liun aree l'aulee, of sisolent it noureau forspue l'acte est accompli. Les phínomines principaux, offerts par elle, sont au nombe de trois, qui se suecedent dans lordres suivant : acentement des individus, moditications mucléares, et séparation définitive des individus préalablement accolés.

$I^{\circ}$ Accolement. - Les individus s'accolent par des réugions correspondantes de leur corps, vitriblos suivant les esproces, ou phutôt suivant la forme extérienre présuntée frar ces espèces. Le plus sourent, les deux pelits ètres neltent leurs faces ventrales en contact, et sunissent ainsi : tels sont les I'tremaxium, les stentor; d'autres, comme los Coleps, se joiguent par lours extrénités antéricures; il cu est enfin dont la conjugaison s'etrectue par les côtés du corps (stylonycha). (Yuel pue soil le mode adopté, cet assemblage offre les mèmes particularités; la cuticule disparait au point de contact, ef les deux proloplasmes se joignent. II s'étahlit ainsi une union intime entre les masses protoplasmiques des individus, mais qui ne ra pas juscu'a la coalescence complete; les organismes en présence restent distincts par le reste de leur corjus, et ronservent tous leurs appendices particuliers. La conjugaison se réduit ici il la simple juxlaposition des proloplasmes, de façon ì permettre aisément l'échange prochain des particules nucléaires.

2. Modificutions nuclécires. - Ces modificalions portent à la fois sur le noyau et sur le micronoyan. Celles de ce dernier sont les plus importantes, car cel amas de substance nucléaire joue le principal ròle.

A. - Le noyau se fragmente sourent en petites parcelles, qui lantòt sont expulsées, et tantôl dispraraissent sur place par atrophic. Parfois, il est conservé, chez les Paramoeium bursuria par exemple; mais dans 
ce cas, il sunit plus tard au futur noyau de nomvelle formation. Dans les denx moles, ce corps nucléaire ne possede ancune fonction.

Il u'en est pas de mème pour le micronoyan. Celui-ei grandit,

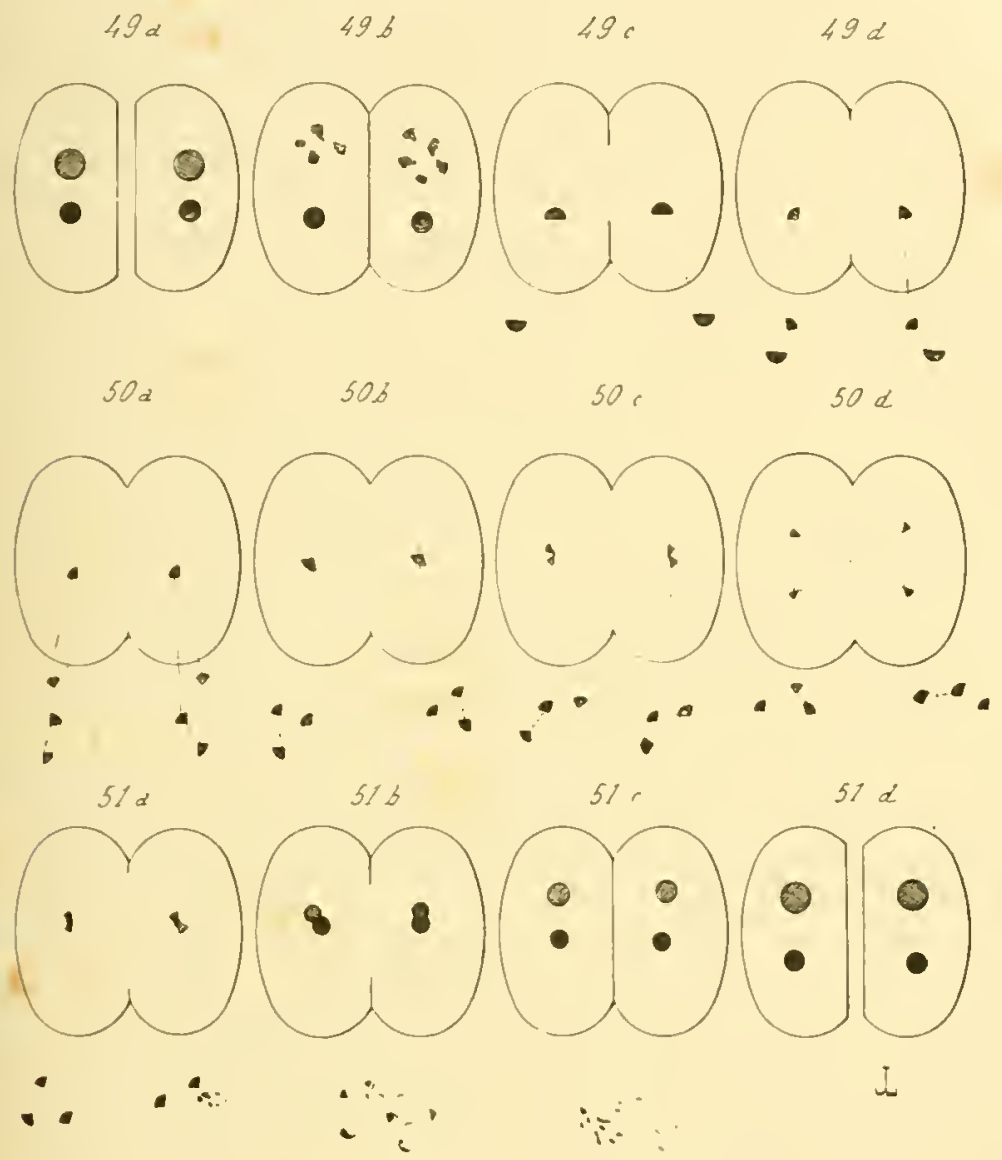

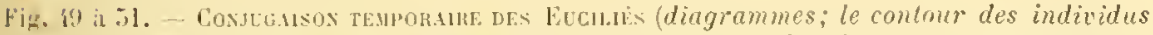
est représcule par un trait, le noyau par un cercle aris, le micronoyau par un cercle noir). - Ln it, dehut des phases; $a$, rapprochement lis individus: $b$, accolement des individus et morcellement de leurs noganx; $c$, premiere division du micronoyau, la frtrtie non ulilisec est supposée rejetee; $d$, nouvelle division du mieronoyau. - En 5l), suite des jhases, jusqu'a l'échange nuclèare; $a$ et $b$, morcellement des frarties non utilisecs du micronoyau; $c$, division de la partie sexuelle du micronoyau en prénoyau mâle el prenoyau femelle; $d$, echange des prenoyax. - lin 51, achevement des phases, justyu'it la sejaration des individus: $a$, union des prenuyaux echanges; $b$, scission des deux masses, issues le celle union, en un noyau el un micronoyam; $c$, achèrement du noyau ct du micronoyau de ehaune individu: $d$. sejaration des individus rajennis.

s'allonge, et se convertit en un filament, qui ue reste point droit, s'incurre plus on moins, et parfois mème se dispose en un peloton. Sa 
sulistance parait se lithérencice en librilles paralléles, quelque peu éparssies vers lo milicu dre lour longuenr, le maniere a simuler mo plapue bqualorialo; le mieronoyan se divise ensuilo en demx parties cgales, le plan de division passant par la playne. Cot élément s'est donc scindé en llenx moitićs. par un procílé qui ne rappelle on rien la karvokinese, et qui correspond à une véritalo segurentation lirrete; rn affiet, on ny tronve point de centrosome, ni de bipartilion des hatonnets pirmaires (on anses primaires) en bitonnets secondaires (on anses jumelles).

Les deux masses émanées du micronoyan se scimdent à leur tour, par les mimes moyens; quatre parcelles de substance nucliaire ont aimsi pris maissan'e. 'Trois l'entre elles sont expulsées, on lien lisparaissunt sur place par résopption, romme relles fuoluites par le noyan; me seule persiste. Celle-ci se livise à son tom en denx parts; ces dernieres sont seules chargées de promluire le rajemissement, et de sulvenir it la genise d'un nouvean novan el d'un autre micronovan.

Ces denx ébóments délinilifs possèlent lone en enx la fomelion sexuelle. Étant donné leur but, il est permis de les comprarer, du noins quant à leur rôle, anx denx novanx de l'ovnle fécondé des Métazoaires: l'un d'eux est un prenoyau mile, et l'autre un mimoymu femelle. Les molifications, subies par le micronoyan, se ramènent done à l'expulsion d'mne parlie de sa substance, suivi, par la division de celle qui reste, en une portion le polarité male, et une portion de polarité fomelle.

l). - Plusieurs autems renlent roir dans celte série de pliénomenes, segmentation répétic du micronovan, et expulsion de fous les segments produils sauf un, l'homologue du rejet drs cellules polaires des Mélazoaires. Au momont de sa maluration, l'ovule de ces Jerniers animanx livise en effel son noyan, deux fois de sule, el repousse an dehors les fragments aiusi engendrós, saml un d'enx, qui est conservo pour devenir le prénoyau lemelle. Il suffit te comparer entre elles les particularitís principales de es deux sorles de laits, pou se rendre compte de leur opjosition, "l le leur profonde divergence. - La genese les cellules polaires est lue ì nne rérilable livision cellulaire karyokinélique, dirigée par un centrosome; les ćlóments expulsés soul eux-mèmes des cellules completes, car me partie dn vilellus accompagne les jar'celles nucliaires dans leur migration an dehors; enlin, le segment conservé reste simple, et persiste tout entier pour constilner un prónoyau mirpue. Par contre, daus la conjugaison des Ciliaires, la production des prapesles, cmanćes du micronoyau, correspond i une fragmentalion le ce deruier, n’utéressant que lui, el mulluent guidée par un centrosome; les corps expulsés sonl seulement des fragments du micronoyau, qui sourent mème se létruisent sur place avant de parvenir an dehors; en dernier lien, le segment conservé se divise en deux parties, fui ont toutes denx un rỏle sexum. Les phlıénomènes sont done loin d'ètre comparables. 
Eu tenant rompte de toules les conditions, et dans la mesure oì il est possille de juger d'après les connaissances acquises, le rejet des cellules polaires, daus les ovules de llólazoaires, est assimilable it une segmentation inégale, el l'expulsion, olsservée chez les Ciliaires, a ume fragmentation d'un noyan, accompagnée de la destruction de la plupart des parcelles produites. Les deux faits ne sont donc mullement homologrues. Hais une comparaison doit ètre établie d’après les indicalions physiologiques, qu’il est permis de lirer des phénomènes. L'émission des cellules polaires a pour effel de diminuer la masse de sulustance

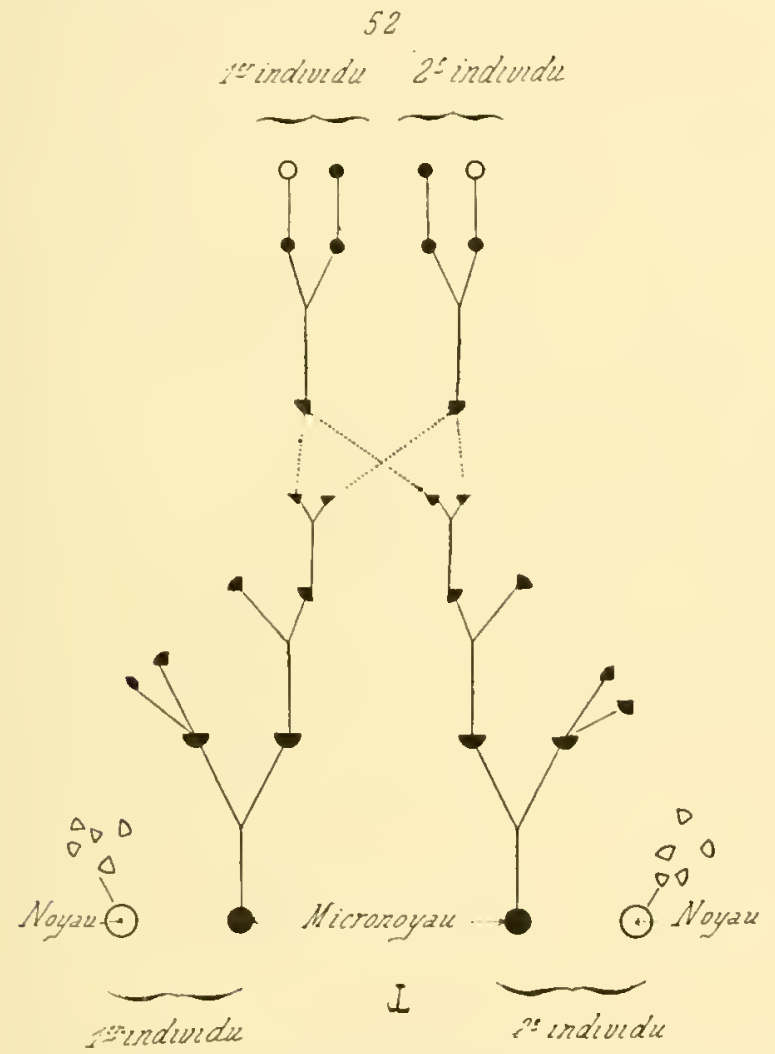

Fì. 52. - Tahleau diagrammatique exprimant les divisions nucleaires de la conjugaison et du rajennissement des Eucilies.

mucléaire pussédée par l'ovule; de mòme l'expulsion constatée chez les Caliaires conjugués. Celle diminution a saus doute pour lunt, d'emprecher l'angrmentation de la quantité do sulsstance nucléaire dins la série des fremerations. Senlement, dans les deux cas, chaque olganisme salisfail, arece les movens qu’il possiole, it celle nécessilé eommune de dimimulion:

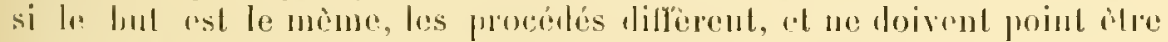
consilérés comme homolognes. L'lomologir résulte de la ressemblance 
complete des formes des oljets, et non de la ressemblance de leurs fonctions.

C. - Chacun des organismes conjugués renferme, au moment oì aplaraissent les deux seğments défnitifs. un pénoyau màle et un prénoyau femelle. Ce dernier ne se léplace point, et reste dans le corps oì il a pris naissance. Il nen est pas de mome pour le premier; le prénoyan màle de chaque individn trarerse la zone de soudure, pour se rapprocher du prénosan femelle de son congénère; il arive à son contact, s'y aceoli, ef finalemont se confond arec hi. lorspue la jonclion est accomplie, chaque organisme conjugné ne contient plus qu'un seul noyan, formé par l'union de son prénoyan femelle avec le prénoyau mile de lautre individu. Lacle principal de la conjugaison est alors achevé, et cet acte se ramène en diffnitive à un échange de substance nneléaire. L'échange élant terminé, le rajemnissement est opérí; il ne reste plus anx deux lnfusoires qu’à se séparer, ponr redevenir libres, et pour recommencer un nouvean cycle de générations tissipares.

I\%. - Les phénomènes sont ici exposés sous un aspect quelque pen schématique; ils sont loin f'ètre aussi réguliers, surtoul quant au nombre des segmonts engeulrés par le micronoyan. Ces variations donnent à l'acte entier son réritahle caraclère, qui consiste simplement en l'échange de parcelles nncléaires. si minimes soient-elles, et en la disparition de toute la sulstance inulile pour col échange. Les faits décrits ci-dessus, peuvent être résumés dans le lablean graphique pré-

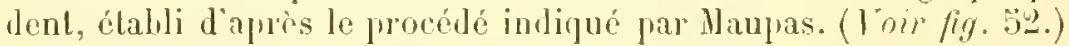

$3^{\circ}$ Séparation des indivilus. - Par l'effet de cef échange, chacun des imdivilus conjugnés conlient un seul corps nucliaire; ce dernier ra donner naissance à un nourrau nicronovau, el à nu aulre novau. En même lemps, les deux etres tentent i se séparer l'un le l'autre; leur zone de jonction se rétrécit de plus en plus, la culicule se reconstitue à nouveau, el, les demx Infusoires se dissocient, en rolrourant leur structurc et leur disposition premières. l'arlois, l'ulómont nuclóaire, issn de la conjugaison, se divise en plusieurs parcelles, dont l'une devient un micronovau, alors que les autres se converlissent en novaux, deslinés i chre répartis dans les individus des premieres générations fissipares, au nombre llun par indivilu. Quoi qu’il en soit, que lélément nucléaire conjugrué se partage senlement en un noyau et un micronoyan, on se scinde en nu micronoyan et phisiours noyan, l'organisme de chaque lnfusoire mis en présence se trouve te nouveau complété; les phénomènes de dégénérescence cessent, et charun d’ux est apte à constituer le premier terme dine longue série le genćations fissipares.

11. Tentaculifères. - La fissiparilé est rare parmi les Teutaculiferes; on l'a constalée chez los représentants de diverses espèces, apparLenant ponr la jluprart anx grenres Acinetu et sphorophrya. Les princi- 
paux procédés de reproduction des Tentaculifères sont la gemmiparité, et la sporulation. Il existe. sous ce rapport, une opposition frappante entre les denx classes des Protozoaires ciliaires; les Euciliés se développent d'ordinaire par fissiparité, et peu par sporulation ou par bourgeomement; tandis que ces denx derniers modes sont presque la règle dans le second groupe de ces animaux. De phus, les phénomènes de conjugaison temporaire, olsservés chez un grand nombre d'Euciliés, manquent peutêtre aux Tentaculifères; Maupas a constaté cepentant, chez ceux-ci, l'union de deux intividus, accompagnée de phénomènes nucléaires semblables à ceux des Euciliés; mais de nouvelles recherches sont encore néressaires sur ce sujet.

Les Acineta mystacina sont les mieux conuus sous le rapport de la fissiparité. Leur corps, monlé sur un pédoncule, el entouré par une logette, se divise de telle sorte que l'un des segments reste dans la cavité de la logelte, le second devenant libre. Ce dernier est entièrement rouvert de cils vibratiles; il nage par leur moyen; puis, ayant trouvé un corps étranger, apte à sa fixation, il hui adhère par une région de son corps, qüil allongo en un pédoncule. Il perd ensuite ses cils vibratiles, acquiert des tentacules, et devient ainsi semblable à son générateur. Le premier segment continue a hahiter la loge primitive, et conserve le pédicule maternel; il ne porte jamais de cils vibratiles, el reste toujours fixé.

Il est intéressant le remarquer la présence de cils vibratiles sur le corps des jemnes Tentaculifères libres; des faits semblables se produisent également dans les ras de gemmiparité el de sporulation. Leur signification est précise : ils correspondent ì un véritable état larvaire, el ténolent les affinjtís étroiles qui unissent les denx classes des Protozoaires ciliaires.

Les larves ciliées des Tentaculifères sont parfois munies d'une bouche temporaire, et offreut, ì jeu de chose près, les caracteres des Euciliés holotriches et hypotriches.

\section{§3. - Gemmiparité.}

Ce procédé reprouluctenr est de heaucoup jhus commun chez les Tentaculifires que chez les Euciliés; en outre, et rontrairement ì ce quil en est pour les Sarcoulaires, la gemmiparité présente tous les caricteres d'un veritalide linurgeomement, el non ceux d'une spormation altérée, ou d'une fissiparité rapidement répétíe un certain nombre de fois. Des sallies proloplasmiques so manifestent en une région du corps; des expansions nucléaires pénètrent dans lemr intérieur, el complitent leur structure; res hourgeous augmentent de dimensions, se śparent ensuite de l'organisme maternol, drvienuent libres, ef se convertissent en nouveanx individus, rapaliles de recommencer le mème cycle érolılif. 
1. Euciliés. - La gemmiparití n’a été olservére juspüici, que chez me sembe espece, appartenant i lopdre des léritriches, at it la famille des Vorlicellines: la spirorhoma gemmipara; los olsservalions faites sur ce sujet sont dues a li. Hertwig. Le rorpls de l'alulle est mu, cest-a-dire déponrru le loge protectrice, et fixé par sa lose, morlifíe an me petite ventouse; l'extremiti opjosie il la réginn de fixation, plus large que celle derniere, porte le péristome, emrouli en mor spirale aux tours nettement risjoinds. Le hourgeon, car la gemmiparité cost simple (un seml bourgeon maissant à la lois), apparait au-dessus de ce priristome. Il se produit, Jans la rógon gemmipar, une sallie protoplasmique, donnant an corps un asprect bosselé; le noyau se partage on dem farties, lout la plus pulite princtpe lans cette saillie; il en rst de mème jour le mirronoyau, pui se divise en deux, puis en fuatre segucnts, jarmi lespuels les denx plus proches du jeune hourgron entrent dans l’inlériem de ce dernier. Le hourgeon est ainsi conslitué par une masse de proloplasme, contenaut nn noya el deux micronoyau, ces élénents élant directement produits par leurs homologues de lorganisme maternel. Dés ce moment, le bourgeon sélire de maniope à rébécir le plus possible sa base d'adhérence; celle dernière s'ofile jeu à jou, juis se rompl; et le pelit ètre se sépare de l’individu qui lui a lomné maissance.

Le hourgeon, devenu libre, ne présente pas l'aspect normal des reprisentants de l'espixe; son corps est ovalaire, on mème prestrue

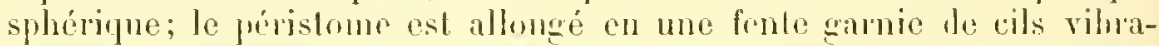
tiles, et non enroule en mo spirale. H lourbillonne dans l'eau, saice ì ces rils, et vit amsi durant puelpue temps. Il est probahle yu il ne tarde

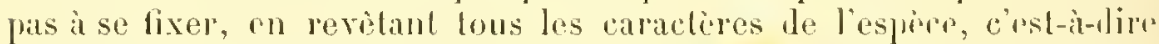
en modifiant l'aspect de son péristome, et en allongeant sárgion hasilaire jour la transformer en une ventonse servant a la fixation; mais le fait na pas été vu l'une maniere frécise.

11. Tentaculifères. - La reproduction par gemmiparité a rló sonvent olservée chez les principaux genres les Tentaculjleres; on est done en droit de la considérer comme normale et haloiluelle, conlraire-

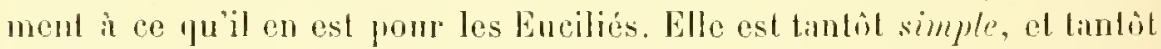
mulliple; dans le premier bas, un seul hourgeon prend maissanes sm le corps maternel; dans le second, l'individu-mere produit, en mime temps, phusieurs bourgeons placés côte à cóle.

$1^{\circ}$ Gemmiparite simple. - A. Ia plupart des Tentaculilioes atherent, à les corps ctrangers, par nue lase allongée en mu pridoncule jus ou moins long; le bourgeon apparait fordinaje sur la patio opposés all pédoncub. Il en est ansi, du moins, chez les uphryodembrom, les

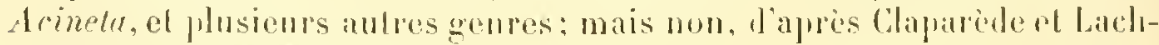

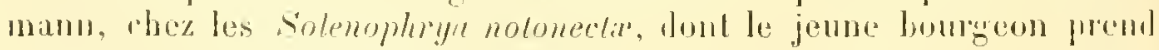
milissince vers lo: milien du corpss.

Qnelle que soit la rogion gemmipare, l's phénomenes sonl comstam- 
ment semblables. Lorganisme des Tentaruliferes parail ne contenir, du moins dans létal présent de nos connaissances, gu in seul noyan; ce dernier sallongr, sétire en liscnil, of envole lune de ses extronilis, la plus petite d'orlinaire, dans la partie du comp où le hourgeon commence ì se furmer. Celui-ci est constilué par une saillie proloplasmíne, pui grandil peu ì preu, en rélrécissant ì mesure sa lase d'adhérence: l'rxyansion moléaire pénidre dans son intéricur, n, dis cet instant, l'organisation du hourgeon esl complète. Il ne lui reste plus qu'ì sr séparer dn corps de lindividu-mire; celle séparalion ne larde pils it s'clfoctuer, el le descendant se trouve ainsi transformé en mu nonvel itre, libre et parfait.

Les 1 cineta divisa offent, dapres Fraipont, une moditication parliculiere de re phénomène. Avant que la lase adhérente du bourgeon ne virnue à se hriser, et celle base est ici allongée en muétroit jédoncule, le protoplisme dr co bourgeon se divise en deux parties: wne promiive couche périphérique fort mince, el me volmminense masse centrale contenant te noyau. La première enveloppe la serombe à la fiçon f'une capsule, el conslitue elfeclivement une vérilable loge, car la masse centrale se sépare seule de l'organisme maternel. I'n orifice se perce au sommel de la conche périphérique; la masse inteme nucléée sort par celle ourerture, parvicut it l'exlérienr, el se convertit en un nowvel ètre; la paroi capsulaire, munie le son pédoncule, reste atlachée au corps de I'individu-mere, el se délruil peu ì pen. Fraipont nomme diverticule généreteur te hourgonn pédiculé qui prend naissance en premier lieu; il raul mieux consildérer colle expansion de lorganisme comme un bourgeon, dont le protoplasme externe se moditie en une coptue prolectrice, el non comme un diverticule, chargé dr prodnirm l'itre définitil par généralion endogène.

B. - Les jeunes bourgeons sont couverts de cils vilualites, an moment oì ils se séparent de lindividn-mòre, el ne portent point de tonlitcules; on doil done les premdre pour de vérilahles larves des Tentaculifires. Tantit les cils viluraliles recouvent lia surface entipe de l'embryon, conme leurs simbiares des linciliésholotriches, el tantiol ils sont forlés par la face ventrale senle; dans ce ternier eas, l'entryon rappelle les Euciliés hypolriches. Le jenne individu nage prendant quelques heures an moyen de ses cils: pmis, as orgines locomoleurs se délruisent, el des tenlacules prennent leur place. La struchre, propro ì l'arlulte vient de faire son alplarition; lormanisme se déplace encore quelyue peu it l'aide de ses nouveanx appendices, persiste ainsi lorspuril

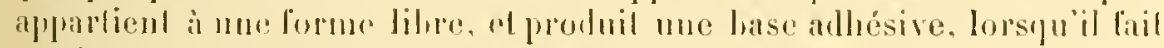

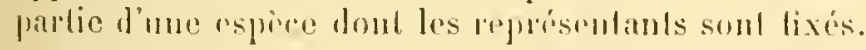

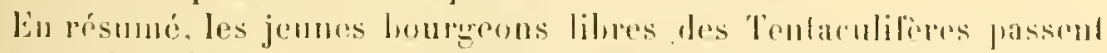

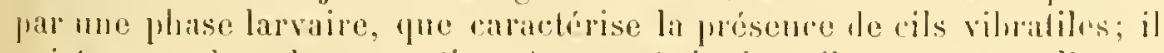

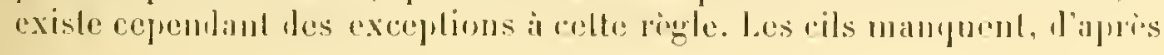


Fraipont, aux cmlirons des Ophryodendron belgicum, lorsque ees embryons sont prodnits jar gemmiparité. Les représentants adultes de cette espece sont munis d'une longue trompe, opposíc a la riggion de tixation du corps, et pourve de sucoirs placés sur son extrimitr libre; ce sont la les seuls fontacules de l'organisme. Ces indivilus ainsi conlormis sont nommís proloscidiems. Ils donnent naissance, par gemmiparití simple el sur la pratie le leur corps qui avoisine la lase de lenr trompe, i les hourgeons, privés à la fois le rils vibratiles et de lentacules. Ces lourgeous, devenus libres, rumpent en se rontractant, et

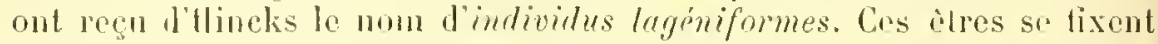
par l'une des extrémitris de leur corps oralaire, el produisent ensuite me lompe, dans la rigion diamétralement opposie a celte base adherente; la trompe engendre elle-mime destentacules, et l'itrelaginiforme se transforme en un indivilu adulte, ou proboscidien. Il est à remaryuer yue les seuls embryous produits par gemmiparitr subissent de felles molitications: Ies Opleyodendron se multiplient anssi par sporulalion, et, lans ee eas. les jeunes spores sont munies de cils vibraliles.

20 Crmmiparitr multiple. - Ce procélé n'a guèe ite observi, daus tous ses ditails, que chez les Podophrya, et notamment chez la I'odophrya gemmipara; les éludes les plus complìtes, sur ces phrinomenes, sout dues à Ch. Rolin et à ll. llertwig.

L’udividu adulle est divisé en deux parties: un corps ayant l'aspect l'un trone, de cone, et un pridoncule tris long, qui surt a attacler l'animal i son support. I a plus petite des loases est somlée an pridoncule; la phus grande, de heaucoup plus ample que la premicre, porte seule des fontacules liort nombrenx. Ces derniers appartiennent a denx types: les uns, lareses minees, sout llisignós prar le nom de filoments préhenseurs: les autres, gros et enurts, rassemblis vers le centre do la grande hase, sont les vrais sucoins. La gemmiparitó so manifeste sur la grambe luser, c’està-elire sur la rigion opposce au pédoncule. Les sucoirs se ritratent somvent, ot se confondent avec le reste de loreanisme, de manive i prudre cette face nue, aumoment ou les hourgeons apparaissent.

limique noyan dn eorjes frerd sa forme primitive; il s'allonge en un hilonnel noweux, reconló sur lui-meme en anse, juis envoie dans tous les seus des expansions fililormes; ces dernières ont un aspeet de massue, la plus mince de leurs extrimilis chant unie au corps uncléaire rentral, of la plus gramle se lourant portie vers la periphrie de l'orgranisme. las expausions les pus nombreuses sout imises par fa face anrexe lu noyan, et se dirigent ress la rigion superienre du corps; l'ur quantilo varie suivint les espeecs, qualre à ciny chez la l'odophryu benedeni, lix à llume, el mème darantagge, chez la l'odophryu gemmiparu.

l'endant que ces plúnomenes se passent, la région superienre du corps, corpespombat i la plus gramde des hases du trone de cone, se déconfe en petites saillies juxtaposées, dont le nombre égale celui des 
l'embryon se diplace par lemr moven, se meut duranl quolques henres, puis s'accolo a un corps obranger; les rils viluralites tombent, al sont remplacés par dos tenlarules, du lyje des filammonts prélinsomes. Cas tenlacules naissent sur la fare conrexe; lanimal rampe avec leur

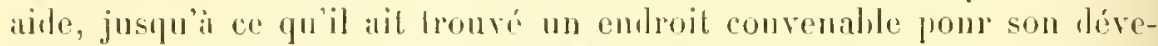
lopprment ultricur. II se fixe alors par sal face roncave, qui s’étire en mon proncule. La face convexe deviont la région supérioure du corjss; olle complete son organisalion en prouluisant les petits suroirs dans sil partie contrale. Entre temps, le noyau a contracté ses nodusilés, et s'ist ramassé en un rorjos ovalaire et sphérique. La structure de l'adulte esl alors entiere.

Dapres R. Hertwig, les omloryons ciliẻs de la Podophraya gemmipara posserlent temporairement une petite honche; celle lonche disparait an moment où les tentacules prennent naissance. La présence d'unr onverlure buccale ust une homologie de plus entre les larves des Tentaculilieres et les Euciliés.

\section{\$4. - Sporulation.}

La spurulation est plus rare chez les Ciliaires que chez les Sarcudaires; elle intervient avec moins de fréquence dans l'évolution vilale des individus. Les Tentaruliföres la présenteraient pourtant phus communénent que les Euciliés. - Quoi qu’il en soit, la sporulation des Ciliaires oftre toujours celle particularite, te ne point montrer de phase zoospore; les spores, en se développant, se courrent le cits viluraliles, et n'allongent jamais mr des extrémités de leur corps en mn fouet, contrairement à ce yu’il en est pour les Sarcorlaires.

Les pliénomines, qui se suecedent dans la produclion des spores, sonl semblahles, puant au foml, chez les Euciliós et les Tentaculifères; ils rappellent ceux déjà dér rits, avec lélail, dans l'exposé consacré aux sarcorlaires. I'lusienrs parlicularités établissenl, cependant, des différences assez grandes entre les denx classes. Les Euciliés s'enkystent arant la spornlation, el les spores sont mises en liberté prar la rupture Je lat paroi cystipue. Il n'en est point ansi chez les Tentaculilères; l'organisme matermed ne s'enkyste jas, conserve sourenl ses appendices, el une parlie senlement de son proboplasme et de son noyan se lrouve employée ì porluire les spores; cette parlie génératrice est de beaucoup plus consideralle que l'antre, mais cependant dle n'est fras couslituce prar he proloplasme entier de l'animal. La sporulation des Tentaculifères prend ainsi l'aspect d'une gemmulution interne, les cmbryons chant mis en liberté par la ruplure de la proroi du corps, en moreginn determinice: les anteurs onl domé à res jennes individus le nom d'embryons endorgines, à rause de leur modo de lormation. Ces derniers subissent, fuul romme ceux engendrés par gemmiparité el par lissiparile, une fuenieme plase évolulive cilice. 
I. Euciliés. - A. La sporulation n'a guère éló olscrrée, parui les reprosentants le celle classe, que cloz nu pelit nomlore d'especes; elle présente des degrés divers de complexicé, allant d’un procédé juimorlial fort simple, el comparable à ume lissiparilé rapile, juspu'à un mode très élevé, caractérisé par la conjugaison permanente de tenx iudividus dissemblables, et par la présence d'un riribable élat larraire. Ce dernicr moven existe chez les lorlicellines senles; les indivilus conjugurs sont des macrogronidies et des microgonidies, dont lorigine est déjả connue; el les spores, en germant, prorlnisent des rmbryous libres, susceptilles de se mulliplier pendant leur vie de liberté. Eu romparant res faits à ceux, léji observés chez divers Mélazoaires, il est permis d’admettre que les Torlicellines présentent une véritalıle alternance de générations, acrompagnéc d'un dimosphisme sexuel.

L'enkystement ne précèle pas foujours la division de l'organisme en spores ; la gonèse d'un kyste n'est point ici, coutrairement aux Sarcodaires, un fhélnomène normal, el possédant par suile une cerlaine imporlance; sa présence est secondaire. Le raractere accessoire de l'enlirstement est, du resle, indiqué par certains faits labituels de l'évolution, du moins chez plusieurs Enciliés, adaptés à des comblilious farliculieres de milien; tels sont la plupart bes Eucilics parasiles, et notamment le Balantidium coli, qui balite lintestin du Corhon, et a élé lronvé flusieurs fois dans l'juteslin de l'homme. Cet Infusoire se mulliplie d'ordinaire par fissiparile transversale. Lorsque certains individus sont entraincis an dehors arec les excróments de leur hôte, leurs monvements s'arrètent, leur's cils cessent de battre, el l'animal sécride une substance chiliueuse destiuée à l'envelopper; celle coyne sert à le protéger contre la dessication. L individu sest enliysté. Si une circonstance heurense permel an liyste de parrenir dans l'ean, la paroi eyslique se brise, l'lufusoire est mis en liherté, el recommence it se monvoir, puis à se mulliplier de nomvean; il en est le mome si le kyste, ou bien si l’animal, redevenu libre, arjoce dans l'intestin d'un etre où il lui soit possille de virre. L'enkystement n'est donc proint suivi de sporulation; cel acte correspond i mue adaptation particulière, nécessitée par les combitions de milicu; son existence, on son alssence, sonl des faits secondaires lans l'évolution vilalo des Euciliés.

li. - Le morle le plus simple de la sporulation a élé oliservé par Mampas chez les Leucoplirys palula; ce mode est aisément ramrné it me dirision fissipare, répétéo rapilement un certain nombre de fois. Un représentant quelconjue de celte espice arote ses mouvements, entre en repos, el, sans produre de kyste, se livise par fissiparite lansrersale en denx segments. Si éélait la me lissiparilé orlinaire, chacmn des segments monerait une vie lilme, durant lapuelle il so partagerait do nonvean; mais il nen est point ainsi dans ce cas particulire Les doux individus engendrés par l'organisme maternel se scindent, de suite 
apres la première hipartilion, en deux aulres segments; ces demiers agissent de mème, et le plénomène continne jusıuà ce que rindividu-mère soit partagé en 39 , ou en 6 '́ peliles masses. L'ensemble de ces divisions s'effectue en quelpues heures. Les noureaux Infusoires ainsi produits, sont nalurellement de laille jus exirui yue leur généraleur; ils sont dépourvus de louche el de cils vilualiles; ces organes ne tardent pas a faire leur apparition. Les jeunes embryous perdent leur aspect inerle, commencenta se mouroir et à se nourrir; ils crandissent avec rapidilé, el revèlent hientót les caractères habiluels de l'espece dont ils font pratie.

Les procédés sont un peu plus complexes chrz direrses autres especes d'Eucilius, Jes Colporla cucullus, les Amplileptus meleayris, el surtoul les lchthyophthirnes mullifilis; ces derniers rivent en parasiles sur la peau des 'Truiles et des Saumons. Un individu adulte cesse de se monvoir, el s'entoure dime paroi crslique épaisse; l'eclosarque el l'endosarque se confondenl en une masse granuleuse, dans laquelle on ne distingue phus aucune trace des differencialions organiques. Cetle masse se divise en deux parties, puis en yualre, puis en huit; la segmentation continue ainsi, jusqu’a ce pue le nombre des fragnents prolophasmiques soil rousilórable, el dépasse plusicurs centaines. Ces fragments sont des spores, renfermées daus la carité du kvste. P'endant que seffertuait son évolulion, l'lufusoire primordial avail quilté son liabilat oldinaire, et s'élait lajssé tomber an fond de l'ean. La paroi cyslique ne larle pas à se lriser, et les jeunes sjores sonl mises en liberla. Ces dernieres ne prarassent pas avoir de membrane propre, contrairement it ce quil en est pour celles Jes Sarcodaires; elles oul l'aspert de pelits corps ovales, comverts de cils vibratiles, el se déplaçant arec rapidité. Lenr organisme n'est pas encore lrès complexe, mais il ne tarde jas i achever sa slruclure; des racuoles contractiles maissent dans le protoplasme, me aire huccale fait son apparilion; la laille augnuente, el fovale du corps s'allénue peu à peu, pour se modifier en une spliere. Les pelils embryons sont alors parvenus a lélal adulle; si, loul en se léplaçanl au moven de lems cils, its viement à rencontrer une Truite ou un Saumon, ils adhèrent à la peau de cel animal, el recommencent un nouveau sycle vilal.

Instu’ici la sporulation consiste en un acle reproulucterr, dont la lurre est relalirement forl courle dans h vie des individus; il n'en est pas de meme jour les Trichorhyncus tuamotensis, qui, d'apres Balloiani, présentent, d'unc faron presque permanente, l'enlisslement suivi de sporulation. Isa livision en spores s'eflectue snivant un procédé fort simple, el rappelle de très près la fissiparité; mais, cependant, la présence d’un kyste donne, à ce phénomène, nu caractère très net de refroduclion sporulaire. - Ln individu délerminé cesse de se mouroir, et s'enveloppe d'un kiste à paroi mince: il se divise en deux ou ruatre segments, capables de devenir autant d'individus. Dans le cas de scission 
en denx parties, cette sprorulation est une fissiparité accompagnéc d'rnfistrment; la division ulléreure de ces demx masses en leux aulres mudilie à preine la simplicité du plénomine. Ponrtant, l'existence d'unc paroi cystique, qui fait comslamment defaut dans les fissiparités ordinaires des Enciliés, permet de considérer l'ensemble de ces faits

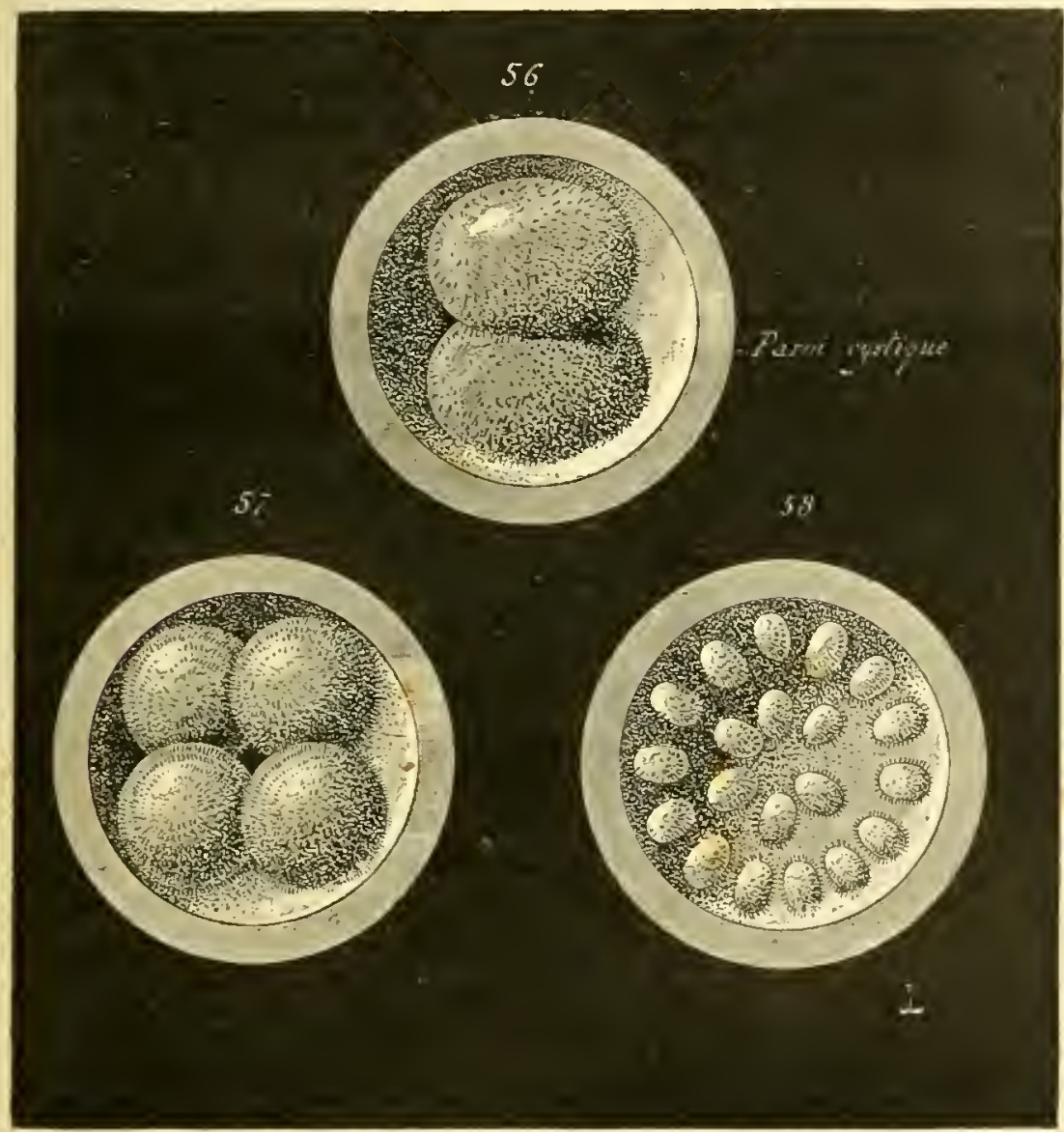

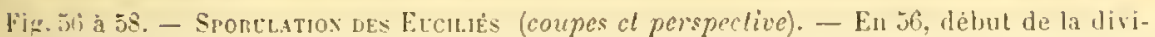
sion sporulaire chez un indiridu enkyste d'Tchthyophthirius mullifilis. - En 57, suite de' la division sporulaire du mème. - En "x, achèrement de celte dirision; les spores, couvcrtes de cils vibratiles, sonl prètes a èclore. (l'après les recherches faites far liontyuet).

comune réponfant à une genose de spores. Les indivilus-filles sont mis en liberté par la rupture de la paroi du kvste; ils minent, pendant un laps de temps relativement contt, queljues jours i peine, une vie libre et indépendante; aprés quoi, chacun d'eux s'enkyste pour recommencer le mème cycle. 
L'exemple des Trichoryuchus, et celui des Leneopliys paula, donnent a la sporulation simple, c'est-à-dire a la sprorulation nullement précédée de conjugajson, sa vériblute signification. La présence, on l'absence, de la pliase d'enkrstrment, ne possident ir:i ancume importance, puisque les représentants le diverses especes sont capalies de s'enkrster sans se diviser cusuite. La sporulation simple des Euciliés est une exagération de la fissiparitri elle loit être considérice comme une reproduction fissipare, se manifestant un grand nombre de fois dans wiu laps de lempis fort court.

C. - Les phénomènes sont plus variés dans le cas de sporulation précédée de conjugaison; el ce modr, olservé jusqu iei chez les seules Iorticellines, présente une complexitó, que même les Sarcodaires à sporulation conjuguće noolirent jas. Les individus destinćs à se fusionner sont au nombre de deux, et different de forme extérienre, daspert général; il existe done une sorte de dimorphisme sexuel, el c'est ici le sent exemple, parmi les Protozoaires, diun lait semhlahle. the plus, les embryous issus de spores ménent pendant un certain temps mue vie lihre et erranle, et se distinguent far là des individus adultes, tonjours fixís sur un corps étranger. Ils sonl susceptibles de se reproluire en cet état. Non semlement, les Jorticellines sulissent des phases larvaires assez longues, mais elles se reproduisent durant le cours de cos phases larvaires, tout comme les Trómalodes parmi les llétazoaires; clles prisentent donc une véritable alternance de générations, en prenant cette expression dans son sons le plus complet. - liexistence de phases larvaires ne ronstitue point la différence entre les Vortirelles et les aulres Ciliaires; les cmbryous produits par ces derniers notfrent pas loujours, dis leur naissance, la forme de leurs parents, el ces dissemblances sont lien nettes chez les Tentarulifrires. Le raractere particulier de l'évolution des Vorticellines porte sur leur multiplicalion a l'état d'embryons lihres.

Les indivilus mis en présence sont: les uns les macrogonidies fixées an moyen de len jédoncule, les autres des mirroyomilies se monrand cu liberté, gràce à leus cils viluatiles. Les premieres, comme les secondes, sont produites par fissiparité, suirant le procédé exposé daus les pages qui prócedent (p. is). Lorsqu'une microgonidie vient ì rencontrer me macrosonidie, elle se fusionnc arec elle; les diverses phases de ce phénomène rappellent, sous le rapport de l'évolution nucléare, celles de la conjugaison temporaire el du rajemnissement des antres Euciliés: sentement la conjugaison est iti défuitive. La fusion sopire sans que la marrogonidie tixée perde son aspect normal; mais, ensuite, elle se létache de son pédoncule, s'entoure d'une paroi cystique transparentu, et fomle. Son péristone, sa couronne de cils, les varuoles de son protojusmo, disparaissent; lindividu ast roustitú par me masse protoplasmique miformément granuleuse, qui ra se 
diviser en spores suivant les procédés habitucls. - La masse se parlage dabord en deux, puis en quadre, et ainsi de suite; lo nombre les segments engendrés est considérable. Le kyste est, en ce moment, constitué par une paroi, qui entoure une carité contenant tous les segments devenus des spores. La paroi rystique se hrise; les spores, mises en Tiberté, sont déponrves de membrane d'envelopje; leur corps, walaire ou piriforme, porte, vers l'une de ses extremilés, une couronne vibratile servant i la natation; une petite bouclue se creuse an centre de celte couronne. Ces jeunes larves, presque semblables it dus mierogonidies, se déplacent en tourhillonnant: clles se reproduisent par lissiparité transversale, et donnent naissance à d'autres itres, qui leur sont identipues frar l'aspect el par la structure. Étant donnce celle multiplication larvaire, un individu enkysté donne naissance à un chiffire délinitif de rejelons, beaucoup plus grand que le nombre des spores engendrées par lui, puisque chaque spore primilive se lransforme en une larve, susceptible de se segmenter un certain nombre de fois.

Les larves offrent toujours la mème organisation, quelle que soit la génération dont elles font partic. Après avoir nazé pendant un certain templs, el mené une vie lilne, elles se fixent par leur région huccale. La houche se ferme, disparait, el cest par ce point que s'eftectue ladherence au support; la couronne vihratile s'atrophie ígalement, ef loule celle prarlie de l'organisme s'allonge pour prodnire le pédoncule. L'extrémilé dn colps, opjosée an prédoncule naissant, s’aplatit, et se garnil de cils vibratiles; ces derniers se disposent en me spirale, qui entoure un orifice buccal nouvellement formí. Le petit itre grossit, des vacuoles contractiles apparaissent dans son protoplasme; toute son organisalion se complete, el ne tarde pas à offrip laspect présenté normalement par les Vorlicelles fixíes.

l.es phases, ainsi exposées, nont pas été observées ì la suite les unes des antres; les connaissinces, sur le dévoloppement conjugué des Vorticelles, se bornent à quelpues constalations éparses, et effecluées far divers antemrs. Hais il est permis, daprès les faits observés et jusqu'it phos ample inlormé, de se représenter l'úvolution de ces ètres comme il est dit plus laum. Hans tous les cas, élant domnée sa complexité remar'pualule, le dévelopjenent des Vorticellines en particulier, et celui des luscilies péritriches en général, appellent te nouvelles recherehes plus précises el plus complètes, porlant de preférence sur les modifications sulies par te noyau.

11. Tentaculifères. - Lal sporulation a dé olservée chez les représentants de divers genres, les ophryodendron par exomple, les

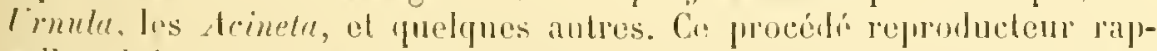
pelle celui le la plupart des Eucitiés. on ce suns yu’il n'est point précédé te conjugraison, et qu'il n'est pats ancompangé denkystement; mais il s'en icarte beateoup, par l'absence de participalion d'une zone du pro- 
loplasme à la genise los spores. [Tn Eucilie on voir de sporulation divise son eorps tout entier, el m laissu rien en dehors de ce phénomène; il nen est pas ainsi pour les Trntaculiferes. Lu protoplasme se divise en lens partios, une conche exlerme assez épaisso, qui porte les appendices et continus à vive, ol une masse inferme, seule chargée le sulvenir a la prouluelion dos spores. Les transfomalions subies par le novau, dans co phénnmone, sont rncore inconnues. La jremière assise restr indivise, et entroure laulre it la facon l'une momlorano d"enveloppe; la seconde so parlage en un celain nomlure de segments, les spores, qui sont mises en liberlé, el lleviennent autant d'individus alultes. La mise en liberté ne seflectue point par la puplure irrégulière de l'envelopje externe, mais par l'apparition d'un orifice plus ou moins netlement limité; les jeunes emlrryons sortent par refle ouverture, et parvionnent au delors.

Ces mmbryons sont riliés, tout comme ceux issus le la fissiparilé el do Ja gemmiparié; leur corps, recourlé sur lui-méme, porte les rils sur sa face concave. La suile de l'évolution ne differe en rien de colle léjà décrite jour les antres larves des Tentaculifères; les cils vibratiles ne tardent pas il lomber, les sucoirs à frentre naissance; col la struclure particuliere it l'adullo fail peu à peu son appariliou.

Cr procédé de sporulation est fort remarpualile, en ce sens que le proloplasmo le l'unlivilu-mère nest jas complotement employé à la genise des individus-filles; sous ce rapport, i existe une rossemblance

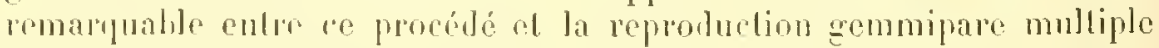
des l'odophrya; la seule ditférence porte sn la silualion des ambryons. Tans co dernier ras, ils se síparont hativement de ]'organisme malernel, apparaissenl a sa surface romme autant Je bourgeons, et se délachent ensuile; contrairement à co qu'il en est pour le premier moule, oì ils aroomplissent loul leur dévelojpement, jusqu à Ja parfaite constitution de lenr struelure larraire. en restant enfermis dans Je corps de leur mère. La diflérence est rolalivement seeomdaire, el il serail permis, sans doule, de considérer la sporulation des 'Teulaculifieres comme répondant à me gemmiparik interne, on l'assimilant à la gemmulation observéc chez un ecrlain nomblu de Mélazoaires.

les anteurs onl lierit celle sporulation soms le nom le génération endogine, el ont désigné les larves elles-mómes comme des embryous endoyines.

\section{RÉSUMÉ}

1. Ixes Protozoaires ciliaires, semblahles en cela aux Prolozoaires sarcolaires, se reproduisent par les trois procélés suivants: lissijarilé, gemmiparili. sporulation.

II. Fissmarté - Deux grompes de phénomenes sont ì considérer dans la lissiparite les Lucilis : la division lissipare, el la conjugaison temporaine pui détermine le rajeunissement de l'organisme. 
La fissiparité est tantôt transversale, Iantôt longitudinale; dans le premier cas, elle est complete: lans le second cas, elle est parfois romplète, parfois incomplète, et parfois inógale. Les phénomènes essentiels de la segmentation ne rarient point; le noyau ef le micronoran se divisent, soit séfrarment, soit apres siolre rémnis, et leur scission en deux parties entraine celte lu protoplasme. La fissiparité transversale existe ehez les llolotriches, les llétérotriches, et les llỵotriches. La fissiparité longitudinale est le propre de la plupart les Péritriches; lorsqu'elle est incomplète, olle est en même temp's égale, ct aboutit à la genèse de colonies; lorsqu'elle est complète, elle est parfois égale, en ce sens que les deux indirilus-filles sont de mème laille et présentent le mème aspect, et elle est parfois inéģale. en ce sens que les descendants sont de faille el l'aspect diflérents. Ce dernier procédé a été signalé ehezles Vorticelles; les petits zoö̈des sont nommés des microgonidies, les gros sont désignés par le terme de macrogonidies.

La fissiparité, répélée durant un grand nombre de fois sans èlre interrompue par la conjugaison temporaire, entraine la dégénérescence des noyaux et la mort le l'organisme. La conjug̨aison empèche cette fin, car elle a pour oljet de donner aux noyaux nne nouvelle vigueur, et de rajeunir ainsi le corps entier.

Le micronoyau seul joue un rôle dans la conjugaisou; il est donc permis de le considérer comme l'agent de la sexualité dans le corps des Euciliés. Les individus, toujours au nombre de deux, s'accolent par des régions similaires. Leur noyau se partage en fragments, qui disparaissent par atrophic; le micronoyan se divise dordinaire en quatre segments, dont trois s'atrophient; celui qui persiste se scinde en deux parties, dont l'une est le prenoran male, et l'autre le prénoyan femelle. Le prénoyau màle du premier imlivilu conjngué va se réunir au prénoyau femelle du second, et inversement, le prénoyau mile du second va se joindre an prénovan femelle du premier; il s'est produit ainsi un échange de substance uncléaire. Ensuite, les individus se séparent l'un de l'autre; leur unique élément, formé par la fusion de deux prénoyaux, se parlage en leux ou phusieurs masses, dont l'une devient un nouveau micronoyau, el dont les autres se convertissent en noyaux.

La fissiparité est rare chez les Tenlaculifères, contrairement aux Euciliés.

ill. Cienmipmé. - lin opposition avec la fissiparité, la reproduction par bourgeonnenent est rare chez les Euciliés, et commune clez les Tentaculifères.

Elle n’a été olsserrée encore, prarmi les Euciliés, que chez une espéce de Spirochona. La gemmiparité est simple, un senl embryon frenaut naissance à la fois; sal rógion d’urigine est situce alu-dessons du péristome. Ce hourgeon, après s’ètre détaché, subit un premier état larvaire libre, puis se fixe, et devient semblable i l'organisme maternel. 
La gemmiparité est tautòt simple, et lantot multiple, chez les Tentaculiferes; clle est simple, lorsyn un bourgeon est formé dans chaque génciation; elle est mullip]e. lorsłue plusienrs houreneons sont engendrés en mème temps. La gemmiparté simple est la plus répandme; le hourgeon apparait sur la partic du rupps, qui est opposie au pédoncule servant à la fixation; il contient m segment du noxam maternel, et,

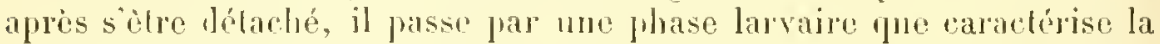
présence de cils vibratiles; les cils tomlunt ensuite, el sont, jemplacés par les funtacules. Les lourgeous des f cinelu divisa se parlageut en deux couchrs, dont l'externe sert d'enchoper, of dont l'aulre, centrale, devient seule lembryon dófinitil'; cest là une transition vers la sporulation des l'entaculileres, qui othre lous les caracteres d'une gemmiparité interne. Les embryons lilwes des f pleryortendron belgicum sont par exceplion, privés de cils viluratiles, el munis de tentacules des leur naissance. La présence de cils vibraliles, sur le corps des lapres, permet de conceroir nettement les relations étroites qui missent les Tentaculifères aux Euciliés.

la gemmiparitó multiple a ité linn étudiro chez les Porloplrya; elle se manifesle, comme le bourgeomement simple, sur la partic du corps opposéc au pédonrule. Le noyau de l'organisme maternel émot un cerlain nombe d'expansions, qui se dirigent vers la fulure region hourzeonnante; celle-ci se décompe en losselures, el il se produit ainsi des petits hourgeons nuclés, fui se driachent peu ir peu de l'organisme matronel. Les bourecons, devenus libres, portent ales rils vilurililos, et mene une petite bumlıe; ces wranes disparaissent ljentöt, el sonl remplacés par des tentacules. La phase larvaure cilice, propre aux Tentaculiferes, ne fait donc point défaut dans re cas particulicr.

IV. Sporultox. - La sporulation se présente moins frépucmment 1he\% les Ciliaires que chez les Sarcoraires; saufl l'exceplion ollerto par les Vorticelles, elle u'est point pródéte conjugaison, el elle est rarement accompagnire d'enkystement.

La sporulation des Euriliés doit itre consilérée comme mue fissiparité exageree, cest-a-dire se manifestant morand nomble de lois lans un laps ale temps fort court; clle est toujours simple, cest-it-aline non probilio de conjugaison, saul rhez les Vorticelles, el présente les degrés

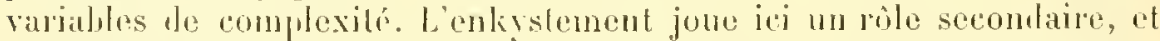
existe parfois sans ynume genose de spores le suive forénent. laes Lencophrys paludu ollient le mode le plus simple; un individu entre en repos, se divise en deux segments comme dans une fissiparjé ordinaire, puis ces segments se partagent à leur tour, et ainsi de suite jusquaux chiffres 320064 . llivers antres Euciliés présentent une complexité plus grande, en ce sens pue l'organisme materuel s'enkyste, ut se livise en un nombre consilfriblue de spores; ces deruieres sont mises en liberté par la rupture de la provi rystique, et portent des cils vibratiles. 
Entin certains Trichorhmolus paraissent se reproduire senlement par une sporulation, pue précede la genese l'un kiste.

la conjugaison est complexe chez les Vorticelles: elle stacompanne de dimorghisme sexnel, l'un des imdividus conjugues ebant me macrogonnidie, ef l'antre une microgonidie. Les spores, mises en libroté par la rupture de la paroi da kiste, se reproduisent par tissiparité dumant le cours de relte phase larvaire libre: les indivilus adultes, étant lisés, ol se multiplianl anssi soms cette forme, les Vorticelles oltrent me réritable alternance de générations.

La sporulation des Tentaculiteres est caractérisée par ce fait. quime partie seulement du protoplasme de l'organisme maternet est emplosée a produre les spores; celle partie est toujours placie dans la région contrale du corps. Celte spornlation est donc assimilable ì me genmiparté interne el multiple, et comparable à la gemmulation de certinins llidazoaires. Les embryons ansi formis passent, fout comme ceux issus de générátions tissipares on gemmipares, par une phase larvaire ciliée. 


\title{
EMBRANCIIEMENT IDS MESOZOARES
}

\author{
C.IAPITRE III
}

DÉVELOPPEMENT DES MESOZOAIRES

\section{\$1. - Considérations générales.}

I. Garactères et Glassification. - Les lésozoaires sont les plus simples de tous les Vetazoaires. Leur organisme se compos d'une masse cellulaire compracte, dans liquelle ne so différencie aucun appareil particulier, el qui ne contirnt aurune ravití.

Cet embranchement contient deux classes :

$1^{\circ}$ Les Iricyémides; dont rembodrrme est représenté par un syncylium contenant plusieurs moyaux.

go Les Orthonectides; dont l'rmlorlerme est conslitué par un anas de cellules distinctes.

II. Généralités sur le développement. - Les llicyémides el les Orthonectides olfrent cette particularilé commune, que leurs ínements sexuels proviennent de l'eudodermo; mais li se bornent les ressemllances. Les Orthonectides sont raiment pourvus d'iléments sexuels, el unisexués; les uns sont males, et les aulres femelles; leur développement est done le résultat d'une lécondation. l'ar contre, lit présence des miles chez les Dicyuniles n'est pas encore ćtablie dune fagon rertaine. Plusienrs anliurs consilèrent comme tels les embryons dits "infusoriformes ", mais le liait n’est pas encore monvé eomplictement; aussi. les jeunes loiryónides provinment-ils, sans qu iil paraisse exister une fécombation préalable, dre l'indorlerme de leurs générateurs.

\section{2. - Développement des Dicyémides.}

les indivilus adultus d’uno mìme ospèce de bicyémides noul pas

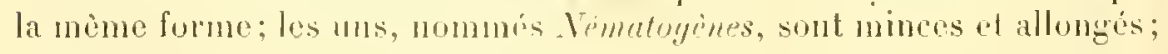


les autres, dits Rhombogines, sont plus courts et un peu plus gros. Chacun d'eux produit un tye special d'embryon, qui leur a valu leur nom. Les emlıryons issus des Yématogènes, on emlryons vermiformes, se développent avec rapidité, sont incapables de vivre dans l'eau de mer, et ressemblent de bonne heure a leur générateur, dont ils ne dittèrent que par la taille; ils le yuiltent pour virre à crité de lui, sans alles flus loin. Il n'en est pas ainsi pour les jeunes issus les Rhombogènes; ceur-là acquièrent un aspect particulier, possèdent mème des petits organes spéciaux (les corps rélringents et l'urue), dont on ignore le rôle exact, peuvent vivre dans l'eau de mer, et semblent deslinés à s'éloigner de l'organisme maternel pour aller faire souche dans un nouvel hiote. Ces embrrons sont dits infusoriformes, à cause de l'abondant tapis de cils vibratiles qui les recourre, el les fait ressembler à Jes Protozoaires ciliaires.

Ces faits, établis autrefois par les recherches de liölliker, et surlout par celles d'El. Van Beneden, seraient l'une plus grande complexilé, d'aprèe les éludes récentes laites par Whitman. Il exisle bien denx types J'individus; mais les différences entre ces tyjes ne portent pas seulement sur la nalure des embryons engendrés. Les uns sont monoyéniques el offrent loujours la forme carartérislique des Nématogènes; ils ne prodnisent que des embryons vermiformes. Les autres sont amphigéniques; ils commencenl par ètre des rhomlogènes, et donnent, en cet état, des embryons infusoriformes; puis ils changent d'aspect, deviennent ¿ leur lour des némalogènes, el nengendrent plus que des embryons rermiformes. L'état de nímatogène est donc le but tinal conslamment alteint par tous les individus; seulement, il est altcint d'emblée chez les bicyémiles monogíniques, et ne l'est yuapres une phase temporaire de rhombogène chez les Amphiginniques. On dome aux individus du second type, qui commenrent par èlre des rhumbogìnes, le nom de mémuloyines secondaires, pour les distinguer de ceux de la furemiere section, qui sont des némulngènes primaires.

Quelle que soil la forme les embryons, leur origine est toujours la mène : chacun des noyanx endodermiques du gincialeur sentoure l'une anriole protoplasmique, yui se limite sur son pourlour; il se produit ainsi une cellule, qui se segmente, el engentre l'organisme du jeune Diçémide.

1. Embryons vermiformes. - La cellule prinilive, yui se téveloppe sins fieondation prialable, el yui est comparable a un orule parthrinogénitique, se divise d'ahord en deux segnents iganx, puis en quatre. Trois des quatre seguents se disposent de maniore it former, par leur assemblage, une petite cupule qui contient le quatriemre; puis ils se partagent eux-memes en nouvelles rollules, angmentent ainsi cu nomber et thatement aneloppent completement lébment central. Lembryon est alors constilué jar une masse cellulaire, composie diune 
collule centrate, do flusicurs cellules piriphripues rassemblios en

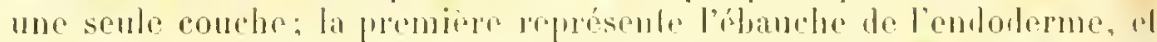

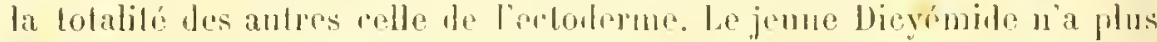

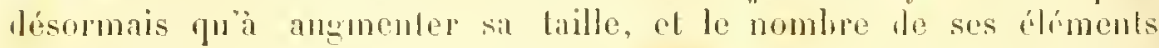

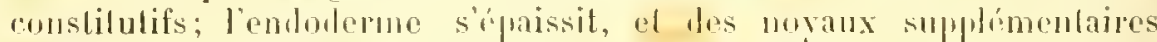
apparaissent dans son infónem; lectoderme acooil lo chiltre do sos cellutes; et l'embryon revet pen a jou la forme de l'abulte. Il quille

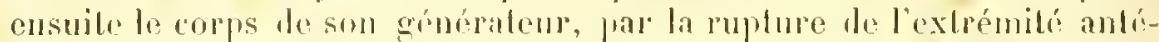
rienre de redornier, el reste, à rôtr de lui, dans l’intériemr du reju do l'loote yu'il babile.

II. Embryons infusoriformes. - Ces embrvons ne sont engen-

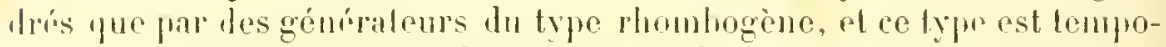
ritre; il comespond it me phase le la vie des individus amphigéniques. Les phénomènes soul plus romplexes que dans la genèe des emloryous vermiformes; ils se passent en deux temps. I) iaborl, le générabur produit, daus son endolerme ot aux dipus de ses noyam, des corps dits infusorigenes; ensuitr, charm le res derniors engendre, ì son lour, un cerlain nombre d'emloryons infusoriformes.

Apres que chacune des cellules, formóes sur place dans linnlorleme lu généraleur, par la télimilation d'une auréole protoplasmique anlour d'un moyau, s'est divisée doux ou trois fojs, les trois on les qualpe biments aimsi produils ahandonnent ume part te leur sulistance; le protoplasme rejelé conslitue moe masse, spmblable au noyau principal W. Temloderme, el yue Whilman a nommere, pour celte raison, le parrmuclés, ou le paranoyau. On a comparí celle expulsion in une gonoso de cellules polatires; il est encorr difticile de se prononcer a cet égarl, mais rependant l’ilentité entre les denx phénomenes est manifesle. Ensuile, les éléments rumbunent i se mulliplier; ils se disposent comme cenx drs

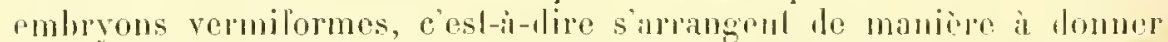
une grosse cellule centrale, culourée par unc assise pépiphérique ayut l'aspot diune cupmle. Le corps infusorigene est alors conslitur, et sa

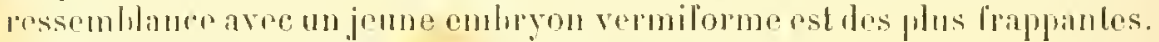
la dilfórence consiste dans la sulle de l'írolution.

laus lis deux cas la cellule centrale représente l'endoderme, el la cupule periphéringe correspoml à lectoderme. Chez los enliryous vermiformes, celle cupule se lerme, enveloppe completemont la cellule

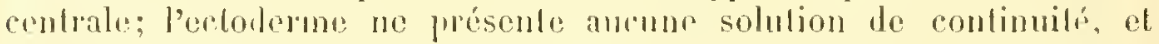

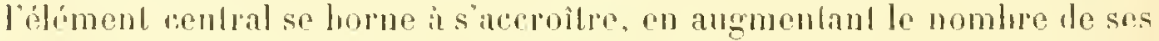
noyaux. Il n'en est pas a ansi pour les corps infusorigenos. Lemp ampulo

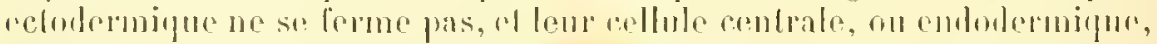

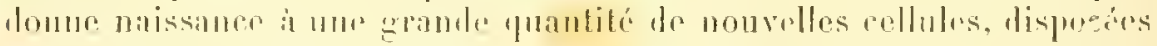

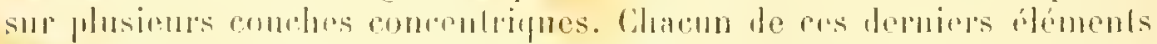

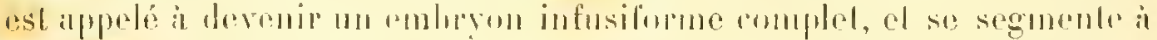

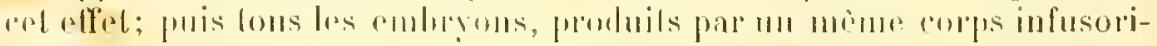


gène, se séparent les mus des aulres, deviennont libros dans l'endodeme Ju génirateur frimorlial, s"y déplacent, el traversent leetorlerme de ce méme génératem jour arriver dans les miliemx pxteriems. Cenx-ci sont
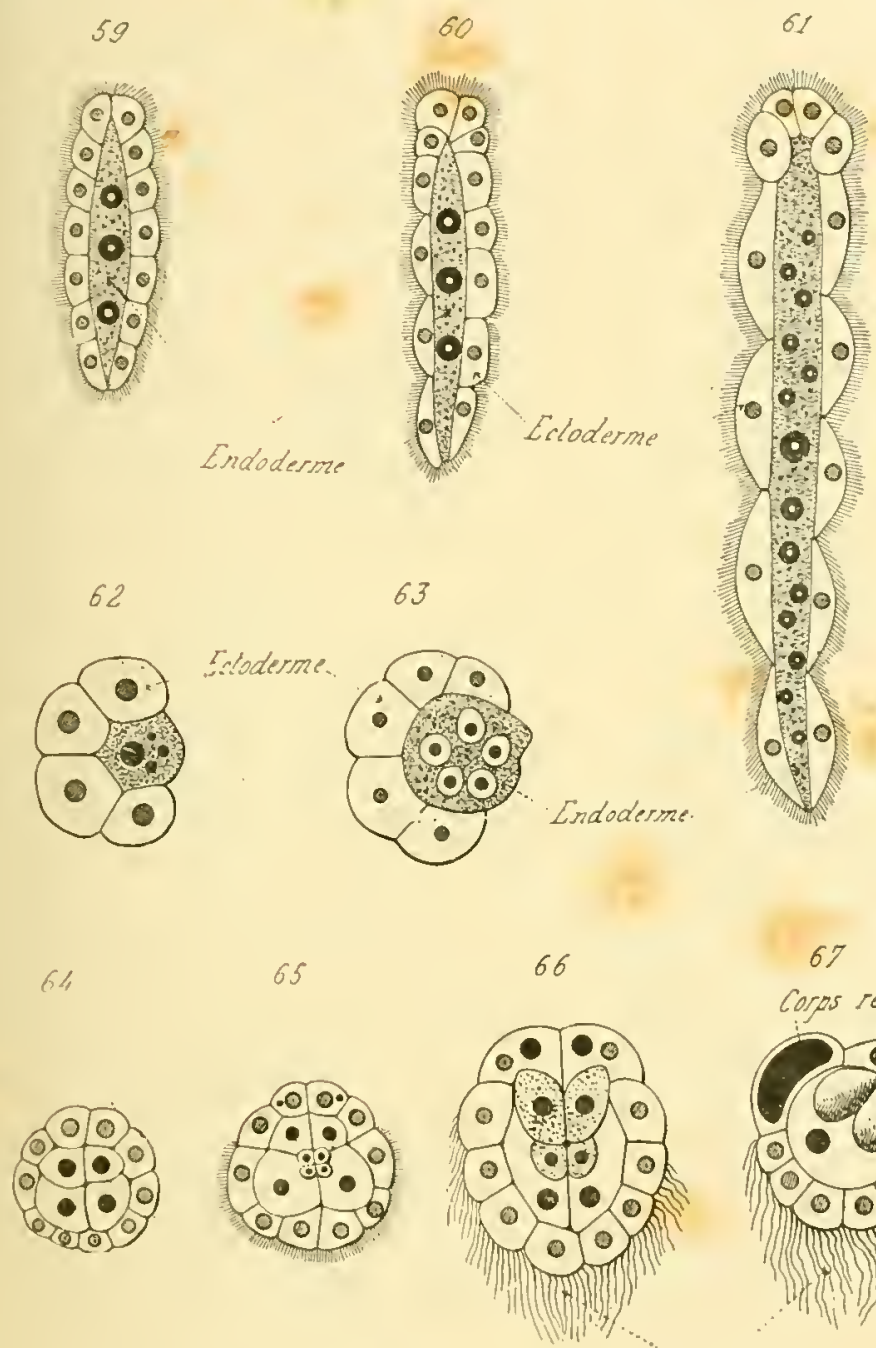

67

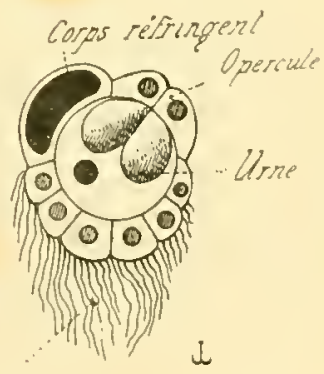

Cils uibraliles

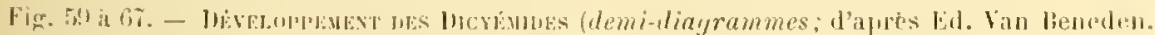

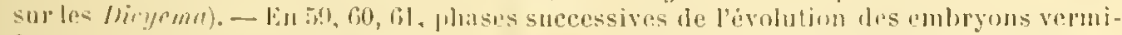

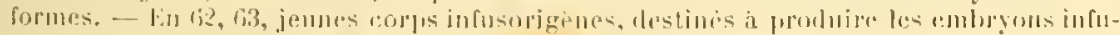

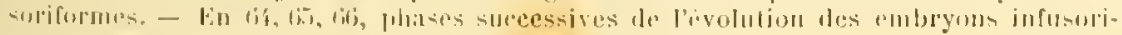
Cormes, - lin tit, mblum infusorifurme complet, vude coté.

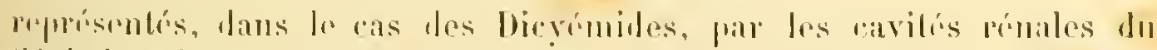
Cipplalopule portem de res piorasites. 
En somme, tandis que chacun des noyaux endodermiques des individus nématogènes dumne directement un embryon vermiforme, ceux des rhombogènes engendrent llabord les corps infusorigenes, ces derniers étant chargés le produire a leur lour les embryons infusoriformes. Il en résulte que lis quantilé de res deruiers ost relativement fort grande, fuisque chapure corps inlusorgène est capahto de donner naissance à un nombro considérable d'entre eux. Ce phénomène de multiplication, daus hequel des emloryons le première génération, arrètés dans lenr développement par l'appantion hative de la faculté reproductrice, founissent des embryous de seconde génération, n’est point particulier aux Dicyémiles; il riste chez d'autres animaux parasites, encore flus complexes qu'eux, par exemple chez cerlains Trématodes.

Comme findique leur $110 m$, les embryons infusoriformes sont couverts de cils vibraliles. Leur organisme se compose d'un ectoderme, qui entoure une masse endodermique. (Quelques-uns des éléments de celle dernière se groupent en une cupule, et limitent un espace, l'urne, remjli pal les autres collules le l'endoderme; celles-ci sont an nombre de quatre, et renferment des granulations. Les deux cellules ectodermiques, placées au-dessus de l'urue, conticunent de volumineux granules réfringents; olles conslituenl l'organe nommé couvercle par les autenr's.

On est aujourd'hui portí à penser que les embryons infusoriformes sont les males des Dicyemides; les granulations des quatre cellules de lume représenteraient les totes, et les fouels souvent placés sur la face profonde du converete seraient les pueues, des spematozoïdes de ces miles. Si cette opinion est exacte, la séric des générations de ces animanx se trouve assez complexe. - Les individus parfaits sont des femelles; parmi ces dernières, les nnes, monogéniques, ne produisent que des femelles; les aulues, amphigúniques, fomnent naissance à des males durant len jeunesse, et à des temelles lans teur vie avancée. En ellet, les indivilus monogéniques sont des nématogines, dont ne derivent que des embryons rermiformes, qui evoluent directement en nouveaux nemalowines; et les imtivilus amphigéniques sont d'aloud les rhombogenes, qui cugendernt des enthyons infusorilormes, esesta-dire des males, el passent ensule a l'étal de némalogenes seconrlaires, dont les semls produits sout des embryous vermilormes.

\section{3. - Développement des Orthonectides.}

Ces animaux sont misexues. La dillience des sexes entrine aree elle une dissemblane de lormes. Les mates sont phus pelits que les

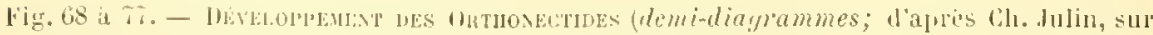
lin Rhopalura triardi). - lin (is, (it), 70, 71, 72, 73; phises successives de l'èolution des

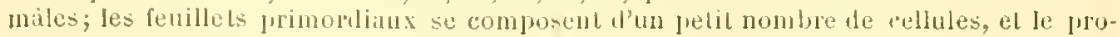




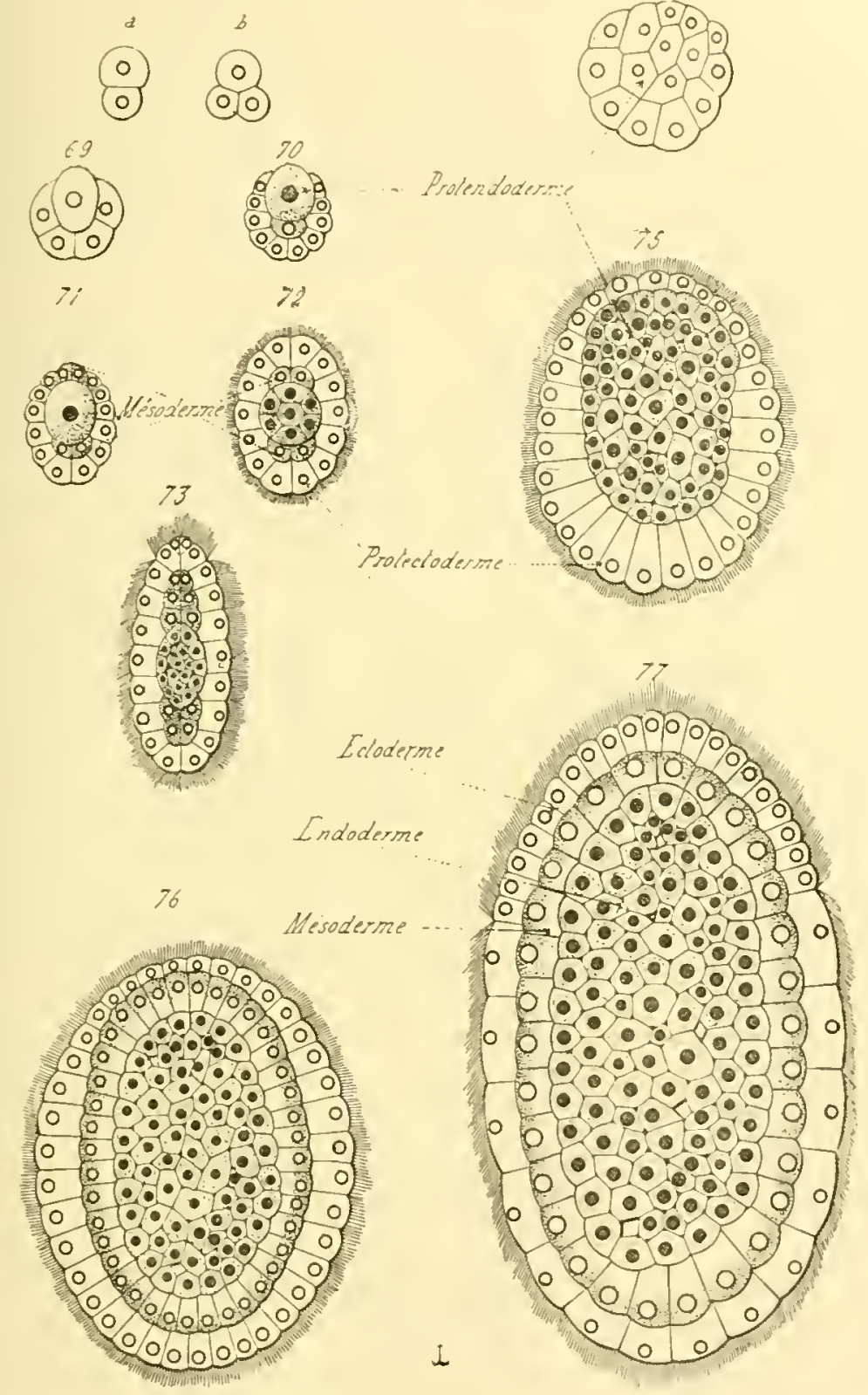

tendoderme se divise précocement en mésoderme et endoderme, - lin $\pi$ it, $75, \pi 6, \pi 7$, phases suecessives de levolution des femelles cylindriques; les feuillets primordiaux deviennent rapidement formes par un grand nombre d'elements, etle protendoderme se dirise, d'une manière tardive, en mésoderme et endoderme. 
femelles; leur retodrune est conslitué par des cullules cuormes dans la région postrieure du rorps, ut leur endorlerme se frowve forl réduil. Les lemelles sont plus grables: les cellulos de leur ecloderme montrent toutes des dimensions presque semblables, et leur endoderme est relalivement rohminoux. Ditns les deux cas, l'endorlome est représenté par une agrógation de cellules, qui se transforment en spermatozoïdes chez le mile, et en ovules ahoz les femelles. Ces dornicres se présentent sous deux aspects dillérents: les unes, dites femelles cylindriques, sont arrondies. é élroiles en dianctre; les antres, nommés femelles aplaties, sonl plates comme lindiqueleur nom, el plus larges fue les premières. A co puil semble, celles-ci (aplatios) ne produisenl que des femelles, et rolles-là que des millís.

La lécondalion n'a pas enore élé hion observée. Les femellas cylindripues se hornent ì expulser leurs ovules. par la ruphre de lemr paroi du corps. Les faits somt plus complexes pomr les femelles aplatios; cellescise divisent en fragments, qui deriennent des petites masses sphéripues el cilies, formées do délnis d'retodrme el d'endoterme; res masses perdent ensuite lems cils, s’accolent à la paroi du corps de lour hòte, ct leurs cellules endodermịues, yui sont des ovules, se développent en (m) hroms.

Les plıses du développenont ditlerent, suivant qüil s’agit les màles ou Jes femelles; elles ont élé smotoul suivies par Ch. Juliu, et par Giarl. Antant quil est permis l'eu juger, daprès les rechembes faites par ces auleurs, il est possiblu de rapporter les procédés, suivis par lovale dans sa segmentalion, et par les feuillets dans leur délimitation, à une planulation direvele.

lovule, yni va produire un imbividu mile, se divise de tefle facon que les premiers llastomères se groupent en une cupule, contenand dans sa cavilé une rrosse collule; celle-ci représente le protendorleme, alors que les élóments périphéripues composent un prolecloderme. Ce dernier achere, tout en saceroissant, el augmentant le nombre de ses cellules, dentourer le volmminenx hastomere central; il se horne i lonner lectoderme détinitif. Pumant que sellectue celte évolution, l'unique fómenl du prolendoderme se srinde a son tour en trois cellules; la plus grosse d'entro elles, en se multipliant, produit lendoderme de l'adulte; les doux antros engemlrent celle assise, intermédiairc ả l'ectolerme et à l'endorternu, gui méribe, en raison de sa situalion, le nom le misoderme.

L'évolution les ovoles, qui domment les imlivilus femelles, rappelle ia précúdente dassez pris. Ia dillérence principale porte sur le proterloderne; celui-ci saceruil plus rapidement que chez les embryons males,

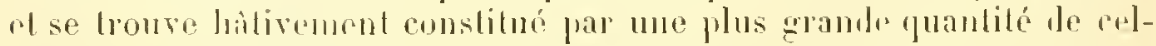

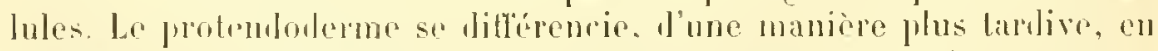
mésoderme el rudodormr. Le premier fistillet est romslitué par une assise simple placéc un ledans de lectoderme; le second est repré- 
senté par un amas cellulaire roluminemx, dont tous les choments, semhables les mis aux autres, ou peu s'en fant, sont rapal, les de devenir des orules.

\section{RE்SUME்}

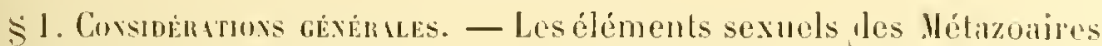
proviennent de l’emdoderme. Ceux des Dicyémides sont formés par les noyaux disséminis dans l’endoderme du généralenr; reux des Ortluncetides sont constilués par les cellules qui composent ce mème endoderme.

S. - Discloppenent des Dicrimoss. - Les emlirvons ales Dicrémides appartienment à deux lypes; les uns sont dits vermiformes i cause de leur aspect, et les autres infusoriformes. Ces derniers sont peut-ètre des miles, et correspondent à des individus pourvus de facultés reproductrices, mais lont lorganisme reste imparfait, comme il en est pour divers autres animaux, tels que les Géphyriens du genre Bonelliu. La structure des générateurs differe suivant la nature des emlorons produits; il est, parmi eux, des individus nimaloyines, qui donnent des mhryons vermiformes, et des individus rhombogenes, qui encendrent des embryons infusoriformes. La disposition propre aux nématogenes cst coustante, contrairement i celle des rhombogines, qui est temporaire. Cette particularité conduit à reconnaitre denx sortes de générateurs : les monogeniques, qui parviennen! d’emblée à l'état de némalogènes, el en demeurent là; et les amphigéniques, qui ollonent d'abord la forme rhomlogène, et passent ensujte a celle de nómatogène.

Pour produire les embryons, chacun les noyan endodermiques du générateur" s'entoure d'une aurćole protoplasmique, el se convertil ainsi en une cellule, qui mérite le nom d'orule. - Dans le cas de la grenose d'embryons vermiformes, lovule se segmente un cerlain nombre de: fois, et engendre mn groupe cellnlaire, comprosé d'un élément central. et لlune assise périphérique, avant l'aspect d’une cupule. Celle-ci se complete par la suite, se ferme, et devient l'ectorlerme; la cellule centride augmente le nombre de ses nosaux, et constitne l'endorlerme. - Les phénomones sout plus complexes lorspüil s’agil des embryons infusorifornes; ils se répurtissent en deux temps. Les ovules ibu générateur commencout par douner, en se segmentant, des corps infusarigines, yui offrent, par leur ectorlerme en cupnle, l'asject des jemmes cmbryous vermilomes. Puis, cet ectoderme restant incomplet, chargue corps infusorigene engendre, aux défens de sa rellule centrate endodemique, un grand nombre d'ovules secondaires, qui deriennent aulaul d'embryons infusoriformes.

S. 3. Diviloppenas nes Onthovecturs. - Pami les imlividus, los uns sont vaiment des males, el les autres des femelles. Celles-ci applarlienuent à denx types : les cylindriques, qui produisent les måles, ot les 
aplaties, qui engendrenl les femelles. Dans les deux cas, chacune des cellules endodromigues est un ovule, destiné à se segmenter jour donner un nouvel individu. Le développoment diffère quelque pen, suivant que l’individu formé est un màle ou une femelle. La segmentation rappelle celle qui se manifeste dans les planulations directes, et fournit nn protenloderme massif, quientoure l'ectoderme: le protentoderme se sulbdivise, par la suile, en un mince mésoderme el un mododerme. Lorsqu'il sagil des nuàles, cette dernière scission est hàlive et s'effectue en un moment oi le protindoderme se compose d'un petit nombre de rellules; l'inverse a lieu pour les femelles. 


\title{
EMBRACHEMENT IES SPONGIMRES
}

\author{
C.IIPITRE II \\ EMBRYOLOGIE DES SPONGIAIRES
}

\section{1.-Considérations générales.}

I. Garactères et classification. - Les Spongiaires sont des CulpnLérés, lont lectoderme est composé de cellules épithéliales plates et à peine différenciées. el dont la paroi lu corps se troure percée de nomlorenx canaux, mettant en communication arec l'extériem les carités internes dont l'organisme est creusé. Les éléments, "pui limitent les portions élargies de ces carités, sont munis de longs cils, ou plutùt de longs funets viluatiles, entonrés à leur lase par une gaine en forme de collerette. Autant qüil est permis d'en juger d'après les connaissances acquises. le protendoderme est ençendré l'après le procété cytulaire, du moins lans les déreloppements alrégés, el non suivant le mode gastrulaire.

Liembranchement de Spongiaires contient deux classes:

$1^{\circ}$ Les Calcisponges, dont lo mésoderme renferme des spicules calcaires;

2. Les Fibrosponges, dont le mésorleme posside, comme sijuelette destiné i soutenir les lissus mous, des fibres cornées phus ou moins distinctes du reste de la sulsstance conjonctive de ce feuillet, ou bien les spicules siliceux, on les deux a la fois. Ia présence des spiculos silicux raut, sourent, le nom de Silicisponges aux représentants de cette classe.

II. Développement en général. - Nos connaissances sur le déreloppenent des spongiaires ne sont pas encore tris complites, et pròtent i des opinions diverses. I'n fail certain porte sur la frésener constante d’une phase blastulaire, au débnt des développenents dilatés; il ne peut done itre question de comparer le corps des liponges aux colonies des 
Choanollagellés formóes par agrégalion, puisque ces colonies sont toujours compactes, el ne renferment point te cavilé rentrate assimilablè ¿ une cavilé hastoculiemue. En so basant sur la seule évolution larvaire des Éponges, la nécosité d'admetto une parenté étroite entre ces òtres of les aulres Métazoaires s'impose, puisque les premieres phases de celte évolution sont los mèmes dans les denx eas, et caraclírisées par la présence d'un étal blastulaire dans los embryogénies dilatón.

Les conlradictions entre les divers faits acquis commencent ensuite. La jeune larve l'Épongre répond à une blastule, dont le hlasloderme entonre une grande cavilé blastoculionne. Les fruillets lérirent de ce bastoderme suivant deux modes principanx. - Le premier procédé esl comparable, en lout, a celui qui caractérise les memos phémonirnes chez les Hydrozoaires; les rudocyles nombreux so détachent du blasbolderme, fombent daus le hlastomple, et remplissent sa cavite; la blastule se lransforme, de colte façon. en mo blastoplanule compacte. Une cavilé de nourelle formation ne tarle jas i se crenser an centre de la masse endocytaire; elle grandit à mosure que h bare sacroît, et déhouche ensuile au dehor's fiar nne onverture; ello deviont ainsi la cavilé interne, son oritire stant l'oscule. Les emlocytes yni la limilent losment l'endoderme; le reste le la couche blastodermique, laisséc it la surface du jeune animal, constilur l'ectoderme; les endocyles placés entre ces deux surfaces épilhỉiales donnont le urésorlerme.

Ce premier procidé ne comporte point te phase gastrulaire; il n'en est pas de même pour le secoml, de beancoup le plus rare. - l.e blastoderme de la lilastule poduil également des endocyles, realivement moins nombrenx que dans le premier cas; puis la biastule saplatit en nue sorte de disque irrónglier, d'abort plan, qui s incurve ensuite pour jrésenter une face concave el unc face comvexe. Sous cetle forme, la larve rappelle juespue une gastrule, mais elle dittere les gastrules vaies en ce que, chez ces derniòes, le feuillet interne prenl naissance en premicr lieu, tantis qu’il est précérlé, ici, par une genise d'endocyles. La lace concave leviont te phus en plus profonde, el simule une cavité entérique, communiquant arec l'extírient par un large entéropore; la larve se fixe sur un corps élranger par les bords de ce derniel orifier, el se convertiten adnltr. Son enteron dovient la cavilé interne, qui comummique bientôl aree le dehors frar un oscule, percé dans la région opposéc à la partic lixée; la portion, du blastoderme, qui limitail la face concare, et par suile l'entéron, se hansforme en entoderme; la seconde portion du hlastoderme, laissé sur la face convexe, prodnit l'evtoderme; ¡uant au mésoderme, il est engendré par les endocytes situés undre le lenillet externe el le fenillet interne.

Co procédé rappelle de trés frès unc évolution gastrulajre, sauf les róserves formules fulus haul. La dillérence avee le premier mode porte sur l'origine le l'ondoderme: ce dernier est ici une persistance directe d'une partie du blastorlerne, alor's qu'il est produit, dans te premier cas, 
par los endocytes. De telles dissemblances soml fort remarimables, car if est curienx de trouver, rassemblés cu un mòne embranchement, Jes deux types cytulaire el gastrulaire: alors quils sont distincts rhez lons les autres lléla\%oaires.

Ce rapide exposé du développement des Spongiaires porle sur les embryogénies dilatées seules; les embryogénies alı́gées se rallachent toutes au développenent eytulaire, el montrenl simplement me produclion plus hailive des endoryles, cenx-ci devenant moins nombremx, plus gros, et se formant parfois dis la phase morulaire.

Les trois feuillets hastodermiques ébanchés, la structure du jeune urganisme est presque complicle. Il ne lui reste plus qu’a produire ses canam, el quà perfectionner sa slructure hislologique. Les spicules ul les filaments sont d’origine mésodermique.

La reproduction sexuée n'existe pas seule chez les Spongiaires; ces animaux se déreloppent aussi par gemmiparité, el par gemmulation. Dans ce dernier cas. plusienrs cellules de l'organisme se groupent en un corps compacl, de forme délerminéc, la gemmule; celle-ci, après s'ètre faconnée, est rejelée au dehor's; elle se lixe ensuite sur mu support, el se convertit en une nourelle Éponge. - La gemmiparilé oflre tous les caracteres d'un véritable bourgeonnemenl; la paroi du corps se souleve en une sallie, ou pénotre un diverticule des cavilés internes; colle saille grandil, s'allonge, et devient un nouvean zooilde. Le diverticule s'est accun dans les mèmes proportions, et, tout en conservant ses l'clations avec la carité maternelle, il s'oure au dehors par un orifice. Très raroment, les zooïdes se séparent les uns des aulres; le plus sonrunt, ils restent unis, el forment iles colonies, dont laspect extérieur se présente suivant leux lypes principaux. Le type le plus simple est de beancoup le moins fréquent; les régions Jalhérence sont étroites, de manièı à rendre les zoö̈les distincts, el à donner à leusemble une allure assez roisine de celle des colonies d'llydrozoaires. Le Lype le plus complexe est aussi te plus commun; les zooüles sont confondus par leur cons ontier, et constituent, par len union, une masse compacte, crensée de corbejlles vibratiles, le canaux, el percée de pores et d'oscules.

\section{2. - Segmentation et feuillets blastodermiques.}

I. Ėléments reproducteurs. - Les éléments reproducteur's, Fovule el le spermatozoüde, sout semblables chez tons les Spongriaires. IIs naissent dans le mésoderme, aux dépens de cellules qui se transforment en ovoblastes, on en spermaboblastes; leur lien d'origine est placé d'halihude dans te voisinage de l'endoderme, cest-it-dire en une rógion on les chéments mulrilifs, alssorhes par les cellules endodermiques, sont abondants. Fiant donnée celte situation, la fécondalion est le pilus souvent interne. 
Les Éponges sunt hermaphroulites, d'ortinate; smutement, les spermatozoüles arrivent il maturité complète arant les orules. Aussi, les rhances sontelles nombreuses pour entrainer la fécondation d'orules, encore renfermés dans les lissus maternels, par des spermalozoüdes venus d’aillenrs. Les éléments màles sont done ohligés de se mouvoir dans l'ean, four arriver il lom destintion. Il n'en est point ainsi pour les déments frmelles, qui restent en place, ou sr borment i prozresser dans l'organisme maternel, cn y subissant mème les premières phases de leur déveloprement. Les larves deviennent libres lorsqu'elles possètent des cils viluatiles: etles déterminent, par leurs mourements, des téchirures locales dans l'enloderme de leur générateur, tombent dans les canaux et les corheilles vituratiles, puis sont rejetées au dehors par les osculos.

Les spermollastes térirint de cellules conjonclives ordinaires. Celles-ci possèdent des prolongements, semblables i des pseudopodes de

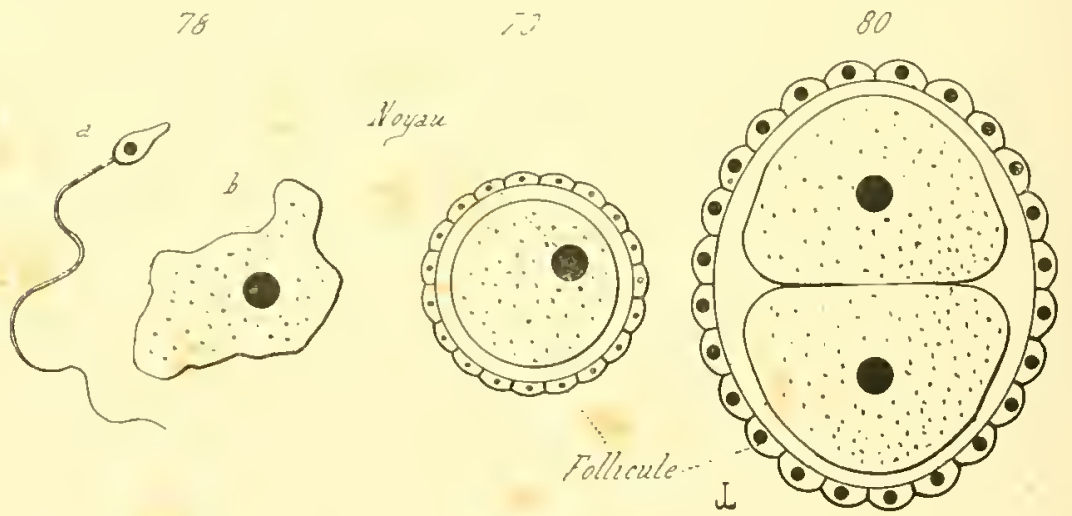

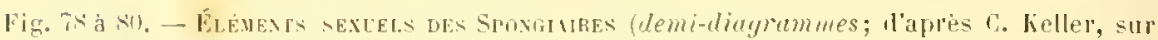
la Chalimula ferrilis). - En is a, sprermatozoide: en Ts b, jeune ovule. - En ri, ovule entonac de son follienle. - En 80, ovule ficondè et divise en deux blastumeres, dans la carilè folliculaire.

Protozoairrs sarcodaires, el servant, de mème, a déplaces l'ólóment dans la substance fondamentale du mésoderme. Au monent où doil arriver la malurití sexuelle, rertaines le ces cellules rétractent leurs expansions, ot sarmomissut; eltes sont ainsi transfomées en spemolilastes, et lả se borment tous les phénomènes de cefte transformation. P'uis chayue spermoblaste se modilie en un spermatogemme à nombreux déments; sourent, les spermatogemmes sont entourés par quelques cellules mésodermigues, assemblées en une mince enveloppe, comparable à un follicule ovulaire. Les cellules hu spermalogemme se convertissent ensuite en spermatozoïdes. Ces derniers soul, chez les Spongiaires, constitués par une lête ovoüle, que suil une longue queue très fine. 
l. évolution des ovoblastes rappelle de tres pros edle des spermohastes, du moins dans le déhut, car ces éléments sont prouluils de la mème façon par les cellules mésoulermiques. Celles qui, parmi ces lernieres, vont devenir des ovules, rétractent lenrs prolongements psendopodiques, puis augmentent de dimensions. Les pisendopodes n'ont pas entierement disparu durant la premiore période de l"accroissemrnt; ils persisteut peudant un certain temps, of déplacent les jeunes éléments femelles dans les tissus de l’Épongée. Ensuile, ces éléments s'arrondissent en grandissant loujours, et se transforment en ovocytes.

Les ovules mùrs ont un diamelre cinq à six fois plus grand, en movenne, que les collules mésodermiques ordinaires; ils sont plongés Jans la substance fondamenlale du feuillet moven, et entourés par un follicule, que divers auteurs désignent à tort sous le nom de chorion. Ce follicule est constitué par une couche unique d'áléments aplatis, el comparalıles a des cellules entothéliales; il parait ètre engendré par les éléments mésodermiques voisins, ‘ui s’apliquent contre la membrane vilelline de l'ovule. l'ourlant, dans reptains cas, l'ovohlaste se divise, suirant los procédés habituels, en deux íléments, donl le plus garos devient l'ovule définitif, et dont le plus pelit produit les cellules folliculaires. Ainsi constitué, l'ovocyte attend sur place les spermatozoüdes 'qui doivent le féconder; mais, aupararant, il émet deux cellules polaires, siluées, apris leur séparation complète du vitellus, entre le vitellus et son follicule. La présence des cellules polaires, dans les oufs des Éponges, arail été longtemps contestée; ces éléments ont élé trourés récemment par Ilagdeburg, chez les I'hlima, et tont prorte a croire qu'il en est de mème pour les autres Spongiaires.

l.élément femelle est done parvenu a maluilé, et l'ovocyte se trouve translormé "n ovule. Le follicule se sépare de hi par places, et laisse, entre ses propres cellules et la memhrane vitelline, une cavilé souvent assez raste. - La fécundalion se prombil alori, et les premières phases du déreloppement seffectuent lans col espace, que limite le follicule.

\section{Segmentation et feuillets blastodermiques en général.}

- les phínomenes de la segmentalion, el le la genese des feuillets blastodermiques, ne se ressemblent pas chez les Ëponges; ils rarient suivan la quanliti du vilellus muloilif eontenu dans le plasma ovulaire, et se modifient en conséquence. Sums re rapporl, los Calrisponges et les fihrosponges prísentent deux séries paralleles, allant des développemeuts les plus simples jusqu'a des types emloryonnaires fort condensés. Le caractère principal de l'alrériation porte ici sur la genèse, de plus en plus hitive, des endocyles. - Les dérelopponents dilatés montrent, a leur lébul, nur hastulo normale, munie d'une ample cavité blaslocelienne; le blastoderme produit, smr sa periphéric culiore, on senlement on une région donnée, les endocytes qui, en se multipliant eux-mc̀mes, remplissent le blastocuele, et produisent ensuite le proten- 
doderme. C'est là le procédé le plus simple. Les modes plus condensés

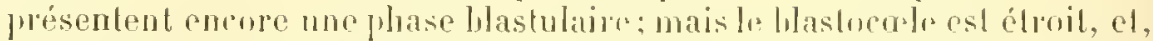
des la formalion de la lilastule. les cellules. yui doirent lommer mais-

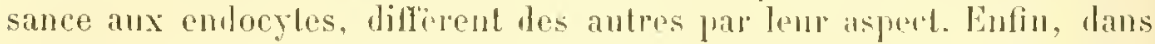
le trpe le plus complexe du díveloppement alorécé, il n'wiste point l'état blastulaire, el lis endocylos so dislinguent des aubres blastomères, dès la phase momlaire.

l'évolution de l"IIalisarea lobularis (Hyxospongres), el celle de diverses Éponges calcaires, n’appartiement en rien à ces deux sérius. Elles montrent parfois un itat blastulaire, semblalide à celui des développenents abrégis; mais les endorytes sont pen nombrems, of joroduisonl le mésontrume seul, landis jue lindoleme lérive, comme lisctorlorme, d'une partie le la rouche hlastonleminue. Cie développoment est considré par les aulouss comme répoudant il une gastunlation.

111. Galcisponges. - 1. - 1'usirurs especes du genre Ascella (A. 1mimordialis, A. blanea) possèdent, d'apres les recherches eflectuées pas O. Schmidt el par E. Ilelschnikotí, un développemenl dilaté. La segmontation, peu conmue, prait ressembler à cello des aulres Calcisponges, et détermine la produclion d'une hlaslule, avec ample cavilé blastocolienne. Les éléments blastolermiques ne sont point semblables; la blastule ayant une forme oralaime. l'un des póles du blastorlerme est formé de collules rylimbriques assez longues, lautre de cellules plus pelites, el contenant des granulalious en assez grand nombre; res rlómenls, puel que soit leur aspert, soul munis de cils vibratiles. luis, les petiles collules acombuent leur aspuet granuleux, perdent lents rils, wt engendreul des embocytes, qui tombent dans la cavite blastoculienno, où ils se mulliplient. Less áments issus do cello multiplication apparliemuent à deux types: les nus sont gros, el renferment de nombreuses gramulations; les autres sont plus pelils, munis d'expansions posudoporliques, el de leinte phus daire. les premicrs se groupent de préférence daus la partie centrale du lilastoecele, les seronds s'jntroposent ì ceux-ci el au blasloderme péripleripue.

lua hirsule s'est aimsi transformée en mo blasloplanule, constituce lia" une couche blastodermique externe, el un amas emlocylaire cenlral. La premiore devient l'ectoderme; la seconde rejrésente le protendoderme, qui doit se scinder en mósuderme el endolerme.-An moment où ces phúnomenes viennent de s'achever, la jeunc larve so dégrage des lissus maternols, ch se met en liberte; elle nage d'ilbord, au mogen des cils vibritiles porlís par les longues cellules de son blastoderme; puis ces appembices lombent, et la hastoplanule se fixe it mu supporl. Une cavité so crense an milien du protemlodeme; clle est entourće par les gronsses cellules gramulumses et rentrales, gui constiluent aimsi l'endo-

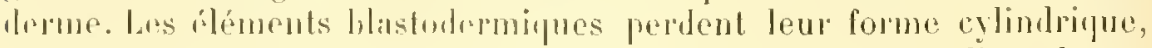
pour devenir cubiques d'abosil, ajlatis ensuile, et donnent l'ectoderme 
de la lare. Enfin, les endocyles à protoplasme clair. 'pui sont situés entre l'endoderme el l'ectoderme, conservent leurs expansions pseulupodiugues, sérètent de la substance conjonclive fondantentale, et se transforment par lá en eellules mésodermiyues.

Les Ascelta se diveloppent done, sans aucune contestation possible, snivant le mode endocrtaire. et ne présentent jamais de véritable état gastrulaire; leur blastute se morlifie en une hastoplanule, par le remplissage du hastocicle an moyen d'endecytes, el le mésoderme avec l'endoderme dérivent de ces áments. Ce procédé est sonvent désigné, par les autenrs allemands, sous le nom de type parenchymulaire, a canse dn lerme Purenchymulu, créé par Hetschnikolf, el emplové par lui pour désigner les blastoplanules.

Il nen est fras ansi clez divers autres Calcispouges, notamment chez les Aseandra, et surtout les siycandra. L'embryogénie de ces dernieres est telle, que la larve parail subir une raie phase gastrulaire. Ce deuxieme mode est lo type - Lmphiblastulaire des auteurs, la blastule des sycandru ayant reru le nom d'Amphiblashula.

B. - Pinmi, les Calcisponges, dont le déreloppement appartient ì ce second mote, les siycandra mphrmus ont été le mienx éludiées jusqu’ici; les observations sur ce sujet sont dues ì F. E. Schulze. liovule fécondé se partage en denx, puis en quatre, et enfin en huit blastomires ígaux; res derniers. au lien d’ètre groupés en une masse arrondic, sont placés les uns à cóté des autres sur un mème plan, leur. forme ctant i peu près celle d'un còne; ils convergent lons rers un mème point central, mais n'y parriennent point, car lenr extrémité tonnée de ce cuté est arrondie. L’auf, ainsi divisé en segments, olfre lans sou ensemble l'aspeed d'un distue, constitué par huit cellules flacées còte à côte. La division des hlastomeres s'ellectue ensuite, de manière que chacun d'enx soit parlagé en denx masses, l'une supérieure, et l'aulre inférieure; les seize noureaux segnents sont donc groupés en deux courhes, chacunce d'elles étant représentée par huit cellules. Une cavité prend uaissance au milieu de l'amas des bistomères, et, en grandissant, fail perdre il l'ovinle son aspeet de disipue, pour hi donner celui d'me sphire; rette cavite est le hastocale. De nouvellas livisions s'elfectuent, la cavité haslucolienne restant relativemont atroite: le nombre des hlastomeres angmente de plus en plus. Ilais, durant res pluenomenes, des ditlérnees dasprect se manifestent entro les divers blements; certuins d'entre anx, rassemblés à l'une des extrémutís du jenne embryon, sont armonlis, et contiennent des gramulitions nombreuses; les autres, en quantité plus grlande, devienneul cylindrigues, el renlerment un protoplasme presigue livalin.

Le délut de la phase blashulaire est altcint; des ce moment, les

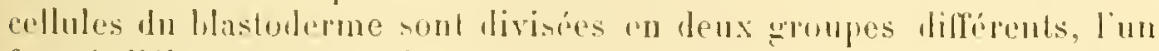
formé d'éléments gramuleux, ret lautre d'élinents i plasma prespue 
homogene. La larve, tonjonls reuferméc dans les tissus mésoderminues maternels, saphatit surtout dans la répion a cellules granulouses; l'rnsemble do ces dernières parait mème s'imvaginer quelque jeu dans la cavili hastocoliemne. - Ces phénomènes sont dépourvus de fonte signilication; ils proviement sans doute de la prossion exercée, far le mésoderme envirmmant. sur la larve entière, car celte derniòre est devenue trop grande pour la raviti habités par l'ovule dout elle lérive; cetle prossion prorbit surtout son elfel sur les éléments grannleux, dont la cohórenco est moindre il cause de len forme arrondie. C’est lì l’étal désigné, par F. E. Schulze, sous te nom de psendogastrula: l'invagination du blastorteme granuleux nayant ici aucune imporlance ( $1^{\text {re }}$ forme blastulaire).

La lare tend alors il devenir lilire; trop grande pour l'espace qui la contient, elle rofoule les tissus voisins jusqu'i la paroi d'un canal, quelle brise pour tomber dans sa cavite. Saisie par les comants d'eau qui traversent le conduit, elle est emportie dans le systime des canalicules do l'Eponge maternello, et finalement rejetice au dehors pa" in oseule.

Des la mise en liberté, fes éliments blastorlumiques. à protoplasme hyalin et contours rylindriques, se munissent de cils viluatiles, yui permeltent à la larve do se léflacer; dautre part, l'ensemble les cellules cranuleuses, cessant l'ètre comprimó far les tissus maternels, se refoule à l'extérieur en une forte saillie. L'embryon libre présente alors un aspect ovalaire, et semble divise en dewx parties, en deux hémiovales superposés: l'un, constitué par les cellules cylindriques munies de cils viluatiles, et l'autre par les rellules granulenses dépourvues de rils. Ces deux moitiés composent le liastorlerme, et forment me cunche continue, autour dune carité centrale. qui est le blastocore. Cette phase blastulaire béfinitive ( 2 forme blastulaire) a reşu le nom d'Amphililastula.

La blastule, ainsi faite, nage pendant quelque templs, gràce à ses cils viluatiles, et gamle le mème aspect. Puis elle se raccourcit suivant son grand axe; alors que le petit axe s"accroit, de facon a acquérir des dimensions supérieures à celles du premier: la lares'aplatit done, et surtout lans la partie constituée par les longues cellules cilićes. Lautre moitié du bistorlerme, formée far les éléments granuleux, reste hombée el convexe; mais la premiure se déprime, devient plane, puis pénètre dans la cavite hastocorlienne. Culle invaginalion continue ì seffocher, jusqu’i ce que la compho des cellules ciliós soil devenue interne, et logée dans le hastorole. La cavilé, limitée par cette couche, communique avec le dohors jar un large orifice, qui est louverture de lin ragi-

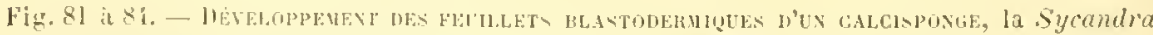
raphanus (conpes diayrammatiques). - In $\mathrm{S1}$, première forme blastulaire (pseudogastrula des ableurs), emcore contenue dins les tissus malepels; l'un des poiles du blastoderme est compose lle cellules claires, l'autre de collules grannleuses et fonces. 


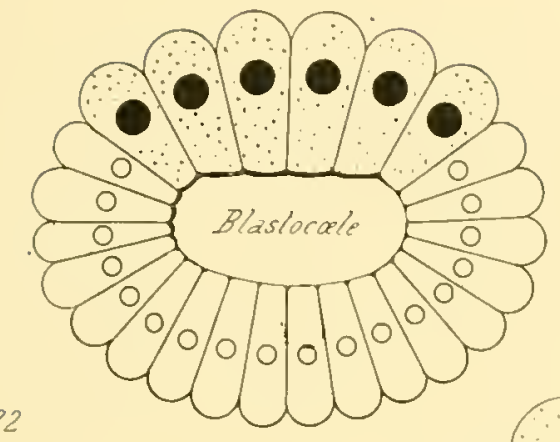

Cellules granuleuses
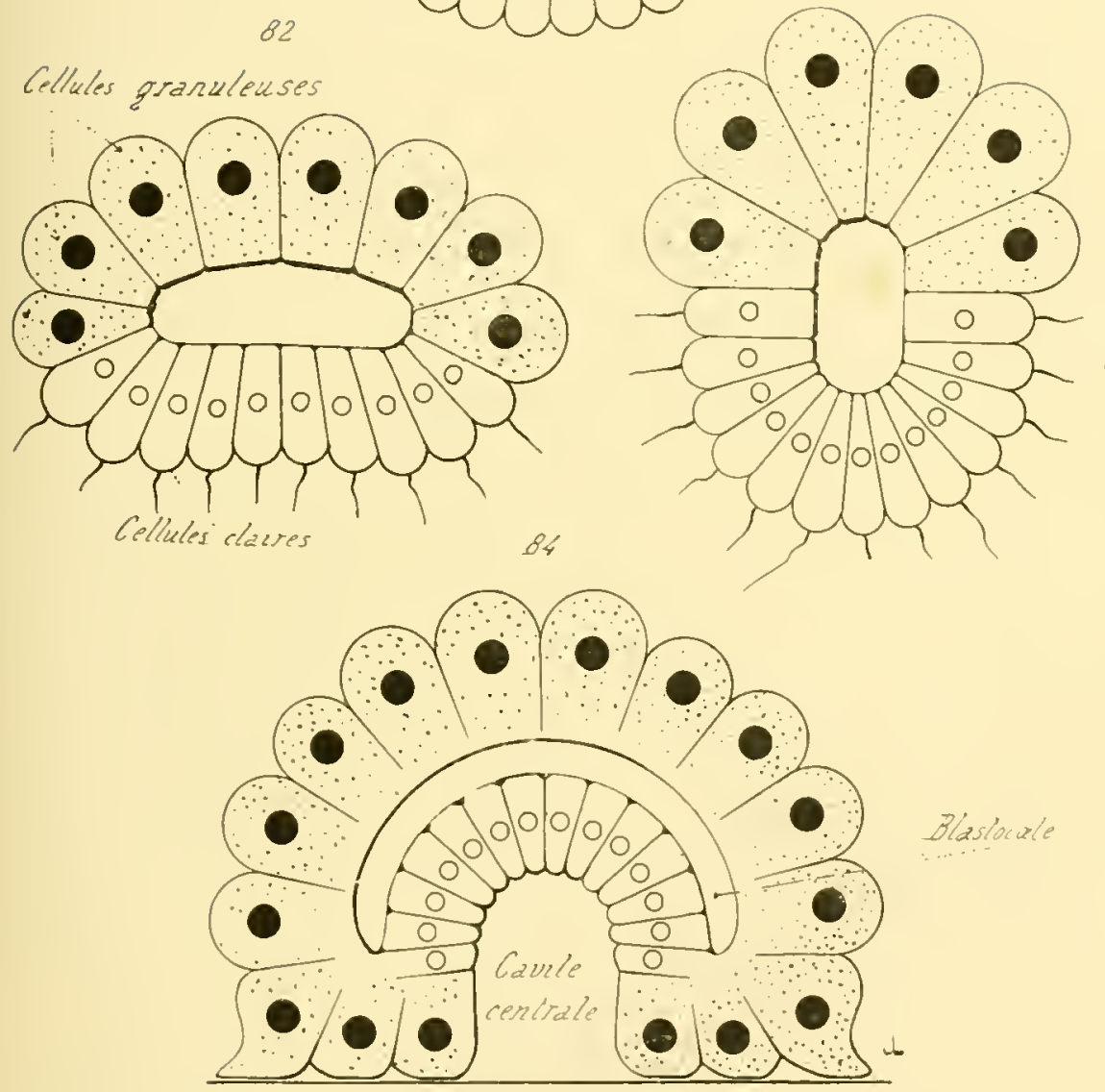

Fin 83, seconde forme Wastulaire (amphiblastuln des auteurs), correspondant it une vir libre. - En 82 (i) y a en interversion dans le numerotagu serie des figures), difult de l'aplatissement et de l'incurvation le la larse. - lin 8i, achévement de l'incurvation et

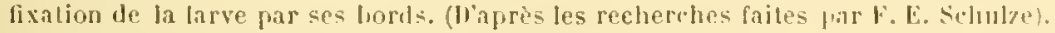

La suite de ce developpement est donne d'apris une Irxosponge, loscarelle lobularis dans les figures $90 \mathrm{el}$ y?. 
nalion. La lave sulixe par les bords dre cel oridir. Entro temps, los collules grandenses produisent des endorytes, yni parviennent dans lo blastocuele, et domment maissance an mésoderme.

La larve présente alors l'asprel flum demi-sphere creuse. Sa paroi est constilure par frois conches, ainsi disposées, r:1 allant de Jehors en delans : l'assise des cellules pranulenses. lamas rulorylairo, el l'assise des rollules ciliérs; celte deminge limble immódiatement la raviló rentrale. Les éléments, placés sur le bort mène de l'ouvertnre, apparliement i l'assise granuleuse, el ce sont eux qui délerminent la fixation de la larve, en émeltant des expansions psendoporliques; quant anx rollules de l'assise interne, ellos conservenl leur lorme "ylindrigue, mais perdent leurs cils vibratiles. He phus, lorilice dr la larve, encore present au moment ois se produil la fixation, se ferme peu à pen, car les élóments granulenx a pseudopodes le resserrent de plus en plus; il limit par disparaile compliclement.

L'embryon est ainsi comverti, de sulte apres sa tixalion, en une visicule creuse, puisque sa cavilé interne ne rommunique flus avec lo dehor's. Autant qu'il est promis d'en juger, d'apres les recher'hes offectués par F. E. Schulze ot par E. Melschnikuli, la triple paroi de celle vésicule proutuit, de la facon suivante, les larois feuillets délinitifs: l'assise externe des celhules gramuleuses devient l'ectoderme; l'assise interne des longues cellules constitue l'endorlume; el enfin les andocyles intermédiarres domnent le mésorlerme.

C. - Ce procédé est cu opposilion llagrante avec le mode observé choz les Ascellu. Dans ce demier cas, l'amas endocylant engendre le mésolerme arec l'endolerme, at la cavité interne se creuse an sein de cel amas. 'an conlre, rhez les sycumba, tes cndocyles donnent naissance au mésoderme seul; l'emdoderme dérive d'une portion du blastoJeme, qui s'est imvaginée dans le hlastorole, el linnterun frovient directoment de la eavite d'invagination. Celle-ci communique done arec l'exlerienr, au moment de son apparilion, landis pue sa correspondante des Ascella commence par ètre close. Mes dissemhlances pareilles exislent anssi parmi les Fibrosponeres; la plupart de ces ternieres présentent un développenent hlasto-planulaire bien net, les endocyles prodnisant à la lois le mésoderme et l'endonderme: par contre, l'llalisarea lobularis subil nno évolulion embryonnaire, comparable à celle dres siyrenulra.

La phupat des autenrs considirent la larve a haslodermo invagini, des sycambre et des IIalisurca, comme nue gastrulr; $\mathrm{cl}$ il est bien cerlain que le mode de lormation de l'endomleme, el de la cavité limitíe

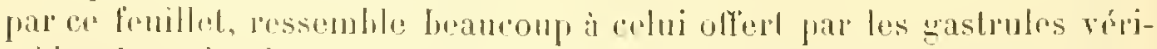

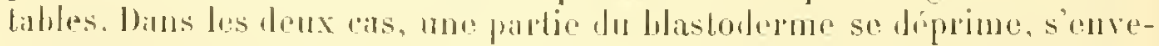

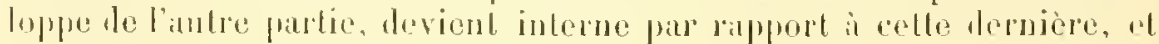

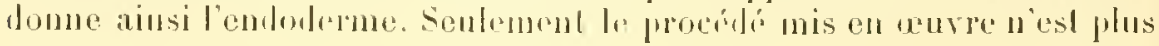


le mème. - Jans les gastrules des Spongiajors, limvagination an déInte pas par mo petite dépression, 'puj augrmente de dinensions dius tous les seus; mais par mne sorte daplatissement de la larve, yui rend progressivenent une moitié du blastodermo interne, par rappoil à l'aulre; en outre, cette invagination me se manifeste pas le suite apres la phase hastulaire, mais bien apres une série de molifications particulières, portant sur l'aspect offert par les éléments lolastodermipues, et sur la durée assez longur du deuxiome élat blastulaire. La forme gastrulaire est tarlive chez les jeunes Épunges; et, lorsqu'elle existe, elle so produit par un procédé comparable à celui des gastrules cugrentrées par incurvalion.

lin admettanl qu’il s'agisse ici de larves gastrulaires, ces larves ditlierent beaucoup de leurs similaires des antres animax. Les dissemhlances ne portent pas seulement sur les procélés génétiques, mais aussi sur la structure génerale.

Les animaux, pourvus de réritables gastrules lans leur développement, sont les Scyphozoaires el les Culomates: cluz ces derniers, le feuillet interne de la gastrule est de valeur double, ear il donne naissance à l'endoderme défuitif, et an mésoderme; chez les premiers. le meme feuillet est simple, car les tissus mésolermiques proviennent de l'ectolerme, ce lirniel avant alors un donble développement. Ces denx moles ne se retronvent point lans lis larves gastrulaires des liponges; l'endorlerme et l'ectoderme sont simples tous les deux, et le mésoleme tout entier provient des enlocytes engendrís, par le lulastoderme, arant que la phase gastrulaire ne fasse son apparition.

Si lone les embryous des Sycundra et des Ilalisarea doivent ètre considérés comme des gastrules, it mumoment lonné de lenr existence, il faut reconnaitre que ces embryons ditlerent de leurs correspondants des aulres animanx, par len procédi lo lormation, el par l'oriçine des feuillets. Mais rien ne proure encore 'pu'il s'agisse inj llun étal gatslolaire, étant donnée lopposition établie entre ret état, et celui ollept par la grande majorite des Spongiaires. Womlinare, chez la plupart de ces derniers, l'endorleme el le mésorlerme sont prorluils en mòne temps frar la masse des condorytes; relte dernière est engendrée par le

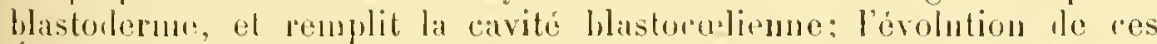
Éponges est une cytulation, ou, pour employer le langage de Hetseh-

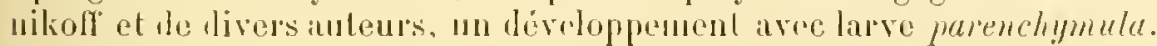
Il est donc étonnant de rencontrer, rho\% quolques antres spongriaires, un porélé bien dilurent, nue gastrulation; ral d'hahitude, los andres embranchements des Mobizoaires presentrol, dans lours embryogénies dilatès, on bien une evolution gastrubire, on lien une ivolution enlulaire. ef non liss deux a la fois.

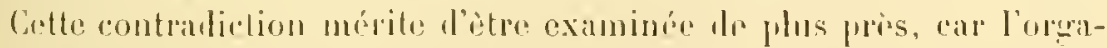

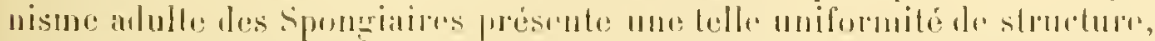

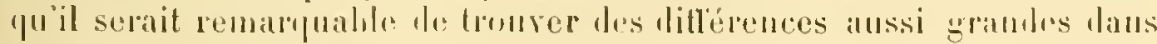
loriggine premiore ales fenillets. 
W. Fibrosponges. - I. Le mode le plus simple du développement est rehi de la plupart dres llyxosponges; l'evolution comporte successivement les trois phases: morulaire lulastulaire, et blastoplanulaire, toutes trois oflant lours parlicularités caractiristiques. - Lovule fécondé se divise ell segunents, el se transforme en une morule compacte. Puis une cavité se cronse au sein lo lamas des blastomirns; rest le blastocole, qui aprarail, grandit. el change l'embryon en un blastule. La jemne Eponge ws alors mise an lilerte; ayant la structure blastulaire spịue, clle est constituée par un lilastoderme, qui entoure mue cavilé lilaslocelienne assez ample; les éléments hlastodermiques sout cylindrifues, ol lous semblables, en ce qu'jls sont tous munis de cils viluatiles. A peine est-il permis lo signaler quelques différences entre plusieurs d'entre unx; les uns, rassemblés vers l'ume des extrémités de l'embryon, élant un pen plus longs el moins gramuleux que les antres. Ia larro est ovalaire; elle nage prondaul quelque temps à l"aje de ses cils. Duraut celle vie lilue, les cellules du bastorleme produisent des endocyles, 'pui parvenuent daus la cavité blastocolieme, et s'y accumulent en se mullipliant. Les endorytes émellent do comples expansions psemdopodiques, 'pui s"anastomosent les unes avec les autres; ils mérileul ainsi le nom de cellukes en rosette, lonné prar Helschnikott.

Ce développement olfre, sous mo forme très simple el comme schématique, la sérje les phases qui caraclérisenl une érolution cylulaire lypique. Il n'en est pas de mème pour les Malisurca (Oscarella) lobularis, d'après les observations effectuées par sollas el par Heider. Le blastoderme de la hlastule, chez les represcutants de celle espece, produil un nombre restreint d'endocytes; la larve blaslulaire s'aplalil, el passe à l'élat de disıue, pui s’incurve en rentant l'une de ses faces convexe, et l'antre concare. Les hords de la premiere se replient, el constituent un lonmelet eirculaire, entunant l'onverlure le la dépression limitée par la face concavo; la larve se fixe par ce bourrelet. Puis ces loris se rapprorluent l'un de l'autre, la dépression ne cessant pas d'exister, et levenant mème plus profonde; finalement ils se soudent, et la dépression se lrouve ainsi lransforméc en unc cavité close. Celle-ci est la cavité interne prinitive; les éléments blastodermiques, pui limilaient la lace concave, produisent lendoderme; eeux de la face comvere engendrent l'ectoderme: et les endocytes, intercalés à ces deux leuillels, domnent naissance an mésolerme.

Celte ívolulion larvaire est semblalle, de tous points, a celle des Caleisponges du genre tiycandrn; dans les denx cas, lendoderme ne dérive point te lamas enlocylaire, mais bicn d'une partic invaginée du blastoderme; la cavilé inlerne ne se creuse pas dans lamas blaslocytaire, mais doil dre cousiclérée, si les observalions faites par Sollas el Heiler sont exactes, comme la persistance direrte le la ravilé de l'inva-

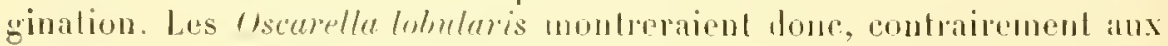
anleses fibrosponges, nne phase gastrulaire, présentant des parlicularilés 
identiques à celles otlertes par l’état correspondant ues Sycaudra. Les considérations, exposées plus haut, lui sont également applicables.

B. - La plupart des Fibrosponges lithidées subissent un développement un pen plus abrégé que celui des llyxosponges; l'abréviation porla sur l'origine des endocytes. Ces derniers soul, chez les llyxosponges, engendrés ilurant la pliase lilastulaire, et produils par le lilastoderme presque entier; il est impossible de reconnaitre, parmi les éléments qui constituent la jeune blastule, cenx qui donnent naissance à des endocrles de ceux qui nen forment point. Les faits sont plus avancés chez les Fibrosponges lithidées; dès le début de la phase blashulaire, et par suite dès la fin le l’état morulaire, certains blastomères, seuls chargés de fournir i la genèse des endocytes, ditrèrent des antres par leur aspec, granuleux. Ils se rassemblent ensuite, à mesure que la blastule grandit. en un groupe situé vers l'une des extrémités de la larve; et les éléments, engendrés par eux, tombent dans la cavilé blastoccelienne. L:abréviation du déveloprement a donc amené denx choses: l'abord, la localisation de la genèse endocytaire dans quelques cellules du blasloderme; et ensuile, la différenciation hàtive de ces dernières, dès la fin de l'état morulaire, ou le commencement de la phase blastulaire.

L'évolution des fenillets n’a pas élé suivie chez loutes les Fibrosponges, appartenant à ce denxième lype embryonnaire; les nombreuses recherches effechuées ont porté, de préférence, sur la forme exlérieure des larves. L'origine des feuillets a été ponrtanl étudiée par C. Keller, sur les embryons de la Chalinula fertilis; et, étant donnée la ressemblance des larves de cette espece avec celles des autres Filrosponges, il est permis d’admettre qu’il en est de mème pour la majorité de ces dernières.

Lovule fécondé se divise en deux blastomères presłue égaux; l'un d'eux est cependant quelque peu plus petit que son congénèe. Mlalgré cette ditrérence primordiale, la segmentation reste ígale, et délermine la formation d'une morule compracle, constituée par deux sortes de hlastomères. Les éléments de l'orule segmenté, semblables les uns aux autres par leur taille, sont groupés en une conche périphérique, placée aulonr d'assises centrales. Les cellules internes renferment de nomloreuses gramulations, et ollirent, pour celle cause, une teinte assez foncée; certains les éléments périphériques, placés les uns à còté des autres, ot groupés vers lune des exlrémités de la morule, ressemblent en cela aux cellules internes; par contre, les antres hastomeres périphériques, contiement un protoplasme clair, et paure en gramules. Donc, si les segments morulaires sont presque iilentipues par leur aspect et par leur taille, ils ditlirent par la slruelure de leur vilellus; certains d'enlre eux, occupant un des poles de l'embryon, et formant loule la masso centrale, soul granuleux; les autres pestent clairs et hyalins, ou pen s'en faul. Il s'est done prodnit ici, des la fin de la phase mornlaire, me diflérenciation des élements de l'unt, semblable ì celle des jeunes embryons de 
Sigcandru: et il fant distinguer igalement entre des collules granuleuses el des cellules claires.

L'étal hlastulaire commence cusuite à se manifestrr. Les cellules gramlenses, cet centrales, s'icartent par place des hastomeres clairs ale la priphrírie; elles laissent entre olles et cesterniers une carilé, qui est le

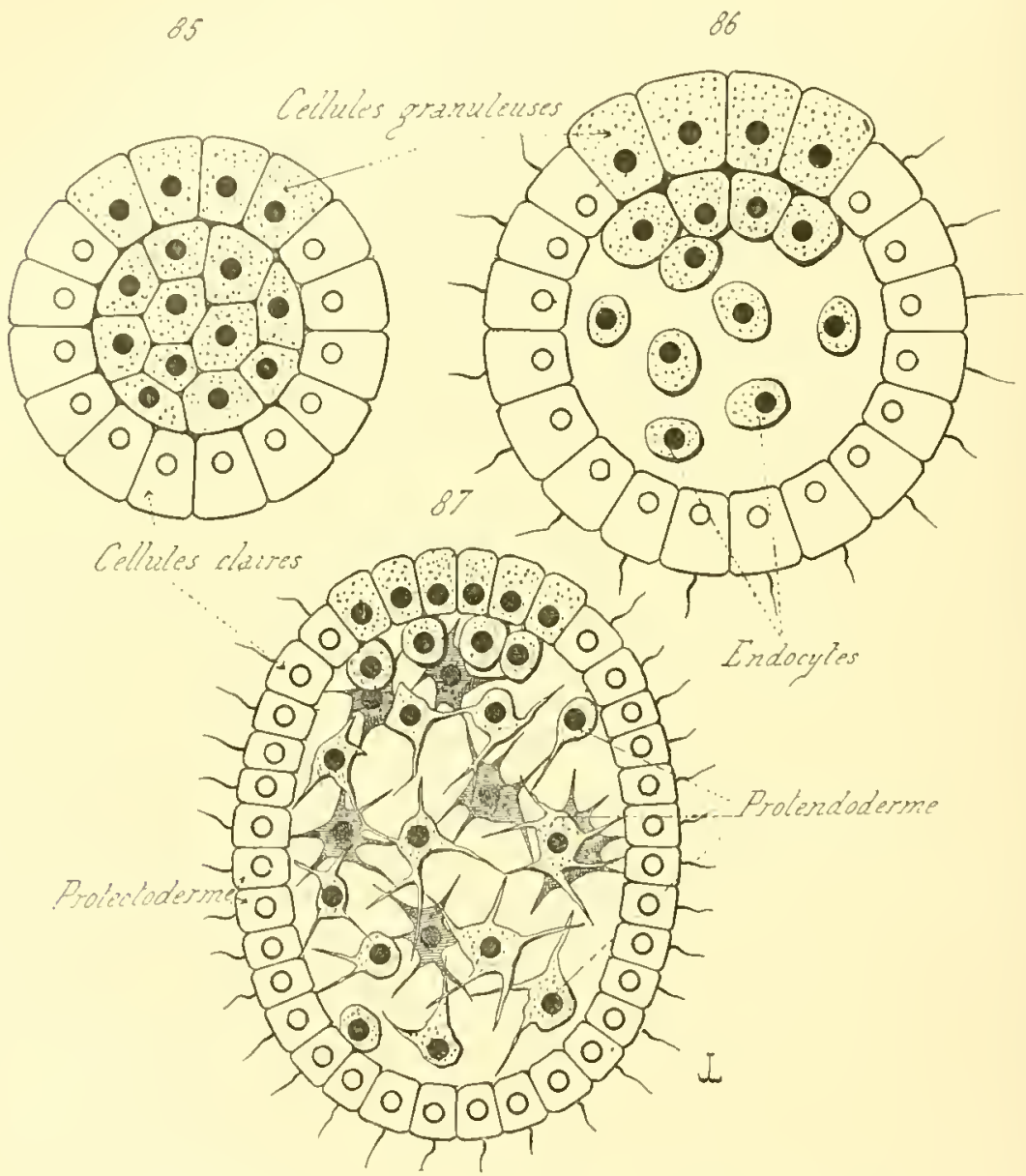

Hig. Si

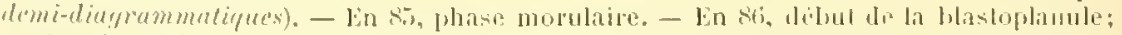

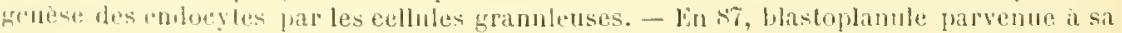

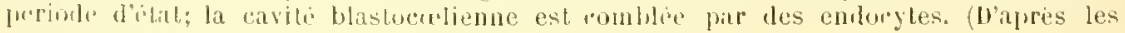
recherches faitrs mar C. Weller sur la Chalinula fertilis).

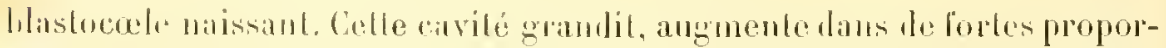

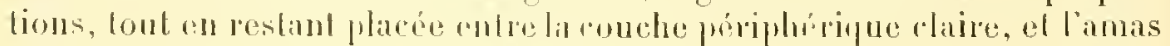

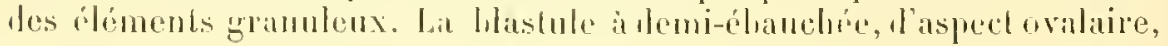


est lone conslituée par me conche blastorlermiqur, formée d'éléments apparlenant a denx lypes. La flus grande parlie du hlasloderme vonsiste en mne assise simple de cellules, dérivant des blastomères ả probojlasme char; l'autre porlion, placce à l'm des pòles de l'emlıyon, est représenlée par un amas de cellules granuleuses, lisposées sm plusienrs couches superposées, el dont l'ensemble s'avance daus la cavilé blastoculicune. Ces éloments produisent des endocyles, qui lombent lans le blastocuce, el s'y mulliplient.

La larve devient lihre vers celle íponne. Ies éléments blastodormiques de conleur claire se convent de fonets vibratiles, conrts d'aborl, phus longs ensuite; grice a leurs momrenculs, le jenne embryon se fraie 11 passage à travers les lissus malernels, gagne les canaux qui parcourent l'ĺponge, el, entrainć frar les courants d'ean, farvient à l'extcriem. Il nage pendant nu cerlain lemps, aranl the se fixer, et grandil durant cette période. Son allure finalr est acquise. lorsqu'il parvient à la phase blastoplanulaire, it l'étal de parenchymula; l'aspect ovalaire, il ollre une paroi limilant une caviti centrale. Celle dernière est occupéc par les endocyles, dont plusicurs commencenl a produire des spicules.

La plupart des Fibrosponges, dn moins de celles dont l'embryogónie a ćlé éludiée, présenlent une phase larvaire libre, semblable à crlle des Chalimulu; celle-ci correspond à un élal blastoplambaire, avec blastoderme divisé en denx zones, el blastoenle rempli d'endocyles; l'une des régions hlaslodermiques, de beancoup julus grande que l'autre, est constilure par des cellules vibratiles el claires, la seconde élant représentéc par un groupe l'élóments granuleux. Les dillérences, entre les diverses formes larvaires, portent sur l'élombe variable de la rógion granuleuse, el sur le nombre el la disposilion des endocyles. Les éléments de la portion granuleuse sont souvent colorís en rouge, ou en blen, par des corpuscules pigmentaires.

C. - Le développenent des feuillets de C'hulimula présente, par rapport à celui des llyxosponges, me abrévialion très acenséc; les ćléments génératems des enducytes lont leur apprarition des l'étal morulaire, el n'altendent point la phase hlastulaire pour prendre naissance. Il existe cependant un élat blastulaire lrès nel, elfechant un passage de la mornle ì la blastoplanule. Lahreviation esl phos gramle encore chez les śpongilla (Ephydaliu) /luvialilis; il n'existe poinl le hlastule, et la phase blasloplanulaire succede imméliatement à la phase morulaire.

l'anf, en se sogmenlanl, produil mue seule morule, composéc d'un flus grand nombre de hlaslonicres que celle des aulpes librosponges. Puis, lorsque la quantitó des blastomères est assez grande, la morule se convertil re suile en lolastoplamule.

Quelques élomenls cxlernes, rassemblés en mo calolle hémisphéripue, perdent la pluparl dos granulations quils contenaient, ol se disposent en unc assise recouvrant la totalite des autres blastomiers. Celle 
assise est l'homologue de lit portion claire, et vibratile, du blastoderme des larves appartenant an second lype le développement L'ensemble les autres hlastomeres comprose un amas compact, qui correspond à la région granuleuse des larves du second type, augmeutée des endocyles. Ces dernières, chez les Chatimula of la plupart des Fibrosponges, sont engendrées peu ì peu frar la zone granulense. Il n'en est point ainsi chez les śpongilla; les enibevtes et la zone granuleuse prenuent, en mème temps, naissance aux dépens des blastomères de l'ovule segmentí, et les premiers ne dérirent point de la sceonde. - Tandis que, dans le denxione mole. la morule produit la blastoplanule par nue série de transformalions successives, cette genèse est directe dans le troisiome procédé.

Une cavité se creuse dans le corps de la larve, el occupe une situation exrentrique; il est permis de l'homologuer a un blastocule de renue tardive, et le dimensions restreintes. Wapris les observations failes par

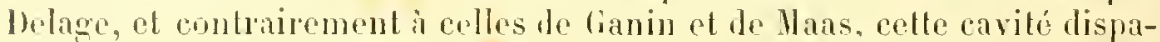
rait les la lixalion de la larve, et nugendre aucune portion des canaux internes.

Les feuillets ont aiusi effectué leur apjarilion, et possèlent la méme origine que leurs correspondants des autres fibrospunges; seulement, ils se sout formés surplace, at provicunent directement des blastomerrs morulaires, sans que leur ávolution présente la série des phases blastulaires caractéristiques du premier el du second procúdé.

\section{3. - Fixation des larves; développement des cavités internes.}

1. Généralités. - A. La larve venant le se fixer, et les feuillets lłastodermiques s'étant lélimités, les canaux destinés à permettre la circulation de l'eau prennent naissance. Les observations, effectuées sur ce sujet, permettent de commitre, dans lems grands traits, les procadis mis en aruve.

Les Eponges sont, ponr la plupart, les organismes colonianx, apparlrmant à deux types. Le plus simple, et le moins fréquent, est caraclérisó par ce fait, que les zoö̈les the la eolonic sont distincts les uns des autres par une assez grande partie de leur corps; ce lype existe sculrment chez quelques Caleisponges. Le second, de beancomple pho eonmun. est remaryunblo en ce que les zoö̈les sunt entierement fusionnis; leur ensemble constitue nn masse, qui parait itre simple, et représente on réalité une colonie. - L’óvolution des embryons diffère, suivant yu’ils apprutienuent à l'un ou a l'autre le ces types. Dans le premier cas, la jenne larve granlit, produit lans son intérieur me seule cavité, creuse son systeme de eauan, ot revèt les paticularilés propres i l'arlulte: ensuite, elle émet, sur ses parois latérales, des petits bourgeons, qui s'accroissent, se développent, el se convertissent en nouveaux individus; 
ume colonie prend ainsi naissance. Des faits semblables se retromvent lorspue les jennes Eponges ne homreonnent pas, ot restent tonjours simples, ainsi qu il en est chez un petit nomlure de Calrisponges.

Les choses sont bien différentes dans le second type; la larve grandit, el me cavité se perce en sa masse; des canaux. communiquant avec l'extérieur, se forment rusuite. Mais. contrairement an jremier cas, l'rnbryon saccroit sans prodnire des bonrgeons latéraux distincts; i angmente de dimensions en conservant son aspect entier; ef tous les phénomènes ultérieurs se bornent à l'apparition de nourelles carités, sur le trajet des livers canaux, cavités qui vont s"ouvril au dehors fral de larges oscules. Il est permis, sans doute, le considéner ce procédé comme mu hourgeonnement: sentement, les jemes bonrgeons restent confondus aree lorganisme qui les engendre.

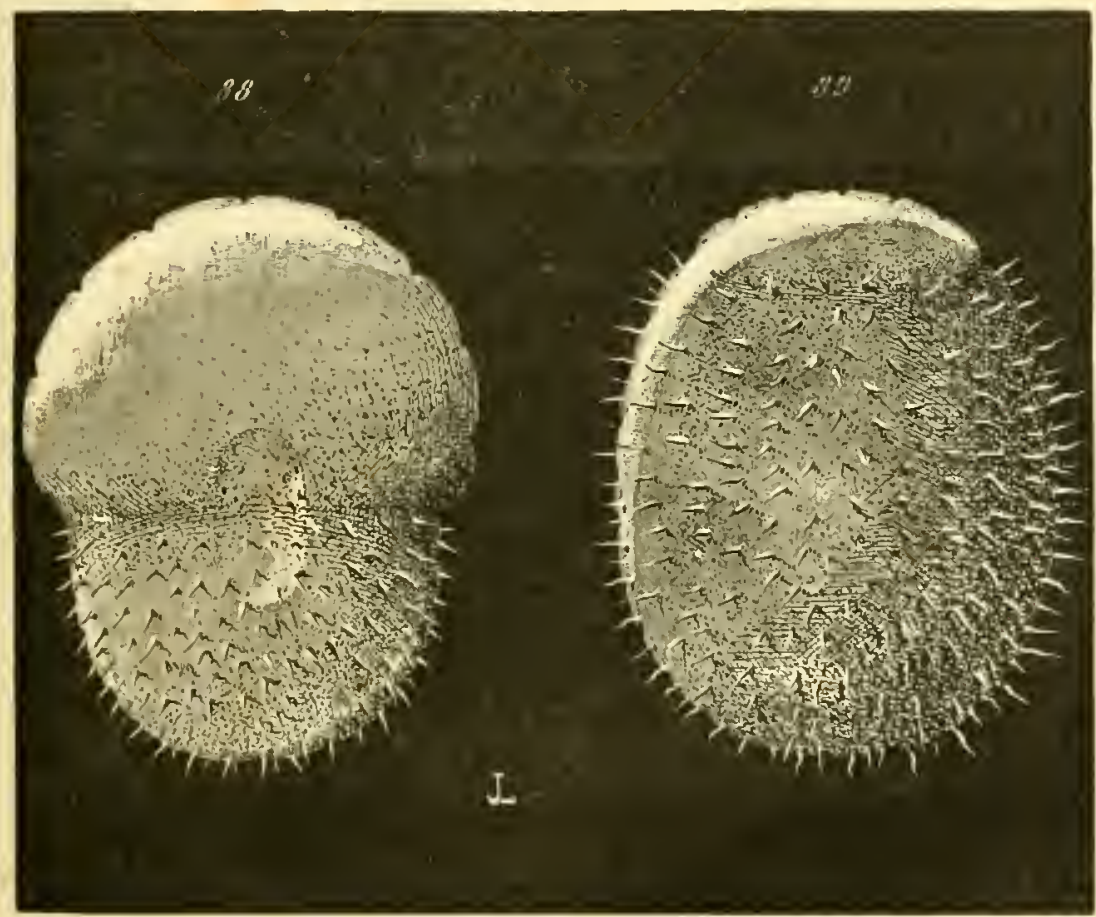

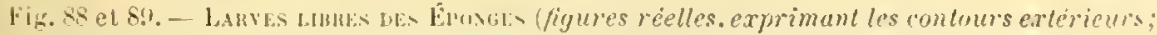
les cils vitoratiles ont ete dessinis un peu plus longs ıue nature, alin de les rendre mieux a[preciables). - lin 88 , Jarve Jont un hemisphere seulement est vibratile; comme le sont celles des $S y r^{\prime} a m b{ }^{\prime}$, dans leur seconde forme blastulaire. - lin 80 , larve courerte prespue en rotier de fouels vibratiles; tomme le sont celles de la plupart des spongiaires.

b. - los larves les spongiaires, étant mises en liberti, nagent

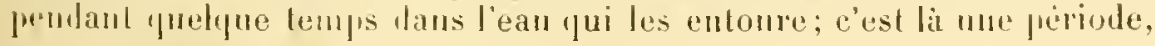


dont la durée varie, i la fois, suivanl les especes. el suivant la nalure des rondilions extrirumes. Pois, elles se tixent ì nu corps ítranger, s'acrolent ì lui, el subissont des modifiations imporlanles, qui les font se convertic en adultes. Elles perilunt len forme rógulièe, presque loujours ovale, et se changent en une masse minco, anx contons irré-

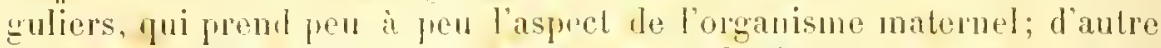
pirt les cavités internes se creusent. et se délimilant daus l’intérieur de lenr corps, en acyuorant l'me maniere hative lem disposition complexe.

La fixation de la larv" s'effoclue de deux façons. La promière n’a élé

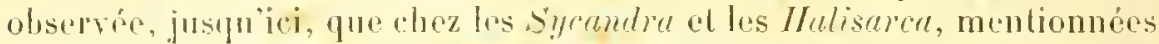
daus le frécédenl paragraphe; l'embryon s’incurve sur lui-mène, et se

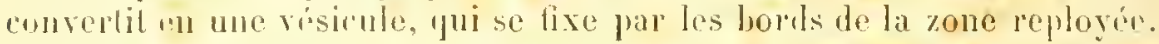
lans la seconde, de beaucoup la plus commune, aucume incurvation ne se prorhil; la larve, oralaire, s'allache à mu support, s'aplatil, et se transforme directement en mo Eponge adulle. La premiere manière concorde, comme les notions expusées dans le $\$ 2$ permellent de le pressenlir, avee l'évolution la plas dilatée; elle sera dite développement incurvé, on iो reploiemenl. La seconde sera nommé, par oplosition, diveloppement massif.

(:- In fail intéressant est oflert par divers Spongriaires. Si, pen apres la lixalion les larves, plusienrs de ces dernières sonl placées cole a cote, et juxtaposées, elles se sondent les unes aux autres en une masse. unipue, yui poursuit son évolution, comme si elle dérivait d'un seul el mome embryon. Tnu telle union, accompagnée to semblaliles conséquences, résulte évidemment le la erande simplicilí organipue de ces èlres. Ces phénomenes onl élé ohservés sur de jeunes Siycundra et C'lione; its sout accidontels, et ne rípondent point à une particularilé normale du dérelopprement.

I1. Développement incurvè, ou à reploiement. - CuLisroxges. - Les riycandra appartiennent a la famille des Syconiles, dont la plupart des rejuésentants sont monozoüpues, on forment des colonies constituées par un petit nombre d'individus distiucls. An moment où la larve, dont les premières phases évolulives ont élé précédemmeul exposées, vient de se fixer, elle a la forme d'me demi-sphère allachée à son support par sa face plane; celle dernièce colrespont à la région munie de l'orifice d’invaginalion. Cel orilice se rélrécil pen à peu, et se forme ensuite, car les cellules, qui le circonscrivicul, sarancent progressivement pour le dore. Linlérienr de l'emloyou esl aceupé par la cavilé de linvagination, qui ne communipue plus aver le dehors.

La lare, convertic on une résicule close, s’allonge perpendiculaireurul à son support, et perd sid forme hémisphérique; elle prend l'aspect

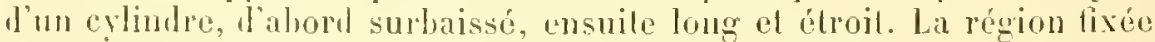
comserve les momos limensions, el reste tomjours plane: la face opposie cesse d'être boubée, et s’aplanil égalenent; l'oscule, c’est-à-dire lorifice 

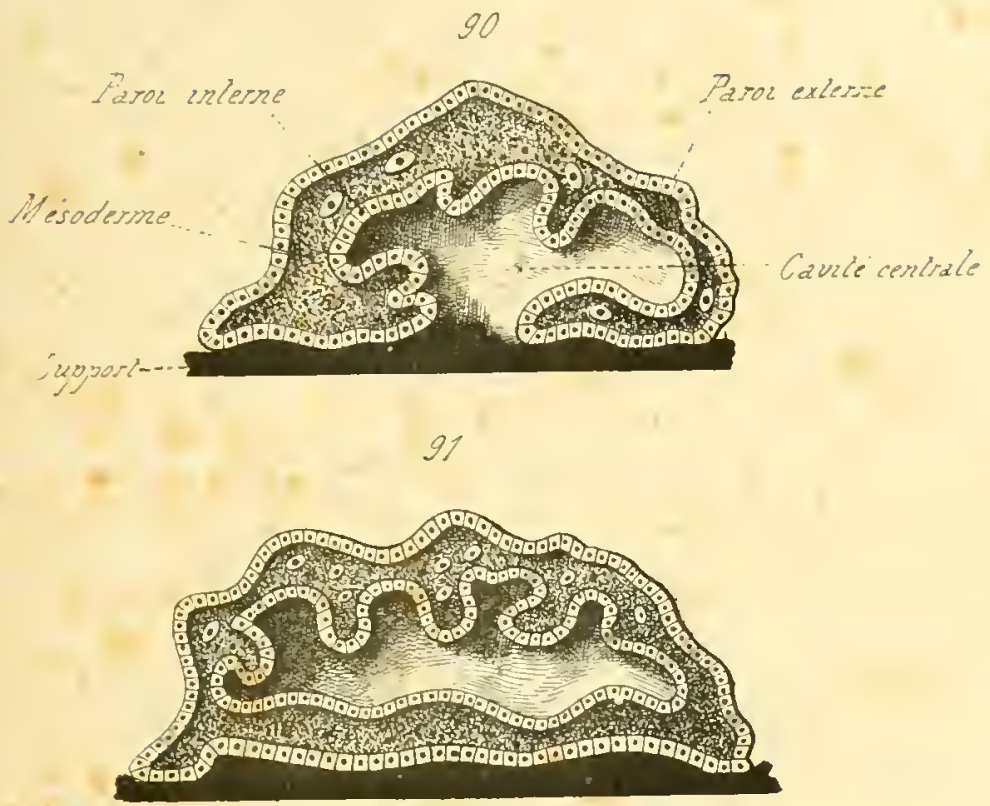

\section{Oscule 92}

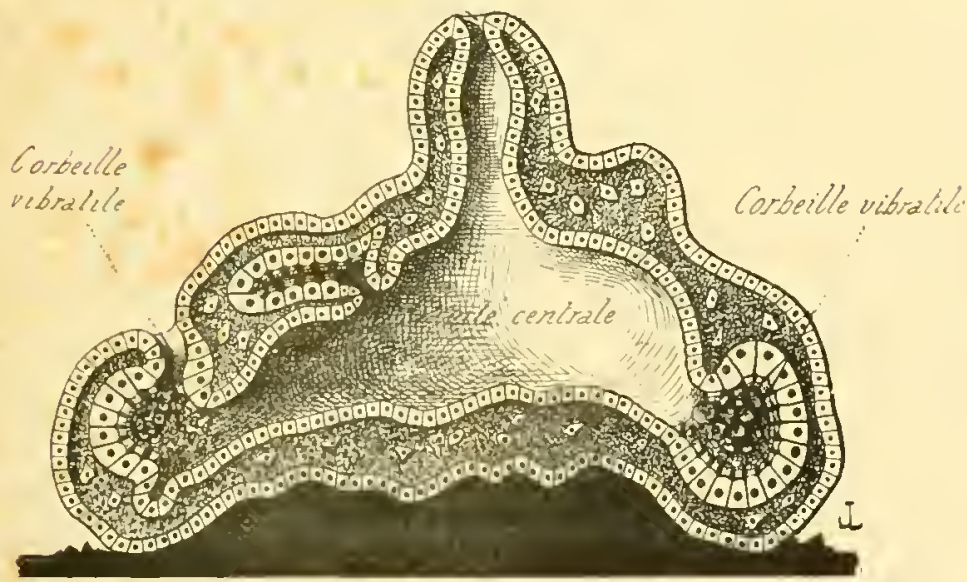

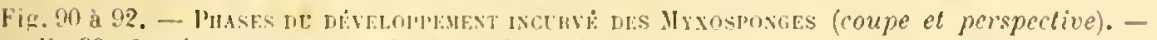
lin @n, fixation jar ses horrs de la larve incurvéc le support est représentè par une plaque noire. - En 91, phas: de visicule close, les borls soitant unis et soudés. - En !12, genèse de l'oscule, et des premières corbeilles vibratiles. (I'aprix's les recherches faites par lleider sur l'Os'arella lobuhteris.)

Ces phases suivent celles des tipures si a 8i. lille servent de base ì la notion exprimée, sous une forme diagrammatique, par les figures 93 a 97 .

ROULF. - Embryologit. 
charéce de faire communipuer la ravití aver he dohors, se peree sur cetle derniere. Lomverture premiere le linvagination ne persiste pas pour devenir l'osonle; celui-ci esl mue lumation nonvelle, navant ancun lapporl arec la précédente, el pronant mème naissance dans une région diamétralement opposée. Le procédé grínólique de l'oseule n’est pas lien connu. Cet orifice alparait, en premier lien, an centre meme de la face pui le porte, el consorve toujonrs sa siluation rentrale; it est entomé de honne heure par des spicules calcairos, jui se disposent en un erclec, présentant rapidement l'aspect te la couroune spiculaire adulte.

Le jeune individu, jarvenu à celle phase de son evolution embryonmaire, possele nue paroi du corps, disposie autour d'une carite centrale; celle-ci communique avec l'extólienr par un oscule, diamétratement opposé à la régrion le tixation. L'ean du dehors pénètre par cel orifice, et rentre libremunt laus la ravité. Les rellules, qui limitent cotte dernière, sont privés de lonets vibratiles, puisiue ces appendices se soul rétractés: mais, pen apros la groèse te l'oscule, de noureaux cils no: lardent pas a se montrer sur olles, arec leur collerelte spéciale. leurs momements determinent des comrants d'eau dans la chambre interne, et permettent ainsi au petil èlre, par le remonvellement incessant de celte eau, de respirer el de se nourrir.

Lorganisation dílinitive est prespue complete, car il ne reste plus qu’a prohuire les canaux, chargés de faire communipuer avec le dehor's la cavilé centrale. Ies premiers de ces conduils se percent rers le miliru du corps, presque à égale distance do la face supériente el do la face infériente; ils lessinent en refle region une courome transversale; plus lard, l'aulpes canaux se creusent sur le reste le fintivilu. leur mode exact de formation nest pas oncore ilucidé, et prète à contrstation.

Mrxospoxgrs. - A. La larve clant fixée, et les feuillets blastodermiques óbanchés, les premiers phénomenes ressemblent anx puécédents. La cavilé interne s'onvio au deluors par nn oscule, peré en me région dianétralement opposée a la patie lixée. Ensuile, les canaux, podnits far des involulions cotodermipues, etablissent de nouvelles communiralions antre la chambre rentrale et l'extériour. Les invaginations de lechelerme ne lonment pourant pas naissance aux canaux entiers; la eavilí émet les diverlinles, qui vont a la rencontre de ces invaginalions, el s'mussent a elles; l’extrumité distale de ces diverticules se renlle en une vésicule, qui se lransforme lientót en une corbeille vibratile. Il faut donc distinguer denx parties, dans chaque comduit : une première

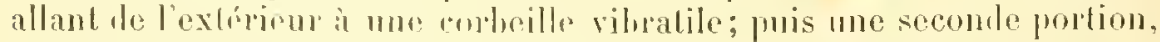
représentée par la cavité vilualile, et par le canal allant de colle-ci ì la cavité interne. A mesure que s'ellectuenl res moditicalions, les tissus revètent lem structure détintive. 
La jeune Ejonge est comslituée par une paroi ćpaisse, percée de canaux et de corheilles vihraliles, qui limite une cavitr centrale celle-ci communique avec le dehors par on oscule. Plusienrs des divertinules ćmis par celle demière, tout en se transformant m corlicilles vilualiles. devienuent plus voluminenx que les andes, et ront délouchor à lexlérion par de larges ouvertures semblables a losculo. Coux-ci sunt comparahles it des homrgeons, pui se développent pour devenir des zoüdes: mais ils ne se dégagent pas de löpaisse proi du corps de l'oryunisme malenel. et jestent confondus arece elle. Les cavités de ces grands diverticules ont Ia mème valear que la premiere chambre interne; dans leur jutérienr viennent dehoucher de pelits canaux, munis de corbeilles viluratiles sur leur trajed, et formés par le mème procédé que les précédents.

B. - Celte évolution permet de comprendre le développement du lacis des conduits, chez la plupart des ribrosponges; plusicurs cavilés waissent en ùme lempss, et produisent séparément leurs canaux el leur oscule. L’abréviation consiste en la disparilion de la juase du lourgeonmement; les chambles dr seconde formation ne proviennent point de l'espace primitif, à la manière de hiverticules engendrés par lui, mais naissent à la fois au sein des tissus.

J'après les faits exposés, les corbeilles vibratiles des Spongiaires colonianx namraient pas tontes la mime importance; les mnes sont mises en relation directe avec le dehors par des oscules; les autres peuvent ètre considérées comme arrêtées dans lenr dévcloppement, et he communiquent avec l'extérienr que par l'entremise des canaux inhalants. Il est permis cependant de les considerer comme des cavilis de zoö̈les, narrivaut pas au mème degré d’individualité que lenrs lomolognes munies l'oscules. Celte différence d'évolution n'est pas trés Chonnante dans le cas particulier des Eponges: les zooïles de la colonir, élant fusionués les uns avec les autres, ont perilu leut indépendance, lew autonomic, et ne possedent plas rue le caractere de cavitís distinctes, creusées dans la masse résultant de l’union de leurs parois. Ces avités parviennent à des degrés variables de ditlérenciation, suivant low situation au sein de la masse générale. Celle-ci se comporte avec les milieux extérienrs comme un seul être, hien quelle soit multiple en réalité, et produite par l’assemblagge de phosienrs judividus.

Combusmox. - Comme le montre l'exposé qui prócide, les domóes. relatives au développenenl incurvé des Eponges, ne sont pas encore hien nombreuses. On se lase copendaul sur elles, pour considérer la ravité interne rles larves d'liponges comme homologue de l'enleron des autres lélazoaires, et pour lui Jonmer la valenr d'ume cavité gastrique. On chend celle notion ì tous les spongiones; daus l'ensomble, les cor-

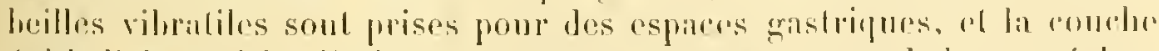

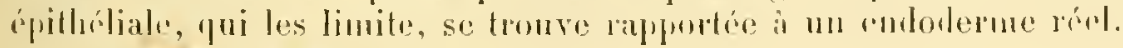

Un certain nombre de ensidéations, hasces sur les ohservations 
déji signalées, et sur celles plus récentes lues a Telagr, autorisent à penser que celle opinion no doit pas atre acceptéc toule entière. Les embryons des Sycandra ef les Ilalisara ne subissent point une gastrulation véritable, cest-à-dirr somblable à relle prósentée par les autres animanx. Le mésorlerme est dójà óbauché au moment où commence l'involution gastrulaire, ef cetle dernière se produit par incurvation. L’incurvation elle-mône n'oflre point les particularifós que lon troure ailleurs, car elle a plutôt les caractòres d"un plissement irrégulier: surtout chez les Malisarca, donl l'embryon s'aplatil en un disque ganfré, qui recourle lentement ses bonds au-rlessous de lui, au lieu d'arriver de suite et avec rapidité au lunt final. D'autre part, dans l'embryogénic condensée des Fibrosponges, l'ectoderme parait participer à la genèse des parois qui circonscrivent les cavités interues. - Si lon rapproche ces faits les uns des autres, on en vient i penser que fes feuillets blastodermiques sont pentètre dílimités deja, el ont acpuis lenrs caracteres propres, an moment ou l'involution so manifeste; les cellules de l'emhryon sont déjà grompées, tr manière a coustituer les lenx fenillets primordiaux, le protretoderme et le protendoderme. Par suite, éest le protectoderne, phacé à la surlace du corps de l'embryon, qui entome la cavité invaginée, et cost lui qui tapisse çralement les dérivés de celle dernière, cest-idire toutos les cavités juternes de l'Eponge, et ses canaux.

Si ces relations sont exactes, le développement et la signitication de l'organisme des spongiaires levront etre compris d'une toute autre façon quion ne l'ahmet aujouldhui. L'embryon produit ses deux feuillets lilastordermiques primordiaux, par le procélé cylulaire; lorspue cetle genèse est acherée, son corps est une blastoplanule compacte, constituée par un protectoderme extérieur et un protendoderme intérienr. Contrairement à ce qu’il en est chez lous les autres Metazoaires, ces deux fenillets restent simples, of ne se dédoublent jamais. La hastoplamule s'aplatit, et se change en un disque, yni saltache au sol; les borls du disque se replient en dessous, de facon à laisser un espace libre entre lui et le support; ces bords se rapprochent l'un de l'aulre, et finalement se somlent. L'espace vide est ainsi comrerli en une carité close, qu'entourent de toutes parts les lissus emloromaires; en outre, l'embryon est transformé en une vésicule. - Éanl dunné ce développement, la cavité centrale est limitée par le protrctoderme, tout comme la surface du corps, puisıne l'embron vésiculaire dérive d'un disque qui s'est incurvé: lo protectoderme est de ce fail divisé en deux parts, l'une extérieure et superficiolle, l'antre intérienre. La première produit l'assise nommée l'evforlormo par tous les auteurs; la secomle foumit l'épilhélium des canaux, of rohi, si remartuable par ses rils à cullereltes, qui tapisse les corheilles viluatiles. Co dernier provient donc du protectomerme, et n'est en rion l'homologne lo l'rudoulerme des antres animaux. De son côté, la cavilé iuterue n'est pas un entéron réel, mais un appareil par- 
ticulier, propre anx Spongiaires, dont on ne retrouve point ailleurs l’équivalent; arec ses délivés, elle constitue un réseau d'espaces et de
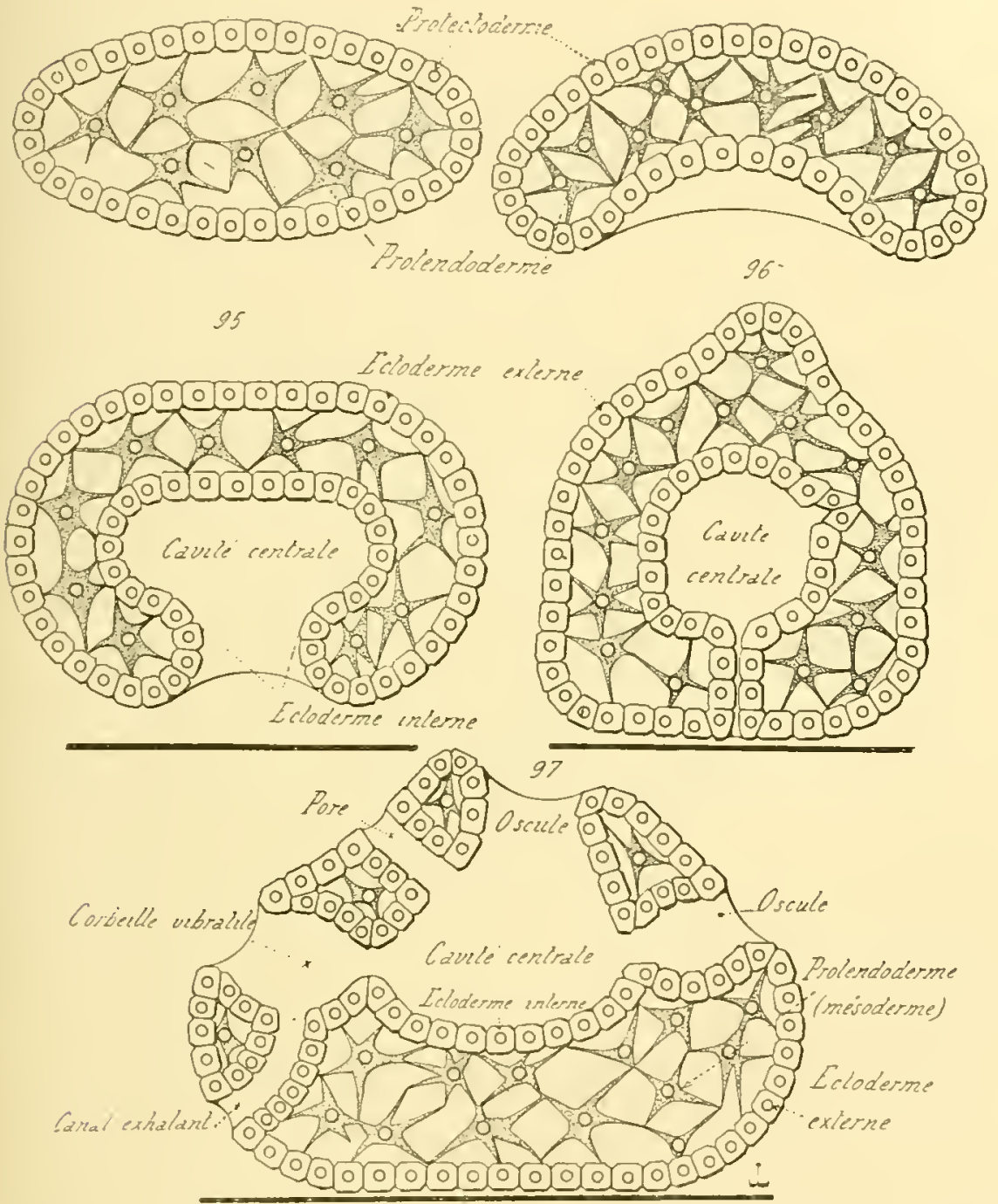

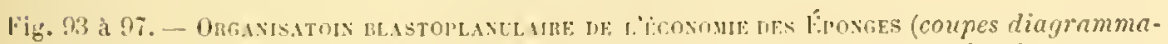
liques, destinees a montrer les pliases qui se succedent, dans le cas des développements dilates). - En 93, bastoplitunle oralaire. - lin 9t, debut de son incurvation. - lin 95, suite de l'incurvation. - En 96 , fin de lincurvalion; le corps de l'embryon, tout en devenant une vesicule close, se fixe a un support. representè par un trait joir. - lin n. elat d"un jeune individu, ayant depasse la pliase de vesirule close, et produisant son lacis de cavilis, aree ses premiers orifices. Cet etat est nommé lihayon par sullas. 
ravilés, assinilalikes à des dópressions superficielles, qui senfoncent dans l'intériem du corps, un se mompliquant. Quant au potemlorlerme,

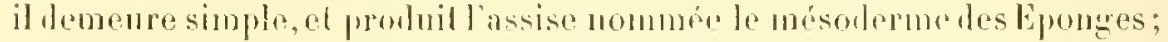
il ne donne point l'endorlerme commo son correspondant des autres Carlentérés, ni le mésonlerme al l'endorleme romme sun similaire des Crelomates, mais fommit sembment une assise intermidiaire, placée entre le protectombrme externe et le protectoderme interne, et mérite, par suile, le terme servant ì la désigner.

En résumó, l'ortanisme des Spongriaires peut èlre ramenó ì nue Hastoplamule, qui saplatit, simpure en se fixant sur un support, ef se

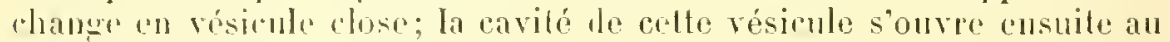
dehors: elle imel, par un réritable bourgeonnement, des expansions ‘ui délouchent également i l'extérienr. et prend un aspect complexe, variable suvant les lypes. Les deux feuillets primordianx, qui ronstituent à eux suuls la hilasloplaumb, pustent simples. Le prolendoderme ue se crense point l'une cavilé comparalıle à l'entéron des autres aniunaux, et se convertit loul entier en mésoulerme. Le protectoderme ne formo jamais qu"ure seule assise cellulaire. lectoderme; celui-ci, a la suite des changements subis par lo corps dans son aspect, se trouve livisé en deux parts : l'ectoderme externe, qui occupe la surlare de lorsanisme; el l'ectorterme interne, qui limite les cavilés intérieures, avec les canaux allant rers lextérieur. Cet ectoderme interne correspond à lemiloderme des autrums.

Tout en se convertissant en une vésicule, l'emlnyon des Spongiaires se lixe a un support par les lorts mèmes de la face incurvée; c'est le rapprochement de ces lords yui effectue le changoment du disque fombé, en mo résicule. la cavilé interne ne larde point, cependant, a s'ouvrir à l'extérieur, par un orifice percé daus la région opposée ì la zone le fixalion; celle onverture est le premier oscule. Lirmbryon, en cel élat, est parvenu i la phaso nomméc Rhagon par Sollas; ses parois si crusent de canaux, destines à faire communiquer, en supplement te l'oseule, la ravité eputrale avee le drhors. Le pelit doe est alors devenu un imbividu complet; los choses en restent là pour les quelques sponeiaires monozoïques. Chez les antres, cet individu initial bourgeonne; celte genese de zorilles élant parfois confuse, et parlois distincte, comme l'imliquent les consilérations préliminaires de ce paragraple.

lanrienme opinion, exprime par llapeliel, qui temb a fare considépela lavilé interue drs Fponges comme un entéron, son oscule comme un cuteropore, ef son épithélium comme nn ondodrame, élail déji batlue en fréche pas les obsuralions récentes. Ceprodant, la phupart

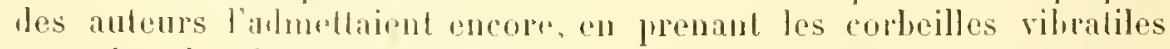

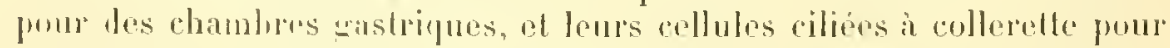
los élanents endodermiques. Il est probilsle que ratle opinion entione

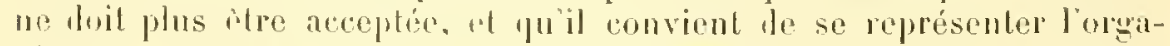
nisme des spongiaires suivant los données préédentes. Mais, el il est 
uécessaire d’insister à cet érand, celles-ci s"appuient encore sur des faits quelpue peu ineomplets. l'our los ramde définilives, il lant étudier la struclure, el le direlojjement des Eronges calcaires en forme de lanes, pour voir si elles ne correspomlent pas à des lypes trìs simples, í des blastoplanules, qui se horment i s'accroitre daus lous Jes sens, sans suliir d’incurvalion.

III. Développement massif. - 1. Les notions précédenles sonl établies d’après Jes tails acpuis sur les léveloppements les plus dilatés: sur ceux qui débuteul jar uno phase blastulaire normale, à hlastoderne simple el composé d'une seule conche de cellules. Les remarymaliles recherches, récemment failes par Delage, leur domnent mn nouvel a|')ui.

Les études de cet auteur onl porté sur qualre especes de fibro-

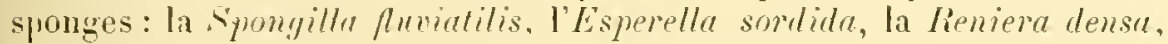

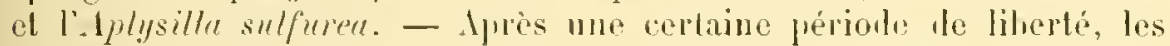
larres de ces ètres, semblables, sous ce rapporl, à celles de la plupart Jes Spongiares, se fixent ì un corps élranger, s'appliquent sur lui, el se doveloppent; elles prodnisent lemrs cavités internes, el lenrs canam, sans subir ancmoe invasinalion comparable à celle des Sycandra, ni à celle des IJalisaren. Cetle parlicularilé était déjà connue avant les observations effectures par llelage; seulement lopposition entre ce fail, et les phémomònes oflerts par ees denx lemiers genres, élait si grande, qu’il devenail diflicile de conclure a son égand, el que la nécessité simposil l'attendre des imvestigalions plus prócises, et mirux suivies. C'es dernières ont élé domnérs prar l'aulour fróciló; elles antorisent à rapporter, an moyen d'une crndensalion de l'évolulion embryomaire, le développement massif, à celui plus dilaté des rigcamdra el des llalisurere.

Les larves des qualre Spongiaires précédentes possident, an moment le leur existence libre, une organisalion complexe. Cetle struclure existe aussi, sans nul doute et lans l'ensemble, a en juger d'aprè les concomances grénérales de forme et d'orolution, cliez tuntes les larves qui ne subissent point, daus lenr embryologie, ce reploirment spricial, rapporté à 1116 gastrulation. - Le protectodrme se compose de denx assises celhulaires: l'nne, exlírienro, consisle en fómonls munis

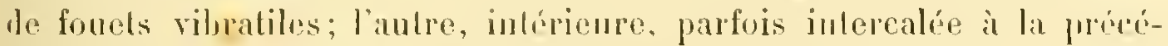
lente par places, est formée d’éléments non ciliés. Ia premièe est dite, par Dulage, liussise des cellules flugelliféres ou cilices, el la secomle l'as-

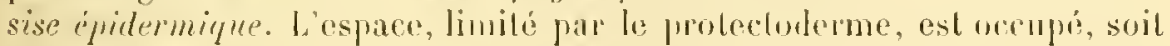
en tolalité, soil en parlie (lorsyu'il existe uno cavilé semblable à celle les śpongilla; voir plus baul, fagce !), par mu ambs cellubire que

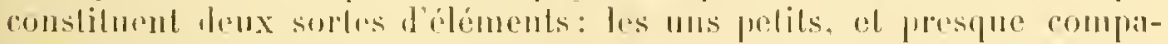
rables aux collules nom llagellifères du prolectoderuse, sout les cellules intermediuires de lodago; los autres, phos gramds, nommes rellutes 
amceboides, émettent des expansions pseulopodịues. - Dans le cas oì les larves sont couvertes, cn lotalite, d'appendices viluratiles, comme il en est, par exemple, pour colles des Spongilles, l'assise llagellifère est continue; elle envelopje le corps entier de chaque embryou. Si le revêtement vibratile n'existe pas, ainsi que le fait se présente d'une manière plus commune, sur l'uu des pôles de l'organisme, l'assise thagellifère ne parvient pas jusqu’ì ce pòle. yui est formé par la couche épidermique, ou par des cellules interméliaires.

La larve se fixe ensuite, i un supjort, par l'une de ses extrémités; elle s'aplatit et prent un aspect irrégulier. Des modifieatious importantes se passent en ello, qui se risument dans le phénomène suivant: les éléments flugellifires quittent la surface du corps, et pénètrent dans la masse de ce demier, ou ils se mélangent aux cellules amoboüles et aux cellules interméliaires. Ils rétractent leur fonel au próalable, ahandonnent leur siluation superficielle, et entrent dans l'intérieur de l'organisme. Ils s unissent ensuite aux éléments amoboüdes ot intermédiaires, ol constituent avec enx un syncytimm. Les phases de cette union varient d'une espéce à l'autro; elles consistent parfois en une sorte d'absorplion des cellules flayellifies frar les éliments amoboïdes, alors qu'ailleurs la soudure s'étalult frar les seules expansious piseudopodiques des cellules mises en cause, el en reste lá; mais le résultal est loujours le mème. - Ce lut attrint, la larve fixce se compose d'un réseau syncytial compact, entomré prar l'assise épidermique, la seule des couches du protectodcrue qui n'ait pas abandonué sa place premicre, et soit demeurée extérieure. Cette assise persiste en sa situation, et devient l'ectorlerme externe, qui revêt la surface du corps entier.

Des cavités se creusent an sein du réseau syncytial, quenveloppe cet ectoderme externe. Ces espaces grandissent, deviennent larges, et donnent les cavités exladantes de l'organisme définitif; d'alorel creusés à nu daus le réseau, ils ne tarlent pas a etre nettement limités par des éléments, qui leur composent une paroi propre, et ne sont autres que les cellules intermédiaires de la larve lihre. De leur coté, les éléments llagollifères se dógagent du réseau synrylial, et se rassemblent en pretits grompes; chacun de ces lerniers se creuse d'une cavilé, qui se met en rapport direct avec l'espace oxhatant le plus roisin, el se convertit en une corlicille viluatile. Ponr cela, les éléments llagelliféres, au milieu desquels elle s'est percéc, et qui l'entourent, produisent a uoureau leur fouet viluatile, l'enveloppent ì sa base d'une collerette, el revètent par ce moyen leur struchure fimale. - les cellules anoboüdes ot, semble-t-il également, les relhules intermédiaires non emplovées à limiter les cavités exhalanles, lesteut en leur place comme éléments figurés du tissu conjonctif de l'alulte.

En résumé, le réscan synurial complend trois sorles d'éléments : les cellules flagellifères, les rellules interméliaires, et les cellules amuboïdes. Le lacis dos catvitós intrrues se creuse en lui, et ses éléments 
fournissent des parois à ces cavités, en les limitant à la maniòce de travées. Les cellules flagellifères entourent directement les rorlreilles vibratiles; de mème, les cellules intermédiaires pour les cavilós exhalantes; les cellules amaboïdes et les éléments intermédiaires, non employés comme leurs congénères, lemeurent dans la sulustance des trarées. - Les cavités intermes se meltent en relalions directes, arec les milienx extérienrs, au moyen de pores et doscules, qui naissent halivement. Eilles se rassemblent aree rapidité, de manière à acquéril une disposition complexe. Jour lacis se ditlérencie, dès le débul, en un système exhalant, composé d'une caviló centrale, ou cloacale, et de cavilés latérales; et un système inbalant, relié aux corbeilles viluratiles, formé de cavités superficielles (ou sululermales) el de canaux inhalants. Les orifices extérieurs de ce lacis sont produits sur place, par l'écartement ou la destruction de cellules; l'oscule se perce de facon à déhoucher dans la cavité centrale, et les pores agissent de même vis-à-vis des canaux inhalants, on de la cavité superficielle.

L'asprect de la jeune Eponge subit des changements considérables, pendant que ces phénomènes se produisent. Le petit otre a pris la forme d'un copps aplati. accolé à son smpport par me large lase, el que soulèvent, frar places, les premiers spicules, engendrés dans ses lissus prar plusieurs des cellules amoboïdes. Sa régrion adhérente s'élend en une plaque mince, la membrane marginale, linitée sur ses doux faces par l'assise épidermique, et renfermant, dans sa masse, quelques éléments conjonclifs. Cost surlout par celle membrane marginale, qui grandit dans tous les sens, que s'etlectue la croissance de l'Eponge.

B. - Les olservalions, elfectuées par Delage, commencenl à l'époque de la vie libre des larves, et ne portent pas sur l'origine de lenrs fenillets. Il est impossible, en conséfuence, the se prononcer avee certilude à l'égard de ces derniers, car les recherches antérienres, failes avant celles de cet auteur, sont insuffisantes pour léciler. Cepcudant, šil nest pas permis de conelure sur les procidris employés prar l'embryon dans la genèse de ses éléments, on est autorisé ì concevoil la ralen et la signifjeation de renx-ci, en se hasant sur la malure les organes quils produisent, et en les comparant il leurs similaires des érolulions dilatées.

Les développements massifs sont condensés, par rapjort à cemx accompagnés du reploiement des embryous. Le fait est indiscutahle; l'alssence ou la courte durce de la phase bhistulaire, le nombro ol la strurlure diverse des diments, la formalion sur place des ravilés intermes, contribuent également i le démonlrer. Ia romparison des

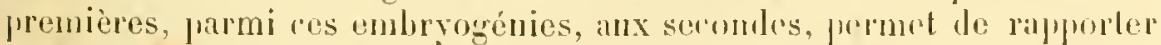
Les particularités, ollertes par celles-lit, à des dóplanoments, on à des omissions, des phénumènes présentés prar celles-ci.

Cela étant donné, le trail sailant do ces développenents massifs est,

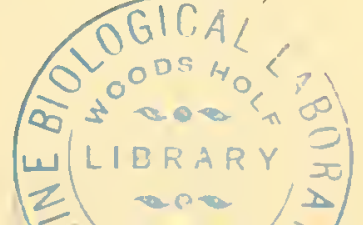




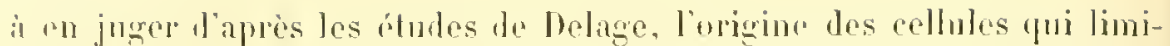
lont les ravités inlernes. Cos derniopes ne sunt pas en plare dies leur

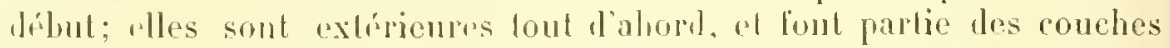
superficielles de lembryon : elles abambonment ensuile leur silualion première, et devienuent intírienres. Ce fait est jatent pour les filéments thauelliferes; illest moins en ce pui louche les collules intrmédiaires, puisyue celles-ci sont placóns un dealans des précédentes, et mólangées aux

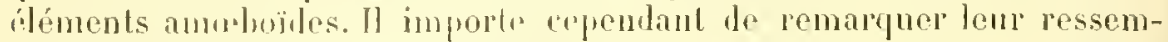
hance avec lis cellulos superficiellos non flagellifires, et, daus certains cas, leur siluation extrioure. lorsumelles contribuent à occuper les rórions larvares dépourvus d’appendices viluraliles. Ces élémenls, a cause do lour disposilion prentiope el de hur crolution, ne penvent etre considépés comme composant nn cudoderme.

Ces drux promisses étanl arouises, la comparaison des décoloppemonts massifs, a romx acomplagnés de reploiemont, permot de concevoir

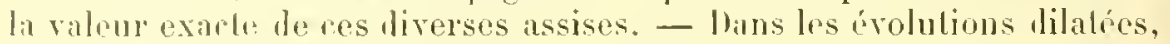
yui romporfent un peploiement, la lave s'aplatit el sincure. Son proloclodrome sa divise en demx rigions : l'mue, extérieure, se compose des rollules granulunses, el donne l'ectoderne rxtorne; l'autre, intérienre, cunslituée par dos rellules ciliées, devient l'ectorlerme interne. Celui-ci limite la ravité interne, formée par l'involution, qui est la première ilnarlue du srstène les arités de leponge; il tapisse les corleilles viluratiles at les uspaces exhatanls. Dans les évolutions massives, aucune inculvalion ne se manifeste: partant, si nulle migration rellulaire ne se produisait, los espaces internes scraient entunrés par des éléments profonds, yui no correspondraiont pas à reux issus de l'ectorlerme interne Ju cas prérilent. Or, les déments llagellifirrs supertiriols, et les cellules intermediaires, abamdomment lour situalion frimilive, pour venir rimonscrire cos espaces. Aussi, it canse de leurs rapports primoriaux, surlout evileuls en ce qui lourhe les rellules tlagellifiores, et de leur rile délinitif, l'onsemble leres demières at des cellules intermédiaires

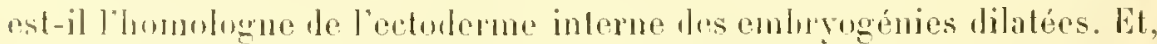

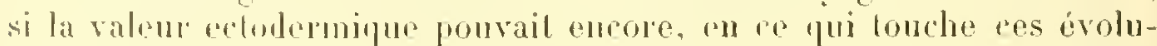
liuns, frèler i discussinn, sous lo prélexte jue le reploiement, malgré son retart ot son allure, ast romparable ì mo invagination gaslrulaire;

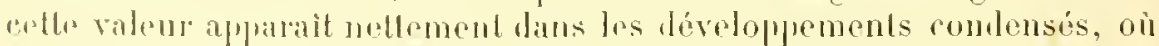
re phrnomone ast amis, car les parois des cavités internos dérivent des assisus superficiolles de la larve.

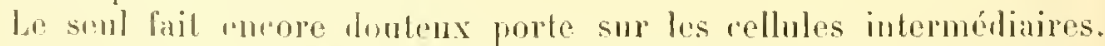

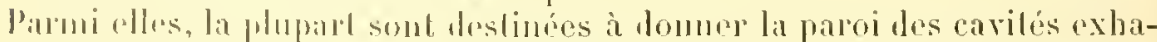
lanles; mais reptanes, non rmployes ì retlo genese, persistont comme

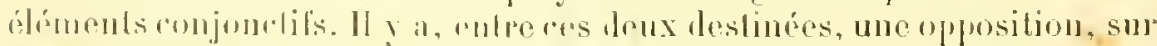

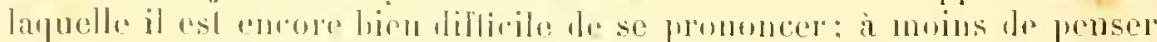

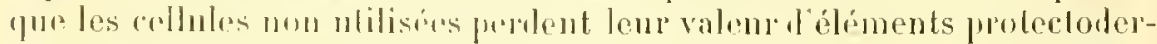

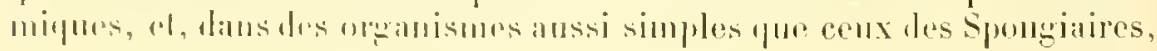


sont rapables de rester en place, sans phus, el de demeurer confondues aved les collules ammeloüdes. Quand it ces dernières, clles corresponden aux éléments du protemdoderme des embrygénies dilatios.

Dans leur essence, les phénomìnes dn développement des spongriaires se ramènent anx domées déjà exposées. Lorunanisme de cos animaux est assimilable à une blastoplanule, tomposée d'un protectoderme et d'un protendoderme. Celle blastoplanule s"incurve, et se tixe par ses hords repliés: la cavité de l'incurvalion est le départ du lacis des ravilés inlernes: la zone protertodermique, qui la limile, devient un ectoderme interne, Jestiné à lapisser les précédcntes cavilés: la région proleclodermique, laissée superticielle, donne l'ectoderme externe, chargó de recouvrir le corps entier; entin, le protendoderme reste comprarl, el conslitue la couche nonmée le mésoderme de res ìtres. - Dans les embryogénies dilatées, les phases se suceèdent telles qu’olles sont indiquées, et comportent une incmration des emluryous. Cotte druicm n’existe pas, et fait défaut par omission, dans les emtryogínies condrnsées. L'ertoderme extorne el l'ectoderme interne sont alors places ensemble dans les régions superticiefles de l'emliryon, of y constiluent un protectoderme à deux assises; quelques béments de ce dernier sont encore épars, sous la forme de cellules intormédiaires, an milieu des éléments (cellules amoloöles) du prolendoderne. La larve esl encoro une blastoplannte, mais dont le prolectoderme est diflérenció sur place. sans incurvalion préalable, en ses deux assises détinitives. Puis, leetoderme exlerne demenre senl en sa siluation; les cellules de l'ectoderme interme s'enfourent dans le protendoderme, s'unissent aux éléments de ce dernier, en donnant un réseau syncylial, et se dégagent d'enx an moment ou les cavités internes se creusent, également sur place; alles se portent alors antour he ces dernières, el les limitent.

Une des particularités tos plus remarijuables dr celte abréviation porte sur la persistanee, comme organes loromolemrs larvaires, des cetlules flargellifères. Mans les développements dilatés, ha zone protectodermique, destince à devenir l'ectodrome interne, est romposée do cellules munies l'appendires vihratiles, ch chargées de produire, apres le reploiement, les parois des cavités internes; ces déments servent d'appareils foconotenrs à la larve fibre, et non incurvée ancore. Celte disposilion jersiste dans les lévoloppements andensés; les cellules protectodurmiques, qui fonrniront les parois des combeilles vibratiles, mlourent tout on une partie du corps de la larre libre, ol, a l'able de lenrs appendices, la déplacent dans loan qui l'nu ironne. Cest sentement apres la fixalion de lembryon, quielles perdent lenrs fouets, et publies quitent la surface de l'organisme ponr derenir internes, junr se disposer antome des cavités en roie d'apparilun. - Tuo lofle persistance drs mèmes éloments

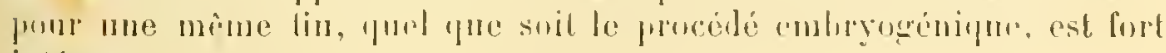
intripessimlur. 


\section{\$4. - Développement du Squelette.}

Les Jyxosponges sont dópourves de lout squelette. Les autres Spongiaires renferment, dans leur mósoderme, drs corps l'aspect rariable, Jestinés ì soutenir las lissus, el pui sont lantüt des spicules, lantôt, comme il en est pour les Cérilosponges, des filaments cornés, rassemblés en uu feuluge serré.

A ce qu’il scmble l’après les olservations éparses, publiées sur ce sujel, les jemnes spicules naissent dans l’intérieur même des cellules mésodermiques; las promiers d'entre eux apparaissent de honne heure, alors que la lare est encore assez jeune, et que les éléments du mésoderme sont à l'élal d'endocytes. Le spicule est produit pas un dépòt de substance calcare, on siliceuse, qui se forme dans le protoplasme mème de la cullulı. Comme ce dépôl continue lonjours à se faire, l'accroissement du spicule en dimensions trud à augmenter la surface de la cellule qui lengendre, ct par suile à diminmer son épaissenr; celle-ci est himbot représentée par une minor pollicule protoplasmique, disposée, antour duspirule, à faron linne envoloppe. A mesure que la celmle grambit, avec le spicule, son novan s" divise, mais non le protoplasme; co procédé ahoutit it 10 chat caractérisé par ce fail, que

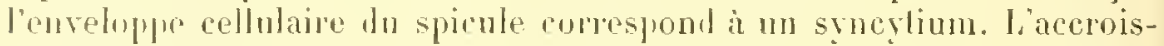
sument s'eflectnant toujours, le syncytium no cesse pas le se maintenir, soit que le protoplasme reste compract, soit quil se divise en luandes anastomosées, el semblaliles a des jisendoporles l'Amoliens. La structure

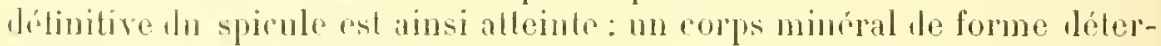
mince, car l'amplitication a suivi une marche prócise el réguliere, re-

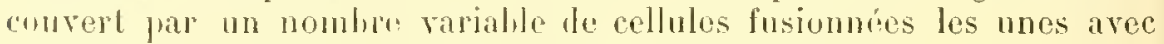
les autres, on sondées par des expansions ambboüles.

Le dévelopgement les filamonts romés ne se manifeste pas de la mime facon. Ces lilaments doirent ète comsidérés comme des portions Ir la sulsstance mésodermique fondamentale, qui auraient acquis une certaine individualilé, "Il se dillérenciant du reste te cette substance, el posséderairnt mo rohipene phus grande; partant, ils ne prenuent pas naissinu dans lonterieur mèno des cellules, mais on luhors d'elles, lout comme la substance mésorleminue elle-mème. Un grompe d'élémonls tigurós déverse, en son milien, une substance intercollulaire, qui

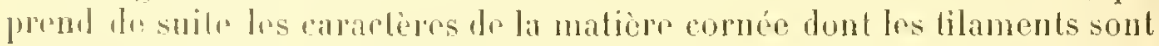

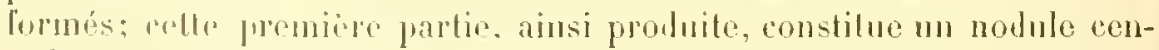

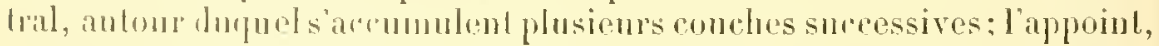
apporti far cos derniones, accoît les dimonsions te la masse, font on

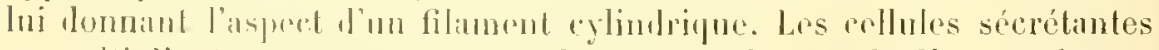

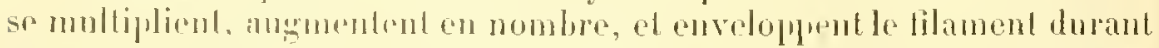

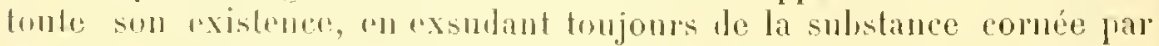

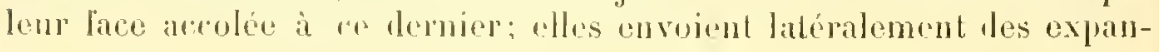


sions qui agissent de mème, et engendrent de nouvelles handes. La croissance du nodule primitif ne s'effectue donc pas suivant une scule direction; celui-ei ímet de nombreuses ramificalions latérales, qui se dirisent elles-mèmes, s'anastomosent entre elles, et produisent un réseau complexe et irrégulier.

Etant donné ce mode de développement, les filaments comés des Cératosponges sont constitués, lorsque leur développenent est assez. arancé, par une série de couches concentriques, emboîtées les unes dans les autres, l'assise externe étant la plus récente.

\section{$\$ 5 .-$ Reproduction asexuée.}

Certaines Calcisponges, appartenant pour la plupart aux familles des Asconides et des Syconides, se reprodnisent par la seule voie sexuie; toutes les antres Éponges prísentent, concuremment avec le déreloppement sexuet, des phénomènes de reproduction opérís sans le conconrs d'orules, ni de spermatozoides.

La reproduction asexure des Éponges s'effretur de denx manimes. Le premier cas revient it la gemmiparité, le second ì la gemmulation.

I. Gemmiparité. - Le bourgennnenent des Éponges se manifeste suivant denx modes. Tanlot, el ce premior mode nexiste que chez certaines Caleisponges, les hourgeons sont, dis leur jemesse, distinets les uns des autres: cet isolement partiel ne cessant jamais d'exister, el se retronrant anssi chez les zooïdes. Tantot, les jeunes bourgeons restent confondus avec le corps de l'individn qui les produit, n’apparaissent jamais au dehors comme des organismes listincts, el celte union persiste aussi pour les zoö̈des formés. Les colonies ainsi faites, different beaucoup des premières par leur aspect. Celles-ci sont constituéces par des individus dont les bases seules sont jointes, les autres portions du corjes étant séparées; celles-lả sont reprósentées par des masses, compactes cn apparence, percées de canaux et de carités, et dans lesquelles il est impossilule de discerner les zoö̈les les mis des autres, car ils sont soudés par la paroi entière de lenr corps.

Quel que soil to ras, to procidr mis en auve est toujours le mème; les différences portont simplement sur le degré de cohrírnce des parois du wross des générateurs, arec celles de leurs descendants. La genése d'un bourgeon consiste, a son díbut, en la production d'un diverticule, par une cavité interne d'un indivih prexistant; ce diverticule sonleve la paroi du eorps de ce demier, et errandit de plus en plus: il se transforme fualement en une résicule. Le bourgeon ost ainsi produit: il possède the paroi aree mos ravili rentrale; il so reuse ensuite d'un osenle ot de canaux inhiolants; son organisme est des lors complet.

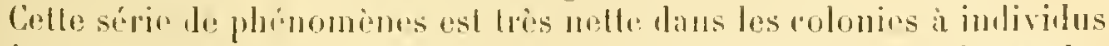
distincis; elle l'est moins dans les autres. Les divertieules, émis par les 

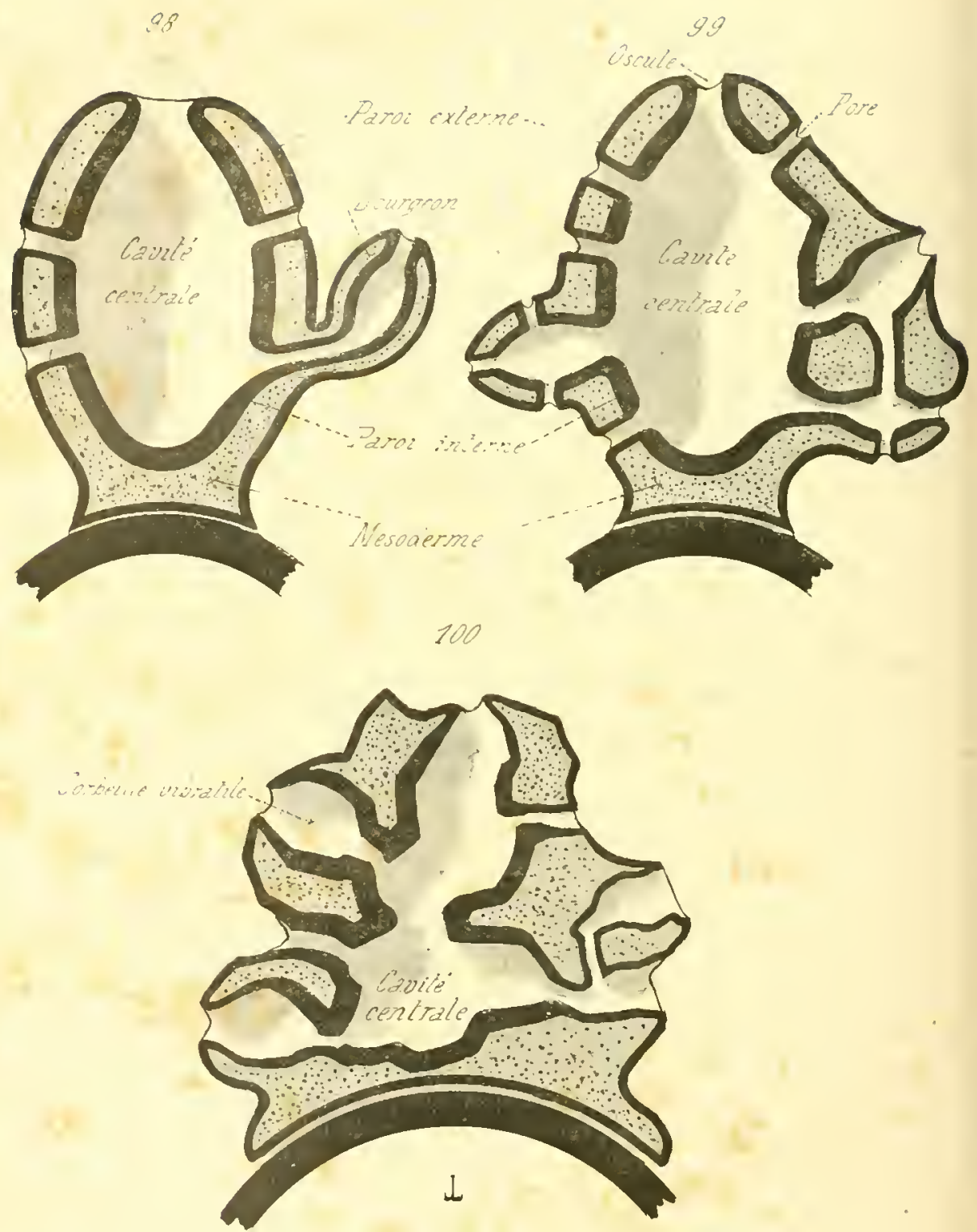

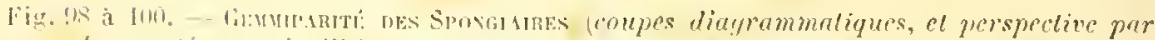

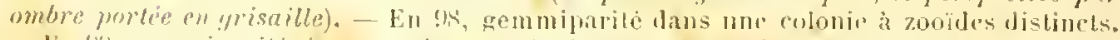

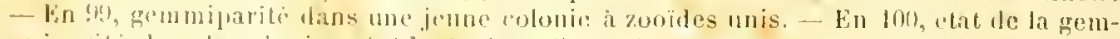

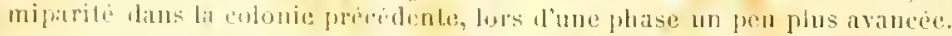

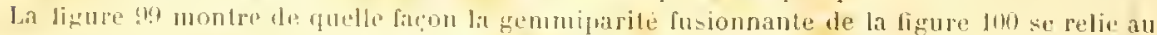
bourgeonncment inolant de la tigure gs. I.es platges noires, placees sous les trois dessins, expriment les supports. 
cavités existantes, ressemblent, dès l'alıord, à des comduits qui traversent le mésoderme pour aller ì la rencontre des canaux iuhalauts; ces conduits se rentlent ensuite en vésicules, qui conservent parfois cette forme sins plus se modifier, et vont ailleurs s'ouvirir au dehors par les osenles, ponr arquérir la valeur complète de cavités intermes. Tous cass phénomènes sont intérienrs, el ne se manifestent an dohors fue prar le percement des oscules; la masse coloniale entière saccroît on dimensions, sans que rien, it la surface, manifoste le travail de proliféralion individuelle elfectué dans l'organisme.

Les colonies à zoö̈les fusionnés possèdent des tissus mésodermiqurs très épais, relativement à ceux des colonies dont les zooïdes sont distincts; l'adhérence les individus s'elfectue, du reste, par ces tissus. L'ectoderme forme, à la surface de la colonie entière, une assise simple, constiluéc par la coalescence des conches ectodermiques appartenant en propre à chaque être.

II. Gemmulation. - Ce procédé de reproduction est ralativement rare; on ne l'a observé que chez direrses espères de Silicisponges. Les gemmules, engendrées prar la colonic nateruelle, appartiennent à deux types : ou bien elles sont externes, et semblalıles i des petits bourgeous extérienrs; ou bien elles sont internes, et plongées dans les lissus mèmes de l'Éponge. La façon dont elles prennent naissance n'est pas encore lien connue; il semble que les seuls leuillets intéressés soient l'ectoderme et le mésoderme. - 11 existerait donc, en re cas, nne contradiclion avec ce qui se plasse chez les autres animanx. D'ordinaire, dans lrs reproductions asexuelles, les destentants dérivent les trois leuillets, on des dépendances les trois fonillets, de leur génératenr. Il n'en serait point ainsi chez les Ejonges, du moins dans la grenèse des gemmules, puisque la sulıstance de ces dernières contient sculement des cellules ectoderminues el mésodermiynes. Cutte contradiction nest pourtant quipparente, si l'on tient compte des considérations exposées à la fin du paragraphe précédent; les éléments, qui tapissent les corleilles vibratiles, proviennent du protertoderme initial, tout comme ceux de l'ertoderme; et ces derniers sont, saus doute, cajables d'engendrer les premiers dans le développement des gemmules.

Les jeunes gemmules sont des corps compacls, constitues par des cellules tassées les uns contre les autres, et possélant une forme détinie, variable suivant les especes. Elles se détachent, après ètre parvenues i mne certaine taille, de la colonic-mere, et vout donner naissance i de nouveaux organismes; des cavités, des cananx, se creusent daus lenr masse, par le procédé déjà signalé chez les larves. Mans loute lenr évolution, les gemmules rippellent de très près les larves qui vienuent de se fixer, et qui complietrut leur structure.

l.es genmules externes, désignées frar les autenrs sous le nom de bourgeons, acquierent rapidement l'allure caractéristique des colonies 
adultes; elles prennent souvent cet aspect, avant de se détacher, surtout sous lo rapport de: la forme et de la disposition des spicules. Ces gemmules cxistent chez un certain nombre l'espèces, appartenant aux genres Tethyn. Tetillu. Rieniert. L.ophocalyx, et i plusieurs genres voisins. Les gemmules intornes sont moins répandues; elles sont parfois dépour-

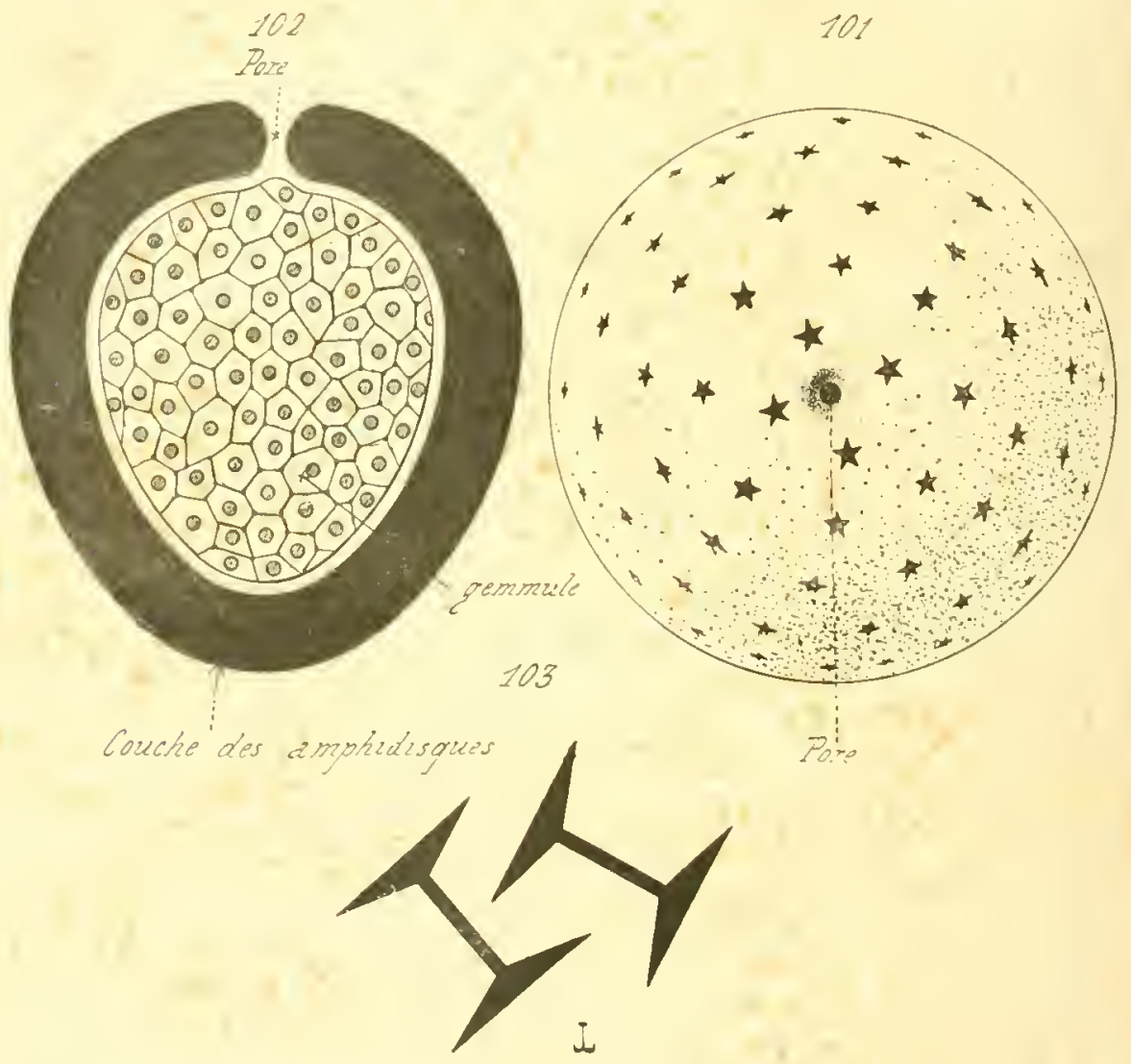

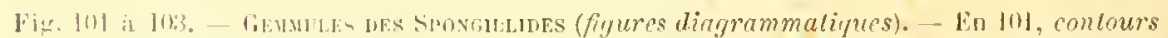
d'une grmmule d'Ephydalim, montrant son pore; les plaques étoilies representent les amphidisquues. llans la realite, les amphidisiues sont de situation moins precise, cal turs les spieules n'affectent pas cetle forme étoilee; plusieurs sont lisses, ou simplement toneux. - In 102, coupe d'nne gemmule de spongillide. La plaque noire, anmulaire, murisule: la conche exteme, privee de spicules chez rrtains des grenres de la famille, "L munio d'amphidispues chez les Ephydatia. - En 103. silhonelte des amphidisijues des Evhyzlatia.

vues lo spieules, et rousistent en un amas cellulaire enveloppr par une memlune protectrice; parfois, dans les gemmules des śpongillides notamment, les cellules périphériques contiennent des spicules, appartenant it un lype particulier', 'qui n'existe pas chez l'adulte. La situation 
des gemmules daus la masse de l'Eponge varie suivant les esproces; les Clione vastifern et les Spongilla les portunt dans la paroi de leurs canaux; les suberites en renferment daus la rérion qui adhère au support soulenant la colonie; enfin, les Chatina oculata les contiennent dans la base de leur pédoncule.

La structure des gemmules internes n'est guère bien connue que pour celles des Spongillides. La gemmule entière, à peu près sphérique, possede, en un point de sa surface, une ouverture assez large, le pore; cel orifice donne accès dans un canal, fui traverse fonte la conche cellulaire externe, et communique ensuite avec un espace élroit, séparant celle-ci des assises internes. Les éléments de ces dernières sont serrés les uns contre les autres, el ce tassement leur danne un contour polyédrique; ils contiennent un protoplasme granulemx. Les cellules de la couche externe offrent une structure différente: Jeur ensemble, qui enveloppe lamas interne, est limité en dehor's et en dedans par une épaisse lınde culiculaire; les cellules elles-mèmes conliennent parfois des spicules. alors que celles des assises centrales n'en renferment point. La présence les spicules, et celle des bandes culiculaires extérieure et intérieure, donment à celte couche un rôle de potection indiscutable. La forme de plusieurs des spicules est remarquable; chacun d'eux cousiste en un bitomnet, portant sur ses donx extrémilés mne plaque circulaire dentée, perpendiculaire à l'axe longitulinal du bàtonnet. Chaque élément contient m de ces spicules, nommés amphidisques à cause de Jeur aspect; par suite, la couche elle-mème est désignée comme l'assise des amphidisques.

Les gemmules inlemes des Spongilles prennent naissance vers la fin de la belle saison. Elles restent, durant tout l'hiver, enfermées dans les tissus maternels, ou bien plongres dans l'eaulorsqu'clles ont été rejetées, et ne modifient en rien leur structure. Iu printemps, lorspue les eaux deviennent tièles, la conche externe se ramollit quelque peu: le prore, qui la traverse, s'élargit; l'anas des cellules centrales s'engage dans son canal ponr parvenir au dehors, el, lorsquil ast lihre, se déreloppe en une nouvelle colonie de spongille.

\section{RÉSUMÉ}

I. - Les Spongiaires se reproduisent par la voie sexuée et par la voie asexuéc; il existe deux moles dans ce lernier cas, la gemmiparité el la gemmulation.

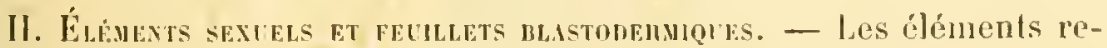
productenrs maissent dans le mésoderme. Les spermohlastes dépivent de cellules, qui rotractent leurs prolongements, el se divisent en spermatocytes; renx-ci évoluent en spmmatozöldes, fui se fraicnt mn passage a travers les tissus pour féconder les ovules voisins, ou parvicment au 
dehors afin d'aller so réunir aux urules d'antres colonies. Les ovules proviennent également de collules, pui rétrartent lours prolongraments ef sentourent d'unc couche lolliculare: les premicres phases du développement se passent daus la cavité limitée par cette druiciere et la larve ue devient lihre quapris avoir alteinf nue assez grande complexité de structure.

La greniso Jes fenillets blastodomiques somble s'effectuer, d'une façongénérale, jar lo procédé cytulaire; diverses Calcisponges (S’ycandra) of Myxosponeres (1/scerella) paraissent rependant juésenter le mode gasfrulaire. - Dans re druice cas, la gastrule est produite far incurvation; le hlastoderme de la blastule donne l'ectoderme et l'endoderme, le mésoderme élanl engendré par des endocytes; la larve, derenue lilure, se fixe par l'orifice de l'involulion.

l)ans le procédé cytulaire, le mésoderme et l'endorlorme sont formés prar les endorylus. Ce procédi présente plusienrs morles secondaires, suivant que l'abréviation du developpement est plus on moins grande. l.e mole l. plus dilaté est offert pal diverses Calcisponges du genre Ascella: l'uvule fécondé, en se segmentant, se convertit an mo morule, puis en mo: hlastule; lo blastoderme de refle derniere produil des endocyles, qui remplissent la cavité hlastorulienme. La blastule s'ist ainsi modifice en mo blastoplanule, avec protectoderme el protendoderme. Un mode plus abrégé rst possédé par los Chalimula (Cératospongos), et la phupart les filuosponges. La molule montre puelques blastomères plus granulenx que les autres, of qui, seuls, produisent des cudocytes; ees deruiers apparaissul lone des la phase mormaire, et n'allendent pas la phase hastulaire, contrairement a ce qu'il rn est dans lo premier ras. Puis la morule se transforme en blastule, colle-ci en blastoplanule, el l'évolution "ontinur comme dans le premier mode. - le procédé le plus alorégé est présenté par les spongilla (Fihrosponges), car la morule se change dimctement en blastoplanule, sans passer par une phase blastulaire bien nettr.

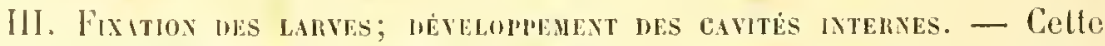
évolntion s'effectue suivant deux moules. - Dans le premier procédé, nommé développement incurvé, rapprorté par les anteurs ì une gastrulation, et qui a été olservé chez les Sycandra et les Oscarella lobularis, la lave est une liastoplanule, romposée d'un protectoderme et d'un protemblerme. Le protectoderne est représenté par une assise cellulaire simplu; lo protendodorme est d’apparition tardive; le développement est, en somme, dilaté. La larve s'incurve en une coupe, ef se fixe ì un support frar ses burils; ins derniers se rapprochent, se soudent, al liumbryou se ronvertit "n une vésiculu "lose. Sa cavilé interne donne naissance anx corbeilles vihaliles of aux chambres exhalantes; la zone frotectodronipue, qui la linilu, constilue un ectoderme intrune, chargé de lapisser ces espares; la zone prolectoderninge, laissée extérieure, 
reconver la surface du corjs, el dome loctodermo axterno. Le protendoderne persiste tout entier comme mésoderme. - Dans le sorond mode, phs condensé, el nommé développement massif, la larve ne s'incurve pas. Le protectoderme se rompose de doux assises rollulaires, dont l'une correspond à l'uctodrune extrrue du cas précódent, el l'autre à l'ectoderme interne; quelyues aulres éléments le ce dernier sonl mélangés anx cellules du protendoderme, yui sont nomlureuses at d'apparition hative. La larve se lixe; les epllules de l'ectoderme interne perentent leur situation supertiricllo, et śunissent aux éléments du protendoderme, ponr fournir un réseau cellulaire complexe. Les premieres élanthes des ravités inlermes se creusent dans ce réseau, ol les collules de l'ectoderme inlerne se prortent autour de ces carités pour former leur fraroi. Le résultat est, ainsi, semblable à celui donné par lincurvation du premier procédé.

IY. Defeloppenext du socelette. - Le squelelte des spongiaires prend maissance lans le mésoderme. Chaque spucule consiste en un dépôt de substance minérale, qui apparail lans le protoplasme d'une rellule mésoderminue; ee spicule grandit aver la cellule qui le produit, el ectle dernière se multiplie, en mème temps quelle angmente le nombre de ses noyan. Elle se transforme ainsi en un syncylum potoplasmique, qui enveloppe le spiculo, et prouluit constamment de la matière minérale jar sa face adhérente au spicule. - Le mème procédé génélique se manifeste jour les filaments cornés, arec celle diflérence que leur sulstance est, dés son délul, extérieure aux cellules génératrices.

Y. Reprodictiox asexuelle. - La gemmijarité des Spongiaires s'effertue l’après deux procédés. Dans l’un, l’imlivilu primitif, qui provient d'une larve, produil des bourgeons distincts à l'extérienr, les zoö̈les derivant dre ces hourgeons restant egalement distincls; dans re ras, la colonie d'Éponge présente l'aspert d'une masse arloreseente. Dans l'autre, l’inlividu primitif possede une épaisse paroi du corps, avec laquelle restont confondus ses bourgeous; daus re dernier cas, la colonie parait simple, alor's qu'elle est constiluée, "In réalité, par un certain rombre le zooïlos fusionnés les uns avec les aulres. Le premirr mode existe clez qurlques Caleisponges, le second chez lous les autres. Spongiares; sanf diverses Calcisponges, appartrnant anx familles dis lsconides el des Syonides, qui no honreconnent jumais. Les boureons sont toujonrs des diverticules emis par les cavilés internes, el limités par la paroi du corps.

La gemmulation consiste en l’assemblate do phusienes rellules, qui so grompent en un colps nommé gemmule, capable de se délacher du générateur, el de rejroduire une nouvelle colonie. les gemmules sont parfois extermos, et parlois internes; ces dernieres, eluez les spongillides nolamment, possedent parfois les spicules (amphidisqurs), dillierents, par leur forme, do cond des adultes. 


\title{
EUBRANCIEUENT IOES IIUROZOAIRES
}

\author{
CIIAPTRE V \\ EMBRYOLOGIE DES HYDROZOAIRES
}

\section{1. - Considérations générales.}

I. Garactères et classification. - A. Les Ilydrozoaires sont des Cixlentérés, donl l'celuderme est ronslitui par les cellules appartenant i plusienrs lypes tistincts, et dont la praroi du corps nest point traversée de cananx metlant la cavilé gastrique en relations directes avec le dehors. Les éléments endorlermiques ne purlent pas de colleretle antour de la loase des rils vilualiles; la cavité gastrique est simple, car elle n’est point subdivisée rn loges par des cloisons; la région périluecale est dressée, ot ne se déprime pas pour former un tube asophagien. Les fenillets hlastoderminues primordianx naissent, dans les embryogénies dibaties, snivant le mode cylulatr. Le lourgeonuement, lorsqu îl exisle, al c'est lit le cas lo plus frépuent, s'eflectue de telle sorte que les individus sonut distincts les mus des autres, et ne se raccordent que par une région restreinte de leup rorps.

les représentants do l'enbranchement des Hydrozoaires présentent dorra aspects : celui de I'olype el relui de Méduse. - Les polypes sont drs individus lixés à un support, de lorme lubuleuse, dont le mésoderme us conslitué frir une mince lamelle de substance fombanentale, placée "ntre l'utolerme it l'endoderme; celte lamelle est dite membrana propria, ou memlwane propre. - Les méduses sont les individus libres, dont l'aspect ripurelle cehui d'une ombrelle, on d'une cloche, el dont le mésoderme est, relativement ì celui des polypes, fort épais. Le corps de torle méduse as divisé en denx parlies. Lune correspond an manclie

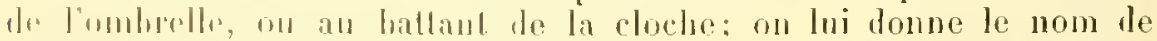
mannhrinm, on le manche. L'antre est élatée en un dòme hímispluérique, portint lo manclse sur le ceulre de sa face inférieure et concave; 
on la désigne par l'expression d'ombrelle. L'ombrelle otfre deux faces : lune supérieure, la sus-ombrelle, qui est en même tomps extorne of convexe; l'autre inférienre, la sous-omlrelle, qui est en mème lemps interne el concave; celle-ci limite la cavité du dôme, qui a lecu les noms de cavite de la cloche, on de cavité de lombrelle, on de cavité ombrellaire, ou de cavilé sous-ombrellare. Ces liverses expressions sont sunonrmes.

Les méduses des Hỵlrozoaires sont jourvues d'un roile, mime expansion, semblable à une collerelte qui surrait le boud de limbrolle. Cette particularité leur vaut souvent le nom de Craspédotes.

B. - Lembranchement contiont deux rlasses:

$1^{\circ}$ Celle des Mydraires: caractérisée par le fail que ses colonies de polypes sont fixées à un support, of no sont point libres. La classe renleme à son tour denx sous-classes : Irs Auhydraires et les Mydroméduses. Les Authydraires comprement les représentants les plus simples du groupe entier; les uns soul isolés, et les autres forment des colonies: lous les individus sont des polypes, at andun d'enx no se converlit jamais en une méduse. l'ar contre. les Irrdroméduses offrent les derx aspects, celui de polype el celui de méduse; les polypes sout rassemblés en colonies polymorplies; les méduses, dans lenr reproduchion. donnent des larves qui, lantôt engendrent une colonie de polypes, el tantít éroluent dirertement en nouvelles méduses. - la sous-classe des duthydraires se ramene aux deux semls orles des Mydrides el des Iydrocorallines. Colle des Hrdroméduses contiont également demx ordres : colui des Hydroméduses diplomorphes, dont chaque esperce otlire les deux sortes d’individus, possede des polypes of les méduses (TululariensAnthoméduses, et Campanulariens-Leploméluses): el celni les IIydroméduses holomorphes, dont lous les représcutants sout des méduses (Varcoméduses et Trachyméduses).

2. Celle des Siphonophores, dans laquelle les rolonjes de polypes ne sont point fixées, el nagent librement dars la mer. Cette classo renferme denx ordres, élahlis par llicekel : les siphomunthes on riphomulides, et les Disconunthés on Visconulides. Les colonies des premiers sont étalées en longueur, les polypes étant insérés sur un axe allongé noumí le rachis; par rontre, celles des seconds sont élargies en surfaro, le rachis olfraut l'aspect diun disque, il liune des laces duruel les polypes sont attachés. Lordre des bisrombides est composó de la famille des Vélellides, qui, parmi tous les Siphomophores. "st la semb i posseder le dimorphisme des individus; certains des zoö̈les do chaqur colonie, chargés d’éléments sexuels, se romvertissent en méduses dı grenle Chrysomitra.

II. Généralités sur le développement. - A. II imporle, atir de bien comprendre los phénomenes du diveloppontul, de se repri-

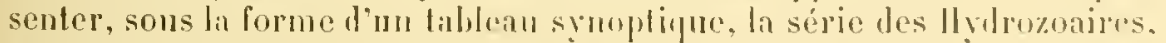
groupés en allant des lypes les phas simples aux plus élevés, el disposés 
en tenant comple, a la fris, dr la structure et de l'aspect des individus. Ce tableau est blabli le la faron suirante :

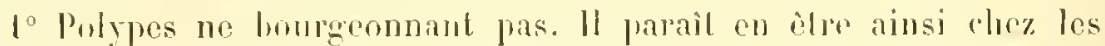
llidribés les moins élevés, qui constiluent le genre l'rohohydra.

zolypes homrgeomnant, mais de fagon que les jemes homgeons se séparent de looganisme malermel. Il ne so produit done aucune colonie dans ee ras (divers lfyloides).

$3^{\circ}$ lobypes hourgeonnant le manì̀e que les zooüdrs restonl unis, el semblables les ms aux aules. Il rxistr donc un assemblage colonial, mais sans anrun polymopphisme (les Mydra par exemple).

$4^{\circ}$ lobpes hourcommant, of restant mis, mais affectant des formes

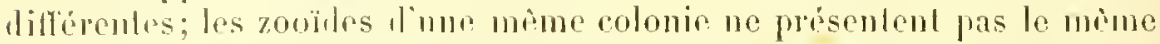
aspect et ne possident pas le mème rìle. Les uns sont adaptés à des fonctions nutritives; les aulres, les gonozoides, sont semls ehargés le produre los éléments sexuels, mais ils demeurent loujours fixrs ì leurs voisins, et ne se détachenl pas. (lliverses Hỵdroméduses diplomorphes.)

:30 Polypes bourgeonmant, ef domnant naissane a des colonies polymorphes, munies de gonozoüles. Senlement, cos lemiers moditient leni disposition, se transfurment en méluses, et se délacheut de la rolonie pour derenir lihres. Soms leur élat le plus complexe, les méduses, les llydrozoaires apparlumant à ce cimpuième type, se séparent de lents congónères, avanl d’avoir engendré lours élóments peproducteurs. Icur isutrment s'eflectue de bomne heure; elles restent libres durant leur vie presque entiòe, prar lefté de la tendance à la diminulion de la phase polype, et à laugunnhation de la phase méduse en durée el en imporlance. (La plupart les Iyvloméduses diplomorphes.)

$6{ }^{\circ}$ lobypes absents. Celle tendance, a la diminution de la phase polype, déternine la suppression rompliele de celle phase; l'auf fécombí, promit par la méluse, ne dom point massane à ull polype, el pngendre diecfrment une méluse, dontrairoment à ce quil en esl daus le cas précédent. (Ifylromeduses holomuphes.)

Co hahleau synoplipue moulre deux chuses : d'alord l'existence, chez les llydrozoairos, de denx modrs reproductenrs, le procidb sexuel of le provédé gemmipare; ensule, la liversilé des évolutions emluyumaires,

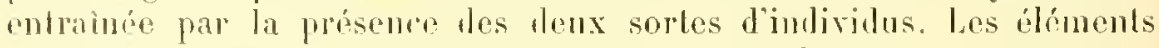
sexuels sont portés par des polypes, rluz les Ilydpozoaires appartenant anx fuate promiers types, el par des méluses chez cenx compris lans

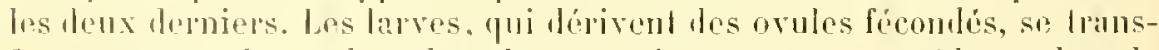
formunl en polypes dius les cind fromiers cas, el en móduses dans lo

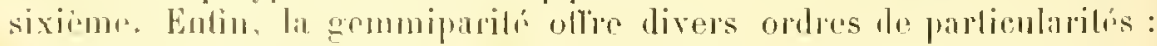

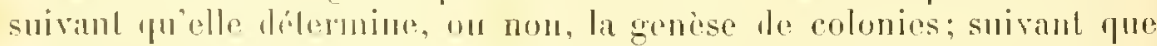

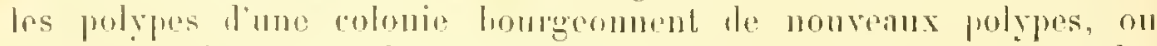

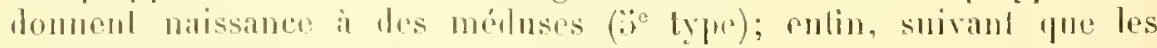
méluses elles-memes, appartenant anx llydrozoaires compris daus be 


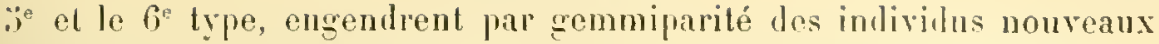
(qui. en ce cas, sout toujours des méluses), ou lien restent simples.

b. - Sous le ripport de la genese des cellules sexuclles. les phónomènes sont semblables, dans l'essence des choses, entre les polypes et les méduses. Les différences principales portent sur la forme des individus sexués, el non sur loriggine, ni sur l’évolution, des élémonts reproducteurs. Il n'en est jas de mine pour le développement les larres. Ces deruieres sulissent denx moles érolutifs hien distinets, suivant quelles domment naissance i des polypes (les cinq premiers types) on a des méduses (6 type). Cest dans le premier morle, senlement que l'on trouve des emlryogénies dilatées; le second est toujours abrégé.

Les développements dilatés s’effectuent suivant le procédé cytulaire.

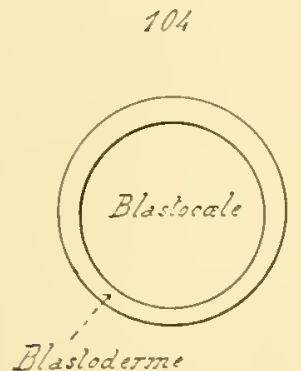

107

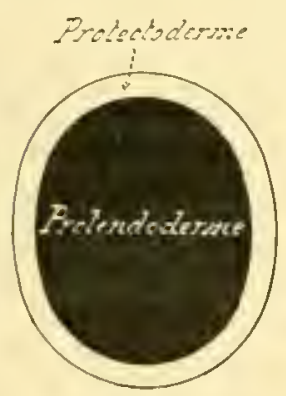

105

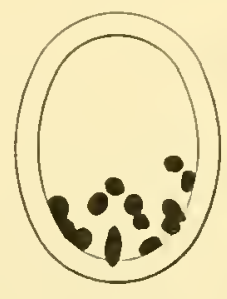

108

\section{6}

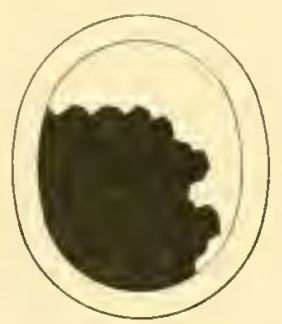

109

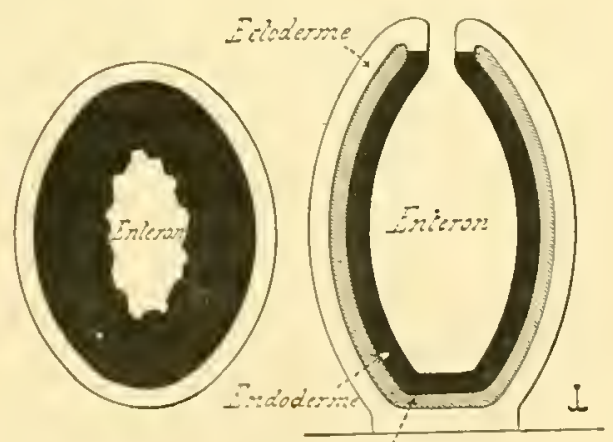

issociesine

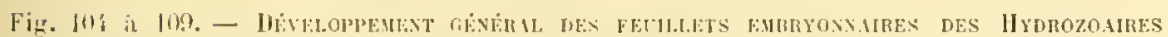
(roupes diagrammaliques; le blanc exprime le blastoderme, et ce qui reste de lui, à l'extéricur du worps, comme protechuleme; le noir exprime le protendoderme; les

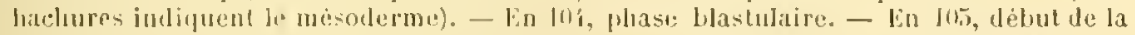
blastoplanule, el genise des premiers enJorytes. - Eu 106, suite de la phase blastopla-

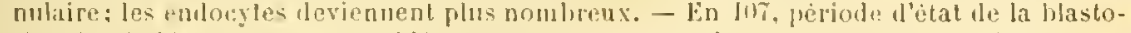
planule; le blastocole ast combli par los culocylas, qui composent un volunumeux protendoderme. - lin los, dobul de lentiron. jui se ereuse dans le probuloderme.-

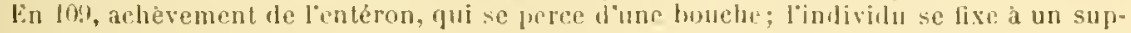
jort, froduit son mince misoderme, el se convertit eu une Ilytrule. 
L'orule fécondé se secrmente, passe prar la phase morulaire, et parrient ¿l l'état lılastulairo. Le hasloderme de la hlastule produil iles endocyles, qui parriennent dans le l, listorule, et l'emplissent; la blastule se convertil ainsi on une blastoplanule. En ce moment, l'embryon possede ses denx feuillets blastodermiques primordianx; le protendoderme est ronstitué par l'ensemlile dus condoryles; le prolectoderme est représenté par Je hastoderme póriphóripne. Le protendoderme demeure simple désormais, et donne l'endoderme do l'adulte. Le frotectoderme a une valeur Jouble; il se converdit bien en ectuderme, mais fournit en surphus un mésoderme plus ou moins épais, tantiot réduit à la membrane propre, tantôt plus rohmineux (onbrelte des méduses), qui se place entre le fenillet externe el l'ondoderme.

Lectoderme larvaire se conror rapidement de cils vibratiles, qui servent à la natation. Cel ṕtal de l'embryon a élé désigné, autrefois, par Ir nom de planula, expression étromlne depuis à unc antre sórir de phénomènes, et ayant perdu sou sens primitif. La larve s'accroit durant sa vio libre; l'ntipnn su creuse dans l'endoderme, et devient la cavilé gastrique le l'alulle; les éliments endodermiques se disposent autour d'elle en une assise simple. yui la limite. L'emtryon olTre alors lanspect d'une vésicula crense, donl la paroi est constituée prar uno louble couche cellulaire; l'assise externe répond à l'ectuderme, nt l'assisu interne a l'endoderme. Il so fixe vers cetle époyue de son évolution. Une loucho se perer dans la région opposée ì la partie fixée; des lentacules apparaissent antonr d'elle, an moven d'úraginalions de la paroi du corps, pui menforment des diverticules de l'entéron. Parfois, la bouche et les lentarules pronnent naissance durant la vir libre de la larve, peu arant le moment de la lixalion.

Le petit itro, ainsi construit, ollie toul laspect d'un jenne polype. Sal houche ne s’atlaisse point lans la cavilé entérique, of reste externe; cefle cavité elle-mème conserve les parris lisses, el ne produil ancune chison. Celle période est la dernière du direloppemenl; et la phase, yui lui correspond, peul porter le nom d'Iryelrula. Lillydrule n’a plus qu’à engendrer une membrane propre, el à revêtir l'aspect définitif de l'adulte, pour alre un polype complet.

La phase Hydrule existe tans tons les héveloppenents d'llydrozoaires qui alwulissent à la production de polypes; elle est parfois allérée dans son allure, mais conserve tonjonrs ses caractires essentiels.

Jans les déwoplopentents abrégés, el lorsque l'embryon doil se convertip en polype, la phaso l, lastulaire est onise; la morule se lransforme directement en une bastoplanule. Les blastomères périphériques de la moruhs se rassemblent on une rombe simple, qui est le protectoderme; les hastomères inturnes se groupent en un amas compact, le protendorlerme. Les denx lenilhets primordianx se délimitent, de suite aprè la période morulaire, salns quapraraisse une phase blashulaire. Une telle abrériation th développenent existe chez un certain nombre d'llydridés; 
elle atteint sa plus grande intensité chez la plupart des Siphonophores, car certains des blastomères internes composent une vérilable réserve vitelline, yui permet à la larve, en la nomrissant, de bourgeonner avant de revètir les caractères de l'adulte.

Le développement est toujours alrégé, lorsque la larve doit donner naissance i une méduse ( $6^{\circ}$ type du tablean synoptique); mais cette abréviation ne présente pas le caractère de relle mise en æurre dans lévolution des polypes. La morule se moditie en nne blastule spéciale, dont les éléments blastodermiques sont fort gros, s'avancent dans le blastocuele, et l'occupent presque entièrement, on mème l'obstrment d'une façon complete. Ensuite, la blastule se transforme directement en méduse. La couche blastodermique se divise en deux assises emboitées, dont l'externe est le protectoderme, et l'interne le protendoderme; la cavité entérique prend naissance par écartement des éléments de ce dernier, el la jeune larve se trouve ainsi constituée. Elle devient rapidement une méduse, et n’offre, durant cette évolution, aucune ressemblance avec un polype.

C. - Les phénomènes de la gemmiparité ne varient guère dans lour essence. La cavité entérique du générateur émet un diverticule, qui soulèye la paroi du corps pour s'en faire une enveloppe particulière; l'ensemble du diverticule et de sa paroi propre grandit, passe à l'état de bourgeon, puis à celui d'indivilu, par l'apparition des divers organes. Etant donné ce procédé génétique, les cavités entériques des descendants communiquent avec l'entéron maternel; ces relations persistent toujours, durant tonte la période d'adhérence des individus les uns avec les autres. Les senles différences, dans la reproduction gemmipare, portent sur la nalnre des producteurs, et sur celle des ètres produits. Les trois principaux modes déjà conuus, et qu'il sera nécesssaire d'étudier en détail, sont : la gemmiparité des polypes qui produisent des polypes; la gemmiparité des polypes qui produisent des méduses; enfin, la gemmiparité des méduses qui jroduisent des méduses.

\section{\&2. - Éléments sexuels.}

L'unisexualité est la règle chez les Ilydrozoaires; un individu déterminé, quelle que soit sa forme, porte des élénents màles, ou lien rles ovules, sans présenter les deux réunis. Cette séparation des sexes s'étend souvent aux colonies de polypes, dont les gonozoüdes sont tous miles, ou tons femelles, suivant le cas; il n'existe gunere d'exception, à cet égard, que parmi les siphonophores, font les colonies, sauf celles de diverses A polemiu of Iniphyes, sont hermaphrodites, of parmi les représentants de la famille des Tubularidées. Une colonie hermaphrodite possirle des gonozö̈des, dont les uns sont milles ot les antres femelles, mélangés sans aucune régularilé, du moins le plus souvent; par contre, 
une colonie unisexuée porle sentement des gonozoïles d'un seul type, soil mite, soit femelle.

I. Développement des éléments sexuels. - Crs éléments sont situés dans lo mésoderme, lorsyn ils onl achevé frur évohution, et forment dans ce feuillet me masse compacte, mais its n'en proviennent pas: ils dérivent loujours de l'ertoderme, on bien de l'endoderme. Lenr origine, sous ce rapport, offre une lixité remarqualue, car elle est constante chez les représentants d'un mème groupe, el ne varie point. Les commissunces acyuises, sur ce sujel, sont dues pour la plupart à Weissmann, qui a trouró lrois lypes de dérelophrement.

bans le premier type, les deux sorles de probluils sexucls, les spermatozoïdes el les ovules, sont fournis par l'ectorterme: tels sont les Irdrozaires inférieurs, les Aulhydraires, el un cerlain nombre de Thibularieus. Les érments reproducteurs proviennent tous de l'endolerme, lans le secont; il en est ainsi pour le plus grant uombre des Serlulariens. Entin, le froisiome lype est caraclérisé par la genèse des spermatozö̈les aux dépens de l'ecloderme, el par celle des orules anx lépens de l'endorlerme: celle donble origine, déja signalée depuis longlemps par Ed. Yan Beneden chez les IIydractinia, a élé olservée par Weissmann chez un certain nombre le Campamularens. II existerail hien un quatrieme lype, dans lequel les spermalozö̈des proviendraient de l'endoderme, el les ovules de lectuderme: mais ce mode supplómentaire, trouvé chez les Eudentrium prar Ciamician, n’est point accepté par W'eissmann, du moins pour les Eudendrium, car les olsservalions du premier auleur seraient fausses i cet égard, el les représenlants de ce enente doivent dre placís, selon Weissmann, dans le second Iype.

Quelle que soil la diversití de l'origine premire, lérolution suivie est toujours la mème. Les éléments rellulaires, qui duivent fournir les produits génitaux, puillent to feuillet aujurl ils apparliennent, et pénètrent dans le mésoderme; leur accumulalion, en une région donnée de l'individu, probut un épaississoment volumineux, ol très appréciable. Jes éloments miles se transforment en spermollastes; les lemelles devienuenl directement les orules; les uns et los autres présentenl mne rerlaine contraclililé, qui les lait se monvoir dans la sulostance mésodermique; ces léplacements, déterminés jar te jeu de courtes expansions psedulopoliques, ne sont jamais bien considérables.

lesénoments sexuels des Aulhydraires, ef cenx d'un eertain nombre de Tubulariens, foul leur apparilion daus le mósoderme du polype ordinaire, ou dans celui du gonozoidh, appres que ces inlividus ont acquis, ou peu s'en laut, leme sloueture complete; l'ensemble des lissus, de la proroi du

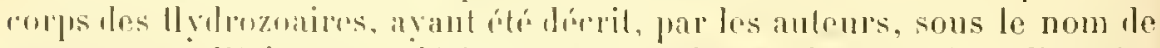

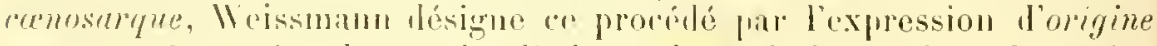
renosarcale. - La pluparl des Ifydroméduses liplommphes, du moins 
celles pourvos de gonozoüdes fixes, on bien de gonozoïles módusaires dont les glandes génitales apparaissent avant la vie lilure, présentent un tont autre mode de développement. Les éléments reproducteurs se façonnent d'abord dans le mésorlerme d'un individn queleonque, ou mème dans relui des slolons qui relient les zoö̈les les uns aux autres; ensuite, la paroi du corps de ces individus. on celle de ces stolons, évolue autour des masses sexuelles, et forme des ponozoüdes, destinés ì contenir ces dernières, en mom moment oì ces masses sont completement ébauchées. Par une extrème alıériation du lévelopjement, les individus sexués premnent naissance après les glanles génilales qu'ils renferment, et non avant elles, contrairement a ce quil en est dans le premier type. - Ce deuxième procédé est désigné, par Weissmann, sous le nom d'origine blastoïdale.

Puis la tendance des gonozoïdes libres, des méduses, à conserver lo plus longtemps possible frur forme définitive, et à posséder leur autonomic individnelle, exercant son elfet, l'origine crenosarcale reparait chez les IIỵlroméduses supérieurs, dont les méduses quittent la colonie dès leur extrème jennesse, el dépourvues encore d'ébauches sexuelles. Ces dernières sont engondrées dans le corps de l"individu, hien apres le moment oì ce dernier a quitté la colonie maternelle; par suite, la genése du zooïde précide cello des éléments reprouluctenrs : lorigine est cenosarcale. - Il existe done denx origines conosarcales: une origine ccenosarcale primaire, celle des Authydraires, qui est le procédé primitif, puisque le déreloppement de la partie somatique de l'indivilu précède celui de la portion sexuelle; et une origine crenosarcale secondaire. La première cede la place, par abréviation du développement, au procédé blastoïdal: l'organisme colonial prend en eflet une grande prépondérance sur la vie individuelle, et les produits génilaux peuvent naitre dans cet organisme, sans que le zooüde destiné à les contrnir soit nécessairement préformé. Ét, en suirant la série ascendante des Il yilrozoaires, le mode blastoïdal disparail, pour permettre lo retour d'une origine conosarcale secondaire, car les individus sexués se séparent bitlivement de l'organisme colonial, tendent ì acquérir une autonomie plus grande que celle des polypes ordinaires, ot, on conséquence, produisent leurs organes sexuels durant leur période de liberté.

II. Structure et situation des éléments sexuels. - A. Les spermatozoüles sont lormés par les spermatoblastes; ces derniers se segmentent, et lonnent naissancr à les spermatogemmes, dont les spermatocytes éroluent en spermatozuïdes. Le corps des élíments miltes est divisé en deux parties : nne lète renfermant le noyau, et une quene fililorme, servant d'organe locomoteur. - Les ovohlastes ne se divisent point l'orhinaire, et charun d'eux probluit un ovile, tassé contre ses

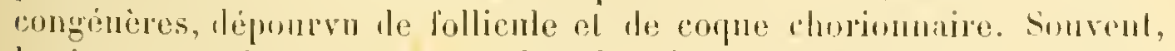
les jennes ovules progressent, daus la substance fondamentale (hn meson- 
derme, au moyen de courts appenlices psendopodiques; ces expansions se raccourcissent durant la croissanre de l'ólément femelle, et l'ornle parvenu à maturité nen montre phus, car son contour est devenu spliérique, on ovalaire.

Les produits sexnels sont rejelés par la rupture de la praroi du corps. Si la paroi se lirise dans sa partie externe, ou ectodermique, les spermatozoïles et les ovules sont déversés directement dans les milieux extérieur's; si la rupture se manifeste sur la face interne, ou endorlermique, ces éléments parriement en premier lien ılans la carité gastrique, et se remlent an delors en passant par l'ouverture luccale.

B. - Les indivilus munis d'organes sexucls sont semblables aux autres, chez les Authydraires; en outre, pour ce qui est de ces derniers, tous les zooïdes l'une mème colonie sont capalıles de devenir sexués, et il n’existe entre eux aucune différence à cet égard. Les conditions sont changées chez les IIyilroméduses et les Siphonophores.

Il faut adopter lans ce cas, en la modifiant quelque peu, la classification proposée par Weissmann, et distinguer jusienrs formes d'individus sexués, de gonozoïles. Une contition, commune ì lous ces idres, est relative au nombre mème de ces gonozoüdes. car certains polypes seuls, et non pas tous ceux d'une colonie, deviennent des individus sexués. Les différences portent sur l'asprect, et sur la complexité de structure, offerts par ces individus.

Le type le plus simple est relui des gonozoïdes, scmblables en tont a des polypes ordinaires, ot se distinguant d'eux par la seule présence de cellules reproductrices lans leur mésorlerme: res gronozoïdes méritent done le nom de Sporophores on de Sporosacs; Iels sont ceux des Cordylophores, par exemple. - P'our le second lype, les individus sexués renferment, dans lenr paroi lu corps, une cavité, comparahle à la cavité sous-ombrellaire des vrajes miduses, mais ne communiquant pas arec le dehors; les canaux gastriques sont alssents. Ces individus montrent déjà un commeneencul dévolution vers la disjosition médusaire, et sont assez fréquents parmi les llydrozoaires; ils méritent d'être désignés plus particulièrement comme de vrais Cionophores. On les trouve notamment chez les Clava, les IIydructiniu, et les genses voisins. - Un type plus ćlevé est celui des Gonophores médusiformes; la cavité close du second type s'est ouverte an dehors, et se prósente comme une véritable cavité sous-ombrellaire; l'aspect se rapprorhe davantage de celui des méduses normales; mais les tentacules, les organes scnsitifs, le voile, font défaut, et les canaux grastriques sont ì peine développés. Tels sont les gonozoïles tes Tubularia et le plusieurs Siphonophores.

Les individus sexués, appartenanl i ces trois premiers types, ne se détachent jamais de lenr colonie, sanl quelques rares exceptions. Le contraire se manifeste dans les formes suivantes, rar les gonozoïdes se séparent toujours de leurs voisins, et ménent une vie libre plus ou 
moins longue. Jusqu’ici, les éléments reproducteurs seuls se séparent des colonies oủ ils ont pris naissance; le phénomène s’étend lésormais aux individus sexués enx-mèmes, puisque les gonozoïdes deviennent libres, en emportant avec eux les glandes génilales dont ils se sont chargés.

Les individus sexués, appartenant au quatrième type, sont des .Védusoides. lls offrent, en tout, la structure les méduses rraies, et possèdent des canaux gastriques; mais ils manquent de lentacules, de vésicules marginales, de voile, el leur manubrium est sourent privé de bouche. Celte dernière particularité montre déjả laabsence de toute nutrition. La rie libre dure par suite fort peu de temps, el les produits sexuels sont déjả formés, lorsque le médnsoïde se délache. Un assez grand nombre de Siphonophores appartieunent à ce quatrième groupe.

Enfin, le type le plus élevé est celui des Yéduses vaies, munies de canaux gastriques, de lentacules, le voile, de vésicules marginales, el dont le manche porte unr bouche. Ce type renferme lui-mème plusieurs séries secondaires, échelonnées suivant la durée de la vie libre, et le degré de complexité de la struclure. Los méduses les plus simples, celles d'un certaiı nombre de Campanulariens par exemple, possèdent téjả leurs cellules sexuelles au moment où elles quittent leur colonie; leurs canaux gastriques sont en petil nombre, qualre le plus souvent; la vie libre est le courte durée. Les méduses les jus complexes se séparent fort jeunes de lenr colonie, et acipuierent des produits reproductenrs durant leur existence pélagique; les canaux gastriques el les tentacules sont sourent fort nombreux; et, par l'ensemble de leur organisation, ces individus se rapprochent heaucoup des Hyilroméduses holomorplues. Entre ces deux formes extrèmes s'étale toule une série l'intermédiaires.

Il faudrait, ensuite, placer an plus haut les llyilroméduses holomorphes, qui prossèdent un organisme de structure fort complexe, et se reprouluisent en ent état, sans jamais retourner à la phase polype.

C. - Li's éléments sexuels des méduses sont: tantút situés lans la paroi du manche (Anthoméduses ou Ocellates), el proviennent alors de l'ectollerme; tautot placés dans la paroi des canaux gastriques (Leptoméduses on Lésiculates; Hydroméduses holomorphes), el, lans ce cas, dérivent sans doute du fenillet endodermique. L’aspect, présenté par les masses sexuelles, dillere suivaut l'origine première; les amas de cellules reproduclices épaississent la base dı manubrim chez les Anthoméduses; ils forment, lans le second mode, des saillies, les gonudes, placées sur la sous-ombrelle.

Les livers types de méduses ne peuvent servir à caractériser avec netteté les gronpes. Ainsi les Monocaulus, par exemple, sont pourvus de gonophores orthnaires, alors que les représentauts lu genre voisin Corymorpha présentent do viaies méduses, appartenant a la série les Steenstrupia. De mème, certaines uéduses dllỵlroméduses diplomorphes rappellent de très près plusieur's llydroméduses holomorphes, 
an point de les laire placer lontes dans le mème gronpe. Le phénomène so eomplique encore, par le fail de la diversilé do's moduses provenant

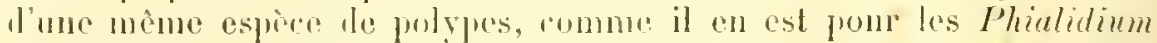
variubile cl les Clytia volubilis; celle diversile porte non sculduent sur l'aspect général, mais encore sul le nombre des lentacules ol des canaux

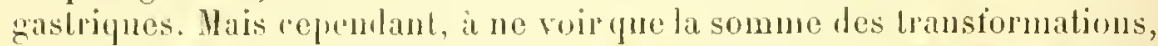
il est permis de comsiblirer la serie de complexite, allant des dullydraires anx llybroméduses lobomorphes, comme répondant a la réalifé des choses.

\section{3. - Segmentation et développement des feuillets blastodermiques.}

1. Considérations générales. - Le léveloplement des feuillets haslodrimiques selfeche, chez los llydrozoaires, suivanl le procédé cylulaire: ces thes ne montrent, dans lem embryogonie, aucun pliénomène comparable à nno gastmalion. Le mode dilaté existe chez la flupart des Aullyalraires el des Ilydromédusos diplomorphes; le mode alorigé, yui dérive hu premier frar lomission d" plusients phases, est caraetérislique des llylroméduses holomorplies at des siphonophores.

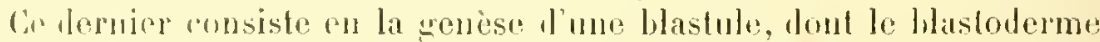
produit des endoeyles; renx-ei remplissunt lo blastocale, ch changenl ainsi la blastule en hlastoplanule. Une cavile se cueuse bientôl dans sa masse, ct deviunt l'untéron; les endocytes su groupent autour d'elle pour constilner l'ondoderme, et le lidastoderne restant se convertit directement en moderne. - Le forillet moyen est engendré secombarrenent fra le fenille extrieur. Las trois rouches pellulaires do l'organisme ont ansi pris naissance, lenr développement s'élant elfeclué d’ajrès le procedé cylubire typique.

Labréviation, qui empèche la renue de l’état blastulaire, el délermine lapparition immodiate d"nne planule, notre pas tonjours les mèmes plithicularilés: elle varie des siphonophores aux llydroméduses lobomopplos. Les larves le ces dernières évoluent en méduses, el ne produisent point do folýpes; aussi l'épais mósoderme de l'ombrolle nail-il de home henre, de suile après l’arrivée de l'élat planulaire: de plus, la morule, conslilure far un pelil nombre do gros blastomeres, se transformo direchnomt, rn planule, far la division de ces blaslomeres

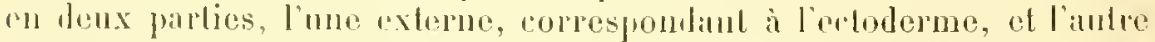
inlerne, 'pui donne l'endodrrme. - las Jlastomeres des morules de Siphonophores sont plus nombreux; centains l'entre enx, remplis de gramulations deutolécilhiguos, servent a la lare de réserve nutritive. $A$ ranse de relte quantité consilérablo d’éléments orulailes, la morule se molitie dirminumb an planule, rar los blasloneres internes sont les cquivalents des endoeyles, et les blastomeres externes cenx des cellules 
cetodermiques des hastoplanules. Enfin, le feuillet moyen alprarait tardivement, tout comme il en est pour les Ilydraires inlérieurs.

Il est donc nécessaire d'étudier. en premicr linu, le lype culnyonnaire dilaté, el d'examiner ensuite, che\% les lyydromédnses lıolomorphes et chez lis Siphonophores, les altérations sulies par hui.

\section{Authydraires et Hydroméduses diplomorphes. - I La} plupart des méduses, appartenant an groupe des Diplomorphes, produisent des ovules qui, après la fécondation, se segmentent, of ívoluent suivant le mode le plus simple. La segmentation orulaire est égale; elle détermine la genèse d'une blastule, dont l'asprect rarie suiraut sou àve. I son début, la blashule est constituce par une petile quantité de volumineux lilastomères, placés autour d’un blastocole étroit; les liastomères se multiplient, augmentent en nombre, diminuent en taille, et le blastorwle s’accroil de son côté; an moment oì cette ívolution est achevée, la blastule présente un blastoderme mince, ot une cavité blastocelienne assez ample. - Parvenue à cetle pliase, la jenne larve est arrondie; elle va s'allonger désormais, prendre un aspect ovalaire, et passer à l'ćtat de blastoplanule. Plusienr's cellules du blastoderme, non pas toutes, situées d'ordinaire à l'mue des extrómités do l'enulryon, se multiplient, et engendrent des endorytes. Cenx-ci tombent dans la cavité blastoculienne, s'y déplacent au moyen d'expausions psendopodipues, et se scindent, de maniere à produire de nonveaux ćléments; cetle genèse s'arrète, lorsque la cavité lilastocolienne est entièrement remplie par eux.

La blastule est devenue une blastoplanule, composée de son protertoderme extérieur, et du protendoderme que constituent les endocytes. lintre temps, le protectoderme se courre somvent de cils vibratiles, qui servent à la larve pour se déplarer, et tournoyer dans l'eau. Le protendoderme compact ne renferme aucun espace vide; c'est aux embryons ainsi constitués que les auteurs ont donné le nom le planules, expression détournée aujourd'hui de son premier sens restreint, pour désigner l'une des phases des développements alrégés. - La larve s'accoil durant cette période de liberté; mue cavité apparait an centre du protendoderme, augmente rapidement de taille, et les endorytes, disposés d'aliom antome d'elle en conches serrées, finissent par ne plus pouvoir former qu'une seule assise pour la limiter. La hastoplanule, ainsi modifiée, ressemble ¿t une vésicule crense, d'aspect ovalaire, nageant daus l'ean par le moyen des cils viluratiles du protectoderne; sa paroi est constituéc par le jorotectoderme lui-mème, el par l'unique rangée interne d'enlocytes prolendodermiques; la cavité contrale est colle qui vient de faire son a pparition. Cette dernière est l'entéron; le protendoderme se convertit en endoderme, ot le protectoderme en fouillet reloderminge. - Los ileux couches somatipues principales, of la cavité entrérique, ont done fris naissimme; la seule moditication qui doit intervenir, prar la snite, est relative an 

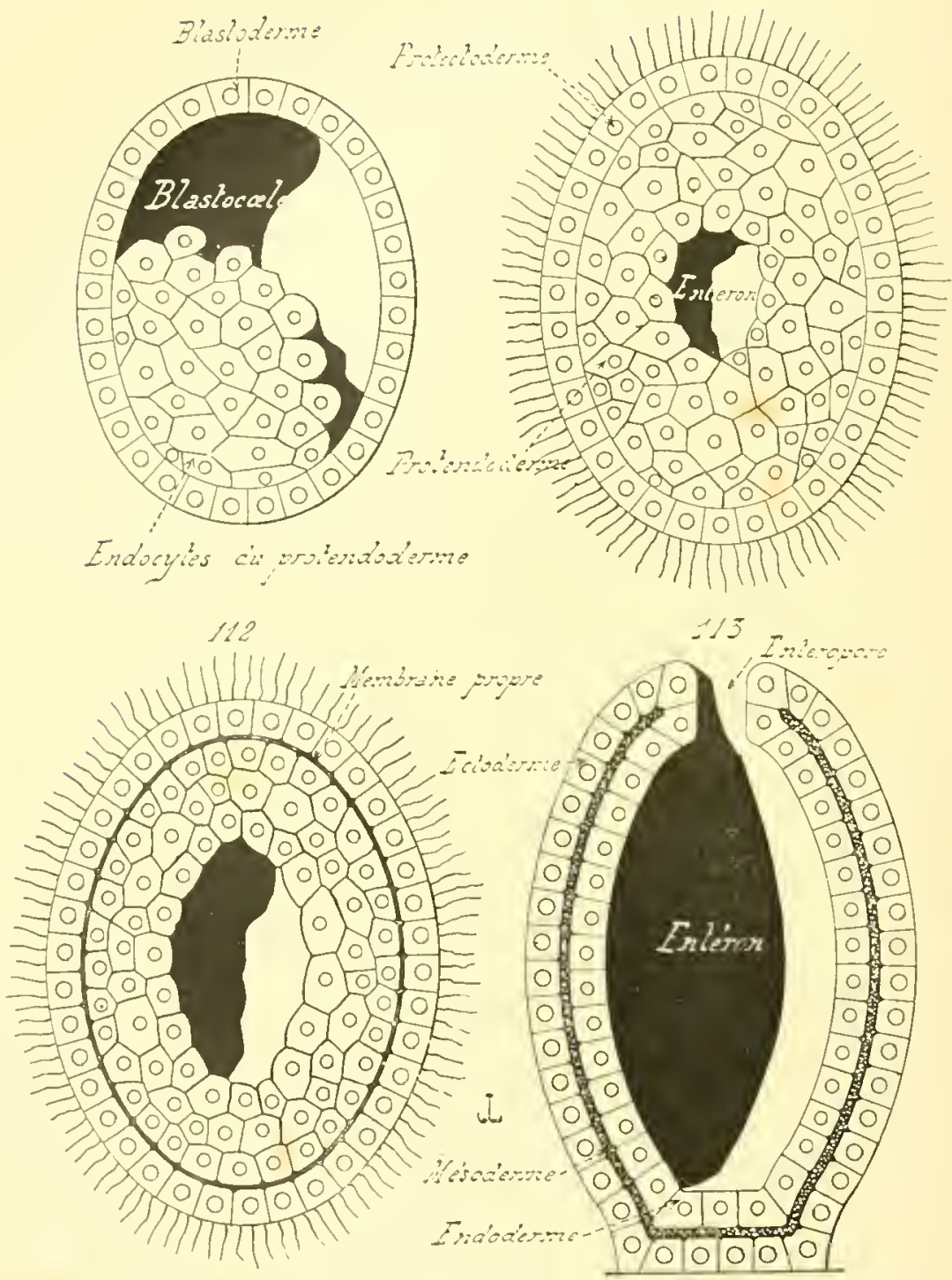

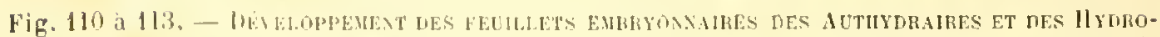

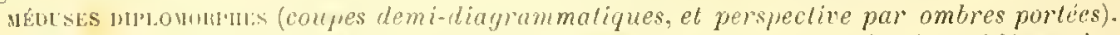
- En 110, milieu d. la phaso blastoplanulaire: le blastocole est a demi comble par les

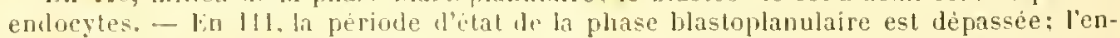
léron commence it se ereuser dans le protendoderme, compraet un peu auparavant: rarfois, les ralueytes du protembleme s'anastomosent paj des prolongements pseudopodiques. - lin 112, suite de lamplifieation de l'entéron. - En 113, achèrement de l'entéron: la larve se tixe, el devient une llydrule. 
développenent dn mésolerme, par l'exsulation d'une substance fondamentale placée entre l'ectoderme el l'endodrome, el frar l'émigration, dans cette sulstance, d'éléments issus des deux leuillets primordiaux, notamment du feuillet extérieur. l’entéron devirnt la cavilé gastrinue.

les premières phases embryominires se sont effectuées. La lane se fixe unsulte par l"mne de ses extrémités, perce mne bouche daus la région opposéc ì la hase d'alluérence, el produit, antom de cet orifice, une cumromne de leulacules: chle se change ainsi en un polype.

go Les phénomenes sont quelque pen abrégés, chez dirers Tubulariens et quelques Authydraires, de manière a elfectuer me transition vers ceux observés chez les Siphonophores et les Hydroméduses holomorphes; cette abréviation porte sur la phase blastulaire, qui est omise. La segmentation, quelque peu inégale, aboutit ì la genèse d'une morule, constituée par une quantité considérable de hlastomères, plus grande que dans le premicr cas déjà décrit; ces éléments sont disposés sur plusicurs couches, les plus gros élant placés au centre, les plus petils el tes plus nombreux à la póriphérie. Celte morule devient directement une blastoplanule; l'ensemble des blastomères périphériques se groupe en nue assise simple el réguliere, qui est le protectoderme; l'amas des rellules centrales correspond a un protendoderme. La phase hastulaire fait don: completement défaul.

liévolution conlinue ensuite, d'apres des procédés semblables ì ceux sigualés dans le premier lype. tes voluminenx éléments internes se divisent en cellules plus petites; la larve s'accroit, augmente de dimensions, et donne naissance, dans son intérieur, à une cavilé entéripue; puis te protectoderme ef le protendoderme se convertissent, clacun pour sa prart, en ectoderme et endoderme. Une particularilé intéressinte consiste dans l'apparition halive des tenlacules; ces orgines maissent an moment où la bonche n'est pas percée, el où la larve nage encore lans l'eau qui l'entome ; celle production hative est une conséquence probable de labréviation du léveloppement. tes larves libres des Tubularia, munies de lentacules, sont commes sous le nom d'Aclimulu.

III. Hydroméduses holomorphes. - $1^{\circ}$ Le procédé le plus simple a élé observé rhez la liviope mucronata; il se rapproche beaucoup de rehui présenté par les Ilydroméduses liplomorphes, car il romporte une plase blastulaire. Cette phase est a peine indiquée ; mais elle n'en fait pas moins son apparition, el le développencnt des Ilydraires supérieurs se relie, par lì, à relui des tlydraires inférieurs.

liovule se segmente, et produit une morme, romstilnéc par un petit nombre de gros hlastomères, assez volumineux pour s'itendre depuis le rentre jusqu’i la périphéric de l’embryon. Cus hastomères scécarlent les uns les antres vers leur extrémité internc, el laissent, en celle place, une petite eavilé, romprarable ì un blaslocule fort étroil; la mornle est 
ainsi devenue une blastule, an hastoderme très épais, el au hlastocele réduit, semblahle à le jeunes larves hastulaires d'llydroméluses diplomorphes. Ces dernières continuent leur évolution, en amplifiant leur cavité l.lastocelienne, angmentant le nombre et diminuant la laille de leurs éléments blastodermiques, et ne produisent les endocyles qu'après avoir elfectué ces premières modifications; par contre, les blastules de hiriope engentrent hàtivement leur's éléments endoeytaires. l'lusieurs de lenr's volumineux l, lastomères, el non pas tous, se divisent en leux parties : une portion externe, qui continne a appartenir au bastoderme: et une interne, yui pénètre dans la cavité blastocelienne. Cello-ci est tellement étroite, que denx ou trois de ces portions internes suftisent pour la remplir. Ces segments intéricurs sont des emdocyles, et la hastule est deronue une blastoplanule.

La hlastophanule de Liriope rappelle done les états correspondants des Hydraires inféricurs, et n’en liffère que prar la taille exazérée, et par le protit nombre, des éléments cellulaires; ret embryon va ensuite produire les fenillets. (Yuplques éléments du blastoderme continuent à donner de voluminoux endocytes, qui s'ajoutent aux précélents, et forment avec eux le protendoderme; puis, ces cellules rentrales sécartent les mes les autres, de façon a laisser, an milieu mème de l'embryon, un espace libre, qui gramdit de phus en plus. Cet espace est la cavité entérique; les endocytes se disposent autour d'elle pour constituer l'endorlerme. Le hastoderme périphérique, après avoir fourni de rette maniere it la genèse tes andocytes, arquiert le caractere d'un protectorlerme, qui roste exlérieur, et derient l'ectoderme de l'adulte.

Une particularites des llolomorphes fait ensuite son apparition. Aussitot après le moment où l'muloderme et l'retoderme sont nettement limités, ot alor's 'jue lit cavité entérique se tronve encore fort élroite, une substance fonlamentale alondante s'intercale entre ces deux feuillets colluliires, et les sépare l'nn le l'autre. Elle est l'abord répandue partout en égale quantité, mais elle ne tarde pas a devenir plus épaisse dans la récion qui correspond à la fulure ombrelle; des éléments, dont la plupart sont engendrés par l'uctudreme, pénètrent dans cette substance, et constituent avec elle un tissu compact, dui compose le mésodermo.

Les trois feuillets blastudermiyues ont done pris naissance, par un frocédé cytulaire fort net, semblable à celui des Aulhydraires et des

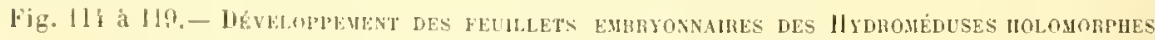
(coupes demi-diayrammatiques).

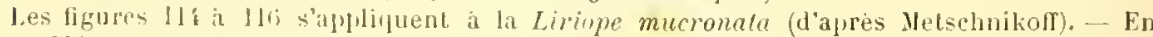
114, geniwe des endocytes. - Bin 115, apparition de l'entéron et du mésoderme. - En I1; accroissencul rapide du mesutlerne, eunstitue par une substance intercellulaire.

Les ligures 117 at ll! s'appliquent à la plupart des autres IJolomorphes (d'apres Fol). lin 117, phase morulaire. - In 118, dilamination des blastomèes, cliargés de delimiter les deux fenillets primordianx. - Lin 119, developpement de l'entẻron el du mésoderme. ('Pal' erreur, dans la ligure 115, . Vesendoderme est mis pour Protendoderme.) 


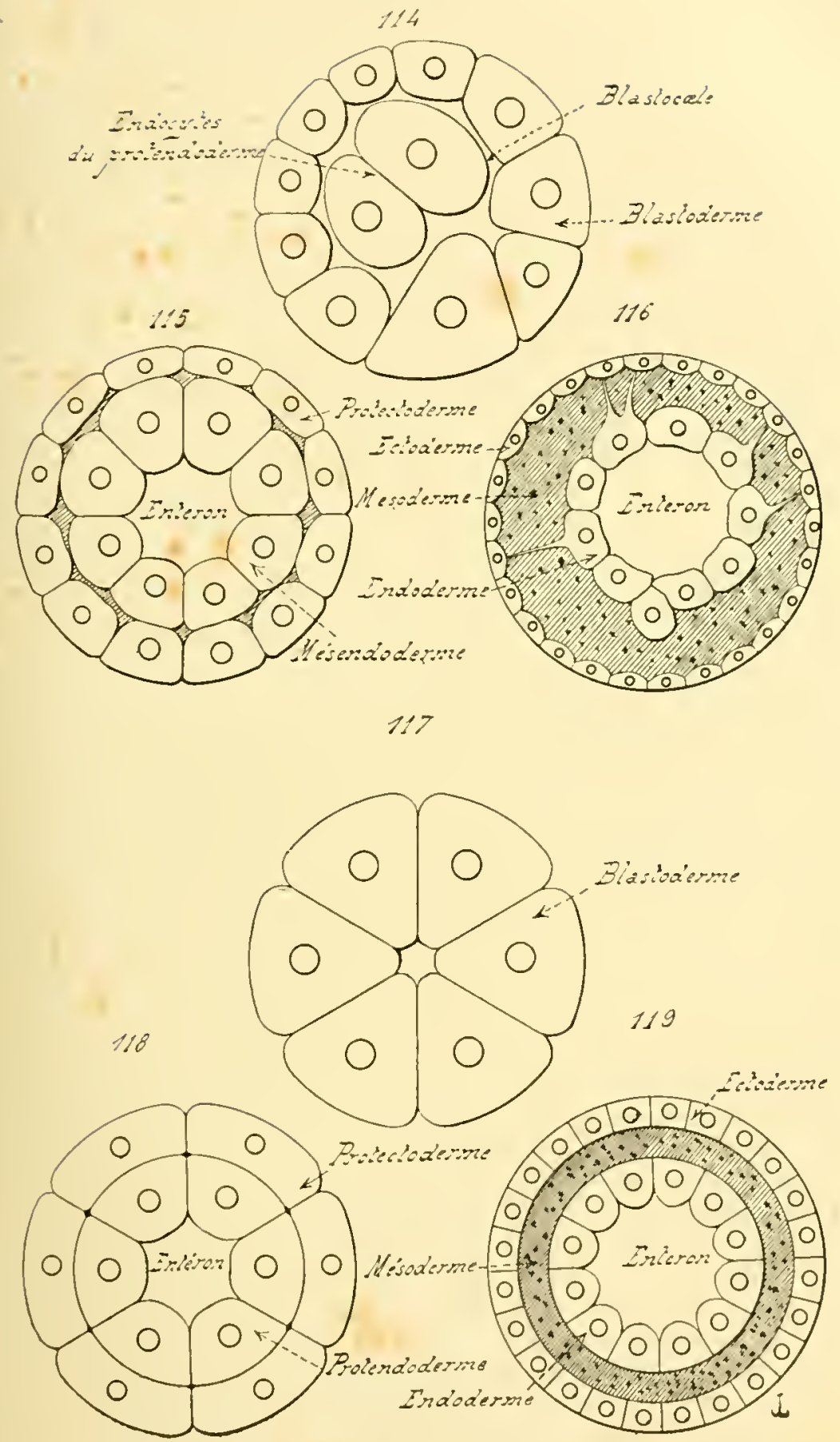

Fig. 114 à 119. 
Hỵlroméduses diplomorphes, mais prísentaut, comme particularité principale, mo ditférencialion hative de l'anderterme el du mésoderme. Ces particularités sont plus acrendués cucore dans les deux modes snivants, car l’abréviation du dévelojpement y est plus considérable.

go Les orules fécondés le lil pluprarl des llolomorphes produisent une morule, semblahle à celle des Liriope, mais yui ne dissocie jamais les régions internes do ses hastomìres pour domner un blastocode, et demeure roupracte; les éléments morulaires sout assez volumineux, pour s'élentro lous depuis le rentre jusqu’à la périphéric de l'emlryon. La

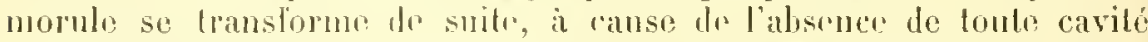
hastocolienne, rn unc hastoplanule comparte. Hais, comme les blastomeres suml groupés en une senle assise, ils se divisent sur place, pralletement a leur lare externe, en leux parlies, l'une interne, l'aule extorne: ce procédé a regu le nom de délamination. La morule s'est. converlie directement en une hlastoplanule, comprosé d'une assise príriphérique, ef d'un amas cellulaire central, constilué par les parties internes iles hastomeres. Ces dernières sont les homologues des endocyles des cas précédenls; leur ensemble constitue l'endoderme; de son côté, l'issisc externe n’est autre que l'ectoderme.

Les aulres phases de lévolution se manifestent comme daus le premier type. Les volumineux et pen nombreux endoryles se divisent de manière a augrmenter en quantité; il en est de mème frour les déments ectodermignes. La blastoplanule s'arroît pendant un certain templs, tout wn restant compacte; parfois, les entocytes se disposent les uns sur les aulres, romme des dispues empilés, chez l'Aglaura hemistomu par exemple. Pruis, une cavité entéríue se creuse au sein de l'endodrime, pour se développer d'après le procódé habituel; el l'épaisse substance fontamentale du mésuderme fait son apparition.

3 La sugmontation des ovules d'. Eginopsis medilerranea diffère, de colle drorite dans le seront cas, par l'existence, dans la morule, d'un nombre considérable de hastomieres disposés sur flusieurs eonches. Aussi la morule se transforme-t-elle direlrment en blastoplanule, sans

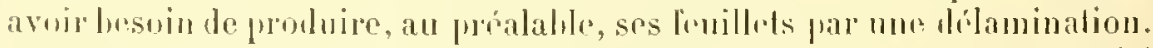

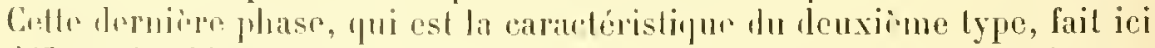
délauf; los lolastomires périjhériques se rassemblent en un ectoderme, ot los sexmonts internes, homologues des endorytes prócédents. représintont l'endoderme. - L'emhryon ist sphéripue vers le début de son élat planulaile; il s'allonge ensuite, devient ovalaire, el donne naissance

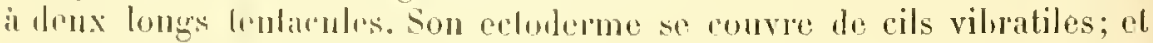
ses cundorytes angmentent on nombre, tuut en étant serrés les uns contre les antres. Cette évolulion continne ainsi durant un cerlain temps ; puis la cavité nutépigue se creuse dans l'rndorlerme: les éléments de ce dernier se groupenl autour d'elle cu un" assise simple, et tous les phénomènes ultérieur's sont semblables a ceux signalés dans les deux premiers cas. 
Le dévoloppement est ici tris abrégé; la phase blastulairp du premier type est omise, el ta produclion des embocytes par labmination, folle fu'elle existe dans le second procélí, manque également. Des la liu de la segmentation, les blastomeres se rassemblent, chez les Eginopsis, le laçon it présenter une Jisposition, que les embryons Jes antres ly yroméduses holomorphes alleignent seulement apres me série le morlitications préliminaires.

IV. Siphonophores. - Les premieres phases emlirynnaires do ces èlres sont remarquahles, en ee qu’olles s’acempagnent de plúnomènes gemmipares. Le homrgeonnement nattend point, pom apparaitre, que la périorle larraire ait ressé d'exister; les zooïdes dr la colonie naissent sur le polype primaire, alors que relui-ci est encore à l'élat d'élauche, et mème vient à pejue de produire ses fenillets blastodermiynes. Ces faits, cejendant. ne molitiont en rien la grenese de ces feuillets, et se rapportent seulement a une gremmiparité précoce, due a la grande prépondérance prise par la vie coloniale sur la vie individuelle, et aussi à une ahreviation considérable de l'embryogénir. - Une sceonde particularité, propre aux larres les siphonophores, tient à la présence, sur l’une de leurs extrémités, d’une dépression ectodermique, qui deviendra la cavité du futur pmemmophore de hatonie. Celle dropession existe Lonjours; lien quelle lisparaisse, par la suite, chez les êtres dont l'organisme colonial est dípourvu de flotten', chez les Discomulides par exemple. Dans ce dernier ras, l'apparition du pneumalophore, apparition qui nahoutit pas, loit ètre prise pour un phénomene alavique.

$1^{\circ}$ L'évolution la plus simple, cl la moins alurégée, a étí olıservée chez. les stephanomia picta, les Physophora, el plusieurs autres Siphonophores; elle rappelle, dans sos traits essenticls, le demxième procélé des Authylraires, et le troisieme des llydroméduses holomorjlies. La segmentalion, égale el régulière, produit une morule, composée par plusieurs conches de blastomires; cette dernière dovienl, sans subir aurume modification, mne blastoplanule, par la seule differenciation de ses couches cellubares en un cotoderme périphóripue, et m emdoderme central. Les éléments eudodermiques sont assez voluminemx, et remplis le granulations deutoplasmiques, qui forment une réserve vilelline. La phase blastulaire est donc omise, puisque la division ovulaire donne directement maissance aux promiores ébauches les fenillets primomiaux.

l.es cellules ectodermiques arquièrent des cils viluratiles, doml la larvo se sert pour se déplarer. La formo do cetto dernic̀ne est es:llo d'un ovale allongri, présentant, sur l’une de ses extrémités, une petite lápression, qui rommunique ares le lehors. Celte dépression est l'ébauche du pnemmatophore, qui ra drsormais sagrandir, et epaissir ses parois, pure prendes son aspect délinitif. Lembryon s'aceroil; la cavití enti-

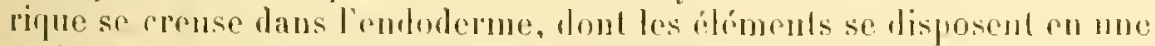

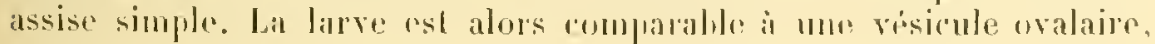




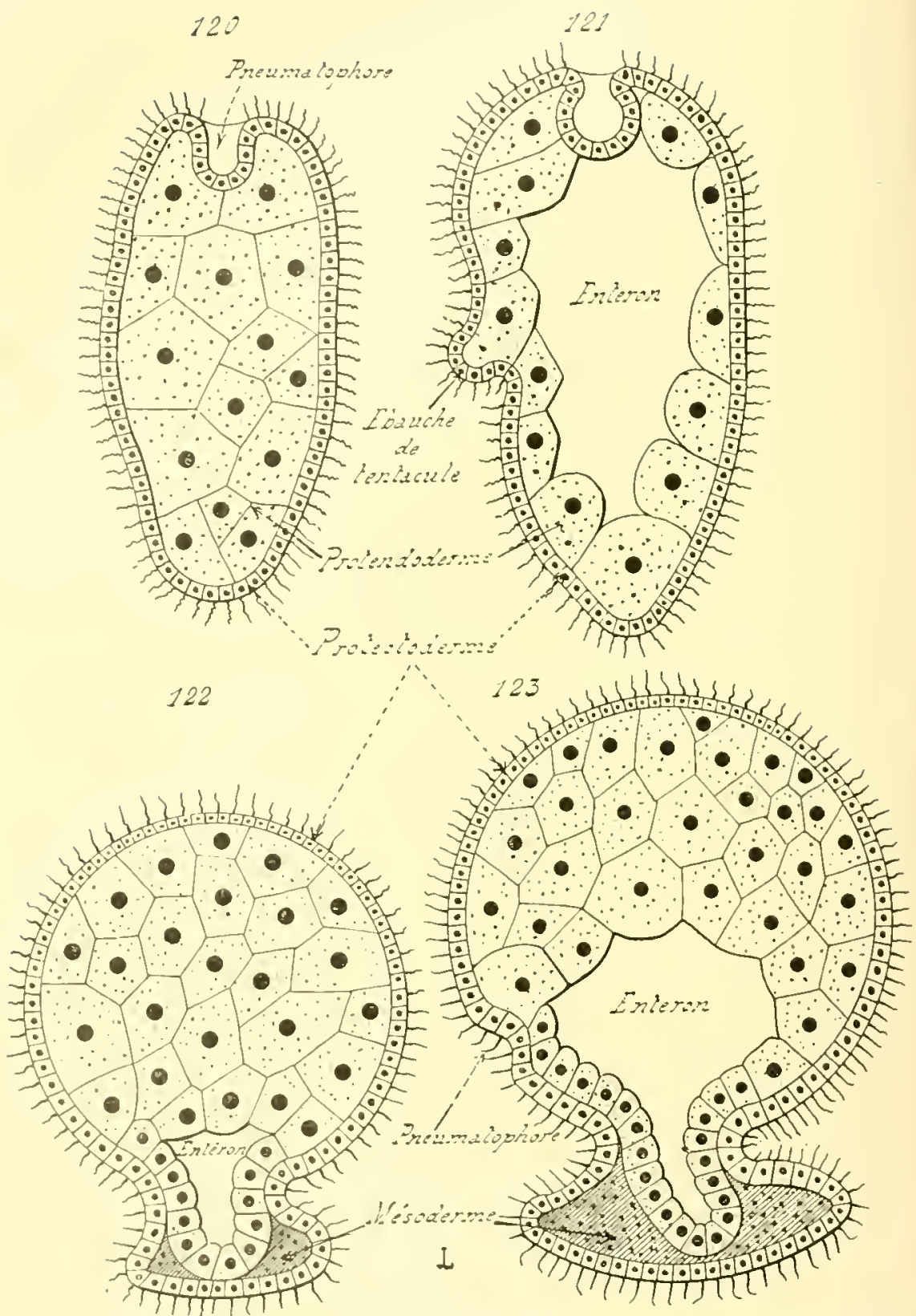

Fig. 120 à 123. - Développenent Ines feujlets Fmbryonxares chez les Siphovophores (coupes médianes, longitudinales, el demi-liagrammatiques). - En 120, jeune larve de Steghanomia pirlum, encore privè l'enteron. - En 121, larve de la méme espèce, plus avancée, et pourvue d'un enteron. - En 122, jeune larve d'Agalmopsis Sarsii. - En 123, larve de la mème espèce, plus avancée. (U'apres les recherches faites par Metschnikoff.) 
close, privée de bouclue, et portant à l'un de ses honts une cavilé pneumatophorique communiquant arec le dehors, mais non avec l'entéron. Le bourgeonnement commence à se manifester dès ce moment; l'ébauche d'un dartylozö̈le apparait sur les còtés du corps, quelque feu an-dessous de l'organe servant de flotteur. Ce jeune lonrgron est constitué par une saillie de la paroi larraire, possédant ainsi les denx fenillets primordianx, et renfermant un diverticule de la cavité entérique.

le mésoderme des stéphanomia, comme celui des autres Siphonophores, est peu développé, dı moins par rapport à relui des méluses. II prend naissance suivant un procédé ilentique à celui des llyilraires, sous la forme d'une mince bande de substance fondamentale, qui s interpose à l'ectoderme et à l'endoderme.

20 Lin mode plus alsrégé est offert par un grand nombre de Siphonophores; il a été bien étudió par lletschnilioff sur les Epitulia aurantiaca. Le développement est, lans son essence, semblable à celui des Stephanomia, car la segmentation de l'ovule aboutit à la genese d'une morule, constituée par plusienrs couches de blastonères, qui se modifie directement en une blastoplanule; seulement, les segments internes, dont l'ensemblo rorrespond à l'endoderme, sont fuhs volumineux, et représentent une réserve nutritive plus abondante. En ontre, le lonrgeconnement commence un pen plus tòt, sans attendre que la cavité entérique ait pris me certaine extension.

l'ectoderme est composé de petites cellules cylindriques, munies de cils vibratiles. l'endoderme consiste en gros blastomères de tailles inégales, remplis de nombreux granules deutoplasmiques. Cette larve, ainsi constituée, et munic d'une cavité entérique naissante, doit ètre prise comme le polype primilif de la colonie, comme le zoïte. Le bourgeonnement fait son apparition dés cette époque; le zoïte borne son évolution à supporter les jeunes hourgeons auxquels il donne naissance, et il leur fournir les matériaux nutritifs qui leur sont nécessaires. Le premicr zooïde juroduit est un futur nectocalyce; l'ectorlerme de la région où il est engendré se sonlive quelque jeu, en me saillie extérieure; les déments endodrumiques, voisins do la saillie, se divisent en me masse de pretiles celtules; une avití se reuse dans cette dernière, et donne l'entéron du jeune bourgeon. Sonvent, ì lépoque où les premiers bourgreons possident déjà tenrs cavités entériques, le zoüte n'est pas enrore fouru de la sienne. Elle apparait cepentant par la suite, et se perce dans l'amas des gros blastomires internes, sans communiquer dis l'abord avee les espaces entériques des hourgeons engendrés; les relations directes ne sélahlissent que plus tard. C"est là un intéressant exemple du déplatement dans le temps.

Les réserves nutritives de l'endoderme du zoïte servent a alinentop la jeune colonie; les hourenons athevent leur écolution, et se transforment, suivint leur siluation, cu nertocalyres, en dactylozoüdes, ou 
en gonozoïdes. Le zoïle prinordial, conservant toujours sa fonction.

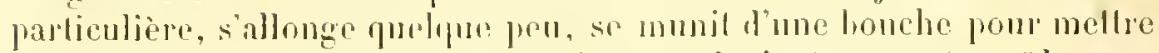
son entéron en rapport aver l'extériens, el devient un gastrozö̈de.

Ce développement, en allant au fond des closes, doit être assimilé à un hourgeonnement de zooülus sur un zö̈le pui dérive l'une larve; mais, i cause de labreviation du développement, el de la présnce d'abondants matériaux allmentaires, le hourgeonuement commence ahrs que le zoïle n’a pas encore achevé son évolulion, el n’a mème pas prorlut son entéron. Anssi, les ravités entériques des zooüles se creusent-elles sur place, en móme lemps que relle du zoite, el indépendamment les unes des autres, pour ne communipuer entru ellis que par la suite; leur valeur morphologique est rependant foujours semlobhe, puisque ces espaces se prercent daus l'endorlerme, ou daus des masses cellulaires qui en proviennent.

3 La condensation des phénomènes emlryonnaires est plus grande encore chez les Agalma, et surtout chez les Crystallö̈des. Le nombre des hastomères, destinés a filre parlie de l'endorlerme, est plus considérable que daus le serond cas; d'on il résulte que les réserves nutritives sont plus abondantes. Ies cllets produits sont tries inrienx; le hourgeonnement commence de bome heure, et preml de suite un diveloppement excessif, alors yur le zoïle élauche à peine ses feuillets. Aussi ce polype primilif oflre-t-il l'aspect d’une grosse vésicule compactr. limition en ilehurs par l'ectoderme. contenant dans son intériemr mu rndoderme a gros granules deutoplasmiques, et portant, sur l'ume te ses faces, plusicurs jemies zoö̈des léjil assez avancés. Le zoïle ost un verpitalle sac vilellin. loul to rôle, laus ces phénomènes primaires du léveloprement, et avaut qu'il ne se transforme en gastrozoüle, est de lonrnir anx hourgeons les matrírianx alimentaires lont il est rhargé.

Une telle disprosition se présente bien ehez les Epitulia, mais elle est moins pronoucée, car le zoïte est pelit par rapport anx honrgeons, et il évolue plus rapidement en gastrozoïde. Ces différences de laille et de temps mises à part, les procédés généliques les feuiltets el de l'entéron sont les mèmes daus les deux cas.

Les Siphonophores, appartenant an troisieme type, presentent done le mode évolutif le plus condensis prit sorit possible de renconlere parmi les Ilydrozoaires. Les reserves deulophasmigurs de leurs emliryous sont tollement alwndantes, puilles angmentent dans les proportions considerables la taille de ha larve, dont ellos retardent le divelopjemont

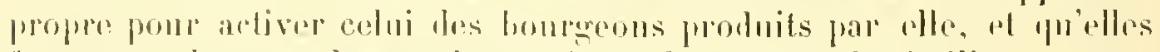
font passer le corps de cette larve it l'étal d'une vésicule vilolline, scrvant

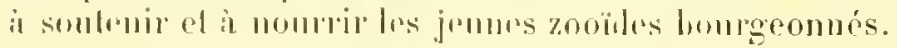

l. Valeur morphologique de l'Entèron. - Phsieur's auteurs

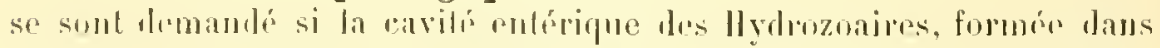
ret amas demtorges pui devirnt linalement lendorlerme, est l'homo- 
logue d'un blastocule. Plusionrs d'entre eux ont décilé la question en faren de l'homologic lolastoculienne, et admettent que l'entéron des larves planulaires d'llyilrozoaires, entéron chargé de devenir linlestin de l'arlulte, n'est autre qu'un hlastocote. Ce dernier persisterait inne, et se transformerail en cavilé gastrinue.

Il suffit de comparer les érolutions abrégées aux développements dilatés, ef de se somvenir que tous deux se rajportent ì une eyulation, pour remetlre les choses en leur vérilahle place. Les emhrogénies dilatérs montrent d’aborl nue phase hlastulaire, avec cavilé blastocolienno évidente; celle cavité est msuite remplio par les mulvertes: le hlastocuele a donc dispraru completement, ou presque en entier. Puis, m nouvel espace vide se perce dans la masse des endocyles, écarte ces derniers les uns des autres, et les reprousse vers la périphéric. Cette cavité n'est don pras me persistance directe du blastocole, puisque ce demier n'existe jlus; dle diffire également du hlastocue par ses rapjorls aree les endocytes, car ceux-ci, au lieu d'ètre séparés les uns des autres, el suspendus dans le blastocuelo, sont groupés en une assise continu, jlacée autour de l'entéron. Ce dernier diffère done du hlastocule par ses relations arec los endocytes, et ne provient pas directement de lui.

En somme, l'enléron prend la place du hastocole, mais n’en thérive pas. La cavité, creusée dans l'amas cnlocytaire drs larves à rmbryogénic condensée, est l'homologue de cet entéron cylulaire, et non celui d'un hlastocrete, car l'apparition du ce dernier est omise dans la série des phases évolutives, a la suite de labréviation du développenent. Les trois morles génétiques des feuillets, chez les Ilydroméduses holomorphes, sont iu reste trè suggestifs sons ce rapport, car ils montrent l'altémution roissante subie par la phase blastulaire.

\section{4. - Formes des Larves.}

1. Considérations générales. - L'aspect extérienr prèsenté par lis larves, el les divers changrments que subissent ces dernières pour parvenir à lichat alulle, forment, ou pru s'en faut, les seules notious artuclement arquises sur le développement final des llydrozoaires. II rst copendant possilute de se représenter les proridés génétiques de plu-

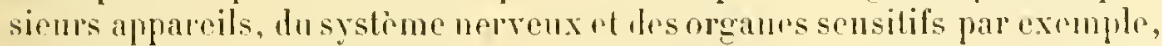
en se basant sur lenr slrurlure définilive. les centres nerveux sont consliturs, rhez los méduses, par une donble eouronue placée sur lis looms le lombrellr, immédiatement au-dessoms de lectodermo, ot far un plexus

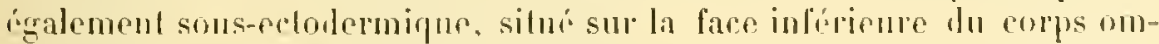
lorellaire. Il rist hion certain, la situalion do ces éléments, el les faits

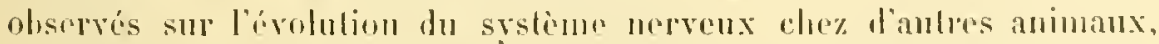
fermettent de lo roire, que los anmeamx et le plexus dópirent de

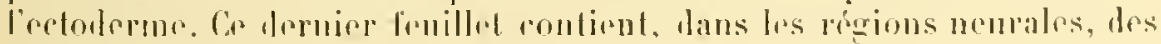
rellules épillélio-nerveuses, dont les parlies protondes of librillares se 
l'assemblent, pour produibe les rombes par leurs anaslomoses; plusieurs de ces cellules quithont mème l"assise cotodermique, et péuètrent daus

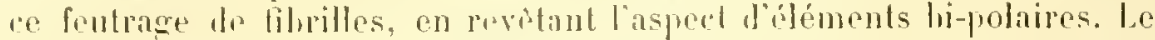
morte de formalion du systeme nervax est ainsi prévu dans son ensemhle. mais ses létails noul pas encole ble raminós par des observations dipectes. Des considépations scmblables s'apjliquent aux vésicules mar ginales, dont les rebalious ef la strueture suffisent pour moulrer qu"elles proviennent d'involutions entodermiques, mais dont les frocédés génélipues ne sont pas completement romnus.

Il fant don" so horner, si l'ou vent rester daus le domaine des faits. à suive les modifieations extéricures, subies frar les larres pontr arpirel il l’ilat adulle, sans pénétrop daus les dítails des changements; les notions, ainsi acquises, fommissent cependant les renseignements circonstanpiés sur les évolutions de la cavitégastrique et des tontacules.

La lare des llyllozoaires appartient à un type spécial, te true Iy-

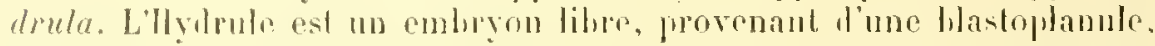
posscilant sur som actoderme iles cils viluatiles, qui lni permettent de nager, portant, sur l’uno de so's extrémités, une houche dont les loves ne s'invaginent pas dans la cavité euterique, et ne lummant jamais nais-

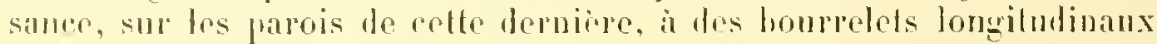
avant la forme de cloisons. L'llydrule nirxiste, avec ses caractères prétis ot mots, que ohez les Hybrozoaims les plus simples, los Authydraires et les llydroméduses diplomorplues. Apres avoir vécu m liherté durant un certain temps, dlo se lixe par l'oxtrémité opposio à colle qui porte l'ori-

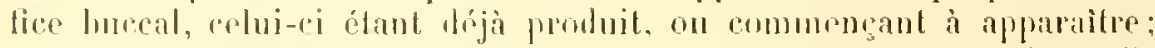

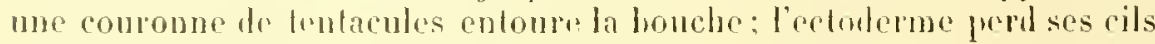
viluatiles; les tissus completent lour struchure; of l'llybule se transorme

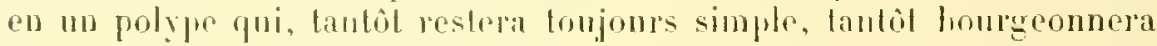
pour engendrer tum rolomir.

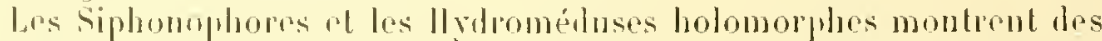

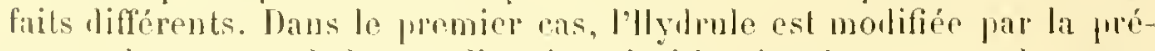
sunce, dans son endoderme, d'un dentobeithe abonelant, et par la voume hative des phénomònes erommigares; en outre, la lapre ne se lise point

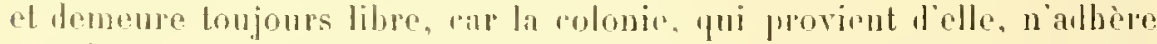

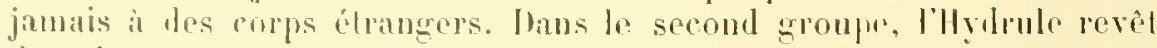
le suite mo aspet particulier, temant ì ce quelle se transformo en wne

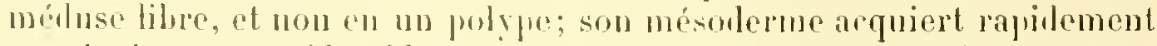

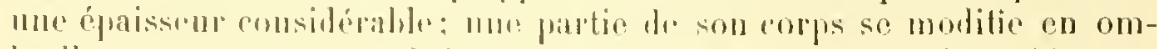

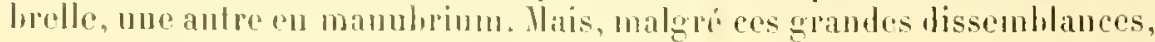

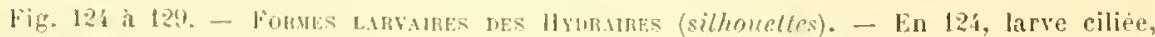

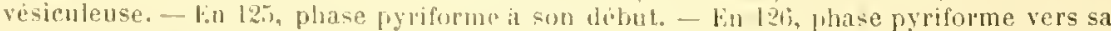
lin. - lin 125, 12\%, 129, phaspu surepssivas de la fixalion, et du développement, de la

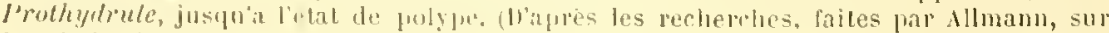
les Eudendrium.) 


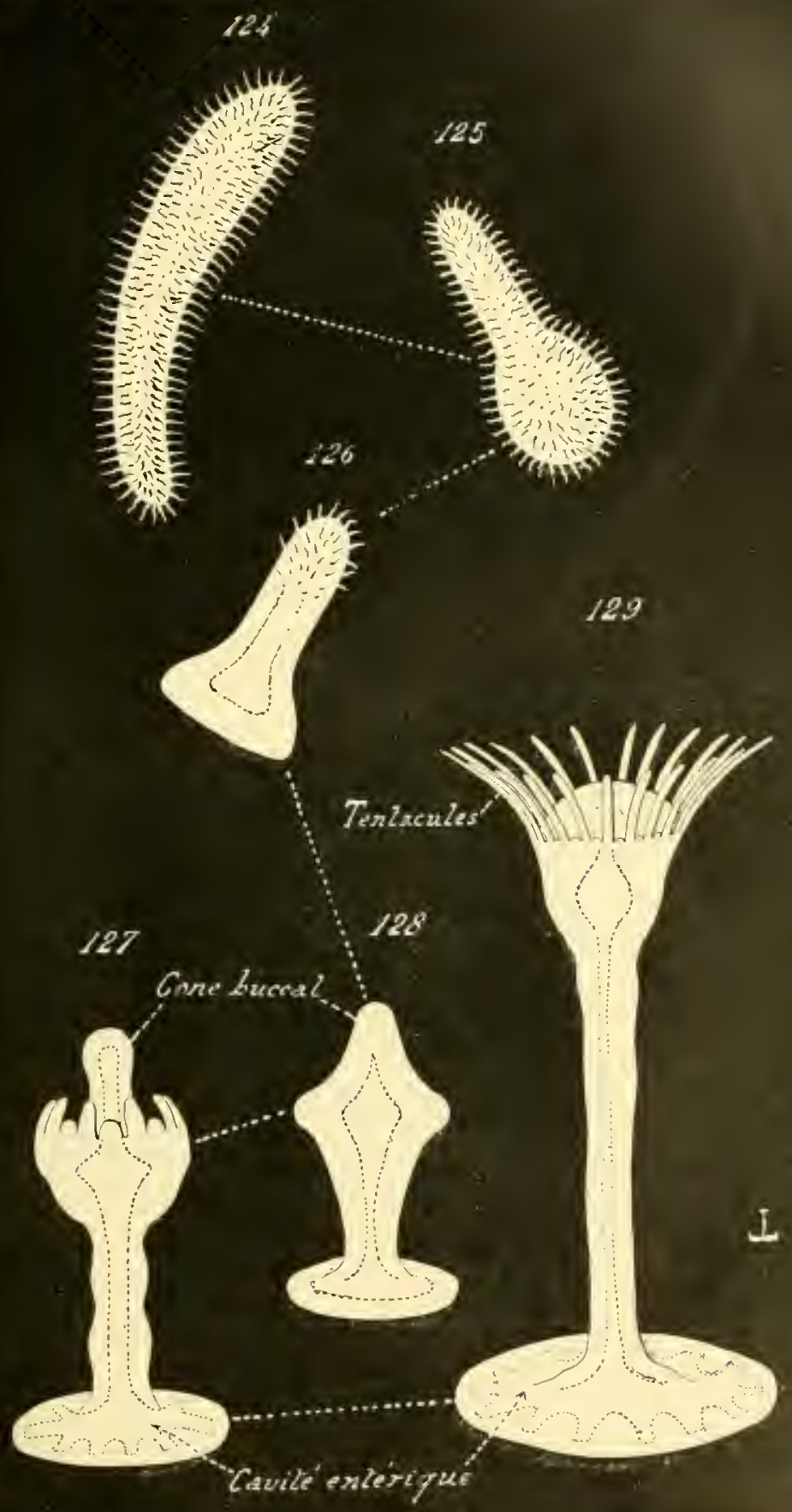

fig. 12 a a 129 
les caracteres essentiels do l"Hylpule ne sont pas altérés, sanf celuid’entre rux yui tient ì la presence dre cils vibuatiles sur l'ectoderme.

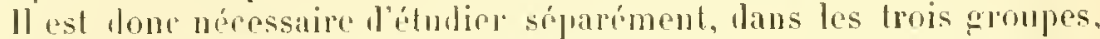
l'évolutionsubie par la larre, en commongant par le morle le plus simple. celni des Authridraires et des Ilvdromóduses diplomorphes, passan tensuite anx Siphonophores, ef leminant par les llyduomóduses holomorphes.

\section{Authydraires et Hydroméduses diplomorphes - l'iro-} lution larvaue est jei prérisén en pen de mots : l"embryon libre se transforme en mu polype fixó, l'aborid simple, qui bourgeonne seulement apres avoir acquis sa sluuture délinilive.

Il fout óliblir loux lyos principanx de ees larves. Les unes produisment los tentaculos péribucciux, pt somvent leur louche, aprés seutre fixies : resont los llylpules ripilalıles, qu’il est permis de nommer des Prolhydrules. Ies andres dounent naissance à ces organes, par une abróm viation du drieloprement, durant leur existence libre : ce sont les larves dites Actimla. Ces derniòes sont do beanconp les plus rares, et divers Tuluularions sout les seuls a les présonter; la plupart les Authydraires et des Ilydroméduses diplomorphlus possèdent la forme Prothydrulu.

labve Protmurata. - Apris le momont où les feuillets hlastodermiques se sont séparés les uns les antres, et délimités, l'embryon nago: an moyen des cils vibratiles dont son ectoderme est convert; sa forme est ovalaire, on parfois mòme eylindrique, tellement est grande la disproportion entre les dimensions de son axe longiludinal et celles de son axe transrersal. Les lenx extrimilós sont semlilables, arrondies, et la lonche n’a pas fait son apparition: la cavité entérique existe rependant, mais petite encore, et s'accroit pen i pen. Cette périorlo dure mo certain trmps: puis le momvement des cils se ralentit, et l'me des moitiés du corps s"ilargit, de maniors a lonner an petil ètre un asject venton: cest la phase pyriforme. Le jeu des rils vihratiles cesse hientiot, et. par lartion le la pesanteur, la larve se laisse choir an fond de l'ean. La région dargie appuru forément sur le sol par nne base assez ample, et

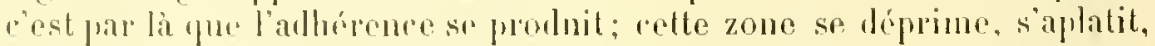

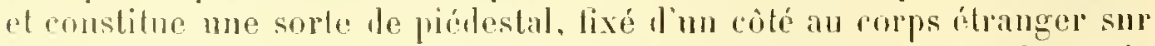
lequel clle est vemur sayjuyer an tombant, portant le lantre la partie amincic le lomeranisme.

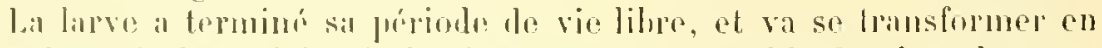

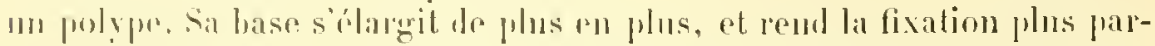

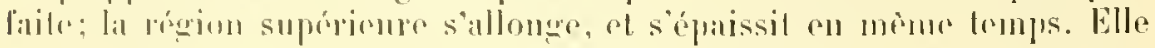
proml somvent mu aspert losangipue, puis sarromdit, el se divise à som lone en deux parties plaros l'me sous lautre. La partie terminale de-

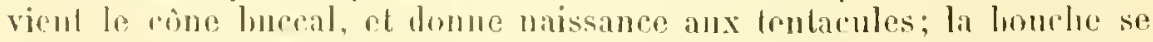

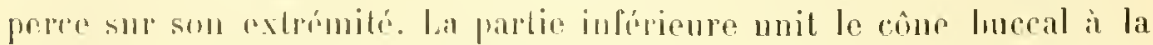

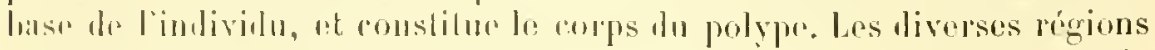

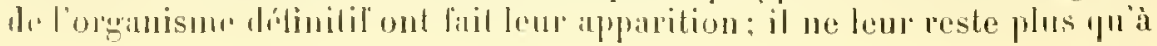


croitue, pour acquérir leur taille liuale, et quáa compléter leur structure intime.

Les tentacules sont formés par des évaginalions de la paroi du coups, placées sur le cone lonceal, autour de la houche. La paroi du cơne se sonlève en quelques petits mamelons, disposés sml me rangée virculaire; ces appendices sont creux, et chacun d'eux contient un diverticule de la cavité entérique. Ils s'allongent ensuite, par la double amplitication de lem fraroi propre et de leur cavité interue, el arrivent de celte laçon à

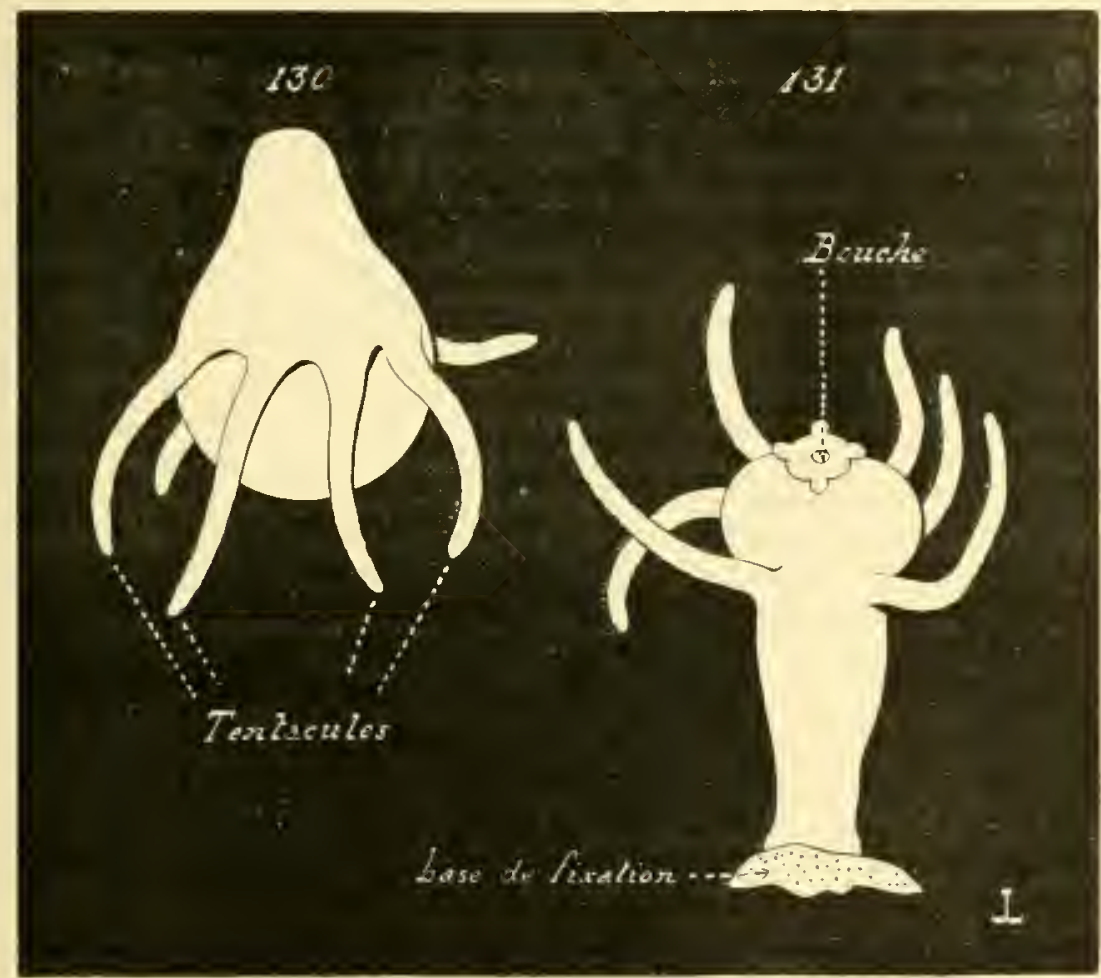

Fig. 130 el 131. - Fomes LiRvines des IIrtmanes (silhouelles). - Liı li30, larve libre, du iype Aclinula, d'une Tubularia coronata. - lin 13!, la mème, plus avancée, au début de sa fixation. (11'apres les recherches failes par llamann.)

l’état parfait. Ėant donnée une telle origine, lemp paroi, dépendance de la paroi du corps, otfire la structure fondamentale de cette dernière, det leur cavité communique loujours avec l'entéron dont ble provient.

Un grand nombe d'Autlyylraires, et de polypes d'llydromóduses, sont

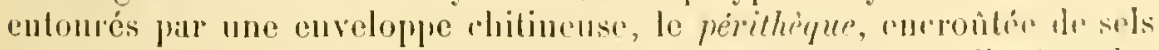
calcaires dans certains cas (Autlydraires appatenant it l'opdere dos IIydrocorallines). La matière amorphe de ce périlheque est exsudéc par 


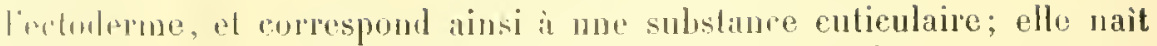
smotent des les preniéris phases de la fixation de la larve.

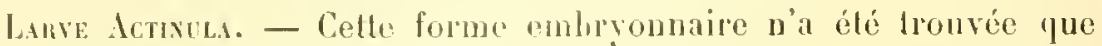
che\% divors Tubulariens. La sérir des phénomènes évolutifs, subie par ellı, est identipne à celle présentée par les Prothydrulu; seuloment, plusienrs lentaculos, situés chez l'adulte à une assez grande distance de la bouche, font lon aprarition durant l'existence lihe, et an moment où l'aspect pyriforme rommence à se nontrer. La larvo Actinula ressemble donc i un petit polyje, muni ibe tentacules, et rommençant à preper sa boncho, mais libre ot non fixć. Cello présence hàtivede quelyues appendires lontaculaires est dur il ba présence, dans l'orule, d'un deuloplasme asse\% abondant, qui accóler les phases évolulives, el détemine une formalion plus rapide des orimes. Les autres tentacules pribureaux, plarés sur los bords memp do la bouche. s'ébauchent vers la fin te la vie lilore, et lors da délıul de: la tixation.

III. Siphonophores. - l.es larves des Siphonophores sont caraclérisées par la juesence hative le jemes hourgeons sur leme corps, yui lon domme nn aspect de pelites eolonies libres. Ces larves appartiennent ì lrux formes prineipales, dont l'nne a été nommće Siphonula par lirokil, et l'antre Misconula. Ces denx types larvaires otfrent, dr mème, un zoïte qui provient direetemont de l'embryon, ot plusienrs zooïdes iunélrís sur luj; leurs litlérences portent sur l'aspect de ce dernier. Les zoijtes des larves, appartenant i la forme siphomula, sout allongés, et froduisont l'axe (on rachis) lo la colonic léfinitive; par contre, reux des liscomula sont aphlatis, ot ils ronstitment, par l'épaississement de leur mósodrome, le rachis discoüro de l'organisme adulte.

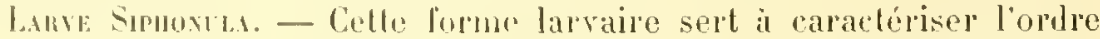
dos Siphomulides. Son aspreet n'est pas tonjon's lo mème che\% les rejrésentants de ce nompe, cal ello comprend doux lypes secondaires, dont l'un uffre tontes los partirnlarités de la siphonula vérilahle, el dont l'antre prossète, en sus, des carartères propres, tenant à l'uxistence. antur th lensemble dos zoniles, d'une cloche prolectrice roluminense, lo nectocalyce. Le promier type mérite d'òtre désigné par l'expression Eusiphonulu; on le rencontre lans le développement des ctres faisant partic des familles suivantes : Physophorides, Aurophorides, Rhisoplyzides, et I'lygsalides. Le second, nommé Calyconula par Ilieckel, ll'rsistt que dans la lamillo drs Culycophorides.

Une Ėusiphonnlu. oncorn jeuns. présente un corps allongé, portant le thulterr, te purmatophoro, sur son extrímité supéricure, el la houche sur son extrámito opposón: re corps nest aube que celui du zoïte, défourvi de tentacules, et muni, sur ses côlés, de bourgeons devenus léja des individus presque complets; le premier hourgeon produit se divelopye, d'ordinairr, "n un lactylozoïde très allongé, dit filament pecheur. L'érolution continue par l'allongement du zoöte et par la genèse 
de nouveaux bourgeons; pami ces derniers, les uns sont latéraux, et se transforment dordinaire en nectocalyces; les autres sont terminaux,
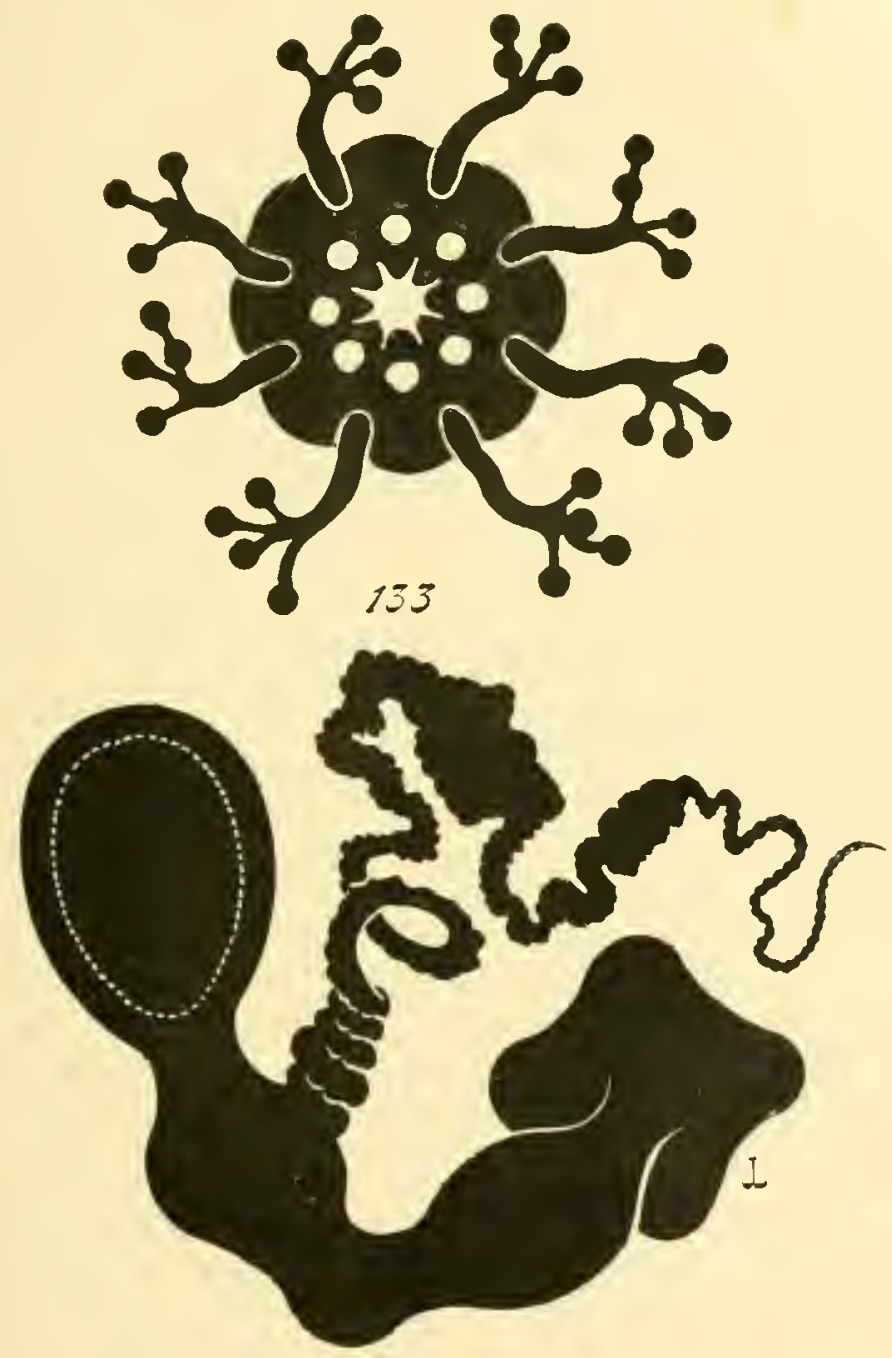

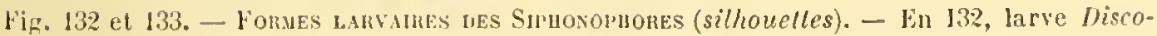
nula de la Disconalia gastroblastu. - En 133, larve Siphonula de l'Alophota giltschinne. (b'après les recherches faites par Ilæckel.)

La Disconula de la ligure 132 est vie par sa fare inférienre: la bouclée est au centre; les ebanches iles liuit gonozö̈des sont plus en dehors; les huit daetylozö̈des ramenx sont places sur les hords. - La Siphonula de la figure 133 est vue de profil; en haut se trouve son pneunatophore, dont la cavite est certsee frar un pointillé blanc; le volumineux cỏne buceal, aux lèrres étalèes, est en bas; le lactylozoüde, enroulé sur lui-mème, s'attache au milieu du corps. 
¿'ost-à-dire places autur de la lunche du zuïle, el se rassemblent en un

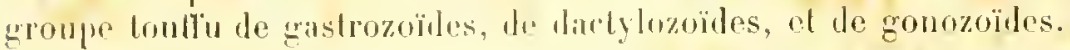

Pres somvent, et suldoul ehez los I'/ysophora, les Agalmopsis, ut les

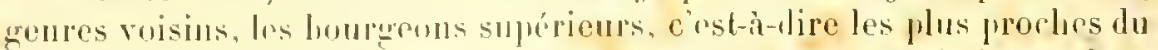
phemmatophore, siplalissont en sélargissant, et en épaississant leur

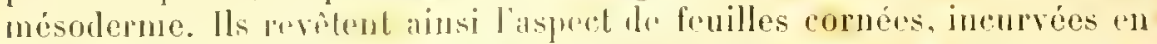

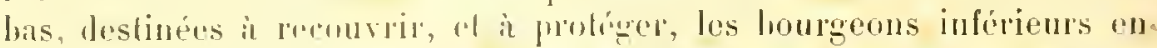
voie de dévolopjerment; res zoö̈les sond des hydrophyllies; semblables

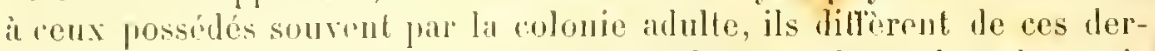
niers par lenr situalion el par leur lin. Ils sont placés daus la partie supérienre de la rulonie, el non à la base, contrairement ì ce qu’il en est pour l'organisme lien développé; de plus, leur existence est temporaire, ear ils sont destinés à se délacher, et i tomber, lorsque leur roile flotertenr est arhevi, cest-a-dire au moment ou le rachis, en s'allongrant, place les jemes zooïdes hors de leur zone d'aclion. Ces hydroplıyllies sont frorisoires, el on doil l's considérer comme des zoö̈les, molitiés de bunne leure pour servir a la protection de leurs congénères, par suite de la prépondérance exeréce par la vie coloniale sur toules les autres manilestations organiques.

Le jremier zooïle, formé far lo zoïle très jeme d'une C'alyconula, devient un nectoralyoe, cest-a-dire nue cloche natatoire tres ample, dont la cavitó parail clue à nne involution ectodermique; cotte cloche pourrait itre consilérée, peutèrr, comme un homologne du puemualophore de l'Eusiphomule, mais latipal, et mullement terminal. La cloche saceroit rapidement, et levient bientôt plus amplo que le zoite. Celui-ci se divise cn deux parties, dont la ligne le síparalion correspond a l'insertion de la cloche sur lui. La rógion inférienro se perce d'una bouche, ot se convertit en 11 gastrozö̈lr, quj bourgoonne sur sa base un dialylozoide allongé, un zonozölde, of une petilo hydrophyllie. La région supéricure restr pendant puelque lemps sans se modifier. - Durant rette période, l'aspert de la junne colonie est bion diflérent le celui d'une Éusiphomelu; l'assemblage se horne, en ellet, ìgrouprer, les uns à coté des antres,

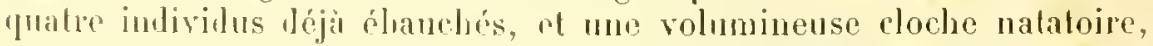
Jont la présence vaut à li larve son nom de Calyconula. I'uis, la partie

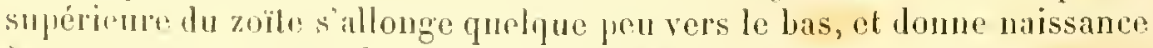
it nIn nowver groupr. de puatre zooïles accompagnés d'une clocke, font en risersant une rogion imlomne, qui fournima plus tard a la genese d’un troisiene groupe: at ainsi de suitr, le léveloppenent de la colonie conlimunt is sillechuer de cette facom.

Jarve Disonula. - Les premieres phases de l'évolulion, sulie par cess larves, ne sonl pas connues. Lu plus jeune enbryon, qui ail été observe, othat lojat nne disposition moloniale. Le zoïte, volmmineux et apliti en forme de disque, purte un potil pnemualophore sur sa face dorsile, el une unerture luccale sur sa face inférieure. Cette dernière 
donne accés dans une cavité entérique assez vaste, entourée par une épaisse paroi dı corps; la cavité émet huil diverticules, semblables it des canaux gastriques de méduses, qui ront déboucher dans un comluit circulaire, placé sur le bord mème de l’individu. Cetle mème région marginale possede huit appendices crenx, lubulaires, dont la lumiere communique arec celle des conduits gastriques; ils produisent, à mesure que la larve auguente en àge, des ramifications sur leurs extrémilés libres. Hieckel, suivant toujours son assimilation des Siphonophores à des colonies de méduses, compare ces appendices a des tentacules; il faut, ce semble, voir en enx des dactylozoïdes, tout en prenant, ả leur égarl, la restriction déjà connue sur la grande ressemblance élablie, chez les Ilydrozoaires, entre les simples tentacules et les zooüdes entiers. L'espace, laissé entre l'insertion des huil dactylozoüdes et la bouche, est ample; il porte, en son milien, une couronne de huit petits bourgeons, qui sont les ébauches des futurs gonozoïles.

Telle est la structure de la larve Discomula, caractéristique du groupe des Disconulides. Sauf par la jrésence de canaux gastripues et d'un conduit annulaire, il est bien difficile de trourer en elle une ressemblance avee une médnse, cal elle manque de voile, de manche, et la comparaison du corps du zoüte arec une ombrelle n'est point lont à fail exacle. L'organisme entier du zoïte est aplati, tandis que l'ombrelle l'une méduse répond seulement à l'une des parties, très développée, de l'inaividu. L'existence de diverticules gastriques parait ètre une conséquence, par analogie fonctionnelle avee les dispositions correspondantes des méduses, de l'épraississement du mésoderme, et des nécessités de la nutrition.

Il est plus logique, semble-t-il, d'assimiler la larve Itisconula à une Hydrule lilsre, aplatie, discoïdale, et bonrgeonnant des zooüdes sur sa face ventrale. Ces derniers paraissent, dès l'abord, consister en de simples appendices du zö̈le primitif, par suile de la prépondérance considérable prise par la vie coloniale sur l'autonomie individuelle; mais ils ont en réalité la valeur d'individus, et doivent ètre considérés comme tels.

W. Hydroméduses holomorphes. - A. Les différences principales entre les larves de ces dernières el celles des autres Hydraires tiennent à leur érolution; les larres des Ilolomorphes se transforment directement en méduses, alors que celles des Aulhydraires et des Diplomorplies deviennent d'ahord des polypes, qui bourgeonnent ensuite, plusieurs des bourgeons se modifiant seuls en médnses. La différence est donc considérable; l'état médusaire se produit directement dans un cas, alor's qu il se manifeste, dans le second, après me sérir de changements, et de générations successives. Cette dissemblance est cependant lien diminuée par une transition, qu'elfectuent les larres des Narcoméduses aplartenant au gense Cunina. 
La lave des Cunina offre en lout l'aspect d'une Hydrule, munie d'une bonche et de denx tenlakules; sentement, la disposilion propue à la módnse commençant déjà í se moutrer, ers appendices sunt insérés

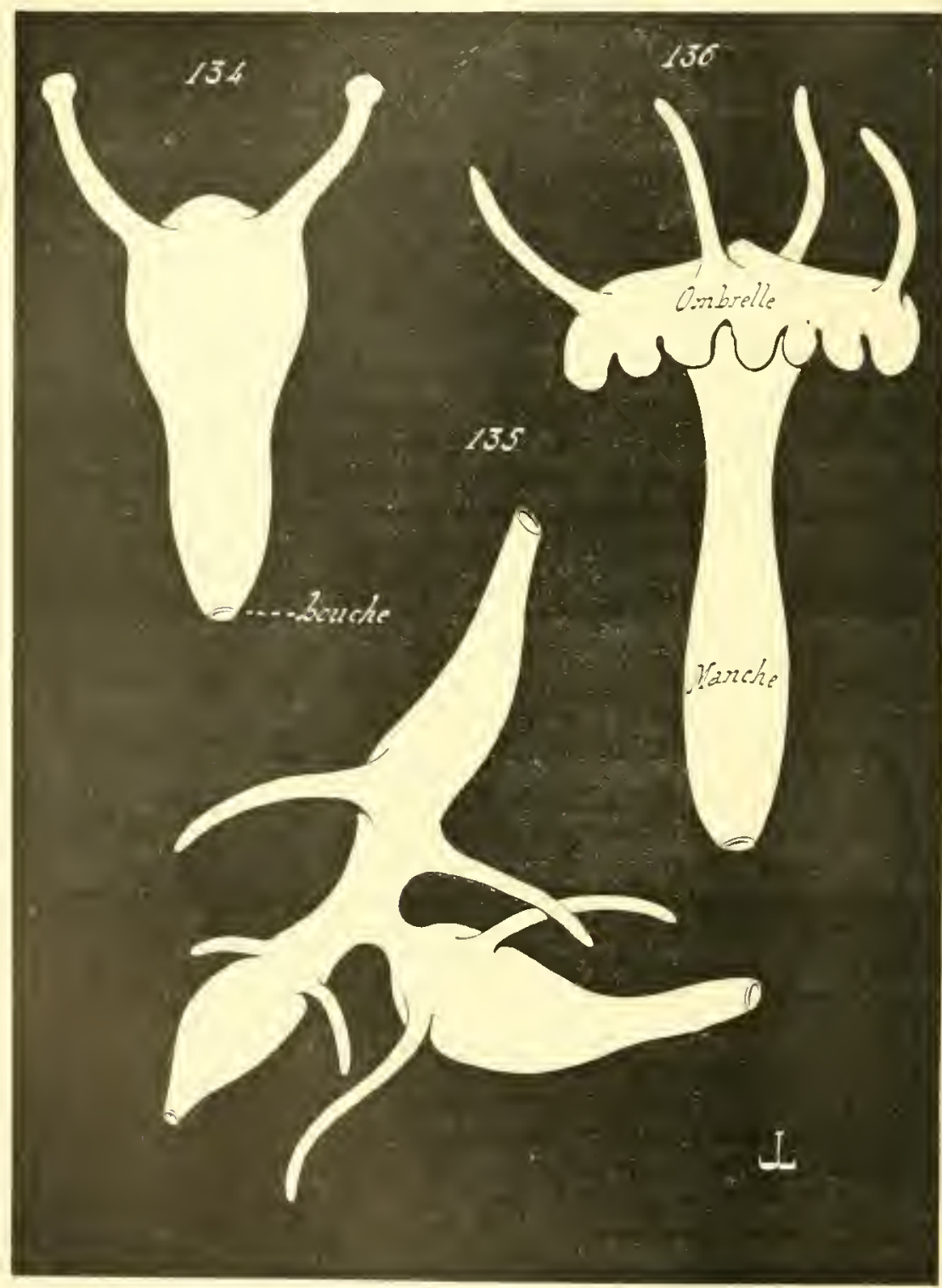

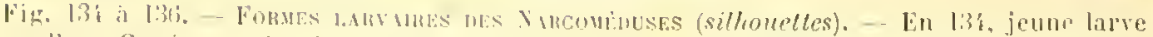

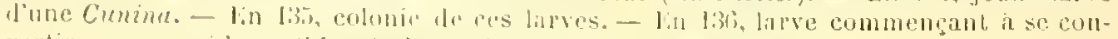

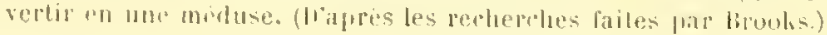


sur la région inférieure de lindividu, et non autour de l'orifice lunceal. Le corjs de l'embryon est divisé en denx parties : l'une supérieure et amincie, portant la bouche; l’autre, inférieure et élargeie, pourvue des tentacules; la larve possède ainsi la lisposition propre it la phase pyriforme des Il ỵdrules. La rógion inférieure sera l'ombrelle, la portion supérienre donnera le manulurinm.

Cette larve bourgeonne en cet étal. Son extrémite inférienre énet un diverticnle, qui s'allonge, et se convertit en un nourel individu; le corps de ce dernier se divise de mème en une partie ombrellaire, mur de tentacules et accolée à la région correspondante du zö̈te primitil, et une partie manubriale. La gemmiparité conlinue ensuite is sexereer de la mème façon, en présentant celte praticularilé, que les żoö̈les ne naissent pas les uns des autres suirant une direction détermince, mais en divers sens; parfois, le jeune bourgeon croit dans une orientation parallèle it l'axe longitulinal de l'individu dont it provient, et parlois dans un sens oblique ou mème perpendiculaire à cel axe. Il se produit ainsi des colonies de jounes polypes, rampant sur leur support, et ne se fixant pas. Puis, ces polypes se sŕparent les uns les antres; apres quoi ils se transforment en méduses. Leur région luccale s'allonge, et constitue le manubrium; leur région élargie s'étale darantage, el se moditie en ombrelle; de nouveaux tentacules s'ajoutent aux deux jremiers; et l'aspert médusaire fait son apyrarition.

l'our bien comprendre la transition opérée par les Cunina, il est hon de résumer les particularités des deux termes extrêmes. Dans le premier cas, celui des llỵdroméduses diplomorphes, l'ovule fécondé produit une larve IIydrula, qui devient un polype fixé; celui-ci bourgeonne d'autres polypes, dont certains senlement revètent la disposition médusaire. Dans le second ras, offert par toutes les Hydroméduses holomorphes, sanf les Cunina, l'ovule fécondé engendre directement une méduse. Les Cunina établissent un passage du premier mode au second, prisque lem ovule férondé Jonue naissance à une larve IIydrula, qui se transforme en un polype lilse; celui-ci bourgeonne de nouveaux polypes, qui deriennent tous des méduses.

Les Eutima subissent, d'après Brooks, un déreloppement comparable à celui des Cunina; mais il n’en est pas de mème jour les autres Sarconéluses, lont la larve se change directrment en une méduse, ol ne présente aucun phénomène gemmipare. Le jeune embryon libre, de forme ovalaire, est constitué par un ectoderme cilié, enveloppant une masse épaisse d'endocytes, qui représente l'endoderme; le mósoderme est peu développé encore, et l'entéron se crense dans l'amas enlocytaire. La bouclic se perce ensuile; denx tentacules prenuent maissance sur la paroi du corps; ces tentarnles sont pleins, et mustitués

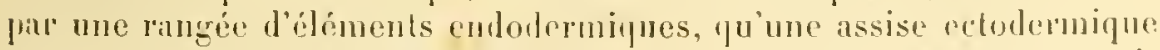
enveloppe. Lat ravité enteringe grandit pun is peu; le mosoderne linit son apparition, et sépaissil heauconp dans la partie du rorjes yui, 
opposée à la bouche, correspund à la région ombrellaire des larves de Cunina. Cette parlic devient effeclivement l'ombrelle, l'antre région persiste comme manubrimn; deux nouveaux tenlacules se façonment entre les denx premiers, sur les hords de l'ombrelle en voie d'accroissement; et la larve se converlit en une jeune méduse.

B. - Les phénomines du développement sont plus alı́égés chez les Trachróduses; car la larve, encore fort jeune, el délimitant à peine ses fenillets blastodermiques, porte dója une vasle région ombrellaire, dont le mésoderme nail halivement, el augmente tres vile. Lembryon a l'aspect d'une résicule sphérique et creuse, aux prois épaisses; sa cavilé interne est l'entéron; sa paroi est constiture par les trois feuillets, rérulierement emboilés, et concentriques. L'ectoderme est représenté par une mince assise de cellutes aplalies, sanf dans la fulure rigion manubriale, où clles sont plus largeses; l'endoderme consiste en une rangée simple de collules pavimnnteuses, disposées antour de la pelite cavilé entérique; el le mésoderme en me masse consilárable de substance fondamentale, plus grosse dans la fulure ombrelle que dans loule autre partie du corps. La subslance mésodermique fait mème défaut dans la rógion manubriale, oì l'ectoderme esl appliqué conlue l'endoderme.

La larve s'accroil, loul en conservant sa forme sphripine. Le mésoderme continue à s’épaissir dans la porlion supérieure, ou ombrellaire, du corps. I'ar contre, dans la région infériemre, l'ecloderme prolifère, el se divise en deux assises cellulaires superposées, du moins l'apres les obsepralions pulliées par Ray Lankester, el par plusieurs autres auteurs. Ces denx lames s'écartent bientôt l'une de l'aulre, cul laissant entre elles une ravilé; il exisle donc, en celte parlie du corps, denx cavilés superposies, lime vomant de se creuser dans l'ectoderme, el l'aulre cormspondant ì l'entron. Ja rouche ectoderminne voisine de celte derniere, et l'eudoulerme quj lui est accolé, se percent l'une ouverture centrale, destince i mettre ces deux espaces en rommunicalion; cet orifice devicudra la houche, at ses hords sallongeront ponr produire le manche. Cetle modificalion s"effectue forsque l'assise ectodermique, qui limile vers l'exlérirur l'espare creux de nouvelle formation, s'est briséc pour liver passage à celle région maumbrale. Le manubrum est donc engendré jar une saillic considérable de la proi buccale; les autres par-

Fig. 137 à 142. - l'onues LARVAmes nes Tracmuninuses froupes médianes et demi-diagrammatiques). - Lin 137, jeune larve, dont Jentiron est eneore central. - En 138, larve plus avancé, dont l'ontiron est levenu inferieur. - En 139, genèse de la playue ectodermigue (ou plaque sous-ombrellaire), au-lessous de l'entéron. - En 140, creusement de la cavili sons-omlirelaire dans la plaque ectodermique. - ln 14, itablissement des communirations directes enfre l'ntéron cl la cavite sous-ombrellaire. - En 142, rupture de: la la roi inferieure le la cavite sous-onbrellatre, permettant a eclle-ci de sourrir au lehors, tot an manche le proeminer librement. (Wapres les reeherches, faites par Metschnikof, et par Ray lankester, sur les Gorgonia et les Liriope).

Ces figures font suite aux fig. 11 . a 119. 

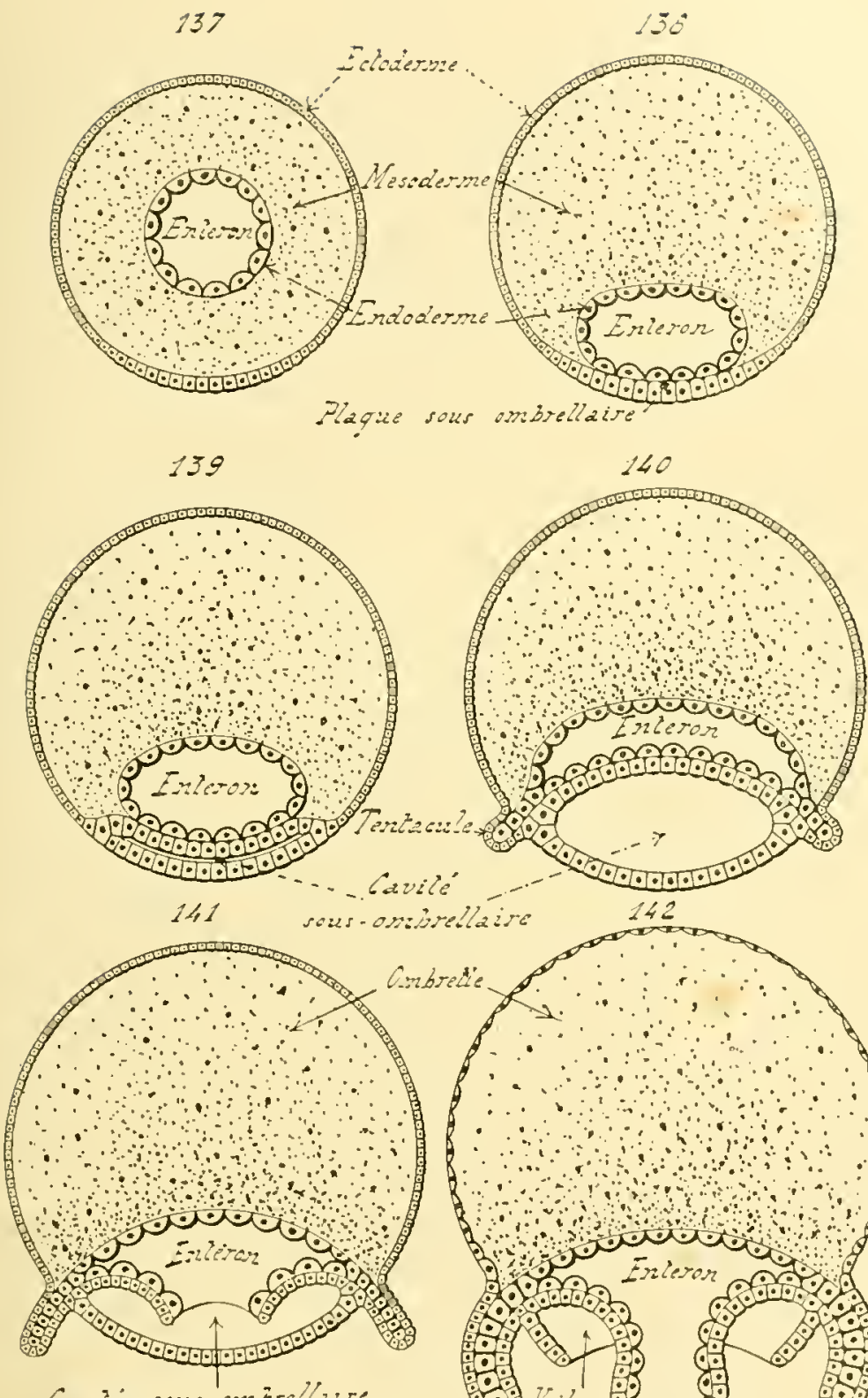

Terzacule
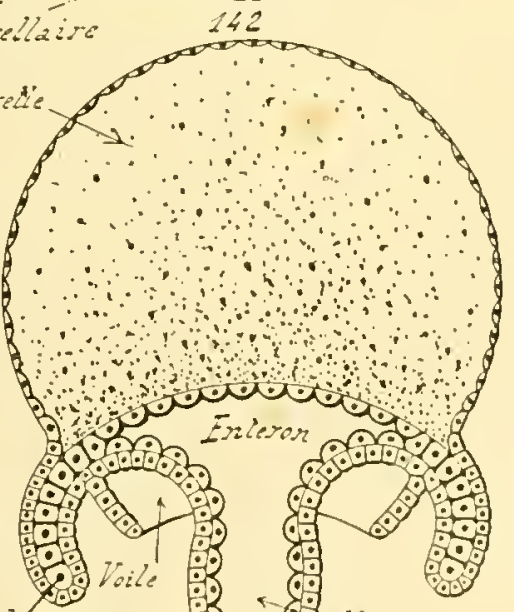

Cavize sous embrellaze

Fig. 137 à 142. 
ties du corps de la lave conservent on clles-mêmes le mésoderme, et constituent l'ombretle.

La cavilé qui a jris naissance lans cette portion l'ecloderme épaissi, nomméc la plarue ectorlermique, de la région inféricure du corps, est l'homologue, comme on le verra jus loin (paragraphe ij), de celle placée, an mème endroit, chez les gonozoüdes des llydroméduses diplomorphes. Elle est limité, en haul el en bas, par une concle épilhéliale d'origine ectodermique; senlement, sa paroi inférienre, et externe en nème lemps, se lurise ponr disparaitre, et la paroi supérieure persiste senle. la région marginale de colle derniere produit le voile, et devient ainsi le lord de l'ombrelle; sa partie centrale est munie du mamulium; toute la zone comprise entre ces deux portions donne la face inférieure de l'ombrelle, la sous-ombrelle. Anssi cette cavití ost-elle souvent désignée, dès son apparition, sous le nom de cavité de la cloche, ou de cavite sous-ombrelluire, juisqu'elle loit former, en délinitive, l'espace limité par la face inférieure de lombrelle, el puisque cet espace porte les dem noms précilós.

Co procédé génétif de l'ombrelle n'est pas tout à fait comparable à celui signalé chez les Narcomíduses, el rappelle, par contre, lo modr, décrit jus loin. propre aux polypes gonozö̈les qui se convertissent en méduses libres. Il no faut pas oublicr, cependant, que le développement de lombrelle des Narcoméduses n'esl pas encore bien connu, et quil existe peut-être, chez clles, une pelite cavité sous-ombrellaire, comparahle à celle dos Trarhyméduses.

Pendant cette érolution, deux tentacules pleins fout lem apparition un pen au-dessus de l'ébauche du voile, et denx antres de ces appendices premnent ensuite naissance. 'Tous les quatre sont placés dans les luturs perrayons de la méduse. Puis, lorsque la disposition médusaire est presque realisée, quatre nourelles expansions teutaculares sont laçonnées entre les premiòres, par conséquent dans les iulerrayons. La j(cune méduse est aimsi munje de huit tentacules, dont quatre perradianx ot quatre interradiaux; les premiers s'atrophient peu à peu et disparaisseml, les autres persistent. Mais, en sus, on voit s'éhaucher, dans les prrayons, et au-dessous de ceux qui existaient déja, quatre bourgeons, qui deviemdront les tentacules perradiaux définitils.

Les appendices, hatifs el temporaires, des larves des Trachyméduses, sont peut-île les homologues des lentacules persistants des Narcoméduses. La yurslion ne prut encore etre résolue, rar il famdrail connailre, mieux quolle no l'est aujompl'hu, l'crolution complete suive par les Ifydromóduses holomorphes, el savoir, an préalable, si le développement des Trachyméluses ast une abroviation de celui des Nareoméduses, on licn si res aleux groupes oflent des emlurggénies distincles el dillérentes. 


\section{\$ 5. - Reproduction asexuée.}

La reproduction asexuće jone un Irés granıl röle dans l'urganisation Jes Ilydrozoaires; grice a elle, des colonies prement naissance, et affectent des formes diverses; elle est la cause l'uue diversilé extrène dans laspect et lans le rôle des individus. Celle reproduction s'efrerlue suivant deux moles : la gemmiparite el la fissiparité. Celle-ci est locaucoup plus rare que la première; on l'a sigualée seulement ehez quelịues méduses, et elle n'existe pas normalement chez les polypes, à moins de traumalismes accidentels, ou de divisions forluites du corps en parties, dont chacmne devient nn nouvel individu; les eas le fissiparité normale, décrits chez les jolypes, appartiennent à une gemmiparilé accompagnée de la séparation des lourgeons produits.

1. Gemmiparité. - La reproduction par hourgeonnement est fort répandue chez les llyılrozoaires; on l'observe tout aussi bien sur les polypes que sur les máduses, mais elle ost de beaucoup plus commune chez les premiers. Cependant, les phénomènes essentiels de la gemmiparilé ne varient guère, juelle que soit la lorme de l'organisme malernel; la série des modes évolutifs lébute loujours par la grenese d’un diverticule de la eavilé gastrique, on de ses dépendances (canaux gastro-vasculaires des méduses). Ce diverticule souleve à son niveau la paroi somalique le son générateur, et délermine ainsi la prouluction d'une saillie, qui est le jeume bonrgeon. Ce dernier continue à croìtre, et, tout en angmentant de dimensions, revêt son allure définitive; il devient un nouvel individu, muni l'une paroi somalique propre, soudée par sa luase à celle de l'organisme malernel, el d'une cavilé gastrique également reliée ì celle du mème organisme. Ces relations étroiles, élablies entre l'ètre producteur et litre produit, persistent souvent durant la vie entière de ces animanx; elles sont interrompues dans le cas de déhiscenre du descendant, c'est-i-dire dans le cas oì ce dernier devient une méduse libre.

Ciemumpate des rolyes. - Cetle gemmiparité doil ètre examinée à un double proint de vue; il faut chtulier d'une part la forme des polypes engendrés par le bourgeonnement, et d'antre part la marche du hourgeonnement lui-mème. Les colonies d'llydrozoaires ne sont pars d'aspect semblalule; olles dilférent heancoup les unes des antres suivant les grenres el les familles; certaines sont toul à fait irrégulières, alor's que d'intres présentent une disposition constante chez lous les représculants de la mème espece. La marde suivie par le lourgeonnement est done importinte á connaître, ar elle rägle l'arrangement mulucl des polypes groupés en colonic.

Forme des Polypes. - Les colonies holomolplues, cont-it-dire les assemblages d’individus semblables, sont rares chez les llydrozonires acluels; les Authydraires sont les seuls it en présenter. Dans ce cals, lous 
les zooïdes possèdent une bonche et des tentacules. Étant d.zné le zoüle primilif, qui dérive de la larve, el constitue le premier polype de la colonie, te second polype est produil par un bourgeon placé sur la paroi du corps de re zoïte. Le bonrgeon, formé comme toujours par un diverlicule de la carilé gastrique, qu'entoure une parlie de la paroi du corps,

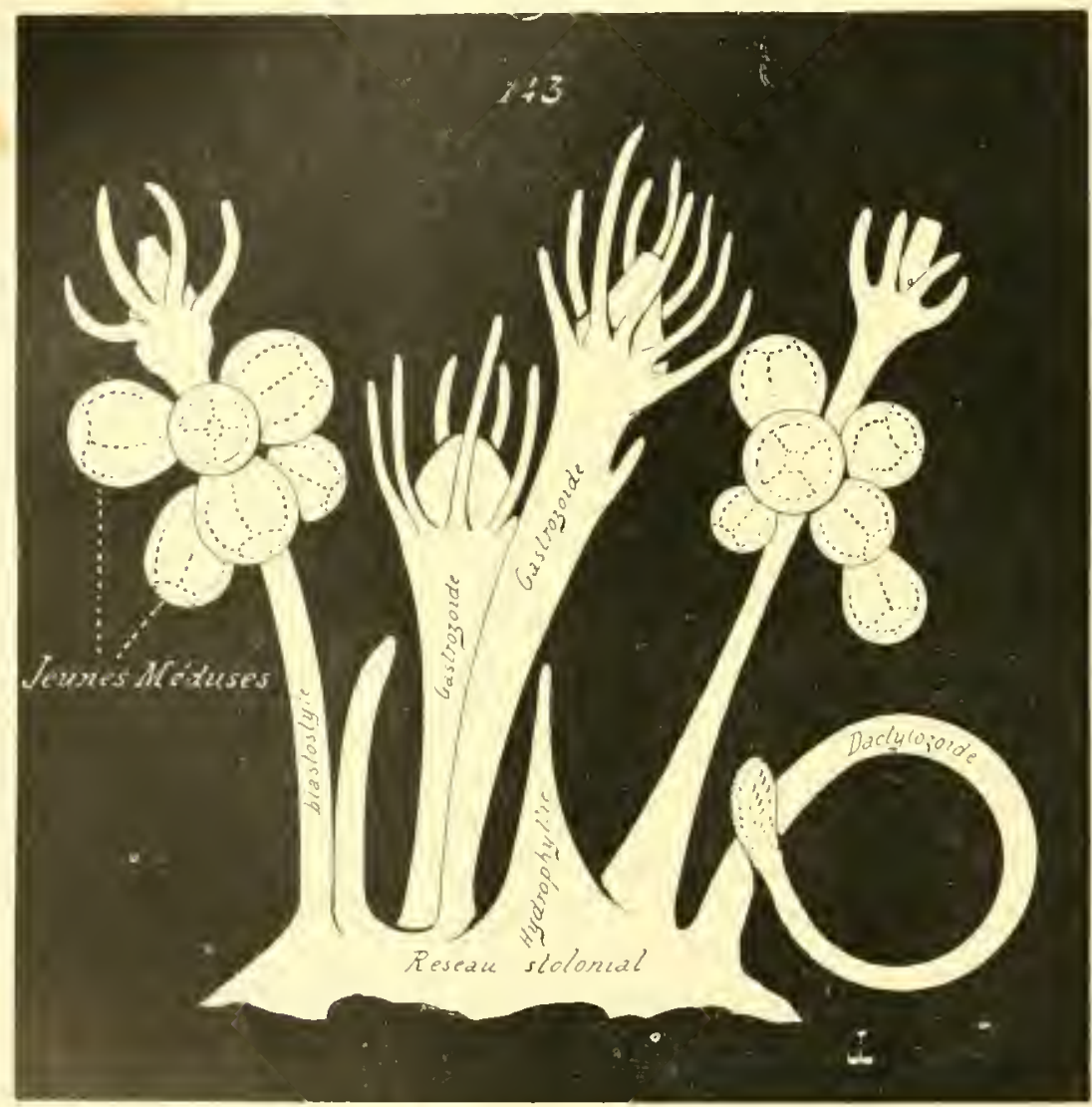

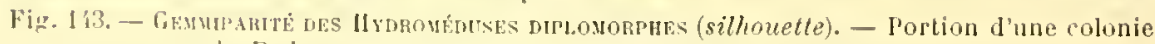
le Pudocoryne carnea; dapres les recherches de froblien.

est d'alord arromdi; il devient ovalaire, sa région d’adhérence ì l'organisure maternel élant assez étroite. La hourhe se perce ensuite sur le sommol de l'extrémité ojjosée à la hase alliérute; des tentacules, produils, conme le bourgeon lui-mèmr, par des diverticules gastriques sonlevaul lit paroi du corpes, naisscut autour de l'orifice buecal; el le second polype revèt ainsi son aspect définilif. Parvenu à cette phase de sen diveloppenent, il est cajrable d'engendrer te nouveaux zooüdes, en suivant le mème procédé; et la colonie s'accroil de celte façon. 
Il est permis de ranger en deux groupes les individus des colonies hétéromorphes; dans le premier groupe sont placés tous cenx donés de fonctions relatives à la nutrition générale, et dans le second les polyıes sexués, dits gonozoïdes. Le développement gemmipare de ceux-là ne s’écarte guère de celui déjà signalé pour les colonies holomorphes; les différences portent sur des détails secondaires, tenant à la forme des individus; il en est le mêne pour les gonozö̈des adhérents, e'est-à-dire pour les sporosacs et les gonophores. Mais les phénomènes du développement sont plus complexes dans le cas des gonozoüdes médusaires.

Les jennes bourgeons de méduses ressemblent entièrement, par leur aspect, à ceux qui doivent se transformer en polypes ordinaires; chacun d'eux est constilné par une saillie hémisphérique contenant une eavité. Cette dernière est un diverticule de la chambre gastrique du polype générateur; sa paroi, assez épaisse, correspond également ì une dépendance de la paroi somatique du mème organisme, el présente donc, en allant de dehors en dedans, une couche ectodermique, une mince membrane propre, et une assise endodermique. Le hourgeon s'accroît, et devient presque sphérique, car sa base l'adhérence se rétrécit de façon à n’être plus qu'un pédoncule étroit; en mème temps, l'ectoderme prolifère dans la région opposée à la base, et produit un amas cellulaire volumineux, qui soulève l'endoderme, el s’avance en coin dans la cavité gastrique. Cet amas grandit de plus en plus, et rétrécit de beaucoup cette dernière cavité; celle-ci, au lieu d'être sphérique et large, ne conslitue bientùt, dans la plus grande partie de son étendue, qu'un espace étroit, entourant la masse ectodermique à la façon d'un sac anıulaire.

Cet espace est toujours limité par l'endoderme. Il otfre deux parois: l'une externe, correspondant à la paroi primitive du lourgeon; l'antre interne, formée par la saillie ectodermique, recouverte par l'endoderme sonlevé devant elle. Il va en se rétrécissant sans cesse, car les deux parois se rapprochent l'une de l'autre, et finissent jar se mettre en contact. L'union n’a pas lieu partoul; quatre points sont réservés, placés à égale dislance les uns des autres; la cavilé anmulaire ne lisparait pas dans ces régions, qui forment ainsi quatre canaux, élendus de la base d'adhérence à l'extrémité libre du bourg’eon. Ces quatre conduits sont les ébanches des quatre premiers canaux gastriques et rudiaires. Ailleurs, les cellules endodermiques, mises en contact, se détrujsent, on se perdent dans la menurane propre, qui s'accroit à ce moment pour derenir l'épaisse sulistance fomlamentale de l'ombrelle.

lintre temps, une caviti se creuse dans la masse retodermique; cot espace, qui est l'éloanche de la cavité sous-ombrellaire, gramdit rapidement, et devient vite assez volumineux. Le hourgeon midusaire, it cette phase de son évolution, renferme lenx cavités : l'une, distale et entomréc par l'ectoderme; l'autre proximale el annulaire, limitíe par l'rudoderme, qui se rétrécit de plus en plus, et se convertit en quatre rananx destimés 


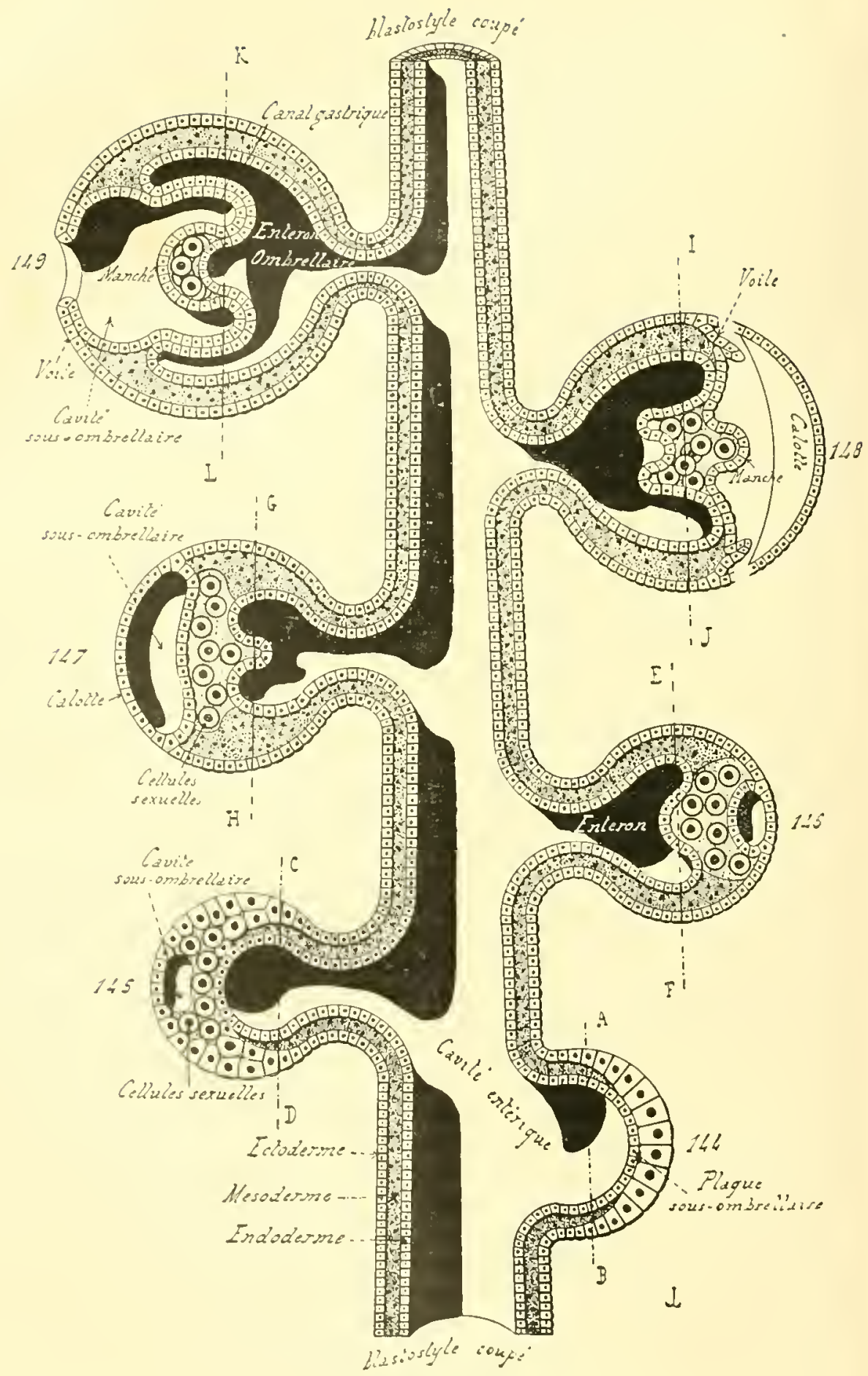

Hig. 144 à 149 . 


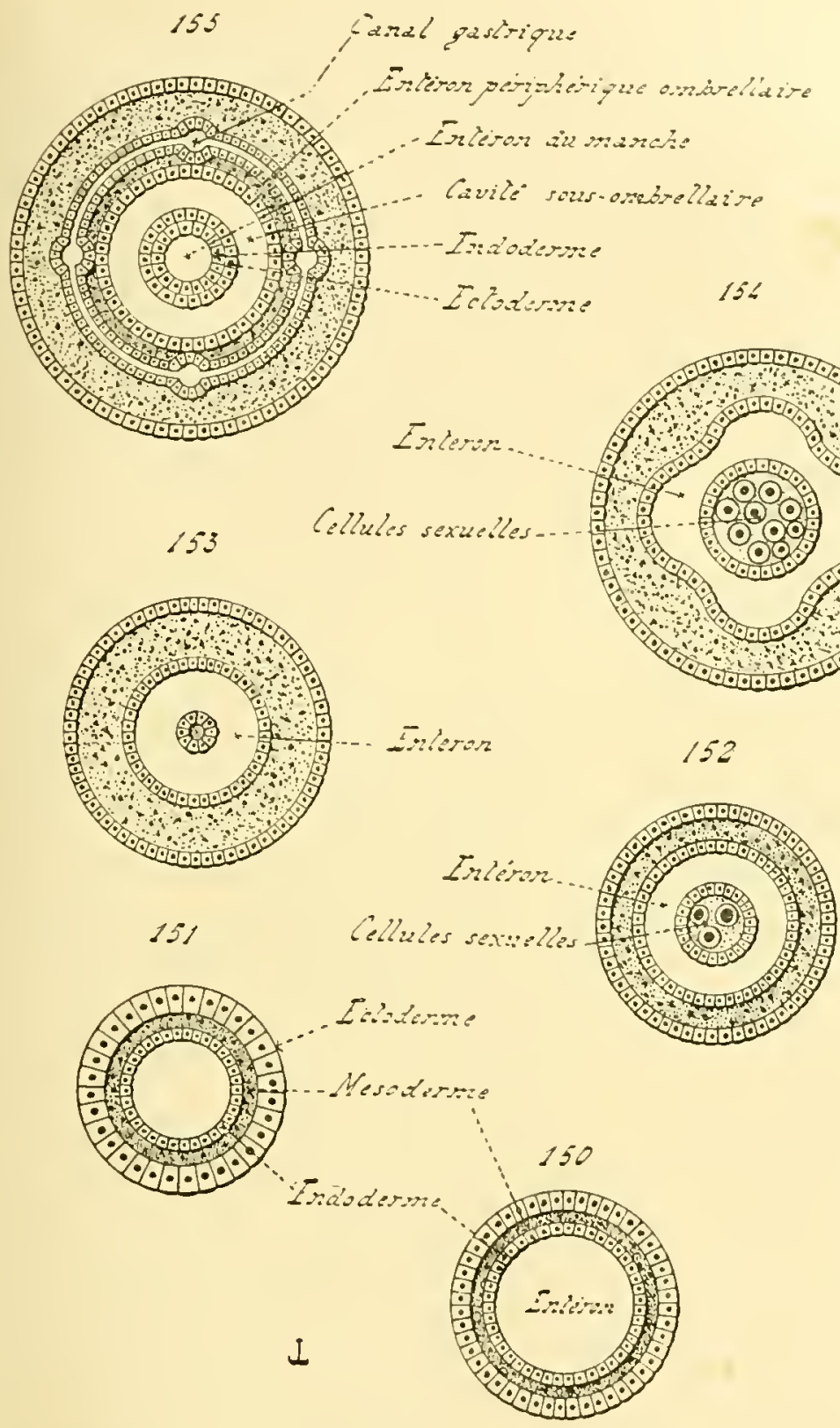

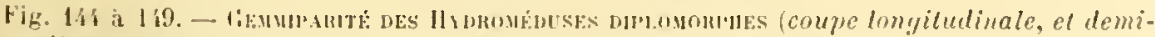
liagrammatique, d'un blustoslyle muni de ses méduses il divers iluls de développement;

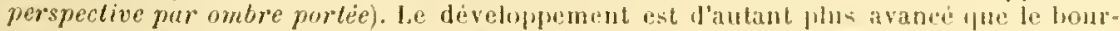
geon médusirire est placé plus laaut dans dans le dessill. les lignes AB, Cll,..., indiquent les plans des ligures 150 a 155.

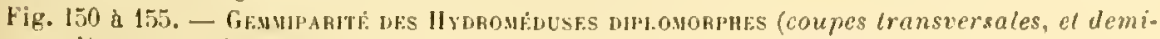
diagrammaliques, des bourgeons médustires représentés dans le dessin précédenl). 
LËGENUE DES FIGURES I4千 \& 155 .

Fig. 1ł 1-150, jeune bourgeon; les cellules de son ectoderme commencent à grandir et à se multiplier, pour clonner la plaque sous-ombrellaire et les cellules sexuelles. - En 145-15l, bourgeon plus ảgé la cavité sous-ombrellaire se ereuse dans la saillie ectoder. mique dérivèe de la plaque sous-ombrellaire du honrgeon précédent. - En 146-152, bourgeon encore plus ágé; la saillie ectotlermiquue s'avance en coin dans l'entéron, ou la cavilé gastrique, dı bourgeon. - lin 14ĩ-L5\%, la saillie ectodermique, et la cavité sousombrellaire qu'elle contrent, sont devenues jus amples. - En 148-154, la saillie ectodermique a rètréci de beautoup l'espace oceupé par la cavitè gastrique; de plus, la paroi externe de la cavité sous-ombrellaire, paroi en forme de calotte, se détruit, de sorte que cette cavile s'ouvre au dehors; le manche et le voile naissent, sous la forme de mameions, sur la face interne, el demeurée en place, de cette même cavité. - En 1491\%, bourgeon très àgé, prêt a se flétacher, ayant acquis loule la structure médusaire; la face, lemeurè en place, de la cavité sous-onbrellaire, s'est acerue, el incurvée en dóme; le manche et le voile sont plus volumineux. A la suite de l'agrandissement pris par la saillie eclodermique, la cavite gastrique, ou entèron, du hourgeon s'est divisee en deux parts : l'entéron ombrellaire froximal, qui reste ample, et devient l'estomac de la méduse: el l'entèron périphérịue ombrellaire, ‘ui se rétrècil sans cesse, sauf en quatre régions destinees à étre les canaux gastriques.

à parcourir la paroi de la carité précédente. Ces derniers sont les camanx radiaires.

La jeune módnse commence déjà à présenter une parlie de sa structure definitive. Au moment où celte ívolution vient à s'achever, elle offre l'aspeet d'une sphère creuse, rattachée par un pédoncule à l'organisme maternel. La cavité listale ne communique pas arec le dehors; sa paroi contient les quatre canaux radiaires, que limite l'eudoderme, ćtendus depuis le sommet libre du lourgeon médosaire jusqu’à son pédoncule; en cette région, ils s'onvent dans une cavité assez vaste, qui communipue, par ce pédoneule, avee la chambre gastrique de l'orgauisme maternel. Celte cavité hasilaire est te seul reste de la cavité froximale primitive du hourgeon; partout aillenrs, comme on l'a vu Ilus baut, celte dernière a disparu devant l'accroissement pris par la saillie ectodermiqur. et ne persiste que sous la forme des quatre canaux léjil déerils.

Les modifications, qui surviennent ensuite, portent sur la cavité disLale, sur l'ébanche de la ravití sons-ombrellaire. Celle-ci continure it s'accroitre; en mème lomps, me tes régions te sa paroi, opposée au péloncule de la jeune módusi, s'amiucit sans cesse, el ròle finalement. La cavité s'ourre ainsi an deluors. L'orifice s'agrandil de plus en plus, ct, romme résultal, le hourgeon peril son aspect de sphère crense; ¿t la suile de ce phénomìne, il prend la forme d'une cloche, on d'une ombrelle, qu'il ronservera lísormais. Lirspace limilí par la face interne de la woche, cest-it-dire la ravité sous-ombrellaire, provient done d"un vile qui se crense daus un amas cellulaire d'origine ectodermique; en conséquence, lépillúlium fui limite cette face est ectodermique luimème, et ne dérive pas de l'endoderme, contrairement à l'assertion de plusicurs anteurs.

Durant ces changements, la substance mésodermique de l'ombrelle 
fail son apparition. A la suile de la disparition des conches emtodermiques mises en contact dans la majeure partir du boureon, "L te leur persistance autour des quatre canaux senls, la jaroi ombrellaire ast principalement constituée par deux assises ectorlermiques, l'une externe et l'autre interne, que les quatre conduits séparent par places l'une de l'autre. Fintre ces deux assises se trouve placée la membrane propre primitive; celle membrane s'épaissil dans les proportions considérables, tout en demeurant entre los deux couches d'ectoderme; elle forme bientiol un amas compaet de substance conjonclive fondamentale, dans lequel les canaux gastriques sont plongés.

La jeune méduse offre déjà son aspect définilif, et il lui reste seulement à compléler son organisation. Le manche, ou manulurum, prenu naissance au sommet, el sur la face interne, te l'omlnelle; la partie de cavité gaslrique, siluée en celle région, émet vers l’exléricur un diverlicule, qui soulè ve la jaroi interne de lombrelle, el s'allonge en un cylindre creux. Celui-ci n'est antre que le manche, dont l'extrémité libre se perce lientot d'une ouverture huceale: le diverlicule lui-mème constitue la region manuluriale du tube digestif; al son sommel, qui communique avec les quatre canaux. Jerient l'estomar de la méduse. Ce dernier s'alouche en outre, par le pédoncule d'adbérence, avec les espaces gastriques de l'organisme maternel.

D'autre part, les extrémités distales des quatre cananx radiaires, roisines lu bord de l'ombrelle, émetlent des expransions parallèles à ce bord; ces diverticules, élant données leur direction et lemr place, arrivent forcément à se toucher, s'anastomosent les uns aree les autres, se soudent en un seul tube, qui pareourt la région ombrellaire marginale, et représente dès lors le canal ammlaire on marginal. He nouveanx canaux, lorsque la móduse doil en possíder plus de quatre, prennent encore naissance aux dépens de direrticules gistripues; les tentacnles naissent également sur le bord de l'ombrelle, an moven de bourgeons émis par les canaux radiaires el par le combuit marginal. - La méduse est alors parvenue à son organisation complète; les éléments sexuels, Ini souvent constituent la majeure parlie de la saillie ectortermique, au milien de laquelle s'est crensée la cavité sons-onlurellaire. jrennent leur asprect définilif; et il ne reste plus au jeune ètre qu’à se séparer de l'organisme dont il provient. Cette déhiscence se prołuil par le rélrécissement du pédoncule, suivi de sa rujture; la méduse, ainsi devenue libre, ra transporter au loin les cellules sexuelles, el disséminer les germes dont elle est chargée.

Les diverses espèces d'Hydroüdes diplomorjhes ne se ressemblent pas, en ce qui tient à la répartition des hourgeons médusaires dans la colonie. l'arfois, ces liourgeons sont répandus irrégulièrement, sans aucun arrangenent précis; assez souvent, ils sont placés nu grand nombre sur lo corps d"individus nourriciers, chargés de les produire, de les mourir, at de les soutenir jusqua leur déliscence. Ces individus ont l’aspect de 


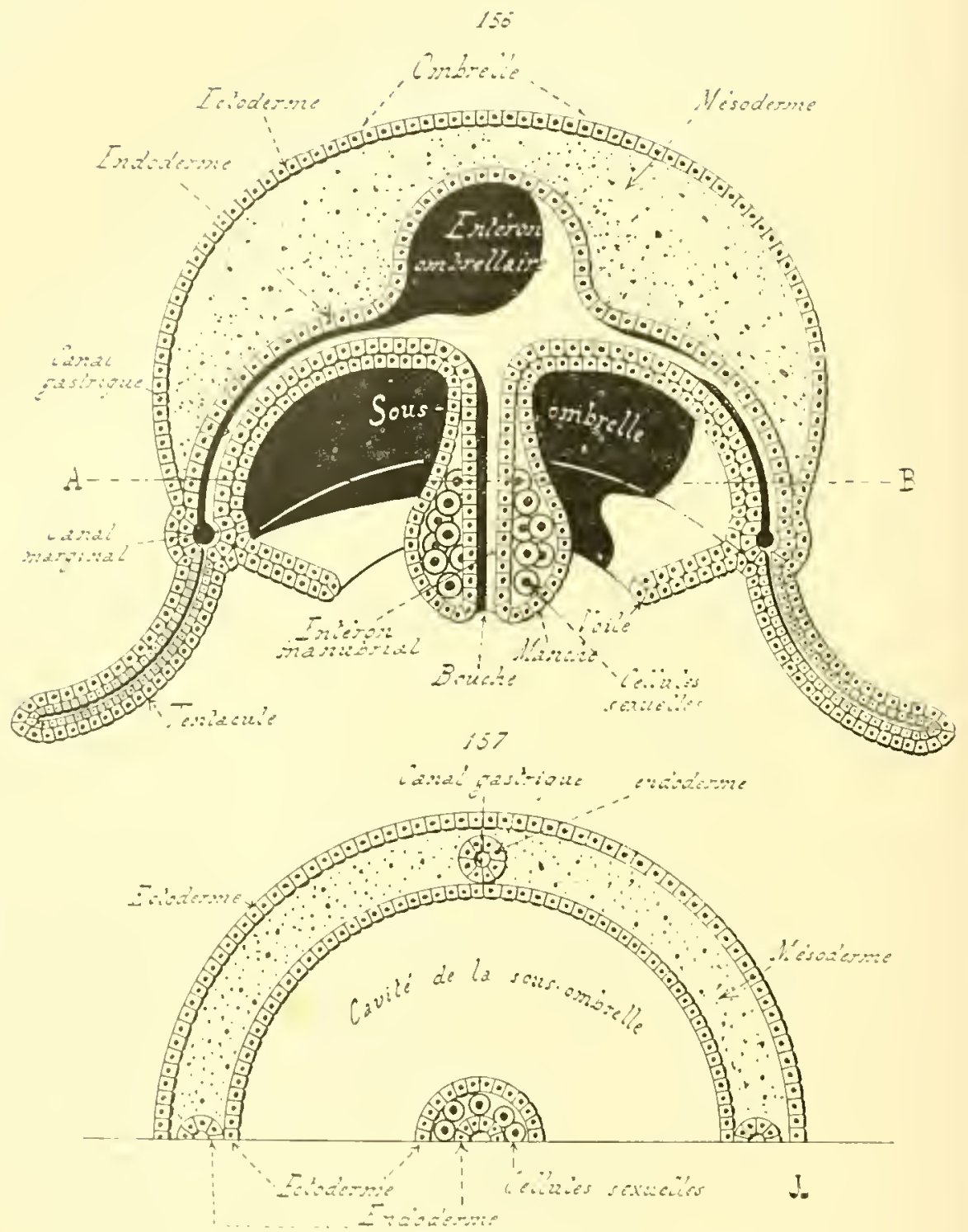

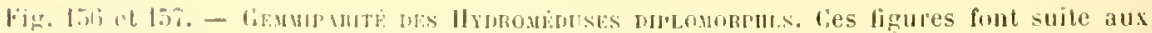

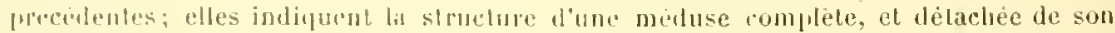
"rencratellt.

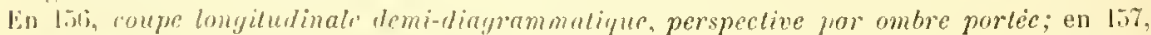

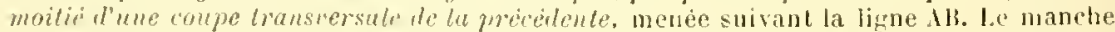

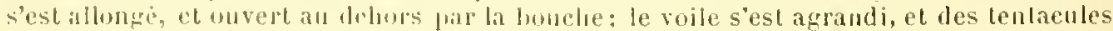

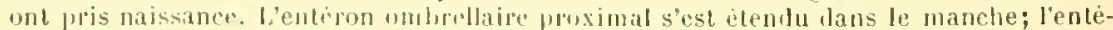

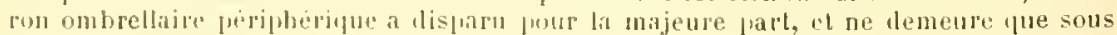

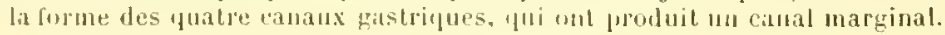


petiles colonnes, portant des grappes de méduses julus on moins díveloppées; on leur a domó le nom particulier de blastostyles.

Marche du bourgeonnement. - Les Ilydraires et les siphonophores diffèrent sous ce rapport; la cause de cefte diversilé est toute mécaniune. les colonies d"Hydraires sont fixces sur un support; partant, il leur est possible de s'étendre suivant les besoins de lenr nutrition génćrale, sans itre obligées d'égaliser leurs parties. Il n'en est pas le même pour les Siphonophores, lont les colonies, à canse de leur blat de liberté, ont besoin d’avoir une forme symétrigue, afin que l'action le la pesantent s'exerce également sur l'ensemble. Aussi la marche du hourgeonnement, chez les Siphonophores, offre-t-elle une régulariti, que sont loin de présenter les colonies d'Ilydrires.

On doit reconnaitre cependant, parmi ces dernicies, deux types principaux : les colonies étemlues en lıuteur, et colles étalées en surface. Dans les premières, le zö̈le primilif, dérivaul de la larre, lourgeonne des zoö̈les sur la paroi de son copps, entre sa lourhe et sa base de fixation; ces lerniers agissent de mime ponl cenx yüils engendrent à leur lour, et ainsi de suite. Il cu résulte $u$ assemblage liranchu, croissant constamment en hauteur, dont les Sertulariens offrent de hons exemples. - Il n'en est fas de mème pour les colonies du seconl lype; le zoïle primitif commence par émellre, dans sa région basilaire, des expansions creuses, en forme de lules, qui rampent sur le support, et auxquelles on donne, tantôt le nom de stolons, fanlòt relui d'hydrorhizes. Les zooüles sont produits par ces expansions, el dorivent le diverticules engemilris prarelles; les nouveaux polypes sont également capables de domer naissance ả l'autres stolous; le bourgeonuement continue à s'eflectuer ainsi, de lelle sorte que la colonie sétale en surface, tous les zoö̈les étant placés les mus à côté des autres, el non monlés les uns sur les autres. Un certain nombre de Tulmbriles, et de Campanularides, apparliennent à ce type.

la marche du léveloppement gemmipare varie suivant les ordres, chez les Siphonophores. Un jeune zoüte d'Ensiphomulide est divisé en trois parties, deux terminales el l’autro intermédiaire. l'extrémilésupérienre, renflée, porte l'élanche du pneumatophore; l'extrémité inférienre, allongrée, munie de l’orifice lunceal, correspond à la région mutritive de l'indivilu, et devient tinalement un gastrozoïle; la parlie intermédiairr, conrte encore, va s'allonger, el donne la lige, le rachis, de la colonie. Celle lige grandit beauconp, alors que le pnemuatuphore s'aceroil relalivement assez peu; et, smr son étrudue, prennent naissance, an mogen de bourgeous, des daclylozoïles, el surtout des imbivilus nageurs, des nectocalyces.

Il existe cependant, sous ce rapport, me cerlane dillúrence entre les familles. le rachis des l'hysophorides produit seutement des zooüles nagenrs; sa région, voisine du gastrozoïde inférieur, s’élargil cu un platcan 
qui hourgeonne de nouveaux gastrozö̈les, des dactylozoüdes ou filaments pèchenrs, el aussi des gonozoïles; tous ces individus sont groupés les uns i cóté des autres sur un espace restreint. - Le rachis les Agalmides, plus long yoe celui des Mysophorides, produit aussi des nectocalyces daus la majeure prartie de son étendue; seulement, sa partie inférieure,

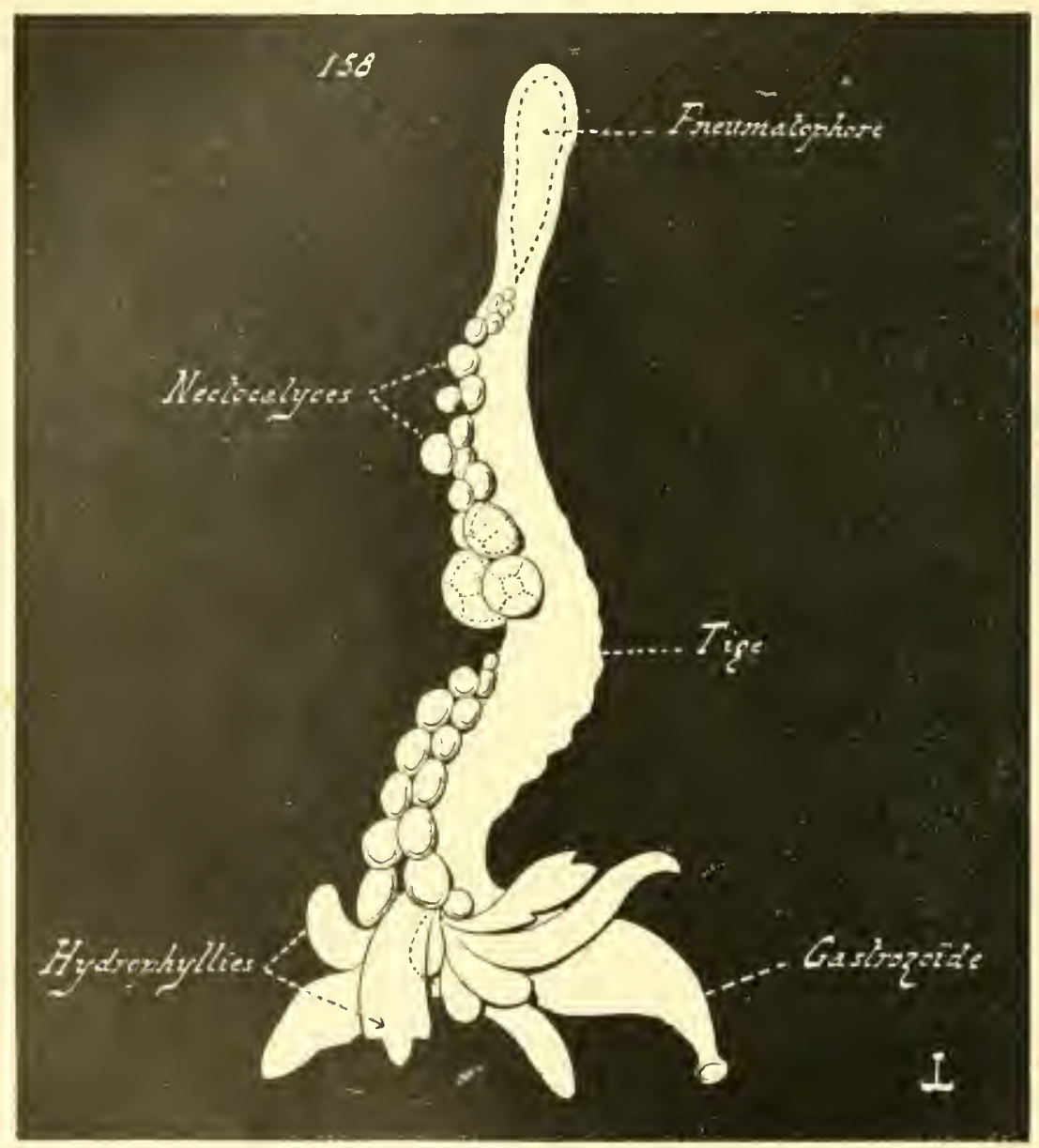

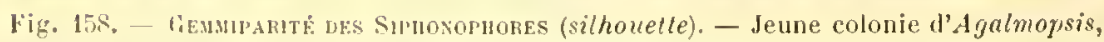
d'apres Gegenbaur.

homologue du plateau de la fréccidente famille, sallonge heaucoup, et devient un mime lige, sur latuello sont étagés les noureanx gastrozö̈ldes, les dactylozoüles, les individus protecteurs on hydrophyllies (encore nommés honcliers), ol les gonozoüles. La genèse de ces polypes présente une certaine rógularité. Les premiers zooïdes, produits par cette 


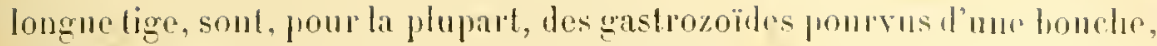

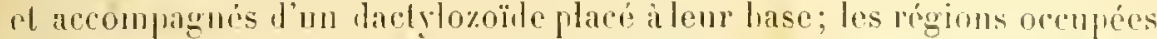
far eux portent te nom le nouds, ef les zones intermélinios polui l'entrẹnads de memier ordre. Dans ces drinieres naissent dre nomvanx

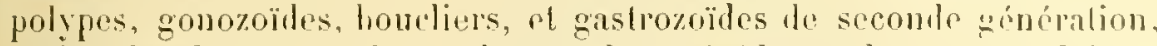
moins développés el phus pelils que les précérlenls; les expracrs laissós entre ces denxiomes gastruzoïdes soul des entre-neuds de second ordre. Ceux-ci sont eux-mèmes capahles le hourgeonuer d"aulres polypes; mais. en góneral, la marche du drveloppoment ne dépasse pas les entre-nceuls de troisime ordre. Le nomlire des individus, placés lans m entre-nomd quelconque, est d'aulant plus grand, que cel cutre-noud ast plus proche de l'exfrémilé inférieure de ta colonie.

La gemmiparité des Calyconulides rapuell. dans ses lraits essentiels celle des Eusiphonulides. Les dithérences principalos portent : sur la partie intermédiaire du zoïle, qui reste comple dans les premiores phases du dévelopement, et słallonge lentement; sur la croissance rapide du premier zoö̈le, qui se modifie en un neclocalyce volumineux; el sur le grompement parliculier des polypes, rassemblés an petiles masses dagées sill la ligre.

La marche du bourgennement des Discomulides n'est pas encore commue. I en juger dapros les plus jeunes élals oliservés, la frarlie médiane du zoïle se rentho heareonp, en s'aplatissant, el devient la plaque circulaire, le disque, le la llisconula; elle porte lébauche du pnemmatophore an centre de sa face supérieure, el la parlie inférieure du zoïle au centre de sa face inférienre. Celle derniere partie devient le gros gastrozoïle central des Discomulides. Les hords de la plaque hourgeonuent huit dactylozoïdes, non pas ensemble, mais sriariment : un fabord, puis trois aulres, ensuile los qualre derniers entro les précédeuts. Enfin, le nomeanx gastroöles, plus petits que les preming, ut des gonozoïdes, naissent, suivant mo symétrie ladiaire, sml la face inférieure lu disque : la jeune colonie revèt ausi son aspect définilif.

Il est à remaryuer yue, chez lous tes siphonophores, la parlie intermédiaire du zoïle devient le support de la colonie, la lige on rachis daus mu cas, le lisque dans l'aulpe.

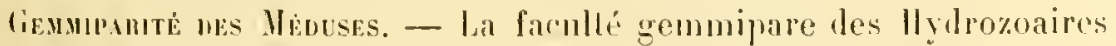
ncxiste fras che\% les polypes seuls, mais aussi chez les méduses; elto y. est cependant moins frequrute.

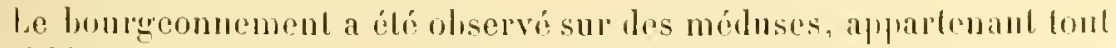
aussi hien a la serve des Iydroméduses diplounorples quä celle des llo-

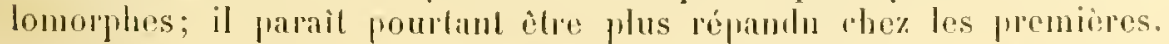
Les bourgeons porbuils se changent lonjours on méduses, smmblables

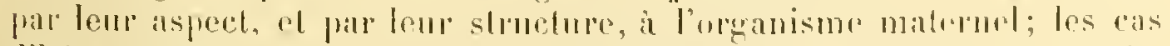

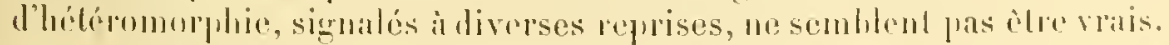

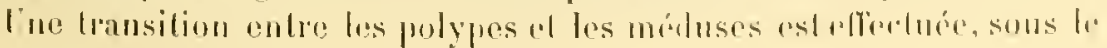


rapport de la gemmipariti, par certains des représentants de la lamille des Cuminides. Commo ou la vu plus lant, les larves de ces animaux ne se transforment point hativement en meduses, mais conservent, pendant assez longtemps, un aspect analogne it celui d'un polype; ils bourgeonnent en cet état, el tous les individus ainsi prontuits se converlissent en méduses, après s'ère disjoints les ums des antres. Les ovules fícombís des Cuminiles tombent, ì re quil semble, dans la cavité gastriqne the lorganisme maternel, el y subissent une vériblile incubation, c'est-à-dire éroluent in larves mumios de leurs bourgeons. Il en résulte que cette cariti contient des ètres nolfrant ancune ressemblance ares le génriateur, car ils ne revetent l'aspect de méduses quaprès avoir 1uilté la chambre stomarale oir ils sont renfermés. Licnsemble de ces phénomènes, autrefois rapporté à une alternance de générations complipgure te parasilisme, paraît se réruire, on le voit, à une inculabion des larves dans la cavité de l'istomac maternet, et à manifestation prérove de la gemmiparité chez ces momes larves.

Les jennos bourgeons, prorluits par les méduses, dirivenl tonjours, romme ceux des prolyjes, le diverticules gastriques sonlevant la paroi du corps. Ia cavité th diverticule évolue en espace stomacal, muni de ses annexes (canaux radiaires el région manubriale de l'appareil digeslif); cet la proi, qui la limite, engendre à son four les divers tissus de lorganisme. Ia siluation de ces hourgeons sur le corj's de la méduse maternelle varie suivant les especes; il existe, sons ce rapport, trois types principaux :

1. Lo type des Sarsia siphonophora, dont les bourgeons naissent sur le manubriun; les plus jeunes et les noins développés sont les plus juoclies de la base do cel organe.

¿o Le type des Sursia prolifera, dont les hourgeons apparaissent sur le borl de l'omhrelhr, i la luase des tentacules. Les Codonium colonophormm constituent mu denxiome exemple de ce fail.

30 Le type des Epenthesis, dont les Jourgeons se forment, sur la faroi inférienre de l'ombrelle, anx défrens de diverlicules émis par les canaux gastriques. Ce type est lo plus rare de lous; les Epenthesis et los Crastroblustu sont, dans l'état actuel de nos connaissances, les senles móluses il lo presonter.

11. Fissiparité. - La reproduction fissipare normale, très rare clıez les llybozodires, ne joue pas un hien grand ròle dans lenr évolution hiolog̈ique. Des expériences, déjà hien anciennes, onl montré que des polypes, coupres en morcenux, ne perdaient pas leur vitalici, licen au contraire; thapue fragment étant cilpable de saceroilde, el de produire ì lui seul un nonvel individu. Des olservations plus récentes, elfectuées

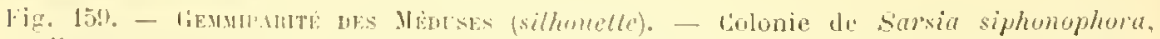

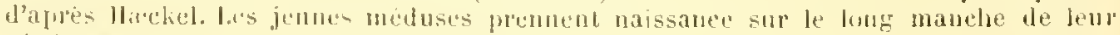
générateur. 


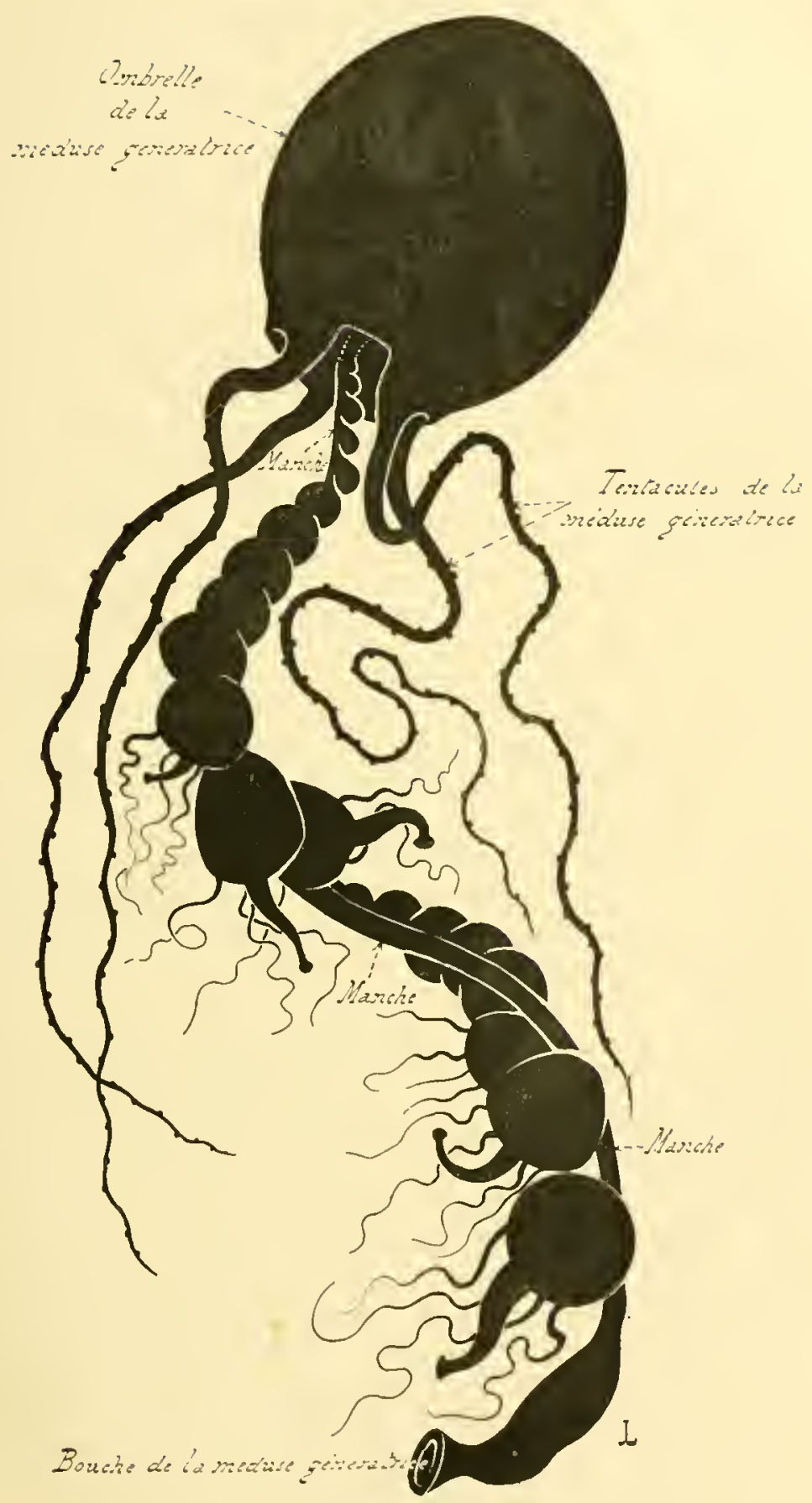

Nig. 159. 
par Ilackel sur des méduses appartenant au genre Thaumantias, dénotent

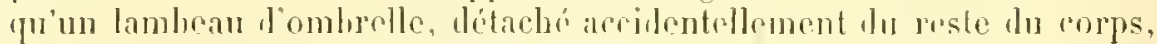
continue il virre, ol se transforme, an homt de pu de jours, en une méduse complinte. Mais ces faits se rapportent il des reprouluctions fissipares fortuitus, of ne constituent point me ivolulion d'halitule; ils permolfent cependant te romeroir qu un lel phénomène soil capable de se manifester, a la suite lavlaplation speriale, chez cortainos espèces, puisque les fragments du copps liun llyalrozoaire queleronque sont capahles de se convertir en individus romplets.

La fissiparite nomale existe dans la realité, mais elle est fort rare; on ne la signalée, of enero ave róserve, que chez diverses especes de polypes appratenant a la scction des huthydritres, ef chez plusiours mólusos placóes dans la sórie dos Diplomorphes. II importe le ne point ranger daus le cas de fissiprití les léhisconces des monluses, qui se sćparent de leurs génóntours: cus dorniers faits se rapportrut à une gemmiprité schizogone, èest-à-ulire à un hourgeonnement suivi de la chule des hourgeons.

lissmanté nes loupes. - Ce procélé a élé ulserré senlement sur les represontunts les genres Protohydra el Microlydra, voisins les llÿlres orlinaires; il sorail promis, d'apres les descriplious des auteurs, ile le consilirer, plutôt romme une gemmiparití arcomplagnée de déhiscence des itres produits, que comme une lissiparilé véribblı. Le polype maternel imel, sul les cités le son corps, un on plusiems homrgeons, qui grandissent, et se transforment en nomveanx indivilus; ces demiers so séparenl du leur mère, snit pendant lenr colution, soil apres leur achirement complet, et ront se fixer non loin d'elle, pour recommenter i parcourir un sembahle crele vital. Si les observations des aulenrs sont exirtes, ce procété reproducteur est évilemment unc gemmiparié sclizoworr.

Fissmante bes Hénose. - On no l'a rencontrie encure que rhez les

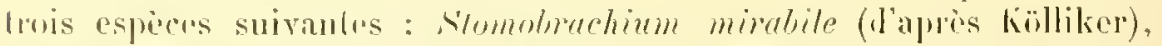

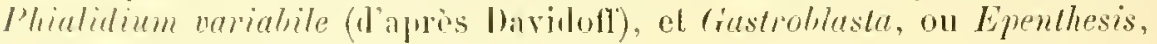

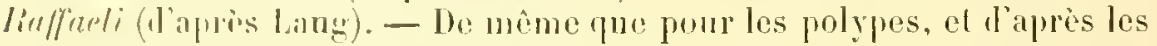

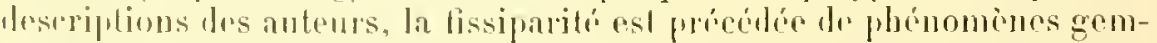
mijares. l'ne liastrobluslu, par exemple, parvenue à son complel dérofoppenent, possede un minul,rium ef quatre cananx gastriques radiaires. An momenl oi l'imbivilu, ainsi constitur, va se reproubire asexuellement, son ombrelle s"allonge et fevient ovalaire; un nouveau manche prond rusuile naissanee, non loin du premicr, aux dépens de sa cavité stomacalr, on d'un dr ses canaux radiaires. Parfois mème, plusieurs manches apparaissent sur la sous-ombrelle, el, rorrélativement a leur ronue, le mumbre des camaux rimliaires augmenle, de telle sorte que rhanne manche aboutisse in une ravité stomarale possédant en moyenne frois a puatre canaux. En sommo. l'individu promitif, il la suile de ces 
lials, s'est transformé en une sorte de colonie, doml tous les zonödrs sont fusionnés les mus arec les antres. Mais, dans llantres cas, les chosus ne semblent pas se passe ainsi; an moment oủ le serom manchu vient d'elre formé, lombrelle se divise entre lui et le premier manubrium; lintivilu s'est ainsi partagé en denx ètres, dont chacun possède un manche ot leux canaux maliaires. Cies leux méduses sont égalemont capables te se diviser par un procélé semblable, la fissiparité élant Lonjours précédée prar la genese l'un manche, de manière que chaque etre soit pourvu de son manubrium.

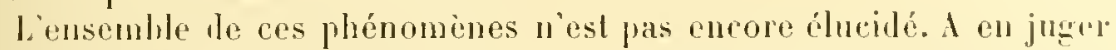
epromlant dapres les observations de Lang, il est permis d’admetlre, du moins ponr les Gastroblasta, que le tout se ramene à un bourgeonnement sur la sous-ombrelle: senlemenl, les bourgeons ne paraissent pas évoluer d'une façon complete, at se bornent i produire leur manche arec leurs canaux raliaires. Parfois, ils sont capables de se séparer les uns les autres; mais dans ce cas, afin de len donner me ombrelle, il faut que celle dela mère sedivise en autant de parlies qułl existe de manches bourgeonnés, chaque fragment constituant l'ombrelle yui doil porter lo: manche en rapport aver Ini.

\section{RÉSUMÉ}

1. - Les Hybrozoaires se reproduisent par voie sexuée, el par roie asexnée; ro deriner mode est representé à la fois par la gemmiparité rat la lissiparite.

II. Lumexts stavels. - L'unisexualité est juesque lonjours la régle; souvent mème, elle s'élend aux colonies.

Les éléments sexuels mûrs sont orlinairement placés dans le mésolerme, mais n'en proviennent pas; ils sont formés par l'ectodeme on par l'endoderme. Il faut reconuaitre sous ce rapport, trois modes principanx : $\perp^{\circ}$ Les spermatozö̈des el les ovules derivent de lecloderme (ex: heancoup te Tubulariens); 20 les spermatozö̈les el les ovules sont produits par l'endoderme (ex: la pluparl des Serlulariens); $3^{\circ}$ les spermalozoïles sont engendrés par l'ectoderue et les ovules par l'endoderme? (ex : nn grand nombre de Campanulariens). - Les llydrozoaires inférieurs nedonneut naissance à lenrs produits sexuels quaprè avoil acheré lenrévolution somatique: c’est l'origine curnosarale mimative. Diverses Ilylromiduses diplomorphes montrent, an contraire, des éléments sexucls

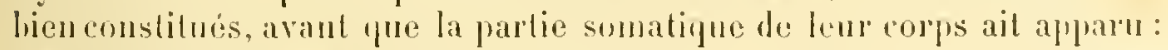
cest l'origine blastoüdale. Entin, les Ilydromeduses diplomorphes les plus

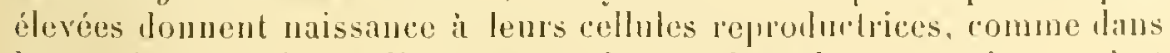

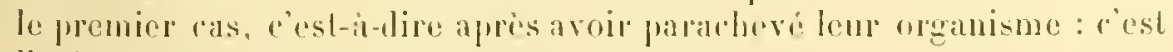
larigine conosarcale secondaire.

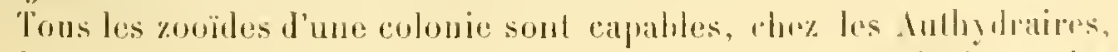

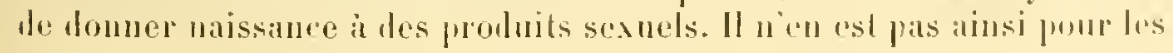


antres Hydrozoaires, dont les colonies renferment des individus, les gonosoïdes, seuls charcés d'engendrer tes éléments de la reprorluction. Les gonozoïles athertent divepes formes, variables avec les groujes; l'aspect le plus simple nst celui des sporosacs; viennent ensuite, suivant une progression croissante sous lo rapport de la complexilé; les gonophores, les gonophores midusiformes, les médusä̈les, ot enfin les méduses. Les cellules sexuelles de res lernieres sont situées dont la paroi du manche chez les Inthoméinses, autour des canaux gastriques chez les Leptoméduses et les llydroméluses holomorphes.

11]. Feculets blastonemules. - Le développement des fenillets hlastodermiques s'effectue suivant le procédé cytulaire.

$1^{\circ}$ Aullydraires el Hylroméduses diplomorphes. - Le mode le plus dilatí est montré par un grand nombre d'llydroméduses diplomorphes. L’ovule féeondé se morlitio en une morule, puis en une hlastule; les éléments du llastoderme engenlront des endocvtes, qui remplissent le blastockele, et la blastule se convertit en une blastoplanule par ce procédé. Le protectolerme devient l'ectoderne, l'entéron se creuse dans l'amas des endocytes, et ces derniers, placés autour de la cavité entérique, produisent l'endorlerme.

Plusieurs Tubulariens at quełques Authỵdraires présentent un développement plus abrégé; la phaso hlastulaire est omise, et la morule so transforme directement en bastoplanule.

qo Hydroméduses holomaphes. - Iarmi les Irdroméduses holomorphes, la Liriope mucronala offre le procédé le plus simple. La segmentation abonlit à une blastule, dont le blastocale est fort réduil, et le blastoderme lrès épais; la liastule se transforme en lılastoplaunle par la division de quelques élóments lilastodermiques en deux parlies, l'une qui resle externe, of l'autre qui parriont dans la cavité blastocoelienue jour y revetir le raralio l'enlocyte. - le dévelopiement de la plupart des llolomorphes est plus condusi: la phase blastulaire est omise, rt la morule se moslitio lirerlement en hastoplanule. Cette morule diflire de celle des Authudraires ot des Ilydroméduses diplomorphes par la laille des ćlémrnts de son blasloderme, qui s’étendent tous depuis le centre de l’ouf jusqu’a la périphérie, et ressemblent à des coines juxtajosés. Crus dimenls se divisent en denx parties, l'une externe, l'autre interue, suivant un plan parallèbe à la surface de l'embryon; la morule est ainsi derrme une hastoplanule; l'ensemble les parties extrones constibue f'ectorlarue, at celui des praties internes peprésente l'endoderme. Ce morle est lísigné par l'expression de délamination.

Les. Eginopsis mídierranen possident anssi nue embryogénie abrégée; seubement, les histomires sout plus petits et plus nombreux que daus le second cas. dussi la morulo devient-elle dipectement une blasloplanule, en suivant des phases semblables à celles présentées par les Aubrgalraires, dans lo second as du premier lype. 
3o Siphonophores. - Les premières phases du développement des Siphonophores sont remarquahles, en ce qu'elles sont aceompagnées de phénomenes gemmipares, et de la production, sur l'une des extrénitís de la lare, d’une dépression ectodermique qui deviondra la cavité du pneumatophore de la colonie. - Le mode le moirs alırégé existe clrez les Stephanomia, les Physophora, ete; il rappelle on tout le secont cas du premier lype et le troisième cas du second. L'ovule fécondé devient une morule, à plusieurs couches concentriques de hastomères, qui se transforme directement en blastoplanule; la phase bastulaire est donc omise. - L'n procédé plus condensé a ćlé olsservé chez la plupart des Siphonophores, les Epibuliu notamment. La phase hlastulaire est rigatement omise; mais, en plus, les endocytes de la hlastoplanule, plus nombreux el plus volumineux que dans le premier cas, constituent une reserve nutritive aboulante. Anssi la jeune larve bourgeonne-t-elle des zooïles sur son propre corps, avant mème que son entéron se soit crensé dans l'endoderme. - Enfin, l'abréviation embryonnaire atteint sou maximum chez les Agalma et les Crystulloüdes, dont l'cndoderme, très volumineux. donne à la larve qui le rontient la forme d'une vésicule vitelline, chargée de matériaux nutritifs, et portant, sur sa région infirieure, plusieurs individus produits far elle an moyen de procridés gemmipares.

Dans tous ces développements, le protectoderme de la blastoplanule derient l'ectoderme de l’individu parfait. L'amas des endocyles, d'ahorl compact, se creuse ensuite d'une cavité, qui prend la place du hastocale saus provenir directement de hui : cetle cavité est l'entéron. Elle est limilée par les endocytes, qui ronstituent ainsi l'endoderme. Le mésoderme, plus ou moins épais, apparait entre ces deux feuillets, et dérive surtout de l'ectorlerme.

II. Fonues des lanves. - La larve typique des Hydrozoaires. l'Iydrula, est un embryon libre, provenant d'une hastoplanule, sourent pourvu de cits viluatiles ectodermiques, muni d'une bouche dont les parois ne s'invaginent pas dans la cavitó entérique, et privé de cloisons gastriques. Cette forme embryonnaire se présente sous plusienrs aspects:

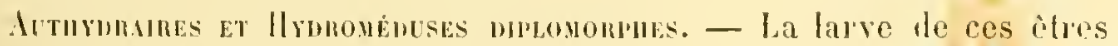
devient un zö̈le, qui se fixe, el bourgeonne des zoö̈des, mais seulement après avoir acquis sa structure dífinitive, el revètu l'aspect nomal d'mu polype. Cette larve se présente lantôt comme me P'rothydrula, dont les tentacules péribuccaux naissent au moment de la fixation, ou pen apris ret instanl; et lantôt comme une Actinulu (diver's Tubulariens), dont les tentacules apparaissent arant la lixalion.

Simoxumones. - Les larves des Siphonophores deviement des zoüles qui ne se fixent jamais, et bonrgeonnent des zorödes avant l'avoil acquis leur structure complète; elles aftectent deux formes principales : celle de siphonula, el celle de Inisconula. La siphomula est la lanve des siphomu- 
lides, caractérisée par sa lormo allonée; la llisconulu, linve des liscon-

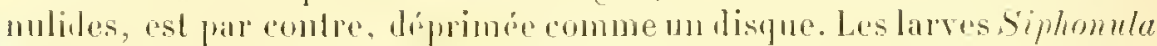

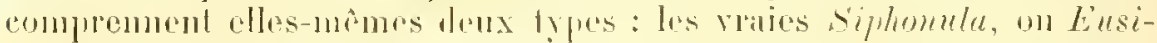

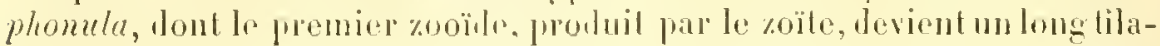
ment pêchenr; et les calycomula, dont le premier zoö̈le se monlifie an une clochr natatoir (nectocalyce) volunineuse, servanl à soutenir l'embryon.

Hrononébes monomonires. - Les larves de ces animam se convertissent directemrnt en méduses, el mo houreoment pas avant d'avoir atteinl leur asprect dótinitil, sauf rho\% les Cunina. Les culbryons de ces

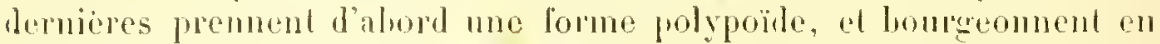
cel étal, lous les zoö̈los produits levenant des méduses; les Cunina effectuent ainsi une transilion des Hydromiduses diplomorphes anx llydroméduses holomorphrs. Elant doméd, dans la pluparl des cas, la lranslormalion directe des imbryons en miduses, le mésorlerme apparail lisivement entre l'ectoderme el l'entulerme, el acyulert de suile mme importance qui n'a point son anulogue chez les larves des autres llybro\%adires. La cavité sous-ombrellaire des Trachyméduses se creuse dans une masse rellulaire l'origine ectodermique, el s'oure plus tarl au dehol's; par contre, celle drs Kareoméduses communique loujours avec l'ixtérum, car l'ombrelle est produile par nn simple ćlargissement de la region supriente du ropps.

1. Repronuction asexuèE. - Celle rejroduction seffectue suivant deus modes: la crommiparité el la fissiparité. Celle-ci, fort rare, doit ère consilérée sans doute comme une gemmiparitó ordinaire, suivie de la dohiscence des bourgeons produits.

Gemumate. - Ce prockli, tres commun, existe chez les polypes et chez les modnses. Dans les lonx eas, il aboulil a la genese de colonies; ses principales phases eonsistent essentiellement en la produclion de diverlicules gastriques, pui soulevent la paroi somalipue maternolle, et ivoluont en murean indivilus.

Le bomreomement des polypes entraine lapparition de nonveans

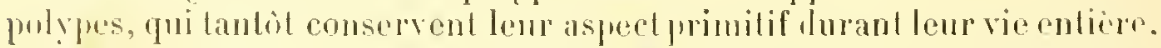

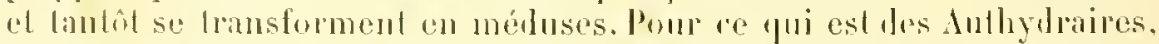

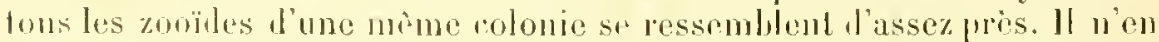
est fas de memo pour les indivilus des eolonies d'Ilydromédnses riplomonphes; las mus restent des polypus alaptís a des fonctions de nutrition génériale (grastrozouldes. dactylozö̈las, etc.), les aulres devicmuenl des gonozoildes, fui rovtent soment l'aspect de méduses. Mans ce dernier cas, l'ectorlorme du jenne houreon ensemdro une masse cellubire,

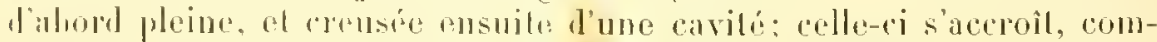
munipue aroe lo dehors par la rupture de sa paroi exlérienre, el devient la caviti soms-ombrellaire. lin tel diveloppenconl a pour elfot de donner

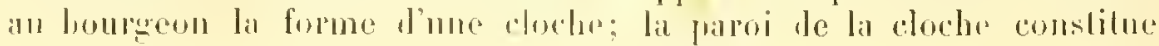


l’ombrelle, yni renferme une cavité gastrique, diviśe en estomac, accompagnée de canaux radiaires el flun canal cirrulaire. L. mancle, on manuhriun, prend naissance au fond de la eloche. - Lal marche du hourgeonnenent est assez peu précise cliez les llyutraires; elle est pru' rontre fort régulière chez les Siphonophores. Lin gúnćral, le zö̈le, qui dérive diredement de la larve, se livise en trois parties: une supérienre qui ne hourgeonne pas, et devirnt le pnemuatophore; nne inférieure, fui dome naissance à la plupart des zoöldes; enfin une intermidiaire, qui se converlit en rachis, et supporte ainsi le reste de la colonie.

La gemmiparité des méduses, observée tout anssi bien chez les IIydroméduses hotomorphes que chez les diplomorphes, ahoulit constamment à la genèse immédiate de nouvelles méduses; sauf cepundant ponr les Cunina, dont les jeunes hourgeons passint au fréalable par une phase polspö̈le. Le bourgeonnement se manifeste, tantôt sur le manulsium, tantôt sur lo burd de l'ombrelle, et lantot sur la sous-ombrelle.

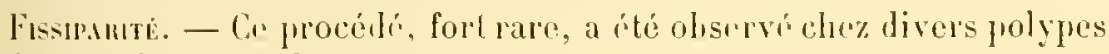
el chez quelques méduses.

La fissiparité des polypes existe chez plusieurs Authydraires, appartenant aux genres Protolightra et Wicrohydra. Elle se ramene i la genese, par gemmiparité, de petits polypes, qui se séparent insuile de l'organisme maternel.

la tissiparité des méduses doit être également considérée comme une gemmiparité ombrellaire, suivie de la clute des lourgeons, chute "fui parait ne pas toujours se manifester. On l'a signalie sculement chro trois espiers. Il esta renarqure que la gemmiparité normate des méduses est accompragnée de la déhiscence les jeunc's méduses provenant des bourgeous; sans dontr, les cas de fissiparité, pour les méduses commo pour les polypes, doivent renhrer dans la série des cas de bourgeonnement schizogone. 


\title{
EMBRANGIIENENT IDSS SGTPIOZOAIRES
}

\author{
C.IAPITRE II \\ EMBRYOLOGIE DES SCYPHOZOAIRES
}

\section{\$1. Considérations générales.}

I. Caractères. - Les Seypbozoaires sont des Colentérés, dont l'eclorlerme est constilué par des cellules appartenant à plusieurs tỵes distincts, et donl la paroi du corps nest pas traverséc de canaux nombreux, destinés à meltre la cavilé gastrique en relations directes aver te dehors. Les éléments endodermiques sont privés de collerettes. La cavité gastrique est livisée an loges par des cloisons; les loges sont, dans certains cas, très réduiles, semblables à des canaux. La région périluccale s’inlléchil dans la cavilé gastrique en un tube, nommé le tule resophagien. Enfin, lans les développements dilatés, les feuillets primordianx naissent suivant le mode gastrulaire. - De mème que les Ilydrozoaires, les Seyphozoaires présentent deux sortes d’individus: des prilypes fixés, et des ótres lilures, dont certains affectent la forme de mérluses.

Comme la classification, et les principales particularilés du développement iles Seyphozoaires. se rattachent étroilement it un certain nomlur de faits acquis depuis peu, quelques considérations próalahles sur les caractires essentiels, el sur les données importantes de la structure, seront ici de quelque utilití.

Les larres subissent une évolution particulière, pour ce qui tomebe à l'onlóron. Lorsque la bunche s'esl percée, de manière à faire communifuer la cavité entripue avec lo lehors, les bords de cel orifice s’inthechissent dans l'intéricur de l'entéron, el s'y lisposent en un tube pendant. Cel appareil, nommé lo hube resophengen, persiste chez l'adulle, el présente Inux ouvortures, placées à ses teux extrémités : lume correspond à la louche primitive, el lonne acrès daus la cavité entérique; l'autre est 
l'orifice externe de la lépression, el communique avec le dehors. Celle-ci est la houche délinitive; la première, persistance de l'ouverture buccale primitire, est Vorifice cesophagien, ou la bonche asophagicnue. Etant donnée celte origine, la face interne du fube osophagien est linitée par un épithélium d'origine ectodermique. - En outre, les parois de la cavité entírique ne restent pas lisses; leur face interne, constituée par l'endolerme, se soubve en mn nombre variable de saillies longitudinales, qui s'élendent sur la paroi, depuis son extrémilé supérieure jusqu’il son extrémilé inférieure. Ces saillies, dites cloisons, découpent la cavité de l'enléron ell un nombre égal de chambres, les loges, lont la disposition el létendue varient suivant les classes: mais l'aspect spécial, résultant de leur présence, ne manque jamais.

Les caractères olferts par l'adulte déconlent directement de cenx présentés par les larves; ils se rapportent, en effet, il l'existence, dans la cavité entérique (nommée encore, suivant les classes, cavité mésentérique, cavité gastrique, carité stomacale), d'un tube asophagien et de cloisons. Il est done inulile d'insister davantage à lemr égard.

Les plus proches parents des Scyphozoaires paraissent ètre les Itydrozoaires. Les relalions entre ces deux groupes sont encore accentuées par la présence, dans chacun, d'individus libres offrant la forme de méduses. Les méduses des Scyphozoaires n’ont cependant, ni l'origine, ni la structure de celles des Ilydrozoaires; les ressemblances iaspect, résultaut dune convergence déterminće par une mème adaptation pélagique. masquent soirent les différences fondamentales. Tantòl les méduses les Scyphozoaires proviennent directement de l'euf fécondé, el tantiot elles sont produites par la division transversale d'un polype primitif; en aucun eas, elles ne dérivent d'un bourgeon engendré jar gemmiparité. De plus, ces méduses présentent des particularilés de structure, que nont proint celles des Hydrozoaires; leur cavité gastrique renferme quatre ipaisses cloisons; un voile el mu manche leur font complètement défaul.

La seule concordance entre les denx formes tient il l'aspect général du corps, disposé en une ombrelle transparente, portant la bonche sur sa face inférieure; mais, cetle corrélation mise a part, tous les auldes délails de l'organisme diffèrent complèlement.

Les Scyphozoaires doivent ètre séparés des Ifydrozoaires pour deux motifs principaux, dont l'un tient au développencont, et l'autre a la structure définitive. Le premier est relatif a l'origine des feuillets hlastotermipues, qui apparaissent suirant le prorété gastrutaire dans los déreloppements dilatés des premiers, ef suivant le mode cytulaire dius ceux des seconds. L'autre ritison porte sur la disposition de lil cavité entérique, on gastrique, et sur la présence d'un tube asophagien. Ce dernier manque constamment aux Hydrozoaires, alors que les seyplonzoaires le présentent loujours. En onlie, la praroi gastrique despremicrs est lisse dans tous les cas, tandis que celle des sceonds est munic de cloisons, plus on moins larges el longues. 
11. Structure générale. - Les ères, yui apparticmnent ì l'emhranchement dos Seyluzoaires, se presentent sous dens formes prin-

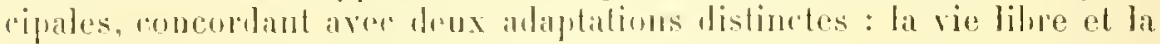

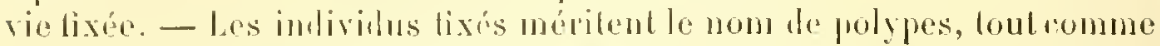

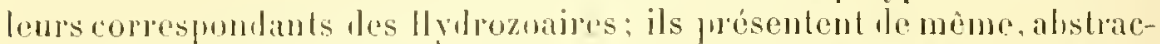
tion faite des dilforences forgantsation, un corps allongr, adherant it un support par une extrinite, el porkant, sur l'antre, la houclue antourée fall nne conronne de tenticules. Les indivilus libres, par contre, offrent plusieuts aspocts ditherents. Les uns rappellent les méduses des Ifydrozoaires par la disposition on ombrelle de leur région supérionro; les antres, font con étant launsparonts comme de vraies méduses, sonl arrondis, ou wralaires, ou allonges. nt no possedent jamais d'umbelle; les lerniers entin doivent itre considérés comme des polypes devenus libres, dont la région basilare lu corps serail convertie en un llotheur.

Parmi hes trois alasses le l'embanchement des Seyhozoaires, celle les Cténuphures ne renferme que des individus libres, appartenant lous

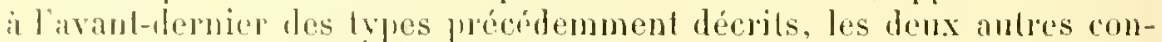
lienuend a la lois des citres lilmes el des alpes fixés. Les premiers ontlous l'asprect médusaire dans la classe des Seyphoméduses; les seconds sont des polypes ronipurs, munis de puatre larges eloisons gastriques, auxinels on a lomno les noms de. Seyphopolypes ou de Seyphistomes. Los indivilus fixés sont trés nombremx parmi les representants de la "lasse des Inllozoaires; désignés d'une facon générale par l'expression

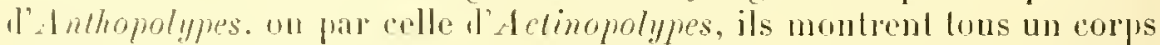
climbrique, portant, dims sa cavite gastrique, un nombre considérable le cloisons minces el larges; ce clitlpe est loujours igal, on supérienr, à huil, du moins pour les especes actuclles. Quant aux animan libres appouterant a cette dasse, leur allureest celle l'un polype, délaché de son support, de manièce que la région d'adhérence soit disposée en une "loche sejvanl de lhollump.

Les aspocts offerts par les Seyphozoaires étant ainsi fles divers, il est néressaire de les examiner avec délaj, en les éludiant dans chacune des loris classos le l'ombranchement.

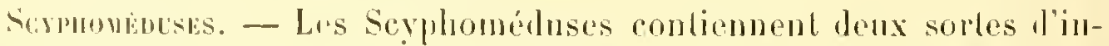
dividus, dont les uns sont lihres ol les antres fixis. Ces deruiors, dits

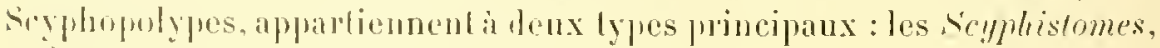

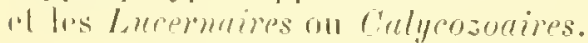

1. - Les seyphistomos n'ristent pas, dans la nature actuclle, it

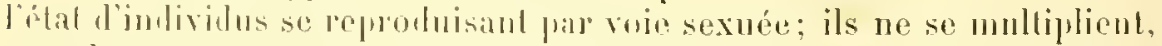
avee lenrs caraclires propres, pue pargemmiparite, el doivent se lrans-

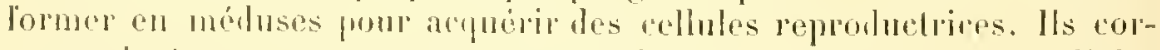
respondent, soms ca rapport, an polyges des llydromeduses diplo-

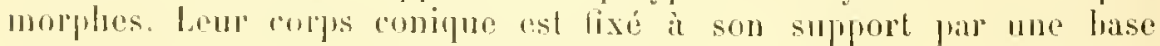

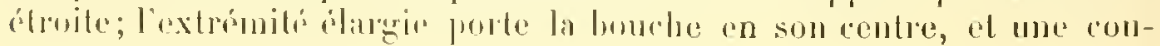


ronne de tentacules sur ses hords. Le nombre des tentaculrs est rariahle, mais il est toujours égal à mo multiple de quatre. Les organes des sens font complitement dílaut. La paroi lu corps, assez épaisse, est romslituée, en allant de dehors en dedans, par un épithélinm colodermique, une mince lamelle mésodermique produite par l'ectoderme, ol un épithélium endorlermique; elle limite une vaste poche gastrique, qur prarcourent quatre cloisons assez larges, s'arançant de la périphórie rers le centre de la cavité, mais ne s'y soudant pas les unes avee les autres.

Etant donnée une telle struchure, qui dérive pourtant d'une disposition lilatćrale primitive, l’animal entier présente une symétrie radiaire. Les plans principaux de srmélrie, au nomlure de yuatre, passent par laxe longitudinal de lindividu et par le milien des loges gastripues: ce sont les perrayons (1 or ordre). Quatre autres plans. les intemayons (Ze ordre). sont les hissectenrs des angles formés par les premiers; ils passent à leur tour par les eloisons yui séparent les loges les unes des autres, ef miritent ainsi le nom de septorayons, qui lenr est accordé parfois. Iluit antres plans de symétrie, les arlayons ( $3^{\circ}$ ordre), sont placés entre les jerrayons et les interrayons. A chacun de ees plans correspond un tenlacule périhureal; l'individn possede done quatre tenlacules perradianx, qualue interradiaux, el huil adradianx. Lorsque le elithre de ees appendices derient supérieur à seize, les nouveanx venus sont placés entre ceux iqui existaient déji, el dans de nouveanx plans d'orientation, les subrayons ('e ordre).

La structure des Lucermaires n'est pas très dillérente de celle montrér par les Seyphistomes. Les principales modifications portent sur l'ajpareil tentaculaire; les quatre tentacules perradiaux et les quatre interradiaux font défant, du moins chez l'animal adulte; les huil appendices adradiaux existent seuls, mais modifiés en courtes et lares grapjes de petits mamelons. Le léveloppement larvaire de ces ètres n'est pas connu; il est cependant probahle qu'il en est pour enx comme pour les scyphistomes : la couronne de tentacules esl complete durant les premières phases de l'évolution, puis certains de ces derniers s’alrophient, alors que les autres sont conservés en se modifiant. Quoirnil en soil, il est permis de considérer les tucernaires comme les ètres semblahles, ou peu s'en faul, aux Seyphistomes, et se reproluisant par voje sumice avec lenrs caracteres parliculiers; ils correspondent done, jarmi lrs seyphoméduses, anx duthydraires des Ilydraires.

B. - De mème que les individus tixés, les types libres des scyphomeduses appartiennent i deux formes principales, mais beancoup phus éloignées l'nue de liuntre que les lucernares ne le sont dus sighhistomes. La premiere est représentée par les Tesseridées, la seconde par les atcaliphes.

L'aspect général est tonjonrs celui d'une méduse; cist-il-dire d'un animal pélagique an corps transparent, dont la région supurienre du 
corps, molifine en une eloche ou une ombrelle, porte des tentacules sur ses bords; senlement, lorganisation des Acalephes est plus complexe que celle des Tesseridées. Cés dernières đloivent ètre considérées comme des Scyphistomes libres, et se reprorluisant par voie sexuée. Elles sont privées d'organes sensitifs du lype de ceux possétés par les Acalèjhes, et portent luil ou seize longs tentacules; dans le premier cas, les appendices perradiaux et inlerradiaux sont seuls développés; les adradianx se sont ajoutés aux précédents dans le second.

Toutes les Seyphoméduses, appartenant à l’ordre des Acalèphes, présentent l'aspeet mélusaire. Les borts te leur ombrelle sont découpés en phsienrs, gínéralement quatre ou huil, lohes égaux, dits lobes marginaur, et portent assez sonvent des tentacules; la bonche est percée an centre dr la sons-ombrelle. Les hords de l'orifice huccal sont tantiot simples, lantot élirés en quatre ou luuit larges expansions, nommés lras lncccaux, parfois lislincles, ailleurs soudées. La cavilé gastrique esl divisée en ruatre larges poches cluez les formes les plus simples; inais dans d'autres cas, le mésoderme de l'ombrelle prenant un accroissement consilérable, ces proches s'étirent, et se convertissent en canaux, qui se ramifient et se disposent en un résean plus on moins complexe. Des orranes des sens, propres aux reprísentants de cel ordre, sont placés entre les lobes marginaux; ces a]prareils romplexes, comparables sans donte ì des tentacules modifiés, et nommés des rhopalies, sont an nomlire de quatre, ou de huil, rarement de donze. Dans le premier cas, ils sont situés sur le trajet des perrayons (Cuboméduses), ou sur celui des interrayons ('éroméduses); sur celui des perrayons et des interrayons dans le second type; ol eutin, dans le demier, sur les perrayons, les inlerrayons, el qualie des adrayons.

On trouve généralement huit ou seize lobes maroinaux. Comme les rhopalies sont placées entre ces lobes, et sur te plan des perrayons et des interrayons, éest-à-dire dans les échancrures marginales, it en résulte fue, dans le cas on il exisle huil lohes, ces dermiers sont tous adradiaux. Par contre. Ior'sque to hord de l'ombrelle est découpé en seize parties, les adrayons enx-mèmos deviennent des échancrures marginales, et les lobes sont alor's silués sur le trajel de seize noureaux plans de symétrie inlermédiaires à ceux léji décrils, qui sont les subrayons ( $4^{\circ}$ ordre). Ces Iraliphes montrent donc une disposition radiaire poussée à l'extrème.

La symétrie radiale les Acalèphes est cependant toute secondaire, comme le montre l'élude du développement. Les jeunes eubryons présentent, dés l'alıord, une orientation lilatérale fort nette, car ils possèlent seulement denx poches gastriques, el parfois deux tentacules; leur corps est ainsi divisé en deux farlies rógales et semblables. La symétrie ra-

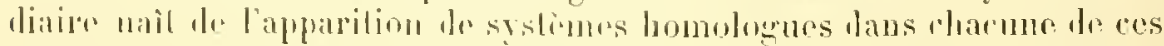
moitiés: pill la genese de deux momelles poches gastriques et de deux lentacules supplémentaires, l’organisme liblatéral est morlitié en un ètre létraradiaire. Cetle disposilion en quadrant esl conservée pår tous les 
A'aléphes, les régrions nouvelles élant toujours au nombre de yuatre, ou d'un multiple ile quatre.

Des phénomènes identiques sont présentés par les représentants les deux antres classes; l'embryon de ces derniers oftre d'abord une symétrie bilatérale, puis une structure tétraraliaire. Celle-ci persiste chez les Chónophores comme chez les Acalèphes. Il en est de même pur divers Inthozvaires (Oclactiniaires, Edwardsices, Monaulées), mais non four les antres; par l'adjonction de pieces supplémentaires anx yuatre primilives, la disposition tétraradiée est transformée en oricutation todécaradiaire. Mais celle-ci dérive de la première, qui doit être considérée comme primitive; elfe persiste, du reste, chez un certain nombre de formes actuelles, après avoir été exclusivement le caractère des formes auciennes (Tétracoralliaires).

II résulte de ce rapile exposé que le corps des Scyphoméduses est plus ou moins disposé suivant une symétrie tétraradiaire. Celle-ci se présente tonjours arec une grande nelteté chez les embryons, mème dans le cas oì elle est altérée par lar suite, el succède à une orientation bilatérale. Des dispositions semblables manquent aux autres Cuelentérés, sauf pourtant aux méduses des Ilyilrozoaires. Seulement, l'organisation en quadrant est tardive (hez ces derniires, puisyue les frolypes ne la montrent point, tandis qu'elle est primilive pour ce yui touche aux sicyphozoaires, car les polypes la possèdent loujours. Et celle des Scyphozoaires prend un caractère spécial, de ce qu'elle est due à la la genèse de cloisons gastriques, organes qui manquent aux Ilydrozoaires.

Axtumzonines. - I a plupart des représentants de cette classe sont des formes fixées. Les types libres, très rares, présentent une structure identique à celle ollerte par les premiers; ils ne diflèrent d'eux que par la modification d'une partie du corps en une cloche remplie de gaz, et servant ainsi de flotlenr (Mynjadées).

A. - Le corps, nommé colonne, est cylindrique; il adhère à mn support par une tos hases, et porte, sur l'antre, une conronne de tentacules, au centre de lanuelle est percée la bouche. Cet orifice donne accès lans le lube osophagien, qui conduil lui-mème dans me vaste cavilé gastrique, découpée sur son pourtour par des cloisons minces el larges. Celte chambre stomacale est soment désignée par l'expression de cavité mésentérique, et l'on emploie aussi le mème qualificatif pour indiquer les cloisons; ce terme devrait cependant ètre ahandonné, car celte cavité provient de l'entéron embryonnaire.

La paroi du corps est constituée, en allant de dehor's en dedins, par un épithélium ectodermipne, mo assise de mésoderme, et un ipithélimn endodermique. Les cloisons gastriques doivent ètre prises pour des saillies dépendant de la face interne de rette praroi, el n'intéressant en rien l'ectoderme; elles présentent mn axe mésonterminge, lecouvert 
par me couche d'endoderme. La paroi somatique est parfois molle; elle est souvent renforere par un réritale squelelte. Suival lenr urigine, los appendices spuelellipues apparliemneul d doux lypes: dans un eas

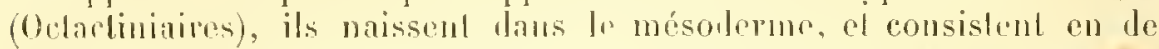
petils spicules; lans un seronel (diverses Oclacliniaines, Marréporiles), ils répondent a un produil de sécrélion ectoderminue, el par suile a une rulirule calearisér, nommée le polypier. - Ce leuxieme cas oflie luimime denx morles secontaires: le polyjicr de cerlains Inthozoaires, ol il en est ainsi pour les Tulipores, se réduit à une loge entouranl l'animal: par contre, rui de la plupart tes Marleporides porle un cerLain nombre de pieces annexes, doul les principales sont les cloisons

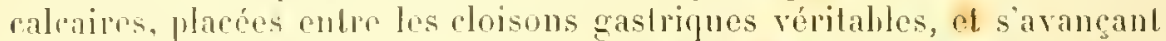
de mému dans la cavilé stomatale. Les Madréporides possiolenl done deux sontes de cluisuns: les unes dures, diles lames calcaires on calcoseples: les aulres, nommérs cloisons molles on surcoseptes, sonl consliluces par thes lissus normanx, el reconvertes par un épithélium endoderminue.

Ia disposition des roisons rst fort importante à connailre, rar, smivanl leur nombre et lem disposition, ces pioces modifient la struclure de l'uranisme. Ellus possedent toujours lasped de membranes mineos, savangant lans lonférienr le la cavilo gaslrique, el jorlant un faiscenn muculaire sur l'une on sur l'antre de leurs faces, jamais smo

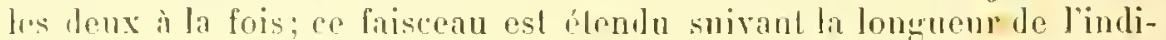
viln. Lorsque los cloisons sonl en minime quanlilé, leur parlie supérimpe so soude par son loul inlerne an lube asophagien; lem partie inlirienro reste libre. car le tule ne descend pas jusque dans la région basilaire do lanimal. si leur nombre est considéralile. les plus grandes d'entre ellos se rémissent seules ì l'ursophage.

Les espaces laissés entre lus cloisous, les loges, correspomient a tes diverlicules périphériques ule la cavité gastrique; ils sont homologurs des jochos gasliques simples, on molifices en mon lacis canaliculaire, des lealèphes. Un tentacule peribuceal est d'ordinaire placé au-ulessus de chacume d'elles. - Ces loges appratiennent à trois formes, suivat la silualion des faisceaux muscularres placés sur les cloisons; refle posilion n’ost pas irrégnlière, ni indéterminée, mais prérise el

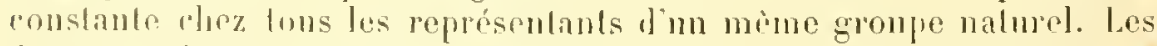
drux premières sortes le loges soul désignées, respeclivement, par les expressions exocele et endocnele; par suile, la troisiène, intermédiaine á cralles-ci, ponrait porter le nom le misocole.

Toutes los loges olaul linilóns sur les cólés par deux cloisons, el chafur chison pusscidaul un laiscean musculaire sur mo seule le ses liaces, les endoceles sonl des loges dont les faces cloisonuaires limilantes

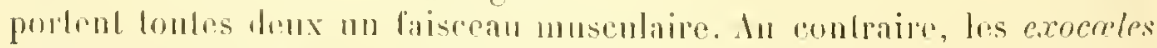
corpespondent i los loges, dont les fares roisonnaires limilanles sont privées le linismanx smomblables. Entin, les mesoceles sont des loges, 
dont une seule des faces cloisonnaires limitantes est ponrwe d'une bande musculaire longitudinale. Ces trois types sont répartis chez les serphozoaires de façon fort réçuliere, el il suffit de parcourir la série des ordres, en allant des plus simples aux plus complexes, pour s'en apercevoir.

B. - Les plus simples des Antlozoaires appartiennent an groupe des Alcyonaires (encore nommés Octactiniaires) et des Edwardsiees; dans les deux cas en effet, les adultes possèdent seulement huit cloisons, el cc nombre est le plus pelit qüil soit possible de trouver chez les représentants actuels de la classe. Les cloisons étant séparées les unes des autres par des distances semlılables, les loges sont forcément égales entre elles; lit disposition tétraradiaire, puiśpue huit est un multiple de quatre, est done ici fort évidente; mais l'organisme offre cependant un vestige de symétrie lilatérale. Deux des huit loges, diamétralement opposées l'une à l'autre, appartiennent à un mème type, tout en lifl'érant de leurs roisines, ef divisent ainsi le corps en deux parties identiques; de plus, en regard te chacune de ces deux loges, le tube asophagien présente une dépression longitudinale, nommée la goullière cesophagienne. Én somme, tout en étant rayonné comme apparence, le corps est bilatéral, la lisposition raliaire étant venue s'ajonter à l'orientation bilatérale primilive. Et la persistance de cette dernière conduit à grouper ainsi les huit loges le l'adulte: une loge impaire antérieure, trois paires de loges latérales, et une logre impaire postérienre. Les deux loges impaires sont semblalles entre elles.

Malgré ces ressemblances étroites touchant à la distribution des parties homologues, les Alcronaires et les Ellwardsiées diffèrent sous le rapport du type des loges. Chez les premiers (Alcyonaires), la loge impaire antérieure est un endocule, la loge impaire postérieure un exocœe, el les trois paires de loges latérales des mésocceles. Il n'en est point ainsi chez les Edwardsiées, dont les deux loges impaires sont des exocules, les loges latérales de la premièro, et de la seconde paire, des mésocales; celles le la troisième paire correspondent à des endocoles.

Le type des Aleyonaires est unique lans la nature achelle, et ne suluit aucune modificalion. II n'en est point ainsi pour celui des Eswarlsiées, qui pent èlre considéré comme le point de départ les dispositions offertes par les autres Anthozoaires. Les principaux groupes de ces derniers sont: les Cronactiniées, les Honanlees, Ies Cérianthidées et les Zounthaires. Les recherches, effectuées récemment sur ce sujet, permettent de rattacher aisément leur structure à celle, plus simple, des Edwardsiées.

Les Monaulées possèdent quatorze cloisons et, par suite, quatorze loges; six nouvelles chambres gastriques, gronpées en trois paires latérales et symétriques, sont donc vennes śajouter anx précédentes. Pour cela, les trois paires latérales primitives se sont subdivisées, de 
manière i former six paires. Ces animaux oflrent done: me loge (exocule) antéricure el imprire, six paires de loges latérales, et une loge (exocule) postérieure ul impaire. Les loges latérales sont alternativement des endreules et des rexoreles, la premiere élant un endocule; sauf la sixjème, qui correspont ì un mésocule.

Les Gonactiniées prósentenl seizo loges: nn exocole antérieur et impair, mn exocole postiricur el impair, el sepl paires le loges lalérales; d'où quatre paires de loges supplémentaires ajoulées aux trois paires primitives. l'our arriver a ce hul, chacme des loges primitives de la premire paire contient deux nouvelles cloisons, el charme des loges, apuartenant i la seronde el a la troisieme paire, renferme une cloison supplénentaire. l'armi les sept loges latérales, la première el la seplieme sont des mésocieles, les antres élant alternativenent des endoculdes al des rxocules.

Les phénomènes sont relativenent plus simples chez les Cérianthilées, bien yne le nombre des cloisons soil considérable. Toutes les cloisons de nouvelle formation sont, en effel, placées dans l'exocole antérienr et impajr; les sejt autres logges primitives ne subissent ancume modilication. Les loges, ainsi dilimitérs par ces choisons supplémentairrs, sont lontes des mésocutes, sanf l'antéricure médiane, qui correspond a un exocule, fout comme la cavité primitive dont elle u'est yu'me minime partic.

Les Zom hathes sont caractérisés par le fail de la substitution t'une symétrie dodécaradiaire au grompement par yuadrant et par vetant. Qualre loges s'ajoutent en eftet aux huit premieres, pour parfairo le chilfre touze, yui ast alors le point de départ d'une nouvelle dispesilion organique. Les quatre nourelles cloisons, nécessaires à la frubluclion de ces lozes supplémentaires, naissent symétriquement, el far paires, dans deux des paires de loges prinitives. Londividu, mumi de douze cloisons, présente : un exocale antérieur el médian, un exocuele postériem al médian, el cinq praires de loges latírales symétriques. La première et la cinquiène de ces dernières sonl les mésocueles, la seconde et la quatrieme des endocorles, les deux loges de la troisieme paire cormspondrnt a des exocoles.

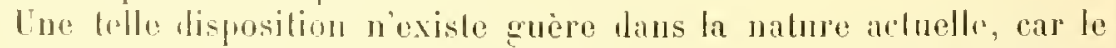

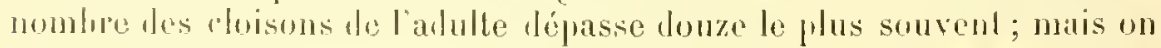
la retronve tunjour's dans les phases du developpement, oì elle sncede

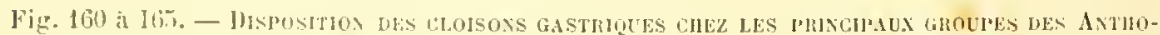

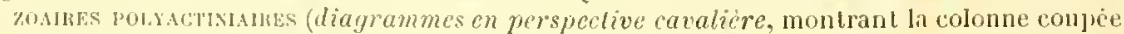
transversalemenl, it une certaine hateur, alin de presenter les eloisons). - lin lin, type

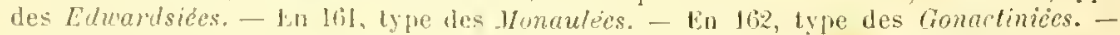
Lin 163, lype des cerianthides. - En lo4, type des zoanthines. - lin los, type des ditiniles, pris a une plase oil le prenter cycle res melasefrtes secondaires est seul developine.

les protoseptes, les leutoseptrs. fos metaseptes primailes, sont designees frar lenrs numeros d'ordre respectifs. 
SCWPIIOZO. $118 \mathrm{E}$
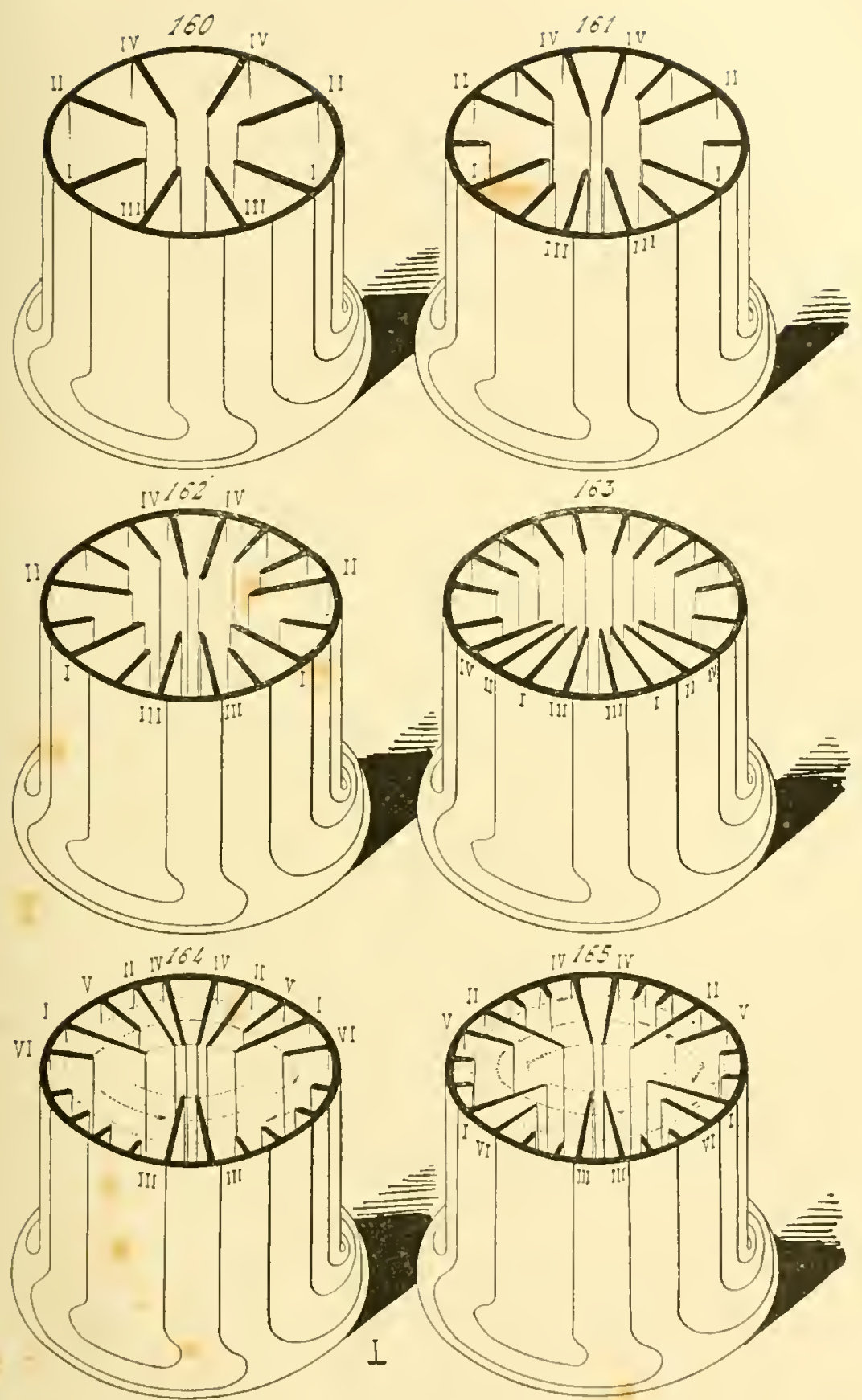

ligh. Ifill is 16i.j. 
ì relle caraclórise par la prisence de luil doisons, semblables à leurs homologues des Edwardsiés. Les cloisons supplementaires sunt siluées

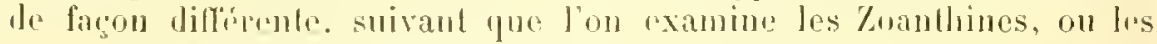
autres rejrésentants du groupe.

Les nouvelles cloisons des \%oanthines sont foules placées dans les deux loges mósoculiques de la cinquieme paire; leurs faisceaux musculaires sont arrangús de façun "que los loges, lélimitées par elles, soient alleruativoment des exnenes el des endocules. Il n'en est point ainsi jour les autres \%onuthaires (Actinides et Madréporides); lenrs cluisons supplementairss naisent riguliopement, deux par denx, sur loule la lace intreme le la ravio gastripue, smivant un mode précis qui sera áudic plus loin; elles sont ainsi groupérs en cycles déterminés. De plus, elles se lrourent disposíes de lelle facon, que la loge, comprise entre doux d'entre elles appartenant ì un uème cycle, soil constamment un endocule.

C. - Si l'on résume lons ces délails d'oreanisalion, en remontant du simple au complexe, on s’apercoit yue les Inthozoaires, semblalues en iela aux Acabephes, offrent la trace évilente d'une symétie hilatérale primitirn, accusée par l'aspect les deux loges impaires et médianes. Une lisposition lébrantiaire el octaradiare se présente ensuite; elle existe seulo clez un rertain nombre de groupes, frami lesquels les Alcyonaires el hes Eitwarlsiées sont les plus importants. Enfin, par ladjonclion de qualre nouvellos loges aux huit primilives, lorganisme devient dodécaradiaire, ol reste ainsi rloc tous les \%oanllaires. La slructure radiée de cos derniers est donc parvenue ì un plus haul degré de conplexilé que celle des autres Anthozoaires.

Langmentalion du nombre des choisons, suivant des regles anssi précises, a mesure fue lon romonte la série des Anthozoaires achuels, est des plus remarquables; elle concorde, en sa marche, el comme on le verra plus loin, arec celle olservée dans l'embryogénir des Anthozoaires les phus élevés. Un court rósumé des notions prócódentes sera utile pour linen metlre en lumiere celle concorlance, a la condition de se servir des termes employés daus l'étude du développement.

Les Acalèphes et les Cónophores possoulent seulement qualre cloisons "lans leur organisme; ce chilfre se montre également chez les embryous des Anflozoaires, au comrs de phases encore peu avancées, d devient plus grand par la suite. Ces cloisons sont les premieres produites, ef moritent le non de protoseptes. - Les Octactiniaires et les Edwardsiées présentent luit abous; puatre nouvelles pièces existent en sus des précédenles: ro sont les denloseples. Ces otres sont ainsi munis de huil

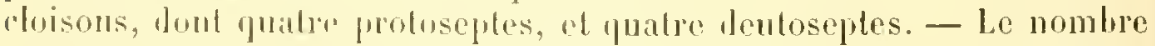
de ces organes est plus considerable encore chez les Polyachiniares iulres yue les lidwardsiese; res appendices supplámentaires seront dits tes mélaseptes. La disposition le ces derniters ne prôle à aucune observa- 
tion particulière pour les Monaulées, les Gonactiniées, les Cérianthidées, et les Zoanthines; mais non pour les Actinides et les Vadréporides. Les métaseptes de ceux-ci appartiennent à leux lypes. Les quatre premières d'entre elles, c'est-à-dire les quatre naissant en premier lien, se comportent en tout, dans leur's procédés génétiques el dans leur disposition, comme les protoseptes et les deutoseptes; clles sont des métaseptes primaires. Les autres, beancoup plus nombreuses que les précédentes, de chiffre variable suivantles gentes, et dites metaseptes secondaires, affectent un arrangement, et offrent nne origine, que les métaseptes primaires n'ont pas. Les protoseptes, les deutoseptes, et les métaseptes primaires naissent par paires chez l'embryon; denx d'entre elles, placées de part et d’antre de la ligne médiane, apparaissent en mème temps pour donner une paire. Les métaseptes secondaires se produisent par couples; les deux formées en mème temps sont juxtaposées, et ne restent séparées que par un étroit espace. - L'ensemble des protoseptes, des deutoseptes et des métaseptes primajres, c'est-ä-lire des premieres cloisons faconnées chez l'embryon des Actinides et des Madréporides, se dispose en un cercle autour de la cavilé gastrique; ce cercle est nommé la courome. Cet ensemble comprend douze cloisons, ainsi disposées : quatre protoseptes, quatre dentoseptes et quatre métaseptes primaires. Les métaseptes secondaires apparaissent en plusieurs fois: tous les couples, cugendrós en mème temps, dessinent également un cercle autour de la cavité gastrijue; la totalité des conples d'un mème àge est dite un cycle. Comme ces cloisous se montrent à diver's intervalles, phusieur's cycles se délimitent ainsi, se mélangent entre eux, et se comlinent avec la couroune, pour lonner un amas cloisonnaire multiple el confus, bien quétabli suivant les lois précises et rézulières.

Afin de se reconnaitre parmiles loges et les cloisons, on les numérote souvent. Les cloisons sont désignées par des chilfres romains; on les énnmère d’après leur ordre l’apparition chez l'enbryon, et on ne désigne ainsi que les paires, les deux éléments de chaque paire étant identiques sous tous les rapports. On ne compte séparément que les cloisons de la comronne, car il est imutile d"agir de mème prour" celles des cycles, à canse de leur genèse simultanée en grand nombre, et par conjles; il suftit, dans ce dernier cas, de connaitre le rang du cyele par rapport a ceux qui le précedent, et ì ceux yui lesuivent. - Ainsi, jarmi les touze cloisons te la conronne, les qualre protoseptes sont nugendrées les promières : leur's deux paires portent les mméros I ot II. P'our la mìme raison, les paires des dentoseptes possedent les chithres III et IV, et celles des métaseptes primaires les chiffres V et V\%. - Le besoin de numéroter les loges est moins grant que celui relatif anx cloisons, calr ces dernirres donnent des renseiguenents suffisant sur la positiondes loges qu'elles encadrent. Cependant, on les énumere parfois, en les désignant pirr des chiffres arabes, l'après leur position en partant de la lignne médiane antérieure, et allant ver's la ligne médiane postérienre. Lal loge 
impare antricure, of la loge impaire postériemre elant sulfisamment raraclérisées par lur emplacemenl, sont mises ì part lans celte sérialion, el n'y complent puint.

CTExomores. - Tons les Cinophores sont les animanx libres, an corps transparent, et an mésoulump épaissi. Leur lorme n'est cependant pas celle l'une méduse; lenr aspeel, varialle suivant les familles, est plutôl celui d’un glolie, ou d'une lame; les tentacules manquent parfois, ou sont en potit nombre (deux) lorspüils existent; enfin, des appareils focomoleurs, meposentes par hoil rangres de pelites paletles, of dont les méduses sont privées, ne lump font jamais dílaul.

La disposition organique semble différer de celle des aulres Seypliozoaires, surtoul rn ce qui lomshe lappareil digestil, mais s'y laisse cependant raltacher avec assez de farilite. Le tulue osophagien, long ef large, ne flolle pas dans la cavitá gastripur, car ses parois épaissies sont soudées à celles lu corps; celte derniere parlicularité est offerte par divers Anlhozoaires. mais y est cependant moins accentuée. Commo le montre l'élude du développenent, ce lube est produit far une dépression de la paroi du corps, a l'exemple de son homologue les Inlhozoaires et des Seyphoméduses; il doil done porter le mème nom, puisquil posserle la mème origine ot les mèmes rapporls, of il ne faut pas le désigner, contrairement ì ce que l'on lait souvent, par l'expression de "tube grstrique. „- La cavité gastrique véritahle, qui lórive de J'entérou embryonatre, présente deux diverticules diamétratrment opposés, semblahles à des canaux courts et Jarges, et ramifiés en deux branches divergenles; celles-ci sc partagent elles-mimes, apres un court trajet, en deux nouvelles farlies. Les diverticules gastriques rappellent donc, par leur disposilion, les combuls émis par l'estomac de livers Acalèphes, el se fraienl de mème un passage à travers le mésoderme compact de la paroi du corps. Senlement, le nombre des rameaux est plus pelit chrz les Clénophores que chez les Scyphoucduses, puisquil est égal à huit; il ne dépasse jamais re chitlpe. Fin outre, chacun d'eux souve dans un canal, qui fail défaul aux Acalophes, placé au-dessous de chacune des huit rangées le paletles. La cavilé gastrique communique arec l'extérienr, non seulument far l'entremise du tube usophangen, mais par colle te leux pelits conduils, qui vont se rendre au lehors, dans mo région diamélralement opposée à la lıouche; celte région est fréquemmont nommée anale, on apicale, à cause de cetle palicularilé.

Malgré ces ditlérences, l'lomologie du lube digoslif des Clénophores, et do celui des antres serphozonires, est indisculable. Tous deux sont en etlel formés de dux jarlies, nn lule asophagien et une cavile gaslripure; Lous denx portent, dans celle derniere cavilé, une cerlaine quanlile de choisons; semlemont, les cloisons les Cténophores sonl larges, f́passes, of converlissenl, en cananx ranifiés, les loges interposées. Ce raractere nótahlil pas, mutre ces aniuaux, et lenrs voisins des antres 


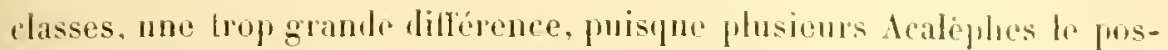
sidlent anssi. - En allant an fonl des choses, los seuls wotails oreraniques, propres aux Clinopliores, louchent aux paletles nalatoiles, of it la présence des onverlures anales; olles ne suftiscut fras, cependant, pour masquer les homologies principales. Et, m rerlu de ces rossenlilances, il comvient de lésigner le tube gastrique, ef lentonnoir des Cténophores, par los noms déjà employés pour les autres Scyplıozoaires, c'est-à-rlire par ceux de tulue msophagren, el de cavité gastrique ou stomacale.

Les Clénophores ont lenrs organes orientés, à la fois, suivant une symétric bilatérale et une symétrie radiaire; ils ne diflèrent point, sous ce nouveau rapporl, des deux classes précédentes. Laxe, qui passe entre les deux onvertures anales et par le centre de la lonche, esl l'axe longitudinal. Le rorps présente en ontre deux autres axes l'oriontation, transverses et perpendiculares an premier; l'un, l'axe sagillal, est parallele au plan de la cavilé gaslrique et du tube asophagien, aplatis tons les deux dans la majorité des cas; l'aulre, l'ax'e transnersal, est perpendiculaire a ce mine plan. Il résulte de cetto disposilion que l'axe sagillal est aussi perpemliculaire a laxe transversal. En faisant passer un plan par lase longiludiual du corps, el par chacune de ces dernières lignes de symétrie, on ohtient deux plans perpendiculaires l'un à l'autre, le plan sugittal et le plan transversal, qui se coupent vers le milien du corps suivant l'axe longitudinal. Ces deux plans déterminent l’orientalion des organes rhez les Clénophores.

Chacun de ces plans partage le corps en denx moitiés symétriques, et prounit ainsi une disposition bilatérale. De plus, étant perpendiculaires l'un à l'autre, ils divisent l'individu en qualre quadrants symótriques : d'où une disposition radiaire. Chaque segment contient ileus canaux longitudinamx, et porte demx rangées de paletles; comme ces appareils sont allongés parallelement a l'axe longrilulinal du corps, on les lésigne par les expressions de canaux meriliens, ot de rungres méritiemes. Dans un quadrant détermine, le canal móridien le plus proche th plan sagillal ast dit sub-sagittal, el sub-transwersal le plus proche du plan transwersal. les noms semblables sont employés pour les bandes des patelles méridiennes : chacun des puadranls est muni d'une rangée sulu-sagitule, of d"une rangéo sub-transurpsale.

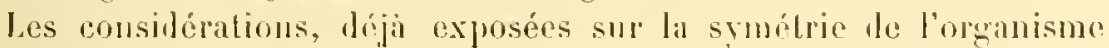
chez les Scyphomédnses et lis Anthozoaires, sont dome enliciencut ipplicables aux Ctónophores.

111. Développement en général. - lo diveloppemont des

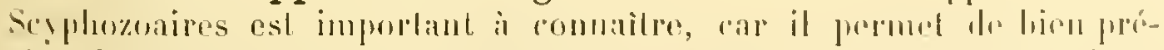

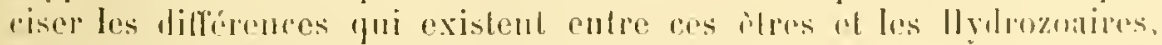

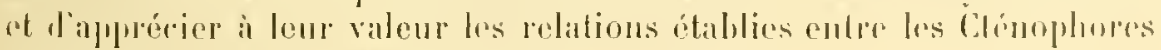
ol les deux antres edasses do l'embranclument. 
Développenents sexcés. - Les embryogrinies dilatées, ponrvues d'une phase hlashulare, sont rares; la plupart les Sryphozoaipes, nolammont les Anthozoaires ot les Cténophores, érolurnt suivant un morle condensé. Elles existent cependaut chez plusienrs représenlants des deux premiers groupes; daus ce ras, une gastrule succide à la blastule. Cette gastrule est produile par invagination. Sa paroi se compose des denx fenillets blastodermiques primorliaux, te protecloulenue et le probudorlerme.
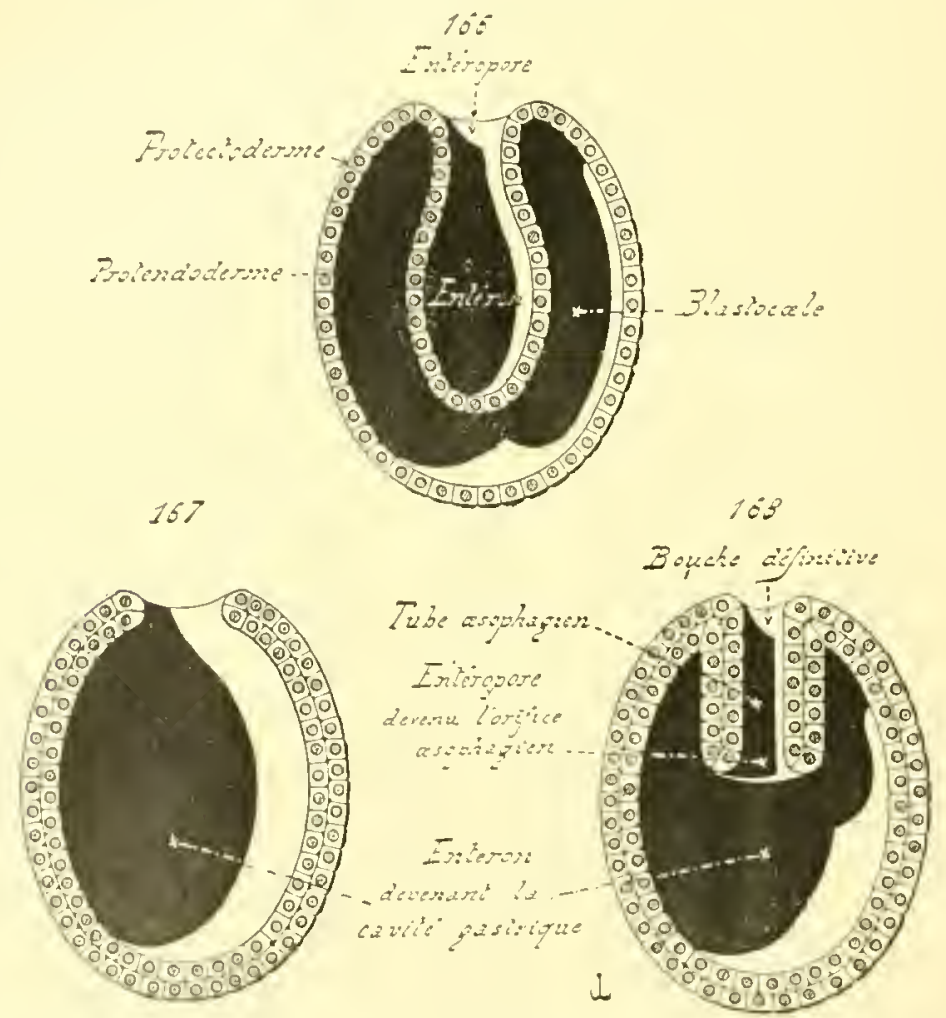

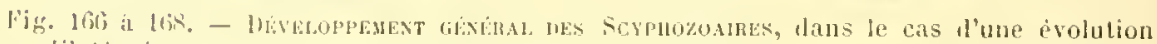

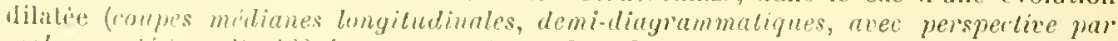

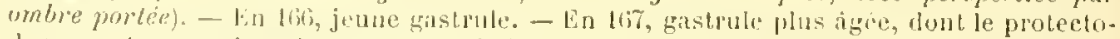
derme est venus siterolur au protentorlerme. - lin lis, embyon plus avance, ayant produit son lule a:sophagien par l'inlléchissement les borls de son entiropore.

Co dernier limile l'mulóron, el horne son röle ì persister comme endoderme délinilit; anssi, pour plus de simplicité, est-il permis de lui donner, diss le débul, re dermier nom. Ie protectorlerme est plus important; il engendre le mósoleme par sa litce protonde, le place ainsi entre lui el l'embulermo, puis se conserve it son tour comme ectoderme définilif. l'ar les mèmes raisons que puécédemment, et à cause de limprorlance 
relativement restreinte du feuillet moyen, on peut accorder au protectoderme, dès son apparition. le nom d'ectoderme, en le prenant pour ce quil doit derenir.

Lorsque la gastrule est complète, c'est-ídire lorsque son enléron est déjà assez ample, l'organisne de l'embryon se réduil à cette carité, qui communique avec le dehors par l'enteropore, et à sa paroi formée par l'ectoderme et l'endoderme. Ces denx feuillets sont W'ahordapplípués l'un contre l'autre; puis le mésolerme nait, sous la forme d'une mince lamelle, et les sépare en se plaçant entre eux. Les cellules ectodermiques se revêtent de cils viluratiles, l'entéropore se retrécit peu à peu, et se ferme, du moins dans la plupart des cas; la larve, ainsi convertie en une sphère creuse, nage an moyen de ses cils.

Lorsque l'embryogénie est condensée, la morule se transforme en une planule compracte. Les blastomères périphériques de cette planule se disposent en une couche ectodermique; puis la cavité entérique se ereuse dans la masse des blastomères internes. Comme l'entéron s'amplifie d'une façon croissante, ces derniers sont peu à peu reponssés vers la périphérie, sétalent au-lessous de l'ectoderne, et s'y rassemblent en une assise continne, qui est l'endoderme. Les éléments ectodermiques se couvrent de cils vibratiles, et, de mème que précédemment, l'embryon offre l'aspect l'une sphère creuse, d'une vésicule, lont la paroi est constituée par deux rangées de cellules : l'ectoderme cu dehors, l'endoderme en dedans. L'entéron devient la cavilé gastrique.

Quel que soit le procélé suivi, lorsque les larves lihıes des Seyphozoaires sont parvenues a celte phase vésiculaire, une dépression de la paroi du corps se manifeste sur l'une des extrémités de l'embryon: celte dépression, cylindrique, s’enfonce dians la chanblue entérique, et y débonche prar un orifice, percé dans sa région profonde; elle prorluit l'ébauche du tube asophagien. Ensuite, des saillies longitudinales, au nombre de deux d'abord, de quatre ensuite, apparaissent sur la face interne de la jaroi du corjes; elles s’avancent dans la cavité gastrique, et représentent les rudiments des premières doisons. Chacune de res saillies est constituće par un repli de l'endoderme, dans laxe duynel s'étend une mince lamelle de mésollerme.

Cette forme embryonnaire, ainsi fitte, existe an début dn développement de tous les Scyphozoaires. Il est permis de lui domer lo nom de Scyphula; par opposition au termo Iydmelu, employé pour désigmer la larve typique des Hydrozoaires.

La Scyphute sulut des modifications diverses, varialıles suivant les classes, el mème suivant les orlres d'une mème classe; mais elle n'en existo pas moins an délut de tontes les évolutions embryonnaires, où clle succede a la phase vésiculaire. Il est utile de suive ses transtromitions daus chacune des chasses de l'embranchement.

Ces changenents ont pour effet de dunner a la serphule l'alspect 


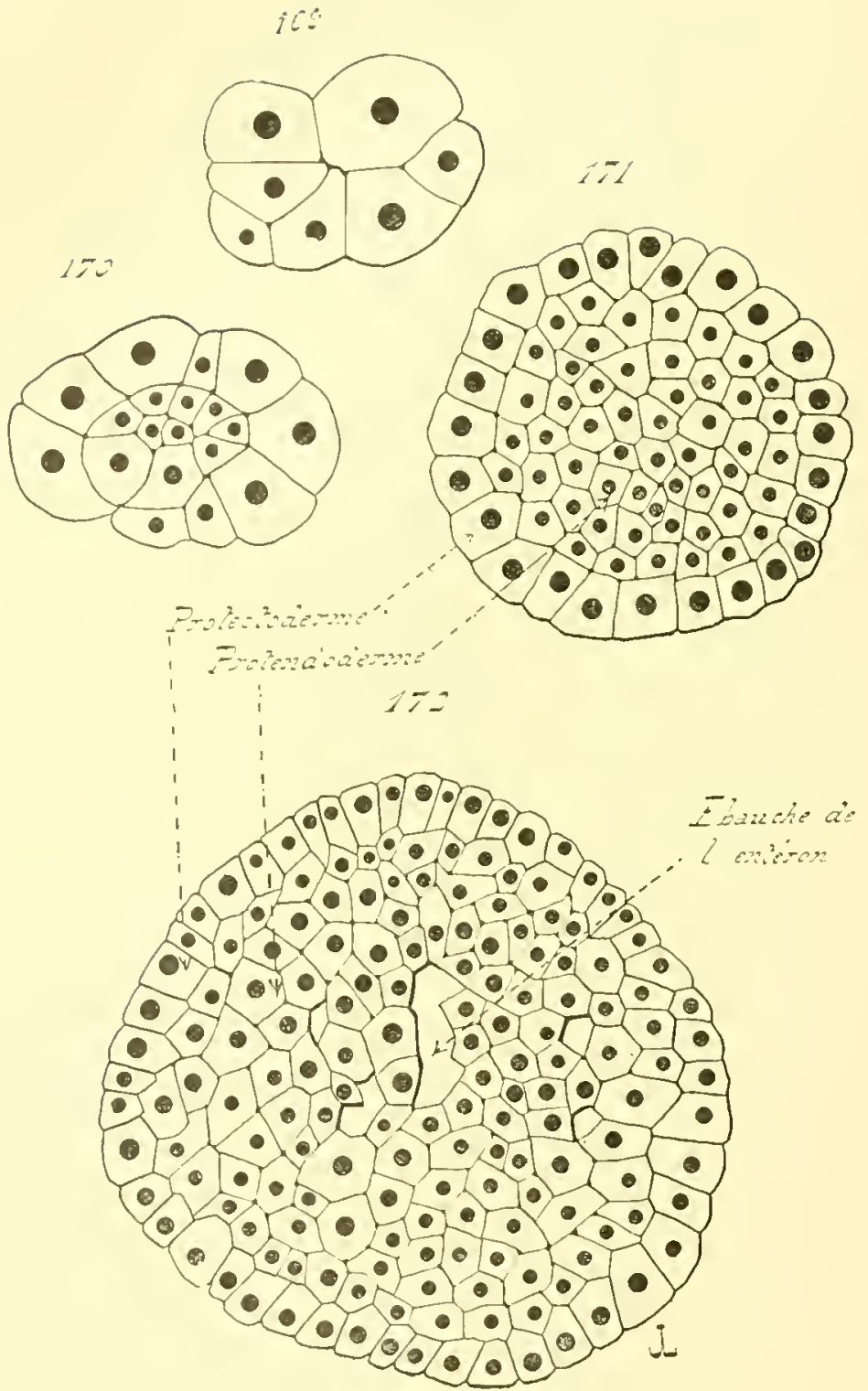

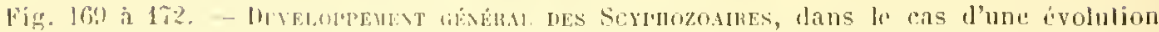

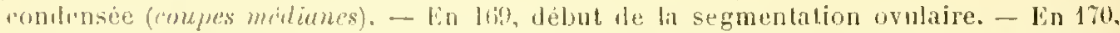
jome moruta. - lin 17\%. jeune planule. forme direetement, aux depens de la morule,

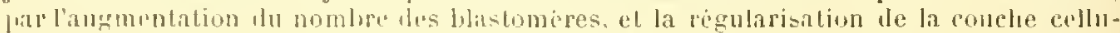

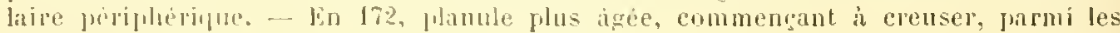

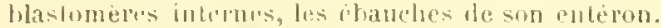

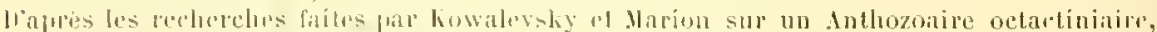

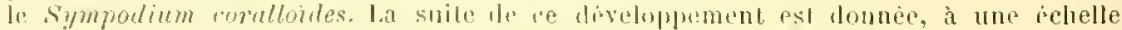

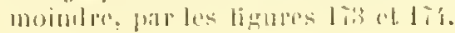


parliculier de l'adulle. Aussi, snivant la elasse, erlle lane se trans-

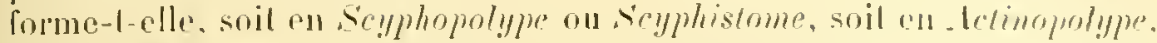

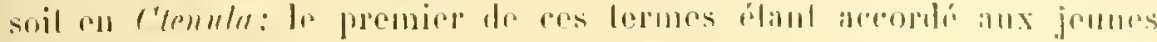
serploméduses, te second aux jeunes Anthozoaires, el te denicr amx jeunes Clénophores.

Scyphoméduses. - Les phases du développement des scyphomóduses ne sont guire comnues que clez les représentants de la sous-classe des Aealephes.

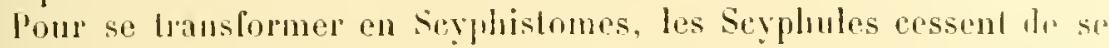
déplarer, et ront alliérer, à

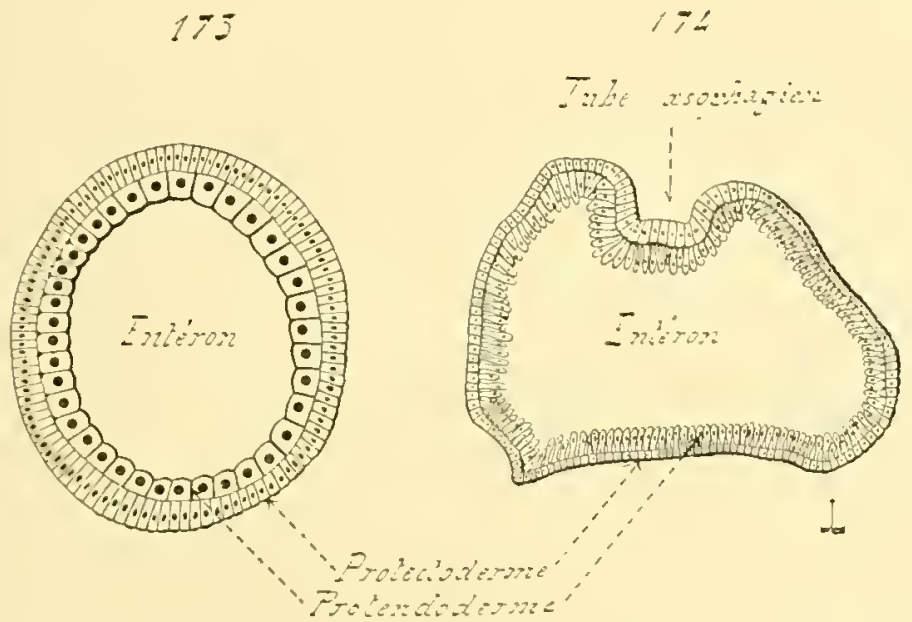

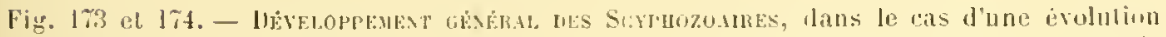
contensee (coupes médiunes). - Vin 173, larve à la plase visiculinire, issue d"unc planule

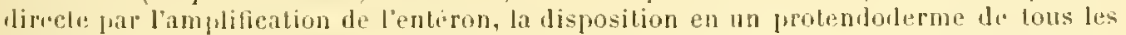
blastomeres internes, et la delimitition en un protectoderme de tous les blastomipus périphiripues. - En lík, embryon trés araneè, produisant son tube nesophagicu, et atteignant ainsi une phase semblable a celle reprèsentèe, pour les evolutions dilatées, dans la figure lok; afin d'y arriver, le fond du tube n'a qu“a se pereer de l'orilice u'sophaqien.

liapris les recherehes faites par liowalevsky et Marion sur un Inthozoaire betaetiniaire. le sympotium coralloüles. Le debut de ce developpentul est donne, a une échelle

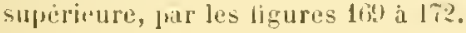

opposée i l'éhauche du Luhr msophagren. Denx poches gastripues

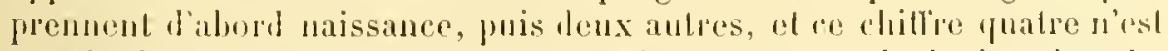
jamais dépassé; Jes lentarules apparaissent aulour de ha houchr. La?

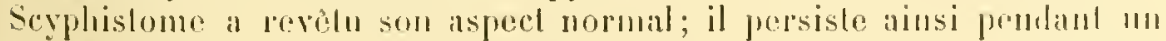

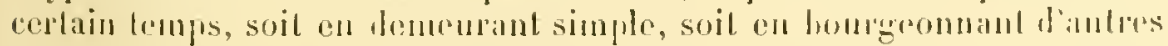
indivilus semblables a ha. Il lui faul ensule se lranslonruer an méduse.

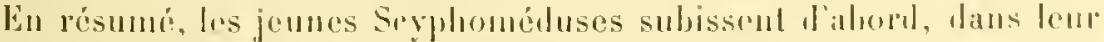

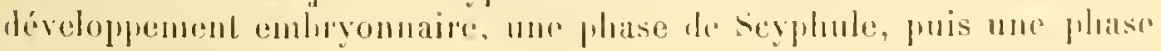


de Scyphistome. - Les Lucernaires et les Tesseridées en restent sans doute ì ce point. Les deatephes vont phus foin, car te seyphistome se convertit en mne jeune méduse pen complexe, dite Eplypra; les Ephypopsis ne poussent pas davantage teur ćvolution, contrairement aux aulres dealiphes, qui compliquent encore leur structure. La modification du scyphistome en Ephyre s'effectue suivant deux procédés : ou l,ien le colps du Scyphistome, loujours fixé dans ce cas (Ju moins d'après les obscrvations acquises), se divise en un certain nombre de segments, qui deviennent autant de pretites méduses; ou bien le corps ne se partage point, of se change tout entier cn une Ephyre. Dans ce dernier cas, lanliot la larve est fixće parfois (A urelia amita), et tantôt clle est libre (Pelagia.)

Anthozoaires. - Les larves de ces animaux, après avoir produit lenrs deux feniltets principanx, s’atlachent à un corps étranger. Elles prenont la forme cylindripue propre ì l'adulte, el engendrent leurs coisuns arec leurs lentacules; deux cloisons naissent d'ahorl, of deux un peu phus larl. Le chiffre quatre élant alteint, les jeunes embryons soul parvenus í la phase seyphulu. Lin cet étal, ils offrent l'aspeel de petils atres, fixés par une de leurs extrémités, munis d'une cavité gastrique renlermanl un tube asophagien avec puatre cloisons, et possédant parfois quelques tentacules périluccaux, bien que ces appendices soient d'ordinaire façonnés plus tardivement. La Scyphule se modifie en Anthopulye, par l'augmentation des cloisons en quanlité, suivant los règles ed dims les limites précédemment exposées, et aussi par l'apparilion dr trutarules, dont le nomhro est égal à celui des loges.

Les diffŕrences avec les scyphoméduses sonl, sous ce rapport, faciles it préciser. Le Sexphistome possède seulement fuatre cloisons avec 'fualre loges gastriques. et porte un chiffre de tentacules péribuccaux de

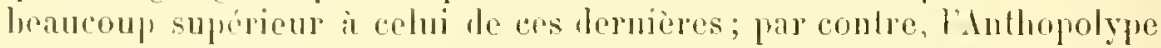
renfrrme toujours huil doisons an moins, avee huit loges gastriques, "l prísente mo nombre le tentacules ígal à relui des loges. Lorganisme J'un. Scyphoméduse est done basé sum la présence ronstante les quatre cloisons primitives, alor's que celui d'un Lnthozoaire est caractérisé par Io chiffro fus élevéde ces appendiecs internes. En outre, le sepphistome so converlil souvent en une méduse, alors que de semblaliles changemouls ne so manifestent jamais chez les Anthozoaires.

Ctinophores. - Ces animaux sont toujours libres, et, hien que s'ayant point de ríriathle forme módusaire, l’épaisseur de leur mésoderme, el la transparence de teur corps, four domnent une certaine resstullance arec les toalephes. Lemp divotoppement esl abringi, el leurs larves ne so tixent jamais. Ia phase Soyphulaire est atteinte do bonne lumpe, car le lube osophagien prend hativement naissance, lout comme les qualre iloisons gastriques; ces dernieres sunt larges, s'avancent presifue jusquan centre de la cavilé entérique, el la découjent en 
quatre poches. - lans certains cas même, les phénomènes embryonmaires chant condensís an possible, lendoderme entior est représouté par une masse cellulaire compacte, qui se divise en quatre parties répontant aux loges; après puoi s'organisent, aux dépens tes cellules même de l’endoderme, les parois latérales de ces loges, c’est-à-dire les qualre cloisons.

La phase Scyphule se manifeste, d'ordinaire, dans l'intérieur des membranes ovulaires; un élat larvaire Jibre, propre aux Clénophores, et powrant ètre désigné sous le nom de Clenulu, Iui succède. Les cloisons gastriques devienuent llès épaisses, à la suite de l'accroissenent exagéré pris par la substance de leur mésoderme; la cavité entériłue, d'abord raste et munie de quatre poches latérales, se modifie en un espace étroit, pourvu de quatre petils diverticules cylindriques; elle commence à présenter J'aspect de l'appareil digestif de l'adulte. Les parois du luhe asoplagien se soudent à la paroi du corps, cette cohésion élant amenée par l’épaississement du mésoderme. Les huit canaux longitudinaux, ou canaux méridiens, font leur apparition; un pelit nomlre de paletles uatatoires naissent au-dessus d'eux, dans la région anale de l’individu. Cetle deruicre présente déjà un organe sensitif assez. dóvelopjé, et porte souvent denx lentacules. Colle lave C'tenula, ainsi constituée, nage au moyen le ses pralettes, et se transforme peu à jeu, durant celte vie libre, en adulte.

La phase embromnaire, antérieure à la Ctenula, correspond à l'élat Seyphulaire des autres classes, puisqu elle est caractérisée, de nème, par Ia présence d'un tube usophagien, et jar la possession de yuatre poches gastriques, séparées par des clojsons. Par contre, la Ćlenula est spéciale aux Clénophores; elle dillère beaucoup de l'Anthopolype et du Scyphistome. Ses particularités tiennent à la disposilion de sa cavilé gastrinue, ¡ui commence à levitir la structure de celle de Jabulte, à l'existence frépuente de deux tenlacules, a celle d'un olgane sensitif jmpair dans la région anale, enfin à la présence de lunil courtes rangées de paletles natatoires. Celle larve évolue directement en adulte, sans oflrir aucun plínoméne de tissijarité.

En somme, tous les Scyphozoaires présentent, au début de leur évolution larvaire, un étal Scyphulaire phus ou moins bien marqué, mais loujours caracterise par la genese d'un tube asoplagien ol le quatre cloisons gastrijues. Ensuite, interviennent les diflérences, car les roprésentauts le chacune des trois classes subissent des phases particuliçes pour compléter leur organisme : les Scyphomeduses passeut par la forme le Scyphistome, les Anthozoaires par celle d'A mhopolype, et les Cténophores jar celle de C'tenula.

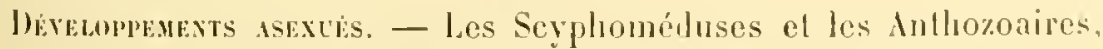

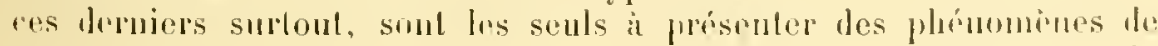
reproduction asexuéc. Cos phénomenes liennent a la lissiparité on à la 
gemmiparié, ces modes existant fous deux dans chacume des classes jécitées.

Le dévelopyement asexué n'est oflert, diez les seyphomóduses, que far les Scyphistomes tixés, du moins dans l'état actuel de nos comaissances; l'une des formes emluromuares des drabples est donc rapable de se reproduire ainsi, alors que l’indivilu délinilif, à l'aspect médusaire, est privé le celte faculté. La grmmiparilé semble ètre le cas le plus fréquent: un Seyphistome détromine, provenant d'une lare, engendre par bourgeonnement de nourranx itres semblables ì lui. Ces derniers demenrent adhérents à leur générateur jendant mn cortain laps de temps, juis se séparent de lui. Il se produit donc. an moins d'une facon momentanée, une colonie aux zooilles peu nombreux, ceux-ei étant semblables entre enx, et au zoiln primitif. Comme les procédés générateurs lu zoïte et des zooïdes sont diflérents, le memier provenant d'un aruf, el les autres de lourgeons, il existe donc, chez les scyphopolypes, une alternance de génération, une mílagenese gremmipare el holomorphe.

La lissifarite parait ctre plus rare; du reste, son alisence ou sa présence sonl sujetles à des rariations accilentelles, dont la cause remonte peut-être à des lilréronces de nulrition. Dans certains eas, le Scyphojolye, au lieu de se transformer toul enticr en une jeune méduse du lye Ephyre, se divise transversaloment en trongons, qui se séparent les uns des autres, et deviement autant de méduses. Chaque segment frésente, au début, la structure du Seyphistome primilif, ou peu s'en faut; la mélagnenose est done également holomorphe. Mais, avant yue la sóparalion ne se soil eflectuće, chacun deux commence déjà il se converlio en Epliyre; et, an moment de la disjonction, les nouveaux zooïles sont dillérents du polype qui les a engemdrés. - Lalternance parait lonc otre hétéromonplie, et c'est amsi que la consilerent les auteurs, bien qu'clle corresponde à une segmentation, dans laquelle les descendants noditient hativement lenr organisme, en lui donnant l'aspect auquel le générateur serait farvenu, sil ne s'élait fras divisé. los auteurs accomlent le nom de strobile au scyphistome ansi fissiparisé.

La žemmiparité et la fissiparité sont très répandues chez les Anthozoanires; smrtout le pronicr de ces procédés, que présentent mormalenent le plus grand nomlore des Oetactiniabes, et la plupart des Marréporides. Les zooides engendres sont, dans la regle, semblables culde enx of au zölte primitif; hes dillérences signalécs partois sont peu importantes, el liennent presifue fonjours au rabougrissement de quelines individus, qui ne farviement pas a atteindre lélat parfait. Ja mélagenese des Anthozoaires est don hulonorplie, comme celle des Scyphopolypes

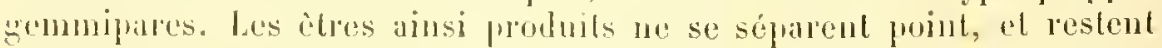
adlérents les mos anx antres; lowr ansemble constilue mor colonic, toujom's composé le nombreux zoojdes, et dont la forme demenre sourent comstante parmi les représentauls d'un mène groupe. 
La tissiparite, ptus rare, n’a guere été signafée que chez divers Zoanthaires; elle ne ressemble en rien a celle des seyphopolypes, car elle est fongiludinale au lieu d'òtre lransversate, el se manifeste toujours chez tous les individus appartenant à me espece déterminér, an liru d'itre accidentelle, ou de faire prafois ledaut. De plus, les zooides sunt semblables entre eux, et sourent ne se séparent point; ils restent unis en une colonie, dont l'aspect général dillère pen, parfois, de celui quoffrenl les colonies issues des développenents gemmifares.

IV. Glassification des Scyphozoaires. - L embrancliement des Scypliozoaires comprend trois classes: los Scyphomeduses. les Aulhozoaires, et les C'ténophores.

Ces derniers animaux sont souvent, et par le pins granif nombre des naturalistes contemporins, rapprochés des lfyilrozoaires, ou bien placés a part dans la série des Colentérés. Leurs aftinités arec les Inthozoaires, el surlout avec les Scyphoméduses, ne paraissent point cependant prèter à trop de conteste. Eilles découlent surtout les phases larvaires. Toul comme les représentants des deux groupes précités, et à f'exchusion des autres Culentérés, les embryons des Clénophores posscident un tube usophagien, el quatre ctoisons gastripues. La phupart des anteurs modernes recomnaissent les liens étroits, yui uni ont les Scyphonéduses aux Inthozoaires; une conclusion semblable s'impose pour les Chénophores.

La présence des paletles nataloires, si caracléristipues, n’est pras un obstacle ì ce rapprochement. E. Ileckel a décrit me Scyphoméduse, la Tesseranthe connectens, dont l'ombrelle porte des séries de playues vibratiles, comparables à celles des Cténophores. Ha découvert également me seconde méduse, la Ctenaria C'tenophora ('uni appartient à Fombranchement des Ilydrozoaires, et à la section des llydroméduses diplomorphes), lont l’asject général rappelle do près celui des Cónophores. Celle miduse porte, sur son ombrelle, huit handes saillantes, convertes de cils viluratifes; les bords de cette ombrelle sont repliés en une sorte l'entonnoir; efle possède, enfin, deux tentacules capables de s"invaginer dans des dépressions ereusées a cet clfol. Ileckirl se base sur cetle simililude remarquahle pour relier les Clinophores and Ilydroméduses. Des questions pareilles ne penvent bue lésolues an moyen ales seukes concordances étahlies dans la disposition grenérale de ladulte, alors yme les données essentielles du développencut leur sont contraires. Cos fails établissent que certaines méduses sont punrues d'ipparcils locomoteurs comparables a cenx des Cienophores; ils démontrent ainsi, et cest li le point le fulus important dus recherches faites far llinckel,

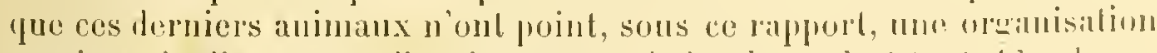

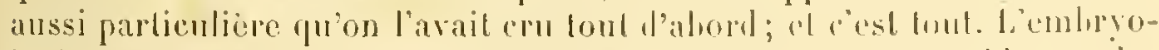
logie intervient alors, pour imliquer la profomde ressemblance des

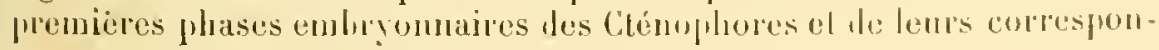


dantes des Scyphoméduses, ou des Anthozoaires; elle permet de conclure ì lexistence d’afinilés naburelles entre ces trois groupes, affinités assez étroiles pour autoriser la réunion de ces èlres en un seul et mène embranchement.

Les trois classes diffiront J'mue de l’autre par la forme générale des individus, el par la lisposition des cloisons gastriques. Les Scyphoméduses ont parfois (Lucrinares) l'aspect de polypes, mais elles sont le plus souvent des máduses, an corps discö̈de et déprimé en ombrelle; dans tous los cas, les choisons et les poches gastriques sont au nombre de quatre, et ne dripassent jamais ce chitfre. - It n'en est point ainsi unur les Anthozoaires, lont les cloisons sont souvent en yuantité consiléralile, toujours suprorieure ì quatre; de plus, ces animaux sont des polypes tixés, et nolfont jamais laspect médusaire. - Enfin, les Citimophores possident biun quatre cloisons, et rippellent en cela les scyphoméduses: mais ces cluisons, déji larges et épaisses chez l'embryon, se soudent les mes anx autres par la suite, s'unissent en me masse voluninense, oi les logos sont réduites a des canaux tubulaires, el à layuelle se joint le tube aesophagien. En surphus, les Clénophores présentent des appareils de propulsion, les palettes locomolrices, disposés régulièrenent sur le corps, et donl les autros Seyphozoaires sont privés. Char une des rangées de paleltes est placée au niveau d'un liverticule les loges primitives, le canal méridien. Quant a ta forme du corjs, elle rappelle hien cello les syypomóduses par l'épaisseur et la transparence Un mósolerme; mais elle en dilfère par l'absence comblete d'aspect médusaire, cal l'organisme n'est jamais aplati en une umbrelle.

Scrunoubuses. - La classe des scyphoméduses contient deux sousdasses: relle des fuloseyphaires el colle des Acaliphes. Ces denx sonsclasses jouent, dans le groupe des Seyphoméduses, le rôle des Authydraires et des Ilydrominluses dans celui des Ilydraires. - Les quatre cloisons des Iuloseyphares sont fort ívidentes, car l'épraisseur du mésorlerme n'est pas trop grande; les organes des sens, du type des rhopalies, font completement lifaut; aussi, celle sous-chasse est-elle encore désignée pau l'expression "Alhopalions ", "pposée à eelle de "Rhopalifères", accordée à la secomle. Cello-ci est caractérisíe prar la constance de l'aspect médusaire; par la grande importance du mésoderme, qui entraine la réduction, et parfois latrojhie, des quatre cloisons primitives; enfin, pra la présence des organes sensitil's marginanx.

La sous-classe des Intosiryluaires renferme deux ordres: celui des lacernaires ou C"alyaosonires, al relui lles Tesseridées. Les caraclèes lu premier prenvenl alre résumés ainsi : corps fixé, polypoïde, portant, au liow le tentaculos allongés, huil groupes de petits appendices cylindripues juxlaposés. Corx des lesseridées se ramènent à la diagnose suivante: corjes libre, medusilorme, portant sur ses bords huit ou seize 
longs tentacules. - La sous-classe des Acalèphes contient également deux ordres : les Tétramères et les Octomires. Les preniers possèdent seulement quatre rhopalies marginales; leurs doisons sont larges, minces, et bien éridentes. Ils sont lepurésentés, dans la nature actuelle, par les Cuboméduses, ponrvus sculement de quatre tentarules (Charyldéides), et les Péroméduses (Périphyllides el P'éricolpides), munis, tantòt de quatre, et tantit de douze appendices tentaculaires. lar contre, les Acalephes octomeres portent huit rhopalies marginales, et parfois mème donze; les bords de l'ombrelle sont décounés, ordinairement, en huit lobes marginaux; enfin, les cloisons, après s'être montrées durant les phases embryonnaires, se réduisent dans certains cas, et s’atrophient. L'ordre des Aealèphes octomères, ou des Discoméduses, contient un grand nombre de familles, quil est permis de ranger en denx tribus, les Catannates, el les Acatamnates. Les représentants de la première tribu ont encore des cloisons fort nettes; ils constituent la famille des Ephyropsidies, et correspondent i la persistance, dans la nature actuelle, de la phase larraire Ephyru, propre aux Acatamnates. Quant à ces lernières, elles rúalisent létat oryanique le plus complexe des Scyphoméduses; les cloisons manquent à l'adulte.

Créxomores. La classification des Cténophores, adoptée actuellement par presque tous les anteurs, semble itre la plus naturelle; elle consiste à diviser to gronpe entier en deux ordros : les Tentuculifères et les Nis, suivant que les indivilus portent des tentacules, ou sont privés de ces appendices. Le second orlire renferme te seul trpe des lieroüdiens. alors que le premier contient toutes les autres familles. Il est nécessaire de signaler, parmi ces dernières, celle des Crilippides, dont les représentants sont caractérisés par une forme générale, légulièrement ovalaire on sphérique, et par une simplicité assezgrande d'organisation. La plupart des Cténophores, dont le déreloppement est comnu, présentent, dans leur jeune àge, une structure qui rappelle de près celle des Cydippes.

Astuozonnes. - Mettant it part les Télracoralliaires fossiles, dont la place exacte dans une classification nature prede a la discussion, la classe des Anthozoaires peut itre partagée en deux sous-classes, caractérisées par la nature les deux loges gastriyues impaires el médianes. - Les formes les plus simples, parmi les Anthozoaires actuets, sont les Alcyonaires et les Edwardsiées, qui possèdent sculement huil cloisons; il n'est cependant pas permis de les placer côte ì côte, car, bien que semblables sous beaucoup de rapports, elles dillèrent l'une de l'autre par la situation des plaques museulaires cloisomnaires. Le lype des Aleyonaires est unique; celuides Edwardsies est bo point de départ de toutes les dispositions oflertes par les Anthozoaires munis de phus de luit cloisons. Des denx loges impaires et mélianes des Aleronaires, l'une est un endocole, et l'antre un exvende; par" contre, ces denx luges sont toujour's des exoceles chez les Ehwardsiées. On est done en droit 


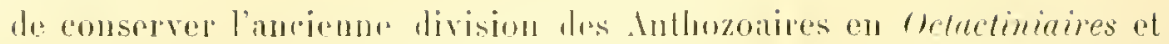

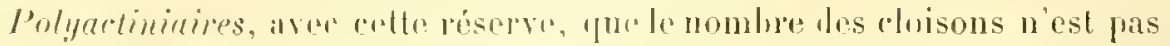

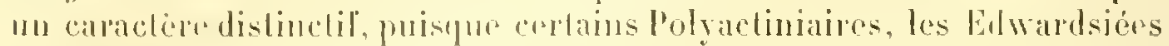
notamment, no portunt pur huit le ors organes, ot ressemblont en cola aux Octatiniaires. (Wunt anx "xpressions choisies pour désiuner ces deux groupres, allas sont justrs, si l'on fait alstraction du chithe des Moisons, on les loges, pour sadresser soulonent i colui des temlacules,

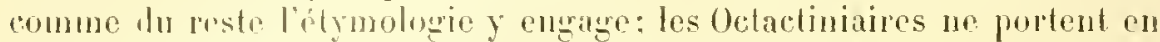
elfet quo huil lentarulos, alors quo les Edwardsiés, les phus simples des Polvalinitires, el los seules à aroir huit cloisums, possélont cepondant scize de cess appendices.

La sous-classe des Octuctiniaires, ainsi caractérisée par te chiflre lunit des lemacules, el par la prósence d'un seml exocule parmi ses deux loges imprares et médianes, renferme trois familles principales, antour desquellos gravitont un certain nombre de familles secondaires. Ces trois grompus sont les Meronidées. les Gorgonidées, et les lennaluliilées.

Les Polyactiniaires, improprement nommés llexactiniares, car leur symétric fondamontale, octoradiaine on dodécaradiaine, n'est mullement hexaradiée, constiluent un type des plus intéressants, par la quantité de ses espèes et la diversité de leur structure. Leurs caractires partiruliers frortent sur le nombre des tentacules, toujours supérieur it lunit, ot sur la nalure des doux loges impaires, fui sont constamment des exocures.

Il est permis de diviser cetle sous-classe en deux ordres: los Octoradies, et les I'olyrarliées. Les premiers possedent seutement huit cloisons, alors que les seconds en renfrment un chiftre plus considérable. L'ordre des Polvatiniamos octoraliées est représenté, dans la nature actuelle, frar la smule famille des Edwardsiées.

liordie des lobactiniaires polyradiés se compose de quatre sousordres : les Monanlées, les Conactiniées, les Cérianthidies, el les \%onnthaires. Les diffépences, établies cutre ces groupes, liennent à la dispusition des métaseples. Les individus passent, en eflet, dans leur diviloplement embromnare, par me phase d'Edwardsice, et sont alors mumis de huil choisons: lis puatre protoseples, et los quatre deutoseptes, 'pui divisent la cavilé gastrique en luil loges primaires. Puis, ils poussent flus bin leur évolution, et de monvelles cloisons, les métaseptes, prenment maissance. Les mélaseples des Homaulées, au nombre de six (trois

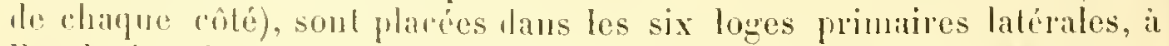
lexclusion des denx lones primaires impaires; celles des Gonactiniées, au nombre do lubil, soml situces comme rolles des Homaulées, daus les six logers primates latriales, l'une do ces ifruiores en renfermant deux au lien d'une senlu; entin, cellus des Ceriantlitres, fort nombrenses,

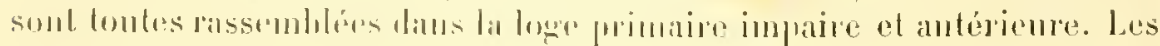
medaseptes des \%oanlatives sont egalement lo'es nombreuses, mais, 
contrairement aux Cérianthidées, elles se groupent sonvent en rveles réguliers. Ce sous-ordre renferme ciny tribus principales: les Mulipathides, encore peu connus, el jui possedent seuloment six tentacules lien déreloppés; les Zoanthines; les Acliniles ou Malacodernués; les Paractinides; entin les Madréporides, encore nommés Sctéroulemés, caractérisés par la présence, autour le leur corps, l'un squelelte calcaire, le polypier.

TIBLEAU UE CLISSIFICATIOX:

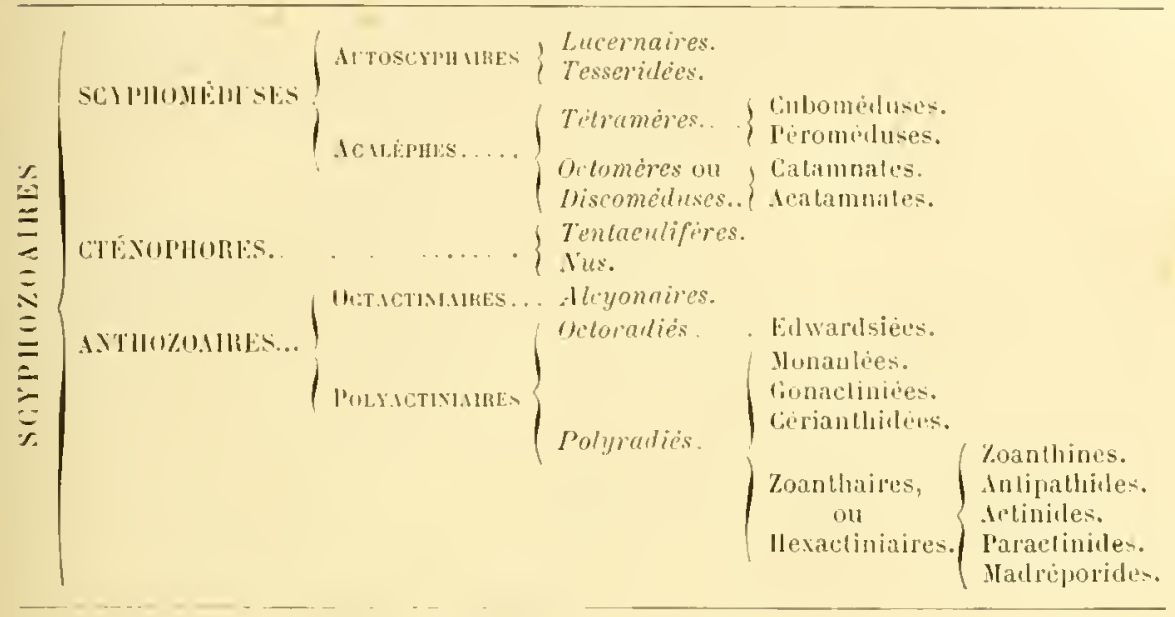

\section{\$2. - Éléments sexuels.}

Les recherches, effectuées sur l'origine exacte des éléments sexuels chez les scyphozoajres, prêtent encore à la discussion. Ces éléments sont orlinarement situés, lorsqu’ils sont déjà parvenus à une phase avancée de leur évolution, dans le mésoderme; et, llu moins dans la plupart des cas, immédiatement au-dessous de l'endoulesme. On pourrait done croire qu'ils proviennent ile ce termier fenillet; mais la somme iles connaissances acquises leur accorle, par contre, me genise mésodermique. Plusieurs cellules du feuillet moyen perient lem aspect étoilé, grandissent, et se transforment, sans aulres modifications, soit rn ovmles, sojt en spermoblastes. Lorsque ees élémenls sont piurvenus it acepuérir lem maturité, la paroi emboleminue se rompl ì lemr niveau, et ils lombent ainsi dans la cavitó gastrique, on dans ses annexes de lit, ils sortent au dehors par louverture buccale.

l.es spermatozoüdes sout, dans la riegle, constilués par une tìte voluminemse, contenant le noyan, et par me quene très mince. Les orules sont arrondis, oll farfojs folvedrifues, it eanse de frur compression muluelle, lorspuils soul lassemblés en grande quantili daus un respace 
restreint. - Les Scyphoméduses, sauf les ('hrysaora, sont misexuées. J. "unisexualité est aussi le cas habitncl four co qui tient aux Anthozoaires; croms de ces derniers sout cependant hermaphrodites, les Cérianthidées par exemple. Lorsque les Anthozoaires forment des colonies, la séparalion les sexes s'étend parfois à ces lernicres; ce fait existe chez un grand nombre doctacliniares donl certaines colonies sont mâles, el certaincs autres femelles. Enfin, tous les Cténophores sont liermaplirodites.

Les glamdes sexuelles des Seyphoméluses sont d'orlinaire au nombre de quatre, sauf chez les Lucemaires; ces demicrs possèlent en effet lıuit groupes d'éléments reproducteurs. Quel que soil leur chiffre, ces amas, sourent color's de teintes vires, et lien appréciables par suite à travers lombrell. Lransparente, font saille dans la cavilé gastrique, et sont placrís à iggalr distance les uns des aulres; cenx dos Acalèphes sont situés daus les interrayons, ceux des Lucernaires dans les huit alrayons. - Les glandes génitales des Inthwoaires se déreloppent dans diverses parlies les doisons gastriyues, et donnent, à la région qu'elles occupent, nn aspect plissi, aisénent reconnaissable. - Celles des Cténophores sont disposées sur le trajel des luil cananx mériliens, tantôt sur lonte la longueur de ces conduits, lantòt (Ceslivés) en quelyues points senlenent de leur étendue; gónéralement, el surtout chez. les Clénophores mus, les ovmles sont placés d"un côté du canal, el les spermatozoïles le l'aulre. La présence des éléments reproducteurs Honne, à la paroi des canaux mériliens, me forme varipuento.

Au moment où les sprrmatozö̈les sout arrivés à maturité, ils lraversent la conche ondodemique par la rupture de celle-ci, tombent dans la cavití gastrique, ou dans les ranaux dépendant de cetle dernière, et sont rojetés au dehors par liorilice huceal. Il n'on est pas tont a fail ainsi pour les ovules; ces demiers parvienment hien dans la cavité gastrique, mais ils y restent d'ordinaire, et y sont fécondés. Ils subissent, toujours renfermés daus colle chambre stomacale, les premières phases de lour développenent, et ne s'ichappent fordinaire yu'au moment où ils sont devenus des laves. dont leetoderme est couvert de cils vibratiles. Le petit ine tompoie dans l'estomac maternel,

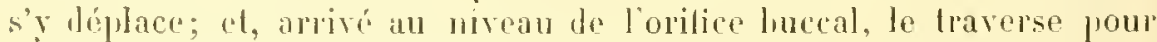
aller à l'extérieur, ol se trourer entièrement libre. Il s'effectue done une incuhation dans la ravilí gastrique llu générateur femelle.

\section{3. - Segmentation et feuillets blastodermiques.}

Le béreloprement du plus grand nombre des Scyphozoaires est condensé: la segmentation abontit a la renese. non dome blastule, mais dime pamme compacte. Colle derniere se creuse ensuite diun vide central, yni devient la carité gastrique; les hlastomieres se disposent, autour de cel espace, sur denx couches, dont l'externe corresponil au 
protectoderme, et l'interne au protendoderme. Puis, le tube asophagien prend naissance, sous l'aspect d'une dépression de celle doulıle paroi; et le mésoderme, dont les béments froviennent du feuillet protectodermique, apparait entre les teux assises cellulaires primordiales. Le protectoderme restant donne l'ectoderme. le protendoderme se convertit en endoderme; et les trois couches somatiques sont complites.

Telles sont. résumées à grands trails, les premières phases embryonnaires de la plupart des Seyphozoaires. Cependant il existe des espèces dont le développement est dilaté; lans ce eas, une blastule se forme. et se modifie, nou en me hlastoplamule semblable à celle des Iydrozoaires, mais en wne gastrule produite par invagination. La présence constante d'une phase gastrulaire, au délut de l'évolution de phusieurs Scyphozoaires appartenint à des grompes divers, permet le comnaitre la valeur exacte les feuillets blastodermiques, et de préciser la nature des procédés mis en murre.

1. Scyphoméduses. - Le dévelofjement les Tesseridées n’est pas encore connu; les seules observations acquises se rafportent à l'évolution des Lucernaires parmi les Autoseyphaires, el à celle des Discoméluses parmi les Acalèphes.

Développements dilatés. - Les emluryogénies, pourvues d'une phase blastulaire, sont encore assez nombreuses, el se rencoutrent toutes chez les espreces appartenant aux formes inféricures des Discoméduses; elles ont étẻ sigualées notamment chez les Ephyropsis, les Pelagia, les Chrysaora, et la Cyanea capillata. Les procédés suivis sont toujours les mèmes.

Lovule féconlé se divise également, et produit une morule; celleci se transforme, par l'écartement des lilastomères et l'apparition d'une cavité centrale, en nne blastule, munie d"un blastoccele assez ample. Les hastomires se disposent en une senle assise, qui représente le hastoHerme. Une partie de ce dernies se líprime et s'enfonce dans la cavité blastocolienne; la gastrule est ainsi engemlrée jar jnvagination. Ia rigion hlastolermique invagince devient le protondoderme; cells qui reste cxterne fournit le protecholeme. Pour pus le simplicité el à cause le leur nature pen complexe, ces deux assises seront nommées, llésormais, l'ectorlerme et l'endoderme.

Les denx funillets blastorlermiques primitifs sont done représentés; ils consliturut, par leur juxtaposition rapile, mue paroi doubla, qui limite la cavité l’invagination. l'entéron pastrulaire. Celle-ci communique d'aloril, avec le dehor's, par un large entéropore; mais les hords de ce demicr se rapprochent de phus en plus, de manière ì lo rélrécir, ct souvent, parait-il, ì le fermer completement. Dims ce cis, la gastrule se convertit en nne rísicule close, dont la cavité est l'culéron embryonnaire, et dout li praroi est composér par l'ectorlerme et l'enclodeme juxtaposés. Des cils viluatiles prement naissance sur les clé- 
ments ectodermiques, et permetlent it la junue larve de se déplacer: une fine membrane propre sintereale aux deux fenillets, ot donne la

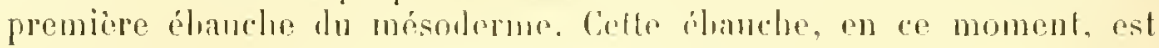
compraralile à une hasale épithéliale, on phutôl à la rémuion des hasales de l'ertoderme el de l'endorlermo; elle s'acroit par la suite, les éléments surajoutés élant l'origine ectodermịue. Les phénomènes évolutifs, qui surviennent phus tarid. ont pour eflet de transformer celle larve en un seyphopolype: ils scrout étudis dans le prochain paragraphe.

Irveloppements condensis. - Ce type inolutif est particulier aux Lucernaires, el a la plupart des Discoméduses les plus élevées en organisation: il est caractérisé par la marehe de la segmentation, qui aloulit direfement it une phase plaumaire, sans jamais montrer le hastule ni de gastrule.

$l^{\circ}$ S'il fant en eroire les observations de Giöle, les Aurelia auria seraient, sous ce rapport, interméliaires aux deux modes frincipaux du dévelopjement. - Lorsiue la segmentation est achevée, la morule derient une hastule, commo dans le premier cas: sculoment le blastocule de cette dernière est petit, et les éléments du blastoderme different de taille. I'lusieurs d'entre enx, groupés en un des poiles de f'embryon, sont plus longs que les autres, el font saillie dans la cavité bastocorlienne; la suite de l'évolution consiste à augmenter encore la longueur de ese cellules, de manière à leur faire emplir te hastocole entier. La hastule, d'ahord creuse, est devenue compacte, el s'est transformée en planule. - Les recherehes eflectuées frar Clans, et par Gïlle, sont ensuile contradictoires pour ce qui tient anx phénomènesulterienrs. l'apres lo premier de ves maturalistes, une petite dépression se manireste dans la rógion hlastodermique à grandes cellules; retle dépression estl'entíron; Jans ce cas, il existerait eucore une phase wastrulaire, bien que très atténuce. Il n'en serait pas ainsi suirant Gïlle, car l'enléron se creuserail, sans provenir d'une invaginalion gastrulaire, dans la masse des longues cellules, par un procindí tont à fait semlilahle à celui que prisentent les rrairs planules déerites plus loin.

(quoiquil on soil, celle diverene d'observations est ici bien secondaire. Il est évident que les planules dérivent des gastrules prar laceumulation de substances deutoplasmiques dans certains hastomères; cenx-ei tembent it se grouper dans la partie centrale te lembryon, et l'entéron se peree an milinu l'enx, sans provenil d'une invagination histodermigne préalabli. Les turetia uffechent une transition entre les gastrules et les planules des s.ryhomínhes. Le dentolícilhe n’est pats cucore assez, abondant, pour accroitre tellement la taille tles hastomeres que le lilastocole snit rompli frar eux; un pelit blastocule, el partant une phase blastulaire, font encore leur apparition. Sculement, l'invagination réelle d'une partie du blastorlerme est, ici, remplacée par l'allongement des blastomions chargers de sulistances nutritires; el ces 
blastomires sont les homolngues de renx qui sonl placés lans la rixion invaginé des vépiahles gastrules. Comme onx, ils donnent l'onderlerme. el, comme eux, ils limilent la cavilé entérique. Quant an procédí

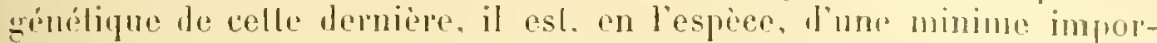
lance; du reste, pent-itre les olservalions de Clans el dre Götle sont-elles exartes toules denx, en re sens que les t urelia effectuant une transilion, cerlains individns présentenl le mode signalé par le prenier de ces auteurs, et certains antres eelni déerit par le second. Ces denx morles ne sont pas en effet bien diflérents l'nn de l'autre: dans un cas, me légàre dépression se manifesle, mais elle n'est pas suffisante pour constiluer la cavité entérique entière, ef clle s'aceroil en prenant la place des éléments culodermiques, qu'elle repousse devant elle; dans le second cas. l'entéron se creuse d'ahord dans la masse endodermique, non loin de la périphérie de l'embryon, et crandil ensuite d'après un procédé identique, e'est-i-dire par le refoulement des ecllules qui lentoment.

Q Dans les développements complètement alrégés, la morule, issue de la segmentation ovulaire, se change en une planule direcle, sans

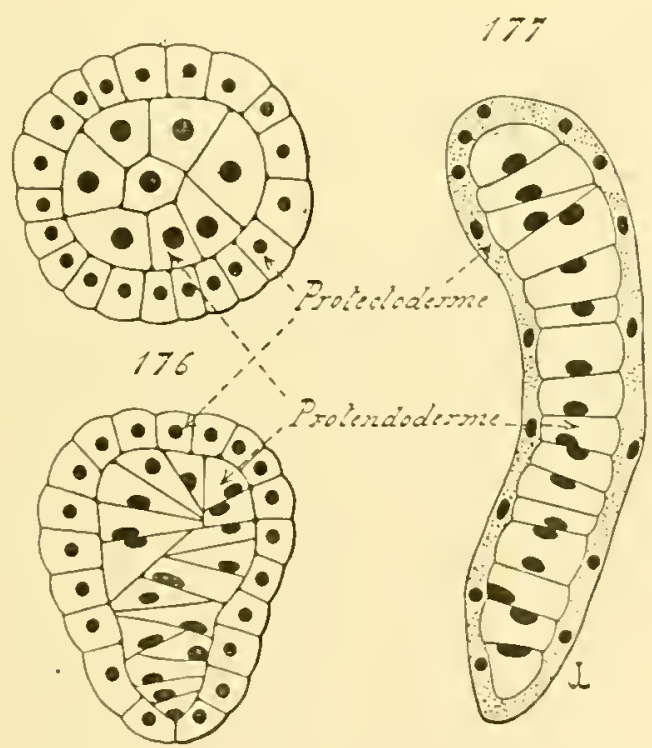

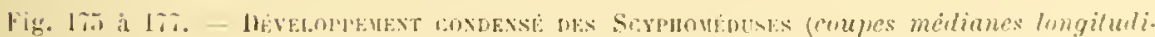

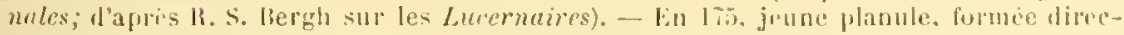
tement. - lin 1it, planule plus avance. - En 17\%. planule encore plus agive aux chiments protendoderminuts empiles a la maniè ule vistues.

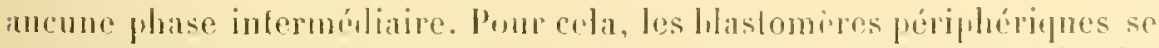
juxlaposent filus étroilement, ol se rassemblent cu mo assise simplo.

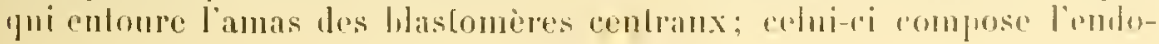


derme, alors que l'assise périphérique représente l'ectoderme. la larve, parrenue à ce moment de son érolution, s'accroìt sourent sans perdre sa compacité; tantol (Lucermairos) clle s’allonge, les blaslomères internes s'empilant les uns sur les autres a la manière de disques; lantot (la plupart des Discoméduses), elle conserve me forme spluérique ou ovalaire, la masse centrale ayant aussi le mime aspect. Sonvent, les cils vibratiles commencent à se montrer" sur les cellutes ectodermiques.

Les phénomenes ultériems nonl guère élé snivis que chez un petit nombre de Discomótuses; it est probable, cependant, quils sont les mémes dans lous les ras. Cnr caviló jrend naissance an sejn de l'amas interne; elle grandil rapidement el refoule derant elle les blastomères de cet amas; cenx-ci, lorsque cet aceroissement alleinl une cerlaine limile, sont grompés en une couche simple, appliquée contre la face interne de l'ectoderme. La flanule compacte s'est donc Lransformée en une vésicule close, dont la paroi est conslituée par la juxlaposition de denx assises cellulaires, lune colodermique, ol laulre endorlermique. lille rn est arrivée a la mème phase que les gastrules déji étudjées, au moment où cos dernirres ont rétréci, on ont fermé, lenr entéropore; la structure est semlilable lans les deux cas, et l'évolution, ultérieurement suivie, est également illentique.

Lorsque lentéroprote des gastrules ne se ferme pas, il devient la bourhe primilive des Scyphopolypes; lorsqu"il se ferme, la louche primitive prend naissance, à noureau, sur l'emplacement aubrofois occupé par lini.

11. Gténophores. - La segmentalion de l'ovule les Cténophores mósente des raractires spéciam el fort remarpuables; il est possible de les dóduire de ceux qu’olfrent les Seyphoméduses an développement alurígé. - L'ensemble le ces parlicularilés consiste en une condensation évolutive plus graule encore, déterminće par la présenre, dans l'uruf, d'une quantilé plus considérahle du leutolécithe. La division de l'ouf est encore égale chez les Seyplomioluses appartonant au deuxieme type du mode condense; clle aboutit a la genese d'une morule, dont los blaslomires sont semblables, et qui se trausforme directement en planule, frar une sorle de séparation des éléments périphériques l’avec les éléments internes. Il n’en est point ainsi ponr les Clémoplones; la segmenlation est ćgale jusqu’i la phase do quatre blastomeres, el devient fort inrigale par la sulte. Ie blastolécilhe s"isole du dentolécithe, se porte en dehors des béments constilurs par ce dernier; et, en angmentant le nombre des rellules yn’il congendre, finil par envelopper completement les hastomires deulobichtiones. line planule compacte prend ainsi maissance par le procébé indirect; et, au monent oil celte planule est constitmée, ses éléments soul déjà disscmblables, les externes élant beaucomp plus pelits que les interues; crux-ej fommissent l'endoderme, el les premiers l'ectoderme. - Une tello ahréviation du développement, qui omed 
la phase représentée par la morule à blastomères identiques, amène une seconde particularité importante. Les éléments figurés lu mésoderme naissent encore assez tard chez les Scyphoméduses; ils sont prouluits par l'ectoderme, bien après l'ajprarition de ce feuiltet. Les Clénopliores sont plus hatifs sous ce rapport : vers l'instant oi l'ectoderme va ctre achevé, certains de ses éléments, groupés en un des poiles do lemliryon, s'accroissent plus vite que les autres, et se multiplient. Ils ronstituent rapidement une masse cellulaire compacte, pui répond à l’éhauche du mésorlerme. Bien plus, comme les principaux organes du corps sont disposés suivant nne symétrie tétraraliaire, cette élauche se divise tress vile en quatre parties, une par quadraut.

En résumé, il faut, re semble, considérer le mode particulier aux Clénophores comme une modification, par une abréviation plus grande, des procédés présentés par les Scyplıoméduses. Chun a bien décrit une grastrulation chez l'Eucharis multicornis; mais, comme cet auteur n'a pas suivi tontes les phases préliminaires qui ahoutissent it la gastrule. il convient, jusqu’à plus ample informé, de se tenir sur la réserve à cet égard.

A. - Lovule des Clénophores. enveloppé par une membrane vitelline. qu'un large espace sépare du vitellus, el dans l'iutérieur durquel ont lieu les premières phases de l'érolution, est constitué par une volumineuse masse dentolécithique, qu'entoure une mince couche de hlastolécithe; celle-ci renferme le noyau de l'ieuf. Le premier plan de division a pour effet de diviser l'ovule fécondé en denx parties égales; le second plan ngit de mème, el l'orule est ainsi partagé en yuatre segments égaux. I mesure que ces phénomènes s'accomplissent, le llastolécithe cesse d'environner le vitellns nutritif, et se ramasse sur l'un des sommets des quatre blastomères mimitifs. Chacun de ceux-ci est tone composé de "leux parties, qui lemleut à s"isoler le plus possible : l'une volumineuse, et presque entièrement forméc to sulustances nutrilives; lantre petite, l,lastolécilhique, et portée par la première. Avant pue la séplaration de res éléments ne se soit efferluée, chaque quadrant se livise à son tour en denx porlions; cola de telle manir pre, que le plan le scission passe it la fois par le vitellus dxolutif el par le vilellus nutritif. Les huit hlastomires, ou octints, ainsi produits. sont donc semblahles aux qualrants primitifs, el sont de mène constilués par lunion dedeux parties dissem-

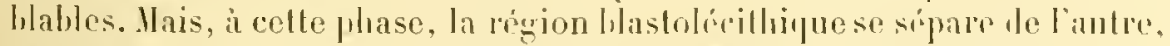

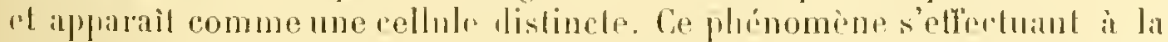

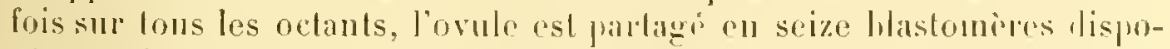
sés sur denx rangées : une assise supéricure mince, composíc par les huil éléments de vileblus évolutif; ot nne conche inférieure tris épaisse. formée par les luit éléments deutolécilhinues.

La segmentalion continue ensule, plus rapidement dans lal rangina supérienre que dans lantre, tontes denx bunt lésormais distintes. Lal 
premiere frond i ruvelopper la secomle. Pour eda, de nourelles masses de blastolécithe, lont chacme est mumic l'un noyan, se séparent des

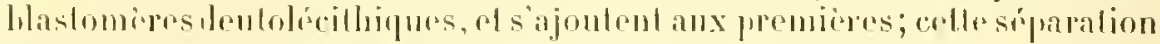

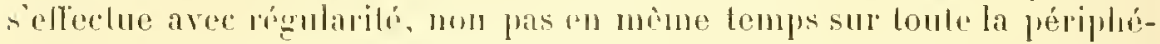
rie de l'enbryon, mais en allanl, des louris de l’assise supérienre, sur les colés, el an Jessons, de l'assise inférieure. Les noşaux, de ces béments ainsi engonulrís, proviennent les corps nucléaires appartenant aux gros bastomires charés de sulostances mulitives.

On assisle done, en suivant celte sélie de phénomines, à l'enveloppe-

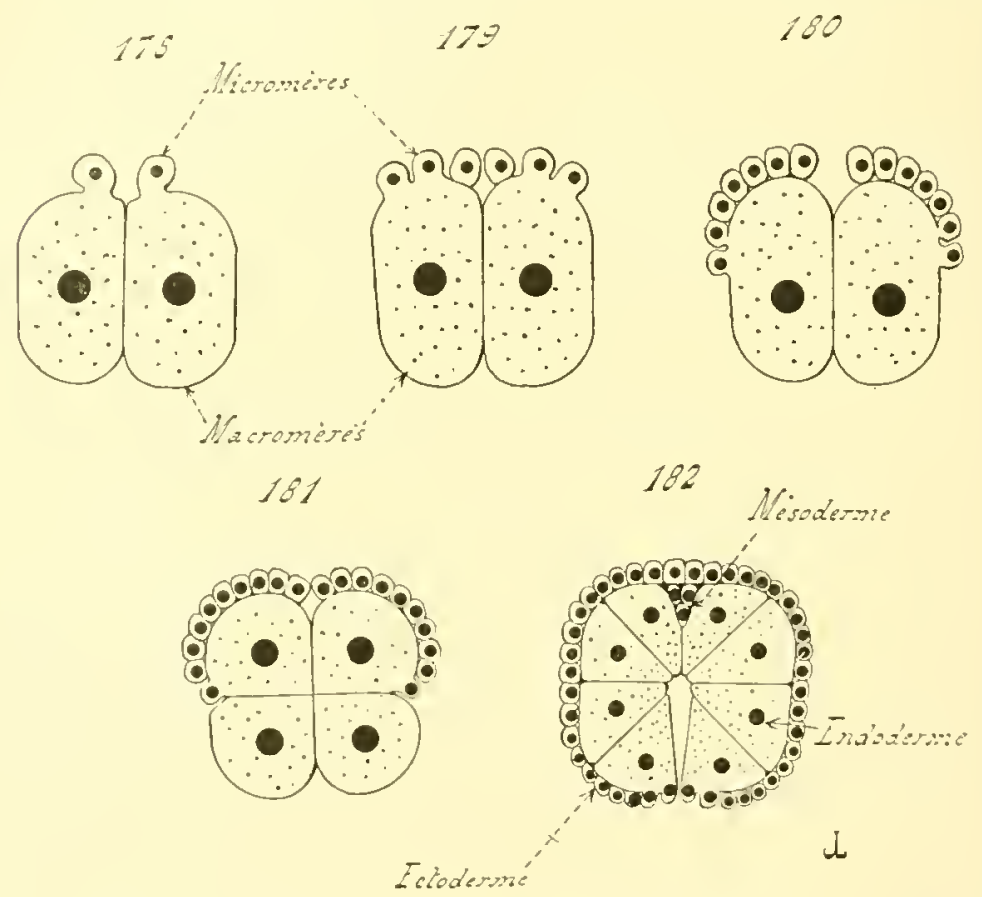

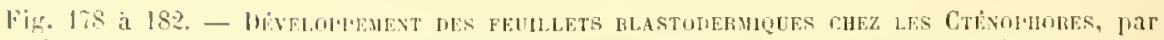
Ju procide de la plabulation indirecte (roupes midianes, diagonmmatipues). - Lin lik.

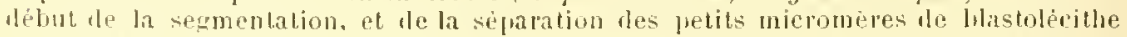
l'avec les gros materompres dentolioilhidues. - En I79, suile dr rette siparation. lin 1:40, la siblaration continue, et les mieromires, augmentant en nombre, entourent

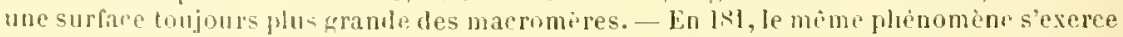
enrore; les micromires se divisent, avee lenteur, en une petite quantite de gros elements. - En lis, l'envelophement les matromeres par les mirromieres est complet; cenx-ci rompusent leetolerme, el promuisent hativement le mesoderme; ceux-lia. devenus un peu plus nombreux, constiluent lendoulerme. el se disposent autour d'une cavité entérique, yui fait alors son apparition.

ment ars cellules a vilellus mulrilil par les pelites rellules de hlastolerilhe. Celles-bi sont engembries par colles-la; les premières produites oc-

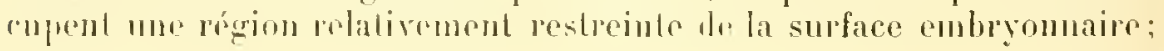


mais, comme de nouvelles viennent sans cesse se juxlajuser and preré-

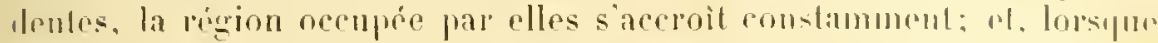

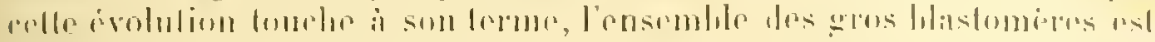

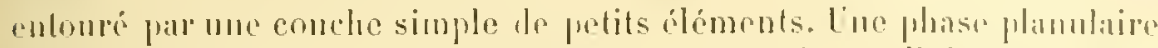

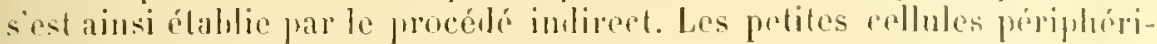

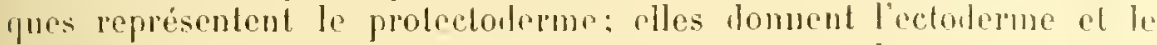
mésolderme. les centrales constiluent l'endarderme seml.

In moment oi les preniers éléments hlastolécithiques se délachent les hastomires primitifs, et se disposent en mo assise peu istembur rncore, une minime cavite sintercale i leur ensemble et i celui les grosses cellules nutritives; celte cavite communique meme arec lo Jehors, par un orifice assez large, préé an milien de la conclse forméc par les premiers. On ne doil pas, semble-t-il, accorder i ces faits une trop grande importance, car on les retronve asse\% somvent daus la genise des planules indirectes, lorsque les dissemblances de taille sont Irès grandes entre les lilastomires; ils paraissent dus it des causes mécaniques. Les hlastomères sont arrondis, et, partant, ne se touclsent que par une region restreinte de leur surface; les plus pelits d'enlre eux tendent a se grouper en une assise continue, et a ne point pénétrer lans les anfractuosilés laissíes entre les plus gros. Il risulte de ces faits qu'un espace lilure assez ample peut, par la foree meme dos choses, s’interposer aux divers éléments ovulaires. - Quant à l’orifice mentionue ci-dessus, sa présence semble être également un cllet „u mode de division. Les lunt premiers des petits hastomeres sont nficessairement assez distanls les uns des autles, puisquils se séprarent des sommets des gros segments ovulaires, et puisque ces sommets ne so lonchent pas. ()r, lorifice correspond précisćment à cet espace laissé entre eux. el qu'il lem est mécessaire de combler, it mesure yüils angmentent en nombre.

B. - La planule indirecte des Chónophores n'est comparable en rien à une rasturule; il n'exisle ici aucun étal blastulaire véritable, ct l'enJoderme nest nullement domé par une invaguation. La marche de la segmentation est telle, quau moment ois elle se termine, los denx fruillels primilifs sont complitement formés, chacum deux élaul conslilus: par des cellules bien diflérentes. comme aspert, de colles de son eomgriniere. Le jeme embryon est une plaumle, produile imlirertement, ot mou par le procédé direct olsceve chez les Seyphomáhses.

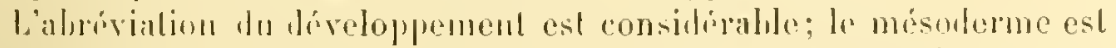

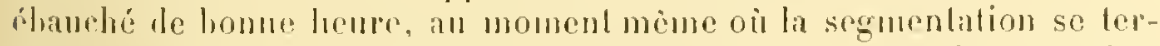
mine, et oi les deux fenillots sont reprosentés. les exllules mésolermiques des seyplozoaires proviemment du protretolerme; mais, dins

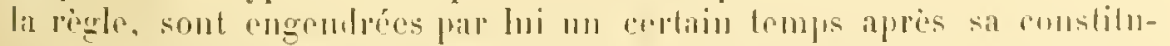
lion détinitive. les phénomènes sont phus rapiłes rhezles Clinophures:

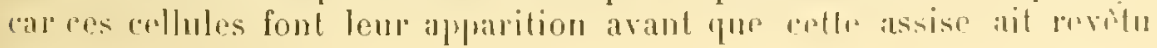


l'aspect d'un feuillot périphérique continu. - Dars celte série de phases, qui consiste a laisser envelopper les gros segments cnlolermiques par les pelits éléments le l'ecloderme, il vient un instant où les sommets inférieurs le ces gros segments sont rncore à découvort; dr ces sommels se lílachunt ensuile, par lo frocédó dójà conum, des pelites cellules de blastolurilbr, qui se juxtaposent a leurs roisines, el achevent ainsi la couche cetorlomique. Alors, Jans la zone où la segmentation orulaire a commencé, plusiems des éléments de ce lenillel vont proliféror. et se multiplier rapulement. Ils constifuent, dans celle récion cmliyonnaire, me pelite masse, yui se divise en loux parlios: unc rangée extérimre, ef un anas interne, placé entre celle-ci at les segmenls enlodermifues. Lassise externe fait partie de l'ectoderme, aupuel he se ratlache par la situation quelle occupe; et l'amas inlerne donne l'ébauche du mésolerme. - Co dornier nest done pras prorluit l'une manièr tarlive, el nost point représenté, au délü le son apparilion, par los cellules qui se séparent isolément d'un relonlerme déjà bien formé ; il consiste, dès l"abord, en un groupr cellubire compact, engronilé par le leuillet externe au momınt où celui-ci virut à juinu de s'élatuher.

l'ondant ce lemps, les cellnles endodermiques, levenues entièrement internes, s'allongent quelque peu, et lour cusemble se divise en deux partios. Une frnte vient. en effel, l'apparailre an milien mème do l'embryon; elles’élargil, el se lransforme nu une cavite hien appróciahle: c'est lentéron qui joml naissame, el se crense au sein le l'amas emlolemique, comme il en ast pour loules les planulıs. - La cavité entéripue, ainsi limitée par les grandes cellulus le l'endorlerme, s'onvere au delors, dans les promiers instauls l, son apparilion, par l'orilier placé. cutre les promiers blastomères, sur la partie supérieuro de l'embryon; mais celle ouverturo accildutelle, n'avant ancune importance mopplogéniqu, no larde point à se formor. Le lube asophagin celorlemique est silué dans le poulo embryonnaire dipectement opposé a col orifice, restabline directement opmosé à la région oì la segmentalion a rommoncé

Les fenillets hastodermiques dos junmes Ctémphomes ont alors ahevé lour ćvolulion romplido, at vont rngendrer les organes et lis lisins do l'ánonomir. Inom mode l'apparilion n'est pas très différoul de

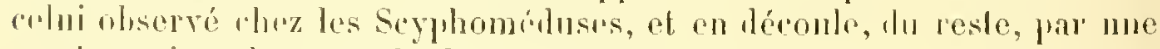
romlensalion plus grande des procinlés amblyomnaires. La sépie, sous

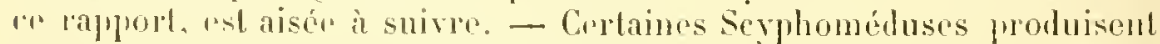

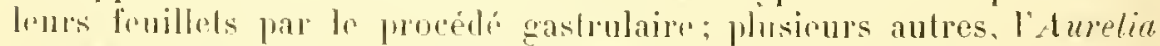
aurila par "xrmple, monlent une gastrulation birn allinnce; enfin, la plupart les l)iscomednses sonl prives le pluas gastrulaire, ot possinlonl mov varie planule. Semlement la quantité du dentoplasme ovulaire élant minime concorr, la planule est directr; la sigmenlation aboulit à une morule, lont tous leshlastomirns sont prosque identiques, puis a unr pla- 
nule, dont les éléments sont groupés en deux fruillels, dissemblablins par laspuet. Jai manche des phénomènes est plus rapide ehez les Cténuploopes le deutolécilhr étant fort abondant, la segmentation en ast gènéce et la dirision devient rapidement inécale; des petits bastumiens. conslitués mniqurment par du blastolécillı, proment naissance lıs un après les autres, dr manièr à onvelopper peu à peu, d'une facon régrelière el continue, las gros segments charés de granulations vitellines. Aussi, lorsque la segmentalion est achevée, c'est-a-dire lorsque cosso la grnèse des petits blastomeres, l'embryon notrie point la slructurr l'une mornle aux iléments presque comparalıles, mais bin cell" d"une jlamule aux éléments forl dissemblables, el léjả grloupés en deux fruillets distincts. La division orularie aboutit done à une planule indirecte.

11]. Anthozoaires. - Ces animaux présentent, sous le rapport de la segmentation, les mimes particularités que les Scyphomóduses. Le

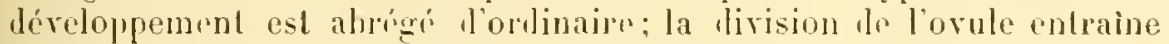
la formation d'une morule, puis celle l'une planule directe. Cependant, plusicurs aspices font exception i celtr regle, car clles montrent une phase blastulaire surve d'un état gastrulaire: telles sont les dctinia equina, les Cerianthus membranaceus, et, sans doute, les linodes vervicosus. Ces espueces ressemhlent, en cela, aux Ephyropsis ot aux I'elagia. frarmi les scyphoméduses.

Jéveloppements dilates. - Les premiers phénomènes de la segmentation ne sont pas très commus encore: il semble cependant que les blastoméres initiaux different quelque pen les uns des antres, pour ce qui a trait a leur taille. La division ovulaire serail done inégale; cetle altération correspond sans doute a la présence, dans le vilellus, de çranules deutolécithiques assez abondanls. In élat morulaire fait ensuite son apparilion, et se convertit en étal hlastulaire. La gastrule est entin produile par le procédé habituel, c’est-à-dire par l'inraginalion, dans la cavité blastocrilienne, d'une partic du hlastoderme.

Durant la phase blastulaire, et au début de la gastrulaire, les cellules de l'emluryon sont semblables les unes aux aulres, el toules culiques. Lorsque loinragination est achevée, les éloments de lendoderne sont appliqués contre la liace interne de l'ectorlerme, et une mince membrane propre se place entre les deux couches. Des cel instant, plusieurs ditlérences d'aspect vont semanifester entre les deux feuillets; les cellules ectodermiques se multiplient activement, et devienment cylindriques. 'Jar contre, celles de l'endoderne s'allongent aussi, mais lans des proportious moinulres, et reuferment de grosses gramulations: clles seront eylimlinues par la suite, mais resteut plus larges jur leurs voisines de l'evtorlerme, ol subissent des dillérenciations moins accentuces.

Lientropore semble ne point se fermer, contrimement à r" yüil cu est pour la plupart des Scyphoméduses au développenent dilaté. Iu 
moment oir tes éments des funillets commencent i pevid lour aspect

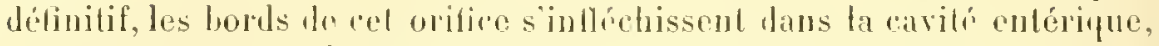
el engendrent le lubr asoplagion. L'entérojore, ainsi ropulé à l'extrémité interne de ce lube, devicnl l'onverture asophastenne, landis que loritice extriont de cotle inlloxion persiste comme bonche définilive de findividu.

Developpemenls comlenses. - Ces léveloppements sont de beaucouph les phus fréquents. On les rencontre chez lous les Oclacliniaires; sauf

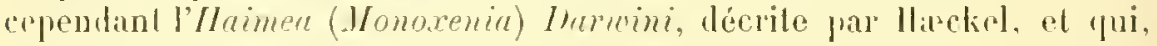
d'après cel auleur, prisente une enbryogónie ditatée. (On les a observés également che\% la plupart des l'olyacliniaires. lls rappetlent en tout leurs correspomdanls les segphomiduses; dans les trux cas, la segmentalion produit une morule, juis une planule directe, entiu une lare vósiculare, doul la paroi est lormée par deux conches cellulaires juxtapostées.

Les premiores phases de la division ovulaire sonl souvent inégales; mais tes dissemblances de lailte s’allément peu à peu, à mesure que la segmentalion avaner; en définitive, les hlastonères de la mornle sont a jeu pres tous semblables. - La morule se change directement en plamble. Les biments emhryonnaires périphériques prennent un aspect "lithórenl de retui présenté par leurs congénères internes; les grosses granulations disparaissent dans leur substance, et sonl remplacóes prar des granules plus nombrenx el phus pelils; lenr forme ette-mime change, car ils s'allongent qualque peu. Jeur ensemble est devenu distinct de lamas dos blastompes centraux disposés en une assise unique, ils composent le protedoderme, alors pue ces derniers doivent touscontribucr

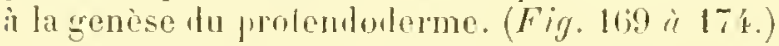

La planule a deux lenillets, diretement produite par la morule an mogende quelques moditications survenues dans tes cellules périphéripues, se converlit en larve résiculaire. Ine cavité se creuse an sein He l'amas des itéments centraux, lantôt d’une manière unique, lantüt sous l'aspeel de phusienrs pelits espaces juxlaposés, yui se lusiomnenl rapidement. Cetle corité est l'entérom: elle s’aceroil, el refoule vers sa priphlicie, an-dessoms de t'echoterme, les cethles internes. La plupart 1) res dernieres sappliquent rontra la face profonde de la conche eclodromique, et conslituent l'emlodeme; tes antros se désorganisent, reslent libres dans la cavité entrique, et s'y résolvent en granules, dont l'embryon se nourit.

Lorsque cetle évolulion esl aclievée, la planule compracte s'est con-

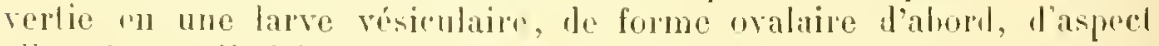
allongra el cylindrique, pir la suile. La spaciense cavité inlerne, l'en-

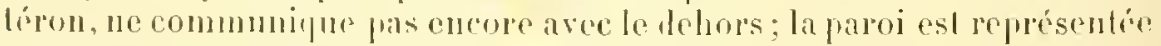

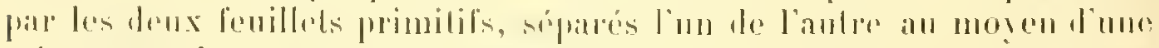

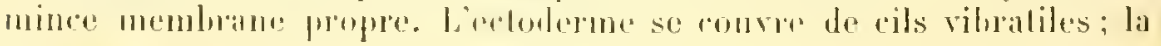




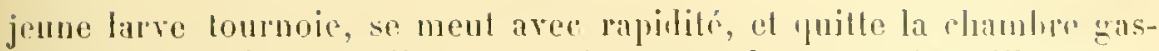
trique maternelle, où elle séjournait jusque li, pour vive lilırement. Celte période de liherté n’est pas fort long̨ue, car l'embryon ne tarde point à se tixer sur un corps étranger, et a s'y convertir col dulluopolype.

An moment ou la tixation soffectue, le tubr asuphagien prend naissance, du moins dans la jlupart des cas. La larve saphatit, nue larege dépression se manifeste dans sa région supérieure, cést-it-tire dans la parlie du corps diamétralement opposée il la lose fixée; celte déprossinn s'acrentue de plus en plus, ef se transforme en un tule, qui s'avanes dans la ravité contérique. Le fond du tube se détruit, de telle sorte que sa cavilé communique avec celle de l'entéron; con orifier interne, yui correspond i la portion détrute, est l'homologue de l'unlíropore thes développements dilatés. L'onverture externe lu tube devient aussi, comme chez ees derniers, la bouche de l'animal adulte.

Les fenillets sont alors entièrement ábanchis, et les orgenanes de lindividu adulte vont faire line apparition. Les cloisms naissent en premier lieu, suivint une marche déteminće. dont l'étule est exposér, avere létails, dans un prochain paragraphe (\$ : i).

\section{\$4. - Formes embryonnaires.}

I. Généralités. - Sauf pour ce qui a trait aux Cténophores, tont te dévclopjement est très condensé. Ia plupart des larves des Anthozoaires et des Scyphoméduses commencent par revètir l'asprect de vésicules ciliées, à la forme oralaire, ou allongée, yui nagent librement; la cavité de.

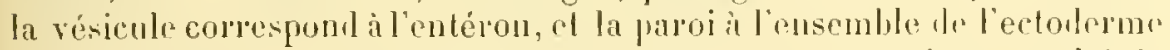
et de l'emfoderme juxtaposés. Cethe phase cmlıryomain est altéréc sous deux ripports chez les Ctrinophores; dabord en ce quelle n'est jas. libre, le jeun: individu restant enfermé, jusqu i l'état de Clenula, daus les enveloppes ovulaires; puis en ce que l'entérou se creuse, presque au moment où diver's orzances, notanment le tube asophagien, ef les quatre roisuns primaires, prennent naissance. - Cette premiere forme larvaire sera désignér prar le nom de phase résiculaire. A colle-ci succède, par l'apparition du tube cesophagien et des quatre cloisons gastriques primaires, l'état de Seyphule. Ces denx types embryonnaires, phase rési-

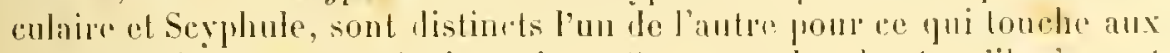

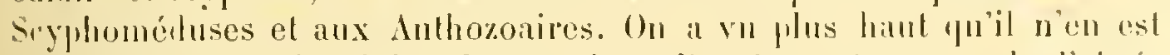
point ainsi pour les Cténophores, dont l'entéron, il cause de l'alitéviation du développement, apparaît cu mème lempis que l'urspliage et les premieres cloisons, ou pen arant enx.

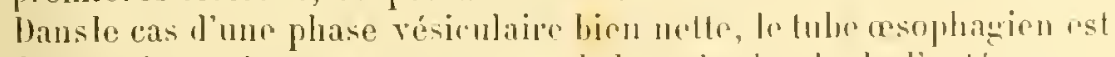

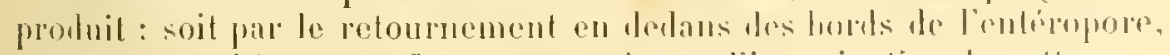

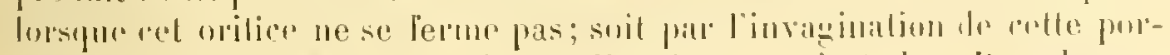
tion de la proroi, placée au point ou l'entéropores sest rlos. Dans le pre- 


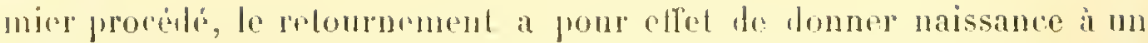

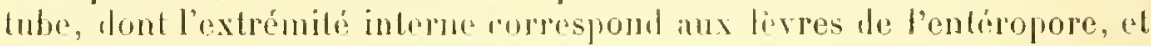
dont l"wrertme interne n'est autre que lenteropore lui-mène; celui-ci devient lonc l'orifice esophagien, ators que l'onverture externe du lube, qui sera la loucle définilive, est limitée par la partic maryinale de la région retounce. - Le fond de l'invaginalion se crense, dans le second proctidé, d’un large trou, qui persiste comme orifice assophagien, landis yue la bouche définitive dérive le l'onverturo externe de l’invagi-

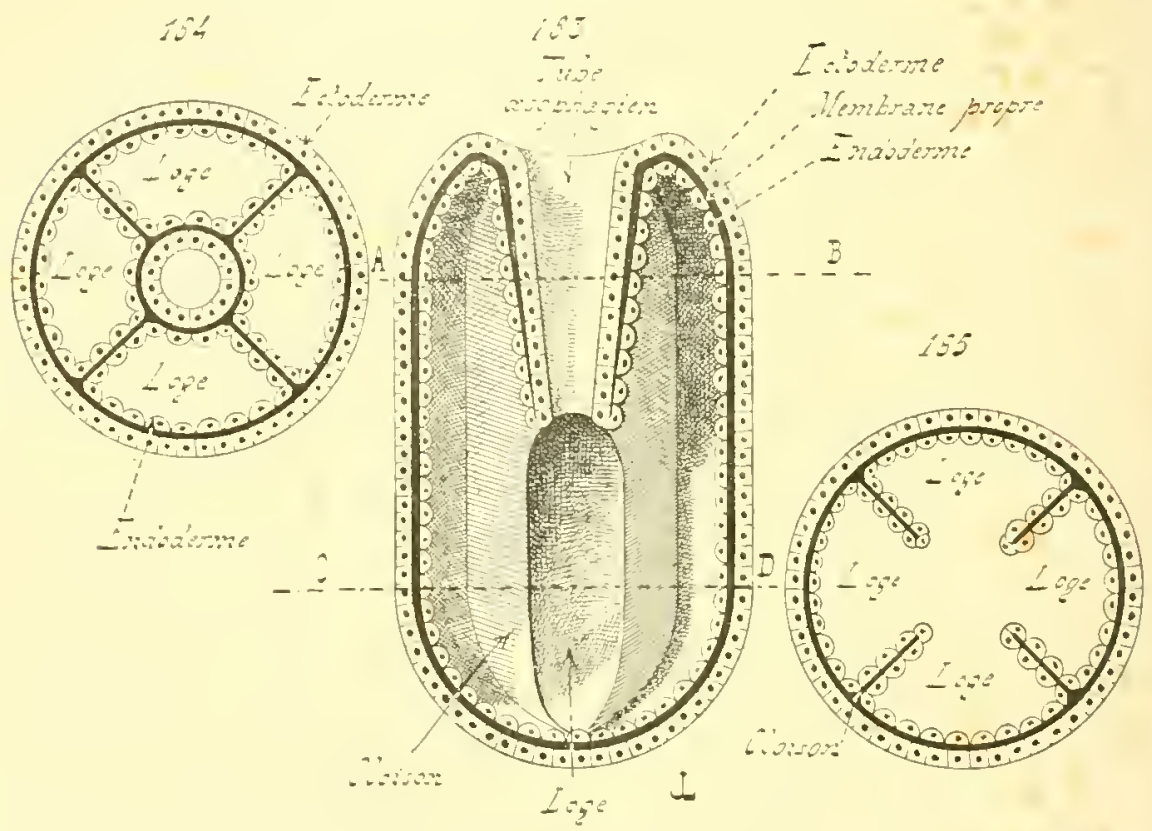

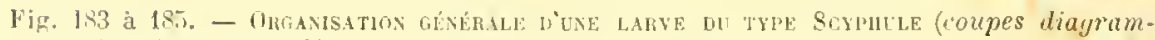
maliques). - Ln 183, roupe longitulinale, médiane, aver nerspective, unontrant la structure complite d'une seyphule, avea son tube a'sophagien, ses cloisons, ses loges, et li composition de ses frais; une moitié seulement de l'être est représentée. - En

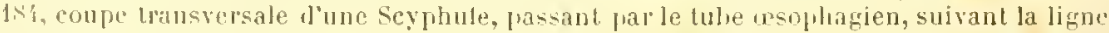
113 de la figure $1 \times 3$, montrant les rapports des loges et des cloisons avec ce tube. lin $1 \times 5$, foupe lanversale menee au-dessous du tuhe asophagien, suivant la ligne fill de la figure lis?.

Ces ligures font suile, fal l'adjonclion des eloisons, à la figure 168.

malion. Jur consingunt, dans les denx ras, fa bouche de l'arlulte est mno formation secomdaire; J'uritire orsophagien est seul fhomotogue de l'en-

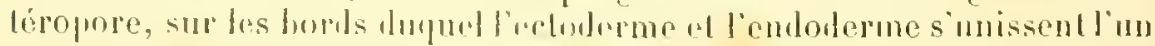

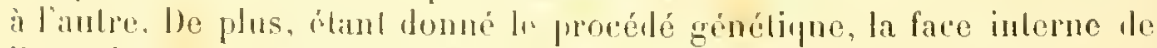

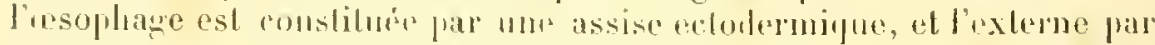
me couche embdermique, contrairement a ce quil en est pom la parvi lit eorps. 
Le tube asophagien des Clénophores est produit par une dépression - cetodermique, placée dans le pule inférieur de l’embryon, écost-à-dire dans la région opposíe à relle ou les premiers élémenls de l'ecloderme se sonl séparés des gros blastomères. Une ouverture forl étroite, homologue d'un entéropore, se perce au foud de celte dépression, au monent où elle pénètre dans l'entéron; la suile le l’évolution correspond a la description donnće ci-dessus pour le deuxieme cas. Les conséquences sont aussi les mèmes: la paroi iuterne du tuhe asophagien est composéc par lectorlerme.

Lontóron embryonuaire devient la cavité gastrique; les quatre cloisons primaires prennent naissance dans son intérieur. Ces cloisons sout toujours données par des replis endortermiques, parallèles à l'axe longiludinal de la larve; la mombrane propre mésodermique pénèrr daus ces replis, el forme leur axe; l'ecloderme ne combibue en rien à celte genèse. Lorsque les développements sont alırégés (Clénophores), les quatre cloisons apparaissent en mème temps; par contre elles naissent en deux fois chez les larves les Scyphoméduses el des Inthozoaires, une premicre paire se montrant arant la seconde.

La phase Scyphule est alleinle, au moment où sont ébauchés le tulue asophagien el les qualre cloisons primilives. Celte phase n'est pas toujours dislincte des autres, et on la roit assez souvent confondue avec la suivante, car les formes l’s larves diffirent déjà, suivant les classes, lorsque se montrent ces organes; mais il n'en est pas moins vaai que l'existence de ces appareils, les seuls prósents dans l'économie en cet inslant de l'évolution, élablis sur un mème modèle el façonnés d'après un mème procédé, donne à toutes ces laıves une ressemblance indiscutable, et une homologie parfaite.

La Scyphute des Siyphoméduses revêt rapidement les caractiores dı scyphislome, en prouluisanl de nombreux tentacules péribuccaux sans accroilre le chillre de ses cluisons. Celle des Anthozoaires devient un Aulhopolype, en augmentanl, suivant des rigles précises, le nombre de sos cloisons, el congendrant des tentacules solon un rapport conslant avec les loges nouvellenunt formées. Enfin, celle dros Ciénophores se modifie cn Cténule par l'élargissement comsidérable, suivi le la sourlure prosque complete, des qualpo cloisons primaires, et anssi par l'appalrilion des rangros de pralelles nalatoires.

11. Scyphoméduses. - Le développement de ces èlros n’esl gruire connu, jusqu’ici, łue rhez les Discoméduses; aussi les consilérations suivantes s'applípuent-elles seulement à ces dernières. Leur larve vósirulaire se fransforme en une Seyphule, yni devient rapidement un Scyphistomr; cusule, celui-ci se modilie en une Ejph!ra, soit directement, soil apriss soure divisé en segments, qui so ronverlissent en antanl de putites liphyres. listin, charpe jenne módnse perfeclionneson organisme, font acquérir les aracleres de l'adulte. - Cependant, il canse des resscom- 
luances manilestes, qui existent entre la structure du scyphistome des

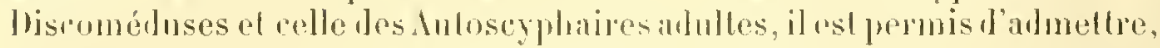
it titre de présonption, due ces dernier's ne dépassent point la phase de scyphistome, el qu ils se bornent, après l'avoir alleinte, it prorluire leurs glandes sexuelles, sans subir d'antres modifications plus importantes. les présomptions semblables s'appliquent ́galement aux Acalephes télameres; leur aranisation rapulle de pris colle des Scyphistomes, lout en montrant mue complexité nn peu plus grande; il est donc probahle que les larres de res animanx subissent d'ahord une phase de siegphule, puis une antre le sicypholype, rt se rhangent en méduses, sans jamais arriver i l'étil d'Fphyre. II serait bon que des recherches fussent elfoctuces sur ce sujel, aulaul pour indiquer les divers phénomènes de celle lransformalion, que pour montrer si le scyphistome de res itres est susceptille de se fissipariser comme relui de diverses Discoméluses; des renseignements rertains à retégard permetlraient de préciser, aver nelfoté, la valeur exacle de la fissiparité du scyjhopolype.

Thois plases snccélent a la scyphule, dans l'évolution embryonnaire les biscoméduses: la premiere porte sur l'aprarition de l'élal de seyphistome, la seconde sur lit modificalion du scyphistome en Ephyre, ala troisiène sur le passage de l'Ephyre à l'étal définitif.

Scrmostume. - La larve vésiculaire, après avoir nagé lilurement pendant un cerlain lemps, se fixe par l'extrómité diamélralement ofposée à celle yui porteria la lube wopophagien, avec la houcbe définilive; la région l'aulhérence s'élargit quelque pen, sm ectoderme s'épaissit, et l'ensimble constilue mu disque de lixation. - Au-lessus de lui, lecorps s'évase en perlant sa forme ovalaire, aplatissant son extrémité orale, ef frenant l'asprect d'un conpe. Le tube osophagien s'ébanclse durant ces modifications, et les yualre cloisons primaires apparaissent presque en mêne temps. Le tube blaryit juelque peu sa paroi, de telle manière gue son orifice extérieur, la bunche définitive, se trouve souvent reporté an sommel d'un petil manclon conique.

Les quatre eloisons sumf produites par des replis de l'endoderme. killes mo naissent pas it fugle listance les nnes des antres, mais sout dispusées de lolle facon, à leur dibut, qu'elles semblent groupées en Joux paires, assezéluignies l'une de l'antre, yui resserrent ì leur nivean la caviló gastrique. l'ar suile, celle-ci prarait divisée, sur son prourtour,

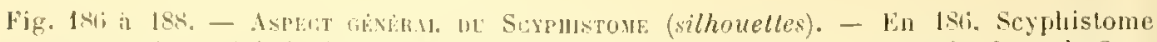

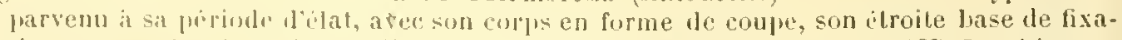
lín, et son cone lucoil an milieu de la couronne des tantacules. - En 187, Scyphistome

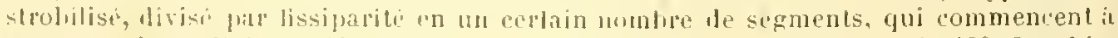

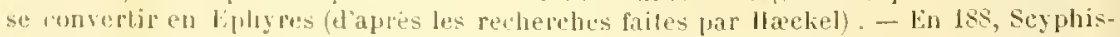
tome non strobilise, se changeant tont inlier en une sente liphyre, dont les lobes de l'onbrelle sont plactis th dedans te la couronne des tentacules d'après les recherches failes par.J, van lieneden sur la Cyanea rupillata). 


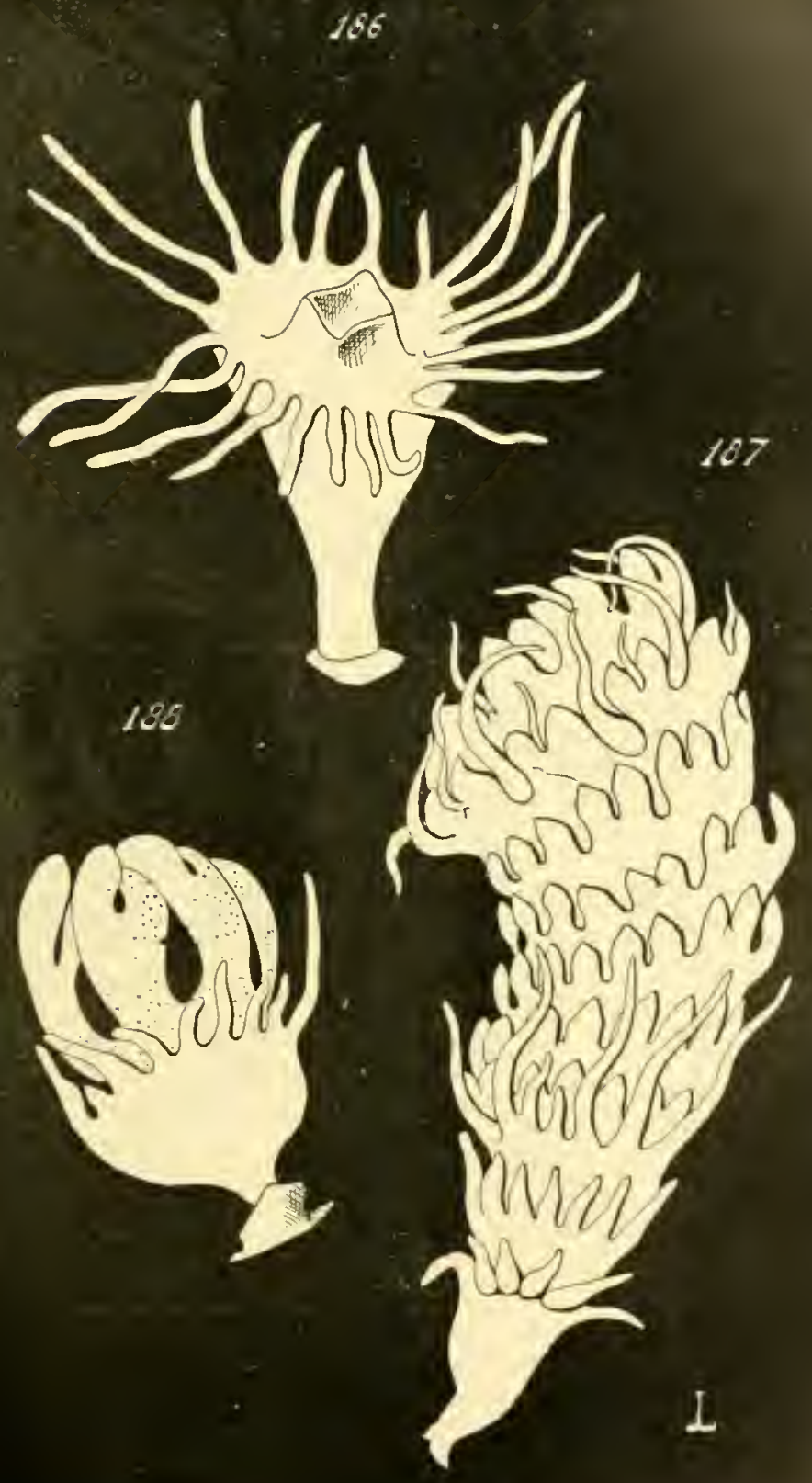

fig. Ist a 185. 
cn deux parties, qui communiquent largement ensemblis. I'uis les cloi-
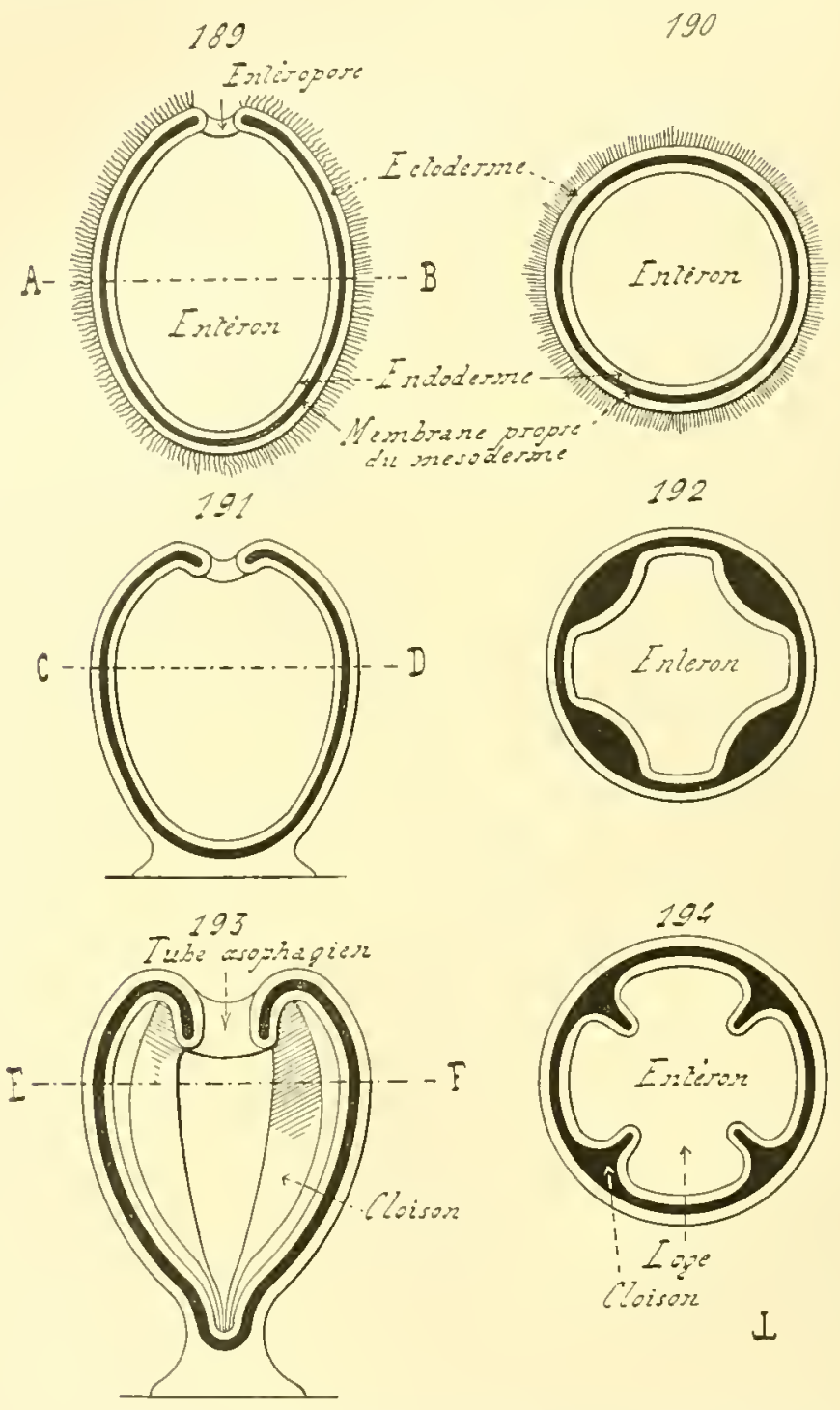

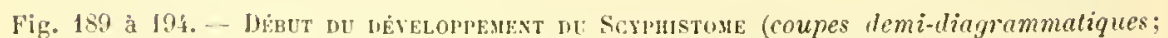
les figures de gauche reprèsentent des coupes medianes el longiludinales, les figures de droite des coupes transversales menées suivant les lignes AH, CI, liF, tracées sur les coupes longitudinales correspondantes). - Ln J89-190, larve á la plase vesiculaire, encore Jibre, nageant au moyen de son ectoderme cilié. - En 19I-192, délut de la fixalion; les bords de l'enléropore commencent a s'inflèchir, et le mésoderuse s'éjraissit en fuatre zones. - En 193-J4, delut de l'état de Scyphistome; l'inflexion des bords de l'entiropore donne le lube asophagien, el J'épaississement du mésoderme les quatre cloisons.

l'étoderme el l'entoderme sont en blant; le mésoderme est en moir. 
sons continuent ì s'avancer lans l'iutricur de la cavité gastrique, et fyalisent les listances qui les sćparent; la symétrie radiale fait alors lranchement son apparilion, ef l'entéron primitif se tromve divisé, jar l'élat de cette évolntion, en ciny chambres, l'une centrale, et les quallor autres périphériques. Ces lemiejes sont les loges; la premiire correspomil il la cavitégastrique proprement lite. Les loges et la cavité communiquent entre elles dans toute l'étemdue hu corps, sauf dans la région asophagienne, où les cloisons vont se souler ì la paroi de l'usophage; l'extrémilé supérienre des loges se lermine donc en cul-ile-sac.

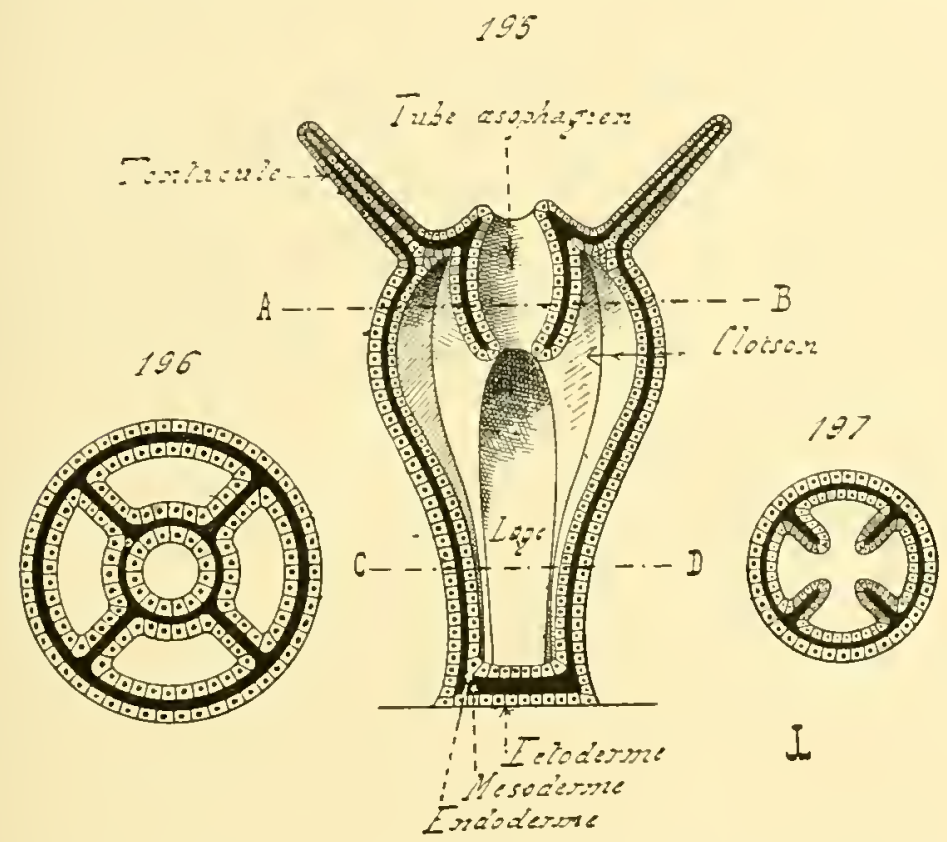

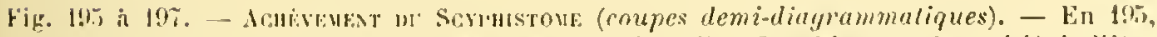
eompe meliane el longitubinale, avee perspertive, d'un siyphistome; la noilie de l'étre esl seule reprisentie; par rapport à la figure 193, le lulw asophagien et les cloisons ont pris plus d'imporlance, el les tentarules ont fait leur apparition. - lin l! i, coupe Imasversile passanl par le tulue asouhagien, suivant la ligne di de la figure lo5. -

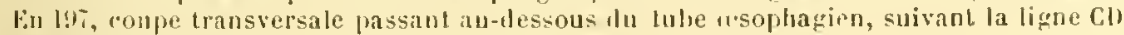
de la mêne ligure.

Ces ligures fout suite aux prividenlos (18!-1!)

Tous ces organes sont disposés d'apres me symotrie raliale, suivaut des perrayons el Jes iuterrayous. Ins quatre pelriyous passent par le milien les loges, et les quatre interrayous par les cloisons.

Quatre tentacules primaires naissent antour de la bonclie; ils sout placés lans les perrayons, et silués par suite an-dessus les loges grastriques. Ils napparaissent jas en mème temps; un premier se forme d’aborl, et s'accroit asse\% vile, puis un second; ces lonx lentacules sont 
disposés au-dessus des deux premières chambres gastriques, limitées par les paires de cloisons encore fort petiles. Jeur présence, en cel instant, donne a la larve une symétrie bilatérale évidente; l'un l'enx est antérienr, l'autre postérieur. Ises denx autres tentacules fuimaires prennent naissance entre les premiers. - Lorsque ces qualre tentacules ont égalisé la dislance qui les sépare, tout comme les loges qu’ils surmontent, quatre nouveaux appendices semblables sélèvent au-1lessus des cloisons, dans les interrayons. Le Scyphistome possèle done luit tentacules, lont quatre perraliaux ef quatre interadianx: luuit autres s'élrauchent plus tard entre ceux-ci, et par conséquent dans les adrayons. Le chiffre 16 étant atteint, les choses en restent fréquemment la; il n'est pourtant pas rare d'olserver une genèse ultérieure le tentacules, qui se manifeste de 8 en 8 , suivant la progression $16 \ldots$ 94... 32...

D'après Götte, l'apparition les quatre tentacules primaires est suivie, non prar celle cles quatre interradiaux, mais des luit alradianx; après quoi l’évolution continuerait de 8 en 8 , comme dans le premier morle, suivant la progression 4... 12... 20... 28... Etant lomée l'importance des axes symétriques interradianx, et la présence constante de tentacules au-dessus des cloisons, lorsque le scyphistome a terminé son évolulion particuliore, il somble plutôt que la première série soit la vraie, et non celle almise par (iiille.

Quoiquil en soit, les rentacules péribuccaux olfrent tous la même structure. Ils sont constitués par un axe central de cellules endodermiques, qu'entonre un revètement d'éléments ectodermiques; ils ne contiennent done, en leur intérieur, aucune cavité.

La structure définilive lu Scyphistome est dès lors acquise. Cet ètre offre l'aspect d'une coupe, fixée par son étroite extrémité inférienre, et portant une couronne de lentacules sur sa large extrémité supérienre. Celle-ci possede la louche en son centre; cet orifice comduit dans le tuhe cesophagien, qui ahoutit lui-mème à la cavité gastrique, livisée sur son pourtour en quatre loges par quatre cloisons. - Quelques morlificalions secondaires sont apportées a l'ensemble. I ne invagination ectorleminue très allongée, la covile cloisommire, s'enlones dans le milien le chacune des quatre cloisons; l'autre part, le sommet de chaque cloison est traversé par un canal, le canal roisommire, lérive dro la cavité gastrique, el qui grandit plus tard dans des proporlions consilérables; enfin, les cloisous se munissent, on leur axe, J'mue hande de fihres musiulaires, le muscle des cloisons. Ces diverses parlicularilés contribuent à donner au Scyphistomo des Discoméduses un aspect spécial, trios voisin de celui présonté par les Auloseyphaires de la famille des Tesserilces. - La plase le scyphistome est alors arrive vors sa lin, el cede la place à l'élat l'Euliyje.

Epura. - A en juger d'ajris lus ressemblances de structure élablies entre Jes Discoméduses inférienres, appartenant a la famille dos Eploy- 
ropsides, et les Ephyres Jarvaires, il est permis d'admettre que ce dernier élat embryonnaire manque aux Acalèphes tétramères et aux dutoscyphaires: cenx-ci présentent, en eflet, une organisation phs simple ine celle des Ephropsides. On pent done croire, bien que les observations fassent défaut à cet égard, que la phase Ephyre est propre aux Discoméduses, les autres représentants de la classe des Scyphoméduses passant directement lu scyphistome à l'élat adulte.

La transformation du Scyphistome en Ejhyre s'effectue suivant denx procédés : on bien elle est simple, un Scyphopolype déterminé se modifiant tout entier en une seule Ephyre; ou lien elle est multiple. le Scyphistome se divisant, par fissiparité transversale, en un certain nombre de segments, qui deriennent autant de petites Ephyres. - Il arrive assez souvent que cette trausformation soit précédée de phénomènes gemmipares : un Seyphopolype donne ainsi naissance à plusieurs autres individus sembJaliles à Jui. Ce homrgeonnement ne doit pas ètre confondu arec la fissiparité dont il est ici question. Celle-ci est une segmentation transversale, qui aboutit à la production de petites méduses; celui-là est une multiplication par gemmiparité réelle, entraìnant la genèse de Scyphopolypes réunis en une petite colonie.

A. Transformation simple. - Les observations, effectuées sur le développement des Discoméduses, élant peu nomhreuses encore, il est impossible de dire si la transformation simple répond à la règle, ou à l'exception: il semble bien qu'elle doive etre prise pour le fait normal. mais de nouvelles études sont nécessaires pour préciser les ilées sur ce sujet. Quoiqu’il en soit, hans ce premier cas, le Seyphistome se morlifie lout entier en Ephyre, sans subir aucune segmentation préalahte. Ce cas présente deux modes: daus l'un, l'embryon primitif, fixé à un support, offre tous les caracteres d'un polype Scyphulaire; dans l'autre, cet emliryon, quelque peu aberrant lans son eusemble, vit en liberté.

Le premier morle a été observé chez les Cyanea capillata et les Aureliu aurim: ces dernièes montrant anssi la transformation multiple. Les principanx cliangements portent: sur la chute les tentacules du Scyphistome, Papparition de huit loles marginanx munis d'organes des sens (rhopalies), lagrandissement de la cavité gastrique, la réduction des cloisons ì la suite de l'excessif développement pris par le camal cloisonnaire, enfin sur la cessation de la vie fixée, el l'aplatissement in corps en une petite méduse lisroüle.

Une Ephyre, parvenue is sou déreloppement compled, peprésente une méduse au corps déprimé, dont les bords de lombrelle portent huit lobes marginanx, développés dans los quatre prerayons ef les quatre interrayons; chacun de ces lobes possede, en son milien, me dipression profonde, qui contient une rhopalie. Les loles marginanx, assez volumineux pour donner au horl de lombelle un aspect erinelé bien accentué, sont creux, denferment des divepticules do la latité ças- 
trique; ces diverticules sont les loges lobaires. - Chacune des huit profondes échancrures alladiales, laissres entre les loles, prósente, en delans d'elle, une paire de polites saillies, qui s'avancenl daus lintérieur de la cavilé gastrique; chaque paire limile aimsi une logre situéce lans l'adrayon correspondant; cellc-ci est nue loge murginale. La caviló gastrique porte donc seize logos périphériques : huil placées dans les lobes marginaux, les loges lohaires; huit dans les échancrures situées entre ces lolves, les loges marginales. Les deux replis, qui circonscrivent chacune des loges marginales, sont nommés des cathammes.

La cavili slomacale, ample el spacieuse, contient, en quatre poinls de sa paroi qui correspondenl aux interrayons, les restes des cloisons du scrolnopolye. Ces cloisons se sonl réduites peu à peu, à la suite du grand développenent juis par le canal cloisonnaire qui les traversait; alles consistrnt an le petits epaississements, munis de trois ou qualre filaments allongós, dits filaments gastriques. Ces derniers commencent ̀̀ se former chez le Scyphistome; ils naissent sur le bort de chacme les quatre foisons, semblables à des sallies qui s'avancent peu ì peu; et, lorsque la cloison a été détruite par le camal cloisonnaire agrandi, ils persistent conme restiges de son ancienne axistence. II est probable que les cathammes répondent également à des restes des cloisons priinitives.

La bouche s'oure sm le milien de la sous-ombrelle; elle est portéc au sommet d'un cône luccal chez les Eplyres jeunes, el devient ensuite percée à fleur de pean, chez les méduses julus àgres, à cause de l'atrophie de ce cone. Son orifice, en forme le croix, présente qualre échancrures profondes, situées dans les perrayous, et précisant la place de ces axes de svnétrie.

il est aisé de suive les changements qui transforment le Seyphopolype en Ephỹe. Le corps s'aplatil, se déprine, cesse lladhérer a un support par son pédoncule : cehi-ci existe hien encore quelque peu au dibul de la vic libre, mais se confond, par la suile, avec le reste de l'ombrelle. Les tentarules s'atrophient, et se debahent. Les lumit lohes

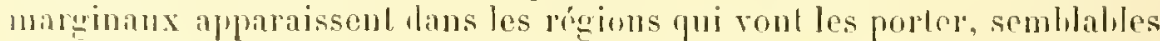
il des saillies do la paroi du corps, fui s'berent pen sen, en entrainant partois los contacules arec elles; ils prennent bapilement leur aspred hilide délinilif, et produisent leurs rhopalies. La région pépistomienno du Scyphistone, cucadrie par les teulacules dahord, puis entoure par les lobes marginaux, ol porlant lil houche en sou centre, devient done la sous-ombrelle de l'liphrre; les autres parlies de l’imlividu, élalées depuis la zone tentaculaire jusqu'i la base fixée, prouluisent la susombrelle, la face supérienre de la méduse. La cavité gaslripue s'élargit, par l'ellet de l'aplatissement du corps; les cloisons se détruisent en

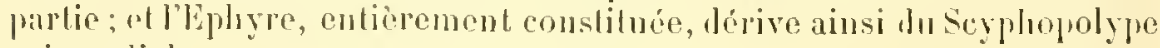
primordial.

La série des phénomènes est beaucoup moins complexe dans le 
second mode, Jorsqu'il sagil de larres libres: la phase seyphistome u'existe pas, est omise dans le cours du développement, et le jeune embryon se transforme en Eplyre sans quiller sa vie errante. Ce morle

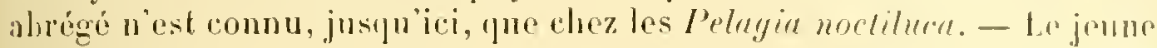
ètre, apres avoir subi les phases gastrulaire el vísiculaire, produit, daus la région supérieure de son corps, un mésorlerme ahondant, qui donne ainsi une ébauche d'omlurelle; les cellules de l'ecloderme, coureptes de cils vibratiles, soutiennent l'individu dans l'eau, et lui permettent de se déplacer. La bouche se perce an centre de la région inférienre, quelque peu déprimée et aplalie; les tentacules lu scyphistome ne fout point leur apparition sur le hord le cette région buccale, mais bien les huit lohes marginaux de l'Ephyre, qui naissent i len' place, au lieu de lenr succéder. La larve vésiculaire se convertit directement en une Ephrye libre, presque semblahle a celles qui proviennent des Scyphistomes, mais ayant en plus un tissu mésodermique abontant. situé dans la partie sujérieure du corps, et semblable, par son volume, à celui de l'ombrelle des alultes. - Ces liverses particularitís permettent de rapporter l'évolution embryonnaire des Pelagia it un développement ahrégé, l'aluéviation étant caraclérisée par l'omission de la phase Scyphistome, et par la genèse hàlive dn mésoderme ombrellaire. Pent-ètre la cause l'une telle condensation doit-elle itre recherchée dans la tenlance à garder une vie libre et pélagique. L'embryon de ces animaux serait une larve adaptative ì stase, et à métamorphose lorusque.

B. Transformation mulliple. - Ce procédé a été observé principalement sur les Aurelia aurita, qui présentent aussi la transformalion simple. Le Scyphopolype s'allonge beaucoup, s'élire en un trone de cóne ì hase étroite, el se divise ensuite, par fissiparité transversale, en plusieur's, dix à douze en moyenne, segments superposés. La fissiparité débute par l'apparition d'étranglements circulaires autour de la paroi du polype; ces sillons deviennent de plus en plus profonds, resserrent i leur uiveau le corps, avec la cavitó gastrigue un il contient, el funalement arrivent an centre de l'embryon. Lorsque l'évolution en est parvenue i ce point, le scyphopolype se trouve partagé en plusieurs scoments discö̈les, empilés les uns sur les antres. Chacun de ses se⿳ments possiole la valeur d'un individu. Cette division, nommée strolilisation par les anteurs, répond ì la production de zooüles par un zö̈te primitif, les zoö̈les devant suive un déreloppement scmblable de lons points à cehui qu'aurait accompli le zoïte, s'il ne s'élait pas fissiparisé.

Chaque zooüle commence par offrir la structure du sicyphistome dont il est une partie, et phssieurs d'entre enx donnent mòme naissance, sur leurs hords, it une couronne de tentacules. Mais relte rowhtion ue ra pas très loin dans ce sens, el, par conlee, regne une tendaure à transformer le plus lüt possible les segments en Ephỵes. Leur région marginale produit huit lobes bifides, avec leurs rhopalies; les cathammes, 
avec les filaments gastriques, font leur apparition; la struclure particulière à l'Ephyre nait ainsi peu à peu. Lorsifur ces faits commencent à

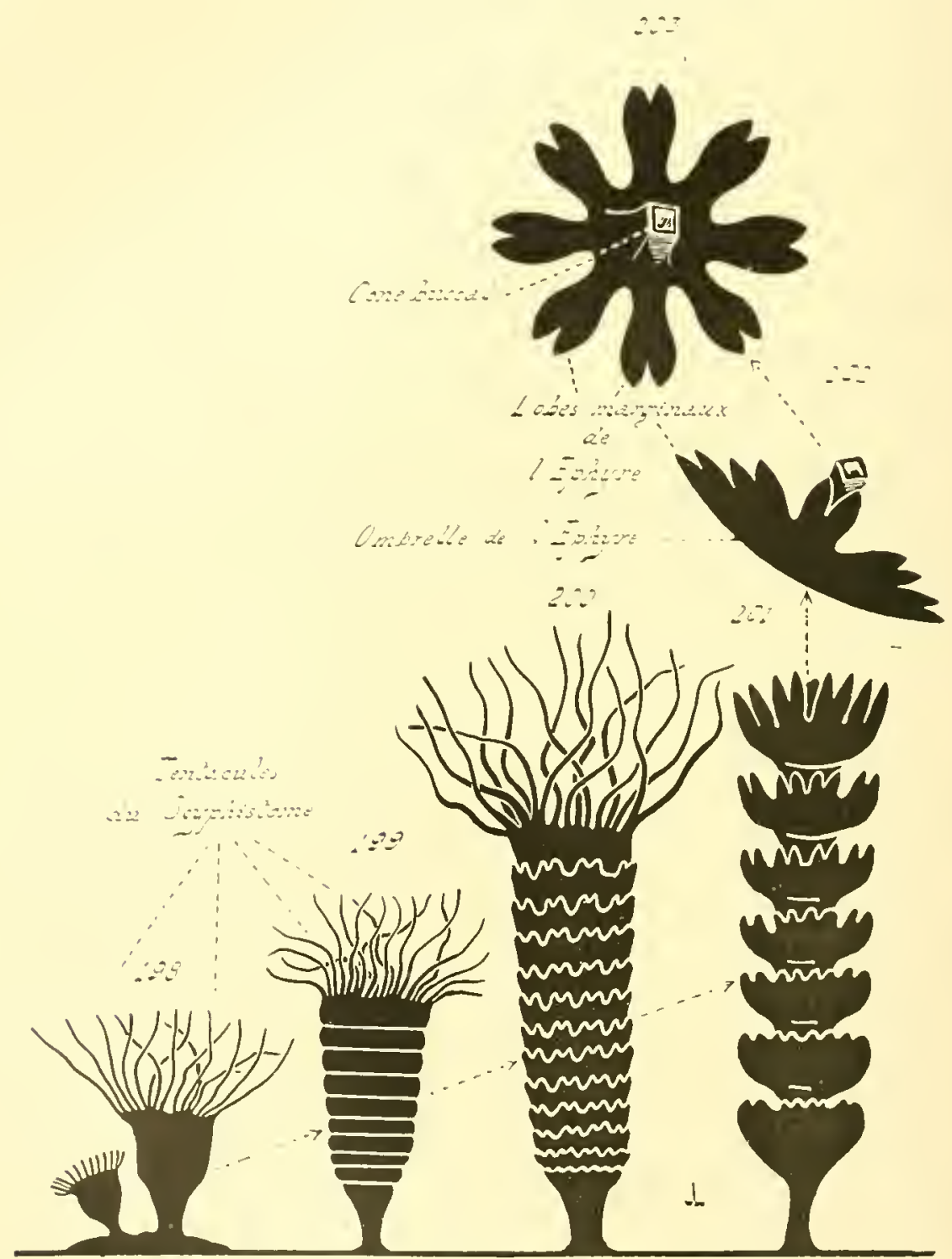

Fig. 1!K a 2013. - Trassfom

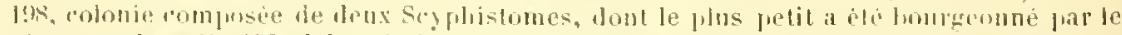
flus grand. En 199, delul de la division fissipare. - En 20n, suite de cetle division; les lurds dos segments commencent a se franger, par l'apparilion des lolves marginatix. - En 211, arlievoment de la divi-ion; les segments, convertis en Ejlyres, se separent

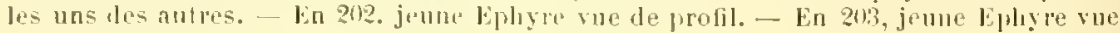
par sa fitee infipiente, ou sous-umbrllaile. 
ètre bien marqués, le Seyphopolype primorilial se trouve constitué par dix on douze Ephyres superposées, encore acrolées, et possídant lrur organisation prestue complete. Lin cel état, le Scyphistome est désigné par lexpression le sirobile.

Puis, les tentacules portés par plusieurs de ces méluses s'atrophient, et tombent; les méduses elles-mèmes se séparent les unes des autres, et nagent librement. Elles ont acquis la structure l'Ephyre, comme si le Scyphistome, dont elles dérivent, avait subi la transformation simple, et vont ensuite passer à l'état adulte définitif.

Ilackel nomme Strobilisation polydiscale cette transformation multiple, par opposition au terme de strobitisation monodiscale qu'il donne à la transformation simple. Cette dernière expression n'est pas très juste, car, les phénomènes de fissiparité faisant défaut, il n’existe aucune strobilisation. Sans doute, le premier de ces modes n'est pas primitif, el dérive du second. La question sera examinée plus loin avec détails; mais il est bon de faire remarquer ici que l'essence de la strobilisalion parait consister en la genèse de tentacules, el de lobes marginaux, sur le corps entier du Scyphistome, et non autour de la bouche seule. Chacune des couronnes supplémentaires de tentacules et de lobes est ensuite capalle de devenir un individu complet, en empruntant au reste de l'organisme une portion de sa cavité gastrique el de sa paroi.

Mèduse dérintTue. - Les modificalions demières, qui doirent changer l'Ephyre en une méduse définitive, sont nulles, ou peu s'en faut, chez les Ephyropsides. Liorganisation de ces dernieres est, en effet, semblable a celle des petites Ephyres; et le senl fail qui intervienne, ticul à l'apparition de huit tentacules dans les échancrures adradiales.

Il n’en est pas de mème pour les IDiscoméduses acalhamnates; leur structure se complique, autant sous le rapport de l'aspect extérieur, que sous celui de la forme présentée par la cavité gastripue el par ses llépendances. Ce dernier ordre de particularités sera examinć dans un prochain paragraphe (\$5); quant aux caractires externes, les principales modifications portent sur le bord de l'ombrelle, et sur la rógion burcale. - La jenne móluse grandit; l'accorssement marginal n’est pas cigal dans tous les points du borl ombrellaire, mais touche de préférence anx luit échancrures alradiales. Celles-ci commencent à s'elficer, et par disparaitre en tant qu'échancrures; mis, les régions qui les renfermaient grossissent davantage, de manière it faire saillie en ilehors des lohes de l'bihyre. Lorsque ce développenent s’est elfectué depuis quelyne temps, les zones arlraliales portent a leur pápiphérie, an lien do sillons profonds, huit larges lourrelets, qui deviennent les huil lobes marginanx de l'adnlte. La substance de res derniers se soutro ave relle des luhes primitifs appartenant a l'kphyre, le faron it se confondre intimement aver eux; el lo senl veslige le l'ancienne existence des apponlices Ephyriens est fourni par les rhophalies, pui restent il leur plare primilive. 
Seulement, à la suite des changremeuls ainsi apportés dans la structure gónérale, ces organes sont silués dans drs échancrures profondes, laissées
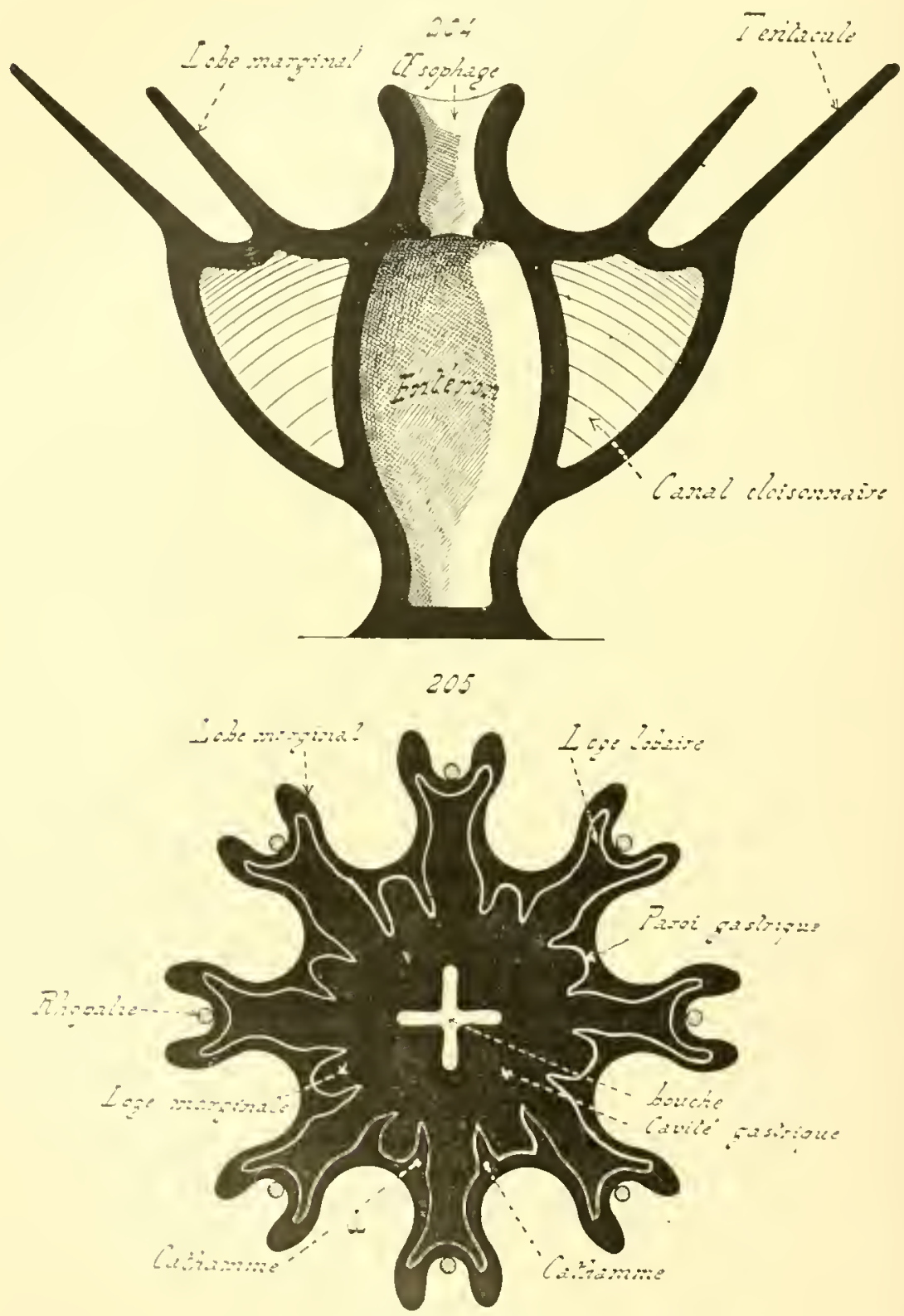

Fig. 201 et 205. - Obus arec perspective. d'un Sicyphistome en voie de devenir tout entier une seule Ephyre; les lobes marginaux de l'liphye se faconnont en dedans des tentacules, et les canaux cloj- 
entre les huil lobes adradiaux qui viennent de prembenaissance. Comme la position tes rhopalies n’a pas varié, les régions qu'elles oceupent correspontent aux perrayons et aux interayous. En surplus, des tentitcules ereux, variables d'un genre à l'autre par le nombre et par l'aspect. se développeat sur le bord de l'ombrelle.

L'ouverture buccale, toujonr's percée an centre mème de la sous-unbrelle, ne conserve pas des levres minces, et rassemblées en un còne surluaissé. Ces lèvres gramlissent dans des proportions consiléralules, el s’épaississent heancoup; elles constituent ainsi yuatre expansions volumineuses, encadrant la bouche far lenr base, et faisant saillie au-ilessous de l'ombrelle : ce sont les lras buccaux. - Ces appeadices subissent, chez les Rhizostomides, une évolution spéciale. Ils sont d'alorul, sur la méduse encore jeune, simples, et séparés les uns des autres. Puis, durant leur accroissement, l'extrémitélibre de chacun d'eux se bifurque; et comme cette hifurcation se produit de honne heure, comme l'agrandissement ultérieur est consilérahle, il en résulte que l'indivilu porte huit bras, an lieu de quatre. Mlais les choses n'en restent point la; chacune de ces expansions buceales émet, à son tour, des banles longues et frangées, dont les unes sont placées non loin de la honche, el dont les autres sont siluées sur l'extrémilé libre du bras. Les jremières, toujonr's externes, sont les replis scupulaires; jarmi les secondes, les unes, les replis dorsaux, sont externes, el les autres, les replis ventraux, sont inlernes. Ceux-ci, plus longs que leurs congénères, s’étendent depuis l'extrémité libre de l'organe jusqu'à l'ouverture buccale, el ront ainsi jusqu'au niveau des replis seapulaires. En outre, les bords minces el frangés des replis, appartenant à les bras voisins, s'atfrontent, et se soudent les uns aux autres; l'ensemble des bras, el de leurs replis soudés, limile done un canal volumineux, qui conlinue l'orifice luccal au-dessous de l'ombrelle, et représente une sorte de grosse trompe. Les lignes de cohérence s’interrompent par places, pour laisser des petites ouvertures, dites sucoirs, qui font conmuniquer le canal arec le dehors; l'ean environnante, entrainant arec elle des animaleules servant à l'alimentation de l'individu, pénètre dans le conduit par ces orifices, arrive juspu'à la bouche, el parvient ainsi dans la cavité stomacale. - Certains ile ces orifices portent, chez les Rhizostomides, les petites expansions lubulaires, semblables à des tentacules très réluils. Les faits sont plus complexes encore chez les Cassiopéides, car les bras se ramifient un grand nombre de fois, se munissent de pelotes urticantes sur leur's extrémités, et présentent des expansions hubulenses, lieancoup plus longues que celles des Rhizostomes.

sonnaires guandissent jour detruire les roisons qu'ils traversent. les lissus de l'orga.

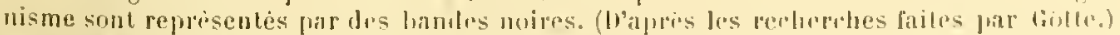

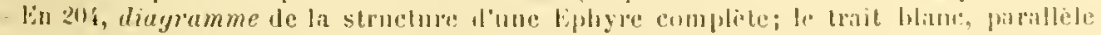
au eontour exteriens, indinge la face interne de la paroi du corps et la limile de lit cavite gastripue. 
III. - Cténophores. - Pendant que s'élandıent, dins l'iutérieur Ju corps, lo lube asopluagion avee les quatre doisons gaslripues, l'emloryon des Clénophores tend i puitler les enveloppes ovulaires, el ì vive en liberte. L'apprarion do l'resophage, el celle des cloisons gui l'accompraguent, jermellent de considérer cetle forme comme une scyphule issue d'un développemenl abrégé, el renfermóe dans les coques ovulaires; ces deux parlicularilés secondares mises de cite, les raraclimes de la siyghule des cténophores we dillèrent en rien de ceux présentés patr l'álat latrvaire coprespondant des Scyphomóduses. Sculement

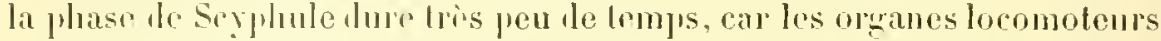
propres anx Clónoluores prenuent naissance de homo henre; la présence ve ces paletles nalatoires ilome il l'embryon de ens animanx un aspect spécial. lien dillírent de celui otferl par les jeunes Anllozoaires, et par les jeunes Scyphoméduses. La larve, qui succide ainsi à l'étal Seyphuare, el nexiste que chez les Cténophores, mérile le nom de C'temula; caractérisée par la prossession de palettes nataloires, elle nage en liberlé, al sulit, duraut colle périoule de son évolulion, les changemonts gui doirent lui donner sa structure détinitive.

Ces morlilicalions ne sont pas toujours semblilles, of raricul suivaut que l'on s’adresse a l'ordre des Tentaculiferes, on à celui des Nus. Les représentants de ce dernier grmupe passent directement de la phase Clémulaire à l'état adulte. Il n'en nst pas ainsi pour les autres. Les Cydjpides seuls, parmi cenx-ci, dérivent immódiatement de la Clémule, sans offrir d'autres lormes larraires. Les autres familles de londre, les Lobés el les Rulanís, présentent l'ahorl la phase de Cténule, puis une seconte fhase semblable, par laspect el par l'organisalion, it l'b́at définitif des Cydippides, et nolamment à colui du genre Mertensin. Celte dernière, propre aux Lohés et aux liuhanés, mérite donc le nom le phase Mertensia, qui lui a été Jonné par Chun; son inportance est fort grante, car elle permet d'admetlre que la famille des Cydippiles représente un type inférieur lles Cténoplores Tentarulifères. Ensuite, l'organisme embryonnaire se convertil en individu parfait.

La sérir des phénomènes est hien nette. Tous les Chémophores, sams aucunr exeption, se présentent, an début de leur vie emlryonnaire lihre, sous une forme C'tenula, qui succide à une indication d'état Seyphulaire. l'uis les Nus et les Cydippides parviennent directement de la Cténule à l’álat alulte, landis que les Lohiés el les Ruhanés passent par une seconde phase larvaire, qui est celle de Cydippide ou de Hertensia. Lexposé suivant sera done divisé en leux parties; la première traitera de la Cténule; la secomle, des changements subis par la Cténule pour arriver a l'organisme détinilif.

l'une Ctexun. - Los souls organes internes de la Clémule sonl jeprésentés par le luhe usophagien el par les quatre cloisons gastriques; cetle larve ne differe donc pas, sous ce rapport, des embryons de Scyphomé- 
Iluses et anthozoaires. Tun au plus, serail-il permis de trourre des dissemblances dans la grande longueur de l'asophagere, che\% la phupart des Cténules, el dans limportance assez considérible prise pal le mísoderme. Mais, si l'organisation fondanentale rappolle ainsi, de tris près, celle des larres des deux autres classes, il n'en est pas de mème pour la forme extéricure.

La Climule est un embryou libre, d'aspect ovalaire le phos somvent. Son extremilé supérieure, qui correspond à la région on les pronicrs éléments le l'ectoderme se sont séparés des blastoncires, porte l'éhutuche de l'unique organe sensitif de l'alulte. L'extrémité inlérieure, liamétralement opprosée à la précédente, posside la bouche détinitive, c'estit-dire lorifice externe du lube esophagien; cet orifice est étroit, allongé en une petite fente. L'ébauche sensitive est constituée far une zone lectoderme ípaissi, dont puelyues cellules renfernent des concrétions. P'arfois, dhez les Tentaculilères seuls, les éluanches des tentacules commencent a se manifester. - Jusquici, les particularités ollertes par la Ctémule ne sont pas très importantes; il n'en est pas de mème pour celles tirées des organes locomotrurs. Les cils vitratiles, si alomdants sur l'ectoderme des larves des Scyphoméduses et des Anthozoaires, font complitement dífaut, et, en teur lien et place, se trouvent huit rangées de palettes natatoires. Ces dernirres sont produites par les cellules ectodermiques qui les portent; leur procélé de formation, peu connu encore, frarait comsister en la genise de petits bitonnets cuticulaires, dabord séprarés, yui se juxtaposent et se soudent ensuite.

Les cananx gastriques nayant pas encore pris naissance aux dépens de lentrirm, les palettes reposent simplement sur l'ectoderme, et on ne troure, au-1 lessous d'elles, aucune Irace des canaux méridiens; l'apparilion de ans appendices locomoteurs précede done celle des conduits qui leur sont annexés chez l’adulte. Leur's huit rangées sont bien situées dans les régions qu'elles doivent occuper sur l'individu définilif, mais elles ne sont pas trèsétemlues; chacune d'clles comprent trois on quatre palettes an plus, el se localise dans la région superieure de la larve, non luin de loryane sensitif. La moitié inférieure de l'animal est privée de ces appendices: plus tard sculement, par une progression lente, les rangées envalıssont tonte la longuemr ales lunit méridiens, en se contimant vers la houche, sur le prolongement de lit direction qu'elles ont líjic.

Cet orlre d'apparition est fort intéressant i examiner, car il est le mème chez tous les Clénophores dont le développenent soil counu : les palettes natatoires naissent en premier licu, lans le voisinge immédiat de l'organe sensitif, avant que la cavité gastrique ne se dispose en un systeme de canaux. Il ast curieux de remarquer que les huit ranges se fagonnent en mèue temps. Cipendant, ì en juger d'après les ohiservitlions ellectuces fror Chun sur l'kecharis mulleornis, il semble que leurs prenters indiees, silnes autour de l'ébauclae sensilive, soient sen- 
lement au nombre de quatre, el placés au-dessus des loges gastriques, dans des espaces conparables aux perrayons des Scyphoméduses. l'uis, chacune des fuatre rangées primilives se lifurque. Il serait utile d'eftecluer sur ce sujet des recherches nonrelles; des éludes complètes à cet egaril permettraient, peut-otre, de rattacher les appentires locomoteurs des Cténophores i des bandes ribratiles d'aspecl spécial, développées dans les perrayons senls, et de mienx préciser les lomologies établies entre la structure les jeunes Cténophores el celle des jeunes Seyphoméduses.

La larve Ctemula, ayant ainsi revêtu son aspect propre, se, modifie pour acquérir les caracteres de l'adulte; sa forme exlérienre change, les rangées de paletles s'allongent par le procédé déjà indiquc; les organes internes acquierent leur structure définitive. L'évolution de ces demiers sera exposée dans le prochain paragraphle, le présent étant consacré aux senles modifications externes.

État défixitif. - Les changemenls sulis par les Clénophores nus (Berö̈liens) sont minimes. La Ctémule, dont l'aspeet rappelle d'assez. frès celui de l'adulte, se borne à s'allonger', et à augmenter de dimensions dans tous les sens; les rangées locomotrices, d'abord localisées au pöle supérieur de l'individn, sélendent sur le corps entier, et parviemment jusqu'auprès de l'orificr buceal; celni-ci, assez étroil au commencement de son apparition, s'élargit pour devenir l'ample ouverture caractéristique de ces ètres. L'organe sensitif revêl peu à peu sa structure définilive. L'embryon arrive ainsi il l'élal jarfail, sans subir aucune modifieation importante. Les Clénophores nus n'offrent point de métamorphoses larvaires bien accentuées.

Il en est de mème, parmi les Clénophores tentacnlés, pour les Cydippirles; seulement les phénomines sont un pen plus complexes, grîce ì la production de deux tentacules, qui deviement de plus en plus volnmineux durant la série des phases érolutives. Ces appendices naissent en deux points diamétralement opprosés, sur la région supérieure, on sensitive, de l'animal; on les voil s'ébaucher dès l'étal Cténulaire. lls sont constitués, en ce moment, par un axe d'éléments mésodermiques, qu'entoure une assise de cellules ectodermirues; lo plan, qui passe par lenrs bases, correspond au plan transversal de symétrie. Les tentacules sont d'abord insirés directement sur la paroi du corps; puis, à mesme que l'évolulion embryonnaire se poursuit, la région qui les porte, ne subissant pas un diveloppenent rgal a celui de ses voisines, se convertit en une dépression de plus en phus granle, an fond de laquelle l'appendice va sattacher. Finalement, celte dípression offre l'aspect

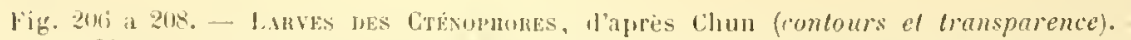

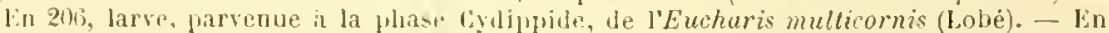

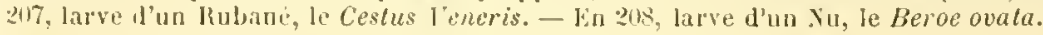




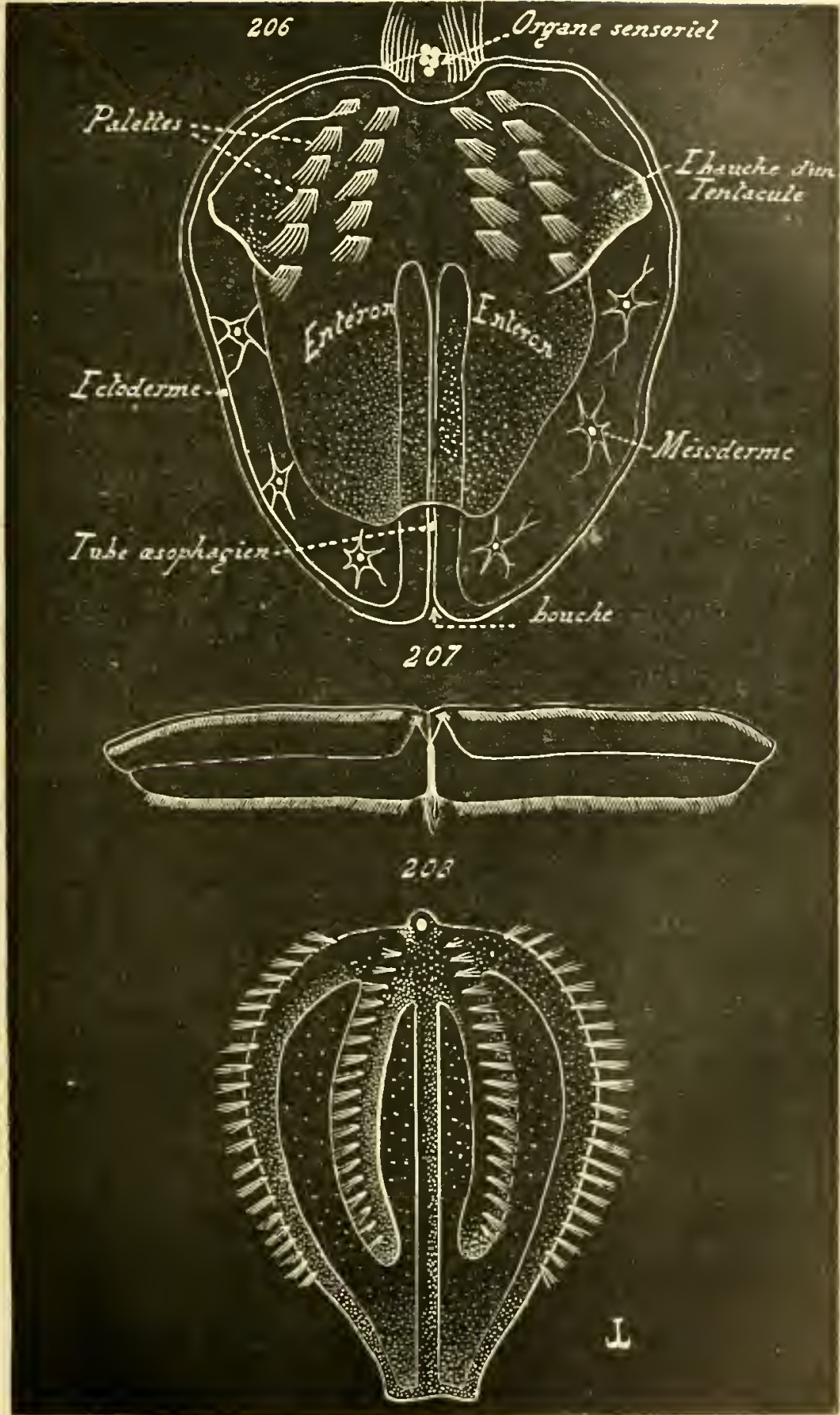


d'une poehe lubulare qui, limitée par l'ectorlerme à cause de son mode d'origine, traverse une ípaisse partic le la paroi somatique, el sourre a Pextérieur par un orifice livrant passage an tentacule. En outre, lon-

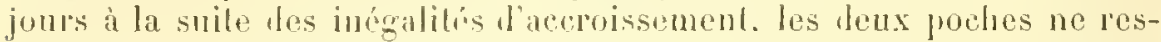
tent pas sur to pôle sensitio de lanimal, mais se trouvent reportées plus bas, el sont mime silures, dans certains cas, at igale distance des deux extrémitís. Le tentacule grandit, el grossil, pendant que seffeetuent ces phénomenes; il porte souveat un eertain nombre de branches secontaires, sumblables it des petits lourgeons formés sur lui, el qui s'allongent peu à peu.

Les melanorphoses larvaires sonl ainsi plus accentuíes chez les Cyclippites que chez les berö̈diens; en effel, elles portent, nun senlement sur lamplitication du corps entier, mais encore sur la geruese ef le dircloppenent de phosicurs organes extirienrs. - Les changements d'aspect sont plus prononcés encore chez les Lobés el les liubanés; ces derniers passent d'ahord par une phase Ctemela, subissent ensuite un second atal, semblable par la forme et par la structure a celui des Cydippides adultes (phase Cydipmide, ou élut de Mertensia). el revìtent enfin les caractiores défnitits.

Les modifications offertes par les Lobés sont moins profondes que celles des linbanés. - Lorspue la jeune larre atteint, pour les premiers, lit phase cydippide, son corps est globuloux, ses tentacules sont díjà lien ébauchís, el enfoncés daus une pelite poche; les rangées de palelles reconvent prespue la moilié supírienre du rorps. L'emburgon s'aplatit ensuite, se tiprime, el s'allonge suivant son axe transversal. Celle phase est nommée, par Chun, l'elut medusoüde; l'expression est mal choisic, ear aucune particularité organique n'autorise à étahlir une concorlance aree les méduses, et les cananx gastripues présentent dija l'aspect propre aux Clínophoros; la seule ressemblance touche à l'excessil dérolopnement pris par le mésoderme conjonclif. Les deux larges expansions, portées par le corps, prement ensuite maissance non loin the l'ouverture buccale; phosienrs des canaux gastriques méridiens émetlent des branches, qui pénétrent dans leur sulstance; les rangées de palctles sallongent encore pour alleindre leur base; of la larre, après avoir ressemblé a nne Cydippide dans le conts de son évolution, urvive à l'étal parfail.

Les mélamorphoses, subies par les Rubanés, sont les plus completes de loules celles présentées prar les Clénophores. L'embryon, après la phase Ciénulaire, passe par un clat de Cydippe. Son corps, ovalaire, porte deus longs tentacules ramiliés, et possiele huil courtes raugées d'urganes locomotenrs, chaque rimgre étant réduite d'ordinare il une seule palete; ans appendices sont pliarés, comme loujonrs, dans la région supérieure de l'indivilu, à une certinine listance de l'élauche sensitive. l'uis, le corps s'aplatit suivant l'axe sagillal; el cel aplatissement

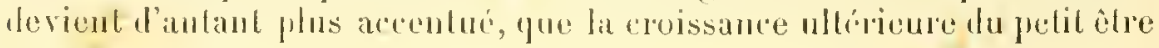


selfectue, pour la plus grande part, suivant l'axe transversal; le corps pert ainsi sa forme globuleuse, et revet peu i peu laspect rubané. Li ne se bornent point les modifications. Les attérations les yhs remar-

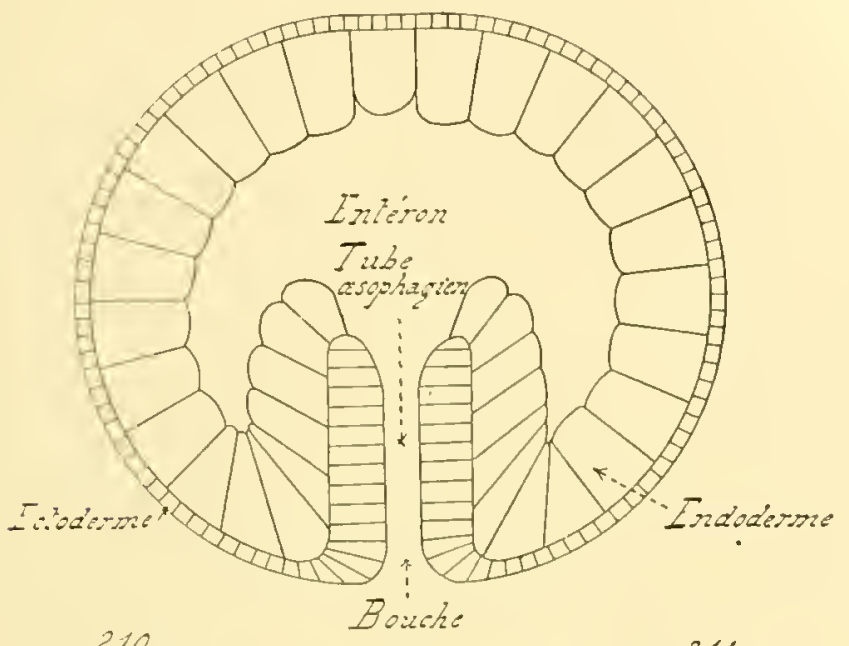

210

211

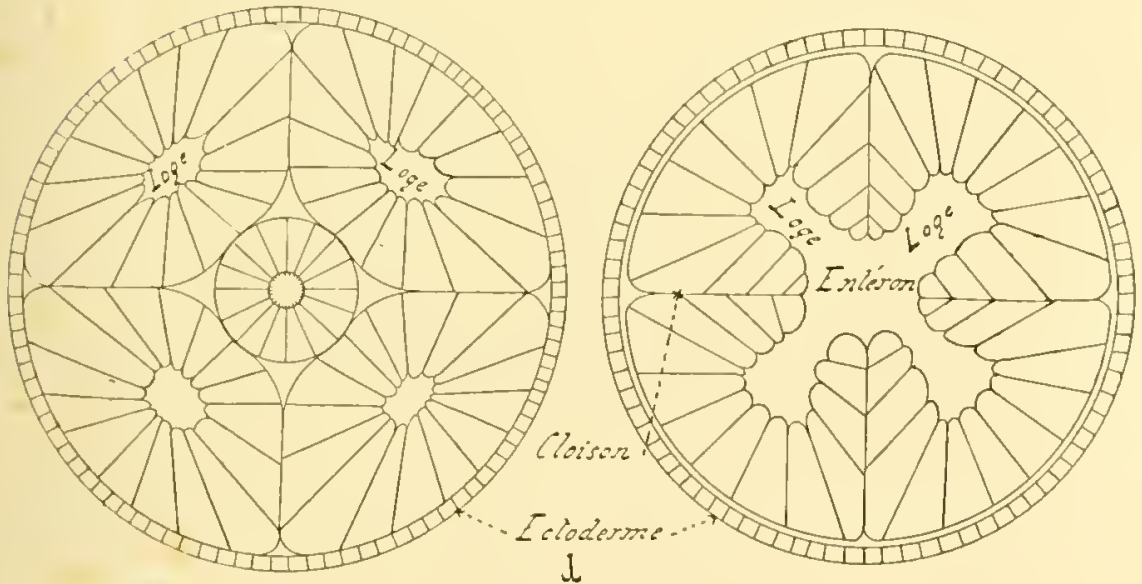

Hig. 209 a 211. - Mrganisation DES LARVES de CTÉxomonis (coupes semi-diagrammaliques). - En 20!), coupe médiane el longitudinale, montrant le tule asopluagien qui s'avance dans l'entéron. - lin 210, coupe transversale pratiufuce au niveau du tube osophagien. - En 211, coupe transversale pratique au niveau de l'enteron, el montrant sa division en yualre loges an mogen de quatre ipaisses cloisons.

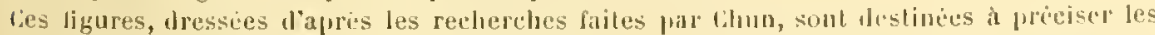
relitions étroites fui unissent lourganisme des jemnes lifinojhores à celui des auldes. sicyphozoaires. Les eoupes, quelles exprinent, onl eti efferluces sur des larbes de Beroe forstialii. 
1uables portrnl sur les rangées locomolrices; 'fuatre d'entre elles conlinuent à croitre, el à s’élendre sur le corps entier; les quatre autres ne changent en rien, el sont seulement roprésentées, chez l'animal parfail, par qualre palelles, qui cncadrent l'appreil sensilif. Les quatre premières s'allongent, mais lenr extension ne dépasse pas le hord sensilif, ou aboral, llu corps.

L'embryon, en s'aplatissant suivant l'axe sagillal pour s'allonger transversalement, preml l'aspect d'une lame mince; celle lame est divisée en deux moiliés par le lube digeslif, on par laxe pui frareour le lube ligestif, en passant par la bouche el l'organe sensilif. L'un des boris de la Jane montre cel organe en son milien, et l'aulre porte la houche; le premier est le hord semsitif, on aboral, al be second le bord oral. Les qualre Jongues rangées de palettes sont seulement placies sur le bord sensilif; elles ne le lépasseul jas, aux loux extrémilís du copps, pour revenir sur le borl oral, el arriver juspu'il ha bouche; en somme, el par rapport aux autres climoplopes, es rangies ne sélenlent pas sur le corp's entir. Jepuis l. poile sensilif jusin'i la bonche, mais senfement sur une moilio du rorps. Lo hord oral entix est ocenpé par des longs filamenls serés, semblables à des cils vilualibes volumineux, sans doute homologues aux palctes par leur wrigine, mais ne provenant point l'elles. - Parmi les pualre longues rangées, ansi limilées an lord aboral, deux sont placées a droile, et los denx antres à ganchu de lorgane sensilil; les lenx promicres, siries de la première paire, s'étalent de l'apparoil sensilif a l'exhémilé droile du ronss; les deux serondes, difos séries de la seconde paire, sétendent du même appareil a l'exlrémilé wanche. Comme le bonl aloral est fort élouil, les deux rangées d'une mème paire sont placées cole à còte, el paralleles; li distame qui les sépare est relativement lorl minime.

Ainsi, les Clénophores rubanés, apròs aroir oflort uno phase de Cydipe durant leur vie embyomatre, subissent des milamorploses romplexes, qui consistent ì domer an corps un aspect rubane, à empécher le diveloppoment de quatre des rangres locomotrices, et a ue permellre celui des quatre aubes que sm le lord prósentant en son milien l'organe sensilif.

II. Anthozoaires. - Whabilude, les larves drs Anthozoaires sont libres, lomsquelles se tromvenl encore sous la lorme visiculaire; alles se tixenl cusuile par leur extrimiléaborale, el proutusent Jeurs doisons gastriques. Cinles-ei naissenl par panes, et, lorsque la seconde de ces pairos vient the faire son apparilion, l'embryon alteint la phase scyphula; puis le nombre des cloisons conlinue à augmenter, el la Sey-

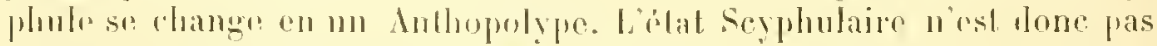

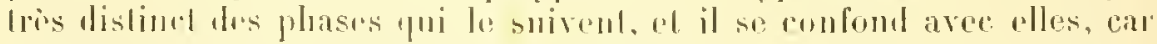
la geniso tes nouvellons moisons gistrignes seffortue sans disconlimile; sa présence est cepentanl manjuée par un lemps d’arrèt, dans la 
série des phénomènes évolutifs. qui contrilue à l'isoler quelque peu des suivants, et à préciser son importance.

l.es tentacules pribuceaux prennent maissance de fort bonne hrure. Ils sont toujours placés au-dessus des loges gastriques; et, comme ces Jemières apparaissent suivant un mole déterminé, qui sera citudié avec détail dans le prochain paragraphe, le nombre des tentacules s'accroît l'après le mime procédé. - Les loges ne sont point formées loutes en mème temps; deux sont d'ahord produites anx dépens de la cavité gasIrique, par lapparition des premieres cloisons: deux antres sont ensuite délimitées par les cloisons le la seconle paire; et l'évolution continue ainsi, le chilfre des cloisons et celui des loges augnenlant suivant une règle pricise. Il en est de mème pour les tentacules; au moment où les deux premières loges viennent liètre façonnées. un tentacule pousse au-dessus de charune d'elles; plus tard. deux autres loges apparaissent, el deux tentacules extérieurs s'ajoutent aux prérélents; plus larl encore, le nombre des loges élant porté a huit. quatre nomveaux appendices naissent autour de la houche. En somme, dans la plupart des cas, la genese des tentacules est étroitement lice à celle les cloisons; les cloisons de nouvelle formation ont pour rüle de délimiter de nourelles loges. et un tentacule se léveloppe au-dessus de chaque loge récemment froduite. - Ces appendices péribuccanx sont foujours creux, contrairement a ce qüil en est pour les Scyphistomes; leur canal interne est un diverticule de la loge gastrique qu'ils surmontent, et leur paroi une dépendance de la paroi du corps.

Lexamen des formes extérieures, prísentées par les larves des Zoanthaires, se réluit done à l'étule lle la pluase vésiculaire, à celle des changements d'aspect subis par le corps, et enfin à celle de la naissance des tentacules, celle-ci ćlant placée sous la dépendance du mode grénétique iles cloisons et res loges gastriques.

A. - Les larres vésiculaires des Anthozonires sont globuleuses, ou ovalaires, dans leur extrène jeunesse; elles sallomgent ensuite, el deviennent remiformes. Les cils vibratiles, qui recourrent leur ectolerme, leur permettent de se déplacer avec facilité; ce quelles font I'hahitude, en tournovant en spirale dans l'ean. - leur entíron s'élargit beancoup durant celte période le lilertí mais à cela se hornent les morlifications intrues, car, l'ordinaire, le tube resophacrien et les cloisous erastriques apparissent plus lard.

lans certains groupes d'Aulhozonires, tels que les Ceriunthiles et los Zounthines, les larves paraissent gamber longlemps cette vie libre, el subir ainsi tous los changements gui lus transforment en adultes. Tel nest pas le ras des Ortactiniaros, ni do la pluparl des bolvactimaires; lembrvon se lixe par nue de ses cxtrémilís, ol los rils vibraliles de son ectorlerme se détruisent. Minsi altarhé a un sulpolt, son

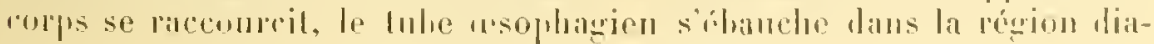


mólralement opposic à li hase fixér, les premiòses cloisons s'avaucent dans la cavité gastrique en dílinilant les premieres loges, et, l'une fagou corrólative, les premiers tentacules maissent antour de la lourhe. Les procélés employós daus la gemiso des cloisons et des loges somt examinés plus loin diune fagon draillée (S i); les renseignements Jomnés à cet cyard sappliquent flune maniere complète aux tentacules, et, en conséquence, quelques indications lrèves sur ces derniers seront ici snffisautes.

Les huit cloisons des ()ctactiniaires apparaissent presque en mème
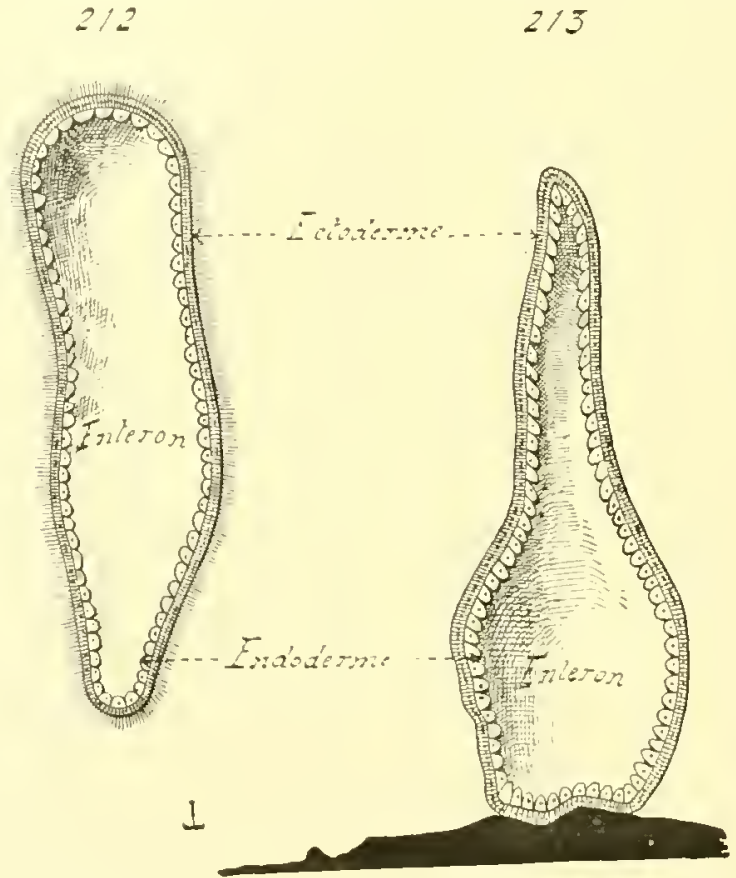

l'ig. 212 el 213. - JARVES DES ANTHOZnIUES (roupes longiludivales et médianes, avec perspective). - En 21?, larve lilme, nageant au moyen des vils vibratiles de son ectoderme. - lin 213, Jarve nn pen plus itgie, et venant le se lixer a un support. - l'apris les lechurches l'aites par liowalevsky et Varion sur un Getacliniaire, le Sympodium coralloüles.

temps, sans doute par une alıéviation du développenent, el il en est de mème pour les tentacules. - Les phases évolutives des Polyactiniaires sont, sons ce rapport, jus longues et plus nettes. Henx tentacules, presque diamétralement opposés, se facomnent des l'aliord, dans la région péribuceale de l’individu, par denx saillies, qui grandissent ct s'allongent pen a pen; chayne sillic, placée an-lessus liune des loges de la première paire, ces loges venant d'ètre engenulrées à Yimslant et existant scules, consiste en un diverticule, émis par la cavité de la logo, qui sou- 
leve la paroi du corps. Ces demx appentices primilils soml somvenl incraux sons le rapport de la longurul丷; detle dissemblance pst, do fous points, romparable a celle qui so manifoste mole les demx promiors lenlacules du Scyphislome. Puis, la plus grande des loges do la promion paire, elant divisée en lrois par la genèse de deux nouvellus choisons, deux autes lentacules vout s'ajouler aux leux premicrs, en surmontant les deux loges qui viennent debe formées. le phiffre les logrs angmentant toujours avec régularité, relui destentacules agil de mènr, ciu ces appendices naissent aree constance au-rlessus de la phuart des loges récemment produiles.

Les procidés génélipues les premiers frnlacules sont assez lien connus; il nen est plus ainsi pour ceux des derniers, ni pour la facon dont ils se groupent afin d'acquirir leur arangement définilil; les seules olservations concluanles ì cel égard ont été effectuces, par de lacazeDulliers, sur des Zoanthaires appartenant à la trihu les Actinidées. Lorsque le nombre des lenlacules, suborilonué à celui des cloisons el des loges, esl arrivé ì douze, ces organes se lisposent en deux ryeles concentrigues : l'un, externe, compose dus six plus grands l'entre eux; l'autre, interue, formé des six plus petits. Les appemdires le ces denx cycles ne sont point placés les uns devant les mutres, mais en alternanec. l'uis, douze nowvean lentacules sont engendrés, el conslituent un troisiome cycle; ils naissent au-dessus des loges supplómentaires, qui viennent de faire leur apparition. Ils sont rassembles en six couples, dont chacun est situé laus l’un des espaces, qui séparent un grand tenlarule du premier cycled'un pelil lentacule du second; ces espaces chant au nombre le louze, el six d'entre eux étant ainsi oceupés par les couples des appendices du troisiome cycle, ces six espaces alferment arec cenx yui restent nus. Tous ces organes sont d'abord groupés d'une facon hien irréculiere; ils s'arangent ensuite sur trois cercles conerntriques, dout le premier se compose les six grands tentacules primilils. le secoml de six, el le hoisieme de louze appendices. Cenx-ci ne correspundent pas exactement an scomd ni au lroisiome cyole, car les leulacules qui constituaient ces derniers se sont confondus, et no repremmot pas exaclement leu place lorsqu'ils se disfrosent de nouveau en couronnes péribucales; certains appendicens du second ecrete apparliemurul rn rialitio au troisione cyole, et, inversement. plusieurs bes six tentit-

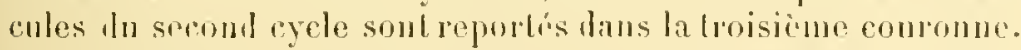

l.e devoloppromenl conlinue d'apres les mèmes procrdis: les nou-

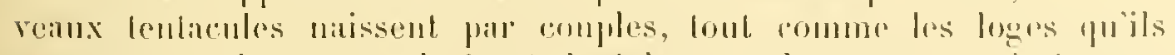

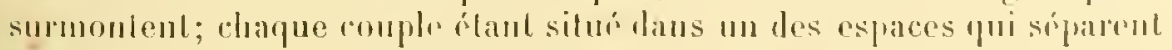

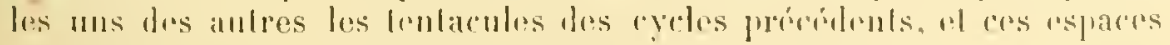
allernanl avec cenx qui ue sont lobjol d'aucune irolulion. - les jounes

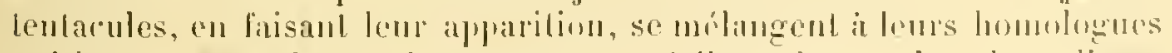

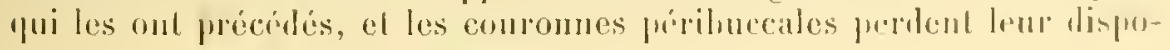


sition régulière; puis, tous ces organes se groupent derechef en cercles définis, les éléments de chaque cercle appartenant parfois à les rycles différents, car ils se rassemllent l'apries leurs rapporls de juxtaposition, non l'après leur ìge.

Le terme cycle désigne ici l'ensemble des tentacules produits en mème temps. Le nombre des éléments constitutifs d'un cycle déterminé est, constamment, le double du chiffre offert par le cycle pricédent, sauf pourtant en ce qui tonche les donze premiers tentacules. Ceux-ci se disposent en deax cycles, dont chacun se compose de six éléments. Les appendices du troisième ycle sont an nombre de louze; cenx lu quatrième au nombre de vingt-qualre; ceux du cinquieme au nombre de quarante-huit; et ainsi de suile. P'ar conséquent, le jeune individu possède 24 tentacules au moment ou le troisième cycle vient de naitre; il en présente 48 lors de la genèse du quatrième cycle, 90 après la formation du cinquième; la quantité de ces organes angmente, suivant celte progression fixe el délerminée. La régularité de ce développement est une conséquence de celle olferte par les cloisons, el par les loges naissantes.

B. - Les larves des Octacliniaires, et nn certain nombre de celles des l'olyactiniaires, produisent leurs premieres cloisons, ef lenrs premiers tentacules, lorsqu'elles sont déji fixées, après cessation de leur vie libre. Les embryons de diver's l'olyactiniaires les engendrent durant leur période le liherté; courerts de cils, et possédant sourent une toulfe vibratile sur l'extrémité alorale du corps, ils nagent pendant que leur's appraroils s'ibauchent, et se fixeut d'habihde apress que les donze cloisons, et les douze tentacules primordiaux, ont pris naissance. - Cette persistance de la vie pélagique est plus accentuée encore chez les Cérianthidées, s’il faut en croire des olservations récentes. Ces animaux habitent les eaux de surface durant lenr jemnesse entière, ut ne se laissent aller au fond qu'au moment oỉ les élóments reproducteurs font leur apparition: la maturité sexnelle, qui est te dernier degré de l’érolution de l"individu, marfue seulement l'instant où cesse la vie libre. Ainsi, les larves des genres Cerianthus et Arachutis, cenx-ci considérés antrefois, ì tort, comme les larves de C'érianthus, se trouventelles libres à des états fort arancés de lenr f́volution, et munies de presque toutes leur's cloisons, el de lous lemrs tentacules.

Ln semblathe mole de vie des emliryons parait exister anssi chez les Zoanthines. Semper, et surtout lid. Yan Beneden, ont décrit des formes embryonnaires libres, munies léjà de six on de donze cloisuns, et rattachées, antant puril est premis d'en juger d'après leur disposilion, à lévohntion des \%oanthines. Ces larves sont curienses, en ce quelles portent, sur l'une des faces de lenr corps, une haude longitudinale, faile de grands cils ribraliles, commençant non loin de l'extrémilé luccale, pour linir assez près de l'extrímilé ahorale: les autres portions 
de l'ectoderme étant lépourvues de cils, cette bande reprísente saus doute lorgane locomoteur du petit ètre. - Cotte disposition, remarquable par elle-mème, devient tries importante, si ou la compare i la structure des rangées de palettes les Cténoplores. Ces deruières penvent ètre assimilées à des assemblages de longs cils juxtaposés; et, sauf par la réunion en palettes, la bande vibratile les larves, observées par Eil. Ian Beneden et par Semper, rappelle les rangées des Ctémophores, l'après leur origine ectodermique, leur orientation longitudinale, et leur structure essenticlle. Seulement, cet organe est unique chez les premières, et demeure propre aux phases embryomaires; tandis que les seconds en possèdent luit durant toute leur vie. Il est intéressant de signaler celte ressemblance, car elle contrihue à rattacher jlus étroitement les Clénophores aux autres Seyphozoaires.

V. - Un petil animal pélagique, découvert par liusch, étudié récemment avec létails par Claus et Viguier, le Tetrapteron (Tetraplatia) volitans, semble devoir ètre considéró comme mue forme larvaire de Scyphozoaire. Le corps de cet ètre, assez polymorphe, se ramène, en somme, a un ovale allongé, portant la louche an centre le son extrémité inférien'e, el muni, vers le milieu de sa longueur, de quatre minces expansions, nommées les ailes. Ces dernjères, formées par les saillies membraneuses de la paroi du corps, sont placées à égale dislance les unes des autres, et possédent leux petits organes des sens poul chacume d'elles. Ces anmexes sensoriels penvent être assimilés à des rhopalies de struchure fort simple; quant aux ailes, elles conconrent, pour la plus grande part, à produire les mourements locomoteurs, car les cils, dont l'ectoderme est recouvert, sont fort courts. L'onverture luccale dome accès dans un tube osophagien, sondé à la paroi du corps, qui conduit dans une spaciense cavjé gastrique, divisée par quatre épaisses cloisons en quatre loges profondes. Ces loges se hifurquent dans la région aborale du corps; quatre des liranches se continuent avec les loges gastriques; les qualre antres alternent avec les premieres. Celles-ci, comparaliles presque aux canaux cloisonnaires du Seyphistome, se reloument rers l'extrémité buccale et se convertissent en quatre conduits longriludinanx, placés à égale distance les uns des autres, entre la cavité stomacale ut lectoderme, dans la substance meme des clojsons. Non bin de la lonche, les canaux longitudinaux s'écartent de l'ecloderme, el vout s'ouvrir daus la cavité gastrique.

La pelite taille le ces amimanx (3 a 5 millimictres), leur privition d'organes sexuels, portent a almettre que ees otres sont des larves, ul nont pas encore attrint leur état définitif; mais la complexilé asso\% grande de leur struchre permet aussi de croire pue rot ćtat u'ost pas fort éloigné, et pu’il ne diflère pas trop, dans som ensemble, do celui qu’ils offrent enx-memes. L'existence des qualpe cloisons, dans la ravitó stomacale, éloigne les Tétraptères des Ilydrozoaires, pom les julcer aroo 
reptilude parmi les seyphozoaires; mais il est enore lien vifficile de se prononcer sur leur siluation exacte. Ia forme génerale du copps, l'ípaisseur dos cloisons gastriques, la présence des qualre cimanx longitudinaux foumis par la civité stomacalde, tendraient il rapprocher ces itres des Clonophores; ils soraient un uroupe de Clénophores lólraradiés, el non ocloraliós it la facon des représentants normanx le cette Classe. I'un antre cotr. l'alssence de palettes natatoires, el la disposition des ailes, donnent à cess animanx une originalité incontestable; en outre, la nature des organes sonsoricls placés sur ces ailes, comme la possession de quatre seules cloisons, contribuent à rapprocher les Tétrajteres des sigphoméduses.

La vérité, autant qu'il est possible de conchre daprès les eonnaissances artucltes, parait c̀tre lans celle peusée que les T'élraplères représenlent les larves, très avancées, d'ètres voisins des Clénophores, ou calles de scrphoméduses inférienres. L'ensemhle de leur économie peut ithe rattaché, sans trop de difficultís, à celui qui serail olfert par un Cténophore, arant conserví la lisposition létraradiaire primitive, el donl le copps ne serait pas livisé en octants. Ia minime complexiló de leur strnclure, le mince déreloppenent de lenr mésoderme, l’absence de cils grompés en palettes, dénotent, d'autre part, la simplicití de ces itres par rapport aux autres Scyphozoaires. L'existence d'organes sensorials, presque semblables it des chatuches te rhopalies, attestent de lenrs relations aree les scyphoméluses.

En somme, si l'on tient comple te toutes ces dispositions, si l'on remaryue la complexilí díji assez grande de l'organisme des Téelraptiores, on en vient it une double supposition : ou bien ces animanx sont les formes larvaires de certains Cínophores à la struclure fort simple. à l’organisme fuadriratić plulòl quoctoradié, et encore incomms; ou hien ils sont les emhryons lihres d'une Seyphoméduse inférieure, d'un Anloseyphaire, ou d'un Tétramère, peut-ète d'une Chargudée. La science arluelle ne permel pas de se prononcer en celte occurence; mais les donmies arquises autorisent il placer, avec me cerlitude presque complète, les alulles des f'élraptères i la base des scyphoméduses, on it celle des Clemoplures, of à resserrer davantage les liens qui unissent entre elles ces deux classes.

\section{5. - Origine des organes internes.}

La larve lort jeune, ne posside, duranl sa phase visiculate, et pour

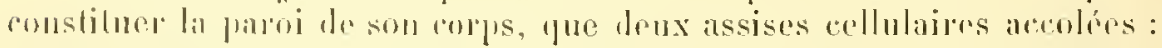

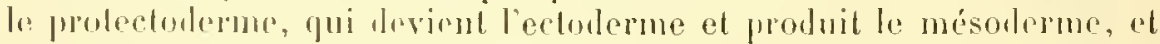

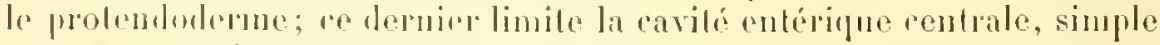
encore, el mullement diflérenciér. Je cette cavité naitra l'estomae de l'adulte, avec ses divers anmexes, loges ou canaux gastrovasculaires; n des deux combes cellulares primudiales dérivent lous les tissus 
définitifs. L'endoderme joue en rela, le plus petil roile; il no se molitio pas dhabitude; ses principanx changements rontistont it transformor parfois plusieurs do ses cellules on ćléments épithélio-musculaires. Les fonctions de l'eetoderme sont phus importantes. - Lutant fuilil est permis d'en juger d'apres les observations acyuises, fe foulled commonow par exsuler vers sa base, of par intercaler, entre lui-míme ef l'cmluderme, une substance fondanentale lomogène: plusicurs de ses propres cellules se divisent, pour envover les produits de leur segmentalion dans cette substance, el former ainsi un lissu muni d'éléments figurés. Ce lissu est le mésoderme, qui s’accroil ensuite pour son propre compte, et sulit les modifications diverses. Ensuite, lorsque l'ectoderme a donné naissance au mésoderme, il conlinue à proliférer pour engendrer les organes des sens, are le résean nerveux de l'individu, et revèt enfin sa disposition définilive.

Le plan des descriptions suivantes est done facile à étałlir. Uno première partie sera consacrée a l'ectoderme et à ses lárivés : le mésoderme daborl, les appareils ir relation ensuite. la seconde partie traitera le l'endoulerme, et des diverses morlifications qu'il est rapahle de présenter; puis de l'entéron, el des changements quiil sulit.

1. Ectoderme. - Ce feuillet est constilué, an hóbut de la pliase vésiculaire, par une assise cellulaire simple, immédiatement juxtaposcée it l'endorlerme; bientôt, une minee lamelle de substance fondamentale, la membrane propre (memlirana propria), apparail entre ces deux couches, et les sépare l'une de l'autre. I'uis, l'endodlerme est désormais inactif. L'ectoderme continue à produire de la substance fondamentale, et envoie plusienrs de ses déments dans l'intérienr de cette dernière: il engendre ainsi un tissu conjonetif, placé en dedans de lui, entre luimème el le feuillel endodermique; ce tissu, susecptilile des lors de se développer par ses propres forces, représente le mésoderme. L'ectoderme fournit ensuite le réseau nerveux avec les portions sensoricllins des organes des sens, el, linalement, différencie ses cellules pour leur ilonner leur strurture définitive.

Itsoumus. - L. Le déreloppement du mésoderme des Ścyphoméduses n'est pas encore très bien connu. Les olservations, effectuées sur ce sujet, ne sont pas anssi nettes que celles pratiquées sur les Cténophores el les Anthozoaires. Le lenillet moyen parait licn provenir tont entier le l'ectoderme, mais it semble aussi que l'endoderne preml une parl, bien minime cependant, à sa genèse; de nomvolles élunles sont nécessiares à cel égarl. lin somme, l'ectoderme exsmde, far sal région profonte, me substance fombanentale, ahombante, homogine, qui commence it apparaitre des la phase seyphistome, el devient smbont épaisse fors des derniers états de l'évolution des Acalephes: pent-ítre,

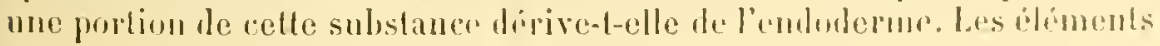


ectodermiques se divisent, ef envoient, dans cette gangue fondanentale, les cellules-filles rósultant de leur divison; celle-ci prend alors laspect d'un tissu complet. susceptille le saccoille pra lui-mème.

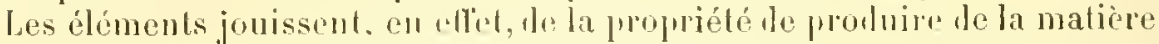
intercellulaire, pour en argmenter la masse, el de se segurnter euxmèmes, afin d'accroitro l'ur nombre: en proliférant de cette façon, ils en arrivent à constituer co mésoderme abondant, qui forme à lui seul la majeure partic lı corps.

L’enbryogénie des t'rnophores étant ahrégéc, les phénomines évolutifs sont assez courts. et il est parfois difficile de saisir leur véritahle caractere; mais cepentant l'origine de leur fenillet moyen est aisée ì reconnaitre. Ce leuillet provient tout entier de l'ectoderme, contrairement à lophion sonvent admise; il apparait lors des dernieres phases Je la segmentation, en mème temps, ou presque en mème temps, que l’ébauche entériqur. Il dérive, en partie, d'éléments ectodermiques déjà en place, et, pour une autre partie, les pelits liastomères qui šisolent, Je la région infurienre drs éléments dentolécithiques, daus le but dachever la conche ectodermique. Puis, soit directement, soil a la suite l'un déplacement sur les côtés de l'ébauche entérique, les cellules du mósoderme viennent se grouprer, et se tasser les nues combe les autres, lans la région supérieme de la larve, ciest-à-dire lans cette zone oì premnent naissance l'organe sensitif avec les palettes natatoires.

Leséléments du fruillet moyen sont alors juxtaposés, et u’ont encore prorkit ancune substance intercellulaire: ils séprarent, a leur niveau, l'ectoderme de l'enduderme, alors que, partoul ailleurs, ces deux feuillets sout directement accolés. - En ce moment. l'entéron s'élargit, les quatre cloisons commencent à se manifester, et la phase C'tenula fait son apparilion. Les cellules du mésoderme augumentont en nombre par leur propre segmentation, et s’insimuent, lans les élauclies cloisonnaires, entre l'ictorrome el l'endoderme; ces éhauches étant au nombre dre quatre, placées il rgale distance les unes dos autres, l'ensemble Ju mósolerme glandil suivant ees quatre directions, el prom la forme d"une croix, fout en rostant lomalisé encore dans la rógion supérieure de la larp. Les denx tenlacules se faconnent alors; ils sont constitués par une saillie de la paroi hu corps, linitée en dehors par l'ectoderme, cl renfermant un amas axial le cellules nésolermiques. I'uis, les cloisons s'épaississent; le fenillet moven s'étend vers l'extrémité inférienre de lembryon, et ses foments produisent de la substance foudamonlale. - Les phenomines nllópenrs noul pas été completement suivis; il semble cependant que l'estorlerme soit capable de donner encore, par le même procido pue choz les Scyphoméduses, at sur sa face interne, des cellules, qui s’ajoutent ì celles déjà comprises daus le leuillet moven. L'ensemble des prórlés mis on rpure se ramènerait donc à une genèse lative et localisée, aux dípens de lectolepme, d'un amas cellulaire, qui

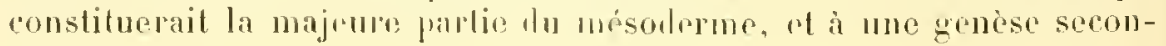




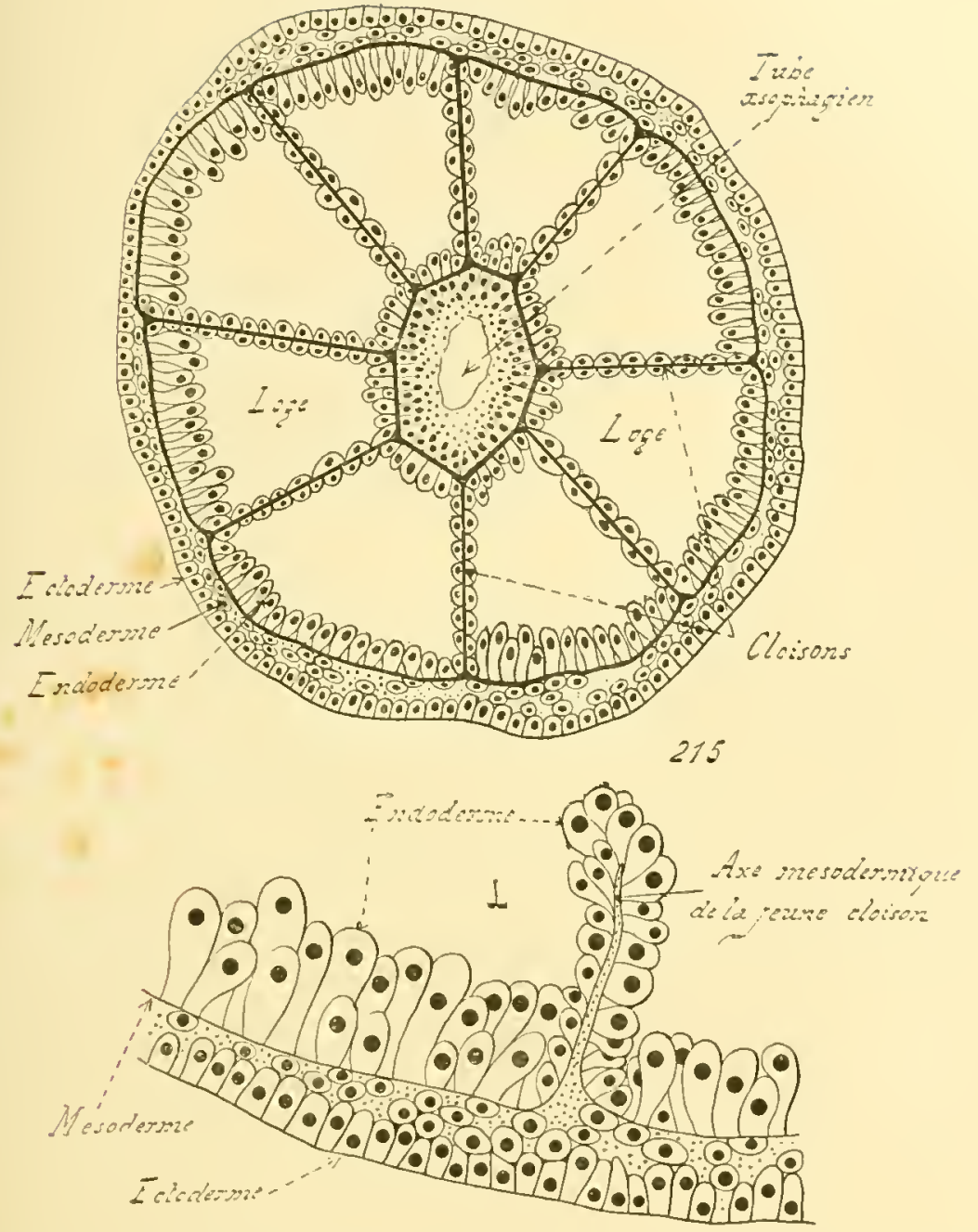

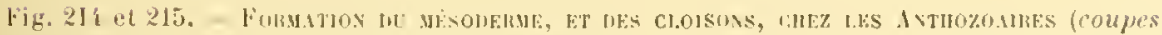
l'ansiersales); d'apres howalevsly et Marion, sur le Sympodium coralloüdes. - Ln ?li.

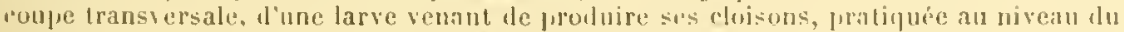

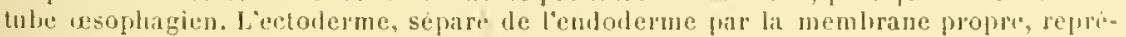
sentée par un trait noir, s'cpaissit par places, alin d'engendrer le mésoderme. - lin 2lí, details, a une plus grande amplilication, de lit formation du méroderme el d’une jeune rloison. Iu-rlessous de lit ranget des cellulas endoderminums, se trouvrnt plucientrs

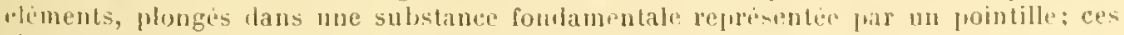
elements froviennent le l'ectoderme, el composent le mesoderme; leur ensemble est sépare de lendoderme par une ligue nette, qui imdipue la numbrane propue, et sur lapuelle tombe la fèche, un peu troj prolongè, du mot mésoderme. 
daire, iparse, toujonrs faite par l'ectoderme, d'éléments isolés, qui completeraient le feuillet mosen en s’adjoignant ì lui.

Les Anthozoaires sont les mienx commus. en ce qui tonche l'origine du mésoderme. Les recherches les plus concluantes furent ellectuées, par Kiowalevsly el Marion, sur les Octacliniaires; clles ont élé conliumées par des observations faites ensuite sur d'autres représentants de la mème elasse. Au moment ou l'embryou se présente sous la forme vésiculaire, la mince membrane propre existe seule; fuis, lorsque les premières cloisons commencent à apparaitre, l'ectoderme exsude rers sa lace interne, ef insinue, entre lni-mème et l'endoderne, mue substance fondamentale, homogène, dont la masse augmente peu à peu. lin mème temps, la plupart des rellules ectodermiques se divisenl; les éléments, qui résultent de la scission, pémètrent lans cetle substance, et constituent avec elle un lissu mésenchymatenx compact. Ces éléments ne demenrent pas inactifs; ils se multiplient par enx-mèmes, continuent ì produire le la matière inlercellulaire, et engendrent ainsi un feuillet épais, placé entre l'ectoderme et l'endoderme, qui n'est autre que le mésoderme.

B. - La plupart des données acquises permettent dadmetlre que le mésoderme des Scyphozoaires provient de l'ectoderme. Ce dernier commence par produire le la substance fondamentale, puis foumit à cette dernière des éléments cellulaires; et ce tissn intermédiaire, ainsi complété, s’accroìt des lors par ses juropres moyens. Les différenciations, „u'il subit ensuite, sont les mêmes pour tous les groupes de l'embranchement; la substance intercellulaire reste aboudante, homogene, et ne prend que fort rarement un aspeet fibrillaire; les éléments figurés émettent des expansions qui s’anastomosent entre elles, el présentent, pour la plupart, la forme des cellules conjonctives normales. - En somme, le mésolerme de ces ètres doit ètre considéré comme un mésenchyme d'origine ectorlermique. Ce fenillet demente compact, et ne se creuse jamais de cavités indépendantes de l'inteslin; les canaux, qui le parourent parfois, dérivent de J'entéron, communiquent toujours aver lui, el sont directement limités par me assise de cellules endodermiques. Il est un pléomésollerme, "qui difère beaucoup, et par son origine, et par son évolution ultéricure, du mésenchyme des Cuclomates.

Plusienrs des b́lments de re fenillet se modifient en filores musculaires; ces dernières proviennent done de cellules mésenchymateuses, et ue ditterent en rien, jar leur aspect ni par leur organisation, des fibres de semblable origine possédées par les autres animanx. Elles ne reprosentent pas tomjomes, i elles seules, les parties contrarliles de loranisme. Il en esl ansi pum les Cómophores, et sans doute pour les dealephos, do moins dams la plupant des cas; mais le conlrabe existe chez les Anlhozoaries. Ceux-ci presentent bien, parfois, dans la paroi de 
leur corps, plusicurs tibres d'origine mésonleminne; mais la phupart de leurs élémeuts contracliles sont des grompes épithélio-muscularies, dependant de lectoderme ou de l'endoderme. Les Anthozoaires monIrenl done, it la fois, des libres musculares d'origine mésenchymateuse, el des fibres d’origine épilhéliale.

Srstene renveux. - Les notions connues, sur l'origine du srsteme nervenx des Scyphozoaires, se bornent à quelques obscrvations ćprars's. suffisantes cependant pour permeltre daffirmer que ce système dirive le l'ectoderme, el conserve, durant la vie entière de lindividu, une grande simplicilé de structure. Plusieurs cellules ectodermiques allongrenl leur région profonde, et se transforment en éléments épithélionerveux. Leurs portions nerveuses, souvent nuclées, s'anastomosent entre elles; elles constituenl, par celle union, un réseau serré, placé immédiatement au-dessous le la couche épithéliale de l'ectoderme. Ce réseau a élé fréqueument décrit, par les auleurs, sous le nom de couche grunuleuse. Celle disposition ne cesse jamais dexister; de tello sorte que le systeme nerveux de ces animaux moulre une struclure loute primilive: l'aspect d'un feulrage de filores nervenses, dircelement relices à l'ectoderme dout elles proviemnent.

L'ectoderme des Inthozoaires possède, à còlé de ses éléments épithéliaux simples, des cellules épithélio-nervenses el épithélio-musculaires. Le réseau nerreux, constitué par les hases anastomosées des promières, est placé entre la conche épillóliale non modifiće el la zone les filures musculaires; celle-ci est formée jar les portions musculares des secondes. Liectoderme de ces êtres est douc nu assemblage complexe, disposé sur trois conches : l'une, externe, composée par les éléments épithéliaux simples, et par les porlions épilhéliales des éléments épiLhéliaux composés; l'aulre, moyenne, la conche granuleuse, représentéc par le réseau nerreux qu'émeltent les cellules épillélio-ncrveuses; la dernière, interne, appuyéc contre le mésoderme, el donnée par los fibres contractiles qui dépendent des cellules épilhélio-musculaires. Cell. disposition se retronve dans le corps presque entier, dans la colonne comme dans les tentacules; elle léconle, au moyen le moditications porlant sur la structure histologique, de l'organisation oflerle a son dént par l'ectoderme.

Les fails sont moins complexes chez les Cténophores el les Seyphoméduses. La plupart de leurs éléments contracliles naissent dans le mésoderme; le feuillet externe de l'embryon se borne a transformer ses parties constilulives en cellules épillséliales simples, el en cellules ípithrio-nerrenses. Eucore ces dernieres ne soml-rlles pas réparties dans l'ectoderme entier, el se troment-elles localisies en plusinus: régions lélerminées. Ces zones paraissent bormées an poile alorant, prut ce qui tienl aux Climophores, el, chuz les Sipploméduses, it diverses parties de la sous-ombrelle, on il la base des oryanes semsilils. 
Organes sensitifs. - Le mode de léveloppement des organes des seus est encore moins bien élucidé que celui du systêne nervenx; il est cependant possible, à cause de la simplicité de ces appareils, d'élablir yuchues presomplions, hasées sur la structure désinilive. - Les rhopalies des Scyplozoaires. grace à leur canal central, qui communique avec le róseau des comluils gaslriques, sonl assimilables ì des pelils lentarules creux; leur paroi est constiluée par un épilhélium ectorlermique, ol mo seconde comche ipilhéliale cmbodermique, que sépare une mime lamelle de mésoderme. Celle-ci disparait vers l'exlrémilé lihe de l'urgane, oi l'ectoderme el l'endoderme se mettent en conLinl direct; de plus, l'endoderme de cetle région, an lieu de constibuer me assise destincé à limileo le canal central, angmente le nombre de ses collules, el promilut m corps compat, volumineux, lobeyste. liectoderme s'aplatit aulour de l'olocyste, el ne présente, en ce point, ancune dillérencialion parliculière; mais it s'epaissit autour de la base des rhopalies, motamment en deux régions déterminćes. lonne de ces dernières se garnit de cellules vibratiles, dout il est lien dilficile de concomil la fouclion rrielle; les élémenls de l'aulre se remplissent de granulations pigmentaires, foumissent mème une pelite conche culiculaire servant de cornce, et composent aimsi mocelle.

Loreane sensilif, si remarufuable et si complexe, flacódans la rigion ahorale da corps des Chinophores. nest guere connu, pour ce qui lient à son développencul, pue dans les premieres phases de son rivolulion. Il ost alors comslitur par m groupe de cellules eclodermiques épaissies, lont les bases s'allongent pour donner le róseau nerveux siluc dans celte pratie de lírenomie, el dont le protoplasme se remplit de granulitions calcaires arrondies; en onlre, plusicurs de ces élruments se recourreul de cils rigides, presque semblaloles à ceux des jeunes pratelles matatoines. - Les granulations ralcaires tendent, ensuile, a sorlir du frutoplasme, et à parronir an hohors; cllos so joignent les unes aux antres pour produire, par leur mion, les vohminemx olohilues de ees animaux, porlés par des pédicules qui maisscnl aussi de l'ecloderme. Lus anlres modilicalions hislogénitiques sont ignories. Chmm, dont les ohservations sont les plus completes à cet égard, s'est presque hornó i surve les changenemls exhrieurs; sos recherches permettent cependanl d'affirmer que l'oryane entier, avec ses plaques polaires et ses lumit bamles eiliées, dérive de l'ectoderme seul. Nlors que l'endoderune est capalile, dims les rhopalies des Seyphozonires, de subrenir a la genese de phosieurs ales collutes sensorielles, loules ces cellutes proviement de l'ectoderme seul, dans l'organe sensilif des Ciénophores.

Les apparails charués, chez les Inthozoaires, te percevoir les sensalions fournics par les milicux extirienrs. sont peu nombreux; ils se réfuisenl anx cellules lactiles éfarses dans l'ectoderme. - Il existe frufois diverses régions, placees an sommet de la colome, que leur pigmentation autorise i considérer comme des ocelles; si cette opinion 
est exacte, ces organes dérivent du fenillet externe, el, lin reste, ne se séparent jamais de lui.

11. Endoderme et entéron. - L'endoderme ne sulit qu'un pelit nombre de changements. Constilué, desson délunt, par une seulis couche épithéliale aux éléments simples, il reste ainsi chez les Clénophores, et se borne à produire parfois, chez les Anthozoaires et les Seyphistomes des Acalèphes, plusieur's cellules épithélio-musculaires; l'ensembte des filres contractiles, appartenant ì ces dernirres, donne les plaques musculaires des cloisons. Les autres éléments de l'endoderme sulissent des différenciations diverses, se transforment en cellules à cnidocils, on se remplissent de granulations hepatiques, mais conservent cependant lewr simplicité primitive.

Si l'enloulerme ne se modifie que fort pru, il n'en est pas de mème pour la carité qu’il limite. Celle-ri, d’abord résiculeuse durant les premières phases larvaires, se modifie par l'apparition du tube osophagien el des quatre cloisons de la Scyphule. Puis, suivant le cas, le nombre des eloisons angrmente, pour diviser la périphérie de l'entéron en loges placées còte à côte; on bien, les quatre cloisons premières sépaississent, el se soudent par places, pour convertir la mème régcion périphérique de l'entéron en canaux anastomosés; ou bien encore, ces organes se détruisent. Le premier mode est celui des Anthozoaires, le second et le troisième appartiennent aux Scyphoméduses et aux Ctinophores. Hais, quel que soit le procidé, la portion centrale de l'entéron primordial reste indivise. s'ourre an dehors par l'entremise du tube cesophagien, el constitue la cavité gastrique de l'adulte; cette cavité communique largement avec les loges, ou avec les canaux, dont on vient de voir l'origine.

Le tube asoplagien, étant toujours produit par une invagination de la paroi du corps, possède, dans sa paroi, une couche ectodermique interne, une assise endodermique externe, et une lamelle intermédiaire de mésoderme. De mème, chez tous les Scyphozoaires, les cloisons sont des sailies lamelleuses, constituées par le mésoderme el par l'endoderme, le premier feuillet étant placé an centre de l'organe, el le second à sa périphérie; ces saillies s’attarhent à la face interne de la paroi du corps, et s’avancent, de là, dans l'intérieur de la cavité entérique. Leur endoderme est tonjours représenté par une assise épithéliale, qui entoure le mésoderne; celui-ci est formé, in son début, par la membrane propre senle, puis par un tissn conjonclif, plus ou moins épais suivant les classes auxinelles on s'adresse. - L'histogenèse est donc la même chez tous les Scypluozoaires, pour ce qui touclie aux annexes de l'entéron. Les différences, entro les divers groupes de l'embranchement, portent seulement sur le nomlue et sur la disposition de ces annexes.

Scrmomencses. - Les transformalions sulies par lentéron ne sont comnues, et il en est de mème pour celles des autres organes, pre che\% 


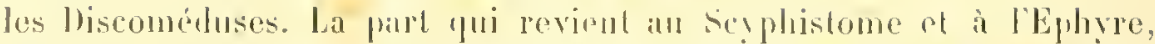

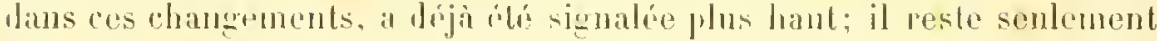

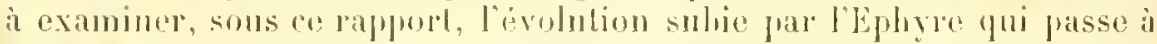
l'étal adulte. Colte évolulion presente des phénomines communs à tous

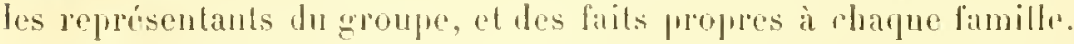

les phémomèms rommuns linment au hube resophagien, da an másoderme des doisons. Le promior do ces appareils, hen marpué chez le

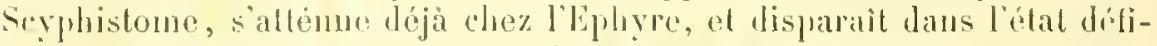
nitif. Le trme disparition ne signilie pas atrophie, mais phutot sondure do ce lube aver lit paroi somatigue voisine; la cohérence est ici due an mrisoderme, yni s'ópaissit aulour de ha houche, el unit à mesure l'usophage arec les parties enviromnantes. - Les doisons pésentent un fait dn mème ordre. Lenr region interne, traverséc par le canal cloisonmaire, disprait en majeure partie; mais leur région externe, soudéc à la paroi du corps, grossit beancoup, par le lait lu mésoderme qui augmente de volume, ot se ronfond en définitive arec relte paroi. Le fouillet mosen de celte derniore s'amplitie, cu outre, dans des juportions consilérables, et se ronvertit an une couche conjonctive volumineuse, placéc entre lectoderme el lentoderme. Cette assise, plus épaisse dans la partie smprifieme de l'animal fue daus sa zone orale, constitue a clle seule, cu mottant à part la couche externe d’épithélimu cetolermiłue, dont l’importance cst minime, loute la masse de lombrelle.

Il ast possilile te gromper en trois sceries les faits particuliers. - La premiore sapplipue a la seule famille lles Eplyyropsides; le mésoderme de ces edros lemenre relativement mince, et la cavié culéripue conserve, sans la moditier en rien, la disposition qu'elle possinle chez l'Ephyre. - Les P'élaydes et les C'yunédes apparticnment à ba secomle séric; leur mésorlerme devient plus épais; les rígions internes des cloisons ayant dispraru, les zones externes sont confonelues avec la paroi du corps; mais la cavité reste raste, ct porte à sa périphére seize logettes, semblables à celles les Ephrropides. Ces deruières se réunissent quatre frar quatre, frour se rassembler en quatre loges fort larges, les proches gastripues, qui communipuent directement avee le dehors par la bouche. Les lowettes pépiphóripurs émettent puelques diverticules en forme de canaux, yui jénèlrent dans le mésoleme du lord de l'ombrelle, et vont dans les lohes marginaux. - Le lenillet moven des furélides, ef surtout colni lles lihizostomides, gui composent la troisieme série, preml une infurtance excessive, el acyuiert un volume rousidérable. Grace à ce téveloprement exagéró, il resserre l'espace athibué aux logetles péri-

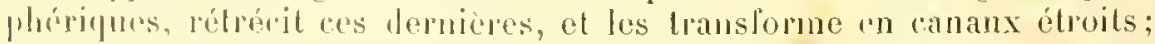
il respecelo semlemont l's quatre poches gastriques, tout en diminuant

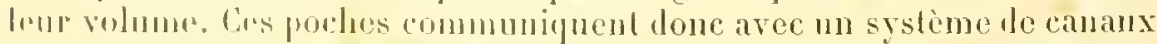

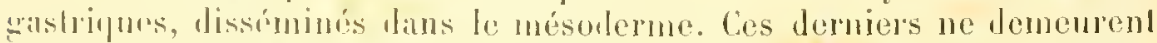
pas imlivis; ils so ramilient, inastmmosent leurs hranches entre elles, al constituent, de celle lingun, mn résean serró, qui parrout la substance 
mósolermique pour lui distrilurer les matérianx mutrilils. Ainsi, les diverses modifications, sulies jar la cavilé entérique frs Discombiluses, découlent du volume açuis par le feuillet moven, celui-ri rapretissant à mesure les espaces périphériques le l'entérou, jour les converliu en callatix.

Coxornones, - Les chanements éprouvés par les Cténophores lienneut à la mène cause que ceux des lihizostomides, car ils sont délerminés par le développement considérable du mésoderme; mais ils sont phus complexes, et s'eflectuent suivaul mo autre direction. - l.c lube cesophagien se soule de mème a la paroi du conps. Les yualre cloisous primilives persistent, sans quaucune de leurs régrous disparaisse; senlement elles s’épaississent beacoup, se réunissent les nnes aux antres suiraul la plus gramle part de leur élemdue, el ne soul plus liscernables les unes des antres, ni séparables, chez l'animal adulte. leur accroissement en rolume est tel, que les loges périphériques de l'entéron primordial sont llansformées en canaux, la partic centrale de ret entéron persistant seule pour derenir la cavilé gastrinue léfinitive. Celle-ci est indivise, et se borne i communiquer arec les canaux radiaires. - be plus, la disposition de ces derniers n'est pas semblalıle a celle offerte prar les Discoméduses. Les conduits gastriques le celles-ci sont tous placés daus un plan horizontal, cest-a-dire perpendiculaire a l'axe rerlical yui passe par la honche. Quelques-uns seulemeut des tuljes gastriques des Cténophores sont ainsi orientés; les aulres canaux, méridiens, siturs sous les rangées le paletles natatoires, s’arrangent parallèlement i l'axe rerlical, el sont par suite longitudinaux. Cette ditlérence est secondaire. L'évolution, en elle-mème, est comparable à celle des Discoméduses; elle tient au rétrécissement des loges, qui se convertissent en canaux, par un effet de la grande extension prise par le mésoderme.

Afin de parvenir à ce but, les quatre loges primilives de la Ctémule se rétrécissent, d'alor'rl par l'allongement, plus accentué en certains points, des cellules de l'endoderme, ensuite par l'épaississement du mésoderme; ces loges se changent ainsi en fentes allongées. Elles se lilupruent, en méme temps, dans leur rézion distale, ou périphérique; le fond de chacune des huit hifurcalions va se placel an-dessous to l'éluauche de la ranģée correspondante de palettes. Celle extrúmité terminale n'est point resserréc frar la suite; elle continue à saccroilre suivant l'axe longitudinal du corps, en accompagnant la rangée locomotrice dans son amplification progressive.

le meme fait n'xiste pas daus la rérion proximale les bifureations; celle-ci diminue pen ì peu de volume, perd son aspert de fente allongre,

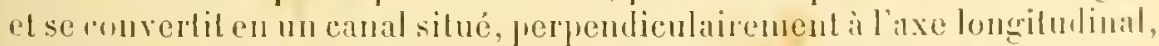
vers le milien du corps. La memo restriction se furduit anssi dans les portions, restées indirises, des quatre loges primitives, dion la lifurration périphéripue est partie; ces \%ones prennent anssi la forme de 
canaux. Chacune d'elles ressemble ì un hule, qui divise son extrémité distale en deux autres conduits, dont chacun ra se jeter daus un des canaux placés sous les palcltes. Entin, ces quatre lubes se soudent deux à deux, et donnent par ce moyen deux canaux principaux, qui s'ourrent dans la porlion cenlrale de l'ontriron; refle dernière étant restée simple, el devonant la cavité gastrique définitive. - Ainsi se trouve conslituée la disposition remarqualole de l’appareil digestif des Cténophores. En simplifianl les faits, l'ensemble de ees phénomènes peut êlre ramené à mne division pripiphórique de l'entéron en quatre loges, dont le fond se subdivise lui-mène en deux parties : doù huit logeltes périphériques. La porlion eculrale de l'entéron persiste comme cavité gastripue; les huil logettrs se moditieni pour produire les huil canaux méridiens, el les huit rananx transverses, on de 3e ordre, qui voul à ces conduits mériliens; les quatre loges consliluent le reste du systeme des canaux gastriques, ciest-i-dire les deux canaux de I er ordre qui partent de l'entéron, et les quatre camaux de Qe ordre allant de ces dernicrs aux conduils de $3^{\mathrm{e}}$ ordre.

De nouveaux changements surviennent, penlant que ces molifications s`effecluent. L'extrémité aborale le la cavité gastrique émet leux diferticules; cenx-ei se rapprochent de l'élauche sensoriclle, se renllent lorsqu'ils sont parvenus dans cette région, ef communipuent consuite avec le dehors, par une pelite ouverture pour charum d'eux. De plus, colte région de la cavité gastrique envoie rgalement denx expansions daus les ébauches tentaculaires, pour donner la cavité placée an milien de chacun le ces organes appendiculaires. - Les Loliés et les Rubanés présentent des transformations plus grandes encore. Certains canaux méridiens des premiers émeltent des branches tubulaires, repliées sur elles-mèmes, qui pénòtrent dans les bhes membranoux appendus à l'organisme. Quant aux seconds, les quatre canaux méridiens, qui devraient accompragner les quatro rangées locomotrices atrophicies, se déruloppent cependant. Mais ils narompagment pas les appendices locomotenrs, juisjue cenx-ci sont absents; jls vont se placer vers le milien du corps, à rigale distance de la louche el de l'organe sensoriel, el suivent l'organisme laus son allongement rubané.

Avtunzonres. - A. J'évolution, subie par lientéron de ces animanx, dilfere brancoup de celle présentée par les Seyphoméduses et par les Chénoplores. Ces derniers sont caractérisés, surlout, par la persistance des quatre cloisons primilives, sins fu'aucun autre organe de mème nature viemo augmentur leur nombre. Par contre, chez les Anthozoaires, de mouvelles cloisons, cn quantité varialle suivant les groupes, s'ajontent aux anciennos, et divisent aimsi la périphérie de l'entéron en une puantité correspondante de Joges; la portion centrale de cet entéron, où les cloisons ne parviennent fras, constitue la cavilé gastrique définitive. De plus, ces apparcils sont minces le plus souvent; leur méso- 
Jerme sépaissit peu, et leurs principales ditférenciations portent sur l'rpilhélimm endodermique, dont plusieurs élóments se changent en celInles a nématorystes, ou en cellules épilhélio-musculairrs. I la suile de cette extension modéréc du mésoderme les cloisons, et anssi de celui du corps, le tube asophagien reste libre, et comme suspendu dans la carilé gastrique: phusieurs des cloisons, les macroseptes, ront se souder ¿ lui dans leur région supérienre, tandis que les autres, moins étendues, n'arrivent pas jusifu'à sa paroi, et demeurent libres : co sont les microseptes. Généralement, et dans chaque groupe déterminé d'Anthozaires, les macroseptes et les microseptes sont disposées suivant un ordre fixé.

Les cloisons, prises en elles-mèmes, se ressemblent beancoup chez tous les représentants de la classe. Leur struclure fondamentale est constante : un axe mésodermique conjonctif, entomé par un épithélium endodermique complexe. Les principales modifications, communes à la plupart des Anthozoaires. tiennent à la genese des organes sexuels, et à celle les filaments urticants. Les uns et les autres sont formés par des proliférations locales du feuillet moyen, qui soulevent l'endoderme, et ilememrent toujour's recouvertes par lui. - En revanche, si la nature des cloisons ne diffère guère d'un Anthozoaire à l'autre, les particularités, touchant le nombre de ces organes, sont tros diverses, et méritent un examen approfondi. Les observations les plus précises, à cet égard, out été laites par de Lacaze-Duthiers; elles ont été coufirmées et étendues, Inut récemment, par un certain nombre d'auteurs, surtout par les frères Hertwig, par lladdon et par Wilson; l'exacte concordance des résultats obtenus autorise a admettre la fixité, et la constance, des lois qüils ont formulées. Il est nécessaire de grouper ces résultats en quelques ensembles bien léterminés, qui serviront de base précise pour apprécier, sous ce rapport, les caracteres des diverses familles.

B. - Siuf chez les Octactiniaires, les cloisons ne prennent jamais naissance en mème temps; quel que soit leur nombre, elles apparaissent paires par paires, jusqu’à ce que le chiffre délinitif soit complété. Ce chiffre varie survant les trilus; certaines d'entre elles possèdent une petite quantité de res appareils, alor's que les antres en montrent bien davantage; partant, comme ces anneses gastripues se faconnent paires par paires, ces derniers animaux, dans lenr évolution. subissent une phase Lemporare, oi ils otlpent mn chithe de cloisons égal à celui prósenté, d'une facon défutive, par les grompes d'Antlozoaires qui ont le plus pestit nomlire de ces organes. - Les premicres cloisons produites sont tonjours plarées de mème facon. Quelles persistent seules, on qu'elles suient accompagnées, par la suite, d'autres appendices semblables à "Hes, elles évoluent de lit mème manièc eho\% tous les Anthozoaires: d'ahord, les premieres d'entre elles, dont sont pourvas tous los représrutants de la classe; ensuite, les cloisons qui nasscut apres celles-ci, qui manquent a plusieurs grompes ayant semlemont nue petite puanlite 
de res appendices, of dont lo mombro varie d'une trilu i l'aulur. On peut nommer les promires dos cloisoms mimmires, ot les secombes des cloisons secondaires; celles-ri soronl ditus des métaseptes, celles-lì des motoseples el les deutoseptes.

Les cloisons primaires des Inthozoaires actuels sont an nombre de huit, et se suldivisent en quatre protoseptes et quatre doutoseptes; cest en effet à ce clithre que se rapporte l'organisation la plus simple. qu il soit possible de trourer parmi les individus adnltes. Ces cloisons ne manquent jamais; elles existent senles ehez les Octactiniaires et les Elwardsiées: elles lont leur apparilion durant les phases larvaires des aulres Anthozoaires, donneut à ces phases temporaires la plus gramderessemblaneo arrel'état définitif des Edwarulsiérs; pnis, les métaseptes prennent naissane, et se milangent aver elles. La quantité, et la disposition rolatro, des cloisons secondaires different d'une tribu à l'aulre, et seront étudióes de pres. - Ouelques mols suffisent au préalable pour les luit cloisons primaires. Elles sont tonjours groupées par paires, el rangées de part et d’autre du plan médian de l'individu, ce plan élant celui qui passe par les deux gouttieres opposées du tnle arsophagien. Les deux cloisons d'une mène paire ne sont pas juxlaposées : la premiere est placée d’un cóté du plan médian, et la scconde de l’aulpe. Toutes deux fout arec cet axe les angles égaux, ou presque égaux.

C. - Les Octactinames sont senlement munis de buit cloisons. Ces appendices vont se réunil à liosophage, el doivent itre considérés comme des macroseptes. Lem urdre d'apparition nest pras hien comm, il cause du peu de temps qui hri est consacré; elles naissent presıue ensemble, et ne se forment point paires par paires, lu moins d'apres los rósultats acquis par les olservateurs qui se sont occupés le celle question. Ce phémomine est dì, sans donte, à l’abrériation embryonnaire, dŕjì accusée par la segmentation, et par la geneso les fenillets blastodermiques. Elles sont produites par huit saillies do la face introne de la paroi somatique, qui s'élemdent, en s’avançant dans la cavité entérique, et dont li partic supricure se soude au lube osophagien. Les plaques musculaires se diblimitent ensuite sur elles, foujours sur me seule de

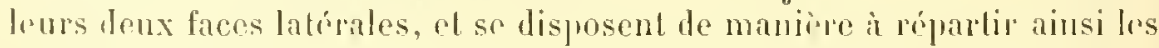
lnges encadrées jar ces cloisons : un endocule médian el antériemr, un exorrale médian et postérieur, et trois mésocoles laléranx (roir les considerations générales du \$ 1).

Les Elwardsices sont, de toules les Pounctixunes, celles donl lorganisme est le plus simplo: elles ne possident, en effet, que les lmil cloisons gastriques primaires, et sont dépourvues le métaseptrs. Ces luit eloisons sont les homolognes de celles yui se fagoment, los premières, daus la cavilé gastripue des autres l'olyactiniaires. Aussi, la mème description s'appliquera-t-elle au développement des cloisons pri- 
maires de toules les l'olyactiniaires; les l'olỵadiérs élant, do beancoup, les micux connues sous ce rapport.

Un certain nombre de donmérs géuérales s’apliquent aux huil cloisons primaires : ellos naissent en quater paipres; les deux choisons d'uno mème paire soul placées le part et d’aulre, et à une égale distance, de la ligne médiane marquée par les goutlièes resophagienues. Sanf ces parlicularités communes, chaque paire oftre, dans son évolution, quelques délajls spéciaux; toutes les quatre n’apparaissent pas en mème tenups, contrajroment ì ce qu'il en est pour les Octactiniaires, mais bien les unes apris les autres. - Les denx cloisons de la premiire paire ne sont pas diamétralement opposées, et se troment assez voisines l'une de l'autre, lout en étant situées de part el l'autre de la ligue médiane, et à une égale distance de cette ligne: leur prósence, et leur position mutuclle, ont pour effet le diviser la ravité gastrique en deux loges inégales, dont l'une, antérieure, est plus gramde que l'autre. l'endant que s’allongent les doisons de la premiire paire, celles de la seconde commencent i se montrep; elles font toutes deux leur apparition dans la grande loge antérienre. - Un temps d'arrict se manifesto alors daus l'évolution de la larve, yui vient d'arriver à la phase ścyphula, et qui ressemble entiojement, jar le nombre el jar la disposition de ses cloisons gastriques, à la Clemuld dos Citénophores, on au seyphistome des scyphoméduses. Ia cavilé gastrique est divisée en qualre loges par quatre protoseptes; celles-ci s’étendent, el proéminent fortement dans l'intéricur de la carité stomacale, puis égalisent les listances qui les séparent, de manive à domer à l'ensemble me symétrie presque prarfaite. Au moment oí s’achève ce phénomine, la cavité gastrique est partagée en quatre loges égales, disposées de la facon suivante par rapport a la ligne médiane : l'une médiane et antérieure, l'autre médiane el postérieure, et deux latérales symétriques.

Les deux paires des deutoseptes naissent ensuile. Les deux doisons de la troisjeme paire apparaissent dans la loge postérieure; et, peu apres, les cloisons de la quatrieme paire commencent i se montrer daus la loge autéricure. Les deux loges latérales pestent done pntières. et non sululivisées; en outre, à cause de leur place, les dentoseples sont plus prochus le la ligne médiane que les protosoples. - Si l'on suit les cloisons primaims sur rodape moitie de la paroi du corps, en partanl dre la région

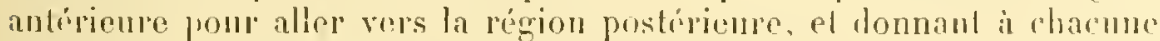
un numero correspondant ì son orlre dapparilion, on ohtient, quello

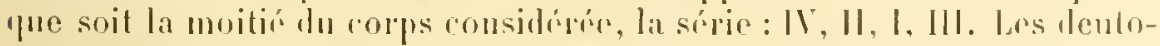
spptes de la fuatriene paire sont antórienres, el enralpent an repoint la ligue médiane; il en est de mome, dans la partie posteriene dr l"urganisme, pour celles de la troisiome paire; les protoseples somi latrialos.

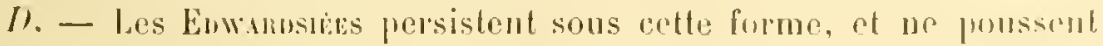
pas plus loin leur évolulion. les huit cloisons samplitient pour se sombro 
au tube esophagien, et deviennent ainsi des macroseptes; en mème trmps, elles rgalisent les espaces qui les séprent, de manièn à rendre identiques les loges qu'elles limilent. Les plaques musculaires prement maissance sur l'une de leurs faces, mas celles-ci ne sont pas les mèmes pour tontes; les handes musenlaires les cloisons 1 , I1, 1, sont engendrées sur la fince tompée vers la régium pustérieure du corjs, et celles des cloisons lll sur lo colí touné vers la région anlérieure.

D'autre part, les huit loges se subdiviseut en : deux impaires el médianes, l'une antéricure, l'aulre postérienre; el six latérales, gronpées en trois paires, les lenx éléments de chaque paire élant placés de part el diantre de la ligne médiane.

Toules les Pournubes, sans aucune exceplion. passent par une phase à huil cloisons, semblable à celle que les Elwardsiées présentent d'une manière permanente. Lenr déreloppement subit un lemps d'arrèt durant cette phase; ce temps est nécessaire pour que les cloisons s’étendent, et igalisent les loges qu'elles rireonscrivent. Les plaques musculaires commencent ì se monlrer, el se déreloppent lnuant la suite de l'évoJution; mais, quel pue soil le moment de lem formation, elles sont toujours disposées comme relles des Elwardsiées. Les huil premières choisons des lolyrariées sont, ndifuitive et sons lous les rapports, les homolognes de celles des Octoradiées. Les différences embre ces deux groupes purtent sculement sur ce lail que des cloisons nourelles, les métaseptes, maissent onsuite rhez les représentants du fremier groupe, alors quelles manquent ehez reux du secoud.

Les diverses tribus des loolyradices dillèrent les unes des antres par le nombre, et par la lisposition, de leurs métaseptes. Les premiers cilats de lour déreloppenent concordent, de tous points, jusqu'an moment où les huit choisons premieres sont bien formées, et leur huit loges égalisées. Cet instant, peudant lequel l'évolution s'arrète quelpue peu, correspond à une phase ocloratiée, lont les Edwarlsiées conslituent le représentant permanent dans lin nature actuelle. Les dissemblances commencent ensuite à se manifester.

La tribu des Moxulés, qui contient senlement le genre reytophorus, est caractérisée par la présence de puatorze cloisons gastripues, comprenant les huit probseptes et leuloseptes normales, plus six mélaseples. Ces deruicres sonl groupées en trois paires, qui apparaissent respeclivement dans les trois paires latérales de loges; la loge médiane antérieure, el la loge méliane postérjeure, ne se subdivisant pas. Ces cloisons secomlaires deviennent des marroseptes, et lemrs playues musculaires naissent sur la liace tomrnée vers la region antérieure du corjs. - Les Cionatixies s'érartont peu des llonaubées. Leurs deux loges médianes ne se scindent point; seulement, l: nomlre des cloisons sceomdaires est de huil; de plus, ces lermières restent loujours des microseples. Les denx logges latérales de la pairu antérieure contiennent demx mélaseples chacune, alors que celles des doux aulres paires ne renforment quime 
seule cloison nourelle. Parmi les huit mélaseptes, celles des trois paires postérieures forment leurs plaques musculaires sur la face lournée vers la région antérieure du corps; par contre, celles de la paire antérienre, placíes de part el d’antre des deux cloisons primaires qui eneadrent la loge médiane et antérieure, ont leur's playues sur la face orientée vers lat région postérieure de l’individu.

La plupart des autres Polyradiées produisent une quantité de métaseptes supérieure á celle offerte par les llonaulées, et par les fionatiniŕes. - Les représentants de la triluu des Cémaxmóes passent d'alord par la phase octoradiée, puis engentrent leurs nombreuses cloisons secondaires; toutes ces dernières naissent dans la loge médiane antérieure, qui grandil beaucoup, et reporte, à cause de son extension, les huit protoseptes et deutoseptes dans la région postérieure du coryss. Les métaseptes se montrent presque en mème temps; il est cependant possible de reconnaitre que les paires les plus jeunes apparaissent torjours en dedans des ancienmes; de cette manière, les premières mélaseptes engendrées sont roisines des proloseptes, et postérieures par rapport aux dernières formées. Celles-ci sont placées dans la région antérieure dı corps; les deux plus récentes encadrent la loge antérieure el médiane. Cetle loge ne correspond donc pas ì celle des Ocloradiées, ni à celle des deux premières tribus des Polyradiées; elle n’est point limitée frar les cloisons de la quatrieme paire, mais par les dernières des mélaseptes produites. En outre, celles-ci sont des microseptes, alors que les antres cloisons serondaires deviennent des macroseptes. Les plaques musculaires de ces cloisons secondaires naissent sur la face qui regarde la région postérienre du corps. - Ces détails, relatifs anx Cérianthidées, diroulent les observations faites par Boveri sur les Arachnactis. Les procedés génélipues les protoseptes ne sont cependant pas bien conuus; mais, daprès la structure offerte par les larves de ces ètres, lor'squelles sont parvennes à la phase octoradiée, la concordance àvec les phrinomènes présentés par les autres Polyactiniaires semble indiscutable.

E. - Les \%onxmmes ressemblent aux Cérianthidées, en ce que le nonlire de leur' métaseptes est consilérable; elles en diflërent, pourtant, par des particularitís importantes, tenant i deux ortres de lints. En prenier lien, les métaseptes ne sont pis localisées dans la logwo anlérinne, et massent sur tonte la périphérie de la cavité gastripne; ensuite, clles appraissont en denx temps, yuatre d'entre elles se lurmant l'alord, les autres se montrant plus tard, d'après nue symétrie qui leur est propre. - La pronluction des ynatre premières métasejules, ajonlines and huit protoseptes et leutoseptes, el se mètanl ì elles, a fromr rlfol de porter it donze le chiffre des cloisons et des logrs. Les antres chisons secomdaires sont engendries diantes un mole partirulier. ot snivant une marche délerminée par ce chiltre donze; le risullal est de transformer la sýmétrie ortoradiée de l'organisme en une disprosition 
Indécaradiée, ou, pour simplitier, en ture orientation hexaradiée. Il existe done denx lypes de cloisons seromlaipes chez les Zoanthaires : le premier type renferme les tuatre primieres d'entres altes, d te second contient toutes les autres. Nin de faciliter la deseriplion, les quatre premières seront nomméns des mitaseptes primuires, of les lernières les métaseptes secondaires. - Les Zoanthidées, les Actinidées, of les lladré-
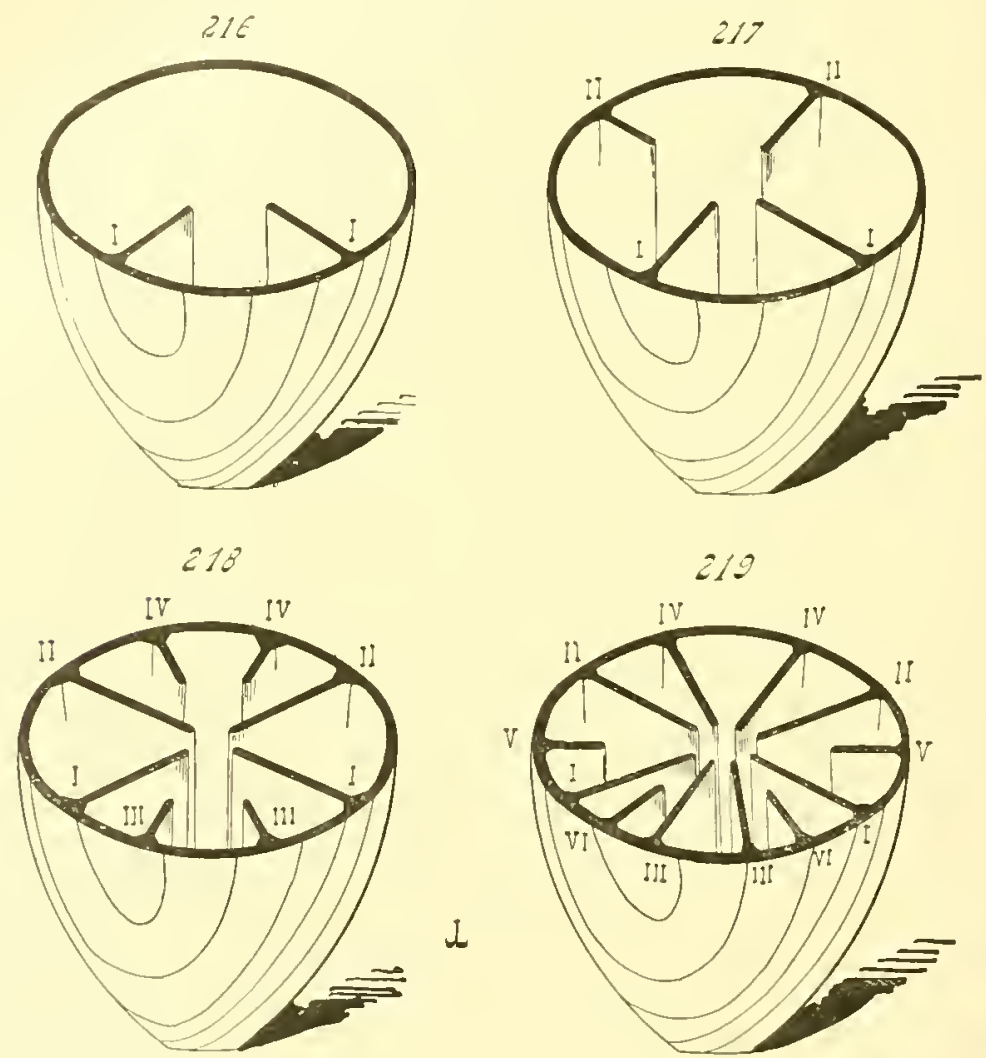

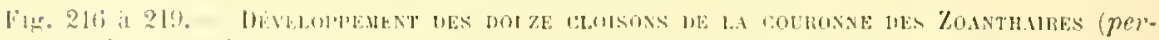

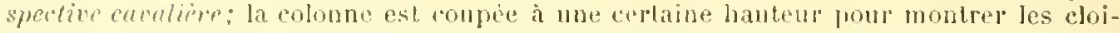

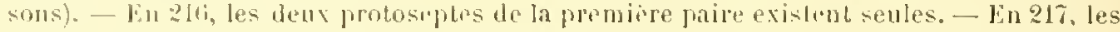
deux protosiples de la seeomble paire ont fait linr apparilon; lembryon est parvenu a

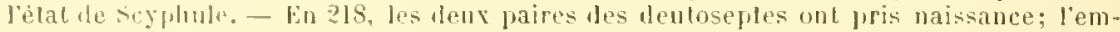
bryon "si arivi a un ant, qui demeure permanent cher les Edwarkiés. - En 2l?, les demx paires des metaseptes primnires ont ele engendrées, el ha couronno se trouve romplète.

Comparer ces figures aux suivantes, qui donnent las phases ultidures lu développoment, en ee qui concerne les drtinides. Les eloisons de la couronne sont designees, en elilfres romains, far leur numè l'ordpe en tant que late d'apparition.

porides sont les seules bion ronnues, sous le rapport de la genèse des choisons; les fails acquis montrent que les quatre mélaseptes primaires 
sont prodnites de la mèn façon duez les reprisentants de res loris groupes, alors que des dissomblanees nombiemses so prosentronl pour los mitaseptes secomiaires.

le procédé mis en ouvre, dans le développement des métasiples primaires, rappelle entierement celui doji signale pour les proloseptos el les dentoseptes; leurs deux paires se montrent, en elfel, l'une apros l'autre, el d'une façon telle que les deux clojsons d'uno mèmo paire soient disposées de part et d'antre le la ligne móliane, a nne égaledistance de cette ligne. - L'une de ces pairrs apparail dans les denx loges latérales, placces entre la première el la trojsieme paire des cloisons déji formées; la secomde dans les deux loges lalérales, silures entre la première et la seconde paire de ces mèmes cloisons. - Ces quatre mélaseptes primajres najssent ả peu de distance; le court intervalle de lemps, qui sépare les moments de leur apparilion, n est pas apprécié de la meme manière par les auteurs. - La paje intercalée aux cloisons I el III serail la dernière venne, smivant les recherches de Lacazemuthiers; alors que l’inverse anrat lien, d'après les frères llerlwign el Wijson. Ces naturalistes se sont adressés, pour fajre leursétules, ì des especes ditlérentes: il faut penser, peut-obre, que l'ordie dapparilion des métaseptes primaires est sujet i varier suivant les types.

Comme les quatre mélaseptes primaires des \%oantlaires sont engendrées de la mime manirre que les huit cloisons primitives, sonl orjentées de la mème facon pas rapport ì la ligne médiane, el se ronfondent arec elles, il en résulte que ces douze appendices gastripues se ressemblent exlrumement, el font partie d'un mème systeme, qui sera nommé la courome. Grice à lem présence, la région púbiphérípur de la cavilè gastripue est diviséc en douze loges, les loges coronules, dont deux sont impaires et médianes, et dix latérales. Les quatre métaseples ont leurs faces i landes musculaires tournées vers la région antérieure du corjs; aussi, en se combinant avec les cloisons primaires, ont-elles pour effet de donner à deux des paires de loges latérales le caractire de

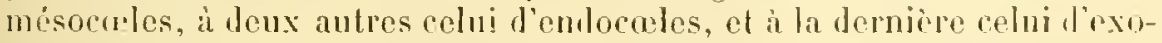
corle; les leux loges impaires sout toujours des exocoles. En driginant la loge impaire antrieure par la leltre $\mathrm{A}$, la loge impaire postérioure par la lethe 13, et les loges latérales par des mumbos comrespomdant it lour situation respective, on oblienl, sur chaque molio du corps, lat serio

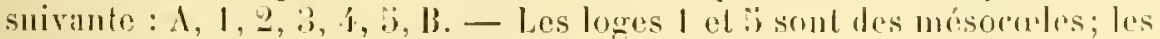
loges 2 el í des culocules: la loge 3 est un exocule.

liun autre cotri, si lon met dans une meme série, comme leur disposition deffnitive y ongage, les donze cloisons coromales, ot si on leur

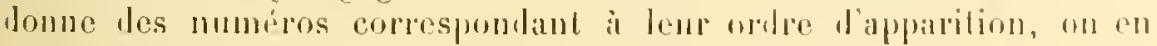

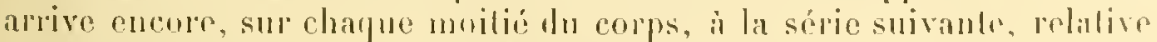
anx cloisons de la conronue : IV, II, V, I, VI, II, on IV, II, II. I, I, II. - Celte séric, exprimée en chitros romains pour la distingner de celle des loges, el daus laquelle, contrairement i celte deruièe, les élémenls 
sont disposés d'après le moment le leur naissance, non d'après leur silualion respertive, est communr, semble-l-il, à lous les Zoanthaires étudiés jusqu'ici.

$F$. L Les dissemblances entre les divers groupes s'établissent ensuite, et sont données par les mélaseptes secondaires. Il est permis de reconnaitre, sous ce rapport, deux groupes frami les Zoanthaires : celui des Zoanthilées l'une part, celui des Actinitées et des lladróporides de l'antue.

Les nétaseptes secondaires des Zourunbés apparaissent toutes dans la:"e paire des loges eoronales, c'est-í dire dans les deux loges comprises entre les cloisons 11 et lll. Ces appendices supplémentaires augmentent en nomlure, à mesure que l'individu avance en àge, et se développent en microseptes ou nu macroseptes; ces deux tyjes de cloisons sont disposés J. maniere a alterner avec régularité, de telle sorte qu'me macrosepte soit encalrée pardeux microseptes. Les faces musculaires sont orientées alternalivement en arant et en arrière; par suite, les loges de nouvelle formation sont les exocules, ou desendocules, les premièes altermant régulièrement avec les secondes. Chacune le ees loges est limilée, à canse de l'allemance des grandes el des petites cloisons, d'un cócé par une microsepte, ef de l'autre par une macrosepte; la microsepte el la macrosepte, qui entourent ainsi le mème endocale, conslituent un couple.

Cet arrangement des métaseptes seconlaires s'étend mème aux cloismo coronales. Les cloisons $1 \mathrm{~V}$ et $\mathrm{V}$ ne parviennent pas à alteindre le lube asophagien, et restent petites, semblables a des microseples; elles alternent aree les cloisons ll et I, yni s’éleudent en macroseptes. Les denx béments lo la paire Yl varient, sous ce rapporl, snivant les genres; elles sont des microseptes che\% les Zoanthus, les Corticifera; elles deviennent des macroseptes chez les Palythoa, les Episoanthus. Erumann, qui a éludié avee délails la structure des Zoanthidées, donne le nom de microlype a la disposition otterte par les premiers gremes, et celui de macrotype a la forme présentée par les seconds.

Las lois du développemenl des mélaseptes secondaires, chez les

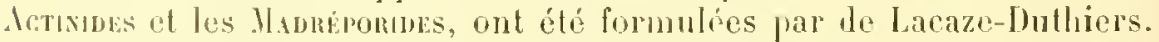
- Ces cloisons naissent, contrairement anx louze premieres, par couples siluás dans nne méme loge, ol non par paires donl les drux éléments se tronvent de part el l'autre le la ligne médiane; les deux mélaseptes l'un mème comple sont juxlaposies, ot non disjointes. Sons ce rapport, les Letiniles rajpellonl les Loanthides; elles leur ressemblent aussi jar l'orientation des fares musculaires, qui divisent les loges en exocueles

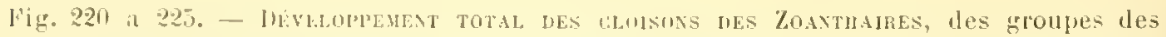
Ietinides el des Madraprides (projection horizontale). - En 220, 221, 222, 223, developpement des douze cloisons de la couronue, réparlies en six paires. Comparer aux ligures précédentes, qui montrent les mẻmes faits en perspeclive. - En 22:4, développe- 

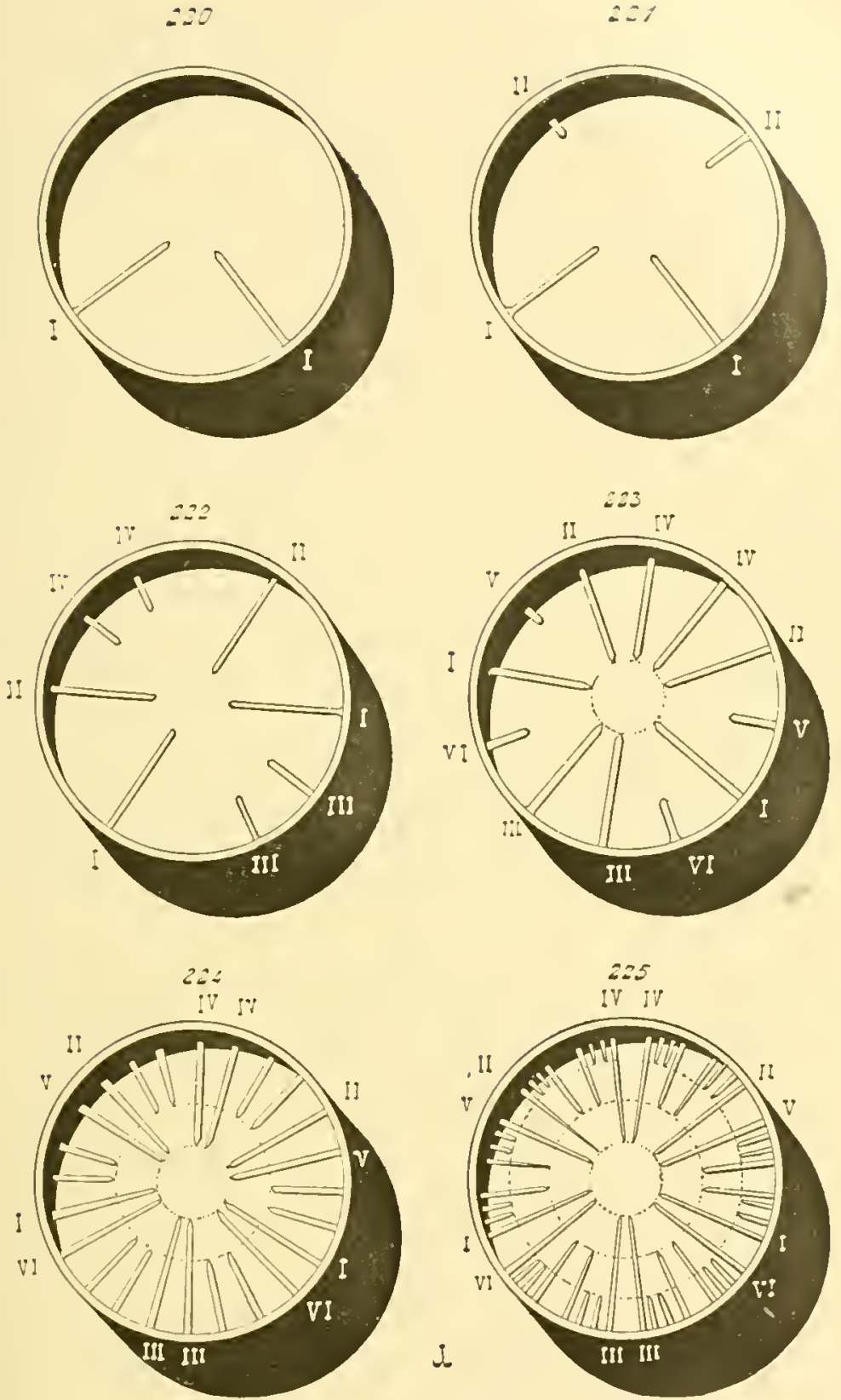

ment des douze mitaseptes seeondaires du premier cyele, gromus en six eouples, dont trois sont places a droile, et trois a gauche. - lin 225, develuppenent des vingt-unalre mitaseptes seeondaires du deuxieme cyele.

les eercles an pointille indiquent les limites internes des cloisons; la circonference interne désigne la couronne, la moyenne le premier eycle, l'externe le deuxième cycle. 
el enfocules allernant avee régulariti; mais elles en dilterent par le lien dorigine des mélaseptes, et pir lenr mode dextension. - Les métaseples secondaires ue sont pas localisres dans mue srule paire des loges latéales, el ne so dévelopgrnt pas de manieres dillérentes. Les deux doisons d'un mème coupla grandissent de la meme lacon, pour derenir rosemble, suivant lr: cas, les maroseptes ou des mieroseples. Les couples sont produitis dans plusieurs drs loges coronales. Celles de ces dernièes, quí renfermenl des mélaseptes, sonl placées a égale dislance les unes des autres; aussi l'ensemble de ces nouvelles cloisons se dispose-t-il avec une restaine régularité, sur le jourtour de la cavité gastriplue.

Toutes les motasples secomdaires de l'alulte ne sont pas engendries en meme temps. In certain nombre d'entre elles apprarail, en premier lieu, sur la périphérie de la cavité gastrigue, el se léveloppe; une nouvelle quantité est ensule faconnéc, Jes régions formalrices occupant aussi le ponrtour entier le la mème cavité; et le phénomène continue à sellectuer jusqu'i ce que le chiffre lofinitil soit alfeint. Il faut réserrer lo nom de cycle à l'ensemble des métaseptes lu mème igge, éest-ì-dire des cloisons nées en mème temps, el clont l'agrandissement s'etferlue de laçon égale jonr loules; on numerote ces cyctes suivant lenr ordr d'appration, te premier édant celui produil lout d"atrord, le second celui qui est engendré peu apres, et ainsi de suite. Le nombre des mélisepules secondaires ust lixe dans chayue cycle, ce chillie étant Lonjours te double de celui ollert par le cycle précédent; ainsi, le pre-

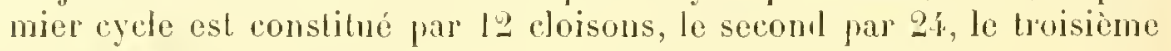
par fs, gle. La progression sous ce rapport, reste constante.

Les mélaseptes sccondarus du premier eycle sont au nombre de douze, réparties en six couples; lrois de ces derniers sont placés à droite de la ligne médiane, et les trois autres à gauche de celle mème ligrue. Les trois couples du meme côtí apparaissent dans les loges coronales 1,3 , $;$; ces loges, ausi disposées en alternance arec celles yui ne montrent pas une semblable genese de cloisons nourelles, sont des mésocules, on des exoceles; les loges dépourvues de mélaseples sont les deux faires d'emdocules latéram, et les deux loges impaires. - Le scrond cycle se comprose de 2 r cloisons, rassemblées en douze couples, six id droilo el six à granclse; les six couples du mème côté maissent de fart ot d'autre des trois couples du premier cycte. Les is cloisons du troisicme cycle sont groupées en vingt-puatre comples, dont douze sont silués a droite, el douze à gauche; les douze couples du mène côté apprarassent de part et l'antre des six eouples dn second cycle. Une évolution semblable se manifostr pour les autres acles, lorsquil en existe; un rycle déleminé formant toujours ses comples le part ot

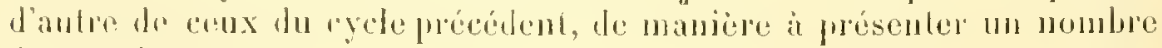
double de cloisons. 
Puel yue soit le eycle, les deux cloisons diun mème rouple grandissent de fiçon égale; les bandes musculares naissent sul lounc de leurs faces, au moment oi lemr borel interne alteint presipue lo quart de la cavité gastrique. Ces bandes sout disposées de telle sorte, quor lit loge circonscrite par les métaseptes d’un seul et mème couple soit un endocule. - Ce fail existe pour tous ces groupes hinaires; el, commo cess derniers se placent côte à côte, en naissant de part el dautre de curs qui les ont précédés, les loges laissées entre les conples sont limitéx par des faces lisses, nullement pourvues de bamdes musculaires, el correspondent par suite à des exocoles. Celle juxtaposition des couples culraine donc, en tant que conséquence. l'alternance des exocoles et des cndocoles, pour ce qui tient aux loges encadrées pas les métaseples secondailes.

l'uisque les comples apparaissent, avec constance, d'un cóté el de l'autre de ceux quj appartiennent aux cycles prócédents, et puisque les couples du jremier crele naissent dans les loges coronales 1, 3, 5; if en resulte que ces loges seules, parmi les douze de la couronne, conliennenl loutes les métaseptes secondaires. Les deux loges impaires, el les loges latérales - el f́, sont toujours à jart dans celte ryolution; lemp cavilé deneure unique, ne se subdivise pas, et conserve, durant tonte la vie de l'animal, son caractére de simplicité.

On a vu plus haut les relations ćlablies cutre la genese des tenlacules, el celle des nouvelles loges. Les lentacules s'elirvent au-dessus de toutes les loges en roic de formation, ef se groupent, par suile, en cyeles comparables à ceux des métaseptes secomilares.

Ci. - Les notions précélentes sont résumées dans le tableau suivant:

lo Larve Scrumbune : 'f protoseples.

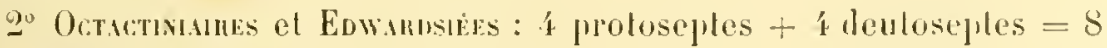
cloisons définilives.

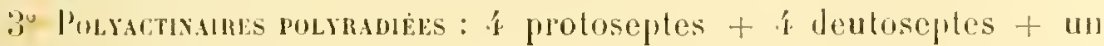
momlire de métaseples varialile suivant les grompes:

A. Momulées : í protoseptes + i dentoseptes + li métasuptus $=1$ r cloisons délinitives.

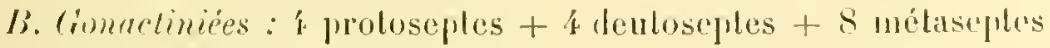
$=16$ cloisons délinitives.

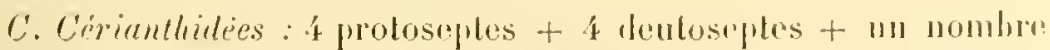
imbélerminé de mélaseptes daus la loge impaite antérienre.

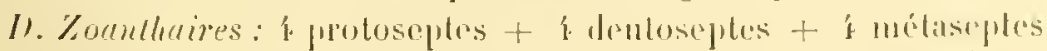
primaires, formant les dou\%e cloisums de la comonne (cloi-

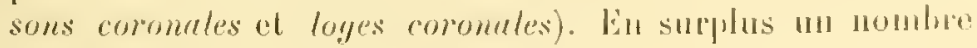
imblerminé de métaseptes secondaires. 
a. Zoonthidées : métaseptes secondaires naissant daus Ia $5^{\mathrm{e}}$ paire des loges coronales.

b. Actiniles ot Madréporides : métaseptes secondaires naissant daus la $1^{r e}$, la $3^{e}$, et la $5^{e}$ paire des loges coronales, ot grompées en cycles d'ìges dillérents. - Un cycle lonné comprent loujours demx fois j]us d'éléments yue celui qui le juricide daus le temps.

Quel que soit le groupe, les protoseptes, les deutoseplos, et los métaseptes primaires, naissul par puires: une paire est caractériséc en re sens, que ses deux aléments constitutifs sont plarís de part, et llautre de la linne módiane, et a une égale distance de cotte demiere. L.os métaseples secondaires naissent par comples : un couplo est caractérisé par ce lait, que ses denx éléments constitutifs sont juxlajosés, el séparés par $11 n$ espare lrès pelit. - La loi du redoublement : "lensemble des cloisons d'un mème ige atteint toujours un chiffre double le celui des chisons qui l’ont immédiatrment précílé dans le temps ", s'applique seulement aux cycles, cest-ì-dire aux ensembles des métascptes seconlaires, qui naisscut par conples, appartiemnent a divers ìges, sont situées dans plusieurs paires des loges coronales, et se trourenl chez les Aclinides et les Madréporides, à Jexclusion des autres Muthozaires. Malgré leurs dissemblances premierres, et la régularité le lenr ordre d'apparition, ces cloisons se mélangent les unes arec les autres, et entomrent de mòne la cavité gastrique de l'adulte, sams qu'on puisse les distinguer, sauf parfois par leur laille : les plus pelites étant les dernières remmes.

\section{\$. - Organes annexes de soutien.}

Cas organes annexes servent à soutenir les tissus mous des individus; ils doivent èlre considérés comme représentant un sipuelette, dont les diverses parties sont lantôt externes, el tantôt internes. Les prices squelelliques sont loujours comprosées frar une substance organique, encrontée le ralcaire; leur ensemble constilue somvent ce que l'on nomme le polypier.

Ces formalions cxistent chez les Anthozoaires seuls, et font constanment délaut aux Scyphoméduses et anx Cténophores; cette absence est saus doute corroblive de la vie libre menéc par ces derniers.

Les maluralistes sont loin l'ètre d'accord à leur sujet; cerlains admeltent que les pièces du squelette sont produites par le mésoderme, el l'autres disent que l'ectoderme seul est mis en cause. Il est rucore difficile de décider entre les assontions aussi différentes. Il faut bien le reconnaitre ceprendant, parmi los observalious effectuées ì cet égard, les principales et les mienx conduiles tendent à montrer que les polypiers des Anthozoaires sont toujours engendiés par l'ectoderme, et döi- 
vent ètre considérés comme des culicules calcarisées. Une exception serait laite pour les petits spicules, disséminés dans les lissus mous de la plupart des Oelactiniaires : ceux-ci dérivent du mésorlerme. Cétte genèse n'est pourtant pas une exception réelle, puisque le feuillel moyen est lui-mème d'origine ectodermique, et d'apparition tardive.

I. Octactiniaires. - A. Les pièces squelettiques de ces animaux appartiennent à deux types bien distincts: d'un côté, les petits spicules disséminés daus le mésoderme, et que l'ou tronve chez tous les représentants dư groupe; d'autre part, les productions, lantôt cornées, lantôt calcaires, qui entourent les zooïles, on qui soutiennent les tissus mous ales colonies.

Si les détails du développement des spicules sont encore ignorés, il n’en eśt pas de mème pour leur origine première, qui est bien comune. Les naturalistes, dont les études ont porté, en ces dernières années, sur l'érolution embryonnaire des Octactiniaires, et notamment liowalersky et llarion, ont montré que ces éléments naissent dans le mésoderme. An unoment où s'ébauche ce feuillet, plusieurs de ses cellules produisent, daus leur protoplasme, une petite concrétion minérale, qui grandit et devient un spicule. La suite des phínonènes n’est pas encore élucidée; il semble cependant résulter, des figures fouruies par les auteurs précilés, que le protoplasme de la cellule génératrice reste placé, sous la forme d'une mince lamelle, autour du sclérite, et angmente les dimensions de ce dernier en lui ajoutant de nouvelle substance. - Le développement des spicules des Octactiniaires rappellerait done, de fort près, celui de leurs similaires des Ejponges.

B. - Sauf un seul genre (IIaimen on Monoxenia), tons les Octactiniaires acluellement connus sont rassemblés en colonies. Dans certinins cas, les zoö̈des, et les colonies constituées par leur union, sont nus, et "offrent aucun restige de squelette, sauf les spicules mésodermiques. Mais, d'ordinaire, tantòt chaque zooüde est situé dans une loge i la paroi plus ou moins épaisse, et lantòt chanue colonie porte, en son centre, une bagnette rigide servant de support. Les opinions diffèrent au sujet de l'origine de ces éléments squelettiques; plusieurs auteurs les font provenir de l'ectoderme, et d'autres du mésoderme. Il est donc utile d'exposer en premier lieu les faits connus sur le développement de ces pièces, et de ne discuter qu'ensuite, en s'appuyant sur ces donuces, la question de provenance.

Lorsque les éléments squeleltiques entourent les zooïles, ils oflrenl l'aspect de loges contenant ces deruier's; l'ensemble de ces loges est un polypier. - Le polypier des Clavularides, el celui des llélioporides, se dépose autour de chayue individu, el grandit avec lui. Cehui des Chvularides est mince, corné; les logres das zooüldrs d'une mime colonie ne se soudent pas les unes anx autres, et se relient senlement par l'en- 
tremise d'une conche cornée, yni revìt les stolons unissant ces zooïdes cntro eux. I'ar contre, celui des llélioprorides s’épaissil beaucoup, el s'incruste de calcaire; les parois les loges se fusionnent, et leur masse conslitue un polypier composé.

L'évolution des Tuliporides est lifférente. D'après les éludes faites par Sidney J. llickson, le zoïte primilif sathache à un support, et proluit, par sa hase, mu lacis de stolons qui s'étalent sur ce dernier'; puis las stolons hourgeonnent des individus sur leur face supériemre, et non athrírente. Les zoö̈les s'entourent alors d'un hub qui les envelopie completement; mais, contrairement it ce ru’il en est pour les Clarularides et les llélioporidns, les choses n’en restent jas là. Chaque zooïde tend constamment à monter dans l'intérienr de son tulse, et a produire te nourelle substance squeleltique sur le hord supérien de celui-ci; le résnltat est que cette loge s'allonge sans cesse par son sommet, tout cn restant lixée au support par sa loase : l'animal se playant toujours dins la région suprérieure de la cavité tubulaire. A mesme que s'effectne cefte ascension, et à des intervalles prestrue égaux, la base du zoö̈de engendre une plaque horizontale, qui obture complètement l'intérieur du tube, el sert de print d'appni. Chaque individu fournit ainsi plusieurs de res plaques, nommées planchers, semblables à des diaphragmes qui traversent la carité, el dont le nombre pent aller jusquà treize el quatorze.

Le développement des axes rigiles, yui soutienuent les colonies des Gorgonidées, et des l'ennatulitées, rappelte, par sés débuts, celui des jemes T'ubipores. Le zö̈le primitif se lixe sur un support, et bonrgeonne latératement plusicurs zoödes placés les uns à cóté des autres. liensemble le ces individus est une petile colonie, qui reprose, par une large surface, sur le support; cette lase produit une conche uniforme de substance squeletlique, dite la membrane linsiluire. La colonie continue à augmenter, par bourgeonnement, le nombre de ses zooüdes, el

ajonter de nouvelles assises à cette membrane; ces assises récentes ne sont pas le dimensions égales sur toute leur étendue, mais so tronvent plus épaisses en leur centre yue sur leur pourtour; la membrane basilaire ne reste dom point plane, ì mesme fu'clle s’accroil, mais, à manso de ent ipaississement central, se lombe en un dôme. - Les nouveaux dínits présenlant toujours la mème disprosition, le dôme se hansse de plus en plus, et soulève la jenne colonie; celle-ci prend elle-mème me forme conrexe, el entomre l'amas de sulsstance squelettique. Le phènomine continnaut saus cesse ì s'elfectuer, d'après le mème procédé, le dimo revêt peu à peu l'aspect d’une bagnetle cylindrique, environnće par les lissus mous el par les zoroüdes de la colonie. Les éléments sefuclettiques sont alors grupués en un axe rigide, qui parcourt la colonie entiere dans le sens de sa longueur, el la sontient. Tantôt cel axe est constitué simplement par une matiere cornée, comme celuj des Gorgones 
el des Pennatules: tantót il s'encroute de calcaire : celui du Corail est un exemple de ce deruicr cas.

Les opinions des auteurs diflerent, au sujel de lorigine de ros produclions; cerlains les font dériver de l'ecloderme, el d'autros du mésoderme. Il faul se souvenir, dans celle discussion, que les seuls íléments, dont la nature mésodermique soit viaiment démontrée, sont des spicules minéraux; ces éléments ne sont janrais cornés. - Les polypiers

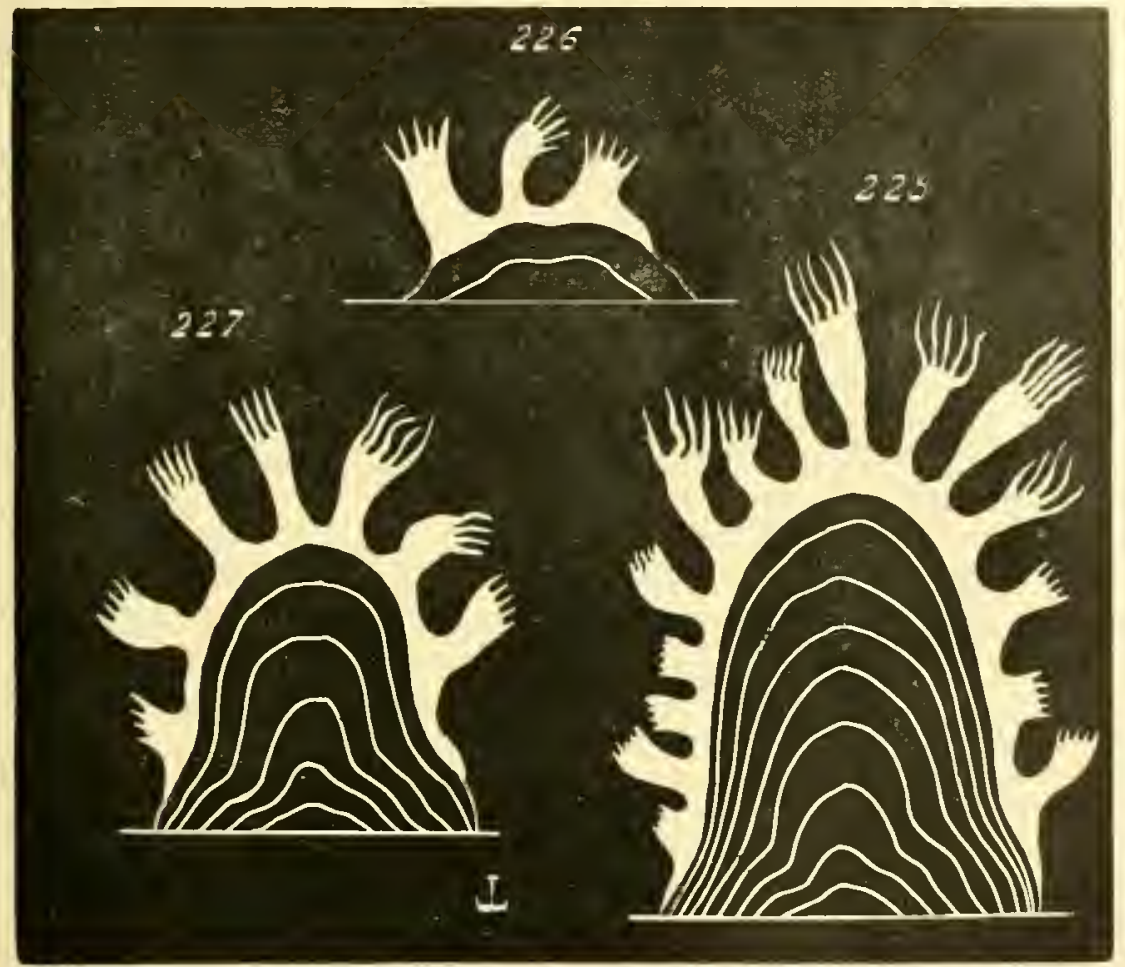

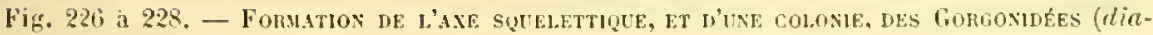
grammes). - En 226, jeune colonie, composée le trois zooildes, et monlée sur un axe encore réduit à l'état le membrane basilaire. - En 227, colonie plus ảgée, dont l'axe s'est exhaussé en dome. - En 228, colonie plus avancé, dont l'axe commence à devenir une baguette eylindrique. - l'après les reclierches faites par l. von kioch.

l.es tissus mous de la colonie, zooïles et sareosome, sont représentès en blanes; l'axe est en noir, avee des lignes d'accroissement blanches.

des Clavularides et des Ilélioporides sont fouruis par l'ectoderme; les cellules de ce feuillet exsudent, par leur face externe, une substance, qui est celle du polypier; ce dernier doil douc ètre considéré comme répondant à une culicule. Il est difficile, par conséguent, élaul donnée la graude ressemblance générale établie entre ces polyjiers al ceux des Tubipores, l'accepter l'opinion de Sidney J. Iljckson; cel auteur indmot. 
en elfet, que les tubes des 'Tubipores sont formés par un feutrage de spicules mésollermịues. Il semble lien, ì cause de cette analogie, rue l'on ait encore atfaire, ici, i une production eclorlermique. - Une apprécialion semblable doit ètre tenue pour l'axe des (iorgonidées; G. von liorh, dont les recherches onl contrilıé pour heaucoup à élucider les phénomènes du développement des jolypiers chez les Aulhozoaires, admet que cet axe est engendró par l'ertorlerme, contrairement à Studer qui le fait provenir dı mésoderme. La nature cornée de la plupart de ces axes, leur disposition en conches successives emboilcées, lenr aspect primilif comme memlrane basilaire, tous ces fails, rémnis, contribuent ì faire accopter l'assertion de (i. von lioch.

Si les opinions émises par les auteurs sont ainsi lissemblables, lien qu'elles soient basées sur les olsservalions directes, cel antagonisme tient à la dilficulté mème de res derniores. L'ectoderme est représenté par une mince assise épithéliale, alors que le mésoderme est fort épais; aussi, l'ectoderme, placé entre le squelelle et le feuillet moyen, peut-il échapper parfois. Et il sullit, en dernier lieu, de rappeler que le polypier des Marléporides, plus complexe encore que celui des Octactiniaires, est cependant produit par le feuillet externe, pour tourner la plupart des probabilités en faveur de lorigine ectodermique de presque lous les élémeuls słuelelliques, cornés ou cornéo-calcaires, des Oclachinaires.

11. Polyactiniaires. - A. Les Madréporides et les Antipalhides sont les seuls lolyactiniares qui soient pourvus d'un squelette. Cielui des premiers est un polyjier d'organisalion complexe, qui entomre chapue individu, el envoie des expansions dans sa cavité gastrique pour souturirles frarlies mulles; celui des seconds est simplemeut représenté par un axe corné, qui supporte les colonies à la manière des axes des Gorgones, le copps des zooüdes restant libre en enlier. Le mode de déve. loppement de ce dernier appareil squeleltipue n’est pas encore lien connu; son origine ectodernjique semble certaine. Quant au polypier des Madréporides, la plupart des auteur's récents le font également provenir de l'ectolerme, par opposition aux auteurs plus anciens, qui disaient l'avoir vu naitre daus le mésoderme.

La romplexilé de ce polypier est sourent fort grande. Chaque indivilu en posside un, phus ou moins dislinel de celui de ses roisins dans le cas des Madrépolides coloniaux, el composé essenliellement par deux prarlics : une épaisse paroi, la muruille, encore nomméc calyce dlans cerlains cas; el des cloisons dures, diles parfois des lames on des calcoseptes, parlant le la face interne de la muraille pour pénélrer daus la cavité gastripue. Ces lames alternent avee les sareoseples, ou cloisons molles, et sont placées dans les emdocoeles que limitent ces dernières. La substance de la muraille, des doisons calcaires, et de leurs annexes secondaires, tels yuo la columelle, les palis, les côtes, ete., est toujours ronslituéc par du calcaire. 
Les rapports du polypier, avec les lissus mous, sont importants it connaitre. La colonne, la paroi molle du corjes ulu zooüle, est plus longue que la muraille, el la dépasse, lorsque l'animal est élalé. La mujaille entoure done la zone inférienre senle de l'individu; lextrémilé superienre, qui porte la bouche et les tentacules, reste lihe, mais peut se rétracter dans la région pourvue de la muraille calcaire. Hin outre, cette dernière nest pas extérieure ì la colonne molle, mais se trouve interne par rapport à elle, et en est même séparée par un espace assez ample. Comme toutes deux sont concentripues, la cavité gastrique est divisée par la muraille en deux parties : l'une, périjiérique, entoure la muraille, el se trouve comprise entre cette derniore et la colonne(cavite ertramurale); l'autre, centrale, est siluée en dedans de la muraille (cavité intramurale). - A cause de celte disposition, une compe transversale d'un Madréporide, muni de son polypier, montre, en allant de dehors en dedans : la colonne avec ses lissus mous, fuis la cavilé gasluque extramurale, la murajlle calcaire ensuile, el en dernier lieu, la cavilé gastrịue intra-murale. Les lames partent de la face interne te la muraille; aussi parcourent-elles la cavité intra-murale seule. l'ar contre, les cloisous molles sont attachées i la face interne de la colonne; aussi leur région basilaire, située dans la partie du corps portant le polypier, est-elle conpíc en denx zones par la muraille, l'une qui traverse la cavité extramurale, et l'autre qui parcourt la cavité gastrique interne. La rígion supérieure le chacune de ces clojsons, placée dans le sommel du corps, oi d'orlinaire le polypies ne parvient pas, reste seule indivise, el semblable ì l'une des sarcoseptes des Polyactiniaires privés de squelette.

B. - La première ébauclıe du polypier des Madréprorides apparaîl, d'labilude, au moment oì la larve fixée posside ses donze premières cloisons molles. Une petile planne calcaire, arrondir, se monlre alors vers le centre de la lase de l'individu : cest la plaque basilaire, qui sert ì joindre forlement cette base au corps étranger servant de support. l'uis, les nodules calcaires, supplémentajres, najssent dans cette mème région lasilaire, entre les clojsons molles; ces worlules se rúunissent en petits groupes silués sous chacune des douze logres de l'animal, el représentent los louze premières lames (cloisons dures). Chacune de cellesci, élant formée par la soudure de trois modules en moyenne, oflre l'aspect l'un Y dont les deux branches divergentes sont tominées en lehors. Le jenne llalréporide possède donc, it celte phase de son évolution, une plapue hasilaire et douze lanes, allermant aveses douze sareoseptes prinilives. Les espaces laissés entre les branches des l' vont alous se remplij de calcaire; puis, passés ainsi à l’élat de masses solides el comfacles, ils crojssent par côté, de maniòre à sunir latéralement les uns aux aulres; cotle union se manifeste en dedans de la colonne, el a pour effet de produire un annean calcaire, situé sous la lose de l'individu. Cet anneau, qui porte les eloisons dures sur sa face inlerne, el se lromre 
entonré par la colonne, est l'ébanche de la muraille, il continuera à s'aceroitre par la suite, fout en conservant les memes redations.

ta colmuelle est indripendante, jar son origine, de la muraille ot des premières lames; elle est engendrée pilr un épaississement central de la plapue basilaire, qui s'allonge, en s’élecant suivant l'axe longitudinal de la cavité gastrique de l'individu. Par contre, les autres annexes squelet-
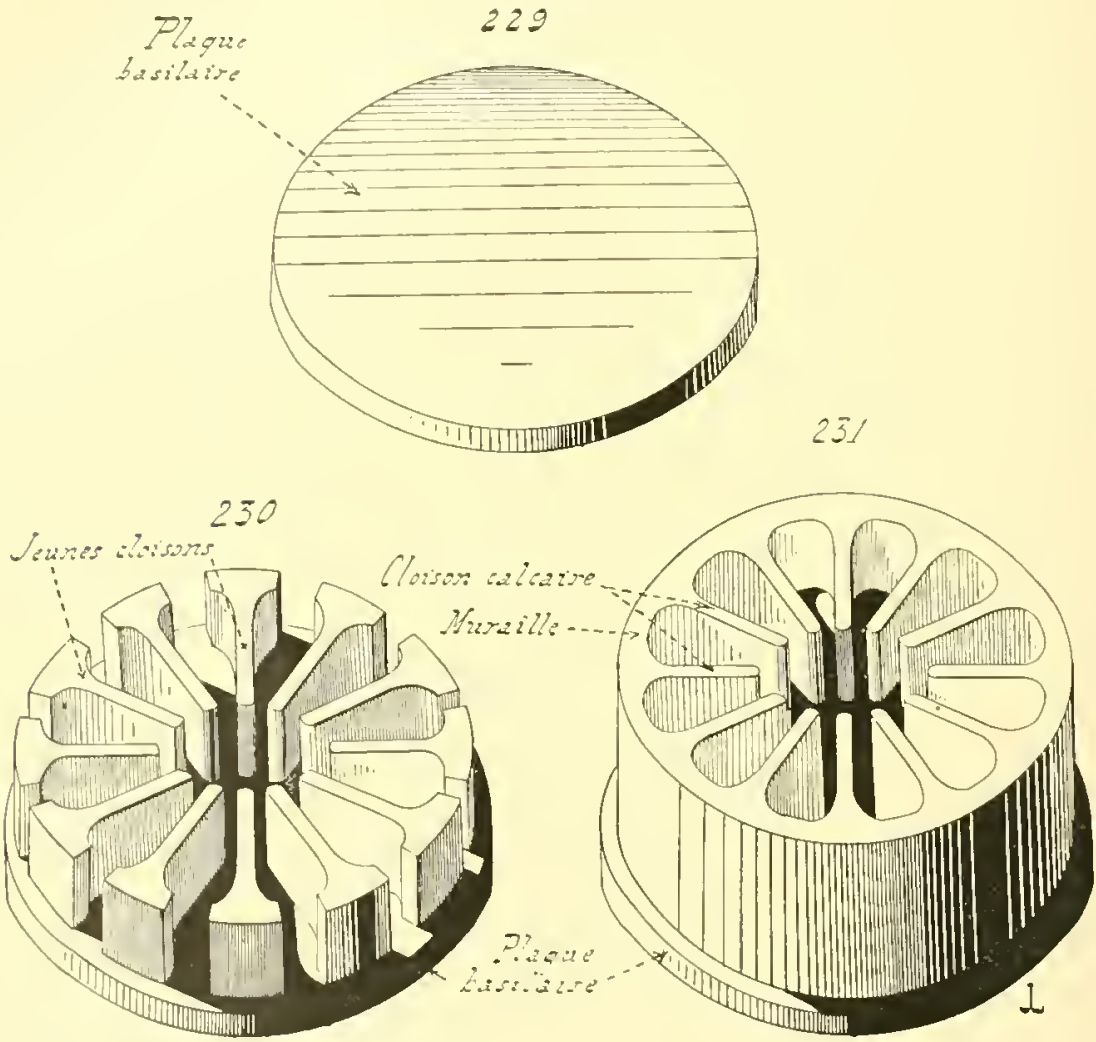

lïg. 229 à 231. - Formation du polypier ofs Mabríporides, considèré en lui-même, et alstraction fate de l'individu qui l'engendre (perspectives). - En 220, Ie polypier en 'sl a l'état de plarue basilaire. - En 230, les cloisons ont jus naissance sur la playue. - En 231, les loris exterieurs les cloisons, en grandissant et se rejoignant, ont proluit la muraille. - (Diagranmes.)

tiques dépendent de la muraille ou des doisons; les plus fréquents d'entre enx, les palis, sont des prolongements verticanx, el parallèles ì la columelle, émis par le hord interne des cloisons dures. Les còles sont des expansions externes de la muraille; les dissépiments, les planchers, et les synapticules, correspontent à des saillies internes du calyce, ou à des excroissances latérales fournies par les cloisons. - Quant à celles-ci, 
le mode de déreloppement des douze premières d'entre elles est bien connu, mais il n'en est pas de mème pour les autres: les chiservations acquises permettent cependant de croire quelles naisseut dums los cudocales, limilées par les métaseptes secondaires, el qu'elles apparaissent par cycles, tout comme ces deruières. Par suite, les lois du déveloplucment les mélaseptes sont applicables, sans nul doute, aux cloisons calcaires. Quant aux douze premières lames, elles se grompent en deux couronnes, dont l'une est composée par six d'entre elles levenues grandes, la scconde par les six autres restées petiles, celles-ci alternant avec celles-là.

C. - On avait admis, pendant longtemps, que le polypier des Madréporides élail produit par le mésoderme; les recherches récentes tendent par contre, a le faire considérer comme une cuticule l'origine ectodermique, encroìtée de calcare, et pénétrant dans l'intélieur des indivilus, grace a des involulions de la paroi du corps. Les cellules ectorermiques chargées de produire cette cuticule sont nommées des calycollustes. La plaque basilaire est engendrée, tout d'abord, par l'ectoderme qui revit la région fixée, la base aplatie, de lindividu; puis, cette mème latse se creuse de plis, rayonnants du centre vers la périphérie, qui se forment au-dessous les loges placées entre les Jouze sal'coseptes pimitives, s'apjrofondissent en pénétrant dans le corps, el font arancer, à leur niveau, la paroi somatique dans la cavilé des loges; la substance les douze premières cloisons dures se dépose dans ces plis. Ceux-ci deviennent toujours de plus en plus profomds, et, par suile, remontent de plus en plus dans les loges gastriques; comme le calcaire continue a se "léposer sans cesse, les cloisons dures angmentent ainsi de hauteur. Isa muraille est produile au moyen d'expansions latérales émises par ces plis, expansions qui se rencontrent, et sunissent. Les autres régions du jolypier sont également exsudies dans l'intérienr de replis secondaires, qui dérivent des précédents. L’épithèque, et les cloisous dures plus rícentes, font seules exception; la première est sćcrélée, lorsurulle existe, par l'ectoderme de la coloune, et se trouve ainsi placée en dobors de l'individu entier. Les secondes rópomlent a des bandes calraires, dóposcors dans les cavités de nouveaux sillons creusés, dans la région hasilaire de l'animal, entre les zones d'insertion des métaseptes sccondaires sul la paroi du colps.

En somme, il fautse représenter cette porlion, le la paroi somatifur, servant a fixer lanimal, comme une membrane cleusíe de sillons nonloroux sur sa face extericure; ces sillous senfoncent ho dohors en dedans,

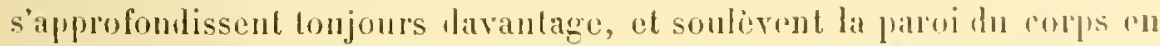
lonrelels, qui pénètrent dans l’intérien de la cavité gastrique. A cause te ce mode de formation, la cavité de ces replis est limiléc far l'eroderme; les élements de ce fenillet jouissent de la propriété de srevéter du calcaire, qui saceumulo dans l'intérien des sillons: il se constilue 
ainsi des pieces squeletliques, recouvertes par la paroi des replis, et servant ả soulenir les tissus mous. Ces pièces, avee les sillons qui leur donnent naissance, s'agencent entre elles l'ume façon régulière, et suivant la symétrie radiale de l'orranisme; elles se disposent en cloisons, qui se soudent les unes aux autres par leurs hords externes pour produire la muraille.

Élant donnée celte évolution. les diverses parties dn polypier ne doi-

232

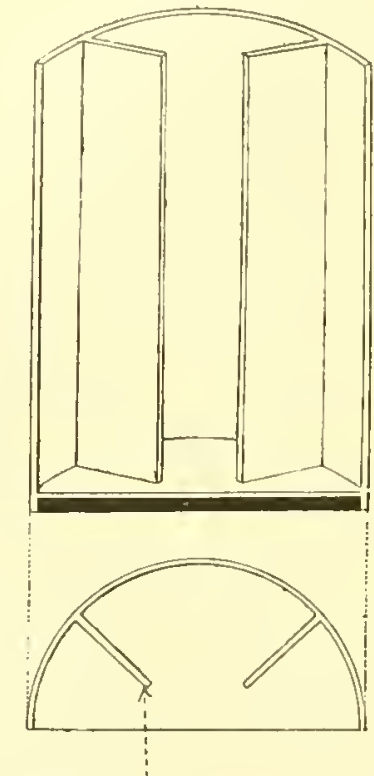

tloison molle
233
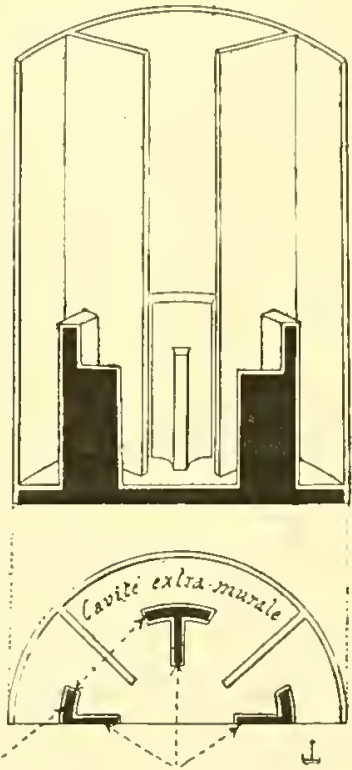

Marálle Cloisons calcaires er woite de fornzizion

Fig. 232 el 233. - Furmatuon du rolyplen lass Madneporides (perspertives cavalices en élivation el coupe). - En 232, le polypier en est a l'élat d'une plapue basilaire, situce sous la colonne. - En 233 , le polypier a produit les cloisons calcairus et la muraille, qui se sont acerues en somlovint devant elles les tissus mous, colonne cloisons molles.

Le polypice est représenté en noir. Ces deux figures indiquent, d'une maniere théorique, el en tenanl compte des relarions avee le corps de l'individu, les méme faits que les deux prócéntes ligures 220 el 231 . lin outre, la figure $23 i$ précise les lisposilions dénolées par la presente figure 233 .

vent jamais être à mu lans le corps; elles sont reconvertes par la paroi des replis oi elles se díposent, el celle-ci nest qu'une portion de la paroi somalique générale, domt dle pussirle toule la structure. Il est probahle, cependant, que le mésorlerme el l'endoderme des replis s'amincissent beaucoup, laissant a l'ectoderme, et à ses calycoblastes, la plus grande importance. Cet amineissement permettrait de comprendre cerlaines 
figures données par les auteurs, oì la murnille est représentée comme si elle traversait direclement, à l'emporte-picce, les lissus des cloisons

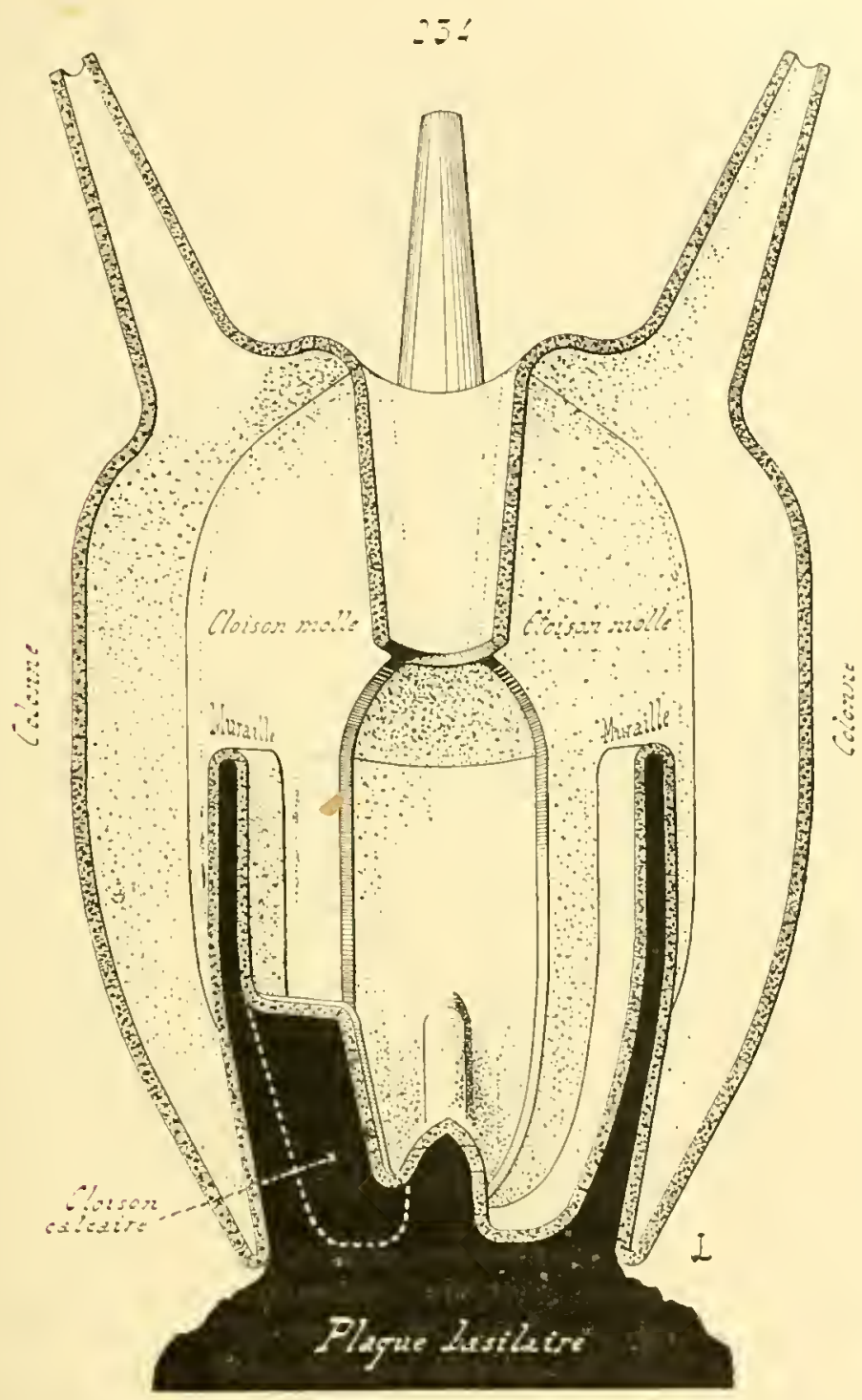

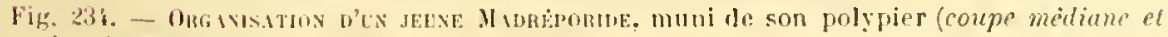
longibulinale. avec perspective). - La substance calcaire est representri. en noir. I.

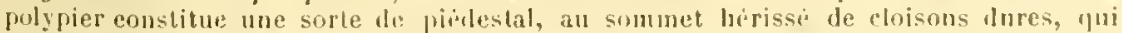
soulevent it lour niveau les tisas nous, les gaufrenten s'y desinant in crux, et s'ou enveloppent. Le diamitre lle la muralle étant plus petit que eelui de la culonne, crlle-ci deborle celle-là, el descent autour de celle dernière à la facon d'une poche anmulaire, dont lespace vide est la cavite extra-murale. 
molles. Il est plus acceptable que cette muraille, engaince par la paroi amincie du repli qui lui donne maissance, sonlève ì son nivean les hases des eloisons molles; le mésoderme de sa paroi recourrante se souılant avec celui de la cloison, et les deux conches endoderminues agissant de mème. De nouvelles recherches sont encore à désirer sur ce proint, afin de montrer la nature prérise des relations étallies entre les tissus mous les replis à cloisons calcaires, et ceux du reste du corps.

\section{7. - Reproduction asexuée.}

I. Généralités. - Les Cténophores ne se reproduisent janais asexuellement; tel n'est pas le cas pour les Scyphoméduses, surtoul pour les Anthozoaires. La multiplication par fissijarité, ou par hourgeonnement, jone, chez ces dernicrs, un grand ride; son importance est moindre chez les Scyphoméduses, car le Scyphistome de diverses Discoméduses la présente seul.

Quels que soient les divers procédés mis en euve, les phénomènes fondamentanx de la reproduction asexuée ne varient pas, ef se ramenent tous aux deux modes habituels : I division fissipare et le bourgeonnement. Dans le premier cas, le zoïte se divise en deux ou en fhlusieurs parties, qui, tantôt restent unies en une colonie, ef tantôt se séparent; chacune de ces parties étant capable de devenir un nouvel être. Dans le second cas, le zoïte émet, en une région quelconque de son corps, une expansion renfermant un diverticule de sa cavité gastrique; ce hourgeon grandit, et se convertit en un individu, possédant aussi la faculté de se reproduire par le mème moyen. liénéralement, les zoö̈des, engendrés par ce procédé, ne se séprarent pas les uns des autres, et demeurent groupés en une colonie.

lorsqu'il existe les colonies chez les Scyphozoaires, les zooïdes, appartenant à un mème assemblage, sont d'ordinaire identiques sous tous les rapports, et ne diffèrent guère entre enx; tous sont pourvus d'organes reproulueteurs, et portent des spermatozoïdes ou des ovules. Le polymorphisme n'existe pas le plus souvent, ou s'accentue heancoup moins, lorsiu'il se manifeste, que celui des colonies d'llytrozoaires.

La reproduction asexuće n’a été constatée, parmi les Scyphoméhuses, que chez les embryous de certaines Discoméluses, au moment où ces jennes individus sont parvenus à la phase de Seyphistomes. Elle se prósnte avec ses deux modes; la gemmiparilé, ayant pour lut de déterminer la création d'une petite colonie de Seyphopolypes semblahes; et la fissiparité, ayant comme objet de diviser, en disques superposés, chacun te ces derniers. - Ce procédé reproducteur est plus commun cliez les Anthozoaires; il contribue pour beaucoup à lonner, à la pluparl des représentants de cotte classe, une physionomie propre, (air' il aboutil, daus la riggle, à la genese de colonies. Le hourgeonne- 
ment existe senl chez les Octactiniaires; sauf un seul genre (Haimea ou Monoxenia), tous les itres compris dans ee groupe sont assembles en colonies; les formes de ces lernieres sont très direrses, mais, quelles que soient leurs variétés d'asprect, l'origine reste la mène, et se réluit à un déreloppement de bourgeons. La plupart des Polyactiniaires dépourvus de polypier restent simples, et ne se reproduisent jamais que sexuellement; par contre, les Madréporides sont presque tous unis en colonies, dont les unes sont engendrées par bourgeonnement, et les autres par fissiparité. - Ainsi, en résumé, les seuls types de Seyphozoaires, qu'il soit nécessaire de signaler sous le rapport de la multiplication asexuée, sont les Scyphopolypes de plusieurs Discoméduses, les Octactiniaires, et les Polyactiniaires.

II. Scyphopolypes. - On n'a constaté, jusqu’ici, aucun phénomène certain de reproduction asexuée normale chez les Scyphoméduses parvenues à l'état adulte, tout aussi bien pour les Autoscyphaires que pour les Acalephes. - Le fait est d'autant plus remarquable, que les Scyphopolypes des Discoméduses représentent, d'une façon passagère, l'organisation permanente des Autoseyphaires, et que ces Seyphopolypes se multiplient asexuellement.

La gemmiparité des Scyphoméduses se manifeste de deux manières : tantôt elle est directe, tantòt stoloniale; ce dernier cas semble ètre le plus fréquent. - Dans le premier mode, la larve, qui dérive de l'ovule après avoir passé par la pluase vésiculaire, se fixe, et émet un pretit bourgeon en une région quelconque de sa paroi somatique; ce bourgeon renferme un diverticule de l'entéron, et sa propre paroi n'est autre qu'une portion de celle de son générateur. Ainsi constitué, il grandit, et devient un nouveau Scyphopolype adhérent au premier. Le phénomène peut s'effectuer encore un certain nombre de fois, toujours restreint cependant, de façon à engendres une colonie, composée d'un petit nombre de zooüles. Ces derniers restent unis frarfois; souvent ils se séparent les uns des autres. - Le hourgeonnement stolonial aboutit aux mèmes effets; l'aspect de la colonie liffirre seul, car le hourgeon, fourni par l'individu primitif, s'allonge en un stolon, sur lequel les nouveaux zooüles prennent naissance. Ceux-ei sont lunc placés còte ì côte, an lien d'ètre superposés comme dans le premier cas.

La fissiparité des scyphopolypes a déjá étí étudicie, car elle constitue le procédé suivant lequel certains d'entre enx gragnent l'état arlulte. Ce phénomène n'est pas normal; tantòt il se prorluit, et tantit il n’existe pas, snivant la quantité de deutolécithe cmmagasince par la larve; aussi doit-on phutôt le considérer comme accilentel. La division est tonjours transversale, c'est-i-dire perpendiculan'e il l'axe longitulinal du corps; elte a pour elfet de découper l'individu en segments superposés, qui ne demeurent pas assemblés en une colonie, mais s’isolent les uns des autres pour évoluer séparément, et se convertir ru jennes 
méduses. Daus le cas oì cotte fissiparité, encore nommée slrobilisation, ne se manifeste pas, ha Scylopolype culier se molitie en me máluse, semblable de lous points i celle pui provient de chacun des segments d'un seyphopmlye divise.

III. Anthozoaires Octactiniaires. - Ces ètres ne prósentent joint de reproduction fissipare. La gemmiparité est le seul mole observé cliez eux; seulement, elle acpuiert une importance considerable, car elle aboutit à la grunèse de colonies, formées par l'union de nombremx zooilles. Ces colonies sont holomorphes pour la phupart; lous les individus portent des organes de nutrition, et de reproduction sexuelle: frarfois cependant, plusieurs d'entre eux sont rabougris, comme atrophiés, el semblent privés d'ovules ou de spermalozoüles. Les divers zoö̈les d'une même colonie, provenant les uns des autres par bourgeonnement, restent unis prar leurs carités gastriques; tous communiquent rusemble, de maniore à répandre les liquiules nutritifs dans l'assemblage entier. Les plénomines du bourgeonmement ne varient point dans leur essence; ils consistent loujours en la prouluction, sur le corps d'un individu primilif, d'une saillie cremse, qui s'allonge, el derient un nouvel être semblable au fremier, ou un stolon qui va hourgeonner à son tour; la cavilé de la saillie est un diverticule de la cavité gastripue dı génératenr.

En alliul an fond des choses, les colonies des Oclactiniaires se resscmblent quant i leur origue, el aux relalions muluelles des ètres qui les constituent. Les ditherences portent seulement sur l'asprect de la colonie, dirigé jar la marche lu hourgeonnement.

La gemmiparitó des Octactiniaires est directe, ou stoloniale. Les dissemblances entre ces denx modes nont aucune importance fondamenlale, car les procédés restent les mèmes; la forme génćrale de la colonie est seule mise en cause, liranchue el ascendanto lans le premier cas, ótalér en surface, el horizontale, laus le second. Un cerlain nombre de cromes, appartrnant à la famille rles Alcyonidés, effectuent une transilion lu bourgoonnement stolonial it la gremmiparite directe; ce passage s'italilit par un raccomrissement des stoluns, de pus en plus prononcé à mesure que l'on suit la séric le ces genres, el qui ra jusqu’a la disparition complete de ces anmexes.

liourgeonnement stolonial. - Le véritalıle bourgronmement stolonial nest guere otlert yue par les Clavularides el les Tubiporiles, gronpes dr: la famille les Mlcyonides; les colonies sélalent en surface. Les Clavularides ne possedent qu'un plan de stolons; le zoïte primordial, issu de la larve, emel, par la hase de son corps, un ou plusicurs slolons cyliudriques, pui s’allongent sur le support, el dounent naissance à des zoö̈les. Coux-ci agissent de nome, ongendrent de nouveaux stolons qui morluisent at"atres individus, el la colonie s'étend de proche en proche. - Par contre, les Tubiporides présentent plusicurs plans de stolons. 
Comme on l'a vu plus haut, les individus sont enfermés dans un tul,e, dout ils oceupent l'extrémité sunérieure; par suite, les expransions, qu'ils émettent, n’adhèrent pas an support de la colonie, mais sont placées an niveau de la partie du tulse qui contient l'animal. Les mèmes faits se renouvelant pour les zooüdes des diverses générations sueressives, les stolons, fournis par les plus jeunes individus, sont situés au-dessus de cenx formés par les individus plus ìgés, et la colonie s'aecroìt en hanteur ì mesure qu'elle s'étale en surface : circonstance qui n'existe pas chez les Clavularides.

Bourgeonnement direct. - Dans ce second mode, de beancoup le plus fréquent, les zooüles sont insérés les uns sur les autres; la colonie gagne surtort en liauteur. Pour arriver i ce but, les jeunes bourgeons, émis par le zoö̈te, sont placés sur lui, un peu au-dessus de sa hase, et se développent, non en stolons, mais en nouveaux individus complets; ces derniers engendrent eux-mêmes d’autres zooüdes par un procédé identique, el la colonie s'amplifie, en prenant un aspect branchn. Il intervient, ensuite, un phénomène, fort rare dans la gemmiparité stoloniale, el qui ne manque jamais dans le cas présent. Le mésoderme des régious de soudure, de tous les individus d'une colonie, s’accroît lans des proportions considérables; comme ces zones correspondent toujours à la base du corps, il en résulte que les bases de tous les zoö̈des sépaississent d'abord, et s'unissent par la suite en mue masse, de laquelle se dégagent seules les extrémités supérieures munies de leurs tentacules. Cette gangue commune constitue la partie principale de la colonje; on lui donne tantôt le nom de ccenenchyme, et tantôt celui de sarcosome; ce dernier terme est préférable, car le premier est employé ígalement pour désigner le tissu calcaire d'union de certains Madréporides. Le sarcosome contient les régions inférieures des cavités gastriques des zooïdes. Ces dernières s’allongent beaucoup, et ressemblent à des canaux cylindriques, qui parcourent la gangue; elles émetteul des diverlicules, anastomosés en un plexus plus ou moins serré, les reliant les unes aux autres, et d'oì partent les expansions dirigées vers la surface du sarcosome pour s'y développer en nonveaux individus parfaits.

La description précédente suffit pour montrer le mode d'accroissement de la colonie. Les eavités gastriques des zooüles récemment formés produisent des rameaux, dont les uns vont s'unir à leurs semblables des zooüdes voisins pour faire partie du réseau général, et dont les autres, soulerant le sareosome qui les entourent, lui empruntent les tissus nécessaires pour donner naissance à d'antres individus. Tous les Octactiniaires it bourgeonnement direet présentent des phénomėnes scmhlables; mais la marche de ce hourgeonnement varie, suivant que l'on s'adresse it des colonies privées le spuclette axial, on il des colonies pourrues d'un axe rigide.

Dans le premier cas, le sarcosome devient fort épais : tels sont les 
Alcronidés. Cependant, si les individus possèdent une épaisse cuticule calcaire (IIćlioporidées), le sarcosome reste mince, car le squelette suffit four supporter la colonie entière. - Le sarcosome s’amincit également dans le second cas, et s'itale, autour de l'axe, en une couche relativement peu épaisse, que parcourent les régions basilaires, allongées en canaux crlindriques, des cavités gastriques; telles sont les Gorgonidées et les l'ennatulidées.

Ainsi sontenues par leur baguette centrale, les colonies, Jans ces deux dernires familles, sont susceptibles do croitre en hauteur, mienx que ne le font les Mrronidés, privées de lout squctelle. Comme la colonie s'amplifie prar le fait mème du hourgeonnement, son ensemble se rani-

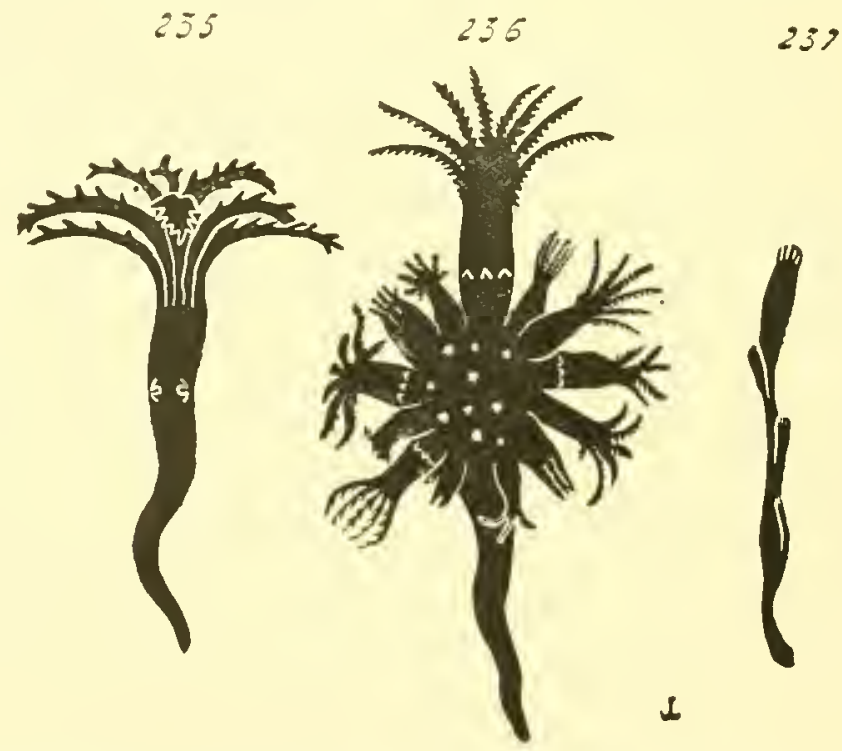

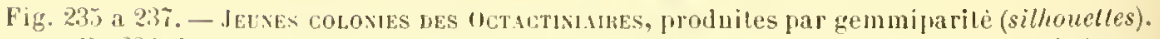
- En 235, jeune colonie d'une Renilla, d'après Wilsun. - En 236, colonie plus ågée. lin 237 , jounc colonie d'une Pcnnalula, d'apres Jungersen.

fie, et prend un aspect liranchu. La disposition des rameaux est irréguliere rhez les Gorgonidées, et varie d'une colonie à une antre, parmi les représentants d’une même espece; il n'en est pas ainsi pour les l'emnatulides, dont les colonies ont une forme précise pour une espèce díterminée. Le fait est ici semblable à celui présenté par les Siphonophores, parmi les llyilrozoaires; aussi voit-on, de même, l'allure propre i l'ensemble s'éhaucher, des l'apparition des premiers lourgeons produits par le zoilte.

A cet 'exari, le rorps dn zoïte s'allonge beanconp, et se divise en trois parlies : une extrémité inférieure, qui demeure simple, et prorluit, en épaississant son mésoderme, la base d'implantation de la colonie; une 
extrémilí supérieure, portant la bouche et les tentacules, nommée le yolype terminal, el qui ne se différencie pas davantage; entin, une région moyenne, qui seule s'amplifie dans des proportions énormes, bourgeonne, el engendre la colonie entière. Le prolype terminal est l'abord plus gros que les zoö̈des fournis par la région moyenne; conme cenx-ci grandissent sans cesse, il finit par devenir semblable à eux, et on ne peut plus le distinguer des autres sur des colonies iggées. - La gemmiparité s'effeclue suirant une marche régulière. Parmi les jeunes bourgeons, les uns se développent forl pen; leurs tentacules napparaissent pras, on restent petits; leur cavité gastrique n'émel aucun diverticule gemmipare, et empèche ainsi la zone qu'elle oceupe d’ètre le point de déparl d’une série he noureaux indivilus; leur organisme apprarait comme un canal, ouvert an dehors pour permettre à l'eau extérieure de pénélrer dans le réseau du sarcosome. Les autres zooïdes, placés, sur la région moyenne, to manière a offrir déjà la disposition propre à l'arlulte, frarviennent à l'ítat parfail. Le sarcosome s'épaissit à leur niveau, émel fes burrgeons en nombre considérable, et ainsi se façonnent des expausions latérales portant des individns complets sur leurs bords. La siluation de ces zooüdes proliferes varie suivant les diver's genres les Pennalulidées; il suffit de recourir à la Torme définitive de la colonie, pour comprendre d'après quelle marche le bourgeonmement s'est effeclué.

IV. Anthozoaires polyactiniaires. - La reproduction asexuelle est très fréquente chez les Madréporides, où elle aboutit toujours ì la grenese de colonies; elle est heaucoup plus rare chez les l'olyacliniaires aux tissus mous. - l'armi ces derniers, les Antipathides ef les Zoanthines présentent, d'une manière constante, des phénomènes gemmipares, of vivent en colonies. Le bourgeonnement des premiers est direct; un axe rigile prend naissance pour soutenir le sarcosome et les zoö̈des, de sorle que l'aspect général rappelle d'une manière frappante celui des Gorgonidées. Le lourgeonnement des secondes s'accomplit, d'ortinaire, suirant le mode stolonial. - $\Lambda$ ces faits, se réluisent les phénomènes nor'maux de reproduction asexuée montrés par les Polyactiniaires, iulres que les Nadréporides; il n’est pas rare, cependant, de rencontrer chez ens ètres, mais dyut manière tout accidentelle, quelques procédés de multiplication fissipare. Ainsi, diverses Actinides se divisent en plusienrs fragments, pui deviennent autant d'individus complets; telle est. entre autres, l'A iptasia lacerata, signalée par Andres; mais ces ras sont rares, et ne doivent pas èlre considérés comme formant un morle reprodurtenr habituel. l'arfois, le plan de division est transversal, au lien d'ètre longriludinal; l'indivilu primitif se trouve alor's partagé en deux zoö̈les placés l'un sur l'aulre, daus la mème situalion mutuelle que les segments d'un scyphoprolyje. Ce procédé remarquable, el fort importimb. a canse de celle concordance, a été observé chez les cionactinie prolifera Sars. 
Mais, en somme, la reproduction asexuée est loin d'acquérir ici la valeur yu'elle posside chez les Madréproriles; cenx-ci la juésentent fort souvent, et, gràce à elle, se grompenl en colonies sontenues par leur stjueletle calcaire; ces deruières alloignent parfois une taille imporlante, el jouent un grant rôle daus la biologie mariue (altols, récifs littoraux). 'Tous les Madréporides ne l'olfient pourlant pas; il n'est pas rare de rencontrer daus la môme fanille, parfois dans le mêne genre, des espèces se reproduisaut frar la seule roie sexuclle, et d'autres espòces pourvues en oulre de procédés mulliplicatems gemmipares, ou fissijares. Los premiers de ces types conservent, duraul leur vie entière, un polypier simple, alors que les secouds présentent un polypier complexe, couslitué par l'assemblage de toules les pieces squeletliques appartenaul aux zooïles de la colonie; dans ce cas, les polypiers sont dils composés. Ces derniers sont tanlò produils par fissiparité, el lantôl par bourgeomement.

Fissipuraté des Manméponoes. - Ce procédé n’a guère été olsservé, jusqu’ici, que chez divers représentants de la famille des Astréidées. La division est loujours longitudinale, c'est-à-dire parallèle à l'axe longriLudinal du corps, élendu de ha houche à la base adhérente; l'aspecl otlert par la colonic dépend de la profondenr a laquelle elle pénètre, en parlant de la bouche, où olle se manifeste en premier lieu.

l'our lien saisir les diverses parlicularités de la fissiparilé des Madréporides, el pour concevoir les formes coloniales qui en dépendent, il faul se représenter d'abord la disposiliondu zoöle primitif, c'est-à-dire le l'individu issu de la larve. Celui-ei ressemble, en tout, à un polype pourvu d'un polypier simple. La base de sil colonme est soulenue par les pieces calcaires de celui-ci, alors que le sommel, pourvu de la bouche et des tentacules, reste libre; en rialité, le polypier conslitue un support il la l'égion tentaculatre nullement encrontée. La fissiparité débute loujours par le haut de cetle dernière; elle commence par diviser la bouche, et la couromne de tentacules, en demx orifices buceaux, dont chacun est entouré par un cercle d'aprendices; puis, elle s'élend au resle de la région lentaculaire, qu'elle partage en deux colonnes placées còte ì côte. bille continue ensuite à pénétrer plus près de la base; mais taulôt elle s'arrète avant de parvenir au polvpier, et tantól elle l'alleinl. Suivant le cas, s'úlablil une forme parliculière de colonie.

Daus le memier cas, la tissiparilé s'exerce, seulemenl, sur le sommel de la colonne du zoïte, et ne s’avance pas jusqua polypier hasilaire. Ce demier domenre dome unique, el ne se fartage point; il porte la région tentaculine, scindéc en deux colonnes juxlaposées, comme deux zooïles monlés sur un seul pédicule. Ces dernières grandissent; elles soul l'oliées l'une i l'autre par lens hases, et celle zone commune s'amplifie et s'épaissil. Elle élait primilivenent arrondic; elle devienl ovalaiıe, en s'accroissant, de préférence, suivant le plan où sont placés les deux 
individus. Elle produit à mesure de nouvelles pièces calcaires, qui s'adjoiguent à celles du polypier; comme sa forme est ovalaire, ces portions calcaires, récemment ajonlées au bord supéricur du polypier,

$$
238 \quad 239 \quad 260
$$
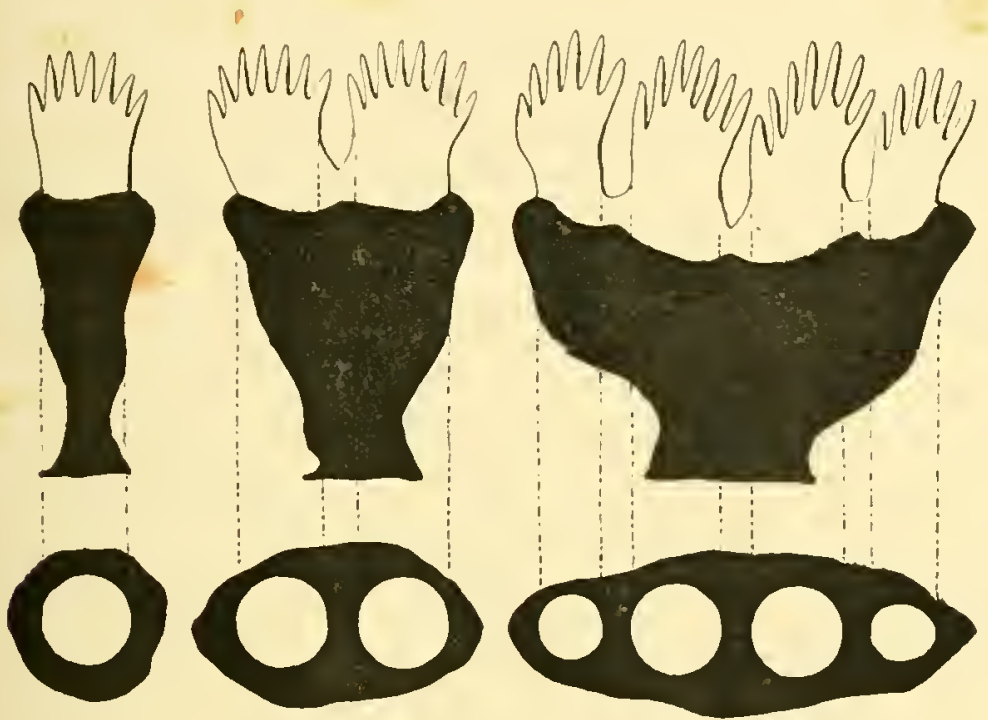

$$
243
$$

$$
2: 2
$$

$$
243
$$
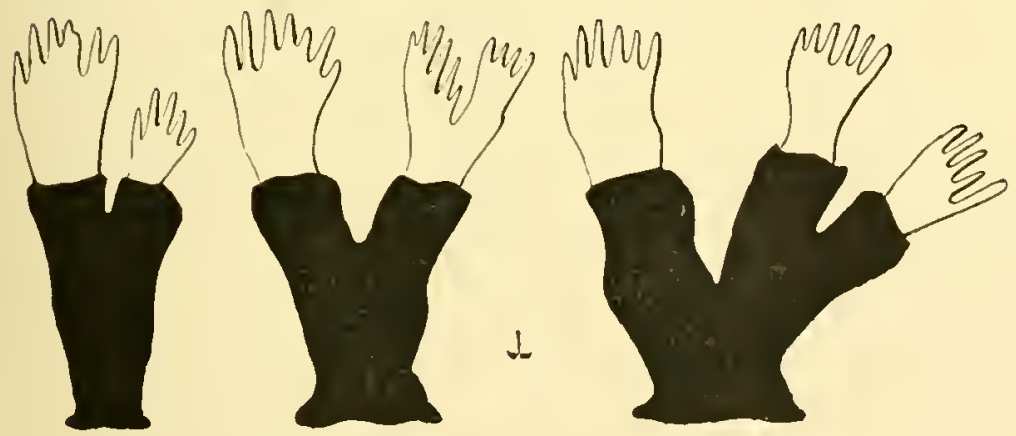

Fig. 238 à 243. - Fissipamtr des Matriponnes (diagrammes). - La sẻrie des figures 238 à 240 s'applique à ce procedé fissipare, dans lequel la division n’atteint que la colonne, et point le polypier; les dessins supérieurs montrent une vue de profil, et les autres, raccordés aux pricedents par des lignes ponetuées, une vue l'en haut. - La sẻrie des figures 2hl a 243 explique ce flocédé fissipare, daus lequed Ja division atteint, à la fois, la colonne et le sommet du polypier. - Ia colonne est representice en bJane, et le polypier en noir.

se disprosent elles-mêmes en ovale. - L'aspect primorial a déja bien changé. Le \%oïte primitif oflrait une région tenticulaire simple, placée 
sur un polypier simple, dont le bord supérieur élait arrondi. Au moment où s'achève l'évolulion précédente, la région tentaculaire du zoïte est divisée en deux zoö̈des juxtaposés, soudés l'un à l'autre par une zone commune, sorte de base ovalaire montée sur un polypier simple, au lord supérieur également ovalaire. Le zoïte a doue produil une colonie de deux individus, munis d'un polypier commun, simple en apparence, puisquil est indivis, mais composé en réalité, puisquil supporte plusieurs zoö̈des. - Le déreloppement de la colonie continue ir s'elfectuer suivant les mèmes procédés. Chacun des deux individus se scinde de nonveau, la fissiparité commengant par le sommet de la rigion tentaculaire, et n’atteignant pas la base, qui reste toujours simple. P'endant que la scission se manifeste, les quatre zooïdes grandissent, s'élargissent, el amplifient de mème leur région hasilaire commune, suivant le plan où ils sont situés; celle région devient alors longnement ovalaire, el comme aplatie, puisquelle soutient quatre individus juxtaposés en éventail. Elle-mème est insérée sur le polypier, et engendre sans cesse, sur sa périphérie entière, do nouvelles pièces calcaires, qui se placent sur le hord supérienr du polypier pour l'agrandir. Le squelette calcaire, lout en restant indivis, s'aplatil donc au lur el à mesure de sa eroissance; il prend également la forme d'un éventail, et porte sur son bord supérieur les zooides disposés sur une seule file.

Deux cas secondaires s'offrent ensuite. - Mans le premier, la tissiparité s'exeree dans le nème plan pour les zoö̈les le toutes les générations; les individus sont placés sur un senl rang, et insérés sur le sommet d'un polypier aplati, plus on moins ondulé. - Dans le second cas, la fissiparté seffectue suivant une certaine direction pour plusieurs générations successives, puis se manileste d'après un sens peppendiculaire, wu ol,ique, an premier, pour d’autres générations; ce phénomène d'inversion pouvant se renouveler a diverses reprises. La colonie prend alors une allure bien différente de celle du premier mode; à chaque changement, correspond l'apparition d'une série de zooüdes placée dans un autre sens que celle qui l'avait précédée, el dont elle provient. Si ces morlifications se produisent un certain nombre de fois, phusiemrs séries divergentes maissent ainsi, chaque série étant montée sur une partie de polypier aplatie en éventail; comme les séries restent reliées les unes aux autres, le polypier est constitué prar l'union d'un certain nombre de pièces dirigées de plusieurs manières, chaque pirce portant une rangée d'indivilus. Toutes ces parties, plus ou moins tlexueuses, sintriguent les unes avee les autres, se sondent, el se confondent plus ou moins; l'ensemble du polypier parait alors formé par la coalescence de nomhreux plis tortuenx. el groupés. Celle disposition existe chez les Méandrines.

Quel que soit le fail, que le polypier devienne droit el simplement nexueux, ou gu'il preme l'aspect tortueux propre aux Méandrines, il 
est iulivis, car la fissiparilé ne descentl pas jusqu’à lui. - Il n’en est plus ainsi pour d'autres types d'Astréides, dont la division atteint la base de la région tentaculaire ( ${ }^{e}$ cas). Celte dernière est elle-mème scinclée; anssi les nouvelles pièces calcaires se disposent-elles en groupes distincts, qui s’insèrent sur le bord supérieur du polypier primilif. Celui-ci, tout en s'aceroissant, prend done un aspect branchu. L'allure délinitive de la colonie varie heaucoup snivant les especes; lantôt les rameaux sont allongés, et séparés; tantôt ils sont courts et massifs; parfois mème, comme chez les Isophyllia, les zooüdes sont tellement rapprochés les uns des autres, qu'ils se sondent par leur muraille; ces modifications sont d'ordre secondaire. - Le fait principal porte sur l'extension du plan de division à toute la région tentaculaire, et an sommet dn polypier, contrairement à ce qu'il en est dans le premier mode, oì ce plan reste localisé an seul sommet de la colonne.

Gemmirarité des Mannépondes. - Le bonrgeonnement est lantôt direct, tantòt stolonial. Dans ce dernier cas, les stolons se munissent euxmèmes d'un squelelte calcaire, s'amplifient beaucoup, se joignent, et constituent ainsi une masse scléreuse, reliant les zooüles les uns aux autres; cetle gangue commune est nommée le cænenchyme. Les relations les zooïdes avec leur conenchyme sont conslantes pour les représentants d'une mème espèce; mais elles varient d'une espèce à l'autre, et offrent presque toutes les combinaisons possibles; aussi jouent-elles un rôle consilérable dans les diagnoses. Tantòt le cenenchyme ol̂̀re l'aspect "'une masse compacte, au sein de laquelle les individus sont placés, et tantôt d'une bande sur laquelle les zooïdes s'élèvent; tantôt il est aplati en lame mince, et tantôt il constitue un feutrage épais; tantòt les zoö̈les insérés sur lui sont distincts les uns des autres, et tantôt ils sont rapprochés au proint le se souler par une portion plus ou moins grande de leur muraille; les dissemblances a cel égard sont des plus nombreuses. - Dans le cas de bourgeonnement direct, l'ensemble du polypier composé prend une forme branchue; les zooüles situés lans les régions inférieures de la colonie, et qui supportent leurs congénères, ápaississent dans des proportions consilérables leur's pièces squeletliques, et meurent ensuite.

Il convient de ne point confondre le cunnchyme rrai des stolons arec un lissu calcaire unissint, qui existe chez livers Madréporides, et provient directement de la muraille. Parfois cette gangue est donnée par le feulrage serré des côtes placées sur le caljce, chez les Heliastrœa pall cxemple; ailleurs, clle est produite par l'entrecroisement des traverses cxothicales (Cialaxea); mais elle ne dírive en rien dres stolons, n'a par suite ancun rapport avec les phénomènes du bourgeonnement, el dipend du sclérenchyme, éest-i-dire du syuelette juopre du polypier. 


\section{8. - Générations alternantes.}

Les Cténophores, itant privés de tonte reproduction asexuée ne montrent point de gŕnérations alternantes. Il n’on est pas de mème pour les Anthozoaires el les Sryphoméduses, qui présentent des phénomènes de fissiparilí, ou de bourgeonnement.

1. Scyphoméduses. - L'alternance de grénérations mandue aux Autoscrphaires, du moins dans l'état actuel de nos connaissances; on la trouve seulement chez celles des [biscoméduses donl les larves, parvenues it la phase de Scyphistome, se multiplienl en se divisant, ou en hourgeonnant. Comme es Discoméduses sont relativement peu nombreuses, conme, en oulre, les représentants d'une mème espece oftrent parfois ces phénomènes asexués, ot parfois ne les montrenl pas, on doil considérer la mélagenèse des scyphoméduses comme un fail d'ordre secondaire, et non pas comme mne circonstance normale, hahiluelle, de l'évolution. - Il semble, antant quil esl permis de conclure d'apres les observations faites par les anteurs, que les phénomènes de la multiplicalion asexuée des larres sont plarés sous l"inlluence de leurs ríserves nutrilives. Suivant que le deulolicithe est abondant dans l'ovule, ou relativement rare, el ces varialions sont fréquentes parmi les individus apparlenant à une senle el même espèce, le scrphislome possède, dans ses cellules endodermiques, des malériaux untrilifs, ou n'en porte poinl; el alors, tantôt il se multiplie pour produire plusieurs aulres larves semllables à lui, et lantôl il évolue directement en méduse.

L’absence de lourgeonnement, el de fissiparité, chez les Autoscyphaires actuels, alors que ces procédés se montrent par accidenl dans le développement des Scyphistomes qui leur correspondent, entraîne donc a admettre que ces phénomènes snrviennent secondairemenl dans l'érolution embryonnaire, el ne représentent point des dispositions essenlielles. Il est rependant remarquable de voir ce bourgeonnement secondaire des scyphistomes aboulir it la genèse d'une pelile colonie de Scyphopolypes, dont les relations, avec les méduses qui dérivent d'eux, ressemblent de près à celles établies entre les Aulhỵdraires el les méduses des Ifydrozoaires. La concordance est frappante; la différence porle seulement sur le moment où la l,lastogenèse ajprarait. Cetle dernière est primilive chez les llydrozoaires, el n'est pas forcément suivie de la transtormalion du polype en méduse; elle est tardive chez les Scy]homéduses, el se trouve loujours aerompagnée jar la modificalion médusaire.

Quriqu'il en soit de ces considérations, la mélagenèse des Scyphoméduses doil ètre considérée comme accidentelte, puisqu'elle n'exisle pas loujours, el comme embryonnaire, puisque la reproduction asexuelle ne s'exnrce que sur des larres.

II. Anthozoaires. - Conlrairement à la précédente, fa mélagenise 
des Anthozoaires se manifeste chez les adultes, et se présente normalement chez tous les représentants des espèces qui la possúdent. Elle est holomorphe dans son essence, le zoïte primitif ayantpour seuloljel, en bourceonnant ou en se divisant, de prodnire des zoö̈les semblables a lui, el groupés en colonies. Pourtant, dans certaius cas, la vie coloniale entraine a sa suite le polymorphisme des individus, mais d'une façon moins prononcée que sur les llydrozoaires; ainsi, chez les l'ennatulides notamment, certains zooïles, petits, et privés de tentacules comme d'organes sexuels, serrent sans donte à l'introduction de l'eau dans les canaux du sarcosome, ou à la sortie le cetle eau, et diffèrent beaucoup de leurs congénères mienx développés. Le polymorphisme paraît atteindre sa plus haute importance chez les lliléporides, où l'on trouve presque les mèmes moditications en dactylozö̈des et gastrozoïdes que celles des IIridrozoaires, combinées arec les groupements réguliers de ces individus. Il est curieux de le remarquer, ces dissemblances existent chez les Octactiniaires seuls, et manquent sonvent aux Madréporides, dont le groupement en colonies est cependant d'une importance au moins égale.

\section{RÉSUMÉ}

I. Coxsidératoxs gixerracs. - L'embranchement des Seyphozoaires contient Irois classes : les Scyphoméduses, les Authozoaires, et les Cténophores. Ces derniers ne se reproduisent que par la roie sexuelle; plusieurs des représeutants des deux premières classes offrent, en surplus, la gremmiparité ou la fissiparité.

II. Élémexts sexlezs. - Les produils sexuels sont placés dans le mésoderme, et paraissent lirer lenr origrine de ce fenillet; ils sont disposés en gronpes, qui soulèrent l'endoderme pour faire saillie dans la carité gastrique de l'individu yui les porte, ef tombent dans rette cavité an moment de leur maturité. C'est là que s'effectue le plus souvent la fécondalion, et que les jeunes sont parfois incubés durant leurs premières phases embryonnaires.

IIl. Seguextation et feullets blastobernores. - Les développements dilatés, assez rares, prisentent constamment un état grastrulaire, et ne montrent jamais de cytulation. Dans les développements alıégés, de lieanconp les plus fréquents, la blastule, el la gastrule qui la suit, sont supprinées; la segmentation aboutit à la genese d'une planule conpacte.

Sryphoméduses. - Diverses formes inférienres des l)iscoméduses pussìlent une embryogénie dilatée; leur ovule, après la sommentation, se transforme en une morule, puis en une blastule, qui devient cllemème une gastrule par invagination; l'ectoderme of l'endoulerme se rapprochent l'un de l'autre, el s'accolent de maniere a amener la disparilion 
complète du blastocole; l'entéropore se ferme souvent. Les Arielia anritu montrent une transitionvers les diveloppenents condensés; Ir

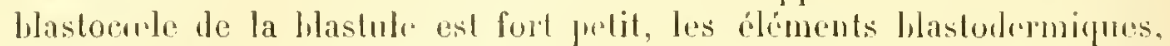
qui doivent constituer l'umdoderme, sont tres longs, de sorte pue l'invagination gastrulaire est peu pronomée. - Le hastocmle fail complètement défaut dans les embryogénies condensées, et la morule, issue de la segmentation, se transforme directement en une planule compacte; l'entéron se creuse ensuite dans le centre de la planule, qui devient ainsi une vésicule creuse, dont la praroi se compose de leux couches te cellules. La conche externe est l'eetoderme, et l'interne l'endoderme.

Cténophores. - Le développenent de ces animaux est fort contensé; leur ovule contient beaucoup de deutolécithe, et les premières phases embryonnaires alsoutissent it unr planule indirecte. La segmentation a pour effet de séparer, du deutolécithe, de nomloreuses petites cellules, qui se disposent tout autour de lui en une couche simple; cotte assise devient l'ectoderme, et produit le mésoderme. Le deutolécithe central se partage en éléments cylindriques, dont l'ensemble représente l'endoderme. Lientéron se creuse entre ces dernier's, el communique ensuite avec le dehor's par un entéropore, percé lans la région où les dernières cellules ectodermiques ont pris naissance.

Anthosoaires. - La genèse des feuillets bastodermiques rappelle de très près celle déjà signalée pour les Scyphoméduses. Les développements dilatís, avec phase gastrulaire, sont peu frénuents; l'ordinaire la segmentation aboutit à une planule directe, qui se transforme en larve vésiculaire, par l'apparition de la cavilé entérique dans le centre de la planule. La paroi de cette larve est constituće par l'ectoderme et l'endoderme juxtaposés.

IV. Fonues embryonyares. - Les jeunes larves des sicyphoméduses, et celles des Anthozoaires, commencent par oflrir une premiere phase vésiculaire déjì indiquée ci-dessus; ensuite, les bords de lemr entéropore s’inlYéchissent dans la cavité entérique pour produire le tube œsophagien, et l'endoderme se souleve en quatre cloisons, qui s'avancent dans l'iutérieur de l'entéron. Cet état, plus ou moins net suivant les types, est celui de scyphule. La scyphule des Scyphoméluses se transtorme en Scyphistome, ou Scyphopolype, par la genèse de nombrenx tentarules péribuccanx; celle des Anthozoaires en Anthopolype, par l'apparition de nouvelles cloisons qui s’ajoutent aux précédentes. La plannle indirecte des Clénophores produit de mème un tube wsophagien, et quatre volumineuses eloisons entéripues; elle devient ainsi nne Sacyphule, qui se transforme en Ctémule par la production de palettes natiloires sur le corps.

Scyphoméluses. - La larve des Serphoméduses, du moins cette des quelyues Discoméduses connues sous le rapprort de l'embryogénie, passe 
par trois phases successives survenaut apros l’élat de Scyphule. - La promiere est celle de seyplisstome on de Scyphopolype: lembryon, fixe par sa hase aborale, renferme, dans sa cavité entérique, derenne la cavilé gastrique ou stomacale, quatre cloisons limilant quatre loges; de nombreux teutacules sont disposés en mne couromne tout autour de l'orifice bucral. - La seconde est celle d'Ephyre, ou de jenne méduse, dont le hord de l'ombrelle porte huit expansjons munjes d'oranes sensoricls; tantót le Seyphistome se modifis directement en Ephyre, et la transformation est dite simple; tantòt il se divise transversalement en disques superposés, qui deviennent autaut de petiles méduses, et celte transformation multiple porte le nom de strobilisation. Le premier cas existe chez les Pelayia noctiluca, dont les larves, adaptées à une vie pélagique, omettent la phase seyphistome, el chez diverses autres bisconéduses, l'Aureliu aurita par exemple, qui présentent aussi la strobilisation. - la troisjème pluse est celle de méduse définilive, caractérisée par l'épaississement considérable de l’ombrelle, par l'apparition de produits sexuels, souvent pas celle de canaux gastriques, et par l'atrophie juns on moins complète des quatre cloisons primitives du scyphopolype. Cette lernière phase existe seutement chez les Acalephes suprérieurs, cu organisation, aux Ephyropsiles, car celles-ci présentent, d'une facon permanente, la structure des Ephyres, et ne poussent pas plus loin lenr évolution.

Clínophores. - La planule indirecte des Cténophores se transforme très rapidement en Scyphule ol en Ctémulo. Coltedenxième forme larvaire rst libre, pélagripue; elle porte, sur son ectoderme, les prenières ébauches les palettes natatoires: son tube wsophagien conduit dans un entéron, lis cavité gastrique, qui contient quatre épaisses cloisons. La Cténule des Berö̈liens passe à létat adulte sans subir de graudes modifieations; relle des Cydippides produit préalablement deux longs tentacules; enfiu. celle des Lobés et des Rubanés commence par subir une preujère phase, dite de Cydippile ou de Mertensia, car elle rappelle enticrement les anjmaus de ce nom, et parvient ensuite i l'état parfait, en émettant des expansions ou en saplatissant.

Anthozoaires. - La larve vésiculaire de ces animaux produit son tube r'sophagien, puis les quatre premières cloisous, el devient me Seyphule. lille engendre, daus sa cavité entérique, de nouvelles cloisons qui s'ajoutent aux précédentes, et divisent en logres la périphérie de l'esléron; des tentacules naissent autour de la houche, et an-ressus de chacune de ces loges. Aussi, comme ces dernières, avec les cloisons qui les limitent, apparajsent suivant une loi régulièe signalée phus has, les lentacules eux-mémes sont engendrés dapres le noume procédé. T'antòt les larves se lixent des l’état seyphulaire, et tinutôt à une période plus avancée de leur évolıtion; certaines mème, celles des Cérianthides 
et des Zoanthines notamment, montrent une tendanee a conserver le plus longtemps possihle mine vie lihre.

V. Développenext hes orgayes internes. - Les organes, et les tissus qui les composent, dérivent senlement de deux feuillets blastorlermiques : l'eetoderme el l'endoderme. L'ectoderme produit le mésoderme, le système nerveux, et la majeure partie des appareils sensitifs. L'endoderme persiste chez l'adulte sans subir de trop grandes modifieations; il limite l'entéron, qui devient la cavité gastrique de l'alulte, et qui subit souvent des changements considérables.

Ectoderme. - Liectoderme engendre le mésoderme chez tous les Scyphozoaires. Ce dernier est d'abord représenté par une mince lamelle anhyste, la membrane propre, placée entre l'ectoderme et l'endorlerme; puis cette membrane s'épaissit, aequiert des cellules qui lui riennent de la couche ectorlermique, et jasse ainsi à l'élat de tissu complet, capable de saccroitre, pour son propre compte, par la segmentation de ses éléments et par la production de nouvelle substance fondamentale. Le mésoderme, eonstitué par des eeflules séparées dès leur origine, plongées dans une substance fondamentale, et nullement réunies en une assise épithéliale, doit donc être considéré comme mésenchymateux; plusieur's de ses éléments se modifient parfois en fibres musculaires, les autres conservant l'aspect de cellules conjonctives. A la suite de la condensation du développement, la majeure parlie du mésoderme des Clénophores constitue un amas épais, situé dans la région aborale de la larve.

L'ectoderme subit ensuite des transformations destinées à permeltre la vie de relation. Plusieurs de ses cellules deviennent des éléments épithélio-museulaires; plusieurs autres se changent en éléments épithélio-nerveux, donl les extrémilés basales, ou nerveuses, se rassemblent en un réseau serré. la couche granuleuse, placé au-dessous de l'assise épithéliale; quelques-uns, enfin, se modifient en éléments à nématocystes. Les organes sensoriels sont généralement produits par l'eetoderme, suivant des procédés histogénétiques encore peu connus. Ponrtant les rhopalies, les corps marginaux des Scyphoméduses, renferment une région d'origine endodermique; cette région est l'otocyste.

Endoderme el entéron. - L'endoderme se différencie moins que l'ectoderme. Ses principanx changements portent sur la genèse d'iléments épithélio-museulaires, et parfois l'éléments à nématocystes; ees phénomènes ne sont pas Łgénéraux, mais plutòt localisés en eertaines régions du corps, chez les scypliomérluses, el surtout chez les Anthozoaires (muscles des cloisons, filaments mésentériques).

L'entéron devient la cavité gastrique, et subit des modifications importantes. - Parmi les Serphoméduses, l'entéron des Autoscyphaires, avec celui des Acalèphes intérieurs, conservent les quatre eloisons du 
Scyphopolype, et restent fort amples. Par contre. l'entéron de la plupart des Discoméduses perd les cloisons, et, à cause de l'ípaississement exagéré du mísoderme le l'ombrelle, se résont, sur sa pripiphérie. en nombreux canaux anastomosés qui parcourent ce mésoderme. L'entéron est ainsi divisé en deux régions: l'une centrale, représentée prar lia cavité gastrique proprement dite; l'autre périphérique, conslituée par l'ensemble des canaux. Ceux-ci communiquent librement entre eux al avec la cavité gastrique; aussi les désigne-t-on par le nom de canaux gastriques, ou par celui de cananx gastro-vasculaires. Ces modifications sont d’autant plus considérables que l'on passe des l'élagides aux Aurélides, et de celles-ei aux Rhizostomides.

les changements, sulis par l'entéron des Cténophores, rappellent, dans leur essence, ceux offerts par les Scyphoméduses. Les quatre cloisons de la larre continuent à s’épraissir, el divisent l'entéron en deux régions : l'une centrale, li cavité gastrique définitive: l’autre péripliérique, divisée en quatre loges étroites par les quatre ctoisons. Celles-ci continuent à s'amplifier, par le fait de l'extensiou du mésoulerme qu’elles contiennent; en mème temps, chaque loge se divise, et produit deux canaux longitudinaux, les canaux méridiens, qui ront se placer sous les rangées de palettes natatoires, denx ranaux transverses de $3^{\text {e }}$ ordre, el un canal transverse de 2e ordre. l'uis, les yuatre canaux transwerses de 2 e ordre se réunissent deux à deux, pour donner deux canaux transverses de $t^{\text {er }}$ ordue. qui débouchent lans la cavité gastrique. En outre, cette dernière s'ouvre au lehor's par des orilices aboraux.

Les modifications, offertes prar l'entéron des Anthozoaires, ne consistent pas en mne genèse de canaux périphériques, mais portent sur l'augmentation du nombre des cloisons gastriques; celle augmentation se prorluit suivant des lois tixes. La présence de ces cloisons, qui s'avancent dans l’intérieur de la cavité gastrique, a pour effet de diviser en loges la périphérie de cette dernière; daus la règle. chaque loge gastrique est surmontée d'un tentacule péribuccal, et se continue avec la cavité de celui-ci. Parmi les cloisons, les unes, dites macroseptes, sont grandes, et ront se somler au tule cesophagien, en traversant toute la cavité gastrique : les autres, nommées microseptes, restent petiles. - II faut diviser les cloisons, suivant leur date de naissance, en cloisons mimaires, qui comprennent quatre protoseptcs et quatre deutoseptes, et on cloisons secondaires, ou métaseptes. Les premières naissent tout d'aloril, et sont au nombre de huit chez les Anthozoaires actuels: elles comprennent les quatre cloisons primitives de la scyphule (protoseptes), plus quatre autres cloisons formées par la suite (ileutoseptes). - Les huit protoseptes et deuloseptes existent seules chez les Octactiniaires et les Elwardsiées. Elles apparaissent presque en mène temps chez les Octactiniaires. - Elles sont formées deux par deux chez les Eilwardsiées. Les deux cloisons l'une mème paire ne sont pas juxtiposées, mais placées de part et d’antre, el à égale distance, de la lignne médiane. 
En len domnant un mumbro correspondant à la date de leur apparition, on voit qu'elles no sonl pas situéns dans le eolps conformémont à eette dite; en partant de la rónou antériene de l'individu, punr aller dans la rúrion postériemr, Ia série est la suivante: II, II, I, III. - Tous les Polyactiniaires, autres que les Elwarlsiées, possédent des mélaseples, "pui naissent aprè les choisons primaires, of s’intercalent à elles. Les Monanlées présentent six métasejutes; les Gonartiniées huil; les Cérianthidées un nombre plus cousidérable, avec cette particularité que toutes los métaseptes sont placées dans la loge antérienre, limitée prar les deutoseptes de Ia $\mathbb{V}^{\mathrm{e}}$ paire. Les mélaseptes des Zoanthaires sont généralement fort nombremses, mais different par leur disposition de celles los Cérianthidées; elles doivent ètre divisées en quatre métaseptes primaires, yui maissent de suite apres les deutoseptes, et en un chiffre variable de metuseptes secondaires, qui apparaissent ensuite. Les quatre mélaseptes primaires sont groupées en deux puires; les deux cloisons le la mème paire sont placóes de part et d'autre de la ligne médiane, comme les protoseptes et les deutoseptes; aussi les quatre mélaseptes primaires Joivent-elles itre considérées comme faisant suite anx denLoseptes, et peut-on donner í leurs deux paires les numéros Y et VI;

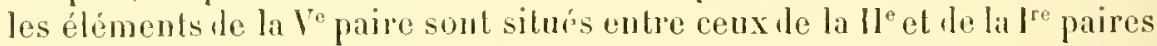
primilives, et cenx de la $1 t^{e}$ paire entre les $f^{\text {re }}$ et Ille paires. En arransonal ces lonze cloisons, el leur dommant des numéros correspundant à leur date l'apprarition, on obtient la série suivante: II, II, I, I, II, II, dans laquelle $V^{\prime}$ et $V^{\prime}$ rrorésentent les métaseptes primaires. L'cusemble de ces louze cloisons entome la cavite gastrique, el constitue la courome, dans les loges de lapurile prenuent naissance les cycles suivants.

Les métaseples secondaires des Zoanthaires sont grompées de facons dithèrentes, suivant les lypes. - Toutes celles des Zoantlidées sont placées dans les denx loges comprises entre les cloisons Ve III. - Par contre, celles des letinides el des Madréporides apparaissent daus phrsienrs des loges périphériques; contrairement aux douze cloisons de la conronne, elles naissent par couples de deux cloisons juxtaposées, et non par paires dont les deux ćléments seraient placés de part et d'autre de la ligne médiane. En oulne, plusieurs comples se montrent a la fois sur toute la péripluérie de l'entéron; l'ensemble des couples d'un mème ìne constitue un cycle; on numórote les cycles suivant leur date d'apfarition. Le premier cycle se compose de six couples, hois d'un coté de la ligne médiane, et trois de l'antre, lómés daus los loges placíes entre les doisons IV ot $I I, Y$ et I, II et III. Le second cyele comprend donze conples, développés de part et d'antre des couples précédents, et par suito forjonrs situés dans les trois paires de loges prócités. Le troisiome cycle renferme vingt-quatre comples, ígalement produits dr prat et d'autre des douze comples an second ryele; el ainsi le suite pour tous les cyeles luturs. Chayue eycle comprend done un mombre de conples doulile de selui orlert par le eycle pui l'a précédé, 
ot ses comples sont constamment situćs l'un colé wot de l'autre de cenx

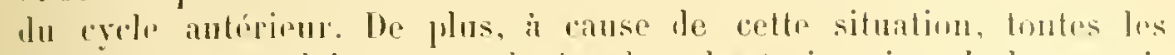
métaseples secondaires sont placées dans les truis paires do loges primitives indiquées ci-dessus.

11. Ongaxes axrexes de soutex. - Ces organes n'ixistent que cle\% les Inthozoaires; ils constituent un squelette destiné i soutenir les lissus.

Octactiniaires. - Le squelette des Octactiniaires se compose de demx sortes de formations: des spicules mésoderminues, et une culicule ectolermique, souvent encroutéc de calcaire. tes spicules sont des petits bìtonnets, produits dans les rellules mésodermiques. Les cuticules ectodermiques ne sont pas toutes disposies de la mime manière; tantôt elles constituent un polypier, destiué à entourer l'individu; tantôt elles se disposent en nime laguetle cylindrique, l'axe, autour de laquelle se groupent les zooïles de la colonie.

Polyactiniaires. - Les Madréporides ot les Antipathides sont les seuls l'olyactiniaires pourvus d'un squelette; celui des Madréporides est un polypier, celui des Antipathides un axe, formé sans doute de la mène facon pue son comespondant des Octactiniaires. - Le polypier des Madréporides est produit par l'ectorlerne, ef correspond à une épraisse cuticule calcariséc; les cellules ectodermịues chargées de l'engendrer sont dites calyroblastes. La base fixée de la colonne, chez les jeunes individus, commence par probluire uno plaque calcaire, la playue basilaire; eusuite cette base se plisse et se crense, sur sa face externe, de sillons radiaires, où se dépose du calcaire; les dépôts calcaires, ainsi fournis, ressemblent a des bandes dirigées du centre vers la périphérie, et sont lésigues sous le nom de lames, de cloisons dures, ou de cloisons calcuires. Puis, ces premiers sillons émettent des diverticules paralleles an hord de la base de la colonne, diverticules qui sécrètent du 'alcaire, et se rejoignent pour se souder; la bise est alors entource l'une rainure, produite par l'union le ces liverticules, contenant une bande calcaire en forme d"anneau, el sourlée aux cloisons dures: cette bande est la muraille. Les sillons, avec leurs diverticules, continnent a devenir de plus en plus protonds, et s'élevent dans l'intérienr du corps: ils donnent i mesure ale nouvelle substance calcaire; c'est ainsi que les lames et la muraille sétendent toujours darantage. Dautres cloisons dures prenuent aussi naissance phus tarl, d'ajués la mene mélhorle, a'est-á-rlire daus l’intérieur de plis qui se cousent sur la face axterne de la base de la colonne; les lames sont toujours situées entre les cloisons molles.

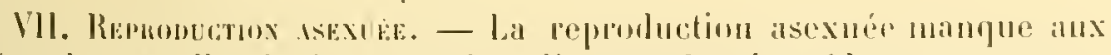

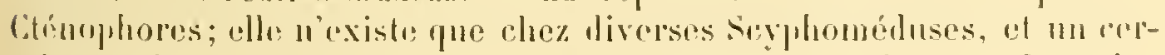
tain nombre d'Anthomoaires. Ellle se manileste par ses denx moles prin- 
cipaux; la fissiparité, et la gemmiparité. Elle aboutit le plus souvent à la genèse de colonies, dont les zooüles communiłuent entre cux frar leurs cavités grastriques, on par des canaux émanés de ces cavités.

Scyphoméduses. - La multiplication asexuéc ne s'exerce que sur les larves de certaines Discomédnses, parvenues à la phase de Scyphistome; elle s'effectue lar gemmiparité on par fissiparité, ef doit ètre consilérée comme arcidentelle (surtout la reproduction fissipare), car tantót elle existe, et tantot elle n'existe pas, rhez los représentants l'une mème espece. La gemmiparité est stoloniale ou directe; la tissiparité, tonjours transversale, correspond à la division en disques superposés nommée strobilisation.

Anthosoaires Octuctiniaires. - Sanf le genre Haimea, tous ces ètres presentent la reproduction par hourgeomement, qui se montre chez les adultes, et non che\% les larves; la fissiparité fait toujours défant. La gemmiparité est tantòt stotoniale, tantòt directe, celle-ci étant de beau"oup la plus fréquente; elle détermine la genèse de colonies, construites sonvent de telle maniere, łue les hases des zooïdes s'épaississent, et se fusionnent en une masse commune nommée le sarcosome; les régions aborales des cavités gastriques s'enfoncent dans le sarcosome, et le parcourent à la manière de ranaux souvent ramifiés et anastomosés. La gemmiparité suit parfois uno marche quelconque, et a seulement pour effet de procurer a l'ensemble colonial sa forme arborescente; tel n'est pas le cas pour les Pennatulides, dont le bonrgeonnement s'effectue suivant une direction fixe, destinée à donner laspoct propre à claque espèce.

Inthozoaires Polyactiniaires. - La reproduction asexuée est surtout le cas des Madréporides; cependant, les Antipathides et les Zoanthines engendrent des colonies par hourgeonnement. - Les colonies de la plupart les Madréporides sont remarquahles en ce que les pièces calcaires de leurs zooïles sont unies cu un ensemble cohérent, nommé polypier composé, par opposition au polypier simple, oflert par cenx des Madréporides qui restent imlivis durant leur vie entière: la mème famille, parfois le mème genre, contiennent des espèces, dont les umes restent simples, et lont hes autres deviennent composées. La reproduction asexure sclfectue par gemmiparití ou par fissiparité. Dans le premicr cas, clle est sonvent stoloniale; les stolons acquièrent eux-mèmes un épais squelette calcaile, el, en se fusionnant, ronstituent un conenchyme, qui joint les zoö̈les de la colonie. Dans le second cas, la division est toujours longibudiuale; elle sellectue suivant deux modes. Le premier mode est caractérisé par ce lait, 'jue la division reste localisée dams le haut de la region orale (ou tentaculaire) de la colonne; le polyfrier demenre indivis, et s'étale en nne lame plus ou moins flexueuse et contournée. - Le plan de division, dans le second mode, atteint toute 
la région tentaculaire de la colonne, et descend jusqu'au polypier; celuici prend alors, en s'accroissant, un aspect branchu.

VIII. Altenxance bes géxénitioxs. - Celle alternance manque anx Clénophores, qui sont privés de toute reproduction sexuée. Fille existe chez les Discoméduses, dont les Scyphistomes lourgeonnent, an se divisent; dans ce cas, la métagenèse est aceidentelle et embryonnaire. Celle des Anthozoaires est adulte, et originellement holomorphe; pourtant, certaines colonies sont polymorphes. 


\title{
EIIBRANCIIEMENT DES PLATIIELIINTIIES
}

\author{
CIIAPITRE VII \\ DÉVELOPPEMENT DES PLATHELMINTHES
}

\$1. - Considérations générales.

I. Garactères et Glassification. - Les Plaflıchminthes, encore nommés Platoles, sont des Schizocolomiens. Lenr corps est aplati, contrairement à cehui des Némathehninthes, et á celui des Trochozoaires, et beancoup moins f́pais que longon large. Très fréquemment, les espaces colomiques sont combles, soit en presque totalité, soit en partie, an moyen d'un tissu particulier, nommé le parenchyme.

Cel embranchement renferme 4 classes:

$1^{\circ}$ Les Turbellaries; dont le corps est couvert de cils viluratiles, privé de ventouses, el de systeme sanguin.

$2^{\circ}$ Les Némertines; qui jossident ́́galement un revêtement vibratile, mais qui offrent en smplus un appareil sanguin, et un organe complexe nommé la trompe.

$3^{\circ}$ Les Trématodes; animaux parasites dont l'ectoderme est nu d'habitude, et qui manquent d'appareil sanguin; mais qui possident mn tulue digestif complexe, et des appareils fixateurs, dits ventouses.

40 Les Cestodes; animaux parasites ì l'ecloderme nu, également lípourvus d'appareil sanguin et souvent munis de rentonses, mais privés, en sus, le tulje digestif, ou n’ayant qu'une cavité digestive fort simple, et presine rudimentaire.

Il convient sans doute, dans l'état présent de la science, de placer, parmi les Mathehminthes, la classe des $D y$ zostomides et celle des $A$ canthacéphales. Ceprendant, te nonvelles étndes sont encore nécessaires pon" se prononcer, d'mue ficron définitive, sur les relations naturelles de ces animaux. dussi ces deux classes ne seront-elles pas étudiées arec celles des Pathehninthes rrais, et feront-elles l'objet de praragraphes spéciaux. 
11. Généralités sur le développement. - Les Plallıelminthes présentent les deux procédés reproulucteurs. Cependant, le umole asexuel ne possède pas chez eux une bien grande importance, sauf lans le cas des Trématodes enloparasites. Quelpues espèces, affratenant à trois des classes de l'embranchement, sont les seules à montrer des généritions formées sans le concours de la sexualité; l'une des classes, colle des Némertines, esl complètement privée d'une telle facullí.

Les aufs des Plathelminthes sont d'ordinaire fort riches en deutolécilhe; aussi, la plupart des développements sont-ils condensés. Le deutolécithe ne préexiste pas dans l'orule, du moins dans la majorité des cas; il lui est donné, au moment de la fécondation, par des cellules annexes, les cellules vitellines, produiles dans des régions spéciales de loraire. Les l'lathelminthes s'écartent, en cela, de tous les autres animaux. - Certaines Némertines sont les seules à posséder des urufs paurres en substances nutritives, el à oflrir par suite des évolutions dilatéés. Dans ce cas, la morule se convertit en une blastule: celle-ci devient à son tonr une gastrule véritable, mmie de deux fenillets, le prolendoderme et le protectoderme. Ces feuillets restent séparés l'un de l'autre par un espace lihre, assez raste, qui correspond ì une persistance le la cavité blastocolienne. Le premier d'entre eux engendre des initiales nombreuses, qui péuètrent dans ectte cavité, el s'y multiplient; elles donnent ainsi naissance an mésolerme; les éléments de ce dernier ne comblent pas l'espate libre, mais laissent entre enx des vides, qui deviennent des lacunes par la suite, el représentent le cuxlome. Le mésoderme érolne suivant le procidé mésenchymatenx; le culome est un véritalıle schizocule.

Dans les cas de développement condensé, les cellules vitellines s'unissent entre eltes, et i l'oospore, ponr former, par leur soulure, un corps compact, qui se convertit en morule, puis en planule, tantòt directe et tantôt indirecte. Certains éléments, placés au centre de la fllanule, et souvent plus gros que les autres, fournissent le mésoderme et l'endoderme; ils constiturnt donc un protendoderme. Les antres ćléments, situés à la périphérie de l'embryon, doment waissance an protecloderme. - Ce dernier fenillet ne reste pas simple d'habitule; il se comprose de deux ou trois conches cellulaires, dont les externes tinissent par se détacher, et doivent ètre considérées comme des enveloppes provisoires, des membranes amniotiques. Parfois, l'alréviation du développement est telle, que les élauches de ces memliranes apparaissent dès le début de la sigmentation ovulaire, el semblent chre des formations autunomes, hien qu'en ríalité elles dépendent de l'ectorlerme. Cette origine des feuillets amniotịues, aux dépens du feuillel exterue, est surtont évidente cliez plusienrs Némertines, qui possèdent nue évolution lilatée, et montrent que le jrotectoderme seul est mis en jen sous ce rapport.

Nos connaissances ne tonchent guère, en ce qui concerne benhyo- 
génie des Platodes, que la genèse des feuillets blastodermiques, et l'aspect général olfert par les emlnyous; l'origine et le développement des organes ne sont pas cneore bien élucités. - Cependanl la science actuelle est documentée d'une façon suflisante sur les migralions fort curieuses des emlryons des Plathelminthes parasites, cesta-dire sur leur transport d'un hôte dans un autre, jusqu à ce qu’ils parviennent à leur liabitat délinitif. la plupart des Trématodes et surtout des Cestorles sont parasites, en elfet, dè leur extrème jeune igge; et l'être dans lequel ils vivent, alor's qu'ils sont i l'élal d'élanches, n'est souvent pas celui capable de leur fournir les circonstances nécessaires pour leur permettre d’alteindre l'état adulte. L’incapacitó du promier hôte à cet igrard ollige les jeunes parasites a se lransporter, soil par euxmèmes, soil passivement - el ce dernier cas est le plus répandu - dans un organisme mienx approprié sous ce rapport. Les hobes transitoires et les hótes définitifs apprartiennent à des groupes d'ètres fort différents comme structure, comme mode de vie, el n'ayant d'autres relations entre eux que celles de mangeur ì mangé; aussi les embryons de ces l'lathelminthes sont-ils forcés d'accomplir des migrations, parfois fort complexes, avant de parrenir à la phase alulte. - b'ordinaire, pour une ispèce donnée de ces parasites, les bòtes transitoires et les hôtes définilifs appartiennent igalement à des groujes donnés; parfois ces Jerniers sont très précis, alors qu'ailleurs l'organisme du parasite est assez plaslique pour lui permetle de virre dans des habitats divers. Mais, souvent, lamplitude du grouje d'hòtes, pour une espèce déterminée de parasite, reste circonscrite à l'espèce ou au genre, et ne déprasse pas les limites de l'ordre ou de la classe.

\section{§ 2. - Éléments sexuels.}

1. Sexualité en général. - Les l'lathelminthes inférieurs, c'està-dire les représentants de la classe des Turluellariés, montrent une asse\% grande variété pour ce qui tient à la répartition des sexes. La plupirt d'entre eux sont hermaphrodites; mais certains, les Microstomides par exemple, sont unisexués. Les faits sont plus constants chez les autres classes de l'emlıranchement: les Némertines, sauf certaines Borlusin, sont unisexures; par contre les Trématodes el les Cestodes, sauf la Bilharsia homatobia et peut-ìtre quelques autres Trémalodes, sont lierma|hrodites.

L'hermaphroditisme est complet, pour ces deux dernières classes. Chaque individu est capable de se féconder hui-mème; et des dispositions spéciales sont destinćes à permettre l'autofécondation, à assurer lo transprort des sprermatozoüdes dans les conduits femelles. Lorsque le mime individu possèle plusienrs groupes de glandes sexnelles, comme il cur est chez la plupart iles Cestodes, chaque groupe est constitué par l'union d'une partie màle et d'une partie femetle, la première lécondant la 
seconde sans rien emprunter parfois, ni rien dommer, aux amas sexuels voisins.

Les phémomènes ne présentent pas la mème régularité chez les Turbellariés. Tantòt l'hermaphroditisme de ces derniers est complet, et tantôt il est incomplet; en outre, il peut arriver que le mème individu possèle, dans le cours de sa vie, ces deux modes de sexualité. Certains Turbellariés Rliabdoceles, appartenant pour la plupart au genıe Mesostomum, produisent deux sortes d'œufs, désignés, suivant le moment de leur grenèse, par les expressions d'œufs d'été et d'œufs d'hiver"; l'existence des premiers concorde arec un hermaphroditisme complet, et colle des seconds avec un hermaphroditisme incomplet. - Chez plusieurs genres de ce mème ordre, la nature incomplète du mélange des sexes est telle, qu'elle aboutit presque à l'unisexualité, car l'un des deux organes génétiques se léveloppe sj peu, qu’il est permis de le considérer conme atroplié, et ne fonctionnant pas. II en est ainsi pour les Prostomum par exemple; cet état établit unc transition vers l'unisexualité parfaite des Microstomides, qui se rattachent aux Némertines.

11. Organes mâles. - La genèse des spermatozoïdes n'offre pas des particularités hien saillantes; elle a été examinée chez les Némertines par A. Sabatier, et chez les Turbellariés par Jensen et Lang. La forme les corpuscules fécondateurs est d'ordinaire celle d'un fuseau, muni d'une longue quene; parfois ce fuseau porte sur le coté des expansions moliles, comparables i des petits fouets, et servant sans doute d'appendices locomoteurs.

Les organes mâles possèdent toujours des conduits particulicrs, distincts des oviducles, qui ont pour rôle de conduire les spermatozoïdes à l'extérieur; aussi est-il nécessaire que des dispositions spéciales interviemnent, dans le cas d'hermaplinoditisme complet, pour permettre l'autofécondation. En somme, ces dispositions se ramènent aux suivantes: l’orifice sexuel màle est placé sur le corps, non loin du pore femelle; les téguments se dépriment, daus la zone que ces ouvertures occupent, en un sillon plus ou moins profond, nommé sinus génital; au moment oủ les spermatozoïdes commencent à arriver non loin de l'orifice extérieur du conduit màle, ce sillon se ferme. Les éléments fécomdateurs emplissent alors la cavité de ce dernier, mais ne peuvent aller au delor's, car l'occlusion est complète; ils s'insinuent dans l'oviducte par le pore femclle, et vont féconder les orules.

111. - Organes femelles. - Ces organes sont remarquables, à cause de leur division fréquente en denx parties, dont chacune est munie de canaux vecteurs spéciaux. La première de ces parties, le germigène, est clıargée de produire les orules, réduits à leur noyau el à une petite quantité de blastolécithe; la seconde, le deutoplasmigène, on encore le vitellogène, a pour ròle de lommer maissance à des éléments cellulaires nucléés, les cellules vitellines, qui serout absorbés par les ovules 
fécondés, ou par les emliryons issus de ces ovules, et serviront à leur nutrition. - Une telle division de l'ovaire, en deux masses aux fonclions distinctes, n’existe gnère, de tous les animaux, que parmi les Plathelminthes. D'ordinaire, l'ovaire est un tout simple, où cellules germinatives véritables el cellules nutritives sont placées les unes à côté des autres; les premieres d'entre elles, qui deviennent les orules, alssorbent les secondes, et se chargent de deutolérithe : cela dans l'intérieur de l'ovaire, et avant tonte fécondation. Il n'en est pas ainsi chez les Plathelminthes; les éléments nutritifs sont formés indépendamment

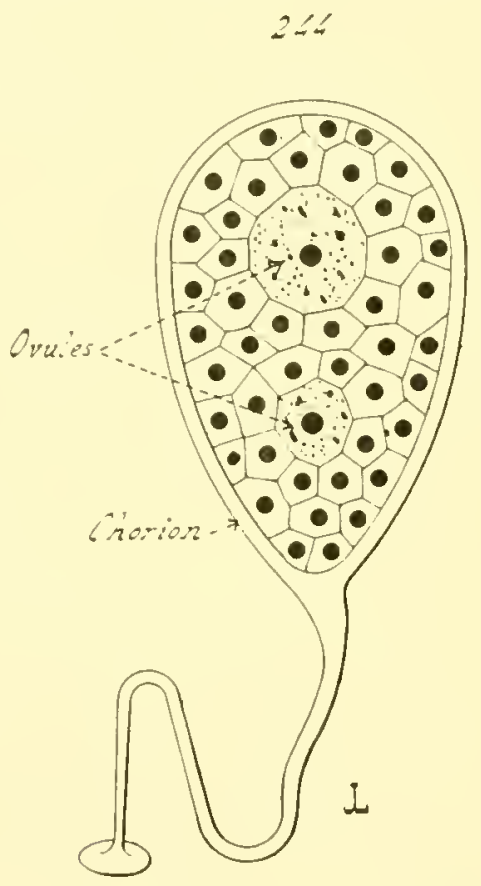

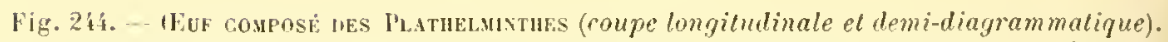
- L'eruf, entourè de son ehorion ųur sallonge en un pérloneule d'attache, contient un pelit nombre d'ovules, el une quantité consideralıle de cellules vitellines; ces demières sont représentèes en hane, les ovules en pointille. - I'après llallez, sur un 'turbellarie rhabdocorle, le Prostomum Steenstrupi.

des rrais ovnles. Cenx-ri sont fécondés par les spermatozoïdes alors qu’ils sont encore réduits à leur hlastolécithe, et ils n'alısorbent les cellules deutolécithiques qu'après la férondation, soit au moment de la segmentation, soit an cours des phases embryonnaires ultérieures.

Les procédés, mis en jeu pour assurer la succession de ces phénomirnes, sont aisés it comprendre. Germigenes et llentoplasmigènes possiJent des conduits spécianx, qui ne s'ourrent pas isolément an dehors, mais sabourhent ensemble; les ovules et les cellules untritives arrivent 
egalement dans cette région de soudure. Celle-ri est dilatón pu nue ampoule, nommée le réceptacle séminal, qui so l’al a l'uuverture sexuelle extérienre par un seul ranal, l'ovilucte. - Lors de la fécondation, les spermatozoïles s insinuent dans loviducte, et parvenuent jusque lans le réceptacle séminal. Celui-ri renferme donc un mélange, en quantité considerable, de spermatozö̈ıs, d'ovules et de collules deutolécilhiques; les premiers féconlent les seconls, et les transforment en oosprores. Apròs quoj, des glanoles amnexées au réceptacle, les glandes cémentaires. ou de la coque, sérètent un mucus abondant, qui s'insinue entre tous ces élóments, et se durcit à mesure. Par l'elfel de sa présence, l’ensemble des oospores et des cellules nutritives se livise en petites masses quentoure le uncus; celni ci se racornit, et sépare peu ả peu res masses les unes des autres, en leur domnant une enveloppe particulière: chacun de res amas porte le nom de cocon. - Le réceplacle séminal contient, après que tous ces phénomènes se sont effectués, un grand nombre de ces coips. Comme les cellules nutritives sont de beaucoup plus aboudantes que les ovules, chaque cocou renferme une petite yuantité d'oospores, sumvent une scule, et un chiffre assez élevé l'élíments vitellins. Dans le cas où plusienrs oospores sont placées côte à côle, une seule l'entre clles se développe doudinaire. les cocons s'engagent ensuile dans l'oviducte, sont expulsés par l'orjice femelle, et arcomplissent leur évolution.

Tous les Pathelminthes présentent ainsi un ovaire divisé en parties distinetes, germigènes el rleutoplasmigènes. Les Némertines, el les Turbellariés dendrocoles appartenant ì la trilu des Polyclades ou des Digonopores, lont seuls exception, car leur ovaire est simple, et la quantité de deutolécithe contenue dans leurs ovules pen considérable.

Un certain nombre de Turbellariés Rbabdorcules, appartenant jour la plupart aux genres Schizostomum et Mesostomum, pondent, suivant les saisons, deux sortes d'oeuls : les aufs d'cle et les aufs d'hiver. Les premiers résultent d’une antofécondation, sout entourés par nne coque mince et transparente, et accomplissent leur développement presque enlier dans l'utérus maternel. Les seconds proviennent d'une fécondation croisé, sont recouverts par une roque dure, ipaisse, de roulrur brune, et pondus vers la fin de la belle saison, saus fưils aient rommencé leur évolution. Its restent en cet étal, durant l'hivrrentier, et ne montrent des phénomènes génétiques quau retour du printemps. Coufs d'été et

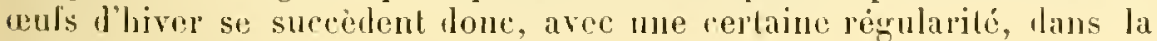
vie ales inulividus.

\section{3. - Développement des feuillets blastodermiques.}

l.es procédés les plus simples, daus la genese des feuillets blastorlermirpes, sont oflerts prar les Témertines, et par les Turbellariés alendrocoles compris dans la tribu des ligonopores. I.es ovules deres animanx 

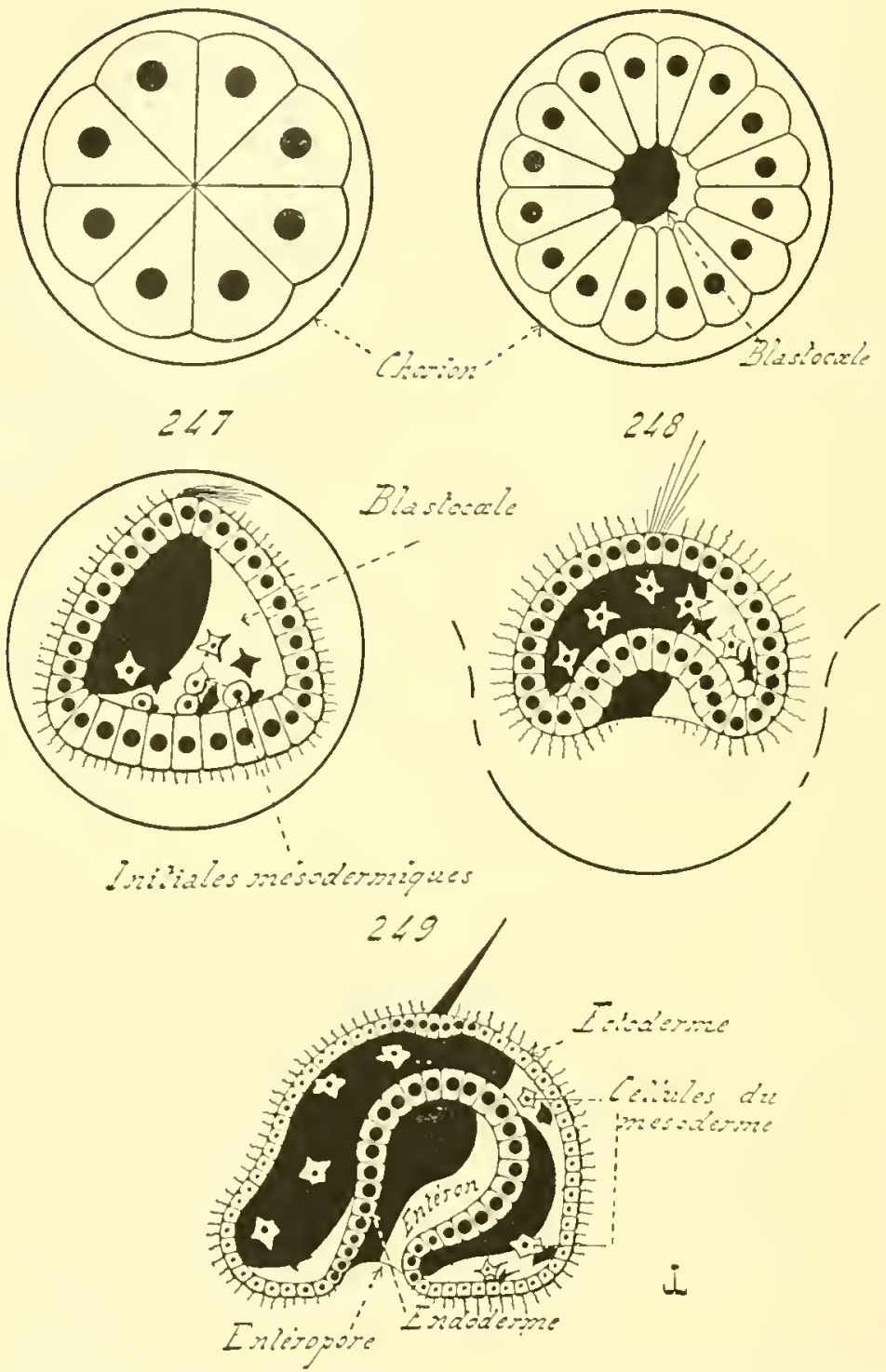

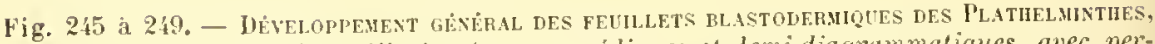
dans le cas d'exolutions dilatées (coupes médianes et lemi-diagrammatiques, avec perspective par ombre portee). - Lin 245, morule. - En 246. blastule jenne. - Ln 247, blastule plus agee, dont les premiers béments du mesoderme se façonnent aux dèpens de ce qui va devenir le protentod crme. - In 24, jeune gastrule; l'embryon devient libre. - En 2t?, yastrule complete, munie de ses trois feuillets, le protendoderme s'étant converti cn endoderme définitif, ajrís avuir lonnè naissance au mésoderme. - D'ậrès les ctules faites par Metschnilon sur une Xémertine, le Lineus lacteus. 
contiemnent me moins grande quantité de dentolécithe que ceux des autres Pathelminthes; ce fait concorle arer l'alssence de deutoplasmigènes, chez les imlividus générateurs. Ces ovules penvent ètre nommés des aufs simples; par opposition avec les eufs composés, ou cocons, de la plupart des Turbellariés, des Trématodes et des Cestodes, formés par l'association d'orules rrais et de cellules vitellines. - Le mode d'alsorption de ces demières, par le blastolécithe des premiers, varie suivant les classes. Ces cellules sont fort nombrenses chez les Turbellarjés qui en possèdent, et absorbées par l'embryon au fur et à mesure de son développement. Celles des cufs de Trématodes sont en quantité moindre; elles sunissent au blastolécithe, dès le début de la segmentation. Enfin, celles des Cestodes paraissent occuper un plus petit espace que leurs correspondantes des Trématodes, et se fusionnent, avec le protoplasme de lovule, arant que la segmentation ne commence.

Dans ce dernier cas, l'œuf complet rappelle d'assez près celui des Dendrocoles digonopores. Pourtant, la possession de deutoplasmigènes par le générateur, et la présence connexe d'un doutolécithe ahondant dans l'œuf, font que le développement des Cestodes ressemble, pour ce qui tient à la genèse des feuillets, à celui les Trématodes. - Ces considérations conduisent à diviser le présent paragraphe en deux parties, Jont la première renferme la description des fenillets blastodermiques produits par les oufs simples, et la seconde celle des phénomènes offerts jar les œufs composés.

I. Eufs simples. - Ces aufs maissent dans un ovaire simple; chacun d'eux est constitué par une cellule unique, et non par une agrégation de cellules. Les Némertines el les Dendrocoles digonopores sont les seuls à posséder de tels aufs. - Le développement des Digonopores est condensé, contrairement à celui de la plupart des Némertines.

Nèmertines. - L'évolution embryonnaire des Némertines présente beaucoup de diversité. Un fait la domine, tenant aux modifications subies par le protectoderme. Dans un cas, ce fenillet reste toujours simple. Dans un autre cas, il se divise, par des procédés variables, en trois assises concentriques, dont linterne seule persiste pour devenir l'ectoJerme définitif. Les denx antres enveloppent, pendant un certain temps, l'embryon entier, à la manière de membranes amniolinues; puis elles sont rejetíes, et ne prennent ancune part à la genèse des organes. Il existe donc, chez les Xémertines, denx types principaux de développements : l'un arec amnios ef l'autre sans amnios; chacun d'eux reuferme des embryogénies dilatées el des emliryogénies condensées. Ils paraissent Jnne ètre lien distincts; cette séparation est d'autant plus accentuée que, dius l'état alctuel de nos connaissances, les Némertines, appartenant à la tribu des Schizonémertines, sont presque les seules à otfrir des déveIoppenents arec amnios. Les autres représentants de la classe ne produisent aucune enveloppe amniotique antour de leurs embryons. - On ne 


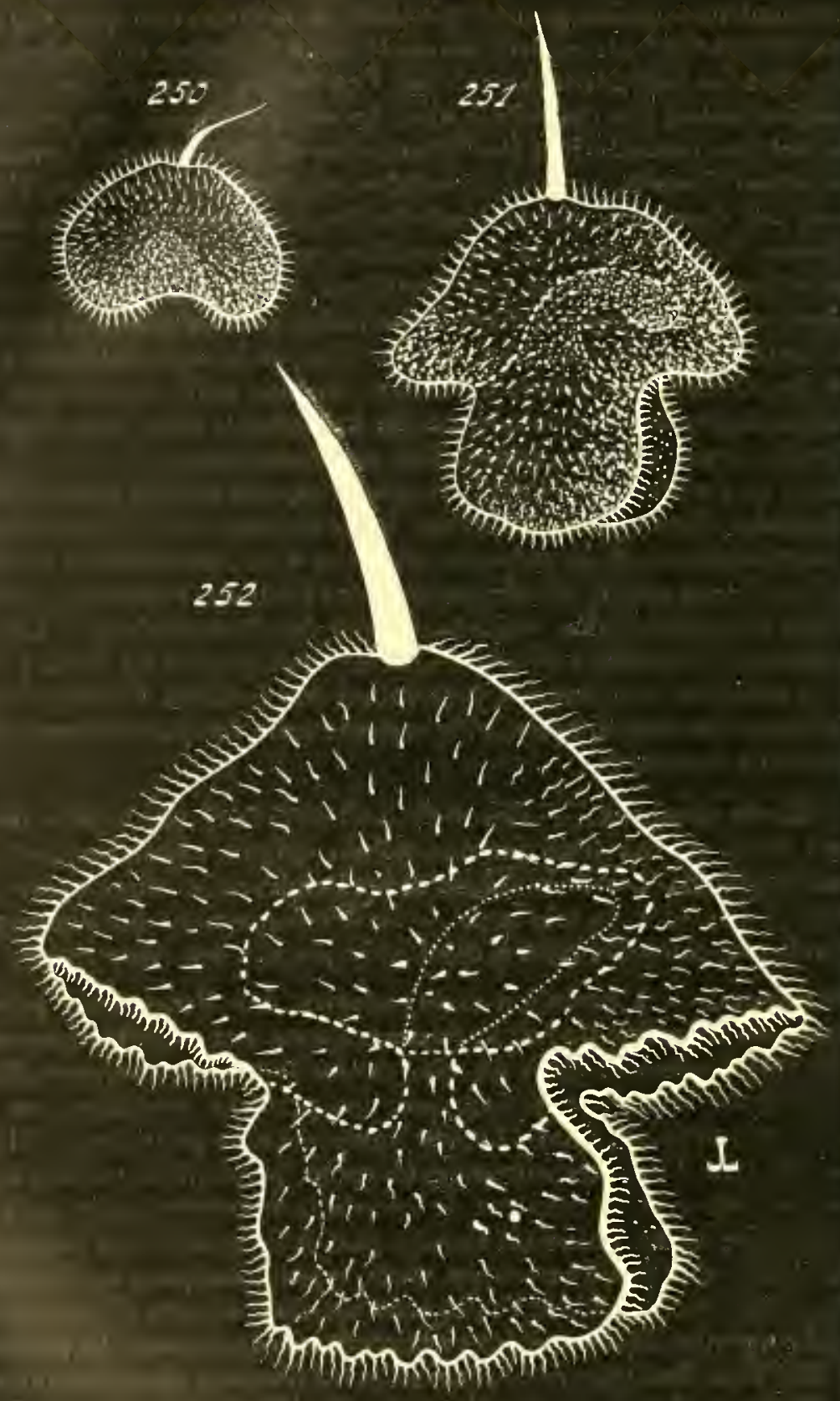


peut encore préciser, avec certitude, les relations qui unissent le premier mode an seeond. La présence d'embryogénies Ires dilatées, dans le lyje des développements sams ammios, "mpeche de le considérer comme réprondant à une abréviation le son contrare. D’un autre côté, certaines formes de Némertines, les C'éphalollrix par exemple, semblent établir, par la chute de lenr ectoderme durant leur vie larvaire, mue transition du premier procédé au second. Il esl nécessaire d’avoir sur cette queslion, pour se prononcer en connaissance de cause, plus de notions que la science achelle n'en comporte.

$1^{\circ}$ Les développements sans amnios sont surtout le propre des IIoplonémertines; parmi eux, les uns sont dilatés, el les autres condensés. Les premiers seffectuent suivant le mole gastrulaire, et les seconds suivant le procédé planulaire. - Dans le premier cas, l'oospore fécondée se segmente, se transforme en une morule conslituéc par un petit nombre de blastomeres, puis en une hlastule avec blastocole étroit et blastoderne épais. Une partie de ce blastoderme s’uvagine, et l'embryon se convertit en gastrule. La partie invaginée donne naissance, avant mème que son refoulement ne s'elfectue, ì plusieurs cellules qui pénètrent daus la eavité blastocolienue; ces cellules sont les initiales mésodermiques. La carité de l’uragination est l'entéron; le feuillet qui la limile, el fon ruit les initiales du mésoderme, correspond donc à un protendoderme. Celıi-ci, par le fait du refoulement qu'il subit, s'avance dans la eavité blastocelicme, mais ne la remplit jas completenent; il laisse, entre lui et la face interne du blastolerme resté extérienr, un vile assez grand, oủ se développe le mésolerme, et pui devient le colome. Les trois feuillets blastodermiques ont alors pris naissance; le blastoderme périphérique estl'ectoderme, le hlasloderme invaginé correspond à l'endoderme, el le mésoderme se trouve plaé entre les deux. Souvent, les élémonts endodermiques, et parfois ceux du mésoderme, s'missent en un syncytium.

Les iéveloppements condensés, décrits far les auleurs comme des embryogénies comprortant des gastrules délaninées, s'ellectuent suivant le mode planulaire direct, et non d'aprè un véritable procédé gastruhare. - Loospore se seguente, el se change directement en une plaunle conpacte, omellant ainsi la phase blastulaire. I'armi les cellules agglonérées qui constituent la planule, les externes représentent l'ectoderme, celles placées jus en derlans donnent naissance au mésorlerme, ef les internes se modilient, les mues en éléments de liendoderne, les

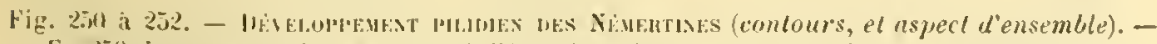
F.n 250, jeune fastrule, parvenue il l'elit dont la structure est donnee far la ligure 248. - lin 2jl, gastrule plus avancé, deja eonvertie en un Jilidium. - En 252, Jilidium complet, renfermant la jeute lemerte dans son intérieur; les contours de la démerte sont représentés par une ligne le traits, el ceux le l'enterun (intestin) par une lignc de points.

Ces larves nagent au moyen des cils vibratiles dont leur ecluderme est couvert. l.es details he leur evolution soni domnes jar les figures $2 \% 3$ i $26 \%$. 


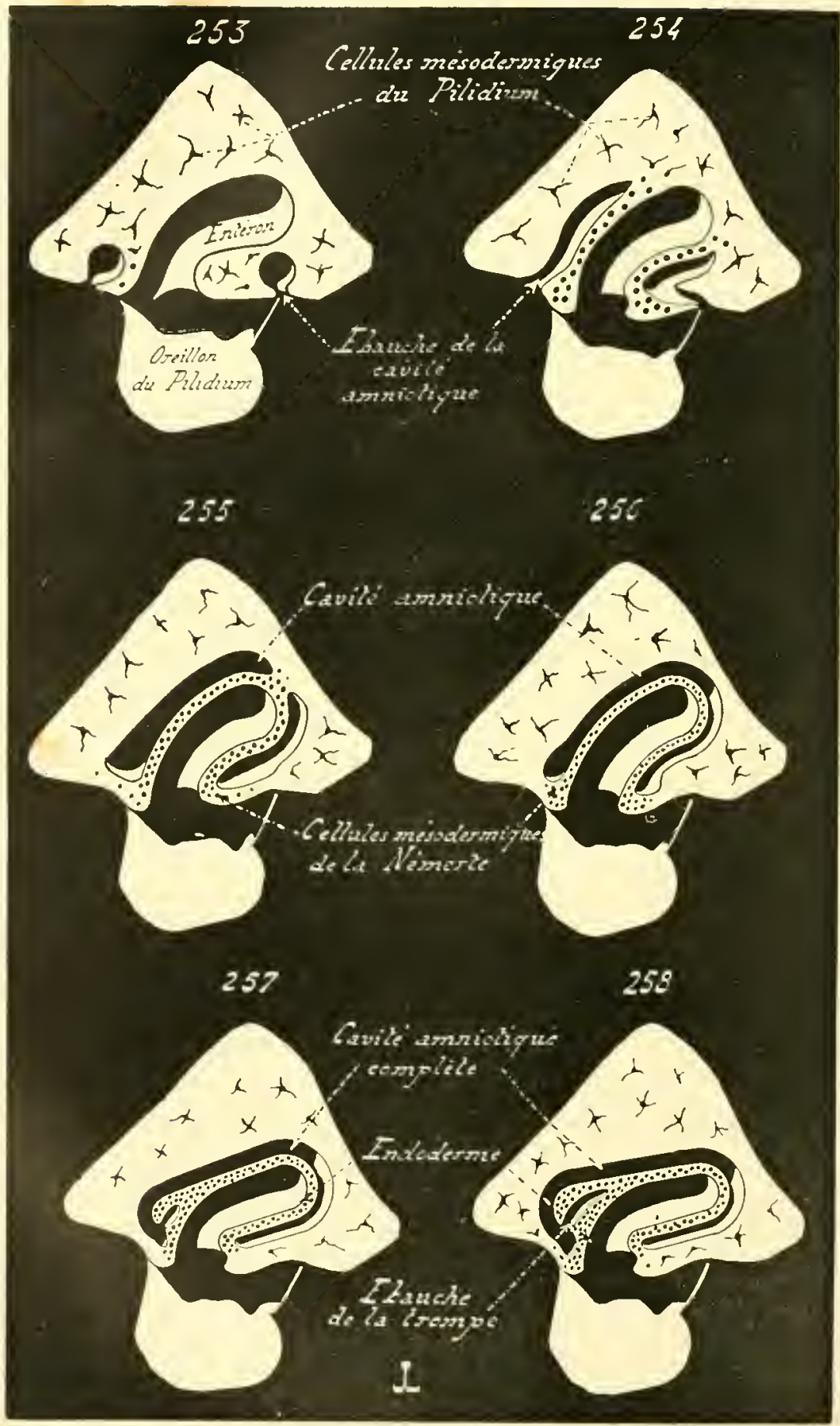


autres en petites masses plasmiques absorliées par ceux-cj comme aliments. Souvent anssi, les cellules endordermiques se rassemblent en un

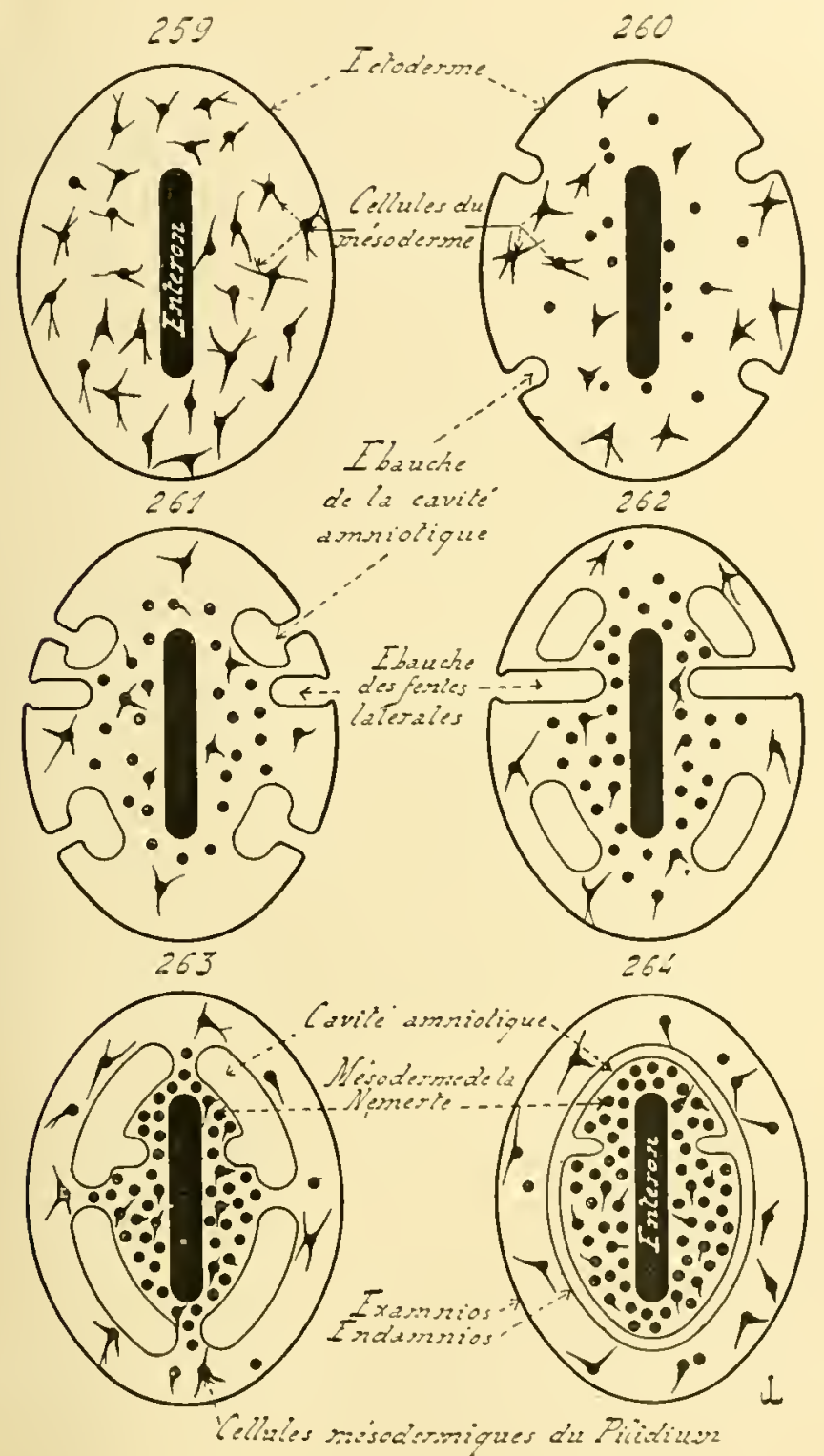

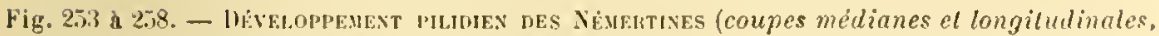
avec perspective par ombre portée; diagrammes). - En 253, jeune Pilidium, parvenn à l'état, dont les confours sont donnés par la figure 251 ; les ébauches des vésienles amnioliques prennent naissance. - En 25 t et 255 , ces vésieules grandissent. - En 250 , elles se joignent, et s'unissent, pour ne former utune cavité; les tissus, que cutle cavité isole 
syneytimm. Les trois ferillets hastodermiques sont alors délimilés. Une carité se creuse dans l'endoderme, ponr devenir l'entéron, qui ne larde pas it sourrir an dehors; et des viles, lestinos a produire les larunes dir colome, apparaissent lans le mésoderme.

go Les dereloppements avec amnios, particuliers aux Schisonémerlines, sc manifestent sous denx formes : l'unt dilatée, et l'autre quelque pen condensée. Celle-ci est comme sous le nom de développement avec larve de llesor; la fremirive sous culni de développement pilulien. de l'expression l'iliblim, emplogre pour désigner la larve propre à re procédé. Ces évolutions sont caractérisées par la livision du protectoderme en trois assises concentripnes, lont linterne, en rapport direct avec le protendoderme, devient l'ectorlerme définitif, et doit purter ce nom. Les deux autres se séprant le la précédente par un espace plus ou moins vaste, et constituent une enveloppe anniolique. Jeslinée à se détacher et il se détruire. Cet amnios étant ainsi romposé par Jenx conches cellulaires superposées, la conche externe peul ètre appelée l'examnios alin d'éviler une périplurase, et l'autre l'endamnios.

Tans les développements pilidiens, l'orule fécondé se segmente, puis se transforme en morule, en blastmle, of enfin ch gastrmle par invagination. Le protectoderme de celte derniere se conve decils vibratiles, qui lui permcllent de nager; une lontle de cils flus longs, semblahle a un plumet, apparait sur sa face supérieure; latéraloment se moutrent deux tohes, semhlahles aux oreilhuns d"un casque; l'où le nom de Pilidium lonné a celte larve. Le protectoderme ne reste pas simple, et prodnit l'annios par le procédé suivant. - Denx paires de petiles dépressions, lont l’une est placée dans la région antérienre de la larve, et lautre daus la rérion postrienre, se dirigent de dehor's co delans; elles refoulent los zones protectuderminges oi elles se façonment, et los enfoncent, dans la cavité hlastucolieme, a la manière de tubes cylindriques. Les orilices

du reste de l'economie larvaire, sont seuls chargè de produire le mẻasome, c'est-à-dire l'urganisme définitif. - En 257, cet organisme, qui conserve comme intestin l'entèron lu Frilidium, précise ses contours, et commence à faconner sa Irompe. - En 258, l'évolution de cette jemne Vemerte approche de sa fin; lorsqu'elle sera terminée, il suffira a l'indivilu de hriser, autour de sa bouche, sa zone l'attache au Pilidium, pour se trouver libre.

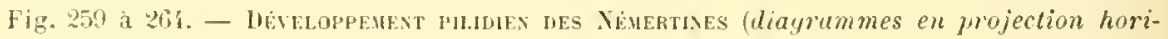
zonlule). Ces ligures completent les precedentes, en frecisant les modifications subies par les faullets; J'cctoderme et ses dèrivés sont reprèsentés pal des lignes; le mésolerme est indique pa ses cellules, dessinées en noir, et l'endoderme, avec l'ontéron qu'il

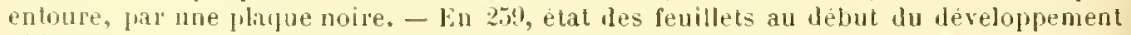
pilidien. - En 260, état plus avancé, qui correspond a relıi de la figure 253, et montre en totalite ce que cette dernière indique par moitiè. - En 261, les vésieules amniotiques grandissent, et les elrauches des fentes latẻales, organes sensitifs de la Yèmerte, font leur apparition. - lin 202 , les vesicules deviennent eloses. - En 263 , elles se sont acerues au point de se rencontrer. - lin 264 , elles sont confondues en une seule cavite amniolique; cet état correspond a celui de la figure 256 .

C.'s figures indiguent, dans leur lotalite et en projection, les faits dunnés en relief, par les figures $253-258$, sur une moitie d'embryon vue par sa I ranche. 
des dépressions ne tardent point i se fermer; les yuatro tules sont ainsi convertis en qual'e petiles rósicules closes, placées, dans la cavité blas-

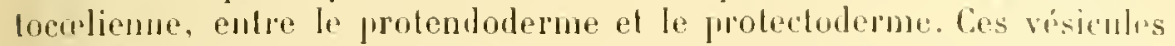
zrandissent d une maniore égale, et comblent pen à peu, en amplifiant leur paroi el lenr eavité, le lılastocole entier; elles appliquent, co faisunt, la face inlerne de leurs parois confre le protendoderme, et la fare piterne contre le protectolermo. Puis comme, rn emplissant le liastorrble, elles sont venues au contact des mues les autres frar lrurs extrémités, ellos se fusionnent, el ne constituent yu’une seule cl immense vésicule, eutomrant le protendoderme, et par suite l'entéron que ce dernirr limite. I.a pras interne de celte vésicule uniqune est accolée an protendoulerms: olla correspond à l'ectoderne défunitif. La cavité vésiculaire, vasle el ample, sépare cetle paroi de l'externe; celle-ci saltaclıe au protectoderme, el constitue avec lui l'enveloppe amniotique; elle représente done l'endamnios, alors que le protectorlerme aequiert la valenr l'un examuios. - Gràce à tous ces plóénomrnes, Je lilidium s’est completement modifié. Son tégument est converti en mne membrane ambiotiłue, deslinée à disparaitre, ot il contient dans son intérieur le jeune embron. L'organisme de ce dernier est encore allaché ả l’amuios par les burls de l'entéropore, que les vésicules ont entourés sans les lisjoindre; mais celte rigrion de somdnre se brise elle-mème, lorsyue l'évolulion amlavonnaire sacheve. l.e protendoderme n'est pas inaclif; il émet les cellules, qui s insinucul entre lui-mème et l'ectoderue définitif, el Jeviennent les initiales muésodermiques. Ces iniliales se multiplient, et des vides se rrensent entro

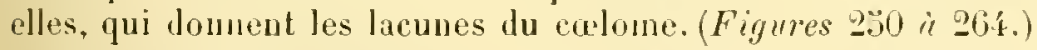

le déueloppement par la larve de Desor concorde, de tous joints, avec celui de la larve pilidienue; il dóbute de même par des plısıs blastulaires el gastrulaires. Il dillère seulement de lui par le procédé grénélique de l’amnios; les qualre zones du protectoderme, intéressées lans ce phénomène. ne prenuent pas l’aspect de vésicules closes, mais acquibent celui de disfues épais ol compacts. Ces dispues se sépalreul des régions yui leur domment naissance, gramlissent tout comme les vésicmles du Pilidinn, el sunissent le même on me conche cellulaire continne, qui rutoure le protendoulerma. liassise interne le cetle conche, directement

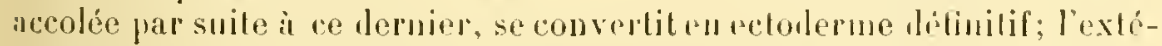
l'ienre sumit an prolectuderme pestant, pour coustiluer aree lui l'ureloppe ammiolique. - Toutes cespluses avolulives me sont point libues. ear

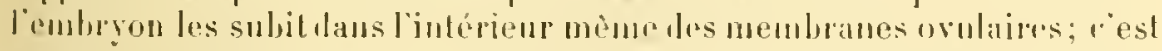

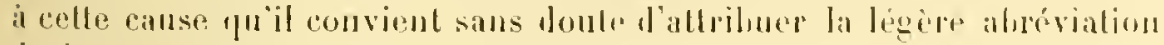
Ju développement, lausformant les vésicules creuses en displues massils, et supprimant les organes focomotenrs de la lane Pilidium. - l'arni

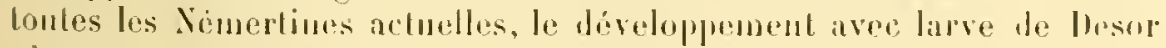

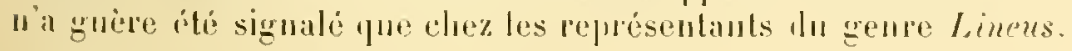

MENonocales biguropones. - le deubolécille est assez aloudant dans 
l'ovule pour que le développenent soit condensé; celui-ri s'eflectue par le procédé planulaire, en omettantl'élat de hlastule, et celui de gastrule. La planule, dans tons les cas connus, est inlirecte. La segmentation commence par ètre égale le flus souvent; puis le blastolécilhe se sépare peu à peududentolécithe, se divise plus rite que lui, ef l'enveloppe complètement. L'embryon s'est ainsi converti, par le mode indirect, en une plannle compacte. l'ensemble des cellules externes, et enveloppantes, représente l'ectoderme; celui des éléments internes, riches en deutolé-

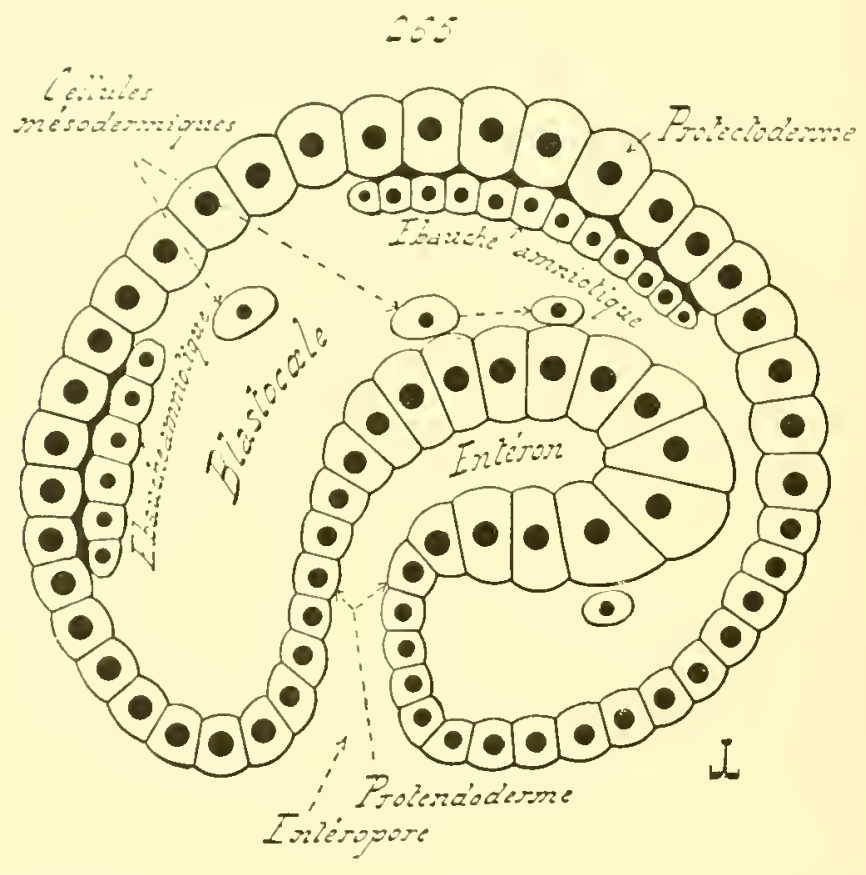

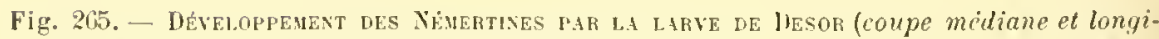
tudinale, demi-diagrammatique). - D'apres Hubreeht, sur une larve de Lineus obscurus. Les ébauches amniotiques sont constituécs par des plaques cellulaires, an lien de consister en vésicules.

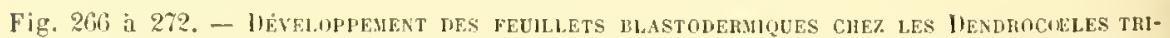
clades (coupes médinnes; l'ovule, et ses blastomeres chargès d'engenurer los feullets, sont en blane; les cellules vitrllines, et la masse nutritive qu'elles forment par leur union, sont en pointillé; les noyaux sont en noir). - En $2($ if, ovule non eneore divisé.En 20\%, ovule segmenté en quatre blastomires qu'entourent les cellules vitulines encore distinctes. - En 208 et 269 , les blastomeres augmentent en nombre, et se diplacent dans la masse nutritive eunstitue par la sombure, de plus en plus aceentuee, des cellules vitellines. - Ln 270, les feuillels trommeneent it se delimiter; les blastodermes devenus exte̊rieurs comprosent l'ectolerme, et les autres, drmeurés internes, produisent l'endoderme et le mesodtrute - Ln 2\%I, celte èvolution continue. - En 272, elle s'achève: l'entéron se creuse au centre la l'embryon, et une bouche, avee un pharynx, prennent baissance pour lui permettre le s'ouvrir au dehors.

llaprès les recherches faites par llallez sur le Dendrocoplum lacteum. Les noyaux des cellules vitellines se detruisent. 


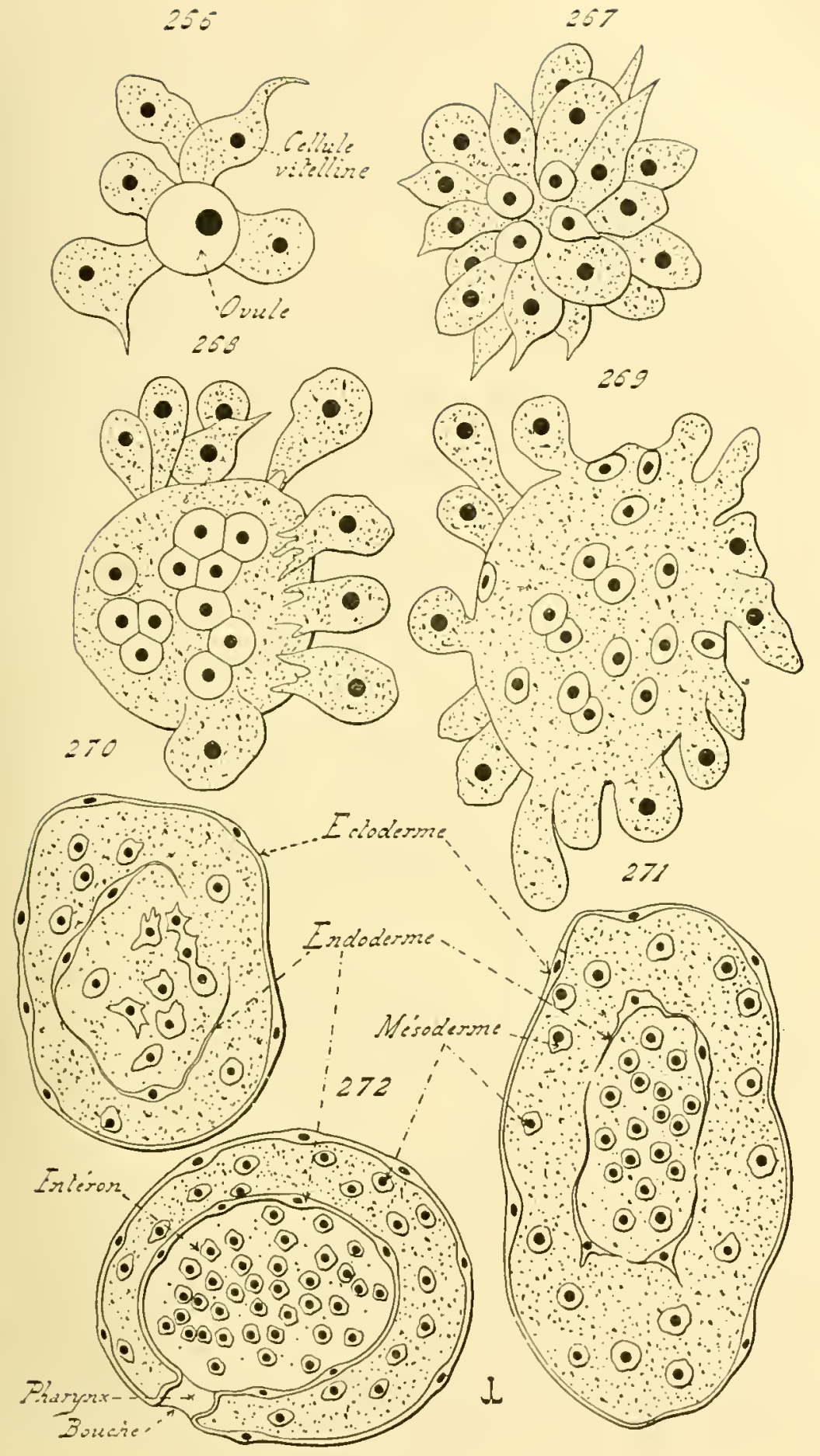

Fig. 260 a 222. 
cithe ef roluminenx, correspond au protendoderme. - Ia question de l’origine du mesoderme n'est pas encore élucidée d'une manirre satisfaisante. Les lessins, Jonnés par luang sur ce sujet, permettent d'armettre qu'il est engendró par lo protendoderme, comme le raisonnement par compraison autorise ì le concevoir. - Le mésoderme, l'endoderme, ef l'entéron 'pui se creuse au sein de ce dernier, évoluent ensuite sur place, en prenant leur aspect ditinitit.

11. Eufs composés, ou cocons. - Ces rufs sont produits par des générateurs aux oraires loubles, c’est-à-dire constitués par des vitellogenes et des deutoplasmigènes distincts. Ils sout formés eux-mèmes par l'association l'une, ou de plusienrs oospores, avec un nombre considrrable le collulos ritellines; cet amas est entouré jar une coque épraisse, le chorion. Géméralement, dans le cas où plusieurs oospores sont placées dans le mòme unf, une seule d'entre elles se développe, la substance des autres itant alsorlsée par celle-ci comme aliment.

Les reufs composés appartiennent aux Turbellariés (Rhalulocreles, et Dendrocoles monogonopores on Triclarles), anx Trématodes, et anx Cestodes; leur évolulion doit être suivie séparément dans chacune des classes. Malhemreusemenl, des locuments pricis sur l'origine exacte les feuillets hlastodermiques lont encore défaut, el l'on est réduit à se contenter de quelques olservations isolées. Cependant les recherches acpuises, et Ifs comparaisons avec les coufs simples, permettent d'établir plusieurs notions communes : les cellutes vitollines sont absorbées, tôt ou tard, par l'onspore qui se développe, ou par l'embryon qui en dérive; le léveloppement, très condensé, s'efleclue par le procédé planulaire; l'ectoderme, pourvu ou non de membranes amniotiques, se sépare rapidement des denx autres fouillets, qui restent unis pendant un certain temps en un protentaderme.

Tirreclariès. - L'évolution des Rhabdocoles n'est pas trìs bien connue, en re qui concerne les feuillets l, lastodermiques; il n'en est pas de mème pour celle iles Iendrocules triclades, grice aux études effectuées par llallez. - A re qu'il semble, les cellules vilellines sont relativement peu nombrenses lans les rufs des Rhablocoles, et, par suite, la grenèse des fouillets rappelle d'assez près celle qui a été décrite comme existant chez les lolyclarles on bigonopores.

Les éléments deutolécithiques sont fort abondants dans le cocon des Triclades, ou ils atteignent, parfois, le cliffre de plusienrs milliers; lenr présence amène mue altération fort enriense. L'oospore se segmente; tout en agissant ainsi, elle s'entoure des cellules vitellines, qui s'unissent pour la plupart en une masse compacte, au milieu de laynelle sont placés les hlastomeres provenant de l'oospore par ses divisions répétées. Ces blastomires, en multipliant eux-mèmes leur nombre au moven de scissions fréquentes, absorloent le vitellus qui les enveloppe, et s'en nourrissent; ils ne restent pas accolés les uns aux autres, et se séparent. Les 
uns traversent la masse vitelline environnante; ils vont s"élaler à sa sulface en une couche continne, qui limite de cette facon tout l'ensemblin, et compose l'ectoderme. D'autres demeurent en place, a jeu dr choses prìs; silués en dedans de l'ectoderme, ils se lornent à se multiplier, et produisent lo mésoderme. Les dernier's de res blastomères conservent lenr position centrale, el constituent l'endoderme, an milien duquel se "reuse l'entéron, dans une période assez tardive du développement.

Les traits essentiels de ces phénomènes si remar|uables sont seuls indiqués. II est probable que leurs caracteres particuliers découlent de la nécessité, pour lembryon, de se nourrir aux lépens des cellules vitellines. C'est à cette cause qußil faut attriluer la désagrégation des blastomères, dlont les plus externes, chargés de donner naissanre i l'ectoderme et au mésolerme, parcourent l'amas des cellules vitellines en s'assimilant leur sulistance. (F'igures 266 is 272 .)

Trémitudes. - L'origine des feuillets blastoulermiques a été étuliée, avec soin, chez les Trématodes endoparasites appartenant à la famille des Distomides. Elle est surtout intéressante en ce qu'elle s'accompagne d'une genèse d'enveloppes amniotiques, semblables á colles les Ximerlines, car elles sont produites par me série de cellules embryonnaires, dont l'ensemble est l'homologue du protectoderme de ces derniers animaux. Lorigine est la mème dans les deux cas; les procédés seuls different, mais ne permettent pas de conclure it l'absence d'homologies, car le développement les Trématodes est très alı'égé, et par suile fort altéré.

L'cuf se compose d'une oospore, et d'un nombre assez restreint, plusieurs dizaines en moyenne, de cellules vitellines. Ces dernières sont ahsorliées par l'oospore, lies le commencement de la segmentation: contrairement à ce qu'il en est chez les Iendrocoles triclades, oil cette alsorption se manifeste plus tarl. L'oospore se divise en segments; en mime temps, les cellules ritellines, se fusionnant entre elles et perdant leurs noyaux, s'unissent peu à pen à ces blastomères. Lorsque tous les éléments vitellins ont disparu par ce moyen, la segmentalion est achevée, el l'oospore se tronve convertie en mo planule formie par le procédé lirect.

Cette plannle ne devient pas libre, mais reste enferme dans lo chorion de l'ixuf. l'armi les cellules qui la constituent, les plus externes représentent le protectorlerme. Un petit nombre d'entre elles, situces en un poole de la planule, el y dessinant une petite calotte, d'ou leur nom de cellules de la calotte, se séparent des autres; elles se multiplient rapidement, de maniire à entourer la planule entière. Celte enroluppre, composíe d'éléments aplatis, est l'homologne de l'amnios du Pililium des Némertines. lille se hrise pen apres, ainsi pur le chorion, pour livere passage à l'embryon qui devient lilire.

liertorlerme se couve de cils viluatiles, pui prermettent il la larve de 

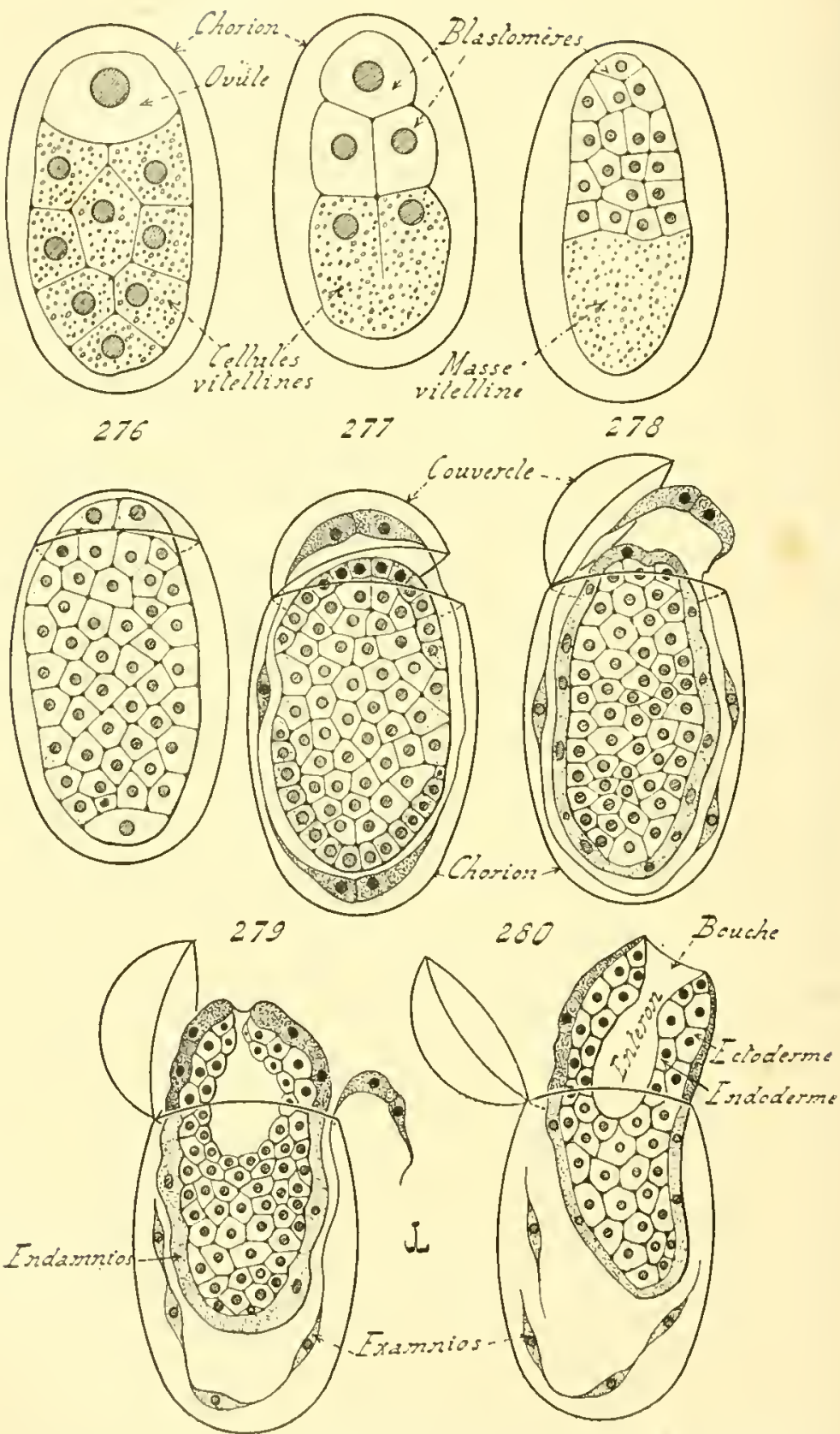

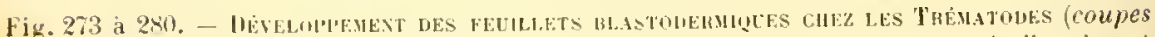
longiludinales demi-diayrammatiques). - Ln 273, cul non encore segmente; l'owule est 
nager. Les autres éléments embryonnaires composent, selon toute évidence, le mésoderme uni à l'endorlerme; mais ces deux feuillets ne se séparent point l'un de l'autre, n’acquièrent point leur structure propre, car les cellules qui les constituent doivent se grouper en petits amas, charés de devenir autant de nowveaux embryons. Du moins, ce phénomène existe habituellement chez les Trématodes Endoparasites; il manque aux Ectoparasites, dont les fenillets doivent, par suite, se dólimiter suivant les procédés habituels; mais des comaissances précises fout défaut sur ve sujet.

Cestones. - l.e déreloppement des Cestodes rappelle de près celui des Trématodes, surtout en ce qui touche l'existence d'enveloppes amniotiques, produites égalenent par un petit nombre de cellules appartenant au protectoderme. La diff́rence principale porte sur ce fait, que les éléments vilellins, jeu nombreux, sonl absorbés frar l'oospore, et assimilés à elle, de suite après la lécoudation, au délut de lì segmentation. Dans ses grands traits, l'évolution embryonnaire des Cestodes est plus abrégée cncore que celle des Trématodes; aussi les cellules initiales de l'amnios se délimitent-elles, sonvent, dès les premières phases de la scission de l'oviule.

L'ouf est entouré par un chorion résistant, et fort épais d'ordinaire. La segmeutation amène la genese d'une planule directe. Tès le début de la division ovulaire. quelques hastomeres se multiplient plus rapidement que les antres; les éléments auxquels ils donnent naissance, et qui entourent le reste de l'emlıryon, constituent une assise périphérique sous-jacente au chorion, et dont le nom véritable serait l'examnios, car elle est l'homologue de la couche correspondante des Némertimes. - Puis, en dedans d'elle, se délinite une nouvelle assise cellulaire, formée aux dépens les blastomères placés inmédiatement sous l'examnios. Celle-ci correspond à l'endamnios les Némertines; les anteurs luj ont donné diflérents noms, celui le manteau pour les Bothriocéphales, et de couche chitinogène pour les Ténias.

L'embryon se débarrasse ensuite de son chorion, et de son examnios. Lorsqu’il doit vivre pendant quelque temps à l'état de larve libre, lendamnios, devenu externe par la chute de l'examnios, se couvre de

représenti en blane, les eellules vitellines contiennent des granulations. - Lin 27 at 2ii, division de l'ovule en blaslomères, el diminution corrélalive des cellules vitellines, ¿ui sont alsorbẻes par ces blastomeres, et s'unissent entre elles au préalable. - Fin $2 \%$, les blastomires existent seuls, el composent une planule directe; le ehorion commence à se fendre. - Li 27\%, une partie du elorion se soulève en un convercle; quelıues-uns les filments externes de la planule se disposent en une membrane, qui se sépare du reste lu corps, el eorrespond à l'examuios dus Nemertines. - lin 2zo, l'embryon se prépare

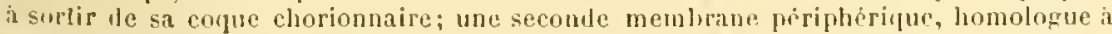
l'emlannios dus ximertines, se dilimile aux dipens des ilements exterues. - lin 279 et 280 , l'embryon ahaudonne son chorion, et, levelu d son endamnios, qui ne tarlera pas a tomber taglement, devient libro. lin petit interon se ereuse au sein de son organisue. l'après les reoherches fabes par Srhauinsland sur le Distomum teretiollo. 
cils viloratiles, qui servent au petit ètre pour nager; par contre, si l'embryon est parasite dès le délıut, l'endamnios ne porte aucun cil. Le premier cas existe chez la plupart des Bothriocéphalidés; le second chez les Téniadés. Quoiqu’il en soit, le jeme Cestode quitte son endamnjos comme il a alıandonné ses autres enveloppes, et l'ectoderme définitif se trouve oceuper sa place à l'extérieur du corps.

Quant aux l,lastomères internes, ils semblent constituer un protendoderme compact, qui se scinde plus tard en mésoderme et endoderme; mais des olsservations complètes sont encore nécessaires à cet égard.

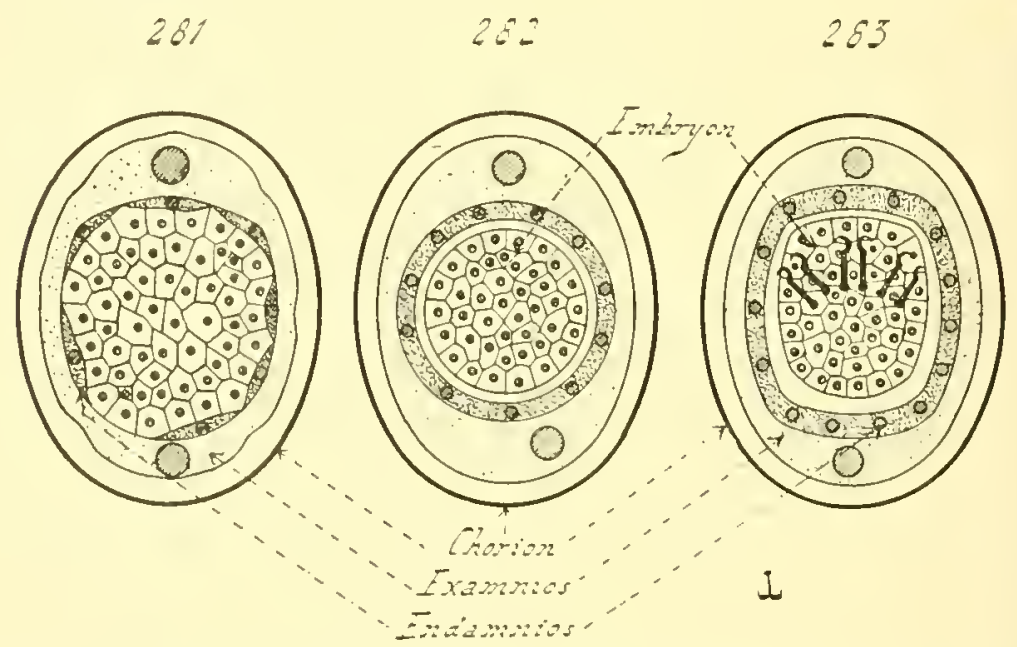

Fig. 281 a 283. - Dévelupedest nes Feullets blastodermoues chez les Cestodes (coupes médianes demi-liagrammaliques). - Les phases préliminaires se rapportent à une planulation directe, semblable a celle des T'rèmatodes, avec celte réserve que les collules vitellines occupent une moins grand. place. - En 28t, délimilation d'un examnios et d'un endamnjos aux dẹpens des blastoméres externes. - En 28?, ces denx membranes rigularisent lenrs contours, et se siparent dn reste de l'embryon. - lin 283, l'enbryon produit ses six crochets, représentés par lles bandes noires, et attend ainsi les circonslances favoralles qui lui permettront de joursuivre son ivolution, en se débarrassant de ses enveloppes amniotiques et de son chorion.

D'après les recherches faites par Schauinsland sur le Bothriocephalus rugosus.

\section{$\$ 4$. - Formes embryonnaires.}

I. Généralités. - Le développement des Plathelminthes comporte, preślue toujours, la présence de larves, car l'embryon se délarrasse de ses enveloppes chorionnaires, et devient libre, avant d'atteindre l'état parfait. Tantit, ces larves vivent en liberté, jusqu'à ce qu'elles parviennent i l'état adulte; tantôt, après une période d’indépendance plus ou moins longue, et parfois mème presque absente, elles s'adaptent an parasitisme. Le premier eas est naturellement celuides l'latodes qui restent 
libres durant leur existence entière, e'est-à-dire, sauf quelınes rares exceptions, des Turbellariés et des Némertines; le second est le propre des animaux parasites, soit des Trénatodes el des Cestodes.

Une autre particularité doit ètre signalée daus l'érolution des Plathelminthes, en tant que formes de leurs embryons. Les larves des Turbellariés sont privées d'enveloppes amniotiques, mais non celles des autres représentants de l'embranchement. Ces membranes sont constamment produites par des cellules appartenant au protectoderne; quelles que soient la condensation et la précocité de leur développement, elles sont situćes de la mème façon par rapport au corps du petit ètre: il est donc permis de les considérer comme lomologues. - Limportance de celle assimilation est fort grande, car elle permet ile concevoir les affinités naturelles des l'lathelminthes parasites, des Trématodes et des Cestodes. Ces animanx se rattichent, sans aucun lonte, anx Némertines Jont les embryons possèdent un amnios, comme le sont ceux des Schizonémertines. Ces dernières se rapprochent, il leur tour, des Turbellariés. Cette seconde induction se hase sur l'existence de types intermédiaires, tels que les Pelagonemertes, Némertimes dont l'intestin est ramifié comme celui des Turbellariés dendrocales, et les Microstomum, Turbellariés pourvus d'une trompe semblable, hien que rédnite, à celle d'une Némertine. La vie parasitaire des Trématodes et des Cestodes ne s'oppose pas a cette relation, puisque certaines Némerlines, Ies Halacobdella, la présentent aussi.

II. Turbellariés et Némertines. - Les larves des Rhablocoles, celles des Dendrocoles Triclades, et celles des Dendrocoles Polyclades appartenant a la famille des Leptoplaniles, quittent leurs membranes chorionnaires à une époque assez avancée de leur évolution, sonvent assez voisine de l'état parfait; elles noffrent, dans leur aspect extérieur, ancune particularité remarquable. - II n’rn est pas tout á fait de mème pour la plupart des Dendrocules Polyclades. Les larres de ces dernicrs alsandonnent hàtivement leur chorion; elles couvrent leur corps d'expansions ciliées, somvent fort longues, qui doment à ces êtres une allure propre, leur servent d'organes locomoteurs, et satrophient it mesure que l'embryon approche de l'age adulte. Cortaines de ces larves ont recu des noms spéciaux : telle est la larve de Müller, qui appartient an genle Yungia. Plisieurs autres, celles de divers Siylochus notamment, rappellent de près le I'ilidium des Schizonćmertines. Une semblable disposition permet, selon toute apparence, de concevoir l'origine de l'amnios du Pilidium; probahlement, cet ammios corresponl à l'extension, autour du corps entier, des appendices portés par les embryous libres les Dendrocales. Il est certainement difficile de comprendre comment un procédé, qui aboutit à la genèse d'expansions extermes, s'est transformé en un second mode, qui consiste à produire des vésicules creuses; mais, si les faits manquent encore sur ce sujet, on preut cepemdant penser, sans 
crainder de trop se tromper, que to premier est te point de départ du second.

Les embryons des Némertimes, appartenant i la scrie de cenx qui sont dépourvus d’amnios, sulissent, il labri de leurs memluranes ovulaires, la plupart des plases de leur évolution. Ceux, qui possèdent un ammios, abandonnent assez tard leur chorion dans le cas des larves de [esor, el précocement dans celui des larves l’ilidiennes. Celles-ri nagent en liberté dans l'eau, grace anx cils viluratiles dont l'examnios est couvert; jendant

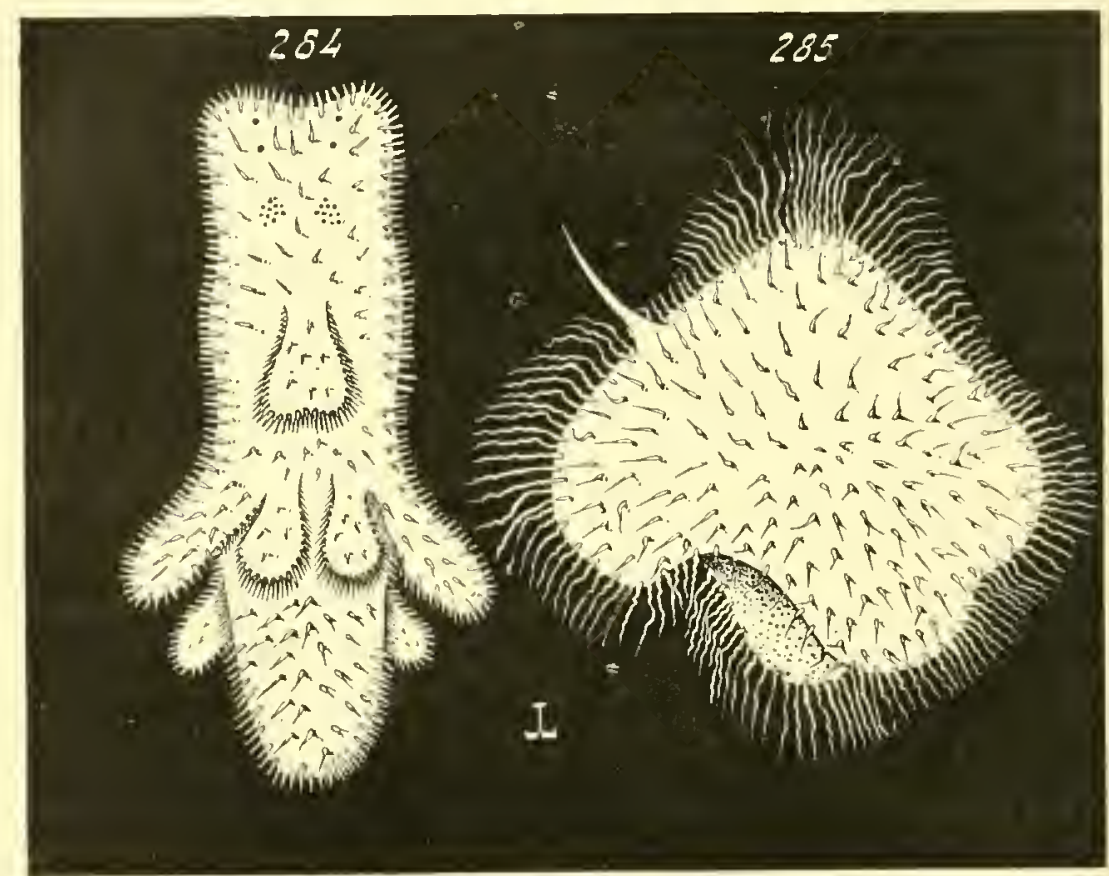

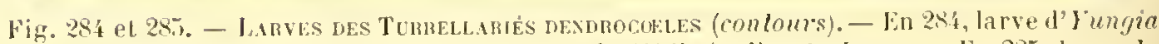
aurantiaca (appartenant au type Jil. larve de Müller); d'après Jang. - En 285, larve de Stylochus pilidium, d'après colle.

ce Lomps, le corps de l'emhryon se converlit en Némerle parlaite. Lorsijue celte évolution est achevéc, le jeune individı est suspendu dans l’intérjeur de sa memlirane ammiotique, à laquelle il ne tient que par les hords de sa bouche; des tiraillements incessants rompent ensuite cetle région le soudure. L’annjos se flélril: le pelil animal le quille, et s'accroît frendant que son enveloppe se létruil. - Il est évilent fu'nne aussi fongue prosistance de l'amnios n’est pas nu phénomène primitif. La larve P'ilidium est une larve secondaire, ì stase, qui lićnéticie de son amuios pour achever son développement, en se servant de hii comme d'un appareil de protection et de locomolion. (Figmes 200 i 232. ) 
III. Trématodes. - Les Trématodes Ectoparasites passent direclement a l'itat adulte, sans oflrir les changements trop considérables dans leur forme extérienre. Le contraire a lien chez les Trématodrs Endoparasites; lenrs métamorphoses sont accompagnées de migrations, c'est-ìdire de passages dans des milieux différents. En outre, ces modifications des Endoparasites se compliquent de phénomènes reproducteurs asexués, tels que la fissiparité el la gemmulation, qui augmentent de beaucoup le nombre des embryons issus d'un senl ouf fécondé.

1. - Le développement libre des Trématoles Ectoparasites est souvent rapide; et les phases larraires sont courtes. Les larves, au moment où elles sortent de l'ouf, possèdent les ébauches de la plupart de leurs organes, et n’ont guère ì acquérir que des rentouses, et des appareils sexuels, pour devenir complètes. Certaines d'entre elles sont pourvues de cils vibratiles, souvent lisposés en couronnes transversales cerclant le corps, qui servent au pelit ètre pour nager.

Parfois, ces types larvaires font complèlement léfaut; le jeune Trématode sort de l'ceuf ì l’élat parfail. Dans certains cas mème, celte éclosion s'effectue, alors que l'ouf n'a pas encore été pondu par son générateur; ce dernier contient alors, dans ses voies sexuelles, le descendant auquel il vient le donner naissance. - Tels sont les Ciyrodactyles, qui offrent jusqư ì trois et mème quatre générations emboiltées les unes dans les autres. Le générateur primorlial produit un seul aetif, qu’il féconde avecses spermatozö̈des; cet cuf évolue de suite pour former un descendant interne. Celui-ci engendre un second descentant, capalıle à son tour d'en fournir un troisième; cela sans que le premier soil expulsé de l’organisme du générateur. Cependant, les rejetons de la seconde el de la troisième généralion ne proviennent pas d'rufs fécondés, car les èlres qui leur donment naissance sont privés d'organes sexuels. Des faits précis manquent à cel égard; les olıservations acruises autorisent à almellre, pourtant, que les blastomères issus de l'ieuf fécoudé ne sont pas tous employés à constiluer le corps du premier descenlant; il en resterait quelques-uns, chargés de sulırenir à la genèse du second, et à celle du troisième. Ce phénomène serait donc en tout semblable í celui que présentent les larves des Trémalodes Endopiarasites.

I. - Il a été indiqué, dans le chapitre précédent, que les emliryous des Endoparasites ynillent, à létat de planule, lenr's membranes protectrices; cette éclosion ne jeut naturellement s'effertuer yque lins l'ean. les memloranes enveloppantes se composent du chorion ovulaire ef de l'amnios; cehi-ci correspond ì l'examnios du Pilidium des Nénertes et des conbryons des Cestodos. La larve, devenue lihre, consiste en 1 u ertonlerme, recouvert de cils viluratiles, yui entoure l'amas des cellules du protendoderme. - Lectoderme ne demenre pas simple; an moment de l'éclosion, et après cet instant, il engendre des éléments, qui se disposent 
en une couche placée au-dessous de lui, et dont quelques-uns vont même se confondre avec les cellules du protendoderme. Ce feuillet s'est ainsi divisé en denx couches, dont l'externe ne va pas tarder ì disparaitre, l"iuterne persistant seule comme ectorlerme définitif. Lassise externe est, en conséquence, l'homologue de l'emlamnios des embryons des Cestodes, et du Pilidium; elle ne se sépare de la larve, dans la plupart des cas, qu'après l'éclosion de celle-ci.

La Jarve, débarrasséc des membranes amnioliques, se compose essentiellement d'un ectoderme et l'un protendorlerme. Sonvent, elle porle, sur sou extrémité antérieure, un aiguillon, nommé rostre, qui l'aide à pŕnétrer dans les tissus d"un animal aqualique, destiné à lui servir "liòte. La plupart des éléments du protendoderme sont arrondis, ou ovalaires, semblables les uns aux autres, et désagrégés; leur ensemble constilue un mésenchyme. Cependant quelques-uns d'entre eux se convertissent en filres musculaires, et se placent sous l'ectoderme. Cette musculature sous-épidermique se dispose sur deux assises : l'une extérienre, formée de fibres dirigíes transversalement; l'autre interne, constiluée par des filıres longitudinales. Souvent ces larves possèdent, en surplus, des ébauches d'appareil excréteur, et des petits ocelles. Les premières sont représentées par leux lubes courts, symctriques, creusés dans le protoplasme des cellules qui les contienuent. Les seconds, au nombre de deux, et juxtaposés, consistent en cellules ectodermiques, dont une part du protoplasme renferme des granulations pigmentaires, et dont l'autre se convertit en une substance transparente.

Sauf les filıes musculaires, et les éléments de l'appareil excréteur, les cellules du protendoderme se ressemblent; il s'ajoute i ces dernières quelques autres cellules originaires de l'ectoderme. - La totalité les hlastomères, cntourés par ce dernier, comprend ainsi ıles éléments empruntés aux trois feuillets blastorlerniques. Elle ne va pas évoluer pour dommer naissance anx organes, mais loit se diviser en plusieurs frarties, véritaliles gemmules, qui deviendront autant de nouveaux emlryons. Ceux-ci percent ensuite l'ectorlerne de leur générateur, et sont capables, soit de se transformer en alultes, soit de présenter encore les mèmes phénomènes de gemmulalion.

Ces faits saccompagnent de clangements d'aspect ef do structure. Cenx des emhryons, qui deviennent dos adultes, ne se multiplient point asuxuellement; comme jls dérivent des premières larves, ils seront désignés par le terme de larves secondaires. Liexpression de larves mimaires sera réservée aux emlıryons qui, se reproduisant par la gemmulation, ne se convertissent point enx-mèmes en adultes. - Les premières larves primaires proviennent directement des oufs fécondés, émis par les généraleurs adulles; le plus souvent, elles donnent naissance, par gemmuIation, à les larves secondaires; mais, parfois, elles engendrent des nonvelles larves primaires le seconde génération. Ce dernier fait peut se renoureler encore; mais finalement, la gemmulation aboutit toujours 
à la genèse de larves secondaires, qui se transforment en adultes. Dans certains cas mime, les premières larves primaires produisent d'antres larves primaires par simple fissiparité, et non par gemmulation. - (Yuel que soit le mode snivi, la larve issue de l'auf fécondé ne se convertit point en adulte, contrairement à ce qu'il en est chez les Trématorles Ectoparasites; elle se multiplie asexuellement et donne ainsi lien ì une

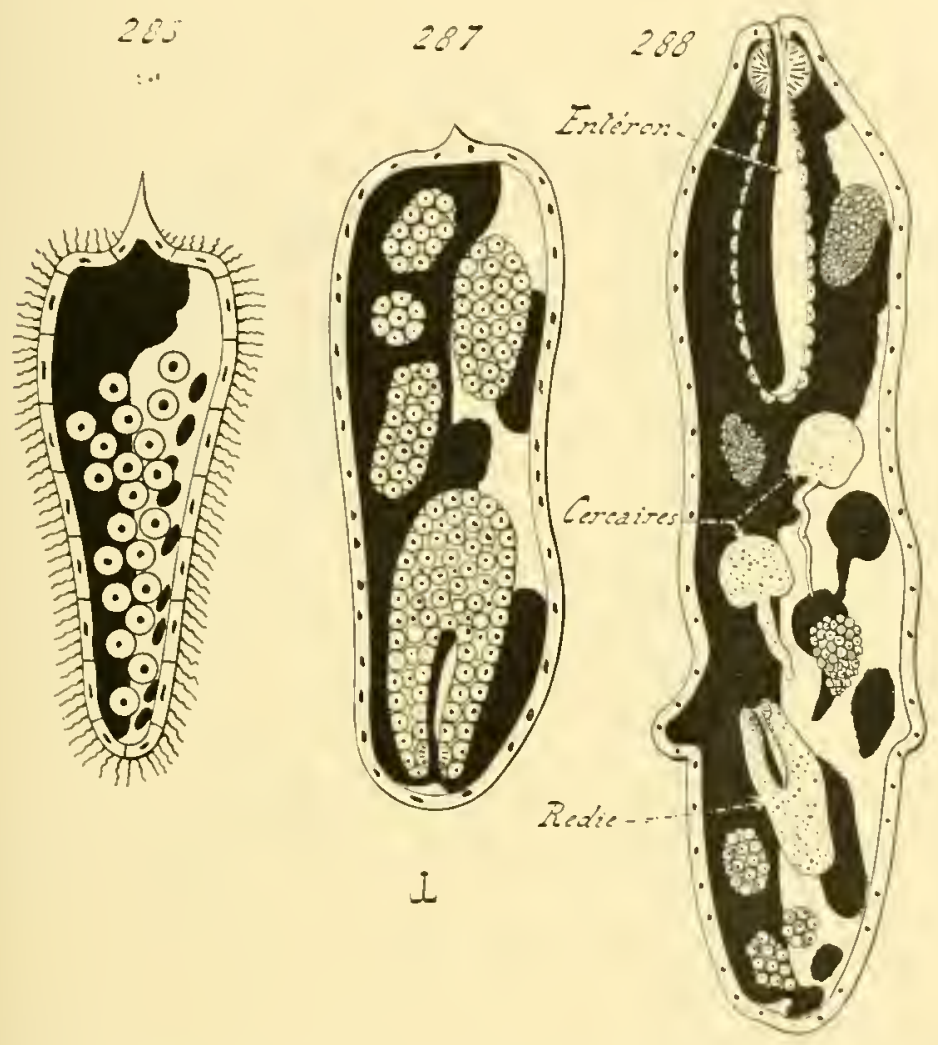

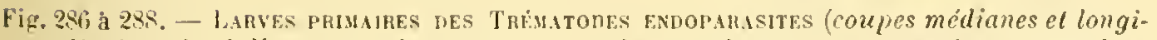
tudinales, demi-diagrammatiques, vues nar la lvanche, avec perspective par ombres portées). - Ë 2sf, jeune larve primaire de première génération, encore libre, nageant au moyen des cils vibratiles dont son ectolerme est rouvert, rt contruant, dans la cavité que cet ectoderme limite, le nombreuses cellules embryonnires non dillèrenciées; sauf en ce qui coneerno le petit entéron, alssent ici, cetto larve n'est autre gue celle de la figure 280, acerue el privèe de son endannıs. - Fon 287, la méme larve. plus ågée, devenue plus graude, est parasite, et convertie en un Sporocysle; ses cellules embryonnaires et internes, plus nombreuses, se rassemblent en gemmules; celles-ci se transforment en larves primaires de seconde generation, pui, fans ce cas farticulier, sont des Rédies. - En 288, une le ces Rédies, devenue indépendante et plus rulumineuse; elle possède un petit enféron dans son extrimiti antérieure, fol foduit, par la gemmulation, tout comme le Sporoeyste dont elle derive, de nouveanx rmbryons, dont les uns sont encore des larves primaires et correspondent à des hédies, et dont les antres sont les larves seeondaires, èest-à-dire des Cereaires.

Cette évolution est celle du Distomum hepalicum. 
allemance de géncíations, ì me hétérogonie hétéromorphe, dont le résultal est d'accroitre le nombre des emlựons émis par un seul génératenr. Celte augnentation concorle avec laulaptation des générateurs à l'endoparasilisme; elle a pour lout de pallier aux pertes inévilables, qui se manifestent parmi les descendants.

C. - La structure des larves primaires se ramene à la disposition snivanto: un ectolerue, représenté par une assise épithéliale simple, entourant un protendoderme, auquel se joignent en surplus quelques éléments ectodermịues. - Ces larves, ainsi constituées, augmentent de volume, lorsqu'elles lrouvent des circonstances favorahles à leur développement; mais elles ne moditient point leur aspert extérienr, qui est à peu près celui d'un cylindre. L'ectoderme accoil sa surface pour suive cel agrandissement, et composer toujours une membrane externe continue; mais non le protendoderme. - Celui-ci, tont en multipliant le chiffre de ses éléments, ne suit pas l'augmentation. et des vides lle plus en plus grands se creusent enlre lui et l'ectorlerme; il se divise lui-mème en plusieurs parties, quo le nouveaux espaces libres séprarent les mnes des autres. Finalement, lorsque cette évolution est bien dessinée, la tarve primaire se trouve changre en un sac, dont la paroi est forméc par l'ectoderme, et dont la cavité contient les fragments lu jrotendoderme désagrégé. - Chacun de ces fragments devient un nonvel embryon, et se compose simptement d'un amas cellulaire. Parmi les éléments de ce dernier, les uns dérivent de l'ectoderme, les autres du protendoderme, de sorte que les leux lenillets hlastodermiques primordiaux sont représentés.

La genèse de ces ombryons de seconde génération est une véritable gemmulation. Certains autenrs la font cependant rentrer dans les cas de gemmiparité, en admeltant qu’il se produit, dans l'intérienr de la larve, des bonrgeons capables de se convertir en embryons. Isa deseription frécédente montre qu’il n'en esl pas ainsi.

Les larves primaires des Trématorles Endoparasites apparlienment à deux formes, dont l'une est nouméc Sporocyste, et la seconde Rédie. Cette dernière est caractérisée par une utilisation spéciale de plusieurs des cellules du prolendoderme, qui ébauchent un rudinent d'intestin, destiné à disparaître. l'ar contre, tous les éléments dn urotendodermedes Sporocystes sont employés a produire des embryons; el ancun d'eux ne sert à laçonner un pelit intestin. Ponrlant, cerlains Sporocystes possèdent, dans la region antrieme le leur corps, une massegranulense, que l'on assinile a me ébauche iutestinale.

Ces larves sont parfois capahles de se reproduire an moyen de la fissifraté; elles domnent alors naissance à de nouveaux alpés semblables à elles, à des tarves primaires. l'arfois anssi, leurs gremmules se converlissent en larves primaires, el non en larves secondaires. Pourlant, dans lous les cas, et après un chiffre restreint de générations, les embryons 
foumis en dernier lieu se convertissent fous en larves secontaires; l'apparition de ces deruieres est, en rffet, le lut de colle reproduction asexuelle.

Cette série de phénomines n'est pas uniforme chez tous les Trémitodes Endoparasites. Elle comporte un certain nombre de cas distincls,
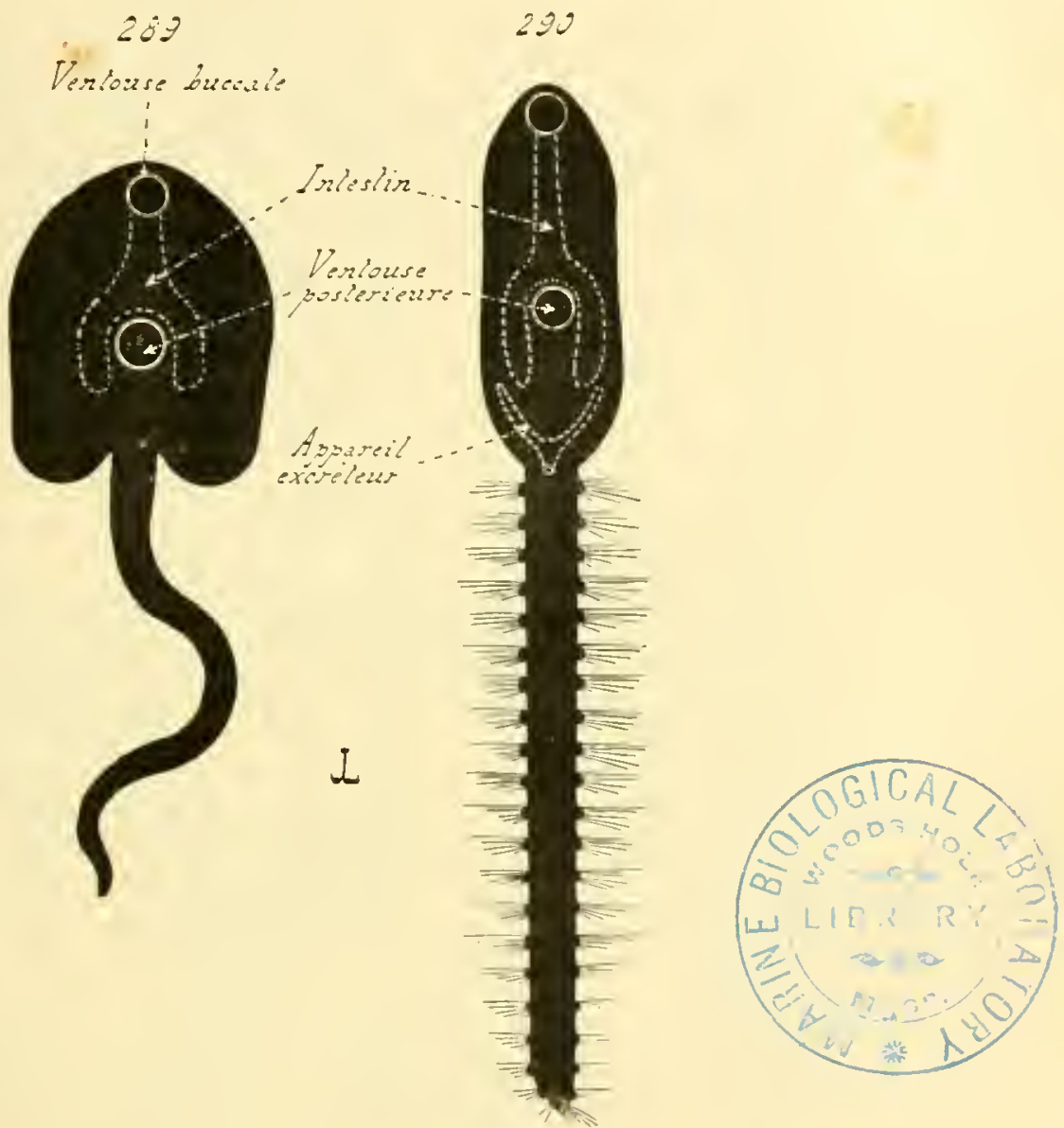

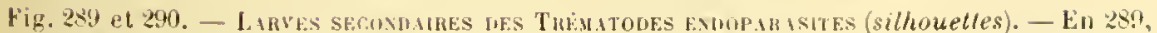
Cereaire du type de reux qui ont la quene incrme, e'est-a-dim lisse : cercairedu Distomum hepalicum. - En żh, Ceratire du type de ceux qui ont la queue armèe, èt-à-dire lérissée de soies : Cercuriu setiferu, il après les recherehes de libu.

dont les différences tiennent au nomlre des générations successives de larves primaires, et an chiffre des embryons produits par chaque générateur. - Sourent, il n’existr qu'une seule génération de ces larres, dont les gemmules deviennent directement des embryous secondaires. 
Plus rarement, deux ou trois de ces générations se succèdent. Ce cas prète mème à liverses variétés secondaires, suivant que les premiers sporocystes engendrent de nouveanx Sporocystes, on hien que les premières Rédies donnent naissance à de nouvelles Rédies, on encore que les premiers Sporocystes produisent des Rédies. Ce lernier phénomène est offert par le Distomum hépaticum. - Sans doute, le nombre des générations n'est point fixe, ni déterminé, chez les embryous d'une mème espèce; il est placé sous la lépendance des circonstances extérieures, et surtout des facilités d'alimentation, en ce sens que les larves primaires, ayant trouvé des circonstances favorables à leur développement, engendrent des embryons secondaires, alors qu'elles sedésorganisent et meurent, après avoir produit de nouvelles larves primaires plus viraces, dans le cas où ces circonstances favorables n’ont pas été rencontrées. D'ordinaire, chaque générateur contient un assez grand nombre de gemmules, à divers élats de développement, qui deviendront de nouveaux embryons; ce nombre nest jamais fixe. Pourtant, chez certaines espèces du genre Monostomum, le générateur ne produit qu’un seul descendant; celui-ci se lıorne à se délıarasser de l'ectoderme du premier, pour devenir libre et indépendant. Ce cas, le plus simple de cenx offerts par les Trématodes Endoparasites, est sans donte primitif; les autres en dérivent par la division du descendant unique en fragments, qui représentent autant de nouvelles gemmules.

L'émission des embryons par leur générateur se produit de deux manières: ou bien l'ectoderme de ce générateur se brise, ou bien il se perce, an préalalle, d'un orifice par lequel sortent les emliryons. Le premier cas est celui des Sporocystes, le second celui de la plupart des Rédies.

D. - Les larves secondaires sont nommées des Cercaires. Leur structure est plus complexe que celle des larves primaires. Toutes les cellules le leur corps sont employées á créer des organes, et non à engendrer des embryons. In tube iligestif, des centres nerveux et des organes

Fig. 291 à 296. - Jivolution nu crsticenoue (silhouelles avec perspectives par ambres portées; la figure 291 exprime un contour extérieur; les figures 292-296 remésentent des coupes medianes demi-diagrammatiques, vues par la (ranchc). - En 291, jeune embryon hexacanthe, Jéponille de ses envelopjes, et faisant suite i celui de la figul'e 283 , avec cette rẻserve que ce derniel s’aplinue à un bothriocéphale. - En 202, le mème coupé, et montrant sa structure compacte. - lin 293, début de la déjression (cavité cystique), qui, en s'amplifiant, donne à l'embryon l'aspect d'une sphère ereuse; une autre cavité, la cavite vésieulaire, indépendante du dehors, se pere également dans l'organisme. Fn 294, res deux espaces augmentent leurs dimensions; la tẻte se faconne au fond de l'invagination rystique. - lin 395 , amplifiration des parties; la cavité vésiculaire divise en deux lames la paroi le la eavité cystique; celle-ci contient le métasome replié sur lui-même, e'est-â-dire la zone embryonnaire qui seule deviendra le corps de l'adulte; celte phase est celle de jeune Scolex. - En 296, des circonstances favorables permettant la suite de l’évolution, le métasome se dévagine, grảce à la présence de la cavití vésiculaire, qui pernet à la lame interne de la paroi cyslique de se soulever en delors de la lame externe. Cette phase est celle de Scolex dévaginè; la vésicule, qui abritait le métasome, va se détruire, el le métasome seul donne l'individu parfait. 


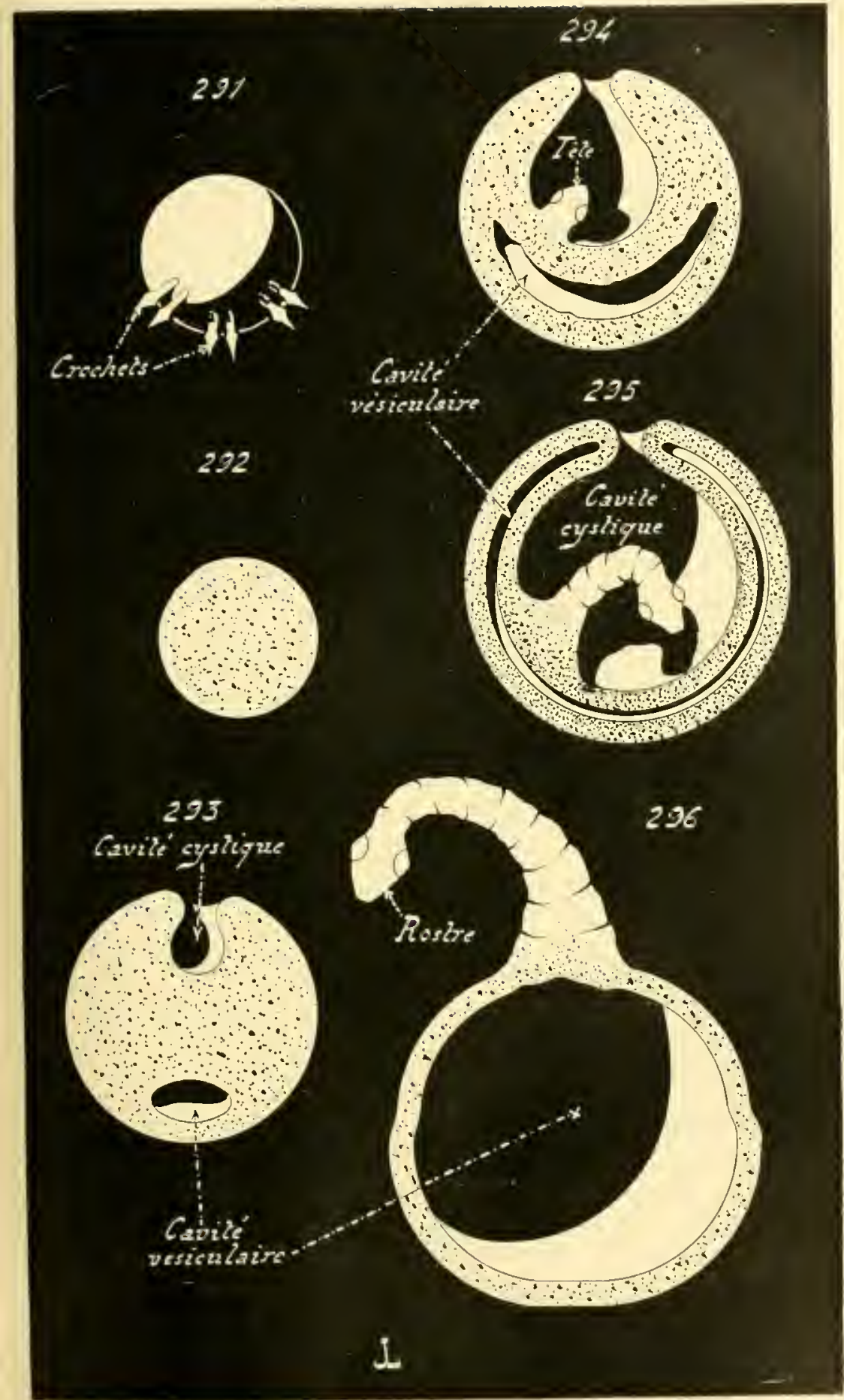


des sens, des canaux excréteurs, s'ébauchent et se romplètent; puis, le jenne embryon perce l'ectorlerme de son ginératenr, et se tronve libre. It se déplace it l'aile l’une longure expansion, placée dans la région postérieme de son corps, at semblable à une quene: d'où son nom. II conserve cel appendice jusqu'au moment où il achève ses migrations, cest-à-dire oì il parvient dans le corps d'un animal capalıle de lui servir d'hòte diffuitif. Il perd alors sa quene, acyuiert des organes sexuels, et arrive à l'état aılulte.

IV. Cestodes. - Le développement des emhryons des Cestodes rappelle son correspomlant des Trématodes, on ce sens qu il s’accompagne de migrations, le transports d'un hite dans un antre; mais il ne se complinue point, sauf dans to cas offert par les larves de divers Téniadés (Tenia echinococcus par exemple), de phénomènes de multiplication asexuelle. - Les observations acquises il ret égarl portent presque toutes sur les Cestorles supérieurs, c’est-à-dire sur les représenlants des fanilles des Bothriocéphalidés et des T'eniadés, principalement sur ces derniers. Aussi les autenrs, se hasant sur elles, accordeul-ils aux Cestodes une évolution tròs compliquée, en tant que changements subis par les embryons dans lenr forme. Il est possilile, en rapprochant les faits commus sur le développement les Bothrioréphahilés, et des formes voisines, de cenx donnés par l'étude des Cestorles inlérienrs, de concevoir, aver plus de prócision, l'embryogénie le ces ètres.

Les emhryons des Cestodes rommencent, dans l'intérieur du chorion, a faconner leurs premieres ébauches, et à prohuire leurs envoloppes amniotiques; ils sont enx-mèmes constitués par un amas de cellules protendorlerminues, 'fue limite un ectoderme. Les liolliriocéphalidés, et sans doute aussi les Cestodes inférieurs, subissent alors mne phase larvaire libre, qui s'effectue lans l'eau. l'embryon perce son chorion, et l'examnios; reconvert par l'endamnios, qui est muni de cils viluraliles et sert d'organe prolecteur et locomoteur, il se déplace, jusqu’a ce fưil rencontre des circonstances favorables pour continner son développement. Les Ténialés ne présentent pas de telles phases libres; ils nahandonnent leur amnios, avec leur chorion, que dans le cas où les milieux extérieurs permettent la suite de l'évolution. Pour les T'éniadés comme pour les Bothriocéphalidés, res circonstances favorables consistent en la rencontre l'un loòte, que l'embryon puisse habiter en parasile.

Au moment oi l'emloryon se déharrasse de ses enveloppes amniotiques, il se comprose toujours d'un protendoderme compact qu'entoure l'ectoderme, mais cet ectoderme porte en plus des crochets, qui servent i l'animal pour perforer les tissus de son hòte. Cet embryon mérite ainsi le nom de laree acanthophore: suivant les types, il possède quatre ou six crochets, d'ou les expressions plus spéciales d'embryon tétracunthe ot dembryon hexucunthe; celte dernière forme est plus répantue rue la première. Les crochets sont disposés en me couronne, qui entoure 
l'extrémité postérienre du corps, el non l’antérieure, contrairement à l'assertion de la plupart des autenrs.

Les Cestodes les plus simples, appartenant an genre Arehigetes, ne poussent pas plus loịn leur développement, el en restent à la phase acanthophore. L’extrémité, opposée à celle qui porte les crochets. sallonge, se convertit en une petile lète suivie d'un cou, et représente ainsi la région antérieure du corps. Comme les autres Cestodes parviennent à une complexilé organique plus grande, caractérisée surtout par l'allongement de l'individu, et par l'augmentation en nombre des glandes sexuelles, il est permisde prendre les Archigetes comme des Cestodes primitifs, équivalant aux phases embryonnaires des Cestodes supérieurs.

Meltant les Archigetes à part, et sans doute aussi les Amphilimidés qui les tonchent de prés, les autres Cestorles, sauf les Téniadés, offrent. après l'état de la larve acanthophore, une autre lisposilion, désig̨née par le nom de phase de l'embryon plérocerque. Les crochels tombent et disparaissent, pendant que la région antérienre s'effile en un cou surmonté d'une pelile lète; puis l'extrémité postéricure, antrefois munie de crochels, sallonge chez les Bothriocéphales en restant compacte, ou bien se convertil, rhez les Tétrarhynques. en une masse ovalaire volumineuse. Sous cette forme, les embryons sont situés dans les tissus de leur hote. Leur tìte est susceptible de se díplacer dans tous les sens, de se contracter, ou mème de s'invaginer dans me dépression qui se creuse en arrière et aulour d'elle. Celte invagination, passagère ici et peu étentue, devient rolumincuse el persistante ehez les Téniadés.

Les embryons des Téniadés passent d'ahort par la phase hexacanthe; les erochets tombent ensuite, mais la région antérieure ne se convertit point en un cou surmonté d'une tète. Cette zone se déprime, et s“invagine peu à peu dans l'extrémité postérieure du corps; la larve, ovalaire en premier lieu, se transforme ainsi on une vésicule, ear la cavilé ıle l'inragination devient fort grande, et cesse mème souvent, par le rapprochement des lèvres de son orifice, de communiquer avee le dehors. Cette larve des Ténias, qui habite en parasile les tissus d'un hòte, el offre l'aspect d'une vésicule creuse, est nommée, par cela mème, Cysticerque; son organisme se réluit ì une paroi, yui entoure une carité. - La face interne de la paroi donne ensuite naissance, par la prolifération d'une de ses parties, an con et à la tête; ces dermiers grandissent beaucoup dans la plupart des eas, et occupent la cavité entière. L'embryon vésiculaire, ainsi pourvu d'une tète et d'un cou internes, est lésigné par l'expression de S'colex. - Pnis, si les migrations s'accomplissent il souhait, si les circonstances favorables ne font point défaut an petit ètre, la parni de la vésicule se flétrit, la lète et le rou passent an travers d'elle pour se rendre libres, le deviennent efleclivement, el donnent en se développant l'organisme délinitif. La vésicule ne joue plus auem ròle, et s'atrophice. 
Il est bien évident que la forme larvaire, dite cysticerque, dérive du plerocerrue par l'accroissement, et par l'importance plins grande, de l'invagination on la tète s'alırite. Seulement, la tète prend naissance après l'invagination, contrairement à ce qui derrait se passer si la chronologie évolutive était conservée. Il ne faut pas cependant attribuer une valeur exagérée à ce déplacement des dates d'apparition, qui résulte de la

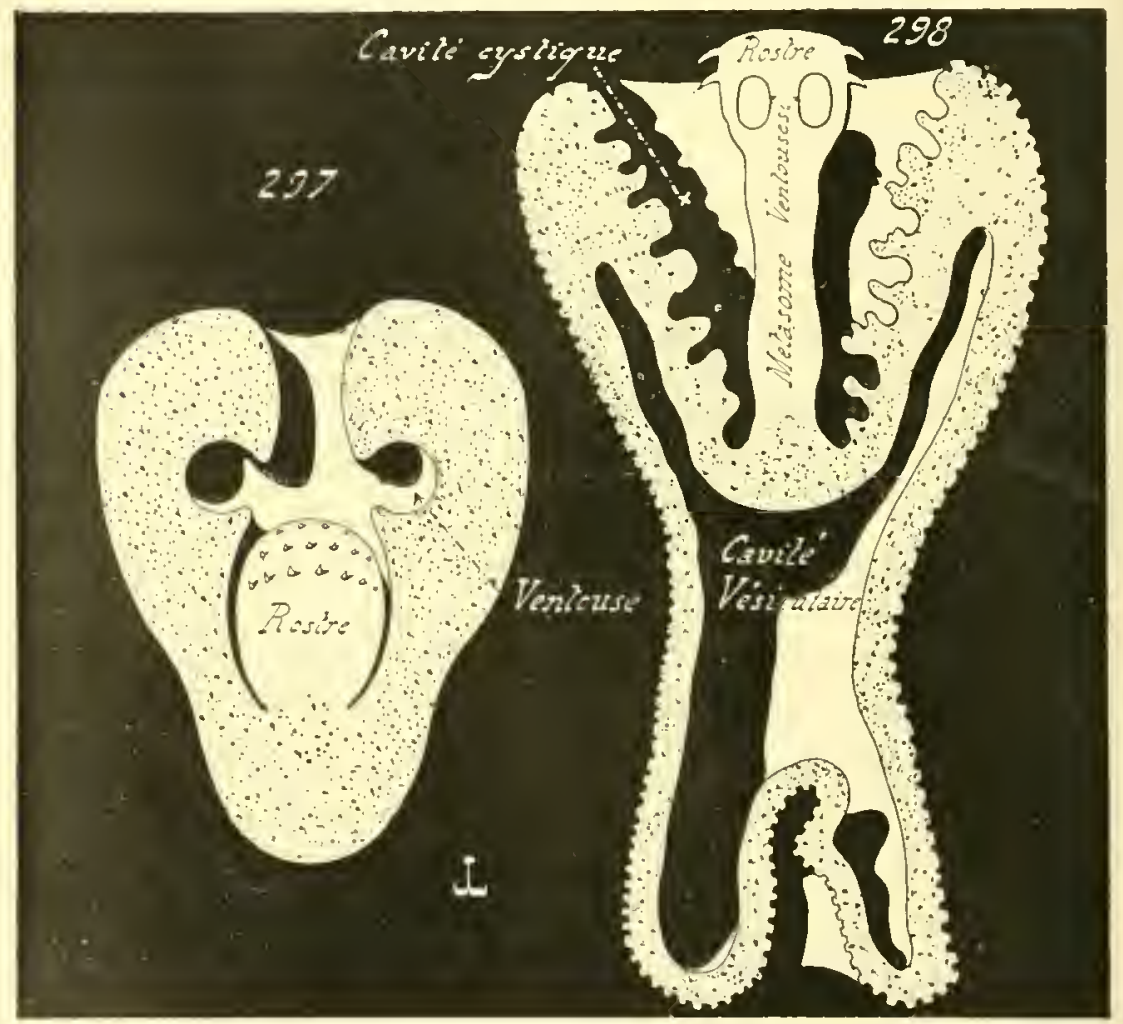

Fig. 297 et 298. - Trpes nf crstuchuoes (coupes médianes et longitudinales, vues par la tranche, avec perspective par ombre portée). - En $20 \%$, eysticerque lu type des cysticer. coüles, dont la rête est invaginèe sur elle-même, en ne laissant saillir que le rostre, et Jont les cavités sont absentes : cysticerıue du Tonia cucumerina, d’après les recherches faites par Leuckart. - En 298 , cysticerque vrai, avec tẻte en plact, Inng mẻtasome et cavites: cysticerque th Tenia serrata, d'après les recherches faites par Moniez. La moitiẻ infiricure de ce Gysticerıue, nommé souvent Cysticercus pisiformis, s'atrophie dans le cours de l'evolution.

condensation du développement; souvent, dans ce cas, un fait tardif, aefuérant une certaine préfondérance, devient plus précoce; les exemples de celte accélération sont très fréquents, et tel est ici le cas. - Partant, la genèse de la tête dans la cavité du Cysticerque est strictement homologue à celle du mème organe chez les larves plérocerques. 
Elle correspond à lallongement de la région antérieure du corps, qui s'effectue au fond d'une dépression au lieu d'ètre extérieure; et on ne peut, en conséquence, Ja considérer comme représentant un bourgeonnement.

\section{5. - Reproduction asexuée et alternance des générations.}

1. Étude générale. - Parmi tous les Plathelminthes, les Trématodes Endoparasites présentent le plus souvent des phénomènes de reproduction asexuée. Pourtant, divers Turbellariés Rhabdocœles et certains Cestodes se multiplient par des moyens analogues. Les procédés, observés chez ces animaux, se rapportent à la fissiparité, à la gemmiparité, et à la gemmulation.

Fissipanite. - La reproduction par fissiparité a été observée chez plusicurs Rhabdocceles, et chez un petit nombre de Trématodes. Ians ce dernier cas, elle est fort rare, et se manifeste seulement sur les larves primaires, notamment sur les Sporocystes. Ces embryons se partagent parfois en deux segments, qui se séparent l'un de l'autre, se complètent, et sont également capables d'engendrer, par gemmulation, de nouvelles larves primaires ou des larves secondaires. - La fissiparité des Rhabdoceles s'exerce sur les adultes, et non sur les jeunes; les Catenula et les Microstomum sont les seuls à la présenter. Les générateur's et les descendants restent unis les uns aux autres par leurs extrémités, et s'assemblent en une colonie linéaire. Comme la fissiparité alterne, chez ces animanx, a vec la reproduction sexnelle, comme, en outre, générateurs et descendants ont mème forme et mème structure, l'alternance est ici une métagenèse holomorphe. (Figures 299 ì 304.)

Genmiratì. - La gemmiparité véritable n’a guère été signalée, parmi les Plathelminthes, que chez les embryons des Tarnia échinococcus et ccenurus; elle se manifeste, alors que ces embryons sont parvenus à la phase de Cysticerque, et vivent dans les lissus d'un hôte leur offrant une nutrition surabondante. Ces Cysticerques gremmipares sont désignés par les expressions d'Échinocoques et d'Hydatides, en ce qui concerne les embryons du Tonia echinococcus, et par celles de Cénures pour les jeunes Ju Tonia ccenurus.

Le Tenia echinococcus adulte vit dans l'intestin du Chien; son cysticerque particulier habite les tissus des Mammifères herbivores ou omnivores, et parfois mème ceux des Oiseaux. L'Echinocoque ne se borne pas à prodnire une senle tête, comme il en est chez les autres Téniadés; il en engendre un nombre souvent fort grand. Sa paroi se compose de deux couches : l'une externe, épaisse, de nature cuticulaire, dite membrane hydatique; l'autre interne, plus mince, de structure peu connue 
encore, el nonumée par les auteurs la membrane germinale. Celle-ci est la parlie vivante de l'èlre; elle émet plusienrs hourgeons; chaque bourgeon correspond i une prolifération hoale de la membrane, et se convertil, par son accuissument, en une vésicule creuse. Ces résicules, dites vésicules proligires, se composent d'une paroi, qui limile une cavité
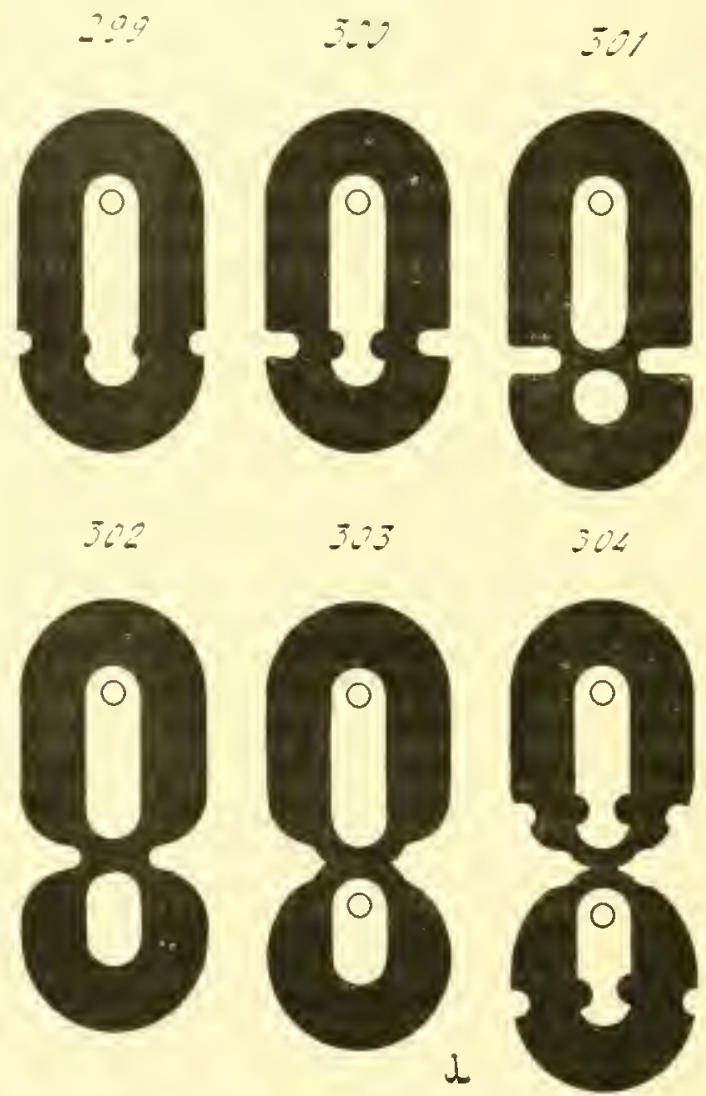

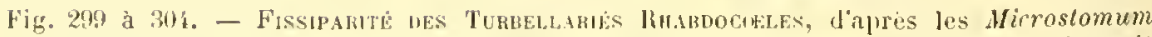
(diagrammes en silhumelles: le noir indigue les tissus, le blant l'intestin, et le petit

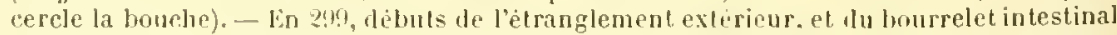
correspontant. - lin 300 t.t 301 , ces phinomènes s'accentuent, et aloulissent it la genèse d'un petit segment postèrieur, muni a’un intestin indipenilant. - En 302, ee segment rèqularise son aspert, et se convertit en un individu, qui demeure adhérent à son génèrateur. - En 303, le descrndant complète son organisme. En 30 , le descendant étant devenu identiufue a son gèuéraleur, tous deux subissent de nouvelles divisions.

centrale; elles proluisoul, sur la fiten interne de celle paroi, et suivant nu procédé analogue i relui ollert jar la membrane germinale, des bourgreous deslinés à se transformer cu tètes. Chacune de ces vésicules est rapable d'engendrer ainsi, en moyenne, lix ì quinze tètes qui, placées 
dans des conditions favorables, peuvent se développer rn autant d’indivjdus parfails. Parfois, de nouvelles résicules, les vésicules secondaires, maissent, non pas sur la face interne de la paroi de l'bchinocoque, mais dans son épaissenr; elles évoluent comme dans le cas précédent, et parriennent, en s'accroissant el traversant à mesure la substance de celle paroi, soil dans la cavilé mène de l'Echinocorue, soit cu dehors de ce dernier, el dans les tissus de l'hóte (Figure 30弓̈).

Ce phénomène de reproduction asexuclle rentre, selon loute évidence, daus les cas de gemmiparité; on doit le considérer comme une exagération du fait habiluel, qui se borne à la production d"une seule tête. Cetle gemmiparilé est interne; ce fait résulte de la disposition propre aux Cysticerques. Pour la bien comprendre, il faudrait supposer lembryon dévaginé, de manière à rappeler les larves plérocerques, et porlant les vésicules proligères appendues à son corps comme antant de petils bourgeons extérienrs. - L'alternance des gémérations des T'enia échinococcus est une mélagenèse hétéromorphe.

Le Tonia canurus adulte habite, comme le précédent, l'intestin du Chien. Son cysticerque ra se loger dans les centres nerveux des Mammifères herlivores, du . Houton de préférence, el cause la maladie nommée le tournis. La gemmiparité de cet embryon est moins connue encore que celle de l'Lchinocoque, dont on ne sait que les phénomènes exlérienrs; elle parait consister senlement en la production, sur la paroi interne du Cénure, de nombreuses tètes, dont le chiffre peut alteindre 400 et 500 .

Gennulation. - Ce procédé reproduclenr est propre anx Trématodes; il n'existe que chez les embryons. Sa manifestation la plus simple semble etre offerte par les Ciyroductylides, en ce sens que les blastomères, fournis par l'auf fécondé, ne sont pas tous chargés de former le lescendant; cerlains d'entre eux sont réservés pour engendrer un ou plusieurs autres individns. Les Trématodes Endoparasites le présentent d'une manière constante; leurs larves primajes, Sporocystes el Rúlies, partagent en fragments l'amas des cellules placées en dedans de leur retoderme, et chacune de ces parcelles se développe en mn nourel itre. Ces phénomines, examinés phus longuement dans le précédent paragraphe, doivent ètre placés parmi les cas le gemmulation. - Lallernance des générations est ici une métagenèse hétéronorpho.

II. Segmentation du corps des Cestodes. - La plupart des anciens auteurs admettaient, et plusicurs naturalistes molernes sont encore de cette opinion, que lorganisme alulte des Cestodes supérienrs ne correspond pas à un seul individu, mais représente une colonie. Le corps de ces animaux est, en eflet, divisé en anneanx, nommés proglottis, sonvent fort nombreux, dont les dernjers, les plus éloignés de la tèle d les plus àgés, sont capables de se dólacher de ronx qui les précidrnt, el de devenin libres. Dans l'esprit de celte théorie, chaque anneau cst un indiviln complet; l'organisme enlier se trouve ainsi constilué par 
me scerie d’individus placés les mo derriire les autres; cette forme de colonie linéaire a reçu le nom ile strobile.

La comparaison los Cestorlos inférieurs aux supricurs, romme l'utude approfondie le l'érolution embryonnaire subie par ces animaux, emperlie l'accepter celte manière de juger les choses. - Le corjs des Cestonles inférionrs, lles Archigetes, des Amphilinu, reste simple, el ne se divise nullemenl en anmaux. Las Liwnles sunt smples éralement; mais lenrs glandes génitales sont nombruses, et composent plusicurs yroupes sexuels, placís a la file les uns derlicre les autres. Chaque groupe, à cause de ses dimensions, souleve à son nivean la paroi du corps, el produit une bosselure. Les Ligules arbltes ofrent donc une série de nodosités, mmmençant rn arrière de la tète, el s'olembat jusqu'à l'extrémilé postérienre de l'oranisme; refle disposition est la première ébanche de la division en anneaux. - II sultit de supposolphus poofonds los étranglements, placés entro les bosselures ues groupes sexuels, ponr olitenir la seission en proglotlis. Cotte dernière est déjà assez prononcéc cher les Bothriocéphales, bien que peu nette encore; clle atleint sa plus grande extension dans le rorjus les Téniadés. - Les annean sont mis les uns aux autres, contionnent dans leur intérime les groupes sexuels, et grandissent à mesure que ces derniers saccroissent et éroluent. Ceux qui, pami eux, sont situés dans la région postérieure de l’animal, renforment des glandes sexuelles atrophiées, dout les fonetions sont accomplies; ils se honucut à ètre sentement des sacs pleins d'unfs fúcondés. Aussi se dubrhent-ils de limlivilu aupued ils appartienment, afu de remplir leur dernier róle, qui esl d'entrainer, hors du corps de l'hôte, ces unfs fécomulís.

Il ne s’agil donc ici. ni l'me fissiparité incomplète aboutissant à la genese d'une colonie linéane, ni l’une allernance de générations. L’organisme d'un Cestode supérienr est simple, comme celui d'un Cestode inférienr; il représentr un senl individu. Tous ces phénomenes se raduisent à une multiplication les glandes sexuelles, deslinéc ả augumenter, d'une facon corrélative, le chiflie des wufs pondus par le même òtre.

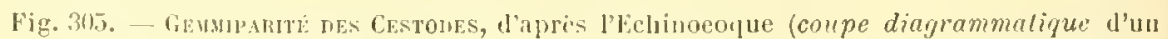

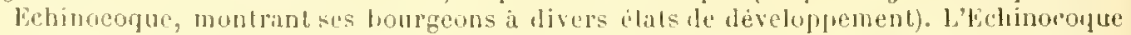
se compose d'unc paroj, limilant une viste cavite ois evoluent les lourgeons; la paroi est formée jar une culieule, dile membrane hydalique, el par une assise organisee, la membrane gominale, designce par erreur sous le nom de membrane proligire. - La moilie sumerieure de la figure est consacre à l'cvolution des bourgeous pui naissent sur la face interue de la membrane germinale; ces bourgeons sont désigués par la lettre 1. Lin $A^{1}$, apparition du bourgeon; en $\Lambda^{2}$, il grandit; en $\Lambda^{3}$, il est devenu une vésicule proligère, "jui lourgeonne des tôtes sur sa paroi interne, ou bien engenulre de nouvelles vésicules proligeres; en $\mathbf{A}^{4}$, les lites grandissınt, et finissent far devenir lilres dans la

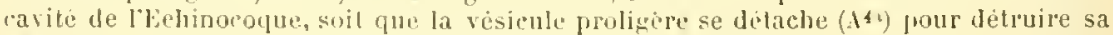
fraroi par la suite, soil qu’elle demenre en place $\left(A^{5}\right)$, sa paroi se detruisant, et les létes se trouvant mises en liberté $\left(\boldsymbol{A}^{*}{ }^{*}\right)$. - la moilié inferieure de la figure est consacrie a l'evolution des bourgcons, 'pui naissent dans l'epaisseur de la paroi de l'Echinoenue; cos hourgeons, drigignes par la lette B, evoluent comme les prédents, et deviennent des vésicules proligures, nommces, Hans ee cas parliculier, des vésicules serondaires. 


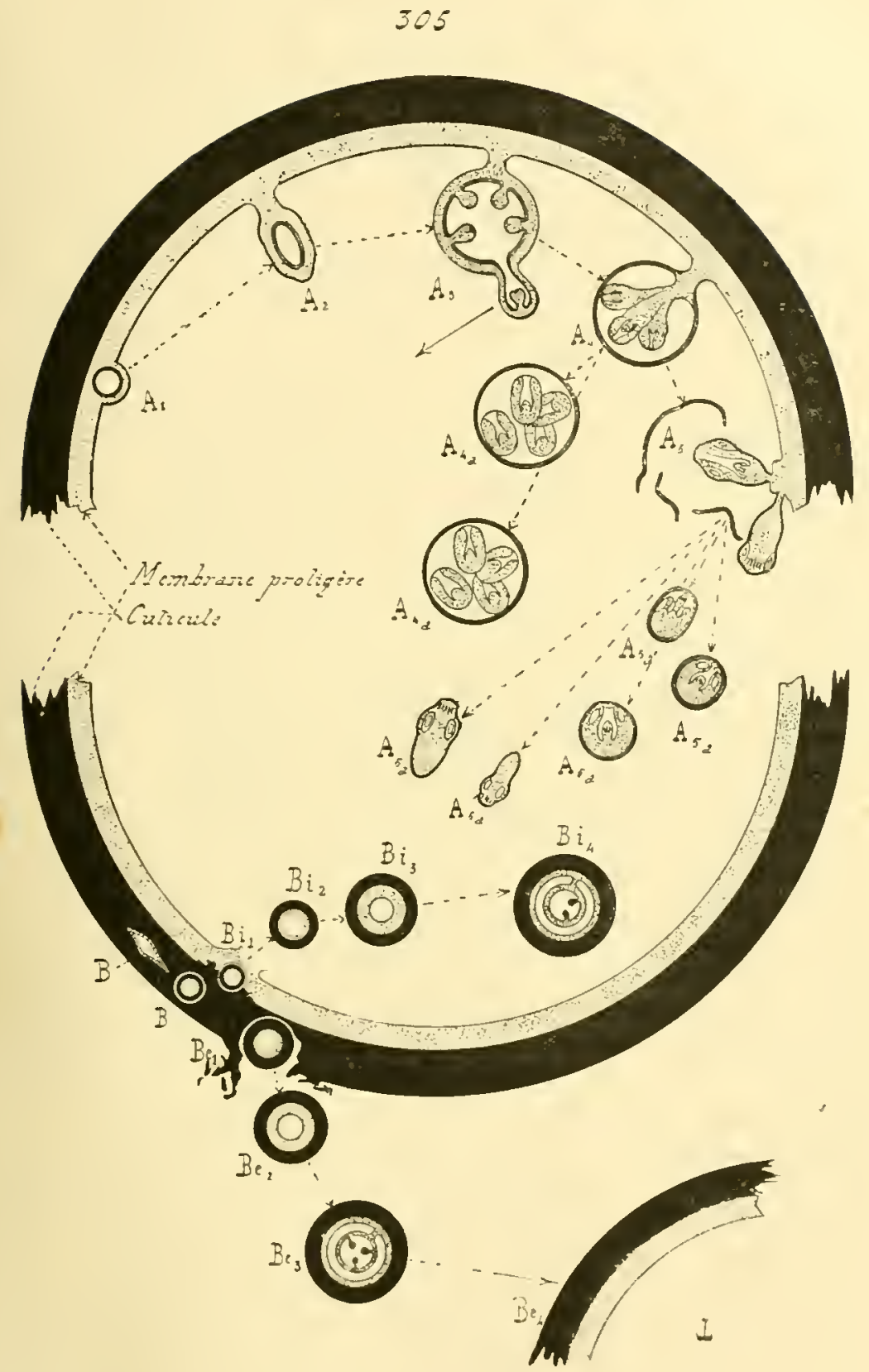

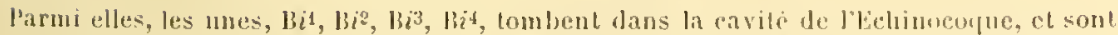

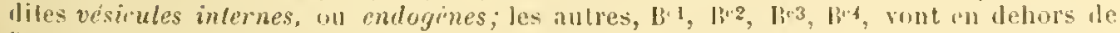
l'lichinocorjue (vesicules externes, ou exogénes), el, s'amplifiant heanenup, leviennut semblables a liour genisaluus. 
- Il ne faut pas onblier pur les Cestodes sont des animaux endoparasites; que leurs emlryous effectuent des migrations complexes, an cours desquelles ils s'égarent soureut; ‘ue, jar suite, la nécessité s"impose d'avoir des embrons nombreux. Les Cestodes parviennent à ce lut en accroissant leurs groupes de glandes génitales; les Trématodes Endoparasites y arrivent par la genmulation de leurs larves, qui augmente le rhiffre des embryous issus d’un seul and. Le résultat est te mîme; les moyens seuls diffirent, et l'ojposition entre res moyens suivis, pour arriver à une uème fin. est fort intéressante à constater.

\section{\&6. - Migrations embryonnaires.}

I. Considérations générales. - Il faut entendre, par l'expression "migration d'un ètre ", son transport d'un milieu dans un aulre. Lorsque la larve el l'adulte d'un être labitent les mêmes localités, il liexiste ancune migration, et cest le cas de lieanconp l'animanx; mais si les larves vivent dans des endroits différents de ceux uccupés par les adultes, il est nécessaire que les premières accomplissent des migrations. Cette obligation est surtont le fait des Lindoparasites. Les aufs pondus par ces derniers ne trouvent point sur place, d'ordinare, les circonstances favorablesà leur développement. Il faut que les embryons aillent les chercher ailleurs, et qu'ils retournent, ensuite, dans un milien semblable à celui qu'habite leur générateur. Les migrations présentent alors une certaine complexilé, atténnée le plus sonvent par nne tolérance assez grande, permettant anx larves de vivre, et d'évoluer, mème dans le cas où les conditions extéricures ne sont pas fout a fait relles qu'il leur faudrait.

Les migrations sont d'ordinaire passives, el indépendantes des cmbryons; aussi, beanconp de ces terniers n'arrivent-ils jamais à les accomplir toutes. Elles sont réalisces le plus sonvent par les hòtes emxmèmes; ceux-ci puisent lenr nouriture lans les milienx environnants, el, si ces milieux contiennent des larves caprahles de vive en parasites dans leur organisme, ers larres ne sont pas digérées, et continuent à exister. Les relations de mangeurs it mangés constituent done, chez les hotes, le factenr principal des migrations de leurs parasites.

Cus transports sont déterminés dans un certain sens, et s'accomplissent suivant une markhe précise, hors de laquelle le parasite dévoyé ne peut plus se développer, et menrt. D'ordinaire, me espèce donnée de Plathelminthe prasite vit it l'état aluite dans le corps d'un hòte donné, et sous forme de larve dans un milieu également donné et invariable. - II ne faudrait pas, cependanl, concevoir cette surcession de phénomènes comme inflexille, comme répondant ì une condition rigoureusement nécessaire; la plasticité du parasite est assez grande pour lui permethe d'habiter, au moins ả l'ótat d'embryon, l'organisme d'hôtes appartenant ì des especes voisines de celle qui serait pour lui la mejlleure. La tolérance á cet égard s'étend sonvent à l'ordre, el mème 
parfois aux ordres voisins. Ainsi le Tenia médiocrnellata qui, adulte, habite l'intestin de l'llomme, est capahle de vive, à l'état larvaire, dans les tissus de la plupart des liaminants; de même encore, le Tccmin echimococcus, adulte dans l’intestin du Chien, vil et se téveloppe, sous sa forme embrronnaire d'hydatile, tont aussi hien dans les viscères de l'Ilomme que dans ceux du Monton. - Mais si la tolérance des larves est assez grande pour leur permettre de conserrer leur vitalité, bien que placées dans des milieux assez différents les uns des autres, il n’en est pas moins vrai que la migralion dernière, celle qui amène le parasite dans son hòte définitif, est rigonreusement déterninée, en re sens qu'elle est subordonnće au mode d'alimentation le ce dernier. Ainsi, ceux des embryons du Tcenia echinococcus, qui parriennent dans un hôte humain, se perfectionnent tont aussi bien, et mème micux, quc ceux établis, par le hasard des migrations, dans le corps d'un Houton; et cependant ces derniers seuls ont des chances d'arriver à l'état adulte, cn pénétrant dans lintestin d'un Chien, car il est assez fréquent que des chiens mangent de la chair de mouton infestée, alor's qu'il faudrait un concours de circonstances extraordinaires, pour que des chiens viennent à se nonrir de la chair d'un homme porteur d'hydatides.

Dans les descriptions suivantes, l'ètre labilé par l'adulte sera nommé lhòte définitif. Il appartient d'ordinaire à une espèce déterminée pour chaque parasite. Cependant la tolérance, assez large, s’applique non seulement aux especes les plus proches, mais encore aux genres et anx ordres roisins: tel est, par exemple, le Distomum hépaticum des Ruminants, qui est capable de vivre, en surcroît, ì létat adulte, chez l'llomme. - Les divers habitals des cmbryons seront désį̣nés jar lexpression d'habitats intermédiaires; ces habitats sont des miliex $x$ on des hotes organisés. Le milieu intermédiaire le plus fréquent est l'ean. Les hòtes intermédiaires appartiemnent, dans la règle, ¿i une espèce Jonnée pour chaque parasite, espèce dont les individus servent de nourriture labbituelle aux hòtes définitifs. Une tolérance assez vasle s'étahlit reprendant pour les hòtes intermédiaires comme pour les autres; tel est le Trenia eclimococcus déjả cilé, dont les embryons se trouvent tunt aussi bien des lissus de l'llomme que de ceux du Moulon. - Mais il ne faut pas oublier que cette tolérance sert senlement à ménager la vitalité du parasite; l'évolulion complète nécessite des circonstances plus serrées et plus précises, lestinées à permeltre sîrement le passage, du parasite, de son milieu intermédiaire dans son véritalıle hoote Jéfinitif.

11. Etude spéciale. - Mcttant à part diverses espèces de parasites, appartenant aux classes des Némerlines el des Turhellariés, el dont l'érolution n'est pas encore lien connue, les seuls Plathelminthes, anxinels s'impose la nécessité des migrations embryomaires, sont les Trímatorles et les Cestodes.

Trématods. - Les migrations n'existent pas, ou sont a peine indi- 
quées. chez la juprart des Ectoparasites; elles acłuièrent pourtant, cliez ceux d'entre enx qui vivent dans les cavitós organiques de lenrs hotes, nue eertaine complexife. Cas depniers établissent, sous ce rapporl, m frassage vers les Endoparasites, ou ces phénomines de migration jossident mue grande importance.

P'resque tous les Ectoparasites vivent sur les légmments de lenrs lootes. Cenx-ci sont des animaux arjualiques: anssi, les prarasites se horment-ils i rejeter leurs urufs léromlés dans l'ean envirommante, el les larves se léveloppent dans cette ean. Après nue certaine frériode de lilerté, Jos larves se fixent aux corps étrangers qu'elles rencontrent; si le hasard los amène sur un ètre capalle de constituer un hòte définitif, elles achèvent leur évolution, pt passent a l'état adulte. La migralion, dans ce cas, n'existe pas à vrai lire; elle consiste en un transport possible de la larve, gràce à sa périoule de vie libre, sur un lôte diflérent de celui 'ju'hahite son généraleur.

Les faits sont plus compliqués pour ceux des Eeloparasites yui labitent, nou les léguments de lemr hôte, mais des cavités ouvertes au dehors, et ne s'enfoucgant pas trop dans l'intérienr du corps : lel est le Polystomum integermum, qui se froure llans la ressie minaire des Grenouilles. Le parasite pond des ouls; ceux-ci, en passant par lorifice roaral del'hôte, tombent dans l'ean. Les embryons éclosent: cenx qui, parmi eux, arrivent a se fixer sur des branchies de Tèrals, se développent seuls; ils se transforment en adultes de petite taille. Pour acquérir leurs dimensions normales, ils sont obligés de passer de la eavité liranchiale dans cellede la ressic urinaire, en parcouranllüutestin eutiej de l’hòle; après quoi, le cycle jecommence. - Les représentants te celte espèce, durant leur périorle de fixation sur les branchies des Tètanls, ressemblent beancoup à des fiyroulactyles, et sont mème capables de se reproduire par des procédés analugrues. Une telle concordance autorise presque it supposer que les (iyrodactyles, ivec leuremarguable emboitement te descendiuts, correspondent peut-ètre à des Polystomes Jont l'évohulion n'est pas terminée.

Les migrations des Trémalorles Emloparasites sont plus compleses encore. Ces òtres, lorsqu'ils sont alultes, habitent d'ordinaire les lissus l'animaux telrestres; et, romme il est néressaire à leurs larves de se lévelopper dans l'eau, le transport au travers de milieux et d'hótesinterméliares acquiert me grande importance. - Le cas le plus simple est offert par les especes, dont les lapres se hornent i vive dans l'eau, et sont absorbées par l'hôte définitil ance sa boisson. Le mode le plus fréquent, et lo plus complexe, ast celui daus lequel les larves commencent far se léplacer librement lans l’eau, puis vout s’étahlir daus les lissus d'un on dr denx lutes intermediaims, qui sont tonjomrs des ètres aquatipnes. Tw est le Mistomum hrpaticum. Cie Trémalode habite, ì l'état adulte, les canaux hépatigues les liuminants, el parfois ceux de l’llomme; ses anfs sont rejetés au dehor's avec les exeréments de l'höte, et ceux 
d'entrecux, qui tombent dans l'eau, écosent seuls. Less larres nigrent dans le milien qui les entoure; s'il en est, parmi olles, qui trouvent a so fixer sul le corps de divers Jolluspnes, tols que les lymnórs, lom évoJution continue. Elles senfoncent dans les tissus de loun's lootes, s'y convertissent en Sporocrstes, el produisent des Rićlies, qui engendrent des Cercaires i lenr tour. Ces derniers, en traversant de nomveau J'organisme de l'hôte, deviennentlibres, et, tantôt se meuvent dans l'eau durant un certain temps, tantót vont se fixer sur des téguments le Mollusijues, ou sur des feuilles de plantes aquatiques. En cet état, ils devienment immohiles, et s'entomrent d'un liyste, composé d’un mucus épais, cluargé lo granulations, que produisent des éléments spécianx, diles cellules cystogénes. Si les Jollusques, ou les régétaux, porteurs du parasite, on encore l'eau ifui les contient, sont alssorlés par des Ruminants, ou prar l'Homme, les Cercaires sont avalés en mème temus, ne sont point digérés, arrivent dans le foie, et sy transforment en adultes.

Les aulrurs décrivent res migrations comme si les luôtes intermédiaires devaient rigoureusement appartenir à une espéce donnée. Il est prohable qu’il n’en est pas ainsi, et que la tolérance est large. Sans loute, l'habitat intermédiaire normal des larres de Trématodes Endoparasites est l'eau. La fixation sur des animan aquatiques est un phénomene plutôt accidentel, capable d’ètre omis sans entraver le développement, et qui a surtout pour effel, en donnant amx embryous mne nutrition suralonlante, de permethe leur multiplication prar gemmules.

Cestoues. - Les migrations des Cestodes comportent deux luabilats intermédiaires successifs, du moins dans la plupart des cas : un milieu d'abord, et un hòte ensuite. - Le milicu est l'eau pour les embryons de presiue tous les représenlants de la classe, sauf pour ceux des Téniadés. Les généraleurs, vivant d'lubitude dans la cavité intestinale des ètres qui les portent, rejettent leurs aeufs, ou lenrs proglottis ploins d'oufs, dans cette cavité, d’où cenx-ci sont entrainés au dehors avec les excréments de l'hote. Cenx qui, parmi ces anfs, sont conduits dans l'eau, arant que les cimonstances extérieures délavorables ne les aient tués, se déreloppent senls; chacun d'eux produit une larve cilice, composée de l'embryon acanthophore, quentoure l'endamuios; co dernier porte des cils viluratiles. - Le milieu intermédiaire est le sol pon les Téniadés. Les proglottis sont rejetés au dehors, avec les exerénenls de l'hôte qui contient leparasite alulte, et tombent sur la terre. La paroi des proglotlis se décompose; mais il n'en est pas ainsi pour les aufs, que protigent d'épaisses coques protectrices. Ceux-ci sont capahles de résister, pemant plusienrs mois, à la dessication, et mène de commencer leur évolution, pour la contimer jusqu’i ce püils soient convertis en embryons aranthophores.

Quel que soit le mode employe, le petit Cestode doit encore passer par l'organisme d'un hote intormediaire, arant de parvenir dans celui de lhote detinitil. Soms la riserve d’une tolérance drja indiquée, ces 
hòtes intermédiaires appartiennent à un groupe déterminé pour chaque parasite. Cenx des Téniadés sont des animanx frrestres; cenx des autres Ceslodes sonl des animaux aluatipues, des Poissons le flus somrent. Il est nécessaire que cel hoble avale la larve lilore, ou, suivant le cas, l'œuf déposé sur' l. sol; lans l'un commedans l'aulre procédé, les petits èlres ne sont pas digérés, el arrivent dans la cavité intestinale de l'hôte. Chaque embryon acanlhophore s'y débarrasse de ses enveloppes ramollies par les sues ligestifs. Il perce ensuite, grâce à ses crochets, la paroi de l'inteslin, et passe, soit directement, soit en se faisant transporter par le torrent circulatoire, dans la profondeur des tissus; il se convertit alors en l'lérocerque, ou en Cysticerque. Les tissus, choisis le préférence, sont les bandes connectives interposées anx faisecaux musculaires, on aux éléments constitutifs des viscères. La présence de la larve, lans ces régions, a pour effet d'y déterminer une petile inflammalion locale, qui se résout par la formation de memluranes filuineuses; l'embryon est ainsi cnlouré d'enveloppes lui composant un liyste, el l'on dit qu'il s'est enkiysté. - Il demenre dans celle siluation, et vit à l'élat latent, sans compliquer davantage son organisme. Il est capalule de rester longtemps sans périr, pendant plusieurs mois, et mème pendant quelques amnées; mais une durée trop longue, sons celte forme. finit par lui ètre funesle. La mort est amenée par le dépồ, el par l'aceumulation lente de sels calcaires dans ses cellules.

Si, avant que cette fin n'ulvienne, les tissus qui contiemnent la larve sont mangés par un animal susceptilile d'ìlre un lrôte définilif, les enveloppes du liyste sont digéréns; le jetit parasile se trouve ainsi déponillé, et lihre dans la cavité intestinale de cel animal. Il dévagine sa tête, se fixe à la paroi de l'intestin, el se convertit en adulte.

Un exemple du premier procélé, de celui jui se raraclérise par l'existence de phases larvaires aqualiques, est offert par un parasite de l'llomme : le Bothriocephahus lutus. Les cufs rejetés éclosent dans l'eau: les larves nagent d'alırd, et colles deulre elles qui sout aralíes par diver's l'oissons d'eau donce, tels que le Brochet et la Lotte, se changent en P'lérocerques dans les muscles de ces hòtes. Si la chair de ces derniers, cuite d'une maniere insuffisante, est alsorbóe parlllomme, les embryons se fransforment en adultes. - In exemple du second mole, dans lequel lo sol est le milieu intermédiaire, est présenté prar un autre parasite de ]'llomme, lo Tronia solium. Ceux qui, parmi les mufs expulsés, sont avalés par des Pores, se ronvertissent en Cysticerpues, ol s'enkystent dans les muscles de ens Jerniers; la maladie, orcasionnée par la présence des prasites cn trop grand nombre, est connue sous le nom de ludrerie. Si, jar la suite, la chair mal enite, on crue, l'un rochon ladre est mangée par l'llomme, les Cysticerques passent a l'ítat adulte dans l'intestin de celui-ci. 


\section{\$ 7. - Développement des Myzostomes.}

1. Considérations générales. - La silualion exacte de ces animanx, daus la série zoologique, prète encore ì leaucoup de controverses, bien que leur organisation définilive soit presque complètement conune. Parmi les auteurs, les uns les placent à côté des Annélides, les autres dans la série des Arthropodes, les derniers enfin les cousidèrent comme étahlissant un passage des premières aux seconds. Ces diverses opinions

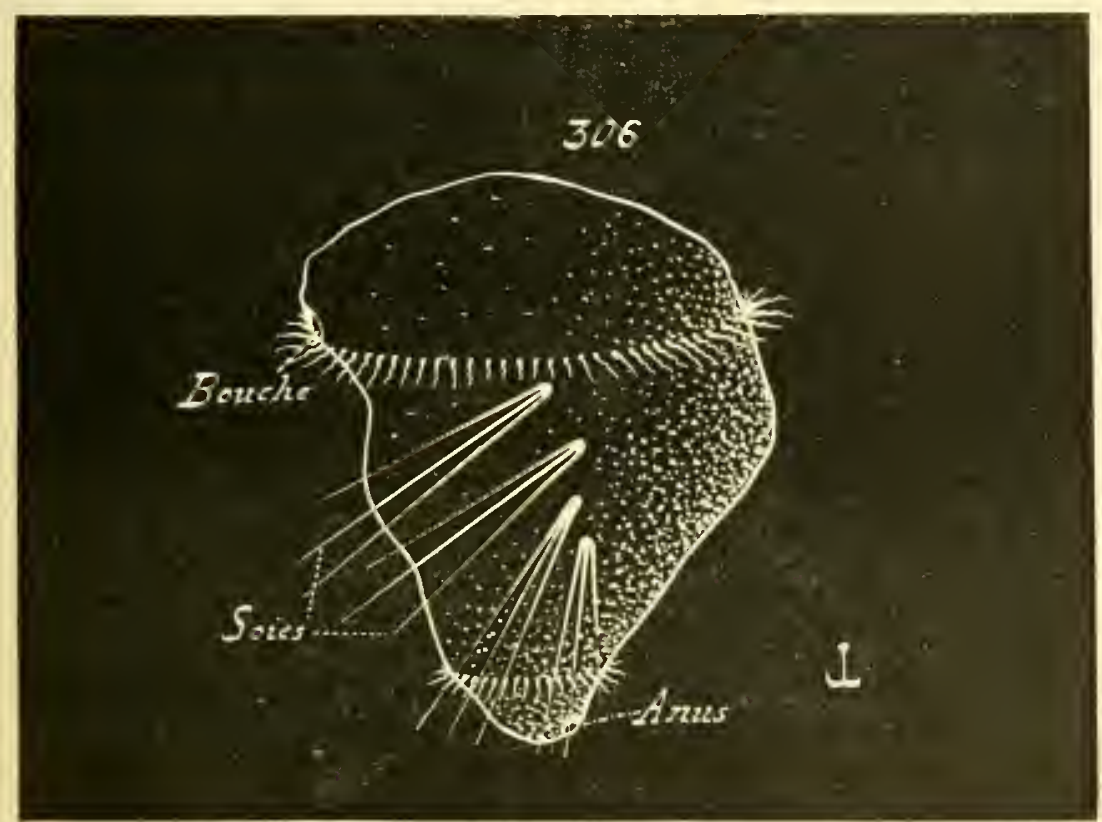

Fig. 306. - LARYe DE MYzostone (contour). - I'après les recherches failes par Bourne.

ne peuvent guère ètre acceptées, si l’on tient compte de tous les faits acquis, et sil'on ne se horne pas à en accueillir quelques-uns pour laisser les autres. Les Myzostomes sonl privés de ces apparrils excréteurs, les népluridies, propres aux Annélicles, et servant pour leancouj à caractériser celles-ci; de plus aucune circonstance ne lénote chez eux l'existeme, dans le unesorlerme, d’une segmentation semblable i colleque présentent les Aunélides. Les Myzostomes ne sont pas davantage des Mrthropodes: les embryons de ces derniers olfrent un aspect parliculier, dù ì l'alisence le rils vibratiles el á la présence de pattes; leur's lemillels lilastodrrmiques se développent suivant un procédé spécial, quel'on ne trouve pas ailleurs; aur'un de ces faits n'est montré par les Myzostomes.

Ces ctres constituent, en réalité, un lype automome, dont la jlace 
fillait itre anpres des lathehmintles. Lenr aspect général, leurs appendires con forme do conchets, lemplorynx protractile, lenr intestin ramifié, lem hormaphoditismo, of la dispusition de leurs whandes sexuelles. sont autant de calacleres pui les rapuruchenl des Vers phats. Malheureusement, les inductions doirent so lorner lì: il serait nécessaire, pour aller plus loin, de hien connaitre les premières phases du developpenent de ces animaux; retest sur ce sujet que les renseignements font léfaut.

11. Développement. - Les lyzostomes sont hermaphrodites, avec progenesturile. Lesuns achirent completement leur évolution, possèlent l'alord des glandes milos, et des lemelles rnsuite. Les autres se bornent à engendrer leurs testicules, et en restent lì : its demement pelits, el coustiluent des males complémentaires, qui s'athabout aux hermaphrodites, el virent sur eux.

Les observations emluryogéninues les plus romplètes sont dues à Bunrme. Laxuf sulit wne segmentation totale et inégale, qui entraine la genese d'une planule imlirecle. Les feuillots se drimilent ensuite par le jocédé habitud à ce genre le planulation. Le prolectoderne se couvre dr. cils vilıatiles; de longues soies provisoires apparaissent en sus, et se rassemblent par petits groujes. L'entéron se rrense dans le protendodermo, et communique aree le lehors par deux orifices: la bouche et l'anus. - la larve prend une forme ovalaire; une comronne ciliée, jacée au niveau de la houche, devient assez toutrue; les deux ouvertures intestinales, dianétralemont opposées, sont situées un peu en derlans des leux extrúmités du corps. Dans son ensemble, cette lave rappelle assez bien la Truehophore des Vers anmolés; mais il ne semble point gu'elle possede des néplarilies, et la sujte de son dévelojpement n’est pas contule.

\section{8. - Développement des Acanthocéphales.}

1. Considérations générales. - On a l'halitule de placer les Iranthoriphales daus l'embrambenent des Némalhelminthes. Le seul fait, qui antorise ce rapluchement, est la forme romle, eylindrigue, du rorps, de ces deux sorles d'inimanx; un réalité, les aftinjlés les premiers,

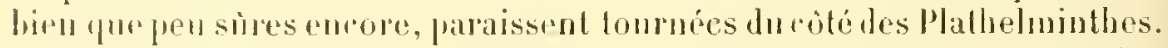

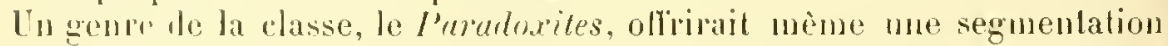
semblable à relle prósentée par lrs Cestodes; do nouvelles ressemblances avec ces lemiers liennent à l'alsence du tube digestil, et à la possession de crochets fixalenrs par la région antérienre de lorganisme. - Los difformors sont cependant lort grandes, ef éloignent les Acanllocephales Jos Patodes, toul ansi lien qur des Nómathehminthes du reste. Elles portent: sur l'existonce l'une trompe probactile dans l'extrémité antérienre du eorps; sur la complexile de l'appareil excréteur; sur la présonce d'organes encore énignaliques, nommes lemnisques; enfin sno une. 
disposition des appareils sexuels, faisant pue les produits reprodurleurs doivent tomber dans la cavité générale avant de parrenir an dohors.

Les Acanthocéphales sont des parasites internes, font conme les Cestodes, et habitent de mème la cavité inlestinale de leurs hòtes. Ils subissent egalement des migrations embromaires, et séjournent chez des hôtes intermédiaires. - Par une particularité intiressante ì uoter chez des animanx endoparasites, el que les Nématodes sont, avec eux. presque les senls à montrer, les adultes sont unisexués, et non hermaphrodiles.

II. Développement. - Les prineipanx renseignements, acquis sur les Acanthocépliales, sont dus i Leuckart; ils sont lien incomplets,
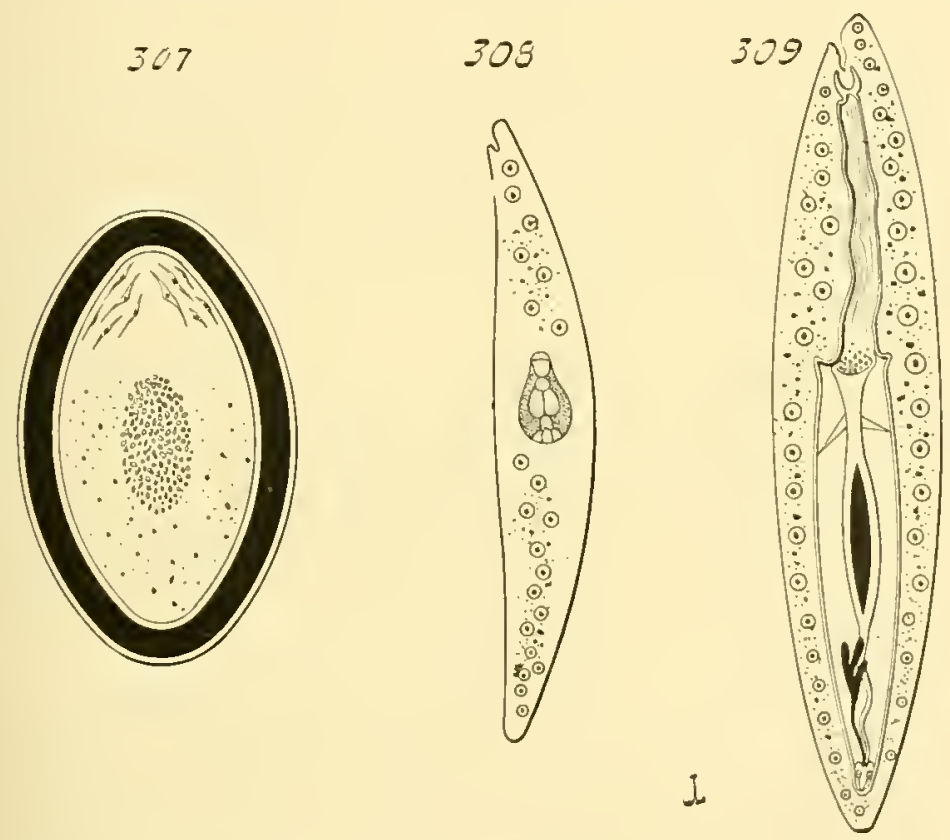

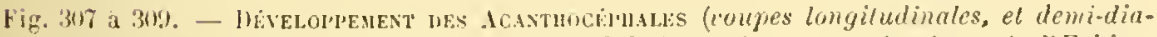
grammatiques; d'après h. Leuckart). - En 3h, jeune larve aeanthophore de l'Echimorhynchus gigas, entourice de ses membranes amoioticues. - Kn :30R, larve plus âgée, -t depouilie de ses memliranes, d'un Echinorynchus proteus; le trait périphéripue indigue la cuticule, au centre se trouve le noyau embryonnaire; entre les deux sont des cellules éparses, qui reprèsentent peut-ètre l'útodermc désagregè. - En 30s, jeun? femelle d'Echinorymchus proteus; l'ectoderme rignlarise ses contours, et lo noyau embryunaire grandit, en produisant l'appareil de la trompe avee les urganes sexuels.

surtout an ce qui touche l'origine des fenillets. L'irolution est tries

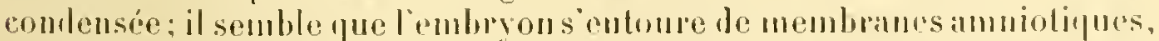
"omme celui des Cestolles, mais la valerer réelle, el la structure exacte, de ces derniores, ne sont pas ílucilées.

lat seguentalion totale, el quelifue pen imingale, ahoutit à lat genese 
d'une planule directe, de forme allongée, qui s'entoure de membranes ípaisses, au nombre de trois. L'extériemre, promi colles-ri, est de nature 'hitineuse; les lenx intermes renferment les éléments cellulaires, qui proviennent de l'emhryon. Cirhi-ci se délimite au sein de ses enve loppes, et porte des crochets sur l'une de ses extrémilés; il resscmble ainsi, d’assez près, it la larve acanthophore des Cestodes; il est permis le lui donner le même nom. - Si les circonslances favorables permettent à l'évolution lle continuer, la larve acantophore se délıarrasse de ses enveloppes, perd ses crochets, et se convertil en un petit Acanthocéphale. Les cellules externes de l'embryon se désagrégent, et deviennent libres; mais elles ne peuvent s'éloigner, car elles sont retenues par une membrane chitineuse qui recouvre le corps entier. La plupart d'entre elles ront se placer au-dessous de cette membrane, et s'y déposent en une couche continue, qui est l'ectoderme. Les éléments internes, qui représentent un protendoderme, ne participent pas à cette lésagrégation; ils restent groupés an une petite masse compacte, désignée par le nom de noyau embryomaire. Cette masse gramlit; elte lonne naissance au ligament de la trompe, aux muscles du mime appareit, ot aux organes sexuels. $\Lambda$ ces notions, se borment les faits connus sur le léveloprements des dcanthocéphates.

Pronlanl que s'effechent les premiers phénomènes de cette évolulion, le petit ètre est silué dans les tissus d'un hôte interméliaire, de la mème faron que les Plérocerques et les Cysticeroues des Cestodes. II s'y entomre d'un lisste, et il attend, pour parvenir à l'ìge adulte, d'ètre transporté dans l'intestin de l'hôte délinitif. Il est lonc possible de donner, à celle période qui suit celle te la larve Acanthophore, te nom te plase latente.

Les migrations des Acantlıocéphales ressemblent rxtrèmement ì celles des Ceslodes; les mèmes considérations leur sont applicahles. Elles comportent denx hahitats intermédiaires suceessifs, un milieu d'abord, el un hôte ensuite. - Le milieu est, suivant les espèces, tantìt l'eau, lantiat le sol; l'hôte est, à son tomr, tantôt un lnvertéliré d'ean donce, lantòt un lnvertébré terrestre. Les hơtes définitifs des adultes sont des Vertébrés d'ordinaire, soit des Poissons, soit des êtres virant sur terre. - Les cenfs du prarasite sont rejelés avec les excriments des hoites; ces mufs ont léja formé, au moment oì ils sont pondus, la larre acanthophore arec ses enveloppes. S’il en est, parmi cux, qui soimt avalés, "lrì̀s un séjour plus ou moins long dans le milieu intermédiaire, par un animal capiable d'être un hôte pour l'embryon, cenx-la se développent senls. La larve acanthoploore se déponille de ses membranes dans la cavilé intestinale de cet hritn, traverse la paroi de lintestin jar le moyen de ses crochets, et va s'étalilir dans les muscles ou dans la cavité générale. Elle s'enliyste alors, el subit sa phase latente. Puis, si cet hôte intermédiaire est mangé prar un second animal, susceptible de devenir 
un hôte définitif, le jeune deanthocéphale n’est pas digéró par ce lernier, sarrete dans son intestin, et sy convertit en adulte.

Ainsi, l'Echinorhynchus polymorphus adulte vil dans l’intestin des oiseaux aqualiques, des l'alunipedes nolamment. Ses embryons, du moins cenx qui parvienment dans l'eau, contimuent à vive, et attendent d'ètre avalés par l'hòte intermédiaire; ils subissent lem phase latente dans le corps des pelits Crustacés des caux donces, notanment dauscelni les Gammarus. Ceux-ci sont également eapables d'ètre des loóles intermédiaires pour les embryous d'autres Acanthocépluales, tels que l'Échinorhynchus proteus des Poissous d'eau douce, et l'Echinorhynchus heruca des Amphiliens.

\section{RE்SUME்}

§ 1. Coxsmératoxs géxénues. - La sexualité est le mode reproducteur le plus fréquent; pourtant la reprouluction asexuelle existe chez les Plathelminthes, mais, sauf dans le cas des Trématodes Eudoparasites, elle ne possede pas une bien grande importance. Les ceufs de la plupartule ees animaux sont riches en deutolécilhe; aussi l'évolulion embryonnaire est-elle comlensée d'habitude, et s'effectue suivant le procédé planulaire. Quelques Némertines font exeeption, et offrent des phases gastrulaires. La genèse des feuillets s'accompagne souvent le ha production, par le protectorlerme, de membranes amniotiques; la formation de ces dernières est parfois arancée, prar déplacement dans le temps, de manière à s'effectuer aux lépens de certains les premiers blastomères. Le déreloppement des l'lathelmintlies parasites s'accompagne, dans beaucoup de cas, de migrations.

§ 2. Elémexts skxuls. - La répartition des sexes est sujette à de grandes diversités suivant les groupes; elle s'accompagne parfois, jrar exemple chez les lihahdocoles du genre Iesostomum, de la geniese d'oufs d'élé et d'oufs d'hiver. - I.e léveloppement des spermatnzoüles ne présente pas de particularités importantes. Le fait te plus saillant est celui qui consiste a permeltre lantofécondation, dans le cas d'hermaphroditisme complet, par la lermeture de l'orifice génilal commun (sinus génital). - Les glandes femelles de tous les Plathelminthes, sauf les Némerlines et les Dendrocueles Polyclates, sont divisées en deux groupres: celui des germigènes, et celui des vitellogènes. I.e prenier donne les ovules, et le second les cellules nutritives (eellules vitellines), destinécs à èlre absorbées par les précédents, durant leur évolution. l.es rufs sont alors constitués par l'mnion d'un on de plusienrs ovules, et le cellules nutritives en nombre souvent considérahle; ils mérileut le nom d'ceufs composés, par opposition à celui d'ou/s simples accorlé anx uvules ordinaires.

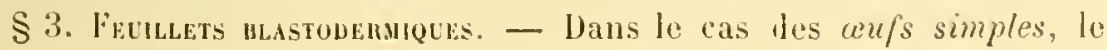


développenent des Némerlines comporte deux modes principanx, suivant fre le protectorlerme reste simple, on suivant qu'il produit mu ammios. Le premier est particulior aux Iloplonómertines; daprès la yuantité du deutoléeithe contenu dans l'aruf, l'embryon se développe par le procédé gastrulaire, ou par lit planulation direcie; le protectoderme se horne it se convertir en eeloderum; le protendoderme se divise en mésoderme el cndorlerme. Les téreloprements avec ammios sont propres aux Schizonémertines: dans le cás des larves du type P'ilidium, les ébanchrs de l'amnios sout formées prar quatro dépressions du protectorlerme, qui se convertissent en vésiculus closes, et s'unissent entre elles; dans celui des larves de llesor, ces mêmes éhauches sont domnées par la çenèse, aux dépens du protectoderme, de guatre plaques cellulaires, qui grandissent, et sunissent de même les unes aux aulres. La membrane amniotique se compose de deux assises, l'examnios extérieur, et l'endumnios interne. - L'érolution des l'olyclades (Digonopores) s'uflectue suivant le type de la planulation indirecte.

Les rufs composés des Triclades (Dendrocales mogonopores) contiennent un grand nombre de cellules vitellines; ces cellules s'unissent. en un syncytium, que parcourent, en l'englobant ef se nourrissant i ses Jépens, les blastomères issus de l'ovule vrai. - Les cellules vitellines sont moins abondantes chez les Trématodes, et sont absorbées de nème par l'ovule. L'ovule fécondé se convertit en une planule directe; par Fet7el d'un déplacement dans le temps, ruelques blastomeres, qui apparlicment viruellement au proterloderme, les cellules de la calotte, jrounisent nue membrane am niolique, homologue de l'examnios des Némeslimes. - Les ruls des Cestodes contiemment moins encore de cellules vitellines que ceux des Trématodes; les feuillets s'ébauchent par le frocédé de la planulation direcle; un blastomère domne hàtirement un examnios, nonmé l'assise gramuleuse. L’embryon se dóbarrasse de cette enveloppe par la suite; mais il possede encore un endamuios placé sous la précédente, et le quitte également un pen plus tard.

S f. Formes enburoxanres. - Le dévelopjement des l'lathelminthes comprorte souvent la présence de larves. Ces dernières sont lantöt libres, et tantöt parasites. Sauf celles des Turbellariés et les lloplonímertines, clles senveloppent provisoirement te membranes amuiotiques.

Les larves de la plupart des Turbellariés nothrent, dans leur disposition extérieure, ancune partirularití remarquable. Celles des Schizonémertines sont entourées prar un amnios, dont elles se débarrassent vers la fin de leur évolution embryonnaire.

Les larres des Trématodes Ectoparasiles ne suhissent point de grandes nétamorphoses, et passent directement à l'état adulte: parlois cependant, le petit être sort de l'wuf à l'état parfait. Chez les Gyrodactyles, cette éclosion a lien asant que l'xul' n'ait été pondu par le génératenr; aussi deux, et mème plusienrs générations d'individus, sontelles 
emboitées les unes dans les autres. - Le développement des Trématorles Endoparasites est plus complexe, car il s'accompagne de phínomènes de reproduction asexuelle par gemmulation. De linuf surt une laree mimaire; celle-ci, dont la struclure est fort simple, se comprose l'une douhle assise cellulaire extérieure, de minces conches musculaires placées en dedans des précédentes, et d'un amas de cellules centrales. L'assise Ja plus extrine, couverte de cils viloratiles, représente l'emlannios, que l'embryon ne tarde pas á quiller. Les larves primaires alparticunent í denx types; les unes possèdent un petit tuhe intestinal, el on les nomme des Rédies; les antres sont privées de cet appareil, ou n'en ont qu'une ébauche, réduile à une masse granuleuse, el on les nomme Sporocystes. Les larves primaires ne deviennent pas des adultes; elles sont seulement chargées de prorluire de nowvelles larves, qu'elles engendrent pardeux moyens, par fissiparité, ou par gemmulation. Wans ce dernier cas, les descendants sunt formés par l'anas des cellules centrales, qui se divise en plusieurs gemmules. La fissiparité donne loujours d'autres larves frimaires comme descendants; il en est parfois ainsi pour la gemmulation; mais, aprés un petit nombre de générations, ce procédé aboutit toujours ì la production d'embryons différents, qui sont des lurves secondaires. Ces dernières, encore nommées des Cercaires, ont une organisalion plus complexe que celle des larves primaires: olles se convertissent, lorsqu'elles rencontrent des circonstances favorables, en individus adultes, el ne subissent aucune reproduction asexnelle.

Le déreloppement des Cestodes varie suivant les types; it olfre prourlint ce caraclère commun, que les larves sont parasites, an moins ver's la fin de leur évolution; sauf dans le cas de diver's Ténias, il ne s’accompagine jamais de reproduclion asexuelle. Le jeune embryon, au moment où il est mis en liberté, mérite le nom de larve acunthophore, car il ast ununi de crochets qui lui permeltent de s'introduire dans les tissns d'un lıùte; tantòt il est tétracanthe, lorsqu’il possède quatre crochets, el lantôt hexacanthe, lorsquil en a six. Les Cestudes les plus simples. comme les Archigetes, en restent à lil phase acanthophore; l'extrémité du corps, opposée à celle qui prorte les crochets, s’allonge en mue pelite tòte. Chez des Cestodes plus élevés, tels que les bothriocéphalidés, il ta phase acanthophore en succede une seconde, celle de l'lerocerque; les crochets tomlient, et mue tìte se forme dans la mème région que celle les Archigetes; cette têle est susceptible de s invinginer dans lo corps. Enfin, cliez les T'éniadés, une pluase de C'ysticerque suil l'état acanthophore; Iinvagination du l'lérocer gue devient roluminense el persistante, de manive à convertir le corps entier en une résicule, dans lapuelle se trouve pacée la tète.

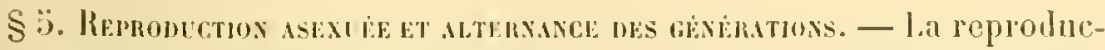
tion asexuefle s'elfectue, chez les l'lathelminthes, suivant trois purocidés: la fissiparité, la gemmiparité, el la gemmulation. - La fissiparité existe 
chez certains Rhabdocoles adultes, et chez les larves primaires de plusienrs Trématodes Endoparasites; lans le premier cas, l'alternance est adulte el holomorphe; dans le second, elle est embryonnaire et également holomorphe. - La gemmiparité est plus rare, on ne l'a trourée que chez les embryons, parremus à la phase Cyslicerque, de divers Ténias, notamment des T. echinococeus et cenurus. Liemliryon, a u lieu de. protuire une seule tète, en engendre plusieurs, ou mème fournit des vésicules, semblahles i lui, qui donnent secondairement maissance à un certain nombre de ces Jemieres; chacmne de ces tites est capable de devenir un individu parfait. Ces Cysticenues bourgeonnants sont nommés des Lichinocorues ou Jes Ilydatides. Lalternance est embryonnaire et hétéromorphe. - La gemmulation n’existe que chez les larves primaires, les Sporocystes et les Rélies, des Trématodes Endoparasites. Lalternance est embryonnaire el hétéromor|phe. Dans le cas où une fissiparité frócèle colte gemmulation, l'alternane létéromorphe succède it une première alternance holomorphe.

lieancoup de natmalistes considerent l'organisme des Cestoiles supérienrs comme réponlant à une colonie linéaire d’individus, à un strobile de proglotlis. Il est probable, ì en juger d'après la structure des Cestodes inférieurs, quil n en est pas ainsi; l'aspect annelé du corps est dì à la division des glandes génitales en nombrenx groupes sexuels distincts, et à la présence, entre ces groupes, d'étranglements légumentaires.

\$ 6. Manatoxs eubroxnanes. - Le déreloppement dos embryons des Trémalorles, et de cenx des Cestodes, s’accompagne sourent de migrations d'un habital dans mn antre. Cestransports sont d'ordinaire passifs en ce qui regarle le parasile, et comportent une cerlaine lolérance, hors de laquelle l'embryon est dévoyé. Les habitals sont des milieux ou des hôtes; les milieux sont le sol on l'eau.

Chez les Trématodes, les migrations sont le fait des Ectoparasiles qui lahilent des cavités superfieielles de leurs hôles, et surtout des Endoparasites. Les larves primaires de ces derniers se déplacent d'abord dans l'eau; elles pénètrent eusuite dans les tissus d'un premier hôte iutermédiaire, et produisent les larves secontaires; celles-ei sont de nouveau mises en liberlé dans l'eau, vont s'enkyster sur un support, et attendent ansi d'être absorbées par l'hôte définilif. Dans certains cas, ees larves secondaires habitent le mème parasile que les larves primaires dont elles provienment, et atlendent que cet loôte intermérliaire soit mangé jar l'hôte définitif.

Les migrations des Cestolles comportent, dans la plupart des cas, deux habitats : un milieu l'abord, un hôte intermérliaire ensuite. Le milien est l'eau pour presque lous les Cestodes, et le sol pour les Téniadés. liembryon ne se convertil en Pérocerque, on en Cysticerque, 'pue dans les lissus le l'hole intermédiaire; il passe dans l’hòte cléfinilif, lorsque l'hôte intermédiaire est mangé par ce dernier. 
\$ 7 . Déneloppenext nes Mrzostones. - Les affinités naturelles de ees animaux ne sont pas enrore élucidées; il semble pourtant que leur place soit ì cûté des Plałhelminthes.

Les feuillets sont produils d'aprís le procédé de la planulation indirecte. La larve porte une couronne vibratile orale, el des soies provisoires. Elle ressemble ainsi à une Trochophore d'Annélide; mais l'alısence de néphridies empèche de lenir cette assimilation pour exacte, du moins jusqu'ì plus ample informé.

§ 8. Développenent des Acanthocéphales. - Les Acanthocéphales sont placés, d'hahitude, parmi les Némathelminllıes; leurs affinités paraissent, cependant, tournćes plutòt du côté des Plathelminthes, notamment des Cestodes.

La segmentation tolale est suivie d'une planulation directe. L'embryon se convertil, par la suite, en une larve acauthophore, qui se transforme en aublte, lorsquelle rencontro des rirconstances lavorables. Ces animaux suhissent des migrations embryomaires, semblahles a colles des Cestodes, et comportant, de mème, un milieu dabort, puis un hote intermédiaire. Le milien est tantôt l'ran, tantôt le sol: l'hôte lantôt un inverlíbré aquatique, tantòt un invertébré lerrestre. 


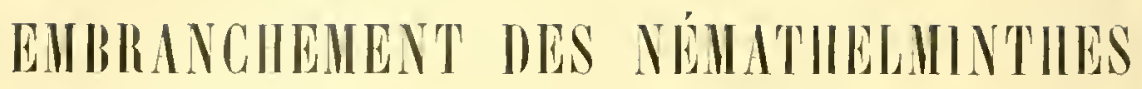

\author{
CIIAPTRE VIII \\ DEVELOPPEMENT DES NEMATHELMINTHES
}

\section{$\$ 1$. - Considérations générales.}

I. Caractères et classification. - Les Nímatheliminthes, encore nommés leers ronds, sont caratérisés par leur corps allongé of cylindrique. Leur cavité générale rst libre, car aucun parenchyme ne l'olsstrue; leurs glandes sexuelles constituent des organes tubuleux aux contours précis.

A. - Les Némathelminthes sont, selon toute évidence. des Schizocolomiens. La yuestion pourrait rependant prèter à des controverses, car le développement de res animanx, itant roudensé, ne monte point les phénmines primitifs dr. la genese du culome. Ceprndant, par comparaisnn avec des emlorogénies, regalement alırégées, des l'lathelminthes ou des 'l'rochozoaires, il est possilile d'aftirmer que le colome des Némathelminthes corresponl à un schizocole, et non ì un entérocoele modifié par déplacement. En effel, les premières éhauches te cette cavité offrent laspect de longues fentes élroites, funi se creusent, à travers les b]astomères du jemne embryon, smr tonte la longueur de ce dernier; ces vestiges ne sont pas localisés dans une région déterminée de lorganisme, et relativement restreinte, par opposition à ce qui existe chez les Entérocolomiens dont lembryogenie est condensée. - Aussi la place des Némathelminthes, antant quil est permis de l'admettre d’après les faits acquis, se tronve-t-elle parmi les Schizocolomiens, ef non ailleurs.

D’autre part, une ressemblance générale avec les Plathelminthes, en re qui touche la disposition et les rapports muluels des principanx organes, conconrt, de son cóté, is motiver un tel rapprochement.

Le rolome n'est jamais comllé par des tissus de remplissage, contrairement à ce que montrent les l'lathelminthes et divers Trorhozoaires; il reste lihre, ef comstitue une ample cavilé, an milieu de laquelle se 
trourent plongés le tube digestif avec les glandes sexuclles. I o mésolerme est réduit à une somatopleure, composée d'une seule assise ul'éléments épilhćlio-musculaires; la splanchnopleure fait toujours dófaut. "t l'endoderme, fui forme à lui seul la praroi intestinale, est à nu dans le colome. Ces particularités sont suffisantes pour caractériser les Xémathelminthes, et les distinguer des autres animaux. Flles s'atténuent, cependant, chez les plus simples représentants du groupe, et permeltent de conceroir les attinites naturelles de ces derniers. - Ces Némathelminthes inférieurs, qui représentent la classe des I'rénémalhelminthes, sont iles ètres de fort petile taille, el microscopiques; partant, leurs tissus el leurs organes se composent d'un chiffre restreint de cellules. Les éléments du mésoderme, pen nombreux, ne sont point rassemblés en une couche épithélio-musculaire; ils s'étendent d'une façon irrégulière à travers le crelome, el émettent des prolongements, qui les unissent les uns aux autres, ou qui ront les rattacher à l'ectoderme ou i l'endoderme. Ces éléments constiluent ainsi un mésenchyme, qui est strictement l'homologue du mésenchyme primaire des Trochozoaires, et de l'ensemble des tissus mésodermiques des Pathelminthes. Seulement, ce mésenchyme est ici fort rédnil, comme quantilé de collules.

Bien que des documents précis fassent encore défant à cet égard, il est permis le croire, en comparant les Prénémathelminthes aux représentants les plus élevés du grouje, que la somatopleure épithélio-nusculaire de ces demiers dérive du mésenchyme des premiers. Comme le dénole l'embryogénie, les cellules de la somatopleure sont rassemblées, dans les phases initiales de l'évolution, en un groupe placé entre l'ectoderme et l'endoderme, lout comme le mésenchyme dont il est ici question; clles se séparent ile l'endodlerme, lors des phases ultérieures, par l'apparition de la ravité culomique entre ce feuillel el leur propre amas, et demeurent accolées à l'retoderme. Elles régularisent ensuile leur disposition, s'arrangent en une seule couche, se convertissent en élémenls épithélio-musculaires, el constituent ainsi la somatoptenre. Ces données embryogéni jues, jointes aux faits tirés de la comparaison des organismes adultes, autorisent à admettre que l'assise épilhéliale, dont se comprose le mésoderme Jes Némathelminthes supérieurs, est l'homologue du petit réseau mésenchymateux des P'rénémathelminthes.

Lrs Trochozoaires montrent, lu reste, des phénomènes semblables. Coux d'entre elı, qui sont pourvus d’un mésolerme épithélial, ne possèdent chez leurs larves qu'un mésenchyme primaire. l'lusieurs des élémenls de ce dernier so rassemblent en amas aux contours précis, et, en se multipliant d'une manicre aclive, prouluisent des couches ipithéliales rérulicres, qui composent le misoderme. Ce fenillel provient don d'un mésenchyme inilial.

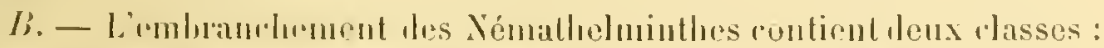

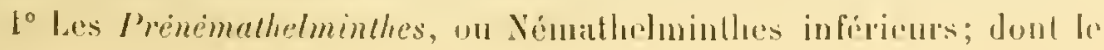


corps prorle souvent ilos cils viluraliles sur sa surface, et dunl le mésoderme est réduil ì quelques élémeuls mésenchỵmateux.

2o Les Vématodes, ou Némallominthes supérienrs; dont le corps, couvert par une épaisse culicule, n'est jamais muni de cils viluatiles, et dont le mésoderme est constilué par une épaisse assise sous-eclodermique d'élémests épithélio-musculaires.

11. Généralités sur le développement. - On ne connail, chez les Némalhelminthes, que la reproduction sexuée.

Le déreloppement des Prénémahchninthes est complichement ignoré. Les faits acquis sur l’embryogénie des Nématodes sont plus nombreux, mais ont prêlé à heancouy de conlestations; des recherches récentes, dues à L. Jammes, permeltent d'élucider plusienrs données obscures, el de concevoir les particularilés essentielles de l'évolution embryonnaire de ces êlres. - Presque lous les Némalorles sonl parasiles, sauf quelques types qui virent dans la mer, on dans la lerre lumide; aussi leur déreloppement s'accompagne-t-i\} te migrations fort curicuses, sourent aussi complexes que celles des Trématorles ou des Cestodes.

\section{$\S 2$. - Sexualité et feuillets blastodermiques.}

I. Sexualité. - Les Némathelminthes sont, pou la plupart, misexués, mòme les espieces farasiles. - Uno controverse existe an sujet de la sexualité des Prónémalhelminhlues, des Gastérolriches surtont; les indivilus adultes sont lous des lemelles, ot ne produisent que des aufs. Cerlains autrurs concluent de là, sojl à la parlhénogenese conslante de ces êtres, ce qui est peu almissihle, soil à leur unjsexualilé, les màles n'étant pas encore comns. Plusieurs olservalions permellent cependant de croire que res animaux sont hermaphrodites, aver progenese mile; les organes miles uaissenl les premiers, et produisenl des spermalozoüdes; puis ils s'atrophient, el laissent la place aux ovaires, qui se développent. Ces fails ont été conslatés sur le jeunes Icthydium et Chretonotus, yui portaient à la fois des spermatozoïles et des orules, ces deruiers élant encore forls pelis. - Quoj quil en soil, à cause de l'exiguilé du corjus du génératenr, el de la grossen des ovules, cenx-ci sont souvent peu nombremx. Les Chatonotus en onl de deux sortes. Les mins, dits aufs d'élé, de laille restreinte, accomplissent leur développement embryonnaire, alors qu'ils sonl encore renfermés dans l'organisme malernel; les autres, nommós axufs dliver, plus gros et protégés par un chorion épais, sont pondus, el vivent à l'élal lalent. durant loule la mauvaje saison.

Les denx parlicularités principales de la sexualité des Prénémathelmiulhes, la progenese mile et la jossibilité de la viviparilé, se retronrenl chez les Némalodes. - Tous ces animanx sonl unisexués d'luabilude; mais certains d'entre eux donnent najssance à des descendants herma- 
phrodites, qui engendrent eux-mèmes de noureaux ètres unisexués; une telle succession de phénomènes rentre done dans les cas de généraration alternante. La métagenése se complique parfois d'hétéromorphisme, car, bien quappartenant à la mème espèce, les individus hermaphlurolites ne ressemblent, ni par leur forme, ni mème par leur mode le vie, aux individus unisexués. Tels sont les représentants du genre lihabdonema, qui, unisexués, vivent dans la terre humide, et étaient placés autrefois dans le genre Rhabditis, alors que les individus hermaphrodites sout dés endoparasites, et oflrent tous les caractères des vrais lihabdonema.

La plupart des Nématodes parasites sulissent des migrations; ces dernieres sont parfois si complexes qu'il serait fort difficile anx adultes, sinon impossible, de se rencontrer pour assurer la fécondation. Wans ce cas, la progenèse se manifeste dans les deux sexes; alors que les indivilus se trourent eucore petits, leurs glandes sexuelles sont développées, et les màles fécondent les femelles. Puis, les premiers meurent; les femelles achèvent seules leur évolution, erandissent beaucoup, et vont sétablir dans leur habilat définitif. Les espèces du genre Filaria montrent ve bons exemples de ces phénomènes.

Généralement, les Nématodes sont ovipares. Les aufs sont entourés par un chorion épais, souvent orné, sur sa face externe, de stries ou de bourrelets. l.es premières phases du développement se passent à l'alrri Ic ce chorion, et, sourent mème arant que les aufs n’aient été expulsés du corps de la mère; cela, surtont chez les Nématores parasites. Le jeune emlryon, déja lien ébauché, reste enfermé dans sa coque; il attend que des circonslances favorables agissent sur lui, pour lui permettre le s'en débarrasser, et d'acherer son évolution. - Parfois, chez les Trichina et les Filaria par exemple, le chorion est relativement mince, et les œufs sont gardés plus longtemps par le générateur; aussi, Jes embryons ćclosent-ils dans les canaux sexuels de ce dernier, qui, par suite, est vivipare. Cette viviparité de certains Nématodes est due à une simple altération des phénomènes normaux de l'oviparité, olferts par les autres représentants de la classe. Parfois, les embryons ne se bornent pas à traverser leur coque; ils déehirent encore les lissus de leur mère, dont its se nontrissent.

11. Feuillets blastodermiques. - I maturation de l'ovocyte, c'est-it-dire sa transformation en ovule par lexpulsion des denx cellules polaires, sa férondation, et les premieres phases de la segmentation, ont donné lieu it un grand nombre d'importantes recherches. Ce sont, nn aflel, les phénomìnes présentés à cet égard par les Xématorles, et examinés dans tous leurs détails a cause des facilités d'étude offertes par ces animanx, yui ont servi de base aux notions possédées aujonrdhui. Les juenicrs, et en mène temas les principaux, des travaux pulliés sur ce sujet, sont dus il lil. viul lienerlen. 


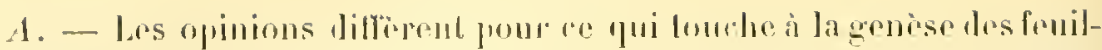

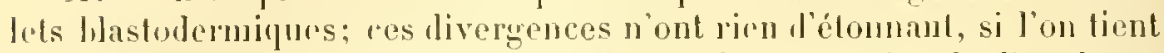
romple dis difficultés d’olservation. Autant la maturation de l'ovule, el sa lécondation, sont faciles à suive, autaul la poduclion des fouillets est malaisée à étudier, ̀̀ rause de la présence, autour de l'ouf, d’un 'horion épais, qui so déprose de suite aprés l’action lu spermalozölde. l'autre part, les arufs sont hop polits pour qüil soil possible d'enlever ce chorion, el de les rxamines à nu. Il laut, de Loule nécessilé, observer par lransparence, il travers la coque; et les recherchos en deviennent des plus délicates eldes plus longues. Aussi les contradictions entre les auteurs sont-elles fort compuchemsibles.

les premiers naturalistes, qui se soient oceuris de ce sujet, sont Bülschli el llallez; Lous deux conchuent à une gaslrulation, ellecture l'une maniere particuliere, voisine du procedé incurvant. Au contraire, (iiille, et aussi, sous certains rapjorts, 0 . Galeb, permellent d'allribuer lagenèse des feuillets à une plaumlation iudirecte. linfin, loutróernment, les travaux, eflectués par L. Jammes, aulorisent à considérer les premiers phénomènes de fúvolution embryonnaire les Nématodes comme se rapportant à une planuhation directe. Ces recherches sont encore inćdiles; leur résumé, non accompagné de figures explicalives, a seul été pullié dans les Comples Rendus de l'Académie des sciences; l’auleur a bien roulu, cependant. m’auloriser à donner les considérations suivantes, avec les lessins qui les accompagnent, el qui viennent de lui.

Sans doute, il est permis détendre, pour le mons a tous les Némalodes parasiles, les résultals trourés par l. Jammes; bien que les éludes 1) ce dernier ajent porté seulement sur les Oxyurns el les Iscaris. La ressemblance est telle, entre les ouls de lous ces animaux, autaul sous le rapprort de la taille que sous celui de la teneur en deulolécilhe, qu'i] en est de même, sans doute, jour les procédés gínétiques des feuillets.

Les observations de Bülschli ont áté faites sur le Cucullanus elegans; celles de Hallez sur l'A myullulu aceti. lans les deux cas, la segmentation amail pour eftol de froduire me morule, aplatie on un disque. Celte lernjère se déprime en son centre, s’ineurve, el prent l'asporel l'une coupe, 'pui derient de plus en phus profomde; la morule s'est aimsi couvertie, par le procédi incurvant, on me gastrule, Jont la cavilé dr dipuession reprísonte l’entéron. - Au délunl, la paroi le la morule se compose de drux plans cellulaires; lorsque la gastrule est complete, le plan intorne, qui limile directemut l'entéron, correspondrail à l'endo-

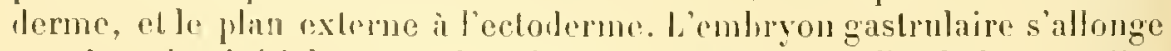
ensuile; drs iniliales mésodermiques se séfrarent de l'endoderme, s’insinucut entre hi et l'ectoderme, el se mulliplient. -- D'apres llallez, crs intiales sont an nombe de deux; chacume d'elles ne larife pas il se diviser en deux éléments; des quatre cellules ainsi produites, les deux antérieures fournissent le mésoderme vrai, el les deux postérieures don- 
nent les gramles sexuelles. Les deux antripieures se segmentent raphilement, el engendrent deux files de cellules, les bandelettes mésondermiques; inlles-ci śétendent le long lu corps de l'embryon, se prartagent longitudinalement en denx parties, of faconnent par ce noyen quatre corlons, qui deviendront les quatre landes musculaires. L'endorlerme persiste roume paroi de lintestin; la lonche dérive de l'rntéropore d'une maniere directe. - Les recherehes de Chatin sur la Trichina spiralis tendent á confirmer celles de lïitschli, et celles de llallez; avec cette différence que, chez celte espèce, l'entéropore se ferme en entier, et la bouche définitive se trouve obligée de se percer a nouveau.

Les diffieultés d'étule, mentionnées plus haut, ont été la cause de lerreur daus laquelle sont tomlés les trois auteurs précités. Au moment ou l'embryon se recourbe, la phase morulaire est dépassée depuis quelque temps, el les feuillets sont déjà ébanchés; les blastomères ont délimité sur place, par le procédé de la planulation directe, un protectoderme et un protendoderme. Seulement, ces phénomènes sont malaisés à voir, sans doute, dans les especes choisies par ces naturalistes comme sojets d'ohservation. - L'incurvation de l'emliryon est le résultat de son extension; ì mesure qu il sébauche aux dípens de l’ovule, il se rétrécit, ef s'allonge en mome temps. Aussi, alors que l'ovule tenait dans l'espace limité par la coque, l'embryon arrive-t-il à ètre plus long que le phus grand diamètre de cet espace; il est obligé, en conséquence, de se replier sur lui-même par ses denx extrémités; c’est ce fait, qui a été pris pour une gastrulation. Au moment où ce phénomíne se manifeste, le protectoderme el le protendoderme sont déjà délimités; el parfois mème, les premiers indices du corlome se sont creusés entre le mésoderme el l'enloderme définitifs.

Les recherches effectuées par Gï̈tte sur le Rhabditis nigrovenosa, et relles de Galeb sur lis Oxyurus, se rapprochent davantage de la réalité. Les études de ce dernier sont incompletes, mais non celles lu premier. - Les orules des Rhabditis se convertissent, par leur segmentation, en planules indirectes, constituées par un petit nombre de blastomères. L'eutéron se creuse, au milieu de la plamle, par l'écartement des cellules yui la composent, et qui se disposent antomp de lui sur deux couches roncentriques; l'assise interne est le protentorterme, qui donne les initialas mésodermiques, ot l'assise raterne le protectoderme. L'embryon s'allonge ensuite, se replie sur lui-uème en s"ineurvaut, car sa longruenr est plus grande que le diametre de l'espace limité par le rhorion; et la honche se perce à l'une de sos extrémités, pour laisser communiquer l'entéron avec le dehors.

Les observations, faites par L. Jammes, se résnment, du moins les principales, daus les leux données suivantes: genese des feuillets par la plamblation directe, et absence d'initiales mésodermiques. - Liovule, après sa fécondation, se segmente; il produit un grand nombre te petits blas- 
tomères, rassemblés en un amas compact, et disposés sur plusieurs conches. Lorsque ce nombre atleint une certaine limite, l'assise périphéripue régularise ses contonrs, et se distingue par la des conches plus profondes. Celles-ci composent le protendoderme, alors que la premiere répond au protectolerme. Ce deruier persiste comme ectorlerme, et ne subit pas d'autres modifications; par contre, le protendoderme se livise en mésoderme et endoderne, el se creuse l'un entéron. Au moment oì celte scission s'effectue, le mésolerme se trouve constitué par un chilfro assez grand de collules; il u'sst done point produit par une petite puanlité d’initiales. - Cepenlant, plusienrs fails, observés par l. Jammes, permettent de compremlre les descriptions se rapportant a une genese d'initiales. Parfois, certaines cellnles du protendoderme sont flus grosses que les autres, et paraissent, à cause de leur taille excessive, remplir un ròle génétique plus important pue leurs voisines. En ne s'arrètanl pas à ces senls phénomènes, el un olservant me grande quantité d'embryous parrenus à un même élat le développement, on s'aperçoil que ces faits représentent une excoption, et que l'existence de grosses rellules est des plus variables, à la fois dans le temps et dans l'espare.

B. - Les études de L. Jammes ont porté sur l'Oxyurus longicollis et sur l'Ascaris lombricoüdes. Les aufs, fort petits, sont entourés par un chorion épais, imperméable, à l'abri duquel l'embryon accomplit toules ses phases érolutives. La plupart des réactifs ne parviennent jas à le traverser. Les phases du développement, en leurs traits esseutiels, se correspondent dans les teux especes.

La segmentation est totale. Tout dialord elle est égale; puis, Iorsque les blastomères sont au nonlıre de huit, ou de seize, parfois nnème arant que ces chiffres ne soient atteints, elle devient inégale. La dissemblance le taille, qui se manileste alors entre les blastomères, et qui ne cesse J'exister par la suite, est le résultat d'une différence chromologique dans la scission. 'fous les blastomeres d'un mène ovule ne se segmentent pas en mème lemps; certains sont en avance, et d'autres en relard; et, comme Ia division s'effectue loujours de faron que chacun se partage en demx masses pareilles, il en résulle que cenx en retard sont deux fois, et mòme puatre fois, plus gros que les parties te cenx cu avance el déji scindés. l’inégalité de la segmentation lans lo temps anène donc, ici comme aillenrs, une inégalité dans l'espace entre les livers blastomères. La répirtition des frros ćlénents, les retardataires, nest nullement précise et réguliere; elle rarie d'un wrule à m autre, pris parmi renx qui remplissent nn meme utems maternel. Ces lilastomeres, fus voluminemx que les autres, ont à torl élé consilérés comne des initiales, ${ }^{\circ}$ est-à-dire comme des eellules a la silnation et is la fonction rigonrensement délerminées; la cause do lenr grossonr, el l’inégalité de leur répartition. conconrent de mème ì démontrer leur alssence complète l'importance particulicis. 
Les blastomères continuent à se diviser; par cela mème, d'une manière générale, leur nombre augmente, et leur taille respective diminue.

$$
310
$$

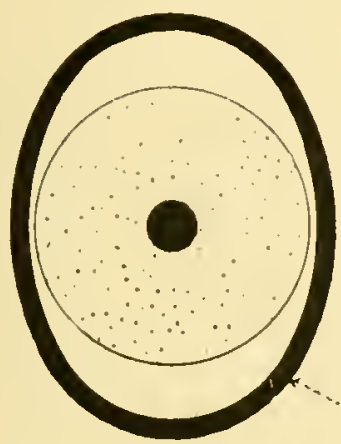

312

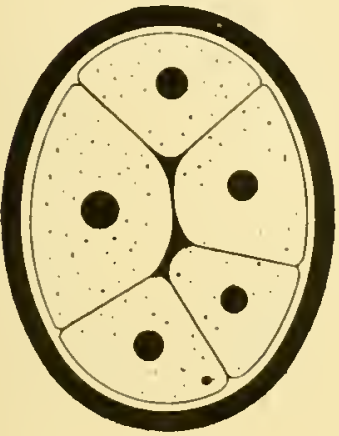

314

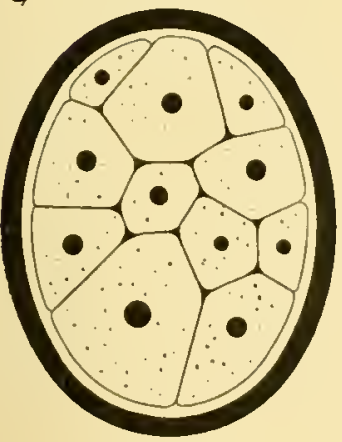

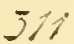
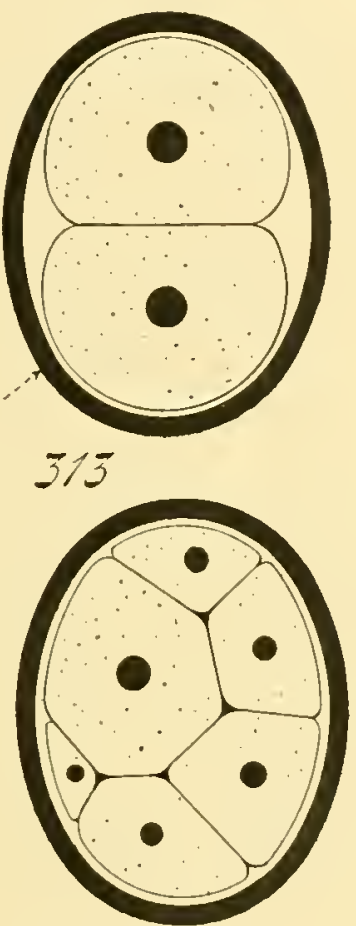

315

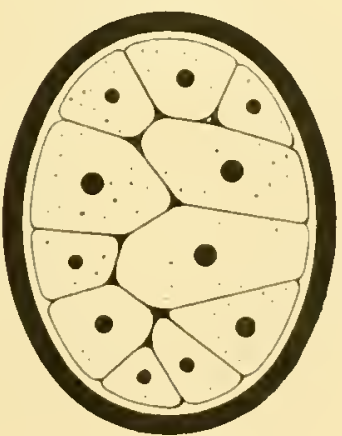

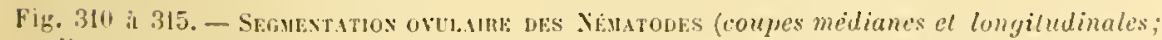
l'apres 1. Janmes). - lin 310, ovule non encore livixe, entonré te sun epais chorion. - Vin 311, division le lovule en deux hlastomèm. - lin 31?, 313, 314, 315, suite de celle tivision, abontissant it un! planulation directe; comme les hastomeres ne s:

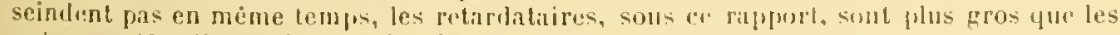
privoces. (Sur l'Ascriris lombricoüdes.) 
liovule, etant onformé dans um. roque impermóahe, nemprunte rien aux milienx extélieurs pour s'aceuoilre; la puantité drs éléments conslitulifis ne prot done augmentel quan détriment des dimonsions de ces mòmes éléments, qui derißnnent plus petits it mesure. Ce phémomene ne cesse d'exister jusquà l'instant on l'embryon est mis en liberté; et celle íclosion n'arrive qu'assez tarl, lorsque les principaux organes sout dejil formes.

Au moment oì les blastomeres sont encore en quantilé exigua, une petite cavilé sedélimile au milieu d'eux, et au centre mème de l'ornle; cet espace ne tarde pas il disuaraitre, car il est rapidement comblé par les ćléments qui l'entomrent. Il est permis de considirer cevile comme répomlant à une cavité hlastocusienne fort étroite, et de durée minime. - la scission continuant loujours à seffectuer dans lous les blastomires, ceux-ci finissent par chtre disposés sur plusieurs rouches concentriques; le nombre de ces dernières est d'abord restreint, mais il arrive jusqu'an chiffre de cing et do six. liembryon est alors converti en une planule compacle, composíe d'une gramle quantilé do cellules; cette planule s'est formée suivant le procédé dilect, par la segmentation do lous les lostomères, etpar la division constaute de chacun d'eux en parties égales, ou pen inégales. La ditférence de synchronisme, sous ce rapport, s'est éteinle peu à peu, à mesure que la planule s'éhauchait; et, lorsque cello derniere est complete, lous ses éléments sont dr lailles semblables, w peu s'en fant.

Alors sceflectue la délimitation des feuillets hastodermiques primordiaux. L’assise les blastonères périphériques régularise ses "untours; ses éléments, au lieu de rester globuleux, leviennent cubiques, s'accolent les uns aux autres par une plus large surface, el aplanissent leur paroi interne. Cette assise se distingue netlement, par ce moyen, les conches plus profondes, et rurésente le protectoderme. Liensemble des liastomeres intemes constitue, à son lour, le protendoderme.

Pendant que se manifeste celle diffirenciation, la planule s'allonge, et se rétrócit d'ume maniore correspondante, de facon a offrir toujours le mome volume. Sa lougueur devient plus gramle que le dianetre de l'espare limite par le chorion; aussi l'embryon est-il obligé de s'inllíchio sul lui-mème. el de se recomrler. Cotle cxtension contime is sexercer sans cesse jar la suite, et lembryon revel peu à peu son aspect délinilil: relui d'un corps allonge, cylindrique, replie un certain nombre le lois au seju le sa copur. Au fur et a mesure le cet allongement et le ce reploiement, les firillets définitifs se dúlimitent ì lem lour, et les organes s'ébauchent.

Des vides se creusent entre les blastomères du protemboleme, et dans l'intriem mème le l'emhryon; ces espares ne larient pas ì s'unir, et à former nne cavité, qui séfrare un corlon celluaire interne des éléments siluós sous le protecloderme. Cette cavilé est la première ébauche du colome, qui mail ainsi, suivant le procélé schizocolien. Le 
romlon iulerue est longilulinal, c'est-it-dire oricutio d'apries le graml axe lu jeune Vématode; il sélemd l'umr extrémilé lu corpls à l’aulre. I ses dem houls, il se confond avec des amas compacts de cellules du protemdoderme, qui ne se distingnenl pas l'opr, en ces regions, le celles du prolecloderme. Ce rordon eylinulrique se compose d"une seule assise d'éléments, lisposés suivant une surface complie, eylimbrique, aulour diunc cavilé centrale encore virluelle; il représente l'endorlerme définilif. Les aulos blaslomères du prolendoulerme inilial, séparés de l'ondoderme par lecolome, restent accoles à la face interne du protectolerme, el constiluent, de leur còté, le mésoderme.

L'embryon conlinue ì sallonger prulant que ces modificalions seflectuent; les éléments mis en cause continurut emx-mèmes à se mulliplier, à augmenler en nombro, el a diminuer en taille. Le culome s’amplifie de son còté; et ces hrois phénomènes concourent également, par le seul elfet de leur mécanisme, i disposer les collules mésoler. miques sur une scule couche. Le petil èlre se compose, en cet instanl de son évolution, sur une coupe transvrisale, ef en allanl de dohors en derlans: dune première assise cellulaire extorne, lo prolectorlerme; dine seconde assiso sous-jacenle a la fuécédente, le mésulermr; du culome; enfin, du cordon endodermique axial. Li conche mésodermique ne comporte denx rangées de cellules que dans des regions resheinles, correspondant sans doute à celles nu s'ébanchent les glandes sexuelles.

l.e cordon axial donne l’intestin. Son extrémilé antérienre, mie an protectoderme, s’épaissit par la multiplicalion de ses cellules, el produit un prelit bourrelel, qui sera la vósicule oesophagienne. A cause de l'union précédente, il est difficile de dire si le pluarynx provieul du jrotendoderme, ou si ses élémenls lérivent du prolectoderme; la présence, sur sa paroi, d'une cuticule semblalile à celle qui reconve le corps, serail une preuve en faveur de la seconde moposition. - Ia honche so perce par écartement des cellules; de müme la cavité intestinale; de mème rncole l'anus, qui uait mu peu en avant de l'extrémité postérienrr du corps. He son cóté, le mésoderme produit les filures musculajes el les gramdes sexuelles; les procidles histogénétiques le res loux formalions ne sont pas encore établis d'unc maniere satisfiasantr.

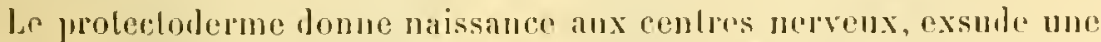

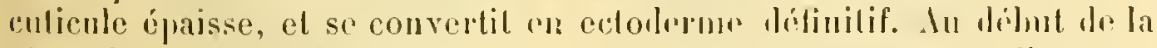

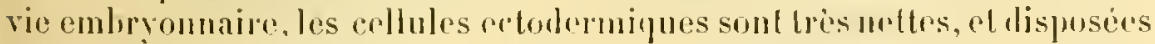
en ume assise épithéliale simple; elles perdeul colle structure jar la sude, émetlent dos expansions fibrillaires, qui s'entrebaront el s'anas-

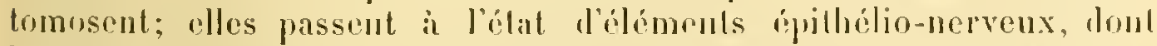

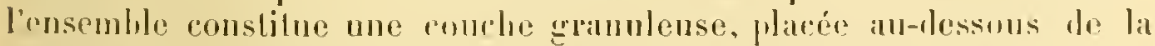
culicule. Celte couche posside la méme organisalion que les rentres ner"veux, qui proviennent d'elle, el lui restent loujours directement accolés; aussi, loit-on consilérer ces organes comme des épaississements 

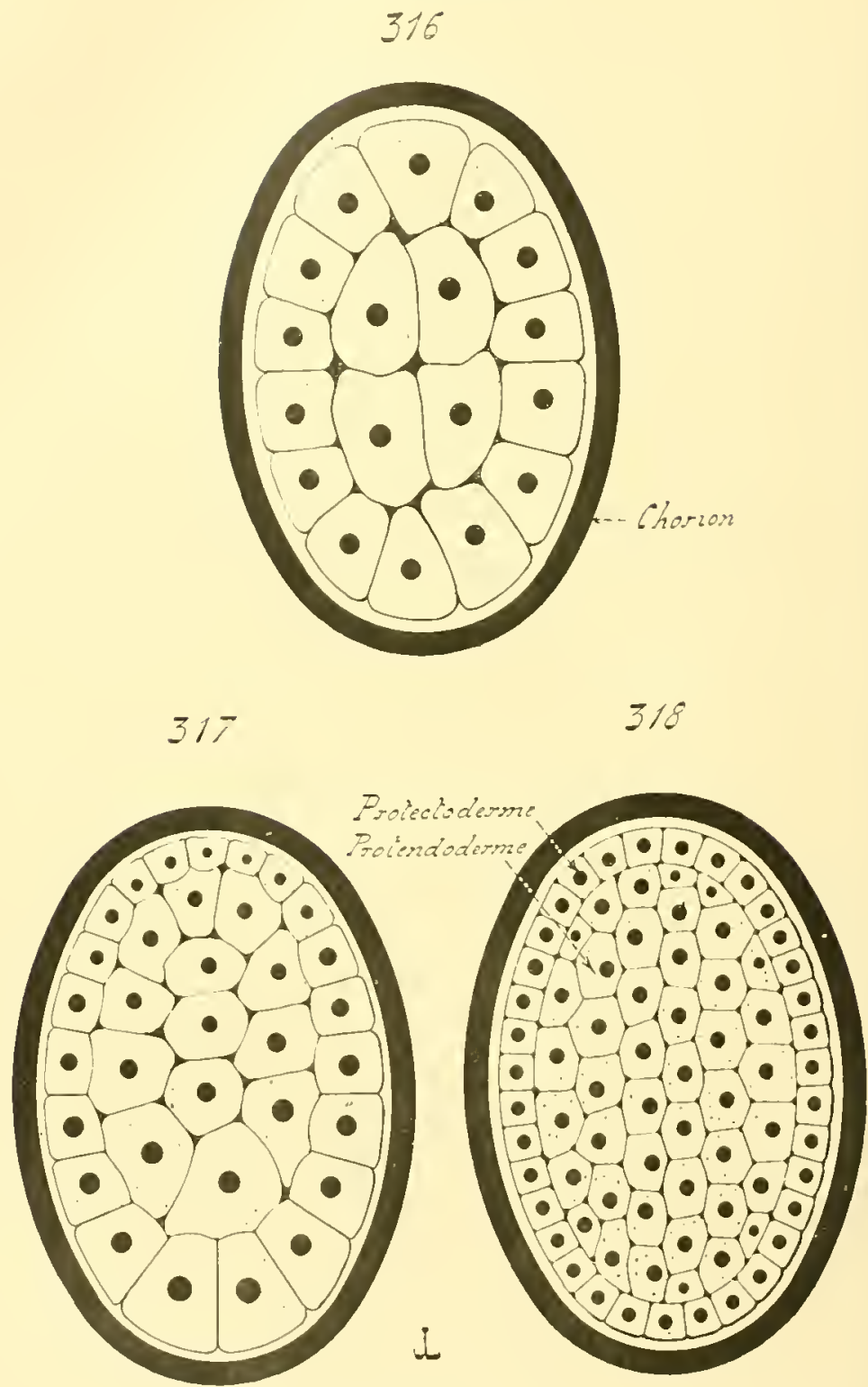

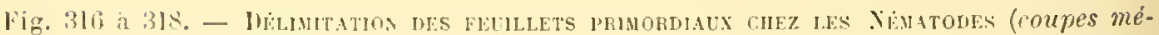
diunes el longiludinales; d'apris: 1 . Jitmmes, sur l'Ascaris lombricoüdes). - Ln 316, jeune planule directe, encore composie l'un pelit nombre de gros blastomèes; celte phase suit de pres celle de la ligure 315 . - lin 317 , les blastomères, continnant a se subdiviser, deviennent plus nombreux; en mème temps. les externes d’entre eux commencent a se distinguer des profonels, et it former une assise bien reconnaissalole. - lin 318 , ces

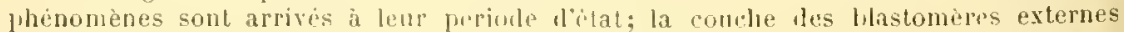
constitue le prolectoderme, alors yus: l'ensenuble de tous les clements internes represente le protendorlerme. 

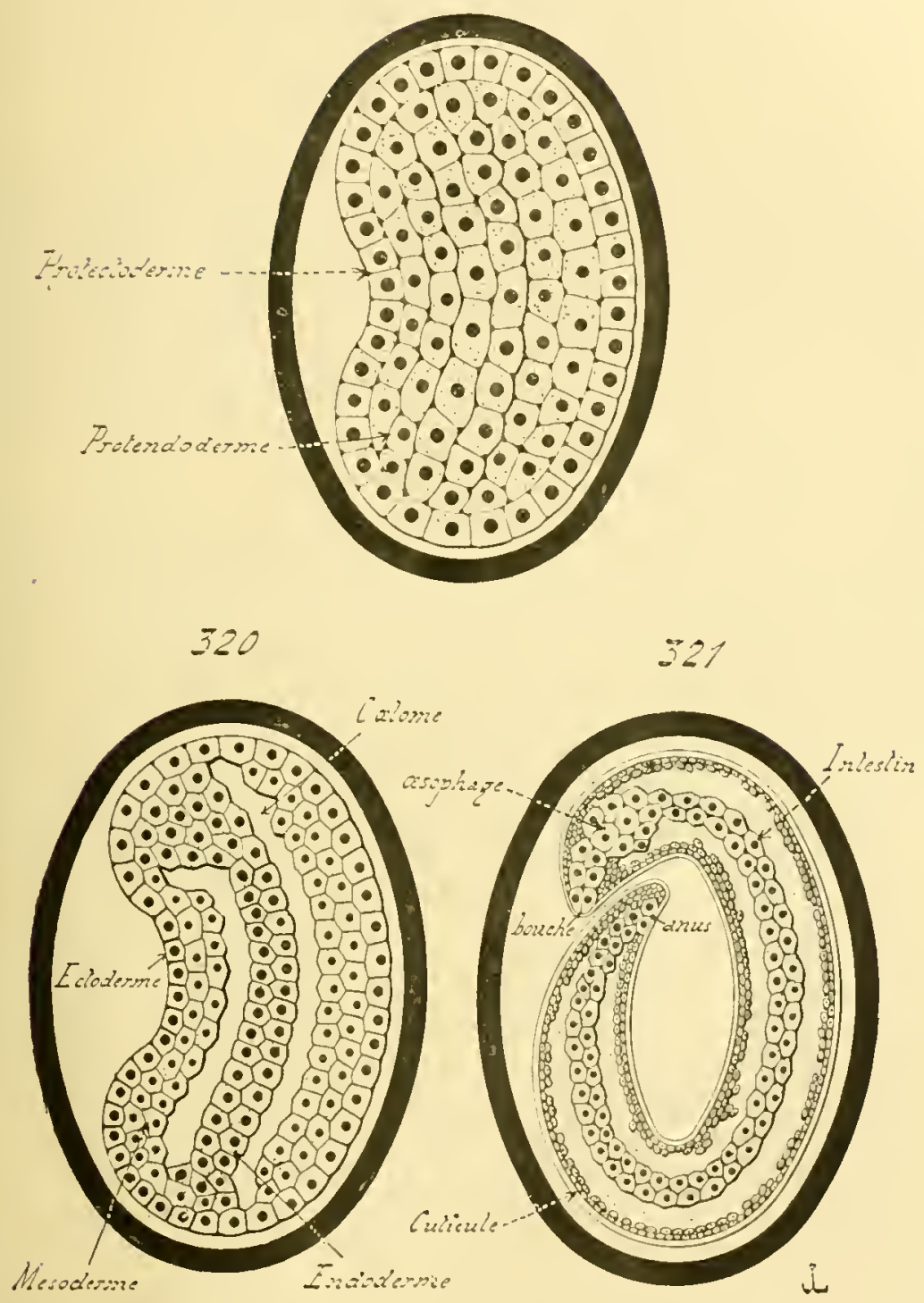

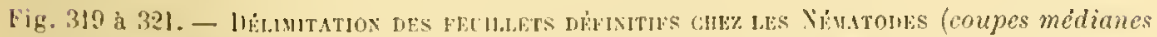
et longinulinales; 1’aples 1. Jammes sur l'Astraris lombricö̈les). - Lin 3t?, fulanule

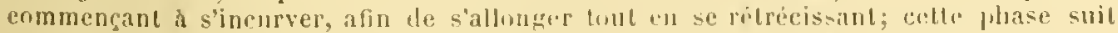
celle de la ligure 318. - En 320, l'ineurvation s'acentue; de flus, le culome se creuse dans le protendoderme. de maniore a separer du mesolerme le corlon endodernigue interne. - t.n 3?I, l'incurvation aboutit au reploiement de l'embryon sur luj-mème; les feuillets sont complets, et eommencent a jroduire les organes. 
lneaux de lassise gramulense, of relle demiere elle-mòme comme un centre nervenx dilus, répandu antom du corps entier. Ces faits ont óté démontrés récemmont, dune manièce complible, jar L. Jammes, sur les Ascarides el les Oxyuribles: Villot avait déjà sonpeonné leur existence, saus les préciser. pour re qui tient aux Condiidés.

\section{$\$ 3 . \quad$ Migrations embryonnaires.}

L.es Nématodes parasites sont malurellement les seuls à suliu des migralions lurant leur vie embryonnaire. Les olservations déjả faites, au sujet des phénomenos semblables prisentés par les frématodes el les Costodes, smit encore applical,hs iri. Ces transports sont passifs d'ordinare, c’est-it-rlire indéfrondants lu parasite, el subordonnés au mole he nutrition de l'hole; lenr succession, hien que rigoneusement délermince sons le rappont du passage l'un milien dans lantre, admet cependaut une cerlaine tolérance, qui, chez les Nématodes, parait êlre plus large yue chez les l'labliminthes.

Tous les Kimalodes nolfint pas des migrations d'une égale comprrxile; il esl promis de recommaitre, parmi eux, à rel égard, trois groupes principax. Les uns, lien que vaiment frarasiles, ne subissent pas des migrations an sems réel du mol, car leurs descendants vivent dans le mêne lote qu'eux. Les Nématodes lu second grompe passent, durant leur existence embryonnaire. daus des labibats intermédiaires. Eutin, les représentants du troisione grompe se rendent igalement dans des liabitats intermédiaires, toul comme cenx du second; mais ils offreut, en plus, cotte particularité de s'y reproduire, les individus vivant dans ces habilats ne ressemblant pas a ceux qui sont parasitos dans l'bôte. Ca troisicme cas comporte lone me vérilable hítéromopplie.

Premur cror pe. - Les migrations sont fort liunlées, s'etfechuent dans F'hôte lui-mème, el ne nécessitent pas des milieux iutermédiaires. Tel est l"Hxyurus vermicularis. Cel aninal habite l"intestin grèle de l'llomme, on on le tronve, dans certains cas, par centaines ef par milliers. Les lemelles pomlent leurs aufs dans la cavilé intestinale même; une parlie le ces derniers est rejetre au drolırs arec les excréments, el rentre dans le premier cas du second groupe; les aulres se développent sur place, mais suivant deux moles. Les ms, otils semblent être l'exceplion, évoluent dans la cavilé de löntestin, et s'y transforment en Oxynres adultes. Les anlres, entrainrs par les matières fécales de lihòte, s'arrètent dans le rectum el sur les hords de l'anus. Quelipues individus romplels sout aussi emportés de la mème façon; leur présence, autour le lorifice anal, déterminn des démangeaisons assez vives, plus intenses

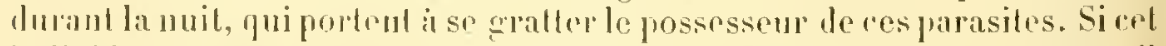
imdivilu est malpropre, s’il ne so netloie pas soigneusement les mains, il conserve des noul's dans les interstives des ongles, et les avale parfois en 
fortant accidentellement les duights à sa bouche. Le's arufs traversent alor's l'estomac, oủ le suc gastrique dissont leur cocon protecteur, et les embryons se convertissenten adultes dans l'intestin. Celte succession de transports, opérés sur un mème hơte, est surtout fréquente chez. les enfants: ce qui explique labondance de ces parasites, dans re cas particulier.

Srcond groupe. - Le second groupe contient les Nématodes parasites, dont les embryons traversent des halitats intermédiaires avant d'arriver dans l'hòte définitif, mais ne se reproduisent pas durant ees migralions. Ce groupe comprend deux types principaux : l'lıabitat intermédiaire est unique dans le premier, et double dans le secomd. Le premier type luimème comporte deux cas, suirant que l'habitat est un milieu, ou lien un hite. L'babitat double du second type se compose de deux hîtes successifs, ou d'un milieu et "lun hơle; seulement, tantôt le milieu est avant l'hóte dans la série des transports, et lantòt l'hòte est avant le milieu : doù trois noureaux procédés. - En somme, le second groupe comprend cinq cas : dans le premier, l'hahitat intermédiaire est un milieu; il est un hôte dans le second; un hờte suivi d'un milieu dans le troisième; un milieu suivi llun lıote dans le quatrieme; entin, il est représenté, dans le cinquième, par leux hòtes successifs.

l.e milien intermédiaire, qui softre dans les migrations du premier cas, est tantòtle sol, tantót l'eau. - L'Oxyurus vermicularis peut encore servir d'exemple pour le premier mode. Les cufs, rejetés avec les excréments, se dessèchent sur le sol, et résistent à cette dessiccation durant un certain temus, grice à l'épaisseur de leur chorion. Leur exiguité leur permet d'ètre soulevés par le vent, et transportés sur les corps étrangers. Sil en est, parmi ces derniers, qui servent il la nourriture de l'Hamme (légumes, liruils, ete...), ces deul's sont introduits dans l'intestin, el y achèrent leur développement. - l'Ascaris lombricoïdes, et l'A nchylostomum duodenale, sont des exemples tu second mode. Les adultes habitent l'intestin de l'Homme; leurs aufs sont rejetés avec les excréments de lhòte. Cenx qui, parmi ces oufs, sont entrainés dans l'eau par le hasaml des circonstances, ne périssent pas, el produisent les combryons dans leur intérienr. Si cette eau est cusuite absorbée par l'llomme, sans qu'elle ait été liltrée au préalahle, on bouillie, la coque chorionnaire se dissout dans le sue gastrique, les enuluyons sont mis en liberté, passent dans l’intestin, et y parriennent à l'état adulte.

Les parasites, pour le second cas, se rendent dans un seul habitat intermediaire, qui est toujours un hôte, jamais un milieu : telles sont les Trichina spiralis. Ces animanx paraissent capables de virre dans l'organisme de la phupart les Mammileres, et se transmeltent de l'un í l'autre par l'unchainement de nangenrs il mangés; lenrs hòtes de prédilaction semblent ètre les Rongeurs, et surtont les Rats. Les parasites ront sélablir dims les bandes de tissu conjonetif, qui mussent intre enx les 
faisceaux musculaires. s'y endystent, el vivent à l'élat latent rlurant fort longtemps, plusienrs mois, el mème plusieurs années. - Lorsquiun lial porten le parasilus est mangé par un autre Ral, les Trichines anliystées, qui sonl des emliryons déjà lien arancés, passent dans l’intestin de ce dernier, el quillent leur kyste, dont la paroi est ramollie par les sucs digestifs the l'hote; elles deviennent actives, achorent leur développement, et gagnent des organes sexuels. Les màtes fécondent les femelles, apris inoi ils meurent; les femelles vivent plus longtemps, et rejettent leurs petits, qui sout déjả complexes au moment oì ils sont pondus. Tous res phénomines se passent dans la cavité intestinale du nourel hite, oi dorienuent libres. par suite, les jennes embryons, yue les femelles promluisent par centaines. Ces emliryons, grìce à des piquants tont leur houche est garnie, percent la praioi intestinale de leur hôte, et, soit directement, soit en s'aidant do la circulation sanguine, péuètrent daus le lissu conjonclif intermusculaire, oì ils s'enliystent. - si, par la suite, le lenxieme Rat est mangé par un troisiome, le cycle recommence de noureau; si le liat est mangć par un Cochon, les mêmes phronominues s'eflectuent, el les jeunes Trichines vont s'enkyster dans la chair de cet animal; si, enfin, celte chair est absorbée, sans etre cuile d'une façon suffisante, par l'llomme, les Trichines se fécondent dans l’intestin le ce dernjer, el les embryons s'établissent dans les muscles du corps. - Le mème hóte porte done ces parasites, el successivement, en leux régions de son organisme : d'abord daus la cavité intestinale, et les Trichines sont alors des adultes quiprovienuent des kystes de l'individu mange; ensuite dans le lissu conjonctif, et ces dermiers sont los descendants des précédents.

Le troisième cas nécessite un double habital intermédiaire : un hôte suivi d'm milieu. Les Filaria sanguinis hominis en offrent un excellent exemple. Ces frarasites vivent dans les vaisseaux sanguins. Ils sont assez fréquents dans les pays chauds, où leur présence produit les maladies nommées éléphantiasis des Arabes, étéphancie, chylurie, hématochylurie. - Les milles férondent les femelles, et celles-ci pondent leurs embryons dans le sang lui-mome; ces demiers sont tros minimes, mais allongés, et semblables déjà à de pelits Nématodes. Si un Moustique vient i piquer un individu porteur de ces parasites, il alsorbe i la fois du sang et des embryons. Cenx-ci ne meurent pas daus l'intestin du Moustique; its y continuent leur développement, et parcomenl le tube digestif entier, on se rapprochant de l'anus. luenr hôte fréquente d'habitude les abords des mares el des cours d'eau; il y rejelle ses excréments, pui entraìnenl avec eux, i leur passage dans le rectum, les jeunes embryons de Filaires. Ces derniers ne périssent point dans l’eau, qui est alors leur milien intermédiaire; ils sont capables d'y vivre longlemps. Si cette ean est avalée par l'llomme, sams ctre fillée ni bouillie, les Filaires parviennent lans l'iulestin; elles traversenl alors la paroi inlestinale, et frassent dans les vaisseanx sanguins, où elles alteignent lenr élal adulte. 
Le quatrime cas comporte, loul comme le troisième. un dumble Labitat inlermédiaire; senlement J'embryon passe par un milien, arant d'arriver dans l'hòte qui doil le transmettre an porteur définitif. Tel est le Dracunculus medinensis, qui appartient, avec J'exemple lu cas précédent, a la famille des Filaridés; le parasite adulte vit dans le tissu conjonclif sous-cutané de l'llomme, oì sa présence délermine une inflammation très vive, accompagnée d'un éconlement de pus séreux. l'adulte est toujours femelle, el celte femelle est vivipare; les embryons sont rejetés au dehors, aree la sérosité qui sort de la plaie. - Ceux de ces embryons, que le lrasard des circonstances amène dans l'eau (lavages, lains), se développent seuls; ils existent ainsi pendant quelque temps, et c'est là leur milieu intermédiaire; mais ils périraient sans donte, s'ils y demeuraient longtemps, car ils ne trouvent point de matériaux nutrilifs suffisants. Ceux qui sont avilés par des petits Crustacés l'eau douce, par des Cyclops notamment, s établissent lans les lissus de ces derniers, y trouvent l'alimentation nécessaire, el vivent pendant une période plus longue. Si, enlin, ces Cyclops sont avalés par l'llomme, avec l'eau des boissons, ils sont tués el digérés par les sucs inteslinaux, mais non les embryons du parasile; ceux-ci gagnent rapidement des organes sexuels; les màles fécondent les femelles, at meurent ensuite. Puis, les femelles traversent la praroi intestinale, cheminent dans le corps en augmenlant beaucoup de taille, el ront, en délinilive, se fixer daus le tissu conjonctif de la peau. - Sans lonte, il n'est pas rigoureusement nécessaire que ces jeunes larves pénètrent au préalahle dans te corps d'un Crustacé; elles sont capables, selon toute probabilité, de passer directement de l'eau dans l'organisme Lumain, mais cette faculté ne doit exister que durant une période assez courte, consécutive à l'expulsion des embryons. Lintroduction dans un liôte intermédiaire est un moyen d'augmenter la durce de la période de vitalité.

Le cinquiène cas s'applique seulement aux Gordiedes. Ces Nématodes sont libres à l'élat adulte, el vivent dans les eaux fraiches des torrents; les aufs y sont pondus par la femelle, et les embryons y éclosent. Ils se mcuvent dans cette eau, et si, au cours de leurs pérégrinations, ils rencontreut des animanx aquatiques, tels que des larves d'Insectes, des Lymnées, ils percent la peau de ces ètres, et péuètrent dans leurs tissus, oì ils s'enkystent. Si, par la suite, et avant que les embryons ne menrent après une trop longue attente, leurs premiers hötes sonl mangés par des Poissons, les enveloppes des kystes se dissolvent; les larves sont mises en liberté dans la cavité intestinale du Poisson, qui est alor's le second hôte. Là, elles commencent par s'enkyster de nouveau dans la paroi mème de l’intestin, puris deviennent mobiles, se déplacent dans

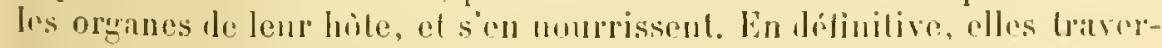
sunt la jean du Poisson de dedans en dehor's, lombent dans l'ean, el y achèvent leur déveloprement. 
Thosstène cinotpe. - Les Nématores, placés daus re groupe, passent dans un habitat intermédiaire, et s'y reproduisent, en surplus des actes générateurs effectués dans l'hôte détinitil : tel est le lihablonema inteslinalis. Ce parasite vit dans l'intestin grète de l'llomme; il est fréquent dans l'Extrême-Orient; sa présence semble contribuer, pour beaucoup, à aggraver la maladie nommue diurrlie de Cochinchine. - Les adultes parasites sont hermaphorlites; leurs cenfs fécondés sont rejetés au dehor's avec les excréments de l'höte. Lorsque ces aufs tombent dans l'ean, ils se développent, el les embryons éclosent. Ces derniers éroluent rajidement, et se transforment en petits Nématodes, pourrus de glandes sexuelles, ne quittant pas l'ean, ou la terre humide qu'ils habitent, et dont l'aspect diffère de celui présentí par les Rhablonema générateurs et eudoparasites. Les dissemblances sont telles, que ces descendants lihres étaient considérés autrefois, avec ceux des autres espèces de Rhabdonema, comme constituant un genre particulier, le genre lihabditis. Les Thabditis possèdent une capsule luccale chitineuse, dont sont privés les Rhabdonema. L'espèce qui dérive du Rhabdonema intestinale est le Ihabditis stercoralis. - Ces Rhabditis sont nnisexués, et non hermaphrodites; les miltes fécondent les femelles, ct cela toujours daus l'eau; les femelles poulent lenrs aufs, et meurent ensuile. Les inds produisent des emliryons, qui ne poussent pas très loin leur évolution, ne parviennent pas à aequérir des organes sexuels, el meurent au bout de quelques jours, si les circonstances les forcent à rester dans l'eau. Par contre, si le hasard permet qu'ils soient avalés, avec l'ean qui lins porte, par l'Homme, ils ne périssent point dans l'intestin de ce dernier, et s'y convertissent en lihalulonema hermaphrodites : d'oir le cycle recommence.

En résumé, les lihaludonema parasites et hormaphrodiles engendrent des Rhabdivis libres et unisexués, yui donnent à leur tour naissance à des Ihabdonema parasites el hermaplurodites, et ainsi de suite. Il existe ici une alternance de gínérations, puișue les descendants dillèrent de lenrs générateur's par le mode do répartition des éléments sexuels, et par leur structure générale. Mais cette surcession de phénonènes ne se produit pas toujours. Parmi les embryons qui proviennent d'un mème lihabdonema, tes uns se transforment en lihablitis, et les autres se modifient di:ectement en nouveaux Rhaldonema. Le passage par le type Rhabditis n'est donc pas nécesaire. En revanche, les observations, faites jusqu'ici, montrent que les descenlants des Rhabditis doirent se convertir en Rhabulonema, afin d'achever leur développement, et d'ètre capables te se rejroduire.

Cet exposé des migrations, suhies frar les Nématodes parasiles, est résumé daus le tableau suivant: 
l'REMEK GROUPE.

Poinl dhabilat

intermediare.

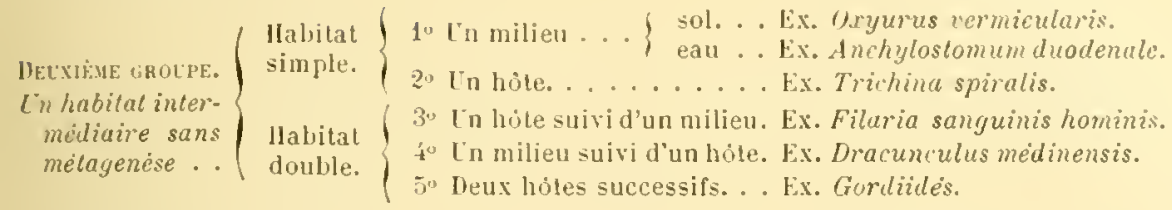

THOLSIEME GIBOTPE

Ln habital inler. médiaive ave" métayenese..
Ex. Rhabdonema intestinatis. avee $R$ habditis stercoralis.

\section{RÉSUMÉ}

\$ 1. Cossidératioxs géxérales. - Les Némathehminthes ne se reproduisent que par la roie sexuelle. Le développement des Nématodes est seul connu; il s'accompagne fréquemment de migrations chez les parasites.

\$2. Sexuluté et fecillets blistodermiel es. - Les Plénémathelminthes sont sans lonte hermaphrodites, arec jugenese mile; certains l'entre eux, les Chatonotus prar exemple, pondent dés wufs d'été et des aufs Iliver. - Les Nématodes sont unisexués pour la plupart; dans certains cas, comme chez les Filaridés, il existe une progenèse pour les individus màles, qui sont capalıles de féconder les femelles avant d'aroir achevé leur déreloppement. Presque tous les Nématodes sont ovipares; leurs (eufs sont entourés par un chorion épais et résislant, à l'alıri duquel l'embryon effectue les phases de son érolution. Les Trichina et les Filaria sont viripares.

Les procédés, employés p̧our la genèse des feuiltets blastodemiques, ont prèté à de nombreuses controverses. D'apries Bülschli, Chatin, et IIallez, la segmentation donne une morule plate, semblable it un disine, qui s"incurve, et se convertit en une gastrule. La gastrulation n'existe pas frour Girtte: les feuillets se délimitent suivant une planulation indirecte. Les études de L. Jammes montrent que la planulation directe est seule mise an cause, et qu’il n’existe point l'initiales mésorlermiques. Chaque ovule se segmente et se convertit en une planule directe. L'assise externe des blastomères de la plannle se délimite ensuite des éléments interues; ceux-ci constituent le prolentoderme, el la couche extérieure derient le prolectoderme. Le protendorlerme se subdivise ensuite, sur place, par la genèse d'une cavité jui lonne le colome, en endoderme interne et mésoderme périphérípue. Celui-ci s'accole à la face profonde du protectoderme, et se sépare complètement de l'enduderme; il fournit les fibres musculaires et les grandes sexuelles. l'en- 
doderme est d'abond reprisenté jar un cordou cellulaire, suspendu daus le calome, qui se creuse cusuite l'une carité intestiuale, et perce la houche arec l'auns. Le proteclorlerme se convertit en ectorderme définilif, coustitué par une couche d'áléments épillélio-nervenx, et produit au préalable la cuticule el les centres nerroux.

\$3. Mhgatrons emmbroxnares. - Ces migralions sout de complexilé diversesuivant les lypes; il est permis de rassmbler tous les faits acyuis, suree sujel, en trois groupes, lout le seconel comprend a sou tour ciuq cas. - Dins le premier groupe, il n'existe pas de migrations d'un habilat à un autre; tel est sonvent l'oxyurus vermicularis. - Le second groupe comporte l'existence de migrations, nullement accompagnées d'alteruance de grénéralions; il reuferme cinq cas. Dans le premier cas, l'unique habilat intermédiaire est un milien; tel est l'Anchylostomum duodenale. Dans le second cas, l'unipue habitat interméliaire est un hòte; lel est la Trichina spiralis. Dans le troisiène cas, l'habitat iutermédiaire se compose d'un lòte suivi d'un milieu; telle est la Filaria sunguinis hominis. Dans le ruatrième cas, l'habitat intermédiaire comprend un milieu suivi d'un hòte; tel est le Dracunculus medinensis. Enfin, daus le cinquième cas, l'habitat intermédiaire se compose de deux hôtes successifs; tels sont les représentants du genre Gordius. - Le troisième groupe est caractérisé par la double présence de migrations et le générations alternantes. Tolles sunt les espèces du greure lihabdonema, qui, parasites, se présentent sous la forme de Rhabronema, libres sous celle de Rhubditis, el se reprodıisent sous ces denx élats. 


\title{
EMBRANCIIEIENT' IDES TROCHOZOAIRES
}

\author{
CHAPITRE IX
}

DÉVELOPPEMENT DES TROCHOZOAIRES

\section{\$1. - Considérations générales.}

I. Caractères et classification. - A. Les Trochozoaires sont des Schizocolomicns, lout comme les Plathelminthes et les Némathelminthes; seulement, lorsque lour rorps est allongé, il n'ost jamais aplati, ni rubané, rt, lorsqu'il est cylindrique, il est souvent livisé en anneaux. Leur caractère essentiel consiste en la présence, dans les phases le l'évolution embryonuaire, et toutes les fois où le développement est dilati, d'une larve Trochophore. Cette larve offre trois particularités principales : elle possède une couronne vihralile oralr; son mésoderme, mésenchymateux à son délut, dérive d'un potit nombre d'initiales; enfin, elle est munie, d'ume manière hâtive, d'un appareil excréteur, composé de deux tuhes symétriques, les reins céphaliques ou prolonéphridies (Figures 322 et 32:3).

Cet appareil excréteur produit celui de ladulte. Ce dernior est également composé par une paire, ou par plusieurs paires, du lubes symétriques, assez courts, ouverts an dehors, qui conmuniqunnt, soit directement (et c'est lí le cas le plus fréqunnt), soit par osmose, avec le culome. Cette disposition est rraiment spéciale anx Trochozoaires, parmi los Schizocolomiens; car les canaux excréteurs des Plathelininthes, el des Némathelminthes, sont toujours au nombre de deux, et ollient l'aspect de conduits, simples ou ramitićs, yui parcourent le corps entier sans aucune solution de continuilé.

B. - L'embranchement des Trochozoaires est le plus riche en classes; il en renformo seize, qui se groupent, d’une façon naturelle, in plusieurs séries. Le tableau suivant renferme les noms dre ces classes, avec l'exposé de lenr's principaux caracteres. 
$1^{\text {er }}$ sous-embranchement, des Prétrochozoaires, ou des Trochozoaires inférienrs. - Organismo des plus simples, ne dipassant guère liatal do la larve Trochophore : cils vibratiles de la couronne oradr. conservés en leur place; mésoderme reprísentí jar quelques cellutes mésenchymateusess.

Ire classe; des Rutifires on Rotuteurs. - Caractères du sous-embranchement.

Qe sous-embranchement, des Eutrochozoaires, oudes Trochozoaires supérieurs. - Organisme parvenant ì une structure plus complexp que celle de la larve Trochophore : comronne vibratile orale disparaissant, ou conservée en recourrant des tentaculł's périburcanx; mésoderme mésenchymateux ou épillélial, mais offranl toujours au moins une région différenciée en un muscle.

$1^{\text {re }}$ seclion; les Monomériques, on Oliqomériques. - Mésoderme épithélial ou mésenchymatenx, contenant, suivant le cas, un oligocolome ou un polyculome, mais jamais livisí en segments réguliers. Néphrilies an nombre d'une paire, ou de derux paires au plus; sauf les cas l'atrophic particll. on de réluction.

$1^{\text {re }}$ série; des Holltsques, on des lélifères. - Comronne orale de la larve souvent élargie en deux lobes. Le mésoderme do l'adulte est toujour's mésenchymaleux; la région luccale est privée de tentacules vrais. Les appendices péribuccaux, que ces animaux possident parfois, sont des lacininres du pien ou des palpes aplatis.

$1^{\text {re }}$ sous-série; Jes l'némoldusores, ou des Mollusques inferieurs. Organisme relativement simple; lranchies absentes ou peu développées; celome parfois privo de cerur. La larve posside, dhabilude, plusienrs couronnes viluratiles transversales.

2 classe; dos tmphinenriens. - Centres nervenx composés d'un collier asophagien, émettant deux paires de nerfs longitudinaux. Un test composé ile spicules, soit isolés, soit rimentés par une gangue calcaire.

$3^{e}$ classe; des Siolénoconques. - Centres nervenx gronjés en ganghions pairs; une coquille homogène, el non pas consliture prar un assemblage de spicules; pas de branchies.

2 sous-série; des Eomounsotes on das Mollusques supérieurs. Organisme relalivemenl éleri; lranchiıs grandes; un polycolome formant un appareil irrigateur complexe. La larve ne prorte, d'ordinaire. que sa couronne vibralile orale.

4e classe; des tcéphules. - Région huccale confondue avec le corps; coquille livalve.

$\xi^{n}$ classo; des rónsteropodes. - Région lunceale délimitée sous la forme d'une tète; coquith: univalve, lorsqu'elte existe; pied ventral.

$6^{*}$ classe; des P'teropodes. - Diflirent des Gastéropodrs en ce pue 
le pied est róduit, parfois livisé en bras courts, et en ce que les épipodes sont voluminerix.

l'elseneer place ressanimaux parmi lrs Gastéropodes opisthobranchrs.

7 classe; des Céphalopodes. - Different des Gastéropiodes en ce que le pied entome la bouche et se divise en bras.

Qe série; des Textacelákes. - Région péribuccale produisant des tentacules, que recourrent, au moins dans leur début, les cils de la couronne orale.

$3^{\circ}$ sous-sério; drs Brachifères. - Régrion péribuccale non rétraclile. Lorsque le corps est eapable de rétraction, ce plónomène s'exerce sul l'organisme entior, et non sur la seule zone péribuccale.

Se classe; des Bryosoaires. - Brachifères calobrachiés, dont les tentacules renferment des expansions du colome, celui-ci étant simple. Tentacules directement insérés sur le corps, sauf le cas des Rhabdopleura; corps nu ou entouré diune loge.

$9^{e}$ classe; des Brachiopodes. - Hrachifères calobruchiès, dont le rolome, simple, envole des expansions dans les tentacules. Ces deruiers sont insérés sur deux rolumineuses languclles, nommées des lras. Le corps est entouré par une coquille bivalve.

$10^{e}$ classe; les Phoronidiens. - Brachifères hématobrachiés, dont le rolome rst double, divisé en une caviti générale et un système sanguin; ce dernier seul envoie des rxpansions daus les bras.

$4^{e}$ sous-série; des lihyncophores. - Région péribuccale rélraclile et convertie en une trompe.

$11^{e}$ classe: des Siponculiens. - Caraclères de la sous-série.

Qe section; des Polymériques. - Mésoderme épithélial ou mésenchymateus, contenant, suivant le cas, un oligocolome ou un polycelome, et divise, soit d'une manière permanenle, soil l'une facon temporaire, en segments réguliers. Téphridies au nombre de plusieurs paires; sauf les cas d'atrophic partielle ou de réduction.

$3^{e}$ série; des Pseunxibluss. - Division sogmentaire momentanée; disparaissant lorsque la larve passe à l'état adulte. Jamais plus de deux paires de néplurielies.

12 elasse; des Echimiens. - Lucune trare de segmentation sul la flaroi du corps; soirs en petil nombre, disposces autour des orifices naturnls.

$13^{\circ}$ chasse; des citernaspidiens. - Paroi du corps de l'adulte montrant les indicrs le segmentation; soies assez nombreuses, groupées en rames.

fe série; des Arisurs. - llivision segumentaire pelmanente. Néphrilies an nombre le plusienrs paires.

1 fo rasse: des Archirmnélides. - Amélirles il la structure relativement simple, privers de sobre et de ventouses. 
10 classe; des Itrudinés. - Annélides à la structure complexa, privées de soies et munies de ventouses.

$16^{\circ}$ classe; des Chétopodes. - Annélides à la structure complexe, privées de ventouses et munics de soies.

11. Généralités sur le développement. - Il est aisé de le concevoir, les phénomines du dévoloppement sont trìs variós chez las Trochozoaires, à cause de l’étendue de l'embranchement et do la dirersité des types qu'il contiont. Pourtant, dans leur ensemble, les procédés employés sont assez uniformes, ot se ramènent à quelipues cas principaux.

La reproduction asexuír est relativement rare; on ne l'a trouvér que chez plusieurs Annélides Chétopodes et la plupart des Bryozoaires. Tantôt elle s'exerce par fissiparité, et tantôt par gémmiparité. - La reproduction sriuelle est de heaucoup le mode génératour le plus fréquent. Les individus des deux sexes sont, d'ordinaire, semblaliles les uns aux autres; parfois, cependant, il existe entre enx les lifférences de forme assez grandes, et les Roliferes, arec quelques Echiuriens, montrent des exemples fort nets d'un tel dimorphisme.

La fécondation est le plus somvent exterme, sanf pour les ètres virant sur la terre, ou possédant une organisation complexe (Mollusques Céphalopodes, Hirudinées, etc.). Les aufs sont d'babitude paures en vitellus nutritif, et subissent une segmentation totale, qui aboutit, soit à une blastulation, soit il une planulation directe on indirecte. Les Mollusques Cáphalopodes sont les seuls ì avoir des arufs télolérilles, munis d'un amas vitellin volumineux, et d'une petile ciratricule.

Dans le cas oì le deutolicithe est rare, les feuillets sont engremtrés par une gastrulation, ou par une planulation; mais les réserves alimentaires disparaissent avec rapidité, et le jeune emlryon sorl de ses enveloppes avec l'aspect d'une larve Trochophore. Cette derniire posside un mésenchyme primaire (dont plusieurs éléments proluisent le mésoderme défnitif), deux néphridies primorliales, el des cils vibratiles ectodermiques. Si le deutolécilbe est trés abondaut, J'embryon ́volue suivant le mode planulaire, et reste enfermé, dans le chorion de l'ruf, jusqu’an moment oủ il approche de l'état parfait. Les feuiltuts premnent naissance sur place, aux dépens des blastomères déjà formés; et les

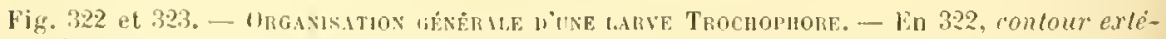
ricur, montrant la houche, l'anus, la plaque éphalique, el la couronne vibratile orale. En 323, coupe mediane et longitudinale, aver perspective, wue par li tranche; entre l'intestin. que limile l'endoderme, al l'ertoderme qui constitue hil surface du corps, st: trouve une cavité, le culome primitif, oi sont places les néphridies primordiales avec les premiers élements du mésolerme. Certains de ces derniers, jrecocemut eonvertis en cellules conjonctives el conjoructivo-museulatres, composent la part fonclionnella dı mésenclıyme primaire; les autres, situes autour de l'anus, avee les néphriılies, conservent toule leur capacité de multipliration, et sont des initiales mésodermiques, chargixes de donner le feuillet moyem lle lorgansme drfinitif. 

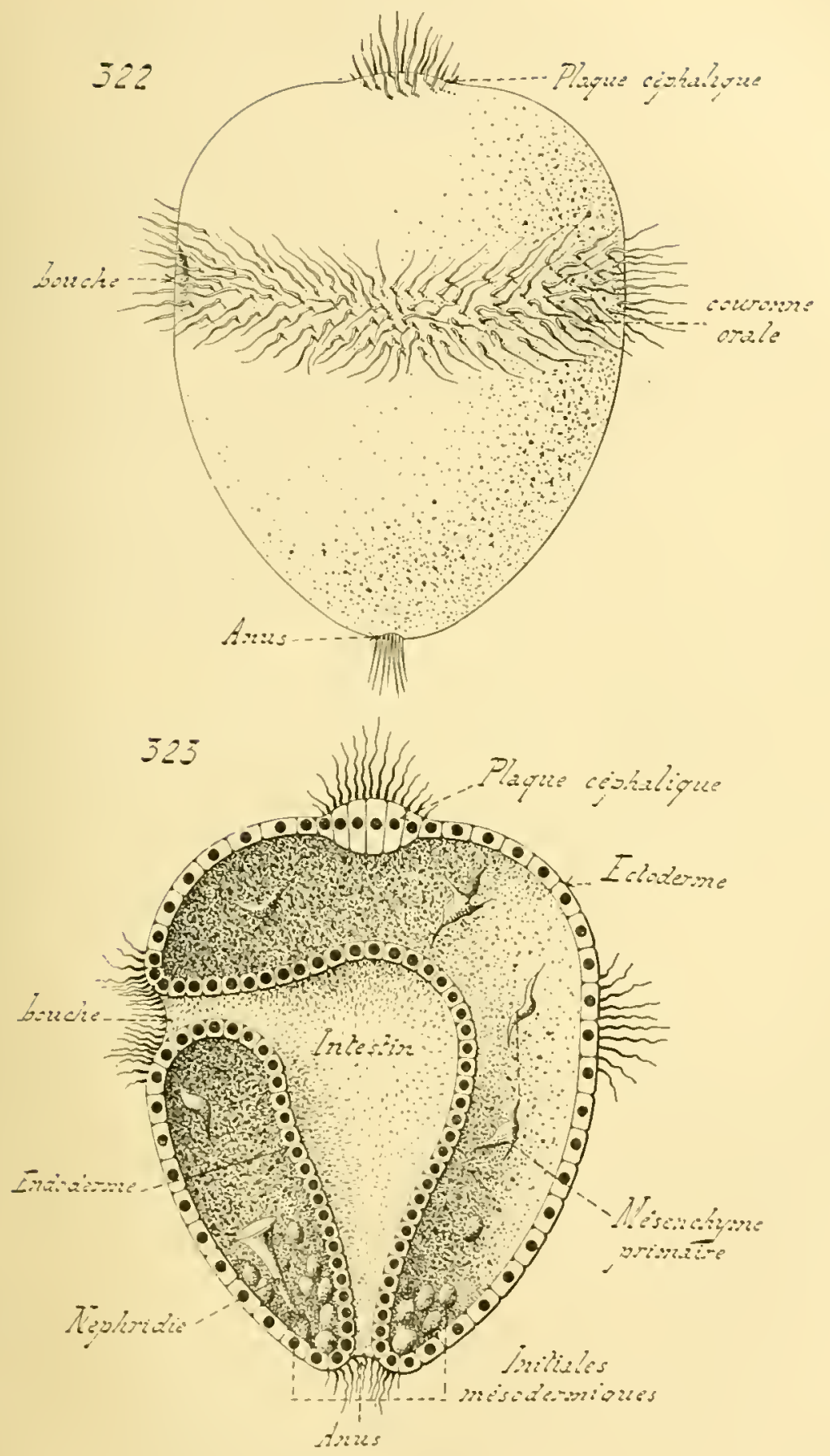

Fig. 322 el 32'? 
ébauches mésodermiques sont représentées, dès leur apparition, par un grand nombre de cellules.

Le mésoderme dórive loujunrs du protendoderme. Cie dernicr commence par envoyer lans la cavilé hlastocutienne, entro lui et le protectoderme, plusieurs cellules, yui se converlissent, jour la phupart, en ćléments conjonctifs, et en libres conjonctivo-musculaires : c'est le mésenchyme primaire les Trochophores (Figures 324 ì 330). Certaines de ces cellules, les demiires venues d'habitude, sont phus grosses que les autres, el se multiplient activement, pour produire le mésoderme délinitif. Il est donc promis de considérer ce dernicr comme une partic du mésenclyme primaine; it prend un accroissement considiralıle, alors que les autres régions, converties hàtivement en éléments dillérenciés, Jemeurent romme elles sont. Ces collules génétiques sont les initiales mésodermiques: leur nombre est variable, el réduit à deux l'ordinaire. Ouelle que soit leur quantité, elles se disjosent souvent en deux grompes symalriques, placés d'un coté ef the l'autre de la ligne médiano. Ces groupes, en grandissant, ef sareroissant par l'augmentation constante dı chiffre de leurs éléments ronstilutifs, se changent en masses cellılaires, les bandelettes mésodermiques, allongées suirant l'axe longitudinal du rorps, et placries de prarl ef d'autro de l'intestin.

Ces bandelelles sont tris nelles dans les larves les l'olymriques; elles le sont moins chez les Monomériques. Celte diffórence lient à ce qu'elles doivent s'allonger, dans l" premier eas, pour se diviser en seg. ments; alors quancun phénomine semblahle n'existe ailleurs. Une antre cause de rotte dissemblance est donnée par la fréquence le l'évolution mésenchymaleuse du mésoderme des Monomériques; les éléments mésodermiques se séparent les uns des autres, on se groupent en petits amas, el ne formont poinl, lans la plupart des cas, dew bandelettes romparables i celles des Anurilides.

La genise du mésenchyme primaire, ef celle des iniliales, sont fort distinctes dans tous les cas oủ le leutulécilhe, itant peu abomlant, permet i l'ovule de produire les feuillets d'aprè le modo gastrulaire. I'ar contre, si le vitellus nutritif existe "n assez grande quantité pour que le procédé planmaire soil amployí, le mésenchyme primaire ne se montre pas; son apparilion est omise dans le conrs des phínomines ivolutifs. Le protemlorlerme se borme i domner naissance, soil am injliales, soit mème, lorsque l'alırériation du développenent est poussée à l'extrème, anx bandeleltes, on ả un gronpe compact de cellules mésolermiques.

Le feuillet moyeu des Trochozoaires est done, dans son type primilif, un produit d'initiales qui dérivent du protendoderme; partant, il est

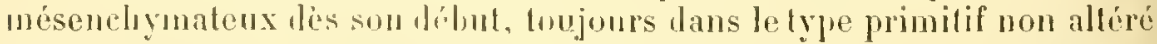
par un deulolécille abmmlant, et le colome qu'il contient correspond a un schizocule. Il se héveloppe ensuile, fantôl d'après le mode ípilliélial, 
Lantòt d'après le mode mésenchymateux, et jamais suivant les deux à la fois. le jrocédé épithélial est plus fréquent que l'aube chez les Polyméripues; les Monomériques offrenl l'imrorse, et, parmi ens, lis Mollusyues présentent un exemple caractérislique d'érolution mésenchymateuse (Figures 33 I i 336 ).

Les organes prennent ensuite naissance aux dépens des feuillets. Les centres nerveux sont toujours, chez l'adulte, composés de deux parties: le cervean, ct une moelle, placée sur la face ventrale du corps, tantôt simple el lantoil divisée en un nombre variable de ganglions. Il semble, d'apres les faits acquis, que ces denx parties se forment indépenlamment l"me de l'aulre, et que leurs ébanches sont impaires el médianes dans l'origine. Elles deviennent doubles par la suite, a moins qu"elles ne le soient dès lenr apparition première, dans le cas d'embryogénies condensées.

L'moloderme produit la paroi épithéliale du tube digeslif et le ses annexes, sauf celle qui aroisine la buuche el l'anus; ces lernières régions, pharymx et rectum, lérivent en etfel de dénressions ectodermiques, du slomeon et du procteon. - Le mésoderme engendre des organes divers, dont les principanx sont la trame conjonclivo-musculaire lu coups, les nipluidies, et les glandes sexuelles. Sil érolue suirant le mode épithélial, il se livise arec netleté en somatopleure el splanchnopleure: mais, Jans le cas contraire, il se dispose sous l'aspect d'un lissu destiné à comher les vides inlerorganiques, ot creusé lui-mène de lacunes qui se groupent souvent, surlont chez les Mollusques, en un appareil circulatoire. Le culome est alors leprésenté frar l'ensemble de ces lacunes; tandis que la cavité générale les mésodermes épithéliaux est un rasle espace, que limile la proroi du corps, et dans laquelle le lube digestif est comme suspendu.

\section{\$2. - Sexualité et éléments sexuels.}

I. Sexualité. - Lunisexualité et l'hermaphrodilisme sont reprósentés cliez les Trochozoaires. Il n'existe, an sujel de lenr réparlition, aucune rigrle lien précise; si ce n’est que les lypes inférieurs, les julus simples comme structure, sont généralement unisexués, alors que les aulres, el d'orlinaire ceux adaptés a me vie lerrestre, sont hermaphrodiles. Cet hermajhrodilisme est somvent incomplet, car la disposition des organes ist lelle, que chaque imlivilu est incapable de se fécomler lui-mène.

Certans Trochozonires oflrent des particularilés lenant an dimopphisme srouel : tels sont les Rolifères, ceplains lichimriens, phusicurs Mollusyurs, el diverses Anmólides. - Les Rolilieres millas sont phus pelits J'orlinato que les femelles; leur tuhe ligeslif est privé l'onverlures

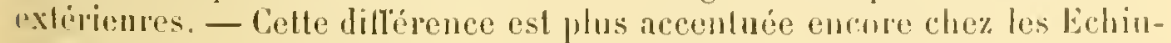

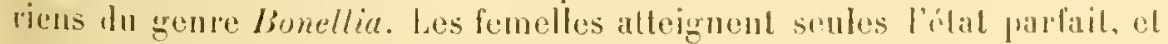




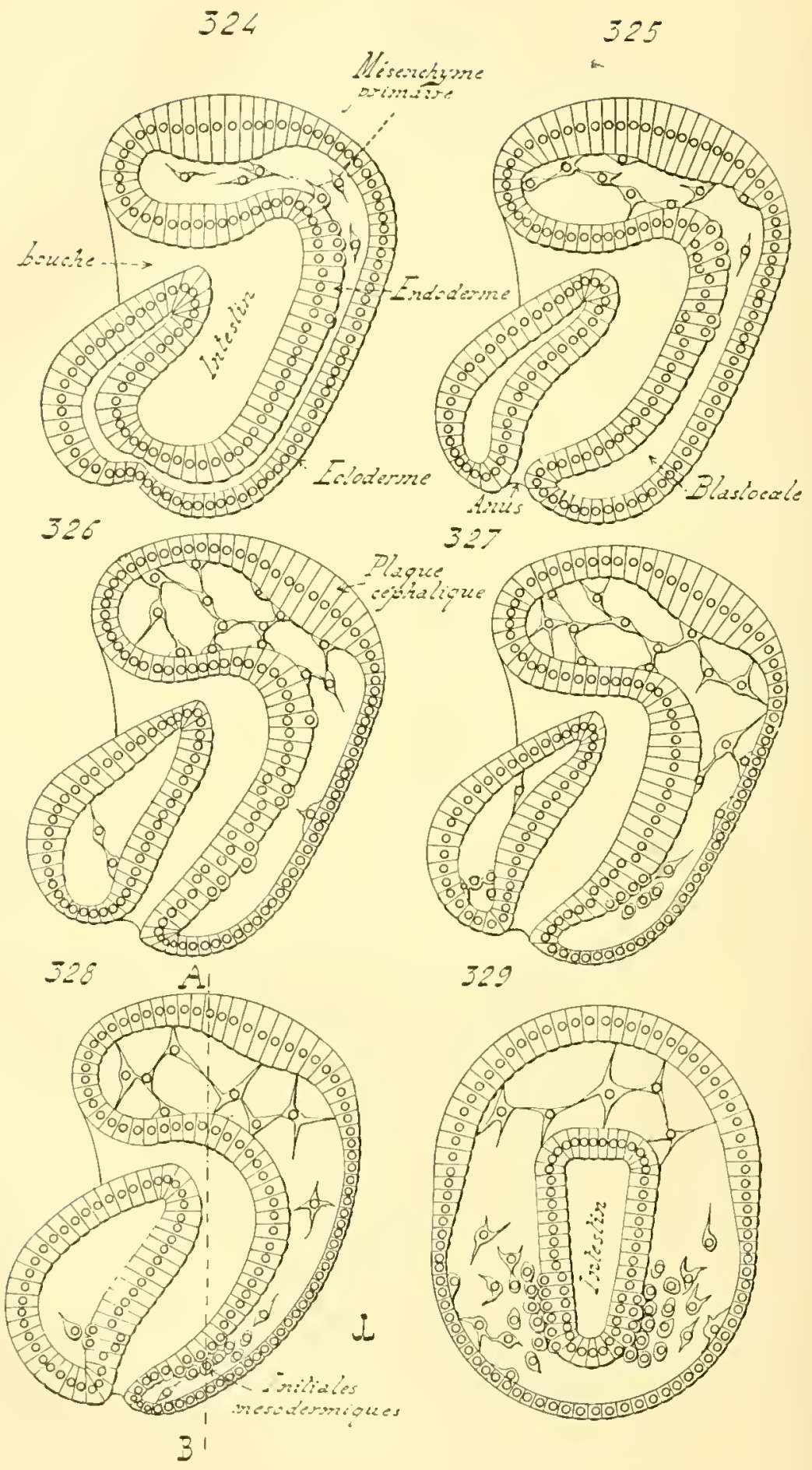


leur organisme devient alors fort complexe; les mâles sunt très petits, microscopiques, virent en parasites dans les voies sexuelles des femelles, et se réduisent ì me minec paroi du corpis, qui entome un testionle volumineux.

Les flhénomènes présentés, sous ce rapport, par rerlaines Annélides, sontplus remarquables, car ils se compliquent l'une reproduction asexuelle par fissi parité. - Tel est l'Autolytus prolifer; mn individu délerminé, privé de glandes sexuelles, lonne naissance par le prorédé fissipare, et dans la région postérieure de son corps, à un lesrendant sexmé. Colui-ei se distingue de son générateur par sa forme générale, et surtout par cełle

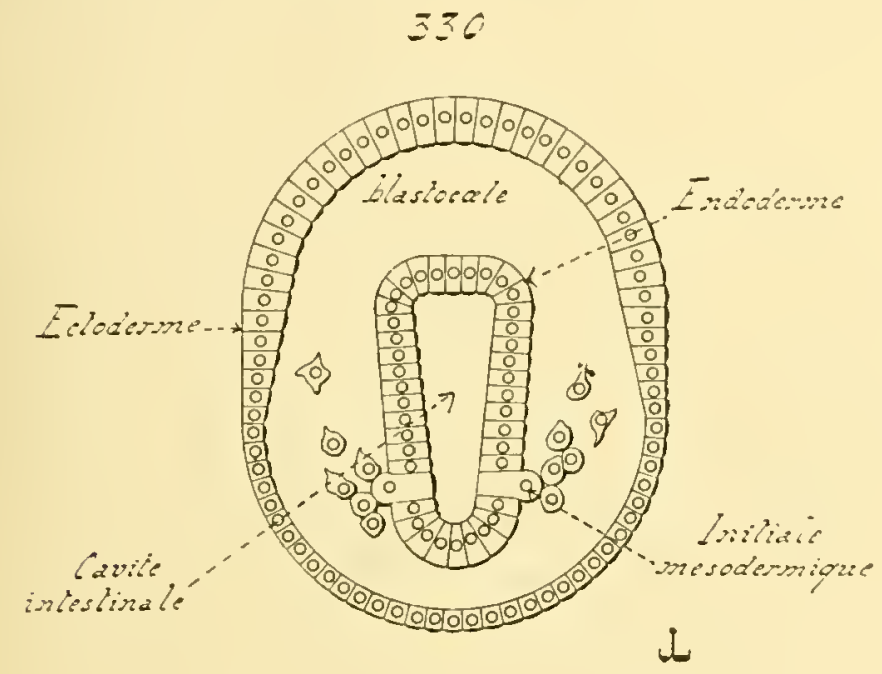

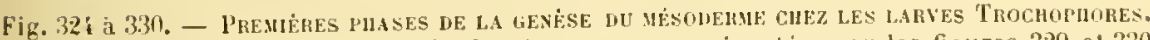
- Loupes midianes ct longiludinales; les coupes roprésentées par les figures 320 el 330 sont orientées perpendiculairement aux autres, "jui passent par la bouche ct l'anus des larves. Ces figures sont dressces d'après l'évolution lu Phoronis Sabaticri). - En 324 . jeune larve, prise à une plase qui succède a l'itat gastrulaire, et fait suite à la disposilion signalée par la figure 365 ; les premiers élèments dı mesoderme naissent ulı protendoderme, lejà disposé sous la forme d'un endoderme peri-intestinal, et non loin de la houche; ils composent un mésenchyme primaire. - En 325 , cette évolution continue, en gagnant d'autres éléments du protendoderme; l'anus fait son apparition. - En 320 ct 327 , la genèse des cellules mésollermiques continue à s'efTectuer. les zones génétiques: se rapprochant de plus en plus le l'anus. - En 328 , la production ves éléments du mésoderme est surtout active aux environs de l'anus; seulement, alors que les prenièrex cellules subissaient des morlifications histoginitinues, perdaient jar la toute capacite de multiplication, et composaient un mésenchyme primaine dilfírencié, les dernières engendrẻes conservent leur puissauce génélique, et donnent les initiales mésolermiques. — In 329, coupe menée suivant la ligne $\Lambda$ li de la figure 328 , et destince á montrer que les principales régions formatrices des initiales mésorlermigues sont au nombre de lleux. - En 330, même disposition, montrant en surplus quo les cellules du protendoderne, chargées de produire les initiales, sont sument pus grosses que leurs voisiues.

le ses parapodes. De plus, ces descendants, étant misexnés, ditrèrent les mus des autres survant lit nature de lear sexualité. Les dissemblances 
sont mème si gramles, que lon avail classé autrefois ces deux sortes ditres dans les genres dilférrnts, en donnant anx individus mailes le nom de Jolyhostrichus Mälleri, el aux femeltes crlui de sucenereis helyolandicu. En ríalité, ces animaux sont des lutolytus prolifer, et appartiennent an rycle los zénérations de co dernier. - Les faits sont tout aussi complexes chez d'autres Anmélides, appartenant au gempe Véreis. Ces derniores rampent d'ordinaire parmi les algues, el sur le foml de la mer. Au moment où la sexualité va se montrer, certuins individus agames prorluisent, par lissiparitó, des descendants considérés, antrefois, comme composant un groupe particulier. le genre Heteronéreis. Parmi cenx-ci, les uns sont màles, et los aulres femelles; les premiers liffèrent des secondes prar leur aspect. Celte alternance de générations a pour but de faciliter la rejuroduction. Los descendants sont en eflet mumis de palettes matatoires, que leurs parents ne jossedent point anssi développées; ils se déplacent rapidement par leur moyen, el disséminent leurs germes sur uII plus grand espace.

Un dimorphisme sexuel se présente parfois rhez plusienrs Mollusques Gasléropodes; mais il est pen prononcé, et n'acquiert jamais l'importanre de celui des Céphaloporles. - L'un des liras du mile, chez ces derniers, se transforme, en s'allongeant ut s'épaississant, pour servir de réceplarle aux amas spermatiques. Ce bras moditic est lit hectocotyle, et les anciens naturalistes lo considéraient comme un animal complet. Lors de l'aceouplement, le mile introduit son hretocotyle dans les roies sexuelles de la lemelle; farlois, cel appendire est cajable de se séparer du corps de l'individu qui le porte, le virre ainsi pendant un certain temps, et de se monvoir prar ses propres forces. Ce dernicr phénomène, que les naluralistes d'autrelois avaicnt olservé, el qui les avait induits en erreur, est offert par certains Céphalopodes appartenant à divers groupes : l'Aryonaula aryo, le Philonexis carence, le Tremoctopus violaceus. - Parfois le rimorphisme sexuel ne se borue pas il lhectocotyle seul; tel est I'Argonauta argo, dont les femellos possélent unr copuille externe, alors que les males sont constamment fípourvis d'une telle enveloppe.

1I. Éléments sexuels. - Les spermalozoïles des Trochozoaires otlient, en général, l'aspect habituel : celui d'éléments, composés d'une yucue, et dune líte épraissie contenant le noyau. Les seules particularités intéressantes, que ces corpuscules fécondateurs montrent parfois, sont présentées par les llollusques Céphalophores.

Cortains Gastéropodes, ot notamment les prosolmanches nuisexués, contiennent deux sortes de spermatozoüdes dans leur testicule. Parmi ces derniers, les uns possèlent lallure normale; les aulres sont gros,

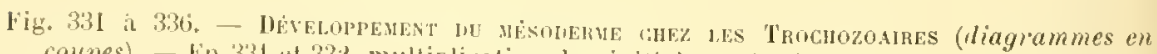
coupes). - bn 331 at 332, multiplication des initiales mesodermiques, représentées par des cercles noirs; ces ligures résument les précéclentes, abstraction faite des élèments 

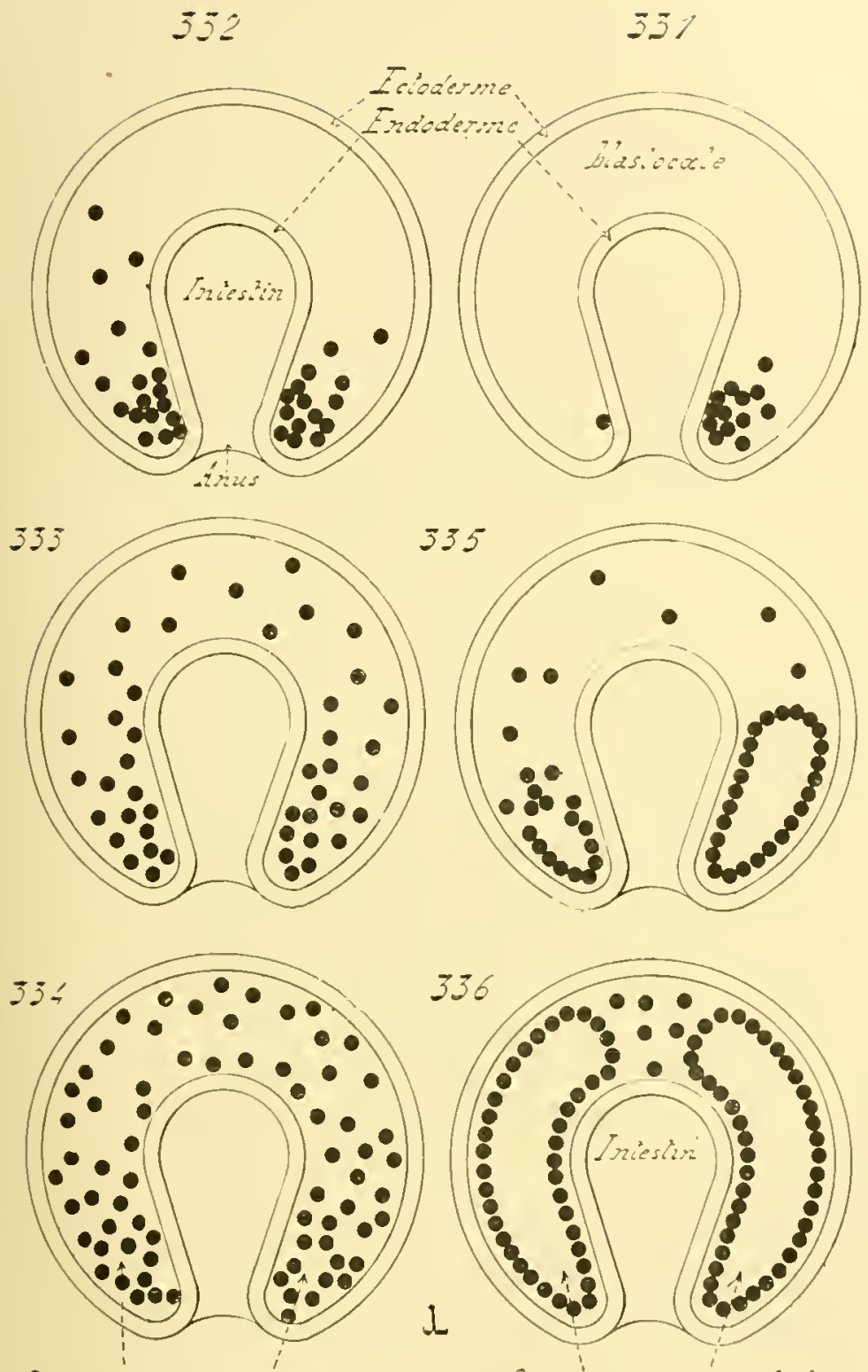

Scaigcealone mesenchymeleux

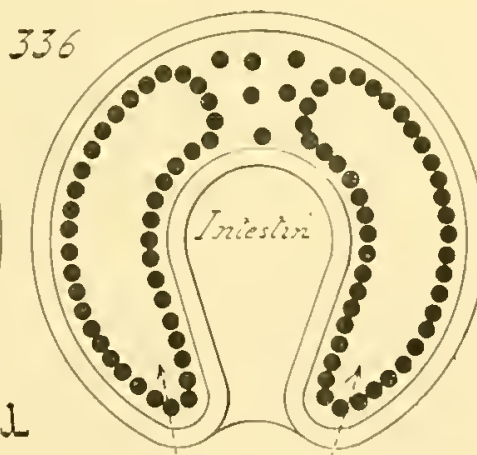

Schiscralome s'sithelial

differencies du mesentlyme primaire. - En 333 et 33 t. developpent mésenchymateux du misorlerme. - Les cellules issues des initiales, tout en augurentant leur nombre et se diflerenciant, conservent la disposition mésenchymatense primitive. - lin 335 et 3331 , developpenent ejpithelial du mesoderme. les cellutes issues des initiales, tout en angmentant leur nombre el se dilférenciant, se groupent en assises épilbeliales, rigulières, yui s'aswablent en deur vesicules symetriques; ces dernieres grandisseut d'une manière "gale, en s'etendant dans le corps entier. 
allongés, et portent, pour cette raison, le nom de spermatosoüdes vermiformes. Cenx-ci sont incapablus d'assurer la fétondation; ils entrent en dégénérescence, et se détruisent, au moment oủ ils paraissent alteiudre leur maturité. En comprant ces Ciastripopodes unisexués aux lypes hermaphrodites, il semble que les élruments vermiformes correspondent à des ovules, dont le léveloppement scrail incomplet.

Les nolions précédentes, sur les hectocolyles des Céphalopodes, dénotent l'existence de spermatophores chez ces derniers. Ces corps sont des tubes cylindriques, alhugés, dont une extrémilé contient l'amas spermatique, entouré par une memlirane épaisse; l’autre extrémité renferme une ligge emroulée sur elle-mème en spirale, el faite d'une subslance capable de se gontler dans l'eau. Cirice à son hectocotyle, le mâle introduit ses spermatophores daus la cavité palléale, et à l'entrée des vojes sexuelles, de la femelle; l'ean de mer, qui cmplit celle cavilé, gonfle la matiere de la spirale. l'ar ce moyen, cetle dernière se détend à la façon d'un ressort, et refoule à mesurr l'anas spermatique dans l'intérieur de l'oviducle.

L'aspect des ovules est maturellement très divers, suivant les groupes des Trochozoaires; les variations tiennent surtoul ì la yuantilé du dentolécithe conlenu dans le vitellus. Un certain nombre de fails remarqualıles sont pourtanl offerts par les enveloppes ovulaires. - Fréquemment, chez les Mollusijues Céphalophores, les glandes, annexées aux organes sexuels, sécrètent un mucus abondaut; ce dernier est chargé, soit de fouruix, à chaque auf, une enveloppe chorionnaire jlus ou moins épaisse, soit d'engluer tous les ovules cu une masse, le cordon nidamentaive, de disposition fort variable suivant les genres. - Les autres Trochozoaires sont privés d'un tel chorion d'habitude, à moins que l'on ne considere comme tel la membrane vitelline, parfois fort épaissie; mais ils offrent assez sourent un follicule. Les ćléments folliculaires dérivent toujours de l'ovogonie au mème titre que l'ovule lui-mème, c'est-ì-dire proviennent d'elle par sa propre segmentation réilérée; l'ovule ne prend donc aucune part direcle à la genèse de son follicule. "Tantôt les cellules de ce dernier se létruisent au moment de la fécondalion, apres sitre accrues parfois, et avoir pris un aspect remarpuable, comme celles des Amphinewiens du genre Chilon. Tantót, avant que la fćcondation ne s'accomplisse, elles sont absorbées pen à peu par l’ovocyle, qui augmente ainsi le volume de sa substance plasmique. Ce dernier phénomène semble ètre assez fréquent chrz les llirudiníes, et les Chétopodes oligochates (Figures $3: 37$ a :3 40 ).

\section{3. - Segmentation et feuillets blastodermiques.}

Bien rue les phénonienes essentiels du développenrnt soient loujours las mèmes, les procédés secondaires sont lellement nombreux el différents, qu'une étude générale serail d'une trop grande diffieulté de lecture. 
Il raut mieux diviser l'ensemble de ces notions, et examiner chayue Iype important l'un apries l'autre.

I. Rotifères. - Les Rotifères ressemblent ì certains Turbellariés, et à divers Arthropodes, en ce qu'ils possident deux sortes d'unfs : les aufs d'été ct les aufs dhiver. Les premiers sont prondus, commo lem nom l'indique, durant la helle saison; leur chorion est mince, et leur

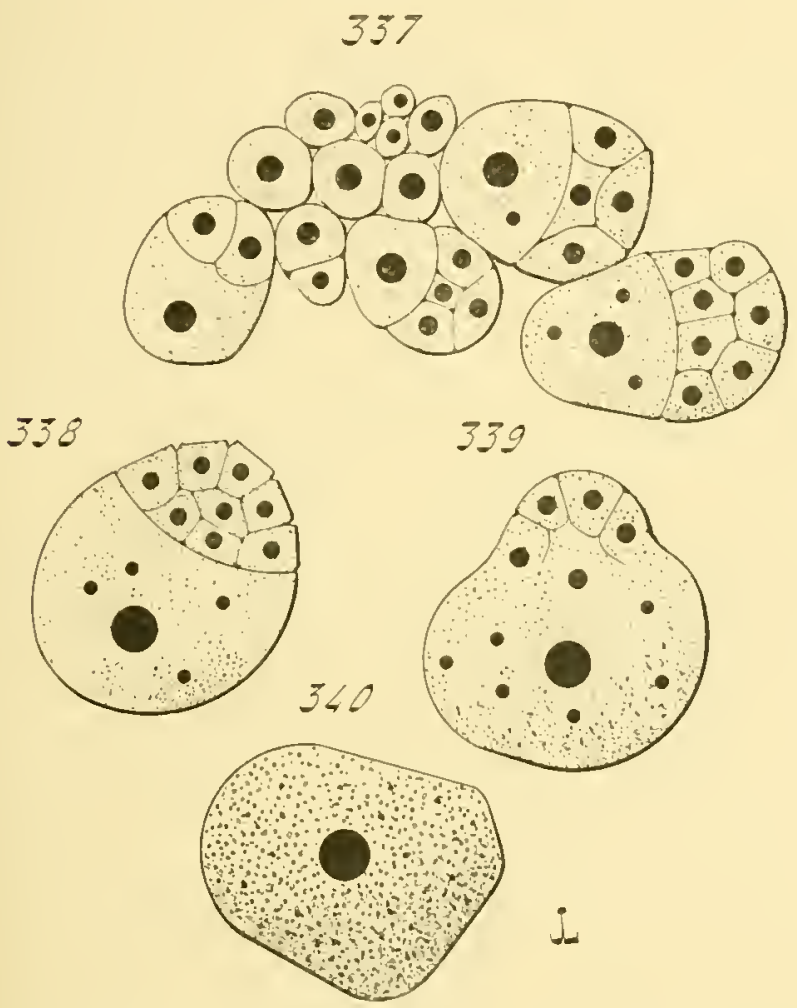

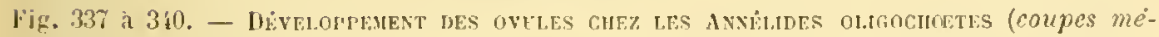
dinnes; daprès les ovules des Encloylrmïdes). - En 337, ovoronies à livers étals de diveloppement; chacune d'elles, par son aceroissement et sa division, doune un ovogemme, dont un senl element grantit poul devenir l'ovocyle. C Celui-ci absorbe ensuite lis autres cellules de l'ovogemme, el les integre a sa propre masse; les phases de cette alsorption sont données par les figures 339 et 330. - En 33i), lovocyle approche cle sa malurite; il a absorbe toutes les cellules proeedentes, dont lus noyaur se sonl détruits à mesure.

Evolution rapide. Les seconds snut produits durant toute l'aunce, mais 'n plus grande abondance dans le eour's de l'automue; ils se segrmentent hativement, puis arètent lenr diveloppement si le froil intervient, et ne le reprennent que daus le cas du retour des rimonstances firorablus. - Les deufs dhiver sont plus gros que les autres, et s'entourent d'un 
chorion plus épais; ils donment naissance à des mâles et à des femelles. Les unfs d'été engendrent dros femelles, mais parfois ils sont capables de fournir des mâles; pourlaul, le nombre de ceux-ci estinférieur à celui des femelles. Il semble résulfor de là yue, au moins durant la belle saison, ces lernières sout sonvent parthénogénéliques.

Les aufs d'hiver sont plus riches en dentolérithe que ceux d'été; l'évolulion, toujonrs abrégée cependant, s'accomplil d'après le mode planulaire. La segunentation est totale; assez souvent, les premières divisions ont pour eflet de partager l'ovule en blastomères semblables; une irrégularilé dans la taille, et dans la répartition des granules vilellins, ne tarle pourtint pas à s'effectuer. Finalement, l'wuf se convertil en wue planule compičle, dont la prơiphérie est constiluée par des petites cellules, alors que le cenlo se compose d'élémeuts plus volumineux, et mieux lournis en deulolécithe. Celle plannlation semble seffectuer suivant un mode intermédiaire entre lo procédé direct, el le procédé indirect. De même que dans ce dernier, les petits blastomeres superficiels sont formés, pour la plupart, les uns apres les autres, et ils enveloppent progressivement les cellules internes; mais, ce faisant, ils se multiplient avec activité, el les éléments, qui proviennent d'eux, contribnent pour une bonne part à faconner la couche périphérique.

La planule achevée, les deux lenillels blastodermiques sont délimités; l'assise externe est le protectolerme, el l'interne le protendoderme. Le premier se convertil en ectoderme, et se borne à produire le ganglion nerveux. Le second est compact; la plus grande partie de ses éléments demeure lassée dans la partie centrale de l'embryon, où elle représente l'endoderme; les autres cellules donment le mésoderme. Celles-ci, un peu plus pelites el phus chargées de grauulations que leurs voisines, constiluent un amas, placé dans la future récrion buccale. Ce dernier se compose, à son débul, l'un pelit nombre d'éléments, trois on quatre; mais ce chillire no tarle pas à augmenter, par leur multiplicalion rapide. Cetle ébauche mésodermique est destinće à fournir les quelques fibres musculaires, et les cellules conjonclives, le l'organisme; elle correspond, sans doute, au mósenchyne primaire des larves des aulres Trochozoaires. - Pendant que le mósolermo lunceal prolilère, de nouveaux élíments se séparent di prolendonderme vers la région postérieure de l'embryon; cenx-ci, en petil nombre égalemenl, puatro en moyemne, sont clatoés de dommer naissance aux glandes sexuelles. - En somme, l'évolution du mésoderme se ramène aux frails snivants : l'abréviation du développement conduil a une planulation telle, que le protendoderme est un feuillet compact; ce feuillet se divise snr place en endoderme el mésoderme; ce dernier, homologue du mósenchyue des Trochophores, se compose de deux masses cellulaires, 'pui se mulliplient arec activilé, dont l'nne engemlre un lissu conjonctivo-musculaire, el dont l'autre foumit les chéments sexucls.

Lendoderme reste solide pendant la plus grande partie des plases 
cmbryonuaires, el se borne a angmenter le nombre de ses collules. Une fente prend naissance sur le corjs, pendant que le mósoderme s'éhanche; cette fente est me dépression de l'echderme, qui s'enlonce Jans l'intérieur de l'embryon, el parait s'y bifurpuer. Les deux loranches de la bifurcation se mettent en rapport avec les extrémilés de l'amas endodermique; puis, semble-t-il, lor'sque l'undorterme s'est crensé d'une cavité digrestive, l'une d'entre elles constilue te pharynx avec la houche, l'antre le rectum arec l'anus. Etant donnée la disposition primitive, la bouche el l'anns se réunissent au fond de la fente. - Cette dernière correspond, en réalité, à un pli du corps, comme si l'cubryon étail courbé en deux. Cehui-ci, renfermé jusque tà dans sa membrane ovuluire, se débarrasse d'elle, se déploie, el la bonche se tronve alor's séparée de l'anus prar un assez grand espace. - Cetle genèse, si curiense, d'un pli du corps par une scission directe à travers lorganisme, el sans que ce dernier se recourbe, est le résultal d'un développement abrégé. Elle n’est pas spéciate aux Rotifères th reste, car on la troure, toujours amenće par la mème cause, chez d’autres animaux, cerlains Crustacés Décapodes par exemple, dont l'anus se creuse chez l'embryon toul ì còlé de la bourlie, la quene se faconnant sur place au-dessous du thorax.

II. Mollusques. - Le développement des fenillets blastodermiques des Vhollusques es des plus intéressants ì éturlier, car il of Tre tous les modes possibtes, depuis la gastrulation normale jusqu'à une planulation indirecte arec aufs télolécilhes, en passant prar des intermédiaires nombrenx. Les altérations, causées par la présence d'un deutolécillse ahondanl, sont très faciles à reconnaìtre. Sans insister sur loutes les transitions, il est bon de dislingruer puatre cas principranx. Ces cas se rapportent: $1^{\circ}$ à un procédé par gastrulation; ${ }^{\circ}$ à une planulation indirecte conduisant à une planule cytulaire; $3^{\circ}$ à une planulation indirecte el lécithique succédant à nne segmentislion totale; $4^{\circ}$ à nne planulation indirecte el lécilhique succéłant à une segmentation partielle, c'est-ì-dire s'exercant sur des cufs télolécilhes. La richesse en vitellus nutritif angmente à mesure que l'on passe du premier cas an quatrième.

to Gastrulation. - Le développement des feuillets bastodermiques, par le procédé gastrulaire, existe chez la plupart les Hollusques inférieurs, on de cenx qui, parmi les antres, ont une organisition relativement simple : les Amplineuriens, les Solénoconques, les llétéropodes, les Pléroprodes, un assez grand nombre de Gastéroprodes et de Lamellibranches, comme la P'uludine, l'Iluitre, elc.

Le type primitif le celte gastrulation estolfert par les l'rémollusfues, el par la phupart des Itéléroprodes et les I'téropodés; il est caractérisé par

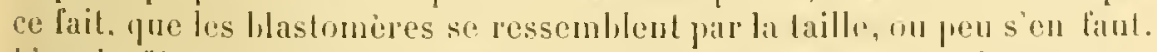
lovule lécondé subit me segmentation totale et figale, on légèrement inégale; il se convertit en une mornle, qui se transforme elle-meme en une blaslule. La cavité blastoculienne de cette dernière est assez élroile, 
car les déments du blastorleme sont relativenent grands. La gastrule frend ensuite naissance par le morle invaginant; l'entéron słapprofondit de plus en plus; l'entéropore, qui présente d'abord l'aspect d'une large lente, so rélróit quelipu pen, pour devenir la bouche définitive. Une exceplion in cet égard ast offortr frar la I'ululine, car l'entéropore de ses larves dememre communus des adultes. - Le protectoderme se borne à augmenter te nomlure de ses béments, et persiste comme ecloderme. Le protrudoderme, lantot śpparé de lni par le reste de la cavilé blastocelienne, lantôl directement accolé a sa lace interne, se divise en endoderme el mésodermo.

Dans le premier cas, certaines cellules du protendoderme produisent des éléments, qui parviemnent dans la cavité blastocolienno', et s'y multiplient; il on est ainsi chez les llétéroporles, par exemple. Cette évolution ¿ lim suivanl le lype mésenchymalenx, qui ne cesse d'exister. l'armi ces fómonls, qui constiluent le mésenchyme primaire, les uns s'organisent précocournt en collules comjonclives, on en tibres musemlaires; les autres

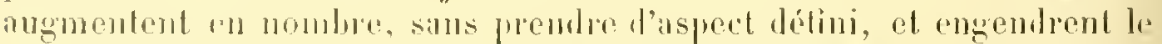
mósoderme délinitif, qui est toujours mésenchymateux. Ces derniers sont lrépuemment désignés jar le nom d'iniliales mésodermiques; ils sont A'ominaire en assez faille quantití. lls se bornent, durant les premieres bhases do l'évolution, à suliu des divisions sucressives, destinées à accroîtue lour chiffre, et ne so différencient quassez tarel en tissus parlaits. Ils sont, au clébut, séparés les uns les autres, el libres dans la raviti blastuculimue; ils se péunissent assez souvent, par la suite, en quelques amas syméliques, dont l'um, lien délimité, est chargé de fournir, a lui seul, le péricarde el le crur.

Dims le second cas, cest-ì-dire dans le cas où le protendorerme, saccolant i la face interne de l'ectoderme, fait disparaitre tout restige de la cavité blastoralienne, les rellules du mésenchyme primaire, qui donnent hilivement quelques briments eonjonetivo-musculaires, n'apparaissent pas, on sont fort réluits. Le feuillel interne se borne ì émethe quelques intiales mésodermiques, qui s’insinuent antre lui el l'ectolerme, el so multiplient pom engendror l'assise moyeme. Lorsque celte derniere rst peprésentíc par un chitlie de cellules assez grand, des vides "prars et irrounliers se creusent dans son intérieur. Ces espaces sont homologues de coux pui, daus le premier cas, correspondent à la cavité blastocalienno presistante, el orcupée parleséléments du mésoderme. Ils evoluent do mome, pour donner maissance anx lacunes conjonctives, qui représentent le colome de ces animaux.

La plupart des Ciastéroporles, el des Lamellibranches, ponrvus du procéclé crastrulaire, offrent mne particularití intéressante, formant une lansilion vers le second morle. La teneur le lorule en dentolécilhe est phus grande que lans les cas prócidents; el ce vitcllus, an lien de se répartir également dans tous les blastomères, se localise dans certains 
d'entre eux, qui sont par là plus volumincux que les autres. Aussi la segmentation, toujours tolale, est-elle inégale; elle aboulit a une morule, puis à une blastule, dont un des pöles est occupé par de gros blastu meres, el l’autre par des éléments plus pelits. Co dernier, le pole formatif des auteurs, est chargé de domer l'ectoderme, alor's que l'antre fournit le protendoderne; cetle disposition n’est pas étomante, car le dentolécilhe s'accumule, d'ordinaire, dans les coltules deslinées à faire partie de l'endoterme. La région des gros blastomères s'invagine, el se convertit en protendoderme; alors que l'anlie, la zone ectodermique de la hlastule, persiste comme ectoderme. La suite de l'évolulion concorte arec celle in premier mode. Le prolendoderme est séfarci de l'ectoderme par un assez raste espace, reste de la cavilé hlaslocolieme, où parviennent les éléments du mésenchyme primaire, el oil se déreloppent, suivant un type mésenchymateux des plus nets, les cellutes mésodermiques.

La Paludina vivipara déreloppe bien ses fenillets blastodermiques l'apres le procidé gastrulaire, mais la gaslrule est façonnée par incurvation, non par isvagimation, et l'entéropore se converlit en anus, contrairement à ce qu'il en est pour les autres Hollusques. Il est très probable qu'une telle dissemblance est le résultat diune tondensation toute particulière de l'embryogénie. La cavilé hlaslocodienne n'existe pas, ou bien est fort réduite; la phase blastulaire est presque omise, car son trait principal, venant de la présence d'un hastocele, fait défaul: l'impulsion invaginante s'exerce cependant, et produit une gastrule par incurvalion. L'emlroit, on l'incurvation se manifeste, correspond à la région postérieure du corps de l'embryon, et l'orifice de cette dépression, qui n'est sans doute pas l'homolague de l'entéropore des gastrules invaginées, demeure comme anus. La houche apparait un peu plus larl, sous la forme d'une dépression ectodermique, qui se dirige vers l'entéron.

20 I'lanulation indirecte produisant une planule cytuluire. - Si l'on suppose, lans le cas précédent, relatif it un assez grand nombre de Lamellibranches et rle Gastéroporles, que les blastomìres de la zone endodermique le la hlastule soient assez grands, assez chargés en deutolécithe, pour emplir la cavité blaslocolieme, l'impulsion gastrulaire, ne pouvant se traduire par une invagination, se manilestera au moyen d'un reconrrement progressif de celle zone par les petils éléments de lit région ectodermique (poile formatif des antrurs). En cola consiste le caractione du second moule. La segmentation aboulit a nue morule, donl los gros hlastomères sont peu à peu recourerts par les pelits; il se prouluit ainsi une planule, d’après le procérlé imlirect. Cefle altération est lia consíquence d'une richesse plus grande de l'orule en deulolécithe; celui-ci s'accumule, comme toujours, dans les díments qui doivent appartenir à l'entoderme, augmente leur taille, el les rend asso\% gros prur que la 


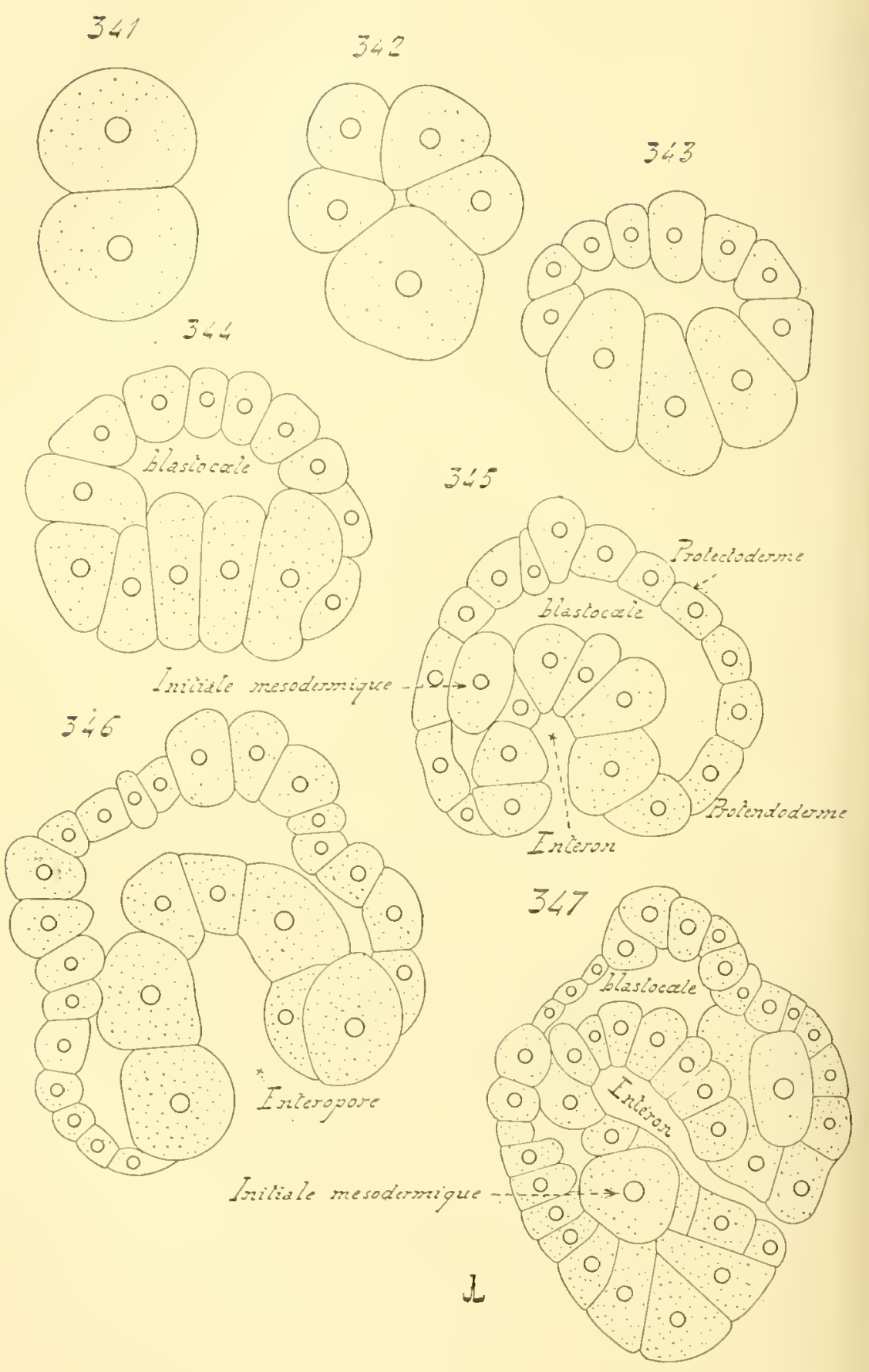

Fig. 341 à 3 i\%. 
cavité blastocolienne ne puisse se creuser dans la morule. Les fiastíroporles pulmonés, la pluparl des Opishobranches, divors Jamellihranches, tels que le Tarel, engendrent, par ce moyen, lems feuillels hastoderminues.

La segmentation est tolàle el inégrale. L’inégalité se montre dies le délut lle la division ovulaire, el s’accentue sans cesse par la suite; ì mesure qu'elle s'elfectuc, les petils blastomères, plus nombreux que les autres, et moins fournis en denlolécilhe, se porlent aulour de ces derniers, et finissent par les envelopper complètement. C’est lả un cxemple

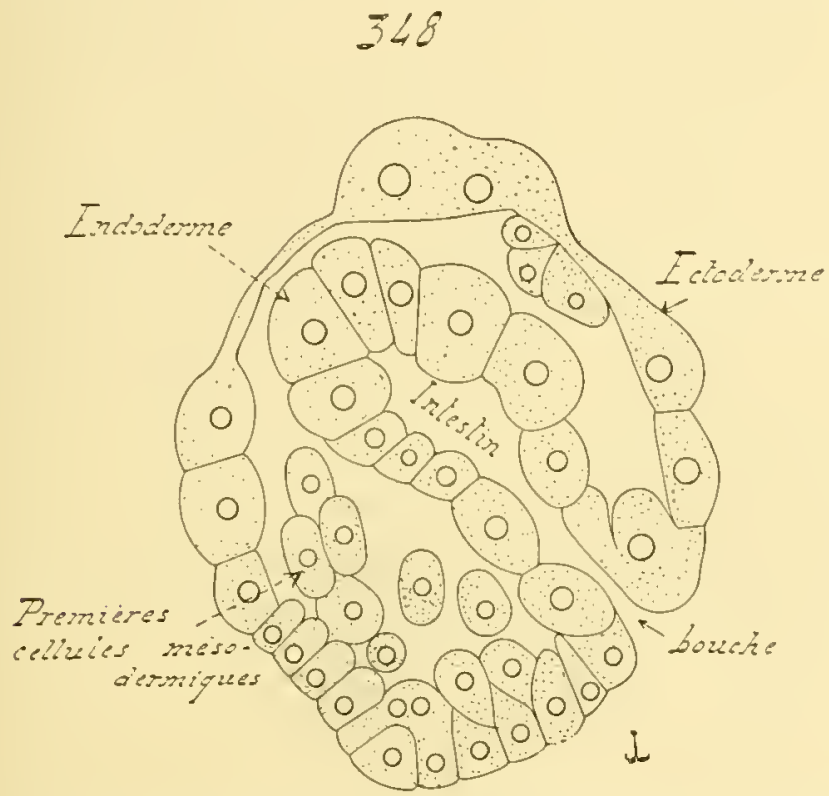

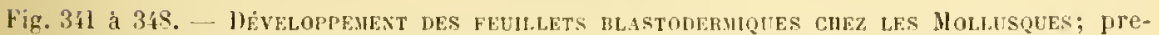
mier cas. (Coupes médianes et longitudinales; d'après liowalevsky sur les Solénoconques Ju genre Dentalium). - lin 34 , segmentation tolale, et d'alord égale, de l'ovule en denx blastomies. - En 342, suite de la segmentation. - Fin 34.3, jeune blastule. lin $3 i$, blastule parvenue á sa périoule d'ètat: les elemenls, chargès de donner le protendoulerme, sont plus gros que les autres, et leur ensemble commence il se llćprimer. - En 34., jeune gastrule; les dẻments le la zone protenloulerminue, d’ahord déprimis, commeneent a s'invağiner dans le blastocule, et circonscrivent dejà un pelit enteron; de folus, eertains d'entre eux produsent des initiales mesolermigues, dont une est

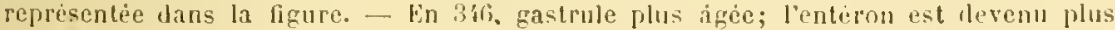
grand. - En 3i7, gistrule eneore plus ȧgé; les iniliales mesodermipues aumentent en

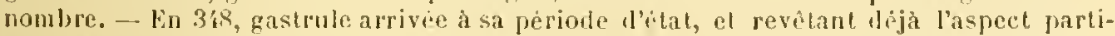
culier aux llentales; l'enteron s'est converti un intestin; le protendoderne s'est sublivise 'n ewloderme détinitif, qui entoure la cavite inlestinale, el en mésolerme, conıosé de cellules mesencliymaleuses qui proviennent des initiales.

Dans la figure 345, un tiret, partant in mot Protendoderme, devrait aller vers les rellules pui limitunt directement l'entéron.

caractíristique de plamulation imlirecte, sucroblant ì une segmontalion lobale, el aboulissant ì une planule cytulaire. Lorsque s'achove celle 
succession de phénomènes, l'cuf est converti en une planule solide, composée d'une assise extérieure de petites cellules, et d'un amas central de gros blastomères jeu nombreux; ceux-ci représentent le protendoderme, et les premiers le protectorlerme. Ce dernier feuillet se borne à persister comme ectoderme définitif. Des gros éléments du protendoderme se séparent quelques cellules un pen plus petites, deux d'ordinaire, qui sont les initiales du mésoterme; le protendoderme se divise ainsi en mésoderme et endorlerme.

P'endant cette évolution, des vides se creusent entre le prolendoderme et l'ectorlerne. Ils sont homologues de ceux qui, dans le premier mode, proriennent directement du liastocule; ils occupent mème situation, subissent mème téreloppement, et n’apparaissent d'une manière aussi tardive, que par suite de lopposition faite par les gros blastomères au creusement hàtif d'une carité hlastocolienne. Cet espace s'amplifie peu à peu, et les initiales mésolermiques, se séparant à la fois les unes des autres el de l'endoderune, deviennent libres daus son intérienr; plusieurs produisent, comme dans le prenier mode, quelques éléments conjonetiro-musculaires définis; les autres se multiplient rapidement, pour fournir le mésoderme de l'adulte. Celles-ci, étant donné leur rờle important, se séparent les premières du protendoderme, et sont relativement plus grosses que leurs voisines. L'évolution du mésoderme se poursuit d’après le mode mésenchymateux.

L'endolerme reste compact, tout d'abord, car les quelques blastomères qui le composent ne se dissocient pas: ils se dirisenl, et augmentent en nombre tout en demenrant accolís. Finalement, une cavité entérique se creuse entre eux. Cette earité est d'abord close; puis deux dépressions ectodermiques, allant à sa rencontre, la font communiquer avec le dehors par une bouche et un anus.

En résumé, ce second morle est une simple modification du premier, due à la présence, dans l'ovule, d'une plus grande quantité de deutolécithe. Ce hernier empeche la gastrulation normale, car il soppose au ereusement d'un blastocoele, et ne permet son apprartion que d'une manière tardire. - Les modes suivants montrent des altérations plus frofondes encore, tenant à l'existence d'un vilellus nutritif plus alonlant. Ces altérations sont telles, qu’elles seraient eapables d’induire en erreur sur l'homologie, et sur la provenance exacte des feuillets, si la série progressive, suivie dans cet exposé, ne mettait pas charue chose en sa place.

3o Planulation indirecte succedunt ì une segmentation totale, et moduistnt une plamele lécithique. - A. Si, partant du second mode, on admet que la teneur en leutolécitlse, phus grande encore, soil telle, que cerlaines cellules de l'endoderme contiennent une quantité considérable Je réserves nutritives, et ne juissent se diviser à cause d'elles, on aura le troisième procédé. (quelques-uns les éléments enreloppés se multi- 
plient seuls, pour produire le mésoderme avec l'endoderme; les autres, peu nombreux el énormes, constituent un amas vitelliu interne, qui est ahsorbi par l'embryou, an fur et a mesure le son évolution. We plus, comme cette richesse en deutolicithe amène une grande condensation du développement, les cellules, qui donnent le mésollerme et l'endoderme par leur multiplication, apparaissent hâtivement, an début de la division ovulaire, el nattendent pas pour cela que l'ectoderme ait entouré tout l'embryon.

Ce procédé est assez rare; il existe chez quelques Gastéropodes. Il est bien comnu, depuis les recherches de Bobretzky sur la Tassa mutabilis.

L'altération des phénomènes est ici fort grande; cependant les homologies ne sont changées en rien, el l'entéropore ne modifie mème pas sa place habituelle. Celte dernière est aisée à roir dans le premier morle, puisque l'entéropore est lorifice mème de l'invagination gastrulaire. Elle l'est moins dans les autres procédés. car ancmne dépression ne se manifeste; et cependant la bonche prend toujours naissance à l'endroit qu’occuperait l'entéropore, s’il s’était formé. l'exposé précédent permet de roir comment le second mode se rattache au premier; l'enveloppement du protendoderme par le protectoderme se ramène, sans difficulté, à un enfoncenent, d̀ une simili-invagination, du premier dans le second. Le point, oì se rejoignent les extrémités du protectoderme recouvant, est lhomologue de l'orifice de l'invagination, si celle-ci s'était crensée; et par suite, ce point est situé exactement à la place de l'entéropore des gastrules. Aussi, toujours en suirant cette homologie, voil-on, dans le second mode, la bouche se percer à l'endroit mème oì le protectoderme se ferme, endroit qui correspond a l'entéropore; il en est de mème dans le troisième procédé.

B. - Ivant que la segmentation ne commence à s'effectuer, chez la Vassa mulabilis, le deutolécithe est à peu près réparti également dans la substance ovulaire. Cejendant, un des poiles de l'auf, où débulera la division, et Jirectement opposé à l'emplacement futur de la bouche, est plus riche en vitellus évolutif. - La segmentation est d'abord totale et inégale, car l'ovmle so partage en deux blastomères, dont le plus petit est celui qui porte le poble à blastolécithe; elle levient ensuite partielle ef fort inégale, car le gros blastomère ne se divise plus. Le vitellus évolutif, yni est abondant dans le petit élément, se ramass de plus en plus en un point disternino de ce dernier; la smanentation continu, a mesure. Anssi le petit hastomere finit-il par se scimler en trois ou quatre grosses cellules, surtont riches en irutolécitle, et un chiffre assez grand d'antres cellules, minuscules, serrées les unes contro les autres, constitues seulement par du vilellus evolulif.

laruf segmenté se compose alors du volumineux hastomè prinitif, et les quelques gros élómeuts, surmontés les minimes cellules, qui proviennent du petit luastomère primordial. La division ovulaire nest pas 
achevée; et cependant, par suite de la dissemblance qu'entraine le deutolécithe abondant. les deux fenillets llastodermiques iniliaux sont délimités. Le protendoderme est représenté par l'ensmble du volumineux blastomère, et les gros élémouts froduits cu second lien. Quant au protectoderme, il est constitué par l'amas, en forme de calotte, des petites cellules blastolécithiques; il n’a plus 'fu'ì se compléter, en enveloppant

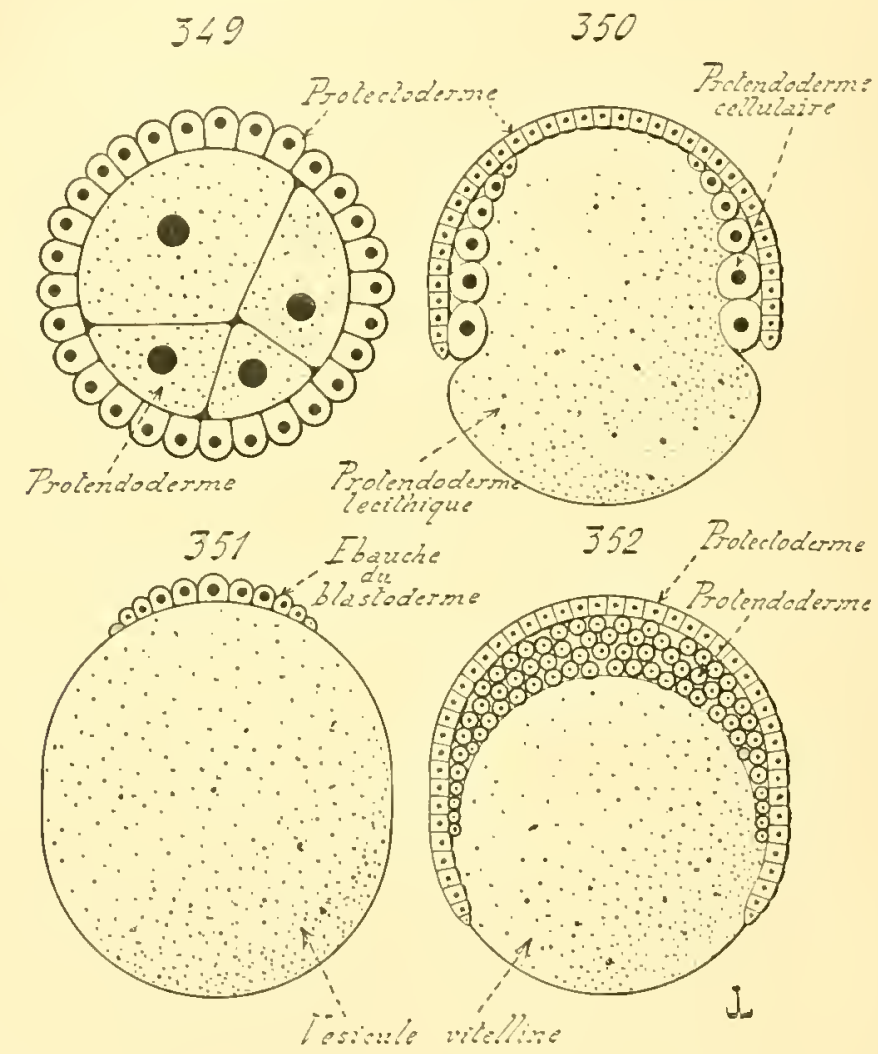

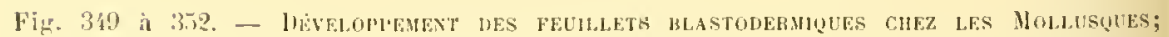
deuxieme, troisiome, et quatrieme cas. (Coupes médianes el longiludinales, diayramma. tiques). - En 34!), deuxième eas : planule cytulaire, succedant á une segmentation totale, et faconnie par le procédé indirect. Les vides se creusent, par la suite, entre le protectoderm, et le protendoderme; colui-ci fournit les initiales mesolermiques, et se perce à son fom llun enteron, qui communique avec le Jehors par une bouche; et la larve devient semblable, comme structure générale, ả celle de la figure 3 is. - En 350, troisième cas: le volumineux blastomerc initial, répondant à un prolendoderme lécithipue, est surmonté par une calotle protectodermique, qui recouvre un protendoderne cellulaire, dont les bliments sont chargés de fournir te mésoderme el. l'endoderme; le protendoderme lécilhinue rst alsortic au fur et a mesure que la calolte progresse, el que les

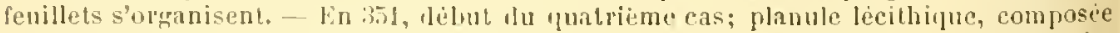
d'une volumincuse vésicule vitelline, que J'comvre un pelib Jlastoderme. - lin 3i2, suite du quatriemo cas; le blastoterme grundil, se livise en feuillets, et faconne le corps, en se nourrissant a mesure du deutolecithe de da vésicule vilelline. 
progressivement le protendoderme, par le mème procédé que lans les

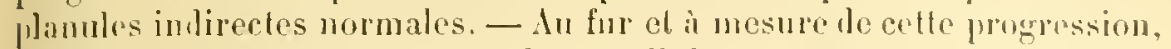
cl peniant quille commence, deux cellules se síparenl du protemloderme, else rangent an-dessous du protectoderme; elles sonlles iniliales mésodermiques, qui se multiplient, el accompagnent re drrnier ılans son mouvement: la plupart les éléments du mrisoderme se placent, en effot, un pen en retrait sous la calotte protectodermique. Inis, lorsque cellu-ci entoure lójì la moitié du protendoderme, les gros élćments, issus du petit blastomere initial, se multiplient à leur tour, et engemlrent los cellules qui agissent comme celles rlu mésoderme, c’est-à-dire se disposent rers les bords de la calotte, et en dessous d'elle. Ces dernières venues constituent l'endoderme délinilif. - Senl, le voluminenx lıastomère ne se segmente jamais; son rôle se borne à servir le réserve uutrilive.

Dès lors, l’érolution se simplifie. L’énorme lılastomère deutolécithique est enveloppé peu a peu par une calotte qui progresse sans cesse; cette calotte n'est autre que le protectoderme, qui entraino au-dessous de lui, ef un peu en arrière de ses hords, les collules du mésorlerme et de l'endodeme. Finalement la calotte, ayant achevé son mouvement, se complete, et se ferme dans la région de l'oul opposée à celle oì la segmentation avait commencé; celle région occupe la place de l'entéropore des gastrules, et c est lì que la boucle prendra naissance; aussi peut-on la nommer la zone buccale de l'embryon. Le prolectoderme est alors représenté par une conche ininterrompue, qui entoure le lılastomère dentolécithiquo, et acquiert, comme dans les cas précédents, la stricte valemr d'un ectoderme. Dans la zone luccale se Irourent, audessous rle cet ectoderne, d'alıord une assise de cellules mésodermiques, puis une rangée d'éléments endodermiques.

Le mésoderme évolue suivant le lype mésenchymateux déjà connu: lo colome lacuneux se perce, au travers de lni, par les procédés halituels; il est done inutile l’insister à leur égard. - Ouant à l'entéron, il se façonne aux dépens d'un espace vide, qui nait entre la rangée endoulermique de la zone buceale, ct le blastomère a deulolécithe. Cette eavilé gramdit lentement; lors de son apparition, elle est limitée en delans par le vitellus du hastomère, el en deluors par l'endoderme; celui-ci l'enveloppe pen à peu, en tapissant la surface du vitellus, et, finalement, l'eutéron se frouve cirrouscrit par l'endorlerme seul. Arant que ce phénomène ne s'achève, le vitellus nutrilil élait capable le pénétrer lirectument lans la cavité enterique; par contre, lorsqu il est lerminé, il n'y arrive que par lillusion, Cet enteron est lomolugne de colui du second mode; car, placé comme il l'est, entre l'omblorlame el le gros hlastomère, ce dernier faisant jartie, origincllenont, du protendoderme, il occupe, dans les lenx cas, la mème situation.

l.es fonillets blastorlormiques ont, les lors, fait lend apparition, ef sont plus qu'éhauchés; ils poursuivent leur évolulion rn prorluisant les lissus et les organes de l'économie, et cela en empruntant sans cesse 
leurs substances nutritives an vitellus dn gros blastomère. Celui-ci constitne une résicule vilelline interne, qui donne à l'embryon la valeur đ‘une planule lécithique, et se résorbe jeu à peu, jusqu’à disparaitre au moment où le déreluppement s'achève. Ce procédé si remarquable découle du second, car, en allant au fond des choses, il ne differe de hij que par une plus grande abondance du deutolécilhe, qui clétermine la présence d'une réserve untritive.

$4^{\circ}$ Planulation indirecte succédant à une segmentation partielle, el aboutissant ì une plamule lécilhique. - A. Ce mode, qui est particulier aux Céphalopodes, dérive du troisième par une richesse, plus grande encore, de l'ovinle en deutolécithe. En conséquence, la majeure partie du vitellus érolutif est, des arant la fécondation, ramassée en une petite cicatricule, que supporte la rohmincuse masse nutritjve; l'œuf est donc télolécithe. Ensuite, en complarant au troisjème mode, ce surcroit de vitellus nutritif n'est pas rȩ́arli également dans l'ovule; tout on élant considérable, il se reporte sur un des còtés de l’euf, de sorte que la zone buccale, homologue de l'entéropore des gastrules, au lieu d'être diamétralement opposée an pôle où la segmentation commence, et où se trouve la cicatricule, lui est contignï. La différence qui existe sous ce rapport, entre le quatrième procédé et le précédent, est toute d'apparence, puisque cette dissymétrje résulte ł’une répartition jnégale du surplus du deutolécilhe.

La genèse des feuillets, dans ce quatrième mole, est aisément comprise d’après le troisieme: il est nécessaire, également, d’avoir sans cesse présente à l'esprit cette notion que, l'amas de deutolécithe contenant encore du vitellus érolutif, les cellules, qui jecouvrent progressivement cet amas, en partant de la cicatricule, ne proviennent pas de cotte dernière mème, mais se létaclıent à mosure du deutolécithe. La cicatricule se horne à leur fournir des noyaux, de proche en proche. Il suffit de se reprorter, dans l'Embryologie générule, au paragraphe consacré à la planulation indirecte, pour concevoir le fait.

I3. - Le quatrieme mode se divise en trois cas principanx, dont le premier se ratlache directement an troisième procédé. Les diflérences "ntre ces types tiennent a la teneur variable de l'œuf en matérianx nutritils, le derniep étant celui dans lequel ceux-ci sont le plus abondants.

te premier cas rapjelle de trís prìs le mode des Vassa; il est relatif aux embryous pélagiques d'un Décapode indéterniné, dont le développement a été suivi par Grenacher. Les différences arec les Nassa sont les suivantes: la vésicule vitelline est beaucoup plus grande; la zone buccale n'est pas tont ì fait diamétralement opposéc à la cicatricnle, où commence la segunentation. Cette cicatricule débute par produire le mantean; le recotrvement du vitellus s'effectue avec lentent, de sorte que reptains organes, plusienrs des bras jar exemple, sont déjá ćlan- 
chés, avant que ce phénomène soit accompli. De même que pour les embrrons de Nassa, la résicule vitelline est interne, c’est-à-dire placée dans ie corps.

Les Argonaules font partic du second cas. Leurs principales parliculiritís tiennent au sac vitellin, plus gros que dans le morle prérédent, et extérieur à l'embryon, an lien l'etre contenu dans son organisme. Puis, à mesure que lévolution progresse, le sac, moitie par résorption, moitić parce que l'embryon l'enveloppe, finit par devenir interne.

Le troisiène eas est offert par les Seiches, les Calmars, elc.; leur vésicule vitelline est si grande, qu'elle est toujours placée en dehors de l'embryon, et lui est appendue; ce fait étail déjà connu d'Aristote. La cicatricule se segmente, pour donner un hastoderme, composé d'abord d'une seule couche de cellules. Ce dernier s'épaissit ensuite, partie par lui-mème, fartie par des emprunts conslants, faits à la masse vitelline, en lui enlevant le reste du blastolécithe qu'elle contient; il se dispose sur plusieurs couches superposées. La multiplication s'effeclur de préférence sur' les borls du blastoderme, toul comme elle se manifeste sur les bords de la calotle chez les Nassa. L'assise externe domne l'ectoderme; les cellules interres, placées entre l'ecloderme et le vilellus, rejrésentent le protendorlerme, et engendrentle mésoderme ef l'endoderme. Ces feuillets éroluent d’une manière semblable à celle ollerle par les Nassa; seulement la bouche, qui, dans le premier cas du présent mode, est encore assez éloignée de la cieatricule el du pelit blastorlerme initial, est iei reportèe sur les bords mêmes de ce dernier, car la vésicule vitelline reste extéricure à l'embryon.

Pendant que le petit ètre s'ébauche au moyen dı llastoderme seul, la vésicule vitelline s'entoure régulièrement, el progressivement, toujours it l'aide l'emprunls faits au dentolécilhe, suivant le mode propre aux planulations indirectes, d'une couche cellulaire à deux assises. L'assise calerne est une dépendance de l'ecloderme; l'assise interne, la membrane péri-vitelline des auteurs, correspond a une prolongation du protendoderme. Toutes denx se bornent ì entourer la résicule, et a lui lournir une membrane enveloppante, qui se complite avec une grande lenleur. Elles ne prement aucune part à la genèse des organes embryonnaires, el disparaissent à mesure que le deutolécithe se résorbe; elles se continuent, dans la zonc blastodermique, avec l'ectoderme ef le prolentoderme de cette dernière.

III. Tentaculifères. - Le type des Tentaculifères, lout en étant représenté dans la nature acluelle par des êtres moins nombreux que celui des Hollnsques, est pourtant moins homogène; if comprend les quatre classes des Brachiopodes, des Bryozoaires, des Phoronidiens et des Sipunculiens. Celle alsence thunité tient it ce que, tout en oltrant une structure relatirement simple, ces animanx, malgré lemts alfinitis embryologiques, editient leur organisme d'après des flans assez diflé- 
rents; contrairement aux Mollusques, qui, semblables en cela aux Arthroporjes et aux Vertébrés, perfectionnent leur íconomie suivant la mème direction. - Dordinaire, les unfs des Teutaculifères sonl paurres en vilellus nutrilif; anssi les développenents gastrulares sont-ils fréquents.

Comme, tout en ayant des affinités indisculables, tout en étant reliées mème dans la nature actuelle par des formes de transition, lelles que les lihabdopleura, qui unissent les Bryozoaires aux Brachiopodes, ces classes sont assez distincles les unes iles autres, il est plus aisé de les éludier séparément. Celte diversité des descriptions n'empèchera pas, cependant, te montrer lidentilé complète des procédés, sauf dans le cas des Brachiopodes, au sujet desłuels il convient de faire de grandes réserves.

Brachopowes. - le développement de ces ètres mérile d'ètre cxaminć à nouveau, jour ce jui lonche aux feuillets blastodermiques. Les recherches des auleurs, el notamment celles eflectuées par Il. de LacazeDuthiers el par kowalevsliy, permeltent de croire à la présence, suivant les types, du mode gastrnlaire on du mode planulaire.

Les observations de liowalersly remontent i 1874; elles ont porté sur l'Argiope Neapolitana. - Lovile, pauvre en deutolécilhe, suhit me segmentalion totale; il se transforne en une morule, puis en une blastule, pourve d’une cavilé blastoculienne assez ample, el, enfin, en mo gastrule par invagination. La gastrule s'accroit quelquo pen; et son cntéropore, qui ne se clôt pas, devient excentrique. Le protecloderme, comme loujours, se converlit en ectoderme définitif. Quant au protendoderme, s’il faut en croire les asserlions de kowalersky, il se partage, eu endoderme el mésoderme, smivant le mocédé entérocálien. L'entéron émet latéralenont denx diverticules symótriques, qui soulivent le protendoderme a len niveau; ces expansions s"insinuent entre l'ectoderme et la couclue lont elles dérivent, ferment leur ouverlure, qui les faisait communiquer avec la cavilé entérique, el se clangent en résicules closes. La gastrule possiole ainsi, dans son hlaslocule, deux vésicules qui grandissent, et comblent peu à peu ce dernier. Lenrs parois fournissent les tissus mésodermịues, et leurs carités produisent le calome. La portion du protendoderme qui n’est pas intéresséc lans ce mourement, el reste aulour de l'entéron, persiste comme endoderme définilif. Le procédé entéroculien est ici, loujours d’apros les éludes publices par Kowalersliy, iles plus nets.

Ces olsservations, élant donnée l'autorilé de l’illustre embryologiste, ont élé acceptées dejuis par tous les naturalistes, et sans aucune restriction; il est probable cependant qu'elles sont en partio incxacles, pour ce quilient à la grenòse entérocrelienne du mésoderme. Les Brachioporles sont, en ellel, tris proches des lirozoaires; la trausilion, effechée des uns anx autres par le grenre líhabdoplezro, contrihue à le prouver. Or les seconds, et cela dune manjere indisculable, engendrent leur feuilled 
moyen par un procédé schizoculien des plus frames. Si, par suite, les deux fails élajent exacts, il faudrail bouleverser loules les notions acquises, d'apres le dévelopjement des autres animaux, sm. l'homologie du mésoderme avec lui-mème dans l'élendue d'un groupe nalurel. Celle homologie serait réelle pour lous les Métazoaires, sauf pour les Bryozoaires el les Brachiopodes. Une telle conclusion paraît inarlmissihle, du moins dans l'état présent de la science embryologique. - En ontre, il convient de ne pas oublier, pour mieux monlrer combien il est juste de réserver celte question des Brachiopodes, que les recherches le kiowalersky nont pas élé poursuivies d'apres la méthode des coupes, dont l'emploi dome seul des résultats certains, dans l'examen de ces transformalious si passagères. L’auleur de ce live se permel l'ajouler, en sus, qu'cn observant, par Iransparence, les premières phases embryomnaires des l'horondiens, il a vo un aspect semblable à celui lécril, el dessiné, par Kowalersky d'après l'Argiope: c'est-à-dire l'entéron divisé, par deux élranglements, en trois parlies communiquant entre elles. Celle disposition était jourlant toule d'apparence; elle résultait le la projection, sur l'enléron, de petits sillons creusés sur l'ectoderme, et semblalles à ceux qui se monlrent aussi chez les larves des Brachiopodes. Cependant l'entéron des I'horonis reste simple, et le celome se forme en dehor's de lui. - Aussi, jusqu'à plus ample informé, semble-t-il phus exact d'admetho que le colomésoderme des lirachiopodes se développe, daus le procédé gastrulaire, suivant un mode idenlique à celuj qui va être décrit pour les Sipunculiens et les l'horonilliens, cest-à-dire par un schizocule qui érolue d’après le lype épilhélial.

Les oliservations de $\mathrm{II}$, de Lacaze-Duthiers onl porté sur les Thecidinm. Les aufs, gros, el plus riches en deulohécithe que ceux les Argiope, se segmentent, et se changent en morules, puis en hastules munies d'un blastocole tris étroit; par suite, aucune invaginalion gastrulaire ne peut se produire. Les blastomères conlinuent it se diviser, el la cavité blastocolienne se comble, par lieffet de cette angmentalion incessante da nombre des cellules. Finalement, l'emliryon est converti en une masse compacte, forméc de plusieurs conches emboilées. La conche externe est lecloderme; les autres représentent le protendoderme. 'Prois cavités, indépendaules les unes des autres, se creusent, semble-l-il, dans ce dernier; la médiane est lentéron, les denx autres correspondent probablement aux espaces culomiques latéranx, anx denx vésicules des embryons d'Argiopes. L'entéron devient ensuite le tube digestif.

Celte indépendance muluelle, chez les Thécidies, les ébauches de l'entéron el du colome, est incapalle de venir a l'appui des réserves signalées plus hant; le développenuent le ces animamx est, en ellel, plus condensé que celui des Arropes, el la discussion, pur ère précise, doil porter sur ces dernieres senles. La condensalion embryonnine est ié dénolée par l’abondance plus grande du deutolécilhe dans l'ovule, 
et par la genèse des feuillets primitifs, qui s'effectme suivant un mode intermédiaire entre la lastulation et la planulation, plus proche encore de celle-ci que de celle-lia. - Ouoiqüil en soit, les olservations concordent pour montrer que les ébauches du colomésoderme sont épithéliales. Sans doute, comme chez les Ploronidiens et les Sipunculiens, la majeure partie hu uésenchyme primaire forme deux handelettes mésodermiques, dont charune se creuse d'une carité culomique; le tout s'accroit ensuite, se régularise à mesure, et affecte peu à peu une disposition épithéliale. Seulement, s’il faut en juger d’après la structure de

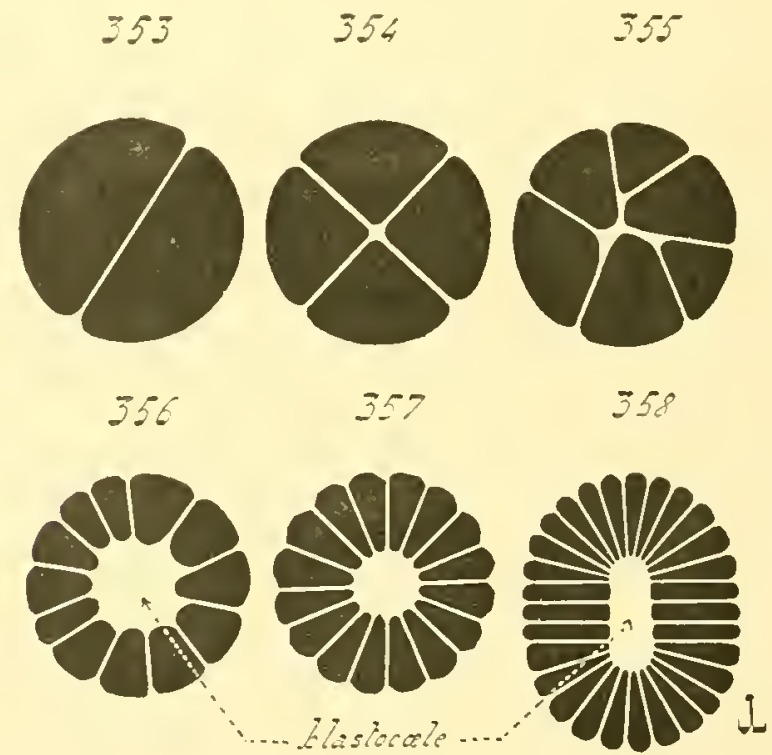

Fig. 353 à $366^{2}$. - Seguentation ovelaire et gentse des feullets primondaux chez les PhoroNidiens (coupes médianes et longitudinales, dessinées en silhouette, chaque cellule élant représentée par une plaque noire; en outre, les coupes des fignres 360 , 363, 365, sont accompagnées de dessins montrant les contours des embryons sur lesquels elles ont étè pratiquées. D'après le Horonis Sabatieri). - En 353, 35t, 355, secrmentation de l'ovule, totale et ègale, nu pru inegale. - Ln 350 et 3.5, genese de la blastule. - En 358, aplaLissement de la blastule, preliminaire a l'incurvation, qui va se manifester. - En 359 , debut de l'ineurvation. - In 300 et 361 , l'incurvation s'accentue; 361 donne le contour de l'embryon, dont la coupe méliane et longitudinale se troure représentée par la figure 360. - En 30 , l'ineurvation ítant à jeu près lerminée, lembryon a nettement revêtu l'aspect d'une gastrule. - lin 303 et 364 , coupe et contour d'un embryon un peu plus àgé, clont l'entèron devient plus profond. - En 305 et 36, , coupe et contour d'une larve plus àgée que la pricédente, el qui ne va pas tarder à produire son mésoderme.

La suite de ce développement, destinẻe á montrer la genèse du mẻsoderme, est donnée, en coupes rẻelles, par les figures 32 i a 330.

l'adulte, car des observations précises noont pas encore été faites à ce sujet, Ie mésoderme las brachiopodes rederient mesenchymalenx; on ne trouve en ellet, lans l'oryanisme délinitif, qu'un polycolome con- 


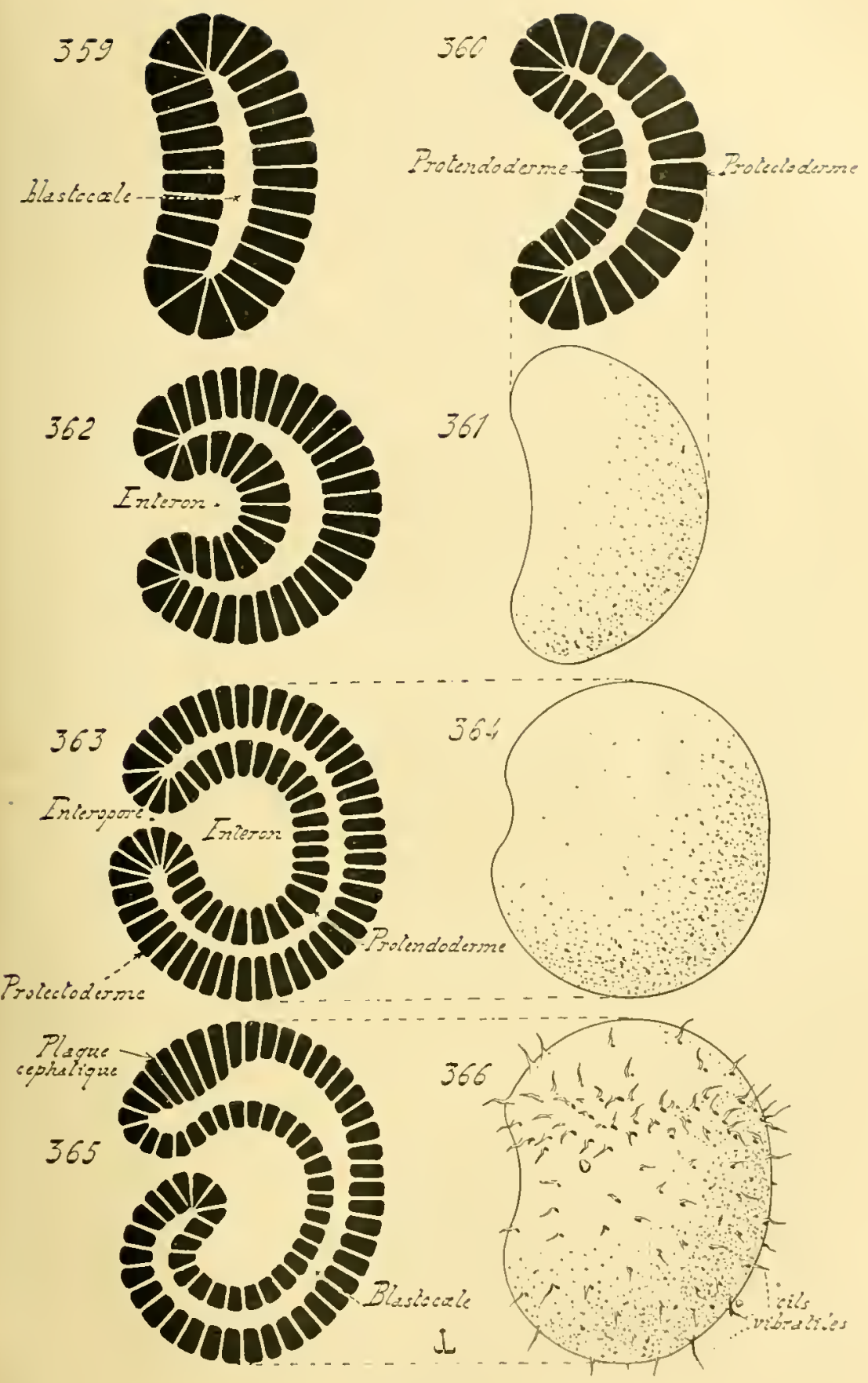

Fig. 359 a 360 . 
verti en m appareilirrigateur, semblable ì cehui des Trochozoaires dont le feuillet moyen est mésenchymateux, et yon en un olignerelome aux. parois réguličres.

Bryozosines. - De même que les Brachiopodes, ces itres montrent, suivant les types, un dévoloppement blastulaire, ou une évolution planulaire. Le premier existe chez les Endoproctes, qu'il est permis de considérer. ì bien Jes égards, comme des lbryozoaires primilifs; le second chez les Ectoproctes, oì il parait ètre fort commun, sinon général.

A. - L'embryogénie des Endoproctes est surlout connue par celle de la Pedicelline, que llatschek a suivie. L'ovule contient peu de deutolécithe; celui qu'il renferme, se ramasse, an fur et à mesure de la segmentation, daus les éléments qui doivent constituer le prolendaderme; cela d'après un procédé analogue an mode déjà signalé jour les llollusques. Ayant passé par la phase morulaire, l'emlryon se transforme en une blastule, mumie d'un blastocule assez étroit, è ılont les lılastomères sont dissemblables. Ceux qui vout donner le protendoderme sont plus gros que les autres; la région qu’ils occupent est somvent nonmée, par les auteurs, le póle végétatif, et l'autre le pôle animal, le mème que chez les Mollusques, et les autres animaux qui offrent de pareils phénomènes. La gastrule prend ensuite naissance par invagination, la zone protendodermique s'enfonçant dans la cavité hlaslocolicnne. L'entéropore se ferme ensuile; les cellules, qui le bordaient, se multiplient pour engendrer la région dite le vestibule de la larve, sur laquelle la liouche, avec l'anus, vont se percer à nouveau, peu après l'occlusion de l'entéropore.

Durant ce temps, le protendoderme se partage en endoderme et mésollerme. Ce dernier dérive de denx cellules volumineuses, les iniliales mésodermiques, qui se séparent du protendoderme non loin de l'entéropore, et se glissent dans les étroits espaces vides, lérivant du blastocuele, placés entre les deux feuillets primordianx. Lassise moyenne des Bryozoaires adultes est presque aussi peu complexe que celle les Rotifères; aussi le mésenchyme primaire a-t-il peu à foire pour atteindre son organisation définitive. Les initiales se divisent; les cellules, qui proviemnent l'elles, se scindent ì leur tour, se sépalent les unes des antres, en produisant de la substance fondamentale, et sulissent me franche érolution mésenchymalense. De même que chez les Rotifères, es cellulrs, qui doivent fournir les ólémenls sexuels, se dólimitent hativement, at roustituent des initiules semelles précoces; l'apparition rapile le ces derniòres est lue sans doute, comme pour les Rotiliores, i la simplicité do structure du mésorlerme.

B. - Un lictoprocte, la Teulra zostericola, étudice par Repiachoti. établit une transition entre la gastrutation el la plamulation. - Une 
Whastule prend naissance, dont les blastomères, au nombre de quatre, dic la zone protendodermique (zone orale on póle végrilatif les anteurs), sout encore plus gros que leurs correspondants de la Pédicelline. Leur face externe ne déborde pas le niveau des éléments de la zone protectodermique, mais leur face interne s'avance, dans la cavité blastocelienne, en une volumineuse saillie. La croissance progressive de cette saillie, qui comble peu à peu le blastocale, est le seul indice de l'invagination. Ce dernier phénomène, assez altéré pour consister en un simple agrandissenent des cellules qu'il atteint, n'aboutit donc pas à la production directe d'une cavité entérique. Celle-ci naît de la façon suivante. l'endant qu’ils s'arancent dans le blastocole, les quatre éléments protendodermiques se divisent de manière à former deux assises cellulaires, et l'entéron se creuse entre elles. Tout en grandissant, ce dernier s'ourre au dehors par un entéropore; de mème que pour les Pédicellines, cet orifice ne tarde pas à se fermer par la suite. - Le protendoderme évolue comme précédemment.

C. - Mans la planulation, fréquente chez les Ectoproctes, l'orule est pourvu d'une réserve abondante de vitellus nutritif. Cependant la segmentation est totale, et mème égale dans son commencement; pour la comprendre, il faut conceroir la sphère orulaire placée suivant une orientation déterminée, et toujours la mème, de manière à présenter des plans verticaux et les plans horizontaux. L'ovule se divise verticalement en deux blastonères, puis en quatre d'après un noureau plan vertical perpendiculaire au premier, puis en huit suivant un plan horizontal; il se partage ensuite en seize, et trente-deux segments, an moren de noureaux plans verticaux, perpendiculaires l'un à l'autre, et bissecteurs des angles formés par les deux premiers. Comme il ne s'est manifesté qu'un seul plan de division horizontal, l'orule est converti en une masse cellulaire solide, constituée par deux assises cellulaires superposées, conprenant seize éléments chacune, et tons égaux. - Une telle régularité n'existe pas toujours; cependant, la présence d'un seul plan horizontal, modifiant l'ovule segmenté en un disque composé de deux couches cellulaires, parait ètre constante.

L’inégalité, entre les blastomères, commence ensuitr. Quatre luastomères centraux de l'assise inférieure grossissent, et deviennent plus rolumineux que les autres; ils loivent former le protendoderme, et sont les homolognes, sous tous les rapports, mème sous celui du nomlıre, de cenx qui constituent la zone protendodermique des embryons de la Tendra. lls composent effectivensent la zone protendodermique les jennes Ectoproctes, car ils s'enfoncent dans l’intérieur de la larve; les autres éléments de la couche inférieure passent en drhors d'eux, pour les séparer de l'extérieur. Ces derniers, joints à cenx de la rangée supérieure, dounent l'ectoderme seul; les quatre internes fonruissent le protondoderme, qui se partage un mésoderme et endoderme suivant des 
llocèdés peu connus encore, mais ne paraissant pas différer beaucouj] de cenx olferts frar les autres liryozoaires. Les rellules endodermiques restent chargées de granulations vitellines durum un temps assez lougr.

Puonoxibrens. - Liovule de ces animax, représentés dans la nature actuelle par nn scul genre, le genre Phoronis, contient une quantilé assez importante de deulolécitle. Cependant, son développement s'effectue suivanl un mode gastrulaire; mais la gaslublation se manifeste par incurvalion, à cause de la gramde taille des blastomères el le la jetitesse du hlastocale. Le type choisi ponr celle description esl le Phoronis Salutieri Roule ( $M$. psammophila Cori), frépuent, en France, dans l'élang de Than, près de Celle.

La segmentation est tolale et égale. Lovinle se modifie en une morule, puis en une blastule, dont la cavité blastodermique est jelite, car les blastomères sont longs, el semblables à des cônes juxtajosés; lous sont égaux, et l'on ne remarque aucune dirision en zones distinctes. l'influence invaginante se fait sentir'; mais ne pouvant introdure une partie du blastoderme dans l'elroit blaslocoele, elle se traduit par unc incurvation totale de l'emluryon. Ce dernier s'aplatil, devient ovalaire, de sphérique qu’il ćtail, el, en mène temps, s incurve à la manière d'un disque, yui se loprimerait en son centre. l'ar l'effel de l'aplatissement, Je hastorlerme est divisé en deux couches juxtaposées par leurs hords: l'une, qu'il est permis de nommer supérieure, et l'autre inféricure, pour mieux faire saisir le phénomène. L 'embryon s'incurvant de plus en plns, la dépression s’acentue a mesture, et sapprofondit sans cesse; partant, l'une des couches, l’inférieure, devient interue par rapport à la supépienre. Lorsque ce mourement est achevé, la blastule se trouve transformée, frar une incurvalion rénibale, en une gastrule; l'entéropore, 'pui correspond à l'oritice le la dripression, d'abord forl large au moment où lincurvation commence, se rétreit de flus en plus, mais ne se ferme pas, el couslilue la bouche (Figures $3: 3 i 3$ i $366 i$ ).

Le protectoderme de la gastrule se convertil en reloderme détinilif. le protendoderne, qui reste séparé de lui prar nu espace dérivé de la cavité blastoculiemue, se purtage en endoderme et mésoderme. l'our cela, il émet, sul toule son étendue, un certain nombre d'éléments, qui parviennent dans l'espace blastoculien, et s'y organisent en un mésenchyme primaire. Certains d'entre eux, roisins le l'anus qui achòve alors de se prercer, se multiplient plus que les aulpes, et se disprosent en leux amas épais, placés symétripnement de part et l'autre de la ligne médiane: les bandelelles mésolermiques. - Ia quanlilé d’iniliales est assez grande, pon pernettro de produire nn mésenchyme primaire abondant. Ine partie de re lemies soronise an m lissn conjonctivomusculaire, qui dessine daus la cavité blastocolienne des travées irrégulieres: l'uutre engendre les landelettes. Colles-ci donnent naissance à presine lout le mésoderme lélinitif. Les juemiers éléments ne consli- 
tuent aucun organe important, si ce nest peul-itre les prois de lippareil cirrulatoire sanguin, composé de vaisseaux, qui renfermenl un plasma charriant les globules rouges. Ces cavités vasculaires proviennent saus doule, et lireclement, du blastrocale; en conséquenee, tos éléments libres du mésenchyme primaire Joivent contribuer, pour la plus grande prat, a la renose de ces glohules. Des observations précises manquenl eneore à cet égard (Figures 32.

Les deux bandelettes, composées à leur délıut le cellules juxtaposées,

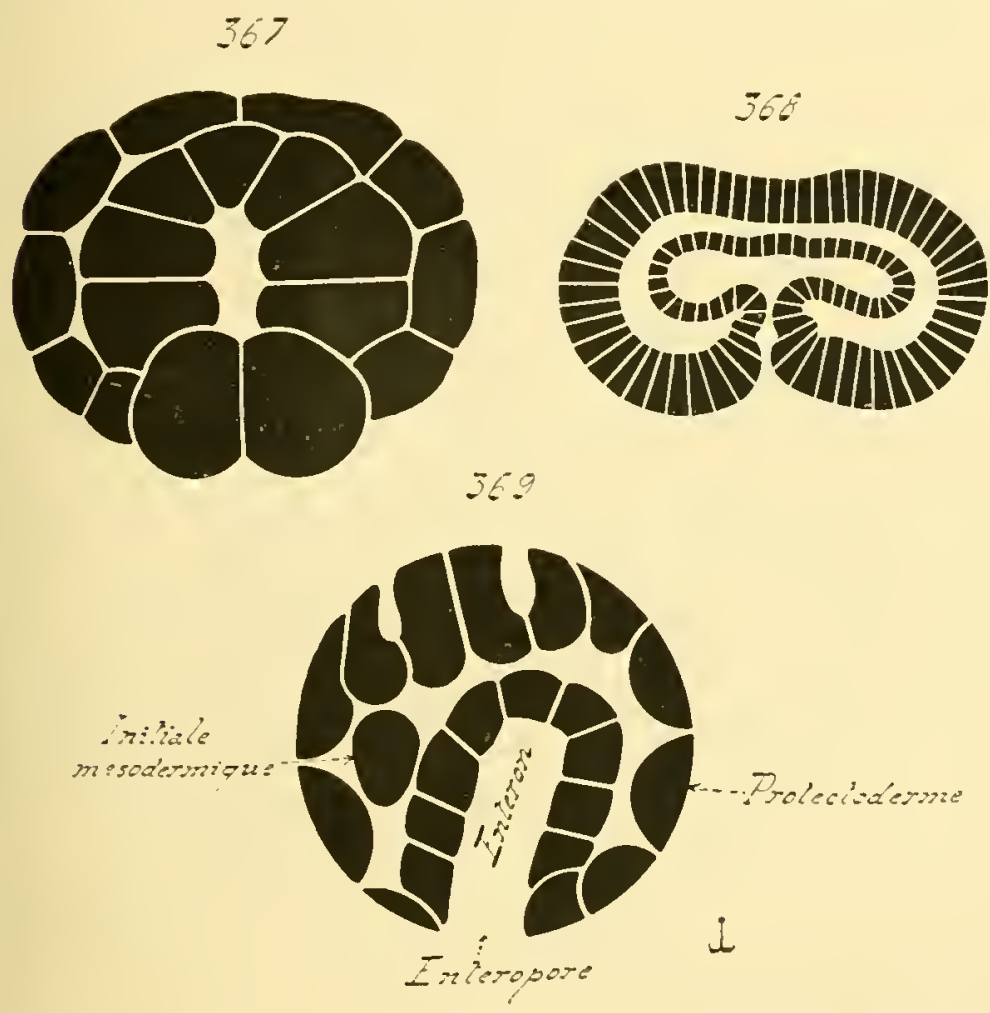

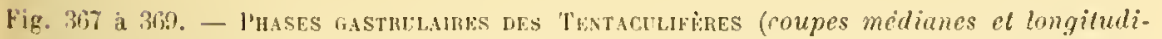
nales, en silhouetles). - En 367, gastrule d'un 13ryozoaire linloprocte, la I'edicellinn echinata; les deux grosses cellule's inférieures sont les initiales mésodermigues. D'après IIatseliek, - lin 3ti8, gastrule d'un Brachiofode, l'Argiope neapolitana; d'apres Kowalevsky. - lin 36!, gastrule d'un Sipuneulien, le Sipunculus nudus; les dewx espares blanes supérieurs sont les eoupes du canal eirculaire qui entoure la plaque céplıalique; l'amnios n'a pas encore pris naissance. W'apris llatscheli.

éroluent ensuite d’après to mode épithélial. Uno cavité se creuse dans charme d'elles, et s'amplitio, en refoulant les éléments qui l'entourent; ceux-ci linjssent par se mettre sur un seul rang, et forment une paroi propre à l'espace qui vient de naitre; ce dernier est l'ćhauche du 
colome, comme la paroi est celle dı mésoderme détinilif. Les handeleftes se sont convorties, par ce moyen, en vésicules closes; celles-ci grandissent, s'applipuent, d'une part contre l'endoderme pour donner une splanchnopleure, de l'antre contre leclorlerme pour produire une somalopleure, et fournissent ainsi le mésorlerme. Tout en s'allongeant, les vésicules, avec la ravité qu’elles contieument, croissent dans le sens de la largeurjustu'à se rencontrer, et à entourer complètement l'endoderme. Le procédé, suivi dans la genese du coelome, est donc un procédé schizocoelien, accompagné du développement éjithélial du mésoderme; il est probable quil en est de mème, au moins dans le déluut, chez les Brachiopodes.

Sipuxiuliens. - Le dévelojpement des feuillets blastodermiques du Sipunculus nudus, pris comme tyje parmi les Sipunculiens, ne s'écarte pas beaucoup, daus ses traits fondamentaux, de celui des Pluoronidiens. Il aboulit à une gastrule; et les élıauches dı mésoderme, tout en provenaut dinitiales, éroluent suivant le type épithélial.

Les principales différences portent : sur la réduction du nombre des initiales mésodermiques, qui tient sans doute à la juésence, dans l'ovule, d'une certaine quantilé de vitellus nutritif; el sur la genèse d'une enveloppe ammiotique, fournie par le protectoderme.

L'ovule sulit une segmentalion tolale, et légèrement inégale; il se transforme en une morule, puis en ume hlastule aux blastomères dissemblables. Plusieurs de ces Jerniers, jus gros el plus riches en deulolécithe que les autres, constituent me rone protendoderminue, semblahle à celle des Bryozoaires el de la plupart des Mollusiues. La gastrule prend uaissance par l'iuvagination de celte zone daus la cavité blastocalienne; pendant que ce mouvement s'effectue, deux cellules, appartenant au protendoderme, se séparent de lui. Ces dernières sont les seules initiales mésorlermiques; ancun autre élément ne se façonne, qui soil destiné à proıłuire un mésenchyme primaire défini. Les iniliales se segmentent à Jeur tour, et engendrent leux bandeletles, placées symétriquement de part el d'autre de la ligne médiane. Celles-ci éroluent, comme leurs correspondantes des Phoronidiens, suivant le morle épithélial; elles se creusent d'une cavilé, qui est l'ébauclıe du cuclome schizoculien, pendant que leurs parois se convertissent en somitopleure ct en splanchnoplenre.

Contrairement à ce qu’il en est chez lous les autres Trochozoaires, le protectolerme ne borne pas sour rôle à persister comme ectoderme définitif; il se livise en deux assises cellulaires, dont l'iuterne seule est le véritable ectoderme, l’aulre étant une membrane ammiotique, destinée à disparaître. Pour cela, l'eutéroprore ne reste pas superficiel. Une dépression se manifeste, dans la zone prolectodermique qui l'encadre, et lo porte au foul diune cavilé assez profonde; les hords de cette dernière se rejoignent alors, et se sumdent. En ce moment, le protectoderme 
de l'emhryon se compose d'une assise eellulaire cxterne el complète, à layuelle s'unit un tube clos, dont une extrémité s'applique contre sa face interne, el dontl'autre aboulit i l'eutéropore; ce tube est la dépression première, qui a pris ce nouvel aspect par la fermeture de son oritice extérieur. L'assise exterue du protectoderme devient, dès lor's, l'amnios. Le tube s'élargit; ses parois s'étalent en suivant la face interne le l'amnios, qu'elles doublent, et persistent comme cetoderme définitif. Un espace assez vaste, la cavité amniotique, sépare ce dernier de l'amnios. - Cel espace s'arrète sur les lords d'une zone étroite, situće dans une région diamétralement opposée à l'endroit où élait l'entéropore. Cette zone, qui est celle de la plaque céphalique, dont il sera fait mention plus loin, subit plusieurs modifications; la principale consiste en l'apparition d'un canal circulaire, destiné à l'entourer. Elle sert, pendant assez longtemps, à tenir l'embryon soudé à sa membrane. Elle s'amincit peu à peu pourtant, et finit par se briser. la larve est alors libre dans l'intérieur de son amnios; elle ne tarde pas à le rompre, à se débarrasser de lui, el à poursuirre son érolution, sans qu'aucune autre enveloppe ne la recourre.

IV. Annélides. - Le type des Innélides se compose d'une certaine quantité de classes, dont plusieurs comprennent des représentants nombreux et divers. Anssi, trouve-ton en lui plusieurs procédés cmbryonnaires distincts, qui ne sont pas variés comme leurs correspondants des Mollusques, mais vont eependant d'une gastrulation normale à une planulation déjá bien accentuée. Il est possible de les rassembler en trois modes principaux : le premier consiste en une simple gastrulation; Ie second en une plannlation directe; el le dernier, qui correspond il la présence dans l'ovule du deutolécithe le plus abondant, en une planulation indirecte. Celui-ci n'existe guère que chez les Hirudinces; le premier ne se tronve que ehez les Archianuéliles el plusiemrs Chétopodes polychetes; on rencontre le denxième chez la plupart des Chétopodes polychetes et oligochutes.

I'remier cas: gastrulation des Lrehiumélides el de plusieurs Polychates. - Ce procédé est relativement rare; les Archiannélides, telles que les Polygordius et les Protodrilus, l'offrent d'une manière constante; plusieurs Polychwetes, comme l'Éupomalus uncinatus, le présentent ćralement. La succession des phénomènes ne diffère pas de celle Jéja connue, pour cenx des Trochozoaires monomériques qui produisent leurs feuillets d'après le mode gastrulaire. Le protectoderme se convertit en ectoderme; le protendoderme émet des initiales, qui pénètrent dins l'espace blastoculien, el donnent un mésenchyme primaire, dont une partie se transforme en éléments conjonctivo-musculaires létinis, et dont l'autre fumrnit deux banılelettes mésorlermiques. Cellesei conthuent lem développement suivant le mode épithélial.

La segmentation est totale et égale, ou totale ct légèroment inégale; 
clle conduit à une hlastule munie d'un blastocrle assez étroit, puis à une gastrule par invagination. Lu moment où se léprime, et s’invagine, la zone blastodermijue qui ra domner le protendoderme, deux cellules, placées symétriquement de part et d’antre de la ligne méliane, se séparent d'elle, et sont les initiules misodermiques, car elles se divisent avec rapidité pour engendrer les landelettes. Elles pénètrent dans la cavité hastocelienne, toujonps interposíes anx deux fenillets primoriliaux, et se placent dans une région voisine lo l'anus, qui se perce en ce moment; l'entéropore ne se ferme pas, et devient la houche. Outre ces deux initiales,
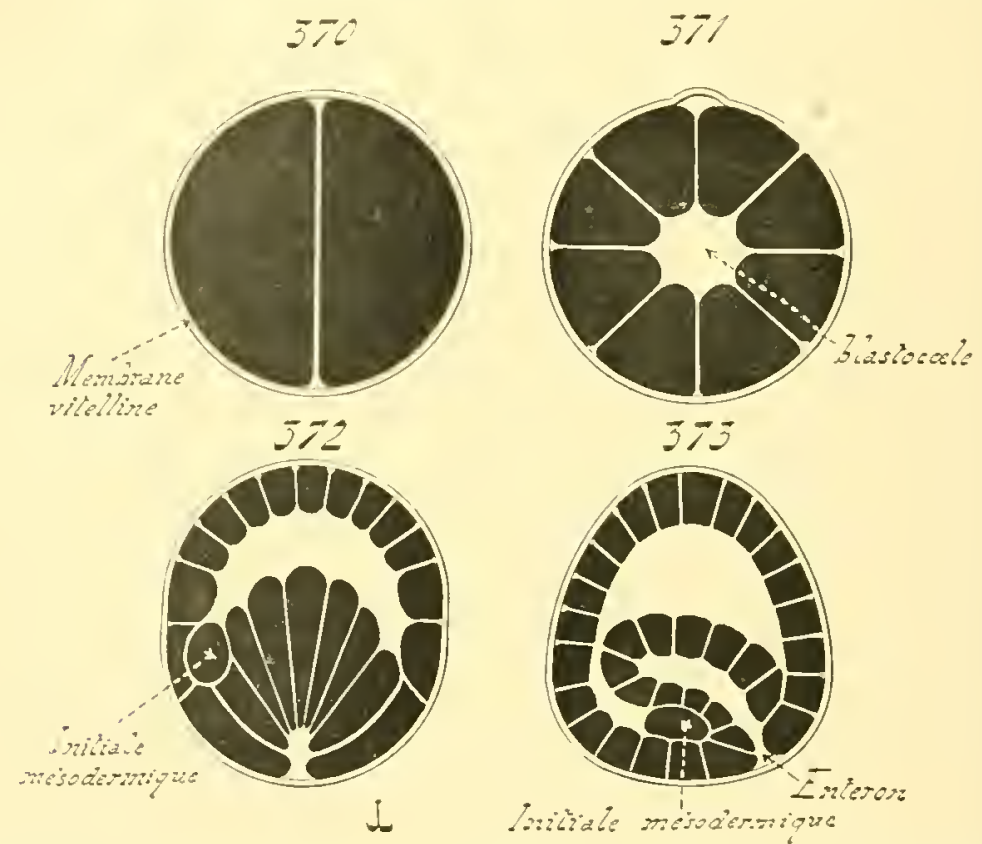

Hig. 370 a 373. - Gistruldtuy chez Les AnNeldes (coupes médianes el longiludinales, en silhouelles). - Fn:370, division de l'ovute en deux lulastomires. - Eu 371 , jenne blastule. - En 372, june gastrule; l'une des deux iniliales mésodermiques commence à se sèparer du prolendoderme. - Ein 373, gastrule parvenue å sa période d'élat.

bapres les recherehes litil's pal' llatschek sur l'Eupomatus uncinatus.

le protendoderme émot. en surplus, quelques autres éléments, qui parviennent dans l'espace blastocuelien, et y conslituent un mésenchỵme primaire. - En somme, le fenillet primordial interne se partage en endoderme el mésoderme. Ce dernier consiste en un mésenchyme primaire, qui se dispose dius le llastocale, el s'y divise en deux parts. Lime, situce dans la zone anale, et produite la première, donne seule les baudelettes mísodermiques; l'autre, répandue dans le reste du corps, y forme un lissu conjonctivo-musculaire, dont les éléments paraissent persister dans la lête de l'animal adulte. 
Les haudelettes évoluent suivant le procédé épillélial. Une carité, l'élanche du culome schizocuelieu, se creuse laus chacune d'elles; leurs cellules se groupent en une assise simple, qui limite ce colome. Ce dernier s'accroil sans cesse, et refonle sa paroi devant lui, pour l'accoler contre l'ectoderme d'un coté, et contro l'endoderme de l'autre; la jartie unie il l'ectoderme devient la somalopleure; la seconde se convertit en splanchnopleure. En outre, les rangées transversales de cellules, placées it des intervalles réguliers, cloisonnent le colome grandissant. Cette modificalion particulière de la cavité colomique est propre aux Trochozoaires polymériques; elle sera cxaminée, avec des détails plus circonstanciés, dans l’un des paragraphes suivants (\$5).

Second cas: plamulation directe de la plupart des Chétopodes polychretes el oligochcetes. - Ce mode semble être le plus répandu de heaucoup; la richesse plus grande de l'ovule, en vitellus nulpitif, fait augmenter, dans des proportions considérahles, le nombre des lilastomères issus de la segmeutation, et empecche la gastrulation. - L'ouf subit 1m! division tolale, et queligue peu in'gale. I'arfois se creuse une petite cavité blastocelienne; mais elle ne tarle pas à disparaitre. Finalement, l'embryon consiste en une masse compracte de collules aggromérées. Ces dernieres sont toutes semblables les unes aux autres, et renferment it la fois du blastolécithe, et les gramules vitellins. En somme, la jlanulation est directe.

l.es feuillets prennent ensuite naissance, anx dépens de ces éléments accumulés. Les blastomèes périphériques perdent lenr forme arrondie ou polyélrique, se serrent les uns contre les autres, deviennent prismatiques, el se disposent en une assise simple, placće à la surface mème de l'embryon: cest le protectoderme, qui, comme loujours, se convertit en ectoderme définitif. Lamas des blastomères internes est le protendoderme. Celui-ci se creuse en son centre d'une cavité, l'entéron; les éléments situés autour d'elle représentent l'endoderme strict; toutes les cellules, laissées entre ce dernier et l'ectoderme, romposent le mésoderme. Ces cellules sont groupées, d'orlinaire, en deux amas, symétrịues par rapport à la ligne médiane, qui ressemblent aux landeletles dı premier cas. Ces amas évolnent, aussi, de la mème manière. Une cavité, l'éluauche du culome, nait daus chacun d'eux, s'accroit sans cesse, se cloisonne, cl divise ainsi, par le fail te son extension, le mesulerme en une somalopleure et une splanchuopleure. L'évolution ı'est, pourtant, pas aussi franchement épitléliale que daus le premier cas; elle se manileste en partie d'après le type mésenchymateux.

lientéron ne tarde pits à s'ouvrir an ilehors, par le moven l'une lionche el d'un anus. - Parvenus ì celle phase, les emliryons ne different pas de ceux fui rentrent dans le premicr monte; mais ils ne sont arrivés ì arquérir leur structure yn au travers de phénomenes plus simples el plus alırégés, la condensation étant un etfel le l'abondance du deutolé- 


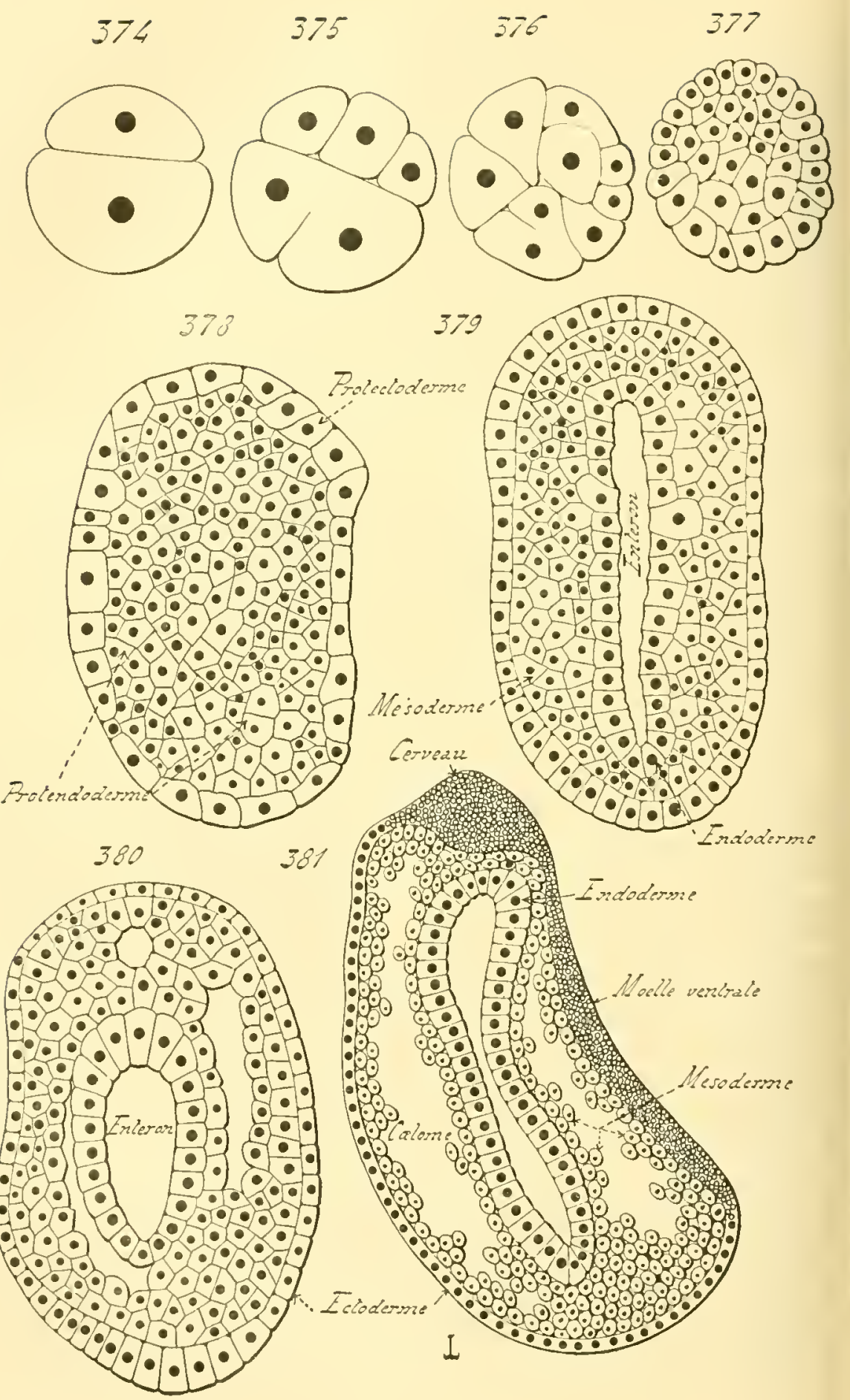


cithe. l'élat gastrulaire est omis, el de mème celui répondant ì la genèse des iniliales; les'blastomères de la planule sont très nombreux, et en quantité suffisante, dès la fin de la segmentation, jour engendrer sur place des bandelettes déjà épaisses. Plusieurs auteurs ont vu pourtant, dans la planule, des cellules plus grosses que les autres, qu'ils considèrent, soit comme des initiales mésodermiques (télollastes), soit comme des initiales néphridiennes (néphralılastes). Des éléments d'un fort volume existent toujours dans les planulations directes, car la segmentation ne suit pas une marche lien égale; mais it ne faut pas leur accorder une valeur trop limilée. En suivant la succession des phénomènes, on roit ces éléments se diviser, et produire des cellules semblables aux autres; ils peuvent avoir une importance prépondérante dans la genèse de cerlaius organes, mais celte prédominance n’est certainement pas exclusive.

Plusieurs embryologistes disent avoir observé la gastrulation chez dirers Oligoclucetes. Les dessins qu’ils ont donnés de ces faits, et les descriptions qui les accompaguent, ne sont pourtant pas très probants; ces naturalistes n’ont pas examiné la série complète des pliases, el n'ont pas élalıli aree certitude l'origine réelle du protendoderme. Sans doule, ils ont considéré, comme répondant à des gastrules incurrées, des embryons planulaires allongés, et recourbés sur eux-mèmes; ce pluénomène est fréquent ehez ces animaux.

Troisieme cas: planulution indirecte des Hirudinées. - L'ovule est, dans ce cas, trẻs chargé de granulations nutritives; mais il est panlécithe, cependant, avant la segmentation, et il n'existe point, chez lui, de cieatricule comparable à celle des llollusques Céphalopodes. - Les Branchiobdella, qu'il est permis, a beaucoup d'égrards, de considérer comme les plus simples des llirndinces, offrent, dans la genèse de leurs fenillets, un procédé intermédiaire entre le troisième mode el le second. Leur planulation est directe, en effet; mais elle détermine la production d'un chiffre très considérable de blastomères, de sorte que le protendoderme est un feuillet plus épais, et plus volumiueux, que son correspondant des Chélopodes.

L'euf des llirudinces est gros, relativement ì celui des autres Annélides; sa segmentation est totale el inégale. Dès les premières divisions, le deutolécithe s'accumule dans des l,lastomères qui, à la suite de ce

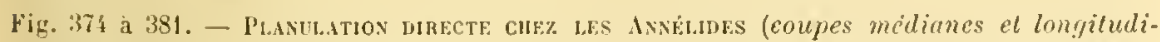
nales; d'après les (ligocholes du genre Enchylrä̈lles). - En 37i, 375, 376, segmentalion lotale, el peu inegale, de l'ovule. - En 37\%, jeune planule directe. - lin 37s, planule, dont le protectoderme et le protendoderme commencent á se distinguer l'un cle l'autre. - En 3in, l'entéron se creuse dans le protendoderme; les blastomies prolendodermiques, qui limitent directement celte cavili, composent fenduderme definitif; les autres blastonicres, plus nombreux, constiluent le mésoderme. - Vin isul, le ealome commenee il se creuser dans le mesoderme. - lin 381 , le celome grandil, pendant que les centres nerveux s'ebauchent aux depens de l'eeloderme. 
phénomène, sont heancoup plus grands que les antres, el se seindent plus lentement. I.a planulation s'effectue d'après le type indirent; des petits éléments, riches en vilellus évolutif, se séparent des blastomères leutolécithirues, se portent à la surface de ces derniers, et, foul en se multipliant arec activité, les enveloppent; un tel recouvrement débute dans la zone oủ la segmentation a commencé. Finalement, l'ovule est converti en un embryon planulaire; celui-ci se compose d'une assise superticielle de pelites cellules, et d'un amas interne de gros blastomères peu nombreux, clıargés le granules vitellins. La premièe est le protectoderme, le second le protendoderme.

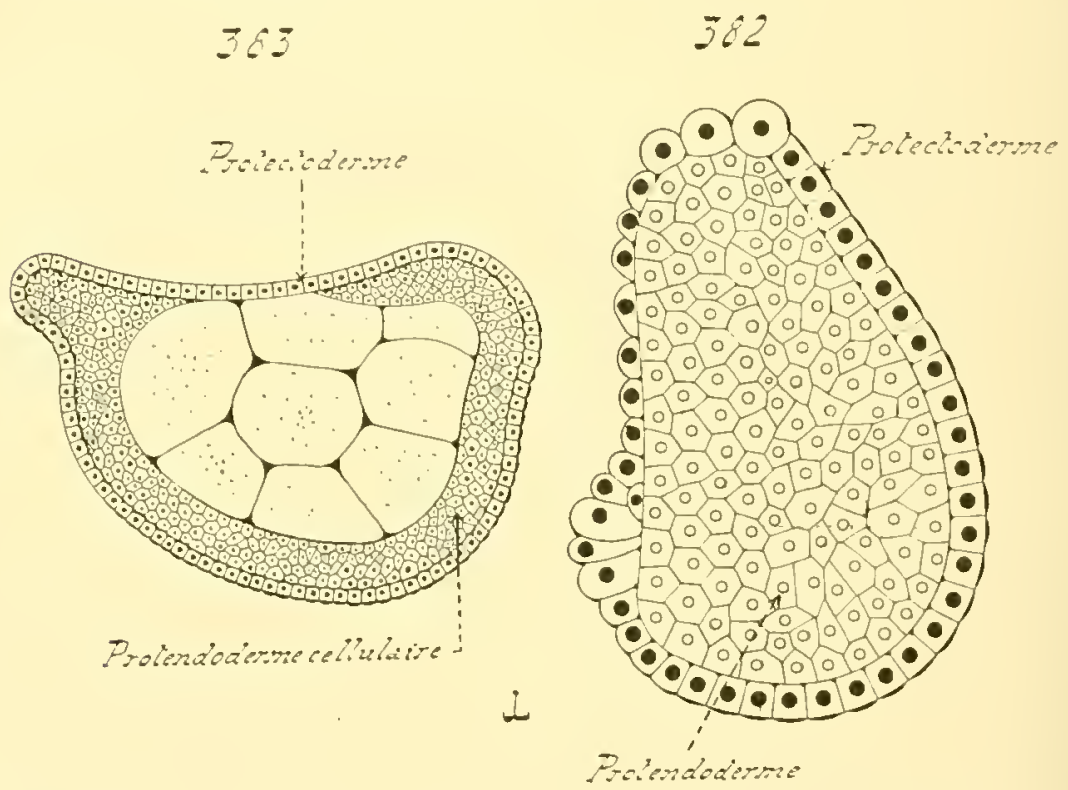

Fig. 382 el 383. - Planulation INDIRECTE des ANibloges (coupes médinnes el longiludinales. diagrammatiques). - En 382, planule d'une Branchiobdelia; d'après les recherches faites par Salensky. - En 3\$3, planule d'une flirudinée du genre Clepsine; le frotendoderme se compose de pelites cellules pèripléripues, qui entourent de volumineux blastomères, clıargés de vitellus nutrilif, et constituant une masse nutritive interno. W'apres les rerherches faites par Niıssbaum.

I mesure que le froillet intérieur se laisse envelopler par l'autre, il sćpare de lui-mème quelques éléments, qui se multiplient avec une certaine rapidité, et sont chargés le donner le mésoderme: anssi pent-on conserver à ces lerniers le nom rénéral d'imitiales mésolermiques, tont en faisant cette réserve, fu’ils sont engendrés dans une planulation, ef non dans le coms d'un Hocédr gastrulaile. Ces initiales proviennent parfois d'un seml hastomère, que l'on reconmail, et que l'on distingue le ses vuisins, dès le lébut de la segmentation. - Tn tel phénomène 
est, sans doute, une conséquence de la comdensation extrème du léveloppement; les ébauches lu feuillet noven, et de ses dérivés, chant produiles el délimitées le plus lòt possible. larmi ces initiales, fes nues, dites téloblastes, forment, par la suite, le tissu conjonclivo-musculaire dn mésoderme; les autres, les néplıroblastes, fournissent les népluridjes; enfin les derujères, les gamollastes, on encore les initiales sexuelles, produisent, comme leur nom l'indique, les organes de la reproduclion.

Le mésoderme se trouve ainsi, presque des son apparilion, divisé en ébauches de ses principales parties coustilutives. II n'en occupe pas moins, dans le corps du jeme embryon, une place relativement minime; et, l'abréviation du développenent s'exerçant loujours sur lui, il se creuse, à la fois, d'un grand nombre de cavités zoonitaires, au lieu de les engendres séparément. les unes après les autres. Le pllus vasle espace est occupé par l'endoderme, Jonl les éléments énormes, tassés en um lout compact, renferment un aboudant deutolécithe. - Celle réserve untriLive, qui, comme chez la Nasse, parmi les Mollusques, comstilue une sorle de vésicule vilelline interne, est absurbée par l'embryon au fur et à mesure de son évolulion; parlant, elle diminue sans cesse, pendant que le mésoderme s'accroit el se complique. 'uis, lorsque le développement embryonnaire est presque terminé, l'emlodeme, ramené ì ses dimensions normales of définitives, se creuse d'une cavité entérique; l'anus el la bouche se percent ensuite. Lientéron contient, pendant quelque temps, des granules vitellins, qui proviennent de l'endoderme placé autour de lui, et servent à nourrir l'embryon.

Celle longue persistance, el cette taille excessive, de la réserre nutrilive endodermique, expliquent laspect simgulier les jeunes llirudinées, qui, du reste, subissent dans leur coque chorionmaire loutes les phases de leur ívolution. Les élrauches des organes ayant me forme allongée, comme la moelle nerveuse, la série des cavites colomiques uaissantes, s'etendent, sur la face ventrale de l'enturyon, depuis l'extrémité antérieure de son corps jusyu’a la récrion postérienre, et cutonrent forcément l'amas vilellin a la manière de condons équatoriaux. Aussi somble-t-il que lembryon soil reconbó sur lnj-mème, lont en enveloppant une résicule vitelline placée sur son dos.

l. Pseudannélides. - Le développenent des fenillets blastodermiques de ces animanx rappelle entierement celui déjả lécril pour les Amolides; il s'eflectur, de mème, smivant denx modes principaux, la grastrubation of lis plammlation, dont la prisenece est lice il la teneur de l'orule en deutolécille. le caractere préjondérant de l’évolution porte sur le mésoderme. Le culome commence jar se cloisonner, lout comme celui les Ambrililes; puis ces cloisons se débruisent, les carités

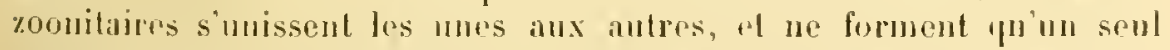
espace périviscéral, qu’unc cavite genérale, comparable a celle des Trochozoaires monomériques. 
Ios représentauls du genre Echiurus offrent, parmi les Echimriens
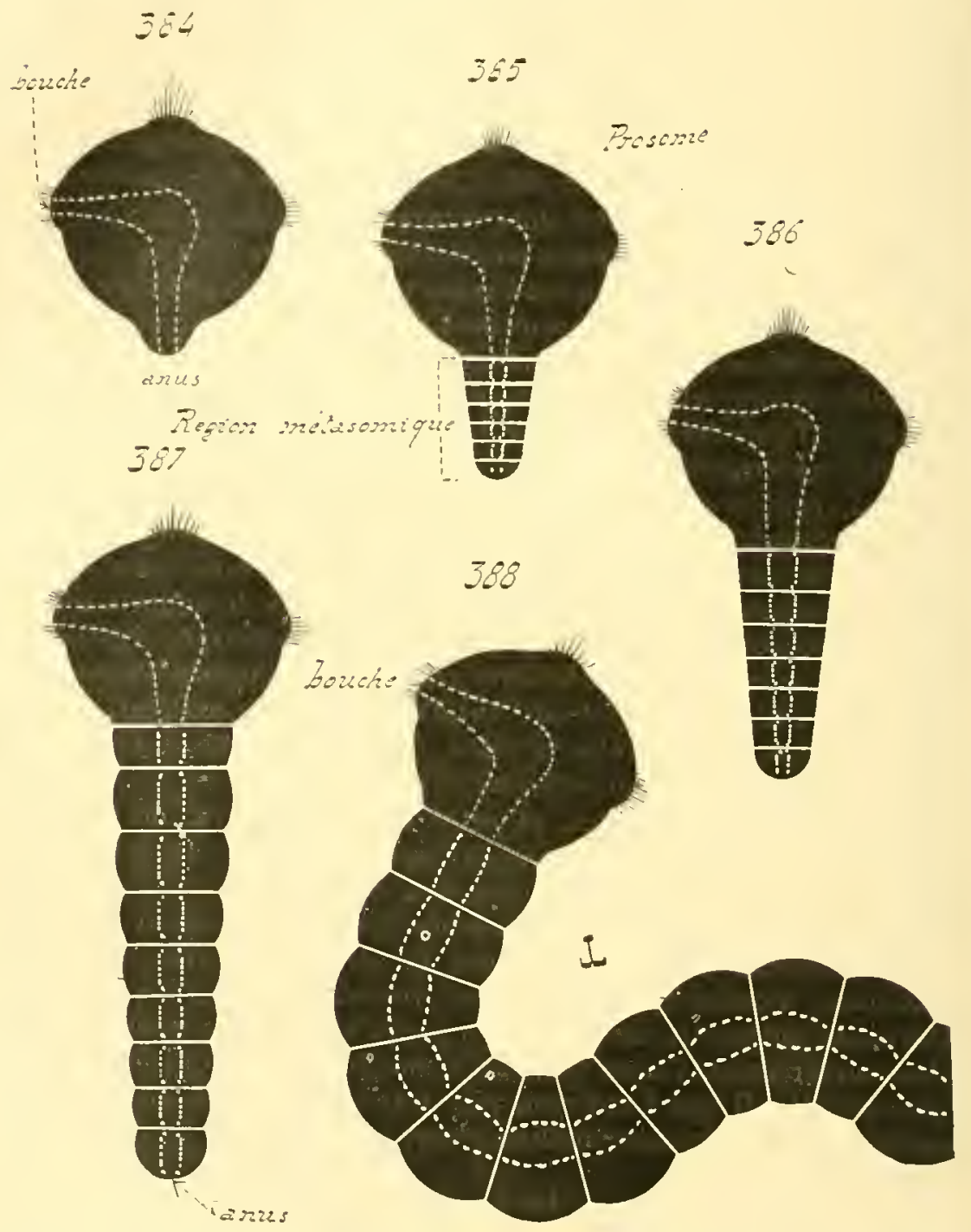

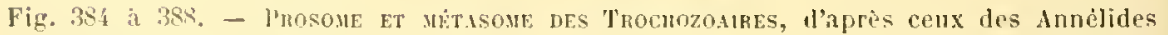
(diayrammes en silhoueltes). - Fn 38, jeune Jarve Troehophore, encor's réduite an prosome seul. - lin 3x, la région anale commence i grandir plus que les autres parties du fretit organisme; elle dunne fresulue toute l'oronomie définitive, èest-à-ılire le métasome;

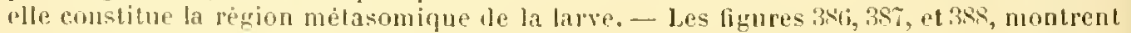
les phases sueessives de l’aceroissement suli par cetle région; thl fournit, à elle seule. le melasome presijue entier, alors yue le prosome, demeure inactif sous ce rapport, devient l'extrimité antẻripure lu corps, et rien de plus.

Ces drssins sont destines a frèciser l'imprortanee, en ce pui concerne le faconnement de l'organisme, des inegalites dans l'amplification du corps de la larve. - Le pointillé.blane indique l'intestin; les traits blanes marjuent l'emplacement des cloisons segmentaires. 
ou Géphỵions armés, le procédé le plus dilaté. les premières phases emlironnaires ne sont guère connues; mais tout porte il croire, il'après la structure des jeunes larres, qu’elles se manifestent par une blastulation, suivie d'une gastrulation. Ces larves ressemblent à celles des Archiannélides; elles possèdent, de mème, un entéron, pourvo l'une bouche et d'un anus, placés dans me situation identique; de mème encore, le protendoderme envoie, dans cet espace, les éléments du mésenchyme primaire; ecux d'entre eux, qui oceupent la rigion anale, sont représentés par denx grosses iniliales mésodermiques; les autres constituent un mésenchyme, qui se dispose dans le llastocuele. Les initiales prorluisent les bandelettes; celles-ci, tout en sallongeant dans lo corjes, se divisent en segments, Jout le nombre va jusqu'à quatorze et quinze. La plupart de ces derniers se creusent d'alord d'une cavité zoonitaire, puis se dissocient en passant à l'état de mésenchyme, et fournissent les globules du liquile colomique. Les parois latérales des segments persistent senles, et sunissent pour constituer la somatopleure el la splanchnopleure.

Les ovules de la plupart des autres Echiuriens, de la Bonellia par exemple, et ceux des Sternaspidieus, contiennent une assez grante quantité le vitellus nutritif; aussi la segmentation conduit-elle à une planulation indirecte, toujour's effectuée d’aprìs le type haljituel, sur lequel il est inutile d’insister. Lassise périphérique des petits blastomères devient le protectoderme: l'amas interne des grandes cellules deutolécithiques fournit, comme d'ordinaire, le protendoderme. Celui-ci se divise, à son tour, en mésollerme el enlloderme; les premières él,auches du premier se montrent dans la région où la rangée enveloppante. protectodermique, s'est fermée. Spengel s'est basé sur ce fait pour admettre que le fenillet moven de la Bonellie dérive de l'ectoderme; il suffit te lire la description qu’il donne de ce phénomène, et d'examiner ses dessins, pour se convaincre du contraire, pour voir que les Bonellies ne font pas exception parmi les Trochozoaires. Le mésoderme évolue ensuite, en acquérant directement son aspect définitif, et ne présente ancune division zoonitaire comparable à celle des lichiures. L'alssence d'une telle segmenlation est, sans doute, un résultat de l'abréviation du développement.

\section{\$ 4. - Formes embryonnaires.}

I. Généralités. - La forme emlirgonnaire fondamentale des Trocho7onires est la larve Trochophore, qui, lans le conrs de l'ivolution.

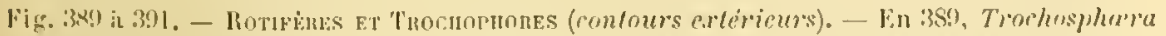
rrqualorialis (thotifére á eorps globuleux); d'apriss les recherches failes par Semper. En 390, liotifere all corps allonge, avee sa couronne orale, et son pienl fourchu. - Lin :301, Trochophore halituelle des innelides, avec sa couronne oral", el la loulte supérieure le cils, qui repose sus la plaque cephalique.

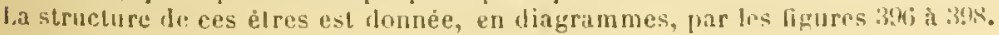


389
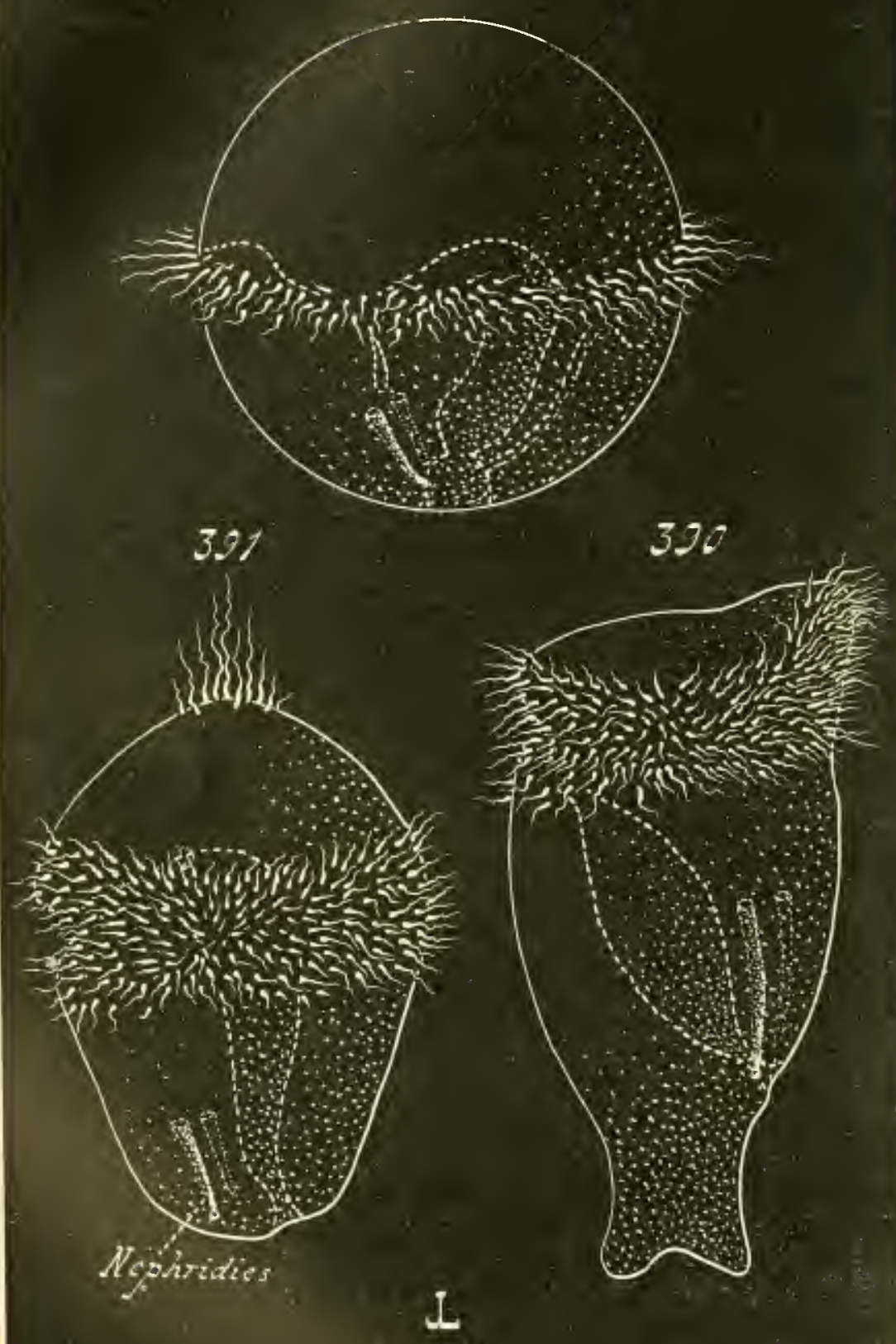


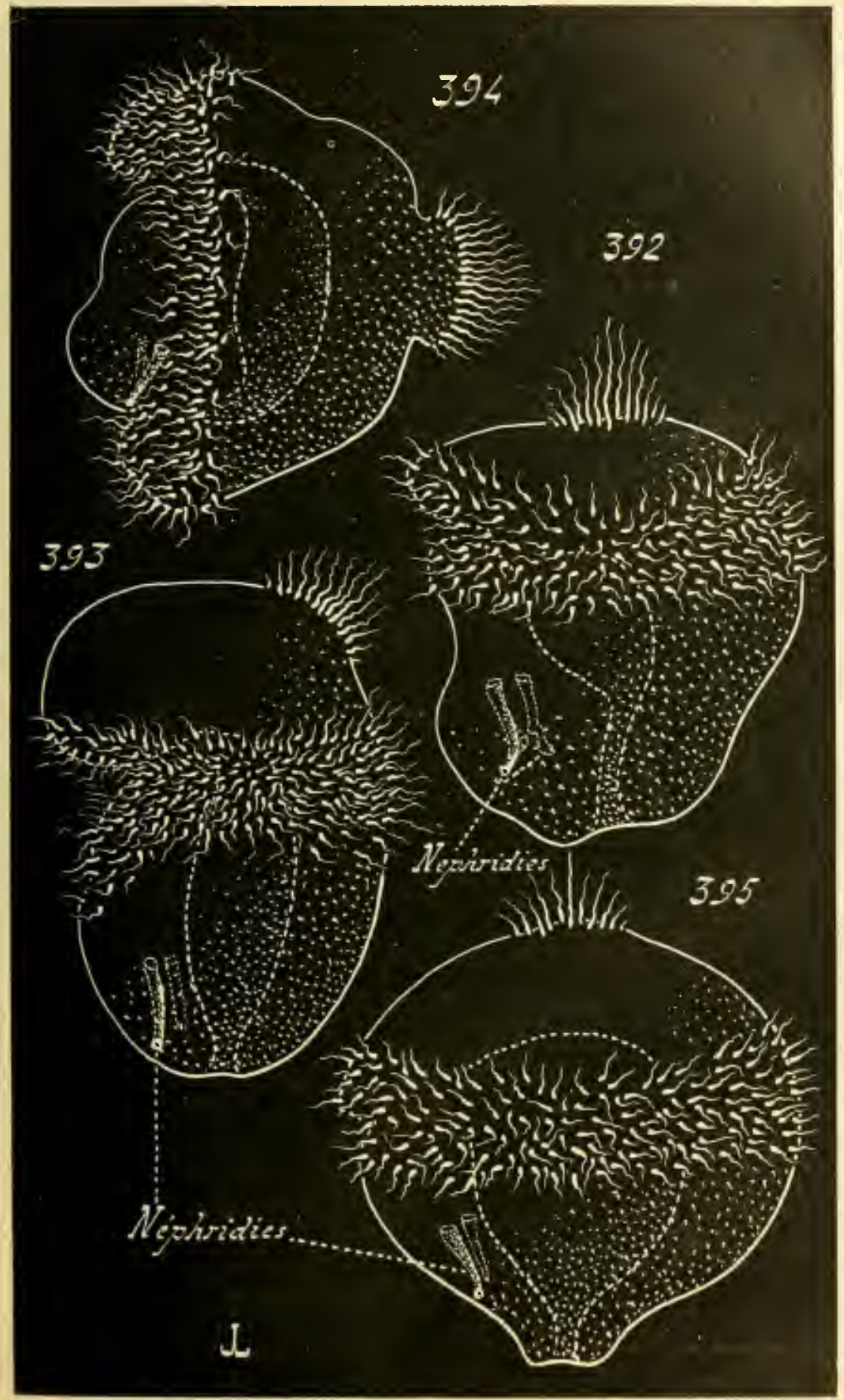


succèle immédialement i la gastrule. Cette larre est caractérisée : par son celoderme cilié, nue conronne orale de cils vilıratiles ne manquant jresfue jamais; par son mésenchyme primaire blastocelicn, frovenant diniliales, dont une partie se développe en mésorlerme définitif, tout en se creusant l'un schizocule; enfiu par la présence d'une paire le néphridies primoraliales (Figures 322 et 323). Ce sont la les caracteres fondamenlaux des lares de lous les Trochozoaires; nais ces particularités sont somvent altéries le plusicurs manieres.

Tout d'abord, les Trochophores ne se ressemblent pas entièrement. La structure essenticlle n'est point modifiée, il est vai, et dénote entre elles l'existence d'aftinités indiscutalıles; mais, ì ces faits prépondérants, s'en ajoutent l'aulpes d'une moimlre valeur, qui donnent aux direrses larvesune physionomie propre. Ainsi, la couronne orale se faconne seule, parfois, alors quailleurs elle est accumpagnée le certains antres cercles ciliés; ello-mòme est disposée de phsieurs facons, assez constantes, dans l'ólendue d'un mème type, pour servil à le caractériser. D'autre part, quelques organes s'ajoutent hâtirement à ceux qui composent essentiellement la structure de la Trochophore; lelle cst, par exemple, la glande coquillère les larves de Mollusques. Enfin, la bonche et l'anus n'vecupent pas toujours la mème situation relative. - lie sont lả cles particularilés secondaires, selon toule évilence, mais yui révèlent, par leur constance, lorsqu'ollos se présentent, lexistence le plusieurs formes larvaires dérivées de la Trochophore. Ces formes correspondent sensiblement aux séries nalurelles; elles permetlent de présmmer que ces dernières se sont établies de fort bonne henre, dans f'évolution grénéalogique, et onl poursuivi leur voie côte à cote, sans se confondre.

En outre, dans chaque lype, la manière d'ètre primitive des embryons subit des changements tenant à deux causes. ba premiere est Jaltération causée prar la présence d'un leutolécilhe abondant; la vic libre se trouve raccourcie, el le développement larvaire se convertil eu léveloppement furtal. La secome rst l'adaptation des larves à une vic libre el pélagique; ces embryous émeltenl des expansions, parfois munies de cils vibratiles, ailleurs pourves de soies, on des denx ensemble, fui leur serrent l'appareils de relation. De tels appendices s'alpuphient ensuite, on ne grandissent pas autant que les autres parties 16 l'iconomie; mais ils n'en contribuent pas moins a lonner, aux ches qui les proplent, un aspect particulier el caracléristigue. - Ve plus, ces cmbryous otirent parfois nu phénomène curieux. Ces appendices les sontiennent lans l'eau, alors que les organes, destinés il persistur, se

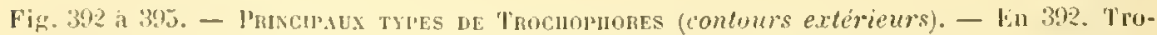
"hophore de Ilollusque. - En 393, I'rochophore de Phoronidien. - En 394, Trochophore de: Bryoznaire. - En 395, Trochophore d'Annelide, au prosome élargi.

Ces lifures font suite aux precedentes; leur structure est domec par les tigures 390 a 402. l'oules sont destinees a montrer l'uniformitè d'aspect, et d'organisalion, des larves 'l'ochophores, ifuels 'pue soient les grompes audquels elles appartiennent. 
perfectionnent sans cesse, ot atteignent peu à peu leur état lófiuitil. P'uis, au moment où ce dernier est açuis, la larve déjà àgée, el presque adulte, se sépare brusquement de ses annexes de relation: telle est l'Aclinotrorue qui se convertit en Phoronis; telles sont encore les larves de diverses Innélides.

La principale cause de ce fait doit ètre recherchée dans la division In corps des Trochophores en un prosome, et un mélasome, qui suivent un accroissement inégal (Figures 384 ì 388). Le métasome comprenil la région oì se trourent les handelettes mésorlermiques; senle, ou peu s'en faut, elle produit le corps de l'adulte. Par contre, le prosome, qui constitue la majeure partie de la Trochojhore, et porte la louche avec la couronne orale, grandit peu, et se horne à devenir la tête de l'adulte. Etant donné que le métasome seul va fournir l'alulte, toules les impulsions évolutives se concentrent en lui. Le prosome joue le rôle d'un appareil de relation, d'une importance secondaire; tantòt il grandit simplement, tantót il émet des expansions cilićes, chargées de soutenir le métasome qui se développe. - Certains auteurs, Kleinenherg entre autres, partent de là pour admettre que le prosone et le métasome sont deux indivilus lifférents, le second étant engendré par le premier, el l'ensemble comprenant alors deux geénérations. Il suffit de comprarer les Trochophores entre elles, en allant toujours tles formes inféricures de chaque type aux plus élevées, pour voir qu’il s’agit de l'agrandissement exagéré, accompagné d'une longue persistance, lu prosome.

Le prosome possède un pelit centre nervenx, qui est l'ébauche du cerveau de l'adulte. Cet organe, la plaque céplualique, on plaque syncipilale des auteurs, est un épaississement ectodermique, placé en avant et au-dessus de la bouche; il émet quelques rameaux, dirigés ver's l'orifice lunceal et rers la couronne orale. Sa situation variable, sujvant les trpes le Trochophores, contribue, pour sa part, a mieux accenturer la physionomic propre à chacun d'eux.

l)ans les cunsidérations précédentes, comme dans les descriptions suivautes, les termes de prosome, el de mélasome, sont détournés quel pue peu de lenr signification, afin de rendre la compréhension plus aisée. Le prosome est, au sens exact lu mot, le corps de la larve. et le métasome celui de l'adulte. Or, en cette étude des embryons de Trochozoaires, et dans le hut de mieux faire saisirl'imporlane des changements éprourés, l'expression métasome sera appliquée, par avance, à cette partic du corps larvaire qui devient presque tout l'organisme adulte; celle du prosome sera restreinte it la zone qui ne s'accroìt pas, et ne constilue qu'une portion exignur de l'écomomie détinitive.

II. Rotifères. - Les liotifères ne lépalssent pas l'état de frochophore, et il est permis de les considérer comme des larves dr Trophozonires, 'fui seraicut sexuces; la forme emulryonnare est donc ici définitive. La couronue orale est transversale. Le cervean, homologue de 
la plarpe cóphalinge, est situé un jen au-dessus de la lourbe; ec dernier orilice se troure, ou peu s'en faut, lianélralement opposé ì l'anus. l'ar la situation relative de la bouche, de l'anus, et du cerveau, le corps est divisé en deux parlies: l'une postéro-supérienre, on dorsale, élendue de la bouche i l'anus, fui runfrrme le cerveau et la rourome; l'autre, antéro-inférieure, ou ventrale, éralement élendue de la bouche à l'anus, yui est opposée ì la prévédente. Colle seconde zone n’offre, prarfois, rien de parliculier, comme il en est pour la Trochosphera xquatorialis, décrite prar Semper. Chez la phupart des aulpes Rotutenrs, sa région inlia-auale s'allonge, plus ou moins, en une sorte de pied, dont l'extrémitó fourchue jorte, dans cerlains ras, une petite glande ì mucus. Cutte région, quj apprail chez les liotifères, prósunte, chez tous les Monomériques, une gramle importance; cest elle qui constilue une honme part du métasome des Tentaruliféres et des Mollusipues. Quant a la courome orale, elle est

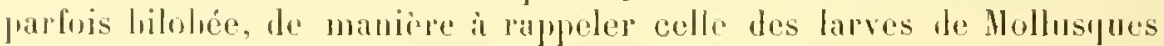
(Figures $389,390,39)(6,397)$.

III. Mollusques. A. - Les conlryons de ces animanx sont lihes le plus souvent, saul' ceux des Céphialopodes el de plusicurs Gastéropodes (l’ulmonés). Ces embryous libres possietunt un aspert prarticulier, du à la disposition de leur couronne vibratile orile, ol à l'apparition préroce d'organes, tels que le pied el la corjuille. - liébauche de celle deruière est une dépression de l'ectoderme, d’ahord remplie du mucus calcaire qu'elle sécrète; juis, le mucus déhordant, el les rígions ectodermiques aroisinantes produisant aussi une substance somblable, la coquille s'élend pen ì peu autour du corps de la larve. Celle lépression est nommée la glande coquillire, i cause de son róle; elle est situéce entre la houche el lanns, plus pris de cedernier oritice gue du prenier, daus la région qui correspond a la face postéro-supérjenre de lorganisme "'un liotiliıe; par suile, cului-ci n’en olfre point l'équivalent. Il n'en est pas ansi purr le pied; cel appendice est strictement l'lomologue We celui tes hotiferes, el se trunve placé de mème, entre la bouche el l'amus, non loin de ce dernier, dans la zone ventrale de ba larve (Figures :392 et 399).

Contrairement anx holatenrs, le pied prend un aceroissement considcrable, aver toute la région qui le porte; cette angmentation est de beauconp supérienre ì celle subie frar la partie opposée. lo cette inégalité drícoule une division du corjss de la larve en jurosome el mélasome; le premier comprend la zone postéro-supérienre de la Trocho1'hore, el le seconl la zone antéro-inférieure. - L'entéropore, jui devient la houdse, est d'aborl placé exactement vers le milieu du corps; a la suite de cel agramlissement inégal, il se reporte en haul, et finit par se trouver terminal. La couronne orale est orientée comme celle des

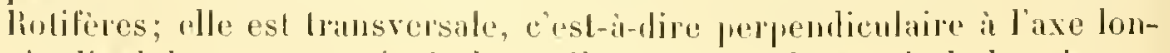
gitudinal du corps, et siluée immédiatenent an-dessus de la bouche. - 
L'organisme d'un Rotifere représente fort bien, d'une manière schémalique, relui d'une Trochophore de Molhusque, en supprimant les glandes sexuclles, aurmentant la taillo du pied, ot ajoulant, sur la face dorsale, une glande copuillère destinée à sécréter la coquille qui entonre le pretit blre. lanus frond naissance, d'orlinaire, apres la glande coquillere. et en arrière d'elle.

B. - Les larves des Mollusques inférieurs, des Mmphineuriens el des Solénoconques, prisentent quelques lispositions spéciales. Len comronne orale ne reste pas simple; elle se divise en nn nombre variable de cercles vibratiles superposés, Lrois le plus souvent, qui, loujours transversaux, surmoutent l'entéropore, et s'élagent depuis cel orifice jusqu’à l'extrémité supérieure du corps; celle-ci porte, en surphus, me louffe vibratile. Parfois, chez les Dentales, ces trois cercles sont séparés les uns des autres par d’assez grandes distances, et insérés smr des hourrelets formés de cellules allongées. Les Solénogastres, parmi les Amplinemriens, exagerent encore cet aspect, an point que le corps le la larve parait ètre scindé en trois segments; ce semhlant de division anmmlaire est dù à l'épaississement de l'ectorlerme dans les zones cilićes. - l'ar contre, la couronme orale les Platygastres (Chiton) est moins développée; elle se parlage tout au plus en leux cercles contigus. Les embryons libres de ces animaux sont souvent désignés par l'expression de larves de Loven, du nom lu naturaliste qui les a étudièes le premier. Ces bandes vibratiles disparaissent à mesure que la bouche, par suite de l'accroissement constant du pierl et du métasome, remonte du milieu du corps vers la région supérieure. Du reste, leur présence n’empèche pas que d'autres parlies de l'ectorlerme soient couvertes de cils; mais ces lerniers sont plus petits que ceux des comromes, el rangés arec me régularib moindre. - Il semble que les larves Jes Amphinemriens cl des Solénoconques sont privées d’un organe, comprarable à la glamle coquillere des embryous des autres Hollusques.

Ceux-ci ofrent un aspect caractéristipue. Dès le moment où les trois feuillets sont élauches, la couronne orale fait son apparition, puis lit glande corpullère dans une région diamétralement opposée ì l'entéropore, ensuite le pied en dessons de ve dernier orifice et non loin de lui, enfin l'anus. Le tube digrestif se replie quelque peu sur lui-mème, at décrit des circonvolutions dans l’interpur du corps. Ia glande coquilline sécrète son mucus calcaire, qui s'étale peu à peu autour de l'embryon, et lui donme me petite coquille fort mince, dans layuelle il est capable de se rétrarter. Entin la rouronne orale, Lonjours simple el non subdivisée, soulargit latéralcunent en deux lohes volumineux; elle acpuiert

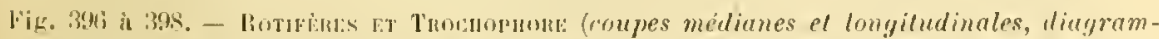

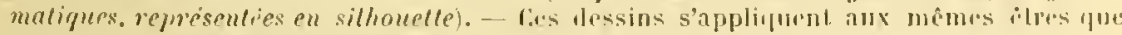

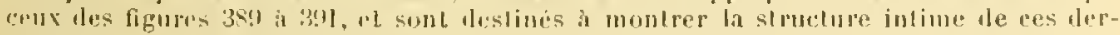
niers. 


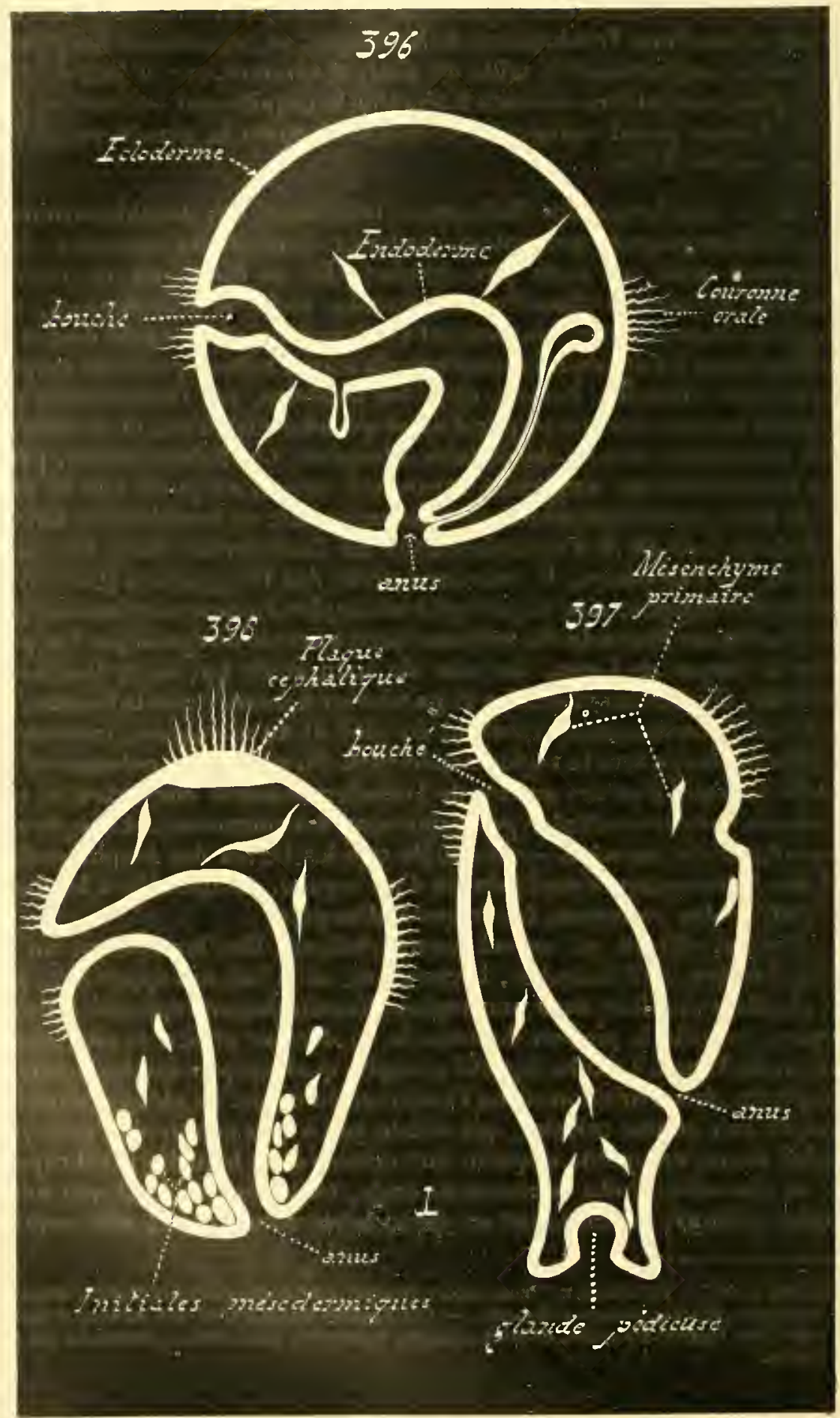




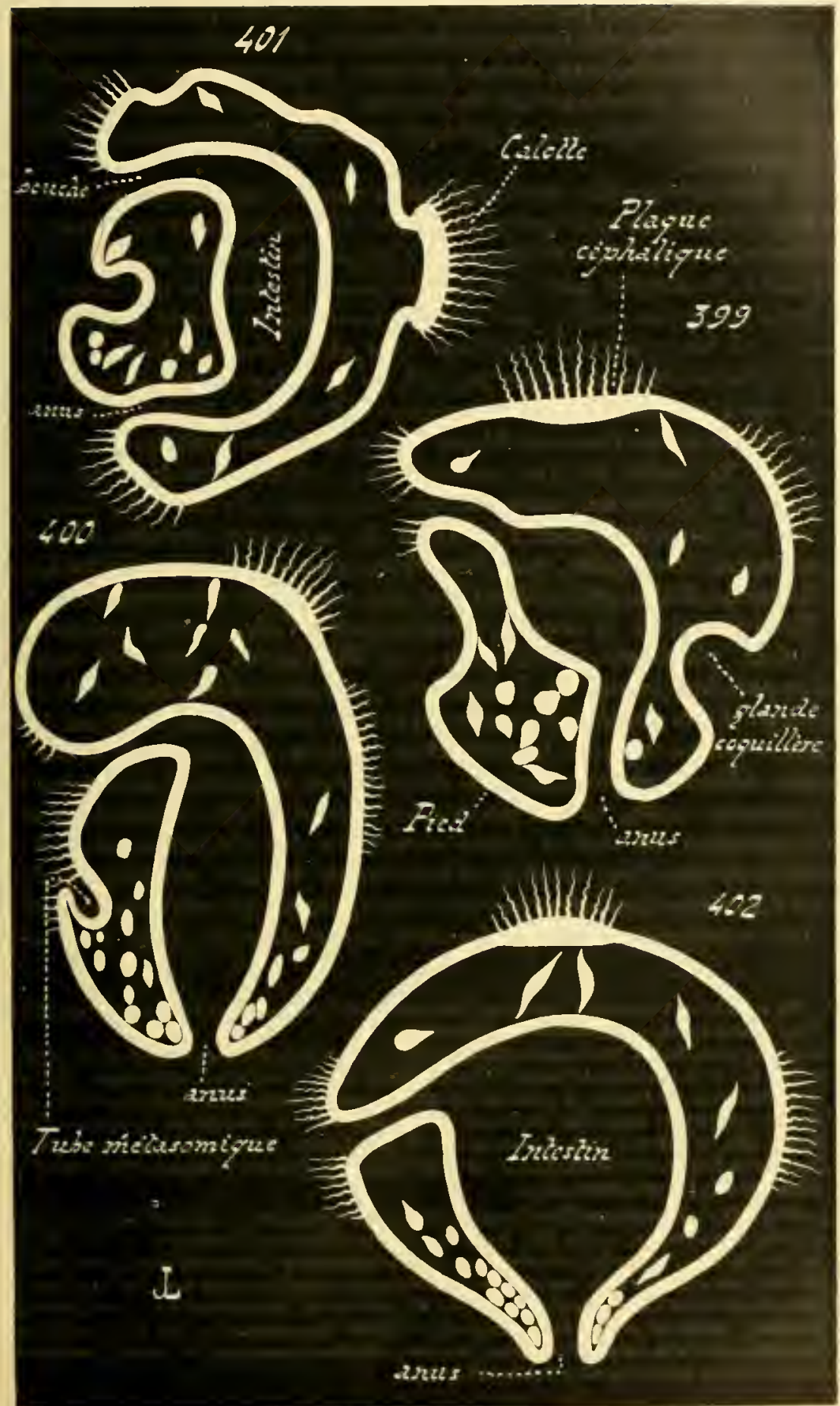


ainsi une disposition particnlière, que l'on exprime par le nom de voile. Le voile, ou velum, des larves de Mollusques, nest antre que la comronne orale de la Trochoplurre, munie dre deux larges expansions placées au mèmr niveau, el sumontant la louclie. Cette larve, ainsi faite, existe ehe\% tous les Acéphales, et prespue tous les Céplıalophores, sauf les Céphalopodes.

La leneur variable en deulolécithe exerce, sur la duréc de la vie larvaire, une influence prépondéranle; les variations à eet égard sont nombrenses parmi les Mollusques. Lorsque le vitellus nutritif est pen abondant, l'ombryou peree de lonne heure le chorion qui l'enveloppe, et nage arec soin roile, en trainant arec lui sa petite coquille. l'ar conlre, si les réserves untritives sont julus considérables, l'embryon reste enfurné dans sa corue jusqu’i ce qu’il les ait épuisées; il ne la quitle qu’i ce moment, dont la venue dilfè̀e d'un type à l'autre; cerlains même ne se trouvent libres qu'à me phase fort voisine de l'état détinitif. Le voile ne s'en montre pas moins, avec tous les autres organes; el, griee aux mouvements ineessants de ses cils, lembryon lourne sur lui-même dans l'intérienr de sa coque orulaire. C'est là le mouvement de rotation, que l'on olserve aussi chez d'autres animaux, mais que les Mollusques olyent arec une constance remarquable.

lians le cas oủ la coquille n'existe pas à l'état adulte, comme il én est chez plusieurs Gastéropodes et l'téropodes, elle fait pourtant son apparition aulour de l'organisme larvaire; elle tombe ensuite, et lisprarait. Cette chute de la coque est suivie, pour ce qui tient aux Ptíropodes Gymuosomes, le la production, autour du corps, de trois couronnes eiliées transversales; ces dernières ne dépendent aucunement de la comronme orale, et ne proviennent point d'elle. Partant, elles ne correspondent en rien ì leurs similaires des Solénoeonques et des Amphinemiens; lemr origine, ot leur venue hardive, contribuent égalemeut à les faire consilérer comme las appareils de uouvelle formalion.

Les embryous des Céphalopoules accomplissent, dans leur coque

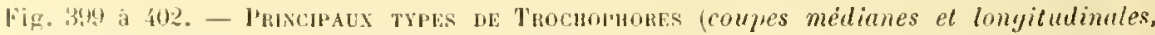
dinyrammaliques, representes en silhouelte).

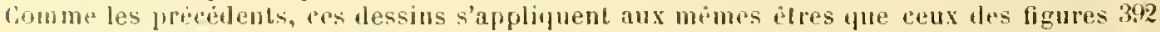

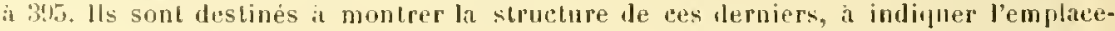
ment varialide de lanus, el cului de la rigion metasumique. la couronne orale, pepresuntee en entier dans les contours exterieurs, est iej domnee en coupe. - Ilaus la figure 401, relalive a une Truehophore de Bryozoaire, la depression, sutuee entre la

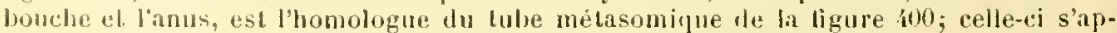
luliqut à une jeune Actinotroutue.

Fig. 403 a $40 ! 9$, - Jarves des Moldusudes (contours ertérieurs). - Jin 403, larve de bentale, d'apres kowalevsliy. - lin fli, lirve de Chiton, laprès Kowalevsliy. - En 405, larve do l'atelle, dont la partie infèrieure est placie dans une pelite corulle; d'apres I'alten. lin 406, larve de Vermel, vue de dos, nontrant sa coquille, el les deux lolies de son voile ciliẻ; diapris de lacaze-Dulliers. - lin for, larve te Pneumodermon (Péropode gymnusome), "ipres la chule de la coquille: d"apres liegenbaur. - En 408, embryon de Ceplatopnde, a la vesieule viltelline interne; d'après Grenacher. - Lin 409, embryon de ciphatopule, a la vesicule vilelline externe. 


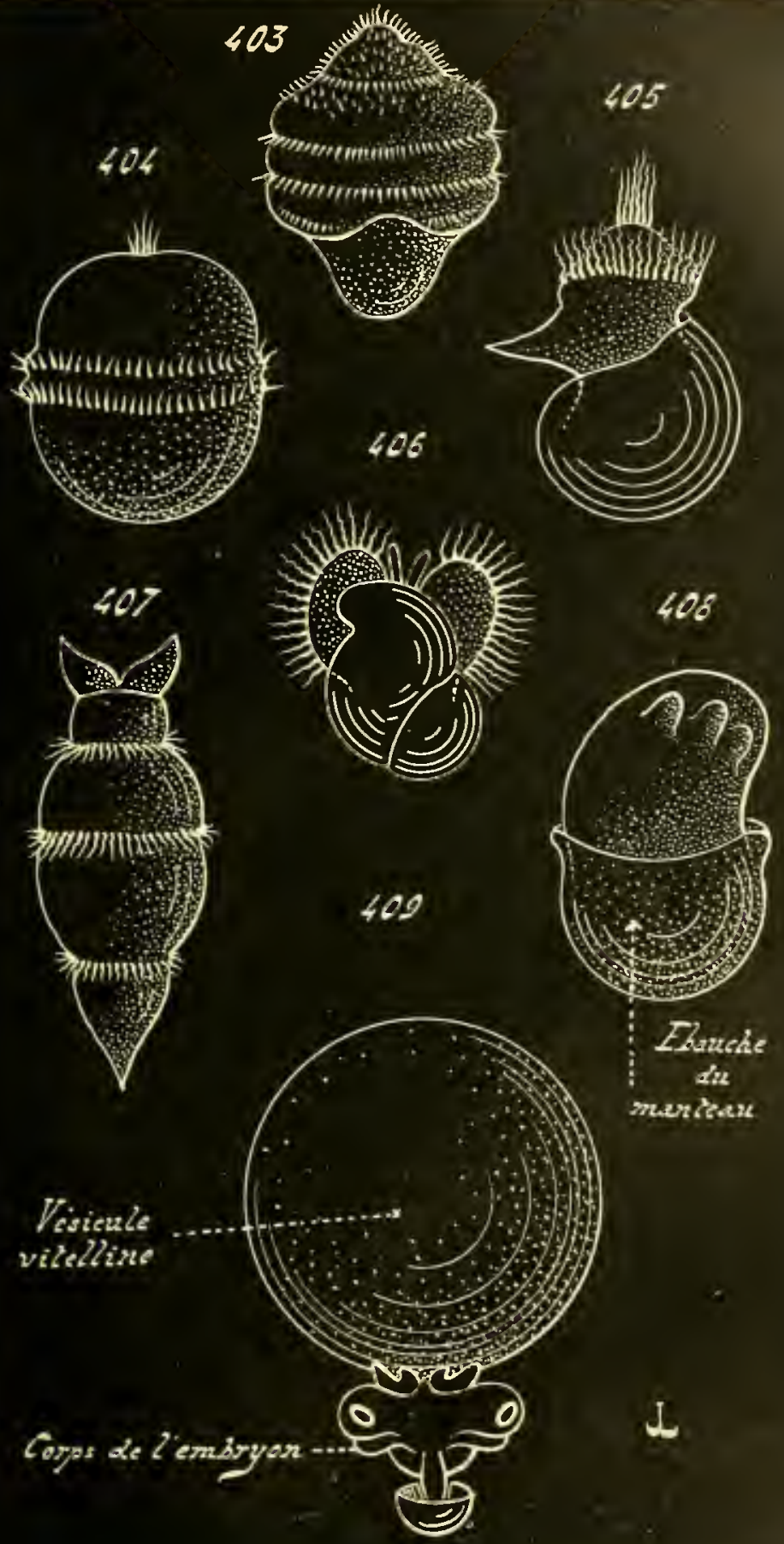




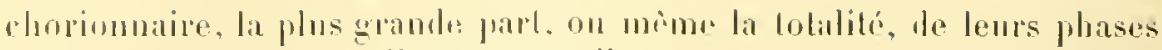
frolutives leur asperel dittire malurellement des uns aux autres, suivant fue la vésicule vilollim est interme, eomme celle les larves pélacripurs

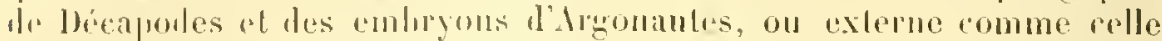
les Sevolus. Il sulfit la so reporter anx fails léja commus, el décrils lans le paragraphe relatil anx lenillets blastorlermiques, (page 380 ) pour so randre complr de ces dissemblanes. - Lorsque la vésienle est

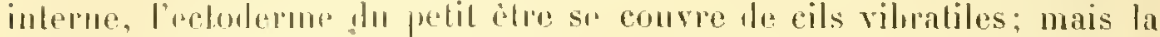

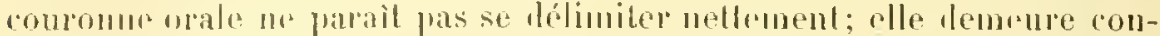

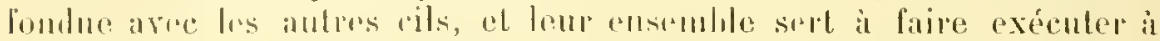

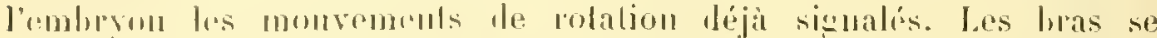

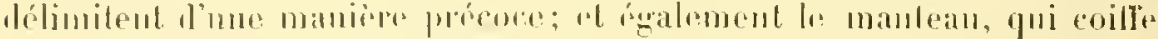

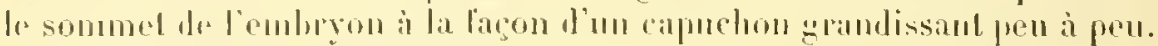

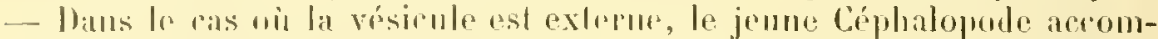

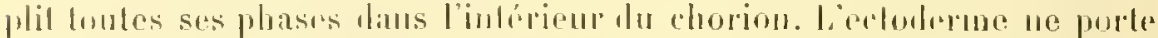

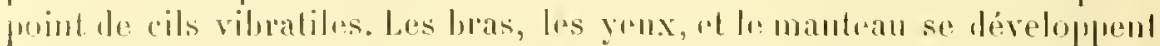

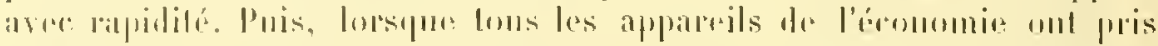

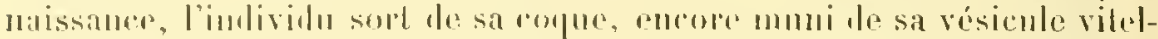

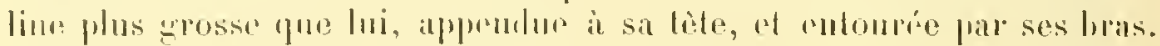

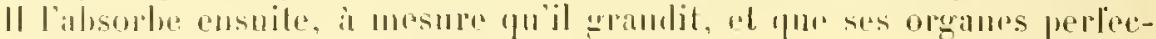

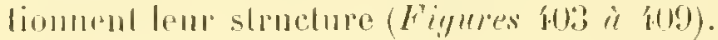

W. Tentaculifères. - De même que pour las formrs embryonmairus des Molluspues, il est móressaire, en ro qui fouche les Trntaculilieres, du se reporter a la lispmilion organipue des Rolateurs. Le corps présente leux axes; l’un transrersal, passant par l'entéroporr; l'aulde

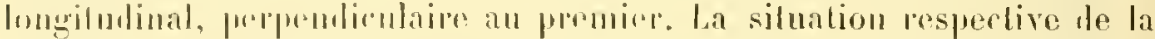

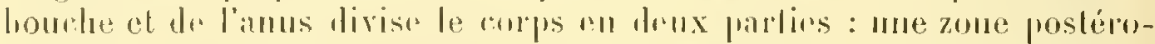

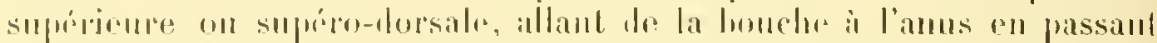

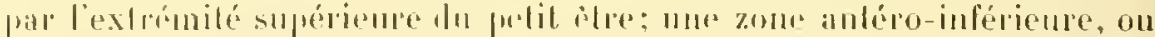

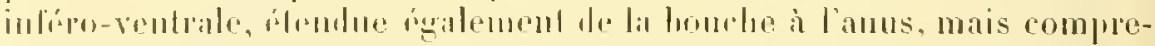

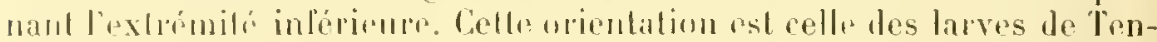

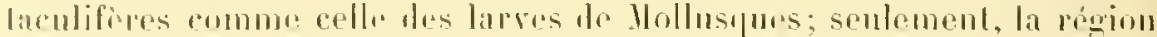

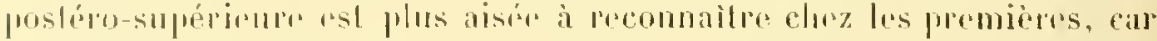

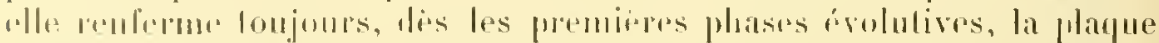

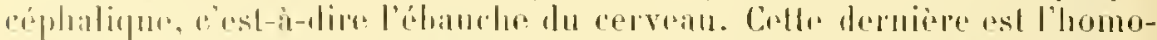

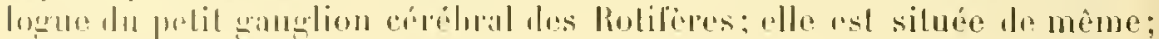

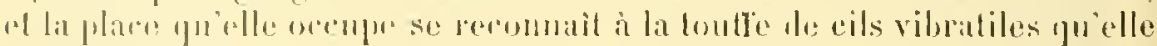
sแlyurle.

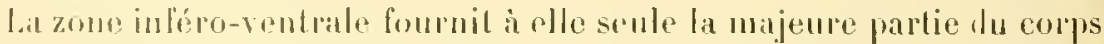

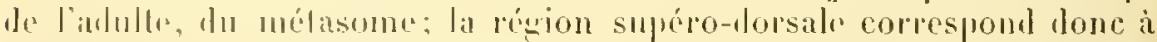
un prosone, fort léveloppé chéz l'embryon, mais qui s'accroil relative-

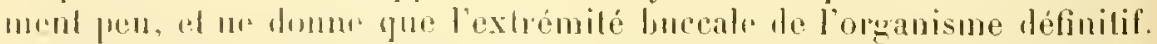

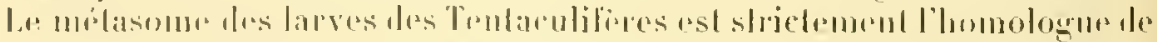

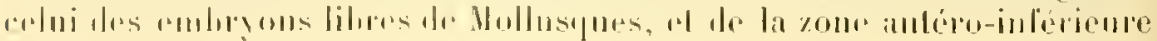


Jrs liolateurs; parlanl, les organes, qui s'y déreloppent de la móm. manjère, sont homologues. - Celle nolion porte a monidére commu

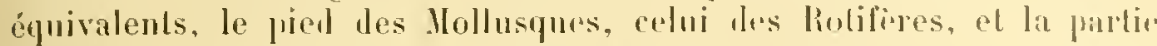
inférienre du corps des Tintaculifieres, quelle que soil sa formo. Cies régioms ne sunt pas disposées d'une facon sumblable; les untes sonl compactes, et les autres creuses; les mues sont gramles, ol les aulres exiguës. Mais celte diversite daspect tient anx divergenes qui sr manifeslent dans l'aceroissement, eomme daus le morle de développoment,

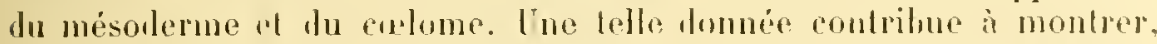
jour sa part, combien sont grandes les affinilés pui relient lous les Honoméripues culre eux, puisque la mème rigion de l'economio embryonnate

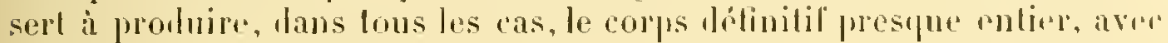
les apprareils yui servent a la fixalion de l’indivilu, ou i sa locomolion.

Les larves des Rhynchifires aprarliennent an lye le moins modilic. ¿ celui qui se rapproche le plus des Rolifires, el iles larves de Polyméripues. les enuluyous lihres des llémalohrachiés, on Phoronidiens, com-

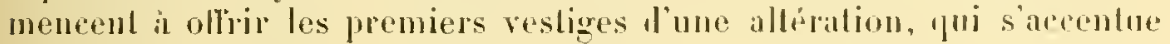
flus encore chez las Bryozoaires.

Ruscurenes ou Supuccuess. - Methant a parl lenvelopro amnjotique. qui n'exisle pas foujums, ear on ne l'a pas signalée chezul'autres gentes que les Siponcles, qui disparait luilivement, et semble ètre m organe aeyuis d'une maniere secondaire, la jeune larve de ces animanx rappelle assez bien, par sa disposition, un Rotaleur; du moins dans ses drails essenlicls. La louche esl placée un peu au-lessous de l'extrémité supériemre. el sur la face antérienre, du corps; l'anns est percé un peu au-dessus de lextrémilé inférieure, el sur la face postéricure; la romronue oralr, siluée all nivean de la levre inférieure de linrifece luceal, quelpue peu plus has que sa correspoudanle des lobatenrs, est hansversale. La plapue réphalipue oceupe la parlie dorsale de lexhromilé supériemre du corps. La région inféro-ventrale, el surtoul la zone placée au-rlessous le l'aums, est presque la senle à gunolir pum domuer le médasume. Elle est l'épuivalent stricl du pied des Rotateurs; elle ripond a un appendice

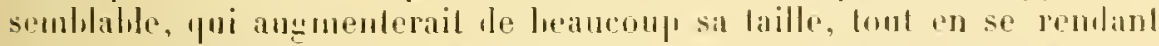

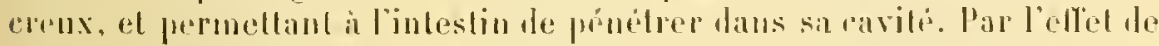

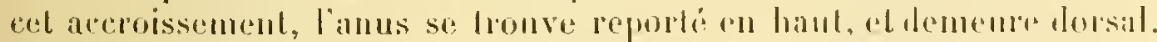
A mesure que ees phénomencs se proulusent, la rigion périburale. devenat rétractile, se convertil en mo trompe (Figure ras.3).

Ilinatumacuies, ou l'monoxmons. - La larve le ees etres est commue

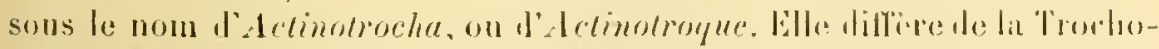
plowre labiluelle des holiferes, des Mollusques, el des sipumouliens, par les caracleres suivants : la conronne orale, an lien debe lransversile. est ohlique de haut en has, el d'avant en arriere: l’ants est reporte phos

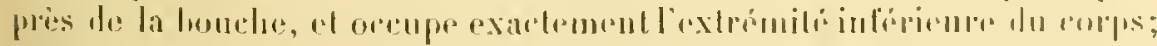

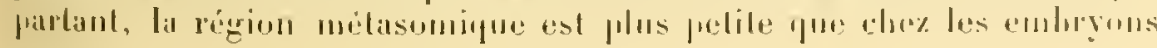


examinés jusqu ici. L'ertoderme entier est couvert de cils vibratiles, notamment dans la région supérienrr; celle-ci surplumbe la houche, et forme une volumineuse levre supririente, le lolwo promol. La coumme orale n’est guere hien drveloppéc que dans sa partir infórienre. La zone, qui la porte, se modifie hientót; elle produit des sailties, d'alorid comparables à des petits mamelons, puis à des tentacules cylindriques et allongés. C'est à leur présence que la larve doit son nom; ces teutacules, d'apparition si hàtive, devienuent ceux de l'adulte.

Le métasnme, qui est entièrement antériemr, et non pas antéro-inférieur comme daus les eas précédents, se dévelopłe d'une manière spréciale. Il se creuse d’une dépression, le tube métusomique, qui pénètre dans l'intérieur du corps, el y grandil. l'uis, rette dépression revient sur elle-mème, se dévagine, et constitue alors un organe tululeux, suspendu i la région ventrale de l'embryon. Ce tulse dévaginé grandit sans cesse, occupe bientót fout l'espace mélasomique; l’intestin de la larve s’infléchit pour pénótrer dans sa cavité. Finalement, cette expansion donne le corps presque entier de l'adulte; le prosome se lormant à fonrnir l'extrémité supérieure, munie de tentacules, et possédant la bonche avec l'anus (Figures 393, 400, 410 is 418, 419).

Burozonnes. - Pour bien concevoir la nature des embryons de Bryozoaires, il est utile de se représenter que chaque indivilu est récllement simple. 'Jusieurs auteurs admettent, en effet, que le Bryozoaire est une colonie composée de denx zooüdes: l'un, le cystide, représente la paroi du corps; l'autre, le polypide, correspond a l'intestin et aux organes internes. Les faits acpuis antorisent i repousser mo telle notion. Il est nécessaire, en smplus, de se rendre comple que la plupart de ces animanx offrent un développement, altéré par le fait que leurs aufs sont déposés daus des loges spéciales, les oécies, ou its évoluent; les phases sont alors modifiées prar des dégénérescences particulières. Il faut, pour les connaitre dans leur intégrité, s'arlresser aux emhryous lilıes les Endoproctes el de certains Ectoproctes. Les larves des premiers sont mues; celles des seconds, connues sous le nom de Cyphonumtes, sont recouvertes par une petite coquille livatre.

Les déviations, déja indipuées rhez tes detinotroques des l'horonidiens, sont phus grandes encore cliez les Bryozoaires. Lat couronue orale, cunrome des auteurs, large, et passiunt par la livere supérieure de la bonche,

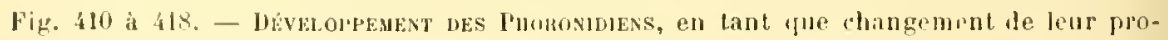
some en metasome (coupes médianes et lonyiludinales, vues par la tranche, aver pejspeclive par ombres portées). - En $4 \mathbf{1 0}$. jeune Trochophore, encore dépourve de lentacules. - En 4 1, le tule métasomique, el les premiers tentacules font lenr apparition; cetle phase corresponl aux états dessinés dans tes ligures 393 , 400, et 419. - En 412 , le Lube mitasomique grandit, tuut en s'enfoncant dans le corps. - En 4l:3, le tulse métasomique comnenee il se devaginer. - bin flí. l'évagination élan acoumplie, le luhe melasomifur, ldvenu extérieur, "onlinme seul t grandir, en entrainant l'intestin dans sa cavile, alors que les autres parties de la lave, qui constituent le prosome, demeurent 


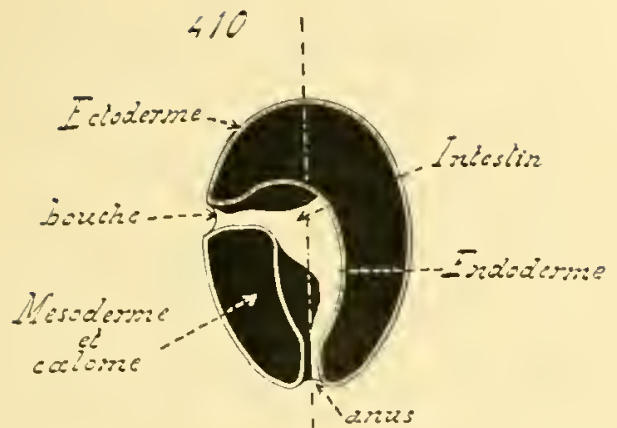

\section{Teniacule}
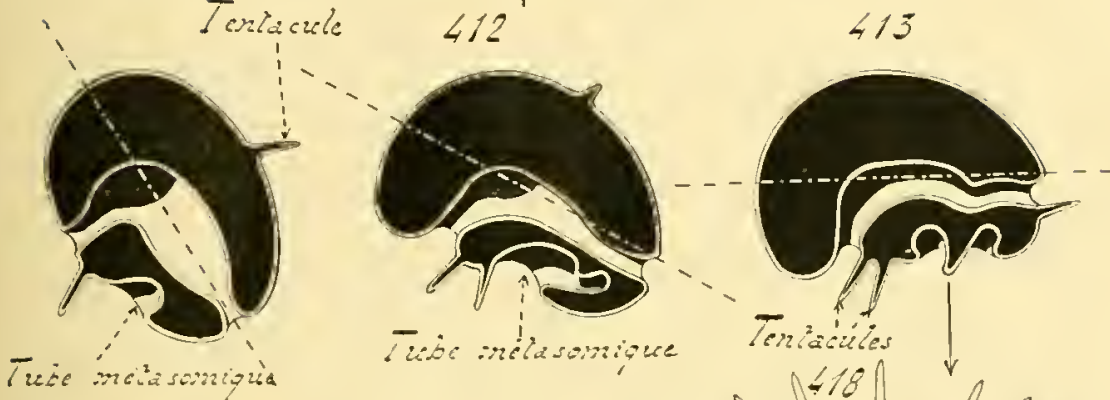

Trie mén soniona

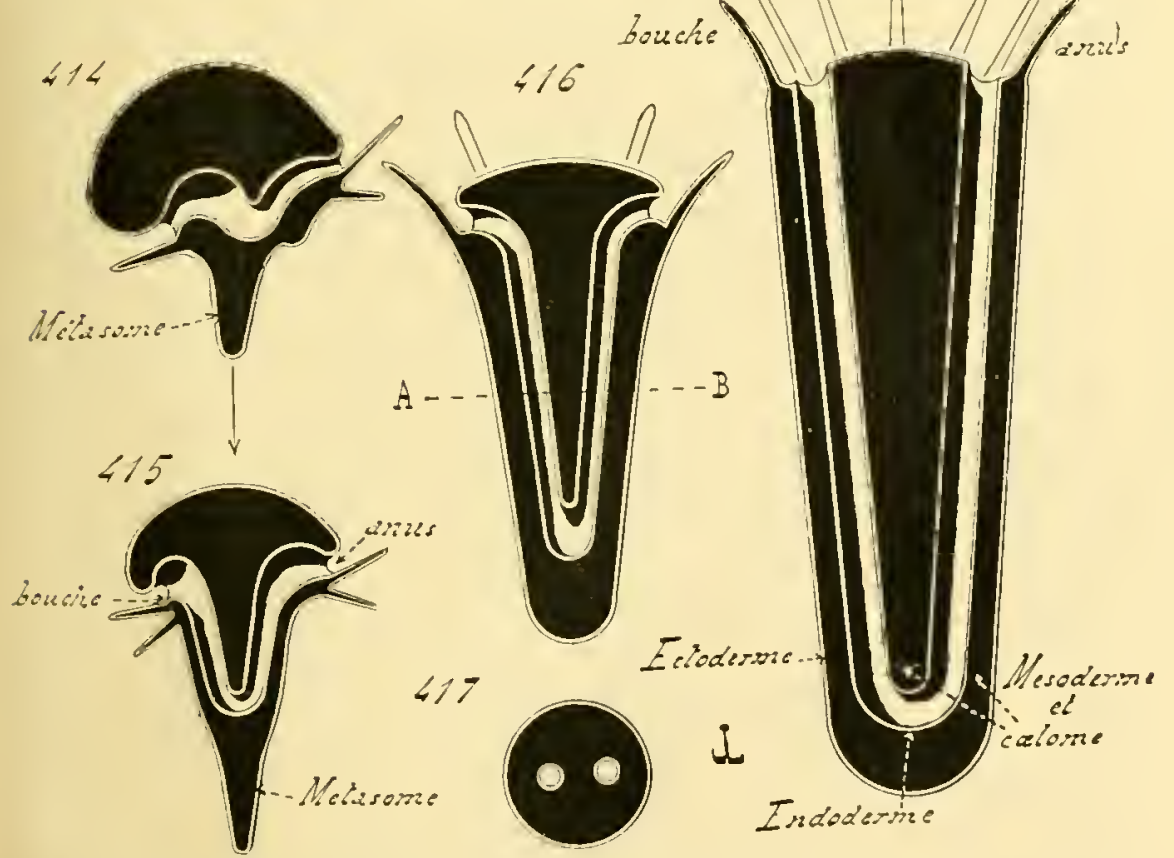

-tationnaires. - Les figures 415 , 416 , et ils, montrent les phases successives de ret accoissement inegal. - lin $\mathrm{i} 17$, est dessinee une conpe Iransversale du jeune individu represente en \& 6 , el mence suivant la ligne a $\mathrm{k}$. 
est franchement uhlique, et compe le corps en deux parlies; de son côté, l'anus, reporté plus près de la liouche que chez l'Actinolroque, dépasse l'ixtrimité inlóriemre, et se trouve situé sur la face antérienre. Partant, le métasome est fort petit. el le prosome relativement tres grand. Ce dernier possede, dans sa rógion liamétralement opposre à la comrome, me gramle playue couverte lu cils vibuatiles : la ralorle, on le disque les anteurs. Cet organn us parliculier aux Bryozoaires; on n'en trouve guère l'équivalont, amoindri, „ue chez les Brachiopodes. Enhe celte calolte el la lrourhe est sitnée mue dépression ectodermique, munje d'un plumel vibratile, homologue de la plaque céphalique des autres Trochohhores. I'usicurs emhrologistes lont consilérée a fort comme un lourgeon; on l'a lésignée par les expressions d'orgune pyriforme, et l'organe dorsal. - Les larves posserlent parfois, en surplus, deux pretites of minces expansions latérales : le manteau.

L'embryon évolue d'une maniere semblable à celledes Actinolroques. Le pelit metasome se creuse d'une invagination ectorlermique, lo tube mélnsomique, qui pénétre dans l’intérieur du corps; les auteurs la nomment, lantôt la rentonse, et tantôt l’organe allésif. Celte dépression se dévagine peu apres sa naissance, ef grandit, pendant pue l’intestin entre lans sa ravité. La couronme orale du prosome se convertit en tentacules; la plapue céphalique lonne le cerveau, el fournit le petil apjareil sensoriel observé chez l’adulte. Ce morle d'accroissement est en tout semhlable à celui les l'horonidiens; et, lo métasome grandissanl seul, l'anus (t) la louche finissent par itre contigus, supérieurs, et proches des tentacules qui proriennent de la comromne orale. Le manteau se réduit, et l'adulte nien porte aucune trace.

Lorspue le développement s'effectue dans lis oécies, tous les organes léja signalés apparaissent, sauf la copuille. Senlenent, certains d'entre rux, lintestin jar exemple, sulissent des dégénérescences momentanées, qui les font se résondre en amas cellulaires. Puis la larve, apres avoir éli mise en liberli, va se tixer sur un corps étranger, pour achever son evolution; los phenomènes léja lécrits se manifestent alors. le lube métasomique prend maissancon, el se cévagine; le mantean se montre mn instant, pun so disagréger hitivement; le métasome grandit seul, ef lorganisme suche comme dans le premier cas (Figures 394, fol, 1:-1, i-1).

Briacmopoms. - Les larves des Brachiojodes dérivent de relles des Bryozoaires, en es sens que le manteau, au lieu de s'atrophier, continue ì grandir, el persiste chez l'adulte, oì il constitue l'appareil du même nom. En ronséquence, la région pui le porte, lans le corps, est volumineuse, el me esse divecuper me grande place. Celle région fait partie lu prosome, et diminue, jau un véribable balancement organique, l'imfurtance lon métasone: co dernier se borne à donner le pédoncule tixafrol de liadnlte, aree les regions aroisinantes. 
A cause de la grandeur de la zone oceupée par le mantean. le rorps de la larve parail ètre divisé en trois segments : le segment moy"u astralui du manteau, ou pulleal; l'un des segments extromes, le segment oral, wi va se percer la bourhe, dome les lras arec lenrs tentarulus; l’autre seguent, qui mérite le nom de pédonculaire, fomrut le pédoncula. Cus frois zones ne sout pas comparaliles aux anneaux des lolymíripues. car elles ne provienneut pas de Ja division du mésoderme el du ralome en trois portions correspondantes; leur présence est le résultat des liffirrences de taille, el d'accroissement, qui s'étalılissent entre les diversos régions de l'embryon.

le manteau, tout comme celui des larves le Bryozoaides, se compose de deux loles, qui maissent sur lo segment palléal. Cos derniers grandissent, d’abord, de manière à envelopper le segment pélonculare: puis ils se relourment, et cucadrunt le segurent oral, de facon il acpuérir leur siluation délinitive. Ouant au segment pédonculaire, il so borne it s’allonger eu un pédoncule, sans s’invaginer au préalable pour se dévaginor par la suite; les vestiges de la Jépression ectodermique des l'horomidiens et des bryozoaires sout accusés, cependant, far la grenise, sur l'extrémilé de ce pédoucule, d’une cavité glandulaire sécrélant un murus adhésif. La coquille est une cuticule calcaire léposée sur les deux lohes dı manleau; elle nait assez tarl, puisque sos fremières traces se montrent, lorsque la larve possede déjà mu nombre assez graud de tentacules.

l.es larves des Brachiopodes, malırré lemrs dissemllances apparentes, sont fort roisines de celles des brvozoaires. Il suffit de supprimer, choz ces dernières, le tube mélasomique, dont l’apparition est tardive; de séparer, par un étranglement, la jartie munie de la conrome orale, du reste du corps; eufin, d’angmentre la taille le la région pourve de la calotle, pour obtenir me larve de brichioporle. La couronne orale des Bryozoaires est représentée prar la bande viluatile, souvent fort large, placéc autom du segment oril des Brachiopodes; ce tlernier grambit Iràtivement, mais sa ressemblance générale, avec la zonc correspondante des Bryozoaires, est cependant imliscutable. Dautre part, la loulle de cils vihratiles, placée au sommet Ju segment pélonculaile, est l’ápuivalrut de la calotte. Ia disposition spéciale aux larves las brachioporles, ot pui leur donne une allure caracléristique, découle du node d’acroissenrent des parties, ces dermières étant essentiellement comparables à cellestes embryoms de Bryozoaires. Au surphus, de meme que cluez la pluparl de ces lerniers, l'entéron consiste cu un sac clos.privé le bouche de daus; ces orifices apparaissent f’une manièe ladrive, el placés non loin l'un de l'autre, comme ceux les Bryozoalipes.

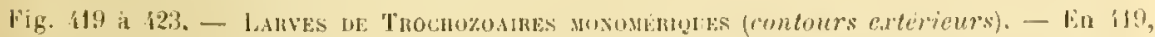

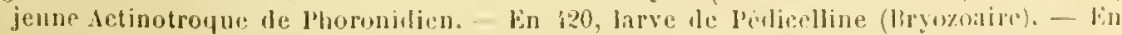

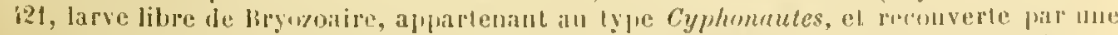

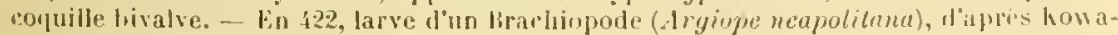

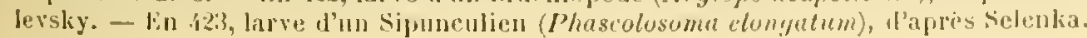




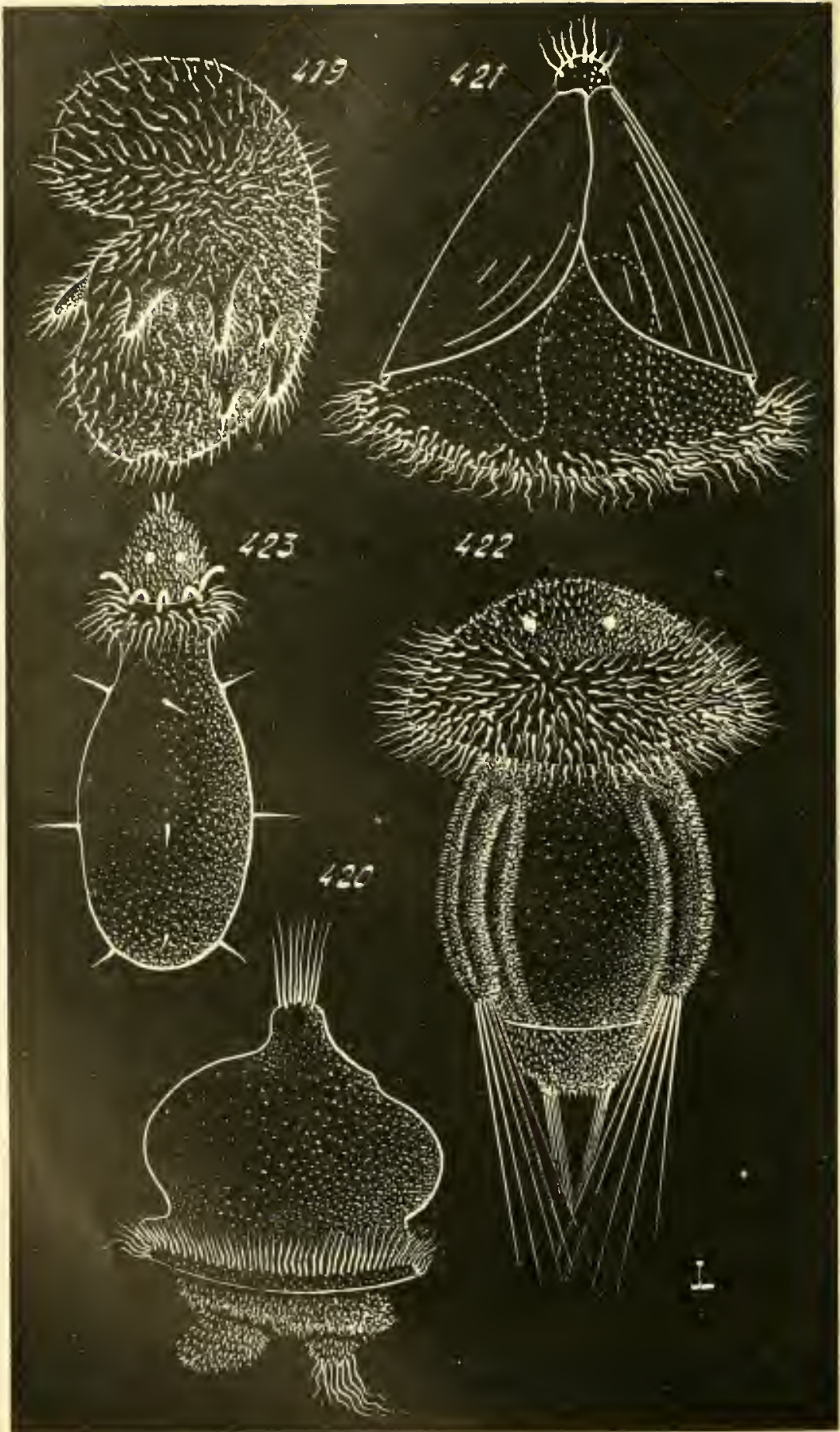




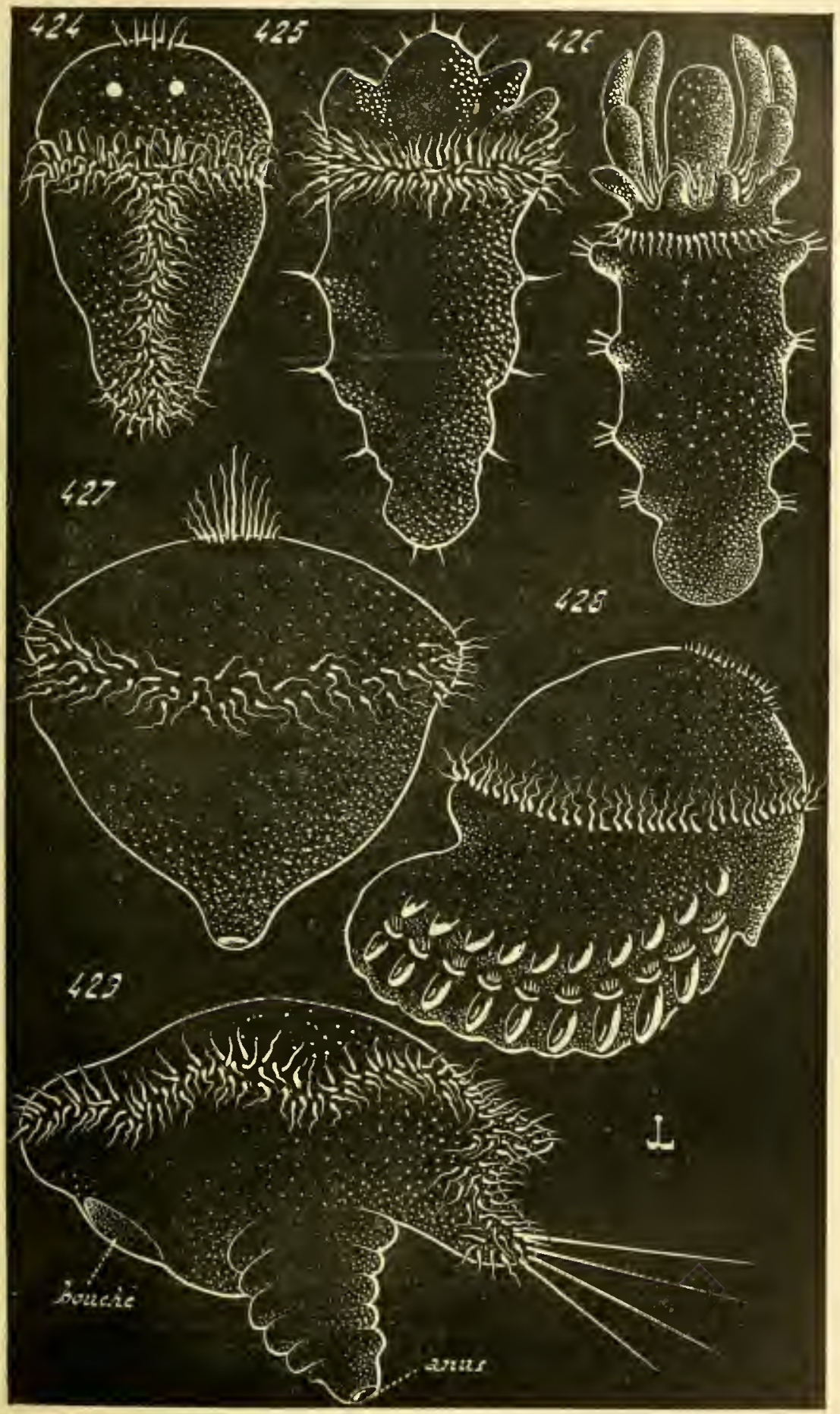


Ces dissemblances, d'atord minimes, deviennent plus accentuées, lors des phases ultérieures le l'évolution embryonnirire. le mode d'accroissement, déji indiqué chez la jenne larve des Brachiopodes, continue dans la mème direction, très différente de celle snivie par les bryozonires. Ce prosome subil une amplificalion presque égale dans loutes ses régions, et se convertit tout entier en métasome; ancun tube métasomique ne prend naissance. Le segment oral continue à s’élargir, et produit les bras avec leurs tentacules. Le segment palléal grandit transversalement, et foumit le mantean, qui sécrèle la coquille sur sa face externe. Le segment pédonculaire augmente de dimensions dans tous les sens, mais de préférence suivant son axe longiludinal, et se change en pédoncule. - Il s'ensuit que le corps du Brachiopode adulte n'est plus comparable à celui du Bryozoaire, lien que les larves soient semblables. L'organisme de ce dernier est presque donné en entier par le tube métasonique, alors que rien de pareil n'existe chez le premier. Les régions tentaculaires seules sont homologues, car toutes deux dérivent d'une mème zone embryonnaire; la couronne tentaculaire des liryozoaires, les liras tentaculifères des Rhabdopleura el des Brachiopodes, proviennent d'une mème région larvaire, conservée chez l'adulte. Par contre, les autres parties du corps ne s'équivalent point; et il est remarquable d'observer que l'économic léfinitive des Brachiopodes correspond à celle des larves de Bryozoaires, acerue, et rendue plus complexe, en conservant l'orientation premiere des organes (Figure 429).

V. Pseudannélides. - Les Trochophores des Pseudannélides, comme celles des Annélides, ont leur corps divisé en un prosome ef un métasome, qui occupent à pen pres le mème emplacement que leurs correspondants des larves de Monomériques, mais non entièrement. Le prosome comprend toute la région supérieure hu corps, qui porte la plaque céphalique à son sommet, la bouche, et la couronne orale. le métasome ne se borne pas, contrairement à ce qu'il en est chez les Monomériques, i la zone inféro-ventrale comprise entre la bouche et l'anus, mais se compose de cette zone, accrue de la partic siluće au mème nivean dans la régrion supéro-dorsale. Anssi, tonte l'extrémité inférieure de la larve apparlient-elle au métasome; l'anus se trouve exactement au sommet de cette extrémilé.

Lorsque les larres sont encore jeunes, et cette notions sapplique aux

Yiğ. 424 à 42!. - IARves D'Axxét.jes (conluurs extérieurs). - En 421, Trochoplore de Dasychone lucullana, munie, en allant de haut en bas, de la touffe ciliè qui surmonte la plaque eeplialipue, de deux ocelles, de sa couronne orale, et de la bande vibratile médullairc. - lin 425, larve plus ảgèe de la mẻme espèce. - En 426, larve encore plus àgée de la même espece, commencant a produire ses filaments branchiaux, et les soies de ses anneanx. - En 427, larve d'un I'olygordius, d'apris llatschek. - En 128, larve de Lopalonhynchus, d'après hleinenberg; la région métasomjenne, deja munie de plusieurs paires de parapodes, est placèe obliquement sous le prosome. - lin 42?, larve Milraria. l'après Melschnikoll. 
Annélides tout aussi bien qu'aux P'seudannélides, le prosomo est d'ordinaire plus rolumineux que le métasome; sa portion la plus large est siluce à la liauteur de la couronne orale. Le métasome est, J'aborl, un petit ajpendice étroit, suspendu au prosome; il s'accroît ensuite dans des proportions considérables, et donue presque tout le corps de l'adulte. Cette amplification est égale dans tout le métasome. Aussi l'anus n’ahandonne-l-il jamais sa siluation première; il occupe toujours l'extrémité inférieure de l'organisme, et éest lì qu'on le retrouve chez l'adiulte.

Parmi les types étudiés juśfu'ici sons le rapport de l'embryogénie, les Echiures sont ceux qui ofl'rentl'évolution lit plus dilatée. Le prosone de leurs embryous libres est relativenent petit, eu égard a celui de la plupart des larves d'Anuélides; leur couronne orale est fort large, de manière à encadrer les deux lèvres de la bouche. La modification la plus curieuse, parmi celles qu'ils subissent, est tout interne, ef tient a la désagrégation des segrments prorduits dans leur mésoderme.- Les autres P'sendannélides connus présentent un développenent plus abrégé. Leur frosone est plus réduit encore, car ses dimensions se rapprochent de leur ćtat final, et leur. métasome plus grand et plus allongé; aussi, leurs larves, au lien d'ìtre globuleuses et oralaires, sont-elles allongćes el rermiformes (Figures 430 et 431).

VI. Annélides. - Les Annélides subissent des évolutions larvaires, ou des évolutions futales, suivant que les ovules sont plus ou moins riches en deutolécithe. - Le second de ces procédés embryogéniques, propres aux Ilirulincies el aux Oligochotes, est peu complexe. Les aufs sont enfermés dans des cocons. C'est à l'abri de cette enveloppe que les embryons poursuiventleur développement; en conséquence, ces derniers IJe sont libres qu'an moment où ils atteignent presque l'état parfait, et ne possèdent point de cils ribratiles sur leur ectoderme, ni de couronne orale. Leurs organes prennent naissance, sur place, d'après le type massif. Les orules segmentés se conrertissent peu à peu en jeunes individus, sans que l'on remar pue, ì l'extérieur, des phénomènes autres que l'accroissenent du corps, el sa division en anueaux.

Leslarves, qui proviennent des oufs paures en réserres nutritives, subissent des changements plus considérables; ceux-ci jortent, en majeure partie, sur le prosome. Le métasome se bor'ne à s'allonger, et à se scinder en anneaux à mesure; tout au plus est-il muni parfois de soies provisoires, ou de conrommes temporaires de cils vibratiles. Le prosome oltre des modificalious plus grandes. Il est, dans l'extrème jeunesse de la larre, plus gros que le métasome; le contraire a lieu plus tard, car il donne senlement l'annean céphalique et l'anneau buccal. II ent muni de la courome orale; celle-ci, transversale et grande, sert it l'embryon comme princjpal organe locomoteur. lie rôle est sans doute la cause de dispositions fort remarduables, yu’il est possible de ramener it un agrandissement considérable et temporaire du prosome, arcom- 
pagné de genèse l'expansions latérales, ciliées, jouant le rôle d'appenlices locomoteurs.

Dans les cas habituels, le prosome est deux ou trois fois plus gros Iue le mélasome, lorsque la larve est jeune, mais point davantage. Les Polıgordius, parmi les Archiannélides, montrent déji un prosome volumineux, mais qui, i part celle augmentalion de taille, ne présente ancun autre phénomène particulier, différant de la règle normale. Les Lopadorhynchus sont plus remarquables. Leur prosome est phus grand encore 'pue celui des larves de Polygordius; il porte au-dessous de lui, incliné un peu ol)liquement, le mélasome, qui érolue, s’accroîl, el se diviso en anneaux. P'uis, lorsque de dernier est déjà lien développri, el posside la plus grande part des caracteres de l'adulle, le prosome, qui servail jusque li l'organe locomolenr, se sépare lurusquement du métasome, sauf la région munic de la bouche, ef l'organisme définilif se trouve constitué. Le prosome, délaché, se désorganise el meurl. - Les faits sont ici tellement distincts, le prosome el le métasome paraissent si bien indépendants, que le second semble ètre un individu à parl, qui aurail élé engeudré par le premier, el serait supporté par lui jusqu'a leur séparation. Kleinenberg a mème élé conduil à considérer ces phénomènes comme répondaut à une alternance de géuéralions. Le prosome est, d'après cel autenr, un animal parliculier, comparahle à un Cudentéré, qui produirait le mélasome, l'Annélide, par une reprouluction asexuclle. Il suffit de comparer les phénomènes les uns aux autres, en suivant la série exposée plus haut, pour rapporter celte évolution à un agrandissement exagéré, suivi de la chule, d’un prosome larvaile.

Eufin, le degró le plus devé qualteigneul ces altéralions, est olTert par la larve nommée I/traria. Le prosome de cetle derniere est muni d'expansions latérales, semblables it des lobes couverts le cils viluatiles, qui servenl d'organes locomoleurs, el sont destinés ì s'atrophier.

Le mélasome est souvent pourva de longues soies temporaires, pui tombent par la suite pour códer la place aux soies permanentes, el de cils vilualiles; ces derniers disparaissent également, pendanl que le corps prerfectionne son organisme. Une bande cilice, la luande medulluire, parait ne jamais mantuer; elle se thige de la houche it l'anus, el suil la ligne médiane ventrale. Elle est le pendant de la touffe que supporte la plaque céphalique, c’est-à-dire l'ébauche du cerveau; elle est, en elfel, placée contre l'ébauche de la moelle nerveuse ventrale. Quant anx antres cils, ils sont diunlaut plus nombreux que la larve est plus jenne, et tomhent it mesure qu’elle arance en ige; souvent, au délout de l’évolulion, ils reconvent lectoderme entier. Parfois, cerlains d'entre enx, rangés syméliquement en coreles transversanx, placés à divers niveaux anlour du conpese se dislinguent des antres par leur longuem phis grande. On s'est basé sur leur absence, ou leur présence, el dans ce dernier cas, 
sur le nombre et la position des cercles qu'ils composent, pour dénommer les types des larves qui les posseilent. Ces divers caracteres ont une valenr bien secondaire; ils ne touchent en rien aux phenomenes essenticls du léveloppement, et nont qu'une durée transitoire (Figures fút i. 499).

Jans certains cas, chez les Lumbriconéreis par exemple, la couronne orale n'est guère discernalıle, car ses éléments ne sont pas plus allongŕs, ni plus touffus, que les cils viluratiles destinés í recouvir, en totalité ou en partie, le reste du corjs; cette larve est dite atroque. Ailleurs, la conromine orale est très nette, à cause de la longueur de ses cils; cette

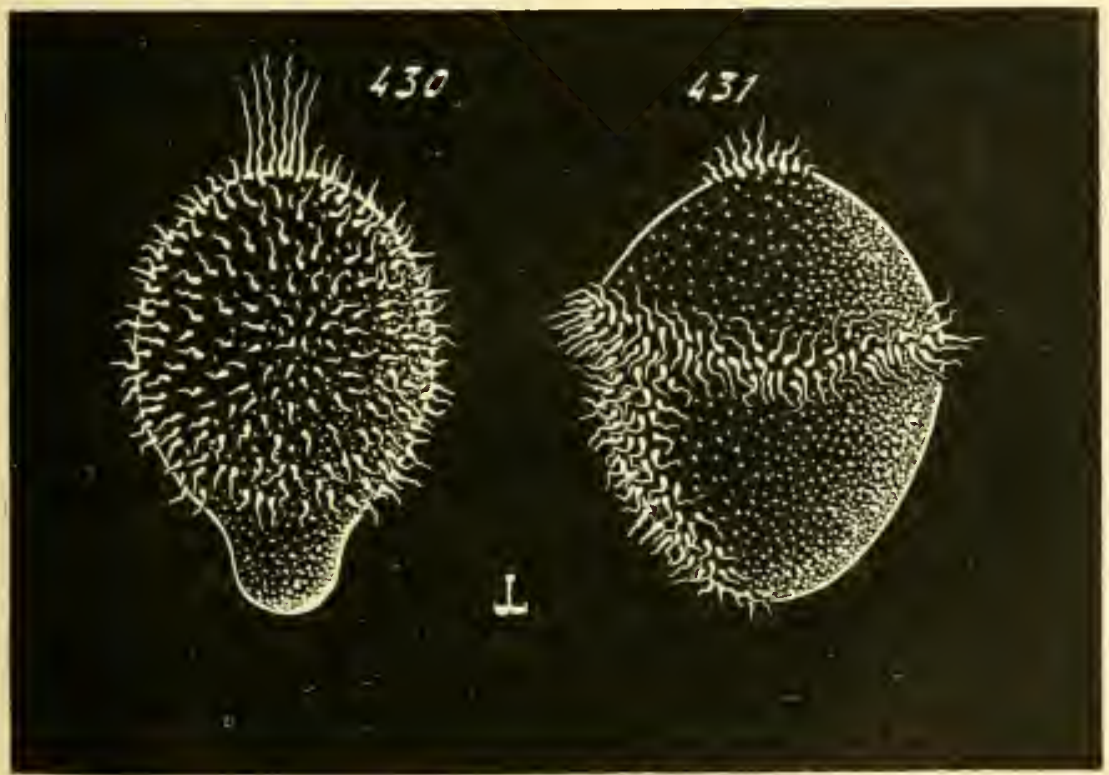

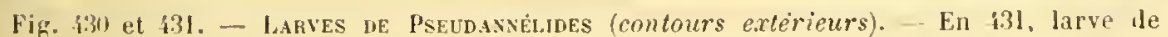
Slernaspis scutala, l'après Rietsel. - En i31, larse l'Frhimrus, d'après llatschek.

structure est la plus fréquente, mais pròte a dịerses variations. Lorsinu ce cerele vibratile est situé vers le milieu lu corps, el fresifue ¿t chale distance des deux extrémités du petit itre, la larve est nommée mésolronue; il en est ainsi chez plusienrs Chéloplieres. Si les cils te la partio dorsale de cette couronne sont plus lones que les antres, la larve

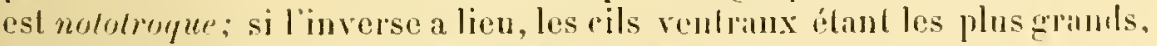
la linve est gustrolroque (Spmo, Verine, par exemplo). Eutin, lans le cas nii des comronmes supplementaires sajontent i la bamle orale, de maniere it cereler lo corps par un cerlain nombre d'anmeans viluatilus el

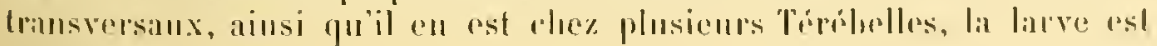
polylrompe. 


\section{\$. - Origine des organes.}

1. Organes d'origine ectodermique. - Le feuillet lilastodermiqne exlérieur, l'ectoderme, lomne naissance aux appareils suivants : les centres nervenx cl, au moins en partie, les organes sensoricls; puis, les appenulices tels que les soies; enfin l'ectoderme définitif. Ce dernier, nommé lien î tort hypoderme par les auteurs, car il répond en tout il un ectoderme réel, n'est autre close que la persistance de l'ectorlerme larvaire, après que celui-ci a subvenu ì loutes les genèses précédemment indiquées. Il conserve, sans la perdre, sa disposition épithéliale, et noffre guère, dans sa structure, que des rariations peu importantes.

Centres nerveux et organes des sens. - A. Les centres nervenx des Trochozoaires sont produits, comme ceux des autres animaux, par l'ertoderme. Leurs élauches apparaissent hàtivement, dès les premicres phases larvaires, et sont au nombre de deux, indépendantes lout d'aboril l'une de l'antre; elles ne se mettent en rolations direetes, quapres aroir acquis une structure déjà complexe. l'ume l'elles appartienl au prosome, et se montre la première : c'est la pluque céphalique. L'autre est la propriété du métasome, et nait pen après la précédente : e'est la plaqne médullaire. Celle-ci ne se montre pas toujours; elle apparait lorsque le métasome, qui la porte, aequiert une certaine taille, et manque, par conséf]uent, aux Rotateurs el aux Bryozoaires. Elle fait également défaut nux Mollusques, non parce qu'elle n'existe point, mais paree qu'elle est représentée par plusieurs éliauches séparées.

La plaque céphalique est située dans le prosome, an-dessus de la louche. Ses éléments se multiplient avec aclivité, et se convertissent en cellules nerveuses; l'ensemble se transforme en un cerveau, qui se sépare de l'ectoderme, et levient indépendant. Cette ébanche rst impaire tont l'alıord. Afin de salisfaire aux exigenees de la srmétrie lilatérale du corps, ses côtés s’aceroissent plus que sa région mäliane; aussi prendelle un aspect bifide, qui s'acrentue sans cesse. En détinitive, le cervenu parait composéde deux ganglions plus on moins distinets. Contrairement a l'avis presque général, il n’est pas permis de conclure de cette organisation à une dualité prenière, les deux ganglions céréhraux commencant par être indépendants, puis se joignant sur la ligne médiane. L'unité de I'él,auche est seule prinitive; la dualití est secondaire. - Dans cerlains cas, chez les Mollısques par exemple, lorsque les drux ganglions cérélraux sont enlièrement isolés l'un de l'autre, la loi l'alréviation, s'exerçant sur leur genese, tend i les faire naitre d'une facon séparée, et le fait en réalité. Seulement, les Mollnsques inférienrs, comme les Dentales, montrent encore la disposition primordiale, car leurs ganglions cérébraux proviennent dr la prolifération active des lords d'mne senle et mème plarue céphalique. 
La plaque médullaire est située, lorsqu'elle existe, sur la fare antéroventrale du métasome, et s’étend le la bouche à l’anns; sa position est souvent dénotée à l'extérieur par une hande viluratile, la bande médullaire déjà signalée. Ses éléments se uultiplient de mème que cenx de la plaque céphalique, et donnent la moelle ventrale de l'adulte. Celle-ci, de par lindépendance parfaite de son ébauche, est d'abord séparće du cervean; puis, son extrémité antérienre émet denx prolongenents, qui vout à la rencontre d'expansions semblables émanées les ganglions céréhranx, et se joignent à elles. Tout en agissant ainsi, ils entourent l'extrémilé antérieure du tube digestif; l'ensemble le ces commissures compose ce que l'on a coutume l'appeler l'anneau asophagien, ou le collier asophaqien.

La plaque médullaire est l'origine ectodermique, et conserve assez souvent, avec l'ectoderme définitif, les mènes rapports de continuité qu'avec l'ectoderme larvaire; aussi n'est-il pas rare de trouver, chez les Annélides surtout, la moelle nerveuse soudée à l'ectorlerme sur tout ou partie de sa longueur. En outre, les exigences de la symétrie bilatérale agissent sur clle comme sur le cervean. - La moelle ventrale est parfois indivise, chez diverses Annélides et che\% phusieurs Tentaculifères par exemple; mais elle est, d'orlinaire, scindée en deux cordons longitudinaux et parallèles. Les considérations relatives à l'unité primitive sont applicables ici, lout comme aux ganglions cérébraux. Tantòt, ces cordons soul somués l’un à l'autre par toute leur ćtendue, et tantót ils ne le sont que de place en place, an moyen de commissures transversales; ces dilférences d’aspect répondent ì les ılegrés divers lans la séparation. Enfin, che\% les Anuélides, dont le corps est divisé en amueanx, les celhules nerveuses le la moelle, au lieu d'ètre réparties également, ou presque également, s'accumulent de préférence dans les régions segmenlaires, et manquent daus les zones ou sont placées les cloisons; en conséquence la moelle, quello soit simple on lji-partite, porte de place en place des ganglions régulièrement espacés. - Les notions précéduntes montrent comment cet aspect, relativenent complexe, découle le la disposition oflerte par la plaque médullaire primitive.

La playue médullaire manque aux cmbryons les Mollusques; cette alsence est secondaire, non primitive. Les appareils nerveux qui, che\% ces animanx, sont homologues de la moelle des autres Trochozoaires, se groupent en deux ou plusieurs paires de ganglions (pedieux, visceraux, et leurs dérivés), dont les composantes sont, pour chacune de ces dernières, séparées et placées symétriquement le part et lautre de la ligno médiance. Labréviation déji montrée par le cerveau, et qui fait naitre chaque ganglion d’une manière indépendante de son symétrique do la mense piirr, excre ici son action. En se basant sur les faits présentis par la planpe céplatique, il est permis de consilérer l'existence de telles ébanches distinctes, comme répondant a mo morcellomont de la plaqur" módullaire. 
b. - Nos connaissanes sur lo diveloppement des organes sensoriels des Truehozoaires sont encore birm imprafailes; plles se loruent a quelpues notions relatives anx yeux de diverses Ambelides, et surtont à cenx des Mollusques. - II convient d'ajouler rependant, que ces organes, étant jour la plupart d’un grande simplicité structurale, ne nécessilent pas de bien gramles modilicalions pour leur genise; colle-ci peul se concevoir l'apurs l’état détinilif. Il d'st aisé dr comprendre, par a pren près, comment juennent maissane des apprareils tactiles formés par ales groupes le cellules i criblocils; des appareils d'olfaction qui sont de simples Jépressions ectodromiques, el dres olgganes andilifs, qui répondent à des déprrssions semblalules, mais fermées et converties en résicules closes. - Ces systimes sonl prodnits par l'ectorlerme seul; quelques lissus mésodermiques s'ajoutent pourtanl it lui dans le ras d'organes complexes, comme le sont les yeux de certains Mollusquos supérieurs, ceux des Céphalopoles dihranchiaux par exemple.

las yeux dos llullusques sont primilivemenl des dopressions ectodurmiques; parfois la dépression est remplacóc par un épaississement, mais cetle sulistitution d'une érolution massive au lye crenx est ici, comme partout, le résultat d'une alıúviation génétique. La zone eclodermique, placée au fond de la cavité, se garnil de granulations pigmentaires, se met en rapport avec des fibr's nervenses qui viennent du nerf optique, el se convertit en rútine. D’orlinaire, l'oritice de la dépression se ferme, par le rapprochement ef la soudure de ses bords, de manicre i changer l’élanche orulaire en une vésicule close. Ia cavile de celle derniere, remplie par un liquide transparent, véritable humen" vitrée, contient en surplus, un cristallin. Colui-ri consiste en un ahondant dépôt culinulare, que sricretr l'ectorlerme de la vésicule; ce lépril prend une forme régulière et globulense. - Les phénomènes en restent là daus la plupart des ras, sauf clıcz les Céphalopordes dilmanchianx. La vésicule oculaire des emJryons de ces ètres s'enfonce dans les lissus sous-cetorlermiques du mésolerme. Ceux-ci lui foumissent des enveloppes, qui lorment mue choroïde, une sclérotique, et mime, en soulevant l'actoderne, donnent des plis superficicls dont les uns, internes, constituent un iris, el les autres, rxternes, me cornée transparente. Le rristallin est ulivisé en denx parties. La pustérieure est renferméc dans la vésicule ormarire, et plongre dans l’humeur vitrée; alle est l’homologue du cristalliu des autres Mollusques. La partic antérieure, plus petitr, est un apprudice

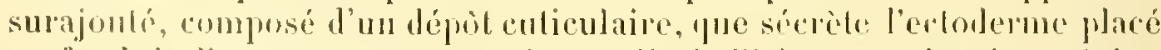

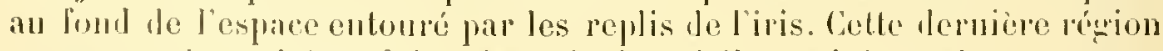
repose sur la cavití oculaire; la cuticule guelle probluit se place en avant du cristallin postérienr.

Soies. - Les soies somt dus latomols de formo variahle, ot de mature

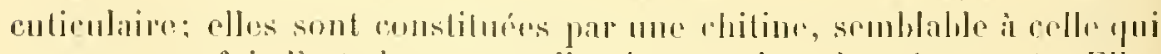

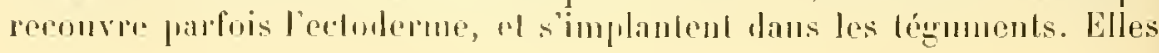


manquent à beaucoup de Trochozoaires; on ne les trouve guère que chez. les Jolymériques, sanf les drohianuéliles et les llipulinos, el chez divors Honomeriques appartenant à la classe dos Brachioporlı. En somme, ros organes sont presque spéciaux aux Trochozoaires polymériques.

On a longtemps cherché pour comnaitre l’origine exacte et le développement des soies. On a peusé, pendant longtemps, qu'olles provenaicut du mésoderme; les observateurs récents s'arcorilent a reconnailre que l'ectoderme seul est intéressé. l'artout oì une soie va prendre naissance, la surface cotodermique se creuse l’ume petite dépression tubuleuse; les

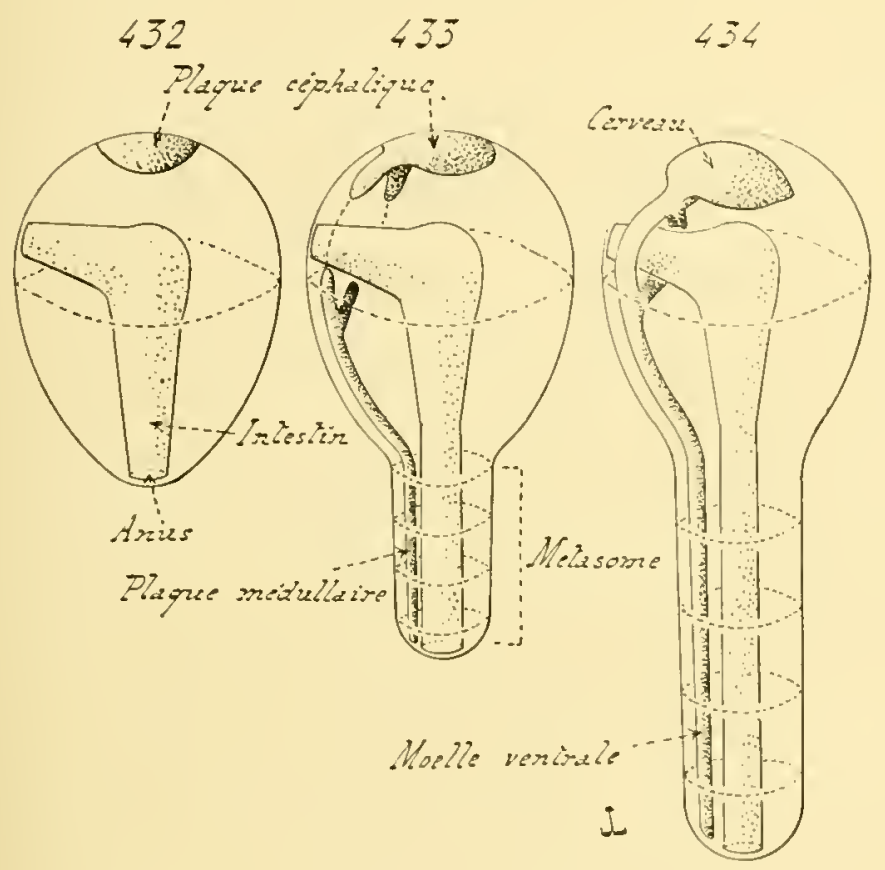

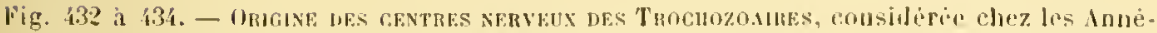
lides, prises pour exenpla: (diayrammes en persyective culaticre). - En i32, Trowhophore reduite au prosome, et ne portant juc l'blanche du cerveiu, sous la forme de filaque

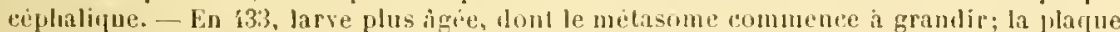
medullire, e'esta-dire l'ebauche de la moelf, prend naissanee dans ee melasome, et envoit deux expansions a la rencontre de prohngements similaires, emis par l'banche

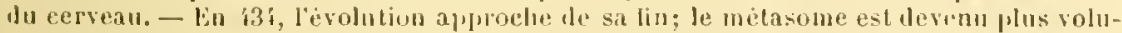
mineux, at les fuatre expansions, unis fu leux commissures qui entourent lit rigion initiale de l'intestin, composent mo collor msoplagien, joirnanl te tervean a la molle ventralr.

cellules qui, par cette cireoustance, se trouvent ammées ì couslituer

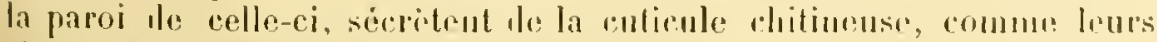

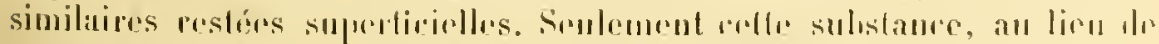

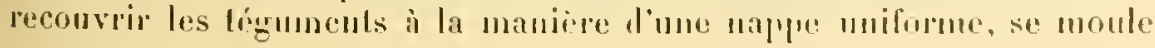


dans la cavité où elle est rejetée, el prend, prar suite, l'aspect d'un bâtonnel rylindrique. Ces éléments, quil est permis de nommer des chitolilastes i canse de lenr róle, contimunt ì exsuder de la matière chilinense, et surtout reux placés an fond de la dépression, la nouvellr matière soulère celle qui axistait déjì, el la repousse en dehors des téguments. Ce phénomène ne cessede se manilester, et la massp culiculaire progresse toujours, en faisant is l'extérieur une saillie de plus en plus forle. Cette masse n'est aulre yu une jeune soie, dont l'allongement est causé par l'apport constaul de nouvelle sulistance at sa base profonde.

Cuticules. - Lieclorlerme de la plupart des Trochozoaires est recouvert par un revêtement culiculaire, d'importance variahle suivant les groupes. Dans un assez grand nombre de cas, celle culicule consiste en une mince couche chitineuse appliquép sur les téguments. Dilleurs elle est plus épraisse, s'encronte de sels calcaires, et conslitue une coquille, destinée a envelopprer tout on pratie de l'animal. Mais, quelle que soit sa siluation léfnilive, la cuticule est toujours un exsudat produit par l'ectoderme, el que cel ecloderme dépose ì sa périphérie.

D'ordinaire, celexsudal s'accole aux téguments, el leur est intimement lié. Ailleurs, il se sépare de l’assise qui lui donne naissanee, et laisse, entre lui et le corps, m espace dans lequel l'individu pent se monvoir. Ce dernier cas est celui des loges des Bryozoaires, des tubes des Plıoronidiens el des Annálides sédentaires, des coquilles univalves d'un certain nombre de Gastiroporles. La substance culiculaire n'est point, alors, engendríe par l'ectoderme entier, mais est produile par une portion seulement de cet ectoderme, el d'une manière incessante, atin que son ensemble grantisse en mime temps que le corps. - Le fait est ivident pour les rorguilles des Mollusques, les loges des liryozoaires, el les tubes des Phoronidiens. Il a été fortement discuté pour ce qui touche aux tubes les Anuélides sédentaires. La pluparl des auteurs ont admis que ces derniers sont fonrnis frar des sécrétions durcies, provenanl d'organes endodermiques ou mésodermiques.II est permis de conclure, d’après les recherches récentes faites par Soulier, que la matière de ces tulies est donuée par des cellules l'origine ectodermípe; ces dernières, afin de subrenir à cetle érenèse, acquierent une taille considérable, et s'allongent beaucoup, en pénétrant dans les tissus sous-jacents ì l'ectorlerme.

Parfois, les régions de l'ectoderme, qui n'appartiennent point anx tinguments, el constituent des annexes à l'intestin, en s'orljoignant ì lui pour former le pharynx el lr rectum, produisent de la substance cuticulaire. Celte drrnière s’assemble, d'ordinaire, en pièces délinies, qui jouent le rible d'organes masticateurs. Celte origine est celle des michoires les Innélides, et de l'armature buerale des lootatems et les Mollusupues.

1I. Organes d'origine endodermique. - licndorlerme se lorne i) donner l'entothélium de l'iutestin, el celni des glandes annexes du 
tulve digestif, dans le cas oì il en existe. Ce fait ust assez rare; en elfed, chez les Trochozoaires, les Innólides et les llollusipues sont presfue les seuls à l'offrir.

III. Organes d'origine mésodermique. - Le feuillet moyen joue d'ordimaire, dans le corps de la pluparl des Trochozoaires, un mile les plus importants ; il est peu développri cliez les liryozoaires, et surtout chez les Rotiferes, mais occupe une place considérable dans l'organisme des autres représentants de l'emliranchement, oì il se pròte ì des modificatious parfois très complexes.ll fommit la musenlature, qui se dispose de manières diverses suirant la sorte d'rrolution subie par le mísolerme, le corlome arec les appareils irrigateurs, et les organes sexuels.

Disposition générale du mésodeme. - A. l.es Monomériques sont, en cela, diflérents des Polymériques, et le fait se concoit aisément. Ie leuillet moyen des premiers est simple, alors que celui des seconls se partage en un certain nombre de segments, placés à la file suivant une série longitudinale; de plus, dans ces deux groures, lantôt le mésoderme sorganise l’après le type épithélial, et tautòt il se convertit en un mésenchyme. Daus ce dernier cas, les tissus mésodermiques sont creusés de nomlıreuses cavilés, et la musculature prend unc disposition assez irréguliere; tandis que, dans le premier, les espaces corlomiques sont grands, et le mésoderme se divise, avec régularilé, en une somatopleure et une splanchnoplente distinctes.

Le mésoderme des lotateurs est repuésentí seulement par quelques collules conjonctives, on conjonctivo-musculaires, placées entre l'ectoderme et l'endoderme. - Celui des Mollusques, franchement édifié suivant lo mode mésenchymateux, est de leaucoup plus complexe et plus volumineux. Il faut le concevoir comme percé le cavités fort nomlureuses, groupées en un appareil circulatoire, et léroupé comme en traves, qui s'entrecroisent dans tous les sens pour limiter ces espaces. Cestravées sont trés ipaisses dans les régions compactes, et plus minces lans les autres; elles sont formées d'une gangue connective, renfermant les libres musculaires, la quantití de cos lemioms étant lans mue relation prócise avec le pouroir coutractile de la région cousilérée. Les filres sont lisses, sauf quelques rares exceptions, et d'origine conjonctive. - Il suil de là qu’il esl impossible de distinguer pntre une somatopleure el me splanchnoplenre; le fenilet moyen entier est partont semblable à Iui-mème; ses senles modifications portent sur l'épaissenr des travées, sur la graneleur des cavités, et sur la richesse en filues musculaires. - Le mésodrerme de la jeme larve est cependant livisí, aree assez de nettetí, rn trois parties. Ses éliments se groupent, pun la plupart, en

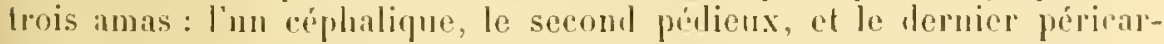
dique. Co dronier senl reste séparé des antres, et donne, comme sun nom

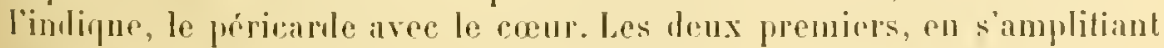
ct sorganisant, sunissent, et ne fout plus yủu tout cohrirent. 
l'armi les Tentaculifères, les liryozoaires montrent, au sujel de leur mésonleme, me simplicito presque rigale à cello dos liolatours. Ce fenillet est comslibé par nu lissu conjonclivo-musculaire pen abondant; les cellules contractiles sonl surlont nomlrenses dans la région inférieure de l'organisme, oir elles formenl le pelit muscle nommé funicule. - Le mésorlerme des Brachiopodes, heaucoup plus complexe, rappelle celui des llolhusques en ce quil esl mósenchymatenx; mais les vidrs lacmaines sont relativement moins nombreux, phus grands, ot ressemblent ì ceux des Mollışues infórienrs. La désagrégalion misenelymateuse est lardive, contrairement ì ce quil en est ehez les Mollusques, où elle se manifeste des la premièr apparition dos initiales du mésoderme. Les ibanches du feuillel moven des Brachiopodes sont épilhéliales, of olles se modilient pour passer à l’élal mésenelymalemx. - Enfu, chez les aulres Tentaculifures, lrs sipmnenliens et les horoniliens, le mésoderme dememr bpillólial, use divise rn splanchnopleme et somaloplemr. Celle-ci prent] senle de l'juportance; elle s'adjoint à l'ectoderme pour composer la paroi somalipue, el fome une musculature assez épaisse. La splanchnopleure s'aceole à l'endoderme; elle forme, antour de hi, une enreloppe qui consiste en unc assise épithéliale simple.

B. - Le mísoderme des Trochozoaires polymériques est caractérisé par sa mature segmentaire. Chaque segment est rreusé l'une carilé propre; il se trouve séjaré, par des cloisons, de celui qui le précéde el de celui yui lr suil. Ces cloisons sont transrersales d'ordinaire, el percées somvont de polits orifees, qui permettent anx viles segmentairs de communipuer ensemble. - Les éhauches du feuillet moyen sont représentées par les deux bandoleltes mésonlemiques, placóes laus la région métasomique, non luin de l'anus, de part el d'antre du lube ligrestif. Dans les leveloppements dilatis, ces lerniires grandissent, et s'allongent avec lo métasome yui les contient. Ce faisant, charume d’elles se

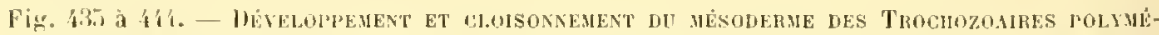
lumbes (les numeros impairs desiguent des roupes médianes et longiludinales. vars par lu tranke, en perspectine inulive; les numios pairs disignent dos coupes thansversales entires, menies suvaut les lignes traces sur les coupes longindinales correspon-

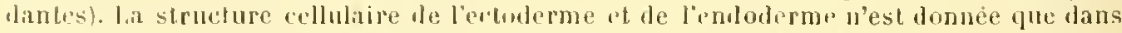

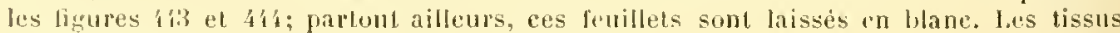
mésorlermiques sunt représentés pitr un finintillé.

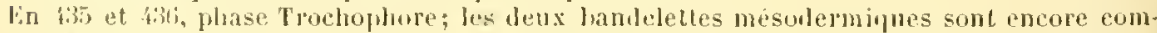

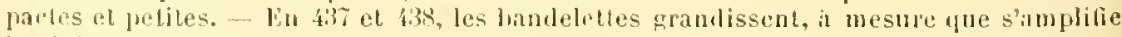
la région inelasomienute qui les contient, se reusent d'une eavite ponr rhacune d'elles, at commencent à revilir un aspert éphlholial. - Ln i3! et ín, les bandelelles s'acerois-

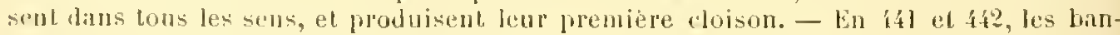
drolles amplissent lo rolph presque entier, entourent l'intestin, el attgmelunt le

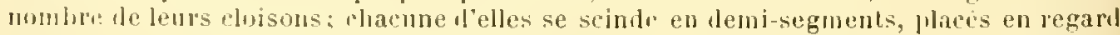

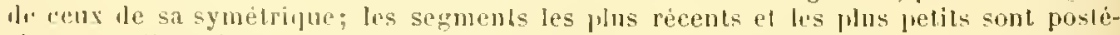

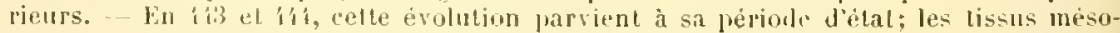

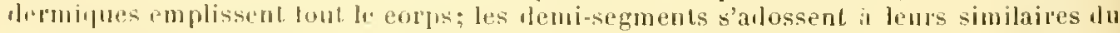

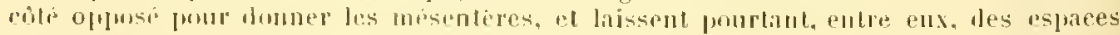
vild:s, issus ofu blistoende initial, qui constituromt le systeme sanguin. 
TRUCHOZO WIRL:
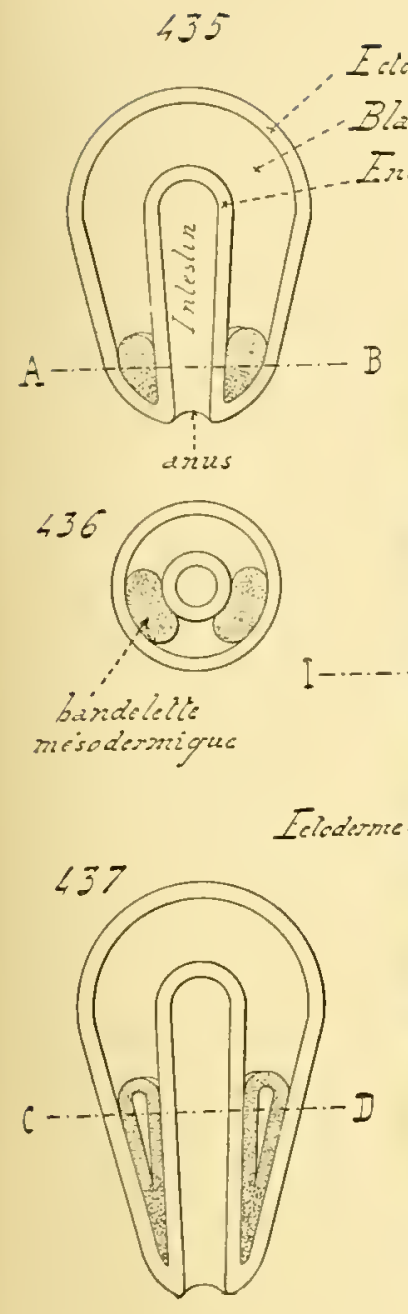

138

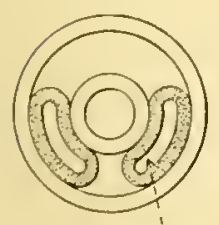

Sckigocatome

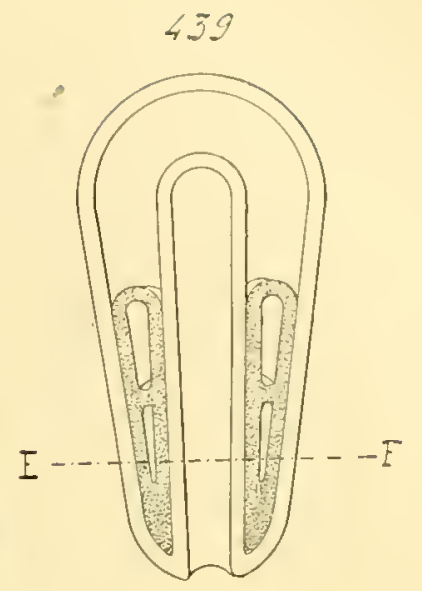

440

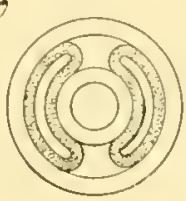

- Coisors

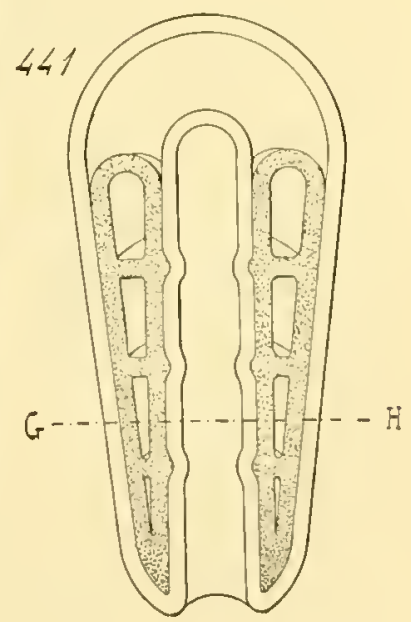

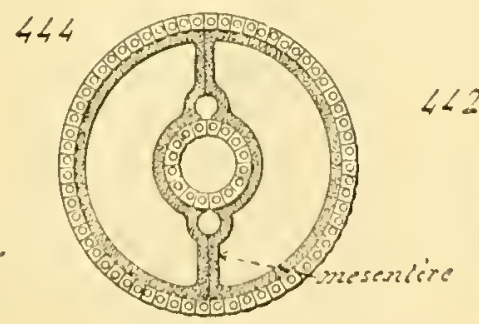

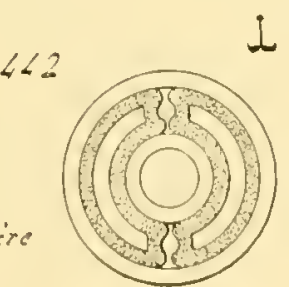

litip. is a lis 
"Mruse de cavités situées i la file, les mones deriere les autres. Ces respaces

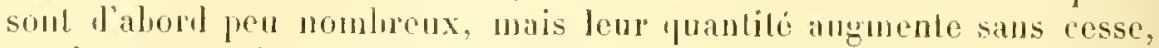

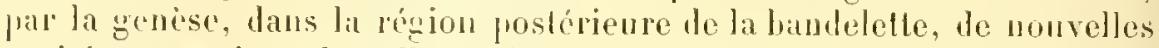
ravilés en arrière de celles yni existent léjà. - Cetle région est plus aclive que les autres à prolifórre, ol i multiplier ses éléments; aussi la bandelette s'accroit-t-nlle, surtout par la production constante de nouvelles cellules dans sa parlic proche de l'anus. Les portions surajoutées cramdissent it lour tour, el poussent tes premicres en avint; elles se frerent do ravités, jrendant que dautres naissenl cu arrière, el agisscnt vis-à-ris d'olles commc elles-nuênes sélaient comportées. - Ce phénomine de gunesu des lissus mésodermiques, dans la région pustérieme el peri-ande: du corps, s'exerer jendant lout l'accroissenonl du métasome, el dure par eouséquent jusquà l'ótat adulle.

Les covités de chajue handelelte sont indépendantes dies leur apparition, et síparés los mnes les aulres par des handes cellubires; elles sont lonc circonscriles par ces bandes en avant el en arrièe, et le sont sur les cỏés par les élémunds mésodermiquesqui s’acolent à l’retoderme ef ì l'rutorlerme. Ces lemicrs domnent la somatopleure el la splanchnopleure; alors que les bandes, restant a Jur place primilive, lomrnissent les cloisons. Cellus-ci m. proviennent done en rien du feuillet somatinue, ni du feuillet splanchuique; alles dérivent, au mème titre queux, de l'ébauche mesoleminue tolale; ces trois parties du feuillet moyen se délimitent ensumble, jar le fail du creusement Jes carités dislinctes. l'nis, ces dernicres, a mesure qu'elles soml repoussées en avant, s'amplilient dans lonles les lireclions. - Chacune d'elles grandit, pour s'étendre dans toule la largenr Ju corps, de puis la ligne mediane ventrale jusqu’à la ligne méliane dorsale, loujours entourée par les couches mésodermiques au sein desquelles elle s'est creusce; elle conslilue, avec sa paroi. un demi-segmenl qui embrasse la moitié dr l’infustin siluée à sa hantenr. Finalemenl, commor les pluénomines so ressemblent dans les leux bandulettes, Jes deni-segmenls placés au mème niveau, dont l'un apparlient à la landelette de droile, et l'aulpe a la bandelefle de gauclue, s'udossent sur les ligues médio-dorsale el médio-ventrale; ils domuent ainsi un segment enlier, qui environne loule la parlie correspondante de l'intestin. - Les zones adossées se résorluent prafois, prour faire communiquel l'une avee l'autre les cavilés des deux demi-segments placés en regard; d'ordinaire, elles demenrent intactes, persistent comme des liamdes médianes reliant la somatopleme a la splanchuoplenre, ol missent, i la ficgon de mesenteres, l’utestin a la paroi du corps.

A lasuite d'un lel déreloppenent, le colome des Trochozoaires l'olyméripues se lrouve lécoujé, fra des cloisons au nombre variable, el souvent consilérable, en ravilis segmentaires, sifuces les nues derriere les antres, et monlurassant l'inlestin. Celle disposilion persiste duranl la vic entiere cluez les Annélides; elle s'atténue, el dis jarail eluz les l'sendannélieles, par la résorplion des cloisons durant les phases larraires. 
Linfin, beaucoup d'llirudinées subissent des changements complraes, par la production de travies conjonclivo-musculajes, qui s'ajoulent anx cloisons primilives, découpent dans tous les sens les cavitís segmenlajres, el s'organjsent en mn véribale mésenchyme compact, d'anlant plus accentué yu'on passe des liranchiobdellides aux Gnatholdelles.

les cloisons me compliquent pas beancouj lent struchure, ol se conprosent de deux assises épitléliales, pue séprare une mince hande connective. La splanchnopleure se réluit égalenent ì une seule cunchn d'épilhélium, ruj s’applique sur l'endoderme, et se modifie de liverses manjères, lout en conservant sa simplicjte. - La somaloplense senle s'épaissil, et se convertit en tissus musculaires. La majeure jrarlie de ces derniers forme des bandes, soit longiludinales, soit transvejsales, qui gardent la disposilion régulière des rangées épilhéliales dont elles dérivent. Les autres portions subissent une dissociation mésenchymatense: plusieurs éléments se portent autour des hases des soies, el s'altachent it elles jour servir i les mouvoir; plusieur's autses, surtont chez les Hirudinées, sétendent iu traver's les cavilés des segments. Mais, quelle que soit la nature de l'évolulion subje, toules ees fibres museulajres ajprartienneut au groupe des éléments conjonclivo-musculaires, donl le sarcoplasme se dépose autour du proloplasme inilial, en l'enveloppant d'une manière complète. - Certains auteur's admellent que l'assisc exlérieure de la musculature, sous-jacente a l'ecloderme, provient de ce fenillet luimème, dout les cellules seraient composées el épilhcilio-musculaires, au lieu d'ètre strictement épithéliales; la chose ne paraîl pas complètement démontrée.

Dans le cas où le développement est abrégé, el ce fait exisle de préfirence chez les Oligachetes el les Ilirudinées, les conches mésodermiques ne présentent point de disposition épilléliale bien régulière, el sulissent en partie une désagrégation mésenchymatense. Les éments se rassemblent ensuite, à mesure "fuils acquièrent leur état défmitif. Comme les bandelettes sont fort grosses dès leur apparilion, un grand nombre de carités segmentajes naissent en mème lemps; mais leur chitlre est d'oulinaire plus pelit que relui de l'adulte. Aussi de nouveaux esprices se crensent-jls, les uns derière les auljes, daus la régrion postéricure du corps, de la mème manière que pour les évolutions dilatées. P'arfois, à cause de celte dissocialion mésenchymateuse, les premieres cavilés formées communiquent largement ensemble, par la destruction des bandes qui devraient les séparer. Elles constituent, dans chaque bandeletle, un grand espace, qui occupe presque toute la longueur du corps de l'embryon. Les cloisons se reforment ensuite, soit au mogen de cellules provenant de la somalopleure, soil par des élóments mésenchỵmateux, yni s'altachent aux prícédentes, el s'organisent comme elles.

C'relome; appareil irrigateur. - l'évolulion des arvilís mísodermį̣ue's varie nécessajrement, suivant la nalure le celle que sulit le 
fenillet moyen lui-même. Lursque ce dernier sorganise d'après le lype épithélial, il est creusé l'm vaste oligoecelome, soit simphe, soil spegmenté, et livisé par les mésentires, ou par les cloisons, en un petit nombre de granils espaces réguliers; en outre, quelques vestiges du blastocole persistent, parfois, autour de l'intestin, restent indépendants thr colome, ne communipuent jamais ave lui, el forment un petit système sangun. Par contre, si le mésoderme est mésenchymatenx, les ébauches du corlome s'unissent ì la cavilé hastoculienne, el, lout en samplitiant sous le double rapport hu nombre et de la taille, se sublirisent en un graml nombre de petits espaces, qui comprosent un polycolome. Ce dernier est rarement diffus; il se lispose en un appareil irrigateur plus on moins régulier, el constitue, en surphus, dans certains cas, un auple dentoralome placé autour des viscères. - Les observations faites sur l'origine de l'appreil irrigateur sont encore pen nombrenses.

Le corlome des Rotifères se réduit ì quelques petites lacunes, percées dans leur mésoderme réduit. - Chlui les Mollusques, acquiert frar contre une importance consiléralile. Le fenillet moyen le cos ètres étant mésenchymatenx, cet appareil s'organise en un polycolome, et se morlife en système circulatoire. l'état le plus simple est présenté par les Solénriconques; les ispaces polyeolomipues sont grands, relativemint peu nombreux, et il n'existe point le circulation régulière dans le liquide pu’ils contiennent; le curur fait défaul. Les autres Mollusques sont en cela phus complexes; les espaees lacunaires sont répartis en grande quantité dans le corps, el groupés avec mo certaine régularité, ile manière à constitner un aprareil ramifié. Lo centre le ce lernier est un curnr, entouré par un périrarde. Les cavités du polyculome possèdent, suivant lenrs relations avee le curnr, le raractère d'artères, ou celui de veines; les premiires ont des contours phus nets, et un trajet plus régulier, fue les canaux veineux. La paroi carliaque est produite frar celle lu péricarde, qui térive elle-mème d'un amas de cellules mésorlermiques, dílimité prérocement.

Les Bryozoaires ont un culome l'une simplicité igale à celle présuntén prar les Rolifères. It consiste en quelques petiles lacunes, situées te préféreuce dans la riggion inféricure du corps; les autres parties du mésoderme se romposent d'une abondante substance fondamentale, renfermant quelques éléments figurés. - $A$ cause de la nature mésenchymatense de leur feuillet moyen, les Brachiopodes rappellent les Mollusques, pour ce qui lient à leurs cavités culomiques; ces dernières composent, dans leur ensemble, un polycolome régulier, modifié en appareil circulatoire. - Enfin, les Sipunculiens et les Phoronilliens, Inont le mésoderme est franchement épithélial, possèdent un raste oligoncolome, séprant la somalopleuro de la splanchnopleure, s'étendant dans l'organisme entier, ot an milipu duruel lintestin est comme suspendu. Des espaces, dérivés sans doute du blastocole, forment en outre 
un systime sanguin, placé dans la paroi du tube digestif, yui atteint sil plus graude complexité chez les Phoronidiens.

A prart son cloisonnement spécial et carartéristique, le crome des Polymérifues, celui des Annélides surtoul, rappelle de près son correspondant des Tentaculifères au mésoderme épithélial. Il est constituc de mène, abslraction faite Jes cloisons, par un vaste oligoculome, dans lequel l'intestin est suspendu par ses mésentères. I còté de lui se trouvenl assez sourent des vaisseaux sanguins intestinaux, †ui répondent ì des dépendances de la cavité blastoculienne.

urgunes excreteurs. - Les appareils excréteurs des Trochozoaires ont toujours, d'une manière fondamentale, l'aspect de tubes, mettant en relation les espaces interorganiques arec le dehors. Ceux de la larve Trochophore, les nephridies primordiales, ou les prolonéphridies, font communiquer le blastocale avec l'extéricur; cela, tantôt d'une façon directe, et tantòt d'une facon indirecte, lor'sque l'oritice interne est obstrué par' une mince lame protoplasmique. Les organes rénaux de l'adulte, les néphridies définitives ou deutonéphridies, mettent de même le calome, quelle que suil sa nature, en rapprort arec les milieux environnants.

Les protonéphridies de la larve sont au nombre de deux; leur place est dans le voisinage de l'anus. Ayant l'aspect de tubes, elles se composeut d'un canal et d'une paroi. Celle-ci est formée d'une pile te cellules superposées, que le canal traverse, en passant dans le protoplasme mème des éléments qui la composent; ce canal est, par suile, intracellulaire. La paroi s'épaissit sourent; le conduit, au lien d'ètre droit, devient llexueux dans un certain nombre de cas, mais son caractère intracellulaire ne cesse point d'exister; et, non seulement il se manifeste dans les prolonćphridies, mais, encore, on le troure assez sourent daus les deutonéphridies qui proviennent d'elles. - C'etle particularilé permet de comprendre ponr quelle raison l'orifice interne des néphridies primordiales est, parfois, obstrué par une lame de protoplasme. Le canal, à cause de sa nalure spéciale, n'a point percé encore, lorsque la larve est jeuse et peu complexe, le sommet de la cellule qui doit prorler cette ouverture interne; les échanges seffectuent par diffusion. I'lus tard, it mesure que l'appareil évolue, cet orilice nait, el les échanges sont alor's directs.

Le développement des protonéphridies dilfëre des Honomériques anı: Polỳméripues.

Les İonomériques appartenant aux classes des Rotateurs, des Bryozoaires, les l'horonidiens et des sijunculiens, ainsi que plusienr's représcutants de la classe des Brachiopoules et du type des llollusques, ne possindent jamais que denx néphridies délinitives; celles-ci sont les persistances directes des prolonéphrilles larvaires. Ces dernières granlissent, anplitienl leur canal, el parvinument a l'état parlail, en mo subissant guere dautres morlifications importantes que celles lenant il lem 
aceroissement. - I'ar contre, cortains Mollusques Gastéroprodes, el quelques Brachinporlos, sont pomrus, dans le cours de lenr axistence, d" puatre néphrilios. Les phinomènes du léveloprement sont encore ignorés pour ce qui toncho aux Brachiopodes, el sont à peine connus dans le cas des Mollusıjues. On sait senlement que les leux protonéphrilies des Brachiopolles s’ajoignent deux néphridies supplémentaires, pour parfaire le nombre drinitif; les comnexions entre ces diverses formations nesont point élucidérs. Quanl aux llollusques, les deux jorotonéphridies disparaisscnt et solrophient; alors que les deux néphridies supplémentaires persistent seules, pour donner les appareils rénaux, les organes de Bojunus, te l'adulte. Souvent même, chez la plupart des Gastéropodes, l'un dra ees derniers jrend un arcroissement considérable. et remplil seul le rôle qui lui est dévolu, pendant que l’autro resto réduil. Ces faits, relalifs à la senèse de pual ne néphridies, dont les leux fremières entrent en dégénérescence, n’ont encore été signalés quo chez divers Gastéropoles; on ne sait, par conséquent, słil convient de les étoudre anx autres Molluspues.

Les protonéphridies des embryons de Polymériques ont à subir une érolution toul'spéciale, pour fournir les dentonéphridies de l'adulte, car celles-ci sont fort nomlireuses, et lisposées par paires, au chiffre d'une paire par segment. Il ost nécessaire que chacune des deux néphridies frimoriales se fragurente, chałue tromron étant chargé de domner un orezane excrétenr déteminé, placé dans un anneau. Et, comme les protonéphrilies sont siluées symélriquement de part et d'autre de la ligne mérliane, comme lents scissions répétíns se manifestent d'une manière égale pon toulos les deux, il en résulte que les tronçons se corresponlent de l'une à l'autre, el forment des paires. Ce dóveloppement prète à une certaine ynanlití te molitications sccondaires, suivant que l'on s’alresse aux Annćlides on anx Psendannélides, el, dans les deux cas, anx embryogénies dilatées on anx développements condensés.

Les larves des Innélides, yui subissent nne évolulion dilatée, on faibloment alırégée, ont leurs protonéphridies crensées de conduils. Tout d'aborl, ces apprareils so trouvent en connexion aroslo hlastocole; puis, i mosure you lo mitasome, où ils sont placés, samplibe, pue les landelettes mésoderminues grandissent tout en se segmentant, ils s’allongent d'une maniơre équivalente. Chacun d'eux émel des branches latérales, yui pénotrent dans les cavilés segmenlaires; les commissures, qui missent ces lameaux entre eux, samincissent pen il peu; el chaque ramean produit un diverticule, allant s'uvrir au dehors dans la région la plus proche. Finalement le tube, qui représentail à lui seul la prolo-

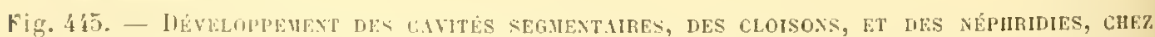
LFS Axxelues; lans le cas de diveloppements condenses (coupe mésliane el longiludiaule, exprimant la strueture de l'extremile postérieure du corpo de l'emliryon d'un Higuchute, ilplartcnant augemre Enchytrédes). - Les cavilés segmentaires et les cloisons prennent naissance sur place, dans la région proche de l'anus. l'ebauche néphri- 
néphridie, a émis les hranches, derrnues aulonomes, indépendantes,

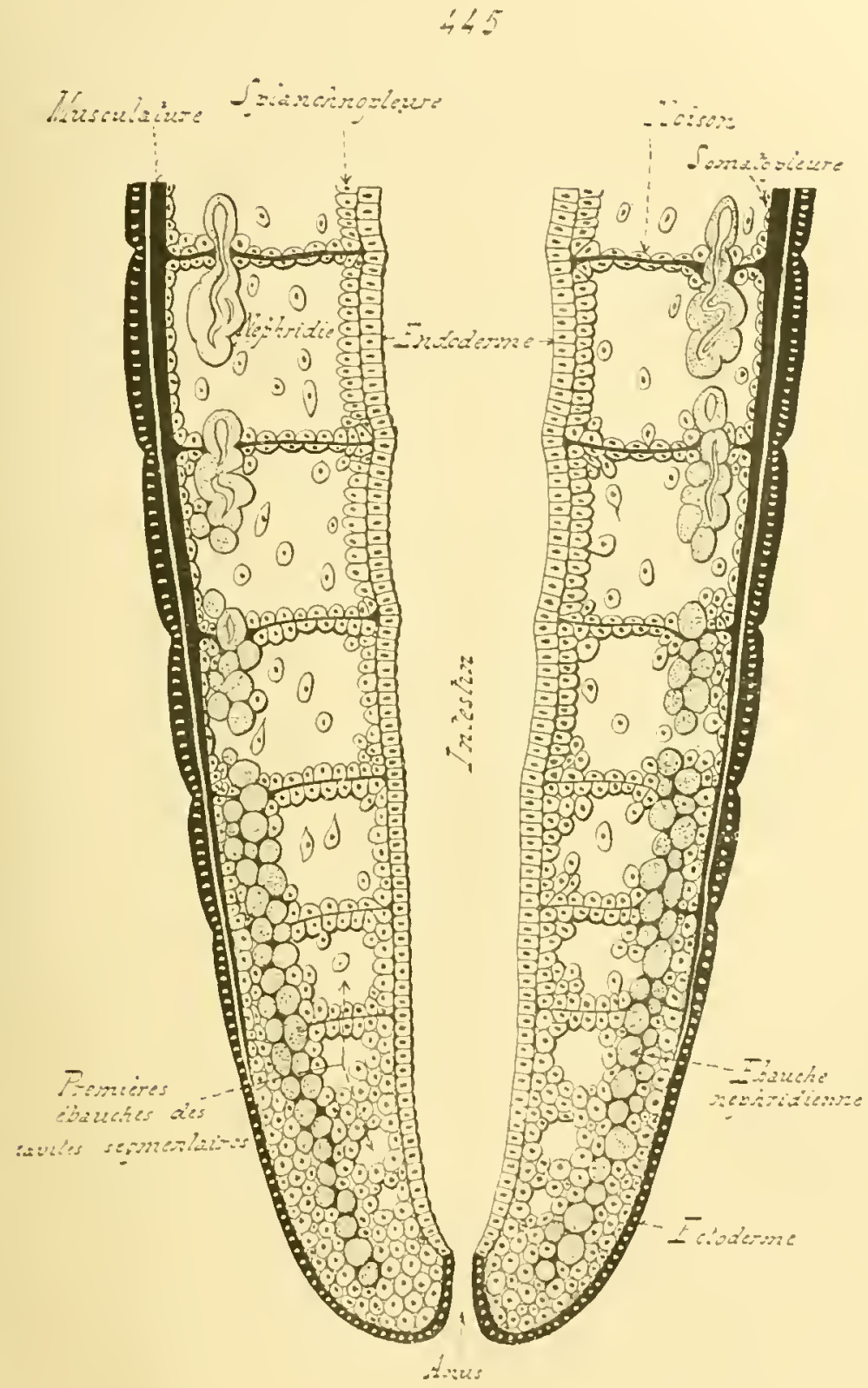

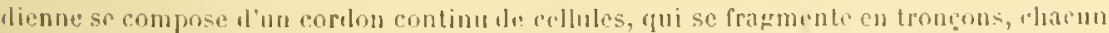

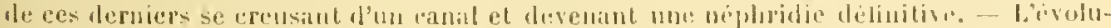

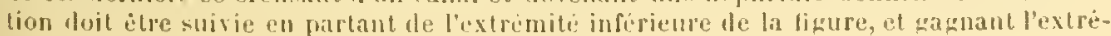
milé sulierieure. 
et munies d'oriliees externes i elles pupres; chaque branche est une deutunéphridie, encore nomme un aryune segmentaire. - Ces modilicaljons, s'exergut à la lois sur les deux méphribles primitives, abontissent à l'aspect dófuntil: des appareils excrélemrs disposés symétripuement, jar paires, dans les anmeaux du corps. On pensait autrefois que le tuhe primitil s'atrophiail, les lranches laterales persistant seules, ef lendnes vaiment indépentantes. Des recherches récentes temdent à montrer qu'il ne disparaît fas d'une manière complete; il reste reprosenté, chez l’alulte, par un cordon, qui relie les organes segmentaires les uns aux antres, derniers restiges de la disposition premiore.

Lorsque le développement est condensé, les ébauches des prolonéphridies consistent en deux cordons cellulaires, étendus lans l'embryon enticr suivant sa longuenr, et ne contenant aucun canal; l'abréviation embryogénique a substitué, iaci comme partout, l'érolution massive à l'évolution creuse. Ces lyandes, dites les curdors néphriclieus, sont placées svonétriquemont de part ef d'autre de l'intestin, en la situation exacte qu'occupent les tubes des prolonéplaridirs dans les dévelojpements dilatés. Elles s'allongent sans cesse, comme l'cmbryoului-mème; cetle amplificalion s'etfectue, en majeure jart, dans leur région postérieure, voisine de l'anus, cest-à-djoe daus cette zone où foutes les áditications mésodermiques se manifestent plus activement ¡u’aillenrs, car elle est l'homologue du métasone des lajes. Quelıues cellules du feuillet moven, placées en celte partio et au bout de chaque cordon, se multiplient avec rapidité; comme elles se dislinguent somvent de leurs voisines par leur taille un pen plus grande, divers auteurs j’écents les ont désignées par le nom de néphroblastes, c'est-à-dire do collules mères des néphridies. Puis, lorsque s'effectue le cloisonnement du mésoderme el de son culome, les cordons se partagent de même en troncons, de telle manière que chaque anneau contienne une paire de es derniers. Ceus-ci se creusent ensuite d'un canal, yui se munit de deux orifices, l'un intérienr, l'autre externe, et les deutonéplridies soul complielement laconnées. Les Oligochutes et les Hirudinées oftrent d'excellents exemples de cette évolution.

Il convieut de reconnaitre chez les P'sendannélides, fout comme chez les Annélides réritables, deux lypes principaux dans la genèse des appareils excréteurs: le promior lié aux développenents dilalés, et le secoud aux embryogénies condensées. Dans le premier mode, les deux protonépluridies s'allongent comme celles des Annélides, et prennent l'aspect de tuhes rameux, mais dont le nombre des branches est restreint. Lorsque le dévclopmenent est condensé, les lentonéphridies paraissent prendre naissance sup place, anx dépens des éléments mésodermiques, sans former au préalable des cordons semblables à ceux des (tigochoeles. Des rerherches sont, du reste, nécessaires à cel ruard; hien quil soit possible de suppléer a lenr absence, au mogen de la comparaison avec les phénomènes présentés par les Amrélides. 
Organes seruels. - Les éléments sexuels soul proubuils daus le misoderme, rt à ses dépens; leurs élbauches ne commeneent gemére à sarruser, qu'au moment oì le jume chre rest drjji voisin de l'ítat adulte. les cellules, quj ilonnent ces ćlınches, ne se séparent le leurs voisines par aucune particularité accessihle ì nos seus; il faut done ronclure de lí (sous cette réserve de l'existence de caractères qui, peut-ètre. ne sont pas appréciables par nos procédés l'iuvestigation), que les Trorhozoaires ne possedent point d'imitiales spxuelles, an sens réel lu wot. On ne roit point, dans leur embryogénie, ni surtout dans leurs développrments dilatés, les blastomères se distingues, dins la segmentation ovmlaire, de cenx qui les entourent, et demenror indiffésents à toute genise orcanique, pour produire sur le tard les glaniles sexuelles. Ce phímomène ne se montre que dans les rvolutions abrigées, et encore ne l'a-t-ou signalé avec certitude que chrz les llirudinées. Cette présence d"initiales sexuelles n'est point, dans ce cas, un mode primitif, puisqu'elle résulte de la condensation embrỵogénique, qui fait se délimiter d"une maniòre plus précoce les ébauchés des appareils.

Lorsque le mésoderme est épiltélial, la mince assise, nommce l'endothélium péritonéul, quilimite l'oligocrelome en recourant la somatoplenre. les cloisons lorsqu’j en existe, et se joignant à la splanchnoplrure, est seule intéressce dans la production des éléments sexuels. Quelques-mes de ses cellules se multiplient avec activité, el donnent des amas, composés, suivant le cas, d'ovogonies ou rle spermogonies. Ces amas ne sont point réparlis irrégulièrement dans le corps; ils sont appendus dorilinaire. soit aux cloisons, soit i des vaisseanx sanguins. Dans le premier cas, et lorsque les clojsons ainsi pourvues sont en nombre limité (Oligochotes, Hirulinées), elles sont julacérs les unes Jerrière los antres; elles forment, par leur ensemble, mue véritable rógion sexuelle, dont la présence est accusée à l'extérionr par une dilatalion du corps it son nivran; cette dernière est dite lo clitellum. - Si le mésoderme est mésenchymateux, les élıauches sexuelles forment de petits groupes, soit compacis et ramassís, soit diffus et iplars daus lecorps, nais qui se tromvent toujours plongés dans les tissus du fenillet moyen. Lorsquil existe un drutocolome, romme il en ast wez les Hollusques supérieurs, rette caviti entonre également les glandes sexuelles, qui prennent par re moyrn res contours définis.

Jes conduits sexucls sont, dans la regle, représentés par les népluridies. In moment oì les spermatozoüles et les ovules sont rapables de parvenir, a cause de leur origine mésolermique, dans les cavités du culomr, les néphrirlies, qui font rommunipurer ceslemiores arec l'exté-

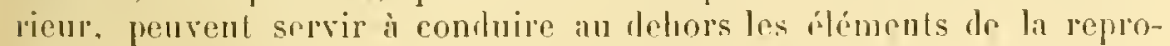
duction. Ils remplissent effectirment ce roile dans un grand nombre de

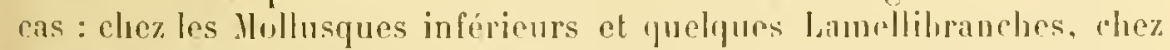

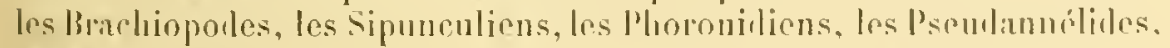
les Archiammílides, et les Annélides Chortoporles, sauf les Oligochu'les ler- 
ricoles. Parfois, et il en est ainsi chez les Oligochnetes limicoles et plusienrs Polychotes, certaines níphrilies, placées dans des régions déterminées, sont spécialement morlifiées en vue de leur ròle sexuel, el grandissent loaucoup is cet effot, toul en prenant un aspect particulier.

Tous les Trorhozoaires, anlres que ceux déjì nommés, possèdent des conduits sexuels distincls les néphridies; ces dernières n’ont alors d'autre emploi que l'excrétion, el ne servont en rien comme canaux vectemrs des élíments de la reproduction. Il est probable que ces conduits spériaux nont point une origine indépendante de celle des néphridies; mais les observalions actuelles n’ont pas encore élucidé le fait d'une maniòre complete. Les recherches les mieux conduites, a cet égard, ont porté sur les Molluspurs liastéropudes et sur les llirudinées. Pour les premiers, les conduils sexucls dérivent de deux ébauches, l'une ectodermique, ahoutissant an dehors, et l'antre mésodermique, domnant la part des cananx qui tient à fa glande; mais il est difficile d'affirmer quoi que ce soil sur leurs relations probables avec les néphridies. - Les olıservations sur los llirudinées sont plus précises; il est juste, sans doute, d'étendre aux Oligochnetes terricoles les conrlusions qu'elles suggèreut. Les éhauches protonéphriliennes se divisent, du moins celles placées dans la région sexuelle du corps, en thux parlies; l'une persiste comme organe excréteur véritable; l'autre, se mellant en relation arec les glandes reproductrices, se convertit en conduil sexuel. Il est indisculable, dans ce cas, que ce dernier possède une origine néphridienne, comme les relations des glandes de la génération, avec les applareils d'excrétion des autres Trochozoaires, autorisaient à le concevoir. Une telle division des néphridies niest pas, Ju reste, un fait limité; des étules récentes, sur les Oligochortes, ont montrí que ces organes se ramifient chez plusieurs de ces animaux. Au surplus, le déreloppement du système excréteur des Innitides suffit pour dénoter la capacilé de ce dernier à émeltre des branches Jatérales, suscoptibles de devenir intépendautes.

\section{\$6. - Reproduction asexuée et alternances de générations.}

La reproduction asexuce est rare chez les Trochozoaires; elle n'existe guère qü chez un petil mombre d'Ammilides, el chez la plupart des Bryozoaires. Elle selfectue suivant les trois modes prineipaux, propres aux llétazoaires : la fissiparité, la gemmiparité, el la gemmulation. Le premier frocécté est particulier aux Imnélides; les denx autres ne se trourent que chez les liryozoaires. Les phénomines de gemmiparité, lécrits par les autenr's comme se manifestant chez les Innélides, se rapportent aux faits de l'arcroissement dı corps.

I. Fissiparité. - 1. Pour concevoir la fissiparité des Annélides, il est nécessaire de se reporter a la struclure du mésoderme de ces ani- 
maux. Ce feuillet, au lieu d'ètre simple et continu, se trouve découpé en segments, placés les uns Jerrière les autres en une file linéaire; res segments ont mème valeur. lans la regle, et sépuivalent. Lem urigine est déjà connue; ils ne prenuent point naissance irréguliorement, el à des intervalles divers, dans le corps entier'; mais sont formés avec précision, et les uns ajrès les autres, dans la régrion postérieure de l'individu. En égard in la larve, cet organisme segmenté répond an métasome, à cette partie, roisine de l'anus, qui s’accroit sente, alor's que le prosome reste presque inactif. II livise son mésoderme, i mesure qu'il s'allonge, la zone de prolifération la plus active étant toujours postérieure.

Un cerlain nombre d'anteurs, et non les moins éminents, considèrent cette disposition comme liée à une structure coloniale; pour eux, le corps d'une Annélide n’est pas simple, mais se compose d'une tile d'individus, rangés les uns frrriere les autres, chaque individu correspondant i un anneau. Le premier zooïle colonial est la tète, cest-à-dire le prosome de la larve; il donne naissance au second zooüde par un bourgeonnement, et celui-ci devient le dernier annean dn corps; puis, par une série le nouveaux bourgeonnements répétés, s'eflectunnt tous en arant de ce dernier anneau, et refoulant à mesure vers la tète les parties engendrées, les autres individus sont produits. - Les notions, acquises aujourd'hui sur l'emlırogogénie des Annélides, n’antorisent pas it admettre une semblalıle opinion, rui paraissait autrefois plus acceptalle. Les premières phases du développement des larves se rapportent ¿ l'amplification exagérée de la région péri-anale, qui fournit presque seule le corps définitif, le métasome, el non à mu bourgeonmement de ce métasome par la zone huccale. les métamères sont formés par la segmentation les handelettes mésodermiques,sans que l'ectorlerme ni l'endoderme soient intéressés dans ce phénomène; ces feuillets se lornent à recevoir l'empreinte de la disposition annelée du mésoderme, inais ne se segmentent point pour leur compte.

S’il s'agissait vraiment d'une genèse d"inlivilus réels, les trois fenillets derraient y praciciper. - Cette particularití, de la disposition sermentaire propre an mésorlerme, se trouve démontréc par l'évolution que subit cette assise chez. les P'sendannélides, et les Jonomériques. l)ans le premier cas, une segmentation commence à se manifrster, puis disparait par l'atrophie des roisons; le corps drmenre simple, et ne possede aucune structure aunelée. Wans le second ras, chez les Siponcles par exemple, les lrandelettes mésoderminurs jeunes sont cu toul semhilables a celles des dnuéliles; elles s'amplitient te mème, en prorluisant les mèmes appareils, et affectant les mènes rapports. Wais elles ne dirisent point leurs cavités par des cloisons, et restent simples, organisation 'jui réagit enrore sur le corps rutier.

Le mésolerme est seul vaiment intéressé dans la grenèse mótamérique. Lorganisme devionl simple on annelé, suirant quil est entier

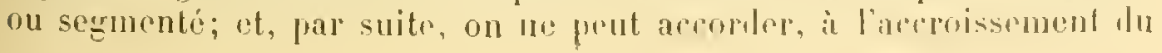


métasome des Annélides, Io caraclere d'un homrgeonmement colonial.

En somme, lanmulation lu corps des Annélides est une disposition lelle, quelle divise mn soul imlivilu "n un cerlain nombre de prarlies similaires, placées los umes lerriere les autres. la premiire, et la phus antérieure, le ces parlies, n'est autre que le prosome; elle ronticut les extrémités anlírienres des handeleltes mésodermiques, ot constitur la téte réclle de l'adulle. - I a nolion de la téte est sujette à des interprétalions diverses chez les Innélides, car les parls mésodermiques, qui pénètrent lans le prosome, composent souvent demx anneaux, lont le second, dit segment huccal, porle la bouche, alors que le premier, le segment réphalique, est situé en arant le cet orifice. En outre, dans certains ras, ces leux anneaux se soudent í plusienrs de cenx qui los suivent, de manière à former une volumineuse région antóriemre, souvent nomméo tète ì son tour. La lèle réelle ules Annélides doit ètre considérée comme ripoulanl an prosome, et comprenant la parlie qui porte la houche arec les zones silnées au nivean le cette onverlure et en arant f'elle.

Le mésoderme parrenant dans le prosome, el s'y organisanl comme dans les antres anneaux, donne aux segmenls céphalique et bnecal le caractère de métamères réels; de mäme, l'anneau poslérienr, nommé le segment anal parce qu’il porle l'anus, correspond à l'extrémilé poslérieure du métasome, el possede me valemr égale ì celle les antres mélamires, tout en revèlant parfois un aspect particulier. A causo le la grante importance prise par le mésoderme dans l’érlificalion de l’économie, el de la simililude fomlamentale des parties qui le composent, on doit consilérer tons les segments comme homorlynames, sil est permis l'employer une lelle expression, comme ayant mème capacité essentielle et mème puissance. - Ce point acquis, il est aisé le conrevoir qu'un segmeut quelconque du corps soit susceptible, dans reptains cas, de se modifier pour levenir enlièrement semblable à une lète, que son ectoderme prolifère pour donner un rerveau, qu'une bouche se perce sur sa face ventrale, ou sur celle le l'anneau suivam, el que des appareils sensilifs se facoment sur lui. Cette transformation esi la base, le point le départ. le la fissiparité des Annélides.

B. - Celte fissiparitó s'exerce par des moyens peu romplexes. Un anneau du corps se convertit en téte; ce changement a lieu sur plare, sans que cel anneau cesse d'adhéres à celui qui le précible, ni ì celui qui lr suit. l'uis, le mótamère prócódent se molifie à son four', se perce d'un anus, el revet l'aspect l'un segmenl anal ordinaire; de mème, l'anneau smivant se façnne mo bonclıe. L imlestin se coupe au nivean le la zone oì se passent ces morlificalions; sa partie antérieure se lermine an nourel anns et se joint à lui, pendant que lo commencement de sa prortir. postérieure se met en rapport avec la bouche qui vient d'etre formée. Lorsque foutes ces mólamorphoses sont accomplios, l'inlividn primorilial 
posside : denx tètes, l'une antérieure, la seconde intercalín aux autres motamires; deux segments ananx; et denx tulos digestil's distincts. Il suffil yue la nourelle tèle so sépare de l'anneau qui li próriole, pour que rel ètre soit divisé en deux individus complets, et lésormais indépendants. - Parfois, ces changements portent sur plusieurs régions ì la livis. de manière à lonner plusieurs tètes.

l'ne telle reproduction asexuelle rentre certainment dans les cas de fissiparité, puisque le corps du générateur se divise pour engendror les desecndants; mais cette fissiparité est remarqualie par les prorélés frielle met en curre, prar celte transformation, sur place, d'anmeanx orlinaires en segments particularisés. Elle n’existe pas chez toutes les Annélides, et ne se trouro que chez un petil nombre de genres, dont les uns appartiennent it la sous-classe des Oligochartes, et les autres i relle des Polychetes. Nalgré sa simplicité. cette fissiparité prète à des variations direrses, dont plusieurs sont fort curieuses, et qu'il est possilule de ranger en deux modes : la fissiparite holomorphe, et la fissiparite heteromorphe. Dans le premier mode, les descendants se ressemblent entre enx comme its ressemblent an ginérateur: jar contre. dans le seconil, les descendants different du générateur, et parfois mème different entre eux, ce qui ahoulit it une héteromorphie simple ou it une héteromorplie double.

Wans la fissiparití holomorphe, les descendants rappellent leur génćrateur, non seulement par leur aspect, mais encore par le fait que tous sont munis de glandes sexuelles, ou sont capalles d'en etre pourvus dans le cours de leur vie. Tels sont les Väs el les Chotogaster parmi les Oligochates; les Syllis prolifera, les Myrianila. les Protula Dysteri, parmi les I'olychrotes. Le générateur se scinde, par le mosen déjà indiqué, en deux ou plusienr's fragements; la partie antérienre du génériteur - qu’il est permis de considérer comme la persistance de ce dernier, puisunil porte sa tète - est en tout semhlable aux aulpes descendants, el produit comme eux, après leur séparation mutuelle, des éléments sexuels. - Les Syllis et les Myriunida font exception en cela, car le premier descendant, qui conserve la lète du génératenr, ne posside jamais d'organes sexuels. Après yue los individus placés en arrière de lui se sont détachés, il s'accroil, et les nouvelles portions formées se divisenl drrechef en indivilus nouveaux. Le génóratenr borme son ròle à produire res deruiers, qui deviennent tous sexués, alors que lui-mème reste toujours agame. Cetle altération du procédé primitif est une transition vers la fissiparité hétéromorphe.

Celle-ci est for rare; on ne l'a muere observie que chez divers duto-

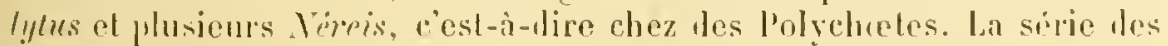

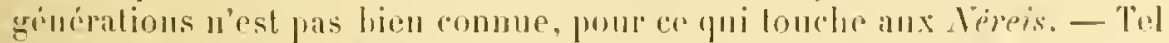
n'est pas le cas des dutolytus. Limlivilu antérieur, lont comme colui des čyllis, et des byrianilu, se borme ì fournir. par l'accroissement al

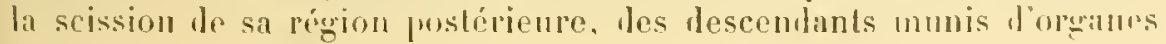


sexuels, alors que luj-mime n'en est jamais pourvin. Ces descendants ne se ressemblent ni par la forme, ni par la sexualité, puisine les uns sont males el les autres femelles. Les différences sont telles que ces trois types avaient élé plarós aulrefois lans des genres séparés; liudividu antérieur, la persistance de la parlie anlérieure du génćratenr, était nommé Auolytus, alors que les descemlants màles étaient compris dans le genre Polybostrichus, et les femelles daus le genre Śacconèreis. Minsi l'Autolytus prolifer dome, comme rejelons sexués, des Polybostrichus Mälleriel des succomereis helgolandica. - Chayue individu d'Autolytus paraît ne fournir qu’un seul sexe de descemlants, et non les deux.

La série des phéuomènes n’est pas encore completement élucidée pour les Néreis. Les représentanls le cerlaines especces oflrent tous les caraclires du genre, lorstuils sont encore dépourvus de ghamdes sexuelles; ils se transforment an moment où leur sexualité apparait, et acpuierent

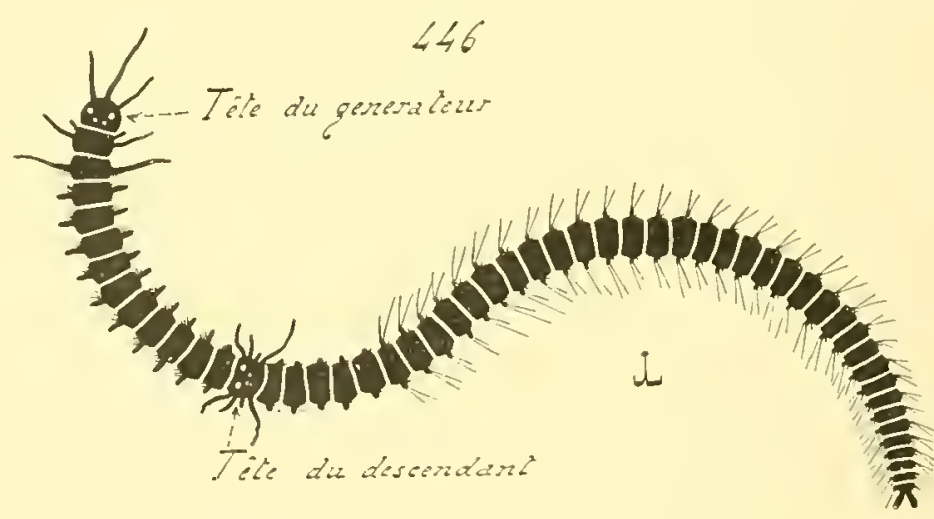

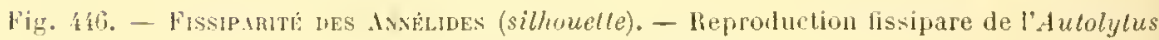
cornulus, d'après A. Agassiz.

des soies plus longues, qui leur servent ponr nager. Leur aspect est alors tellement diflérent de celui qu'ils montraient d'abord, qu'on les avait autrefois plarés dans le gemre Mtétronéreis. Plusieurs inlividus du genre Néreis sont lone capahles de se converlir en Hètéronéreis. Senlement, it cùté des Néreis asexuées qui se modilient en Hétéronéreis sexuces, on a vu des Néreis ponrvues de glandes génilales, apprartenant ì la mème espece, el ne se changeant pas. On connaîl mème teux formes de ces derniòrs: l'une unisexuée, l'aulre hermaphrodite; comme on a houvé ileux lypes d’lléléronércis, l'un màte el l'autre femelle, dillérents l'après le nombrede leurs anneanx. Ainsi, la mène espèce, el la N'preis Dumerilii a ćlé le mienx étudiée suns ce rapport, se présente sous quatre aspects ditlérents, el mème ciny, en y joignant l'élal agame primordial; denx de ces aspects se rapportent i la forme Ilétéronéreis, et les trois antres it celte de Néreis. Mais on ignore les relations qui missent ces 
types entre eux, ot J'on ne sait s'il s'agit d'une fissiparité hétéromorphe. semblable a celle des Autolytus, ce qui est très purbable, on hien l'une modification d’individus entiers, nullement accompragnée de phénomìnes fissipares.

Quel que soilte mode de la fissiparité, Je lobe anal de charque deseendant, et surtont de celıi qui provient directement du générateur, entre en prolifération active pour remplacer les anneaux qui viennent de se détarler. Son mésoderme multiplie ses chéments, et s'organise, tont comme il le fait dans la région postérieure du mótasome des larves. C'est un véritable retour a l'état embryonnaire qui se manifeste dans cetle partie du corps. Aussi, celle-ci s'allonge-t-elle, et s'accroit-elle, jusqu"i ce que l’étal définitif soit alteint. Lorsque cel élat comporte de nouvelles scissions, les segments produits en dernier lien se détachent encore; après quoi le phénomène recommence. - On a parfois consiléré ce fait comme un bonrgeommement des descendants par l'individu antérienr. Une telle interprétation parail inexacte. Les données précédentes suffisent pour établir yu'il s'agit seulement d'un accroissement de la région postériemre du corps, aceroissement suivi de scission, la chose se répétant un certain nomhre de fois durant la vie du généraleur. Ce phénomène se ramène à une fissiparité, constamment renouvelée sur une partie rui repousse sans cesse.

11. Gemmiparité et gemmulation. - Ces deux procédés de la reproduction asexuclle n'existent que chez les liryozoaires. Tous les représentants de cette classe présentent la gemmi rarité. La gemmulalion est d'une répartition plus restreinte; on ne la trouve, d'habitude, jue chez les liryozoaires i'eau douce, el surtont chez les Phylactolemes tels que les Cristatelles et les Plumutelles. Les gemmules ont élé nommées des statoblastes par Allmann; ce terme a été conservé depuis pour les désigner.

Lil gemmiparité aboutit toujours, sauf chez les Loxosomes, à la production de colonies; les descendants ne se séparent pas de leurs génératenrs, et leur restent unis par une portion le lenr corjs. Cus assemhages colonianx ont d'ordinaire une forme précise. pour chatue espece. Les recherches effectuées sur le lourgennement des Bryozoaires sont nombreuses, mais encore incomplètes dans ce yni tient il l'origine réelle des organes. S'il faut en juger d'a pres les recherches léja anciennes de Nilsche, et celles plus récentes de Iladilon, surtont de Darenport, l'éhauche du jeune embryon est constituce prar mu anas de cellules, placé an-rlussous de l'ectoderme dn gínérateur, soit en mo partie du rorps de ce dernior, soit sur des stolons émis par lui. - P'armi ces élíments, les uns, immédiatement situés sons l'ectederme, et composant par suite le mésoderme de l'ébanche, domment te funicule, et le tissu ronjonctivor musculaire de l'économie. Les cellutes plus internes, qui répondrnt par

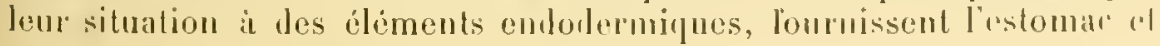


l'intestin; me cavilá se crenso enlre elles, ef devient la cavilé digeslive; efle dispose, autour l'elle, res cellules infernes pour s'en faire une parni. Quant à l'ertoderme, il produit le ganglion nervenx, et s'ipaissil, en s'arjoignant une parlie du mésorlerme, pour engendrer les tentacules périhuccanx. Il se soulive, par places, cu petits mamelons, dans l'intérieur desquels pémoitrent des éléments mésodermiques; ces mamelons sallongent pen à peu eu tentacules.

En résmó, les élauchrs des homrgons contiennent les trois feuillets. qui évoluent commo leurs similaires des embryons issus d'oufs fécondés, el funnissont les mòmes organes. Mais l'origine exacte des éléments qui constitnenl ces trois feuillets, ou plubit leur genese anx dópens des courhes correspondantes de l'économie du génirateur. n’est pas élucirlíe d'une manière complète. - Du reste, les notions relatives à la gemmiparité les Bryozoaires sout obscurcies, dans la plupart des travaux pulbliés sur ce sujet, par la préoccupation constante dr trouver, soit que lorganisme de ces ètres est une colonie le deux individus, le cystide et le polypide, dout le secoml est hourgeonn' par le premier, soit de démontrer le contraire. Les partisans le l'bypolhese coloniale consirbrent l'ectoderme lu générateur, ou celui le son stolon, comme répomiant au cystide, of l'ensemble des autres éléments du bourgeon comme formant le polypide, c'est-it-lire l'intestin arec les autres appareits inlernes. Cetle hypothise est inexacte; le déreloppement des embryons, el la compamison les bryozoaires avec les classes roisines, le prourent suffisamment.

Certains auteurs, Hatschek cotre autres, ont regarié comme un lonurgeon la dépression ectodermique, que portent, en avanl de la bouche, la plupart des larres de liryozonires. Cét appareil, désigné sous les noms l'organe myriforme, ou d'organe dorsal, semble plutòt appelé a jouer un Jôle sensitif qu'à remplir toute autre fonction, et, en tout cas, ne possede ancune propriété gemmipare. lar la lisparait une thérie, qui tendait ì faire considérer l'évolution embryonnare d'un Bryozoaire comme comprenant la succession de leux individus. Dans l'espril de cette théorie, proposéc par Balfom, lorgane lorsal, envisagé comme un vérilable hourceon, se développerail seul pour domner le corps de ladulte, alors qur toules les autres régions de la larve satrophieraient et dispal'aitraient.

La gemmulation est spéciale anx lirvozoaires d'ean donce. Elle ne se manifesle gruère que vers la fin le l'élé; elle a pour résultat de produire des germes, capables de résister aux intempóries de l'hiver, et dr se dévelopjer au printemps, alors que les colonies sont détruiles. la mème cause produit les résultats identiques chez les Spongiaires. l, origine axacte des gemmules, des statoblastes, n'ist pas encore bien connue. Chacun de ces apprails naìt sur le funicule du générateur, daus le mrsoderme par suile, mais la praticipation, probable, de l'ectoderme 
et de l'endoderme à cette grenèse n'est pas décrite. Les gemmules sont aplaties et discoüdes, à la manière de lentilles licconvexes; lenrs hords épaissis, et formant bourrelet, portent parfois de longs piquants eroclus, servant il les suspendre aux corps étrangers, chez les Cristutclles notamment; leurs deux faces sonl prolégées par une eutieule chitineuse. Limsi construits, les staboblastes, mis en liberté par la destruction des individus qui leur donnent naissance, passent l'hiver sans périr. Au printemps, Iorsque les canx deviennent tiedes, les couches protectrices disparaissent; et les éléments cellulaires, déjả nombreux, ayant presque ébauché la plupart des organes, se disposent pour revètir lenr aspeel définitif. L’individu, ainsi produit, engendre de suile, par gemmiparité, une nouvelle colonie.

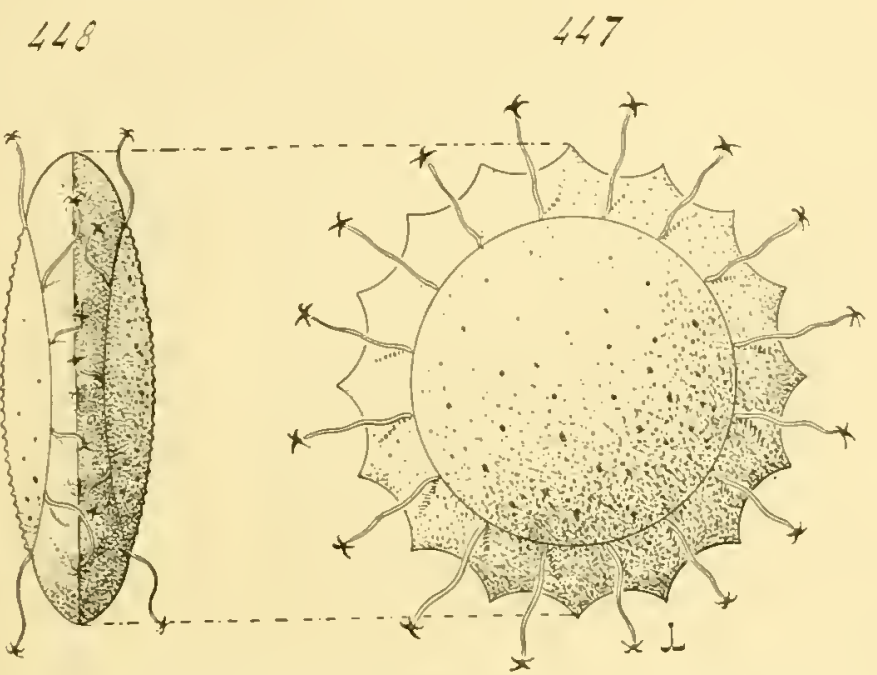

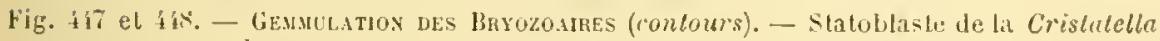

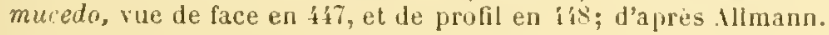

\section{RÉSUMÉ}

$\$$ t. Coxshématoss gésénales. - La reproduction asexuelle est relatirement rare; on ne l’a guère signalée que chez les Bryozoaires et diverses Amélides. La sexualiti est le mode reproducteur le plus furquent. - Les développements dilatés s'effectuent d'ajrès le type gastrulaire. Le protendoderme de la gastrule domne le mésoderme pas le moyen d'initiales mésodermiques; après quoi, il devient l'endoderme détinilif. Ces initiales produisent d'abord un mésenchyme primaire, dont certains éléments se différencient hàtivenent en cellules conjonctives, on conjonctivo-musculaires, sans aller plus loin, el dont d'autres se multiplient activement, pour engendrer deux bandelettes mesodermiques. 
\$ 2. Soxuhte et Élémexts sexuels. - Luniscxualití et l'hermaphroditisme existent chez les Trochozoaires. sans aucune répartition bicn frécise. Linnisexualité se complique parfois de dimorphisme sexuel, chez les Rotifies, divers Mollusques, plusieurs Ammélides, et les Echiuriens appartenant au genre Bonellia. l'armi les Mollusques Gastéropodes, la plupart des Prosobranches unisexués possedent deux formes de spermatozö̈des; les autres Troclozoaires nont qu'une sorte de ces éléments.

3. Segmentation et fellllets blastonebmoles. - Les pliénoménes essentiels élant conslants sous ce rapport, les procédés de formation sont très variables, el diffèrent souvont d'un type ì l'autre.

Les Rolifires ont deux sortes d'ruf's : les aufs d'éte el les aufs d'hiver. Les premiers, a coque mince, sont produits d'habilude par des femellos parthénogénétiques; les seconds, plus gros, plus riches en deulolécilho, et pourvus d'un chorion plus épais que les précédents, résultent de la fécondation. La segmentation tolale ahoutit à unc planule compacte, dont les béments se grompent snr place 'n un protectoderme et un protendolerme; celui-ci se divise en mésorlerme el endodrme. Un sillon superficiel pénidre dans le corps de l'embryon, et le seinde en deux parties yuj s'écartrnt l'une de l'autre en se rabattant.

Los procides offerts par les Mollusques sont des phus divers, et constitucnt une sério montrant des altérations de plus en plus grandes, à mesure que la quantilé tu deutolécilhe contenn dans l'ouf est elle-mème phus considéralile. Ces procédés penvent ètre groupés en qualre tyjes prinripaux. - Le prenior comprorte une gastrulation; ilest le plus fréquent, car les Amphineuriens, les Solínoconques, les llétéropodes, les Pléroporles, beaucoup de Lamellibranches el de Gasteropodes, le présentent. la segmentation, loujours tolale, est tantôt égale, lantôt inégale; ce dernier cas intervient lorsque le lentolécithe est assez abondant. Le probendoderme de la gastrule domne les juiliales mésodormiques, qui lombent daus la cavité hlastocolienne, ou, si cetle derniéro mangue, par suite de l'accolement lu protendoderme au protectoderme, qui s insinucnt entre cos deux feulles. Lenténore devient la bouche le ladulte; sauf chez les I'aludimu vivipura, oì elle se convertit en anus; ce fait est sans doute connexe an modr gaslrulaire ollert prar cet animal, qui comporte une incurvation, ct non une invagrination. - Le deuxième lype correspond à une plamulation indirecte, qui donne une planmle cytulaire; il existe chezles Gastéropodes Pumonés et Opistohranches, el chez plusieurs Lamelliliranches. L'ovule contient beaucoup plus de deutolécithe que dans le premier cas; la segmentation est cependant totale, mais fort inégale. Le hoisiome type comporte, comme le second, nne segmentation totale el une planulation indirecte, mais ahontil il une planule lécithique. Le denlolécille est assez alondant four constituer unc masse compacte, comparalife à une pretite visicule vilelline interne. II en est ainsi cluez la 
Nassa mutalitis. - Enfin dans le quatrieme tỵpe, la quantité de deutolécithe étant fort grande, la segmentation est partielle: la planulation, indirecte, Ilome une planule lécithique. Ce trpe cmbryonnaire ne se frouve que chez les Céphalopodes; Fembryon de ces animaux est pourru d'une vésicule vitelline, dont les dimensions et la disposition sont assez variables. Parfois, tout en étant plus grosse que celle du troisième tas, elle est interne comme elle; plus volnmineuse chez les Argonautes, elle est d'abord externe à l'embryon, mais s'enfonce par la suite dans le corps de ce dernier'; enfin chez les Seiches, les Calmar's, etc., cette vésicule est assez grosse pour demenrer toujours extérieure au corps le l'embryon.

Le déreloppement des Brachiopodes prète à contestations. Il s'effectue d'après le mode gastrulaire, lorsque l'orule est paurre en deutolécithe; il en est ainsi, par exemple, chez les Argiope ćtudiées par liowalevsky. L'origine du mésoderme serait entérocalienne, d'après ce dernier auteur; le fait n'est guère acceptable, étant données les relations étroites qui unissent les Brachiopodes aux autres Trochozoaires. Che\% les Thécidies, dont l'ưnf contient une réserve nutritive assez considérable, la segmentation est totale, comme dans le cas précédent, mais la gastrulation fait défaut.

Parmi les Bryozoaires, les Enloproctes, appartenant an genre I'edicellinn, subissent un développement dilaté, qui comporte une gastrulation. L'évolution embryomaire des Eetoproetes est plus condensée; la segmentation est totale, el parfois égale, mais les feuillets se délimitent dapris le type des planulations directes. Un Ectoprorte, la Tendra zosterieola, effectue une transition entre ces deux procédés.

Les Phoronidiens subissent une embrrogénie dilatée. Leurs ovules, par leur segmentation, se convertissent en blastules, puis en gastrulrs incurvées. Du protendoderme de ces dernières se détachent de nombreuses cellules mésodermiques, dont certaines, placées dans la région anale, fourmissent les bandelettes mésorlermiques.

Le développement des Sipunculiens concorde, dans ses traits généranx, avec relui des lhoronidiens. Il en diffère, du moins en te qui touche une espece le la classe, le signunculus mudus, par la lormation d'un' menbrane amniotique, produite par l'ectorlerme larvaire, et dont l'embryou se débarrasse llume manière hàtive.

La genèse des feuillets blastodermiques n'est pas uniforme chez les Annélides; elle comprend, suivant la quantité du deutolécitlıe contenn dans le vitellus ovulaire, trois cas principaux. - Le premicr, relatirement rare, et le plus dilaté, se rapporte à unc castrulation; il existe chez les Archiannélides, el che\% plusienrs l'olychotes lels que l'Eupomalus uncinutus. Le protendoderme de la gastrule donne des éléments mésollermiques, dont les uns constituent hitivement un mésenchyme primaire, et dont les antres so multiplient aver rapicliti prom produire les deux bandelettes mésodermiques; ces dernières éroluent d’après to 
mode épithélial. - Le second cas consiste en une planulation directe; il rest très répandu chez Ja julupart res Chétopodes Polychues et Oligochuetes. La quantilé le deutolécillu: est alors plus grande que dans le promier cas; le chilfre des hastomeres produits par fa segmentation est considérable. Une cavité, l'entéron, se creuse au centre de lenr amas; liss blastomeres qui l'entourent composentl'entoderme; les cellules embryonuaires jériphériques donuent l'ectoderme; enfin, les cellules intermédiaires, comprises antre les denx fenillets précédents, comstiturnt le mésolerme, au milieu duquel se perernt les espaces corlomiques. Dans le fruisiome cas, propre aux Ilirudinées, le deutolécithe étant phus abonlant encore, la planulation est indirecte. Le's b]astomères centranx sout fort gros, et représentent me rolumineuse réserve mutritive.

Les l'semdannélides rajpellent Jes Aunélides sous le rapport de la genose des foullets. Le type gastrulaire cxiste chez les Echiums par exrmple; le fype à planulation indirecte chez les Bonellia ch hes sternaspis.

S f. Fonmes embryoxunes. - La forme embryonnaire fondamentale des Trochozoaires est la lare Trochophore. Cette larve est essentiellement caractérisée par son ectoderme cilié, une courunn orale de ces cils ribratiles ne manquant presque jamais; par son mésenchyme primaire blastocolien, issu d’initiales, et dont une partio se développe en mésoderme définitif: enfin, par la présence l’une paire de néphridies primordiales. Cos caracteres principanx ne font jamais téfaut; il s"y ajoute cependant, suivant hes groupes les Trochozoaires, des particularités d'ordre secondaire, qui ont pour eflet de donner plusiens types de Trochophores. Las phus fréquentes de ces particularités tiennent à la quantité varialle du deutolécithe, el à l'accroissement inécal du corps de l'embryon, du prosome; une partia restreinte de ce dernier étant seule chargée de derenir la plus grande part du corps de l'achulte, du métasone.

Les Rotifères ne dépassent pas l'élat de Trochophore. II est permis de les considérer comme des Trochophores qui seraient sexuées.

Il n'en est pas ainsi pour les Mollusques, dont lorganisme est souvent frès complexe. Lemrs larves sont carartérisées par Ja possession de lenx organes, qui leur sont spéciaux, le pied el la glande coquillière; sauf la présence te celle-ci, elles rappellent the près, jar leur aspect général, les Rolifires adultes. - Les Jarves des Amphineuriens Solénograstres el celles les Solénoconjues possèdent trois rouronnes ribratiles transversales; celles des Amphinemriens Platygastres en ont deux; eutin, les larves libres des autres Mollusques n'en ont yu'une, 'qui s'élargit souvent sul ses deux còtés, et prend par là un aspect propre, hi ayaut valu le $n$ on spécial de voile. Cirace à ces componnes, l'enbryon, avant sa mise en lihcrté, fournoric dans sa coque chorionnaire, par un monvement de rotation sur lui-nène. Le monent le cette mise en liberté 
varie quelque pen suivant les Iypes; d'ordinaire, elle est assez jurécoro chez la plupart des représeutants du groupe; elle est tarlive chez les Céphaloproles, qui subissent daus lenr coque presque toutes les pluases de leur évolulion.

D’une manière générale, chez les Tentaculiferes, la région inferoventrale du corps de la larre donne la majenre pratie du corps de l'adulte, et, à cel effet, s'accroit heaucoup plus que les antres. l'our ce qui est des sipunculiens, les métamorphoses embryonnaires se homent presque, apres la chute de l'enveloppe amniotique, à cette amplification. l.es phénomènes sont plus complexes 'hez les Phoronidiens. La larve de ces animaux, dite Actinotrocha, produit, entre sa bouche el son anus, un tube, le tube mélasomique, qui commence par s'enfoncer dans lintérieur du corps, puis se déragine, devient extérienr, el fournit, en entrainant les organes dans sa carilé, presque toute l'économie définilive. - Des changements analogues existent également cluez les Bryozoaires, et comportent de mème la formation, avec l'éragination, d'un tube mélasomique. Seulement, dans la plupart des cas, le déreloppement s'effectue dans des loges, nommées oécies, et s'accompagne de dégénérescences passagères, encore peu connues. - Les larves des Bracliopodes ont un corps divisé en lrois segments, d'abord pen dissemblables, et qui croissent ensuile de façons inégales. L'un d'enx donne le pédoncule, l'intermédiaire le manteau, et le troisième les luras avec la région buccale.

L'emhryogénie des Psendannélides comporte toujours la présence de larves, de lorme el de complexilé variables suivant la teneur en deutolécithe. La région anale du prosome grandit plus que les autres parties du corps, mais de manière à laisser l'anus oceuper une position lerminale. Dans le cas des développements dilatés, des cloisons se délimilent dans les bandeletles mésodermiques, leur donnent une structure annelée, et se détruisent ensuite; ces plúnomènes ne paraissent pas exister lorsque l’embryogénic est condensée.

Les Annélides subissent des évolutions fulales, ou des évolutions lavaires, surant que les ovules sont plus ou moins riches en dentolécithe. Les premières sont propres aux ()ligochotes ot aux llirudinées; les rufs sonl enfermés dans les cocons. Les embryons s'y façonnent, et les quittent au moment ou ils sont presque parvenus ì l'état adulte. Au contraire, la plupart des l'olychates offrent des phases larvaires, et des métamorplioses extéricures; leurs larves se perfoctionnent peu à peu, durant leur vie lilne, of prouluisent, dans leurs liandelottes mésodermiques, des cloisons qui ne se détruisent pas. La région péri-anal." le leur corps contient ces bandeletles; elle saceroil plus que la zone placer an mivean de la bouche, et donue la majen pe part lo lorganisme difinitif. Ia zone buceale se horne à fournir le segment céplablipur, ol le segment luuccal. Elle est frarfois, lors de la mise en liberte des larves, el pendant les premières périodes de l'existence de ces lemières, plus 
large que la régron péri-anale, et la soutient dans l'oau; ces disproportions cessent prar la suite. Sonvent, los larres des Annólides portent des cils et des soies proyisoires.

\$5. Onigixe des onghrs. - L'eclorlerme donne naissance au système nerveux ot i ses dépendances sensitives; aux appendices, tels que les soies el la cuticule; après quoi. il se convertit en ectoderme délinitif. Les centres nerveux dérivent essentiellement de deux ibauches distinctes, la playue crphalique of la plaque médullaire: chacune de ces éluauches se divise, avec plus on moins le rapidité, en leux parties symétriques, placies de part et d'antre de l'axe médian du corps. La plaque cophalique engendre le cerveau, et la plaque médullaire la moelle ventrale; toutes deux s'unissent par des commissures. Cetto origine est des micux caractérisées en ce qui tonche les Ammélides; elle est moins netle chez. les dlollusques, dont les ganglions naissent, dn moins la phupart, indépendamment les uns des autres. - Les appareils sensitifs, dont la prorenaner est le mieux connue, sont les yeux. Les portions importantes de ces organes sont données pas l'ectoderme; parfois, chez certains Céphaloporles par exemple, des tissus misodermiques s'arljoignent it elles, el fournissent des membranes annexes. - Les soies sont des dópûts de substance cuticulaire, exsulés lans des dépressions tubuleuses de l'ectoderme; ils prennent, a cause le leur origine, une forme de bagnette, et graudissent par l'apport constant de nouvelle matière à leur base prolonde. Les cuticules, soit simplement chitineuses, soit encroitées de sels calcaires, authérentes au corps ou formant des loges, sont produites par l'retorlerme, rxsulées jar lıi, et déposées à sa surface.

lienloderme horne som rôle à fommir l'ópithólimm de l'intestin, et celui des slandes amuexes du tube digestif.

Le mésoulerme engendre la musculature, le corlome avec lappareil imigateur, les organes excrétenr's el sexuels. La disposition de tous ces appareils, el snrtout celle du colome, varie suivant la nature du développement que subit le fenillel moven. D'unc facon générale, le mésoderme des l'olymóriques se subdivise en annears, encore nommés segments ou métumères, dont los cavités sont séparées les unes des autres par des cloisons, dites parlois des dissepiments; ancun fait comparable ne so manifestr chez les Monomóriques. - Le mésorlerme des Rotifires se réduit au seul mésenchyme primaire. Celui des Bryozoaires est à peine plus complexe. Celui jes Hollusques et des lirachiopodes est franchement mésenchrmateux. Enfin celui des Phoronidions el des Sipuneuliens est iputhélial. Parmi les Polymériques, les cloisons demeurent rutières chez les Annélides, et se ditruisent au cours le la vic larvaire des Psemlannélides: les spoments, quelles délimitent, naissent les uns apres les autres, et les uns derriere les autres, lans la région postíriroure du corps. La nature du rolome varie selon colle du mésorlerme 
qui le contient, et se troure dans mor relation étroite avec elle. - Les premières ébauches des appareils excréteurs, les niphridies mimordiales ou protonéphridies, consistent en deux tules itendus de la cavití blastocrlieme à l'extérieur: ces appareils se mettent par la suite, et tout en se compliquant, en rapport arec le calome crensé dans le mésoderme. Ils se bornent a grandir chez les Honomériques, en portant parfois leur nombre a quatre (certains Mollusques el Brachiopodes). Ils se divisent en troucons chrz les Polymérigues, rhacune des paires de ces derniers se rattachant à un segment du corps; d'où leur nom frépuent d'organes segmentaires. - Les éléments sexuels sont engendrés par des cellules mésodermiques. Les conduits vecteurs sont représentés, dans la rẻgle, par des néphriblies, ou par des canaux, spécialisés dinns leurs fonctions, qui paraissent avoir une origine néphridienne.

\$ 6. - Repronlction asexlelle lit alternayce de géxébatioss. La reproduction asexuelle des Trochozoaires s'exerce par la fissiparité, par la grmmiparite, ou par la gemmulation. La fissiparité est propre a plusieurs Annélides; elle répond à une fragmentation de leur corps annelé en deux ou plusieurs tronçons. dont l'anneau antérieur se convertit en une lète. Lialternance, qui en résulte dans les ggénérations, est tantôt holomorphe, tantôt hétéromorphe. - La gemmiparité n’existe que chez les liryozoaires; encore assez peu connue dans ses procédés, elle aboutit ì la genèse de colonies. - La gemmulation est spéciale aux Bryozoaires d'eau douce; les gemmules, dites sourent des statolilastes, naissent sur le funicule de leur ténérateur. 


\title{
EMBRANCIEMENT IES ARTIIROPODES
}

\author{
CIIAPITRE X \\ DÉVELOPPEMENT DES ARTHROPODES
}

\section{\$1. - Considérations générales.}

1. Garactères et classification. - Les Arthropodes sont des Colomates schizoculomiens. A ce titre, leur mésoderme est creusé d'un calome, qui nait et se développe suivant le mode schizocolien, et s'organise en un polycolome; il est, en eftet, constitué par des cavités nombreuses, qui s'agencent entre elles pour donner l'aplareil irrigateur de l'économie. En outre, les Arthropodes se distinguent des antres Schizocolomiens par deux caracteres prineipaux : leur protendoderme est mésenchymateux à son déhut, nullement épithélial, et engendré par le bastoderme d'après un frocédé qui ressemble à une cytulation; leur corps est muni d'appendices latéraux, groupés symétriquement par paires, et Jivisés en segments, dits articles, mobiles les uns sur les autres. Cette dernière prarticularité a valu son nom à l'emlranchement, el juslifie également l'ancicnne expression d'Articulés, usitćc autrefois dans le mème lust.

L'embranchement des Arthropodes comprend trois séries, qui ont la valeur de sous-embranchements: les Acères on Allantennés, les Dicères ou Biantennés, et les Tétracères oll Quadriantennés. Ces derniers, caractérisés par la présence de deux paires d’antemes sur la têle, se composent des seuls Ćrustacés, divisés en Entomostracés ef Malacostracés. Le second sous-embranchement, dont les représentants ne sont pourvas que d'une paire l'antennes, reuferme deux classes : los Myriapodes et les Insectes. Enfu le premier groupe contient les Trilobites, les Hérostomatés, les Pycrogonides, et les Arachnides, qui ne portent point d'antennes sur leur tète. 
fer Sous-emliranchement, ou des Acères. - l'as l'autennes. II renleme pualue rlasses :

$1^{\circ}$ La rlasse des Triblites; dont le nombe des paires d'appendices varie suivant les genres, d dout le corps est divisé en trois lohes jar deux sjllons longitudinaux : d'où leur nour.

Q La classe des Mérostomatés; dont le nombre les paires d'appendices est égral à douze, du moins chez les représentants actuels du groupe. Cette rlasse n'est représentée, aujonrd'lui, que par m genre, le gemre Limulus.

:30 La classe les I'ycnogonides. Leur corps possèle seulement sept paires d'appendices.

$4^{\circ}$ La classe des Arachnides; caractérisée par la présence de six paires d'appendices sur le corps, dont les deux premières encadrent la bouche, et servent à la préhemsion des aliments.

ge Sous-emhranchement, ou les Dicères. - La lète porte deux antenues. Ce groupe contient deux classes:

$3^{\circ}$ La classe des Myriapodes; dont le nombre des paires dappendices varic suivant les genres, les segments du corps élant presque semblables.

$6^{\circ}$ La rlasse des Insecles, ou Hexapodes. Le chiffre des paires d'appendices est fixe, el égal à sept, donl une paire d'antennes, trois paires de pieces luccales, et trois paires de pattes locomotrices; cette derniere particularité est expromée par le terme "d'llexaporles ". Tous les segments du corps sont groupés en lrois régions dissemblables : une lète, mu thorax, et un abdomen.

3 Sous-embranchement, ou des Tètracères. - Ce groupe, caraclérisé jar la présence de quatre autonnes suj la lète, et désigné d’une. maniere comrante par le nom de Crustacés, renferme deux classes :

$7^{\circ}$ La classe des Entomostraces; dont le nombre des paires d'appendives varie suivant les genres, el dont les segments du corps sont d'ordinaire presque semblables, sauf ceux yui constiluent la tèle par leur réuniou.

$S^{\circ}$ La classe des Malacostracés. Ie nomlre des paires d'appendices est lixe, el égal a dix-neuf, abslraction faite les pédoncules oculaires, qui ne sonl pas des appendices rais. Ces membres se décomposent ainsi: deux paires d'anteunes, el dix-sept paires de pijces, dont les antéricures servent i la próluension des aliments, et les postérieures ì la locomotion. siuf les cas d'alrophie, qui sont rares, les chilfres des appareils masticaleurs el des locomoteurs diffirent d'un ordre à l'aulre, leur total Jounant toujours dix-sept paires. Norlinaire, les six derniers segments du rorps, yui portent les six dermieres paires de pattes, se groupent en un ildomen. 
11. Gènéralités sur le développement. - La reprouluction des Arthropodes s'effectue toujours prir le mode sexuel, mais se manifeste: parlois sans fécondation; les cas de parthénogenèse sont, "n eflet, très fréquents chez ces etres, surtout punr ce qui tient aux Eutomostracés el anx Insectes. II est bien entendu - comme, du reste, dans tous les développements parthénozénéliques - que ce procédé reproducteur se présente parmi les représentants d’une seute génération, on d’un petit nombre de générations successives, mais cède toujours la place, en un moment donné, à la lécondation; ajurès quoi, il intervient de nouveau, et détermine ainsi une alternance de générations par hítérogonie.

Les ovules contionnent, d'ordinaire, une funntité considéralıle de réserves nutritives; les couls pauves en deutolécilhe sont peu nombreux, el ne se trouvent guère que chez les tintomostracés. Les anfs riches en materiaux de réserve alimentaire apjpartioment an tyje centrolécille, qui est propre aux Arthropodes; ceci revient à dire que le blastoderme embryonnaire se dispose tout autour du vitellus, qui reste central, et l'enveloppe en entier, contrairement anx faits présentés par les autres animaux. La formation des feuillets ne s'effectue point d'après le procédé gastrulaire vrai. Le hlasloderme émel des éléments, qui péncitrent dans le vitellus central, et y engendrent le mésoderme avec l'endoderme; les premières ébauches le ces leux feuillets représentont le jrotendoderme, et sont mésenclymateuses. Les dépressions fonrnies par le blastoderme, el qui constituent des parties de l'inlestin, ne doivent point ètre considérées comme des cavités gastrulaires, car elles ne donnent ni l'entéron, ni l'endoderme; elles correspondent ì un stomeon el à un procteon, produits d'une manière précoce, et susceptibles d'acquérir. dans le corps, une grande extension.

Malgré la présence d'un vitellus mutritif abondant, les phases larvaires sont fréquentes, surtout chez les Crustacés et les Insectes; mais ces larves sont secondaires, du moins pour hes Insectes; et ce caractère est fort probable pour les Crustacés. Las emhryons libres, tout comme les adultes, reconvent lenr corps d'une cuticule chitineuse assez épaisse, et portent souvent des expransions, éfines ou aiguillons, lestinées ì disparailre; ils quittent, à mesure qu'ils s'accroissent, la cuticule qui les protège et les enserre, el s'en débarrassent is la manière d'un fourrean; ce phénomine, qui se répute un certain nombre de fois pendant la vie larvaire, et se retrouve chez l'adulte duranl l'agrandissement de son corps, a reçu le nom de mue. - Lorsque la jeune larve ahandonne son enveloppe ovulaire, clle est contonrie deja par une cuticule, qui s'oppose à son amplitication, rar ella lui comprose une sorte de gaine inerte; l'embryon est obligé de la quillar pur grandir, ef en reproduit une nouvelle anssitot après la chute de la jurmière; il se manileste par la un certain nombre de mues périouliques, qui séparent les phases les unes des autres. P'arfois, chez les Insectes notamment, ces mues, et surtont lit dernime, qui prépare te passage, de la larve iggée, à l'étal adulte, sont accompagruées d'une des- 
Luction les lissus: les éléments de ces derniers so desagrigunt, après quoi ils comslituent ì noureau les organes définilils : ce phémomine "st désigné par l'expression d'histolyse. Quant aux mues dos adultes, elles existent seulement dins le eas d'une longue durée vitale, el de la prósence dinne enticule épaisse, dite carapace; elles sont lries marquées chez les Cirustacés supérieurs appartenant à l'ordre des Décapodes.

Le tube digestif derive de trois ébauchos distinctes, qui se réunissent et se soudent. La premiere est l'entéron, yui donne l'intestiu mogen et le foie. Les deux autres sont le stomeon et le procteon, qui sallongent. beaucoup, et deviennenl souvent complexes; le premier fournit l’inteslin antéricur, le sccond l'inlestin postéricur. - 1 cause de la nature mésenchvmateuse du mésoderme, le colome est un polyculome, oryanisé en un apprareil circulatoire muni d'm casur, et dont les arliores ont des contours mieux limités, des trajels plus nets, fue les reines; chez les Arthropodes de grande taille, wn deuloculome s'élablit autour des principaux viscopes, mais lemeure souvent relié au reste du jolyculome par des roies directes, et contient, jar suite, du sang. - Les organes respuratoires dérivent, lantól de patles modifiées et lancllenses, tantöl de parties de pattes transformées dans le mème sens, et tanlòt de dépressions des léguments, qui affectrul, suivant les groupes, l'aspect de poches (poumons), ou de lubes ramifiés (trachees). - Les appareils excréteurs ne proviennent jamais ln mésoderme; ils sont produits par des lépressions ectodermiques, fournies, soit par les léguments, soit, et le plus souvent, par le procteon (lubes de Malpighi). - ( uant aux glandes scxuelles, elles naissent dans le feuillet moyen et à ses dépens, sams que leurs premieres ébauches soient indiquées, des la segmentation, sous l'élat diniliales; les oviductes et les canaux déféreuts, c'est-à-dire les zones des conduils sexuels qui se mettent directement en rapport avec les glandes, sont également d'origine mésodermique; mais toutes les autres régrous, pourvues de noms divers suivant leurs fonclions, uterns, cuntux ¿jaculateurs, elc., découlent de l'ectoderme.

Quant à l'hétérogonie, qui prèle souvent à des phénomines remarquables, elle porte seulement sur l’alternance des générations parthénogénétiques avec celles issues de la fécondation.

\section{\$2. - Sexualité et éléments sexuels.}

I. Sexualité. - Sous le rapport de la répartilion des sexes, la riggle, chez les Arthropodes, est l'mnisexnalité, liéc a la fécondation; celte rigrle soutfre cependant plnsienrs exceplions, présentées surtoul par les Crustacés, les lnseeles, et qui tiennent, soit a la parthénogenese, soit à l'hemuaphroditisme.

Crusluces. - Certains Eutomostraces, faisant partie do lordre des Plyglopodes, sont parllićnogénetiques; lels sont lat pilupart des Clado- 
cires, et certains Branchiopodes, comme les Artemia et les Apus. - Les femelles des clatocires produsent des un/s d'ele ch les wufs dhiver; comme lenr nom l'indipue, less premiers sont engendrés durant la belle saison, et se développent sans léconlation; ils sont plus pelils que les anlues, et plus paurres en vitellus nutritif. Les généralions parthénogónéliques se succident ainsi pemlant l'été, en ne lonnant jamais que des lemelles; sauf les súries qui apparaissent vers l'entrée de l'automne, et comportent la présence de mảles; les femelles de ces dirnieres lournissent alor's des unl's al'hiver, qui sont l'écondés, mais ne doivent éclore qu'au prinfomps suivant. Ces orufs passent l'hiver dans l'eau, protégés contre les intempéries par leur coque éjaisse, et par une portion dorsale lu test maternel, qui s'est lélachée pour les envelopper; cette dernière nembrane est nommée l'ẻphippium. - Les phénomènes offerts par les Branchioprodes sout semblables anx précédents; ils sont cependant moins réguliers, semble-t-il, en ce sens quc les malles, fort rares, n’aparaissent pas toujours durant l'automne; cette rareté des miles est telle, que la plupart d'entre eux ne sont comnus que depuis ces lerwieres années.

L'hermaphroditisme existe chez certains Entomoshacés appartenant ¿t l’ordre des Cirrhipèdes, el clıez plusieurs Malacostracés Edriophllahmes. - La faculté, chez les premiers, d’avoir les leux sexes, parait liée à la fixalion te lindividu sur des corps étrangers, qui empeche tout monvement, et nuit ainsi aux rapprochements fécondateurs; on la trouve surtout chez les Balanides et les Lépadides. Mais elle n'est pas constante; ainsi certains Scalpellides, lels que les Cryplophialus et les Alcippe, possèdent à la fois des individus hermaphrodites, et des femelles strictes; d'aulres Scalpellides, les Ima jar exemple, et aussi les Rhizocéphales, sonl bien hermaphrorlites, mais montrent en surplus les màles complémentaires, pelits, et capables de se déplacer, soit au moven de cils viluratiles, soit par l'entremise de pattes. - La plupart des Edriophthalmes ont une sorte d’hermapluroditisme atténué, qui consiste à linie dévelopyer des orules dans une part du testicule des miles, ou des spermatozoüles dans une zone de l'ovaire; mais ces éléments supplémentaires ne jarviennent point à matmité, le sorte jue les individus sont vraiment mâles ou femelles. Ce phénomène est plus accentué encore chez divers lsopodes, apjartenant a la famille les Cymothoüles; les individus commencent par ètre miles, fonctioment comme tels, et possedent trois pares de lesticnles; puis, ces organes s'atrophient en partie, les régions restantes se modifiant dans lenr structure pour se convertir en ovaires; lanimal est alors devenu mne femelte. Certains autres Isopodes, adaptós à une vie frasilaire, rangés lans les familles des Cryptomisciens et des lintonisciens, sont également hermaphrodites, mais possedent en sus, tout crommo les Cirrhipèdes déjà signalés, des màles complémentaires. (ijard et Bonnier, qui onl ifoconvert cette disposition, pensent fue les lesticules des indivilus lermaphrodites ne remplissent leur ròle que dmant la junnesse le ces leruiers; plus tard, les ovaires 
acquièrent une suprématie marqué, au point fuil est presque permis de considérr l'anjmal comme une femelle; les miles complimentaires servent, alors, a féconder les ovules engendrés par ces hermaphrodites aux orajres prépondérauls. Ces denx sortes d’ètres difléreut beaucoup par leur aspect, car les premiers conservent presque la formo habituelle des tsopodes normaux, alors que les scconds sont lrès modiliés par leur parasilisme.

Insectes. - L'hermaphrolitisme n'existe jamais chez les Insectes, mais, en revanche, la parlıénogenèse est assez fréquente; on l'a olsservíe notamment chez des llémiplères (ex. : Aplijłes), chez des Lépidoptries (ex. : Psyche, solenobia), chez des llynéuopteres (ex. : Cynipides). Elle est parfois accidentelle, et les Abeilles, ainsi que les antres IIýnénoplires vivant en suciélé, en offrent de fréquents exemples; dans ce cas particulier, les ovules parthénogénétiques niengendrent que des màles, phénomène désigné par Giard sous le nom d'arrénotokie; elle est égalenent accilentelle chez plusieurs Lépidoplères, tels que le Bombux mori, cerlains Pieris, etc. Partont ailleurs, elle est normale, ex existe d'habilade. dans les gémérations qui se succèdent durant la helle saison; elle abontil donc, loul comme il en est pour les Crustacés inférieurs, à faire distingoer entre des aeufs l'élé el des aufs l'hiver, les [uremier's étant capables d'évoluer sans aucune union préalable avec des éléments màles.

La parthénogenèse des Insectes est d'orlinaire le cas d'individus parvenus a l'élat adulte, on ne différant de cel élat que frar des praticalarités secondaires, comme l'absence t'ailes. Une lelle privation de ces organes locomotemrs ne doil point, sans doute, ctre prise comme un fait lonnant, a l'individu qui la possede, le caraclioe de larve, car on la rencoutre chez d'autres représentanls de la classe, ou elle parait lice au made de rie, el surtout au parasitisme; il conrient, par suite, de lai accorter la mème signification dans le ras des femelles parthénogénéliques dépourrues d'ailes, car précisément ces lemelles halitent en parasiles sur des végétaux. - La genese, par des larves véribables, d'ovutes susceplibles de se développer, c’est-it-dire la pédogenése, est fort rare; on ne l'a signalée que chez certains lliptères appartenant anx genres Cecidomya (Miaslor), et Chironomus.

Un pliénomine remarquable est offert par les lusectes vivant en societé : les Formicides, les Apiles, les Vespides, parmi les IIyménoptirres; les Termitides parmi les l'sendonévopteres. Les fonclions reproductrices sont le propre de plusiears individus, dont certains sont miles ou femelles, et nappartiennent yu’a eux seuls; les autres, souvent les phus nomlueux, onl leurs organes géulaux atrophisis, et ne possedent pas de fonctions antres, que l'accomplissement des travaux nécessitís par la vie sociale. Ces derniers sont originellement des femelles, dont les ovaires ne se déreloppent pas, les glandes annexies aux combits sexuels rlant parfois converties en appareils vemimenx (Apides of les- 
fiiles); on les nomme géméralement des Veutres, et, d'une manic̀re plus

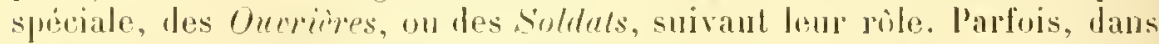
rhacune de ces soriélés, et les llueilles ollient de ce fait un excellent exemple, il n'existe qu une lemelle, la reine, seule chargte de produre les aufs; les prenicis ovules, pondus par elle, évoluent sans ètre lécondés, ol doment les nales, les F'aux-bourdons" ceux-ci imprigrnent ensuite de leur sprome les orules foumis en dernier lieu, qui engenJrent alors des femelles; ces derniores, snivant la nouriture yui leur est apportéc, évoluent en femclles completes, ou en neulres.

II. Eléments sexuels. - Les spermatozoüdes de la plupart des Cruslacés sont remaryuables, en ce qu’ils possident une quantilé assez gramde de substance plasmique; loin d'ètre presyue róduits à leur noyau, ou à la vésicule fü l’emplace ce dernjer, el combairement à ce qửil en 'st d'habilule pour les autres animax, leur protoplasme est abondant. Calni-ci smel des expansions semblables a des fonels, qui servent a l'élément pour se déplacer, el dont le nombre, comme la situation, varient suivanl les espèces. Ainsi, les spermatozö̈des de l'lecrevisse sout arondis, et chacun d'ux porte nn nombre considérable de fouets qui rayonnent aulour de lui; reux du Homad, munis senlemenl de lrois ou quatre de ces appendices, sont cylindriques; entin, ceux de la langouste, spliériques, ont deux fouets divergents. Ces exemples suffisent pour donner unc idéc de la diversité d'aspeet ollerte par ces cellules sexuelles.

Les spermatozoïles des autres Arlhropodes, el surtoul ceux des tusectes, se rapprochent davantage de la forme habituelle; leur lête, souvent fort mince, porte nne lomgue puene choite ell llexible. P'arfois, la lete est pourvor, sur sa puinte antérieme, de denx petiles liges comparaliles à les crochets.

La spermatogenèse des Arlhropodes a prèté, durant ces dernières annés, à un grand nombre de travaux; les plus récentes, el les plus completes, de ces éludes, sont dues it $\Lambda$. Salıatier. Li's remaryuables recherches de rob auten lraitent, du moins celles pulices en entier juspüici, des Crustarés Déaporles. - Lorsque les testicules de ces èlres sumt encore a l'état le repus, ils se comprosent d'un assemblage de lubes remx, dont la paroi est constitué par un tissu conjonclil; relui-ci renforme des ecllules, houl les unes sont plongées dans son épaissenr, et lont les antres sarrangent en wne conche endolliéliale, qui limile la cavilé du lubr. Ces édanents se multiplient, des le débul de l'activité sexulle; ol lem prolifuration a pour resultal d'engendrer des masses proloplasmiques semées de noyaux, vérilalıles phasmodes nuclés. Ces

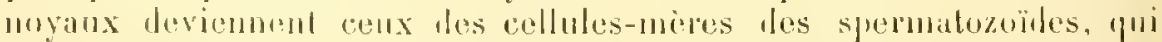

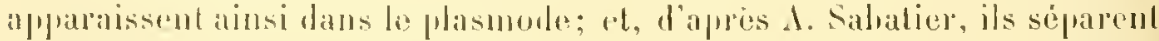
de lemo sulsilace, au préalable, mue certaine yuantité de matiere plas-

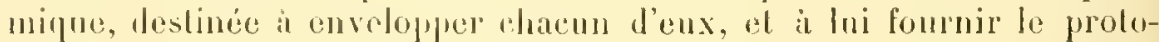
plasme qui le convertil en une cellule complete; par contre, suivant 
Grobben et Gilson, les noyaux cunservent len intégritr. ot le protoplasme de la cellule dérive linne partie le celui du plasmonle. Las élimentsmères, les spermoblastes, ainsi changés en cellules entières, se mulliplient it leur tour, soit d’après le procédé direct, soit l'apues le morle indirect, celui-ci étant le plus frépuent, et donnent parlà les spermatozoüles. - En conséquence, ces derniers, à leur délunt, sont des cellnlos a la structure normale, pourves d'un noyau et dun protoplasme; ils subissent ensuite, à mesure qu'ils approchent de leur maturité, des modifirations importantes, dont le hut est le rabougrissement, parfois mème l'atrophie complète, du noyan. Chez les Cariles (Palémons), cet élément leneure cncore, mais après avoir perdu une grande partie de sa nucléine. La llimimution du noyau est plus prononcée, en ce qui concerne les autres Décaporles, et se complique jar la genèse d'une vésicule particulière, qui se sulsstitue au corps nucléaire, pour conslituer la majenre part du spermatozoïde. Cetle vésicule nait dans le protoplasme, lout près du noyan; elle samplifie, pendant que celni-ci se rédnit; sa proi contient des grains chromatiques, dont la plupart se disposent en une calotte, et suvant un diamètre; la premicre est somvent dite la téte du spermatozoide, a cause de ses grandes dimensions, et le second est nommé la tigelle.

Des changements semblables, ayant également pour objet la destruction du noyan, et l'apparition d'une vésicule, qui prend sa place, ont été signalés chez des Insectes de phusieurs ordres. Il est encore impossible de se prononcer sur la signification exacte de ces plénomènes. II faudrait, pour se renseigner à cet igard, connaitre le début de ces transformations, en le cherchant parmi les Crustacés inférieurs, et savoir le rơle jonć par la vésicule dans la fécondalion. Ét c’est préciśrment sur ces deux points que la science actuelle est a pen près muctte. Cipendant, le fait que les l'alémons, c’est-à-dire les plus simples des Déraprodes étudiés juspüici, sont privés le la vésicule possedée par les autres dans leurs spermatozoüles, tendrait a montrer qüil s'agit, en cela, de modifications lucalisées, d'une valeur relativemeut seconlaire, ot lićes pent-ètre anx procédés suivant lesquels saccomplissent la copulation et la fécondation.

Le développement des ovules se manifeste, chez tons les Irthroporles, l'aprés les mèmes procédés fondamentaux. Les jennes ovaires sont constitués par des groupes l'ovoblastes, rangés de manières différentes suivint les types. Chanue ovolilaste se divise un certain nombre le fois pour probluire un ovogenme, dont les éléments sont d'abord toms semhaliles, on peu sen fant; puis, un senl de ces elrmonts grossit pun se romvertir en ovocyte, ot en ovule; les autres se roluisent a mesure, ot

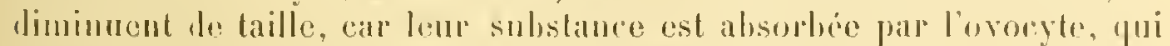

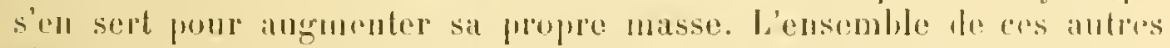

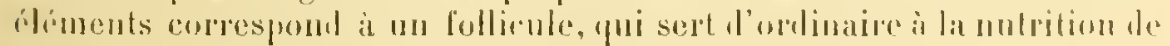
l'urveyte entoné par lui, et disparait plus on moins tót. 
Ce phénomène offre. chez les lusectes. quelques caractères partirulirrs. les ovines le cos animaux somt formós de tubes rlimbiques, qui s'ourrent dans loviducte; les extrémilós listates de ees derniers portent les ovolulastes. Ceux-ci se segmentent, el produisent les orogemmes, qui s'arancent dans le lube amyuel ils appartiennent, et eela a mesure qu ils évoluent, car les premiers engendrés sonl poussús par les autres plus jeunes. Legroujement. des cellules de l'orogemme, en ovocyte é éléments folliculaires. soffectue lurant celle progression; la cellule la phis interne le chaque orogrmme, qui est placée lans l'axe mène du cylindre, devient l'ovocyle, et ses voisines se groupent autom d'elle pour donner le

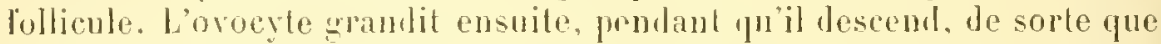
les aufs les plus gros sont les plus áloignes de lextrémité libre du tube. Les éments du follimble presistent durant un temps assez longr. autour de l'ovule, chez divers lusectes, les Orlhoplines par exemple, les libellules; dans la plupart des autres cas, frur nombre est assez grand pour leur lermeltre le fournir, et un follicule duralile, el un amas de cellules nutritives destinées ì ètre absorbées par l'ovocyte, dont elles servent a accroitre la masse.

\section{$\$ 3$. - Segmentation et feuillets blastodermiques.}

1. Segmentation. - Les ovules des Arthropodes sont remarquables ('n ce qußils contiement, dans l’immense majorité des cas, un deutolécithe abondant; aussi les développements sont-ils presque loujours planulaires, sauf coux de divers Crustacís Entonostracés, tels que les Mö̈na, les Ćelochilus, qui montrent des hlastules; encore ces dernieres ne possèdent-elles qu'une éluoite cavité hlastoculienne. De plus, be vitellus untritif s'amasse, durant la segmentalion, dans la région centrale de l'ovule, de manière à se laisser entourer par le blastolécilhe; ce dernier se partage en cellules, forme ansi le blastoderme, et enveloppe le deutolérithe, qui se trouve constituor une réserve vilelline interne: d'où le nom, déju signalé, de centrolecithes donní i ces ovmles. La vésirule vilclline, au lieu d'ètre juxlaposée au corps de l'embryon, est placée dans son intériem.

Cette disposition remarquable se complique par un mode particulier de segmentalion. La division ovulaire s'effectue souvent de telle façon, que les blastomeres, an licu l'ètre arrondis, sont coniques, el font converger leurs sommets vers le centre de lovule; ils ressemblent i antant de bitomels, rayonnants autour de ce point central. luis, dans "hacun dleux, le noyau se porte, avec le blastolécilhe, vers la base du cône, qui est en deliors puistue le sommet est au contre, et une division se manifeste, pui scinde le sogmont en lenx parties : l'me externe, composée par le blastolécille el renfermant le noyau; laule interne, multement nucléés, constiture par le vitellus nulitif. - Ce procédr. assez fréquent chez les Cruslacés, se modifie lorsque le nomble des 
novaux est trop grand pour que tous soient capables te parvenil dans les zones extérieures des blastomères; ceux laissés inlérieurs sonl iulaul de corps, aulour desquels se délimitent des cellules, cl les segrments de l'orule, au lieu d'être coniques, sont polygonaux. Ce pliénomìne s'elforlue comme si chaque blastomère conique du premier mode renail à renfermer plusieurs noyaux, el se partageait en fragments superposés correspondant á ces noyaux; ces fragments ayant un contour polyédrique, la disposilion conipue cesserait d'exister, pour meltre en sa place un groupement polygonal. Ce dernier procédé a élé rencontré chez łpuelques Myriapodes.

Le vilellus enlier se segmente dans les cas précedents, el la division est lotale : l'uuf est lolohlastique. - Mais, si la quantilé du deutolécilhe
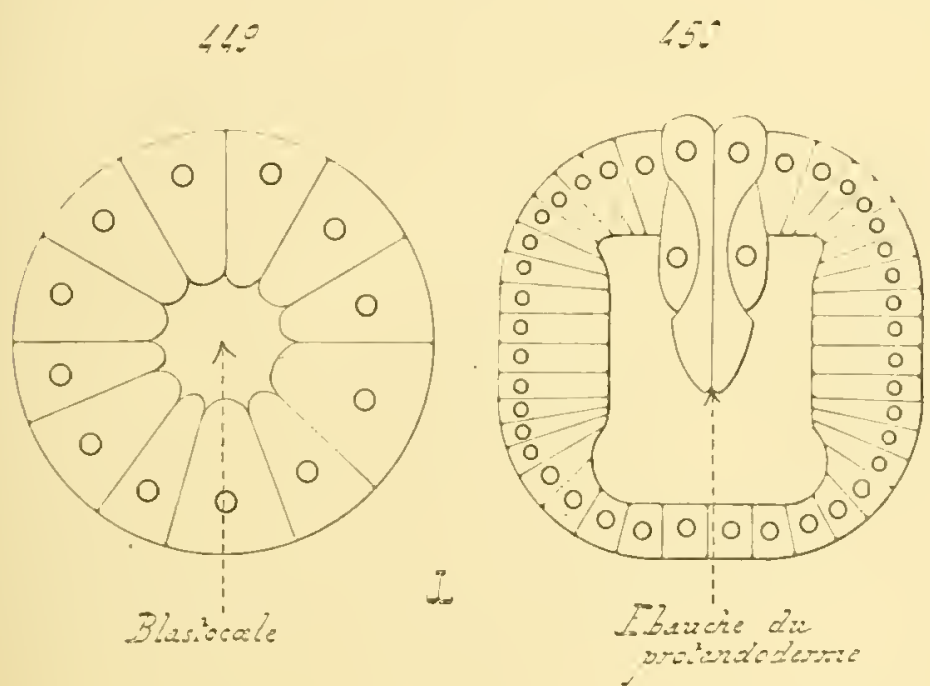

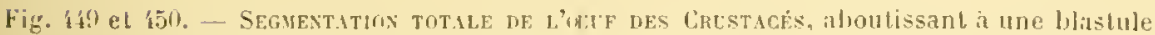
(roupes meditines, demi-dingrammatiques; d'apres Groblen sur le f'etochilus septentrionalis). - En 499, jeune blastule. - Ln 60, hlastule plus igic, dont plusieurs blastomères se multiplient pour engendrer le protendoderme. Cetle plase est considérée, à tort, comme répondant a une gastrulation modilice; vlle ne dillìe, de sa similaire des plamules centrolécilhes des autres Arthropodes, fue par labsence de vitelhus nutritif dans la cavité pue limit. le blistoderne.

est très considérable, l'ovole devient méroblastique, et son vitellus évolulif se scinde seul, pour engendrer to blastoderme; la nature de celle division varie suivant quelte provient de l'un ou de l'aulre des denx cals pricedents. S’il s’agil des Crustacés on des Arachnides, donl la segmen-

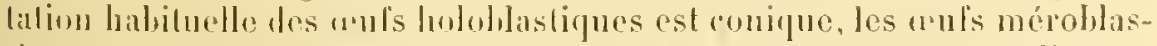
tipues portent une cicatrirule, qui, apres lis lécontation, grandil lout en se parlageant en cellules, el s'étend antonr du dentolécithe jusqu’i l'envelopper complètement. Les phénomènes sont dilférents pour' cequi 
est des Insectes; il n'existe aucune cicatricule; le novan fécondé se divise, dars l'interieur de l'ovule, en um rertain nomlro de fragments, qui s'entourent de blastolúcithe, el domnent ainsi des rellules complètes. Celles-ci se déplacent vers la périphérie de l'ovule. s'y élalent, el ne tardent pas à composer une conche complate : le hlastoderme.

Crustaces Extonostuaces. - Les ovules de ces animanx conliennent, en général, une moins grande quantilí de vilellus nutrilif que ceux des Malacostrarés; aussi, dans certains cas, fort rares cependant, la segmentation aloutit-rle i me lilastule. Tels sont les Jöna parmi les Cladorères, et les Celochilus parmi les Copéporles. La division est totale, quelque pen incugale cependaut, et donne une lolastule aux volumineux bléments blastolermiques, qui restreiguent de lieaucoup l'espare occupé par le blastocole; ces éléments ont la forme d'un trone de còne. - Si l'on aupuose que le dentolécille soit plus abondant, de manière ì augmenter le volume le ces cellules jusqu ì los faile ariver an centre de la blastule, en supprimant toute cavile blastocolienne, ce mode de segmentation sera converli en un second procésle, qui fournira une planule; les blastomères de celle dernière, venant tous converger au centre de l'embryou, et s'effilant à mesure, auront un aspect ronique. Cette disposilion, yưil est aisé de déduive de la précédente par l’augmentation de la masse du deutolécilhe, et qui est fréquente chez les llalacostracés, se trouve chez divers Copépodes libres; lovule fouruit, en se segmentant entierement, une planule, dout les blastomeres coniques šrradient autour du centre. Entỉn, si la quanlité du vitellus nutritif est plus grande encore, comme il en est pour la plupart des Ciurhipèdes et rles Copréporles parasiles, l'ovule derient mérohlastique: le vitellus évolutil constitue une cicatricule, qui se segmente seule, et enveloppe peu ì peu le deutolécithe, afin ule produire le blastoderme.

Ces deux derniers procélés existent également chez les Malacostracés, où ils ont été mioux étudiés.

Crustacis Malacostraces. - Les ovules des Malacostracés ahoutissent a mo planule par leur segmentation: seulement colle-ci s'accomplit suivant deux modes. 'lantót elle est tolale. et l'ouf ne porte ancune ricalricule; lantôt ello est particlle, et la majoure flarl du hlastolérille se rassemlile en un petit amas cicatriculaile, qui contient le noyau fécondé. I)ans le premier cas, les ovules sont holoblastiques, et múroblastipues dans le second; la répartilion de ces denx procédés n’est nullement en rapport avec la classilication maturelle du groupe.

A. - I al seymentation tolale existe chez prespue tous les Décapoules, romme l'licurevisse (Astueus), qui est somvent donnée comme exemple, et dirers Elriophthalmes, notamment la plupart des Amphipodes, et beauroup d'lsoporles, tels pue les Asellus. - Le deutolécithe de lovile est I'abori intimement mélangé an vitellus civolutif; aussi la segmentation 
atteint-elle limuf entier. Elle est parfois égale. parfois inégrale, mais s'effectue de telle manière que les plans de division soient loujours dirigés suivant les rayons de l'ovule. Ainsi, l'oruf fécondé se converlit en une planule, dont les blastomères sont orientés suivant ces rayons; les cellules sont coniques, leurs sommets ahoutissent an centre de la planule, et leurs bases occupent sa périphéric. - Chaque błastomere contient un noyau; celui-ci se déplace, gagne la zone externe de l'élément auquel il appartient, accompagné en cela par le hastolócithe. Bientôt, le blastomère est divisé en deux parts : l'une interne, non nuclééc, et composée par le vitellus nutritif; l'autre externe, nucléé, et forméc par le vitellus évolutil. Ces deux parties se séparent l'une de l’autre par une membrane, et l'élément primitif se trouve scinlé mu denx cellules, l'une périphérique, et l'autre centrale. - Ces phénomènes se produisent lans tous les blastomères; le résultat est un partag̨e de la planule en deux couches, dont l'une enveloppe l'antre; la première, ou enveloppante, se compose des cellules jériphériques munies de noyaux; la seconde, ou centrale, ue comprend que les zones internes, coustituées seulement par des réserves nutritives. L’assise extérieure est le blastoderme, qui va proliférer pour donner les leuillets, les tissus et les organes. La conche interne n'a d'autres fonctions que de fournir, à la précédente, les matériaux alimentaires qui lui sont utiles; ses parlies intégrantes se fusioment par places, se divisent ailleurs en petits fragments polygonaux, mais nen composent pas moins une vésicule vitelline, privée de noyanx, et incapable par là de joner un rôle diject dans la genèse des cellules cmluronmaires.

La délimitation du blasloderme, aux ilépens des lilastomères coniques, ne se manifeste pas toujours de la même façou. Les Décapodes paraissent offrir en cela un mode rapide, car tous les segments se divisent presque eu mème temps, pour produire leur cellule externe nuclééc el leur amas vitellin interne; les différences, eutre ces animaux, tiennent plutôt au chiffre des segments engendrés, et à leur netteté phs ou moins grande. Les blastomèes les planules d'Ecrevisse, par exemple, sont nombreux et hien listincts; par contre, leurs correspoudants des Eupagurus sont phus gros, moins aboudants par suite el unis par lenrs extrémitós internes. La division ne pénètre fras, ulans de dernier cas, jusqu'au centre mème de l'ovule; l'influence. qui tend i fusionner en uue seule masse les réserves vitellines, se laisse déjà pressentir. - Chez certains Erriophthahmes, tels que les Asellus, la

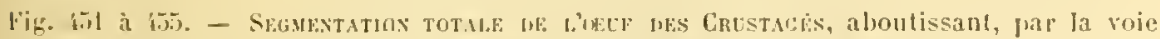
directe, á une planule centrolecille (coupes mélianes el contour ertérieur, d'apres l'Asetlus aqualicus). En 4.j, dèbut de la segmentation totale, el rałonnante. - En fit?, sule de cette segmentation. - En fis3, le vitellus evolutif, indique pas un printille, so: porle. aver les noyaux, a la peripherie de l'aruf; cetle separation, entre les lenx vilellus.

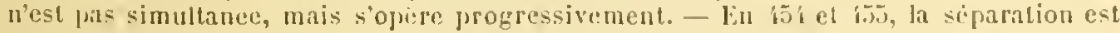
presque achevé; le vilellus évolulif s'est eonurè en pelites vellules, gui composent le

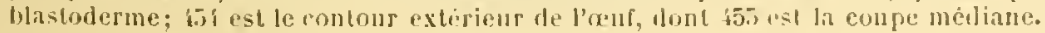



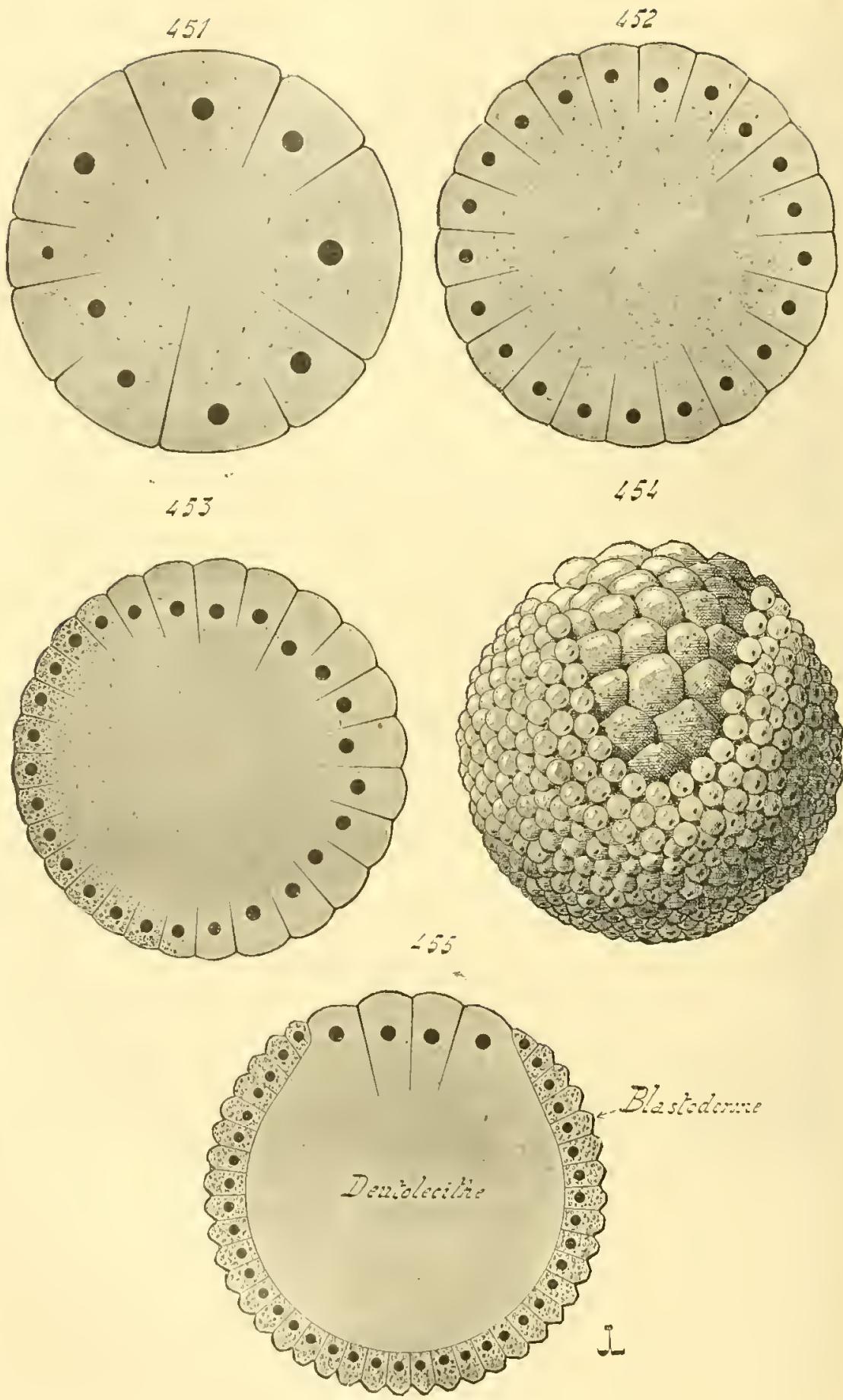
délimilation du hastodeme ne s'effectue pas partout en mène temps;

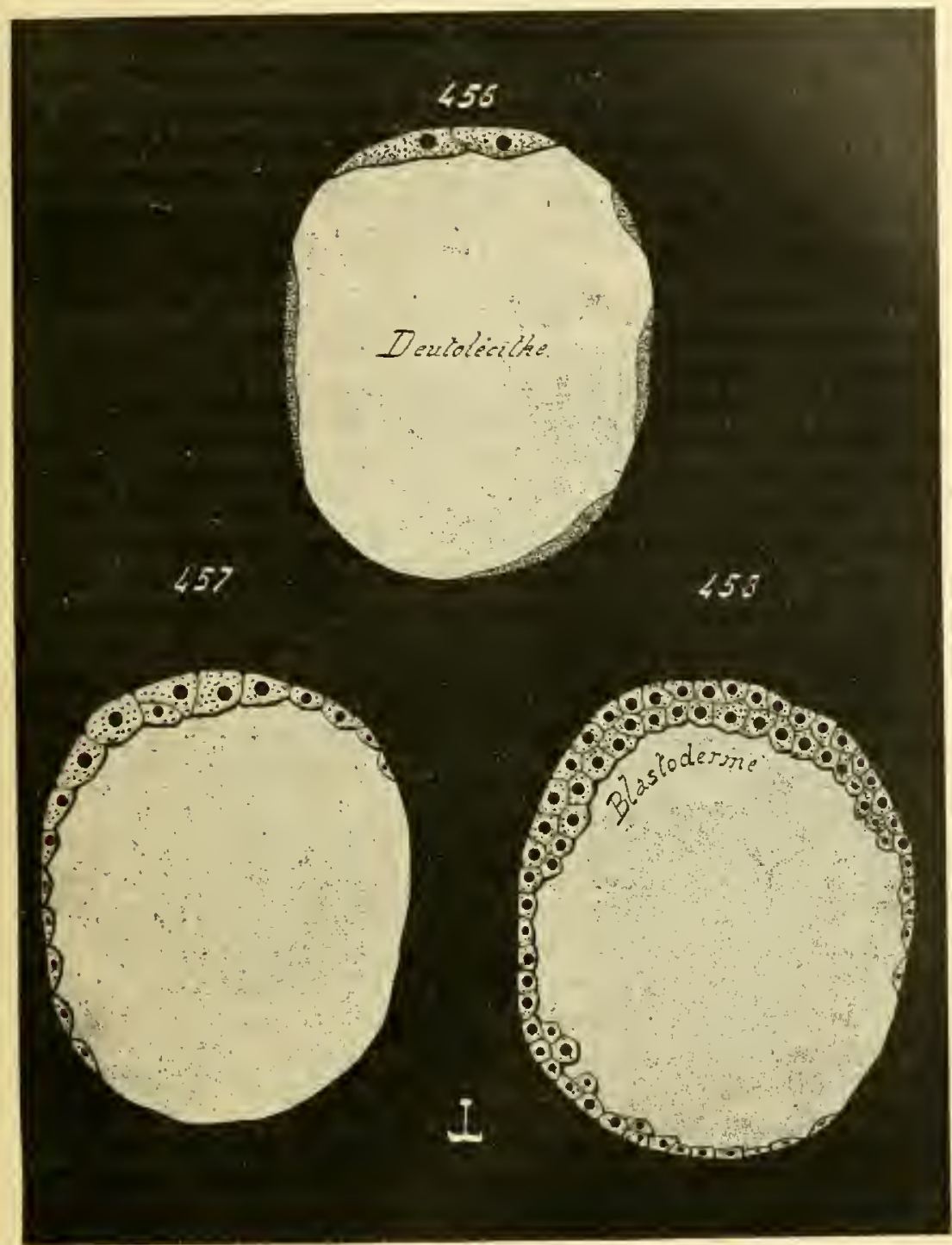

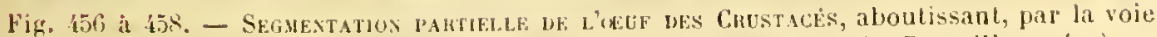
indirecte, à une planule centrolecithe (coupes médianes, d'apres le Porcellio scaber). lin $65 f$, délout de la segnentation; le latut de la figure porte la cicatricule, scindée en deux blastomieres; la majeure partie de l'ueul consiste en un deutolécille, unui ne se segmente pas, et se recouvre, nar places, d'ilots de vitellus évolutif, dont le plus volumineux est la cicatricule. - Vil 457 , suite dr. la segmentation; le blastolécithe priphivique se concrète en cellules, qui enveloppent progressivement le deutotioithe. - lin 4is. ces cellules externes composent le blastoderme, et ont entourc deja le deutolecithe presque enties.

Roule, - Emhrologie. 
elle commence dans une région déterminée de la planule, qui correspond a la place ou doit se façonner la tète de l'individu, et s'étend peu à peu antour de l'embryon, en gagnant plus vite sur la face ventrale yue sur la face dorsale. Cette région, ou débute la délimitation, correspond à la cicatricule des cenfs méroblastiques; on n’a qu’à supposer l'absence, dans les ovules des 4 sellus, de la segmentation rayonnante, pour obtenir un cuf, dont me zone s'accroit senle afin de produire le blastoderme, c'est-à-dire un ouf muni d'une cicatricule, celle-ci étant seule chargée de donner les éléments blastodermiques.

B. - Les ovules méroblastiques sont plus rares que les autres; les exemples les mieux connus sont fournis par certains Edriophthalmes appartenant à l'ordre des Isopodes, comme les Oniscus, les Porcellio, les Cymothoa. Chaque ovule porte une petite cicatricule dans la région oir s'ćbauchera la lète, et, par suite, dans une situation semblable à celle montrée par la zone oú délute le blastorlerme des Asellus. La cicatricule contient seule le noyau fécondé; toutes les autres portions de l'uuf sont entièrement privées de corps nucléaires, et constituées seulement par du vitellus nutritif; elles ne prennent aucune part directe à la genèse des cellules qui édifient l'organisme embryonnaire, car ces dernières proviennent sans exception de la cicatricule. Celle-ci se segmente, el s'étend à mesure autour de l'ovule, on plutôt dı volumineux amas nutritif qui compose la plus grante partie de celui-ci; la planulation est donc indirecte, puisque le biastolécithe entoure pen à peu le deutolécithe; et, comme tonjours lans ce cas, cetle extension s'effectue, non par les propres forces te la cicatricule seule, mais par l'emprunt constant de vitellus érolutif a la réserve nutritive. Toul le blastolécithe de l'ovule n'est point employé à composer la cicatricule; celui qui reste, et ‘ui est mélangé au deutoléeithe, se sépare peu ì peu de ce dernier, en s'adjoignant aux bords de cette cicatricule; et, comme cette séparation ne se fait pas prartout en mème temps, mais progresse d'une extrémité à l'autre de l'auf, il semble que la cicatricule s'élend avec régularité autour du vitelhs nutritif pour l'environner.

Lorsque ce phénomène est achevé, l'amas deutolécithique est enveloppé par une couche cellulaire, dont l'origine première se rapporte à la cicatricule; cetle couche est le hlastoderme. Bien que la segmentation ait élé partielle el non totale, lien que le vilellus nutritif ne se divise pas, le résultat est done semblalle a celui jue donnent les ovules holoblastiques : le lolastoderme est représenté par une assise de cellules, qui entoure complètement une vésicule vitelline compracte, et interne. De ce l.lastoterme, et de lui seul, proviennent les feuillets et les organes; la vésicnle sert à nourrir l'embryon durant cette genèse.

Ménostomates, Prenogonibes, diacunides. - La segmentation des ovules de ces animaux s'effectue comme chez les Crustacés, et ahoutit de mème a des planules, dont le blastorlerme est jériphérique, et dont la vési- 
cule vitelline se trouve centrale. Les variations, déja signalées pour les Crustacés, et découlant de labondance jus on moins grande du deutulécithe, existent également clıez ces ètres. D’une manicre grénérale, les wufs sout holoblastiques; cerlains cependant, ceux des Scorpions par exemple, et sans doute aussi ceuxides Limules, sont méroblastiques.

Les procédés les plus simples sont offerts, d’après les études de Mor'gan, frar les Prenogonides, el aussi par certains Arachnides de petile taille, comme les Psculo-seopionides el les Acariens. La segmentation est lotale; cllo divise l'auf en un certain nombre de voluminemx blastomères coniques; chacun de ces derniers se partage ensuile en deux parties, l'une externe nuelééc, et l'autre inlerne constiluée par le seul vilellus mutritif. Toutes les zones internes ales blastomeres se fusionmont pour lonner la vésicule vitulline centrale. Par contre, les zones externes demenrent distincles, et continuent it se scindor; elles fonrnissent ainsi une assise cellulaire, qui enveloppe l'amas vitellin, et conslitue le blastoderme.

Des faits semblables se manifestent chez les Aranéides; seulement les ovules ćtant plus gros, leurs blastomeres sont plus nombreux, plus allongés, el leur forme conique se tronve mieux accentuée. Parfois, s il faut en juger d'apres l's ohservations de H. Ludwig sur les Philodromus limbutus, Jorientation ravonnée se dessine, dans le vitellus, avant loute segmentation préalable. Puis, le noyau fécondé se divise, cntrainant la bijarlition de l'orule entier; ces deux hlastoméres se seindent à leur tour suivant leurs rayous; el ainsi de suite, jusqu’à ce que l'ucuf soit pragé en nombreux blastomères coniques, šrradiant autonr d'un mème cenlre. Les phénomenes déji connus se manifestent alors, car le novau et le blastolécithe de chaque blastomère se portent à la périphérie de ce dernier; ce momvement a pour effet de diviser les segments coniques en deux parties, l'une exlerme nucléce, l'autre interne privée de noyau, el composée de vilellus nutritif. liensemhle des zones externes envelojpe celui des antres; ces dernières se fusionnent pour donner la vésicule vitelline centrale; les premières restent séparées, conlinuent à se diviser, el façonnent une assise périphérique, qui est le l,astoderme. - Le mode employé est lonc semblable, en tout, il celui présenté par les ovules holoblasliques des Crustacés; il demcure cependant plusicurs noyux plongés dans la masse vilelline, el qui serviront plus lard a produire une part des feuillets. - l'arfois, celle masse se partage cu gros segments polvedriques, et ce fait existe igalement dez les Crustacés. Les auleurs inclinent à considérer ees segments comme des cellules; leur privalion de noyans, sauf lans le cas oi plusieurs de ces corps rustent internes, ot leur utilisution comme réserves nulritives, empechent llacrepter nue parpille opinion.

La segmentation est partielle, el les mvales sont méroblastingus, elhez les Scorpioniles et, semble-t-il anssi, chez les Jérostomatés; la marohe des phénomenes esl enlierencut comparalule i celle presentee par les 
ovales semblables de certains Crustaces. Lionf porte une cicatricule, qui se uivise senle cu cellules, et porluit le hlastoderme; celui-ci s'úlale. pen à peu à la surlace du vitellus untritif, et linit par l'envelopperentièrement. De mème encore qur chez les Crustacés, cette progression du blastoderme est lente, assez lente pour que les premières régious engendríes s"épaississeıt, pendant qu elle s'effectue, et donnent les feuillets embryonnaires sous la forme de plusicurs assises cellulares superposées.

Mrnapodes et Insbetes. - L’abondance du vilellus nutritif est telle, dans l'ovule de ces animaux, que la segmentation est partielle, el üin-

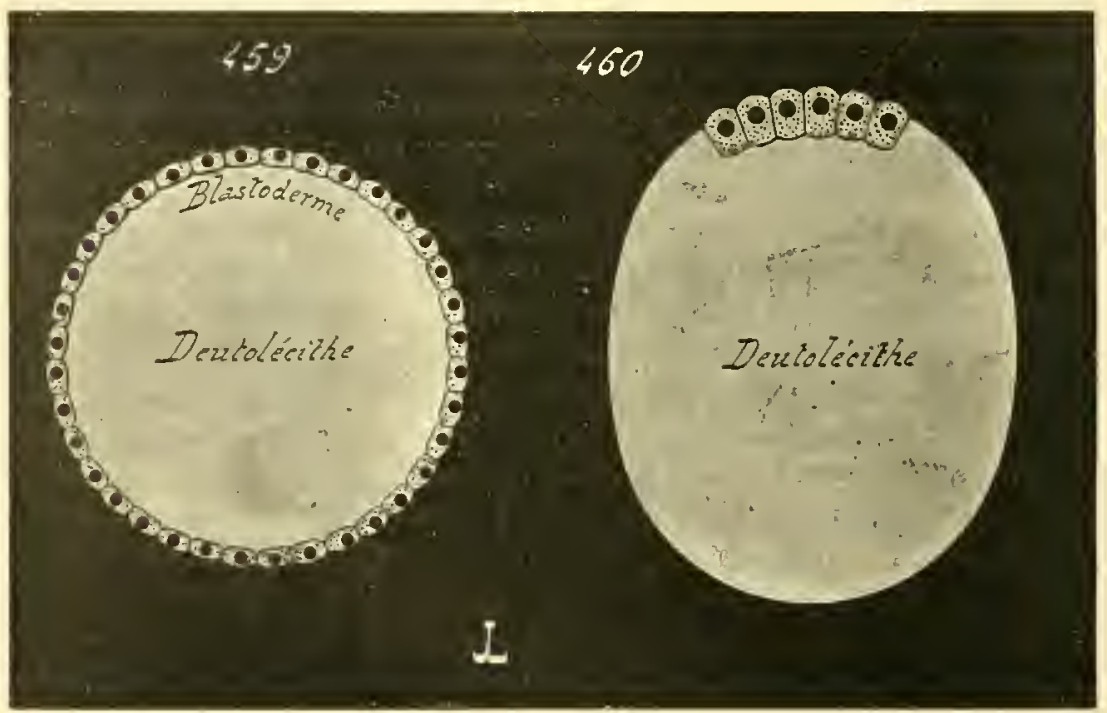

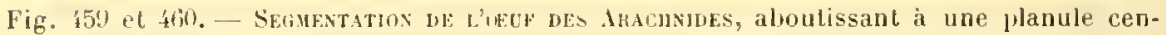
trolecithe (coupes médianes). - En 459, tin de la segmentation chez une Lycosa; cette segmentation est lotale, s'efteclue eumme celle des figures 451 à 455 , et conduit an même resultat. - En $4 \%$, lébul d'une segmentation partielle, semblable à celle les figurcs 456 a f5s: chez los scomiunides, d'apries les recherches failes par Netschnikoll.

lér'rss: en rien le dentolécilhe; seulement, il n'existe point de cicatricule, comprable i celle des ovules méroblastiques de certains Mrachnides el Cirustacés. Le blastolécithe est répamlu presque également dans tont le protoplasme ovulaire, et s'amasse autour des corps nucléaires qui provienment de la division du noyau fécondé; lous les noyaux-filles s'entourent ainsi d'une conche plasmique, el émigrent ensuite vers la périphérie de l'ovule; ils s'y rassemblent en une assise, qui est le blastoderme. Le hut atteint est donc semblable à celui que présentent les antres Arthropodes; la segmentation aboutit a la genèse d"un blastodrome, qui enveloppe me vésicule vitelline interne; mais cetle segmentation n'est pas holoblastique. 
Ine seule exception à celte règle est offerte par divers Mrriapodes, appartenant it lordre des Chilognathes. leur division ovulaire, tolale, rappelle celle de divers Arachniles, tels que les Acariens, les l'semloscorpionides, el celle de laplupart des lyenogonides. lianf se segmente

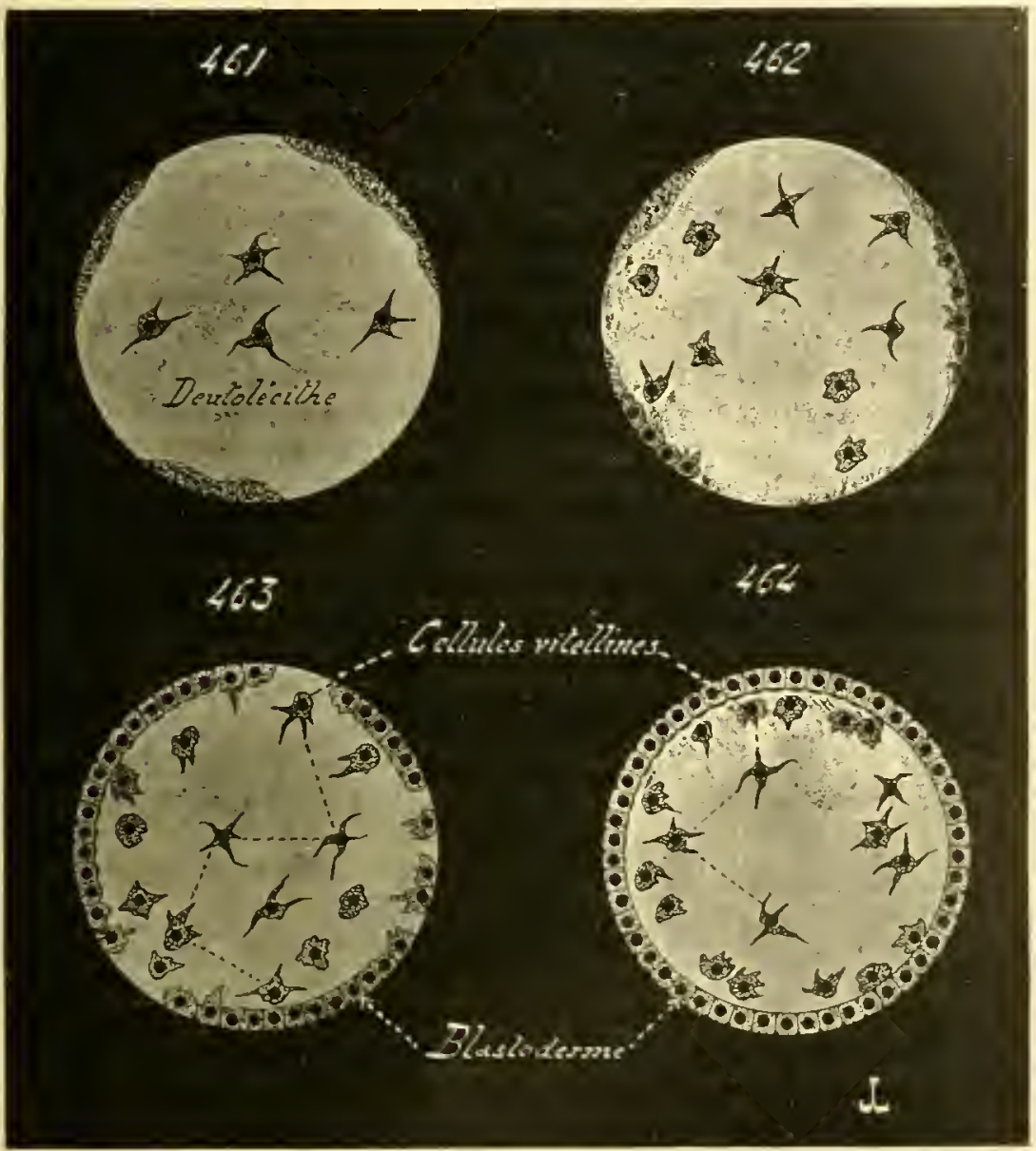

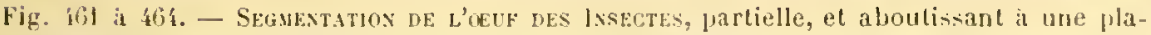
nule centroleithe (eoupes médianes, et demi-diayrammatiques, en ce sens que les cellules sont plus grosses et moins nomlireuses que dans la nature). - En fol, delut de la seguentation; quelques ilots de blastoléeithe sont épars à la surface du vitellus nutritif, qui constitue, de beauroup, la majeure partie de l'üuf, et les premiores cellules lu Wastoderme prennent naissance. - lin 402 , les ètements hastodermiulues augmentent. en nombre, et se portent à la periplierie le l'ovule, oi ils fouruisent des noyaux aux ilots de liastolècithe; ceux-ci se concrètent igalement en cellules. - En ic3, suite le relle segmentation, et de cette migration vers l'extérieur. - En 46i, fin de la segmentalion; lous les elements cellulaires composent un blastulerme pxtem" colorent, "l un lastodirme interne dissocie: celui-ci est cunstitue frar les cellules qui doul pu truver le la place: a la surfice le liauf. 
en quelques volumineux blastomères; les noyaux de ces lerniers, an lieu de rester internes, se portent vers la jériphérie, accompagnés par le lilastolécilhe; charpe blastomere se livise aiusi an denx zones, l'mne inlrome, qui composera la vésicule vilelline en se confounlaul aree ses voisines, et l'antre extírieure, nuclée, qui se partagera, et constitnera aree ses similaires la conclıe blastorlermique.

Les aufs des autres Myriapodes el cenx des lnsectes sout méroblastiques; leur dentolécithr ne se segmente jamais. Après la fécondation, le noyau, quii est situé dans l'intérienr de l'ovmle, se partage en fragmenls, qui se scindent ì lomr tour, et re phénomène continue ì s'eltectuer. lendant quil se manifeste, les éléments mucléaires se rapprochent de la périphérie de l'urul', el chacun d'eux s'entoure d'une auréole de blastolécithe, quil emprunte an vitellus voisin; ces denx monvements connexes ont prour effot de disposer, sur le pourtour de l'orule, des corps complexes, dont chacun est conslitué prar une masse proloplasmique pourve d'un noyau, et correspont par conséquent it une vraie cellule. Ces corps cellulaires donnent naissance au lilastoderme; ils se divisent avec rapidité, el ne tardent pas ì prodnire mne assise, qui entonre completement le vitellus. La segnenlation est alors achevée; clle a converti l'ovule en une planule, composée d'un hlasloderme extérieur, enveJoppant une vísicule vitelline interne. - Diverses morlifications i ce procédé ont été signalées par plusieurs autenrs; elles ne portent point. sur les phénomenes essentiols, mais sur le nombre des noyaux formés en prenier lien, el sur la rapidité te leur transport vers la périphérie.

Les noyaux ne viennent pas tous se placer à la surface de l'uruf; plusirurs sarrètent en chemin, el demeurent plongés dans la sulbstance vitolline; ce phénomene n'est pas, du reste, particulier aux Insortus, el se retrouve parfois chez les Arachuides et les Crustacis. Ces noyaux s'entourent, comme les autres, l'une auroble protoplasmique, ol façonnent ainsi des cellutos complites. Colles-ci ne dithrent le leurs correspondantes du blastorlerme que par leur situation; elles jonent lo môme ròle qu'elles, el prennent une part égale it la production des ferillats. Ces dorniers sont, cu etỉet, engendrés par des éléments qui se détacliont du l, histoderme, et pénèlrent dans le vilellus; ils en viennent lone à occuper une siluation semblable a celle des cellules tont il est ici puestion. ch res deux ordres de formations évoluent de la mème maniere. - Ces cellules internes, qui n’arrivent point ì la périphérie de l'orule, ne font pas parlic du blastonlerme, toul en se comportant comme les édements issus de re dernier, el dont on a souvent míconnu la provenance, sont nommées par les antenl's, ì cause de lenr position, descellules vitellines; on leur a attribur des fonctions diverses lans la genèse les fenillets el lles organes, et les contradictions sont nombrenses à cel ígard. Én réalilé, ces cellules vilelliues doivent alre considérées comme des ćléments du blastoderme, qui me parriennent point is sétaler autour du vitellus. 
restent en dedans te la couche blastodermique normale, mais, ả part cette différence de position, agissent en tout comme les cellules blastodermiques. Elles ont mème origine, ne naissent point spontanément lans le vitellıs, et ne jouent aucun rile particulier gui n'appartienue également an blastoderme vai. Dans ce transport vers la périphérie des éléments cellulaires, les premiers formés arrivent effectivement ì la surface, et constituent le blastoderme réel; les autres demenrent internes, et ce sont eux que l'on désigne par l'expression de cellules vitellines. Ces cellules sont done, en allant au fond des choses, des éléments blastodermiques, et se comportent comme tels.

II. Développement des feuillets blastodermiques. Considér $a-$ tions gènérales. - Ce développement se manifeste, chez les Arthropodes. d'après un procédé propre à ces animaux, et que l'on ne retrouve point ailleurs. Les notions, qui vont ètre exposées, déconlent pour la plupart d'observations récentes, effectuées par l'auteur de cet onvrage; elles n'ont pas encore été soumises au contróle de la vérification par l'autres naturalistes, mais leur concordance parfaite avec des faits dejì connus, et signalés nombre de fois, permettent de les considérer romme répondant, au moins dans leur ensemble, à la réalité des choses.

Pour donner les feuillets, le bastoderme émet des cellules, qui pénètrent dans le vitellus sous-jacent. A cet effet, ses éléments se divisent séparément, et tangentiellement à la surface de l'embryon; la partie externe de chacun d'eux continue à appartenir à la couche lilastodermique, et la portion interne se détache de la précédente, pour entrer dans la zone périphérique de la vésicule vilelline. Ce phénomène s’accomplit sur toute létendue du blastoderme; les cellules internes sont, d'après leur formation, isolées et distinctes les unes des autres; elles ímetlent des expansions pseulopodiques, et, ì la manière de phagocytes, se nourrissent du vitellus, dans l'intérieur duquel elles sont plongées. Elles ollrent, en détinitive, tous les caractères d'éléments mésenchymateux. - La première phase de la genèse des fenillets consiste donc en la prodnction, par le hlastorlerme, d'un mésenchyme, qui s"insinue dans le vitellus sousjacent, se nourrit de lui, et se l'assimile en le faisant disparaitre í mesure. Cette apparition d'un tissu mésenchymateux se manifesle aux dépens dn blastoderme entier, mais est plus active dans deux régions symétriques, parallèles à l'axe longitndinal de l'emlıryon, placées de part et d'autre, et non loin, de la ligne mésliane ventrale.

Ce tissu mésenchymatenx riest autre que le protendoderme, qui ra donner a la fois le mésoderme el l'endaderme; lorsque le hastoderme. a subrenu à sa formation, il persisle lui-mème comme ccloderme ì la surface de l'embryon. Parmi les cellules protendodermipues, plusienrs, qui se rassemblent en denx tiles régnliòres, dontl'une est situés it droita. el l'autre il ganche, de la ligne midiane ventrale, produisent plus spercia- 
lement l'endoderme. Cies ilemx rangres sinloncent dans le vitellus, ıu’elles décompent comme à l'emporte-piece, et vont à leur rencontre mutuelle, après quoi elles se réunissont et se soudent. Quel que soit leur procéde de jouction, elles entourent une grande parl du vitellus ceutral, et délimitent un espace clos, rempli tont d'abord par ce vitellus. Celuici disparait par rósomtion, car les cellules embodermiques l'absorbent comme aliment, et il laisse en sa place un espace vide, limité par l'endoderme. Cet espace est l'entéron, destiné à devenir l'intestin moyen; anssi, un grand nombre l'auteurs le désignent-ils par un nom spécial : celui de mésentéron.

La zone, pacée entre l'endoderme et le hastoderne, qui correspond a la partie périphrerique de l’amas vilellin, est oecupée par du dentolécilhe, contenant encore plusienrs des bioments protendorlermiques sous-jacents an bistoderme; ces dermiers engendrent le mésoderme. Ils ne perilent point len nature méscnchymatense, el ne se grompent pas en rangres régulieres; ils émettenf des expansions en forme de psendoporles, alsorbent, grice í elles, le vitellus nutritif qui les enveloppe, et se segmentent avec rapilité pour augmenter lenr nombre. Bientôt le deutolécithe disparait completement, et les cellules mésorermiques se tronvent seules, non point rassemblées en amas compracts, mais éparses, el limilant des espaces irréguliers, remplis par un liquide; ces derniers représentent les premières élauches du polycolome. La plupart de ces cellules se comrertissent, par la suite, en fibres musculaires, les antres domment des éléments coujonctifs, ou des globules sanguins, mais leur disposition mésenchymateuse ne cesse pas d'exister.

En somme, le blastoderme engendre, sur sa face profomle et alluérente an vilellus, un lissu mésenchymateux : le protendoderme. Il se divise ainsi en un ectorlerme, qui reste épilhélial, ol un protentoderme mésenchymateux. Celui-ci se partage a son tour, el hitivement, en denx élanches enlodermiqnes, distinetes l'unc de l'autre dés lenr origine, régulicres el rpithéliales, et en un mésoderme mésenchymatenx alifus.

t'intestin antéricur et l'intestin postérienr naissent ensuite, soit en meme temps, soit à pen d'intervalles l'un de l'autre; lous denx sont faconnés par des dépressions ectodermiques. Ils s'enfoncent daus le corps he linmbryon, el vont i la rencontre le l'entúron, avee qui ils s'ahonchant. Cos diprossions correspondent an stomeon el au procteon des aulpes animanx, qui prenment ici un développement considérable. La mime précocilé s'applique également aux centres neveux, sur la genese despluels l’abréviation emlryonnaire exerce son inllnence; l'ectoderme produit en efiet lens ébauches, sur la face dorsale de l'extrémité intépienre du corps, el sur la face ventralr, pen apres l’émission les premiores cellules protendrulerminges, alors pue le hastoderme,

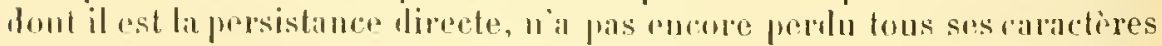
géuétipues. 
Il suit de lia, et il semble que ce soit un fail constant chez lous les Arthropodes, que l'entéron el l'endorlerme, c'est-ì-dire le mésontirnon des auleurs el sa paroi, ne proviennent point d'une lépression gaslrnlaire, puisfu ils sont prodnits sur place, dans l’intérienr nòme le l’enliryon, et aux dépens d'un protendoderme d’abord mósenchymatewx; li gastrulation réelle manque à ces animax. Plusienrs anteurs disent cependant l’avoir rencontrée; lels sont Groblıen pour divers lintomostritcés (.Hoina, Cetnchilus), Giarl et Bounier pour plusieurs Isopodes parasites du groupe des Entonisciens, Reichenbach et Bobretzly pour cerlains Décapodes (Astacus, Palomon). (Ces auteurs ont confondu la genèse dı stomeon, si roluminenx chez ces ètres, avec celle de l'enlíron réel. Celuici, qui donne l'intestin moyen arec le foic, est toujours d'origine inlerne, et ne dépend en rien d'une gastrulation. Les dépressions ectodermiques, destinées a fouruir le stomeon et le procleon, sont précoces, et naissent alors que l'ecloderme n'est pas encore tres dislinct du protendodermo. sous-jacent. Celle hite d'apparition a fait admellue que l'me de ces dipressions est l'homologue de l'invagiuation gastrulaire des autres cutres. Il suflit de suive l’évolution complide des Arthropodes, jour se convaincre que lem entéron n’a rien de commmn arec ces dépressious, qui se bornent à fournir l’inlestin antirienr et l’ulestin postrienr. Le développement excessif pris par ces lemiers a cucore coulrihú. pour sa part, à motiver une lelle confusion,

D'autres embryologistes onl igalement voulu iclrouver, lans le phénomène de la progression des deux ébanches endodermiques au sein de la vésicule vilelline, les traces d'une zastrulalion; les frères llerlwig, par exemple, ont émis celte opinion pour les lusecles. En comparant les fails, offerts par les gastrules normales, à ceux prósentés par les Arthropores, on saisit le défaul de concorrance a rel égarl. L'ébanche flune invagination gastmlaire est simple; elle est nne repression, dirigrie de dehors en dedans, qui se crense dans le hastoderme, el s'enfonce Ioujours davantage dans le corps de l'emliryon. Les Arthropodes ue montrent rien de pareil; l’endortorme est roprésenti, à son dálont, par un choix de cellules dans le protendoderme mésenchymatonx, eelui-ci blant produit par le hastoderme sur sa fare profomde; ses chaurhes sont an nombre de deux, et siparies l'une le l'aule dies leur origine. l.es phinomines ne se correspondent donc nullement; et il est impossible d'accepler l’apprécialion proposíc prar les l'reres llertwiğ.

Du reste. la comparaison des premièes phases embryonnaires des Arthropodes, avec celles des autres animanx, permetlail déjäd'arriver ì ces crinclusions. Toutes les fois ou les omles contiemenl une grande quantiti de réserves unlritives, l'origine grastrulaire des fenillels cede le pars il la planulation, éest-i-hlire a une grenese telle, que los foullets premurul naissance sur plico, direclement, anx dipens les blemonts hastouler-

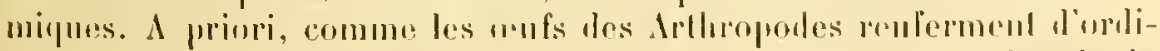
naire un deutolécilse alombanl, los molions, fommies par l'embryolegio 
gínérale, autorisent à croire que leurs feuillets sont formés thaprès le mode planulaire, et a suspecter toute apparence gastrulaire. Quant aux cufs de ces Crustacís, qui donnent des blastules par leur segmentation,

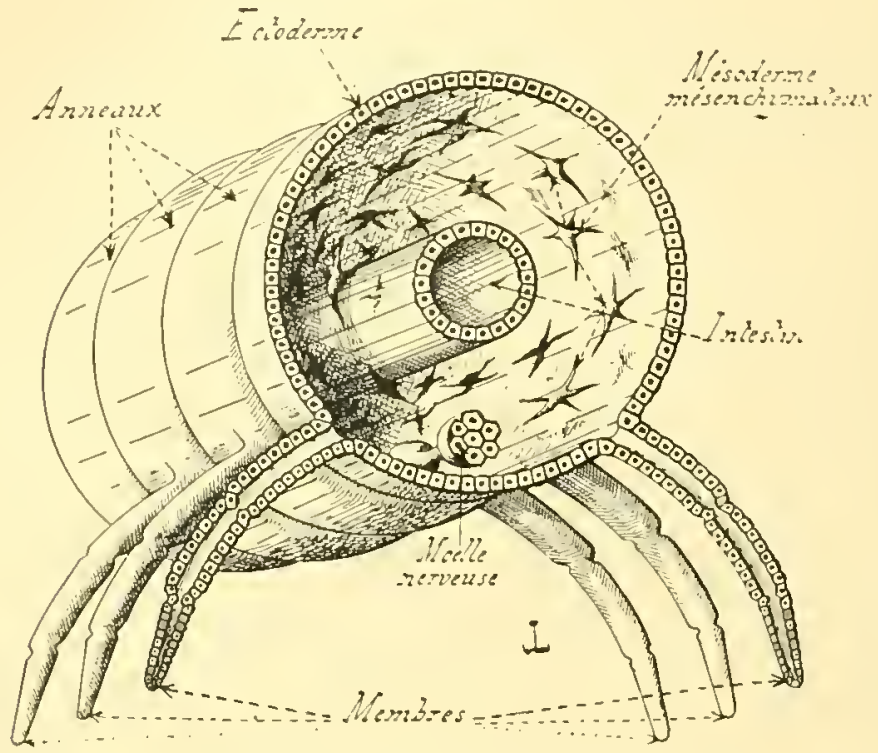

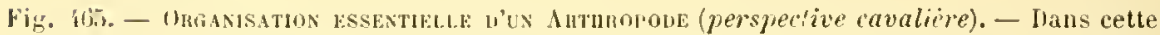
figure se trouve une coupe, at layuelle on devia rapporter les dessins suivants, relatifs aid diveloppement des feullets, afin de les voir dans l'espace. lorganisme se compose d'un ectoderme exterieur, d'un endoderme qui limite l'intestin, et d'un misoderme mésenchymateux; les membres sont des saillies superficielles, cireonscrites par l'ectolorme, et dans lesqunlles le mésoderme júnetre.

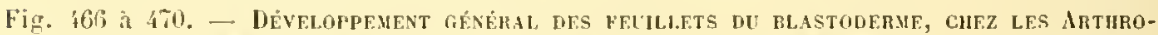
confs (coupes diagrammaliques, rues par la trunche, avec perspective). - Wn 460, coupe transersale d'un emliryon senant de depasser la phase planulaire; le blastoderme externe engendre, el émet en dedans de lui, des cellules éparses, qui pẻnêtrent dans le deutoléeithe, s'y mèlangent aux élements du blastoderme interne, lorspu'il en existe, et composent avec eux un mesenchyme. - En 467 , coupe transversale d'un embryon un peu plus agi; le mésenchyme précident augmente d'importance, et devient le protendo. lerme, alors que le blastomère demeuré pèriphèrique persiste comme ectoderne; parmi les iléments du protendoderme, certains conservent la disposition mésenehymateuse, alor fue les autres se rassemblent en denx bandes ejpitheliales et symétriques; le proLectoderne angendre ta moelle nerveuse, sur la face ventrale du corps. - En 469, roupe longitudinale, to miane, de l'emblyon précedent, abstraction faite de la moulfe ner-

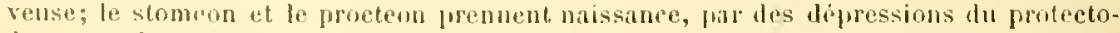
deme. - Va fiv, coupe transvirsile d'un ambryon fus age, dont les fenillets délinitifs se sont délimitis; l' protectodırme donne seulement l'ectoderme; le protendorlerme se divise en un moloderme épithélial, et un mesoderme misenchymateux; l'endoderme est frouluit par la junction des deux bandes représenties dans la figure 467. - En 47\%, coupe longitudinale, et mediane, de l'embryon prédedent, abstraction faite de la moelle ner. velse; le stomeon et lo proctron st sont allonges pour se convertir en intestin antirieur et intestin pustivieur: londulernı limito un petit entéron mèdian, qui devient l'intestin musen. 


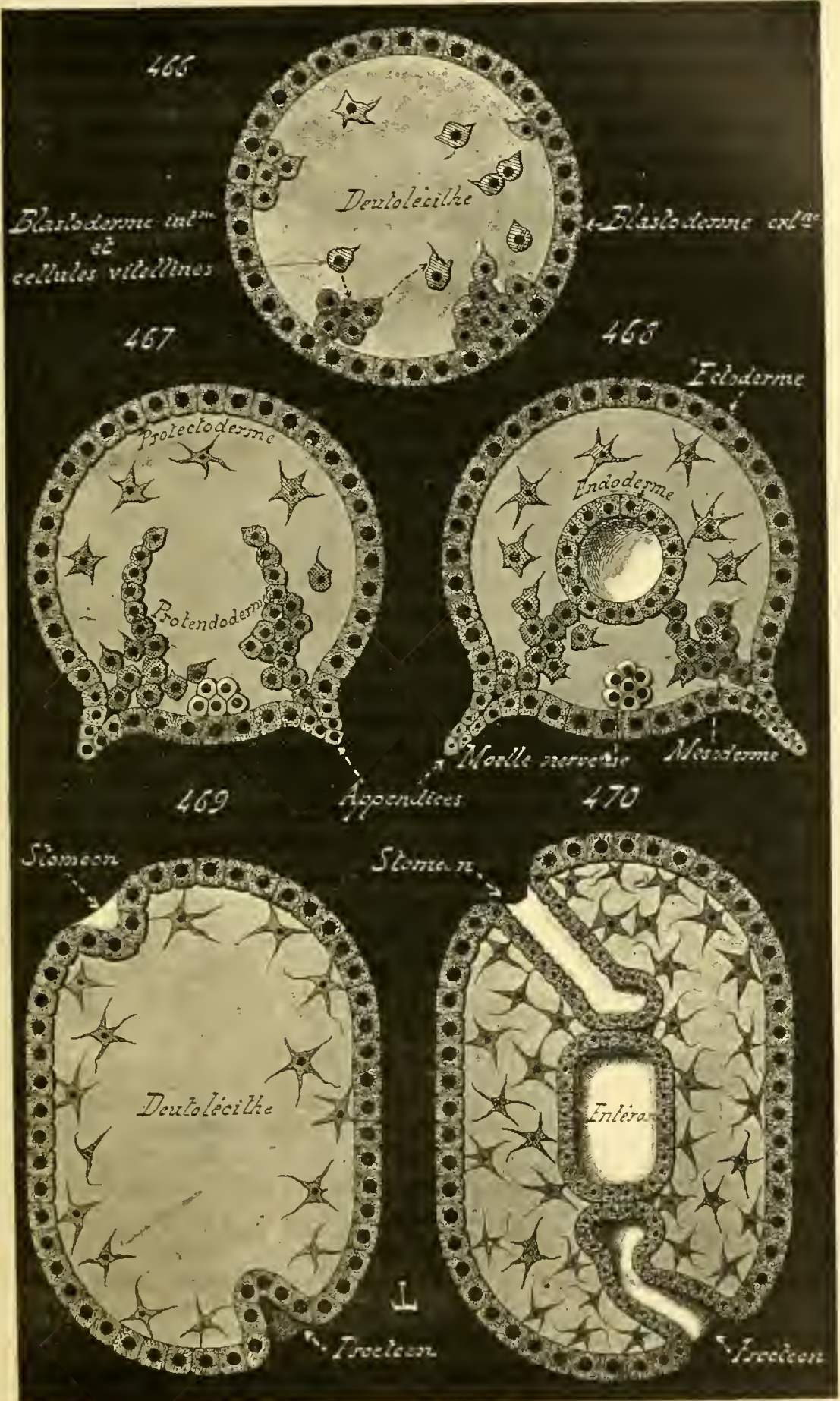


et qui levraient montrer par suite une gastrulation réelle, leur dépression ectodermique, qui a étí considérée comme une cavité gastrulaire, n'est autre que le stomeon. Du reste, la plupart de ces derniers animaux se rattachent à des atres, dont les urufs, chargés de vilellus nutritif, se développent suivant le procédé planulaire: cette conclusion est surtout applicalile aux Crustacés prarasites, qui constituent le groupe des Entouisciens. Lcur's ovules, semblables en cela a ceux des Iammifères placentaires, doivent étre considérŕs comme des ovules fécitliques, dont le vitellus nutritif sest réduit, et ne penvent montrer lans leur intégrité les phases de l'ívolution.

Ces considérations priliminaires permettent de comprendre, dans leurs grands traits, les particularités les plus importantes da diveloppement des feuillets basloderniques chez les Arlhropodes. II suffit, dès lurs, pour avoir des notions plus complètes, de suive les délails princifrax daus chacum des trois gramds groupes de l'embrauchement, chez nn Cristaci, che\% un Arachnide, et elez un lnsecte. Le point de départ est le mène dans les trois cas : un hlastoderme enveloppant une vésicule vitelline interne. En ellel, quel que soit le mode de la segmentation, les bastomères se groupent toujours de manière il comproser un blastoderme, yui enloure une réserve mutritive plus ou moins grosse.

Custricts. - Les Cloportes du genre P'oreellio peuvent ètre choisis romme exemple. Ces animax présentent, cependant, une altération du procédé habiluel, qui consisle dans la lentenr avec ladpelle le blastorlerme environne l'amas vitellin; cette lenteur est telle, que les premières parties du blastolerme prouluisent les feuillets, et mème les ibtuaches digestires et nerveuses, alors que les autres sont encore en voie de progression autour du vitellus. Cette progression est plus rapide sur la face ventrale, tout en commençant par l'extrómité antérieure, par la future tète de lindividu; aussi le llastoderme se ferme-t-il sur le dos, ot ce phénomène est fréquent chez les autres Arthropodes. L'altíration porte seulement sur de peu de hate du mourement enveloppant; le résultat est semblable a celui pui s’accomplit. lorsque le blastoderme est linmé presspue d'un seul coup, comme chez les Lerevisses par exemple: aussi est-il aisé d’en laire abstraction.

l'eu apres les premiers indices le la segmentation du hlastoderme, et de la genrise du protendoderme, se manifestent, sur la ligne médiane ventrale, et sur la fice dorsale de l'extrómité antérienre, les vestiges inilianx du système nervoux; le l, lastoderme, par suite de l'alréviation du développenent, se comporte, dans ees régions, comme sil élait déja l'ameń à u’̀tre qu'un simple cetoderne, et les épaississements cellulaires qu'il fournit sont les origines des centres nerveux. L'élıanche antérienre, la plaque céphalique, correspond an délunt des ganglions céréloranx; la prolifíration médiane el ventrale, la plaque médullaire, n’est autre que le commencement te la moelle, de la chaine nervense ven- 
trale. - En oulre, de part et d'autre de la rigion antérieure de la platpue médullaire, les éléments du protendoderme se muliplicnt sur m assez. grand espace; les zones de multipliabtion sont au nombre de lleux, of parallèles, dans leur ensemble, à l'axe longitudinal du corps; l'unc est placée à droite, et l'autre à gauche de la plaque médullaire. Les cellules qui les constituent sont d'abord groupées en amas dillus, et plusienrs d'entre elles émeltent des expansions pseudopodiques; elles sont donc mésenchyumateuses. Elles ne tardent pas a se rassembler cn conches régulières; loutes les cellules đu mème còté ne doment qu'une seule assise simple, qui se rourbe en un croissaut, lont la concinvité est fournée vers le centre du vitellus, el qui grandit sams cesse par ha segmentation de ses éléments. Ces assises, au nombre de denx, représentent les ébauches de l'endorlerme. - l'enlant yu'elles prennent naissance, les autres jarties dı protendorlerue subissent des divisions actives, qui out pour eflet de les scinder en cellules nombreuses; ces dermieres lemenrent éparses lans le vitellus sous-jacent, et sont chargées de donner le mésoderne. laes élanches de l'endoderme et du mésoderme ne sont pas distinctes; elles sont unies et confondues dans la réalité des faits, et leur ensemble correspond à un groupe de cellules mésenchymateuses, produites par le hlastoderme. Senlement, les éhauches entodermiques prolifèrent plus vite que les autres, prennent tres rapideunent un aspect parliculier, et se délimitent d'une maniire précoce. Toutes poursuivent désormais leur évolution sans se confombre.

Les deux couches endoderuniques continuent à progresser dans liutérieur de la vésicule vitelline. leur forme en croissant s'accentue sans cesse, car leurs hords s'avancent dans le vitellus en se rapprochant de son centre; chacune d'elles prend l'aspect d'une curetle. Daus leur progression constante, les deux cureltes se rencontrent par lems bords, et se soulent; leur ensemble constitue alors une résicule close, impraire et médiane, dont la cavilé est remplie par le leutolécithe qu'olles ont emprisonné dans leur accroissement. Cetle résicule est l'entéron, et sa paroi l'endoderme réel; elle ne donne aucune partie de l'jutestin proprement dit, et est employée tout entière à probluire le foie; à cel cllet, clle se scinde en leux lubes, qui se sublivisent enx-mèmes par la suite. - l’intestin moyen des Crustacés se rénluil, en elfel, au foie sent; et cette particularite expligue pour quelle raison cet organe n'est pas seulement une glande, mais encore, el surtout, une région ou les alimeuts sont rendus assimilables, et absorbés par osmose. Toutes les autres zones alu tube digestif de ces animanx proviennent du stomeon et du procteon.

Le deutolécithe, contenu dans les leux tubes entéripues primorliaux, qui représente la plus grande part le la vésicule vitelline primitive, est absorlué pen à peu par l'endoderme qui les limite; il sert alonc à l'alimentation de l'embryon, el c'est l'entonlerme lui-mene, le fouillet mutritif, qui remplit en cela le principal róle, tont comne chez l'adulte. 
Le mésoderme se constitue à son tour, pendant que s'eflectuent ces plúnomènes; ses éléments sout plongés daus cette région du vitellus nutritif, qui reste extérieure à l'endoderme - car ce dernier progresse à une eertaine distance du blastoderne - el se trouve placée par conséquent entre ce hlastoderme et les tulhes entériques. Les cellules du fenillel moyen naissent aux dépens de la couche blastoderminue entière; cependant, il existe des zones principales de prolifération sur la face ventrale du corps, dans les points oi doirent se faronner Ies appendices. Ce fait n’a rien d'étonnant, puisque ces organes empruntent an mésoulerme, pour leur développement, la plus grande partie de sa masse. Les éléments mésodermiques se nourrissent aux dépens du deutolécilhe qui les entoure; ils l'alısorbent peu à peu, et le font ainsi disparaitre. Ils évoluent suivant le procédé mésenchymateux typique, et se rassemblent en grompes, qui laissent entre eux des espraces libres, ébauches premieres des cavités lacunaires du culome.

Ces cavités se creusent tout d'alord, du moins pour la plupart, daus les jenues appendices, et, comme ces lerniers sont rangís régulièrement par paires, les cavités naissantes sont aussi disprosées de mème. Plusieurs auteurs ont voulu voir, dans ce fait, une segmentation métamérique du mésoderme, comparable ì celle des Annélides et des Vertéln'és; il n'en est rien, car l'aspect de ces espaces est ume simple conséquence de leur situation.

Les feuillets blastodermiques sont dès lors complètement formés. L'ectoderme donne les centres nerveux, le stomeon et le procteon; l'endollerme fonmit les tubes hépatiques, qu'il vaudrait mieux nommer tubes enteriques, vu leur provenance et leur rôle; quant au mésoderme, il engendre le tissu conjonctivo-nusculaire du corps entier, el l'appareil circulatoire. Souvent, à cause de la connexité de position qui s'établit,

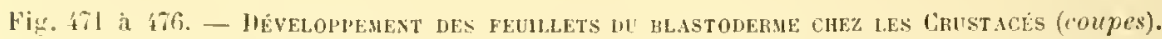
- In 47, roupe transversale d'un embryon achevaut la genese de son hlastoderme; celui-ei envabit la surface du deutolecille, et produit les dements qui pénétrent dans ce dernier, en se joignant aux cellules du blastoderme interne, moins nombreuses iei (fue thez les Insectes. - En 472 , coupu transversale d'un embryon un peu plus dige; la part exterieure du blastoderme prend lc caractere de protectoderme, qui enguble la moelle nerveuse, et la part interieure celui de protendoderme. - En 473 , coupe transversale d’un embryon encore julus age, dont les appendices commencent a s'ébaucher; le proteclolerme devient leetoderme stricl: le protendoderme se divise en deux elouches endoderniques, épithéliales, et un mesoderme mésenchymateux, qui pénèlre dans les appendices, et se creuse leja de lacunes colomiques. - En $\{7$, coupe longitudinale du mème, passant quelque peu sur les côtés de la ligne nuediane, de manière à alteindre l'une des ibauclies endodermiques, pour montrer sa forme encore incomplète, et sa façon de penetrer a l'emporte-piece dans le deutolécithe. - En f75, coupe transversale

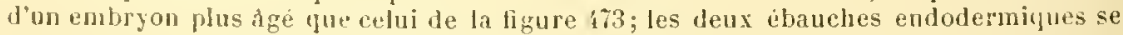
sunt unies, el composent une seul. vesicule, uns laquelle le deutolecithe commence à disparaitre. - En ho, coupe longitudinale du mème, montrant la vésicule endodermique complete le stomeon et le proeteon, deju ebauches en 47 , ont pris une plus grande extension.

La suite de cette évolution, qui s'applique plus particuticrement aux wufs télolicithes, est donnce dans les figures 572 a $5 \% 5$. 


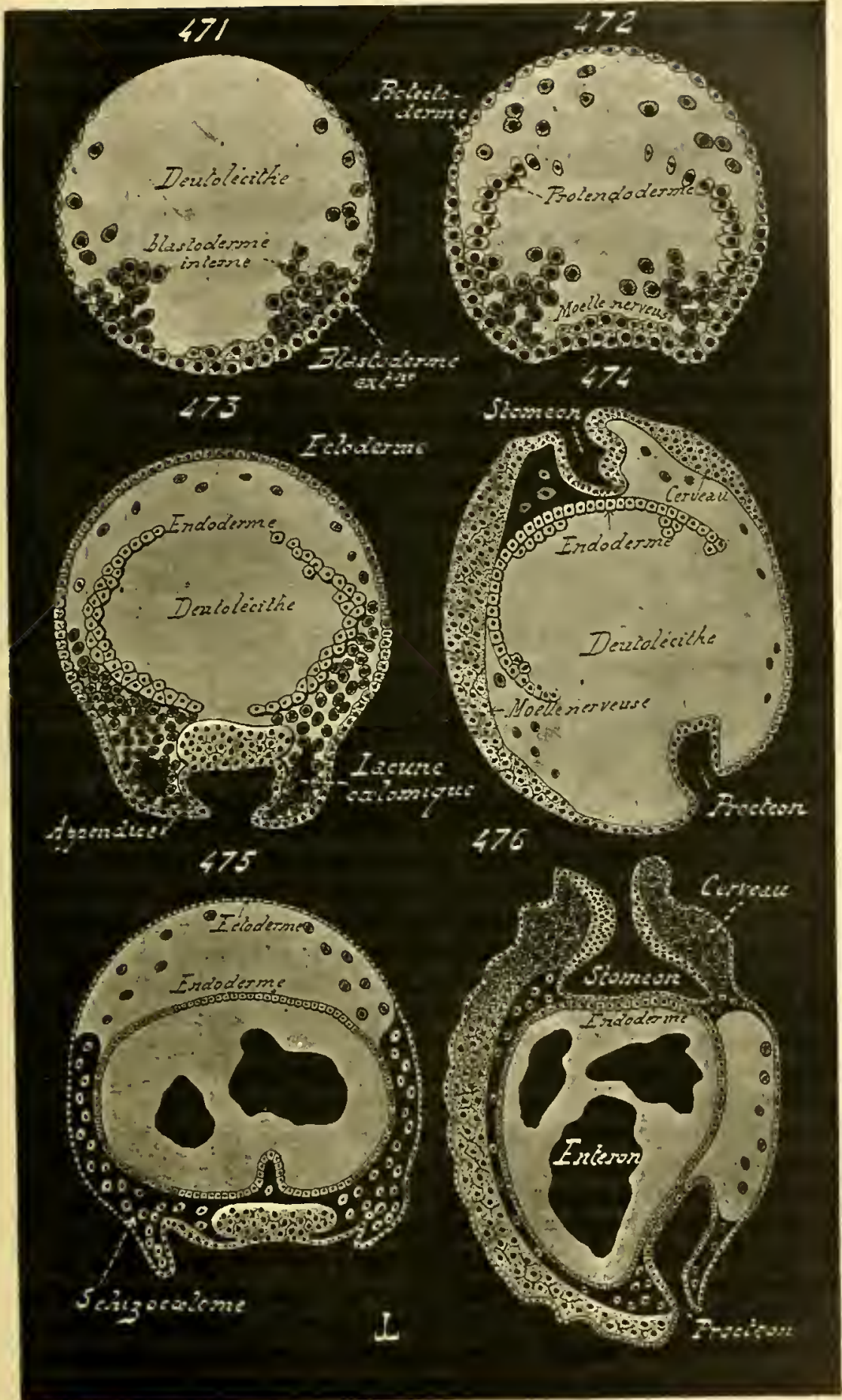


sur la ligne méliane ventrale, entro les bianches eudorlermiques et celles te la moelle nervense, f'ousemble de ces zones froliférautes est désigné frar l'expression de bundelefte ou de plaque ventrale. Cotle handelelle existe chez les embryons les anles Arthropodes, mais présente somvent des caractères particuliers qui vont être signalés.

Aracunors. - Le diveloppement des feuillets blastodermigues de ces animaux n’est pas enticrement élucidé; les observations les jus completes, à eet éguml, sout dues i Balfour. Les faits commo dénutent mue grande ressomblance de ces phénomiones évolutifs avec leurs corresponliunts des Crustaters.

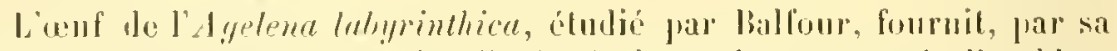
segmentation, la plamulo hahituelle des Arthropodes, composée dun hlastorlerme périphérịue el l'une vésicule vitelline cenlrale. Celle-ri contient des noyaux, autour desquels le vilellus évolutif se condense, from constituor ules cellules completes, les cellules vitellines des auteurs. Ces dernieres,

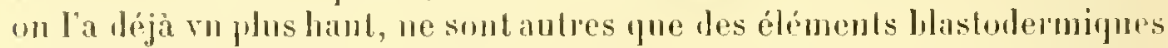
Lardifs, restés internes a colte oneurrence, et prenant part a lil genese des fenillets, lout comme cenx qui parriement à êle extéricurs ; seulenent, ¿ cause de leur siluation profonde, ils ne contribuent cu rien a la production de l'ectoderme, et hornent leur rỏe à jarticiper à celle du mésolerme, el de l'endoderme. le blastoderme émel les cellules, yui jénẻtrent lans la vésicule nutrilive, sły mélangent à celles qui s’y trouvent dojił; el toutes deux contrilsuent également à constituer le prolendoderme. Ces phénomènes existent chez les Crustacés, oil plusienrs auleurs les ont signalés; teur signification est la mème; ils sont seulemeut plus prononcrís ehez les Arachnides.

Sans trop insister sur les phénomenes secondaires du dévelopjement, relatifs à la marche suvie par le lilastoderme dans sa progression, ce dernier s’épaissit sur la face ventrale, et sur l'extrémité antérieure, de l'enluryon; ses élíments s'allungent, et se divisent le maniere il produire plusicurs couches rollulaires superposées. Celle prolifération délute vers l'extrémité an lérienro, oì elle donne le cumulus mimilif des anten's, c'est-à-dire un amas local de cellules hativement formées, et s'élend sur la faeo ventrale du corps. Colle extension est dabord conluse; elle finit par se localiser sur la ligne médiane, où la multiplication est plus aclive. lua ligne mérliane porte done une plaque ventrale, constiluée par deux ou trois assises de cellules; cette platue, qui s'étend le lextrómité antérienre du corps à l’extrémité postírienre, représente l'union le l'ébanche le la moelle nerveuse avec celle du mésoderme des appendices; elle comprend ainsi deux parties, qui doivent ètre considérées comme dislinctes. L'ébanche de la moelle se compose de cellules, demenrant reliées antre elles et à l'ectoderme; les éléments, qui apjartiennent i celle utu mésorderme, se séparent ılı blastoderme, celui-cj prenant dès lors les caractères d'ectoderme, s'allient aux cellules vitellines, et se multiplient 
pour engendrer le feuillet moyeu, par los mèmes procélés que rlhez los Crustarís. Dur reste, toutes les cellules mésoderminurs ne sonl pas produites par la plaqne ventrale, ear elte dernicre lompil soulument, on peu s'en faul, relles des appendices; les antres, qui composent le fenillet moyen dans le corps proprement dil, sont formées par le reste du hlasloderme.

La provenance de l'endoderme n'est pas hien conmue. A en juger l'après les olsservations faites par Balfour. les rellules vilellines, c'est-ìdire, et ce nom leur ponvient davantage, les fiments hlaslodermiques tardifs on intermes, jouent dans celte genese le rôle le plus importanl. Ce fail n’a rien qui doive élonmer, puisque les élanches de l'endoderme sont placées en dedans de celles du mésorlerme; el les cellułes vilellines, qui sont déjà internes, se tronveul tonles porlées pour les fournir. Le procédé génélique en lui-mème n’a pas été observé; le seul fait certain est que l'endoderme, avec l'entéron, sont d’origine iuterne, et ne śébanchent poinl far un procélé qui prisse che assimilé à une gastrulalion. Conlrairement à ce qu'il en est pour les Cimslacés, l'entéron ne se horme pas a donner le foie; il engendre bien cel oreane, mais produit aussi nn intestin moyen assez étemlu, qui compromal tonle la parlic située entre lestomac (exchu, car celui-ci est mue dépendance du stomeon) el l'ampoule rectale.

E. Metschnilioli a décrit avec détails le développement des Scorpions, du moins pour ec qui touche aux divers aspecls prisentis par leurs embryons; il siernale la présence, autour de ces derniers, d'une envelopje amniolique, quil compare à celle des lusceles, el à laquelle il accorle la mème origine, sans donner heancoup de raisons à l'appui de cette opinion.

En résumé, l'embryogénie des Arachnides nécessile encore de nonvelles recherches, sous le rapport de l'origino des fenillets blastodermiques, of dérolution suivie par eux. Cependant, les laits acpuis autol'iseul ì peuser 'pu'il en est pour ces animanx comme pour' les Crustacés et pour les lusectes; leur liastorlerme entier, l'ensemble des éléments périphériques el des éléments inlernes, produit un protendorlerme mésenchynateux, qui se dédonble en embalerme ol mésnderme, sans qu’ancune partionlarité dénole, mòme à l'iblat de traces, une origine gastrulaire réelle.

Ixsectes. - Le developpenent iles feuillots embrronuaires est remar-

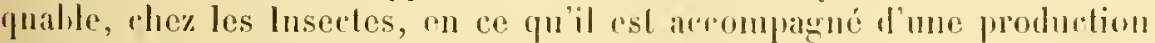
de monbranes amnioliques, qui envelojpent pen ì pen l'muluyou entice,

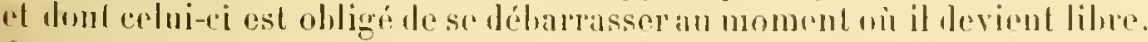

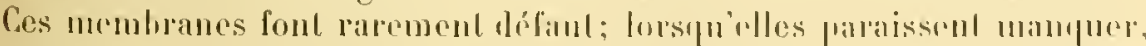

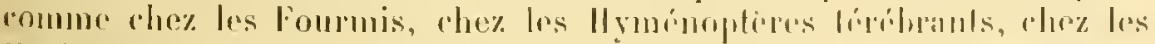

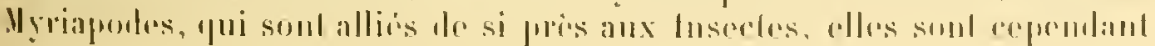


représentées par quelques collules éparses, extérieures ả l'embryon, et maintenues autour de lui par la coque ovulaire; res cas paraissent done correspondre, plutiol à une atrophie secondaire de ecs enveloppes, ‘ju'à wue absence complete et originelle.

Il importe également d’avoir hien préscnte à l'esprit celte notion, que les cellules vitellines des auteurs, aussi fréquentes chez les Insectes que chez les Arachuides, ne sont autres que des éléments blastodermiques tardil's et internes. I.es naluralistes qui ont étudié le développement des Insectes, et il faut citcr parmi eux lowalevsy, Hohrn, Graber, Ileiler, Wheeler. 'Tichomirof, ont longuement lisserté sur l'origine et le rôle le ces élóments, et ont ahouti i des assertions contradictoires. Cette diversité d'opinion provient surtont te ee fait, que la plupart de ces auteurs ont méconum le ròle des cellules vitellines, qu ils considerent. comme des éléments particuliers, n"ayant ancun rapport avec le blastoderme. Ën réalité, ce dernier se compose de deux prarties: l'une externe, cohérente, le blastoderme extérieur, qui enloure la vésicule vitelline: l'autre interne, dissociće, le blastoderme interne, constiluée prar des celluleséparses dans la vésicule vitelline. La première donne l'ectoderme, et la part du protendoderme où le mésoderme jone le plus grand rôle; la seconde produit surtout l'autre part du protendoderme, celle qui devient l'endoderme. Les éléments fournis par la prenière pénètrent dans le vitellus, se mélangent ì ceux du blastoderme interne, et tous concourent egalement à engendrer le protemloderme. Telle est la manière suivant laquelle il convient de concevoij les bases génétiques des fenillets.

A. - Au moment oì le blastoderme externe est représenté par une couche cellulaire complète, placée autour de la vésicule vitelline, il s'épaissit sur la face ventrale de l'embryon: cette zone plus épaisse s'étend de l'extrémité postérienre du corps à l'extrémité antérieure, et constitue la plaque ventrale des auteurs. Cette derniore est formée par l’union de denx ébauches: line, placée sur la ligne médiane, doit donner la moelle nervense; l’autre, composée de deux parties lomgeant les côtés de la précérlente, est chargée de fournir le mésoderme des ajpendices. Les changements, subis par les cellules qui composent ces ébanches, portent sur l’allongement de celles-lả, puis sul leurs divisions répétées; plusieurs plans cellulaires superposés prenuent ainsinaissance, ceux de la moelle nervense restant coliérents, et cenx du mésoderme se dissociant, pour revèti un aspect mésenchymateux pen accentué.

La playue ventrate nollre pas la meme disposilion chez tous les embryons des lusectes; elle est parfois localisée au milien de la face ventrate, et s"étend ailleurs de manière à occuper cette face tout entière; parfois mène, elle frugresse davantage, et recouve une partie de la région dorsale. Ce sont lit des variations secondaires, qui nothent aucunc imprortance génétique. Fréquemment, la plaque ne demenre point plane, et se creuse, de fasou a prendre la forme d'un sillon; dans 
certains cas, et sur une portion de son étendue, vers son extrinili. postérieure d'ordinaje, celui-ci se convertit en un canal, frar le rapprochement ef la soudure de ses bords. A cause de cel aspeet, les autenis désiguent souvent le sillon de la plaque ventrale par le noun de goutciere mimitive, ou par celui de gonttiere germinative. Plusieurs d'entro eus veulent mème voir en lui les dernières traces d'un entéron gastrulaire; comme le blastoderme de cette gonttiere ne produit pas l'enloderme, une lelle opinion ne peul ètre acceptéc. - l'enloderme et le mésoderme des Insectes proviennent, comme leurs correspondants des Porcellio, pris conme exemple de Crustacés, d’un prolendoderme mésenchymateux. faconné anx lépens lu hlastoderme, et sur sa face profonde.les parties de ce prolendorlerme, qui doivent donner le mésoderme des aplendices et l'eudoderme, sont siluées sur les cótés de l'ébauche nerveuse, et par suile dans une region qui ocenpe les hords de la gouttiere germirative; anssi, les éléments embryonnaires se multiplient-ils, dans cetle zone, avec une aclivile suffisante pour motiver ce nom. Mais tout le feuillet moyen, sauf celui des appendices, est engendré par le reste du blastoderme, et il ne faut point perdre de vue que le protendoderme est un feuillet ayant pastout la même valeur, et la mème origine. Sa multiplication est seulement plus rapide sur la face ventrale de l'embryon, de part et d'autre de la moelle nerveuse, parce que cette face porte les appendices, et que l'endoderme commence à s'ébaucher dans cette région.

Il suit de lì, que les premières ébauches du mésoderme sont celles deslinées à fommir les lissus conjonctivo-musculaires des appendices; elles acquièrent rapidement un volume assez grand. En outre, comme les membres sout régulièrement disposés par paires, placées, ou peu s'en faut, ¿̇ égale dislance les unes les autıes, ces ébauches mésodermiques se plient ì cettestructure, et se divisent en segments rangés à la file, chaque segment correspondant à la paire d'appendices située à son niveau. I'lusieurs auteurs voient, dans cette organisation, l'inlice dune ressemhlance avec les Innilides, et s'aulorisent le ce fait pour admettre que le mésolerme des Arthropodes est divisé en unctamères, tout comme celui des Trochozoaires polymériques. - Or, il convient de le reconnailre, une telle division mótamérique n’alteint que celte part du mésorleme embryonnaire annexéc anx appendices naissants; elle ne s’alresse qu’a la zone périphérique de ces rbauches, rhargées de pénétrer dins les membres, et nou i leur zone profonde, mie an feuillet moyen du reste du corps, et présentant les mèmes caracleres que lui; clle sialténue à mesure que l'évolution sacheve, et niest plus dinotée, chez l"alulte, que par les plis des tégmments; elle manque, enfin, il loutes les rógions mosodermiques ue faisant point partie de la platue ventrale. I en jugrer dapros ces particularités, dapres la commexité établic entro l'aspect seguente du mésoderme rentral el la disposilion régulieje des paires d'appendices, on est en droit de romplure que los secombl de ces 
faits est la cause du premier, l'organisation métamérirue étant d'autant plus accenture que l'embryogénie est plus abrégée. - Les mèmes consi-

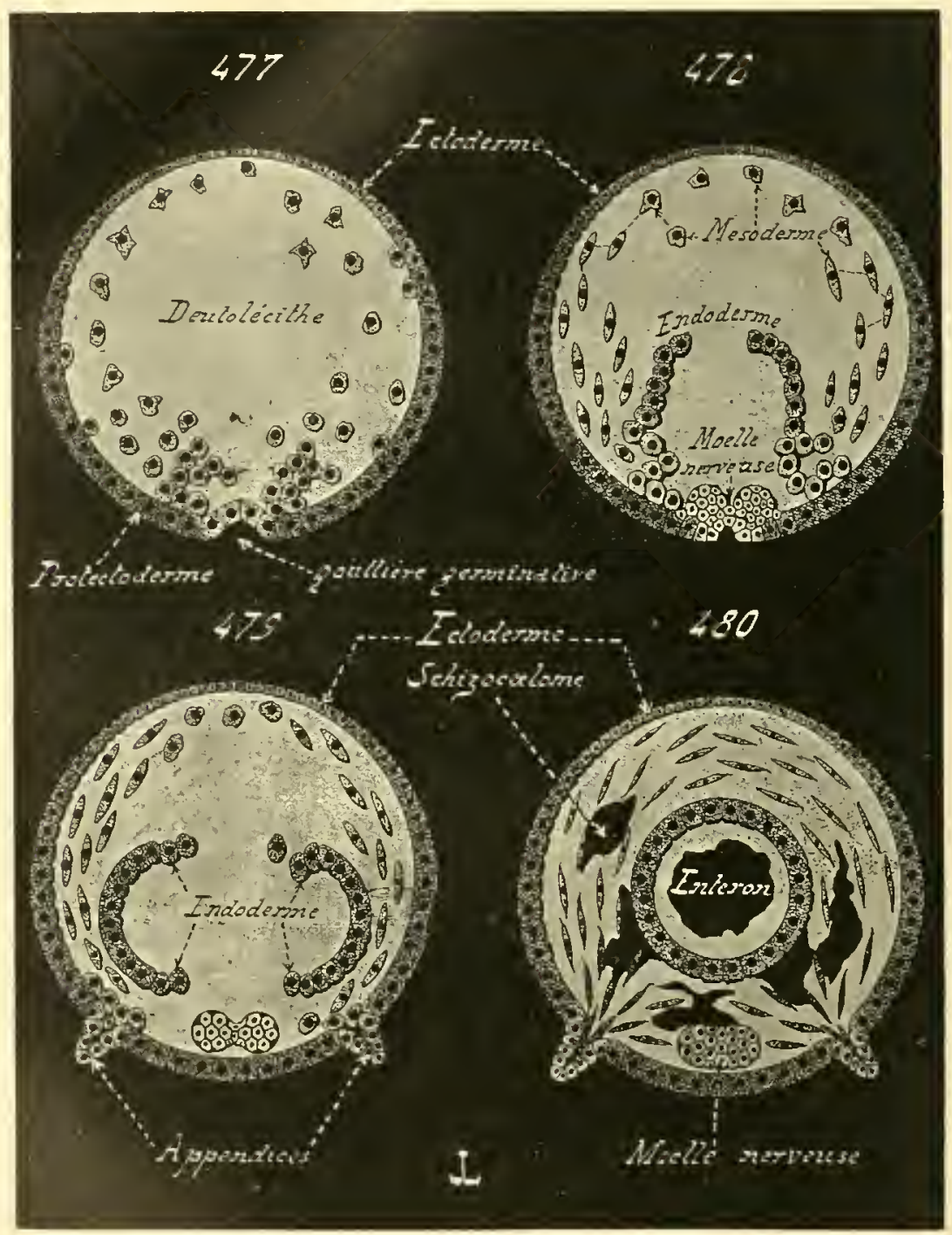

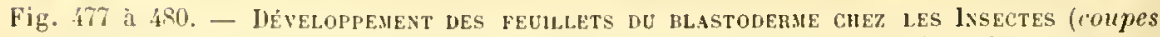
transversales), - Ln 477, phase identique à celle de la figure 472; le blastoderme externe est devenu le protectoderme, et les cléments du protendoderme sont placés au-ilessons de lui. - En 478, phase identiçue à celle de la figure 473 ; le protendoderme se subdivise en mésolerme, el dewx èbauches endodermiques. - En 479, phase un peu plus avantée; les appendites jrennent naissance, et les deux parties de l'endoderme se rigularisent en s'amplifiant. - En 480, phase dentique à celle de la figure 475; lendoderme s'est fermé, par la jonction de ses deux ibauches; et le deutolicithe rommence a disparaitre Jar places. - Ces figures font suile i celles des muméros 401 i $40 \%$. 
dérations sont applicables aux Arachnides et aux Crustacés, chez lesquels on a voulu retrouver également les traces d'une disposition annelée.

L'aspect, offert par les premières régions endodermiques, n'est pas encore bien connu. Cependant, des observations récentes permettent

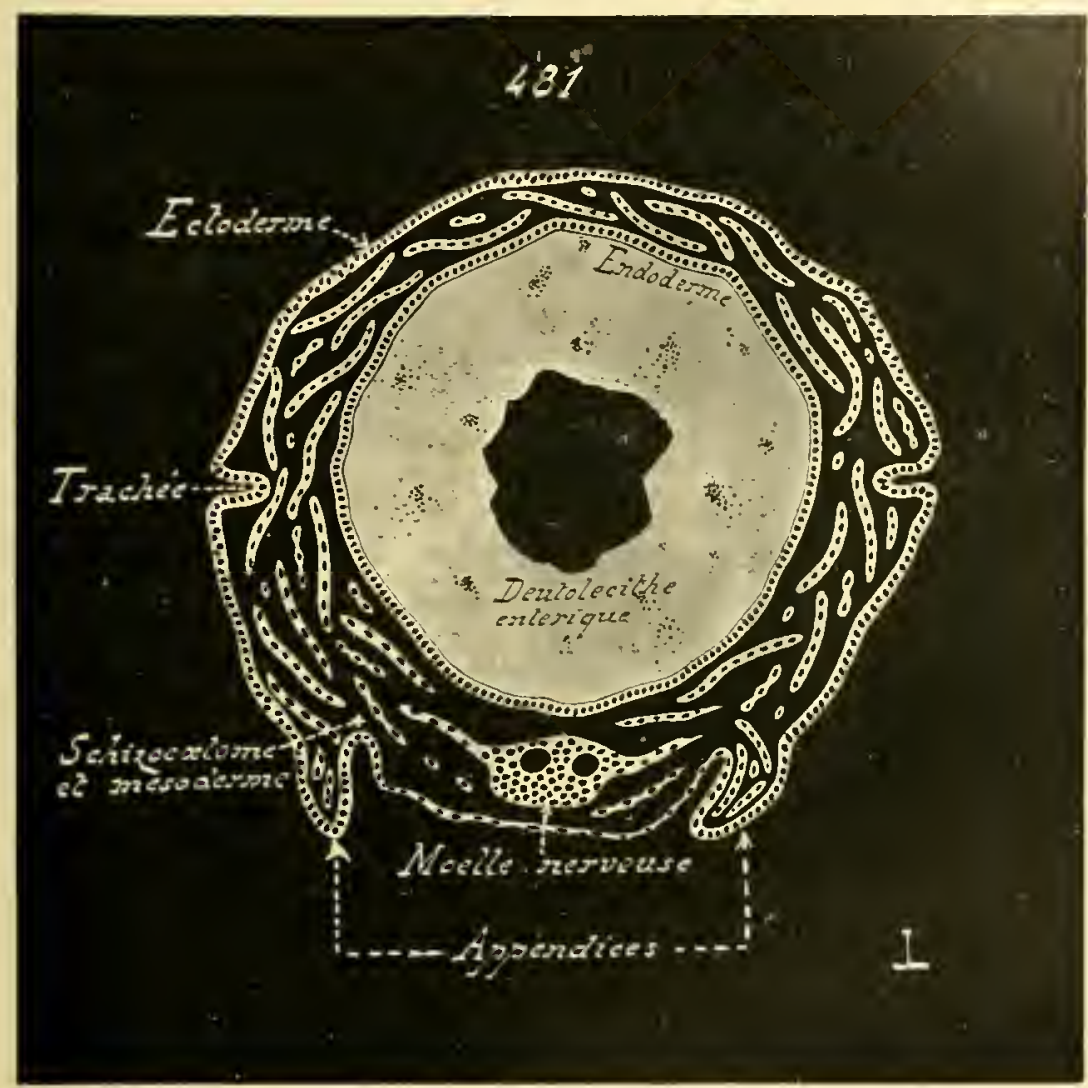

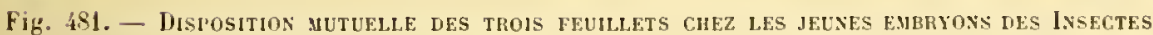
(coupe transversale). - L'ectoderme, extèrieur, recouvre le corps avec les appendices, et commence à produire des trachees; la moelle nerveuse siust séparèe de lui. - Le vitellus a completement disparu dans l'espace réservẻ au mesoderme; celui-ci s'est organisè, l'après le type mésenchymateux, en travées qui s'entrecroisent, el limitent les lacunes du colome; il pènetre dans les appendiees; la pluparl de ses élements sont des filores muschlaires a plusieurs noyaux. - L'enloderme, composé par une assise ejpilhéliale simple, entoure un espace entérique, encore oceupé, sur sa péripliérie, par du deutolècithe.

d'admettre qu'il en est, pour ces animaux, comme pour les Porcellio (Crustacés) déjà décrits. I.es ébauches endodermiques sout au nombre de deux, et se dégagent du protendoderme profond, dans une rigion qui correspond aux bords de la plaque ventrale, ou de la gouttière grer- 
minative, pour employer l'expression propre. Ces handes cellulares s'avaucent dans le vitelius central, vont a la rencontre l'une de l'antre, et se sowdent, en emprisomnant, dans l'esprace quelles limitent, une gramle partie de la vésicule vitelline. La suhstauce nutrilive llisparaît peu à per, alısorbée par les éléments endodermiques, et laisse en sa place un vile, l'entéron. - L'entéron des Insectes devient l'intestin moven, souvent désigné par le terme de ventricule chylifipue, et le foié qui lui est annexé; il contribue ainsi à produire une partie dn canal intestinal, bien restreinte il est vrai, mais qui existe cependant, alors que son lromologue des Cirustacés foumit le foie seul. Il est probahle que les notions, relatives à la fonction digestive dı loie des Crustacés, sont applicables à l'organe similaire des Insectes.

B. - Pendant que s'effectuent ces phénomènes, l'embryon se recourre, lans la grande majorité des cas, d'une enveloppe amniotique, qui l'entoure tout entier. Cutte enveloppe doit être considérée comme formée par deux replis de la région superticielle du corps; ces derniers se soudent, pour ne constitner quine seule membrane, apres quoi ils s'étendent aulonr de l'animal. A cause de leur origine, ces replis sont constitués par du vitellus en leur milieu, et par nne conche cellulaire, de provenance llastodermique, à l'extérieur. Nu moment oủ ils prennent naissance, sm la face inférieure de l'embryon, et de part et d'autre de la plarpe ventrale, ils ofrent l'aspect de deux bourrelets longitudinaux; ils grandissent ensuite, et se convertissent en lames, qui se reploient au-dessous de la plaque rentrale. Chacune de ces dernières présemte une face interne, tommée vers la plaque, et une face externe tournée vers le lehors; ces deux faces sont constituées par un épithélium cellulaire, provenant du hlastoderme; entre elles est une bande le vitellus nutritif, yui existait dans les hourrelets primordiaux, et se conserve, tout en s'amincissant, dans les replis en voie l'extension. Lorsque ceux-ci se sont suudés, et ont entouré completement l'embryon, la hande vitelline disparaît d'ordinaire par résorption, et l'enveloppe amniotique se compose seulement des deux couches épithéliales accolées. L’assise interne est nommée par les auteurs l'ammios, et l'externe la sereuse, par comparaison avec leurs correspondantes des Vertélsés supériemrs; il raut miens, pour éviter des confusions inévitables, qui se sont prodnites du reste, désigner l'interne par l'expression endamios, et l'externe par celle d'examnios.

Les demx replis amniotiques primordiaux uaissent, d'habitule, au moment oi la plaque ventrale entre en prolifération. Ils ont tout d'alsord l'aspect de bourrelets, lormés par les parties superficielles de l'embryon, cest-à-dire par des épaississements locanx ılı vitellns, que limite en lehors le blastorlerme; ainsi constitués, ils sont situés sur les cơtés de la plaque ventrale, ot s'étendent comme il est dit plus haut. Ils s'allongent de maniere á se rapprocher des deux extrémités de l'embryon, et s'élargissent en mème temps, pour venir au-dessous de la plaque ventrale; ils 
ressemblent alors ì des lames, dont chacune présente un bord lilure, it un hord adhérent an corps. Les hords lilires des denx lames tinissent par s'aflronter, puisquils ront, dans leur extension, il la rencontre l'un d, l'autre: ils s'accolent alors, et se soudent; les denx membranes n'en composent plus qu’une seule, placée comme un pont au-dessous de la face inférienre de l'embryon. Les bords alluérents, lorsque cette coalescence est acherie, et mème arant qu'elle ne se produise, ne demeurent pas lans la mème position; ils remontent de plus en plus baut sur les côtós lu corps, et parriennent jusqu’a la face dorsale. Arrivés là, leurs insertions sur l'emliryon se rapprochent, se rencontrent, et se réunissent; le pont amniofique, localisé tout d’abord à la région ventrale, après avoir ainsi frogressé par ses deux côtés sur les llanes lu corps, au moyen l'un véritalle clivage qui sètend de plus en plus, parvient dans la région dorsale, y unit ses deux bouts, el constitue dès lors un fourreau cylindrique. Pendant que cette enreloppe gagne en hauteur, elle progresse igalement en avant et en arrière par le même procédé, double l'extrémité antérieure, l'extrémité postérieure, et finalement entoure complètement l'embryon. La membrane amniotique est alors forméc, avec son examnios, son endamnios, et la bande vilelline interealaire.

I)'habitude, les replis amniotiques sont minces, et il en est de mème pour la lame centrale de vitellus; mais parfois ils sont épais, cetle amplification étant le fait de la bande vitelline, qui atteint un volume consilérable. Il en est ainsi chez les Lépidopteres, par exemple; leur amnios, fort épais, contient dans sa substance une grande quantité de vitellus, et, lorsqu'il se brise, ce dernirr se répand aulour de l'embryon, qui s’en nourrit. - Ce phénomène est plus accentué encore chez les Hémiptères, et surtout ehez les Liluellulides; la majenre partie du vitellus ovulaire passe dans les replis amnioliques, de sorte que l'embryon se trouve entouré far son vitellus, au lieu de l'envelopper lui-nuème; la genése de l'amnios se réduit presque à une pénítration de la plaque ventrale dans la résicule vitelline, de manière à la faire prarvenir an centre de rette dernière, et a placer autour d'elle lout le deutolécithe. Celui-ci sert. comme toujours, à la nutrition le l'embryon; il se résorlue à mesure, et les parties, yui disparaissent en dernier lieu, sont celles qui recouvent la face torsale de I'animal.

l.es Insectes qui possèlent un amnios, sont d'orlinaire complitement

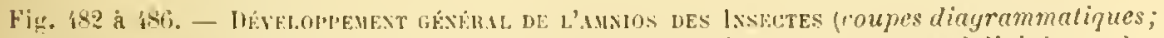
le schizocrelome est représenté comme s'il étail cntirit, et non pas suludivisi par des traves misoderminues: l'organisation rielle est donne par les ligures judedenles). -

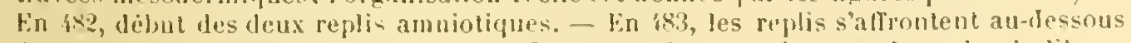
de la face ventrale de l'emliryon. - En 48, les replis se sourlent par leurs borrls libres, penlant que les bords adhejents remontent sur les lanes de l'emlirgn. - lin iso, les burds allierents se sont reneontres au-dessus de la face dursale, et l'umios s'st converti

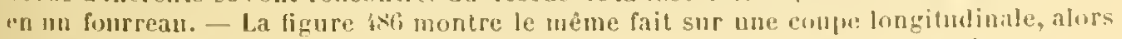

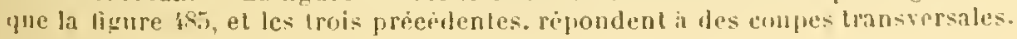




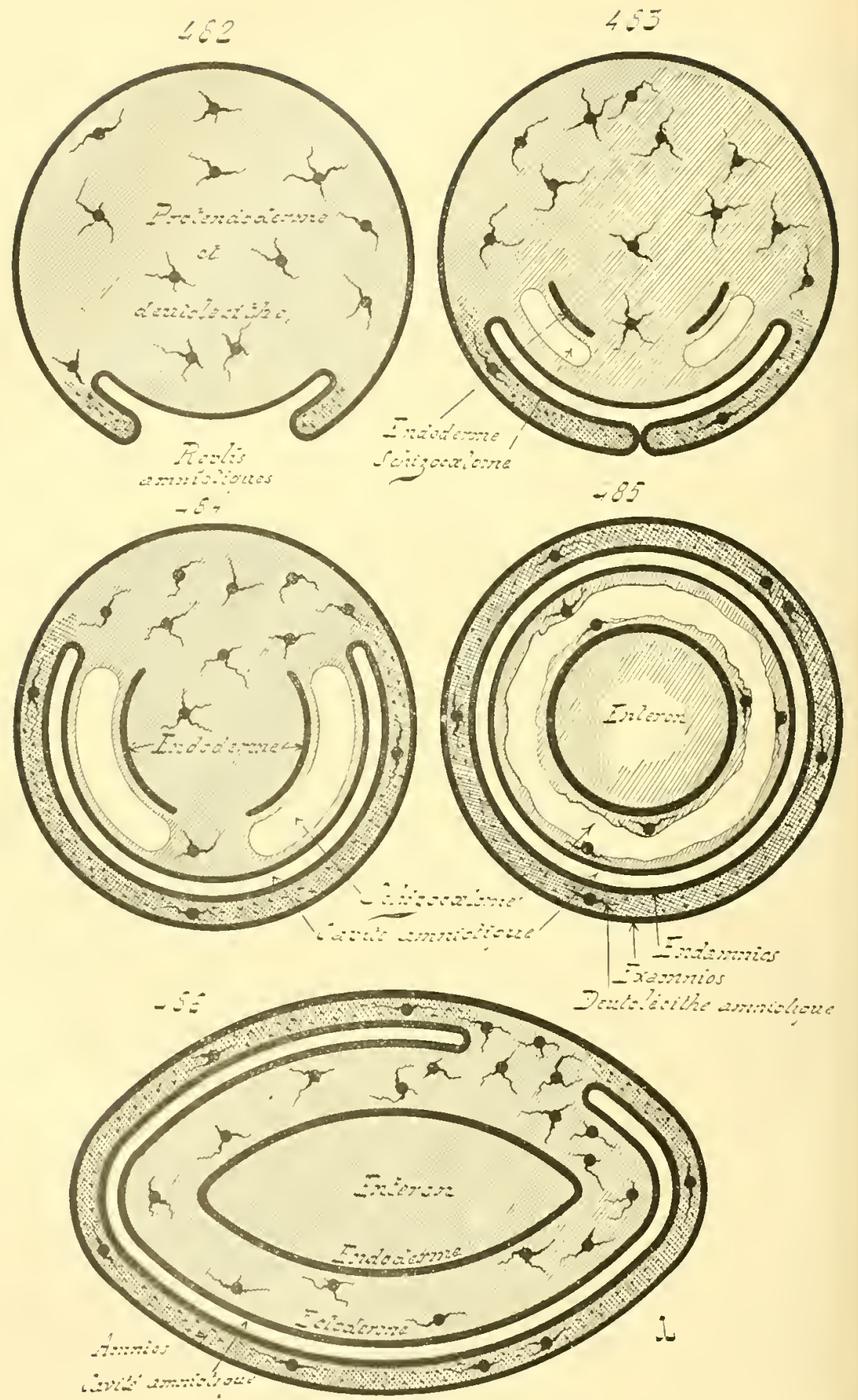



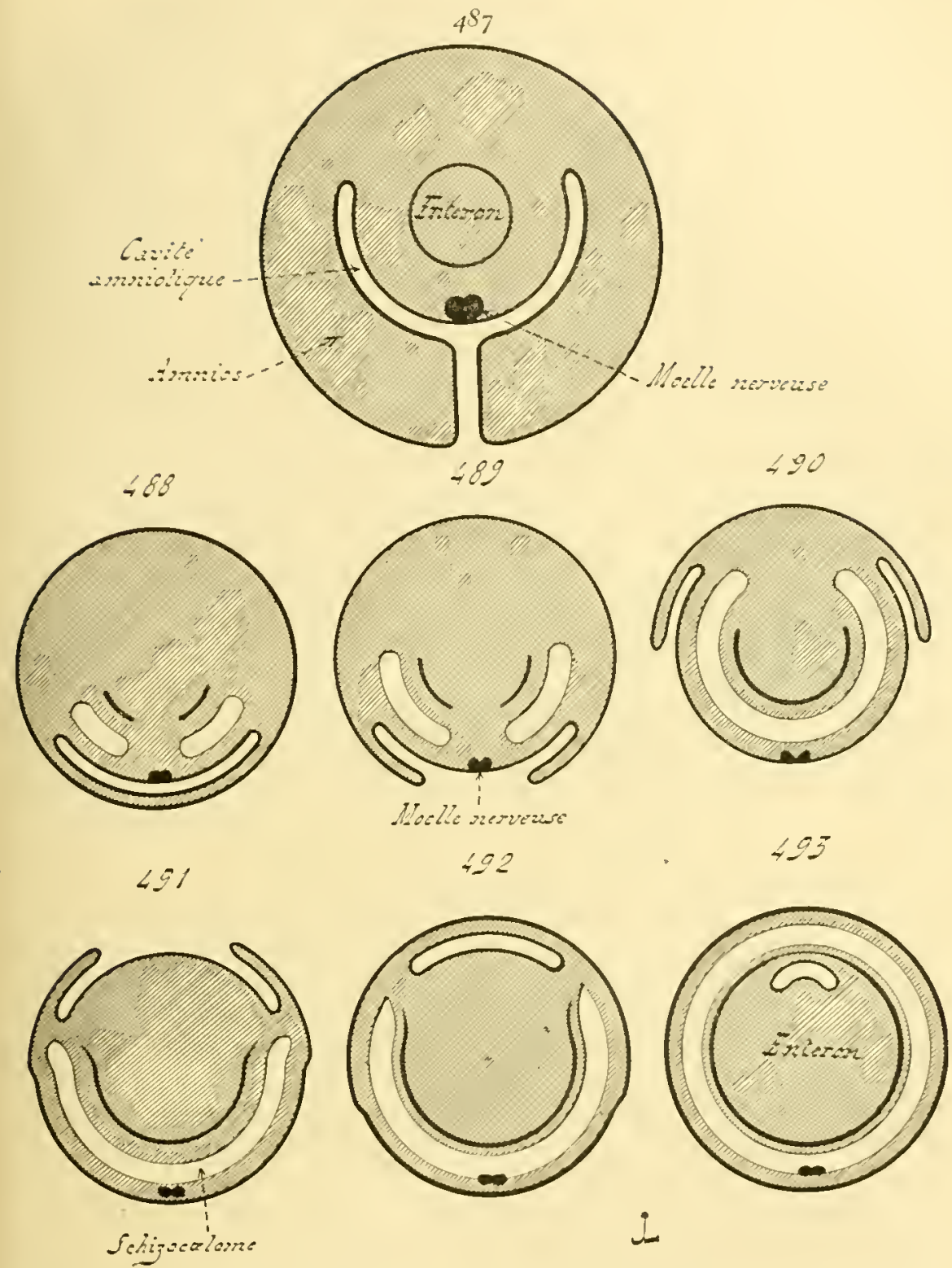

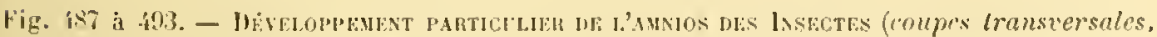
el diagrammaliques). - En ist (figure superieure); amnios ipais des embryons le lićpi-

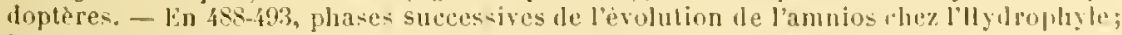
les deux replis amniotiques se disjoigneut apris s'elle soudés, et remontint sur les llanes du corps, pour constituer le canal dorsal, yui est pris dans l'espute laisso it l'en. téron, et disparait ensuite.

bans ces figures, comme dans celles de la planche frécelente, le deutolécille est exprimi par des hachures, el les couches cellulaires soul représentees par des traits. 
enviromós par lui; cette membrane se résorbe avant l'éclosion de lindiviju. el, si alle ne l'est pas à cr moment, elle se léchire pour permettre cette opération. En ronséquence, l'ammios donble en dedans la coque choriomnaire, el contrilue, pour sa part, à assurer la protection de l'embryon. - 11 n'en est, cepemdant, jas loujours ainsi, et l'Hydrophyle monlre un exemple du contraire. Chez cet anjmal, les deux replis amniotigues se soudent l'un a l'autre, comme d'ordinaire, au-dessous de la plaque ventrale; puis, lorsque les hords alhérents remontent vers la face dorsale, les borids libres se désunissent, el les deux replis se séparent de nouveau. Claque lame amniotique progresse alors sur les llanes lle l'individu, en gagnant la région dorsale, et se rétrécit à mesure; au moment oì elle alteint cette zone, elle est réduile à une mince saillie. Les deux refulis, ainsi ramenés à des dimonsions fort restreintes, se rapprochenl l'un de l'autre sur la face supérienre de l'embryon; puis, lorsque la distance quiles sépare est assez petile, ils se renrersent sur eux-mèmes, rt se ploient, de manière à faire atfronter leurs bords lilues pour les souder à nouveau. Hs constituent par la mne memluane amniolique en forme de pont, mais de dimensions minimes, el placée au-dessus de la face dorsale de l'embryon, au lieu de se lrouver sous la région rentrale. L'esprace clos, laissé cutre cette membrane el le corps, a recu, à cause de sa siluation, le nom de canal dorsul; il diminne pen ì pen d’amplilude, et disparait hâtivement, avec la membrane qui le limite vers le delors, sans laisser ancune trace. - Il est prohahle yue cette succession de phénomenes correspond is une atrophie seconlaire l'un amnios antrefois complet, et qu'il ne convient pas le lui accorder une antre signification.

\section{\$4. - Formes embryonnaires.}

La phuprt des Arlhropodes, et il n'uxiste guère d'exception à cet égard qur pomr la généralité des Arachnides, sulissent drs métamorphoses extérienres, et sortent de leurs coques ovulaires à l'élat de larves plus uu moins complètes. Cependant, les représentants des classes, autres que celles des drachuides, ne présentent pas lous de lelles transformations; phsieurs les montrent moins prononcées, et alors quils sont renfermés dans lenrs unveloppes, mais ces exceptions constilnent la minorilé. Un lait à remarquer porte, tout au moins pour ce qui est des lnsectes, sur l'absence exclusive de métamorphoses extérienres chez les lyjes les plus simples du grompe, les Thysanomes et un hon nombre d'Orthoptères; il faut en conclure que les larres des Insectes sont seconlaires, c'est-it-dire onl été introduites secondairement dans l'évolution embryomaire le plusieur's de es ètres, alors quelles manquent aux moins élevés l'entre eux. l’areille conclusion est également applicable, semble-t-il, aux cmbryous libres des Crustacés; car les lintomostracés inférieurs (Cladocères), et les Malacostracés inférienrs (Nébaliens, Elrophlillalmes), sout prives de phases larvaires. 
Les changements subis, par les embryons. daus leur aspect gremeral. tienuent surtout au nombre et i la disposition des apjendices. Cenx, de ces deruiers, qui appartiennent ì la région antérieure de lourganisme, naissent tout d'abold, et existent seuls; puis apparaissent, aver les autres parties du corps, les appendices qui lenr sont altachés. Livolubion est done dominée par la genèse, en '[uantité toujours phus grande, le prieces appendiculaires, jusquau moment ò̀ le chiffre définilif est allejut; parfois mème ce chilfre est dépassé, el cerlajus de ces organes s'atorfhient, de manière à ne point exister chez l'adulte. Les Scorpionides, les Aranéules, montrent un exemple de ce dernier cas il en est de mème joul* certains Insectes, dont les larves possedent parfois des paltes aludominales, alors que les aulultes en sont privés.

Il suit de là que les embryons des Arthropodes commencent par naroir qu'un nombre restreint d'appendices, qüils augmentent peu à peu prar la suite, en procédant avec régularité à cetle genèse; elle clébule, dans la règle, par l'extrémité antérieure du corps, et finit parl'extrémité postérieure. Si les métamorphoses sont intemes, ce mode sérié de développement nest parfois pas tres net, mais n'en existe pas moins. Lorsque les mélamorploses sont externes, il est mieux reconnaissable et plus évideut, car les membres ont me ubilití fonctionnelle, et servent aux cmlıryons pour se déplacer daus les milieux extérieurs. Telles sont les larves les plus simples des Cruslacés, appartenant au tyje dit Tauplius; elles ne jossèdent que trois paires de pattes, et ceprendaut ces organes sont assez grands, et assez bien formés, pour remplir le rôle de rames.

I. Grustacés. - Les phases larraires, sulies par les divers représentants de ce groupe, sont nombreuses et complexes, surtout pour re qui tient aux plus élevés d'entre eux, à certains des Malacostracés Podophthalmes. Il est i signaler, cependant, que la plus simple de ees phases, celle dout le nombre dappendices est le plus petit, sc retrume avee des caractères semblables chez plusieurs de ces amimaux. чui appartiennent tout aussi bien ả la classe des Malacostracés qua à celle des Entomostracés. Cel élat correspond it la possessiou, frar lembryon, de trois parres de palces; il porte le nom de Vaupleus. - Les larves vles Entomostraces, qui débutent par la plase de Nauplius lans la série de leurs mótamorphoses extérieures, complotent ensujte le nombre de leurs membres, et se rapprochent d mesure le l'état parfait; sauf le cas le régression, concurlant arec une alaptation à la vie parasilaire, comme il en est ponr les Rhizocéplaales. - Les transformations. subies par les emliryous maupliens des halacostracés, sont plus prolondes; elles consistent en une sérje d'états larvaires, quj se suceivleml les uns les antres, en ofliant toujours un chithie plus grand d'appendices, ef maspect extérieur plus voisin de celui de I'adulte. I.e plus important de ces citats est celui dit \%oe; les enbryons libres sont alors munis le huit fraires 
de pattes, Jes trois du Nauplius se trouvant augmenlées de cinq supplémentaires. De nonvean membres prennent ensuile naissance, délerminant l'apparition d'aulles phases, qui se suivent ainsi, jusqu'au moment oì l'organisme est achevé. Les Crustacés supérieurs, les Décapodes, montrent, en accomplissant cette série évolulive, plusieurs aspects transitorres, qui rappellenl les dispositions permanentes d’animaux plus simples, celles des Schizopodes par exemple; de mème, les Décapodes lirachyures offrent, dans le cours de leur embryogénie, une forme de Décapode macroure. Ces ressemblances autorisent, sans aucun doute, à étalılir, l’après elles, les affinités naturelles de ces èlres.

lues lares des Cruslacés soul des larves à stases, c’est-à-dire sujettes it des arrèts plus ou moins longs lans lemr évolution embryonnaire; ces inlermptions correspondent à des persistances, durant un temps variable, de cerlains élats, tels jue ceux de Nauplius et de Zoć. Ces embryons s'entourent, en effel, d'une culicule, qui s'oppose à tout accroissement, el à loute modificalion extérienre; jl leur faul quilter celle enveloppe, loules les fois où le corps subit des changements importants. Les organes nouveaux, appendices ou aulres, s'ébauchenl sous la cuticule; puis, lorsqu'ils ont atteint un certain degré de perfection, cetle dernière se rompl, el la larve se présente hrusquement avec une structure plus complexe. Les larves des Crustacés, du moins la plupart d'entre elles, subissent done des métamorphoses brusques, accompagnées de mues; le nombre de ces dernières est souvent consilérable, surtout chez ceux des Malacostracés qui abandonnent leur coque ovulaire à l'élal de Nauplins.

Ce demier état, qui se présente avec une telle fréquence chez un certain nombre de Crustacés appartenant aux principaux groupes, est caractérisé, dans tons les cas, par le nomhre et par la disposilion des appendices, qui ne varient point. Ces organes sont au nombre de trois paires : ceux de la première soul simples, et cenx des deux autres sont liranés, e’est-it-dire ont leurs extrémités libres en forme de fonrches. Ce sont là les particularitís essentielles, que possèdent avec constance Loutes les larves naupliennes. Parfois cependant, el ce fail, fort rare, existe, par exemple, chez les Phyllopodes lu genre A pus, l'une des paires est à peine développée au moment de l'éclosion, de sorle que le Nauplius de ces animaux est muni seulement de quatre paltes.

Crustacés entomostracis. - Celte classe contient un cerlain nombre d'ordres, (gu'il est possible de grouper en trois séries; la première contient les Jhyllopodes, la seconde renferme Jes Ostracodes avec les Cirrhipèdes et les Rhizocéphliales, el la troisième les Copépodes seuls.

A. - Les Phyllopodes, appartenanl au sous-ordre des Cladocères, sont les moins élevés de tous les Cruslacés; ils ne subissent point de métanorphoses exlérieures; ils ont Jéjà achevé leur évolution, ou peu s'en faul, au moment oit ils quitlent leurs enveloppes ovulaires. - Il n'en 
est point ainsi pour ceux qui constituent le sous-ordice des Branchio-

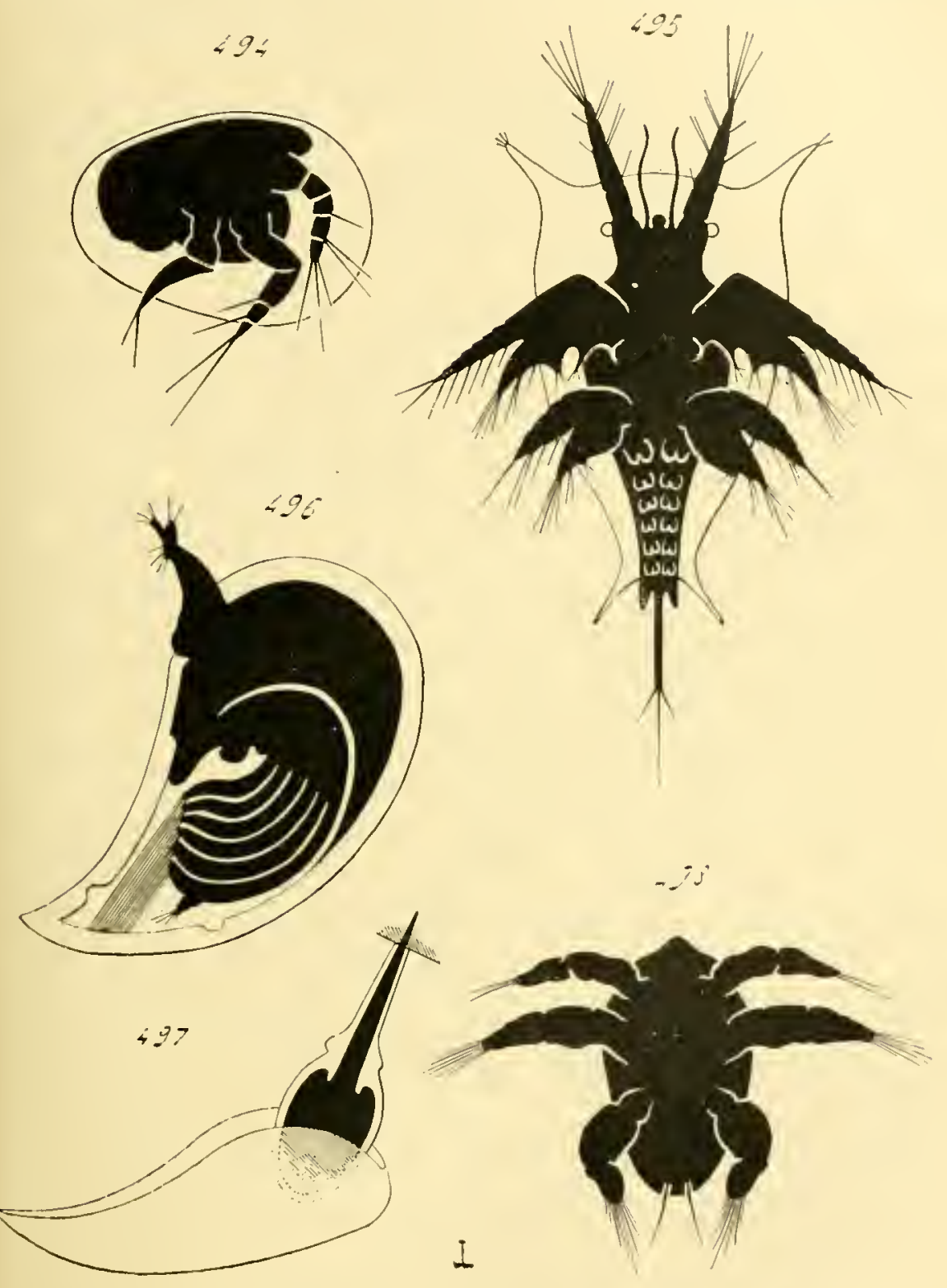

Fig. 494 ì 498. - I.ARves mes Caustacés entomostuchs (silhouelles). - lin fyi, Mauplius de

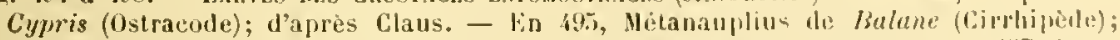

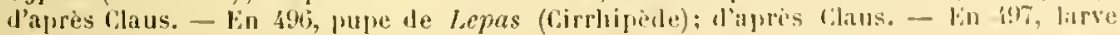

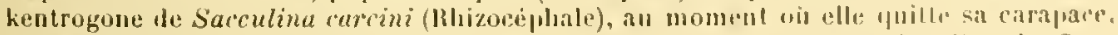

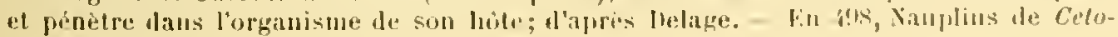
chilus (copripole); d'apres liroblien. 
podes; ces derniers abandonnent leur coque à l'ítat de Namplius; parfois. et notamment chez les Estheria, la paire antérienre des appendices est presiue atrophice. lec corjes de ces larves nampliennes est ovalaire, et porte en arant les parires de pattes ju'jl possede; il s'allonge par sa région postérieure, ef produit a mesure de nouveaux membres, cefte genese s'effectunt avec régularité d'avant en arrièe. De mème que chez tous les Crustacés, les appendices larvaires s'organisent suivant leur rang; les deux paires antérieures domnent les antennes, les pièces de la troisiome paire se convertissent en mandilules, et les suivantes fournissenl, diares leur position sur le corps, les michoires et les paltes.

I'. - Ceux des Ostracodes qui vivent daus la mer, comme les Cylhere, ressemhlont en cela amx Pliyllopodes cladoceres, et ne subissent point le mátamorphoses extériemes; par contre, les Ostracodes deau dunce, et surtout les Cymis, quittent lenr coque ovulaire à l'élat de Nauplius. Cette larve est remarquable, car clle montre déja la disposition zénólale le l'organisme alulle, hien que ses appendices soient moins nombreus; elle est recouverte fir nne rarapace bivalve, qui n'a plus 'ju’a s'accroitre pour devenir celle de l'animal délinitif. Les principanx des changements, uflerts par ces embryons, portent sur la genèse des quatre paires complómentares d’appendices, genèse qui s'effeche en arrieve de celles existant déjà, el sur la transformation de ces dernières en antemnes et mandibules.

les Cirrhipèdes présentent drs métamorploses extéricures très complexes. Ils sortent de lem's enveloppes chorionmaires à l'état de Vauplius; le corps de cette larve posside une forme caractiristique, celle l'un écusson, à cause le l'rlargissement de sa région antérieure; sa fare dorsale est recourerte jar une mince carapace, qui ne tarde pas à se ruplier sur les côtés pour entonner l'animal enties, et à devenir livalve romme relle des Ostracodes. - Le Namplius mue ensuite, et se convertit en Métunuplius; l'aspect général n’a pas changé, mais la région postérienre, on abrominale, s'est allongée, el porte sept à huit parires de pattes, en sus des trois ilu Nauplius. Ces dernières sont grandes, et servent i l'embryon pour nager; les denx premières des apprentices complémentaires (qualrième el cimpuième de la sćrie complete) sont courtes, plates, et deviendront les ćlauclıes des futures màchoires; les cimp ou six antres sont un peu plus grandes, of rappellent d'assez près

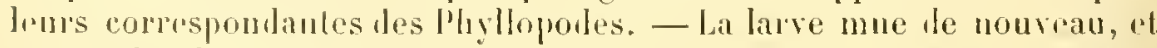
passe ì la phase lite d'ostracode, on de Cypris, ul mieux encore de mupe ou de nymple, can les relations avec les Ostracoles, assez lointaines, tioment seulemeul a la lorme bivalve de la carapace. Les appendives le la preniere paine (antennes de la premicre paire) élargissent lenr lase, oir se rembent les conduits l'uno glande, la ylumde cémentaire, qui sécrote un mons servant à l'animal pour se fixor sur un support; ceux de la seconde paire (antommes de la denxieme paire) satrophient; renx 
de la troisieme paire se rapprochent de ceux dos deux maires suivantes (michoires), el commencent ì prendre la forme le manlibulos; enfiu, ceux placés dans la régrion abdominale s’allongent en loaguelles, ot montrent déjà leur aspeet définitif.

La larve, ainsi composée, enveloppée par sa carajace livalve, unune d’un uril impair simple, et de deux veux composés latélaux, nağe fundant sa transformation de Hétanauplius en pupe; la parlic dorsale l." son corps contient des matériaux nutritifs abondants, utilisés pour permeltre les métamorphoses futures. Bille se fixe ensuite ì un support frar la lase de ses premières antennes, par son extrémité céphalique en conséquence, el subil un dernier clangement, accompagné de muc, qui la convertit ru animal parfail. Son extrómité antéricure, lixéc, s’allongedans le cas oì l'ałulte possèle un pédoncule, el lonne ce dernicr organe; ses seconles antennes et ses deux yeux composés s’atrophient d'une manière définilive; ses trois paires de pièces buccales se rapprochent les mues des aulres, et encadrent la bouche, tout en restant fort pelites; ses appendices abdominaux prenuent leur aspect caractrislique le cirrhes; enfin, apres la mue qui entraine la chute de la cuticule propre à la pupe, les téguments apparaissent, recouverts par les pièees de la carapace calraire. l individu a terminé dès lors son évohution.

l.es Rhizocéphales subissent des transformations emlryonnaires fort remarqual,les, saramment étudiées par Itelage sur la Succulinu carcini. L'évolution ressemblo de tous points, par son débul, à celle des Cirbipioles. Les larves abandonnent leur coque ovulaire, lorsqu'elles sout à l'état de Nauplius; elles subissent ensuite quatre mues successives, la derniere aboutissant à me phase Ostracode, encore dite phase Cypris. Elles nagent durant ees metamorphoses; et celles l'entre elles qui parviennent ì s'altacher, au moment oi elles atteigneut la phase de Cypris, sur de jeunes Crabes àgés de trois ou quatre mois, dont la culicule est eneore mince, achèrent senles leur développement; ce deruier est tout de régression. L'embryon s’altache i son hôte par ses antennes, etperil ses paltes aver les régions qui les portent; sa zone ałhérente, qui correspond a l'extrémité céplualique du corps, produit nn lard, qui hui permel de pereer la carapace du Crabe, et de pénétrer tout entier daus son corps: d'où le nom de larve lientrogone lonné a cet itat. L L'emhryon. levenu parasile interne, et lérhul í yuelques assises cellulaires, se lousforme cusuile en animal parfail, dont lorganisme est des phus simplos. Les couches qui le constiluent domnent naissance sur place, par des séries de délaminations on de clivages, anx appareils de l'économir, el, ce faisant, il grossit. Son extromilé antérioure omet de nombrenses expansions, les racines on suroirs, qui se lépandent dans loules les rógions de lhòte pour en aspirer les sues; sa région postricure. bevenue lort volumineuse, somleve is son niveau les linguncuts du

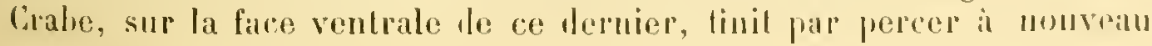


la carapace en pressant sur elle de dedans en delrors, el fail saillic à l'extérien. L'état lólinitil est alors atteint.

Il est nécessaire de se convaincre que les larves lentrogones sont secombares; le fait est cerlain, étant donnés leur état parasilaire, et les phrinomènes régressif́s qu'elles préseulent. l'artant, les changements qu'elles subissent pour produire leurs organes, et notamment le mantean de l'adulte, n’ont aucune siguification essentielle; leurs délaminations coprespondent simplement a la substilulion du développenent massif an type crux. I'nn antre coté, la sacculina carcini est certainement un des types de Rhizocéphales, dont l'adapuation parasitaire est la phis compliete; entre los Cirrhipedes mullement parasites, et les Rhizocéphales anx larves kentrogones inlernes, il est sans doule des inlermédiaires, des types le jassage, qui sont seulement les parasites extemes. - Celle notion permet de comprentre les observations déjả anciennes de F. Miiller, avec relles plus rónentes de Giarl, qui sappliquent à des Rhizocóphales se lixant sur leur hrite il l'état al'Ostracorle, et se hornant à enfoncer dins l'organisme be cel hoble, non pas lem corps entier, mais seulement leur extróniló antériemre mure de ses suçoirs.

C. - Les larves des Copépodes libres éclosent a l’étal de Nauplius. Leur form rappelle d'assez pres celle des embryons correspondants les J'hyllopodrs; lenr corps est ovalaire, et se termine en arriere par deux soies divergentes; celle extrémilé postérienre ne tarie pas, lu reste, à devenir fourchue, comme celle de l'alulte; m petil ril impair est placé entre les antennes de la premiere paire. La larve mue ensuite; celte métamorphose correspond à la genèse de la frutrieme paire d'appenlices, qui domne les premieres màchoires. - Une nouvelle mue se manifeste un peu plus tard, et converlit l'embryon en un Métumanplius; sa région postricure s'allonge, et commence ì se segmenter; trois antres paires l'appendices (cimpuiène, sixicme, el septieme) prennent maissance, dont la premiore fommit les secondes michoires de l'aulute, et dont les deux antres deviemneul les patles antérieures. - La larve mue encore une fois, et se transforme en un jeune Copepode, état nommé souvent phase Cyctops, du nom de l'un lles représentants les phus simples le lordre. Sa rógion postŕrienre, on abdominale, commence à montrel son aspect définitif, hien que tous ses anmeaux ne soient pas présents; la rógion anlerienre, qui porte les appendices, s’élargit en un céplialothorax; les deux on trois dernieres paires de pattes sont engendróes. Entin. apris une antre siple de mues, durant lespuelles se délimitent les anneanx manpuants, el se faconuent d'une manièe définitive los antenues el les pioces huccales, la larve passe a l'état parfait.

Les Coprépoules parasites sulissent aussi des mólamorploses extérioures; mais l'alı'vialion embromnaigr exeres sur clles som influence, o les rend moins romplexes pio reolles des formes libres. La plupart

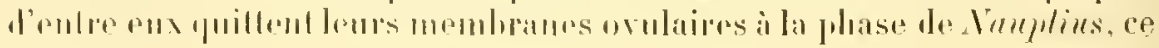


dernier ne jossedant parfois, au moment de son relosion, tuedrux praires

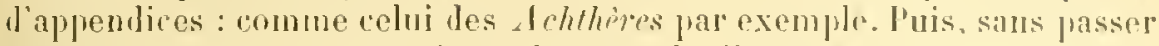
par la série des mues qui conduisent de l'état Nouplien à celui de Cyclops, ils parviennent hrusquement à ce dernier, en no sulissant it cet effet qu'me seule mue; celle-ci se manifeste, somrent, presiue de suite après l'éclosion dn Sauplius. Les deux on trois ternirmes palires de patles, qui commencent a se montrer lors de la phase Crelous, ne sont point engendrées d'ordinaire; le plus, les autres appendices présentent déjà leur aspect définitif, et, suivant le cas, s’atrophient presipue, ou so convertissent en cjochets. - Ensuite, les jeunes larves Cyclopéennes gagnent des organes sexuels; les miles restent en cel état, et se cramponnent aux femelles; celles-ri grossissent heaucoup, perlent toute trace de segmentalion en anneax, subissut en somme une mólamorphose rogressive, et se fixent sur les téguments de l'hóte, anquel elles avaient adhérí déjà, lors de leur étal de Cyclops. Dans le cas ou le parasitisme est le plus complet, chez les Lernéides et les Lernénporles, la femelle se laisse féconder par le måle, lorsqu'elle est encore à la phase Cyclops, ou peu après celle phase.

Lahréviation du développement embryonnaire est telle chez certains Copéprodes parasites, appartenant aux genres Amchorella, Brachiella, Hessia, et Lerneopoda, que l'élat ile Nauplius est interne; il se manifeste lorsque l'embryon est encore renfermé dans les membranes orulaires, el ce dernier éclót sous la forme de Cyclops. Il en est de mème pour les représentants (Argulus, Cryropellis) du remarquable groupe les Branchiures.

Cnustacis Malicostracis. - Lomdre le moins élevé de cette classe, el qu'il est permis de considérer comme primitif par rapport aux autres, cst celui des Vébaliens, encore nommés Leplostracés; ce groupe est roisin de certains Ihyllopodes supérieurs, notamment des Artemiu. De lui se dégagent deux sóries, dont line est relle des Elriophthahmes avec ses trois orlres (Amplipodes, Lémodipodes, lsopodes), et l'autre celle des Podophthalmes; colte dernière comprend à son tom deux sulıdivisions principales, l'une hornce aux seuls stomapodes, et l'autro contemant les Cumacés, les Schizopodes, et les Décapodes.

A. - Le déveloprenent des Nébaliens s'eflretue sans ancune mélamorphose extérieure complexe; la róserve vilelline ost ronsidérable dans l'uuf, el les appendices naiss’nt rógulierement les uns derrière les autres, sans olfrir aucunc stase correspondant à l’élat de Namplius, ou à une phase ultéricure. An moment où l'embryon éclót, il porte encore. sur son tos une part de sa vésicule vilelline, ét tous ses appendices sont déjì présents, bion füóbauchés pour la plupart. Ces derniers so pres-

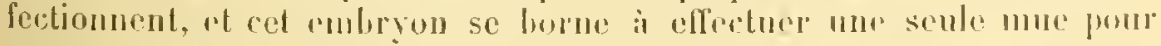
passer it l'ólat parfait.

RoULE. - EMERYoLOGIE. 
li. - Lus mèmes dommires sapplinuent, daus leur ensemble, à tous les Edriophthalmes; ces animaux faronnent leurs appendices, alor's qu'ils sonl encore contenus dans leur coque ovulaire, el belosent avec lontes leurs palles. Un fait parliculier consiste lans la production, autour de l'embryon, nolanment chez les Isopodes, et durant la genèse des premiers appendices, diune line menbrane semblable à une cuti-

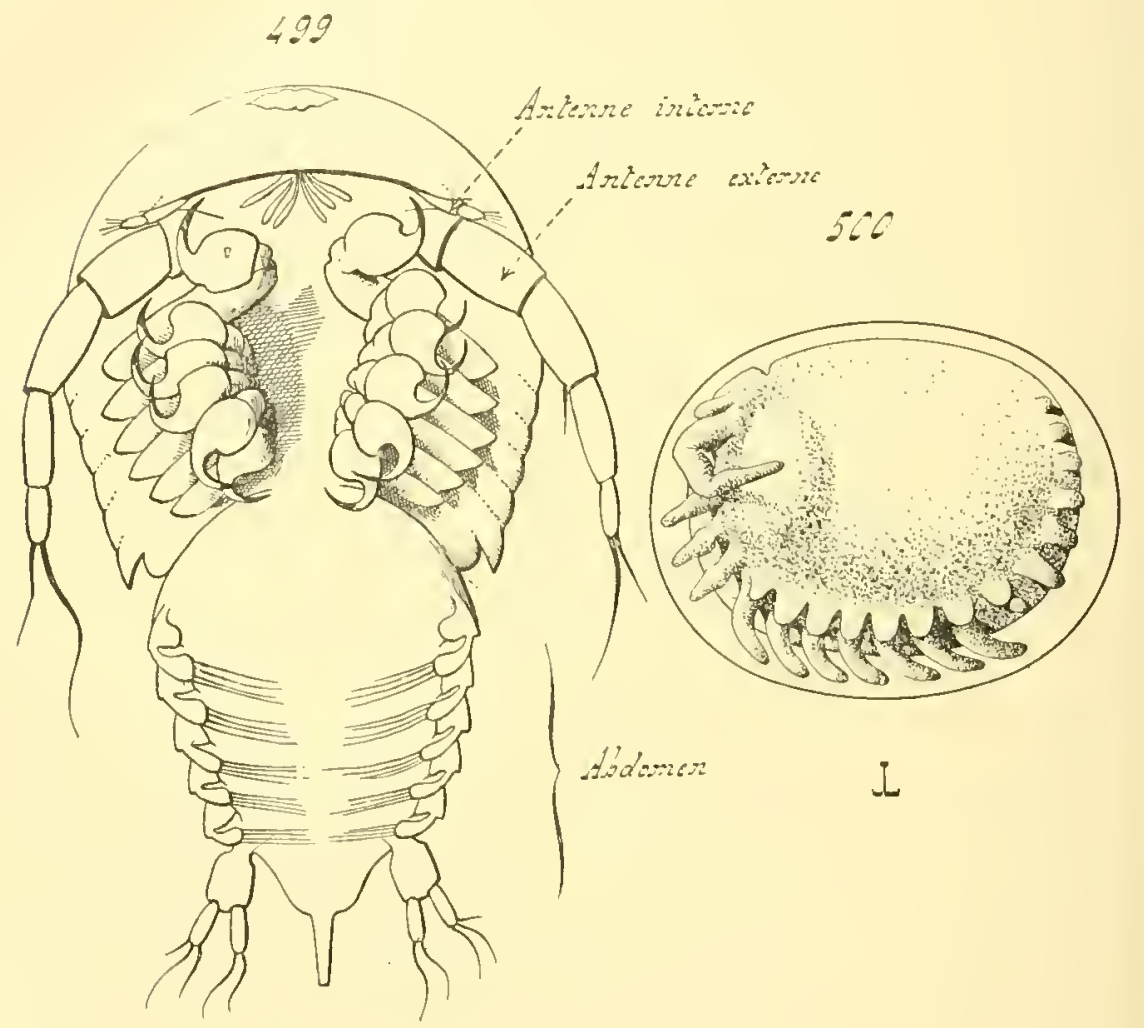

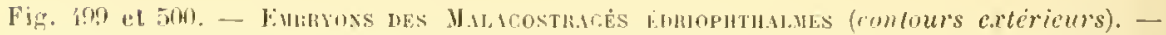

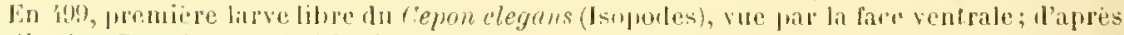

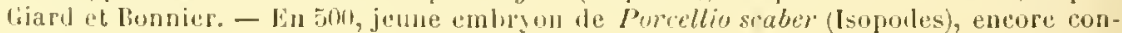
tenu dians sa compe, et vu de profil.

cule, Ini double en dedans la coque de l'ovole; les aulenrs voient, dans celle membrane, l'homologue de la cuticule les larves naupliennes, el admellent que les Edriophllsalmes passenl prar un étal de Nauplius, interne au lien d’ètre extéricur. - La généralisation est un peu forée. l'époque, vers largurlle cette membrane apparail, ne concorde pas exactement aver relle où l'ombryon possinle sublenent trois paires diaprembices; il nexiste point de stase, d'arrà évolutif, si minime soil-il, à ce dernier moment; le dépròt d'une culicule pent dépentre d'une autre cause, 


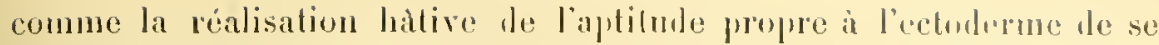
convrir dune earapace; entin, alors que les Crustacés à métanorphoses extéricures offrent un grand nombre le mues sucessives, et par suite de genèses cuticulaires, les Edriophthalmes se bornent à celle signalíc. Toutes ces considérations empòchent d'accepter l'opinion des auteurs; et il fant adurettre que les Edriophthalmes engendrent lenrs appendices comme les Nébaliens, sans othrir le stases correspondantes à celles des métamorphoses extérieures des autres Crustacés.

Cenx qui sont libres, parmi les Amphiporles, les lémodiporles, ou les Isoporles, sortent presque parfaits de leurs membranes ovulicires. Leurs aufs contiennent une aboulaute réserve nutritive, qui n'est souvent pas entièrement consommée au moment de l'éclosion. Les jeunes, à l'époqne de leur mise en liberté, ne diffèrent guère des adultes que par des détails secondaires; le septiène anneau thoracique est petit, et ses appendices sont réluits à des moignons; plusicur's des articles des pattes manquent encore; mais, ces phénomènes mis à part, l'organisalion est complète. L’animal n’a plus qu’à grandir pour devenir parfail.

Par contre, Ies Edriophlthalmes parasites subissent des métamorphoses extérieures assez compliquées; ils sortent de l'ceuf dans un élat qui rappelle de près son corresponlant des formes libres, mais, au lieu de s'accroître régulièrement, ils subissent des modifications régressives, qui leur donnent peu à peu leur aspect définilif et asymétrique. Leurs pattes se réduisent à le petits crochels, on mème s'atrophient; parfois, chez les Hypérines par exemple, les appendices ablominanx ne se montrent point. Ces elıangements sont d'ordinaire moins prononcés chez les mâles; ces derniers demeurent petits, et capables de se déplacer, alors que les femelles sont immobiles; pareil phénomène a déjà été signalé chez les Copépodes parasites. - De telles métamorphoses sont surtout complexes chez les lsopodes arlaptés au parasitisme, et ont été bien étudiées par Giard et Bonnier. Ainsi, les jeunes loniens, au moment où ils quittent leurs aufs, ressemblent en tout ì des petits lsopodes libres, et surtout ì des Sphéromes; ils passent ensuite par nu étal cryptoniscien, aiusi nommé, ear ils rappellent alorsles Cryptoniscus, Isopodes parasites moins nodifiés qu'eux; ils subissent plus tard une nouvelle plase phryeroüde, on ils ressemlilent à l'autres Isoporles parasites du genre I'hryeus; el parviennent entin, après celte série de molitications régressives de plus en plus profondes, ì leur structure définitive.

C. - Les métamorphoses subies par les Stomapodes sout des pilus remarquables, mais encore pen comnes. L'embryon sort de l'muf, muni des dix premieres paires l'appentices; du moins ce chittre sapplipne-t-il anx plus jennes larves olservées, gui mesurent environ donx millimetres de longuenr. Ces vingt membres compunonent : les quatre antemnes, les deux mandilmles, les qualre mirhoires, of lis dix patlesmìchoires. Ces dernieres sont rejetées en arrière, nullement ranassées 
encore autour de la houche, et servout i la locomotion. Lo corps, lecunvert en dessus par une carajace rabaltue sur les cótés, et terminée en avant par une longue épine, jorte en arricre une courte région aplatie, chargée de se segmenter pour tonner les trois derniers anneaux lhoraciques, et cenx le l’ablomen. - Les transformations ullérieures s’accomplissent à travers une série de mues. La région postérieure grandit, et se divise comme il est wit ci-dessus; les apprendices aldomiuaux jrennent naissance, mais non reux des trois derniers segments du Horax, qui n'apparaissent yue fort tard; les deux paires anléricures des pattesmichoires se replient vers la bouche, et s'accroissent, pendant que les trois aulres satrophitut; les yeux pédonculés, qui ne cessent d’exister depuis le déluut des mólamorphoses, sont très volumineux. Finalement l'embryon passe à un élat dit Erichthus, lont l'aspect général rappelle presque colui de l'adulte, d'après la taille de l'ablomen, et la forme des deux premiores paires le palles-mâchoires. Les trois autres (des paires de pattes-màchoires) reparaissent par la suile. Les frois paires des anueaux postérieurs du thorax sont engendrées en derrier lieu. - Une autre série de métamorphoses larvaires des Stomapodes est eclle qui couduit à la phase Alima. Cello-ci ditlère des Erichthus en ce que les trois dernières. des ciny paires initiales de pattes-màchoires, ne s'ébauchent point hâtivement, pour se délruire ensuite; ces appendices prennenl naissance à peu près en môme temps que ceux des trois anneaux thoraciques postérieurs, et vers la fin de l'érolution embryonnaire.

D. - Les Gumacés, par leur tourmure générale, ressemblent à des larves le lécaporles; ils représentent le premier degrú de la série qui, partant des Nébaliens, conduit à ces lerniers. Les réserves vilellines de leurs unufs sont ahondantes: aussi, leur développement rappelle-t-il celui

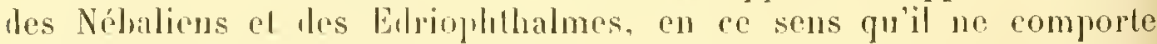
aucune mótamorphoso extérirure. Au moment oi leurs larves éclosent, elles possèdent tous leurs appendires, moins la lemiere paire des memblues thoraciquos, ot les pattes de l'abdomen; celles-ci prennent naissance par la suite, sauf clie\% la femclle, où les pattes abrominales ne se montrent point.

la plupart des Schizopodes rapjellent les Cumacés par leur node d'évolulion embryounaire, car les jeunes abandonnent leurs enveloppes orulaires lorspüils possedent tous leurs appendices, on peu s'en faut; certains rependant, notamment les Euphurasia, font excephion, el subissent des métamorphoses extérieures complexes. Les larves sortent de leur coque à l'état de Vauplius; celui-ci, dont le corps est ovalaire, est muni de ses trois paires de patles réglementaires. Il mue, et passe a la forme le Hetunantius; il possèle alors trois autres paires l'appendices, ce quilait six ru lont. - L'embryon mue de nonveau, el subit des changemonts comsilérables: Dana arait fommé a celte troisieme phase le nom le Calyplopis, et Claus l'a léduul,lée en deux états, correspondant à des 


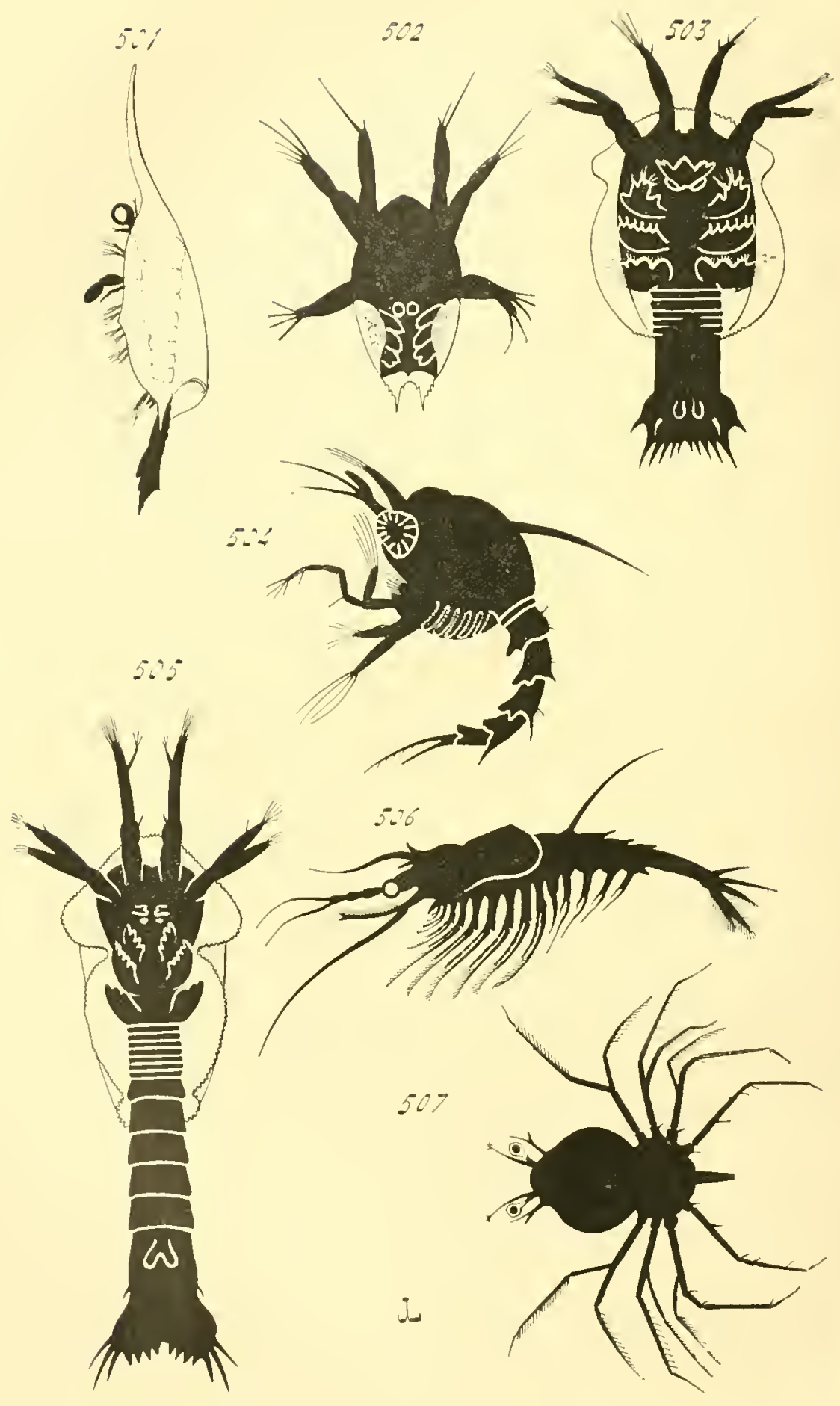


longtemps, un nom particulier; tels sont les I'hyllosomes, larrs des Décapodes macroures appartenant aux familles des scyllarines (Errevisses de mer), et des Palinurides (Langonstes). Ces larves ont un corps aplati, transparent, réduit presque au céphalotorax, el portant, dans sa région postérienre, mu abdomen fort pelit; elles répondent, presque, l'après le nombre de leur's appendices, à l'élat śchisopode du développement normal. A l'instant où elles éclosent, elles possident, en eflet: les denx paires d’antennes ( $1^{\text {ro }}{ }^{\circ}$ paires de la série tolale), la paire des mamlibules $\left(3^{\circ}\right)$, les deux des machoires $\left(1^{0}-3^{e}\right)$; la premire des paltesmàchoires $\left(6^{e}\right)$ fait dílant: les deux autres $\left(7^{*}-S^{e}\right)$, avee les trois des

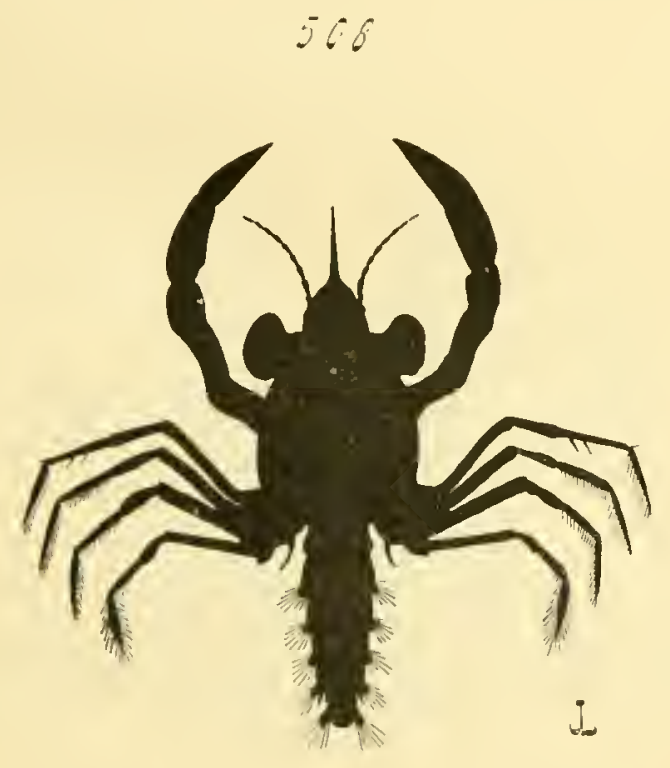

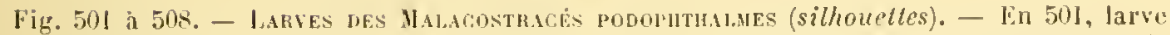
Erichthus d'une Squille (Stomapore); l'après Claus. - lin 5itr, Nauplius d'Euphausia (Schizopode); d'après Yetselinikoft. - En 503, l'rotozoe d'Euphausia; d'apris Chaus. -

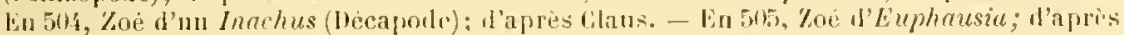

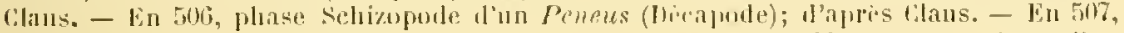

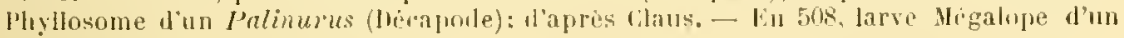
Portunus (llécapode); d'a près Claus.

premières palles thoraciqnes $\left(9^{\circ}-10^{\circ}-11^{\circ}\right)$, sont lien représentées, el grantes; les autres membres, rest-à-lire ceux de l'abdomen, el les deux dernières paires du lhopax, ne sont pas encore formés. Les Phyllosomes ne sont donc pas lout anssi avanés que les Schizopodes réels, mais se trouvent, cependiut, de heaucoup supérieurs aux Zoés par le nombre de lemrs membres. Lem transformation an adulte, el les pro-

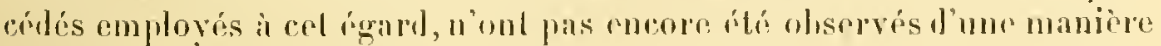
complinte. 
los allíations par abrévialion de développement sont assez rares; elles no sont guòre montróes que par les Hacroures de la familla des Astacilés (Homard, Ecrevisse), el par la plupart des brachyures. - Les Astacidés sortent de l'uuf sous un état Schizopode lijà bien accontué; et mème certains d'entre eux, lecrevisse jar exemple, possèdent presque toms leurs appendices an moment de lem ćclosion; la phase Zorienue est honc absente. - Les locapodrs bracluyres (Crabes) quittent bien leurs enveloppes ovmlaires a l'état le \%oé. mais la mue qui suit cette derniere, au lien de domner a l'umbryon une forme de Schizopode, le ronduit à un nouvelle phase dite Hégalope; l'état de Schizopode est ainsi onis dans le cours des plúnomènes ŕvolutifs. Les larves Mégalopes ressemblent assez à des Décapodes anomoures; leur aldomen, tout en étant restreint, ut situé daus le prolongement du corps, est relativement phus gros que celui de l'adulte. Ces emhryons, qui possedent tous leurs ipponilices, se complòtent en subissant une série de métamorphoses. accomplayécs de mues, pendant lesquelles leur céphabothorax devient volmminem, el leur almomen se recombe sous ce dernier.

11. Acères ou Allantennès (I'ycrogonides, Mérostomutés, Arachnirles). - Les représentants acluels des denx juemières classes montrent des métamorphoses extérieures complexes. Il n'en est point ainsi pour les Arachnides, dont les iutéressantes modifirations, au sujel du nombre des appendices, s'effecturnt abors que l'embryon n'est pas encore libre; pourtant, certains Acariens, ef les Linguatules, subissent des changements externes, surtout importants chez cos derniers.

Prcxogonols. - Au moment où les emhryons de ces animaux sortent de leur coque orulaire, ils possedent trois paires l'appendices, lout comme le Namplius des Crustacés; mais on ne peut trop se haser sur cetle ressemblance pour admeltre la complete homologie le ces denx types larvaires, car ces appendices diffèrent extrèmement comme forme, et ne produisent point les mèmes membrus. Ceux des jennes Pyonogonides sonl gramls, et servent à l'animal pour se cramyonner aux colonies d'llydraires, sur lesquelles il vit; les lenx de la première paire sont terminés par de forles piuces, rt les quatre autres par des crochets solides. Le corpes aplati rappelle assez hien, prar sa disposilion d'ensemble, celui de l'adulle. Celle phase larvaire a bie nommér I'rotonymyhon par llieck, qui l'a décourerles.

Les quatre paires complomentaires dappendices prement ensuite massance aree régularité, l'aprós leur range, en arrière de la troisieme:

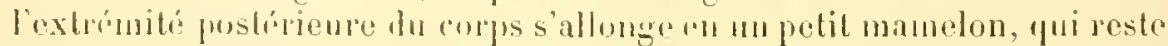
lort court, el représente l'ablomon. La rógion orales avame pomr domner

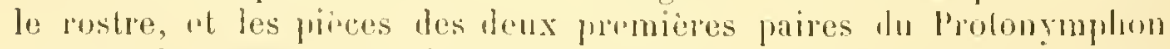
revelont leur aspect définitit, en s’aljoignant à ce dernier. Celles de la

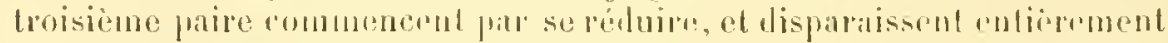

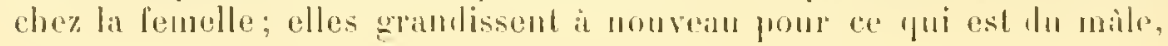


et leviennent les pattes ovigires. Quant anx yuatr paires complémentaires, elles ne cessent de s'accroìtre ponr donner les memlurs locomoleurs de l'adulte.

Menostonates. - Le genre Limule est le seul a constitur cette classe dans la natme actuelle. Mors que l'embryon de ces animaux est encore renfermé dans ses membranes orulaires, et dans son épais chorion, il produit tout d'ahord, et presque en meme trmps, ses six fraires de pattes thoracipues, saus offrir aucune stase répondant à l'époque où

\section{0}

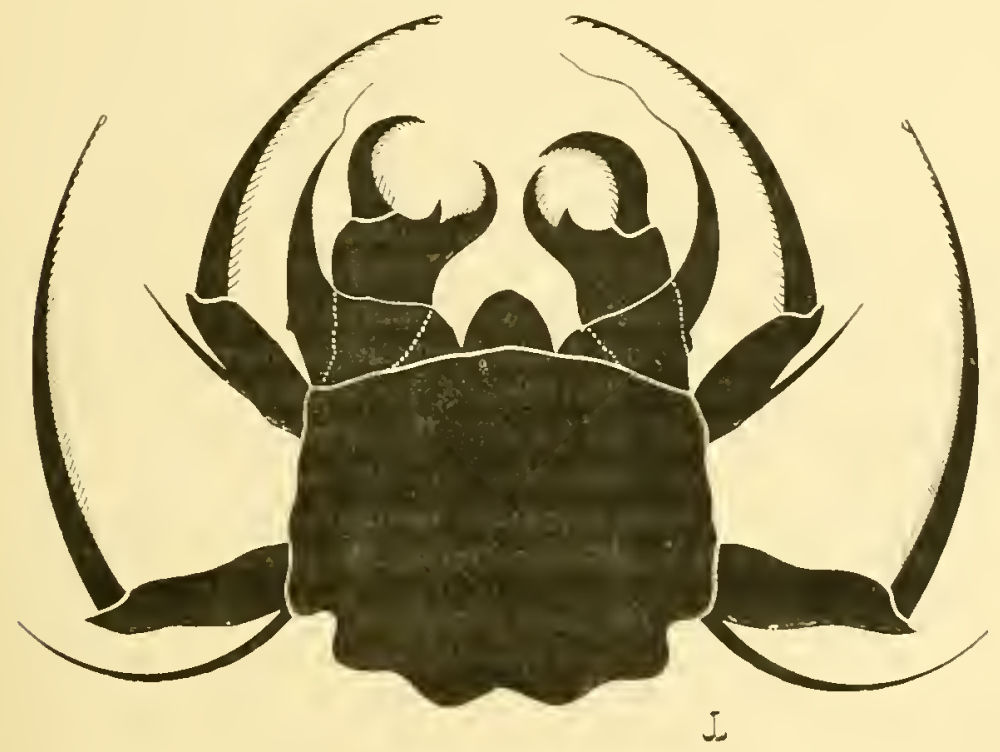

Fig. 509. - LARe des Prenogoxides (silhouelle). - I'rotonymphon d'une Ammothea longipes: d'après lloek.

Lrois paires seules sont présentes; puis il donne naissance aux trois premieres jaires $\left(7^{\circ}-9^{\circ}\right.$ de la série tolale) de l’abdomen, les denx antérienriss étant plus grosses que la derniere. - la larve ćclól ensuite, et offre, en ce moment, unc telle ressemblancr avec les anciens Trilobites, que l'on a accordé í cette plase le nom d'rint de Trilohile. Le corps est divisé en demx regions, m céphilothorix antérienr. qui rappelle entiorement son correspondant des Tribolitos, et mu ablomen conlonm comme celui de ces dernicrs êtres. Le crophlothorax porte sur sa lace ventrale les six frenièes paires de pattes; labmomen "st divisó nettenent en menf anneaux, dont le dernier est léhanche du futur aiguilon caudal; les trois premiers segments ahlominam sont munis de primes de pattes 
lamelleuses, Jout l'apparition est signalie plus haut: les quatre furemiopes do cos paltos sont plus fortus pue les deux aulars.

Ges larves mignt dims la mer, et se converlissent en arlultes fout rol subissunt une sirie le murs. Ies anneaux abdominanx deviennonl pou ì peu moins nets, par l'offacement des plis qui les séparent; les

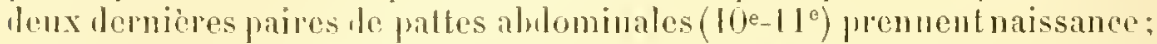
l'aignillon cambal s'allonge; les appwolices réphalolloraciques prennenl lemp aspect détinitif. Lo Tribulife se transforme en limule. The lelle sirir dr pbases lamaires est tres importante pour connaitre exactement los affinitís maburlles des Mérostomatés; les Tribulites constituent sabs loule nu grompe primitif, anpuel les limules se raceorlent, el dont, frar linterméliane dres Gigantostracrs fossiles, qui ont avec les Scorpionides des affuitós étroiles, les Arachnides se mapprochent aussi.

Aracuxmes. - Ies wufs le ces animan contiennent le nombremses riserves mutrilives; aussi leurs embryons, sabl ceux des Acariens et les linguabules, acomplissent-jis leur lévoloppement entier alors qüils sont contrnus dans leurs enveloppes chorionnaires. Cependant, ils subissont des métunorphoses internes, intéressantes à étudier, surtout an ce qui touche le nombre des appendices; les embryons possident, en etrel, une plus grande quantité de membres que n'en ont les aulutes correspondants, of ce fait est d’une hante importane pour établir les affinités des frachnides. - Dondinaire, les oufs sont pondus peu de temps apris la fécondation; les femelles de cerlains types les conservent pomplant daus leurs voies sexuelles, wi ils accomplissent la majeure parlie de leur rolution. Les Arachudes vivipares appartiennent à l'ordre les sroppionides, el a la famille des Oribatides parmi les deariens.

1. - Les Aranéides, les Scorpionides, el leurs aurexes (Pseudoscorpioniles, l'halangiles), se ressemblent an sujet des phénomènes généranx de lemrs mélamorphoses internes. La vésicule vilelline étant volumineuse, et les premières ébanches de l'ombryon naissant sur sa fice veutrale, ces ćlauches sont recourbées autour d'olle suivant un. \%onr épuatoriale, otolirent ainsi mue flexion lorsale, c'est-a-dire à concavib superienre, la concavilé embrassant la base de la résicule; phs

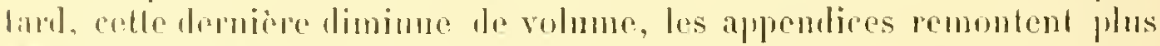
haul leurs basos d’insortion, el l'embryon devient plan, ou mème présente nue flexion ventrale, mais peu prononcée.

Les premiers indices de l'organisme embryounaire apparaissent dans la région antérionro de la vésicule vilelline, et s'étendent sur sa face vantrale; ils se scymentent i mesure qu'ils s'allongent, l'apparition prócoce d'unc division ammolire itanl, sans doule, l’un des résultats de l'aloréviation du dévolopement. Fin arant du premier anneau, el placée font it fail rers l'extrémité antérieure de l'emliryon, se tronve une région volmmincuse. sur layuclle se perce le stomeon; elle doit domner la la majeuro parlic de la tide, et represente le lobe mocephalinue des au- 
leurs. En arrière a'elle se délimitent les six anneaux du céphabothorax. sur chacmn desquels s'ébauche mne paire d"appendices, qui ne lardo pas a s'allonger, el ì se scinder ả mesure en articles. An moment où res six segments sont déjì dessinés, l’alıdomen, placé derrièe le deruier d'unlre eux, est encore petit; il grandit, en doublant l'extrémité postéricurr do la vésicule, se portant sur sa face dorsale, et se prarlage en anmeaux à son tour; la scission procéde davant en arjére, et se troure d'autant phus accentuce que les régions alteintes sont fus voisines du thorax. I. nombre des segments abdominam est de dowe chez les Scorpionidas, of de dix chez les Arachniles.

La particularité la plus importante de celte evolution embryonmairu se manifeste alors. Les premiers anneaux de labdomen se munissent de palles, au nombre d'une paire par segment; il en nait six paires chez. les Scorpionides, dont la dernière est assez pelite, et quatre chez les Aranéiłes. Ces appendices demeurent à l'état d'élıuches, el sembłalıles ì des moignons; ils s'atrophient ensuite, alors que les douze memlires du céphabothorax revètent leur aspect définitif. Les ılenx premiers de ceuxci donnent les mandibules, on chélicères; les deux autres fournissent les màchoires, on pédipalpes; enfin les huil derniers se convertissent en paltes locomotrices. Le corps de l'embryon s'achève. pendant que ces transformations s'effectuent; l'abjomen reste segmenté chez les Scorpionides, les Pseudoscospionides, les lhalangides, et perd toute trace d'anmulation cluez les Aranéides. - Ce dernier fait, joint à la présence de douze anneaux dans l'abdomen des Scorpions, et id celle de six paires de pattes provisoires chez ces mêmes animaux, lend à les faire cousidérer comme représentant le tỵe primilif de la classe des Irachnides. Cetle induction est encore confirméc par la grande ressemblance qui existe entre les Scorpionides actuels, et les Gigantostracés fossiles.

B. - Les Acariens subissent des métamorplıses extérieures, plus ou moins complexes suivant les types; d'ordinaire, l'embryon éclôt alors qu'il possède cinf paires d'appendices, les deux premièes servant de pieces luccales, el les trois autres jount le role d'organes locomolenrs: la possession de six paltes ambulatoires a valu a cette larve le nom de larve hexaporle. Une véritable stase se manifeste alors dans la sérir liss phases évolutives; elle dure parfois plusiems mois, jus longtempsmeme que la vie adulte. La sixième jaire d’appendices prend ensuite naissance, et constitue la quatrième paire res patles locomotrices; l'animal est ainsi devenu parfait. - Avant son éclosion, l'embryon probuit un petit abiomen, divisé au plus en denx anneaux, privé d’appendices iransitoires, ot qui se confond, par la suite, avec le céphalothorax. Les denx premiores faires de membres se rapprochent pour faire partic le la lrompe hurale; les trois antres paires ( $3^{\circ}-3^{\circ}$ de la série totale) disparaissent parfois, jout repraitre plus tard; enfin une membrane cuticulaire se dispose sourrnt autour du corps, el constitue une enveloppe, nonmóe le deulovum par les 
auteurs, yni double en dedans la conne ovulaire. Dans certains cas, et motamment chez les Iydrachnides, dont les mélamorphoses complexes sont exposées plus loin, cefte membrane levient très nelte, et l'espace. laissé entre elle el l'embryon, se remplit le cellules libres, dont on ne connait pas la vérilable nalure.

Les Acariens appartenant i la famille des Mydrachnides se trumront

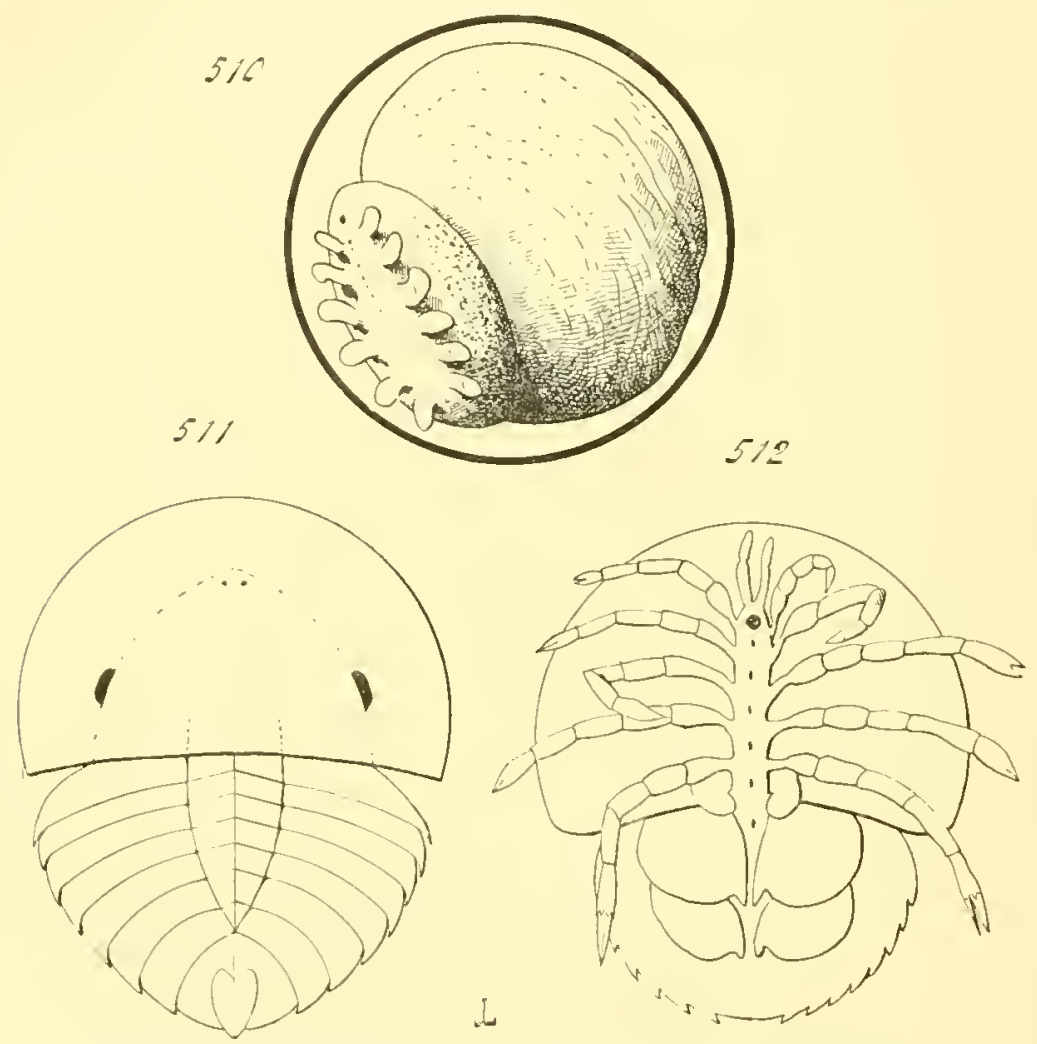

Fig. ilo a 512. - Formes embromalnes des Mérostomatés (contours extérieurs). - En j10, jeune embryon, encore enferme dans sa coque, el montrant, au-dessous de sa volumineuse vesicule vilelline, les ebauches de ses six premières paires d'appendices: d'après Packard. - lin 511 , phase de Trilohite, ve par la face dorsale; daprès lingsley. En 512 , le mime embryon, vil fra la face ventrale.

libres lorsqu ils sont atultes, mais parasites des lusectes et des .llollusques d'eau douce lorsyüils sont encore des larves; aussi, cette ataptation parasilaire s'aceompagne-t-elle de changements considerables. La larve hexaporle de ces ctres se lebamise d'abord le sa conne el ensuite le son leulovum; Jrienme libre, elle se met a la recherehe dun hôte, frinetre dans ses tissus, y reste immobjle, et s'entonre l'une envelopje cuticulaire. Celle-cj se gonfle, et auguente le volume de la cavité quible 
limite, ou te petit embryon peut dis lors se mouroir a l'ajse; les six pattes locomolrices se réduisent id des mamelons: wne phase de mue
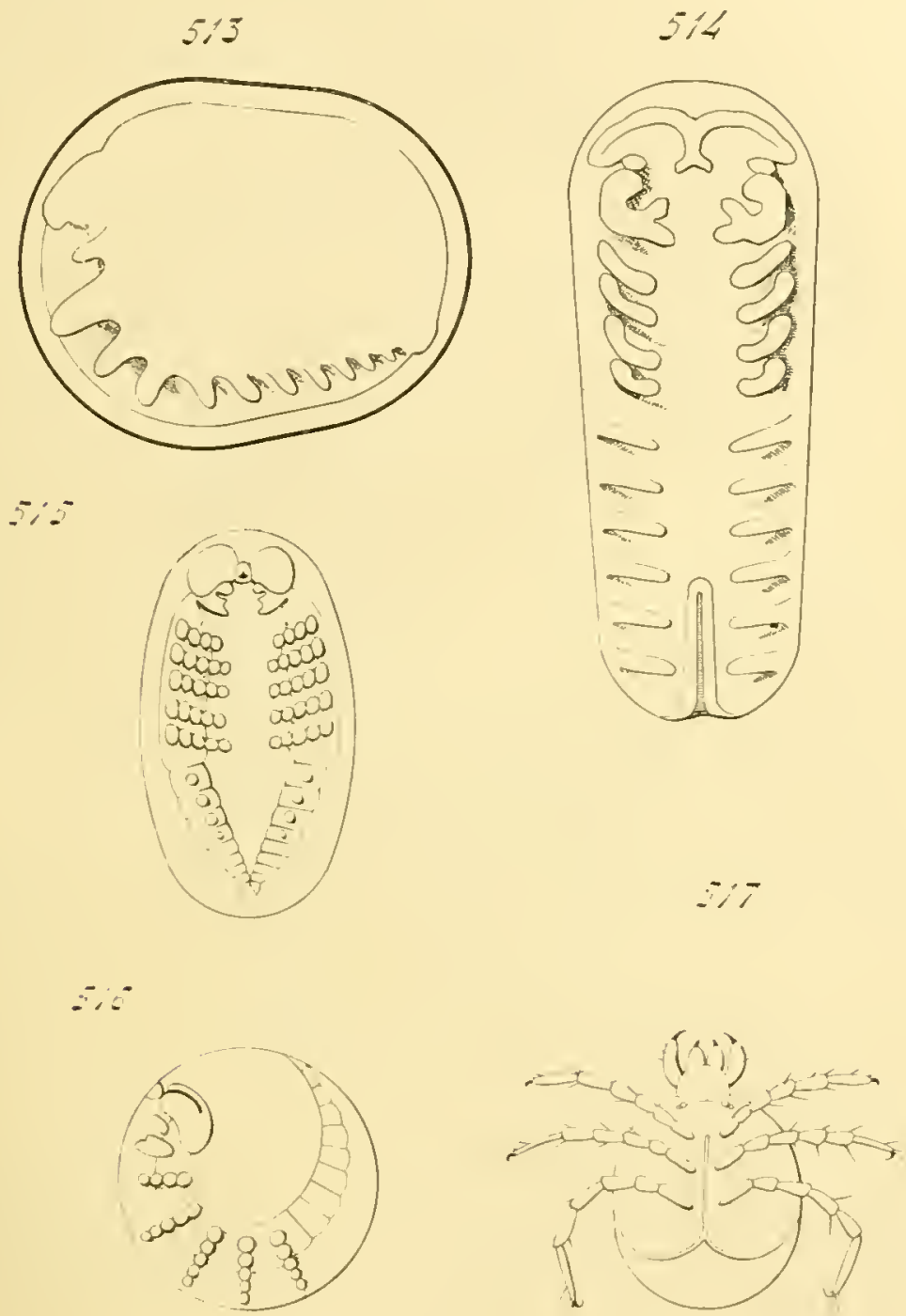

i

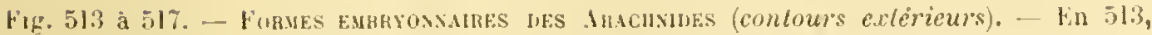
jeune embryon de Scorpion, enfermé dans sa eoque, vu de protil, et produisant ses

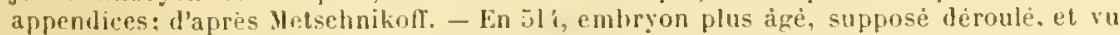
par la face ventrale. de maniere is montrer ses appendices permanents (en haut), el ses

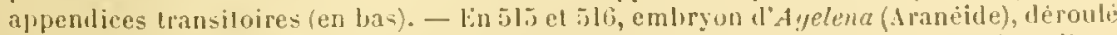
el vu par la face ventrale en 515 , en place et vu de protil en 516 ; les quatre paires d'appendices transitoires sont lessines dans la figure 515 (au Las); d'après Balfour. - lin 5l7, larve hexapole d'une Hydratene (Acarien). 
usl ansi alleinte. P’uis les membres se lévelopjent de nouvean; la rjualrieme jaire de palles ( 6 de la série tolale) se montre en arrière d'enx; la larve mue encore, cest-á-dire se délarrasse de son enveloppe. Elle al prespue alteinl, des lors, l'élal parfail; mais, d'ondinaire, elle s'entoure une fois de julus l'une nourelle cuticule, pendanl qu'elle achère de morlitier ses pièces luccales. Entin, elle mue une dernière fois, quilte son hote, et josséde son aspect définitif.

C. - Le déroloppement des Linguatules n'est encore connu, l'apries les étules de Leuckart, que pour une espece de ce grouje, et lans me partie semlement des métamorphoses, et des migrations embryonmaires. Cetle alssence de renseignements est fort regrettable, car il est impossible de se frononcer avec certitude, daus l'état présent de la science, sul les aftinités réelles le ces animaux; c’est tout au plus si la succession de mues cuticulaires nombreuses, et l'existence de pieces chitineuses fui ressemblent à des ébauches de membres, autorisent à jenser qüils doivent ètre placés parmi les Arthropodes. - Lespice ohservée cst le l'entastomum tenioùles, pui habite les fosses nasales de certains Ilammifères carnivores, comme le Chien et le Loup; les oufs sont rejelés avec le mucns nasal, et tombent sur le sol. L'embryon, que chacun l'eux renferme, a déjà commencé son évolution; son corps ovalaire, terminé en arrière par une sorte de queue cylindrique, porte en avant la lonche munie d'une épine, et, sur les côtés, deux paires de membres non divisés en articles, pourvus de fortes grifles.

Si ces cufs, déposés sur le sol et déjả développés, sont avalés par des Mammifieres herbivores, des Rongeurs ou des Ruminants, les embryons se débarrassent de leurs coques ovulaires, et de l'enveloppe culiculaire qu’ils s'étaient formée; cetle chute est déterminée par l'action dissolvanle du suc gastrique de l'hôle. Les larves se meuvent, dans l'organisme de ce dernier, par le moyen de leurs crochets, et vont d'ordinaire s'enkyster dans les pommons, ou dans le foic; elles perdent lemrs appenlices, et deviennent immobiles. Elles suhissent ensnite, sur place, un nombre comsidérahle de mues sucessires, pendant lesquelles elles se rapprochent de phus en plus de l'ótat adulte, et qui durent fort longlemps, six il hnit mois envilon. Leul corps sallonge, se divise en anneaux; leurs arganes s'buachent; les deux paires de crochels, que porte l’iudividn fraflait, prennent naissance de part et l'aulre de la bonehe, et n'ont rien de commun avec les puatre appendices de l'embryon contenu daus l'uruf. - Les l'entaslomes possirlent donc, dans le cours de leurévolulion, quatre paires de membres, anxpuels il faut joindre l'épine luccale prinilive, resle probable de pieces presque atrophiées; ce sont la les sculs faits qui permetlent de les comprendre parmi les Arthropodes, el à rillse do ce nomble d’apjendires, i cause aussi le laspect présenté par rertans Acariens vermiformes tols pue les leimodex, de les ranger, plus sprecialemenl, aupois des Arachnides. 


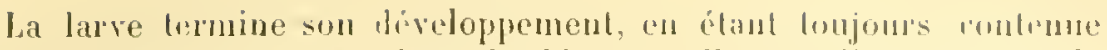

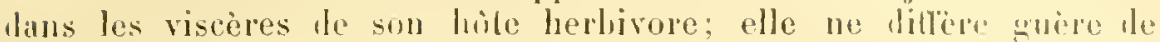
l'arulte que par la nature incomplete de ses organes sexuels; sil prerfection est telle, qu'on l'arait déerite autrefois comme unc spèce particulière, le Pentastomum denticulatum de Rudolphi. In cet itat, olle est capable de se mouroir dans l'organisme de lhòte; mais ces déflarements ne sont jamais lien considéralles, et sont coupés par des périorles de repos. - Si, par la suite des choses, le hasard fait que l'aninal, porteur de ces Lingnatules, soit mangé par un Carnivore, par un Chien, on un Renard, ou un Loup, etc, la larve n’est point digérée; elle rampe, daus

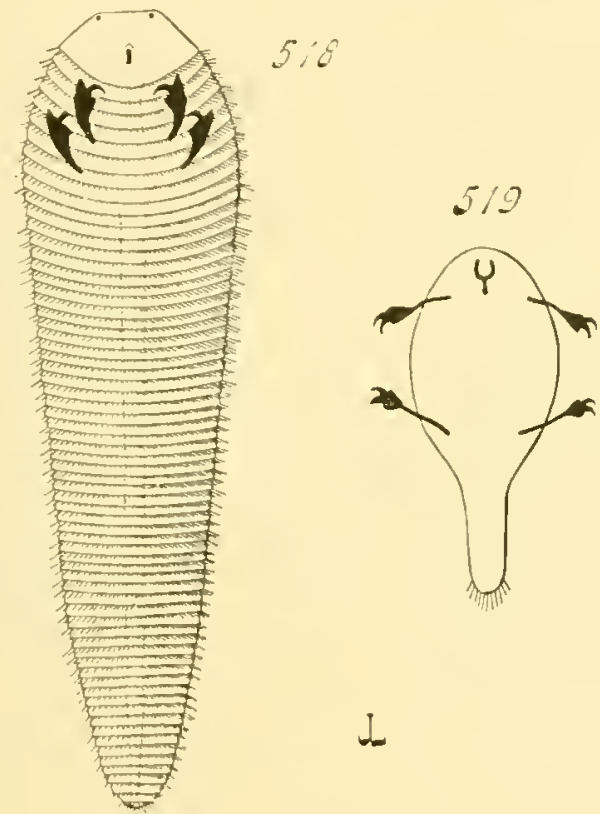

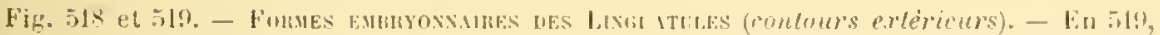

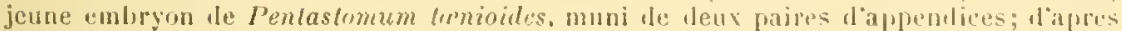
leucliart. - lin is (il g a eu interversim dans le mumerulage des figures), embryon

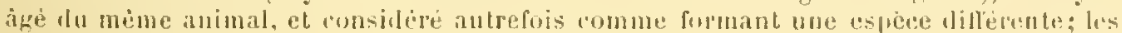
leux pares de rochets avoisinent la petite bouche mediane; les conluurs de l'unteslin sont indiques par un pointille. liapres leucliart.

le corps de ce nouvel hôte, en remontant de l'arriore-bonche daus les fosses nasales, ou elle se fixe; clle acheve alors de perfectionner sc's alpareils reproducteurs, el passe à l'étit parliat.

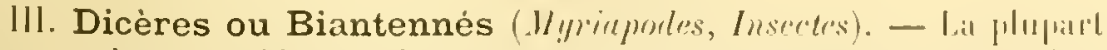
de ces animan subissent des métamorphoses extirimues; il noriste. guere d'exceptions, a cel égard, que pour un petit nombre de Ilyria- 
poules, comme les soblopendres, et pour les luscetes inlobicurs. Cos métamorphoses saccompağnent de mues, souvent nomhreuses; mais, malgré leur présence, les larves, an moment de leur éclosion, possèdent me structure déjả hien complexe. Les changements portent, pour la plus grande part, snr la gonse de noweanx membres chez les Myriaproles, l'alrophie de membres supplémentares pour les Insectes; ef somvent, surtout chez ces derniers animax, sur la destruction, ou l'histolyse, des organes larvaires, suivie de l'édification, à l'aide des éléments issus de cotte histolyse, des appareits définitifs.

Au moment oì elles quittrut lemrs membranes ovulaires, les larves de la plupart des Mrriapodes prossibent senlement trois paires de pattes locomotricos; doù découle une ressemblance frappante avec l'élal définitif des lusectes. Il résulte de ce lait, que l'on prourrait considérer ces dermiers comme réalisant, d'une maniore permanente, une phase transitoire les Myriapodes; il n'en est rien. car les lnsectes les plus simples portent, sur leurs amneaux aldominaux, les pièces qui correspondent à des membres réduits, et ils ressemblent de près à divers Myriapodes adultes, constiluant les ordres tes Pauroporles el des Symphyles (Scolopentrelle). - Ces compraraisons permettent d'almeltre, avec certitule, que les Insectes se rattachent i des animaux comprables aux Myriapodes actuels, el pourvis de pattes abdominales; ces appendices. encore présents à l'état de vestiges chez les Insectes inférieurs, et dans les pièces terminales du corps le plusieurs aulres représenlanls de la classe, manquent partout aillemrs. Du reste, bien que les larves des Insectes soient secondaires, hion que, far suite, on ne doive pas trop se baser sur elles, l'existence de pattes, sur les segments abdominaux de plusienrs d'entre elles est, pourtant une indication de plus ilans l'élude de ces affinités.

Mrnuponis. - La plupart de ces êtres sont ovipares; cerlains d'entre eux pourtant, et notamment les Scolopendres, sont vivipares. Les memes Scolopentres, contrailement i ce quil en est pour les autres types de la classe, ne sulissent point de mélamorphoses extérieures; ce denxième phénomène est la conséquence du premier.

Les changements de forme sont plus nombreux, el plus profonds, chez les Chilognathes que chez les Chilopores; ils s'accomplissent it lravers une séric de mues, souvent fort nombreuses, car, partois, chaque genèse d'une paire de membres est accompagnée d'une chute culiculaire. - Les emlryons produisent déjà, alors quils sont enfermés encore dans leurs membranos ovnlaires, la plupart de leurs appendices antérieurs. Les strongylosoma, parmi les Chilognathes, possèdent neuf paires do membres an moment de leur éclosion; les trois dernieres sont encore a l'état l'élanches, ef leux d'entre elles sont placées sur un mime segment ducorps: les trois moyemes servent a la larve jour se mouroir; les trois premiches constituent, suivant leur rang, les 
antemes, les mandilules, et les premiores machoires. Sans que lo fail soit encore promvé, il est probable que la premiere paire des approndices moyens ('́ de la série totale) est chargíc de donner les secomiles màchoures, on du moins les pieces qui leuréyuivalent. - Les embryons des Iules, a l’instant oì ils éclosent, sont pourvus de dix paires do membres, unc de plus que leurs correspondants du grente précédent; les six premières paires sont conformées comme celles des larves le Slrongylosome, les quatre autres sont petiles, et ne remplissent ancun ròle, tout en étant bien visibles. Un phénomine à remarquer, frarmi ceux
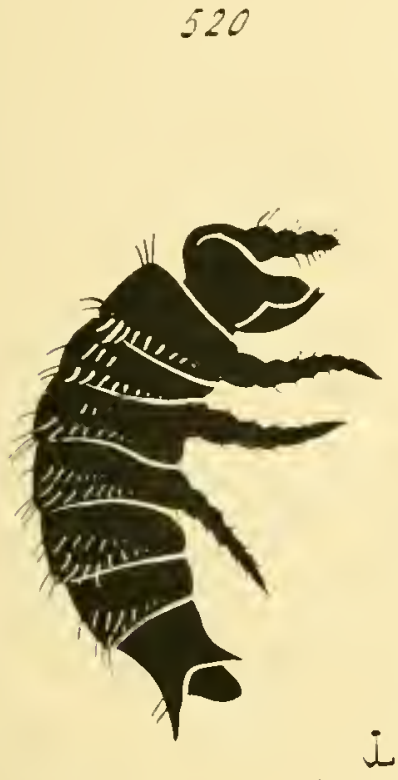

521

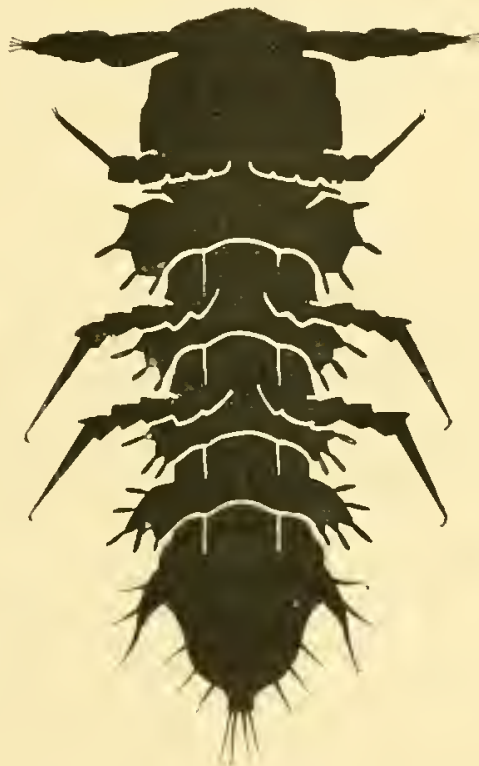

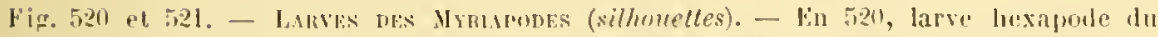
Strongylusoma fiuerini, vue de prolil; d'apres Metselinilioll. - Lin 521, lave liexapole du Polydesmus romplanalus, vue par la face ventrale; d'apries von liath.

que moutrent les Chilognathes daus leur évolution, porte smr la division tu corps en segments; relle-ci napparait quapres la geuese des six paires de memlires antérieur's. - Les notions acquises sont cucore insuflisantes, pour élucirler la question relalive à la présence de denx paires de memlires sur certinins anneaux.

La sermentation est précoce chez les Chilopodes; les apuendices

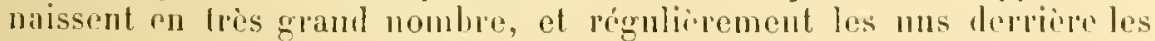
anles, non pas lous ensemble; anssi les jennes, fonicloment échs, possident-ils déja mo quanlili assor forte dappendices. Los Lillobius en 
ont dix paires, dont les six dernieres servent a la beomolion; les quatre autres constiluent les antennes, les mandiluules, les premieres et les secondes mâchoires; les memhres complémentairos, silués en arrière des précédents, prenuent naissance par la suile, durant la vic libre de l'individu. Les ścutigères présentent des phénomènes semblables. Le nombre des appendices est plus considérable, chez les tréphiles, lors de la chule de lenrs memluanes ovulaires; entin, il est complet ehez les scolopendres, au moment de la ponte, el égal ì celui de l'adulte.

Ixsecres; métamorphoses embryonnaires dans leur ensemble. - L’élude des métanor phoses, subies par les embryons de la plujart des lnsectes, est des plus intéressantes; elle prète ì de nombreuses considérations, à canse des procédẻs divers, suivant lesquels ces changements s'effechent. Aussi sera-t-elle divisée en trois parties, dont la premiere traitera des untamorplioses dans leur ensemble, la seeonde des principaux types spéciaux de celles-ci, et dout la derniere sera consacrée anx altérations subies par les organes embryonuares dans le conrs de ces modificalions.

A. - Les larves des Insectes sortent de l'auf, alors qu'elles possedent déjá une slructure assez complcxe, el des organes lien développés, sauf les yeux qui sont fort simples, el les ailes qui manquent; aussi, avant leur éclosion, présentent-elles des phénomènes généliques importants. Elles s'entourent l'un amnios, dont on a vu plus haut l'origine, produisent la phupart hes apprareils de feur économie, amassent somenl dans leur région dorsale iles matériaux nutritil's, dont l'ensemble ronstilue le corps udipeux, et donnent naissance a leur's membres. Ceuxci ne se forment point d'avant en arrière avec rígularité, el il existe mème à cel égard une diversité assez grande; parlois, les antemnes el les pières hnecales se montrent les premières, et ailleurs, les appendices thoraciques ajparaissent tout d'abord; ancune règle précise ne se manifeste en cela, et il n'est mème pas rare de voir lous les membres, 'fuelle que soil leur silualion, se délimiter en même lemps.

Lorganisme se divise en segments, avant que les appendices ne sóbanchent; Io chiffre le plus élevé el le plus frétyuent de ees anneaux ast de dix-sept, dont quatre pour la lite, trois pour te thorax, et dix pour l'ablumen; parfois, cepentant, il descend à seize (Lípilepteres), el mème it quinze (bijulires), la diminution portint sur labblonen seul, el nun sur les antres régions. - Les segments sont lons semblahles dabord, 011 peu s'en fant; ils se fémnissent ensuite comme il est dil ci-dessus, apres avoir produit lenr's appendices. Les quitre antérieurs donnent la licte; les truis autres $\left(5^{\circ}-7^{0}\right.$ de la síric lotale) restent assez distincts, et composent le thorax; les derniers se soudcul phus on moins suivant les types, el conslituent l'abdumen. Somvent ceux-ci portent des membres qui, semblables sous ce rapporl anx palles smpplémentaires des Scorpiuns of des Araignées, s'atrophient, el the passent point à l'adulte; 
cepremant, il est des cas où plusiems de ces pièes persistent arós l'éclosion, el servent à la larve pour se déplacer. Ces appendices fonctionnels sont dils des fausses-paltes, et les larves, les chenilles, des lépidoptères en fournissent un bon exemple.

Le premier segment du corps, qui domne l'extrémilé antérienre de la tèle, subil des modifications protondes; il émet latéralement, el en avaul de lui, doux expansions symétriques, les lobes procéphaliques. Les antennes se dégagent de ees lobes, el le stomeon se peree en arriore d'eux. Cetle situation premiere des antennes fail que ces pioces sont ventrales tout d'abord, el non dorsales comme elles le deviement plus lard.

R. - Les embryons éclosent ensuile, en se débarassant ì la fois de leurs membranes amnioliques, souvent alrophiées vers celle époque, el de leurs coques orulaires; les urufs ayant élé pondus par le générateur dans un milieu favorable, les jeunes sout tout portés pour puiser leur nourilure, el achever leur ivolulion. Il est pourtant des lnsectes vivipares, nullement ovipares; el, survant les types, les legrés de cetle viviparilé sont plus ou moins accusćs. Cerlains, comme divers liphlères du genre Sarcophaya, la Tinea vivipara d'Australje, plusieurs Coléoplères appartenant aux familles des Cluysoméliles el des staphyliniles, mellent au monde leurs pelits sous la forme de larves. Les représentants de la section des lliptères, désignée à cause de reli par le nom de Pupipares, agissent de mème; mais, an moment de la ponte, les larves sont tellement arancées daus leur développement, qu'elles passent de suile a la phase de mepe, pri précede la renue de l'étal parfait. Entin, la pluparl des llémiplères du sous-ordre des Phylophlires, ou des l'ucerous, rejetlent leurs petits entièrement achevés; ce phénomène n'exisle guẻre, cependant, que chez les générateurs partlénogénéliques de ces animaux, el manque aux femelles féeondées.

suivant les types d'lnsecles, les embryons fraichement érlos sont plus ou moins développés. Chez cerlains d'entre eux, appartenant aux sections des Thysanoures el des llémipteres aptères, les jennes sont parfails à l’instant même do lenr arrivéclans le monde extérieur, el ne subissent pur suite aucune mélamorphose; ces lusecles sont dils amélabromires de ce fait. Les autres représentants de la classe, nonmés Kolomilaholnives, subissent pay conlre des molamorphoses, all jls puittent it

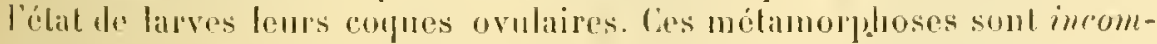
plices, on complites. Hans lo premior cas, l'embryon libro ne dilfire guere de l'adulte que jar l'absence d'ailes, et par la petilesse des yeux; anssi est-il permis de le consiléres, non comme mu embryon réel, mais comme un adulte imparfait.

Les vaies molamorphoses, les somles amxjuelles ce mom mirile, rhoz

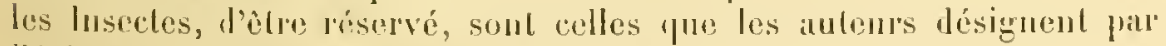

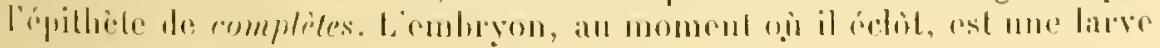



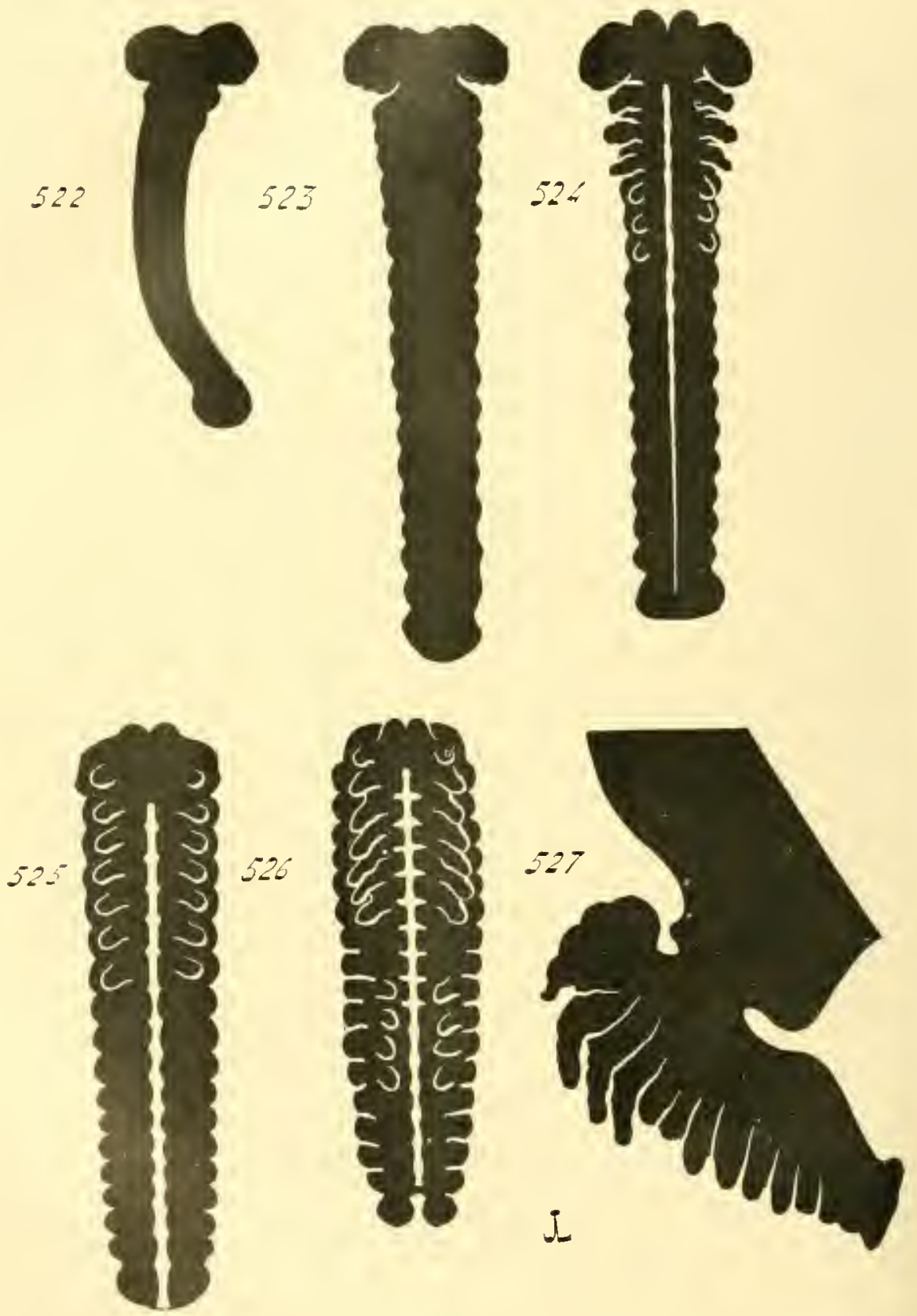

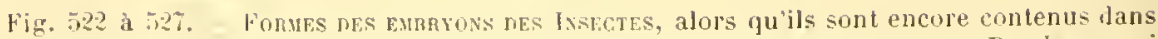
leur enjue (silhouettes); ces figures s'applifuent phus specialement au Bombyx mori (Ver an soie: Iépiloptères), d'après les rirherches te Tichomirotl, ot les miennes. lin 522, emluron de trois jours, montrant en haut ses lobes procephaliques. - In 523, 
réelle, différant de l'adulte par son corps allongé, souvent vermiforme,

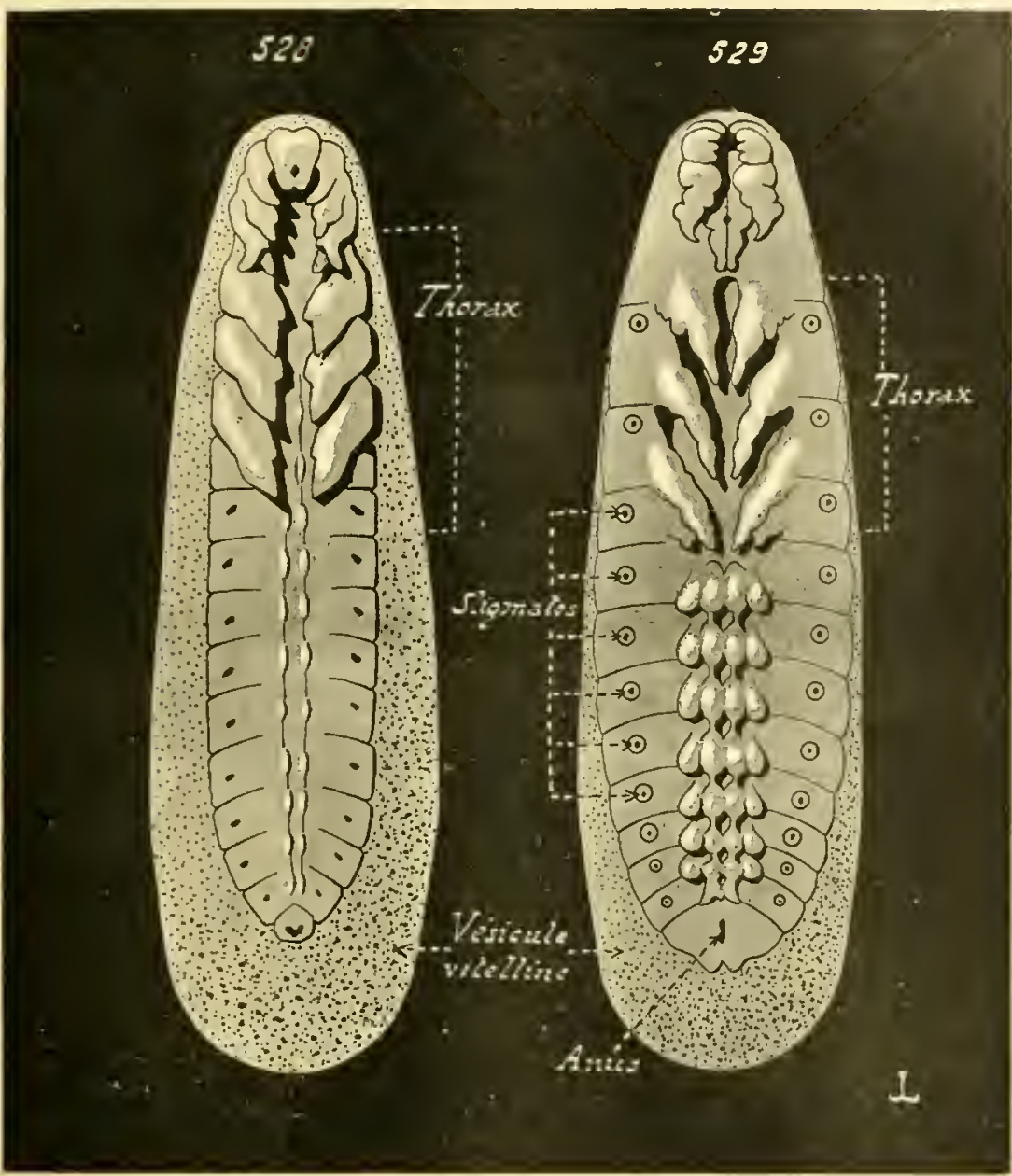

rmbryon de ciuy jours, accusant un debut d'annulation. - En 524, embryon de sept jour's; les paires des appendices jermanents commencent a se montrer. - En 525, embryon de neuf jours; ces appendices grandissent; la moelle nerreuse, représentee par une bande blanelie et midiane, accentue ses contours. - Lin 526, embryon de onze jours; fualre paires d'appendiees transitoires (fausses-pattes) preunent naissance sur lahdomen, dans la moilie infériense de la figure. - En 527, le méme embryon, vu de jrofil, et rattaché a ee qui lui reste de son vitellus nutritif. liembryon éclit ensuite sous la forme d'une larve.

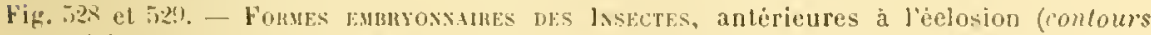
extéricurs; de même yue les précélentes, ces figules montrent la face ventrale de lenloryon, et présentent, en surjus, la vesieule vitelliue; chez les lejpidoptèr, la unajeure part de cette derniere passe dans l'amnios). - lin 52. l'embryon est plus joune yu'en 529. Cis deux ligures montrent les mèmes faits que celles qui les preciolent : l'aspeet les embryons, alors qu'ils sont contenus dans leurs coques. - l'apris les lecherelies faites prar lleider sur l'Ilydrophile (Colcopteres). 
son alsence d'ailes, la pelitesse de ses yeux el mome la privalion de ces organes, son molle de vie. son alimmlation parliruliere, Ires dissenhlable d'halibule de celle de l’individu parfail, el nécessitant des pieres buceales, avee nn appareil ligerstif, conformés l'ume maniële spriviale. - Ces larves grandissent, en sulissanl des mues plus ou moins nombreuses, jusqu'au moment où elles alleignent lenr période d'élat. qui se maintient peudant une durie de temps somvent lorl longue. Elles se converlissent ensuilo en arlultes: pour cela, eltes entrent dans uno phase de torpeur el de repos, soil conslante, soit coupre par des intervalles de molitité; el, enveloppées dans leur culicule, qui leul sert d'enveloppe prolectrice, olles sulissent les modificalions ayant pont lout de translormer les organes larvaires en lenrs correspondants définitifs; l'embryon, à cette phase, porte le nom le mpe, ou de nymphe. Les pupes le certains Insectes, de plusiemrs Lépidoplères notammenl, et le ler à soie (Bmblyx mori) offre de ce fail un frappant exemple, s'enlourent au préalalile d'une coque, le cocon, tissée avec les filaments juxtaposés: ces mymphes particulines sout diles les chrysalides. Entin, lorsque la modification funale est termince, achevant ainsi la longue série des métamorphoses, lanimal mue une lernière fois, se lébarasse de sa cuticule nymphate, puis de son cocon lorsquil ru posside un, el se troure parvenu à l'élal parfail; les descripleurs le nomment alors imago.

C'est durant la phase de pupe que les organes, donl la larve est privíc, comme les volumineux yeux composés el les ailes, prennent maissance; ils sont prorluils par les épaississements lissulaires, les histoblastes, ou disques imuginaux, donl l'élulle sera faite plus loin. Dans le eas oil les membres, après s'ètre élauchés sur l'organisme embryonuaire encore contenu dans sa copue ovulaire, s'atrophient par la suile, el manquent i la larve, comme reux les llouches par exemple, ils se forment à mouveau, chez la pupe, aux dépens d'autres disques imaginaux. Entin, toujours duranl cette période nymphale, cerlains organes larvaires, appelés a sulir des changements consilérables, ne les eftecluent point en modifiant leur struelure déjà aẹuise, mais se dissocient en leurs éléments, pour se reconstiluer de suite apres, et arfuerir en mème lemps len disposilion délimilive; en pluénomène remarquable de dissociation est l'histolyse.

C: - Les considérations, déji dommés dans les paragraphes précédents sul los embryous libres des Arthropodes, oul démontré que les larves des lnseetes sont secondaires; elles manpuent aux Thysanoures, les moins élrés de la rlasso, qui subissent un développement direct; el elles se comportenl en loul comme des larves arlaptatives. Elles présentent des mors fréquentes, el de deux sortes, los mos servant seulement à permellre l'acroissement do l’indivilu, les aulres, dites mues de perfectionuement, élant líces à les modilicalions de struclure. - En outre, elles vivent, d'ordinaire, penlant tries longtemps sous leur 


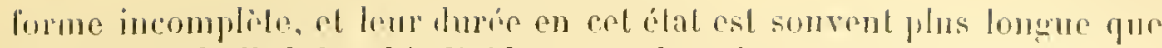
lexistence de lamblte; l'indivilu passe Jone la majenre jarlie de sa vio comme larve, et présente ì cel égarl une longue slase; de lous les anjmaux, les Insectes sont certainement les plus remarrualules sous ce rapport. Linsi, le llannoton (Jelolontha vulgaris) reste une larve pendant quatro ans, el ne dure qu'un été eomme individu parlait; les Mousliqurs ( $r$ 'nex) ont également une vie embryonnaje embrassant phusienrs années; les lépiloptères, les Ephémérines, les Libellules, les llyménoplieres, saus montrer dans ce phénomène une aussi grande accentnalion, passent cependant comme larves prosque toule lenr existence. - C'rst a ce moment que leur alimentalion est la plus exeessive; les indjvidus se nourrissent avec alondancr, et possident des piéces buccales capables de léchirer, el de mìcher, les lissus animamx el végélanx: alor's qu’ils se contentent souvent, lorsquils sont parvenus il l'úlat parlail, d’aspirer des sucs quils pmisenl sur divers ches. L'alulte n'a guere dautre role que celui de la reproduction; il s'y juche de suite, lès le moment où il a lranchi la phase de pupe, et meurt apros l'avoir accompli. Par contre, la vie nutritive est dévolue a la lare seule, yui parait plus capalile de s'adapter aux milieux exterienrs, et accumule en rlle, par son alimentation outréc, los substances nćcessaires à l'activilé génératrice de l'arlulle ailé qu'ello deviendra par la suile.

Sous ce rapport des fonctions de reproduction, l'Insecte ailé, l'imago, joue, ris-à-ris de sa larve, le mème rôle que les méduses des Colentérés Ilydrozoaires envers leurs polypes. Ces flemiers sont immobiles, tout comme les larves des lusectes sont donées de facultés de déplacement restreinles, el, la loi de la rlissémination des germes exercant son influence, les móduses el les individus ailés sont chargés d'effectuer celle dissémiuation. Toutes proportions garlées. la mème canse cutraîne des effets comparables, quant à lenr but; el de plus, ì la suite d'adaplations parliculicres fui permetlent un venue précoce de la parthénogenèse, certains Insectes en viement a se reprodnire sous la forme al'adultes incomplets et privés dailes, ou sous celle de larves vérilaliles. La concorlance de ces etres, avec les polypes doués de leur pouvoir hourgeonnant, se manifeste encore en ce point.

Insectis; lypes parliculiers des milumorphoses. - I.es Thysanoures ne subissent ancun changement exlérieur. - La pluparl des Orthoptères et di.s Hémiptères présentent des métanophoses fort incomplibles; leurs embryous, au moment oì ils iclosent, ne dillèrent guire Jos alultes que par labsence dailes; eus appendices prennent rapule-

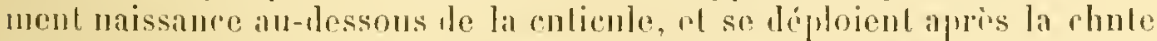

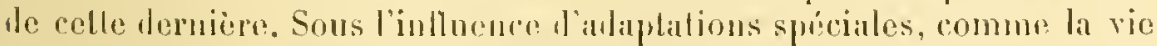
souteraine ef le parasilisme, il arrive parfois yme ces ailes ne su layonnent point. - Labsence de cos olganes locomolomes nest dome pas un

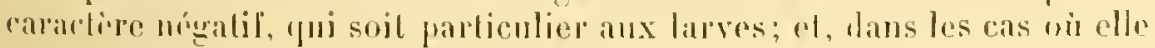


concorle avec une structure complète des autres appareils de l'économie, on ue doil lui accorder aucune signification aulre.que celle d'un effet des adaplations signalées plus haul. Ainsi, phusiens autenrs considereul comme des larves les lemelles parthénogénétiques des Pucerons, parce qu’elles sont privées d'ailes; res fencles sont cependant des adulles; lenr imperfeclion, en ce qui louche les appendices locomoteurs, lient à leur vie parasitare, el la parthénogenèse n’est pas une propriélé exclusive des cmlryons, puisque d'autres Insectes arlultes el ailés l'ont parfois. 11 faut considérer ces chres comme appartenant id deux formes, lout les struclures dillérentes sont liées au mode de vie: l'une composée d’individus parasites el ajurires, l'autre représentée par des individus ailés, el capables de se féconder.

Certains Orthoptires sulissent cependant des mriamorphoses compleles; ce sont les Ephemeriles et les Libellutides. Lenrs larves vivent dans l'eau, demenrent fort longlemps en cet élat, et ollrent un tres grand nombre de mues. Cellos des Eimémeres possedent, sur chaque rôté le leul corps, six à sept lanelles renfermant des lrachées, et servant sans doute a la respiralion, doò le nom de branches truchéennes qui lenr a ilé domne; ces organes fombent aree les dernieres mues, qui prócedent la venue de l'animal prail.

Les métamorphoses, subies par les Diptères, sont complites; lemrs larves apparticnnent ả demx tyjes, el olfrenl ce caractère commun d'être tonjours privées de prattes. Celles des Aplanipleres et des Némocères, sanf les Gallicoles el les Tipulides, possident une tête aisément reconnaissable, munie somvent d'antennes de petits ocelles; leurs pirces bucrales sont capables d" mieher. Celles des Brachyceres, ol des deux deruirres fanilles précédentes, onl une trite lort exigü̈, presque cachée daus le premier annean du thorax, dont les pibes luccales sont réruites, et comsistent frópuemment en deux petits rorhets. Dans les deux cas, le corps, divisé en segments, porte sonvent des épines lisposées en conromnes transversales. - les larves des Némocires, aver celles des Tanystomes parmi les Brachyrires, sonl diles orlhoraphes, pare que leur cuticule de mue se fend, avant de lomber, suivant une ligne troite; par contre, celles des autres Braclyceres sont nommées cycloraphes, d'apres la direction combe de leur ligne correspondante de ruplure. Au moment de la dernière mue, tantôt les pupes alandonnent leurs enveloppes cuticulaires, ot sont par suite capables de se monvoir, lautot clles restent enfermées dans celles-ci, el demenrent immobiles.

Les larres des Lépidoptẻres, vulgairement désignées par l’expression de chenilles, sont nellement caraclérisées; leurs mélamorphoses sont complètes. Lem tète, voluminense, bien distincle du corps, porte des antennes, trois paires d'ocelles, el de forles pièces luccales disposées pour minher. Chacmu des frois ammeanx lhoraciques est mmmi dime 
paire de pattes bien développées; en outre, plusieurs des segments abdominaux possident également des pattes courtes et molles, destinées a disparaitre lors de la transformation derniere en adulte, et connues sous le nom de fausses-pattes. Ces appendices supplémentaires sont d'habitude au nombre de cinq paires, insérées sur le troisiome anneau abdominal, le quatrième, le cinquiòme, le sixième, et le dernier; les Grométrines

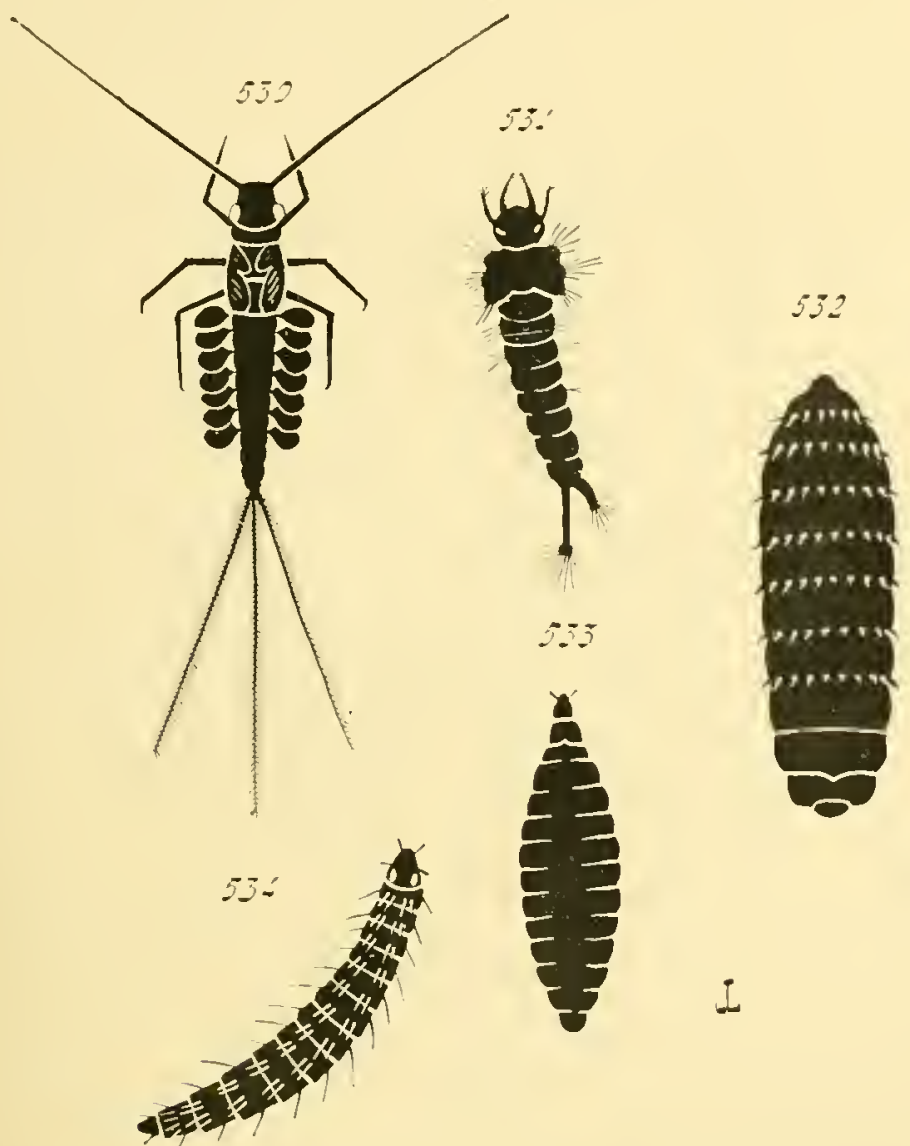

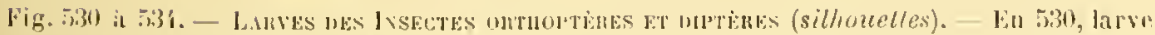

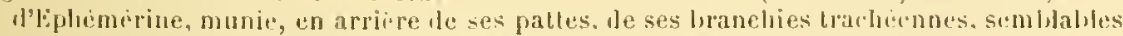

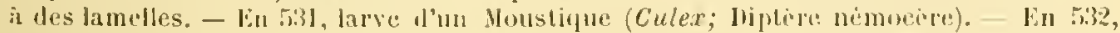

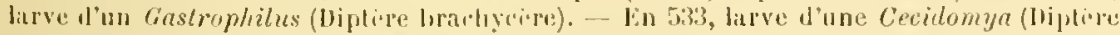

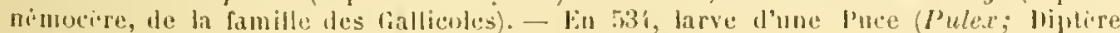
aphaniplite).

cependant n'en ont que deux on trois paires, qui correspondent anx postérieures des précédentes. - la métamorphose nyuphale, destinće i convertir la larve en adulte, suflectur de facons iliverses; parlusis. 
chez les lanessu par expmple, la larve se suspend par son ablomen à un supporl, el reste enveloppro daus sa culicule seule; ailleus, des glandes, anmexóes à la région buccale du lube digeslif, sécriblent un murus, qui dureit à l'air, of sort par un prolit orilice, peré non loin de

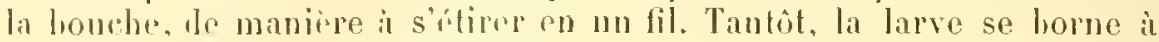
unir cutre elles, aver ce lilament, plusieurs fenilles pour s'en faire un alıi: tanlòl, elle s'envelopje elle-mème d'un cocon. quelle tisse avec lui. Ce dernier cas est colui des Bombycines: le lil le leur cocon n'est antri que la soio. - Les nymphes des Leppibptires sont sourmt nommórs des chrysulides; celle expression, l'un usage assez génóral, leur est plus particuliorement appliquée.

Les larves des Névroptères, el celles des Trichoptères présentent Jes milamorphoses compleles. Les pemieres ont un corps sourent allongé, muni d"une tète listincte. pourvue l'anlennes, d'ocelles, el ale lortes machoires en pince; lew lhorax porte trois paires de pattes. Parfois, les uymphes s'entourent d'un cocon, parexemple celles des Hyrméléonlidees; aileurs elles restent lihres, et sont mème capaliles de se monvoir yuelque peu. Les larves des lléméroliidres se nourrissent l'oufs d'Iraignées ou de Pucerons; et, Jorsqu"elles nut subi leur première mue, après ùtre arrires lans un lien riche en matérianx alimentaires, elles rabougrissent leurs paltes, qui deviennent semblables il de courts moignons. Ce phínomine, causé par le mode le vie, rappelle l'hypermétamorphose des Coléoplères vésicants, qui sera lécrite plus loin. - Les larves des Trichoptires vivent dans l'ean, et se forment souvent les gaines lubulaires, à l’aide de unemu gravierquelles agglulinent par du muens: de mome que celles des Vérropleres, leur lèle est distincte du reste dn corps, et leur lhorax porte trois paires le pattes.

l.es mötamorphoses des Strepsistères ressemblent de prós à cellos des Coléoptìres vésicants, ol sont produites du reste par la mème cause: l'arlaptation au parasilisme. Les générateurs présentent un limorphisme sexuel des plus remaryuales; le male senl parvient i l'elat partait, et possinle lles ailes; la femelle n"abandonne point sa culicule nymphale, 'jui lui constibe un fourreau, et probuil ses anfs, sans jamais devenir complite, par un véritalle phénomène de progenèse. - Les larres fraichement écloses sont mobiles, el se déplacent à l'aile de leurs lrois pairrs de paltes lhoraciques hien développées; sil leur est possible, dans cel clat, de parvenir sur des larves d"lyménoptires, d'Aheilles on 10 (inipes, elles pónchent dans le corps de ces derniires, se nourrissent le leursurganes, et acherent lenr érohution. Elles subissent, toul d'abord, ume mur, qui les change en larves de la deuxieme forme, caractérisées par leur alsenco de patles; puis, un jeu plus tarl, elles deviennent des pupes, dans l'intéleur mìme de lablomen des embryons d'llyménoptìes qui leur servent d'hrites. Ies jeunes Strejrsistires femelles ne poussent pas jus luin leur développemenl: les ravages, qu elles font 
daus loryanisme de lem höte, ne sont pas assez gramls pour enfrainer la mort de celui-ci, encore caprable de se comvertir en alulte: aussi se trouvent-elles nolmalement placées lans l’abdomen des liuepes, ou des . Heilles, el ne laissent saillir à l'extérieur que Jeur téte el leur thorax. Les miles, par contre, abandonnent leur enveloppe de pupe, deviennut complètement libres. et voltigent i la recherche des femelles parasites: ils meurent de suile apres la fócondalion accomplic. - Les denx types successifs, présentés par les larves des Strepsistieres, rappellent, en foul, leurs correspondants des Coléoplères résicants.

Les larves des Coléoptères, donl les mélamorphoses sont complèes, apparliennent ì plusieurs formes. - Celles res Curcutioniles, des Bostrychides, des Cérambycides, sont privées de paltes, ou n’en ont que de fort petites, el ressemblent par là à celles des Dipteres. Celles des Lamellicornes. du Hanneton par exemple (Jelolontha), sont molles, anaJogues à des rlucuilles de Lépilnpteres, el pourvues de six paltes thoraciques lien formées. - Le type le plus fréquent est celui, ılans lequel la larve fraìchencul éclose se présente sous l'aspect de triongulin: ce lerme, emplové d"alond pourles seuls Cohioplères vésicants, peut servir également pour tous ceux, des autres représentants de l'orlie, qui rentrent dans ce cas. Le triongulin offre un corps allongé, nellement rlivisé en lète, thorax, et alubmen; la tète est muic d'antennes, d'ocelles, el de pièces buccales sourent lrès fortes, disposées pour micher; le thorax porte trois paires de pattes, dont le dernier article est conique (ongle), l'où la nom de la larve ; lablomen, dont les segments sont lres nets, possirle parfois des rudiments de fausses-palles.

Celte larve est trìs arile; elle subit des mues nomlireuses, parmi lesqueltes il faut distingner, J'apri's Brauer, des mues d'accroissement et des mues de developpement. Ces derniores, plus longues que les aulres ì sefficher, correspondent à des changements dans l'alhure embryonnaire. Elles sont an nombre de quatre, et divisent l'évolution entière en cing phases distinctes, dont la jremierr est celle le triongulin, et la derniere l'état parfait; la leuxiome el la troisiome phase dilferent pen du trinugulin, si ce n'est par la taille plus grande et par les apyendices mieux lormés: Ia "fuatrieme est celle de nvomple, ou te pupe.

l.es Colroplipes vesicunts, qui constituent la liunille des Méloüdiens. subisscut des métamor jhoses comportant les cinf phases précédentes: mais, a rause de fadaplation dre leurs larves an parasitisme, la serondro phase ef la froisiome ditherent de leurs rorpespomblantes des aulres Coléptires, el rappellent, dans leur ensemble, les blats muluymmaires des autres Insectes igalement jarasites lans lem jemesse, fols fue les Strepsisteres, el los llémérobiintées parmi les Névopptires. laes changements complexes, oflerts par les le eloüliens, sont désignés par los antrurs sons le nonn d'lypermétamorphose; lirauer, Riloy, Kïnckel d'llerculais. lieauregard, ont démontré que celle-ci n'est autre que la métamorphosu 
habituelle de la plupart des Coléoptères, accentuée seulement par des modifications de forme plus considérables que d'labilude. Ces modificalions, causées par le parasilisme, sont du mime ordre, et aloutissent au mème résultal, que cettes les autres lnsecles signalés julus haut; ces dernier's offrent donc une hypermétamorphose analogue à celle des Méloüdiens, caractérisée, de mème, par la mollesse des téguments, et par l'atrophie presque complite des pattes.

beauregard a contribué. pour heaucoup, à élucider la nature des changements sulis par les llélö̈liens, léjá esıuissée dans ses grands traits
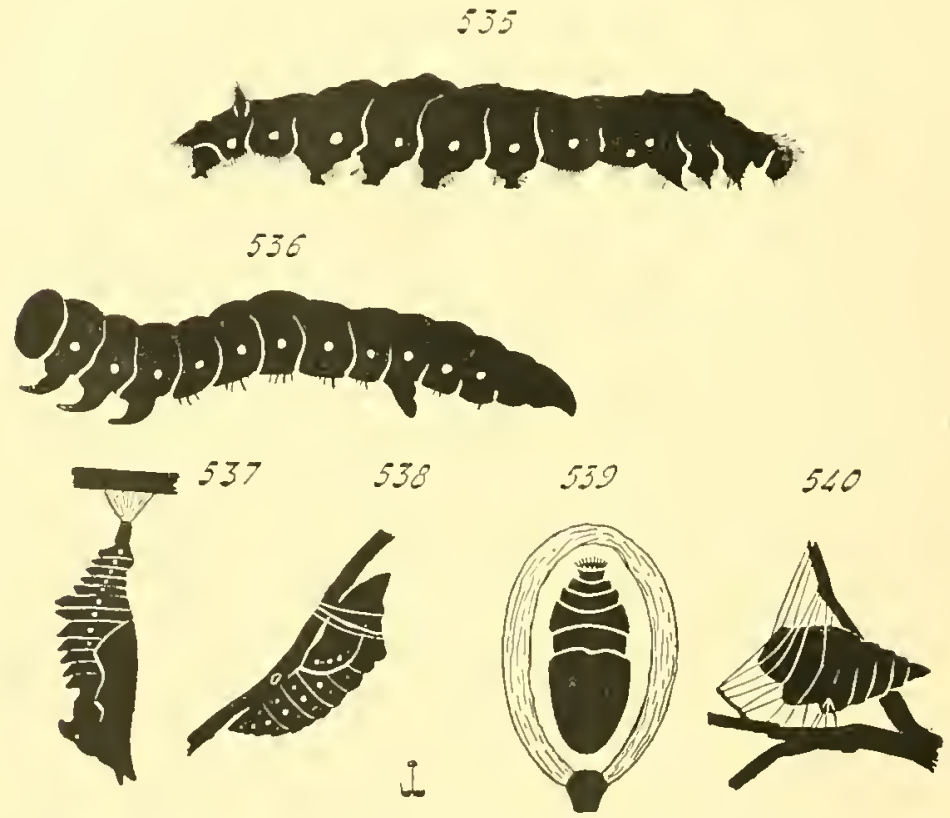

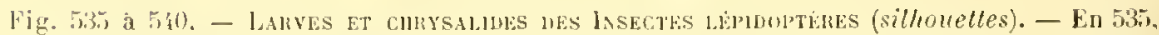
chenille d'un Bombyx. - En 53 i, chenille d'une fiemritrine du gen re Hiberwia. - Fin 533 , chrysalide dite suspendue: cx.: I'anessa. - En 538, chrysalide alite succincle, munie sevlement de quelipes filaments soyeux, qui hi composent une pelite ceinture de sonlien; ex.: Pieris. - Lin 539, chrysalide enveloppè d'un cocon soyeux; ex.: Bombyx. Ln 540 , chryalide intermérliaire entre les deux frecidentes, dite enroulée, el possedant plus le filaments soyeux que celle te la figure 338 , mais moins que dans les cocons complets; ex, : Abraxas.

par Filure. - Les larves sortent des aufs sous l'aspect de triongulius. Suivant les grenres, les unrs attendent qu'un hasard favorable leur permetle de s'acrocher au corps d'un llỵménoptère, qui les transporte dans sa ruchr: (Veloe, Sitaris); les autres (Lylla) s'entoncent lans le sol pour aller il la recherche des uils d'llyménoptieres fonisseurs; d'autres entin (Mylabris, Epicunta) agissent le mème ponr trouver des nids dorthoplires : Sauterilles, Criquets, on autres. Lorsque ces circons- 
fances aranlageuses se réalisent, le triongulin subit sa premiire mue de développement, el se convertil en denxième larve.

Les denxicmes larves s'accroissent beancoup; suivant le cas, clles se gorgent du miel conservé dans les ruches, ou dévorent hes arufs des nids, et parvienneut, à travers le nombreuses mues orlinaires, à unn taille considérable; la vie untritive de l’indivilu seflectue prespue fout entière á cette époque. Elles ressemblent beaucoup aux larves des Lamellicornes, sont molles comme elles, munies de palles lris courtes,
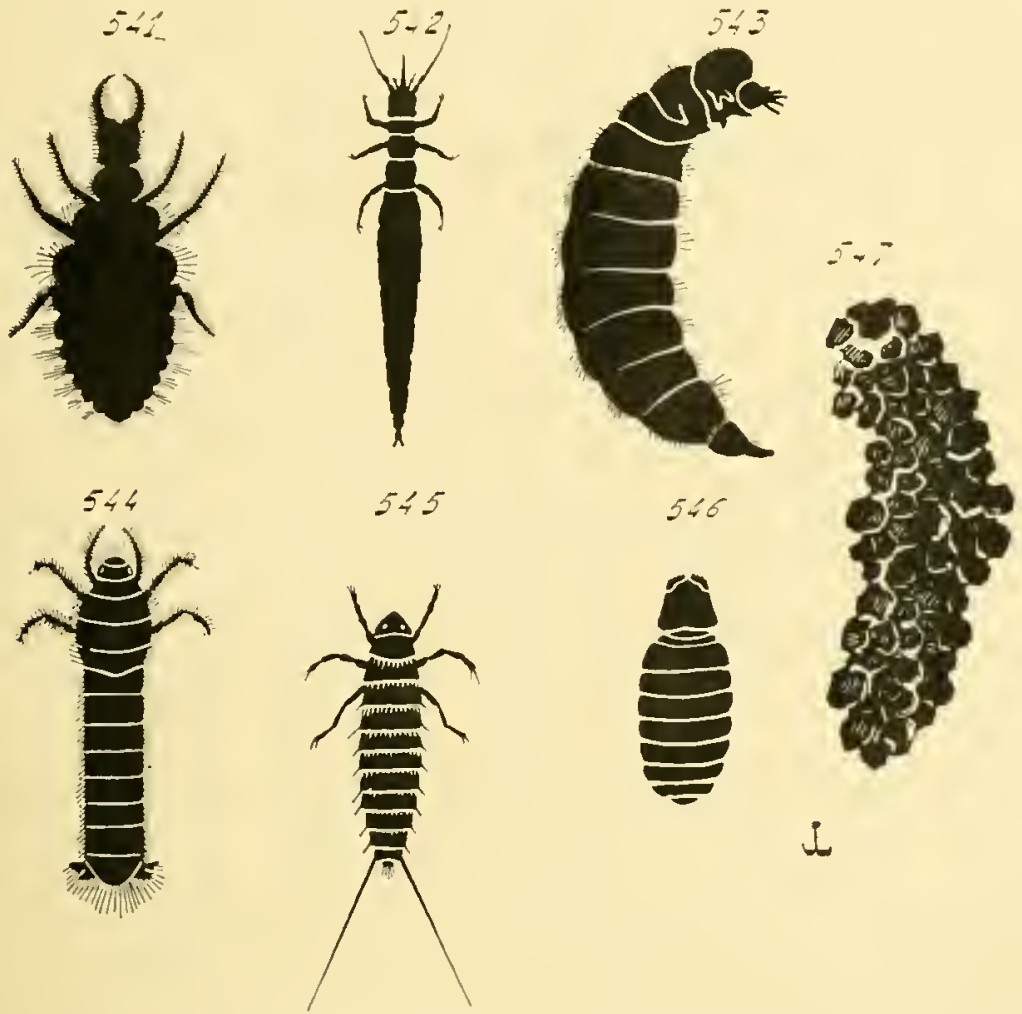

i

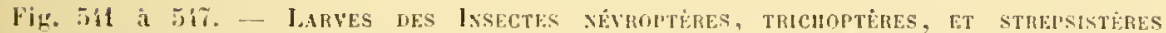
(silhouelles). - En jil, larve d'une Fourmi-lion (Myrmeleo; Nèyroptires). - lin ifi, première larve d'une Mantispa (Névroptère de la lanille des llèmcrobiidees); d'apres lirauer. - lin ít3, seconde larve du mème animal. - lin 5í, larve, leponilie de son fourreau de gravier, d'une Phrygane (Trichoptere). le fourreau est rejresente dans la

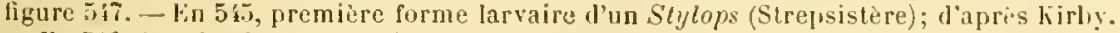
- Lin 54f, femelle du même animal, conservant l'aspect de la seconde forme larvaire.

et réduites à des moignons: aussi, à canse de relle analogic, lenr donnet-on le nom de larves scarabéoüles. Colles, qui vivent dans des ruches. restent scilentaires; elles ne quittent point lo lien on elles trouvent leur alimentalion, et se laissent entourer, comme d'anlant le gaines. 
far les rulicules des liverses mues qu'elles subissent. Par contre, les larros, yui se nourrissont dienfs, sonl capaliles de se déplacer, et se

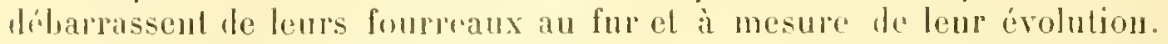
Colte diflérence l'état, entre les liverses formes d'embryons, s'explique par leurs adaplations respectives, el par les nécessilés de lour nutrition.

Les deuximes larves subissent ensuite leur seconde mue de développement. Les embryons sont alors ronvertis an troisiemes lanves, somblables aux srombes, mais ne mangeanl joint, à cause de l'atrophic de leurs pièces luceales. Ia vie nutritive est des lors achevée; lin lividu parcourl avec lapilité les antres plases de son évolution. pour parvenir ì l'état parfait. Les lissus embryonmaires se lélruisent par le phénomène d'histolyse, et l'histogencse les nouveaux organes commence à s'elfecLuer. L’histolyse cesse vers la tin de la période des troisicunes larres; ces dernières présentent alors leu troisieme mue de développement, qui les convertit en pupes, ou nymphes, presque immoliles. L'hislogenèse conlinue ì s’affrmes, termine son action, et l'animal, subissant alors sa qualicme el dernière mue de développement, passe à l'état d'imago, c'est-ì-dige parvient à l'étal adulte.

Les métamorpluoses des Hyménoptères sont toujours complètes; alles liffèrent d'un groupe ì l'autre, la diversité à ét égard paraissant résulter de la lissemblance des adajtations. Le premier sons-ordre de ces anmaux, celui des Térélrants, contient trois tribus: les Phylophages, les Ciallicoles, et les Eutomophayes; chacun de ces groupes présente un lype spécial de changenents enbryonnaires. We même, les leprósentants du second soms-ordre, celui des Porte-aignillous, oll'rent également, sous ce rapport, un mode particulier.

Les larves des l'hylophages (Tenthredo, Sirex) ressemblent a des chenilles de lépidoptères; elles sont molles, présentent nne tète bien distincte, munie de deux ocelles, el pourvues de pieces masticatrices; leur llorax porte lrois paires de patles, el, de plus. l'ablomen possede, suivant le cas, six, sepll ou lunil paires de fausses-palles, plus courtes yuc les précédentes. - Les unfs des Crallicoles sont déposés, par les limelles, dans les cavités quelles crensent en des lissus régólaux: tanlöt les lapresécloses restent dans ces loges, el lantöt elles se déplacent, pour aller vive en parasiles sur des Prucerous, ou sur des larves de Dipleres. Les métanorphoses hu second cas ne sont fas trés bien ilucidies; celles dn premier lyje sont remanduables, en re sens que la frésence de la lave détermine une imitalion des tissus végélaux roisins: ces derniers proliferent, et produisent une excroissance volumineuse, bien comme soms le nom de galle. Liembryon vit dans celte dernive, et se nourrit des éléments yui la composent; il possède, i cel eftel. de fortes pieces masticalrices, mais il est privé de palles.

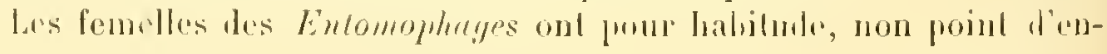


foncer leurs cul's dans des lissus végétaux, mais dans des organismes d'animaux, el principalement dans les lares d'aulres lnsectes. Les embryous éclos se nourissent anx dépens des visrères de leur hüle. qu'ils habilent en qualité d'endoparasites, et où ils subissent leurs mues; partant, ils ne l'abaulonuent qu'au moment oì ils onl alteinl leur étal parfail. Celte adaptation au prasitisme amene, dans l'embryogénie, des morlilicalions très remarquables; celles-ei ne soul grèe élucidres cependanl que d’après les Plalygaster, étudiés par Ganin, dont les embryous vivent dans le corps des larves de Cécilomyes (Dipléres némocires). Tout d'abord, les wufs sont paures en réserves nulritives. Les procédós géméliques des femillets sont serondaires par suile: les descriptions. données jusqu’ici sur ce sujet, soul fort incomplèles; ils demantent de nouvelles recherches, pour essayer de les rallacher aux modes primitil's présentés par les autres Insecles. Au monent où l'embryon ćchot, son corps allongé, et renflé en avant, porle en arrière quatre soies livergenles, dont deux fort longues; il ressemble, de trés loin il est vrai. el saus que celle analogie implique aucune ilée d'affinilé réclle, aux Crustacés Copépoles du genre Cyclops, doù le nom de larve cyclopéenne lonné à cet Étal. Colle larve ne possède que trois paires d'appendices, fort réduils, comprables à des crochets, ou à des moigmons converts le petits piquants, et lui servant pour se déplacer dans l'organisme le son hôle. Il est encore impossible d'établir une concordance entre ces paltes, el les membres normaux des autres lusectes. - Cotle pliase peut èlre dite de la memiere larve.

L'animal mue ensuile, et se convertit en seconde lare; il jerd. durant la mue, sa région postérieure munie de soies, sa culicule, et se transforme en un corps régulièrement ovalaire. nullemrut segmenté, el complètement privé l'appendices. - Une monvelle mue inlervienl cnsuile, après laquelle l’individu passe à l’état le troisieme larve. Il est toujours ovalaire, mais plus allongé quau moment de la phase précélente; les membres lni fout encore défaut, mais le corps est divisé en segments, parmi lesquels il est déjà possible de recomnaitre la disposition défuilive. l'embryon est toujours contenu, durant cetle longue série de changements, lans l'organisme do son hrite; il devient ensuite mue pure, of subil sos lansformations finales. Des pattes, des ailes, des reus lui naissent; et, se dépronillant à la fois de sa enticule nympluale nt des ligmuruts de son loble, yui existent sents i celte rpoqur, il sort au deluors, ot se présenle il l'elat parfail. - liensemble de ex modiliealions constitue une lypernélamorplsose; lont comme il en est pon les Colépheres résicants, pum los strepsistejes, ef pour les Nevroguteres llu groupe des Hémérohidiées. Seulement, ces changemonts sont ici plus considéraliles yue parloul aillem's, fout en étant anemes par la méme canse, el s'accompagnent d'une réduclion fort mpiense ales malériaux mulrilifs de l'unf. Bien que nos commaissances sur ces morlifoalions soienl encore restreintes, il rst cepentant indisculable, comme on l’a vu plus haul, 
qu'elles sout sreondaires, nullement primitives, et liées à la vie parasilaire.

Les IIyménopteres porte-aignillons agissent parfois romme les Entomophages, c'est-it-dire pondent leurs arufs dans le corps de divers animaux; tels sont les Chrysidiles, et les Iletéromynes, dont la série des métamorphoses, incompletement observer doit rappeter sans toute celle des Entomophages eux-mêmes. - Les autres l'orte-aiguillons pondent leurs oufs de telle maniere, que les larves, lor's le leur éclosion, trou-

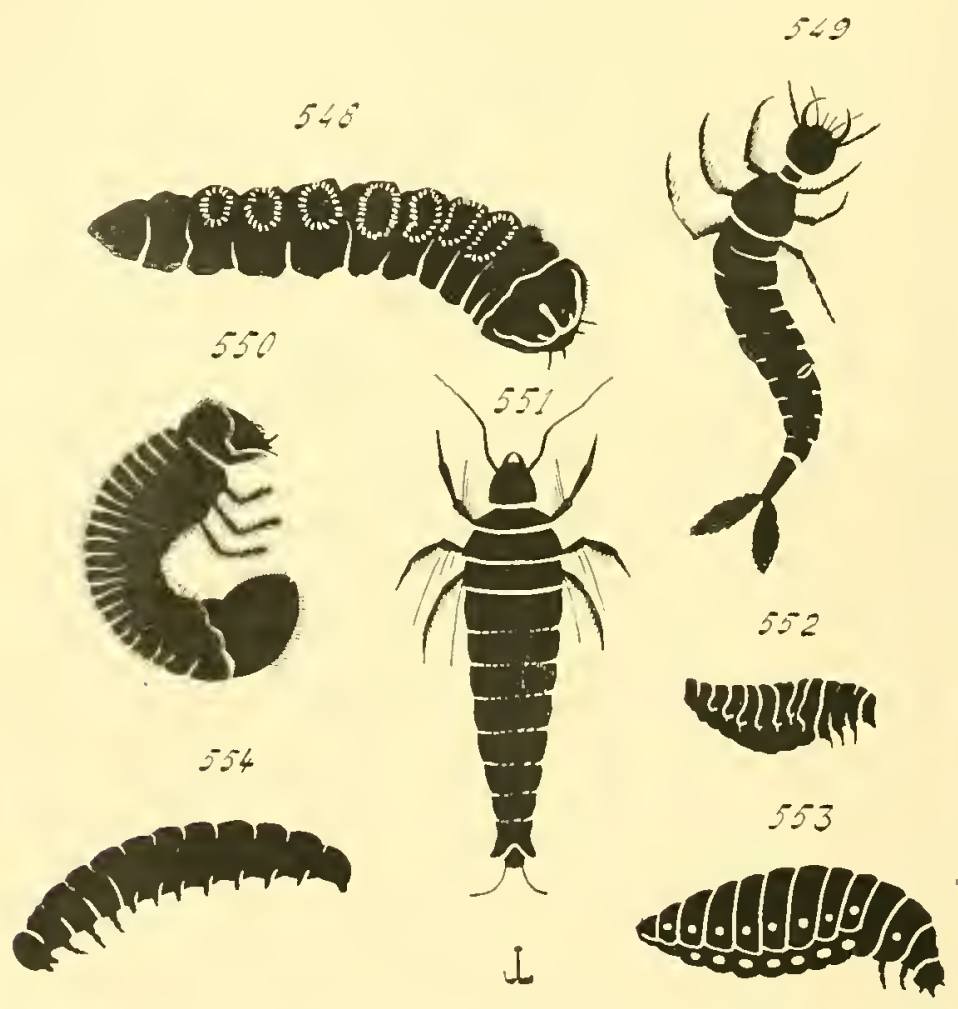

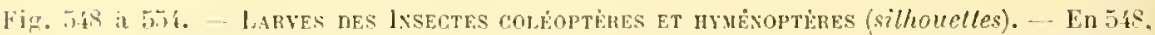
larve d'un Ceramby $x$ (Colioptire le la famille des Cérambyciles). - Ln 549, larve, ou briongulin. d'un Dytiscus (Colioptire de la famille les lygtiscides). - Ln i50, larve d'un Janncton (1/cholontha; Coleopleres lamellicornes). - En 5is, premierc larve, ou triongulin, d'un Sitaris (Coleoptere de la famille les Miloüdiens); l'apris labre. - En Wh's,

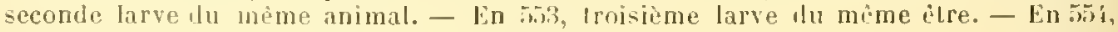
larve d'un Tenthrcto (Hyménoplère pliylophage).

vent aupros dielles les matérianx alimentaires qui leur sont utiles; parfois mèmo, dans le ras l'llyménoptères réunis en sociétés, certains individus meutres (ourripres) sont sprécialement charés de recueillir la monriture destince anx embryons, de l'apprêter, et de la leur domer. 
Ces aliments, chrz les Fouisseurs, enusistent en Insectes tuŕs, on sim-

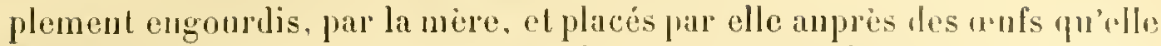
vient de pontre, le déposer dans le sol; ils sont des amas de pollen chez les Bourdons, des morceiux d'lusecles fraîchement tués chez les Guèpes (Vespides), Ju miel, c'est-i-dire du nectar floral à demi digéré, chez les Abeilles. - Les larves, munies d'une petite tète, dont les mandibules seules sont bien développées, se trouvent completement dépour-

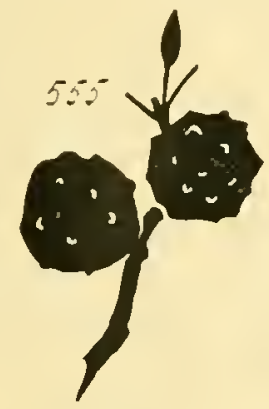

$550^{\circ}$

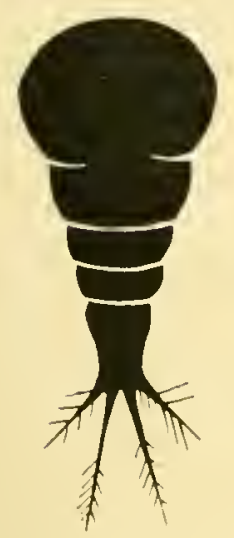

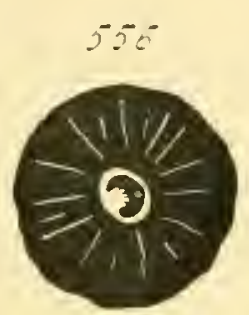

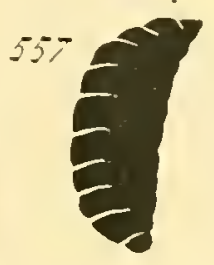

\section{9}
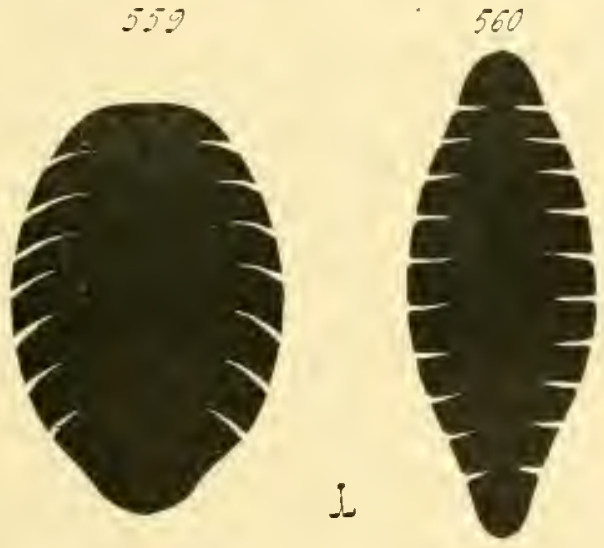

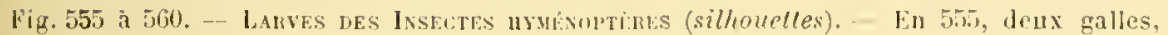
produites sur un jeune rameau de Chene par la presence de dews larves de Cynips (IIyménoptere gallieole). - In 5it, une de ces galles, coupèe et vue par la tranche, montrant sa cavilé centrale, habilée par la larve. - Ln 5.7, larve d'une Ibeille (Apis; IJyménoptère forte-aiguillon). - En 558, première larve, ou larve cyclopeenne, d'un

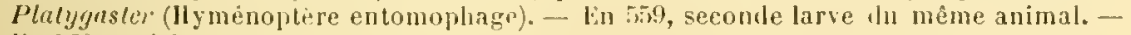
lin ifon, troisieme larve du mème ètre.

vues de pattes. Elles subissent plusienrs mues, et parviennent pen it peu it l'état de nymplie; cot état est précéclé, chez les Abeilles et les Ginểes, par une pliase juéalahle, dite de pseudomymphe, durant largulle l'animal s"installe pour prohture son cocon. Il sentoure cusnite l'une emveloppe, le cacon, composée de filaments soyeux qu'il sécrète, subit dans son inté- 
rieur ses deruières transformations, et sort ì l'élat parfait. Les corps likncluatres et allongés, que lou trouve dans les foumilièes, et que lon nomme orlinairement des oufs de Fourmis, ne sont pas les wuts véribbles, mais hien les corons le ces animaux.

Ixsectes; mélamorphoses des organes embryonnaires. A. - Au moment oì les larves des Insectes subissent leurs dernieres modifications, où elles parviennent a l'ílat de pupes, il leur faut supporter des changements comsidérables, plus grands qu'aueun te ceux oflerts daus la partie précédente te la vie embryonnaire. Elles sont privées diailes, dyeux composés, souront de membres; ces appareils doivent mendre naissance pendant la phase nymphale, et durant cetle phase seule, car its manquent constamment aux larres, el existent toujours chez les adultes. Lussi, les pupes prósentent-clles, dans les régions de leur corps qui doivent servir à la grnèse de res appareils, des zones épaissies, doul les tissus sonl en prolifération aclive, et qui fomrnissent les syslemes organiques complémenlaires; ces zones soul lis histolulustes de liunckel d'llereulajs, lus lisques imaginaux de Veissmann et de Viallanes.

D’aulpe part, la structure des larves est fort différente de celle des adultes, surtoul an a qui louche le tube digeslif el los muscles. Les larves sont munies, d'halilude, doroanes masticalents, et loroient lenrs aliments, lissus végélaux ou lissus animaux; leur apparejl digeslif est adapté joul rendre assimilables, et absorloce, te lelles substances nulrilives. Par contre, la plupart des alultes, notamment ceux des Diplipes, se borneut a aspirr dros sucs, el leur inlestin se conforme à ce nouvel état de chosus, fort différent du premier. Pareille opposition exisle dans los muscles; ceux des larres sont disposés de maniere à permeltre an corps des mourements de replation; ceux des adultes sont arrangris de facon à agir de préférence sur tes ailes et des paltes: apfendices qui manquent aux larves, toujours les premieres el souvent les secondes. Il faut donc, de toule nécessilé, que des modifications considérables se manifestent dans ces organes, pour dégager l'élal définitif des dispositions larvaires.

Ces changements ne s'effrchent point par la simple transformation des ayprareils de l'embryou, par la seule juxtaposilion les nouvelles parlies nécessaires, el par la disparilion des inuliles. Une refoule complèle intervient, nécessitée sans doule par la crandeur et l'amplitude des modificalions qui doirenl se faire. Les organes larvaires se détruisenl, soit directement, soit par phagocytose, et se dissocient en leurs celhules conslitulives; es dernieres perdent la complexilé de structure qu'elles possérlaient, devionnent libres, et retournent à l'élal embryonnaire, cost-ídire se convertissent en éléments lont le proloplasme noest pas liflérencié. Tous les appareils déjit formés se rósolrent en un mésendyme, semblable ì celui de l'embryon encore forl jeune, reviennent

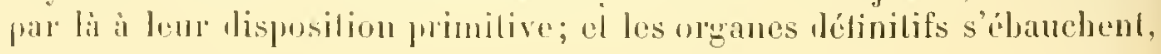


el se façonnent, aux dépens de ce tissu. - Celte lésagrégation, qui consiste, dans son essence, en un retour à l'élal mésenchrmaleux initial dn protendoderme, est lésignée par le nom d’histolyse; elle répond ì me destruction de la structure fonctionnelle des larves, pour édifier, a laile des matériaux ainsi prouluits, la stuclure fonclionnelle des adultes. Un phénomène d'histogenise el d'organogenese suit en effel celte histolyse, ot a pour résultal d'engendrer les appareils ullimes de lindivilı.

La phase de pupe n'est done pas senlement une période plus ou unoins longue de la vie lavaire, durant laquelle l'embryon ne suhit qu'une métamorphose cxlérieure ot une mue le sa culicule. Elle s'accomplagne de Iranslormations profondes, qui toutes ont pour luat de produire l'organisme de l'adulte. Ces changements sout de deux sortes : les uns consistent en la genèse les formations nourelles, yeux composés, ailes, membres le cas échéant, au moven de disques imaginaux; les autres se composent d'mne destruction des systimes existants, d'une histolyse, pour rroonstiluer, avee les éléments désagrégés, l’économic dútinilive.

P. - La présence de la phase nymphale, dans le développement cmbryonnaire des Insectes à métamorphoses, doit être cherchéc sans doute, avec Lubhock et Balfour, dans l'ampleur même des morlificalions que la larve sulit lor's de colle période. - In moment ou la vic larvaire embrasse toute l'existence le nutrition el d'accroissement de l'individu, la vie alulte se bornant a la consommalion des fonclions sexuelles, celle existence embryomnaire libre nécessite une alimentalion active. Lorsque les larres se nourrissent de substances solides, leurs pièces buccales sont fortes, disposées comme celles des Insectes amétalolaires, et leurs membres sont léveloppés; lorsqu'elles sont destinées à alısorber des substances moins compactes, el a vivre en parasites, les membres leur font difaul, el de mome la phurat des pioces lumeates. Tout cu elles dénote des arlaptations étroitrs de lenr organisme entier aux circonslances envirnnnantes, entrainant des lispositions il clles propres, comparables laus lem ensemlite a celles qui sont promanoules vlez les lusertes inférienrs, ot lort ditiérentes de colles yüelles aurout phus tard, lorsfu'clles seront parrenurs à lialat alulle.

Aussi les mélamorphoses, qui doivent les convertir en adultes, sontelles considérables et profondes; certaius de leurs organes se létruisent poul se régénérer, el l'autres prennent naissance pour se développer avee rapiclité. Pendant que la larve en ast à rette périoule de son évolution, los morlifications apportérs sont très grrandes, et il lui est impossiblo de se nourrir, ni de se déplacer, puisque son tube digestif et ses muscles se dólont en partic. Elle reste immohile, par conséquent, plongrie lans une sorte de torjeur, de vie latente, durant laquelle se manifestent tous les phénomenes gromitipues, of puillo quitle au moment oi ils sont acherés. Cetle forpenr est causéc, non senlenent par la 
lésagrégation de la plupart des appareils le mouvement, mais encorc par ce fait que toules les forces vilales le l'orcanisme sont appliquées a la production des nouveaux apprabeils. Il est des pupes mobiles cepenlant; mais celles-la ne subissent que des changenents minimes; el les pupes inertes, de leancoup les plus fréquentes, sont aussi celles dout les transformations sont les julus grandes. En outre, afin de se protéger, la pupe s'entoure d'une épaisse culicule, qu'elle ahandonnera lorsqu'elle sera parvenue il l'élal partait. ou mème, dans certains cas, l'enveloppes qu'elle se constitue en assemblant les corps étrangers, on en tissant autour d'ello nur cocon.

Il est donc probable que l'élat de pupe, ou de nymphe, arec sa longue période de repos, est dà à la nécessité, pour l individu, de se prêlır, en rofle époque do son existence, à des modifications aussi profondes ifue celles relatives i la gruese les disfues imaginaux, et surtunt il l'histolyse.

C. - Les Insectes amótabolaires ne snbissent point de métamorphoses extérieures; partant, ils ue possident jamais te disques inaginaux, et ne frésenleut aucune histolyse de leurs organes. l'areil fait existe chez la plupart des Orthopteres, des llémiptires, dont les métamorphoses sonl incomplites; le jeunr, au moment où il éclôt, est seulcment privé d'ailes; cesappendices prennent directement naissance sur lo corps, lorspu'ils doivent se former, et les muscles se disposent pour los monvoir, kans yu’il se manifeste ancun phónomène parliculier. Mène daus le cas oi les changenents larvires sont assez complexes. comme ceux des liphémères et des Libelhules par exemple (Orthoptères pseudonévroptères), ils ne comportent point d'histolyse réelle, ni aucune genèse de dispues imaginaux; les appareils larvaires, inuliles à l'adulte, disparaissent au moment de la mue, et ceux des organes définitifs, qui manquent à la larve, se produisent sur place aux lépens des éléments existant déjà.

Ces remarqualiles phónomones géuétiquos sont propros amx larves des Insectes holomélabulairs, à mlles yui supjortenl des métanorphoses nombruses of profondes. Ils ne sunt pas entierement connus, car on ne les a gruère óludiés jusıu’ici pue ebez des lípidoplìres, et des liptères; mais tout porle à croire, d'apres les faits acquis, qu'ils sont partout ilentiques lans leur essence, et qu'ils different seulement par des poinls sreondaires, comme le nombre des disques imaginaux. Les oliservalions les plus complites, qui airnl élé pulılices sur un tel sujel, sont durs i kïnckel d'llerculais, ì Weissmann, à Ganin, ḋ Viallanes, et il kowalevsliy.

L'étal le plus simple, sous ce rapport, est offert par cerlains Diptères nénocies, tels que les Corethro, dont la phase nymphale est fort courte.

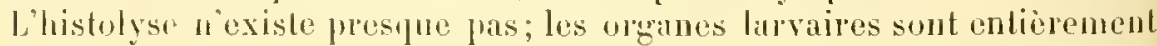
conservés, ou peu s'on faut, pour passer à l'adulte; el les principaux 
changements se bornent à l'hislogenèse, c'est-à-lire ì la production des ippareils définitifs dont la larve est privée. Ces ternicrs prennent naissance, en puisant leurs matériamx dans des amas de cellules mósondermiques qui n’avaient point encore élé utilisés. - Les memlres locomoteurs sont formés au moven de disques imaginanx. Chacun des trois anneaux du thorax porte deux pairos de res disques, lune dorsale et l'autre ventrale. Ces organes eorrespontent à des zones oì l'ectorlerme to la larve s’épaissit, et s’adjoint une assise d'élóments mésodermiques; ils naissent aux dépens de la paroi des trachées, ef non loin des stigmates, ou sattaehent aux terminaisons tes nerfs. Les trois paires des disques ventraux grandissent, ot doment, en se développant, les trois paires de pattes thoraciques. Ces disques ne sont, an fond des ehoses, que les ébauches de ces membres. La paire postérieure des disques dorsaux fournit les halancier's, les ailes atrophiées, alors que la moyenne produit les ailes vérilahles; la paire antérieure ne prend aneune part it la genèse des appendiees locomoteurs, et horne son ròle à engendrer une portion des téguments dorsanx du premirr anneau thoracique.

Les olservations faites sur les lépidoptères sont encore lien pen nombreuses; elles suffisent cependant pour dénoter me certaine concordance aree les Dipteres némocères. L'histolyse ne joue jas un grand ròle; des destructions se produisent bien dans le mésoderme, sans doute par phagocylose, el surtout dans les museles, mais elles ne sout pas très considérables; la larwo contient en elle-même de nombrewx éléments cellulaires qu'elle n'a pas employés, et la pupe se sert de ces éléments pour façonner les organes définitifs qu'elle doit produire. Les principaux, des pluénomènes de ce développement, portent sur la présence de disques imaginaux, qui donnent naissance aux appendices locomoteurs, aux ailes el aux palles.

Les morlifieations embryonnaires sont plus complexes, chez les Dipteres lurachycères, que partoul ailleurs; elles liennent ì la fois ì une histolyse profonde, el à la présenee de nombrenx disques imaginanx. Les observations, faites à leur ígard, ont porté sur des Syrjhides (Tolucelle) et sur les Huscides; les premieres sont dues à liunckel d'llerculiris, les secondes ì Ganin, a Viallanes, et i liowalevsky. Iopuis la publieation de ces travaux, quelques nouveaux fitits isolés ont élé acyuis; mais il serait ntile l'étendre anx antres lnsectes, smitout en s’aidant des conseiencienses recherches de Viallanes, les notions fournies parl l'itule des larves de lipteres.

I\% - Il fant concevoir ces moditications, daus lenr ensemble, comme s'effectuant de la manière suivante. Les larves des l)ipliers, an monent où elles deviennent des pupes, sont privées d'yeux composés, de

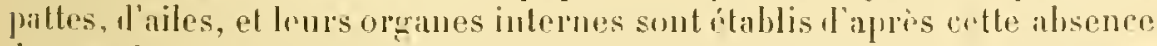
de membres, et d'après leurs adoplations partienliores. Ces mrames se détruisent par histolyse; lenr's dóments ronstitutifs su dissociont, per- 
834

CHAPTRE, MXIËU:

dent lears camoliores propres, el pefommont a l'élat embrommaire.

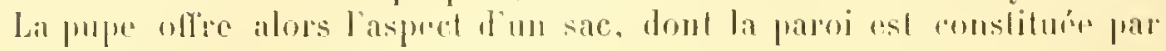

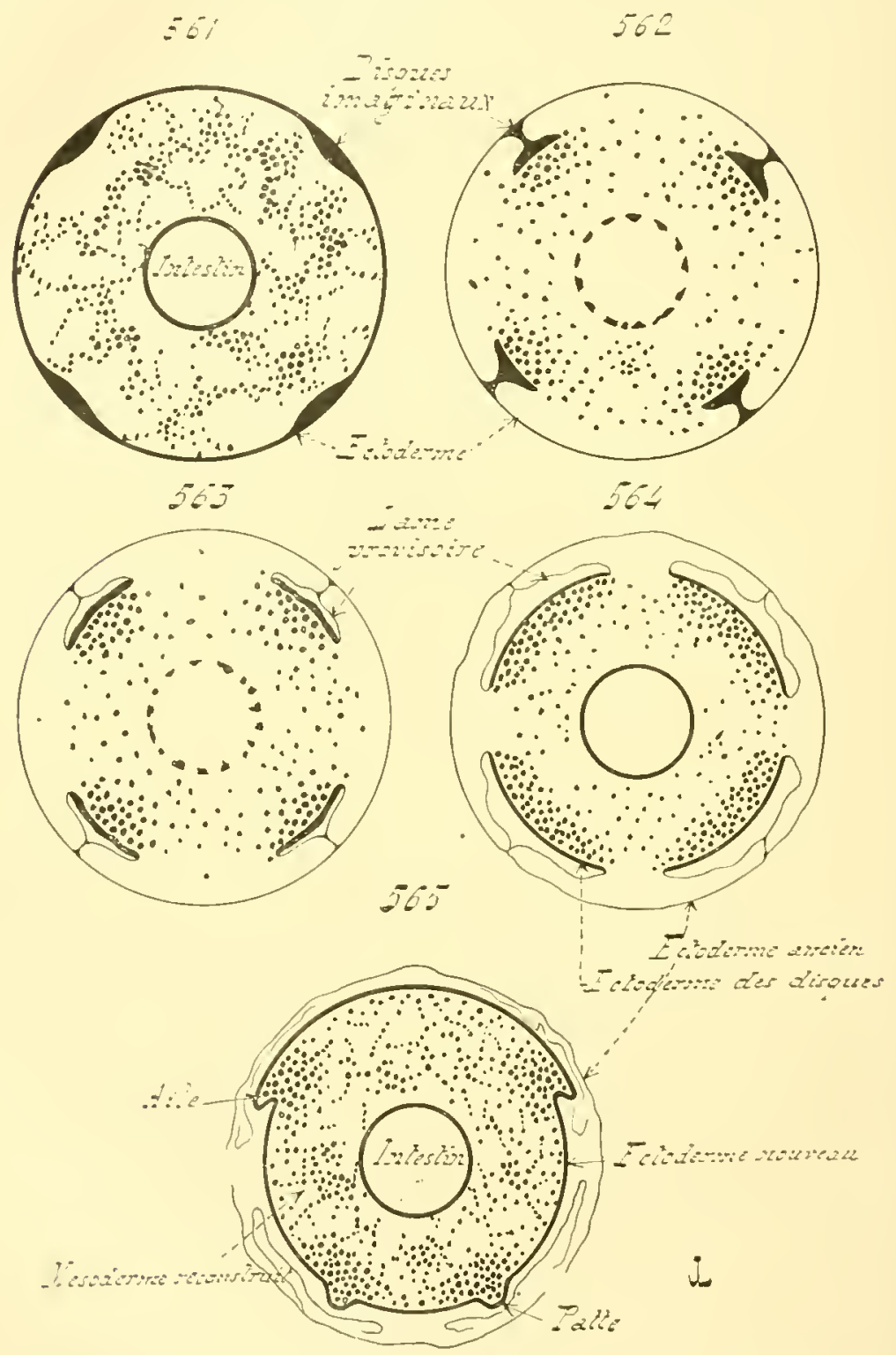

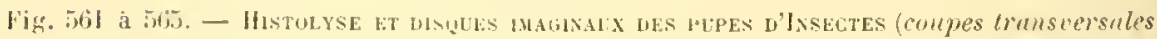
diagrammatiques). - En silit, larve prête a se convertir en pupe; an niveau le la coupe, yuatre ipaississements evtodermiques sont les chauches d'autant de disques imagilltux; la mesolerme est olganjé en travees, qui Jimitent les latunes sanguines; l'inteslin esl ontier. - In 562 , Jes distues imaginaux grandissent, régularisent leurs contours, 
les léguments, et donl la cavité est remplie frar ces rellules cmlorvonnaires, aux dépens desquelles l'histogrenese va facommer les appareils définilits. - Cette désagrégation altrint les téguments cux-momms: l'ectoderme de la lète el celui du llorax se détachent, de sorte que leur basale siule sert à limiter la cavilé où su lrourent les cellules intanes; celui de l'abdomen persiste, mais prolifire de maniere à former au-dessous de lui une nouvelle couche ectolermique, après quoi il se délache également, el se détruit. En somme, la larve des lluscides, apres aroir possivé des apprareils fouclionnels assez complexes, retourne, par une vérilable régression, ì l’étal qu'elle prósentait au délnt mème de son

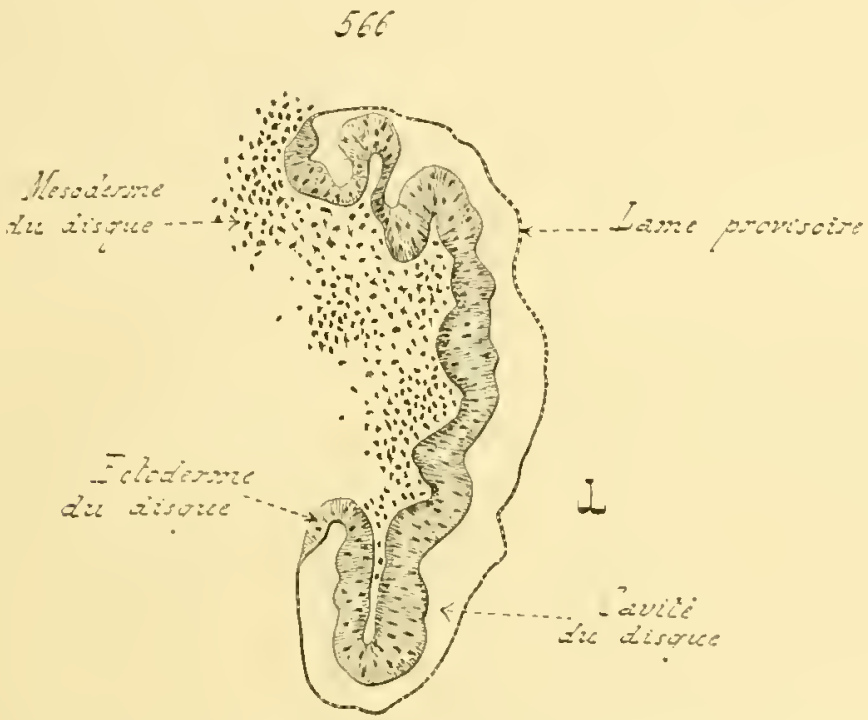

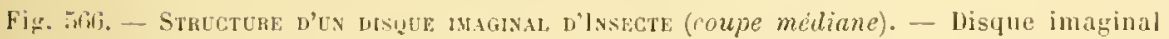
de l'aile, cliez une pupe de la Tipula giganteu. l'apries liallanes.

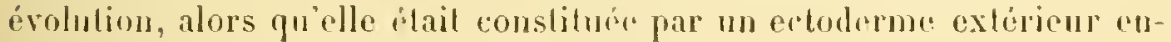
tomrant un protendoderme mésenchyoualeux.

et se detachent en partic de l'ectoderme. L'listolyse du nuesolerme commence; ses elements non differencies, glohules du sang et cellules conjonetives, agissent comme frlıgoeytes, et létrusent les éfiments dillèrencies, notamment le sarcoplasme les libres musculaires. L'histolyse atteint igalement l'intestin. - En 5fi3, ces plienomènes conti. nuent i s"eflectner. Chacun des disques imaginaux se crense de sa fente de clivage, de manière a jroduire sa lane provisoire; les étements mésolermijues retournent a letat embryonnaire, el la plujart d'entre rus s'aunexent aux disques precilents. - lin fifi, les disques inaginaux grandissent et s'élalent; les Jeux de la paire dorsale se rappro-

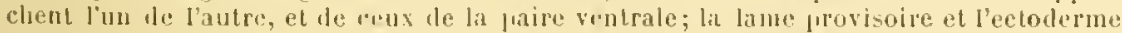

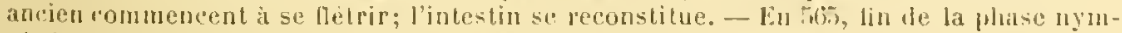
fliale. lorganogenèse s'achive: les dispues imaginaux se soudent los uns aux autres, et reconstituent les téguments; le mesoderme probut it nomveau des nusres anx contours precis; et hes membres, illes et fattes, frennent naissance aus dejens de pes deux feuillets, peudant pue les anciens toguments de la larve se debchent, et tombent. 
Les ilisıues imaginanx prennent naissance avant que l'histolyse ne commence, et pendant qu'elle s'eflectue; ils sont prouluits par l'ectoderme, auquel s’arljoignent des éléments mésodermiqnes, et ont l'aspect, lorsqu'ils sont bien complets, de potits corps blanes, placés dans la cavité interne de la larve, en dedans de l'ectoderme. Its sont régulièrement disposés par paires, partout ou ils existent, et s'altachent à la face interne de l'ectorlerme jar le moyen d'un petit pédicule. Lorsyue l'histolyse est terminée, an moment oì les éléments embryonnaires, qui les entourent, entrent dans la póriode d’histogenèse, enx-mêmes grandissent et prolifèrent. - Les segments, qui les possèdent, "m ont denx paires thabitule, l'une dorsale et l'autre ventrale; les denx disques de chaque paire s'accroissent, en s'étalant, jusqu’a ce qu’ils se rencontrent; après quoi ils se somlent. II en est de mème pour l'ensemble des deux paires, qui s'unissent sur les côtés du segment; malgré la chute de son ectoderme larvaire, celui-ci se trouve donc offrir nue nouvelle paroi, 'jui lui est donnée par les disłues; il aequiert ainsi ses téguments définitifs. Et, lorsque l'annean porte des appendices, ces derniers sont produits par les nouveaux léguments issus des disques, auxquels s’ajoutent, pour engendrer les museles, les éléments mésodermiques jue les disques contenaient.

Chaque partie dn corps renferme des disques imaginanx. La tète en contient trois paires d'abord, et quatre ensuite, par le dédoublement de la première paire; parfois, chez la Volncelle, le chiffre quatre est atteint de suite. La première paire donne les antennes et les téguments voisins, la seconde paire les yeux composés, la troisième ef la yuatrième fournissent l'ectoderme de la face inférieure de la tète, avec les pièces buccales. - Le thorax en renferme six paires, denx paires par annean, l'une dorsale el l'autre rentrale; les trois paires inférieures engendrent les téguments de la face ventrale, et les pattes locomotrices; les trois paires supérienres constituent les téguments de la face dorsale, avec, ponr les deux dernières, les ailes et les balanciers. - Chacun des anneaux de l'abdomen porte deux paires de disques, l'nne dorsale et l'autre ventrale; ces derniers diflèrent de leurs homologues de la tète et Ju thorax par leur apparition tardive, rar ils naissent durant la période nymphale, au lieu de s'ébancher quelque temps avant, et par leur shructure phus simple; ils sont déponróns de la lame provisoire qui existe chez les premiers, et dont on verril jus loin la nature. Ces disques se lorment it engendrer, an-dessous de l'ertoderme larvaire dont ils provionnent, les tŕguments définilifs de l’individu; ils grandissent, en s'étalant tout comme les autres, se rejoignent, et se soulent pour composer nne couche romplete; après quoi l'ectoderme larvaire, placé en dehor's d’eux, se détache, el meurt.

Les disques imaginaux de la tèle, et ceux du thorax, jrésentent, dans leur strncture, une complexité assez grande. Leur première ébauche est 
un épaississement local, sur une étendue restreinte, le l'echoderme larvaire; celle région épaissic słavance dans l’intérieur dn rorps de la larve, en restant unie à l'ectonterne par un pédoncule de plus en plus mince. Les cellules qui la constiluent, et qui sont loules d'origine ectodermique, se multiplient activement; l'ensemble juenl lientüt l'aspect d'une lame épaisse, on d'un dispue plus on moins incurvé. Cetle lame se divise ensuite, par m véritable clivage, en deux couches superpusées; l'une externe el mince, lautre interne et plus forte; la fente de clivige grandil, et se transforme en mue cavité assez vasle. - La conche externe est dile la lame provisoire; léjà lort minre an moment de son apparition, elle diminue encore, et finatrment disparait, d’où son nom. L'assise interne ne se létruit pas; elle persislr, et représente la région eclodermique du disque, celle qui va grandir pour donner les tiguments définitifs. En ledans le cette assise, el faisant partie du disque, se trouvent des cellules, qui produisent plus lari les muscles les téguments et des membres. Cianin pense que ces éléments proviement de l'assise interne du disque, de l'ectoderme jar suile; v'est li mue contradiction avec les domées de l'enbryologie gúnérale, qui démolent loujours la parfaite indépendance des feuillets. Les rerherches accomplies par Viallanes montrent, conformément à ces données, que les cellules des disques dérivent du mésorlerme de la larve, et correspondent, soit à des éléments coelomiques (globules llu sang) qui s'ajoutent aux disques, soit à des éléments issus de l'histolyse des aprareils du feuillel moven.

Chaque lisque présente dès lors nne disposition complexe. Il a la forme l'une lame épaisse, presque gloluleuse, que sa couche provisoire rattache, par un petit pédicule, à la fince interne le l'ectorlerme larvaire. Son assise interne, incurvée en dedans, conlient dans sa coucavilé un certain nombre de cellules mésodermiques. Durant la période nympluale, l'ectoderme larvaire, le pédicule, el la lane provisoire disparaissent; l'assise interne demenre seule avec son mésoderme, el le disque répon! ainsi à un assemblage d'éléments ectodermiques el mésorlermiques. Il grandit, en s'étalant jusqu'à rencontrer ses roisius pour se souder arec eux; l'ectoderme du disque, étanl extérieur, donne par suile la partie des téguments qui lui correspond; le mésolerme, interne, se lronve placé en dedans, et fournit les muscles nouveaux. Les chanches des inembres sont de simples expansions des dispues, revitues par la ronche ectodermique, renfrumant daus leur intérieur des élóments du fenillet moyen, el constiluant leurs fibres contractiles aree ces derniers.

E. - Pemlant que les disques imagninam, formós avant le commencement de la période nymphale, se diveloppent pour prouluiro los líguments de l'adulte, ses membres, et les muscles quils renlorment, l'histolyse létruit les organes internes, c’est-il-dire frs musclos du corps, los trachées, le lube digestif, une partie des centres nepveux, lo corps arli- 
peux, et les convertilencellules embryonnaires. Ces dernieres se groupent ensuite, et sedillérencient, pour so prèler à l'histogenèse, el pour cogrondrer los lissus avec los orananes détinitifs.

L'histolyse des muscles s'aceomplit de deux maniènes. Ians un eas, le sarcoplasme, la sulistance contraclile de la filure, disparait peu í peu. Les rpcherches, eflectuées pas liowalersky, ont montré que les globules du sang de la larve, et sans doute quelques cellules coujouctives, jouent le ròle le phagoevtes, dans celte rísorption; ils rougent le sareoplasme, et le délruisent. İ'élément n’est hientot représenté que par son novau, entouré de sa mince auréole de proloplasme granuleux, non diflérencié; il corresjonil, eu cel état, it une cellule embryonnaire. Dans l'autre cas, le sarcoplasme disparait également, mais le noyau ol son anréole protoplasmique se multiplicut, pou dounes de nomlireux éléments embr" par Viallanes, et petites boules it noymux par Weissmann.

L'histolyse du corps adipeux, fort remarpuable, n'est pas encore lien élucidée dans sa signification. Ce corps se comproso d'un anas complact lo cellules, riches en granulations grajsseuses, et placé dans la région dorsale de la larve. Chacume de ces dernieres se remplit, en un court esprace de temps, de gros granules, divisés en deux parties : l'une centrale, aisément colorable par les róactifs hislologriques tels que le carnin; l'anbrexterne, formant une auréole à la première. Les cellules adipeuses, chargies de ces granules, sont les grosses houles ì moyaux de Weissmann; elles se létruisent prar la suite, et les grauules qu'elles contiennent sont mis en libertí. Cenx-ci ressemblent aux aules éléments embryonuaires, cl sont certainemenl des cellules completes, dont la zono centrale est le noyau. Leur naissance serait done inlerne, puisqu'elles apparaissent dins l'élément adipeux, tout comme les cellules du blastoderme des Insectes se forment dans l'intérieur mème lu vilellus; des renseignements plus détaillés à cel égard, ct portant de préférence sur les morlifications subies jar le noyau, seraicnt nécessaires.

Le tube digestif se détruit également par histolyse. Ses trois parties, l'mbéron, le procteon, el le stomeon, dissorient leurs éléments; mais il semble que ces alerniers ne se mélangent fas aux autres, et restent it pru près en place. pour domer à nouveau les régions dout ils proviennent. les Irachées disparaissent aussi; les cellules. d'origine ectodernique, qui comstibunt lemrs parois, se séparent les unes des autres, jelouruent ì l'étal cmbrommare, el se melent aux autres éléments similaires de la larve. Les éluis chitineux de ces tules respiraloires persistent seuls, frembut en cerlain tempi, et se dripuisent ensuite.

lin résumé, les cellules, quj s’alaient dillérenciées el accolérs pour

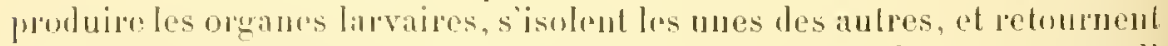
ita forme embryomaire; l'intériem. du corps de la larve est rempli par res éléments, qui composent pra lí un abondant mésenclụme, conn- 
paralle à celui qui ronstitue le feuillet mogen, lors des premiòres plases de lévohution. Ces cellules mésenchymaleuses su joignent de nou veau par la suite, se disposent daus le but de façonner des organes réguliers. se différencient à mesure, pour la seconde fois, suivant les procridés histogénétiques habitnels, et protuisent ainsi l'économie définitive.

\section{5. - Origine des organes.}

Les observations, faites sur la genèse des organes des Arthroporles, sont déjả assez. nombrenses; mais elles touchent seulement à quelques types particuliers, et n'embrassent pas le groupe entier. Lilles suffisent, cependant, pour dénoter une remarquable concordance, entre les diverses classes. sous le rapjort des procédés employés, et de la structure définitivement acquise; les pliénomìnes sont identiques quant au fond, et no different guère que par les détails. Aussi, les notions suceinctes qui suivent permettront-elles davoir une ilée suftisante de ce léveloppement, et de le consilérer comme s'appliquant à la majorité des Arthropodes, sinon à tous.

1. Appendices. $-A$. Tous les appendices, malgré la diversité de leurs formes et de leur structure, ont mème organisation essentielle, et sont engendrés par les mèmes mosens. Ils dérivent de petites saillies, régulièrement placres par paires sur les téguments, qui se composent d'ume assise externe de cellules ectodermiques, entourant une cavité centrale remplie d'éléments mésodermiques. La saillie grandit, se convertil en un mamelon, pui devient de plus en plus long, el se divise it mesure en articles par les étranglements anuulaires, mais en conserrant la mème structure. Son ectoderme se recouvre d'une culicule, et donne les téguments lu membre; son mésorlerme se creuse de carités qui, communiquant avec le systeme circulatoire du corps, servent au sané pour pénétrer et se déplacer dans la patle, et ses cellules se transforment, pour la plupart, en filres musculaires. Ce sont tá les plus importantes des modifications que suhissent les appendices, el lous les présentent; les autres particularités tiennent à la taille, ou à la lorme, sont secondaires par suite, puisqu'elles n'atteignent point la structure fonlamentale, el se concoivent d'après l'asperl détinilil.

I3. - Les appendices véritables du corps des Arthroporles, ceux qui mpritent réellement ce nom, sont régulirrement disposés par paires placies it la file, les mes elerière les autres; ils existent rhez tous les représentauts du groupe, sauf quelques rares cas d'une atrophicentraince par l'adiptation an parasitisme. Les premiers d'onlre enx appraissent d'une maniore précoes sno l'organisme embryonnaire, dies les phases intialdes de l'ácolution. - Il est cependant un certain nombre d'expansions extérieures, que certains Arthroporles possidenl, nom diantres, el

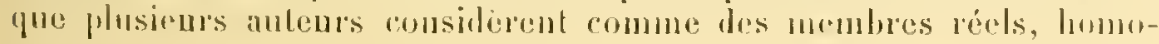


lognes aux autres apjendices, ayant la même nature essentielle et la mème significalion yu eux. Tels sont les yeux composés des Crustacés supérieurs, souvenl montés sur des pédoncules; certains naturalistes ítendent mème, à tous les veux composés des Arthropodes, la valeur quils aceortent à ceux de ces Crustacés. Ils se hasent, pour ce faire, sur la jrésence d'un pédoneule dans certains cas, pédoncule comparable à un membre; st sur te fait qu'une masse ganglionnaire particulière. appartenant an cerveau, est testinée à imerver ces appareils, tont comme les ganglions de la muelle nerveuse voutrale innervent la phupart des antres anpendices.

Crpundant, l'embryologir et l'analomie comparée s'acerrilent égalemant pour contronver celte opinion. Le fait que les veux composés recoivent leurs fibres nervenses de ganglions spéciaux, et volumineux, s'expliqne de lui-mème, comme du reste lous les phénomènes similaires que présentent les autres animaux, par l'excessif développement de ces ycux; du moment où ces organes sont fort gros, of jonent un rôle imporlant. leur rapacilé d"innervalion se trouve obtre dans les mêmes proportions. Les centres mervenx se disposent, ot se modilient, daprìs les appareils anxquels ils envoient leurs nerfs, mais ne regglent pas, et ne dirigent pas, le développement de ces derniers; ils ne font que le suivre, et s'y prèter. - D'antre part, les Arthropodes, dont les yeux sont montés sur des púdoncules, apjartiennent tous à la série des Crustarés, el anx types les plus complexes de cette série, aux Branchiopodes supériemrs (Artemia) parmi les Entomostracés, aux P'orlophthalmes parmi les Mlalacostracís: tons les représentants inférieur's de ces classes ont des yeux ì lleur de peau. Cette compraison suftit pour lémontrer que la présence d'un pódoncule est un caraetère d'ordre élevé, qui manque aux plus simples des Crustacés. Comme les membres de ces derniers sont rigonrensement les homologues, d'après leur siluation, de ceux des Podophthalmes, il s'ensuit que les pédoncules oculaires sont des formations nouvelles, surajoutées aux appendices réełs des régions oủ ils sont plarés, el cotte absence de synchronisme empieche d'établir entre eux une homologie complète.

De plus, en suivant le développenent des appareils visuels chez les rmbryous, on s'apercoit que les yeux composés des arbutes répondent a me multiplication les yeux simples, des ucelles, des larves. Ces ocelles sont mème les seuls orgaues to la vue chez un assez grand nombre d'Irthropodes, la pinpart des Entomostracés, les Arachnilles, elc. Les veux simples ne sunt certainement point des appendices; ils sont constitués prar quelques collules ectorlermiques, qui se morlifient en vue de leur fonction, toul en conservant leur place; du moment où l'ail romposé n'est yn'un mil simple perfectionné prar multiplication, et par accroissement, la mime valeur doit tre accurlée au premier comme au second. El, en résmué. les yeux, quels qu'ils soient, ne peuvent point ètre considirós comme homolugues à les appendices rícls, comme répondant à 
des membres arlaptés à un rôle semsilif, nualgré les péloncules pui lus portent dans certain cas.

La mème conclusion doit ètre appliquér aux ailes de la plupart des Inscetes. Ces appareils ne sont pas des membres préexistants, el lransformés en rue dune adaptation locomotrice spiciale, mais bien dos formations nouvelles. Tout porte à croire, comme (iegenlanr l'a suggéré le premier, qu’il est permis de los comparer aux branchies trachéennes de certaines larves d'Insectes, à celles des Epliémérines par exemple. Ces organes sont des expansions légumentaires lamelleuses, qui renferment des trachées dans leur intérieur, l'oủ leur nom; elles servent ì la respiration en permettant. an travers le leurs parois, l'échange des gaz entre l'eau qui les baigne, et l’air contenu dans les tubes trachéens. Les ailes seraient des branchies trachéennes fort amples, délonnces dr. leurs fonctions premieres par une alaptation à la vie terrestre, at servant à l'individu pour s'élever dans l’air.

Les emliryons de certains Irthropoles, ct notamment coux des Coustacés Edriophthalmes, possèdent sur leur corps des appemlices complémentaires, qui naissent précocement, et disparaissent d'habilude arant la fin de l'úvolution; l'ensemble de ees appareils est désigné sous le nom dorgane dorsal. Laspect de ce dernier est très variable; il se compose souvent de deux lugguetles, plus ou moins longues, plaries symatripuement le part et diatre le la ligne médiane, sur la fare dorsale le londivilu. - La signifieation rócle de ces expansions est encore incomne; il est certain cependant quelles ne sont point des aprendices rrajs, vu leur position dorsale, tout i fail en dehors de la série réguliorc des membres rérilables. Bessels et Dohrn les considèrent comme les homologues des épines, qui hérissent la carapace des larves zoécnnes d'autres Crustacés; Nïsshaum les compare à des enveloppes amniotiques qui seraient fort rédnites. Il est cucore impossible de se prononcer rn connaissance de canse.

Entin, le labre, la live supériente, des Insectes est pris, par cer-

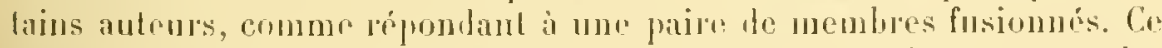
lillne forme nne saillie, en avant de la honcho de ces animaux, entre les autenues ( ${ }^{\text {re }}$ paire de membres de la séric totale) et les mandibubes (20 paire de membres de la série lotale); il est parfois bifide, ce qui tend i lui accorder une origine linaire, el sa situation permet de le comprarer à la seconde paire d’antennes des Crustacés. Dans la penséc de ces maturalistes, la disposition les appendices serait la méme cluez les Crustacés el les lusertes, chez les Télraciores et les bicères; la première paire d'antennes des premiers correspondrait à l'minue paire d'antennes les seconds, la seconde paire l'antennes an labre, les mandilules aux mandibules, les premières maichoires les uns aux premiòres màchrires des antres, et ainsi de snite. - Cetle assinilation me peut ctre acopplé. le développenent montre que le labre est, des sa premiére apparition, 
me piece impaire et simple; il nest done point constitué par denx parlies sondécs, el ne doil pas être assimilé i mne paire d’apendices. Il nest qu'un hourrelel place en avant do la bouche, el rien de plus.

C’. La discussion précélente contribue à próciser lrs nolinns, relatives aux homolngies les appendiees, entre lis trois sous-embranchements des Arthopodes. Ces homologies existenl vaiment, en re seus que corlains memlires des uns sont comparables i ceux des aulres, elinversement; mais elles ne sont point dénolées frar l'aspect, ni par les lonclions, de ces membres. Elles le sont prar la silualion de ces derniers sur leur corps, par leur muméro d’ordre en parlant de l'exlrémilé anlériome, la fremièrégégion produile chez l'emhryon. Les mandibules des uns ne srnt pas homologues aux mandibules des autres; elles lour sont simplement analogues, la ressemblance dícoulant ici le l'ideulilé des fonclions. Il faut, pour établir les homolozies réelles, s'ajpuyer sur la disposilion rigulierement sérice des appendices, quelles que soient les transformalions subies par ces derniers; les appendices de la première paire des uns rorrespomtent à ceux lo la premiòre paire des autres, el aimsi de suile. (On en vient, alors, à citablir les relalions suivantes, qui portent seulement sur les premiers membres, mais yüil est facile l'ibudre aux aulres.

\begin{tabular}{|c|c|c|c|}
\hline SERIE TOTALE. & $\begin{array}{l}\text { AcEnes } \\
\text { (Arawlinides). } \\
\text { - }\end{array}$ & $\begin{array}{l}\text { Unciars } \\
\text { (Myriapoles, insurtes). }\end{array}$ & $\begin{array}{l}\text { TÉrRALÉRES } \\
\text { (Cruslarés). } \\
\text { - }\end{array}$ \\
\hline $\begin{array}{l}\text { le paile. } \\
2 \text { paire. } \\
3 " \text { paire. }\end{array}$ & $\begin{array}{l}\text { Mandihules. } \\
\text { Michoires. } \\
\text { loumieres pattes lo- } \\
\text { comolrices. }\end{array}$ & $\begin{array}{l}\text { Intennes. } \\
\text { Mandibules. } \\
\text { I'remieres michoires. }\end{array}$ & $\begin{array}{c}\text { l'renières antennes. } \\
\text { Secondes antennes. } \\
\text { Mandibules. }\end{array}$ \\
\hline is paire. & $\begin{array}{c}\text { Seconiles palles lo- } \\
\text { comotrices. }\end{array}$ & Seconiles malchoires. & Premières máchoires. \\
\hline 5e pairu. & $\begin{array}{c}\text { Troisticmes patles lo- } \\
\text { romotrices. }\end{array}$ & $\begin{array}{l}\text { I'remieres palles lo- } \\
\text { comotrices. }\end{array}$ & Secondes máchoires. \\
\hline lite. & lite. & Ite. & Ele. \\
\hline
\end{tabular}

Co lablean montre la corrélation quil comient d'adopter, ponr se remile comple des homologies eulre les appendices. Ces dernieres dépendent de la siluation sur le corps, et non des adaplatious fonctionmelles. Celles-i paraissent aroir éti "ausées, daus leurs diversilés, prar la position de la bouche, qui lantôt se peree an njvean de la première paire (Acipes), m menc un peu en avanl d'elle, el tantôt an niveau des

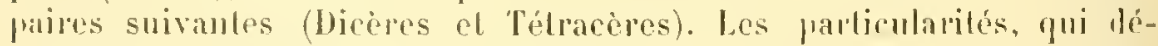
coulent de l'emplacemont variable de la bouche, ne sont pas capables de modifier des lomologies déjà ćlablies, ou en voje de s’étalılir; el. par sulle, cest la situalion muluelle des appondices püil enovient seutement "invorger en parrille rimeonstance. 
Phusieurs naturalistes premnent a l'inverse cette manière de rounprendre les choses, et se liasent sur la posilion de la bonche, pour établir les homologies entre les appendiess des divers Arthropodrs. Ils arlmettent, au préalable, que la place de l'onverture huccale reste fixe, et la mème chez tous les représentants de l'embranchement, at ils partent le cette prómisse, pour comparer entre elles les paires d'appendices d'après leur arrangenent par rapport à la bonche. lls considerent comme homologues les appendices peu nombrenx yni naissent en avant d'elle, et distingnent entre des membres prébuccaux et des membres postbuceaux. - Sans insister sur la difficulté où l'on est sonrent pour décider que lel appendice est placé en avant, on an niveau, de l'oritice luccal, cette façon d'ćtablir les ressemblances ne pent ìtre suivie. Aurun fait ne permet de penser que la bouche se perce rigourensement an mème point, chez les emliryons de tous les Arthropodes; cette ourepture est toujours anlérienre, el presque terminale, mais nos comnaissances se limitent a cette constatation, el l'on ne peut aller plus loin, lorsqu'il s'agit d'organes d'une telle petitesse, situés dans un espace aussi restreinl. Les points de repère manquent, pour apurécier la place relative de la bonehe, el roir si elle est constante; et l'on ne doit point, en toute logique, choisir les appendices pour faire cette comparaison, lor'spur l'on reut classer ensuile ces mèmes appendicrs suivant leur siluation par rapport à l'orifice lunceal.

En tenant compte des phénomines tols qưils se présentent, on est ohligé d'assimiler entre elles les paires de mombres, d'après leur' numéro d'ordre, r'est-à-dire d’après leur disposition muluelle, quelles que soient leurs adaptalions et leurs formes, en élaguant les pédoncules oculaires et le labre, qui ne sont pas des appendices réels. Là se bornent, parmi les notions acquises, les seuls faits ayant un caractere suffisant de précision.

II. Téguments. - A. Les tíguments des Arthropodes, malgré leur gramde complexití, offrent une structure ámentaire assez simple. Ils se composent essentiel]ement d'un épillıélium sécréteur, nommé jrar les

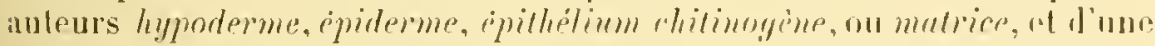
cuticule d'ipaisseur variahle; celle-ci forme une cirrapare, alor's que celui-là correspond à l'ectoderme. Ce dernier engendre la carapace, quelie que soil sa composition, en exsudant la sulistance anhyste qui la roustitue. D’après quelques olıservations éparses, pen compréhensibles cncore, el effectuces pour la plupart sur iles Insectes, les phénomines sont difficiles à suivre - l'ectoderme, composé de collules cylindri'jues, commence par produire sa basale, qui l’isole, ol le sépare du mésoderme; puis, sa face externe so recouve d'un platean assez épais, homogène, et continu, la portion fournie par chaupue cellule se soudant avec ses roisines. Ce plateau est la premire indication de la cuticule; une substance anligste, produle par l'celoulerme, s'interrale culre hii at ce dernier, el lorme une couche d'ahoril transparente, qui jannit 
par la suite. Celle conclue est me nourelle assise culiculaire; d'aulres fuantilés de sulstance anhyste, poursuivaul la mème évolulion, naissent en dessous d'elle; pt le phénomène continue à s'effectner de celle façon. Le platean primilif ost sans cesse repoussé an dohors, et éloigné de l'ecloderme, les zonr's cuticulaires les plus récentes élant aussi les plus proches le ce feuillel cellulaire. - Lorsque les téguments porlent des poils, chacun te ces derniers correspond au sommet étiré, et convert de culicule, d'mue cellule celodermique plus volumineuse que les autres. l'lusieurs auleurs donnent un nom parliculier à cet álément : celui de cellule trichogine.

liexsudalion est tres hâlive d'ordinaire; elle commence durant les premieres phases du développement, el a pour effet de produire, antour de l'emliryou, des membranes culiculaires, qui l'enlourenl el lui servent d'envelopjes. Aussi. le pelil être est-jl obligé do se délıarasse de ces membranes pour continuer son évolution, soil yu’il augnenle de faille, soit qu'il moditie son aspect exlérieur; celle nécessilé est la cause des mues embryonnaires, dójà décriles a leur place, el pour chaque groupe pris en particulier, dans le paragraphe précídent. - Ces mues sont de denx sorles, el les termes, "jui les désignent, indiquent jarlinilement leur nature: les unes soul des mues d'accroisscment, par lesquelles l'embyon, en grandissant, brise l'enveloppe yui l'enserre d'une facon lrop élioilo: les antres sont des mues de transformation, encore nommécs mues de développement, an moyen despuelles l'ombryon, domnan maissince i de nomveanx organes extérienrs, et nolamment ì des appendiees, ou modilianl de beaucoup sa forme générale, ahandonne sa premiere culicule qui, par sa rigilité, s'opprosait ì la genèse de ces productions supplémentaires. Souvent, la mẻme mue présente le doub]e caraclère daccroissement el de transformation, chez la plupart des larves de Crustacés par exemple; ailleurs, el notamment chez les embryons des lnsectes smpérienrs, me même mue apparlient d'luabilude ì l'un, on a l'aulle, de ces denx lypes.

l'arfois, los mues ne sont jas spéciales aux embryons, el existent encole cluez l'adulle; les Custacés superients offreut des exemples bien connus de ce phenomene. l ans ce cas, les mues sont loujonrs d'arroissemenl.

L'ecloderme est supporlé par une assise conjonctive, plus ou moins épaisse suivanl la laille de l’individu, el pui a reçu, a cause de sa situalion, le nom de derme; celte couche se relie étroilement aux handes conjonctivo-musentaires, gui limilent les lacnnes colomiques oì circule le sang. l’anatomie dénote déjà la natme de ce derme, qui paraîl ère une hiprenlance du mésoderme; l'embryologie conlime ces données. l'assisr sous-ectoderminue est engendrée par des cellules du feuillet moyen, qui vienment se placer an-dessous de l'ectoderne, el prodnisent le lissu conjonclif auyuel il est fail allusion. 
I3. - Les téguments de certains Crustarés inférieurs, appartenaul aux ordres des Phyllopodes, des Cstracodes, des Cirrhipedes, et des lihisocéphales, portent deux expransions symétriques, entourant lo corjes ì Jroile et à gauche, étendues d'une manière variable suivant les types, et dont l'ensemble est désigné par le terme de mantean, comme son correspondant des Mollusinues. Les relations du mantean avec le corps établissent que ces deux parties sont des replis de téguments; l'embryologrie alıoutit au mème bul.

Le mantrau possède deux origines différentes. - Chez les Phyllopodes, les Ostracodes, et les Cirrhipedes, du moins chez les types dont le développement est connu, les tézuments de la larve émetlent, sur la face dorsale du corjıs, deux expansions symétriques, et placées de part et d'autre de la ligne médiane. Ces expansions grandissent de laul en bas, progressent de manirre í recourrir les côtŕs de l'embryon, parviennent, dans certains cas, jusque sur sa face ventrale, et constituent ainsi les deux parties du manteau. Ce dernier est done vrainent une dépendance des léçuments dorsaux, constiluée par deux replis qui ront en s'accroissant. - - Tel n'est pas le cas prour les Rhizocéphales, si l'on en juge d'après les observations faites par Delage sur la Sacculina curcini. Le manteau est ici faconné sur place, par les assises cellulaires périphériques de l'embryon, et ne dérive en rien d'expansions émises frar les téguments dorsaux; les cellules, qui composent ces assises, sorganisent pour produire les éléments de cet apjareil, sans perdre lenr situation première. Delage s’appuie, sur cette différence de développement, pour adnettre que le manteau des Rhizocéphales n'est pas l'homologue de celui des Cirrhipides. Il est difficile d'accepter une telle opinion. - Les embryons des Sacculines sont déjà parasites, au moment où ils engendrent leur manteau, et plongés dans les tissus de leurs hôtes; les caractères qu'ils présentent sonl, d'une manière manifeste, en relation étroite avec lenr état le parasitisme; et conme, malgré la dissemblance d'origine, le nuanteau des Rhizocéphales offre la mème structure fondamentale et la meme disposition essentielle rue celui des Cirrhipides, tout porte à croire qu'il s'agit ici d'un déplacement dans l'espace, comprablile à ceux qui se manifestent fréquemment dans les embryogénies condensées, et chez les emlıryons sccondaires. - Les larves des Sacculines sont, selon tonte évilence, des embryons secondaires, adaptés a une vie parasitaire complite, et ne peuvent servir pour renrerser des homologies établies d'après l'auntomic comparée, et d'après les emluryologies dilatées, subies par d'autres représentants de leur groupe.

111. Centres nerveux. - A. Les Irthropodes sont remarquables par la constance de structure le leurs centres nerveux. Ces organes sont divisés en leux parties : l'une située dans la lète, et en avant In: la bouche; l'autre placée en arriere le cet oritice, et s'étendaut plus 
ou moins loin rers lextrómití postérieure du corps. La premiore esl un copreau, la secomble me moelle reutrale; foutes leux communiquent entre elles an moyen unn collier asophagien. Sauf chez nn certain nombre l'Entomostracés, el il asl à remaryuer que ces êlres sont en même temps les plus simples des Arthropodes achuels, le cerveau et la moelle ventrale sont scindés en deux moiliés symćtriques, disposćes de part el l'autre de la ligne médiane, et unies jar des commissures transversalos, on hien joiules directement, sur la ligne médiane ellemème, suivant une étendue variable diapres les types. Chacuno de es moitiós est elle-mêue diviséc en ganglions. placés à la file les ans derrière les antres, ol mis on rommunication frar les commissures longitudimales plus on moins lareres el grosses. - Le cervean est simple, on parlagé en deux el trois ganglions. Le momline les ganglions de la moelle veulrale est des plus divers, suivint les groupes consilérés; mais, asse\% souvent, ce chiflie "st ru raport ave colui des swgmonts, chacun de ces dernirs portant une paire de masses ganglionnaires. Cr fait ust loin, cependant, d'otre la rogle; les Arthroporles inféricurs possédent moins

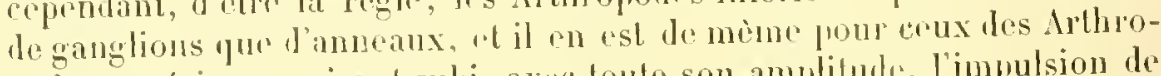
podes supériens qui ont suli, arre lonte son amplitudr, l'impulsion de coalescence. Dans lo premieg eas, la morll. renlrah n'int pas aussi

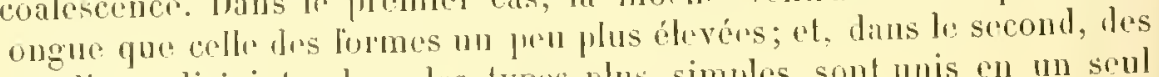
ganglions, disjoints chrz des types plus simples, sont unis an un seul colps innervaut plusierurs sergments.

Le cerveau est simple chez un assez grand nombre d'Enlomostracés; Loul au plus présente-1-il, plus on moins marpuée, mne scissure médiane le divisant en deux lohes. Cihez les Malacostracés, notamuent les Décapodes, el les Dicères (Insectes et Myriapodes), il est divisé en trois parties nommées, suivant leur situation en allant d'avant en alriere, molocerelnon, deutncerebron el tritocerebron. Le protocerebron des Décapodes et colui des bicieres inmervent les yeux; le dentocerebron des premicrs innerve les premiores antenues, ot celni des seconds les seules antennes qui existent chez ces lyjes; enfin, le trilucerehon des premiers envoie dos nerts anx sprondes antenues, ef colui des secomls an labre. Des itudes sur le corveau des Entumostracés, des Edriophthalmes, el des l'odophlbahnes inléricus's, sont nécessaires ponr comprendre de quelle maniore une structure si complexe se raccorle a la disposilion élémentaire, olscrve chez queljues Entomostracés. Ces études serout d'un grand poids, pour eoncevoin la signitication exacte des diverses parties du cerreau dos drthropoles. - Chez les Lères, le cervean tomprend senlement denx parts, un protocerebron, et un dentocerebron, dont la premiere innerve les yeux, et la seconde les appendices de la première jaile.

Panui les régions qui conslibent les centres uerveux des Arthropodes,

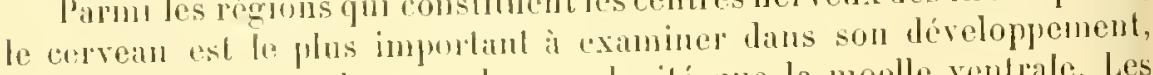
rar il presente nue plus graude complexilé que la moelle ventrale. Les 
recherches sur ce sujel sont assez nombreuses; les plus récentes, el les plus completes, sont dues ì Graber, à Patten, ì Whecler, surtout à Viallanes; elles ont porté, pour la plupart, sur les lnsectes, mais la constance de structure du système nervenx, chez les Mrthropodes, autorise a élendre à l'embranchement entier les fails principaux, observés sur les représentants d'une de ses classes.

B. - Les moins élevés des Arthropodes, sur lesquels on ait étudié le développement des centres nerveux, sont des Malacostracés édriophthalmes de l'ordre des lsopodes, notamment des Oniscus el des Porcellio. L'ćbauche des centres est engendrée par l'ectoderme; elle est simple, inpaire, et médio-ventrale; elle consiste en un cordon cellulaire continu, qui s'étend, sur la ligne médiane ventrale, depuis l'extrémilé antérieure jusqu'à l'exlrémité postérieure du corps, el en partie interrompu au niveau le la bouche. - Son origine est des jlus simples; partout où elle doit se présenter, les cellules eclodermiques prolifèrent sur leur face profonde, el d'une manière active; les éléments ainsi produils restent serrés les uns contre les autres, ef leur ensemble fait saillie dans lintérieur de l'embryon; les conlours extérieurs de ce dernier ne changent pas. Lorsque ce développenenl est avancé, la zone proliférante est semblable i un cordon, qui prarcomt le corps entier, s'apjuic sur l'ectoderme par sa base, et forme lonmelel dans l'organisme. - Ce cordon est d'abord très volumineux, par rapport aux dimensions de l'embryon; la disproportion cesse par la suite, car le reste de l'économie grandit plus se sépare à mesure de l'ectoderme dont il provient. I.es régions nrincipales sont au nombre de trois : l'une, antérieure, placée en avant de la houche, et très volumineuse, donne le cervan; la seconde, moyenne, se partage en deux bandes qui encadrent la bouche, ot fournissent le collier asophagien; la troisiène, fostéricure el de leancoup la plus longue,

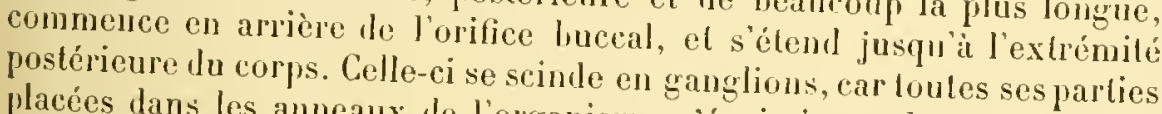
placées dans les anneaux le l'organisme s'épitississent beaucoup, alors que celles siluées sur les lignes de jonclion des mènes ameaux restent relalivement minces; lorsque cette ćvolution s'est poursuivie pendant un cerlain temps, la lroisième région de l'élouche nerveuse ressemble à In cordon noueux, dont les nodosités, placées à égale distance les unes des autres, el assez rapprochées, correspondent à ces parties épaissies. La moclle nerveuse ventrale s'est ainsi constiluée aux dépens de cette troisieme région; les nodosités sont les ganglions; les régions restées minces, el íloites, sont les comnectifs longitulinaux, qui missent entrc eux les ganglions, en maintenant la continuité dans la chaine entière.

A mesure que l'ébanche nerveuse se dillérencie, elle se divise, d'autre frar, en deux bandes paralleles, ot juxtaposées sul la ligne médiane. te rordon quelle forme ne demeare pas simple et impair; il devient double, 
c'est-a-dire composé de deux hankes parallieles, pui parcourent le corps, et s'unissent dr place en place au moyen dre conncelifs fonsverses. Celle morlification est smbunt ividente dans la mochle ventrale. Elle s'etlectue par le procédé hidhituel. L'éhaucho primilive ollie l'aspect d’un corlun simple, dont la seclion transiersale est un demi-cercle, ou peu s'en faut; la base du demi-cercle s'allache à l'ectoderme sur loquel repose le coldor, et dont il provient; le contour est libre dans le corps de l'embryon, ou it alfecte avec les élémenls mósodermiques des rapports de contiguité. La croissance ullérieure de ce cordon ne sellectue pas dune maniere érale dans loutes ses partics; en se représentant la précédente section transversale, les còtés du cordon grandissent seuls, alors que la base et li: sommet ne varient guire. La forme chuge lapidement, et devient plus complexe; on peut se la tigurer en aujoiguant, à chaque còlé de la section primilire, une nouvelle surface en demi-cerele. - Ces régions latérales continnent à augmonter de taille, en s'élendant à la fois sur les flanes, el an-dessus, du cordon primitif. En somme, ce dernier, au lien de conserver sa disposition simple, ef sa forme de demi-cylindre couché, se divise, par le failde son accroissemenl inégal, cu deux liandes parallèles, jointes par leur base; il esl crensé, en son milien, d'une rainure qui sépare ces deux bandes, et qui correspond au sommet du demi-cercle inilial, laissé en sa place, el n’ayant point changé. Les deux bandes latérales, qui ne sont autres que les côtés le l’él,auche premiere, continuent à grandio, alors qur la base el le sommet de celle ébauche ne varient poinl. Aussi, dès que ces phénomènes onl pris une certaine extension, la base, pui mnit les centres nerveux à l'ecloderme, se tronve fort réduite, et linit mème par disparailre, les centres élant alors autonomes de ce fait; ct le sommet, surplombé par les masses latérales en voie d'accroissenent constant, se trouve reporté au fond d'une rainure de plus en phus profonde. En outre, dans les zones oi les cordons latéraux se disjoignent l'un de l'autre, cette rainure s'enfonce dans le lissu qui unil ces cordons, de maniè à atteindo leur base commune, et à les isoler complètement.

C. - Lébauche des centres nepreux est engendréc par l'ectoderme, comme che\% lous les autres animanx. Au mument où commence celle genese, l'cetoderme se compos. d'une assise collulaire, simple et rounlière, qui entoure le corps contier. Celle disposilion est aussi celle de la rógion nelreuse; aussi, les éléments ectodermilues, compris daus cette dernière, proliférent-ils par leur lace prolonde seule. Lorspue la première fhase de leur multiplication s'est eflectuce, l'ectorlerme de la région nervouse est conslitur par leux couches cellulaires superposées, el non par une seule; la couche axterne ost l'ocloderme lui-nène, la couche interne est l'ensemble des élements fommis par la lace profonde de la précélente. - lons toules les zones da corps wi ront naitre des centres nelveux, leceloderne se lrouve ansi composé, an début mène du déve- 
loppement, par deux assises; l'exterue rontimue a faire palie de l'ectoJerme, l’interne donne les lissus nervenx. La rourhe pxlorme produit libu rocore, loujours par sa face profonde, el durant un rertain tempes, des éléments qui s’adjoignent à cos tissus, of su comvertissont on collules

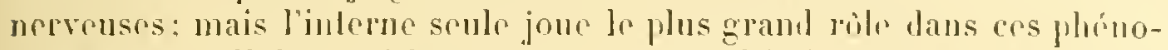
menes. les collules, tui la composent, se multiplient actirement, of faconnont ainsi los iléments neproux. Aussj les auteurs les ont-ils désignóns par des expressions parliculierrs. Viallanes les nommo des cellules gangliogènes, cl Wheder dos neurolilastes. - Cos lermes sont justifiós dans cortains cas, lorsqu’il s'agit, par exemplr, du corvoun los lusictes, oi ces cellulos sont phus gramles que los foments neveux quilles engenlrent: mais, en gréral, ils me sappliqunt il aucun fail raiment particulier. Toutes les cellules remloryonnaires se multiplient, dr manière à

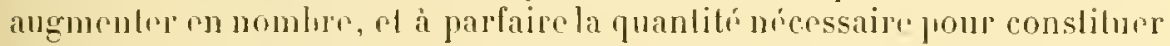
les lissus de ladulto; ot, lorsque los cellulis-mìes ot los collules-fillos sont semblalıles, les unes no méritont pas plus de nom spreial que les aulres. Dans le cas les contres noproux dos Arlhroporles, les plemiors

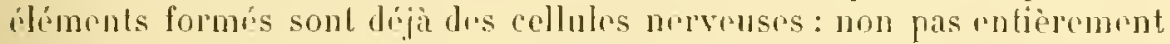
différenciós commo culles de l'adullr, ol capables do lonclionner, mais embryonnaires, cost-i-dire n'ayant l'aulro but et dautre objet que d'accroitro leur nombre.

Les premiers éléments des b́bauches nerveuses, etant ainsi engenJrés par l'ecloderme, el sur la face profonde le ce deruier, continuent ì prolilérer aclivement. L'ébanche s'aceroil done avec rapidilé, el prend la forme de corlon simple déjà signalée; à cetle époque, elle est conslituée par des cellules ètroilement serrées les unes coutre les autres. La substance filırilaire prend ensuite naissance, à peu pres rers le momenl oi se manifesle l'areroissement bilatéral du cordon nerveux; elle apprait dans la région inlerne de l'élatuche, sur le contour de cotle

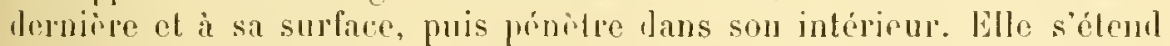
plus tarl dans tes corlous latérax. en perdant sa siluation superficielle pour Jevenir renlrale, et conserve lésormais celle posilion. - Les centres nerveux des Isopoles sont alors conslitués. Malgré la romplexité Je leur structure définitive, ils dérivent d'une ébauclie simple, entierement romposée de cellules l’orignine ectoderminue, et placée sur la ligne méliane ventrale de l'rmbruon.

I). - Deux faits sonl a remar(uor dans co développement: la conlimuiti de libbauche, et sa naturo simple. Le premire d'rntre eux est important, en co sens yu'il routrilue jour sa prart à bloigner les Artho-

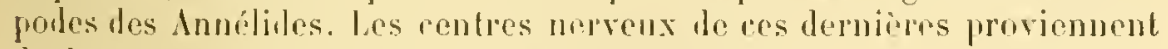
le deux ébanches dislincles, la plaque éphalique et la plaque módullaire.

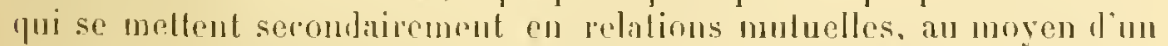
collier usophagien, mais commencent par blye sipares; la papure crphalinue donte le cervean, et la plapue médullaire lonruil la moelle 
ventrale. II nen est pas ainsi chor les Irthropoles; lour ébauche nervense est unique, contime dipuis l'extrónité antérieure du corps jusquà lextrémitó postériemre, el so divise ultérienrementen errrean el moelle ventrale. Cos demx parties essenticles des centres nerveux ont done mème origine, provionnent d’un mème élément fondamental, el ne peuvent être considórés comme des organes distincts. Sous ce rajport, les Arthropodes et les Annéliles sont en opposition flagrante.

La seconde particularité lient a la nature simple de l'éluache nerreuse, qui se compose tout d'abord d'un unipue cordon impair et midian, el nedevient fouldr, cest-à-dire formó de deux loamdes palallèles, que par la suite. Cr lait, nettement offert par les embryons des lsopodes, est à rapprocler le la disposition simple et impaire, possédée sourent par les Entomostracós, c'ost-à-rlire par les Arthropodes inférieurs. Ainsi présenté, il açuiert une importance considérable. En elfet, les centres nerveux des animaux hilatéraux délutent toujours par une ébauche impaire el médiane, qui devient double par la suite. Les Annélides et les Vertélurés fommissent en cela d'excellents exemples. - Les Arthropodes ne font pas exeeption à la règle. Les plus élevés d'entre eux montrent bien une origine domble pour lenrs centres nerveux; ces derniers naissent, et apparaissent tout d'abord, sous la forme de deux corlons parallèles el juxtaposés; mais il n’en est pas de mème chez les Arthropodes inférieurs. En appliquant i ces données les notions générales de l'embryologic, on est comluit à rapporter la provenance double, des Arthropodes les plus complexes, a me omission dans le développement; la phase relative ì l'ébauche simple el impaire manque, ou bien est a peine représentée, an moment de la formation des deux banles voisines par une senle el mème zone ectodermique. El, pour conclure, il est permis de considérer les centres nerveux des Arthropodes comme dérivaut, dans leur essence el en allant au fond des choses, d'une élauche continue, simple, impaire, et placée sur la ligne médiane ventrale du corps.

E. - Les faits qui précédent sont relatifs anx Crustacés EdrioJhthalmes, c'est-ì-dire à des Arlhroporles d'une certaine infériorité organirue. Ceux qui suivent se rapportent à des Mrthropodes supérieurs, à des lnsectes. Les recherches cflectuées ont, en effel, touché de préférence à ces derniers inimaux; el. la grande ressemblance élablic entre les systimes nepreux de lous les représentants de celte classe, qui se retronve encore entre eux et cenx des Crustacés décapodes, permet l'élendre a ces derniers, et à tous les Insectes, les données principrales acquises sur quelques-uns. Les olsteprations les plus récentes, les plus complirtes, et les plus digues de créance, sont dues a Viallanes; elles ont porté sur un Insecte orthoptère, la Mantis religiosa; elles sont suivies pour la plus gramle part, laus le prósent exposé.

Les premiers vestiges des centres nervex sont représentés par deux 
cordons, qui proviennent de l'ectoderme suivant le procídé déjà indiqué pour les Isopodes; ils commencent par apparaitre vers l'extrémité antérieure du corps de l'embryon, dans les loles procéplsaliques, et s'étendent de là jusqu’à l'extrémité postérieure. Cet accroissiment si:

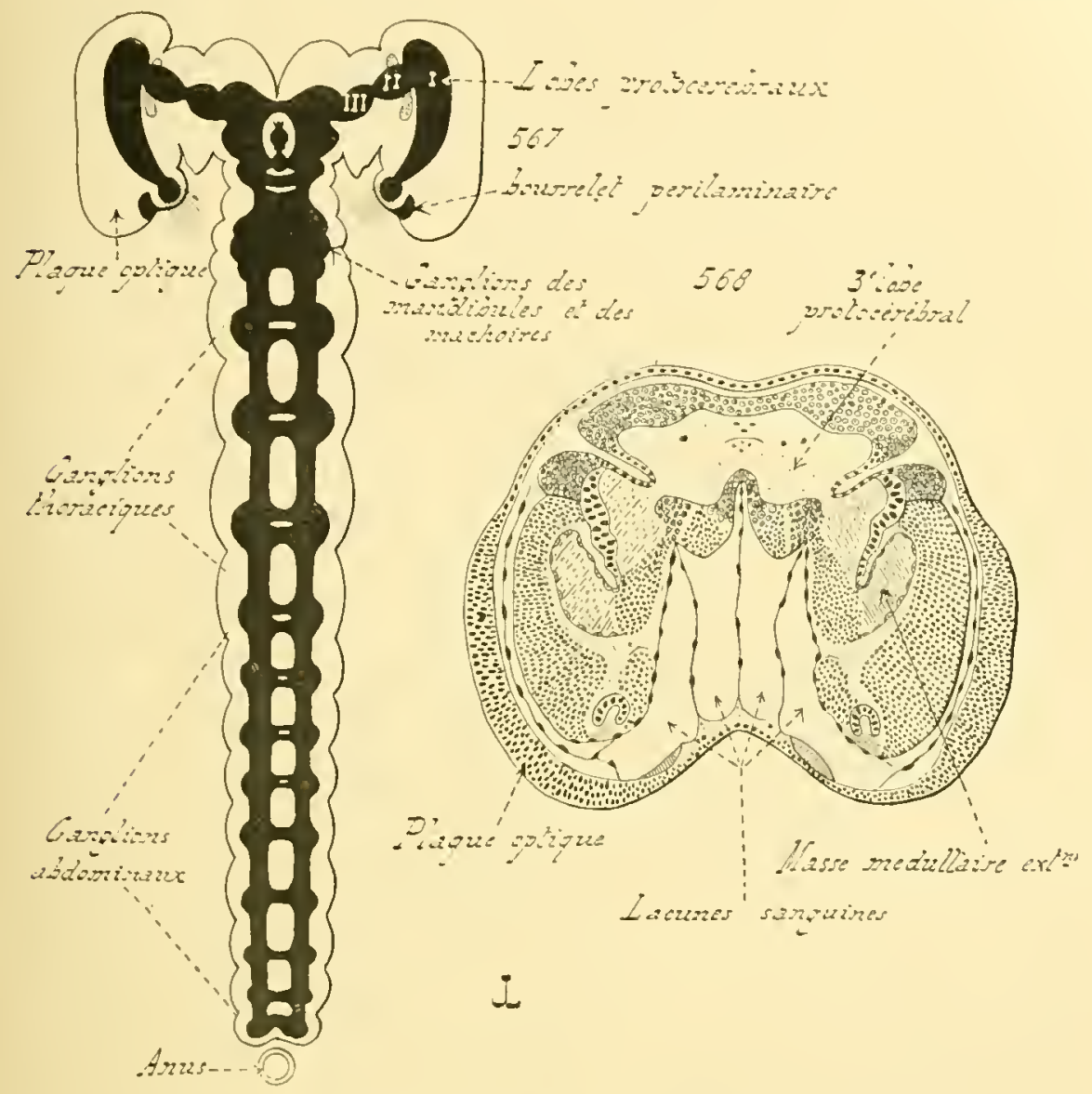

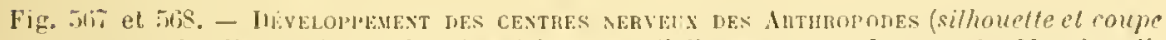
Wanswersale; d'ajuis lus recherilies failes par Viallanes sur un Inscote, la Monlis religiosa). - lin 5ti, ibauche des centres nerveux d"un embyon diji avince; les aspaces lajses en blanc eypriment les ropions cellulaires, les cspaces noirs les regions fibril-

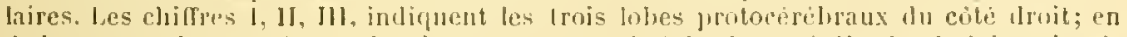

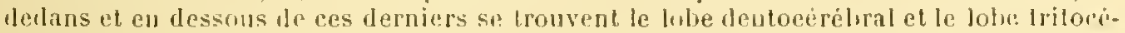
rébral; le ganglion frontal et le ginglion stomaco-esoplatgien, impaij's, sont placés dass l'espace encardré far l'ensemble des lobes leutocirijuaux et tritocirebraux dus deux

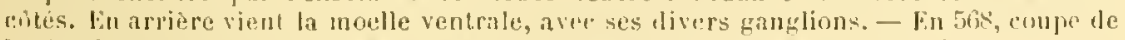

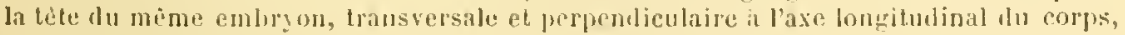
passant au niveau dé troisiemes loles protocerubrus, et montrat la complexilè dt: libanche riribrale. les deux petits corps, en formu de fer a chevil, situis soms les masses medulaires externes eorresjondantes, sont les derniers vestirns des bumrotets périlaminaires. 


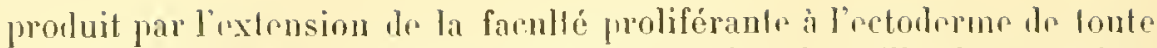
la région norvouse, rt non par laugmentalion de faille drs premires rudiments formés. - Do mêur que elez los Isopodis al tous les Arthropordes, les indications indialos du systime nervoux saccusent hiti-

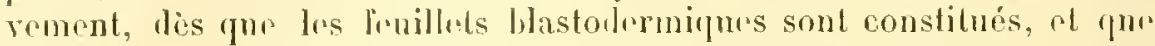
l'reloderme a rovèlu sos raracteres propres. - An momml oủ ees phénomònes s'achèvent, l'élanclu nurveuse so compose di doux cordons parallèles, très proches dr la ligne médianr ventrale, et s'élrudant des lobes proréphalipurs à la région caudale. L'évolution ra diavant rn arrière; r il en rst dr mêmo pour toutes les manifustations du développement, qui commenent laus la région antípiemr. des corlons, pour progresser vers l'rextrómilé postériemre.

Les loux cordons s'écarlent l'un de l'autre on avant, ot so recourbont en lehors; chacm d'oux lorme, dans celle zone, Irois renthements places l'un derrière l'autre. Lionsemble dre ces renflements rst l'ébauclu du

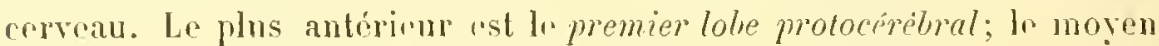
est nommé second lobe protocérébral; quanl an tornicr, if so divise hàtivement en trois nouveaux lolu's, llésignés par Viallanes, ot en allant d'arant on ariere, jar les trrmes do troisicme lobe protocéribrel, do lobo deutocérébral, et de lobe trilocérébral. II rxiste done rn tout cing lubes; los trois premiers fournissunt lo protocerebron, le quatriome donne lo

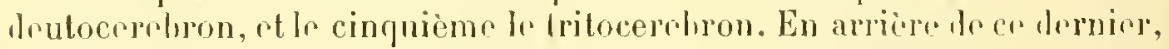

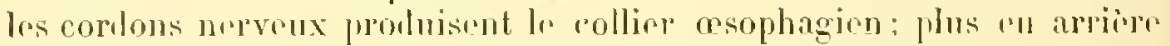

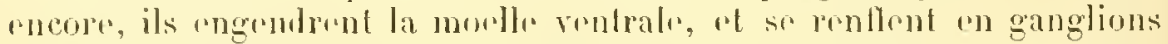
dans chaque annean. I s tissus dos denx cordons saltachont, par lour base, al lectoderme qui lis a produits; un espace étroit lis séparo in cottr région basilaire, el cest dans cot espace que najsinnt los commissurrs transversalos missant les divers ganglions.

Le développement du dentocereliron, celui du lritocerelıon, el également celui ile la moelle ventralo, noffrent ancume parlicularité essentielle; les phénomenes offerts rappellent cenx yui sontsignalés, dans les pages précédentes, comme sappliquant an Isoporles. 11 importe seulement de se souvenir, ici comme chez les anlres Irthropoules, que toutes les molifications ívolutives ne s'elfectuent pas simultanément lans l'étendue de l'áhauche entiere, mais progressent de proche en proche, et ront l'avant en arrière.

Le développement du protocereliron est phus complaxe; cette région nerveuse est en effet tris différenciée chez ladulte; sa part la phus importante se compose des demx ganglions optiques. Les faits, déji indipues, montrent que son iluanche est triple; olle comprend frois lolies placés l’un derriore l'autre, col ocoupant loute l'extrémilé antérieure des corlons nervenx. Chacun do ces lolus fournit une zone particuliere du prolocerehrou. - Les descriplious qui suirent, comme cellos qui pré-

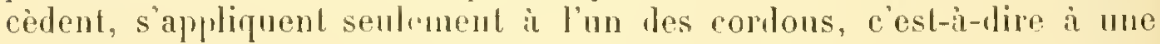
moilié de l'ébauche nerreuse, l'autre suivant une ivolution identipue. 
An moment de la formation du premier lobr motocérilural, et au niveau oì il ra apparaître, l’ectoderme embryonnairo sépaissit. ol so prage en deux rouches cellulaires superposées. I.e phinomóne est don" semblable de lous points à celui qui se manifeste aillenrs; senlenent, une ditférence s'étalılit, au sujet de la couche cellulaire exlerne. lans los autres régions nerveuses, cette assise prsiste comme ectorlerme définitif; ici, elle subit des différenciations considérables, et prorluit l'ail comjosé : aussi mérite-t-clle le nom de piaque optique, qui lui a été dommi. liassise interne, par contre, engendre, comme dans les autres élanches, les cellules nerreuses. Elle se sépare compliotoment, et de lonne henre, de la plaque oplique; elle fournit les éliments nervenx jar sa face jrofonle seule; elle présente ainsi une certaine autonomie, que les auteurs expriment en la nommant couche des cellules gangliogines, on encore couche des neuroblnstes. Les éléments, qui la coustiluent, sont plus gros que les cellules provenanl d'eux; aussi se distinguent-ils de ces dernieves pendant un certain temps, et composent-ils a la surlace de leur amas une assisc d'aspect particulier. Ils ne tardent pas, du reste, à cesser de se multiplier, car les cellules nelveuses prolifèrent par elles-memes; ils ıliminuent de taille, et ne lorment bientòt qu'une mince banle, étalée sur la face externe du lobe.

Entre temps, la substance fibrillaire se montre dans la régrion profonde du lobe, et à sa surface; elle ne rouserve point celte siluation, pénetre dansla substance mème du lobe, et levient centrale. Les cellules nerveuses continuent à proliférer actirement; leur masse s'accroìt sans cesse, déloorde de chaque eólé le resle de la couche des cellules gangliogènes, et les surplombe. Celles-ci paraissent ainsi pénétrer dans l'intérienr du lolıe; leur ensemlıle a été nommé le bourrelet périlaminaire, par Viallanes, dans ses premieres recherches; elles nengendrent aurun organe particulier, et s'atrophient. Elles devicment, d'aliord, presque semblables aux collules ectodermirues de l'arlulte, puis clles disparaissent compliotement.

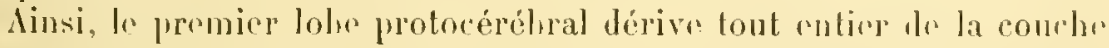

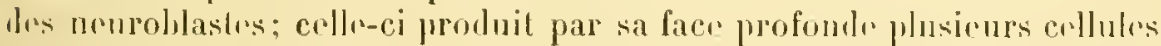

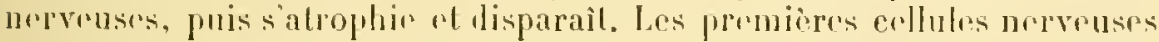

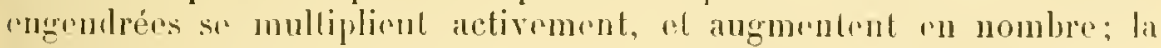
substance fibrillair prenol naissance, périphérịur ot interne d’ahorel, conlrale msuite. - l'élanula du promier lobe protocérélral se com-

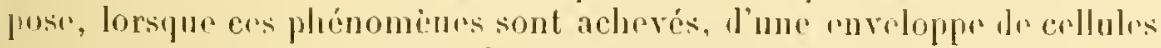

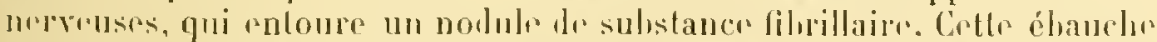
val donner : la lame ganglionnabe, li cliresma externe, la masse médullaim extrrme, ot los filmes post-retiniennes.

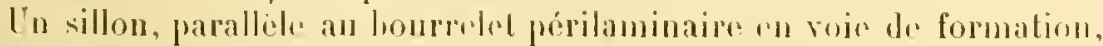

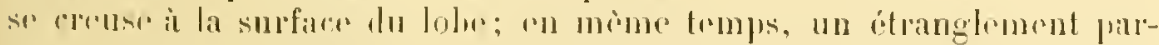

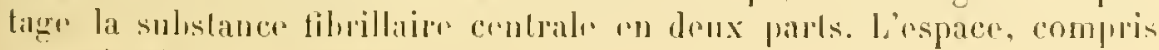

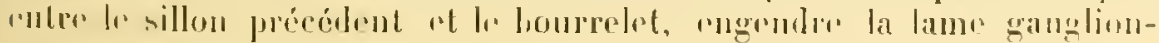


naire: Irs cellutes périphériques de cet rspace domment l'assise externr,

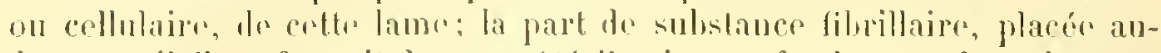
dessous dielles, fournil de son rôté l'assise pofondr, ou de substance ponctuér. Le reste de ta surfaer du bole se convertit rn la couche rexterne, l'écorce ganglionnaire, dr la massi médullairo externe: la scoonde part de sulstance fibrillaire produit à son tour la voluminuuse assise de substance poncturie, qui porte plus spécialomont lo nom do masse médullaire externe. L'étranghonent, constitué par llss filrilles, qui joint l'ume à lautro lus dux parts ale la substance fibrilaire centralu, pressisto à son tour comme chiasma externe.

Les libres post-rétinirnnos apparaissont, torspur frestrois promières régions sont déjà élıuchées. Ellos sont émises par l’asciso interne do la lam ganglionnaire, et ront se joindre a la plaque optique, qui se transforme en er momont pour dorrnit l'mil composé. Ce phénomène est dres plus romarquables. La plaque optiqure, ést-a-dire l'ébaucho de

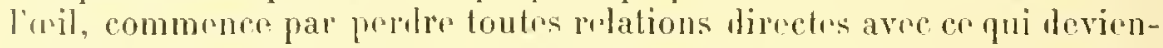
dra la plus importante part do ganglion optique; puis des conncxions

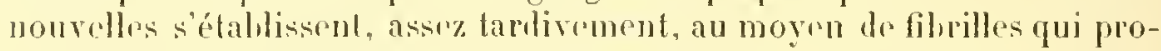
virmment de lune les ébauches de ce ganglion. - ll ne faut point l'ouhlier eepondant, lus premicres indicalions do tieil, w eefles du ganglion, ont uno origino commonr, anx dépens do la memr zome ectodrmique; l'interruption des rapports directs paraît due ici à un omission do phases, car lo lévoloppement des Jnsectes est toujours condensé, et ne semble pas constituer une condition essenticlle le cette érolution. Du reste, plusieurs ont vu, chez d'antres husectes, les ćbauches des ganglions opliqnes conserver tonjours des relations directes avec la plaque optipue.

dinsi que te fait remarquer Viallanes, lo ganglion optique de la Mante ressemble, aı moment oì ces phénomines s'achevent, ì celui d’une larve de Diptères lors de sa métamorphose. Les molifications, qui se produisent ensuite dans le premier, rappellent celles qui se manifestent dans le second, lorsque s'elfretue la métamorphose en imago. Lrs fibres post-rétiniennes devirnnent phus courtes, et tirent smo la lame ganglionnaire dont elles frovirnnent; celle-ci sort du lobe protocérébral qui la contenait, et rient s'étaler au-dessous de l'oil. En mème temps, les fibres "lu chiasma externe s'allongent, tirées à leur tour par la lame ganglionnaire, à laquelle elles s'attachent par une de leurs extrémités.

les molifurations sulies par le druxieme lobe protocérélral, el par le troisiome, sont de beaucoup moins complexes yue les précédentes. le début est le mèmr; l’ectodrome s’épraissit pour fournir les ébauches, el se divise en dewx assises: sentrmont, l'assise externe persiste comme ectoderme normal, ef no prend aucum part ì la genese de l'ail composé; en consionurnce, les lapports d’adhérence, établis entre lui ot l'assise interue, durent pendant un lemps assez long. Celle-ci engendre dos cellules nerveuses, donées elles-mémes de la faculté de multiplication; un 
épiais amas d'éléments nerrox prend ainsi naissance. La sulstance filvillaire apparait sur la facr interne le cet amas, pnis prietre dans son intérieur pour devenir ecntrale. En somme, les phénomenes offerts prar ces ébauches ne dithẻent on rien de cenx présentés par la moelle ventrale: alors que ceux du premier lobe protocérélual sont très altérés par la transformation de l'assise extérieure en neil composé, el par la haute complexité à laquelle Joit parvenir l’ébauchr.

La substance fibrillaire du second lobe protociribral donne la masse médullaire interne du ganglion optique, qu'enlourut los cellules périphériques de ce serombl lobe. La région rétrécie, qui muit er dernire an promier lole protocérébral, prond nu aspect fibrillaire, ef fournit le chiasma interne. D’aulre part, la région rétrécir correspondante, qui unit lo second lolor au troisiome, se comvrtit égalemrnt rn un faiscean de fibrilles, qui est lo norf optique. Le troisiène lobe protocirébral d'un côté se joint à son congénère sur la ligne médianr, avant qur la sulsstance fibrillaire ne vienmo ì se montrer; lorsque celle-ci apparait, l'muion continue à prosistor, en soffectuant par son mutromise. Toutos los régions, ainsi formérs, constituent cette zone lu protocerebron qui rst placée entre los deux ganglions optiqurs.

Le prolocereluon est dès lors complet. Il dérive do trois ébauchus, dr lrois lobes placés à la suite l'un derrière lauler; los deux premiers domnant, de chaque côté de la ligue médiane, lo ganglion optique, of l. troisième proluisant la région intermédiaire anx denx ganglions, qui les unit l'un ì l'antro.

Toujours d’après les études dr Viallanes, les norfs proviennout dis centrus nerveux; lours ébauclies sont semblahles à des loourgeons, qui naissent aux dépeus de cos centres, et s'étirent do plus en plus en s'allongrant dans le corps.

Les centres nerveux de la vie organique, le ganglion frontal ol les ganglions stomaco-oesopluagiens, paraissent avoir, lu moins chrz la Mante, mo origine indépendante. Ils sont angendrés par l'assise épitléliale qui constitue la proi du stomron, et dans la récion dorsale do er dernirr; commo cultrassise provient à son lour de l'ectoderme, lorigine. fomlamontale n'ost point différunte de collo offerte jar los auters régions merreusis. - Io ganglion frontal "st, d'ahord, racendé an tritrecrehron par des commissures conrties et larges, somblalules a celles qui

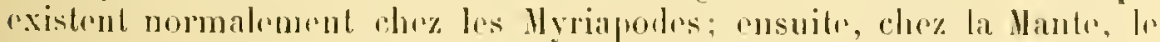
ganglion frontal se léplace, s'écarte du trilocerolon en se placant plus loin lo lui "n arant, et les commissures samincissent tout on sallongonul.

F. - Las consilérations, qui précèlunt, découlunt de la plupart des

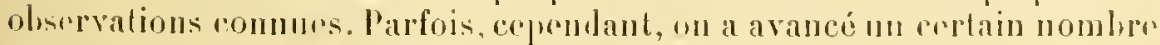
do netions dillúrentes, qui méritent d’èrosignalérs, ot deutro disculérs. 
Ainsi Xïssbaum, dans son itude sur l'ombryologir d'un Crustacé schizó-

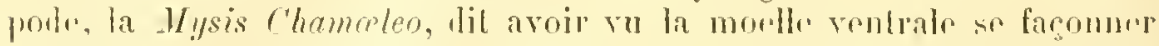

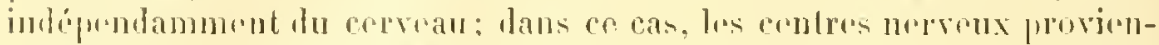

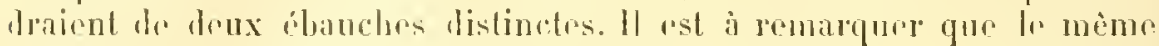
phómomèno apparent so manifostr. chez les Isopodes, où la conlinuite du corton nerroux est interrompure par la houchr. Mais colte inloremtion

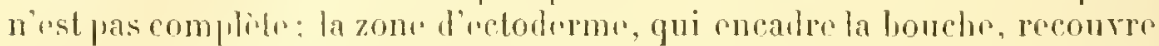

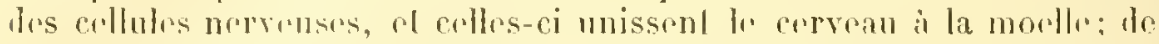

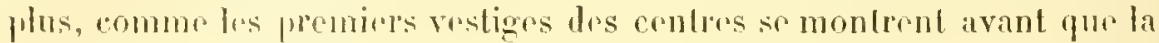
bonche no se prece, la conlinuilé est parfaite des lo début du dévelopj"imont.

II est a remarquer, que l'éhauche norvense, chez la Mysis Chamoleo, sr compos do drux corlons parallips: cenx-ci sont tres proches l'un dr. l'autre, ot mis sur la ligne médian. par une hande de jonction. En somm", rle est impaire, rt montre sulement une amplificalion considérahlo do sus côtés, scmblahle à colle offorlo par les lsoprodrs, mais plus halive. Par subr lus nolions. tirées de léludo le ces derniers aumaux, leur sont applicalites.

IV. Organes des sens. - Coxsueratons géxérales. - Les seuls organes sonsitifs, dont lo dévoloppromont ail éló étudié d'umr manjèro suffisante, sont los voux. Encore, los notions obtennis ue sont-ellos pas lres complibles. EHes suffisent equmbant pour promettro d'affirmel que ces apparejis froviennent directement de l'ectorlerme: leurs été-

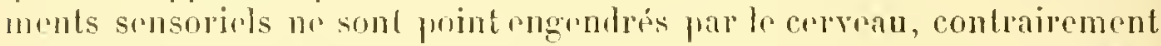
¿ lopinion ćmiso aubrobis par Bobrolzky. - La réalité est que los ébauches dos veux, aroc collos du cerveau, dérirnt dune memo zonr ecto-

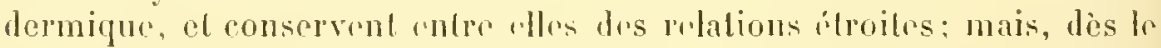

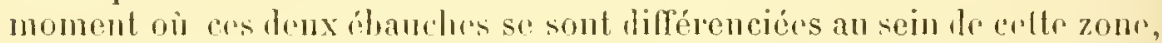

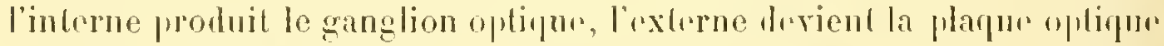
el lomme l'uil, sans qur l'on voie aucune partic di la sceondr so déga"urle ensuilu de la promierr.

Los apraroils visurels dos Arthropodes appartionnent à doux typus principaux : les yeux simples, nncore nommós acelles, cl los yeux composés. Ainsi que Paltrn a ponr heaucoup contribus à le démontror, il nexiste cutr: eux aucune dillérence essmbelle. Cet auleur a hasé son opinion sur un rerlain nombre de faits, dout plusicurs ont été reconnus comme indxacts; mais les lonmées suivanles paraissent vérjliques. Les diveloppements les plus simples, et diverses parlicularités analomiques, antorisent à considérer les yeux des Arthropules comme ripondant à des ropions ectodermiques léprimées. et cuncaves; ces régions sont les coupes optiques. Ilans cerlains cas (divers Chilopodes par exemple), la coupe optinue persiste telle quelle, el devient un aril: sa cavilé se r'mplit d"un milien lyalin, pui laisso passer les rayons lmminenx: 
les éléments de sa paroi se converlissent en cellules rélinirmus. le plus souvent. la coupe se clob, el se convertit en une vésicule optique; prar l'effet de cette fermelure, la résicule est immódiatoment placécen dalims de l'ectoderme, qui forme nn pont au-dessus delle. La zone echollermique, qui peconve directement la résicule, constitue une cornée; la cuticule, qu'elle produil, s’épaissil souvenl dans le cas les ocelles, ef donne un corps lenticulaire, transparent, placé en dehors de liuil. La ravité de la résicule disparail entièrement; la portion de paroi, qui la limile du cốé de la cornée, s'amincil, s’atrophie en son milien, cirst¿-lile vers l'axe central de l'organe, et se relie sur les côtés aux aulres porlions praciétales. Celles-ci, qui correspondent ax cotés el au fond de la vésicule primilive, composent la région sensorielle de l'appreil visucl. L.eurs éléments s'allongent: à cause de l'amincissement el de l'atrophie de la paroi externe. ils se mettent en conlact direct arec les cellules de la cornée, el s'appuient contre elles. En allant de dehors en doulans, sur un wil ainsi constilué, on lroure : la cornée, recourerle par sa cuticule; el la réline, qui se trouve placée immédialement au-lessuns d’ełle.

Ces demx couches sont les assises fomlamentales des yeux do: la gramle majorilé des Aithropoles, tout iussi bien dans les ocelles que dans les yeux composés. La cornée se rattache par ses borls, et s'unit, a l'ecloderme du reste du corps, avec lepuel elle se continue; la réline, bien que d'origine ectodermique, constilue, à cause le son mode de formalion, une parlje indépendante, qui se relie élroilement aux fibres nelveuses émanées du cerveau. l'arfois, cetle liaison existe dès le lélıut, l'b́lsauche du ganglion oplique restant altachée far quelques traclus i la plaque oplique; parfois celte liaison est tardive, l'ébauche el la plapue commencent fral se séprer, fuis s'unissent de nouveau. Selon loule évilence, ce second mode est secondare par rapport an premier, qui est primitif.

Les liflérencers, entre lus ocelles al les yeux composés, s'élablissent dans la disposilion de cos drux assisus foudamonlales. La comén ot la

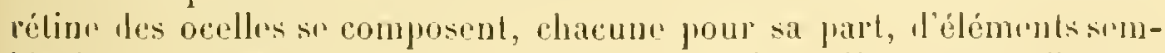
blablos hes uns aus auldes, ou pro dissemblables; clles offient l'aspret

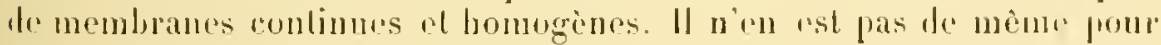
les geux composés, pui sont lu roste plus grands of plus volumineux que les veelles. Les collules do lems assises so rassemblent rn pedils groujess distincls, el an un nombre délerminé pour chacun le ces grouprs. Ces derniers sont identipues sous lous les lapports, anlanl par la laill: yue par la puandilé des éléments constilulilis; ces puantilés élant, du reste, susceptibles te varjer, mais daus iles limites assoz élouites,

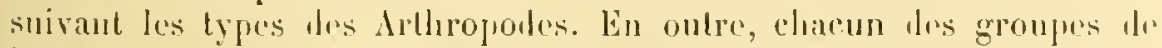
l'unr des assisos s'mnil intimenent à colui, des groupes ld la sircondr,

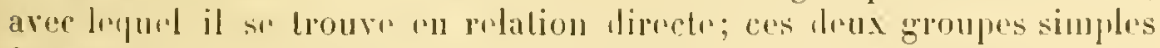
formont lonc, par leur association, un groupe plus complise, comprenant une partio rstrme on cornécume, el une partie interne ou réti- 
nimule. Cos cusembles complexes comstiturnt autant d'unités visuelles, qui doment, par leur réunion, l'oil composé; chacun l'cux oflre mème

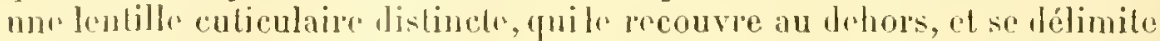
de ses voisines par un légro lobord en saillie. Ces unités sont dès lors aisémont séparables sur toule leur étendue : on leur a domé le nom l'ommatidies. - L'áil composé est donc un assemblagr" d'ommatidies; alors que l’ocedhr ast à lui soul unn unité visurlla.

L.'s notions qui précèlıut, ot dout la plupart, avec l'ilée générale, geviennent à latten, déconlent à la fois de l'élude des phémomènes du dereloppement, chle la compraraison des types oculaires les plus simples aux plus complexes. 'lourtant, le díveloppement des yeux no s'eflectur pas toujours au mogen d'une lépression eclodernique, qui se transforme en résicule optique; assez souvent, la plaque oplique ne s’invagine pas, el se horne a s’épaissir. Elle se divise ensuite, par une sorte de rlivage, en deux assises, dont l'externe correspond à l'éluauche cornéenue, et l’inlerne à l'ébauche rétinienne; la disposition définitive, el la suite de l'évolution, sont donc semblalıles dans les deux cas. Le mode épaissi est sans doute une abréviation, par l'omission de la phase invaginée, lu mode incurvé et il ne convient pas d'accorder une grande valeur à leurs dissemblances. Bien plus, certains Arlbopodes, pourvus de plusieurs yeux, produisent les uns d'apres le premier mode, et les autres d'après le sccond, quoique ces appareils, parvenus à leur élat complet, soicnt identiques; tels sont, d'après les recherches publiées par Patten, les ocelles des larves d'Acilius (Insecte coléoptère), dont les uns naissent d’après le type à vésicule ophlique plus ou moins netle, el lont les autres sont engendrés par un épaississement ectodermique.

Ocelles. - Les cousidéralions préliminaires renferment la plupart des données. acquises sur le développement des ocelles. Ces apparcils existent surtout chez les Irthropodes acères, oủ ils constifuent les seuls organes visuels de l'adulte; et chez un certain nombre de larves d'lnsectes, où ils disparaissent l'habitude. vers la fin des métamorphoses, your être remplacés par les yeux composés.

L'évolution des ocelles Jes Acères n'est pas encore bien conuue. Les recherehes les plus complètes, sur ce sujet, sont dues à Morgan, et portent sur un Pycnogonide, le Tamystylum orbiculare. Les ocelles sont jroduits, comme toujours, par l'ertoderme; leurs éléments se divisent en mre partie pigmontée profoncle, et une zone périphérique plus claire; la cuticule ectodermique s'épaissit au-dessus le chacun d'cux, pour former ume assise transparente, frolégeant l'ail, tonl en se laissant traverser par les radiations lumineuses.

Le dévelopjement des vcelles des Insceles a prèté, dans ces deruiers temps, à une étule approfondio de la part de Palten; elle porte sur les larves des fcilius, genle le la famille les Dytiscides. Ces yeux, sauf le 


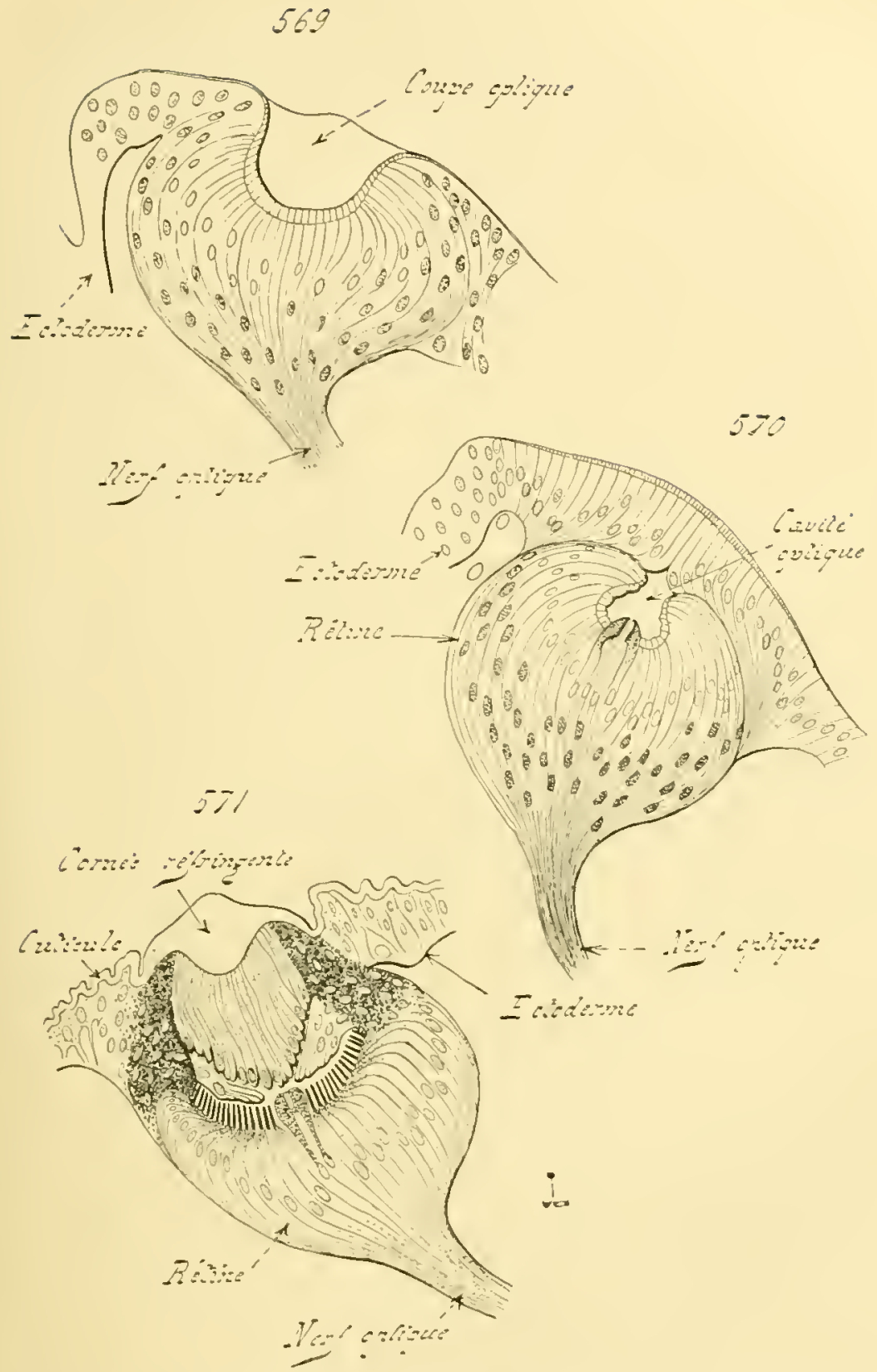

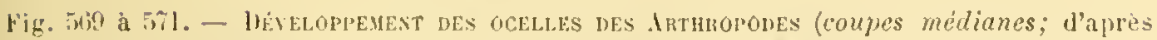
les recherches faites par Patten sur les lisertes du genre dilius). Ces ocelles sont ceux de la einquième paire. - In itt?, delut de l'orqane, sous laspect de conpe optique. -

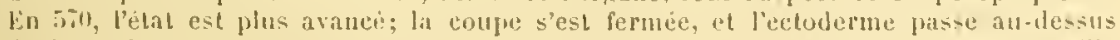

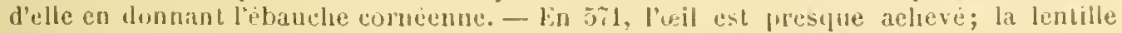

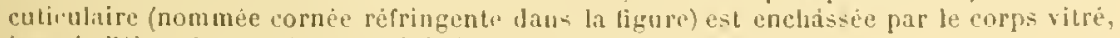
isal de l'ebauche cornceune, celui-ci itant enboite par la reline. 
premierel lo troisieme, maissent suivant le morle à visicule optipne; la eoupe optífue. c'est-à-dire la lépression ectodermique, apparaî en premier licti, puis se forme par le ressurement de son orifice, et par le jassage, au-dessus d'elle, de l'ertoderme envilomant. Celte zomo ectodermique, qui recourre ainsi la vésicule, est l'ébauche cornéenne; les parois le la résicule, interrompues du cóté te cetle derniore, el bien développées seulement sur les cótés et en derlans, conslituent lébanche rétinienne; toules deux évoluent d'une manicre paralliele, pour parfaire l'ocelle. - Les rellules de l'ébanche cornéenne s'allongent beaucoup, et de dohors en iledans; leur progression vers l'intérieur a pour eflet de leur faire emplio la cavité de la vésicule, qu' illes comblent, puis de les appliquer. par leur face intorm, contre la face externe de l'ébanche rétinienne. L'allongement étant plus accentué dans l’s cellules centrales que dans celles placées a la périphérie, la facr interne dre l'ébauche cornéenne rist fortement ronvexe; comme elle s’applique élroilement contre la face externe de la rétine, colle-ri conserve une forme concave, et onchisse cellr-là à la maniòre l'un capuchon. Ensuitz, les éléments conérns deviennent transparruts, et leur ensmble constituc la rógion nommer le corps vitré. Ils sont recourerts prar une assise ruticulaire, qui sépajsit heancoup virs le milinu de la surface de l'oxil, el premd l'aspect d'une lentille; celte dernière s'enchàsse à son tour dans la face extrine du corps vitré, en lui donnant égalıment un forme concave.

L'ébanchr rélinienne se convertit simplement en rétine. Les cellulos

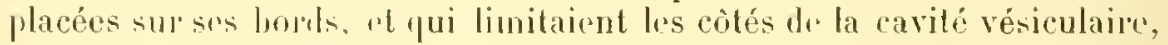
s'intléchisient quelque peu dans cette cavité, alors quelle commence ì disparaitre, etsintercalent, mais sentemrnt sur le pourtour de la rétinc, montre cette dernière el l’ébauche cornéenne. Ces éléments ur dillè̀ent point, prar leur évolution, do cenx qui appartienuent à la rétine proprement dite. Tous grandisient, se changent en longues cellules cylindriques, dont les rxtrémités pofondrs sont unies au ganglion optique par des filnes nerveuses, el lont les extrémités périphériques sont en contact direct avec le fond du corps vilié.

lorsfue cette double évolution rist truninée, l'occlle présente un aspect sphérique on ovalaire, la majuure partic dr lasphère ou dre l'ovale étant plongée dans les lissus, et ne faisant pas saillo au deluors. Il est constitué, en allant de lehor's en ledans, par toois corps rmboités l'un lans l'autre: la lentille cuticulaire, parfois nomméc cristallin; lo corps vitré, qui rnchàsse le fond de cette lentille; la rétine, qui enchasse lo four

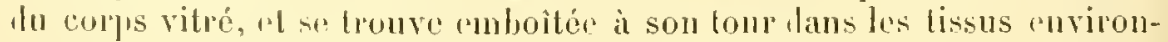
nants. La lentille cuticulaire se continue latéralement arec la cuticule qui reconver le corpss; de mèmo lo colps vilré avec l'ectoderme; la rétine forme un systeme indépendant, dont les senles relations sont avec 1. ganglion optique.

Dans le cas oil locelle est engendré par une zone épaissie, el non invaginé, de lectoderne, cette zone, conslituéc par plusjeurs assises de 
cellules, se dédouble, et se divise en deux conclies sujerposées. La couche externe estl'ébanche cornéenne, el l'interne l’ébanche rétinienue. Toutes leux, dès leur délimitation, prounisent les appareils défiuilifs. d'après des prorédés semblables à cenx léjì décrits.

Yeux composés. - 1. La struclure de ces organes a été l'objet, turant ces dernières années, de numbrenses recherches. En ISS6, Patten a émis, sur ce sujet, une opinion, qui promettait de comprendre d'unc maniere simple certaines dispositions, inexplicalıles sans elle, et qui, en conséquence, a élé acceptée rapidement par la plupart des naturalisles. Cependant, les récentes itudes de l'arkel", et relles de Viallanes, montrent l'inexaclitude des donnérs fommirs jar l'altrn.

En suivant les observations faites far Viallanes sur la Langouste, l’uil comprosé de crt animal olfro une struclum très compliquér. Limité

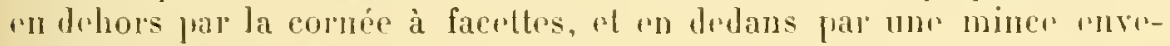
loppr ditr membrane basale. col organr "st conslilué par un gerand nombre d'ommatidies plongées dans un tissu missant. II rst permis d"

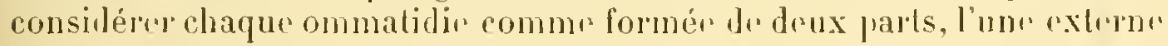

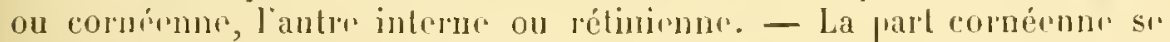

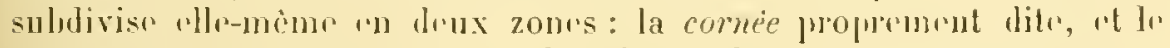
cristallin. La cornér so comprosin de collulus, lus cellules cornéagrnes, au

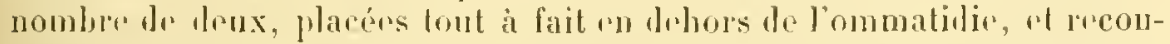

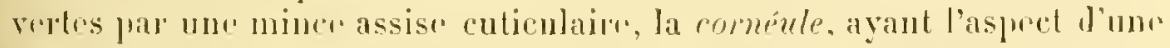
lontill. I. cristallin "st ronstitué par los cellules cristallimiennes. ct par l. cône. loss promièrss sont an nombre dr quatre, el situérs immédiatemornl sous les élémonts cornécus. Le srcond correspond à nnu longue baguette de sulistance transparrile, yui est la plus grande masso de lommalidir, et traverse la rétim joursaltachur à la mumbrane basale;

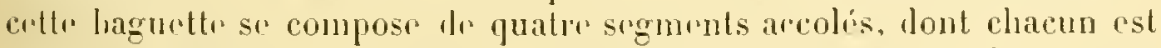
placé rxactrment sous liun. dos collules cristallinirnmes. En la prenant

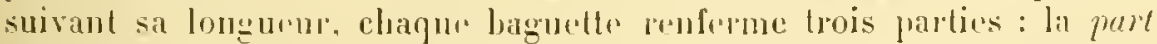
cristallime du conn, élargir, et ru rolations linectes irre lus rellulus cristallinionnes; la part vitree, plus étroitr et plus longur, qui arrive au contact de la rétinr; rnfin la part filamenteuse, yui trarrise la retinc "nlière suivant son épaissom, of lans laquelle los pualre sigmemts se

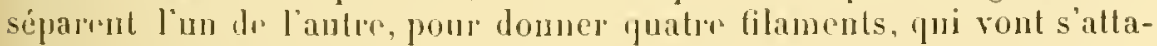
chro a la memhinan basale.

La partir rétinionne de chaque ommatidio at dordinairo nomméc la rétinule. I no rétimulr su composo d'un bilonnet contral, lo rlublome, yu'entoumut sept cellules, dites cellules ratiniennes. L' rhaludome se lermine cu pointr du cóté lu cono cristallinien, et portr sept cótrs sail-

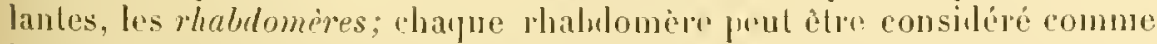
l'exhémilé dn cylindro-axe d’unæ tibre nerveuso, qui franchit la memluanr basalr prour pénétrer lans la rétimulp. Les collules rélinionues sont remplios par un pigment: et charmu des sept eylindre-axes. yoi 
parvinnent ì toute ommatidie, traverse l'une des sejt cellulos rétiniennes, pour se lominer daus l’un des sept ruabdomeres.

le lissu unissant, qui rolie les ommatidies los unes aux autros, nost pas le mème dans toutrol'épaissour dre l'ail comprosé; sa diversité a pour effet do partager cet organo en trois parties, dont chacume est caractérisée par un aspect spícial. An niveau des cellules cornéag̉enes, des cellules cristalliniennes, ot dr li part cristalline du côno, ce lissu est constilué par un amas lo vigment, yui formo, en cette région et à rhaque ommatidie, une vérilable gaine; c'est la region extérieure, qui se montre completement noire, lorsqu'on examine l'uil pris dans son entier. Le lissu unissant, au niveau les parts vilrées, et jusyu’aux rétinules, se compose diun substance transparenle, demi-liquide, semblable i cell. yui constilue ces parts vitrées elles-mèmes; "est ici la région moyeme, livaline el presque lluide, de lirancoup la plus épaisse. Enfin, les rélinules sont séparées les unes des autres jar dos cellules remplies d'un piọment abondant, qui est noir par lransparence, et blanc par réflexion; aussi cette zou", semble-t-elle faile, lorsyuon examine l'intérieur d'un wil composé entier, diune matiore crayeuse; cellr-ci n'est antre que l'ensemble des cellules pigmentaires, placées au niveau des rétinules.

I. - Celte description, qui découle des recherches eflechúes par Viallanes, donne déjà yuelques indurtions au sujet du diveloppenont des parties, an moins pour chaque ommatidie prise en particulier. Les cellules rornéagenes lournissent la cornéule, selon toute ívidence: leurs raprorts de juxtaposition avec les cellules eristalliniennes permettent de croire que loutes dérivent l’unc móme ébauche; de plus, les segments du cône, étanl constitués jar une sulistance amorphe et non figurce, sout evidemment los productions engendées par les cellules cristalliniemnes auxiunfles ils correspondent: ces jroductions sont de l'ordre les basales, et peuvent èle prises pour des hasales accrues dans ume certaine direction. Liensemble de ces éléments représconte la région corméenne d’ébauche optique. - Les autres parlies, qui se réduisent ¿ la rétimule, constituent, par contre, la région rótinienne de la mème éhauche. le rhaludome est formé sans doute par la jourtion des rluabdomères, cenx-ci élant eux-mèmes les terminaisons sensoriclles des tibres nerveuses qui se rendrut a l'organe. les cellulas rétiniennes composent la zone pigmentér, el absorbante, de la rétinule, dont le rlabdome est la zone impressionnable. La région rétinienne est, dans le développement de l'uil, en rapport direct avec l'ébauche du ganglion optique; que des rommunications existent entre toutes deux dès les premières phases de l'ćvolution, on pue ces l'elations se manifostent d'une maniire Lardive, les rhabulomeras doivent ètre considérés comme des expansions, émises par les cellules du ganglion optique, qui demenrent en place dans l'ébauche rélinicme, alors yuc les éments dont elles proviennent s'é-

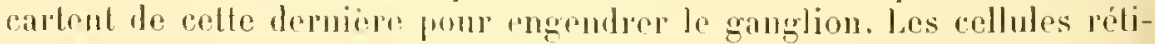


niennes, par contre, me changent pas te situation, et restrut entières, afiu de constituer l'assise pigmentéc de la zone sensitive de l'reil.

Cos lounces reposent sur des présomptions, et non sur des observations réelles: mais tout porte a les accepter, et a croire que les faits démontreront leur exactitude, si lou veut hien se reporter aux phénomènes géméraux du développement des yeux, et aux layports de contiguité étahlis entre les diverses paries. - En somme, la plaque optique, qui dérive de la mème zone ectodermique que le ganglion optique, et se réunil à lui par des tractus destinés à se transformer en filues nerreuses, s’épaissit, augmente le nombre de ses éléments coustitutifs, les dispose sur plusieurs rangées smperposées, et se divise en deux courhes: l'une externe, ou parlie cornćenne, lautre interne, ou partie rétinienne. la première donne les éluauches de la cornée, et du cristallin, de loutes les ommatidies; la seconde fournit celles des rélinules, auxquelles s’ajoutent los extrémités des filsres nerveuses. qui unissent l’appareil optique à son ganglion.

Les récentes recherches, ellectuées sur la structure des yeux composés, empèchent d’accepter la plupart des notions émises autrefois sur le développement de ces organes; le nouvelles observations sont ici nécessaires, pour conmailı avec précision les phases te ce dévelopfement, l'origine réelle des ommatidies, et celle du tissu unissant. Mais, si lon ne pent cucore indiquer les délails de ces pliénomènes, lours traits gínéraux se laissent pourtant deviner: c'est d'apris eux quil convient d'interpréter les études faites sur un tel sujet, el notamment les dernières et los plus complites d'entre elles, dues à Niisshaum et à kingsley.

Ces deux aulenrs ont portés leurs recherches sur des Crustacés supélienrs, appartenant i la section des l'odophthalmes; le prentier a examiné un Schizopode, la Mysis chamceleo, el le sccond un Décapode, le Crangon vulgaris, dont Bobretzky s'était autrefois occupé. - D'aprìs lingsley, la zone ectodermique, servant d'ébauche à l'ocil el au cerveau, se deprine, et produit une cavitó qui se ferme; elle se converlit en une vésicule aplatie, dont l'étroile caviti se comllo le rellules, dites mésodermiques par cet autenr: la paroi externe de la résicule lonne liril. et la paroi interue représente l'ébauche lu ganglion optique. Cette cavitć, si elle existe raiment, nest pas l'homologue de la compe optique, ni de la vésicule optiquo, signalées dans l’évolution des ocelles.

la plupart des auteurs s'accordent i dire que les ébauches des yeux romprosés proviennent de plaques optiques épaissies, colles-ci se rélimitant, par un simple clivage, lins l'ectorlerme des régions oculaires, et non par une invaginalion. Le nomlıc des cellules de claque plaque optipur angrmente daus des proportiuns ronsilérables; ces béments s’asemblent en plusieurs assises superposées, au milieu desyuelles ne tarlent pas it se inontrel les premiores indieations du rostallin les ommatidies. Lar 
plaque optique se converlil en oril, sans que l'on ait hien recomm jusqu’ioi les provenances rielles dos parties, ni les moditications hislogénéliques subies. - Les drscriptions lonnées sont sourent contratictoires; les oliservations, sur lissquelles elles reposent, ont été failes avant que l'on ait approfondi la sturehre redle des yenx composés; ef il est impossible l’aller plus loin dans m tel rxposé, sans être obligé l'opposer les mnes aux antrus les opinions diverses les auteurs. Les sculs phénomenes, gui semblent hors de conleste, tienuent: à la division de la plaque optique en loux couches, lont l'externe faraît produire les éléments cornéens et l’intrunc coux de la rélinule; et a la dillérenciation rapide des ommalidies daus l'ébaurho, par lo groupenent régulier des cellules de cetle dernière. - Les cellules hu tissn missant paraissent provenir ules élóments, qui ne sont point compris dans ces groupes cellulaires chargés de se ronvertir en ommatidies. Cependant, plusieurs naturalistes font provenir certaines d'entre olles du mésuderme, lail pen comprélensible, si fon lient comple le l'mnité génélique de la région qui doil produne l'aeil composé, et son centre nerveux.

C. - Les notions, exposóes di-dessus, portent sur los yeux qui se développent directement, sins subir ancme altération, ni ancune stase lenant aux métamorphoses hrvaires; tels sont ceux des Crustacés, el des lusecles amétabolaires. II n’en est pas do mème chez les Insectes qui subissent des mélamorphoses complexes; leurs larves ne possèdent point l'yeux composés, et sont juivées l'appareils visuets, ou sont semlement munies l'urelles: aussi les reux composés se montrent-ils rers la lin de la vie havaire, an moment de la druicre mélamorphose, et, comme la phuart des autres organes, dérivent-ils de disques imagrinanx. La strueture de ces demiors est connuc, depuis les observatious de Viallanes sur les larves des Diptirres. - Chaque ail compose provient d'un disque imaginal paticulier, relié an ganglion optique par une lige, la lige oplique; ce disque oftre me membrane provisoire cxlerne, destince à lisparaitre, semblable anx formations similaires des antres b́bauches imaginalus, ot mne assise interne, chargée de produine liril, dite la couche oplogene. Celte dernienr est l'homolognu de la plaque optique des autres Nothropolus: olle est conslitue par phusicurs rangécs superposées de reltules reloderminues, tomb les internes se rattarhent anx fibres nerveuses qui conslituent la tige optique pra lour reunion. Celle-ci est l'assemblage des fibres émises par le granglion optique: ellus vout s"ipanouir sous la couche optogene, puur se rendre à ses éléments. - Au moment où s"elleche la mćlamorphose lejnicre. la membrane provisoire satrophie, les hords du lisque imaginal vout se sombler anx disques voisins pour ne lasseg entre enx aucme solulion de conlinuité, et le disque lui-mème sulit des molifications histogénétiques peu connues,

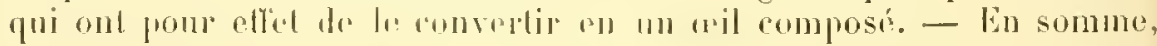
l'uil comprosé des lusides i modamorphoses ost engendré, sauf les 
phénomines propres awx dispues imaginaux, par les mimes moyens que cehi des autres Irthropodes.

1. Appareil digestif et ses annexes. - l.es plénomines du développement des leuillets blastodermiques laissent pressentir les phases essenticlles de lévolution du lube ligestif. Cet appareil est foumi par trois ébauches : l'une antérienre, la seconde movenne, et la troisiome postérieure. La première el la dernière dérivent de l'ectollerme; celle-ci est le procteon, celle-là le stomeon. La leuxiỏme provient du protendoderme, et reprísente l'eutéron des Arlluropodes; à cause lle sa situation interméliaire, la plupart les auteurs la désignent par le terme mesentéron. - Ces trois ébauches sont d'abord distinctes les unes des autres, et complètement séparées: chacune l’elles prend naissance à l'écarl. Puis, lout en grandissant. elles se rapprochent, s'accolent jar leurs faces en conlact; les parois unissantes disparaissent en ces zones de jonction, et laissent, a leur place, des ourertures qui les fout communiquer entre elles. Dis ce moment, l’unite de l'apprareil digestif est faite.

Les phases de ce développement s'enchainent, et s'eflectuent d'ume manière parallèle. Aprìs que lo blastorlerme s'est déposé à la surface le lemliryon, ou penlant quil se complile, il engendre les éléments du protendojerme, qui se séparent de lui, et se disposent en dedans de sa face interne. Celle émission aclıvée, le blastolerme a perdu ses caraclères primilifs te feuillet embryonnaire unique et fomlamental, el se trouve converti en protecloderme, ou plus simplement en ectoderme, puisque le premier lorue son rôle à devenir le ilernier. Une sélection sétablit farmi les bíments lu potendoderme : les uns conservent une disposition mésenchymateuse; et doment le mésoderme, alors que d'autres s'arrangent en deux couches régulières, et produisent l'endoderme. - Ces deux conches, en grandissant et sunissant, limitent, dans la région centrale de l'embryon, un espace assez vaste. Ce dernier est d'abord occupé par du vilellus nutritif: celui-ci disparait par résorption. et laisse dés lors une cavilé libre, l'entéron, environnée par l'assise endodermique. lintre temps, l'ectoderme engendre, à chacune des extrómilis Ju corps, une dipression, qui s'enfonce dans l’inlórieur le l'embryon, et so rilpuroche aimsi de la vésicule entripique centrale: l'invaginalion antírieure est le stomeon, et la postérienre le procteon. Toutes deux ont la forme de boyanx eylindriques, qui s’étendent de plus en plus loin dans lorganisme embryonnaire; dans lenr progression, elles jencontrent la cavité entérique, et se joignent ì elle, do manic̀re à ne constituer qu un seul canal, partant de la région antérieure du corps, pareurant le stomeon, traversant la résioule entérique, et frarcomrant de nomrean le procteon pour abontir à l'extrémité postérieure. Le tuhe diurestif est ansi complet, et simple, hien gne provenant de trois abanches lislinctes.

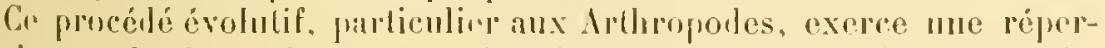

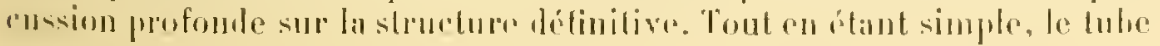


digestif dr. l'adulte est nettement divisé en trois parties placées bont it bout: l'intestin antérieur, l'intestin moyen, el l'intestin postérieur. La première dérive du stomeon, la scende le l'entéron, at la drruière du proctron; la louche est lorifice extrrm de la dépression stoméale, "t l'anus celui de l'invagination proctéaln. - Pour en arriver à former' ainsi des régrions fort élendurs dr lintestin, le jrocteon at le stomeon acquièrent, chez las Arthroporles, uno longueur plus gramdr que chez les antres animan. Leur extension rarir. du reste, suivant les classes; les Crustacés sout, à proprement parler, privés d"intestin moyen, car

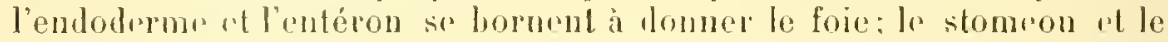
frocteon viennent directement en contact, et le canal digestif ne se compose que dre l'intestin an térieur el dr l’intestin postérieur. Par contru, les deères et les Ilicères posiedent un intestiu moyan lixn développé, dont le foie est un annexre, funi sunit d’un còté à lintestin antérieur, at do l'autro à l'intestin postérinur.

Les phases de l'évolution du tube digestil ne sout guère connues que chez divers Crustacés et Insertes. Leur ressemblance est telle cependant, et, d'autre part, les concordances de la disprosition ultime sont si grandes chez tous les Arthroprodes, qu'il est prermis de les considérer comme pouvant siapliquer à tous les représentants de l'embranchement.

Stoneox et ses nxwexes. - Le stomeon engendre l'intestin antéricur, c'est-i-dire l'uesophage et l'estomac. 11 prend naissance, non pras tout it fait à l'extrémité antérieure du corps, mais un peu au-dessous de cette extrémité, vers la face reutrale; la date de son appration est précoce, et concorde avec les premiers phénomènes de la genèse tes éléments entodermiques. Il consiste, ì son début, en une dépression ectorlermique semblable à un cul-de-sac; sa cavité, assez larg", communique lilırement avec l'extéricur; sa paroi est constituée par une seule assise le cellules. Tout en we moditiant que fort pen son tiamètre transversal, la dépression senfonce dans le corps de l'embryou, et pénètre it la fois en hant ot en dedans; elle prend l'aspect d'un lube cylinlripue, à cavité ample. et it paroi simple, qui sr rapproche du centre mème de lorganisme. Celte exteusion cesse, lorsque le stomeon rencontre l'entéron chez les Insectes, ou le procteon chez les Crustacés; elle ne va pas tres loin, comparativement à ce dernier, et ne dépasse guère, en moyenne, he liers on le quart antérieur in corps. Au moment ou l'allongenent approche de son terme, le fond du stomeon s'élargit en une ampoule destince a se convertir en estomac. Celui-ci s'applique, suivant le groupe, contre la praroi entérique, ou contre celle du procteon; les régions d'accolement se rósorbent, et la cavité stoméale, qui il conservé sa communication directe avec le dehors, s'abonche en sus avec les autres parlies du tube digestil.

L’épithélium, qui coustilue la paroi de l’intestin autérieur, est done 
tout entier dorigine ectodermique. Cetle provenance explinure la présence, sur lui, d'une cuticule chitinense, somblable a celle rovolant l'ectolerme extéricur, el pourrue parfois d'une disposition complipuér. Elle permet éralement de comprendre la wenèse, dans l'estomac de rertaius Crustacés (Eerevisse), de concrétions calcaires, fournies par un procédé comparable à relni de la carapaco; la substance de ces dépuits est un produit de sécrétion de l'épithélimm stomacal, tout commo la carapace est domée par l'ectoderme des téguments.

Les glamles ammexes du stomeon sont assez nombreuses; les unes sont dites glandes serricigenes, et les autres glandes salivaires. Les premières existent seulement chez les larves de divers Insectes, celles de certains Lépiloptères par exemple; elles servent à sécréter la soie, dont sentourent ces embryons pour tisser leur cocon. Les secondres sont

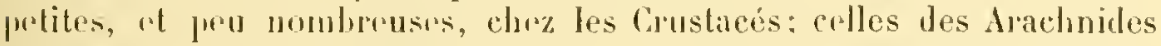
ont une importance plus grande, el surtout celles des Insectes, qui atleigneut, dans certains cas, une complexilé extrème. - Quelles que soient leur structure et leuss fonctions, foutes les glandes, dont on a pu suive le développement, dérirent dexpansions émises par la régron autéricure du stomeon. ou par les lords de l’oritice huccal: leur épithélimm est done l'origine ectodermique, comme leurs comexions permetlaient déja de le jressentir.

Procteos et ses axiexes. - Abstraction faite de sa situation particulière, le frocteon se faconne de la mème manièe que le stomeon. Il se montre toul d’abord, non pas rers l'extrémité postérieure de l'embryon, mais au-dessus, et empiète sur la face dorsale; il apparait, sourent, un peu plus tôt que le stomeon, et, au lien de s'étendre d'avant en arrière, il progresse darribre en avant, pour atteindre le centre du corps en partant de la région postérjeure. - A part ces différences, foutes de situation, la marche de son accrojssement est semblable a celle de li dépression stoméale. - L’invagination se compose d'une cavité, qu'rntoure une simple assise cellulaire; elle sallonge. en fuenant une forme roliulripue, et pénètre dans l'intérieur de l'organisme. Ce mourement l'extrusion est plus prononcé que celui du slomeun; le procteon déprasse J'habitudr te milien du corps, et parvient juspue dans la moitié antériente. ponr se metle en rapport avec linténon, on avee lintestin antérieur. Il conserve la mème largeur sur lonte son étendue, et ne présente, sur son trajet, anrme dilatation anx limites prérises et an ròle déterminé.

l.es annexes du procten sont les tubes de Malpighi. Ces appareils sont essentiellenent des diverticules de la région oi ils sattachent; leur tissu glindulaire est d’origine actorminue. Deux modes se présentent dans lenr origine : on lien la paroi procliale énset des appendices cellulaires pleius, dans lesquels me cavite contrale se peree par la suitr; on hien cette paroi engende des depressions renses, yui se 
bornent à s’acroilre. Ces Jenx procédés ont blé roncontrós par les au-

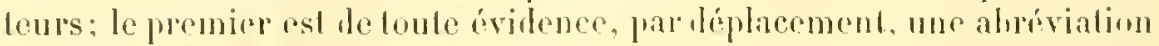
dil second.

Exténon et ses axexes. - A. L intestiu moyen des Arthruportes apparlient à deux types. Colni des Cruslaces nexisto prespue pas, ou consiste en une zone fort courte du canal digeslif, servant à muir linlestin antérienr aver l’intestin postérjenr: l'entéron entier est employé à prorluire le foic. Par contre, cluez les Arachnides, les Myriapodes, et les Insectes, l'entépon se convertil en une rósirule allongér, yni se joint en avant an fond du slomeon, en arrière au fond du procteon, et constitue un véritable inlestin moyen; l'organe, désigné sous le nom de foie, est, dans ce cas, un ensemble le liverliculesemis secondairement par rette vésicule entérique. - Les prorédés formalifs different entre ces deux types, du moins aulant qu’il est permis d'en juger d'apres les faits connus; daus le premier, lentóron se livise rapidemont on deux parties symétriques, plasées de part el d'autre le la ligne médianr, pui sont les ébanches des lohes hépatiques: tans le second, il reste indivis, ot compose une vésicule simple, chargée de produire ensuile les annexes hépaliques. Mais ces dissemblances ne si monlrent quan moment ou

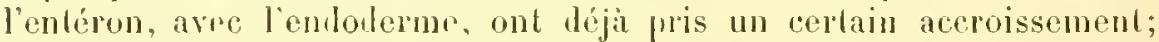
les premieres phases sont identiques che\% les Crustacés et les Insectes. Une description domme pour les premiers sapplique donc anx seconds; seules, les Arachnides ne sont pas cncore bien commes sous ce rapport, mais la concordance de leur structure fondamentale, avec celle des insectes, autorise à leur étendre les résultats dounés par l'étude de ces ilernicers.

Les parlirularités essenticlles des premièes phases ont été exposées dans l’élude du léveloppement des fenillets (payes fit i is6). Les éléments du protendoderme sont engendrés en majeure partie, el sont par suile phus nombreux, dans la région ventrale de l'embryon; la phupart l'entre eux sont disposés en deux hamles, fongitndinales et symétriques, placées de part et d'autre de la ligne médiane; ćest aux dépens de res handes que l'ondorlerme premd naissance. Chacune d'olles froduit, lans la région anlérieure le l'embryon, et au moven de ses éléments les plus profonts, une pelite plaque composée thune seule assise de cellules; les leux plaques, ainsi engendrées par les deux bandes, sont parfaitement

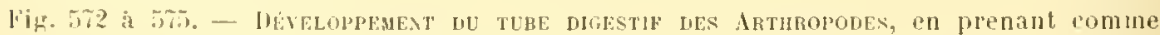

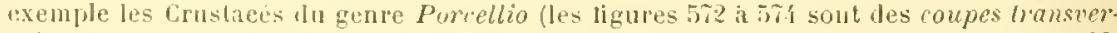
sules; la lizure 575 exprime nne coupe longitudinale, el à peu mis médiune). - En $57 \%$, les deux lubes enteriques vitennent de se faconner par la subdivision de l'entéron; le procteon et le stomeon sont enenre courts. - En 573, les deux lohes eommencent it s'isoler, et le procteun est parvenu au-dessus d'enx. - En rit, les deux lolies sont séparés; Je eneur prend naissace sur lo procteun. - En 5\%, coupe longitudinale de l'embryon precident, passint par l'un tes leux lobes enteriques, et montrant les connexions mutuelles des trois eluauchu's intestinales.

le drutolecithe, qui disparait it mesture qute l'evolution frogresse, est exprimi par des 


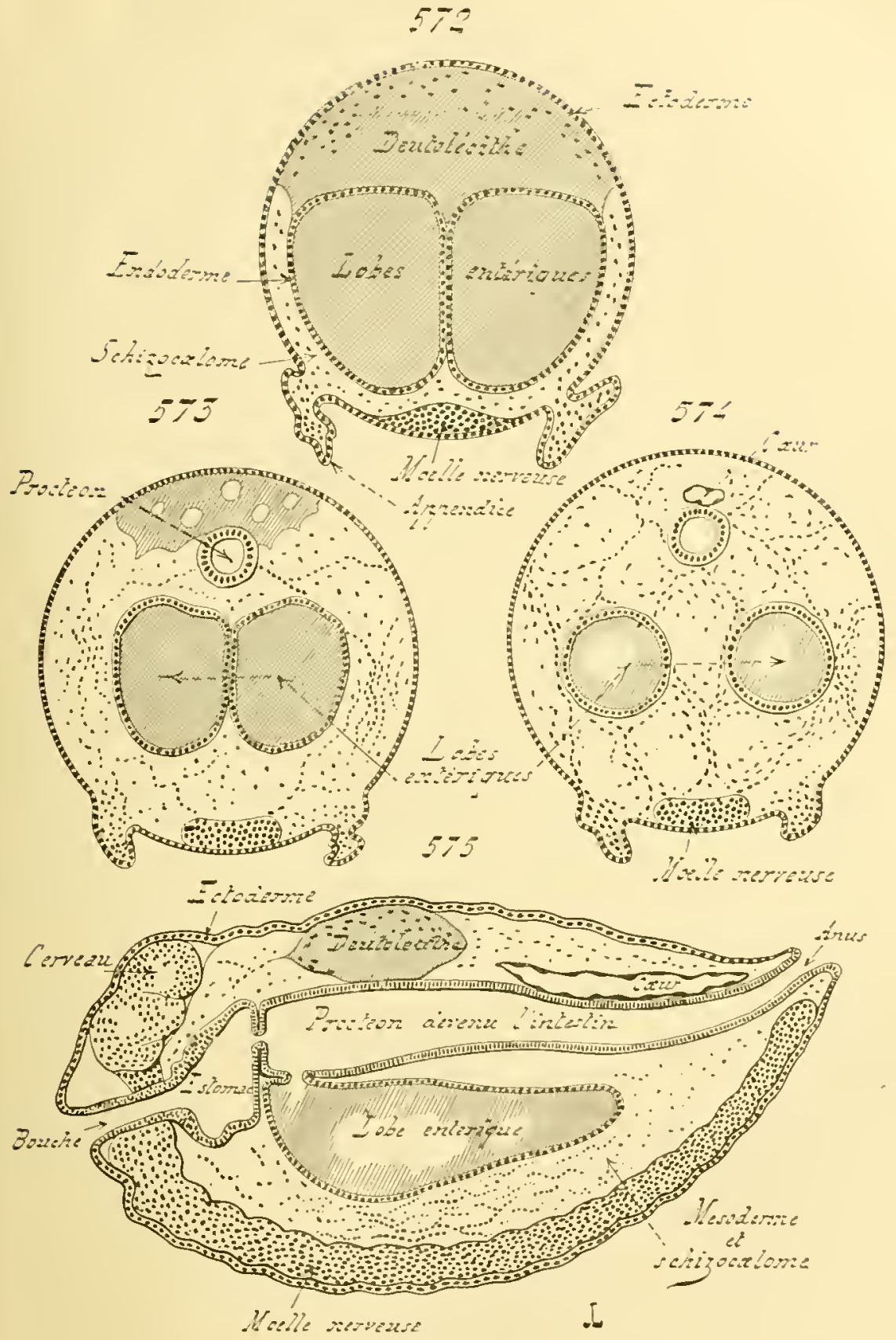

Fig. 32 is $3 \%$.

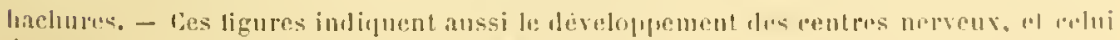
llu colunu: illes fout sulle all fisures ĩl it izti. 
symétriques, et situces au mime niveau, le parl et l'autre de la ligne médiane. - Elles sacroissont daus tous les sens, mais surtout du colé le l'extrómité jostérieuro de l’oramisure; el, ce faisant, elles conservent leur disposilion simple, c'est-il-dire demenrent coustiluées par une seule assise de cellules. Trut on s'accroissant, elles s’uncurvent en dedans, de maniere a rapprocher leurs hords sur toule leur élendue; elles prennent l'aspeel de deux cupules égales, se faisanl face par leurs cavilés, el venant a se toucher par leurs loords suuls. Comme leur taille est assez grande, elles limitent au sein mème de l'embryon, el dans ledeutolécithe qui s'y houve, un espace assez volumineux, rempli de sulislance vitelline; cetle derniere est emprisonnce par les cupules, lorsque leurs hords arrivent ì se meltre en contact. L’éluncho entérique est dès lors constituée. - La paroi des cupules, toujours représentée jar une seule assise cellulaire, rst l'oudorterme; l'espace linité par ces jarois deviemdra la cavité entérique de l'embryon, el plus lard la cavité de l'intestin moyen de l'adulte. Cet espace est, à son déhut, el ì cause mème du mode de développenent, oceupé par du deutolécille; celui-ci sert a la nutrilion du pelit ètre, car il est absorbé par les cellules endodermiques, qui l'outonrent; il disfarail peu à peu, laissant à sa place nue cavilé libre.

Celte évolution, décrite d'apres le Porcellín pris comme type de Ciruslacé, se retrouve, avec ses mêmes qualités d’aspect el de relations, chez les lnsectes. Cependant, les nombroux auteurs, ocrupés à celte question, sont loin de s'rntendre à cel égard; la confusion porte mème sur les trmes quils emploient. Celle divergence n'est pourlant juapparente, du moins en majeure part; sauf quelques erreurs d'olservation, faites en un moment où la technique n’élail pas aussi précise quà l’éjroque présente, elle louche plutôt a l'interprótation des lails qu aux faits euxmèmes. Les lnsech's jósontent, en eflet, dans la genese de lenrs feuillels, liverses particularités, qu’il suffit le mentionner pour évaluer lours ronséquences.

li. - Le hastoderme de ces animanx se livise en deux parlies, par un rlfet de son mole de formation, qui se ramene à une émigration, vers la périphérie, derellules froduites dans l’intérien de la massc ovulaire. Lunc de ces partios, le blastoterme réel, constilue une couche suporlicille; lautre, le blastoderme interne, se compose d'éléments u'aynt pu se placer à la surface de l'auf, el demenrant plongés dans le deutolecilhe. Ces cellules vitellines, pour employer l'expression consalcré, existent rhez les Cuastacés, mais elles y sont moins nombreuses. leur valeur essentielle est celle l'éléments blastodermiques; seulement, i) canse de lan siluation profonde, elles ne prenuent aucune part a la grenise de l'ectorlerme, ot se bornent a engendrer wue porlion du protendoderme. - Comme, dans beancoup de cas, le deulolécithe se partage ru segrments polyédriques, i la surlace desquels s'étalent les cellules

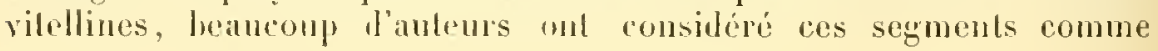


autant ifre cellules veritalules, ronstitures par me volmmincuse portion dentolćcilhique, el me misre zone de protoplasme ordinaire el nuclér. L'ensemble de ee dembléeithe était alors direrit commo mu endoderme mimave. Celle opinion est inexacte; to drulolécille est une substanco nutrilive, privée de noyaux lui appartenant cu propre, ne possinant par suite aucune structure cellulaire réritable; il est mn amas de uralières untritives, at rien de plus. Les cellules yu’il coutient sout des élíments hlastorlermiques, chargés de produire le protendoderme. Parfois, res dernières s’élalont à la surface des masses dentolécithiques, el les enve:loppent en partic avec leurs expansions psentopodipues: ces relations som toutes de routiguité, el correspondent à l'une des phases de l’absorplion du deutolécilhe par phagorytose.

Lexpression endoderme primaire doit donc stre chassíc de la terminologie. - 11 an est de mêne pour celle d'endoderme secondare. On a lésigné denx choses avec ce lernier nom; l'épillsélimm du stomeon, dans le cas où le stomeon lui-mème a élé pris junr une invagination rastrulaire; et l'endoderme réel, yui se dégage du prolendoderme daus l'intérieur de lembryon. L’épiltélium du stomson est l’origine cotodermique; il donne la paroi de l’intestin antérieur; le terme d'endoderme secondaire ne peut donc lui ètre applinué. Quant au véritable endoderme, il ne lui est nul hesoin d'un qualificatif spécial, puisıu’il représente seul, depuis l'instant de son apparition et à lous les moments le la vie, le fenillet interne.

Les lusectes ollreut une seconde particularité. Beaucoup d'entrc eux possident, sur leur face ventrale et suivant une ligne médiane lougitudiuale, une goultiro primitive; celle-ci n’est aulre qu'une dépression le la plaque ventrale, el n’a pas l’imporlance fonclamenlale. Les árments du protendoderme sont produits, en plus grande quantité qu'ailleurs, par le blastoderme qui revet les deux parois latérales de la goutliore; à cause de lenr origine, ils conslituent rapilement les denx handes ventrales protendodermiques, dont il est question plus haut. Eusmile. les collules de l'endoderme se légagent avec précocilé de ces bandes venlrales. - Sauf quelques délails, les autrurs s’accordcnt sur ces phémomines; mais ils ne s'entendent pas an sujet de l'interprétalion qu il

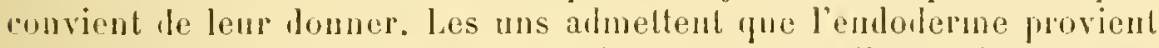
directement de la gouttiere germinalive; el, comme ils considerent que la paroi de cette gontliere a dejà revotu les caracteres ef les propriétés d'un ectoderme, ils font engendrer l'enduderme par l'retodermo. H'antres, el les frous Hertwig notamment, assimilont la croissance des plaques

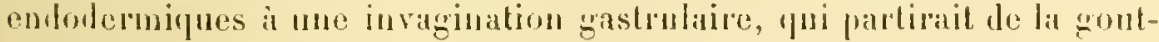

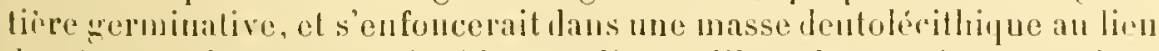

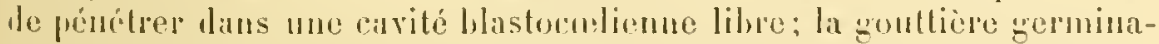

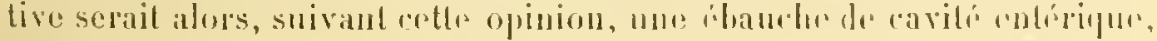

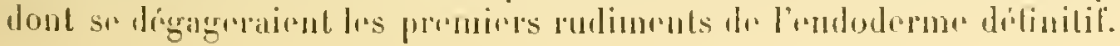




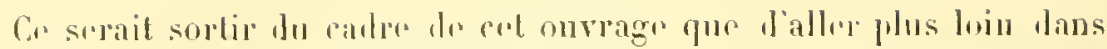

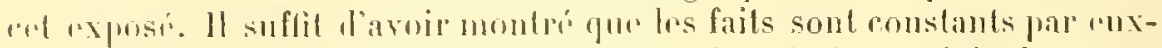
memms, so molomvent, dans la plupart dos descriptions originales, ave lrurs raracterrs essentiols; lis divergences sur ces phrinomenos portent

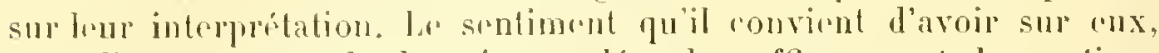
dans l'état présent do la scirnce, lieoulr suffisamment des nolions dija fommirs, pour quil soit utile d'insister davantago. - Au moment

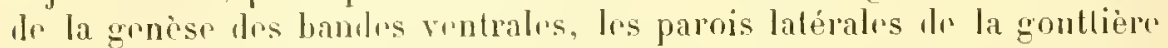

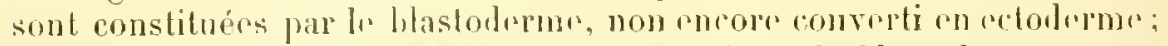

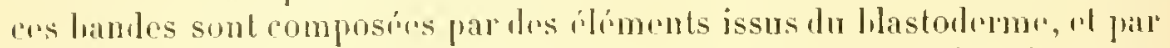

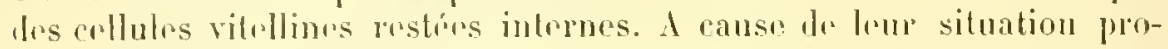
fonde, ers depriere prennent la plus grande part il la grnesu dos élan-

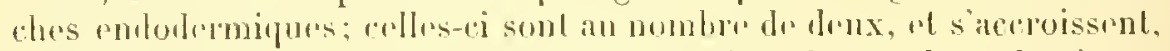
on prenant laspuet dre cupules destimés a saccolor par leurs bords. las oliservations récentes de Tichomirolf, de Wiehler (in me prenant

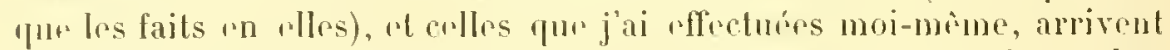

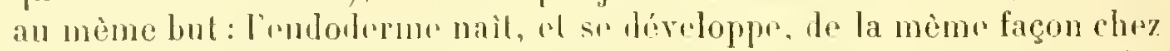

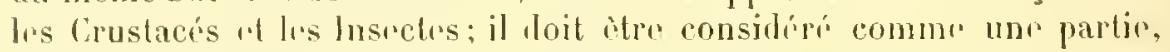
drvenue epithéliale, d'un protrndoderme mésenchymatrux dès son délut: la disposition misenchymateuse de ce fenillet initial nixst consrevín qur par lo mésonlopmo.

C. - Si les éluauches de l'entéron sont identiques, elles dillèrent des Crustacés aux Insectes sous le rapport le lem évolution ullime. l'intestin moyen des Cruslacés n'existe pas, ou n'est représenté yue par uno conrte zone tubulaire, lestiné à joindre l’intestin antérienr à l’intestin prostérieur, et sur laquelle s’attachent les appendices hépatiques. L'entéron n'est guère employé qu'à produire ces derniers; ils offrent l'aspect de diverticules creux, simples on ramifiés, qui se rendent à la zone précédente, el s'ouvrent par la daus le canal digestif. Pour les engendrer, les deux rupules entériques rapprochent leurs borls, suivant la marche indiquée plus haut, les accolent, el les soudent l'un à l'aulre; après celte réunion, lenr ensemble constitue une sorte de vésicule remplie de deutolécithe, et placée dans l'intérieur de l'embryon. - Au moment où res phénomènes se passent, le fond du stomeon sirst joint an fond du procteon, de manicre ì former mo canal digestif complet; l'extrómité antérienre de Ia vésicule entérique se mat en relation avec ce canal, el léhouche dans sa cavité, en la région mème où s'est cellectuée la jonction du slomeon arec le proteon. Ensuite, la vésicule se livise on doux lohes, pui se séparent dius lenr partie postorienre, el deviement distincts; celle scission progresse peu à pen en avant, do manjère à parlager l'óbauche entérique en deux moitiés; mais elle s'arrète, yuelıue peu arant l'extrémité antérieure. Celle-ci reste indivise, et donne un tule, dans lequel déhouchent les deux lobes, ouvert lui-mème dans le ranal digestil. Ces loles représentent les ibaurhes du foie drol'ardulte; ils 
demenrent simples, ou se divisent par des scissions longitulinalus, suirant le trpe de la structure finale. - C'est ainsi que l'aspeet définitif de l'appareil digestif est réalisé : un canal, continu de la bourhe ả l'anus, avec lequel communiquent des appendices hépatiques, phus on moins volumineux et nombreux. Ians cet appareil ainsi constitué, ces appendices sont les seules parties, dont la carité dérive de l'entéron embryonnaire, et dont les prarois soient conslituées jar un épilhélimm d'orignine endodermique.

Les choses ne sont pas tout i fait semblables cher les lusectes. Les deux cupules se rencontrent snivant le plan médian et longitudinal de lindividu, satfrontent par lenrs bords enliers, et sunissent par les régions ainsi mises en contact. Celte sondure effectnée, les cupnles forment, dans la partie ecutrale du corps, une vésicule. dont la paroi est constituée par l'endoderme, el dont la cavité se trouve remplic par du vitellus nutritif. Ce dernier disparaìt par résorption, et la cavité devient libre; de plus, elle s'unit en avant au fond du stomeon, of en arrière an fond du procteon. La vésicule entérique fait alors partie du canal inteslinal, el occupe une situalion intermédiaire à l'intestin antérieur et i l'intestin postérieur; elle représente l'intestin moyen de res animanx, et plus spécialement l'organe nommé le ventricule chylifique. Ce ternier conserve parfois des parois lisses; aillenrs, il émet des diverticules plus on moins nombrenx, désignés jar les expressions de glandes gastriques, ou de glandes hépuliques, on encore, dans l'ensemble, par relle de foie. - Il est probable, hien que l'on n'en sache rien d'après l'observation directe, que les phénumines du développement de l'entéron sont, chez les Arachnides, identiques à ceux des lnsectes. du moins dans Irurs trails essentiels; la grande ressemblance des dispositions défnitives parait le témontrer.

L'origine des glandes de l'intestin moyen, fonjours engendrées par l'entíron embryounaire, et leur ròle dans l'économie, qui est, non senlement de sérréter des lipuides a ferments direstifs, mais encore de conconrir à l'absorption des substances alimentaires, s'élievent contre la valeur damexes, ot le nom de foie, qui leur sont souvent accordés. Ces apparils composent, en réalité, une prarlie essentielle et principale du tule digestif, et en représentent, dans certains ras, chez les Crustacés par excmple, la senle région rrainent endodermique. I'autre part, leurs fonctions ne sont pas strictement glandulaires, puisque l'absorption des aliments est parmi elles; elles sont plus complexes que la simple lonetion hépatique du foie des Vertéhrés. Lussi serait-il utile de supprimer le terme de glande, el le qualificalif d'hépatique, pour employer seuleutenl, afin de désigner ces organes, l'expression de lobes enteriques.

V1. Appareils de la respiration. - Ces appareils sont varies cho\% les Irlluropodrs, et appartienment in trois tripes principanx: les bronchies, les poches légumentaires improprement nommés des. 
poumons, et les traches. On ne connaît hien, l’apries des observations dircetes, que le développemenl des trachées; cependant, les données, acpuises par lanalomie comprée, permeltent de lournir quelques infuctions sur l’écolution rubryonuaje des deux premicas types.

Les branchies sont des paltes entieres, ou des parties de paltes, modifires en vue de servir it la respiration; elles offrent la mème structure essentielle que les appendices normaux, mais avec ne cuticule lies mince et presque absente, el les cananx vasulajes nombrenx. Elles naissent de la mème façon que les appendices; leurs ébauches sont comparahles à des petils mamelons, linités par une assise ectodermique, et contenaul de nombreux béments lu mésorleme. A mosure que l'apprareil s'accroit, des viles se creusent entre ces derniers; ces espaces deviennunt les canaux rasculaires de l'organe, el se metlent en relation avec ceux du reste du corps. La hranchie prend ensuile son aspect parliculire, el rariable suivant les groupes.

Les poches pulmonaires sont des dépressions des trignments. Ces lemiers s'enfoncent, dans chacune des régions où va prondre naissance un de ces systèmes, et prouluisent des cavités en cul-de-sac; l'ouverture de l'invagination persistr romme orifice de la poche. Juis, la paroi de rette dernière so souleve pas places, en donnant de minces lamelles juxtaposérs, qui augmentent la surface fonclionnelle, et constituent, sous le rapport du roble joué, la part principale de l'appareil. Ces lamelles consistent en un axe mésouruniqur, renfermant des vaisseanx nomlimix, qü recouve une assise ectodemique. - La graule ressemhlaner, établir entre les Srorpions et les limules, autourse à rapprocher los organes respiratoiros des premiers de cenx des scoondes; plusienrs opinions ont été données à col égard, mais rllıs exprimunt senlument drs rues de linsprit, el no sont pas encore confimérs pror l'obsrration. Tout prorle a croin cependant, que l'hypolhèse, émise par Ray lankester, trudant à consiléror les pochos frispiraloires drs Scoppions comm assimilables ả dos branchirs de limules, cnfoncées daus des lépressions des téguments, apròs la réduction et l'atrophic de l'appendice qui los porte, concorde arec les faits.

On a ahmis pendani longtemps qur les trachérs étaient dorigine

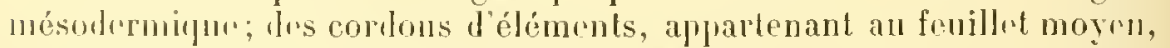
St: serairnt repusés d’une ravité axiale, la cavilé trachérnmr, qui s'unirait serondairement is l'relodrrme poul débouchre au dehors; les ramificalions trachirnnes seraient des rxpansions, appartenant à ces élémonts mésodermiqurs, al percéns elles-mèmes d’un vile cuntral. Toules les observations réentrs ont confirmé, par contre, les assertions de liowalersky; l'apries celles-ci, les trachérs sont des involutions des

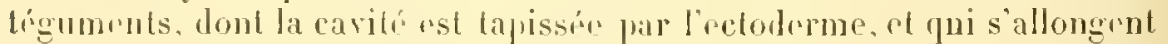
daus le corps an se ramifiant. - Sous re rapurt, il rest permis d'assi-

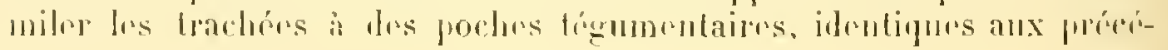




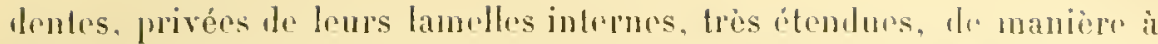
drrenir eylindriques, et pourrues de ramifications. La prosmon do res organes est dans une corrólation manifestro are la vie aromenum des Arlbropodes quila montrent; lextension du risuan trachéen est drestimo

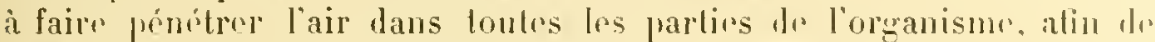
lavoriser mo pespiration active. el d'allóger le corps par un prociols semlilable à celui des sacs acrions, el des os pnemmatipues, des Oisuaux. Colte corrilation est tolla, qu'il rst sans doutr promis de conclur. l'après rlle, à un rapport do causo à rffet.

Los trachers drivent de deperssions relodrmiques qui sinfoncent dans l'intérienr de l'économio; l'orifice externe de chaque invagination no so fermo pas, ol persisto pour donnor le stigmate; les rameaux apparaissent hativement, lu moins dans la regle. Une ćlauchr trachícnne offre l'aspect d'un lubo ì étroite lumière; sa paroi so compos' lume seule assise de cellulis rectodermiques, longues whion netles. Co's dernieres produisent une couche cuticulaire, qui limile immódiahment la cavité, deviont l'intima, la membrane propre, de l'organo. Cotls assise rst d’abord transparento et épaisso; cllos'amincil par la suite, toul en se chitinisant, et laiss' un plus grand espace à la cavilé centralo.

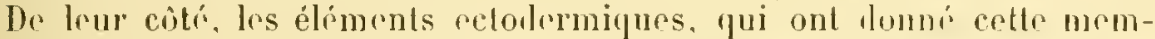
brane, saplatissent, et se riduisenl presqur à leurs novaux. La Irachio possèdr dès lors son aspect dífinilif; "lle lappolla dr tous points, sous le rapport de sa structure fondamentalr. les liguments dont clle dérive. - Lassise cuticulaire port" souvent dres zones ipaissies, qui dessinenl un riseau, 0u. plus friqurmment, des anneaux placís les uns aupres des autres, ot simmlant une disposilion spiralir. Ces zones sont cellas diposies an promirr linu; alles conservent, par suite, une plus grranile ipaissur que leurs roisinns.

111. Appareil irrigateur, et tissus dérivés du mésoderme. - Cossuentoss géxerales. - A. Le développement, et la struclure essentielle, dn fenillet moyen, sont idenliques chez tous les Arthropordes. l.e protendoderme inilial est constitué par un mésenchyme, dont les élóments sont placés en dedaus du blastoulerme qui les engendre. Ine part d'entre eux s'assembleut, par la suite, pour lonner une assise épillıliale, lendoderme; les autres conservent le caractire mésenclyymaleux, se multiplient, se disprosent entre liendoderme el le blastoderme devenu l'ectoderme, el se groupent en amas. Le deutolécithe, qui les entoure, lisparait par résorplion phagocytaire, car il sert à la nourriture de l'embryon; les lissus mósoulermiques ne comblent pas tous les viles prorenant le celte disparilion, et les cavités laissées libres représentent le culome. Ce dernier est un polycolome d'origine mésenchymateuse, qui fournil lappareil irrigateur de l'organisme; dans cerlains cis, chez les Crustacés supérieurs par exemple, il dome en surplus mu leuloculome, une cavite périviscoralo, dont les limiles piriphriques se confomlınl 
avecellus du vériblite appareil cireulatoire. Les lissus du fenillet moyen rnecendrent mo lrame conjonctivo-musculaire, dont les landes limitent los lacunes sanguines; frms b́léments les plus nombreux sonl des fibres musculaires slrícs, rassemblós lans certaines régions, nolamment sur la face ventrale de l'uranisme el ress la base des appendices, en laiscraux volumineux, anx conlours précis. qui sont des muscles bien délerminés.

Les naturalistus avant itulic l'rvolution du fenillat moven, chez les Althoporles, onl emis, à son égard, des opinions diverses el contradictoirus; el, le mine que pour l'endorleme, les divergences sont loules

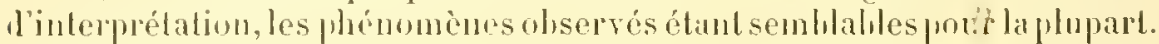
les principales discussions portent sur la nature, el sur limportance, llu róle jomi par les cellules vitellines dans la genese du mésoderme. Ces rellules sont de vrais aléments bastodermiques, el non des lormations produitos de toutes pieces dans lo deutolícilhe; lenr protoplasme est rmprunté an vilellus formatif dissémine dans la substance orulaire, el leul novan derive du prónoyau femelle fóconde. A cause de leur situaliun interse, ellos rontribuent a engendrer le protendoderme, dont le mesoderme jrovient, el le protemdoderuse seul. Il convient seulement de ure point len accorder une valenr particuliere: sans revenir ici sur des phónomènes déjí déerits an sujul des fenillets hlastodermiques el le l'entéron, il importe de se sourmir que ors rellules foul partie du l,astolerme initial, ut no doiront leur situation interne qu’à une rause mécanique : elles ne penvent so placer autom lle l'ovule, la surface de ce deruier dant deja ocrupée par les premiers fommis des éléments hlastorlermipnes.

In anlre molil de discussions lient an lait de savoir si les ébauches du mésoderme sont livisées en segments, romme celles du leuillet moyen des Innélides el des Verlélırós, on si la disposition mélaméripue est absente, Vu phénoméne rertain, décril par la plupart des observatemrs, est relatif au gromproment les cellules mésolermiques siluces dans la rogion ventrale du corps: ees leruieres se rassemblent en amas éganx, placés régulièrement les uns leprière les aulres, chacum d'emx se lrouvant an-dessus d'un appendice, et pénćtrant dans son inléricur. La flupall de ces amas contienneut des cavilés, el ofrent l'aspect de métamires cronx, dillérenciés dans lo fouillet moven. - Se hasant sur celte disposilion pui est exacte, el so manifeste rhez tousles drthroporles, m certain nombre de naluralistes, parmi lesquels il convient de ciler balfunr, comsidéront ees masses comme de vrais segments, el admettent que le mésolerme se divise en mélamères, homolognes de cenx des Trochozonion polyméripues, on des Vertébrés.

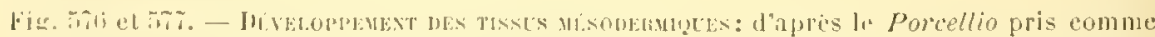
"Xemple (portions grossies des figures prededentes). - lin sifi, portion grussie (Eauthe et

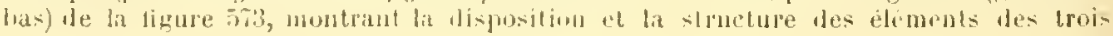


Si le fait est réel, il nen est pas de míne pour l'interprétalion. Il

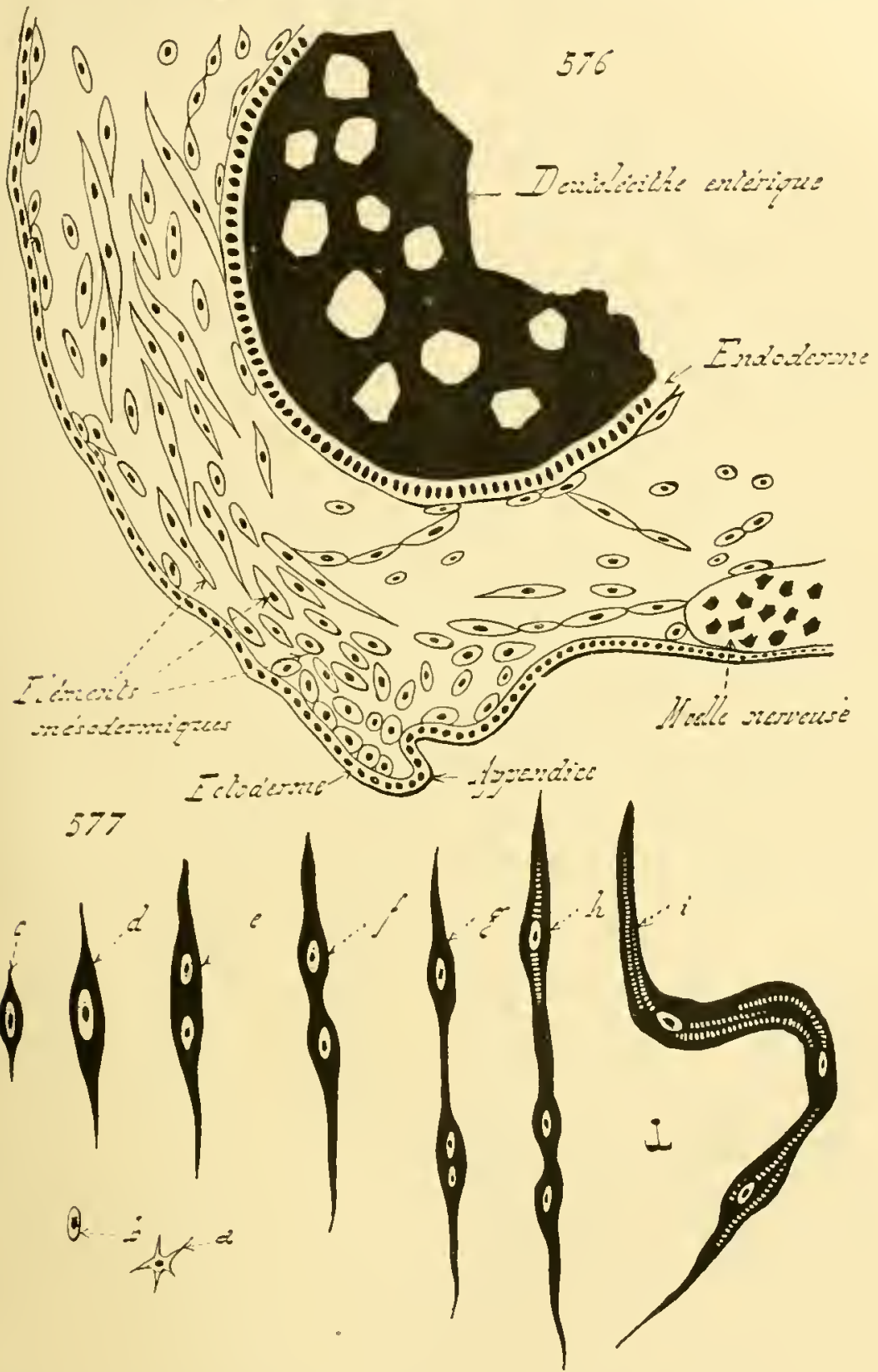

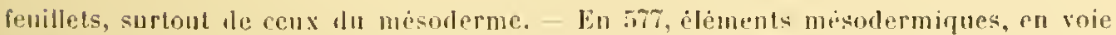
de se convertir en filures musculaires; la sulistane ontractile est exprime par les espaces noirs. 
suflit, pour s'en rende compte, d'otulier toules les particularités du développrement du feullet moyen, en n'omettant ancune delles, el nen relenant pas rertaines pour délaisser les autres; puis, de suive l'évolution ultime des lissus prouluits par les ébauches mésodermiques.

B. - En prenant les choses dans leur unsemble, le protendoderme est engendré sur toute la périphérie le l'embryon. Hais, comme l'endo-

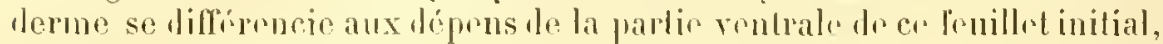
commu les appendices, lans la composition despueds le mrsoderme cotre pour unr gramli part, naissent igalement sur la face ventrale de l'emleryon, lis bemonts du protendorlerme sont leauconp plus nom-

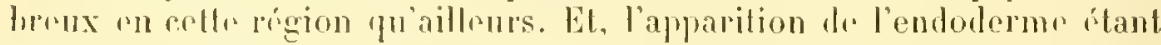
próroce, de même colle des appendiers, la potundoderme se montre tout l'aborl daus la zomr infrienro dre l'unlurom, ot y acquiert rapidement

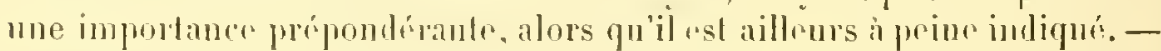
si, parmi les denx fonillels issus du protomolodrme, on fait alsstraction de lindodorme, qui prisents uno crolution et une slpuelure particu-

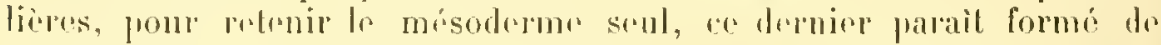

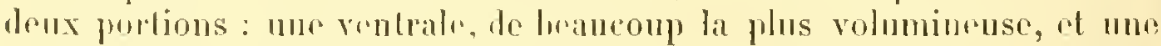
autre Gatio-rlorsale. La promiere rst ronstituér par mo part dre ces deux bankes, dont il a déja ifo fait mention an sujet do lintron, placées

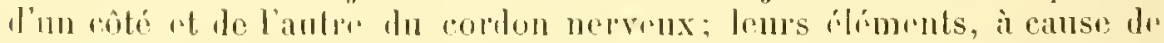
lour nombre, sont serrís el tassís. La seconde se compose dre cellules

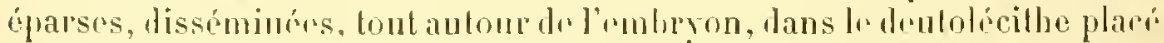
sous le liastoderme. Lrs étrmonls du misodrrmo, qüils apparlicnnent à l'une ou a l'autre dre crs doux sections, frovionneul de cenx du pro-

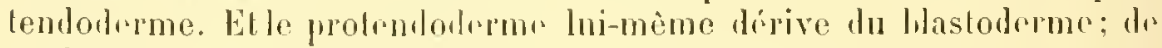
ce druirer surtout, dans le cas oì les cellules vilullines sont peu nombreuses, chez les Crustacés par rxemple; des cellules vitellines pour Ia majenre prot, lorspue rellos-ci sont ahondantes, comme it cu esl chez les Insceles. Les cellules vitelliues reprósentent, dans co deruirr mode, une. sorte de blastorlermo interne.

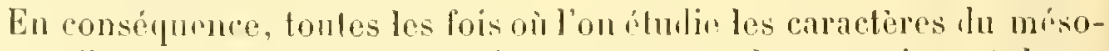
lomen, il est noressaire dr mo point séparep ees leux parties, et de ne

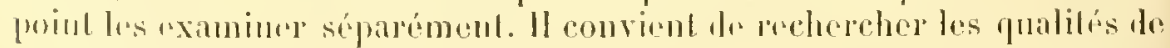

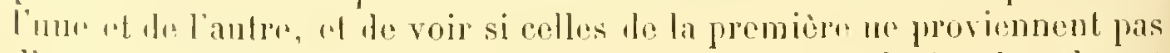
l'une moditioation de celles dr la scconde. La part latéro-dorsale est franchroment misurelymatense; par conter, la rontrale, composie d'élémonts sorés, nulfement épars, est de disposition rónglière of précise. Én les enmparant entre cllos, of olservant la facon dont elles se relient, on "u vient à voir dur la part vontrale ost essontieflement dre meme struclure: quo la dopsale; senlonent, i cause de la multiplicalion plus rapide,

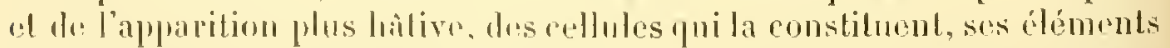
sont tassos au lien l'bte lisperses, et se frouvent groupes en bandes

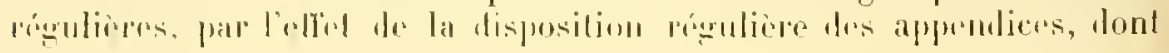


ils doivent engendrer les tissus. Le mésolerme de la région ventrale du corps est mésemchymateux, tout comme celni dn reste de l'oryanisme;

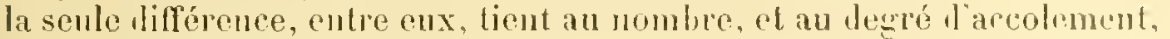
de lenrs cilóments.

Le fenillet latéro-dorsal demenre un mésenchyme, el ne perd jamais ce caractère, par la suite; le mésoderne ventral parvient également à acquéru une franche disprsition mésenchymateuse, mais apres aroiı subi quelques rhanguments speciaux. - Chacune de res leux bandes, placée au-dessus de l'une des deux rangérs lappendices ébanchés, se divise en deux zones, lune externe, l'antre interne; la limitr ontre res denx zones n'est pas tranchée, car clles se lient par des transitions insensilles. Les cellules de la région intrmo se séparent les unes drs autres, se répanlent dans le deutolécilhe, et loment un mésenchyme ventral, qui s'unit à celui placé sur les côtés de l’organisme; celles de la région externe, situés immódiatement au dedans dro lectoderme, fournissent le mésoderme des appendices. - Chanue éhauchr d'apprndice est semblable à un petit mamelnu coniqur, implanté sur la face ventralo de l'embryon; ces ruliments oceupent la place définitive de l'organe quils ongendrent, ot se disposent, id des distances égales les uns des autres, in deux rangées parallèles cot symétriques, placées d'un côté el le l'autre de la ligne médiane. Les élóments de la zone externe du mésoderme ventral sont destinés à ces apprndices; ils sont, frar suitr, très nombreux, serrés en une masse dense au niveau de chacun de res dernicrs, et manquent presque dans les regions intermeiliaires. Comme les ébauches apprendiculaires sont séparées par les distances igales, la zone externe se divise en masses égales, placées à la file en une série longitudinale; elle somble partagée en segments, les spgments étant placís an-dlessus des apprudices, et les espaces inter-segmentaires se trourant siturs daus les rigions intermidiaires.

La disposition métamérique du mésoderme est, ainsi, en corrélation évilente aver la prósence des apjendices sur la face rentrale du ropps. Si une partie de la région ventrale de ee feullet est divisce en segrments,

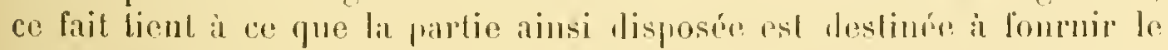
mésolerme des appendices; of ces derniers sont igalement dislants. Si ce mesolerme ventral est plus compract, plus voluminemx quo celui du reste du corps, ce denxieme phénomene est dù à la grenese hàtive des b́auches appendiculaires, auxipuclles leurs tissus sont rapilement fouruis. - La strurture métanérique est done secomiaire; elle estébroitement licie ì la genise des appendices, et dépend d'ello; olle ost un ellot de celte derniere. Eille nost point prinilive, contrairemont in celle dos Anmedides ef les Vertebrés, ol n’ppartient pas an propre an fonillet moyen. Eille

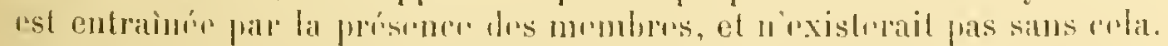

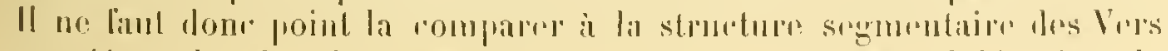

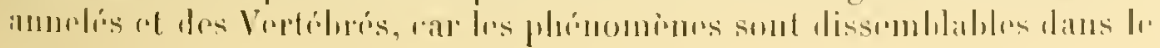


trmps at lans liasparr, ol ne sont point homologues. - En sommr, si

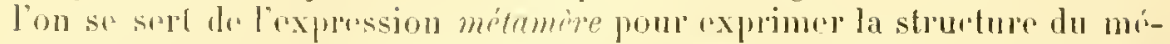

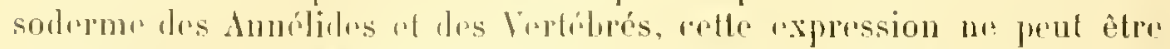

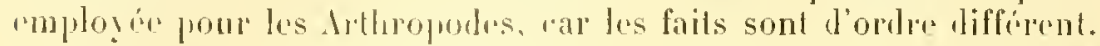

En outre, cetle fansse disposition mélamérique ne persiste pas. A

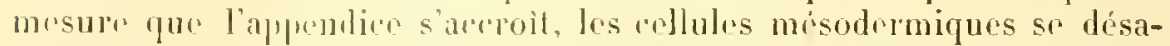

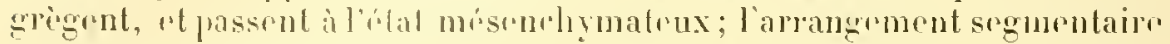

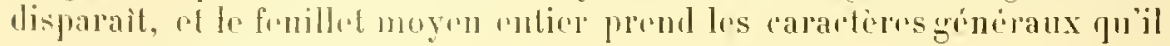
conserve disolmais.

Coprentant. les phomomenes partiruliors, qui so manifretont dans la

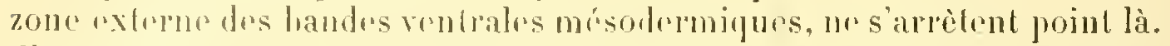

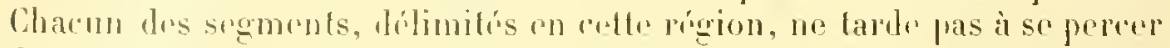

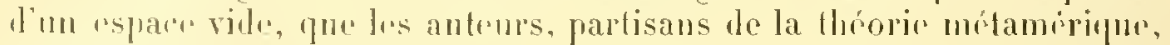

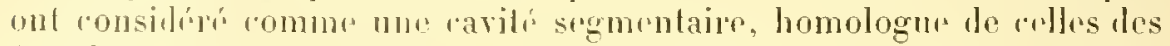

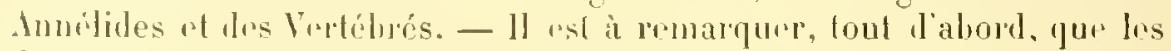
denx faits un sont pas rutierrment romparables. Ces cavités su mensent.

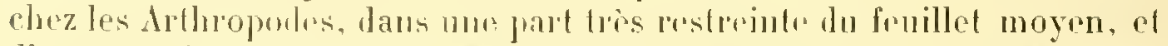

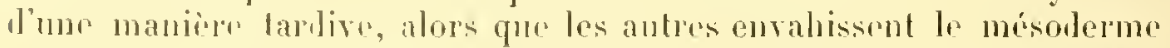

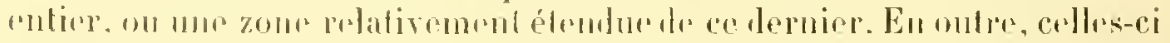

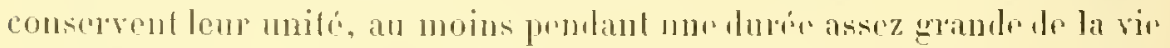
cmloyomaire; il nom est pas ainsi pour les Arthroporles. Leurs cavités, fort petitus lorsifu'elles su montrent, ne s'amplitient pas davantage; leurs paruis su désagreunt, "l plusienrs de leurs óloments se disséminent dans les mpaces qüils rommunient à limiter. Plusieurs autres cavites, jlentiques à la premiore, prennont naissance à côlí d’olle, et úvoluent de mème; loules s"anastomosent ensuite, et joduisent un lacis de conluils irréguliers, creusés cutre les éléments mésodermiques. - En résumé, ces espaces sont les ébauclues les canaux sanguins de l'appendice of de la région ventrale dn corps, et la cavité segmentaire n'est autre yue la premiere indiration de ces canaux.

1. - Linsi, dans son díroloppenent, le mésoderme des Arthrojodes sa comportr rommo mn vai mésenclyme. Certaines de ses zones offrent

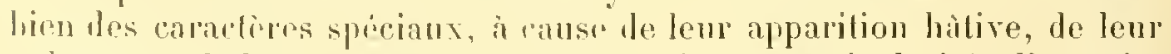
volumu. ef le leur comprarité iniliale; mais ces particularités disparaissont frar la suile. (ie mósenchyme angmente sans cesse le nombre de ses ibumonts, prar la mulipliration répétée de cenx yni existent deja; des ravites se ereusent lans les amas cellulaires aimsi produits, el s’unissent culur cllos; res cavités représentent le colome des Arthropodes. Ce demin se convertil rn nu polyerolome, dont les diverses parties sigucent rutre clles, jonr lomer in appareil irrigatenr homolympha-

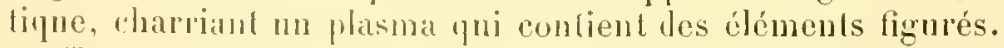

Tout en croluant, ot sous la rapport le son histogenesr, le mésoderme

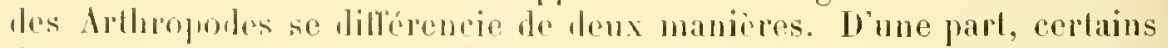
de ses éléments restent cohérents, réunis en m amas solide, compael, 
et se modifient presque tous en filores musulaires, qui se disposent. par la suite, l'après le type voulu par la sluchure dítinitive. Daulre part, il se reuse de cavités, dans lesquelles les rlémouts frisius pxislent un plasma liquide, destiné à les remplir: apres yuoi, plusirurs de ces derniers, ne subissant aurun changenenl spécial, et conservant leu

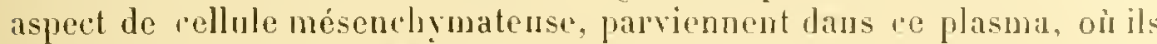
se trourent libres. Ce tissu liquide, qui circule lans les cavilés du feuillet moven, est l'hunolymphe, habituellement désignre par le nom de sang. Ses éléments figurés sont issus de la segrmentatiou des premières cellules rejelées daus les ébaurhes rasculaires.

Le feuillel moyen, en devenant un mésenchỵme pereé d'un polỹoelome, produit ainsi deux sortes de tissus : des lissus musmulaires, qui constituent la parlir solide et comprarle du mésorlermr: el les tissus à substance fondamentale liquide, dont l'ensemble repúseute l'appareil irrigateur. Il convient "lajonter, aux tissus solides issus dı mésoderme, un amas cellulaire spécial, désigné par l'expression de corps adipeux, et placé lans la rigion dorsale de certains embryons.

Tissus miscclarres. - Les éliments mósodelmiques, destinés à engrendrer les liandes musculaires de liadulte, se multiplient, el sarrangent sur place. l.es moditications, que subissent leurs divers amas. sont donc presque nulles; elles se rapportent foutes a un accoissement en taille, ef à une délimitation plus précise. Par contre, les rhangrments otrerts par les éléments enx-mèmes sont plus importants. Charun l'eux est, à son début, une cellule mésen hymateuse, formée par un proloplasme granulenx, at nullement diflérencié; il duit fonruir une fibse musculare.

A cel effet, l'élément rétrarte les expansions psendoporlipues yu’il émettait tout d'abord, et devient ovalaire, on splririque: puis, il augemente de taille, les nourelles portions produites étant constiluées jar du sarcoplasme, et non par du protoplasme urdinaire. Le sarcoplasme se dépose tout autonr de l’élément inilial; mais il est plus épais en deux régions diametraloment opposées, oì la genose de nourelle substance sera loujours plus ahondante qu'ailleurs; res légions s'areroissent done: avec plus de rapidié que les autres. A rause le ces phénomènes, la rellule pred sa forme premiere, et s'allonge, puisunil n'y a point égalití laus les dépòts qui lentourent; elle devient longuemunt ovalaine, puis cylimrique. Le sarcoplasme prenant tonjonss de l'extension. l'riment se converlit en une fibre musculaire, dont la substince contraclile cureloppe le protoplasme initial; colui-ci contient l. noyau. - I mosure que la filgre aumente sus dimensions, l'unipuc noyan se divise en drux par-

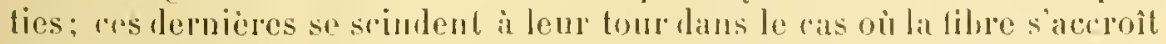

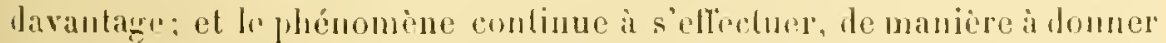

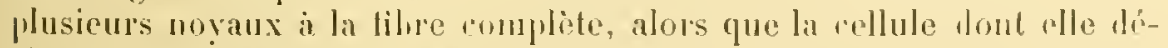
rive ne contemait qu'un senl dr les colps. Les noyaux secondaibes ne? restent pas juxtaposés: ils s'ecautent les uns les autres, prodiut pute 
l'élóment erandit, ol se répartissont ì livers niveanx. linalement, la

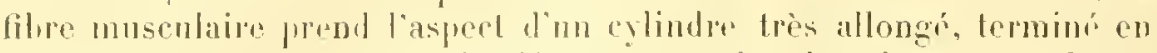
pointe it sosextrémilés jarfois bifurynées. ol dunt la sulstancr renferme

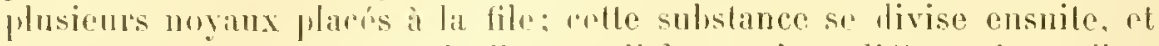

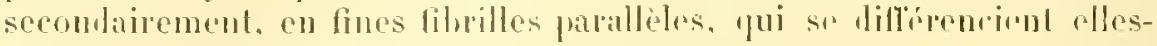
memrs en disques superposis.

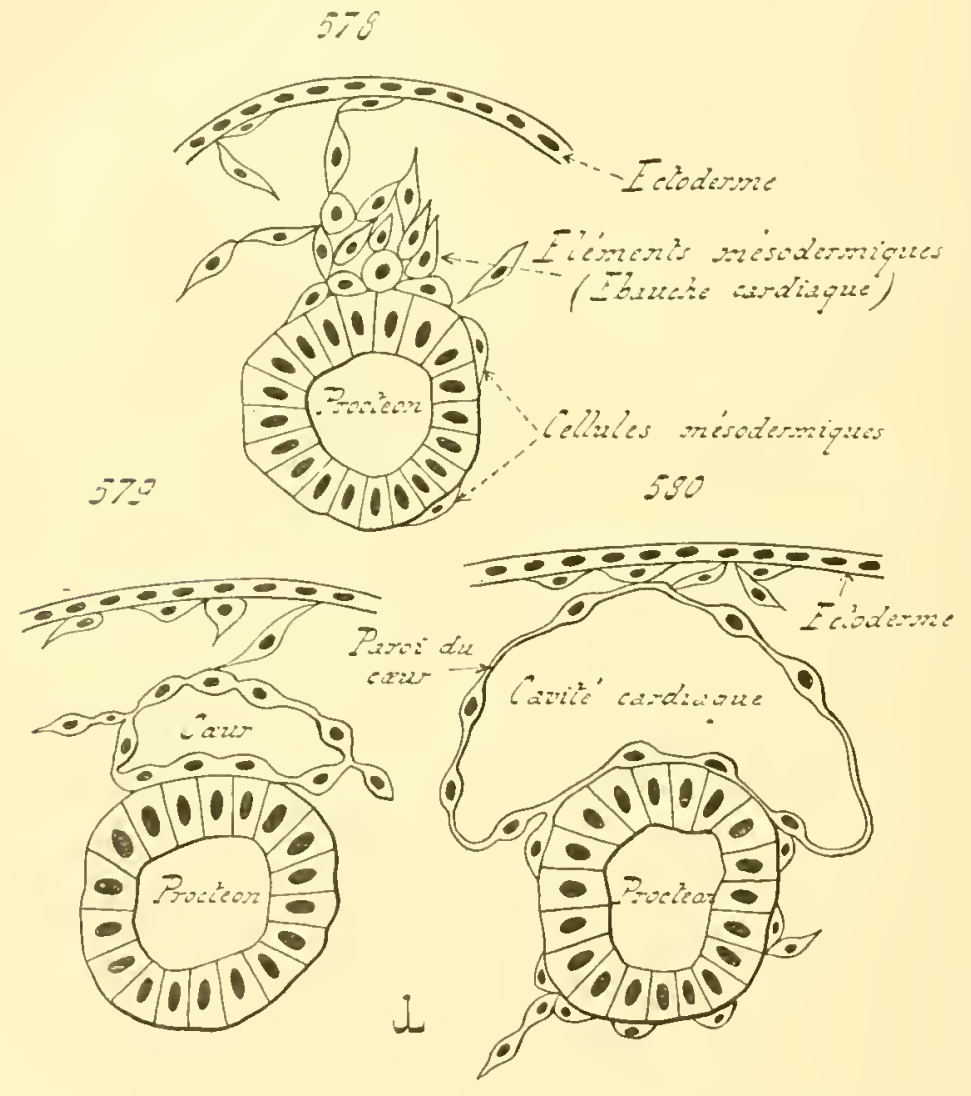

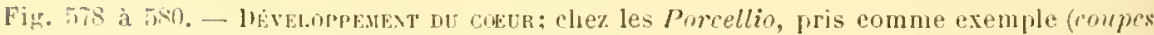

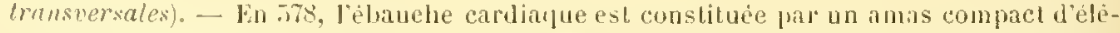
ments mésomlermiques, place sur le proeteon. - Lin rog, ectle ébauche grandit, el se

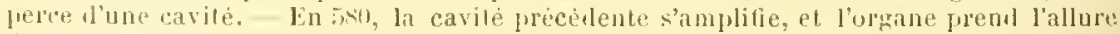
mitinitive du carur.

Ges ligures expriment des furtions grossies de coupes transversales dembryons, semblables a celle yui est represintee en $5 \%$.

Corps abmix. - Ce nom sert i disigner un anas de cellules, chargies de sulstaners mulrilives, placies dans la région dorsale dn corps chez un gratul nombre de larves d'lusectes, of chez divers embrrons de Cruslacés. Lorgane, ainsi conuposí, na point de liniles priphiripues lien pri- 


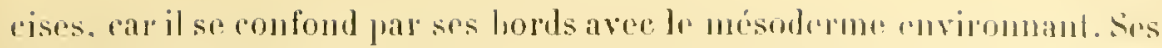

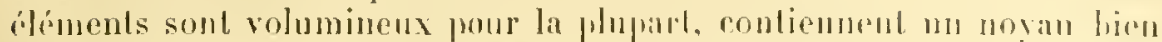
net, el reulermont de nombleuses gramulatons graisseusos. Son róle est louble; diune prat, et cest lit sa fonclion lit plus imporlante, il constilus. une ahomdante ríserve untrilive, yui sert is l'embryon pour effectues son développemeut: d’autre bart. il accumule dans sa masse des matériamx de désassimilalion, et représente une sorle de rein acommulatrmu.

Le corps adjuenx est rmendré par le mésoderme. le deutolicilhr,

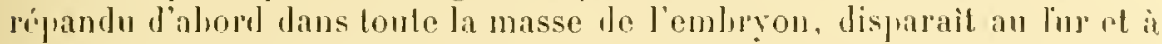
mesure du diveloproment, car il est ahsorlor jar les collules lu mósoderme et de lendoderme, qui jouent en cela un roble de pluagocyles; retle disparition procide avec régulariti de la rógion rentrale vers la rigrion dorsale; les dernjères parelles sont Jome silures dams la zome dorsale de l'organjsme. Ies élimeuls mrsolermiques, placrs dans celle partie du corps, se saisissent de colte sulıstance mutrilive, et lis font pénéllep daus leur proboplasme, sous la forme de nombrenx granules: en mòne temps, jls se multiplienl aver rapidite, de maniòre il bifier us amas considérahle, qui est le corjs adipeux. l'ar suile, ce dernier est d'origine mésodermique. Il ne faul point l'oullier, les asserlious des auteurs quj font provenir cet orgaur des rellules vitellines, ou dre lendoderme secondaire, reviennent en réaljté à la préridente, car les rellules vilellines sont les élémeuts du blastorlerue interue, Jont le ròle est de fouruir directemont, blant dommée sa siluation, à la genise lu mésoderme.

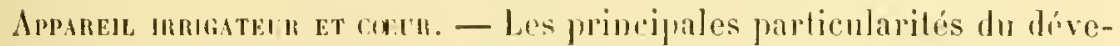
loppement de l'appaseil jurigateur sont drija connues, d’après les ronsidrrations próédentes. Cel appareil jeprésente a lui seul le roelome des Arlhropodes: il est dorigine schizoculiemne, et se ronvertil cu un polyoulome, plaré dans un mósoderme méspmohymaleux: sos plasura, el seséléments figuris, lérjenl diroetemunt des reflules mésrnchymatruses de l'ibauche mésodermique. Ses ravilós ronservent le carartire de lacunes non endiguées, cest-it-dibe de ananx privés de parois propres ot

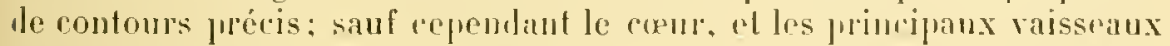
qui, partant de lui pour sc dirigger vers la préphére, peuvent jorter le nom diartères.

Cepemdant la genese du remr, aver celle des arteres, pentrent dans la regrle commune, ot ne s’en écartont pas. Lenr paroi, l'migine móso-

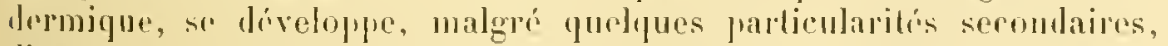

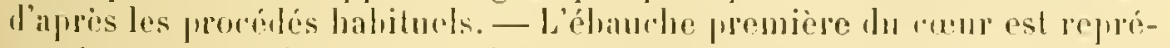

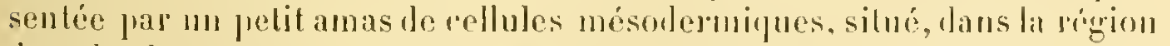
dorsale du rorpes et sur la ligur médiane, an-dessus de l'un des pouli-

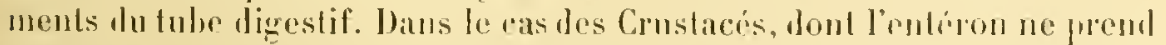

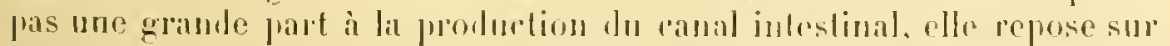

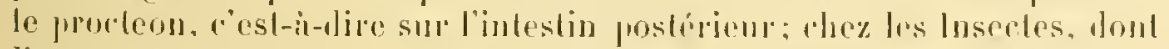

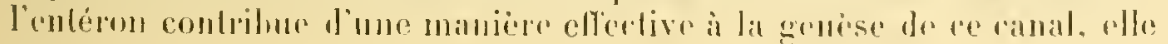




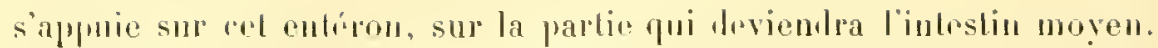
Cello éhauche s'allongesuivant l'axe fongitulinal du corjs, toul m restant comprote; fuis, olle se crense d'unu seule cavité axiale, origine de la caviti cardiaque. Celle lernirive gramdit te phus en phus, suivant sa louguenr el suivant sa lingeur; les éléments qui la limitent, el dont le nombre cesse assez rapidement d'angmonter. sont obligés de s'iplatir pour suivre cet arcroissemnt: ils subissent, en mème lemps, tes modificalions smmblahlı́s à relles que présentent les cellules-mères des fibres musrulaires. La minre fraroi rarliaque se conslitue par ce plrorédé; l'organe entice prent hàlivement son aspert dofinitif, el commence souvent a battre, alors ipue l'enbryon n'est pas ancore éclos.

l'ébauche dn cunr, on du vaissean dorsal, pour employer une expression fréquemment usitée, se relie en arant, ot en arriire, aux ruiliments des principaux vaisseaux. Ces derniers se façoment par un prorédé identique i rehi du cuur, mais en subissant un accroissement transversal moindre; ils se joignent, de lenr côté, anx lacunes th polycolome, le façon a étalılir une continuité parfaite lans tout l'apprareil irrigalenr. Fréfnemment, les lacunes placées autour lu curnr s'anastomosent largement entre elles, el forment une poche, dite cavité péricardique; suivant le legré te complexilé alteinl par l'organisme, cette poche conserve des ratations nomlreuses arec le reste de l'appareil, ou lien s'endign. completement, et ne communipue qu'avec les sinus rame-

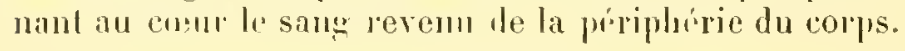

VIII. Organes sexuels. - Sous le rapport de leur díveloppement, les organes sexuets des Arllurporles se comprosent de deux parties : d'um colk, les glandes sexuelles elles-mimes, avec les comluits unis à elles, ovidnctes et cananx déférents; de l'antre, les canaux qui, commençant ì l'extrémití des oviductes el des ranaux déférents, débouchent à l'ixti-

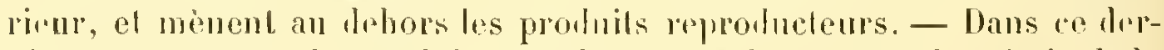
nier cas eutrent: le conduit éjaculateur ot lr réceptacle síminal, le vagin el l'uliorus, avec leurs glandes annexes.

Ces derniers appareils sont d'origine ertodermique; ils dérivent d'involutions tigumentaires. Lenr évolution no st guère connus que chez les Insectes. A en juger suivant les olservalions de Nüsshaum, len's élanches serairnt toujours paires el symétrigues, mème dans les groupes où l'organo dre l'adulte est impair; Hans er dernier ras, les denx bauches s'unissent sur la ligure médiane. Cir fail neest pas coustant, d'iprès Witlaczil: les premiers ruliments du vagin de la femelle, et du conduit ajaculateur du mile, sont, elum les Aphides, vraiment impairs ut simples. - Cess diflérences tiomnent, saus doute, à des phénomines de déplacement daus l'esprace: it ist permis de peusere, étant donnée la dualití des glandrs sexuclles, pue lours combits excréteurs sont doubles dans l'blat le plus simple, ol que leur unití est secondaire, dne it une sondure, an lien fietre primitive. - Les glandes amexes de ces appareils pro- 


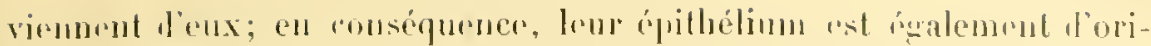
gine ectodermique.

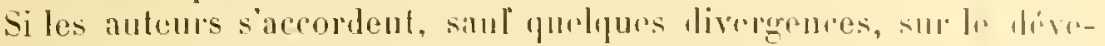

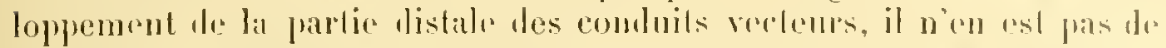
mème pour la partie proximale, el surloul pour les ghmors spimelles.

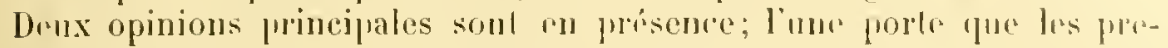

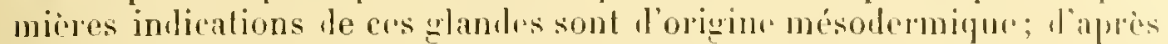

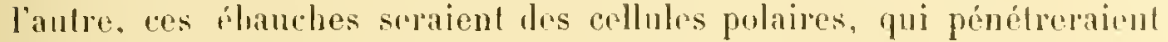
dans l’utériour de l'subryon, al y donneraionl, en so multipliant, les amas d'ilémenls reproulucterrs.

Colle sroonte assertion a étr émise tonl d'ahorl par Lenckart, ot par

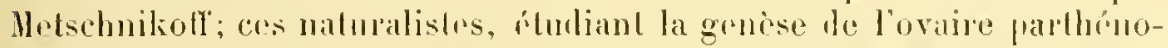
génílique, pncorc nommó pseudovaire, des larves des Minstor, onl vu lis bluanches drecel organe provinir des rellules polaires. Le mèmo fait a ćté rohouví récemment, jar Balliani, chez les Chironomus, ot apjur sur des olservalions dignes de rrance. - Ce phénomène sécarlo à un lel degri des donnies de l'embugologie gincrale pour ce qui tourhr l'origine des collules sexmelles, puil serail ulile de le contimur a nourean, en le rerherchant choz d'autres lusectes ol ll antris Arthroponlis. Il sorait néeessaire, au smpplus, d'ilablir unc distinction ontre les vaios cellules polaires, ot les premiors ifrmonts blastodermiques produits; plusiours de ces durniers se léplacrnt dans la masse ovulaire, parviennènt jusquà la surface de l'ouf, et y font mème saillie, puis s'enfonernt dans lo deutolícilhe pour y passer a l'itat do cellules vitullines. Ces éléments ne sont point des cellules polaires; colles-ci naisscnt avant la fécondation, ou bien an moment mème où olle se produit; alor's que les éléments blastodermiques ne se développent quapres cet acle. II conviendrait done, en de lelles recherehes, de ne point confondre res leux corps entre eux, et d'examiner li genese des glandes sexuelles che\% des embryons issus d'aufs fécondés, et non d'ovules prathénogénétiques; la fécondation faisant défaut lans ce dernior cas, il est phus difticile de distinguer nettement entre les cellules polaires et les prenières cellules du blastoderme.

La plupart des nalualistes inclinenl it penser que les blutuches des glandes sexuelles sont l'origino mósoderminue, et se monlrent hativement, des l’instant le la dólimilation des fenillets. Ces élanches sont au nombre de deux, placées symétriquemml le parl et d'autre du tube Jigrestif et ulu cenu; elles sont ronstilures par ales éléments non aliférenciós encore, yui se lassonl les uns combe les autres, et se multiplient ardivment, pour dommer, suivant lo cas, des ovohlastes ou des spermoblastes. Les relations exiletes de ces puliments, aroc roux des

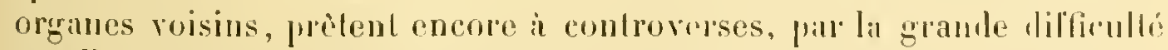

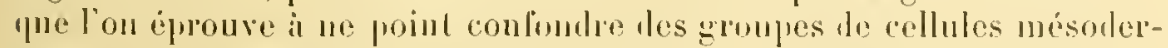
miques omlinaires arec les virilables éhanches sexurllos : les choments daul prespue semblahles dans les deux ras, el la nreessilo sumposant 


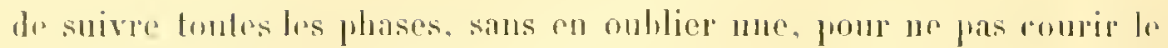
risque de se tromper.

Parfois, la sexualité entrume à sa suite un dimorplismo. Assez sonvent. les miles ne ditrèrent drs femelles que par des lélails secondaires. jui liennent ì la dissembance th roule joué lans l'acte féeondateur. Les màles possèdent des pinces. des rrochels, destinés ì saisir les femelles; celles-ci sont munies de tarirres, l'oviscaptes, chargées d'assmer la ponte dans des conditions déterminées. - lilleurs, les différences vont plus boin. Sans entrer ici dans beancoup de tétails, qui apparliemnent plutil a l"anatomio comprée, il est bon de signalor quelques données générales. Chez la phupart des Crustacés parasites, la femelle acquiert mo taille plus considórable que le màle, et prend une forme dissymétrique; lo mile demenre plus petit, presente quelques caractires embryominares, el conserve les appendices capables de lui servir pour se déplacer, rechereher, el trouver les femelles. Un semblable dimorphisme, comparable quant à la cause, existe chez phsieurs Inscetes : la femelle rst privée d’ailes, alor's que le mile en est pourvu. Tels sont les Lampyres ou Vers luisants, plusienrs Bomlycides, les Strepsistires, efc.

\section{§6. - Alternances de générations.}

La reproduction des Arthropodes est toujours sexuelle. Elle s'effectue suivant ses leux procédés : la fécondation, el la parthénogenose. Cette dernière n'cxiste pas rhez tous les Arthroporles, mais seulement chez. divers Entomostracés el plusieurs Insectes. Sa présence entraine à sa suite mne alternance de générations, qui est une hétérogonie, puisque la reproduction asexucle fait constamment kefaut.

Cmstaces. - L'hétérogonie des Crustaećs parthénogénéliques est ahulte el holonorphe; les individus non fécondants ofliont la mème structure que cenx sommis à la fécondation, le mème aspect général, el lous sont adultes. Comme l'indique la juemière partie du second parasraphe de ce chapilre, la parthénogenese, ot par suite l'hétérogonic, "xistent chez la prande majorite des Cladoceres, el chez livers Brandhiopodes, tels que les Artemia et les Apus.

lisictes. - Lhótérogonie est plus variée chez les Insecles. Elle aprarlient à trois types prucipan : l'hélérogonie embryonnaire, encore nommée pédogenise; l’hétérogonie adulte et holomorplie; l'hétérogronie alulte ot hictromorplie.

Le mode le plus simple, éest-it-dire l'hèterogonie alulte et holomorphe, qui consiste seulement en l'alsonce de màles durant un nombre variable le gruerations, est anssi le moins fripuent. Il est somvent accilentel, en ce sens que la parthénogencese qui l'ancue à sa suite, est elle-mème 


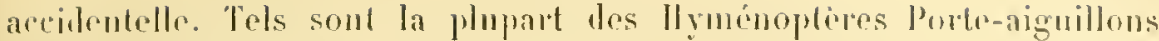
vivant en sociélés, ot corlains lépiloptìres apparlenant anx grones I'omby., I'ieris, I'syche, et solenolin.

Lihetroyonie adulte et hétéromorphe ast plus dépandue; elle se montre chez los llémiptères de la sechon des lhyophthires, el chez les llvmonoptires gallicoles; elle est toujours nomale, et non accirlentelle. - Le procédé le moins complexe est celui les Hyménopteres grallicoles; les indivilus lécondauts et les individus parthénogénéliques différno de forme; assez, parfois, pour quion ail place les uns et les autres dans des espèces distinctes, et mòme dans des genres diffónents; Lous sont ailés. Souvent, les dissemblances, corrélatives des procédés reproulucterrs, ne s'arrètent pas i la lorme du corps, mais sadressent curalemunt aux procólés de ponte. - Ainsi, les Teras terminalis femelles, el fécondées, léposent leurs aufs dans les lourgeons placés à l'extrémité des buanches des Chènes: la prósence de ces coufs thitermine, aux dipens des tissus végétaux. la production de galles. Les anfs fécomdés donment les imlividus parthénogénétiques, dont on arait fait une espece particuliore, classéc dans un autre genue, la Biorhiza aptera. Ces indivilus non fícondants vout placer lenrs aeufs sur les jacines des Chènes, on leur présence amène également la genese de galles. Do: ces oufs parthénogrinétiques sortent des Teras terminalis mìles ot femelles; ces dernieres produisent. a leur lour, des galles sur les lranclıes, et les géméralions continuent à se succéder suivant cet orlre.

Les phénomènes de l'hétérogonic hriléromorphe sont plus complexes chez les Hémipteres Phytophthires. - Le point de départ est, sans lonte. lesingulier dimorphisme sexuel des màles, que prósentent certains reprisentants de la famille des Coccides, et surtout la Tachardia lacea. Les gíncrations sont toujours fécondantes, et se suivent sans hítérogronie relle, mais cerlaines sont remarquables par l'exiguiti, ef par l'amoindrissement, du Joile du mile. Dans le con'ant do l'hiver, en dínembe et janvice (il s'agil ici d’une espece des pays chauds), les larves relosent, ol deviennent adulles. Elles se fixent sur divers vígitaux, et se recourrent do laque. Les lemolles sont toujours privies d'ailes; les males acquirrent ces organes par contre, an mombre de deux, et recherchent les femelles prur les fromder. He es wufs naissenl, en septembre, les males et des femelles; celles-ci ne dilterent pas beancoup des prócilentes, mais non les males; aes derniers sont aptères, fécondent les femelles des leur éclosion, el menrent ensnite. La duréde la vie est fous

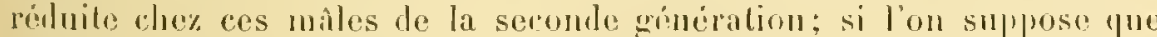
cette diminulion parvienne jusqu’a me disparilion complite, les lemelles dété seront privées le fécomblion, el une hetérogonie se prósentera,

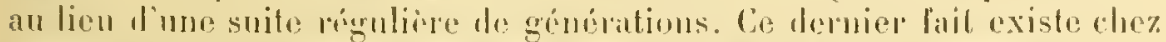

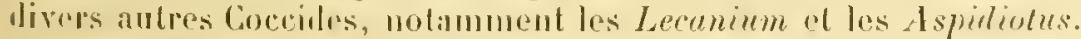

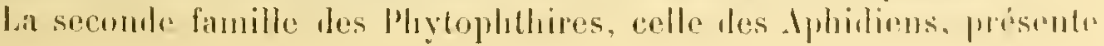


Jenx sortes d'hétérogonie hétéromorphe: dans lime, les femelles prarthémgánétiques sont vivipares; lans l'antre, semblables en cela à leurs correspondantes des Cocrides, ellos sont ovipares. La premire est celle des Aphiles et des Pemphigides; la seconde celle des Chermes el des l'hylloxere. Le mode de vin diffire d'apres la nature de la reproduction.

Les fomclles prarthónogénétipues sont vivipares ehez les Aphides; leur glande sexmell., nommée psendovaire, est privée de réceptacle séminal. Lecurs générations se suceident lurant la leelle saison; les individus sont lixés, en parasites externes, sur divers régélanx, oì leur présence amine souvent la production l'excroissances particulières: ces ilres sont dépourvus d'ailes, dans la règle, mais parfois plusieurs dentre enx se trourent capaliles d'en produire, et de se déplacer par leur moyen. lers l’antomne, les riprésentants, les génćrations quj existent alor's, engendrent des descendants des deux sexes, los uns males, les antres femelles. Celles-ci. d'ordinaire, sont privées d'ailes, alors que les mâles en possident; le tulıe digestif des uns et des autres est normal. Les mailes fécomdent les femelles; ces dernic̀res ne sont point vivipares, mais pomlent des aufs, qui passent l'hiver, el despuels sortent, au printemps, les premieres femelles parthénogénétiques, chargíes de recommencer le crole des générations. - Pareille snccession de phénoménes existe chez les Pemphigides: seulement, les individus fécondants sont privés de rostre et dr tube digestif; leur unique rôle est de se reprodure par la fécombation.

Chez les Chermes et les Phylloxera, les femelles parthénogénéliques sonl ovipares. tout conme les femelles fécondantes. Les faits sont plus simples dans le premier gemre que dans le second, car les uns possèlent seulement deux sortes de générations surcessives, alors que les autres en ont trois. - Les unfs lícondés des Chermes donnent, au printemps, des femelles prarthénogénátiques, qui pondent à leur tour des aufs, dont les embryons deviennent des femelles fécondantes; les unes et les autres sont aptìres, ou ailées, sans que l'on ait pur reconnaître encore la corrélation ćlablie entre la présence des ailes el la nature de la reproduction, car les màtes sont inconmus. - Les phénomenes offerts frar les Phylloxeru sont phus romplexes que cenx des (thermes; its consistent en la succession de trois tỵes de générations. Ainsi, chez le Plyylloxera de la Vigne (Phylloxera vastatrix), l'ouf férondé est déposé jar la femelle sous l'nurce des ceps : d'où son nom d'ceuf d'hiver. An printemps, ce dronier donne un individu parthénogénétique, privé d’ailes, qui pond à son tour des unfs, d'oir sortent des ètres semblables à lui, également aptères et frathénogénéliques; plusieurs générations se succèdent ainsi, yni vivent sur les fenilles de la plante, et se nourrissent de ses smes. Apres un cerlain tomps, variable suivant les variélés de Vigne, les individus non fécondants, et privés d'ailes, descendent le long de la sonche, et vont s'établir sur les racines. l'uis, vers la tin de l'été, les générateurs parlhénogénítiques donnent les descendants, privés comme eux de la 
fécondalion, mais pourvus d'ailes. Les individus, appartenanl à ce deuxiène type de génération, s’envolent, disséminent ainsi l'espioe, et pondent ensuite des aul's le deux sortes, les mus gros, et les antris petits. Les premiers éclosent en jroduisant des femelles, et hes seconds en fournissant des mìles. Ces individus sexućs constiluent un troisiente type de générations; ils possident des ailes, mais sont privés de tube digeslif, comme leurs correspondants tes Pemphigus parmi les Aphides vivipares. Les males ficomdent les femelles; et, cet arte apréré, ces derniores pondent les anfs l'hiver, qu'elles déposent sous l'ricorce des ceps; après quoi le cycle recommence.

La pedogenese, est-itdire la parlhénogemise embryomnaire, n'existe. avec l’hétérogonir qui en découle, que rhez les Diplires némocires des genres Chironomus el Miastor. Les ceufs lécondés, dans ce drrnier genrer, sont placís par la femelle sous l'écorce des arbres; ils produisenl, luraut l'hiver, des larves, chez lesquelles les ovaires se développent rapidement. el dont les omfs se séparenl les uns des autres, pour devenir libres dans la cavili générale. Ces rufs iclosent, lout en restant enferués dans l'organisme de la larve ginératrice, et ionnent de nouvelles larres; ces dernieres se nourrissent aux dépens des orgaues de leur mère, pl lurisent ensuite ses tiguments pour parrenje an dehors. Elles-memrs snlissent une ivolution semblable, et engendrent it leur lour, par un puréde identique, d’autres grinerations de larves. La reproulution romlime de cetle maniore jusqu'au printemps, oil les derniers descendauts cossent d'acquéril aussi rapilement la malurilé scxuelle, jour se développer en individus adultes et fícondants.

\section{RÉS UM É}

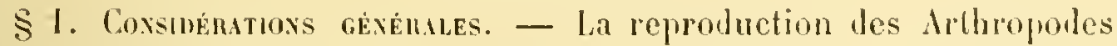
est toujonrs sexuée; elle comporte la fécondalion el la parllínogenise. Celle-ci n'existe pas chez tous les Arlnroporles; on l'ohserve fréquemment chez divers lintomostracés el plusieurs lusectes.

S 2. Sexralite et probuts sexi fas. - Les Arthopodes soul, pour la pluparl, unisexués. Certaius sont cependant hermaphrodites; il en est ainsi pour livers Eulomostracés appartenant à l'ordre des Cirrhipides, el pour phusieurs Isopodes; l'hermaphroditisme se complique parlojs de la présence de mâles complémentaires, comme ceux des Rhirocéphales, et de divers Sealpellides parmi les Cirrhipedes. Plusienrs Insecles, réunis en sociélés, sont remarquables en ce que les fonctions reproductrices appartiennent ì quelques individus, et non à tous; tels sont les Termitiiles parmi les l'sendo-nérroplères, les Formicides, les dpiles, et les Vespriles, pami les llyuéuoptères.

l.es spermalozoïdes des Comstaces pussident, aulon de lem moy au, 
unc puantifi de proloplasme plus gramle pue la quantilé habiluelle: ils portent un ou plusirurs fouets. Cenx des autres dithroporles offrent le plus souvent l'aspect molinaire. - Les ovoblastes se segmentent dans leur diveloppement, et dument des ovocytes, dont rhacun est entouré par me assise folliculaire; reux de la plupart des Insectes produisent, en surplus du follicule, et annexé de mène it lovocyle, momas de cellules nutrilives.

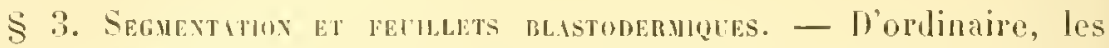
ovules des Arthropodes contiennent un deulolérithe aboutant; aussi, le dóveloppenent est-il plus ou moins rondensé. La segmentation s'etfertue de relle sorte que le deutolécilhe reste interne et rentral, d'ou le nom de centrolécilhes donné à ces ovules; les blastomères sont souvent coniques, el šrralient autour lu centre de l'ovule. - Les Cruslacés Entomostracés possident trois types principaux de segmentation : une sogmentation totale ahoutissant à une lulastule (Celochilus, lloina); une segmentation totale donnant une planule directe (divers Copépodes libres); une segmentalion prarlielle aboulissant à une planule indirecte (Copépodes parasites). Les Malacostracés ne possedent que les deux lerniers : la planulation directe el la planulation indirecte; colle-ci est moins réfrundue que la précédente. - ll en est de mème pon les Aceres: la segrmentation totale, prorluisanl me planule direcle, existe chez les l'ycnogonides, les l'seudo-scorpionides, les Icariens, les dranéites; la segmentation partielle. el la planulation indirecte. se trourent chez les Seroplioniles, el, semble-t-il, chez les Mérostomatés. - Sauf quelques Myriapodes appartenant à l'ordre des Cibiloguathes, chui montrent une segmentilion totale, la segmentation est toujours prarticlle chez les autres Ilyriajodes, et chez les Insectes; seulement, il n'existe pas de cicatricule. Le noyan lécondé se livise en segments dans l’inlérieur de l'ovinle; chacun dé ces segments s'entoure d'une zone de blastolécithe, afin le constiluer une collule complete; apres quoi, toutes ces cellules sr portent vers la surface de l'arif, oì elles se disposent en une seule couche, pui est le hlastorlermo. Lorsyue celui-ci est romplet, plusieurs des émemls sont encore plongés daus le vitellus ovulaire; ces derniers correspontent anx rellules vitellines des antenrs, et constiluent une sorle le blastolerme inlerne.

Chez lous les Mrlhopodes, an moment où la segmentation s'arhève, l'uvule se compose d'une assise cellulaire extriente, le hlastorlerme, qui enloure un anas deulolécilhique plus on moins volumineux, el lormant une visioule vitelline interne. Le blastoderme engendro, sur sa face profonde, des celhules éparses, qui pénètrent dans le deutolécilhe sous-jacent, oủ olles so multipliont ensuite d’elles-mèmes. Ces éléments, yui se mélangent aux cellules vilellines, lorsquil exisle de ces dernieres, comstituent un lissu mésenchymalens, puisquelles sont éparses el

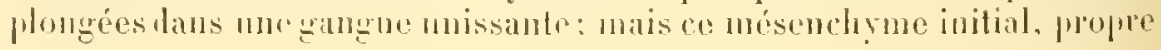


aux Arthropoles, se trouve ètre d'une uature particuliere, car la gangue est du deutolécithe, et ne lérive point les éléments du tissu. - l.es deux feuillets blastorlermiques primordiaux ont alors fait leur apparition; le mésenchyme sous-jacent au blastoderme représente le protendulrome, et le blastoderme restant, quj conserve sa situation périphérique et sa structure épithéliale, persiste comme ectoderme. Le protemlodrinus so divise à son tour enmésorlerme et endodeme. Plusieurs de ses élóments, groupés en deux masses symétriques et rentrales, se rassemblumt, de. manière à former deux courhes épithriliales. incurvées en cuvette; les deuxi cuvettes se rapprochent par leurs hords, ot se soudent en une vésicule. Celle-ci est lentéron, dont la cavití renferme le deutolécitho. emprisonné lors de l'accroissement de ses leux ébauches ; l'assise épithéliale, qui la limite, constitue elle-mème l'endoderme. Les autres éléments du protendoderme, situés entre l'ectorlerme et cet enloderme qui vient de prenilre naissance, composent fo mésolterme, de disposition mésenchymateuse. Ensuite, un stomeon et un procteon tris longs sontengenHrés par des dépressions de l'ectolrrme, qui s'enfonernt dans le deutolécithe intrrnr, ot revètont l'aspuct le leux tubes, l'un antérienr, l'autre postérieur, illant s'unir à l'entérom. Le deutolécithe, contruu dans re lemier, disparait par résorption, et laisso à sa place un cavité; culte lernicresabouche en avant avec cello du stomeon, ot en arrière arec colludu procteon. Ces trois organes constiturnt, frar lour soubur, lr. tube digestifentire.

Chez les Crustacés, "ul prenant l' l'orcellio commi type, lo blastoderme après avoir donné naissancr anx premières collules du protrumblerme, se comporto hàtivement comme retodermo dans l'extrémitó antélirure, et sur la face ventralo de l'rmbryon. Il produit, en cris régions, deux masses collulaires, la plaque céplialique ot la plaque médullaire, "ncore nommée plaque ventrale; la premièr est l'ébauchu du corvan, cl la seconde collo de la mocllo nervouse runtralr. las deux assisos épithéliales, qui su dégagont du protendodrrme pour constibue linulolerme ot limitor l'entéron, naissent dr part ot l'intre dr la plaqur mélullaire. La suitr du développrment concorelo aver los notions géné-

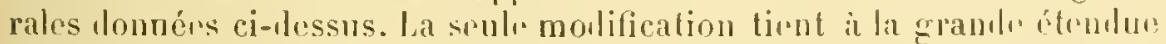

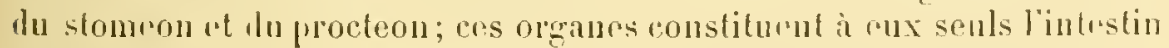

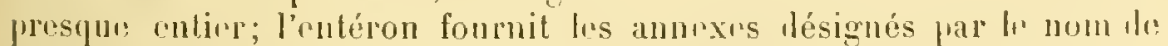
tubes liépatiqurs. - La lélimitation des fouillots hlastorlomiqurs iles

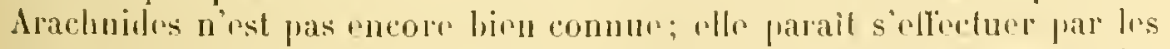

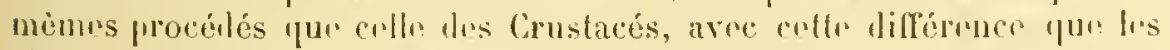

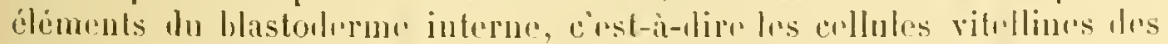

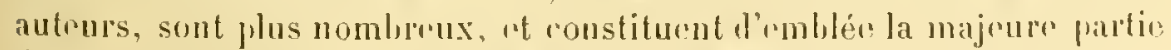

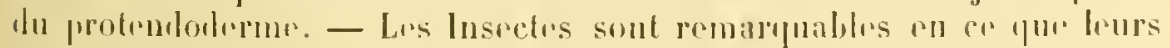

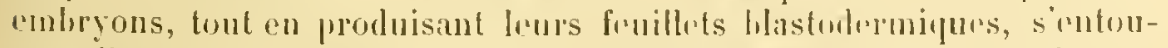

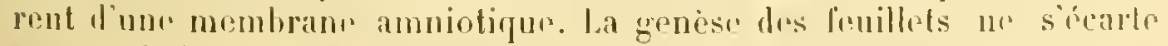

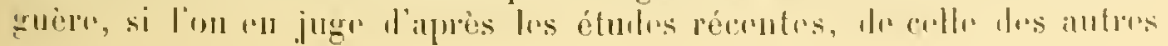


Arthonorles; la plapur venlrale so crense souvent d'un sillon, nommé la

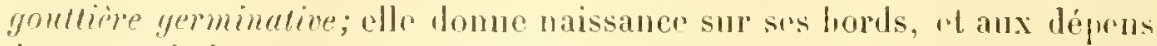

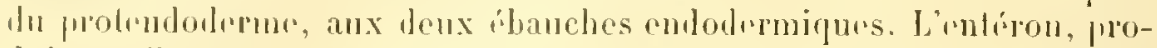
duit frar l'union we cos dorniors, ne drvicut pas le foir soul, rontraire-

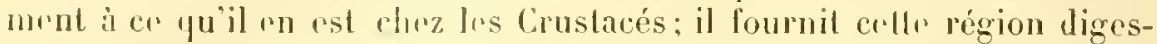
live, ditr l’intrstin moyen. L’annios est rngendré far la soudure de drux replis, faconnés aux lípens des couphos superficiolles dr l'embryon,

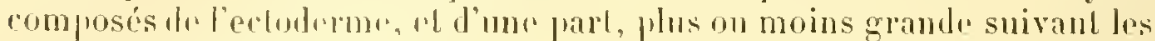
typos, du drutolicillu sous-jacent. Cesmplis naissenl, sur la face ventrah

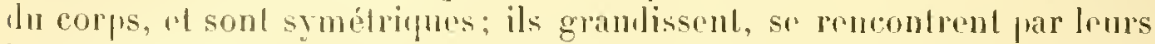

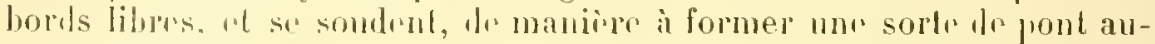

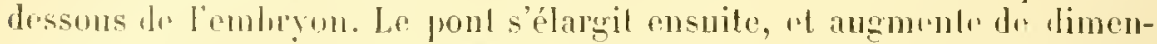
sions, "m a suns ifur sos lasus d’insertion sur le corps so déplacent, w remontonl vers la rógion dorsale, oì finalement elles se rémissent; le punt est alors converli en me gaine, qui enveloppe lont l'embryon, domble an dedans le chorion de l'unti, el se détruil freu de temps avant l’éclusion. Cefle série le phénomènes est la plus comslanle: parfois les replis amnioliques sont très épais, chez les léfidoplères par exemple, el renferment en eux-mèmes presque font lo dentolérilhe ovulaire. Ailleurs, choz lilyblophyle, Jes drux replis, lont ru restant minces, se sóprent apres stotr unis, of, foul en so déplacant el remoulant vers la face dor-

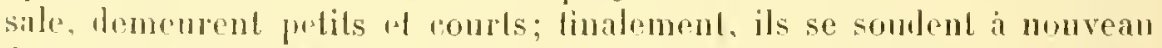
dins la rogion dorsile de l'umbryon, el limilent, entre enx el le corps, 111 conduit, le conal dorsal, jui ne persiste pats, el disparail.

$\S$ f. Formes enbromsires. - Un grand nombre d'Arlhropodes éclosenl à l'état de larves, et subissent des métamorphoses extérienres; ces lernières portent de préférence sur les aprendices, dont le chiffre augmente. ou diminuc, suivant le cas.

Sauf divers Entomostracés, ef les Ellrophthalmes, la plupart des Crustacés quiltent leurs coyues ovulaires sous la forme dite Nauplius,

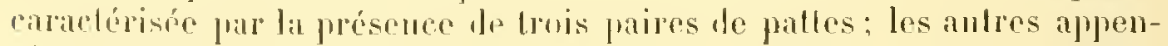

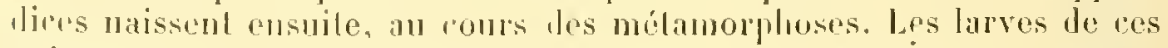
animanx sont i sluses; lenrs metamorphoses sonl brusques, et acconpagníes de mues de la culicula. - Parmi les Entomoslracés, les Cladocirres sorlent de l'ouf à l'élat parfait, les l'hyllopodes ì l'élat de Nauplius. Les ()slracorles marins ressemblent en cela aux Cladorìres, et les Ostracodes l'ean donce aux P'hyllopodes. Les Cirrhipiodes subissent des mélamorplioses uxtorioures; ils offrent d'aloril l'aspect de Nauplizes, puis celni le Vétunanplins, enfin colui de mpe munie l'nne carapace bivalve; ces larves se lixonl ensule à un support par leur extrémilé antérience. el se converlissent en adulles. Les Rhizocéplates abandonnent de mème lours coupes i l'élal dr Namplius, el passenl ensuile, apres avoir subi

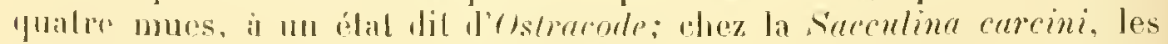

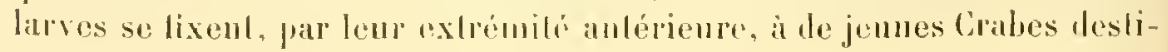


nés à devenir leurs hòtes, pénètrent dans lintérieur do leurs corps suns la forme de larves Kentrogones, imettent leurs suçoirs par celte mume extrénité antéricure, et se conrertissent cu adultes. Waprès les itudes de F. Mäler et celles de Giard, cortains Rhizocéphales devienncul adultes et parasites sans entrer dans lorganisme de leurs hòtes, ot se bornent a se fixer sur leur carapace. Les Copépodes liliros et plusirurs Copépodes parasites sont mis en liberté commr Teuplius, et passont par une phase Cyclops; divers Coprepodes farasites ne quittent leurs "nveloppes ovulaires quà l'étal de Cyclops; il en est de mène pour hes Branchiures.

Parni les Ilalacostracés, les Yébaliens et les Edriophthalmes libres ne possèdent pas de mélamorploses extéjeures, ou nien ont que de fort restreintes; les Edriophthalmes parasites rn subissunt, par contre, d'assez complexes, notamment les Isopodes appartenant a la famille des Bopyrions, et aux familles annexos. - Les Stomaporles quittont lem's corpues sous lasprect dembryons munis de dix paires de paltes; ils se changent ensuite cu Alimes, on un Erichtes, et passent à l'état prarfait. Les Cumacés n’out point d" métamorphoses extérieures; il en est de même pour les Schizopodes, sauf lios Euplumsiu et quelipes aulpes genres, qui offrent d'abord l'aspect de Vauplius; ces larves deviennent successivement des Jélunauplius, des I'rolosoess, des Zoés, des Furcilia, dos Cyrlopia, puis se comstituent en adultes. Parmi les Décapudes, certains, comme les Peneus, parcourent une série dr métamorphos's larraires, et offrent successivement les phases de $N^{\top}$ auplius, de IVetanuuplius, de Protozoé, de Zoé, de Schizopode, a jrès quoi ils sont parlaits. Plusieurs offrent des changements particuliers; les Scyllarines et les Paliuurides quitlent leurs envelopres sous l'aspect de l'hyllosomes. Jes Istacides sons cehi de Schizopode, "t les Macrunres sous ceux de Zoe et de Mégalope.

Les Mérostomatés et Jes l’yenogonides sont presque les seuls, parmi les Acères, à présenter les métamorphoses cxtérieures; les changements, subis par la plupart des lrarlundes, se passent a labrj des coques orulaires, siuf pour certains dcariens et pour les linguatules. - Les Pyenogonidesquitlent leurs enveloppes á l'élat le I'rotonymphon, munj de lrois paires de pattes: cusuite les quitre autres paires naissent les mues apros les autres. - Les Limules, les seuls Ilérostomatés actucls, deviement libres Iorsqu'clles sont munies de neul paires d'appendices, et sous une forme dite, i cause de son aspect, phase de Trilobile; puis, elles se convertissent en adultes. - Les Arancides et les Scorpionides, arec leurs groupes annexes, ne sulisscut que des métamorploses internes; les cmbryons possedent un aldomen voluninemx, divisé en dix segments chez les premières, en douze chez los sccosds, et muni de fuatre paires d'appendices pour les Iranéides, et le six pour les sorpionides: ces membies ablominaux disparaisscent eusuite, et manquent à l'alulte. - La plupart des deariens quittent lenes envolopes alors quils ne possedent encore que rime parres diaprendices, dont lrois sont destinces 
à la focomotion : d'où le nom de larve hexaporte. Avant son iclosion, l'embrym ral enfermó dans nme membrane culiculaire, dile deutovum. Les larves hexipodes des llydrachuides pénchent daus les tissus l'un bite, y passent à l'état de jupe, et redeviennent libres pour alteindre l'état jorfait. - Chez los Linguatules, et d'après le Pentastumum leprioides, les arufs fécontés sont rejrtris au dehors, déposés sur le sol, et avalés par des Herhivores; les embryons éclosent, se fixent dans les joumous ou dans le foic le ces premiers hôles, et y achevent presque lenr organisme: puis, si ces hòtes sonl mangés par les Carnivores, les embryons parviement dans l'arière-boncheol dans les fosses nasales de ces derniers, wt passent à l'étal adulte.

La plupart des Dicères, sauf rertains Myriapoles, comme les Scolopendres, et sauf les lusectes inférieurs, subissent des mótamorphoses extéricures; dans le ras oin ces dernières sont complexes, eltes saccompagnent d"une histolyse, c'est-à-lirc d'une disagrégation des organes de l'eubryon en leus éléments, suivie d'une reconstitution. - Les Myriapodes viripares. Ies Scolopendres entre antres, nont point de métamorploses externes; les ovipares en préseutent, plus accentućes chez les Chiloguathes que chez les Chilopodes. Les premiers ne posscilent guire que nouf on hix parres d'appendices an moment de leur ćclosion, alors que, l'habitude, les seconds en ont un plus grand nombre.

l'armi les lusectos, les Thysanoures et les llémipteres aptères sout privés le métamorphoses; ils sont dits amétaboluires le ce fail. Les antres représentauls de la classe, pourvus de metanorphoses, sonl nommés holométabolaires; Jans ce lornier cas, les mélamorphoses sont souvent completes. en re sens que ta larve diffère extrêmement de l'adulte par sa forme; elles sont incompletes, lorsque l'emfryon ne se distingue de ladulte que par l'absence d'ailes, el par la pelitesse, on par la privation. des yeux. Dans les métamorphoses complites, la larve subit un certain nombre de mues et he changements extérieurs, avant de parvenir a un état linal, dit de pupe, durant lequel clle est souvent immolile; la pupe se converlit ensuite en imago, c'est-a-dire en ałulte. Lorsine ces modifications sont tres prononcées, la plnpart des organes larvaires se détruisent dmant la jhase de pure, sulissent me histolyse, apris laquelle conx de l'adnte se recoustruisint an moyen de corps spéciaux, nommés disyues imaginumx.

Les métanorphoses incomplites sont le propre de la plupart des llumipteres et des Orthoptères; cepemhant. phusienrs le ces derniers, tes Ephémérides el les Libellulides, subissent des métamorphoses completes. les Diplies oflrent égalencol les métamorphoses completes; lenrs larves sont privies de patles. l'ar contre, celles des lépiloplères, dites chemilles, otlient trois paires te pattes thoracipues, et plusieurs paires Io funses-puttes, insóróes sul les ameamx de l'aludomen; des faits analocruos sont donnés par les Vévoptères et les Trichoplères. Les ombryons desstropsisteres sunt remaryuates en ce qu'ils halitent en parasiles te 
corps de divers llyménoptires, et rabougrissent alors leurs pattes; I0 màle seul parvient à l'état adulte. Les larves drs Colíoplères appartiennent à plusienrs types; celles des Curculio rappollent celles des biptères, et celles des Lamellicomns les chenillos des Lépidoptères; les phus foéqurntes, nommíes des triongulins, sont caractérisées jar la présence de six fortes pattes lloraciques, dontlarticle terninal est un ongle conique. Les Coléoptères vísicants subissent les changrements plus complexes que les autres représentants de l'ordre; ils oflrent une hypermélamorphose, déterminée par l'adaptation de lenrs larves à une vie parasitaire, el durant laquelle ces derniẻres, en rúduisant la longuenr de leurs pattes, deviennent semblables à celles des Lamellicornes, d'où leur nom de larves scarabiö̈les. - Parmi les lyménoplères, les Térébranls phytophages possèdent des embrrous semblables à ceux des Lépidoptères; les larves les Térébrauts gallicoles, privées de pattes, vivent dans des galles régétales léterminćes par leur présence; enfin, celles des Térébrants entomophages, parasites dans l'organisme d'autres Insectes, sulissent plusieurs phases, dont la plus remarquable est celle de larve cyclopéenne. Les larves des llyménoptères porte-aiguillons sont, d'ordinaire, privées de patles, et s'entomrent d"un cocon, dans lequel elles procèdent à leurs transformations finales.

Durant la phase de pupe, et lorsque la dissemblance de structure est grande entre la larve el l'adulte, les embryous de la plupart des lnsectes holométabolaires présentent deux ordres de phéuomènes : d'une part, ils produisent des organes nouveaux, les yeux composés par exemple; d'autre part, ils détruisent par histolyse les organes anciens, pour procéder, au moyen des éléments retomrnés à l'état embryonnaire, à l'éditication des appareils de l'adulte. Cette hislogenèse s'eflectue aux dépens des lisques imaginaux, zones cellulaires composées d'éléments ectodermiques et d'éléments mésodermiques, formies sur la paroi du corps, et destinies à s'accroitre pour engendrer les organes. W'après les données acyuises, liclat le plus simple, sous ce rapport, est oflert par cerlains Diptères némocères, tels que les Corethra, el par les Lépriloptères; les phénomènes histolytiques sont peu jpononeés, et les disques imaginaux, en petit nombre, se lornent à donner les appendices locomoteurs. Les modifications sout phus complexes chez les Diptères brachycères, car l'histolyse est alors tris maryure, el les disques imagrinamx sont nomInenx; la plupart des organes larvaires, et les téguments de certaines régrons du rorps, se désagrigent en leurséléments constitutifs, pour se reformer a nouveau. Les disques imaginaux sont répartis far paires; la lète contient dahord trois de res paires, et quatre ensuite, le thorax six paires, et chacun les anmeamx ablominaux deux paires. Chapue disipue imaginal offre l'aspect l'une lame ipaisse, incurée en conpe, constiluce far une assise ectorlermique, renformant dans sa concavilé des éliments du mésoderme, et reconverte en lehors prar une lame provisoire, d'origine ectorlermigue. 


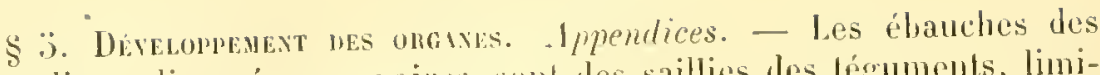
appendices, disposées par paires, sont des saillies des léguments, limitées frar une assise cotodermique, of contenant dos cellules du mésoderme. Ces ébanches sallongrul, ut granlissent pour revètir leur aspect définitif: en mème lemps, elles se divisent en articles. Les pédoncules ocnlares de ceplains Cruslacés ne doivent point etre considérés comme des appendices vais; il en est de müme pour les ailes, el pour le labre. des Insectes. Les homologies des membres, entre les trois sous-embranchements des Arthropodes, ne jeirvent etre données que par la siluation muluelle de ces organes sur le corps, par leur numéro dordre en partant de lextrémilé antérieure, et non par leurs formes, ni par leurs fonctions.

Teguments. - L'ectoderme de l'embryon persiste comme ectoderme de l'alulte. Il exsude d'ordinaire, sur sa lias externe, une culicule épaisse, pui conslitue une carapare; celle carapace se délache de l'organisme à diverses leprises, duranl la vic de l"individu; parmi ces mues, et en raison de leur cause déterminaule, les unes sout dites mues d'accroissement. el les antres mues de transformation. Le manteau de certains Entomostraces se compose de leux replis symétripues, émis par la lace dorsale des téguments: celui de plusieurs Rhizocéphales (Sacculina carcini) est produil sur place, par un véritable clivage.

Centres nervenx. - Les centres nerrenx sont engendrés par l'ectoderme. Lenr ćbauche est inpaire chez plusicurs lsoporles; elle consiste en un corton, dont la région placée en avant de la bonche se convertit en cerveau, les autres parties domnaul la moelle ventrale; de plus, ee cordon se lent shivant sa longurur, le minire à se partager en deux baudes paralletes el symétripues; les denx parlicularités les phus importantes de ce dévoloppement consistent en la continuité, et en la mature simple, le l'ébauche. Chez les autres Arthropodes, dont l'érolution embryonnaire est connue, et qui sont plus élevés dans la série que les lsopodes, la phase simple de lübanche est omise; celle-ci consiste, dès son débul, en Jeux bandes paralleles juxlaposées. Les deux extrémités antériemres de ces bandes domnent le cerveau; chacune d'elles se scinde en trois lobes chez les lnsectes, puis en cinf, par la division ultérieure du dernicr en trois parties. Le premier, le second, el le hoisième, de ces cinq lobes prodnisent le protocerebron, le quatrième engendre le deutocerelron, el le cinquieme le tritocerehron. Le développement du protocerehron, dout la part la plus importante est le ganglion optique, est relativement amplexe; lo prenier lobe fournit la lane ganglionnaire, le chiasma externe, la masse médullaire externe, el les fihres post-rétiniennes: le second lohe engendre la masse médullaire interme, sunit au premier lohe par lo chiasma inferue ot au troisieme par le nerf optique: onlin, le lmoisiène lobr se joint, sur li ligne médiane, à son con- 


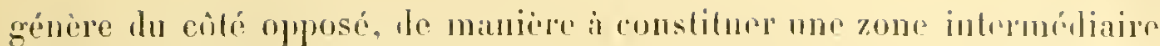
anx deux ganglions optiques.

Organes des sens. - Les seuls organes sensitifs, donl le divrloppement soit à peu pres connu, sont les yeux: ces apjareils sont engendrés par f'ectoderme: leurs ébauches sont en connexions ritroites aver cullos du rerveau. linctoderme dr ros ébauches se divise en deux assisos, dont l'extérieure doune la patie cornéenne do l'sil, et dont l'interne, en relalion aree le ganglion optique, fournit la partie rétinienne. Tantôt cetle division seffectur par un clivage sur plare. et tantôt par la grnèse d'une dépression, la coupe optique. qui se ferme, et se converlil en une vésirule optique. Les ocelles pronnent naissance par res drux procédés; l’ćbaurhe cornéenne devient le corps vitré. ct produit une lentille cutirulaire dite cristallin; l'ébauchr rétinienne dome la rétine. Les phénomenes histogénétiques sont moins lien élucités en re qui touche les reux composis. Lóbanche cormícnne engendre sans doute la roruéule, los rellutes cornéagènes, los cellules crislalliniennes, et los segments du "onn, de toutes les ommatidies. Lélnauche robinienne fournit, de son coiti, la ritinule, arec ses rhablomeres et son rhabdome, des memes ommatilies. Le lissu interstilier, ou inter-ommatilial, térive les cellules qui ne sont pas employes à la grenese des ommalidies. En somme, dans la plaque optique, qui est l'ilanuhr totale de l'oil composé, se délimitent rote à rôte un certain nombre lihanches sprondaires, dont charune se compose d'une part rornéenne, d'une part rétinienne, et se convertit en une seule ommatilie. Dans le ras des Insertes à métamorphoses romplexes, les larves ne possident point lyeux composés; res organes naissont au moment les derniores mitamorphoses, ef chacun deux provient d'un disque imaginal partionlior.

Appareil digestif et ses ammexes. - Cel appareil est formé par l'union de trois ébauches, distincles toul d'ahorl: le stomeon, le proctéon, et l'entéron (mésentéron jes auleurs). - Le stoméon proluit lintestin antéricur, l'osophage et l'estomac, avec leurs annexes glandulaires, lorsqu'il existe de ces lerniers. Le procteon fournit l'intestiu postérieur, avec ses annexes glandulaires, et notamment les tubes de Malpighi des Insecles. Les parois épithéliales de ces deux éluaurhes sont données, ¿̀ cause de leur origrine, par l'ectoderme. - Lentéron est l'espace limité par l'endoderme embryonnaire; d'aboril rempli par du dentolécithe, il se vile ì mesure de l'alsorption de ce deruicr, et se convertit on une vésicule. Il engenilre le foie, cest-il-dire l'ensemble les tubes hipaliques, des Crustacís; le canal ligestif de ces animaux n'est donc constitué que par te slomeon el par le proetron. Par contre, les Insectes, les Myriapodes, el sans doute aussi les Arachniles, possedent un intestin moyen, qui derive directement de l'entions; ce dernier fait lone partir du canal digestif froprement dit, ne se lorme pas ì otre un amnexe le ce dernier, el conslitue ure rogion intermódiaire au stomenn et au procteon. 
Appareils de la respimation. - Los branchios sont des appoulicos, on des dépendances diapendires, modifiós en vue de la respiration. les poumons le certains Arachnides sont des dípressions des tégumenls. La mème origine est anssi celle des trachées; ces organes correspondent i des involutions ectoderniques, fubuleuses, qui s'enfoncent dans l'intérienr du corjs, et s'y divisent en hranches.

Appareil irrigateur, et lissus dérives du mesoderme. - le protendoderme des Arthropodes est un tissu mésenchymaleux; l'endoulerme, qui dérive de ce leuillet inilial, acynierl me disposilion épilhéliale; le mésoderme conserve la struchure mésenchymateuse. Hes vides, dont l'ensemble compose un schizoecelome, se crensent dans le mésoderme; ces espares lacunaires deviennent nombreux, ot sunissent en un polyrulome, qui est l'appareil irrigateur le res animanx. La motamérisation, que plusienrs auteurs disent avoir rue dans le fenillet moyen des Arthrojoules, est due ì ce fail. que les éléments du mósollerme ventral se rassemblent en grande puantití virs la base des appendices, ces derniers Clant placés à égale distance les mns lerrière les antres; la cavité, qui se crense dans l’intérieur de ces ébauches d’appenlices, est la prenière lacune formée dans l’amas mésodermique de chacune d'elles. - Jes lissus mésodermiques sollilféreneient, sur place, en filres museulaires, ou en hrmolymphe, jlasma rhargé d'éléments figurés: ce plasma remplit les villes in fenillet mosen, el y circule. Pour proshine une tibre musculaire, ehaque cellule mésenchvmatense sentonre de sarcoplasme, et grandil par le dépôt incessant le sulsslance contractile; elle finit par levenir cylindrique, et augmente, à mesure quelle saccroît, le nombre le ses novanx par leur division répétée. - Le colps alipeux est constitué par un amas le cellules mísontermigues, placées dans la rógion lorsale de l'embryon, et conlenant des granulalions nutrilives. - Le conur est engendré frar une masse cellulaire, siluće au-rlessus de l'enléron des Insectes, ou du provtron des Cruslacés, qui provient du mésolerme, et sallonge en se rreusint l'une cavilé centrale; celle derniore leviendra la cavité carliague.

Organes sexuels. - Lorigine des glanules sexuclles prète encore à contradictions. Daprès plusiems autents, l’èlanche de ces organes proviendrail des collules polaires; elle serait d"origine mésodermique d"apres les autres. Les combuils sexnels, sanf lenrs régions imméliatement moies aux glandes, el ıni ont la mème provenance quelles, dérivent de l'rectoderme. Parfois la sexualité comporle un dimorphisme phs on moins prononer.

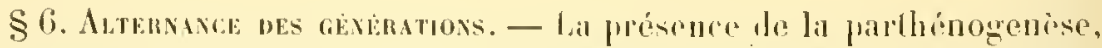
che\% plusienrs Crustacés el lusectes, entrame à sa suite me lritérogonie. l'hétérogonje des Custacés existe chez ha phuprl des Clarlocères; elle 


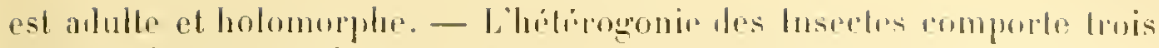
types. Colle de certains Lipidopteres el Ilyménopleps porte-ajunillons est une hélérogonie alulte, et holomorphe. Celle ales Ilymunoplerrs zallicoles et des llémiptères Phytophthires ast une hélérogonie adulte at hétromorphe, lont le point de lepart se trouve, pour ces ilerniers, choz. rertains Coccides; les femelles parthénogénétiques des Cocciles, les Chermes, et des Phylloxera, sont ovipares; celles des Aphides el des l'emphigriles sont viripares. Enfin, lhélrerogonic le plusienrs Diptères némocères, apparlemant aux genres Chironomus et hiustor, est emliryounairs. 


\title{
EUBRACHEMENT DES CUOETOCONATHES
}

\author{
CIIAPITRE II \\ DEVELOPPEMENT DES CHETOGNATHES
}

\section{\$1.-Considérations générales.}

I. Garactères. - Conlomates Jont le rulome provint directemint de l'mutéron larvaire, par un double plissement de la paroi de ce dernier. Le mésoderme, simple, est tout eutier l'origine épitbéliale. Des appareils excrétaurs définis font défaul. Les centres nerveux sont représentés flar dem masses ganglionnaires, dont l'ume, placée dans la tête, est supérienre par rapport an tube dignstif, et lont l'autre, silnér vers le milien du corps, est inférinure à ce mème apparril.

Cet embranchement ne conticut qu'un petit nombre de genres, dont le plus conuu est le genre siagithe

II. Développement en général. - L'embryolog̣ie, el l'organisation, de cres êtres ont élé ítulibes par Bütschli, Cirassi. el O. Hertwig. La structure en est fort simplr, aussi pou complexe que celle des Nématodes, aupries dusquels on les classe parfois; sauf les ganglions nerveux, les muscles cripaliques, ot les glantes sexuelles, qui conslituent des masses cellutaires de quelpure volume, lo reste du corps se compose simlement to couches iputhélialus. on l'assises épiltélio-musculaires. Aussi, la connaissance dre trur cmliryologie se róduit-elle à enlle de lévolution des feuillets hastodermiques, qui produisent ces assises sans subir des moditieations lien grandes.

La reproduetion des Clurtognathes est sexuce. - Denx faits sont it remarquer daus lo diveloppement: l'origine du colomo, et celle des f́léments sexucls. Contrirement ì re qu'il en ost chro los autres Entérocalomiens, tr coelome n’est point engrndré prar deux diverticules, émanés de l'entéron, qui se reneontrent, et s'unissent pour former un 
senl tout; il rst simplr lors de son délunt. car il dérive dirrectement dr la la majeure partir de l'ontéron larraire, l'autro partie šisolant pour donner Jintestin. Les Cloctognathes offent de plus lo seul rxemplo, parmi fous les animanx à l'évolulion rmbryonnairn dilatér, d'une origine préroee des éluanches sexurlles; ces lernières, représentées par un petit nombre dre cellules, qui constiluent ainsi de véritalıles initiales, so diflérencient dès le commencement do la phasr gastrulaire.

\section{2. - Segmentation et développement des feuillets.}

\section{Segmentation et genèse des feuillets embryonnaires. -} Les ragilla, seuls trpes dont l'embryogénie soit counur. sont hermaphrodites, et rejettent dans l'rau lenrs oufs, aree leurs spermalozoüdes; la féconlation est rxtérieurr yar suite. Les roufs féconlés sont entonrés par une membrane vitolline, et par un chorion: les jounes subissent, a l'abri de celte coque, los promières phases de leur évolution, el ne diffirent pas trop de l'adulte, an moment où ils éclosint.

La segmentation, régulièr ó égale, a pour effot lo convertir lovule fécondé en une morule, juis en une blastule; le blaslocele de cette drerniire est étroit, el son blastoderme se compose de culules cylindriques assoz allongées. La hlastule se transforme, par le procéré invaginant, en une gastrule; fo lastocutr disparait ì mesure qur linvagination saccentue, et le protenlorlerme va saccoler exactement au protectoderme. - Pendant que ce ilernier phénomène se manifeste, l'entéropore se rétróit de plus en plus, et ne tarle pas à se fermer. D’antre part, deux des ecllules dn protendoderme, placées dans une région diamétralement opposée à l'entéropore, granlissent plus que leurs roisines, et se dislingment d'elles, gràce à leur taille plus consilérable; elles sont les initiales sexuelles déjà signalées, et se multiplirnt, durant les phases ultérieures du développement, ponr engendrer les organes de la reproluction.

Au moment oì l'entéroporo se pripare à se clore, et où se lélimilent les initiales sexuelles, le prolendoulerne se soulève en deux régions juxtaposées, contiguris ì celles qu'ocenpent les initiales, et de mème opposies i l'entéropore. Ces lenx zones forment loux replis, dont les parois ne se composint que d'éléments protendodermiques, et it la genése lesquels le protectorlerme ne prend aurune part; en s’allongeanl, elles s'avanent dans la carité entérique, et, daus teur extension, elles entrainent aver ellos les initiales sexuelles, quelles portent sur leur hord lilore. A la suite de lapparition de ces leplis, le fond de lenteron. r'est-ii-dirr la face opposie a l'entriropore, s'est divisé en trois culs-rlesac, l"un médian et les deux autres latérux: le premier est chargé de Jonner l'intestin drinitif: les denx autes, joints i tonte celte partio le l'entéron qui avoisine l'entéropore, el n’est pas comprise dans les rulsle-sac, produisent le ecelome. Chacun des doux replis limile la loge 


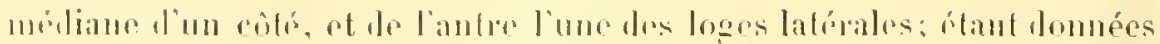
leur urigine ef leur nature, charmu deax se compose de demx assises cellulaires juxlaposées, qui sunissent par leur borl libre, et se jojguent, à leur liase. avee le reste du jrotendorlerme.

Lorsque ces plénominos nnt déji pris nur cortaine extonsion, la cavité entérique so lrouve livisér un denx zones : l’une simple, et roisine dr l'entiropore, l'antre protonde, el partacée an trois culs-de-sac contigus. Ces derniers communipuent lapement, au moment de leur apparition, et pemant lem croissance, avec la zone simple, mais les fails ne lambent pas a changer" - Les deux replis se soudent de manière

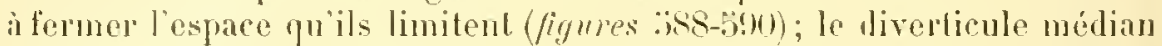
levient ainsi isolá, et inlépendant de la zone simple comme de sos deux voisins. Il représente des lors l'éluauche intestinale, car les culs-rle-sac latéraux s'unissent à la zone simple, pour conslituer le curlome par leur ensemble. La majeure jartir de lientéron embryonnaire est done employé ì produre le colome, conlrairement ì ee quil en est chez les autres Entérocolomiens; de plus, l'ólauche tre cermier, lien que montrant déjà une disposition bilatrale, a cause dr la prósence des deux culs-rle-sac laćraux et srmétriques, est simple, el non double, puisque la zone voisine de l'nntéropore ne se sublivise point. Ces deux particularités éloignent les Cholognathes de lous les antres animaux, dont le calome esl d'origine autériugue.

liontion de l'embryou s'est ainsi seinlé on colome et inlestin; de mème, le prolendoderme s'ost divisé en mésoderme el endoderme. Chaque repli est formé par une paroi double, et présente loux faces, lune proximale el tournér vars le divrolicule intestinal, l'autre distale ol limilant le diverticule arlomique plaré le son rité. Les deux laces proximalos les replis dounent la couche endodermique; et les ileux faces distales, jointes an prolendoderme non compris dans le souleyement qui a fourni les replis, produisont le mésolerme.

l'endant ques'ellectuent ces divel's phénomènes, l'entéropore se ferme, et se trouve clos au moment ou l'intestin so sépare du colome; ce dernior est ainsi isolé du dehors, lorsqu il se lélimite pour revélir ses caractèrs particuliers. l'autre part, une drepession se crouse daus le prolectoderme, en une region opposée à celle yuocmpait l'entéropore: ellr s'approfomlit, et se convertit en mn potil luhe, qui, lout en conservant son orifice, s'unit à l'ébanchr intrstinale. Celle-ci communique douc

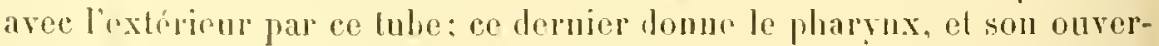
ture la bonche.

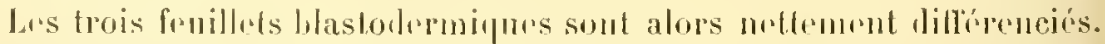

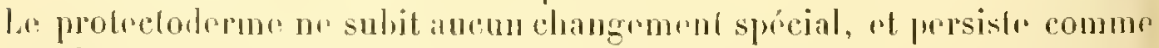

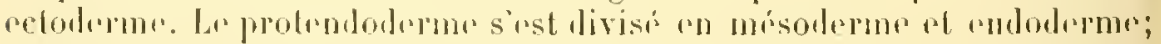

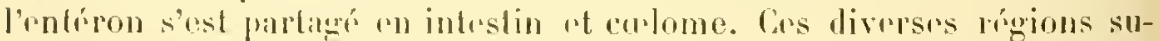

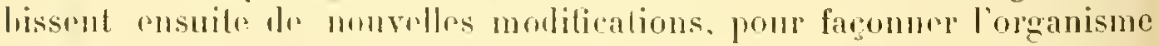
définitif. 
II. Phases ultèrieures du développement. - l'arrmu in at

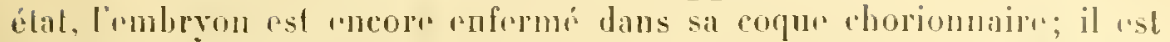
sphrique, ou largement ovalaire. Des lurs, son corpes va sallonger pump derenir cylindrique, et se courlera sur lui-mème dans lespace que limite la coqure; lagrandissement est surtout le fait de la rígion poste-

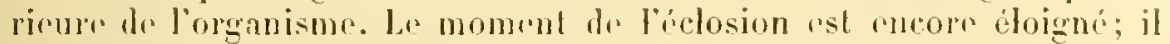
arriv lorsque le putit ètre a prisgur complété sa slruchure entièr.

Lictoderme n'offre aucums particularití saiflante, sauf colle de tonner naissance aux centres nerroux. Ce feniffet s'ípaissit, en sa rógion módiano, dans l'extrímiti antérieure du corps, ot la moitié antérieure to la partie vontrale. La cordon, ainsi engendré, est plus volumineux à ses deux houts qu'en son milieu; il représente l'ébauche des rentres nerreux, et se sépare, dans la suile, de rectoderme qui la produit. Le bout le l'extrémite antírienre donne lo cervean, el la masse de la face ventrate fonmit le ganglion ventral; le reste du cordon, qui unit le premier à la secomle, persiste pour former les commissures péri-arsophagiennes.

l'endoderme el le tulie digestif ne présentent point, de teur côté, des modifieations hien grandes. L'ébanche intestiuale offre l'ispect d'un tube, fermé en arrière, el ourert en arant par la bouche; sa cavité est fort étroite, et son extrémilé postérieure, suspendue dans le colome, atteint à jeine le milieu du corps. Cette ébauche est composée de deux parties : l'une antérieure, d'origine ectodermique, qui possède la bouclıe, el produil le pharynx; l'autre postérieure, engendrée par l'entéron larvaire, ot limitée jar l'endoderme, donne l'intestin proprement dit. Cefle-ci se rapproche, par son extrémité distale, de la face dorsale du corps; clle se soude, sur la ligne médiane, it la paroi de cette région: une auverlure se perce lans la zone de soudure, permet ainsi a l'intestin de communiyuer avec le dehors par un second orifice, et devient l'anus. Le lube digestif est alors complet. La perforation, qui ahoutit a la genise de l'anus, est assez tardive dans les phases th développement.

Les changements les plus profonds portent, dans févolution des Churtognathes, sur le mésoderme el le colome. - Ce dernier grandit beaucoup, de manière il se convertir en une ample carité, simple cn arriere, et poussant deux divorticules vers l'extrimitélnocale du corpss; étant donnée lun origine, ces derniers encadrent l’untestin. La région anterioure de chacun l'eux so divise transversalement, par une cloison, en deux prarts; la première, pelite et close, se tronve placén an nivean de l'hanche pharygienne; la seconde, plus grande, se continne en arriere arec le cutome simple de la région postérieure de l'organisme. Celle-ci lome fo culome du corps, et colle-ti le colome ciphaliqur, car la partic du corps, qui lui correspond, devient la tide de ladulte. Le colome céphalipue disparait par la snite. Le calome du corps grandit au contrine, et persiste durant la vie entire: comme la cavité céphialipue est de dimension rostreinte, il posside encore lasprect hu colome ini- 
604

C.IAPITHF ON\%ENF.
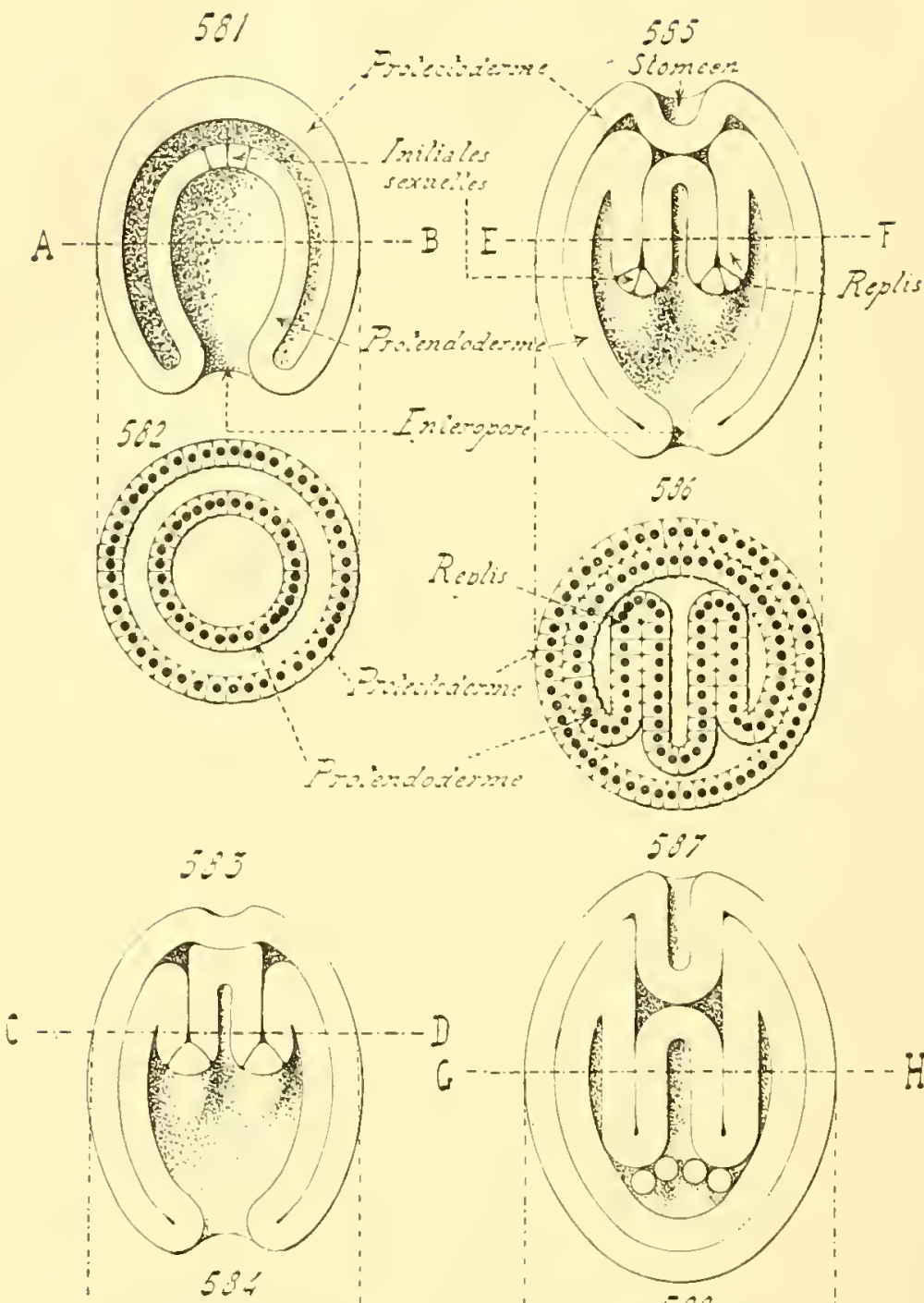

589
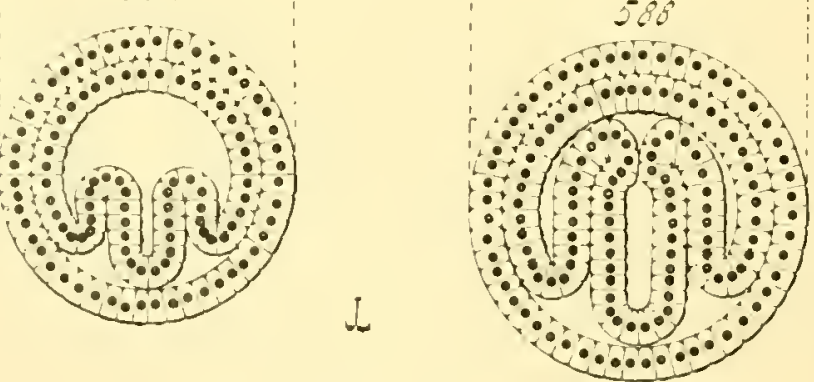

Fig. 581 a 596 . (Pour la legente, voir p. tior.) 

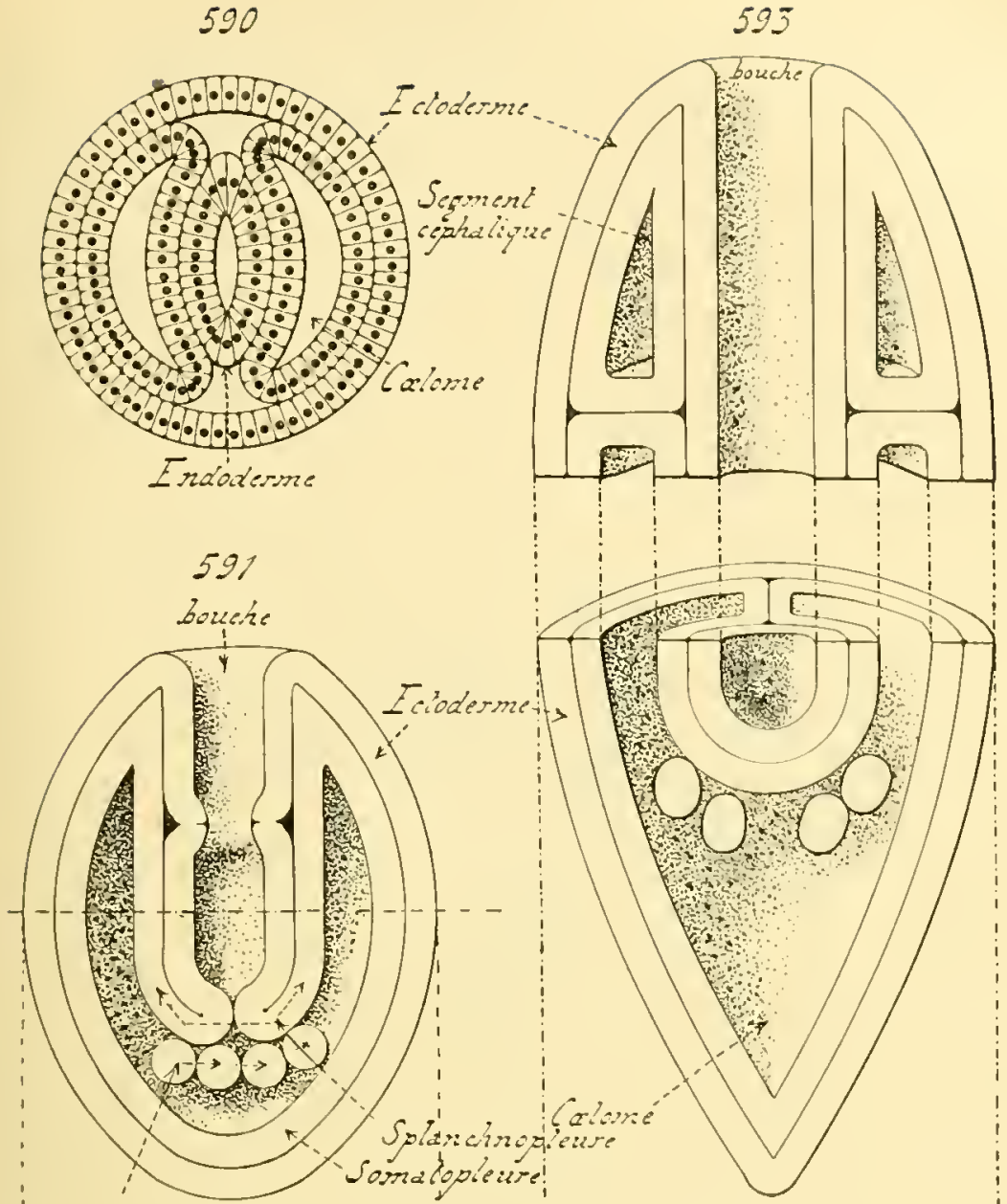

Jriviales sexuclies 592
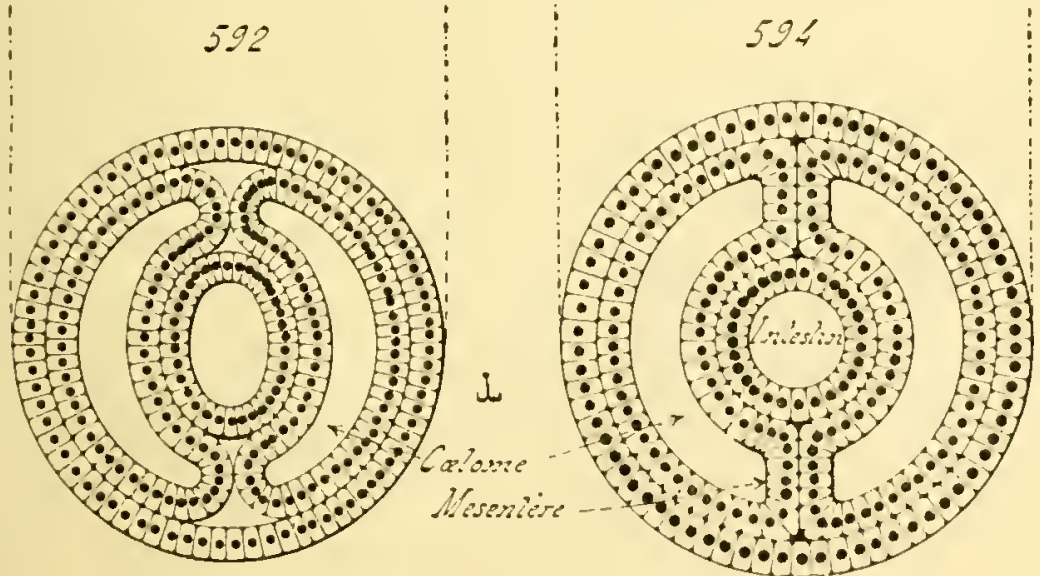
lial, w non encore divisé, cest-i-elire celle l'un espace simple et postérieur, poussant ru arant deux divreticules; l'aceroissement est surtout

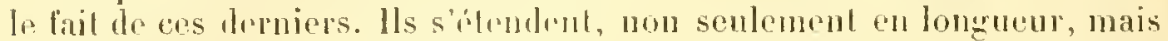
encoredans le sens transversal, el entourent lintestin; ils se rencontrent alors sur la face dorsale el la face ventrale du corps, envelopjent le fube digestif llune manière complete, et s'arlosirnt l'un à l'autre en ces deux régions. Les zoues alossés no lisparaissent pas; elles persistent sous la forme dr bantes. les mésentères, qui s'insèreut d'un côté sur la paroi intestiuale, le l'autre sur celle du corps, et soutiennent le lube digestif dans l'intérien de lorganisme. - Ces mósentèes oflrent l'aspect de Jenx doisons, l'une mólians el ventratr, l'aulo médiane of dorsale, qui séparnt l'un de l'autre, el isolent, les deux diverticules culomiques: ils s'itendunt en arrière par la snile, lans le colome simple postérieur, el le divisent de mème on deux pats. Le culome du corjes est alors srimlé en deux moities, lune droile, laulor ganchr; cetle disposition reste définitive.

l'ar la préscuce du culome, le mésoderme du corps se compose de deux fruillrts. La splanchnoplrurrest constiluée par celte parlir du mésoderme des diverticules, qui s'aplulipue contre l'intrstin; la somatopleur.

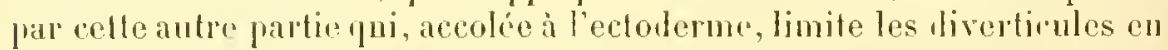
dehors, et aussi loule la portion simple du culome. La somatopleure smint à la splanchnoplenro an moyen des mésentiores, et de la cloison qui arroble en arriore les cavitós céphaliques. Le fenillet mésodrrmique viscéral se comvertit en un endothélium, tapissant la lace "xleme dis la paroi inteslinale. Le fenillot prariclat dome, tout en conservant sa disposition épilhéliale et ne la prerlant jamais, la musculature du corps. Les fails sont moins bien conmus ponr le mésoderme céphalique : les eavités eulomiques disparaissent, semble-t-il, ot le mésodormo s'emploje a jroduire les divers muscles périluceaux. La cloison, qui limile un arrière les cavilós céphaliqurs, prosiste chez ladulte sous la lorme d'une membran : cello-ci se dégage de liextrémité antérienre des mésentìres, jour se porter oblipuement vers la paroi du corps.

hes initiales sexuelles, étant soulrées par les deux roplis lbu pro-

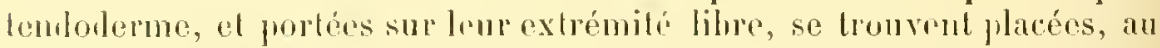
moment ou ces replis so soudent par ces extrémités pour former lintes-

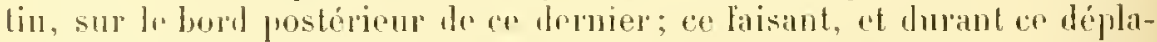
crmont, ellos so divisent en leux frats, dr facon à jouduire qualro initiales. Collos-ri so rassomblont en denx grouprs, de denx cellules chat'fur, dont l'un se place à looitr, et l'autre à ganche, du lube digestil. Cilarun des groupes conserve lésormats sa siluation, et se rompose de frux flémonls plarés à la file: ces derniers se multiplient par la suilo, l'antóricur donnant l'ovalie, et le postéricur lo lesticule. 


\section{RÉSUMÉ}

S 1. Coxsmentors Gixhules. - Lrs Cholognathes se reproduisent seulement par la roie sexuée. Les particularités les plus imporlantes d. leur développement st rapportont : a la genese du culome au moyen de replis protendodermiques yni s'arancent daus l'entéron, et a la prósence tris préroce d'initiales sexuellis.

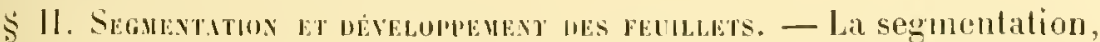

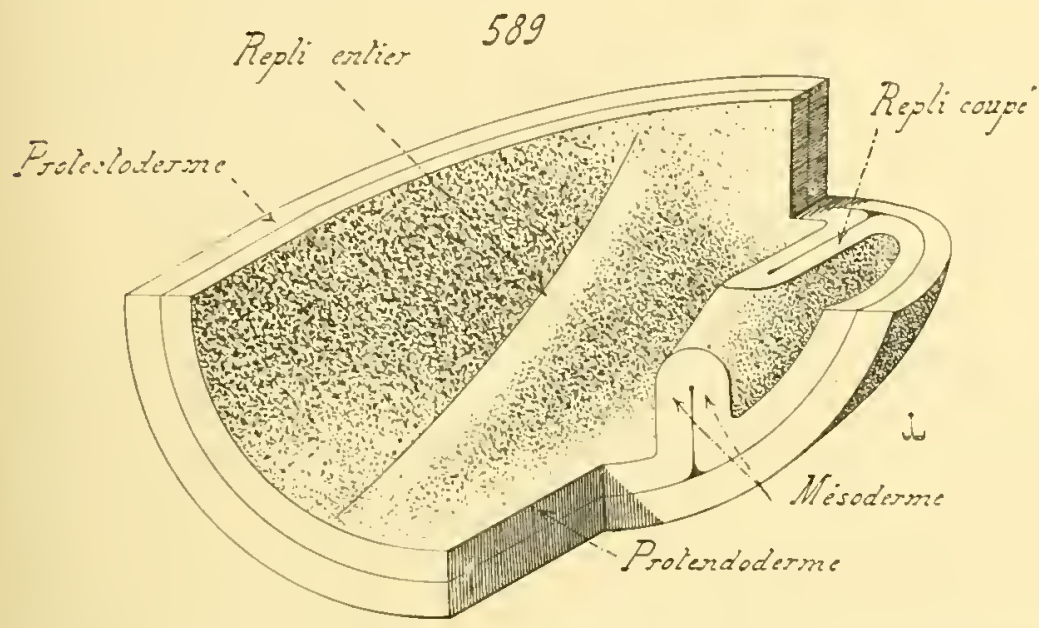

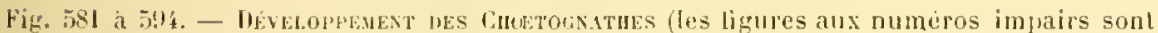
des corpes meilianes et lonjiludinales, atec jerspective, vues par la tranche; les ligures aux numeros pairs sont des roupes transversales, enticres, menées suivant les lignes, correspondantes, l'acées sur les précédentes; la structure cellulaire n'est indiquée que sur les coupes transversales). - Lin $5 x 1$ et is?, nhase gastlulaire; les initiales scxuelles comnencent a se délimiter. - En 583 et 584 , les deux replis du proteudoderuse prennent naissance. - Ces replis sillongent en 585 e 6.86 , pendaul que l'entéropore commence it se fermer, el le stomeon a se creuser. - lin 587 et is8, ces phenomtes s'acentuent encore, el les divertieules latéraux sont presiue isolés le la poche mediane: culle-ci levient l'entiron.

La figure $5 \$ 9$ reprèsente une coupe de l'embryon prècédent, menée suivant divers plans, afin de montrer la nature exacte des deux roplss du protendoderme. Ces derniers sout "quelque peu obliques, et leur extension a pour ellet de suulever la region yui les polte, un lui donnant la forne d'un boyau, qui s'abouche avec le stomeon d'un cote; ct qui, de l'autre, rétrecit peu à peu son orilice, de maniere à le clore. Confrairemsnt à co que semblent montrer les coupes trausversales, les replis no délutent point par s'accoler, pour so souder a la fois sur toute leur longueur; leus union procèle de prodie en proche, en allant d'avant en arrière.

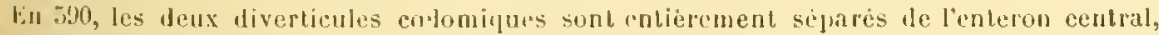

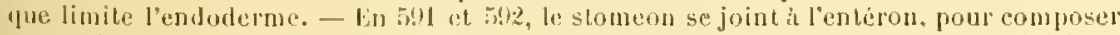
avec lui un intestin complet, dont la région postrieure est presuge close: les iniliales

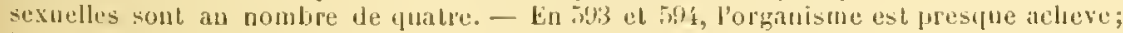
te sepment cephalique du culome, et les misentères, ont pris nitssance; l'intestin s'est ferme dans sa partie posterienre, et l'anus ue lardera pas a se percer; les initialcs sevuelles out pris lenr position definitive.

H'après les recherelses faites par lbistschli et 0 . Ilertwiz. 
égale, domne une morule, puis une blastule, enfin me gastrule; le protendoderme invaginé va s'appliquer contre le protecloderme, of fait dispraitre lo blastocale; l's initiales sexuelles, an nombre de denx, se différencient dans le protendorlerme, en une région opposće à l'entéropore. Le protendoderme se souleve dans cette mème région, et produit deux replis contigus, qui grandissent en s’ançant dans la cavité entérique de la gastrule. Ces replis, tout en s'étendant justjùi dépasser le milieu de cette cavité, se sondent par leurs bords libres; la portion d'entéron, qu'ils omprisonnent ainsi, devient l'intestin; le resle de l'entéron persiste comme colome. L'entéron est alor's divisé en intestin el colome, et sa paroi, c’est-à-dire le protendoderme qui le limite, se trouve également partagé en endoderme, qui entomre l’intestin, et en mésoderme, qui entoure le colome. - Pendant que s'ellechent ces changements, l'entéroprore se ferme; une dépression ectodernique, qui apparait dans une région opposéc à celle qu'occupait l'entéropore, ra s'unir à l'intestin, et donne la bouche avec le-pharyix.

Le protectoderme se converit on ectoderme, et produit les centres nervenx au moyen d'une scule ébauche continue. L'intestin, qui communique avec le dehors par le pharyux et la bouche, se perce en surplus d'un anus dorsal. Le cuelome grandit beancoup, et se cloisonne transversalement, dans sa régrom antérieure, pour engendrer des cavités céphaliques, qui disparaissent par la suile. Tout en s'accroissant, ses deux parties latérales entourent l'intestin, et s'adossont l'une à l'autre au-dessus et au-dessous de cel organe; les régions accolées persistent comme mésentères. Le mésoderme céphalique produit les muscles buccaux, et la somatopleure dome, dans le reste du corps, la musculature qui s'y trouve. - Les initiales sexuelles, dont le nombre est porté à quatre, se divisent en deux groupes; rlacun de ces derniers se compose d'un élémenl antérieur et d'un élément postérieur; le premier fournit l'ovaire, et le sccond le testicule. 


\title{
EMBRANCHEMENT
}

\section{DE: \\ NEPIIROPIORES OU ONTCHOPHORES}

\section{C.IAPITRE III}

\author{
DÉVELOPPEMENT DES ONYCHOPHORES
}

\section{\$1. - Considérations générales.}

I. Garactères. - Les Néphrophores, ou Onychophores, sont des Colomates dont le celome semble produit par deux diverlicules entéríques, qui šisolent de l'entéron, et s’étendent dans le corps. Le mésoderme, de structure épithéliale tout d'abord, prend par la suite une disposition mésenchymatense. Les appareils excrèteur's sont étahlis d'après le type des néphridies des Annélides; ils consistent en tubes nombrenx. groupés par paires, dont charun fait communiquer le colome avec le dehors. Les centres nerveux sont constitués par un cerveau, d'où partent deux cordons médullaires distincts, assez éloignés l'un de l'autre, qui parcourent l'organisme entier sur sa face ventrale. L'appareil respiratoire est composé de trachées, disséminées sans ordre régulier.

Ces caractères réunis contribuent ì faire de ces êtres un embranchement particulier, qui ne se rattache à ancun autre. Comme le montrent les phénomines dn développenent, les néphridirs, qui rappellont de pris relles des Annélides, lorsqu'elles sont complètes, en diffirrent cependant par leur origine, et ne leur sont pas homologues; la ressemhlance est le fait d'une simple analogie. Wautre part, la ggenèse des feuillets ne concorde en rien avec celle olferte par les Arthropodes, pas plus, du reste, que les traits essentiels de l'ívolution des appendices. Ces animanx sont raiment à part dans la série des Colomates; seule, l'origine entérique de leur corlome permet de les classer parmi les lintírocolomiens; encore, ce dernier phúnomène, signalé par lialfour, et digne de créance í cause de la grande autorité de ce naturaliste, n'a-t-il pas été revu depuis, dans les mèmes conditions.

L'embranchement des Niphlophores, on des Onychophores, ne con- 
tient, dans Ia nature achelle, qu'un seul genre, lo genre Ieripatus, dont les diverses espices habitent l'Ampiqune équatoriale, le sud de l'Afrique. ot la Youvello-Zólamele.

II. Développement en général. - Lil reproduction des Péripales s'exerce seulement d apris le mode sexurl.

Gulre les particularitós de l'orgine, el le l'érolution, de la plupart les organes, l'enbryogénie offre un certain nombre le caractìres, qui contribuent pour heaucoup a angmenter les singularités de cet animal si remarpuable. Apres la fécondation, les neufs sont conservés par la femclle dans son ulérus, oi les embryons se développent; la paroi utérine fournit à ces lernicrs une enveloppe amniotique, et un placenta. L'entéroprore, on du moins l'orifice qui parait lui correspondre, s'allonge extrumement ì la surfare du corps de l'emlryon, s'étrangle en son miliou, oì il se fermo, et se livise ainsi en deux ouvertures, dont l'une devicut la bouche, et l'autre l'anus. Les appendices, el surtout les antennes, semblent d̀re plubôt de larges expansions tégumentaires, qui rigularisont ensuite leur forme, que des membres réels, fixés dòs leur Jélul dans un aspect préris, comme cenx des Arthroporles parexemple. Linfin, dans l'óvolution de ces apprndices, comme dans celle du colome, des néphridies, des conduits sexuels, les Péripates oftrent des caraclères spéciaux, que l'on ne trouve pas ailleurs, et qui contribuent ì faire d'eux un groupe des plus distincls. La liaison un'ils paraissent établir entre les Annélides. el los Arluropodes mmis de trachées, liaison qui leur vaut souvent le nom de I'rotruchéates, est loute de surface; elle s’appuie sur les ressemblances suporlicielles, non sur des homologies réelles.

Les autrurs aỵut étulié la struchure, et lo développenent, des l'éripales, soul assez nombreux: les principaux d'entre eux sont balfour, Gaffron, kennel, lloseley el Serlgrick. L'organisation de l'adulte est à peu près élablie, el ne prête pas à de grandes contestations. Il n'en est pas tout à fait ale mème pour l'embryogénie; les divergences, plus nomhreuses, portent sur l'origine des ébauches organijues, ou sur la valeur ‘u’il convient de lemr donner. Certains phénomines, comme le léveloppement entéroculien de la cavití générale, lel que l'a vu balfour, meritent te nouvelles ronfimations.

\section{2. - Segmentation et développement des feuillets.}

I. Phénomènes extérieurs à l'embryon. - Les aufs fécondés

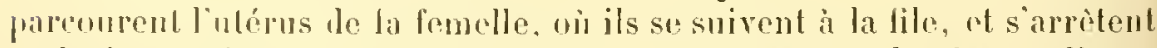
it plusieurs nirranx. La proi ulérine s’élargil antour de chacun d'eux,

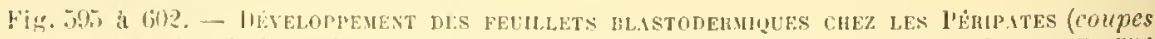
transversules, it demi dingrammaliques). - En 505, debul de la segmentation. - En 516 et $5 \%$, achevement le la segmentation; les règions internes des blastomères s'unissent en un spllcylium nuclée. - lin isg, la disposition syncytiale s'étend à l'uruf entier. au 

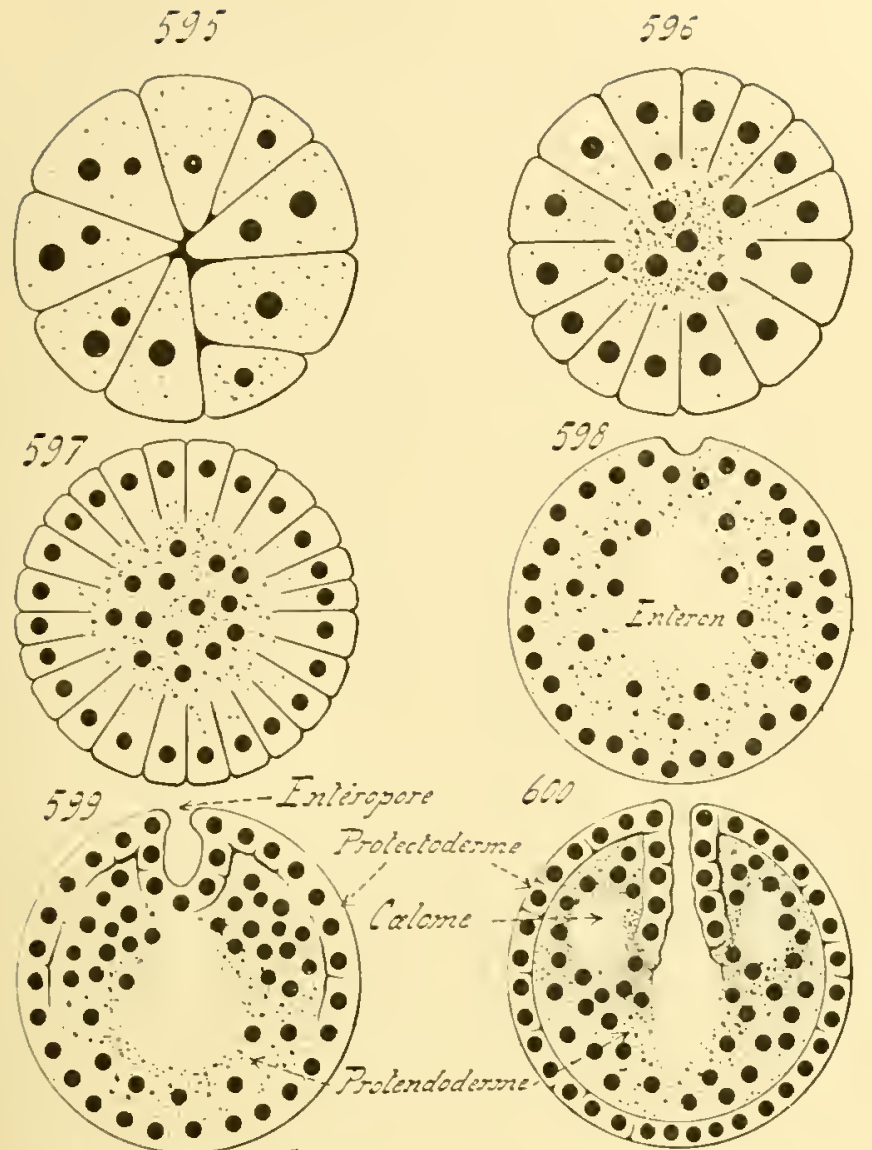

660
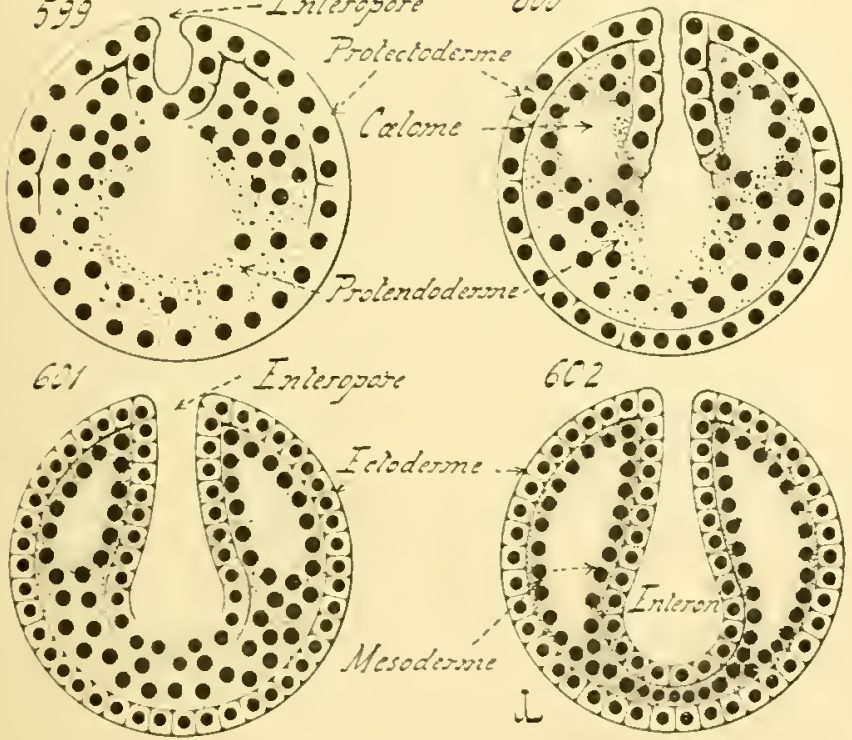

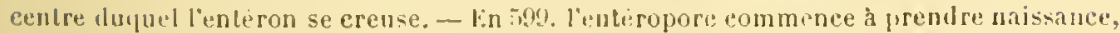
p.l le protectolerme à se délimiter. - En 600 , l'enteropore s"abourhe avec l'entiron, r:t, tout autour de l'entiopore, le protendoderme sẹpassit, en se reusant de denx cavilés

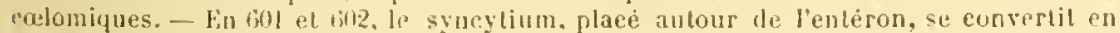
un endoderne, pendant que les eavites culomiques grandissent, limilees par le mésolerme, issu du prolendoderme restant.

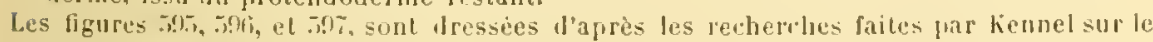
Jeripalus Lidwardsi; les autres l'aprè- les itules de: lalfour et de Sedgwieli sur le Peripalus crapensis. 
four former mo sorle de poche dans lapuelle l'uruf est placé, el se resserro dans les espares intermérliares, on la lumicre ulérine se troure,

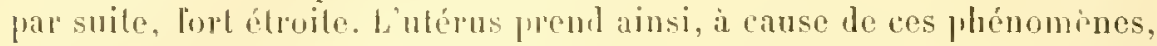
et dans la région occupee par les emliryons, placés les mos aprós les aulpes, un aspeet noneux. - Chacme les poches produites, qui penvent porter le nom de vesicules incubatrices, car l'embjon y subit une rérilable inculation, se ferme completement. Dans les zomes oi la cavili le la poche so continue arec celles des espraces resserrés et intermódiaires, le rétrécissment, plus prononcé yuarlllenss, liait alloronler, el finalement sonder, les portions de prorois mises en frésence; chaque résicule incuhatrice, frourne le son wuf, devient close, el inlépendante le ses roisines, comme lu reste de la cavité ulérine.

Lespace creux lo la vésicule est de heaucoup phus grand que l'ovule; a mesure que celui-ci se déreloppe en combron, il s'acroit, et le remplit peu à pren. Plus tard, lien que la vésirule augunente le limensions, par suitr le la pression fue l'embryon exere sur clle, relle amplilicalion est trop minime four suffire a l'allongement lu petit ètre, ol ce dernier sconoule sur lui-mènc, afin le lenir dans celle cavilé restreinte.

lianf ne restr pas libre daus la vésicule; il s'accole a mo zone de sa paroi, el se soutle à elle. La paroi utérine ne dememre pas inerte, lorsque

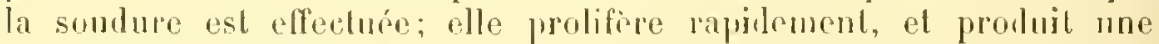
masse rellulaire, qui s'avance dans la cavifi de la vísicule, en emporlant lieuf ave elle. Cello masse rignlarise sa forme, pentant que lovale se segmente, el se comvertit en emluyon. Elle se divise en deux parts : l'ume, large, qui se tient attachée à la proi utrine, et se confond avec elle; lanhe plus mince, rylindripue, qui s'muit a la lace lorsale de l'embryon, non loin de son exlrinité antérieure, dans la région occupée par le juemier segment du cospls. Celle-là a regu le nom le placemtu, el la seconde celui de cordon placentuire. Ces deux organes tépendent de la frar utérine, w non le l'embryon lui-mème; ils sont pleius, el ne conlienuent aucune caviló.

Les phénomènes me s’arrèlent pas lì. In momont oì l'urule s’allache à l'ulérus, la prolilération de ce lernier, qui abontil a l'rbauche du placenta, a pour affol de lonner me masse cellulaipe yui enchàsse,

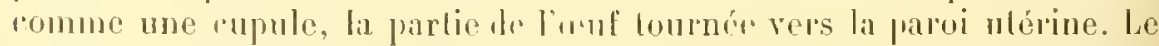
fond le celle cupule s'ruissil, el se souleve, pour loumir sent le placenta el lo corlon déja lécrits; les burds continucul à s'étendre, le maniere à entonler l'ovule, mais à mne certaine distance, el sans sumir a lui. Dans ce monvenent, res loorls funssonl par se renrontrer ol par se souter, en enveloppant le jemne rmbryon; cethe pratie marginale de la cupule forme ainsi une membrune ammiotique, qui délimite, dans la cavili te la vésicule incubalries, une seconde cavilé où se lrouve placé l'cmliryon. Cot amnios est constitué par une assice de cellules aplaties, assez irrégulicre laus sa forme, incomplede par places, el se détruisant

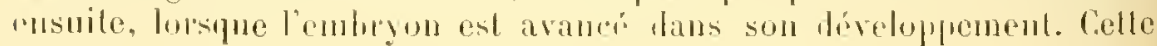




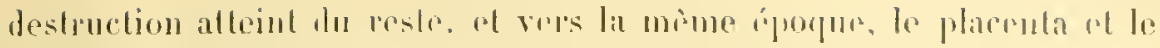
corilon.

Il convient de lo moler, les rxprossions ammins, placentu. romblon, implipuent seulement une idée d’analogir arre les organes la mome nom, que présentent les embryons les Verlébrés, el non un molion da réelle homologic. liamnios, le placenta, le corlon des Vealélurís sont des produits de l'embron; ils sont engrudrés iri par la paroi utérine. rest-àdire jar l'organisme maternel. Leur rile est sans doule d. nutrilion. en foumissanl par osmose, an germe, les aliments nreessaires, ol de fixalion. en lattachant à la proroi de la visiente qui le conlinnt. linsi qüil "n est pour l" placrnta dautres animanx, Jes salpes par exemple. lidentité hu nom indique soulement mo ressmblane dans les retalions, et rien de jlus.

11. Phénomènes propres à l'embryon. - La sugmentalion, ul les procélés géméliques des feuillels lilastodermiques. sonl dus plus

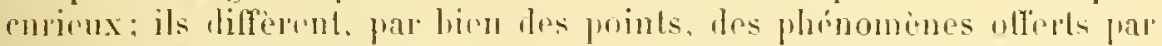
tes autres animaux. Leurs prorlicularitís essentielles so ramiment aux données suivantes: la segmentalion aboutit i mo planule lirecled dans lajuelle se creuse un ruléron. qui communique arec li lehors par un

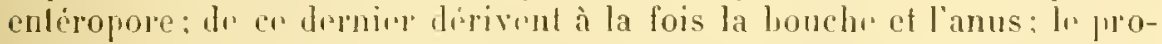
Irnilodrume, an lien de se liviser sur loute son élendue en mésoderm.

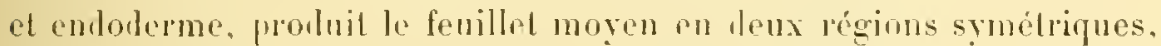
et roisines do l'entéropror", lout romine il an rest choz les Entérorrelomiens an déreloppement comdensé: enfin. les cellules des leux feuillels primordiaux sont, pour la plupart, confondues en un syncylium, dans lopuel la place dos collules nest aceusée qur par la présence de lours noyaux. Cu dernior fail est plus prononcé dans le protendorlorme que dans le jolretorterme.

La sogmentation donne uno plamule divecte, dans laquello les blas-

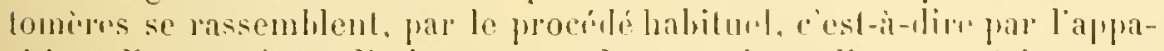
pilion diune mince limilantr. en deux assises, lune rxlirienre el

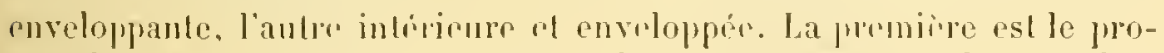

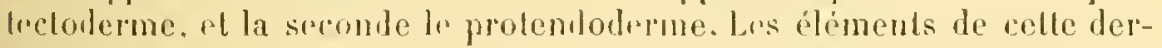
nirre sont mis en un syncytium: crux le la premiere sont assez. distincts, longs at eylindriques. Le protectodrrme no sulit pas de grands

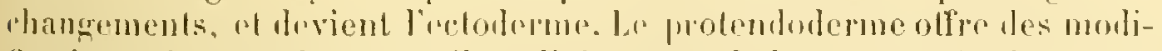
ficalions plus ílemlues, car il se diviso en enturlerme el mésolterme, el se pereo de cavilis, qui se converlissent. suivanl leur silualion, en "ntion i.t "n cuelomin.

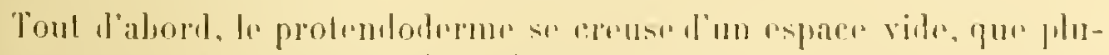

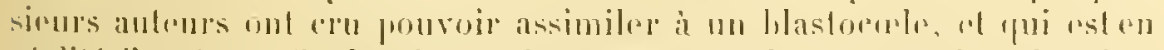

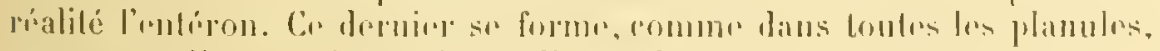

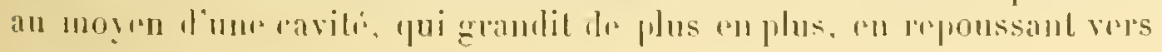


la périphérie les éléments du protentoderme, et se limitant par eux. En oulre, un entéropore prend naissance, el s'amnexe it ret entéron; son évolulion a été bien snivie par lialfour, el Sedęwick, sur les embryous du Periputus copensis. Comme il n’existe point ici de gastrulation víri-

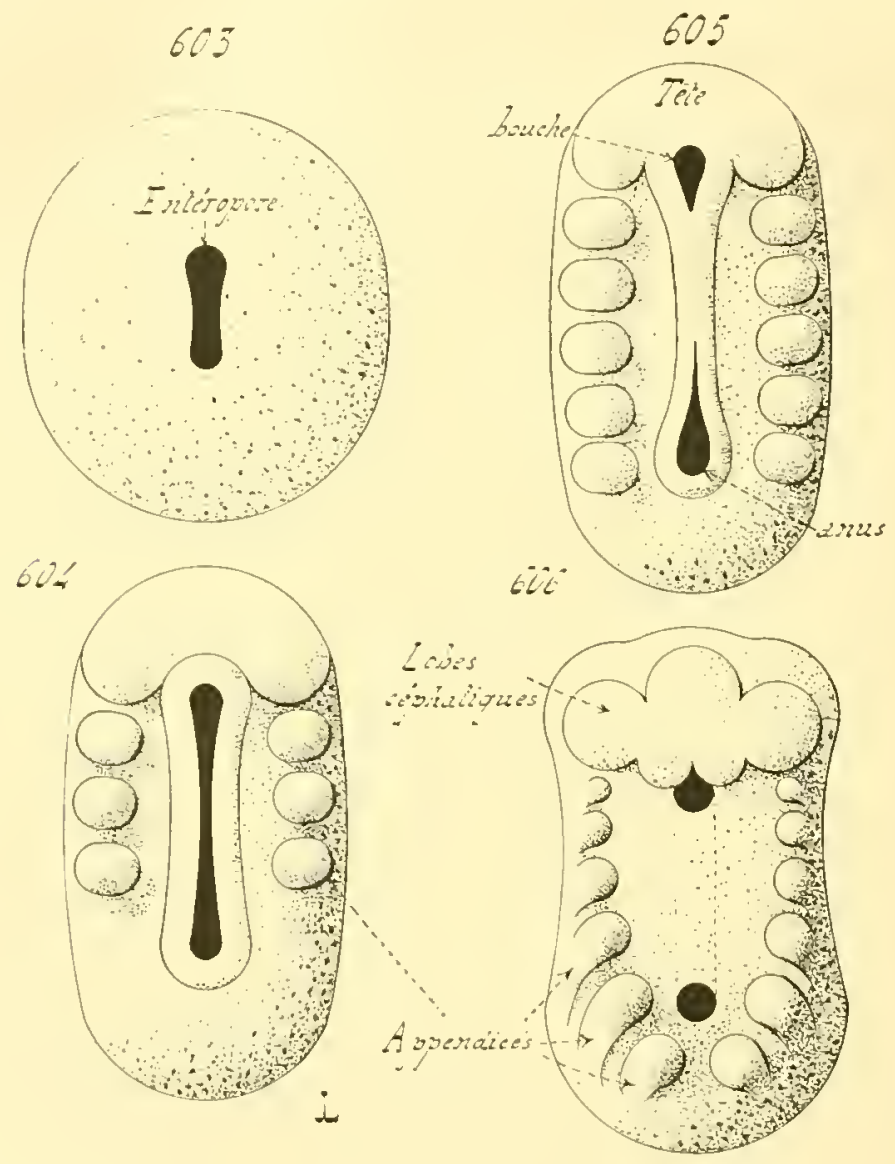

Fì. 603 is 600 .

lalule, l'entéropore n'est pas l'orifice d'une iuvaginalion qui fait défaut, mais nne ouverhre place entre les hlastomères dr la plannle, et chargée do faire communipuer l'entéron avec le Jehors. Son apparition est indépentante de relle de l'sutéron; lons denx naissent presque en mème temps, et s'abouchent l'm avee l'antre. - La valemr l'entéropore doit, sans loute, ètre accordée it cet rritice, car il aftecte les connexions d'un entéropore riel, se montre d'une manière précoce, et produit, par la suite, les ouvertures ligestives; ses caractiores particuliers, lenant ì son 
procédé génétique, peuvent ère attriburs à unc combusation embryonnaire, it un déplacement dans le temps.
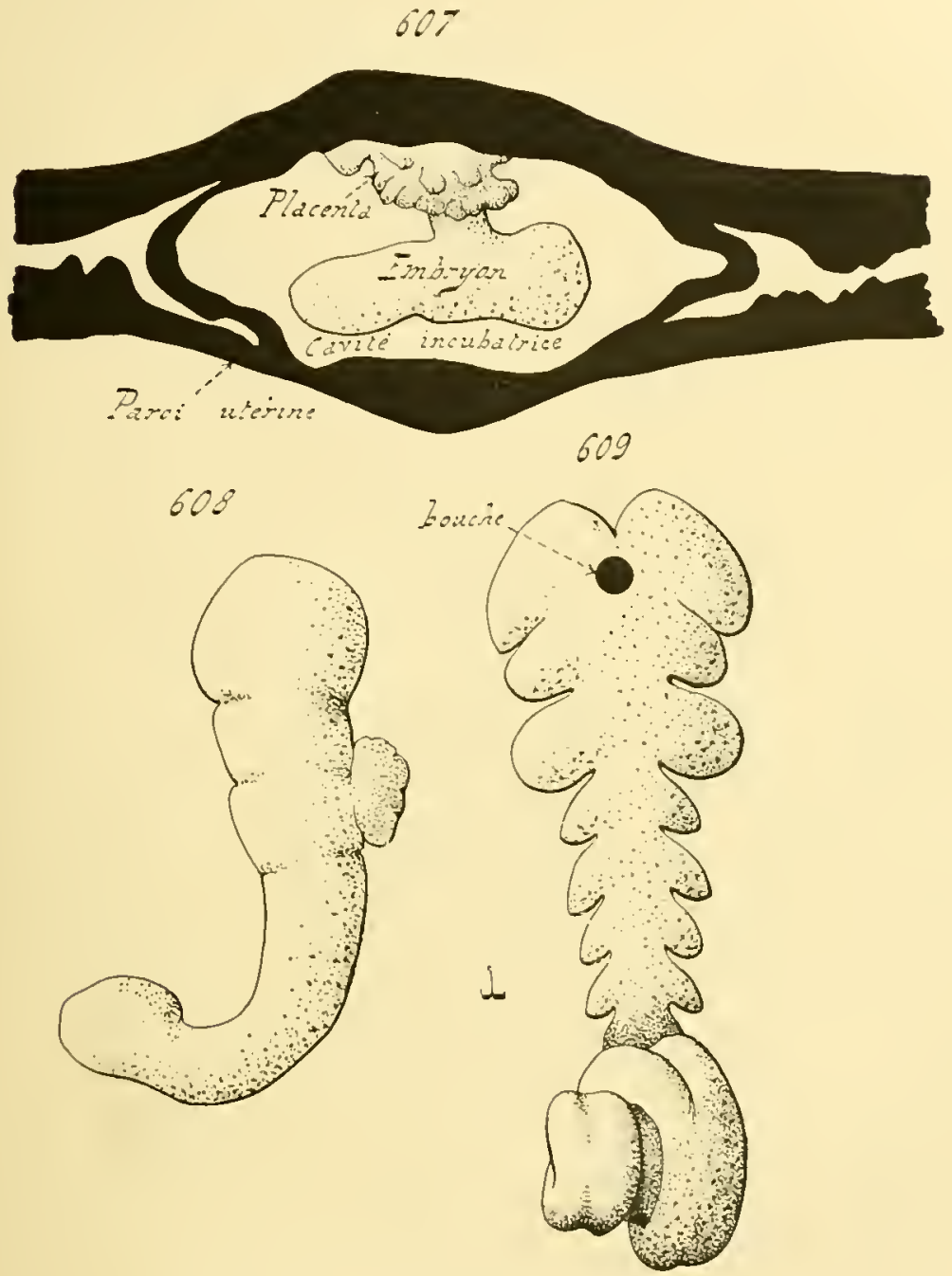

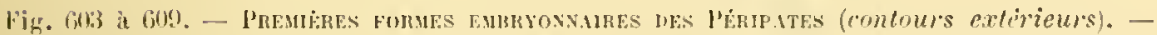
lin 6113, toul jeune umbryon, vu par la face ventralı, et montrant son entèropore encur

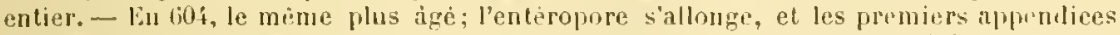
apparaissent. - Fin bon, le mime, encore plus avanci; l'enteropore s'est divise cu bou'be el anus, et de nouveaux appendices prennent naissance. - En 606, embryon plus diveloprut que le juevelent, flont la région prostèreure commence à gramlir. lin tor, jeune embryon, en place dans si cavite iucubatrice, et muni de ses annexes. - lin 6 ils, embryon

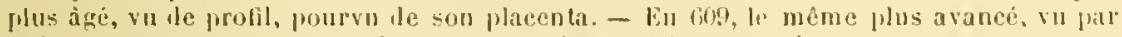
la face ventrilt:, et montraut l'enroulement de sa rigion posterieure.

l.es ligures 6013 a 600 sont drussies d'apres les observations faltes par sedgwicli sur le Peripalus capensis; les figures for a lolog d'apres les etules do lienuel sur le l'eripatus Edurerisi. 
Lat planule s'ost alors convertie on ine vósiculecreuse, dont la ravité est leutéron, et tont la praroi se compose du protectoderme et du protendoterme accolés. La ravité cutŕripue, d’ahoril restreinte, grantit de plus en plus; el l'entéropore s'allonge, de manière à atteindre une longueur, pui égale envirm la moilié de crlle du corps, et mime darantage. II s'élend sur la face ventrale le l'emhryon, pui est alors de forme ovalaire, et ses deux bonts sont placés ì égale distance de l'extrémité antórieure et le l'extrémitó postérieure le l'organisme. Tout en s'accroissant, il reste largement liént dans ses régions extrèmes, mais se rétrécit en son milieu; te rétrécissement s’acentue toujours en celte leruiere zone, et ra jusıu”i une firmeture complìte. - l'entérojore, d'abord nnique el allongé, s’est ainsi converti en deux onvertures sépracées, el placées. sur la ligne médiane the la face ventrale du corps, l'une non loin de l'extrímití antérienre de l'économie. l'antre non loin de l'extrémité posterienre. La première derient la bouche. el la seconde l'anus; tontes denx conservent, en effet, avec la cavité entérique, tes relations aflectées par l'entéropore initial. Elles s'arrondissent, et sécartent de plus en plus l'une de l'antre, ì mesure que l'embryon s'accroît.

Ces phénomènes effectués. l’intestin est déjà plus qu’éhanché. La cavité entérique, munie de son unique entéropore, s’est changée en mn conduil intestinal allongé, pourva d'une bonche ef d'un anus. Nlors que se manifestaient les premieres phases de cette évolution, le protendoUrme s’était divisé en endoderme et mésolerme, et le colome se crensait dans ce dernicr. - Le protmdoderme šépaissit en deux régrions srmetriques. placées de prart el d'autre de la ligne midiane, el voisines de l'entíroprore. Deux bonrelets prennent ainsi naissance, qui sisolent du protentoderme, el sinterealent, dans la région qüils occupent, entre lui et l'edtorlerme: ces hourrelels sont les ihauches du mésoderme, et le protendoderme restanl. qui forme une couche mince autour de l'entéron, persiste comme endoderme définitif. Une ravití apparail dans -hacun des bourrelets. el représente les premiers rudiments du colome. - Dapres Balfour, ces espaces ne se creusent pas isolément dans les íbanches mésodermiques, mais proviennent de diverticules émis par l'entiron, qui péniotrent dans ces ihanches, se ferment ensuite, et se convertissent en résicnles closes, n’ayant plus qu à grandir pour donner le colome. Ce dernier serait done engendró d'après le procédé entérorolien normal, an moven de deux diverticules stmetriques, fournis par C'entiron, qui s’accroissent ensuile de façon à entourer ce ternier. Chapue lontrelel, ainsi muni de sa cavite colomique propre, grandil en fruitrant culpe lectoderme el l'endoderme; ses premires indications appraraissent non boin de lintíropore. sur la face ventrale du corps de l'embryon, et l'ampliticalion s'etfrectue, en progressant vers la face dorsale. Les denx moilies du mrisnderme se rejoignent alors en cette rigion dorsale, et occupent, dans l'organisme, leur situation difinitive.

A son léhut, et pendant son extension, le mésorterme est franche- 


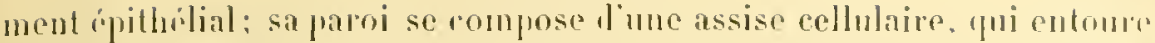
une cavité culomirue simple. Ce rarartere disparait par la suite; lo fenillel moyen passe à létat mósonchymatenx, rar il imet dos expansions qui se croisent en tous sens, et divisent le colome en vastrs litcunes. De plus, el à cause mème de cefte évolulion mésenchrmatruse, le mésoderne, s̈il faul en eroire les olservations de lialfour, ne se partage pas en somiles.

Les trois feuillets blastodermiques sont alor's dólinitis. Lectoderme produit les centres nervenx; lendoderme se borme a domner la paroi intestinale; du mésorterme et lu culome lérivent la musculature, l'apm pareil irrigateur, et la majeure part des organes sexurls. Les appendires sont des expansions des téguments. dans la composition desquels entrent a la fois l'ectoderme ef le mésoderme; les néphridies sonf, par opposition, des involutions tégumentaires, qui prótuent dans les lacunes culomiques, où elles s’ourrent. Les lrachées sont également des dépressions Jes léguments, mais qui demeurent closes.

\section{3. - Formes embryonnaires et développement particulier des organes.}

I. Formes embryonnaires. - L'iruf fécondé est d'abord alromdi, ou largement oralaire; il ne conserve point cette forme pendunt quil se convertit en embryon, ef s'accroit de préférence suivant une seule dimension; aussi l'embryon est-il allongé, cot aspect allant toujours en s'accentuant davantage. An moment où l'entéropore vient de se scinder en bouche et anus, oủ le placenta est encore bien déreloppé, lorganisme, environ trois fois plus long que large, produit ses premiers appendices. Sou extrímité antéricure grossit un peu plus que le reste du corps, et donne l'ébauche de la tète, qu'un sillon médian peu profond partage en deux moitiés latérales, et symétriques: la bourhe est situce, sur la face ventrale de l'économie, immoliatement en arriore de rette zone épaissie, dont les deux composantes peuvent ètre lésignées par l'expression de lobes céphaliques. - Les premiers appendices naissent par pares, placées les mnes derriere les autres, et an nomlire de trois on quatre. Les leux membres d’une mème paire sont disposis syomélriquement, sur un mème plan transversal, et sumserent sur la faco reutrale, de part el d'aulpe de la ligne médiane, a égale distance de celle ligne et des deux crités de l'emhryon. l'hus tarl, il mesure qüils s'aceroissent, ils s'écrtent davantage du plan médian, et deviennent latéraux. D’autres appendices se montrent cusuite, derrière les précédents, ckouprs par

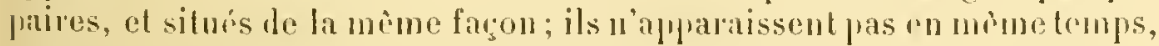
leur ordre d'apparition procédant rigonreusement l'avat en arrière.

lin somme, les membres anteriends sont les premiers lormes, ot les postéricurs les derniers parus. Les regions qui los portent sont un peu plus rolunineuses que les autres; aussi les parties du corps, placées 
au niveau des paires d'appendices, sont-elles plus larges que les zones intrumédiares; celle disposition donne i l'ombryon muspect segmenté. Une lellr segmentation est hien différente de celle des Annelides, car elle ne śćlend pas au mésorlermo: smmblable, en cela, à celle des Arthroporles, olle est causée par la prósence des membres, par la prolifération plus aclive des tissus dans les rógions qui possèlent ces derniers, el n'a pas dautre signification. - Apres l'apparilion des cinq on six



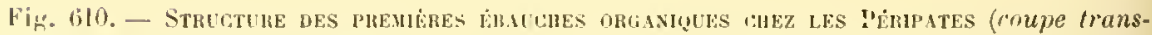
versule, à demi diagrammatique). - L'ectoderme est la persistance directe du protectoderme; il engendre les centres nerveux. L'intestin, central, est entouré par l'endoderme. Le mésolerme, d'abor épithélial, ou peu s'en faut, et scindé en une somatopleure et une splanchnopleure, comme le montre la figure 602 , ne tarde pas a subir tine désagrégation mesenclymaleuse, et à limiter les lacunes d'un polycalome.

liette tigure est dressé d'aprios les recherches combinées dis auleurs, notamment celles de kennel rt de Sodgwick.

premiires paires d'appendices, et pendant la genèse de celles qui les suivent, les teux lolies réphaliques s'allongent par luur extrémité antéricure el dorsale. Chacune des denx axpansions, ansi produiles, continue à croilre, loul en régularisant sa forme, qui rest, hientôt, nellement cylindripue; sa base d'implantalion cesse d'otre dilluse, pour se cerner, 
et se rendre phus précise. Ces expansions acquierent des lors l'aspect l'appendices limités sur tonte lour étendur, couservent lenr mème siluation, el deviennent les heux antrnnes de l'animal parfait. Celle genese parliculière des antenues est à remarquer; ces apjendices, au moment ou ils naissent, nont pas de contours juecis, et ressemblent plutót à les expansions le la région yni les porte: leur aspect se régu-

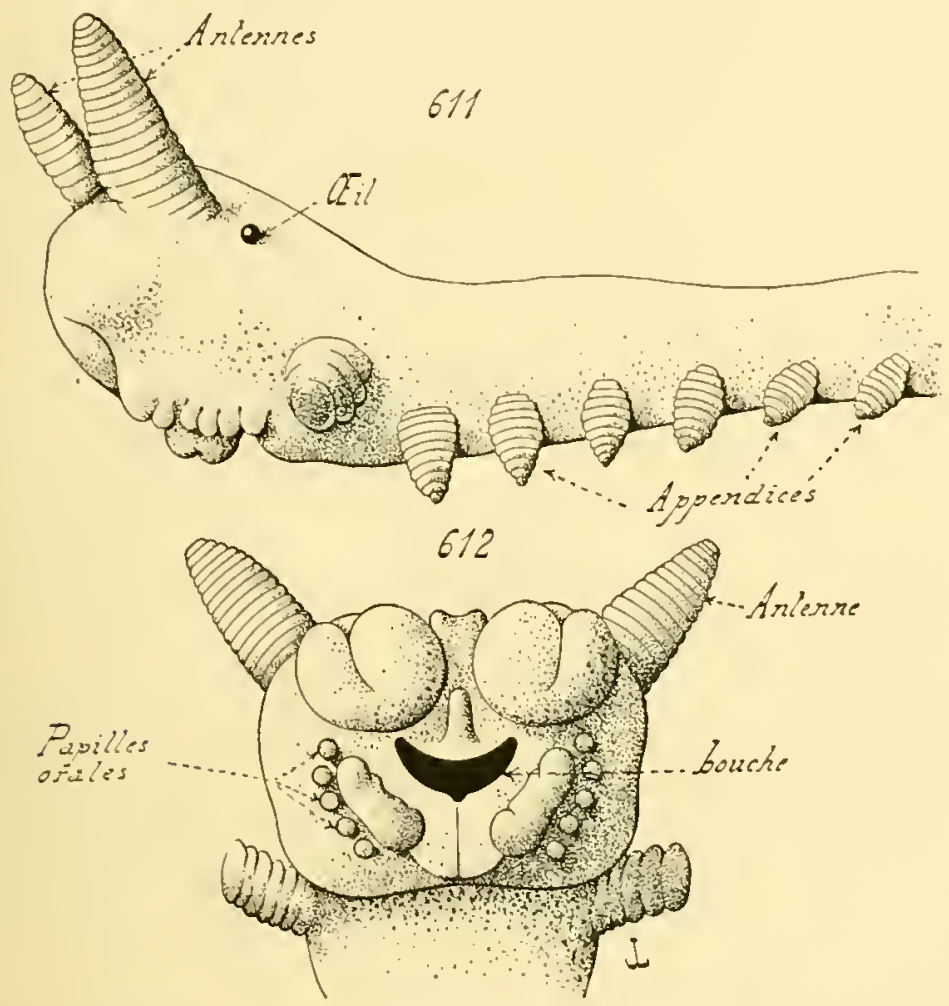

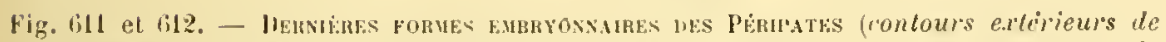

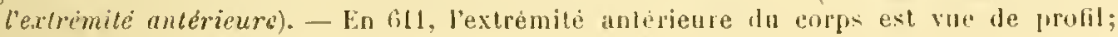
clle se presente par la face ventrale dans la figure bil.

Japres les recherches faites par hennel sur le Periputus Edumalsi.

larise par la suite, mais cetle rectilmle n'ixiste pas an délul. Ce fail se présente pour les autres membres; senlement il uest pas aussi prononer.

lemanl que les antenues s'allongent, que le corps s'accroil par son extrúmité postérienre, et que les dernieres pairos de pattes lont len" applarition, des modilicalions importantes seffocturnt sur la face van-

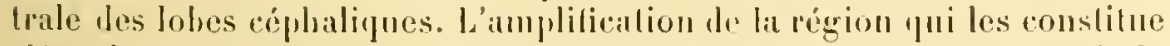
s'étend un peu plus en arrièe, de manièe à dépasser le nivean de la bonche, el celui de la premiere paire de membres. Une large dépression 


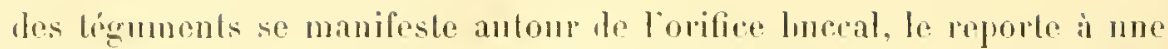
rertaine urofondeur dans le rorps, et constibe fr stomeon, qui devionda le pharynx. - Les appendices do la promière paire sont pris dans cette dépression, se placent sur les bords de l'onverture sloméale. qui est la houche définitive, et donnent les denx mandibules de l'animal. Un gros épaississement, impair et médian dès sum téhut, qui n’a point par suite hir valeur d'une coalescence d'appentices, se montre en avant de celle bouche, et s'areroît de maniere à la surplomber; il fournit la leve supérirme, si volumineuse, le l'arlulte. Thes excroissances mamelonnées, rancées en deux files, dont chacune est pharée en dehors l'une mandihule. produisent les petites papilles buceales. Les membres de la seronde paire so reportent en avant, tout en restant latéraux, et ne pénétrant pas dans le stomeon; ils arrivent an niveau de la louche, le dépassent mòme, et deviennent les deux pattes glandulaires de l’adulte, sur lesquelles délouchent les ghlantes séricigènes. Enfin, un second épaississement, placé en arrière de la bonche, se convertil en unc lère inférieure, moins forte que la supripieure. - $\Lambda n$ moment oì le stomeon se perce, son orifice extérienr esl tris large, et occupe un vaste espace; i] se rétrícil par la suite, au moyen du rapprochement des tiverses parties qui l'encalrent, pendant que to stomeon s'etend dans fintéricur du corps pour se convertir en un pharynx. La houche primitive, qui dérive de l'entéropore, ne conserve plus sa situation superficielle, el devient l'orifice yui fail communiquer le pharyx avee l'intestin; la bouche de ladulte n’est autre. comme l’explique le développenent ci-itessus exposé, Ine l'onverture du stomeon, rentue plus étroile el plus réguliere.

Les antres appentives du rorps acpuierent pen is pen lent forme léfnitive. Ils s’allongent, en devenant largement roniques, jrésentent les itranglements transversanx, qui leur donnent un aspect annelí, et demenrent an la position qu’ils occupent des lrur début. Lenr unique

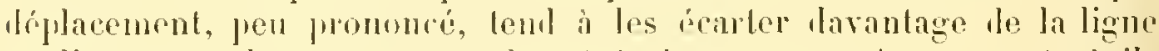
méliane. pour les reporter sur les côtés ln corps. - An moment oì ils sont lous produits, l'emhryon est heancoup trop long pour l'espace étroit Iue lui laisse lia vésicule inculatrice; il se recourbe, semroule plusieurs lois sur hui-mème, ot conserve celte furme jusqu'au moment de l'éclosion. Lenrontement est surlout le fait de la région postérienre du corps.

11. Origine des organes. - C'est surtout aux recherehes de liemel, que l'on doit de connaîlre les principales phases du développement des oreranis.

Linclinderme engendre los centres nervenx, et les tégunents avec leurs diprentances, cesti-dire lus griffes qui lerminent les pattes, les uíphridies, et tos trachées. - Les centres nerveux dérivent de denx cordons redodermiques, placris sur la face ventrale du corps, non loin de la ligne méliane; luurs volumineuses extrómités antérienres sont silnées 
dans les fobes céphaliques, el les remplissent en entier. Crs extrónitós, jointes l'une à l'autre, représentent l'ébauche du crrveau; les aulres parties des cordons doment les demx nert's ventraux. Lunion des ledux moiliés du cerveau, el la contignitó, sur la ligne médio-ventrale, les aulres zones de l'éhauche nerreuse, permet sans doute de penser que relle ébaurlze est impaire et mérlianc à son début, comme relles des autres animaux lilatéranx, pourvus dr centres nervenx limités; de nonvelles in restigalions sonl encore núcessaires ì cet égard. Le cerrean et les nerfs ventranx se séparent, par la suite, de l'ectoderme qui leur a donné naissance. Cependant, en des points symétriques, et disposés par paires qui correspondent à celles des pattes, l'ectoderme demeure épaissi, et fournit des petites jlatyues, rattachíes aux centres nerveux, anxquelles on accorte le nom l'organes ventrax.

Les léguments sont essentiellement conslitués par l'eclorlerme, anquel s'unit une mince couche mésorlermique sous-jacente; it cette dernière assise viennent s'atlachre les borls périphériques les bantes qui limitent les lacunes de la cavité générale. Les griffes, qui terminent les pattes, sont des pièces chilineuses, déposées dans de petites dípressions ectodermiqurs, et s'accroissant par leur base it'implantation; I'après leur origine el leur morle l'élongalion, elles rapprellent les soies dont sont munis phusicurs lypes le Ver's. - Les méphridies naissent a la base tes paltes, el conservent cetle position; i chaque paire de ces membres. sauf la première et l'avant-ılernière, correspond une paire de néphritles. Chacun de ces organes commence par une involution ectortermique, placée en rerlans de la patte, et sur sa base mème; semblable a un pelit tulie crenx, ouvert au dehors, il s'enfonce dans l'organisme, el se mut en rapport arec le culom", dans lequel il débouche; le fube s'allonge rusuite, tout en se repliant un cerlain nombre de fois sur lui-mème, et ronstilue, par ce moven, la néphridie téfnitive. - Les trachées se forment comme les nóphrilirs, at dérivent de dépressions ertorlermiques; senlement, ces drinières restent closes, el se ranifient, leurs liranches élant closes elles-mèmes. Les homologies établies entre les néphrities rt les trachées, l'apri-s leur origine, sont les plus importantes: elles permettent de peuser que, peut-itre, les népluridies se rapportent a des Irachées délournées de lrurs fonctions premieres, pour servir comme organes excréleurs.

Les phases principales de l'évolution du tube digeslif sont exposées dans les paragraphes précédents. La paroi intestinale est constituce par l'endoderme, et sa cavilé par l'entéron. A cet intestin primorial s'annexent un stomeon, el mn procteon. la premier, latre el spacinix, auquel s'ajoutent les mandihules, et que supplombent lis deux lives, Home le pharynx. Le procteon est phus petit; il oflre l'aspect d'un romt rectum, an moyen duquel le lube digestif s'oure an dehors pill' l'anus.

Du mésoderme dérive la trame conjonctivo-musculaire de l'orga- 
nisme, el lu crelume la ravití générale du corps. transformée en appareil irrigateur. - $\Lambda$ son déluul, le mésoderme est épithélial; le corlome le livise en une somatoplenr arjacente a l'ectoderme, et me splanchuopleure accolée à l'endoderme. Cependant, it mesure que le colome grandit, en amplifiant avec lui les deux assises mésortermiques qui le limitent, le raractire epithélial de ces dernieres resse d'àtre aussi mar-
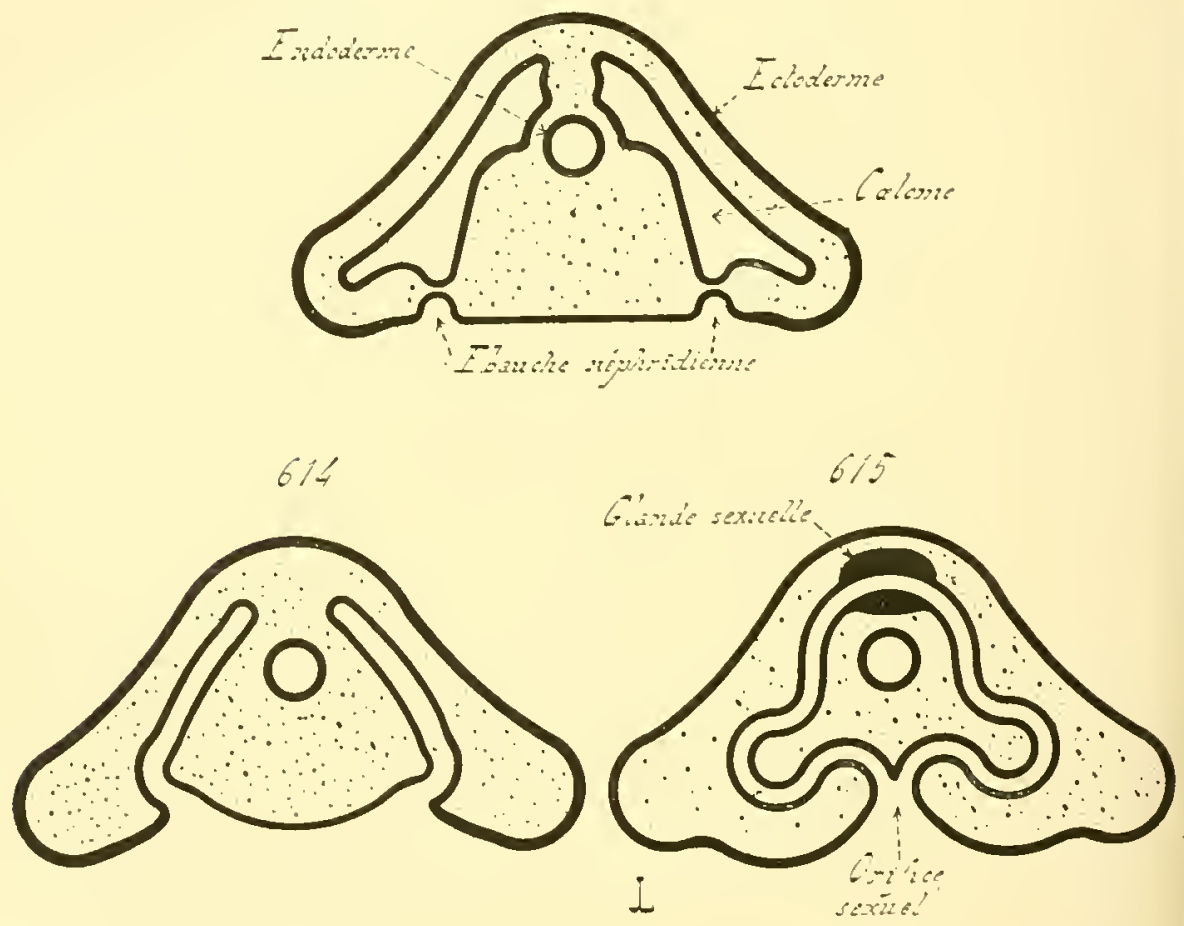

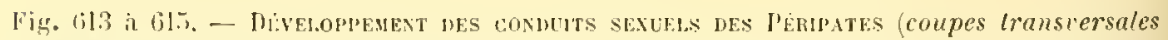
diagrammaliques). - En (il3, les bauches niphridiennes prennent naissance, au moyen te dejuressions ectodemiques. - In 614 , elles se sont unies aux cavilés culomiques du segment oi elles se sont creusẻes. - En 6J.5, ces ravités rolomiques se sont jointes l’ane à l'aulre; la glande sexnelle se lagonne dans ia région lle soudure, et les cavités cur.Iomigues jowent le rôle de conduits vecteurs; leurs deux orifices extirieurs se rapprochent, pour n'en faire yu'un seul.

Ces figures s'atressent p]us particulierement au diveloppement des organes femelles. I.es figures (j) 3 et 61 í s'appliquent également à l'évolution des népluridies, en supposant que, l'ensemble des choses demeurint en l'élat de la ligure 614 , le corlome se cloisonnât en lacunes, et le tube neplırilial grandisse, en s'enroulant sur lui-même. - D'après les recherches faites frar kinnol sur le Peripatus capensis.

qué. Mlusienr's cellules se litachent de leurs feuillets, tombent daus la cavité colomique, ou elles se multiplient, et prouluisent „les handes, à la 
direction non précise, qui cloisonnent cette cavite, en so ratlachant à la somalopleme d'une part el a la splanchnoplemre de l'autro. Cette lésagrégation continue ì s'exercer, pentant que les deux éluauches mésodermiques augmentent llimportance, et se rejoignent sur la face dorsale du corps. Lorsque es phénoménes sont acherés, le crolome est divisé en vastes sinus. qui communiquent entre eux, et le mésoderme forme une lrame conjonclivo-musculaire, destinée à limiter res espaces; celle trame est plus épaiss' an-dessous de l'ectoderme, et surtout ver's les appendices, que lans les autres régions du corps. Le fenillet moyen, d'alırl épithélial, est ainsi devenu mésenchymateux; seulement le mésenchyme, quil constitue, est hehe, car les cavitís lout il est percé sont vastes pour la plupart. Trois d'entre elles, plus réguliores que les autres, entonrent l’intestin et les denx corlons nervenx.

La désagrégation mésenchymaleuse n’a pas encore commené au moment ou les antennes, les appendices antérienrs, et les premières néphridies, prenment naissance. Le colome se prolonge dans ces appendiees, et leur lonne nne cavilé centrale, qui ne tarde pas à sr cloisonner par la suite, et à se diviser en lacunes. Ce phénomène, surtont accentué dans les antennes, contribue, jour sa part, ì lonner aux élıamches des membres le caractère d'expansions diffuses du corps, el non d'organcs aux conlours précis dès leur dẻlut. Te leur cuté, les néphridies commencent par s'ourrir lans un colome simple, jour ne plus communiquer ensuite quavec un réseau lacunaire. Ce rernier, qui dérive ainsi du calome prar un cloisonnement irrégulier, représente la cavité générale du corps. et se modifie en un appareil irrigateur; les globules sanguins sont constilués par les éléments mésenclýmateux demenrés libres, et non engagés dans la trame conjonctivo-mustulaire.

Les glandes suxuelles sont produites par le mésoderme de la région postérienre du corps. Des carités lacunaires, qui s’isolent da côté de l'appareil irrigatenr, lonnent les cavités des oviductes el celles des canaux déférents; plusieurs de leur's élíments mésodermiques, placés dans lenr région dorsale, devienuent des ovolastes ou des spermatoblastes. $\Lambda$ canse de lemr origine, les cavités sexulles sont d'abort closes, et me communiquent pas avec le deluors. Les méphridies de l'avant-deruicu segment, détournées ue leu rôle initial, s'abouchent avec elles, comme lenrs similaires s'ourrent dans les lacunes colomiques du reste du corps; elles lonr permetfent de rejeter les produits reproductenrs. Les orifices extérieur's de ces leux néphridies sont d'ahord séparés; ils se rapprochont par la suite, et une dépression des téguments les fait s'ouvir lous deux daus me juche, qui communique arec l'extérieur par In seul orifice; cette poclie donne le ragin de la frmelle, et le conduit ijaculateur ilu male. 


\section{$\$ 4$. - Discussion relative aux phases embryonnaires des Péripates.}

I. Discussion. - La position des Périjates, dans une classilicalion naturelle, prète à contestations. On arait d'alrord placé ces animaux parmi les Annélides; les recherehes récentes, dont les premières sont dues à lloseley, ayant montré que ces êtres possèdent des trachées comme appareil respiratoire, les opinions ont penché ver's des affinités arec les Arthroporles trachéates. Balfour, surtont, s'est montré trés eatégorique à ce sujet, et les uaturalistes modernes sont presque tous de son avis. Lussi, le senliment commun est-il que les Péripates sont des animaux ambigus, oflrant à la fois des caracteres d'Annélides arec des particularités d'Arthroporles, et interméliaires à ces deux groupes; la présence des néphridies les rapproche des ums, et celle des trachées les fait ranger parmi les autres.

Une question de cette nature ne peut ètre tranchée que par la comuassance approfondie des phases cmbryonuaires. Les Péripates sont, en elfet, lellement spéciaux à tant d'égaris, que les affinités naturelles doivent être posées par les premiers phrnomènes du développement, seules capables de dénoter les homologies réelles des organes. La structure anatomique entre bien en compte; mais son importance, sous ce rapport, est relativement secondaire. Toutes les fois où il s'agit d’apprécier, arec exactitude, les caractères fondamentaux d'un groupe ayant une valeur semblable i celle mise ici en canse, l'embryologic fournit les données principates, et mérite d'être consilérée arant tout.

Dans une trlle discussion, la structure segmentaire de l'organisme doit ètre mise à part. Celte disposition métamérique n’est pas comprarable à celle des Annélides, car elle ne prorte point, à son début, sur le mésoderme, pour atteindre ensuite les autres fenillets. Elle est, comme chez les Arthropoiles, en corrélation manifeste arec la présence des membres, disposés en paires que séparent des distances égales; elle dépend des appentices, n’est point primitive, et affecte les léguments seuls. Elle n'a aucune signifieation particuliere dans la recherche des affinités naturelles.

Les relations arec les Annélidrs sont élablies, arant tout, d'après la frésence, dans les deox cas, dorganes excréteurs bitis sur le plan des néphridies. Sous le rapport de la strueture définitive, lia concordance est manifeste entre les appareils des uns et cenx des autres; mais il n'en est plus de même quant à l'origine. Quel que soit le mode du développement, quiil soit dilaté on comlensé, les éhauches néphridienmes des Innélides proviennent d'un cordon cellulaire, formé par le mésoderme, yni se segmente en tronçons pour les produire; ces ébauches dérivent, ponr chanue côté du corps, l"un cordon simple el continu. Parcil fait n’existe pas chez les léripates; charpue néphridie est, des son déhut, 
imlépendante dr ses similaires; ef, an surphus, res organes sont inginIrés par des involutions ectorlermiques, de manière à n’avoir aver le mésoderme aurune relation l’orgugine. Les néphridies des Innélides sont mésodermiques el dŕpendantes, celles des l'éripates cctodermiques of isolées les leur apparition: il n'existe done aucune bomologie entrecolles.

La grande ressemhlance des appareils excréteurs est le principal argument donné pour rapprocher les Périprates des Vers annelés. Celle similitude est réelle; elle va mème jusqu'à permettre des relations identiques entre les organes sexuels et ces apparcils; mais elle réside seulement daus la forme définitive, et non dans l'origine, ni dans le développement. Elle répond à une analogie, point à une homologie. Et, à cette différence profonle, établie entre ces deux grompes d’animaux, s'en ajoutent d'autres, qui tiennent i diverses particularités de l'embryogénie. La genèse du feuillet moyen n'est pas comparable, entre les planules directes des Annélides el célles des Péripates; de mème celle les centres nerveux; de mème cncore celle de la majeure partic des conduits sexuels.

Les dissemblances sont aussi prononcées avec les Arthropoles quarec les Annéliles. Les l'éripates possèrlent bien des trarlıées, lout comme les Trachéales; seulement. les relations se hornent à ce caractère commun. Encore les trachées les Péripates, par lenr répartition uniforme sur tout le corps, par leurs rimilications touflues, oflient-elles un aspert que ne montrent jamais relles des Irthropodes. - le raractire essentiel, et fondamental, de ces derniers animaux, ne lient pas à la présence de pattes divisées en articles, mais aux procédés gémétiques lles feuillets emliyonuaires. L'auf fécondé commence par ploduire une couche blastodermique, de laquelle dérive nu protendonlerme mósenchymateux, alors qu'clle-mème persiste comme ectoderme; du protendoderme se dégagent cusuite un endorlerme épithélial, constitué jar leux élauches symétriques, et mu mésoderme mésenchymateux dìs son débul; en outre, le stomeon et le procteon sont fort longs, et lournissent la plus granile partie du tube digestif. - Sauf quelques particularités de létails, ces phénomienes se présentent arec une comstance remaryuahle chez tous les Irthroportes, el font entièrement défaul anx Péripates. Chez ces deruiers. lizuf fécondé foumit, en mème temps, le protectoderme el le protenloderme; celni-ci lonne naissance a deux banches mésolermiques, apres ijuoi, tout en demenrant simple, il devient l'endorlerme définitif; le feuillet moyen est tout l'aborl épithólial, et ne subit que par la suite une désagrágation mésenchyonaleuse; entiu, le stomeon et le procteon restent courts, de telle manière que le tube digestif presque entier provient le l'entéron. - L’opposition entre les Arthroporles el les l'éripalos est lone consilérable; elle ne porte pas senlement sur un fait. mais sur tous les phénomenes principaux dn drveloppement. Il n'est pas jusqu'aux appendices, qui ne litriernt laus les deux eas. Cenx des Arlbropodes sont divisés, en arlicles lien listincts, mohiles les uns sur les autres, par des sillous forfouds; lis le moment de lonr apparition, ils ont des 
contours réguliers el ume hase limiléc; lo culome nenvoie pas, daus leur intéricur, unc expansion qu’entonre une assise mésodermique épilléliale. Chez les Péripates, les arlicles sonl moins bien maryués; les membres ont, au moment de leur formalion, l'aspect l'expansions du corps, el non celni d'organes déterminés; enfin. la ravité crelomique, encore limitée par un mósoderme épithélial, émet pour eux des diverticules.

Les Onychophores ne peuvent lonc che rapprochés des Arthropodes, ni los Mmélides. Linpinion ronrante, qui lend i les considérer comme

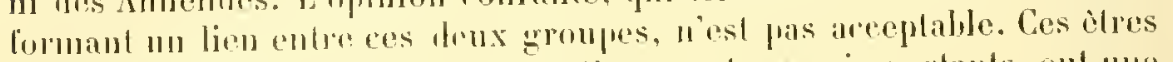
sont rraiment a part: of lens caracteres sont assez impurtants, ont nue

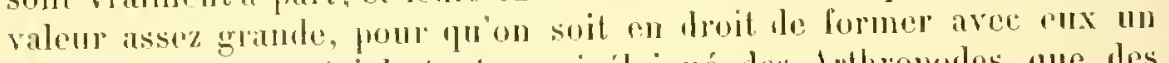
embranchement special, lout aussi étoigné des Irthropodes que des Trochozoaires.

11. Gonclusion. - La conctusion, quil ionvient de tirer d'une telle disenssion, est en partie indipne dans les ligurs précédentes. Les Péri-

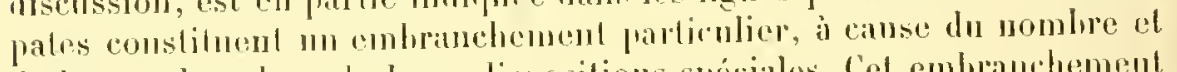
de la grande valeur dr. lenrs dispositions spéciales. Cet embranthement apprartient a la série des Culomates, puisque le celome existe vraiment; mais il s'agit de savoir s'il entre dans la section des Eutérocolomiens, ou dans celle des Schizoratomiens. La question est délicate à résoudre; le dévoloppement des léripates est condensé, cl il est, dans ce cas, hien difficile de se prononcer: car on ne peut alors aftirmer, avec certilude, si me particnlarilé lomnéce esl primitive, on si elte résulte d'un déplacement, soit dans le tempis, soit dans l'espace. La condensation n'est pas très acrenturie chez les Péripates, puisquinn entéropore prend encore naissance, malgré la planulation directe; elle existe cependant, ef ce fail suftit pour tenir sur la reserve. Il est cepentant possihle d'ohtenir quelques indications, on comprant l'embryogénie de ces êtres avec des héreloprements similaires de Sclizocotomiens, el d'Entérocolomiens.

Chez les premiers, dans te cas de planulation directe, te protendoderme so divise, frar une véritahle délamination, en mésoderme el endoderme. Lentéron se creuse ans le centre de la planule; les blastomeres qui l'entourent donn'int l'eutoderme, et tous les aulres, sitnés culre ce deruier et lectoderme, composent le mésoderme; des som début, ce dernic. leuillet est déja volumineux, et enveloppe la plus grande pirrt, sinon la totalití, de l'entoderme. les cavilís calomigues se percent ensuite daus li. misoderme, sans jamais offrir de connexions directes avec l'antiron. - Cies phinomènes n'existent point chez les Entérocelomiens, dans le cas de flannlation. Lr frotendoderme prolitere activement dans le voisinige de la rígion qu'ornperait l'entéropore, sil existail, ol oil sa place est mème marruée par moleger sillon; les zones de prolifération sont au nombre de deux, placées symétriquement de part el l'aulre de l'entéropore. Denx ébanches mésodermiques naissent 
ainsi, qui se séparent du prolemloderme, ot sélendent daus le corps.

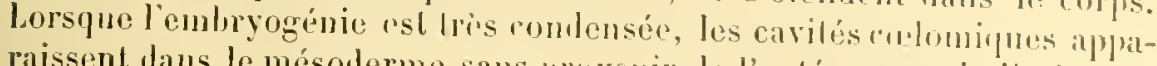

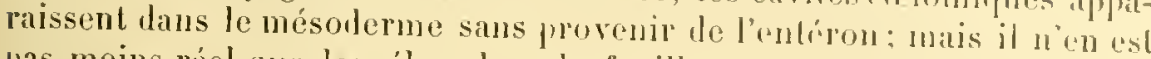
pas moins réel que les bluanches lu feulled moyen, ainsi localisces el disprosées, sont fort diflérenles de leurs similares des Shizorrelomiens, et aisément reconnaissahles. Elles correspondent it des diverlicules entériques, daus lesquels la cavité se crouse dune manière tarlive el indépendanle, par un double déplacenent dans le temps el dans l'espace.

Ce dernier ras est, sims nul doule, colui des léripales. Balfour est le

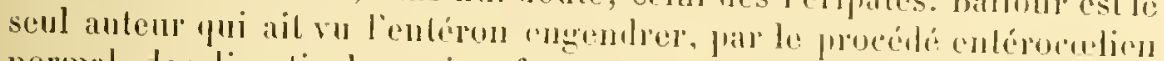

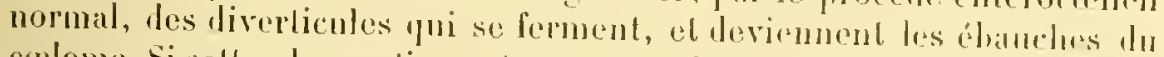
colome. Si celle olservation ast exilcte, el le nom de lantemprernel de le croire, ces animan soml, sans contosle possible, des Enlírorolomiens.

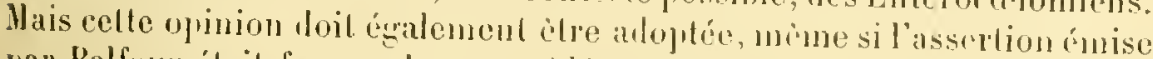
par Balfour était fansse. Les procédés, employés par le inésuderno des Péripates pour prendre naissanee, en supposint fue sun rolume soil loujours indépendant de l'entérou, rappellent de lonl pròs lours sinilaires présentés par le leuillet moyen des Entéroculonicus an dévolojpement condensé, el non ceux des schizocurlomiens.

Cette longue discussion est aisée à résumer: les fails acquis antorisent à peuser que les l'éripales comstiluent, a eux seuls, un grompe bien tranché, ayant la valeur d'eubranchement, dislinct a lis fois des Arthropodes comme les Anmélides, et dont la place se troure, sans doute, dans la série des Entéroculonjens.

\section{RÉSUMÉ}

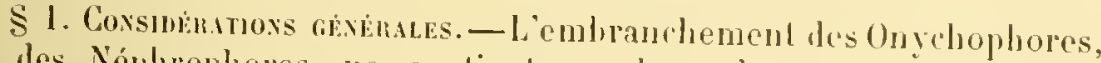
ou des Néphrophores, ne contiunl que le senl gente l'eripulus. La reproduction s'exerce par la voie sexudle; elle whre un cellain nombre de particulariles importantes, qui font à cegroupe mes place it part dans la séric des Coulomales.

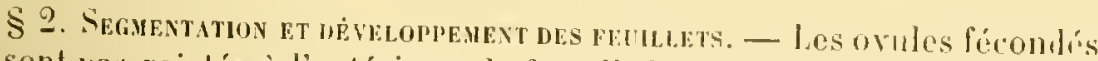
ne sont pas rejelés à l'extérieur; la feunelle les fouscrve daus son mlirus, qui délimite, autour de chacun d’eux, me cavité imcuhalrice close; l'en-

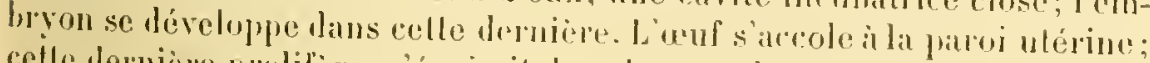
cetle derniere probliere, s'upaissil dams la zomo de contarl, el produil une

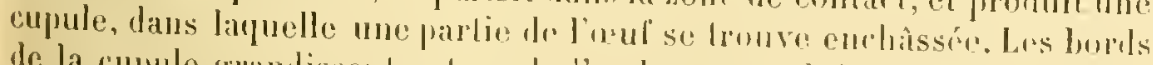

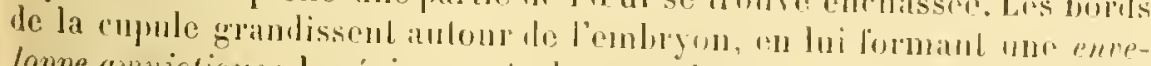

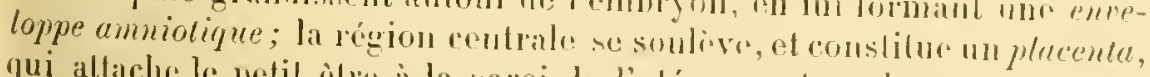

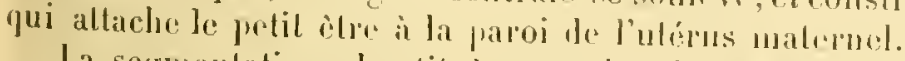

La segmentation aboulil a moe planule directe, daus lapunde les

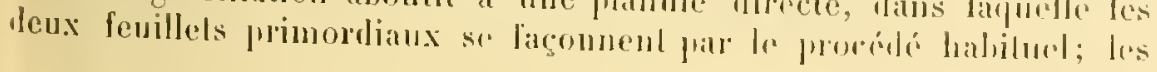


Wastombes centraux se groupent en un protendodrme, qui soisole, an moyen d'une mince limitante, des l,lastomères périphériques; l'ensemble de ces derniers est le protectoderme. Les éléments de ces assises, et notamment ceux dn prolendoderme, sont confondus en un syncylium. lientéron se crense dans le protentoderme; un enléropore prend naissance, bien gre le dévelopjement comporte une planulation, et non une gastrulation; cet oritice s'allonge, s'étrangle en son milieu, el se divise en deux ouvertures, dont l'antérieure est la bouche de l'embryon, la postérienre l'anus. - Le protectoderme se convertit en ectoderme. Le protendoderme s'épaissil en deux régions symótriques, et voisines de l'entéropore, qui deviennent les élrauches du mésoderme; le reste du protendoderme donne l'endoderme définilif. Chacune des ébauches mésodermiques se creuse d'une cavité colomique, qui, d’après Balfour, tirerait son origine d'un diverlicule émis prar l'entéron, et correspondrait ì un véritahle entérocole. Ces lenx élauches grandissont ensuite, conservent pendant quelyue temps une disposilion épithéliale, puis passent ì l'élat mésenchymaleux. L'intéron fournil la cavilé intestinale.

\$3. Formes manrownames et développenext particl lier lues onganes. L’embryon s'allonge à mesure qu il érolue; son extrémité antérieure s’épaissit. se divise en denx lobes cephatiques par un sillon peu profond, et représente l'ébanche de la tèlr. Les appendices maissent par paires, leur ortre d'apparition allant d'avant en arrière; lenrs bases sont d'abord confondues avee les parois du corps, et se précisent ensuite; les deux anteunes sont produites par l'élongation de la zone antéro-dorsale des lobes céphalinues. Les appendices de la première paire, les antrnmes élant mises à part, donnent les mandibules; ceux de la seconde paire deviennent les paltes séricigines; enfin, ceux des paires postérieures conslituent les membres qui servent a la locomotion. Un stomeon, large d'aloru, plus étroit ensuite, su prerce, dans la région périlucceale, pour engendrer le pharyux; son orifice externe est la houclie léfinitive.

Les centres nervenx dérivent de l'ectoderme: leurs élauches sont donlıles, mais contiguiis, fait qui permel de croire i leur provenance d'un premier rudiment simple et impair; elles donnent to cervean el les deux nerfs ventraux. L'ectorlerme fournil également: les soies de l'extrémitó des pattes, qui sont des pièces chilineuses; les néphridies, engendrées par des dépressions de l'ectoderme: et les trachíes, lont l'origine est semblable à relle des néphridies, mais qui restent closes, au lieu de s'ouvrir dans les espaces colomiques. Lienléron se convertit en eavité digestive, ì laquelle s'annexe un stomeon et un procleon, de heancoup plus courls que leurs correspondants des Arlhropodes. Le mésoderme, d’ahord ípithélial, devient mésenchymaleux par la suite; aussi le corlome, simple à sou début, ne tarde-t-il pas à se diviser en vastes sinus, qui constituent la carité générale lu corps, et se disposent en un appareil irrigatenr. Les glandes sexuelles, et lenrs carités, sont 
produites par des espaces culomiques, qui s'isolent, avec leurs parois, du reste du feuillet moyen; les nephridies le l'avant-dernière paire s'annexent à elles, pour leur permettre de communiquer avec le dehors.

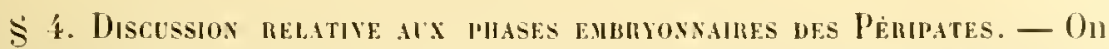
admet, d'ordinaire, que ces animanx sont intermédiaires aux Innilides et aux Arthropodes, puisquils possèdent à la fois des néphridies el des trachées; cependant, les lifférences, itablies entre eux et ces derniers groupes. sont fort grandes. Les níphrillies des Annélides proviennent du mésorlerme, et sont formées par la division en tronģons l'une éhauche continue; celles des l'éripates sont toujours indépendantes les unes des autres, et tirent leur origine de l'ectoderme. Les caractères essentiels des Arthropodes sont basés sur une genèse les feuillets embryonnaires, et une prédominance du stomeon et du procteon dans la composition de lintestin, que les Péripates ne montrent jamais: les trachées ellesmèmes, et aussi les appendices, sont dissemblables dans les deux cas.

Les Péripates offrent des caractères spéciaux d'une assez grande importance, et d'une raleur suffisante, pour motiver la création d'un embranchement. Las procédés, employés dans la formation du feuillet moyen, permettent de croire, lien que le développenent de ces ètres soit assez condensé, que cet mbranchenent doit ètré placé dans la série des lintérocolomiens. 


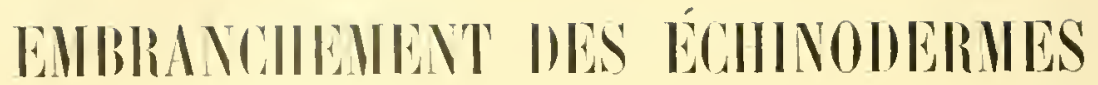

\author{
CHIPITRE NIII
}

DÉVELOPPEMENT DES ECHINODERMES

\section{\$1. - Considérations générales.}

1. Garactères et classification. - Cinctinus. - L'cmbranchemont des lidhondermes ist nu des plus nalurels. Ces animaux sont caratérisis, avant lont, par la prossession d'un appareil, dit le systime

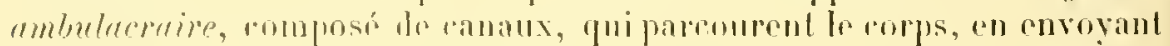
des expansions dans des appendices exlóriems; reux-ci selvonla la loeo-

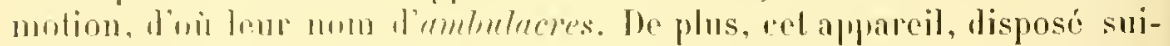

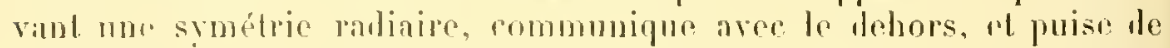
l'anu dans les milienx miromanls, ar tous les behinodermes vivent

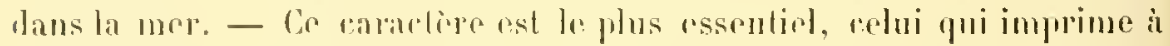
lorganisme sum allure particuliere, mais it n'est pas le sent. Lembranchement apparliont ì la sépie des Entérondomions ì diverticules; l'en-

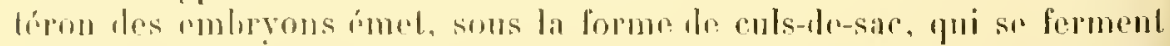

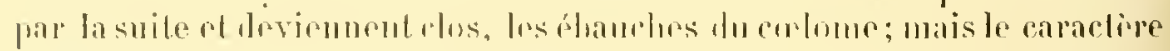

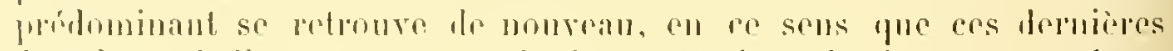

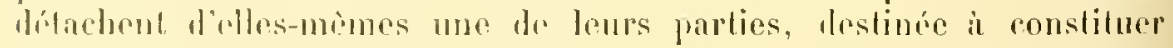

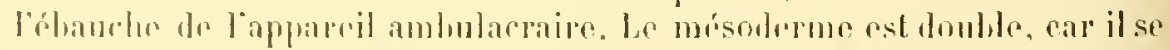

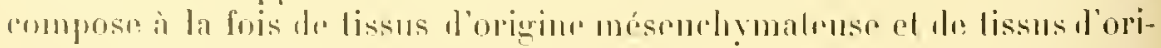

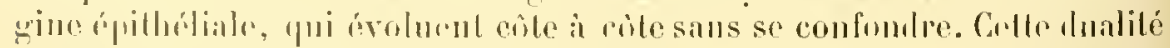

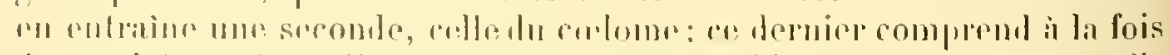

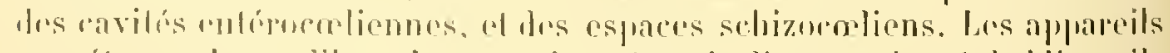

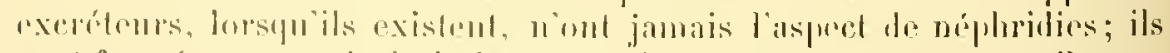
sont formís par un lapis de lacmones schizoculiemues. Les apprareils res-

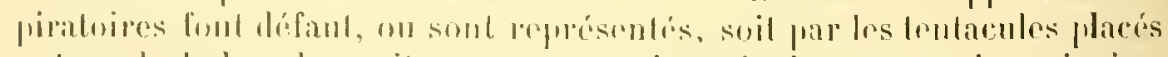

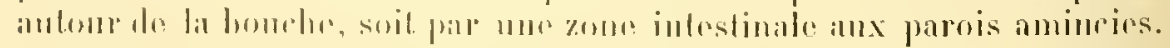

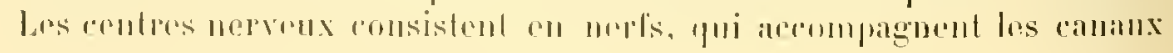




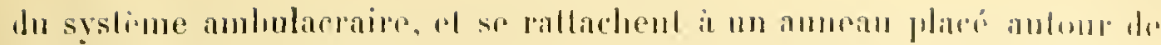

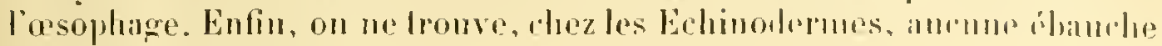
de corile ilorsale.

Les représentants de er groupe sout placés, comme lum développrement te romporte, parmi les Entérocolomiens dont le colome froml maissance au moyen de liverticules; ils se troment lone situés nou foin des Vortébrés. Les affuilés, entre ces leus emluancluments, vont mème plus loin que l'origine commmo des cavilés colomiques. Wans les deux cas, le mísolerne est double, et ronstitur fia f'umion de drux farties, l'une mésenchymaleuse, l’autre épilléliale la premiore driviout, les les phases iniliales de lembryogénio, de la secombr, on hien du protendolerme. Chacun te ces froullots mésodermiques contient des cavilés. qui luj sont propres: le mésoleme mésenchymatenx renferme les espaces lacmaires, qui proviennant originairemenl du hastorole, ne sont jamais en connexions lirectes avec l'intestin. ef doment par len ensemble un schizocole: te mesonterme ipithélial posside de vastes cavitís, libres et simples le plus sonvent, dont les ćbanches sont fommies frar leutíron, el qui composent un entérocule. Les lichimoulermes, comme les Vertélurés, sont fonc pourvos do deux mósolermes, lun mésenchymatenx, l’antre ópithéfial, et le alenx rofomes séparés el dislincts, moligocmlome rulérocolien, el mn jolyculome sclizocolien, dontles connexions, forspu'elles se produisent, sont seeombairs.

Les ressemblances avec les Vertélués dépassent mine los plónomines oflerts par le lenillel moyen. Les Eehinowermes nont point, ì rai live, dorganes respiraloires spécianx; los óchanges gazenx se manjestent il lavers toules les parois assez minces pour les prmellar,

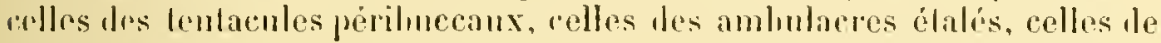

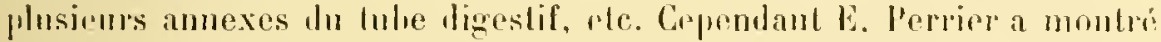
que, dans certains eas, clez los Eohiniles, pas axemplo, mo partie de

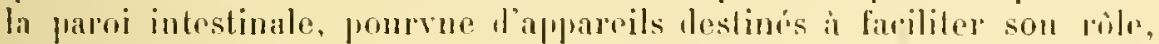

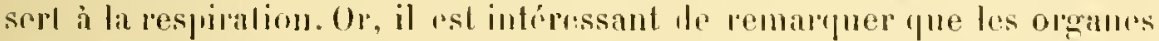
respipaloires les Vertélurs, of roux des animanx apparlouant. comme

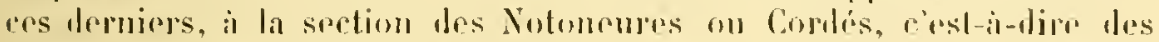

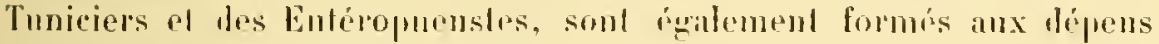
d'une portion de l'apparojl aligrstif.

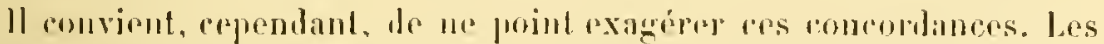

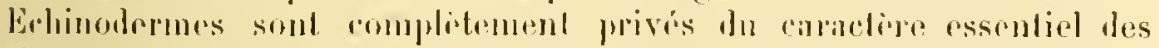
Solonemes: lours contres noproux me soml jamais dorsamx, ni an

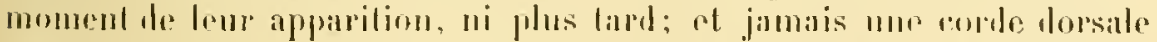

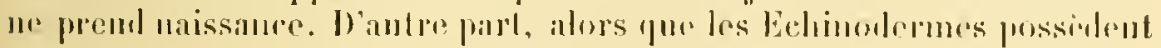
tonjours wn appareil ambularpaire, les Sotonemres sont constamment

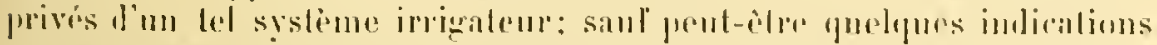

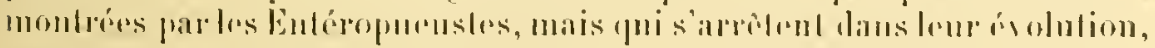

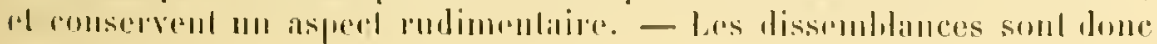


fort grandes entre les Noloneures of les Echinodermes. Pourtant, elles ne masquent pas les alfinilés déjà signalées, yui antorisent à placer ces deux groupes dans mo mème section des Cirlomates.

I'ne dernire particularité des Echinotermes, qui lenr est également commune arec phusirnrs les Notoneures, porte sur l'entéropore. Cet orifice se ferme parfois, chrz les premiers, soit pour rester défniliveuneul ainsi, soil four s'uurrir derechef dans une autre partie du corps (ce dernier cas est relui des Crinö̈des, le précédent celui des Ophiures et the diverses Astirides); mais, lorsqu'il demenre ouverl, et Jorsquit presiste jusqu’ì l'orgamisme adulte, il devient l'anns de ce dernier. La bonche est loujours un orifice de nouvelle formation.

Cussmatiox. - Lembranchement des kichinodermes renlerme six classes :

1" Les Holothurides; dont le cor|'s est allongrá, et dont les téguments, sils renferment de nombreux spicules ralcaires, ne contiennent point les plaques assmmllées en un tesl cohérent.

2o Les Cystides; anxipuels il convient de rémnir les Blastö̈des. Ces animaux sont fossiles. Leur corp's, globuleux, possède un lest, el se lixe à un support au moyen d’un pédoncule plus ou moins long: les espaces occupés par les ambulacres, el nommés aires ambulacraires, sont délimilés chez les Blastö̈les, mais non chez les Cistides.

30 Les Echinides; au corps globuleux on aplati, libre, dépourvu te bras, el aux aires ambulacraires toujours dislinctes.

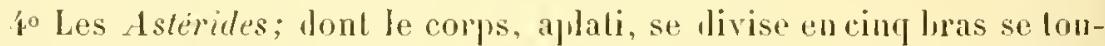
chant par leurs lases; chacuu le ces bras prorte, sur sa face ventrale, un sillon, le sillon ambulacraire, qui est toujours ouvert; les glandes sexuelles sont placées daus l'inlérienr des hras. Le madréporite, cest-àdire la plarue percée qui permel à l'appareil ambulacraire de communiquer avec le drhors, est dorsal.

3 Les Ophimides. Leur corpas, aplali, est muni de bras donl les bases sont listinctes, el séparées par un pspare appreciable; le sillon ambulacraire esl formé par un revètement de plaques; les glandes sexuelles ne pénètrent point dans les liras, et restent dans le disque, ou corpes proproment dit; culin. le madréporite est ventral.

$6^{\circ}$ Les Crinoidtes. Lenr corps. ramassé, porte des liras munis de branches latérales, dites pinnules, qui contienuent les glandes sexuelles; d'ordinaire, el sauf l'axeption des Comalulides. l'anmal est tixé à un support par un pédoneule. Ce leprier existe pourtant, chez les larves des Comalules; mais l'animal s’en téharrasse vers la lin de la périote embryonaire, el demrure libre désormais.

Ces six classes se laissent grouper en leux sous-cmbranchements : les Cystomorphes at les Brachiés. Cenx-ci, qui compremnent les trois der- 
nières flasses, sont caratérisés far la division du corps, du moins vers

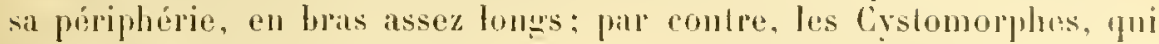
renlerment les trois premiores classes, sunt glolublax, romme lemp mon l'indique, et sont privés de hras, ou bien en ont de fort currts. - Custe division n'est pourtant pas très naturelle. I en juger d"apres l'organisation et les phémomènes du développenent, les llolothurides cunstituent, a elles seules, une serrie particulière; il en est de mème pour lrs Crinö̈les; el aussi pour l'ensemble des Erhiniles, des Astériles, et des Ophinrides. Ces derniers déunis composent un groupe spécial, qui so ratlache aux Ilolothmies, et noflice ancune ressemblance avec les linoïles; si ce n'est par les lispositions propres i tous les Echinodermes. Comme les Cystiles sont fossiles, leur lest seul est connu, et l'on ne peut, par suite, juger avec exactitude de leurs relations. II scmble cependant, d’après la structure de leurs tégumeuls, yu’ils se rapprochent des Holothuries, pou leur servir de lien, aver les finüles d'une part, et, de l'autre, avec la série les Echinides, les Astiuriles et lles Ophiuridrs.

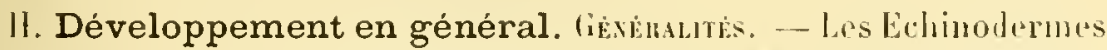
out prèté, lans ces deruières années, à de nombreuses rerberehes. Les mincipanx auteurs, qui se soient ocenpes de ces animaux, sont: L. Perriur, Kirhler, lrouho, Motschniliolf, Igassiz, Ludwigr, IJamann, Selenka. H. Carpenter, etc. Ceprendant les études ont porté, le préférence, sur les fails de lorganisalion défnitive, sur les métamorphoses larraires, et lorigine des feuillets blastorlermiques; les modifications embryonnaires, sulies par les apparpils, ne sont pas encore bien conmues, ou sont lícrites de manicres diversus, surtout en ce yui tonche les parties de l'appareil irrigateur. Les contradjelions fréquentes, qui existent encore ì cet endroit, proviennent, pomr la plupart, le l'absence de locuments précis sur l'embryogénie, sur le rôle joué en cela par les feuillets; elles rmphrbent sonvent de se prononcer, avec corlitude, surla signilication do plusieurs systimes.

La reproduction des Echinorlermes est prespue toujoms sexuella. les diveloppenrents asexnés sont fort rares, et se manifestent, dans lo cas de leur présence, soil par la fissiparité, soit par la gemmjparité. le dévelojpement sexmel est remarpuahte, en ce yüil s'effectue, dans la rigle, suivant le mole dilati; les Echinodermes offrent prespue, i cet igard, le seul exemple d'un rmbranchement fort nombrenx it varie. dont les représentants, quelle que soit la classe il lapurlle ils appar-

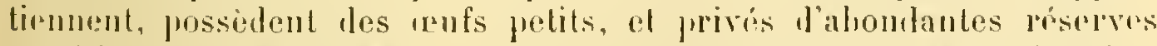
mulritives. La segmentalion, folale et egale le plus souvent, alontit it une: blastule, munie l'mu ample blastocme, qui sis convertit en mo? gastrule par le procédé juvaginant normal.

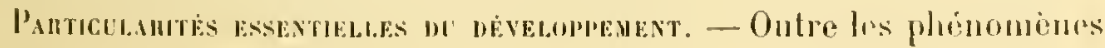

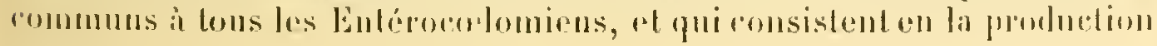




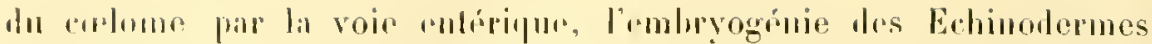

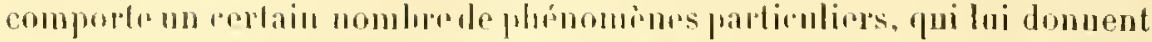
une origimalifindiscutalıle. Ces pluénumines sont an nombre le lrois: le premier lient à la dualib du mósodermo et te ses cavités: le secomel à la genese de lappareil anhulacraire; le dernier a la complexité fréyuente des mélamorphoses subies par les larves.

$1^{\circ}$ La dualité du fonillot moyen u'est pas spéciale aux Éhinodermes, puispun les Toptébrós la prísentent lo leur colde; cependant, bien que les phinomenos soienl lomolognes el comprarables, ils conservont, chez lis fremires, mo simplicilé pue fos seconts noul pas. Lr mésoderme mó-

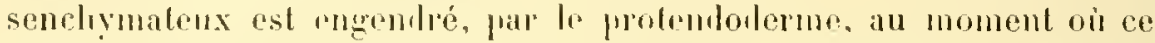
Homier se divise en endoderme et mésoderme épilhólial, on avant ce moment; ses éléments lombent dans la cavité hastoculienne, s'y mul-

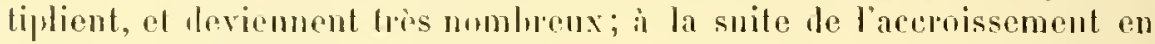
volume du mósolrme brithilial, ils sont pris entre les assises de ce demirr, et l'ectodrom, on l'omloderme. Cenx-ci ne sont donc pas direetement accotós aux lissus qui lérivent to l'épilhélio-mósoderme, mais

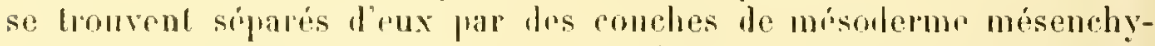
maleux. - Cas dernioms sont an nombre de lenx: liune, le somalo-

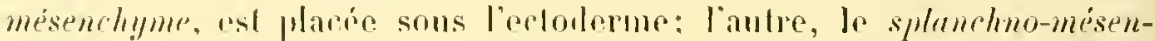

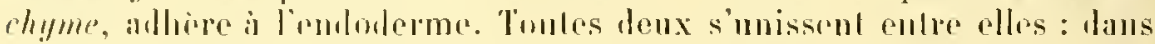
les zomes qui molourent les orifices du lube digestil, an niveau desquelles

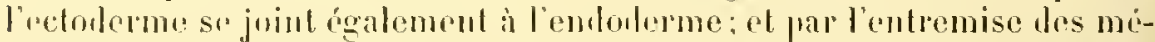

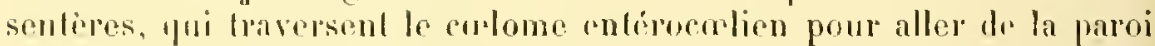
intestinale a la paroi somalique. Sauf cesderuèes rxpansions, al celles

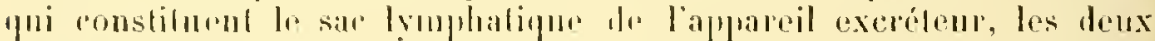
assises du mésolleme mésenchymaloux reslent simples, ef ne pénetrent

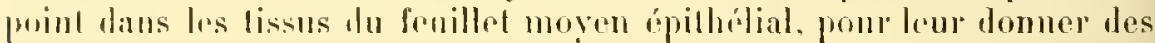

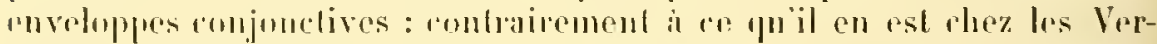

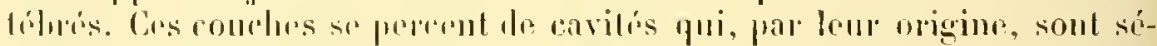

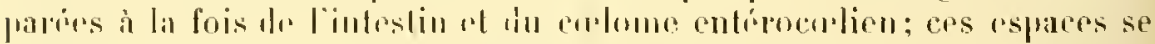

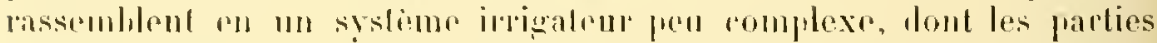

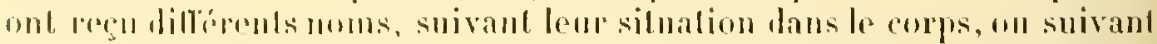

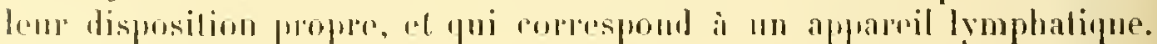

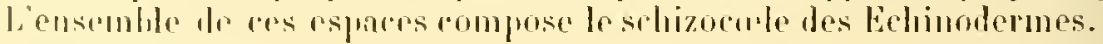

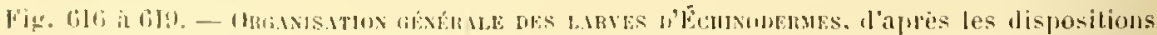

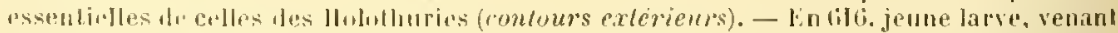

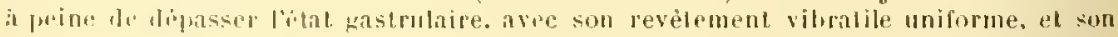

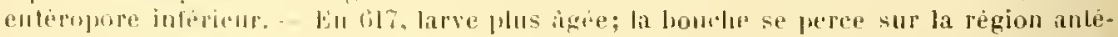

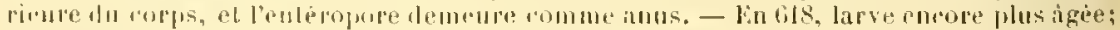

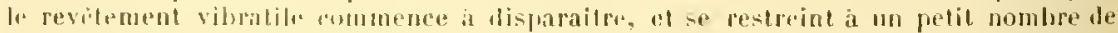

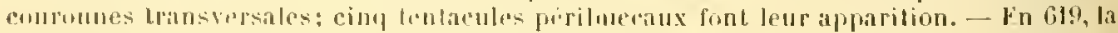

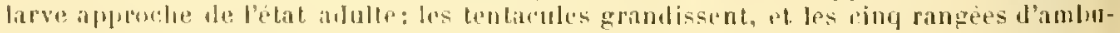

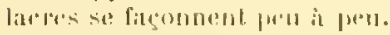

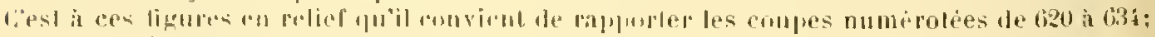

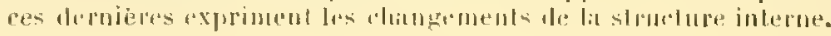




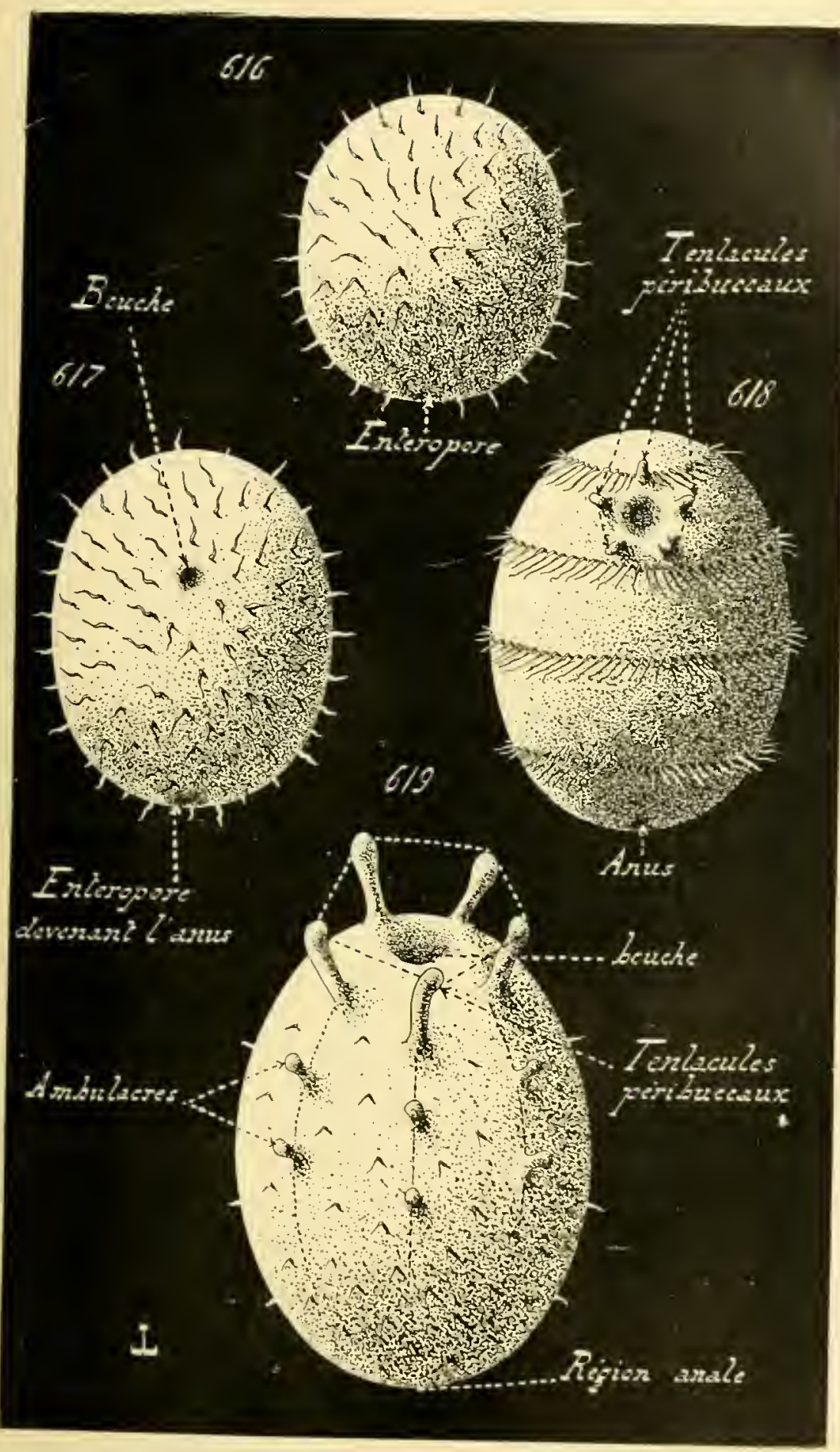

Fig. 611\% ส̇ 619 
Cetle simplirité se retrourr dans l'́pillélio-mésoderme. Quel que soit lo procédé employé par ce rlemier pour prendre naissance, et la diversité à ret égrd porte sur le nombre des éluaches, non sur leur frovenance qui ast lonjours enterique, re feuillet se trouve divisé en denx parties: l'une droite, dite entérocaledroit; l'autre gauche, nommée enterocale quuche. Chacune l'elles contient nue cavité colomique. Ces leux moitiés grandissent dans le corps, et y occupent un espace consilórable, en cuton lant lintestin; elles sunissent ensnite, poul ne former 'pu'un senl tout, yui se cloisonne au moyen cle mésentères jeu nombrrux. L'arcroissement est surtont le fait clu curome, qni augmente de heancoup son volume initial, et applique sa paroi, cest-à-dire le mésolerme épithélial, snr le splanrhno-mésenchyme d’un côté, el sur le somatomésenchyne de lautre. - La premiere zone, accolée au splanchnomésenchyme, est la splanchuoplenre; toutes deux, jointes i l'enloderme, composent la parri intestinale. La seconde est la somatopleure; adhérente au somato-mésenchyme, qui la sépare le l'ectolerme, elle conslitue, aide de ces deux ilerniers fenillets, la paroi du corps. La splandhnopleure et la somatoplemres'unissent, l'une à l'autre, au miveau des orifices ligustil's, et par les mésenteres, dont la partie axiale est hien fournie frar le mésorlerme mésenchymateux, mais dont la surlace est occupée frar un endothólium qui dórive le l’épithélio-mésoderme. Contrairement ¿ ce que montrent lus Vertébrés, les deux feuillets engendrés par le mésoderme ipithelial lemeurent simples, ne se segmentent pas en métamères, et ne se plissent point pour produire tes muscles; sauf quelques faisceanx museulaires, leur plus grande part est employée à domer l'endothélium péritonral, qui limite le culome entérocurlien.

Co dernirs constitue d'habiturte, dans l'intericur du corps, me vaste cavité à peine sublivisre, un oligormlome, contenant un liquile plasmique, charge d'élíments figurés. A cause de son origine, qui comporte la présence de deux diverticules émanín le l'entéron, Semon attrilure, anx larves le la pupart des Echinodermes, le nom grinérique de Dipleurulu. Ce trime est mal choisi, car il s"applique également anx embryons de tous les Entéroraloniens lont l'entérorrle se compose, a son début. te leux résicnles; cette expression serait rajnale de raractériser les Vertéhrés aussi lỉen que lrs Echinodemmes; le mienx est de ne pas jemployer.

Lorsque los deux parties du linillet moyen so sont délimitéen, l'enliryon des Edhinoterues possede une structure complexe. La paroi somatipue se compose, un allant de lehors en dedans, de lertorlerme, du somato-mesenchyme, et dr: la somatopleure: la paroi intestiuale rst constituce, en allant également le vehors en dedans, par la splinchnoplenre, le splanchno-mésenchyme, ot l'endodepme. Celui-ci limite imméliatemnt la vavité intestinale, comme l'ectoderme reconve la surface du rorps entier. Ces denx parois, pui s'unissmut an nivean des orilices ligsestifs, sont sípanées l'uno de l'autre, daus l'intérienr de l'organisme, 
par un vaste espace rempli de liquide : l'oligocelome entrorulion. Celui-ci est directement horué par la somatopleure ef par la splanolunplenre. Le somato-músenchyme of le splanchno-mésenchyme sout euxmèmes crensés de larues, qui composent un polycolome schizocmlion. liéconomie coutient ainsi frois sortes de cavités, indépendanles les unes des autres au moment où les diverses partios du mésoderme sont prásentes, et ne communiquant pas entre elles : la caviti intestinale, loligoculome entírocolien, et le polycolome schizocuelien: dorénavant, et pour alréger, ces deux Jerniores seront désignées par les seuls noms l'oligocolome, et de polycrelome. A ces trois types de carités s'en ajoute un quatrième, l’appareil ambulacraire.

20 A. - L'éhanche de l"appareil amhulacrairo porte le nom d’hydrocrele; elle constitue une résicule placée lans le corjs, et comprosée J'une cavité, que limite une paroi. Elle provient dn premier ruliment de l'entérocole. - En prenant les phénomènes les plus simples, tels qu’ils se présentent dans la plupart des développenents dilatés, ce fremier ruliment est impair, el se létache du lond de l'entéron, c'est-idire de la région opjosce à l'entéropore. On peut, il cause de son apparilion hàtive, et du rôle qu'il ra jomer, le drísigner par l'expression de protenterocale. Il se livise, ensuite, en trois parties: l'mne, encore simple el impaire, qui est l'hydrocule: les deux antres, symetrinues, ot lormant une paire de vésiculrs semblables. Ces drinières sont los deux entérocoles dítinitifs, l’entérocule droit et l'entrirocale gauche. - Uu peu avaut que cette scission ne se produise, et pendant quelle s'effeche, la zone, chargée de donner l'hydrocole, imet un canal, qui va s'ourrir au dehors, dans la région dorsale el postérieure de l'embryon; re canal reste la propurité de l'hydrocule, lorsyue la sciparation des trois rísicules est lerminée, et lui permet de communiquer avec l'extérieur, alor's que les deux entéroroles drmeurent alos. Ce conduit 'st nommó le lube

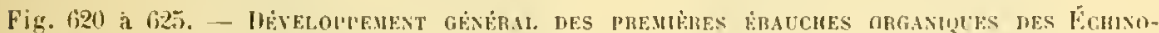
DERUEs foupes mélianes el langitudinales, avec perspective. ces coupes doivent itre rapportées aux contours extèrieurs des dessins précédents: elles sont menèes suivant. un plan longitulinal, el perpeneliculaire au plan de la fage sur laquelle ees deruiers sont tracès, c'est-i-dire d"avant en arriere). - En fien, phase gastrulaire, leponelant à la figure $6 \mathrm{ili}$; le mesenchyme est flate dans la eavile blastocelienne, représentèe en noir. - En 621, phase plus avancée; le foncl le l'entèron commenee à se separer, par un ètranglement annulaire, du restr lle la cavité cnlérique. - lin 622 , etat plus avanci; le fond de l'cnteron s'est complìlemeni dètaché, el constitue le protenté rocole. - Fin 623 , le protentėrocolc grandit, et commenre a se diviser en trais parlies, lont l'une est médiane, et dont les deux autres sont latėrales. - En fi2', phase plus avancée, réponlant ì la figure 6l\%. Les trois parties du protentẻrocole sont levenues indépentantes: les deux laterales sont les eutẻrocoles, dont l'un tlangue l'enteron a drojte, et l'autr" a gauche; la méliane est l'hydrocula, qui èmet un liverticule vers la region dorsale du corps; le stomeon se creuse sur la face ventrale de lorganisme. - En $62 \%$, les deux enti: rocmes ont grandi; l'hydrociule s'est ouvert au dehors pal l'hyllopore, dorsal; ct l. stomeon, font l'orifice exterieur est la bouche, s'allonec pour alles rejoindre l'enterun, 'pui devient l'intestin.

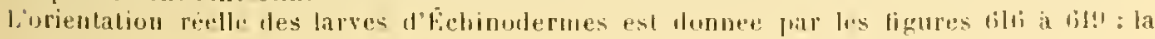



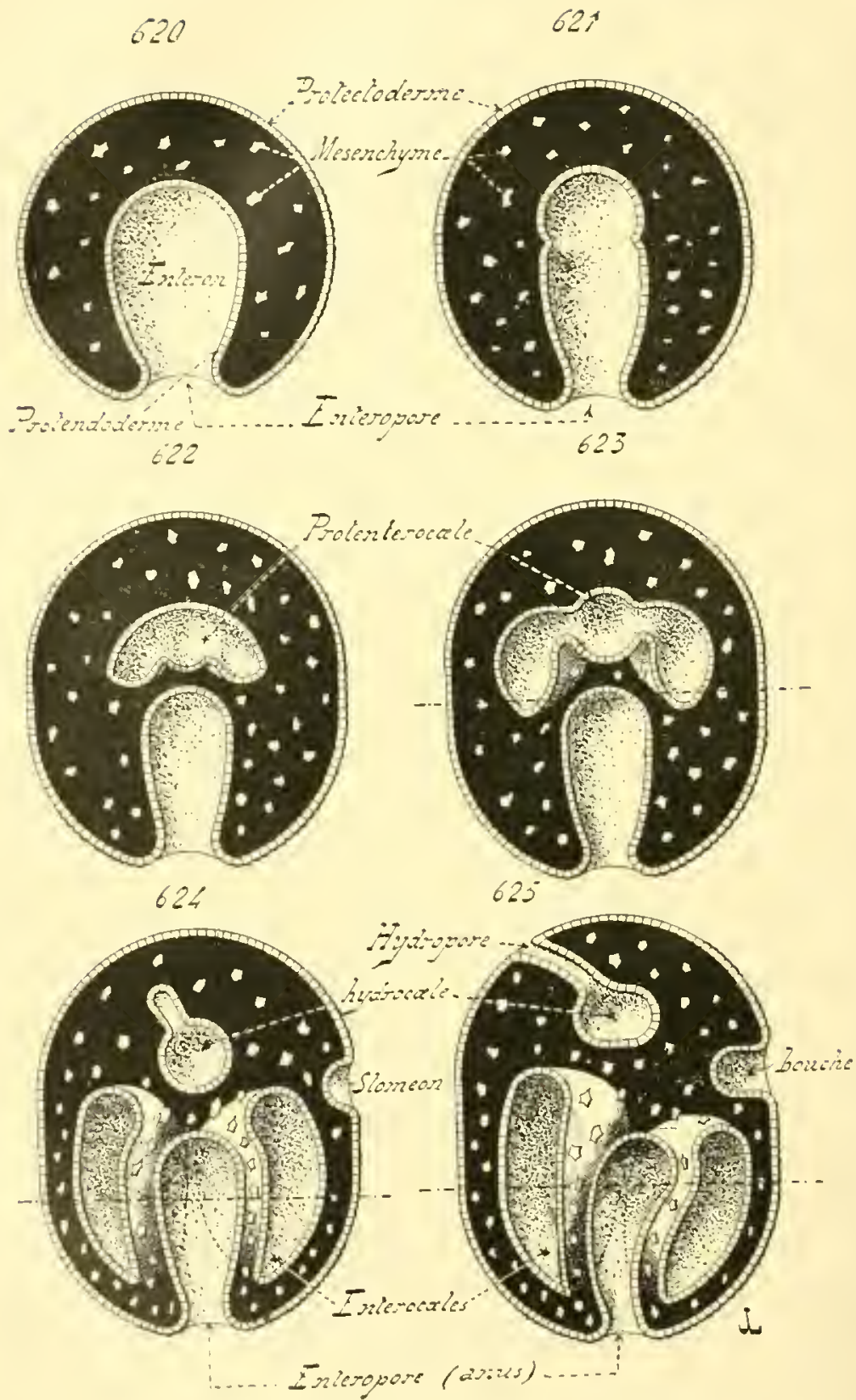

bourhe est antirieure, et l'lydropore postérieur, ou dorsal. l'i, afin de montrer ces deux orifices, et d'indiguer la disposition des enterocules, ee qui est antérieur dans la rèalité est repurtè à droite, el ce qui est postẻrieur à gauche: le plan de ces coupes est exaetement antéro-postèrieur. 
hydrophore, el sou orifice extérieur le pore dorsal; à cause lles thangr-

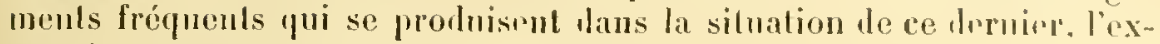
plession hydropore serait plus justilice.

lilyolrocole est alors comslilui. Il se compose amme vésicule, du lube hydrophore, el de l'hydropore. A cause lle sil provenance, ses rapforls aver les autres feniliets sont semblables a cenx des rutrocorles;
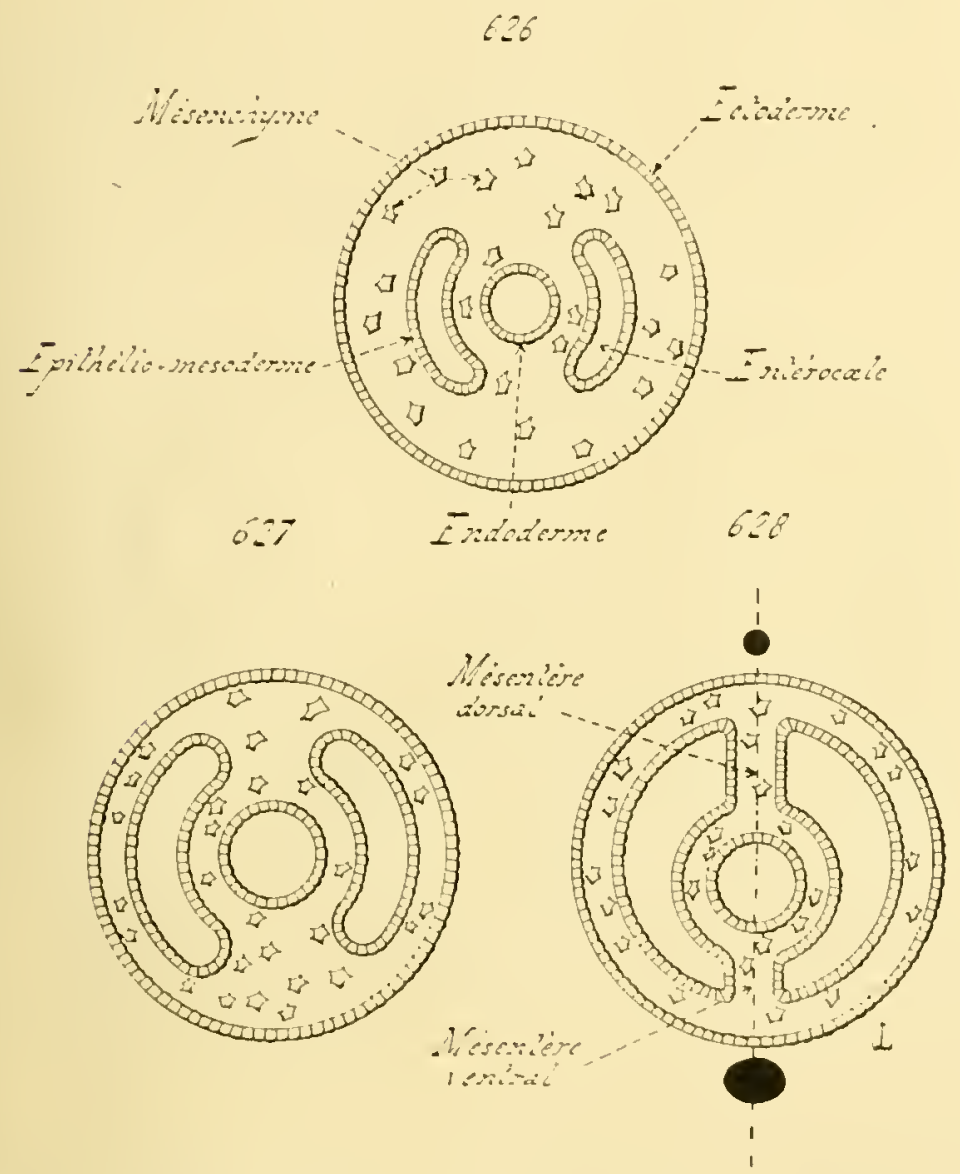

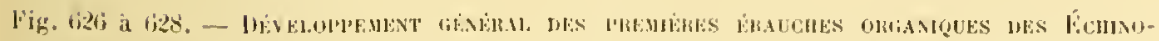
Dkills (roupe's transversules des trois derniers des dessins procolents; les lignes tracéts sur reux-ci imdiouent la dirertion des plans de celles-lä). - lin 62 li, coupe Iransversale réjondant à la ligure 623 ; les entérocueles, le droit et le gauche, limites par l'upilléliomesoderme, sont plongés dins le mesenclyme, el encore petits. - lin 627, coupe transversale rèjondant a la figure 624 ; les denx entérocules grandissent. - lin 628, coupe transversale repondant in la ligure $(225$; les deux tuteroutes ont acquis leul laille définilive, el demeurent séparés par deux mestnteres, l'un lorsal el l'autre ventral. La

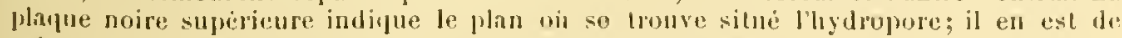
mine, au sujet le la houcle:, jour la jlanne noire infericure.

Ces ligures montrent de quelle maniere le mesenchyme coloure l'intestin avee les cnterocules, et entre dans la constilution des mesentieres. 
il est, de mème, entomé pro le mésoderme mésenchrmalenx, at celte disposition persiste. pour lui comme pour ses dépendances, juśfue dans l'organisme définitil. Les leux entérocoles, dans leur extension autour Je l'entéron, se rencontrent, sur la ligne médiane, dans la région ventrale comme dans la région dorsale de l'emliryon, et sarlossent l'm a l'antre; les régions alossees composent les mósentères : le tube hydrophore est contem dans le mésentire dorsal.

Lentéron restant sallongre, ensisile, far son extrimité opposće ì l'entéropore: la nouvelle région produile va souvrir au dehors par une ouverture, pacre sur la fare ventrale, on antírieure, lu corps, et qui deviendra la houche de l'adulte. L’intestin possede rès lors leux orifices: l'entéropore, yui se convertit en anus, et la bonche le nonvelle formalion. Ces orifices sont sćparís par me assez grande listance, bien que la lonche noccupe pas une silualion diamótralement opposée à celle de l'ontéropore, el soit reportée sur la face vonlrale. - Comme la partic intestinale récente provient dı fond de l'entéron, l’uì s'était délaché précédemment le proteutérocnele, l'hỵlrocole, qui dérive de ce dernier, est contign i cette zone du tube diwestif. Tout en conservant ses commnnications, avec le dehor's, par l'entremise du canal hylrophore, sa vésicule s'applique contre cette rígion de l'intestin, et l'entoure à la manière d'un amneau; ce dernier persiste désormais daus le colps, et donne l'anneau hydrophore, sonvent nommé annean ambulacraire. Celui-ci émel cing diverticules, egralement distants, qui se dirigent vers l'extérieur, soulèvent ì leur niveau liectolerme avec le somalo-mésenchyme, el, en grandissant, produisent cinq tentacules placés autour le la houche: le nombre de res tentacules augmenle parfois dans la suile, mais en conservant toujours une symétrie radiale, étahlic sur le chiffre cing. Enfin. ce mème anneau envoic ciny aulres expansions, également disposées suivant une symétrie radiale, dout la direction ost inverse de celle des précélrutes; elles s’étemdent dans le corps, cn pénétrant dans le somato-mésenchyme, el s’insinuent, ainsi, entre la somatopleure et l'ectoderme. Ces cinq diverticules prennent, dans lenr accroissement, une forme tubulaire el cylindrique, et leviennent les cinq vaisseaux ambulacraires.

Les principales parlies le l'appareil ambulacraire ont alors pris naissance; elles sont tontes lormées par une élauche commune, l’hyvilrocule, qui provient à son tour du protentérocole. Cet lyydrocole se modilie en une vésicule, qui communique avec le dehors par le tule hydropliore muni le son hydropore; la vésicule entoure l'intestin próbuceal à la lacon d'un annean, et émet reux sortes d'expansions, font les unes se convertissent n tentacules placés autour le la lowrhe, ef les autres en vaisseatx ambulacraires. Les organes engendres jar l'hydrocole, ou plulót par l'annean hỵdrophore qui dérive de lni, apparliennent donc à lenx systemes: Ie systeme des lentacules péribuccaux, el l'appreil atubularaine. 
b. - Arant que les organes d'origine hydroculienue n'aient acpuis leur disposilion définitive, la symétrie du corps était franchement bilaférale. Lientéron el l'hydrocole élaient impairs et médians, et les deus entérocales se tromvient placés de part el diautre de la ligno médiane. Cette disposition lilatérale existe encore, mais à l'élat d'indicalion. dans l'économic de l’alulte, an sujet le certains appareils, notamment du tube digeslif, de ses aumexes, el parfois du lube liydrophore, dans le cas on il reste simple: elle est plus jrononcée chez les Holothuries que chez les antres Echinodermes. Ce Ilernier lait, joint à la struclude de divers organes, tend it faire considérer les Holollumides comme les moins élevés les Echilodermes commus, puisque lrur orientation grénérale se rapproche davantage de celle montrée par la larve. - Senlement, celte symétrie hilatérale est ensuite, non pas détruite, mais cachée sous la nouvelle disposition radiale, et quinyuennale, anenie par larrangement de l'appareil amlulacraire. La lome générale du corps, toujours placée sous la dépendance étroite du groupement des appendices locomoleurs, se modifie suirant celle symétrie rayomnéc; les organes, qui dirigent les relations de l'individn avec les milienx extéricurs, comme les cenlres nervenx, agrissent de mème; et la disposition premiòre se trouve changée. l céconomie des Echinorlermes est ainsi orientẻe d'après denx plans de symétrie : l'mo primitif el bilatriral, senl lont d'alord, et dont quelques systemes montrent encore les trates; l'antre, secondaire et rarlial, qui prend de lieancoup la prédominance, et regrle la formo générale du corps.

Il serail intéressanl de savoir comment la disposilion quinquenmair. jrend najsance dans l'éronomie; mallenreusemeut, les recherches effectuées sont encore insulfisautes. Dans la plujart dis cas, les ciny expansions de l'anneau hylrophore apparaissent en même temps. Cependant, comme cette disposition succède ì la symétrje bilatérale, on peut admellre que celle-là dérive de celle-ci, par l'apport le nouveaux éliments, qui s’ajouleut aux préexislants, et lenr levicuneut égaux. l)aules animanx montrent ígalement mne orientation ladiale, les sicyphozoaires par exemple; el ce fait avail autrefois conduil a places tous ¿es etres daus un mème groupe, celui des liayonnes. Senlement, lorienlabion des Scyphozoaires est élablie d'apues le chiflre quatre, et on sait comment rlle dérje do la symétrie bilatérale : par la genèse d’une nouvelle paire d'éléments, interealís aux deux formés en premier lien. Celle lisposition en quadrant se modifie à son lour, lans cerlains cas, el devient une symétrie par donze, on par six; les données acounises prermettent de comprendre snivant juel moyen ce changement parvicut à sc minfester. [] n'mest pas ausi pour les lichinodemes; lenr symétrie quinfuennaire est sirement une altération d. la symétrie hilatérale, mais on ne sait encore an juste d'ajures quels procédés ollo se produit.

30 Le jemmo cmblugn so lacounc, diune maniere frécoce, suivant ROULE, - FMER YOLOGHE. 
une orientation radiale, dont les premières indications sout foumies par les cinq tentacules primorliaux placés antour de la bouche, et par les cinq vaisseaux ambulacraires. Tous les Echinolemmes, qui subissent une évolution dilatée, et ne présenteul pas des mélamorphoses larvaires trop accentuées, passent par une phase ainsi caractérisée. Leurs larves possètent: un intestin, mmni d'une bouclue et d'un anus; deux entérocoles, l'un droit el l'autre gauche: un annean hydrophore, cinq lentacules péribuccaux, et cinq élrauchos de vaisseaux ambulacraires. Cette larve Lypique, et fondamentale, a été nomméc Pentactula par Semou; la présence d'une l'entaclule dans le cours du développrement, toules les fois où l’évolution embryounaire n'est pas trop modifiée par des phénomènes d'adaplation secondaire, est la caractéristiıue des Echinodermes. Ces lispositions se retrowvent mème, avec leur structure exacte, lien que leur ordre d’apparilion soil changé par un déplacement dans le temps, chez ceux qui présentent des embryogénies altérées par des stases, ou par des destructions dorganes. Il est dono permis de prendre la larve lentactule pour te type essentiel, anquel se rapportent les développ. ments de tous les Echinodermes.

Les Holothuries montreutle mienx cette forme embryomnaire, dans le cours de lenr évolution. Leur prosome, rest-i-dire le corps de leurs larves, ne présente point d’iditicalions à lui particulicres, cl destinées à disparaitre vers ta fin du developpement, ou n'en olipe yue fort peu. Le mème phénomène existe chez les Crinoïdes, abstraction faite de la chute pédonculaire, spéciale anx Comatules; mais il concorde, dans ce cas, avec une embryogénie légòement condensée, et accompagnée par la désagrégation, par l'histolyse, de quelques orgaues internes, qui se réédilient par la surte. - Il n'en est plus te mème ponr les Echinides, les Ophiurides, ni pour les Astiriles. Les larves de ces animanx possèdent Jes appendices de formes variables, qui lem sout propres, en ce sens quils s'atrophient au moment où l'embryon passe a l'état adulte, et destinés à assurer les déplacements de ces petits êtres. Ces appendices extérieurs apparticnnent a deux types principanx: les uns sont des expansions, plus on moins lobées on frangres, comertes de cils ribraliles, qui assurent directement la locomotion; les antros sont des bras, des longues baguetles cylindripues et pleines, pomrnes parfois de spicules calcaires, qui soutiennent le corps dans l'eau a la manière de balanciers. - L'aspect de ces organes larvaires, qui dépendent strictement du prosome, et ne participent en rien au faconnement de l'écononie détinilive, du mótasome, permet de comprendre leur mile et leur signification. Les adultes, parmi les Echinodermes précités, sont pourvus d’apparcils locomoteur's, mats leurs déplacements sont restreints; si les embryons ćtaient eux-mèmes incapables de se mouroir, les conditions faroubles i la vie, el fournies par les milieux extérieurs, seraient rapidement iusuffisantes, à cause du graud nombre d’iudividus acemmulés dans 111 mène espace. La nécessile de la dissémination des jennes exence ici, 
comme sur lous les etres organisés, son influence: lrs larves possèlent des organes spéciaux, qu'clles utilisent pour se transporter au loin. Certajus de ces dejniers sont des lohes, ou des comronmes ciliées, qui servent directement a la locomotion; les antres sont les bras allongés
et rigides, qui soutiennent le corps, oflrent me grande prise aux cou-
rants marins, et permettent aux em rants marins, et permettent aux embryons d'ète classćs i une grande
distance de leurs génératenrs.

La présence de ces amnexes donne an prosome un aspect spécial, aisément recomnaissable, et bien difiérent de celuj du métasome. A cause de leur róle important, ces appendices sont volumineux, et constitment une grande part do l'organisme lajvaire. Comme ils disparaissent en tolalité vers la fin de l'érolution embryonnaire, juisquils ne passent restreinte du prosome, qui de ce dernier est fagonnć par une régrion costreinte du prosome, qui grandit seule. - Les anricus naturalistes considérajent presque ce phénomène comme répondant à une allernance ères fort simples, représentant adulte donnait, apres fécondation. des naient ensujte, sur un cóté de leur corps, de génération, qui bourgeondevenir des Echinodermes complets, te noureaux êtres capables de apres quoi le cycle recommencait. Cies particularités consistent seulement. Une telle interprétation est inexacte. entre le prosome et le métasome enton muc disproportion considérable uitif, semblable à celle que montrent divers autres anjmaux, plusienrs
Trochozoaires par exemple. Le prosome est muni d'appareils locomoteurs, qui lui appartiennent spécialement, el ne doivent poreils locomoà l'édification de l'organisme adulte; ces a doivent point contribuer les porte, sont destinés à disparaitle au appendices, avec la zone qui métasome prend naissance aux lépens cours du développement, et le s'accroit scule, alors que le reste du prosome s'atroplice. Ce phénonéme ne s'accompagne d’aucun bourgeomnement; il répond à une inégalité
d'accroissement de l'organisme larvaire.

$A$ canse de ces faits, les larves des lichir

morphoses très accentuées. Ces dernières codemes subissent des métaquentes, durant lesquelles les annexes locomotportent des stases fréfonclions, et ne changent pas l'allure, ou locomotours accomplissent leurs que le métasome s'ébanche, et se perfectiome, modifient très peu, pendant du prosome. Une telle stase, puifectionne, aux dépens d'une partie méne allure générale, alase, qui permet il la larve de conserver la

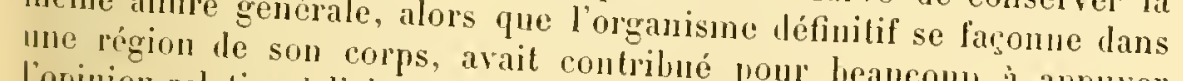
l'opinion relative i l'alternance.

Les emliryous libes des lechino.

daires, mais des larves adaptatives. Tous les sout pas des larves seconchement possédent des phases larvaires daus le coursentants de lembranlu moins ceux de la malure achelle il dans le conrs de leuróvolution, infruluction secondare l'embryons il ne pent doncetre question d'me 

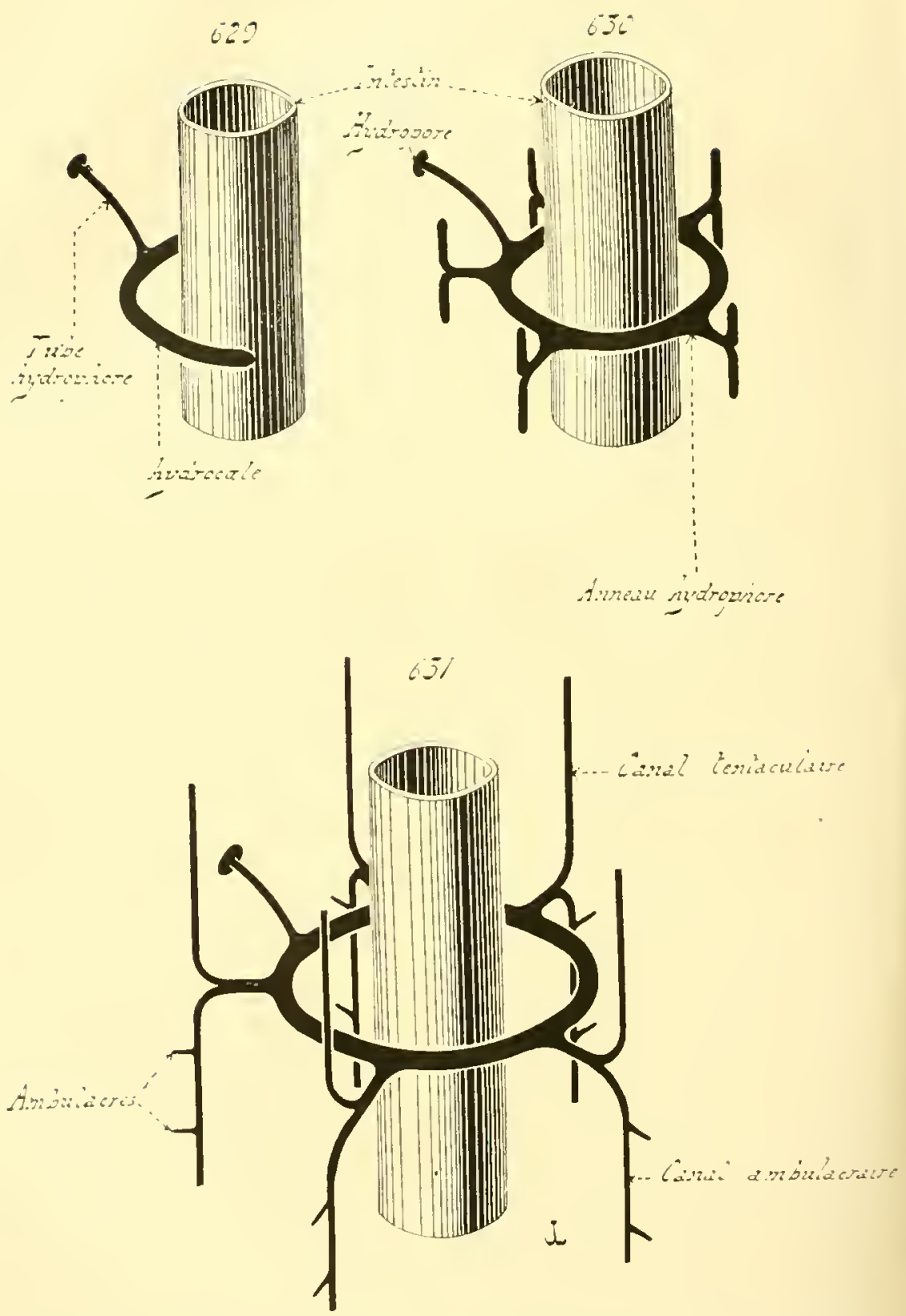

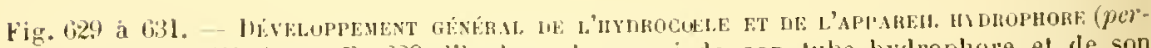
spective cavaliere). - En $(229$ l'hydrocole, muni de son tube hydrophore et de son hydropore, commence à s'ítendre autour de lintestin. - En 630, ce mouvement est Lermine, et l'hydrocorde enserre l'intestin à da manicre d'une bague. Cet anneau hydro-

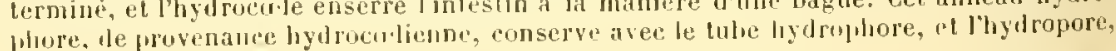



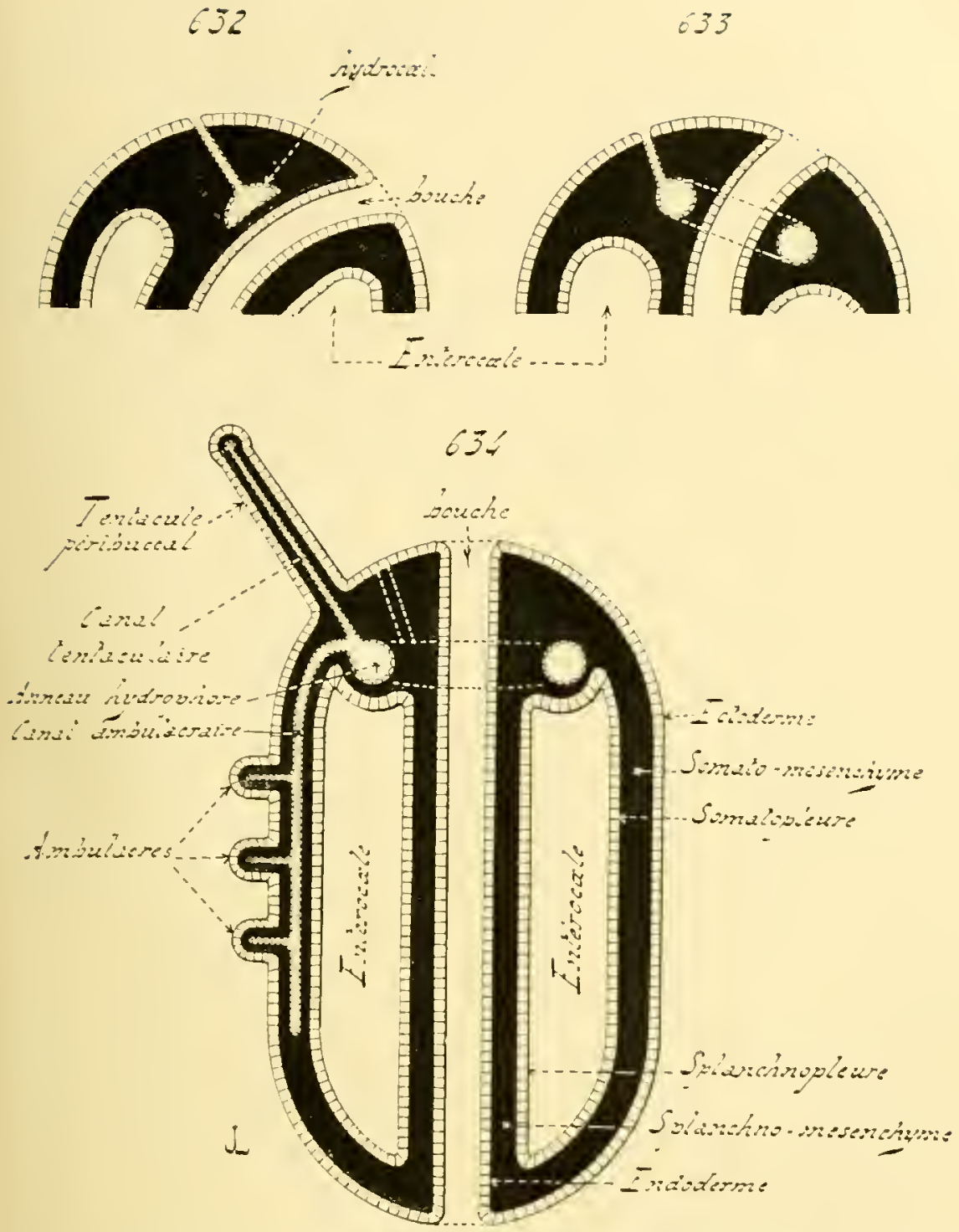

les relations de l'èluuclie llont il dérive; il cummence à émettre des diverticules cylin. Jrigues, an nombre de cinf, qui sunt les premieres indications des canaux tentaculiares péribuccaux et des canaux anbulacraires; celle plase est souvent dite de la roselle ambulniraire. ou de la roselle hydrophore. - bin ti3l, lette ivolution est terminé; l'appareil lydrophore cot complet.

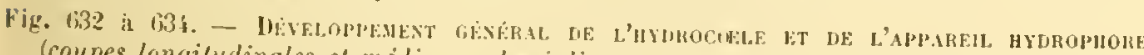
lcoupes longiludinales el médianes, demi-diayrammaliques; la ligure fi3t est seule com-

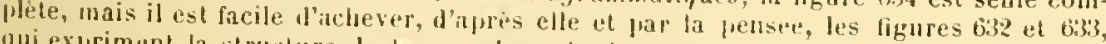
qui expriment la struchre de la zon" luecale du rorps). - Ca's ligures completent les

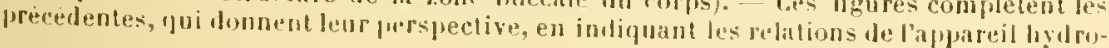


conme il en est che\% les Insectes, par exemple. Ces larves sont adaptatives; lents caractires particuliers, qui leur sont personnels, et que l'aululte ne présente point, sont le résultat d'une aulaptation aux circonstances extérieures, lestinée ì leur permettre un déplacement plus aisé. et une dissémination plus grande.

Coxcucstox. - 1. Eu faisant alsstraction de ces mélamorphoses des larves, dont la valeur vient seulement de la forme montrée par ces Jernières, cette forme étant spéciale à l'embranchement, et ne se tronvant point chez les autres animaux, les caractères essentiels se réduisent a la dualité du mésoderme, et à la présence de l'appareil hydrophore. Cette seconde parlicularité est plus importante que la première, car la dualité du feuillet moyen se retrouve chez les Vertébrés, alors que le systime hydrophore, arec les organes produits prar lui, sont vraiment spéciaux aux Echinodermes, et n'existent mulle part ailleurs. Il est donc nécessaire de se représenter comment ret appareil prend naissance dans l'économic, el de comeroir sa signification précise.

$\Lambda$ ce sujet, si l'on élague les faits secondaires pour retenir ceux ru’il est permis, d'après l'emliryogénie, de considérer comme fondamentaux, on aboutit ì la notion de la larve l'entactule, telle qu'elle estétahlie plus haut. Le système hydrophore de cette larve crnsiste en mn annean, placé aulour de la région préhuceale du canal digestif, qui communique avec le dehors par le moven de son tube hydrophore, et envoie cinq diverticules dans les cinq tentacules situés de manière à encadrer la bouche. Plus tarl, les cinq raisseanx ambulacraires se montrent à leur tour; ils émetlent vers le dehors des expansions, les ambulacres, qui ont arec eux, el avec la paroi du corps, des relations identiques à celles des tentacules avec l'annean hydrophore; comme l'origine est la mème dans les deux cas, les ambulacres sont donc les homologues des tentacules péribuccaux. La communication avec l'extérieur, par l'entremise du tube hydrophore et de l'hydropore, est destiméce, sans nul donte, il assurer le fonetionnement de ces appendices. P'our déterminer leur extension, l'eau environnante eutre dans l'appareil, en pénétrant par l'hydropore, arrive dans lannean, et gonfle les tentacules avec les ambulacres; dans leur rétraction, le lípuile en surcroì est expulsé an hehors par le mème chemin. L'ensemlle constilue un système hydrostatique, dont l'usage est possible, grice à l'emploi de lean extérieure.

En se représentant les phénomènes, tels quilis se passent dans les développements les plus dilatés, dans ceux des Ilolothurides et des lichiniles par exemple, la genèse de l'hylrocole ollie les phases sui-

phore avec les autres feuillets de lorganisme; le déplacement fréquent, subi par la bonche, qui d’antérieure devient terminale, à mesure que le corps grandit el se perfectionne, est egalement exposé par ces figures.

l.es dispositions, dénotées par coupe sur la ligure 634, sont exprimées en perspective par la figure 643. 
rantes. Le foud de l'ontéron donne to protentérocule: puis. ce dernion étant prodnit, sallonge pour former la bouche; en mème temps, le protentérocule émet le tube hyitrophore, et pousse deux expansions lalérales qui encadrent l'entéron. Aussi, lurant un certain temps, te protentérocole rommunique-t-il arec le lelıors. Les expansions latérales grandissent ensnite, pour devenir les denx entérocules; le liquide, contenu dans leur cavité. acquiert, par consípuent, un rôle nutritif, que le mélange constant avec l'eau environnante est capable d’altérer. La portion, à laquelle s'mit le tule hydrophore, se sépare alors, et s’isole lu reste pour constituer l'hylrocoele; les deux entérocoles, également isolés l'nu de l'autre par cette mème scission, jouent désormais leurs fonctions relatives aux échanges nutritifs, et n'en acquièrent point d'autres. Des tentacules maissent antonr le la bonche, et se disposent en un cercle complet; Ihydrocole lenr fournit leurs cavités centrates, quiles rendent capables de s'allonger et de se rétracter, et se convertit ì son tour en mu anneau, afin que ses diverticules soient placés comme les appendices auxquels ils se distrilment.

Parfois, te fond de l'entéron engendre le tube hyidrophore, avant de se délimiter lui-mème pour fournir le protentérocolr. If convient, sans doute, le considérer ce phénomène comme le résultat d'un déplacement dans le temps. Limportance le ce tube est telle, dans l'organisme, que les premières phases embryomaires sont consacrées à le produire. D'autres animaux offrent de fréquents exemples d'une telle hàte génélique, connexe ì la haute valour de l'appareil produit; ainsi, les Vertéhrés Craniotes façonnent rapidement les ébauches de leur cuur et de leur rein, alors que ces organes, à en juger l'après la structure des Vertélorés Acraniens, devraient prendre naissance un peu plus tard.

B. - Les notions rolatives à la I'entactule, qui résmment les données essentielles de la morphogenèse embrounaire des Echinorlermes actuels, permettent de concevoir', it un titre purement subjectif, l'existence, dans la morphogenèse ancestrale de ces mèmes êtres. d'un tỵpe, le Pentazoon, qui a élé la souche dont ces animanx sont issus. - Le Pentazoon dérivait, sans doute, d'une gastrule, dont lo hastocrile renfermait des ćléments mésenchymateux fournis par le protentoderme, et pourve, en outre, d'un crrlome d'origine entérípe, d'un protentérocrile simple et impair. Il possélait une lonehe et un anus; la loncle était encalrée par cinq tenlacnles. Le protentérocolle. dégagé de l'entéron, se divisait en deux régions: l'me préhuceale, rui entourait l'osophage, et envoyait des expansions lans les lintacules; l'autre, príri-entérifuc, composcé de deux lohes, l'mu droit et l'autre gauche: la premiere communiquait avec le dehors par le moyen l'un tulie livilrophore.

In ce l'entazonn, dont l'anrienue exislence est dicelée par les Pontactntes actuclles, sont sortis les Echinoltermes. Lat region próhuccale du protentirocules'est sréparre de l'autre, frour constitner, a elle sente, l'ap- 
pareil hvdrophore. Les deux lohes de la seconde région se sont accus, pour donner une volmunemse eavilé inlérienre, l'oligocolome. A la

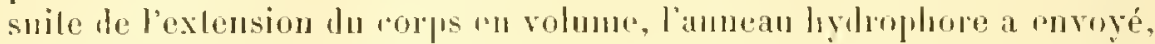
daus les léguments, des vaisseanx ambulacraires, mumis dappendices supplémentaires semblahes aux tentacules. Le mésenchyme du blastocule n'a pas disparu, mais a mulliplié ses éléments, qui se sonl disposés en couches interposées à l'endoderme, ou à l'ecloderme, et à lous les organes issus du protentérocule juitial. Le lentazoon, à la slucture si simple, a prouluil ainsi, par me série de moditications ellectuées dans ses diverses parlies, des Echinohrmes complexs. - Cetle conception, qui permel de se représenter lorigine de l'embranchenent entier, découle foul entiere des phémomenes ohjectils montrés, dans leur développencul, par les lichinodermes achels. en lem conservant lems qualités relalives au lemps el it l'esprace. (In jeut done almeltre qu'elle exprime, dans ses trails généraux, des faits réels, bien quils n’apartiennent plus à lobservalion directe.

\section{2. - Sexualité et développement des deux feuillets blastodermiques primordiaux.}

1. Considérations générales. SExw tute. - Sauf quelpues rares exceplions, les Echinotermes sont misexués. Les exceplions connues se rapportent: à une Ophiuride, Y'Amphiura squamata; à wne Aslíride, l'Asterina gibbosa; enfin, al plusieurs especes l'llolothurides apjartenant aux genres synapla el Anapta. L'bermaphodilisme te ces lernières, et celui le l'Amplizura squamata, sont élablis de telle sorte, que les glandes sexuelles conticment. en même temps, les wvules el les spermatozoïdes; tel n'est pas le cas pour les Asterinn gibbosa, tont l'hermaphrodilisme est protambique, elarpue individu commencant par ètre mâle, el levenant femelle par la suile. - Il romvient, sans doule, de ne point accorder une lop gramle imporlance à ces phénomènes; les g.landes i la double sexualilé ressemblent enlièrement à celles possédées par les aulres représentants lu groupe.

Les jeunes testicules sont constilués par les amas de spermolnasles. A en juger d'après les études de Jensen sur la Cucumaria frondosa, chaque spermoblaste se divise, au moyen de scissions répétées, en un cerlain nombre le spermatorytes, sans qu’il se prowluse mu cylophore; les spermatocyles restent assembles, pemant quelque lemps, en un spermalogemme, puis ils se converlissent en spermalozoüdes. el se létachent les uns des autres. tes spermalogemmes alhèenl, durant lemr evolution, a la paroi lu tuhe testiculaje dont ils provienuent; ils sonl arpondis d'habitule; cenx des Conalules (Crinoïles) sont allongés, rylmbiques, el contienment une cavilé ceutrale. Les spermatozö̈les possèbent laspect hahilud, ol se composent d'une tète chloblouse, ou

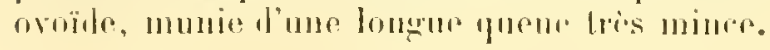


Les ovaires jeunes ressemblent aux lesticules du mome ige:ils sont formes par l'minion de nombreux ovolilastes ilentiques, et qui émultent.

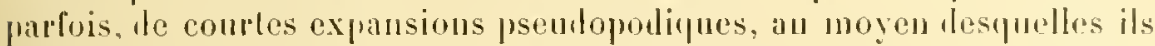
se déplacent quelque peu. Contrairement à ce quil en est pour les randes miles, tous les ovolılastes ne parvienment pas a ilomer des ovules. Cenx qui y arrivent ne sulussent ancune modilicalion spriciale; ils absotbent la sulistance des autres, qui leur servent ainsi l'aliments, ou s'en entourent parfois, chez les Comatules parexemple, à la fason d'une vourche folliculaire. - Les ovules, lorsqüils sont miùs, sont cureloppis, dans la grande majorité des cas, par nne mince membrane vilelline; chez la plupart les Ilolothurides et liverses Astériles, cette memhrane, un peu plus épraisse, est percée lle pelits cananx, qui la traversent the part en part. Le vitellus ne renterme yu'un potil nombre de granulations dentolécithiques. La vésicule germinative porte parlois, ihez les Ilolothuriles notamment, des ponchuations, dites taches germinutives, qui consistent en lépressions arpondies de la paroi uncléaire, remplies par une sulıstance réfringente. - Les aufs les Echinodermes sont d'omlinairr fort petits, a cause de labsenee, ou de la rareté, du vitellus mutrilif. Quelques espèces vivipares, on dont les emhryons subissent des métamorploses restreintes, comme l'Asterina gibbosi par exemple, font exception, rar" leurs ovules sont plus volumineus, et atteignent mème un millimitre de liamille.

La fócomlation est externe d'bahitude. Le màle rejetle ses bíments reproduclenrs dans l'eau enviromante, et la femelle agit l'ume maniene identique. Le développement des arufs fécondés s'etfectue, de mème, dans l'ean, en dehors des générateurs, et sans ancune relation avec eux. Il existe pourtant quelques exceptions a cet égurd. - Corlaines Astérides léposent leurs weufs sous des rocliers, et ne se horment pas à les lancer dans les milienx cxtérieurs : telle est l'Asterina gibbosa. Vil plus grand nombre d'autres especes d'Lichinodermes recueillent lenrs germos, et les placent dans des poches spéciales, on les attachent à une rógion domnée de leur corps, afin de leur faire smbir mo rérilable inculation. On rencontre ces especes dans toutes les classes des Echinodernes, sauf dans celle des Crinoïdes. Il en est ainsi pour le Phyllophorus umu, le Psolus ephippiger, et quelques autres, chez les Ilololluriles; pour le Cidaris

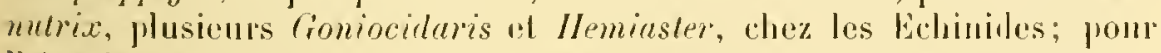
l'Amphiura squamata et diverses Ophiacantha, chez les Ophiurites; contiu pour un grand nombre d’Astérides appartenant i la famille des I'téres-

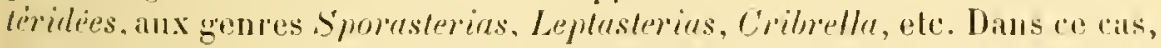
et il ranse mème de cette inculation, les métamorphoses larvares sonl reslreinles; souvent les jounes ne sont mis en liberte, par leur mere, yu'apres avoir acheve leurs phases embryomaires. I. oviparité a ainsi

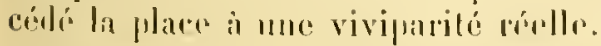

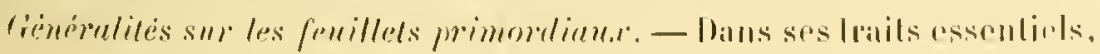


la genèse des deux fenillels primordianx est uniforme chez les Echinodermes. Comme lovole est ponvre en malériaux nutritil's, l'évolution est toujours dilatée, sanf quelques abrévialions particulières, el la desfluction des organes propres ì la larve. - La segmentation, totale, ef sonvent égale, donne nne hlastule, dont le blastoderme entoure une ample cavité blastoecelienne; la lhaslule se convertil en gastrule par le procédé invaginant. la protectoderme de celte dernière ne subit pas de grands
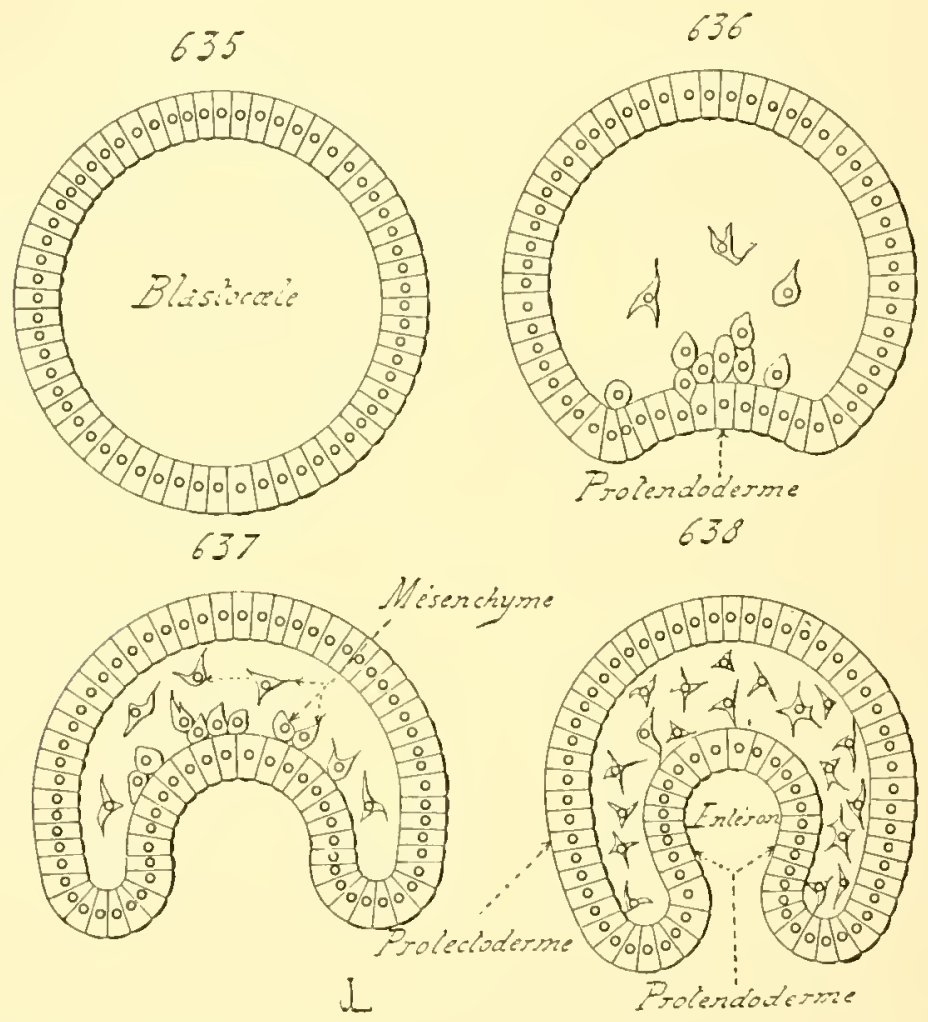

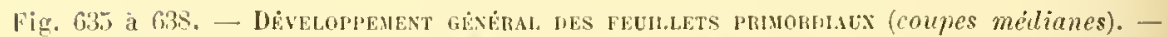
En (i3i, phase blastulaire. - En 636, delut de la gastrulation inviginante; la zone blastodermiłue, qui doit devenir le protendoderme, conmence à produire des éléments mésenhymateux; ceux-ci vont Jans le hastoctele. - Ln 637, suite de la gastrulation; le protendolerme continue it s'enfoncer. - En biss, achèvement de la gastrulation; la gastrule se compose d'un protectoderme et d'un protendoderme, entre lesquels se trouve un abondant mésencliyme.

changemenls; il persiste tel quel, en qualité d'erloderme dílinilif. Le protendoderme offre les modilications plus profondes. II commence par produire l'une des deux parls du feuillet moyen, la part mésenchymaleuse; plusieurs de ses éléments se divisent, el envoient les nouvelles cellules dans la cavité blaslocolienne. Parvenues dans celle-ci, ces 
cellules angmentent en nombre par leurs propres moyens, et ronstiluent le mésenchyome mésodermique; par ronséquent, rolui-ci est, à son débul. placé entre te protectoderme et le protendoderme. Ensuite, de dernior fenillet fournit le protentérocole, el se partage de ce fait en endoderme définitif el unésoderme épithélial. L'endoderme persiste autour de l'entíron pour levenir la paroi intestinale, ef l'entéropore demenre comme anns; eet orifice ne se ferme guère, dans le cours du développement, que chez les Crinoïdes, les Ophiurides, et diverses Astérides.

Cetle sériation des phénomènes est la plus fréquente. I'arfois cependant, à la suite d'un déplacement dans le temps, et par une précocité, les premiers éléments mésenchymateux naissent arant que la phase gastrulaire n’ail apparu; ils se délachent, dans ce eas, du blastoderme de la blastule, ce hlastoderme n'étant pas encore divisí en protendoderme et protectoderme. Tous les éléments du blastorlerme ne concourent pas à la genèse du mésenchyme, mais seulement certains d'entre eux, voisins les uns des autres, el groupés en petil nombre; phusieurs auteurs désignent ces derniers par l'cxpression d'initiales du mesenchyme. - II est nécessaire de ne point accorder à ces initiales une importance trop grande, ni de les consibérer comme ayant une signification différente de celles, des autres cellules blastodermiques, qui loivent donner le protectoderme et le protendoderme. Le mésenchyme n’est point un feuillet primordial, au mème titre que ces deux derniers: sa valeur est moindre. Il fait partie du mésoderme, tont comme les parois les entérocoles et celles de l'hydrocicle, et dérive secondairement du protendoderme. II faut le remarquer, en effet, ces initiales sont précisément placées dans la zone blastodermique qui va s'inraginer pour devenir le fenillel primordial interne, el non ailleurs; hien que leur apparition soit quelque peu antérieure à celle de l’invagination gastrulaire, leur origine protendodermique est cependant indiscutahle. Leur venue précoce estle résultat d'un déplacement dans le temps. Il convientrait done, semble-t-jl, de ne point trop employer le terme d'initiales pour les désigner, car ce mol, daus son acceplion courante, implique une ilée trop prócise pour elles, et une imporlance trop grande.

\section{Développements particuliers des feuillets blastoder-} miques primordiaux. Ilourmirmos. - Les phénomènes te cet orilre sont surtout connus, chez les Ilolothmides, d'apres les recherches de Selenka sur la Symapla digitata el l'Iolothuria helulosa. La segmentation, totale et igrale, donne une blastule munie d'un ample hastocole. Les éléments du blastorlerme, prismatiques, et assez allongés, commencent it se convir de cils viluraliles des la phase hastulaire; ces derniers permettent an pelit embryon de tomrnoyer, dans l'espace limilé par la memlirane vitelline, jusqu'au moment prochain oì celle-ci se lnise pour le laisser libre. La gastrule est ensuite produite par le procódé invaginant; la zone blastodermique qui s'invagine, el se convertit ansi en protendoderme, 
pst relativement restromte. A l'instant où se manilestent les premieres phases do la gastrulation, el oi le protendoderme s'élumche, co fenillet engembre les cellules lu mésenchyme, qui tombent daus la cavité blastocolienne, et sy multiplient. L’éporpue oì naissent ces cellules est plus

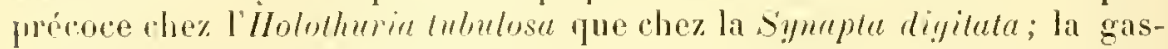
trulation s’indique i peine, pour ce qui est de celle-li, lorsque les premiers élémenls mésenolymateux font leur apparilion. Celle diversilé daus lo lemps justifie les considerations déjá émises, au sujel de la valeur rélle les iniliales signalíes plus lant.

Les deux leuillets primordiaux sont alors formés, ainsi qu'me des deux parts du mésoderme dófinitif. La cavité blastoculienue, dans laquelle sont siluées los cellules de celle part mésenchrmateuse, el où ellos se multiplient, sumble remplie par un plasma loué l’une certaine ronsistance. Les cellules du misencluyme sont plongees dans ce plasma.

Écuxnes. - Les phénomònes gínéran de la segmentation, el de la genèse des fenillets primorlianx des Echinides, sont semblahles à lenrs correspondants les llolohlhurides. La scission ovulaire, lolale et égale, ahoutil i me hlastule, deusíe d'un vaste hastocuele, dont le blastolerme se munil de cils vilsatiles, el qui se comverlit en une gastrule, par l’invagination d’une partie relativement restreinte de ce blastoderme. La particubarié principale consiste en la genese frópuente des premiores cellules misenchymatenses, arant que l'invagination n'ail commenci à se manifesler. Ce pluénoméne a été olssorvé par Selenka chez divers Echindiens, et par Promho ehez les Cidariliens; son extension, si elle n'est pas générale, ot propre í tous les Echiniles, car les observations acquises ne permettent pas the l'aftimer, est du moins assez grande.

l'lusiuurs auteurs consilierent ces rellules comme ayant une importance partionlière. D’après anx, elles se dithérencient an sein du blastoderme, avant la production des deux fenillets primordianx, dans le but spricial dengendrer le mésenchyme mésorlermique. Leur nombre est limité à deux; on, s’il est plus grand, elles se rassemblent en deux groupes symétriques et contigus. Enfin, toujours d'ajpès la même opinion, elles rappelleraient les initiales mésodermiques des Annélides. Iussi leur a-t-on donné, d'après ce rapprochement, le nom d'initiales du mésenehrome.

Trois firits sonl ì remarquer dans ce phénomène. D'aprò les figures Jumbes par los antem's, el notamment par Solenka, la régularité de rópartion de ees initiales est moindre, que les descriptions fournies piar ces mèmes anteurs ne lombaient a le faire croire; la comparaison arec les iniliales mósodermiques les Ammolides est, en cela, trop forcée. Lil riggion lı hastoderme, à laquelle appartiennent ces iniliales, rt doù

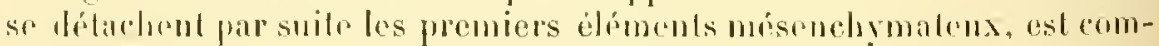

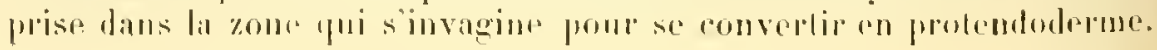


Entin, cette derniere, lont en s'invaginant, émet encore de monvelles cellules mésenchymateuses, qui parviement dans la cavilé blastoco-
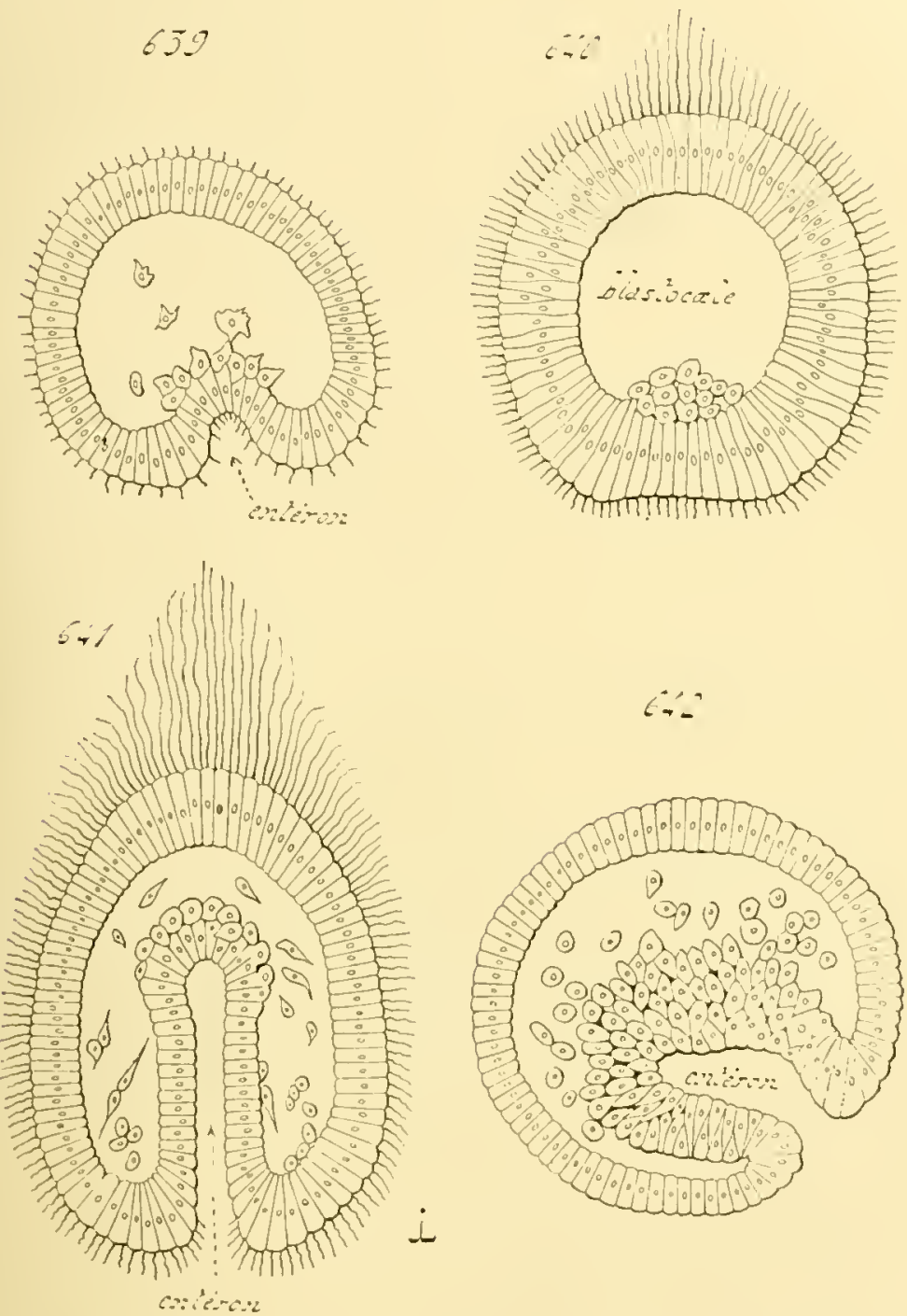

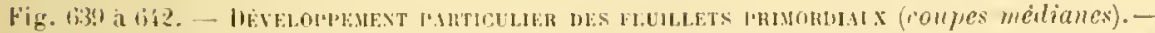
En 6i39, jenne gastrule d'une Inolothoride, l'Iotothuria tubulosa; d'apris les rocherehes faites par selenka. - En lío, début de la gastrublion, et de lil production du mesenchyme, chez un Echinide, le Dorocidaris papillula; d'apris les recherehes faites par

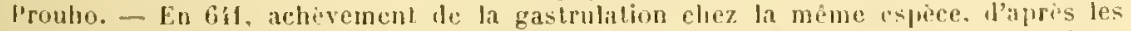

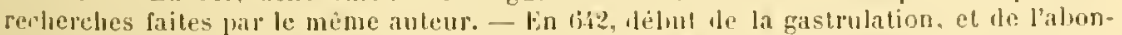

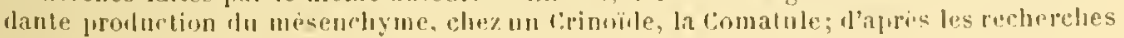
faites jar Jury. 
liennr tout comme les précédentes, s'ajoutent à elles, el subissent la mème évolulion. Si l'on rapproche ces lrois particularilés de ta notion otlerte par l'embryogénie les Hololhuries, el relative aux déplacements dans le temps, qui se manifestent au sujet de l'apparition des premiers éléments du mésoderme mésenchymaleux, on en arrive à la conclusion déjả fajte : les cellules de la part mésenchymatense du leuillet mojen lérivent du protendoderme; leur genèse, en un moment où la gasliulalion ne s'est pas encore produite, est le résultat d'un déplacement dans le temps, par précocilé; enlin, les éléments blaslodermiques qui, dans ce dernier ras, leur donnen! naissance, onl une valeur slriclement égale à celle des antres éléments du prolendoderme, el ne méritent point de nom particulier, si l'on veut exprimer pas ce teme autre chose qu'un simple rơle génétique.

Astérnes et Opmundes. - Les plínomènes oflerls far ces animaux ne diffèrent pas des précédents. L'ovule, entouré par une memlirane vitelline souvent épaisse, subit une segmentation lotale et égale; les l,lastomeres sonl quelque peu disssemblables, au déhut de la scission, chez l'Asterina gibbosa, mais ils leviennent illentiques par la suite. A la blastule succide une gastrule, prodnile par invaguation. Les élóments du mésenchyme sont engendrés par le prolendoderme, au moment où celuji se forme, et pendant qu'il se délimite; ce moment est assez tardif chez I'Asterinu gibbosa. Ce fait, avec le précédent, relalif a la même espèce, est dù sans doule à la légere condensation embryogénique montrée par ces animaux.

I'après divers auteurs, les cellules, qui donnent naissance aux éléments mésenchymaleux, serinent des initiales semblables a celles des Echinides, ditlérenciées d'une manière précoce au seju du hlastoderme, el emportées avec le prolendoderme dans l’iuraginalion qu'il subit.Les recherches eflectuées par d'autres naturalistes, nolamment par Iletschmiliolf, permettent de penser qu’il n’en est pas ainsi. Les considéralious déjà émises an sujet des Echinides sont également applicables aux Astérides el aux Ophiurides : le mésenchyme est un frodnil du prolendolerme, au móme lilre que le mésollerme épilhélial.

Carroünes. - Le développement des Crinoüdes n'est connu que d’après relui des Comatules, éest-à-dje des représentants les plus complexes le la classe, l'alssence de pédoncule étant mise a part. Les premières phases de l'évoluliou emlryounaire se passent sur les pinnules maternelles. L'ovule fócondé otlie me segmentation totale, et quelque peu inégale, qui donne pombant une blastule, dont les blastomères sont sembliales. Une gastrulation invanante s'efreclue ensmite, el les cellnlos llu mésenclyoure ne prenment naissance, aux dépens du prolendoderme, ynan moment oì ce lemicr fenillet a acynis presque toule som cxlension; la plupart d'entre ules sont engendrées par les éléments 
protendodermiques silués au fond de l'entẻron, dans la région diamétralement opposée à l'entéropore.

Les Comalules sont remarquables en ce que l'entéropore de leur embryon se ferme d'une manière très hàlive, le suile aplòs la gastrulation; cet instant concorde avec celui ou la production des cellules du mésenchyne est le plus alıondant. I'entéron se convertit, pal ce moyen, en une vósicule close, placée dans le blastocale, et entouréc par les éléments mésenclymateux, qu'enveloppe lui-mème le protectolerme.

\section{\$3. - Développement des feuillets définitifs, des entérocœles, et de l'hydrocœle.}

\section{Gonsidérations générales. - Notions priliminaires. - Iu} moment où sont délimilés les deux feuillets primordiaux, l'embryon des Echinodernes consiste en une gastrule, composée l'un protectoderme el d'un protendoderme. Le premier est extérieur, souvent couvert de cils vibratiles, qui servent ì la larre pour se mouvoir; le second entoure l'entéron. Entre les deux se troure placée la carité blastocalienne, qu’oceupent les éléments mésenchỵmatenx, dont le nombre angmente par leur mulliplication incessante.

Le protecloderme se convertit en ectoderme définitif, et n'offre, i cel égard, rien de particulier. Toules les morlifications importantes sont le fait du prolendoderme, qui a déjà engendré le mésenchy̧me, et qui va se diviser en endoderme définitif el mésoderme épithélial; ce dernier, à son tour, se partage, avec la cavité quil limile, en entérocetes et en hỵdrocole. Le mésenelyyme, une fois produil, accroit sa masse par ses propres moyens, et ne présente aucun caractère remarquable, si ce n'est sa situation; il entoure le protendoderme, el il enveloppe par suite lous les organes qui en dérivent. Ces derniers sont ainsi plongés dans le mésenchyme, et conservent désormais celle disposition. Les phénomènes essentiels portent done sur la scission, du protendoderme, en endoderme définilif et mésoderme épithélial. Lébauche de celui-ci, arec l'espace qu'il circonscril, est le motenterocale; apris l'aroir fournie, le protendorlerne restant devient l'endoderme définitif, el l'entéron restant représente, de son côté, la première indication de la carilé intestinale.

Eindoderme définitif et entéron. - L'emlsyon des Echinodermes, au moment oi il aequiert les cararteres d'une gastrule, est d'une forme ovale asso large. Son corps présente done deux extrémilés: l'une munie de l'entéropore, el l'autre pleine, privée de tout orifice. Comme l'entéropore devient, sanl'modilicalions secondaires, l'anus de l'adulte, il est permis de désigner, par anticipation, la régron qui le porte, jar le nom d'extrimité inférieure: l'autre zone est, par suile, l'extremite supérieure. Lientéron, à son début, est hressé dans l’intérienr de la litrve; 
son exlrémiti inférienre déhouche au dehors par l'entéropore; son extrémité smpérieure se termine un rul-de-sac.

Coci ótant, le protemblobme se détache du cul-de-sac supérienr de l'enteron. Apres sa délimitation, et sa conversion en une vésicule indépendante, l'entéron, diminur de toute la partie qui a servi à proubure retle vésicule, ofre cepondant la mème disposilion gínérale quavant cetle genise. Sa région inférienre ne se modifie guèc. l'ar conlre, la region supreicure siallonge, et, ce faisant, sincurve vers la face anterieure du corps, en laissant le protentérocule sur sa gauche el en haut. Cette extonsion a jour elfel de faire luter le fond de lisutínon contre l'ectoderme, m peu an-dessons de l'extrómilé supéricure de la larve; les zones mises en contact se détruisent ensuite, et une onverlure se perce, qui fait communipuer avec l'extérieur la partie de l'entéron opposée it l'entripore, L'méron possède ainsi deux orifices : l'entropore primorlial, qui persiste comme anus défintif, el l'onverture de nourelle formation, qui devient ba bouche. - Dans cerlains eas, et lorsque les mélamorphoses larvaires sont très prononcées, la houche se ferme an moment oì la larve se convertit en adulte, el un nouvel orifice buccal se crense non loin de celui qui disparait.

Mésoderme épilhélial, entérocales et hydrocale. - Le mésoderme épithélial est celte partie qui se détache du protendoderme, et comstitue une parri anx leux entérocoles et a l'hydrocole. Sa formation noffre pas la mème série de phénomènes chez tous les lichinodermes: clle comporte un certain nombre de particularités, qui correspondent pour la plupart i des déplacements dans le temps, el parfois a des díplarements daus l'espace.

1. - Le cas le plus simple, le plus fréguent, qui rxiste d'ordinaire cho\% les Holothurides al les Echinidus, est cehui résmmé dius les ronsidéralions générales. Le cul-de-sac supérienr de l’entéron s’élargit quelque pu, lis la fin de la phase gastruhare, et prend l'aspect d'un disque phus ou moins aphati; la région, par lapuelle ce disque sunil à l'entéron unn modifié, se rosserre de plus en plus; finalement, le cul-de-sac élargi se convertil en une résicule close, indópendante désormais de l'eutéron yui lui a fonmi: naissance, el lyayant fibs avec hi aucune comnexion. Celte vésiculu est le protenterocele. Elle engendre, dans sa région postérieure, mu pelit diverlirule en forme de tube, yui s’allonge, Laverse la cavilé litastormbicune, et se met en rapporl avec l'ectoderme; la zone d'arcolement se détruit, el, ì sa place, se creuse un orifice chtroil, qui fermel an rombut le s'ouvir an lehors. Celle ouverture est l'hydropore, "neorr nommi pore dorsal: la comduit est lui-mème le canal h.ylrophore.

le prolentopocule consiste, à celle phase de son évolution, en me

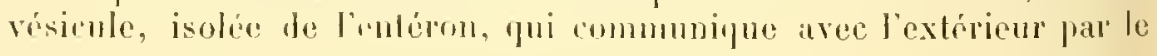


canal hyolrophore. Comme il doil produire l'appareil ambularaire, avec la paroi des entripocoles, les auteurs le nomment souront, it lexemple

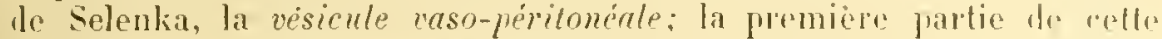
expression sapplique aux vaisseaux ambulacraires, et la secoudr il la paroi entéroculienne, qui est assimilable à un péritoine. La caviló du protentérocale est libre, hien que restreintr; sa paroi propre se compose d'une seule couche de cellules épithéliales. Sa farrexterne est directement en contact avoc le plasma, et les éliments misenchyoutemx, qui rmplissent le blastocode.

Le protentérocule s’incurre ensuite, el prend l'aspect d'une coupe. yni menchsserait le fond de l'entéron. Les borks de la coupe ne sont pas droits, mais sinueux, car ils s'allongent en deux regions diamétralenenf opposées, lune droite, et l'autre ganche. Ces denx régions contimunt a sallonger plus que les autres, leur extension flant lirigée en has, cest-a-dire vers l'extrité inférieure du corps, de maniore i les placer de part et d'autre de l'rutéron. Finalement, ces deux parties, semblables à des divroticules symélriques du protentírocale, se séparent de ce deruier, deviennent indépendantes de lui, et se convortissent en résicules rloses. - le protentrocuelr s'est ainsi divisé en trois trongons: lun impair el módian, les deux autres pairs, ef lateraux par rapjort a lentéron. Le premier, qui peut ìre consiléré comme la persistance directe de la rógion médiane de la vósiculu primitive, cst l'hydroccele: le canal hvilrophore contimue à lui ètro annexé, el lui permel d'avoir les relations directes, et effectires, car la lumiere du canal nest pas virtuclle, arec le dehors. Les dens autres sont les entéroceles, l'un droil. et l'autre granche; tous deux sont des organes clos, ontiorement formés, plongés dans le lalastocrele oì jls sont rntourés prar les éléments du mésenchyme, et n'arant aucune commion avec l'extirieur, ni avec l'entéron.

B.-Celle série de phénomènes est habiturllo; sa répartition générale, dans tous les cas où se manifestent le moins le lésagrégations orunniques et de lermetures l’orificrs, son caractíre dr simplicité, temlentà la faire consilérer comme répondant a un état primilit. lille sulit parfois les variations, qui consistent, jour la pluparl, en déplacements. 'Tantôl, le canal hvilrophore est produit par' le fond le l'entéron, avant 'pue cette extrémité supérieure se soil elle-mème convertie en protentérocule. dilleurs, le foul de l'entéron imel demx expansions latirales. yui se séparent, le lui, se placent l'une in sa droite, liuntre ì sa gauche.

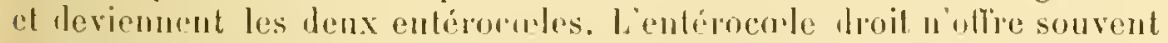

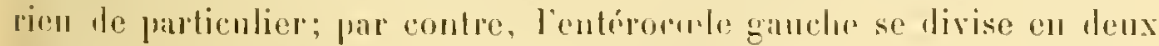
parts, l'une suprienre qui est l'hvlrocule, lantre inférieure, qui Jonne l"entiocorle sauche definitil. Dans eortains cas, et sans loute par extension de cette propriélé gérélique de l’enlérocuele gauche. l'en-

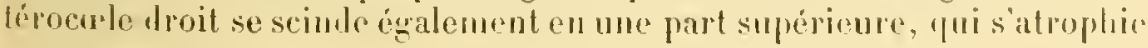


fra la suite, et une past inféricure qui persisle seule comme entéro-

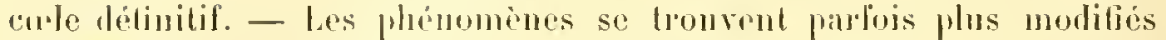
enrore. L'entérou inel les deux entrirocoles; le lroit suit son évoln-

\section{$6 \div 3$}

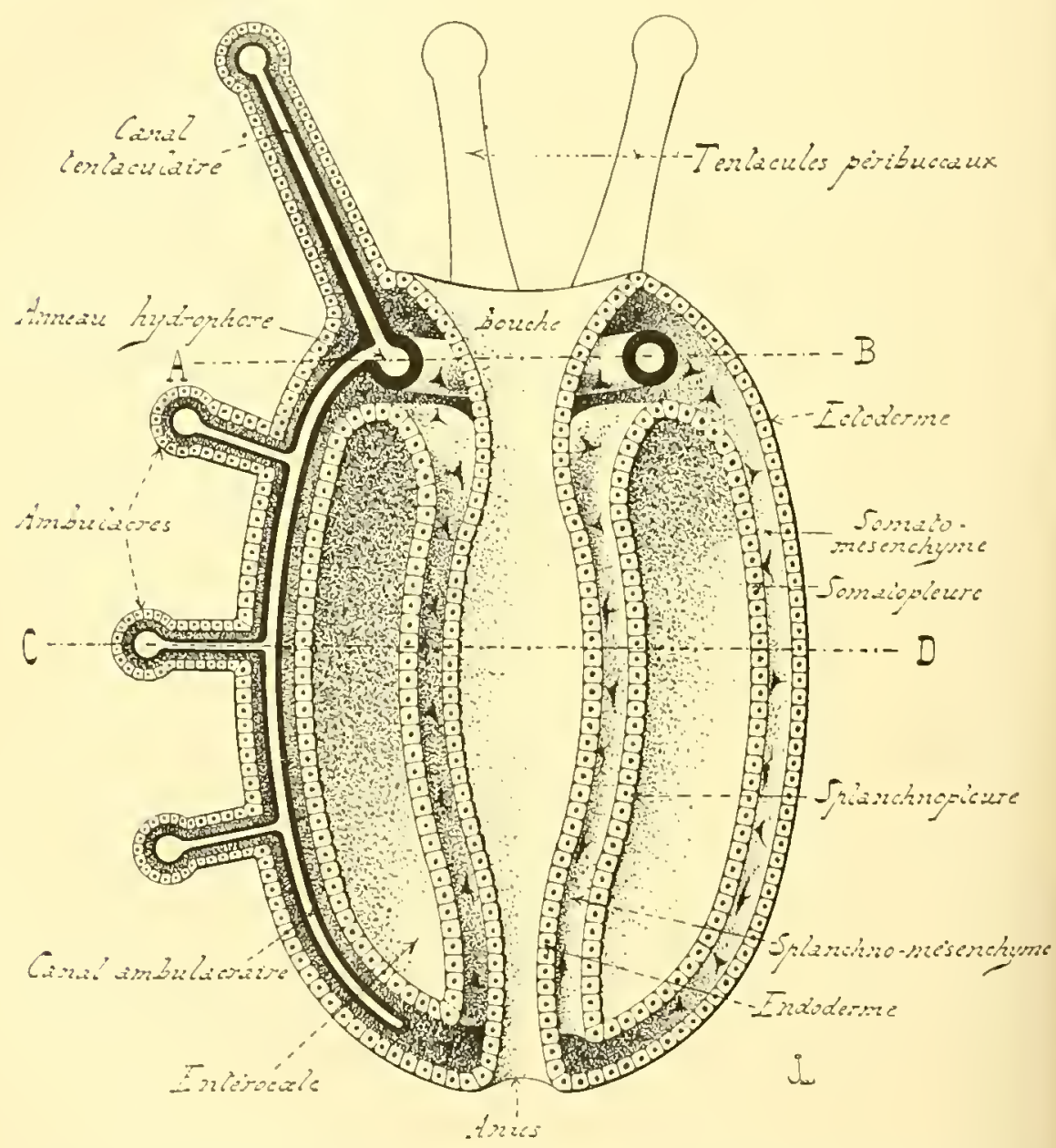

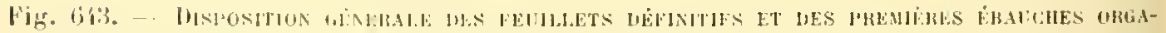

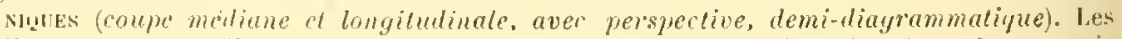

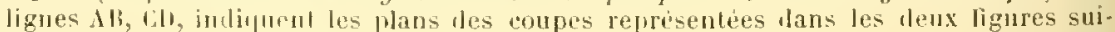
vantes.

lion normale; le ginche fournil tout d'abosd le ranal hydrophore, puis it donne maissance at Ihydrocmle, non par une scission, mais en le pro- 


\section{$6: 4$}

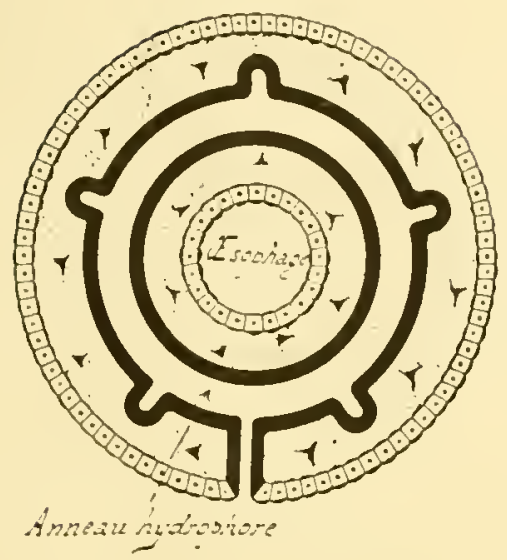

$5-5$

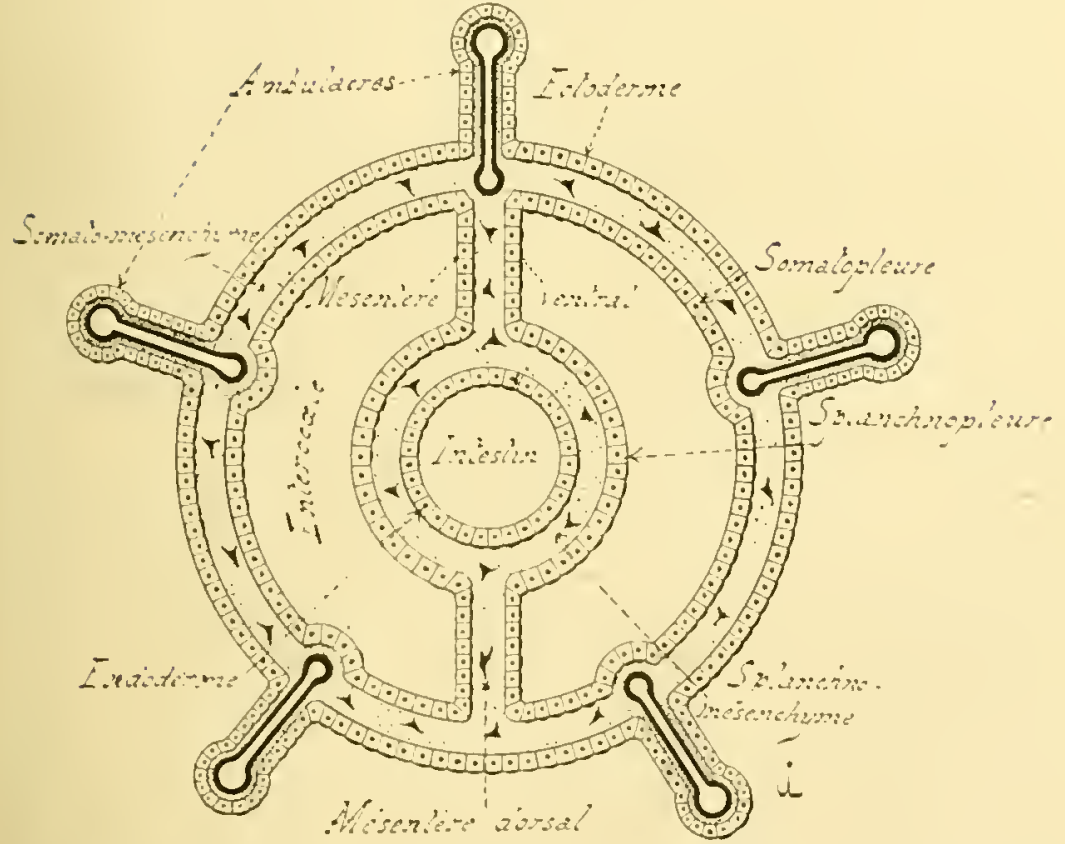

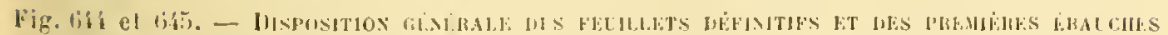

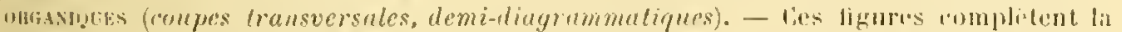
pricidentı, oi los plaus des coupes quelles representent sone indipurs par les ligni's

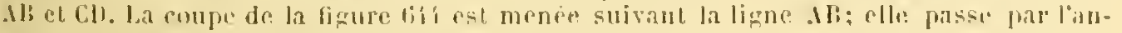

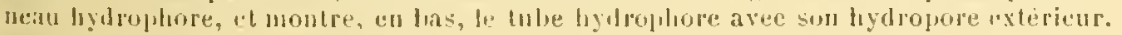

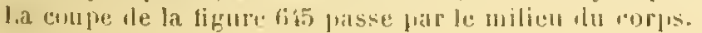




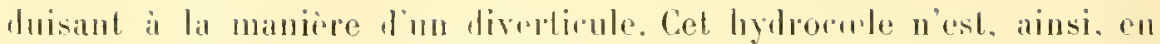
relation avec to dehors tue par l'entremise de l'enlérocule dont il provient. Cos ronnexions dispariassenl plus lapd: la zone d"union. entre l'hylrorude et le canal hylrophore, se sépare de l'entérocole anquel elle apprartient, el se rallache par la in systime lyvdrocolien. Laltéralion des plases habituclles a cependant f́té considérable. hien que l'élal défnilif ne soil pas changé. Les Astrima giblosa offrent mo excellent exemple de ce dernior fail; el, dume manière gónérale, tous les Echinodermes vivipares, on mmois l'aul's volumineux, présentent des cmloryogénies ainsi modilies, alors que les autres sulissent le déreloppement indiguo on premier lien. Celte remarque contribue, pour sa fart, à faire considérer celui-ri comme normal.

C. - Sumf déplacements secondaires lans l'esprace, cumme en montrent les Comalules, les nulirocoles flampuent l'entéron i droile et a ganche. Cilıcun deux so composo d'une paroi el d'une cavilé; celle-ci est parfois assez ample. aillenrs lris restreinte el frespue virluelle; les varialions, en pareil cas, sont d’importance minime, cal cel espace ne tarde pas a prendre une grande rxlension. La proi rsl conslitnie par une senle assise de cellules épilbéliales. - Les entérorules s'implitient en mème lemps que le corps, l'aceroissement ćtant surlout te fait dr teur cavití, car liur paroi reste simple. Dans lenr augmentalion en rolume, ils entonrent lentéron le toutes parts, ol s'avancent rers les extrémilés le la larve, de maniere a occuper tout l'intóriour de lorganisme. Ils s’alossent l'un a l'autre, durant ces phénoménes, sur la ligne móliane dorsale ef la ligne móliane ventrale, au-rlessus et in dessous de l'entiron devenu l’intestin: leurs zones d'acolemenl ne disparaissent pas, et domment les misentires. - Cies derniers ntfrentlaspect le minces lames, ‘ui, l’après leur origine, s'altarhent d’un coto i la paroi de lintestiu, el de l'antre a celle du corps; la disposition réguliore, qu'ils montrent Lond d'abord, se modilie plus tard, et lans des proportions variables snivant les types, rav ils accompragnent l’inleslin dans ses circonvolutions, el aumentent souvent en nomlipe, tonf en revilant des aspects divers. les changements. qu’ils subissent aimsi, nont gure etr suivis; il est rpendant possilile de sin faire une ilce saffisante, en comparant leur disposition premiore ì relle püils possedent chez l'adulle.

l'ar le fait mème de len' extension, chacun des entópocoles divis"

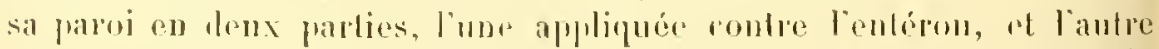

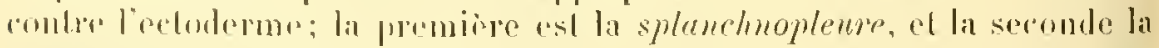
somatopleme. Ainsi qu'il a élé démontre dans les considérations grénrrales, ces leux lenillels ne sont pas direclement arcolés ì l'endorleme, ni à l'ertodermo; ils sont sróparés d'enx par une assise d'éléments mésenchymatema. Le plúnomine est aisé à compuendre, puisque les entérocoples, à leur délubl. snol plares dans le lilastocule. el enlumrés par les cellules dn mésenchymo. Ces rapports ne ressent poinl d'exisler; tomjonrs 


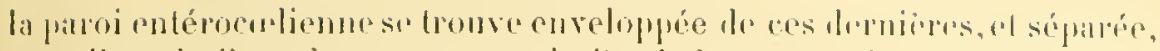

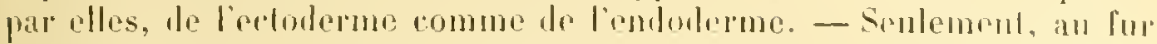
ef il mesure de leur arcroissement, les entérocoldes jestreignent lo hastocole i l'espace quiverupent les áments mósonchynatenx; ondrinitire, ils lassent ceux-ei en deux ronches, dont lune ast placíe sous l'ectoderme, ef l'antre rontre l'endortorme. La premiere est le somatomésenchyme, et la seronde le splunchno-mésenchumne. - les misenteres contiennent eux-mèmes, en leur milieu, une certaims quantité le misonchyme, emprisonoc lors de l'aceolement des rntiporroles, et sriparant, line de lautre, les deux couches ippithibliales superficiolles de la lame mésentírique, qui proviennent des parois entérocolienues. De mème que cos couches missent la somatoplenre à la splanchnopleure, de mème l'assise misenchymateuse intermediaire joint le somato-misenchyme au splanchno-mósenchyme.

I). - Pendant que les entírocudes subissent les phónomènes de leur accroissement, l'hydrocole ne lemenre pas inactil; ses modifications sont même plus précoces, et plus rapides. Sauf encore les faits de déplacements seconduires, comme il en riste dans les développements condensés, et surtoul danscenx des Comatules, il sétire en un tube, qui entoure l'irsophage, a la maniere d'un annean; cela, tont en conservant ses connexions arec le dehor's par l'internédiaire du tube hỵlrophore. Cet auneau est l'unneau hydrophore, habitucllement nommé l'unnean ambulacraire; cette lerniere expression n'esh vaic qu'en partie, car cet organe doit produire, non seulement le système des cavités ambulacraires, mais encore, et avant ce dernier, cehui des cavilés tentaculaires. - L’anneau offre deux cavités : l'espace circulaire qu'il limite, à cause de sa forme; et sa lumicre propre. Le premier est peu important; d'hatbitude, il contient larsophage, dies les premieres phases le l'évohulion: a moins que, par un déplacement dans le temprs, ces redations ne soient tardires. La lumière, wl cavití propre de l'annean, subit des modifications considérables. Elle émet cinq liverticules sur son pourtour. placés it égale distance les uns des autres, yui compspondent aux premicres ébauclies des cavités tentarnlaires; lenr frósence donne, à l'annean entier, une ressemblunegrossiere ave une lleur il cint pétales, f'où son nom, donné à cette phase de l'ávolution, de rosctte ambulucraire, quil vaudrait micux changer, arre une phus granle precision, far cehi de rosette hydrophore. Le tulse hyilrophore persiste, en maintenant toujours

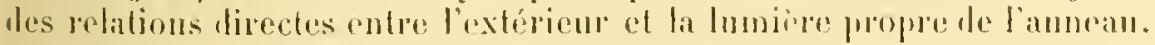
lo nouveand diverticules naissent ensuite, d'apriss une symétric radiale el quinquennaire, pous produre les vaisseanx ambulicraires.

lihydrocole est, il sond dílut, tont comme les entérocorles, plaré dins la cavite bastocolienne, et enturró par los élóments du mésenchyme; ares comnexions ne cessent pas l'exister. 1 mesure que les entérocorles

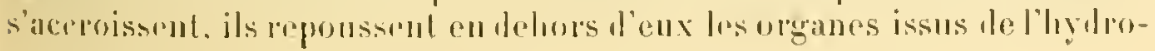


ruele, el les placent enlor lenrs popros parois el l'moloderme, ciesti-dire dans le somato-mésonchrme, ou lans le mésenchyoue des mésen-

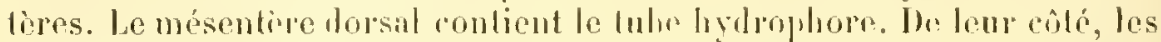

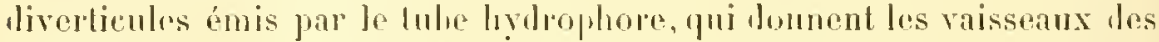
tentacules et les vaisseams ambulacraires, sortendrnt dans le somalomésenchymo, eulre la sumatoplenre et l'ectorlerme, et sont entourés par lui.

Cette disposition ahoulit an risultal suivant. lilydroculs primilif se compose J'une paroi, constilure par une seule assise de cellules épithéliales, et lune ravile. Celle-ci reste simple, ne se cloisomne pas, el sétenrl dans tons les organes, yui dérivent le l'hydrocule, pour leur fournir leurs avilés jarticulions. La paroi conserve écalement sa simplicité primitive. Iussi, les vaisseaux fentaculaires el ambulacrares consistent-ils en nne cavilé centrale, entourée par une assise épilluéliale qui dérive de la paroi de l'hyolrocule; celte assise est, i son tour, plongée dans le somalo-mésenchyms, et envelopróe jrar lui. - Dautre parl, les appendices de ces raisseanx, amlulacles et lenlacules, sont des apparcils qui soulirent l'ectoderme, placé a leur niveau, pour faire saillic an dehors. En conséquence, leurs parois se composent de lrois couches, d'origines diffémentes, emboilées les mues dans les autres: l’interne est l’assise épilhélialo, yui movient de celle des vaisseaux, et apparlient à l'épilluélio-mésoderme; la moyemne est conslituée par une expansion du somato-misenchyme; l'externe est formcie par l'ecloderme.

Résuné et coscusun. - Prndant quo s'eflectuent res phénomines, les principaux linéanents de l'organisalion lles Echinodermes s'élablissent, et, s’ils se modifient el se complipuent en délail, conservent leur mème disposition grunérale. - L'économie de ces animaux se compose, en somme, d'un certain nombre de parois el de cavilés, infriquées d'une facon róguliore el constante. Au centro se trouve la cavilé digestive, munic le ses denx orifices, el enturric par la paroi inlestinale; en dehors est l'épaisse prooi somatique; entre les leux s'itend le volnmineux oligocalome, qui provient des denx enterocales. - La paroi inlestinale est constiluée, en allant de delans en dehors, par l'endoderme, le splanchno-mesenchyme et la splanchuppleure; la parri somaliqne comprend, de son còlé, dans la mème direction, la somalopleure, le somato-mésenchyme, el l'ectoderme. Les vaisseaux ambulacraires, el les nerfs qui les accompagnonl, sont placés dans le somato-mésen-

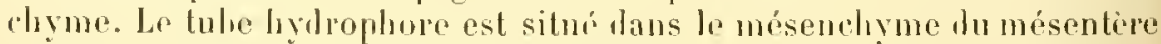
lorsal. Ce demier s'épaissil d’halibule, en une zone localisée, pour lomner mu organe qui a resu divers noms (cour, oryane ovoüde, organe dorsal, corps plastidogine), ut qui, par sun origine rl sa stunclure, est assimilable ì 111 gandion lympluatique.

Les ravilés ambulacraires sont autonomes, of communipuent seulement, d'une manjire direote, avre le lehors; elles nollonl, sanl les 

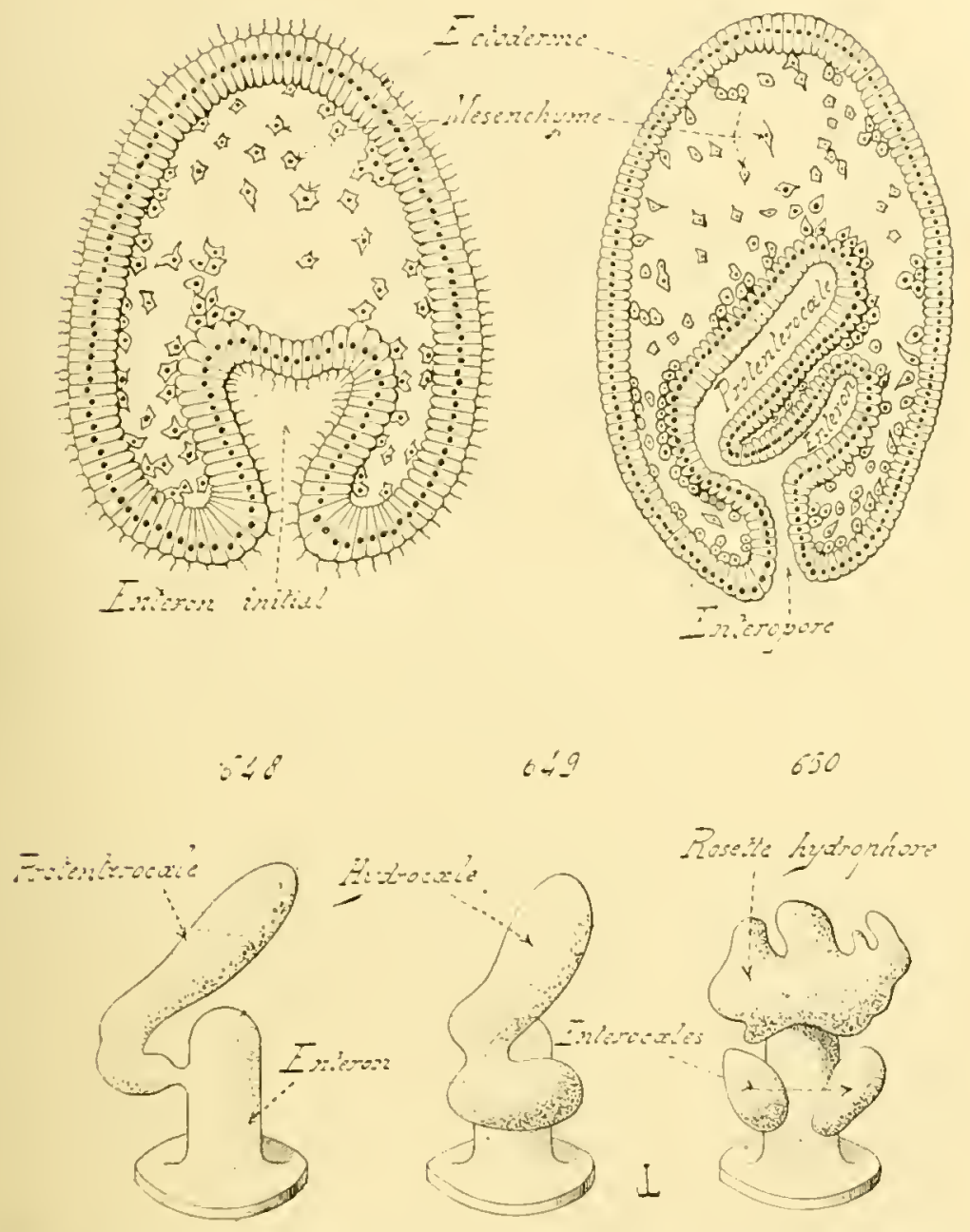

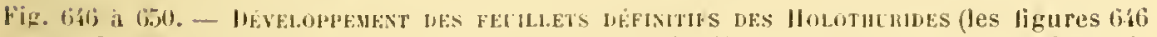
et diar se rapportent a des cuupes médianes et longiludinales; l's figures 648 a 6.0 expriment les contours de l'entèron el de ses dérives, alistraction faite du mésenelıyme, et

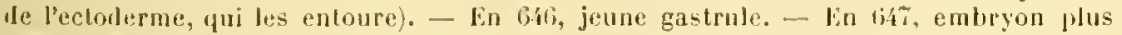
avance, lont lenteron a probluit le protenterocole. - lin 6.ts, rolief simplific de la disposition préedente, relative à l'entéron et all protentérocole. - En 139 , le protenlérorele s'est disjoint de l'enteron; il commence a se subdiviser en deux resicules. Fin tio, cette division est acheve; la vesicule superieute est l'hydrocote, qui se change Jabivenent en rosette hydrophore; la visicule inforieure so seinde en deux parts, qui sont les deux enteroenles. - llapres les reclierelues faites par selenka sur la cucumariu cloliolum. 
par les Crimö̈les. ancume enmoxion de regenme aved loligoeudome, ni arec l’intestin, bien que l'éhauche de l'hydrocele ait été en rapport avec ces lumiers. D’antre part, les lenx assises du mésenchyme se crensent de viles lacmaires, pui ont recu des moms divers ef nombremx, el sont indipendants, yar leur arine mene, des cavites ambulacraires comme de l'oligoculome; leur ensemble constilue un polyculome. I en juger d'apris l'organisme dífnitif, des relations lirectes paraissent s'étalilir entre ce dernier et loligoculome; ces relations sont serondaires, el n'existent point los l'abord. Le polycofome est un véritable appareil lymphatique tres simple, homologine de colni des Vertébrés, qui est igalement rensé dans le mésenchyme; alostraction faite de la division de ce leruier en une part strictement lymphatique et une part sanguine.

lues modilieations internes, subies par les parois, lors de la genese des organes, nont pas encore eló suivies d'me maniine complible. 1 en juger d'apres les renseignements domnés par los autenrs, le mésenchyme produit des tissus conjonctifs et conjomrtivo-musculaires, la somatoplenre of la splanchnopleme fommissent le revêtement emothélial de l'oligoenlome, lectoderme persiste comme épillélimn a la surface Ju corps, ef l'endoderne comme épithélimn inlestirad. - Toutela musculature ne serait poultant pas l'origine mésenchymateuse. I'apris les recherches de Semon sm les llolothurides, les tibres musculaires de l"intestin antérieur proviend’aient seules du mésenchyme: celles de l'intestin moven et de l’intestin postérieur dériveraient de la splanchuopleure, et celles le la paroi du corps en feraicnt de mème pour la somatopteme, y compris les cind roluminenses bambles musculaires ambularaires.

\section{Développements particuliers des feuillets blastoder-} miques définitifs. Ilobotmunos. - Si le résultal timal, qui consiste en la formation, aux dépens de l'entéron primordial, de denx entérocolles et d'un hydrorate, est le mene chez toules les lolothurides, les procédés emploýs sont sujels à variations. - Le mode le plus simple estoffert par l'Hololumia hubulosı. Le fond de l'entéron, cest-à-dire le 'nl-rle-sac supérieur le eet organe, se sépare du resle par un étranglement, yui s'accentue de phus en plus. et se convertit en mne vésicule close: le protentérocute. Celni-ci, l’aboril sphérique, s`allonge en sélemdant vers l'extrémilé inlérienre de la darre, el deviont ovadaire; il imel, comme un diverticule, el sur la prarlie de sa paroi pui regarde la fice dorsale du corps, le fube hy drophore; celui-ci se dirige en ligur droile, à lavers le blastucrolo, vers l'outoderme de cette liace, s'mit à l'épithélium ectodermique, et suvre au dehors. Son orifice est situé presque a égate distance do l’extrémilé supérienre el deflextrémité inférienre de Forganisme larvaire. Entre temps, le protentérocole continne à sallonger, tout en demenrant simple; mn étranglement ne tamle pas à se mani-

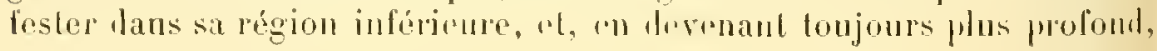




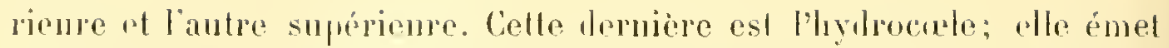
le tube hrobophore, quisouve au telors, el aceomplit ensuite ses trans-

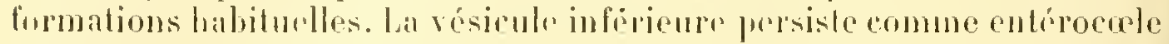

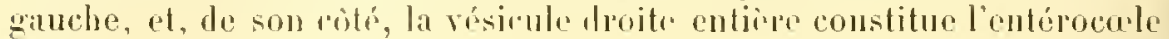
droit.

Par compraison ave le liveloppement des Holothmries, les Echiniıles montront un doulile déplarement dans lo tempis el lans l'espace. Le protentérorral se suldivise en vésicule lroite et vésirnle ganche, celle-ci se partageant ensuite en hrdrocole et entérocule gauchr, ef la première domnant ì elle scule tout l'entérocole droit; alors que, chez les

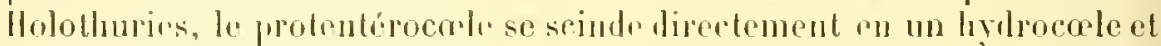
une vésicule inlérienre, qui se roupe en demx four lonner les denx entérocorles. Lisolement de l'hỵlrocurle est un fait primaire cliez les Ilolothurios, abors püil est secombire chez los Echiniles.

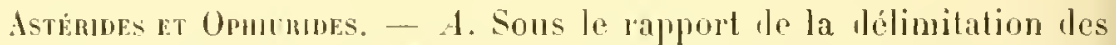
fonillets lilastorlermiques detinitifs, les Echinjles constituent me transition entre los Holothurides l'nne part. et les Astériles avec les Ophiurides de l’autre. Chez eux, le cul-ile-sac supérienr de l'eutéron commence par émettre deux divertioules latérax; mais ces derniers ne se siparentpas isolément de la région yui leur donne naissance, car, avaul qưil en suit ainsi, cette régrion se dlithérencir de l’entéron pour donner un protentéromle; elle est constituée par l'ensemble des deux diverticules, qui continuent à s'étendre, et, ce faisant, se distinguent l'un de l'antre pour devenil indépendants. - Il n'en ust pas de mèmu chez les Astériles, ni les Ophimides; les deux diverticules se forment, puis s'allongent, sans que lour hase commune se scintle de l'enteron en donnant un protentérocucle; ils se séparent isolément de l'entéron qui les proluit, et cunslituent ainsi, d’emblée, denx vésicules closes. Le protentérocole fail don défaut en tant qu'organe indivis; il est représenté prar l'ensemble de ces denx vésicules distinctes. Le phrinomine nest pas cependant lume constance parfaite, du moins pour ce qui touche anx Astirilus; car il est les exrmples ou la hase communo des diverticules pirvient à s̈isoler de l'entépon, et à donner un protentérocale, qui se ilivise rapidement en vésicule lroite el vésicule gauche, par la lélimitation bative de res liverticules.

Ce lernier fait existerait, d'apres les recherches te ciïtte, chr'z l'Asteracanthion glacialis. Le cul-rle-sac supérieur lo l'entéron émet les leux diverticules latéraux, et, en mème temps, šisole du reste de la paroi cutérique pour constituer le protentérocale. Celui-ci fournit le tulue hydrophore: et les diverticules, en restreignant peu à peu leurs régions minssantes, se siparent l'un de l'autre. Il nen est pas ainsi chez d'autres Astérides, dont les divodicules datiran so scindent isolément de l'entéron. - Yuoipu'it rn soit, ces diverticules suivent me érolution comparalile à celle présentée par les Erhiniles. Le diverticule droil se ron- 


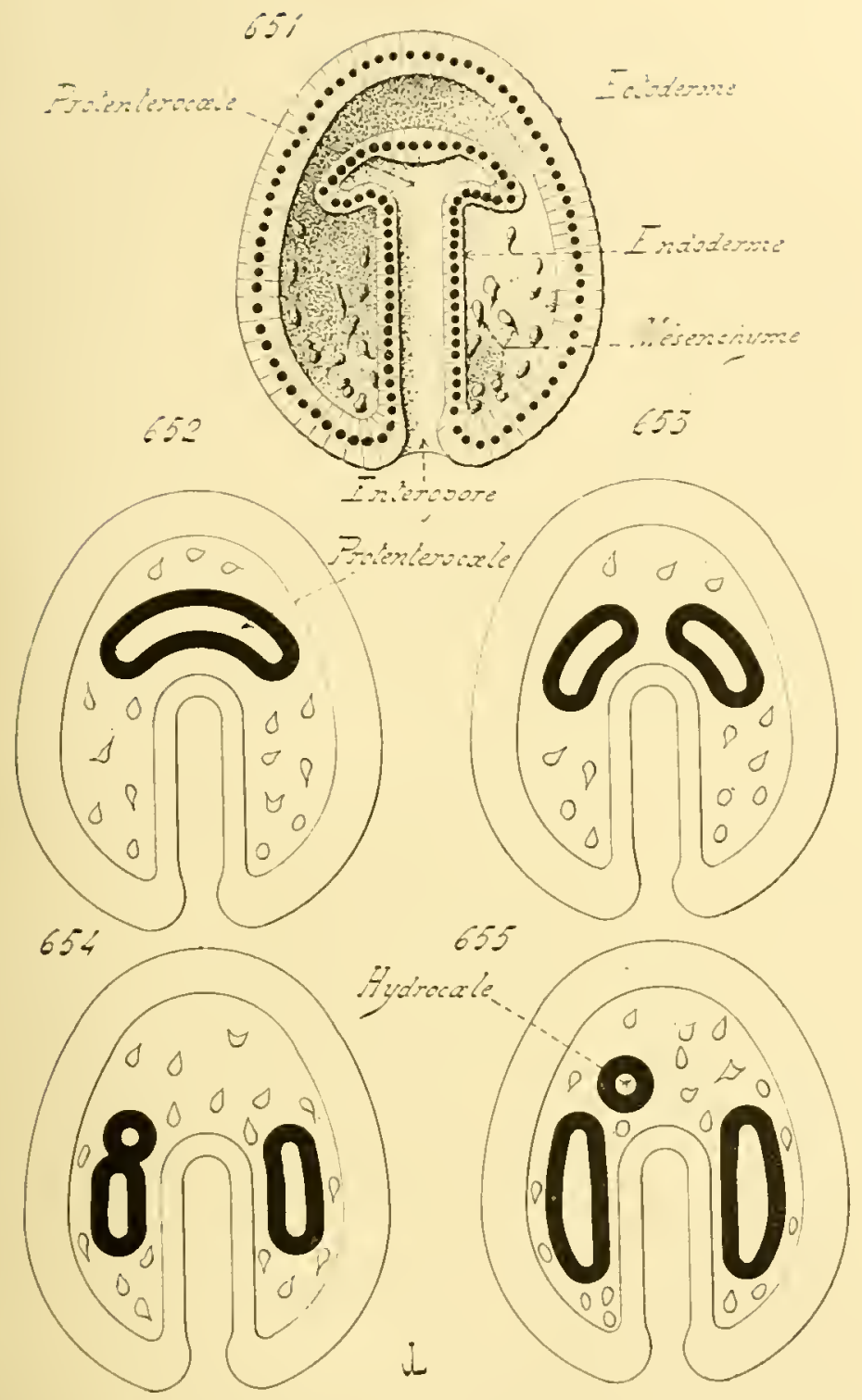

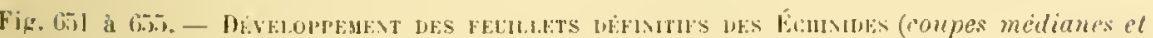

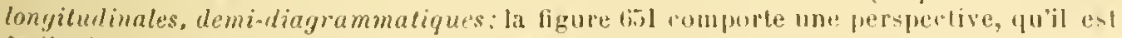
facile de se representer pour les quatre autues dessins; dans ces derniers, la paroi du protentirocule, el celle de ses derives, sont an noir). - En bist, achevenent de la gas:trulition; te fond de lenteron s'elargit pour donner le protenterocala. - lin 6ie, le protenterocate devient indipendant. - Lin (iji3, il se sciude an deux visioules, l'une Jroite, et l'autre gauehe. - Fin 65i, la vesicule droite demente loul entive conme entirocole droit, alors que li vesicule ganche se divise en deux parls sujerpusees. - bin

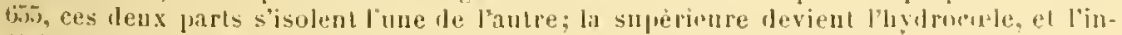
ferieure l'entirocusle gawhe. 
vertit tonl enties en entérocole droil; le diverticule gauche se divise en un hybocole, qui est supérienr, el un entéfocole gauche. Pour A. Igassiz, le livertionle droil se comprorterail à la maniere de celui des Ophiurides, el se partagerait, foul comme le gauche, en deux rísicules; "Faprès le mème anteur, la résiculo droil. supérieure prendrail part ì

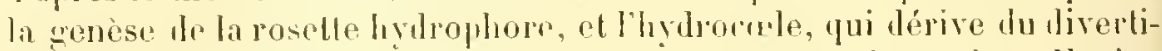
rule ganche, no serail fras seul à subvenir à celte formation. Il n'en est pas ainsi "laprès Metsuhnikofl, Hont les óturles montrent que la seule ébauche de l'apparil hybophore enties est l'hylrocele, ce leruier prorenant le la vésicule gäuche, qui s'est divisée en deux autres vésicules,

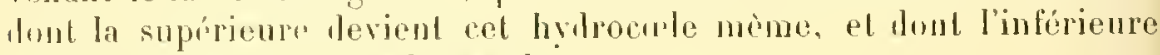
persistremme entérocele ganche.

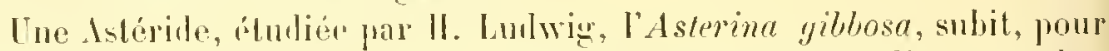
ce qui tient a lorigne les funillets, une évolulion particulive, résultat probalile d'une condensation du développemenl; celle condensalion est arrusée par la grossenr les muls. pui conliennent une assez grande quantité de deutulépilhe, par l'absunce de métamorphoses larvaires acrontuces, el par l'histolyse de plusienrs organes. - Les deux diverticules symélriques, émis par le cul-ulr-sac supérieur de l'entéron, grandissent rapidrment, lout en restant unis à la région qui leur donne naissance. Cetle derniere se sṕpare ensuite, par un élrangloment, du reste le l'entéron, et se convertit en un protentérocale voluminenx, romposé d'une prart indivise, el de deux gramls diverticules latésaux. Ces d'Jnites sareroissent aux drpens de la première, el finalement celle-ci lisplarât, laissant ces expansions isolées l'une le l'aulre, converlies en deux resicules closes el indépendantes, l'une droile, lantre gauche. - La vésicule droile devirul, comme loujouss, l'entérocule droil. La resicnle gauche commence par emelle le lube hylrophore, qui lui permel le communiquer aver lr. dehors; puis elle lome naissance a l'hyolrocole, non par un étrangtenent, mais en le poduisanl a la manière d'un diverticule; le reste de la vésicule persiste comne entérocole gauche. Cette disposition a pour ettet de mettre le tube hydrophore en relation directe avec l'entirocule ganche, ol non avec l'hydrocule; la cavilé de ce lernier n'est en rapport avee celle du lube hylpophore, que par linlermédiare de I'entérocule. Celte structurr disparait par la suile. La région, munic du tube hydrophore, se séprare du reste de lentérocule, loul rn contimunt à simir à l'hvilrormle; elle se confoud ave ce dernier, el lorganisation deviont momale. lientédorulo gauche est ilos, alors que

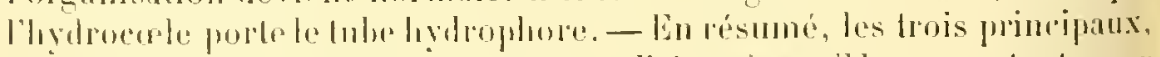

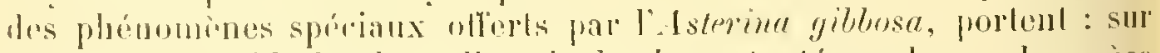
la naissance rapide des denx diverliculesslu prolentérocule, sur la genèse

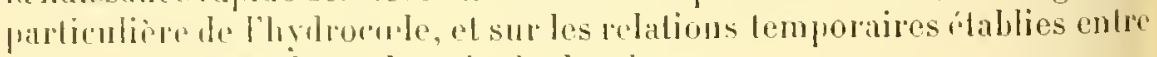
fentérocubre gancho el le tube hylrophore.

D'après les recherches des anturrs, les Ophimriles olfrent des moditi- 
calions remaryuables, en ee qui touche la genese des rntirucules ot di l'hylrocele. Les deux divertirules, émis par le cul-de-sar supirirur d. l'entéron, se séparent isolément do celui-ci, et se ronvertissont en résicules closes, dont la cavité est fort petite, on mène fait déji défout; dans ce ternier cas, elle preml uaissaner durant les pluases ultérieures lu díveloppenent. Ces résicules se placent, l'ume it droile, l'autre it gauche, de lentéron; puis toutes deux si divisent en deux segments. Lorsyue celte scission est acherée, la larre possède quatre résicules listinctes, issues des deux direrticules primoldiaux, et lont l'ensemble représente les lérivés lu protentérocule : une vésicule gauche supérieure, une vésicule gauche inféricure, une résicule droite supérieure, el une vésirule droite inférienre. - Les deux vésicules inlérieures deviennent les deux entérocoles, dontl'un 'st gauche, etl'autre droit. La vésicule gauche supérieure se convertit an byilrocele; elle émet le tube bydrophore, qui va sourrir au dehors par l'hydropore. L'ívolution de la vésicule droite supérieure n'est pas encore ctudiée completement; un lait certain sst qu'clle satrophie, et disparaìt. Seulement, tantôt cette atrophlie parait ètre immédiate; el tantôt elle est tardive, jermeltant à cette vésicule de gramlir quelque peu, el de prouluire un lube hydrophore, qui se détruit ensuite, tont conme la partie dont il provient. Il est intéressant. dans cr. cas, de constater lextension à la vésicule droite, par voie de symétric fonctionnelle et bilatérale, de la faculté de so convertir en un hyjlrocole, bien que cet hydrocule soit superthu et destiné à dispraraître.

B. - lin suivant, an sujet de la production des fenillets blastodermiques léfinitifs, la série qui va ıles llolothurides aux Ophiurides, en passant par les Echinides et les Astérides, on observe denx faits principaux. D’abord, l’identité parfaite du résultat: quel que soit le mode génélique employé, trois vésicules, disposées de la mème manière dans le corps, l'entérocule droit, l'entérocale gauche, et l'hy'lrocule, sont chargées de donner naissance aux mèmes organes, et se trourent exister seules à un monent dounć. Ensuite, la régulière sériation des altérations présentées, qui sont le plus en plus grandes à mesure que lon remonte les Ilolothuriles aux Ophiuriles.

Che\% les Holothurides, le protentérocule se détache de l'entéron sous la forme l'une résicule globuleuse, qui se divise, ensuite, pour donner l'hyilrocule et los deux untérocales, l'hydrocule offrant les rapports itroils de connexité avee l'ontiprocale ganche. Aussi, les Echiniles commonent-ils à montrer les premières b́hanches de ces trois organes

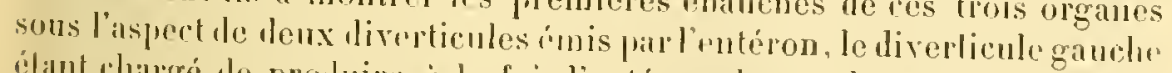

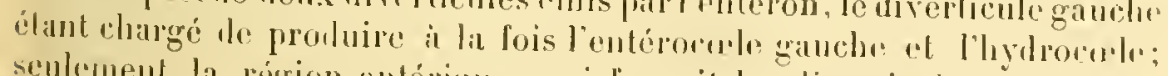
senlement, la rigion entérique, qui lournit les divertionles, s'isule, at devint mu protentérocule simple, lont les diverticules sont les deux parlies, qui ne tardent pas à se séparer l'une de lautre. La's Astérides

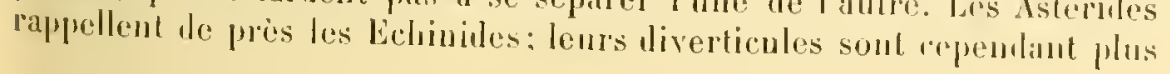


volumineux, an monent oì le protentérocole se délache, et la partie indivise de ce denier se troure fort restreinle. linfin, chez les Ophin-

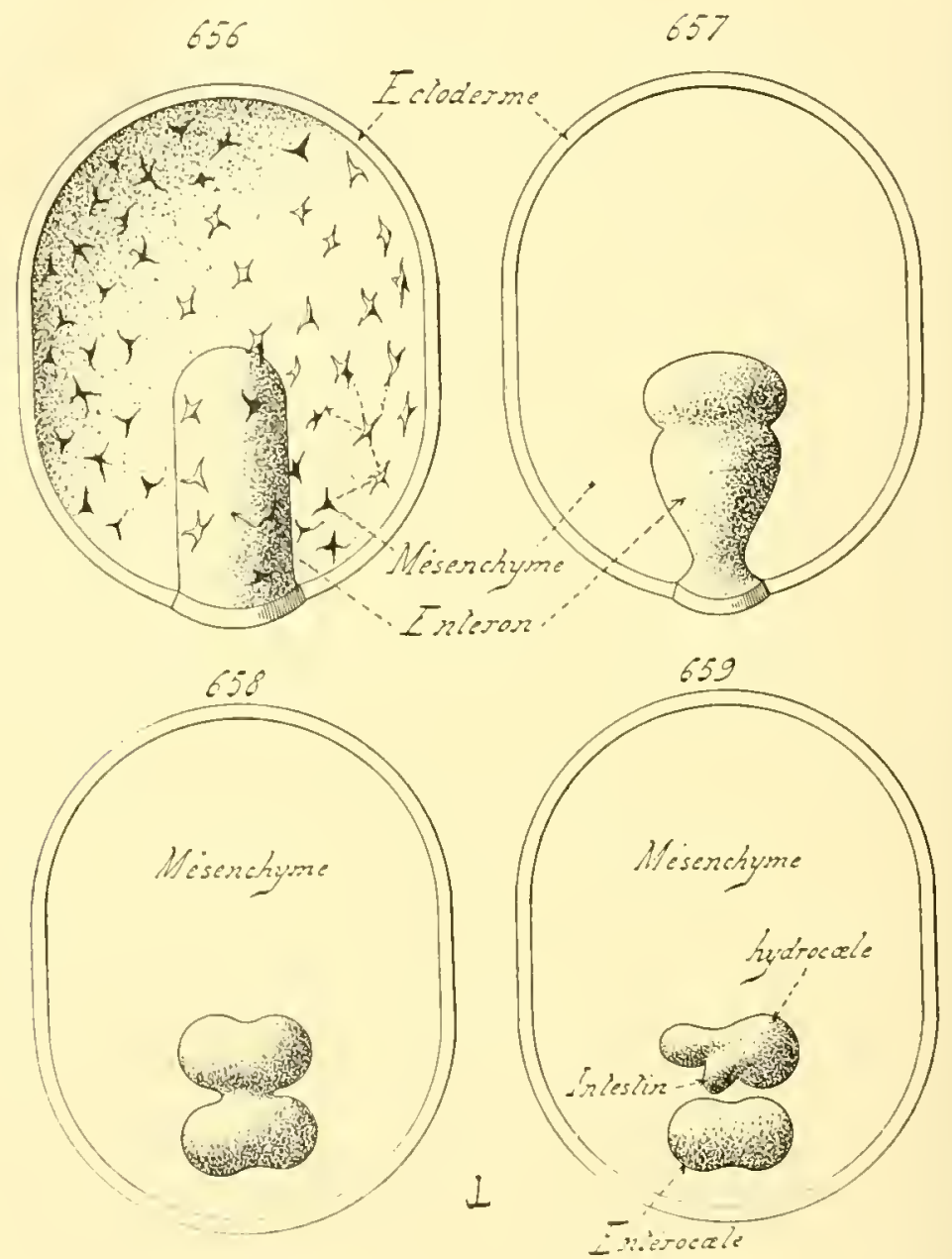

Fig. (hat a cron (Les légendes accompagnent les figures suivantes.)

rides, cette partie indivise n’existe plus, cl les denx diverlicules se séparent de l'enlérou, inlépendanment l'unde l'autre. Te plus, el plusieurs anteurs disent avoir rehouvé des phónomines analogues chez les Astériles et les Echinides, le diverticule droit produit, toul comme le gauche, 11 rudiment d'hydromle; mais ce deprier n'aboutit pas, car l'lyydrocuele récl, chargé de domner l'appareil aquifère de l'adulte, est toujours en relation directe avec l'enlérourle ganche. - Celte série de modificalions, do plus en plus accentuées, correspond à un diplacement dans lo 
lemps et dans l'espace, le plus en plus promoncé i mesure qur l'on passo des llolothurides aux ()phiurides; le résultat ultiurétant toujums le mome.
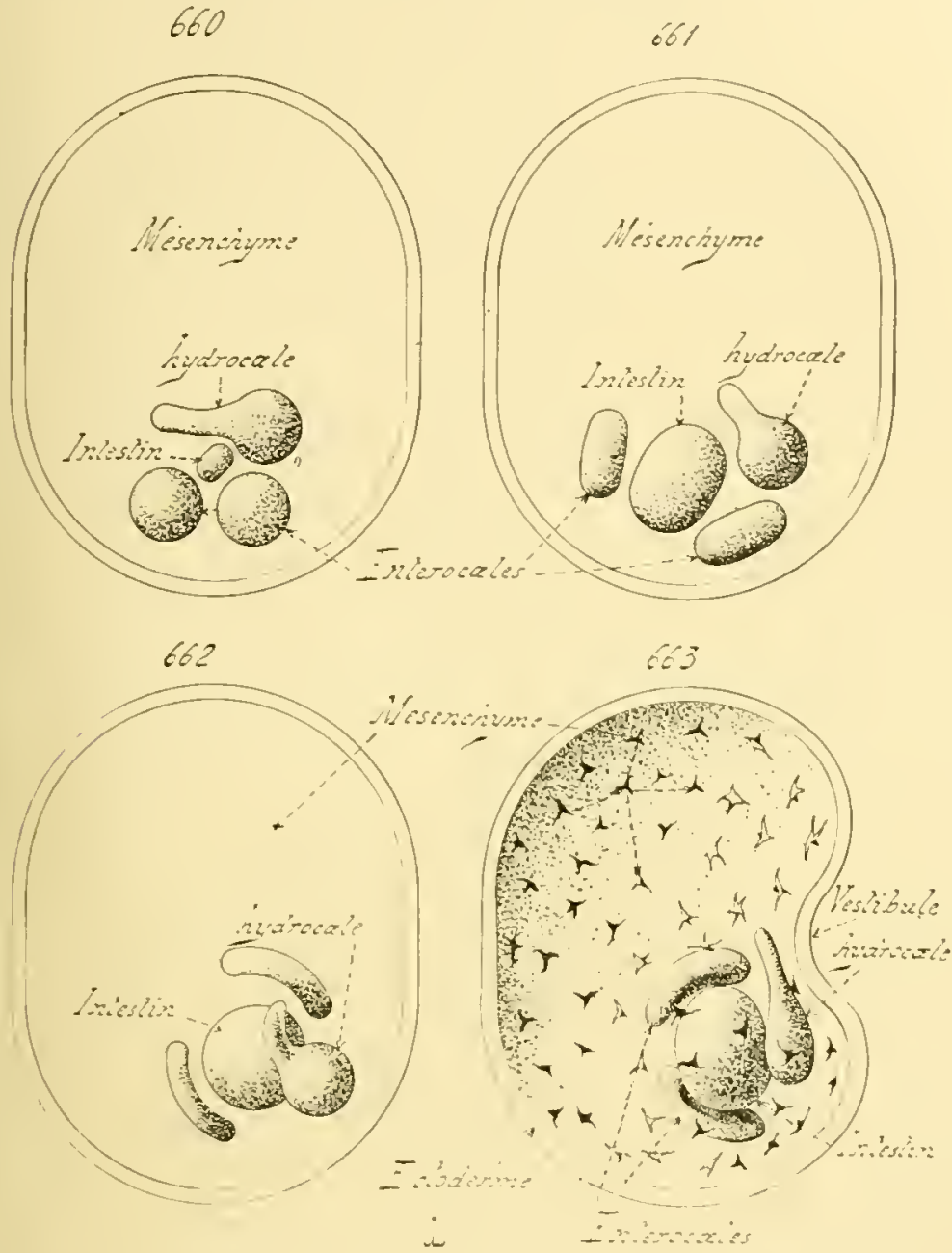

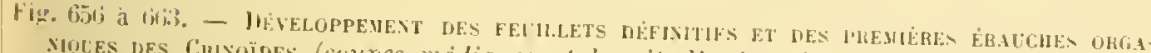
Nigces des ChwoÏDEs (coupes médianes el longitudinules, demi-diagrammatiques, ave perspective; dans le lut de rendre les desins plus clairs, le mesenelıme, qui ne lail

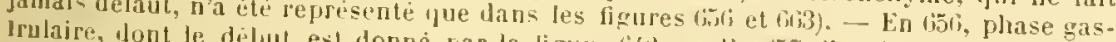

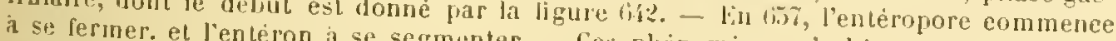
lis!, l'ontéron primordial est divise en - Ces plienmmines s'achivent en tiss. - En scinde pour fournir les leux parties. - lin 600 , la part inférieure se errle et intestin.

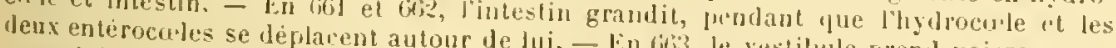

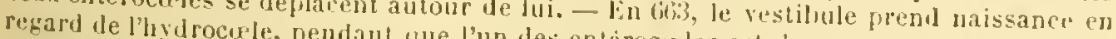
el l'autre presque inferrieur. true

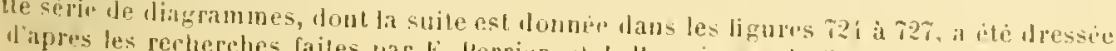

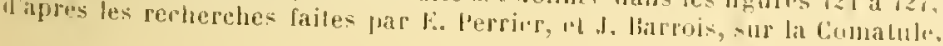


Comoïbs. - On ne connaîl, du développemont de ces animanx, que celui des pulus modiliés d'entre enx, des Comatules; cl celle évolution oflre des caracleres spéciaux, qui résullent d'altribations plus grandes encore que celles décriles jusqu'ici. Ces caraclieps sont dus : a une abréviation considérable du développement; an renversement des organes, consciculif a la proximité de la bouche el he l'anus chez l'adulte; cnfin, à l'allongement, en un pédoncule, He la région opposée il l'entéropore. Cetle légion, qui est supérieure chez la larve, quand on la compare it celle des antres Echinoulermes, est inférieme lans l'organisme définilif; et, par extension, les antenrs la décrivent égalonent comme inférieure chez licmbryon. Alin de permetle les comparaisons, celle cxtrémilé sera considéréc comme supérieure dans l'exposé suivant; il suffira the se la représenter comme derantservir plus larl, par sa transformation en un pédoncule, a la fixation de lindividu. Quaul an renversement, il a pour cfict le rendre inférienr, c'est-à-lire lo placer dans la région entéroporienne, re qui ćtail à gaurhe, et de renłre supérieur, de disposer dans la région pédonculaire, ce qui élait à droite.

Lu moment oì l'entéropore su ferme, l'entéron, converti en une vésienle closu, crense, of glohuteuse, nost pas exartement silué dans le coulre the la larve; il occupe sa zone inférieure, el roste ainsi voisiu de l'endroit on l'entéropore existait. Celle zone inféricure deviendra le ca-

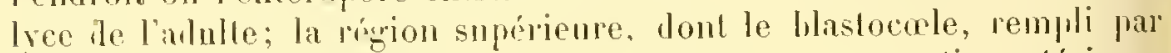
ios éloments mésenchymatenx, ne contient aucnne partie entérique, sallongera en un pófoncule. - Lientíron perd sa forme sphérique, et s'étrangle transversalement on son milieu; il offre l'aspect d'un bissac,

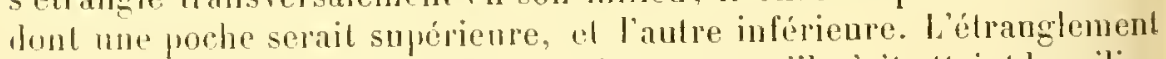
devient de plus en plus profond; nais, avant qu'il n’ait alleint le milieu du hissac, et n’ait isolé les denx poches l'une de l'aulre, la zone, qui unit ces dornieres, émel deux diverlicules lubuleux, le promier placé en avant. et le surond en arriore. Tous denx s'allongenl, non pas en sécurtant de la zone quiles produil, mais en s'appuyaut sur elle; loul en grandissint vers ta region inforienre te lention, ils saccolent dabord it h zone drunion, puis à la poche inférienre, et enlourent celle lernière i la maniore diun amnean prestue complet. Cette progression annulaire est surlont le fait du diverticul antérienr, car lo postérieur ne larde pas à resser son exfension, el ì lisparaître.

La vésicule entérique présente ainsi l'aspect d'un bissac, ou d'un sablier, dont la zonc, yui sert dunion aux deux poclies, porte un appendice tululaire entourant la poche inférienre, et formant autour l'ulle un anneau presque complet. Les deux poches se séparent emsnite l'une de l'antre, jar le letrécissement constant de la région unissante, et se convertissent en denx vésicules cluses el listinctes: la scission seffectue de telle sorte que l'appentice tubulenx, lout en environnant la vésicule inférienre, soit inséró sur la vésicule supéricure. - Celle-ci est l'hydrocule, el son

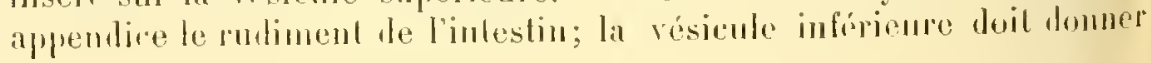


les deux entérocules. P'our cela, celle dernière s'étrangle en son milien. comme si l'anneau, façonné antour l'elle par l'éluauche intestinale, so resserrait de plus eu plus; elle se partage en deux autres résicules, l'une dioite, qui est l'entérocule droil, ul l'antre gauche, qui est l'entéroéch gauche. Pendant ce temps, la vésicule supérieure se compose d'une splrie crense, munie d’un appendice tubuleux. La sphère s"aplatit, s'ílargit, prend l'aspect d'une cornue, dont la panse serait l'hwlrocuele, et fo bec le lube hyilrophore. Lappendice lubuleux se sćpare a son tour, el sisole; il devient également une résicule close, qui ast destinée ì produire l'intestin de l'adulte.

An moment ò̀ ces phémomènes s'achèvent, l'embryon contient, dans sa moilio inférieure, el outre les ćléments mésenchymatenx, quatre vésicules, distinctes les unes des autres, et groupées en un amas, dont l'ibiuche intestinale occupe le centre. L'hyllocole, arec son tulie livilrophor", est supérixur, alors que les denx entéroceles, l'un placé à droile, rt l'autre à gauche, sont inférienrs. - Une inversion se produit 'usuite, déterminée par un rotentissement hatif du changement d'orientation des organes. L'entérocole gauche demeure inférienr, et devient presque médian; l'entérocule lroit passe au-dessus de l'intestin, el se trouve suprieur par rapport à lui. Les deux enlérocoles ont ainsi perdu leur disposition premiere, el les expressions droit et gauche cossent de leur ètre applicables, pour otre remplacées par les termes supérieur el infërieur.

Ibstraction faite de la fermelure de l'entriogrore, yui a jour but de translomer l'entriron en une vésicule close, au lieu de lui permettre de s'onvrir an dehors, les résultats définilifs sont, chez les Comatules, identipues à ceux les autres Echinodrrmes. Ces phénomenes ont loujours pour ellet dengender deux enterocurles, el un hỵhocale muni de son lube hyglophore. - Les allérations, dues ìne condensalion du développrement, sont plus profondes que chez les autres Echinodermes, el se raménent anx particulatís suivantes : l'entíroporese forme, el l'entéron prinordial se convertil en un vésicule creuse l'untéron ne donne point de protentérocosle simple, et produil l'hylrocusle indépendamment drs entrirocules; ces drunicrs sunt engendres d'abord, et derivent d'une "banche commune; entin, comme l'hydrocule s'isole "n dernier lien, il resl" uni, pendant quelque temps, a cotle parlie de l'entéron qui doit fonruir l’inlestin. Le fait le plus saillant consiste en l'absence lu protenlérocule, muni de ses diverticulıs droil et ganche, le ganche engendrant ¿ la fois l'enlérocuele gauche el l'hrolrocole; l'hydrocuele est ici formi, par l'enteron, d'une manicre direcle. Ces altérations, qui résultent de liplacements, n'ont aucume signification farticuliere, et n'altèrent en rien l'homologie des organes, puisqua lorigine de ces dermiers of leur disposition définitive ne clangent pas; ces altérations noxistent que

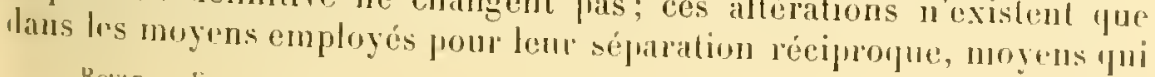


soul très variés che\% les lehinodermes, el natteigneul juint le fond mène les pliénomines gémétipues.

\section{\$ 4. - Formes embryonnaires et origine des organes.}

I. Considérations générales sur les organes. - \ı moment ou tous les feuillels blastolermiques sont lélimités. l'embryon des Echjnolermes posside léji une structure complexe. La paroi de son corps est constituée par trois couches de lissus: l'ectoderme, le somalo-mésenchyme, el la somatopleure. De meme, sa paroi intestinale so compose de loois assises : l'emloderme, le splanchno-mésenchyme et la sjlanchnoplenre. Ces deux parois sont séparées linc de lantre pre vaste olignculome, d'urjgine entérocolieme. Cet organisme offre déjà les particulariés essentielles le l'ichinoderme adulte: les cananx ambulacraires s'étendent, suivant une symétrie radiale, dams le somato-mésenclyme de la paroi du corps, et émettent, le place en place, les diverticules yui deviemdrout les ambulacres. Sauf les modilications secoudajes, et destinées à disparaître, qui tiennent à l’aspeet spécial des larves de ces animaux, la disposition gónérale de l'économie est déja ébauchée dans ses grands trails; et il est permis te conceroir, des ce moment, avec une précision suftisante, l’origine les priucipan appareils.

Panor on coms. - En ramenant à sa plus graude simplicité la structure de la paroi du corps des Lchinolirmes, on la voit constituce de la maniore suivante. En dehors, et recouvant celle paroi avec ses dépendances, estum épithélium; en lessous, se trouve une couche conjonclive épaisse, contenanl dans sa masse les sjicules, ou les playnes calcaires, qui constituent le test de ces animanx, ot renfermant amssi des fibres musculaires; enfin, tout en dedans, est située une seconde assise épithéliale, qui concourt à limiter loligocolone. Cette paroi est fréquenment munie dappendices, dont les principaux sont les piyuants. La composition deces lerniers n'est pas dilléreule de relle le la paroi qui les pussede; olle comporte les mèmes romrurs, disposées de la mème facon, arec la meme struchue lombunemlale; sauf la secondr assise epitheliate, yui fajt defaut.

Cette dernière n'est autre que la persistance directe, et i peine modiliée, de la somatopleure. De mème, l'épilhílium extérieur correspond à l'ectorlerme. Toutes les mollilicalions importantes portent sur le somalomesencliyme, yui donne la couche conjonclive jutermédiaire, avec ses plaques calcaires, ef m cerlain nombre de ses fibres musculaires, sinon toutes.

Less sicules et les plaques calcairos sont engendrées par les éléments du somato-mésenchyme, et ne dérivent pas le l'ectoderme, ni de l'épithélio-mésoderme. Partont on lim the ces corps va prendre naissance, 
se tromve un grouje de cellules mesonchymalenses; la sulislance calcaire se dépose au milien de colui-ci. Elle est scevécé par los éléments cellulaires, et exsudée en dehors l'eux; l'exsudation n'est point indétermincé, mais dirigée sur un point précis, fui est le centre le l'anns. Le dípul calcaire grandit, tant que dure la sćerélion de ses éléments formateurs, qui lemvloppent, et, suivant lenr disposition muluelle, dirigent son accroissement en vue d'un aspect délerminé. - I.es promiéres pioces calcaires sont, d'habilude, de longues bagucttes deslinícs i sontenir les aprendices temporaires des larves i mólamorphoses; par contre, des planurs larges et minees, semlilables i celles du test délinitif, prennent naissance dans la rigion qui donne plus spécialement le corps de l'adulte. Mans le cas oi les métamorphoses font défant, les loguelles calcaires ne se monlrent point, et les premières pièces sont les plaques deja menliommóes. - Ces dernièes ne s'élıuchent pas d'ume façon inléterminée; d'orlinaire, les plaques formées tout d'abord sont au nombre de dix, et appraraissent presque en mòme temps; elles sont rassemblées cn deux groupes, dont l'un entonre lientérocole gauche, cl l'autre l'entérocéle lloit. Le sort de ces plaques est fixé, car elles ne se confomlent point arec celles qui sont engendrées prar la suite; les cimp du groupe gauche deviennent notamment les pices orales des Crinoïles, ou les pieces terminales (ocellaires) des Astérides. Les einq] de droite se disposent antour d'une nomvelle plapue, la centro-dorsale, qui nait peu après elles, et se convertissent en basales chez les Crinoïdes, ou en génitales chez les Echinides. - Les antres picces lu test a juraraissent ensuite, fonjours engrendrées de la mème manière dans le sonato-mésenchyme, ef se déprosent entrr les deux gronpes précédents, pendaut que le corjes entier revèt son allure définilive. l'armi elles, l'une tourc, de laçon à se laisser lraverser par lui; l'ébauche de celte plaque se montre à droite de l'hydropore chez les Echinides et les Astérides, el i ganche de ce même orifice pour ee qui est des Ophiurjes.

Les piquants des Echinodermes apjlarliennent a plusicurs types. Tantil, ils sont de simples expansions coniques, el pointues, des plaques qui les portent; dans ce cas, leur origine esl facile al concevoir, car elle se ramène í celle de la plaque elle-mème. Tantot, ils sont des appendices

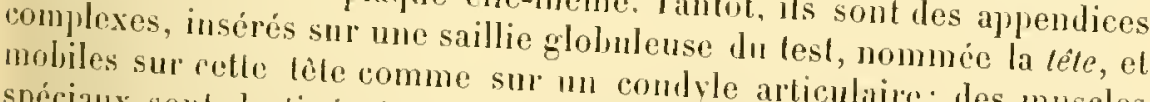
spéciaux sont destimis i assurer les comle articulaire; des museles pipuanls sont propros aux linger les mouvements de l'urgane. - lies

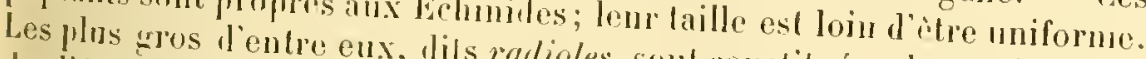
de l'ipithílium ectoder, lils rarlioles, sont constitués, abstraction laile lames calcaires, cremé pui les enveloppe, par mu lentrage de moplle centrilr, a tissu lactie racuoles, el divisi en trois conches : une

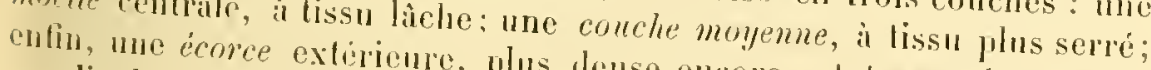
canalicules, rui rout du lehor alus dense encore, ol traversée par des 
Celte structuree xiste aussi chez les petits pinpunts ordinaires; seulement l'écorce fait defaut. - Quelles que soirnt la taille el la constitution, l'élanche d"un piquant offre l'aspert d'une pelite saillie hémisphérique, et compacte, dévelopróe sur la paroi du corps; ce mamelon se compose d’une assise ectoderminue externe, el d’un amas conlral d'éléments du somato-mésenchyme, en voie de déposer du calcairs. La saillie grandit et s'allonge; alors yu’elle est assez courte, elle se divise transversalement en deux prarties. l'une attachée à la proi du rorps, l'autre insérée sur la première. Celle-li dome la títe du jiquant; elle se horne ì s'élar-

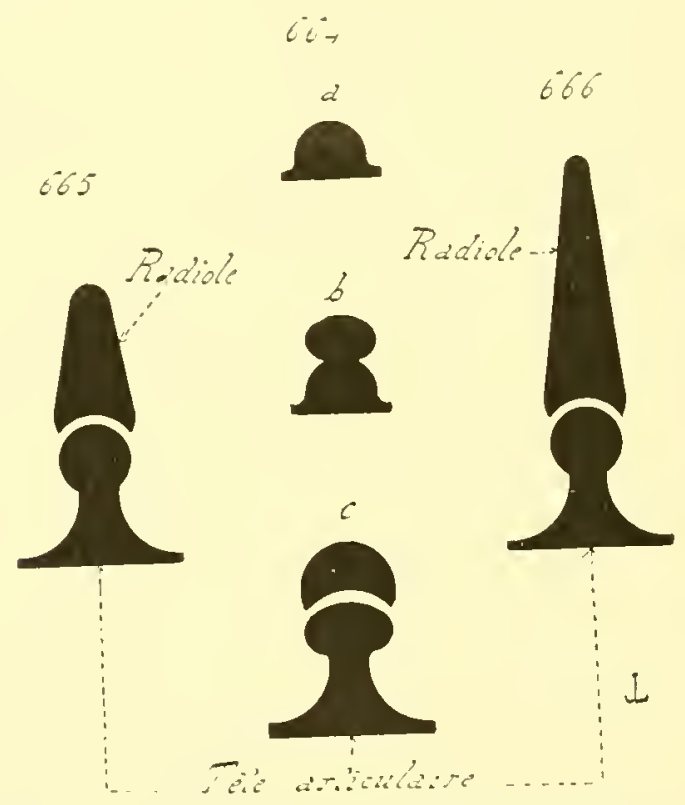

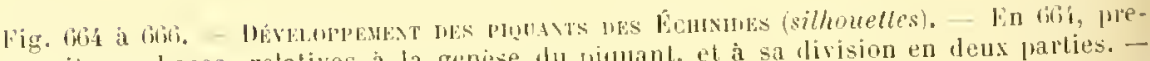
mieres phases, relatives à la genise du fiquant, et à sa lirision en deus parties. -

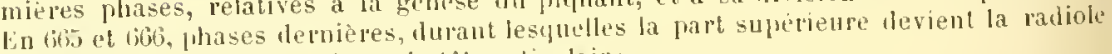
elle-mime, et la part iuférieure lí lête artioulairr.

gir, en conservant la mime forme. La seconde produit le pinuant luimème, of samplifie à cet ellet, an moyen d'une continnolle sécrétion de calcaire. Aufur el à mesure du dépùt, la moelle el la couche movenne se ditlérencient sur place: l'écorce des radioles ne se montre qu'en dernjer lin. Plusicurs des rellules llu somalo-mésenchyme, placées autour de la tẻle, ne jouent ancun rôle dans l'exsudation calcaire; elles se convertissent en filres nusculaires, fui sunsèrent sur la hase du pípuant l'ume part, sur la lète et sur la paroi du corps d'autre parl, et servent it mouvoir l'aplendice. - Sonvent, chapue radiole est entourée, 
i sa basu, par des piquauts plus pretits: erux-ci prement toujouls naissame avant la radiole.

l.es notions, qui précident, sont données d’après les études de l'rullu. l.e mème autenr a également foumi des indications sur le diveloppement des pédicellaires. Ces organes ont une origrine semblable a celle des piquants: leurs ébauches consistent en des saillies le la paroi du corps, composées d'une assise ectodernique, ef d'un amas cellulaile appartenant an somato-mésenchyne. La saillie grandit et s'allonge; en mème temps, son sommet se divise en lenx ou trois parties, suivant le cas, pour donner les denx on trois pinces dn pédicellaire; la base ne se modifie point, et se horne i s'útirer en un pídoneule. L'appendice est alors entirement constitue; ses fibres musculaires sont produites, sans doute, comme celles des piquants, par les rellules du somato-mésenchrme.l.es premiers pédicellaires se montrent de fort bonne heure dans la série des phases évolutives, puisqüil existe dojà de ces appendices sur des linves, jui terminent i peine leurs mélanorphoses, nont pas encore perdu lenrs organes temporaires, et commencent a revetir laspect définitif.

Srstèn xenver. - Les uotions relatives à lorigine, el au développement, des centres nervenx sont encore insuffisantes; lanatomie de ce sỵstène a seule élé étuliée, jusqüici, d’une manière approfondie. Les relations étroites, que les nerfs amhulacraires des Astérides affectentavec l'ectolerme, permettent de croire que les premiers sont engendrés par le second. La mème conclusion s'applique également anx Holothurides, anx Echinides, el anx Oplimides; lemrs nerfs, bien que séparés de l'retoderme, sont pourtant assez roisins de lui pour quil soit possible le conclure, l'après ce rapport de contignité, à une relation d'origine; les données fournies par l'étule des Astériles accorlent à celte opiniou la pulus grande créance. - La difficulté prorte sur les Crinö̈les, dout les centres nerveux sont lisposís en trois groupes : un systeme comparable i celıi des autres Echinolermes; un systeme ahoral, qui fournit des nerfs an priloncule, et lomme un gros nerf radiaire à chaque hras: enfin. me lande nerveuse sous-ectodermique, placée dans le sillon des bras. le premier et le dernier de ces groupes provienuent, sans doute, de l'ectoderme; mais l'iloignement "lu second, et du fenillet externe, est tel, que les présomptions en faven d'une origine ectodermigue sont difficiles à appuyer. Nilmeltre une antre provenance, pour ce denxicme groupe, concorderait pen avec les donneses de l'embryologie Eronerale; celles-ri montrent les centres nerveux comme issus de l'ectoderme, dans tous les cas on il est possible de voir, par l'olservation directe, leur véribale print de départ. De nouvelles íludes sonl encore nécessaires sur ce sujet, ct non senlement pour les Crinoüles, mais encore pour tous les antres lichinodermes.

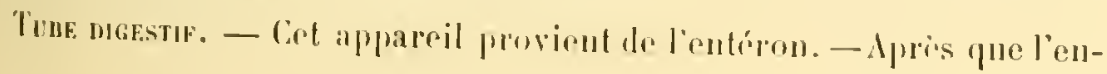




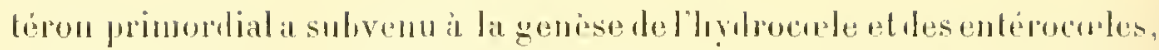
ce qui reste de cet organe, et jui mérite le nom d'entéron définitif, se développe pour se convertir en intestin. Dans lr cas oì l'entéropore persiste comme un orifice tomjours ouvert, il devient l'anus; s'il se ferme, l'anus se perce directoment dans la situation voulue par l'organisation délinitive. - La bouclse est toujours une ouverture dr nouvelh formation; l'entéron, apres sa séparation d'avee le protentérocule et ses dérivés, se recombe sur lui-mène, et se rapproche de la face interno de l'ectoderme. Ce feuillet s"infléchit, d'autre part, dans cette région dont l'entéron s'approche, et produit une dépression; celle-ci s'avance ver's l'entéron, el se soude í lui. Les parois en contact se résorbent, et un deuxiène orifice, la bouche, se tronve ainsi rréé. La dépression ectorlermiqur ne disparait pas; elle représente le slomeon, el lonne l'uesophage de l'adultr. - La situalion dr la houche, rhez la larve, neconcorde pas avec sa prosition létinitive; cettr ouverture est placée sur la face antéricure du corps, et jarlois à égale listance de l'extrémitŕ supérieure et de l'extrémité inférienre. L'aceroissement de l'organisme s'etfectue, ensuite, de façon à lui faire occuper une position terminale, soit que l'anus lui reste diamétralement opposé, soit qu'il vienne se creuser plus ou moins près l'elle.

Appareil irrigaterir. - A. Cet appareil atteint, chez les Echinodermes, une complexilé, ot une régularité de disposition, que les autres animaux ne montrent guère. Il est essentiellement constitué par trois parties distinctes: l'oligoculome, d'origine entéroculienne: le polyculome, d'origine schizocolienne; el l'appareil hydrophore, d'origine hydrocalienne. Comme le dénote l'óvolution des feuillets blastodermiques, res trois parties, à cause de leur provenance, sont séparées les unes les autres dès l'isolement le leurs ébauches, el demenrent distinctes; leurs cavités ne communiquent pas rntre elles, el toutes les trois accomplissent còte à còte, sans se confondre, les phases de lenr dévelopiement. - Ces phases ne sont pas toutes connues, et le faconnement de ret appareil comporte encore beaucoup do faits inexpliqués. En atfot, l'anatomie enseigne que ces trojs systènes présentent sourent, chez l'arlulte, des connexions étroites, et mettent leurs cavités en relations direcles; ce's relations sont secondaires de toute évidence, rar elles manquent aux embryons, et ne se trourent que dans l'oryanisme définitif: olles existent cependant, et l'on ignore le moment oì elles se produisenl. ainsi que leur valeur exactr. Ces rapports ont, en surplus, comme rísultat, de pròter í des doutes sur l'origine de certaines cavités du corps, creusées tans le somato-mésenchyme, et placées antour de flusieurs organes, tels que les nerfs el les canaux ambulacraires. Ces cavités, d'après leur aspect ef leur structure, paraissent appartenir au polyeatome. Cependant, leurs relations directes avec l'oligoculome obligent à une certaine réserve ì leur égard; il est permis de se demanter sices 
connexions sont primilive, ot indiquent lit proxenanee; ou lien si elles sont secondaires, et dénotent seulenent que ces espaces, diabord séparés et dorigrines diflérentes, se sonl ensuite abonchís l'un avec l'aulre. La réalité drs choses semble itre que ces cavités anmexes, creusées lans le somato-mésenclyme, et engainant les nerl's et les canaux amlmucraires, appartiennint au polyculome; celle opinion sera suivie dans le prósent exposé, mais elle demande à etre appuyée sur des observations lirectes, car elle n’ost Lasée que sur des présomptions lirées des donneres anatomiques.

Il est deux notions qu'il importe avant tout de préciser. Au moment wii ses trois feuillets se délimilent, la larve contient dans son corps, trois systènes de cavités, indépendants les mus des autres : les entérucoles, lihylrocole arec ses amexes, el les lacunes creusées dans le somatomésenchyme conno dans le splanchno-mésenchymo. De mème, l'adulte possede aussi trois systémes le cavités, nettement caractérisés, et diffèremoies, par la disposition et la structure propre i chacun d'eux, bien qu'ils aient parfois les relations directes : le vaste oligocolome, souvent nommé la cavilé générale du corps: l'nusemble de l'appareil ambulacraire et de l'appareil tentaculaire; entiu, les sinus qui se trouvent dans la paroi intestinale, dans la paroi du corps, et qui composent un polyculone. Autant qu'il est permis d'en juger d'après les faits acquis, l'olizroculome dérive des entérocales, l’appareil hydrophore entier provient de l'hydrocule. el tous les sinus du polycalome se percent dans les couches du mésenchyme. Par suite, la cavilé générale du corps de l’adulte mérite le nom d'entéroccelome, et l'ensemble des simus polycolomiques celui de sihroculome.

B. - Lentéroculome est une vaste cavilé placée entre la paroi de l'intestin el celle du corjes; il est luaversé par lles mésenteres, yui le découpent en chambres secondaires, plus ou moins nombreuses suivant les lypes. Il est formé par les leux entérocoles, qui, en grandissant, entourent l’intestin entier, et s'étrudent entre luj el les téguments. Il se compose d’une paroi el d'un contenu. - La paroi provient directement de celle des entérocales; sa jartie externe, sous-jacenle au somatomésenchyme, el accolée à lui, est la somalopleure; sa partie interne, soudíe au splanchno-nésenchyme, est la splanchnopleure. Le contenu secompose l'un plasma liquile. el de nombremx éléments figurés. Comme, vhez l'adultr, plusieurs de ces ulerniers jouissut du pouvoir le multipliration, il rst premis we penser que tous sont engendrés par yuelqurs éléments primitifs, placés, an début de la vie drol’individu, daus les cavitis muterocmlienmes. Lorigrine exacte de ces cellules primordiales n'a pas encore été constatée l'me manière rertaine; a en juger d'après divors phénomènes otlerts par l'adulte, ils provicunent, sans doute, du misenchyme les misentères, et correspondent i dos collules mésenclımaleuses, qui anrairnt traversé. par diapédise, la paroi de ces méserr- 
tires four tomber dans les espaces entéroculiens. Eurllet. le mésintère, qui contirut le tube lydrophore dans son épaisseur, posside également nu olgane parliculior, disigné par plusienrs nons, ponvu de toute la

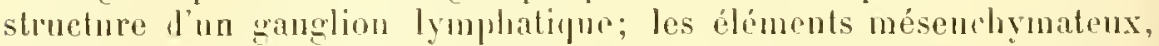
suspendus dans les cavitís le eol appareil, se léplacent à l'aile d'expansions pseulopodifurs, et sont capables le passer au travers des parois mésentériques pour arriver dans l'nntroerlome. Ces phénomènes, offerts par l'adulte, existent sans doute, et à plus fortr raison, chez les indivilus très jemes, à cause de l'excessivr vilalité gruétique des lissus. - Les parois Jes entérocreles paraissent navoir ancun rólo dans la production de ces fóments tigurés; la plupart des olservations les montrent toujours entieres, et privérs đr toute désagrégation particulière.

C. - Le schizoculome est constitué par un réseau lacunaire, creusé dams le tissu conjonrtif tes demx foullets mésenchymatemx. Il se eompose de deux parts, de deux laeis distincts: l'un. somatique, développé dans le somato-mésunchymo; l'autre. splanchnique, situé dans le splanehnomésenchyme. Ces denx systemes, loes mots chez les Echinodermes dont le corps est cylindrique on globuleux, comme l'est celui des Iolothurides el celui des Echinides, sont séparés l'un de liaulle, ol paraissent n'avoir entre enx ancune eonnexion directe. Lorigine de leurs cavilés est celle de toutes les lacunes conjonctives: la sulistance fomlamentale se dilférencie sur place, an moment de son dípot, en me portion qui reste soliue, et forme la gangue réelle du tissu conjonctif, et en une portion liquide. Cette dorniore est enveloppée, entignée par la prócédente; les espaces qu'vlle oecupe sont les lacmnes crensions dans le tissu.

La part somatique du schizocolome est représentée par des espaces qui entourent les eanaux, et les nerfs ambulacraires, soit sur toute leur étendue, soit sur une zone restreinte de leur surlace; les plus fréquents sont les carités sous-ambulacraires des auteurs, lont le nom indique suffisamment les commexious. (In ne saurait micux comparep ces ravités qu’aux gaines lymphatiques des vaisseaux sanguins des Vertébrós supériens: l'homologie entre ees denx formations est rompliote sous tous les rapports. Leur strueture lacunaire, leur siluation réciproque, leur origine anx dépens du mésenchyme, concordent dans les denx eas.

Le schizocolome splanelunique est, à son tour, livisé en deux systèmes particuliers, qui communiquent entre eux : l'un intestiual, et l'autre mésentérique. - le système schizoralomique intestinal, nommé par les auteurs appureil sanguin, ou apmareil absorbanl, est constilué par un lacis facunaire, crensé lans la paroi intestinale; ce risean aboutit it un sinus, ou à un ensemble de sinus, placé dans la région asuphagienne qu'entonre l'ammeau hylrophore: ces simus unissent lapparcil intestinal au ș̣stime mésentérique. - Co dernier est développé dans l'ópaissenr du mésentère dorsal, oì il ust voisin du tube hydrophore. Il consiste essentiellement en un sinus, qui longe re tube, of en mn plexus lacu- 


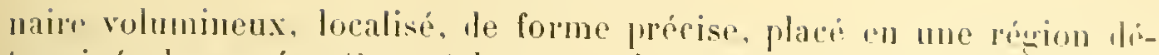
termince de ce mésentere, et laus sa substance. le siums, dout R. huhlor a le premier reconum l'existence, dóbonche lans les cavités du plexus. Celui-ci représente un véritable ganylion lymphatique, et mérito, d’apross son origine el sa structure, de conserver ce nom: les autrurs le designent par des expressions nombreuses, dont les principales sont colles de comr, d'organe dorsal, de glamle ovoüde, et d'appareil plastidogine. De mème que les ganglions lymphatiques des Vertélués, il consiste en un lacis serré, et nettement localisé. le lacunes percées dans le tissu conjonctif du mésenuryme. - Le liquide renfermé daus ses cavités est un plasma, chargé d'ahomdants éléments fignués; ces reruiers s'y multiplient aree activite, d'ou le nom d'apparoil plastidogine, yne les auteurs. récents aceordent à l'organe entier. Les iléments figurés dérivent de cellules du mésenchyme, prises dans le plasma, au moment oir ce dernier se rliférencie au sein de la substance conjonctive fondamentale. fls affoctent des aspects đivers; les seuls, pourvos du ponvoir multiplicateur, sont munis l'expansions semblables a des psendopodes de Protozoaijes; comparables en tout i des globules lymphatiques de Vertébrés, jls sont capaliles de traverser, par diapédese, les parois conjonctives de linrs lacunes, comme les surfaces épithéliales du mésentère. 11 est possilute que cemx d'entre eux, qui parviennent, en se déplaçant ainsi, dans la cavité de lintéroculome, chez l'individu fort jeune, sont chargés d'engendrer les éléments figurés contenus dans cette dernièe.

La senle signifieation, qu’il soil possible de domner du schizoeurome des Echinodermes, est le l'assimiler à celui des Vertélorés. Lappareil irrigateur de ces derniers se compose également de denx parties : un entérocmlome, quj fournit la carité ahdominale, arec los cavités pleurale et fréricardique; un schizocolome, creusé dans le mésenchyme, divisé en un appareil sanguin et un appareil lymphatique. La provenance, la disposition générale, les rapporls avec les autres fenillets, du schizocorlome des Echinolermes, sont jdentiques le tous points aux particularitís correspoulantes de celui des Vertébrés. La principale ilifférence porte sur l'extrème simplicité lu premier, comparé ì la complexité du second. Celui-ci est djvisé en mn résean sanguin ot un résean lymphatique, dont les éléments figurós el les parois des ramaux vectenrs sont lissemblables. Jar contre, le premier ne comprorte aurun systeme sanguin véritable, éest-i-dire ancune partie modifiée dans un but spécial et pour les fouctions parlieulières; toutes ses eavités otfrent une oryanisation iggale, ot des éléments figmrés ilentiqurs. Ses earactères concorilent

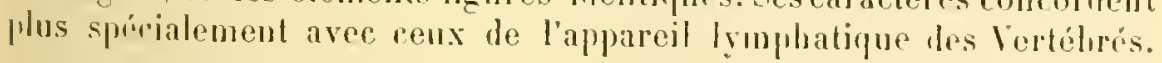

1). - Lappareil hydrophore se rompose de demx parties, liume centrale, lautre péripherique. - La premièce est conslituée par un anneau, yni entoure l'orsophage, et pal un canal, diugé de col annean vers l'extrienier. Le canal est le hebe hydrophore, sourent mommé, muroro, 
comal pirvenx, on camal du salle: l'anneau est l'amenu hybrophore, désigné d'labitude par l'expression d'ammen amhalacraire. Ce lerme nindique pas loules ses qualités, car l'organe est en relation, non seulement arec l'appreil des raisseaux ambulacraires réels, mais encore avec celui des canaux teutarulaimes. Horlinaire, chez les Echiniles, les Astórides, et les Ophimbides, le tube hyolpophore est continu. Celui de la phupart des llobolhurides se divise en leux portious, lont lexterne, atlarhéc à lis paroi du corps, lisparait: l’unterne reste seule, el souve daus l'entéroculome. Ie même fait exisle chez les Crinoüdes, arec celte diflérrnce que les deux parties persistent, s'ourrent également dans l'enlíroralome, et parfois augmentent en nombre. - La zone périphérijue le l'appareil ligdrophore se divise, a son tour, en deux systemes: l'un lentaculaire, laubre ambularaire. Le premier consiste en canaux qui se rendent aux tentacules placés aulour de la bonche; il demenre, dans le cas où les tentacules sonl conservés eux-mèmes, et deviennenl assez volumineux; ce deruier fait n'est guère offert que par les Echiniles, et surtout par les IJolothurides. Le systiome ambulacraire manque seulement à rertaines llolothuribrs; il se compose essentiellement de rinq conduits, les canuux ambulacrares, on vaisseau ambulacraires, qui parcourent la paroi du corps, et dout les cavités communiquent avec celles des ambulacres.

La parlie centrale de l'appareil hydrophore est produite la première; elle derive directement de l’hydrocule embryonnaire. Celte vésicule imel le tube hydrophore, gui va sourrir au dehors par l'hydropore; l'un des mésentères produits par l'adossement des deux entérocoles, le uríseulere dorsal, s'établil de manièce à possciler ce lube dans son épaisseur. La vésicule elle-mème s'élend autour le l'asophage, et l'enveloppe; elle se converlit directement en l'anneau hydrophore. Dans le cas oì les métamorphoses larvailes sout complexes, l'oesophage fait défaut, ou hien se délruit pour se reformer phus tarl; l'anneau hydrophore nen lrenl pas moins naissance, par l’allongemenl de la vésicule en un fulıe qui se recourbe sur lui-mone, et levient annulaire; seulement. rel anneau n'entonle aurm organe prartirulier.

le systeme tentaculaire est, d'habitude, la premiere zone engendrée le la partie périphérique; l'anneau hỵdrophoro émel ciny liverticules, placés à égale distance les uns des autres, el passe àl lélal, déjà signalé, le rosette hydrophore. Les expansions grandissent, soulevent la paroi du rorps en ring mamelons; cenx-ri saccoissent à leur lour, el devienucul les tentarules périhur"aux. La liase, de thacun de ces diverticules ainsi convertis en cunaux tentaculaires, rest-à-clire la région atlachée à J'anneau hylrophore, produit un autre livertionle, dirigé ver's l'cxtrénité anale de l'embryon, et longeant le corps; ce nouvel organe est un canal umbulucraire. Ce dernier est, à son dél,ul, une dépendaure du ronduit tentarulaire; romme les tentarules salrophicnt frar la suite, ou hien ne 
possedront qu une importance inférieure a relle des ambularles. les cind ranaux ambularaires deviennent plus volumineux que les vaisseanx tentarulaires dont ils dípient, el ronstituent, rhez ladulte, le sustimo prélominant. Les ronnexions primitives sont cependant ronservíes; les ranaux aubulacraires ne se rendent pas diredement it l'annenu hrifophore, mais se joignent, d'ahord, aux ranaux tentarulaires. C'est ta branche d'union, de l'un des premiers aver l'un des seronds, yni s'insim. sur launeau. Ces ring hrauches d'union sont les persistinces direntes des rinq diverticules, qui constituent tout d'abord la roselte hridrophore.

Iles connexions secondaires s'ilahlissent, chez la plupart des Erhinodermes, entre l'apprareil hidrophore el l'entéroculome, ou le schizorwome. - Les relations directes avec l'entéromelome sont les mienx ronnues sous le rapport de l'origine; on les trouve chez les Crinoüdes, et les llolohurides, sauf la plupart des Elasipoles. Pour re qui est des Crinoïdes, le lube hydrophore se divise en leux parties indépenılantes, qui sourrent égalenent daus l'entíroculome; aussi l'anneau hydrophore ne communique-t-il, aver le dehors, que prar l'entremise de ce dernier. Chez les llolothurides, le tulue hydrophore de la larve est entier lout l'ahord, et lébourhe ì l'exterricur': puis, sa régrion adlıérente à l'anneau hydrophore persiste seule, l'hrilropore se lermant, el la zone attenante se délruisant. La premiè région dencure suspendue dans l'entérorclome, el se prere d'une ou de plusienrs ouvertures, destinces ì la faire aboucher avec la ravité de ce dernier. - Cetle série de phénomènes estronnue daprés des olservations directes, el d'apròs les inductions lirées de la structure définitive; la certilude n’est plus aussi grande. pour ce qui ticnt aux relations de l'appareil hydrophore aver le schizorolome. Hes oritires permettent aux canaux du premier de rommuniquer aver les sinus du sccond; mais, du moins dans la plupart des cas, ces ouverlures sonl itroites, relativement au volume des deux sistimes, et ue farilitent point des l'apports aussi complets que ceux élablis avec l'entéroccelone. De plus, on ignore la marche suivie pour produire ces connexions; limatomie ne fournit, a ret égard, aucune présomption. Toul re qu’il est permis d'aftirmer se rapporte a la valeur morphogénétique. Ces relations. dirertes sont secondaires, el non primitives; elles manquent aux embryous, a cause mème de l'origine de ses feuillets, et n'existent que daus les organismes parvenus à leur ćlat définilif.

Aprana excréteus. - Les produits de désassimilation s'acrumulent, chr\% les Echinodermes, i mesure que la vie de Mindivilu se prolonge, daus la plupart des cellules du mésench yme, oudans les éléments figurís de l'appareil irrigateur. Les cellules, desinées à renfermer ces produits, retrartent leurs expansions pseudoporliques, et subissent une degénirescente granuleuse. Copemlant, el bien que los composés désassimilis se répartissent ainsi daus l'organisme entier, ils sont phus nombrenx dans le ganglion lymphalique, annexé au tulue hydrophore; aussi in 
deruier, comme lount lómontré réemment des expériences laites par A. Lowalersky, peut-il atre pris pour un appareil "xeréten spécialisé. Le ganglion lymphatique est situé dans le mésentère qui contient également le lube hrdrophore; en ne consilérant que ses raracteres essentiels, on doit le ronsilérer comme unr prolifération locale, reusée de nombreuses ravités larmaires, lu mísenclyome de ce nésentere. Ses larunes communiquent aver le sinus. pui longe le tule hrdrophore, en joignant la zone mésentérique du selizoculome splanchinique à la zone iutestinale. Ce sinus est parfois assez voluminenx pour engainer to tuhe hvidrophore sur son parcours, el pour envelopper anssinne part. du ganglion lympluatique; il en est ainsi chez les Astériles, par exemple (sinus axial). - Les lacunes du ganglion sont, d'un côté, en relations directes avec celles du schizorolome intestinal, pui reçoirent les aliments rentus assimilahles; d'un aulre rôté, elles ne sonl séparées, de la cavilé le l'entípocolome, que par les minces surfaces épithéliales lu mésentère; les échanges osmotiques sont done trè faciles entre elles et celle dernière, et il est permis de comprendre, d'après cette disposition, son fonclionnement on tant qu'appareil excréteur. Les Lchiuiles offrent pourtant, à cet égard, me structure particuliere; un canal, onvert au delıors, aceomprague sur son trajet, le tube hydrophore, pénitse dans le ganglion lomplatique, ot s'v tormine en cul-te-sar; les prouluits de désassimilation de ces êtres sont donc capables de parrenir directement à l'extérieur.

Les notions précédentes suffisent dújà, pour indiquer l'origine du ganglion lymphatique. Cet appareil est dirertement formé sur place, dans le mésenchrme du mésentòre qui porte le tube hydrophore, contre la paroi de co deruier, el anx dépens de ce mésenchrome lui-même. La provenance du canal excréteur des Echinides n'est pas Lrès connue; ses relations avec le dehors permettent de penser que ce conduit dérive, peutitre, dune involution ectoderminue.

Orgines sexues. - L'origine exacte des cellules sexuelles des Eehinodermes, n’est pas encore élucidée; de même celle de leurs conduits vecteurs. Les senls faits importants, précisés par les récentes recherches, portent sur l'étroite comnexité étahlie entre le ganglion lrmphatique et les ébanches génitales. Ce ganglion est un résean lacunaire volumineux, localisé dans le mésenthrme du mésentire dorsal de l'emhryon; or, le ruliment des glandes sexuelles est une expransion de la zone mésentéripue qui rontient le ganglion.

Le ganglion lymphatique les llolothuries est, relativement à celui liss autres Echinodermes, petit et diffus; cependant, les promiers vesliges de l'appareil reprorlurleur sont en rapport a vec lui. - Chez les aulres représentants de l'embranchement, les organes sexuels sont divisés, sanf le cas d'atrophies secondaires, ou colui de soudures provenant de déplacements, en cinq masses. L'ébatuche génitale prent, lout d'abord, pour les former, $m$ aspert pentagonal (pentagone genital); puis elle 
s'acroit dans la direction des ciny angles du putagonn. Ces derniones parties grandissenl senles. et se sćparent les unes des autres, prom domner les ciny masses. Celles-ci sont localisées en mor région thter-

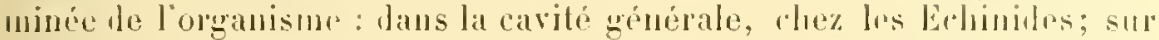
le pourtour du disque, chez les Astérides rt les Ophinriłbs; ou birn

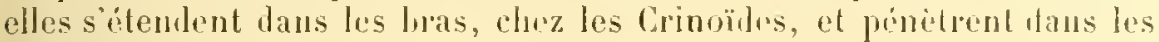
pinumles.

Le moment, oì cesébanches génitales apparaissent daus l'économie, est tarlil, car il se trouve placé vers la fin de la période embrvonnaire. probahlement, il correspond à celui oi ces chauches se différencient en tant quoryanes délimilés; sans doute, les premières cellules sexuelles élaient déjà faconnces au préalable. Celles-ci proviennent-elles du mésenchryme du mésentire, ou bien de l'ípithélio-mésoderme qui revì la surlace de ce dernier? Les fails acquis ne permettent pas encore de se prononcer à cet égard. Les probabilités serarent plutôt en faveur d'une origine mésenchymateuse: mais c'est la tout ce qu'il est possihle d'avancer.

Plusicurs auteurs, et nolamment Proulio au sujel Jes Echinides, disent que l'ébanche génitale est wisine du ganglion lymphatique, mais n'en provient pas; elle naitrait, anx dépens du mésentère fui le contient, non loin de lui, et de maniere a lui ètre commexe. Cette domme laisse entière la difficulté précédente. Le mésentère est composé par du mésenchyme et par de l'épithélio-mésoderme; le ganglion lymphalique n'est autre qu'une prolifération locale le ce mésencliync; et, que lébauche provienue du ganglion, ou du mésentère seul, loujours du mésenchyme et de l'épithélio-mésoderme entrent dans la structme. la solntion de cette difficulté offre un granl intérèt, car il s"agit de connaitre le feuillet qui donne naissance anx cellules sexuelles.

la délimitation tarlive de l’ébaucle génitale peul itre étallic, en prenant comme exemple les recherches léjà mentiomécs, faites par Proulo sur l'Échinus lividus. An moment oì les métanorphoses larvaires sunt aclevées, et oul l’udividu possèrle dejà sou aspeet léfintif, lien que sa laille soit les plus minimes, les glandes sexuclles n'existent fas encore. Aimsi, les jennes exemplaires, mesurant I millimètre de diamelre, ont bien, dans lem lest, les rinq plaques génitales; mais ces dernicres sont encore privies de lenrs pores, et les mones reproductemrs sont absents; de son cotr, le ganglion lymphalique est rmbimentaire. La dillérenciation ne commence guèe a setlectuer que sur des individus avant trois millimetres de dianctre; l’éhanche génilate prent naissance vers la pointe infériente (lournée vers l"anus) dn ganglion Iymphatique, sous la lorme d'une expansion, qui s’accoit ell se rapprochant du sommel inférieur de la paroi du colps, c'est-it-dire te la région anale (périmorte). Iorspue le petit Exhinide ollie six milli-

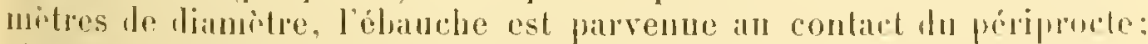

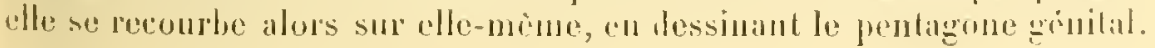


Les cinn angtes du pentagone s'accoissent seuls par la suile; charnn d'enx se place dans la zone interambulacraire la plus proche. Ils se séparent lís uns des anlres, et donnent ainsi les cin! glandes sexinelles de l'adulte. Les pores génilaux ne se percent, sur les plaques correspondantes, yuan moment oì les cinq glandes se délimitent.

\section{Considérations générales sur les formes embryon-} naires. - La plupart des Echinolermes, parvenus à leur maturilé sexuelle, rejetlent leurs ćémenls repuoducteurs dans l'ean qui les entoure; aussi la fécondation est-elle exlerne, el les mélamorphoses sulies par les embryons sont-elles également exlérieures. Ces changemeuls te lorme sont sourent considérables; les larves possèdent des appendices parliculiers, qui dispraraissent au moment où elles se convertissent en adultes. Dans certains cas, dont l'émumération a été donnéc phus haul (page 6i9), les ovules sonl conservés par les lemelles dans me partie de leur corps, el incubés, on fixés à des corps étrangers: les métamorphoses sont alors restreinles, ou mème fonl complitement défint. Ces derniers plénomènes sont relatirement rares. Etanl donnée leur présence, il convient de distinguer entre les Echinodermes à mélamorphoses complètes, el cenx ì mélamorphoses incomplóles ou absentes.

Hétamorphoses completes. - . L. Comme l'ovule fécondé est sphérique, on largement ovalaire, la larve tris jeune, qui dérive de cel orule, est elle-nène globuleuse; celle forme ne persiste point, el ne tarde pas à se moditier. Au moment où l'embryon parvienl à l'élal gastrulaire, el commence à dépasser cet élal, son ecloderme entier se courre le cils vilıraliles; la larve est alors miformément, et complirlement, riliée. Celte plase, qui existe an début du développenent de prosque tous les Eehinodermes aux métamorphoses complèles, mérite, prar suite, le nom de phase première. - les ébanches des entérocules el de l’hrdrocule commencent à se délimiler; l'hydrocale produil le lube hydrophore; el les principanx caracties de la l’enlaclule, c'est-i-dire de la larve fondamentale des Echinodermes, se manifestent déjil. Comme celte disposilion premièr des cils vilualiles est commune i tous les reprisenlants du groupe, comme elle s'oltre avec conslance dans presque lous les développencnts dilalés, il est permis de s'úlever, d’aprés elle, il la notion subjective du I'entasoon ancestral, el de se représenter cel elle hypolhélique comme recouvert d'un tapis serré et complet de cils vilualiles, qui hui perneltaient de se déplacer En ramenant les faits à leurs donnés oljeclives el linectes, il est important de constater l'existence d'un élal primitif, commun ì lous les Echinodrumes, dupuel se digagent les modificalions parliculieres i chayue classe.

Ces modilicalions sonl de deux ordres. Les mues consistent en la localisation des rils vilualiles sur rertaines régions de l'orgunisme larvaire, el en leur dispration dans les antres zones; ces cils se rassem- 
bent en bandes, sinueuses d'ordinaire, ou bien cerclant le corps comme des anneaux, el montées sur des bourrelets; la production des bourrelets est due à ce phénomène, 'fue les collules ectodermiques, porrvos de cils rilmaliles, sont plus longues que les autres, et, par conséquninl, se dessinent en sajlie. Les autr's changements tiennent it l'extension de cortaines parties $\downarrow$ u corps en appendices temporaires, plus ou moins allongés, yni disparaissent vers la fin des métamorphoses, et ne passent pas à l'adulte. Ces expransions, convertes de rils viluatiles, sont parfois soutenues prar des spicules calcaires, et sont ailleurs privées de ces spicules; mais elles ont torjours l'aspect de haguettes cylindriques, on cylindroconiques, insirees sur l'organisme larvaire. - Ces detix ordres de phrumènes sont séparés chez certains Echinodermes; ailleurs, ils coexistent, on lien se succedent dans l'évolution d'un mème embryon. Il convient de reconnaitre, à cet égarı, parmi les elasses de l'embrancliement, trois groupes principanx. Le premier renferme seulement les llolothorides; il correspond a un étal relativement simple, dont so légage celui du second groupe, contenant les Lchinides, les Istérides, arec les Ophiurides, et celui dn troisiome, yui se borne aux Crinö̈des.

Les Ilolothurides, lorsquelles sulissent des métanorjhoses complètes, commencent par présenter la phase premiere. Ensuite, elles passent à un état dit Auricularia ; les cils vibratiles se groupent en une longue bande, qui entoure, tont en lécrivant des sinuosités sur le corjs, la région buccale. Cette bande se fragmente; ses tronçons se disposent en ciny corlons circulaires, yui rerclent le corjss a la manire d'autant d’anneanx: ce troisicme état est désigné par le terme de pupe. La pupe se convertit alors en adulte.

Si l'on prend l'unique l,ande sinueuse des Auricularia, an moment oủ elle se divise en deux segments; si l'on s'arrite í cette phase, la scission n'allant pas plus boin, et ne parvenant pas á donner ciny troncons; si, en ontre, l'on dispose ces deux bandes de manière á les rendre sinueuses à leur tonr, et à leur faire parcourir une crande partio du corps, on iura la Bipinumia, la jeune larve des Astérides. Cos derniers animaux offrent d'abord la phase premicre, puis passent a l'iblat de Bipinnaria, qui est une phase A uricularin modifice romme il est dit précédemment. - A ce second tyje larvilire des Istíriles, en succide un troisiome, nommé Brachiolaria; le corps de l'emliryon, lout en possédant ses deux londes, émet des bras, des expansions cylimdriques assez. rourtes, et transitoires, car elles ne persistent pas chez l'arlulte.

D'autre part, si l'on s'arrète ì une Auricularia non encore complite,

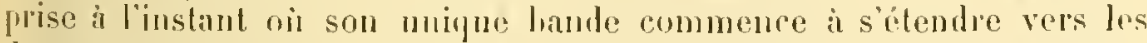
Jenx extrémités du corps, el si on localiso celte hamle daus la régrion suprérienre de l'organisme, dans celle qui porte la houche, on obliendrit

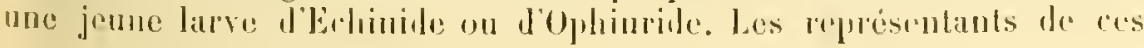


demx classes passent d'ahord par la phase première, puis leurs cils vibratiles se rassemblent pn un rombon sinuenx, place dans la région hucale. Cette bande grandil ensuite; elle produit les expansions cylindriques, qui s'allongent extrènement, et dépassint de beancoup le rorps. Ces expansions, coureutes do cils vilualiles, sont dites des bras; la larve, munie de ces appentices, est nommíe I'luteus. - Les bras du I'/uteus sonl phos longs que renx de la Brachiolarin des Aslérides; ils possedent, ponr les sontenir, des spicules ralcaires, dont cetle dernière est privéc. Its sont an nombere do lonit dhahitude, rhez les Echinides lout aussi hion que chez les thhiurides; ce chilfre s'ileve à dix chez les Spatangides, it cause dr la production de deux appendices supplémentaires, flus petits que les autres. Ces expansions ne naissent pas en même lemps; elles se montrent par paires aves régularité. les deux éléments l'une mine frape étant placés de part et l'aule de l'axe central de l'écomomie.

Les bras de la Rracholarin, comme cenx du Plutens, font partie de lorganisme larvaire; ils entrent dans la constitulion du prosome, mais disparaissent ensuite, et ne contribuent nullement à former le métasome, le rorps détinitil. Aussi, lorsque ce alernier commence ì se lélimiter, il n'empruntr à la larve, pour se faconner, qu'une part restreinte de son corps, et laisse de coté les appendices, avec les régions qui les supportent. Pendant ce trmps, et grace à ces mèmes apprndices, converts de cils viluatiles, la larve continue à niger, à se déplacer, et conserve sa mène allure générale. - De là découlent les particularités remarquables dı déveloplement des Echinides, des Astérides et des Ophinrides, que J. Mïller a, lepuis de nombreuses annérs, mises en hmièe lime maniere si parlate. Le mitasome, le jenne lichinolerme, ponr momployer l'expression dos anciens auteurs, se diflérencie sur la larve, à la manière d'un polit hourgeon, qui grandirail, tout en empruntant à l'ibre. qui le porte, la sulistance nécessaire pour former son économie. Ce bourgeon s'accioit, alors yue le porteur conserve la mème taille et la mème structure; il devient seul m animal parfait, le portenr se détruisant, ol disparaissant. Cetle intéressante série de phénomènes est lue ì lixtreme dilférence d'aspect élablie entre la larve el l'arlulte, et non i III bonrgeonnement du seconl par la premièe. Le prosome frossede de rolmmineuses expansions, qui hi appartiennent en propre, dont la taille et la disposilion donnent à la larve sa physionomie particulière; et le mitasome se difimite, frar suile, dans mue rigion restreinte de ce prosome. Comme ce mótasome offre demblè, dis son apparition, ses

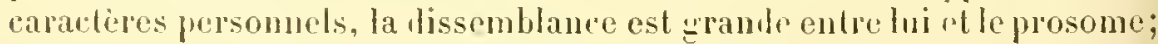
ot comme les annexes tomporaires ule ce dernier s'atrophicul a mesure pue te promier saceroit, celte dissemblance dans l'esplace se double d'une ditférence dans le temps, qui rend ropposilion encore plus aceentuer.

Des changements aussi prononcés nexistent point che\% les llolothu- 
rides, et nou plus chez les Crinö̈des. Les embryons de res derniers sont "ahord cerclés par des handes vibraliles anumlaires, qui entourent le corps, et doment a la larve une forme identique à celle des pupes d'llolothuries. I cause de cette ressemlilance, la mème expression "pupe " peut etre appliquée anx jeunes Crinoïles. La pupe se convertil en arlulte par la suite. - II importe de remarquer, au sujet de cette classe des Echinodermes, que le déreloppement de ses représentants n'est connu que par celui les Comatules, c'est-à-rlire des plus récents el des plus complexes d'entre eux, abstraction faite de l'alisence de pédoncule; de plus, el comme l'a montré l'origine des feuillets blastoJermiques, l'écolulion embryonnaire de ces animaux offre des traces indiscutables de conlensalion. Or, en comparant les larves des Comatules i celles des Holothurides, la ressemblance s̈impose, saul au sujel Je la phase Auriculnria, qui manyue aux premières, et existe toujours chez les secondes. Cette aliscnce d’un tel état est-elle générale, et commune i tous les Criuoïdes actuels; ou s'agit-il d'une omission spéciale aux Comatules? Il est encore impossible de se prononcer sur ce sujet. Quoiqu'il en soil à cel égaril, la chute de la ligge fait passer les Comatules par une phase larvaire supplímentaire, dont les autres Crinoïles sont privés, celle de larve pédonculée. En effet, tous les Crinoüdes, sauf les Comatules, possèdent une tige qui les fixe à des supports; cet organe nait hàtivement, et persiste chez l'adulte. Les Comatules en juoduisent un, tout comme les autres représentants de la classe: mais olles l'alanlonnent ensuite, et deviennent libres; elles passent donc, dune manirire transitoire, par un état, qui demeure et persiste cloz les autres crinoïdes.

B. - Lis métamorplioses raterues, subies par les larves des Echinolermes, sont lone variées, it diverses suivant los classes, linn que les formı's qu'ellos détuminent soient des modifications d'un mèmo état inilial, celui de la pluase premiòre. Hais, si les changemonts extrienrs sont différunts, il n'en est pas de mèmo pour ceux des organos iutermes; ceux-ci, sauf les délails particuliers et secondaires de la structure définitive, éroluent d'après un senl plan, ot llune façon illentique. Celfr. ressemblance du développement est surtout évidentr en ce qui concome lappareil irrigalour; malgré les divers modes employés pour faconner so's principalıs élouchrs, cellis-ci se relrourenl tonjours an mème nombre el disposées le la mème façon. - Nussi, plusieurs de cos ébauclues agrissent-rlles, pour donner a certaines régrious exterues drs larves un aspeet comparable, quelles que soient les allurs grénérales de: cos embryons; ce fail su présonte notammont dans la région péribuceale,
et dans ses tentacules.

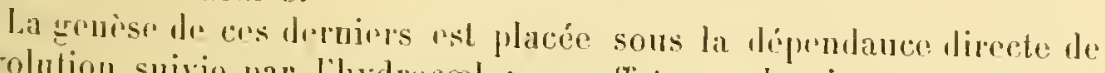

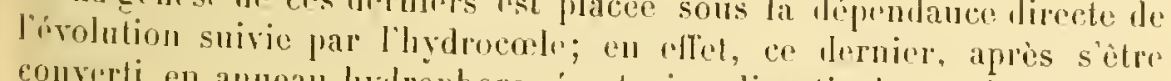
comverti en anucau hydrophore, émet cinq dirroticules, pui soulinut 
la proi du corps aulour do la lumche. ol produsent les lentacules péribucaux. Jèno dans le cas oir eos appendices ne so dévoloppent pas Javanlage, oi ils restent petits ot s'atrophicul meme, ha larvolos josside aulour de son orifice huceal; el, a cause do l'riguilé du corps do cette dorniore, ils paraissont voluminemx ef ollent un certaine importance. La légion qui les porle, et qui pourait êtro désigné par l'exprossion de sone tentuculaire, othro la mene disposition chrz tous les emhryous des Echinodirmes. - Irant qur lanumu hydrophore we commence à

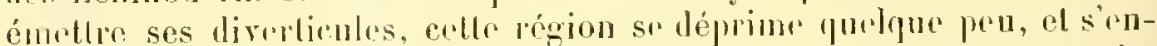
fonce dans le corps. La dépression est parfois large el peu prolonde, chez les Hololhurides par exrmple, oir elle esl surtoul dénolée par ses lrorls, qui comsistent en épais bourrelels; clle est aillemrs fulus gramle el plus ample, et, parfuis mème, son orifice extérieur se ferme, lıi domnant l'aspect l'une cavilé close. Les autenrs ont désigné cet enfoncement far plusienrs noms, dout les principarx sont ceux d'umbo, de disque, et de restibule; i cause les acceptions spéciales dos denx premirres expressinns, ta lemièc mérile seule d'etro conservée. - Les tenlacules péribuceaux premment naissance au fond du veslibule; ils sallongent toul d'alıord dans la ravilé vestilubare, puis font saillie au dehors, soit en passant par l'orificr le la dépression, soil en brisant sa paroi externe, dans te cas oi l'ouverture vestilubaire s'est fermée. Cetle Jernière parlicularilé est assez fréquente; on l'a signalée chez les Comalules parmi les Crinoüles, et chez les spatangides parmi les Echinides.

l.e vestibule, c'est-í-1lire la dépression prortuile par la zone oil se développent les lontacules péribueraux, est done une formalion commune i tous les rmlurous des Echinodermes, et phus on moins développre. La première imlicalion en est offerte par les llolollumiles; la

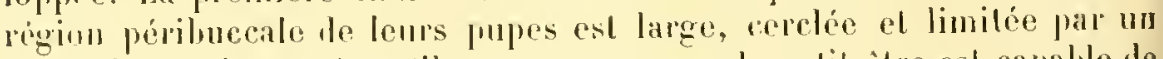
bourolet épais, el rétraclile, en ce sens que le pelil etre est capable de la retracter dans son corps, aree les tentacules quelle porte, ou de la projeler au dehors, pour étalor ces mêmes tentacules. Si l'on suppose une dépression plus profomle, entonréc par un bourrelet plus haul, qui la surplombe en partie ou en tolalité, et cache la base des contacules, on ohtient le vestilule des antres larves; il esl devenu un organe d'aspect plus préois, mienx délimile, el, par cola mime, privé de la faculté de rélaction de colni lles llalothuries. De plus, au lien l'otre situé sur l'me des exlromités du corps, if est latéral d'halibude, car la frouche larvaire est latérale elle-mème; les Comatules font exception, car leur

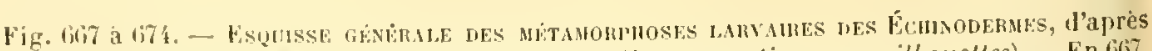
celles des Fuhinides (roupes longitudinales el diagrammatiques, en silhouelles). - En 667 , jeune larve, lors de la plase premiere. - En 608 et 1699 , genèse des bras, et déplacement progressif dis orifices digestifs. - En 670 , 1371 , 672 , les bras gianulissent, et la larve

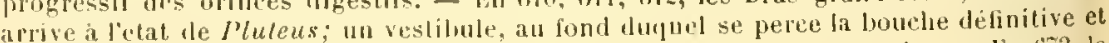
se façonnent les tentaeules peribuecaux, se creuse sur son côti gaucle. - En 6r3, le 
vestilute, volumineux et clos, est tominal, comme celui plus pefit et

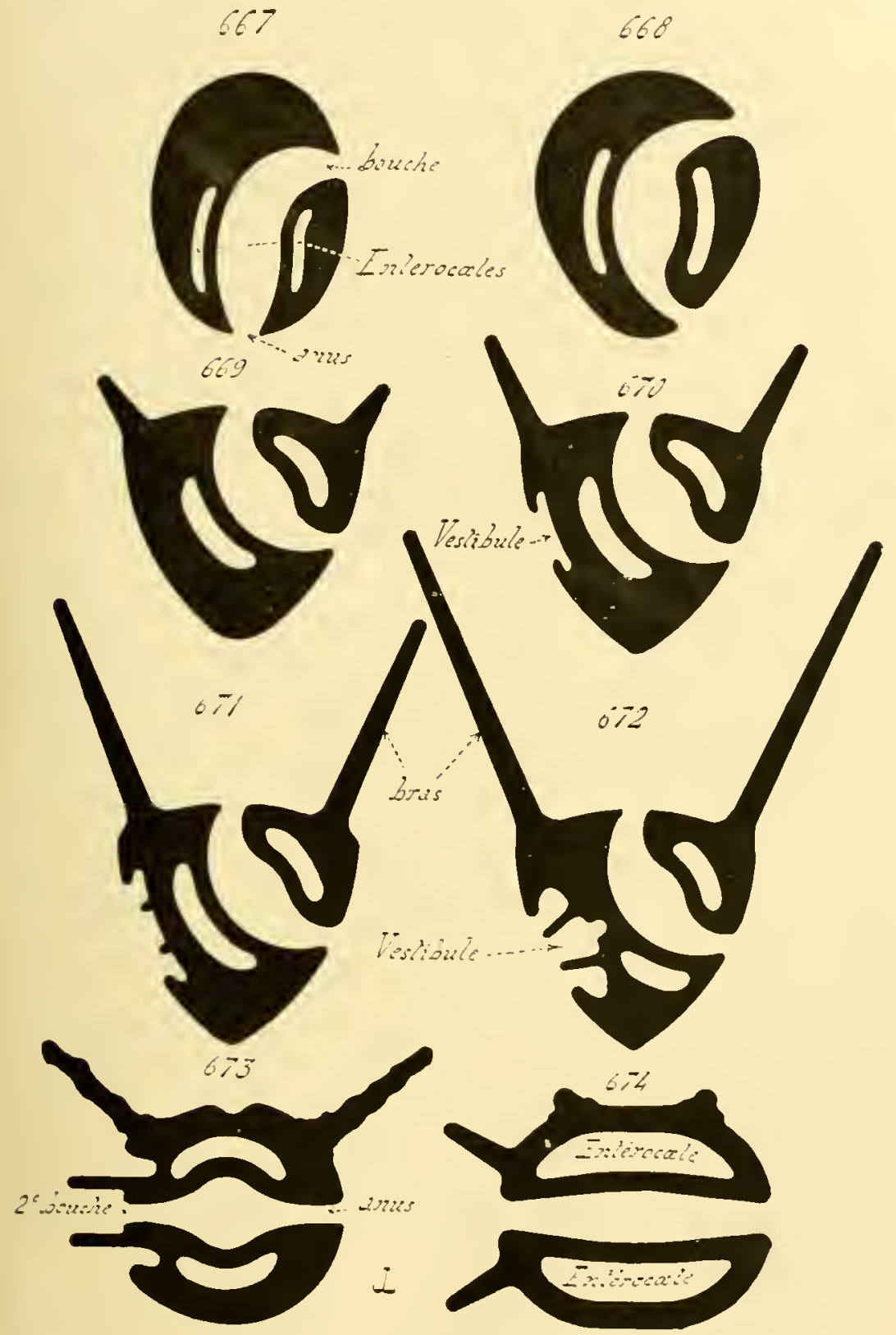

Pluteus commence à se convertir en adulle; les luras se rahougrissent. la bouclur provisnire se ferme, el l'intestin se raccorte is lil hotche didinitive; les entirocides ont clange l'aspect géniral llun juune boluinide. 
moius hien marqué des larres d’llololhuries. - Quelle que soit sa disposition, to vestilumle est un olgane temporaire, spécial à la larve, yui manque ì l'animal partait. Tout au plus peut-on considérer la zone péribuccale des Ilolothuries adultes comme lérivant de lui, à cause de son peu d’importance cltez la larve, qui lui permet l’èce conservé, en effaçanl le bourrelel périphérique; cette zone est rétractile du reste. tont comme l'appareil donl elle provient. Le restibule les autres Echinodermes disparait vers la fin des mélanorphoses, et l'adulte n’en montre aucun vestige. Les teutacules peribnccaux eux-mêmes ne persistont guère que chez les llolothuricles et les Echinides; ils restent petits, el s'atrophient mème, chez les représentants des trois aulres rlasses.

C. - le caractère purticulier des changements extérieurs. subis frar les larves des Echinodermes, lore à se demander si ces métanurphoses sont primitives, ou si elles sont secondaires. Les lormes embryonnaires, telles que les Arricularia, les Brachiolaria, les Irluteus, qui existent à l'éporue actuelle dans l'évolution individuelle des Echinodermes, correspondent-elles à un rappel atavique d'organismes ancesIraux, ou lien à des molifications secondaires, résultanl d'adaplations spéciales amx larves. Les solutions à de telles demandes sont loujours des plus délicates a donner, car l'on est obligé de raisonner d'après une série de comparaisons, ef l’inductions, qui s'enchaînent; et la certitude matérielle fait constamment défaut. Cependant, an sujet des Echinorlermes, les métamorphoses sont telles, que la l’éponse est assez aisée.

Les plus simples, parmi les représentants actuels de l'embranchement, sont les llolothmides. (1r, les mélamorphoses, lorsıu'elles existent, sont moins prononcées chez elles que dans les autres classes, ear elles lonchent seulement anx cils vibratiles, et ne comportent aucume production de bras. Les Eehinides, les Astérides, et les Ophiurides, suhissent, par contre, les changements extorieurs tris accentués. Les Ophimides, Jont lorganisation definitive est cependant plus dissemblable, que celle des Astéries, de la structure des Echinides, possident mue larve identipue ì celle de ces lernicrs, alors que les embryons des Astérides appartiennent à on tout autre type. De plus, les Comalules, et par suite les Crinoïles, sont aussi éloignés des llolothurides, simon davantage, que les autres rlasses de l'emhranchement; pourtant, elles passent par une phase de pupe, comparahle de tous points à l'état correspoudant les embrions d'llolothuries.

En tenant rompte de res trois faits, la notion simpose que les formes larvaires des Erhinodermes, du moins les formes extérieures, ne sout mullement en rapport aver les affinilés décelées parl'évolution des organes internes, el par la disposition dólinitive de ces mêmes organes.

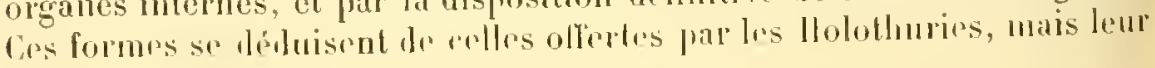




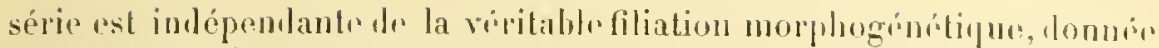

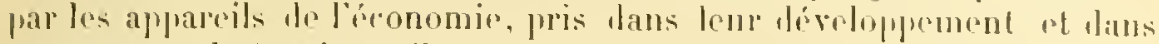

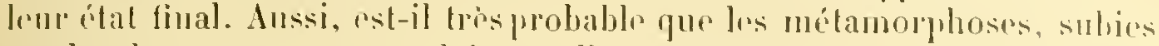
par les larres, sont seromlaires; olles se sont introduites après coup

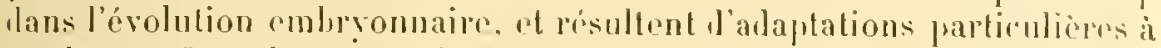

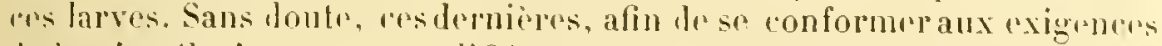
de la vie jélagique, ont modific en consiquenere la disposition de leurs rils vihraliles, et ont protuit das bras pour se déplaere et se soutenir Jans l'eau. Cetle opinion ne renferme que des notions sulyjectives, et ne peut ètre drimontrie parl'olsorration dircete; cependant, les faits aequir premettrul de la considérer comme exprimant la ríalité des chose's.

Il est méessaire de faire mo réserva au sujw de crs phases larvaires.

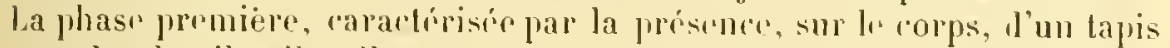
complet de cils vibratiles, est rommune à tous les rmbryous d'EchinoJermis: elle n'est done fas sreonlairn, mais bion primitive, et se troum i sal place dans l'évolution indiviluelle, romme elle l'a ché sans dontr dans l'évolution ancestrale. La mème asseption sapplique ì lílat de pupe dos llolothnries et des Crinoüldes; son existence ronnexe, aver les mèmes partirularités essenticlles, lans drux groupes aussi distincts, et sa simplieití mème, ral il ne comportr ni banle vibratilı sinneuse, ni possession de liras, autorisent a penser qü il est égalrment primitif. les senles larves soromlaires seraicnt les formes pourvurs dre bras, ou de bandes vibratiles a sinuositís, l'est-à-dire les Auricularia des Holothurides, les Pluteus des Exhinides u ldes Ophiurilles, enfin les Bipinnaria et les Brachiolaria dis Astéribles.

Ces dernieps embryons, ot notamment reux des Echinides, des Astirides, el des Ophiurides, sont, cn outre, des larves à stases. L'aspret général, et l'allure extírienre, du prosome, sont conservés, en eftot, pendant que les organes internes s'ibaurbent, et que le mitasome commence. a se délimiter. La forme totale lo la larve sulit une véritable stase, alors que les appareils de l'éronomir poursuivent leur dévolopjement, ef se complètent. - La présence de ress stases est une probalilité de jlus, יn faveur lw l'opinion portant que lis métamorphoses sont sweondaires. D’halitude, les larves i stases, w a mues, ou a chute d'appendices arlaplatifs, ne représentent point un souvenir temporaire l'un état ancestral; leurs caractires particuliers, el transitoires, resultent d'arlaptations qui leur sont propres.

Enfin, un lurnier fait rontribure, pour sa part, ả lémontrer la minime importance, sous lo rapport de la morphogeness, de "rs transfor-

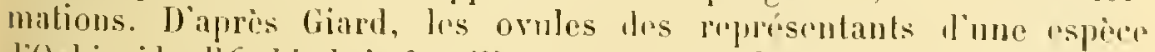
")phinride, l'Ophinthrix fragilis, ne so ressemblent pas, an ec qui tonchu lour teneur an deutolécithe; los uns contienment un amas assez gramit de granulations mutritires, les autres moins, et les derniers fort peu. Crux-ci, en se développant, loment les Pluleus complets: les soromls fournissent des Pluleus imparfaits; enfin, lus premier's so don- 


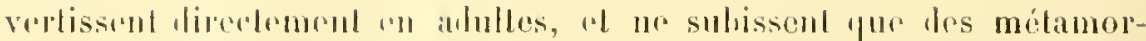
phoses lres restreinles. [ne anssi gramle diversile implique une grante variation dans la puissmere de l'hérédilé; mo lelle varialion concorherait pen aver nne mophogunese de haute valeur, romme colle yni existerait, si ces élals hrvaires rappelaienl des formes ancestrales.

Hétamorphoses restreintes ou nulles. - Ce cas est relativement rare; les Echinodermes vivipares, ou cenx dont les anfs, volumineux, con-

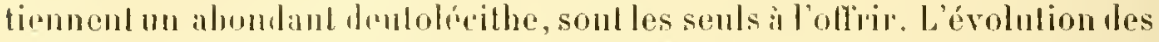
organes inlermes est semblable i celle prosenter far les embryous à mélamopploses; la seule différence porle sur l'alisence des appareils allaptalifs, fest-it-diredes hamles viluatiles et desluas. Celte absence est farlois completr, el les mélamomphoses soul unlles. Aillems, elle est parlielle; les appendires larvaires existent, bien que petits el déformés, et les métamorphoses sont alors restreintes. La privation les appendices de locomolion et le sonticn, montrée par les embryons des Enhinolermes vivipares, qui n'ont nul hesoin d'enx puisyu’ils ne se déplacent

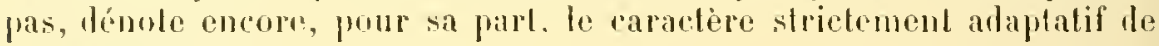
ces appareils.

Il est dome possible de suive, daus la plupart des classes des Echinodırmes, une súrie qui ra le l'alssence des métamorphoses à l'existence de clangenents extérienrs tròs prononcés; rette série est offerle, mème par les représentants d'une soule especo, comme l'indique le précédent exemple relatif i l'ophinhlux fragilis. Celle série a-t-elle poul point de départ l’absence de métamorphoses? On rettr privation est-rll. sucondairr? Cette derniore opinion rst sans doule la vonir; l'ahsence de mélamorphoses n'ist point primilive ehez les Enhinodermes actuels, et elle corrospoml i mealrophir des appendices alaplatifs, non it mo apparition premiere et encore rulimentaire. En effel, les Echinodermes qui la prisentent sont vivipares, ou pourvus d'urufs i deutolécithe abondaul. Ces deux phénomènes ne sont jamais primordianx chez les animanx; ils dérivent secombarement, a la suite l’adaptions parliculières, le l’uviparité, comme du manque de réserves untritives. En conséquence, la privalion d'appendices larvaires, qui lécumb d'enx, est elle-mème sieomlaire.

Le véribhle type initial du développement des lichinodermes est la lame premire; son levetement de cils vilualiles, el la disposilion propre

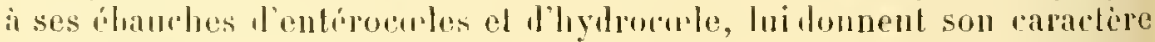

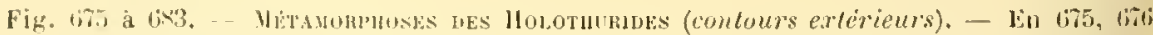
et tir , amplification progressive de la couronne vibratile peribuceale; le pelil cercle

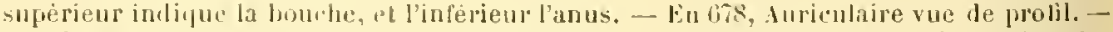

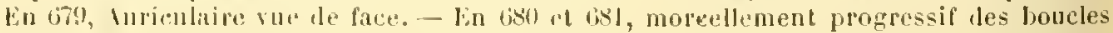

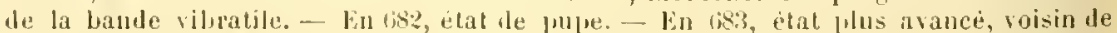

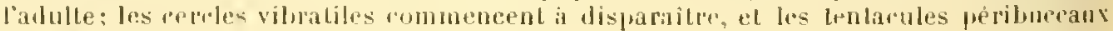

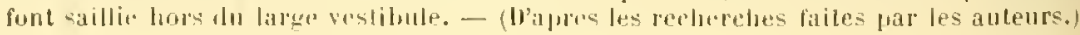



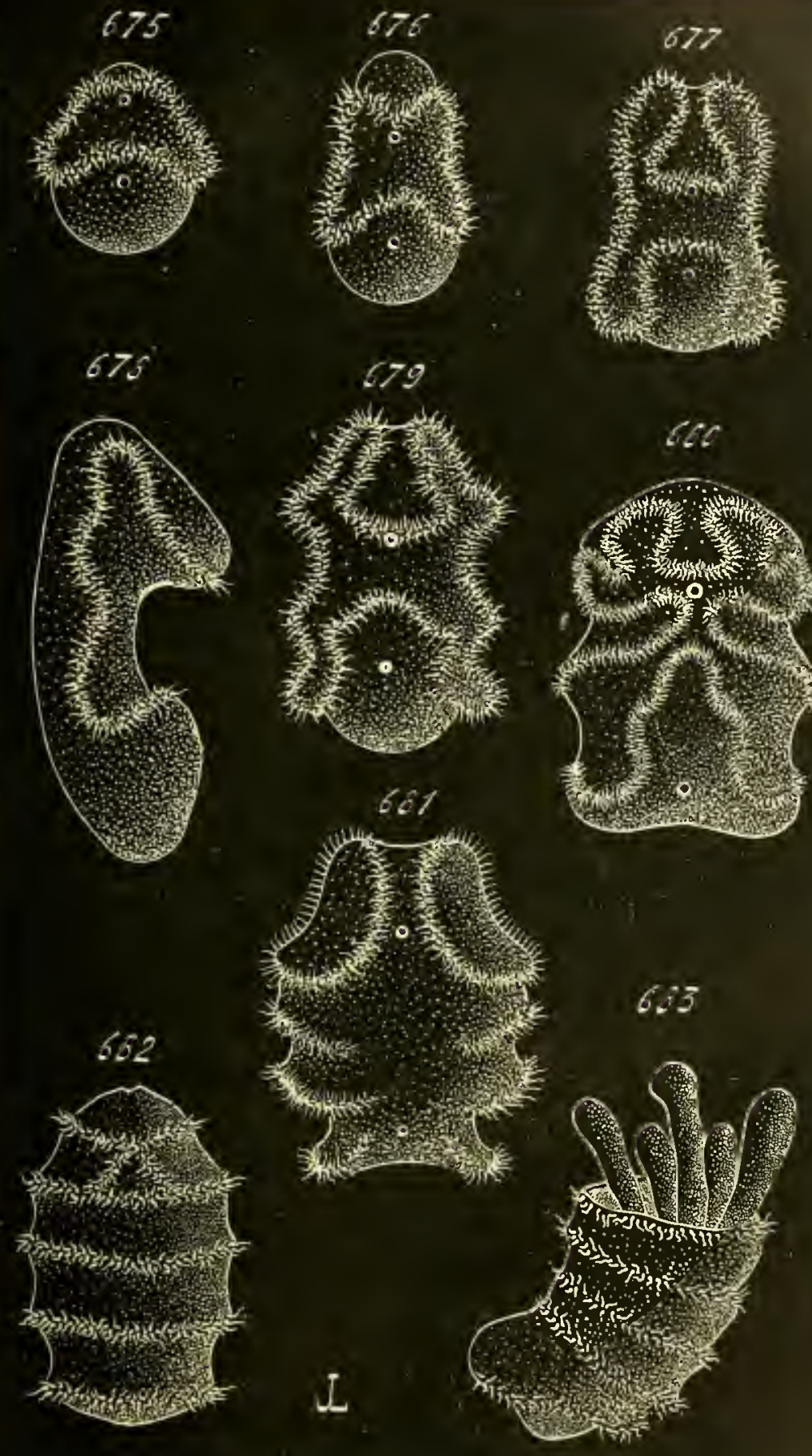
dr. P'entactule. De cette larve dérivent tout d'aboul les lormes aux métamorphoses complexes, rausées prar ha présence d'appendices adaptatifs, qui permettent aux embryons de mener une vir pélagique el dont ils doivent se dépuniller pour passer ì l’élat adulte, où le mole de vie n’est plus le mime. Enfin, des larves ì mélanorphoses arrentuées si dígagent, par un changement l'adaptation, celles à métamorphoses restreintes on nulles; ces embryons cessent l'able pélagirjues, restent immolites, et les appembires, devenant inuliles, se restreignent, on disparaissent en totalité. - Le point dr départ de tous ces rhangements, plus ou moins complexes, doil itre pris, sans doule, dans le déreloppement des llolothuriles, aver ses trois phases de larve premiore, d'Auringlaire, el de pupe.

III. - Développement particulier des Holothurides. - La plupart des représentants do cetle classe subissent drs métamorphoses complètes, el se présentent, dans ce cas, à un moment donmé de leur évolution larvaire, sous la forme dite Aurimlaria. Parfois, mais plus rarement, colte pluase est omise, et les métamorphoses sont restreintes. Enfin, plusienrs llolothurites offrent un dévelopiement direct, et les changements externes sont nuls.

Hétamorphoses complétes. - La jeme larve montre l'aborl la phase premiere; elte passe ensuite ì l'état d'Auricularia, puis à celui do pupe, ut se convertil finalement en individu parfait.

La phase première apparait de suite après la gastrulation. Pendant que s'ébauchent les entérocałes et l'hylrocorle. Tecloderme entier se reconve de cils vibraliles, qui prermellenl au petil ètre de se déplacer. En ontre, le corps de la larve sallonge, et devient denx ou frois fois plus haut que large; l'anus, c'est-a-dire l'entéropore converli un orifice anal, abandonne sa siluation lerminale, et inférieure, pour remonter puelque peu sur le corps, et se placer sur la face antérieure. La louche frend naissance également sur la face antérienre, on ventrale, de lorganisme; elle esl un orifice assez large, surplombé par la volumineuse extrémité supérioure de la larve, constilnant le lobe préoral des aulenrs, et qui serait mieux nommée le lobe sus-buccul. Cefle région s'élargit dans le seus Iransversal, de manière à proéminer au-dessus de la boucle.

P'endant que se produisent ces moditications, dans l'allure générale et dans l'arringement des orifices digestifs, les cils viluatiles changent lenrs dispositions; la phase premìre est alors lépassée, et la larve se transforme en Auriculariu. Les cils commencent par disparaitre sur le corps enlier, sauf lans une région anmulaire, qui enloure la bonche; cette région constilue ainsi une bande vibratile, destinée à s’accroitre en devenant sinueuse. - Sille débute par s'élargir latéralement, en prenant une forme quadrangulaire; puis, elle s'accroit dans le sens de 
ses puatre angles. Les lenx angles smperiem's remontent sul le lohe sus-buceal, qửils encadrent à droite ot à ganche; le mème les angles inférienr's descendent vers l'extrémité inférieure, quils atteigncut, et encadrent également. Chacun de ces angles constitue une large boucle viluatile, dout les hords sont oudulés; et ces quatre boucles s'unissent a la partic, laisséc en place autour de la lonclue, de la région aumbaire primitive. La couronne péribuccale a donc changé l'aspect; an linu ur consister en un anneau, elle est devonue une hande viluatile trè étendue, qui parcourt le corps entier, en lécrivanl le nombreuses sinuosités: ces deruitures, sur chacun des colés du corps, simulent les contours d'une oreille, d’ò le nom d'Auricularia donné a la larve en cet ítat. Ces métamorphoses ont été suivies par .l. Mïller d'une maniere complète. Il est nécessaire de bien se représenter cette volumineuse bande vilualile comme une couronne périlucrale très étendue; la lonche est toujours placée dans l'espace qu'elle limite, et l'anus est laissé en delıors d'elle, car il est situé entre les deux boncles inférieures.

Ensuite, l'Auricularia se convertil en nue pupe. Les quatre houcles viluratiles contimuent à grandir, et s'élargissent; leurs simuosités leviennent plus accentuées; chacune d'elles se compose de leux loucles plus petiles. Cette scission devient de plus en plus prononcée; et. finalement, chaque boucle se divise, grosso modo, en deux troucons. Des quatre appendices vibratiles primitil's, deux étaient disposés sur un des côtés de lorganisme, et deux sur l'autre coté; lorsque la division est effectuée. quatre troncons se trowvent placés d'une part, et quatre d'autre part, à des niveaux différents, sur le corps de la larve. Chacun des premiers s'amplifie, de manière à s'unir à celui des quatre seconds situé ì la mème hauteur, et à former avec lui une couroune viluatile qui entoure transversalement le corps. He plus, la portion périluccale de la couronne primitive s'accroit, el constitue une conronne viluatile, supplémentaire; le nombre de ces anneaux, cerclant le corps, est ainsi porté a rinq. C’est là le chiffre définilif, et la phase de pupe se trouve atteinte. - La séric de ces changements surcessifs est décrile a ver une précision, qui niexiste pas toujours, car les phémomenes ne sont pas aussi bien délerminés. Il faut concevoir leur ensemble romme se ramenant aux faits suvants : la hande: vibratile le l'Auriculaire devient, tout en granlissant, de plus en plus simeuse; les sinuosités, à leur tour, s’accentuent saus cesse, s’aprofondissent, et finissent par moreeler l'unique bande en plusieurs tronçous; puis les trourous d"un côté se réunissent ì ceux le lautre pour constituer cim hamiles vibratiles transversales.

Lorsque la jeune larve est parvenue à l'élat le pupe, sa lorme est encore cylimirique, ou plutot lougmoment ovalaire. Les ciny comrommes vibratiles s'élagent ì diverses hauteurs sur la corps, depuis l'extrémilé supérieure jusıu’à l'extrémité inférieure, et, à peu de chose pròs, se plarent í égale distance les mnes des antres. Une seule lientre clles est située au-rlessus de la bouche, les quatre autres sont inférieures a cet 
orifice. - Lit zone vestibulaire fait ensuite son apparition. La larve

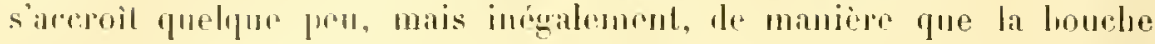

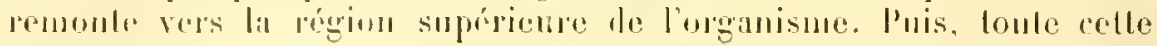

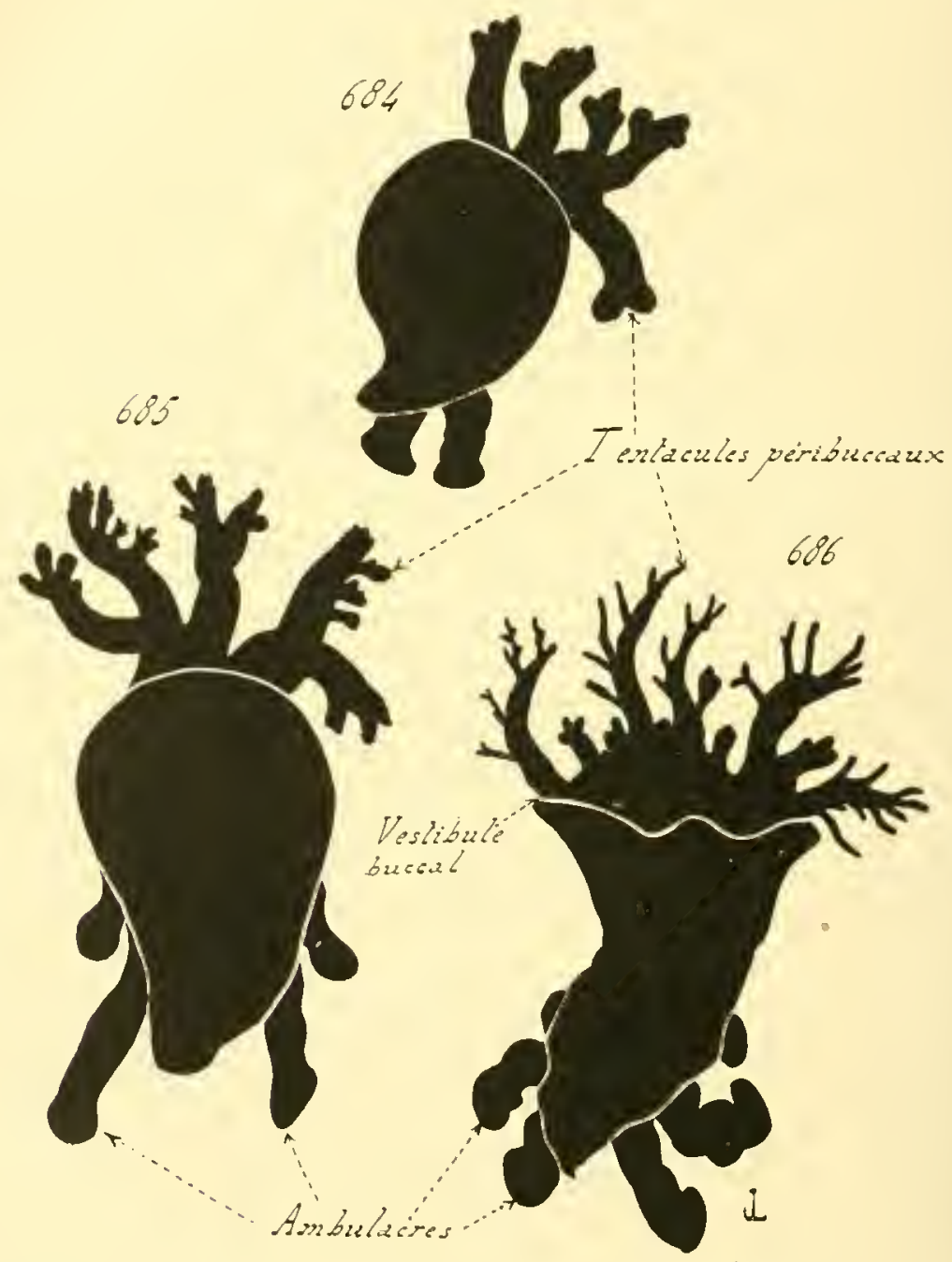

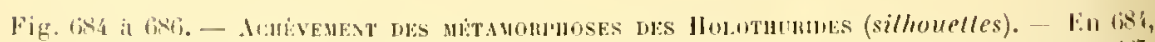
jeme indisidu, muni te ses tenlacules peribuccaux, et de deux ambulacts. - bin 185 , indivilu plus âgé. - lin ikf, individu plus avace encope, pourvu d'un grand nombre

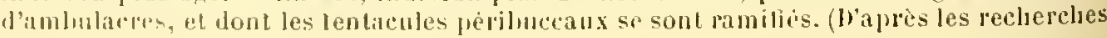
faiter par Selenka sur l'llolothuria lubulosa.

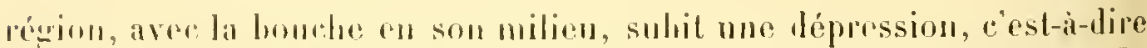

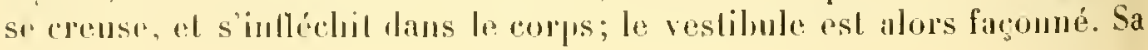


disposilion nest point tixe ni préce, car il est rapalule de conlatiotions diverses, de projections an dehors snivies dr refractions; mais il n'in existe pas moins, ef les tentacules porribucaux nassent au fond do sil cavilé. Ces appendives s’allongent rapidement, en levenant cylindriques; ils ne tardent pas a dépasser le vestilute, et à laire saillie au dehors. I). son coté, la zone restibuhare s’élargeit; sa limile périphérique se tromve marquée par un epais hourrelet, comrert de cils vibratiles.

Les quatre comonnes viluratiles infra-huceales continuont à jersister, pendant que ces changenents se produisent; mais, commos lo conps de li larve angmente en laille, el par suite en poids, elles sonl lientiol insullisantes, ef le petit ètre, cessanl de nager, lombe an fond le fean. Il se convertil alors en andulte, el possede deja les rudiments de loms ses miganes, fui n’ont qu’à grandir prom passer a l’ólal parl'ait ; ils ne sulissent, i cet eflel, aucune lésagrégatim, ni ancunc destruction. saul les handes vibratiles, pui fiuissent par disparaitre.

Metumorphoses restreintes on nulles. - Dapris les recherches de Selenka, les Cucumariu dofiolum ofpriraient des métamorphoses resfreintes. Lembryon parvent à la phase premiore, puis se transforme

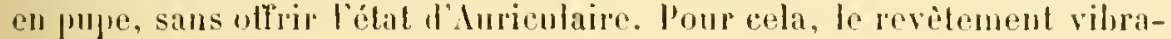
tile le la larve premiere lisparait prar places, et persiste semlement un cing zones circulaires, qui ronstituent ansi cinq conronnes transversales. Les modifications relatives à la pupe, et dout les principales portent sur le déplacement de la louche, la réduction du lobe sus-luccal, et l'apparition de la région vestibulaire munie do ses tentarules, selfectuent de la mème manière que cluez les pupes issues d'Auriculaires.

A en juger d'aprios les observations de Kowalevsky sur les Psolus, les llolothuriles vivipares seraient dipourves de loule mitamorphose; le mvetement viluatile ferait mème défaut. Le jeme cmbryon se convertit directement en adulto.

Urigine des organes. - Les particularitios intéressantes et rommoss, offertes par les llobothurics à cel égard, se rapportent au test ot a l'appareil anbulacraire.

Au sujet du test, et au moment oì les ammeaux viluatiles de la pupe disparaissent, dix playues calcaires maissent dans le somato-mésenchymo périluccal; cing dentre olles sont placres dans les zonrs amfulactaires. et ciny lans los zones interambulacraires. Hillos reprosentent les premieres indiralions du lest. Helles correspondent, sams donte, anx dix plapues habituelles des embryous des antres Eehinodremes; mais, comme on noest pas encore lres fixé sur le developpenent ultériend des antres formations comespondantes, il est dillicile de se prononere an sujel de lenr homologic.

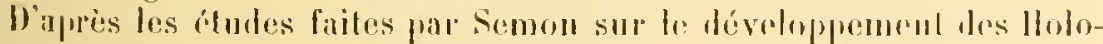

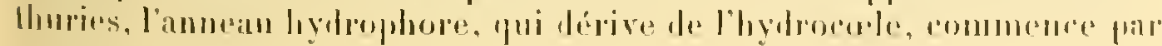


omellre les cind diverlicules, chargés de se converlir en tentacules prirbuccaux. Puss, il produit, entre les précédents, cinc aulres diverlicules, qui deviendroul les canaux ambulacraires; l'un de ces lemiers, de qualriome an suivant l'orilru arlopté dans le numérotage de ces organes, est diamébralement opposé an lube lyilrophore de la larve. Semon se haso sur res fails, pour almellre que les canaux ambulacraires des $110-$ lollumides no correspondent pas a cenx des aulres lichinoulermes, el lem sont seulement analogues. En effet, lorsiu il existe des teutacules chez l'alulte, les comluils amhulacraires se dégagent de ceux qui se rendent a ces appendices. el ne s'allachent point directement, en dehors d'enx,

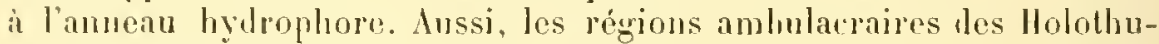
rides correspondraient-elles aux régions interambulacraires les aubes Echjumlermes, el réciprorpement.

Il est impossible d'accepler, dans leur enticr, les consóquences d'ume tolle opjuion, el didmethe que les canaux ambulacrioes des llobothuriles ne soient point les homologues de ceux des aulres Echinodermes. Lrs premicrs sont idenlipues anx seconds, sous to double rapprort de leur origine, el de leus situalion dans le somalo-mésenchýne de la paroj du corps; la ressemblance parfaite dans le lemps el dass l'espace, qui est la condition nécessaire de toute lomologie, est ici réalisée de tous points. La seule différence porte sur le molle rle jonction de ces comiluils et le l'ammean lydrophore; cette dissemblance est secondaire, car elle se ramène à un déplacement de faible amplitude. Au moment ou se conslitue le tube hylrophore, et on se délimilent les premiòes éluauches des cananx lentarulaires el des canaux ambulacrajres, il n'existe encore aucune division thu corps entier en zones ambulacraires el zones interambulacraires: cette ditripentiation me s'effeche quapres l'achevement des condnils ambulacraires. Aussi, les disposilions muluelles de ces ébauches et du iulie hydrophoren'engagent-elles en rien la symétrie définilive de l'organisme; ef l'on ne peul se haser sur elles ponr concluse a l'absence d'homologies.

Les llolothurides appartemant à l'ordre des Apoles sont privées d'ambulacres; celle absence se borne aux ambulacres seuls chez les llolpadidées; elle s’élend aux canaux ambulacraires eux-mèmes chez les Symplidés. L'apprareil hydophore de ces lerniers se compose seulemont dr l'amean, el des momluits temlaculaires. A re qu’jl semlile d'apris le développement, celle alsence est primitive, et ne correspond pas à mo alroplije secondaire.

IV. Développement particulier des Échinides. - Le développement embryonnaire des Echiniles est caractérisé par la présence d'une torme larvaire, dile Iluteus; celle forme nest cependant pas spéciale aux Echiniles, car on la rehouve, avec ses memes parlicularilés, el sauf queliues morlificalions secondaires, chez les Ophimrides. l.e I'luteus est une larve conique, dont le sommel est inférieur, el dont 
la large base, tournée en haul, porte la bouche en son centre, at sur sil périphérie huit ou dix hras disposés par paires; res appendices sont couverts de cils vibratiles, car ils corresponelent à des lobes formés prar la couronne vibratile péribuccale, et sont soutenus par des baguetles calcaires. Ces dernières sont lantôt lisses, et tantôt percées de trous placés ì la file, en une série régulière, yui leur donnent un aspect treillisse; elles ne manquent jantis, bien que, parfois, elles fassent léfaut à certains ues loras, plus petits que leurs roisins.

Les Echinides vivipares, à en juger d'après l'Hemiaster australis citudié par Agassiz, sont privés d'une tolle phase larvaire; lemrs mélamorphoses sont nulles, et l'embryon se dérelopje directement en adulte. - Lorsine les mélamorphoses existent, le petit itre commence par wilirir la phase première, passe ensuite à l'élat de Pluteus, el se convertit finalement en adulte. Cette sérje de phénomènes présente donc quatre parlies: la genèse du Pluteus, les divers aspects offerts par le Pluteus, la genese de ladulte envisagé lans sa forme extérieure, enfiu les particularités de l'origine des organes.

Cenèse du Pluteus. - Après la gastrulation, l'embryon passe à la phase premiere. En cet état, il est entièrement couvert de cils vilıratiles. Ces derniers diminuent ensuite de nombre, et se restreignent i une étroite couronne péribuccale, montée sur un bourrelel; cette unique lande vibratile prend rapidement de l'extension, et, ce faisant, devient qualrangulaire. Les ressemblances arec les phases correspondantes, offertes par les larves premières d'llolothurides qui se convertissent en Auriculaires, sont des plus lirappantes. - Ceprendant, quelıues dillérences se manifestent dans l'aspect extérieur des emlryons. l'extrémité supéricure, le lobe sus-buccal des llolothurides, est ici heaucoup moins rolumineux, et la bouche se trouve, presque, être terminale; d'autre part, et comme corollaire, l'anus est reporté plus haut sur le corps que celui des larves d'llolothurides, et laisse an-dlessous de lui une longue extrémilé inférieure, qui a resu le nom de lobe anal. En comparant une larve d'Echinide, en voie de se transformer en Pluteus, a une larve d'Holothuride prète à se convertir en Auriculariu, la première est presque privée de lube sus-luecal et posside un lube anal, alor's que l'iuverse se manifeste chez la seconde. Ces dissemblances, qui résultent ane position dillérente des orifices digestifs, ne s’arrètent point là; elles portent ensuite sur le morle d'accroissement de la comrome viluratile péribuccale, et deviennent alors très prononcées.

La couronnr périluccale les larves d'llolothurides s'allonge dans le sens de ses quatre angles, de telle manière que deux d'entre eux s'avanrant vors l'extrémilé supérieure de l'animal, et les deux autres vers l'extrémité inférieure; en somme, son aceroissement s'ellectue dans le sens de l'axe longitudinal de l'embryon. Il n'en est point de mème pour les

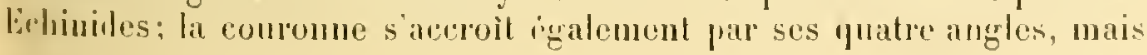


daus un sens plutot lransversal; en outre, au lien de s'blendre en dierivant des sinuosités sur le corps lui-mème, elle se renthe en lobes, qui font saillie au-drssus de la paroi du corps, el grandissent en s'allongeant. Ces bolses linissent par constituer des aprondices voluminemx, cylinuliques, hrancoup plus lougs que larges, disposés autour du petit ètre, el encalrant la bonche; ils ne sont pas rulierrment silués dans une silualion loansversale a l'organismr, mais sont lirigés i la fois en luaul el en dehors. - An moment oì ils ont acyuis me certaine taille, l'allure génépale dr la lave a completemunt changé. An linu d’avoir un asfrect massil, comme l'duriculaire des Holollurides, celle-ci porte des appendices, qui rayonnent autour d'ulle, et la soutiennent dans l'ean. Elle se compose d'un corps proprement dit, w drobras; la présence de ces lepuers, anxpuels une lare base d'implantation est micessaire, el leur sifuation antour de la houche, dome au premier une forme conique, le sommet du cone ripoudant an lolie anal.

les loras me naissent point d’une lacon irréguliere: ils apparaissent par pairrs. Les deux premicres paires sunt produites par les quatre angles de la couronne périluccalı. Les deux angles supérieurs par rapuort i la louche, se borncont à s'allonger an-dessus le l'exhémité supcrionre du corps: les deux autres commencent par s'élendre col has, puis se recourlient sur enx-mèmes par leur exlrumité, de façon it levenir transversaux d'aborl, et supérieurs ensuite, toul comme leurs congénères. Les drux bras des angles supériemrs, les plus pries de la bonche, sont dits untérienrs pour celle raison; les deux autres sont les lras proterieurs. - l'uis, deux autres bras naissent le part et d'autre, el en dolors, des bras antórieurs; ils sont latéraux par rapport à ces derniers, puisqüils suml plus éloignés de la bouche, ot portent en consépuence le mom de luas antéro-lutérux. Une qualrieme paire se montre un peu plus tard; ses deux éléments sout formós en dedans des liras antérieurs; anssi. Ies désigne-l-on par lexpression de bras antérointernes. Enlin, mais senlement chez les spalangiles, un neuviome ef un dixieme lons, coustituant une cinquieme paire, prennent naissance non loin les antóro-latíranx, el entre l'antérieur el lo postérieur du méme coilí; ces leux bras, a canse de leur situalion lout à fail exlérienre, sont dits antéro-externes. - Il importe de concevoir que, daus la dresciption précébutr, Jes deux bras dnne mome paire sont placés de prat el l'aulde de la bouche, et dans une position symélrique par rapport it eet orifice.

Cus ajpendices, lorsqu’ils ont alteint leur développement complet, ne sont poinl de tailles égales; l’inégalité à cet rgarl varie, du reste, suivanl les gronpes l’Echiniles. En crénéral, les hras antérienrs elles bras antéo-lateraux sont plus lougs que les autres; lans le cas oi deux autres apjendices prennent un grand développement, les hras postririenrs sont les in loressés. - Crs organes sout couverts le cils viluatiles;

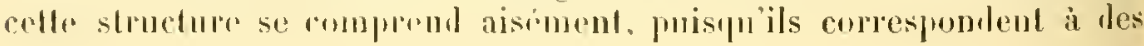


expansions, accrues dans un rertain sems, de la comromme viluritile péribuccale. - Ces apprndices ciliés ne sont pas, du resto, les suruls appareils locomoteurs de la larve. l.e Plutens de plusieurs lichiniles, el notamment celui des Echinilces, possèle en surplus, sur les coités de la hase d'implantation les hras, quatre larges hamles viluatiles, nommées épulelles, a canse de lew situation. En outre, lo lohe anal, yn il

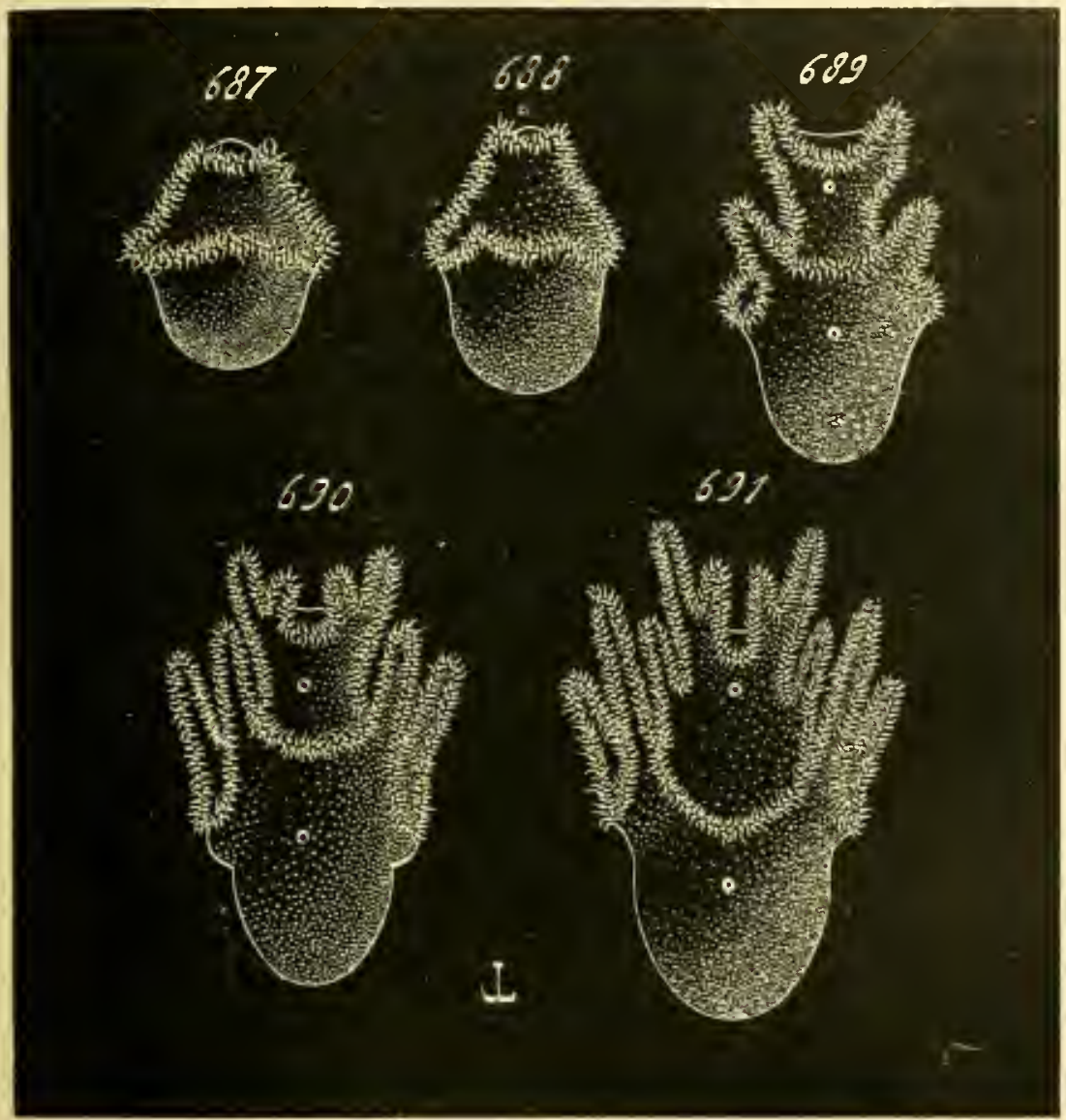

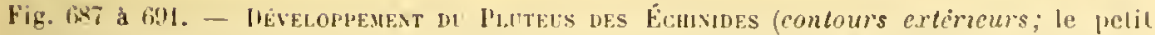
rerele superieur indique la bouclic, el l'inferienr l'anus). - lin 687 el (RSx, amplificalion progressive de la couronn. peribuceale. - In 689,690 el 691 , phases successives de la genèse des luas, aux dépens de celle couronne. (Ibaprès les recherelies fititus par les auteurs, el notamment par J. Miiller.)

reste simple, on qu’il émutte ì son lour des expansions, comme il rn rst clız. les Cidaridions, est reveitu de cils vibratiles, soit en totalité, soit ril partic.

les liras sont soutenus par des spicules calcaires, qur produisent les 
cellules du mésenchyme. En eflet, ces lras sont des expansions émises par la parlie, de la jaroi du corps, qui supporte la couronne péribuccale; ils sont reux, et lenr ravité communique avec les espaces du schizocrolome larvaire, espaces qui proviennent a lrur tomr du blastocuele; les cellules du mésenrlyme, ou les spicules engendrés par elles, sont done capables de pénétrer dans leur intérieur. - Les premières élauches de ces spicules sont au nomlre de denx, placées t'une façon sỵmétrique de part of l'antre de l'axe longitudinal lu corps; elles naissent dans te mésenchyme du lobe anal. Elles offrent l'aspect de baguettes, qui s'allongent saus resse, en se rapprochant de l’extrémilé supérieure de l'organisme. Larvenu au nivean de la base d'implantation des loras, lont les teux premières paires sont alor's à l'élat-d'éhauches, chacmu de ces deux spicules émet deux lranches, lont l'une pénètre dans le lras antéricur le son cóté, et la scconde dans le bras jostérienr; de plus, les denx spicules s'unissent l'un ì l'autre au moyen d'un hàlonnet transversal, situé jlus ou moins laut daus le corps. Les cellules mésenchymateuses, placées dans les luras antéro-latéraux, produisent à leur tour deux spicules, un pour chaque bras, qui s'allongent par leurs denx extrémités, et dont les liases ront finalement s'unir au șstème précćdent. - Lappareil squelettique des appendices larvaires est alors complet; sauf quelques petits bàtonnets, sourent séparés les uns des autres, car ils ne parviennent pas it s'unir aux parties principales du squelette, qui naissent dans les autres liras, ou dans le mésenchyme du corps proprement dit.

Au moment oi tontes ces formations sont acheries, l'état de Pluterus est atteint.

Diverses formes du Plutens. - Un Pluteus offre nne forme caractéristique, et aisément reconnaissable. Son corps en tronc de cône, á sommet inférienr, porte sur sa face supéricure les bras, semblables à de longues baguettes tournées en haut of en dehors. Les plus gramiles, parmi ces bagnettes, ont une longueur sourent égale an donble, ou an triple, de celle lu corps; elles encalrent, par leurs bases, la zone bncrale de la larve, el servent í la fois romme organes de soutien dans l'eau, et comme appareils locomoteurs. L'organisme est lui-mème assez complexe; outre ses éléments mésenchymateux et ses spicules calcaires, il renferme le tube digestil, muni l'une bouche et l'un anus, avec les ćlranches des entérocoles et de Thydrocole. Ainsi constitué, il nage it la surface de la mer. et se laisse entrainer au loin par les courants.

Ce type larvaire n'est pas semblable it lui-meme chez fons les Echiniides; il comporte plusieurs variétés secondaires, dont chacune, autant qu'il est permis d'en jugere d'après les comnaissances acquises, est raractéristique de l'un des principaux groupes de la classe. La généralisation est, en ce cas, quelque pen prématurée; mais tous les faits entrainent it la considerer comme exarte. Les ditrérences entre ces 
varićtés liennent au nombre, ou à la longueur, des bras, el à la présence on a labsence d'appendices supplementaires. - Il est nécessairc de remarpuer que ces dirergences sont établies d'apres nue morenue. Comme le démontrent les observations de l'rouho sur les larves du Dorocidaris papillata, il n'est pas rare de trourer des Pluteus anolmaux, qui possedent plus de bras quils n'en devaient aroir, on qui prósentent, en ronplément, des particularités spéciales à une antre variété.

D'apries ceux des Arbacia el des Dorocidaris, les Iluteus des Cidaridiens sont caractérisés prar la disposilion de leurs bras, et par l'existence, sur le lobe anal, d'une paire d'appendices supplémentaires. Qualre des liras sunt i pen près deux fois plus long's que les anlres, et rassemblés en deux groupes latéraux, de deux lıas chacun; ces organes, soutenus par des spicules treillissés, correspondent à ceux de la parre postérieure et de la paire antéro-latérale. - Le lobe anal émel deus expansions, dites auriculaires, placées, avec sýmétrie, de part el d’antre de l'axe médian. Ces auriculaires sont longues, cylindriques, chez les Arbacia, ct soulemues par des spicules ralcaires; celles des Horocidaris sont plus courtes, plus larges, et ne contiennent point de spicules prarticuliers. Il u'existe jamais d'épaulettes vibratiles.

Par contre, et d'aprés les larves des Echinus, les Pluteus des Echimidées possèdent quatre épaulelles, mais sont loujour's privés l'anriculaires; le lobe anal se lerminc on une pointe monsse. - Les huit bras sont, à peu de chose près, aussi longs les uns que les autres, leur longueur élant environ le double de celle du corps. Quatre d'entre eux constiluent un groupe médian, dont la base d’implantation est plus élevée que celle les quatre autres; cenx-ci sont rassemblés en deux groupes latéraus, dont chacua comprend denx bras.

Enfin, parmi les Exhinides irréguliers, les Plutens des Spatangides sont raractérisés par la présence d'une cinquieme paire de bras, qui restent courts, el par celle de trois appendices insérés sur le lobe anal. Lim de ces derniers, médian, se présenle comme une baguette rylindrique, doml haxe longilubimal contimue celnidu corps; les demx anlres, semblables an précélent jrar leur forme, sont latéraux, symélriques par rapport a lui, et divergent en bas ef en dehors, a partir de leur base l'implanlation. Ces expansions sunt sontenues par des baguelles calcarres, et ressemblent ainsi aux bras, dont ils ne diflèenl que par leur situalion sur l'organisme. De lenr côté, les lunit bras sont à pen prìs anssi grmuls les mos que les autres, mais lenr longueur ne dépasse pas celle du corps, - Les larves des Clypéastriles ne sont guere commes que d’apres celles décriles, far J. Mïller, comme se rapporlant à l'Ĺchinocyamus pusillus. Les trois hagnelles supplémentaires des Spatangides leur fonl complélement défanl; anssi le lohe anal est-il arondi, el relalivment plus large que celui des l'hleus appartenant aux antros variélés. larmi les bras, six semblenl etre plus grands que les antres. sans que 
Icur longueur dépasse celle du corps. En somme, les Pluteus des Clypéastrides rappellent ceux des spatangides, si l'on supprime à ces derniers les trois baguetles anales, ef si l'on diminue quelque pen la taille de l'nne des paires de liras.

Genese de lorganisme définitif. - A. Les modifirations subies par la larve I'luteus, lors de sa transformation en Echinide adulte, onl été éludiées par 1. Miiller. A. Agassiz, et E. Metselınikott. Ce dernier auteur, qui a porté ses recherches sur un Echinildé, l'Echimus lividus, et sur un Spatangide, le Schizaster camuliferus, a pour beaucoup contribué à élucider la nature de ces changements.

Par rapport à l'organisme délinilif, au mélasome de l'adulte, le corps du Plufeus n'est qu'un prosome, dont certaines parties sont destinćes à disparaitre, et dont l'allure générale doit se modifier extrèmement. Les organes cadues sont les appendires locomoteurs et de soutien, notamment les hras avec leur squelelle calcaire, et aussi diverses régions du tulue digncstif. Ces dernières sont la lourhe el l'oesophage de la larve, qui doivent être remplacés par d'antres formations correspondantes. I'un autre côté, et abstraction faite des appendices, le prosome du Pluteus est conique; à mesure quil se converlil en un Oursin, tes angles s'émonssent, s'arrondissent, el le corps devient globuleux. L'axe longitudinal du prosome passe, à peu de chose près, par la bouche larvaire, qu'encadrent les loras, et par le sommet du lobe anal; celui du mélasome passe, au moins dans les premières phases de la genèse de ce dernier, par le vestilute, ot so trouve itre presque perpendiculaire an premior. Ces changements l'orientalion générals, joints au volume des organes lestinés à satrophier, ou à disparaitre par phagocylose, ćtablissent une grande dissemblance entre le prosome et le métasome, ef font que la métamorphose de l'un en l'autre est des plus importantes.

Cerlains organes continuent à se développer, pendant que celte métamorphose s'effeclne; et il est nécessaire de se les représenter, durant la série des phases, comme se perfectionnant sans cesse, suivant les procédés déja connus. Les entérocoles grandissent, et enveloppent peu à peu lentéron, sans itre atleints par tes changements extérieurs; et de mème le mésenchyme, qui mullịlie le nombre de ses déments.

B. - Au moment oì les larves de l'Echinus lividus se convertissent en Pluteus, of nì elles prossedent quatre hras, l'hydrocole se détache des entérocrules, et devient un organe distinet. Les entéroceles, semblables à des disques plats, dont la eavité centrale est presque virtuelle,

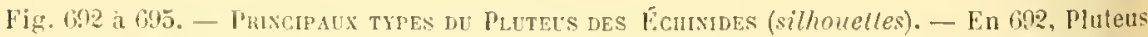

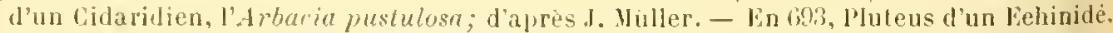
l'Erhinus drobrachiensis; d'après A. Agassiz. - En 69. Pluteus d'un Spatangide, le Spatangus purpureas; d'apres J. Mulles'. - En 005, Pluteus d'un Clypeastride du genre Éhinocyamus; d'apres J. Muller. 
ËCHIYODERMES
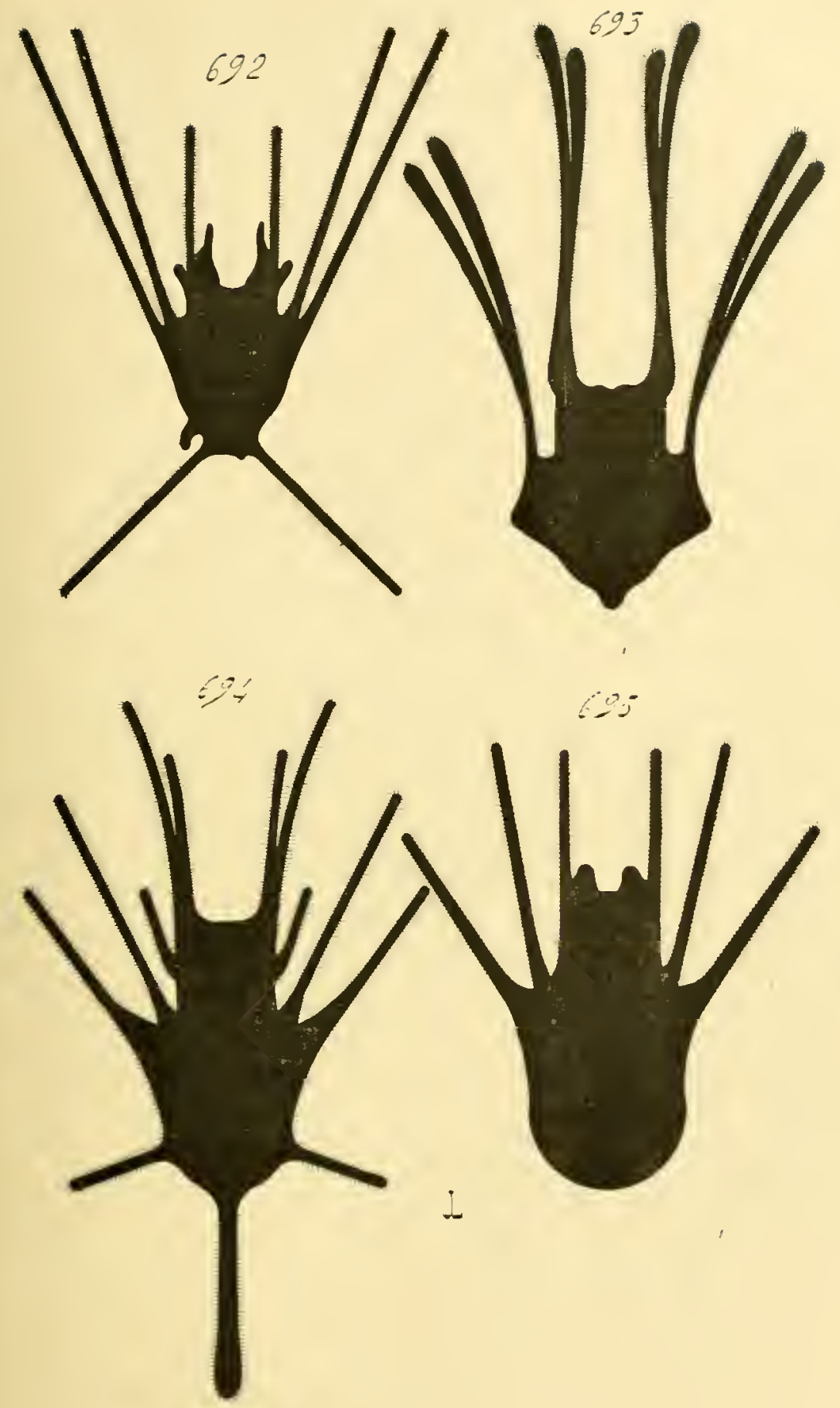

rig. 692 is 695. 
s'applifuent contre l'entéron, qu'ils vont entourer pendant les modifications surantes. L'hydrocole, muni tu tube hrdrophore, se renfle en une vésicule globuleuse, sur laquelle vont purter les principaux changements; l'ensemble de ect appareil, en cel instant de l'évolution, rappelle de pres, par son aspect, une cormue, lont la vésicule serail la parise, et dont le tube hyylrophore serait te bec. La vésicule doit se convertir en nn anneau hydrophore, yui se met lui-nême en relations directes avec le restibule, dont la genese va commencer. Seutrment, et parr un déplacement dans l'espace, ce restibule n’est point produit par la rémion qui entoure la bouche de la larve, mais far celle ou se percera la bonche définitive.

Lorsque les hras de la troisieme paire commencent a pousser, une zone circulaire de l'ectoderme de la lare, placée entre les bases d'implantation du hras antérieur el du hras postérieur du côté gauche, et un peu au-dessous de ces hases, s'épaissit par l'allongement de ses cellutes. Cette zone, d'alord très petite, grandit aux dépens de l'ectoderme non morlilié qui l'entonre, et se déprime en même temjs; elle prend l'aspect d'une curette, qui s'approfondit, en s'eufonçant de plus en plus dans le corps, et qui linit par toucher la résicule hydroculienne. Celle zone incurvée est l'ibanche du vestibule. - Dis le moment oi elle s'est mise en rapport direct avec la résicule de l'hytroculo, ces leux régions angmentent leur's surlaces de coulact, el s'accroissent it mrsure. Il en résulte un changement de leur forme. Le fond de l'élrauche vestiludaire s'aplatil; de mème l'hydrocele s'élargit, el devient moins épais. Ce dernier émel latéralement cing lobes, et se convertit en une roselle hydrophore. De son cóté, le vestibule devient plus ample dans sa région prolonde, et plus étroit lans sa partic superficielle, car son orifice se rélrécil de plus en plus; cette ouverture, fort large au moment où il avait l'aspect de cuvette, se rapetisse par le rapprorhement de ses bords, sans parvenir cependant à se fermer. - Le vestibule est alors complet. II constilue l'organe que J. Häller avait autrefois nommé l'umlo des larves d'Oursin. It présente, à peu près la forme d'un hallon au col court, et au fond large et aplati: sa cavité communique avec te dehor's par l'ouverture rétrécie de l'inragination prenière, qui mérite le nom d'orifice vestibutaire. Le fond est en contact direct avee la rosette hydrophore; cependant, quelques éléments mésenchymatenx s intercalent entre enx. Enlin, ses parois sont constituées par une couche épithéliale, qui provient de l'ectoderne. Par suite du retrécissement de l'orifice vestibulaire, el de l'élargissement du foml, les bords du premier surplombent le second; comme ces bords sont destinés à s'eflacer par la suite, Metsrhnikolr" désigne lenr ensemble par l'expression d'amnios. Ce lerme possede une signification trop précise pour atre amployé ici; les apjareils dont il ost question sont les parois du vestibule, el rien de plus.

Les phénomènes, déja signalés an sujat du développenent général des organes, se manifestent ensuite. Les cind lobes de ia roselle hyilro- 
phore grandissent pour donner les cinq tentacules périluneciux; ils sonlevent, dans leur accroissement. le fond du vestilule, et stavancent. semblables à des lulies cylimdriques, dans la cavité do ce dernier. Ils remplissent lientót rottr cavilé entiore, élargissent lorifice vestilubire en erartant ses bords, et foul saillie an dehors: les hords s'effacent peu i peu, el se confonmlent avec les régions ruvironnantes. Le restiluule disparait alors en tant qu“appareil listimet; il représente une formation parliculiere aux larves, qui rontient les banches les tentacules périlueraus, et cesse ensuite l'exister; l’arlulte n'en fossede ancum restige.

Pendant que sallongent les tentacules, el que lo restibule ilisparait. le corps de la larve peril sa forme premiore; il se renl globuleux, tout en grandissant. Les lras ne suivent point rel arroissement; aussi, deviennent-ils pelits, par rapport au restr le l'organisme, et leurs spicules calcaires se brisent en morrean. Ia bouche se ferme, el l'irsopluge sc lésagrège; me nouvelle invaginalion stonéale se perce an milien du vestibule, et va s'unir à l'entéron. Son orifice persiste comme bouche défnilive; celle-ci, par sa situation, est quelque pen inférieure a la précédente, et située plus à gauche; laxe de symétrie de l’organisme a done changé lle disposition. - Toul en s’élargissant pour s’appliquer contre le fond in vestilule, la rosetle hydrophome se transformait en un annean; sentement, l'espace central le cet anneau hydrophore ne contenait aucun organe particulier. Les fails changent lors de la genèse du nouveau stomeon: ce dernier s'enfonce lans le corps de telle manière, qu’il pénètre au travers le cet espace, el se fait entourer par l’anneau. - La lisposition linale est alor's réalisée; le stomeon devient l'osopluage, autour duquel se frouve placé l'annean hydrophore. Celle disposilion n’est atteinle qu’après une série de phénomènes, qui correspoulent à autant do léplacements ataptalifs, el propres aux larves: production d'un stomeon primaire. muni d'une bonche primaire; transformation de l'hydrocole en un annean, qui n'entoure aurun organe: enfin, genese d'un stomeon secondaire, qui passe au travers de cel anneau. et l'une louche secondaire definilive.

l’aspert du métasome s'affume lójà. Le corps est globulenx: les liras ne sont plus les appendiers principaux, car ils restent stationnaires et sitrophionl, mais bien les tentacules péribucraux, au moyen desquels le petil d̀re se déplace. Les premièresplaques du test commencent

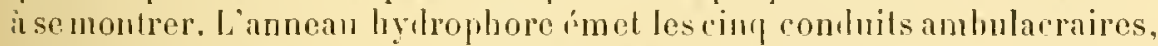
qui prombisent i lenr lour des ambulacres; les premiers nés d'entre ceux-ci sont rolativement gros. et tout ì fait semblables aux tentacules; cotte illentite de struclure iniliale, jointe i la communaulé dorigine, demontrent la parfaite lomologie de ees donx sortes d'appareils. Des pédienlares apparaissent su la paroi dn corps. - Le jeune Oursin est alor's firgonno. Sa laille est encore dres plus pestreinles, car plle dóprase de pen relle du Pluleus donl il provient: mais son aspecl grieral est

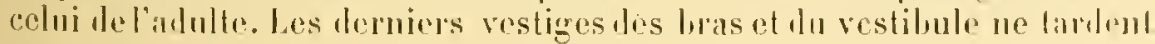




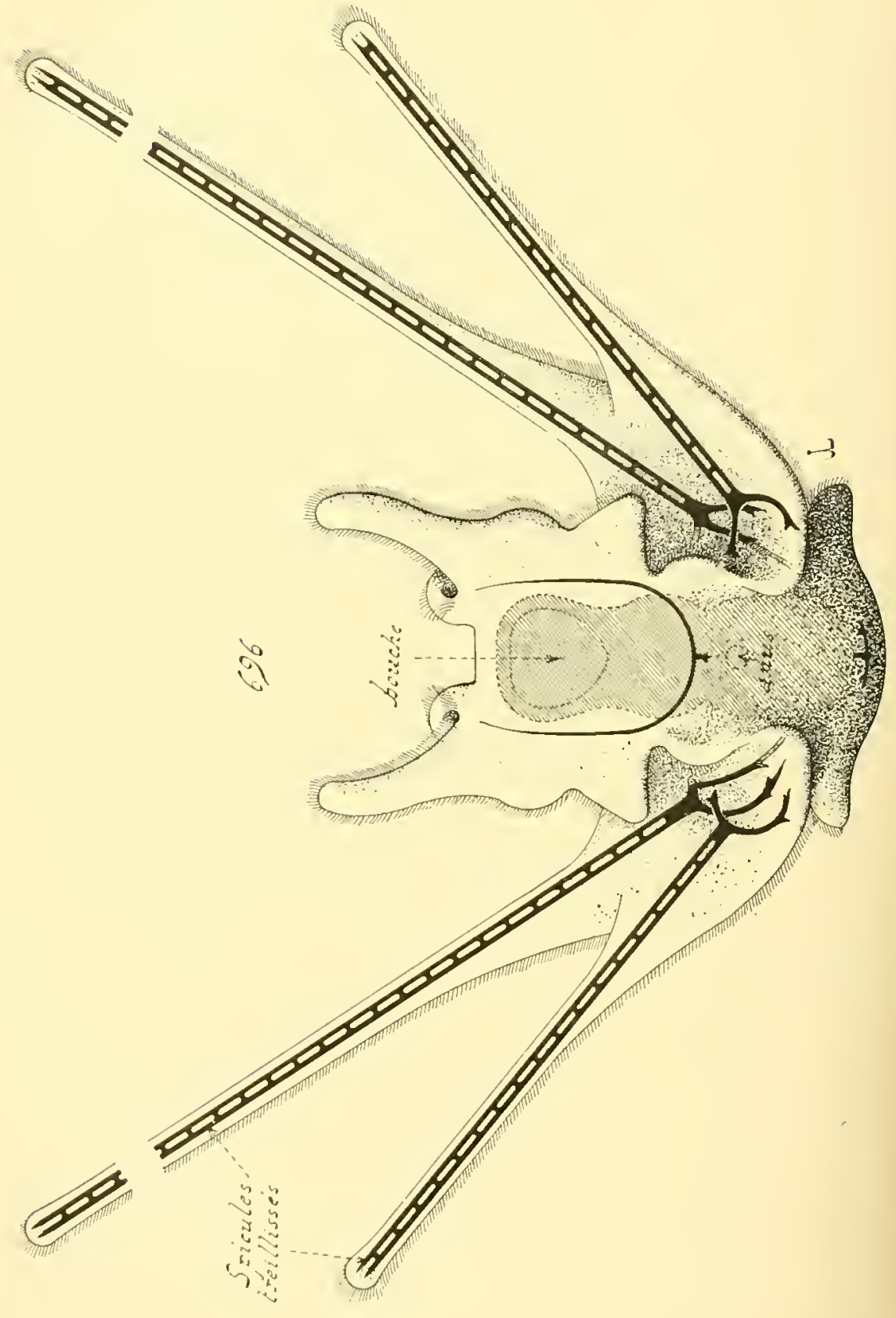


pas il disparaitre. 11 ne lui reste plus, désormais, quà grandir dans la mème direction, et à perfectiomer ses organes intornes.

On avait accordé, antrefois, an vestifule, une imporlance considérable, car on admettait que le corps entior de l'Oursin était prestjue produit par lui; Wanrès les anciens autenrs, le Pluteus lonnail maissance is eet aplareil, qui s’accroissait seul, el engendrait l'ètre définitif, pendant que la harve primitive s'atrophiait, et disparaissait. Les étutes plus

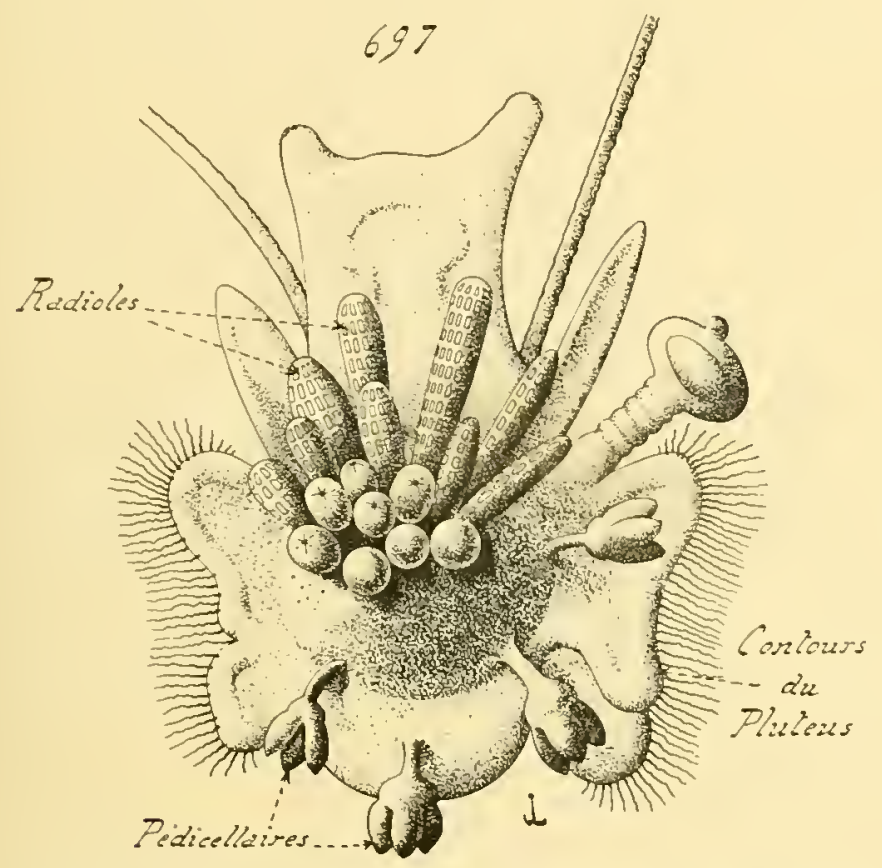

Fig. 69\%. -- Achivenest dE 1.A METAMORPIOSE DEs F́chivines (rontours extérieurs). - Ispeet d'un Pluteus, qui revêt dejả la forme d'un pelit Echinide, rabougrit ses bras, el produit ses premieres radioles, ses premiers ambulacres et ses premiers pédicellaires. - b'après J. Iluller sur un Echinide, l'Echinus lividus.

récentes ont permis de ramener les choses il leur juste valeur: il importe Je les considérer comme il est dit dans l'exposé jrécédent. (Figneres 607 ì (674.)

Le développement du Schizaster canaliferus, pris comme type de Spatangile, concorte avec celui de L'Erhinus lividus. La seule différence frorte sur le vestibule. Lors de l'accroissement de rot appareil, ses bords, en se rapproehant, finissent par se souder en fermant son orifice, et se

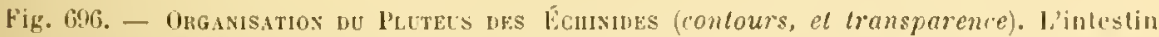
est indique par les hachures. - J'apres Jroulio, sur un Cidaridien, le Ilorocidaris papillata. Cette larve esl àgèe de trois mois; elle est vue par sa lace posterieure. 
rassemblent en me voute, qui smmonte les éluamlos drs lentacules: la cavité vestilmaire est close de re fait. Cette lisposition ne dure pas longtemps; les teutacules, en grandissant, el ajures avoir empli la cavité, pressent sur relfe voule, et la lrisent pour parrouir au dehors. Cette rupture onlraine à sa suite la disparilion du vestilule, rar les fragments Jaissés en plare s'atrojhient. - Mussi. Jes larves des Srhisuster, tout comme rolles des Echmus, perdent-elles lemps restibules, mais fra lles procédés dissemblables. Le mode, oflert par les premiores, peut être

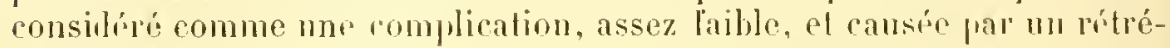
cissement plus prononcŕ les horls de lorifice, de celui juésenté par les serondes.

Origine des organes. - Irs faits comnus, sur un pareil sujet, sont encore lien pen nombrenx, et s'accorbont arec les donnés exposées an lé\}ut du présent pragraphe. Les plus importanls d'entre eux s'appliquent an lest; ils sont élalilis d'aprìs les recherches accomplies par A. Agassiz, ef pal loven.

Parmi les Echinides réguliers, les Cidariliens acquierent rapidement, sous ce rapport, leur aspect définitif. Par contre, tous les autres Echinides passent, au préalable, par une phase, qui rappelle un Cidaridien complet l’après la disposition du test, el qui mérite, cn conséquence, le nom de phase cidaribienne. Cette phase est caractérisée jar le petil nombre relatif des plaques, par la simplicité et la contimuité les zones amlunlaraires, et par la grande laille des premieres radioles. - Les jeunes lichinoïdér montrent rnsuite, après la plıse cidaridienne, un élal de Diadématile. Il en est presque de môme pour les Salénilles, qui conservent, en surplus, me des dispositions iniliales: me plaque anale netlement délimitée.

Les changements les plus considirables sont prisentes par les Echinides irréguliers. prar les Clypéastrides ot les Spatangides. - Les premiers sulissent tont d'ahord la phase cidaridienne. En ce moment de leur évolution. leur tesl, composi d'un chiffrr restreint de plaques, est wralaire ou sphérique; les radioles existantes sont grandes, el montées sur de gros tuberoules: enfin, les zones ambulacraires sont simples, Jroites, el n’affoctent nullement mn aspect pétalö̈le. Puis, Jes individus prenment lenrs raractères délinitifs. - l'areils phénomènes sont offerts par les Spalangiles, en ce sens que ces animaux passent an próalable par une fluse cidaridienne; ils ne revitent quensmite la disposilion propre a l'adulte. Il est à remarquer que les Spatangides arducls, en quittant l'élat de Cidaridion, el rommencant à se transformer prour parvenir au but final, ressemblent anx premicrs Spatangides apparus sur le globe, anx Echinoneiles les terains secundaires.

Les Cilaridions sont done les senls, parmi les Echinides, qui arrivent directement i lótal parfail; tous les autres représentants de la classe passent liahorl par une phase ridarilienne. La série olferte, dans ce 
cas, par l'évolution emluronnaire des lichinides, concorde de fous points avec celle que donne la palcontologie.

\section{Développement particulier des Astérides. - Tous les} représentanls de celle classe noffrent pas un developpement ä mritamorphoses extrieures. Cerlains d'entre eux sont rivipares, on lien possident des mufs volumineux. el riches en deulolicille; aussi leurs embryons ne montrent-ils que des changements minimes, du moins en ce qui touche leur allure générale. Mans le cas de métamorphoses complites, la larve premire se converlit en une Bipinnaria, qui se transforme à son tonr en Brachiolaria; après quoi relle-ci passe à l'élat adulte.

Hetrmorphoses complites; genise de In Biminnaria et de la Brachiolaria. - A. La jenne larve des Istériles, parvenue a la phase gustrulaire, est entierement comverte de cils ribratiles; comme cluez les autres embryons libres des Echinodermes, la pluprart rle ces cils ne tarlent pas à disparaitre, et ceux qui restent se rassomblent en deux couronmes roncentriques. La plus petile de ces dernièes entomre la houche; cet orifice norcupe point, cependant, le rentro mème le l'esprace limité par la couronne, et se trouve placé daus la région inférieure de cel espace. La seconde, phus large, passe entre la bouche et l'aums, et enveloppe la précidentr. - De mème que chez les Auricularia des Holothurides, la partie du corps qui sumonte la bouche, et constitue l'exIrimité supérieure de la larve, est très haute el tres grande; elle forme un lohe sus-luccal (lole préoral les auteurs) voluminemx, placé audessus de la houche, et composant à lui seul un pen plus le la moitié le lorganisme enlier. Les denx comronnes ne sont pas parfaitement rirculaires: après avoir entomé l'orifice lucral, elles remontent sur ce. lole, et prennent un aspect anguleux.

Gegenhaur a. le premier, fail olserver que les modifications, sulies par les larves d'Astérides qui se transforment en Bipimaires, sont illeuliques à celles oflertes par les larves d'llolollumides qui se comverlissent en Auriculaires. Dans les deux cas, les cils viluatiles se restrejfuent à noccuper qu"un espace périluceal, et l'extrémitrisupérieure hu petit ìro jrent mu accroissement consilrable, de maniore à reporter ha louche vers le milieu du corps. Seulement, il nexiste qu'ue senle pouronne chez les larves des Itolothurides, alors que celles des Astriviles en montrent denx. - l'ourtant, il est permis de penser que la disposi-

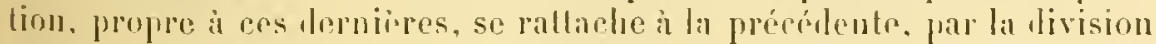
en demx tromcons de limique couromme les jemes Mrimbares. In moment oì cellr-ei grandit, le premier résultalule son amplilication est

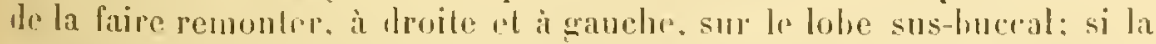
srission, qui se manifésle un peu plus tard, soffectuait alors, eftr courome moique serait partagre en lleux antres, lisposées comme celles 
des jeunes lipinnaires. In minime déplacement dans le temps permet ainsi de rallachro le type des nues à rehi des auldes.

bes l'instant où les deux couronnes se sont dílimitées, el existent senles comme zones viluraliles, la forme propre à la Bipinnaria saffirme, el ne fait yue saccentuer. - La larve aumente quelque peu sa laille, mais en conservant loujours les mêmes dimensions relatives de son volumineux lolse sus-huceal. De leur còté, les couromes s'accroissent, en conservant leur indépendance vis-a-ris l'me de l'autre, feur siluation muluelle, et en adoplant un procédé mixte, tenant à la fois de cohi des Auriculariu et de celui des Pluteus. - Comme chez les premières, les couronnes s’alargissent en grandissant, et décrivent des sinuosités. La pelite bande interne est toujonrs la plus restreinte des deux. Elle surplombe directement la houche, et se localise sur la face antérieure du lobe sus-buceal, d'où son nom de couronne pré-orale donné par les autemrs, qu'il faudrait convertir, phus justement, en ceux de sus-orale ou de sus-buccule. La conronne externe jrend une extension plus grande; non senlement elle remonte, comme la précélente, sur le lobe susbuccal, mais encore elie descend, des deux còtés, à droite et à gauche, jusque sur l'extrémité inférieure de l'organisme, el gagne de là vers la face postérieure. Les auteurs la désignent par l'expression de couronne post-orale; le terme de courome marginale serail mieux en situation, car cet appendice vibratile encadre les coités du corps entier, dine extrémité à l'autre, en émetlant des expansions sinuenses sur la face antérieure et sur lit face postérieure de la larve.

li. - Lorsque les denx couronnes s'élendent, el deviennent sinueuses, le type de la IBipimaria est achevé; it se convertit, par la snite, en celui dit Brachiolarict. Jnsqu'ici, l'extension s'est produile d'après lr procédé propre aux Auriculaires; elle va progresser, ensuile, d’après celıi montré par le Pluleus des Lchinides. Les sinuosités des couronnes, ou du moins la plupart d'entre elles, ne restentpas appliquées à la surface du corps; elles se soulevent en pelits mamelons, qui grandissent en s'étirant, et se convertissent en antant de pelits lras, d'expansions cylindriques, ou cylindro-coniques, courertes de cils vihratiles, et insérérs sur le corps par leur base. La Bipinnaria s'est alor's transformée en une Brachiolaria. - Les bras de cette dernière diffèrent de ceux du Pluteus par plusieurs caraclères : ils sont engendrís par deux couronnes vibratiles, et non par une senle; ils raymnont autour du corps entier, el ne sont pas localisés à l'extrémité supérieure; ils sonl relativement plus courts; enfin, ils sont loujours privés de spicules calcaires.

La longuenr, el le nombre, des bras, varient suivant les espèces auxquelles apprarliennent les larves. A cause de leur lisposition, el comme il est aisé de se le représenter d’après les parlieularités précédentes, l'aspect général d'une Lrachiolaria est fort différent de cehi 
d'un Plutens. - Parmi ces bras, trois, un peu plus courts el plus liarges

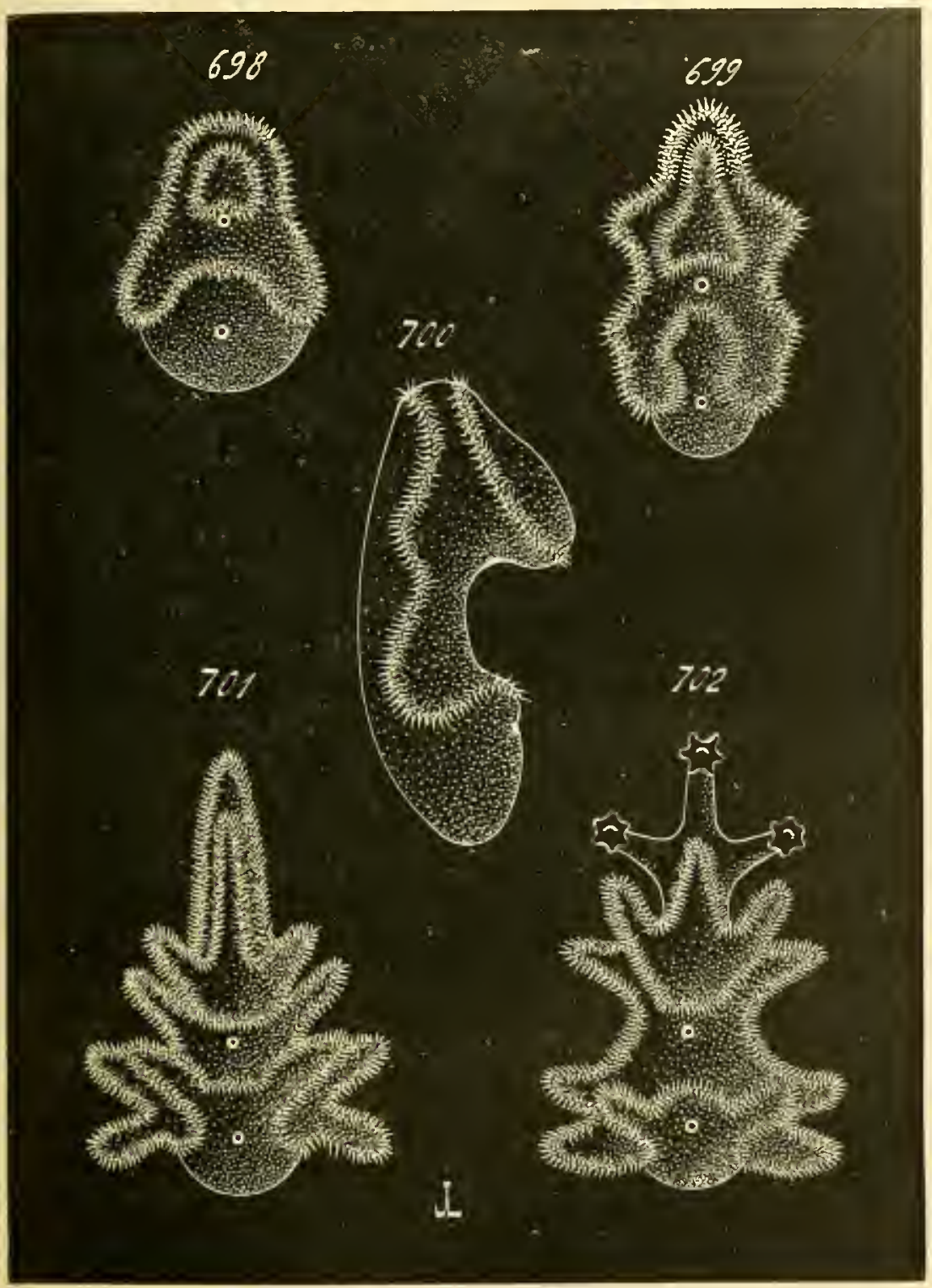

Fig. 698 a 702. - Métamonphoses des Astérides (contuurs extérieurs; les Jarves se prèsentent par leur bace auterture, sur iaquelle la bonche cst muquec par le futit cercle snpérieur, et l'anus est signalé par le petil cercle inférienr). - En 698, jenne larvr Jijuinnaire, manie de ses deux eouronnes vibraliles. - Ln 699 , larve plus avancie, dout les eonronnes onl grandi. - Lin 7(0), la mẻme, vue de profil. - Ln 701, jeune lirachiolaire. - lin 702, larve brachiolaire jresque achevée. - (W'après les recherches failes par les auteurs, el notamment jar I. Hüller.) 
que les autres, dont l'un rost millian, les deux autres élant laléraux, sont implantés sur la région supérienre de lorganisme; ils y occupent le sommet du lohe sus-lmceal. Ces trois appendices sont souvent couverts de peliles papilles, nolammenl sur teur extrémité libre, el paraissent n'avoir, par opposition aux aulres, aucun rapport aver les couronnes vilualiles. A cause de teur aspect spérial, et de teur presence presque ronstante, on lemr a donné un nom parliculier : celui de lons lorachiolaires.

loune maniỏe générale, et au sujet dn développement des liras, la comronue sus-orale donne naissance, par sa région supérieure, à deux he ces appendires; ceux-ci sont placés symétriquemenl par rapport à la bouche, el conslituent une paire orale et anterieure (orale el ventrale dans la trminologie al'Massiz). l'arfois, un troisieme hras, antrieur, impair et médian, placé entre les deux de la paire pricédente, se dévetoppe aux dépens de celle mème comonne. - La conronne marginale, ¿t cause lle sa situalion plus extérieme, de sa grande élendue, produit un plus grand nombe de ces expansions. Ello engendre, en parlanl de l'exlrémité inférieure du corps el remonlant vers l'exlrémilé supérieure, wne première paire anule et inférieure (on méliane), wne seconde paire anale et postérieure (ou dorsale), nne troisième paire anule ef antirieure (ou ventrale), une qualrieme paire orale ef posterieure (ou dorsate), enfin un long liras supérieur el impair (antirieur et dorsal d'apris Igassiz). Lrs doux bras de chaque paire sont placés, lune manièe symétrique, do part el d"autre de laxe médian; ceux des trois premières paires sont i peu pris silués. comme leur nom l'julique, au nivean de la région anale; ceux de la qualrieme paire au niveau de la lonche; enfin lo hras impar et supérieur surmonte lont l'organismo. - Des trois bras brachiolaires, le médian, est produit par la lase du hras supérienr et impair; les deus antres sonl formés, do incme, par les hases les lras apparlenant à la paire orale el postérieure.

La larve Brachiolaire est alors complète. Elle se léplace, et se soutienl dans l'eau, par le moven de ses hras comverts de cils vibratiles; dle ne tarle pas ì passer ì l’élal ablulte. Les consilíralions, déjà exposies sur lamplitude des módamorphoses subies, et rapplies au sujet In I'luteus des Echinides, sont, ici, igalement applicables, sans "fu'il soil utile l'insister davantagre it teur égard; la diflérence de formes est, an rlfot, lies grame entre le prosome de la birnchiolariu el le mitasome d'Astérile quil doil dorner.

Cienise de lorganisme definitif. - 1. De mème que pour le Pluteus. le mélasome n'est engendré que par une région restreinte de la Brachiolaria, par rello qui porlo le tube digestil dans son inlériour: lo corps entier le l'Astérile s"óluanche autour le lintestin de la larve. - An point he vue des mollificatius qu'il est appelé à subir. l'organisme de ba Brachiolaire se compose le lmois parties : les bras, le lobe sus-fuccal, ot la 
région sous-buccale. Celle-ci est un peu plus petite que le lole précédent, ou l'égale tout au plus en dimensions; cepeudant, elle est seule chargée de donner le métasome, de se convertir en Astéride compléte. Le lobe sus-buccal et les loras ne subissent plus aueun accroissement; its restent slationnaires, ol finissent par s'annihiler peu à peu, à cause de l'extension considérable prise frar la région sous-lunceale, et de la grande diflérence de laille élablie entre le corps de l'Astéride et celui de la Brachiolaire. Ces annexes, qui occupent une part importante du prosome larvaire. n'entrent point daus la constilution du mélasome; il imporle de se les représenter, durant la suite des métanor phoses, comme devenant inertes, perdant peu à peu leur autonomie, et se confondant avec le reste du corps. A ce qu'il semble, ils ne sont point rejetés, et se bornent à ne point s'accroilre.

La région inférieure de la larve, étendue depuis le vireau de la bouche jusqu’ à l'extrémité inférieure du pelit ètre, est seule mise en cause daus les changements qui se manilestent. Celte région est à pen près globuleuse, au noment où les premières modilirations apparaissent; son accroissement ullérieur ne s'effectue pas l'une manière égale lans lous les sens, de manière à lıi conserver son aspect gloluuleux, mais de façon à la transformer en un organisme aplati, el divisé, sur ses borls, en cing lobes volumineux. Dans ce dernier, la zone centrale et aplatic constitue le disque de l'Astéride; les eing lobes sont les cinq bras de ladulte; la face anale correspond au cóté droit de la larve, et la face buccale à son côté ganche. Par suite, l'aceroissement est surtoul considérable dans le sens antéro-postérieur, el nolamment suivant l'axelongitudinal des rinq liras de l'Astéride, qui grandissent sans cesse; il est moins prononcé dans le sens transversal, de droite à ganche, car il a seulcment pour effel de donner au disque son épaissen', ses dimensions de la bouche il l'anus.

Les débuts de cette nétamorphose consistent en un dépòt de spicules calcaires, dans le somalo-mésenchyme du côté droit. Ces spieules, an nombre de cinq, se rassemblent en un pentagone, el représentent les premières ébauches des plaques de la face anale de l'Astéride. Le nom de face anale n’est pas toujours mérité, car l'anus manque í plusieurs représentants de la classe; aussi plusieurs anteurs lui prélẻrent-ils coux de face dorsale, ou de face abaclinale; mais, mème en l'alssence de cel oritice, la situation de cette zone du corps ne varie pras, et le terme de face anale permet dr mienx comprendre la série des changements. Le somato-mésenchyone du còté gauche ne possède encore ancune plạue calcaire, alors que le cóté droil porte déja ces cinc spicules. Ce côté gauche renferme, dans son intérieur, l'hydrocule, qui se convertit en une rosetle hyihophore; d'après Iletschnikotl, cet appareil a l'aspect d'un anneau fermé, et celui d'nu croissanl d'après Igassiz. Quoiqu'il en soit ì cet éraril, les ciny diverticules de la rosette soulirent les tiguments larvaires a leur niveau, et produisent ainsi des petits tentacules; seule- 
ment, les descrijtions, données par les deux auleurs précilés, ne permetturt pas encore le saroir s'il existe un vestibule, semblable a celui des Erhinides.

A ce moment de la métanorphose, la rígion sous-luccale de la Brachiolaire porte, sur son còté gauche, la rosethe hydrophore, et sur son côté droit, les cinq spicules précilés, qui constituent les premiers rudiments des plaques de la liace anale lu lisque; le côté gauche ıleviendra, de son coté, la fare huccale (encole nomnée actinale ou ventrale) du mêm. lisque. Ces deux faces ne sont point parallèles; l'ensemble des cing spicules est oliligue sur le corps, le manière à former un angle assez onvert arec le plan de la face luccale, el celui de la rosette livglrophore. Les choses se régularisent par la suile.

L'hyilropose, la boriche, et l'anus, n'ont pas encore quillé leur situation premiere, c'est-à-lire celles quils ont chez la brachiolaire. L'hylrophore est postérieur; alors que la bouche el l'anus sont antérieurs, la première étant placée vers le haut de la région larvaire qui se moditie en mitasome, et le second se trouvant vers le bas de celte même rógion. A canse de l'accroissement rapide, pris par le dépôt calcaire formé sur le côtí droit de la larve, ces trois ouvertures sont à peu près situées sur les hords de ce dépôt. Cette position change ensuite; ces orifiees commencent à se déplacer quelque peu, de manière à se reprorter, l’anus et l'hydropore sur le côté droit, el la bonche sur le côté ganche, de la Brachiolaire. Lorsque ce premier report est effectué, ils conservent désormais lenr situation, el ne participent point à l'extension ultérieure du métasome. Aussi la bouche est-elle placée au centre de la face huccale du disque, qui dérive du rôté gauche de la larve; de son côté lanus occupe, lorsłu’il ne soliture point par la suite, le centre de la lace anale, et Thydropore, lout en étant excentrique, est-il également percé sur cette face anale lu disque.

B. - La Brachiolaire porte déjì, dans la région inlérieure de son corps, l'élanche, en forme d'Astéride, et bien reconnaissalile, de son métasome. Celte région est encore globuleuse; pourtant, elle possède, sur son côté droit, le rudiment calcaire de la face anale du disque, et, sur son coitr gauche, la rosette hydrophore de la future face buccale. L'aceroissement continne désolmais lans le sens antézo-postérieur, car ces deux cótés rout s’amplitier, et s'étendre par leur pourtour, suivant le plan le leur surlace. Il faut se représenter ces côtés comme deux cuveltes, fortement lombées, accolées par leurs hords, el grandissant par ces bords même en s’aplatissant à mesure; la région de soudure correspond à la zone antéro-postérieure de l'organisme larvaire. Comme le roté droit drvient la lace anale de l'adulte, et le cóté ganche la face buccale, cette région l'union est marginale daus l'organisme détinitif, et constitue les bords des hras de l'istéride.

L'amplilication du mélasome s'eflectue, de préférence, suivant cinq 
axes raliaires, également distants, de manière à donner les cinq lıas le l'adulte. Sur la face anale, l'elargissement so manifeste par le lépoit incessant de nourelles plaques calcaires; celles-ci uaissent au milieu de celles qui existaient déjà, el les repoussent vers la périphérie. Au moment oir les dix premieres plaques out apparu, les bords de celte face émettent cinq prolongemonts, qui grandissent seuls, el deviemnent les bras. - Sur la face rentrale, les cing diverticules de la rosette livdrophore produisent, de lenr cuté. cinq expansions, qui se posent audessous des prolongements précites, et constituent les canaux ambulacraires le fiadulle. Chaque canal s'allonge, à mesure que son hras correspondant siccroit, et engeulre des ambulacres de place en place. - Le métasome revêt ainsi son aspect définitif, el s'amplifie sans cesse; l'amplification étant toujour's dirigée lu centre vers l'extérienr, de manière á repousser au dehor's les parties les phus anciennes.

Le lobe sus-buccal, et les appendices de la Brachiolaire, s'attémuenl. rapidement; ils disparaissent an moment où les cinq loras commencent à se délimiter, el à s'élendre.

Les lascriptions précédentes ont élé faites, pour la majeure part, d'apres les recherches publices par $A$. Agassiz. D'apres cet auteur, la honche ef l'anus de la Brachiolaibe persistent, pour lonner les orifices correspondants de l’Astéride, et se bornent à se déplarer. Les recherches entreprises par Metschnilioff montrent, par contre, et sous ce rapport, une certaine ressemblance avec ce qui se passe chez les Echinides; la bonche et l'anus larvaires se fermeraient, et le tube digestif du metasome scrait obligé de produire à nouvean ces ouvertures. Comme le pense Balfour, cos deux phénomènes existent peutètre, en ce sens que rerlaines larves d'Asterides possèlent le premier, et certaines antres le serond; la ditlérence à cet égard serait due à un déplacement dans l’espace, lié lui-mème à la rapidité variable des métamorphoses, el à la romplexilé diverse des lisposilions adaptalives.

Metumorphoses restreintes ou mulles. - Les Astérides sont intéressautes à ce sujel, car elles ollirent une sériation parfaite, depuis la présence de métamorphoses complètes, jusyu’a l’absrnce de res changements larvaires. Cetle sériation contrilue, pour beanconp, i élablir lopinion exposéc plus haut, relative à l'origine des mélamorphoses des Echinodermes. Les larves, à muditications restreintes, des Istérides, possèdent les appendices, fui ne leur servent à rien, semble-t-il, el qu’il est permis, par conséquent, de considérer comme des appendices brachiolaires rn voic d'atrophic, existant encore par l'etfet de l'atavisme.

Che\% les Elhinaster et les Asteracanthion vivipares, les larves passent tont ilahori par la phase premiòre. Elles produisent ensuite des expansions eylindriques, an nombre variable suivant les esperes, mais toujours restreint, qui, selon foute rvidence, sont romparables à drs appendices de Brachiolaire. Ces organes unt pour unique fonction d'altacher 
les embryons a l'appareil incubateur de leur mère. Ils disparaissent bientôt, jendant que le ućtasome s'ébauche et se romplète.

La réduction est plus grande cucore chez les Asterina gibbosa, étudices par Luwwig. La lare, après avoir subi la phase fremière, ne proluit aucun bras, mais elle porte encore son voluminenx lobe sus-buceal. Ce dernier s'allonge transversalement, par rapporl à rette partie du prosome qui renferme le lube digestif et se convertit en Astéride; il couslilue une masse aux contours peu précis, donnant à l'ensemble du corps la forme d'un T majuscule, dont il représente la branche supérieure et lorizontale. Luwwign le nomme l'organe larvaire; son homologie avec le lobe sus-luceal des lirarhiolaires est pourtant imbiscutable. Cet appareil disparaît par la suite, en ressant de s'arcroitre, et mème

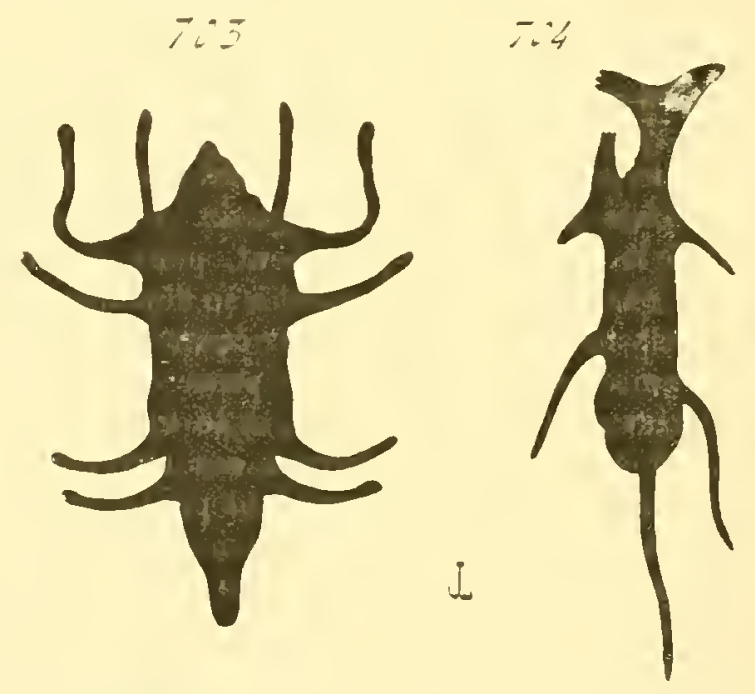

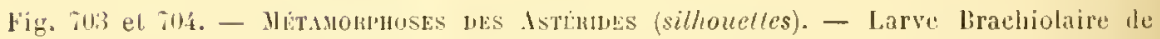
l'Asteracaullion pallidus, vue d. face et he profil. (I'apres A. Agassiz.)

s'atrophiant en partie, à mesure que la jenne Asterido prend naissance.

Entin, chez les Peraster miliaris, il semble que l'embryon ne produise aucun bras, et nengentre pas de lobe sus-lnceal. Les premiers états nout pas élé observés encore (lioren et Daniclssen); mais la larve, déjà avancée, se couvertil tout entière en une Asléride; sa bouche et son anus ne passent pas ì l'adulte, qui se forme à lui-mème ces deux orifices dans leur situalion détinilive. - Lit rélurtion des appendices adiptatifs du prosone est alors romplete; il n'existe jri ancune métamorphose bien accentuce.

Origine des momes. - Les priuripaux faits particuliers el tomnus, sur l'orighine des organes chez les Istérides, sont relatifs au test et a l’intestin. 
lour se reprisinter la marche, suivie par lo lest dans son évolution, if importe de roncevoir le plúnomène dejic indigur, tenant an mode dapparition des planues; relles-ri naissent en dedans de relles qui pxistent dójà, et repoussent, à mesure qu’elles grandissent, ces dernieres vers le dehors. Le drueloppement procinle du reutre vers la férjphélie. - Ceri étant, les premiers indices dı test sont ronstitués par les ciun plaques, produiles surle coté droit de la Brachiolaire, c'est-il-dire sur la future fare anale de l'Astéride. Ces ring plaques iniliales sont groupées en un ensemble de torme pentagonale. Bientôt. cinq antres nouvelles plaques naissent au rentre de ce pentagone, c'est-i-dire en dedans Jes próédentes, et rejettent quelque peu celles-ci rers le delırs; puis, une autre plaque isolíe se délimite, en outre. au milieu mème du pelit test aiusi élanché. La jeune Astéride, qui se façonne aux dépens de la rigion inférieure de la brachiolaire, possèle done onze plaques sur sa face anale. Ia playue isolíc est la centro-torsale; les cinq premières
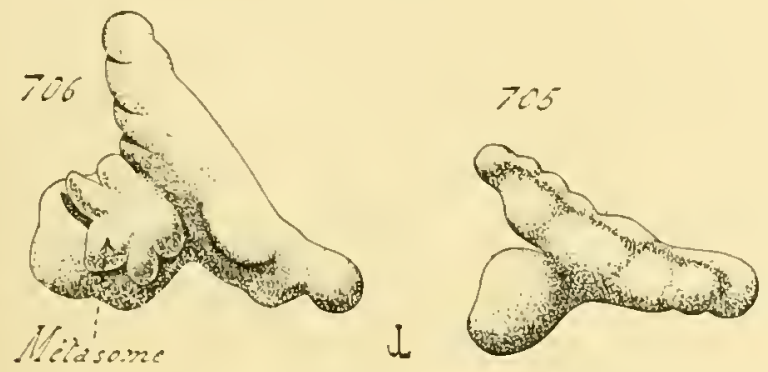

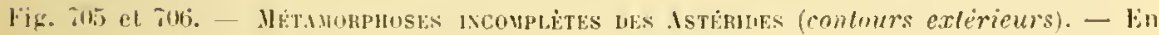
(0)., jeune larve de l'dstevina gihbosa, munie de son volumineux lobe sus-buccal (organe larvaire) transverse. - lin im, larve plus avancie, et commençant it chancher le mélasome de: la jeune Aateride. (U'apres Ludwig.)

plaques sont placées au-dessus des ring diverticules de la rosette hỵlrophore, el sont radiules par suite; les cinf autres alternent avec celles-ci, et sout interradiales. - Liensemble lle res on\%e playues est encore simple; les ring ipaississements, destinis a devenir les bras, 1 e tarlent pas à se montrer; ils apparaissent dans les régions or"upées far les plaques radiales. Celles-ci, i cause le l'arroissement incessant. lirigé du centre vers la périphérie, sont constamment reportérs il l'extrémité libre des hras, et s'y maintiement; elles ronstituent les plarues lerminales délinitives. Par contre, les cinq interradiales restent en leur place, et devimnent les busules de l'Istéride alulte. la inorso-centralo persiste an milien du disque.

bes plaques naissent eusuite sur la fire hucralu de la jeune Astérile, et autour dr la bourhe: les premières apparues sont representées par les

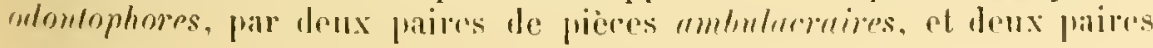




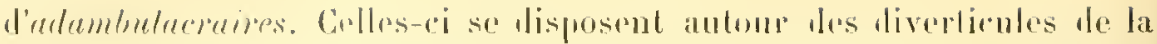
roselte hydrophore, de maniere a les acrompaguer daus lemr extension, et a faire partie les bras; les odontophores, par opposition, sont siluées dans les régions interradiales, et demenrent ainsi. - Iu moment oi se diflérencient res plapues buecales, le nouveanx éléments du test apparaissent sur la face anale; is deviennent les premieres maryinules des

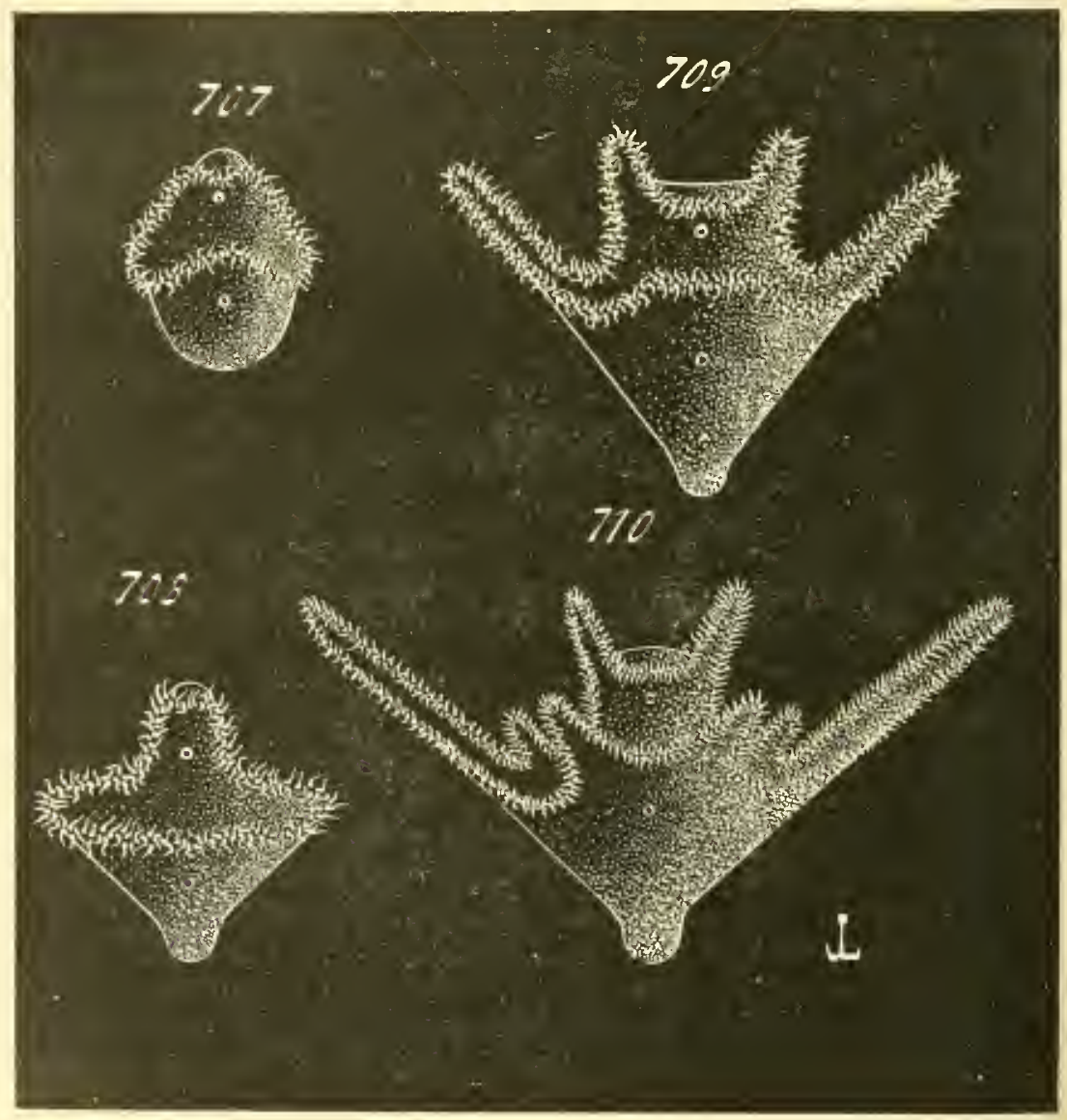

l'ig. 707 à 310. - Métamorphosis des OPHuRdors (contours exterieurs; le petil cercle supélieur indique la bouche, et l'infèrieur l'anus). - En 707, larve fort jeune. - En 7us, larve commençant à amplifier sa couronne vibratile. - En 709, lave encore plus avancée, dont les bras latèranx sont dejà volumineux. - En 710, jeune Pluleus. - (W'après les recherches failes prir les auteurs, et notamment par J. Huller.)

Lras, et les calycinules. Les bras grandissent ensuile, par la genese incessante de pières supplémentaires an dedaus des terminales: celles-ri occupent toujours l'extrémité libre de ces appendices. 
Les principiux changements, sulis par le lube ligestif, touchent it sus deux oritiens, î li houclıe el à l'anus. Sil faut en juger d'après les olservalions faites par Agassiz, ces denx ouvertures persistent de la Brachiolaire à l'Astéride adulte, et se borment à se déplacer comme il est dit plus hant. Cependant, certaines larves ì métamorphoses agiraient, suivant Metschuilioff, commerelles des Echinides, fermeraient leur bouche et leur anus, et produiraient à nouveau ces deux oritices, dans leur situation définitive, à un moment déji avancé de lévolution. Ce dernier cas est fréruent "hez les emlipons dont les mílamorphoses sont restreintes, ou nulles. - Chez l'Isterina giblosa, la jeune larve possede une bonche et un anus, placés de la mème lason que reux des Bra-

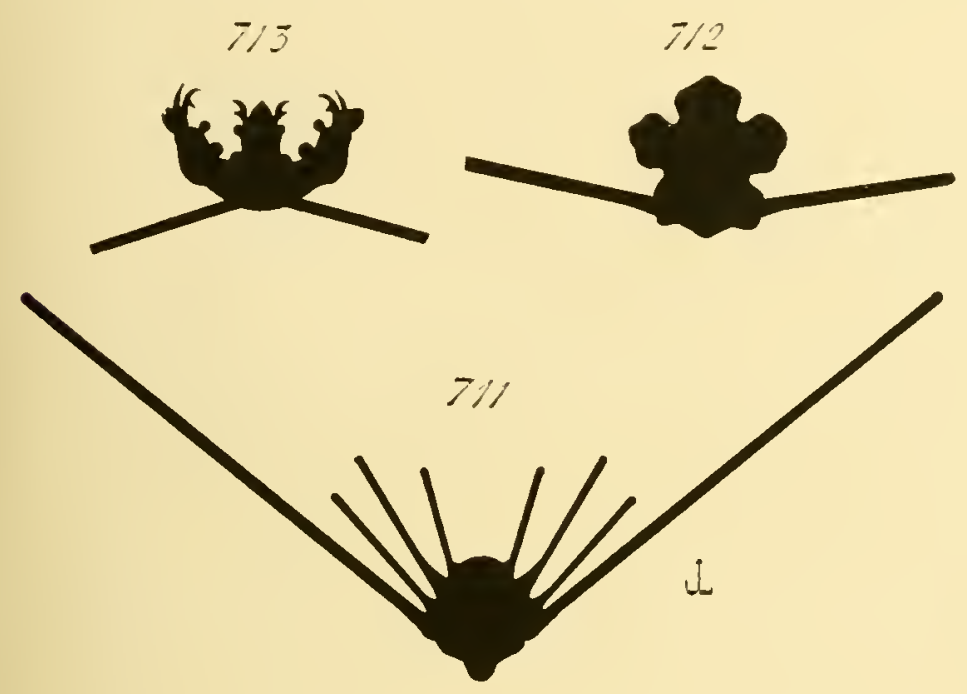

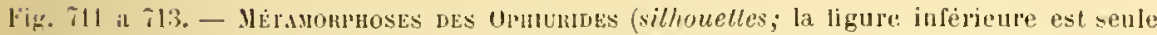
compléte, les lıras latèrax ne sont representis qu'en partic dans les deux dessins supérieurs). - lin 711 , Pluteus complet, muni de ses longs bras latèrax. - En 712 , début de la transformation en métasome de la région sous-buccale du prosome. - En 713 , suite de cette métamorphose finale; le inétasome offre déjá l'ispect d'un petit Ophiure, encore soutenu par les bras latéraux lu prosome. - (lvaprès les lecherches faites par J. Iluller sur l'Ophivthrix fragilis.)

chiolaires; ces onvertures ne tarlent pas à se clore, et le petit ètre reste privé, pendant un certain temps, de lonte communication entre son intestin et le dehors. l'uis, une nouvelle bonche se perce au centre de la face luccale, entre les plaques qui s’y sont déjà délimitées; et, de mine, l'anus se perce au centre de la face anale, dans une région qui correspoml sensiblement à relle oecupée par l'orifice larvaire correspondaut. Le mème phénomène se retrouve chez les embryons des Pleraster miliaris, éludiés par Koren at Manielssen. Ces demiers possèdent une

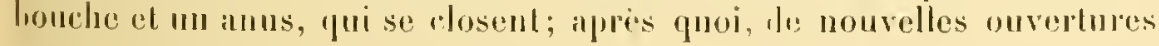




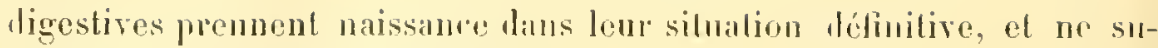
lissent point d'aulres changements.

1'. Développement particulier des Ophiurides. - Le développenent embryonnaire des oplinuides tient, a la fois, le celui des Exhinides, el de celui ales Istrides. Il rappelle l'évolulion des premiers, en ce que le prosome de la larve a la forme d"un l'/uteus; il ressemble a celle des serondes, par re lail que le mélasome de l'alulte porte ring bras, et se fagonno dr la mime maniere que colni les Asléries. La zone du prosome, clargée de se convrulir en mélasome, est la même que dans les deux lasses précédentes : c'est la rógion iul'érieure le la larve, renfermant le fule digeslif dans son intérieur, et plarée au-dessous des appendires embryonnaires.

Tons les Ophimides no possèdent pas les métamorphoses complites. Ceux d'entre eux, qui sont vivipares, uoltrent que des rhangements restreiuls. Tel esl, par exemple, l'. Implizura squamala, dont les larves ne montrent que les rudiments des bras; sant un de ces appendires, produit d"une manière tardive, alor's que l'éluanche lu jeune Oplıiure est déjà bien reconnaissalıle, el qui contient, dans son intériem, un spicnle calcaire. Io mème que pour les autres Echinodermes, les léveloppements à modifieations restreintes ne ditfërent, de ceux anx mótamorphoses compleles, que par l'alsence des orgaues spéciaux aux larves; celte dissemhance mise a part, le corps, dans ses contours extéricurs comme dans ses organes internes, se façonne suivant dres procédés identiques.

Les phénomènes, qui aboutissent à la genese du Phuteus. rapjellent completement leurs similaires des Erhinides; il est imutile. par conséquent, d’insister à leur égard. Les seules diffórences portent sur le nombre, el sur te mode d'apjarilion, des bras. Ces derniers sont an chiffre de huit, grompes en qualre paires; deux d'entre eux, nommés bras lutéraux, et placés symélidjuenent de part rt d'aulle de l'axe mélian, sont raracléristiques les Ophimides. En chol, non seulement ils manquent aux larves correspondantes des Echinides, mais encore ils jrennent, chez celles des Ophiures, un accroissement considérahle; ils divergent sur le corps, et représentent lewx longs halanciers, destinés à soutenir l'embryon dans l'eau. Jamais aucun des bras du Pluteus des Echiniles n'acquiert me lelle Jongueu"; aussi, les larves des Ophiurides semblent-elles itre plus pelites, par rapport i lemr bras, que celles des Onrsins. Les autres bras sonl phus comrts. - Jaus le développement, les luas lateraux naissent les premiers; puis apparaissent deux bras antérieurs, leux bras postérieurs, el enfin deux bras antéro-latéraur. Ces appendices sont soutenus par les baguetles calcaires.

Anlant qu il est permis de condme d'apres les fails connus, les larves des Ophiurides amx mélamorphoses completes sonl semblables les unes anx autres, el ne liffirent entre olles que fort peu, contrairement à ce 
quil en est prour les Echindes. qui offrent diverses formes de Plutens. Les principales dissemblances portent sur la taille des hras, autres que les bras latéranx, el qui sont, lantöt assez longs, lauliot courts, el parlois mène à peine indiqués. Les embryons libres des Ophinides sont privés d'ipauletles, de laguelles anales, on d'auriculaires, de ces appendices supplementaires qui existent parfois chez les Echinides.

La genese du métasome est ilentipue í celle offerte par les Astérides; seulenent, au lieu de s'etlectuer aux dépens de la région inférieure d'une Bhirhiolaire, elle se manifeste anx dépens de la région inférienre d'un l'lutrus. Linnique différence prorte sur le squelette des bras, yui minyun aux lirachiolaires, et existe chez le Pluters; ce squelette ne passe point il l'adulte, rar il se résorloc, et disparail. La houche de la larve persiste. et ne se ferme point; l'anus seul se clòt, et ne se reforme phus, var les Ophiures sont tous privés d'un tel oriliee.

Vll. Développement particulier des Crinoides. - Les Comatules seules sont connues, parmi les représentants de celte classe, sous le rapport du développenent. Cependant, comme ces animanx passent, d'une manière temporaire, lors des phases de leur évolution, par un ital voisin de celui qui est permanent chez les aulres Crinö̈des munis d'un pédoncule durant toute lenr vie, il est permis d'étendre à ces dernicrs les rísultats fournis par l'étude des Comatules, el de considérer res résullats comme s’applipuanl, lans leurs trails généraux, aux Rhizorrimes al anx Pentacrines. II faut sentement consilérer cenx-ri comme s’arrètant, l'une facon définitive, ì un état fixé et pédonculé, que les Comatules se boruent i traverser, pour devenir libres ensuite.

L'embryogénie des contuatulides a prèté a le nombreases recherehes;

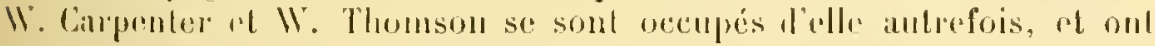

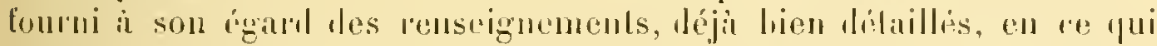
touche les métamorphoses extéricures, et la geness lu lest. Plus l’ócemment, des ohservalions completes ont bté laites sur elle pall livers auteurs, iu premier rang desquels il convient de citer .1. Barrois, Bury. Götte, Perrier. Sauf quelques parlicularilés relatives i l'appareil irrigateur, et i la production des centres nerveux, sur lesquelles les naturalistes précilés ne sont pas d'accord, ou hien n'ont encore donné que des résultats incomplets, les phénomenes principanx de l'évolution curhryonnaire des Crinoïdes sont désormais ćluridés. Les plus imprortants le ces phénomònes, pui paraissent ètre il l'abri de lont conteshe, seront sculs signalés dans l'exposé suivint.

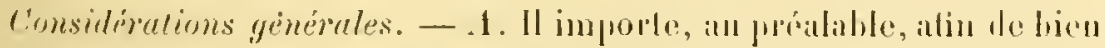
se représenter tontes les phases du développement des Comalules, de

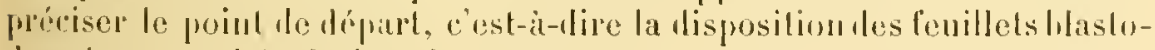
derminues, el l'évolution du prosome. - Mn moment vì les fenillets

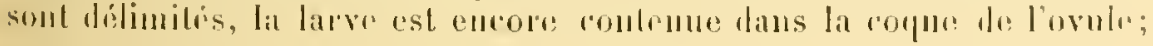




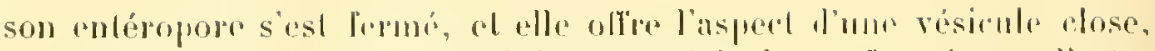

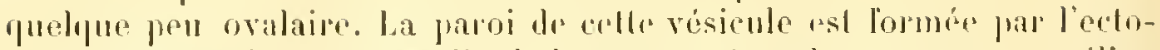
lerme; sa cavilé est remplie l'ólóments mésenclunateux, au milieu lesquels se loument puatre autres rósicules : liulestio, l'hydrucule, al

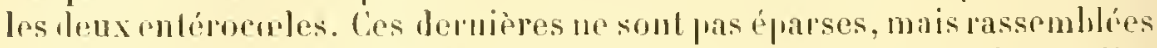
en un groupe, silur dans la régron inférieure dr la larve, rost-ả-dire

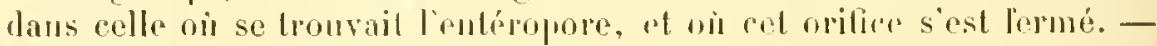
Malgré leur roisinage, at leurs commexions primilives, res résicules sont distincles les unes des autres, el ne rommuniquenl pas entre elles. L’intestiu est situé au milien, dans lru ensemble; l'entérocale droit est devenu supérieur, tout en bunt ences's quelque peu oblique; dr mème l'entérocole ganche est inlérieur; entin l'hydrocule est latéral, el placé, sur les rotós dr l’intrstiu, dans la zone oì va se fircomuer le veslibule. Cet hrilrocaso est rmeore mo vésicmle, qui commence cepemlant à émeltre le lube ligdrophorr.

Lientérocule droit a le gaurle occupaient d'aborl lour situation mormale; ils se déplacent eusuite, au moment où l'untropopore se rôl, leur chenin parcomu étant mesuró par un are dr 90\%. Aussi. le premier devient-il supérieur par rapprort à l'intestin. c'est-it-dire se plare-t-il audessus de ce dernier, landis que le second se trouve silué an-dessous le ce même organo. Ce renversement est le résultat, en ro qui regarle les entérocoeles, de la lorsion de $90^{\circ}$ sulie par lecorps entier ; ce reurersement est déplacé dans le trmps, et avanci.

Lorsque la larve est devenue lihre, le stomeon frend maissance. II apparaît comme un refoulement de l'ectolerme, placi au niveau de l'intestin. Lorifice extérieur de cetle invagination esl, par suile, l'lomologue de la bouche des larves des autres Echinodermes, et ce mème nom doit lui ctre accorlé; seulement, le stomeon reste fermé dans son extrémilé interne, et ne se met pas en communicalion arec l'intestin. La bouclie est à peu pres siluce vers le milieudu corps, ì égale distance dr l'extrémité supérienre el del'extrémité inférieure de la larvo. Toute la région quila surplombe, et qui constitue a elle seule la moitiédelorganisme. est, ì cause de sa siluation daus le temps el dans l'espace, l'homologue du lobe sus-buccal (lobe préoral des auleurs) des embryous libres des autres Echinodermes; il est aussi volmminenx, par linpoirt an reste du ropps, que son correspondant des larves d'Holothurides el d'Astérides, des Auriculaires et des lipinnaires. - Mais intervient alors une dilference comsidérable entre ces groupes. Les Ilolothuriles et les Astériles sonl des animaux libres; le lobe sus-luccal de lenrs emlurons ne sacroit pas, reste slationnaire, at finalemonl se confond ave les antres régions de l'économic. l'ar contre. les Crinoïdes sont des animaux fixís, an moins dans leur jemu àge, el teur firation s'alablit prérisement par re lobe sus-lunecul. Cel organe s'allonge, au lieu de disparaîtse, ot so convertit en un pédoncule, qui atlache lindividu à m support. Dans les premières phases du développrement, lentélocule droil, qui est devenu 
supérienr, pénètre dans ce péloncule, el lui fournit mu cavité axials. Tous les antenrs dérvivent le pédoncule descirinoüldrs comme infériour; en rialiti, et par eomparaison avec los aulres larves des lichinolermos, on doit te consilérer comme supérient. Cette orientalion sera senle ałmise daus le présent exposé.

B. - Il convient done de se représenter l'organisme des Crinoïles, romme orienté d'une manière différente le celui les autres Echinodermes, comme déplacé de $90^{\circ}$ dans l'espafe, bien que le joint de dípart soit le mème. - Chez les Echinodermes, sauf les Crinoüles, le plan qui passe frar la bouche el frar l'anus de l'adulte (en prenant res oritices dans leur situation halituelle, et liamétralement opposés) est à peu près transversal, par rapport à l'axe longitudinal de la larve; ce déplacement résulte de l'atrophie du lobe sus-buecal, liès gros chez l'embryon, qui ne s’accroit pras, el ne eonstitue qu’une région insignifiante du rorps de l'adulte. Or, chez les Crinoüdes, ce lohe persiste, grandit, et devient nne partie importante de l'économie; aussi, l'orientation primitive le la larve est-elle conservée. L’anus le l’adulte est exactement situé ì la place qu'or'upait l'entéropore dans les premiers instauts le l'irolution, et la bonche vient se reporter auprès rle fui. Tous les organes se disprosent d'une manière connexe à celle symétrie particulière, el l'orientation générale est ainsi morlitiée. Comme l'ixe principal du métasome des autres Echinodermes fait un angle de $90^{\circ}$ arec relui tu prosome de leurs larves; comme l'axe prineipal du prosone les Crinoüdes persiste, el derient celui du métasome; il en résulte que la disposition du métasoine des Crinoïles doil ètre consilérée, comme se rapportant à une différence angulaire de $90^{\circ}$ avec celle dn mélasome des autres Echinodermes.

Il est hors des limites de cet ourrage d'aller plus loin, dans l'examen des changements d'orientation du mélasome des Echinodermes par rapport an prosome de lenrs larves. - Cependant. il est nécessaire l'iudiquer ce fait que, dans l'exposé prícédent, les Echinides, aver les Astérides el les Ophimrides, ont été pris comme types d'opposition aux Crinoüles, à cause de la lifférence parfaite qui s'étahlit entre eux sous ce rapport. - Les Holothuriles doivent être mises il part. Toul comme chez les Echinides, les Ophiures, et les Astéries, les régions du prosome supéricures à la houche, qu’elles soient représentées par un lohe sus-buccil. ou seulement par des bras, disparaissent et s'atrophient: l'anus reste en place. La bouche scule est transportée dans me rígion diamítralement opposée à l'anus. Anssi, pour ce qui est des llolothuries, l'axe principal du prosome devient-il celui du mélasome, font comme "he\% les Crinoüdes; mais l’inversion existe encore, d'une amplilude de 1st). Lin effet, la bonche des llolothmries se reporte (du moins celle de

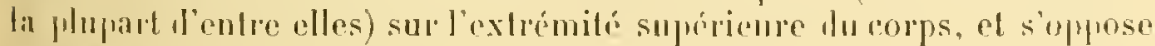

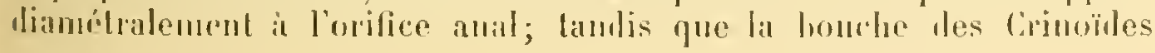


émigre sur l'estrémité inl'ériemre de l'organisme, et vient se placer a còté le l'anus. - lít, sous ce rapport, il est important de voir commencer, chez certains représentauls de la classe des llolothurides, cette migration raractéristique des Crinö̈des, en ce sens yue le corps se recourlie sur

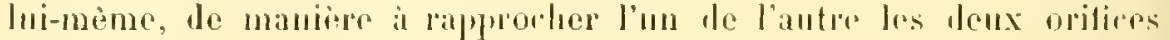
digneslifs.

Celte disoussinn se résume daus les considérations smivantos. Cho\%
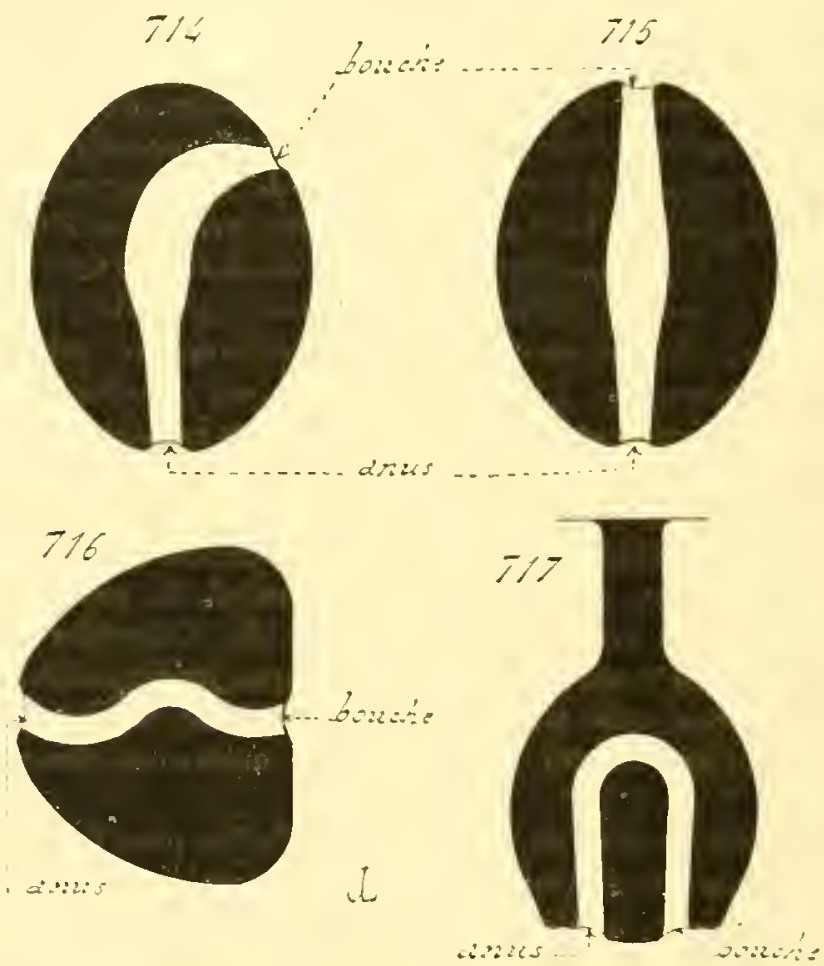

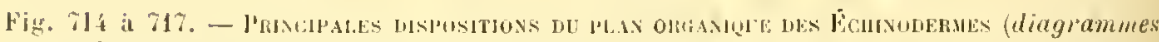

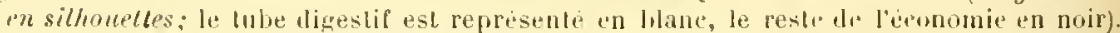
- lin 714, organisme essentiel d'une larve: l'anus est infèrieur, la louche antèrieure. Lin 715, organisme de la jlupapt des IJolotJurides; l'anus est iulérjeur, la honclie supi.

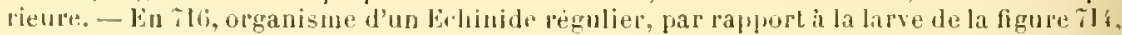

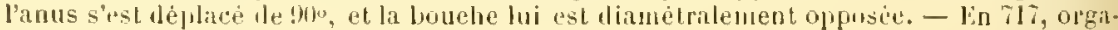
nisme thun Crinoide; lit bouclu: et l'anus sont inférieurs.

tous les Echinorlermes, les ouvertures intestimales du prosome larvaire sout ainsi disposées : l'anus occupe l'extrémité inféricure, et la lrourhe se trouve reportér sur la fare ventable, du corps. Ces orifices sulissent des migrations lirerses, a mesure que le prosome se comvrotil en métasome; leurs changenents de situalion entrainent renx le l’intestiu (car il est étemdu de l'une à l’autre), dont les déplacements déterminent, a lenr tour, ceux des antres organes. Clay les lloluthurides, l'anus reste 
stationnaire sur l'extrénité intérirme du corps; la bouche seule se déplace, et, tantót va ocenper l'extrómité supérieure, tantót reste percée sur la face ventrale du corps, lantit se range a coté de l'anus. Il en est de mème pour lıs Crinö̈des : l'anus est infirrienr, et l'une maniore constante, la louche est située à còté de lui. Les fails changent en re yui regarde les lirhinides, les Istérides, ol les Ophiurides; la bouche senle: -st stationmaire: l'anus émigre, remonte sur la face ventrale du furosome, el soppose diametraloment it la prócilente ouvorture.

C'. - La larve iles Comalules se fixe ensnite par son ixtrémité superienre, izst-idjre par son lobe sus-luccal: la bouche étint loujours placée sur la face antéricure, on ventrale, le son corps. Le vestibule prend alors maissance. Toule la zone péribuceale devient une dépression volumineuse, qui s'enfonce dans le corps, et se confond avec le stomeon. car celui-ci n’est qưu simple cul-de-sac. Cetle dépression est l'úbauche dı vestibule; elle ne pénètre pas directement dans le corps, majs d'une maniere oblique, de facon a se rendre sur l'extrémile inférienre de la larve. En mème temps, elle ferme son orifice extérienr, el devient unc vésicule close. Lorsque le vestibule est arrivé a occuper une position infériem’e, el diamétralement opposée à la zone de fixalion, les tentacules prennent naissance sur son plancher; ces appendices grandissent, brisent la paroi vestilubaire, qui s'ouve, el lout alors saillie an dehors. La louche el l'anus se percent ensuite smr ce mème plancher. La régrion fixéc s'allonge en se relrécissant, et se convertit en un pédoncule; les organes internes s'éhauchent peu ì peu. En délinitive la jeune larve. aimsi altachée ì un support par son lohe sus-bnceal étiré en un pied, se change en un Crinoüde fixé. - Elle se sipare bientiot de re péfoncule,

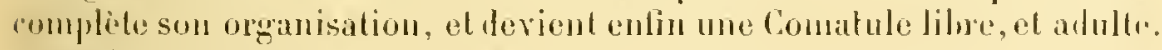
Cetle dernierc phase est spéciale aux Comatules, et manque anx aulrus représentants de la classe.

Tels sont, esquissés dans leurs qrands traits, les principaux phénoménes du développement des Comatules. Il est permis de les grouper en trois phases prineipales; la premiere, la promière phese libre, va depuis l'échosion jusqu’a la fixation de la larve; la deuxiome, la phuse fixée, comprend tous les changenents subis pall l'embryou durant sou existence d'etre allaché a un support; enfin la derniere, la serome phase lilme, se ripprorte anx modilications qui completent l'organisme, après sat séparalion d'avee son pédoncule. La denxieme phase (lixée) se compose, à son tour, de leux états : le premier en date, l'alat cystidéen, est celui daus lepued la jeune larre, touten ayant déji mn test, est encure privée de bras, et pesscmble ansi a mu Cystidé; le second, lélat pentacrinoüde, est celui oil l'embryon, muni i la fois de bras et le pédoncule, rappelle, par sa structure, ine Pentacrine alulte. - Les chamgenents de la forme extérieure sonl teltement liés a cenx sulis par les organcs internes, qu il est necessaire de les itudier en meme lompr. 


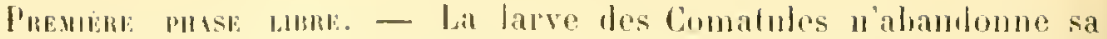

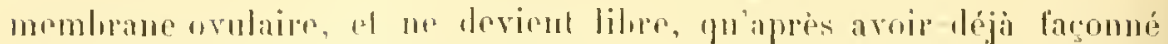
phusirurs do ses urganes, probluil ses romronmes vilubtiles, et les dix

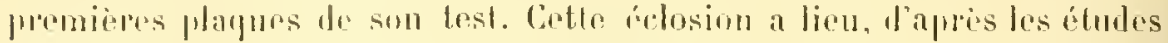

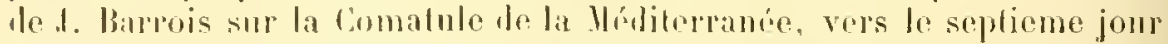

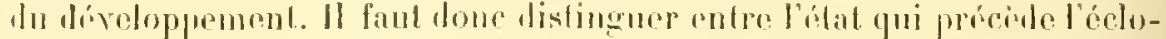

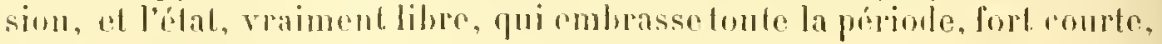
comprise muler léchosion el fo momrut de la fixation.

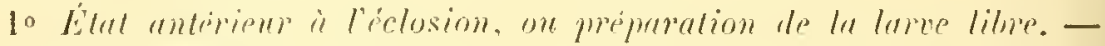
1. La lare, ronlenur daus son emvolofpe, rsl de forme ovalaire. Au

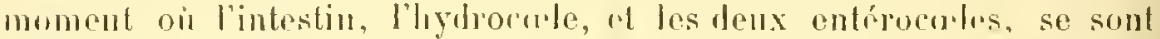
séparós los uns des autres, ol commencent a se déplacer, pour acquérir

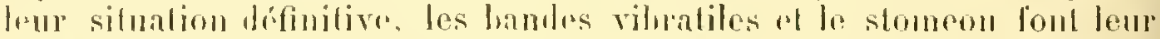

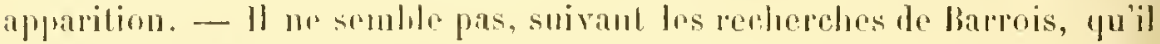
axisl. mo phase premiere, semblable i celle des anloes Eehinodermes,

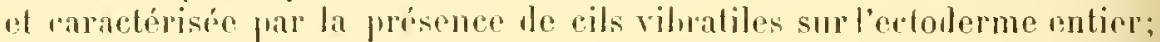
les comomos vilmatiles se delimilent, de prime abord, dans les points qu'elles doivent ocemper, ef nulle autre zone relodermipue ne sp couve de tels appendires. Ces rouromes sont au nombre degualre; à peu près placécs ì ligale distance les mes des antres, elles entourent le rorps a la manibe de coreles transversanx. La larve porte en surplus, sur le summet de son lole sus-bnceal, cest-at-dire dans la région luture de fixalion, une toulfe de cils ribraliles, nommón parfois li calolte. A côlé de celte touffe, et située également sur le sommel ıu futur pédoncule, se moulre une pelite zone aplatie, qui se déprime quelque peu; c'est par cetle zone, dite fossetle firatrice. que s'effectuera la lixation de l’individu sur un support. A leur délut, qui correspond au moment oì l'entéron primomlial se divise en deux parties, les quatre comomes vibratiles sont minces. of tres voisines les unes des antres; elles s’élargissent ensuite, ef sécartent ì mesure, le maniere à ucenper lenr siluation définitive. signalér plus haul.

Le slomeon so forme, an moven d'une dépression ectodermipue, vers le milien de la lace ventrale (antipienre) Ju corps, an niveau meme de Jintestiu. Il conserve toujours l'aspect d'un cul-de-sac, ne prinètre pas profondément lans lorganisme, et ue se met pas en communication lirecte arec la ravité intestinale; il disparait au moment de la fixation de la larve, car il se ronfond avec la dépression qui donne l'éhanche du vostilule. Lorifice exlérieur du stomeon ust souvent lésigné par le nom de fossetle ventrale; il ost, on ríaliti, l'Jomologne de la bouche des antres

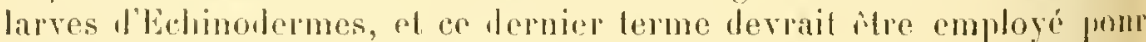
le désigner. Comme il esl pulque pen allongé suivant l'axe longitudinal

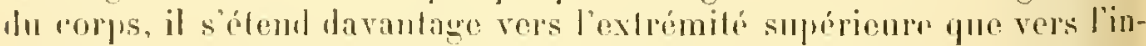

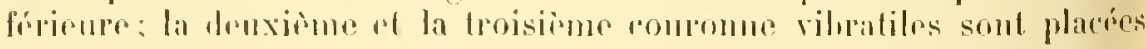

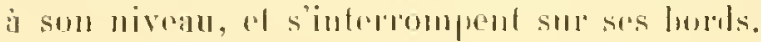


parallèles les mus aux antres, et orientés suivant un sens transversal, perpendiculaire au erran! axe du pérloncule: ils dóposent ensuite la sulustance ralcaire, chapue groupe produisanl un disque. Iluit il dix de res disques empilés sont ainsi formós; le plus élevé d'entre enx, placó

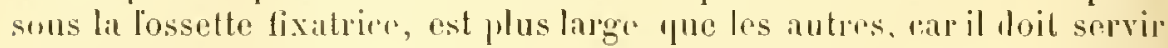
i altacher limlivilu an support. Le lópiot calcaire commence, pour rhaque disqur, vers le centre du prolonenle, autour du rordon axial, et

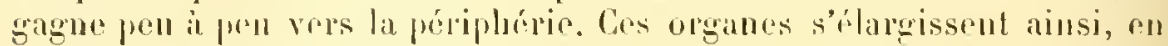
progressant dr dedans en dehor's.

Le mósouclyome alycimal fommit de son coté les dix fremières playnes lu test du calyce; ces dernièras se faconnent lans le somatomésencliyme, comme leurs homologues des autres lichinolermes. Elles sont rassemblées en deux rangées, de ciny plapues chacune: ces deux rangérs sont superposées, l’une étant lout à fait terminale et inférienre, l'autre ćlant romprise entre la précólento el le commencement du pédoncule. Les cinq plaques terminales sont los oroles; les riny antres sont les hasales. I'apries . I. Barrois, res plaques naissent en mome temps. - Il nen est pas ainsi pour le pédoncule, dout les dispues se développent les uns aptós les autres; l'ordre géuétipue so dirige rn cela de haul en bas. La premièe plaque produite rst tout à fail terminale, el située au sommet dn lohe sus-liuccal; c’est par elle que la larve s'attache à un corps étranger, et les antenrs la nomment la plaque basilaire. Ainsi que f'errier l'a démontré, cette dernière est l'homologue de la centro-dorsale lles autres Echinolermes, car elle nail la première pami les pieces dı pédoncule, et se lrouve placre, ì son déhul, au centre lu grompe formé par les orales et les hasales. Le terme de piére centro-dorsale, appliqué ¿ la paroi calcaire du ralvor de l'alulle, est done inexact, car relte

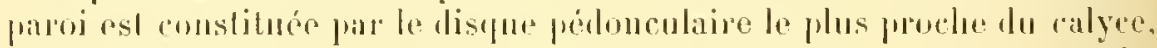

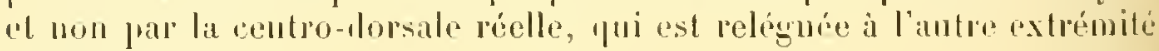
du pédoncule.

lu ce moment de son évolution, la larve pere son envelopre, devient libre, et nage à l'aile de ses conronues vibratiles.

go Élut de liberté comsiculif à l'éclosion. - La litrve libre est d'une lorme ovalaire allongée. Elle est entomréc par ses quatre comromes vibraliles, et porte la calotle sur sa face supurienre; la partie périphéripue de cette dernière se sépare quelpue pen de sa partie centrale, de faron à donner un cimpuieme corcle viluatile, l'itentue restreinte. I la hase le la calotte so trouve li fossette lixatrice; et. sur la face rinlrale

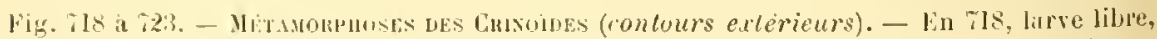
monlint pa transparence ses premieres plarues. - Eu \%19, larve libre plus igè au debut du fagonnement du vestibule. - En Fe0, larve an commencement de la fixation.

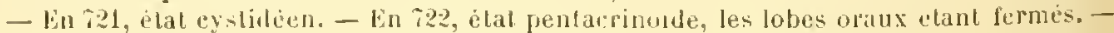
lin 723 , mėue etıl, les lobes oraux élaut unverts, et laissant saillir les tenlarules avec les ebaluches des hiras. - (Wapres les recherches fales par II. Tliomson sur les Comauiles.) 


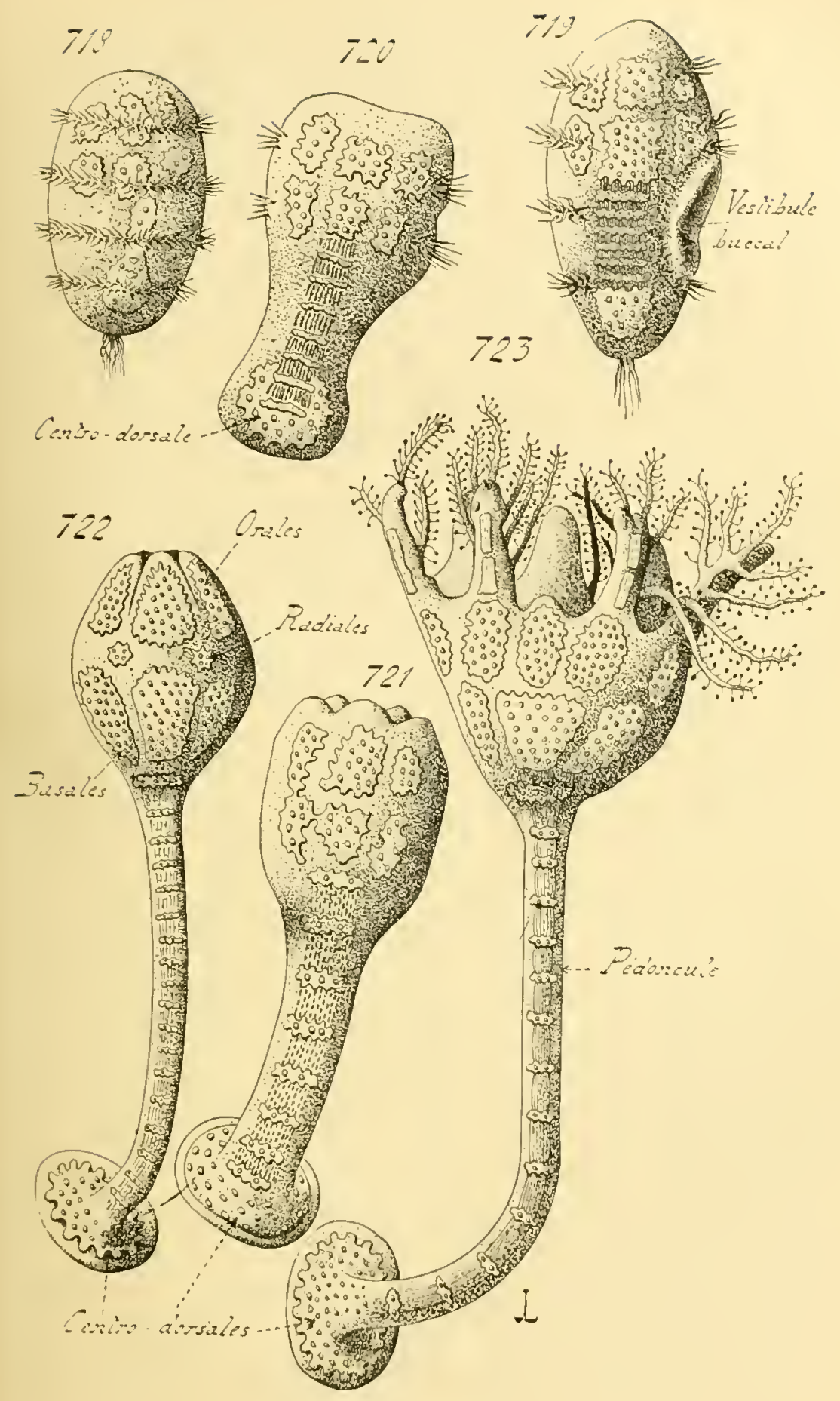

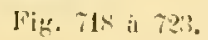


du ropps, diprime el aplatice, est percéc la fossellr ventrale des auteurs, la lonche on réalitr. - En cel élat, la larve rappelle de très près, par son aspect extérienr, une pupe d'llololhurie. Elle dillère pourtant de colle donnière par plusieurs points : elle ne dérive pas d'une durieulaire, et parvient directement à la structure quielle possède; elle renferme, dans son mésenchyme, les premiers articles du pédoncule, dont les Ilolothuries sont constamment privées; elle conserve son lobe suslucral, et le convertit en un pédoncule de fixation; enfin, la houche vicul se reporter sur l'extrémilé inférieure du corps, an lien de remonler sur l'rxtromilé superieure, comme il en est chez la plupart des Hololhurides. La ressembance de celle phase larvaiue des Crinoïdes, arec la pupe précédente, mérite cependaut l'ètre signalće; car elle lémoigne d'allinilés étroites entre les deux classes.

En ce moment, les denx entérocules ont pris leur silualion définilive. lientérocole droil est devenu supérieur, et le gauche inférieur: le jromier émet un liverlicule, qui pénètre dans la région axiale du lohe sus-luccal. Lintestin se présente encoro comme une résicule, pesque gloluleuse, completement enchissée par les entérocoles et par l'hydro'ule; l'entérocale lroit, on supérieur, emlı́asse sa moitié supérieure; l'entérocule gauche, ou inférieur, entoure la parlie postérieure de sa moilié inférienre; la roselle hydrophore et le canal du sable saccolent ¿ la parlic antérieure, on ventrale, le celle méme moitié. Ces deux derniers organes séparent l’intestin du stomenn; celui-ci pénètre dans le corj's, jusqu' a leur niveau, mais ne va pas plus loin, el ne s'ouvre pas lans la cavité intestinale. La roselte hydrophore conserve son aspect de croissant; seulement ses deux extrémilés se rapprochent l'une de l’aube, et ce développenent, en continuant à s'ellectuer daus la mème diochion, ne va jas larder a lui donner une forme ammulaire complète.

La durce de cette vie libre est tries comte. La larve, apres avoir tourbillonmé pentant juelque tenıps, se fixe à un corps élranger, si le hasard lui permet „len renconlrer un. Elle sallache a lui par sa fosselte fixalrive, placéc au sommet du lobe sus-luccal; ce dernicr se rélrécit alors, s'allongra, et se convertil en un pérloncule. Calte dernière expression sera, par suite, seule emplovée désormais; il suftit de se représenter que le perloncule des crinoïhes n'est antre que le lobe sus-buceal de leurs larves.

l'us: rase. - De suile apres le moment oil la larve s'est allachée i 111 support, fous les appendices vilualiles disparaissent, el la disposition extérienre de l'organisme pédonculé s’élanche déjà. En ellel, la région pérlonculaire devient plus étroite que la région adycinale, et aiusi s'élablit la dillérenee entre les teux parlies lu corps, dillérence qui s'acenulue de plus en plus, à mesureque les elats suivants se déroulent. - Ces étals sont an nombre de deux : le premicr est l'étal cystertrén, le second l'etat pentacrinoüde. 


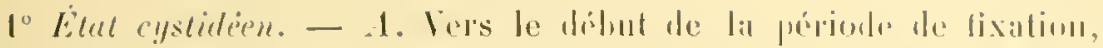
reptaines régions du colps subissent mo ligere desagrigation. dimsi, l'apres bury, les cellules endudermiques se multiplient de maniore it faire parrenir, dans la cavilé intestinale, les éléments puodles engendrent, et à la comblel avec enx. He mène, les cellules de l'ectoderume se désargrègent fuclque peu, et émettent, prar leur face profonde, des expansions, qui pénélrent dans le mésenchyme sous-jacent. Cette disposition cesse lexister, vers la lin de la présente phase, oí la couche ectodermipue reprend res contours rexuliers et distincts.

le corps se divise en mn péloncule el mu ralyce. Le premier grandit de prefirence suivant sa longucur; anssi frarait-il se rélrécir l’ume matnière constante. Le second saucroit dans fons les sens, ef conserve son aspect globuleux. Ia lissemblance, motre ces deux régions, vil ainsi, devenant de plus en plus profonde; et lenr zone de jonction, d'abord dilluse et peu précise, se trouve etre de plus en plus limitio. - Le nombre des disfjues raleaires lu púdoncule angmente, et atleint le chitrie de quinze ou seize; les nouveaux élóments sont froduits dans l'extrimité proximale de ce predoncule, cest-a-lire dans cette partic pui s'unit an calree. - Dautre part, mais seulement rers la fin le l'état isslidéen, el le début de l'état pentacrinoïle, des plapues supplémentaires, au nombre de cinn, naissent dans le sumato-mésenchyme du ralyce; celles-ci sont les radiales. Elles sont, le tuntes manières. placées cutre les orales et les basales qui existent déjà. Ces dernières sont dispusies he telle sorte, qu mue orale est situce au-dessous d'une basale, en suivant l'axe longitudinal Wu corps. Chayue orale est separée he sa basale correspondante frar un assez lange espace transversal de lissu non calcitié; le mene, chaque file, composéc d'une rrale el d'une basale, est séparée les rangées roisines par un espace analogue, mais longitudinal; or, chapue raliale se forme dans lune des ciny intersections le ces espraces.

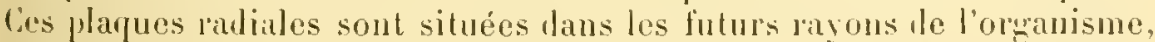
romme leur nom l'indique du reste; tamlis que les ciny files d'orales el le bisiales sont placées dans les interrayons.

Le vestilute prent naissance le suite apres le moment de la fixation. L'espace péribucal se déprime, et se confond avec le stomeon próexistant. de maniere à ne faire avec lui qu une seule t mème invagrination. Celle-ci, an lien de pénétrer directomunt dans le corps, ollinue vers lextrémité distale du calyee, et ohture rn mème temps son orilice exterieur; elle se convertil jar la en more résicule close, volmuinense, dout la paroi est limitée par un épithélinm d'origine ectodemninuc : l'ébanchu du vestibule. - Cotle vesicule vestibulare continue i se doplaced suirant la direction qu'elle a léji frise, et finit par oceupes cutièrement l'extrémite distale lu calyce, éest-it-dire vette région qui correspund au sommet inferienr du corps de la lave, oi l'entéropose s'est lemé. La

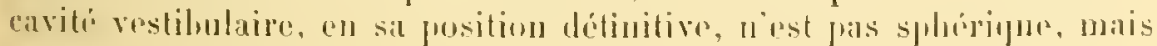

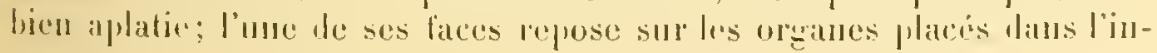




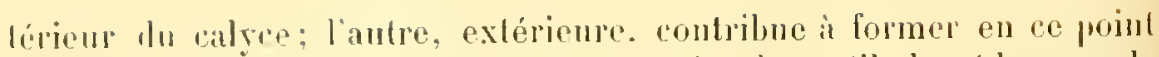
la plaroi calycinale. la première ust le plancher du vestibule, of la seconde le dime: cette deruiove expression peut utre itendue, non seulement à la paroj prople du veslibule, mais encore a loule la paroi de celte jégion furealyee. Sur lo planches ne tapleront pas à nailre les tentacules pérjluncaux, et í se percer la houche avec l'anus: le lome est destiué à somril, pour faire communiquer la cavité vestilubiare avec le dehors, el laisser saillir les tentacules. La praroi du dome renfrrme les plarues orales dans sa masse.

B. - Le lube digestif est, au commencement le l'élal eyslidéen, uno vésicule gloluleuse remplie de cellules, et presque compacte. Il grandit, sa cavilé interne angmente, à son tour. te dimensions, pour Jonnes la cavité inlestinale. 'Tout en s'amplifiant, ce tube s'dllonge el se recourlue sur lui-même en croissant. Lrs deux extrénités du croissant se rapprochent lu plancher lu vestilule, el s'accolent i lui; la boulde se perce dans l'une dos régious de somdure, el l'anus dans l'autre. - II résulte le relte évolution que l'anus se crense, exactement, lans nue région correspondante à celle où l'entéropore initial s'est fermé: il est ainsi l'homologme, en tant que prosition sur le corps, de colui des autres Echinodermes. Wautre part, la louche, an lien de lui ètre diamétralement opposée, lui est presipue accoléc, et occupe arec lui, jar rajport an prosome larvaire, me siluation inféricure. Celte forme de I'intestin nest réaliséc que vers la fin le l'oblat eyslidécn, et le lébut le l'état pentacinoirle.

Les entérococles subissent, ì leur tour, des modilications imporfantes, corribatives de celles présentées par l’intestin. Lancien entérocole droil, le supéricur lésormais, conserve l'aspect d'une calolte, qui enchasse le haut de la courhure intestimale; sa cavilé est fort étroite, souvent ì peine discernalile. tes auteurs le nomment sac péritonéal, ou encose sac aboral, paree qu'il est le plus éloigné de la honche. lientérocole inférieur, le gauche primitif, commence par enlourer, it la maniege l'm anneau, la région asoplagienne de l'intestin. Les deux cxtrémités de cel annean ne viennent pourtant pas an contact, el restent séparées l"une de l'aulre par un espace rempli de cellules mésenchymateuses; c'est aux dipens de ce mésenchyme, qui se conlinne arec le somato-mésencliymo lu calvee el le cordon pédonculaire, fue se diveloppe le ganglion Iymphatipue des cinö̈des, l'oryane axial et lorgane spongioux les auleurs. Le mósenchyme le l'óbauche de ce anglion se lie, également, ave celui pris dans la commure intestinale. et qui contrilue, de sou cote, a produire mue part du ganglion. Lume des extrémités de l'anneau entérocolicu s’inlléchit, de manière à púnétrer lans ee mésenchyme intra-intestinal; elle y constitue l'espace libre, nommó par les auteurs la crvite columellaire. Celle cavité est, en effel, une sorte d'axe, de rolumello, autour de laqueltr so disposent le mésen- 
chyme splanchnique, ou intra-intestinal, et l’intestin lui-mème. I ientérocule inférieur est également lésigné, par les auteurs, sous les expressions de sac péricesophagien, et le sac oral. - Les deux entérocieles, en entomant lintestin, l'un a la manière d'une calotte, et l'autre à la façon d'un anneau, se replient autour de lui; les extrémités de chacun d'eux ne viement pas an contact l'une de l'antre. l'espare intermédiaire ronstitue, pour chacun d'eux, un mésentère longifudinal. Le mésenturu inférienr (mésentère longitudinal oral de l'errier) est celui décrit dans les ligrnes prócédentes; le mésentère supérieur (mésentère longitudinal aloral de l'errier) va rejoindre le mésenchyme du pédoncule. De plus, dans leur reploiement autour de l'intestin, l'un des entérocceles est placé au-dessus de lautre, el se trouve séparé de lui par un espace, rempli de cellules mésenchỵmateuses, qui constitue un nouveau mésentère, à la direction transversale : sa situation málite ì ce dernier le nom de mésentire intermédiaire. C'est par l'entremise de ce mésentire que le mósen"lyme splanchnique et le mésenchyme du mésentère inférieur se joignent au mésenchrme du mésentère supérieur, et par là à celui du pédoncule.

La deseription précédente montre, en somme, que lous les organes internes sont séparés les uns des autres par des coussinets de mésenclỵme; cenx-ci prennent des dispositions connexes ì celles quoffrent ces organes eux-mèmes, et restent toujours unis les uns aux autres, i travers les interstices que laissent entre eux les appareils. Il est nécessaire d'avoir, dans la conception de ces phases évolutives, présente à lesprit, la répartition de ce mésenchyne en une sorte de gangue communc. Cetle notion s'applique également à la description suivante, qui porte sur le systène hỵlrophore.

C. - Les rhangements subis par ce systeme sont assez complexes, mais peurent ètre résumés en quelques donuées essentielles. - Tout J'abord, l'ensemble de l'appareil est latéral par rapport à l'intestin, et situé cutre re dernier et la première ébanr.le de la dépression restilulaire; il perd ensuite celle position iniliale, et accompagne le reslibule daus sa migration. Toujours jlacé en dedans de lui, et en rapport direct avec son plancher, il finit ainsi par se trouver lans la région terminale du ealyce, où parvient également le vestibule, el oi vont prende naissance les tentarules, la louche, et l'anus. - Le tube hydrophore siallonge pendant ee lransfert, et sourre an dehors; son hydropore est percé dans la riggion dorsale, ou postérieure, de cette extrémité du calyce, c’est-à-dire dans une zone diamétralement opposée à celle qu'ocenpaient la louche, et le vestibule, ì leur délıut. D'après Barrois, la partie du lube lydrophore, roisine de l'hylropore, se renfle, et constitue li cavité anpullaire nommée par Perricr le sac parictul; suivant Perrier lui-mème, re sac serait une dépendance de l'entérocule iuférieur. - Les modifications ultirieures, subies par ce tube hydrophore, ne sont 
pas encore completenutul élucilés. Il semble cependant, à en juger l'apres les résullats ultimes de son érolulion, quil so met de nouveau en relations directes aver la roselte hydrophore, el quil s'unit ì elle, comme chez les autres Echinodermes, pour lui permoltre de communiquer arer le delurs. Puis il sedivise, vers son milieu, en deux troncons, dont l'un s'ouvre à l'extérieur par l'hỵopore, et lont l'autre reste appendu a la rosette; cette scission sinffectue do lelle sorle, que les deux segments s'ourrent le mèm dans la cavité de l'untérocale inférieur. Cette druière est donc interméliaire a la rosetle hyllophore et a l'eau du dehors; c'est par son cntremise que relle-ci est capable do pénétrer dans celle-là. Ces transformalions se produisent vers la liu de l'état cystidéen.

La rusette hydrophose est, ì cause de son déplarement lié à celui du vestibule, placée en dedans du plaucher de ce dernier. Elle se convertit en un annean fermé, par le rapprochement, at la soudure, le ses deux extrémités. La nonvelle invarginalion stoméale, yui donne naissance à la bouche et à l'usophage définitifs, traverse la cavité de cet anucau; ainsi se trouve jéalisée la structure ultime : l'anmeau hydrophore entourant la paroi asophagienne. - Les cinq diverticules de cet appareil, déjà élauchés lor's des phases précélentes, grandissent, el soulevent ì leur niveau le plancher du vestibule; ces porlions soulevées sont d'abord les petils mamelons, qui s'allongent, et se couvertissent en expansions cylindriques. Ces dernieres sont, par suite, au nombre de cinq, el environnent, ì cause le leur origine, l'ouverture luccale; elles représentent les premicrs tentacules bucranx. - Ceux-ci ne restent las simples; chacun l'eux, alors qu’j est encore assez petit, se ramilie en trois hranches, vers sa base adhérente. Les trois lianches s'allongent égalemenl, el la larve possède alors quinze lentacules, groupés en cinq faisceaux. La production le branches nourelles ne sarète pas à ce chilfre, car chacun des tentacules primaires produil, en surplus, deux aulres expansions; le nombre total est alor's porté it vingl-ciny. Linsi, a cause le la simplicité première des teulacules périlurcaux, puis de leur division en trois branclues, el enfin te leur suission en cinf rameanx, la lare possede d'aboril ring tentacules, ensujle quinze, et vingt-cinl] an lernier lien.

le lome du vestilule so brisc pemlant pue ees lentacules grandissent. Sa ruplure nost fras irrégulierr, à cause de la présence, daus son épaisseur, les riny plaques uralıs; les lignes de division sont placées daus les ciny espaces, non calcifiés, 'pui séparent les plaques les unes des autres, el sútendent du sommet du dòme aux plaques radiales. Les lohes ainsi prorluits ne se étachent pas. et ne s'alrophicul poinl; it son gré, l'animal peul les écarter les uns des auljes, de manière à laisser sa cavité vestibulaire communiquer lihrement el largement arec le dehors, ou lien les roployer, de füon ì fermer licrméliquement celle mème arite. Dins le premier cas, les tentacules s'in'adient dans l'eau envi- 
romnante, el sont capables de saisir les menus objets, ponr les transmettre ì la bouche quils entourent; dans le sceond, il se replient sur cux-mèmes, et restent abrités par le lòme, qui s’est refermé. Ces cinı lobes oraul ont des contom's précis, et sont semblables les uns aux antres; chacun d'eus, étant donnce son origine, contient unc plaque orale clans son épaisseur.

I). - L'état cystidéen est alors atteint, et la larve va subir les morlifications qui découlent le l'état pentacrinoïde. - Son corps est nettement divisé en calyce et pédoncule; les articles pélonculaires sont nomlreux, et alteignent environ le chiffre de seize; les plaques du calyce se composent de cinc] basales, de cinq radiales, et de cinq orales mobiles. La cavité vestibulaire occuje sa situation définitive, terminale, et souvre, ou se clót, par le jeu des lobes oraux, qui renferment les plaques orales. I. intestin est muni d'une bouche et d'un anus; la bouche est entourée de cing groujes de tentacules péribuccaux, chaque groupe comprenant cinq tentacules. L'entéroccele supérieur, l'ancien droit, est levenu la cavité péritonéale; l'entérocule inférieur, l'ancien gauche, s'est converti en sac prioesophagion. La rosette hydrophorr s'est transformée ì son lour en annean hyhophore, qui entoure l'osophage; de cet anneau part un segment du tube hydrophore, qui sonve dans le sac périusophagien; ef le ce lernier frart le second segment du lube hydrophore, qui déliouche au dehors. - Mors commence l'état pentat-
crinoïde.

Eilat pentacrinoüle. - Cet ćtat est, avant tout, caractérisé par l'ajparition des bras de l'adulte.

A. - Le pédoncule conserve sa forme allongée, ot eylindrigue. Le calyce preml son aspect conique définitif. Le plancher du vestibule, muni de la bouche, de l'anus, et des tentacules, recouvert par les plaques orales, s'aplatit, et donne le disque de l'adulte; il correspond à la base du cône. Les cótés, 'jui se rétrécissent peu à peu, et vont s'unir an pédoncule, constituent le calyce proprement dit. Le sijuelette de celui-ci est représenté par les cinq basales, et les cing radiales. Ces dernières sont situées dans la région mème où les còtés se réunissent a la luase, on le calyce se joint au lisque, "t, par conséquent, lans la zone ou le corps ollie sa plus grande largeur.

Les bras naissent dans cette \%one. Charmn d'enx est formé, à son délunt, jar un soulèvement le la paroi ln corjs, placé an nivedu d'une plaque radiale, et dans lequel pénétrent des expansions des deux entodocules et de l'anncan hylrophore. Ces régions soulevées s'allongent, en devenant cylindriques, et ne tardent pas ì se diviser en denx pirties, fui grandissent egalement; chaque bras se compose alors diune base commune, inserée sur la radiale, et de denx luas secondaires. Ces derniers se scindent egralencut en plusicurs branches, de flus en phos nom- 
hreuses, qui constituent les pinnules de l'adulte. - Charpue bras contient un diverticule de la rosellr hydrophore, qui lui est fourni par la hase du tentacule péribuccal correspontunt; cetle base s'accole au bras en voie de développenent, se ramilie, se divise comme lui, et lui donne son canal ambulacraire. Les entérocmles se prolongent igalenent dans chaque bras; leurs diverlicules sont séparés l"un de l'autro par un plancher. L'expansion le l'nutéromle gatuche, devenu le sac jériosophagien, est, d'après L. P'errier, la cavité sous-tentucularie du bras complet; celle de l'entérocule droit, c’ust-a-dire du sac pririloníal, est la cavité caliaque du mème appendice. De mème que dans le corps, dont les bras ne sont qu" dis prolongrments, un mésenchym ass"z aloniant est placé entre l'ectorlerme et les parois de ces cavilés; ce mésenclygme se continue avec celui du calyce, auquel il se relie directement. - Le nombre des plarues radiales, qui supportent les bras, augmente l'une manière commexc au développrument le ces derniers; il était le cim l'alord, et devient bientirt égal à quinze, car deux plaques ratiales supplémentaires apparaissent au-dessus de chacune les cinq jrécédentes.

$B$. - Les autres phénomènes importants, qui caractérisent l'état pentacrinoïle portent sur les entéroca!les, le mésenclyyme, et l’aplareil hydrophore. - Chacun des deux entéracoles cumet, comme it est dit ci-dessus, une expansion pour chacm des bras. En ontre, le sac perilonéal (ancien droit, ancien supérieur) possédait un diverticule, qui pénétrail dans la zone d'union du pédonoule el lu calyce. Ce diverlicule se sépare, par un plancher, de la cavité a laquelle il appartient, el se subdivise en cinq espaces au moyen de rinq cloisons; il constitue l'organe cloisonne de Porrier. Cette genèse s'eflectue de telle sorte, que la base du ganghion lymphatique se continue avec le mésenchyme que ces cloisons contiennent elles-mèmrs. We son côlé, la cavité columellaire, émise par le sar périrsophagien (ancien entérocule gauche, ancien entérocule inférieur), persiste dans la situation qu'elle occupe, an centre de la rourbure intestinale; c'est d'elle que dérive, sans doule, la ravilé axiale de lerrier. Cetle cavité axiale entoure te ganglion lymplatique.

Ce dernier est constitué far le mésenclyme splanchnique, et par celui situé daus les mésenteres longitulinaux. Il forme un cordon cellulaire, l'organe axial de l'errer, qui part du sommel du calyce, oì il traverse l'organe cloisonné el rejoint le nésencliyme du pédoncule,

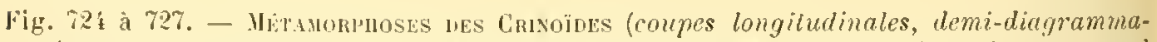
tiques, acer nerspective). - En 72h, lelut le la fixation par le lobe sus-lunceal; correspond a la figure 720. - lin 725, tat plus avance; le vestilule se déplace pour devenir inferieur. - lin 726 , etat ejstiben; correspond à la figure 721 . - Lin 727 , état pentacrinoïde; correspond aux lighres 722 et 723.

Les plapues ne sont indijuées que dans la figure 727. - (I'après les recherches faites par

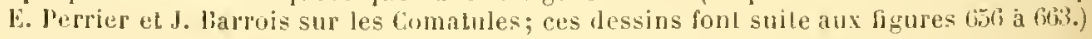


pour parcomir le corps, suivant son axe, afin de se mapprocher du planrher du vestibule : l'oì lo terme emplové par l'auteur précité. Son extrémité, dans cette lernière région, se confond avec le mésenchyne qui entoure l'asophage et l'anneau hylrophore. Ce lernier prouluit un laris de cavités lacunaires, auquel Ludwig a donné un nom particulier : l'organe spongfieux. De plus, le mésenchyme le ce ganglion se raccorle avec celui qui, placé dans les hras en rojesle développement, se prolonge jusıue lans les pinmules. Sujvant la juste comparaison faite par Perrjer, cette ébauche hu ganglion lymphatique (l'organe axial de cet anteur) parait étre un trone, dont l'extrémité porte rinq branclies, qui pénètrent dans les hras, et envojent des ramifications lans les pinnules. Ces derniers raneanx se convertissent en cellules sexuelles; et c'est ainsi que les éléments reproductenrs des Crinoïles sont placés lans les pinnules des bras.

L'appareil hydrophore se complique. Vers la fin de l'état cystidéen, il se compose seulement d'un annea hyllophore, imetlant les canaux Jes tentacules, et d’un seul Inlue hydrophorr. Ce lernier, de son côté, comprend deux parties, l"une atlachée à l'anneau, et l'autre aux téguments. Celle-là est un tuhe hydrophore définitif; celle-ci répond au premicr entomoir vibratile; toutes deux s'ouvent daus le sae périusophagien, qui leur permet ainsi le communiquer entre elles. - Durant l'élat pentacrinoïde, l'anneau hydrophore produit, en surplus, cinq canaux ambulacraires, qui accompagnent les hras dans leur cxtension, et quatre nouveaux tubes hydropliores. Ces lerniers sont constitués par des diverticules de l'anneau, qui s'ouvrent, de mème que celui existant déjà, dans le sac péricesophagien (dapries Ludwig et II. Carpenter), et sont placés dans les interrayons; ils s'attarhent douc à l'annean hyilrophore, rntre les canaux ambulacraires précitís. De plus, et l'une façon connexe à cette wenese de nouveaux tubes hyolrophores, quatre entonnoirs vibratiles supplémentaires sont formés sur le disque, dans la mème situalion que les tubes hylrophores correspondants, et ront également déboucher dans le sac péricesophagien. La larve posside alors cinq tubes hydrophores, el cinq entonnoirs viluatiles, placés dans les interragons, communiquant tous avec le sac pério'sophagirn, qui leur sert le réservoir et d’intermédiaire commun. - Cet élat persiste durant toute la vie chez les lihizocrinides; il est lemporaire, par contre, chez les Perutacrinides et les Comatulides, car le nombre de ces appareils, pour cequi lient anx reprósentants de cesdenx fanilles, ra angmenter.

C. - A co moment le son exolulion, la larve les Comalules abandonne sun póloncule; sun ralyce se détache, et devient libre. la leuxieme phase libre, quj induit à l'état adulte, commence alors.

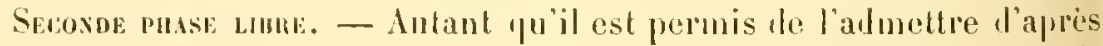
lenr état délinitif, les I'entacrinides cn restent a la fin de l'état précé- 
dent. désigné par leur propre nom, el ne joussent pas plus loin leur

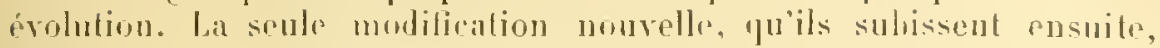
consiste en une augmentation considérable du nombre des tubes hvelrophores el des entonnoirs vibratiles; les nomveaux conduits formés sont disposés de la mème manière que les rinq existant déjả, et affecteut des connexions identiques. Le pédoncule persiste, et sert à atlacher l'indivilu sur un corps élranger. - Par contre, les Comalulides augmentent igalement le chiffre de leurs entonnoirs el de leurs tubes, tout comme les l'entacrines; mais chaque individu délache son calyce de son peedoncule, après quoi celui-ci se désorganise, alors que le calyce représente ¿ lui seul lorganisme parfait. An moment le cette séparation, chaque liras ne porle encore que denx pinnules, ef le premier rang les cirries fixés sur lo calyce est seul présent. Les bras s’allongent par la suite, et produisent de nouvelles pinnules: tout comme la paroi calycinale donne naissance à des rirrhes supplémentaires.

Les cirrlos oul mòme origine que les lras, ot dérivent également d'extruflexions le la paroi du corps; mais ces régions soulevées, et semblables a les petits mamelons, sont situées sur le sommet du calree, non loin de la région par laquelle ce dernier simissait au pédoncule. Cas sallies s'allongent, tout en demrurant minces, et premnent une lorme rylindrique; des pieces calcaires, semblables à des disques superposés, se façonnent dans leur sulystance, et leur doment un aspect auticulé. En ontre, l'organe cloisonné, c'est-à-dire l'expansion lerminale du sac péritonéal (ancien entírocule droit, ou supérieur), envoie, dans elıaque cirrhe, deux direrticules, dont l'ensemble constitue a ces appendices une double cavité axiale. - Saul ces relations d'une partie de lentérocıle avec les cirrhes, el qui ne peuvent exister, car les cavitis entérocoliennes ne paraissent pas ailleurs se prolonger dans le pédoncule, les mèmes notions d'origine doivent s'appliquer aux cirrhes placés sur les pédoncules des autres Crinoüles.

Alors que les plaques orales persistent chez divers reprósentants de la classe (Rhizocrinides par exemple). elles disparaissent chez les Comalulides, bien que les lobes oraux correspondants sojent conservés. En outre, et toujonrs che\% res dernières, les plaques basales se soudent les unes aux aulres on mu seul corps, nommé la roselle, qui se place dans le sommet lu ralyce, et ! limite la hase de lorgane choisomur. Lirticle teminal du pédoncule reste abléront au calyce. lors de la séparation, ot zrandit lieaucoup. Il constibe finalement, i lui soul,

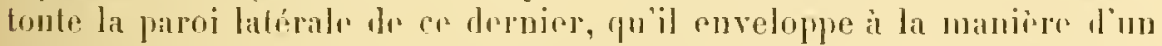

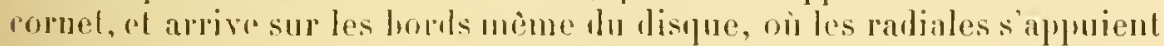
sur hui. la plupart des auleurs designent retle piece par le lerme de centro-dorsale; rette expression, yui permet de croise a wo homologie avec la veribalo centro-rlorsale des autres lichinodermes, est faulive. Il rambat mieux la remplacer par relle de rornet, pui indique suffisamment sa forme el ses ripports. - lo plus, des petites playues cal- 
caires, disséminées sans ordre, naissent dans les téguments du disque; l'nne de ces plaques, un peu plus grande que les antres, entoure l'anus, et mérite le nom de plaque anale.

La jeune Comatule est alor's complète; son érolution embryonuaire pent être considéréc comme achevée. Le nombre de ses entomuoirs vibratiles et de ses tubes hyilrophores s'est accru daus des proportions considérables, sans qu'il existo aucun rapport précis entre la quantité les uns et celle des autres. Les baudes, qui séparent l'une de l'autre les deux cavilés axiales de chaque bras, ou de chaque cirrhe, se détruisent par places, et permettent des communications lrápuentes el irrégulières entre ces espaces. En somme, l'organisme détinitif est achevé, et sa taille est déjà assez grande; il ne lui reste plus qu'il l'augmenter eucore quelque pen, ponr devenir adulte, et itre capable de se reproduire.

Appendick. - Dans cette description du développement des Crinoüdes, el surtout dans sa fremière prartie, tous les organes de l'économie ont été considérés comme placés dans une situilion telle, que le pédoncule se trouvait supérieur, et le calyce inférieur. Cette disposition est voulue par le développement lui-mème, juisque le prosome les larves des Crinoïdes est identique à celui des larves des autres Exchinodermes; afin d'établir les homologies les diverses parties du corjos, il est nécessaire de conserver à tous ces embryons une orientation commune. - Au moment oì l'état adulte est atteint, cette nécessité devient moins impérieuse. Quelle que soit, en effet, la disposition de l'intestin et dr ses orifices dans le métasome, par rapport í celle qu'il affectait daus le prosome, les appareils se groupent aulour du tube digestif, chez lons les Echinodermes, d'une manière symétrique el identique. Il sultit alors, afin de romparer les diverses struchres, de flacer l'intestin d'une maniòre uniforme chez tous les représentants de l'embranchement. Il est permis de choisir un plan quelconque le symétrie, et de se passer, comme guide en celte occurrence, de la disposition première domnée par le jrosome, puisqu'elle se modifie de facon varialile suivant les types. La plupart des anatomisles s'accordent, sur ce sujet. pour disposer les lichinodermes avec la bouche en haut, et pour tout rapporter ì celle orientation.

Dans ce cas, le pédoncule des Crinö̈des devient inférieur, comme l'anus el la bonche se trouvent oceuper la face supéricure du calyce.

Cependant, il est utile de ne pas l'oublier, cette orientation est tonte de convention, et elle est nécessitée par les commodités de la comparaison anatomique. Aussitôt que l'on se reporte aux lomologies dans le temps, la disposition première du prosome est la seule base fondanentale et logique, et les relilious, aver les termes qui les exprimont, doivent être choisies comme elles le sont dans les descriptions précélenles. 


\section{5. - Reproduction asexuelle.}

La reproduction asexnelle ne posside pas, chez les Echinodermes, unc bien grande imprortance. Il est permis de la consilérer comme une amplification de la propriété de régénérer certaines parties létruites. Ainsi les llolothuries, ou bien les Crinö̈des, ayant perdu, par une cause juelconque, un fragrment, on la totalité, de leir intestin, jouissent de la faculté de prodnire in nowrean ces apprareils, et de rederenir complets. Les Astérides et les Ophiurides bourgeonnent, parfois, des hras supplémentaires. Si, au lieu de se horner à un seul organe, cette facullé sétend a l'économie entière, en ce seus qu'elle est capalıle d'engendrer, ì ses lépens, $n$ individu complet, on obtient une véritable reproduclion asexuelle. Seulcment, cette reproduction ne joue pas un grand rôle dans la vie des Echinodermes.

La reproduction asexuelle s'ellectue suivant drux modes : la fissiparile el la gemmiparite.

Fissipante. - Ce procílé existe chez divers représcutants des denx classes des Astérides ef des Ophiurides. - Ainsi que l'a remarqué E. Perrier, il se manifeste de denx manieres. Dans un premier mode, le génératenr se partage en deux moitiés semblables, qui se complètent par la suite; ce fait a été constaté cliez un assez grand nombre d’espèces appartenant aux genres I'olyasterias, Ly!taster, Nanaster, Cribrella. Asterina, Iphiocnida, Ophiolhela, Ophiocoma, Ophiactis. Dans le second mode, un bras se détache de l'organisme du générateur, et devient ì lui seul un individu parfail; ce phènomène est accidentel chez divers Astérides, comme l'Asterias glacialis; il devient normal, et habituel, chez plusieurs especes les genres Withrodia el Linckiu.

(iemurarité - Plusienrs anteurs ont considéré comme ted le second mode de la fissiparité, dans le ras où le hras commence à se convertir en un individu complet, alors quil est encore allaché au générateur. Telle est. d'après les frères Sarasin, la Linchice multifora. Liun lles liras bourgeonne, ì son extrémité libre, des petits bras supplémentaires, el se transforme, ainsi, en une pelite Astérie appendue a la grande; ensuite, il se dítache, et devient indépendant. Ces phénomènes gemmipares rentrent ividemment dans les cas de fissiparité, avec celte littérence yu’ils s'areonpagnent de progenese : le descendant se lacomme avant de s'ètre séparè de son génératenr.

\section{RÉSUMÉ}

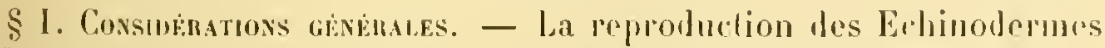
soffectue presque tonjours par la voie sexuelle; quelyurs reprisontants de l'embanchement présentent, pourlant, des phénomenes de tissiparitic ou de gremmiparití. 
Le développrment des Echinolemes comporte trois particularilés principales. - to la fenillel moyen se compose d"un épillublio-meso-

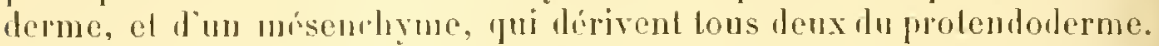
2. De l'entéron primoritial se détache une vésicule, le protentírocole, qui se sublirise i son lour en trois autres vésionles, les denx muterocoles el lihvirorole; la proi de tous ces organes provient du prolendolerme, ef len cavité de l'enléron. les parois des demx entéroceles, dont l'mn est plací a droile daus le corps, et l'aulse a gauche, conslituent l'épillélio-mésoderme sus-visé. L'hỵdrocele s'ouve au dehors par un luhe livilrophore; aprós quoi il se recourbe aulour le l'arsophage, et donne m annean hyilrophore, qui émel des diverlicules chargís de derenir les canaux tentaculaires el les canaux ambulacraires. Ces derniers appareils se disposent suirant me symótrie raliale el quinquenmaire. 3" Les larves posseilent souvent des appemlices temporaires, à elles propres, yui ne passent pas à l'adulte, el qui leur Jomnent un aspeet fort lifferent de l'ôlre parfail. Celle dissemblance entre le prosome ef le mélasome est, sans loute, le résultat d"une adaptation particuliere aux larves.

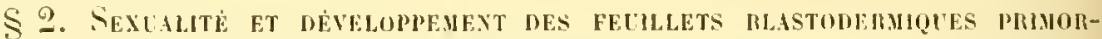
buax. - Presque lous les Echinodermes sont unisexuis. Ja freombation est extérieure d’habilule; pourlant, rertaines especes sont muarquables en ce sens que les femelles font subir, à leurs ovules, une vérilable incubation lans une rigion donnée de leur corps. - D'ordinaire, les ovules sont paures en deulolécitle, el la segmentation aloulit a nne blastulalion, suivie l'unc gastrulation. Iu moment ou le protendoderme commence à s'invaginer, plusienrs de ses étéments se mulliplient arec activiti, et donnent les promiires cellules du mésenclıyue.

l.es phénomènes, olferls à cel égard. par les Ilolohluuriles. ne s'ícartent pas de la précédente régle grinérale. Chezles Eehinides, les premieres cellules mésenchymaleuses premnent naissance avant que l'invagination grastrulaire n’ait délumb́ mais elles sont prouluiles, cepenuant, par la région qui deviendra le protendodeme. Il en est de mène pour les $\Lambda$ stérides el les Ophiniles. Enfin, chez les Crinoüles, l'entropore se perme de suile apres que l'invaginalion gastrulare est laite, el l'entéron se convertit en me vésirule close.

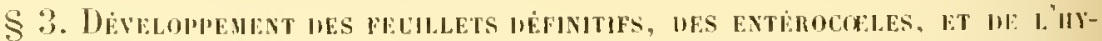
mocele. - I. Au moment oì il acheve ses feuillels primomiaus, l'embryon des Eehinulermes se compose d"un prolectorlerme, d'um proleniloderme, et renferme déji m mésoderme misenchymaleux, qui provient du protendorlernn. Ce alernier produit ensuile lis mésoderme épilucial; apris quoi, il presiste comme endoderme dáfinilif. Le protectoderme se borne ì donner l'ectoderme de l'adulte.

Apres que l'ibauche du mrósoderme épilhílial s'est séparée, sous la 
forme du protentérocule. de l'entrom pui limite le protendorlerme, cort entéron sallonge, et süncurve, de maniire à se rapprocher de la paroi antérieure, ou ventrale, du corps. Il sumit it cette paroi, et mu orifice. qui devient la bouche, se peree dans la zone de soudure. licntiopore. lorsqül ne se ferme pas, persiste comme amus drfinitif.

Jans la sirie des phénomènes labituels de la genense des entérocases el ile l'hydrocale. le protentérocmle commeure par se séparer lu culde-sac supricur de l'entéron; il imet ensuite un canal, le tuhe hylrophore, qui se soude a l'ectoderme, daus la région dorsale, ou postrírieure, du corps, et s'ourre à lextérieur par un orifice, l'hydropore. l'uis, il produit leux expansions latérales, qui s'isolent de lui, el se convertissent en vésicules closes; ces derniores sont les entérocules, dont l'un. l'entéroccele droit, se place sur le còtí droit de l'intestin, el l'autre, l'entérocrele gauche, se met sur le còtó gauche du mème organe. Enfin, la partie restaute du protentérocule, qui lemeure en relation disecte avec le tuhe hylrophore. et prend igalement l'aspect d'une résicule creuse, devient l'hydroccele. - Ces phénomènes sont parfois moditiés sous le rapport du mode de síparation de ces trois résicules, qui naissent les unes des autres de manières diverses; mais le but est toujours le mème, et semblable à celui du jrocébé habituel. - Les entérocreles grandissent en enveloppant l’intestin; ils finissent par s'adosser l'un i l'autre dans la rigion antérieure et dans la régrion postérieure du corps: ces zones d'allossement constituent les mésentires. La cavité des entérocoles donne l'entéroccelome, habituellement nommi la cavité générale du corps; leur paroi externe fournit la somatopleure, et leur paroi interne la splanchnopleure. - Liydrocale s'allonge en un tube cylindrique, qui se recourbe sur lui-mème, et se convertit en un auneau, l'anneal hylrophore, place antour de l'asophage. Cet anneau rmet des expansions, les canaux tentaculares, destinés aux tentacules piribuccaux, et les canaux ambulacraires, destinés aux ambulacres. - Il faut conceroir lous ces appareils, lérivés du protentérocole, et qui composent l’épithélio-mésoderme de lorganisme, comme plongés lans le mésoderme mrisenchymateux, et siparés par lui, soit les uns des autres, soit de l'ectoderme ou le l'endoderme.

II. En ce qui regarde les Holothurivles, le proródé le plus simple rst offert par l'IOolothmria tubolosa; il ne s'écarte pas du mode habituel décrit ri-dessus. - La Cucumaria doliolum diffire du cas précélent, en re que la scission, de l'entéron primordial en protentírococle el rutriron lefinitil, s'eflectue suivant me direction lomeritudinale, et non transressale. - Eufin, chez la Synapta digitata, le protentirocule prouluit le tube hylrophore, avant qüil se soit lui-nêmr séparc de l'entéron.

Les Echinides présentent sous ce rapport un prociblé unitorme. Le cul-de-sac supérieur de l'entéron saplatil eu un disque, qui s’isole du reste de l'eutéron, et devient le protentérocule; ce dernier se sublivise 
ensuile. et domne denx vésicules, l'ume droite, l'autre gauche. Ia première persiste tout entior comme entérocole droit: la secomle se partage en denx antros rósicules, l'une sujélienre, qui dorient l'hỹdroenle, et l'aulre inlérieurr, yui se convertit en entérocole gauche.

le mome phénomone existe chez divers représentants des classes drs Istérides et des Ophiurides; il est, par contre, modifiédans plusieurs aulies cas. - Ainsi, he\% l'Asterina giblosa, les deux vésicules, émises par le potrotérocole. atteignent un assez grand rolume avant de se séparer, et la vésicule gauche produit le tule hydropliore, avant de domner nassance, sous la forme d'un diverticule, à l'ébauche de l'hydrocole; par la suite. le luhe hylrophore se rarordo a ce dernier. Chez beancoup dophiuritrs, le cul-rle-sac supérieur le l'entéron émel directement deux diverticules, qui se séparent de hui, el se convertissent en vísicules, l'unc droile et l'autre gauche. Celle-ri so divise en entérocome gambe et lychocmle; la premiore parait se partager de la mème laçon, seulement sou segment supérieur. qui fait le pendant ll. l'hydrocule de la vésicule cauche, s'atrophic. Ce cas les Ophimrides se rapporte à celui des Echinides, en omettant la phase de délimilation préalalıle l'un prolentérocule imprair.

Le lobe sus-lunecal de l'embryon des Crinoüles persiste, an lieu de disparaître comme celui des autres Eehinodermes, et Homne le pédoncule; d'autre prat. la bouche vient se placer à côté de l'anus, daus la rógion opposéc à ce pérloneule; il résulte de re fait, dans la disposition des organes, une inversion de $90^{\circ}$. - Lientéron, par la fermelure de l'entéropore, se convertit en mne vésicule close; celle-ci, au moyen d'un blanglement transwersal, se divise en deux parties. l'une supérieure, l'autre inférieure. Celle dernière se partage à son tour on deux autres, prar une fissure perpendirulaire au prenier étranglement; ces deux segrments sont les drox entérocoeles, dont l'un est droit, l'autre gauche. La prartie smpérieure émet un diverticule, qui donne l'intestin, et persiste ensuite comme hylpocole muni de son tule hydrophore. lintestin grandit rapilement, et les trois autres parlies se déplacent pour l'entourp"; cest en ce léplacement que consistr l’inversion. lientérocole droit levient supérieur, le gauche inférienr, et l’hýdrocole antérieur.

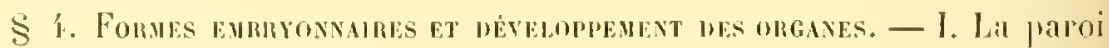
Ju corps so comprose essentiellement de trois assises: l'ertoderme, le somato-mésemelyume, et la somatoplenre. L'ertorlerme persiste comme ¿́phlólium extérieur. Le somato-mésenchyme produit un lissu conjonetivo-musculaire, ol les élóments caleaiors du test: les radioles, les pípuants, ol les pridicellaires, sont des sailles locales, "t recouvertes prar l'ectoderme, de ce somato-misenchyme. Eufiu, la somatopleure se convortil on un endothólimm príritonéal. el jaraît donner aussi des fibres musculaires.

l.es origines les remtres nerveux ne sout pas encole bien romnues; 
cependant, l'analonie comparée permel de concevoir que leurs parlies primiprales dérivent de l'ectoderme. - Le lube digestif provinul de l'entéron larvaire; l'entéropore se convertit en anus, du moins dans la plupart des cas; la houche est mo orilice le nouvelle formation, uni correspoud à l'ourerture externe d'un stomeon donnant l'asophage.

Lappareil irricateur se compose de trois parties : un enléroralome, un schizoculome, et mn systeme hydrophore. Le premier est mu oligo"ulome fourni par les deux entérorules; le second un polycolone. qui lérive des viles rreusés dans le mésenchyme, el dont l'ensemble compose un espace sehizoculien; le ternier provient de l'hylrocule. Ces trois parlies sont, a leur délunt, et au moment ou lenrs ébauches se dólimilent, dislinıtes les moes des antres, el complètement séparées quant à leur's carilés; les romnexions serondaires s'établissent parfois entro elles, Jans la suite de l'irolution. - L'entérocelome est rraversé par les mésenteres, phus on moins ramplexes. Le schizoculome se divise en deux systèmes : l'un, somatịue, qui lonne les cavités sous-ambulacraires; liautre, splanchnique, qui comprend un résean lacunaire intestinal, et un ganglion lymphatique. L'appareil hydrophore est produit lout entier par l'hydrocule.

L’appareil exrrélenr est représenté par le ganghion Irmplatique du schizocolome. - L'élanclie les glamles sexuelles apparait lans le roisinagre du ganglion; il est encore impossible te téciler si les premiers éléments reproducteurs proviennent de la substauce mème du ganglion. ou de l'endothélium réritonéal qui l'entoure: daus le premier ras, res eléments seraient d'origrine mésenchymatense, et ils proviendraient, dans le second, de l'épithélio-mésoderme.

II. La plupart des Echinodermes subissent, dans leur développement embryonnaire, des métamorphoses completes; certains, cependant, en suppurtent le restrointes, ou mème en sont dépourvus.

Jans le eas de mólanorphoses completes, la larve passe par une phrse mremière, on elle est complètement converte de cils vibratiles. lille subit ensuite des modifications de leux sortes: les cils se localisent en certaines régions, offrant l’aspect de bandessinueuses; le corps émet les expansions eylindripues, el allongées, qui disparaissent an moment oì l'embryon se convertil en alulte. l'arlois, es deux types de changements sont réunis; el parlois, rlez les llolothurides par exemple, le premier existe seul. Souvent, la région péribuccale sæinlléchit en une défression, plus on noins surplombée par ses hords, et parfois conplidement lermée par eux, dans le foml de lapuelle naissent les tenlacules pribuccaux; ectle lépression est le vestibule. qui s’atropuhe ensuite. - La présence de ces appendices provisoires, que la larre posside, el que l'arlulte n'a plus, établil nue différence considérable

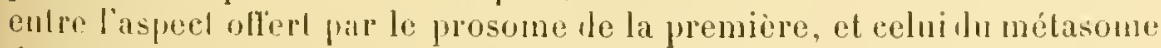
du second. Celte ditiérence domne ans metamorploses mue grande 
anplitule. La possession te res appentices est secombiare, non primilive; les larres des lichinoulermes sont des larves adajtalives, el à stases.

les métamorphoses restreintes, ou nulles, consistent essentiellement dans la réduction, ou dans l’alsence, des préccidents appendices larraires.

11I. La phupart des Ilolothuries subissent des métamorphoses rompletes; certaines, pourtant, offrent des métamorphoses restreintes, ou nulles.

I ans le cas des métamorploses complètes, la larve passe par la phase première, et possède alors un volmminemx lole sus-buccal. P’uis, les cils vibratiles se restreignent à nue pelile courome péribuccale, qui grandit par ses côtés, devient sinneuse, et parcourt alors le corps entier; la larve passe ainsi à l'étal d'A luricularia. Ensuite, la bande viluratile sinueuse se partage en conj troncons, pui entourent le corps à la maniore diulant de couronnes vibratiles; la larve est alors parvenue ì l’alat de pupe. Enfin, le lobe sus-buceal se réduit, les tentacules périluccaux font leur apparition, les rils tombent, et la juye passe à l'étal arlulte. - Les Cucumaria doliolum ofl'rent les métamorphoses restreintes, en ce sens que l'embryon arrive directement le la phase premiere à l'état de pupe. Les l'solns ne subissent ancune métamorphose.

IV. Sauf les esperes vivipares, telles que l'llemiaster anstralis, lons les Echinides subissent des mélamorphoses complites.

L'embryon sulit la phase premirire, et parvient ensuite à l'état le Pluteus. Jour cela, les cils vibratiles se restreignent à une couromue prírurcale, comme chez les I uricularia; seulement, cetle couronne, au lieu de devenir simplenent sinueuse, sallonge, avee la région qui la porte, en expansions cylindriques nommées des brus, el disposées prar praires (quatre ou ciny) de part el d'autre de l'ase de la larve. Ces bras sont restinés ả soutenir l'embryon dans l'eau, et à lui permettre de se mouvoir; ils sont maintenns par des spicules calcaires, l'origine mésenchymatruse, qui ne passent pas a l'adulte. En outre, le I'luters posside nn lobe anal, que l'A uricularia ne présente pas. - Il riste, chez les lichinides, plusienrs formes de I'muteus. Celui des Cidaridiens porte denx auriculaires anales; celui des lichinides est privé d'auriculaires, el pourvu l'épaulettes cilices; celni des Spatangides présente nne cinquième paire de luas supplémentaires, el trois baguettes anales; relui des clypeastrides est muni l'un lolse anal volumineux el arrondi.

l'our se converlir en adulte, le l'lutens perd pen à peu ses bras. Ce faisant, il produit son vestilule dans la région qui possède l'hydrocule dans son interien; ce lernier se ronvertit en un anneau lydrophore. et les tentacules péribuceaux prennent naissance lans le fond du vestibule. Le corps de la larve, d'aborl conipue, devient peu à peu globuleux. Jorsque les hras sont déji a demi atrophiés. la houche défnitive se perce an milieu du vestibule, de maniere a laire entomer l'usophage 
far l'anneau hylrophore; la bouche provisoire du Pluteus et son usophage disparaissent. L'anus conserve sa situation. L'aspect du jeune Uursin s’affirme ainsi de plus en plus; son corps dérive seulement d'une partie de celui de la larve, puisqur les bras s'atrophient. - Chez les Spatangus, la paroi du vestibule se ferme an-ılessus des tentacules péribuccaux, el sebrise ensuite, afin de laisser passer ces derniers.

Iprés que le jeune lichinide s'est ébauché anx dépens du I'luteus, et dans les phases ultérieures du développenent, des différences se manilestent entre les diverses familles. Les Cidaridiens parviennent directement à leur état défnitif; alor's que les antres Eichinides sulsissent une phase, préalable, de Cidaridien.

Y. - Les Astérides viripares, el celles dont les aufs contienneul un abonlant deutolécilhe, offrent des métamorphoses restreintes ou nulles. Les antres présentent des métamorphoses complètes.

Dans ce dernier cas, les premières modifications, subies par la larve. rappellent de près celles de l'Auricularia des llolothurides; seulement, elles aboulissent ì la genèse de deux bandes concentriques et péribuccales, au lieu d'une senle; cette larve particulière est nommée Bipinnarin. Ensuite, tout comme chez le I'luteus, ces bandes se soulevent en petits mamelons, en bras, dont la présence fait passer la larre a l'état de Brachiolaria; ces bras diflèrent de ceux du I'luteus par plusicurs caracteres, dont les principaux consistent en ce yu'ils sont plus courts, et privés de spicules calcaires. - Puis, de mème que pour le Pluteus, la prartie du corps de la Brachiolaire, qui porte le lube digestif dans son intérieur, se convertil seule en Astéride; les autres régions, et notanment les l,as, s'atrophient, el disparaissent. Cette partie grandit dans le sens antéro-postérieur, et se convertit en un disque, qui revèt hàlivement un aspect étoilé. D’après Igassiz, la loouche el l'anus de la larve jersistent, et donnent les orifices correspondants de ladulte; le contraire aurait lieu, daprès les recherches de lletschnilioff.

Les métamorphoses restreintes comportent plusieurs types. Chez les Echinaster et les Asteracanthion vivipares, les bras prennent encore naissance, mais sont petits ot peu nombreux. Ces hras n'existent plus chez l'Asterina gibbosa; seulement le lohe sus-buccal est encore volunineux. Enfin, les embryous du P'teraster miliaris ne montrent plus, ni bras, ni lobe siss-buccal.

Les premiers rudiments du lest apparaissent chez la Brachiolaire, el dirigent le changement de son corps en celni de l'adulte. Ils se composent de dix plaques, auxpuelles ne larde pas à sajouter une rentrodorsale; tous sont placés sur la füure face anale de l'Astéride, qui correspond au côté ulroit de la Brachiolaire. D’autres plaques naissent ensuite sur la face louccale. Leur nombre augmente peu il peu, d'unc manière connexe it laceroissement du corps, en procédant pour la

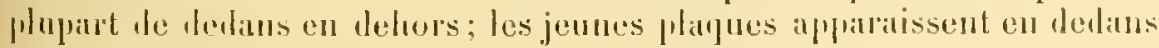


de celles qui existent dejaj, el sont repousscies vers la périplérie prar celles qui se forment ensuile.

11. - Les Ophimrides vivipares, telles que l'Ampliura styamata, ne subissent que des métanorphoses restreintes. Les aulres présentent des mélamorphoses complites. - Dans ce dernier cas, l'embryon se change en mo I"heres, tout comme celui des Echinides; seulement les liras, au nombrr de yuatre pares, me sont pas disposés de la mème facon, et deux d'entre cux sont trè longs, plus longs que lenrs similaires des Echinides. Ensuile ce Pluteus se convertit en un Ophiuride, par les mones moyens ifuemploie une Brachiolaire pour se transformer en Istéride.

111. - Le déreloppement des Crinoüles n’esl connu que par celui des Comalules. Les métamorphoses extérieures de ces amiman sont moins complexes que celles de la plupart des autres Echinodermes, car elles ne s'accompagnent pas de la genise, suivie de la disparilion, l'appendices provisoires. Inue des parlicularités les plus saillantes de celle évolution consiste dans ce fail, tue le volumineux lobe sus-lnccal, an Jieu de s'atrophier à la facon de son homologne des autres lares d'Echinodermes, grandit comme le reste dn corps, et donme le pédoncule de l'adulte. En oulre, l'anus conscrvant sa situation infërieure, la bouche défintive se peree à cotíde lui. La disposilion des organes dans l'économie des Grinoïdes est, prar suite, différente, comme orientaliou, de celle offerte par les autres Echinodrrmes; ces organes sont déplacés, dans l'espace, de $90 "$. Les premier's indices de ce déplacement se manifestent chez. ipuelques Ilolothuriles.

Arant l'éclosion, la larve produit, sur son corps, quatre couronnes viluatiles, transversales, el une toulfe vibralile supérieure, la calolle. lne dépression, la fossetle ventrale, apparaît sur sa face ventrale, ou anlérieure. Ins deux entérocoles, l’un est supérieur, l’autre inférienr; J'hylrocule commence à se conrertir en un anneau hydrophore; l'intestin est encore une vésicule close; tous ces organes sont plongés dans un mésenchyme alondant. - Le corps commence à se liviser en pédoncule el calyce, car le lohe sus-luccal s’allonge, et se rétrécit en môme lemps; les premicres plaques calycinales. les cinq busales et les cinc orales, naissent dans le mésenchyme du calyco; ol les premiers disques pédonculaires apparaissent dans celui du pédoncule. Dans le ralyce, los orales sunt inféricures, et les lasales supérieures; le premier formé des disłues pédonculaires, qui est reporté an sommet lu pédoncule, et sert à fixer l'animal ì un support, correspond à la centro-dorsale des autres Eehinodermes. - La larve ahandonme alors ses membranos orulaires, nage pendaul quelque temps au moyen de ses comronues viluatiles, puis se fixe par le sommet de son lolie sus-buccal, devenu

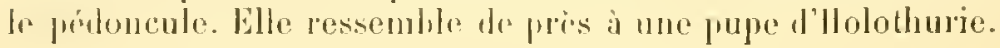


He suite apres la tixation, les conromes vilurates disparaissent, et la division du corps en calyce et pridoncule contimue à s’affirmer.

La larve passe d'ahord par rétat cystidien. Cinq radiales se montrent sur le calyce, entre les orales et les basales; de nouveaux disques pédonculaires sajontent aux précédents. La fossette rentrale s'approfondit, ot se convertit en une vésicule close, qui se déplace pour gagner l'extrémité inférieure du calyce: elle devient alors un vestibule fermé, limité par un plancheret un dòme. L intestin s’allonge, se courbe en un croissant, dont les deux pointes atteignent le plancher du vestibule, se soudent à lui, et s'y percent d'une bouche et d’un anus. L'entérorole inférieur entoure l'oesophage, el levient le sac périorsophagien; l'entérocule supérieur recourre l̈intestin, d domne lesac pèritonéal; ces deux sacs sont séparés l'un de l'autre par un mésentere intermédiaire. Le mésenchyome, placé dans la conrbure intestinale, fournit la première élıanche du ganglion lymphatique. L’anneau hydrophore est placé contre le plancher du vestihule; celui-ci prodnit les tenlacules péribuccaux, dans chacun desquels l’anneau hylropliore envoie un canal. Les tentacules sont d'alord au nombre de ciny; puis chacun d'eux se ramifie en trois branches d'abord, en cing ensuite; ce fait porte leur nomlre à quinze, puis a vingt-cinq. Tout en guandissant, ils lırjsent le dôme lu veslibule; celuici se fend en cinq lobes oraux, lont chacm contient une plaque orale, et que l'animal sonlève on abaisse à la façon d'autant d'opercules.

La larve, toujours lixée par son péloncule, parvient ensuile à l'état pentacrinoüde. Les liras font leur apparition au-dessus des cinq radiales, et grandissent en produisant leurs premières pimules; clacun deux corresponl a une saillic de la zone superticielle du corps, renfermant une expansion de chacun des entérocules, et une part du mésenchyme. La prartie supérieure du sac péritonéal se sépare de hu, et dome lorgane cloisomné. Le gauglion lymphatinue émet des lurathes dans les lıras, ct dans les pinnules, où leur's cellules se convertissent en éléments sexuels. Le tube hyllophore se divise en deux parties, qui s'ouvent toutes denx dans le sac périosophagien : un tube hydrophore défnilif. pui communique en surphs avec l'ammoan hydrophore; et un entomoir

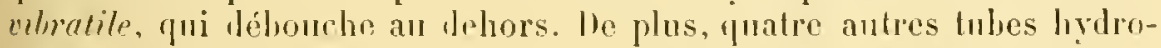
phores, of quatre nourrax entonnoirs viluraliles, proment naissance, (nilfrectant les mèmos commexious que leurs préléresseurs; l'embryon jossiole en tout ciny des uns, ret riny des autres.

la jeune Comalule abandonn: alors som pédoncule, devient libre derechef, et passe à l'élat adulte. Les tubes hrolrojholes et les entonnoirs viluratiles angmentent en numlue, dans des proportious consirlérables. I.es cirrlıes, qui sétajent déjì montrés lors le l'état pentacrinoüle, arquierent lemr aspect lélinitif; ainsi que les liras, munis de leurs pinmles. Les planpes orales dispanaisent: les liasales se sourlent en un seul rorps, nommés la roselle: "ntin, le derniej artirle dn pédoncule,

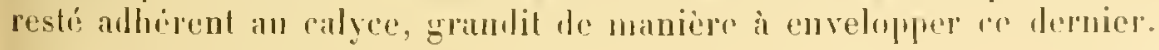

ROULE. - EMHRYOLOGIE 
S. Liephoduction asexuele. - Ce mode de reproduction est rare chez les Echinodermes; il revient, en somme, it une fissifarité, qui est elle-même une exagération de la rénoration de cerlains appareils, détruits par accident. Cette fissjparité existe chez un certain nombre d’Astérides at Ophiurides, dont un bras détaché se convertil en un nouvel individu. Tantút ce développement n’a lieu qu’aprés l’isolement lu bras, el tantòt avant cet instant; dans ce ternier cas, on a assimilé à une gemmiparité cette progenèse asexuelle, suivie d. fissiparilé. 


\title{
EMBRANCIENENT IES ENTÉROPSEUSTES
}

\author{
CIIAPITRE IIT \\ DÉVELOPPEMENT DES ENTEROPNEUSTES
}

\section{\$1. - Considérations générales.}

1. Garactères. - Les Entéropneustes sont les Entéroculomiens. Ils doivent c̀tre placés, parmi ces deruiers, à côté des Tuniciers et des lertébrés; ils font partie, en conséquence, de la section des Notoneures. Leurs centres nerveux ne sont point, pourtant, exclusirement dorsaux, par opposition à ce quil en est cliez les représentants des deux autres embranchements de leur série; ils se composent d'un cordon dorsal, silué au-dessus du tube digestif, el d'un cordon rentral. La nolocorde appraraîl, chezl'embryon, l'une mauière précoce, el persiste bons l'organisme de l'adulte; elle est d'étendue restreinte, car elle se borne à oceuper la région antérienre de l'économic. Le corps. allongé, vermiforme, est divisé en trois régions de longucurs inégales : la lète, encore nommée la trompe, le collier, et le trone, on corps proprement dit. - Le terme d'Entéropneustrs est dì it me disposition de strueture propre a tous les Notonem'es : la part iniliale du lube digestif est convertie en un appareil respiratoire, yui rommmnique avec le dehor's par
le moyen d'orifices spéciaux.

L'embranchement n'est représenté, dans la nature actuelle, que par III genre : le Balanoylossus.

II. Généralités sur le développement. - Les Balanoglosses se reproduiscut seulcment par la voie sexuelle, et an moyen de la féeondation. Les sexes sont séparés. - L.eur cubryogénie, lonjour's dilatée, comporte la présence de métamorphoses extéricures, el de phases larvaires lilıres; celles-ci sont plus complexes ren ce qui lonche les espièces d'embryon secos du genre (IS. minutus), el alontissent is une forme d'embryon secondaire, connue depuis longlemp's sons le nom der Tor- 


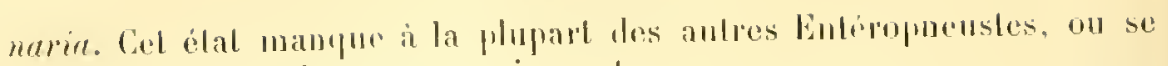
tonve, chez eux, boaucoup moins net.

Lentéron loune le mésorlerme, et son molome, suivant le procédé entérocolien. Les ébauches culomiques sunl au nombre de ciny : l'une, anlérieure, impaire el médiane; les qualm autres, groupées en deux paires, placées l'une dorriere l'aulre, lont los élémenls soul laléranx et symétriques. Les cellules les parois mésoderminues évoluent de leux laçons : d'un cóté, plusieurs l'entre elles se délachent de la conche dont elles font parlie, émigrent entre cette dernière el l'ectorlerme, s'y multiplient, el produisent un mésenchyme; de l'antre, celles qui continuent à composer les parois lemenent ru leur place, ronservent leur disposition épilhóliale, ot limilent les cavilis colomiques de l'adulte. le fenillel moyen des lintoropneustes est double, par conséquent, tout romme celui des Echinolermes, el celui des Vertélrés; il se conpose d'un mésolerne mésenchymaleux et l'un ipilbélio-mésorferme. Le premier se creuse de nombrenses cavités lacumaires, agencées en 111 polycolome, en 110 systeme vaseulaire, el se molific en un abondaul tissu conjonctivo-musculaire. Le secomb reste peu complexe, semble-l-il, el se borne a foumir les parois des cavilís entérocoliennes. Celles-ci constituent, le leur rôté, un oligocolome, livisé en trois zones principales, l'une situce dans la lmompe, la seconde dans le collien. el la lroisieme dans le trome.

L'entéron primordial, avint engendré les ébauches culomiques, persiste comme tulue digestif; son protendorlerme, apres aroir subvenu it la genese du feuillel moyen, demeno en qualité d'emblorme détinilif. Lextrimilé antérienre de ce tube émel nu diventicule dirigé pu avant. nomme, par les anteurs, le diverticule phoryngien: les parois te ce lernier sulissent des modifications, comparables de lous points a celles

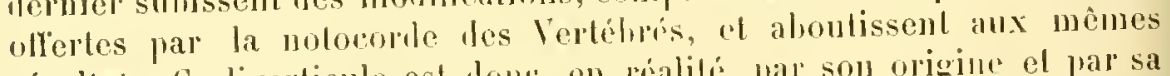
résultals. Ce diverticule est don", en rialilí pal sou origine el prar sa struclure, par sa siluation laus le temps comme daus l'espace, l'homologue de celle notocorde; son élendue est senlement plus restreinle. be phus, la regrion iniliale du luhe ligestif, converlic an une lananchie, probluil, daus sa parni al entro les tentes hrambiales, des pieces de soulien, dout la substance est semblable it celle du divertionle pharygiell.

\section{$\$ 2$. - Développement des feuillets, et formes embryonnaires des Entéropneustes.}

I. Origine et développement des feuillets blastodermiques. - Les farliculatilis, se rallachant il cel ordre de faits, sont surloul commes d'apris les abudes entreprises par Bateson sur le bulanoglossus Kovalenstigi. - liovule, petil, el paurere en malériaux mulrilifs, subil nue segmentation tolale el egale, qui aboutil à megastrulation, elfectué 


$$
\begin{aligned}
& 0 \\
& 0
\end{aligned}
$$


Mapurs le procedfe inviginant. La gastrule. arondie et globuleuse. posside une profonde cavité entérique, dont l'entéropore parait devenir l'anus do l'arlulte; la bouche est un orifice de formation nouvelle. Le protentoderme ef le protectoderme de cette gastrule sont síparés l'un de l'autre par un espace étroit. dernier restige de la cavité hastocolienne. Le protectolderme se borme à lommer les centres nervenx: après quoi il se ennvertit en l'ectoderme léfinitif. Le protendoderme subit les molifications plus grandes; car il engendre au préalable le fenillet mosen, et ne devient l'endoderme qu'ensuile.

La larve, d'ahord sphírique, s’allonge, et passe à une forme ovalaire. L'amus oecupe l'une des extrémitís de l'ovale, celle quil est permis de qualitier. des lors, comme inférieure. In stomeon se perce au-dessous de l'extrémité opposíe, supérieure par conséquent: il s’unit ì l'entéron, et lui foumil une houche, de manière it le laisser communiquer arec le dehors par deux orifices; ces ouverlures sont conserrées désormais el demeurent chez ladulle. Etant donnie la place qu"elle occupe dìs son origine, la bouche se tronve surmontée par toute la région supérieure de la larve; cette zone représente un lobe sus-buceni (le lolie préoral des anteurs), destiné à devenir la trompe de l'individu parfait.

Puis. l'entéron émet cinq diverlicules : quatre latéraux, deux étant placés à droite, of les deux autres à gauche; plus un cinquième, impair et médian. Celui-ci est antérieur; il pénètre daus le lobre sus-buceal de l'embryon, s'applique contre l'ectoderme, et se sépare du reste de l'entíron; l'espace, quil limile. Iome la cavitíde la trompe, et sa paroi les tissus sous-ectodermiques. si complrxes chez l'adulte, de cetle mème région. - Les quatre diverticules latéranx sont, a cause de leur disposition originelle, grompés en deux paires : l'une postérieure el l'autre intermédiaire, cest-à-dire situce entre la précédente el l'éhauche de la trompe. Ces deux paires éroluent de la mème façon : leurs deux ébanches constitutives, symétriques et égales, se séparent le l'entéron, et grandissent autour ile lui, le manière ì l'envelopper; cetle extension s'effrectue suivant me lirection lransversale, perpendiculaire à laxe longritulinal du corps de l'embryon. Ainsi acerues, les ébauclıes àune mème paire sadossent en deux points, sur la ligne médiane dorsale el sur la ligne médiane ventrale; leurs zones de jonctinn constiluent dos mésenteres. - Si les développements propres aux denx paires de diverlicules comrorlent dans leurs traits essentiels, il n'en est pas de mème pour plusieurs ditails secondaires, dont les primeipaux tiennent i leurs dimensions respectives, el a lem situation lans léconomie. Les ćbauches de la premicre paire, de la paire intermédiaire, sont relativement petites, ot ne súlargissent que fort peu; elles se disposent, après avoir entouré la partie d"entíron placée ì leur niveau, en un anneau creux el étroil, dont la paroi donne les lissus mésoleminipes du collier, et dont l'espare vild persiste comme cavilé te cetle mème région. Prar contre, les diverticules de la seconde paire, ou postérieure. 
ne se bornent pas i envelopper l'entéron; ils s'allongenl en màme lemps que lo tronc, et produisent le corlome, avec le mésoderme do cette zone de l'organisme, la plus volumineuse de heauroup.

Du moment où l'entirnn a fourni les ring diverticules jpérédents. et oì ceux-ci se sont séparés el isolís de lui, il demeure comme tube digestif, el conserve les deux urifices, la louche et l'anus, qüil possède drjả; sa paroi limitante acquiert strictement la valeur d'endoderme, et garde sa disposition épithéliale. - De pareils faits n'existent pas dans les cinf éluauches mésollermiques: leurs parois sont bien épithéliales a leur début, comme le protendoderme dont elles dérivent, mais elles ne conservent retle structure qu'en partie. Plusieurs de leurs éléments se délachent d'elles, et surlout ceux de la somatoplenre. le cette zone appliquée contro l'ectoderme dans la progression aulour de l'entéron. Ces cellules s insinuent entre l'ectoderme et la couche dont elles proviennent. se multiplient lans cet espace, et y donnent un mésenchrme alondant; ce dernier sépare lis somatoplenre du feuillet cxterne. Cotte "isagrégation mésenchymateuse. qui lonne anx Entéropneustrs un donble feuillet moym, se manifeste dans toutes les ébauches mésodermiques; seulement, elle est moins accentuér. dans celles de la trompe et du collier que dans celles du trone.

Par l'effet de ce díloullement du mésoderme, et de la conversion d'une part de ce dernier en un mésenchyme, tous les fruillets emlrronnaires sont des lors reprisentés.

11. Formes larvaires. - Le développement des Balanoglosses, du moins celui des espèces connues sous ce rapport. s'accompagne toujours de mélamorphoses extérieures, et comporte la présencedelarves, mises en liberté d'une manière précoce. L'ívolution, le perfectionnement de lorganisme, s'effectuent pendant cofte vie libre, et hative, de l'individu. - Les embryons appartiennent ì denx types prinoipaux : le promier, spécial à liune des espèces méditerranéennes, est caractérisé par la possession de larges bandes viluatiles sinueuses, et par une stase asser. longue; dans le second, les cils viluratiles sont relativement peu nombreux, et l’embryogénie procède avec régularile. Ce dernier, déjà signalé par A. Agassiz, est surtout connu depuis les olsservations faites par Bateson sur le R. Konalevsliyj; il peut être lésigné par l'expression de lype direct. Le premier. a cause du nom accorlé par les auteurs ì la forme larvaire qui lui correspond, sera dit le type is Tornaria, on le type Tornarien.

Trpe Dinect. - Les changements d'aspect, olferls par l'emliryon, sont, dans ce cas, relativement pen complexes; rógulierement sériés, ils ne s'arcompagnent d'aucune stase. Au moment oit la gastrule commence a devenir ovalaire, une combonne transversale de cils viluatiles apparait autour de son extrémilé infórieme; relte bande, rireulaire et uullement 
simense, encondre un espace, qui ripond ì colle rigion, frominate el inlériente, an rentre de lapuelle se frouve precé l'anus. lle plus, une

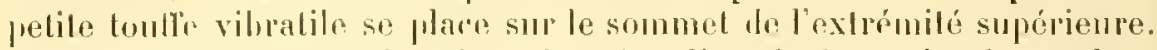

Dès linstant oì s'élanchent les cimp direrlicules colomiques, lem. posilion dans le corps sarense à l'oxtericur : deux comstrictions anmulaires, situres à pen de listance liune de lanlue, ot lransversales, se creusent sur l'ectoderme. La première est placée an nivean de la limile

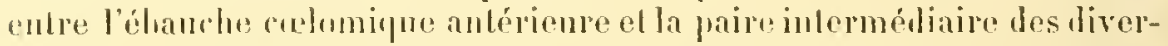

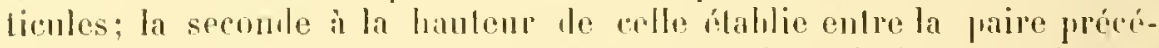
denle et la paire postérienre. L'organisme ast done divisé en trois par-

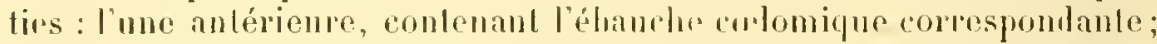
lanle moyenne, qui renferme la paire inlermédiaim; la lernjore poslérieure, pourvore, dans son inléricur, de la seconde paire de res mèmes diverticules. Cette scission, ainsi produil, l'une maniere hàlive, domente désormais; la zom antérienro devieul la trompe, la mosenue lome le collier, el la prostérieure le trons.

Les changements, subis ensuite par la larve, se rapportent i lallongement des parlies, el i l'acpuisilion de leur aspect timal; ils se laissent concevoir par la comparaison d'un jeme embron à un individu adulte. La trompe el le collier grandissenl peu, en raison le l'exlension énorme prise par le tronc. La première prol sa forme arombie, el seflile quolque pen. Le second, font en conservant la disposition qu’il oflre déja, sélargil légirement, et porle la hombe sur sa face ventrale. Le trone s'accoit d'une maniere régulière el constante, de préférence suivant sou axe longitulinal; l'anus orenpe tonjonrs son extrémité postérieme, el la courome viluratile, yui l'onserrail, ne larde pas à disparailre. Les principales des molibicalious, subies par celte rógion de l'urganisme, liennent à la genese les onvertures hranchiales, percées paire par paire, sirr sa face dorsale, et en arriope du collier.

True Tomanex. - A. La larve Tomaria s'érarte de la précédente par le développement plus riche de sa couverture vihratile. An moment oì elle est encore forl jeunc, oì elle vient i peine de diphsser l'élal gasIrulaire et de pereer sa bourhe, ellu pussede deja deux courommes de ces appendices locomoteurs. Ces banles sonl inégales, ol ne sont point disposées ì la manière de corrles transversanx. Limm, sus-buceule, la promale des anlous, pelite, surplombe diroblement la bouche, ol va lepuis cel orilice jusqu'i l'exlrémilé supéricure alucorps. L'autre, marginale, fort grande, part de l'extrómilé inférieure le la larve, remonte sur les còlés de celle-ci, pour arriver lans la région supéricure, jusqu’à

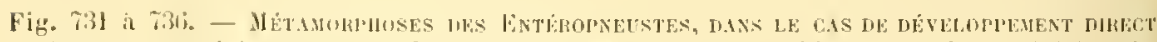
(contours extérimus). - En 731, jeune larve. - En 732 el 733, délnt de la division du corps en ses trois parties. - Ln T3h, li: segment anterieur eommence a prendre l'asplect

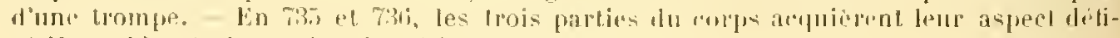

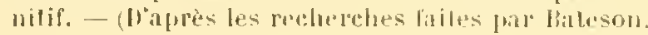




$$
731 \div 736
$$

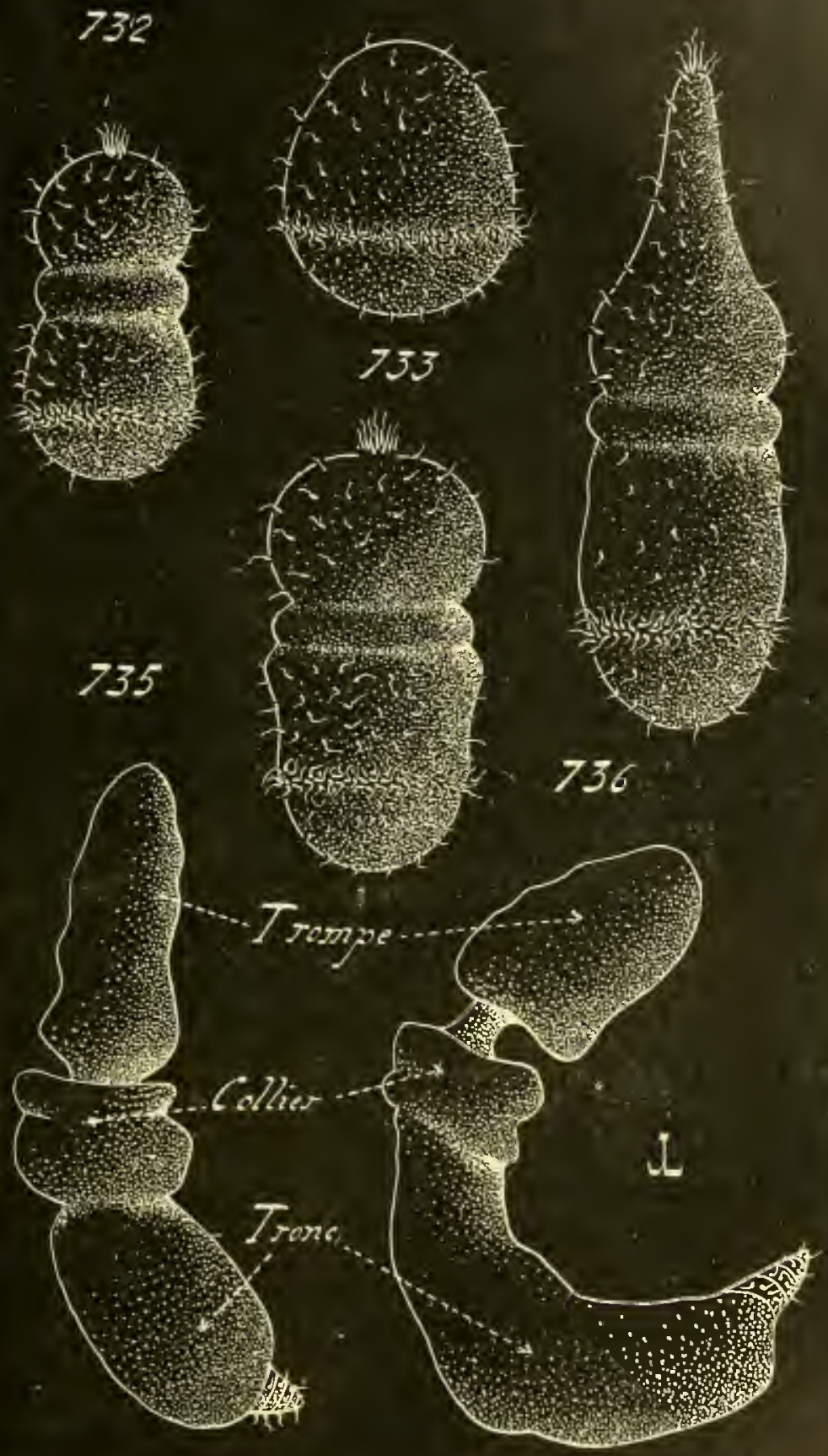


presque lombler la premiore. Hans som ensemble. elle est disposée de ficon a laisser liums en deluors d'olle, et à encadrer foule la lace antérienre du petit organisme. lans larpuele se fromve placée la louche. Ces denx comronnes sont donc i pen pris concentriques: linterne, pelite, surmonte l'orifice luccal; lexterue, de beaneoup la plus crante. entonre l'espace entier, an milien duquel est siluce eetle onverture.

la larve gramlit ensuite. Les annexes viluatiles suivent son extension, mais avec nue exagriation marquée; aussi, le mème que leurs correspondants des embryons des Erhinodermes, its deviemnent sinucux, frepivent des ondulations à la surlace du corps, lout en conservant leur lisposilion relative. De plus. une troisiome couronne fait son apparition, an dessous de la marginale, ef toul autom le lianus; celle-ci, réguliere el Iransversalr. eqnivant à l’unique lramle signalée lans le type direct. et lui est homolognc. Une petite touffe. igalement semblable a celle de la frrmière larve, nait sur l'extrímité supréricure du copps, où elle unit les sommels des deux conromnes sus-lincale et marginale. - En somme. la Tornarie, parvenue à cette phase de son évolution, ne diffè guè de la larve précédente que par la possession supplémentaire de ces deux corlons viliratiles.

Ainsi faite. la Tormaric demeure en sa forme, tout en produisant la jhupart de ses ébauches organiques, notamment les diverticules colomipues, et les premiers vestiges des appareils situés dans la trompe. Elle subil mo véritable stase. Puis, dans l'espace de quelques liemes, elle se convertit en un jeune Balanoglosse, ou plutôt en un embryon oflrant déji l'aspect caractéristipue de l'adulte: elle aboutit, avec lìte el en peu le temps, an résultat progressivement amené dans le tỵe direct. Son lobe sus-hmecal prend l'allure d'ume trompe; le corps produit ses paires de fentes lran hiales; le collier se lobimite entre les deux précédentes régions, an moyen de constrictions transversales, semblables à celles des larves dont le developjement est direct. Les componnes vibratiles sinueuses perdent leur rógularité l'aspect, el cessent l'ütre reconnaissables, car l'ectoderme entier est couvert de cils vihratiles, qui ne tardent pas, du reste, à tomber, malgré leur venue peu précoce; seul. le cercle transversal reste plus longlemps en sa position initiale. Apris la disparilion du revedement viluatile, la larve oltre tomle la forme de l'adulte; alle ne diflere de ce dernier que par sa petite taille, ef par l'étal l'ébauche de la plupart de ses organes intermes.

Par unc antre lissemblaner avec les développements diuects, la Tormaric produit hativement un cortain nomline d'apparreils, dont la présence lui donne mo certaine originalité de structurc. Liélanche

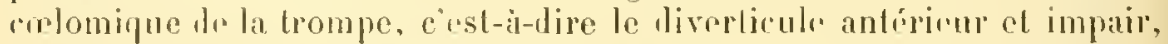
est engendré done manière pricore, alor's que la larve est eneorr lort jemne, el qu les paires intermérliaire et postérieme ne sont pas mème judiquées: ello se loge dans lo lobr sus-lunecal, et pousse mo rombuit qui. allant sousrir au dehors, lui premot de communiquer avoc liextérienr. 


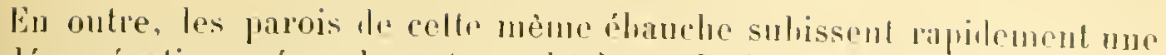
désagrégation mésenclı̀mateuse hàlive; plusicurs Jos ćlóments adlulaires, ainsi formés, se guroupent ru une pelite vésienlr pulsalile, vlile le cour. - Ces organes prement hion maissance dans lns larves du troe direct, mais d'une facon plus tardire. Leur genese rapile cluez la Tornaria, la concordame frappante établic entre l'ébauclue cumomifur. munic de son canal, et l'lydrocole les Echinolermes, ont confluilun certain nombre d'auteurs, molamment Mrschnikotr, il rapprocher retle larro de celles de res derniers animanx, et a almettre entre elles loxistence l'aftinités étroites.

B. - lies Tomaries sont des embryons secondaires. Elles derivent, comme les larves du lype direct, d’un ovule pauve en matériaux mulritifs; elles aboutissent iu mème résultal, car les lliflérenres spécifiques, établies entre les Balanoglosses adultos de la Jéditerranée et les autres. sont moindres que les dissemblances cmlirymmaires. Partant, les ammexes supplémentaires correspondent i une risposition surajoulće à la structure normale, el destiné a disparailpe, puisquelle est propre ì la larro, el ne passe pas à l'arhulte; leur présence constitue un caractire embryonnaire strict. Et, rapprochée de la slase, de la production hative d"un certain nombre d"appareils, elle affrme la réalité de la nolion précódenle. - Le type direct, privé de phase Tornaria, est, dans l'étal présent de nos connaissances, le seul qui soil vament fondamental.

On ne peut donc se haser sur l'organisation propre aux Tornaries pour conchure, d’après elle, an sujet des affinjlés nahurelles de l'ombranclement entier. I.es relations avec les Echimodermes sont daulanl moins évidenles, que les larves de la plupart de ces animaux sont ellesmimes secondaires. Les ressemblanres sont fort Jointaines enlre les dispositions essentielles de ces embryons; elles dérivent des homologies primordiales établies entre lous les Entéroculomiens, et dues à la genese idenlique de lem feuillet moyen et de ses caviles; elles nont pas jaul'e porlíe. - En pénélrant ılars les lélails, l’éhaucho eoelomique autérieure des Tornaries n'est quiun diverticule, produit rapidement avec son canal; leur cour, et leurs deux paires les autres expansjons mesodermiques, font défaul anx Erhinolermes: leurs bandes vilualiles, Ioul en devemant simurusos, se modifient, el se succerlent, suivant des procédés que les larves de ces derniers ne prisentent jamais. Les roncordances soul, toules proportions carrées, plutòl superficielles; toul en dénolanl, malgré toul, la réalité d'une origiur commmne, primorliale, renant de l’identilé des premiers liméamculs du fouillel moyem.

Les relalions les plus proches des linćropmeustes sont du roté des Tuniciers el iles Vertébre; clles sarcusent par la prísence l'me notocorile, frar celle d'un corlon ncrveux Jorsal, et prar le rile respiraloiro de la rrigion digestive antérienre. Ces lous unbranchemenls rémis eonstituent mu groupe homogine. celui des Notoneures. opprisalile it lil 
serlion dos Erhinodormes; ils diflèrent de ros derniess par leur posses-

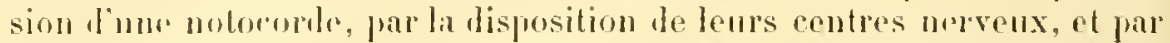
lem privation d'apparail hydrophore. - Mas as doux scrous offrent cependant me homologio fondamentale, due a la genise communc de lenr mósoderme aux dépens de diverlicules entéripues, el, lans certains cas, à la communicalion directe avec le dehors de plusienrs parties de leurs cavités misoulermiques. les Entéropnenstes étant, il lieancoup d'érards, les plus simples les Notoneures, montrent mieux que les autres ces ressemblances essentielles, surtout areusées duns les premirires phases du développement, el renforcies par des adaptalions serondares. senlement, ces ressemblances ne doivent pas masijuer les aflinités les plus directros, lommées du roté des autres Kolonemres.

III. Origine première des organes. - Le protectorlerme donne les centres nerreux, el se convertit en ectorlerme détinitif. - Les oliservalions dues à Bateson, et celles faites par Spengel, diffèrent quelque pen au sujet du premier aspeel des ćbanches nervenses, surlout de celles du corton dorsal. D'après le premier anteur, l'ectoderme s'épaissit dans toute la zone où "r corlon prent naissance; après quoi cette bande, trinsformće en centre nervenx, se plie en une gontlière, puis en un canal, et s'enfonce dans les tégnments; la lumière du ranal persisterait dans sa région antérieure, et ses parois seraient mème couvertes de cils vibratiles. Suivant Spengel, l'origine de l'axe dorsal serait en toul semblable a celle de son correspondant des Tuniciers et des Vertíbrés : $m$ sillon se creuse, aux dépens le l'ectoderme, sur la ligne médiane dorsale, el se convertit en un canal par le rapprochement, suivi de la soudure, de ses hords; les cellules de la paroi du conduit se convertissent en éléments nervenx, et la cavité disparait. - I'opposition entre ces domnées est minime, car elle porte sur le moment oì la dépression prend naissance. $A$ en juger d'après les recherches entreprises par h. Kahler sur des Balanoglosses adnlles, les observations elfertuées par spengel seraient plus dignes de créance. Le cordon complet est plein, privé de canal central; ses denx extrémités se rattachent ì l'eefoderme, el se continuent avec lui.

le mésoderme, épithélial à son déluul, sulit, par lit snite, unr désažrégation mésenchymatense. Il conserwe cependant, d'une manière assez nelle, sa division en trois parties : l'mue flacíe dans la trompe, lit soconde dans le collier, et la troisième dans le trone. Les cavités coelomiques de ces trois zones, ou du moins les restiges qui subsistent d'elles, continuent ì demeurer indépendantes; en revanche, les espaces creunés dans le mésenchyme, et agenés en un polyewome, communiq̨uent

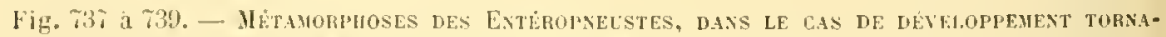
IuEx (contours extericurs). - En 737, jeune larve Tornaria. - En 738, Tornaria plus avanire. - lin 73:), Tornaria presugu convertic en un balanoglosse. - (U'après les re-

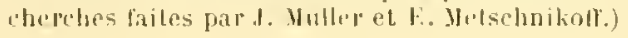




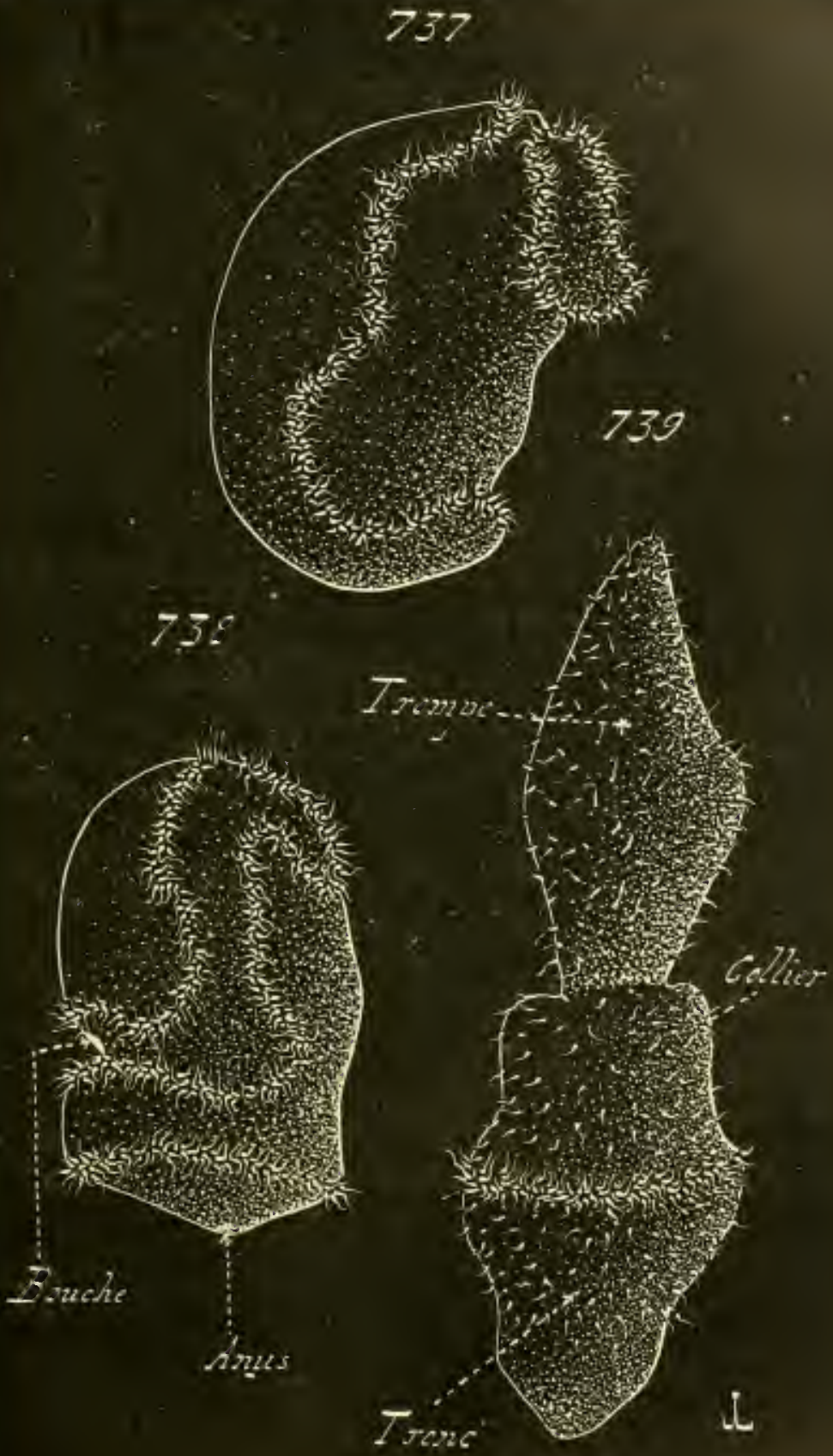




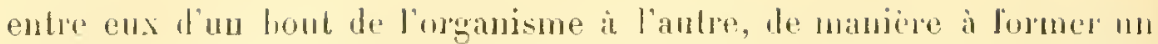
appareil cirenlatoire sanguin. - loa désagrégation misenchymateuse du mésoderme silué dans le fronc esl complète; les cellules perdent leur lisposilion ipitheliale of regulire, pour se grouper en une trame conjonctivo-musrulaire. Plusienrs des élements de cello dernière, rassemlilés dans la réginn branchiate du corjs, doment naissance aux glandes sexuelles. - Le feuillet moyen du collier el celuj de la lrompe ne subissent pas en entier la transformation mésenclumaleuse. Les cavités coelomiques, hien que réduites, persistenl ancore; clles communiquent avec le dehors far lo moyen de lrois canaux, dont deux appartiennent au collier, el m il la trompe. Celui-ci porte son oritice extérieur sur la face lorsale de l'organe qui le contient; les deux autres débouchenl dans la première parie dos fentes luanchiales. Ces conduils sont assimilables à ceux qui mettent en rapport, avec les milieux envirounants, plusieurs des espaces entérockliens des liertélrés acraniens, el des Echinodermes; leur présence dínote une temlance commune, chez tous les Entínoculomins, it la possession de relalions tirectes entre leur entéroculome, on une part de ce lernies, el le dehors. Le mésenchrne de la frompe lonne un ganghon lymphatique, nommé par les anleurs la glamle proboscidienne, ou la glande de la trompe, dont la slunclure est identique à celle de l'appareil correspondant des Echinorlermes. Une licune misenchrmateuse, aux conlours régnliers, dans laquelle aboutissent les principaux vaisseaux sanguins, se lélimile, pour engenIrev l'organe nommé le recur.

liendoderme et la cavié entérique subissent des modificalions comploxes; ils donnent le tube digestif avec son revetement épilhélial, la notocosle, et le systeme branchial. linteslin derive le l'entéron par le simple accroissement de celui-ci. - Sa notocornde est poduite par m lirroticule de la région iniliale de l'entéson: colte expansion, lite le divertacule pharyngien, se dirigr en avant, el pénètre dans la base de la trompe. Sa venue est hàlive. Loratane est dojà voluminemx, lorsque l'embryou ne posside encore qu'une paire de lentes branchiales. Toul en mandissant, ses cellules deviennent vacuolaires, el prennent l'aspect caractéristipur des déments de la notocorde des Vertélrés. - Les porlics lumchiales naissent par paires, dont lus éléments se disposent arec régularité sur la face dorsale du corprs, de part et liaulro de la ligne médiane. Elles consistent en diverticules creux, émis par la zone intestinale silué en arriere du collier'; tout en s'accroissant, elles ront buter contre l'potolermo placé à leur niveau, s'nnissent à lui, ot s'ouvent

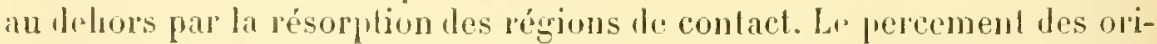
lices, assez larili", est plus préce clez les embryons du lype Tormarien que chez les autres. Ces expansions, converties rn canax branchiaux, plissent ensuite leurs parois, el prennent une disposilion compliquée;

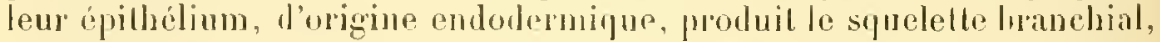
constimé par des pieces en forme de lourches à frois lents. 


\section{RÉSUMÉ}

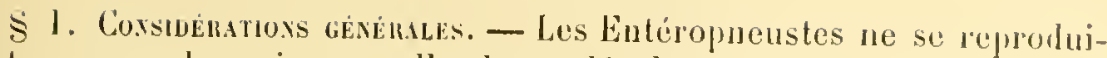
sent que par la voie sexuelle. Leur développement, dilaté, comporte la présence de phases larvaires lihres. L'une de leurs larres est commue, depuis longtemps, sous le nom de Tornaria.

\$ 2. Origine les feullets ; momes mabroxnames. - La segmentalion de l'ovule fécondé aloutit ì une gastrule, composée de son protectoderme et de son protendorlerme. Celui-ci donne le feuillet moven l'après le procélé entérocalien; il émet, a cet effet, cinq diverticules, l'un impair et antérieur, les quatre autres groupés en deux paires. Les cavités de ces expransions comstituent le củlome, qui s'alténue par la suite, ef disparait en partie; leurs parois représentent le mésoderme, dont beaucoup d'éléments évoluent suivant le mole mésenchymateux.

Sous le rapport des formes emblyonnaires, le déreloppement des Entéropneustes appartient i deux types: le type direct, et le type Tornarien. Dans le premier, la larve acyuiert rapidement, et d'unc manière presque directe, l'aspect le l'alulte; la région de son organisme, placée au niveau du diverticule colomique impair, se convertit en la trompe; celle, située à la hauleur de la première paire des mèmes élauches, devient le collier; le reste, qui renferme la seconde paire, lonne le tronc. Dans le denxieme type, la larve, dilr Tornaria, se comre au préalable d'un riche revêtenrent vibratile, "t sulijt une stase assez longue; elle sulıit, par la suite, des morlifications semblables à celles lu cas ju'écédent.

L. protectoderme engendre les centres nerveux; il devient ensuit. l'ectoderme définitif. - Le mésoderme subit une désagrégation mésenchymateuse, complète dans le tronc, incomplitı dans le collier et la trompe, où persistent les cavités culomiłjurs; ces dernières commumiquent avec le dehors par l'entremise de canaux particuliers. - L'entéron donne le tube digestif, dont la partic initiale se convertit, par la genese d'expansions ouvertes à l'extérieur', in un appareil lıranchial. Il produit en surplus, dans sa région antérienre, le diverticule plaryngien, dont les cellulrs prennent l'asprect caractérisliqur des éléments de la notocorde les Vertébrés. 


\title{
EMBRANCIIENENT IES TUNGIERS
}

\author{
CHIPITRE IT
}

DÉVELOPPEMENT DES TUNICIERS

\section{\$1. - Considérations générales.}

I. Caractères et classification. - Les Tuniciers somt des Notoneures. $\Lambda$ re tilre, leurs centres nerveux sont dorsaux, et représentés par un cordon longitudinal, le neuraxe, placé an-dessus du tube digestif. La région postérieure de ce cordon est sontenuc par une notocorde; son extrómilé antérieure, plus large que les autres parties, constitue un cerveau. Le mésolerme est entièrement mésenchymateux. Linfin, l'cetoderme protuil une cuticule épaisse, d'une uature particulière, fui enveloppe le corps, et a reçu les anteurs le nom de hunique : J'ou l'expression de Tuniciers, employée pour désigner l'embranchement.

1. - Ces caractères ne se montrent pas toujours an complet. Les plus simples des Tuniciers, qui composent la classe des Pérennicordes, sont les seuls ì les oflrir on totalité; les antres représentants dn groupe, les Caducicordes, n'en ont qu'nue partic. En effet, ees lemiers, quii, lor's de leur àge adulte, vivent lixés à des supports, possident hicu, dmant leurs phases embryomnaires, une notororte postétienre; mais relle-ci disparail complidement, el manyne à l'animal parfait. Les deux termes employés ci-dessus expriment, avec justesse, celte opposilion de la structure organique.

De mime que chez les antres Notonenres, l'appareil de la respiration est funrni par la région antéricure du tube digestif. Comme les Tuniciers, sans aucune exception, sont des ètres aquatipues, cet appareil est

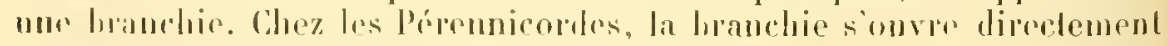
au dehors frar deux conduits. II n'en est pas de meme pour les Caduci- 
cordes, dont lorgane correspondant est entouré par un espace libre, la cavite péribrunchiale, qui débouche à l'extéricur, el communique, au surplus, par de nombreux orifices, avec la cavité de la branchie: les relittions de celte derniere, avec les milieux enviromnants, sont done assurées, d'une manière indirecte, par la cavité périlranchiale. Cet esprace lihre est l'origine tardive, el manque sonvent aux larres des Calucicordes, hien que celles-ci possèdent déja une branchie: les rapports de cet appareil arec le dehors sont alors effectues par deux comduits, idenliques à ceux des Pérennicordes, puoique leur situation dans le corps soit ditférente (ceux des l'éremicordes sont ventriux, et dorsanx cenx des larres des Caducicordes). C'est par l'élargissement de ces conduits que s’élahlit la cavité péribranchiale de l'adulte. - Aussi, à beauconp d'égards, les l'érennicordes reprósentent-ils la permanence d'un état enbryonnaire, et temporaire, des Caduricordes.

la localisation de la notocorde dans la région postérieure du corps, et son alssence d'extension vers l'extrémité antéricure, vaut souvent ì ces ètres le nom l'Urocordés.

B. - L'embranchement des T'uniciers renfermo deux classes, dont les considérations précédentes montrent les raractères distinctifs.

$1^{\circ}$ La classe des Pérennicorles; dont la notocorde persiste clurant lit vie entière, dont le cordon nerreux est tres long, ef dont lorganisme est privé de carité périlranchiale.

2. La classe des Cuducicordes; dont la notocorde n'existe que durant les phases embryonnaires, dont le cordon nerreux est fort conrt, et lont l'organisme possède une cavité périlınanchiale.

Les Pérennicorles sont tous des animaux lihres; suuf quelques exceptions, hornées anx trois lamilles des l'yrosomides, des Silpides, et des Doliolides, les Calucicordes sont les itres fixés.

\section{II. - Généralités sur le développement. - La reproduction} des Tuniciers s'ellectue de deux manieres: par la voie sexuelle, of par le procédé asexucl. La preniore comporte la fécondation, el jamais la parthénogenese. Le seeond correspond it me gemmiparité, souvent coloniale, pirfois fissurante, et pouvant se ramener, dans ce dernier cas,

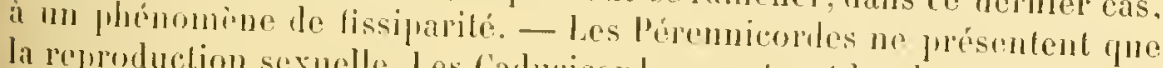
la reproduclion sexuelle. Les Caducicordes mentrent les deux; quelyuesuns d'entre eux, nommés Ascidies simples de ce fait, ressemblent aux Péremicordes rn ce pu'ils se reproduisent seulement par la fécondation; les autres, plus nombroux, et lésignés par les termes d'Ascidies compasées, d'Ascidies sociales, possèdent it la fois la fécombation el lat gemmiparité. Ce ternier moele jone, chez enx, un rôle consilérable, en tant que mogen d'engendrer des deseendants.

1. - Le développement des l'érenniendes n'est prespue pas connu. Cepentant, comme les Calducicordes, on du moins ceux d'entre oux (ot 
ils forment la majorití) qui sulissent des embryologies dilatées, passent par une structure temporairo. semblable à l'organisalion permanente de ces Péremnicomles, il est promis d"appliquer it cenx-ci les nolions oblenues par lólude rle cenx-là. - La phupart des Caducicorles ne renferment, dans leurs orules, que de mimines malériaux nutrilifs; aussi, abandomnont-ils leurs enveloppes a l'élat de ladres moliles, pui se dŕplacent et se menvent durant qurlque tomjus, après funoi elles se fixent à un corps élranger, devienment inertes, el se converlissent en adultes. Les mélamorphoses de crs animax otrent done une custaine romplexité. Ce sont los larves des Caducicondes qui montrent, durant leur état de libros mourements, des ressemblances frappantes arre los l'érennicordes alultes, dout rllos partagent, du reste, le mode dre vir.

Ces larves sont aisement reconmaissables. Lum corps, privé de cils viluraliles, el déji recomverl d’une mince lunique, porte, dans sa région

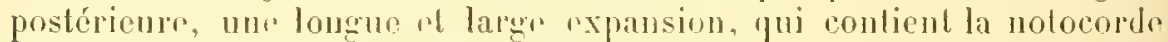
dans sa massu, el où s'étend lr cordon morvenx. Cet apjumbice surt à l'mmbryon pour nagere, at lui permulte de su déplacer: il a recu le nom de queue; l'embyon lui-mène ast désigné, de son côté, ol a cause dr la presence de colle quene, par lexprossion dr larve wodele. Apres une certaine périodr dr lilorlé, la larve se fixe par son extromité anlérienro. el restr désormais immolile; sa queue crsse de coiltr, "l salrophir. pendiut que les autres parties alu corpis grandissont; l'rmbryon so conreplit en m Cadnciconde adulte. - Li's représuntants des trois familles, signaléss plus haut, font seuls exceplion it celle riggle; mais l'exception no porto qu" sur la lixation. Conle-di no se produil point, puisque ees

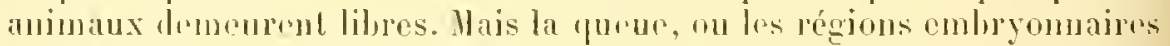
qui hui correspondent, disparaisunl également, aves les organes quelles

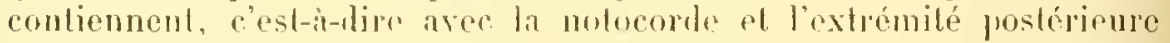
dos contres nervenx.

Lexistence dr larves urodeles, chez les Tuniciers, ast commus depuis longtomps. Carst A. Kowalersty qui, le pronier, montra toule l'importaneo do celle disposition, an sujet des aftuités naturelles de ces animax.

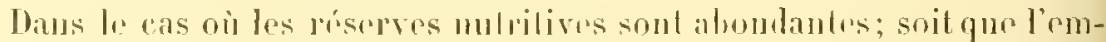

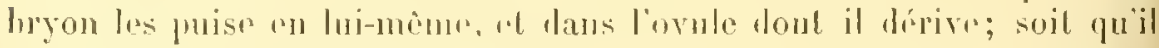
les emprunte a l'organisme maternol, comme il en ist chez les Salprs munies de: lonr placenla, la phase de lave urodidr ast omise. Coprendant, colle omission n'est pas complede, car los organes contenus dans la queur, nt nolanment la notocorde, sont nucom représulis par quelqurs élémrnts, placés dans la situation qu’ils occuneraient, s’ils atloignainul leur dérolopponent normal; il sagit donc d'une réduction, et non d'une absence entière.

Autanl quil est pemis d'en juger d'apris les fails, les larves modeles des Caduciondos mo sout pas des larves adaphatives, mais des em-

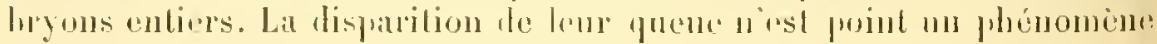




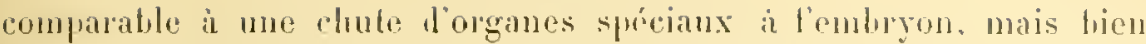
latrophie d'un appareil, qui se lroure à sa place dans le tamps, ef drvirnt inutile. La comparaison des larves des Calucicordes anx Pónmnicordrs impose cette conclusion. - Si la quene des embryons urodès itait, pour les Tuniciers, un organe adaplatif, "t semblable, par rxemple. aux hras des larvos des Echinodermes, les Pérennicordes la perdroinul tout comme les Caducicordes; or, il nen est pas ainsi, puisque les premiers la conservint. En s’élevant ì la notion subjectivr de la géníalogie, la qurue des Tuniciers est un appareil ancestral, maintenu chez les Pérennicordes, qui conservent une vie libre: apparaissant encore, par atavisme, chez les ambryons des Caduricordes; ef salrophiant ensuite, à cause de la fixation de ces derniers, qui la rend inutile et superflue. lille n'est point comparable aux bras, ni aux autres appendices locomoteurs, des larves les lichinodermes, qui sont rraimenl des organes sjóciaux à ces larves, el nont jamais existé chez les premiers, et les plus simples, des représentants de l'embranchement; du moins dans la limile où il nous est permis de comprendre, et de concevoir, los choses d'antrefois, d'apris les phénomènes actuels de l'embryologie.

B. - La base essentielle de la reproduction asexuelle des Tuniciers est. ehez ceux qui possident ce procéló, la gemmiparite stolomiale. Le générateur émet, par une rigion le son corps, des stolons, composés par des éléments empruntés aux trois feuillets; les descendants sont produits prar ces stolous.

Les Asridies composées ne sont pas les seules à porter des stolons; certaines Ascidies simples, les Cionides par exemple, en possident également. Mais ces Arrnier's ne sont point des stolons gemmipares: ils sont les stolons fixateurs, qui servent a atlacher l'individu a son support, et dans la composition desquels entrent seulement deux feuillets, f'ectoderme el le músorlerme. Une expansion, énise par l'endoderme de l'imliviclu, fait tonjours défaut aux stolons fixateurs; alors qu'elle ne manque jamais aux stolons gemmipares.

La gemmiparilé des Tuniciers aboutit, dans la grande majorité des cas, à la proluction d'une colonic; suivant la position des zones hourgeonnantes du génćrateur, et suivant la mar lue dn homgennement himòme, la disposition mutuelle des zooüles rst indéterminée, ou bien alfecte une cerlaine rigularite et une cerlaine précision. Ce dernier cas est celui des Tunicirrs gemmipares dont les colonios sont libres, cesti-dire des Pyrosomides, des Salpides, el des Doliolides; el de plysienrs Iscillius composés appartenaul à lia famille dos Botryllides.

l)ordinaire, le générateur attend, pour prouluile ees stolons gemmipares, el pour donner des descundants, deetre parvenu lui-mème à l’élat adulte. t.es phénomenes sont dillërents chez les représentants des qualre familles précédentres. ol surtont chez reux dont les colonies sont libres; la cause de ee fail doit ètre chereluéc, sans nul doute, dans lat 
nécossité de produire hatirement un assemblage colonial capable de se soutenir dans l'eau, car la queue des embryons est tris rédnile. - le générateur produil son slolon gemnipare, alors qu’il se trouve encore i lélat larvaire. La larve des Botryllides lourgeonne vaiment de nouveaux individus; mais tr stolon embryonmine des Prosomes, des Salpes, et drs Ioliolides, par me condensation el ume abréviation plus grandes encore de cus phénomones, se segmente transversalement en plusieurs tronçons, dont chacun devieut un descentant. La gemmiparité stoloniale s'est ainsi convertie en une sorte de fissiparité, ou plutiot de gemmiparité tissurante. Comme le laissent pressentir les notions exposées ci-dessus, ce dernier procédé n'est qu'une modification de l'ordinaire mode bourgeonnant des Tunicirrs.

\section{$\$ 2$. - Sexualité et développement des feuillets blastodermiques.}

I. Sexualité. - Tous les Tuniciers sont hermaphrodites. Les éléments sexuels mùrissent presque en même temps, ct sont rejelés, par le générateur, à des momenls très proches l'uu de l'aulre, simon ensemble; le là, l'anlofécondation est-elle fort pussible. La fécondation croisée existe purlaul : dans lecas, tres frépuent chez les Tumicier's, oì pusieurs individus sont placéscôte à côte, el parvennent, vers la mème époune, ¿a lenr malurilé sexuelte. Comme ces ètres rejellent, dans l'eau environnante, leurs éléments reproductenrs, les spermalozoïdes des uns peurent rencontrer les orules des autres, el les féconder. Mais au préalable, el en sortant des conduits sexnels d'un individu délerminé, ces éléments traversent sa cavité cloarale, el son siphon cloacal, où ils se mélangent, el se fécontent aussi. - II n'existe donc, chez les Tuniciess, ancune progrnèse, soil des élíments mìtes, soil des éléments femelles. Pourlanl, dans certains eas, chez les Salpides par exemple, les ovules prennent naissance avant les spernalozoüdes, el sout déja bien reconnaissables dans te rorpes, alor's que les testirules sont a prime ébanchés. Hais ce phénomène rentre dins la règle précédente, car la maturité, cl la jossibilité de la féeondation, arrivent au mème moment, on pen s'en faul, pour toules les rellutes reprorluctrires.

l.e téveloppement des spermatozoindes ne présente ancune particularite importante. Il n'en est pas lout à lail ansi pour celui des ovules, qui a pròté, dans res lemieres années, à de nombrenses discussions.

L'ornte des Tuniciers est presque lonjours entouré par un follicule, placé en drhor's lu vitellus; parfois, entre ce alemier et le follicule, se trourr en surphs une coveloppe assuz épaisse, formée d'une substance homogène et transparente, jui ressemble a celle de la tunique de l'adulte. Dans la plupart des cas, les collutes folliculitires sont grandes, el contiennent nu prolophasme racuolaire; ailleurs, el chez les llolgu- 
liles par exemple, plles sont petites, of les varuoles sont moins nom-

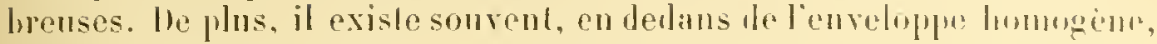
une scconde assise cellulaire, qui sapplique coulle le vitellus, et couslilue la conche du testa, on des cellules granuleuses. Les memliranes ovulaires sont dès lors d'une grande complexite. En allant de dedans en dehors, et partant de la surface du vitellus, on trouve : la courhe des crllules gramuleuses, l'enveloppe homogène, et enfin le follicule, qui se livise parfois, lui-mème, en lenx assises concentriques, et s'entonre à sa pépiphérie d'une memblane limilante. Ce follicule, soit simple, soit doulble, ne fait presque jamais défaut; l'enreloppo homogine, et l'assise granuleuse, sont moins fripuentes.

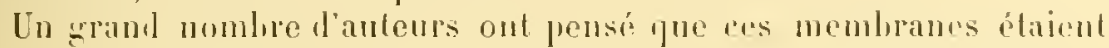
les prouluctions lirectes de l'ovule. Ce dernier, tout en grandissant pour atteindre ses dimensions définitives, séparait lle son novau ıles parcelles nucléaires, qui se dirigeajent vers la périphérie du vilellus, s'y entonraient l'une zone protoplasmique, el sy convertissaient en cellnles. Les observations faites par Il. de Laraze-Inthiers sur les Ilolgulides, et relles, plus récentes, effectuées par Eul. van Beneden et Julin sur les Clavelinides, montrent qüil n'en est pas ainsi. Hans les jennes ovaires. les ovoblastes se divisent en oroeyles et rellules folliculaires. Les premiers grandissent souls pour se converlir en ovules ríritables, et deviennent rapidement plus volumineux que les secondes; celles-ci restent petites, et se disposent autourdes précédents, qu'elles enveloppent d'une manière complète. Tantòt les cellules folliculaires ne composent qu'une assise simple; el tantot, tout en entourant charne oroeyte, se groupent sur deux rangées concentriques, dont linterne constitue la conche granuleuse, et dont l'extérieure représente le follicule définitil. Dans le cas où ce lernier so composo de deux rangées cellulaires, celle conche externe se livise, an surjulus, en lenx assises emboìtées. De mème, l'enveloppe homogine est également produite par les cellules folliculaires. qui l'exsudent de leur substance, tout comme la tunique le l'arulte est exsudée par l'ertorleme. Entin. ancune de ces membranes orulaires nest directement engendrée par lovoryte; elles proviennent toutes des éléments folliculaires, qui dérivent à lenr lour des ovohlastes primordiaux.

Au moment où l'ovocrle arrive i maturité, res membranes se dŕlachent, el se séfrarent de lui par une sérir de désagréģations parlielles. La fécondation est alors possible, car le ritellus se trouve à mu. Pourtant, le spermatozoïle s'unit parfois a l'ovule, alors que celle désagrégation commence à peine, et qu'un orifice restreint lui permet de passer; les premières phases embryonnaires seffectuent, dans ce cas. i l'abri de ces enveloppes, qui sont plus on moins romplies. Mais elles ne durent jamais longtemps, et l'embryon les quilte d'une manière hative, soit qu'il sorte hor's de l'espace qu'elles limilent, suit puelles acherentile tombre par moreran. 
II. Segmentation et feuillets blastodermiques primordiaux. - Les ovules dr la plupall des Tuniciors ne contiemment gure

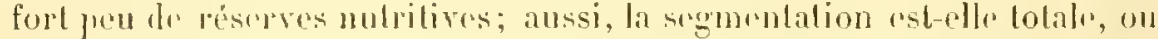
pen inégale, el alsoulit-elle à une blastulation suivie d'une gastrubalion.

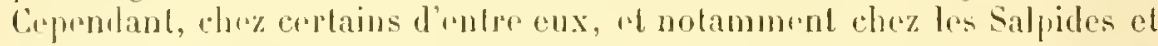
lis Prosomides, les materiaux denblelecthiques sont plus aloulants, el

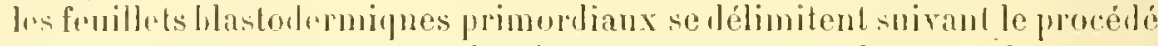

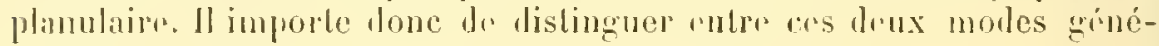
liques les fenillats, la blastulation el la planulation.

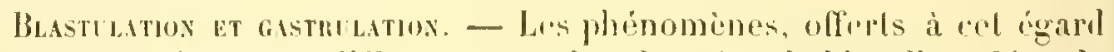
par les Tuniciers, ne different pas des ronmées habiluelles. Lovule fécondé se smomrnte. of so conrertit en me blastule. munie d'une cavití hastocrolienne assu ample; la zone hastodermique, charece de s"inviginem dans cette cavili pour domer le protemdoderme, se laisse sonvent distinguer de l'aulre par la taille plus grande de ses éléments constilutifs. Cetle zone s'invagine, of l'emluryon se convertil en une gastrule, munie de son protendoderme, de son protectoderme. at de son entéron: les denx funillets sont an contact l'un de l'autre, et saccolent étroitement par leurs faces mises en présence, de faron ì faire disparaille toul vestige de la cavilé hlastocrolienne.

Cerlaines Ascidies olfrent un procédé intermédiaire cutre la bastulation el la planulation; telle est, par exemple, l'Ascidiella aspersa étudiée prar Chahry. liovule subit une segmentation tolale el igrale; il se convertit en une hastule, donl to bastocole est tres étroit, et qui ressemble de près, par cela meme, it une planule directe. Lne gastrulation se manifeste ceprendant: mais, ì cause de l'exiguité de la cavité blastocolienne, elle ne peut s'etrecluer par invagination. Elle se produit par le mole incurvant. La blastule s'aplatil, et se recourbe en une couje, qui s'approlondit de plus en phus; elle se translorme, par ce moyen, en une grastrule, semliblile à celle du cas précédent.

Plavistox, - La plamblation s'effectue, suivant le eas, l'après le procédé direel, ou d'après le mode indirect. Ce dernier est, comme tonjours, lié ì la présence, dans l'ovule, l'une grandir quantité de deutolicillie.

I'lanulationdirecte. - Ce type de planulation est offert par les Salpes. l'ovule subil me segmentalion totale, el presque égale; il se convertil, par l'etrel de cette segmentation, en me planule lireste, composée de denx assises cellulaires, lont l'externe enveloppe l'interne, et lui est directement arcolér. La conche extérieure est le prolceloderme, el l"inlérieure corresponl au protentodeme. La première n’ust pas complète tout d'abord, war clle laisse la secomle saillir litrement, ef se trouver a 111. sur un espace restreint de la surface de l'emhryon. Cet espace est l'homulugne de Tentéropore de la gastrule; il disprirait ensule, par la 
fermatma du protectoderme, qui entommentirsement le feuillet interne.

A en juger dapres les olservalions de kimalerslis, u rellos de Torlaro, lo prolendorlerme se sépare par places du prolectorlerme, peu ipres lenr delimitalion muluelle. Ces viles eorrespondent, sans mul Joule, it la cavilé blastocerlienne du cas prócelent; ils sont élroils, semblables it des fentes, s'missent entre pux pour donner un soul espace, ulisparaissent ensule, loul comme lans la gastrulalion. Lem

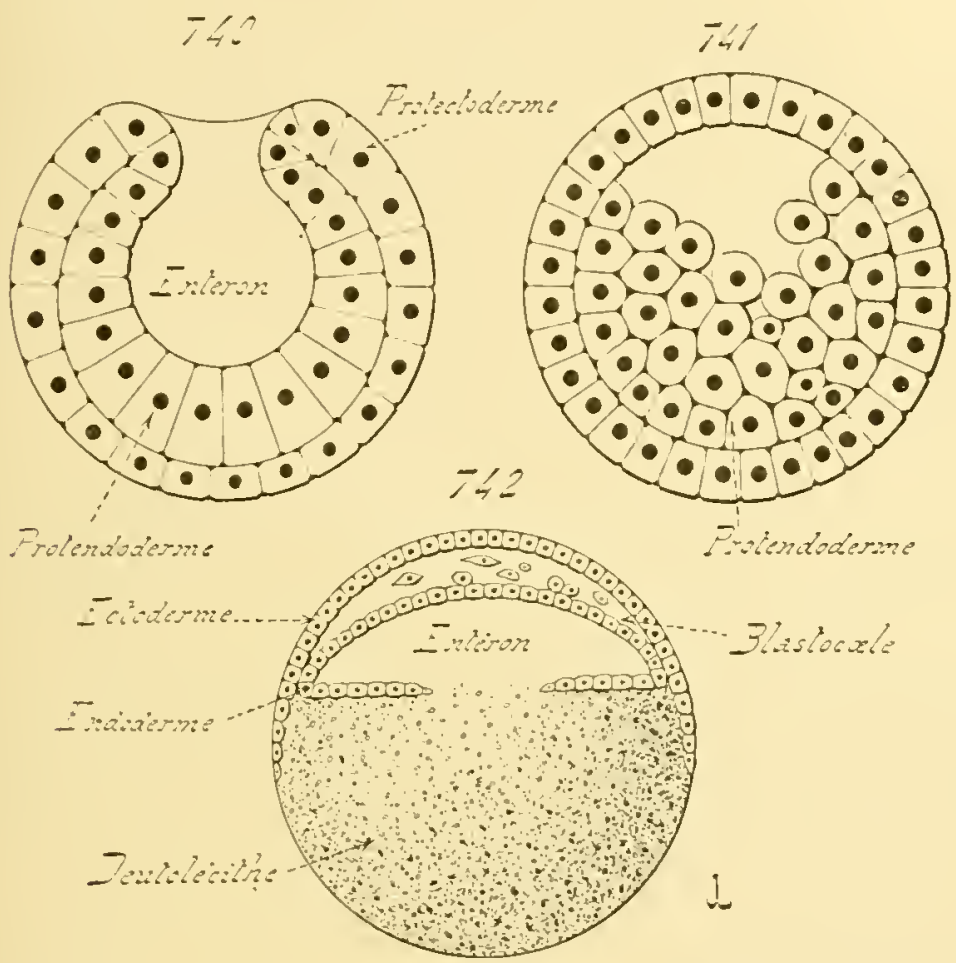

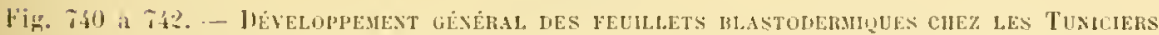
(coupes mediunes, a demi diagrammaliques). - Iin Tit), gastrule venant le se façonner, et sucédant a une blastule. - En 7\%1. planulo direcle d'une salpe. - lin 7t?, planule indirecte d'un l'yrosome, prise au moment où l'enloderme se replie sur lui-mène puta' entourer l'entéron.

jrésence est le résullat d'un rappel atavique, ol na pas d’antre signification. ni ancune antre imporlance grenélipue. Is sont mòme capables le mantuer, cal Salensky avoue ne les avoir poinl rencontrés lans ses recherches.

Lentéron se creuse ensuile dans le prolendobleme, par simple

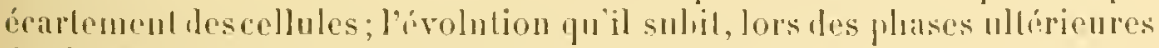
lu diveloppement, ne dilfiere pas du type habilucl. 
I'lumblation indiverte. - Los l'yrosomides offrent wa remple de ee

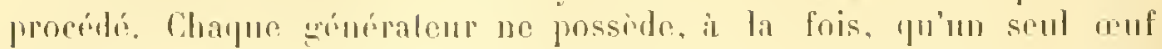
fécondé, qüil conserve dans son oviducle; lovule sonlive a son njeau la paroi de ce romduil, el s’en enveloppe à la façon l'ume capsulo. L'embryon n'est rejeló, de loviducte lans la ravilé péribranchiale, et decelleci dans les milienx enviromants, quiu moment oil son organisme a donné naissance, par un moyen exposé plus loim, ì une jemne colonie composée de qualpe imdividus.

Le deulolécilhe osl forl alomdant; le blaslolécilhe consliluo une cicaIricule, qui su sermontr seule. Cellori produil rapidrment un groupe

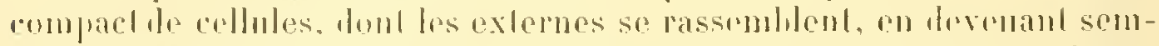
bables les moesan autres el siacolant intimement par leurs bords, en

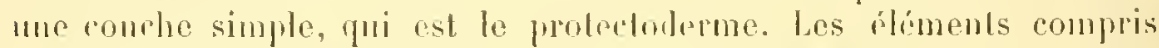
entre ce fenillet, ol la parlie du reulolicilhe placíe au miveande la cicaIricule, constilurnt, de lour côlé, Je prolendoulerme. Colni-ci augmente sur jlace to nombre de ses cellules, landis que le prolectoderme s'átend

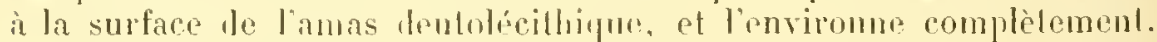
Col amas rejursente dies lors nor réritalıle vésicule vilelline, qui porle,

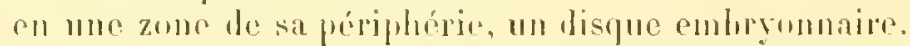

les cellules poulemolermiques se divisent à leur lour en deux groupes. Les plus internes, directement appliquées contre le deutolécilhe, se disposeul en une assise ópilhóliale; les aulres, placées entre les précédentes el celles lu proteclorlerme, passent i l'b́lat mésenchymaleux, el réalismot de prime aloril celle strubture, que les autres Tuniciers, anx dirroppoments moins conlensés. montrent dune maniore plus lardive. Jes promières consliluonl l'endoderme défunitif, el les aulres le mésoderme. liendonirme roplie ses londs en dessous de lui, et se soulive, par son milieu, an-dessus du dentolérithe anquel il s'accolait, pour délimiter ainsi unc cavité, yưil enloure peu à peu. Cetle cavité est l’entéron.

1II. Feuillets blastodermiques définitifs, et organes primordiaux; mésoderme, notocorde, et neuraxe. - le suile apri's la genèse des leuillets hlastonlermigues primordiaux, le prolendorlerme se divise en mésolerme et endoderme. Dans les développemenls par gaslrulalion, le mésoderme est produil d’aprìs le procédé entérocolien, et ses prarois, ì lour déluut, sout ćpilhélialos; juis, los collulos de ces parois

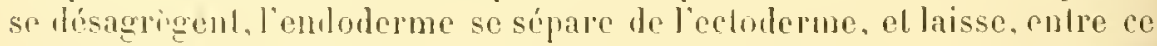
lemier et lui-memo, les espaces vides, ou pénitrent ces cellules; lo fenillel moven passe a l'élal mésenchyoualeax. Lorsque l'érolution

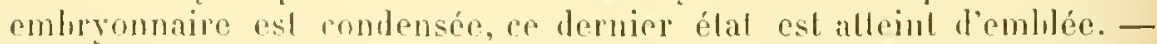
En oulde, quelpues cellules endoulermiques, siluces sur la face dorsale et la ligne médiane de l'entéron, se séparent de feurs roisines, el so rassemblent en $11 n$ rordon solide, placé, dans celle région, entre l'endo-

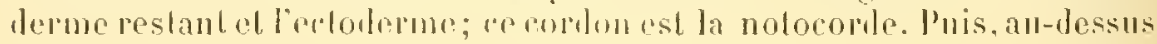


mème de cette nolocorde, l'ectoderme se déprime cu une gonldirpo longiludinale, qui se ferme par lo rapprochement el lit sombure de ses bords; elle se Iransforme en un canal, soulenu par la molocorde. Co canal est le nenraxe.

Les denx fenillels primordiaux sont mis en canse lans ces phronomines. Le prolecloderme dome le nemraxe, el su borne cusuile à persister comme ectoderme. Le protendoderme problnit la nolocorde par sa région dorsale, engondre le mésoderme par ses denx faces latérales, ol, après avoir sulvenu à ces grenèses, devinnl l'cudoderme téfinilif. l'enléron est conservé comme ravité digestive, Junt la volumineuse

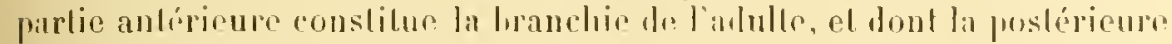
fonruil l’iulestin vérilable. - les lails blant connus dans loul ensemble, leurs parlicularités levionnent plus aisées à conceroir, el ì suive, soil dans les développemenls gastrulaires, soit daus les diveloppements planulaires.

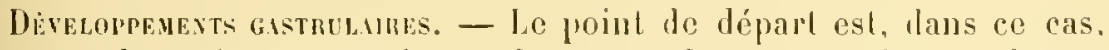
une gastrule, qui se convertil, par la genose de son mésolerme, de son neuraxe, el de sa notoeorde, en mo larve urodele. Wu suivant la sírio chronologique des phénomìnes présentés par l’embryon, la gasluule commence par changer le forme, produit ensuile l'éhanche le sa nolocorle, celle du nemraxe, enfin colle de son feuillet moyen, apris quoi elle revèt l'aspect de larre modede.

1o Changements de forme de la gastrule. - An moment où clle vient de prendre naissanere, la gastrule ist glohuleuse; sou entéropore est cenlral, en ec sens que l'axe passant par lui, el par l’exlrémilé qui lui est opposéc, correspond à un dianèlre de la spliere gastrulaire. Cotle allure disparail rapidement, car l'emhryon s'accroil, de préférence, suivant une direction perpendiculaire ail diamètre prócédent. La sphère primilive se converlit ainsi nn un ovale allongé, donl le grand axe esl dirigé suivant celte ligne de plus ample cxtension, el dont le pelit axe n'est aulre que l'ancien diamolre de la gastrule. Le premier sera desormais l'axe longiludinal de la larve, el le seconl l'axe lransversal.

Cel accroissenent, suivant l'axe longitulinal, ne s'ellectue pas d'une manière égale de part et d'aulre de l'entéropore, et n'a pas pour effel Je laisser col oritice dans une silnation mérliane. En so reportant a la gastrule primilive et globuleuse, il est permis do concevoir nn plan passant par l'entíropore, el divisant l'embryon en denx hémispbères éganx. 0r, l'extension suivant l'axe longiludinal se produit semlement daus l'un des hémisplières, qui drvient bramroup plus grand que l'aulre, laissé indemue. Aussi l'entéropore crsse-l-il d'èlre médian, ul se lronvet-il reporté à l'une dos extrémités de l'ovale.

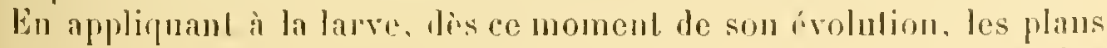

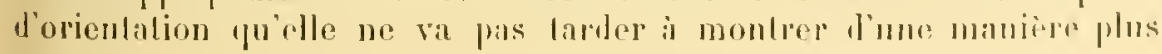


nelte, il est possible do huj reconnaîlo deux laces el deux exlrómites. liune drs fares est sujréreure, ou dossale, el lantre in lérirurr, on renlale; la premièe porte l'enlíropore, la secoude est pleine. Des deux

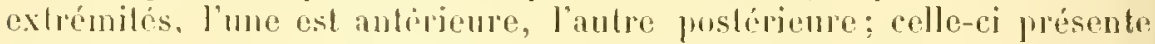
l'entéropore sur sa parlie Jorsale; celle-là noflie aucun orilice, lien

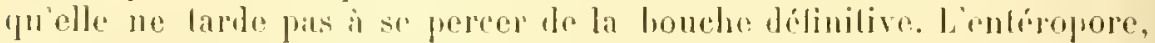
qui ocrupr une situation i la fois postérieure el sujérieure, est uestiné, non pas il disparailre le suile, mais il etre enfermé dans la première éhauche du nemraxe.

Qu Crenise de la notocomle. - L'entéron de la gastrule suit, el accompagne, l'aceroissement particulier subi par celle-ci. Il prend également une forme ovalaje, el se prósente comme une cavité, dont les relations aree le dehors sont assurées par un orifice, l'entéropore prostérieur et supréreur. Toule la volumineuse région anlérienre de la cavilé entéloijue est close, ol oflre l’aspect d'un cul-te-sac. De son còté, le prolendoderme resto directemenl accolé contre la tace interno de l'reloderme. Lentiron se livise, ensuite, en deux parts, au moyon d'un étranglement transversal, „u sépare l’extrémilé antérieure del'extrémité postérienre; cet ranglement esl place de facon il jendre la juemiore plus grande que la scronde. Celle-ri, qui est postérieure, el qui possète l’enféropore, est chargée de donner naissance a la notocorde et an mésoderme; prespue toutes les cellules qui la composent sont employées dans celle genise; celles laisses inlemmes finissent par se dosagréger, el jar sc confomlue avec les céments misenchymaleux du feuillet moyen. La parlio antíricure de l’emlérnu. close, el formant une vésicule imbrnc, persiste telle juello durant la production des élauches précédentes, el domme plus fard la lunnchie el lintestin : doù son nom de vesirule lnanchio-intestinale. En somme, et au moyen de cel étranglemenl, fentéron primondial se diviso en teux zones généliques: l'une anterienre, et lmanchio-intestinale: la seconde posterieure, el cordo-mésolevmique.

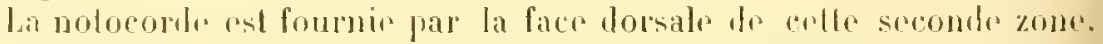
Les drux rangés dr collules, flacés sur la partir madiane, et suivant

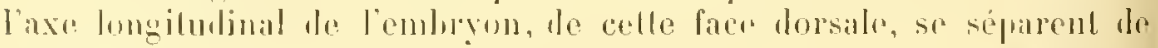

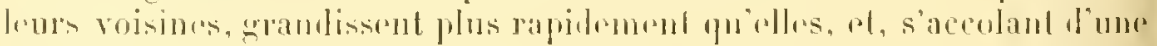

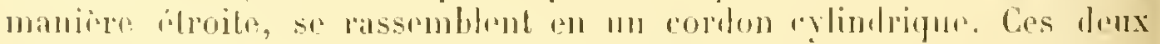

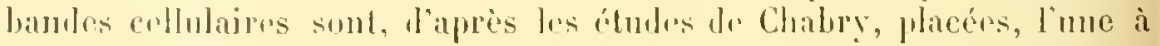

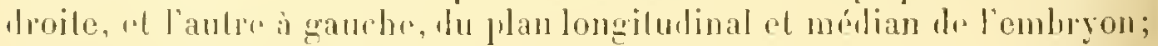

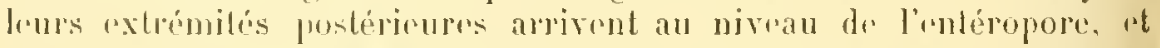

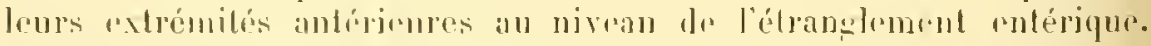

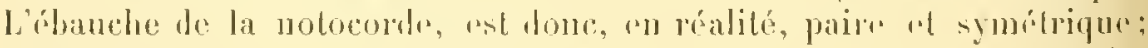

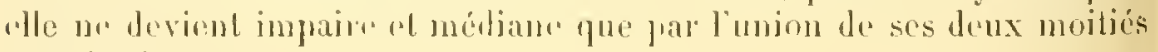
consilutives.

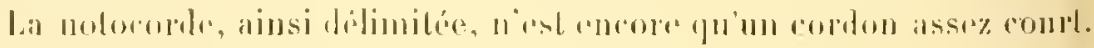




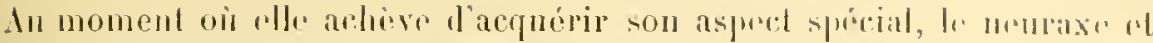

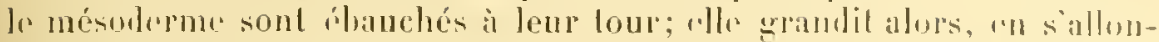

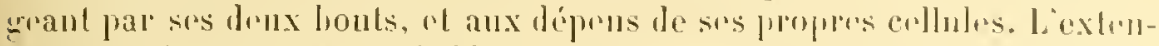
sion antérirure at assuz faiblr, car la notocorde reste loujours quelene?

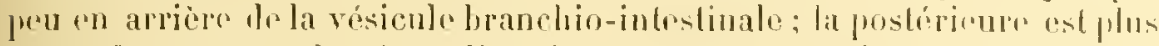

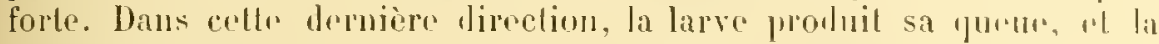

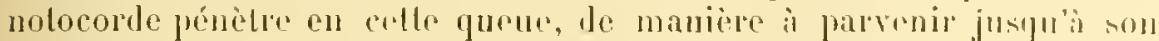
"xtrémité lilıre, et a la sontenir sur toute sa longruenr. - Ein allanl an fond des choses, la qurue dérive do colte partir de lembryon, qui constiluc l'extrémité postílicure do l'ovale, ot se trouve en arrière de l'entéropore: la notocordr, ébanchér rn avant te l'entéropore, s'étend do préférencr, par la suitr, "n arrière dr la zone occupér par cot orificr. La mème marche "st suivir par le nenrax", arec celle differrner que celui-ci s'allonge, en surplus, par son autre hout, de maniore ì parronir aussi jusque sur l'rxtromilé antérienre de l'embryon.

$3^{\circ}$ Genese du nembxe. - A. Lo promirr rudiunnt de cot organe prond naissance sur le bord mome dre l'enteropore, et en avint dr lui. Durant lis phases de la transformation de la gastruld gloluleuse en une larve ovalaire, l’entéropore change d'asprect; d’arondi, il drviont élroit, somblable à une fonte, el lransversal. Il offro donc denx lèves, l'mn.

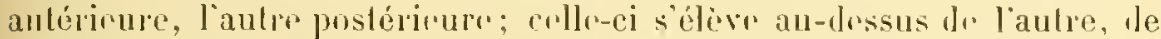
manière à la surplomber, puis grandit cn sallongeant. el passant ì la fois sur l'entéroporr et sur la levpre antériour. Elle est comparable, dans son extension, ì une languette médiane, qui s’accroil suivant l'axe longitudinal de l’emluryon, el s'étend vers l'extrémité antérieure de ce dernier; dans cel agrandissement, elle communce par recomrir l'entiroporo qu'elle limitail jusque-lì, puis le borl autériem de rel orjfice, enfin la partic médiane de la lace lorsale de la larve.

En mème temps, el d’une façon connexe il co développenunt, relte parlie médiane subil plusienrs modifications. Au licn dr pestro plane, elle se creuse d'un sillon, que la langurthr précélente reconvere a la fagon d'un opercule. Ce changement ne s'accomplit pas a la lois sur tonte l'étendur de la face dorsalo endurvonmaire; il dibule sur le bord

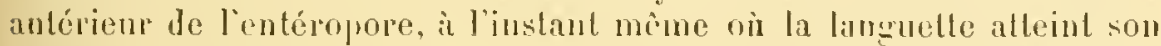

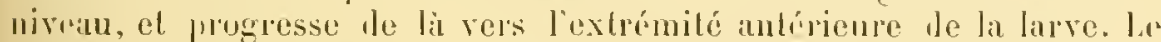
sillon s'étend ainsi de l'entéropore rers cetto extrénilé, el sa genèse accompagne colle de la languelle; tous denx, l'mnu rocourraul l'aulie, s" prolongenl a mesure, du cóté le la région autérienr de l'embrron. En outre, el pembut cet accoissement, les bords de la langmolle se

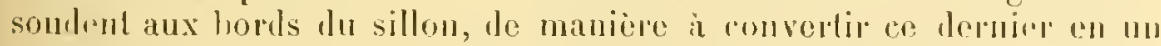
cunal cylindripue. Toute celle évolntion se róduil, ren résumé, à la pro-

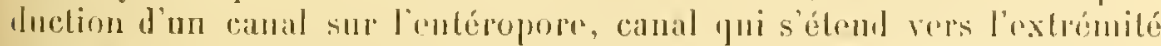

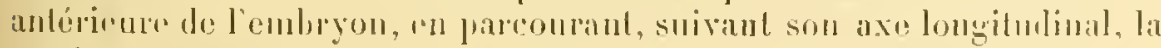

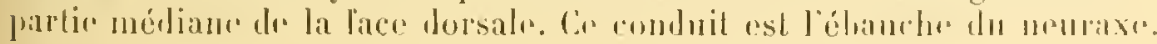




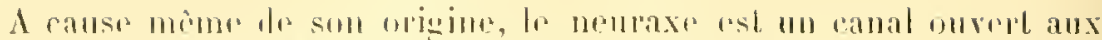

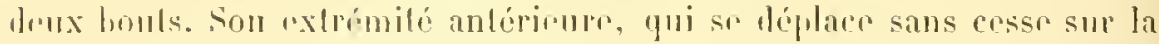
région dorsate do l'ombryon, ot se tronve lonjours reportér plus avant,

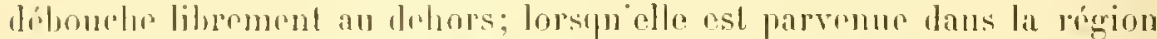

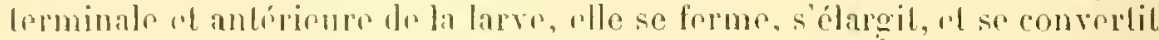

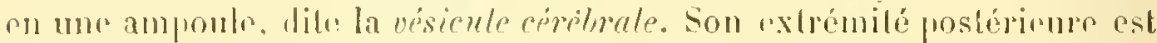
roprésentée par l’antépopor lui-mème. puisyuc la premièró élauche du canal est domuc par la live postérienre de col orifice, recouvant la leve antorienre; la lumière du nemaxe communique done, par lo

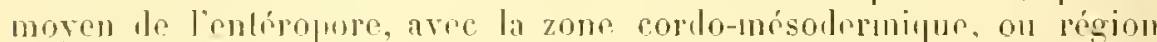
pustirinure, de l'ontion primordial. - Cas comexims rappellent de

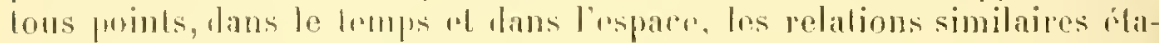
hlies, entre los organes correspomlants, cher los emhryons dis Vertélores. Inssi est-il permis de Jomer le mìmu nom, celni dr comluil neurentérique, ì cello courlo portion lus lèves le l'entripopore, qui met en rapport to neuraxe avre l'entéron. - Cos rapports disparaissont haliremont. I a zone corto-mésolormique dr l'entéron peril ses caractions propres, car elle est employér lout muliope à engendrer la nolocorde ot

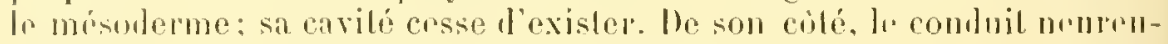
tóriqu se ferme regalement, et lestrumilí postérieme du neuraxe drvioul alose, foul romme l’extrémitó anlérieure.

I mesure pur s'effertunnt ces phénomines, la région postérieure de lembryon s'allome ponr lonner la quoue. Lo nenraxe, devenu clos far son extrémilé corresponlante, pénèlre dans cetle région, et s'étend jusqu'i son lout libre, en so lenant toujours placé au-dessus de la notocorde. - linsi, les rapports dr laxe nerveux avec les autres parties du rneps, ol la mareho de son devoloppement, sont aisés i élablir. Cot axe est silue sur la liene médio-dorsale de lorganisme, et ra de l'exírimilé antériouro do ce lernicr à son extremito postérienre; il est placé audessus do la nolocorlo, qui ropose elle-mème, du moins à son débul, sur la zone postérienre de l'enléron primordial. Les relalions sont done: somblahles à celles offertes par les Vrobébrés : lo neuraxe supérienr à la notorople, supirieure olle-mime à l'entíron. Itaule part, l'ébanche nervense apparail sur los hords lo l'entéropore, s'élend de li en avant, el ensuite en arriere, de cel orifice, on du niveau aumel il rst place; la ressemblanee aved Ins fails correspondants, monlrós par les embryous los Verlibrus, esl donc complide.

IB. - Élant domni son mode de produclion, le nemraxe n’est pas à mu sur lo corps, el se trouve reconvert par mo assise eclodermique. En effol, la languetle formór par la levere de l'entéropore se compose de doux romehos rollulaires superposios; dr meme, les horts du sillon sont

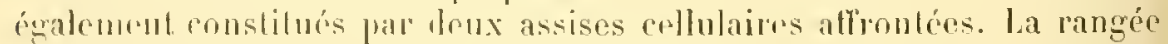
interue do lune se rémit anx rangées inlerues des aulres, pour fournir la paloi propere hu muraxe: et la rangée exlerue de la languelle se 
soude aux assises externes des horls du sillon, ponr couslituer, autoul' et all-ilessus du neuraxe, une couche continue, yui se relie lateralement à l'cetoderme du reste du corps.

Par suile de son origine, la paroi du neuraxe est de provenance ectodermique. - Cependanl Melsehnikofl' n'est pas de cel avis, cu ce yui louclie la face torsale te sa paroi, cest-à-rlire la face qui dérire de la languelte. Celle dernière est lonnéc par le bord postérienr de l'entéroporr, où l'endoderme se joint à l'ectoderme; el celle languelle se trouverail composée, de ee fail, par nue double assise collulaire, dont l'externe et supériure lérira de l'ectoderne, el dont l’interne ou inférienre provient de l'entoderme. Comme la couche interne confribue seule, comme il est dit plus luaut, à donner la proi dorsale du nemraxe, il en résulte que cette dernière est d'origine endodermique. - Une telle interpétation est un peu forcée. Les hords de l'entéropore ne sont pas formés par l'endoderme uni ì l'ectodrme, mais par l'ectoderne scul; lemlorlerme commence un peu plus bas, dans la cavité entéripue. Au moment où l'invagination gastrulaiıe vient de s'elfectuer, el ou les lères de l'enléropore se rapprochent, ce phénoméne s'accompagne d'une légère involution ectolermique supplementaire, qui reporle l'endoderme plus profondément, el laisso l'ectoderme seul superficiel. Ca fail est aisé à reconuaitre, par suite de la dilférence de taille des éléments; les cellules endodermiques sont, d'halitude, plus grosses que celles de l'ectoderune. Aussi, les bords de l'entéropore soul-ils constilués uniquement jar des élémeuls d'origine ectodermique, el la languetle est-clle, de son côté, donnée loul entiere par l'ectoderne.

$1^{\circ}$ Conèse du mésodeme. - A. Les premières ébanchus du feuillet moyen font leur apparition aux dépeus de la zone col‘lo-mésodermique (ou zone postérieure) de l'entéron prinordial, quelques inslants après la formalion des premiers rudiments de la nolocorde el du neuraxe. Ces chauches sont conslituées frar des juaques cellulaires, d’aspect épillı́lial, ¡ui se dégagent du protendoderme de celte zone entérique postérieure, et restent accolées contre l'ectuderme; ces playues, qui maissent ainsi lans la région postérieure de l'animal, s'avancent, a mesure qu'elles grandissont, rers la region antrienre de ce lernier, ef sumsinuent alors entre la panoi endodernique de la vésicule lonnchio-inteslinale, et l'ectoulerme. Ces trois couches cellulaires sout, en celle partie de l'embryon, étroitement unies les unes aux autres, el we laissent entre elles aucun interstice. Toules les trois alfectent une disposilion épithéliale, et s'emboitent muluellement, comme autant d'assises concentrijues. autour de la cavilé de cetle vésicule.

les éluauches mésorlermiques sont au nomlue de lrois: deux latérales et symélriques, la derniere ventrale el médiane. Celle-ci fail parfois defant, car lid. van Beneden el dulin ne l'ont point trouvée rhez la

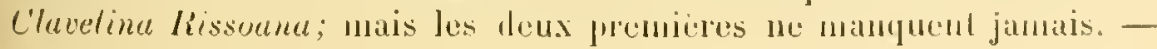


L'élambe vonfale est comstituéc par nne assise cellulaire simple, romprosée senlement de teux files fléléments, placées côte ì côle; chacune de ces files est située d'une part de la ligne médiane. Cette playue fait presque le penuant, sur la lace infericurr de la zone cordomésulermique de l'entéron, de la notocorle supérieure. Elle se raltache, far son lioul antéricur, à l'extrémité postérieure de la vésicule branchiointestinale, el conserve, durant un temps assez long, cetle alhérence. Elle se clisagrige par la suite, toul comme les plaques latérales, et passe à l'ulat mésenchymateux.

les b́louches latérales ollrent tonjours, à leur début, l'aspect de plaques épilféliales, disposées ssmétriquement, de part el d'aulre de la ligue médiane, sur les deux colés de l'eutéron qui leur a tonné uaissance. lies bauches se présentent de leux manières; ou hien elles se comprosent, ulans leur totalité, l'une soule assise cellulaire; ou hien rette simplicité existe senlement dans nne de leurs parties, l’aulre élant constilue par leux conches cellulaires superposées. La premiere lisposition paraît èlre la plus fréquente. - La seconde, moins communc, a été examinés ave soin par Ed. van buseden el Julin sur la Claveline hissouna: elle oltie nue particularité des plus importantes. In espace vile, éloit, somblable a une lente, sépar. l'une de l'autre les deux conches le la rógion double: el cet espace communique avec la cavité entínque, on plutis arec la eavité de cette zone entérique chargée d'rngendrer les plaques mésodermiques. Les relalions élahlies des lors, dans le temps el dans l'espare, eutre l'cukrirou el les playues latérales, sont illentipues, de lous points, avec culles qui existent entre un entriron J'Entéroculomien el les entérocales qui dérivent de lui. La fente des plinjues latérales est un cutrirocole véribble; et les parois épithéliales, qui la limitent, composent une somaloplenre el mue splanchnoplrure.

Cette disposilion, qui permet de rapporter la genese du feuillet moven des Tuniciors au procédé entérocolien, ef de placer ces animanx frami les lintrocolomiens, est partielle, en er sens qu elle su trouve sumlement lans une région de chaque jlaque mésorlermique, et non dans libauche cutiore. De plus, elle est temporaire, car les cellules de ces

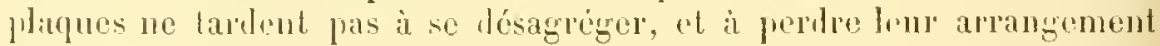
éprthélial, pour passer a l'état mésenchynatenx. Son apparition, bien que fugare et d'une application restreinte, est cependant de lin plus haute imprortance; car clle promet de conceroir la valour exacte du mésorlerme des Tumiciers, el les affinités naturelles dr ces animaux.

l'. - Deux phenomones interviennent, an moment oi les chanches du mésoderme sont délimitres, qui contribuent à modifier la structure le ce fenillet. I، premier consiste dans l'extension, on me quene, de la rrgion postrieure de l'embryon; celle extrémití grandit, s'allonge, tout en demenrant plus étroile que le reste du corps. el se ronvertil en un appendive canclal, lans lequel princtrent la notocorde el te neuraxe, 
l'un portant l'autre. Le second se rapporte il l'élargissement de toute lit partie de loorganisme, placée en avant de la quene; cette croissancr, tout en étant minime, a cependant pour offet de siprarer l'ectorleme de lendoderme, et te faire apparaitre, entre cux, une cavili assez rastr, dans laquelle sont placées les plarjues mésolemiques. Cilles-ri se dísagrègent alors; lenrs cellules se siparent les unes des antres, et le mósoderme, primilivement épithélial, devient mésenchrmaleux.

Cette cariti, qui se creuse de celto maniere entre lectorlerme et l'endorlerme, peut ètre considérie, à cause le sa situation, comme répondant ì un retour du blastoccele. Celui-ci a été ammihilé, lors de la production de la gastrule, par l'adossement du protendoderme an protectoderme; puis. après la genèse dı mésodermr, ces leux feuillets se séparent de nouveau; le blastocule fail alors une ríapparition. Les collules du mísolerme deviennent libres dans sa cavité, s'yultiplient. el y produisent les divers tissus du feuillet moven. Dans le cas où les plaques latirales contionnent une cavité entérocolienne, celle-ci se confonl, prar le fait de la désagrégation de ses parois, arec les espacers nouvellement produits, of ne se distingue plus d'ux. Ce vide crensé entre l'nndoderme et l'ectoderme, ou sont plongées les cellules du mésoderme levenu mésenchrmaleux, est semblable à lui-mème dans toute son élendue, et se comporte comme un schizoculome.

Les Tuniciers offrent, ainsi, un fait des phus remarquables. Leur mésoderme commence par être ápitsélial, ot par limiter une paire de cavités entéroceliennes. Ensuite, il se désagrige, el répartit ses éléments daus la carité blasloculienne, avec laquelle sunissent ef se coufondent les précédentes. l'ensemble constitue, dès lors, un mésoderme mésenchymatemx, yui achève son évolution, d’apés m procédé identique it celui que les Schizoculomiens prísentent sons ce rapport. Aux dépens de ces espaces misolermiques primitifs, prennent naissance. de mème que chez les Schizocalomiens, et par les mèmes moyens, un polycolome converli en appareil irrigateur, des cavités sexuelles, et parfois un teutocolome donnant une cavité générale lu corps.

Les descriptions précédentes s’appliquent à la genèse du schizocnle. les modifications, subies par lo mésoderme, romportent igalement des particularités intriressantes.

C. - La plarue mésodermique ventrale, lorstu’elle existe, s’étent, par son extrémilé postérienre, dans la queue en voie d'allongement; elle se confond arec les zones correspondantes, qui dérivent des plaques latírales, ef subit le mème sort. Son extrémilè antérieure, laissée dans le corps proprement dit, se désagròge, et rontribue i faconner les jremières Chanches dn péricarde et du creur. - Dans le cas où les plarues latérales sont simples, chacune d'elles se divise transversalement en deux tronçons, loun antérienr, loutre postériemr. Le premier demeure dans le corples,

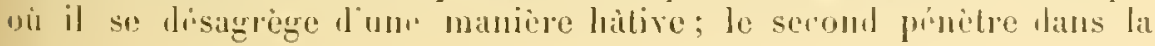


yueue, se place sur l'um les cótis de la notucorde el du neurase, el va. arec ces organm, justgu il l'ustrémité libre de l'appentice. Celle division
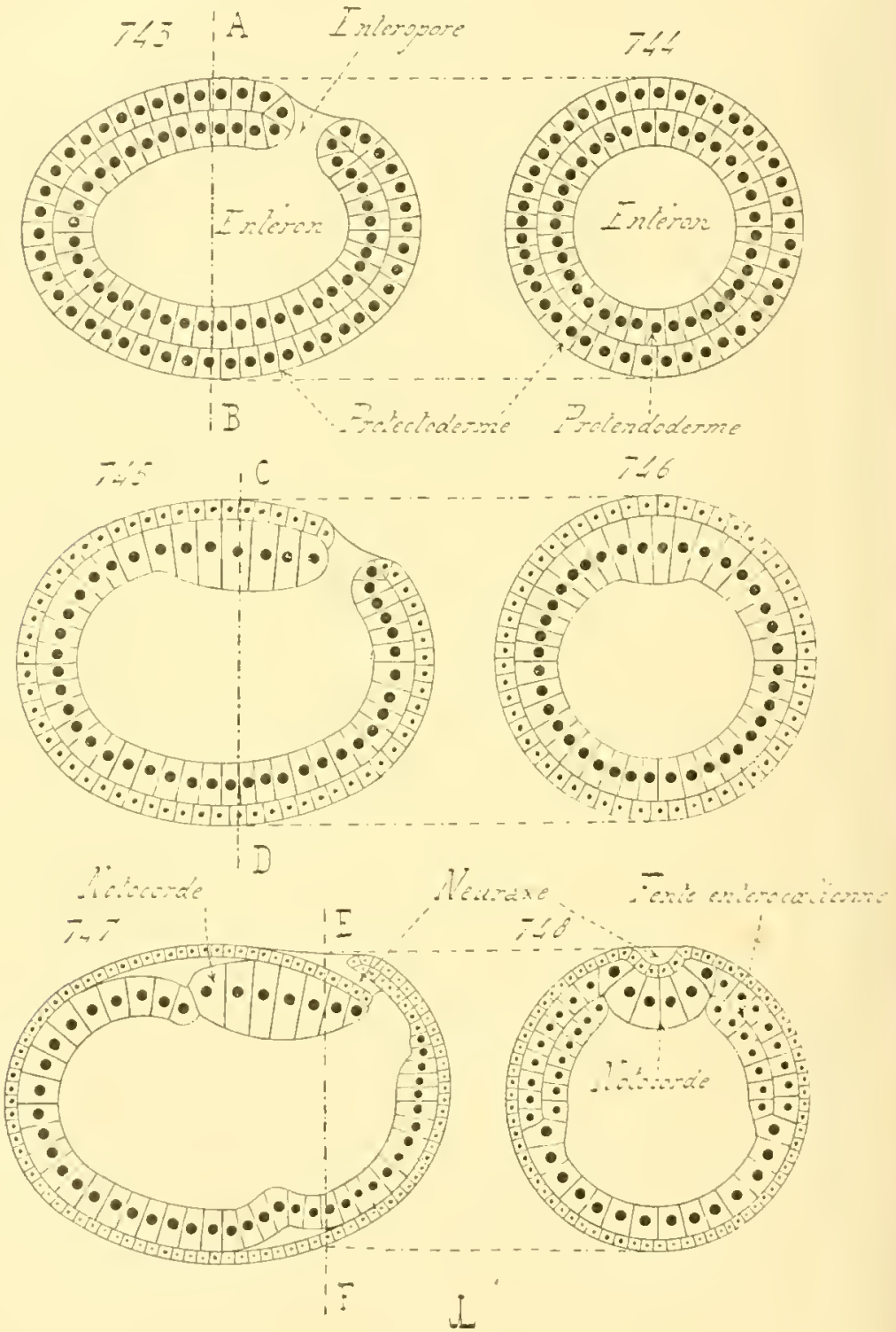

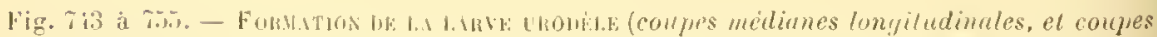
bransversules; les plan- drees dernieres sunt indiques, sur les fremieres, par des lignes correspondantes; ees conjus sont d demi diagrammatiques; les cellules viloulermiques ont the dessinees fuls conftes fur nature, atin de rendre les caviles mieux apprè-

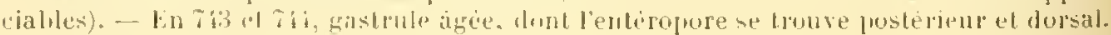

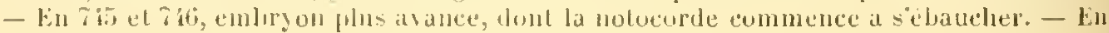



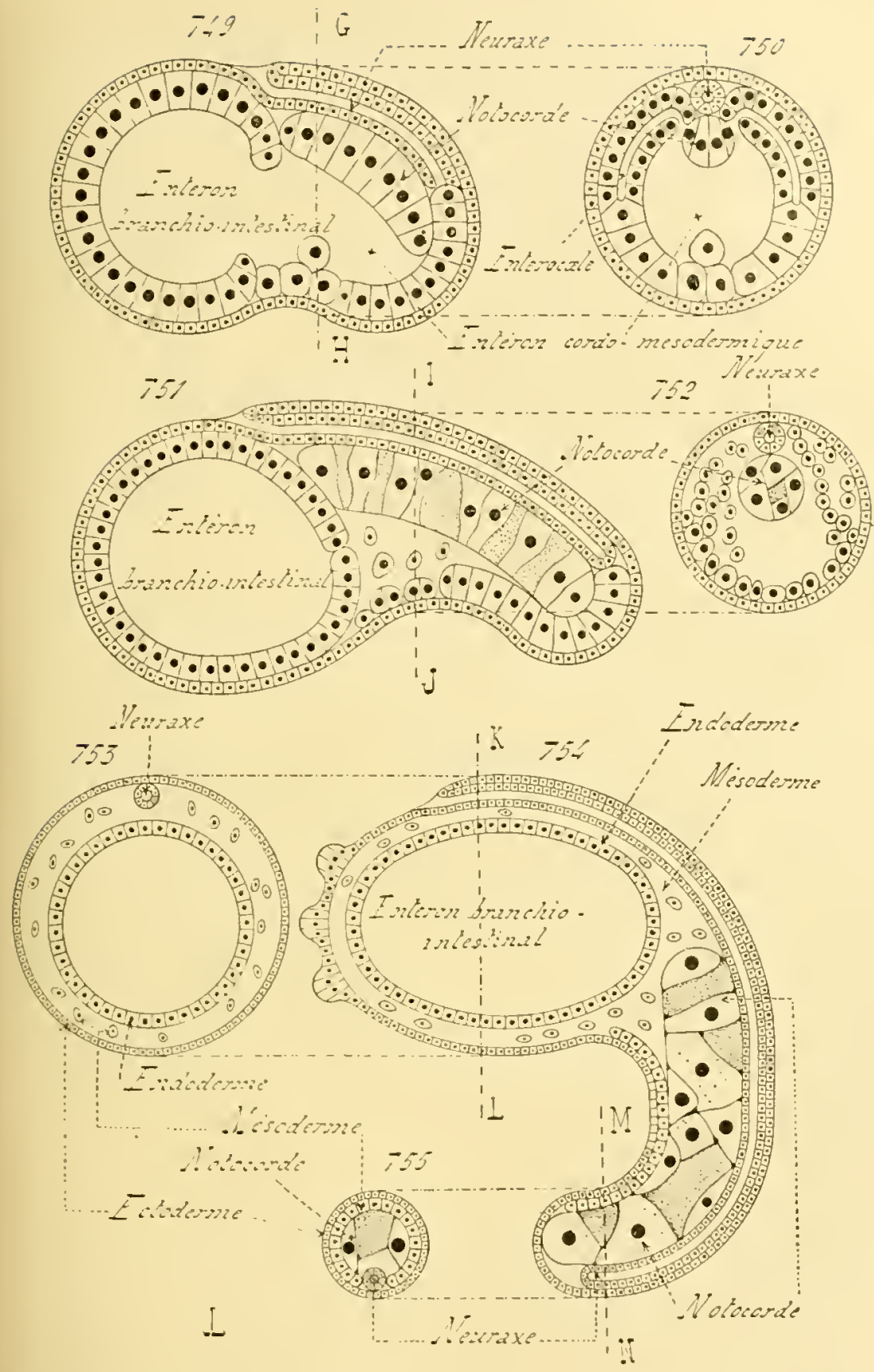

$7 \mathrm{i} 7$ et 748 , debut de la division de l'entèron en une vésicule antericure (branchio-inteslinale) et une vésicule postèrieure (cordo-mésodermique); la coupe transversale, dessinie

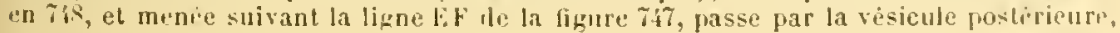


en denx segments, des plapues latirales du mésoderme, est d'une grande valeur, car clle implique une mélamérie du feuillet moyen des Tuniciers; elle a été signalíe, notamment, jar Seeliger sur les Clarelines, el par Chalury sur les Ascidielles. - Entiu, dans le cas ou les plaques laterales offent une patic dumble, la division en deux segments se manifeste encorc. La zonc louble correspond, en ellet, an métamère antérienr de la disposilion frécódente; elle reste de mème dans le corps, et se llésagrige pour devonir mésenchymaleuse. La zone simple est l'homologue du segment postíricur; lout comme son correspomlant, elle péuetre dans la quene, en se plaçant sur les côtés de la notocorde et du nenraxe.

Ainsi, le mésolerme se divise en deux segments, dout chacun est constitué par l'ensemble de deux moitiés, plarées au mème niveau, des plaques latérales. L'embryon, prorluisant mne queue dans sa région postérienre, el se scindant, par là, en corps proprement dit el appendice caulal, le segment antériour appartient au corps, el le segment postérieur à la quene; le premier est un segment somatique, et le sceond un segment caulal. - I'ne lelle métamérisation est-elle primilive et comparable à colle qui se manifeste, chez les Lutéropmeusles et les Vertélurés, avant toute ditlérenciation de l'organisme en régions distinctes? Ou lien rst-clle secondaire, et le résullat de la scission de l'économie en tronc et queue? I] est bien difticile de se prononcer à cet égarl. Les rolations ćtroites qui unissent les Tuniciers aux embranchements précédents, et le fail que la segmentation mésolermique s'effectue d'une manière précoce, vienneul a l'appui de la première opinion. D'autre part, la répartition si remarquable, el si precise, du premier segment dans le corps et du second dans la quene, serail en faveur de la deuxieme appróciation. Il te semble cependant, lopinion première est la plus cxacte; en la corrigeant par celle Jonnée, que la zone du corps correspondante an sogment postérienr s'accroit d'une manière lardive, par rapport a lautre, ef dans um direction déterminée, en fournissant l'appendice caulat. Lextension tardive de la queue est explicable ellemòme, du moins en ce qui regarde les Caducicordes, par un déplacenent dans de lemps, causé lui-mème par un retentissement précoce de la destruction fulure de cet organe. Mais, il s’agil ici d'une série de consi-

ct montre l'ebatche le la notocorde en haut, avee les teux èbauches mésodermique laterales, lont les cellules sont disposedes sur fleux rangs. - En 749 et 750 , le neuraxe, léjä indipué lors les precedents etats, sallonge, et la division en leux parts le l'entéron primortial s'acentue; la fente, laissée entre les temx rangées cellulaires te elacune les éhauches mesudermiques, communicue avec l'entéron à la maniere d'un entèroeale. - En 7.1 et 72, la région posterieure du corps s'allonge en une quene, et l'embryon eommence a revelir l'aspect d'unc larve modele; la notocorte el le neuraxe sont faconnés; le segment anterienr du mésoderne subit la lésagrégation mésenehymateuses alors que le sument posterieur, place dans la queue, demeure épithélial. - En 753 , 754 , et 755, la larve urodele arrive à sa période d'ètal: il ne lui reste qu'á fermer en avant son neuraxe, et "u’à le thlatel en une vésicule cerèbrale; les papilles adhésives naissent sur l'extrémiti" anterieure đlu corps. 
dirations et linductions ahstraites, auxinelles nanquent les notions oljectives, el que des recherches approfondies sur le déreloppement des l'érennicordes parriendront seules a apuyer, et à dímontrer.

Quoiqu'il en soil, si la métamérie des Tuniciers est vraiment primitive, les plaques latérales de ces animaux se divisent en un mème nombre de scgments que Jeurs correspondantes lles Entéropneustes. Cette remarque est les plus importantes, car, non seulement elle autorise à rapprocher d"une manière julus élroile ces deux embranchements, mais cucore elle permel de concevoir lorigine de la métaméric multiple du mésoderne des Vertébrés. Cette dernicre n'est pas primilire; elle est secondaire, el dérive le celle des Entérojnenstes et des Tuniciers lrar l'augmentation croissante du nombre des segments.

Les deux métamères mésolermiques ne subissent pas une mème évolution. Les deux moitiés du segment anlérieur. Ja lloite el la gauche, se désagrègent, et deviennent mésenchymateuses. Les deux parties correspondantes dn segment postérienr conservent une disprosition épithéliale; chacune d'elles se place sur l'un des côtés de Ja nolocorrle, el s’étend jusqu’au bout de la queue. La notocorde de cel appendice est ainsi flantuée, à droite et à gauche, par ces deux baudes cellulaires, pui sont étroitenent serrées entre olle et l'ectoderme périplérique, car aucume fente blastocolienne ne fait sou apparition dans cetle région de l'organisme. Les cellules le ces plaques se transforment rapidoment en fibres musculaires, disposées d’une façon régulière, les unes derrière les autres, depuis l'extrémité proximale de la queue jusłu’à son extrémité distale. Ces filıres sont chargées de monvoir l'apprndice, el de déterminer ainsi les déplacements du petit ètre dans l'eau qui l'entoure.

$5^{\circ}$ Développement général des parties. - Au moment oủ toutes les ébauches précédentes achèvent de se constituer, et commencent à se compléter, l'aspect de larve urodẻle est déjả lien net. L'embrvon est encore contenu dans les enveloppes orulaires, soit que ces dernières aient élé conservées en tolalité, snit quil reste seulement les iuterues J'entre elles; son organisme est divisé en tronc et queue. Celte derniẻre ne possède pas encore toute sa longuenr, mais sa forme, et sondiamètre plus étroit, la caractérisent d'une façon suffisaute; elle est repliée sous. la face ventrale du corps. L'entéron, d'abord simple et muni de son entéropore, s'est divisé en une résicule Jranchio-intestinale antéricure, et une zone cordo-mósolermique postérieure. Celle-ri engendre la notocorle laus sa régiou lorsale, le mésorlerme par ses cólés, et par sa face ventrale; ce leruier rudiment mésodermique fait parlois léfant. Entin, le bord postérieur de l'entérojore grandil, et s'allonge en avant, sur la face dorsale du corps; il se soude aux deux leves d'un sillon qui se creuse sur celle face, et doune ainsi le neuraxe,

En cet instant, la queue commence à se montrer et à sétendre. Lat notororle pénitre dans son intériour, aty drmenro tout entiere; olle 
ne fait point partic du corps proprement dit, et appartient spécialement i la queue. Le neuraxe parcourt également lout lappendice candal, et se place au-rlessus de la motocolule; mais il s'allonge, en surplus, jusqu’à l'extrémité antérieure du trone. Ses denx extrémités se lement, de manière à le convertir en un canal clos. lont le lont antérieur se roufle en une vésicule cérélorale. Chacune des deux plaques latérales du mésoderme se divise endeux parties, l'une aulérienre, l'autre postérieure; les deux partios placées au mème niveau constiluenl un seguent mésoJermique. Le segrment mésodrmique antérienr, d’alord épithélial, se Jísagrỏge, el passe à l'élat mésenchỵmateux; sa cavilé entérocolienne, lorsiuclle existe, se confond avec liensemble du schizocale; ce segment appartient au corps, ef pent ìtre consiléré comme somalique. Le segment postérienr, dit segment candal, est destiné i la queue; il pénètre lans cel appendior, en plaçant ses deux parts coustitulives sur les côtés de la nolocorle; il conserve sa disposition épithéliale, et se convertit en une playue de filres musculaires, placées à la file.

Les antros modifications essentielles, que subit la larve avant son éclosion, portent sur l'allongement de la quenc, smr la production d'une mince cuticule tunicale, sur la complication lu neuraxe et le la vésicule branchio-intestinale, enfin sur la genèse des papilles fixatrices. Ces changements sont du ressort le l'étude des formes embryonnaires.

Développenexts planulames. - Cot opdre de développenents est caracLérisé par la réduction, el même par l'omission, le certaines des phases. qui se succèlent mutuellemrnt lans les emlıyogénies dilatées.

In moment oì les feuillets hastodermiques primordiaux achevent de se délimiter, le mésollerme fait déjà son apparilion. True fente se creuse entre le protertoderme et le protondorlerme. Les cellules périphériques de ce dernier se détackent le lui, parviennent isolément dans celte cavilé nouvelle, el s'y multiplient: elles composent un mésenchyme, qui représente a lui seul toul le fenillet moyen. Les éléments protendoulermiques profonuls restent assemblés en une assiseépithéliale, qui continue à limiter la cavité entérique, et constitue l'endoderme Jifintif. - Cet espacr, peré entre les denx feuillets primordiaux, est l'homologne du schizocale des diveloppements gastrulaires, et le mésoderme syormanise d'emblée, soms la forme mésenchymateuse, saus passer ai préalahle par un état épithélial.

Une notocorle prend également naissance, llu moins dans la plupart les cas, et so fagonne aux dépens de l'endonderue. Senlement, elle est lieauconp moins étendue, et elle oflre mn aspect moins précis, que sa rorrespondante des embryogénies dilatíes; rlle est constituée par un amas cellulaire compact, ile forme irrégulièe, assez restreint comme étendue, auquel les auteurs ont somrent domé le nom d'éléoblaste. Parfois, ce dernice terme a été employé, non seulement pour absigner ce rubliment de nolocorde, propre anx évolutions planulaires des Tuni- 
ciers, mais aussi pour qualifier la petite queue qui le contient. Mimsi, chez diverses Molgublides, "t clıce les Pyrosomides, l'ombryon posside une nolocorde rulimentaire; seulement, la régrion, yui la contient, ne se distingue point du reste du corps, lemeure confondue aree lui, et ne prend jamais l'aspect d'un appendice caudal. Par contre, dans d'autres cas, chez les Salpides par exemple, les emhryons, issus d'aufs fécondés, restreignent la zone placéc autour de leur petite notocorde, le manière a lui donner l'allure d'une queue des plus minimes, semblable ì un moignon appendu à la partie postérienre de l'animal. - Ces phénomènes concourent à démontrer la mème notion, que la notocorde, avec la zone qui la renferme, se réduisent daus les développements planulaires, et possèdent simplement la valeur d'organes ataviques. La notocorde est toujours d'une importance restreinte: mais l'embryon des Salpes ébauche encore, autour l'elle, une queue recomaissable, bien que fort pelite: tandis que celui ales Pyrosomes, el de plusieurs Molgulides, se borne à la conserver dans l'intéricur de son corps, sans produire d'appendice caulal.

Une telle réduction, si accentuée en ce qui touche la notocorde, atteint moins le neuraxe. Le principal changement, qui s'elfectue en lui, consiste parfois en sa production aux dépens l'une zone cetodermique épaissie, et non d'une zone rectodermique incurvée; lo procédé massif se substitue au procédé invaginant, par le déplacement, dans le temps, de la date d'apparition de sa cavité axiale. De plus, l'entéropore faisant souvent hófiut, les premières ébauches de cet apparcil se délimitent, sans offrir aucune des parlicularités spéciales aux embryogénies dilatées; de son cûté, le canal neurentérique fait défaut. Pourtant, ces ébauches naissent dans la région qu'occuperait l’entéropore, si cet orifice existait. - La premiere indication lu neuraxe se compose, chez les Jyrosomides, d'une plaque ectodermique épaissie; cette plaque ne tarile pas à se creuser d'un sillon, dont les bords se rapprochent et se soudent, pour le convertir en un canal, qui est le neuraxe. Celui-ci grandil ensuite, et s'étend sur la face dorsalr le l'embryon. L'évolution suivie, sous co rapport, par les Salpes, serait plus condensér qur celle des lyyosones, car la phase, relative à la genise d’un sillon, est omise: le neuraxe dérive d’une hande ectodermique épraissie, qui se sépare lu resto du feuillet externe, et dont la posilion, sur lo corps, est semblable a celle du sillon des autres emliryous des Tuniciers. Il est il remarpuer en sus, notamment dans lo cas des Salpes, que lo nuraxe est d'habilude assez court, et qüil se localise, d'une maniere hative, lans celtr region mblyonuaire qui correspond à l'extrémité antéricure des larves mrodeles.

\section{3. - Formes embryonnaires.}

1. Considérations générales. - les culpryons des Tuniciurs approliennent i deux types principaux : les emliryons simples, et les 
embryons yemmipares. - Las premirrs cmploient toute leur puissance génétique à fagonner lenrs organes, sans jamais produire de descundants par un procídó reproducteur asrxué: soil que la gemmiparité n'existe pas cluez cux, soit qu'elle se manifesto senlement à l'état adulte. Les seconds, an contraire, engendrent dus descendanls, par la voie gemmiparr, avant de parvenir cux-mèmes à l'état parfait. Ils offrent, en conséqurner, une vérilable progrnèse asexuelle, lont le résullat est parfois, commo los Pyrosomes en oflrent un excellent ex'mple, d'empêchror lour fropre irolution. Aussi, chez ces animaux, les embryons, issus d'un reuf fécondé, n’arrivent-ils janais à compléter leur organisme; leur unique rôle est de lonner naissance, par le mole asexuel, à des descondants qui, seuls, drvienmont adultes.

La possession d'embryons gemmipares est liée à la présence, dans liouf qui les produit, d'abondantes réserves nutritives, et, par suite, a un lévaloppement souvont plaumlaire. Ello commence à se montrer chez los botrylides, ct atteint sa plus grande amplitude chez les l'yrosomides, les Salpides, et les Doliolides.

11. Embryons simples. - Ces derniers se présentent sous deux formes : celle de larve urodèle, el colle d'embryon anoure. L La première est de beancoup la plus répandue. Ia seconde n’a guère été signalée que chez diverses Molgulides, et paraît correspondre a la présence, dans lovule, l'une assez grande quantilé de deutélocithe; sa répartition est des plus remarquables, en ce sens que, parmi des especes fort voisines, les unes se reproluisent par des larves urodèles, et les autres par des embryons anoures. - Les différences, entre ces deux modes de développement, sont dénotées par les termes qui les indiquent. La première forme est caractérisée par la présence d'une queue, et la seconde par l'absence de ce mème appeudice.

Larves urodéles. - Ce type de larve est très fréquent: il existe chez la plupart des Ascidies simples el des $\Lambda$ scidies composées. Ces embryons possèdent, lans la région postériemre de leur corps, une longue et large queue. qui leur sert pour se mowroir. Cet appendice est soutenu parla notocorde; cette dernière lui est spéciale, en ce sens qu'elle ne s'étend pas dans le corps proprement dit. Le neuraxe est placé an-dessus d'elle, et va jusqu'à l'extrémité libre te la queue.

Les livers organes te la larve modeles ebanchent, alors que celle-ci est encore renfermée lans ses membranes ovulaires. Les principaux phénomènes génétiques portent: sur le façonnement le la queue, sur les complications du neuraxe el celles de la vésicule hranchio-intestinale, enfin surl'apparition lo papilles adhésives, et d'une mince conche lunicale. - La larve est ensuite mise en liherté; clle nage daus l'a pu pendant un cerlain temps; puis, ayant rencontré un support, se fixe a lui par son

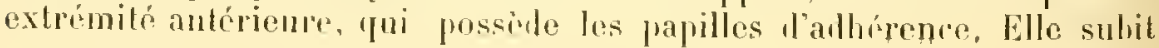


alors une métamorphose régressive particlle, dont le fait essentiel consiste en l'atrophie. et la disparition de la queue; celte régyession est la senle qui se manifeste, car les autres organes s'achèrent, et deviement plus complexes. Le terme de régression ne doit ìtre emplové qu'en l'appliquant it la queue, aux systemes contenus dans cet apjendice, nt non aux autres appareils de l'économie.

Les métamorplioses, suhies par les larves nrodòles, se divisent done en deux trmps; d'abord, lr façonnement de la larve, jusqu'à son éclosion; ensuite, la vie libre de cette larve, sa fixation à un support, et les changements qui accompagnent ce dernier fait. - l'ordinaire, ces phénomènes sont assez rapides. Il suffit d'un ou de deux jours, depuis le début de la segmentation, pour que la larve soit en état d'éclore. Le deuxiome temps est plus long; la période de lilierté, qui ne correspond à aucune modification importante, se maintient pendant plusieurs jours; et les changements, consécutifs à la fixalion, ont me lurée plus grande encore.

$1^{\circ}$ Fraconnement de ln larve urodèle, jusqu'ì l'éclosion. - A. La quene se délimite l'une manièr précoce; elle est lonnée prar l'extrémité postérieure de l'embryon, qui s'allonge, fout en derenant plus étroite que le corps proprement dit. Cefte région, ainsi convertie en une queue, se replie sous la face ventrale du trone, car les membranes orulaires, trop étroites, ne lui permettent pas de rester droite. linitée par une assise ectodermique, elle contient, dans son intérienr, la partie postérieure du neuraxe, la notocorde, et des tibres misculaires disposées avec régularité.

La partie caudale du neuraxe ne diffère pas de la partie somatipue: elle est seulement un pen plus rétrécie. Elle offro l'aspect d'un canal, terminé en cul-de-sac dans son bout postérieur, et se raccordant au neuraxe somatique par son extrémité antérieure. De place en place, et à des intervalles réguliers, elle présente, d’ajrès les observalions faites par lï̈pffer sur les larves de l'Ascidia mentula, des zones d'émission de petits nerfs, destinés aux fibres musculaires. Ces nerfs, qui ne se montrent qu'assez tard, ont une existence des plus fugaces, car, el toujours d’après les études le kiüptfer, ils se détruisent peu après aroir élé formés. Une telle brièveté (quelques secontes) a fait metlre en doute, el avec juste raison, l'exactiturle de ces olservations, qu'il serait utile de confirmer à nouvean. - Ceprnilant, la quene drs larves urodèles des Carlucicordes est tellement semblable à celle des Pérennicordes adultes, qu'il est permis d'appliquer à la première les notions connues sur la seconde. Or, lo neuraxe de cette dernière possèle des renflements gangliomnaires, placés ì intervalles ígaux, qui émettent des nerfs, dont les uns se rendrut aux fibres musculaires, ef les autres aux cellules de linetoderme; cenx-ci ont été comparés aux racines sensitives des nerfs rachidiens des Vertébrés, el ceux-li anx racines motriers. - Dans le 
cas, assez frécfuent, oir la qurue de la lapre rst relativenent courte, la partie caudale du neuraxe est peu développée, et réduite prosque à une simple ébauche.

La notocorde se composo d'un cordon solidr, résistant, doué diune assez graude ćlasticitó, élcudu l’une extrémité à l'autre de l'appendice caudal, et le soutenant ì la manière d'un véritable słuelette interne. Son premier rudiment consiste on mo playue cellulaire, formée de deux l'angées l'éléments juxtaposés; cenx-ei s’iutriquent, par la suite, de façon à ne constituer qu'une seule tiłe, dont les cellules sont placées les unes derriere les autres. - Cetle disposition se moditie encore; car, dans son état final, la notocorde rst formée d'une baguette solide de substance anhyste et homogène, qu'entoure une mince gaine de celluli's plates. Survant kïplfer, celte substance se dépose lans l'intérieur de chacun des premiers élémouts, grandit de manière à acquérir un rolume considérable, relègue le noyau avec le protoplasme sur un de ses côtés, fruis s'unit ì colle le lélément précédent et le l'élément suivant: elle devient continue d'un bout à l'autre de la notocorde. Les faits sont lilférents, l'après lrs autres auteurs. La substance lomogene est d'origino intercellulaire, et non intracellulaire; elle est prorluite pas les cellules primitives, se dépuse entre elles, et, de nouvelles quantités s'ajoutant sans cesse aux précédentes, elle prend un accroissement cousidérablr. l)abord situéc entre ses éliments producteurs, lorsque sa masse est rncore minime, elle consiste en pelits lisques séparés, qui alternent avec les éléments; par l’effet le l'angmentation incessante de volume, ces disfues rejettent les rellules sur leurs cotćs, sunissent les uns avec les antres, el composent ainsi la baguette solide el anhyste. - 11 serait intéressant de connaitre avec prúcision les diverses pliases essentielles de cette évolutiou, afin de pouvoir comparer le développenent de la notocorde des Tuniciers avec celui de l'appareil correspondant des Vertébrés.

La notocorile est hanquée, à droite et à gauche, par des plaques musculaires, resserrées entre elle el l'ectoderme; ces derniòres dérivent des éléments du segrment mósodermique caudal. Chacune d'elles comprend deux un trois fibres musculaires, placées còte à côte, insérées sur la notocorde d'une part, et sur la face interne de l'ectoderme d'autre part. Lenrs insertions indiquent lemr róle, qui est de comber la quene sur elle-meme pas des mouvements de va-et-vient, et de servir ainsi a la locomotion de l’animal. Sur phacun des côtés, ces plaques, de tailles presque égales, ou pen inógales, se suivent, les unes derriore les autres, avec régularité; la plaque d'un côté est presque située an mème niveau que celle de l'autre côlé, el forme une paire avec elle. - Cette disposition régulière rapuelle, de très près, celle des mèmes éléments dans la quene persistanto des Tuniciers pérennicordes. Celle-ci ollue, cependant, une structure plus complexe, que pent-ctre les quenes temporaires de certaines larves urodeles sont capaloles d'olfrir, en applipuant, à ce cas 
particulier des Tuniciers. les lois générales de l'hérédité. De placr en place. le neuraxe des Pérennicordes porte des épaississemonts, comparables à des granglions, formés d'un chilfre restreint de cellules nerveuses (Langerlans), qui émollent drs nerfs destinés à l'ectoderme; de plus, ce mème meuraxe enroie d'autres nerfs anx plaques musenlaires, les rameanx nervoux se dégageanl du neuraxe entre les playues.

La queue des larves urodeles des Caducicordes est strictement lhomologue de celle des Pérenuicordes; partant, elle présente les mèmes organes disposés de la mème facon; d'antant plus, que ces organes soul indispensables au fonctionnement de l'aprareil entier. Seutement. Ia queue des larves urodìles n’a qu'une exislence tries brève; elle disparait hàlivement, et mème reste, parfois, assez peu développée; la moindre abréviation de l'embryogénie restreint, on empèche, son évolulion entière. Aussi, les principaux systemes prennent-ils senls naissance, comme la nolocorde el le neuraxe; les antres délails secondaires ne s'ébauchent mème pas, ou n'onl qu'une durée des plus fugaces. - II I'en est pas moins rrai que, par application des lois de l'embryologie générale, la quene des larves urodèles doil üre prise eomme répondant entièrement à celle des Pérennicordes, comme possédant d'une manière virtuelle la mème organisalion, mais ue parvenant pas à l'acquérir Cordinaire, à cause du relentissement causé par sa disparition prochaine. P'ar suite, la structure de l'appendice candal des larves n’a d'aulre intérèt, que la comparaison avec celle du mème appendice des Pérennicordes, el la mesure des altérations produites. La queue des Péremicordes, élaut la plus diflérenciée, est la seule à examiner, de préférence. pour élalilir les traits essentiels de l'organisation.

Se basanl sur la répartilion régulière des plaques musculaires, el sur leur mode d'innervation, El. van Beneden el Julin considirent la quene des Tuniciers comme élant segmentée; chacune des paires de plaques correspondrait. d'après eux, à un segment musculaire (myomere ou myotome), des Verlébrés. Liaprendice candal comprendrait ainsi plusienrs myotomes, placés les uns derrière les aulres. - Celle opinion esl forl soulenable, mais elle n'est appuyce que sur les présomptions: les faits pris en enx-mèmes, tonte autre dounce miss a part, sonl opposés à de tels rapprochements. - Les myolomes des Vertélrés sont, à leur début. les vésicules creuses, dontles cavilés dérivent les espares eulérocoliens; ces cavilés disparaissent ensuite, pendant qu une partic des parois s. converlil en filies musculaires. Les playues musculaires candales des Tuniciers proviennent d'une assise cellulaire minje, el nullement percie, en conséqurnce, de vidrs internes; de plus, lous lo:s éléments do ces plaques se transforment en libres musculaires. Les procídés gínoliques sout des plus dissemblables eutre les deux cas. - Les auteur's précités objectent, il la vérité, que le mode particulier aux Tuniciers se rapporte à celui des Vertéhrés, par Comission des cavilís segmentaires. 
Mais, dans toutrs les substitutions du type massif au type creux, le nombre des collules constitulives de l'élatuche n'est pas diminur. Or, dans le cas présent, non sculement la pluase d'apparition des carités est omise, mais cucore lia quantité des éléments de chaque mélamère est reduite dans des proportions consilírables.

A en juger d'apres les faits, il semble plutôt qu'il n'existe aucune homologie entre ces deux dispositions, el que leur ressemblance résulte plulôt de rauses toules mécaniques. - La queue des Tunicier's se meut, comme le corps des Vertébrés inférieurs, par des mourements oscillatoires de droite a gauche; dans les denx cas m axe rigide et interne, aupuel les filres musculaires s'attachent par leur extrémité proximale, sontient le corps. Dans le lint de permettre ce mouvenent, ces fibres se disposent, de part el d'autre de l'axe, on plusienrs sérirs régulières et prosque égales, placérs les unes derriem les autres. Chacume des parties mises on eause parviont a ce résultat, avec les moyens qu'ell posside: lus Vertébrés inférieurs avec leurs diverticules colomiques dorsaux, qui se convertissent en myotomes; les Tunicin's avec les rangérs cellulaires, rt latérales à la notocorde, de leur queue. Mais, lans l'origina, ces dernières ne correspondent en rien aux diverticules précédents, si ce n'est par te fait quidles appartienuent au même feuillet. - La reclerche des canses, qui ont provoqui l'apparition d'une structure déterminée, est utilu an lijologir, mais il convient de me se prononere sur olles qu'avec de grandes résirves, car les moyens, dont nous nons servons pour les concevoir, sont des plus insuffisants: ils se horment à l'étude de ceux yui nous sont accessibles, prarmi les résultals atteints. Cepenılant, comme les citres organisés sont placés sous la dépendance directe des milieux yui les enlourent, et ohligés de s’adapter à eux, il est possible de pressentir ers canses par l'examen des relations étalılies entro l'ohjet, ses qualités propresé, ot celles des circonstances qui l'enviroment. - En ce qui concron. les Tuniciers "l less Vertébrés, ces relations paraissent assez nettes, pour quil soit permis de conclure comme il est dit prócédemment.

B. - Pentant que l'appendico caulal s'ébauche, et se complète, un' mince couche lunicale ajplaraît aulour de l'ectoderme antier. Cette tunique correspond à un exsuilat dn fenillet ectortermique, constitué par une sulıslance lomogine, et comparable à une cuticuls, dans laquelle pénìnent des crllules détachées de l'ectodernu. Ces derniers éléments ur meurent pas da suila; ils subissent une dégénérescence particulière, dont les primeijales phasus sont décrites dans le paragraphe suirant; ils émetlent sonront des expansions irrégulières.

l'ecloderme de l'extrémité antérienro du corps prouluit trois papilles voluminrmses, yui serviront à la larre, après sa vir de liberté, pour se fixer à un support. Chacune de ces papilles répond à une région oủ les cellules ectodermiques sont plus longurs qu'ailleurs; le résultat est mn 
cxhaussement, qui constitur la papille ello-meme. Les cellules sont l'aboul eylindriques et semblables; puis, durant la vie libre. la plupart d'entre rlies produisent du mucns, quelles déversent au dehors, la: laçon a faire un conssinet muneux sur l'extrémité antérienre de l'embryon;

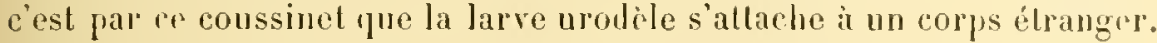

Balfom compare ces papilles, et cette opinion a été accrptéc par un certain nombred'auteurs, anx apparrils adhésifs des larves des cianoïles; il en conelut qüils représentent les organes très anciens, possédés prar les ancètros communs drs Tuniciers el des Vertébrés, el conservés par plusieurs des descemlants actuels. - Ciest là ume donnée toule subjurtive; nous ne connaissons la structure dos animaux disparms, lu moins de ceux qui n'ont laissé ancun fossile, que par des présomplions lasées sur le développement embryonmair des animaux actuels. Ces présomptions acqnièrent quelque cerlitule, daus le eas ou l'on frul suive, en toutes les emliryogénics dilatées des ètres mis en cause, la formation des organes examinés; la constance d'apparition génétique, et l'identité dans le temps et dans l'espace, autorisent a proser que ces organes sont vaiment lomologues, et proviement sans doute dun appareil plus simple, possélé autrefois par les ancètres le ces êtres actuels. La crrtitude est appuyce sur le raisomemont senl, mais les lois de l'embryologie générale lui donnent une grande créance. - Or', l'homologir et la constance d'apparition n'existent pas, en ce qui touche les papilles arluésires des larres des luniciers, et eelles des larres des franöldes. Elles fout délaut aux Pérennicorles parmi les premiers, el aux Acranieus parmi les Vertébrús inférieurs, plus simples encore que les Ganoüdes; la continuité dans le temps, dans la géníalogie, n'est pas parfaite. Ces organes sont seulement analogues; leur origine ectorlermicue s'explique par leur rôle; et leur situation commune, dans la région antérienre du corps, par les habitudes des animaux considérés.

C. - Lorsque le neuraxe s’est déjà lien délimité, el avancé jusqu’à atteindre l'extrémité antérienre de l'embryon, il se ferme ì ses deux bouts, et prend l'aspect d'un lube elos, dont la lumière est fort étroito. Son bout antériem se renlle ensuite, pendant que som bout postérieur s'étend dans la quene en voie de formalion. La dilatation autúrienre se sépare, frar un étranglement lien marqué, lı reste du neuraxe; ainsi s'étahlit la division de cel organe en deux parts, la vésicule cérébrale ot le cordon ruchidien. - 11 est lien difticile de certifier que ces deux régious sont entierement les homologues le leurs correspondantes des Vertélurés; mais les ressemblances, dans le temps el daus l'uspace, sont telles, qu’il est permis de croire i l'exislence de ces lomolugios, in moins dans l'ensemble.

Le corlon machidien se divise, it son tomm, en deux autres: unp moelle

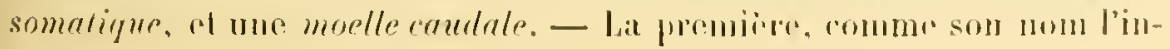


dipue, est renformó dans lo corps proprement dit, el la secomle daus la quene. Cello-là ditliore de celle-ci en ce quelle est un pun plus large, el en re yude nost point supportie par la notocorle; elle se place andessus du tube digestif. l'ar contre, la moclle caulale, plus étroite que la juécédente, repose sur la nolocorde; celle-ci n’étant en relation directe aver ancune région inlestinale, du moins lorspu'elle a rèètu son aspect définilil. - $-\Lambda$ leur lélut, les parois rachidiennes sont entièrement cellulaires, el composées d'éléments épilhéliaux: pussieurs de ces leruirrs ne tarlent pas i ćmethe des expausions filıjllaires, qui se rassemblenten une mince conche, placée autour te lenrs cellulıs producluces. La paroi de la moelle est alors constituée par deux assises, emhoîlées aulour de la petile cavilé contrale: une assise exlérienre, fibrillaire; et mue assise intéricure, cellulaire. La conclıe fihrillaire est surtout ipajsse autom du plancher de la moclle somatique; elle diminue pen it peu l'arant en arrière, el manque autom de la moelle candale.

La résicule cériluale se préseule sous deux aspecls. Parfois, elle reste simple; ajlleurs elle se divise, par un élranglement lransversal, en Jenx vésicules, l'unc antérieure, et l’autre postérieure, dontles cavités communiquent entre elles. La vésicule antérieure termine le nouraxe en avant; la jostéricure se raccorde à la précédente d'une part, el à la moelle somatigne diantre part. La premiore, plus volumineuse que l'autre, conlirul une ample cavité, que limilent des parois miuces. La cavité de la vésicule postérieure est plus restremle; en revanche, ses parois sont plus épaisses. La zone dorsale de ces dernieres est couslituée par des collules anx contours entjers; la zone veutrale par un réseau de cellules ganglionnaires et de filuilles.

Une lelle disposition suggire la pensie, que ces vésicules correspondent à celles produites à l'extrémité antérienre du neuraxe des embryons le Vortúbrés, el chargées de donner l'encéphale; elles leur seraient lomologues, et leurs cavilés équivandraient, de leur còté, aux cavilés ventriculailes de ces mèmes Vertélıes. Cette homologie parait certaine; d'autant plus que le bout antérieur du neuraxe de l'dmphioxus est dilaté en un rudiment de vésicule cérébrale. Les centres nerveux des larves de 'funiciers rappelhent aiusi, de très près, ceux du phus simple de luns les Vertélorés, et ollrent, comme cus derniers, nne slructure des moins complexes. Il est possible lu leur appliquer los termes do vésicules cérébrales of de ventricules, le moelle rachidienne el de canal de l'épendyme, el l'exprimer par là les homologies d'une manjère plus nelte. Il est bon cependant ile le reuarquer, ces ressemblances ne sont exactes qua à la conlition d'ètres prisos en général, dans la lolalité des disposi-

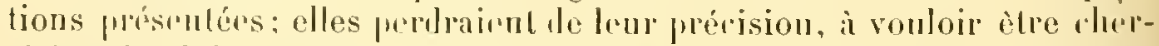
chés plus boin. Rien ne prouva qur la vésioule cépéluale des larves des

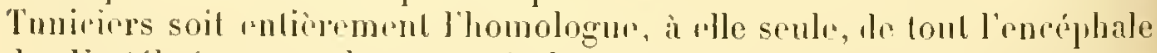
Jes Vertélorés: fur, de son rotr, lrur moelle soil l'équivalent do toute

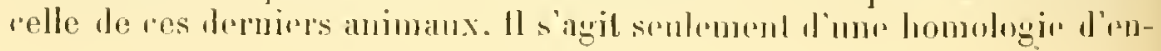


semhle, et non d'une homologie réalisée daus tous les délails serondirires de la strueture.

La vésicule réréhrale des larves de Tnniciers, semblable i sa correspondante des l'érennicordes, contient des organes sensilifs. Ces derniers sont au nomlire de leux; et, lien que l'on ne soil pas fixé sur leurs fonclions réelles, l'un a élé considéré par kowalersky comme servant i la vision, el l'autre à l’audilion. Ce roule prósumé semble exister vraiment rliez le premier; les présomptions sont moins forles pour le scconcl, car son élément principal est piomenté, lout romme s’il appartenail ì un appareil visucl. - Jans le cas où la vésicule cérébrale est unique, ces deux organes se développent aux dépens le sa paroi, et font saillie dans sa cavité; lorsłu'elle est louble, ils sont placés, avec les mêmes relations d'origine et de fosition, dans la vésicule antérienre. - le lieu, dans lequel ils sont silués, étant ì peu près splićrique, tous deux sont séparés, l'un de l'autre, jar une distance qui igale ì pen près le liers on le quart d'un grand cercle. Ces rapports muluels sont loujours conservés, mais non ceux qüils affecteut aver la vésirule; les larves l'une mème esjère, et parfois l'une mème ponte, diffincnt eutre clles sous re rapport, car ces organes sont tantôt placés un peu plus haut daus la vésicule, tantôt un peu plus bas, sans qu’il y ait de règle prérise a ret égard. D’orlinaire, l’appareil visurl est supéricur ì l’autre. Lorsque tous deux vienneut, parfois, à se porter au mème niveau, ils se disposent d'une manjère symétrífue par sajport àla ligne médiane, l'un à droite, et le second à gauche. Cette dernjère disposilion se concoil, rar ces orgunes, tout en élant impairs, ne sonl pas médians.

L’ocelle est silué sur le còlé droil de la vésicule cérélıale, el presque toujours dlans la région supérjeure de ce còté. Sa premièrébauche consiste en une cellule, ou en un petit nombre de cellules, qui se remplissent de granulations pigmentaires; ces éléments appartiennent à la proj de la vésicule, el gramlissent en formaut une saillix; cetle dernière s'avance dans la cavité vésiculaire. D’autres cellules de cette paroi so groupent aulour des bases profondes des éléments pigmentés, et les enchàssent à la manière d'une cajsule; elles constiluent la couche nommée rétine. - Ensuite, les éléments jigmentés léposent, sur leur base lihre, sur celle qui pénètre laus la cavilé de la vésicule cérébrale, une sulsstance culiculaire de forme délerminée. Cette sulsstance se divise en deux parties : l'une, taillée en lenlille li-convexe, s’applinue directement sur les cellules pigmentaires, qui l'enveloppent nuême quelque peu; l'autre, semblable i me calotte transparente, plus épaisse en son milieu que sur ses horls, recourre la précédente. I.emr aspect, et leur situation mutuelle, ont fait donner le nom de cristallin i la premiere, et celui de cornée à la seconde. - Le fait important de celle évolution cousiste en la genèse d'um appareil visuel, aux dépens de la paroj célébrale. Toutes proprortions garlées, la ressemblance de ce plućnoniène, 
aroc celui de la production de la rétine des Vertélués par une expansion de l'élauche du cerrean, est des plus frappantes. La mème particularité existe chez l'Amphioxus, dont le petit ocelle, encore plus imprarfail que celui des larves de Tuniciers, se développe aux dépens de la proi du nemaxe. Celle disposition commune permel do concevoir de quelle manière l'oeil des V'erlélurés cranioles s'est constitué. La partie essenticlle de cet wil est mue expansion d'origine cérélnale, qui formait à elle senle l'apjareil visuel primitif; elle s’est arjoint d'autres régions de provenance tégumentaire, jour ne donner que la rétine de l'organe définilif. De mème encore que chez les larves des Tuniciers, cet wil primordial, et interne, était capable de fonclionner, gràce à la transparence des léguments qui le recouvraient.

L'ajprareil amlitif est toul aussi complexe que l'ocelle. Il consiste essentiellement en une petite saillie, la créte auditive fou crête acoustique), sur laquello repose un ololithe; ce dernier n'appuie pas directement sur la ercte, mais sur des soies rigrides portées par celte derrière. La crêle nest pas autre chose quiun exhaussement local de la paroi cómbalr, dont les cellules sont plus longues qu'ailleurs; elle est située d'labitude, comme l'ocelle, sur le cóté droit de la résicule du cerveau, et intérienroment a ce dernier. - Lotolibe n'est pas prodnil, semblet-il, jar la crête audilive; d'après les recherches de Kowalersly, il dériverait le la face supéricure le la paroi cérébralte. Une cellule de celte face s’allonge, s’avance dans la cavilé de la vésicule, et se remplit de pigment; elle parcourt une parlie de celte cavilé, ra apyliquer son extrémité lilıre sur la crête audilive, et constitue lotolithe. Celui-ci, lorsqu’il s'est dalimité, est arondi, et pigmenté sur la face qui regarde la carité céróluale. We son côti, el l’une manière connexe à cette érolulion, la crófe audilive s'ébauche; elte se creuse, au-dessous des sojes jorlant l'ololithe, d'un petit vide rempli par une sulsstance incolore.

Ces deux organes, ainsi conslitués, occupent une situation remarquable. Ils sont impairs, et, contrairement i la phupart des organes impairs, ils sont asymétriques, non pas médians. Leur petit volume, et, par suite, leur failıle poids, expliquent d’une manière mécanique la persis-

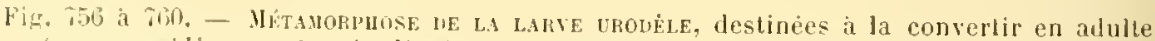
(coupes medianes el longitudinales, avec perspective; la moitie anterieure de la paroi tu corps est enlevee, de facon à montrer en place les organes internes). - Ln 756, larve urodele, commencant à façonner ses deux fentes branehiales, e'est-ä-dire ses ebauches de la eavile férilıancliale. - En 757 , larve dejà fixce, liminuant sa queue; les deux fentes Jranchiales ont pris un aspeel lubuleux. - En 75s, la quene n'est plus 'pu'un moignon: les fentes branchiales stelargissent autour de la branchie, afin de donner les sacs périhranchiaux, ereusés de leurs cavitès pèribranchiales. - En 7ig, les saes peribranchiaux reconvent une part assez grande de la branchie; les siphons commentent a s'allonger. - lin 80 , lorganisation partieulière de l'arılte est déjá indiquée; les deux saes peribranchiaux entourent la branchie entiere.

Juran cette melamorjhose, le neurase et le tube digestif aequièrent leur disposition lefinitive. Les phases de l'extension des sacs péribranchiaux, du déveloprement des cavites peribrancliales et de la cavite chacale, sont représentes, sur des coupes transversales, par les ligures 700 à $7 \%$. 


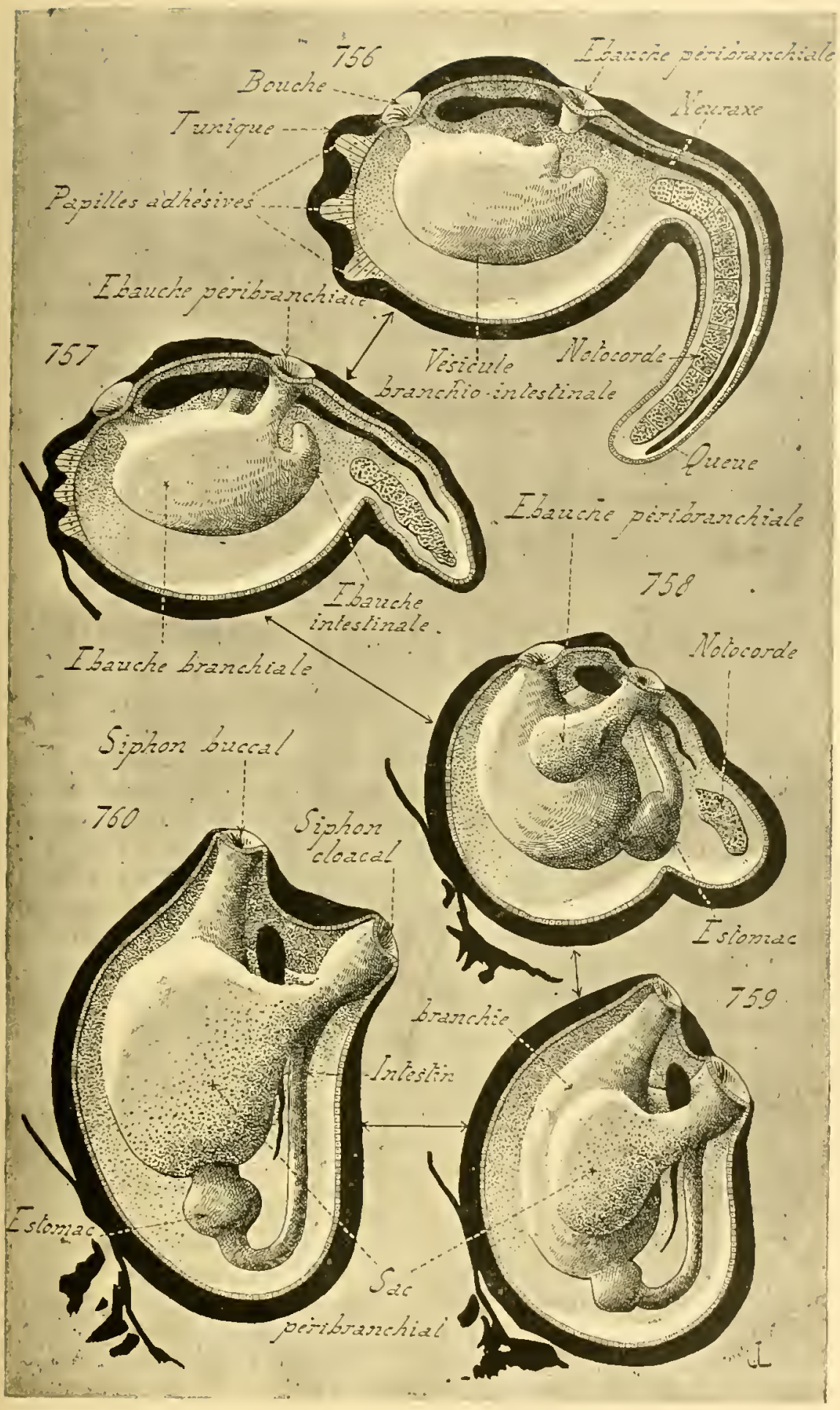


lance de colle assmétric, cal l"excidaul, yu’ils donnent au còté droit du corps, est lles plus minimes. - La canse de celle asymétrie est plus difficile a chercher. Wapres Clabry, ces deux apparejls sont virtuellement doubles, dacume le leurs portions constitulives étant placre de prat et d'autre de la ligne móliane; seulement, celle du cólé gaucle ne se forme pas, et celle de la face droitr parvient seule à se faconner. Au sujet de l'otolithe, cel anteur observe que celui des Appendiculaires est siluó ì gauche, et que les Pyrosomes ont deux de ces organes, l'un droit, l'autre ganche; en comprant ces leux faits à celui présenté par les larves urodèles, il est permis de penser que ces derujures possèrlent regalement deux ololithes, dont le rroit seul arrive à un développement complet. En ce qui concerne l'ocelle, la Jualilé est plus évidente; en cliet. un cerlain nombre de larves morlèles sont ponvues accidentellement de deux de ces apparrils, disposés d'une manière symétrique par rapport a la ligno médiane. les cmbryons munis d'un seul ocelle portent seulement l'organe droit, le gauche ne sibauchant pas. - Cies considérations autorisent à almollre que l'asymétrie, et l'imparité, des apparcils semsitifs sont secondaires; la praté symétrique est le phénomène fonclamenlal.

1). - Arant la transformation ile l'emliryon en une larve urodele, l'entéron primordial s'est divisé un deux zones: l'ume antérieure, el lorambhio-intestinale: laulre postérieure, el cordo-mésodermique. Celle-ci a disparu par le fait le la genese, ì ses lépens, des ébauches de la notocorle et du fenillet moven. Ces dernieres empruntent, pour se faconner, tous les élómenls qui la consliluent, el. lorsqu’eltes ont pris naissance, la zone n’existe plus; sa cavié, fort étroite, et parfois riltuellr, s'est confondue, prar suile de la disagrégalion de ses cellules dernnues mésodermiqurs, arec le schizoculome. La zone anlérieure persiste, converlie en une roluminerse vésicule close, renferméc daus le corps de la larve; elle se diflérencie hàtivement en branchie el inleslin.

Cette différencialion s'eflectue de drux manieres. - Dans le cas qui parail alre le plus frópuent, un pli se forme sur la face inférieme de la paroi de la vésirule hranchio-intestinale, et dans sa région postérieure. Ce pli s'élirre, romme me petite cloison transrersale, lans la

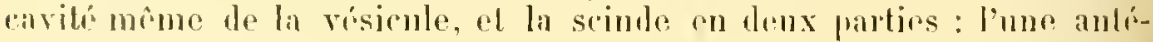
rienre el grande, l'autre postépicure at pelite. Ces lenx parties ne se séparml pas complolement, el communiquenl enlre elles par lenr rógion smérieure; la premiope devionl la luanchio, et la secomle l’inteslin. Ia vésicule s'ist domr moditién al'une lacon prococe, arant l'éclosion do la larve, dans lo lut de ilonner les denx zones principales du lube digestif lófinilif. - le second prorirlé a élé observé, par Eul. van Benelen et Juliu, sur la Clanelina Rissonna. I a vísicule branchio-intestiuale pousse, dans son exlrémilé postérienre, un divertieule, qui se convertit seul en 
intestin, la vésicule demeurant elle-mème comme branchie. Ce mode génétique correspond sans doute in une altération lu précédent. Au moment où, dans le premicr cas, le pli commence it remonter dans la cavité de la vésicule, l'élıauche intestinale ressemble it un diverticule émis jar la vésicule: si, par omission le ce pli, cette éluauche prent directement naissance à la manière d’une expansion, lr second procédé est obtenu.

L’utestin est plus petit que la branchie; l'ćvolution quil subit est differente. Il sintléchit sur lui-meme, et prent l'aspect d'une anse, dont une seule des extrémités sattache d la branchie, et communique arec elle. Cet orifice de communication, entre la carité branchiale of la cavité intestinale, persiste chez l'adulte romme l'orifice cesophagien (bouche, bouche osophagienne, Jes auteurs). L'autre extrémité ust close, in cul-de-sac; alle no tarde pas a s'ouvrir dans l'une les deux fentes liranchiales, qui se percent sur la face dorsale de la larve, au-dessus et un peu en avant de l'intestin, pendaut que "romicr se complete, et accentuc darantage son aspect d'anse.

Lébauche branchiale a la forme l'une grosse vésicule, placéc dans la partir antérieure du corjes de la larve, oi clle occupe un rsprace considérable, et portant l'iutestin apjendu ì son extrémité postérieure. La cavité de cette vésicule sst grande, et sil paroi, fort mince, comprosée d'unc sculc assise de cellules. Cet organe, ainsi coustitué, va s’ouvrir à l'extéricur au moyen de denx fentes branchiales, lomologues des organes du mème nom dés Vertélrés, et méritant, cu conséquence, d’âtre désignéus par unc expression identique. - Ces fentes lranchiales dérivent, comme leurs équivalentes des Vertél,és, de deux paires l'ébauches distiuctes, l'une provenant de l'ectorlerme dorsal, et l'autr. de l'endoderme liranchial. Deux dépressions ectorlermipues se creusent, sur la face dorsale de la larve, de part et d'autre du neuraxe médian, et audessus de la région postérioure de la vésiculo branchiale. Deux diverticules correspondants sont emis par celle druiere; chacun se dirige vers la dípression ectodermique qui le surplombe, ot sunit i elle. L'enscmble de ces appareils, ainsi fusionnés, constituc deux tubes symétriques. mettant en communication dircete la cavité branchiale arec le dehors; les orifices externes de ces tubes sont dorsanx.

Ces deux organes étaient connus depuis longtemps, et leur structure, leur mode de naissance, avaint prèté a léancoup de contestations. Dans ces dernières annérs seulement, les recherches failes par plusienrs auteurs, et notamment jar Ed. van Buneden et Julion, ont ilucide la plupart des phénomènes qui les tonchrint. Ces tubes sont strictenent, at entièrement, les homologues, ainsi fuc l'ont fait remarquer ces derniors naturalistes, des fentes branchiales des Vertélerés; on leur avait domné antrefois los noms de résicules cloncules, de lubes atrinux, drutrimm; mais lexpression qui les désigne ici lour convient seule. - Cous aplatreils 
fersistrnt chez los funiciers pérennicordes, aroe les mèmes dispositions

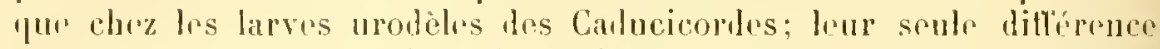
porte sur lour situation daus l'urganisme, car ils sont rentraux, au licu lètre dorsanx. En cet état, ils correspondent, sous tous les rapports, dans l'espace comme dans le temps, a deux des fintes branchiales des Vortibros acraniens et des eraniotes. - Seulrment, ils subissent ensuite, pour ce qui est los Caducicordes, une évolution spéciale, yur los l'éronnicololos, ni les Vertóbrés, no montrunt jamais. Ils s'ílargissent, samplifient latóralement, te maniere a rnvelopur la branchie, et réunissent leurs orifices extenes en unn soule onvertnre; ils constituent ainsi un ample espare libr, onvert an hohors, nommé la cavité péribranchiale. Au moven de pores prerés dans la paroi de la loranchie, la cavité le cette leruiere communique avec celle qui l'entoure, et, par co moyen, avec le dohors. - Les phrinomines, relatifs à la genese de cet appareil, commencent a se montrol avant l'éclosion, du moins dans ta plupart drs cas. Ils n'atteignent leur plus grande amplitude qu'après l'éclosion, et vers le délut de la fixation. Aussi, seront-ils décrits daus le paragraphe relatif au développenent des orgames.

Les portions principales lu tule digestif sont, dès lors, représentées. Ce système organique est. chez l'adulte, divisé en deux régrons essentielles, la branchie et l’intestin; ees denx régions sont déjà indiquées chez la larve, antérienrement à son éclosion. D’un autre côté, soit un pu avant ce dernirr fait, soit un pou apres, les orilices de co systeme, la bouche el l'anus, prennent naissance. - La bonche se perce vers l'extrémité antérieure et la face dorsale du corps, un peu au-dessus des papilles albésives, et sur la ligne médiane. Une lépression ectodermique, le stomeon, s'enfonee daus le corps, en passant au devant de la vésicule réribrale, et va joimler la zomr antérieme de la branchie; lonitice rxlerne de cette invagination est la bouche. Sa contigninté aroc la vésicule céróbrate fait que, dans la plupart les cas, cetle deruivere sourre dans le stomeon, el rommunique par lí. d'une maniò'e indirecte, avec le dehors. - Des phénomines semblables se manifestunt pour la production de l'anus, arec cette dillirence que la dépression est lournie par la zone ertolermique de l'une des fentes hranchiales. liextrémité distale, el close, de lintestin, se rapproche de la fonte liranchiale qui lavoisine, soil la droilo, soit la ganche (et parfois les larves d'me mème espéce diffirent sous ce rapport), puis s'mnit à elle. lianus se perce ainsi; et le tube digestif de la larve s'ouve à l'extérieur par deux oriliees.

Les laits essenticls de co développenent se résument dans les trois notions suivantes: l'entéron primordial se sublivise en deux zones, l'une branchio-intestinale, l'antre cordo-mésodermique; celle-ci disparầl, apres avoir prorluil los ihanches de la nolocordo et du feullet moyen; celle-là persiste lont entière, ot se dilférencie en une branchie ef in intestin. - Comme l'out lait remarquer avec raison Ed. van 
Beneden el Julin, celte évolulion concorde de tons joinls avar colle yur présentent les Vertébrís acraniens. Seulement, tandis que la notororde des Tunicjers progresse en irriem, et ne s'iteml pas mil ant, cello de l'Amphioxus gagne par ses deux extrémités, el parcourt le corps entier d'un bout il l'autre. La disparition d’unc partie de l'entéron des Tuniciers so retrouve également choz l's Verlébrés, dont celte régjon, qui constilue l'intestin post-anal, sr résorbe durant les phases cmbryonnaires. Chrz les uns comme chez les autres, la zone de l'entéron frimordial, qui avoisine l'entéropore, froduit la notocordr ot le fenillet moyrn; msuite, l'entéroporr, converti d'aborl en canal neurentérique, finit par disparaitre, of lanus se perce un peu en avant du niveau qu'il occupait. La partie de l'entéron, comprise entre le niveau d" l'entéropore cl l'anus, devient poslérjemre à ce lernier, et forme un inlestin post-anal, destimí à s'atrophicr plus ou moins rapidement.

2o Éclosion et fixation de la larve urodile. — 1. La larru, parvenue a ce dogré de développement, perce les enveloppes qui l'culourint encore, et leviont libre. Son organisme est netlement divisé en tronc et quene. Le premier, gros el volumineux, presque sphérique on largement ovalaire, porte en arant les papilles adhésives, el, sur sa face dorsale, la bouche arec les doux fentes branchiales. La queur, Jongue el plus mince, d'abord recourbée sous le corps, se redrisse, el devient horizontale. - Lembryon nage par son entremise; mais sa molilité n'est pas lrès grande. A en jngrer l'après celles élevées lans m aquarium, ces larves se diplacenl, pendant un temps fort court, par quel ques saceades de leur queue, puis devienn'ut immoliles, el se laissent tomber. Ce fait est sans doutr en relation avec le but qu clles poursuivent, trouver un lieu pourant leur servir de support; res monvements rapides, suivis de longurs slases, duran! lesquelles les larves se laissent choir sur un corps résistant, aprés quoi elles se remellent en marche, sont destinés, semble-t-il, a leur permettre de trouver un endroit favorable. Elles se meuvent lant qu'elles ne l'ont pas rencontré. - Durant leur natalion, elles raplellent d'assez jrès, lans leur aspect général, les létards des Amphilions, el celte compraraison a souvent élé faite.

Lorsque lembryon mouble a enfin trouve un support convenable, il

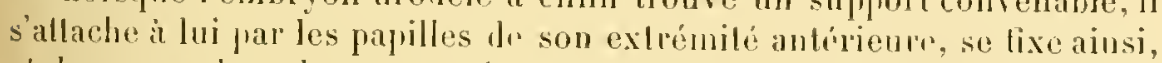
ot demenre alors dans cellr situation. Il subit des moditieations considepables, dont les mes, exposées dans lo pillagraphe suivant, liennent.

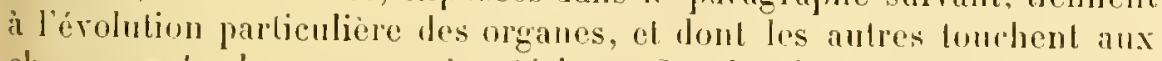
changements de son asperl extérieur. Ces dernies's portenl sur derix orlres de chosı's : sur lix moditication do lorme en elle-mème, considéréc indépendamment du miljen extérieur; el sur la nouvelle orientation lưse par l'organisme.

B. - 1)u moment oì la larve vient de s'allacher i son support, elle subil, dans son aspect général, des transformations complexes. La 
quene perl ses contours réguliers, devient variqueuse, el se plisse en divers sens; re faisant, elle se rétracte de manière à se confondre avec le reste du corps. La plupart des béments qui la coustifuent, el surtout les cellules lu nemraxe de la notocorle, se détruisent par clasmatose, ef se brisent en mouns fragments. Quelques-mues des cellules mésodermiques abamdoment leur saroplasme, qui se détruit, el se réduisent a leur protoplasme uon modifié; ru cel étal, ils sont peu a peu ramenés, au fur et a mesure do latrophir de la queue, dans le lronc, oil ils se melangont anx antros parties du fenillet moven.

Entro temps, ef pendant cette régénérescrnce de l’aplendice caurlal, le corps augmente l'épaissenr de sa tunique: celle-ri forme, autour du petit itre, une rnveloppe aux cuntoms irréguliers, Jense et compacte, an milien d. laquelle sont places les organes. Laspect de la larre a beanconp changé; cette dernièe nest plus qu'une petite masse, aux limites indropises w variahles, attachce à son support par me large hase; la cuticule tunicale, à causo de son épaisseur, entre pour une homne part dans le volume total. - Lembryon persiste, pendant un temps assez. long, dans cette lisposition; les organes se complietent durant colle priode, ot revètout leur struclure définitive. le corps s'allonge suivant mo direction détermince. produit ses deux siphons, acquicrt son allure particuliere; ef l'adulte so degage ainsi de cette pelite masse encroùtante, qu'était levenue, après sa fixation, la larve urodile.

l)ans lo cas, fort rare, où le développement comprorte la présence l'une larve urodicle, el oì l'adultrest libre, les modifications précédentes ne seffectuent qu'en partie. Le jenne embryon, muni de sa queue, est motomé par nue lumique, ipaisse rt transparente. Il se convertit directement en alutte, par l'atrophie progressive de son appendice caudal, et par la chute des assises externes de son enveloppe tunicale. - Cet ensemble do faits n'est montré que par les Doliolides, parmi les Tuniciers libres; car les embryons des Salpes n'ont qu'un rudiment de yueue, et cenx les l'yrosomes sout compliotument privés d'un tel organe.

Au moment on l'adulte se higage de l'embryon fixé, et grambit, sa rroissance ne sellectue pas toujours suvant le plan dorganisation jossidi par la larve urodide; et meme, les directions de cutte croissance varient, parmi les Tuniciers caducicordes, d’un groupe i l’autre. Il est nécessaire de recomaitre, sous ce rapport, deux types principaux.

L'organisme de la Jarve rost disposé de telle manière que son axe longitudiual entier soit aussi celui de sa branchie; en ontre, ce dernier apparril est situé au-rlossons dr lextrémiti antéricme du nemaxe, et, simf la plare des papilles adhrsives, la bouchr so brouve ôtre antériemre ct lerminale. - Les Tunicjers libres, anx colonies linéaires, comme les Salpes et les lloliolides, of certains Tumiriers tixés, tels gue les bollenia (1) supprimant leur pédonemle d’attale), sont les seuls à othirencore, 
Jans lenr économie détinitive, une semblable lisposilion, el ì conservor l'orientation larvaire. I)u moment oi ces derniers se fixent, ils grimdissent normalement à leur support, sans rien changer aux relalions muluelles de leurs organes.

Pareils faits n'existent pas chez la plupart des autres Tunicirrs. Les appareils ne grandissent point suivant la direction quils affectaient chez
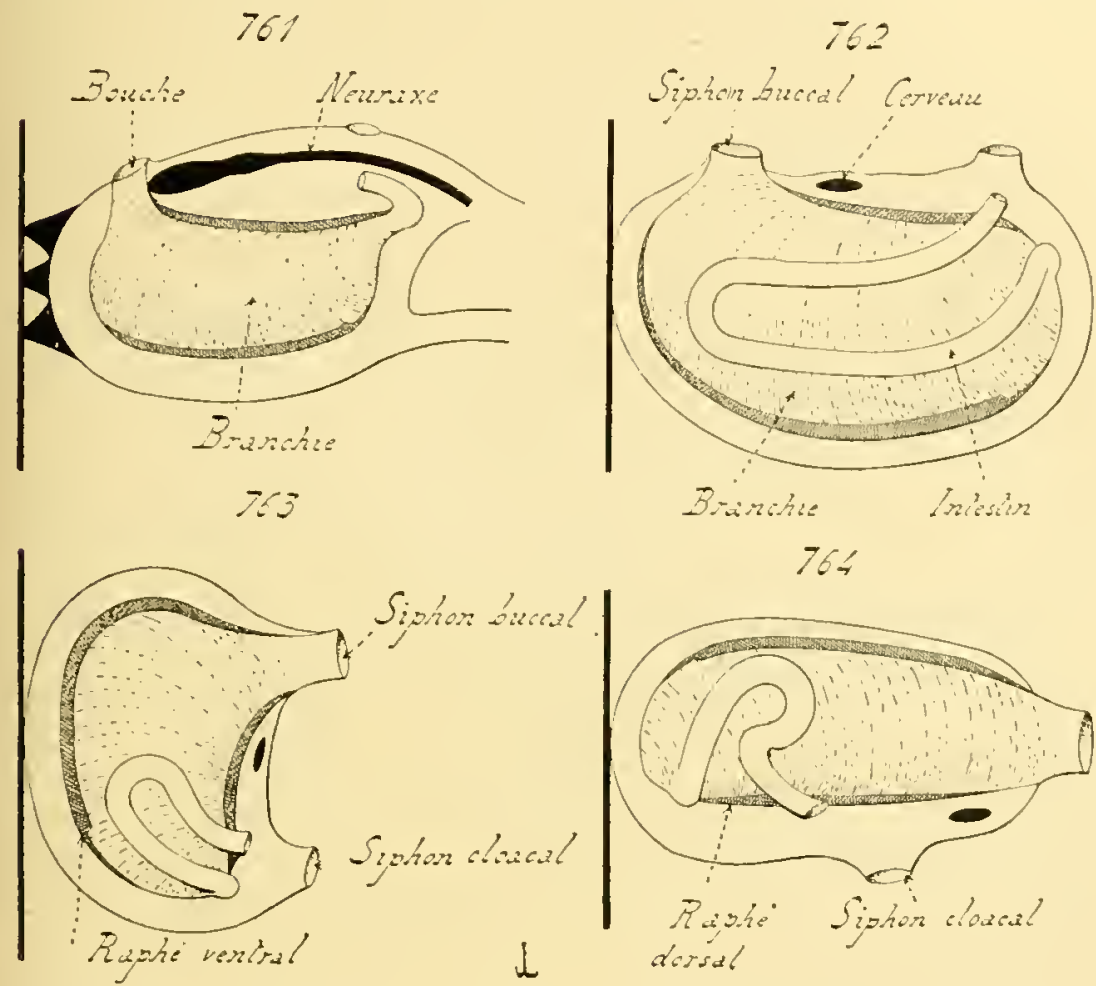

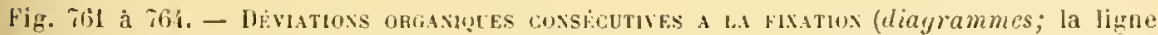
noire représente le support). - En 761, larve urodèle (le début de la queue est seul lessinè) se fixant pr ses papilles adhésives. - En 702, Tunicier conservant l'orientation organigue te la larve : comme le font les Bollenia par'exemple, leur pédoncule d'attathe étant mis i part. - En $7(3)$, deviation de $50^{\circ}$; il en est ainsi (thez beaucoup de cynthiadies et de Holgulidées. - En i6i, déviation de $180^{\circ}$, comme il en est chez beaucoup de l'lallusiadées.

la larve; le corps entier de l'adulte se dispose l'une maniere licn dillírente de l'arrangement primitif. Lorsque la larve se lixe, lit bouche est sitnée à côté même de la zone adhérente, alor's qu'alle est l'orl d̂lognée, chez l'adulte, de celte hase immohile; loms les organes accompaguent la louche lans sa migration. - Aussi, en prenant le support conme plan fixe, et rapportant it lui les divers changements effectués, on voif qun 
l'amplitule de ces déplaroments attuint parfois $90^{\circ}$, et mème 1 soo; le

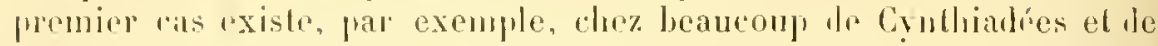

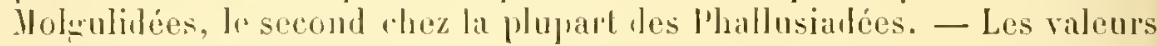
ansulaires donnies cidessus sont senlement des points de reprire, deslinos a montrer l'importance des modilications accomplies; elles varient guclque peu suivant les conditions rxternes, el sonl susceptibles deetre plus grandes, ou plus potites, parmi les représentants d’une mène espece. - Dune manibrr générale. les luniciers, lont les siphons paraissent placis an méme nivean, et sont peu dissemblables, ofluent unr dillérence, far rapport i l’axe d'orientation de la larve urodele, d"une valeur angulaire moyenne dr 90; cenx, tont les siphons sont éloignrs, el te tailles différintes, présentent une diflérence d"une valem angulaire comprise enlas: 100 el 1800.

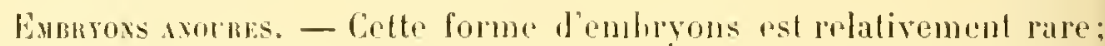
son exemple leplus saillanl. w te mieux connu, est domé par plusiens's aspeces de la lamille des Molgulibles. Ces especes no se dislinguent, par aucun antre caractire spécial, de culles dont le dóvolopement comporte des larves mrodeles; cependant, en se basant sur leur particularité embryonnaire, De lacaze-Duthiers a crée, aver les premiires, le genre Anurella. - Cettcopinion est logique, hien qu' alle ñait pas éti acceplée par tous les naturalistrs. Nos groupes reclassification ne sont pas absolus, et u'existent pas dans la nature; ils répondent seuloment à nos besoins de méthode, aidés par les interruptions que le temps amème. dans la série des èlres. Rien n’ohlige ì ne raractriser des groupes secondaires, comme des gemes on les trihus. que pra des qualités de l'adulte, ì l'exclusion des antres; et rien noblige, en sus, i ne premlre, parmi ces ynalités, que celles lomant ì la forme. Dans une lonme mćlhode de classification, on doil rhoisio foms les caractères, quels qu’ils sojent et tels quils se préscntent; et on me peut juger de leur valeur qur d"ajpis lem cunstance et lemr date d'appartion. Le fait d'avoir un déreloppement conlense, el le montrer des embryous anomrs, est. en lui-même. d'une

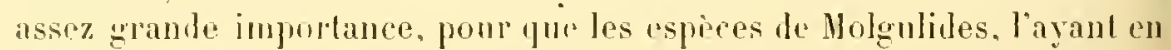
lour possession, soient séparées des autres, el mises dans un genre special.

Le trail rssenticl des emluyons anoures est leur privation de queue; aussileur forme gémírale, gloliulense on ovaline, est-elle fros différente de eello montrée par les larres nrodeles. La notocorde existe liven à létat de rudiment; mais ses quelfuns cellules constilutives no sout pas assez nomlineuses pour amenr. la production d'un appendice les contenant, el elle restenl enformors dans l. corps. A colte absence de queur s'ajonle oncorr mo assiez grande combensation du léveloppement, qui lait so convertir les embryons en adultes, sans montrer ancun te ces changrments, ollorts prar les larves moleles veuant de se fixer.

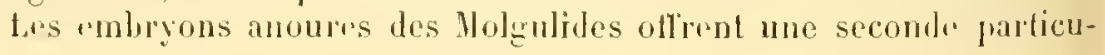


larile intéressante. Peu apres leur misr en librerté, rest-it-lirr prou apres leur sortic hors des envoloppes ovmlaires, lrul corjs émul des expansions eylindriqurs assez longues; cos derniorrs sont rassemblées en denx grompes, dont ehacun est plaré sur l’un des cóces du corps, ut possidr trois, ou denx, de ces appendices; lenr chiffre tolal élant einq. Ces rxpansions ont la forme de baguell's ereusis; leur paroi se compose l'une assise cellulaire ectodermiqur, reconverte d'une mince conche lunicale; lenr cavilé centrale communique avec les respaces du sehizocoe-

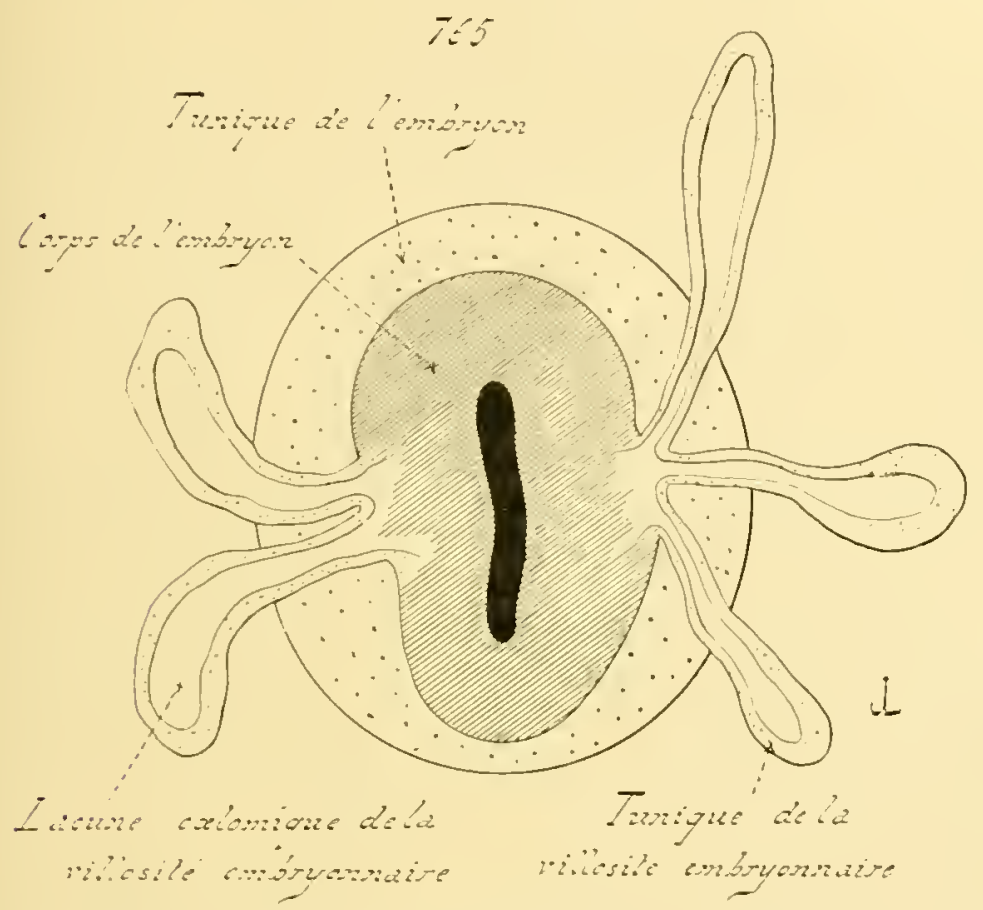

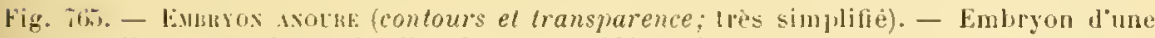
Amurella, fenre de li famille des Molgulidees, d'apres ll. de lacaze-fluthiers. Cet embryon, prive de queue. ext hitivement pourvu de villosites, de stoluns fixateurs; il est vi par sa face inferitule.

lomr: en rísuné, ces organes ne sont antros que des saillios de la paroi du corps embryonnaire. Elanl domnées leur origine et len struclure, res anmexes doivent élre considérés comme homologues it drs stolons fixateurs. - La tunique de la plupart des Nolgulides adulles, comme cellr, du resle, de dirres aulres Tuniciers fixés, "sl comberle, en tolalité on en partic, d'expansions somvent nonmeres des villosites. Ces villosilés sont, "nl somme, des défendances de la paroi du corps; elles se composent d'un lissu mésoulormique, quenturre me assise coloder- 
mique, enveloppéc elle-mème jar une cumbe hnicale. Elles ne dirierent des stolons reproduclem's yue par l'absence de collules endodermiques dans leur masse, absence conncxe i lenr privation de facultés gemmjpares: aussi le terme de stolons fixateurs, indiquant a la fois lours affinités el leurs seules fonclions, parait-il priféralle a celui de villosilés. Cos expansions des rmbryons frairhemont éclos sont des stolons fixateurs de venne lutive, dont la cavité centrale, reliér à un sehizocolome non cucole diflérencié en apparoil circulatoire, demeure liéante, rt dont la part mésodamique se trowre fort peu développér, sinon presque alssente, car, an moment de lenr apparition, la paroi du corps rst surtout constiture par l'ectoderme.

11 imporle de se représenter que les praticularités, offertes par les embryons anoures, résultent d'une comlensation du développement, ef comportent, par suite, des déplacements et des omissions. La réduction do la notocorile, el l'absence de la queue, ne sont pas les seuls caractères possédés; d'autres orąanes sont également alteints par les mèmes fliénomènes. Le nenraxe est surlout remarquahle sons ce rapport; il reste petit, el aequiert libectement sa structure léfuilive, sans olfrir aucune dilatalion comprarable a la vésicule cérélrale des larves urodeles.

HI. Embryons gemmipares. - Lil prósence d'embryons gemmipares, cest-it-dire d'embryons susceptibles de se reproduire par la gremmiparité, sans allendre pour cela d'ètre arrivés à l'état adulte, est due à l'apparilion précoce de la faculté hourgeonnante, à une véritable frogenesc asexuclle. Sa veme domne a ces embryons une allure parliculiere, que les larves simples ne montrent jamais. Elle concorde, d'habitule, arec une combensation du développenent, entrainée par l'abondance des matériax mutritifs aceumulés dans l'ovule. Elle s'acrompagne donc, dans la plupart des cas, de réduction, ou mène domission, des organes propirs aux larves modiles.

Les Tumiriers, ponrvus d'embryons gemmipares, constituent les ynatre familles des Botryllides, des Pyrosomides, des Salpides, el des Doliolides. Cependant, ceilains antres Tuniciers, hourceonnant a l'étal adulle, el notamment certains [ijhlosomides (Diplosoma-Astellimm-spongiforme, Diplosomoïdes Lacazei), sont rapalıles d'avoir aussi de tels descendants. Il conrient, sans doute, de rechercher, parmi les représentants de ces derniers genres, les premieres indications de la progenese gemmipare. l'armi ces quatre familles, les botryllides possedent l'évolution la plus lilatée, et donuent des larves urodieles. Il en est de mème four les Doliolides; seulement la queue commence a diminuer de longuenr. Cetle réduction est plus accentuée encore chez les Salpes; elle alteint son comble chez les l'yoromides, où cet apjendice n'existe plus.

l.es dispositions spéciales aux embryons gemmipares tiennent à deux ordres de considerations: les unes portent sur les annexes qui leur sont particuliers, el les antres sur la durce de leur vie. 
Axrexes des embroxs gemulpares. - Ces anmexes sont de deux sortes. l.es premiers sont des annexes reproducteurs, et consistent en stolons gemmipares, ou en jeunes lourgeons. l.es seconds sont des anmexes nuritifs, et se eomposent, soit d'une vésicule vitelline, soit d'un placenta.

10. Imexes reproducteurs. - Chaque emliryon ne porte d'habitude qu'un seul de ces annexes. Celui-ci est un stolon gemmipare, ou ur jeune bourgeon. Entiorement semblables à ceux qui prennent maissance Jans le bourgeonnement normal et arulte, ces derniers se composent de dépendances des trois feuillets. Chaque stolon romprend une partie endorlermique, une portion mésorlermigue, et une comche ectoderminue extérieure. le stolon gemmipare et embryonnaire ne diffère, en somme, de celui des adultes, que par sa venue précoce.

Ainsi, la genmiparicé est un procédé reprodueteur, fréquent chez les Tuniciers calucicordes. Dans un grand nombre de eas, elle intervient au moment oì le générateur arrive à l'état adulte, et le slolon gemmipare prend alors naissanee. Mais parfois, clıez les représentants des quatre familles précitées, la faculté homigeomnante se manifeste alors que le génératcur est encore un emlıyon; ce dernicr est, en conséquence, muni d'un stolon. Celui-ci constitue un annexe particulier, dont sont privés à la fois les embryons des Tunieiers qui ne lourgronnent jamais, et ceuxdes Tuniciers qui ne bourgeonnentqu’à l’état adulte.

2o Annexes numilifs. - Cette seconde sorte dappendices existe senlement chez les Pyrosomides el les Salpiles. Elle consiste, pour les premicrs, cn me vésicule vitelline, ot en un placenla pour les seconds.

Lovule des Pyrosomes, fort volumineux, contient du deutolécithe en abondance. L'émbryou s'éhauche aux dépens d’une petile cicatricule; il prorte, appendu à sa face ventrale, fout le deutolécille. qui hui compose une vésicule vitelline de forte laille. Avant mème llavoir engemdré la plupart de ses orzanes, il émet un stolon gemmipare, qui donne naissance, sur place, ì quatre descendants. liensemble de ceux-ci et d. lembryon est porté par la vésicule vilelline, dont le dentolécithe sert à les alimenter. Les premiers ont été nommés, par lluxley, les Asciliozoüdes; le générateur est dit le Cyallosoüle. Le cyathozoïle menrt ensuite, n’acliève pas son développenent; les quatre asciliozoüdes se complètent seuls, en puisant dans la vésicule vitelline, yui se rapetisse à mesure, les matériaux nécessaires jour sulirenir à leur ćvolution.

l,e cas des Salpes est plus compliquí. Ces animaux renferment licu, dans leurs ovules, me certaine quantité de deufolicilhe: mais celle quantiti, moindre que celle des l'yosomes, est insullisante. l'emloryon. au moyen d’un organe justement nommé placenta, emprunte ì l’écomonic maternelle les élémeuts utiles a son alimontation. Les olusrrvitions alcomplies, sur le développement de eel annexe nutritif, sont tres nom- 
hreuses: mais elles ne concordent pas en beancoup de points. Les fails suivants, choisis parmi les principaux, paraissent homs te conteste: ils se réparlissent en trois phases successives, dout la premiere consiste en la lormation d’une chambre inculatrice, la seconde en la genese du placenta, et la derniore en la périonle d’étal de ce dernier. La julupart des domées exposées sont dues aux recherches de J. Barrois.

Chaque générateur, chez les Salpes, ne possede qu'un axuf. Celni-ci est placó lans une cavilé, l'ovocapsule, reliée a la cavilé péribranchiale par un large oviduele. L'ovocapsule se contond avec l'oviducle pour former avec lui un seul esprace, qui se ferme, se convertit en une vésirule close, el devieul la chambre incubatrice (encore nommée cavité folliculure). Tout ru agissant ainsi, la région occupée par cetle chambre se soulève, de facon à faire une forle saillie dans la cavilé périluranchiale; les zones mises en contact, dont les unes composent la paroi de la chambre (paroi souvent nommée le follicule), et les autres celle de la cavilé périlıranchiale, s'unissent en une seule membrane, quilimite toule la partie soulevée. La base de la chambre demeure plongée dans les tissus sous-jacunts, ou se lrouve un voluminenx sinus sanguin, le sinus placentaire. La région, qui repose sur le sinus, sera dite la plaque placentaire, car ćest à ses dépens que le placenta va se faconner. Ce dernier se comprose de doux parties: l'une firtale. lautre matemelle.

En cet iuslant. lorule s'est segmenté. el a produit l's deux feuillels haslodermiques primordiaux. Le jume embryon se rapproche de la plaque placentaire, us’acole à elle. Cellr plaque s’épaissil cn son milieu, et fomne mo saillie rolumineuse, qui pénetre dans la eavilé du sinus placentaire, el y reste suspeudue a la manjère d’un battant de cloche : loù son nom, aceordé par Barrois. Ensuilr, elle s’épaissil sur ses bords; les zones phus ipaisses contribuent a limiler le sinus plarentaire, ef rappellent. d'après lour silualion prar rapport au ballant, la cloclse ellemème. Tonte celle parlie comploxe représente le placenta muternel. De son côté, chez l'embryon, la zone ectoderminue, en contart aver la plapue placemaire, s'épaissit par l'allongement le ses rellules, el produit un lisyue accolé au placenla maternel: ce disyue est le placenta fatal.

l'embryon, loujours conteun dans sa chambro incubatrice close, est donc attaché, par son placenta fulal, is celle région, de la prosoi de la clambre, qui se convolit en un placenta maternel. Ces denx placentas sont d’abord accolés l’un ì l’aulre; ils s’écarlent ensuile, de manière a laisser "nlpe eux un espace libre, la cavite placentaire. Cot espace se mel, i son lour, on relations directes aver lo sinus placentaire. Le sang, contenu dans es dernier, peul donc púnétrer dans la cavité placentaire, oi il imigne la smrface du placrula fartal. el. semble-t-il. lraverser er dernier, pour entrer dans le culome emliryonnaire; il fait passer. au pulil èlre renlermé daus la chambro incubatrice. les malériaux mulritifs qui lui sont nécessaires. - l'embryon, ainsi alimenté, n'est rendu libre quan moment où il a deja parcouru un grant nombre des 
phases de son direlopurment. La mise en libroté s'eflectue par la rupture des parois de la chambre incubatrice, précedée, au préalable, piar latrophie de la plus grande part des lissus jlacontaires. Celte ruphur permot a l'embryon de jarvenir dans la cavité périluanchiale de son générateur, d’où il est rejeté au dehors. Lembryon possède alors un rudiment drouenc dans la région postérium de son corps, el porte encor, ilpendu a sa lace ventrale, ee qui lui resle de la masse de ses denx pla-

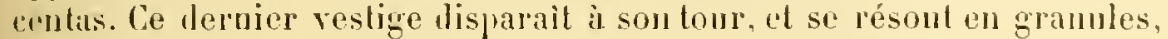
qui restent emprisonnés dans la tuniqur, oì ils se détruisent.

Toule celle évolution se ramine, en somme, aux faits suivants. Liauf dromeure conlenu dans l'oriducte, et se met en raplort, tout en se segmontant et produisant les feuillets, avec mo partiede lit paroide celui-ci; la zone de contact s'épaissit, autant du coté de la paroi oviductale que lecolui de lectoderme rmbryomaire, at dome le placenta. Ce dernier se crense l'une cavilé, qui, communiquant ála lois avec l'appareil sanguin lu ginérateur et le calom de l'umlurom, permet au sang du premier d'arriver dans lorganisme du second, et de le nomrir. - Cette sérir de phénomines, simple en apparence, est ru réalité fort complrxe. Elle saugmente parfois de plissements. et de destrurtions, de parois. dinsi, chez la śalpa maxima, étudiée par Barrois, la base de la saillir, formée dans la cavité pérjhranchiale par la chambre incubatrice, se souleve en m repli anmulare, qui entoure celte sallie; efle conslitue une membrane eurcloplyante, nommće l'utérus par Barrois, pendant que la paroi propure. de la chambre incubatuce disparait. Ces remplacements ne paraissent pas exister clez d'autres espèces de Salpes. Io plus, si le placenta futal pillaît ètre d'origine ectodermique, la valeur 'xacte, des lissus mis en cause dans la genèse lu placenta maternel, prete à discussions, et ne peut ètre élucidée arec les donmées acquises, malgré le grand nombre le celles-ci.

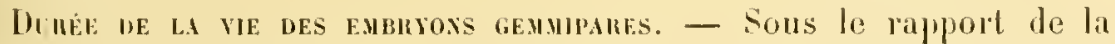
durie de leur existence, les embryons gemmipars soml ripartis endeux siries. Dans la premiere, ils produisent lenr stolon reproductenr, qui donne los lescendants par bourgeonnement, wt achevent lenrorganisme: ils continuent a vivre. l'ar contre, cenx de la seconde sérje engendrent leur stolon gemmipare, puis ne poussent pas davantage leur évolution propre, et menrent hativemont. Toute lemr embryogénie consisto it ébucher leurs principanx organes, et jouer, d'me maniere prócore, le rôle de générateur; apris quoi ils disparaissont. - Crtte opprosition est des plus intéressantes. La progenose asexuelle, ditrésente en cela de le progenese sexmelle, narecte done pas, dume manirie constante, le développement personncl du génératemr; elle l"interronpt encertains ras, ef non en l'autres. Il est possiblr, sans doute, de voir, dans les arlajtitions particulieres, les canses d'me talle liffúrence.

C'est parmi les Ascilies composées que se lrouront les orighines de cos 
Irux séries. - Le point de lépart de la premières est oflert par les Diplosomides et lis Didemnides. Certains représentants de ces deux familles ébanchent hàtivement les stolons gemmipares, alors qu’ils n’ont pas entierement achevé leur économie; ces individus, toul en produisant des lescendants d'une manière précoce, complètent leur organisme, et passent à l'état adulte. Les mêmes faits sout oflerts prar les Salpides et les Moliolides, sans douto a canse de leur vie lilre, et de la disposition linéaire de leur colonie, qui permet à tous les zoö̈des de se développer a l'aise. - Les particularilés de la seconde série sont causées, semble-t-il, par la lorme massive de la colonie, el par l'arrangement régulier les zooïles, qui emprichent les premiersengenlrés dle s'accroître. l.e début, sous ce rapport, est Jonné par les Botryllides, parmi les Ascidies composées; l'embryou gemmipare meurt, et de mème disparaissent ses bourceons des fremières générations, jusqu’an moment ou le chitrre des descendants, appartenant aux générations ultérieures, est suffisant pour constiluer un système étoilé complet. Le mêne fait se retronve chez les l'yrosomides; le cyathozoïle disparait, après avoir façonné, aux dépens de son stolon gemmipare, les quatre premiers ascidiozoïles. Ceux-ci se groupent hàlivement, de maniire ì constituer une élıanche de colonie ayant l'aspect de Lonnean, et laissent à part J'embryon primitif, le cyathozoïle, qui se désorganise et meurt.

\section{\&4. - Origine des organes.}

I. Considèrations générales. - t'origine des organes Jes Tunirides a prèté à de nombreuses ræecherches. l'ourtant, elle est loin d'ètre élucilce l'une manière complete; soit que les faits la tonchant se lrouront encore inconnus, soit que cenx obsorvés aient été interprélés de facons différentes.

Les modifications suhies par les appareils, dans leur dévoloppencnt, sont assez complexes, lorsqu'elles portent sur un embryon ayant passé par l'état urodèle; rlles sont moindres dans le cas des emliryons anonres, rl des descendants issus de la grommiparité. Les bourgeons, étantattarhés i leur générateur et nourris par lui, so romportent romme des ovules munis d'une abondante réserve mutritive; aussi, les organes se façonnent-ils sur place, el d’une manière directe, par des procédés souvent très différents de crux olferts par les larves urodèles. Ces phénomenes ne sont pas spéciaux aux Tuniciors, ot se retronvent dans la reprodurlion gemmipare de tous les animanx. Lours dissemblances, parfois considérablis, aver "rux présentís par les évolutions dilatées, permeltrut dr comprendre les divergences d'appréciations établies, dans rertains cas, entre les auleurs.

Les phangements sulis par les larves urodèles, étant lins plus complexes, doivont être pris romme guides. Il est aisé de concevoir les antres, l'après rux, en se les représentant comme moins étundus. 
11. Aspect extérieur, et téguments. - L'asprut général de l'adulte est ru grande partir dirigé par la forme de la tuniqur. L'animal est d'un ovale plus ou moins allongé, renourert par la ruticulr tunicale. qui agglutine parfois les rorps élrangers, al lorminé par ses deus siphons. Ces derniers manquent aux rmbryons; ils rorreppondent it des élongations tufulaires des bords de la bouche, nt de cenx de la dépression cloacale: l'un rst dit le siphon buccal, l'autre le siphon cloacul.

Les téguments sr composent, rn allant de dehors en detans, de la tunique, dre l'ectoderme, d'un derme sous-jarent; l'onsemble dre res denx dernières assises est parfois nommé lr mantean. Lintordermo dirive directement de celui de la larve. Le derme est conslituc par une trame conjonctivo-musculaire, que produisent les cellules mésodrrmiques placées sous le fruillet externe. Ce derme, qui n’est guem hinn speciallisé que chez les Ascilies dont lorganisme est assez romplexe, doit ètre pris ‘omme la partie périphérique du mésodrrmo mísenchymaleux; les larunes, dont il est creusé, sont plus étroites et plus serrées yur rellrs du reste du rorpis.

La tunique est une cuticule exsudée par l'ertodrme, et rjetér sur sa face extérieure; elle est sans resse produite par l'animal, depuis te dithut des phases embryomaires; ses courhes dacroissement sont sourent reconuaissables. La genèse drecte ruticulr nolfre pas seulement les caractères d'un exsudal; des collules ectodermiques se détachent de l'assise à laquelle elles appartiennent, pénètrent dans la substance culjculaire, et y jouent le rơlr d’élénents lig̨urés. Ce pluénomène est assimilable a une desquamation partielle el contiuse, endiguée par la tumique, qui empèche ces ecllules de parvenir dans les milieux extérieurs. - Lorsquils sont ainsi détachés do leurs voisins, ces éléments s'arrondissent, conservent leur vitalité pendant un temps assez long, et émetteut des expansions jiseudopodiques; ils ressemblent, en lout, à des cellutes du tissu conjonctif sous-ectodermique. Ils subissent ensujte me dégénérescence particulière, qui s'offectur de deux façous. Ou lien. dans le cas ou la lunique riste miner, ils se risortient, par "lasmatose, en un amas de pelits granules, qui finissent par se dissocier, el par disparaitre. On bien, lorsque la Lunique est très épaisso, ils se remplissont de pelites enclaves liquides; celles-ci se rénnissent en mne grosse racuole, ot relèguent, sur les cótis de l'ámént, le novau et he proloplasme. Lenr ćrolntion rapuelle de près celle des celhules adipeuses, sauf par la nature de la substance enclavie. Linsi morlitis, ils sont très gros, arrondis, cl síprés les uns des autres par des espraces itroits; l'ensemble de la tunique prend alors un aspect vesiculeux tes plus remarpualies.

lowalersky admet que des cellules du feuillet moven, appartenant au derme, sont capables de traverser l'ectodermu, et de parvenir dans la tunique. Le fait pent arriver: les collules mósonlermigues, munies d"expansions amorboüles, sont susceptibhes, sans doute, de lraversere par diapridese, une couche épithéliah sembible a celle de l'echodrome. Mais 
il est indisculable que l'retolerme est la prinripale malrico, sinon la seulo, de la sulsstanere tunicalr, el que la majorite des eloments, con-

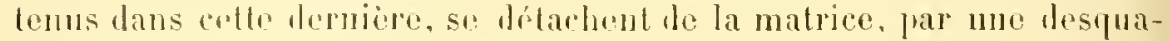
mation partiell. et contimulle.

[II. Centres nerveux et glande neurale. - A. Los morlifications les contres norrux ont bis suivies, par El. van Beneden et Julin, sur la

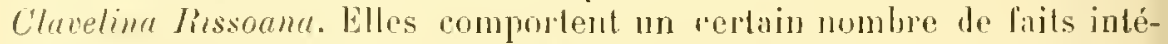
ressants, résumís lams les llomméos sujvantrs: la moelle caulalı dispa-

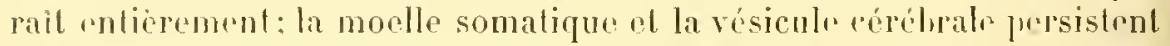
pour donner, la fromione le cordon viscéral, et la secono le cervean: las régions lojic ditfirenciérs, dans ces deux dernires élauchrs, soit en cellules ganglionnaires, soil en élements sunsoriels, me pronent aucune frarl à ce lévolopemont.

En ce ruj touche la vésiculo cérébrale, toutos los partios épilhéliales W. sa prai proliferent activement, et produisent les cellules ganglionnaires; cotte multiplination comporte une angmentation de volume, dont l’un des atlels est de combler la carilé de la vésicule. Les denx organes sernsoricls se dŕsag̨regrnt; leurs élémenls se délachrnt de la zono qui les portait, ot so mélangent aux cellules mésodermiqurs avoisinantes. Le cervoau, cest-a-dire lo petit at mnipue ganglion nerveux do l'adulte, prend aimsi naissance. l'ar ]'accroissement de ses dimensions, et par la disparition le la cavité centrale, il acquiert peu ì peu, ru provenant de la vésicule rórélralr, son aspert definitif.

La moelle somatique (yanylion du trone, pour kowalevsliy ; portion viscérale du myélencéphale, pour Ed. van Beneilen et lulin) ile la larve urouble peut se ramener à un tulıe, dont la paroi est, en majenre partie, formée de cellules épilhéliales, et le quelques cellules ganglionnaires disséminées; ces dernières sont plus nombreuses dans la région inférieure le la paroi. ()r, scumblables en cela aux éléments sensoriels et ganglionnaires de la vésicule cérébrale, ces collules se désagrègent, el ront se porter dans le mésoderme; les zones épithéliales, scules, s’accroissent et so modifient. - Elles proliferent, et obturent la cavité centrale de la moclle somatique. Celle dernière se convertil eu un corton plein, composé de cellules nervenses el de fibrilles, el flaró, sur la ligne médiane dorsale, dans la paroi le la liranchie. Ce cordon, le cordon visceral d'Eıl. van lieneden et Julin, se ratlache on avant, chez l'aululte, a l'extrémitó jostérienre du rervean; son origine, sa struture, el sa siluation gartiouliore, permettraient prespue le le désigner par le terme de moelle, pour micux exprimpr les lomologies de res centres nervenx avec ceux des Vortélrés. - La moelle camdale se désagrège, el se détruil sur place, en mône tomps que les autres organes de la quene; plusieurs de ses éléments se mélangent aux cellules mésorlerminues du corps, et fraraissent èlle alısorlées par cos dernieres, qui agrissenl vis-d̀-vis d'en à la façon de phagocyles. 
b. - L'origine exacte, el la signifinalion do la glande nenralo (glomere hypoyanglionnaire, glande prenervieme, ylande hypophysaire), priblonl rnore a controverses. Le fail hors te ronleste est le survat : rolte glante, aver son canal excléteur, nommé d'hahilude l'argane vibratile, dérive, chez les larves urodèles, l’une déjnession dr la proroi anlérienre de la loranchie, dépression qui s'applique eonlre la vésicule rérebule, el subil son irolution parliculière. - Les ronteslations portent sur plusicurs points : sur la question de savoir si cet enfoncemenl donne à lui seule toule la grlande; sur ses rapports aver la vésicule céribrale; sur sa nalure léelle; enfin sur ses homologies.

D'apres Eıl. van Benelen et Julin, qui onl éludié res phénomenes d'une manière plus approfondie que les antres anteurs, celte dépression. nommćc par eux le cecum hypophysaire, est prouluile par l'extrémilé anlérieur de la branchie; sa paroi dérive le l'rndoderme branchial. Elle ra à la rencontre de la vésicule rérébrale, qui envoic vers clle un pelil diverlicule (cul-de-sac cérébral de ces auleurs), mais restr close. Toul en conservant ces relalions élroiles, de conliguilé, avec la résinule en voic de domner le cerreau, elle romplique sa sliurlure, el devient la glande neurale; son ourerlure dans la rarite luampliale demeure héante, el comslitue à son tour l'organe vihratile. Enfin, pour ces naluralistes, cel appareil est l'homologue de l'hyjophyso des emluryons des Vertébrés.

la plupart le ces fails sont contestis par les autres naturalistes, qui onl étudic cel organe. - Tout d'abord, il est encore impossible d'affirmes si la paroi de l'blbauche est l'origine erlotermique, ou si clle provient de l'endoderme. La dépression, ou, dans les déreloppements condensés, le cordon cellulaire qui lui correspond, maîl exaclement dans la zone d'union de la branchic avec le stomeon; or, si la paroi luanchiale est endodermique, celle du stomeon est couslituće par l'ertoderme, ot il parail plutól que liss premiers vestiges de la glande lérivent de cel erloderne stoméal. - Plusiems auleurs ont vu celle éluanche sourrir lans la carilé de la vésicule cérélrale; ainsi qu'il est dil plus haul, coltr dernière s'abourhe somvnt avec le stomenu, el relle communicalion se lrouve iri viséc. le conduit emlier, qui mèm de la vésicule an stomeon, parail prendre parl a la genese de la glanle nenrale: en conséquence, celle-ei conlionl, dans sa structure, une jorlion d'origina nerreuse. He julus, dans les développements rondensés, l'exlómilé antérieure dn neuraxe engendre, dapres les drscriplions faites, celte glande

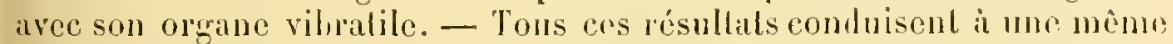
fin : la grande neurale, avee son confuit spécial, dérive du canal qui relie la vésicule cérébrale an stomeon. Ce canal se ferme du côté de la vésirule, pendanl que celle-ci se converlit en cervean; il se complique, en émellant des liranches latérales, el domne l'appareil glambulaime, tel

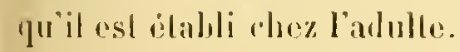

Il convienl de remarquer, à cel égard, que les donnces fournies par 
Ed. van bencelen et Julin sunt plus acceptables, of plus conformes aux indications de l'omlryologie générale. Si l'origine nerveuse était exacte. les Tuniciers offiraient le seul ras d'une glanle, annexée an lube digestif, Jont lébauche proviendrait du cerveau. Sans donte s'agit-il, en re cas, de communicalions secondaires, étahlies entre deux organes d’origines différentes. La puestion est cependant en litige, et appelle de nouvelles recherches.

Ce probleme offre une certaine importance, it cause de l'homologie accordée à la grlaude neurale par Ed. van Beneden et Julin. Ces auteurs la comparent a l'hypopliyse des Vertébrés, et admettent, en surplus, fue res deux appareils, donés le fonctions excrétrices, représentent les restes des organes rénaux, possédés jar les ancètres rounmuns des V'ertébrés el des Tuniciers. - Celte dernière assertion. toute suljertive, échappe à l'olservation. - La glande neurale des Tuniciers ne joue aucun rôle excréteur, car loreranisme de res animaux est pourvu d'un rein, tantüt diffus dans l'économie, et constitué par des cellules conjonctives j’̣gmentées, lantût localisé en certaines régions, el f'aspert précis. La ressemblance de celte glande aver l'hypophyse est frappante; mais elle ne suffit pas pour ronclure à une homologie. Afin l'être exarte, et conforme à la loi de la fixitédes connexions, l'homologie doit êtrecomplète, dans le temps comme dans l'espace, chez tous les animanx mis en rause; ces conditions sont nécessaires pour la rendre indisculable. Et, comme les Vertélrés raniotes sont les seuls à ètre munis d’une hypophyse; comme, malgré leur évolution franchement dilatée, les Vertébrés acraniens, les plus proches des Tuniciers, en sont privés, l'opinion signalée, pour se tenir tans les limites des conclusions immédiates venant des faits, ne semble guire acceptable.

IV. Tube digestif et cavité péribranchiale. - Au moment où se fixe la larve urodele, son tube digestif se comprose de deux parties lien distinctes: l'une, antérieure el volumineuse, semlılalle à une vésicule ovalaire qui remplit la majeure partie du corps; l'autre, postérieure el tubuleuse, beaucoup plus étroitr que la précédente. La première est l'ébauche lıran hiale, la seconde l’ébauche intestinale. La branchies ourre au dehors par la bouche, pereée a fleur de pean, en avant de la vésicule cérćbrale; l'inlestin débonche, par l'anus, dans l'une des deux fentes branchiales. l'ensemble de ces ébauches constilur, en somme, un tube, de largeurs inégales sur son étendur, el suspendu dansk schizoculome; rette carité, remplie frar les éléments mésodermiques libres, le sépare de la face interne de l'ectoderme. - Ces relations premieres ne tardent fas a être moditiéns du tont au lout, avant mème la fixation, par la genese d'une caviti. qui s'élale autour de l'ébauche hranchiale, el communique directement aree le lehors. Ce nouvel espace, que tous les Caduricordes possedent sans exception, el dont les Tumiciers pérennirordes sont seuls privós, est la cavité péritranchiale. Sal venue altère 
tellement les dispositions du tube digestif, que son dévolopement duit ètre comun pour permetle de les saisir.

Cavite pembraxchulf. - A. Celle cavilé se présente, rhez l'adulte. "omme un espace entouraul la hranchir entiere, sauf mo élroite hamle, méliane el inférienre, de celle-ci; retle bande est dirertenent sondée i la prai du ropjes, alors qurs les aulres parties de la hranchie sont sejparérs de retle même paroi par toule l’épaisseur de la ravité jéribranchiale.

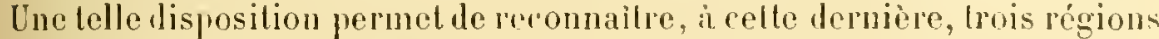
primeipales : deux latírales, symétriques, plarées autour des cótés de la bramhie; l'aubre, impaire el dorsale, située an-dessus de la fare sujerienre de ret organc. - Les deux régions latérales rommuniquent largement avec la zone dorsale, el s'unissent à elle sans ancum solution de rontinuité, dr manièr i ne former qu'un seul lout. La partie dorsale cst la cavile cloacale; clle s'abourhe aver le Jehors par le moven du siphon rluacal. L’une les régions latérales porte le nom de cavilé péribranchiale droite, el l'autre celui de cavité périluranchiale gauche: toutes deux n'ont de relations entre elles que frar l'entromise la la ravilé "loarale, avo" qui elles sout en rapport, puisqu'clles se terminent en rul-cle-sar sur la bande inférienre dinion entre la branchie el la praroi do rorps.

La cavité péribranchiale possede une membrane limilante, constituéc par une semle assise de rellules épilléliales; retle membrane se soude avec les tissus contre lesquels elle est appliquée, el n’en est point discernable. A cause de la forme, el de la siluation intermédiaire, dr la ravité, cetle rouche se divise en leux jarls : l'une qui horno l'espare péribranchial en dehors, et l'antre quile circonscril en dedans. La purenièr est le feuillet externe, el la seconde le feuillet interne. Le fenillel cxlerne est accolé a la face interne de la paroi du rorps, el rompose, sur cette face, une assise dite de l'épithélium péribranchial; le fonillel inlerne s'allarhe i la face externe de la jaroi brambiale, el s'mil si lien à cello deruiere, qu'il est impossible, chez l'adulte, de l'en distinguer.

La paroi du corps est formée par me couche épillóliale extérjeure, l'ectorlerme, et par un lissu conjonctivo-musculaire sous-jarent, on le sang riroule; le feuilet externe de la cavilé périlranchiale s'accole in re dernier, el reste séparé de l'ertoderme par des tissus crensés de lacnnes sanguines. De mème, la paroi de la luranchie se compose d"une assise épilhéliale intérieure, l'emlorlerme. el d'une trame conjonclivo-musculaire, périphéripue, moins épaisse que celle de la fraroi du corps; le feuillet interue n'est lonc pas adlóerent a l'endoderme, nais se tronve isolé de lui gar nu riche risean lanmaire, on circule le sing. Celle slanclure des membranes exisle lout antour de la branchie; ed, comme red organe occuje, dius le corjes, un espare considérable, elle est développro sur de grandes surlaces. - Une lelle disposition, arec sa romplexili. est produle en cutier par l'évolulion particuliere que subissent lis derx fentes liranchiales. 
B. - Ces feutes sont denx tulos symétriques, et dorsanx, qui font commmniquer direetement la eavití de la branchie aver les milienx extériens; à rause de Jeur situation, foune est droite, el l'autre gauche. Charune d'elles dérive do denx ébauches, de deux dépressions opjosées, qui ront a leur rencontro mutuelle, et s'unissent par leurs extrímilés "u contact. L'mue de ces dépressions se manifeste sur la paroi du corps, et se trouve limitón par un ṕpithólium de provenaner ectoderminue. laulre est un divertirule de la brandhie; sa paroi est, par suile, dorigine enlodeminue. - En ect élat, ces deux tulies sont les homologmes le Ienrs correspondants des bejennicordes, et des fentes branchiales des Vertólorés; senlement, ils sulbissent des moditications, que ne présentent jamais lenrs similaires de res derniers grompes d'animanx.

Chacun deux, tont en restant reux el pourvu d'une ample cavití, s'élargit, et s'étale en un disque. yui s'arcole contre la proi branchiale, pour s’insinuer entro cette dernièe ol la paroi du corps. L'élas"gissement est inégal, en re sens qu’il est plus prononcé sur les fares antrienre, postirienro, el externe, des tubes, yue sur leur fare interne. Comme il va en saccentmant, it a pour elfel d'amplifier ces deux disfues, qui saccroissent en s'altarbant ane partie loujours plus grande te la paroi hranchiale, et tinissent par l'envelopper toul entiere. le tulse droit donne ainsi la ravité perriluanchiale droile, et le tube ganche fom nit la cavité périnaurhiale gaurhe. - En avant, ces appareils se terminent en cul-ile-sac, antour de la limite antérieure de la branchie; en has, ils cessent égalemenl, en laissant entre enx l'étroite bande d'union mentionnée fulus hant; et de même en arrìre, où ils laissent une haude analogue, fort mince, dans lapuclle la paroi lranchiale est simple, non recomverte par la cavité péribranchiale el ses feuillets. Celte étroite zone postrieure porte un organe spécial, pui la dénote : le raphé postérieur, encore nommé sillon rétro-pharyngien. De mème la bande inférieure est munie d'un appareil marquant sa place: Ja goultire ventrale, encore dite raphe ventral, ou gouthiere h!ppobranchiale. Enfin, la limite antérienr les cavités périhranchiales sur la luanchio est signaléc par la prósence, sur la paroi hranchiale elle-meme, d'une gonttiere circulaile, la gontlive pericoronale.

lin somme, les denx fentes branchiales primitives s'élargissent, et se ronvertissent en disques rreux, qui enveloppent la luanchio entiere, sauf deux ítroites bandes médianes, l’une ventrale, et l'antre postrioure. les prois de res disijues sont constituées par nne assise épitléliale simple. Leur proi externe s’aplique contre la face interne de la jaroi du corps, et lonne le feuillot externe de la cavité péribranchiale; leur fraroi internes'acrole i la lace externe de la propi branchiale, et fournit

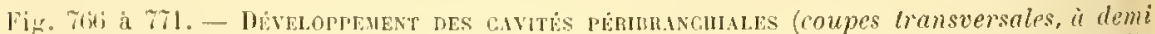

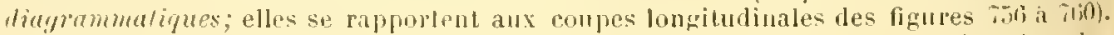
- En 606, jeune larve urodede, dont la branchie est encore entiere. - En r67, debul des 

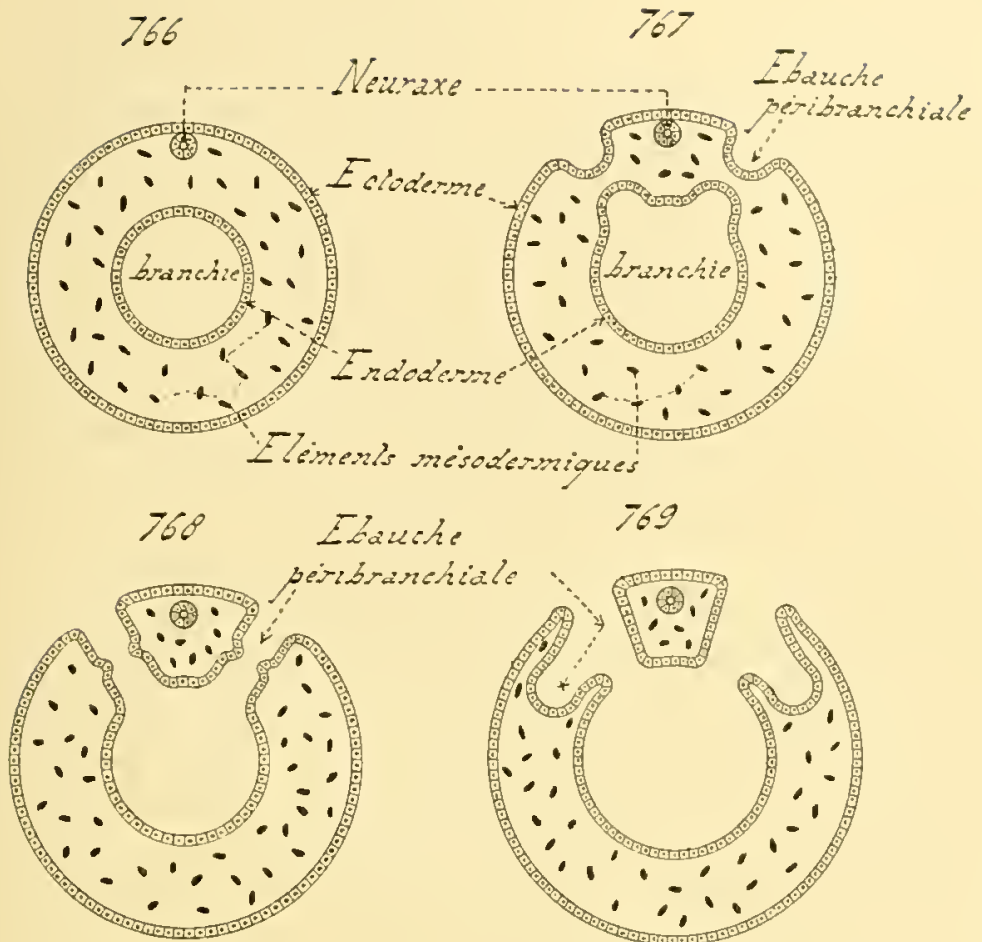

769

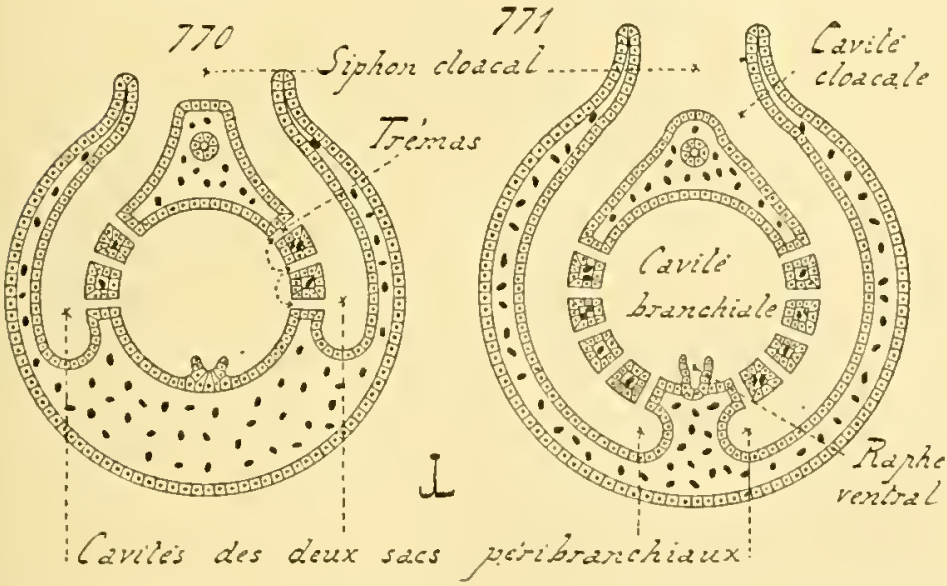

deur fentes luranchiales; chacune d'elles nait de la soudure d'une dépression ectodermique avec un diverticule branchial. - lin ins, les fentes branchiales sont terminees: elles vont. s'elargir pour devenir les ébituches des civites peribranchiales. - lin iro, début de cet ẻlargissement. - l’n 7an, suit: de celte amplification; des trèmas se percent dans les zones de contact; la région, intermediairt aux saes pribranchiaux, s'afraise.

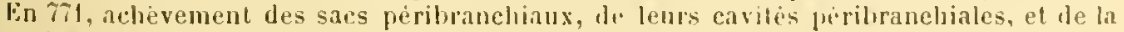
cavil. cloarale: les horls de lorifice exterieur de cette derniere s'allongent on un siploun cloacal. 
le fenillet interne. Les ilements masodermiques emprisonués, durant la propession de ros distues, rntre les membranes limitantes de ees derniers, el l'ectoderme de la paroi lu corps d'un côté, ou l'endoderme liranrhal de l'autre, frodusent la frame ronjonetivo-museulaire, arec les espares sanguins, qui síparent les unes des autres ces conches ipithélialrs. - Larrolement du fenillet externe i la paroidu corps ne comporte ancun phemomine particulier. l'ar contre, l'mion du feuillet interne a la paroi hranchiale se complique de la genese les ourerlures, destimes à mellre en rapports directs la cavité de la lranchie aver les espaces périlumnhianx. Ces orifices. tantiot nommis tremas, el tantôt sligmales, se perent partout ou le feuillet interne se sonde i la proi brameliale, et jamais ailhurs. Aiusi que le fait remantuer Vau lienellen avee juste raison, ces ourertures sout, à canse do leur origine, spreiales aux Tuniciers rarlucicordes, el ne se rapportent i rien de re qui existe chez les Vertrilrés.

les drux fentes hranchiales délourlınt, an début, sur la face dorsale du corjs, ot de part el l'autr" de la ligne mediane. Liespace intermeliaire, gui les séparr, ne reste pras eu sa situation, et subit un arcroissement moindre qur les autres parties de lorganisme; aussi, an lien de domenter superficil, s’alfaisse-t-il, ot s’enfonce-t-il dans l’intérion de l'individu. Il se transforme en nne caviti, mélian et impaire, an fond de latuelle sourrent les deux feutes branchiales, en roie de domner les vides périluanchiaux: retle cavití, qui provieut aimsi d'un enfoncement de l'espace intermuliaire jrécilé, est l’élowehe de la cavité cloacale. Elle grandit, tont en conservant ses commpxions aver les ravilés périhranchales, de maniom à s'étendre sur la face dorsale entiere de la

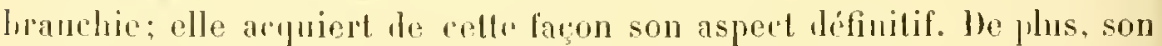

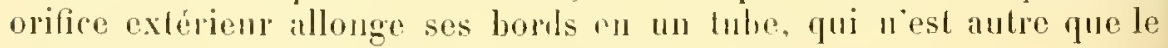
siphon cloncal. La disposition mlime est alors atteinte.

C. - Ces Jonnées dérivent, pour la majenre part, des recherches faites par Ed. van lieneden el Julin; elles démoutrent que les cavités péribrandiales de l'adulte correspondent i des fentes branchiales élargies, ayant angmenti la surlace de rombur de leurs parois arec celles de la bianchic. Ces loules sont formées par deux abauches, l'une ectodermique. el l'autre endorlermique; cette double origine s'applique done, un couscruence, anx espraces issus de ces organes. Selriblement, le feuillet externe des cavités wílifranchiales preut etre considéré comme provenant de la partie ectodermique des fentes; et de mème pour le feuillet interne, vis-i-vis de la zone endodernique des mèmes apprareils. Mlaisla Jémarcation nest pas tranchéo; léjà, lans les fentes tubuleuses, il est impossiblede savoir oì se relient la portion ectodermique et la portion emdodermique, car la paroi épithéliale ollie partont me struclure identique; il en est do mine pour les carilés péribranchiales. En revanche,

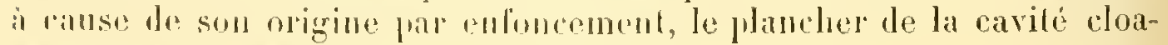
ale terive tout enlier de l'ectuderne. 


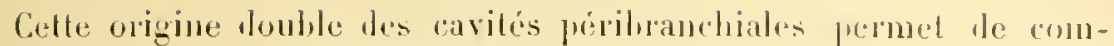
mendre bes oppositions qui se manifestent, daus les procédés génibiques, lorsque les développements sont comlensés. - Les espaces fréribranchianx des individus, issus de la gemmijarite, sont directement produits par la branchie, et limitós en conséquence par une paroi endodermique. L'ébauche branchiale primilive se divise, an moyen de deux constrictions parallèles, en une partic médiane, et leux parlies latérales: la premiere devient la liranchice et les autres donnent les fremiers rudiments des deux cavités péribranchiales. l'uis, une dripression ectudermique foumit la carité cloacale, munie le son siphon; et, s'unissant aux denx espaces précilés, grandissant arec eux, elle engendre les zones qui dérivent de l'ectoderme. - D'autre part, daus l'ívolution fort condensée des Pyrosones, les premieres indications des cavilés périlıranchiales sont donnces par denx dépressions eclorlemiques dorsales, symótriques, et homologrues des deux dépressions qui constituent, chez les larves urodèles, les régions exterues des fenles branchiales. Seulement, au lien de saburbler de suite avec les liverlicules endodermiques, ces dépressions s'enfoncent dans le corps de l'embryon, du cyathozöde, et se converlissent en tubes; ceux-ci s’allongent, et pénêtrent dans lorganisme de chacun des quatre ascidiozoüdes bourgeonnés par cet embrvon. L’éluache hranchiale de ces derniers agit ensuite, comme dans le cas fricúdent. Elle émet, far constriction, deux diverticules laléraux, qui s’unissent aux deux tules; et, de cette union, apròs l'accroissement le l'ensemble, et la formation du siphon cloacal. résultent les deux ravitós périluanchiales, avec leur part ectodermique et leur part entodermique.

Ainsi, a rause de celte double origrine fondamentale, montrie par les évolutions dilatées, les premirrs restiges des espaces périhranchiaux naissent de manjeres diffúpentes, suivant les types, dans les liveloppements rondensés ef les bourgeonnements. Mais le rósultat atteint rst tonjours le mimr, et identique à celui quolfrent les embryogénies larvaires.

Ébucane bnaxcmale. - Cetle ébaucle provient de la partie antériemre de l'entíson; sa paroi épillúliate est, en consinpuenre, de provenance endodermignus. Aver sa grande taille, et l’importance du rólr joué prar clle daus le corps, la branchic, qui dérive de rette chanche, est thomologue de la région respiratoire hranchialo des Vertélrrés; clle allecte senlenrut aver ses fentes, élargies en cavités péribranchiales, lus eonnexions que ces derniers animamx ne prósentent jamais. Il est premis de la ronsidérer comme un pharyux voluminenx, fort agrandi, tout rn conservant ses relations normales aver les autres parties du tulw digestil, ef ronverti en un appareil respiratoire.

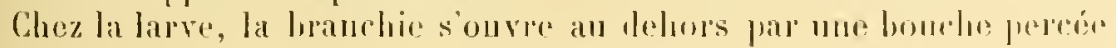

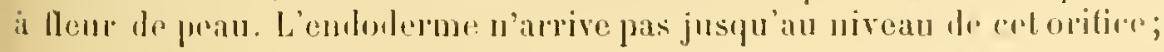


un stomeon, déjà mentionné, constitue l’ontrée de la cavilé luranchiale. Pendant que l'embryon se convertit en alulte, les levres de la bonche s'allongent en un tube cylindrique, faisant lo pendaut du siphon cloacal Jéjàl décrit, et nommé le siphon buccal. Etant donnćc son origine, ce dernier est, en entier, produit par le stomron; aussi, sa proi interne est-rlle formée jar un épithélinm le provenance colodermípue, souvent recouvert par une couche Imnicale; celle-ci a été dite la tunique réfléchie par De Lacaze-Duthiers. - La ligue l'umion de l'erloderme du stomeon, el de l'eudoderme de la branchip, est marquée par une goutliere anmulaire, la goutlipre péricoronale; celle dernière dérive de l'endoderme branchial. Les premières indications de l'organe vibratile, c'est-à-dire de l'oritice excréteur de la glande neurale, se montrent sur cetle ligne mème, mais en arant de la gonltiere péricoronale; clles empiètent sur l'ectoderme du stomeon, el paraissent en dépendre.

Partonl ou le fenillet interne de la cavité péribranchiale s'accole a la lranchic, of ne rompose avec la paroi de cet organe quine soule el mème membrane, les orifices, les trèmas, se percent au travers de cette dernière. L’épilhélium, yui constitue ce fenillet, est d’abord séparé de l'épilhélium branchial prar un espace, oủ se tromrent emprisonnés des éléments mésodeminques; puis, lans des régions disposées, d’une manicr réguliere, en rangées placées les unes derrière les autres, ces leux surfaces épithéliales viennent directement an contact; ces régrons, nombreuses et jelites, sont celles oì les trémas prennent naissance. Les collules des deux conches accolées grandissent, et acquièrent un aspect rglindrique; clacune des zones le sombure premd une forme ovale, aux contums précis: puis, une lente. semblable à nne boutounière, se (reuse daus chacume de ces jaques ovalaires, el, en s’ace roissant quelque pen, devient un tréma. Les éléments cellulaires, an milieu desquels elle s’est percée, persistent en lenr place, et donnent l'épithélium trématique. - Ces onvertures ne sont pas toutes produites à la fois; elles naissent au fur et a mesure de l'enveloppement de la luanchie par les cavilés périlranchiales. Les fremirres d'entre olles sont dorsales, et réparties sans grande précision; la rignlarili de leur disposition ne commence à se montrer que par la suite. Parfois, les trémas se divisent, an moyen de coustriclions, en plusienrs fentes, qui se convertissent en autant d'orilires, semblables aux antres.

Les régions, laissées entre lins zones de somlure, dans lesquelles le fenillet interne riste sépror de l'endoderme branchial frar ides espaces schizocolomiens. remplis d'éléments mésodermiques, donnent les bundes inter-trématiques. Comme les trimas sont des trous ovalaires, anx limiles nettes et prócises, les bandes constiment un résean autom d'enx; et, à cause de lenl povenance, elles contiement des cavités sanmuines, amples et spacieuses. - Ces organes denenrent ainsi chez la phupart des Ascillies composées, dont l'économie r.st de structure pren 
élevée: ils se compliquent chez les autres Caduricortes, et surtont

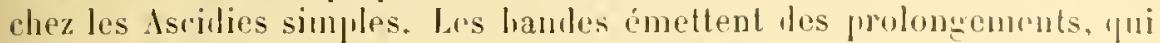
somvent se ramifient à lem tour, et, s'unissant entre enx, [umbuisentlus cutes de diverses lailles, dont la presence rend si compleac la faroi liranchiale. Les expansions, chargées de domer les cótes, massmit sur la faco interne du réseau les bandes: d'autres su façoment sur la face extrue, traversent, a cause dr leur situation, la cavité péribranchialr. vont se souder à la paroj du corps, et foumissent les poutrelles dermulobranchiales.

Dans les parties auxquelles ne saltach pas le fenillet intrue les espaces féribranchiaux, la paroi de la branchie engendre, sur place, le système de gouttiòes déjì signale, qui, partant de la gouttione péricoronale, et antérieure, parviout à l'oritico usopliagien en passant par la gouttiere ventrale et par la goutlère postérieure; l'épithélium de ces sillons est dorigine endodermique. - Ia gouttire ventrale est la plus importante de tontes, autant par sa laille yue par sa signification. Ello est ilentique a celle placée, en la mème situation, dans la branchie urs Vertélorés acraniens; som extrémité antérieure ust homologne, jar suite, de la portion impare de la glande tlinoüde des Vertébrés craniotes. Elle représente, hez les Vertélurés acraniens rommechoz les Tuniciers. le type le plus simple des disprositions soms lesquelles se montre cette grande; aussi le nom de gonltiere thyroüdienne pourait-il lui etre accordé, afin de mieux indinner ses aflinités.

Ébache intestinale. - Cette él,anche offore, tont d'ahord, l'aspect d'un tube recourbé en anse, lont l'extrémilé antérjeure s'ouve lans la luanrhe, et l'extrémité postérieme dans l'une des fentes hranchiales. La première ouverture ne se ferme pas, demeure en sa situation premiere,

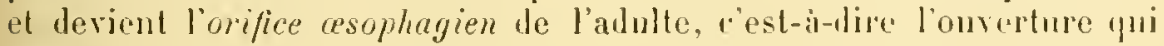
élablit des communications directes entre la cavile brawhiale el la cavité intestinale. La seconde extrémité persiste égalenent en sa plare: mais, a cause de l'élargissement des fentes luanchiales, et le l’enfoncement de la région cloacale, ellr tinit jar déboucher dans la cavité formée par cette derniere. - De plus, léhauche se divise en frois prarties. Ia région courluée de l'anse s'élargit plus que les autres, et donne l'estomac; les annexes portérs par elle, ot somvent nommérs lo foie, sont des diverticules de la cavité stomacale. La zone, interposio a l'estoma et i l'oritice asophagien, conserve les dimensions restrointes, et se ronrertit en asophnge. Enfin, la riogion, situce entre l'ustomac et l'orilice anal, s'allonge, et produit l’intestin, avec sa comblure.

I. Appareil irrigateur. - Mpres la désagrimation lu misoderme, les éléments le ce leuillet composont un mésenchymo cpars dans

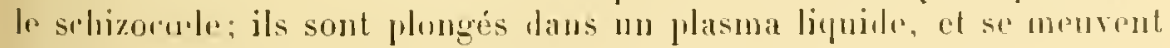
dans toutes les dirertions. Ia trame conjonctivo-musculaire de forgat- 


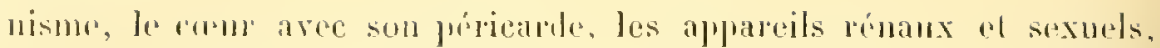
frrmunt naissance i lems dépens. La plupart des espares, laissés entre מux durant les plases de ce diveloppement, lomnent a lem tour lappareil irrigatern. En somme, les systemes de l'excrétion et de la reprodurlion mis i part, le mísoderme entier so dispose suivant me struclume méscuchymateuse, of sous la forme d'un réseau spongiemx, dont les mailles sont les lacunes sanguines; mn cumr, entomé l'un péricarde, sannese i ces deruieres. Les traves du rósean sont constituées par un

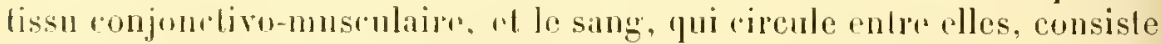

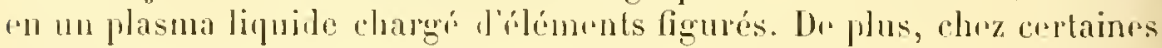
Ascidius assez blevées dans la séric, un deutocoplome périviscéral s’ajoute aux autres ravités déji creusies dans lo feuillet moyen. Celles-ri se réparlissint dour en trois systèmes : lappareil irrigateur proprement

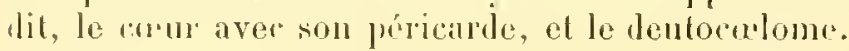

Aprakil magrtur. - Iu moment oì le mésoderme se désagrège, la cavité lilastoculienne s'est reusée i nouveau, sous la forme d'une

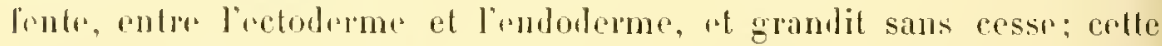

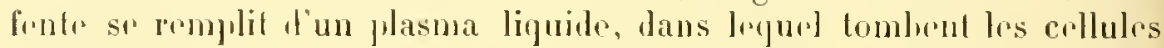
mésodrrmiques dissociérs. Il rosl permis d"assimilor à un solizocalr, ren prount eo lorme dans son sens le phus élemlu, et ne lui aceoriant

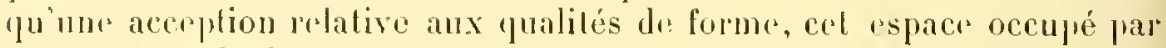
les cléments du ferillut moynu. Contrairement i ce quil on ast chez les Srhizocolomiens véritahles, ent rspace nest pas primilif; sa prísence correspond i un róapration secondaim lu hastocole, accompragnér

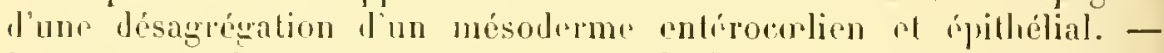
lorsque ces phénomenes sont achrés. le fruillet moyen offre tous les caracteros d'un mésemelivme, dont la substaner fomdamentale serait liijude; il rst interposé à l'ectodermo ot à l'undoderme, ou à leurs dérivés, qui conscrvent me disposition épillúliale.

Los élimonls du ro mésinchyme, loujours plongés dans un plasma, angmentrut en nombre par une multiplicalion incessante. I'lusiens no tardent pas a exsuler, ot à doposer autour d'eux, une subslance fondamentalo solide; its prouluisurt un tissu conjonctif rmbryommaire, et arénlaire, car ils sunt répartis irégulièremrnt dans le schizocrale. Ils

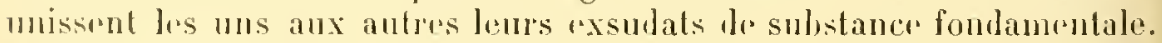
Vn résıan conjonctil a lareres maillos, plaró rutre les organes faconnés it elle époqur, prond ainsi naissance; les mailles sont occupées par le plisma liquide, dans lequel se trourout les collules no produisaut point antour drelles unt gangue comparle. Ce róseau eroît en importance, à

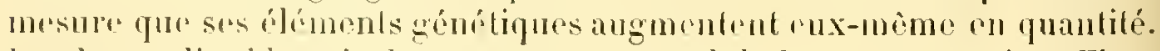
le plasma liquide agil de memr, avec ses globules an suspension. Fina-

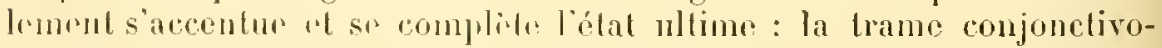
musculaire forme un lac is srim, ut cremsé d'ispaces lacunaires, où rirrule lo sang. La trame so constitur par l'aprort de nourelle substance 


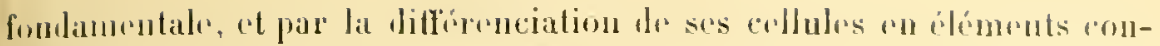
jonctifs, on en fibres musenaires; lr sang proviont diretrnent du plasma initial, qui conserve sa structure, el se borne à aceroitre son rolume, aree le nombro de sis éléments figurés. Bitant donné l'asprect de cos derniers, qui imettent des expansions psendopodiques, of somportent comme des globules Iymphatipues, lo sang les T'uniciors mórite plutôt le nom d'hemolymphe.

Ainsi s'établit la disposition lacmaire de l'appareil irrigatrur des adultes. Comme celte organisation autorisait it le pressentir, le développement s'effectue suivant un type mésenchymateux des plus nets.

Cueun et réncande. - Les observations faites jusqu'ici sur la genèse de ces organ's sont contradictoires, el sourent difticiles it interpréter. La seule donnée importante, qui soil hors de conteste, porte sur l'origine mèure des ébauches: elles proviennent de la vésicule hranchiale, ot naissent, aux dépens de sa paroi, sur la ligne médiane et dans sal région postérieure.

A. - A en juger d'après les notions aequises, te ceur el te péricarde so forment de denx manières, suivant que l'embryon appartient à la série des Tuniciers privís dr la faculté gemmipar, ou suivant qu'il rentre dans celle des Tunicier's eapables de se reprohice par bourgeonnement. - Dans le premier cas, l'ilauche consisto en unc prolifération locale, impaire et médiane, de la paroi branchiale. - Dans te second cas, la genèse le cette chauche est liée à colle dr l'axe endodermique du stolon yemmipare. Cel axe, nommé par Bul. van Brnedrn et Julin le hue épicardique, "st produit d'une manière bàlivin; il donne naissance an péricarde et au cour. Il est engendré, dans une région semblablr a celle où le cour se dílimite d'apres le premier modr, par deux amas cellulaires, issus de la praroi luranchiale. Ces derniers, les cylindres procardiques d'Ed. van Beneden et Julin, s'allongent, el se creusent d'un cavité centrale; ce faisant, ils s'accolent l'un a l'aulre par leurs extrimilés libres, unissent en cette région linlrs cavités respectives, et s'onvent en surplus dans la branchie; ils constituent, le celte maniore, un systime tuhulenx, ollirant l'aspect d'un Y majuscule, dont les branches suprérieures déhonchnt dans la cavité hranchiale, alors que la hanche inférinre demrure close. L'exlrémití distale de celle dermione se sépare du reste du systeme, at donne nur vésicule formée, qui est l'ébanchr.

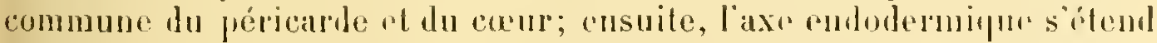

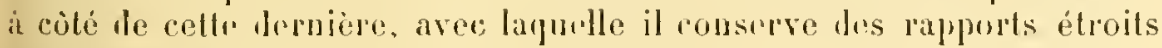
de contigunlé (de lit viont le nom arcoplé par les antenrs préédents), at s'étend jusque dans la région ou doit se lagonner le stolon gemmiparm.

Lil. van Beneden et Julin se basent sur colte partirularité des Ascillies hourgeonnautes, 'ju'ils ont étudice chez la Clavelinu líssouna, pour en 
conclure que l’ensemble lu cum el du péricarde lérive de leux ćlbauches; ces dernières sont les rylindres procardiqnes, qui s'unissent, et donnent, pal leur soudure, l'unique rudiment commun de ces denx parties de l"appareil irrigateur. Il semble plutôt qu’il s'agit ici d'organes de valeur lifférente, ayant entre eux les comnexions génétiques d'une importance seconlaire. - le bourgeonnement n'est pas un phénomène primitif chez les Tuniciers, puisque la farulté gemmipare manłu" aux représentants de Ia classe des Pórrinicoriles. La pluparl de ces derniers sont cependant ponrvis d'un coenr; l'existence de cet appareil n'est donc pas liée a colle de l'axe enlodermirue des stolons gemmipares. Les crlindres procardiques n'ont pas l'autre but que de fournir cel axe chez les Ascidies bourgeonnanles; $\mathrm{el}$, comme ils naissent hativement, fumme ils sont formés lans la région chargée le produire le péricarle avec le curur, ils déplacent l'ébauche de ces dorniers, ot l'entrainent arec eux. Aussi celte ébauclıe se dégagı-l-elle de la zone de soulure des evliulres procardipues, an lien ale provenil directement de la branchie. Les Asciilies simples, qui nont pas de stolon gemmipare, el sont privirs par

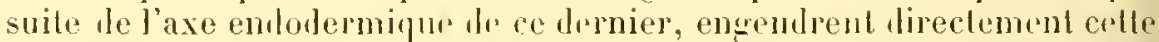
ébauchr, simple it impaire des son délunt, aux dépens de leur proi branchiale. - En résumé, le rudinrul commun du fricicarde el du cour est essentiellement unique of impair.

Une suconde furstion se pose ensuite. Co rudiment dérive de la jaroi branchiale; or' à ce monent da l'évolution, cellc-ci consiste en unt assise l'épithélium entorlermique; la conséfuence en est done, que cette éhauche dérive de l'endorlerme. Une telle opinion est aceeptée par la plupart des auteurs ayant olsorvéces phénomines, entre autrus par Serliger, Eil. van Bencilen, et Julin. - Crpendant, chez les Ascidies simples, les premières indications de l'élouche se manifestent au moment ou le mésoleme, produit par la vésicule corilo-mésodermique de l'entéron primorlial, commence à peine à se désagréger; plusicurs des éléments issus le folle dósagrégation, ol surfout de celle de la plapue ventrale, saccolent à I'ábauche, et ne s’en séfrarul joint. De plus, l’allure gínérale des cellules le celle lernière ressemble à celle des cellules du fenillet moven. Il est permis de se demander, daus ce cas, si la vésicule branchiale, en cet instant des phases emloryonnaires, ne possède pas la mèno raleur génélique que la vésicule corlo-mésodermique, el si sa paroi ne correspond pas à nn protendoderme, capable encore de se ditrérencier en endoderme el mésolterme. Unr telle ditlírenciation serait squertfue dans la branchie presque entiore, qui donne seulement lorgane de la respiration, mais elle pourrait se manilester dans la récrion destince a engendrer le péricarde el le cuens. - Celle r'éserve est ulilu, ear elle autorise à soupromner que l'origine du cour rst semblable à celle des antris parlies du feuillet muren, et notanment de l'appareil irrigateur. 11 est, en effet, difficile de romprendre comment lorgane rental du systime cimulatoire serait d'une autre 
cxelusiva dians les developjemonts gemmipares. Dans la mesure ou les motions commes auturisent il combure, on pourait penser que le second

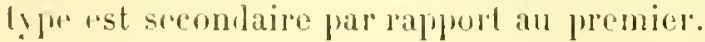

Der tocalone. - Celle cavitr, enrorr nommire cavité générale, ou cavité périviscérale, n'xistr que chez m nombre restreint de Tuniciers. Elle manque a tous los Caducicondes lihres, ainsi graux Ascidies composées: rlle lait son apparition, en suivant la série dr complexití eroissante des ebres, chez les Rhopalona, pour atlcindresa plus grande ampleur chez les Cionides; elle persiste rncore, bien que reslreinte, dans l'organisme dos Phallusialies, et fail défaut aux Cynthios eomm aux Molgules. - De mene que sa similaire des Molluspues et des Arthroporles, elle correspond in une pralie Ju sclizocole, pui s'est sciparre des autres rigions converlies rn un appareil irrigatenr: "lle constilue, autour des viscères, une eaviti, dans lapuelle ces drruires peuvent subir les conlrartions et los déplacoments nícessitís jar leur pôle.

Son originr: est des jus simples; elle dérive directement du schizocole larvaire. Lr réseau conjonctivo-musculaire, chargé de lonner naissance a l'aprareil irrigateur, organise son laveis dr lravérs contre l'ecloderme el contre l'endoderme: le lébut de ce réseau, sauf quclques hanıles anaslomotiques "l intronédiaires, consiste en deux plaques, dont chacune est accolér a l'mn de ces fenillets. Ln espace de schizocole libre reste intcrposi rulre ces denx plaqurs. La jaut, de cet espare, situén dans la rrigion hranchiale du corps, dispraît à la suitr de la genese les cavités périhranchiales, pui envahissunt hr lieu occujé par elle, Mais la part placéc aulour de l’intestin lemeure en sa position, of prisiste ainsi dans l'organismo definitil. Los larunes sanguines du réseau, qui, an délıut, dommmiquent arec ell., se ferment d. son côlé, et cessent loute con-

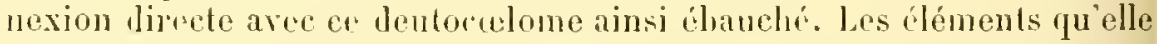
ronticnt produisent un petit nombre de lames mésentíripues, qui la traversent pour aller "le la paroi intestinale à la paroi du corju; el cenx, qui ne sont point intéressés dans cetle formation, tombont en dégénélostence pour la phupart.

V1. Appareils rénaux et sexuels. - Les organes rínaux des fluniriers se jrésentent sous leux formes. Dins lunn, plus frépuente, ils consistent en amas locaux de cellules pirmentés, et chargies de romprosés le desassimilation. Dans l’autre, ils sont constitués par des vésiculins closes, doul les cavilis se remplissent de produits molés. 'lantót, chez les Molgulides par cxemple, il n'existe yume seule de cos vésiculus dans l’úconomie; tanlól, romme chez les l'hallusiadées, ces olonanes sont numbrom, et accumulós dans le tissuroujonetif de la jaroi du corps. - Au sujet du premier cas, les cellules r'unales sont des élémonts mrsolermiques frajpés de diggénéresence grinulense, el qui accumulent an eux-mines les trichels vilaux des regions avoisinantes; 
elles rétractent leurs expansions, deviennent arronlies ou ovalaires, el restent disséminées dans l'organisme, ou se rassemblent en plus crande quantité dans des regions données. En ce qui tonche la seronde forme, chaque vésicule provient d'un amas compact de cellules mésoderniques; cet amas se creusr d'une cavité, ou parriennent les produits de la dísassimilation, et dont la paroi est consliture par les rellules elles-mèmes. Quel que soit le tỵpe, ces organes sont privés de produits excriteurs, et forment un rein d'accumulation.

Les documents les plus précis, de ceux donnés sur la genese des appareils sexuels, sont dus à Van Beneden a Julin; ils proviennent des représentants de trois especes: la Clavelina lissoana, la I'erophora Listeri, ot l'Ascidiella (Phallusia) scabroides. - Les Tuniciers sont hermaphrodites. A en juger d'après les faits acquis, l'ébauche de leurs organes sexuels dérive du mésoderme; elle est unique et impaire, et se sublivise d'une manière secondaire en deux parties, dont liune est màle, et l'autre femelle.

Quelques-unes des celtules du nésorlerme se rassembleut en un amas compart, placé dans lanse que décrit l’intestin; rel amas se reuse d'une carité, el se convertil en une vésicule. Entre temps, cette dernière émet un cordon cellulaire, le cordon génital, dirigé vers la carité cloacale. La vésicule sexuelle grandit, et se scinde en deux parlies, dont l'une rst l'ábanche du lesticule, l'autre celle do l'ovaire. Tout d'abori, la premiire s'ourre lans la seronde, pendant que le cordon génital se lransforme en un conduit crenx, par l'apparition d'une lumiere dans son intérienr; puis, la rroissance des organes se dirigr de telle manière, que le conduit se partage à son tour en denx canaux accolés, dont l'un est en relations directes arec le testicule, et l'autre avec l'ovaim: colui-ciest l'oviducte, celui-là le canal déférent. La disposition défnition de l'apprareil est alors atteinte; le testicule et l'oraire se hornent à s'accroitre, en revètant leur aspert propre, et variable suivant les trpers.

\section{$\$ 5$. - Reproduction asexuelle et alternance des générations.}

I. Considérations générales. - Les Tuniciers sont les plus complexes des animanx pourves d'une reproduction asexuclle; aussi les procélés, employés par celte dernière pour s'rxercer, se présentent-ils avec une allure particulière, connex" à la snpériorité organique, el pue les autres ètres n'offrent pas a un tel degré. De plus, ces procédés, lout en étant uniformes quant i liurs manifestations essentielles, comportent plusieurs modes secondaires et dillérents, que les recherches acturlles permettent de relier les uns anx autres, du moins en prartic. L'étule de ces divers phénomènes ofre donc mo grande importance, 
non senlement en ce qui louche lrs Tuniciers pris en eux-mèmes, mais en ce qui regarde la reproduclion asexuelle considérée dans son ensemble.

A. - Les Tuniciers infricurs, qui composent la classe des Pérennicordes, se mulliplirul par la voie sexuelle, ol jamais llaulre facon. La peproduction asexulle appartient en jupre aux Tumiciers supépieurs, aux Carlucicorles; elle est lone secondaire, et non pas essenlielle. Elle nexiste pas chez lous les Caducicordes, mais seulement chez quelquesuns denlre eux. chez reux qui possedent l'organisme le plus simple. Ainsi, lout en manyuant aux Tuniciers les moins complexes, elle est cependant liée, rhez les ètres qui la présentent, à une curtaine infériorilí de structure. Elle s'exeree, lans ses trails fombamentaux, par la gemmipariti, el s'adjoinl, dans corlains cas, des procédés fissipares.

La ropartition thverse to la gemmipariti, parmi les Caducicordes, avait porte, autrefois, i liviser ces ilres en Ascidies simples et Ascidies composés. Lus premiores sont celles yui ne bourgeoment jamais, el les secondes celles qui ollont te contraire, qui se reproduisent par la voie gemmipare; cetlo classification, tris commode lout rn ítant srstémalique, est pncore souvent mmployíe, i cause to sa commodilé mème. — On partagrail mime on deux groupes la série les Iscillies composérs, suivant les relations alleclées enlre enx par les génélateurs el leurs descendants. Ia reprouluclion asexuelle des Caducicorles aboulit loujours il la genese d'une solonie, lont les zooïles sont tantót plongés dans une gangue commune, fonrnie par leurs tunipues soulées en un tout cohérent, et laulôl séparés les uns des aulres sur la plus grante part de leur élendue. Celles-ci sonl les Ascidies sociales, dont les colonies se composent de zooïdes unis entre eux par leurs bases, ou insérés sur un lacis commun de slolous; les premières sont les vaies Ascilies composées. ou Ascidies agrégées, donl chaque colonie no conslilue qu une senle masse, aux conlours défnis, car tous ses zooüdes sonlenlièrement noyés lans la gangue lunicale, el n'aflieurent i sa surface que par leurs orifices siphonanx. - De tolles particularilis mo peurent plus aujourd'hui servir le base a une classificalion malurelle, car elles sont ile valeur tres secondaire. Les Ascidies simples comprement, en réalilé, deux groupes dislincls, dont l'un, celui des Cionidrs ol des Phallusides. se relie aux Ascilies sociales, et par li anx listomides, qui sont des Ascidies composícs; el dont l'aulre, celui des Molgules el des Cynthies, se rattache aux Ascidies composées appartenant à la famille des Polystyélinées, et sans loute aussi a celle des Bolryllides.

Ine opposilion les plus curieuses s'établil, chez les Tuniciers caducicorles, entre la taille des individus, et la présence, ou l'alsence, de la faculté gemmipare. Les Ascidies simples, yui ne bourgeonnent jamais, sont en mome lomps les plus grandes de loules. Par contre, les Ascilies comprosées sont heanconp plus peliles; comme si la propriélé lonrgeon- 
nante, mnie ì la vie coloniale, avait à la fois rostreint le dévoloppement des zooïdes en limonsions, et donnr it lassemlilago colonial le pouvoir d'augmenter de volume par le suul accroissement du chiffre des indivilus, non frar celui de lpur taille. La sórie, qui va des Ascillies soriales aux Cionides, est intéressantr, en ce sous quelle montre une amplitication de phus en plus grande des limensions, a mesure que la renmiparité perd de son importance; de mème, la diflérence drs Polrstrélinées, qui bourgeonnent et sont petites, et des strólinées, semhlables anx précélintes, mais privérs dr bourgeonnement el jus grandes. Ce rapport entre la taille des ètres consilérés, et leur pouvoir de reproduction asexuelle, entraine dans la jensée, par sa constance mène, unr relation le cause a eflet: il contrilue, pour sa part, à montrep combien une division des Ascilies, 'n simples et composées, font eu ćtant aisée et fort tangihle, s'accorde peu arec les aftinités nalurelles.

B. - La gemmiparité na pas encore ététudiée chez tous les Tuniciers qui la présontent, el les olservations aryuises sont parfois contradictoires. Il est possible, cependant, de dégager le res recherches un certain nombre de faits essentiels, qui constituent la lase fondamentale de ce molv reproducteur. - Le génératenr fonrnit au jemne hourgeon, produit par lui, et destiné à devenir un descendant, des éléments empruntés aux trois fenillets qui le composent lui-mème; des sa jurrmière apparition, le lomrgeon estdonc formé de trois assises cellulaires emboitées, l'externe d'origine ectodermique, l"interne de provenance endodermique, et la moyenne issue du mésoderme de liále qui lui donne maissance. Ces trois couches évoluent, et se dévelopjent, de manière à fournir les mèmes organes que leurs corresponlantes des embryogénies larraires, mais avec une abréviation fort accusée. Cette drenière résultr de l’union du générateur et le son lescendant; le premier procure au serond les matériaux nécessaires frour son alimentation. et jone vis-a-ris dolui, sous ce rapport, le rolo d’une vésicule vitelline. Cos matériaux sont lonnés par le sang, car te mésoderme du jeum lonrgeon contient des vaisseaux sanguins, qui communiqueut arec ceux dr son génélalenr: il est, par ce moyen, nourri dume maniere constante, jusqu’à son achèement. Au moment oi l'organisme du desinndant est capable de se suffire à lui-mème, ces relations vasculaires disparaissent rho diverses Ascidies composées; elles persistrnt chrz plusieurs autres. les Botryllides par exemple, ot la plupart Ires Iscidies sociales.

Autint yưil est permis d'en juger d’après les faits connus, la part endodermique du jeune hourgeon provient de la branchie dugénérateur, ou dr la zone endodermique de ses cavités périluranchiales. Elle soulive derant clle, en grandissant, le mésoderme et l'ectorlerme placés au niveau de son extrémité libre en roie l'extension, et s'entoure dirux: l'allauche gemmipare est alors constituée. Dans le ras ou la conche interne, l’axe endoderninge, de cette derniere, derive de la liranchic, 
elle traverse prafois la région postérieurr du rorps du générateur, en contractant drs connexions étroites ave lr périorde et le curu de ce dernier: elle n'est autre que l'épiearle, léjà mentionné dans l’étudo du. développesuent dn rour.

La gemmiprarité est tantôt stoloniale, tantôt dirorle. I)ans cr dernier cas, le générateur produit directement son loscendant sur une zone de son corps. - Daus le jremier, il émet au préalable des stolons, plus ou moins longs, sur lesquels prennent naissance les bourgeons. Chaque stolon se ramène, rn somme, à un tube, contenant l'axe endodermique en son rentre, antour de lui un mésollerme muni de lacunes sanguines, et à l'extériem une assise ectolrmique rovêtue d'une cuticule tunicale. A rause de sa situation, el de sa provenance, l'axe endodermique est tantôt nommé lume stoloniale, tantôt cloison stoloniale, on lame épicardique. - Les stolons donnent les descendants de denx manieres. On bien, ils se bornent à s’ópaissir par plares, les zomrs épraissius étant los hourgeons; et ce fait existe chez la plupart dos Ascidies soriales. Ou hien ils se sogmentent, par me véritable fissiparité, cluaque. troncon devenant un individn particulier. Cette gemmiparité romplexe, en re sens qu'elle sadjoint des phénomines de division, est assez répandue; les salpes en othpent un excellent exemple.

Enfin, la gemmipraté n’est pas toujours spéciale aux adultes, et les embryons de critains Caducicordes sont rapables de la posséder. Ce bourgeonnement précoce fait son apparilion che\% diverses Ascidies composées; elle atteint sa plus granıle imprortance chez les Pyrosomes et les Salpes, oì elle ronstitue un phénoménr régulier du développement.

II. Développement des bourgeons. - L'étude le ce développement romprend quatre parties. La première se rapporte à la frovenance des bourgrons, éest-it-dire à leur position sur le généraleur; la seconde, aux procédés employés dans leur formation, dans lenr naissance; la troisième à leur évolution particulière; enfin la quatrième aux divroses formos coloniales prodnites par la gemmiparité. - Les recherches faites sur ces quatro sujets n'ont pas rncore ćté étendnes à toutes los familles des Ascidies gemmipares; los plus completes d'entre elles roncernent seulement les Thaliacées, les Botryllides, les l'érophores, et les Clavelines.

Provexage nes botrghons. - Les cas romms sur nu tel sujet se rapprortent ì trois modes principanx : le bourgeonement péribranchial, l. hourgeonnement pylorique, et entin le bourgeonnement basilaire.

Dans le premier jucocélé, et comme l'indique l'expression destinée à le désigner, la gemmiparité se manifeste sur les côtés du corjss du génératemr, au niveau de sa cavité périluranchiale. Une portion endodermique de la paroi do cette dernière séprassit, el donne une masse cellulaire, 'pui grandit ver's l'extérieur. lille souleve, pendant son accrois- 
sement, le mésoderme et l'ectoderme situés à sa hanteur, et donne de? celle façon, gràce à rette adjontion supplénentaire de tissus l'origine ectodermique et mésolemique, un jemne homrgeon; relui-roi élıurlue son organisme aver les trois feuillels quil possive, el so ronvertit rn un nouvel individu. Ce mode gemmipare, lont les bolryllides ulfient un exemple, se rapporte ì un bourgeonnement direrl. Le générateur se borne à prombire, sur une de ses faces, un mamelon en saillie, qui devient un desrendant; il ne donne pas de stolon.

l.e second prorédé est fréquent rhez les Didemnides et les Jiplosomides; il rorrespond de mème à une genese direrle, el nullement stoluniale. Lexpression de bourgeomement resophagien serait, dans re ads.

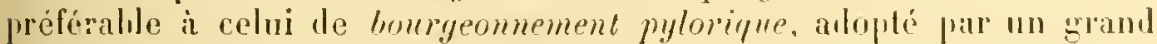
nombre l'aulens, car l'asophage ost rharge de fournir la partie endodermique du desrendant. - Une modiliralion ruriense te re proréle existerail chez plusieurs représentants le res deux fanilles : le nourel individu serail produil en lenx fois, an moven de lenx bourgeons émis par un mème génératenr, distincts d'ahort, al mis ensuile. Liun te res hourgeons est le provenanre asophagienue, el lanle d'origine piribranchiale, comme lans le premier ras. Tous deux se joignent, el se soudent; dans retle coalesrenre, le premier lonne l'intestin, el le serand la bran hie avec la part endodermique le la ravité périhranchiale.

Le trojsieme mode est le plus frépuent de tous. La branchie du génrraleur émcl nne expansion tubuleuse, le forme el de longueur variables suivant les Yyprs, qui est l'axe endodermique, on l'épraide, lejjà signalé a plusieurs reprises; des tissus de provenance mésolerminjue el une conche d'ectoderme se disposent anlour de colte expansion, pour conslituer avec elle un appareil, oì les trois feuillets sont représentés. Cet appendice romplexe est un véritable stolon, lont la situation varie sujvant la forme mème du corps de l’èlre qui le possivle. Son ivolution s'effectuc rgalement lapures des prorélés divers. Il est permis de reconnaitre, sous ce domble rapport, trois types pindipan: rolui de la plupart rles Ascirlies sociales; celni lles l'olyrliniles; entin la disposilion offerte par les Thaliarées.

Le corps des Ascilirs soriales porte, sur sa région inférienre, des stolons, anx dépens desquels prennent naissance les desiendants. Ia longurur de ces expansions, et leurs relations muluelles, varient d'un genre i l'aulre, et patois l'me esfrece à ses voisines; mais. ros moli-

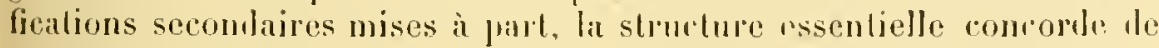
tous proints. Chapue stolon contient m lronçon do laxe endorlesminue, "L hourgeonne, au moynn l'épaississements hoaux les lissus yui lo constituent. - Tel nest pas le cas des l'olocliniles. Lr stolon de rhayne individu parail conlinuer le rorps on has, ot lormer mu piolinule plus ou moins net: celui-ci renfermo à la fois l'axe crubolerminue, of les glandes sexuchlos, dont les anl's soul volumineus pour la plupart, el lien développos. Ce stolon se divise ensuite, par des constrictions trans- 
versales, en trongons placés a la lile; chacun de ces derniers est capalile de se convertir en un nouvel individu. La reproduction asexuelle no consiste pas seulement en une gommiparité, mais en un hourgeonnement complipui de phénomenes fissipares. Le générateur produit, commo dans le premier cas, un stolon gemmipare; mais ce lermier, au hem de s'épaissil par plares pour domer le jpunes hourgeons, ou de se transformer tout entier en un être romplot, se scinde, par une véritahle fissiparite, en segments destimis a deranir des Ascidies adultes. - Le développement, offert par les lolycliuiles, permol de comprendre colui des Thaliacérs, et dr le ratlacher a la gemmiparité hahiturlle des autres Tuniciers. Le corps lu géniratem porte un stolon, engrndré l'un' manive hitive, et plaré sur la face ventrale de l'organisme, non loin du corme. Cr stolon rontient de mème des glandes sexurlles, dont les ovaires sunls paraissent hien formés; il so divise en segments, souvent tres nombreux, dont rharun renforme, outre des déprudances des trois feuillets possédés par lo stolon lui-míme, nne part dr l'appareil sexuel. Tous res troncons se convertissent, par la suite, et rhacun pour son comptr, en indivilus parfaits.

Nassure des boungeoss. - Dans la mesure oil il est possible de juger d'apres les résultats conmus, le développement premier des jeunes bourgeons est le même chez tous les Tumiciers gemmipares. Il consiste en la formalion d'une ébauclıe composée des trois fenillets emhoìtés, dont les éléments sont empruntés à leurs correspomiants du générateur, el au srin le laturlle se creuse une cavité, la vésicule mimitive le la plupart لles auteurs; cotte lernière est l'homologue de la vésicule entérique, de lenteron. Jes larves, et le mòme nom peut la désigner. Cettc cavité est limité directement par les cellules de l'assise endorlermique. - Mais, si les premiòres phases de l'óvolulion des hourgrous sont identiques, à n'examiner que leurs types foudamentanx, les procédés, suivant lesquels elles se manilestent, dillèent d'apriss la nature de la gemmiparité.

Les ótules, faites par Ell. van Beneden et lulin sur le lourgeonnementiles Clavelines, ont montré que l'axe endodermique des stolons provient de la branchie lu génératenr; il cause de ses connexions átroites avec le péricarle et le cour de ce dernier. cel axe a été nommé ipicarde par les auteurs précités. Bien quil soit simple dans le stolon, ses éloauhos sont an nombre de deux : le fond de la branchie produit Jenx expransious, les cylindres mocardiques des mimes naturalistes, qui sunissent, par leurs extrémités libres, en un seul corps; celui-ci s'accroit, s’allonge, reste simple lésormais, et constitue l'épicarde. Tout en granulissant, il soulovo levant lui les tissus mésodermiques placés à son nireau, et s'entoure d'eux. Ces tissus se composent d'une trame conjonctive, et le sinus sanguins longitudinaux, yui continuent à faire partie du résean vasculaire lu générateur. Ces sinus sont au nombre de lenx; l'un est placé sur l'axe endodermipue, et l'autre au-dessous de 
ce mène axe; le premiel esl le simus sus-épicardique, of le second le simus sous-épicardique. Lorsque l'accroissement de ces deux premicres assises est suftisant pour déterminer la produclion d'une saillic smr l'organisme: du générateur, la zone eclodermique soulevée entoule le mésoderne lu stolon, el complicte aiusi la slructure de ce bernjer.

Les récentes recherches, faites par l'izon sur les Bolryllides, auto-

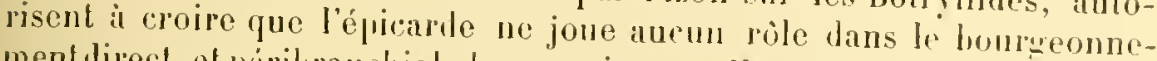
ment disect, et périlmanchial, le ces animax. lne région, d'origrine endodermique, de la paroi des cavités péribranchial's, entre en juolifération active, et s'épaissit; ce faisant, elle refoule levant elle, en graudissant vers le dehors, les lissus mésonlermiques el ectoderniques silués à sa hauteur, s'envelopped'eux, el conslitue avecleur aide un jeune lourgeon complet. l'ar cette origrine unème, la cavité périluranchiale émet lans l’intéricur da ce dernir un diverlicule, qui devient la vésicule nutérique. - Les deux cylindres procarliques existent cependant chez les botrylles, et occmpent une siluation semblable à celle de leurs similaires des Clavelines; mais its n'ont aurme fonction gemmipare. Ils offrent laspect dexpansions tubuleuses, annexées aux cavilés péribranchiales, qui s'élendent autour des viscères, et les enveloppent en se moulant sur leurs parois. Il importe de ne pas confoudpe ces dépendances de l'appareil branchial arec le teutoculome, offerl far diverses Iscilies simplis, les Cionidées notamment; les rapports avec J'inteslin sont les mèmes dans les deux cas, mais les provenances sont dilférentes.

Évolution des bochaeoss. - Cetle érolution a été suivie par plusieurs auteurs, sur des Tuniciers divers, notamment par liowalersky sur les Pérophores, par Ed. van Beneden et Julin sur la Claveline, par Pizon sur les Botryllides. Les résultals principaux ronrordent daus ces lrois cas, el autorisent à penser que les dommécs suivantes sont ipplicaliles it Loutes les Ascidies gemmipares.

Le jenne bourgeon consiste en une cavilí entingune, la resicule interne on vésicule primilive tes auteurs, yu'entourenl les trois assises d'endoderme, de mésoderme, et l'ectoderme. Ces deux drrnièes couclies se comportent comme daus les développements larvaires, et noffrent aucune particularité trol' accentuce. Il n'en est pas de mime pour lendoderme; celui-ci se moditie dapres des procédés, fort distincts de ceus qui se manifestent cliez les larves, el comparables a ceux montrís par les embryogénies rondensies.

La paroi endodermique de la cavité entérique ne donne amrune nolocorde. - Dans le cas des hourgeonnements directs, culle carilé dérive d'un diverticule emis par les espaces péribranchiaux. Dans les phéuomines gemmipares accompagues de la gencse d'un épicarde, cot axe enılodermique se compose de deux couches cellulairas accolíes, qui s'écartent l'ume de liautre daus la zome oil le bourgeon promil majsance, et lassent entre elles un vide : la cavilé entérique alle-moner. 
Chez la Claveline, cette ravité, avec l'endorlerme pui la limite, et lui conslitue une paroi, se livise transversalementen deux portions inégales; la postérienre. plus petile, est chargée le lonuer le péricarle: l'antérieme foumil la luanchio, l’inteslin, l'épicarde, et la majeure partic rles ravilis péribranchiales. - I cet effet, la portion antérienre se scinde, au moven de lewx étranglements longitudinaux et parallirles, en trois segments juxtaposés. Le tronçn mélian se convertit en luanchir et intestin: son extrémité antérieure s'ilargit, et se transforme en sac luanchial: son extrúmité postérjeure lemenre étroite, et persiste comme intestin. les leux segments latéraux, qui thanpuent le précédent a droile et il gauche, produisent les leux cavités péribranchiales, on du moins lrs portions le res cavitis qui sont limitées par l'endoleme; la cavilé cloacale, chargée de fournir la frart ectodermique, est le venue larlive, et fruml naissance par une lépression lorsale les léguments. Enhin, l'épirarle est engendsé prar la branolice dı jenne bourgeon, de la mème manjere que chez les larves. - La partie postérieure de la cavité enté-

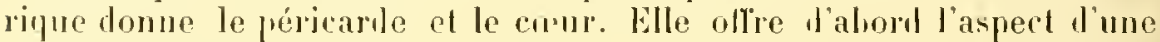
vísicule creuse; un sillon apparait sur une zone le sa paroi, et se lisprime on une gouttière profonde; lépicarle, produit par la loranchie en cet instant de l’évolution, s’aplique sur les lèves de la goultière, et contribue a convertir cette dernière en m canal. Celui-ci est le cocur; à cause mòme de sa provenance, il est renfermé dans le reste de la vésicule péricardingue.

Ine telle origine est fort différente, comme le font remarquer Eil. ran Beneden et Julin, de celle montrie par les larves. Cliez ces deruieres, la vésjcule péricarlique nest pas indipentante lès l'aloul; elle provient scondairement ile l'épicarde, alors que le contraire a lieu chez les hourgeons. Les lissemblances vont mème plus loin encore, car elles s'étunilunt aux relatious établies enl’e lo cour et les sinus sanguins de l'épicarle. le curur, chez les indivilus issus de larves, est placé audessous de l'axe endodermique, c'est-à-dire lecet épicarde mème; aussi, le courant sanguin sous-épicardique se jette-t-il dans liextrémité postérieure de cet orgine. I'ar rontre, cette extrémité postérienre du cueur est, dans l'économie des julividus issus de hourgeons, plarée au-ulessus le l’épicarde; le eonrant sous-épicardipue ne peut alors parvenir a elle, et ra aboutir ¿ l’oxtrémití antérieure du mème appareil. - Ces lillérences d'origine, l'évolution, ot le siluation lifinilive, coustatées sur les Clavelines par les anteurs precités, montrent rombien est profonde l'altération amenée far la gemmiparité daus les phémomènes lu dévoloppement. Cette altération consiste cu mo condensation très accentuée; aussi nest-il pas possible, lans la riggle, le s’adresser à l'évolubon des bourgeons, pour concevoir les domées fondamentales de la genese des organes.

lionus coloxulfs. - La gemmiparité détermine, chez les Tunjeiers yui la présentent, la genèse le colonies. Les descendants restent unis à 
leurs générateurs par une portion plus ou moins grande de lour tunique; celle-ci ronstitue souvent une gangue communr, an soin de larpulle ils sont plongís.

Il existe deux types colonianx chez les Tunieiers. Dans lir premier. les zoö̈des sont disceruables les uns des antres, car leurs tuniques ne sont somlées que par une faible zone de leur étendue; dans le second, ils sont entièrement enveloppés par la tunique commune, que charun d'eux contribue à produre pour sa part. Le premier type est colui des Ascidies sociales, des Salpides, el des Doliolides; les colonies de celles-là n'ont point de forme bien arrètie, et s'itendent dans tous les sens; fos assemblages de celles-ci sont linéaires, les individus itant placésles uns derrière les autres, et constituant une sorte de chaine, dont la longuem est en rapport avec leur nombre. - Le second type est ollert jar les Ascidies agrégées, et par les l'yrosomes.

La phupart des colonies d'Ascidies agrégées n'out point d'aspert arrèté. Leur allure générale diffère cependant d'un genre à l'autre, suivant lorganisation particuliere des zooïles, et permet souvent de les reconnaitre; quoiqu'il en soit, l'aecroissement de l'assemblage en limensions ne suit aucune régle lien précise. - Les Botrylliles font pourtant exception; les individus se disposent, dans me mème colonie, en plnsieurs groupes ovalaires, on ils s'arrangent à la manière des rayons l'une roue. Ces groupes, dits systemes, sont remarquables en ce que clacun deux possc̀do une cavité cloacale commune, dans laduelle dél,ouclient les cavilés péribranchiales des zoödes qui le composent. - La régularité est plus gramle encore chez les Pyrosomides, dont les colonics offrent l'aspect dronneaux, largement ouverts à lrurs deux extrémilés; la paroi du tonneau est constituée par les individus plongés dans leur gangue tunicale, et sa cavité correspond a la chambre cloarale commune. Cetle disposition curieuse, connexe à une adaptation très prononcée il la vie pélagique, commence à fajre son apparition clucz une Ascillie sociale ordinaire, se rattachant it la famille des Didemnides: le genre C'olocormus. Les colonies de cet aninal présentent la lorme de coupes profondes, cylindriques, aux parois presque verticalrs, et rappellent de près celles des l'yrosomes: mais elles sont tixées, el non pas libres.

Clıez heaucoup des Ascidies gemmipares, le génératenr donue to descendant, et cesse ensuite de communiquer directement arec lai. Les fenillets dn jeune bourgeon se contiment bien avec lew's correspondants de l'indivilu productenr, maisinterrompent ces relationslorsqu'ils ont engendré les organes, lorsque le hourgeon est devenu un itre complet: les adhérences n'existent plus que par la substance tunjeale. Les Ascidies munies de stolons bien díveloppés, et les Butrylles, s'irartent de ratte disposition. Les botrylles surtoul, à en juger d'apries les observations do Pizon, ollriraient, sous ce rapport, me structure complexe. Non sculpment les sinus sanguins des desecndants demenrent reliés i cend le 
leurs grécraleurs, et s’ahouchent entre eux après la mort et la désagrégalion do ces loniers, mais encore ils omettent des cananx, qui parrourent la tmoique commune, ot vonl se jeter daus un grand conduit rolloctenr. Cir dernier, le vasseau roloniul péripherique, placé sur les bords de la colonie, qu'il entoure, est un róservoir général, dans lequel souvent tous les canaux parliculiers issus des zoö̈les. La colonic est ainsi parourue d'expansions fubuleuses, comparablis à dos stolons prives de la facullógemmipase, renfermant du sang, el où proviennent les élóments entraînés suivant les nécessités de la vie coloniale : la plupart des ovules, el les matériaux mutrilifs issus de la desagregation des individus morls.

\section{I. Marche de la gemmiparité, et générations alternantes.}

- Cossoénatoxs givérales. - A. La présence de la facullé gemmipare procure, anx Tumiciers qui la possèdent, un double pouvoir reproducteur; d'une part, ils produisent des aufs el des spermalozoïles, destinés a s'unir par la fécondalion, ot à donner des larves; d'autre part, ils engendrent des bourgeons. les descendants sont fournis de deux manières, - apparliennent i deux types de génciralions. - Ces générations se sucredent d'un' facon confuse, et indétermince, chez le plus grand nombre des Iscidies bourgeomnantes; elles alternent entre elles avec irrégularilé, car chaque individu se trouve capable de porter a la fois des éléments s'xuels et des bourgeons; celte répartition uniforme empêche toute précision daus l'allernance. Il n'en est pas de mème pour plusieurs aulres de ces Ascidies; une sorle d'antagonisme s'iblablit entre la reproduclion fécondante el le bourgeonnement; la première se réduit, el dimjmue d’importance, à mesure que le second joue un rôle plus considérable. Les individus gemmipares possident bien des ćléments sexucls; mais ils ne sont pas capables de les mùrir, ou ne peuvent achever quine partic d'entre eux; ils transmellent alors res éléments, encore imparfaits, ans bourgeons quils rngendrent. Les individus issus de cesderniers se lrouvent posséler, lans ce cas, des produits fécondatemrs, nou ébauchés par enx, el provenanl lu généraleur.

Une promiere indication le res phénomènes existe chez plusieurs Ascidies suriales, et agrégées; en revanche, ces faits atteignent toute leur ampleur chez les Pyrosomes, et surloul chez les Salpes. - Ainsi, pour ce qui est des premiores, les jeunes Clavelines issnes de la féconlation, provenanl de larves urodeles fixées, et transformées en adultes, rostent stérilus quant à la reproduction sexurelle; elles se bornent à prohuire des hourgreons, qui se convertissent en nouveaux individus; cenxci possideul des orules el des spermalozö̈des. - les Bolryllides offrent des disposilions amalogues, quoique moins aceentuées. Chaqne individu engendre, il la fois, des aléments sexuels el des hourgeons, et possede, en conséquence, les deux procédés reproducteurs; cependant, il ne murit pas tous ses ovmles, ch garle un petit nombre pour lui-meme, 
pour sa propre fécondation, el transmed les antres il ses bourgeons, anx descemlants qu il fournit par gemmiparilé. Ceux-ci conservent ces ovulus venus de leur ginérateur, les achèvent comme šils leur appartenainul, el les fécondent arec lenrs spermatozoüdes. Ein outre, ees lescendants agissent, à lenr tour, de la mème façon; tont an complétint les ovmles préédents, ils en produisent pour leur propre comple, quils reprortent à Jenrs lourgeons, el le cycle conlinue a se déroulor de celle manjère. - Les plínomènes sont ruserrés, che\% les Salpides, dans des limites plus précises. L’individu, issu de la fécondation, est seul capable de bourzeonner; il engendre ses descendants prar la voie asexuette, mais ces llerniers sont privés de loute faculté gremmipare, et ne se reproduisent que pa! la fícondation. Cette exclusion entraine une grande régularité dans l'alternance des générateurs, dont les uns ne donnent des descendants que par le frocélé sexuel, et les autres que pir un mode asexur. De plus, les individus incapables de bourgeonner n'engendrent réellement, en fait de glandes, que leurs testicules; "hacun d'eux possède bien un ovule, mais ce dernier est produit par l’individu bourgeonnant, qui le transmel, comme ehez les Botryll's, a son descendant. En somme, Jenbryou issu dr la fécondation se convertil en un ètre capable de bourgeomner, el muni diun ovaire conlonant de nombrenx ovules; cel êloe injtial, ce zoüle, angendre par gemmiparité dos descendants, ì chacun desquels il donne un des ovules de son ovaire; ces descendants ne possèdent aucune propriété gemmipare, el se bornent à façonner des testicules, lont les spermatozoïles sont chargís de féromber cet ovule.

B. - P'hsieurs auteurs, el Brooks entre autres, se sont hasés sur ces particularités pour admetle que les Ascidies bourgeomnantes, Salpes conprises, el surtout ces dernières, noflient aucune alternance de générations, du moment oi tous les individus soul pourvus d'iéments sexuels. - Lalternance de générations, la mitagenese, ne consiste pas exchusivement en une succession régulière do générations sexuclles el de générations agames; en pareil cas, ce nest pas la régularité qui fail l'altronance. Il suftil, pour qu'elle existe, que les représentants d'un meme lype soient munis de deux modes reproducteurs; le risultat est que ces représentants sont d’origrines différenles, car les uns se lrouvent engendrés d'une maniore, les seconds ulume antre, et tous so succèlent daus le temps, de facon a alterner suivant nue matehe plus ou moins rigoureuse el dólerminée. Jorsque tous les représentants possèfeut los deux morles, l'alternance est confusi, irrouliore, mais existe pourtant, bien quelle ue soil soumise à aucune loi. Jorstur ces deux modes sont exclusifs, certains individus ayantle premier, el cerlaims antres lr second, la mélagenese procedr suivant me dirrelion frónise. Mais il y a allurnatce, quel quo suil te cas.

En ce pui tomcle plus partienlierement les Salpes, la métagenoso consiste en mue succession de femelles gremmipares, ef d'hermaphoulites 
prives do la faculti hourgeonnaule; succession des phus regulières, en pronant les lemes femelles ot hermuphroulites dans l'acceplion roulue par

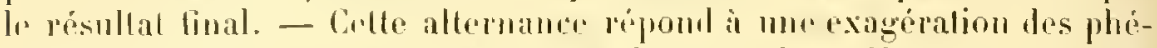
nomines otlerts pitr les Pyosomes of les Bolrylles. Chez ces demiers, l'opposition entre les fomelles gemmipares, et les hermaplarodites non homrgoomants, no so manifeste pas encore d"ume maniine complete, mais elle commence is simliquer. En uffet, chaque indiviln se comporte.

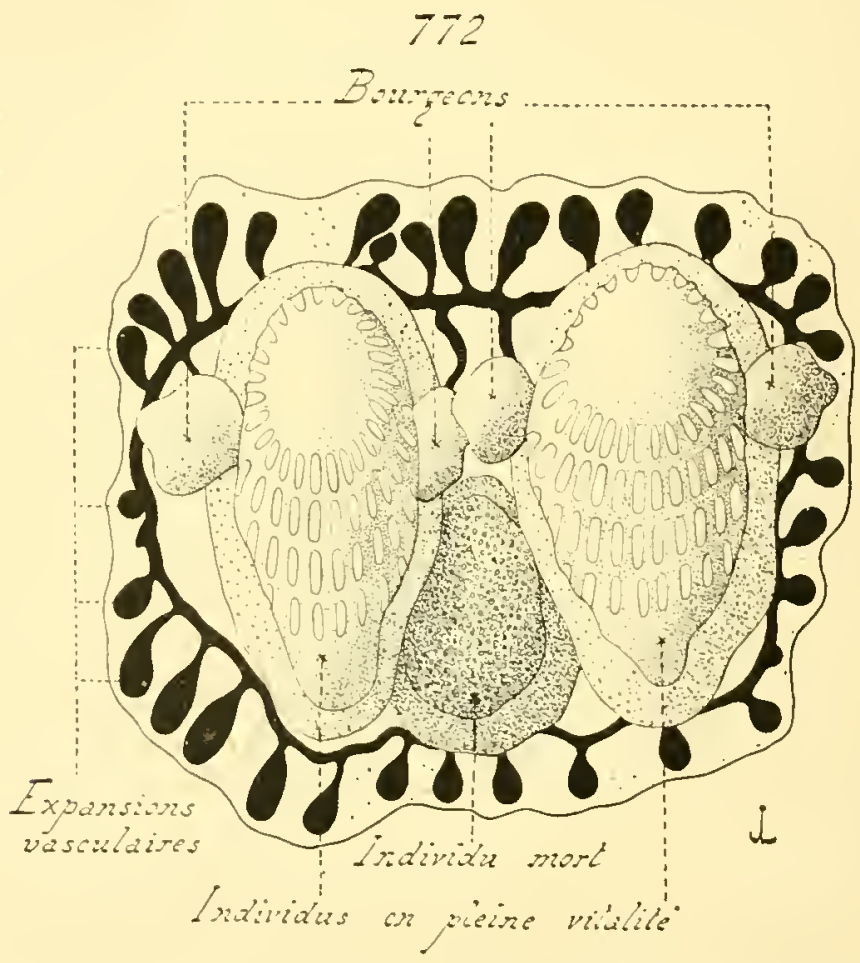

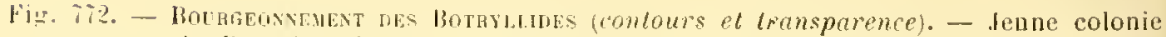
du Botryllus Sichosseri, d'apres lis recherches faites par P'izon.

dans le courant de son rxistence, l'une part comme los femelles gemmipares des Salpes, el diutre part comme les hermaphodites. ll transmel lien des ovules, comme los premiores, aux descendants quil engendre far hourgeommoment; mais it produit en surplus, comme les seconds. des lesticules, dout les spermatozoüdes sont destinés à féconder plusieurs ovules quil gardo pour lui-mème. Il suffil dimaginer la répartition exclusive lu ces lux manifeslations vitales, pom oblenir l'allemance

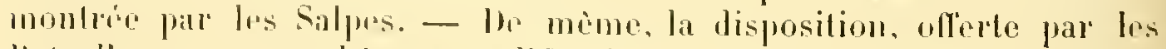
kotrylles, corvespont i ume modilication des phénomènes normaux, pró- 
sentis par la plupart des autres dseidies. Dans le eas de ees derniores. chayue individu, lout en lourgeomnant. lout en fournissant des desern-

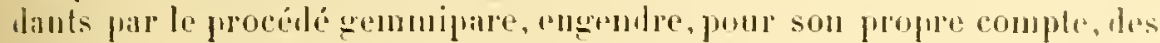
ovules ave des spermatozoildes, el se mproduit par la roie sexuelle. En supposant qu'un zoö̈de transmelte, à chacun de ses descrndants formés par le mode asexue, me part de ses grandes sexuelles, en la faisant pénétrer dans le jenne hourgeon, on obtient le fait signalí chez les Botrylles et chez les Prosomes. Lit celtr transmission commence a se manifester chez les l'olyelinides, dout le stolon gemmipare, nommé le

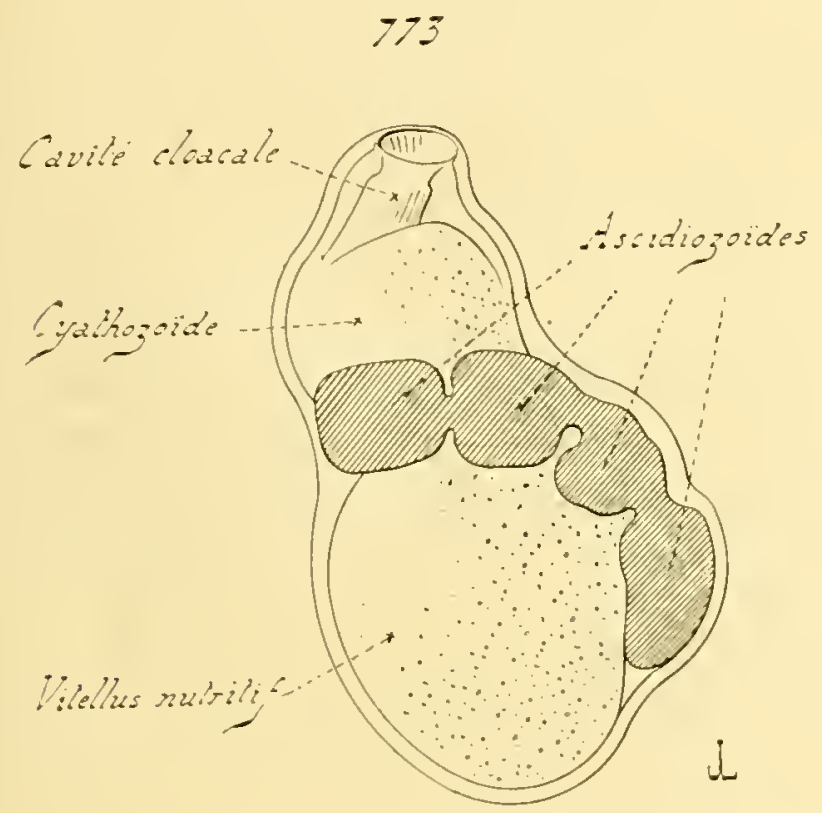

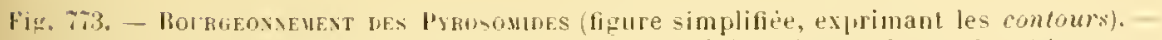
Jennc colonie de Pyrosume, com posee des qualre ascidiozouldes, et du cyallozoide encore muni de sa vesicule de vitellus nutrilif; d'apres les recherches faites fiar howalevsly.

post-abdomen de ces animanx, ronfermules organes sexuels. et en dome des parties il chacun des descendants.

Les Tuniciers bourgeonnants se répartissent donc, sous le double rappont de la régulariti altermante, et de la transmission des orules, en une série, qui ra des Ascidies comprosées ordinaires jusqu'aux Salpes, en passant par les Botrylles et les Pyrosomes. - Lin ce qui fouche les representants de ces trois dernits's groupes, et avec uniformité. la faculté gemmiparr se manifoste d'une manire tris promo chez les individus issus de la fécondation: elle existr déja chro les cmbryons fort jemes. Comme on l'a vu daus le pararraphe consacré aus formes emluyou- 
naires, cette parlicularité s’indique chez plusienrs Ascidies composées, appartenant aux familles des lidemuides et des Diplosomiles; elle se borne à prendre ailleurs une constance plus grande, el une répartition plus complete.

Un fait important, lans la transmission des cellules srixulles, consiste en re qu'un tel report s'adresse aux ovules seuls, el non aux spermatozoïdes. l’individu gemmipare donne à ses hourgeons des ovules, ot nullement des éléments miles; chaque descendant bourgeonné est obligé de prodnire nn lesticule pour luj-mème, atin le pouvoir féconder l'ovule qui lui est échn. Co phénomenr confirme, pour sa part, la réalité dos notions exposées dans mon Embryologie générale. Dans la fécondalion, el par une véritalıle division du travail, l'ovule renferme, non seulement loule la substance protoplasmique lestinée à laçouncr les premières ébanches cmbryonnaires, mais encore toute la puissance d'hérédité; il transmel celte puissance aux orules du descendant, à la condilion que crux-ci se délimilent rapidement, dans un tissu non encore dilféroncié, ni jourvu le fonclions particulières. La production de ces dernjers est, par suite, forciment hitive. Aussi l'individu, issu d'un auf l'ócondé, ongendre-t-il lui-mème, l'une manière plécoce, des ovules, qu’il donne ì ses descendants foumis par gemmiparile; ces ovules sont recueillis par ces derniers, accus et muris par eux, el finalement fécondés par leurs propres spermalozoïdes. Ceux-ci ne font que donner limpulsion rajennissante, chargée de metle en branle tontes les forces vitales accumulées dans l'ovule; lens pouroir gémétique, moindre que celui dr lovule, leur permet de provenir, d'une facon plus lointaine el relatirenent moins directe, les éléments issus des blastomères de l'ouf fécondé.

C. - Dans les étudrs parliculires qui suivent, les Botryllides, les l'yrosomiles, les salpiles et les Doliolides, seront seules examinées. Les notions, relalives aux autres familles des Tuniciers hourgeonnants, qui montrent les ébauches de tous les phénomènes specianx ollerts par les premières, découlenl suffisamment les considérations précédentes, pour quil soit nécessaire d̈insister davanlage a lem égard.

Botrylues. - Le développement des colonjes de Botryllides a été budić récemment, par l'izon, l'une manière complete. Le hourgeonnement de ces animanx est péribranchial; chaque génératem donne naissance a deux descendauts, placés latéralement sur sou corps, l'un à droite el l'autre à gauche. Lr point de départ d'une colonie est, comme toujours, un indivilu issu de la fécondation, provenant d'un oeuf fécondé, et subissant des phases lavaires.

Cet indivilu hourgeoune, frar une progenèse gemmipare, alors qu'il est mne larve, el qu'il achere à peine sa cavité péribranchiale; il n’a pas rncore quilté, en ce moment de son évolution, la colonie matemelle. II 
engemdre les deux bourgeons normanx, mais celui de ganchre arortr: le droit se développe seul, et devieul un descendaul, de seconde génération par rapport i son généraleur larvaire, qui représrulr la première géneration. Le descendant produit, à son tomr, deux bourgeons, qui si complètent tous deux, el se convertissent en individus le troisieme generution; entre lemps, le générateur larvaire, on de première génération, meurt el se disagrige. Chacun des denx descemlants de troisième génération donne, de son côté, naissance à deux lonrgeons, qui se lransforment en individus jarfails; ces derniers, an momlne de quatre lans lenr ensemble, conslituent une quatrième génération; le zooüde de seconde généralion meurt alors, et se désorganise. Puis, clacun des quatre représentanls de la quatrième génération donne encore deux hourgeons, d'où huil individus d’une cinquième série; cenx-ci foumissent à lem lour, par les mêmes moyeus, seize zooïdes de sixime génération. Les deux descendants de la trojsième génération disparaissent, frappés de dégénérescence; el la jeune colonie se tronve constiluée par lís zooüdus des quatrième, cinquième, et sixième générations. Les membres d'une mème série se rassemblent en systèmes, se groupent antour d'un cloaque commun, et acquièrent prar la lenr aspect définitif.

La colonie ne cesse de s'accroitre par des procélés identiques, car le hourgeonnement est continu, et de telle maniere quelle contient tonjours trois générations snecessives de zooüdes. En elfel, les indivilus de la quatriène sérje meurent après avoir alteint l'étal adulte, après avoir produit leurs éléments sexuels, et disparaissent; entre lemps, les membres de la sixième géníration engendrent un septieme gronpe de descendants. P'endant que ces dernier's grandissent, les représenlants de la cinquieme génération parviennent ì lenr àge alultr, el meurent ensuite. Ces phénomines se succèdont avec constance, de façon que loute colonie so compose de trois ordres dr zooïles, les uns adultes, les autres plus jeunes, el les lerniers à l'élat de lourgeons engendrés par les précédents. - L'assemblage s’accroil ainsi d'une manière contiune et réguliere; sauf les cas de destruction accidentelle de zooïdes, ou de migralion de bourgeons en deliors du sỵstème aupuel leurs génératenrs appartiennent.

Cette succession de faits est halituelle et normale: l'origine de la colonie enticre se rapportant ì un seul individu, it me larve issue de la fécondation. Parfois, lo hasarl fait que plusien's larves, appartenant is une mème espice, se trouvent placées côle il cóte; elles se sondent alors par leurs luniques, el constiluent, au moyen do cette simple agrígation, un premier systene, me génération initiale, capalble l'engendrer par bourgeonuement de nouvelles séries. Dans diutres cas, les larves demenrent daus le roanue commun du systione dont leur généraleur fail parlie, el y produisent des descendauls, qui s̈ulerwalent parmi les membres les plus jeunes de ce systeme, pour gramlir avec enx.

ha marelo de ce dérelopiement est rendue plus complexe par la 


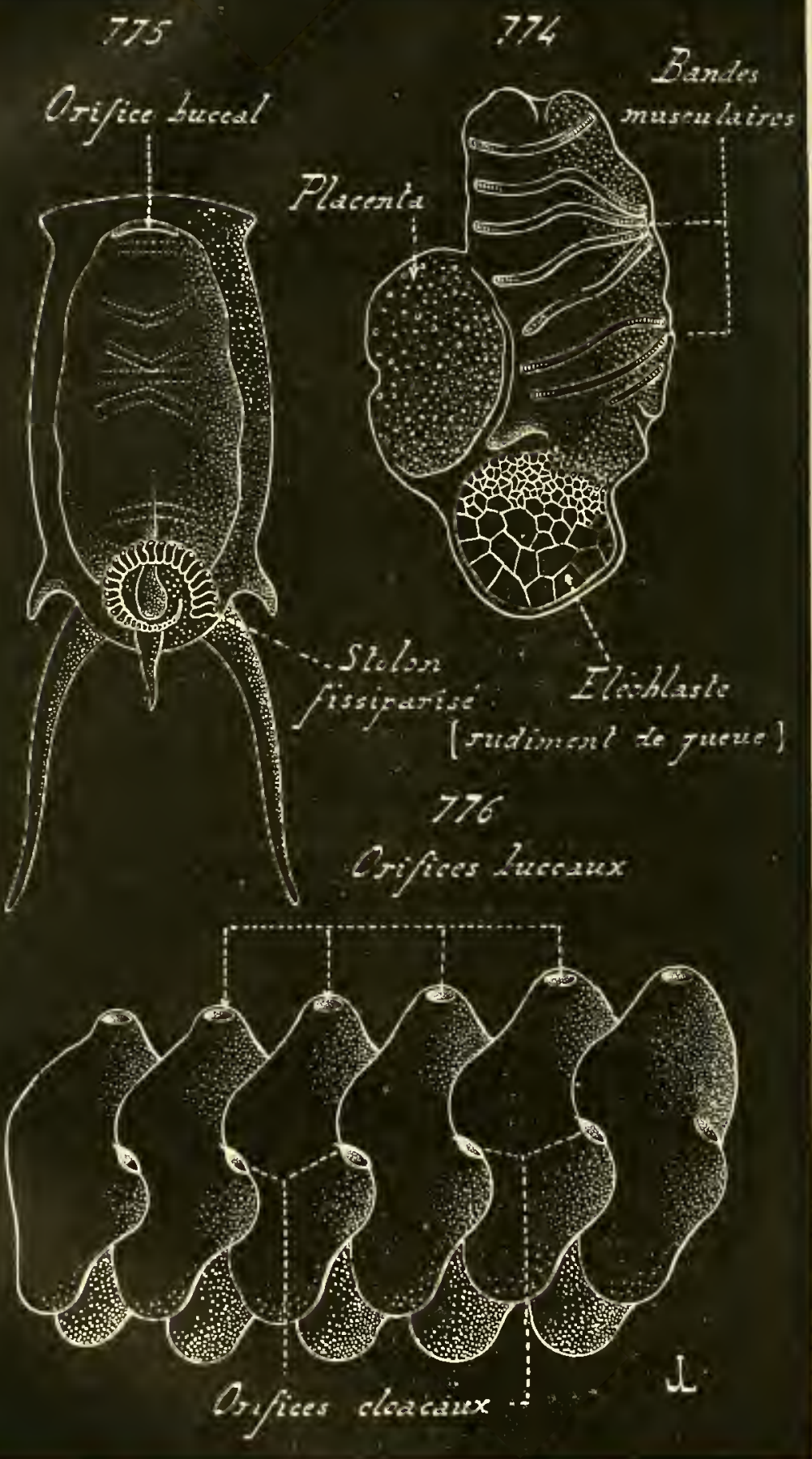


lentenr de la genèse des éléments sexuels, el par la migration contimur. de la plupart d'entre eux, le chaque générateur a ses desremdauls poduits par la gemmiparite. - La jenne lare initiale dr toute colonie posside des glandes sexuelles, peu complexes encore, mais dont puelyues orules sont déja bien formés; elle les transmet à son lescendant de secomle géneration, qui les reporte à ses loux hourgeons chargés de devenir les imlividus de la troisieme grénéralion et ainsi de suile jusqu”a

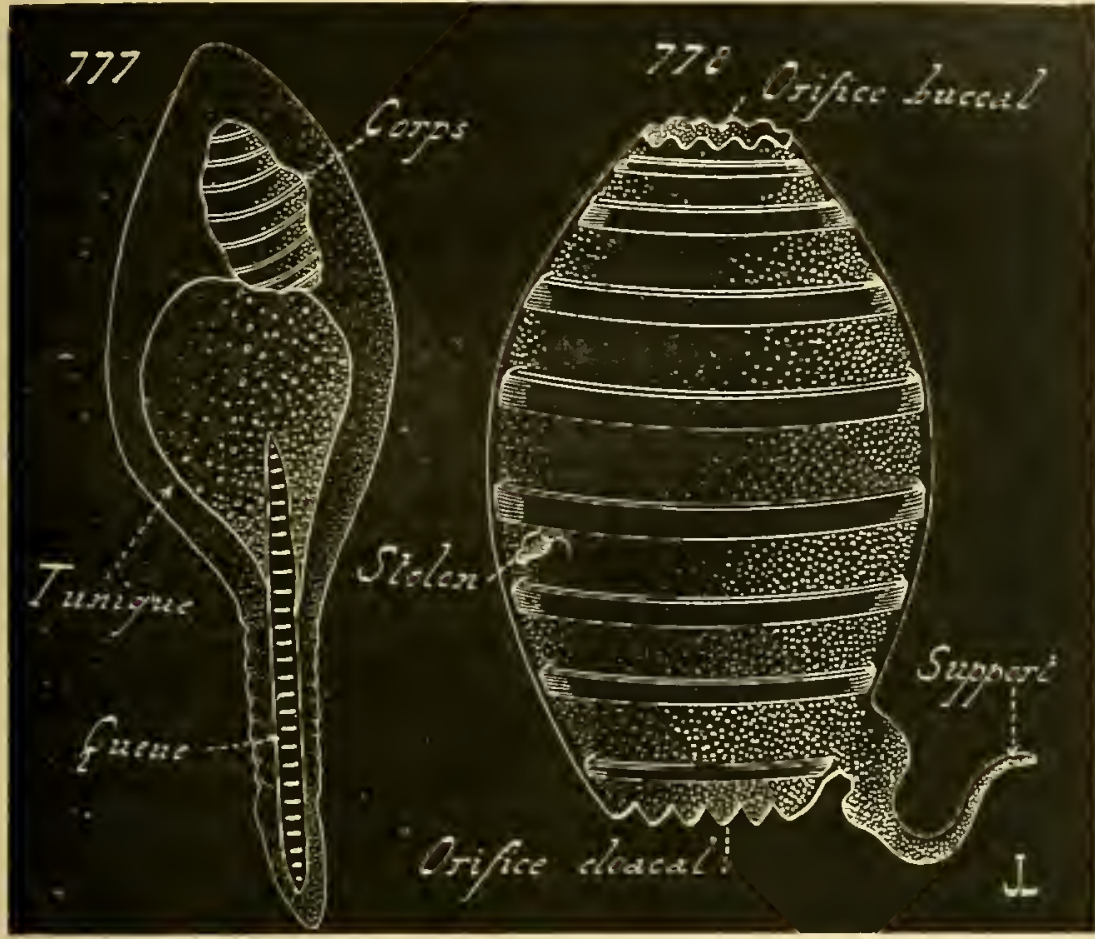

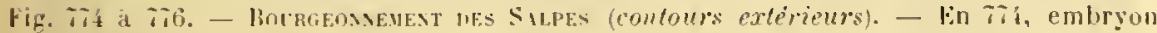
avance, encore muni le son éléoblaste, el lu reste de on placenta; va de cóte. En 7\%. le mème devenu adulte, el "ouverti en une femell. femmipare, ou silpe sols. laire; vu jar sa face ventrale, de maniere a montrer son stolon. - En riti, fortion grossie du stolon precident, montrant la chaine de Salpes, d'udividus liermaphrodites, ficondants, el non gemmipares, qui le conslifue. - (1) apres les recherohes faites par lirobtien sur la siolya demarrativa.)

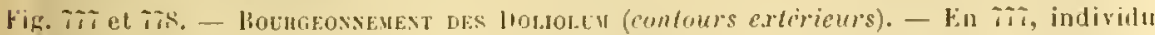
le la première génération, issu d'un cruf féconde, ncore à l'ciat de larve urodele. lin Tis, le meme, ayant perdu ses appendices larvaires, el commençanl a produire son stolon et son sumport; vu de profil. - (l'apres les recherches faites par lirohtren et Ilianin.)

la sixiène où à la septieme série. Les élements sexuels se complètent durant ce report continuel, et arrivent ì maturité chez les zooüdes de ces 
deux depuieres générations; senlement, les testicules devancent les ovaires, de sorle que ces zooïles sont des mảles stricts. Ils transmettent leurs ovules, imparfails encore, à leurs bourgeons; les individus, issus de res lerniors, achirent ces teufs, produisent les lesticules, sont dios lors hermaphrorlites, et fonctionnent commetels. Dès ce moment, l'hermaphroditisme est la regle pour toutes les générations successives formées par gemmiparité. - Cet hermaphroditismo se complique alors de la transmission des ovules. Cluaque zooïde est encore tros jenne lorsqu'il commence ì bourgeonner; ses glandes sexuelles, à l'élat d'ébauches, renferment pourlant des ovules assez avances. Or, le report précédent. étalıli lès le délunt le la rolonie, existe encore; seulement, il s'exerce sur des éléments proclıes de leur maturiti, el se manifeste sur des individus que ne frappe jas une mort trop précoce. Aussi, chaque zooïde conserve pour lui ses tosticules, aver deux on trois de sis plus gros ovules, el transmet à sús deux bourgeons son excédent lejeunescellules fomelles; il reste done hermaphrorlite, en somme, et rapable de fonclionner comme reprouturteur sexuel. De leur côté, ses bourgeons, tout ru grandissant et passant à l'état adulte, produisent des lesticules et de nouveaux ovules, füils ajoutent à ceux provenant de leur générateur; ils bourgeonnont dr leur côté, gardent pour eux-mêmes deux ou trois les aufs, el transmettent les autres à leurs descendants. Ce phénomène continne à s'offectuer, suivant les mèmes moyens, dans toute la sélie les générations suivantes.

En résumé, rt meltant à part les dispositions, of̉ertes en premier licu dans la colonie naissante, qui résultent du lent accroissement des rellules sexuelles, opposé à la rapidité du bourgeonnement, les zooüdes sont des individus hermaphrodites el gemmipares. Ils conservent pour enx leurs testicules avec plusieurs ovules, el reportent leurs autres aufs, plus jeunes, à leurs lescenulants prouluits par grmmiparité.

Prosombes. - Les phénomónes offerts juar lis Pyosomiles sont presque semblables te tous poiuls à leurs correspondants des Botrytles; ils ne ditlèrent d'eux que par des détails de valeur fort serondaire. L'un le res détails louche à la genese première de la rolonie, el l'autre an nombre des ovules transmis. - Loouf des Pyosomes, riche en dentokrithe, possèlo une grosse vésicule vitelline; il est conservé, par son gránérateur, daus la ravité príribanchiale de ce dernier, et y subit les plases initiales de son développement. Le jemne embryon, juásur sa vésicule, et venant i peine l'élianclıer son neuraxe avec sa cavité périlıranchiale, allonge son extrémilé antérieure, el la livise en quatre segments par autant do coustrictions transversales. Charmn de ces derniers devient un nouvel individu, un ascidiozoide, pour emploger l'expression usitée: l'emliryon initial, le cyathozoïde, qui les a engendrés, ne tarle pas i mourir el i lisparaitre, en ne laissant que sa ravité roacale. les puatre asritiozö̈les, imdivilus de seconde génération, grandissent 
en enreloppant la vésicule vitelline; celle-ri diminue à mesure, rar ses réserves alimentaires sont absorbées par eux, et employées à leur accroissement. Finalement, ils se disposent en une rouronne, autour de la cavité rloarale du cyathozoïde, dans laquelle dúbourhent, lorsque la cavité vitelline est résorbée, leurs propres espaces péribranchiaux; cette cavili est la première indication du volumineux rloaque commun de la colonie. - Le générateur, qui possédait l'nuf inilial de tout ce srstème, rejette alors celte jeune colonie. Celle-ci, devenue litre, s'accroit pour son propre compte, et par gemmiparité, en disposant ses zooïdes autour du rloaque commun, et pronant sa forme caractéristique de tonneall.

La différence aver les Botrylles porte sur ce fait, que le jeuue embryon produit, par une gemmiparité compliquée de fissiparité, quatre individus de seconde génération, et non $u n$ seul. Sauf cette dissemblance, et celle entrainée par l'aspect mème de la colonie, tous les autres phénomènes concordent. Les íléments sexuels mùrissent à mesure que se succèdent les premières générations gemmipares; les testicules sont complets tout d'abord, de manière a remlre miles les jeunes colonies, constituées par un chiffre restreint de zooüles; les individus deviennent hermaphrodites par la suite, et transmettent à leurs bonrgeons leur excédent d'ovules. Seulement. et en cela consiste la dernière différence arec les Botryllides, ils ne gardent pour eux qu'un seul auf. Aussi, dans les colonies adultes des P'yrosomides, chaque ètre ne possède-t-il qu’un œuf, qüil féconde avec ses spermatozoïdes, et quil conserve dans sa cavité péribranchiale, pour lui faire sulir les premières phases de son développement.

SAlpines, - La succession des phénomines gemmipares, offerts par par les Pyrosomides, se dégage de celle des Botryllides par la répartifion d'un seul orule dans chaque individu sexué; sauf ce fait. la transmission des éléments sexuels s'elfectue l'une manière constante, d'une génération a l'autre, car tous les indivirlus sont capables de hourgeonner. Ceci étant. si l'on suppose que re report s'eflectue une fois pour toutes, par l'incapacité gemmipare des zooïdes pourvus l'ovules, on obtient le cas des Salpes. L'individu, issu de la fécondalion, hourgeonue des descendants anxquels il transmet ses rufs; et le phénomene en reste là, car ces descendants sont privés de tout pouvoir hourgeonnant.

De mème tue chez les Prosomes, chaque individn sexué ne porte

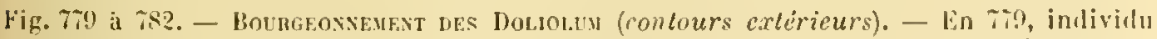
de première generation, plus avaneé que celui de la figure $7 \rightarrow R$, et produisant, aux depens de son stolon, des bourgeons, qui vont s'atlacler au supjort pour devenir les individus de la seconde gencration. - En $R 80$, détails grossis du stolon qui se fissiparise. lin 781, hourgeon détaché, en voie de deplarement, sur le corps du génerateur, à l'aide de ses prolongements contraetiles. - En 782 , délails grossis du support, autuel viennent s'attacher les bourgeons préédents. - (1)'aprés les recherches faites frar l'lianin.) 


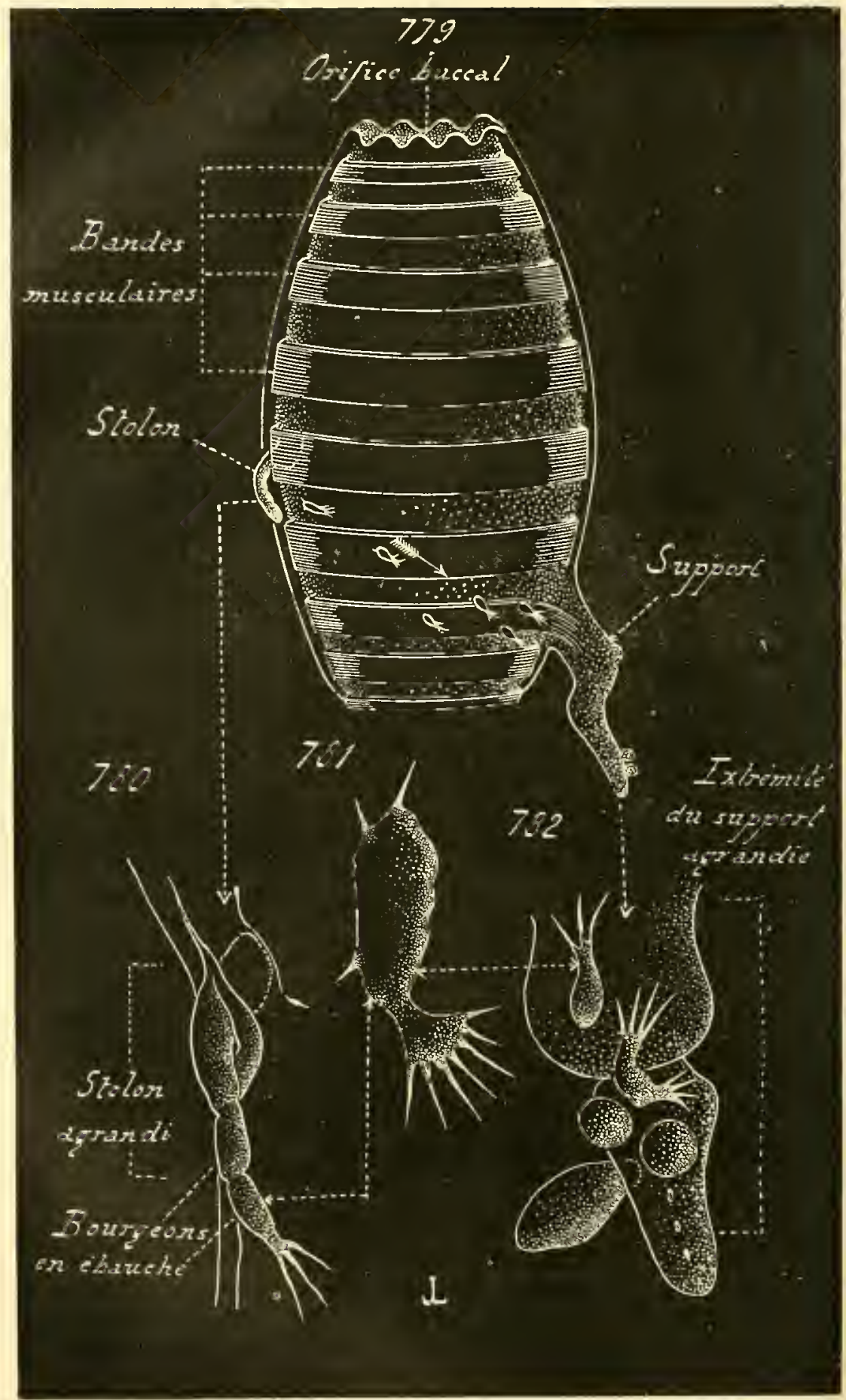




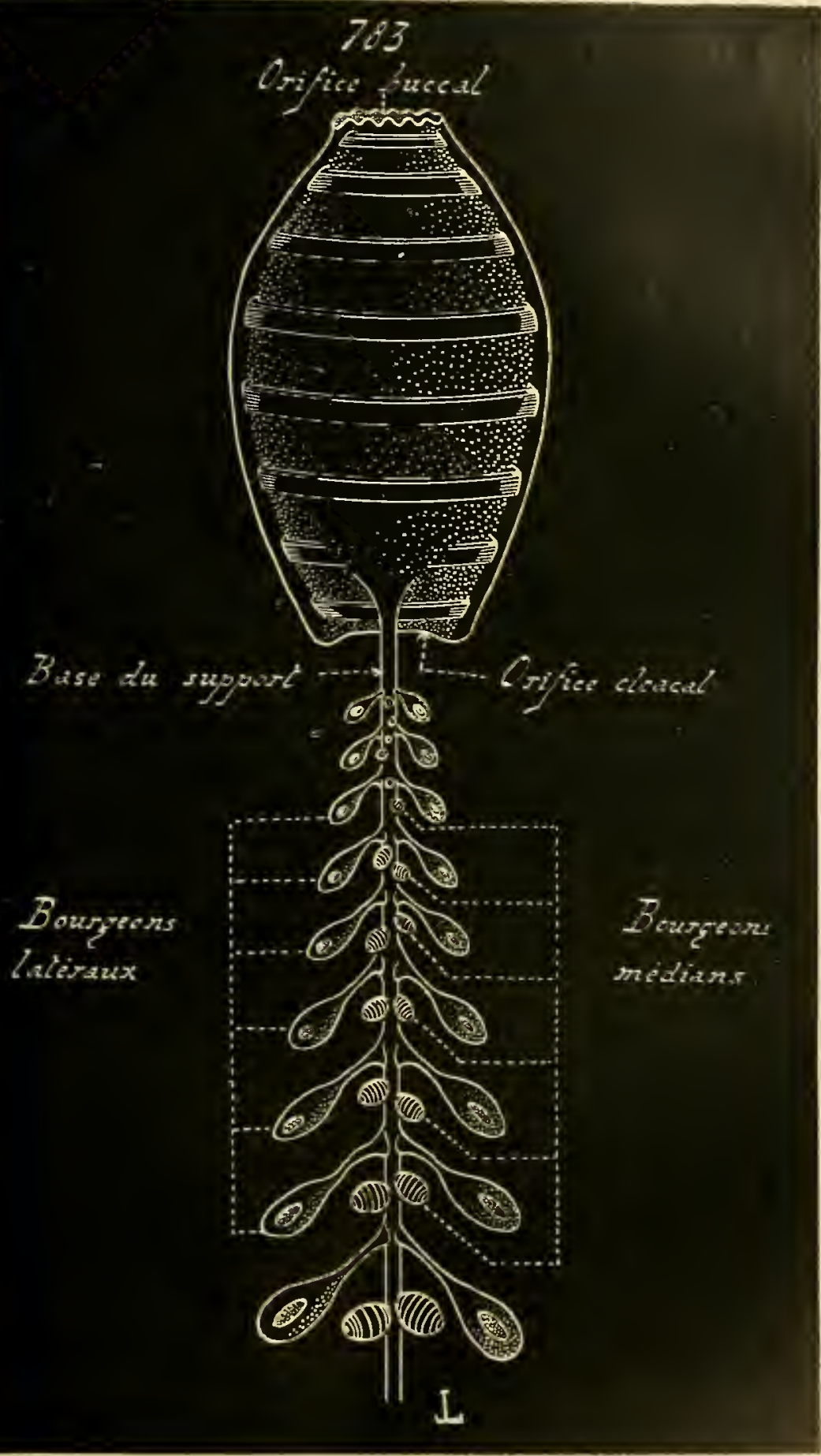


qu'un seul wuf, 'pưil féconde avec les spermalozoïdes de son teslicule. Il le conserve durant un cerlain temps, en le nourissant, comme il est dil daus le paragraphe (III), a l'aide d'un placenlat. Cel weuf domne un cmbryon, qui produil lativement une grlande sexuelle, surtoul composée l'ormles; le plus, el toujours avec la mème précocité, cet embryon engrendre, surle cóté droit de son corps el non loin du coeur, un stolon. - Ce Jernier, conformé suivant la maniẻe habituelle des Tuniciers qui possedent de ces apparcils reproducteurs, se compose d'un axe endodermique, entouré de sinus sanguins el d'une couche ectodermique; il renferme en sus les jemes ovules. Il sallonge, devient volumineux, et se livise on segments, groupés l'habilule sur leux rangées; chacun de ces segments est lisjrosé de manière ì contenir un des orules. Ces troncons se converlissent eu aulant dindivilus parfaits, pendant que l'emliryon inilial achève, de son coté, son propre organisme. - La colonie se compose alors de denx seules généralions: la première est représentée par l'unique individu issu de l'ouf fécondé; l'autre par lous les zoö̈des, placés les uns derrière les antres à la manière des anneaux d'me chaîne, et provenant de la segmenlation du stolon émis par le frécident. La reprouluction gemmipare en reste là, ef ne ra pas plus loin; rombairement à re qu’il en est chez les Pyrosomiles et les Bolryllides.

Lètre inilial, ayant transmis tous ses orules à ses descendants, est stérile désormais; il se sépare mème de ces derniers, et demeure incapable le tunte reproduction ultérieure. les descendants sont privés, he leur còté, le toute faculté gemmipare; mais ils possèdent des aufs. Chacun d'eux prołuil un lesticule, destiné à féconder l'unique ovule ¡püil porte, el ıui lui a été transmis par son générateur; l'auf fécondé est le point de llépart d"une nouvelle colonic, qui recommenre le cycle. - Tandis que le gónérateur est solitaire, les descendants sonl unis en une chaine, où ils se trouvenl placés sur deux rangées, el qui se morrelle souvent en plusieurs parts.

Celle alternance, qui se dégage le relle des Prosomes par la supjression complete de tout bourgeonmement dis la secomde génération, consiste, en somme, en la succession d'une l'emelle gemmipare et l'hermaphrodites non bourgeonnants. I.e lerme hermaphrodile est employé, iri, prour désigner lo résullal final; les zooïles de scconde génération ne sont, sous le rappolt des organes engendrés par eux, que des mâles, porteurs d'ovules qüils nont pas fournis. Il est nécessaire, pourlant, de ne joint s'exagéres l'imporlance de ce fait, simple alténualion de celui présenté par les Butrylles el les l'yrosomes, lont le lourgeomement est continu, et dont les individus sont capables d'en-

Fig. 783. - Bourgeonnement DFs 1)ololuy (nontours extérieurs; l'individu est vu jal sa faee dorsale: une partie seulement du support est représentèe). - Individu de première gincrition, plus avance que colui de la figure 77?, muni d'un long support dorsal, aupuel sont fixés les nombreux bourgeons émis par son stolon ventral. - (IJ'aprés les reelucrelses failes par Gegenbaur.) 
gendrer a la fois desovaires et les lesticules, lout en recevant des ovules de leurs ascemonts direets.

Dolounes. - Les Salpides et les l'yrosomides constituenl les drux termes extrèmes de la mélagenèse offerte par les Tuniciers nageurs et bonrgeommants. Chez les derniers, plusienrs généralions gemmipares se succident, avec transmission d'ovules; chez les premirres, une sente de ces générations est produite, après quoi la gemmijarité cesse, jour laisser la place à la fécondation. Les Doliolum sonl, à cet égard, intermédiaires entre ces deux types, car ils offrent deux séries successives d'individus engendrés par voie de hourgeonnement. Seulement, le dimorphisme remarquable des zoö̉des de la première génération bourgeonnée, et l’isolement de ces mèmes zooüdes, suivi de leur agrégation ultérienre, doment à la mélagenèse de ces ètres une allure complexe, qui nécessile, afin de la hien saisir, son étude après celle des Salpes.

Lauf fócondé se convertit en une larve modele. La quene de cette dernière est pretite, mais elle suffit cependant ponr déplacer l'animal, quoique avec lenteur; elle ne tarde pas à s'atrophier, et l'embryon passe ¿l l'étal adulte. Il est l'équivalent, en ce moment de son évolution, de la femelle gemmipare des Salpes, du cyathozoïde des Pyrosomes, el reprísente une première génération, composée d'un seul individu. Il rappelle de près la précédente femelle gemmipare, liflérences grinériques mises à parl; il porte de mème un stolon, situé non loin du coul, et clargé, de produire les zooïdes le la seconde génération. Mais il jossede, en surplus, sur la face dorsale de l'extrémité poslérieure de son corps, un appendice solide, en forme de baguella, que son roble permel de nommer le support.

Le stolon, bourgeonué par le généraleur initial, donne naissance par la voie fissipare, tout comme cher. les Saljes, aux descendants de la seconde génération; seulement ces derniers, an lieu de rester unis en un chaine, se séparent les uns des autres, et de l’individu qui les engendre, an fur et à mesure de leur production. Encoro pourvus d'une organisation rudimenlaire, leurs tíguments émettent des expansions contractiles, qui leur permettent de ramper sur leur génrialemr, el de prorvenir jusyuà son appendice dorsal, jusqua support. Ils s'allachent it ce dernier, étirent lemr hase adhérente en m petit pédicule, et demeurent en celle place. - Dès lors, m dimorphisme se manifeste entre enx. Cenx rui, parmi ces ètres de seconde génération, lomologmes des quatre ascidiozoüdes des pyosomes el des ammeanx de la cluaine des Salpes, sont silués sur les culés du support, se convertissent en individus nomriciers; les autres, posés sur la face dorsale du mome appendice, sont senls donés d'un pouvoir gemmipare. Les premiers deviennent rolumineux, s'aphatissent quelque pen, ef prennent l'aspect d'une cuiller an manche court; ils sont privés de cavites peribranchiales et de siphon cloacal; leur loranchie communique directement avec le dehors; leur rôlc 
est de subrenir aux nécessités vilales des seconds. Ceux-ri grandissent;

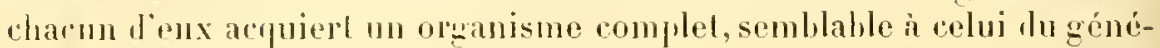

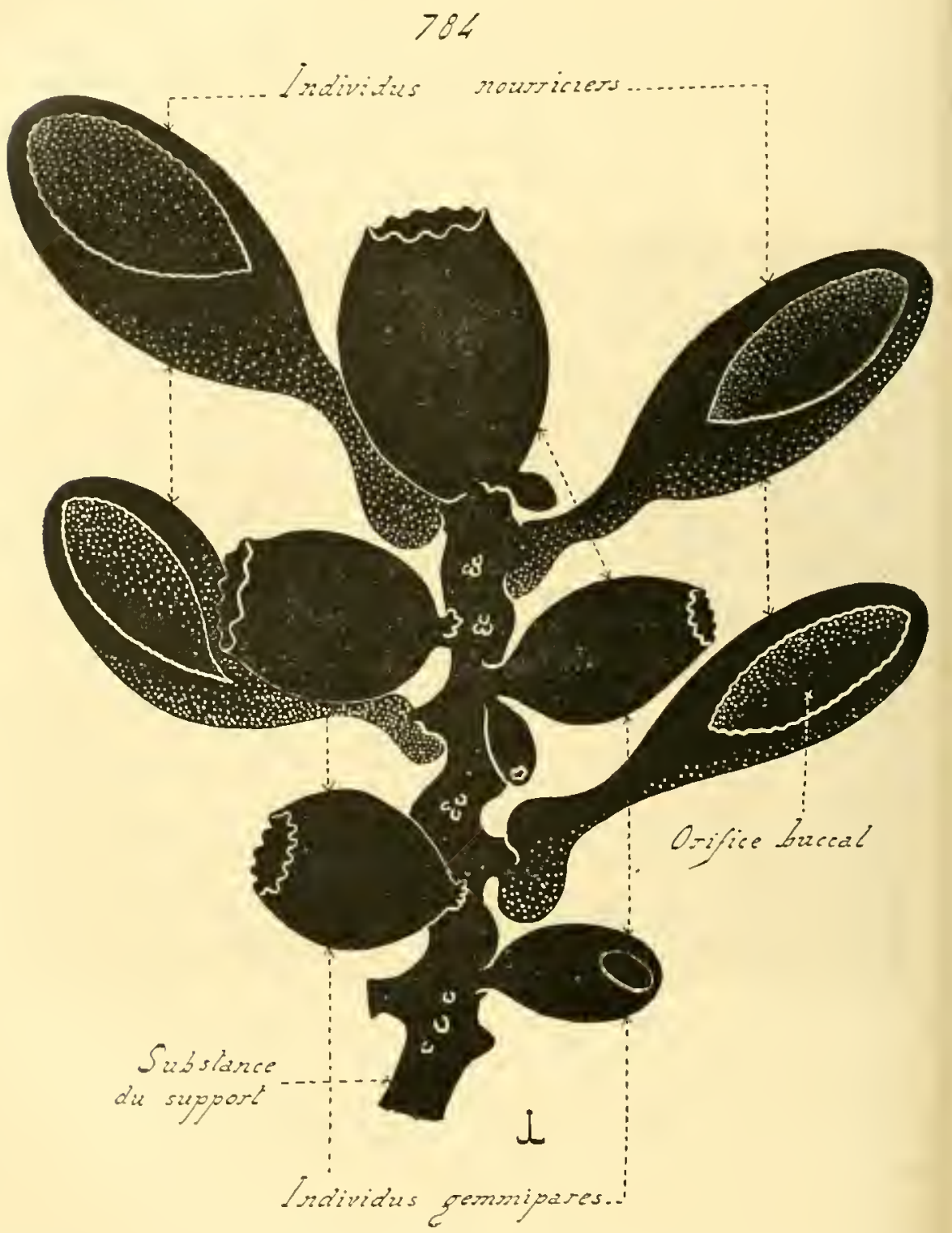

Fig. Zsł. - liolmagnewest des lmblolum (silhouelte). - Fragment grossi du support dorsal d'un individu de première gencration, muni des bourgeons converlis en individus de la seconde gincration: les hourgeons latéraux sont devenus des indivilus nourriciers, et los lourgeons medians des individus gemmilıres. - (1)après les recherehes faites par liogenbanr.) 
ratemr initial, et pourva de mime d'un stolon comme d"un support dor'sal.

Ces plenomenes ne sont encore commus que dans lour emsembla, ot on ignore plusicurs particularités des relations ansi rbblies, parmi ces ètres, soit entre eux, soit avec leur support. Quoj yu'il eu soit, pendant (que les représentants de la seconde génripation grinulissent, el se transforment de denx manières sur l'appendice oir tons sont attachés. l’unique membre de la première génération, le générateur initial issu de la

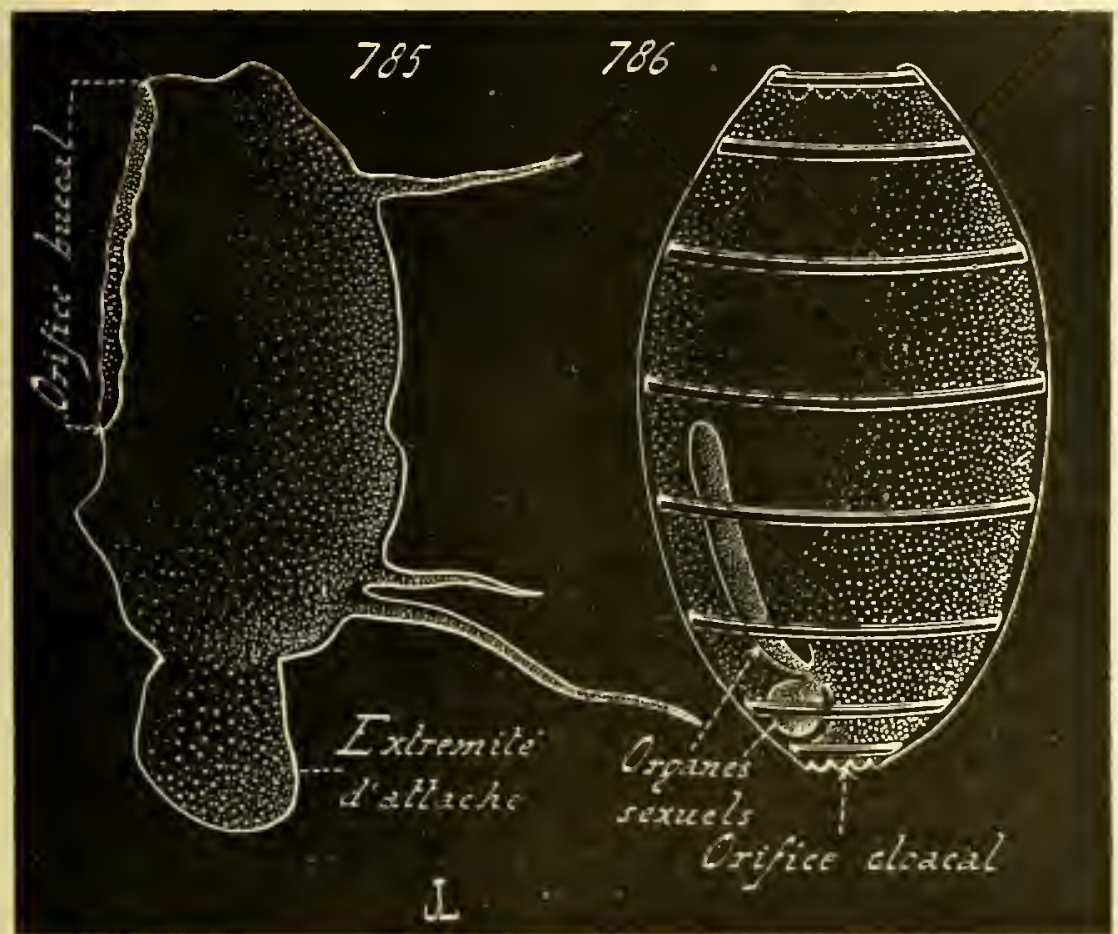

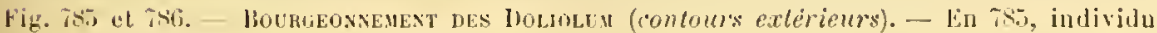
nourricier de la seconde génération, vu de profil. - - En Fig, individu sexué r:t non hourfuemant, de lit troisieme gènération, issu du bourgeonuemont des individus gemmo. pares de la seconde géneration. - (l)apres les recherches faites par lirobben.)

fécombation, meurt, et se lésorranise. Son support resle sem, muni de tous les zoödes de la deuxieme sorie. Parmi ces derniers, les indivilus nourriciers, ayaut accompli leur rôle, meurent à leur tour, el disparaissent; les individus gemmipares continuent i vive, se détachent, ef deviennent libres.

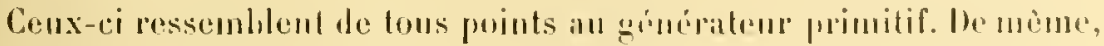

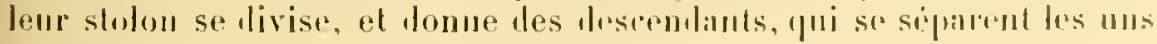


des autres. Ces drinirrs coustituent une troisipme generation de zoö̈des, en cousidérant l'ensemble de cette succession, et répoudent a la scoonde série des èlres formés par lourgeonnement. Ils graudissent, passent à l'étal adulte, mais sont privis de loule faculté gemmipare; seulement, ils possèlent des oryanes sexuels, et se reproduisent par la lírondation. Après quoi, leurs aufs férondés recommencent le ryele.

Colle métagenose comporte done lalternance de trois générations d’injividus. Lionf fécondé donne un ètre, rui reprósente i lui seul la premiere série, el se reproduit par voje gremmipare; les descendants qu’il engendre appartienneut à deux formes, les uns privés de loute propriété génétique, les autres pourvus seulement le la faculté bourgeonnante; enfin, les bourgeons foumis par ces derniers se développent en indivilus d’une troisiène génération, privés de la propriété gemmipare, mais munis l'organes sexuels, et capables de fécondalion. Ceux-ci domnenl des oufs fécondís, qui raminent une nouvelle alternance. Ces phénomènes s'accompagneut de l’isolement des àtres produils, qui se séparent les uns des aulres comme de leur générateur; sauf le cas de l'agrégation sur le support Jorsal, secondaire et consécutive à la séparation sur le slolon gremmipare.

La transmission des aut's s'effectue, chez les Doliolum, comne chez les Tuniciers précélemment étudiés. Les individus gemmipares de la seconde génération faconnent des orules, qüils ne murrissent pas; ils les transmellent, encore imparfails, à lenrs descenlants de la troisième série. Ceux-ci les achìveul, engondrent un lesticule, el les fécondent avec les spermalozoïdes de ‘e dernier. - Les considérations, déjả exprimées au sujet des salpes el des I'yrosomes, sont, par suite, ajplicables atx. Doliolides.

\section{RÉSUME்}

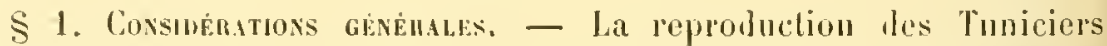
sclfectue de denx manjixes: par la voie sexuelle, el par la gemmiparité. Cotle dernielo n'existe yue chez plusienrs représentants de la classe des Cadncicordes, oi clle détermine la formation de colonies. - Les lérennicorles reprosentent, a l'átal persistant, une phase transiloire du developpemenl dilaté des Caducicorles. Colle phase est celle de lave urodèle, dans laquelle l'embryon possiole nne quene, sontenue par une notocorde d'origine endorlerminue, et un neurase dorsal. Je mésorlerme, de provenance entérocolienue, évolue suivant le procélé mésenchymatenx.

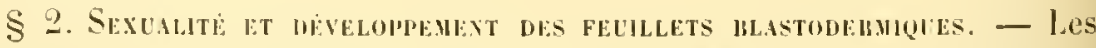
Tuniciers sont hermaphrodites. Leurs spermatozoïles se composent d'une queue liliforme, et d'une petile tète allongée. Lemrs orules sont entourés d'enveloppes complexes, dont les éléments figurés ne sont pas engendrés par l'ovule lui-mime, el proviennenl de cellules extérieures 
à lui; en somme, lovoblaste primitil se segmente, cl lomm nu ovorylo central, quenvironnent de nombreux chements folliculairos, placés souvent sur plusieurs rangées.

Suivant la quantité des réserves mutrilives possélées par l'orule. lo léveloppement inilial s'effectue par le mole gastrulaire. on d'aprés le: procédé planulaire. Ia gastrulation se manifeste d'apris les procédés hahituels. - La planulation es tantòt directe, tantôt indirecte; la premiore existe chez.les Salpes, la seconde ehez les Pyosomiles.

Les deux fruillets blastorlermiques primordianx étant élauchés. I. protectoderme donne l'ectoderme et le neuraxe, le protemlorlerme fournit l'endoderme, le mésoderme, et la notocorde. Less procédés different, suivant qüil s’agit d’un léveloppement gastrulaire. ou d'un développement planulaire. - Dans le premier cas. la gastrule change de forme. devient oralaire; lentéropore oecupe la face dorsale de son extrémité postérienre. L’entéron, limité par le protendoderme, se divise, au moyen d'un étranglement transversal, en deux résicules: l'une antérieure, ou branchio-intestinale, l'autre postérieure, ou cordo-mésodermique; celle-ci se raceorde ì l'entéropore. La nolocorde est produite par les cellules dorsales et médianes de la vésicule postérienre:elle s’étend ensuile dans la queue en voic de formation. En mème lemps, le neuraxe se délimite, sur la face dorsale de la lars, comme un sillon, creusé aux dépens de l'ectoderme, qui se convertit en un tube par le rapprochement de ses lèrres; il apparail sur les hords mèmes lle l'entéropore, et. comme sa cavilé communique par là avec celle de ce demier, celui-ci correspond à un canal neurentérique, qui ne tarde pas ì se fermer. luis, les parois latérale el rentralo de la résicule postólieure donnent l. mésoderme; les deux ébauches les plus importantes de ce alernier. fournies par les parois latérales, se ramènent en somme à deux diverlicules entéroculiens, dont l'entérocurar, fort étroit, se réduit à une fenle. Chacun de res diverticules se livise en deux seguents, l'un anterieur, l'autre postorienr; le preminr, qui posside la cisvité entróncolienne, se lésagrege, el se convrtit on mn mésenclyme; le secoml, constilué par une simple plaque cellulaire, prinetre dans la quene, dont il engendre la musculature. La quene prend naissance dans la rogion postérieure du corps de la larve; elle comtient la musculature précédente, la notocorde, el l'extrénilé postérirne du nenraxe, celle-ci ćlant placrí au-dessus de la notocorile. - Les développements plamulaires se ramenent, par des omissions el des diplacements, anx irolutions gastrulaires; la queue ne prond point uaissance, on bien reslo rédnite.

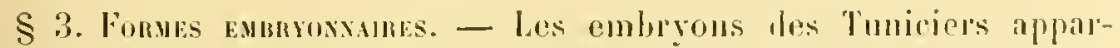
lienment a lenx lypes: les embryoms simples, at les mulmons gommipares. Les premiers se hornent il compléler leno orwanisme; les antres donnent naissance, en surcroì, far nne progenese asexudle, id des lescendants. 
Les embryous simples se présentent sous deux formes: les larves urodèles, et les embryous auoures. - Les larves urodèles sont très répandues; clles existent daus les développenents dilatés. Leur quene est prorluite avant l'éclosion; ses fibres musculaires se disposent, avec régularité, en plarjues parallèles et successives, anxquelles le neuraxe listribue des filets nerveux, et que plusieurs auteurs assimilent aux myomères des lertébrés. L'ectorlerme se reconvre d'une mince conche tunicale. liextrémilé antérieure du corps engemdre trois papilles alliésives. Le neuraxe se rentle en avant, dans celte mème extrémitć antérieure du corps, el donne une vésicule cérébrale; le reste du neuraxe constitue une moelle dorsale, dont me partie est somalique, placée dans te corps, et dont lautre partie, le beaucoup la plus longue, se lrouve ilre caudale, située lans la queue; la vésicule cérébrale contient leux organes sensoriels et asymétriques, l'un nommé l'ocelle, le second l'otolithe, et débouche souvent dans le stomeon, qui vient de se creuser. La résicule antérieure de l'entéron primordial, ou vésieule branchio-intestinale, se différencie en branchie et intestin. La première s'ouvre an dehors par trois orifices : l'un impair, médian, et antérienr, est la bouche, qui dérive d'une courte dépression stoméale; les deux autres, les fentes branchiales, dorsales et symétriques, sont produiles par l'union de diverticnles branchiaux et le diverticules ectodermiques. La larve est mise en liberté; elle nage, se léplace à l'aile de sa queue, puis se fixe à un sujport par les papilles adhésives de son extrémité antérienre. La quene s'atrophie alors, avec lous les organes, notocorde, moelle caudale, plaques musculaires, qu'elle contient; la tunique s'épaissit; et toute l'économie se conplète, d'apres une orientation variable suivant les types. - Les emliryons anoures ne sont guère connus que chez plusieurs Molguliles; ils sont privés de queut, et possèlent hativement des petils stolons fixaleurs.

Les embryons gemmijares commencent à se monlrer chez diverses Ascidies composées appartenant à la famille des Didemnides; ils existent normalement chez tous les Tuniciers nageurs, autres que les Pérennicorles. Ils possedent des annexes de denx sorles: des annexes reprolucleurs, qui sont des stolous gemmipares ou des jeunrs hourgeons; des annexes nutritifs, qui consistent en une vésicule vitelline, on en un placenta. Le premier cas est celui des Jyrosomes, lo second celui des Salpes. Tautôt les embryons gemmipares achivent leur évolution propre, comme chez les Salpes. Tautòt ils l'arrêtent, et menrent d'une manière précoce, comme il en est pour les Botrylles et les Pyrosomes; dans ce cas, la progeuèse est plus hàtive que daus le précédent.

$\$$ 4. Oragne hes onganes. - Les procédés mis en curre diffèrent, dans la plupart des cas, suivant que l'embryon dérive d'une larve, ou l'un bourgeon.

La tuniqu est une cuticule exsulée par l'ectoderme, contenant iles 
cellules ectodermiques desquamées, qui ronservent leur vilialite. ed sulissent des altérations de plusieurs sortes.

Les collules, non différenciées encore, de la vésicule répébrala et il. la moelle somatique, produisent les rentres nervex rompucts de l'adulti: le cervean el le rordon viscéral. - liorigine exacte de la glande? nenrale, et de son organe vibratilr, n’est pas encore ilucilée; il scmble lien que cet appareil ne soit pas l'homologue dr. l'hypophyse des Vertélirés.

L'intestin est déjá ébauché dans le corps de la larve urodele; il so borne à se rompléter. - Les deux fentes branchiales s'élargóissent de maniere à envelopper la branchie entière, et lonnent les cavitós péribranchiales; eı outre, la région, oì elles sourent au dehor's, se déprime, el levient la cavité cloacale. Celle-ci est ainsi limitéc jar l'ectoderme, alors que les parois des cavilés périlıanchiales se composent d'une part cetodeminue et d'une part endodermique. Partont où les prois péribranchiales sappliquent contre les parois branchiales. des onvertures se percent, de manièr à unellow en communication l'espace cntouré par les premicres avec celui quenvelopjenlles secondes; ces orilices sont les trémas, les ouvertures luanchiales.

L'appareil irrigateur est représenté par les vides lacumaires, creusés entre les travées du mósoderme mésencliymateux; il correspond a un polycolome, auquel s'annexr parfois un deutocolome péri-intestinal. le cuen est prouluit par le péricarde; celui-ci dérive d'un amas cellulaire formé aux dépens de la paroi branchiale, ou lien, dans le cas des Aseidies hourgeonnantes, de l'axe endodermique des stolons. Ce dernier, souvent nommé l’épicarde, provient ǵgalencut de la branchie; lorigine essentielle est done la mème dans les denx procédés.

Les appareils rénaux et sexuels sont engendrés par les éléments du mésoderme.

\$ dios bourgeonnantes appartienuent a la seule classo des Tuniciers caruricordes. Elles sont dites Ascidies composées, par opposition anx 1scidies simples, qui ne hourgeonnent jamais, mais colte dillérence n" saccorde pas avec les affinilés nalurelles; elles forment des colonies, dout les zoö̈des sont rolativement plus petits que les indivilus des Ascidies simples. les ébauches des jemnes bourgeons se composent de dépendances les trois fenillets le leur générateur; le lourgeonnement esl tantôt stolouial, tantòt direct.

Suvant les grompes, les hourgeoms se disposent de truis maniomes sur le générateur. Dans le hourgeonnement pépiliranchial, ils proviennent de la proi des cavités péribranchiales, cho\% les liotryllides, par exemple; dans le bourgeonnement pyloripue, on asoplangion, ils dépendent de l'uesophage du générateur (Jirlemniles); entin, daus lar

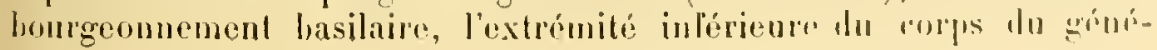


rateu prouluit un stolon, qui domne les bourgeons, soil par me gemmiparité vérilable, soit par fissiparité. Chaque jeune bourgeon consiste en une vésicnle, homologuc de la cavité entérique des larves, entourée par me assise endodermique, quenveloppent à leur tour des lissus mésodermiques el ectoderminnes. Ces deux derniers doment, respeclivement, le mésoderne el l'ecloderme de l’individu qui dérive du bourgeou. La vésicule interue, d’aprìs les recherches failes sur les Claveliues, se divise en deux parts, dont la postérieure produit le póricarde avec le conr, el dont lantíricure fournit la branchie, ses cavités péribranchiales, l’intestin, et l'axe endodermique, ou'l'épicarde, du stolon que l'individu issı du hourgeon engendre à nouveau. - Les formes colonjales des Ascidies bourgoonnantes sont très diverses; chez les Ascidies sociales, les indivilus sont encore dislincts; ils sont entierenent plongés, chez les Ascidies agrégées, dans une tunique commune à tous. I'orlinaire, les zooïdes ne sont soudés que par leur tumique; les Botrylles possèdent en surplus un systeme vasculaire colonial.

Assez souvenl, laltemance des générations cst confuse, cau chaque individu est capable i la fois de fécondation el de gemmiparité; il en est ainsi chez la plupart des Ascidies composées. - 'arfois cependant, certaines générations sont prirées, à intervalles réguliers, soit de la leproduction sexuelle, soil de la faculté gemmipare, et l'alternance se trouve alor's plus précise. Flle se complique souvent de la transmission, jar le génélateur, de ses ovules aux descendants qu’j bourgeonne. Ces phénomines sonl offerts par les Bolrylles, les Pyrosomes, les Salpes, et les Doliolides. 


\title{
EMBRANCIIEMENT IDES TERTÉBRES
}

\author{
CHAPITRE XTI
}

\section{LES FEUILLETS BLASTODERMIQUES DES VERTÉBRÉS}

\section{\$1. - Considérations générales.}

1. Caractères et classification. - A. Parmi les Notoneures, les Vertébrés constituent l'embranchement le plus important. el le mieux caractérisé. leurs centres nervenx sont dorsaux d'une manièe exclusive; ils consistent en un cordon, en un neuraxe plus ou noins complexe, placé an-dessus d'une notocorde, qui repose elle-mème sur le tulı digeslif. Aucune des parties de ces deux organes ne disparaît au cours du développement embryonnaire; non seulemint tontes persistent, mais encore elles se différencient souvent ì l'extrème, et parviennent à une hauteur de structure que les antres Notoneures ne montrent jamais. lin outre, les Vertébrés sont caractérisés par deux dispositions. à eux spéciales. Leur nolocorde ne se borne pas a occuper la région postérieure de leur corps; elle s'élend jusque dams la tète. Leur fenillet moyen se sublivise en un mésenchỵme al un épilhélio-mésoderme. La zone dorsale de ce dernier se partage, d'une façon riguliere, cu segments placés à la file les uns derrière les autres. Le premier donne une lrame conjonetive-musculaire, intercalée à tous les organes de líconomie, aux dépens le laquelle se façonne le sifuclette, ot dont les cavités, qui composent un polyculome, s’agencent en un systeme sanguin et un systeme lymphatique.

Les particularités offertes par le mésoderme, et par la notocorde. sont vraiment propres aux Vertébrés : aucun autre Notoneure ne les présente. - l'lusieurs dispositions supptrmentaires serainnt encore citractéristiques, mais à un legré moindre yue les précriduntes, car elles font défaut i l'un des groupes de l'embranchement, à celui des Acraniens. 
Un spuelette interne, dont les pieces fremiores se pacent, autour he la notoconle. le manière à l'muchàsser. se délinite dans le mésenclume; il manque aux Acraniens, mais existe fonjours lans le corps des autres Vertólós. Ces pieces primordiales, qui entomrent la notoeorde comme aulant d'anneanx, sont diles les vertibres : d'ou le nom de I'ertébrés, accorlé à l'emhranchenent entien. Ce lerme n'est point juste, car il ne sapplipue pas i tous; mais il a l'avaulage d'exprimer, au sujet lu squelelle, pris a part, une conslante disposilion segmentaire; el, en lui donnant me acception géuriale, en considérant quil lénote une des applications principales de la structure urétamérique lu feuillet moyen, structure cigalement possédée par les Acraniens, il est permis de le conserver, et de l'emplover. - Cependant, plusieurs auteurs préfèrent se servir le l’exprrssion le Cephalocomles. Celle-ci imlique l'extension prise frar la notucorde des Vertébrés, qui parcourt, en ellot, Je corps entier, lepuis son extronilí antiricure jusqu’à son extrémilé postérienre.

Ine seconle particularité, dont les Araniens sont privés, et dont les autres Tertébrés se troureul pourvus, tient à la nature spéciale de l'appareil excréleur. Ce dernier possèle une lisposilion segmentaire, nouveau résultat de la métamórie du fenillet nuven; il consiste, du moins dans ses premiers linéaments, en tubes, groupés symétripuement et par paires de part et l'autre de la ligne médiane. Ces canaux s'ouvrent tous lans les espaces culominuos le l’épithélio-mésoderme, ou, à léfant, s'annexent des vaisseaux sangruins; ceux du mỏne côté débonchent, nn sus, dans un camal collecteur, qui ahoulit au dehors. Worlinaire, une part de cel ajprareil excréteu fonctionne comme conduil vecteur des ćléments sexuels, el se modifie en conséquence.

13. - Lembranchenuent des Vertébrés contient onze classes, froupées en plusieurs sections, rémues elles-mèmes en deux sousembranchements.

Ier Sous-embranchement, on des Acraniens. - Pas de squelette interue, et par consépuent de crine, ni d'apprareil excréleur. La notocorde seule joue le ròle de supprort organique. - Ce sous-embrancliement ne reulerme qu'une classe, à son tour repósentie, daus la uature actuelle, far un genre unique : le genre Ampliox'us.

Q. Sous-pmbranchement, ou des Graniotes. - Th squelelle interne, produit par le mésenchyuc, et délimilé fout d'abord autour de la notocorle; la rógion antérienre de ce squelette s’élargil en un crane, lestiné á asclore un espace oì se frouve placée l'extrénilé antérienre du seuraxe,

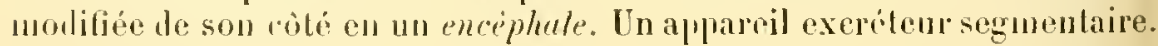
- Ce suus-embrumchement reuferme les dix autres classes, groupées en leux sections.

I $^{\text {re }}$ Section, on des Ciroustomis. - Syuelelte interne de slruclure

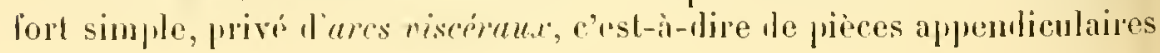


placées au-dessous du cråne. - Celle section se rélnil a la classe du mème nom, constiluée seulrment far deux familles, relle des l'étromysonides, el relle des Myxinides.

ge Section. on des Cixitnostones. - Squelelle interne de slpuclure complexe, tonjours pourvu d'ares viscéraux. - Celle section conticnt deux séries, d'imporlances inégales sous le rapport dn noulue, el de la diversilé. des classes.

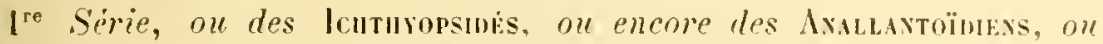

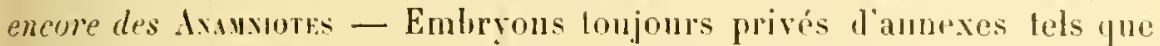
lamnios el la vésicnte allanlö̈lle. - Celle sério renferme six rlasses.

Classe des rélaciens. - Sipueletle carlilagineux: fentes liranchiales déhouchant à nu sur le corps. du moins dans la rogte; téguments rouverts de nomlureuses écailles placoïdes, peliles papilles drpmiques ossifiées. Hes nageoires.

Classe des Ganoides. - Squelette cartilagineux, u ossifié en parlie: fentes branchiales recourertes par un opercule: téguments munis de grandes écailles ossifiées, of lisposées en séries régulières. Des nageoires pourvues dr fulcres. écailles en forme de elıevrons.

Classe des Téléostëens. - sipuelolte emlièrmont ossemx: fentes branchiales revourertes par un oprocule. Des nageoires.

Clusse des Dipneustes. - Squeletle cartilagineux; me respiration branchiale el une respiration pulmonaire. Des nageoires.

Clusse des Stégncéphales. - Vertéturés lossiles, se rapprochant des Amphibieus actuels, mais plus complexes ct phus divers.

Classe des Amphibiens. - Squelette ossifié en majeur partie, in moins dans la regle. Une respiration branchialo el me respiration pulmonaire, parfois exchusives. Des membros à doigts, dans le cas ou los mombres existent.

2e Servie, ou des Allaxtoïdexs, ou des Awxiotes. - Emblyons trujours entourés par un ensemble de membranes, lit l'amnios, et pourvus d'une vésicule, la vésicule allantoüle, destinér à promellse lenr respiration on à assurer lour nutrilion. Ces annexes sont propres à l'umbryon, el disparaissent au moment oì cr dernjer se convertit en ahullo. - Celte srip renferme les Samropsidés et les Mammifores: ces derniers se bornent à la classe du mème nom: les premiers romprennent les liepliles el les Oiseanx.

Samropsides: classes des lieptiles et des Oisenux. - Tëgumonts courerts d'écailles ou de plumes; un senl condyle a los ocripital; plusienrs aortes, ou une seule aorle provenant de l'un des arcs aortipues droils de l'embryon; pas de rorps ralleux lans l'encéplıale.

Hammiferes. - Téguments couverts de poils: des glaudrs mammaires; denx conlyles occipitaux; me seule aorle, lont la crosse provient de lun des ares aortiyuos gauclues de l'emloryon: 11 corjs callum plus ou moins développé. 


\section{Considérations générales sur le développement.}

4. Les Vertélués se reproduisent par la voie sexuelle seulo; celle-ci, a son lour, ne romporte pue la fécondation, ef jamais la parthriogenise. Linnisexualité rest la rigle; les cas d'hermaphroditisme réel, c'esta-dipe de possession, par un mime individn, le lestirnles et d'ovaires capables d'artivité fonctionnelle, sont des plus rares.

Les variations sont très nombreuses, parmi les reprisentants de l'embranchement, pour ce qui touche a la tenenr de l'ovule en dentolícithe. lies dévelopjements dilatís se tromvent relativement pen nombreux; les leuillets sont alors produits d'après le mode gastrulaire invaginant. Les embryogénies condensies sont plus frriquentes; rlles sellectuent suivant des frocédis divers, yui dépendent de l'abondance variable des matrianx nutritifs accumulés dans l'auf. Les altérations sont d"autant plus grandes que cos réserves sont elles-mèmes plus volumineuses. Les Vurtébrés montrent, à cet égard, une série des plus intéressantes, et des mieux graduées, allant depuis des évolntions franchement dilatées jusqu'à des dévelopjements condensés au possible. Parmi tous les groupes naturels du monde animal, ces ètres sont les seuls à offrir ainsi les deux extrèmes, reliós l'un a l'autre par des transitions mémagées, indiquant à mesure l’ampleur des changements, en raison de la richesse en deutolécithe. Iussi, leur étude est-elle des plus importantes, pour établir les donnces relatives à la nature des modifications introduites, dans la marche du développement embryonnaire, par la présence d'un vitellus nutrilif alondant.

Le premier eflut de la segmentation ovulaire est d'engendrer les denx feuillots hlastodermiques primordiaux, le protectodeme el lo protendodrrme. - Ce dernier fonrmit la notocorde et le mésoderme; après quoi, il demoure dans l'organisme comme endoderme lélinitif. La notocorde provient de sa face dorsale : plusieurs des cellules placées en celte région, sur me bande médiane et longitudinale, se séparent de lui, et sagencent en un corlon compact. Le mésoderme est produit, d'une manière fondamentale et dans les embryogénies dilatées, snivant le mode entérocuslirn; l'entéron émet leux liverlicules, latéraux et symétriques, dans sa partic voisine de l'entéropore. Ces expansions s’insiuurnt entre le protendoderme, qui les engendre, et le protectoderme, se sćparent du premier, ot leviennent aulonomes; elles représentent les fremières ébauches du fenillet moyen. - Le protectodeme domne naissance an neuraxe, et persiste, jar la suite, en qualité d'ectoderme définitif. Le neuraxe s’indique, des l'abord, comme un sillon placé sur la face dorsale et la liegne médiane du corps; il druntr sur l'entéropore mème, et s'étend de là vors le pôle opposé dr l'embryon. Il se ferme à mesure; et se convertit en un canal, situé sous l'ectoderme qui se referme au-dessus le lui, el sur la notocordo. Ce canal représente, a lui senl, l'ébanche initiale de tous les centres nervenx de l'adulte.

Ces trois apprareils, issus des deux feuillels blastodermiques primor- 
diaux, le nenraxe, la nolocorde, el le mésollerme, naissent l'une manière a peu pres synchronique. L'embryon, en cetle phase première de son évolution, rappelle, lans ses traits essentiels, un embryon de Tunicier; il possède, de mène, un ectoderme, un endoderme, un fenillet moyen intercalaire, un neuraxe el une nolocorde. La suile du développement dillère dans les denx eas, car ces trois systimes noureaux parviennent à une complexilé extrême, alors que leurs correspondants des Tuniciers demeurent stationnaires, ou se désagrègent, ou mème satrophient. Seuls, les restes des deux feuillets primilifs conservent une structure simple; l'ectoderme ne suljit guère de modifieations que dans les annexes des téguments; l'endoderme donne l'épithélium de l"intestin, et celui de ses glandes.

Les principales complications sont le fait du mésoderıne. Celui-ci, par sa désagrégation partielle, se dédoulıle en un mésenchyme et un éjithélio-mésoderme. Le premier se creuse d'un polrcœlome, disposé en un appareil irrigateur également double, composé d'un système sanguin el d'un système lymphatique. L'épilhélio-mésoderme entoure la carité cơlomique d'origine entéroçelienne, c'est-it-dire l'entérocrilome. Tuutes deux, paroi el cavité, se divisent, dans leur région dorsale, en segments placés ì la file; cette scission se nanifeste, en mème temps, dans les deux ébanches; puis, ces métamères se séprarent de la zone veutrale, qui demeure simple. l'épilhélio-mésoderne s'est alors scindé en quatre parties : deux ventrales, enlières, et symétriques; deux autres dorsales, on latéro-dorsales, également symétriques, Jont chacune consiste en une séric de pelites vésicules placées les unes derrière les autres. Les parois de ces segments mésodermiques domnent presque toute la muséulature dn corps; leurs cavités disparaissent. Par contre, l'entérocalome des bandes ventrales persiste, el trandit; il fournit la cavilé alılominale, on la cavité péritonéale, avec ses annexes, tels que la cavité péricardique et la cavité pleurale; ses parois restent épithéliales en majorité, et constituent les limitantes endothéliales de ces espaces. - La complexité açuise par la nolocorde n’est pas précisément de son fait; elle est due a la genèse, par le mésencliyme qui l'entoure, de pièces sịuelettiques nombreuses, et rolumineuses. Ces pieces s'orlonnent d'apres me disposition réglée par la structure métanérịue de l’épithélio-mésodlerme; du moins dans leurs traits essentiels. Enfin, le nenraxe sélargit dans son extrémité antérjeure pour donner l'encéphale, el proulnit de nombreux rameaux nerveux, sur l'arrangement desquels la métamérie du feuillet moyen exerce encore une action intense.

B. - Souvent d'autres phẻnomènes intervienment, qui contrilıent, ponr leur part, a augmenter la complication des procédés suivis, lans lnur développement, par les embryous des Vertébrés. - Lorsque les matérianx untrilifs, acenmules dans l'ovule, sont très abondanls, leur résorption est lente, et s'elf'ectue durant toute la période embryommaire; 
aussi le petit itre porte-t-il, annexé à sou corps, el diminuant de rolume à mesure que lui-mème se prerfectionne, mo vésicule vilelline. Celle-ci se compose the l'ensemhle des réserves alimentaires. - D'autre part, les Reptiles, les Oiseanx, el les Mammifères, c’est-à-lire les représentants de la section des Amniotes, ou des Allantoïdiens, se faconnent, pendant lenr déreloppement, les appendices spécianx: ces derniers sont des annexes embryonnaires stricts, car ils disparaissent au moment ou l̈individu parvienl à son état définitif. L'un est l'ammios, membrane envelopfante a double fenillet, formée aux dépens de l'ectodeme el de la somaInpleure du petit organisme. liantre est la vésicule allantoüde, appareil volumineux, comparahle à une expansion, engendrée par la région anale de l'intestin, qui s'étendrait au dehors du corłıs. L'allantö̈le se borne, chez les lieptiles, les (Jiseanx, les Mammifires monotrèmes, et les Didelphes, i dombler en dedans les conches chorionnaires extérieures. Elle lomme, clıe\% les Mammiferes monodelphes, le placenta, organe destiné à permettre, frar la voie sanguine, des ćchanges nutrilifs entre la mèe et te fintus.

Une tellecomplicalion des fhénomènes zénétiques, soit qüils correspondent a des formations d'organes persislants, soit quils aboulissent à la production d'annexes embryounaires. délermine, an fur el à mesure dn développement, des elangements considerahles lans l'allure de l'embryon. Ces mélamorphoses sont parfois externes; il en est ainsi, par exemple, chez un certain nombre de Vertélı́s inférienrs, tels que les Aeraniens, les Cyclostomes, les Ganoïles, les Amphibiens. Jont les unfs sont petits, et pauves en matériaux nutrilifs. - Plus souvent, elles sont internes, et se passent i l'abri des coques de liuuf, on s'effectuent dans l’intéricur des voies sexuelles du géncirateur femelle. Le premier cas se ramìne à une oviparité; la mère pond ses aufs, fécondés au préalable, on au moment mòme le la ponte; le petit embryon s'ébanche llans l’intérieur lu chorion dr ces derniers: tels sont la plupart des Sélaciens, les Téléostéens. des Reptiles, tous les Oiseaux, et les Mammifires monotrimes. Le second ras réponl à une viviparité; les changements d'aspect, subis par le jeune itre, s'effectuent daus les conduits sexuels de son générateur, oì il demenre enfermé jusqu’à son éclosion.

\section{2. - Des éléments sexuels.}

I. De la sexualité. - Ir monext de la sexualiti. - Dordinaire, les Vertébrés ne se reproduisent quaprès ètre parvonus à l'état arnlte; ce dernier ne consiste pas seulement en l'achevement de l'organisme entier, mais encore en l'acquisition de ses dimensions définitives. Il faut que l'économie soit complète, sons le double rapport de la structure et de la laille, pour permeltre à la fécontation de s'effectuer.

Il est ceprmbant les eas, fort rares, de progenese. Ceux-ci sont ofterts par llivers Amphibiens urodèles. - Le point de départ doit ètre 
pris, sous re rapport, lans des phénomènes accidentels, montrés par plusieurs des representants de cet ordre, et notamment par les Tritous. Cas ères, avant de parrenir à leur perfection, passent par une phase de perennibrunche, dite ainsi parce quils ressemblent it d'aulres Lrodides.

\section{7}

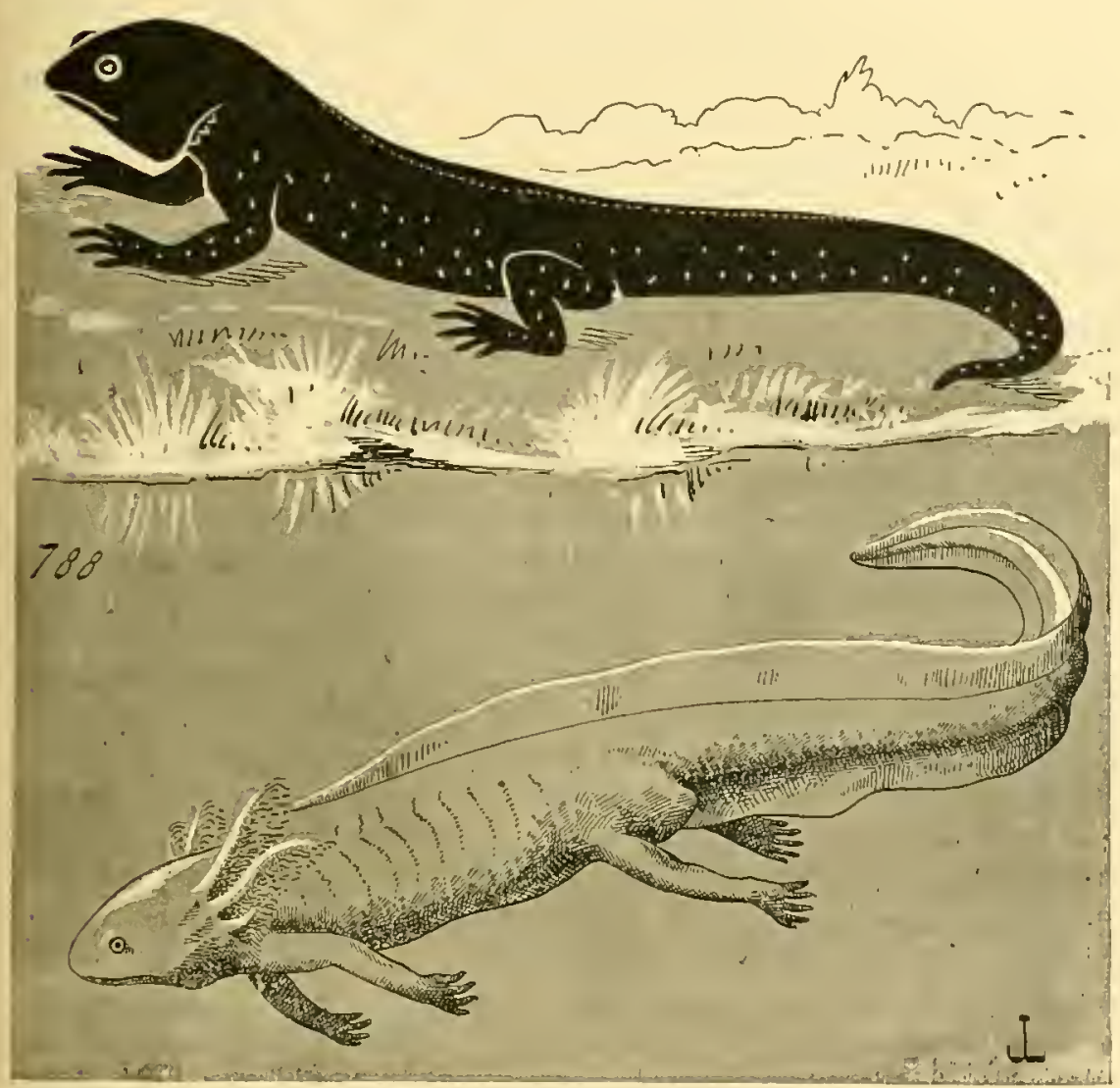

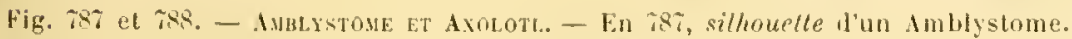
lin Txs, comlours de sa larve perennibanche (1xoloti).

composant le groupe du mème nom; ils possèdent alors des lurauchics extemes. bons la regle, les individus perdent res apjendices respiratoires, arrivent it l'élat adulte, et ne se reprodnisent qu'a ce momont.

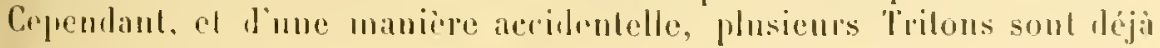


rapables de fícumdation, posserlent les glandes sexuelles susceptibles l'aclivité fonclionnclle, alors qu'ils portent encore leurs liranchies exlérieures.

Cette progenèse, aceidenlelle chez les Urodèles yui dépassont l'ílat de pérennibranche, de vient normale, el habituelle, chez plusicurs l'érenniluanches rais, notamment chez les Amblystome el les Batrachoseps. La dernière dus plases larvairrs de res animanx est caractérisée par lit possession de longues hranchirs externes, el par colle d'une nageoire caulale; les adultes sont privós de cette nageoire, et leurs brambies se trouvent internes pour la plus grande part. Sous la premiere forme, les individus virent dans l'ean; el sur le bord des mares, des roisseaux. mais en somme sur tere, dans la seconde. Or, si une rause quelconque vient à obliger ces itrus à demenrer dans l'ean. les glandes sexuelles n’en font pas moins leur apparition. et parviennent in malurité; les génératenrs, loul en étant encorr les larves, se fécondent, el de leurs anfs sortent des descendants, également capables diune reproduction prématurée. I'après les oliservations faites, cette progenèse dure prarfois, l'une manière constante et sans interruption, pendant plusieurs généralions. - On avail placé, autrefois. ces larves sexuées dans des geures dittérnts de reux des adnltes, ear on les considérait comme adultes rllesmìmes, à cause de leur pmuroir fécondant. L'erreur a élé reconnue, pour la premiere fois, par Duncril an sujet des Amblystomes: leurs larves sexuclles étaient lésiguées sous le nom de Siredon (Axololl). Cope a signalé un fail semblable pour les Batrachoseps, dont les larves sexuelles seraient les Henolurunchus.

Liorigine de cette progunese, an moins en ce qui tonche les dmblyslomes, pent ètre cherchíe dans les labiludes de ces animaux. Cenx-ci sr lécontrnt presque de suilr après lenr l'ansformalion dernière, nlors füils soul cueore dans l'eau; les femelles pondent des paquets d'rufs. sur lesquels les mìles déposent leurs spermatophores, e'ust-i-dire des masses de spermatozöles. Puis, tons les indivilus abandommonl four ancien milien, of vont vive en des endroils humides, lans la monsse, soms des feuilles on des caillonx: les anfs seuls restenl dans l'ean, ou ils ielosent. - II suffit d'un léger déplacement dans le lemps, d'un relard dans la mótamophose ullime, qui consiste en la chute de quelques appendices cxternes, on d'un avancement dans la maturité des glandes sexuelles, pour amener la proguèse. Celle-ci n'a doue pas, en allant au font les choses, toule l'importance qu'elle parail posséder an premicr aliond.

Natrre de la sexualute. - les Vertílués sont dans la rigle, unisexués; les excepulious, it bel ígarl, se tronvent etre fort rares. L'hermaphrodilisme se rapportr, en cutte unatière, a denx cas : l'hermaphroditisme vrai et l'hermaphroditisme appurent. Le premier est celui des glandes sexurlles elles-mènes, le seul, par suite, qui méritr ce nom: le second rist celui des conduits on los anuexis sexuels. 
4. - Lhermaphroditisme vori est de beancoup ho moins commmn: il consiste en ce lait. quiun iudiviulu déterminé possiale dos glanulus sexuclles dr deux sortes, les unes produisant des orules capaliles d"a lriver i malurile. les aules dommant des spermalozoührs dours du pouvoir fécondant. On ne le trouve guère a l'élal normal ct hahituel. yuc choz les Téléostéens apparlenant aux familles des serrunidés et ins sparilés; ces animaux ont leurs ovaires divisés en lonx zones, wont la première contiont les ovules, et la seconde dos spermatozoüles. Wo mème, les Cyclostomes de la famille dis Myxililés commencent par être miles, el deviemmont ensuite des femelles.

En revanche, cel hermaphroulitisme se manifeste assuz souvent it l'étal acciblentel, el se retrouve chez presque lous les Vertóbrés, mème les plus élevés en organisation. - On l’a signalí fréquemment chez les Crapauds (Bufo); les testicules de ces animaux sont sumontés par un appareil, dil l'organe de Bidder, qui n'est autre qu'un oraire, ronfermant des oufs assez déreloppés. Bourne a décrit, comme existant chez une Rana lemporaria, et spengel chez un Pelobales fuscus, une glandr sexuello composée de deux parties: la premiere contenait ales follicules ovulaires, des ovules avec leurs couches enveloppantes; la seconde élait pourvue de spermatozoïles. Ces deux régions sunissaient intimement; sur leur ligne le jonclion, les follicules de la premirre se mélangeaient aux tubes spermatiques de la seconde. le meme fait a chrignaló. plusieurs fois, comme se montrant chez des loissons (Morue. Ilareny), Hes Oiseaux. les Mammifères, el mène chez l'llomme. Ainsi lleppner a vu, sur un Homme, l'un des testicules renfermer des folliculos de Graff, alors que l’autre était normal. - Cet hermaphroulitisme accilcutel n'est point capable d'aboulir a une fócondation, bien quexistant dans la glandr mème. L’impossilililé. à cet égam, vient de deux causes : la maturilé souvent incomplète de lune des sorles lléléments soxurls: l'absence de conduils destinés à permottre la fícondation, el as assurer l'nxpulsion les aufs fícondés, on des rmliryons qui en risultent.

b. - Lhomaphroditisme apprarent est celui des ronduits sexuels, on des annexes exlérieurs de ces condnits, on rncore des disposilions propres aux sexes.

Le premier existe chez les embryons, encore fort jemes, dos Amniotes; il résulte le l’unité l'orierine, malgré leur diversite finalo. des conduils mâles et des combuts lemelles. Cos deux tỵes de cananx

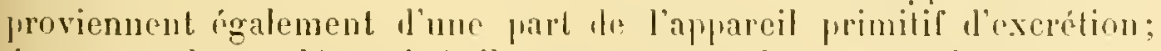
daus un embryon délerminé, ils se composent de fuatre lubrs, groupris en deux paires, dont l'me est placén ì droite, et lautre ì granche, de la ligne méliane. Les deux tubes de chaque paire commencent fra suivre un accroissement presque scmblable; puis, snivanl le sexe, l'un d'eux achève senl son évolution, l'iulle drmenranl slationnaire. le conduit developpé che\% la mile est dil to canal de Itronlf, al colui de lat 
fomello le romal de Mäller. Les dispositions deviennent donc diffírentes frar la suite, mais chos débutent par itre ibentiques; celle assimilation so trouve d'autant plus grande, que le canal frappé dedéchéance ne disjarait pras enliopement, et contracte des rapports étroils, mais de contiguïté sunle, aver la glambe scxurlle a laquelle il napparticnt pas en ríalité. - Ces relatious sout plus seruées au moment où le cluoix s'élablit entre les deux ramaux, ef plus grandes chez la femelle que chez le mile: le canal de Woolf pénctre dans le jeune ovaire, et y engenulre un lacis de rameaux, hien que l'ovilucte riel provienne lu canal de Mïller. - Phusieurs auteurs voient, lans ce phónomène, l'indication d'un hermaphroditisme foudanental, et primitif, qui se change en mnisexualité lans le cours de l'embryogénie, par la prédominance de l'un des appareils sur l'autre. Cepremant, eet lemaphoulitisme n'en est raimenl pas un; il n'est quapparent, car il porte sur les canaux vecteurs, et nou sur les glandes elles-mèmes. Il résulte, oumme il est dit plus haut, de l'unité d'origine de ces conduils, qui se développent l’une façon presque égale jusqu'an moment oi l'un d'eux prend l'avance, ef de l'alisence d'atrophie complète de l'appareil non utilisé. L'expression la julus convenable, susceptible de rembe le micux la mature los choses, est celle d'indifference sexuelle, et non d'hermaphroditisme. L'embryon, en ces phases initiales de son évolution, est encore indiflérent quant an sexe: il n’a pas de sexualité marquér, appréciable à nos seus; el, au moment où uno scxualité déterminée naîl dans la glande, le canal corresjondant so perfectionne seul jusqu'i complive structure. alors que l'autre demenre stationnaire, on peu s'en faut.

In second lype d"hermaphodilisme apparent est dommi par la disposition des annexes sexuets. Ces derniers proviennent des conduits précédents, et des tégumınts qui entourent leurs orifices extérieurs; ils sont arrangés de manieres disscmblables survant les sexes. Or, jl arrive parfois, et d'une façon tout accidentelle, qu'un individu déterminé possede, soit les anmexes les leux srxes, soit des appendices imparfaits et ambigus; des exemples de ces faits lératologiques sont assez fréquents, el plusieurs ont étó signalés, clıez l'llomme mème, à diverses reprises. L'hermaphrodilisne est ici tout d'apparence, en ce sens que l'individu n'est pourvu, en somme, que d'une senle sexualité; il est muni d'ovaires, on te testicules, et non des deux ensemble. L'expression d'hermaphrodilisme, arec sa siguificalion précise et complète, ne peut c̀tre appliquée it de tels phénomènes.

Enfin, un troisiome lype l'hermaphoulitisme apparent est donné par les apanages de la sexualité. Beaucoup de Vertélurés offrent un dimorphisme sexucl; los miles et les lenelles different par la coloration, ou far la jossession daus un ras, et labsence dans le secoud. l’écailles, de phumes, de poils, de hois, ou d'autres appendices particuliers. Il existe assez somvent, ef par un nouvean fait téralologique, que des indivilus, appartemant à un sexe létermine, offrent cependant les apanages de 


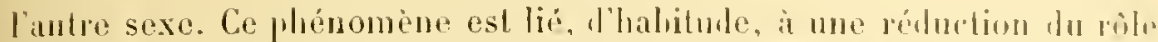

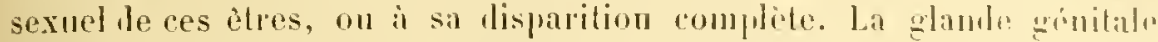
existo hien; mais elle est imapable de fonclionner an coltior. - Cos cas d'hermaphrorlitisme sont également l'applarence, au ils ticunont aux semls attributs sexuels, el ne touchenten rien les gamles : celles-ci sont des oraires, on des testicules, et non les deux ì la fois.

11. Des spermatozoides. - Les éléments màles sont engendris lans les tubes síminifieres lu lesticule. Lorsque l'organe est an rejos. chacum de ces tubes est presque rempli de cellules ì jeu pros semblables. tassces les unes conlre les aulres sur plusiem's conches, et assez nomlireuses pour ne laisser an canal qu'une lumicre fort étroite. Les choses changent au monent où la glande entre lans sa période d'artiviti. Les éléments se mulliplient rapidement, et se dillírencient en cellules de Jeux sortes. Les mes sont lomgues, cylimliques, et séparées les nnes les aulres par des espaces assez grands; les aulres, aromlies, gloluleuses, emplissent ces espaces. Celles-ci, dites cellules testiculaires, ou encore cellules rondes, subissent des divisions tres fréquentes, effectuées par kiryokinese, et augmentent heaucoup leur nombre. les premieres, nommées cellules it pied. cellules en chundelier, cellules de soutien, cellules de Serloli, demenrent à pen pres stationnaires, dies linstant oi elles sont parvenues ì lrur période d'état.

Etant donnée la présence dr res denx sortrs d’éléments, lorigine exacl. des spermatozoïdes prète rnoor it controvarses. Jes travanx publiés sur un tel sujet sont des plus nombeux, souvont combarloloires, of sappliquent il la plupart des rasses de Vertébrés; parmi les autrurs, les uns font provenir les spermatozö̈des des rellules lesticulaires, les autres des cellules dr soulien, les derniers les denx a ha fors. - I ru juger dapres les travaux les plus récents ut les mieux combluts, la verité parait ètre en faveur de la première opinion. Lus spermoblastes, renfermés dans les jeunes tubes séminiferes, se multijlient avro arlivité pour donner des spermatogemmes. Ces dermiers sont serrés les mus coutro los autres, à cause dr leur grande quantité, et de leur situation dans un tube étroil, mais n"en suirent pas moins lrur crolulion halitmelle, hien quon ne puisse distinguer lours limites. La cellule centrale de chacm deux devientle rytophore; chui-ci s'allongr, s'arcole par une de ses exlrémités a la paroi lu lule, et se convertit en me cellule de soutien, ponrve de son aspert particulier. Les spermalocytes ne sout autres que les collules tosticulaires des auteurs, qui subissent bes divisions répétées, dans le but d'accroitre lenr nombre, el finissent par se transformer en spermatozoïdes. - Il comvient. semble-t-il, d'rxplinuer de cette maniore, ot atin de la racorder à cello des autres animamx, la spermatogenise des lirlélués. les cellules lesticubaires sont serules chargées de fommir les spermatorö̈les; les allules de somlien romt, it cot igard, aucun ròle génótiqur. 
Les spermalozö̈des de lous les Vertélós ollrent une structure sembable, du moins daus leurs grands lails. Ils se composent toujours d'une léte et l'une longue quene. - La substance de celle demiòe est divisé en peliles tibrilles parallèles, peu lisceruables, groupées en deux lilaments: l'eusemblo de ces derujers, unis sur loule leur étendue par un cimrnt, constilue la queue; d'après l'arker, ces deux cordons seraient séparés l'un de liautre, el distincls, chez les Dipneustes du genre Protopterus. La partio de la quene, qui saltache à la tèle, est souvent borkée d'une simple lamelle protoplasmique, comparable à une crile minuscule; parlois, chez divers Amphibiens urodeles par exemple, celle crete sallonge, sur le reste de l'appendice, en une membrane ondulante. - La tele est la portion la plus large du spermatozoüle. Ses varialions d'aspect sont lris nombreuses, suivant les genres; elles vonl depuis une forme globuleuse jusqu'à une disprosilion en batomel, tanlôt droil, lantôt arqué, cl tantôl simueux; mais, malgré ces apparences diverses, sus relations et son allure générale ne rlungent point.

III. Des ovules. - La genise des arules soflectue fresque en deux temps, chez les Verhíbrés. Le premier temps va de la produclion de lovoliaste à la formation de l'orosemme; le second comprend les changements, subis par l’ovogemme, jusquà la déliscence de son ovoate. Durant le premier, lovoblaste se segmente un grand nombre le fors, et se converlil en un corps pluricellulaire, l'ovosemme; dans le deuxiame, les éléments de ce dernier se différencient en un ovocyle el flusicurs cellules folliculaires, celles-ci entourant celui-là. lovocyle lombe ensuile, apròs s'elre, au préalable, transformé en un ovule par l'expulsion de ses rellules polaires. - L'ovaire des Vertébrés fomelles contient um quanlití comsidérable de ces ovogemmes. l'resque tous, parmi ces demiers, mùnissent an mìme instant, et expulsent en méme lemps leurs ovules, du moins chez la plupart des représentants inférienrs de l'embranchement. Pal contre, chez les types supérieurs, Jont la fécondalion ne s'exerce a la fois que sur un chilfre restreint des ovules, la majorité des orogemmes ne joue aucun rôle aclif. Ainsi, l'ovaire dr la Femme conticut, en moyenne, de 30,000 i 10,000 de ces corps; quelques-mos a peine, dont les ovules sont rejelés lors des menstrues mensurlles, parconrent toutes les phases de lear léveloppenent.

1. - Les ovoryles, nowore nommés ourles primordiaux, sont l'abord silués a la surface de la jeune glande lenulle; ils s'y trouvenl mélangés à d'aulres éloments rallulaires, plus pelits queux. L'ensemble compose une

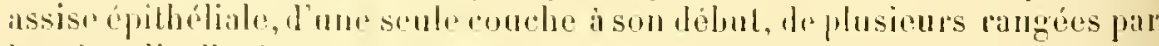

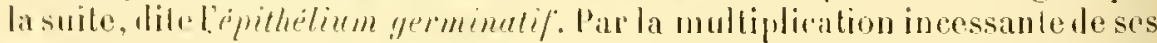

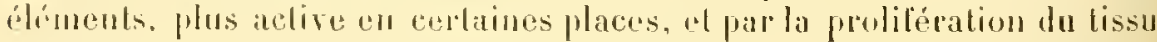
conjonetil sous-jacent, lophthilimm germinalif envoie des expansions dans l'interienr be l'ovaire. Ces expansions, souvent nommees les tubes 
de Iflüger, ollient l'aspect de cordons pleins; etles sétembent dans la substance périphérique de l'ovaire on elles constiturnt unr conche corlicale; elles sont séparées les unes des antres jar des hambes eonjonctives. Les élénents de ces cordons sonl ceux de l'ípithélimm graminatil. at appartiennent de meme is denx types. Cenx-ci correspondent anx denx sortes de cellules des ovogemmes. - A son rommenremrnt. l'apithélium

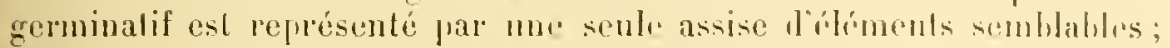
renx-ci se multiplient par karvolinise, augmentent lemr nombre dins des proportions considérables, et, re laisint, se différencient, les un en ovocytes, les autres en celfules folliculaires; les purmicts sont caractírisés par leur laille plus grande. Én somme. les éléments primordiaux de l'épithélium germinatif sont des ovohlastrs, qui, toul en demeurant rassemblés en un tout cohérent, se segmentent, et domnent des vrogemmes placís còte à còte, confondus sur lenr linites. Ces ovogemmes comprement, comme cliez les autres animaux, un orocrle volumineux, et de nombrenses eellules folliculaires plus restreintes; aussi, dès que les orocrtes se diflérencient de re yui les entoure, el re moment est vite atteint, l'épithélium crrminalif entier parait-il constitué far plusieurs ruuches d'éléments, dont les uns sont ggros, les autres plus petits et plus nomlırenx. Cet épithélinm correstond, en réalité, ì ume assise formée te nombremx ovogemmes intimemint mélangés.

La genese des cortons de la couche corticale est un rósullat de la multiplication des orogemmes, plus active par plares, ot do lit prolifération du lissn conjonclif sitno sous l'épithélinm germinatil. Chacun de ces cordons est conslitué comme l'assise llont il dérive, cest-it-lire se compose de plusieurs orogemmes juxtaposés. Il liost pas rare, Jurant ces phénomènes génétiques fort actifs, que plusieur's orocytes viennent à se rencontrer et ise lourher ils s'unissent, daus ce cas, en mu syncytiom, destiné i ne devenir qu'un sen! ovole, par la destruction de tons les noraux, sauf un. Ces corps complexes sont dits, parfois, des nids dovules. De mème, les ovocytes alssorhent, fiar un frocédé semblable, Husienrs des cellulus folliculaires roisines, et aummontent de taille à leur's dépens. - Linsi, denx fhénomenes s'eflectuent d'une manière prarallile. Wune parl, la pénétralion des wogemmes; ceux-ci abaulonnent la surface da jeune oraire, et pénètrent dans son intiricur. D'autre part, laceroissement des wrocytes de ces ovugemmes: cette amplification s'effeclue par une alsopption des filiments voisins. Les dispositions olfortes par les Vertétrés ne sécartent done fas de relles présentées par les antres animaux; sauf guelques parlicularités, d'importance secontaire sons le rapport de l'ovogenosis, at dent la prin-

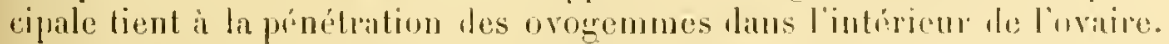

Jeux autres modifieations se produisent ensuite. - Les ovongummes,

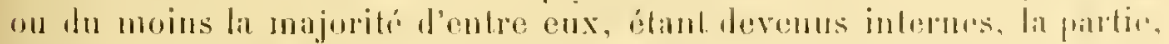

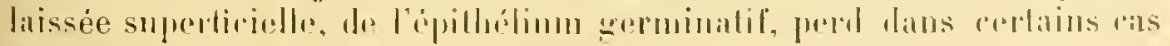

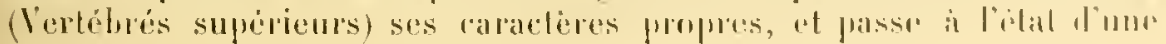


assise indiflérenle, simple, composéc de cellules semblables. Cette assise demrure inerte quant à la genese des ovules, et persiste ainsi i la surface de l'ovaire atcheve; elle s'mnil, par ses bords, à l'endothélium péritonéal. Tonte l’activité productrirr est concentrée dans les ovogrommes internes. Liensemble te ces derniers est mime sipari. de la conche précédente et superficielle, par une bande de tissu conjonctif. le plus, par la proliféralion constante des bandes connctives interposées anx cordons ovariens, cenx-cj sont morcelés, el divisés en fragments. Chacun de ces lerniers se rompose d'un rhillie restroint l'ovocytes, parfois mème d'un seul, entourés de nombreuses cellules folliculaires. Guel que soit le cas, le résultat atteint est le mème. Chaque tronçon s'arrondit, prend une forme régulière, el ne contient plus qu'un seul ovoryte; soit que les supplémentaires se résorlent, soit quils sunissent à celui quj lemenre, ponr contribur a son accroissement. Les rordons ont alor's perdu leur aspect initial; ils soul partagés en un certain nombre de corps spluériques, dont chacun renferme un ovocyte. Ces corps réponJent, en réalité, à autant d'orogemmes, et nom devrait hur ètre accordé; l'expression de follicules avoriens, on mume drofollicules tout rourl, est cependant d'un usage géméral, malgré son inexactitude. car elle désigne le toul par une de ses parlies.

L'ovaire est alors arrivé, ou peu s'en faut, à sa période d'útat. Sa substance est divisée en deux parts: nn bulbe central, constilué par un tissu conjonctivo-musculaire, richement vascularisé, et privé d'ovogemmes, car les cordons n’ont pas pénétré jusqu’ì lui; el une couche corticale. Celle-ci se composr, en allant de dehors en ledans : du reste le l'épitıélium gelminatif; de la bande conjonclive sous-jacente; et de lamas des ovogemmes. Ces lermirrs subissent ensuite des llangements, yni ont pour effel de leur donner leur structure complète. - Pundant ce temps, l'épilhélinm germinatif foumit te nouveaux corlons, dont l’évolution est semblable à celle le leurs frélécessenrs. Il en est du moins ainsj cle\% presque tous les Verlébrésinfíricurs, et mème quelques Mammifères, comme les Chanves-souris. Dans l'antres cas, la production les ovogemmes s'eflectue dams le conrs des premières périorles de l'existence, et cesse ensuite; ainsi, chez la femme, les la denxìme ou la troisième année, l'ovaire n'engendre plus d'ovogummes. La phrpart les Vertébrés supérieurs entrent dans ce type; sauf l'instant de la cessation, d’autant plus tardif que le chiflre des ovules, rujetés par l'ovaire durant la vie du générateur, est plus considirable.

B. - Dis que les orogemmes sont séprarés les uns les autres, et listinets, js subissent des morlifications, qui se succivent jusquan moment le leur maturité, et de l'expulsion de leur ovule. Parmi ces changements, les uns sont les mèmes chez tous les Vertélırís, les autres diflérent suivant les groupes.

Les premiers ont trait à l'isolement de l'ovogemme, à l'accroissement 
de lovocyte, et à sa maturation. - La trame conjonctive de liuvidre donne, a chaque orogemme, une enveloppe particulièr, asso danse, qui lui forme une paroi propre. En dedans lde cette paroi se trume lorogemme, constilué par l'ovoryte entouré le ses cellules follinulaires: celles-ci, fort nombreuses, loules semblables. tassies parrois sur plusieurs conches, composent une membrane épaisse. disprosíe antour te l'orocyte. - Ce dernier s'accroil. el grandit; il emprunte ses matériaux mutritifs aux cellules folliculaires, qui les puisent ollesmèmes dans le tissu de l'envelophe conjonclive, riche en capillaires sanguins el lymphatiques. We plus, il s'entonre thue membran' vitelline, la sone pellucide les auteurs, assn'z épaisse, et souvent perríe w. canalicules, darrs lesquels s'engagent les expansions émises par les cellules folliculaires. - Enfin, l'ovocyte mùrit, c'est-ä-dire se conrirtit en orule prar le rejet de deux cellules polaires. Ce phénomène n’a pas élé observé ehez lous les Verlébrés. On l'a signalé chez des représentants de classes diverses : des Hammifères, des Amplibiens, des Sélaciens. Ce fail, joint anx données de l'embryologie générale, permet de croire à sa présence constante. D’apres les résultals acquis. l'expulsion des cellules polaires s'effectue quelque temps arant la chute de l'orule yui les émet, el non au mème instant.

Les modifications dissemblables se rapportent it deux ordres de faits: ì la forme défnitive de l'orogemme, et au moment de la chute de l'orule.

Aulant qu'il est permis de généraliser d’après les notions connnes. el sans trop procéder d'une manière exelusive, il est permis de grouper les Verlébrés, sous le rapport de l'aspect olfert par l'orogemme, en deux séries. - La première renferme la pluprart des représentants de l'embranchement, sauf les llammifères. les cellules folliculaires s'allongent, en rayonmant autour de l'orule, et deviennent eylindriques. Leur cnsemble demenre compact. - Tel n'est pas le ras des Mammifères. Leurs éléments folliculaires commencent bien par s’allonger, comme dans la premiere série: mais ils se divisent à mesurr, el se partagent en un nombre considérahle de petites cellules cuhifues, ilisjosées sur fylusieurs couches concentriques. Cette assise folliculaire, d'une disposition spéciale, est depuis longtemp's désignée par les auteurs sous le nom de membrane granuleuse. De phus. me cavití, remplie l'un liquide, su creuse dans cette assise, el grandil rapidenent; il cel elfid, elle refoule autour d'elle toutes les cellules du follienle, et l'orule luimène. l'ovogemme, entouré par son enveloppe conjonclive, cesse l'èlre compact; il est converti en une vésicule creuse, dont la volumineuse carité contient un liquile, el dont la paroi est conslitue par ses propres élements, ovule el cellules folliculaires. La région werupér par lorule est plus éfaisse que les antres, à cause de la gramble laille de re dernier; cllı fail saillie daus la cavité centrale. lille porte nn uon parliculier : celui de cumulus proligire, on de disque proligere. Cet ovogernmes 
erenx des Mammiferes esl lésigné, d'habitude, par les expressions de vesicule de Cirulf, on de follicule de Graff; l'anatomiste de re nom est, en effel, le promier qui l'ail signalé, en le prenanl poul l'ovule lui-nème.

les ovulrs, parvenus a inaturité, som mis en liberté par la rupture de leur follicule. - Daus le cas des Vertébrés inléricurs, des unfs, en quanlité considérahle, sont expulsés en mène lemps; étant donnée la silualion de lovare dans l'organisme, ils tombent dans la cavité abdominale, ou ils sonl jris prar les canaux sexuels. - Les Sauropsirlés, les Mammiferes, el mème un certain nombre de Vertébrés inférieurs, la phupart des Sélaciens par exemple, jondent un chilhre d'ovules plus jestreint; parfois mème, ce chilf’re ne dépasse pas un ou deux. D'ordimaire, chez ces animanx, les anfs s'engageut, des leur expulsion de lovaire, dans les conduits sexuels, can ceux-ci appliquent leur pavillon sur la glande femelle, el suppriment ainsi la traverséc do la cavité abdominale.

Lovogemme des Mammifires, à cause de sa laille considríable, due à la possession d'une vaste carité centrale, forme mo sorte de petite plaie, a la surlace de l'ovaire, après la chute de l'ovule qu'il contenail; celle plaie, occasionnée par un trammatisme natmel et très localisé, se répare el se cicatrise. Lorsque l'ovule a élé fécondé, la région sexuelle esl le siege d’une congestion intense, nécessitée par la genese du placenla; cotte congestion relentil sur l'ovaire. Les léluis le l'ovogemme, ainsi suralimentes, grandissent; mne certaine quanlité de sang, lue it la ruplure des vaisseanx de l'enveloppe conjonclive, lor's de l'expulsion de lovule, emplit la cavilé rentralı; les cellules folliculaires anguentent en nombre, puis se lésolvent en granulations; des phagoeyles pénètrent dans l’apprareil ainsi modifié, s'y mulliplient, et y subissent de mème une dégénérescence granuleuse par clasmatose. En somme, l'ovogemme entier subil des phénomines pathologiques d'hypertrophie, suivis l"une atrophie, yni fait disparaitre loutes les productions nourelles, ne laissant en place qu'un nodnle conjonclif, plus pelilque l'ovogrmme primorilial. Au commencement de ces modificalions, le sang extravasé, et coagulé, donne à l'appareil une leinte jame rougeàtre : l'oì le nom decorps junne, accorté à l'ovogemmu ainsi transformé. - Dans le cas où l'ovule n’a pas élé fécondé, la congrestion de la région sexuello n'existe pas, ot les phases d'hypertrophie sont heancoup moins aecentuées. L'ovogenme onvert, rempli de sang exlravasé, se répare lirectement, et s'alrophie; il ressemble an précelent, mais il est plus pelit; on le nomme alors mon funx corps jumbe.

Ces phónominus, relalifs i la ggenese des vésientes de Grafl, et aux molilications qui suimol la chule de leurs ornles, nout gucre élé ćludiés que clıez les Mammilióres supérieurs; du moins lans tous lenrs délails. (Jn ne sail trop, par suite, comment les raltacher and particularilís oflertes par les antros lemébes. 
IV. De la fécondation et de la gestation. - N"une minniiru génórale, les Vertébrés intérieurs, c’est-a-dire les Acraniens, les Cuclustomes, el les lchtlyopsides, sont ovipares, el pourvus d'une fécondalion exlerne; les saurojisibes sont igalement wripares, mais avec fécondation interne: enfu, les Mammiferes sont vivipares, of leur fécondation se trouve forcément ètre interne. - Les lemelles des premiers rejeflent dans le milieu qui les entoure, et ce milien est l'eau, leurs mil's nou encore imprégnés: les mìles s'approchent de ces dernirs, ot irposent sur eux leur sperme, à moins, fail encore friquent, quils ne l'expulsent des sa maturilé, laissant, à des circonstances faromaliles de tempis el de lieu, le soin d'amener la lécombation. Les mảles les Sampupidés, munis d'organes copulatenrs, Ju moins dans le plus grand nombre drs cas, lancent, par leur moyen, le sperme dans les conduits sexuels femelles; les spermatozoïdes remontent dans ces derniers, sapprochent de l'ovaire, des aufs parvenus à maturitó, et les fécontent; cenx-ci, ainsi fócondés, sont immédiatement pomlus par les femelles, mais ne parienuent an lehors quaprès s'ètre unis aux éliments màles. Enfu, rliez les Manmifères, le màle fait également parvenir son sperme dans l'oviducle de liı femelle, el la fécombation s'eflectue sur l'ovaine, on non loin de lui: mais, moins quelyues rares axceptions, la femelle conserve, dans mue région donnéc de ses voies sexuelles, dite l'utérus ou la matrice, ses roufs fécondés, el les grarle pendant qu’ils éroluent en embryous. Cenxci sont rejetés au moment où, sauf par la taille, leur organisme est complet, ou lien approche de son achèvement.

Ces trois jrocédés, dans leur ensemlıle, sont listrilıués d'une maniere assez precise; ils permellent de suivre, sous ce rapport, la conplexité croissante oflerto par les Vertébrés. Cependaut. leur répratilion supporte des exceptions assez nombreuses.

Les Acraniens sont miscsués, ef ovipares; leur fécondation est extérieure. - Il en est de mème chez les Cyclostomes; senlement les phénomenes sont compliques, dans le cas des Myxinilés, par lit présence de l'hermaphroditisme. A en juger l'apris la moyenue les olsservations faites, la fécondation nécessite pourtant l'emploi de deux imlividus, el non celui d'un senl. Tolormaphroditisne des Myines est suceessif: l'ètre commence par ètre mile, el ne devient femelle qu'au momenl wi il termine son aceroissement. Inas le premier étal, la partie postérinure de la glande sexuelle achove senle son évolulion; elle ne contient yno hes spermatozö̈les, el l’indivilu foncliomne alors comme male. Plus tard, celle régrion s'atrophic; l'extrémití antérieure de lapparcil se développe ì son tour, el ne lonne que des ornles; l'animal est sénlement

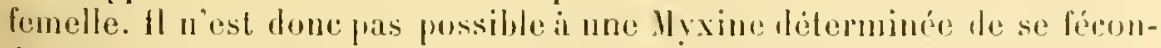

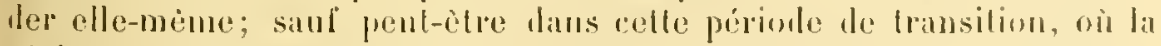

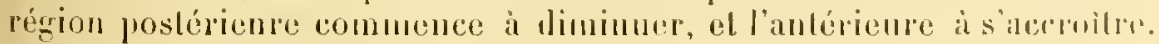

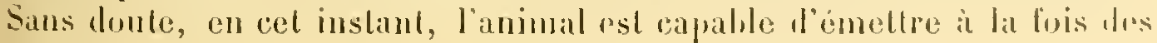


spermalozö̈les el des ovules mirs, qui se rencontrent, soil dans la

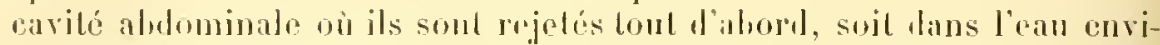
ronmante oil ils pariennent ensule, w s'unissent; il y aurail alors une antofécomlation.

Par nne exceplion, les mieux caractérisées parmi celles que présentrut les lchthyopsidés, les Sélaciens ont une l'ícondalion inlerne, el les males sonl pourvus, à cel effet, d'organes copulateurs; en outre, la plupart de ces amimanx soul vivipares. - Les Sélaciens ovipares rappellent los simmopsidés; le màle envoie son sperme dans les oviductes do la femelle, el cetle demiòe pond les aufs déjá fúcondés: ceux-ci sout entourés d'une épaisse corue comée. - Les principaux des Sélacjens vivipares apparliennenl aux genres Curchurias, Mustelus, et Torpedo. A la suile lune grande dimimulion dans la laille les glandes sécrélrices le la corfue, celle dernière est fort mince; les aufs fécondés sarrèlent dans un ulérus, partie de l'oviducle plus larere que les régrions voisines, el s'y developpent; la femelle met an monde, par ce moven, des petits lout formés. l'arfois mème, chon le Iustelus levis par "xemple, chezles C'archarias, il se produil un placenta.

Les Ganoüles et les Dijuneustes sont des ovijares, à la fécondalion externe. - les phénomènes sont des phus divers chez les léléostéeus. l'resune tous les représenlants de celle classe sont, comme les précédents, des animaux ovipares, dont la fécondation esl rxtérieure; le mile rejelte ses spermalozoides dans l'ean, la femelle agit le mème pour ses wrules, el la fécondalion s'elfeclue lors des renconlres fortuiles de res éléments sexuels. I'usicurs espices oll'rent cependant des phénomènes parliculiers. - Les mos sont hermaphrodiles. Cet hermaplurodilisme est régulier et normal chez les Serranidís el les Sparidés; lous les individus possident des ovaires, qui conliennent un lesticnle dans les parois de lrur oviducle. Seulement, les lesticules des Sorranidés arrivent a maturitir en mòme temps que los ovaires, d'où résulte une aulofécondation; alors que les lisposilions correspondantes des Sparidés ne paraissent pas synchrones, d'oi fécondation croisí, malgré l'hermaphroditisme. Ce dernier "as ast aussi celui, semble-t-il, les léléostérus pourvus accidentelloment de l'hermaphroblisme; tels divers Scombélides du gemre Scomber (Maquereau), plusicurs Clupéilés (Hareng) el Gadilés (Morne). - Iresque loutrs les femelles des Tóbostéms se hornent a rejeler lenrs ovinles, non lécondés encore, dans l'rau qui les environne. Parlois cependant, au moven de matériaux itrangers, le mile élablit me sorte de nill, oủ la femelle vient pondre, et ou il dépose ensuite son sperme; les Einoches sont surloml remarquables a cel égard. Il s'étahlit alors mne incubation dans er mil, car les anfs fécondés commencent à s'y développer. Ce phénomène effeclue une lransition vers la viviparité, en ce sens qur lincubalion, au lien d’ètre opérée en dehors re l’individu, s’eflicetue alors lans une partie du rorps du génératour.

La premience judication de celte riviparilé des Téléostéens consisto en 
ce fait, que les oufs sont lien pondus par la femellr. el férondes luors de ses roies sexuelles, mais sonl conserris ensuite, soit par elle, suit par le màlr, dans une rigion où ils se ronvertissent en cunlurons. les

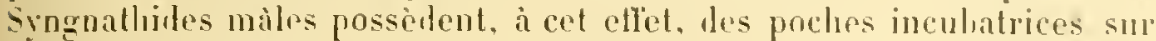
leur face ventrale, formées par leurs téguments, ou ils portent les petits; les Chromis pater-familias incubent dans leur bouche. Les fomelles, chez d'autres espèces, accomplissent ce ròle; tels les Asmerlo hatrachus, et surtout les Solenostomum, qui gardent leurs muls attachés sur leur face rentrale, soit par simple adlórence (Aspredo), soit par la produrtion d'une ravité incubatrice, domée par la sondure des nagreoires ventrales (Solénostomes). Quel que soit le procédé, les descendants, au moment oì ils deviemment libres daus les milieux rxtirienrs, et où ils sont abandonnós par lenrs générateurs, sont presque complets. - l'élat ullime de cetle viviparité se préscnte, lorsiue lincubation a lien dans l'ovilucle; elle rappelle alors celle des Sílaciens vivipares; tels sont les Sébastes, les Embiolocides, les Cyprinodontides, et beaucoup de lilennides. La région où se trouvent les embryons est proche de l'ovaire; parfois même. ces ètres commenrent à se dérelopper sur place, daus la glande sexuell. mème. W'habitude, la paroi conjonctive des ovogemues renferme de nombremx capillaires sanguins: lovule de chaque ovogemure est fécomdi sur l'ovaire, car la fécombation est interue, et se dévelople de suite. le jeune embryon se nourril, par endosmose, aux dépens du sang contenu dans la paroi conjonctire; il passe peu ì peu, tout en s'alimentant he cette manière, dans la région élargie de lovidurte. Cluez les Cyprinodontides, la vésicule vitelline de l'embryon produril, en surplus, des villosités. qui pénètrunt lans des anfrartuosités rorrespondantes le lenvelopye conjonrtive, el composent un sorte wr plarenta. Les phrinomènes offerts par les Blennides du genre Zoarces sont plus complexes encore; les embryons se nourrissent, en faisant parronil dans leur intestiu un liquide, renfermé daus une ravité dont lovare est creusé. el oir ils sont eux-mèmes placés.

Les Amphiliens offrent, en ce quj roncerne res pluénomenes, une série comparalile a la prorivlente. - la plupart des Lrouleles sont des ovipares i la férondation extericure; le mile et la fomelle rejettent lenrs produits scauels dans l'eau; mais le hasad ne joue pas un roh anssi ronsidérable que rluez la majorité des Téléostéens, car, an moment le la miturité fécondatrice, le male poursuit la femellı, ot lérerse son sperme sur les rufs, au moment mème où colle-ci les pond. Ce fail permet dr comprendre lrs lispositions présentées par les Inomes: celles-ri se ramènent à une sorle daceouplenent. la forombation étant rxlérirure cncore. Le màle saisit la fomelle, approche son oritive roical de relui de celtr deruiore, et ficonde les arufs, avec son sprime, au fur et a mesure de lenr sortie. - Dans cerlains cas, cette imprégnalion extirieure, aceompagnée d'aceouplement, se double d'unr inculsation. Clet. 
les llytes obstetricans, Ir male se borne il onroulor, autour de ses pathes, le paquet d'eufs léconılís; il s'enlonce ensuite lans la trore bumile, ot lemeure ainsi, jusquau moment où les embryons commencent à être déji bien formés. Les phénomènes sont un peu plus complexes chez les l'ipa, les Rhinoderma. Ies Notodelphys; le mile, au lieu de garder les arufs, les dépose surla face dorsale du rorps de la femelle, oì s'ellectne l'inculation, dans dus poches disposées ì cet relfet; les Notodelphys nont qu'une porbe incubatriru pour tons les embryons, alors que les Pigra rn ont plusirurs, une pour chaque ambryon. - Ces animaux sont encore ovipares; Jour fócondation est externe. Mais lour incnbation prermet de passer à la viviparité qu'othrent plusicurs espèces d'Amphibiens, lels que les Urodèles apparlenant í deux espeees de Salamandres, la Salamandra atra el la š. maeulosa. L'inculation s'effectue alors dans l'oviducte, el les petils sont rejetés lorsqu'ils sont toul formés; ce changement de procédé amène la viviparité, et nécessite nue fécondation interne.

Les Reptiles et les Oiseaux sont tous ovipares, sauf de rares exceptions. Leur fécondation est toujours interne; les miles possèlent, ì cel effet, des organes d'accouplement. D'habitude, après l'arcouplement, les Reptiles fomelles placent leurs rufs, fécondés el pondus, dans un mulroil ahrité, et les abandonment. Quelques Oiseaux agissent ainsi; mais la plupart de ces derniers construisent mu nid, où les anfs sont léprosés, et courís, soit par la femelle, soit par le male, soil, et tour i tour, par les denx; dans ce dernier cas, comme dans le second, le màle concourt à l’élification du nid, fahrigué au moven de matériaux ítrangors, intriqués les uns avec les autres, ou accolés prar un mucus partirulier. - Les Sauropsiłés vivipares sont fort rares; ils appartiennent il la classe des lieptiles, et aux deux ordres les Ophidiens et des Sauriens. Les premicrs sont les Vipures, les IIydrophis; Irs seconds sont les Orrets (Scincoüdés). Après la fécondation, la femelle, au lien le pondre ses unfs, les conserve dans son oviducte; les embryons y éclosenl, y parcomrent la plupart des phases de leur développement, el sont rejetés ensuite. La riviparité de res animaux est donc nne morlification, relatirement simple, le l'oviparité habituelle, car elle résulle d'un retard laus le moment de la ponte, tous les autres phénomènes étant illenliques.

La classe des Mammifères contient it la fois des animaux ovipares et des vivipares. Malgré cetle diversité, lous ces itres ollrent deux caraclires conmuns: la fécondation, toujours interne, s'elfectue au moyen l'organes cojulateurs; les petits, encore très faibles an moment oì ils sont rejetés lans les milieux rxtérieurs, sont nourris par la femelle, alimentés par le lait qu’elle sécrète, el protégés par alle. - Les Honotrèmes sont ovipares. L'Ornithorhymine femelle pont leux œufs, quelle ne conserve pas sur elle, el qu'elte place dans une sorte de nill, arrangé au fond de son terrier. L'Eehilné est plus avancé dans la série qui va 
de l'oviparité à la viviparilé; la femelle poul un seul anf, qu'elle garde avec elle, el quelle dépose dans une cavité incubatrice, sa poclre malsupiale, placér sur l'ahlomen. J'Eehilné élahlit, par lì, une transition entre loviparite franche des Ornithorhynumes at la riviparile dos aulres Hammifères: cenx-ci conservent les ands fícondés lans lours roies sexuelles, oi ils se convertissent en embryons. - l'armi les Mammifères vivipares, les Marsupianx, encore nommes Ililelphes pour la raison suivaute, sont à peine supérieurs aux Echidnés. Les femelles fécondées gardent bien leurs ovules dans leurs oviducles, oi les embryons sulissent me premiere gestation; mais elles expulsent hatirement ees derniers, bien arant que leur organisme soil achevé, el les recueillent dans la poche marsupiale. les petils terminent la lent développement, duranl celte seconde grestation. Lal seule difierence, élablie entre les Marsupiaux el l'kehiduc, est semblahle à celle menlionnée cutre les Reptiles vivipares el les ovipares; elle porte sur un retard dans le moment de la ponte, sur une prolongalion du sijomr des rufs fécoulés dans les voies sexurlles de la femelle. - Les Mammiferes monoulelphes composent le terme ultime. La poche marsupiale, et la seconde gestation par suile, sont supprimées. Les orules fécondris s'arrètent dans loviducle de la femelle, oni ils oreupent me région spiriale, destinéc à les recevoir, lulerus; ils s'y ronverlissent en embryons, el y parcourent toutos les phases de leur ivolulion. Ils sont alimentris par le placenta, Iont les Didelphes et les Monotrimes sont privós, et sont mis au monde lorsque leur organisme as acheve, ou pen s'en fant; l'allaitement maternel leur suftit ensuite pour terminrr leur déseloppement.

La viviparilé, olferte par la majorité des llammifères, se relie ainsi a l'oviparité dos Oruilhorhynques, semblable à son lour, al lo lous points, i celle des lieptiles el des Uiscaux. La transilion est effectuée par los Eichirlnis el les lidelphes.

\section{3. - Des feuillets blastodermiques en général, et de l'origine première des organes.}

Les Vertébrés ne se ressemblent point, sous le rapjort de la grenese de leurs fenillets hlastodermiques. Jes diflörences sont tres grandes des uns aux autres, en ce qui regarde ces phénomènes; elles sont causces par les altóralions qu'entrainent les exigences de la nutrition embryonnaire, et répondent ì des déplacenents considerables, soit dans le temps, soit dans l'espace, voire mème à des omissions. Pourtant, ces dissemblances natleignent gucie que les procódes employis; Ies dnnnées essentielles du développement ne varient pas. Ces dernieres sout indiquées, avee une précision suffisante, par les faits connus des évolulious dilatées; elles permettent de comprendre, ensuite, la nalure et la valenr Jes modifications inlroduites dans les embryogénies condensées. 
I. Donnèes essentielles du développement des feuillets blastodermiques. - Les fenillets des Vertéluris sont, comme cenx les autres Colomates, an nombre de trois, et disposés de mèmo: l'ertodrrme, le mésoderme, el l'endoderme. Comme la première, el la dernière, de res assises, prorluisent liativenent deux organes, le neuraxe et la notocorle, qui règlent la disposition les autres parties du corps; comme la formation de ces deux apprareils est étroitement liée i celle des fenillets eux-mèmes; la présente étude s’appliquera à tous ces éléments fondamentaux de l'économie.

(iexése des reuhlets hlastodermoques prinorducx. - Dans les embryoginies dilatées, ces fenillets sont engendrés par une gastrulation invaginante. l'ovule fécondé se segmente, se convertit en une mornle, puis en une hlastule; cette dernière se transforme, ì son tour, en une gastrule, par l'invagination d'uno partie du hastoderme dans l'autre. Én ce moment de son évolution, l'organisme embryonnaire se compose seulement des tenx feuillets primortianx : le protectoderme en dehor's, el le protentuderme en dedaus. Le premier occupe la surface de l'embryon; le second limite la cavité entérique. Celle-ci communipur aver l'extérieur par l'entéropore; cet orifice, d'abord central, devient excentripue pen à peu, à la suite de l'aceroissement inégal pris par le petit être. 'Tout comme chez les Tuniejers, il est reporté dans une région postérienre cl dorsale. Les premières éhauches du neuraxe naissent sur ses hords, et, par leur apparition, déterminent sa fermeture.

Le protectoderme produit le neuraxe, et se convertit tout entier en ertoderme définitif. Le protendoderme subit des modifications plus romplexes; il domne d'aloril naissance, el en mème temps, ì la notoconde, ainsi qu'au mésoderme; après quoi, il demenre comme muluderme définitif. Le mésoderme se suldivise, à son tour, en mésenchyme el épithólio-mésolderme. Celui-ci partage sa région dorsale en segments, disposés. par paires, a la tile les uns des autres; ces lemiersse séparent de la zone ventrale, qui temenre entière, et se convertissent en flayues musculaires.

Les principaux des phénomines génétiques, offerts par los feuillets blastodermiques primordianx, se rapportent done à la formation, el au développement, du mésoderme, du neuraxe, et de la notocorde. Le protectoderme jestant levient l'ertoderme, ou l'épiderme, pui recouvre le corps. Le protendoderme, le son còté, donne l'épithélium de l'intestin et de ses ammexes. L'entéron, à son lour, persiste comme cavité de ce dernier systime organique; l'abort clos, au moment oi le neuraxe commence ì s'éluancher sur los lèves de l'entéropore, il ne larde pas à souvrir au dehors par deux ouvertures nouvelfrs, Ia louche et l'anus. Tontes deux sont les uritices extérien's de deux dépressions ectodermiques, le stomeon el lo procteon, qui vont à la rencontre de l'entéron pour s'unir a lui : la première fournit la cavité buccale, aver une part 
du pharyx; la seconde donme une parlie dn rectum. Le stomeon prend naissance dans la région antérieure du corps, an-dessous de l'extrémiti de ce dernier, dans une zone opposéc a l’ancien antéropore; la procteon se delimite également sur la face ventrale de l'organisme. el, Jans ses traits essentiels, un peu en avant du nivem transversal pui passerait par l'emplacement de l'entéropore fermé.

GeNése et développenext du nesodenue : to cienise. - L'évolulion du feuillel moyen des Vertébrés se résume dans les données suivantes. Les ébauches du mésoderme sont au nomlıre de de ux; symétriques, elles se trourent placées de part ef l'autre de la ligne médiane; elles correspoudent à des entérocules, c’est-i-dire à des diverticules émanés le l'entéron; elles ne tardent pas a derenir. des résicules closes, par la fermeture de leur orifice de communication arec la cavité entérípe. Tu fait de leur apparition, le protendoderme initial se trouve suldivisé ess endoderme définitif et mésoderme. - Les deux jarls de é derniej grandissent également, et sinsinuent, à mesure, cutre l'ectoderme et lendoderme. Leur accroissement comporte l'amgmentation, par une prolifération constante, du nombre des cellules ile leurs parois. Tous les nouveaux éléments produits ne dencurent jas daus la paroi mème, de manière ì la constitues en ce qui les regarde: cette disposition est celle de quelques-uns d'entre eux, mais non des antres. Ces lemiers abandoment les assises, à forme régulière el à struclure épithéliale, dont ils proviennent, et ront en dehors l'ellies; ils se grlissent, de cette façon, cntre ces couches d'un côté, al, suivant le cats, l'ectorlerme ou l'endoderme de l'autre: ils séparent, du feuillet exterue de l'organisme. ou du feuillet interne, les parois mésodermiques memieres. En agissant ainsi, ils conservent l'aspect mésenchymateux. quils avaient des leur début.

Le mésoderme s'est donc sululivisé, à son tour, en deux parls : l'une eppithéliale, l'épithélio-mésuderme, rejrésentée prar les assises rígulières qui continuent directement les prois les entérurudes prinordiaux; la seconde mésenchymateuse, engendrée prar la précédente. et située en delurs d'elle. Le fenillet moỵen des lertélorés est doulule, par consiquent; chacuse de ses leux composantes contient un système particulies, et indépendant, de cavilés. - Les vides, creusés daus l’épillhiliomésoderne, dérivent des cavités placíes dans les denx entrirocules; celles-ci ont été engendrées, te leur culé, par l'espace entérique, dont elles sont des diverticules. Liensemble de ces vides répond it un enterocelome. Celui-ci se cloisonne bien, pendant pue son feuillet limitant se scinde en segments: mais les cloisons ne tardent pas i disparailue, el les seules parts persistantes de l'entéroculone sont amples, el simples. Eilles composent un uligocalome, quj comprend lit euvité prírionéale, ou abdominale, ou générale, de tous les lestébrés, et la cavité péricardique, aree la cavité pleurale, de quelpues-uns d'entre ax. - Las cavilés. 


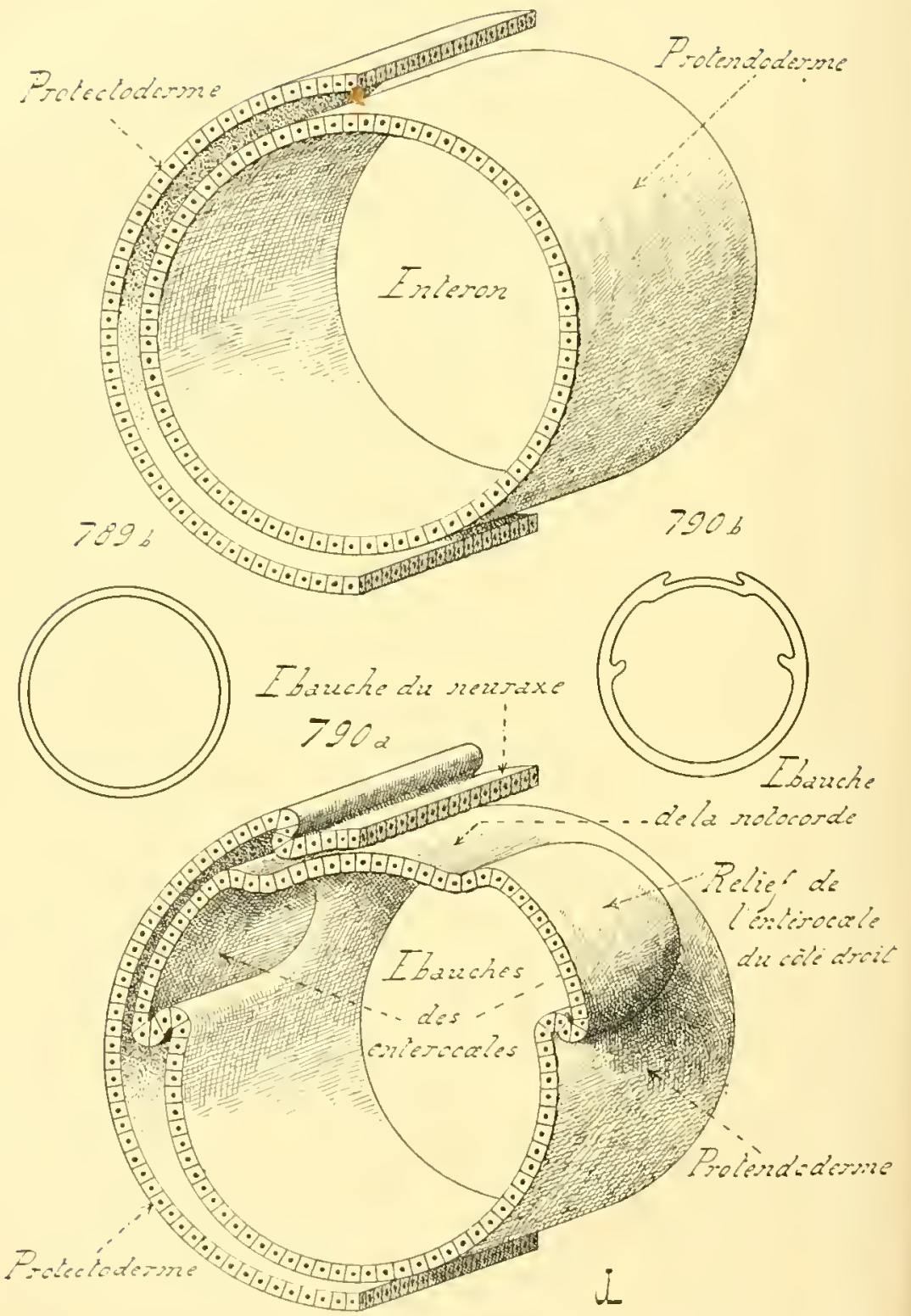

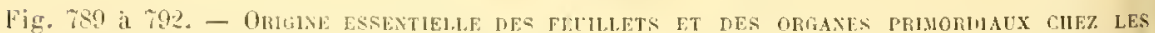
Vertibrés (persjeclines cavalières, diumrommatiques; les omlures sont données sur deux de ces figures, afin le mieux proiser la disposition gronerale; les dessins, designes par la lettre $b$, indiquent, l'une maniere tres simplitice, Jes changements sulis par 
VERTEHIES

S83

$-9 / 2$

Lazuche
at id noloce-do

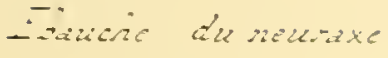

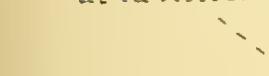

Fieroca
faushe
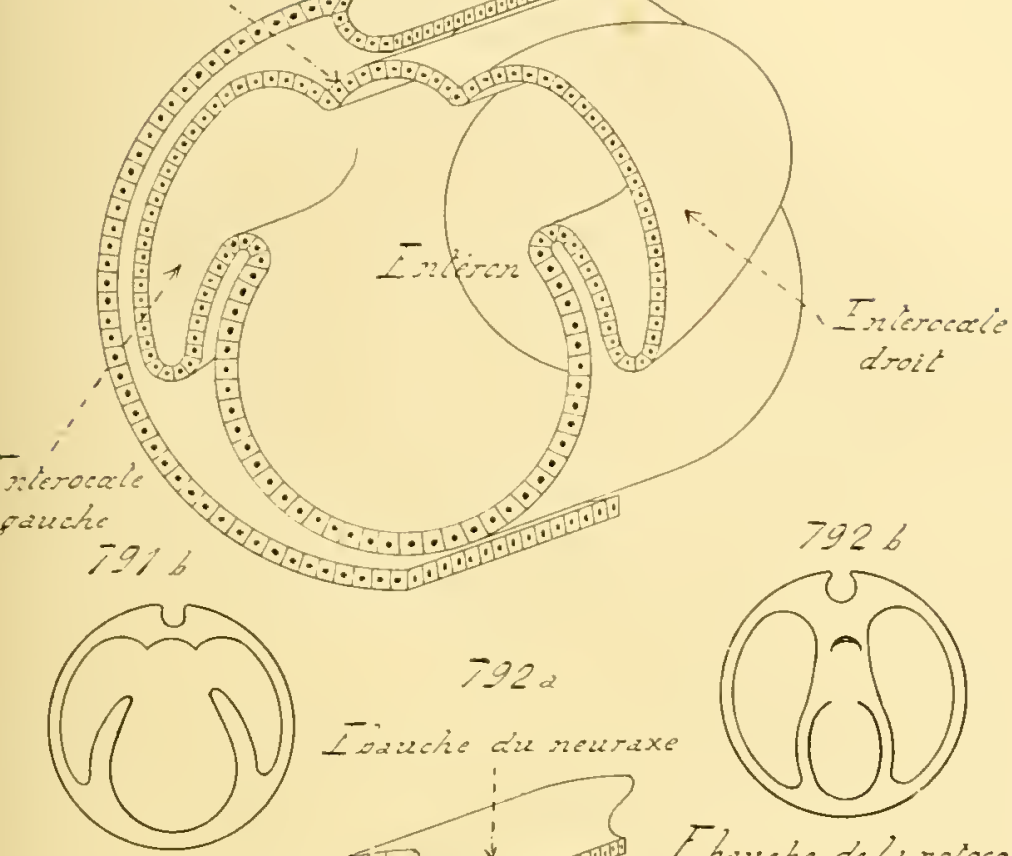

droit

$-92$

Lozucie aiz newraxe

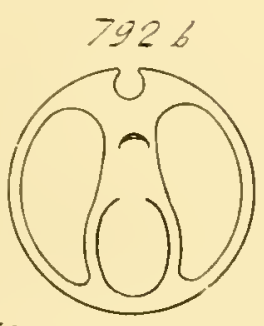

Ebauche de larobesorét

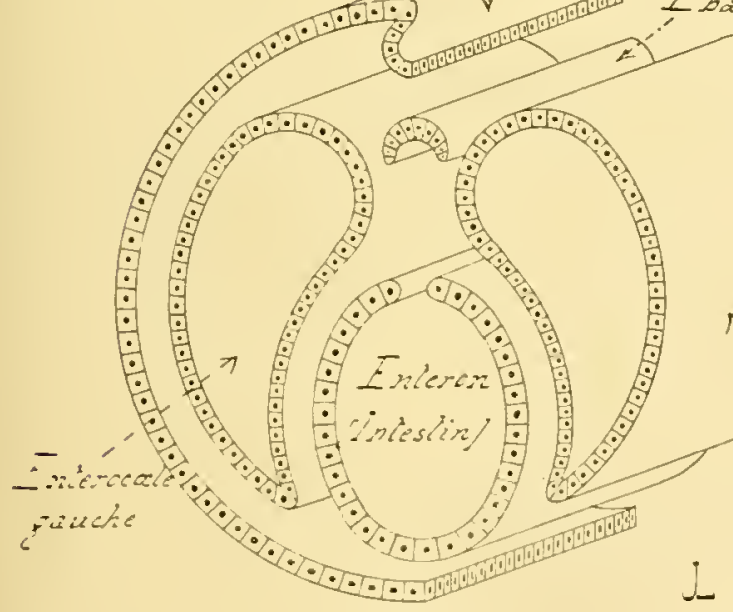

les feuillets primordiaus. - Ces figures doirent étre prises comme exprimant l'aspeet W'une partie decoupce dans l'emlirynn. I.e protectoderme a eli enleví sur la drojte, alin le laisser voir le protendoderme; il t'st aise de le completer par la pensée, car il entume l'embryon entier). 
percées dans le mésolterme mésenchymateux, sont toujours, à chacun des moments de len ívolution, indépendantes de l'entéron comme de l'entéroculome. Elles se crensent sur place, dans le mésenchyne luimème, et par le procédé luabiluel. Le mésenchyme embryomaire est un lissu muqueux les anciens auleu's, constitué par des cellules nombreuses, plongées dans une gangue connertive homogene et gélatineuse; des porlions de relle gangue se liquétient, tout en contenant des éléments tigurés, qui sonl convertis en glohules de re fail; d'antre prarl, des groupes cellulaires exsudent me sulistance fondamentale, liquide des l'abord, dans laquelle parriennent plusieurs des rellules exsudantes. l'ar ces deux moyens prennent naissance des vides irréguliers, anastomosés entre emx, et remplis d’un plasma quj clurrie des éléments ligurés. A cause de leur origine, ces espares forment un schizocuelome, romparable, par sa provenance, à celui qui existe seul che\% les animaux appartenant à la série des Schizoculomiens. Lenr nombre augrmente saus cesse, el les nouveaux renus se raccordent aux anciens, de manière a maintenir l'unité du systeme entier, et à leur permelle de commuuiquer tous les uns avec les aubes: leur cusemble ronslitue un réseau serré, une trane spongieuse, yui régularise sa disposition ponr se convertir en un appareil irrigaleur. En résımé, res espaces sehizoculomicns composent un polyculome, frar opposition aus cavilés entérocolomiennes, toujours assemblées en mn oligoculone.

La dualité du fenillel moyen entraine done, comme mue consépuence nécessairo, celle des cavilés mésodermiques. - Le mésenchyme se borne à prolifúrer, el à se dilférencier, surant les exigences de l'aceroissement du corps el les organes. - L'épithélio-mésoderme subil par contre, des changenonls l'aspect établis sur un modele nniforme, commun à lous les Tertébrés. Il est permis de se le représenter comme composé de leux résicules allongées, plarées sul les côtés de l'entélon, l’une à Jroite, et l'aulre à gauche. Ces vésicules grandissent dans lous les sens; elles s'élendent en longueur, el parviennent dansl’extrémilé antérjeure du corps comme dans l'rxtrémité postérienre; elles croissent en hautenr, el arrivent dans la région lorsale te l'organisme comme dans la région ventrale. Tunten agissant ainsi, chacune d'elles se divise pn segments dans sa zone supérienre, ou dorsale, el sul toute son étemlue; les plans de division sonl lansversaux, perpendiculaires à l’axe longiludinal du corps,

En 789, les deux feuillets primordiaux existent seuls; la section appartient à un emloryon fui vient de depasser la phase gastrulaire, et de prendre, en sallongeant, une forme cylindrique. - En 790, genèse des leux cntérocules, et premieres indications du neuraxe et de la notocorde. - En 791 , ces derniers organes précisent leurs contonrs, pendant que les enterocules grandissent. - En 792, la notocorde, parvenue a la phase de goutlière corlale, s'est isolèe du protendolerme; de mème, les entérocoles sont devenus indépendants de l'entéron, qu'jls flanquent a droite et à gauche; enfin, le neuraxe est arrive a la phase de groutlière medullaire.

La suite de ces phénomenes est donnée par les figures 793 et 794 . Cet ensemble de dessins est complété par les figures 795 à 801 , qui monlrent la méme évolution clans son entier cl dans l'espice. 


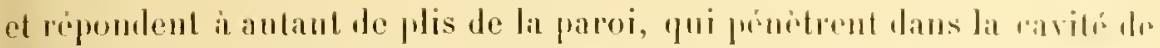
la résicule. Sauf ehez l'A mphioxus, celte segmentation demenre hotalisir dans la parlie lorsale de chaque résicule, el ne va pas dans la partie rentrale; celle-ci reste indivise. Les troncons des denx rísieules sont placés au mème niveau, de fayon à se disposer en paires situćes les unes derriere les antres, et dont les composantes se trouvent réparlies, poul chacune d'elles, l'une ì droite, l'autre ì gauche de l'entéron. Ces segments finissent par se śpparer de la région ventral. indivise, el deviennent indépendants; on les nomme les mésosomiles, ou encore des provertibres, ou des protovertibres, ou des segments primordianx. Leurs cavitis disparaissent; lenrs parois se ronvertissent en fibres musculaires, et donnent presque lonte la musculature striće de l’organisme. Par contre, la cavité le la zone ventrale, et indivise, fonmil la cavilé péritonéale, avec les espaces plenraux el péricardiques, el ne sobture pas; sa paroi ne subit point de lifférenciation musculaire, et persiste comme un endohtúlium, llestimó à limiler es ravitís.

Ainsi. le fenillet moven se dérloulle en un épithé]io-mésoderme el un méscnehrme. - Le premier subit une segmentation, presque comparalıle is relle offerte par les Troclıozoaires polymériques (Annélidrs), aver celte opposilion qu'elle s'exerce sur un svstème d’origine différente, d'où déconle une ahsence complèle t'homologie entre res deux phrinomènes. La mélamórisation des Annélides s'eflectue sur mn mésorlerme entier, el engendré par des initiales; celle des Verlóbrés sur un mésoderme diminué de moilié, et de provenance entérocolienne. La dissemhlane l’opigine est iles plus netles. - Le mésenchyme remplit les espaces laissés entre l’ápilhélio-mésoderme d'un ròlé, l’ectolerme et l'enloderme del'autre.

go Développement de lépilhélio-mésoderme. - L'épithélio-mésoderme est la contimution directe des chanches entipocolionnes, dont il conserve les parois épithéliales. Aussi, alsstraction faile lu mésenelivme quil engendre, consiste-l-il en denx rísicules allongées, llauquant l'enléron sur la droile el sur la gauche. Chacme de ces derniòres renferme une cavité, l'euléroculome; ses parois, s'appliquant sur l'ecloderme d'une part, et sur l'endorlerme de l'autre, se composent l'une somalopleure et d'une splanchnopleure. Ces vésicules se livisent ensuite, d’une maniere concomilante, en segments placis a la tile, en mésosomites. gronpers par paires lisposées Iransversalement. Cetle scission s'offectur. i en juger l'apros les lails arquis, l'une façon dillicrente rhez les

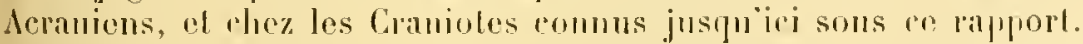

lin re tui regarde les premiers, la seguentation des rulimorules en mósosomites est compliete; olle part de la region dorsale des élauches mósoleruirues, el pénètro jusıfue dans la zone rentrale. Celle-ci ne roste point simple, par consépuent; mais cet étal est souloment trmporairr. car les cloisons ventrales disparaissent, en permellant aux ravilos de 
cotle région de communipuer entre elles, alors quelles lemenrent en place dans la partie dorsale. En ontre, les moitiés dorsales des segments se síparent des moitiés ventrales; celles-ei, unies par la résorplion de leurs cloisous, constituent une vaste cavité simple; celles-là, devenues imlépenlantes, perdent leur vide central, et lransforment leurs parois en faisceaux musculaires. - Ces dernier's résultals sont alleints l'emblée chez les Vertébrés craniotes. Chacune des leux ébanches te l’épithélio-mésoderme se scinlr, suivant son axe longitulinal, en deux parts, l'une supérieure, et l’autre inférieure. La part supérieure se divise seule en mésosomiles; elle correspond il la tolalité les moitiés lorsales du lenillet moven de l'Imphioxus. La part inférieure, souvent nommée plaque latérale, ì cause de sa siluation dans le corps, reste simple, et parvent, le suile, al l'étal acquis par les Acraniens d"une manièe secondaire, au moyen dime lestruction ues cloisons déja formées.

Dans l'état le plus simple, offert par les Acraniens, chaque mésosomite contient une cavilé: celle-cj disparail, au fur et à mesure de l'amplification prise par les parois qui la limitrnt. Ces dernieres, lont en entonrant la cavilé centrale, s'appliquent contre l'ecloderme d'un coté, et contre l'endoderme le l'autre; la première part est la somatopheure du mésosomite, la seconde en est la splauthnopleurr. A leur débul. ces parois sont constitures par des cellules épithéliales. Celle disposition change parla suite; les éléments de la splanchuoplenue se comverlissent en filores musrulaires, alors que cenx le la somalopleure conservent frur structure premiere. - Ies phónomines ilentipnes se manifestent chez les Craniotes, mais ave quelıues modifirations. Les cavités lles mésosomites maissent d'une maniere tarlive, par un déplacement dans le temps, consérutif a la combensation du développement embryonnaire; les segments sout d'abord compacts, et devienuent creux par la suile, saus que leur cavité, inlépendante dès son débul, soil directement engendrée parun espace entéroculien. Ce fail est le résultat de la compacité premiore les éhanches le l’épithélio-mésolerme, qui sont privées le lout vide central. Les exceptions à cet égarl se trouvent des plus rares; elles ne'sont guere données que par queløues Ganoüdes el Amplihiens, dont l'évolution est assez dilatéc. les parois de chaque mósosomite sont, comme les précédenles, composées par l'union d'une somatoplenre et d'une splanchnopleure; celle-ci fournit la musculatme, penlant que la cavité disparaît.

l)es oppositions analogues, entre les Acraniens et la plupart des Craniotes, s'élablissent an sujet des plaques latérales. Chez les premiers,

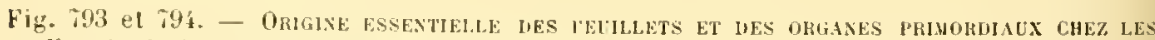
VentEB (perispertives canalires, diagrammaliques; ces ligures font suite aux préceJentes, ut les mèmes consitèations leur sont applicables). - En 793 , le neuraxe s'est converti en un canal, et la notoeorde en un cordon plein; J'intestin s'est refermé dans sa zone dorsale; chacun des enterocules commence a se diviser, suivant un plan longitudinal, en une plaque literale et une rangee de mesosomites. - Fn igh, cette division 


$$
19-9
$$
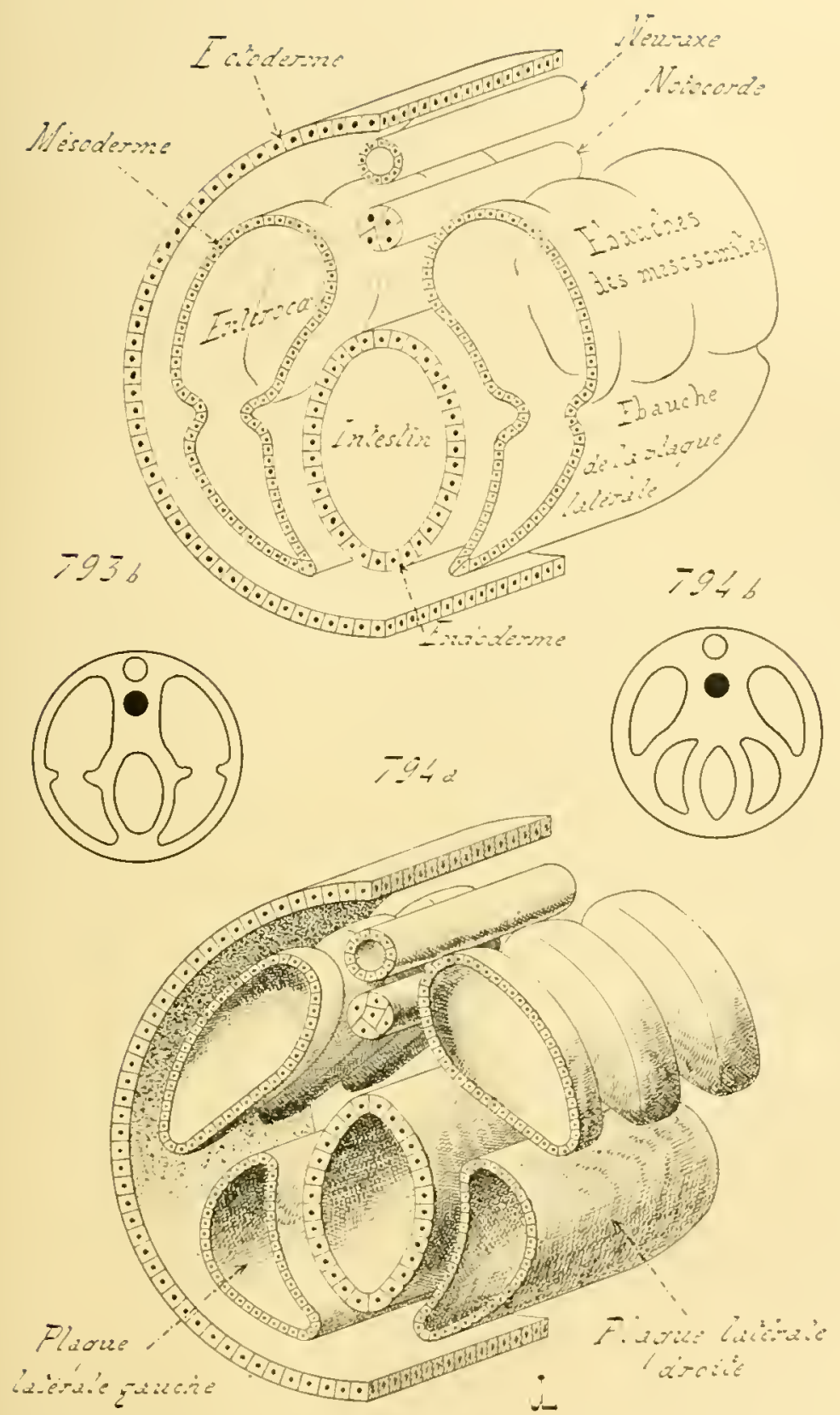

est accomplie; chacune des plaques laterales est surmontie d'une rangre de mesosomites placés à la file. 
et commo il est dit plus haut, les moiliés infrieures des mésosomites, toutes pourves d'une ravití, se relient entre elles par la résorption do lours cloisons, pemlant qur les moitiés supériomes deviennent indépendantes. Chez les Craniolos, les ébauches de l'épithélin-mésoderme sont failes, des l'aboul, comme si toules les parts inférieures du cas précédent ćlaient unies an moment mème de leur apparition; le phénomène du cloisonnement rentral, et celui de la destruction des cloisons, sont omis. Cemx des Craniotes pourrus l'une évolulion suffisamment dilatée, jossèlent morore des éhanches épithélio-mésodermíues crouses; aussi leurs plapues latérales, qui répondent aux moitiés inférieures de cos áhanches, renforment-elles des cavités, fort pelites rependant, des l'instant dr leur dilimitation. Par contre, les plaques latérales. chez l'immense majorité dos Craniotes, sont dahord compactes, comme les rilıanches mésollemiques dont elles proviennent, et lours espaces villes ne se creusent que par la suite. - Qnoiquil en soit de ces déplacemeuts dans lo lemps, chacmne des deux plaques latérales finit par contenir une cavite simple, qui samplifie, tout en conservant son unité. Par lr fait de four acroissement, les deux plaques grandissent, le maniere i envelopper l'entéron de l'embryon, el ì passer, par lenr bord supériour, en dedans des mésosomiles. Elles sarlossent, et s'accolent l'une i l'autre, sur la ligne méliane ventrale du corps, au-dessous de l'entéron devenu l'intestin; elles s'adossent de mème an-dessus de l'entéron, et sous les organes, notocorde et premières indications du squelette, qui sumplombaicut celui-là tout d'abord. Les récions d'accolement sont les éhanches des misenteres. Les deux cavités des plaques. lien que séparés liune de l'aulre far les mésentères, ne conslituent cependant, à cause de la mincemr te ces lemiers, el de lemr destruction partielle, qu'un seul loul : la cavité peritonéale, avec ses dépendances, les ravités pleurale el périrarliqur. lorsquelles existent. Les parois de res plaques conservent leur disposition épithéliale, ot constiluent les assises d'endothólium, qui limitent les espaces précélents.

La division en mésosomites déhute lans relle parlie du rorps cm. hryonnaire, qui deviembra l'extrómití antérieure du tronc de l'adulte; de lin, elle sétend i la fois en avant el en alrière, s'avancant dans la trite l'un côté, el pénilrant, de l'autre, dans le reste de lorganisme.

En résumé, l’épithélio-misoderme, composé de deux banchrs symétriques, se scindo en quatre parts. deux par bibuche, dont l'une est suppricure, l'autre inféricure. Les deux parts infópienres sont les plaques laterales, qui gramissent en ruveloppant l'intestin; leur cavité devient la caviló prólomsale, et leurs parois donnent l'endothélium périlonéal, qui cirouscrit relte derniope; les denx parts supérienres se scindent en mésosomitrs; crux-ei se rorrespondent d'une part í l'autre, de façon à tre groupés par paires. Tous ces segments suluissent une irolulion, romparable quanl an fond. Chacun d'eux renferme 
une ravile, qui doil disparaitro, pendant que ses parois prolifirent artivement.

$A$ cause du nombre, et de la complexili, des systimes angendrís par les mésosomites, los auteurs ont donnc aux diverses légious de res derniers, et afin d'éviter des pépiphases, des noms spériaus, dout lousage est assez commode. Chaque mésosomile se compose de trois partirs: l'une supirioure, l'épimere; l'autre moyenne, lo misomére; la derniere infírieure. l'hypomere. La promicre. Ir firaucoup la plus volumineuse, donne seule los faisecaux musculaires, et miritr, par là, les nouveaux tromes de myotome, ou dr myompre. ou de plaque musculaire: sa raviti lis jarait entierement. La moxenue fournit los canalienles de l"um drs apparcils rxeritrurs : du mésonrphros. Sa paroi ot sa ravité ron-

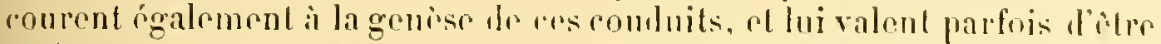

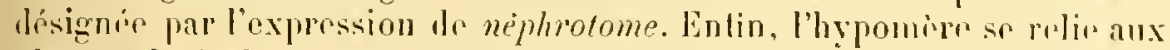
plaques latiralos; sa ravilí ot sa paroi, dans quolyurs-uns des mésosomitos antérieurs du trone, donnent les ranalicules du proncploros, du rein primorilial.

30 Développement du mésorlerme mésenrlymateux. - Iu momont où cettr secondr partio is misoderme commener a se montrie, la notocorde rt le neuraxe existent dejà: ils sont plarés, l’un au-dessus de l’autre, Ir tout surplombant l'onléron, dans la légion dorsale do l'ombryon. Les drux entírocolos, les éhanches du fenillotmoven entire, sont, à leur tour, silués sur lis rôtés do l'entéron, el possòleñl uno strurlurr. épithélialo. Tout on grandissant, its se didonblent ru ipithélio-mésoderme el en mésenchyme; dr lours parois se libachent un reptain nombre dr collules indépendaules, qui sont los generatrices de ce dernicr; alors qur las éléments, laissés en lour place, dr manièr à conserver la disposition épithélial. promière, donnent l’épithélio-nésoderme. - La goniso du mésenchyme dur un trmps assez long, rar sos collules s̈isolent ì des intervalleš divers, et nullemont riguliers; olle scofrerlue pendant que les parois épilhélialos so molifient, ot produisent les mésosomites aver les plaqurs latéralos. - te mésenchyme, semble-t-il d'apres ces faits, provientrait do l'ipilhélio-mésoderme. La

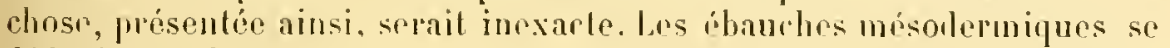
déloublent, dans la réalité, en mo part fipithiliale ret um parl mósonchymateuse; seulement, puisque res élauches sont épithéliales ellesmèmes, la premièe de aes parts est tem contimation dirnele. Commo la gonese du misenchyme est asirz longur, ello rommener lis lappit-

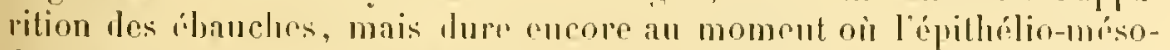
lerme est déjà bien caractírisé. En défnilive, ees deux moiliós du

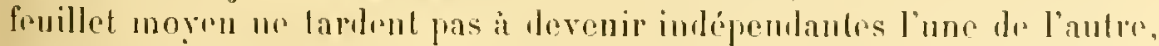
¿̀ s’aceroitre par leurs propres fores, of à se juxtaposer ifroitement, à s'arcompagner daus tous lrurs changements d'aspert et de slurbure, sans se ronfondre désormais. 

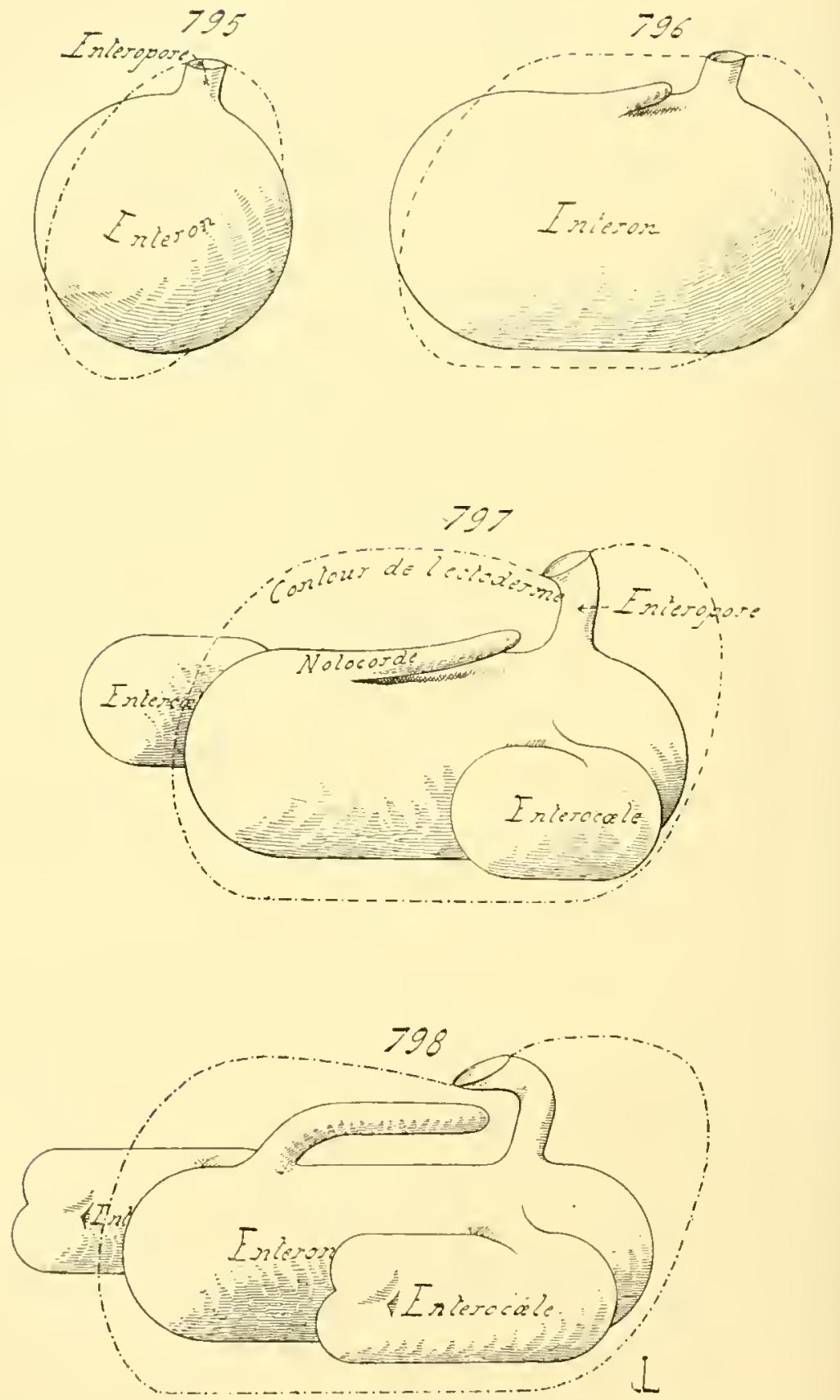

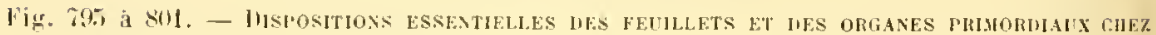

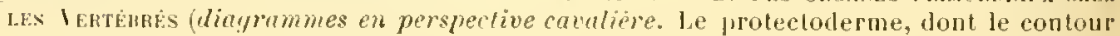
est indique par un pointille, est suppose absent pour laisser voir l'intérieur de l'em- 

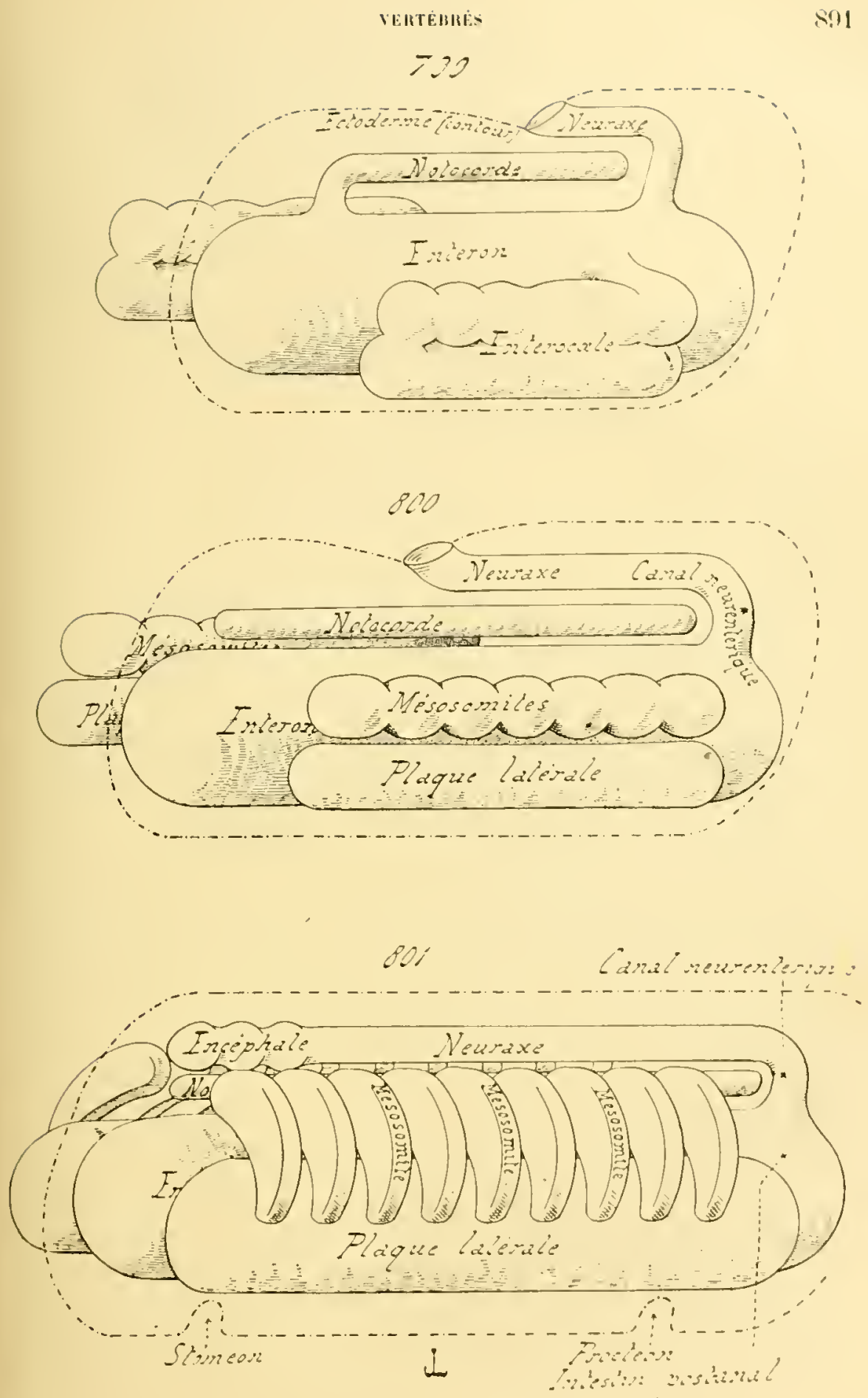


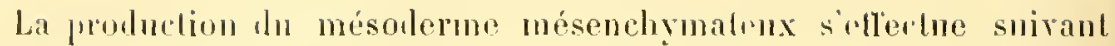
les procólés habituelí. Le mósoderme épithélial, qui lui ılonme naissance, est, a son dribul, placé entre l'ectoderme et l’endoderme; sa somatoplenre ast aceolíe ì la face inforne tu promicr, et sa splanchnopleure il la face externe du second. I.es cellulis ile sa paroi se multiplient: plusieurs les élrments, aimsi faconnós, ne continuent pas ì appartenir it la paroi mème, se légagent, et se portent con dehors d'elle; suivant lenr situation, les uns ront se placer entre l'ectoderme et la somatoplenre dont ils proviement, los autros entre l'endoderme ot la splanchnoplenre. - Les premiers ćléments du mésenchrme ont alors fail leur appration; ils maissent indéfremlamment les nns des autres, ì les intervalles divers l'xpace et le temps; ils exsment une substarce fomlamentale, qui les enveloppe, à travers lapurlle ils émettent de longues expansions psendoporliques, et oi ils sont mème capables de se déplacer. Leur nombre augmente saus cesse, soit par leur propre multiplication, soit par des formations supplímentaires, aux dépens de l’épithélio-mésoulerme, d'autres rellules semblables i eux; celte derniore source d'origine ne tarle pas, lu reste, a s'épuiser, et la multiplication propre est bientit le seul procédé suivi par le mésolerme mésenchymateux dams son accroissement. - Il semblr, surlout en ce qui conecrne les développements embryonnaires frès eondensés, que l'endorlerme soit capable de fommir des élóments, en petit nombre, an mésenchỵe, ces éléments étant destinés a faronner les parois des premiires bbanches vasculaires. Si de tels faits sont exacts, et, lans crécolutions, il faut se mettre en garle contre la gramle ressemblance mutuelle iles cellules de tous les fenillets. Inur importance est ales plus minimes. Ces embryogénies sont fort condensies; les feuillets, arre les promiers vestiges les organes, sont prouluits sur place et en bàte. Le protrniloderme se lélaminr en mésodermo ot endolerme; celui-la se livise rapirlement en mésosomites, plarnes latérales. rt mésenchrme: il n'est lone pas étonnant de roir, llans ces phases initiales de l'emluryogénic, purlpues rellules, destinées au mésenehyme, provenir de lendodrme, puisque ce dernier vient a peinr de se siparer

luryon: les contours extirieurs des appareils internes sont seuls reprisentes; le misoderme mésenchymateux, qu'il faut concevoir à la facon d'une gangue enveloppant ces derniers, n'est pas dessine).

lin 79\%, l'embryon en est a la phase gastrulaire. - En $790^{2}$. cette phase est dépassée l'en. bryon s'allonge, de manieje à rendre son enteropore fosterieur et dorsal. - lin $79 \%$, la notocople at los deux untroroles commencent à s'ébancher. - En ros, ces appreils

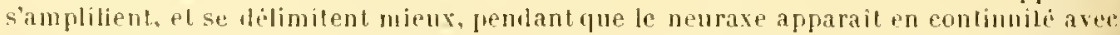
l'enticropore. - lin 799 . le newrixe el la nolocorde acquicent lears dispositions ditinilives; les enteroenles se subdivisent en playue Jaterale et rangie de misosomiles. En 800 , cette sublivision est accomplie: la notoeorde est independante; le neuraxe s'al-

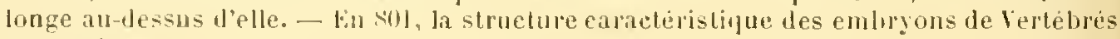
ist atteinte.

Ces dessins completent les figures numerntecs de T8n à 794, qui montrent les mimes faits sur des sections lansversiles d'emliryons vues par la tranche. llautre part, les figures 802 a 80 achèvent de préciser ces notions, plus spécialenent en ce pui conccrne le misoderne, el d'après des anjus transversales d'embryons. 
du protendoderne, quil'engentre aussi bien que le mésoderme épillıćlial et le mésoderme mésenchymaleux. L’origine, et la valen", de ces éléments complémentaires, sont aussi celles de leur's similares, avec lesquels ils se confondent; il s'agit seulement, en l'especer, d'un légel déplacement dans le temps el dans l'espace.

Les licux de formation du mésoderme mésenchymateux sont très étenlus: l'après les éludes faites par less auleurs récents, notamment par Van Wijhe et par Rabl, ils comprement prosque toute la periphérie de l'épithálio-nésoderme. L'endroit principal, ou la prolifération est le plus artive, serait enpendant la splanchuppleure de l'extrémité inférieure Jus mésosomites. - La splanchnopleure, de la région supéricure dr chacun de res derniers, se convertit en un myotome, se différencie en fibres musculaires, et fournit quelques éléments mésenchymateux; la plupart de ceux-ei naissent de la liase du myotome, et de la zone qui lui succède, du mésomère. Les cellules du mésench yme se dégagent de leur paroi génératrice, se portent en dehors d'elle, it se disposent autour de la notocorde el du neuraxe, placés en cette région; leur nombre augmente rapidement, et elles conslituent bicntôt un amas épais. La partie de cel amas, située autour de la notocorde, produit les premières ébanches du squelette vertébral ; aussi désigne-t-on souvent, par l'expression de sclerotome, la masse mésenchymateuse engendrée par li splanchnopleure de chaque mésosomite, ou, plus exactement, la zone interne de cette masse, qui engaine la corde dorsale. - La somatopleure des mésosomites se désagriege de son còté, et se convertit lout entièré en éléments mésenchymateux, silués contre la l'ace interne de l'ectoderme. - Ainsi, dans leurérolution, les mésosomites perdent leur cavité, transforment leur somatopleure en un tissu mésenchymateux, leur splanchnopleur" en faisceanx musculaires, et produisent en surplus, anx dépens de cette dernière, des cellules de mesenchyme, dont plusicur's composent les selérotomes, et sont les génératrices du squelette. - De mème, la somatopleure et la splanchnopleure des plaques latérales, lont en conservant leur disposition réguliere, el demeurant comme endothélium, dégagent d'elles sles éléments mésenchymateux; renx qui naissent de la première se placent sous l'ectoderme de l'embryon, les autres s'étalent contre la face externe de l'endoderme.

1 cause mème de sa provenance multiple, le mésolerme mésenchymateux constilue une gangue, qui se moule dans les espaces interorganirjues, et enveloppe tous les systèmes de l'économie. Malgré celte forme irréguliere, il est cepentant possille de distingner en lui deux feuillets principaux : un somato-mésenchyme, et nn splanchmo-mésenchyme. Le prenier est le moins volumineux; engendré par la somatopleure de l'épithélio-mésodermo, il s'applique contre la face interne de l'ectoderme, et compose une bande intermédiaire i colle-la et a celleci, qui les sépare l'une de lantre. L.e splanchno-mésencliyne est plus 
épais, surlout dans la région lorsale du corps; il entoure les organes
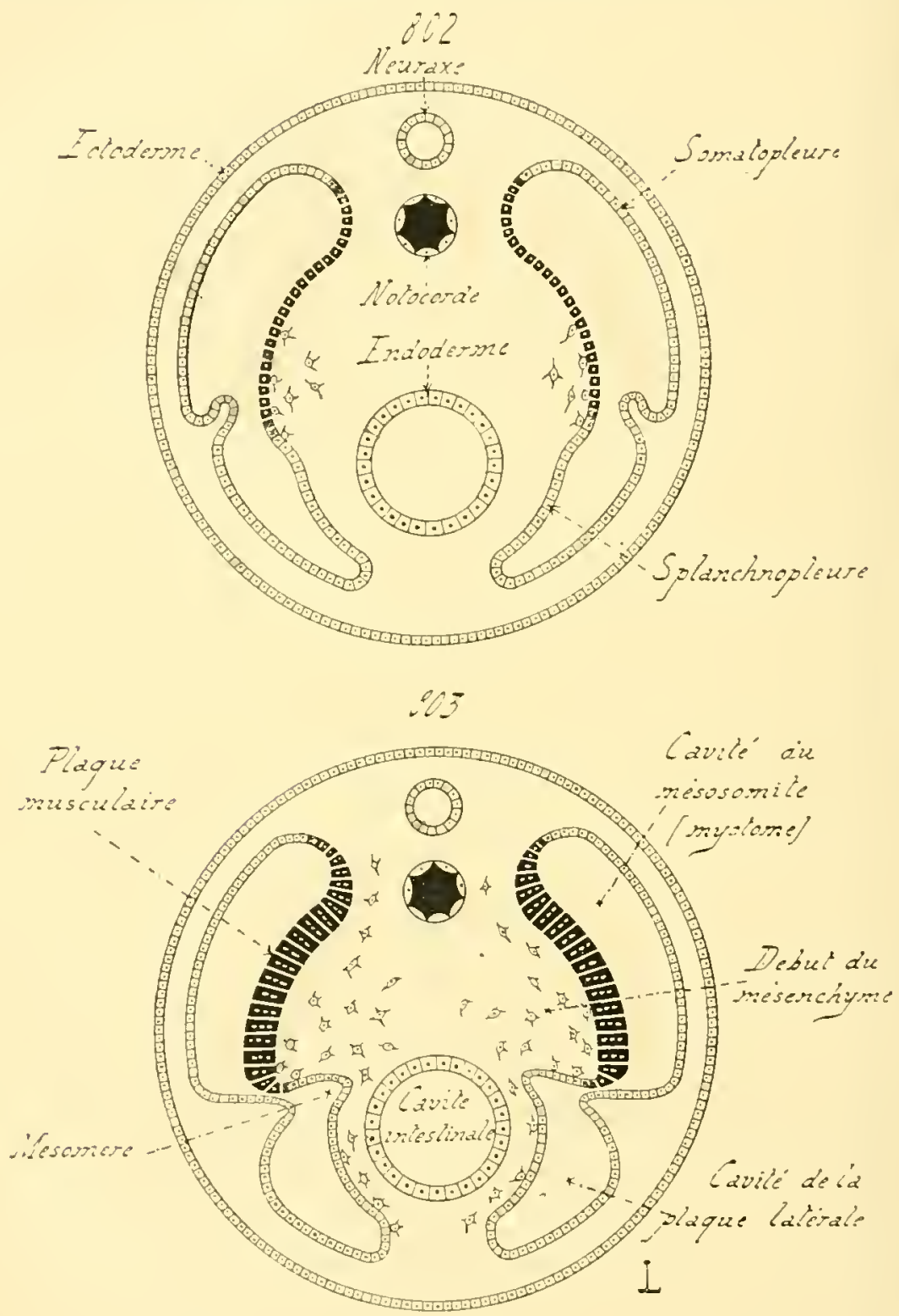

Fig. 802 à 80\%. - Pinses essentielles du dévfloppeaent du Mésoderme des Vertérrés (coupes transversales demi-diayrammatiques; ces eonjes complelont celles dessinees dans les figures numérotées de 789 ì 794 ). - En 802, phase de la figure 793; les leux entérocoles, avec leur somatopleure et leur splanehnopleure. commencent à se diviser longitudinalement. - En 803, la splanchnopleure du myotome sepaissit, et les cellules du mésenchyme mésodermiøue, léjá ébauchces lors de l'ètat prẻcètent, continuent á prendre 
médians, le neuraxe, la notocorde, et l'entéron; il est très développí
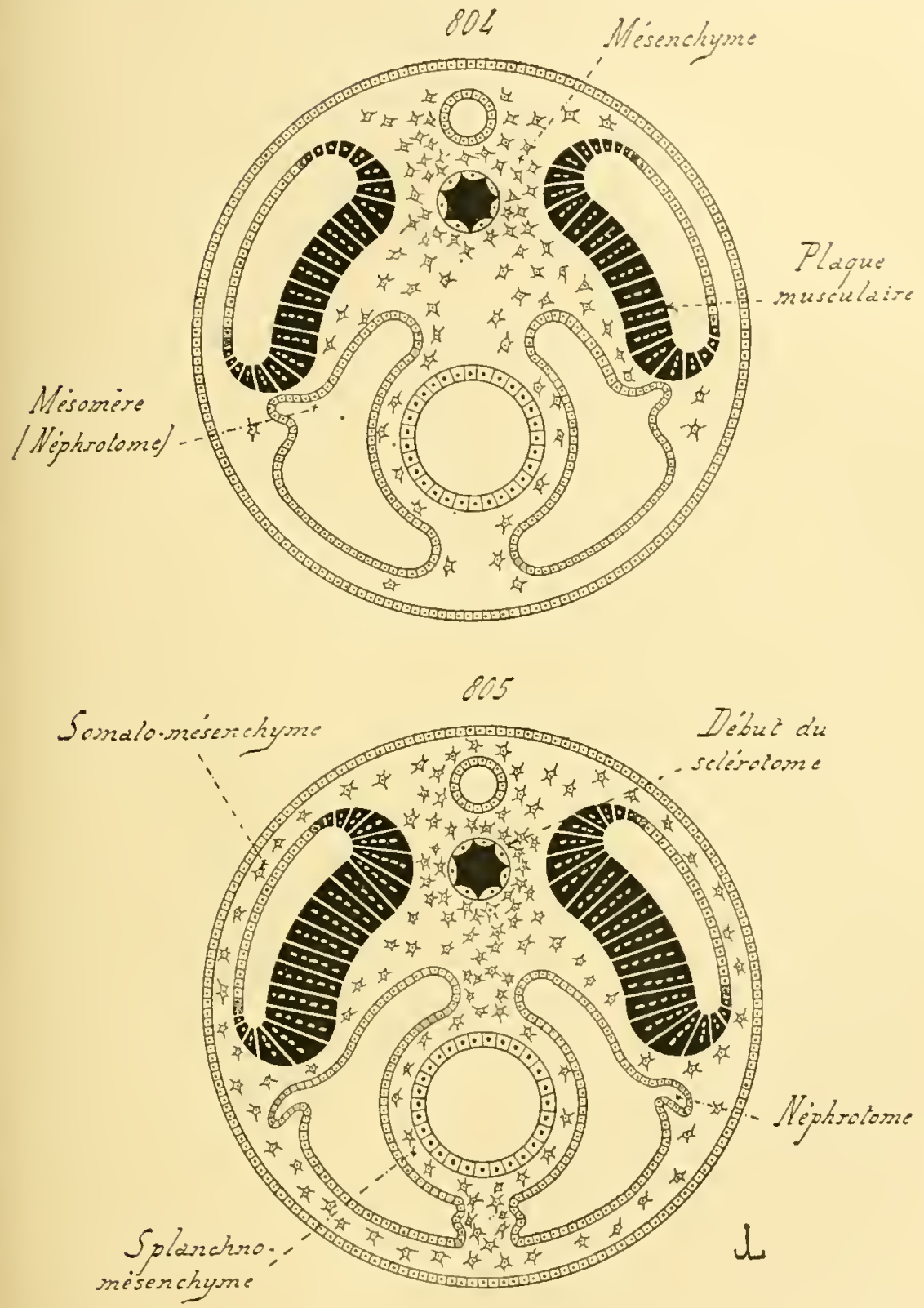

naissanee. - En so', les misosomites se sonl sẻparès des plaques lalirales; les plaques musculaires eontiunent à s’éaissir. - In 805, les plapues latirales grandiscent autour de l'intestin, pendant "put le mrsenchym. et les plarpus musculares augmentent d'importance. - l.a suite le retle évolution est donnée dans les ligures sing cet sot. 
antonr de la notocorde. Issu de la splanchnopleure de l'épilhélio-nésoderme, il occupe dans l'économie, el ì son délut, une silualion interne, qui change par la suite; il accompagne, en ellet, les myotomes dans leur évolulion complese, et se répland avec eux dans toui le corps. Les leux feuillets lu mésoderme mésenchynaleux ne deneurent pas indépentants; ils se raccorilenl l'un à liautre dans loules les zones où les assises de l'épithélio-mésoderme viemunt s'adosser, e'est-a-dire dans les mésentires. L'adossement n’est pas complel: mo espace étroit se trouve laissé entre les deux assises au contact; ce vile se remplil d'éléments mésenchymateux, qui relient le fuillet externe du mésenchyme total au feuillet interne.

Le mésodermo mésenchymateux est chargé de prołuire tous les lissus conjonctifs de l'organisme, quelle que soil leur nature, quelle que soil la struclure de leurs éléments fizurés et de leur substance fondamentale. Ces tissus forment une enveloppe à tousles appareils, à loutes les comprosantes du corps, meme les plus minimes; la raison de cetle disposition est lonnée par leur origine mème. Dès son commencement, le mésenchyme embryomnaire, dont ils proviennent, conslitue une gangue, une gaine commune, à lous les systemes déjà engendrés; il na yu'i conserver celte allure premiere, tout en se dillérencianl, et suivant les diverses modilications subies par l'économie, pour se trouver dans sa siluation définitive. — Le somato-mésenchyme domne le derme des téguments. Le splanchno-mésenchyme prète ì des dóveloppements plus complexes. La part issue des plaques latérales sert à façonner le tissu conjonctivo-musculaire de la paroi inlestimale. Celle qui tire les mésosomites sa provenance se subdivise; les éléments placés aulour de la notocorle fournissent les b́bauches du sipuelette; les autres s'annexent anx myotomes dans leur accroissement el leurs changements, s insinuent entre leurs plis, et les accompagnent dans le corps entier, dont ils produisent la gangue conjonclive générale; d'autres, enfin, suivent de mème le squelette dans ses modifications, soil pour engendrer de nouvelles picices squeletlique, soit pour domner les ligaments el les lendons. - En somme, la disposition du mésenchyme reste toujours semblable à elle-mêne, depuis son dóhut jusqu’à son établissement définitif; ce fenillet mésodermique enveloppe lous les ajprareils, comble tous les espraces interorganiques, ol subit a cet effet, soit pour servir de gangue unissante, soil pour servir de soulien, des diţérencialions nombreuses.

le plus, et tout en agissant ainsi, il se creuse de cavilés. Ces lernières, comme il est dit plus haut, répondent a un schizoculome. Très nombreuses, et agencées les mes arec les autres, elles composent l'appareil imigaleur he l'économie, avec ses deux systemes principaux, le systime sanguin el le systime lymphatipue.

Nermax. - Les données fondamentales de la genese du neuraxe somt imdiqués par l'évolution des Acraniens, la plus dilatée de loutes 
les embryogénies des Vertélrés. Dans leurs traits essenticls, les phénomenes offerts rappellent, de tous points, lenrs similaires des Tuniciers. Le neuraxe prend naissance sur la face dorsale du corps, anx déprens de l'ectoderme de cette région. et sur la ligne midiane; il présente W'aborl l'aspect d'une gouttiore, juis celui l'nu canal, étendu d'unte extrémité de l'organisme à l'autre. l'ar son cxtrémité postérieure, la eavité du neuraxe communique avec culle de lentéron; la zone d'union est le canal neurentérique.

Les Acraniens passent, dans lenr développement, par une pliase zilstrulaire. De mème que celle des Tuniciers, leur gastrule subil une extension inégale, et s’allonge de préférence suivant une seule direction, de manière à rendre l'entéropore postérieur el dorsal. Toute une bande ectodermique, médiane et longitudinale, placíe sur la face dorsale de l'embryon, étendue de juis l'entéropore jusyu'à l'extrémité antérieure du corps, est appelée à devenir le neuraxe; sa modification, dans ce sens, seffectue en mème lemps que naissent la notocorde el le misodeme; elle est done des plus précoces. Celte baude commence par s'infléchir, par sincurver, et prendre la forme d'ume gonttive largement ouverte; celle-ci est dite la goutlière médullaire, puisqu'clle est l'ébauche d'une moelle nerveuse, tout comme la bande elle-mème est nommée la plaque médullaire. Lorsque l'aspect de gouttière est acqnis, l'ectoderme, qui limite ses bords, prolifére, et passe au-dessus d'elle comme un pont, pour fermer sa cavité; ce reconvrement s'effectue au moven de deux lamelles ectodermiques, qui s'avancent, el se soudent l'une à l'autre. De p'us, la gouttière médullaire, bien que fermée par la lame recouvrante, el devenue interne, continue à s’ucurver, el se convertit, par le rapproelıement et l'union de ses propres bows, en un canal cylindrique; celui-ci est le neuraxe définitif.

La plaque médullaire s’étend, en arrière, jusque sur la lèvre antérieure de l'entéropore. P'endant qu'elle s'incurve, el se recouvre de la hande ectodermique, celle-ci s'unit à la levre postérieure de cel orifice: le pont recourraut passe ainsi au-dessus le l'entéropore, et l'empèche Jésormais de communiquer avec le dehors. En revanche, la goutlière médullaire conserve ses connexions arec la livre antérieure; son sillon s'ourre dans l'entéron. Ces relations demeurent encore, au moment où la gouttiere s'est convertie en un eanal; la cavité du neuraxe se relie it celle de l'entéron par le mogen de l'entéropore, celui-ci étant fermé du cóté de l'extérieur par la läne recourante. Cette région, qui correspond à l'entéropore, et mit le neuraxe avec l'entéron, est le canal nenrentérique. Ces rapports cessent ensuite; mais ils existent au début du déreloppenent embryonuaire, et se tronvent aussi chez les Craniotes.

De tels phénomènes, offerts par les Acraniens, sont égalenent montrés par les Craniotes, sauf quelques déplacements daus le temps. Lin lés romparant, dans leur ensemble, il lemrs similaires des l'nuiciers, il est permis de peuser que los indications domnes par les diraniens sunt. 
elles-mèmes, altérées quelque peu. Les traits essentiels de la genèse du neuraxe des Virtébrés sont, sans doute, identiques à ceux qui découlent de l'étude des larves urodèles les Tuniciers : un sillon se creuse, sur la ligne médiane dorsale de l'embryon, aux dépens de la lèvre antérieure de l'entíropore, al progresse de là vers l'exlrémité antérieure du corps, loul en se convertissant en un canal; l'ecloderme se referme au-dessus de ce canal, en se soudant à la levre postérienre de l'entéropore, pour clore cet orifice vers l'extérieur, ot le convertir en un canal neurentérique.

Notoconne. - La notocorde dérive du protendodeme. Ce feuillet lui donne naissance au moment mème oì il produit, sur ses côlés, les deux élranches du fenillel moven. La rígion génélique est, sous ce rapporl, une bande dorsale, longitudinale el médiane: elle ocenpe l'espace compris entre les leux précédentes ébauches mésolermiques. - De même que chez les Tuniciers, le prolendoderme se sublivise en quatre prarlies: l'me dorsalr, impraire et médiane; deux lalérales, paires el symétriques; la derniere venlrale, impaire el médiane comme la première. La part ventrale est la plus étendue; aprés que les autres se sont séparées d'elle, elle se referme antour de l'entéron, conserve sa disposition épithéliale simple, et donne l'enloderme défnilif, èest-à-llire l'épillhélium de l'intestin el de ses annexes. Les deux parties latérales sont les ébauches du mésoderme. Lnfin, la hande dorsale fournit la notocorde; la situation de celle-ci dans l'organisme esl un effel te son origine; quelle que soit sa destinéc, variable suivant les groupes de l'embranchement, la notocorde demrurren la place où elle a élé façonnée. Elle est médiane, lorsale, longitudinale, siluée au-dessous du neuraxe, qu'elle sontient, it an-dessus de l'intestin, que limite l'eudoderme.

A son débul, dans les dévelopjements dilatís, tels que ceux des Acraniens el de plusicurs Amphibiens, l'éhauche de la notocorde esl une plaque cellulaire simple, longue el assez large. Celle plaque devient indéprendante, an moment oì les ólianches mésodermiques arquicrent elles-mémes leur anlonomie, el se séparent du protendoderme. Elle s'incurve alor's, el se ploie en une gouttière, dont la cavilí est inférieure, touruse en sons inverse de relle lu neuraxe à son commencement; cet asprect a fait irrer, pour la listinguer, le terme de gouttiere cordale. Ciellecti reste largement ouverte, el ne se ferme pas; cependant, la notorombre so convertil en un bitonnet eylindrique. Celte derniere forme est alleinte par le propre resserremont de l'organe; la uolocorde se ramasse sur elle-mine, sépaissil aux dépens de sa largeur, perd à mesure sa disposilion incurvée, et se convertit en un cordon cellulaire plein. - Ce demier aspert est aequis d'emblée, dans les embryogénies conlrnsées, et ne surcide a aucune phase de goulliere corlale. La notocorde, lorsqu'elle se délinile aux dépens lu protendodr rme, est déjà comparłe.

Tont en se modifiant ainsi, l'éluauche do la notocorde augmente le 
nombre de ses rellules; elle s'mvoloppe, el sisole de er yui l'entuupe,
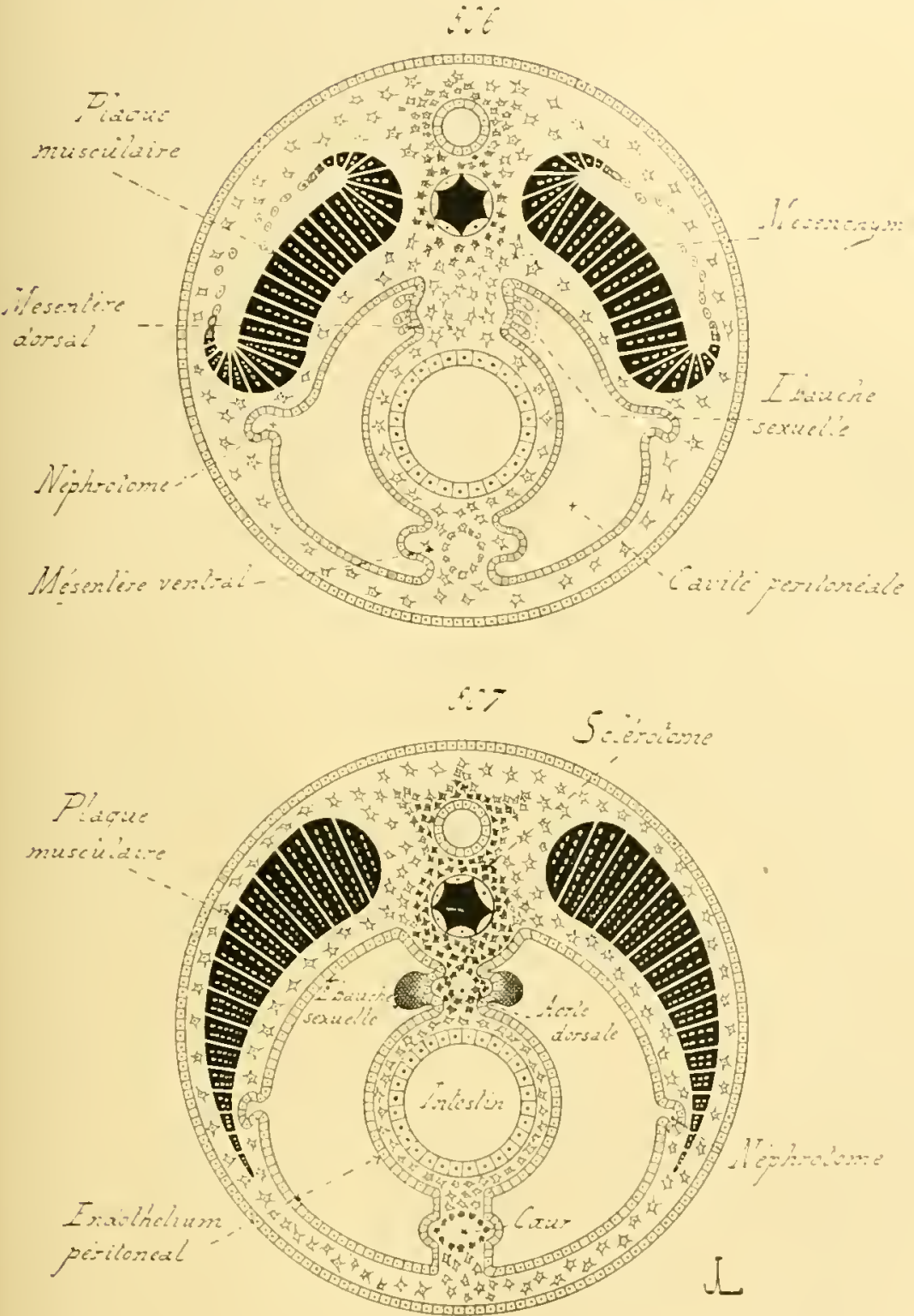

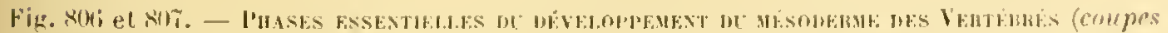

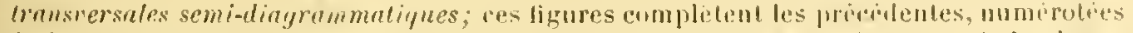

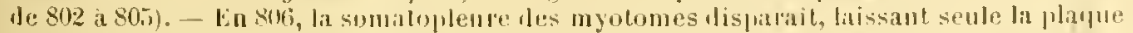

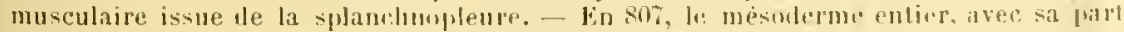
épithèliale el musculaire, el sat part mésenelymatense, altoint sa disponsition dofinilive. el engendre les bastolu- des urganes gui dèrivent de lui. 
par me mince memlinane anlyystr. homogène, dite l'étui de la notocorde. Ses éléments supertivels, silnís un dedans de l'étui, s’ippliyuent sur la face interne de ce deruicr, (pu'ils lapissent a la maniẻre d'un endothélium; ce sont eux, sans doule. qui produisent la substance de la membrane envoloppante. Les antres cellules, plus internes, graudisseut beaucoup, el subissent me dégénérescencr vacnolaire; la matiere, Joul lens vanoles sout emplies, est hyaline ol transparente. Lorsque la notocorde est arrivé à sa période d'élal, chacune de ses cellules, autres que les superficiclles, conlient une vacuole si grande, que son protoplasme el sou noyau soul rulégués sur sa périphérie, et rẻduits à une mincr lamelle recourlóe en croissaul, tout comme il en est dans les iléments du lissu adipreux.

La nolocorde existe seule chez les Acraniens. Celle des Cranjotes est hatirement entouréc par le mésolerme mésenchymateux, far les éléments des sclérotomes, quilui doment une gaine épaisse, et produisent ì mesure les premières picees du squeletle, les corps rertébranx. Ceux-ci envoppent la notocorde, qui passe an travers d'enx comme le lien au travers des graius d'un chapelet. - l)aus lévolution ultérieure, tantôt la nolocorde est conservée, surtout dans les espaces laissés entre les colps vertébraux, et lantôt elle lisparaì, ou n’est grajóe yưà l'élat de vestiges fort réduits. L'étude de ces deux fins de la notocorle entre daus celle du développement du squelette.

Résumé - An moment oủ les denx fenillets blastodermiques primorllianx sonlseuls représentés, et alıstraction faite des altirations causées par les condensations du développement, l’organisme des embryous des Tertébrés est les plus simples; il ne ditlère pas de celui des embryous des luvertébrés, et se raméne ì une gastrule. Le protectoderme entoure le protendoderme, yui limsite, à son tour, une cavité centrale, l'entéron destiné à deveruir l’intestin; celle cavité communique avec le dehors par un entéroprore jostérieur el dorsal.

Lorsque les lenillets primordiaux ont engendré les feuillets défiuilifs, avee le neuraxe el la motocorde, l'organisme est devenu lieaucoup plus complexe. Le corps, allongé, est limilí, it sa surface, par l'ectorlerme délinilif. L'entéron, conservé daus la région centrale de l’économie, est intouré par l'endoderme défuitif; sou untéroprore s'est fermé, el un procteon, avec un stomeon, lui permeltent le s'ouvrir à l"extériems par ileux orifies de nonrelle formalion, l’anus et la bonche. L'muléron, ainsi converti en intestin, est surmonté, sur la ligue médiane, par la notocorde, d'origine protemlonlernique; celle-ci supporte, le son cóté, le neuraxe, de provenance protectodernigue; ces deux demicrs appareils s'étendent dans le corjs entier, depuis son extrémité antériemre jusqu'à son extrémilé postérieure, de manière à dépasser l'entéron en avant, et surlout en arrièce. Sonvent, nue part de l'entéron se prolonge, anlessous de la notoconte, lerriere le ujreau oceujé par l'auns; celle 
expansion, dite limtestin post-rmal, disparail ensuile. Iinfin, le mesoderme, d'abord localisé sur les deux crités du prolembleme pui l'engenrlre, acquiert une importance considéralile, el prépondérinte, sons le double raprort du nombre de ses éliments constitutil's, et des liversos diflérenciations quils subissent. Il se divise en un epilheilio-mósonterne el un mésenchyme. Le premier se partage à son tour en mésosomites, segments disposés sur deux rangées symétriques, et en deux playues latérales: celles-ci donnent la cavité abdominale aver ses dépendances, l'eudothélium péritonéal, et les premières ébaublos sexuelles; cenx-lit fouruissent la plus grante part de la musculature. Le second se réprand entre tous les organes, el leur conslitue une gaine commune, au sein de laquelle ils sont plongés; il produit tous les tissus conjonctil's du corps, ceux qui servent vraiment le gangue unissante, comme ceux qui constituent le squelette, et ceux yni président aux échanges nutritils.

Tous les appareils de l'économie nont plus alors qu’i se laçonner aux dépens des ébanches, ainsi b́blies dans leur disposition propre comme dans leurs rapports mutuels.

\section{Modifications introduites, dans le développement des} feuillets blastodermiques, par les condensations embryonnaires. - Ces modifications sont de plusienrs sortes, el dissemblahles entre elles. Flles atteignent tous les fenillets, la notocorde, ef le nenrixe, et réponlent, soit it des déplacements, soit mème à des onissions. Lilles doirent ètre suivies, comme les données essentielles de ce développement, dans leurs diverses phases. lilles résultent, d'habitude, d'une acrumulation, dans l'ơuf, d'alondants matérianx mutritifs.

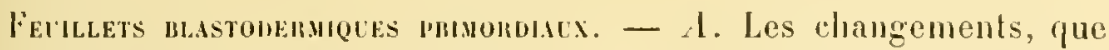
subit le protectoderme, sont relatirement peru complexes. Les uns tiennent it ses relations générales arec le protrndoderme; elles se rapporthut aux dispositions présentées par "é demier, quil actompanne daus son extension, en se bornant à le recouvrir. les antres portent sur sa struclure particuliere. - Tans les diveloppements dilatés, le protectoderme est constitué par une assise épilhéliale simple, yui se convertit tout entiere un l'ectoderme détinitil, tout en subvenant, dius sa rigion dorsale, à la genèse du neuraxe. Il en est de mine dans lia phupart des ivolutions comlensées; mais non dans celles, assez dilations encore, des Amphibiens at des fianö̈les, ni dans celles des Téléostéens. Souvout, dhez ces derniers animan, le protectoderme embryonnair se divise on deux assises cellulaires, emloitées l'une daus l'autre; il othe l'aspect d'un membrane épithéliale ì denx conches. Les antents ont nommé lame épidermique la rangée extérieure, et lame nerveuse la rangée interne; relle-ci est, en effot, chargie de produce le nuras", comme, du reste, tuus les apparils dorigine ectorlermigue. Elle est lit

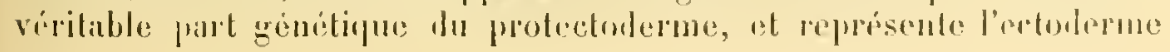


réel, l'autre élant presque inerle, el finissant par se détacher du corps. Ce phénomine répond. sans nul doute, à une multiplication hâlive du prolectorlerme, el à une dilléponcialion rapille, des assises produiles, en une conchr concis ol une couche muquense, semblable à celle qui se manilestr plus laril, daus l'ectoderme parvenu à sa púriode d'étal.

B. - Ies modifications, présentíes par le protendoderme, sonl, de lreancoup, les pulus consilimables. Ce fait se concoit aisément, l'après les nécessilés le la mutrition embryonmaire. Ces dernières sont les causes directes des altóralions subies jar les phrinomènes du développement;

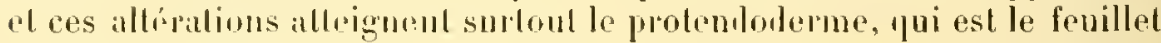
mulritif primumial.

les Verlébrés offrent, il cel égalul,sous le rapport des changements amenris daus l'origine of la nalum des fouillols bastorlemiques, une

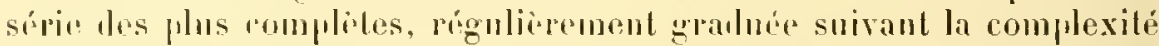
croissanle dres morlitirations oflertes. Les principales, parmi crlles-ci, porleul: sur la marelse de la stementation ovulaire; sur la forme du prolendorlerme; eulin sur celle te l'entron et de son entéropore. Elles soml d’autanl plus accenluées qur lon pemonte des Acraniens anx Ver-

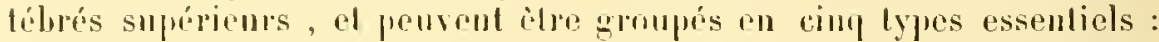
te type des Araniens, qui rst le plus simplu; celni de la plupart des Cyclostomes, drs tianoïles, el des Amphiliens; relui des Súlaciens, el, avec puelques molificalions, ules Triféstécns; celui des Sauropsidés, qui, sans doute, sipplipue figalement anx Manmiferes monolicmes; enfin celui des Mammifires vivipares. - Dans le prósent exposé, les parlicnlarités imporlantes seront seules indiguries, el avec hrievelé, afin de montrer lenr liaison; leur laseription plus ammplele est donnée dans les paragraphes suivauls.

$1{ }^{\circ}$ Limfles Araniens est pelil, pauve en deulolécithe. Sa seumentalion est lolale, daboral égale, ensule quelpue peu inégale. Lovole

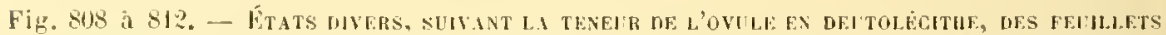

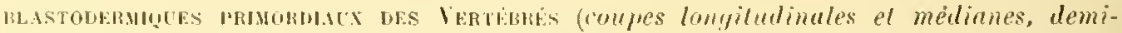
diayrammaliques, d'umbryons furronus i la ment phase, au moment oil les fenillets

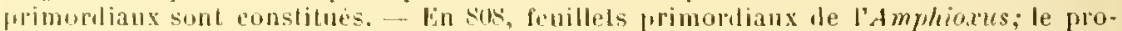

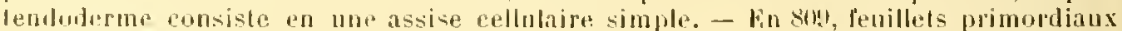

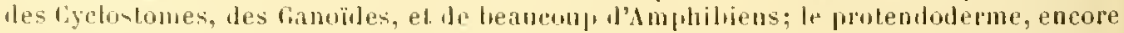

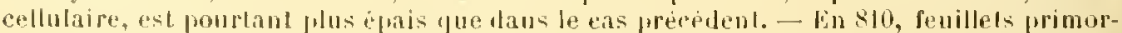

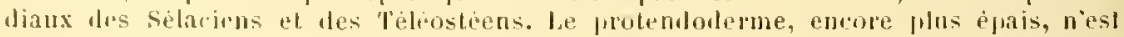
cellulaire que dans sa region rupèienre, oil se facoune semlement l'embryon; la région inferinure, julus voluminuuse, consiste four la majenre part en un amas de vilellus nutrilif, et cumpose une visicule vitellin. (zone filla-embryonnaire). - lin sll, feullets primorliaux des sauropsides, disposes, en lenl ensemble, comme dans le eas probedent.

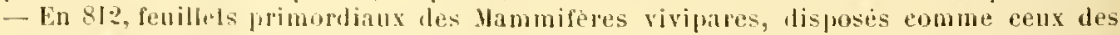

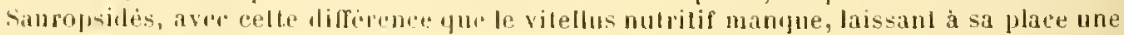
eavilé emplie al'm lingule (eavili para-vilelline).

Celle planche montre, d'une maniere comparative, los prineipales des alteralions amenees, par la presenee du deulolecille, lans la disposition des feuillets des Verlebrés. 


\section{8}

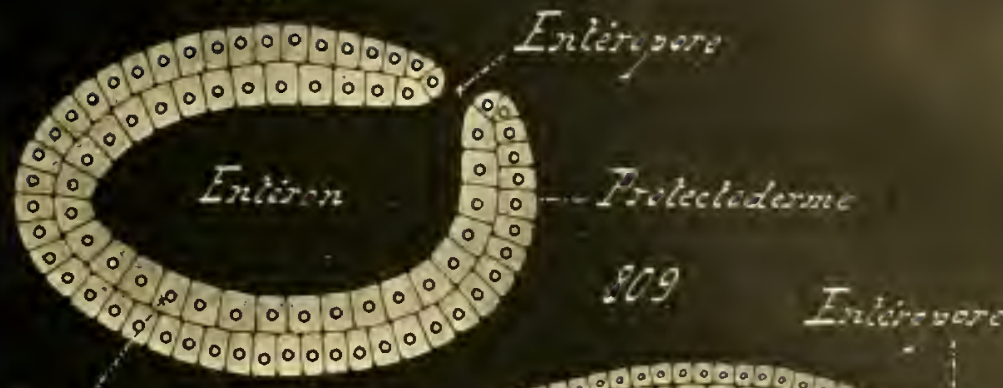

Protondaterme

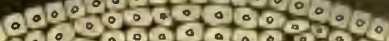
$0 \% 0 \% 0000 \%$

$8 \%$

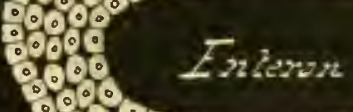

00.0

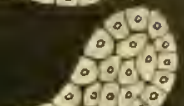

010.00

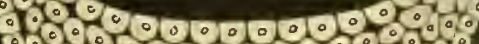

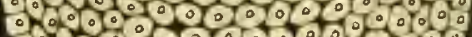

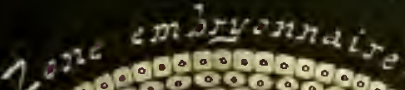

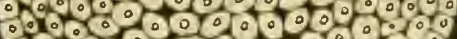

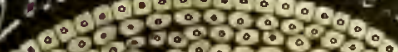
$\% 0 \%$ \% 01000

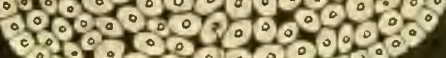

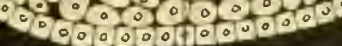
\%o: Enleran o o $0 \%$ + $+\% 00$

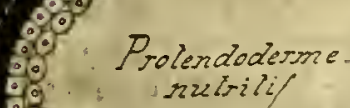

Frabendolerme nubiest

\section{E/1}

O. Vesicule vilellinef

$1 \%$

${ }_{S_{2}}$

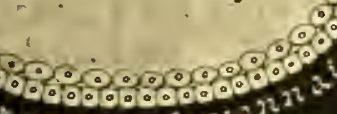

baratem2 $2 y^{2} y^{2} z^{2}$

\%

o:

$$
\text { Ectederme }
$$

\section{i/2}

-00000
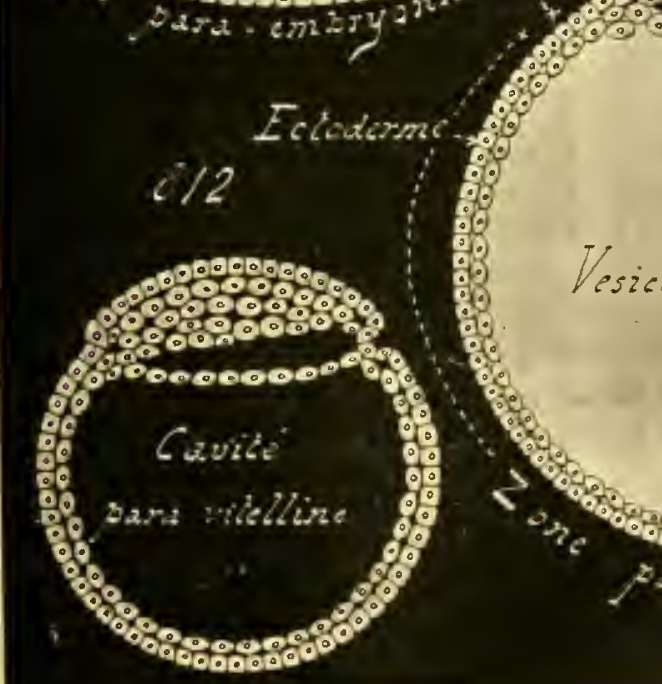

- Frierrese

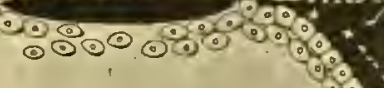


seguncuté so convertit on mue morule, puis en une blastule simple, ciest-it-1lie composée d'un blastoderme dont l'assise cellulaire rst unique. La luastule se trusforme en une gastrule par juggination; l'entéropore est d'ahord médian. Lá castrule s'allonge rnsuil. d'une manière imégale; lintéron, ample et spacienx, entiomement limité par un polrmboleme simple, suil celte extension. L'entiprpore devient postérieur et dorsal: jl prond lispect "lnne fente transversale, quelque peu recourbie en un croissant. dont la concaviti serait touruée vers la régjon antérjeure de l'organisme emblyonnaire.

$2^{\circ}$ Les anfs de la pluprart des Cycloslomes, des Ganoïdes, et des Implitriens, sont encore petils; mais ils conliennent une phus grande quantité de dentolécilhe que ceus des Acraniens. Les matériaux ne sont pas également répartis dans l'ovule; ils sont accumulés, de préférence, dans une région qu'il est fresmis de qualifier l'inferieure, car elle donne la zone runtrale di colp's; les anteurs la nommaient le póle végétalif. La segmentation est totile; parfois égale au dólut, toujours inégrale vers sa fin. L'inégalité est due à la dissemblance de taille des blastomères supérieurs et des blastomères inférieurs; ceux-ci, mieux fournis un deutolécilhe, sont plus gros que les autres. L’ovule segmenté se converlit en une blastule stratifiée; les blastomères infrurieur's sont, en effet, disposés sur plusieurs couches, of diminuent d'autant l'ampleur de la cavité hlastoculiemne. - La blastule se trausforme en une gastrule par invagination. L’invagination ue s'effectue pas au milieu du hlastodeme supérieur de la bastula, mais sur sou horl postériemr el dorsal, dans sa zone te jonction avec le blastoderme inférienr; anssi, l’entéropore occupe-t-il d'emblée sa situation défuitive, saus la devoir a une inégalité d’accroissement, consécutive à la gastrulation. A cause de sa position, J'invagination atteint a la fois la prart Hu hastoleme superieur, et celle du blastorlerme juférieur, 'pui encalrent l'entéroprope; la fremière de ces leux régions s'enfonce phus rapidement que la seconde, sans doute it la laveur l’unc activité génétique plus grande de ses éléments, nullement entravés dans len multiplicalion par la présence de matériaux nutrilifs. - Iu moment oủ linvagination est complète, la zone dorsale el l'extrémité supérieure du protendoulerne sont constituées frar une assise cellulaire simple; celle-ci dérive tout entière lu blastoderme supérieur. La zone ventrale du mème fenillet est représentéc par plusicurs rangées le grosses cellules à dentolícithe, issues du hlastoderme inférienr; elle tient, dans l'organisme emtoryomaire, nue phace considérable. L'entóron est spacienx, moins ceprudant que celui des Acraniens, car son étendue est diminuée frar l’ampleur du protendoderme ventral. L'entéropore est postérjeur et dorsal; dés son commencement, il othe l'aspect d"un croissant, i concavité antérienre; sa levre antérienre présente parfois, en son milieu, une petite échancinte. Celle-ci est la preniere indicition de la ligne mimilive des jennos embryous de Samopsidés. 
3 Le cas des Sélaciens et des Télérostérns est des phus importants, car il explique les phénomènes présentés par les sauropsidés dins la geniese de leurs feuillets primordiaux; il permet le les raltacher i ceux du type précédent. - Les aufs sont voluminenx, et ribhes en ileutolícilhr. La snbstance nutritive, beaucoup phos ahondante que erfle des embroms appartenant aux deux premiers types, est cependinut siturn daus unc mème position; elle occupe la place du blistoderme inférient des Ganoïles et des Amphibiens. Mais, comme résnltat de son volume et de son importance, elle est incapable de se segmenter, de se diviser en biastomères. La segmentation atteint seulement la partie supéricnre le l'ovule, ou le blastolícithe s'est ramassé, et dont l'étendue, au début du développement, est des plus restreintes.

En conséquence, l'uuf des Sélaciens est livisé en deux parts. - Lal premiere, for't grosse, est constiluée par lamas les matériaux mutritifs; elle ne se scinde pas en cellules, sanf en quelques régions, et sert it l'alimentation de l'embryon; anssi est-elle résorbée peu ì peu. Ilomologue lu lolastoderme inférienr du second type, elle représintrane vésicule vitelline, placée au-dessous le l'organisme embryonnaire. Beaucoup d'anteurs la désignent par l'ex]r'ession de vésicule oinbilicale; son identité complète arec les annexes similaires les autres animaux, et la nécessité de couper court à des confusions de noms, portent à préférer le premier terme pour tous les Vertélrés, el à l'employer d'une manière exclusive. - La seconde part est une cicutricule, posée sur lo vitellus mutritif, et entièrenent composée de llastolécithe. Cetle cicatricule se segmente senle, pour lonner l'organisme embryonnaire. lille est done une part formative, contrairement it lit précédente, qui est unc part nulritive.

La segmentation est partielle; elle atteinl la cicatricule seule. Celle-ci se divise en plusienrs assises celhulaires superposées, dont l'exterue représente le protectoderne: tontes lis antres composent la premiere ébanche du protendorlerme. L'ensemble de ces assise's est, d'une manière stricte, l'homologue du blastoderme supérienr du second type; mais, comme il est seul a façonner le cor'ps de l'embryon, à produire ses cellules constitulives, la majeure portion de l'homologue du blastoderme inférieur fonctionnant en qualité de résicule vitelline et nutrilive, le terme de blastorlerme, sans ancun autre pualificatif, lui convient seul. - Dans la comparaison entre l'ovule segmenté dn second type et son correspondant du troisième, le blastoderne suprírienr le celui-là devirnt l'unique hastoderme de celui-ci, car le blastoderme inférieur de l'un s'est converti en la vísicule vitelline, an rôle exclusivement mutrilil, de l'antre. Celte conversion s'ellectue par l'accumulation, en quantité plus considérable, les matérianx deutolécilhinues daus la zone qui correspond an blastorlerme inférieur.

L'ovule segrmenté des Sélaciens est nue plannle lécillnique; un petil blastocude se crense eependiut entre les preniers éléments lu proten- 


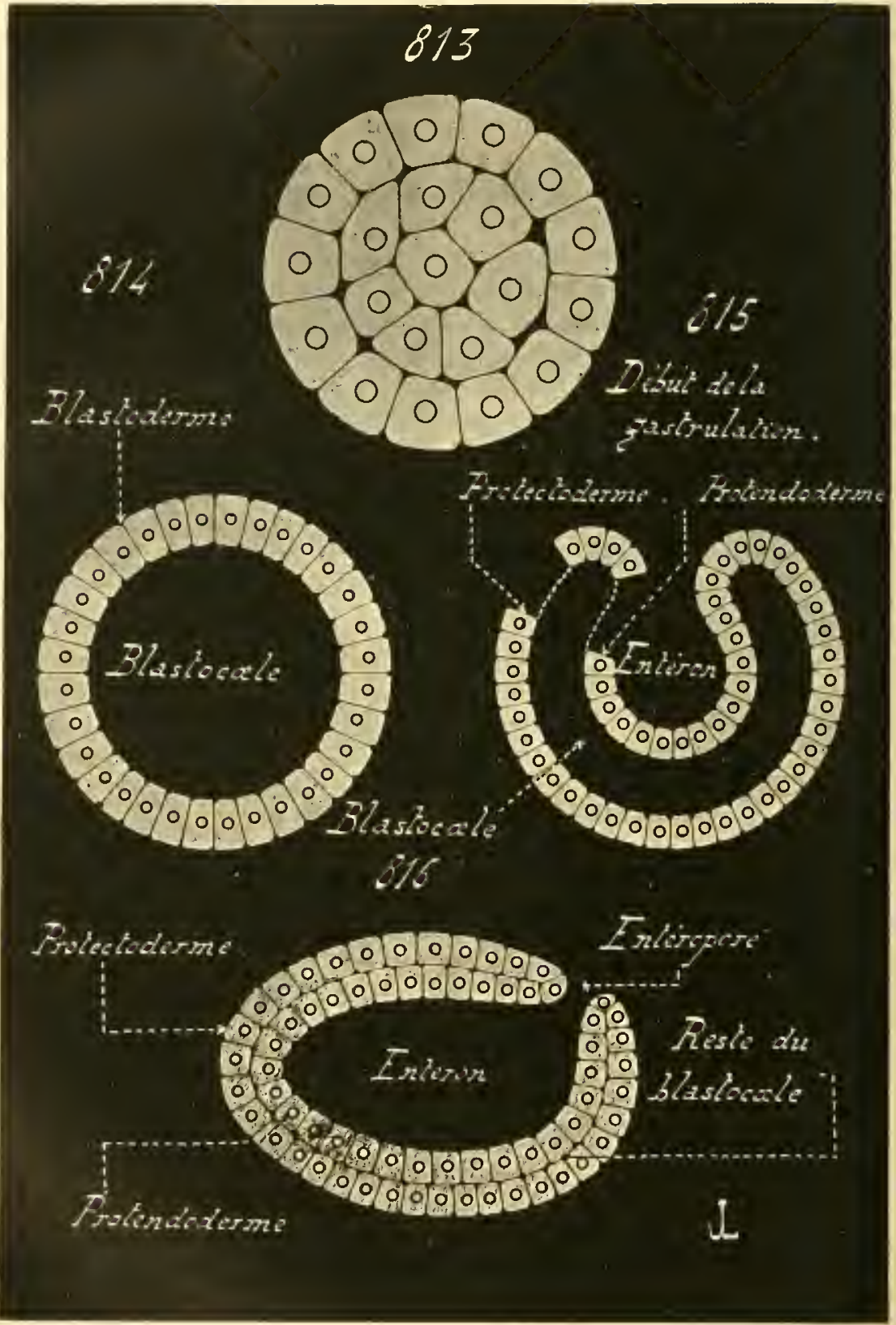

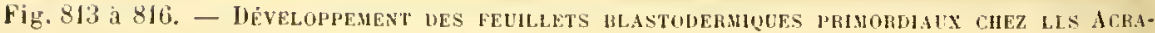
sess (coupes médianes et longitudinules, à demi diayrammatiques). - In 813, morule. - En 814, blastule. - En 815, jeune gastrule (les cellules on élé entevées par places pour faciliter la lecture de la légende). - En 816. gastrule allongèe, dont l'entéropore esl levenu supérieur el dorsal, semblable à celle de la figure 808 . 


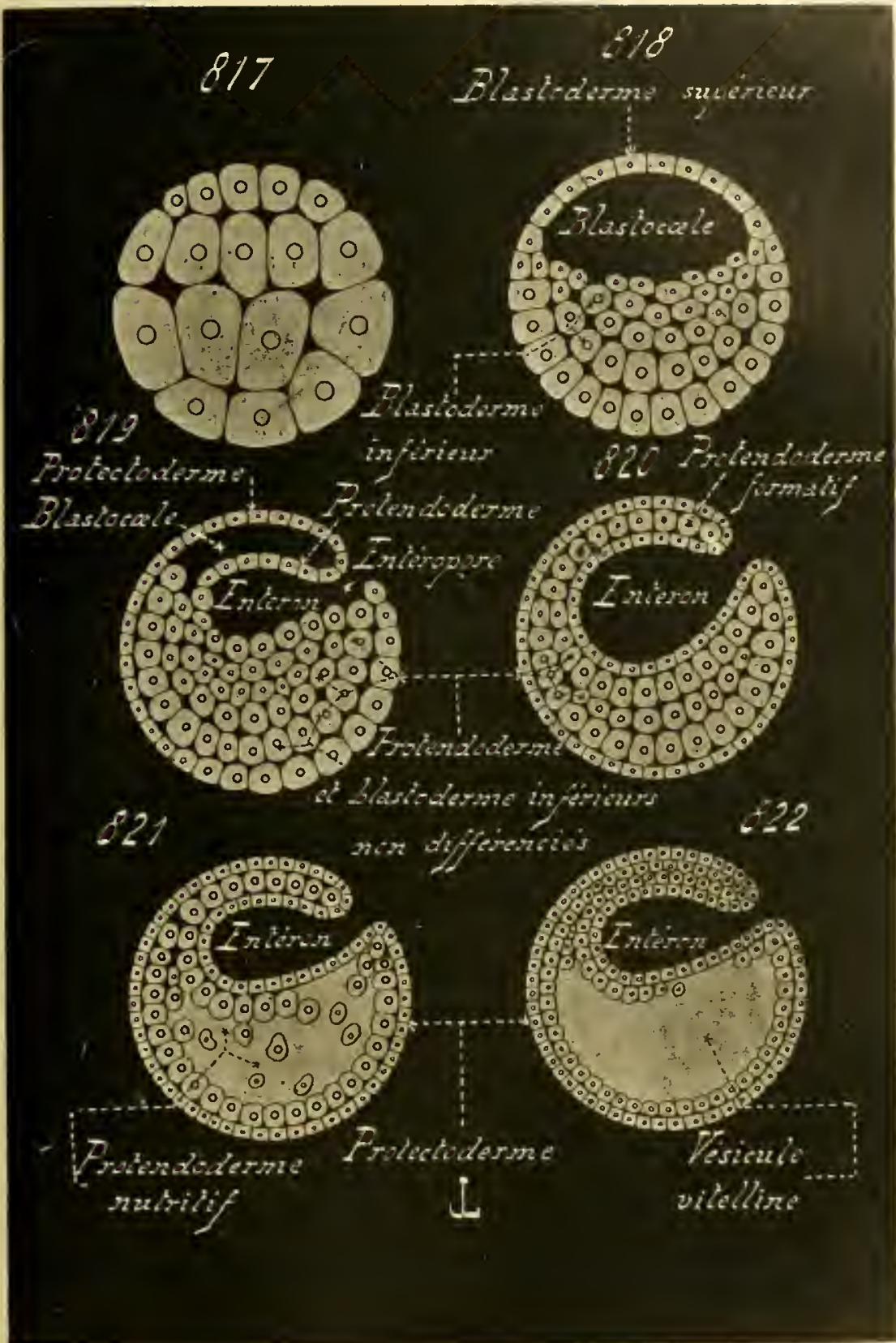

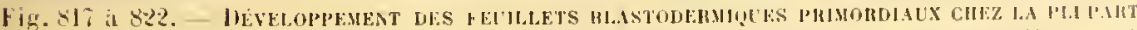

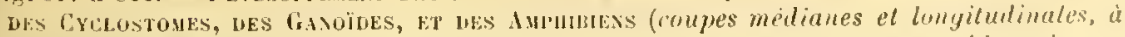
demi diagrammaliques). - En 817 , morule. - En \$18, bastule, aver son blastonlerme

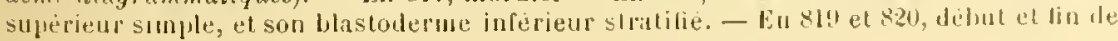


doderme, mais lisparait l'une manière hative. - L'entéron, et le protendoderme qui le limite, sont probluits en deux temps, et de deux façons : mi-partie par invagination, mi-partie par un clivage sur place. Une dípression gastrulaire se manifeste sur le hord postérieur du blastoderme, en une zone correspondante à celle où se tronve l'entéropore, dans le second type. Celte dépression a pour effet de recourbersur ellemème, et en dedans, cette région ıu bor'd blastodermique, en la faisant pénétrer entre le blastorlerme et la résicnle vitelline. Tam lis que la partie reeourbie s'accole aux cellules blastodermiques aver lesquelles elle se trouve en contact, elle sécarte de la substance vitelline, et ménage un vide entre cette lernière et elle-mène; ce vide, à cause de son origine, est strictement l'homologue le l'entéron engendré, par une dépression gastrulaire, dans les deux premiers types. Seulement, la conche limitante de cet entéron n'est donnée que par l'un iles bords du blastoderme, et elle ne fournit pas le protendoderme entier.

L'assise la plas profonde du blastoderme repose sur la région supérieure le la vésicule vitolline, et se tronve on contact direct avec le Ieutolécithe. Pendant que l'espace précélent, résultat d'une invagination, s'approfondit, cetle assise se sépare du deutolécithe, an moyen d'un véritable clivage, effectué sur place, et laisse un vide entre elle et lui. Ce vide s'unit à l'espace invaginé, et tous deux, ainsi confondus, constituent lésormais la cavité entérique. De son còté, l'assise blastodermique profonde se soude au rehord qui entoure linvagination, el comjose avec lui la moitié dorsale du protendoderme. L'entéron, le par sa provenance, est d'abor limité en luas par le deutolécithe de la vésjeule vitelline; des cellules ne tardent pas à prenilre naissance dans cette bande vitelline linitante, et à fournir une rangée complète, qui se joint à la précédente. La cavité cntérique est alors circonscrite, de lous les côtés, frar une couche cellulaire. - L'entéropore, c'est-à-dire l'orifice extérieur de la petite dépression gastrulaire, se trouve, dès son lélıut, dans sa situation postérieure, et offre de mème son aspect de croissint. De ses deux lèves, l'antérieure seule est constituée, dès l'abord, par des cellules; la postérieure est formée par du deutolécithe. C'ette lèvre postérienre devient cellulaire à son tour, lorsque s'ébauche la moitié ventrale du protendoderme; et, vers eette époque, l'entéropore, a rant de disparaître, se convertit en un canal neurentérique.

En résumant les dispositions essentielles du troisieme lype, el les comparant à celles du second, on aboutit aux données suivantes. Dans le second lype, la segmentation, totale encore, aboutit à une planulation et à une gastrulation; cependant, le blastoderme inlérieur est

la gastrulation, dans le cas oi le jrotendoderme inférieur demeure cellulaire. - Fin $\$ 21$ et 822 , début el fin ale la gastrulation, dans le cas ou le protendoderme inférieur se convertil par places en un amas nutritif, qui compose me pelite visicule vitelline.

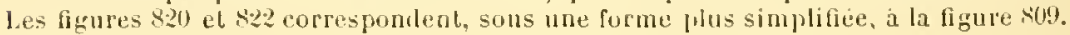


composé par l'assemblage de plusienr's assises cellulaires, alor's yue le blastoderme supérieur est simple. Liinvagination gastrulaire sothoctue dans une région postérienre et dorsale, sur la ligne de jonction dn blastorlerme supérieur et du blasloderme inférieur. Aussi, la partic dorsale du protendoderme est-elle fournie par le premier, ct la partie ventrale par le second; de mòme, la levre antérieuro de l'entéropore est faile par le premier, et la lère postéricurc par le second. - l'ar contre, dans le troisième type, tout ce qui corresponl au blastoderme inféricur est transformé en une volumineuse vésicule vitelline. Én conséquentr. le blastoderme supérieur est la seute part cellulaire le l'embryon, la seule qui mérite le nom de blastoderme; au lieu de consister en unv couche cellulaire simple, il se compose hàtivement de plusieurs assises superposées. La résicule vilelline ne se segmenlant jamais, elle demeure toujours distincte 1 u blastoderme, représenté, à son début, arant toute scission, par une cicalricule d'étenulne restreinte. Linvagination gastrulaire se produit encore, et s'etrectue lans la mème région que celle du second type, sur la ligne de jonclion lu blastoderme et de la vésicule vitelline, cest-ì-dire sur le bord et lans la zone postérienre du premier. Cetle invagination est, par suile. limilée l'un côté par le blastoderme, de l'autre par le dentolérithe; de même, la lèvre antéricure de l'entéropore est constituée par le premier, el la lívé postérienre par le second. Mais, contrairement a ce qu’il en est dans le second trpe, cette dépression ne lonne pas lout l'entéron; la majeure part di ce dernier résulte d'un clivage, de l'apparition l'une lente entre le blastoderme profond et le vitellus auquel it s'accole.

La genese tardive du protendoderme ventral est déjà indiquée par la lenteur que mettent à s’invaginer, dans le second tỹpe, les éléments du blastorlerme inférieur".

En somme, dans le lroisieme type, le protendoderne est produit en leux fois; au lieu d'aroir une origine unique, comme dans les deux premiers cas, il dérive de deux ébauches. Liune de ces dernières esl représentíe par les assises cellulaires profondes du blastorlerme, l'autro par le bord postérieur, replié sur lui-mène, et comme invagriné, de ce mème blastoderme. Celle-ci mérite, par suite, le nom l'ébunche marginale, et la première celui l'élanche centrale. - Ces ébauches ne sont siparées, el distinctes, ']u'en apparence; łans la réalité, elles composent un tont uniqur, car elles proviennent toutrs denx du blastodrime, ou bien tu blastolécithe épars ì la surface de la vésicule vilelline, el concrété en cellules destinées a limiter la région rentrale le l'entéron. Elles répondent ì deux zones actives de prolifération, lont l'une, la marginale, est un rappel hérérliaire de la gastrulation, el dont l'autre,

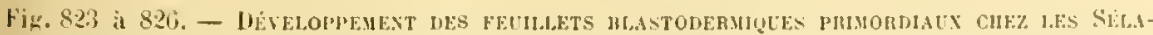

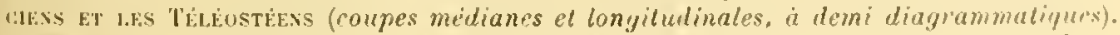

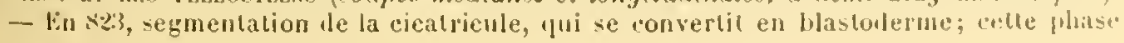




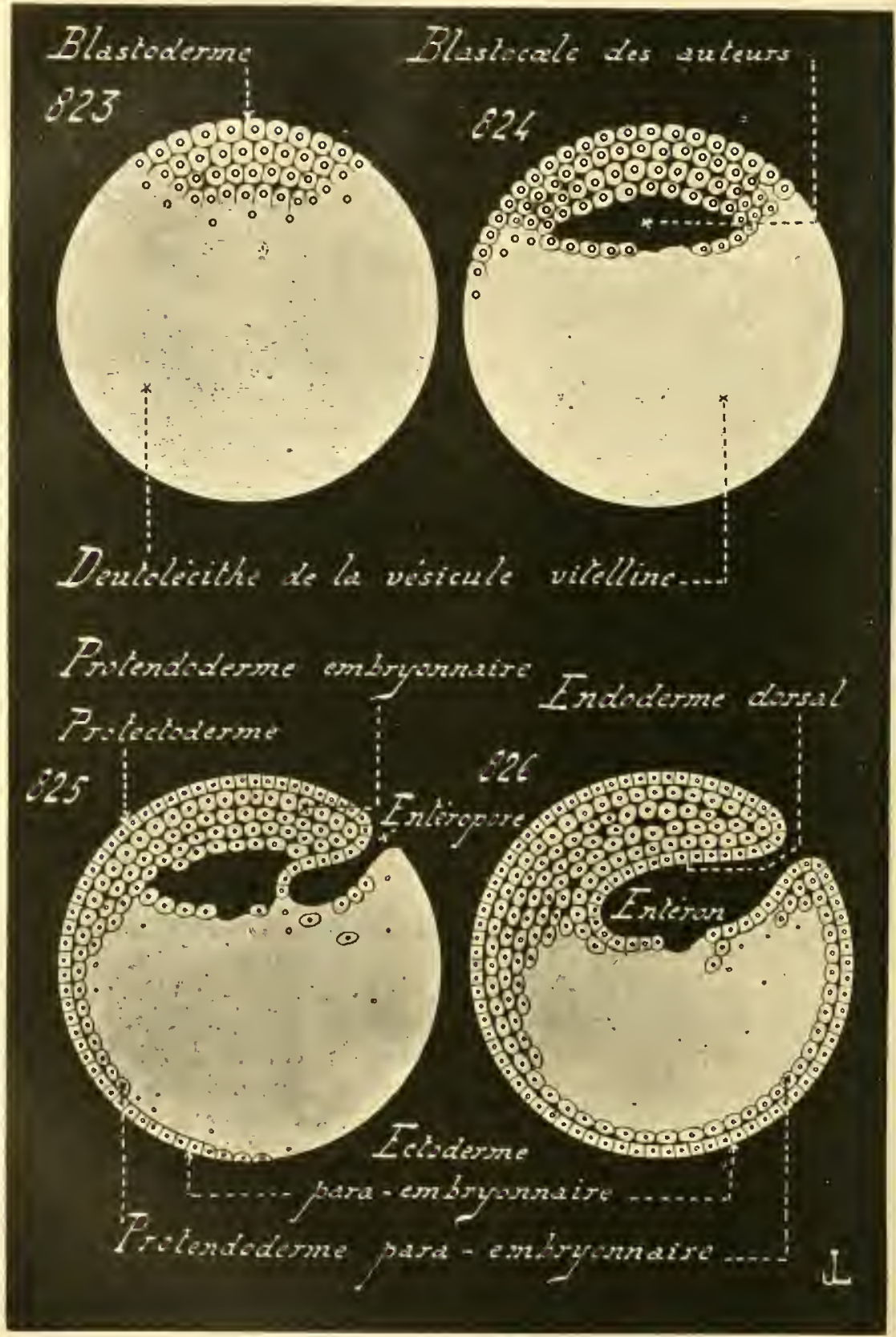

correspond à celle de la morule des cas précédents. - Fin 824 , phase correspondante à celle de la llastule des cas précélents. - En 825, debut de la gastrulation. - En 82fi, achèvement de la gastrulation cette ligure est, en plus simple, l'équivalent de la figlire sto du tableau seneral. 


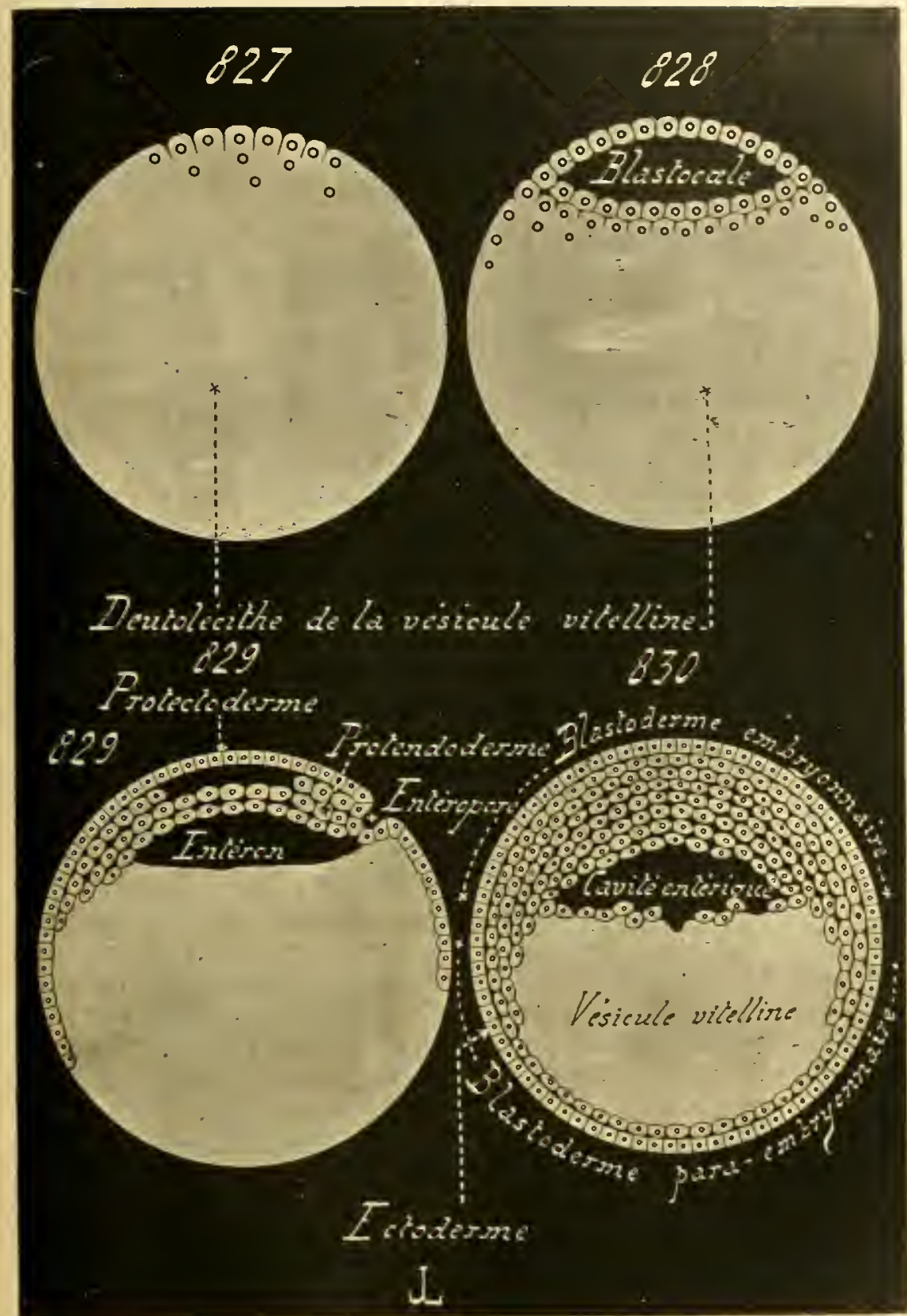

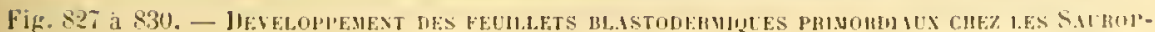
subis (roupes médianes el longilulinales, $\dot{n}$ demi dingrommaliques). - Fn k27, dibul de la segmentation de la cicatricule. - tin s:s, phase correspondante a celle de la blastule des cas prèdents. - En 829, indication tres amnindrie d'une gastrulation. - fin 831 , 
la rentrale, résulte d'une genèse bàtive de blastomères nombreux. $\Lambda$ ce litre, le troisième type est important, car il etlectue un passage entre la gastrulation et la planulation; une part du protendorlerme est engendrée suivant le premier le ces procédés, et l'autre part d'apris le second.

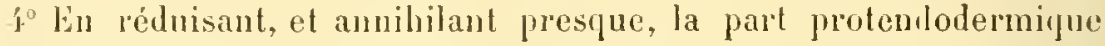
Jonnée par la gastrulation dans le troisième type, et ne laissant sulssister yue celle fournie par la planulation, par le clivage sur place, on olitient les particularités essentielles du quatrième type de formation des feuillets primordianx. Celui-ci est offert jar tous les Sanropsidés, et, sans doute, à en jugrer d'après la structure des aul's, prar les llammifères oripares.

L'ouf, volumineux, est pourvu en abondance de matériaux nutritifs; la majeure partie du lastolécithe est, avant toute segmentation, rassemblée en une petite cicatricule. La disposition générale est semblable a celle que montrent les Sélaciens; aussi, les premières phases du lévoloppement anènent-elles les mèmes résultats. L'ensemble du deutoléeilhe donne une grosse vésicule vitelline, sur laquelle repose le bastorlerme, issu de la cicatricule par la division répétće de celle-ci; l'ovule est converti en une planule lécithique, dont le lılastoderme se compose de plusicur's assises cellulaires superposées. - Parmi ces dernières, la couche externe répond au protectoderme. Toules les autres représentent le protendoderme; leur ensemble s'écarte quelque pen du deutolécilhe, auquel elles s'accolaient, pour laisser entre eux un vidle étroit; cette fente est l'homologue de l'entéron produit, dans le troisième tỵe, par le clivage sur place. Elle ne parvient pas cependant à devenir une cavité spacieuse; limitée en haut par les cellules du protendoderme, en bas par le deutolécithe superficiel de la vésicule vitelline, elle demeure en cet état, pendant que le nombre des l,lastomères s'accroit avec rapilité. Le vitellus nutritif reste toujours peu éloigné de la rangée cellulaire profonle lu protendoderme; et la cavité entérique n'arrive à sc limiter yue par li reploiement, sur elle-mème, de cette rangée. La couche collulaire s’incurve en une gouttiere, qui s'approfondit sans cesse, rapproche ses bords l'un de l'autre, les soutle, et se convertit par là en un canal; ce dernier, façonné par ce moyen dans la zone supérieure de la visicule vitelline, est la première indication de l'intestin.

Lin risumé, le prolendoderme et l'entéron sont produits sur place, suivant un procédé flanulaire, et non prar une invaginalion gastrulaire. Ceprenlant, un souvenir de cette dernière, moins prononcé que celui dı troisiène type, demense encore. Tout au début de la segmentation cica-

achèvement des feuillets primordiaux par une mulliplication eellulaire failc sur place; la vésicule vilellin est, en réalité, plus volumineuse. Cette figure est, en plus sinuple. l'tipuivaleul de la figure 811 alu taloleau ginnial. 


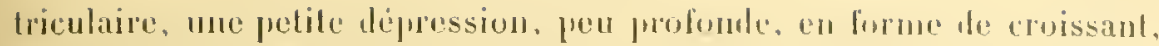
freml najssance sur le bornl postipreur de cettre cicatricule; lat silualion el l'aspect de celle depression autorisent ì la consichere, sins nul dunte, comme l'homologue de l'enteropore les trois premiers types. In livro antéricure de l'enfonrement porte, en son milieu, une petile entaille, déjà indiquice daus le secomd cas. Celte derniere grandit, pendant que la dépression elle-meme diminue d'amplear: elle s'allunge suivanl laxe de la ricatricule. Hejà connue des anciens auteurs, yui l'avaient nomme la ligne primiliee, celle entaille disparait, non pas en se comblant, mais en se trourant prise dans libauche du neuraxe, yui la ronvertil en ranal

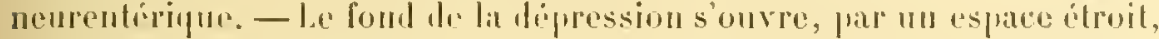

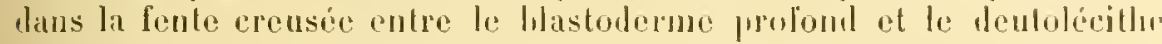
vitellin. Cotle fente est la première indication de l'enléron; ajusi se trouvent réalisées, par suite, des communicatiuns directes de l'entéron arre le dehors, jar le moyen de l'entéropore, semblables à celles yui résultent d'une gastrulation vérilable. Seulenent, ces connexions sont deplacées dans le temps, et tardives; de plus, elles n'ont aucun rapport arec lia grenese réelle du protendoderme, façoné sur place: elles répondent à un rappel héréditaire, fort amoindri.

lien que ee restige de zrastrulation se lrowre des plus restreints, et que l'ébauche iniliale da protendoderme soit directement faits aux dépens du blastoderme profond, la joblifération des éléments de ce fenillet est des plus actives autour des horis de cet enteropore. les deux frovenauces, marginale el centrale, déjà signalies, dans le troisieme lye, en ce pui concerme lo protendoderme, se retrouvent cncore.

Jans le qualrieme trpe, comme dans le truisieme, la vésicule vitelline est envelopjec, peu ì peu, par des membranes, pue lonrnissent les deux fenillets primoriaux. Ces derniers, tout en proliférant daus la zone formative de l'emhrom, et lomnant l'oranisme lui-meme, saceroissent fatr lemrs bords; ceux-ci grandissent, el, semblables à drs lanes minces, entourent rompletement, far ane frugression conslante, te deutolécithe. - Ces phénomenes sont de l'urdre de cenxy yri caratérisent les planmations indirectes.

5"Jusqüici, les déplacements et les umissions, quoinue consilératbles, n'ont el'autre lint que de remplacer la gatstrulation par mue plamulation indirecte. Las altérations sunt plus grames enoure lans le cas des Mammifères vivipares. On anra mo ider sultisamment exacle de leur

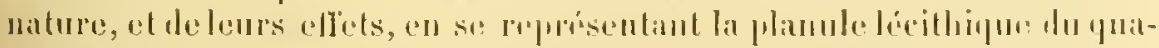

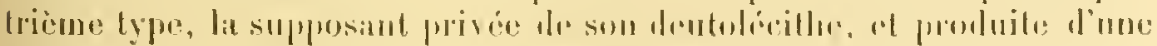

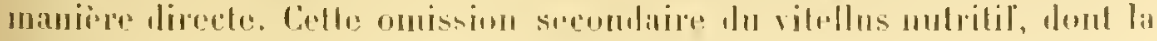

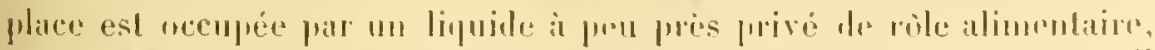

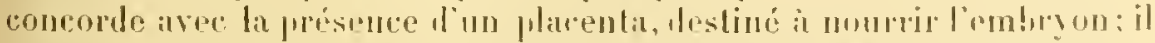

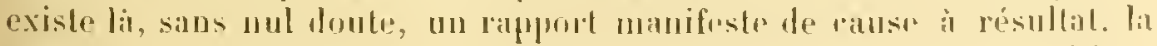
genise d'un placrnta ayant entraine la réduction, puis la disparitiun, 
de tout le dentolécilhe. Une nouvelle conséyuence de ce phénomène est la petilosse des ovules, puispu'un vilollus abondant n'est plus pour leur domner une laille considérahle. Les anfs ressemblent à ceux des denx premiers types: celte diminution de volume est ici secondaire, non primitive, et se trouve connexe à une condensation du développement, fhus accentuée encore que lans lo quatrième cas.

Cette condensation a pour effel d'entrainer J'omission de l'une des prarticularilés caracléristiques du troisième el du quatrièmr lype : la possession, par l'embryon, d'unc volumineuse vésicule vitelline. Elle déterminr également la production directe, sur place, de l'enveloppe de retle résicule, et d'une maniire hàtive, dés la fin te la segmentalion. Aussi est-il possible te distinguer encore entre une part formative el une part untrilive, lien pue cetle deruiere soil petite. Emplie par un liquide failbement untrilif, el deslinće sonvent à s'alrophier aver rapidité, elle est $\mathrm{un}$ rappel héréditaire, très amoindri, de la grosse vésicule vilelline des Sélaciens, des Sarropsidés, et des Mammifères ovipares. - Ces altérations supplémentaires mises ì part, la grnese des fenillets primorlianx s'effertur, dans ses traits essentiels, comme chez les V'erlébrés précédents. La principale des différnces porte sur le nombre restreint des blastomères qui constiluent, ì lem dibnt, les ábanches de ces fruillets. Celte diminntion est, à son tour, nue conséquence dr la petilesse les ovules.

Hésoderme. - Les altérations, introdnites dans la genèse du fenillet moyen, déconlent de relles présentées par le protendoderme. Le fait se conçoit aisémint; le mésollerme élant une des parts dn protendoderme, lallure de celni-ci intlue sur la disposition de celni-lì. - Le fenillet primordial interne se livise en endorleme et mésoderme. Les changements amenés dans la structure du premier sont des plus minimes; ils se laissent pressentir l'après les consilérations données sur le protendoderme lui-mime. Les principaux portent sur la juxtaposition de rette assise arec une vésicule vilelline. Les résultals sonl loujour's les mèmes: l'endolerme se compose llune conche épithéliale simple, lisposée autour le l'entéron. Les morlitications les plus consilérables alteignent le mésoulerme, soit it cause le sa grande importance dans l'organisme, soil it canse des diftérenciations quiil subit.

l.es ćbauches mésodermiques des Acraniens sont au nombre de denx. Symétripues prar rapport au plan mélian du corps, elles se légagent du protendoderme dans la région antériemre de ce dernier, c’est-î-dire dans la zone opposée àl'entéropore. Ces ébanches sont des entérocules creux, dont les ravités s'onvent dans l'entéron. Elles grandissent, en amplifiant leur base d'insertion sur le protendoderme, et les rapprochant de l'entéroprore; ce faisant, elles se dirisent à mesure en mésosomiles, qui deviennent indépendants. Lorsque ce double mouvement génélique atteint le niveau de l'entéroprore, colni-ci est en roie de devenir le canal 
nementérique; la zone quil occupe, soit lextremité postérirma dn corps, s'allonge alors: les ćlauches mésollemiques suivent eottr extension, dépassent le niveau de l'entripopore, et rontiunont ì se scinder en segments. - En sommr, les ébauches mésodermiques sont des rutérocoeles émis par l'entéron: leurs premiers restiges naissent en avant if lentéropore, sur les côtés de l'entéron el de la notocordr: pnis, elles sont encore le siège d'une multiplication active, lorsqu'elles parviennent au niveau de l'entéropore, et le dípassent.

Les développoments plus condensís que l'évolution des Arianiurs. cenx de la plupart des Amphibiens et les Ganoïles, montrent déjà plusieurs altérations de ces phénomènes. Le protendoderma est, des la fin de la gastrulation, composé par plusieurs assises cellulaires; aussi, les denx ébanches mésodermiques se délimitent-elles, sur place, aux dépers de ces assises. Elles consistent en lemx masses de cellules, placées sum les côtés de l'entéron, le manièe a occuper la position exacte de leurs similaires des Acraniens; l'autre part, les éliments protendodermiques, situés au niveau de l'entéroporo. se multiplient avec activité, et se raccorlent aux élanches précédentes. Le double mouvement des Acraniens est ici converti cn une double origine. - De plus, chacune les bandes mésodermíues se creuse l'une carité; celle-ci est indépendante, dés l'aliorl, de l'entéron, et n'en provient pas; elle souvre parfois dans l'intérieur de re dernier, l'orifice de jonction étant l'une durée fugace, mais ne dérive pas de lui. Par un léplacement dans l'espace, les cavités entéroculiennes prennent naissance d'une manière directe, sans que l'entéron les émette a la façon de diverticules; un rappel de l’érolution dilatée se manifeste lien an moven d'une ouverture temporaire, mais là se hornent les phénomènes. - Le mésollerme commence par régulariser sa disposition; tout en ayant une structure epithéliale, il se divise en mésosomites, en plaques latérales, et produit le mésenchyme. Il lćlute par ètre épilhélial en entier : et c'est seulement aprís avoir possédé un tel aspect, qu’il se partage en épithélio-mésoderme et mésoderme mésenchymateux.

L'altération est plus grande encore chez les Sélaciens. Les élıunches dn feuillet moven sont compactes dès leur apparition, et se délimitent sur place, aux dépens les nombreuses rellules du protemloderme. La double origrine, déjà indiquće dans le cas précédent, ost plus nette encore. La notocorile étant façonnée laus la masse du protendoulerma, et provenant d'une lande cellulaire midiane, les autres ćlóments du mème feuillet prolifèrent, avec activito, sur la droite el sur la gauche de cette bande; ces éliments domment mo part du mésolerms, mn. première ébauche cemlrale. W'un autre côté, les rellules protemlodermiques, voisines de l'entipopore, se mulliplient en abondance; sanf celles qui doivent appartenir à l'endoderme, la majorité d"ontre clles est employece i compléter le mrsodermo; elles composent l'ibaucle mur-

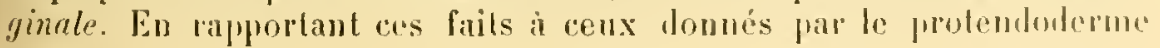




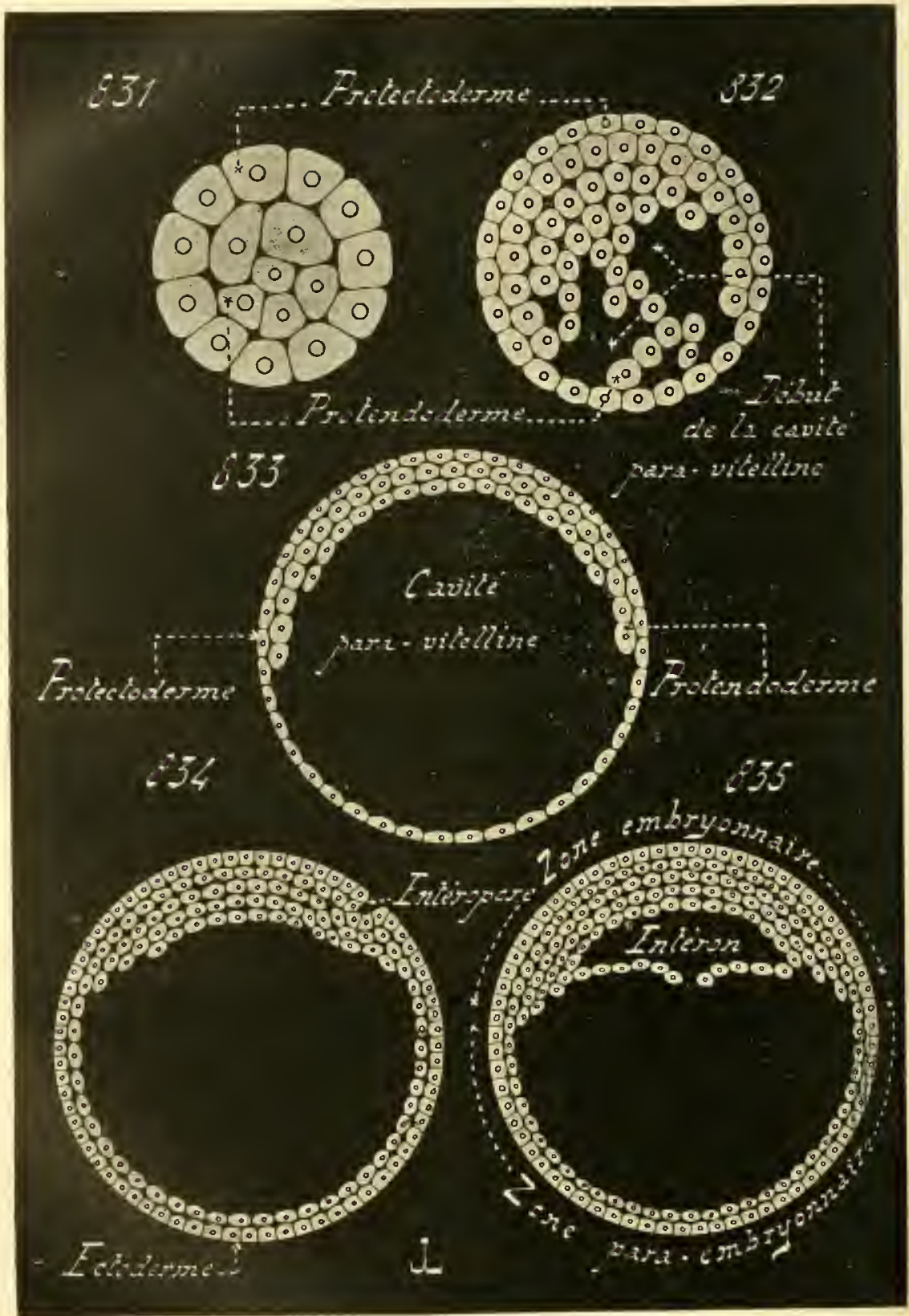

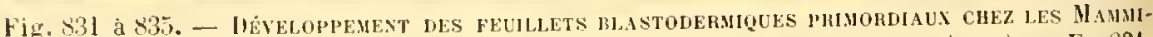
Finds Vhipans (coupes médianes et longiludinales, à demi diayrammaliques). - En 831 . début le la segmentation ovulaire. - En 832 , achèvement de la segmentation, et genese des ébanches de la cavité para-vitelline. - En 833 , cavilé para-vilelline parvenue à sa periole d'état. - En 83 et 835 , pliases correspondantes à celles (ules Sauropsides) numé- 


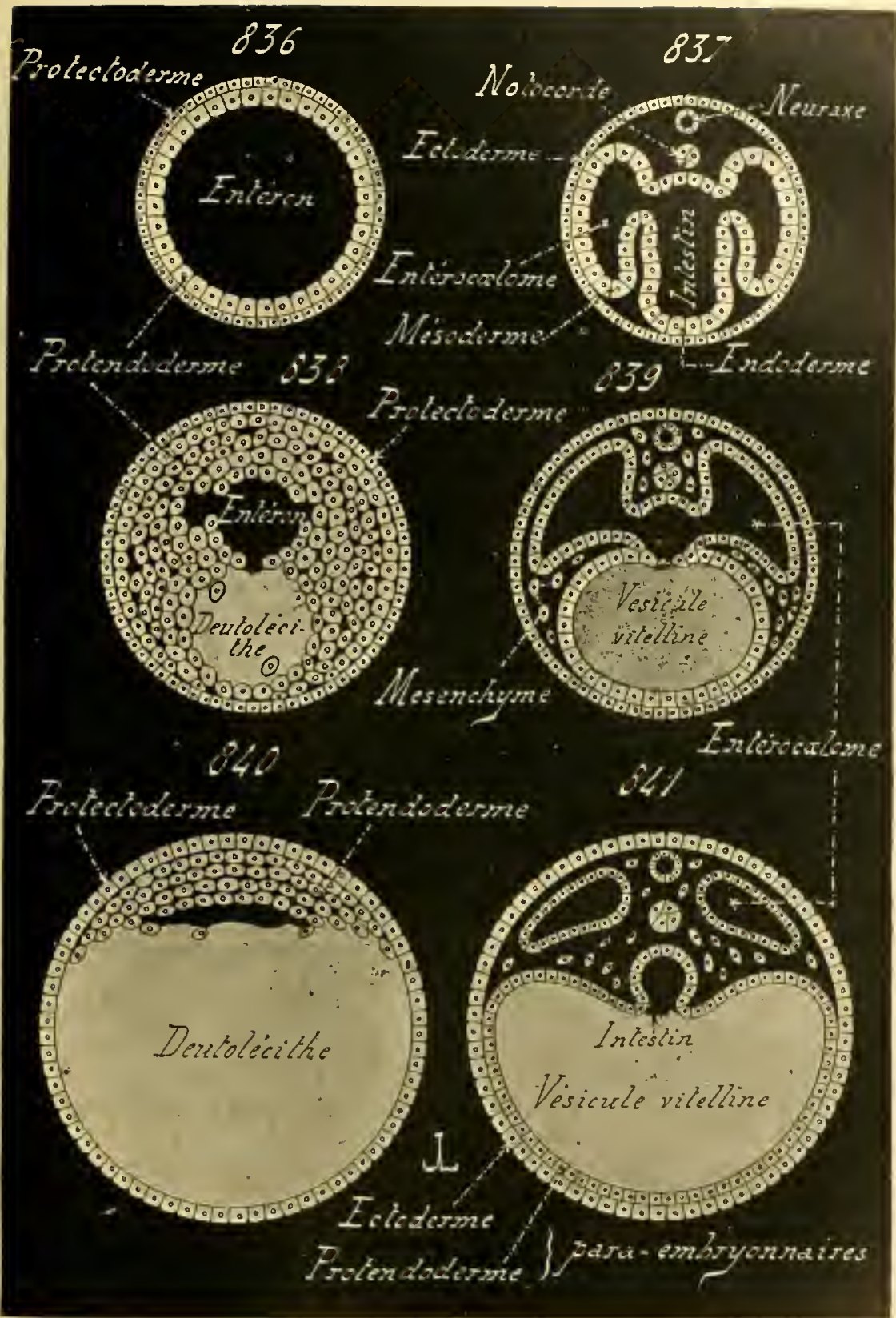

rotées 829 et 830 ; la difference essenticlle porte sur l'ahsence de deutolecilhe cher les IIammifires.

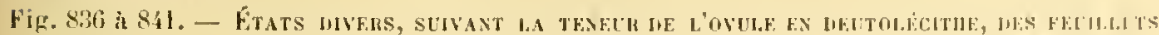

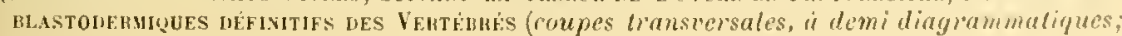


dans sa genise, st souvenant pue ee feuillet est, dis son commeneement, constitué frar plusicurs assises superposées, il est aisé de comprendre la formation du mésoderme, ear ce dernicr dérive du protendodermu presque entier, sauf la failhe portion comsacrér à fournir l'endoderne. Ces teux ebauches ont reru d'autres noms; ainsi, Ralil désign l'ébauche centrale par le terme de mesodeme gastral, el la marginale par celui de mésoderme péristomal. - Au moment mème où le feuillet moyen se délimile, par l’isolement de la notocorte, et par la régularisation de la conche endodermique, il possèle une structure épilbéliale. Il ne tarde pas à se scinder en épilhélio-mésoderme et mésınchyme; les premiers éléments mésenchymaleux se síparent de hri. alors que les cavités de l'épilhélio-mésorlerme so creusent à peine. Celles-ci sont tonjours indépendantes le lentéron, et ne s'alouchent jamais avec lui.

Les modifications offertes, laus la genise le leur mésoderme, par les embryons des Vertébrés amniotes, rappellent le près leurs similaires les Sélaciens. La condensalion les plénomènes serail cependant un peu plus grande. Ainsi, les élauches mésoulermiques, lès leur délimilation sur place, sont divisées en épilhélio-mésorlerme et en mésenchyme. la plupart des rellules te ces élauches se rasscmblent en conches, qui devirnnent régulières, ot donnent les plaques latérales avee les mésosomites; mais d'autres éliments, laissés entre les précétentes et l'ectoderme, ou l'endoderme, demenrent épars, et contribuent, en se multipliant, a produire le mésenchyme. Ces faits sont mieux marqués chez les Sauropsidés que chez les Mammiferes vivipares, à cause de li gramle quantilé lles hastomères arcumulés par la segnentation de leur cicatricule.

Neuraxe et notuconoe. - 1. Le nemraxe des Vertélirés lérive toujours le la plaque medullaire senle. Celle-ci est une hande cctorlermique. médiane ol longitudinale, placée sur la face torsale de l'organisme emIryomaire, en avant le l'entéropore; ses cellules conslitutives. en voic de prolifération active, sont cylindriques, allongócs, et, par là, se distinguent nettement de leurs voisines, appartenant à l'ectoderme non noditié. Chez les Acraniens, la plaque médnllaire sincure liahord en une goullière: celle-ci s'enlonce dans le corps, par le passage de l'ictoderne an-dessus ielle, el se convertit en un canal, te neuraxe léfnitif. la partirularilé essentielte de celle genese, l’incurvation de

elfes se raceordent aux sections longiludinales, numérotes 808 , 809 , el 810 , du tableau géneral des feuillets primordiaux). - En 836 , leuilets primordiaux l'un leranien, comme

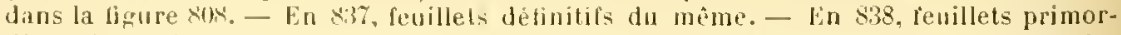
diaux de la plupirt les Cyolostomes, hes lianoüdes, et des implibiens; eomme dans les fipures 809,820 , et $\$ 22$. - lin $83 \%$, feuillets definitifs les mémes. dans le cas ou les entérocules s'atouchent avec l'entémon, comme il en est thez le Triton par exemple. -

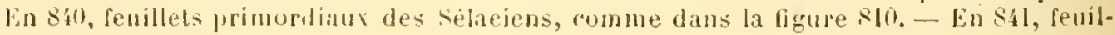
lets definilifs des mimes. 
lébauche en un sillon qui se freme, se retuove dans lo développentent des Cranioles, sauf dins celui des Cyclostonnes ot des Pólrostious, mais avec quelques altérations. Dis son dobut, la conthure so manileste dejà. en ee sens que les hords le la playue sont yuelpue peu suríleves; fors bords sont nommés les bourrelets mélullaries, ou les replis mélullaires. Chacm de ces hords se compose d'une doulile rangée cellulaire, dont l’interne, fournér vers le milien de la plaque, ust constituée par drs éléments de l'ébanche nervense, et dont l'externe eonsiste en de l'ectoderme non moditié. Les deux replis se rapprochent ensuite l'un do lautre; ils s'affrontent, se soudent, et transforment la plapue on un canal clos. La fermeture ne s'accomplit pas en mème temps sur toutr la longueur du neuraxe; elle commence daus une région qui correspond sensiblement au futur cerveau moyen, et s'étrnd, le lit, en avant et en arrière. Inrant re mourement, la plaque, d'alord a peu pres plane, se change en une goutlière, dite la goultipre médullaive, puis en un condnit cylindripue, le canal médulluire, ou neuraxe détinitif.

Les phases ditlërent en ce qui concerne les Cyclostones et les Téléostéens; l’incurvation fail défaut. La plaque médullaire proliliere activement, augmente le nombre de ses cellules, el se convertil en un cordon plein, cylindrique. Au liu et a mesure de cette multiplication, l'ectorlerme non modifié s'avance au-lessus de lui, de manière à lo recourrir. Puis. lorsque le corlon est devenu interne, et couvert par l'ectoderme, il se crense d'une cavité axiale, et ofl're l'aspect d'un canal: le résultat est lone semblable à celui du prensier procédé. - Ce mode évolulif est mne altération de son correspondant les teraniens, altération causée far un doulle déplacement dans le temps et dans l'espace, par la substitution du type massif au type cremx. Il suffit, pour olitenir les fails présents, de se reporter aux pliénomènes mis en cause chez les deraniens, en supprimant l'incurvalion; sauf celle dernière, tous les autres phéuomènes concordent.

liextrémité postérieure du neuraxe s'abouche arec l'untéropore, quelle que soit la forme de ce dernier. L'ectorlerme placé au-4lessus de l'ébauche nervense sunil, a celui qui recouve cet orifice, pour le fermer; aussi la lumiere du neuraxe se trouve-l-elle avoir des connexions directes aver la cavité entérique, ces relations élant assuries par l'entiropore. C.e dernier mérile donc le nom do conal neurentivique, qui hui a été domé. Ces rupports sont temporaires, et lisparaissent rapillement.

B. - Pour les développements lilatés, dans reux qui correspondent aux deux premiers types de la genese dos feuillels primorliaux (Aeraniens. Cyelostomes, Ginoïles, Amphibiens). l'ébandue de la notocorde commence souvent par suncurver plus ou moins; elle deviont la goultiere corlale. Pruis, elle s'ipaissil, fait disparaitre le sillon dont alle setait cuensie, et se converlit en mn corlon cylindripue, comparl. Ce dernier itat est atteint d'emble dans lévoludion embryomuandes 
V'ertébrés autres qur les précédents; la phase de la goultiore cordale est mise. L'ibauche de la nolocorle so délimite sur place daus le probro-

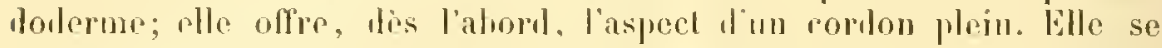
faconne en sa posilion détinitive, aux dépens des cellules protendorlermiques sibures survat lo fulur axo longitulinal de l'embryon. Sa délimilation rest lo's prócoce. - Nistraction faite le lassise la phus prolimble (parmi les conches yui composent le protendoderme), dont le

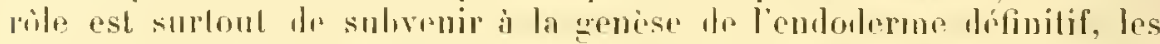
áments, placés sur la droite et sur la gauche do la joune nolocorle,

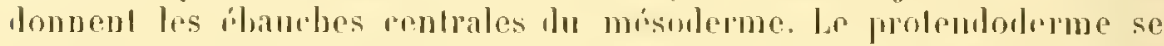
dillípencie lonc, sur place, en ses lrois parlies essemliclles : la notrocorle, le misomlerme, ot lectodermo.

\section{\$4. - Développement des feuillets blastodermiques chez les Acraniens.}

les principales des parlicularilés de ce liveloppemonl sonl signalées daus le précélent paragraphr. Il suftit do les rappeler ici, en les disposanl suivant leur orile daus le temps.

1. - liovule, privé de réserves mutrilives, est tries petit; il mesure, en moyenur, de nu dixiome i drux dixiemes de millimitre de diamitre. Sa segmentation, d'aloril égale, ne larde pas i devenir quelque peu inégale: les plus žos des blastomieres sont destinés a sönveginer, dans la gastrulation, pour fournir le protemloderme. Lauf segmenté se convertit dahort en une morule, puis en wne blastulo pourve diun ample blastocole, entin en une gastrul par invagination. Fn ce moment, les cils vibratiles, lont les premiers apparaissent lors do la phase hlasLulaire, se diveloppent sm le protectolerme. Ia lave se bébarrasse de la fine membrane qui lenveloppait, devient libre, cl nage au moyen de ces appendices locomotrurs.

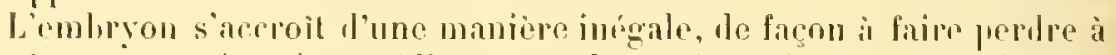

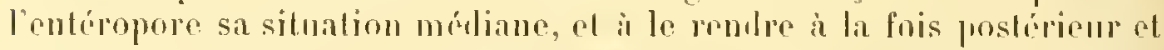
lorsal. L invagination gastrulaire sacheve durant ce temps; elle est assoz profomb pour areoler exactement le protectoderme an protindo-

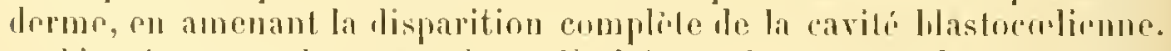
- L'entéron, ample el spaciens, limilá par le protemloderme, fouruit alors les élumeles du misoderme, sous la forme de denx diverticules entéroculirus. Ces depuiers prement uaissance dans la rógion antérieure le l'entáron, lans celle qui est opposíe il l'enteropure, cl sur ses còtés:

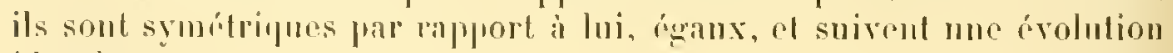
iilentioue.

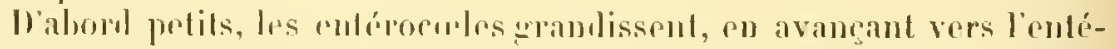
ropore lrurs hases d implanlation, ot laissant on place Inurs zones déjà formées. Ce faisant, ils se divisenl en mésosonites, par la genèse de 
doisons transiresales, qui sectionnent lem ravité. Cos leux monvaments sont sunchrones, et connexes, au point que chacun des mésosomites. cu se séparant de celui qui le précide, communique aver la civití entérigue, dont il parait àtre un liverticule proulnit d'une maniere imbeprodante. En réalite, cet aspect est le rísultit de la juxlaposition précise de drux phrnomines, dont l'un porte sur l'amplitication des antírncules, el le second sur leur division an segments. Les nifices, par lespuels les mésosomites s’alouchent arec lentéron, ue fardont pas it se fermer. - La paroi des entérocwles ronsistr en nue assise épithílialn simplin; lour cavile est ample, bitivement distinctr de lentéron, dont elle est un diverlieule; les cloisons de sectionmemnt sont des replis de la paroi, qui s’avancent dans la cavité, et la partagent en tronegons. Ces replis apparaissent, en premier lien. sur le borl dorsal des entérocules, ef sóteudent de li vers le howl rentral.

Contrairement à ce quil en est chez. les Crnniotes, la division segrmentaire atteint les éluanches mésodermiques ontières, ef n'en minage aucune partio. Lorspue cette scission est terminée, le feuillet moyen est representé par deux rangées parallibles el symétriques de mésosomiles, disposées sur les coblós de l'entéron devenu l’intestin. Une larve, igner de vingt-rfuatre henres, posside, en moymue, dix-sept de ces segmeuts daus chaque rangée; le chilfre définitit, ottert jar l'adulte, est de soixante-leux. - Tout dahord, les mesosomites, siparés los mos dos autres par les rloisons complites, s'blondent transversalement de la région dorsale du corps i la région rentrale; chacun d'eux se scinle, par la suite, an moyen d'un plan horizontal, en deux parties, l’une supírienre, l'autre inférienre. La premire se convertil en une plaque musculaire (myotome, ou myomire); sa caviti disparait, et sa splanchnopleure s'épraissit, tout en se transformant en fihres musculaires. Tontes les plajues musculairrs l'une mime rangée restent séparées, et distincles les unesiles antrus; leurs cloisons demenront en place, d devicunent mème phus lenses. le contraire se manifeste dans lus partios infirieures des mososomites; celles d’une mème raugée s'unissent les mos aux antres. par la résorption de leurs cloisons sciparatrices, el ronfumlent lenrs vides parliculires en un senl espace simple. Colni-ri, homolngur de son similaire

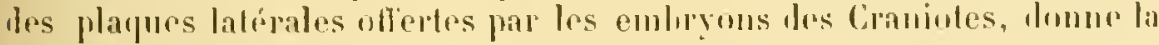
cavilé alulominale de l'aululte.

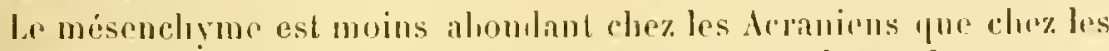
autres Vertétrés; lles olservations directes, el complites, font rncoro défant sur son origine, mais, à en juger d’après soll ispret el sa disposition, sa provenance ne liffire pas de celle présentée par les Craniotos.

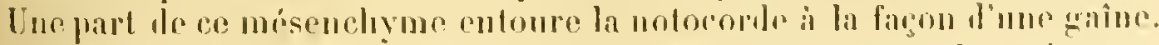

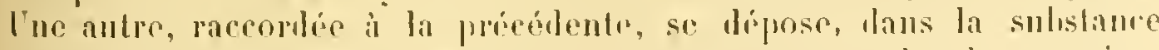
môme des cloisons qui séparent les myolomes, eulm les doux assises

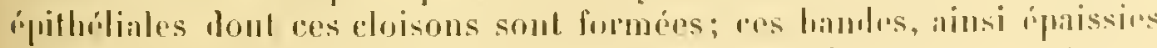

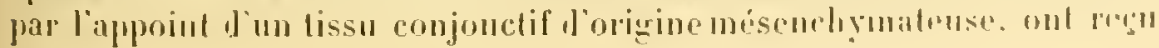


le nom de myocommes. Entin, le nouvelles conches de mésenohyme sont placées entre les mésosomites et l'ectoderme, on l'puluderme.

B. - Penlant que le feuillet moyen se conslilue, et se complite, le prolendoderme donne nassance à la notocorle. Celle-ci se délimile aux lépuns de la hando dorsiale, placéc en avant de l'entéropore, "ntro les loses d'implantation les denx entérocoles. Au moment oì ces bases se resserrenl, pour séparer de l'entéron l’s ébauches mésodermiques, la lande dorsalo se trouv indipendante te ce fail, et isolée du fruillet dont nllo dérive. Ello commence par s’incurver légèrment, sa concavilé élant lournée rn bas; olle un est alors à la phaso do goultiere cordale. Puis, olle so ramasiesur allo-meme, as convertilen un corlon eylindrique, ot compact : la notocorde difinitive.

Dr son côlé, le nenras: séluauche, sur la face dorsale du corps, aux déprens dı prolectoderme, l'une façon connexp a la geniso de la notocorłr. Toule un nowville bande, rxactrment siluée au-dessus dr cell. dromière, al la recouvrant, se délimile dans le protectoderme dorsal, en avant de l'entéropor'r; elle devient la plaque médullaire, encadrée, sul ses bords, far l'ectoderme non modilié. Celle plaque se courhe en un sillon, at se convertit en goulliere médullaire; l'ecloderme, qui l'entoure, passi au-ffessus d'ell', à la manière l'un pout. Puis, drvenue internr, el toujours supérieure à la notocorde, la gouttière contiums son mourement d'incurvalion, rapproche ses bords l'un de l'aulle, ws lansforme en m lula freme, cylindripur : le neuraxe définitif. - Le pont ectodermique, et la paroi supérionre du tube, s'unissent, en arrière, à la léve postérieure dr l'entéropore; d’antre part, la paroi inférienre du tube norven se continur avec la livre antérieure de ce durnier orjfice; en conséquence, la lumiere du neuraxe se joint à celle de l'ruléropore, el, par ce moyen, à la cavité dr l'entéron. L'entéropore est la zone de communication entro le nenraxe el l'intéron; il rst le canal neurentérique. Cr canal est dr durér passagere; il nu Lardo pas a se clore. - Le lubr mélullaire est alors fermé en arrière, el lrmminé rn cul-rle-sac; il grandit, dr manière à dépasser le niveau te l'ancien entéroprope, à pénélrer dans la régrion postérienre du corps, qui prenl alors naissance. Do mème, il se lerme en avant. A cause d' son origine aux dépens d'une involulion supreficielle de l'retoderme, sa lumièr commenco par sourrir au dehors, dans son extrémilé anlériour ; cet orifice drmenre pondant qunque temps, pus disparait à son tour. Le nenraxe est alor's clos sur lonte son étendue.

C.- Lorsqur le mésodrrme el la nolocorde so sont séparés du prolemloderme, cului-ci, converli de ca fait en l'endolermo définilif, se Irouve incomplel. Il a perilı lonle sa paroi supérieure, el se loone à possibler ses parois latérales ut vintrale. Il ne larde pas à se refremer autour do la cavité enteripue, par l'extension rors le haul dr ses denx 
cótés, qui se rémissent el se somblent. - Limberon est alors mue visicule, destinée à fournir l’intestin. Il est clos, car l'entíropore, changé en canal neurentérique, a probu toule connexion avoc le dehors. Denx oritices le nourelle formalion, la houche "I l'anus, se perecul ensuili. - Lanus prend naissance, sur la face ventrale du eopps. en sa posilion

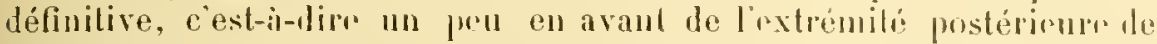
l'organisme; il est médian des son apparition, et correspond à l'orifin extériur d'un conrt procteon, qui va s'ahoucher avee la cavilé intestinale. La bouche est égalemınt vontrale, mais antérieuro; sa promieru ébauche est latérale (gauche), et no tleviont médiane que par la suile. Plusieurs anteurs se sont appuyés sur celte parlicularilé pour admetle que cet orifice est l'homologsue d’mo des fentes branchiales : la premièce de loutes, délournée de son rólo afin de servir d'ouverture principale au tube digestif. - Une telle opinion n'est guipe acceptable; la houche se creuse au milieu d'une zone épaissie, et quelque pen déprimée, de lecloderme; cetle zone est mu vrai stomeon; de lelles disposilions génćtiques font défaul aux vaies fentes branchiales. Lasymélrie première de lorifice luccal est, saus donte, le résultat de la produclion, par l'extrémité antérieure de l'entéron, d'un certain nombre de liverlicules. qui repoussent la bouche sur un côté, pour la laisser devenir médiane lorsqu'eux-mèmes régularisent leur disposition.

Il existe trois de ces diverticules, faconnés par l'embryon, soil un peu avant la houche, soit en mème temps. - l'un l'entre enx mst médian el impair; il donne l’organe nommé, par les auleurs, la glonde en massue, ou la glande claviforme. Pour la former, la paroi infériome de l'intestin se creuse, an nivean de la future bouche, liun sillon dirigé transversalement. Ce sillon se ferme, s’isole, se converlil en un canal indépendant, el s’accroit par ses extrémilés, de manière à embrasser la moitié ventrale le l'inteslin sur la droite el sur la ganche. Liexlrémilé gauche va s'accoler à l'ectoderme, el s'ouvre au dehors, dans la région mème où la hombe va se pereer, de façon à communipuer arec elle. Liextrumilé droite reste elose, et devient la glande elle-mème, dont te róle exact est inconnu. - Les deux autres diverlicules sout pairs et symétriques. Ils se dégagent le l'extrémité antérienre de l'entron, i une phase précoce du développement, alors que l'embryon posside senlemenl sepl mésosomiles, et en avant du premier de cenx-ci. leur dispusition initiale, leur allure, permetlent presque de les considérer commo deux mésosomiles antériours, rngendrés d'une manièe indépendante. Lun drux, celui dedroite, se sépare de l'entéron, el, tout en conservint sa cavité centrale, va recuper l'extrimité antérienre du corps. Le second. celui dr ganche, sisole également, mais demenre en sa place, el souro

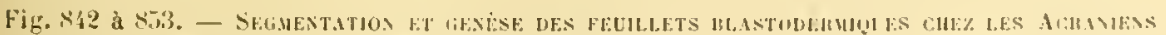

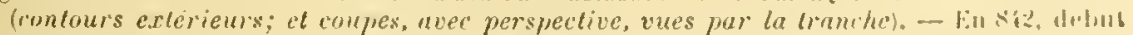

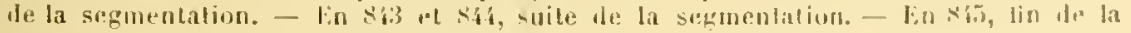




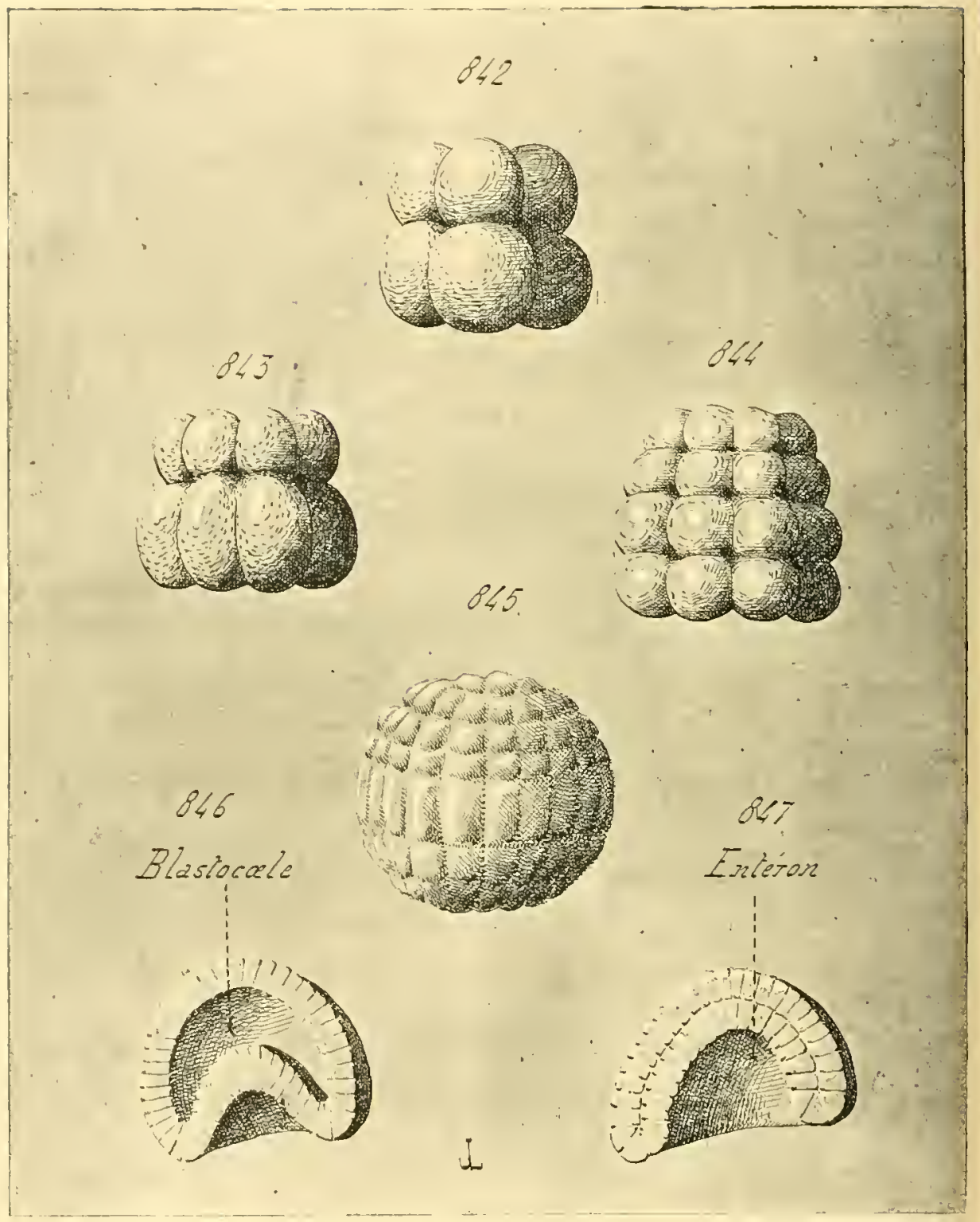

segmentation. - En sir, délut de la gastrulation. - En \$47. achevement de la gastrulation. - lin \&is, la gitstrule commence à sallonger, pour rendie exeentrique l'entero-

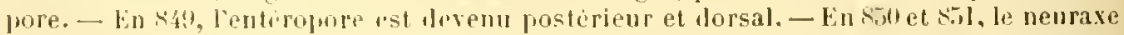

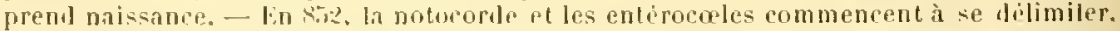

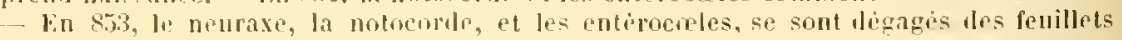
primoriliaux.

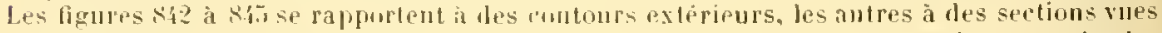
par leur tranchre - (lingres les recherdes faites par llatschek.) - Voir en surplus les figures $\$(15,813$ a 816.836 el $\$ 3 \%$. 


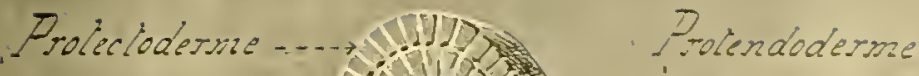

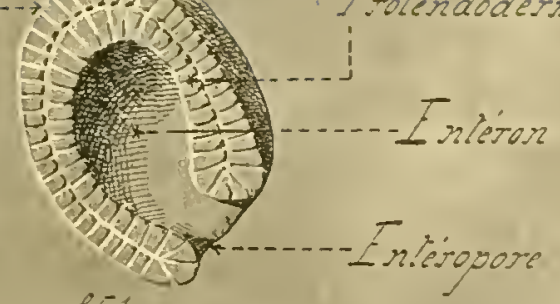

851

Potectoderme

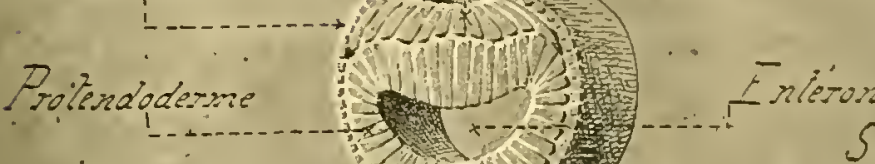

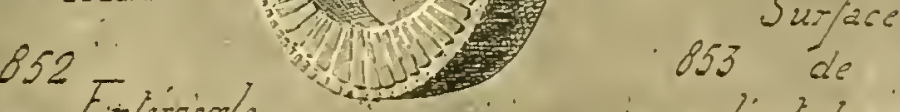

Wolocorde Errérocale

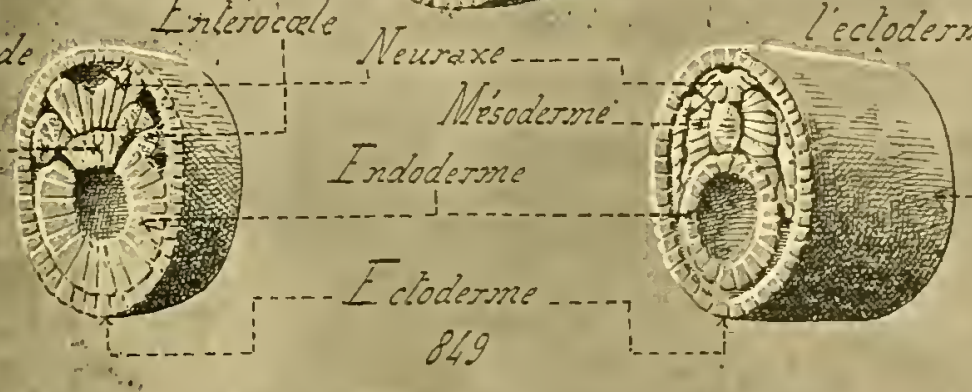

Prolectoderne

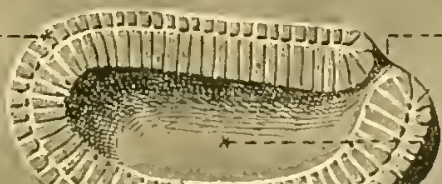

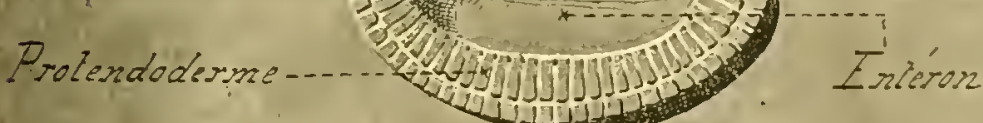

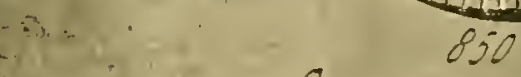

Canal diz neuraxe

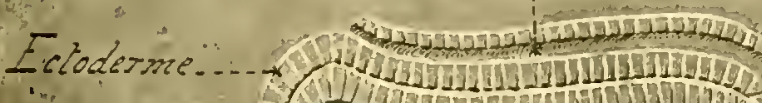

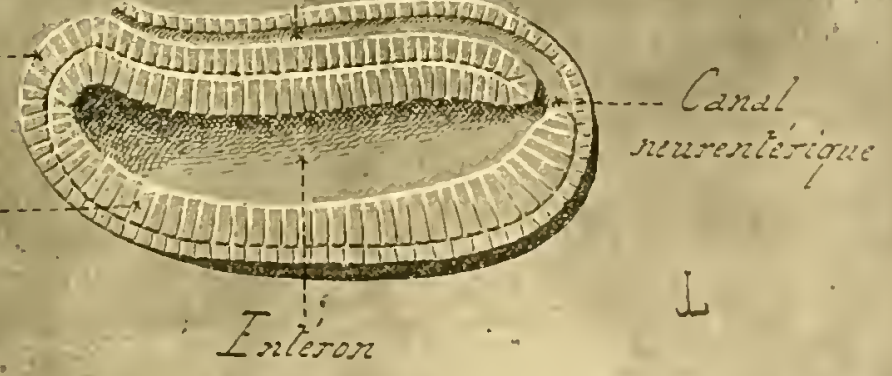


au dehors pa un oritice situé sur le côté ganche de l'extrémité antérieure rle l'animal.

La valeur exacte de ces diverticules n’est pas encore élucidée. Leur provenance, lenr structure, empèchent de considérer chacun d'eux, soit comme l'homologue de l'hypophyse des embryons de Vertéhrés craniotes, soit comme l'homologue de la glande nenrale des Tuniciers. Par contre, ils rappellent de près, du moins à leur début, les liverlicules que certains Entérocalomiens dégagent de leur entéron ponr les faire sourrir au lelors; en cela, ils se rapprochent du protmiérocole des Echinodermes, et dn carome céphalique des Entéropneustes. Ces affinités premières disparaissent ensuite, à cause des diflérences considérables introduites dans leur évolution ultérienre. - Il est cependant nécessaire de se convaincre de lexistence de ces affinités. Ces dernières déuotent la réalité lim phénoméne commun aux jeunes embryons de la plupart des Entérocolomiens : la présence d'orilices permettant à plusieurs des vésicules entérocceliennes, sinon à tontes, de communiquer avec fo dehors.

En l'état des choses. Lout ce qu'il est permis d'avancer au sujet des deux diverticules, pairs et symétriques, des Acraniens, consiste à les romparer, pent-ètre, anx premières ébanches rénales des embryons de Craniotes. Les faits acquis auforisent i considérer ces dernieres, issues les mésosomites, comme lépondant à un rappel atavique l'organes onverts au dehors. Celte dernière disposition, indiquée chez les Craniotes par l'origine superficielle du canal où se rendent ces chauches, serait complète et persistante chez les Acranicus.

\section{\$5. - Développement des feuillets blastodermiques chez les Cyclostomes.}

Tout en étant encore dilaté, of comportant la prósence d'une gastrulation, le développenent des Cyclostomes est pourtant plus comlensé que celui des Acraniens. Cettr évolution n'est guère connue que d'apres des éludes faites sur les Lamproies (Iétromyzon).

A. - Limuf, assez voluminenx, mesmre environ un millimetrs de diamehre; il contiont une certaine quantité de deutolécithe, qui saccumule dans sa region inférienre, el cause flusieurs aftérations. Les traits généraux du développenent rappellent de près leurs similaires de la plupart dros Ganoïles, et les Imphiliens.

La segmentation est tolale, et inégale d'embie. Le deutolécithe, amassé dans la partie infírieure de l'auf, rend plus volumineux que les autres les błastomères situés dans cette zone. La segmentation ahoutit cependant à une hlastulation; seutement, la blastule contient un petit blastocole, à canse du grand nomlre et de la taille des segments proMuits. - La liastule est stratitiée. Son blastoderme est divisé en Jeus 
régions semblables id deux cuvetles, anx parois épaisses, yui se somderaient par lenrs bords en entonraut la cavité hlastoculienue. La curetle sujérienre, plus petite que l'autre, el de surface moindre que reltr d’un bémisphère, se compose de pelits hlastoméres, privés de deutolécithre, disposés sur deux ou trois rangées. la ruvelle inférieure, de loanconp plus grande que l'hémisphère, est irés épaisse, car sa jaroi se tromr constituée par l'assemblage de nombrenx hastomires, pourvis de deutolécithe, el volumineux. La quantité de ces éléments est telle, que cettr zone inférienre du blastoderme est à peu près pleine; le lilastocorle, relégué daus la cuvette supéricure, est, parłả, rendu excentrique.

La gastrulation, asymétrique, intéresse surtout Je b]astoderme supé. rieur. la dépression se manifeste, a son début, dans une région postirieure el dorsale, en appliquant par arance l’orientation que possédera bientòt l'organisme enthryonnaire; son orilice extérieur', c'est-ì-lire l'entéropore, demenre en ce licu, n’émigre pas, et occupe ainsi, de prime abord, une situation quil atteint chez les Acraniens a la snite d'un déplacement. L'entéropore est exactement, daus la région précédente, creusé sur la lig̣ne de jonction du hlastoderme supérienr et du blastoderme inférieur. - Un pen avant que la gastrulation ne commence, el pendant son déhut, le blaslocorle s'anplifie, en laissant intact le llastoderme infórieur, et augmentant la snrface du blastoderme supérieur, aux dépens de l'épaisseur de sa paroi; aussi, cetle dernière finit-elle par être composée d'une seule couche cellulaire.

L'axe de l'invagination gastrulaire n'est pas dirigé vers le centre de la blastule. Celte dépression, au fur et à mesure qu'elle s'enfonce dans l'embryon, s'oriente obliquement, de manière à pénétrer dans le bastocale excentrique, et à glisser sur le blastoderme inférieur. Parmi ses cellules limitantes, les unes appartiennent à la zone supérieure du lhlastoderme, el les autres à la zone inférieure, puisque son ébauclıe se façonne sur la ligne de contact le ces deux régions. Les ćléments issus du blastoderme supérienr n'ont qu'à se multiplier, en demeurant semblables a leurs générateurs, pour suivre l'accroissement de la dépression invaginée; les cellules, données par le h]astoderme infirieur, se segmentent activement, deviennent plus pelites, el accompagnent également la dépression pour lui former sa paroi ventrate, mais sont plus grosses eependant que les éléments supérieurs. Sauf par Irur taille un pen plus restreinte, elles ne diffèrent pas des antres cellules du hlastoderme inférienr, avec lesquelles elles sont en rajport direct.

La gastrule achevée appartient au tyje des gastrules stratifiérs. La disposition première de la blastule n'a pas changé; sauf le remplacement de la eavití blastocolienne, close el indépendante du dehors, par "m entéron gastrulaire, qui communique avec l'extérienr an moyen d'un entéropore postérieur et dorsal. les deux zomrs hastulaires, la lurelte supérieure el la ruvelte inférieure, sont conservées encore. La région inférieure, "n pen plus restreinte cepentant, ressemble it mu hémisfthère 
plein, composí te nombreux of volumineux blastomères, chargés de deutolécithe, et tassés les uns contre les autres. La cuvette supérieure est creuse, car alle contient l'entéron, la carité de la dépression gastrulairr. Celte cavilé est pelite; elte offre, à peu de chose près, l'aspectid'un tulie, dont la paroi ventrate est formée par des cellules appartenant au blastoderme inférieur, la paroi dorsale, aver les coités, par des éléments du blastoderne supérieur, - Lin somme, l'embryon entier se compose d'une carilé entérique, yu’enlunre une paroi à l’épaisseur incigale. Cette épaisseur, réduite it ses limiles les plus restreinlrs vers le sommet de

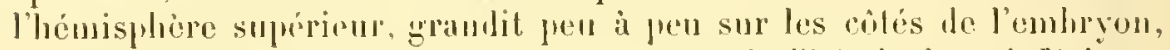
frour parvenir a son comble vers le sommet de lhémisphère inlérienr; aussi l'entéron est-il excentrịue, et placé dans la région lorsale de l'organisme.

Les denx feuillets primorliaux se délimitent pendant que la gastru-
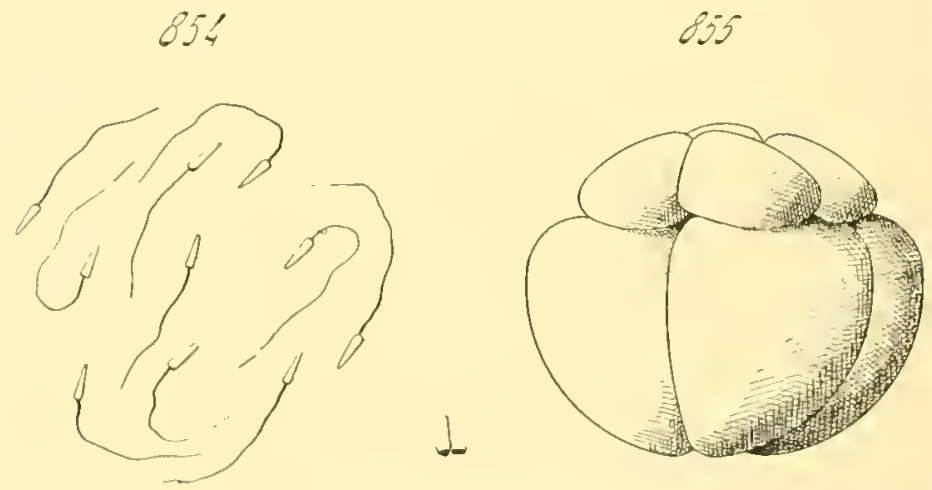

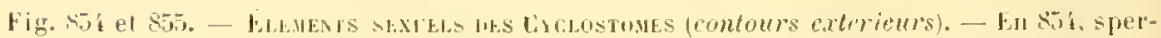
matrzordes du Petromyzon flucutilis. - En 855, ovule du mème, au dèlıut ele sa segmentation. - (l'aples Artiur li. Slipuley.)

lation selfectue. - Leur lélinnitation est rapide dans la zone supérieure de l'emhryon, el déconle de la gastrulation elle-mème. Celle zone, chez la blastule, se comprose d'une senle assise cellulare, yui se replic sur elle-mème pour donner la paroi dorsale de l'entéron: la partie repliće est le prolendoderme; colle pui demenre en place devient le protectoderme. - Il n'on est pas de mime dians les autres régions embliryonnaires, ou le procédé employé rappelle celui des planulations indirectes. A cause du grand nombre tes dilistomires aceumulés, et disposés sur plusieurs rangs, dans l'hromisphère inférienr, les cellules qui limitent directemnt l'entéru, en has ef sur les côtés, ne représententgu'me part restreinte du protendoderme: tous les antres éléments inlérienrs, mullement intéressis lans la dipression trastrolaire, complosent un épais blastoderme encore indilférent, qui va se diviser en protectoderme el protendorterme. 
La séparation mutuelle de ces deux feuillets commence sur les hords le l'hémisphère supérieur, el gagne jeu i peu, de colle région marerinale, le sommet de l'hémisphire inférieur, où elle s'achive. Cetle séparalion seflectue par la segmentation rapile des hastomies superficiels;

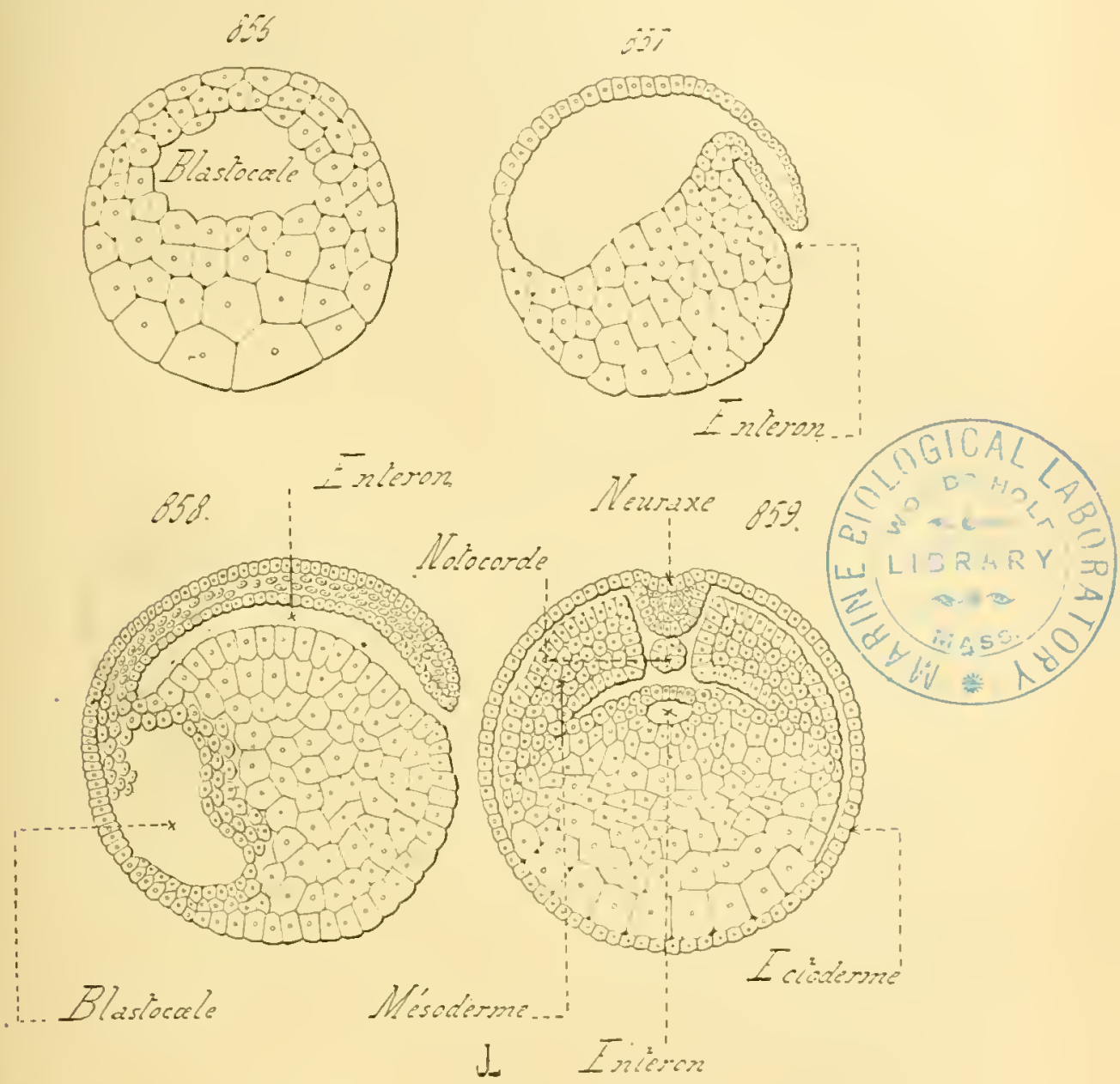

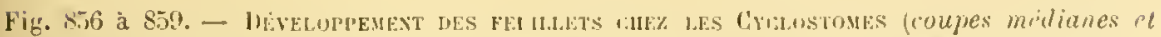

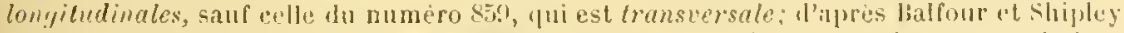
sur le Petromyzan furiatilis). - En 856, Hastule. - lin $85 \%$, délut de la gistrulation. - En N5s, achievement de la fistrulation. - Vin 85?. état plus avanci, montrant les ébau*lies de la notocorde, du neuraxe, et du mésoderme.

Ces dessins montrent, daus leur rualité, les phènomenes exprimes sous une formuc diagrammatique dans les figuressit a 20.

cenx-ri se partagent en petites cellules externes, et collules intéricurus phos volumineuses. Les premires regularisent lem forme, deviennenl

ROULE. - EMrRYULOMIF. 
semblables à celles du protectoderme supérieur, se joignent à elles, et continuent ce fenillet sur la face ventrale du rorps. Les autres se confondent avec les éléments plus profonds, el composent avec eux le protendoderme. - Celte lélimilalion n’est pas instantanée; elle est ménagée, et s'effectue lentement, avec régularité, en procédant suivant la direction déjà signalée. Ia lenteur est telle que la part protendodermique, située dans la rígion dorsale de l'embryon, a déjà fourui les ébauches de la notocorde arec celles du mésolejme, alor's que la part ventrale ne s'est pas encore drisunie du protectoderme.

B. - Les deux feuillels blastoderminues primordiaux sont, dès lors. distin'ts l'un de l'antre.

Le protectoderme consiste en une assise cellulaire simple, quilimite la surface de l'embryon. Il donne naissance au neuraxe, sur la ligne médiane dorsale du corps, et en avant le l'entéropore. Seulement, la plaque médullaire ne s’incurve pas en une goullière médullaire, deslinée à se convertir en un canal par l'accentuation de sa conrluure; elle s’épaissit, par l'augmentalion du nombre de ses éléments, el devient un rorton plein. Celui-ci se sépare du proteclorlerme qui l'engendre, et se creuse ensuite d'une lumière axiale. D'après Calberla et Scott, cette lumière ne serail pas tout à fait indépendante, à son début, du dehors; elle offrirait l'aspect d'une fente, creusée dans la plaque médullaire épaissie, qui cesserait hitivement de commmniquer avec l'extérieur. Après la genèse du neuraxe, le protectoderme persiste comme ectoderme léfinitif.

le protendodeme est beancoup plus volumineus que le feuillet externe; il se compose de lous les autres éléments embryonnaires, et enveloppe l'entéron cxcentrique. Assez mince daus sa parlie dorsale, où il n'est formé que d'une seule assise cellulaire, il est plus épais sur les côtés, et surlout dans la zone ventrale, ou il comprend tous les blastomères deutolécithiques accumulés en celle région. - Une telle disposition le divise en deux parts : l'une fomative, l'aulre nutritive.

La part nutritive est représentée par les blastomères chargés de dentolécithe, qui composent tout l'hémisphère inférieur de l'embryon. abstraction faite de l'ectoderme environnant, destiné à les envelopper. L'ensemble de ces éléments compose une véritahle vésicule vitelline, lıomologue de celle des autres Vertéhrés, mais plus petite, et formée de cellules distinctes, au lien de consister en un volumineux amas de vilellus non figuré. Ces éliments se résorbent peu à pen, à mesure que l'embion évolue, et sulviennont aux néressités de sa nutrition. I.eur masse diminue d'une maniore connexe; lorsquils sont résorbés, les demiers d'entre eux, réduits à mue comche simple, donnent la paroi ventrale de l'entéron, el constituent ainsi la jart ventrale de l'endoderme. Celte fin n’arrive quaprès l'ćclosion de l'embryon, el mème apres nn certain temps de vie libre, cest-a-dire dans le courant de la 
troisiome semaine, en ce qui concerne les lamproies. Comme l'emliryon s’arcroil de préférence jar son extrémiti suprícure el anléricirr. lamas les cellules vitellines prodnit une grosse sallie sur la face venIrale de lorganisme, saillie qui devient postérienre à mesure qu'clle. diminue de volumo.

La part formative se localise anx élóments protendodermiques disposés sur les côtés el au-drssus de liutéron; sa zone supérieure so compose d'une seule assise cullulaire; ses zones latirales consistent en plusienrs couches d'éléments lassés les uns contre les autres. - La zone supérieure donne la notocorde. Ses éléments prolifèrent avec activité, el ne tardent jas à fournir un corlon cellulaire plein, situé au-dessous lu neuraxe. Le cordon est l'ébauche de la notocorile; cetle ébauche offre l'abord la phase de gouttière cordale. puis passe i son étal définitif de haguelle cylindrique el compacte. - Les régious latérales engendrent le mésolerme, ut aussi une rangée cellulaire qui, passant au-dessous de la notocorde apris sa délimitalion, ferme l'entéron en haul, et constitue la part dorsale le l'endoderme. Tous ces éléments latéraux se multiplient rapidement, et donnent deux bandes, Jont l'une est placée sur la uroite, et l'autre sur la gauche, de la cavité entérique. I.es julus internes d'entre eux, qui limitent directement cette deruibre, se disposent en une seule assise, destinée a fermer l'entéron sur les côtés, el, en se raccordantà la part dorsale ainsi qu'à la part reulrale de l'endoderme, à fournir les zones latérales du feuillet interne. Les autres éléments composent les denx éhauches mésodermiques. Chacme de celles-ci se creuse dune cavité centrale, homologue de l'entérocole des Acraniens, mais qui, contrairement à sa similaire de certains Imphilsiens, paraìt ètre toujours indépendante, el ne jamais se raccorder, d'une manière temporaire, à la cavilé entérique. Puis, chaque illauchr, suivaul le procédé habiluel, fournit le mésenchrme, el se sululivise en une pląue latérale, surmontée d'une rangée de mésosomites.

Les phénomènes, relatifs à la genèse el au diveloplement des feuillels frimordiaux, y compris la formation de la plupart des mésosomites, seffectuent pendant que l'embryon est encore eufermé dans sa coque. lls duront de deux à trois semaines. L'éclosion a lien ensuile.

\section{6. - Développement des feuillets blastodermiques chez les Ichthyopsidés.}

Les feuillets blastodermiques des lchllyyopsidés se léveloppent suivant deux procédés principaux, dont l'un se rapporte à une évolution assez dilatóc, ct l'autre à une emlıyogénic rondenséc. Le premicr existe

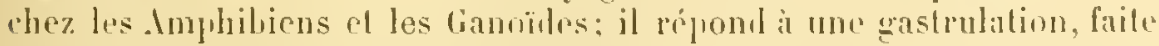
de sorte pu une partic du probendorlerme soit me riserve mutritive. lin se représentant celle partie comme angmenté de volume, ayant perdu 
toute struclure cellulaire, el ronvertie en une vísicule vitelline, on obtient le second mode; celui-ci est de règle chez les Sélaciens et les Téléostécns.

I. Développements dilatés. - Les évolutions de ce genre raprellent de fort pres leur similaire des Cyclostomes; elles comportent de mème une gastrulation asymétrique, el la division du protendoderme rn une part formatrice et une part nutritive, les deux élant également comprosées de cellules. l’embryogénie des Amphibiens, du moins de cenx qui sont ovipares ol déposent lenrs aufs daus l'ean, est un pen plus dilatéc que celle dos lianoïlos.

Aspumers. - A. les semls Amphibiens, dont te développement soit connu d’une manière à peu pros complète. sont les Grenonilles et les Trilons. Ceux-ci appatiennent au groupe des animax ovipares, pui pondent dans l'eau; sans doute, les phénomines, offerts frar enx, sont applicables aux emlirous dr lems congénìnes avant les mèmes habitudes. Les Amphibicus vivipares, ou qui placent leurs mufs, soit dans la terre humide, soil dans dos cavilés incubalriees dépendant des téguments, subissent une évolulion condensíc. dont les ditails no sont pas encore

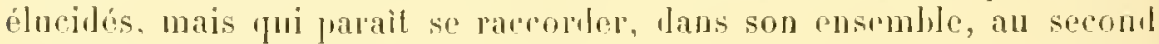
morle ales Ichthyopsidés.

Le léveloppement du Triton est plus dilaté que celui de la Grenouille; ce caractiro est décelí par la simplicité premiere du protectoderme, par la petitesse relative de la zone nutritive du protendoderme, enfin par le fail que les premierréluauches les cavités entérocoliennes słabouchent avec l'entéron. Sauf ces partirnlarités, les données essontielles, relatives à la genèse des fenillots, concovlent cutre elles. Ces derniers sont, de fous points, semblables à leurs correspondunts des Cyclostomes. Les altérations causées, lans l’embryogénie, par la présence de matériaux uutrilifs, sont identiques, qunles que soient les classes mises cn cause de ces V'ertébrés inférieurs, pour une mème quantilé moyenne de ces matériaux.

Somvent, chez les Amplibiens, et il en est ainsi chez la Grenonille, le vilellus contient des granulations pigmentaires. Ces deruicres sont loujonrs répartics d'une manière exclusive; elles s'aceumulent dans le lastoderme suporieur, dans cehi qui contient le moins de deutolécithe. - Toutes les pluases, relatives a la lélimitation des leuillets, el a la genese des premièes ébauches organiques, s'ellectuent alors que l'embryon se troure encore ronlenu lans sa membranc vitelline; l'éclosion a lieu ensuite.

La segmentation ovnlaire, parfois égale à son rébut, finil toujours par êlre inrgale. Elle aloutit à une blastulo stratitice, dont le blastocorle est axeentrique. Le blastoderne est divisé en deux zones, en denx 
hemispheres, l’un superrieur, l’autre inférienr. Celui-ci, composí de cellules assez volumineuses, pourrues te nombrenx granules deulu-

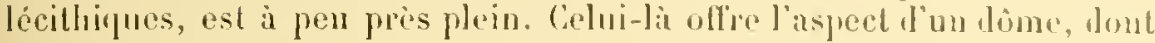
les bords reposent sur l'hémisphère inlérieur: la cavité, dont il est
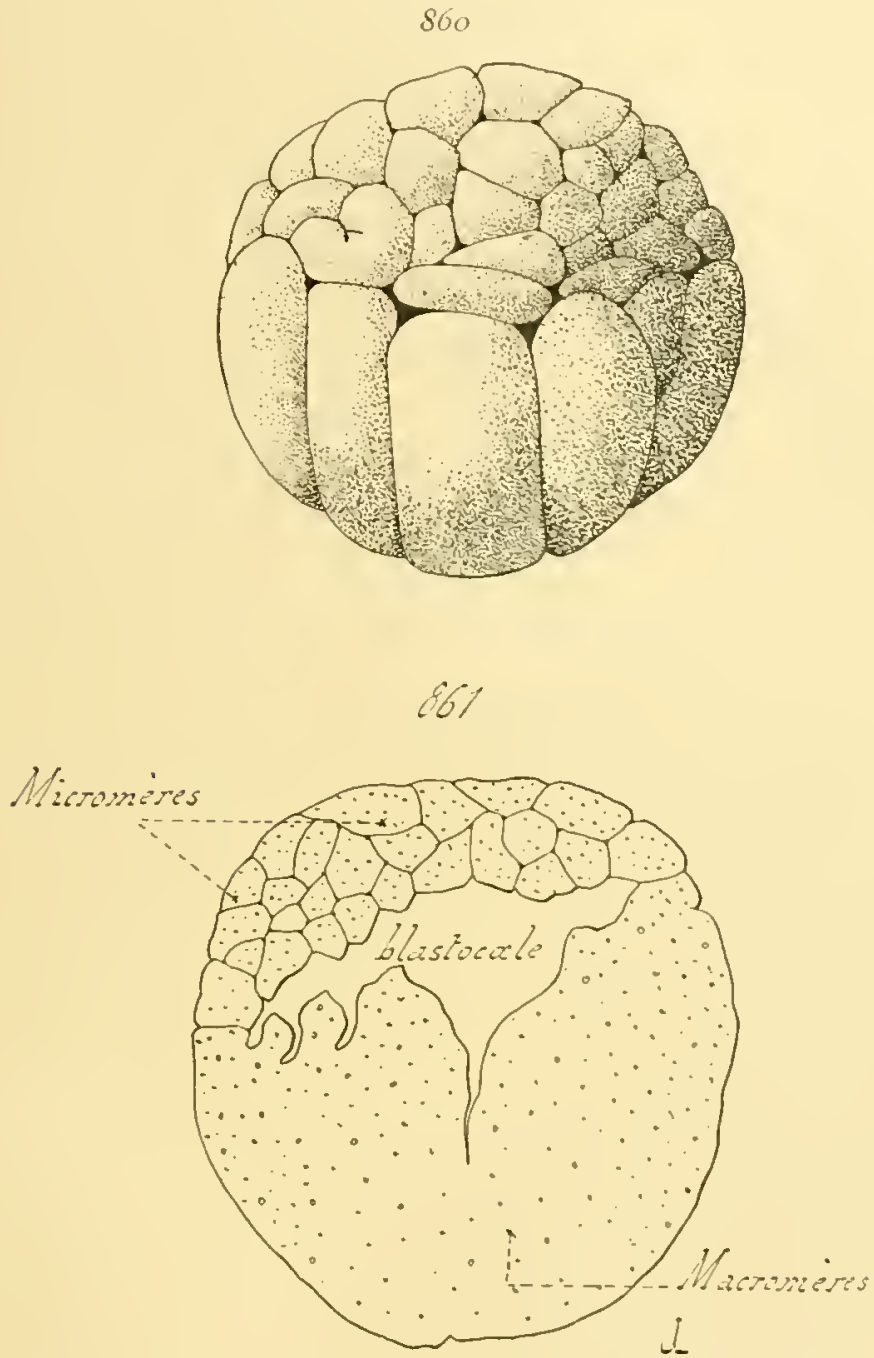

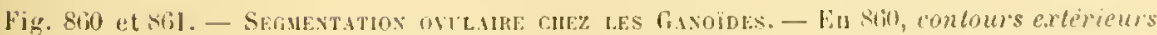
d'une jeune blastule. - lin slil, coupe midiane de lit méme. - b’apres les retherehes faites par Salensliy sur un Sturionien, le sterlet (Acip'nser ruhenus).

creusé, répond au luastocule; et sa paroi, asse\% mince, consiste en un petit mombre d'assises cellulaires, deux i cimy rn moyenue. - les denx

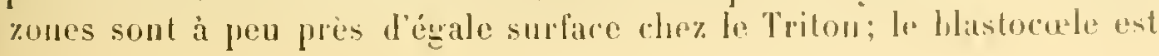


ample. Par contre, diez la firenomille, la zom inferinno, cest-it-dire

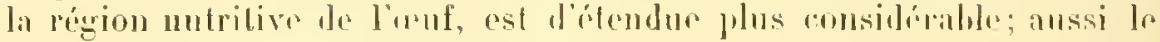
blastocule cost-il relativemenl pelit.

La gastrulation, as ymotripue, rappelle sa correspondante des Cycloslomes. Le mourement d'invaginalion se double d’une dillérenciation, sur julace, des cellules qui entourent l'entéron; il est surtoul marqué lans la partie déprenlante de la zone blastonlerminue supérieure, et l'est i peine dans celle issue de la zone inférieure; les ćléments de cette derniere restent en leus position. et limitent la région ventrale de l'entéron, comme ils limitaient, dans la blastule, la région ventrale du hlastocale. - Lentéropore occupe d'emblée sa situation défnitive. Postériour et dorsal, il est placé sur la ligne le jonction du blastonlerme supérieur el dı lılastoderme inférienr; sa levre supérieure est donnée par le premier, et sa livre inférieure par le second. Colte derniore, surtout chez la Grenouille, s'épaissit an point le honcher l'entéropore; celte occlusion, fonte temporaire, ne tarle pas ì cesser. La part épaissie a reç d’Erker le $n$ rom de louchon vilellin, qui lui a été couservé.

Les fenillets primordiaux se délimitent, a mesure que la gastrulation s'effectue. Lum délimitation rommence dans le blastoleme supérieur. et sétend avec régulariti, comme lans un plamulation intirecte, an bastolerme inférieur, - Dans lo premier, la part lemenrée externe, el non intéresséc dans l’invagination gastrulare, représente le prolecfodermo; il se sépare, an moyen d'une luasale, de la part interne el invaginée, c’est-à-dire du protenloderme. Puis, les éléments superficiels du blastoderme intéricur se multiplient avec activité; les plus externes d'entre eux se jojgnent aux cellules du protectoderme supériour, drviennent semblables in ellos, el s'isolent par une basale de leurs congénires plus profon»s. Lr protectorlormo scétenıl aiusi, avec régularité et l'nn mouvement continu, depuis l, blastoderme supérieur et les environs de l'entéropore, jusqu'au sommet du hastoderme inférieur. Clız le Triton, le protectodorme esl, à son délut, composé d'une assise cellulaire. Celle-ci se lédouhle hientit en lenx rouchrs concrntriques : l'une externe, la lame épidermique des auteurs; l'autre interne, la lame nerveuse. Ce dédoublement est atleint d’emblér chez la Grenomille; le protectoderme, dis son commencement, consiste on deux lames cellulaires emboitées. - Le fenillel externe prend part, tont eulier, ì la genes du nruraxr, quj seffectue suivanl lo procódé de la goutliere médullaire; sculement, la comche interne jonc l" plus grand rôle dans la production de cet organe. Il en est de mome pour tous les autres appareils issus du protectoderme; la conche interne est la principale intéresséc.

Dn moment oi le protrelodermes sest constitué, le frotendoderme, semblable do toutes manieres à cului des embryons de Cyclostomes, consiste en une volmmineuse masse celhlaire, disposée autour d'un entéron excentripue ot smprirur; il ast divisé, de mène, ru mno part 
formatrice, el mne part nutritive. - Colle-ci comprend lous les élénents de l'ancien hlastolerme inférieur, sanf ceux, peu nombreux et supel-

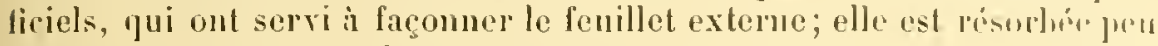
à peu, sur place, ses derniores cellules étant anployérs il limiler la région ventrale de la cavité entériłue, c’est-à-dire à donner l'eudorleruse ventral. - La part formatrice se multiplie activement, par contre, et se scinde en trois ébauches. L'une d'elles est domnée par les cellules placres au-dessus de la cavité entérique; se séparant ıle ses voisines, elle passe à l'état de gouttiore cordale, et se convertit en notocorle définitive. L'aulve est fournie par drs ćléments, qui s'assemblent (n mne couche ‘prithéliale simple, destince à circonscrire l’espace entérique sur ses côtés el en dessus; elle se rattache à l'endoderme ventral, et, conslituant ainsi l'endoderme latéro-dorsal, elle contribue, aidée le la précédente, ¿̀ limiter l'entéron ilevenu la cavité intestinale. Enfin, tous les autres éléments, de beaucoup les plus alıomlauts, de la part formatrice, façonnent le mésoderne. Rassemblés en demx bandes, dont l'une est placée sur la Iroite de l'entérou, et l'autre sur la gauche, ils prolifèrent avec activité, et augmentent sans cesse en nombre. Chacune des handes se sullivise en plaque latérale el rangée de mésosomites, lout en fournissant le mésenchyme. Avant que cette scission ne se produise, et pendanl qu'elle s'effectue, le premicr vestige de la cavité colomique se creuse dans son intérieur. Chez le Triton, d’après O. Hertwig, cette cavité s'ouvre dans l'entéron, pour devenir ensuite indépentante de lni. Une telle conuexion est importante, en re qu'elle sert de transition entre le développement dilaté des Acraniens el l'évolution condensée de la plupart des Craniotes; elle montre de quelle façon un double léplacement, dans le temps et dans l'espace, altère les procédés employẻs, au point de convertir, en une genèse indépendante, nue production de diverticules entériques.

B. - Les Amphiliens vivipares, et ceux dont les aufs m sont pas pondus dans l'eau, subissent un développement plus condensé que les précédents. Cette condensation est surtout accuséc par la taille, plus grande encore que chez la Grenouille, de la parl nutritive du protendoderme. Dans certains cas mème, cette part se trouve converlie en nne veritable vésicule vitelliue, par l'union de toutes les cellules deutolécithiques qui la composent. Mais les phinomenes relatifs a la genise, et à l'évolution des feuillets blastodromiques, ne sont pas encore élucidés d'une manière complète; les rommaissances ì cet égard se hornent ì quelques olsservations, dont lis mienx conduites touchent seulement i l'aspect extérieur les embryons, et sout exposées dans le chapitr traitant des formes embryonnaires ıles Vertélués. les faits acquis permettent, pourtant, de penser que les procédés employés, dans le développement des feuillets el des organes, se rapportent i leurs similaires les Sélaciens, ou des Sauropsilés, e'est-à-1lire i ceux offerts par les 
Vertébrés dont les embryous sont munis d'unc abondante réserve Intilitive.

Les rroherches lis plus approfondies ont été faites, par les frères Sarisin, sur un Gymnophione, I'Epicrum glulimosum. Les auts de cet animal sont phus volumineux que ceux les autres Amphibiens; ils mesmrent, en moyenue, huit id dix millimctres de longuenr, sur denx ou brois de largeur; celle augmentation est due à la présence, en quantité flus considérable, de malériaux nutritifs, et il celle d'uno enveloppe allomineuse. Ces auls sont pondus dans la terre; la femelle, suivant les hahitudes do ces itres, se creuse un terrier, y lépose ses ormles, et s'enroule automr d'eux pour lus couver. - Le vitellus est divisé en une petite cicalricule, formée de blastolécilhe, el une grosse vésicule vilelline. La cicatricule se segmente srule, pond donner l'cmbryon entier; la vésicule vitelline sert a nomrir ce ternirr durant son dévoloppement, et porte ì cel effet, dans sa pror, de nombreux vaisseaux sanguins destinés à dóterminer sil résorplion. - L'évolution embryonnaire des Gymnophiones differe donce el de beaucoup, de celle ollerte par la majorité des autres Amphiliens; elle se raccorde an type des ambryogronies condensées. La segmentation s'effectue alors que l'unf est encoro enlermé dans l'oviducte malernel; la fécondation est, par conséquent. interne.

C. - lne telle opposition est des plus importantes à constater. Dans f'rensemble d'un groupe de grande amplifude, d'un embranchement aux reprósentants nombrenx, la condensation du dévelomenent ambryonnaire est, dius la rogle, l'apanage des ctres dont l'organisme est le plus eomplexe: cu co pui touche les Vertéhrós, la comparaison des Aeraniens anx Camiotes, on celle des Crolostomes i la phpart des Gmahostomes, ou encore celle de la majorité des Anamniotes anx Amniotes, pronve la réalité de rette domée. - Nais la cluse ressr dielre précise dans l'étemlue des groupes dr plus hable importance; car elle est subordonnce aux alaptations particulières de chacune des petites sections de ec grompe. Ainsi, pami les Imphibiens, les Gymnophiomes ont la structure la plus simplr, les Urodibles et les . Inoures l'oranisme le plus eomplexe; el cepremant, l'évolution emliryomnaire des premiers est le lieancoup plus condensé que celle ules siconts. Bien plus, parmi coux-ei, la pilnpart subissent un développemont dilaté, alor's que certains aulres, à lit suile des circonstances spiciales dans lesquelles s'effectur la ponte, présuntent des phénomones génétiques plus condensés.

La combrosalion du déreloppement parait done otre le but unique, vers lequel temdent deux rauses différentes. W'une part, la complexité organique : les rifos les plus ilevés, dans une série maturelle, ont les embryous les mirux prolégés, les mieux nomris an moven d'aliments funrnis par le génératem, el empruntés a sa propre substance. D’autre part, les ataptations partirulières, an premier rang desyuctles se tron- 
vent les circonstances de la ponte: la ponte hors de l'eau roncorvle arere

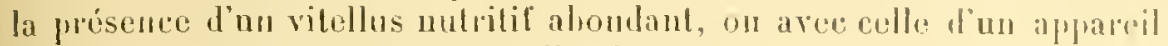
plarentaire, destinć ì alimenter l’embryon.

La notion de res deux ranses livel'ses, agissant msemble pour aboutir à mu mème hut, permet de comprentre lat répartilion incirale, opposée en apparence à la série de romplrxilí oronaique, des développements condensés el des évolulions lilalées volız los leptébrés. De mème que ponr lous les animanx, l'ensemble de res itres, en suirant les affinilés naturelles, n’est pas disposé l'apres une senle ligne, allant des Acraniens aux Mammiferes, mais bien en phusienrs branches divergentes, se rallachant divers niveaux. Les groupes plarés à ces niveanx ofrent, d’une manière constante, soit des embryogénies dilatées seules, soit des évolutions dilatées el d'autres plus on moins rondensées: par contre, les groupes, qui correspondent aux branches divergentes, prosentent tous, el d'une facon exclusive, des developpements condensis.

Ainsi, les deraniens el les Crrlostomes, les moins élprés des Verlébrés, auxquels se ratlachent les Cinathostomes, subissent ane embryogrínie dilatie. Au-dessus d"enx, les hanoüles se raccorlenl, d'une jrart aux Téléostéens et aux Sélaciens, de l'autre, prar les Dipneustes, anx Amphibiens; aussi le développenent embryonnaipe des Ganoïdes est-ii plus dilaté que celui des Télíostéens et des Sálaciens. - De leur côté, les Amphiliens, derniere survivance actuelle des stégocéphahos disparus. correspondent an premier lerme des Vortébrés terestres. Leurs rolalions élroites avecles Ganoüdes, combinées aveo des habilndes aquatiques, permettent a la plupart d'entre eux de conserver une évolution dilatéc; alors yue d'autres, virant sur le sol, prósenteut des phénomines grinctiques plus condeusés. Les Ammiotes, pour lespuels la vie terrestro est la rigrle, el la vie aqualique une exception secondaire, dícoulent de cotte seromle sirie, el offrent toujonts un developpement rondensé.

la situation zoologique des Imphibiens, et la diversité de leurs habitudes de poule, expliquent les dissemlilances de leurs procidés embrvounailes. Pumi ces animaux, les uns fout subir à leurs ovules fícumles mue segmentation totale, et les antres mue segmentation parlielle; les premiers montrent rucore une gastrulation, el les seconds une planulation indirecte. Bien que les Amphibiens soient, de tous las Jihllyopsilés, les plus proches des Vurtónés amniotes, l'évolution do certans d'entre enx, celle du Triton par exemplu, est julus dilatée yne sa correspondante les Ganoïles; et, comme comectil, l'enluryogénie de plusients antres ost anssi comdenséc que rolle des Sólaciens, nu que celle des lieptiles et des Oiseaux.

Aussi, en s'en lenant a lorigine les feuillets embryonmires, les Amphibiens doivent-ils otre étulićs les premiors, pami les Anammiotes: ils présentent, en etrat, les procédés les phus divers, ol montrent dins purble mesure ees derniers découlent, a la fois, de la position \%ouloginue

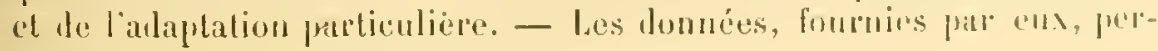


metlent ile comprendre, d’aul're part, la varićlé offerte, sur ce même

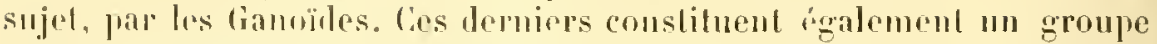
dro hifuralimn, ampuel se lallachent phusienrs classes; el des consiléralious similaires leur sont applicables.
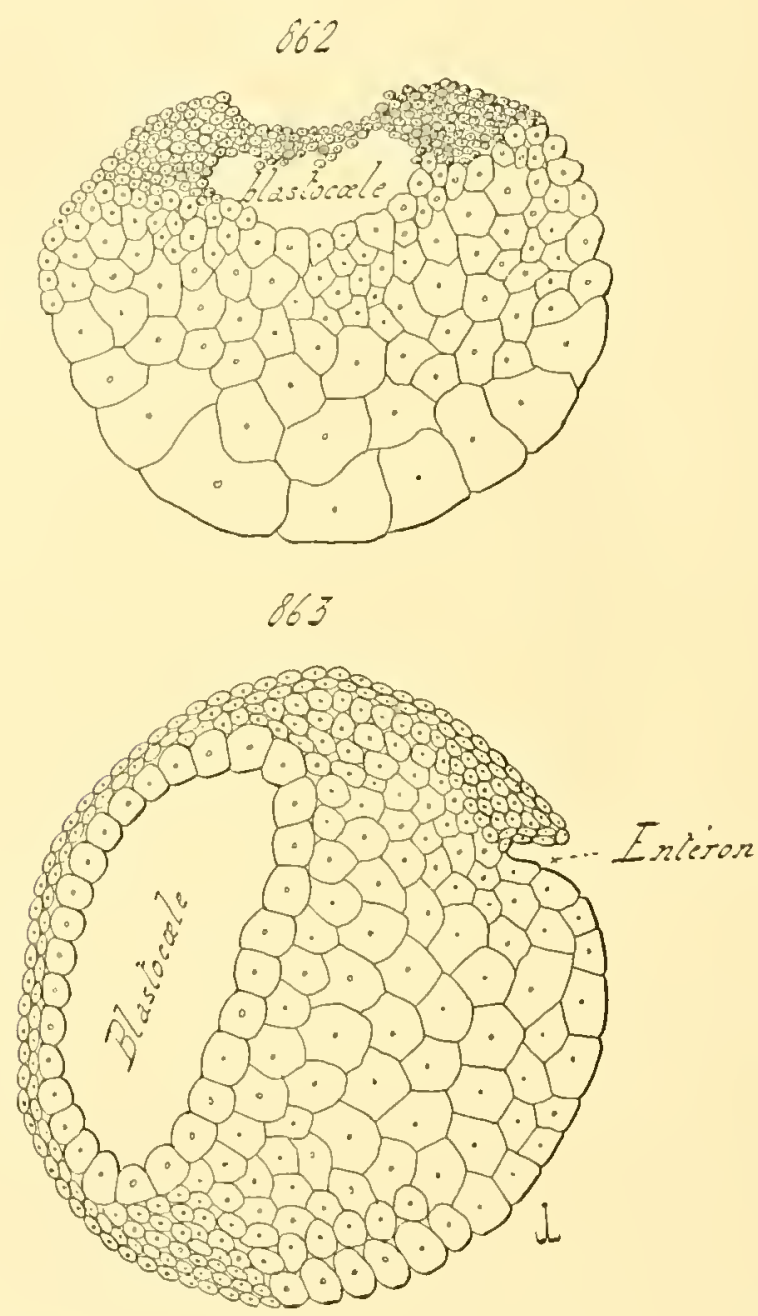

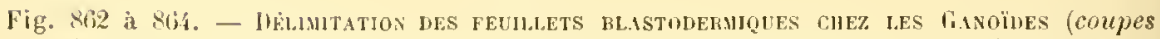
médianes). - En 86?, blastule. - En \$ 83, dèlut de la gastrulation. - En 864, gastrule. - l'aprit's les recherches faites par Salensliy sur un Sturionien, le Sterlet (Acipenser ruthenus). Cies figures font suite aux preedentes (siil et sil).

Gavoïoss. - Mbslraction faile de leurs rapports avec les Dipneustes et les Amphiliens, ces ètres se rarcordent, en surplus, aux Sélaciens et aux Téléostéens. leurs aftinilés avec les premiers sont plus lointaines 
quiavec cenx-ci : rlles sont données par des représentants, displantus, de

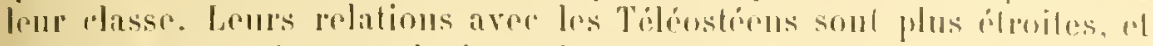
sont mème assurées par plusicurs des aspeces atednelles. Or, le liveloppement des Téléostéens est condensí. Anssi, les fints acruis sur l'mubryogende des Ganoïles se rapportent-ils i denx types : l'un. caractiristique des Sturionides, correspond i me ivolution dilatée, presture semblable à celle dos cyclostomes, et à celle des Amphiliens dont la ponte s'etlectue dans l'ean; l'antre, particulier aux Lépinlostéicles, les plus proches des Téléustéens, est lié ì une évolution plus condeusée yu. la précédente. Le second type elfectue une transition entre lo premier

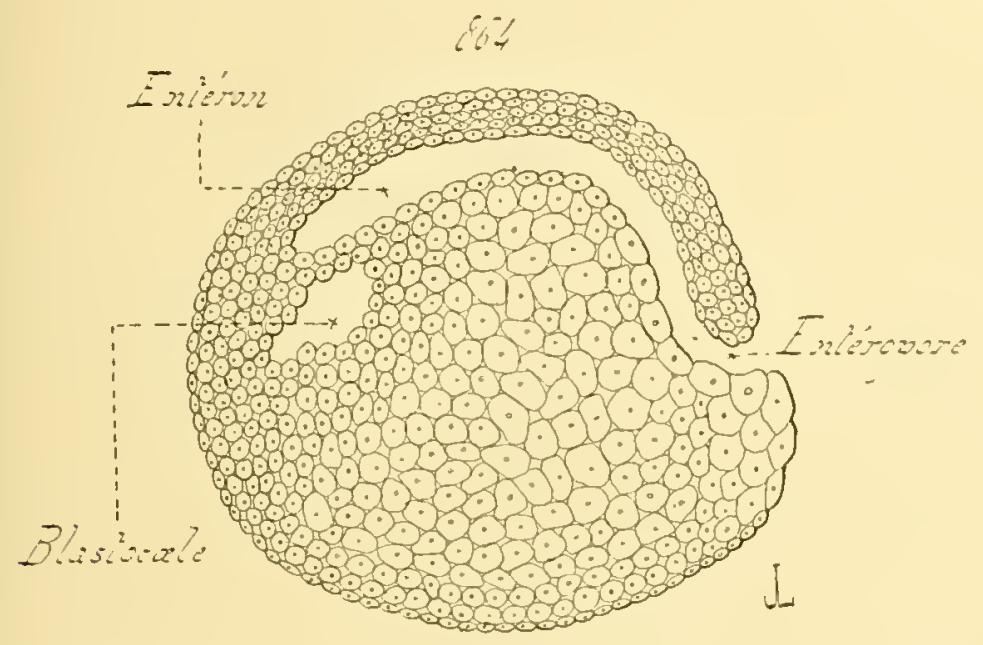

ch le mode spécial anx Téléostéens; il est silué presque in égale dislance de l'un et de l'autre.

A. - Dans son ensemble, le dévelopłrement des fenillets blastodermiques, el des organes primordianx, se manifeste, rloz les sturioniens, par les mèmes moyens que celui de la (irenouille. Il est senlement un pen plus condensó, a la suite de la prisence d'me plus grande quantitio

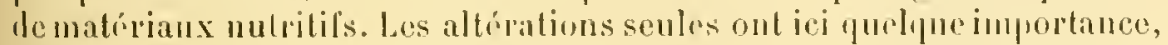
les autres procédés étint identigues il lenrs corrospondinls des Amphiliens.

Liovule mesure cuviron denx millimetres de dianche. Sil segmentation est totale, et incigale l'emblie. lavule segmenté se comrerlit en une llastule stratifiée. dont le hastoderme se divise "ll mor volumineuse part nutritive, ol me petite fart lormatrice. La premiere, homologue du blastoderuc inlérion des Amphihiens, est pleine, comprosice de cellules chargées de deutolécithe; la seconde, homologen du blas- 
loderme supériour des mômes animaux, [rósente l'aspret d'un dome, reposant jar ses hords sur la précédeute. La cavité du dome répond au blastocele, relativement petil et étroit.

La gastrulation est asymétrifue: ses diverses phases ne dilferent pas de leurs similaires des Mnphibicns, non plus que la siluation de l'entéropore. Seulemont, lo blastorlerme inférieur ne s’invagine pas, i vai dire. La partie lı hlastoderme supérieur, placéc au nivean de l'entripopore, se replie sur clle-mème, en pénétrant dans le blastocole, et glisso sur la face supérienre ulu blastoderme inférieur. Pendant que ce mourement s'ctlectue, le repli laisse, entre celte lerniore face el luimème, un espace vide. Cet espare est la cavité entéripur., l'élıauche de la future cavité inteslinale; à cause le son origine, il est limité, en haut par la zone repluyéc du blastodermesupérieur, en las par la face supélirulr, laissée en place, du blastoderme inforieur. - Cotle absenc. l’invagination, en ce yui touche ce Jeruier, saccuse loji, chez la Grenouille, prar la lenteur que celle région met à s'invaginer, el par le preu le profondenr da: la dépression qui dépend d'elle.

Jès la fiu de la segmentalion, le protectorlerme est divisé en deux couches concentrifues, du moins celui du blastorlerme supérieur. Ce feullet sótend eusuite, d’une faron rógulière, sur le lılastoderme inférienr, d'apris le mode des planulations indireetes : non pas rn s'accroissant par ses propres forees, mais en s'ajoulant, avec régularilí, de nouvelles cellules issurs de la multiplication des élémenls superficiels le re hastudeme inlérieur. - Lébanche du neuraxe prond d’abord, rt aver netteté, laspect de gonltione médullaire.

Le protendoderme de la gastrule, tout comme le blastoderme inilial de la blastule, se loouve divisé en deux parts : l'une nutritive, l'autre formatrice. 'Toutrs deux roncourent à limiter un petit mutron excentripue; la première est siturn en las, la seconde en haut el sur les cótés. La part nutritive est, loutes proportions gardées, plus volumineuse que sa correspondante le la Grenouille; aussi, les allérations causées par sa présence sont-elles plus considirables.

Chez la Grenonille, les collules à deutolécilhe demeurent distinetes; alles sont résorlées peu à pen, et les rlernières d'entre elles domment limiloderme ventral. - Il nen est plus de mème chez les Slurioniens. Lus cellules de la part mutritive s'unissent les unes aree les autres; elles se conlondent, de maniere i former une seule masse, entirrement comjosév de deutolécille, el comparable à une vésicule vitelline. Celte résicule nost pas prinitive, car elle ne préexiste pas à la segmuntation; elle est secondaire, elle résulte d'une coalescence d'éléments uutritifs, mais elle n'en existe pas moins. He plus, comme cos cellules sont miInoment composées de granulatious leutolécilhiques, leur seul rôle est le servir a l'alimentation ale l'embryon; il leur est impossible de fournir les éments figurés, lonćs de capacilé génétique, et destinés a façonner lendoderne rentral. Ce dernier est produit par la zone formatrice. 
Celle-ci s'étend par ses còtés, te maniere à envelopprer la masse mutritive, et ì donner non seulement l'endoderme latéro-dorsal, nais cncore l'endoderme ventral. - L’amas vitellin est ainsi enferué dans l'intestin lui-mème. II est contenu daus cette partie de lappareil, qui deviemlrat l'estomac. Sa disposition est due à une exagération de l'áal offert palr la Grenouille; son rolume, plus grmol que celui montrí par ce dernicr animal, suffisant pour le convertir en une résicule vitelline secondaire, n'est pourtant pas asse\% considérable pour le transformer en une résicule nutritive indépendante de l'intestin lui-mòme. tl est placé encore dans la cavité intestinale, el reste aceumulé le plus longtemps dans l'intérieur de l'estomac. Les vésicules vitellines fus volmminrnses, annexées à l’intestin au lieu d'ìtre situées dans sal carité, sont siluées. par contre, chez les Vertébrés qui en possèdent, en arricre de l'estomar et du foie.

La part formatrice du protendoderme prolifère activement. Elle provient du repli fourni par le blastoderme supérienr: elle enveloppe l'entéron sur' les cotés, et en hant. La hase de l'entéron est d'abord limitéc par la zone nutritive; les bords de la région formatrice entourent cette zone, comme il est dit plus laut, et donnent, à l'espace occupé par elle, la valeur d'un annexe de la carité entérique. lussi, lorsque la masse vitelline est résorluée, le vide, demeuré en sa place, fait-il parlie de lacavilé entẻrique elle-mème, ou plutòt de la cavité ligestive, qui dérive d'elle. - Les autres éléments, de beancoup les plus nombreux, de la part formatrice, produisent les mèmes organes que lenr's similaires de la (irenouille, et de la mème façon : la notocorde, le mésoderme, ot l'endoderme.

B. - Le développement les Lépidostées, pins condensé que celui des Sturioniens, presque semblable à l'érolution des Téléostéens, a été étudié par Igassiz, Balfour, et W. N. Parker. Bien que connu d'une manière incomplète, les olsservations faites suffisent pour concevoir l'importance, el la nature, des procédés employés.

L'œul, plus gros que relui des Esturgeons, mesure, en moyenue, trois millimètres de diametre. La segmentation rst totale, mais plus inégale encore que celle des ovules de Sturioniens. L'alsence dr lilastocole, bien que non démontrée l'une façon suftisante, parait probable: toutr phase blastulaire fait done défaut, et l'wul' segmenté se converlit en une plamule. - Le blastoderme supérieur, sauf par la privation de blastocole, raprelle celui des listurgeons; il est senlement phus petit, par rapport an blastoderme inférieur. Celui-ci, volmuneus, se divise en mn petit nombre de gros blastomires, qui ne tardent jas ì se confondre et à s'unir en une vésicule vitelline. Cette coalescence est plus hailive que dans le cas précédent; clle porte, en outre, sur me moins grandr quantité d'éléments, puisque la segmentalion atteint it peine cette prartie de lovule. - En somme, la geniese du blastoderme s'efteclue d'après 111 
procédé intermédiaire a la segmentalion totale et à la segrmentalion parlielle.

Les phases de la Jélimilation des fenillets primordianx nont pas élé conslatées. Pourtaut, la resscumlanee ginérale de cello évolulion, avee celle des Téléostrens, autoriś it penser que lo mode suivi est idenlique a colui montrí par cos derniers animaux : un léger reploiement, sur luimêne, du blastoderme supírienr, aceompag̨né d'un clivage sur place.

Les élémeuts superticiels du blastoderme supérieur composent la première ébanche du proterloderme; cello-ci sétend à la surface dublasLoderme inférienr, sans dloulr d’après le moven haliluel, en empruntant a cu Jernier le proloplasme nécessatro pour laconner ses cellules sup-

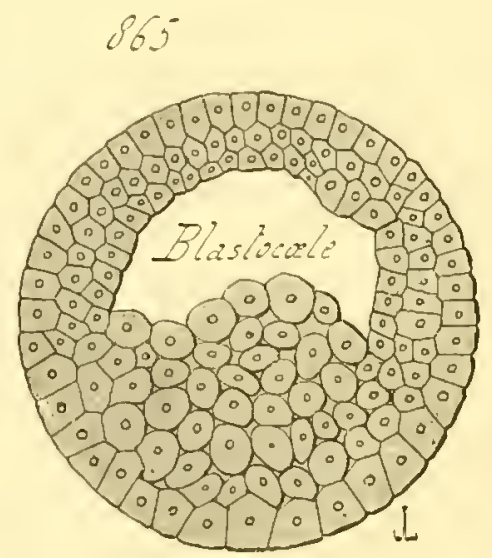

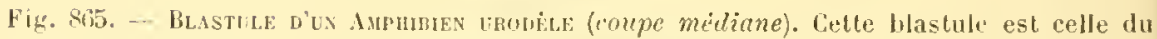
Triton. I'apres 11 . Hertwig.

plémentaires, el se lormant ì Jeur louruir leurs novaux. - Comme chez les T'éléostéens, l'éhauche du ncuraxe est massive; elle est produite par l'épaississement le la plaque médulanire, et non par son incurration en gonttione.

Les allérations les plus grandes portent sur le protendoderme. Par un déplacement dans le lemps, Ja division de ce lernier. en une zone formalrice el une zone nutrilive. se manifeste dès le dóbul de la segmenlalion ovulaire. La région nulritive est délimitée d"une façon trè halive; -lle su lrouve composée prar l'ensemble des gros blastomères, chargés ıle dentolécilhe, qui constilurut la majenre partie de l'ouf, el s'unissent en une vésicule vitelline. Colle-ci est trop grosse pour ètre placée daus la cavité entírique de l’ombryon; elle so horne à lui chro appendue. Elle forme un annexe volumimon, an-dessus dupuel se délimilent les appareils du pelil ctre, el dessine une sailie ventrale, d'amplitude considérable, quj diminue de taille à nuesure que l"embryon augmente la sienne. 
Cette vésicule, ainsi devenue un appendice embryonnare, au lion d'etro renfermée dans l'intestin, s'ouve dans ce dernier par m orifice, silué immédiatement en arrière de l'élıauche dn foic.

La disposition, ollerte par les Lépidostées, est une exagération do celle des Stmrioniens, qui est, ì son lour, une accenluation de celle de li Grenouille. En parlant de l’état présenté par cetle dernièe, les allérations sont causées par un double déplacement dans le temps et dans l'espace : lans le temps, par la délimitalion de plus en plus précoce de la zone nutritive du protendoderme; tans l'espace, par l'angmontation

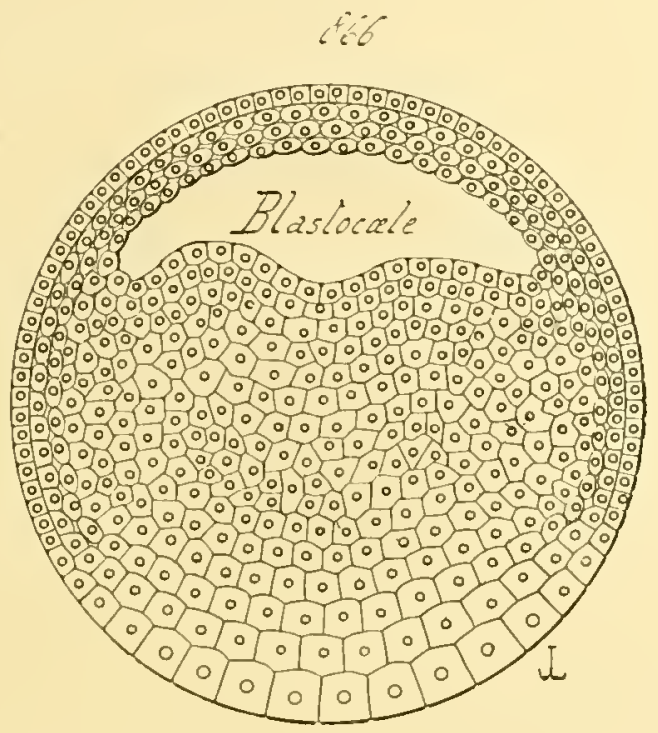

Fig. 860. - Blastule d'us Ampunas axoche (coupe mediane). - Celle blastule est celle de la Grenouille.

Pour celte figure, comme pour la précidente, les traits essentiels des phases ultérieures du développement sont donnés, l'une manière demi-diagrammatíque, par les ligures numérotées de 817 à $\$ 22$; ils rappellent de prís leurs correspondants des Ganoïdes Sturioniens (fig. 860 à $86 i$ ).

du volume de cette zone. Wabrord pelite, interne, el constamment cellulaire chez la Grenouille; elle devient plus grosse, interne encore, at non figurée vers sa lin, chez l'Esturgeon; pour" se tronver énorme, externe, et non ligurée presque dès son déhnt. rhez le Lépidostée. Sil'on suppose, dies lors, que cetle absence de struchure cellulaire, el que sa délimitation, soient plus précoces encore; que celle zone untritive ronslitue, avant tonte segmentation, $n$ amas vitollin ne se livisant jamais, el demeurant comme nue vésicule annexé an corps de l'embryou, on obliendra la disposition des T'ćléostéens el les sílaciens. La résicule 
vitelline de ces derniers, comme celle des Imniotes du reste, esl strictement l'homologne dr la part nutritive du protemloderme, telle qu'elle se montre dans les lévelopjements dilatés des autres Vertébrés; elle est une région polendodermique, privée de structure cellulaire, et hàlivement halimitée, pour servir d'aliment à l'embryon; elle n'a pas d'aulre raleur. La série précidente le démontre d'unr facon suffisante.

11. Développements condensés. - Dans ces évolutions, les matériaux nutritifs le l'unf sont accumblés en quantilé considérable; len présence amène la division de ce lernier en deux parties, l'une pelite el seulement composée de blastolécithe, l'autre volumincuse el surtout riclue en lintolicilhe. Anssi, avant toute segmentation, lovule se trouve-t-il constitué par une grosse masse mulritive, sur layuelle repose une petite cicatricule. Celle-ci se segmente seule, el donne la plupart des éléments figurés de l’organisme. Celle-là ne sulit aucune scission: elle se borne, tout en servant de réserve alimentaire, à expulser le sa masse les parcelles de blastolécithe qu'elle contient encore, et à les employer, après leur conversion en cellules, soil à paracherer l'endolerme, soil à se façonner une paroi enveloppante. - Les Poissons, ponrvos d’embryogúnies condensées, sont les Téléostéens el les Sélaciens. La répartition de ces développements est exclusive; tous les animanx, compris dans ces deux classes, el connus sous ce rapport, se ressemlilent completement, et ne dilfèrent que par des détails d'une minime improrlance. La diversité si remarqualile, propre aux évolulions dilatées, nexiste point ici. (Fig. 823 i 896.$)$

Tébéostísss. - L. L'ovule le ces animanx est petit, lien que muni l'ahondantes réscrves nutritives. Une fipaisse membrane vitelline, perrée de nomlırenx canalicules élroits, dirigés snivant les rayons, l'enveloppe. Le lifastolécithe est d'abord disposé autour du rolumineux amas deutolécillique, de manière à l'entonrer, soit en totalité, soil, et plus fróquemment, en partie. An moment de la maturité, la majorité duvitellus évolutif se ramasse sur lui-mène, et sarumule en une pelite cicalricule. Une onvertme, dite le micromyle, percée an nivean de rette dernire, à lravers la membrane vitelline, permel ans spermalozoüles de parvenir jusqu'à elle; la cicatricule rontienl en ellet, romme torjours, le prénoyan femelle. - Cette partic de l'enf est exartement séparée dn deutolécithe. Celni-ci doit composer la vésicule vitellino; il est permis le donner à son ensemble, et prar anticipation, ce nom pour le désigner. La ciralricule repose sur une zone de sa surface, quil est permis d'indiquer par le terme de zone cicutriculaire. Celte derniere est constitué par un mélange de deutolécithe el de blastolécithe. Aussi, à mesure que la cicatricule se segmente, le vilellus évolutif, placé dans la zone cicatriculaire de la résicule vitulline, se sépare-t-il du vitellus nutritif; il s'organise en éléments figurés, anxquels les cellules de la cicatricule 
fournissent des noyaux. Ces éléments s’ajoutent il coux dont la ceiratricule est déja formée, et rontribuent à donner une part du protrndodrrine. Une lelle origine est aisée à comprendre, puişue la résicnle vilellino entière a la valenr d'une région protendoderninge, dólinitée d'uns manière hàlive. - Le mème mélange des deux vitellus, el la mème? séparation, existent encore à la surface de la vésicule vilelline, et jon'nl un grand rôle dans la production de la paroi de cette vésicule. Le hlastolécille, ainsi laissé dans la zone superficielle de l'amas nulrilif, est un reste de celui qui, arant la maturation de l'orule, enveloppait co dernier.

la ciralricule se segmente seule, el se livise en pelits blastomires semblables, disposés sur plusieurs conches. La tolalité de ces cléments offre l'aspect l'une masse compacte, placée sur la zone ciralriculaire de la vésicule vitelline. Le blastocole parait manquer, du moins lans la phupart des cas; plusieurs auteurs ont, pourtant, signalé la présence. "n une région de la cicatricule segmentée, l'une petile carilé, comparable à un blastocole, ef qui ne tarde pas à lisparaitre. Tont en se divisant, la cicalricule s'annexe, dans sa région profonde, des cellules façonnées aux dépens de la zone ricatriculaire, suirant le procélé signalé déjả. Fille grandit ainsi, non seulement en éfraisseur, mais encore en surface, el se convertit en un disque blastodermique, qui recourre, à la manière d'une calotte, une part de plus en jlus grande de la vésicul vitelline. Cependant, malgré cetle extension, les organes des emliryons s’éluauchent seulement aux dépens des blasiomères silués dans la zune 'qu'occupait la cicatricule; les nouvelles portions produites, surajoutérs an disque hastodermique, et qui enveloppent la vésicule vitelline, nont d'iutre róle que de fournir a cette dernicie sa paroi.

Le rrai rudiment embryounaire se borne, par suite, à la région de la cicatricule. La délimitation des feuillets s'effectue sur plare. par un simple clirage. Parmi les assises cellulaires superposées. la plus exhirieure régularise ses contours, se sépare ainsi des couches protondis, if constilue désormais le prolectoderme; les rangées internes, de lintr còté. représentent le protrndoderme. - Cependant, un rappel de gastrulation s' manifeste encore. Sur le bord postéricur du disque, en une région qui. par sa situation, rorrespond à l'entéropore des enubryogénios dilatées, le blastoderme jrolifere plus activement yu'ailleurs. Cetle multiplicalion a pour effel d'épaissir celfe région, et de lui donner l'asjeel d'un manelon légèrement saillant; les auteurs désignent ce dernier par les termes de moluberance caudale. on le bourgeon caudal. Ce mamelon est thomologue des lèvres de l'entéropore, soudées l'une ì l'autre de façon ì ne laisser entre elles aucun espace ville. La prolifération, en cel endroit, est tellement active, el le délimitation précise, que les phénuménes se passent comme si le borl, tout en s'accroissant, se repliait sur lui-mème, pour s’insinuer entre la partie blastodermique demeurée en place, d la zone eicatriculaire de la résicule vitelline. La puntration est asso 
exacte pour ne laisser aucun vide eutre les régions mises en présence. En somme, ce fait est semblalile à son rorrespondant du blastoderme supérienr des Canoüles. - Les éléments de la protubérance caudale se mélangent à leurs similaires du reste du blastolerme; ils composent le protendoderme. Ce feutllet est de même origine lans tonte son étendue; sa caparité gémétique esl seulement plus grande au niveau de cette protulérance, par une persistance des phases projres aux évolutions dilatées.

Le protectoderme se subdivise ensuite, tout en s'élendant comme il sera dil plus loin, en deux assises concentriques. Il donne le neuraxe, placé sur la ligno médiane du hlastoderme, en avant de la protulérance candale. D’aprés Ilenneguy, lont les oliservations out porté sur l'embryon de la lruite, la plaque médullaire commenee, dans certains cas, par se creuser l'un sillon itroit. Mais ce dernier, lorsłu il existe, ne parvient jamais à se convertir en une gontlière ample. La plaque s'épaissil, of se Iransforme en un corlon plein, qui pénètre dans les tissus embryonnaires, et se sépare alors de l'ectoderme, reformé au-dessus de lui. Une cavité se creuse ensuite dans ce corlon, et le parcourt en entier suivant son axe. Cet espace s'unit plus tard à l'ébauche de l'entéron, ef donne ainsi, au-dessous de la protubérance caudale, un canal neurentérique, de lurée temporaire.

Le protendoderme se suinde, sur place, en notucorde, endoderme, et mésoderme. Ce fuillet correspond strictement i la part formatrice du protendoderme des évolutions dilatées. Composé par un grand nombre de cellules semblables, groupées sur julusieurs rangées, ses éléments se rassemblent eu amas dislincts, qui représentent autant d’ébauches particulirres. - Les cullules, silnées au-dessous du neuraxe, se réunissent, et façonnent, saus subir aucun déplacement, l'ébauche de la notocorde. - Les ćléments placris sous relte demiere, entre elle et la zone riratrirulaire de la vésicule vitelline, produisent l'endoderme. Ceux-là sont, toul "l'abord, disposés en une assise simple, presque aussi large que le hlasloderme, étalée à la surface du vilellus. Leur raugée replie ses -ôtés, les fait pénétrer entre elle-mème et le deutolérithe, el les soude finalement; elle s'est ainsi lransformée en une double couche. Une cavité se creuse lientót entre les deux jlaques le cette rourhe; elle répond à l'entriron, et donne la ravité intestinale. Son ílouche se montre en premier lieu, au-dessous et un peu en avant de la protubérance caudale: elle s'úlargit avec rapidité, el se converlit en une vésicule, qui s'mit au neuraxe parl'entremise du canal neurentérique. Cet espace est dit la wesicule de Ḱüffer, du nom du naturaliste qui l’a découvert; des discussions fréjuentes ont eu lien à son snjet; autant qu'il est permis de le penser d'aprẻs les faits acquis, et comme Balfour l'avait déja présumé, elle estléquiralent de la zone postérieure de la cavité entérique, et se montre avant les autres régions de l"appareil dont elle fait partic. - Enfin, les éléments. de beaucoup les plus nombreux, qui ne sont pas 
utilisés dans la greniese de la notocorde et de l'endoderme, prouluisent le mésoderme. Certains d’entre eux se rassemblent en deux handes, dont l'une est placée à droite, et l'autre à gauche, de la notocorte: charpue l,ande se creuse d'un espace vide, et se livise en mésosomites. Les plaques latérales se lélimilent ensuite, en prenant avec précocité, tont comme les mésosomites, une disposition franchement épithéliale. l.es cellules mésodermiques, placées autour de crś ébauches le l’épilhéliomésoderme, el comprises entre l'ertoterne d'une part, l'endoderme et la zone cicatriculaire (de la vésicule vitelline) d'autre part, se multiplient, et sont destinées à fournir le mésenchyme. Elles sont en plus grand nombre daus les régions, téjả signaléres romme étant les principales zones de production de ce feuillel.

b. - A mesure que ces phénomènes s'efferluent, dans la région de l'ancienne cicatricule, le blastoderme s'étenıl autour de la résicule vitolline, el l'enveloppe, en lui lomnanl une paroi. Cette extension progresse lentement, et avec régularité, depuis le bord de la cicatricule primilive. jusqu’à l’extrémité opposée de la résirule vitelline. - In tel accroissement n'est pas le fait ilu blastoderme entier; il atteint seulement, semblet-il, l'ertoderme et le mésenchyme; les autres feuillets ny sont pas intéressés. En outre, il ne s'effechue pas, dans la réalité. par l'amplitication du blastoderme en surface, mais lien par l'adjonetion régulierement sériée, aux bords de ce dernier, de nouvelles cellules ditférencices à la surface de la vésicule vitelline. Cette arljonction se prorluit suivant le procédé commun à toutes les planulations indirectes. Les zones superficielles de la vésicule contiennent du lilastolécithe; cehui-ri se concrète en cellules, auxquelles les éléments déja formés procurent des noyaux. Celte différenciation commence sur le loord de la cicatricule, et progresse de là vers lextrémité opposée. Les cellules engendrées sont disposíes en un petit nombre de couches, qui se raccordent à lectoderme el au mésorlerme mésenchỵmateux du blastoderme, le manière ì faire partie de leur systime.

La vésicule vitelline est ainsi pourrne l'une paroi propre, qui la suspend au corps de l'embryon. Celui-ci est façonné par le senl lilastoderme, développé aux dépens de la ciratrioule; aussi la paroi ne jouet-elle aucun röle génétique, et se réduit-elle à mesure que le dentolécithe est résorlié. - Cette vésicule constitue un annexe volumineux, appendu à la face veutuale de l'embryon; clle diminue d'amplitude. pendant pue celui-ci grandit et perfectionne sou organisme.

Contrairement à son homologue des fanoüdes, la résicule les Tóléostéens, semlilahle en cela à sa rorrespomlante des Sélaciens et les Amniotes, ne tarle pas a perdre toute connexion directe arec la ravité entérique. Au moment on l'endodermereplie ses bords, et les rapproche pour les unir, l'ensemble du deutoléeithe est comme situr dans un raste espace, annexéa l'entéron eneore virtuel. Lesconnexions raplpellent, 
a cel égard, celles montrées par les lépilostŕes. Elles disparaissent lapidement, mais à des legrés variables suivant les types. - La fermeture de l'endourme ne s'elfectue pas, en mème temps. sur toute l'étendue de ce l'urillet; les régions, oit les hords ne sont pas encore soulés, permellent i la cavilé intestinale, déjà ébaurhée, de rommuniquer directement avec son annexe, rempli the lleutolécithe et composant une vésicule vitelline. L'orifice de communication est situé en arriore de l'blaurhe du foie. l'uis, cet orifice se ferme à son tour; la résicule et l’intestiu sont dès lors indépendants. En ce moment, des nombreux vaisseaux sanguins, raccordés à ecux du corps le l'embryou, se crensent dans la paroi vitrlline. Le sang, contenu dans ces vaisseaux, sert i résorloe lo dentolécithe, et i portes, dans l'organisme lui-même, les matóriaux mutritifs qu’il a puisés dans la vésirule.

Les données précérlentes sappliquent i la julupart des faits acquis. bans la nalure, les rariations sont nombenses, entre les divers ambryons des Téléostéens. sous le rajport de la taille de la vésicnle vilelline, pour un mine tye moven. En général, sa fermeture, du cóté de lintestin, est l’antant jus rapila yu'ello est elle-mème plus grosse; sa resorption se trouve, par suite, l'aulant plus lente. Certains d'entre eux ressemblent anx lipidosties, alors que plusiours autres sont jomrves d'un annexe mutritif beanroup plus volmmineux. Dans l'ensemble, an moment de l'éclosion dn petil être. la vésicule vitelline, bien que diminuée, est emcore asse\% grosse; olle disparait par la suite.

Sélariess. - Ite développenrul de ces animanx rappelle beancoup celui des Téléostéens; il en dithere par certainos particularilés, lrès appréciables en lant que disposilions extérienres, mais, en réalité, d'ane importance serondaire. La vésicule vitelline est plus grosse, relalivement à la cicatricule; l'ectoderme se compose d'une seule conche cellulaire, et le neuraxe évolue suivant le lype le la goultière médullaire. - Les ressemblances londamentales, établies entre l'embryoánie des Sélaciens el celle des Téléostéens, jointes à ce fait. que la llupart des íbauches organiques de ces derriers se lacoment suivant le mode massil, ont suggéré i balfour la penséc suivante : les Téléosténs actuels sont issus d'aucêtres, dont les anfs étaient plus gros que les leurs, et qui se léveloppaient d’après un procédé identique a celui les Sélariens. Cette donnéc suljoutive ne semble pas trè acceptable, en mison des relations itroiles pui mnissent les l'oissons osseux aux Ganoïdes, autant sous le rapjort de la structure anatomique que sous celui des phénomònes embryonnaires. J`évolulion les Téléostéens, et relle des Sélaciens, paraissent plutôt se ratlacluer à des altérations diverses d'un mème développement primordial: relui des Ganoüdes franchement cartilagineux. Ces changements sont du mème orlpe, aboutissent presque aux mèmes résultats, mais offrent cependant quelques ilissemblances. 


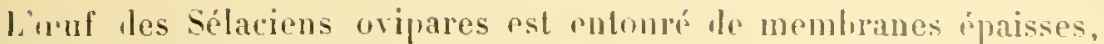
réparties en deux couches. Lönterne d'entr. clles est mo issise allumincuse. qui entomre directement lu vitellus: lexterme est me cuque cornée, destinée a jrotéger l'ensemble. Ces lonx conches existent également aulour des ovules des sélaciens vivipares; alles sont pourlaut plus minces, surtout en ce qui touchr la coutue cornée. ch disparaissent rapillement.

Lovulo est divisi en denx parties: la protite coleatricule, pt la voluminersu vésicule vitelline. La premiope se compose sentement de blasto-

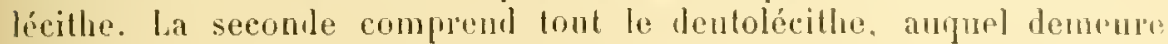
mélangée une certaine quantilé de vitellus évolulif. Celle-ci est surtout placée dans la zone cicatriculaire, et dans les régious superficielles do la résicule; de mème que la cicalricule, elle est chargée de domej des éléments figurés. Ces dernjers sont destinés a fommir l'endoderme rentral, et la paroi de la résicule vitelline; toutes les antres cellules de l'organisme proviennent de la cicatricule. - Les phénomènes sont done semblahles à ceux montrés par les Téléostéens, et à ceux qui se laissent pressentir, en supposant une condensation érolutive plus grande, d’après les développements dilatés des autres lehlhyopsidés.

La fécondation opérée. la cicatricule se sẹmente seule, et donne le blastoderme emliryonnaire, homologue du blastolejom supérieur des développements dilatés. Celuj-ri se compose de plusieurs assises rellulaires superposées, et se reuse d'une carité hastocalienne assez ample; il repose sur la zone cicalriculare de la vésioule vitelline. l'uis. rers son bord postérieur, dans la région qui correspond a l'entéropore des embryogénies dilatées, el à la protulérance candale des Télóostciens. la multiplication rellulaire devient plus active. Cette prolifération abonJante se double dun mouvement tel, que lo hord parait se replier en ledans; tout en agissant ainsi, ce dernier se souleve quelque pen anJessus de la vésicule vitelline, le manière ì laisser, eutre elle el lui, un espace apprériable. - Celte invagination, 'pui atteint seulement le hlastoderme, ne correspond pas tout a fail a ume déprission qui se (rense; elle soffeclue surloul par une mulliplication active, commençant sur le borl du blastoderme pour pénétrer plus profomlément, avangant arec régularité dans ce sens, et se compliquant d'une délimitation plus parfaite entre le vitellus nutritif et les cellules issues de la cicatricule. Dautre part, elle ne s’étend pas très loin, et se lorne à intéresser la région postrienredu blastaderme. Mais, malgrié son allure spéciale et sa profondeur minime, elle est strictement l'homologne, par toutes ses qualités, le linvagination gastrulairo des développenents dilatés. L'inpulsion déprimante nexiste plus gure, ot se tratuit par une prolifiration cellubios ahomdante, accompagróe duu soulevement des nouvelles parties produiles; mais son inlluence existe encore. Loulite de l'espace crensi, entre la resicule vilelline et le borl blastodernipue, est un ontóropore véjitable; sa levre supéloure est donnée par lu rebord, 
et se trouve cellulaire; sa livre inférieure, fournie par la vésicule, esl constituée par du vilellus mutritif. (Fiy. 823 ì 826 .)

En ce moment de son évolution, l'uul' des Sélariens est parvenu à In etat, "püll est permis d'assimiler a la phase gastrulaire les embryogénies dilatées. Il se compose l'un blastoderne à plusieurs assises cellulaires, dont la région postérieure limite, en haut el sur ses côtés, un pelit espace libre. Ce dernier est l'entéron; sa paroi ventrale est repuésentée par la zone supérienre (zone cicatriculaire) d'une volumineuse vésicule vitelline, sur laquelle te blastodeme est placé. I'entéron s'onve au delıars par un entéropore étenilu, recourlié sur lui-mème ell IIn croissant. - La ressemblauce générale avec une gastrule asymétrique de Cyclostome, d'Amphibien, ou de Gianoïde, est manifeste. Il suffit, dans celle-ci. de rentre plus épais le blastoderme supérienr, de diminuer l'aspace laissé à l'entéron, et d'amplifier le blastoderme inférieur, tout en le convertissant eu une vésicule vitelline, pour oblenir la phase achrelle de l'embryon des Sélaciens. Aussi, les phénomènes de la délimitation des feuillets concordent-ils dans les deux cas, sauf en ce yui concerne les allérations causées par la présence l'une aboulante masse nutritive.

Par un avancement lans le temps, le protectolerme se lifférencie, aux dépens les lilastomires superticiels de la cicatricule, dies les premières phases le la segmentation. Il est ronstitué par une seule assise cellulaire, et donne rapilement la gouttiore médullaire. - Le protenloderme comprend tous les hastomires profonds, rangés sur plusienrs couches. Cenx d'entre eux, qui sont placés au-rlessons du neuraxe, engendrent la notocorle. Les éléments, situés sous cette dernirre, se rasicumblent en une assise épithéliale, yui enveloppe l'untéron dans ses parties supríjeures et latérales, et s'appuie par ses hords sur le vitellus le la vesicule: cette assise fournit l'endoderme latéral et dorsal. Eufin, toutes les antres cellules, le heaucoup les phus nombreuses, placées sur les côtés des élanches de la nolocorde et de l'endoderme, produisent de mésoulerme; relui-ci s'organise hàtivement en mésosomites, plaques latéliales, et donne naissance au mésenchyme. - Ce protendoderme, isisu le la cicatricule, est l'homologue de la part lonnatrice du protendoderme des embryogénies rilatées. Tout en se différenciant, il augmente le nomlre de ses ćléments constitutifs, par la muliplication incessante de cenx yni existent léjà. Les principales régions proliférantes sont au nombre lle leux: l'me, marginale (peristomale dr liabl), répond aux lives de l'entéropore: l'antre, centrale (gastrale de Rahl), aux côtés de la notocorilo.

La vésicnle vitolline conlicul une certaine puantité de blastolécithe, placée dans ses zones superticielles; ce vitellus se concrète en cellules, auxprelles les éléments cicatriculaires les polıs proches foumissent leurs noyaux. - Les cellules, ainsi fiçonnées dans la région située au-dessous 
Je l'entéron (zone cicatriculaire d" la vésicule vitelline), limitent cu los cette cavité, et donnent l'endoderme ventral; elles se sombent il l'endolerme latéro-dorsal déjà ébauché. - Lientéron est, dios lors, enveloppé par une assise épithéliale, qui le sépare du dentolérithe vitellin. Cet isolement n'est pas complet: l'endorlerme vontral reste interrompu, pendant un temps assez long, en un point, qui permet an vitellus de passer directement en la cavité intestinale, dérivéc le l'entéron. Celte régrion de communication s'allonge mème, ì mesure que l'embryou érolue, el forme un cordon creux, dit le cordon vilellin, ou le cordon ombilical, au moyen duquel la résieule vitelliue se trouve suspendue i la face ventrale ju petil ètre. Ce cordon ne se ferme, et ne s'atrophice ensuite, quan moment où la vésicule est presque vidée, of l’embryon près d'éclore.

D’autre part, les cellules, produites aux dépens du blastolécithe vitellin, dans les autres zones superficielles de Ja vésicule, s’ajoutent aux bords du blastoderme issu de la cicatricule. Cette adjonction jrocide avec l'égularité, en Jébulant par ces lıords, et s'avançant à mesure autour de la résicule, pour l'entourer tout entière; la derniore zone recouverte répond à la lèv'e inférieure de l’entéropore. - Ces éléments, disposés sur plusieurs couches, se raccorlent à ceux du blastoderme cicatriculaire, et composent de mème un ectoderne, un mésoderne mésenchymateux, et un endoderme. Celui-ci n’est guère dévelopró que dans le cordon vilellin. Le mésenchyme se creuse de vaisseaux sangrins, qui s'unissent à ceux de lembryon, et ailent à la résorption du vitellus. Une paroi vitelline complexc preml ainsi naissance.

Les diverses particularités offertes, par les embryons des Sélaciens, en ce qui touche les éléments non engendrés par le hlastolécithe initial de la cicatricule, rappellent exactement leurs similaires des embryons des Sauropsidés. Les mèmes considérations leul sout applieables.

\section{$\$ 7 .-$ Développement des feuillets blastodermiques chez les Sauropsidés.}

I. Considérations générales. - Les obselvations, acquises sul' le développement des Reptiles, et sur celui des Oiseaux, sout aujourl'hui fort nombreuses. Elles ne concernent pas tous les groupes secondirires de ces classes, et touchent senlement i quelques-mus d'entre enx; mais la structure mniforme des reufs, chez ces ètres, permet d'étendre ì lous les résultats donués par quelques-uns. l)ans la limite des commaissances actuelles, ces résultats sont eux-mèmes identiques; saul quelques variations de détails, d’importance fort minime. Les Samopsillés paraissent avoir une évolution emhronuare semblable; ils ne montrent point la diversité prisentée par les lehthyopsides, ni celle, noindre cependant, offerte par les Mammifires. 
1. - Les unfs de ees animax sont voluminemx el complexes. Lorule, après sa fécomblion sur l'ovaile mème, el sa chule, s'entoure, en pareourant t'oviducle, d'envelopjes épaisses, dont les unes servent a protéger le futur embryon, el les antres ì lialimenter. Ainsi revolu le ces roques emboilées, il est rejetí au dehors, sauf dans le cas lles lieptiles viripares, el se développe. Les annexes nutrilifs sont absorbés, durant cette périoule, par lembryon; puis, Jorsque ce dernier est achevé, il brise les annexes protectenrs, les derniers qui existent encore, ot se trouve lihre. Les lieptiles vivipares subissent les mèmes phénomèurs, avee la différence que ceux-ci se manifestent dans l'oviducte maternel, au lieu le s'effectuer dans les milienx extérienrs.

tioule seul, alsstrartion faite de ses enveloppes, et tel quil provient de l'ovaire, est entouré d'une fine membrane vilolline. Sa substance contient une quantité considérable de leutolécithe, aussi grande, en moyenne, que culle offerte par les sélaciens; arssi, la structure est-elle semblable dans les deux cas. La majeure partic du blastolécithe est séparée du restr drelovule; colui-ci compose une volnmineuse vésieule vitelline, et la premiare mue petite cicalricule.

La cicatricule n'est formée que pas dıvilellus évolutif; elle renferme le prénoyan femelle. - La structure de la vésicule vilelline est plus complexe. Non seulement cette dernière conticnt tout le deutolécithe de l'unf, mais encore elle comprend une certaine portion de blaslolécilhe, non employée dans la cieatricule. Celte portion complémontair. est située dans la région superticielle de la vósicule; une de ses parts, placée sous la cicatricule, conslitue une sone cicalriculaire; le restant est disposé hor's de la cicatricule, antour du deutolécithe enticr. - La zone cicatıculaire, composée le vilellus mulıjif uni à lu blaslolécithe, établit une transilion entre la cicalricnle, franchement évolutive, el la vésirule; assez épaisse, elle s'enfonce dans celle dernière, et, à cause de son aspert, de ses globules vitellins plus petits, les auleurs la lésignent souvent par le terme de vilellus blanc. Sa richesse en deutolécilhe augmente dans ses courhes profondes, el, inversement, diminue rers ses régions périplériques, disposées sous la cicatricule, où le vitellus érolulif est plus aboudant. Ces dejnières sont destinées à fournir, a la cicalicule, un appoint considérahle pour la genése des cellules blastodermiques. Le lilastolécithe, réparti dans la périphérie de la résicule vilelline, y est plus intimement mélangé an dentolécithe. Sa séparation, d'arec ce ternier, est plus lardive el plus lente; elle a ponr elfel de permettre la prouluction ile la paroi vitelline.

La structure de cet orule, airsi constitue, rappelle essentiellement, dans ses grands trails, eelle des sélaciens; celle ressemblance facilite sa comparaison avece la disposition présentée par cenx tes lohlhyopsidés qui subjssent un développement dilaté. - La cicalricule, jojule anx régrions superficielles de la zone cicatriculaire, correspond ì cette partie 
ovulaire qui donne le blastoderme supérieur. Toutes los aulues zonus de l'uruf, de beaucoup les plus cousidérables. sont les lumonlogues do la partie chargée de prorluire le blastoderne inféricur. Par nne altéralion

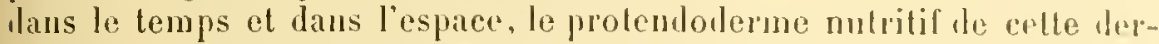
nière se trouve converti, avant toute segmenlation, en une massu compacte, mullement liguríe, et destinée à alimenter l'embryou, sans se convertir en cellules; sauf sa zone superficielle, contenant unc cerlaine quantité de hastolécille, fui se transforme en cilcments collulairos, chargés de donner une paroi. - Celle organisalion de l'ovule entraìne les mèmes comséquences que clıez les Sélaciens. La cicalıicule seule. complétée par les couches superficielles de la zone cicalriculaire, engendre le corps de l'embryon. La vésicule vilelline serl seulement it nourrir ce dernier; et sa proi n'a d'autre rôle que de la limiter vars l'extérienr, sans fournir aucun élément à l'économie dífinitive. L'ovule est ainsi divisé en deux parts : l'une formative, ou blustorlermirue, ou embryonnaive; l'autre nutritive, on vitelline, on part-embryonnaire. La première se scinde completement en cellules, qui se répartissent en trois fenillets, et engendrent le corps; ciest sur elle que porte le développement à son début. La seconde se concrèle en cellules dans sa périplérie seule; rette évolution commence sur les bords le la zone ricatriculaire, et, de là, s’étend peu à peu a toute la surface de la vísioule vitelline.

l.es enveloupes de l'avule sont grouperes en hrois conches distincles: une assise albumineuse en dedans, une membrune corqullère an milien, et une coque en dehors. - Celle-ci entoure l'auf entier, el protige l'ensemble; son épaisseur varie, en moyeune, suivant les dimensions le l'euf, et se trouve d'aulant plus grande que le volume de ce dernier est plus considérable. Elle est encroùlée de calcaire; en géníral. la quantité de cette sulistance est plus pelito chez les linpliles que chez les Oiseaux, l'où une certaine élasticité des aufs de la plupart de cenx-li. - La membrane coquillèe se compose de deux fenillets, constitués par une sulstance anlyste resistante, et dits, smirant leu silualion muluclle, l'un la lame externe, l'autre la lame interne. An moment le leur alépit, l'espace creusé entre ces lanes est virlucl; il devient riel par la suile, car il se remplit l'air, infiltré ì travers les frores dont la coyur est creusée. Cet air augrmente le volume i mesmbe yue l'unf, pontu au préalable, devient plus àgé; il s'accunule, de prélépence, en l'une dos extrénités de l'auf; la place, qu'il y occupe, porte le nom de chambro ì air. - Labumine est, de beanroup, l'envelopje la plus épaisse; elle remplit l'espace considérable, laissé entre la lane interne de la menbrane coquillèe et la membrane vitelline. Ellu conlient, en denx régions diamétralement opposies, les tortillons d'une sulıstance alluminensis très dense. La présence de ces tortillons, dils chalazes, est due an munvement de rotalion sur lui-mène que subit l'ovule, on doscombant l'ovilucte, a mesure que les couches d'allumine se déjosent aulour de lui. 
Les risprositions essentielles d." cette structure existent, avec quelques variantes d'importance secondaire, chez tous les Sauropsidés. Les principales des altérations sont offertes par les Reptiles vivipares; la coque, avec la membrane coquilliere, sont rédnites; et l'envelopje albumineuse se trouve également amoindrie. - Ces enveloppes sont anhystes, el ne contiemnent aucun élément figuré. La coque et la membrane coquillère sont perméables à l'air; elles endiguent l'albumine, liffnente, protègent l'embryon en l'isolant des milienx extérienrs, et permettent sa respiration en se laissant traverser par l'air du dehors. L'albumine est uu aliment; non seulement le petit être se nomrit aux dépens de sa vésicule vitelline, mais encore à ceux de son enveloppe allummineuse. Ce fait n’a guère été étudic, avec détail, que chez nn petit nombre l'Oisraux, le l'oulet entre autres; J'uniformité le structmre de l'uuf, chez tous les Sanropsilés, permet d'admethe quil en est de mène ailleurs.

13. - Une telle organisation de l'ovmle est la canse d'altérations considérables daus le lévelopjement. La comdensation évolutive est plus prononcée encore que chez les Silaciens.

Les feuillets blastodermiques prennent naissance suivant le procédé planulaire indirect. Les premiers phénomènes emlıyogéniques alıontissent à la prodnction d'une plauule lécilhique, dans lagnelle l'espace occupé par le deutolécithe est fort grand. Cependant, malgré la présence rxclusive de la planulation, un rappel du mode gastrulaire se manifeste encore, moins accentué que celui les Sélaciens, mais, pourtant, dune netteté suffisante. - La cicatricule, complétée par une part de la zone cicatriculaile, se segmente; elle se divise en plusieurs assises superposées de blastomères. Ces couches donnent surplace, en délimitantmieux leur's contours et se façonnant en ébauclses listinctes, Jes feuillets lılastoderminges. Ces faits concorlent avec ceux propres aux planulations; ils se terminent prar un phémomine d'euveloppement progressif de la vésicule vitelline, an moyen de cellnles qui lui composent une paroi. Les rararteres essentiels les planules indirectes sont ainsi des mienx marqués.

Mais, en surplus, un retour de la gastrulation se produil, daus me zone homologue, par sa situation. de la région eutéroporienne des gastrules rraies; rette zone est. comme chez les Sélaciens, le bort pos-

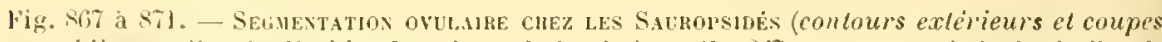
médianes; 1'après Mallias Iuval sur le l'oulet). - lin 867, structure génèrale de l'oeuf; la petite cicatricule de blastolecithe repose sur un volumineux amas de vitellus nutritif (le jante lle l'ur'), qui deviendra la vésicule vitelline; l'uruí nst entourè par une coque calcaire, fu'un espace rempli l'albumine sẻpare du jaune. Cette figure (voir aussi la fig. 973 et les suivantes) explime le contour gèeral de l'ouf entier, en supposant la coutue coupre, el l'allumine enlevée, pour laisser voir l'ovule, essentiellement composé du jaune et de la cieatricule; les autres figures sappliquent a des coupes médianes de la cicalricule seule et des régions avoisinantes, fort grossies, ct prises à des phases de plus en phus avanceres dans la segmentation. - Fn sfis, dehut de la segmentation. - 


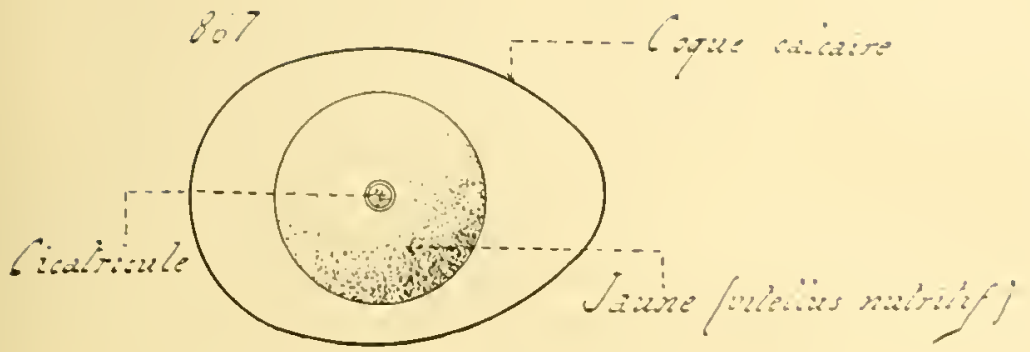

\section{8}

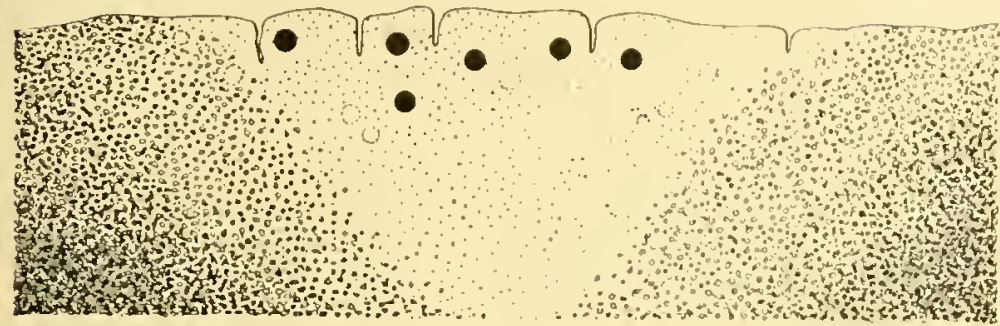

869

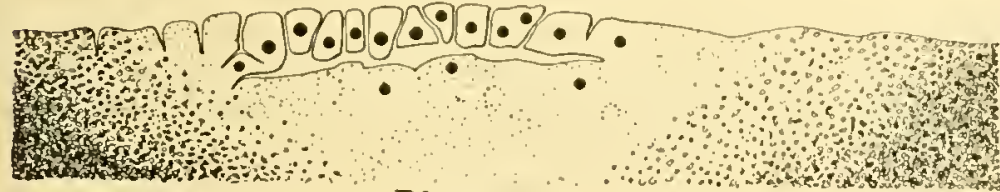

870

Blastocale

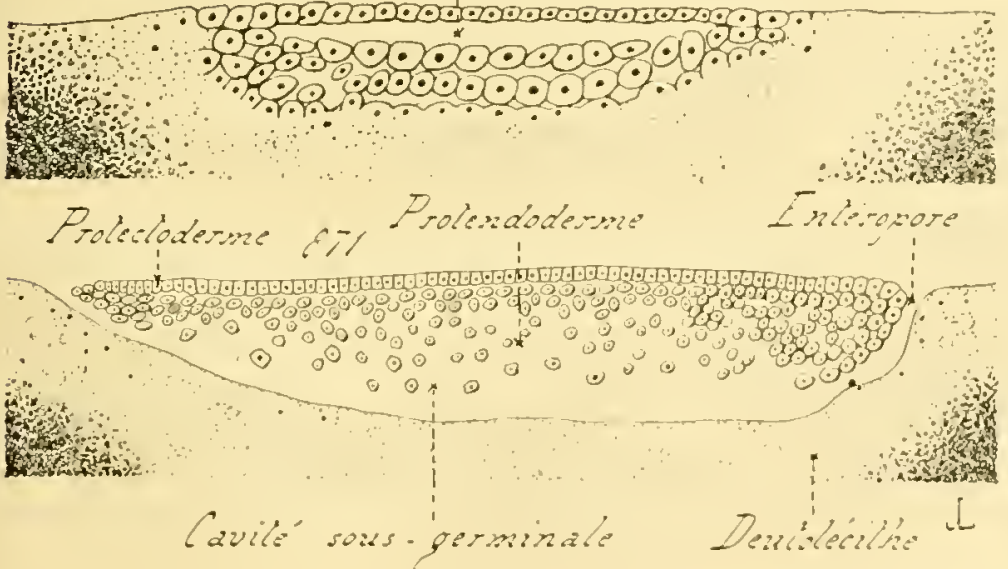

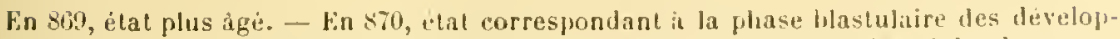
pements dilatés des Vertibrés inférieurs. - En 871, elat correspoudant à la phase firstrulaire des développenents dilatés des lertébres inférieurs; la eavitu sous-germinale est l'homologue de l'entéron les gastrules. 
lérieur de la cicalrinule. Céborl, aux contours précis, est le siège d’une multiplication rellulaice intonse, qui l'epaissit, ot le convertit en un lourrelet saillant, recourbé sur lui-mine en coissant. Ce bourrelet en croissant, on hourrelet hlastodermique, est l'homologne strich des lèrres sondées d'un entéropore; souvent mème, il se creused'un sillon, qui correspond ì la cavité le l'entéropore; et, dans lous los cas, il émet, par le milien de sa face concave, nne expansion en forme le goutlière, le sillon primitif, on la ligne primitive, doüt les hords sulissent également une prolifération des plus actives. De son côté, le bourrelet, arec les rógions cicatriculailes qui l'avoisinent, se soulevent au-rlessus de la parlie sous-jacente de la vésicule vitelline, el laissent entre elle et eux un espace vide; co demicr communique, par une fente mince, de durée minime, aver le sillon hu bourrelet. Les connexions sont ici semblables, le tous points, a celles d'un entéron avec son entéropore. Ces relations sont fugaces; elles disparaissent par la suite; elles se montrent cependant avec toutes les qualités voulues daus lo temps el dans l'espace, pour préciser les homologies. Le sillon primitif se ferme par le rapprochement le ses hords, et devient le canal neurentirique.

la ressemblance complete de ces rigions avec la zone entéroporienne des gastrules saftime dans toutes les particularilés fondamenlales. La genise, ot le déreloppement, du lourrelet en croissant, complètent, par me gaslutulion, les phénomènes de la formation des feuillets suivant le mode planulaire. Celte gastrulation est anomulnie; elle est loin d'être aussi prononcée que son équivalente des développements dilatés; elle existe pourtant, el montre toute l'ampleur de la puissance hérédilaire daus les pluénomenes évolutifs, puisquelle se manifeste au sein d'une planulation des plus franches. Seulement, elle ne consiste pas en une invagination, ui en un reploiemrnt du bord justériens; elle s'effectue par une multiplication plus active daus la zone entroporienne, sem[.] ible a colle produite lans la rógion similaire les gastrules, mais ou les éléments nouveaux deneurent dans leur silualion et ne se déplacent. fas. Des deux impulsions qui agissent sur les gastrules, l'une multiplicalrice, et augmentant le chiffre des cellules du blastoderme, l'autre invaginante, et modiliant la disposition muturlle des cellules pour les disposer autonr d'une cavité entérique qui se creuse, la première persiste seule dans le développement des Sauropsidés. Ét, lorsque tont le l.lastolécillı. de la cicatricule s'est converti en hlastomènes, par le mème moyen que le blastolécilhe d'un orule a l'évolution dilatée se transforme en morule el en blastule, la prolifération de ces hlastomeres est plus active lans une zone lıomologue de celle où se manifestent, chez la blastule de ces érolutions dilatées, l'impulsion de mulliplieation et celle d'invacination.

En comprarant, d'appès ces données, les premières phases dudévelopfrement des Samropsilés ¿̀ leurs similaires des lchllyopsidés dont l'embryogénie est dilatée. Ia division de la cicatricule en blastomères 
correspond à la geuèse l'une morule et l'unc hlastule; parofós mine, un petit blastocole se creuse, et rend plus précise cette assimilation.

C. - Tout en subissant ces liverses phases, qui se surajoutent, ef se complitent mutuellement, la cicatricule se divise en hastumires, of saccroìt. Elle grandit suivant toutes ses dimensions. Elle augmente son épaisseur, en empruntant du nowrean blastolécithe, destiné it se convertir en cellules, à la zone cicatriculaire qui lui est sous-jacente. Elle s’amplifie en surface, aux dépens du vitellus évolutit, qui se dégrage, antour l’elle, de la vésicule vitelline, et s'organise lle mème en cellules. La ricatricule ressemble à un disfuc, d’abord mince et útroit, posé sur une part restreinte de la vésicule vitelliue, qui croit en surface ct en épaisseur par un emprunt constant de nouvelle substance formatrive ¿ la vésjcule qui la porte. - Trois phénoménes se passent en mème temps, et contribuent à donner son aspect à la cieatricule : la division ile cette lernière en cellules, son amplification llans tous les sens, et, rorollaire de celle-ci, l'emprunt du hlastolécithe destiné igalement à se convertir en cellules. La cicatricule se transforme. par lá, en lilastoderme embryonnaire. Elle constitue la zone embryonnaire de l'ouf.

Celle-r.i est plus large que la ricatricule initiale, dont elle est issue. et recouvre, à la facon d'une petile calotte, la zone cicatriculaire de li vésicule vitelline, avec les parlies roisines. Son bor] est dillus, nolfre pas de limites précises, et se confond arec la surface lle la rósicule ritelline; sauf dans sa région postérjenre, munic du bourrelet l,lastodermique, qui se soulève quelıue peu au-dessus de cette surface, of offre un contour très net. La bande d'union, entre le borl de la cicatricule et les parties vitellines qui l'encadrent, est le siege d'une production incessante de cellules. Celles-ci s’ajontent les unes aux autres, se disposent à la surface de la vésicule vilelline, et envahissent peu ì pen cette donière, par une extension progressive. L'ensemble de ces nouveaux éléments constitue le blastoderme vitellin, ou para-cmbryonmaire. Il est destiné à envelopper la vésicule vitelline, à lui fournir une paroi, mais ne prend aucune part à la genèse les appareils de l'économie. Lorsque cette paroi est complète, après s'être ébauchée smr le boril de la zone embryonnaire, el avoir recomvert progressivement la vésicule vitelline, la tótalité le l'embryon et de son annexe vitelliu p’ésente une disposition complexe. l'ébauche mème de l'embryon consiste en un anas cellulaire. de faible volume à son lélunt : la zone emlryomnaire, placée i la surface de la vésicule vitelline. Celle-ci, de heanconp plus grosse jue la précédente, est entource par me paroi, qui lui appartient en projue et représente la zone para-embryonnaire lu blastorlermo cutier. Cette derniè est destinée à disparaître. Un halancement se manifeste, par la suite, entre les deux parties lu pelit ètre. La zone embromnaire grandit sans cesse, tout en compliquant sa structure, et emprontr purr salimenter, à la résicule vitelline, les matériaux nécessairés; celle-ri 
se réduit a mesnre, el sa paroi, le blastoderme para-embryonnaire, s'atrophie d'une manièe comnexe. Finalement, au moment le l'éclosion, la résicule vitelline est vilée, le blastoderme para-embryonnaire est irgalement détruit; et le jeune animal consiste en un ensemble d'organes, issu de la zone embryonnaire seule, forméc elle-mème par la cicatricule et le blastolécithe qui l’avoisine immédiatenent.

Ces phénomènes sont étroitement liés depuis leur déhut. La cicatricule se continue, par sa face profonde, avec le blastolécille de la zone cicalritulaire; elle s'annexe ce lernier, an fur et à mesure quelle se divise; les parties annexées, anxquelles elle fournit des noyaux, se conerétent, à leur tour, en cellules. le mème, ses borls reposent sur un coussinet de hlastolécilhe, appartenant à la vésicule vitelline, où les noyaux, qu'elle envoie, subissent des divisions répétées, et augmentent leur nombre. Ce coussinet, nommé le hourrelet vitellin, semblable à un épaississement anmulaire, sur lequel sappuient les loords de la cicatricule, se résout en cellules, que celte dernière s’annexe également. Tous ces phénomènes se suivent arec régularité, et ne sont point séparés; la cicatricule grandil dans tous les sens, et surtout en surface, s'étend ulu centre vers la périphérie en s’ajoutant lu nouveau vitellus formatif; elle se scinle en cellules, avec ces zones surajoulées, suivaut la mème direction, c’est-à-dire du centre vers la périphérie. - Cette progression réguliere existe aussi dans le développement du blastoderme para-conhryonnaire. Du moment où la zone embryonnaire atteint sa largenr définitive, ses ćléments s'arrangent, et se différencient, pour donner les éloauches des feuillets et des appareils; mais ses bords continuent à sétaler, par un emprunt constant à la vésicule vitelline. Les nouvelles portions produites, dont la genése détrimine également la production d'un hourrelet vitellin, ne sont pas chargées d'engendrer les appareils de l'éronomie; elles sont destinćes à fournir une paroi vitelline, qui disparait après avoir joué son rôle, et ne passe pas à lorganisme délinitif.

En somme, l'ovule entior des Sauropsidés comprend, avant loute segmentation, du hastolécithe et du deutolérithe. La quantité de ce dernier est considérable; le premier se sépare le lui, et s'amasse dans les parties superficielles de l'ovule; cette concentration est plus nette dans la région qui contient le noyau. Celte région est la cicatricule, qui se segmente la première. Tout en agissant ainsi, elle grandit en s'annexant le blastolécithe superficiel, hi fournissant les noyaux, et lui permetlaut ainsi de se résondre en rellules. Cetle annexion n'est pas indéterminée; elle procèle avec régularité depuis les bords de la cicatricule primitive jusıu'à l'extrémité ovulaire opposée; elle a pour effet de reconvrir la surface entière du deutolécithe, par un ensemble dassises cellulaires qui romposent le hastodermo total. - La région de la cicatricule, accrue d'une partie lu blastolécilhe qui l'entoure, produit seule l'organisme léfinitif; elle donne la sone embryonnaire du blastoderme total. Senle, elle s’épaissit, augmente sans cesse le nombre de ses cellules, et se 
diflérencie. - Le hlastoderme restant u'est jamais formé que d'un iniffre restreint d'assises cellulaires; it ne se différencic pas, el se horme it entourer le dentolécithe, à lui foumir une paroi; il reprósente la sone parembryonnaire du blastoderme lotal, et disparaìt peu it pen, it mesure que la zone embryonnaire se perfectionne. Le deutolécithe et sa paroi constituent une vésirule vilelline, lestinéc al alimenter la zone embryonnaire, pendant qu'elle se téveloppe pour levenil l'embryou.

D. - De nouveanx phénomènes rompliquent encore lévolution des Sauropsidés. Ces animaux apłarliennent, parmi les Verlébrés, à la section des Mlantoüliens, dite encore section des Amniotes; en conséquence, ehacun de leurs embryons possèle un amnios el une vésicule allantoïde. - L'amnios est produit par des replis de la zone para-embryonnaire. Celle-ci, lans sa région proximale, qui s unit immédiatement a la zone "mbryonnaire, se divise en leux lames par une sorte de elivage. la lame interne demeure accolée à la vésieule vilelline. la lame externe se soulève en quatre replis, qui s'amplifient, de manièe à entourerl'embryon sur ses côtés, puis à passer au-dessus de lui, pour s'y réunir el s'y souder. L'ensemble de ces replis cuveloppe l'emloryon, et constitue l'ammios. La venue de ce lernier est précoce; ses premières élıuches apjaraissent peu apres la délimitation des fenillets. - La genese de la vésicule allantö̈le est un peu plus tardive. Celte vésicule est une dépendance de l'extrémité postérieure du corjs embryonnaire; elle s'étend hors de co dernier, pénètre dans la fente de clivage du blastoderme para-embryonnaire, el y granlit.

La présence de ces ébauches supplémeıtaires lonne, aux jeunes embryons des Sauropsidés, me complexité considérable, lelle que ceux des Sélaciens, privés à la fois d'amnios el d'allantoüde, n'en montrent point. Ces nouveaux organes ne passent pas à l'adulle; ils sont les annexes embryonnaires, dont il est jermis le faire abstraction, puisin'ils proviennent, d'une manière secondaire, du blastoderme déjả complet. Ils dilferent en cela de la vésicule vitelline, yui correspond à un prutendoderme non liguré, différencié d'une façon hàlive, et charé d'alimenter le petit ctre. Leur étude apjartient à relle les appendices le liembryon.

\section{Feuillets primordiaux du blastoderme embryonnaire.}

- Les recherches, eftectuées sur le développement des Simropsilés, sont des plus nombreuses; elles portent principaleneut sur les Oiseaux, le Poulet le préfirence. La grande ressemblance les anfs de tous ces Vertibrés permel d'étemlre, aux autres Sauropsidés, les résultats fournis par l'examen le ce dernier animal. - Cejendant, malegró te chitlire cxcessif des études entreprises, les conteslations ont été frépuentes sur divers points importants; la canse en est due a la eundensation extrime de l’évolution, a la présence l'un vitellus abondant, yui remdent les 
oliservations des plus délicates el des plus difficiles, pour peu quion veuille les faire avec précision. Én ces llernières années, M. Duval, rassemllanl el romplitant ses premières investigations sur l'embryogénic du Poulet, a pulilie un ouvrage devenu classipur, prenant le petit ètre à son léhul, et le suivant daus toules ses phases, jusqu'a son élat parfait. Lo nombre, la valeur, et la nelteté, les résultats obtenus par cet auleur, font de son élude, en ce qui touche le déreloppement des Verlébrés supérieurs, le guide le plus autorisé.

A. - La cicatricule, constituée par mn pelil amas de blastolécithe, renferme le novau de l'unf; olle est posée sur la vésicule vilolline. Hille se divise, toul en sannexant le blastolecithe roisin, et lonne le blastoderme embryonnaire, encore nommé, à cause de son aspect et de soll rôle, le disque germimatif, ou le disque blastodermique. - L'orientation de ce dernier, mòme des sa premièe indication, n’est pas indéterminée; elle est constante. En le supposant divisé en denx moitiés, de telle laçon que l'une de ces moitiés donne la partie antérieure du corps de l'embryon, et l'autre la partie postérienre. la ligne de division est tonjours perpendiculaire au graul axe de l'ouf enlier, c'est-à-dire à l'axe longiludinal qui passe par le gros bout el le petit bout de ce dernier. La moitié, répondant à la future parlie postérieure du corps, se lrouve sur la gauche de ce grand axe, et l'aulle sur la droile. Lin se représentant l'uuf placé devant soi, avee l’ gros bout à droite, et le petit ì grauche, la moitié anlérienre est siluée en avant, et la moitié postérieure en arrière, de l'axe longitudinal. - La multiplication cellulaire, et la différencialion des éléments formés, prorident, dès le délunt des phases éolutives, arec une plus grande rapidilé lans la moilié postérieure. Celle-ci est, en effet, chargée de produire cette région, homologne de l'extrémilé postériemre, portant l'entéroprore, des gastrules données par les développements dilalís.

Le noyan de liruf se segmente mn certain nombre de fois; les parcelles nurléaires se réprandent dans le protoplasme de la cicalricule, el se scindent a leur tour. I'nne maniere connexe, le proloplasme se parlage en cellules, qui se concretent autour le ces noyaux. Ces deux phénomènes continuent à s'eflectuer; les parcelles nucléaires, encore libres, augmentent sans cesse en nombre, ot le polophasme environnant les entoule pour produire aulant de rellules; d'antre parl, les éléments, ainsi fournis, se mullijlient, en surplus, par des scissions répétées. Un troisieme phrinomène intervient, synchrone aux denx premiers: la ciratricule grandil, en s'annexant le blaslolécithe voisin, et lui procnrant des noyaux. - Pal ces lois impulsions génétiques, qui se manifestent en mène temps, la cicatricule grandit dans lous les sens, el se convertit, à mesure, en hastomeres. Ceux-ci s'arrangent en plusieurs assises superposées. Les noyaux, encore libres dans le proloplasme, sont sourent nommés des mérorytes; ils ne liffèreul des antres que par leur 
jeunesse plus grande, qui ne leur jermel pas encorr l'ille flacés au centre de cellules distinctes; ce dernier fait ne farde pas à intervenir it leur égard.

Au moment où la cicatricule se trouve composée de deux assises de hlastomères, une cavité étroite, semblable it une fente de clivage, se creuse entre ces deux couches. La rangée externe se souleve quelinu peu, et forme un dòme très-surbaissé, qui s’appuie, par ses lobls, sur le reste de la cicatricule. Celte cavité persiste pendaul un temps asse\% long, el ne disparait guère qu’à l'instant oì le bonrrelet postírieur s'éluauche à son tour. Celte durée, el cetle siluation, permettent d'assimiler cel espace à un lilastocole, notamment à celui possélé par les blastules stratifiées des Cyclostomes, des Ganö̈des, et des Amphiliens. Les relations sont semblahles dans les deux cas. Aussi, malgré sa minime itendue, peut-on considérer cette cavité comme homologue d'un blastocale, comme répontant ì un rappel très amoindri de ce lernier, capable mème de manquer chez certains Sauropsidés, à eause de son peu d'imporlance. Sa venue autorise à considérer la présente phase comme similaire de la blastule des embryogénies dilatées. De mène que chez celle-ci, la rangée supérieure fait partie du protectoderme, et la rangée inférieure lu protendoderme.

13. - Le nombre des assises de blastomeres continue a augmenter; il atteint rapidement le chiffre de quatre et de cinq: l'ensemble constilue un blastoderme embryonnaire, déjả bien accusé. Lin te moment, le lord postérieur de re dernier s'épaissit, pour domer le bourrelet en eroissant; et son assise profonde se souleve au-dessus du deulolérithe. Ce soulèvement débute dans la région postérieure du hlastoderme, concorlant ainsi avec la genèse du bourrelet, et savance jusque dans la région antérieme. Une telle connexion première avec le lourrelet. qui correspond aux lievres soudées l'un entéropore, - el le sens lw. l'extension, doment à cet espace la valeur d'une vavité entérique, l'une dépression gastrulaire, produite sur place par un rlivage, au lieu de provenir d'une invagination réelle. La poussée invaginante s'accuse encore dans la direction que suit le rlivage: mais elle est it l'itat l'iudice. Celte cavite, nommíe par les auleurs la cavite soms-germinale, s'avance lans la moitio antérieure lu blastoderme, toujours placée entre relui-ri el le deutolécithe; elle s'élargit à mesure. Les luastomèrrs les plus profonds se dissorient quelipue peu les uns des autres, et, tout en augmentant leur nombre par des scissions réprótées, demeurent comme suspendus dans sa région sujérieure.

La cavité sous-germinale ne disparait pas. Peu apris sa formalion. l'assise hlastodermique la plus interne prend l'aspert al'une couche continue, semblahle à une lame. Cette couche est lemboterme détinitif; elle limite en haut la cavile. Celle-ci graudit, el ronstitue un espace, rempli d'un liquide transparent, plaré au-dessous de la majeure parlie 
962

CH.PITRE SEIZIĖME

675

Fetron aricreure burd libre de lectoderne

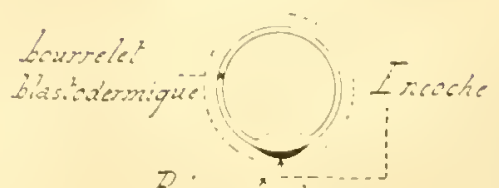

Rejoor posterciere

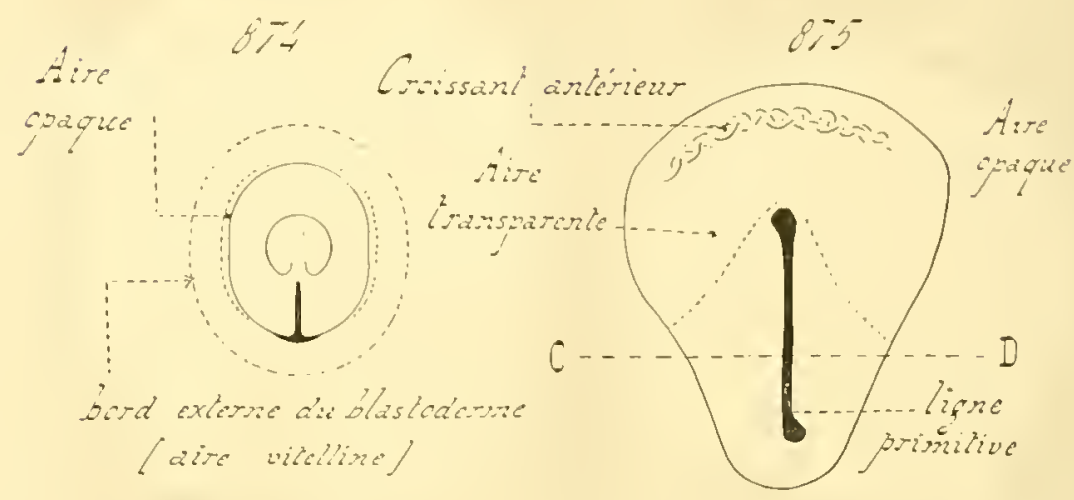

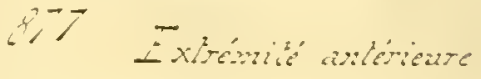

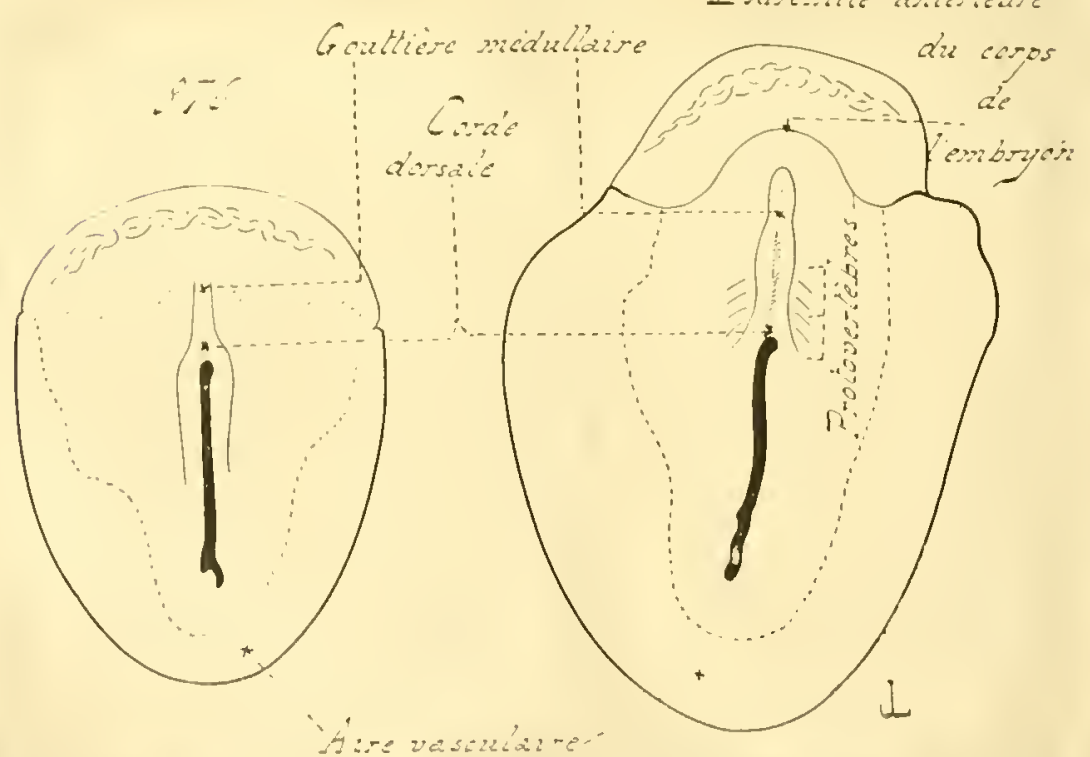

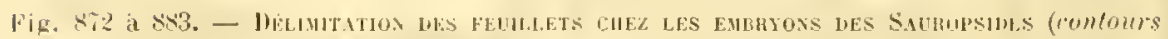

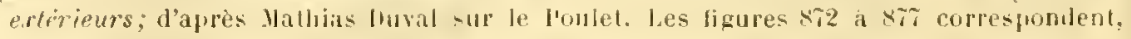




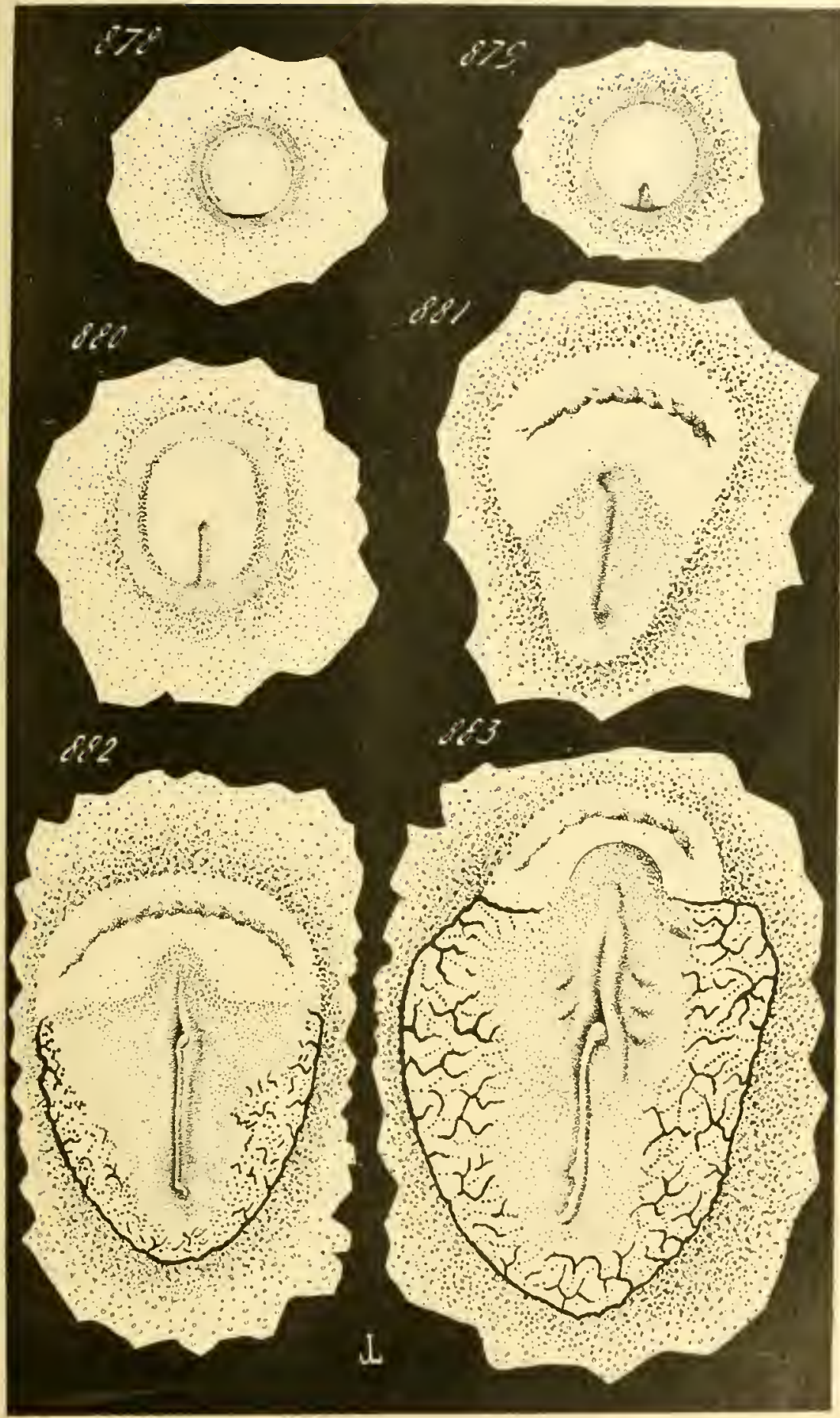


du jeune hastonerme embryonmaire; cette ilerniere jent done itre aisement enlevéo lu vitellus, of tranche par sa transparence, lorsquon l'examine ì la lumiere transmise : l'où son nom l'arip tromsparente.

La carité sous-germinale lemenre ainsi, penlant fue les fenillets

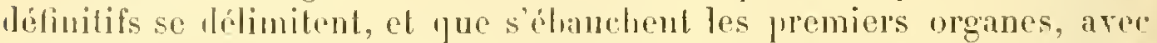
lis amnexes dr l’emliryon. Elle augmente en surfare, "ar elle accomprague l'endoderme dans son cxtension croissante: elle est plus large sous l'extrémité antérienre de la \%one cmbronnaire, que sons l'extrómité postérieure. Le leulolérithe, situé au-dessous d'elle, ne rontient aucun noyau; il se comrertit progressivement en un liquile nutritif, qui remflit la cavité olle-mème, pour che alısorlé à mesure par les cellules endodermiques. Dans la suite, lorstue l'endoderme, semblable jusyu'alors à une lame plane ou failıment concave, se replie sur huimòme pour se transformer en $u$ canal digestif, il englole, dans son mouvement, une rart de la caviti sous-germinale, qui entre ainsi dans la ronstitution de lintestin. - Cette cavité demeure loraliséc an-dessous du centre de la zone embryomaire, natteint pas les lords de celle-ci, et ne prariont point dans la zone para-embryonnaire.

L'origrine el la fin de cel espace précisent sa véritable nature. Ce vide, creusé sons le blastorlerme, est l'homologne, comme l'a démontró II. Dural, de l'enlín des vaies gastrules. Il commence par commuuiquer, avee le dehors, an moyen l'un orifice enteroporien; il est limité, d'un côté par le correspondant de l'endoderme formalif, de l'autre par celui de l'endodermi nutrilif, des gastrules d'Amphibiens: le liquide. dont il est rempli. sert à l'alimentation de l'embryon; il persiste, an moins en partie, dans l'organisme léfinitif : son caractère de ravilé entérique est, en somme, les mienx accusés. - Peut-êlre, celle cavilé n'existe-t-elle pas, avec tontes ses parlirularités essentielles, chrz tous les embrons des Sanropsidés; elle parail cependant ne jamais manquer, en n'ayant parfois qu'une etemlne restreinte.

l'une façon plus simple, et diagrammatique, it celles numèrotees de 578 a 883 ; ces dernieres expriment les dispositions réelles, telles yu'elles se présentent lorsqu'on examine de lace une cicallicule en roie de devenir un embryon; la cicatricule est seule dessinec, avec une petite partic des légions paru-embryonnaires qui l'entourent). - En 872 et 878 , genèse de l'encoche posterieure, c'est-ib-dire du bourrelet. enteroporien, muni de son sillon en croissant; la coupe, dessince lans la figure 57 , est menee suivant l'axe longitudinal d'une cieatricule parvenue a cet elat. - En 8.3 et 879 , dẻbut de la ligne primilive; la coupe, dessince lans lit figure s.4, est menèe suivant le plan AB Irace sur c. lessin, e'est-a-dire par l'extrémite anlérieure de la ligne primitive. - En sif el s'on, extension longitudinale de la ligne primitive, pendant que le sillon en croissant se raccoureit. - Jin $875 \mathrm{el} 8 \mathrm{~B}]$, la ligne primilive existe seule: le trail Cu indique le plan de

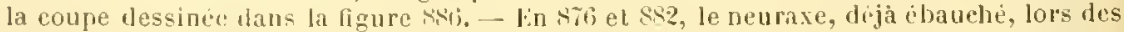
phases pricidentes, en avant de la ligue primilive, tommence a prendre l'aspect de

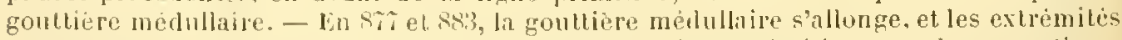
postérieures les roplis qui la burdent encadrent la ligne primitive pour la convertir en canal neurentérique; les premiers mésosomites (rotoverlibres) font leur apparition.

les phases suivantes de l'érolution embryonnaire sont expriniees prar les figures numerolées lle 973 i 
C. - Quoi qu'il en soit à ret égarl, le moment où lo blastoderme, composé d'un cerlain nomlure d'issises suproposties, est épaissi dans son borl postéricur par la prósencedu hourrelet eu croissant, et séprá du vitellus par la cavité sons-remuinsle, se trouve ètre l’énuivilent strict de celui on la phase grastrulaire se manifeste dans les doveloppements dilatés. Les deux fenillets primordianx. pui araient déjà commencé a se délimiter, achevent de se distiuguer l'un le l'autre. - leur délimitation s'efrectue par clivage, par dólamination. I. assise externe les blastomeres, déjá séparée de l’assise plus profonde par le petit lilastocale de la phase hlastulare, arhève de réculariser ses routours, et devient le protectoderme; il se compose ale petiles cellules cubiques. ou cylindripues, juxlaposées. Ia raugée prolomile, arcompagnée de toutes celles qui prennent naissance au-dessous d'elle, constitue le prutenloderme. Ce feuillet est formé par phsienrs couches superposies. trois ou quatre en moyenne, de cellules arronties, ou ovalaires, laissant entre elles des espaces viles, d'ampleur variable. Ces espraces se relient ¿l la cavilé sous-germinale.

Cette délimitation s'accompagne d'mue multiplication intense; les deux phénomènes s'eflectuent en mème tumps. La juolifération cellulaire est surtout active an niveau lu hord postricur du blastoderme, où elle a pronr résultat de jroduire le bourrelet en croissant. Celui-ci, encore nommé bourrelet blastodermique, hourrelet germinatif, mirilerait plutòt. ì cause de son homologie, lo terne de hourrelet enteroporien. Il se creuse, suivant sa longuenr, d'une fentectroite, pui rommunique, durantun tenuss assez loug, avec la cavité sous-greminale, et lo divise en denx parls, bomologrues do la lève antérieure el le la lèrre postérienre d'un entéropore; de son cóté, la fente répond í l'entéropore lni-mème. - Par un fait, que montrent déja les Imphiliens, mais plus accentué ici, la livre antérieure émet une expansion, qui s’avance propendiculairement an bourcelet. Cetle expansion est le sillon mimilif, on la ligne mimilice; elle grandit, a mesure que le hourrelet s'efface; l'atrophie de ce dernier commence par ses denx extrémilés. La cavité du sillon sonvre, en arrière, dans la fente du croissant; te meme les replis, qui l'encalrent, se continuent avec la live antérienre dn lourrelet. La totalite de la ligne primitive est donc un diverticule, émis par ce homrolet, et rlirgé en avaul, perpendiculairement à lui. - Cos particularités. cl notamment celles touchaut a la taille des fentes hu lowrolet du sillon, semblent phus prononcées chez les lieptiles yue rhe\% les Oiseanx; du moins, dapres les oliservations faites sur le developpenent des sauriens ef des Chéloniens.

la region entipoporienne des Sanpopsidés, en désignant, par ce nom,

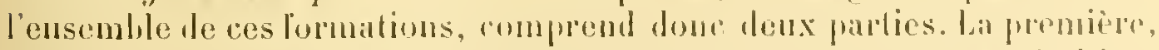
en tant qu'aparition, est le bomreled; la seconde est la ligmerimitive.

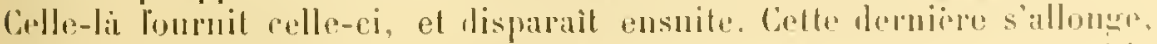

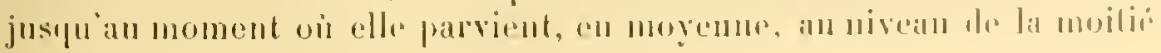


anteriente du lilastonlarme. - La platue modullaire commence, alors a

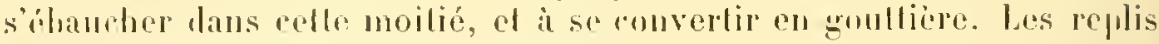

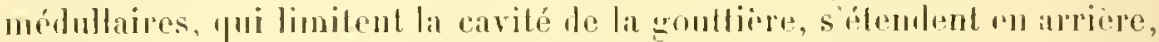

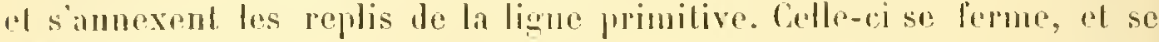
transforme en ranal neurentéripue, qui disparaìl ćgalement par la suite, apres avoir communiqué, pendant un cerlain temps, soit aver la cavilé sous-germinalo, soit avec les pretils espares viles laissés entre les cellulẹs du prolendoderme postéricur.

l.a région entéroporienne est le siegr l’une mulliplication active. Collo-ci alteint surtout le protendoulrum, car le potectoderme se burne

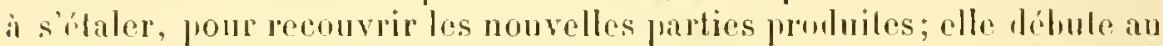
nivan du lonrelet, pour entinuer le long do la ligno primilive. Dans foules ces zones, les éléments du protendodcrue augmenlent sans cesse on mumbre, el avec rapidilé, alors quailleurs leur prolifération est heancoup plus faible. - Laccroissement do ce fenillet s'effeche, de préférence, laus la région qui correspond à l'entéropore des gastrules; clle est moindre dans les autres parties dn hlastodrom.

the tels phónomines permeltent de comprembre les livergenees élalilies entre les auteurs. Parmi ces lorniers, les nns almetlent fue les fenillets primordianx se dílimitent an moyen d'une délamination, les aules avancent qu’ils prennent maissance prar gastrulation. En réalilé, les denx disposilions coexistent. - lans me genese gastrulaire, le blastorlorme augmente le nombre de ses béments, lont en invaginant me le ses prarties: la zone qui s'invagine est le siege d'une multipliation jus intense que celle lencurant extérioure, puisquelle accroil sar surface dans de plus grandes proporlions. Ia proliféralion est inégale, lien que l’inégalité soit relativement pen matquée. Le bastodermo alıme gastrule subit aimsi deux impulsions, l’une d'invagination, lambe le mulliplieation inégale. - Colle derniere senle existe lans le hastodrume

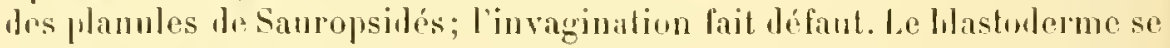
livise en phusiurs assises cellulaires superposées, grandit, ut s’opaissit; sentrment, cetle prolifóration est plus artive lans des zones pui correspoulent rxaclement aux rigions sommises, chez los pastrules, i l imvagonition. Les assises se delimitent, sur place, en profedodermu ef pro-

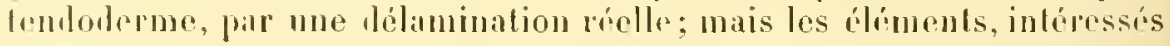
dans celle délanination, sont produits, on plus gramde alomdance, dins nue région, qui conserve ainsi l'une des impulsions gastrulaires. - La lobmination planulaire et la gastrublion existent dumc i la fois, celle lerniere étant privée de son mouvement invaginant, et se hornant ì la multiplicalion cellulaire plus active. Eu survant, dans le précélent frara-

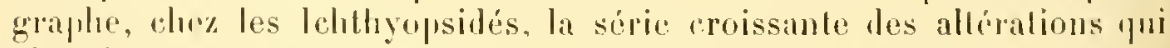
aboutissent aux farlicularilés montrés par les Samropsides, on roit l'anplen de l’impulsion invaginante se réslnige pen ì pen, et la dálaminalion plambaire premlee, mesure, mor imporlance de plus on plus

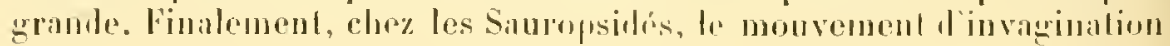




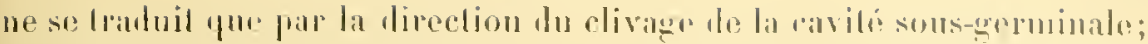

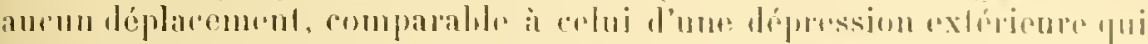

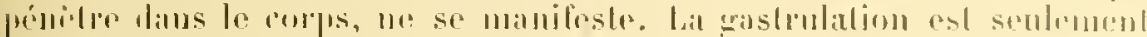

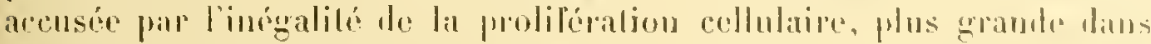

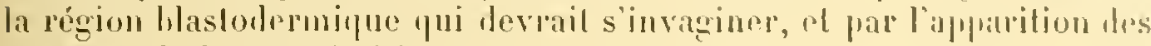
fentes ale la ligne primilive.

\section{Feuillets définitifs du blastoderme embryonnaire. -}

1. - De suile apres leur délimilation, et pendant quelle s'effectue, hrs

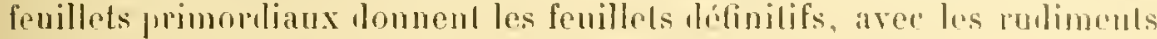

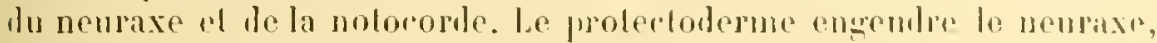
at prisiste comme ectorlerme détinitif. la protemboleme se sublivise

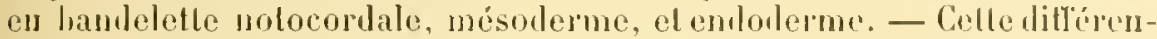
cialion, qui aboutit à la production, sous la forme l'élanches dislincles les unes des aulres, des trois fenillels el de lemrs annexes, ne se promluit pas, en mème temps, lans toule l'élemdue de la zone mbloronnaire; de plus, elle uallend poinl, pour se manifreler, que la mulliplicalion iles hlastomires, lont le lut rst d'engemdrer les fenillets primoriliaux, soit acherée. Elle commence à se monler dans la moilié puslírienre de la zone embryonmire, el gagne, do là, vers la moilie antérione, en procédant du centre vers la périphérie, la moitié postérienre offre dijà des assises fort nettes, et de mème le milieu te la moilicintérieure, alor's pue les hords le celle demièr sonl encore composés de hlastomeres indif-

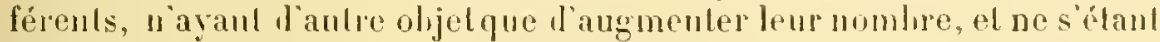
jas groupés en un protectoderme el un protendoderme. Tue Lellt disprosilion les alteint ensuite; mais, pendant que le mouveneul de différenciation parvent sur eux, la zone embryonnaire augmente sa surface, cl les mourelles régions margrinales sont encore indifforentes à lenr lomr. la dillirencialion n'est donc pas simultanéc: elle commence dans celle proplie, le la zone embryomnaire, on la mulliplicalion est la plus rapide, el procide de là, en irralianl vers les autres parlies. Sa direclion est, lans ce sens, la mime que celle suivie par le momvemenl de mulliplioaLion; celui-ci commence d'ahorl, el se monle en premier lien; la dillirencialion se manifeste ensuile.

Une lolle commexile, dans une mome zone endryonmaire, de régions

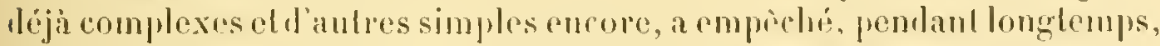

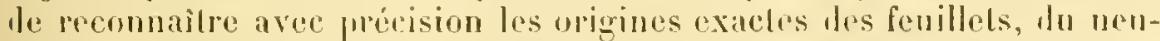
raxe, el de la notocorde. la dilticulté, sous ce rapport élail angurulée par l'exhòme ressemblance le la plupart des íbémenls culpe eux. Aussi les divergencrs, entre les embrvologistes, ont-elles di cousiderables.

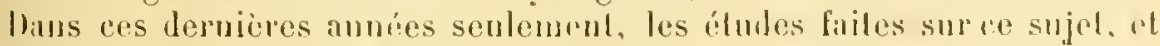
molamment colles de H. Muval, ont permis de saisir les phémominns récls.

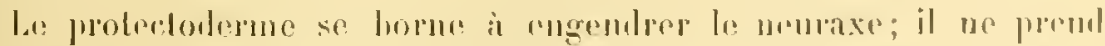

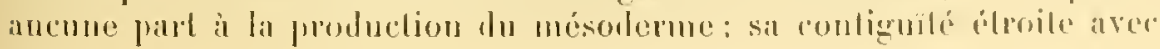


les rubiments de ce dernirr, en certaines parties, surtout vers les bords de la ligne primilive, est la cause des erreurs commises par plusienrs auteurs. Le protendoderme se divise en trois ébanches. Parmi ses éléments, reux placés an-dessous du neuraxe se rassemblent en un cordon compact, qui est la notoconle. Les autres, de leaucoup les plus nombrenx, sont groupés en plusienrs assises, dont la plus profonle recouvre la ravité sous-germinale. Celle-ci devient l'endoderme délinitif. Celles-li composentle mésoderme; leurs éléments sontrépartis en deux groupes, lont l'un est placé à droite, el l'antre à gauche, de la nolocorde; chacun l'eux donne l'épithélio-mésoderme et le mésenchyo de la moitié correspondante du corps. - La grunèse de toules ces élıaches, c'est-it-dire la dillérencialion des fenillets primorliaux, commence dans la région entéroporienue, an nivean du hourelel postérieur et de la ligne primitive, pomr gagner les autres parties dr la zone embryonnare. C'est en appliquant d'une façon prémalurée, à ces autres parties simples encore, les résultats déji foumis par cetle région, et se laissant tromper par la ressemblance descellules entre elles, que beanconp d'auteurs sont arrivés ¿̀ des notions dillérentes de celles qui prérident.

le protecloderme consisto en me assise cellulaire simple, placée à la surface le la zone embryonnaire; cette structure persiste lans l'ectolerme définitif. 11 donne naissance au neuraxe. La première indication de ce dernier apparait, en avant de l'extrémilé antérieure le la ligno primilive, sous la forme d"une plaque, la plarue médullaire, constiluée jar plusieurs couches cellulaires superposées. Ces rangées supplémentaires proviennent de la multiplication rapide de l'unique assise première. La plaque ayant l'aspect d'un ovale, dont le grand axe est sur le prolongement le l'axe longitudinal de la ligne primitive, les couches sont plus nombreuses sur la région axiale mòme de la plaque, que sur ses bords; la premicre comprend cinq à six de ces rangées, alors que les borts en ont deux seulement, el se confondent pen à pen avec l'ectorlerme simple arrisinant. - Etant ilonnée son orientation par rapport à la ligne primi-

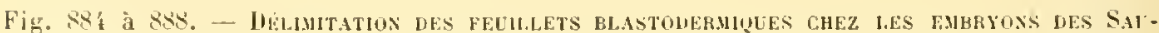
nopsinis coupes transversales; d'après Mathias lhuval, sur le Poulet. Les figures se rapportent aux précédentes, destinces a montrer les contours extérieurs; par erreur.

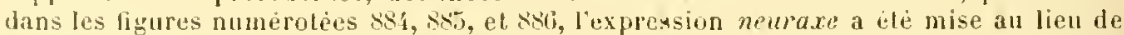

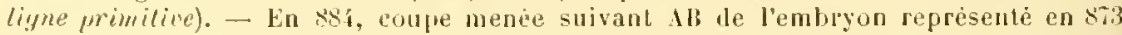
ei s79; celle coupe passe par lextrumite anterieure de la ligne primitive. - En 885 , coupe scomblalule, mais faite dans un blastoderme quelıue peu flus agè, et plus élendu en surface. - Ln \$\$6, coupe menée suivant Cl), dans l'emblyon représenté en 875 et 181 ; les trois feuillets sont délimités les uns des autres; l'ectoderme est fort èpais dans la ligue primitive. - En $\$ 8 \%$, coupe transversale passant par le neuraxe (gouttiore midullaire) d'un embryon parvenu à la phase représentee en 877 et 883 . I a gouttiè medullaire est encore largement ouverte, et limitè par des relıords, jui sont les replis mejullaires; au-dessous d'elle se trouve un amas cellulaire, qui n'est autre que la notocorde. En \$\$8, coupe semblable, mais faile dans un embryon quelifue peu plus ágé, ct destinèe i montrer le dèbut de la fermeture de la gouttiere mudulaire, et de sa conversion en an canal. - le trait, qui parcourt toute la planche en passant par la ligne primilive ét le neuraxe, indicue le milieu de l'organisme embryonuare. 


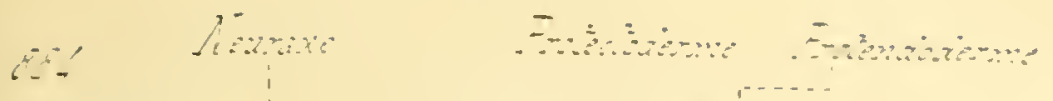

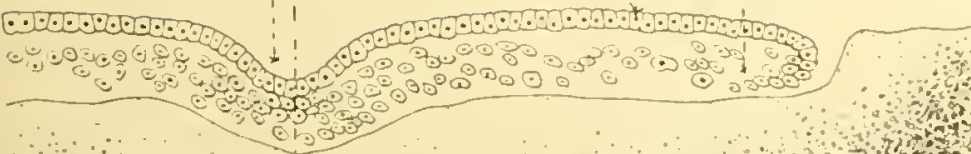

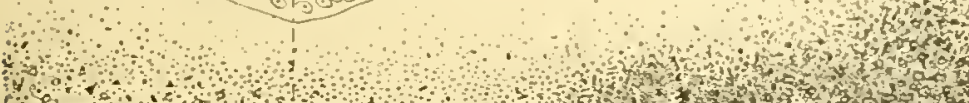

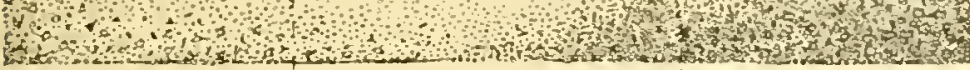

Ii5

Lemiolecinge

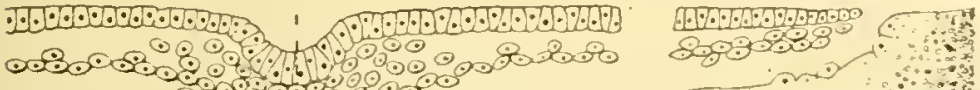

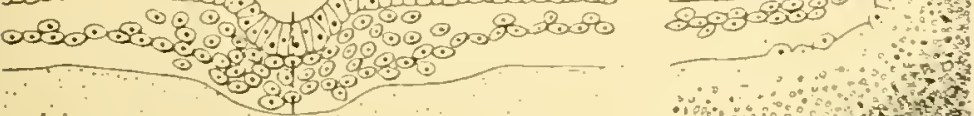
Hor

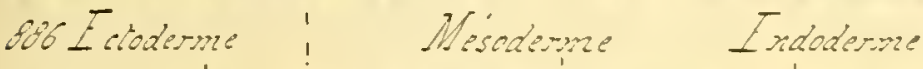

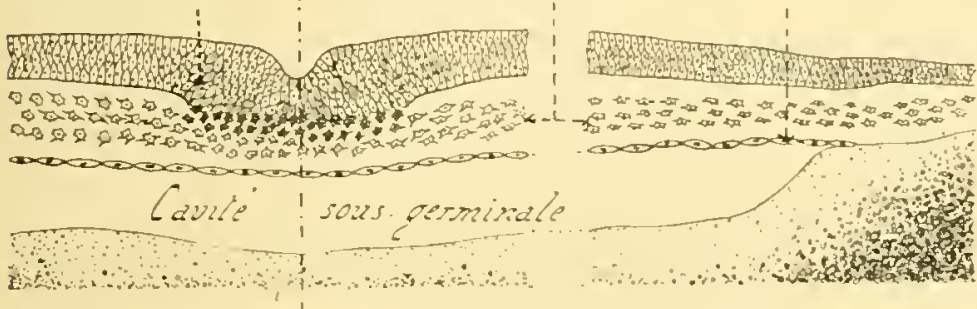

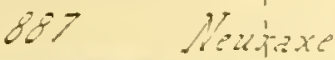

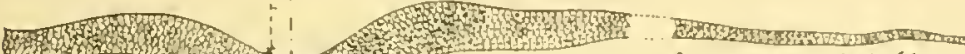

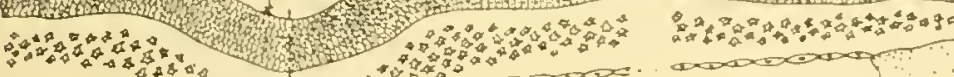

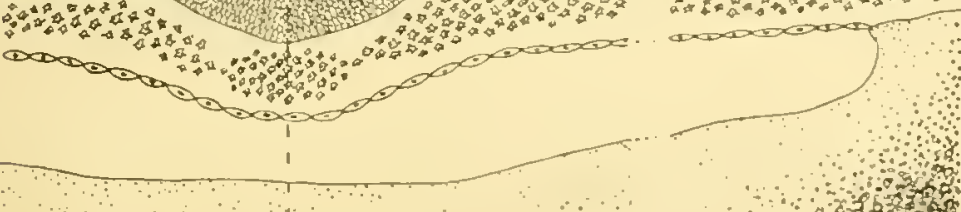

ig.

Eonzche a's mesosomiles

4

G日, D.

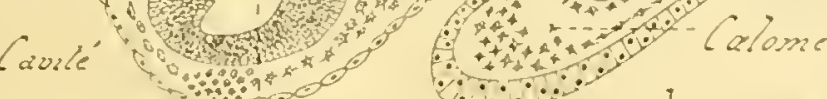
sous-germinate $\because \cdots$

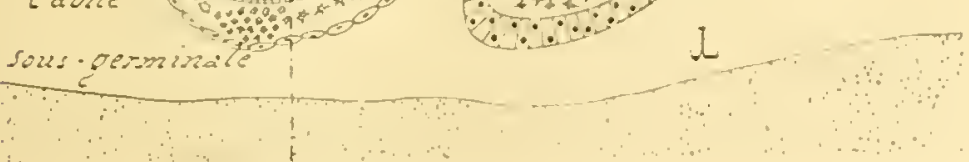


live, la playne médullaire se trouve, comme celle terniere, perpondirulaire an plan du hourcelet postérieur; elle marque désormais laxe

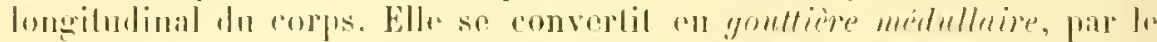

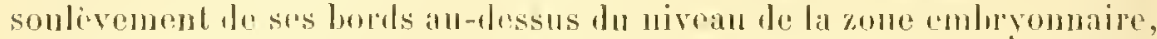
at frar la dépression de sa partie axiale. La gontlière se transforme, it son tour, en un canal, par l'amplification croissante le la dépression, el parl'affrontement, suivi de la soudure, des lords soulevés. Lébauche du neurase est, des lors, complete. Comme chez les autres Cranioles. la fermeture de la gouttione médullaire n’est pas simultané sur toute l'élembe de cel organe. Elle commenes dans la partie rorrespondante an futur rervan mogen, of progresse, dr li, en avant el milriere. Elle liest termince, chez le l'oulet, yu'au moment oủ durze mésosomites se sont délimités dans le mésoderme.

1 cause te sa silnation, le neuraxe contracte des rapports étroits avee la ligne primitive. Lorsqu'il en est a la plase de groutlière médullair', ses bords, souvent nommés les replis métulluires, divergent queline peu dans sa région pustólienre, of muluassent lextrémité antérieure de la ligne: la fenle crensée dans eette lerniere est encore onverte. Linfare losangique, ainsi laissi antre les rógions mises en prisence, est tit te simes thomloridal; cet espace n'a pas d'autre inportance que celle venant de sa forme et de sa situation, et son nom n̈implipue ancune connexion avee les organes désiqnés, laus l'économie dítinitive, par une expression identique. Celle rógion postérieure du meuraxe sallonge rapitement, en accompagnant laccoissement du corps, qui s'eflectue de préfímed dans les zones placies a son nivean; co firisant, elle se ferme, ol se convertit en ramal. $A$ la suite de cette extension continue, la ligm primitive est sans cesse reportée plus loin, dans l'extrémité postérieure du corps; elle se frrme igalenent, et devient un cantl, dont la lumière se continue avec celle du neuraxe.

Ce conduit, issu de la ligne primitive, est l'homologne du comal neurentérique des ambryogénies dilatées. Il provient, de mòme, le l'entéropore, on d'une région pui lui correspoml; et il s'abouche, an avant, arec le mentaxe. Sonlenent, il ne pent conduire dans une cavité entérique alırnte, on prospue absentr; il se termine, par son extrimité postélinure, entre les béments du prolendoderme, l'ordinaire entre cenx qui ront composer, ou composent díji, l'élatuche de la notocorde. - Le canal nenrentéripne se forme ensuile, et se tétruil. Mais avant yue velle lin ue survionne, la cavité intestinale se délimite; el la lumière du canal s'alonche avec la partio, de celle cavite, qui correspond is l'intestin post-anal. Ces connexions sont les plus fugaces; le canal ne larde pas a disparaitre, el de mème l'intestin post-anal, de liegon à ne liasser, dans l'éronomin de l'adulte aucune trace de ces relalions embryonnaires. A ce quil semble d'apres les recherelies des intentr, de tels rapports sont sommis a

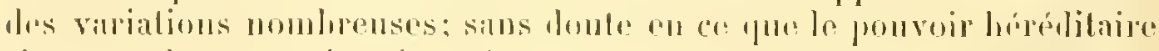

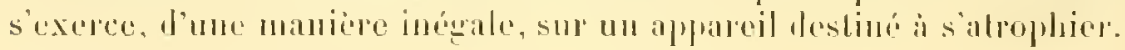




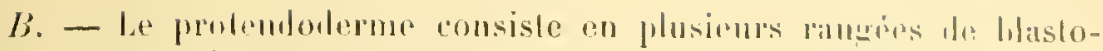

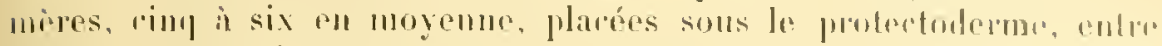

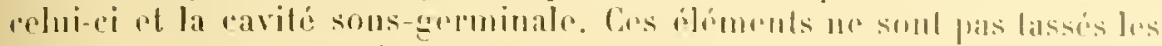

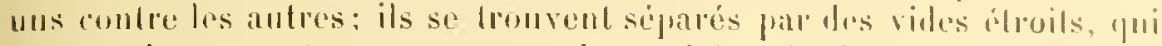

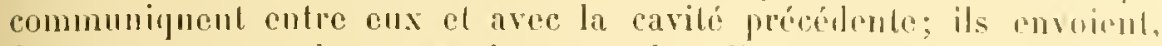
dans ces espaces, les expansious proudopodiques. lls sont semblahles les uns aux autres, et se mulliplient avec rapiliti. l.and poulifération est surlout artive dans la région de la ligne furmitive, cel, des l'apparition lu nenraxe, au niveau le "e dernier.

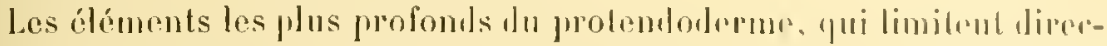
frment la cavilé soms-germinale, ne lamlent pas à se distimguer les

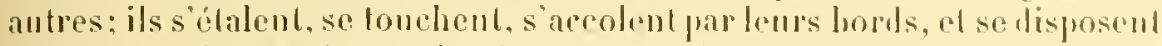
en une couche rontimue, simple. Cette assisr est lendoderme délinilil. Sa première indicalion se montre daus la moitic postérieure de la zone cmbrvomaire, au-dessous de la ligne primilive. Elle gagne en surface

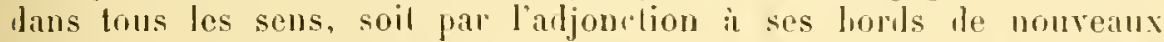
cléments du protendoderme, soit prar la multiplicalion des collulos qu'elle posside déjà. Lin définitive, alle conslitue une lame, comprosíe d'une suble rangre fóléments, dalée au-dessus de la carilé sousgerminale.

Les autres cellules du protendoderme domuent la notororde el to mésoderme. - Celles qui, parmi elles, se tronvent placées sous l'íluarer du neuraxe et sous la ligne primilive, rélra.tent leurs jrolongenculs. tout en augmentant leur nombre, el se tasseut les mes coutre les aulris. Elles ne tardent pas i constituer mu corlon compact, cylimbiqur, exactement posé audessums du nenraxe. Ce corlon est la notocomir. Cette derniore a déjà levitu ses caracleres essenticls; elle n’a plus qüi

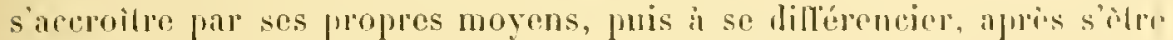

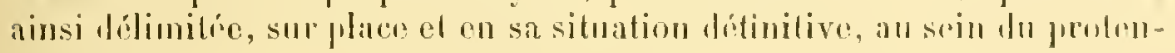
loderne.

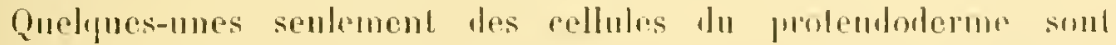

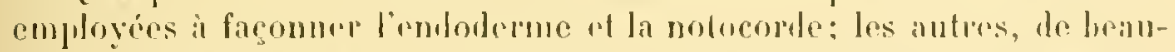

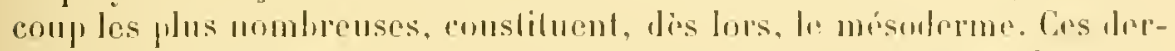

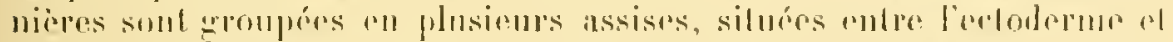

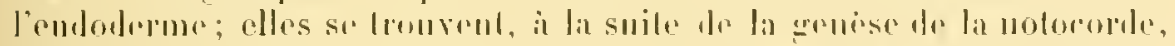

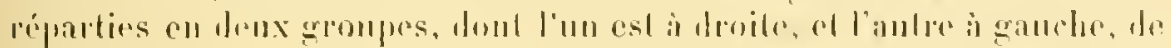

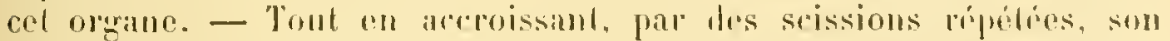
volume lotal. le fenillel mogen se dillérencir, sur place, en épilléliomisoderme el mósenchyme. Par une condensation extreme de l'ivelution, et an moven d'un doulw doplacement dans le temps et dans l'espace, tomles les prolies, qui drivent les murs des andres dams les

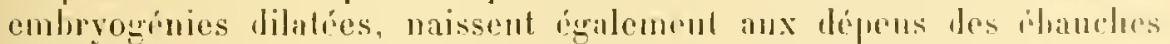

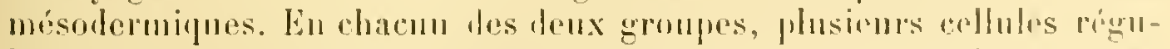

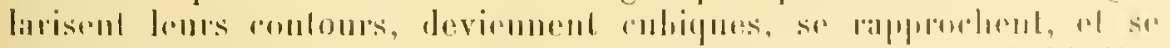

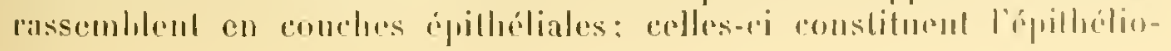


mésorlerme, et domnent les mésosomites, aver les plinges latérales. Les autres cellules, phacées en dchors des précédentes, contre l'ectodome ou l'ouloderme, conservent lour aspect primitif, l'exagèrent mème, remplissent d'une sulustance fondamentale leurs vides do séparation, et composent lo mésenchyme.

Ce Jernier n’est donc pras un prorhit de l'épilhélio-nésoderme, contrairement ì cr qui se passe dans les évolutions lilatées. Il est, dès son dóbul, indépendant de lui, et tous deux sr délinitent à part dans l'ébauche totale du mésoderme. Celte indépendance est secondaire pourtant; elle est un des résultals de l’abondance des blastomères produits dans les embryogénies condensées; gràce à celle quantité considérable d'éléunculs accumulés, les premières cellules du mésenchymo sont distinctes de celles de l'úpithélio-mésodermr. Cependant, les unes et les autres ont mine origine; les éléments initiaux du feuillet moven sont les homologues stricts de ceux qui composent l'épithélio-mésorterme des développenents dilatés, et ces éléments engendrent les autres, y compris ceux du mésenchyme. La provenance de ce dernier, dans ses liases essentielles, u’ost done pas changée; l'altération, conséquence de la condensation exlrème des phénomènes embryonnaires, porte sur les procédés employés, et sur enx seuls. Le mésenchyme, en définitive. est homologue ¿ lui-mème lans toute la série des Vertébrés.

La condensation du développement a pour secomd effet de donner, des leur apparition, aux parties de l'épithélio-mésoderme, leurs dimensions relatives presque complètes. Elles n'onl plus qu'i suive l'accroissement du corps. Les ébauches de ces parties se creusent de leur entéroculome, et se convertissent rapidementen mésosomites on plaques latérales. - Le prenier mésosomite se délimite en avant de l'extrémité antéricure de la ligne prinitive. Ses sinilaires se faconnent en arrière de lui. La région quils orcupent est done la seule, ou peu s'en faut, ì augmenter les dimensions de l'embryon suivant son axe longitudinal, car chacun des nonveaux mésosomites prend maissance cutre son prócédent et cette extrémité de la ligne primitive.

IV. Blastoderme para-embryonnaire, ou vitellin. - A. Ce hastoderme entome le deulolécithe de la résicule vitelline, et lui forme uno paroi. Lorsqu'il est complet, il se compose des trois feuillets, disposís dans leur ordre d'habitude. Il est une tépendance du blastoderme cmbryonnaire; les bords le ce dernier, dans leur arcroissement aux dépens du hlastolórithe superliciel, dépassent la zone chargée de façonner lorganisme définitif, s'élemlent autour de la vésicule vitelline, et l'enveloppent entierenent. - Ine telle extension n'est pas simultanće; efle s'ellectue lentement, el avec régularité, en partant du pourtour de la zone emliyonnaire, et gagnant peu à peu, après avoir circonvenu le deutolécithe entier, la région opposée ì cette dernière. Chez le l'oulet, at atin te donner un exemple de la lenteur apportée, ce mouvenent 
l'approche de sa fin que vers le septième jour dr lincubalion, apris avoir commencé dans le courant du jremier jour. La progression réguliere du blastoderme para-emlnyonnaire s'elleclue suivant le lype projer

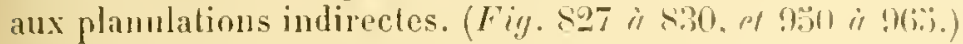

La région oì ce blastoderme vient ì se clore. oi do deutulérithe est recouvert en dernier lien, differe de son équivalente des sélaciens of des Téléostéens. Élle correspond, chez ceux-ci, à lit lère postérieure de l'entéropore; alors qu’elle est, chez les Sauropsidés, diamítraloment opposée it la zone embryonnaire. De plus, en re qui tunche ces derniers animaux, l’évolution comportı des phénomènes d'un ordre spécial, dus il la genèse l'annexes, lels que l'annios et la vésicule allantoüde. lont les lchthyopsidés sont privés. Il existe, sans doute, un rapport de cause i elfel entre la présence, ou l'absencé, de ces appendices, et le déplacoment de la zone de fermeture. En effet, l'allantö̈de des Sauropsiles, it peine éhauchíe, se trouve situéc au nivean hu bourclel cutéroporien. Sa venue, comme celle des replis amniotipues du reste. détermine la production, autour du dentolérithe voisin, de couches cellulaires 110mhreuses.

liextension continuedu bastoderme para-embryonnaire se manifeste aux dépens du blastolécithe superficiel de la vésicule vitelline. Ce hastolécithe se concrète en cellules, auxquelles les noyaux sont fournis par des éléments, déjà élauchés arant elles. - Le vitellus évolutif se dégage du deutolécithe; il constitue une masse plasmique, ou les noyaux se multiplient, el augmentent leur nomlre. L.e blastolécithe se dispose antour de plusieurs de ces noyaux, pour domer des cellules entières; les autres parcelles nucléaires continuent it se scinder, pour se rendre dans le noureau vitellus érolutif, qui ra se dégager dans la zone voisine. Ce double mourement, drisolement du blastolécithe. et de multiplication nucléaire connexe, gagne de proche en proche. aver rígularité: il a pour effet d'entonrer is mesure, de couches collulaires distinctes, la résicule vitelline. - Ce mourement est la suite Je celui qui, s'exerent sur la cicatricule an délut des phases évolutives, ahoutit i la genèse des feuillets de la zone eml,ryomaire. Les noyaux, silués dans la rigion marginale de celle derniere, donnent ceux du blastoderme para-emlıryonnaire, et ils proviennent eux-mèmes du noyau de la cicatricule.

Les fibénomènes se déroulent dans l'ordre suivant. La cicatricule se résout en cellules; son unique noyau se scinde í cet ellet. La ditférenciation cellulaire n'est pas simultanée; clle progresse du centre vers lit périphérie. Les hords sont constitués par une masse protoplasminue, non encore convertie en éléments figurés, of contenant des parcelles mucléaires, issues du noyau primordial. Ces lords s'élalent en surface. of se concrètent it mesure en cellules: ils sétendent par l'annexion préalahle, et constante, du hlastolécithe superticiel. Ils commencent par enverel des noyax dans la baude de vitellus écolutif qui sisole: puis, colle-ci 
se lransforme en rellules, el, ce faisant, émet quelques-mus de ses corps nucléares dans uno nouvelle hamde évolulive en voie de séparation. Cello-ci agit comme la précédente, et ainsi le suilo, juspu'an moment oi le blastoderme para-embryonmaire est complet. - l,es noyaux de ce demier sont aimsi les descemlants lu noyau primitif de l'wuf fécomée. et ne naissent pas sponlanement lans le vitellus. La bamle de hastoléilhe, encore simple, et non concrétée en cellules, ofl're l'aspect d'un syncylium plurinuclée. Elle se déplace sans resse a la surfacede la vésirule vilelline, so montrant en premier lien dans la cicatricule, of s'ulfuJant loujours plus loin, semblable ì un annean plastipue qui s'élargit. C'est, en somme, i cetle unique impulsion qualiontissent tons les mourement précités. La hande est plus gpaisse dans la zonr embryonnaire. a cause de la plus grande quantilé "ile hlastoléthe lestince à la former,

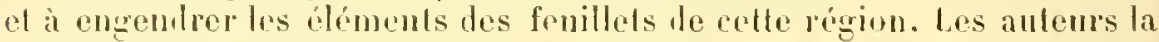
désignent par plusienrs tromes : murnille germinative, bonrreled vitellin, rempart du germe, elc. En délinitive, elle ast une lambe blastalécilhique, prouluite par un emprunt constant a la vésicule vilellinc, et dout la sulsslance se renonvelle sans cesse, en frenant a mesure une organisation cellulaire.

B. - II suil de là que le blastoderme para-embryonnaire est me dépendance dn llastonderme embryonnaire, dont il limere par sa struelure et par sa fin. Il se borne, en ellet, a produire les trois feuillets, sans se morlifier lavantage, el a former la paroi de la vésicule vitelline. pour satrophier avec elle, lorsque sachevent les phases du développement. - Ses leuillets se raccordent a cemx qui façonent l'emliryonluimème. Lectoderme se compose d'une seule couche de cellules superficielles; il se deblimile le premier, anx dípeus de la bande hlaslolérithijue, ot déhorle ainsi, d'une maniere très accusée, les fenillets sons-jacents. Le mísoderme se rattache à celui de l'embryon. Entin, l'endorleme, directement en contacl arec le deutolécithe, consiste en une assise épithéliale irrégulicre, eapable même de manquer par places, on reprísenlíe par une conche protoplasmique, semic de noyax. - Dans lextension de l'ensemble, l'embderme est en retrail sous le mésoderme, en relrait lui-mème par rapport à l'ectoderme.

l'errlant que s'effectue ce développement, le hastoderme embryon-

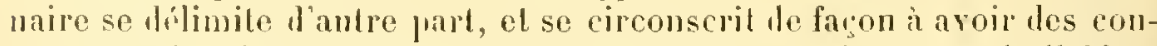
lours prócis. Liextension tolale du blastoderme entier est assimilalile a celle dinc calotte, d'abord restreinte i la cicatricule, puis scialant en surface, de manière à coilter une partie tonjours plus çrande de la vésicule vilelline. Au moment oì cette extension a depassé, d'une cerlaine fuantité, les anciennes limensions de la cicatricule, la zone embryonnaire se trouve constiluće; font ce qui se forme ensuite, au delá alecelle leruicre, appartiont à la \%one para-embryonnaire, ì la paroi de la vésicule vilelline. - Cetle quantiléest la mème, à peu de chose près, rhez 


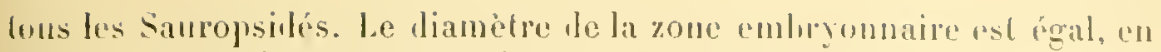
moyeune, à lrois ou quatre fois celui de la cicatricule. Celte zome saucroit ensuite. pour son propre comple, daus toutes les dimensions, en longueur, largeur, commo en ípaisseur; elle n'a plus que dos rapports de runtiguïlé, sans resse plus restreints, avec la vésicule vilelline. (ellr-

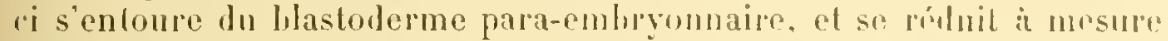
que la pré.élente se léveloppe; sa paroise dillerencir hien an phsieurs lrigrions, nommées par les auteur's l'aire vitellme et l'aire opuque (fulure

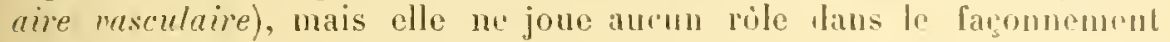
direrl de lorganisme definitif.

La délinitation entrela zone embrommaire, et la zone para-conluryonmaire, se prodnit, dans son fait essendiel, prar le mime procíde qur. chez les Sélaciens : an moyen de plis crensés, antour de la premione, de laron a la circonserire. EḦe esl. cependanl, rendue plus romplexe pal la genise d'annexes specianx, les replis amniotiques. An monient ou la zone combryomaine atteint sa taille d'état, et ou la zone para-embryonnaire commence à prenlre naissance au deli de la prónderule, un sillon se creuse, dans libluache de la secunde. tont automr le la premirire; ce sillon est, au niveau des hords antérieur el postérieur dı lılastuderme embryonnaire, plus profond quailleurs. Les prarois du sillon se soulivent en puatre replis, qui grandissent, el savancent au-dessus de lit zone emlirgonnaire pour la recouvir : ces nowreaux appareils sout dits les replis amniotipues, car, par leur coalesence futmre, ils toment l'amnios. J'uis, el d'une maniere colrélative, leurs bases l'insertion se resserrenl de plus en plus, de manière i creuser davantage le sillon inilial. La zonc embryonaire se trouve ainsi séparée, frar un étranglemenl sans eesse plus profond. de la vésicule vilalline sur lapuelle elle reprosail an début, et que le hlastoderme para-embryonnare ennlinue à enselopper. Finalement, elle n'est plus raltachée a la visioule que patr un pédicule étroit, le cordon vitellin.

Un lel étranglement a pour efrot de diminuer l'itrmulue des lignes dinnion entre les feuillots correspondants des deux zonrs. Lille a jour ohjul, romme seroml resultal, de faire perdre, aux leuillets de la zone embryonnaire, lem disposition de lames planes, ou failulement conraves,

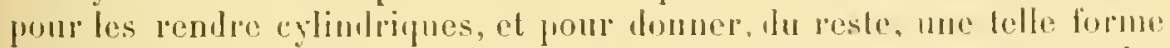
à l'ensemble de la zone embryonnaire. Ce poploiement atteint tous los fenilleb. - liendoderme se recourbe, fout en se sombraut au-dessus

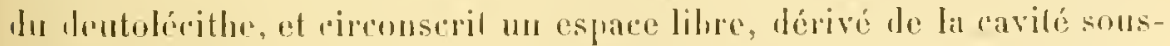
germinale, qui devient la ravité inleslimale létinitive. Toul ru subissant

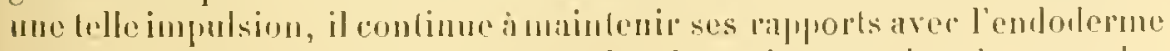
para-embryonmine, mais par une hatule unissante de plus en plus

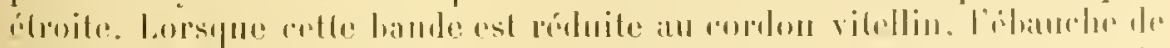

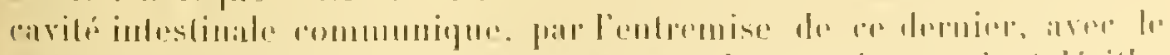

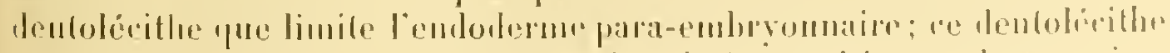

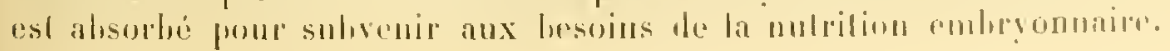


Plus tard, telte communicalion s’obstrue; la cavité intestinale devient iudúpendante; el la résorplion du vitellus s’effeche an moyen des vaisseaux sanguins crensés lans le mésoderme de la paroi vitelline. - Le mésodermo emlryomnaire se replic romme l'nnloderme, de manière ì entonrere derniur; de mème l'erlorlerme. Le cordon vilellin, ì cause de son origine, se trouve constitué par des couches appartenaul aux trois fonillets, et e’est par lenr entremise que les assises de la zone embryonwaire se raccordent a renx te la zone para-embryomnaire. (Fig. 9:30 is 98.0.$)$

\section{8. - Développement des feuillets blastodermiques chez les Mammifères.}

1. Considérations générales. - A. Parmi les llammifères, les uus sont oripares. et les autres vivipares; ceux-la se bornent aux senls Monotrèmes; ceux-ci comprennent, de beancoup, la majorilé des représentants de la classe. Parmi les Mammifères vivipares, les uns sont privís de placenta, alors que les embryons des autres sont pourvus d'un tel organe. Les premiers, dits Implacentaires de ce fait, ne se composent que des Marsupiaux. Les seconls, plus nombreux, sont nommés les Mammiferes Placentaires. Ceux-ci, seuls, sont connus en ce jui touche le développement de leurs fenillets lilastodermirpues.

Les recherehes, en ce sens, sont des plus délicates, a cause de la petilesse des ovules, et de la profonteur oil ils se trouvent placís dans l'organisme maternel. Aussi, après lieaucoup de controverses, les priucipales parlicularités de cette évolntion n’ont-elles été élucidées que dans ces dernicres années; et plusieurs dispositions essentielles sontelles ignorées encore, ou expliquées flune manière insuffisante, surtout en ce qui concerne la différenciation du protendoderme. Les observalions sur le développement des llonotrèmes, el sur celui des Implacentaires, étant à peu près nulles, les points de repère manquent pour comprendre, avec prérision, les traits fondamentaux des phases offertes par les Placentaires. Il faut, le loute nécessité, procéder par induction lans les comparaisons, puisque les faits manquent, et passer outre à celle alssence, pour élablir les parallèles entre la genèse lılastodermique des Placentaires ef celle des autres Vertébrés. Ces comparaisons paraissent justes; tout semble le prouver; mais elles ne seront vraiment assises qu'au moment ou l'embryogenie des Mammiferes inférieurs sera connue. - Les principaux, des auteurs ayant traité celte question, sont Kölliker, Ilis, Ed. van Beneden, el surlout M. Duval.

Les Mammiferes ovipares pondent de gros wufs, identiques ì cenx des Sauropsidés, et ponrrus, de même, l'un dentolécilhe abondant; l'embryou s'ébauche aux dépens d'une cicatrirule. Toul porte à penser, élant domnée une lelle concordance, que les phases tu développement 
des feuillets rappellent, chez ces animaux, leurs similaires des samplsidés, du moins dans les plus importants de len's caractires. Lin efrot. parmi les Vertélırís examinés sous ce rapport, les Sólariens, les Sanropsidés, el les llammifères ovipares, ofrent des particularilés identiques. en re qui touche la structure de leurs uufs. La gromese des feuillets s'effectue d'une manière presque semblable chez les représentants les Jenx premiers moupes; el rependant, les ditlérences l'organisition générale sont plus grandes, entre les Sćlaciens et les Saurousidés, qu'cutre reux-ci et les Monotrèmes. Toutes les probabilités sont done en faveur de celte opinion, que le blastorlerme des Mammifores ovjparn: est produit de la mème facon que celui des ()iseaux el des heptiles.

L'évolution des feuillets, chez les Mammiferes Implacentaires, est totalement inconnue. Labsenre de documents à cet égarl est regrettalile, car ces animaux sont placés entre les Monotrèmes et les Placentaires, et il serait important de savoir jusqu’i quel degré cetle transition se répereute sur les phases du développenent. Pourtant, ces dernicies doivent se rapprorher, sans loute, de celles otlertes par les vais l'lacentaires. Les aufs des Marsupiaux sont petits, romme ceux de ces dedniers, et privés de deutolécithe; les effets le cette privation sont, prubahlement, semblables dans les leux cas. - Le défaut de réscrvors alimentaires dans l'ovule est comexe au mode le mutrilion de l'emliron. Celui-ci commence par émettre des villosités, qui s’atlachent aux parois le l'utérus maternel, et lui permettent de puiser par osmose, daus les lissus du générateur, une certaine quantité de substances uutritives. l'uis l'embryon, encore imparfait, est exjulsé des rojes sexuclles de la mèe, et placé, par cette dernière, dans la poche marsupiale qu'clle porte au devant de l’ahdomen; arrivé là, il se cramponne aux télines qui s'y trouvent, et, se nourrissant du lail exsulé par elles, complite son organisme. Celle alimentation extra-ovulare, quoique ne sexercyant fras au moven d'un placenta, entraine cependant des résultats scmblables i cenx quielle lonne chez les Mammifeles placentaires; du moins, tout paraît le démontrer.

l'. - Les embryons des Mammiferes placentaires possident un platrenta. A l'aide de cet organe, richement vascularisé, leur sang puise, dans relui de l'utérus materuel, les matériaux alimenlaires suffisants ponr fermetlre l'eflectuer le léveloppement enticr. L'existence de rel appareil de nutrition conrorle arec labsen"e le deulolécithe dans lorule; ce dernjer lait est sùrement une consépuence lu premior, par un rapport de anse à etlot. - La privalion de vitellus mutritif cutraine, dans les phrinomenes ir l'évolution, des chaugrements considérables. Les Mammifires les plus simples sont les Mumblomes, dont les ands,

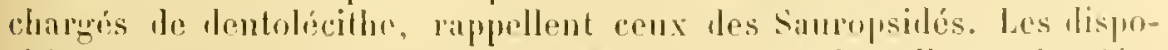

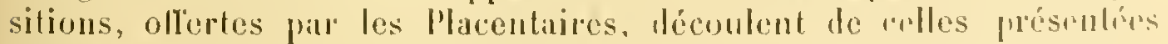

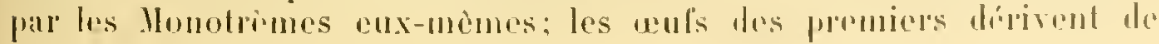


reux des seconds, par la dininution rroissante du dentolécithe, lise it la production d'un plarenla. Labsence de vilellus nulrilif n'esl pas primitive, contrairement à re qu'il en est chez les Vertélırés inférieurs, mais lien serondaire. I'artant, de nouvelles modificalions, consécutives au défanl de ce vitellus et entrainćes par lui, s’ajoulent à celles existant déjil chez les Siluropsidés, et rentent extrème l'altération gínérale des phasos érohutives. Celle-ci offre mème plusienrs legrés de complexité, suivant les types de Placentaires, car il sy ajoute liverses particularités temant à la genèse du placenta, organe dont les Monotrèmes of les Sauropsidés sont privés, el ì l'alrophie d'une part du hlastoderme paraemleronnaire.

Tout d'alonl, l'ovule est petit; son diamitre atleint ralrement un millimertre. La segmentation est totale, el non particlle; elle est parlois égale, parfois inégale, mais. lans lous les cas, l'orule se srinde en entier, el couvertit toule sa masse en hiastomères figurés. - Ces deux faits se conçoisont aisiment. Du moment où l'ovule est privé de dentolérilhe, ce dernicr n'augmente plus, dans des proportions énormes, le volume tolal; l'cuf romplet ripond seusilidement a la seule cicatricule, augmentée du l,lastolécithe superficiel, des Sauropsidés. W'aulre prart, fruisque le deulolécithe n'existe pas, l'ovule se compose seulement de vilellus évolutif, ‘ui se résout en cellules, en hlastomèr's, tout comme la vésirule et le lolastolécithe superficiel du cas précédent.

Le hasloderme et ses fenillets primorliaux sont produits par la plamulation directe. En une phase oì la segmentation est dija avancie, l'orule se compose d'un amas de hastomères tassés les uns contre les autres: l'assise périphérique de ces derniers est le protectorlerme, et l'eusemble des cellules interues constilue le protendoderme. - La substilution d’une planule directe à la planule indirecte des Samopsidés, el saus doute des Honol trèmes, se conf̧oit de mème, d'après l'alısence du denIolécithe. Puisque ce dernier fait défaut, certains des éléments ligurés jout pas à l'entomrer progressivement, pour lui domer une paroi: lous les hastomires sont formés sur place, et serrés les uns contre les autres.

survient ensuite un phénomène, qui consiste en un rappel héréditaire de la vésicule vilelliur des Sauropsidés el des Honotrèmes. Des viles so creusent entre to protectoderme et le protendoderme; ces rspares s'unissent en me eavité pui grandit sans cesse, eu séparant l'in de ces feuillets de l'autre, el de telle manière que le protendoderme demenre, uon pas central, mais accolé à une portion du protertoderme. Ce mourement est dù ì cette prarticularité, que la cavité se hroure excentrique ì son origine. La genise de celte dernicre a pour elf'el d'aceroilre de lieaucoup les dimensions to l'ovule, et de lui donner l'aspect d'une rósicule rreuse. La paroi de la vésicule est constiluée par le prolectoderme, portant, en une zone de sa face interne, l'amas des cellules du protendoderme; clle est ainsi plus épaisse en eetle deruiere que dans ses autres parlies. 
Celle rigiou. où se trompent assembles les álements du protemloderme, donme seule l'organisme de l'embryon; dle esll'houmolugue striet Je la sone embryonnaire les Sanropsidés, el mérite d'ètre désiguée jar le mème terme. Les autres parties, l’éluiles, à leur délut, au seul prolectoderme, ne jouent ancun roble laus la grenise des appareils de l'íconomic difinitive; clles composent, en conséquence, une ane partembryomnatie, ou non-emlnyonnaire, ou vilelline, comme lent's similaires des Sauropsidés. Enfin, la ravitio de la vésicule, remplic d’un liquile lyalin, coagulable, dont les propriélés nutritives sont médiocres. répond à l'espace occupé, chez les Sauropsidis, par le deutulécithe. Ced espace est ici heaucoup jus élroit, et réduit à me cavité, privée de tout vilellus nutrilif, contenant un liquide a la plare; il est permis de lui donner te nom de caviti para-vitelline, pour indiquer, in la fois, son lomologie et son caractere scromlaire. Mans le cas où la zone paracmbryonnaire ne se detruit pas, et ne s'atrophie que sur la fin du développement, elle constitue, avec la cavilé para-vilelline qu'elle limite, une pelile vésicule apjendue à la face ventrale le l'embryon, dans la mème siluation que son homologue des Samropsidés, et jésignéc, dès lors, par les mèmes noms: cenx de vésicule vitelline. ou de vésicule ombilicule.

Cetle forme de planule est parliculiere anx llammifieres vivipares. Elle n'est pas une blastule, puisque les Jeux feuillets primorliaux sont đéjì ébauchés, el distincts l’un de l'autre, au moment où les premiers restiges de la cavite para-vitelline font leur apparition. l'expression de blaslocyle, employic d’labilude pour la désigner, dinole semlement son aspect de vésicule génélique, et ne préroise point sa véritalile nalure. Ce corps embryonuaire est, dans la réalité des faits, me planule rouse. ume caloplanule. - Celte coloplanule, Iont les Mammiferes vivipares seuls montrent un exemple pami les animaux, lórive sccundairement l'une planule lécilhique, par la perte du deutolécithe que conticul collo depuiope. Le vitellus disparn lasse a sa place une cavile, emplie pa un liquide mullement mulritif; relte disparilion est l'unique rause de lallure speciale offerlo par la corloplanule, aussi lien dans sa slructuro que dans son mode de développenent. I.a cavití para-vitelline u'est en rien comparable à un libstocole; elle ripond a l'espace occupe par le deutolicithe des aufs des Sauropsidés et iles Mammifieres ovipares, luimème lomologne de la part untrilive du protendoderme des aufs des Ichthyopsidés. Cetle cavité est une dépendance de l'entéron, trís modifiéc, dans ses rapprorts et sil lisposilion, par des phenomionos temant à ses divers aspocts daus la série des Verdílorès.

C. - Les allérations, préscutées par los Mammifires vivipares dans

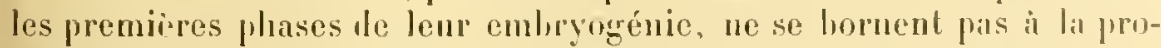
duclion dunc coloplanule. Eilles poptent, ensuite, sur la genose des leuillets définitifs, el sur la tin de la zone pana-embryommaice. 
Les laits relatifs à la lormation des feuillets défuilifs ne sontijas encore élucilés l'une manière complète. A en juger d'aprés les données aeguises, ils se délimitent, Jans leur ensemlile, comme leurs corresjondants des Sauropsidés, el par les mèmes frocélés. Seulement, le nomlire des blastomires, qui composent le protendoderme, est heaucoup plus restreintque chez ces derniers animanx; ce feuillel se trouve constilué, au plus, par deux ou trois assises cellulaires. Ine telle dimimution du chiffre des áments est une conséquence directe de la petitesse des ovules, líterminéo a son tour par le défant du deutolí cithe. La privation du vitellus mutritif est, ici encore, la canse essenliplle de laltération apportée.

Chez certains Mammilères vivipares, et, semble-t-il, surtout chez ceux lont la taille est petilr, el dont la durée de geslation esl courte, le placenla preml maissance d’une laçon précoce, et commence à s'éhaucher au moment mòme où la caloplanule se constitue. Ainsi que ㄱ. Duval l’a démontré daus ses remarqualiles rerherches, celte élanche placentaire est produite par une région ectodermique de l'embryon. Celle-ci s'épaissil, des lors, el acquiert un grand rolume, l'aceroissement élant le fait du feullet externe seul. Une telle augmenLation de masse lonne, aux culoplanules de res animaux, un aspect quecelles des autres Mammiféres vivipares ne montrent pas; il est dì ả une altération supplémentaire, causée par la gencse hàtive de l'appareil nutritif embryonmaire.

La zone para-embryomaire est de structure plus simple que son lomologne des Sauropsidés. Bien quielle entome me cavite privée de fonclions réelles, elle est heaucoup plus élendue que la zone cmbryounare, et constitue la majeure part de la surface de la coloplanule. Sa faroi se cumpose dn protecloderme, augmenté, par la suite, d'une assise protendorlermique. - Contrairement à celle des Samojsidés, celte zone est produite toute a la fois, ef non par un enveloppement progressil; elle est engendrée d"une maniere directe. et non pas indirecte. Au moment oì, la segmentalion flant avancér. la planule se fronve encore 'ompacte, la cavilé para-vilelline se creuse el gramlit, de facon a accrollu' la laille de l'ensemble, el a relouler le protendorlerme dans la région ‘ni devient la zone emloryonnaire. Par lo seul fail te cette apparition, ut te rot agramlissement, le protectorlerme demeure en place, et se burne à angmenter le nonlure le ses élénents, pour suive l'amplificalion générale de la planule. Tonte la portion de ce feuillel, laissce à part le la zone emluryomaire, constitne la zone para-emlryonnaire. Cetle lernière rst ainsi produite l'emblíe, et occupe, dès son déhut, sa position drinitive; rontrairement i celle les Sanropsidés, et sans doute aussi a cellu des Mammifieres ovipares, qui commence à se moutrer sur les borls du blastodermo emliryonnaire, et, de lit, progresse rigulierement antom du deutolécilue ponr l'envelopper al lui donure sa proi.

La cavilé para-vitelline, et la zone para-embryonnaire, yui la limite 
sur la plus grande partie de son ctendue, orenjent un espracr considr-

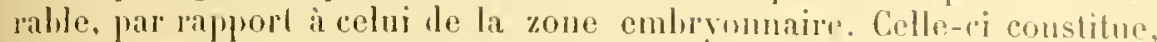
en définilive, une petile masse cellulaire, se confondant par ses fords arec le blastoderme para-embryomaire, et somblable a mm calotte, do dimensions restreintes, appuyant sur le liquile donl la rarilé de lit coloplanule est emplie. Cetle calotte est le siège de proliférations fort actives, jui ont pour effet l'accroître son rolume, son poils, et le la faire peser davantage sur ce liquide. Aussi, toul en se convertissant en cmluyon, elle s'enfonce lans la cavité para-vitelline. Celle pénétration est de profondenr varialule J'apris les types de Mammifires; et, suivant le cas. les destinées de cel espace et le la zone para-embryonnaire sont différentes.

Chez la plupart des Mammifères, l'enfoncement u'est pas consilérable. La zone para-embryonnare, et la cavité para-vitelline, lemenrent en leur plare; elles ne s'accroissent pas, ou grandissent fort peu, et, en somme, restent stationnaires. La zone emliryomaire augmente, par contre, ses dimensions d'une facon constante; elle se convertit en embryon, enveloppé de son amnios, el pourvu de sou placenta. Les parlies extra-emhryonnaires de la culoplanule perdent peu ì peu, par ce moven, en demenrant passires et inertes, lenr importance premiore. Elles ne tarlent pas à constiluer un annexe de taille minime, appendu à la face rentrale du folus; elles lorment nue vésirule vitelline, privés de tout róle, et n’ayant d’autre valeur que celle d'un rappel héréditaire de la voluminense vésicule vilelline, vaiment fonclionnelle, des Sanropsidés et les Mammifères ovipares.

Les faits sont diflérents chez certains Rongenrs. Lal calotte embryonnaire, avec les régions avoisinantes le la zone para-emliyonnaire, régions qüil est permis de désigner, dans leur ensemble, par le lerme de bande proximale, s'enfoncent profonlément dans la cavilé frara-vitelline. Celte pénétration s'effectue à la manière d’une invaginalion; la totalité de la zone embryonnaire, et de la hande proximale de la zone para-rmbryonnaire, s’invaginent dans la hande distale de cette dernicio, el s'en enveloppent conme d'une cupule. - lianf se compose le denx parlies : I'une invaginante, représentée par la hamle distale de la zone para-embryonnaire; l'autre invaginće, forméc par la bamle proximale de celle-ci, augmentíe de la zone embryonnaire. Dans ce mourement, et par le seul effet le son mécanisme. la partie invaginée tourne en delans re qui était superficiel, et en kehors ce qui etait interne; son protendoderme devient extérieur, par raprort an jrotectoderme. He plus, la bande distale se désorganise, el se détruit par la suile; le petit embryon n’est constilué, désurmais, que par la portion invarinée. Colle-ci, ayant an lehors, par le fait de son inllexion, ce qui devrail etre inlerme, fuat avoir une disposition inverse de celle possridé par les embryons momanx des antros Inammifires. 
Ce phenomène remarquable, comm depuis longlemps, n’a éli explifué que dans ces dernieres années, par les études de Selenka, et surtout par celles de .I. Mural. Une telle inversion des feuillets blastodermiques était une des principales objections, sinon la plus importante, à la notion de l'homologie des leuillels primordianx, fuisque les dérivés du protectuderme semblaient èlre internes par rapport í ceux du prolemloderme. Les observations, complèles el précises, failes par Il. Duval, onl élucidé cetle difficulté. - L'inversion des fenillets n'a ancune significalim, an sujet mème de la valeur propre à ces feuillets: elle est le résultat d'une invagination te la zone embryomaire, el dos parties avoisinantes, dans la cavité para-vitelline, suivie de la destruclion des régions non invaginées. La cavilé para-vilelline lisparait, prar l'elfel de celle atrophie. - Ce phénomine othre du reste, suivant les genres de Rongeur's, plusieurs degrés de complexité, découverts par M. Duval, dont l'importance mutuelle a élé précisée par lui, et qui permellent de relier aux phases normales du développement lis allérations les phis profondes.

De tous les Mammilères examinés à cel égard, les Rongeurs sont les seuls a offrig de telles particularités. Le placenta de ces animaux est condensé en un seul corps, qui prend naissance d'une manière précoce. à rause du pen de durée de la gestalion. Contrairement á ce qu’il en est chez la plupart des autres représentants de la classe, la zone embryonnaire aequiert rapidement, des la planulation, une masse considérable, "qui pèse sur le liquide de la cavité para-vilelline. Sans loule, il existe dans ces phénomenes un rapport de canse à ellet. L'inversion des fenillels esl le résultal de l'invaginalion le la réggion cembryonnaire, due elle-mème it l'atcroissement hàlif de cette zone.

I). - L'alsence de vilellus nutrilif dans l'ovule, et la présence d'un placenta destiné it le remplacer sons le rapport fonctionnel, sont les deux causes de toutes les altéralions, si complexes, présentées par les Mammilères vivipares dans la genèse de leurs feuillels. Ces allérations s’ajoutent a celles déja possélées par les Sauropsilés. Parmi eltes, les unes sont communes a lous les représeutants de la elasse, el liennent, soil it la segmentation el a la genese de la coloplaunle, soil a la délimitalion des feuillets; les autres sont spéciales à quelques-uns, et consistent en une inversion des couches blastohrminnes. Ces trois ordres le phénomènes olfrent, a leur lour, des parlicularités importantes.

\section{Segmentation, et genèse de la coloplanule. - A. Les} ovules les Ilammifères vivipares sonl très petits: ceux do la Femme mesnrul, en moyeme, lepuis un quarl jusqu’à un cinquieme de millimetre de diancitre. Ces dimensions sont également celles de la phrpart des Mammifires placentaires. - L'ovole, entonré par une fine membrane vilelline, est, rn oulre, dunblé d'une couche anhỵsle, lransparente, assez. épaisse, la zone pllucide les autents, qui l'envolople à l'exterienr. 
Ceth membrane est exsulde par les collules follientairm adjacenles it

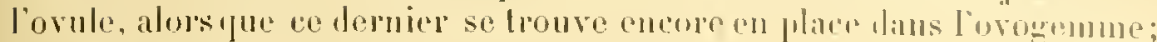
elle est parcourue de fins comutux maliaibes.

Au moment oir, sur lovaire, un corlain nomble d'ovules, valdiall, suivanl les types, est parvenu a maturité, foule la rogion sexuchle de la femalle est le siege d"unr inlense congestion sanguinc. las íporpes de: poussée congestive, dont la cause est sans loutr lur il nu rédlexe ancné par l'élat de malurilé des a’ufs, revienment il des intervalles pririo-

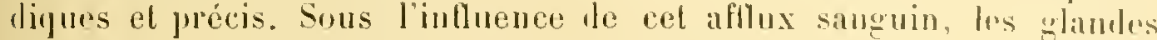

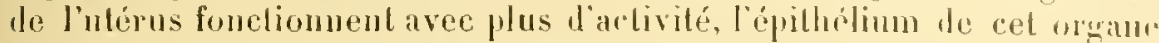
se despuame en majemre partic, el des lémorihagies lorales se manfestrnt; l'ensemble de ces produits, qui sorteut de la cavilé ulériur, of parviennent au dehors, conslitue Irs menstrues, et les exerela du rul. De mème, el par l'effed de celle congestion, qui alleint égalenont les raisseanx ovariens, les ovogemmes (follicules de (irafi), doul les orules sont mùrs, se laissenl rempliy jar une quanlilé considérable de sermm; ils sont ainsi distendus, jusıu“à dépasser les limiles de leur élasticité, "L crèvent finaloment. Lavul. est alorsmis en liberté, el rejeté snu la périphéric de l'ovairo.

Le pavillon de la trompe, fuelque pen élargei a la suitr de la congeslion générale de l’appareil sexuel, s’applique plus ractement sur mo porlion plus large de la surface ovarienne. Les ovules sonl saisis par lui, du moins ceux placés lans sa zonr d'action, el parcourent le canal de la lrompe, pour arviver dans l'ulérus; les wufs, laissés en dehors du pavillon, ne lardeul pas ì s'aluphlur el à jérir, sauf le cas où des sper-

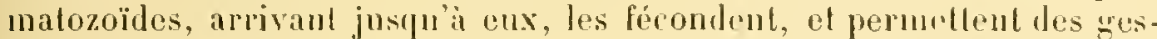
tations extratutérines. Toul en suivanl la trompe, les orulos s'entourent d'mur couche albumineuse, assez mince, exsulée par l'epithélimm pui tapisse le canal. Colle assise épilhóliale, munirdrocils vilualiles, chassin les ovules par lrur moven, ot les fait parvenir dans la cavité utrime.

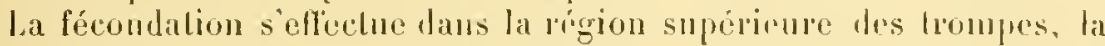
plus proche de l'ovaire, el parlois sur ce dernicy organe lui-menc. Ces zones sonl. en effel, les senles on l'ovule ne soit pas culonlé par la couche allumineuse, hop épitisse el Irop tense, fui sopposerait it la pénébration du spermatozoüle. - Livvule, fécondé, se scanmente lont en parcourant la loompe, el, arrivé dans la raviti nlérine, dont la paroi est encore fortement congestionnée, il saecole a mo protic de celle paroi. Il demenre désomais en celle place, of y sulit loulos les phases de son développemenl; sil présence détemune, dans les lissus te l"ulóms, des modiliciblions ronsidérables, dont le lut est, soil de lui lomer des

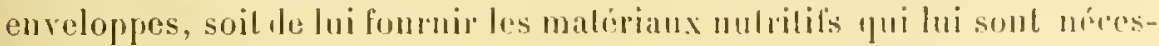
saires (roir le rhapilos XIII).

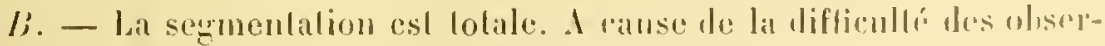

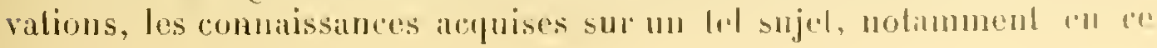


qui touche les premiors phémomenes de la division orulaire, sont des plus rares. l'après Ėl. van lieneden et Julin, qui ont éludié celle scission sur des Chéiroplìres in gemse T'espertilio, elle serail inégale ì son délut. Mais les fails ne tardent pas à se régulariser, car la plupart des

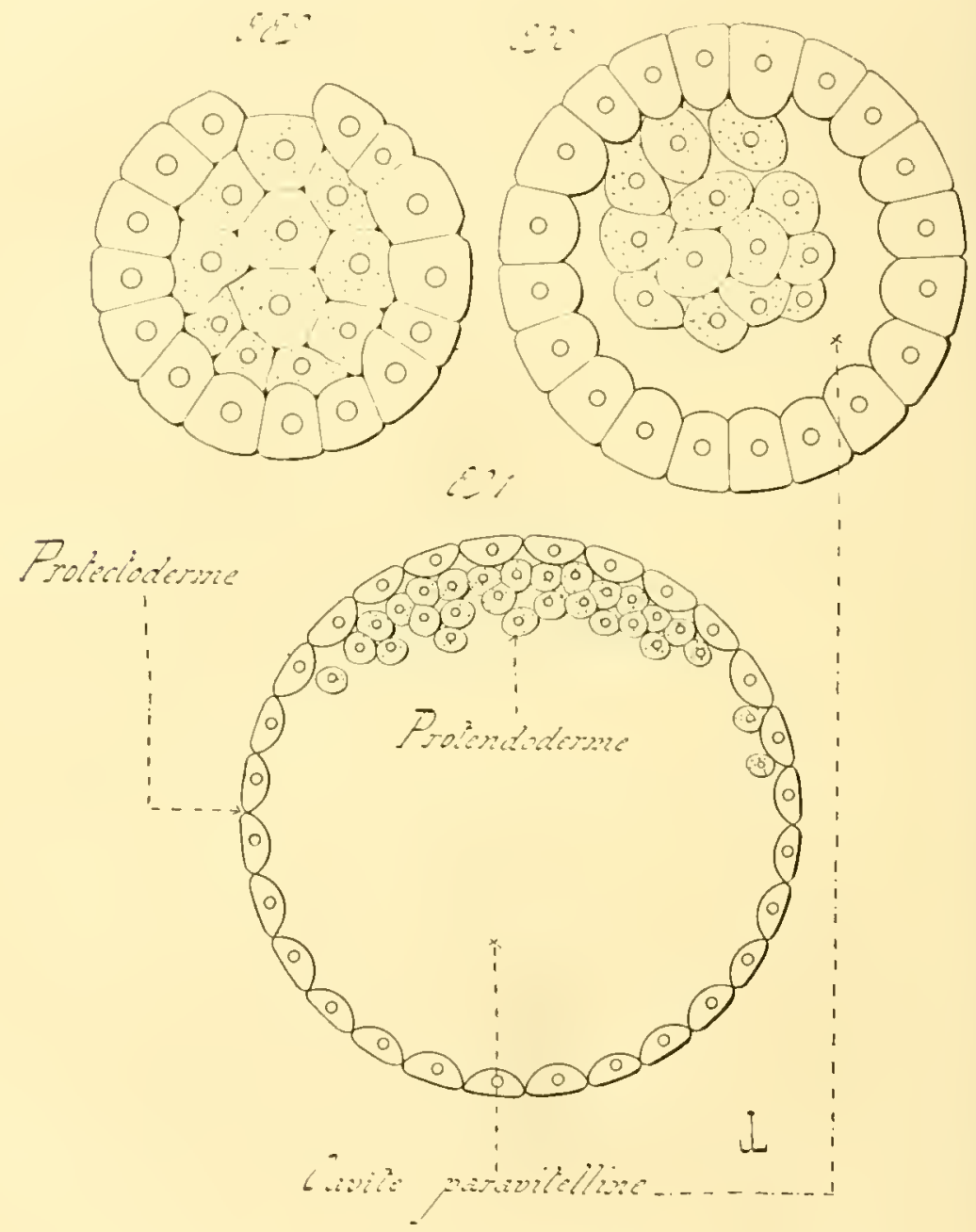

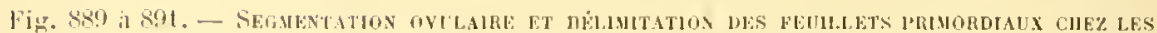

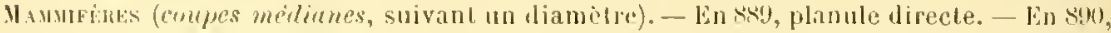
debut de la phase do culoplanule, par l'apharition de la caviti para-vitelline. - lin 491 , coloplanule jadrenue à sa periobe d'otat, et possidant st:s deux fouillets primordiaux entierement delimilis.

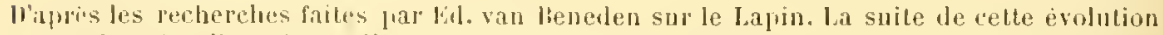

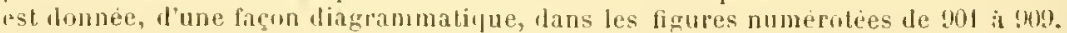

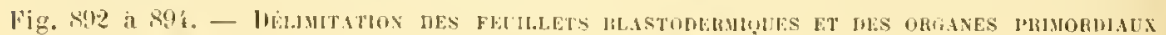

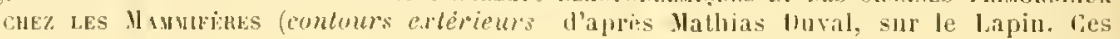




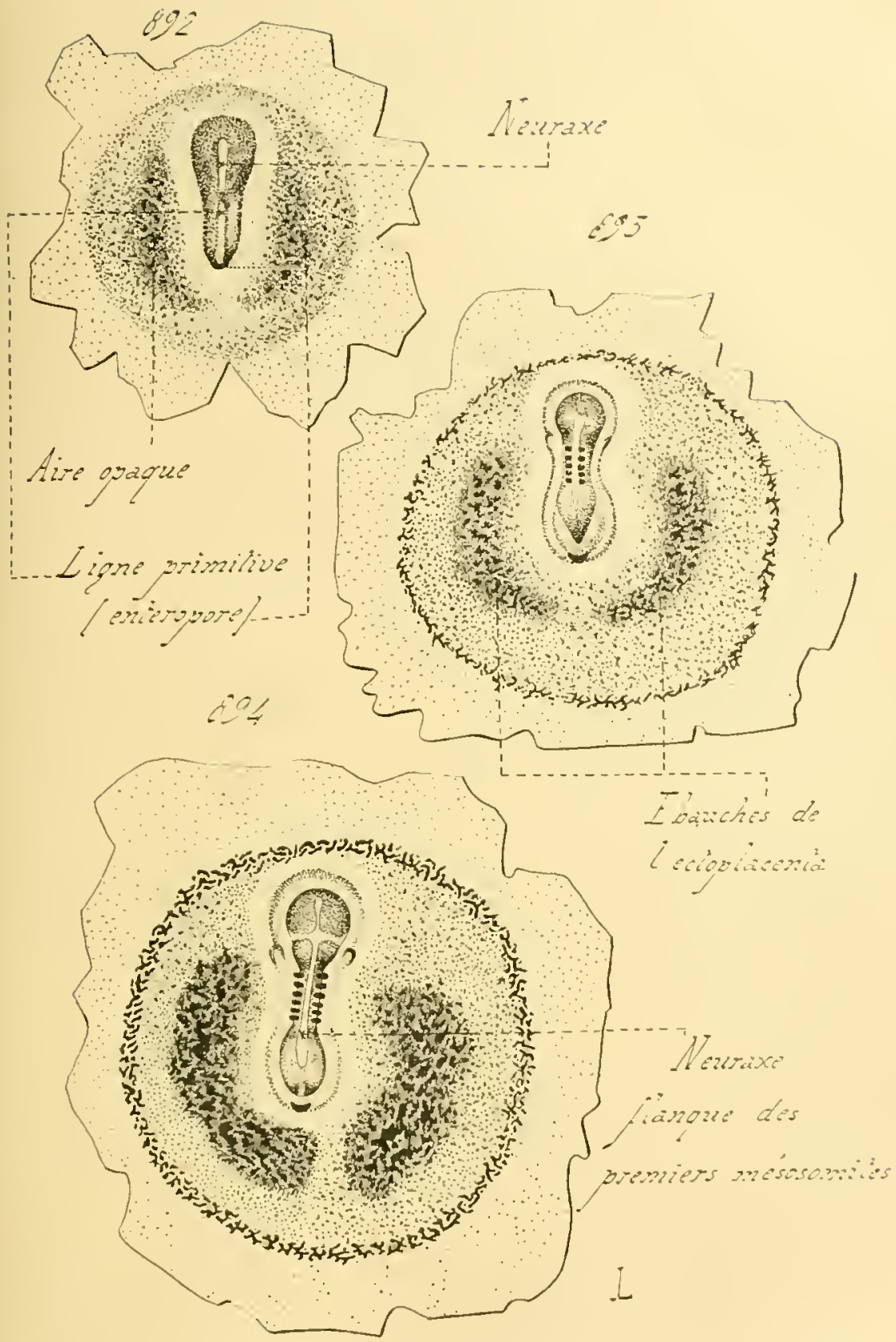

figures expriment les disfositions de la zone cmbryonumire, vor an entief et de face;

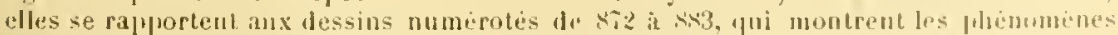
rorrespondants des sauropsides. The la ressemblince generale des uns at des aulres, il

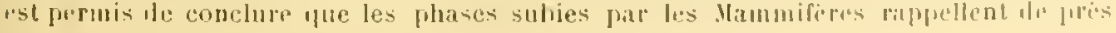


lormments, dommós par los aulrums an sujet des phases dernien's de la sromentalion, montront les luastomires écranx, on presque égaux.

La seguentalion, se prouluisant sur place, et par la division répétée des éléments, abontit à une planulation direcle. La planule se compose d'un petit nombre de lastomires, tassés en un amas compract. Les cellules périphériques deviemnent cubiques, préciseut leurs contomrs, et constituent une assise, séparée, par une ligne assez nelle, des éléments internes. L'ensemble de ros derniers est le protendorlerme; l'assise cxtérienpe représente le protectorlerme. Les phénomènes. projpres aux planulations directes, se montrent ainsi dans lem intégrité, quoipue sexercant sur un nombre restreint d'éléments. - Suivant Lid. van lieneden, le protectoderme de la planule serait, chez le Lapin el le Inurin, interrompu sur un pelit espace, yui ne lande pas du reste à se combler; ce vide serait, pour cel auleur, le correspondant l'un entéropore. L.es recherches, etlectures jar d'autres naturalistes, montrenl, par contre, fưne liğne primitive, homologue de l'entéropore des antres Vertóbrés, prem naissance dans la zone embryonnare, en nne phase plus avancée de l'évolution; l'intermption locale, observée prar Ld. van lieneden, n'aurait, frar conséptuent, ancume valeur particulière.

la planule compacte se convertit en une culoplanule, Ce phénomène setfectue pendanl que les blastomeres se multiplient. Ces deux mouvements, le creusement l'une cavité rentrale et l'augmentation du chillie Jes cellules, se manifestent d"me manière parallele, et so superposent, pour lonner au corps embryonnaire sa structure linale de vésicule. - Les premiers vestiges de la cavité apparaissent entre le protectoJerme el le proterdoderure, non pas sur toute la surface de séparation de ces fenillets, mais sur une partic de cette deruiere. La cavilé, à son lélıt, est en forme de cupule; elle grandit sans eesse, s'amplifie dans les proportions considóphles, el arcroit, d'une maniere ronnexe; le volume de la planule. He son coté, le protectoderme, afin de suivre relle angmentation, multiplie ses cellules, lout en les laissant disposées sur une seule rangée. - l'étal de coloplanule est rapidement atteint. l'ar l'aceroissement continu de la cavité, l'embryon devient mo vésicule, lont la paroi est constituée par le protectoderme; le protendoderme empose une petile masse cellulaire, accolée a une region restreinte du purtectoderme, et contre la face interne de cetle derniore. Cette région est la zone embryoumaire; toutes les autres parties de la vésicule conslibent lat zone prata-embryommaire.

celles les Saropsilles). - Ln \$og, premiere apparition du neuraxe, en avant d'une ligne primitive a peu pres semblable a celle du Publet; celle phase est sensiblement equiva-

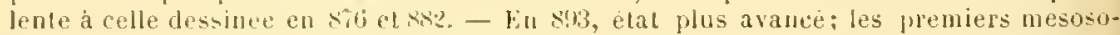
miles prenuent niassance, ainsi que les elanehes de l'ectuplacenta; un dernier vestige de la ligne primitive est encure pursent lans la region posterienre (iuferienre dans la figure de l'embryon. - lin s!l, etal folus avanee encore; lembryon s'est agrandi. el les mesusumiles soni devenus plus nombleux. 


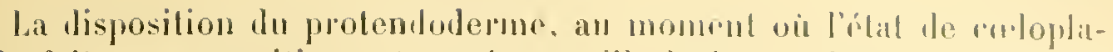
mule fail son apparition, el pendanl yüil sacheve, n'ast pas lat mome

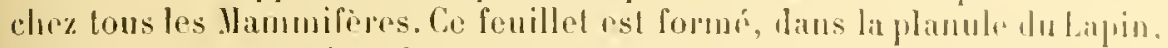
par un certain nombre d'assises cellulaires; it "st réduit. Hans celle du Rill, à me petile quantité d'éléments assez gros, rangés, lans la mone embryonnaire, sur une seule comblue; il consiste, che\% les Ciheiroplires, en mu syncylium, en une masse cullulaje parsemie de noyaux. - Ces

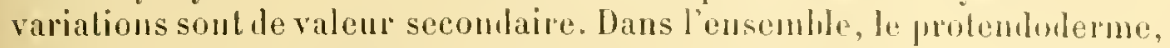

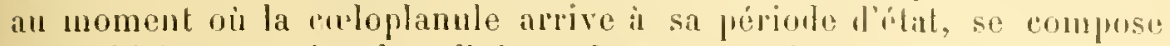
d'un chilfie restreint de cellules, plidées sous le protectolerme do li rone embryonnaire. Ce nombre est dr beaucoup inférieur i celui présemté, lans la phase correspondante, par son luomologue tes Sauropridés, et saus loute aussi des Mammiferes ovipares. Comme les mullijlications cellulaires ne cessent de s'effecher, celle quantilé augmente sans cosse, dans des proporlions variables suivant limporlance du point de départ, el permet bientöt de subrenir a la gencse des feuillets détinitifs.

111. Feuillets définitifs. - In moment oil s’achivent les phases relatives i la genise de la culoplanule, l'aul des llammiferes vivipares rappelle, lans ses trails essentiels, celıi les Sauropsilés, en supposaut compliete la paroi vitelline de ce dernier. Il en dillere par sa laille plus pelite, et surlout par labsence de vilellus mutrilil" l'espace, oceupé par ce lernier, est représenté par une ample cavité, la cavilé para-vilelline, emplie d'un liquide. - La paroi de la coloplanule est nettement divisés. en deux parties : une petite zone embryomaire, ol mus large zone paritembryonnaire. La premièe, dite encore aire embryonmire, ou tuche embryonnare, comprend les deux fenillets primorlianx, le protectoderme el le prolendoderme. Ia seconde, nommíc par les auleurs sone vitelline, ou aire non-embryomaire, se compose seulemont du protectoderme, lont les éléments sont disposés sur une seule conche. L'óvolulion le ces deux parties est différente.

A. - Le probedoderme de la zone embryomaire oflue des aspects divers. - Dans le cas qui parail le plus liépuent, oil le placenla est d'origne tardive, il est constilué par me seule assise rellulaire, dont les éléments, sommis it mo multiplicalion aclive, sont culipues. Sans doute par l'effet de celte prolilérition intense, l"assise est double pal" places, les cellules supplémentaires étand de forme aplatie; l'ensemble de ces dernieres est dit la conche de linuber. I cause de sil malurr. celle couche lisparail, comme comme l'out montré ballour el lleapr. par l'interealation de ses éléments entre les autres. - Iorspue fo placenta est de genese précoce, le protectuderme angmente rapidemont d'épaissemr, et se compose le fulusiemrs rangés cellulaires superposés:

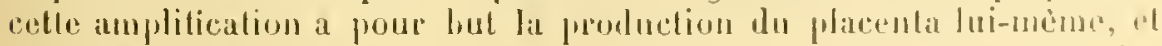
relle des élanches des replis ammioliques. Aimsi que l'onl dimontré les 
remarqualiles reclicrolies faitrs par 11 . Tuval, les juemiers linéaments de l'appareil nutrilil cmbrymnaire sont fournis par le prolcetoderme; at co fenillet sulit, par suile, un accroissement papide dans le ras où cet organe est engendro d'une manière hative. Une lelle particularité est olferte par les longeurs aux renillets invertis, comme le Cobaye, le Rat, la Souris, ele.

Arant que la culoplanule n'ait atteint loute son extension, le protendoderme comprend parfois plusieurs rangées cellulaires. Il finit rependant par ne plus se composer que d'une couche, semblable a une lame étalée sous le prolectoderme de la zone embryonnaire, el accolée ì la face interne de ce fouillet. Cétélat simple est, dans cerlains cas, uolamment dans ceux relatifs a une rapide genese placenlaire, produit d’emliléc. Les cellules protendodermiques ne sont pras serrées les unes controles autres; elles imetlent des prolongements psendopodiques, qui les relient, s’allongent on se rélraclent, et sont mème capables de les léplacer. Tout en agissant ainsi, elles augmentent en nomlire par leur propre multiplicalion; lent couclıe gagne sans cesse en largenr, et dépasse la zone embryonnaire, pour sétendre au-ilessons du protectoderme de la zone para-embryonnaire. - Les parlies qui dépassent, et appartiennent ainsi i celle dernière zone, sonl simples, el composées d'une seule assise de cellules. Celles qui demeurent dans la zone embryonnaire se dédonblent hàtivement en mésorlerme et endoderme délinilifs.

Les observations touchant la genèso du mésoderme sont encore pen nombreuses. Les éludes dres auciens auteurs, avec celles, plus récentes, Taites par Heape, et surtout par 11 . Tuval dans ses travaux sur le plarenta des Rongeurs, autorisont i admettreque les phases sont semblables à celles montrérs par lus Sauropsidés; les scules différences importantes liennent an volume restreint, laus le cas les llammifères viviparıs, du feuillet mis en cause. Un bourrelet en croissant se faconne dans la région poslérirurr de la zone emhryonnaire, et so creuse mème l"un étroit sillon. Une ligne primitive, idenilique de toms points à sa correspourante iles Samropsidés, fait son apparilion en avant de ce bouruelet, cl en arriore de la fulur ébauche du nruraxe. Cello dernière est limitée par deux roplis médullares, qui entourent l'rxtrémité adjacente de la ligne primitive. La forme of les relations des partics produites sont exactrment ronservées en leur plare; tout porte à proser que les phénomènes, offreturs chez les Sauropsidés, se rebourent, avec leurs qualités de temps et de liru. chez les Mammileres vivipares.

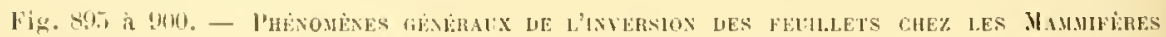
foupes midiunes diagrimmaliques; d'après Mathias Iuval. Lectodermo ist repri-

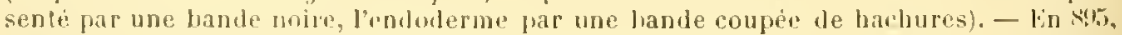
culoplanule complite. jrise au moment ou l'endolerme achève de circonscrire la cavile fara-vilelline entiele; lus rejplis amnioliques font leur apparilion. at encalrent l'etroile zone emliryonnaire, au milieu le laquelle est le neuraxe. - En $\$ 06$, debut de la descente le la zone embryonnaire dans la cavite para-vitelline: les replis amniotigues gran.

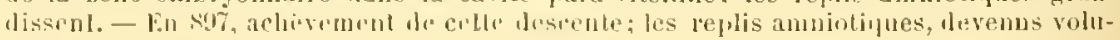




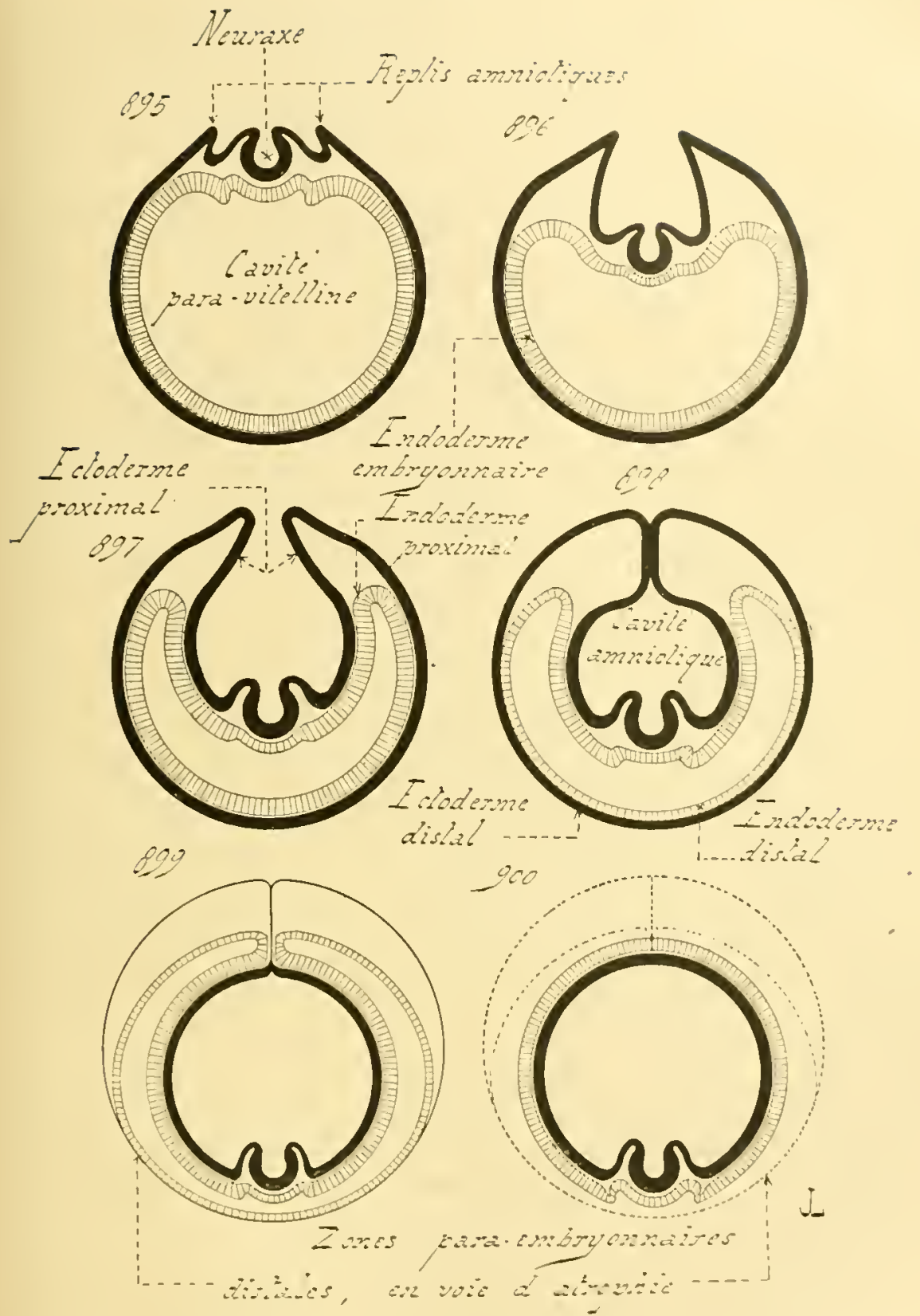

mineux, se rapproclunt mutuellement. - lin s!s, les replis amniolipues sunissent, d"

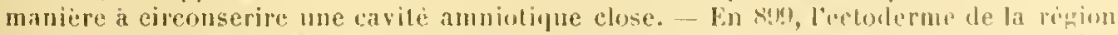

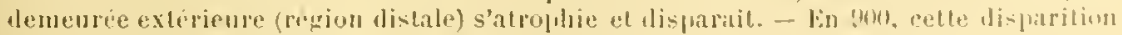

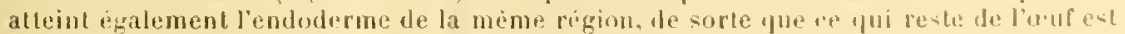
limitè à l'extèrieur par le l'endoderme. 
Les dissomblances ticmuent à drux particularités. lóabord à ce que la zone mblyonnairr. tont en produisant les fenillets définilifs, est suspendur au-dessus d'une cavité para-vitelline, an lien d'ètre placée sur mue cavité sous-grrumale, relativement étroite, et creuséc tans un volumineux amas de vitellus nulritif. La seconde diflérence est lue i la structure dn protentoderme qui, dans la zone embryonnaire, se romfose, au mompnt oì il va se différencier, d'unc seule conche cellulaire. - Cette assise, par sa prolifération, ne tarde pas à levenir double. La rangée interne, loulnée vers lis cavité para-vitelline, représente l'endolerme délinitif; alle su rallache, par ses boris, au protendoderme de la zone para-embryonnaire. la seconde rangéc, comprise entre la précédente ot le protectoderme, est le mésoderme. Elle est le siège de multiplicalions actives, qui la divisent en denx et plusieurs conches, chargées le fournir los diverses parties du feuillet moyen. Cette différenciation commence dans la région postérienre du blastorlorme, et continue sur les côtés de la ligne primitive. Une telle parlicularité contrilue i affirmer l'opinion relative à la parfaite ressemblance entre les Sauropisidés, ef los Mammifores vivipares, sous le rapport des phases principalos de la genèse de leurs fenillets.

13. - Lorsque la culoplanule achève de se constiluer, lazone paraembryonnaire est, de ce fait, entière; elle ne présente aurune solution de continuité, car elle a été formée d'une manièc directe, par la persistance, en leur situation première, des blastomères périphériques. Ce frocéłé génétique est dillérent de celui montré par les Sauropsidés, lont la zone cormespondante se façonne peu à peu, au lien d'ètre complicte des l’abord. In rappel de la disposition des Sauropsidés est pourlant ufert par les Mammiferes vivipares, en ce qui concerne le protendoderme; il contribue, lle son côté, ì bien jréciser celte lonnée, yue, sauf les altérations entraînées par l'absence de vitellus nutrilif, l'évolution de ces derniers animanx ost semblable, dans ses traits essontiels, a relle des premiris.

La paroi de la zone para-emlıryonnaire se compose, à son délut, l'une seule assise de cellules, qui appartiennent au protectoderme. Parfois. quelpues éléments protendodermiques sont situés en ledans d'elle; mais, peu nombreux, ils ne constituent pas me conche continue. La tolalité du protendoderme est allée se placer dans la zone embryonmaire. - l'uis, a mesure que ce feuillet, frar sa prolifération, se divise en plusieurs rangées cellulaires superposées, il s'aceroît également par ses luords, de manièce a clépasser les limites de la zone embryonnaire, et a s'avancer sous le protectoderme para-embryonnaire. liextension, dans ce sens, continue progressivement, suirant le procédé des Sauropsidés, jusq̨u'au moment où ce lernier fenillet est, tout entier, doublé l'une seconde assise cellulaire, dépendance du polemdoderme embryonnaire. Anssi, dans son amplificalion, relui-ci offre-t-il l'aspect dime 


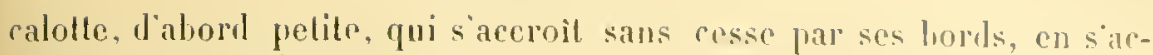
colant à uno partic toujours plus grande ste la face interme du puotrortolerme. passe a létal dr calotte hémisphériłue, ot finil, en augmentant loujours. par atteindre celui de sphire compline. La rigrion, ou cet rubahissement so termine, el oì se rejoignent lesextrimités de la ralotle, est, comme chez les Sauropsidés, diamélralement opposéc it la mone cmbrvonnaire.

Ces phromenenes termines, la cavité para-vitelline se lrour limité par une paroi complexe, que composent des béments appartruant anx deux fouillets primordianx. Sauf le potil nombre des collules constitulives, les disposilions sont identiques à cebles des aufs des saumopidés. - Le protectoderme est formé de cellules ajulaties, et non point eulinpues. ou eylindriques, comme celles de son correspondant de la zone emluyounaire. Les éléments du protendoderme sont munis d'expansions jucnJopodiques. - Dans le cas de culoplanulos invaginées, et de fenillets invrlis, le juol'ndoderme de la zone invaginée n'est séparé, que par un espace restreint, de celui de la zone invaginante; cet espace nest untre que la carité para-vitelline, amoindrie par le fait mème de la pénétralion du blastonterme embryonnaire dans son intirieur. tes deux couches protendodermiques, mises en présence, envoient, a travers le vide étroit laissć entre elles, plusieurs de leurs expansions; celles-ri s'anastomosmul ell un réseau, parfois assez serré. Celtr lisposition remarquable est d'importance très secondaire; elle résult. du rapprochement proulnit par l'invaginalion, n'a pas d'autrr valrur, el manque aux coloplanules dont la cavité para-vilelline demrure ample.

Le prolecloderme de la zone embryomaire donne le neuraxe, el prosiste comme ectorlerme définitif ; le potendoderme lomruit la notocorde. lo mesorlerme et l'endodrime. Le lenillet cxtrune le la zone para-em-

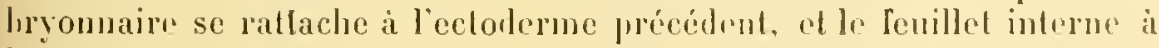
l'endodermo; aussi les termos, servant i lésigner les couches auxquelles ils se raccordent, jurvont-ils lour ètre appliqués.

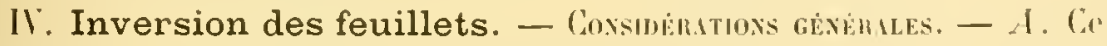
phénomene n’a été signalé que choz des Rongenıs. Déconvert jar Bischort sur le Cobayr, il a élé élndir, ensuile, par plusicurs autemrs. notamment par Reichert ot par linplyor. Ses diverses allures, et sa signilication particuliere, n’ont été suivies el explipuées que daus res lerniores aunées, grrice aux travaux de Selenka, et surtoul à ceux de ll. llirval.

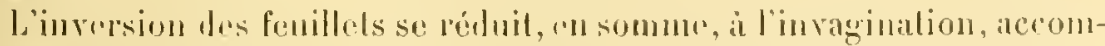

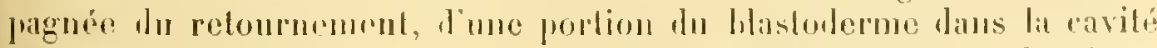

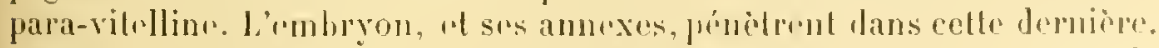
Dr plus, la majeme part de la zon" para-molnyomaine, au lien de

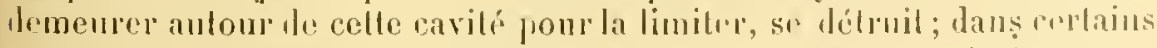

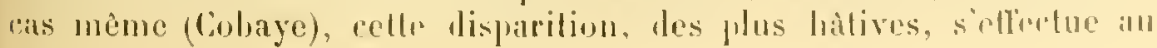


moment où la couplanule achève le se constilucr. Dans celte descente, complingée de rotournement, le protendoderme de la zone invaginée so

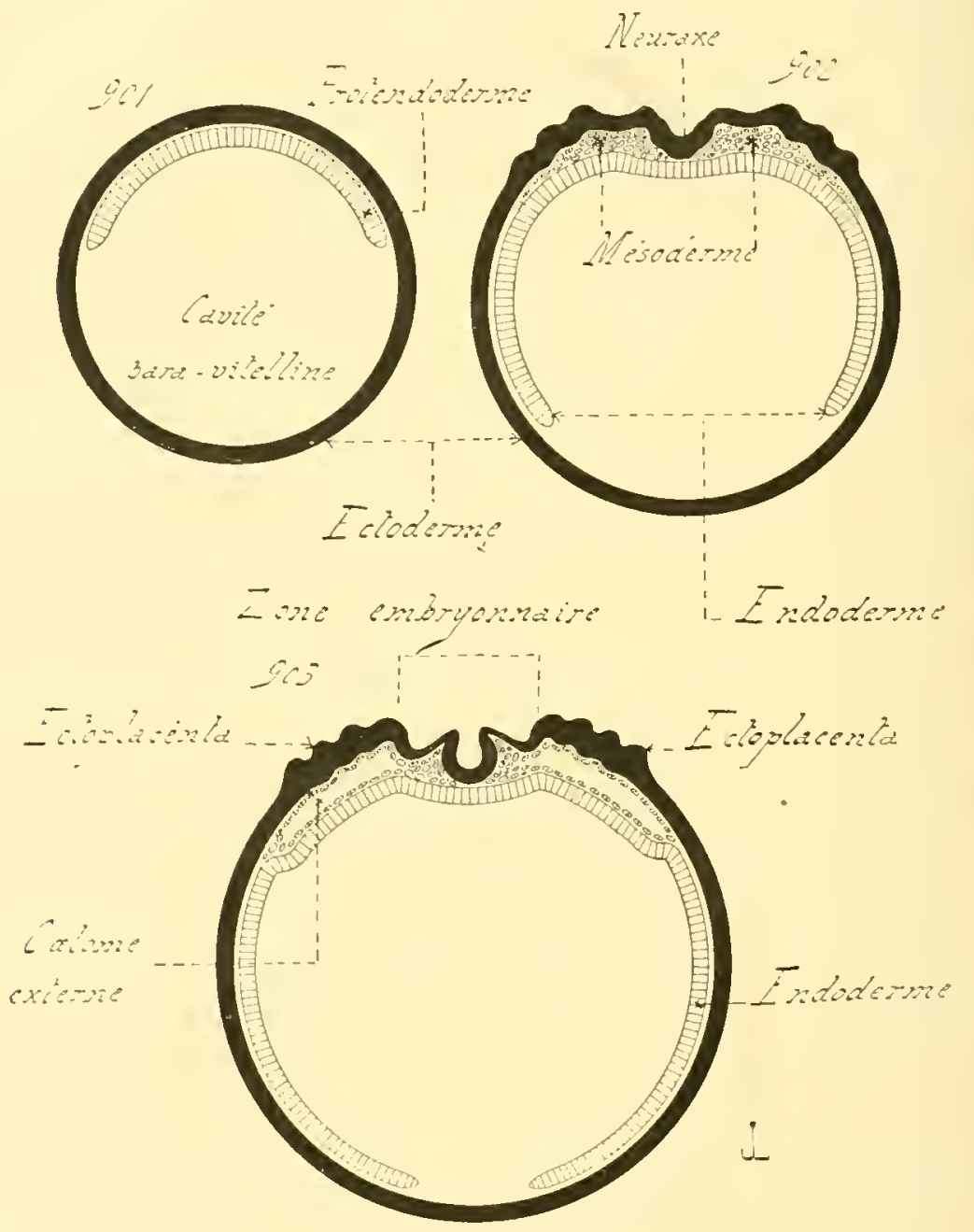

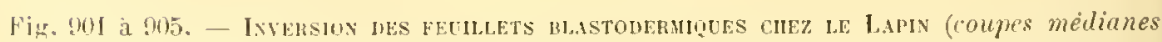
et diayrummaliques; d'apries Matlias liural. - L'eetoderme est représente par une frande noire, l'endoderme et le protendoterme par une hande conjee de linelures, le mésoderme par de pretites cellules juxtaposèes). - En nol, culoplanule prise au moment vil le frotenloderme est eurore localise dans la zone embryonnaire; cette figure exprime, sous une forme diagrammatịnte. les pluenomines montrés dans leur réaliti par la figure $\$ 91$. - lin !0?. le protentoderme s'étend autour de la eavité para-ritelline, et produit le mesaderme dans la zune embryonnaire. - En 903, la zone embryonnaire précise ses contours; eneadrie jar les leux ébauches de l'ectoplacenta. "lle porte le neuraxe

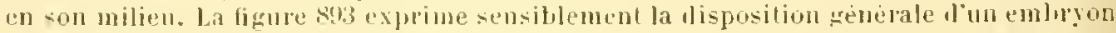
parvenu à cette plase. - In !ofi, la zone embryonnaire, en fermant son neuraxe et produisant sa notocorde, continue a se completer, pendant yue les replis amniotigues 


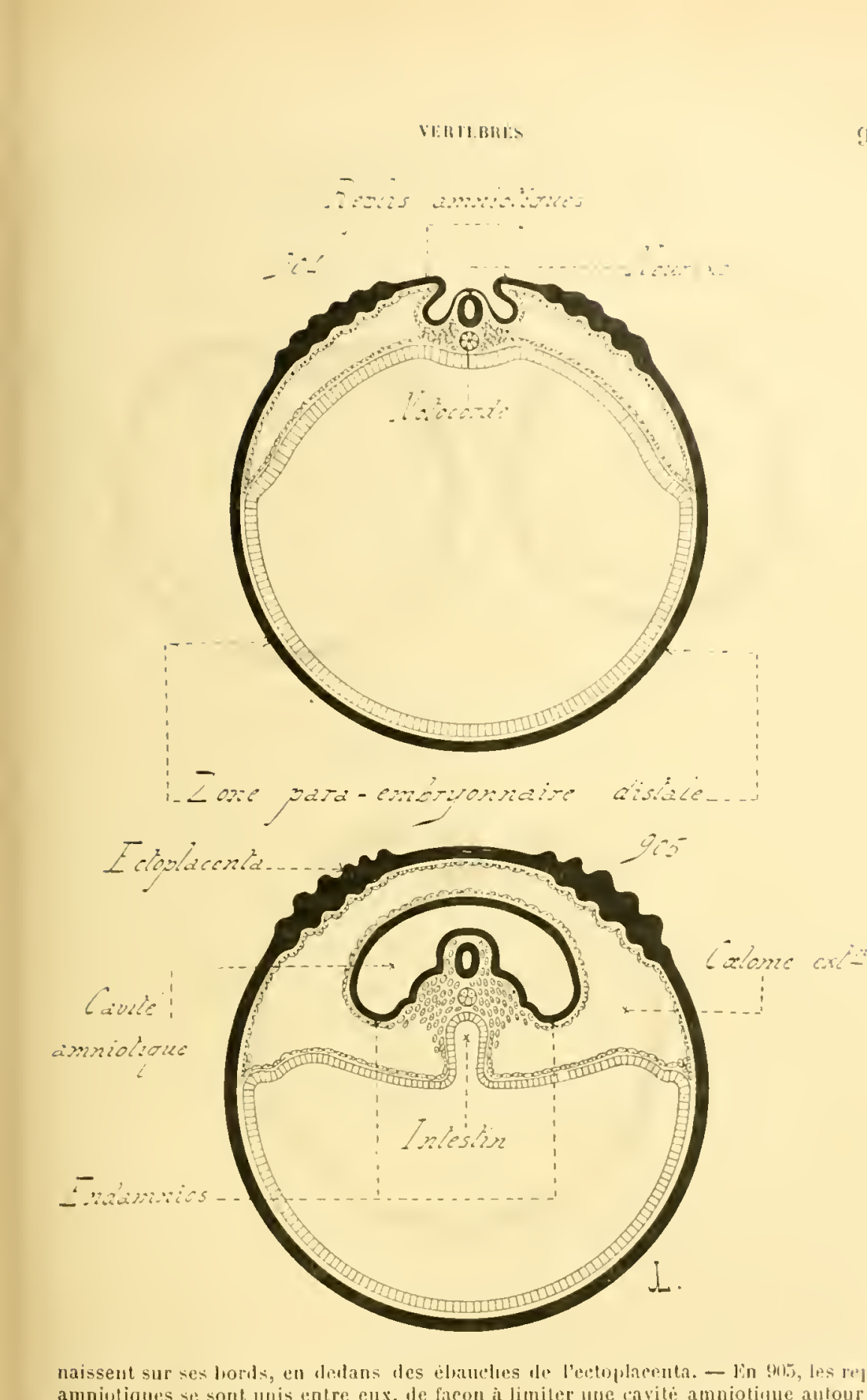


trouve reporté nn dehors du protectoderme. Les fenillots primordianx occupent ansi mor situation inverse de cello quils devajent avoir. Celle disposilion nonvelle naltère en rien lenr valonr morphogénéliqur, ot ne chango multement les rolations mutuelles des organes qui proviemnent l'eux; elle est due seulement à une genese plus précoce des annexes de lembryon, el il mo hite plus gramde dans leur accrojssement.

La creloplanule des liongeurs, lout in ébanchant les premiers linéaments des éhauches organiqurs, on mime avant de les engendrer, produil, antour de sa zone embryonnaire, l'ammios el le placenta. Contrimement à lours correspondauts des autres llammifères, ces deux appentices najssent halivement, et s'amplifient avant lout antrr appareil. la region, occupée par rux, guandit daus lous les sens, de manirye à faire sajllie, m même trmps, hors de la surface de la culoplanule, et dans la eavilé prara-vilelline de celle-ci. L'aceroissement, suivant celle demiere disection, a pour effet de dépriner d'ahort, et d'invaginer ensuile dans celle cavilé, les parlies intéressées dans ces phénomines. Cetle pénétration, loute passive, due à liextension précoce les annexes, se donble par la spule action de son mécanisme, du retournement les régions mises en canse. - las feuillets ont alors perdu leur disposiliou pemic̀e, ot sont invertis. Hais un tel changemont nalteint que leurs portions destimés a foumir les anurxes, canses de tous ces phémomènes; et il a pour résultal de tomner d'emblée, a ces amnexes, lenr struchre délinitive, que lems similaires des antres Mammilères ne possedent quapres un certain nombre de modifications. Celle inversion répond, avant lont, i une condensation du lévoloppement, portant sur les appendices cmbryommares. Les aulees partjes du hlastoderme, chargés de prodnire l'économie elle-mème, at non ses annexes, se Jornent ì ètre déplacées, en pénétrant dans lintéricur de la cavité para-vilelline, ả perdre lem siluation suproticiolle pour drvenir intermes, mais conservenl leur organisation primitive.

L’inversion nest pas la meme chez tous les liongenrs. Elle offre des

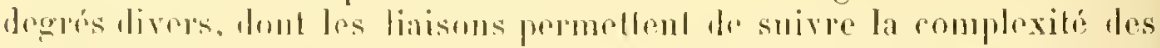

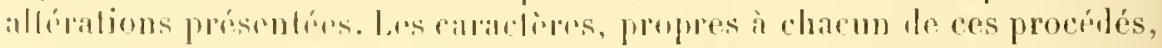

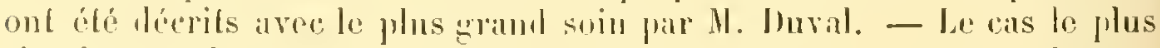
simple sol celui du Lapin. La coloplanule so constitue; sa zone enbryonnaire se subdivise en fruillets, et produit le neuraxe. Les replis annioliques prennent naissance autour de rette zone, grandisient, el l'enveloppenl; lomr face externe engendre le placenta. Ces ammexes s'accrojssent, acquiècut rapidement une grante importance, pendant que l'ébanche de l'embryou desecul lans la cavilé para-vitelline, embainant avec elle la paroi profomle de ces memes ammexes. Celle-ri, par l'eflet de la descente, se retomrur, et inverlit ses fenjllets; ce phénomine est lardif, relalivement aux atues Rongenrs. En outre, la région frara-embryonnaire, non inlipessé dans l’invaguation, demeure longtemps avant de se détruire. - Labréviation est plus gramde chez le Cimpragnol, le liat et la souris. 
Pendant que la culoplanule se délimile, et que le protendodorne s'élond lans la zone para-embryonnaire, le protectuderme de la zone rumbryonnaire s'épaissit, pour lonner les ébauches de l’amuins ot du placenta. Ces deruires sont de venue phus hitive pue dans lo premier cas; rlles jénètrent, pour satisfaire à leur accoissement ralpide, lans la cavilí para-vitelline, en retournant sur eux-mèmes les faillets fui les constiluent. Les premiers linóaments de l'amnios el du placenta sont d'aliom unis ; ils se séparent liruntôt l'um de l'autre, et, vers celle ćpoyu", la \%on"

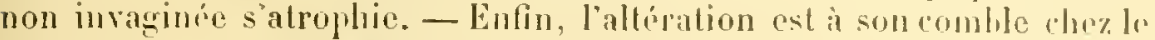
Cobaye. l'épaississemrut, chargé de former l'ammios et le placenta, commence à prendre naissance au mument où la cavité para-vilolline se creuse dans la roloplanule; le diplacement, par pérocité, de co phénomène génétique ast les julus accenturs. De plus, le protendodermo ne s’étend pas dans la zonr para-embryonmare; rollr-ci demenle conslituce par la seule assise des cellules protertorlermiques, yui se détruil hitivement, lorsque l'ammius et le placenta, encore composés de collules unies en une masse compactr, s’isolent le lour ébauche communi.

b. - Malgré leur diversili, les particularités les plus importanles, de ces trois degrés de l'iuversion, demeurrnt l's momes, à peu de rhose pres. - Le blastoderme entier de la culpplanule des Mammiferes peut ètre consilóré comme formé de trois parlies : la zone emluryonnaire, la bande proximale de la zone para-emlnyonnaire, ot la liande listale te cette mène zone. La premiere est d'étendue fort restreinte; elle comprend la portion du hlasloderme chargóe de façonmer l'embryou; sil surface, minime, ne dépasse pas de beaucoup les environs immédiats dı neuraxe. La seconde entoure la précédente, et va des hords de crile-ci à ceux de la bando distale. Elle a pour ol.jet de prouluire les annexes de l'embryon, l'amnios et le placonta; aussi ses feuillots acrutiorent-ils une importance considérable, et son protendoderme se divise-t-il en endoderme et mésoulerme, celui-ci élant destiné a subir des mudifications complexes. La bande dislalo de la zome para-embryomaire ne posside

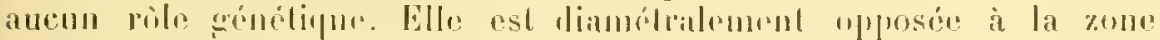
embryomaire, mais rlle occupe une surfaco beancoup plus grande, qui alleint sourent, et dépasse parfois, relle d'un hémisphere. A cause de son défaut de fonction, son joulenloulerme demenre souvent simple; cetl. particularité la distingue, sous le rapport de la structure, de la hamle proximale.

Ces lrois parties, maleré leur livergone d'urganisation el de destinéc, sont unies les unes aux autres; loutes trois concommut à composer la

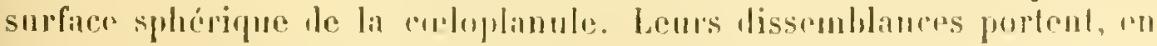
majorité, sur leur protendodrme; lenr protectorlerme comstitue mn

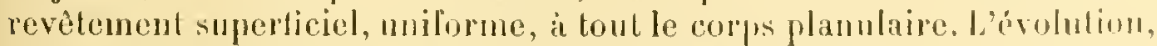
subie par chacune delles dans l'inversion, est dillórente.

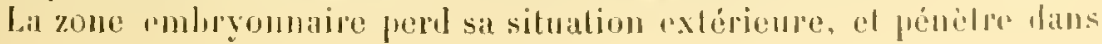


la cavite para-vilellim, elle s’enfonce à des profondeurs variables suivant les types. Mais elle conserve sa lisposition premiere; ses feuillets

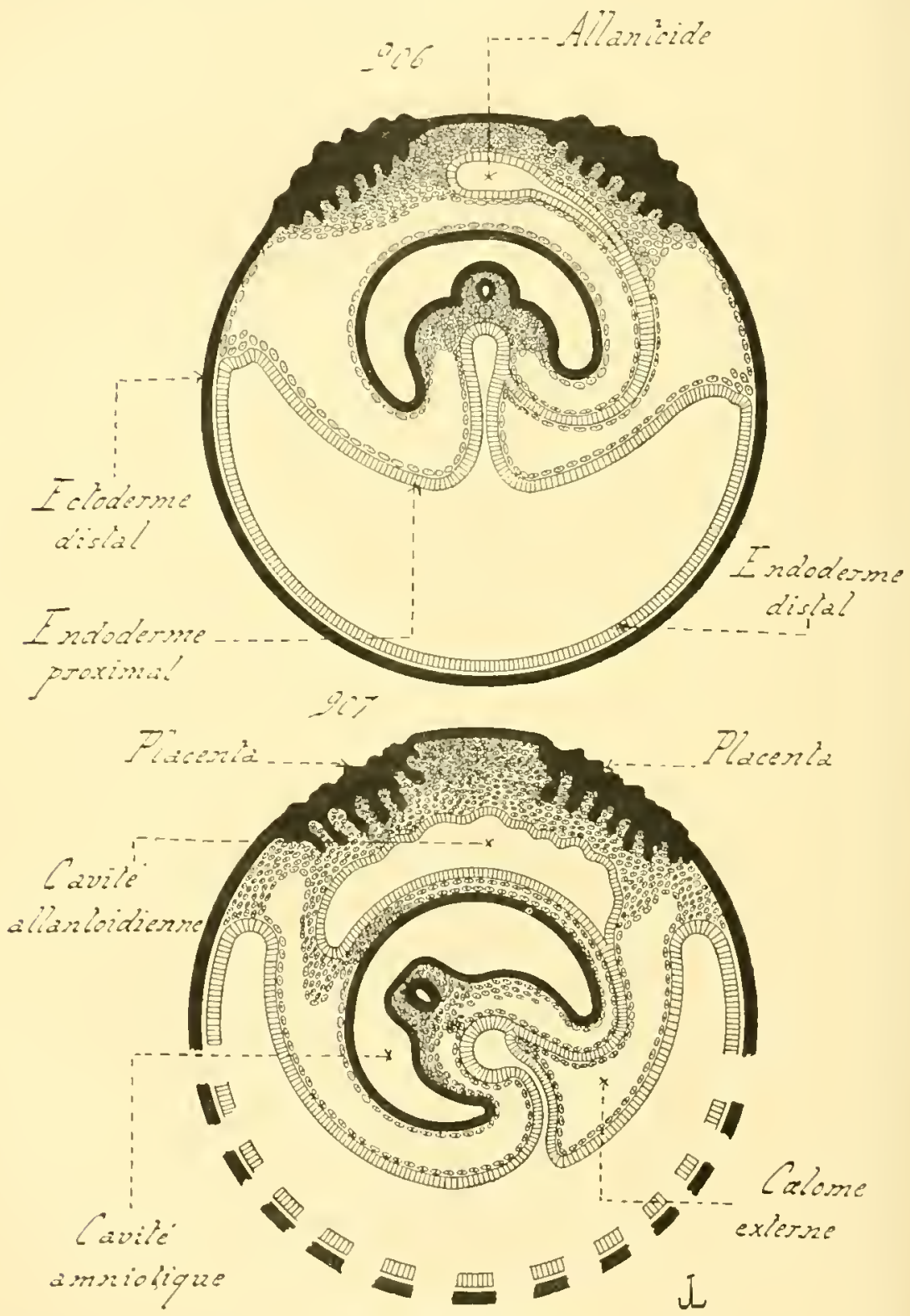

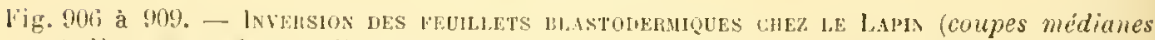
et diagrammaliques; d'après Mathias louval. Les fignues font suite aux frèèdentes,

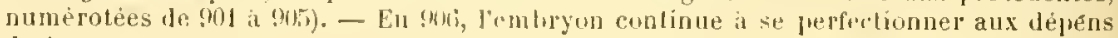
de la zone cmbryonnaire, et produit la visicule allantoide. - En $90 \%$, l'ectoderme el 
demeurent en place, et ne subissent ancun changement. - Tel n'est pas le cas de la bandre proximale de la zone para-embryomaire, sur laquelle
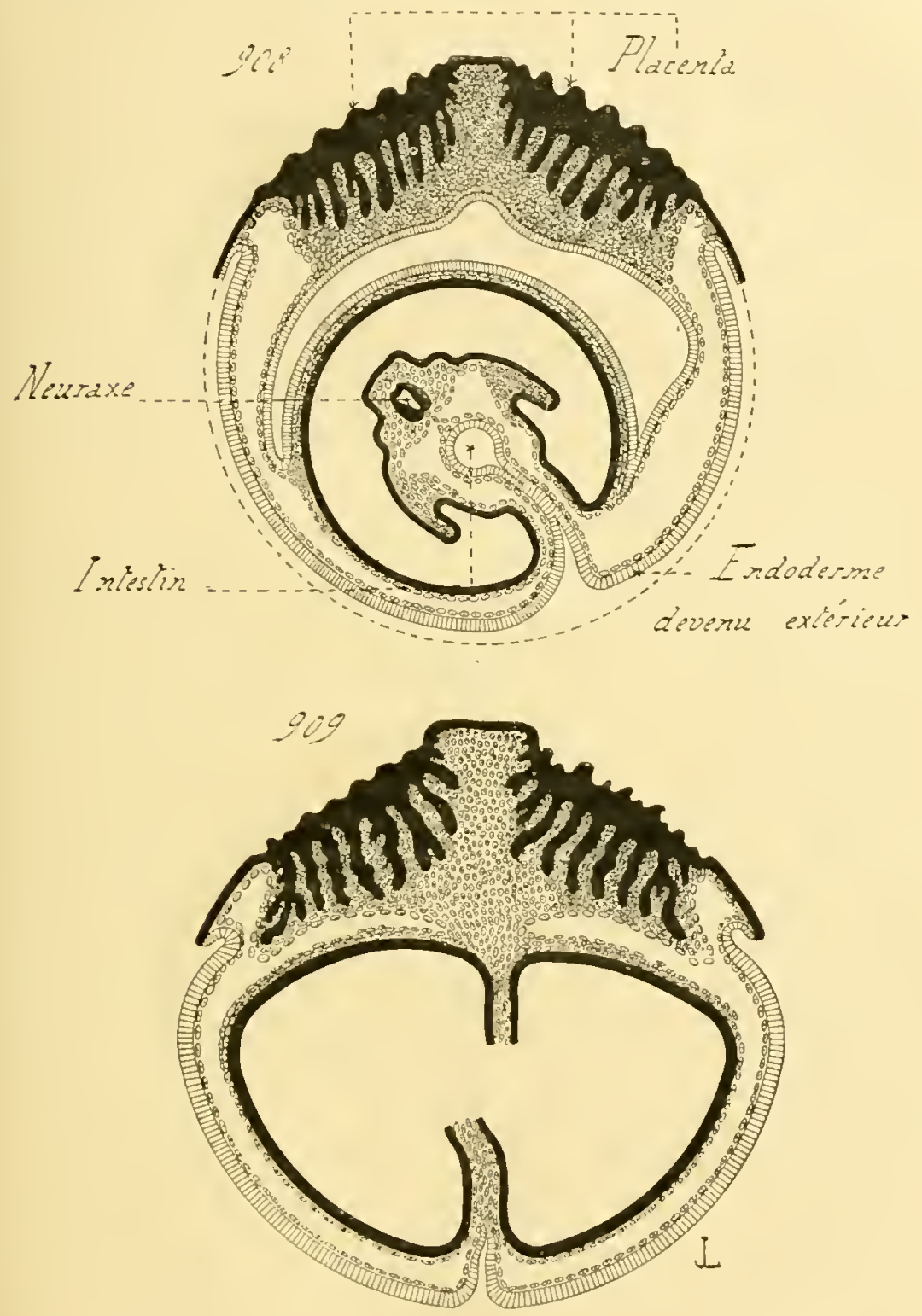

Jindoderme demeurés extrieurs (ectolerme distal et endoderme distal) commencent i s'atrophier. - Fn mos, cette atrophie sarbeve. - lin gns, it la sulte de celte atrophic, l'embryon, squi n'est pas desine daus la figure, est entoure denreloppes, dont lextirieure se trouve recouverte par une couche endorlermique, sanf dans les regions placentaires. 
porte la majeure firl das effets de linversiou. En accompaguant le mouvanent dr lescente de la zone embryounaire, elle se léprime et soinvagint: ce faisant, olle se letomrue sur elle-mème, et lourme son endoderme en dolors. Cel eudulerme moximal se maintient toujours dans la mème pusilion far rapjort à la eavilé prara-vitelline, el conlinue i se trouver en contacl dired avec le lipuide dont elle est emplie; seulement, au lien de la recourrir à la facon d'un dome convexe, il est intléchi dans son intérieur. - Enfin, la lande distale, qui ne possède aucune fonction génétique, s’amincit peu à jeu, et finit par se détruire. A son début, cetle hande enveloppe loute la parlie iuféricure de la cavité fra-vilelline, et l'isole des milienx environnants; apres sa disparition, l'espace circonscrit prat elle se trouve largement ouvert. Il demeure, cependant, aussi hien lólinité qu'arant cetle alrophie. En effel, à mesure ques'elloctuent ces changements, la paroj de l'utérus maternel, à laquelle sadosse la culoplanule, s'liypertrophic parfois, "l produil une memluane, la caluque, fui entowr celte dernicre. El, au moment oi la hande distale cesse l'enveloprer la cavité para-vilelline, la carluque prend sa place pour jomer le mine rôle.

Inversion des feuillels chez le Lupin. - A. Lovule de la Lapine, étant parvenu a la pluase de culoplaumle, est sphérique; sa vaste ravité paravilulline est limitée, sur sa plus grande élendue, par l'ectoderme; le frotendoderme oreupe un esfrare restreint, daus la zons embryonnaire. Cedernier fenillel s'iccroit snivant le mode habituel, el s'étale au-dessous de l'ectoderme, en prenaut une surdace loujours plus considérablr; il possèle bientôt l’aspert d’une calolle hémisphérique. An moment où il lépasse cel étal, il produit les premierr's cellules mésodermịues, el se divise par lả en mésoderme el eudorlerme. - Cellediflérenciation uatteint pas le frotendorlerme tout entier; elle se localise dans la zone embryonnaire et la bande proximale de la zone para-embryonnair; l'ensemble te res denx partios rorrespond i la région où le protendoderme est parvenu tout dabord, el comprend presiue tout l'hémisphire supérieur

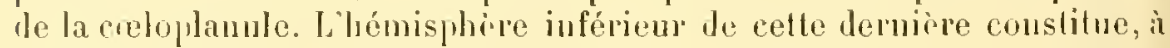
alle seule, la bande distale de la zone para-embryonuaire. Le protenforlerme s'y élend par la suite, et so place sous l'ectodrome, de maniore a le loublre; mais il y drmonro indivis, el consorve sa simplicité.

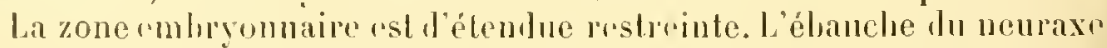

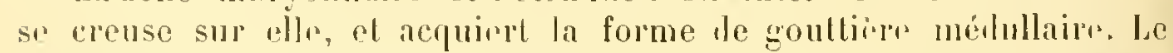

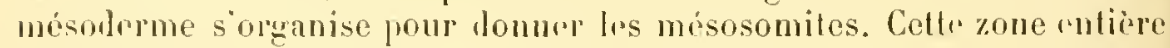
se cireonscril aroe unr assez grandr nolleté; elle faconue les diverses partios d. lembryon, pendiut pur sa voisine, la loude puximale dr la zone para-embryonuaire, subil iles morlifications complexis, retengendre les annexis, l'immios arec l: placenla.

Cette hamle proximalo entoure la zone embryonnaire. Son mésoderme, tout auturm de relle dromiere, se creuse, daus sa lotalilé, d'une 
fente, qui ne tarde pas à samplifier, el á devenir une vaste cavité. Cettu derniere, le calome externe, ou la cavite plenro-péritonéale, les autenrs. s'étend depuis les horls de la zone embryonnaire jusqu'à cenx de la bande distale; elle oceupe ainsi la masse enlière le la bande proximale. Sa présence a pour effel de cliver cette derniere en deux lames : l'une exlerne ou supérienre, l'autre interne on inférienre. Celle-ci repose directement sur la cavilé para-viteline (cavilé de lu vésicule ombilicale, des auteurs); clle se compose de l'endoderme en dedaus, el d'une assise mésodermique en tlehors. Celle-lì forme la surface externe de la hande proximale, et reconvre la fente qui vient le se reuser; elle se compose de l'ectoderme en lehor's, et d'une assise mésodermique en derlans. Depuis la périphérie, la substance de ła hande proximale se réparlit ainsi en couches diverses : l'ectoderme; un première assise nésorlermique (lame fibro-culanée des auteurs); la cavilé du culome externe; la seconde assise mésodermique (lame fibro-intestinale des autenrs); enfin, la cavití para-vilelline.

La lame externe de la hande proximale donne l'amnios el le placenta. - Les rejlis amnioliques, produits par ell', se soulerent de manière à surplomber la zone embryomaire; ils s'adossent au-dessus de cette dernière, s’unissent, et engendrent l'amnios. La cavité ammiolique, laissíe entre eux et l'embryon, s'acroît par le resserrement de leurs hases, de maniòre à enveloppre te petit êtıe, el, devenant iudépenlante arec ses prarois, à l'accompagner dans ses déplacements. Les replis de l'amnios prennent naissance autom de la zone embryomaire. - En dehors d'enx s'ébanchent les deux farties du placenta; une telle division, du ruliment placentaire en leux prots, est spéciale au Lajin. l.ectorlerme et le mésoderme de cetle region prolifierent actirement; la vésicule allantö̈le, engendrée vers cette éjorjue, parvient dans ces tissus, y distribue ses vaisseanx sanguins, et lem permet de probuire le placenla. - La lame externe nest pas toute employée à ces deux greneses. Une bandeletle assez large, directement adjacente à la lande listale, deneure à l'écart de ces phénomènes: son ectoderme el son mésoderme restent sans proliférer beaucouj. Mathias Inval lui a donné le nom de lame, ou de loandelette, inter-ombilico-placentaire.

B. - Une lełle activité génétique, manifestée dans la zone rmbryonnaire, et dans les parties de la baude proximale qui l'avoisinent, a pour effet damener une amplification considrahle les rógions mises en cause. liensemble de l'embryon, el de ses anmexes, s'est accul pendant qu'elle s'uffectuait, mais n’a pras perilı sa forme splériquo. Aussi, ces régions prolifirantes grandissent-elles aux lippens de l'espace ocenpé jar la cavité para-vilcline, el pinètrent-elles lans l’intériem de rotte derniore. Ce faisaul, olles entrainent avec olles la lame inlerne de la bande proximale, la dépriment, et la reburnent de delors en dedans.

Cetle lame interne, à son libut, prossed.r laspeet d'un dome, qui re- 
romvirait la moilié smpérienre le la ravilé para-vilelline; elle s'elend lo la zone embryonnaire i la lande dislale de la zone para-embryonnaire. I mesme inu lombryon, arec la lame exterme le la bande i layuelle elle appalient elle-mòme, s’accroissent lans tons les sens, ot senfoncent dans la cavité para-vitelline, clle sinlléchit avec eux. Elle commence, an délut de sa lépression, par pessembler à nu planeher horizontal, silné i peu pros vers le milien de l'ouf, ot juesque équatorial. Elle ne tarle pas ì se liprimer lavantage, et ì devenir comeave, le convexe quelle était ì son commencement. La face iuterne. constituée par l'endoderme, se trouve alors extérieure. - les feuillets qui composent cette lame interne sont ainsi inverlis dans loule lenr étendue; la cause de cello inversion étant la descente de l'embryou, el le ses amexes, lans la cavité para-vitelline.

La bande distale de la zone embryonnaire, qui forme, i elle senle. lout l'hómisphère inférieur de la crlojlanule, demenre indemne; elle ne participe à aucun de ces changements, et conserve sa siluation premirer. Seulement, lorsque linrersion est lijaj bien marquée, an moment oì la eavité para-vilelline se tronve ríluite à une fonte, laissie entre ollemème et la lame interne de la bande proximale, elle se détruit. Ses éléments se désagrègent, et s'atrophient. Sa lisparition est complète, sauf une portion restreinte, laissée comme une collerelte antour du bord de la bande proximale, dans la région où la lame externe de celle derniire se continue avec la lame interne; cetle colleretle circulaire rst nommée, par II. Duval, la sone résidrelle.

A la suite de l'inversion le la lame interne, et le l'atrophie de la bande distale, les dispositions générales des annexes embryonnaires sonl changées du toul an tont, et trés diflérentes de celles possédées par les autres Mammifires. L'imliryon est bien, comme partout, placé dans une caviti, que limite l'amnios; ce lernicr est lien entouré, à son lour, sur une pratie de sa surface, par le colome externe, et porte sur l'autre l'allantoïle avec son placenta. Jais, sanf l'espace occupi par ce lernier. la périphérie lu corps embryomaire est constituíe frar la lame interne seule, dont l'endoderme est tourné en dehors. La bande distale, arec son ectoderme et son somato-mésenchyme, ayant disparu, l'extérieur de liruf est circonscrit par une conche endodermique.

Cette structure finale, qui est le hut atleint par l"inversion des feuillets, entraine, de son côté, Jes conséquences spéciales dans les rapports mutmols dos annexes entre eux. Chez le lapin, un tel cliangement, dans les relatious des appareils, est tardif. Lembryon commence it s'ibaucher, it produire son nouraxe el ses mésosomiles, avant de Jescendre dans la cavitó para-vilelline poul l'olstruer; son placenta et son amnios, engendrés sépariment, sont déjà complexes an moment où l'inversion, nécessilíe par leur accroissement, s'effectue dans la lame interne. Les autres Rongenrs ofrent, en ces phénomènes, une conlensalion heaucoup plus grande. 
Inversion des fenillets che le Campaynol, le Rat el la Souris. A. - La coloplanule du Campagnol, de même que celle lu lapin, est sphérique à son lébut; son protendoulerme est également localisé dans un espace restreint, qui correspond a la zone cmbryonnaire, angmentée de la lande proximale d'une partie le la zone para-embryonnaire. De mème encore, le protendoderme s’amplifie, pour s'étaler dans la bande proximale tout entière, et parvenir ensuite lans la lande distale. Senlement, par opposition aver le phénomène correspondant du lapin, des les premieres phases de eet accroissement hil feuillet interne, l'ectolerme de la zone embryonnaire, et celui de la bande proximale. grandissent et s'épaississent dans des proportious consilérahles. pour produire le placenta et l'amnios. Par une ahréviation du développement, les ébauches le ces appendices apparaissent ici d'une manière plus préeoce, et n’attendent pas, pour cr faire, que le protendoderme ait entouré toute la cavité para-vilelline. La région ectodermirue épaisse forme un corps compract, qui occupe liun des pôles de la creloplanule; son accroissement détermine celui de cette dernixro, qui prenul. en angmentant de dimensions, un aspect ovalaire.

la masse ectodermique ne tarde pas à se creuser llune cavilá. nommée par M. Duval, à eause de son origine, la cavilé ectodermique; l'expression de cavité amnio-placentaire pourrait également lui stre accorlée, élant donnée sa fin. Cet espace, d'ahord semblable à me fente étroite, s'amplifie; il divise la sulistance de celte masse en deux couches, l’une supérieure et externe, l’autre inférienre et interne. La premiere recouvre la cavité ectodermique, a la laçon d'un dôme. La seconde, par l'eflet le l'accroissement de l'espace qu'elle concourt ì limiter, šinfléchit, et šinvagine dans la cavité para-vitelline, placée an-dessous d'elle. Elle repose sur le protendoderme. Celui-ci, an début de ces modifications, était silué sous la couclı interne; à la suite le l'invagination de cette dernière, il la doulıle, et entoure sa face externe. Il se troure, finalement, posé en dehors d'elle, puisque cette assise interne, le convexe quelle était, devient concave; les objets, l'ahori placés sons elle, lui sont extérienrs par la suite. lintre temps, le protenloderme continne à sétaler, el à revelir une étendue toujours phus grande, daus la lande distale de la coloplanule, de la face interne de l'ectoderme, jusquau moment oì il circonscrit toute la ravité paravitelline.

La corloplanule du Campagnol est alors convertie en un corps complexe, de forme ovalaire, qui conticul leux espaces viles, indépendants l'un le l’antre: la cavité ectodermique on amnio-placentaire, el la cavité para-vitelline. La premiere, limitée par des assises d'origine ectolermique, est interne par rapport i la seconde; sauf en sa partie superieure, qui est superficiclle. Ja seconde, circonscrite par le protendoderme, entoure la majeure portion de la précédente. Sa paroi extérieure est l'équivalent striet de la bande distale de la coeloplanute du Lapin. Sa 


$$
\begin{aligned}
& 0 \text { (3) } \\
& \text { (3) (6) }
\end{aligned}
$$



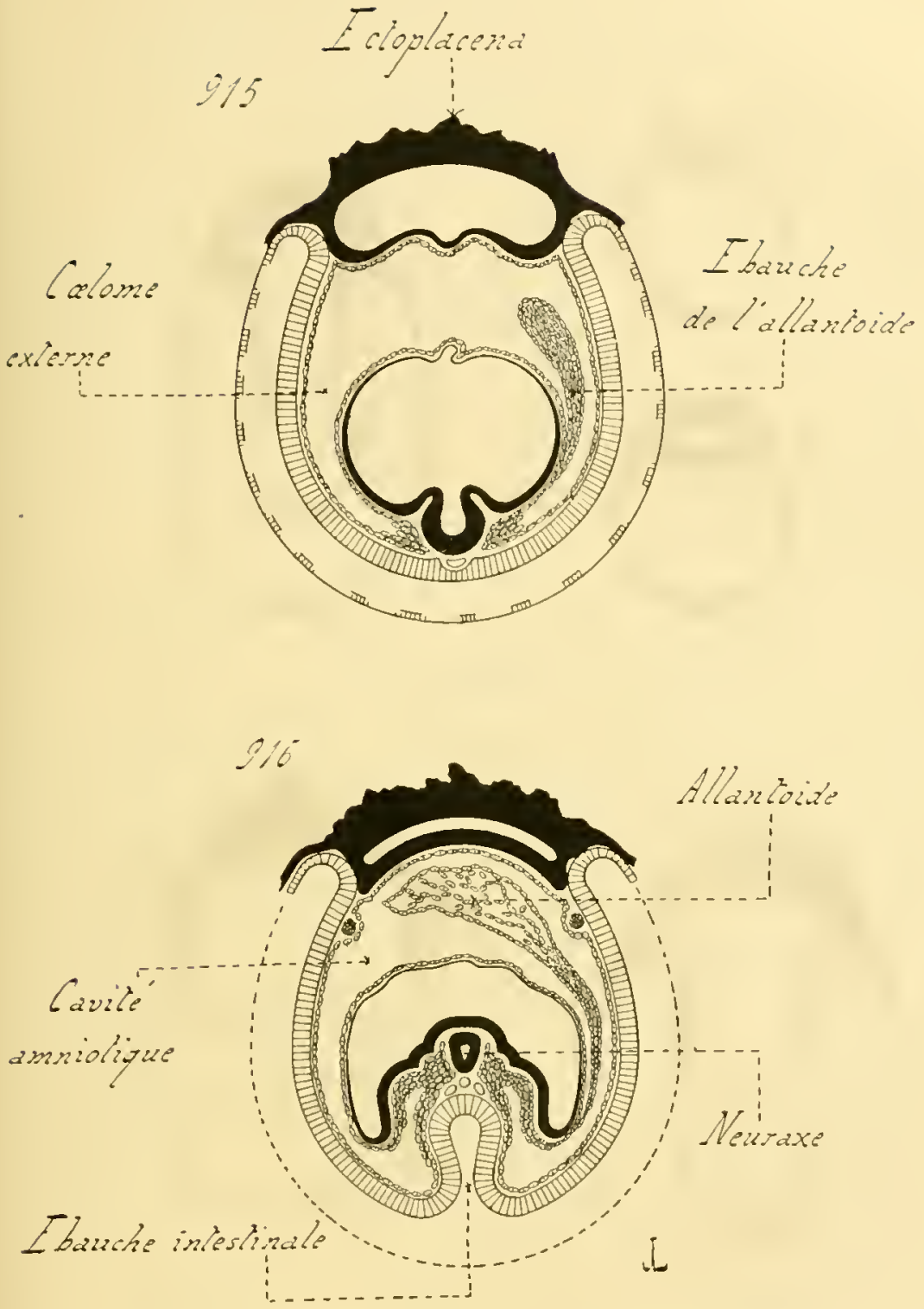

tions considérables. - lin !li3, eette eavité commence a se liviser en lleux parts, er la

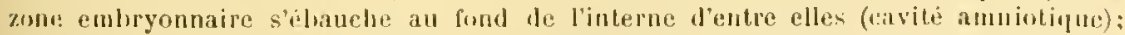
lectolerme distal disparait en partic. - Fin 914, fa caviti evtoplacentaire et la cavite amuintiques sont distinctes loue de l'antre; le nenraxe prend nassance au fond le cetle deruicre; l'ecloderme distal a prespue disparu. - En !I5, pendaut que lus organes

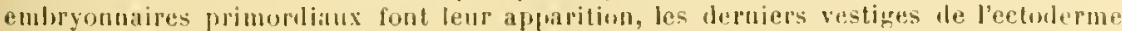

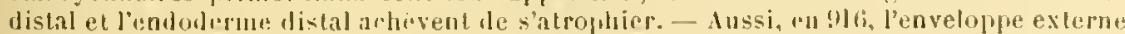

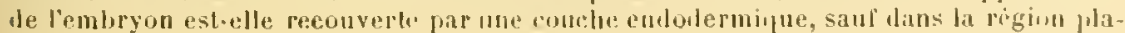
eenlaire. 
paroi inlerme, qui la sépare de la caviti ecloderumique, est l'homologue dra lame jutrine de la lande proximale de la mème curloplanule, angmentée de la zone cmbrymuare, de l'élanche ammiotique, et lime part de l'élunche placontaire. La conche supérieure, do la masse ectolerminure promitive, conserve sa situation arralessus de la cavité ectoJermique et lonne l'autre part lu placenta.

Le colome externe lait ensuile son apparilion, il la manière d"une fonle annulaire et transversale. placée, autour le la cavié ectodernique, vers te milien de son blenduc. En cette région, lo protendodrome, qui louble la face externe de l'ectoderme, se livise an endoderne el mésoderme: le curome externe se creuse dans ce dernier, autour de l'ectolermo. Ciette lente Eranulit, en resserrant, à son niveau, re dernier fenillet, et le faisant piótrer, i la faron d'un diaphragmo, daus la raviti ectulermipue. Ce resserrement s'accentue sans cesse, et a jour dernjer offet de partager cotte cavité en deux espaces désormais indépendants, l'un supérienr el l'antre infírieur. Le premier est la cavite erlopiacentaire, qui se comble ensuite; le seconl est la cavite amniolique, qui persiste. Comme l'emlıyon se façonne dans la partie inférieure de la carité ectodermique. ce deuxiome espace se trouve placé au-dessus de lui, el s'accroît pour l'envelopper.

Le colome externe sépare l’amnios du placenta. Ces denx derniers appendices lérivent des parois de la cavité ectodermique; celles-ci, en s'amplifiant, ont pénétré lans la cavité para-vitelline, pour l'olstruer en majeure partie. Tout en agissant ainsi, elles ont repoussiderant elles l'endoderme, dont elles se sont enveloppés ì la manière diune calotte. Ce feuillet rst, par là, devrnu nxtérieur à elles, comme à leurs dérivés, et les recouve. - La disposition finale est semblable à celle du Lapin ; seulement, elle ost produite plus rapidement, el avec une plus grande conJensation des procédés emplovés. La cirloplanule du Lapin, arant toute pinétration, produit, autour de sa zom emliryonnaire, les premiers linéaments le lamnios ef du placenta; le tout s"eufonce ensuite dans la cavité para-vitelline, et se laisse entonrer par l'endorlerme qui limite cotle dernière. Dans la cwloplanule du Campagnol, une région ectoderuique commence par prolifrer, et lescemd dans la cavilé para-vitellime en se revetant de lendoderme; l'embryon et ses appendices ne se laconnent quaprès la pénétration effectuée.

De mème que cher le Lapin, la hande distale de la coloplanule du Campagnol disparait, en laissant seulement mo étroite zone résiduelle. Cette atrophie est flus précoce que sa rorrespondante tu Lapin.

li. - Les phénomènes prósentés par le lial et la Souris, dans l'inversion te leurs fenillets, rappellent lenrs similaires du Campagnol. Ils en different, cependant, par deux dispositions, qui correspondent a me coudensation évolutive encore plus grande, à une accentuation plus marquée des changements tenulus vers l'inversion. 
La masse ectodemique prend loilivenumt naissance, el se creuse d'nue cavilé. Seulement, lapparilion de cette dernière est plus tardive que chez le Campagnol; les modifications ultérieures sont, pourlanl, identiqnes. - La bande distale satrophie d'une façon plus précoce que sa corjespondante du Campagnol. La lisparition nattend pas, pour se manifester, 'pue les ébanches de l'amuios et du placenta soient séparées l'une de lautre; elle commence à s'elfectuer au moment où le protendoderme de cette hande achève de se compléter, et où la carilé ammioplacentaire est encore indivise.

Le Rat et la Somris présentent ainsi une précocité, plus grande encore que le Campagnol, de l'inversion des feuillels. - Les ju'emier's vestiges de ce phénomène sont oflerts par le Lapin : l'embryon prorluit ses annexes, et s'enfonce ensuite dans la cavité de sa củoplanule, de manjère à rendre superficielle une prarlie de l'endoderme de cette dernière. Le Campagnol marque un degró de plus; les annexes embryonnaires sont plus précoces, et, jar leus apparition, rendent l'inversion plus hitive. Le fait est plus prononcé encore chez le Rat et la souris. Lin ces luois cas, la banle distale de la caloplanule, nullement intéresséc dans la genèse de l'embryon comme dans celle de ses appendices, se délruil; son atrophie est d'autant plus rapide que linversion est elle-mème plus avancée dans le temps. - Si l'on suppose cette accentuation, dont les étapes sont ainsi suivios par degrés, devenue tellc, que la cavité amnio-placentaire ne se crense plus, que le protendorlerme ne s’élende pas dans la lounde distale, el que l'ectorlerme de celte dernière disparaisse pen après l'achevenent de la coloplanule, on obtient les faits offerts par le Cobaye. La structure praradoxale en apparence, du jemne embryon de cel animal, se relie à celle préseutée par les autres liongeurs, el constilue le lerme ullime d'une série d'altérations loujours plus profondes.

Inversion des feuillets chez le Cobaye. - Lu moment mème où la coeloplanule se constitue, ehez cet animal, aux dépens de l'orule segmenté, l'épaississement ectodermique prend uaissance au-dessus du protendoderme, accumulé dans une région qui correspond à la \%one embryonnaire angmentée de la bande proximale de la zone para-embryonnaire. Cel ectoderme épaissi est l’équivalent de celui du Campagnol, comme de celnj dn liat; senlenent, il est de venue plus hative encore. We plus, il s'accroît rapidement, sans se creusel d'une cavité amnio-placentaire. L’apparition de cette eavilé élait déjì lien retardée chez le Rat, par comparaison avec le Campagnol; ce retard se transforme, ehez le Colıaye, en une omission complète.

la masse ectodermique s'aceroìt de manière a pénétrer dans la cavité frara-vitelline. Elle repousse le protendorlerme devant elle, et s'en coilfe; ce dernier fenillel levient, en conscipnence, extéricur frar

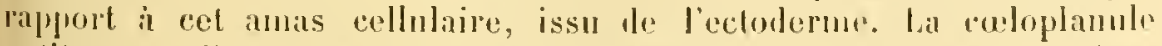
enticre grandil également, de façon ì revelir un aspect ovalaire, qui va 
en s'accentuant. Penlant que s'accomplit ce double mouvement damplification, dont l'un porte sur la totalité de la curloplannle, et l'autre sur l'amas ectodermique contenu dans cello derniére, l'ectoderme de la hande distale satrophie, rt lisparait. Sa fin est si hitive, que le prolendorlerme ne s'accroil point pour le doubler en dedans; elle survient, par une précocité extrúme, des les prenières phases de l'évolution.

Tous ces phénomines répondent à ceux oflerts par les autres Rongeurs; ils ne diffirent d'eux que par leur plus grande accentuation, el leur proulnction plus rapide. Sanf celle altération micux marquée, ils sont hu mème ordre. Et ils ont pour risultal de donner an jeune embryon de Cobaye, des son commencement, une structure inverse de celle qui existe d'ordinaire. Cet cmbryon, à cause de l'atrophic précoce de son ectorlerme distal, qui circonscrivat la majenre partie do la cueloplanule, se trouve rérluil ì 11 amas ectorlermique compact, "u'enveloppe, sauf en une calotte de minime itendue, l'assise protendodermique. Cotte calolte n'est autre que la région, dentenrée superticielle, où l'épaississement s'est manifesté tont d'abord; elle est clargée de produire la presque tolatilé dn placenta.

L'embryon grandit ensuite, en conservant sa forme ovalaire, et maintenant les dispositions lésormais acquises. Le protendoderme reste extérieur. - L'organisme, avec sa motocorle et ses foullels, s'éluanche dans l'extrémité diamétralement opposée à la calolte placentaire. Toutes les autres parties le l'ouf fommissent les annexes. La masse ectodermipue se divise en deux moiliés, au moyen d'un étranglement suivi de scission. L'espace internédiaire n'est autre que le colome externe; d'abord limité sur ses côtés par le protendoderme enveloppant, en haut et en luas par les moitiés précídentes, il ne tarde pas à s'emlonrer l'une conche mésodermique, produite par le protendoderme, et qui grandit dans tous les sens pou le circonscrire. Ainsi que le fait remarquer M. Duval, l'abréviation évolutive est telle, chez le Cobaye, que la carité tu culome exterue prend naissance avant ses popres parois, avant le

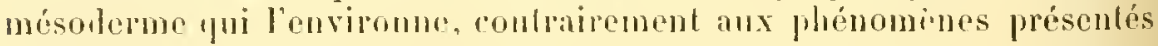
ailleurs.

Le culome externe s'anplitie, el acquiert bientôt un volume plus grand que celui des antres partics. Comme cel accroissement est rapide, comme il est déjà consilérable en minoment on le corps de l’embryon est i peine ébauché, l'uuf du Cohave parait correspondre, en cette

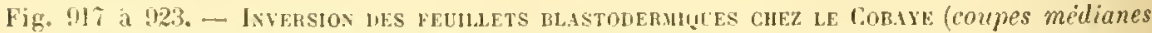
et diayrummatiques; d'apres Mathias lluval. Les ligures sont exprimées de la même manjere que les préedenles, numbolos de 001 a 916. yui se rapportent an lapin et au

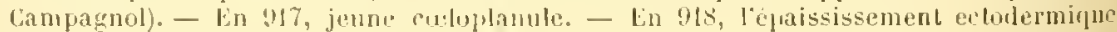
superieur grandil, el se divise en deux masses, pendant que l'ectoderme distal commence à s`alrophier. - En 9I?, celle allophie s'acheve, sans yu'aucun endoderme distal preme naissance. - lin 920, l'épaississement ectodermique se divise en deux parls, dont la supérieure, chargé de donner l'echoplacenta, se creuse l'une "avilé. I la suite de la disparition lative de l'utoderume distal, et de l'absence de genèse d'endoulerune 
phase, à une coeloplanule, a une vésicule creuse, dans laquelle les rulalions habituelles sont changérs lu tout au tont. Dans la réalité. cent

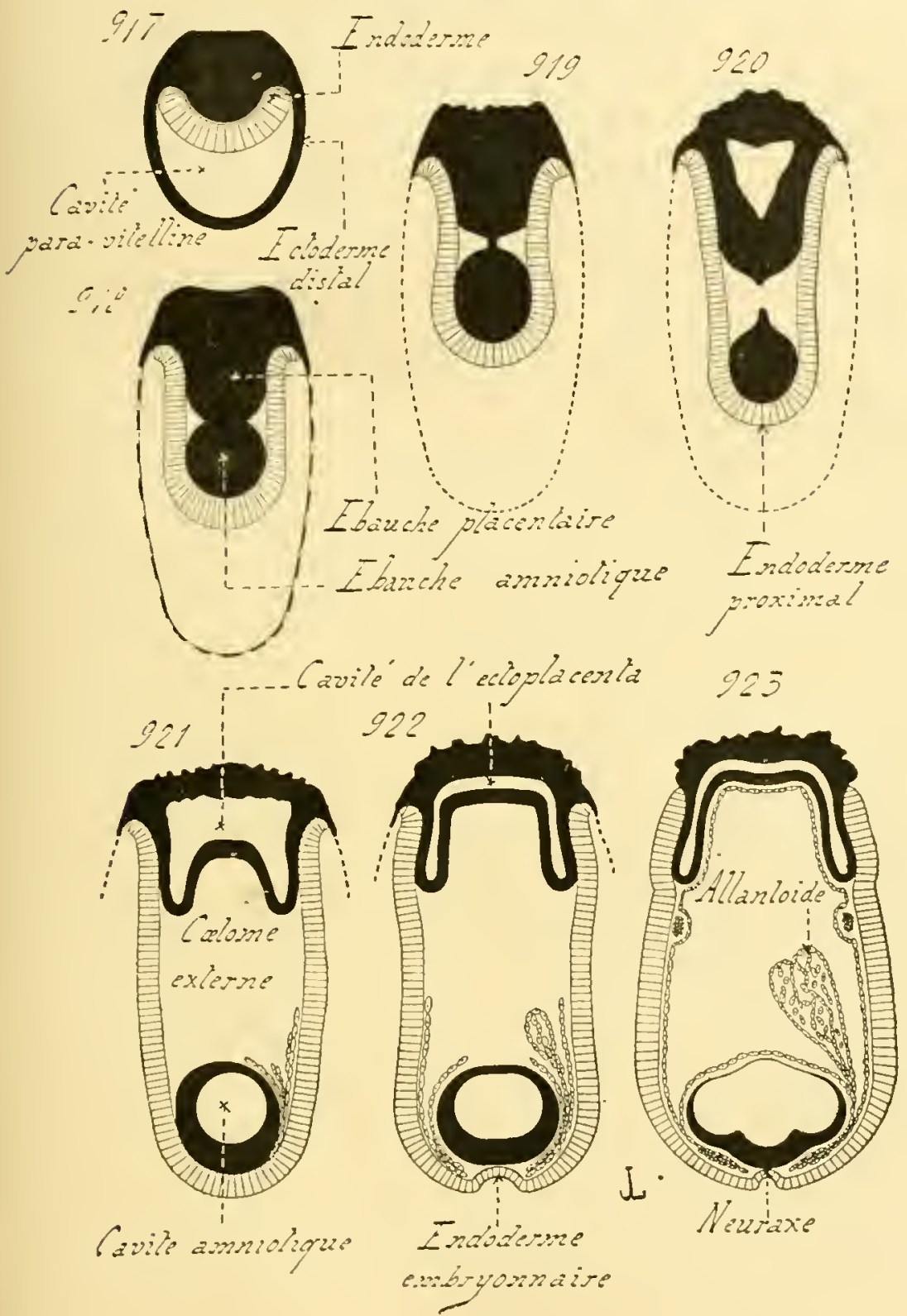

distal, l'ensemble d" l'embryon est limiti a l'intérient par une eouche endodermique. -

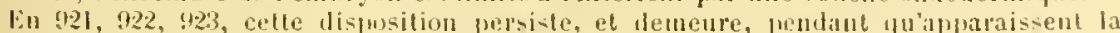
cavite amniotique el les organes le limbryon. 
"ruf n'est plus une culoplanule; il a léprassé celle pliase, dont la durée so tronve des plus courles, et il a élé le siège d'altéralious considérables, dont l'effet est de hui domer l'organisation qu'il possede. Ces altérations sont semblables à celles qui ressortent de l'inversion des feuillets des antres Rongeurs, mais avec une importance plus grande, ot d'une venue phus hàtive. Leur résullat esl de convertir l'auf en une vésicule, limitée extérieurrment par l'endoderme, porlant le placenta sur l'une Je ses extrimités, l'l sur l'antre la zone embryonnaire surmontée de l'amnios. Ces deux annexes, lo placenta et l'amnios, dérivent respectivement dr's moitiés de la masse ectodermique, que le colome externe sépare l'une de l'autre.

En résumé, le Colaye n’est point à part dans la série des Mammifères. ies feuillets sout engendrés jar les mèmes moyens que ceux des autres riprésentants Jo la classe, ef produits par une endoplanule. Sonlement, ils sont soumis, an moment même de leur genèse, ì un reuversinent que les autres Rongenrs montrent aussi, mais d'une façon flus tardive. EL les divers degrés offerts à cet égard, cn parlant du Lapin pour aboulir an Cobaye, perncttent de ratlacher ces phénomènes aux phases normales et halituelles: en les ramenant à des alléralions, d'abord minimes et lentes a venir, puis, par leur accentuation lonjours phus grande daus le mème sens, importanles et précoces.

\section{RÉSUMÉ}

\$1. Coxsuénatuos géxénalis. - Les particularités essentielles, el raiment raractéristiques des Vertébrés, sont donuées par leur nolocorde et par leur feuillet moyen. La premiòre s'étend dans le corps entier, et ne reste pas linitée a la quene. Le second se sublivise en un mésenchyme el un épithélio-nésoderme; celui-ci est produil par deux ébauches, dont les régions lorsales se subdivisent en segments.

Ces animaux ne se reproduisent qu'au moyen de la fécondalion. L'unisexnalité est de riogle; lhermaphroditisme est très rare.

Les varialions sont tries grandes en ce qui louche le développenent les linillets. - llans ses trails essentiels, cetle érolution comporle la genèse préalable des deux feuillels primordiaux. Le protectoderme domne le nenraxe, et persiste comme ectoderme détinitif. Le protendoderme produit la notocorde, avec le feuillet moyen, et demeure ensuite comme endoderme. Les diverses complicalions de la structure sont dues, avant toul, au mésodorme. - Les allérations, souvent considérables, offertes par ce développement, liennent, soit à la présence I'abondantes réserves nutritives, qui composent une vésicule vitelline, soil ì celle d'annexes embryonnaires, tels que l'amnios el l'allunloüle les Sanropsidés et les Mammifieres.

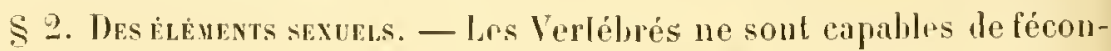

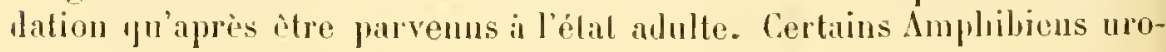


dèles possèdent seuls de la progenèse, en ce sens qu'ils sout susceptibles de se reproduire dans le cours de leur demiere phase larvaire. La uninime différence, établie entre celte phase el l’élat adulte, enlève à ce plénomène beaucoup de son inportance apparente.

L'hermaphroditisme vai, porhut sur les glandes sexuelles ellesmèmes, est des plus rares. Les Cyclostomes de la famille des llyxinidés, avec les Téléostéens appartenaut aux familles des śerranilés etıles Sparidés. le présentent seuls d'une manicre à peu près habituelle, et rapable d'aloutir. Partont ailleurs, il rst accilentel; le plus, les dispositions organiques l'empèchent d'avoir un résultat quelconque. - L'hermapliroditisme apparent, qui n’atteint pas les glandes, vaiment unisexuées, el touche senlement aux anuexes reprorlucteurs, est plus fréquent, mais tonjours accidentel. Tous les groupes de Vertébrés peuvent l'otlirir. II s'exerer sur les conduits sexuels, on sur leur amexes immédials, ou sur les apanages de la sexualité.

Lorigine des spermatozoüdes ne diffëre pas, dans le fond des choses, de celle des autres animanx. Ses diverses phases offrent des qualitis spéciales de forme, a cause de la disposition tubuleuse des testicules. Les cytophores s'attachent a la paroi des tulies testiculaires, et s'allougent en bitonnels, qui supportent des spermatocytes arrondis.

Les mèmes consilérations sont applicables aux ovules, sauf quelques dispositions particulières. Les ovogemmes sont engendrés par l'épithódium germinatif, qui tapisse la surfice de l’ovaire. Leurs éléments se ditlírencient, drune manicre hative, en ovocytes volnminenx, et collnles folliculaires plus petites. A la suite d'un accroissement abondant et inégal, ils pénètrent dans la trame ovarienue, sous la forme de cordons pleins, qui sont morcelés par la prolifération du tissu conjonctif enviromnant. Chaque tronçon ne contient, en définitive, soit à la suite de résorptions, soit d'une firçon directe, qu'un seul ovocyte, entouré de son follicule. Lovocyte grandit, el se convertit en ovule par l'émission de deux cellules polaires; aprés quoi il est expnlsé. - Lovogemme des Mammifires se cremse d'une ravité centrate, et se lausforme, parre moren, "n un vésicule, dite le lollirule de ciratr.

Dans l'ensemble, les Acraniens, les Cyclostomes, ot les Ichthyopsidés, sont ovipares, arue une fécondation extérienre; les Sanropsidés sont oripares, mais avec fécondation interne; ef les $1 /$ anmiferes sont vivipares. Cefte regrte souffre cependant de nombreuses exceptions. Parmi les lchthyopsidés, la plupart des Sćlaciens sont vivipres, avec plusieurs Téléostécus et Amphibiens. He mème, plusienrs Reptiles, appartenant aux ordres des Sanriens el des Ophidiens, mettent an monle lenrs petits virants. Enfin, les Mammifires monotremes sont oripares; et, parmi les antres représentants de la classe, les l)idelphes font sulbir it leurs petits nue secomle gestation dans lenr poche marsupiale.

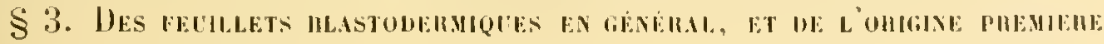


Des ongaves. - Les phases du développement dos feuillets, et de la genese des organes, sont semblaliles, quant au fond, chez tous les lertélrés. Elles subissent pourlant, daus les proeédés suivant lesquels elles se manifestent, des altérations souvent très grandes, tenant à des déplacements, ou à des omissions, el causies surtout par la présence de matériaux nutritifs.

I. Dans les développements dilatés, les fenillets primordianx sont donnés par une gastrulation invaginante. I.es principanx des phénomènes génétiques se rapportent ensuitr à la formation, et à l’évolution, du mésoderme ot ile la notocorde.

lo mésoderme se dédouble en épithólio-mésoderme el mésenchyme. Il est engendré par drux entérocoles symétriques, qui grandissent, el pémirent enlre l'ectorlerme el l'endodermo. les parois de ces éhauches sont épilhúliales. Tout rn sampliliant, elles légagont d'ellesmèmes pulusienr's iléments, qui se portent hors d'elles de ce fail, s'accolent il l'ectoderme ou à l'endodrme, séparent ces feuillets des parois entérocrolienmos. et composent le mésenchyme. Les assises restantes conservent leur disposilion épithóliale, ot couslituent l'épithélio-mésoderme. - Co dernier est la persistance directe des éluatches premières; colles-ci étant an nombre de leux, il est formé de deux parties symétriques, qui subissonl une évolulion idenlique. Chacune d'elles, chez les Acraniens, se divise, transversalement, en segments placés à la tile; tous ces troncons se scimlenl, par la suile, en drux moitiós superposées; les moiliés dorsales demeurent dislinctrs, alors que les moiliés ventrales s"mnissent, pour reconstituer un ensemble simple. Il n'en est pas lont a fait ainsichez les Graniotes, bien que le résultat ultime soil le mème; la région dorsale, dans chacume des denx ébanches, se partage en segments séparis, qui s"isolent de la zone rentrale, demenranl indivise. Les denx zones ventrales, dites les plaques latérales, erandissent, el entourent l'entéron; elles donnent la cavilé abdominale, avec ses dépenlances. Les segments dorsaux sont les mésosomites; l'espace central disfraraill dans chacun d'eux, alor's que la plupart de leurs cellules se eonvertissent en fibres musculaires. - Les premiers éléments du mésenchyme proviennent des ébauches entérocrolienues; les auţes dérjvent, soil de la mulliplication des précédents, soit d'un emprunt, hilivement interrompu, fait à l'épithélio-mésorleme. Les comprosantes de cette part du fenillet moyen sont an nombre de drux : mn somato-mésenchyme, et mn splancino-mésenchyme; toul comme lépithélio-mésonlrme comprend une somaloplenre el une splanchmopleme. Les deux premiers acrompagnent les demx autres dans lenrs modificalions, en les entourant d'me gangue, et los séparant de l'ectoderme et de l'endoderme. De plus, ils se oreusent de cavités nombreuses, agencées en un appareil irrigateur double : le système sanguin el le système lymphatique. 
La diveloppement du neuraxe est illentipun, dans ses traits essonticls, a relui de son homologne des Tuniciers. L'entiropore levient postirieur et dorsal; une bande ectodermirue, míliane et longitulinalr, la plaque médullaire, se lélimite en arant de lui, el s'étend jusıue sur l'extrémiti antérieure du corps. Ce faisant, elle ne reste point plane; elle se ploie en un sillon, dil la gouttiere médullaire, dont les bords se rapprochent, et se soudent l'un í l'autre. le sillon est alor's converli en un canal, au-dessus duquel l'ectoderme se reconstitue. Ce canal est le ncuraxe, chargi de produire les ceules nerveux de l'organisme; il s'ouvre, par son extrómiti postérieure, dans l'entéropore. Celui-ci se ferme vers le dehors, et constitue le canal neurentivique, qui unit la cavité du neuraxe à celle de l'entéron.

La notocorde lérive du protendoderme, comme celle des Tuniciers; elle est engendrée par une hande de cellules, qui se diggage te la zone médiane el dorsale de ce fenillet, el se place au-tlessous du neuraxe, de manière à l'accompagner. Cette bande, devenue indépendante, se convertil en un cordon massif; cel état ultime est sourent précédé, dans lis érolutions dilatées, par une pluase où la bande est ployée en une youtlière cordale. La notocorde s'enveloppe ensuile d'une memlrane, nommce l'shi de la notocorde; ct la plupart de ses ćléments se remplissent le grosses vacuoles.

II. Les altérations, introduiles dans le développement des fenillets, sont de plusieurs ordres. Elles dépendent, en majorité, de l'abondance du deutolécithe amassé dans l'ovule.

Les altérations du protectoderme sont peu nombreuses, et peu prononcées. La plus importante tient à sa division, cher les Amphiliens, les Ganoïdes el les Téléostéens, en deux lames emboitées.

Les changements subis par le protendoderme sont les phus considérables; ils se groupent en cinq types, sériés, suivant lenr complexilé, depuis les Acranicns jusquanx 1 ammiferes. Le premier type est celui des Acraniens : le deulolécithe fait défaut. Le seconl est celui des Cyclostomes, des Amphiliens, el des (ianoïlles; le dentolicithe, plus abondaut, donne une grande ipaisseur i la partie inférieure du blastorlerme, mais la laisse pourtant se convertir en collules. Le troisieme est colui des Sélaciens el des Téléostéens; cette partie inféricure est devenne une vésicnle vitelline, nullement cellulaire. Le quatrième type est offert pir les Sauropsidés; une vésicule vitelline, semblable it celle des Sólaciens, constitue la majeure part de l'ovule entier. Enfiu, les Mammifères vivipares composent le rinquieme: type; la vésicule vilelline existe encore, mais, a la suilu de la possession d'un placenta par l'ombryon, elle est petite, el ne contient qunun liquide privé de rôle untritif. - Les procédís génétiques des fenillets clangent a mesure. Le protendoderme des Arraniens est produit par une gastrulation franche, et symétrique. Celui drs Cyclostomes, des Cianoüdres, des Amphibiens, dérive diune gastrulation 
asymétrique el d’amplitude restreinte. Celui des Sélacions el des Télćosféens provient, mi-partie d'une grastrulation, mi-partie d'une planulation. Enfin, celui des Sauropsidés et des Mammifères est engendré par la voie planulaire, hien qu'un rappel hérédilaire de la gastrulation se manifeste encore par le creusement d'un entéropore, et par une multiplication des blastomères plus active autour de ce dernier.

Les altérations, subies par le mésoderme, lécoulent de celles dn protondoderme: celui-là est, en effel, une partie de celui-ci. les princijales d'entre elles portent sur les communicalions citablies entre la cavité entérique el les cavités colomiques. Ces connexions sont des plus neltes chez los Arraniens; les ébanches mésodermiques sont des entérocueles, dont les cavités rípondent à des liverticules de l'entéron. Eilles s'atténuent chez les Cyclostomes, les Ganoïdes, et les Amphibiens; les cavités colomịues se creusent, d’une manière indépendante, dans les ébauches dı mésoderme, unais sourrent encore, parfois et durant un laps de lemps fort court, dans l'entíron. Elles font défaul aux autres Vertébrés.

La plus importante des altérations, introduites dans la genese du neuraxe, est lonnée par les Cyclostomes et les Téléostéens : cet organe prenil naissance sous la forme d'un cordon plein.

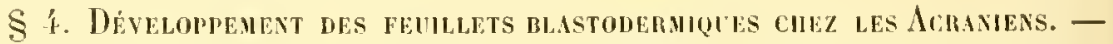
l'ovule segmenté doune me gastrule par invagination, dont l'entéropore devient postérieur el dorsal. L'embryon s’allonge; il prond nu aspect cylindripue, pendant que les denx entripocoles se dégagent de l'entéron, ei se divisent à mesure en segments. Celte scission est complète ; seulement, les régions lorsales de tous les segments demeurent distinctes, et se convertissent en plaques musculaires, alors que les régions ventrales du même côté s'unissent entre elles, tout en se séparant des précédentes. Trois diverticules se dégagent de l'extrémité antérieure de l'entéron, et produisent les appareils, au rôle peu comnn, dont denx s'onvent an dehors. L'irolution entione s'aromplit sans qu'il existe ancome péservo nulriliva.

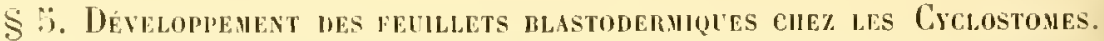
- Ce déveloprement n'est comou que chez les Lamproies, dont l'ovule ruferme une certaine quantilé de deutolécithe, suffisante pour entrainer des altéralions évolutives. La segmentation est folale, mais inégale. La hastule est stratifiée; son blastocule est petit; son blastoderme se divise en denx zones, l'une supérieure, aux parois minees, l'aulre inférienre, anx parois épaisses et formes par les blastomires qui contiennent le vitellus nutritif. La gastrulation allecte surtont la zone supérieure; l'enléropore est postérieur el dorsal d’emblíc. La zone supérienre se déprime fortument pour fommir l'entéron, alor's que le blastoderme inférienr ne sintléehit pas, a vrai lire. La cavité entérique est pelite; située dans la 
partie supérieure de la gastrule, sa paroi inférienro est constituér frar fo volumineux amas des lilastomeres à deutolécithe.

Le protectoderme su façonn aux dépens les cellul's superficielles dre l'umbryon; sa délimitation commence dans lat région supérieure dre ro dernior, el gagne de proche en proche la zone inférieure. Le protendoderme, représenté par tous les autres éléments de la gastrule, comprend deux parts : l'une nutritive, l'autre formatrice. I a première se compose le tous les hlaslomères a deutolécithe; placés sous l'untéron, ils so résorbent peu ì peu, et les drrniess d'ontre eux domont l'endoderme ventral. la seconde consiste en une assisu cellulaire, quj anveloppe l'rntéron en haut et sur ses còtés; elle prolifère activement, el fournit l'endoderme latéro-dorsal, la notocorde, et le mésoderme. Les cavités calomiques de co dernier sont toujours indéproulantes le l'entéron.

S 6. DÉVELOPPEMENT DES FEIILLETS BL.ISTODERMIQLES CHEZ LES ICHTHYOPSUÉS. - Ces deruiers animaux possèrlent drs évolutions dilatées, et d'antros condrusées. Les promjères appartiennent à la majorité les Amphiliens, et aux Ganoïdes; les secondes anx Téléostérns pt aux Sélaciens.

les Implibiens ovipares, qui poudent leurs aenfs dans l'eau, subissent un direloppement dilaté; tels sont les Tritons et les Gronouillrs. L'évolution des secondes est quelque peu plus condensíe que celle das premiers; wlle rapelle de près cellr drs Cyclostomrs, et comporte, de mìme. un division lu jrotendorlerme en une part formative el une part nutrilive. Un phénomène important, offert par lo Triton, consiste en la communication temporaire du culome nassant el de l'entéron. - Les Amphiliens vivipares, on ceux dont les unfs ne sont pas pondus dans l'uu, possètent un! embryogénie condenséc, 'jui, dans certains cas, rapjelle celle des Téléostéens, on relle des sélaciens, et comporte de mème la présence d'une vésicule vilellinr. - Lne telle divrrsité s'rxplique par la situation zoologique des Amplibiens, et par la nature de leurs adaptations.

Les fianoïdes élablissont une trausition, on ce yui concerne la crenèse des fruillets, du type présenté par les Amphihiens ovipares à celui des Téléostéens. Les Sturioniens olfrent le mode le plus dilaté; semblable à son correspondant de la Grenomille, il "In dilfire par une plus grande abondance de matériaux nutritifs. Aussi, la part nutritive du protendoderme est-elle plus volumineuse, et constituc-t-elle nne petile vésicnle vitelline, qui finit par se trouver située lans la cavité stomacale d. l'emhryon. Le deutolécithe est plus considéralile rncore lans l'ovule des lépildostées. En conséquence, la part nutritive lu protendoderme, qui le contient, se différencie hàtivement du reste de l'uuf, se divise à peine en quelques cellules énormes, yui ne tardent pas à s'unir, et se convertit en une vésicule vitelline assez grosse; celle-ci, trop lorte poun èlre contrnue dans l'estomac de l'embryon, reste appendue à l'intestiu, et formo un annexe embryonnaire. - La disposition des Lépidostées est 
un exagération de celle des Stmioniens, qui est, à son lour, une exagération de celle des Imphibiens et des Crelostomes. Comme elle est presyne semblable à celle des Tólóostéens orl des Sélaciens, ells permet de comprendre les rapports qui juignent les développenents dilatis anx évolutions contensées : par une ampliticalion de l'endoderme vintral, 'fui crossil démesurément en ronservant le deutolécilhe, pert toute strueture cellulairr, el se dillérencie, lans l'auf, d'une manière hàlive.

Jans les développenents condensés, l'uuf est divisé en deux parties: une pelite cicalricule, composée de blastolécilhe, ef un volumineux amas vilullin, constilué par du deutolécilhe. Ce dernier est destiıé à donner mo rósicule vitellime, appendne au corps de l'embryon, et *hargée de le nourrir; la cicalricule, a ugmentée d'unr certaine quantité de vitellus évolulif, encore éparse dans les régions superticielles de la précédente vésicule, donne seule l'organisme enlier.

Chez les Téléostéens, la cicatricule se segmente, el produit plusieurs assises de hastomères; l'ensemble de res dernières est le disque blastodermique. Ce dernier sépaissit lans sa région postérieure, an moyen l'une multiplication cellulaire plus intense, et engendre la protulérance wamlale; celle-ci est placére lans nue région correspondante à celle oerupée, dans les développements lilatés. par l'eutéropore. Les firuillets se délimitent sur place, aux dépens des blaslomères. La vésicule vilelline s'entoure d'une paroi, fonrnie par l'extension de la zone marginale du disque blastolermique. - l'évolution des sélaciens rappelle celle des Téléostéens, sauf quelques différences, de valeur srondaire. L'extrémité postérieme du disque hastodermique ne se horne pas ì s’épaissir; elle se soulève au-dessus du dentolécithe sous-jacent, le manière à ménager, enfre elle cot lui, une potile cavité entériqur. Un rappel de la gastrulation se manifoste ainsi dans cetle érolution planulaire.

S 7. JEVELOPREMEXT DES FEULLLTS BLASTODEMMQUES CHEZ LES SAUROPSIDÉS. - Tous les Sauropsidés paraissent avoir un développement semblable, lonl romdensé. Leurs anfs sont complexes. Liovule so compose d'une cicatricule el d'un voluminenx amas vitollin; il est entonré par une epaisse assise alhumincuse, une membrane coquillere, el une coquille "xléréne. La cicatricule, acerue par l'appoint d'une cerlaine quantité de biastolécilhe mélangér au deutolécithe, donne sonle l'or'ranisme; elle compose, fal" sa segmentation, la zone embryonnaire du blastoderme. Cette zone étend ses bords de maniere á envelopper tout l'amas vilellin, et à lui fournil mue paroi; celle-ci est la zome para-cmbryomaire du l.lastoderme, yui lrome son roble à entourer le vilellus untritif, se réduit avec lui, et ne preml aucume part an faronnement de l'économie.

La cicatricule se divise en blistomères, qui se disposont sur filusieurs assises superposées. Iu moment oi ces dernières sont au nombre de demx, me petite cavile, homologue d'un blaslocole, se creuse rntre elles, et disparail ensuile. Puis, le chilfre des couchrs continnc à 
angmenter. Lorsquil alleint qualre ou cinq. l'ensemble de res rangées, qui constituent la zone embromnaje, so sonlève au-tessus du vilellus sous-jacent, el laisse, entre eux, un espace, homologue de l'intéron des grastrules de lertébrés inférienrs, ol nommé la cavilé sous-egraninale. I'antre part, la région postériemre de la zone embryomnaine s'épaisil en un bourretel, qui se perce l'une fente, lomologue a'un enléropore, allant s'aboucher avec la cavilé puécédente : un raphel wo grastululation s'effectue par là dans ce développement plannlaire. Puis, le milien tu hourrelé émet une expansion, dirigée en avant, el creusée d'un sillon : la ligne primilive, destinée ì devenir, au moins en prortie, le canal ueurentérique.

Lassise cellutaire extórieure le la zone embryonnaire conslitur l'ectoderme. Elle engendre le neuraxe suivant le procédi d'incurvation en goultière; l'élanche de cel appareil nail en avant de la ligne primitive. Toutes les antres couches de blastomères représentent le protendoderme. Les éléments, situés sous le neuraxe el la ligne primitive, doment la notocorile; les autros produisent le mésodeme.

l'endant que la zone embryonnaire engendre bes feuillets ot les pudiments des organes, ses hords grandissent, el envolopprout hroutolécitho par un mourement régulier el progressif. Ces rogions romplémentares forment le l, lastoderme para-emloromaire; elles se séparenl de la zone embryonmaire au moyen de plis, d'oì nait l'amnios. Ces plis s'enfoncent de maniore a rétrécir la bande d'union entre les denx zones, el i la converlir en m cordon vilellin. Les phénomènos sont semblables à cenx présentés par les Sélaciens, llu moins dans leurs traits ossentiels; ils en diffirent par la genese des amexes tels yue l'amnios et l'allantoïle, et par la situation du lieu oi s'achove le blastoderme para-embryonmaire. Celte rigion est, chez les lchlhyopsilés, placée an nivean de l'exlrémité postéricure de la zone enulsyomaire, alor's fu'elle se lrouve reprortée, chez les Samropsidés, dans la parlic ovulaire diamétralement opposée a cetle zone.

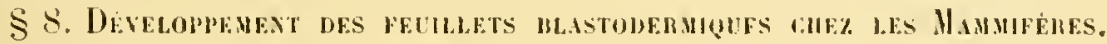
- Jami ces animanx, les Monolremes sonl ovipanes, les Didelples vivipares et i domble gestalion, les Monorlelplaes vivipares el i grostation simple; en outre, les rmlryons des lidelphes sont privés de placenla, alors que cenx des Monodelphes en possiolont un, dou les termes J'Iuplacentaires et de Plitentaires souvent donnés a ces deux sectious. Le dóveloppement des Monoulelphes est senl connu; sans donte, en co qui louchr les phénoménes de l'évolution des fenillets el las principanx organes, crui des Didelphes lui ressemble, alor's que colni les Monoleimes se rapporto à son correspondant des Sauropsidés. Les phases de la genise des fenillets découlent, cliez les Monoulelplors, de rolles gui sont ollortes par les Replibes el les Oiseanx, el n'en diffirent que par des allérations complémentaires, dues a l'absener de lont dentolécillec. 
L'ovule est fort pwlit. La segmentalion, Lolale, ahoutit i une planulation directe; le protectodermo et le protendoderme se délimitent sur place dans la planule. P'nis une cavilé se creuse an sein de cette demière. cutre les denx feuillets primordiaux, el convertit la plamule en une vésicule creuse, la culoplanule; la paroi de rette résienle est constituée prar le protectoderme; le protendoderme consiste en un groupe de cellules, ramassé contre la face interne d'une partie dı feullet extérieur. Cette partie représente la zone embryonnaire de la coloplannle; le reste de la paroi vésiculaire compose la zone para-embryonnaire.

la zone embromnaire donne, a elle seule, fout l'organisme de l'embryon. Autant qu'il est permis d'en juger d'après les faits acquis, les phas's de la genese des feuillets définitifs, el des organes, ressemblent al leurs similaires des Sauropsilés, el s'accompagnent des mèmes phénomìnes; sauf crs différences, ‘u’ancm dentolécilhe n'existe ici, el que le nombre les collules du protrndoderme est, à son début, des plus restreints. Tout en agissant ainsi dans la zone embryonnaire, li protendoderme s'étend lans la zone para-emhryonnaire, et double l'ectoderme qui, jusqu’à re moment, constituait ì lui seul la paroi de cetle dernière.

Chez la plupart des liongenr's, la zone embryomnaire, arec les parties aroisinantes de la zone para-embryonnaire, parlies yu'il est jwimis de désigner, dans leur ensemlile, par le lerme de bande proximale, descend dans la cavité de la culoplanulr; i la suitr de ce mouviment, les feuillets de cetle bante proximale se relournent de dehors en dedans, de maniere a acquérir une disposition inverse de l'arrangement normal. Ce fait est désigné par l'expression d'inversion des fenillets; il se complique de l'atrophie des régions para-enbryonnaires hrmeurées en place, it non intéressées dans ce phéuomène; l'embryon esl alor's anveloppé par la senle bande proximale retournée, dont l'endoderme est situé en dehors, an lieu d'ùtre en dedans. Cette inversion oţre plusienrs degrés de complrxité, el de précocité dans le temps, qui se groupent en une série, la raltachant aux dispositions habituelles. Le Lapin présente le terme le plus simple, le Cobaye le plus élevé; les états intermédiaires sont donnés prar le Ral, la Souris et le Campagnol. 


\section{EMBRANCIIEMENT DES TERTÉBRES}

\section{CHAPITRE TIII}

\section{LES FORMES ET LES ANNEXES DES EMBRYONS DES VERTÉBRÉS}

\section{1. - Considérations générales.}

I. Plan de l'organisme embryonnaire. - Les embryons des Vertóbrés sont moins dissemblables, entre eux, que leurs correspondants des autres embranchements d’animaux. Ils olfrent une unité d'allures générales, el de disposition organique, que les autres êtres ne prósentent pas à un tel degré. Sous ce rapport, l'opposition entre les Vertébrés et les Trochozoaires, par exemple, ou les Arthropodes, on mène les 'Tuniciers, est les plus frappantes. - Une telle constance tient à deux causes. D’abord au maintien, sans destructions ni altérations trop grandes, du plan de strueture qui s'élablit des les premières phases du déreloppement: I'emhryon produit une notocorde an-dessus de son intestiu, son axe nerveux sur la notocorde, et conserve ces appareils en lenr place, les compliquant parfois dans des proportions extrèmes, mais ne les amoindrissant pas. Ensuite a ce fail, que l'évolution procède avee régularité, en allant du simple au composé, sans comporter aucune stase troj longue.

Cependant, malgré celte unité fondanentale, des dissemblances se manifestent entre les emliryons des divers types de Vertébrés. Les eauses de ces dillérences sont multiples. Les mes tiennent à la complexité, jus on moins grande, de l'économie définitive; les autres il la nature du développement, s’il est larvaire on furlal; les dernicres il la présence, on il l'alsence, l'anmexes propres ì l'embryon, et, lans le cas de la présence, il la strurture el ì la disposition de ces appendices.

les premieres de ces causes se liissent aisiment pressentir. Des Arranions anx Amniotes, la divergence est grante, en ce qui tonche lorganisme de l'adulte; el cetle divergence exerce forcentent ne 
intluence sur l'évolution. Jes larves des premiers possedent, en elfet. des systemes presque rudimentairs, eu égard à cenx des emluyons des seconds. - I) autre part, les devoloppements fobux comportent l'existence d'appendices nulrilifs, el nolamment d'une vésicule vilelline, dont sont privés les développements larvaires; ceux-ci ollirent, à leur tour, dans la plupart des cas, plusieurs annexes adaptatifs, qui manquent anx premiers. Les relations avec le monde extérieur sonl différentes; dans los uns, le pelit etre est conservé dans le corps maternel, on enveloppé lans des coques fournies par ce dernier, de manicre a se trourer isolé du dehors. 11 n'en est pas ainsi pour les autres, où l'embryon est directement con rapport arec les milienx extérienrs, se déptare en eux, et y puise les malíliaus nécessaires i son alimentalion.

En somme, les principales dissemblances entre les embryons des Verlélurs, abstraction faile de la nabure le l'évolution, el de la complexité varialıle de lorganisme définitif, tiemnent à l'élat de leurs anmexes particulier's. De tous les aninaux, les Vertéhrés sont ceux qui portent le phus de ces appareils, propres à l'embryon, lestinés à mienx assurer sa vie nutritive arec sa vio lo relation, el i disparaître lorsque liotre passe à la phase adulte. Cies appendices, fort nombreus, sont l'importance variable; parmi eux, renx qui possèlent la plus grande valeur, i canse de leur ròle ou de leur réparlition, sont : la vésicule vitelline, l'amnios, el la vésicule allantoüde. La premièro est me réserve mutritive, composée de leutolécillıe, qui assure l’alimentation de l'emhryon pendant son développenent. Le second astume membrane enveloppante, placre autour lu petit itre, et limitant m inspace, la covite amniotique, dans laquelle colui-ci est plongé, où il peut exécuter quelques mouvements de faible amplitude, sans nuire à ce qui l'entonre. La troisieme est une expansion, imise par la région postérienre de l'intestin cmbryonnaire, qui s'étale 'n dehors de l'organisme fuelal. Son rôle est louble; dans le cas d'oriparite, elle remplit surtout une fonction respiratoire; dans le cas de viviparité, elle constitue souvent un appareil, le placenta, chargé de permettre, dans sa substance el par osmose, des échanges nulritifs entre le sang de la mère et celui de lembryon.

La réparlition de ces appendices, en lant que série de yuantilé et de romplexili, suit assez hien, et accompagne d'assez pres, la classification nalurelle des Vertélorés. Les Lrianiens sont privés le lout annese: embryonnaire. La vésicule vitelline apjarait chez les lchthyopsidés; mais clle cxiste seute, comme appareil de ce lype, car l'ammios et lallantö̈le font loujoms lélaut. Ces lerniers appendices se montrent semlement chez les plus élevés des lerlébrés, chez les Sauropsidés cl les Mammifies; ceux-ci composent, de ce lait, le groupe des Amniotrs ou des Allantöldiens; ils portent, en surjulus, la vésicule vitelline déja possélée par les lehthyopsidés. La complexité embryonnaire est, dès lors, fout graude, it la suite le la présence de ces orranes complémentaires. Elle atleint son comble chez les Hammifères supérieurs, oì la 
résicule allantoïde se convertit en un placenta. - Les deux séries, relle de la réparlition des appendices de l'embryon, el celle de la classitication, se superprosent done avee une exactitude asse\% gramde.

llais cette juxfaposition n’est raiment précise, qu’à la condition d'ètre prise dans son ensemble; en réalité, les phénomines sont phus complexes. Les Vertélnés supérieur's sont lien ceux qui portent le plus d'annexes embryomaires, et les Vertélnés inférieurs ceux qui en ont le moins; seulement, la distribution te ces appareils n'est pas exclusive. Elle est souvent altérée par des modifications particulières, et par ce fai qur les appendires des embryons des Vertélirés ne se bornent pas à la vésicule vitelline, ni à l'allantoüde, ni a l’amnios. Il en est, parmi res ètres, dont les annexes, soit de nutrition, soit de relation, n'appartiennent à aucun des trois précédents. D'm autre còté, tous les Ichlhyopsidés et Lous les Amniotes ne possedent pas une vésicule vitelline développée à un égal degré, autant sous le rapport de la taille, que sous celui de la durée el de la complexité le structure. - A ce sujet. les variations et les dissemhlances sont des plus grantes, parfois mème entre des animanx fort voisins, car elles déprendent des adaptations spéciales aux embryons. Aussi, la série générale ne doit-elle itre acceptée que dans son ensemble, comme liée à celle de la complexité organịue, rar clle n'exprime qu'une partie des phénomènes récls.

II. Formes embryonnaires des Vertèbrès. - Dérelopenexts Lamanns. - Les évolutions embryonnaires avec larves manquent aux Amniotes; elles sont le propre des Tertélrés inlérieurs, mais nexistent pas che\% tous. Les variations, sous ce rapport, sont données par les lehth yopsidés. - Les Acraniens el les Cyclostomes subissent d'une façon constante des phases larvaires. Des états ífuivalents sont également possédés, chez les Ichthyopsidés, par liss Ganoïles et jar beancoup d'Amphibiens; ils sont un peu moins accentués chez les Téléostéens, el manquent aux Sélaciens.

Je son cóté, le moment de l’éclosion des larves est sujet a diversité; il est placé sous la dépendance stricte de la juantité du deutolécilhe accumuló dans l'ovule, et varie comme rette dernière. Les jennes Acraniens sont rejetés dans les milieux extérieurs des les promierres phases de leur évolution. Cette époque est quelque peu tardive dans le cas des Ganoïdes et des Imphiliens: et se tronve l'utre davantage en ce qui touche les Téléostéens. Le retard, dans cette série, est dr plus en plus frononcé, jusqu i atteindre l'omission de toute phase larvaire, of anener le déveloprement liebal, jue présentent les sélaciens avec plusieur's Imphibiens. - Le degré de complexilé acpuis par la larre, in l'instant ou ello échot, est en rapprort direct avec lit situation de ex moment dans le tempıs : plus l'éclosion est lardive, plus l'organisme larvaire est complet.

Les larves des Vertélurés sout aisément reconnaissables. Leur jri- 
valion le revotement vilumlile (sauf chez l'Amphioxus), leur structure élevée, et élablic suivant un plan commun, leur corpss allongé, leur donment $n$ aspect raractéristique. Eilles sont loujours aquatiques, móme relles appartenant ì lles générateurs dont l'habitat est lerrestre, comme il en est pour divers Imphibiens. Elles noflient aucun phénomine de reproduction agame, ni, sauf le cas des Amblystomes, de progenese sexuelle. Leurs appendices adaptatifs, lorsquils existent, consistent en épines supplémentaires, ou rn appareils nageurs, ou en disqu's adhésifs, et ne modifient pas de heaucoup leur allure générale; contrairement à ce qu’il en est rlez leaucoup d'autres animaux, surtout che\% les Trochozoaires, l'accroissement du corps procede suivant mno mème direction, el ne subit pas de trop grandes inégalités. Enfin, les stases sont rau'es, on peu maryuées; les plus considérables et les plus ronstantes sont celles des tètards des Imphiliens anoures, qui persistent sous leur forme pendant un lemps assez long, aJors que leur économie se complete, el subissent, pour passer ì l’élat aululte, une mílamorplose relativement inusque.

En somme, les lifférences entre les larves el les adultes sont moins acentuées, chez les Vertélurés, que rhez les Invertéliés. La plus prononcéc d'enlire elles, abstraction faile de celles lonnées par la strurlure organique, tient ì la juésence, dans heauroup de ras, d'unp petile vésicule vilolline appendue à la face ventrale de lembryon. Celle visicule est composée par le deulolécilhe non absorbé éncore, an moment oi líclosion se prodnit; sa taille est en fonclion, el de la 'juantilé initiale du deutolócilhe amassé dans l'ovule, et de la date de la mise en liberti, el de l'atge de la larve depuis celle date. - Elle fail défaut anx Acraniens. Elle est fort réduite chez les Cyclostomes, et les Amphiliens à évolution larvaire, où elle lisparaì pen après l’éclosion. Enfin, elle est plus volumineuse chez les Ganoüles et surlout chez les Téléostéens, oi sa durée est, en conséquence, plus grande. - La laille le celte résicule esl en relation avec le retard apporté dans l'éclosion Ies larves; elle est d'aulaut plus forte que ce relard est plus grand. La transilion vers les Sélaciens, dont le développement est fu'tal, et dout los embryous possèdent une grosse vésicule vilelline, s'accuse encore à ce sujel.

Dévelopements roraix. - A. Cetle sorte de développements est de règle che\% les Amniol's. Les embryons de ces animanx sont rejetés, dans lus milicux extélieurs, an moment oi ils achèvent lemr organisme. l'armi les lchllyopsiles, les Siblaciens sont les sunls à montrer, d'une manière constanle, de tels phénomines. Les aulres représentants du groupe subissent les évolulions larvaires, sauf quelques exceplious Jonnées par les Anphibiens, et par les Téléostéens. La majorité de ces derniers, au monent oi ils éclosent, ont une struclure tellement rulimentaire, 'pu'il est phutôt permis de les considrirer comme des larves. 
Les développements fotaux, en tant que relations de l'embryon avec ce qui l'environne, appartiennent à leux types : celui des animaux oripares, ot celui des animanx viripares (chapitre XVT, paragraphe?. page 875). - Daus le premier cas, le petil étre est situé hors de lorganisme maternel. Il nest point libre cependant, ni entouré par les milieux extérieurs, contrairement ì ce qu'il en est pour les larves; il se trouve enveloppé le membranes, et de coqurs, fournies par cet organisme, qui l’isolent lu dehors. Il est obligé, lorsque son ívolution est triminée, de se débarrasser, afin d'éclore, de ce qui lui reste de ces coques. - [lans le second type, l'embryou est contenu dans une partie du corps de son générateur, les voies sexuelles d'ordinaire. Son déreloppement achevé, il quitte sa région incubatricr, et parvient dans le monde extérieur.

Les embryous, qui subissent de telles évolutions, sont caractérisés, d'une manière générale, par la possession de voluminenx appendices. Ces derniers se rapportent, soit à la vésicule vitelline, soit a la vésicule allantoïde, soit aux deux en mème temps. - Les lehthyopsidés sont seulement pourvus d'un gros annexe vitellin, composé de deutolécithe, où ils puisent les matériaux nécessaires au facounement de leur économie. Parmi les Amniotes, les Sauropsidés, avec les llammifères ovipares, sont munis à la fois, et d'une vésicule vitelline qui leur sert de réserve nutrive, et d'une vésicule allantoïde, dont le principal rôle est de permettre la respiration embryonnaire. Lnfin, les Ilammiferes vivipares ne possìlent qu’une vésicule vitelline réduite, et privée de touto fonction réelle; mais, en revanche, leur allantoüle acłuiert, dans la plupart des cas, une grande importance, et se convertit en un placenta.

Les stases manquent aux développements fetaux. Liembryon poursuit son ivolution suivant une marche régulière, et complique sa forme générale, comme ses organes internes, sans aucun, temps d'arrêt.

B. - A cause do l'opposition établie, entre les développements larvaires of les léveloppements foctaux, sous fo rapport de la quantité du

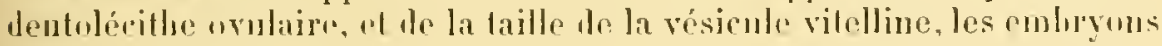
des denx types different, comme allure d’ensemble, les leurs premieres phases. Cette opposition n’est pas tranchée: des transitions nombreuses, qu'offrent parfois les représentants d'une mème classe (Amphibiens par exemple), relient l'un des extremmes à l'autre. Mais elle est juste en général.

Daus les développements larvaires franes, l'ovule contient peu de vitellus mutritif. Sa segmentation, totale, ahoulit ì un état gastrulaire assez nel; les premières ébauches arganiqurs sont crenses d'emblée, ef non massives. Le deutolécithe, non employé dans ces phases initiales, est pen abondant; il constitue un annexe ile taille restreinte, dont la résorption ne tarde pas i s'effectuer, précédant de heaurnup l'achèvement de l'íconomie. Én somme, l'orule tout entier est employé ả 
façonmo l’embryon: ancune partic, issue de lui, nest destime à dispamitre sans passer" il l’adulte.

Il nin rist pas de meme dans les diveloppenents folaux. Lovule, Liè volumineux à rause Ir l'alondance du dentolécithe, subil une segmentation particlle. Ia cicatrienle se livise tout d'aboril, donnant les premiers éléments du blastorlerme: puis, cette couche lilastodermique ruveloppe, jar une progression régnliere, l'ovule entier. Mais tont ce hlastoderme n'est pas employé à produre l'organisme: une seule de ses parties remplit co ròle. Cotte lernière, dite la sone embryonnare, ist composée de lolastomères issus de la cicatricule, et les régions avoisinantes. Le reste du blastoderme conslitue une zone para-embryonmare, dont l'un des robles est d'envelopper le deutolécilhe, de fournir une paroi à la réserv mulrilive. Cette paroi vilelline diminne it mesure que la réserve se résorle; olle ne prend aucune action a la genese lo l’óconomie. - Contrairement à ce yüil en est daus les rrolutions larvaires, l'orule n'ist pas employé tout entier i engendrer les ééments du corps le l'embryon; une de ses parls, consacrée exclusivement à l’alimentation lu prit èlre, rst laissér en dehors de ce phénomènc.

Los développements fotaux ne se ressmmlent pas i col égard; ils dilfirent entre rux sous plusieurs rapports, bien que le risultat atteint soit tonjours le mime. - La segmentation est partielle cluez tous los lertibrés qui les prisentent, sanf chez los Mammifiros vivipares. Lovulede res depuiers sulit une segmentation tolale; mais eppendant les hastomeres so disposent de manire ì composer une zone embryonmaire ot une zone para-embryomaire. La fin est donc constantr, si te procédé varis.

Enr nomvelle dissemblance se manifesle parmi les cas relatifs a la seguentation partielle. - Le blastodrme promel toujours naissance, en premier liru, dans la cicatriculr, qui est unr pretitr partie de l'ovule entirr; il progresse, de là, aulomr iles aulros régions ovulaires, composés par le vitellus nutritif, de manière à les envelopper. Ce deruier commonce flonc par ètre à nu, ou, plus exactement, par otre en conlact direct avec les enveloppes ovmlaires, poul' se trourer séparé d'illes, par la suite, au moyen d'une couche blastolermique. Ia zone laisstie à nu lóbutr par ctro fort grande, et liminur de surface, à mesure que le blastoderme avance, somblable à une calotte, partant de la cicalieule, qui s'anplifierait de plus en plus. Cette zono est souvent lite le blastopore vitellin; co terme est fautil, car alle n'a ancune connexion génétique aver le véritablo hlaslopore, ou rntéropore, de l'embryon. En progressant torjours, la calolte blastolerminue finit par alfronter ses liords, et les souler; linveloppement du dentolécithe r'st alors complet, par la fermeturr le ectle calotte. - La région de l'ovule, on celle occhusion saccomplit, ditlew des lehthyopsides aux Amniotes. Chez les premiers, ellr est placée non loin de la cicatricule initiale, sur le lord 
mèue de ba zon embryonnaire. et au nivean de la liver posterienre dre lentriropore. on des formations homologues silmós en ce point. Che\% les smeonds, la formelure s'effectue dans nue partie de l'ovule diaméIratement opposée à la cicatrienle, ot, en consíyuencer, à la zone embryonnaire qui dérivo d'rllo; la rencontre, et la somlnre, des bords dn lilastodame enrobpant, se manifestent fort loin dn bourreleten croissant, et wr la ligne primitire, qui sont les homologues de l'méroporr.

Lutin, une dernière différence sétalulit entre les Amniotes, el cenx des Ichthyopsidés qui sont pourvus l'une évolution fortale. - Las cmbryons de ces derniers possèdent senlinent, en fait d'annexes. Jenr roluminensir vésicule vitelline, entourée par le blastoderme para-embryominare; ils sont directement en contact avec lenrs coques orulaires, on les parois de leur cavité incubalrice. Il n’en est pas ainsi chez les Amniotes. La zone para-embryonnaire de leurs embryons se divise en deux handes: l'une proximale, cust-it-dire rirconserivant, il la manière d'un anneau, la zone embryomaire; l'autre distule, qui enveloppe le reste de l'orule. Celle-ci rappelle la zone para-embryonnairo entiire des Ichthyopsidés, et ne subit aucune modification spéciale. l'ar contre, la premiere se transforme el se complique, on produisant l'amnios, qui s'étend autour de l'ètre, et lui constilue une memlirane protectrice; de plus, dle si creuse d'une cavité, daus laquelle s'élale la résicule allantoïde. - L'embryon des Amnioles est, par là, fort différent de celui des lehthyopsidés. Non seulement, il porte un appenlice, l'allantoüde, dont ce dernier est toujours privé; mais encore il est enveloppé par des membranes amniotiques, qui manquent constamment ailleurs.

C. - liembryon, dont le développement est futal, se tronve placé dans une cavité aux dimensions restreintes el tixes. A cause le l'aceroissement qu'il sulit, un moment survient où il est trop lonğ pour cel espace; il est alors obligć de se recourber sur lui-mème. - Cefte conrlure ne s'ellectue pas dans un mème plan: lr petit ètre est, d'une façon plus ou moins prononcée, enroulé en spirale. lille est surtout accentuée dans le cas on laxe longitudinal du corps est de heancoup phus grand que laxe transversal, comme il en est chez les sélaciens, et nolanment che\% les Ophidiens. Sa projection dépasse alors une rirconférence complète, el la spirale décrit plusicurs ton's. b'ordinaire, l'embryon se borne is ère courbe en are.

Cette involution est double; elle se comprose d'une courlure somatique, ot d'une flexion cranienne. Ial premiere, générale, s’apllique à l'organisme entier; elle varie d'amplitude suivant les types, on, plus exactement, suivant les limensions que ces types présentent dans les trois sons. - La secomle est plus spéciale. Ville consiste dans le reploirment is angle droil. et parfois mème it angle aign, de la région prérrale de la tète; toute la partie, situce en avant le la bouche, s’infléchit 
sur elle-mème, ct se replie vers la face ventrale du corps. La bouche est alors lournée en delans; l'extrémilí antérieure du corps se trouve placée au niveau dn crveau moyen, au licu de correspondre, comme elle le fera plus tard, el romuse elle le faisail an début, an cervean anlérieur.

la llexion cranicnne n'est point primilive; elle est d'apparition relalivement lardive. Elle se montre an moment ou l'élıauche cérébrale est Jéjì complexe, livisée en ses zones principales, el où la notocorde est complete. En cel instanl, la région préorale s’inlléchil, comme si elle se pliait autour de l'extrémité antérieure de la nolocorle; au lieu le rester dirigée suivant l'axe longifulinal du corps, ells décrit sur cel axe un angle lien marqué. - Cetle llexion manque anx développements larvaires. Ses premiores indications se manifestent dans les embryogénies quelque pen condensies, ou les éclosions ne sont pas précoces; tels sont les Amphibiens, les Ganoïdes, les Télíostéens, chez lesquels elle siefrace hitivement. Elle exisle surtout daus les évolutions fortalos, chez les Sćlaciens et les Amniotes, el demeure pendant un lemps assez long.

Les causes de la flexion cranienne ne sont pas tròs connues; elles sont multiples, sans doute. Son alısence chez les larves, sa présence lans les développements fotanx, el son accentuation l'autant plus grande que l'ćvolution ast clle-míme plus condensée, autorisent à jerser quelle est une des formes de la conrhure totale de l'embryon. Ce type de courhure est plus constaut, mionx localisé el marqui, que lantre; mais tous deux sont des résullats du mome ordro. - Sa locali-

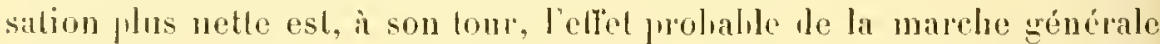
de l'emlryogénie. La notucorde, avec les ébauches sipuelettipues qui commencent à l'entourer, est un axe résistanl, capable de donner au corps une rigidité assez forte; et, commo elle ne s'étend pas jusque dans l'extrénitó antérieure de l'économie, un point faible se trouve placé en avant d'elle. l'ar le simple accroissement inégral des parties, sans mème qüil cxiste des pressions extérieures susceptilules de déterminer une courlure, la région préurale est obligée le lourner autour de ce point libile, et le se ployer en dodans; linégalite d"extension est la cause,

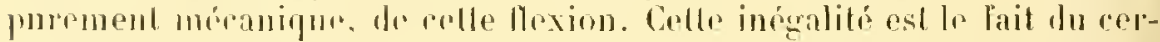
vean moyın, qui gramdit phus rapidement pue le cervean antirieur, et force, frai ce moyen, loute la région placée a son niveau, ef en avant de lui, de s’inlléchir autour lu point faible. - C'est à de tels jluénomènes yu'il convieut, sans doute, de rapporter la cause de la llexion cranienme, cl de sa constance. La disposilion se régularise par la suite. Les pièces du squelelle cíphalique premuent naissance, et sonliennent les lissus mous de la lète; les autres parties de l'ruciphale s'accroissent de leur rite; ef la llexion s'efface ì mesure, jour disparaitue completement.

1II. Annexes embryonnaires. - Ces anucxes, parliculiers à l'emlryon, el ne parvenant pas à lorganisme adulte, sont nombrem chez les Verlébrés. Leur origine cst fort diverse, comme lem structure. 
Ils appartiennent a deux types principanx : les mus sont fournis par la mère, el les autres par l'emlıryon lui-mème. Les premiers, les amexes d'origine matemelle, comprenuent, de leur côté, deux groupes. l'lusienrs: d'entre eux sont produits par l'oraire maternel, et font partie de lia substance de l'ovule; ils seront dits annexes d'origine ovulaire. Les antres proviennent de régions autres que l'ovaire, et sont placés autour de l'ovule, ou hien autour de l'embryon yui dérive de re drrnier; ils scront nommés annexes d'origine extra-ovuluire. - Les annexes d'arigine embryonnaire sont ígalement fort livers; mais ils oflrent ce caractere commun, d’ètre engendrés prar l'économic de l'embryon, et de n’aroir aucune relation de provenance avec l'organisme le la mere.

Anvexes domgixe extha-ovilanize - Les annexes de cette sorte n’existent guère que dans les déreloppements fatanx. Les érolutions larvaires en prossèlent anssi; senlement, ils sont peu importants sousle rapprort le la masse, sont quittés par l'embryon d'une manière hàlive, et ne peuvent, en conséquence, étre considérés comme des appendices réels, d’une cerlaine durée.

Chez les Vertébrés ovipares, l'ovule est entouré par des menuluanes épaisses, de nature variable, et de fonctions différentes. Les unes servent à le protéger; elles consistent en coques chorionnaires, parfois incrustées de sels calcaires, et possédant, de ce fait, mne grande dureté. Les autres concourent également a la protection de l'embryon, mais ils jouent, en surplus, un róle nutritif. Telle est l'albumine; l'amas de celle substance isole le petit ètre du delors, el diminue, pendant que lérolution progresse, car il est absorljé à mesure pour les liesoins de l'alimentation; parfois même, chez certains Saurojsidés (le Poulet, par exemple), un appareil, qui dépend de la vésicule allantoïde, est chargé d'assurer cette résorption.

Les embryons des Vertélorés vivipares possedent souvent des annexes d'origine extra-ovulaire. Les parois des cavités incubatrices, formées, chez divers Imphihiens, sur diverses régions lu corps des générateurs, appartiennent a cette série. Ces appendices sont surtout complexes cherz les Hammifères. Le placentil de ces ètres, prodnit par l'allintoüde, est d'origine fotale; mais il contient les vaisseaux, et du sang, le provemance maternelle. Le sang de la mère est chargé de donner, à cehui du feetus, les matériaux nécessaires pour nutretenir la vitalité de l'économie. En outre, chez plusieurs des llammifères vivipares, la paroi utérine de la mère s'hypertrophie, au contact de limbryon, dans des proportions considérables; ces zomes épaissies sétentent, de manière à entourer ce dernine, soil in tolalité, soil en partie, de membranes enveloppantes. Ces apjrendices, fournis prar l'utérus maternel, et destinés à isoler l'ovule du côté de la cavité ntérine, sont dits des carluques; leur nom est justitić parlenr durée, car ils s'anincissent prentant que la gestation s'aceomplit, et se détachent, pour ètre rejelés lor's de lia plarturition. 
Axxrass bontcise ovruarr. - Ces annexes sont représentés par to dentolécithe acrumulé dans l'ovule. Lr vilellus mutritif est droprovenance matopnelle; il samasse à mesure que l'ovule spandit dans l'ovatre, el alteinl son volume total, an moment oil ce dernier abandonne l'organe qui lui a donné uaissance. Il se rúsolbe au cours des phases embryonnaires, el diminue d'une maniore connexe an temps consacré ì ces dernierrs. Anssi, Jans le cas où il est peu abondant, il ne constitur aucum aprendice lien net; par contre, lansle cas contraire, il forme nn annexe de grande tailie, suspendu à la faco rentrale de l'embryon, el d"mo longue durée, a cause do ses limensions rxeessives et do da lenterr de la résorption. Cet annexo est la vésicule vitelline, encore nommie, il cause de ses rapports, vésicule ombilicale.

La vésicule vilelline existe chez la plupart des larves a l'éclosion tardive; parmi ces deriniores, rellos drs Ganoüdes et des Amphiliens en ollont de fréquents exemples. Soulomont, par l'effet de sa petile taille, elle disparait hitivement, et s'attache au corps de l'emliryon par nne large lase. Une disposilion semblable est ufferte par les 'Téléostéens, avec cette dillérence qur la vésirule rst plus volnminense; sa grande taille est surtont appréciable au moment de l'éclosion. - l'annexe vitellin atteint los froporlions considerables chez les Sulaciens et les Amniotes, sauf les Mammifères vivipares : cest-à-rlire chr\% les Vrrtélrés dont le lévoloppement rst fortal. Il constitur un corps sphripipue, dont les dimensions diminuent a mesure que l'embryon évolue, of suspendu an copps de ce deprise par un long coldon, le cordon vitellin, on cordon ombilical, beaucoup plus élooit quiclle. la vésicule vilelline tes llammifires vivipares whe lien la memo forme et les mimes rapports, mais sous des dimensions moindles, par un balancement avec lo placenta allantö̈lien, que possèdent la plupart de ces animaux.

Les embryons des sélarirus vivipares portent une vésicule vitelline. Celle-ci contractr parlois des adlı́rences avec la paroi de l'oviducte materuel; les zones mises en conlact s’lypertrophient, el lem ensemblo constitue un vérilahle placenla, au moyen duquel des échanges nutrilifs selfectuent entro l'économie de la mire et celle du furtus. Ce placenta vitellin possèle, en somme, des fonctions idenliques à celles de son similair. des Mammilères placentaires: son origino senle est lifférente, puisıu”il dérive le la vésicule vitelline, au lien l'atro fonmi par la vésieml. allantoïle.

Anxexls dougune emnroxware. - Ces aunexes, lout en ayant une provenance commune, sont les plus nomlireux et les plus variés. lls nont aucune rolation génélique aver l’organisme du général'ul; l'embryon leur donne maissance aux lépens des appareils qu’il a déjá élauchés. l.es mo servent il la nutrilion de l'animal, en prenant ce termedans son sens le plus large, el lui faisant comprendre, non seuloment laalimentation réelle, mais encore l'alsorption d'oxygene, la respiration. Les 
autres ont pour roble d'assurer les relations de l'embryon avec en qui l'entoure.

Les amexes nutritifs, de provenance embryonnaire, sont oflerts par les Amuiotes, el par les Amphibiens. - Ils consistent, chez ces lerniers, en organes détournés de leurs fonctions hahiluelles, hỵertrophiés dans des proportions souvent considéraliles, et altachís anx prarois de l'appareil incubateur des génératenrs. Ces annexes sont, suivant les types, lantôt des branchies (Gymnophiones), lantôt la queue (Hy/lodes martinicensis), tantôt des saillies tégumentaires de labdomen (lianu opisthodon), elc. Malgré leur diversité, ces appendices ont un rôle identique; ils sont chargés de contracter des adhérences avec les parois de l'organe incubateur, et de permettre ainsi des échanges entre le sang de la mère el celui du fotus. Ils jouent, en somme, un ròle placentaire.

Les annexes nutritifs des Amniotes sont moins variés; ils sont représentés par la seule vésicule allantoüle. Celle dernière est un diverticule émis par la zone, de l'intestin postérieur, oi ahoulissent les conduits rénaux. Tout on conservant ses connexions ave sa région d'origine, cel appendier grandit hors du corps de l'embryon, et aequiert mu volume considérable; il est souvent creusé d'une cavilé centrale, lans laquelle parvient l'urine. Lorsigue lo déreloppement est achevé, la vésicule, déjà dégénérée en partie, disparait, sanl'sa zone d’allache à l'intestin; celle-ci demeure dans l'économie définilive, et, conservant ses rajrports initiaux, devient la vessie urinaire de l'adulte. - l'allantoille des Amnioles ovipares se borne à sélendre hors de l'embryon, el à se placer en dolans des membranes qui entourent ce dermicr; celles-ci so laissent traverser par l'air venant du dehor's, et les nombreux vaisseaux sanguins, creusés dans sa paroi, juisent en ret air l'oxygène nécessaire ì la respiration. Chez les Mammiferes vivipares, appartenant ì la section les Monodelphes, ou des Placentaires, la vésicule allantoüle s'accole, p'ill une partie de sa surface, à la proroi de l'ulérus malernel; la zone d’atlaclue s'épaissit, et constitue le placenta de ces animaux. Une telle formation n'existe pras chez les Dilelphes, qui sont prives d'un placenta de provenance altantoüdienne. La parturition de ces animanx est très précoce : Fombryon est rejelé eneore imprafail, el il subit une secondr gestalion dans la poche marsupiale de sa mère.

Les amnexes de relation, d'origine rmbryomiaire, diffirent des développements larvaires aux évolutions lietales. - lans les premiers, ils consistent en petits appentices, destinés it mienx assurer l'alaptation do la larve anx milieux qui l'entonrent. Tels sont les appareils de protection et de défonse, comme les épines, portées par les jeunes de plusieurs Téléostéons, yni tombent au moment ou l'animal atteint sa taille dédinitive. Tels sont encore les dispues allhésits, platés sur l'extrémiti antirienre de la tèle, cluy los larves des fianoüdrs. Les plus complexes des annexes de relation sont représentés par le lece corné, muni de dents, 
les lètards d'Amphibicus; ces appendices, propres a l'embryon, sont destinés à pernullre son alimentalion.

Les déveluppements foetaux de tous les Amniotes sont caraclérisés par la prisence d'un anuexede relation, l'amnios, produil par l'embryon. Cet annexe est destiné it entonrer l'animal, et il limilor autour de lui une cavilé remplic de liquile. Il se compose de leux membranss, séparéos l'mos de l'autre par un viste espace, dont l'inlerne semle limite la

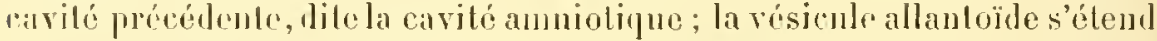
dans cet espace intermédiaire. - La membrane externe, reléguée ainsi en lehors de l'allantoïle, contracte sourent des adhérences, chez les Mammifères placentaires, soil avec les portions allantö̈diennes non uliliscés dans la genrise du placenta, soil avec les carluques lorsquelles cxistent. Ces zones accolérs entourent l'espace ou l'allantoïde est placée, el occupent la périphérie de loul ce qui constitue l'organisme embryonnaire, apprndices compris; elles composent le chorion embryonnaire des anleurs. Ce non leur est vah par leur siluation extérieure, comparable à celle d'un chorion ovulaire par ripjort à l'ovule.

Résuné. - Malgré leur nombre, et leur dirrorité comme origine et comme structure, les annexes embryonnaires des Vertébrés se laissent rapporter, en tant ıue fonctions, ì deux lypes principaux. Dans l'un, ils consistent en organes de relation, surlout en membranes destinces à envelopper l'inclividu, el à l'isoler des milieux extérieur's : tels sont l'amnios, lis chorions. les coques ovulaires. Daus l'autre, its sont chargés d'assurre l’alimentalion de l'utre, el appartiennent à denx groupes, suivant que le léveloppement s'elfectue par oviparilé, ou par viviparilé. lans le cas les évolulions oviprares. l'appendice nulrilif principal est la vésicule vilelline, complétéc par la conche allumineuse; la vésicule allantoïde sert romme appareil dresperation. Daus les évolutions vivipares, la vésicule vitelline se lrouve forl amoindrie. el remplacée, dans son rüle, par un placenta.

Lorigine de ce dernier organe est des plus variables. Le placenta Ins Sélaciens est donué par la vésicule vitelline elle-mème; celui des Mammifères placentaires par la résicule allantoïde; entin, les Amphibiens, lont le développenent est condensé, possèdent ales urganes, de provenances dilférenles suivant les tyjes, mais doul la fonclion est toujours le permethe des échanges mulilifs entre la mère et le foetus. Chacun le ces orgaues ne donne pas un placenla réel, lélimilé et circonscrit, mais le róle existe pourtant. - Une telle genese d'appareils placentaires, produits rhez les représentants d'un aussi grand nombre de groupes, est un des caractères les phus frappants de l'embryogénie des Vertébrés. lille ne se retronve, it nn pareil legré, dans aucun aulre embrancliement; des incubalions existent lien, parfois, mais n'entraìnenl pas la formation l'un appareil spécial, destiné à relier la vie nutrilive du descendant a celle de son ginéraleur. Les seuls lnvertebrés, ponrrus d'un 
placenta, sont les Péripates (Onychophores), el les Silpes (Tuniciers); celle petite quantité ditres ainsi munis fait mienx ressontir oncone la prépondérance ollerte, à cel égarl, par les lertélorés.

\section{$\S 2$. - Formes embryonnaires des Acraniens et des Cyclostomes.}

1. Acraniens. - Le dévelopjement de l'Amphioxus est larvaire m entier. l'al' opposilion aux autres Vertélnés, non seulement l'éclosion est tres hilive, mais encore l'embryon est convert de cils vibraliles, durant une période assez longue; un tel revètement fail toujours défaut aux larves des Craniotes.

Au moment de sa mise en liberté, l'embryon atteint i peine la plase gastrulaire. Son ectolerme porte des cils viluatiles, qui lui servent pour se déplacer daus l'eau; sa forme est celle d'mesphère. Ce dermier aspect ne tarle pas i se modifier: la larve devient, par la prédominance de linne des directions d'accroissement, suivant wne progression réguliere. ovale d'aboril, cylindrique ensuite. Tout en cluangrant ses conlonis, elle conserve ses cils vibratiles, et facomne ses organes interues. Vers le déhut du deuxième jour, yui suit l’instant de la lécondation, les deux extrénitís du corps, arrondies jusque-là, s'effilent en pointe, comme elles le sont chez l'adulte; la région postéricure produit la nageorre caudale. Ia bouche et l'anus se percent vers cetle époque, et permettent à l'entéron, fermé à la suite de l'occlusion de l'entéropore dans le comrant du premier jour, de communiquer avee le dehors. Les cils vibraliles commencent à disparaìtre; ceux qui jersistent en dernier lieu augmentent de longueur, et tombent ensuite. L'inulividu, après leur chute, se meut en oudulant, et en agitant sa nageoire caudale; ce mode de locomotion est désormais conservé.

La larve de l'Amphiome acquicrt ainsi sa structure définitive, par la complicalion régulière el croissante de son organisme, menant toujours une vie libre, et ne subissant pas de stase réelle.

II. Cyclostomes. - Le dévoloppement de la Lamproie est le seul qui soil commu diune maniore complete. - l'ar rapport à l'A mphioxus. la larve de cet animal ectot dume maniè tarlive, deux ou hois semaines apros la fécomblion; anssi possede-t-elle, an momenl de sit mise en liluerté, la pluparl de ses b́anches organiques, et prespue tous ses mésosomites. La durée de la vie liuraire, forl longue, est le plusieurs ammées; l'arcroissoment de l’imlividu s'eftectue pendant relte période. l'uis l'animal, par une métamorphose hrusque, passe ì l'élat adule: cette dernière plase persisle a freine pendant quelipes mois, nécessaires ponr amener la maturicé les appareils sexuels, et la lícondation; apris quoi, la Lamproie meurt.

Les Cyelostomes sont presque les seuls des Verléluris it offrim de lels 
phonomines: une slase aussi longue de la larve, et une hrieveté aussi grande de l'existence sous la forme adulte. Les faits rappellent de pres leurs simjaires les Iusectes à métamorphoses : loute la vie nutritive de l'indivilu s'elfectue alors qu'il est une larve; l'état ablulte, relativement comrt, est senlement destiné à permettre la reproduction. - Les larves des Lanproies sont connues sous les noms d'Ammocetes, de Lamprillons, ou de Lamprisons, Jorsqu'elles sont encore pelites. Elles jossident, au moment de leur mélamorphose en adulte, toutes lemrs dimensions, et ne s'accroissent plus; la larve ìgée est aussi grande que l'adulte, qui provient d'elle par sa transformation.

Metamorphoses de l'embryon avant son éclosion. - L'ovule contient une certaine quantité de vilellus nutrilif, quj constitue une pelite vésicule vitelline, attachée an corps de l'emlıron par une large luase. Cette rísicule est déjả résorliée, presıue en entier, à l'époque de la mise en liberté. Sa forme est, à peu pris, celle d'une splière; comme sa résorption s'elfectue l'une maniere egale, cel aspeet ne cesse d'exister, quelles yue soient les variations le taille.

L'extrémilé antérienre du corpss le l'enbryou se déliunite la première; elle grandit rapidement, et se replie sur elle-mème, autour de la vésicule vitelline, afin de pouvoir tenir dans l'espace restrejut limité jar la coque de l'ceuf. La vésicule constitue un appendice volumineux, attaché à la région postérieure de l'organisme. Celle disposition diflère de celle que présentent los autres lertélirés, dont l'annexe correspondant se trouve souvent placé à égale distance des denx extrémités du corps. - lienbryon conlinue à s'accroitre, el la vesicule à diminuer, par un véritable balancenent, puisıue la seconde foumit au premier les matóriaux mutritils qui lui sont nécessaires. Finalenent, lorsque approclıe l'instant de l'éclosion, la larve est allongée, et cylindrique; sa région postérieure, a cause de la présence du reste de l’apjendice vitellin, est seutement plus épaisse que l'autre.

La larve est ensuite mise en liberté. Son corps est opaque, car la plupart de ses éléments rouliement des granutes deutolécithiques, provenant de la vésicule vitulline. Celle-ci, par sa résorption continue, el qui, en ce moment, approrlue le sil fin, ne tarde pas à donner à l'extrémité postérienre sa forme défuilive. - L'embryon est encore lourl, t pen mobile. Sa rivacité s'accroît à mesureque l'évolution progresse.

Métamorphoses de lembryon en Ammocate. - Depnis l'instant de l'échosion, le changement de la lave en Ammocrete avance avec rapidité; il s'accomplit en trois ou quatre semaines. Arrje ensuite la période

Fig. 924 à 929. - Formes embryonsumes dfs Crclostomes, d'après celles des Lamjroies (contours extérieurs). - En 924, 125 , et 120 , phases préables a l'éclosion. - En $92 \%$, jeune embryon au moment le l'belusion. - En 928 el 929 , Ammocutes. - (Les figures numerotees de 424 a 427 sull drensees d'apres les recherches failes frar uwsjanisliufT.) 


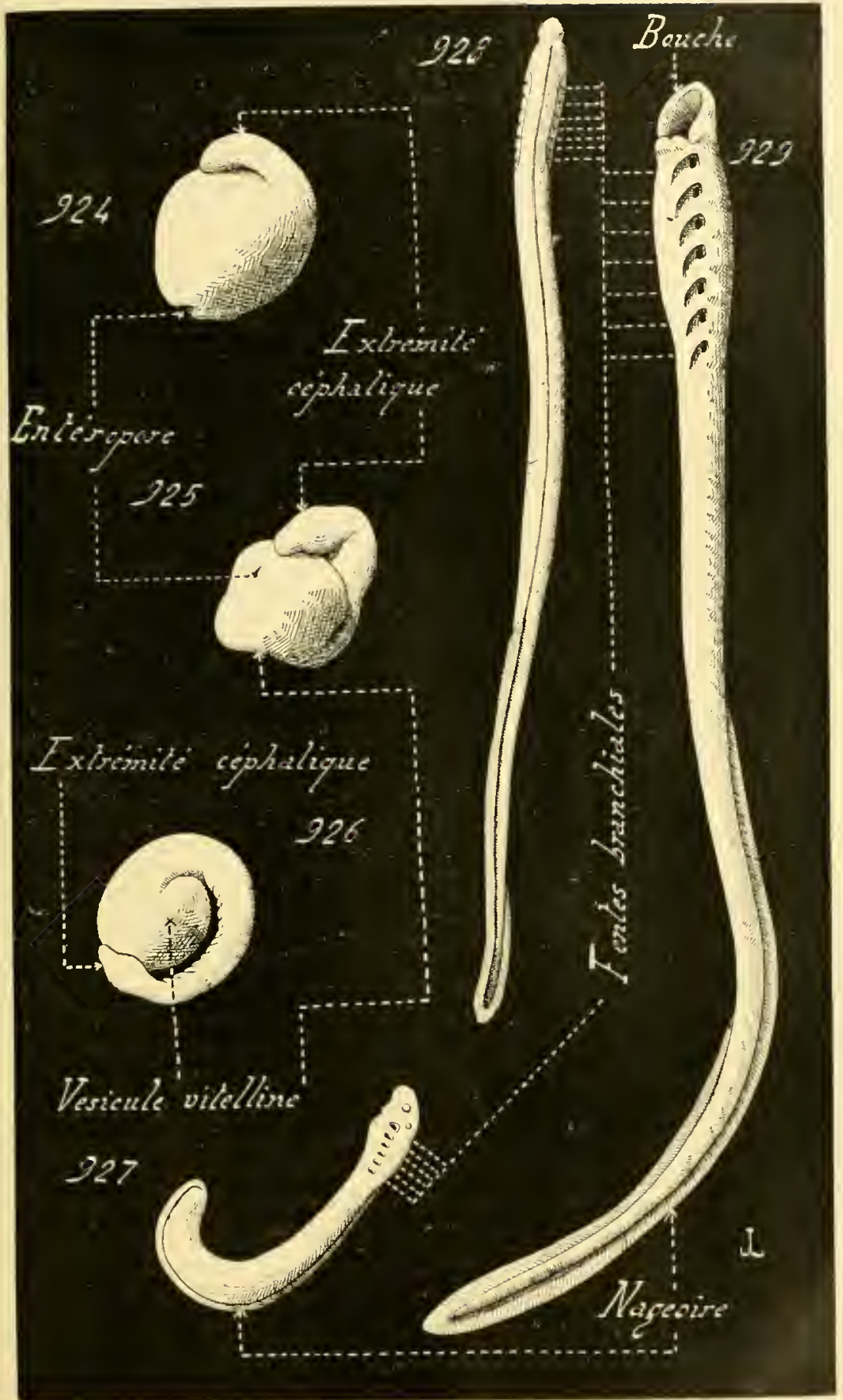


l'état, durant laquelle l'Ammocote crandil, amplitie sa taille, sans modifier son organisme; celle-ci dure rle trois ì quatre années.

le corps de la larve s'allonge, tont en couservant une forme eylindrifur, et se lormant à s'effiler daus son extrénité postérieure. Une nageoire lorsale et une nageoire ventrale, également continues, śétenJent sur le corps, el se joignent l'une i l'autre en contoumant cette extrémiti. - Lo stomeon, léjà éhauché, un pen avant l'éclosion, sur la face ventrale de l’imlividu, et un peu en arriòre du hout antérieur de son organisme, s'approfonlit, et se met en rapport aves l'entéron. La fossette olfactive, également rentrale, se crense devant elle par une dépression des téguments. Demx petits yeux prennent maissance sur les cótés le la tète, do part et d'autre de la ligne médiane; seulement, ils demeurent cachés sous la peau, qui les recourre à la manière d'un voile.

Les appareils contimuent à se façonner, par uno différenciation roissante, et leurs élémeuts absorbent les granules deutolérithiques qui leur viennent de la vésicule vitelline; aussi la larve perd-elle sou opacité première. Le stomeon grandit, et se convertit en un ample veslibule, dont l'ourerture externe est la bouche. La lèro sujérienre de ret orifice samplifie dans les proportions rousilérables; cette cxtension a pour effet de donner. il la louche, une forme en croissant, ou en fer à cheval, et de reporter la fossette olfactive sur la face dorsale le la tète. Des papilles, lisposées sur une rangée circulaire, prennent naissance an fond da vestilule buceal. La région antérieure de l'entéron émet, par ses côtés, les diverticules, qui s'ourrent au delor's, et deviennent les fentes branchiales.

Ces métamorphoses de l'aspect extérieur, accompagnées par le façonnement des appareils de l'économie, s'effectuent en un temps relativement court, quelques semaines à peine. Elles ont pour effet de convertir la lave en un petit Ammocote. - Celui-ci se borme, ensuite, a compléter la structure propre aux cellules le ses orgaucs, et à grandir, sans sulir d'autres changements. Il vit dans les cours d'eau, oil il s'enfonce lans la vase, ot se nourrit de monus délıris organiques, et de petites proies. Sa croissance est lente; elle dure lrois années, en moyenne. Sa faille augmente lans des proportions extrèmes, car c'est sous retle lorme l'Ammocete rur l'indivielu atteint ses dimensions léfinitives. Il passe ensuite a l'état adulte, saus les modifier le beancoup. les Lamproies alultes, lu moins les représentants drs grosses especes (Petromyzon murims et I'. fluviutilis), mesurent, environ, de $0^{\mathrm{m}}, 50$ ) cenlimètres ì l mètre de longueur.

Vetamorphoses de l 1 mmocote en adulte. - Ces rhangements derniers sont asse\% lorusques, of so passent en quelques semaines; ils attrignent l'embryon, non dans sa taille, mais dans sa disposition organique. Plusieurs de ses apparrils se compliquent, alors que d'autres se simplifient. En somme, les systimes de relation et le reproulurtion se 
perfectionnent, alors que ceux de la nutrition diminuent quefyur peu dimportancr. De tels phénomènes concorlent avec ce fait, que la rie nutrilive de l"indivilu s'accomplit durant la période larvaire.

Les lèvres de la bouche s’épaississent: par ce moyrn, cel orifire perd sa forme en croissant, et devient circulaire; les dents prennent naissance sur toute la paroi du vestibule lueral. Les yeux ahandonnent leur situation profonde, el se placent ì lleur de pean; ils sont, des lors, capables d'activité fonctionnelle. La nageoire dorsale gramlit, et se divise en deux parts. - De leur côté. plusieurs des organes internes sulissent des rhangements considérables. te systime des carlilages squalettiques de la tete, et des fentes liranchiales, se complique; charm des orifices extérieur's de ces dernières s'entonre d'une lève saillante. Le ranal hépatique el la vésicule bilinire s'atrophient: le foie cesse de sonvir, par suite, dans l'intestin. L'encéphale épaissit sa substance aux déjens de ses cavités ventrirulaires; le périrarde se convertit en un sac clos, qui isole la cavité péricardique de la carité générale. Les reins s'atrophient, et sont remplacés par de nouveanx tulies urinifères. produits par les uretieres; ceux-ci, d'après Iohrn, cessent de s'ourrir lans le rectum, et de former aver lui un cloaque commun. Entin, les glandes sexuelles arrivent it maturité.

La métamorphose des Ammocriles on Lamproies adultes seffectue durant l'automne, et le commencement de liher. Elle sachire pendant la manvaise saison, et la reproduction se fait peu après sa terminaisun. au début du printemps. L'époque du frai passée, les Lamproies perdent de leur vivacité, et ne tardent pas à périr.

\section{$\S 3$. - Formes et annexes embryonnaires des Ichthyopsidés.}

1. Amphibiens. - Ces animaux possèlent les deux sortes de développements, les évolutions foctales ef les évolutions larvaires, reliées en surplus par des intermédiaires, et non pas entierement distinctes. Des trois orilres de la classe, lins Uroulèles et les Anoures sont les senls. cepenilant, à montrer les deux types, arec les transitions qui les missent: les fiymnophiones, dn moins tans l'état présent lles comaissances aequises, ollirent un mode unipue.

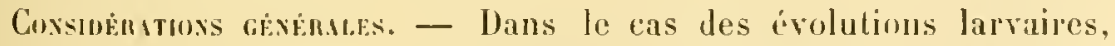
lovule renferme une petite quantité le deutolécithe: en consénuence, l'embryon est privé dr vésicule vitelline, on en porle une de taille restrointe, rapidrment résorfoée. Cependant, le vitellus nutritif est rncore assez abondant pour permettre a l'iudividn de faconner ses forillets. at les éhauches do ses organes, alors qu il est encore contenu dans sil corpue chorionnaire; l'éclosion est assez tardive. - fantòt les évolulions futales saecompagnent de la viviparité, et tantiot de l'oviparré. Quoi- 
qu il en soit, la masse du deutolécithe, répartio dans l'ovule, est sul-

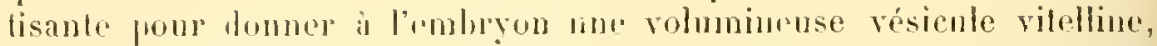
dont la lubér est longure, a cause de sa taille. Lin oulre, la phupart de ces embryons sont pourros d'appareils destinés, soit à peruettro leur respiration, soit à effechner les échanges nutrilifs avec l'économie maternelle. Ces appareils ne sont pas nouveaux; ils correspondent à des organes dont les larves des autres Amphibiens sont munies, mais détomrnés de lem usage pour se prèlel à l'aubes fonctions: lenr struchure se morlifir, con rapport avec leur ròle. - Les intermédiaires, onlue les deux évolutions, sont caractérisés par les divers degrés qu’ils montrent, dans les limensions croissantes de la vésicule vilelline, et dans le relard du moment de l'éclosion.

L'une des principales particularilés lu développement ilis Amplibiens consiste en ha possession de branchies. Le petit etue commence par aroir une respiration hanchiale, que remplace ensuite la respiration pulmonaire; cependant, certains de ces ètres (l'éremilranches) conservent, en parlie, el inrant len vie enticre, leurs premiers apprareits respiraloires. - Le développenent de ces lranchirs est assez complexe. Iranl que léclosion ne se fasse, et que le slomeon ne se joigne à l'entéron, l'extrémité autúricure le co dernier rmet, par ses cotés, un cerlain nombre de diverticules symetriques, dont le chilfre varie entre deux et ciny paires. Ces rxpmsions souvrent au dehors, soil au moment Je l'éclosion, soit par la suile, el deviennent les fentes branchiales; le stomeon sest alors joint a l'entépon, el ces lenter sont capables de rejeter an dehors l'eau qui rntre lans la cavité buccale; mais elles ne sont pas les organes respriratoires réels. Ces derniers sont représentés par les appendices volumineux, lles saillies des tégmments, produits, sur los còtes de la tète, dans la région des fentes branchiales, el contre ces deniores; étant honnér leur provenance, ces appendices, dits les branchies externes, ont une surface constiluée par un épithélium ectodermique. Les bases de loules les branchies d"un mème cólé sont reconvertes frar un repli de ha peau, nommi l'opercule, comme son correspondant las loissons: sentement, il dittèe de ce demier en re yn'il est mou, el privé de loule piece squelettique. I cause de la position des branchios externes par rapport anx lontes hranchiales, l'opercule jecouve res dernibres, puisyu’il s"appuie sur los hases des premieres; aussi, alors qum les oritices internes des lentes sont distincts tes uns des autres, les orifices rxternes se trourent caches par lopereule, ch sourent daus la cavite pu'il limite. Celle-ei ne communique avre le

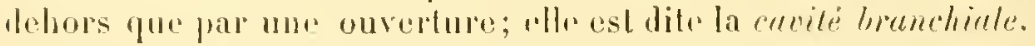

Tons les Amplibiens présentent de tels phénomines, et arrivent, dans leur développenent, a pusséler mn appareil respiratoire ansi constifur. Des differences s'élahlissent entre eux par la suite, d'apres les

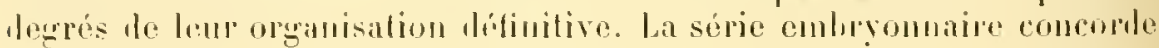
exactendent arec la serie analomignr; il cet égard, les Amplibiens 
domnent un des principaux, parmi les movens de demonstration de la loi embryologique relative a la concordance. - Les larves de ces ètres, dans la périonle oi elles sont munies de branchies, portent égalcment une quene, souvent garnie de nageoires medianes; elles se déplacent dans l'ean qu'elles labitent. Les Urodeles de la section les Pérennibranches ne poussent pas plus loin leur développenent; ils conservent leur queue et leurs branchies externes, lout en rédnisant ces dernières ponrtant, el possédant aussi une respiration pulmonaire. Les Lrodiles de la tribu des Dérotrèmes avancent davantage; ils gardent lent quene, mais perdent leurs hranchics externes; senlement, ils conservent en leur place l'opereule, et l'une des fentes branchiales (celle placée entre le troisième el le quatrième are branchial). Ces animanx, qui composent, daus lordre des Urodèles, le sous-ordre les "lchlhyoüdes „, ont, à cause de lenr structure, une vie plutôt aquatique que terrestre. Les larves des autros Urodèles, appartenant ì lil série des Salamandrines, débutent par offrir la structure, et l’existence, des Pérennibranches; elles passent rnsuite i l'état de "Dérolrème, jar la chute de leurs branchies; puis elles ferment, en outıe, leur cavité branchiale, mais conservent leur quene, et parviennent à l"état arulte, oi la respiration est seulement pulmonaire. Eutin, les larvesdes Inoures subissent plusieurs phases sucressives, lont chacune correspond à l'un des types précédents, conservé dans son ordre; mais elles ne se hornent pas à perdre leurs branchies externes, el í clore leur cavité branchiale; leur quene s'atrophie en surplus, el manque à l'organisme définitif.

Les Amplibiens monlrunt une sériation régulière des élapes de lenr développement, chacun de leurs groupes s'arrètant à l'une des slations de la commune voie suivie. Les plus simples, les Pérennibramehes, sont également ceux qui achèvent le plus tòt leur évolıtion embryonnaire; ils conservent, d'une manière défunitive, les organes que les larres des autres représentants de la elisse portent également. Les plus élevés, les Anoures, vont plus loin que tous; ils passent par la pluase do Pérennibranche, comme par les états intermédiaires, supélienrs a cello-ci; et ils perilent les appareils larvaires, temporaires chezeux, prermaneuts aillen's.

Gruxopmoxes. - Les particularités essentiolles du déveloprement de ces etres sont surlout connues, l'apres les recherehes failes par les fropes Sarasin. Lovnle est riche en dentolécithe; anssi, l'embryon est-il ponru d'une voluninense vésicule vitelline, et passe-t-il, enfermé dans sa conue, par prespue toutes les phases de son evolution. Cette résioule, sphropique, ust directement allachice ì la face ventrale du corps, sitns l'entremise dun corlon; sa paroi rst tries vaseulaire. L'enbryon, dius son délont, s'enroule autour d'elle. Elle diminue sans cesse, par l'effed de sa lésorption constante, mais, à cause de sa taille, ne disparait puassey

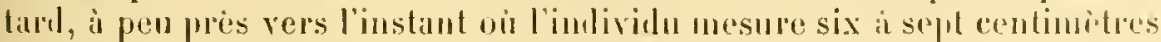
de longraeur. 
La vésicule vilelline sert seutement à alimenter l'ombryon. Ce lernier, bien que renfermé lans sa coque ovulaire, respire an moven de ses hranchies exlrmes, on l'appendices yui leur correspondent sans Ioute; mais ces organos, au lieu de puiser l'oxygène lans l'eau, à la manière de leurs lromologues des larves libres, le prement dans l'air qui traverse les memliranes des aeufs. La mère pond, en elfet, ces derniers dans la terre liumile, et s'enronle autour d'eux pour mieux empêchrela dessiceation; mais, en somme, la respiration est plutôt aérienue. - Ces appareils diffirent suivant les types. Ceux te l'Epicriun glutinosum, lisposés par paires et rameux, rappellent, de tous points, les l,ranchies externes des larves des autres Amphibiens. Cenx de la Cecilia compressicanda sont au nombre de leux, placés symétriquement le part et d'autre de la tète; ils consistent en granłs lobes aplatis, plissés, richement vasularisés, qui sappliquent, pour mieux remplir leur fonction, contro la coque ovulaire, et enveloppent, par suile, le corps presque entier à la facon d'un manteau.

Le déreloppement est presqur fotal, étant donnée l'abondance du vitellus unlritif. Au moment de l'éclosion, lorganisme est acheró, ou peu s'en faut. Les approndices respiratoires tombent, soit un peu arant la mise en liberté des individus, soit un peu après. - Les jeunes rappellent les Urodìles de la trilu des Dérotrèmes: ils sont privés des lranchies extérienres, mais possèdent encore une fente lıanchiale. Ils vivent dans l'eau, où ils se déplaceut en ondulant. Puis la fente liranchiale disparaît à son tour; les individus quittent l'eau, pour ramper sur le sol, et habiter la terre humide.

UrodéLes. - Les Irodèles montrent, suivant les types, des évolutions larvaires et des évolutions fortales. Celles-ci sont pen nombrenses; elles apparliennent ì doux espèces de Salamandrines : la Salamandra maculosa, et surtonl la Salamandra atra.

L'éclosion est assez tardive, dans le cas des développements larvaires. Lembryon, an moment de sa mise en liberté, porte trois paires de branchies externes, rameuses; il possede, en surplus, qualre paires de fentes Irancliales, sauf clıcz les I'roteus et les Menobrunchus, oì il ne sun forme que denx. Fin arriore de la houche, et sur la facr ventrale du eorjs, sont placés deux appendices symétriqurs, dipendances des tromments, somblahles ì des disques épaissis, portés sur un pédoncule. Ces applareils sont les ventouses des auteurs; cenx Jes Amblystomu punctatum acquierent, lapres Clarlie, une longueur assez grande, devienuent presque cylindriquus, el, à cause de leur rôle, ont été nommés des balanciers. La quene, munie d'une nageoire, est le principal organe loconotenr. Les menbris antérienrs sont représentés par de petits moignnous, silués en arrière des branchies; les membres postérieurs nexistent pas encore.

La larve, ainsi faite, se léplace daus l'eau, bu ell" respire avee ses 
branchics. Elle grossit, et acquiert lentement ses dimensions finales. Les membres postérieur's font leur apparition, en avant te la base de la queue; mais ils ne grandissent vraiment, ot ne parriemnent à leur taille d'état, qu'au moment où la larve est déjì grande. - Les métamorphoses, durant cette période de liberté, sont presque nulles chrz les l'érenniluranches el les Dérotrèmes; clles se bornenl í la croissance de l'individu, a celle des membres, et it la réduction partielle des branchies. Elles sont plus complexes chez les Salamandrines, qui perilent leurs loranchies externes et liurs fentes branchiales, el ferment en supplus leur cavité branchiale.

Un remarquable effet de lexiguïté des métamorphoses, et des minimes dilférences élablies entre la larve àgée el l’adulte des Urodèles, est lia présence de la progenèse sexnelle. l'arfois, les appareils sexuels arrivent ì maturité dans l'organisme de larves dont la croissance est achevée, et auxquelles il ne reste plus, pour derenir aclultes, 'lu'à subir l'atrophie, partielle ou totale. de leurs appenlices lranchiaux. - D'après les auteurs, une telle progenèse existe, nais à l'élat accidentel, chez les Urodèles les plus élevés, chez les Salamandrines; quelques indivilus de Triton taniutus, et de Triton alpestris, l'ont montrée. Elle est, par contre, presque habituelle chez plusieurs des Utrotèles les plus simples, chez divers Pérennibranclses, sans doute i cause de la petile dissemblance de structure qui sépare, des adultes, les larres dont la croissance est terminée. Tels sont les Amblystoma, dont les larres sexuées sont les Siredon (Axolotl); et probablement les Butrachoseps, dont les larves sexuées sont les Henobranchus. Sans donle, autant qu'il est permis de le présumer d'après les expériences faites par $\mathbf{l}$. von Chauvin, la métamorphose est placée, au moins en partie, sous l'intluence des conditions extérieures. Si les circonstances sont telles que l'indivilu puisse continner à vivre dans l'eau, il grarde ses caractères de larve, mirrit ses éléments sexuels, et se reproduit sous celte forme. Si, par contre, des circonstances opposées l'obligent à employer la respiralion pulmonaire, ses poumons s'amplifient et achèvent de se développer, les branchies s’atrophient pour la plus grande part, la cavité branchiale se clòt presque entierrment, et les nageoires tombent; en somme, lindividu perd tont ce qui lni était utile prour la vie aquatique, et gagne, en revanche, tout ce qui lui est nécessaire pour pemeltre l'existence terrestre. Mais, quelle que soit l'adaptation, les glandes scxuelles se completent au temps vouln, et accomplissent leur ròle, dans l'un ou l'autre cas.

L.es Salamandra maculose et atra sont vivipares; leur développenent est fortal, d'une manière complète, surtout en re qui concerne la seconde espèce. Le dentolécithe est plus abondant que chez les autres Urodides, el l'embryon porte une vésicule vitelline lien apprarente. La gestation est plus courte chez la S. maculosu. Les jeunes, an moment où ils sont rejetis hor's de l'oviducte maternel, grortent encore leurs 
hrauchies externes, tris longues, et ramifiées. Ces appendices, produits litivement, existent lája lorsfue les petits sont contenus dans le corps de leur mère; appliqués contre la paroi de l'oviducte, ils permettent

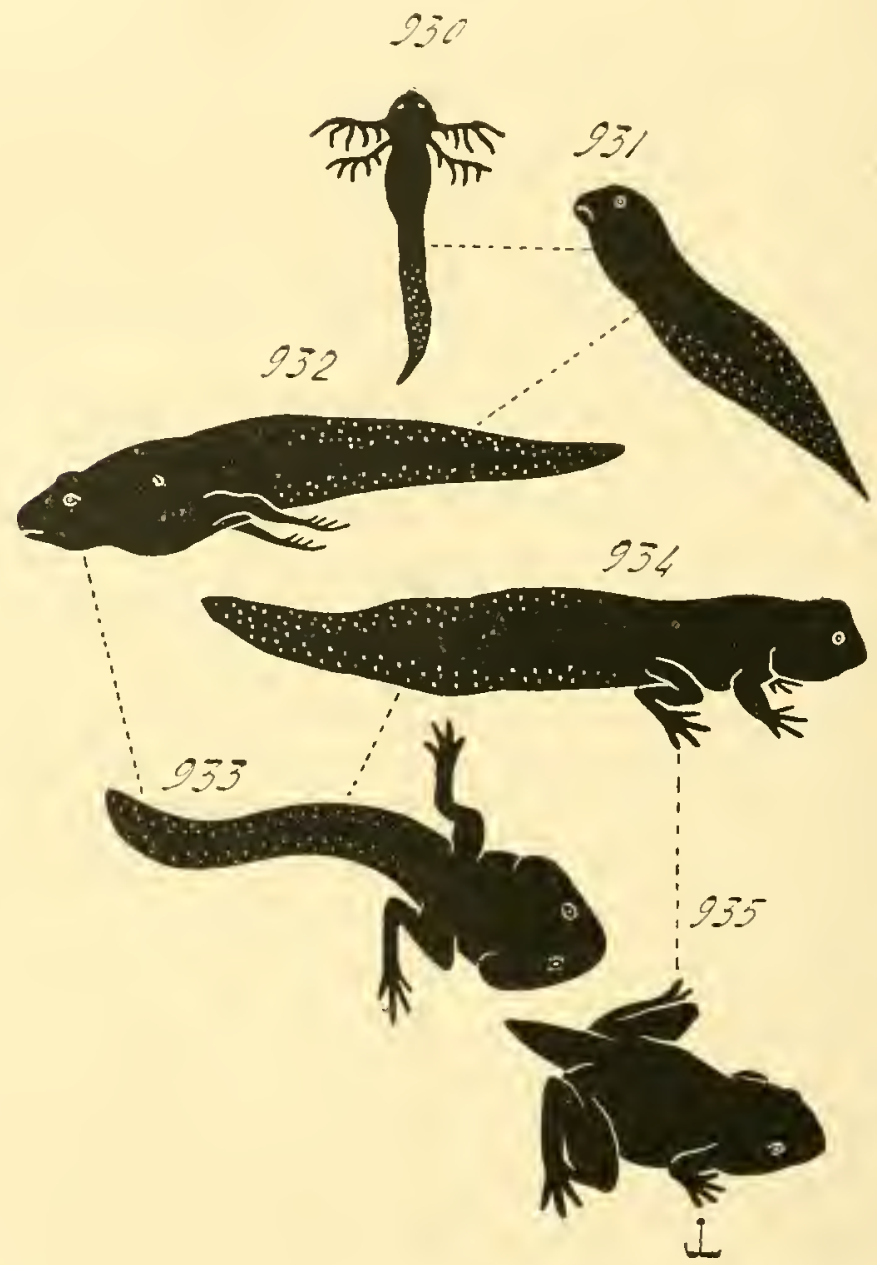

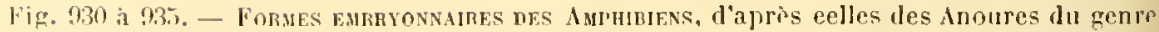
firenouille (silhouettes). - En 930. jeune têtard muni de ses branehies externes. En 931, ces dernieres ont disparu. - En 932, les membres commeneent a apparaitre. En 933. 921, (1) 135, lorganisme se perfeetionne, et parvient à son ètat clèfinitif, pendant 'jue la gueue s'atrophic.

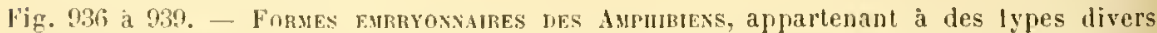
(rontours erterieurs). - Ein 93i, larve de Dactylethra capensis; l'apres les recherches fintes prir l'arker. - En 937, larve d'un Triton, munie de ses houppes tranehiales extérioures. - lin 938, jense salamautra utra, encore munie de ses volumineuses branehies temporailes; l'après les recherehos faites par II. von Chauvin. - En 939, embryon d'un Gymnophione, la Cecilin compressicnula; J'après les recherehes faites par les frères Sarasiu. 


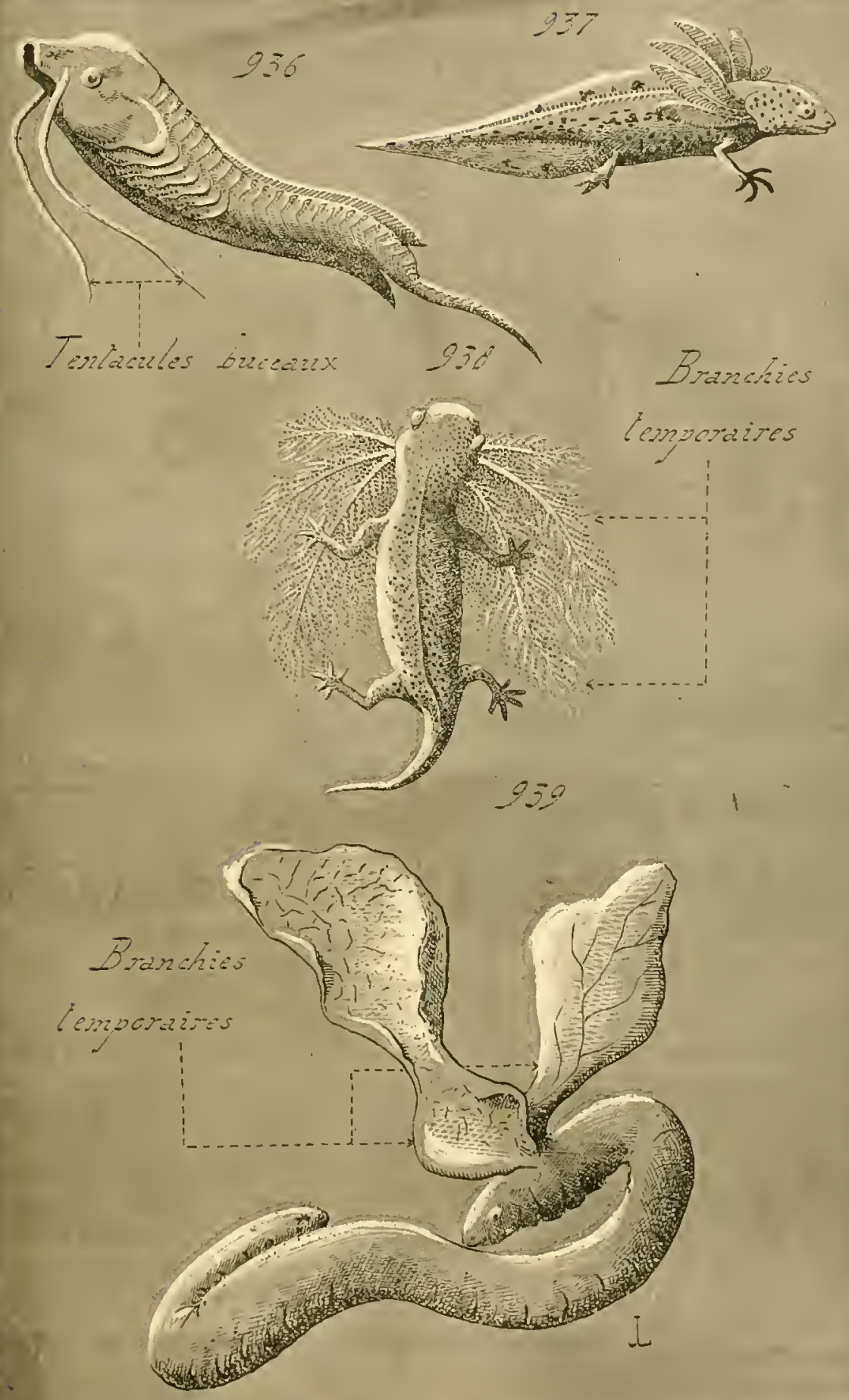


sans doute, a leur niveau et par osmose, des échanges mutritifs entre le sang du générateur et cefui de l'embryon. Ce róle est, sans doute, la raison de leur taille excessive, compráe à celle de leurs homologues des larves libres. - La gestation de la S. atra est complète. Les petits, à l'rpoyue le leur mise en liberté, ont achevé leur organisme, et sont privés de hranchies externes. Celles-ei existent cependant, anssi liveloppées que leurs correspondantes de la $\%$. maculosa; mais elles tombent avant la parturition. La longue durée de la grestation entraìne, frour l'embryon, la nécessitó d'une alimentation aboudante, à laquelle ne suftisent pas la vósicule vitelline, ni les échanges nutritifs. Aussi, de tous les cufs fécondés que contient l'organisme maternel, deux seulement se dóvoloppent; les autres servent à nourir ces dirniers.

Arounes. - Les Anoures offrent, comme les Trodèles, des développements dont les uns sont larvaires, et les autres furtaux. Les premiers sont les plus fréquents; toutefois, les seconds sont pourtant plus communs que leurs similaires des Urodeles. - Les évolutions foclales se ressemblent, à peu de chose près; les embryons sont pourvus d'une voluunineuse vésicule vitelline, ot d'apjendices divers, qui leur servent, soit pour la respiration seule, dans le cas d'oviparité, soit, dans le cas de viviparité, pour des échanges, à la tois nutritifs et respiratoiros, avec le sang du générateur. Les évolulions larvaires sont plus variées, et comportent des métamorphoses mieux accentuces. Ces changements sont de deux sortes; les uns se passent dans l'intérien do la roque ovulaire, ct précòdent l'éclosion; les autres s'effectuent chez la larve libre, et ont pour effet de la convertir en adulte. Les larves des Anoures sont somvent nommées des tétards; elles ne sont pas entièrment semblables, different quelque peu suivant les gemres, et appartiennent à plusicurs types.

A. Développement avant l'éclosion. - Mème dans les évolulions larvaires, le dentolécithe ovulaire est assez aboudant pour constituer une petite vésicule vitelline. Celle-ci s'attache par me large base au corps le l'embryon, et n'est appréciable que pro la forte saillie qu'elle détermine sous la face ventrale de ce dernier. Ce bombement satténne à mesure que le développement progresse; il existe encore, quoique pen accentué, au moment de l'éclosion, et ne tarde pas à disparaître ensuite.

L'organisme se façonne peu à peu dans ses conlours extérieurs. Ses fremiers linéanents se dessinent an-dessus de la vésicule nutritive, ef s'anplifient au détriment de celte demiore. Le corps s'étend, et se divise en ses principales régions. Il se recourbe sur lui-mème, car il s'accroît suivant son axe longitulinal, et se rétrécil suivant l'axe transversal; il devient rapidement lrop long pon la cavité de la coque ovulaire, et se trouve obligé de se ployer; la conrbure atteint surtout l'extrémité posté- 
rieure, la quene, de l'embryon. Ce dernier organe est placé en arrière de l'insertion de la résicule vitelline sur le corjes; il grandit, ol sis munit de deux nageoires mcidianes, l'une dorsale el l'aulre ventrale, qui se continuent en contourmant sa pointe terminale.

Le stomeon et le procteon se creusent, par des dipressions de l'ecderme, et vonta la rencontre de l'entéron; mais ils sindiquent ì peine, tant que l'éclosion n'est pas effechućc. En arriere de la louche, et sur la face ventrale de l'organisme. l'ectoderme froduit, en s'épaississant, deux plaques circulaires, les disques adhesifs, ou ventouses, des auteurs, homologues des appareils correspondants des larves d'Urodèles. - La région antérieure de l'entéron émel les cinł paires de diverticules, qui doirent se transformer en fentes hranchiales; ces expansions s'étendent le dedans en dehors, el ne s'ouvent pas encore à l'cxtérieur. Les loranchies extermes prement naissance, sur les tégumenls, à lemr niveau: elles commencent à s'amplifier, et açuièrent un aspect rameux.

L'éclosion s'etfectue vers celte éporjue. Le moment oì elle intervicut dans l'évolution n'est pas le mine chez tous les types, et vare suivant un certain nombre de conditions, lont la juemière tient a la taille de la résicule vilelline. Cet instant concorde, dans la plupart des développements larvaires, avec l'époque où les appareils branchiaux, déjà élıanchés, approchent de leur structure d'état. - Les jeunes lar'ves sonl I'abord engluées dans les déloris de leurs coques; elless'en débarrassent en agritant leur queue, et se meuvent dans l'eau qui les cntoure. Les fentes branchiales, dans leur j’ogression de l'intérieur vers l’extérieur, finissent par léboucher au dehor's, sauf la première (ly̧o-mandilunlaire), et sont recouvertes par les bases des branchies externes, el par l'opercule, qui commence ì se montrer. Les pelils tètarls se nourrissent, en premier lieu, aus dépens de ce pui leur reste de la vésicule vitelline, mais le stomeon et le procteon ne tardent pas à s'uurrir dans l'entéron, en domnant à l'appareil digrestif son organisation complete d'un tube muni de deux orifices extérieurs, la bouche et l"anus. - La larve est capable, dis lor's, de s'alimenter directement dans l'ean oì elle nage; elle estherbivore. Il ne lui reste qu’a grandir, el yu’a subjr la deuxieme série de ses métamorphoses, destinées à la conduire jusquà l'étal parfait.

B. Wétamorphoses nostérienres ì l'éclosion; translormalion du tètard en arlulte. - Celte série de métanorphoses comprent trois périontes principales, ainsi lue les antenrs, el Inges notamment, l'ont recommu. Dans la premiere, consecutive a l'éclosion, la larve perd ses luanchies extermes, avec ses ventouses. Eille ne possinle, dans le cours de la seconde, aucun appendice exlórieur, sauti la "guene; sa houche porte les annexes supplémentares, qui consistenl en lives courertes de dents speciales, et aceompagnés flun loe corne. Entin, pendant la lnoisiene

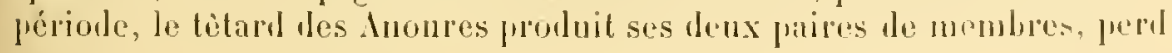


sa purne avec les furérlents annexes buccaux, remplace la respiration branchiale par la respiration pulnomaire, et parvient i l'état adultr.

La premieré éporpo est surtont caraclérisće par la substitution progressire des luanchies internes anx branchies externes. Les leux oper-

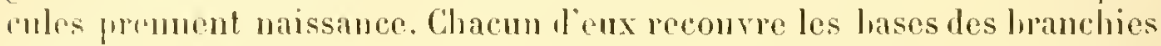
externes placées de son côté. Ces dernieres diminnent de longueur, à mesur qüil samplifie, et satrophient a partir de leur extrumiti libre; leur lisparition prorede dí telle maniere, quelles paraissent rentrer lans le corps, rn s'enfonçant sous loprenule. - Colui-ci limite, vers le dehors. la cavité branchiale; l'oritice extérieurdreetle cavité, circonscrit par le bord de lopereulu et prar la region que cette lame recourre, est lósigni par le terme dre spiracle (spriraculum). Lionverture droito se ferme, chez les larves de la plupart des Anoures: la caviti brauchiale correspondante va dóloucher, frar un conduit Lansversal, dans son homolugue du côté sauche: celli-cj conserve somb son spiracle, des fors impair ol asvmétrique. Hes eanses diflépentes aboulissent pourtant,

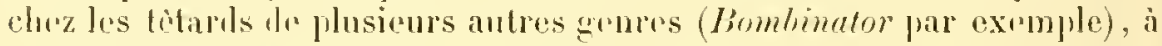
un mème résultat: les deux ourrtures se rapprochent l'me dri l'autre, par leur léplacement sur la face ventrale du corps, ot s'unissent en un spiracle commun : l'animal no possedr qu'un scul oritice loranchial, comme dans lo premier cas. Ces ouvertures ne demenrent distincles, of inléprndantes, quo chez les tètarls ıles Dactyledhra; ceux-ci oflrent, en surplus, d’autres particularités importantes.

Les branchies externes disparaissant, de nouveanx appendices respiraloires se forment a leur placr; mais ils sont eachés sous l'operenle, et meritent vaiment, jar suile, le nom de branchies internes, que les autrurs frum ont donni. Ces annexes hranchianx sont des sallies, richemonl vasenlarisces, des parois des fontes hranchiales; ils paraissont correspombe à teurs similaires des Cyclostomes et des Sclaciens. Les uns sont insérés sur fe borl rxlérieur des fentes branchiales; les autres sont plus profunds. - La larve respire, par leur mosun, à la manière res Prissums. Sa vic est aquatique; ello avale constamment de l'eau par la bouche, la fait pénétrer lans ses fentes branchiales, pour irriguer ses branchios ot permettre les échanges gazonx. puis la rejettr par son spiracle.

La promière périodr est assez courtı. La seconde est plus longue; la larv" saceroît heaucoup pendant quelle s'eflectue. Le têlard est privé l'appendiers latéraux; son organsme se compose d'un corps, glohuleux ou ovalaire, yoe lermine en arriere une longue at large queue, munie d'un amplo naceoire médiane; il se menl, ot se léplace avee activité, au moyen le rel organc. Son vitellus nutrilif est completement résorfé des la premiemépupue: anssi est-il obligé do se nourrir aux dépens de ce pui lientoure. Il ast horbivore. Il possindr, a cet eflet, mone armature fuccale complexe, pui lui est propre, et qui tombe an moment de sa trimslormation en adulte. 
La cavité buccale est précédée par une vasto dépression des léuuments, produilr par l'amplilicalion de la région exlérienre du stomron, et lite le vestibule mecal. Cette poche a la forme d'm entonnoir, aplali de haut en has, dont le fond, ouvert daus la cavité buccals, porte le bec, corné. - Celui-ci se compose de dem mamlibules, rpaisses ot résislantes, line supérieure ot l'autre inférjenre, qui se ferment en se croisant. La substance de ces piéces se compose lu cellules épilermiques, liératinisćes, allongées en fuseau, qui s’intriquent les unes arre les autres. - Lr vestibule est garni, sur son pourlowr, de bonrelels munis de papilles; ces hourrelets, nommés les divros externes, limilent le vaste orifice extériem de cel appareil. Les parois du vestihule portent, en surplns, des replis sajllants, placés en dedans des précédents, el désigrnés, en conséquence, par le trime de léves internes, ou de lames pectinées; celle droniere expression leur viont de leur structure, car leur hord lilre porto une, deux, on trois rangées de dents, groupérs comme celles d'un prigne. Chacume de ces lonts est une cellule épidermique, grossie, kéralinisée, dout le sommet libre se munit souvent de petites aspiérilés. La substance mème de chaque lère interne se compose d'un amas local d'élémcuts ipidermiques, an sein duquel se différenciont les collules destinces à so convertir en dents; ces dernieres s'aplatissent, tout en grandissant, se superprosent a la manière de lisques, et s'étagent au-dessous de chacune des dents comées. Celles qui, parmi ces dernières, vienment à tomber, sont remplacées par les éléments sur lesquels elles reposaient, el la substitution continue ainsi, au fur el a mesure des chules.

Cot apparcil est a'une grande importance pour le tètarl, car il lui permet dr saisir ses aliments, ef de les léchirer en menues parcelles. Comme l'onl montré Ch. van Bambeke et lléron-Royer, il varie, dans ses dispositions, suivant les types.

La troisième période les changements comprend les métamorphoses finales, qui aboutissent à l'élat adulte. - le titarl domne naissance. presque en mème lemps, à ses deux pajres de membres. Les anléricurs se faconnent sous les opreules, les postérieurs lans la zone d'union de la queue el du corps; la silnation cachée des fuemiers fail que les seconds sont seuls apprarents, au déhut. Les dents, et le bec, du vestilnle buccal, se détachent el tombent. La quewe diminue de longueur, ot s'atrophie peu à peu, par la lestruction et la résorpliou plagocytaire des lissus qui la composent; les leucoeytes sont les agents arlifs de celte résorption. Les fontes hranchiales se forment; les limanchies inlernes of lopercule sont rejetos; les poumons, pui avaind lojil rommenón a fourliomner, sont désolmais les semls orgines clanlegés de la respiralion. -

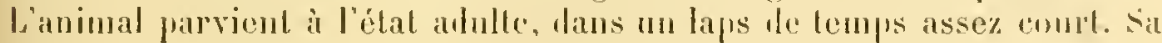
métamorphose est accompagnée de changements considérables dans son économie; ceux-ci portent, en plus gramd nombre, sur le lule digestif, 
pui se raccompit pour se ronlormer en vue d"une alimentation ramivore, et sur l'appareil sanguin, pui se modifie d'une manière connexe à l'établissement de la respiration julnomaire.

C. Diverses formes de trilards. - Les titards des Anoures ne se ressemblent pas; ils diffirent des mus aux autres sous plusieurs rapports, notanmont en ce qui fouche la taille. la coloration, el la disposition du vestibulo luccal. Ces dissemblances, el surtoul celles relatives ì celte lernière particularité, sont suffisantes pour caractériser les espéces, el jour les dislinguer, Ju moins dans un grand nombre de cas. - La forme génórale, seule, ne varie gucire; elle dome anx larves de la plupart des Anomes mue allure spériale, qui permel aisément de les reconnailre.

Cependant ifuelques-nues, fort peu nombreuses, de ces larres, offrent des caractires propres, yui les éloignent des aulres. - Linsi, le tètard dn Pseudis paradoxa parvient à une taille consilérable, égale í celle de l'adulte, et parfois mème supérieure. L'accroissement, la vie mutrilive, de l'individu, s'accomplissent en enlier durant les phases larvaires; la ressemblance, sous ce rapport, avec les Cyclostomes, est frappante. - Mais l'altération la plus grande est celle d'un rejurésentant do la tribu des Aglosses, le Mactylethra. Les larves de cel animal sont Iros lifférentes des tèlards ordinaires. Leur corps, allongé, se termine, en arant, par une tèle aplatie. el, en arriere, par une quene filliforme, que les nageoires recouvrent seulement en partie. Le vestibule buccal, privé de ses appendices cornés, porte, à chacm des deux angles de son orifico externe, un long tilament. Les denx orifices lunchiaux sont conservés en leur place. Enfin, l’opercule ne recouve pointles ébauches les membres anlérieurs, yui sont à mu. Sans doute, les dispositions spéciales a celte larvo, que l'arker a étudiées, nofînenl aucunc imporlance, en tant qur: rappel ataviqur'; elles concordent, tries probablement, arre des condilions al'existence, auxquelles les tètards des autres Anoures ne sont pas sommis.

1). Léveloppements ficlaux. - Les évolulions fotales des Amphiliens anoures ne sont pas ctablies sur un mème plan. Elles dillïrent, entre ellos, sous deux rapports principanx: d'aborl, en ce qui touche l'abonlance du vilellus nutritif, et, par suite, le moment de l'éclosion; en seconl lieu, suivanl que le générateur est ovipare, ou vivipare. Au sujet de la quantiké du deutolécithe, le volume de la vésicule vilelline, appendue an corps de l'emliryon, est d'autant plus grand que cette réserve alimentaire est plus considérable. De plus, dans le cas d'oviparité, l'organisue folal porte des appendices vascularisés, qui lui servent comme apprareil respiratoine; ces annexes correspondent à des organes, font les larves soul hien munies, mais développés et accrus en vue le lem rôle. Si le généraleur est vivipare, ces appendices existent 
encore; seulement, ils sapplipuent contre les parois de la carite inculatrice, et, jar osmose, alisorlıent i la fois loxygene du sang matrinel, el, sans doute, quelques matériaux nutritifs. Les liffépences entre l'oviparité el la viviparité tienment done à ce fait mèmo, qui dépend du génératrur, et non aux formes embryonnaires: celles-ri sont sourent semblables daus les denx cas.

l'évolution condensée et complicle, dans laquelle les jeunes crosent il un étal fort roisin de ladulte, sinon ave mn corps acheri, est asse\% rare. La plupart des I'ipa (vivipares), et surtout l'llylodes martinicensis, avec la liana opisthodon (ovipares), sont presque les seuls à lotirir; l'alimentation fotale est sullisante pour permettre à l'embryou de terminer son organisme. - Partoul ailleurs, l'éclosion précide quelqur peu la venue de l'état adulte; les petits sont mis en liberté sous la forme le tètards, encore munis d'une queue, et capaliles de vivre dans l'eau.

lors appendiecs vascularisés, lestinés à permoltre la respiration $\mathrm{em}-$ bryonnaire, sont divers. Les plus fréquents d'entre enx roprespondrut aux bran hies r.xtermes des larves; resolganes lemement plus longtemps yue rhoz res dernieres, ot sirvent au foetus pour absorber de loxyènt, soit a lavers la roqur do son ceuf, soit a travers la paroi do la ravité incubatrice qui lo contient. Lorsque l̈instant dr l’éclosion approrhe, res anurxus tomlent, at le juune sen trouve privi. - llans le cas où l'érolution fretale est complete, ces branchies reternes paraissent insuffisantes pour la fonction qui leur ast dévolue; elles sont supplées daborl, al remplacées ensuite, par dos rógions du eorps, arrures daus lours dimensions, ot richement vasumarisces. Cottrégion rost la qurur, rhuz les Pipa. qui sont des vivipares; il an 'st do mème chez les Ilylodes martinicensis, lien que l'oviparití soit ici la règle. Jimlıryon des liana opisthodon, égalemeul ovijares, possede jar rontere, sul la face ventrale ife son

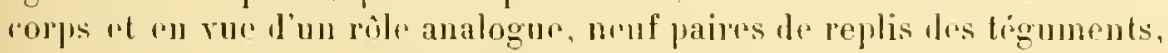

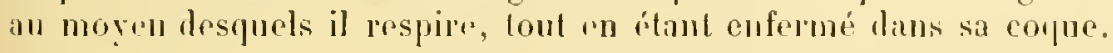

11. Ganoïdes. - Les souls Ganö̈les, lont le trivoppement se trouve

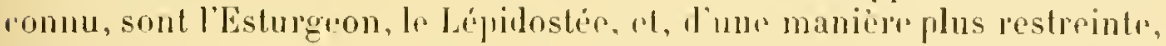
le Polypterr. Tous sulissunt une érolution larvaire. L'éclosion est assez.

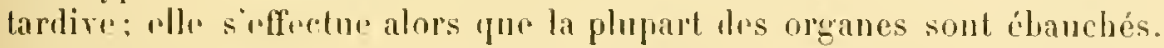
Ce rrtarl ust dì à la présunce, lans l'ovule, d'une assez grande quantití de vitellus nutritif, plus ronsidrable cher lo lepilostér qur chez l'listurgroul. Les mitamorphosis larvaires ronsistrnt surtout en l'aceroissemmut du rorps, acrompagué du façomemont des appareils de l'économie. Los appendices embryonnaires, pen nombremx, sont représentrs par la vésicula vitrlline, et par des hranchies rxternes. Ia disposition le la promièru, nt l'existence dos sucondes, lapprochent, i la fois, le développre

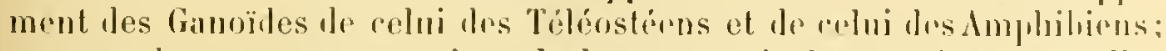

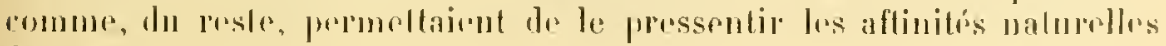
le ress inimanx. 
Le vilellus nutritif est moins abondant dans lovule de l'Esturgron que dans celui du Lípidostre: sal massu est, pourtant, assez volumineuse

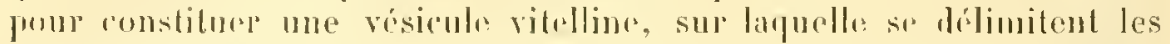
permiers linianents du corjs de l'embron. L'ébauche embryonnaire occupe, à pen de chose pres, tunte la surface de l'hémisphere supérieur de la vésicule, ot sobtale sur clle, sans resserer sa zone d'union en un cordon vitellin. Aussi cerlains organes, deslinés à ètre reportís sur la firec ventrale lu corps, alor's que la vésicule sera résorlée, se facommentils à côté d'appareils dorsaux; tol est, notamment, le remr, lont le ruliment prend naissanne en aviul de la tete. Un tel diplacement dans l'espace est la consípuenece de la lurme affectée par l'annexe nutritif; celuj-ci conslitue une éplicse saillie boubée, sur la face ventrale du corps, ot repousse dans la region dorsale lous les systimes qui dojvent, flus Lard, prendre sa place. - Ivee les progries do l'évolution, le corpes augmente de laille, el la vésirule vitelline diminue de volume. La lête, et surtout la queur, dépassent cettedernjère, en arant et con arrière; mais leurs limiles, dans leurs lignes do jonction, sont encore conluses, ar la résicule s'insere tonjours, sur le corps, par me large base. An moment W: l'éclosion, elle se frésente rncore conme un gros mamelon, en saillie sur la face ventrale dr. l'économie: l'embryon mesure alors six a sept millimitres de longueur, at ne la résulbe que dans le cours de sa vie lilire.

Les phénomènes sont 1 peu dissemblables chez le Lépidostée, i cause de la plus grandr taille do la vósicule vitelline. Par suite, le corps de l'embryon se listingue nicux d'elle, et l'embrasse in partie comme i) en est chez les Téléostiens. L'instant de l'éclosion est, malgré ces dimensions phus fortes, presifue pareil it relui de l'listurgron; senlement la résicul ritellinu est, au moment mème de la mise en liberté des larves, un peu plus voluminemse.

Les larves fraichement ineloses sont tres petites, par rapport it la taille

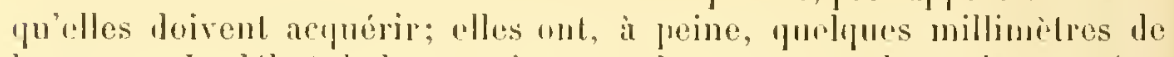
longnemr. Le début de leur croissance s'aceompagur dre quelopes métamophoses, moins prononcées pourtant que celles des Amphiliens, dont

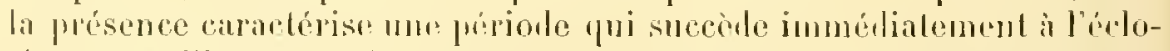

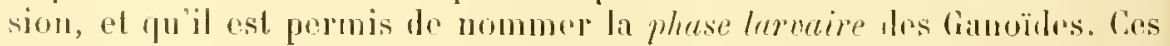
rhangements acomplis, l'indivilu, bien quacern lans des proportions assez fortes, est encore de limensions restreintes; il posside pourtant

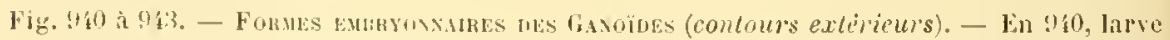

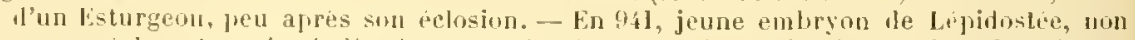
encore éclos, et a peine indipue sur sa voluminense vesicule vitedine. - En!lie, ombryon

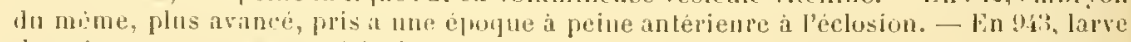
lu mime, jen apris son iclosion.

Les trois premieres ligures sont domnees d'apres les recherches de lialfour; la derniere est Iresice d'apres les recherelars do: I'arlier. 


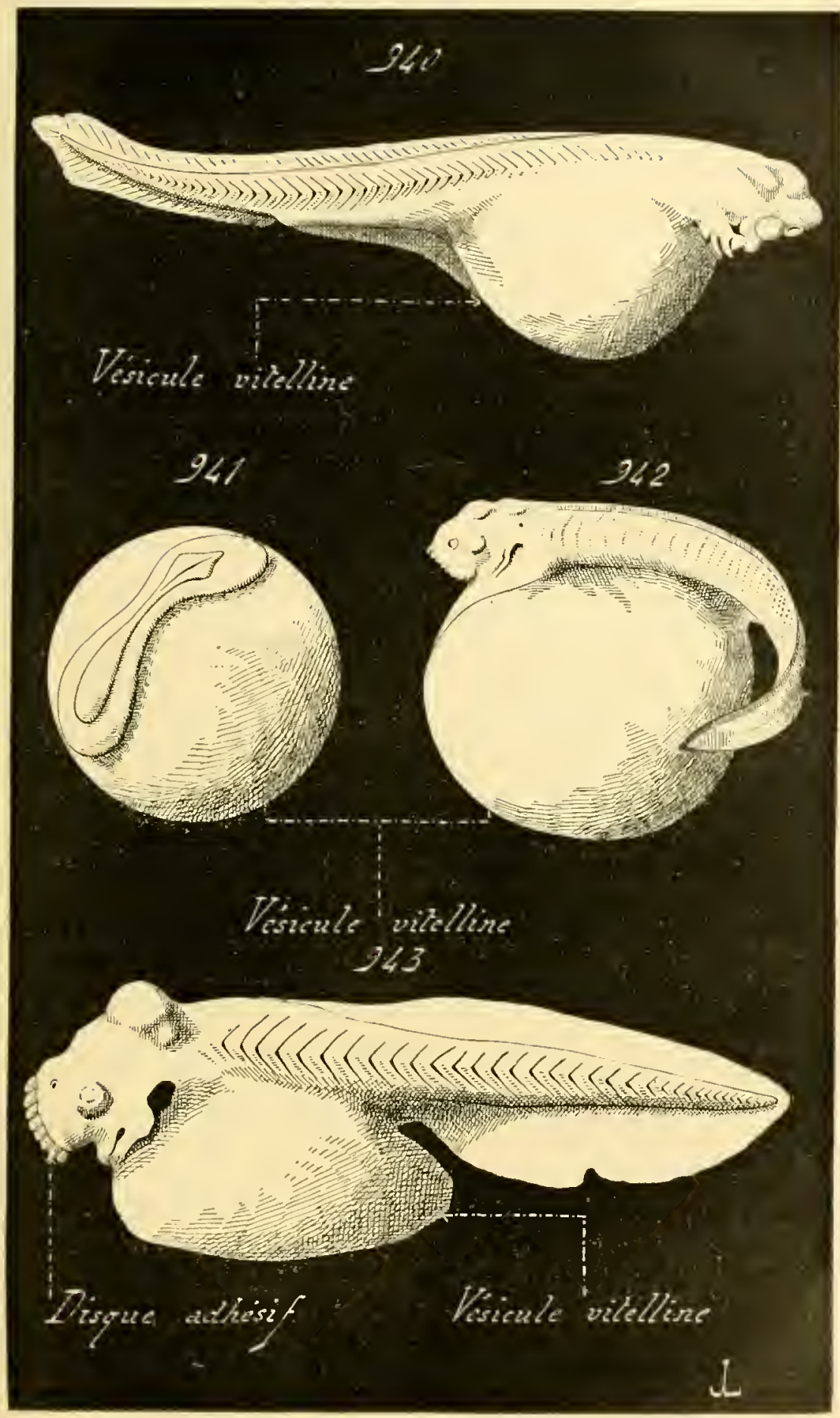


Lonte l'organisation de l'adulte, dont il differe seulement par la taille. Il est parvenu à l’état jeune; et ria plus qu’à granolir, qu’à murrir ses glandes sexuelhs, pour levenir semblable ì ses générateurs.

La larve libre est, it son délunt, munie d"une vésicule vilelline, qui liminue pendant que le corps grossit, et ne tarte pas a disparaitre. Cot annexe, par sa privation de corton, rappelle son homologue des Amphihirns et des Téléostérns: ello est intermédiaire, d’après sa taille, entre relle des premiers et colle des secomb, plus grande qur celle-lì el plus petite que colle-ci. - La quene est longue et large; ellr portr, sur sa lace dorsale "t sa lace ventrale, une nageoire moliane et continue, semblahle à celle des telarls d'Imphibiens. Mais elle ne lisparait pas en entier; certaines de sos parties demeurent ì leur plaer. pour donner les nageoires impraires, of postérienres. Je ladulte. La rigion dorsale de la bande de nagroire. sitnce sur l'extrémité libre de la queue, s`atrophie, tantis que la zone ventrale persiste, et samplifie: aussi, la disposition hétérocerque so sulistilue-t-rlle it l'homocerquic initiale.

La louche, du moins celle des larves d'Esturgens, porte les dents sur les mathoires. Ces organes different de reux drs tètards d'Amphibiens, en co qüils ont une origine semblable ì relle les lents véritables, et sont prodnits, a la lois, par l'épiderne et le derme sous-jacent. Ils tombent, vers le quatrieme mois consículif à l’éclosion. - Des mamelons, grompris en une plapue rirrulaire, et midianr, se déreloppent, en avant de la homble, anx lépens de l'ertolerme. Ils sont surtout arcusés chez les larves les Lépidosties, auxquelles ils servent pour s'attachrr et arlié-

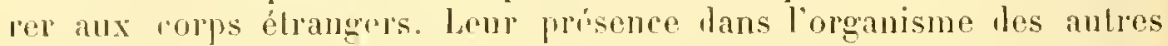
Ganoilles est encore sujetle i contestations; lirn que les jemes Esturgeons portent, en la meme situation, yuatre saillies cylintriques, probablement homologmos les appendires précédents, et deslinées peul-êtr. à devenir les larbillons de l'adultr. Cet annexe embromnairo priste pendant longtemps: les levres huceales les larves de Lépidostée s'allongent rn deux màchoires proeminentes, munies de dents, et les lorniers vesligres de la playue arlurive conslituent me masse charmue, placée sur l'extrémité lihre do la mandibule superieme. - Plusienrs anteurs, balfrum entre autpres, ont romparí cet appareil aux papilles adhesives des larves urodieles les'Tuniciors. Liabsemede tels anuexes chez les embryons Jos deraniens ef cenx drs Cyolostomes, jointe à l'inrgalilé de leur répartition chezles fanö̈les eux-mimes, eréent me interuption dans la concorlance, el empechent darepter me folle homologie. Lexistenes d'appendices semblables sur le corps les têtards I'Amphibiens. mais siluós an arrière de la lom qu’il słagit ici d’une analogic par cunvergence fonclionnelle.

lendant que les fentos loranchiales precut lours oritices extérieurs. lopereule prend maissane, sur chacun des côtés de la lôte, en arrière de la lente lyo-mandibulaire, el sélend au-dessus dielles pon les recomvir. Lemrs ouvertures se garnissent le papilles vascularisées, dis- 
posées sur plusieurs rangées, qui, malgré leur petife taille, rappellent assez les branchies externes des tètards d'Amphibiens; celte ressemblance est surtont le fait des larves de l'olyptères, munies d'une paire de longs appendices branchiaux, produits prar des saillies tégumentaires. - Les nageoires paires naissent après l'éclosion.

La larre parvient ensuite ì l'état adulte, far m accroissement of un perfectionnement continus, progressifs, de lout son corps. Sauf la résicule vitelline, résorbée en entier dans les trois on quatre semaines cousécutives ì l'áclosion, les autres appendires qui lui sont propres ne sont pas très volumineux, et lrur disparilion ne modifie pas de leaucoup l'asprect général de l'économie.

III. Téléostéens. - La plupart des reprísentants de cette classe sont des animaux ovipares, dont la fécondation est extérieure. Malgré la petilesse des ovules, l'évolution est quasi frotale, à cause de l'alionlance du vitellus nutritif. Cependant l'éclosion, assez hâtive, s'effectur alors que l'organisme n'est pas encore complel; aussi l'embryon, devenu libre, est-il pourvu d'une grosse vésicule ritelline, qui se résorbe pendant quil achère son économie. Cette période de liberté, durant laquelle le corps se termine, en s’alimentant do préférence aux dépens de son annexe vitellin. peut ètre nommée la phase larvaire des Téléostéens. D’habilude, relte phase n’offre aucune mélamorphose importante, si ce n'est la dimimution progressive de la vésicule nutritive, at furelques changements apporlés dans la disposition des nagenires. l'ourtant, chez certains types. des morlifications assez grandes, jui portent sur la présence d’appendices supplémentaires, ou sur des dériatious organiques, šintroduisent dans ce développement; elles varient d'un groupe a l'autre chez les ètres qui lrs présentent, et introduisent quelyur diversité dans l'évolution uniforme de ces animanx. - Les Téléostéens viripares, peu nombreux, sont à peine connus, en ce qui tourbe la présence et la situation des appendices destinés à assurer, soit la respiration, soit la nutrition, du fatus.

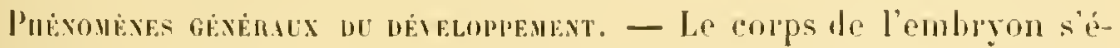
bauche sur l'bémisphère supérieur de la résicule vilelline. par un frocéde scmblable i celui des Ganoïdes. Il acpuiert rapidement me forme cylindrique, et, a causu de sa longuenr, s'enronle autour de la vésicule, "fn'il embrasse, suivant une bande inuatoriale, sur une grande dendue. - L'érlosion s'effectue d'une manière précoce, alors que l'annex mutritil n’est pas enrope résorbé. les princijales des ébanclues organinues ont cependant pris maissancr. La quene, volumineuse, mulue d'une nageoire impaire el médiane rontinue, défasse de beancoup an arriere la zone d’iusertion de la vísicule sur le corps, ut sert it l'imli-

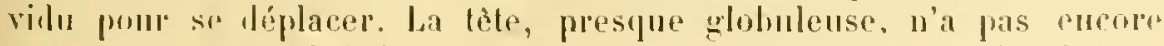
rerètn son aspect léfinitif: elle porle rependant des yenx roluminemx, 
plus grands que ceux do l'arulle, par rapport à la Laille le lorganisme.

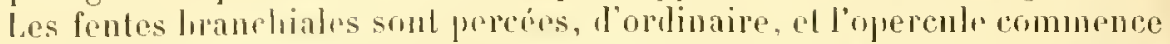
$\therefore$ les peeunvir. Ces fontres possident somvent dos papilles, saillies dévoloppées sur lurus prarois, ef assez forles pour proéminer an dehors, l'unc quantiti variablo suivant les types. Ces appendices sont homologues, sans doule, dr leurs similaires des ranoïdes; ils se réduisent, ì mesure que l'évolution progresse: ils correspondent anx premiers repulis apparus sur la muquense luachiale, amplifiés des l'abord daus les proportions excessives.

La lare se mull an moyen de sa queue. Celle-ci porte, sur sa ligne moliane, une nageoine voulrale el nne autre lorsale, itembes depuis le nivean de la vósicule vitelline jusqu’a l’extranité libre de celle quene;

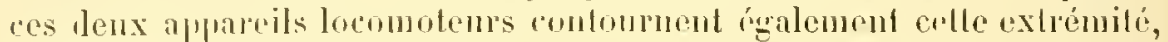

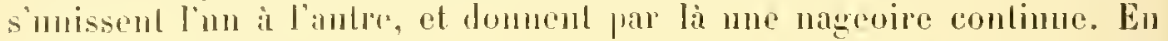
somme, les fails rappellent leurs correspondants des Ganoülos et des Amphibiens. - Pour fonrnir les mageoires te ladulte, celte bande unique s’alrophie par places, et samplific aillems. Entre autres, les dorsales et l’anale se constilment, el se délimitent, prar l'accroissement de la zone qui leur correspond, ef par la disparilion des régions intermédiaires. La candale nest conserve en som allure initiale, avec ceprobant quelques hyportrophies complémentaires, que chez un petit nombre de types, par exemple la plupart des Gadidés et des Salmonidés. Elle subil, d'ordinaire, une translormalion complexe. O'abord homogene, sa partio ventrale saccruit seule, alors quo la parlic dorsale reste slationnaire; elle devient, di.s lors, asymétrique, d'autant phis que l’amplilication de la bande venIrale replic sur elle-mène, et rejelle en hant, l'extremité de la notocorde, recliligne juspue-là. Pnis, celle zone ventrale continuant a grandip d'une manirire égalo, ello peral, par l'etlet de son extension, sa position inférieure, pour su rendre lerminale, et donuer, à elle seule, une candale symélrique.

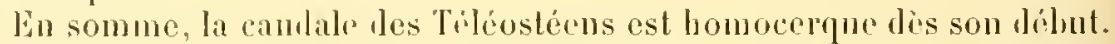
Elle devient hélérocripue, par l'angurntation do sa moitié ventrale,

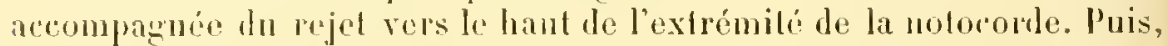
la moilié ventrale grandissant loujours, ot d'une facon cigale dans toules ses parlies, finil par occuper la region trominale du ropeps, el par consliluer à ellr senle la ramble symélrique de l’adulle : "l'ò̀ relour de l'lomocerquie, mais d'une manjere apparente, car la disposition léterocerque esl conservée daus ses trails essenliels. En ellel, l'cxtrémité motorordale dejulie warde sun aspert, ot s'entomre d'une piece squelettique, qui constitue l'uroslyle le lorganisme acheré. Je son eôté, la moilié dorsale de la candale primilise salroplic prospne romplebment. - Le parallélismo élabli, i cel ryard, entre les Ganoïdes el les Tréléosféens, est d'une grande imporlance, an sujel de leurs aftinités maturelles. Tous leux, dans leurs phases rmloyomaires, ont un meme point de départ: une caudale homocerpue, et conlinue. Tous deux subissent 
ensuito me moditication somblahle: la moitio dorsale de eelle cumble

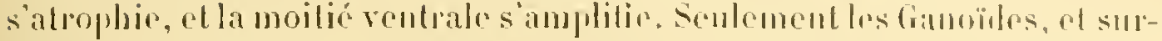

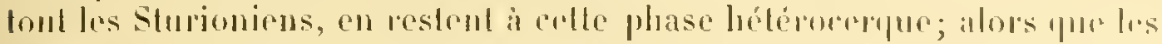
'élénsterus poussent phus loin leur évolution, en ramenant la disposition homocerpue, par lagrandissement phos considérable encore de la moilis ventrale, et le report de rette dernière dans unr situation terminale.

fendant que res changements se produisent dans les nageoires, la

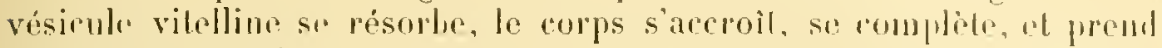
son allure délinitive. Lindividu arrive alors il l'état parlial, et ne diffire de ladulle yor par si taille exigü.

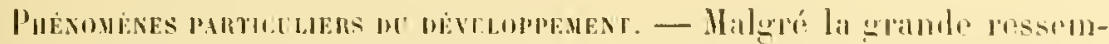
blance, rntre tous les Téléostérus, des primeipales panticularilés de lent

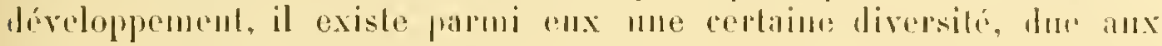
aspeels rariables présuntés par la résiculr vilelliue, par lo corpes dans son allure gricerale, par los magroires, on par l'exislence de pelits appendices supplémmlaires, tols pue des aiguillons. Ces alcórations sunt plus prononcérs chez les uns que chez les autres.

Bion que la vésicule vilelline me manjue prespue jamais, sa taille est pourtant sujelle à varitions. Tantôt, chez l, simmon far exrmple, elle est relativement petite, el sumsire sur le corps par une large hase; olle rappelle son homologn" des hanoïdes, el conslibue mu volumineus manclon, faisant saillir sur la lincr ventrale de l'embryon. Nillenrs, elle est plus grande, tontes proportions gardées, presque splériqu, et s'altache ả l'organisme par une hande élroite, qui correspond is un comlun vitellin. - Quoi rüil an soil, la vésicule mulritive se resonlm, pendant qu" l'évolution ronlinne. La résorption de ses matériaux alimen-

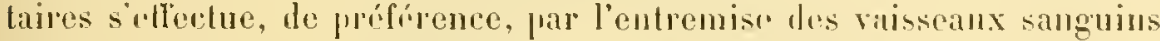
dont sa paroi est pourve. rar son ouverture daus lintestin parait se cermor précorement.

Certains Téléostéens possedent, dmant leur jemnesse, des ćpines, qui tombent cusuite, ef dont l'adulte est, par consépuent, prive. Tels sont

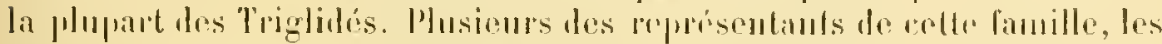

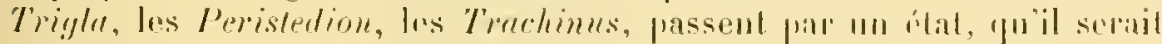

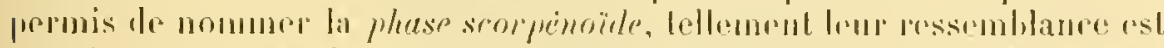

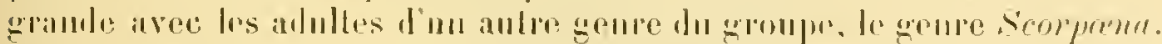

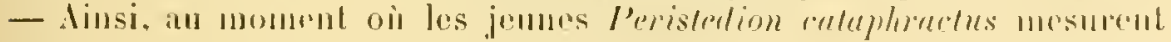

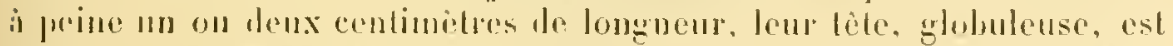

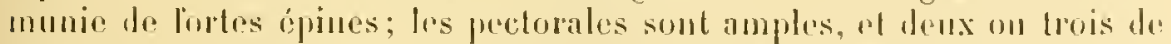

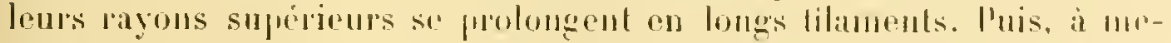

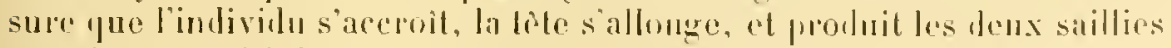

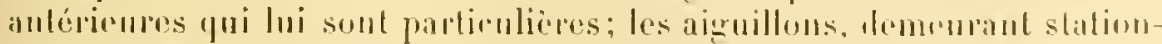

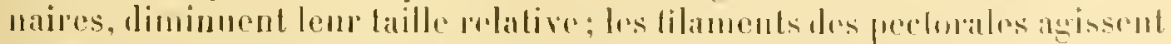

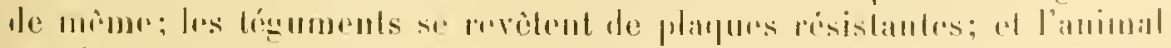
parvent it l'étal alulte. 
Les métamorphoses portent, clız d’autres Téléostcens, sur les nagroires. Ainsi, frarmi les Lophobranches, les jounes Vérophis sont pourvus de pertorales très moliles, qui disparaissent ensnite. In autre

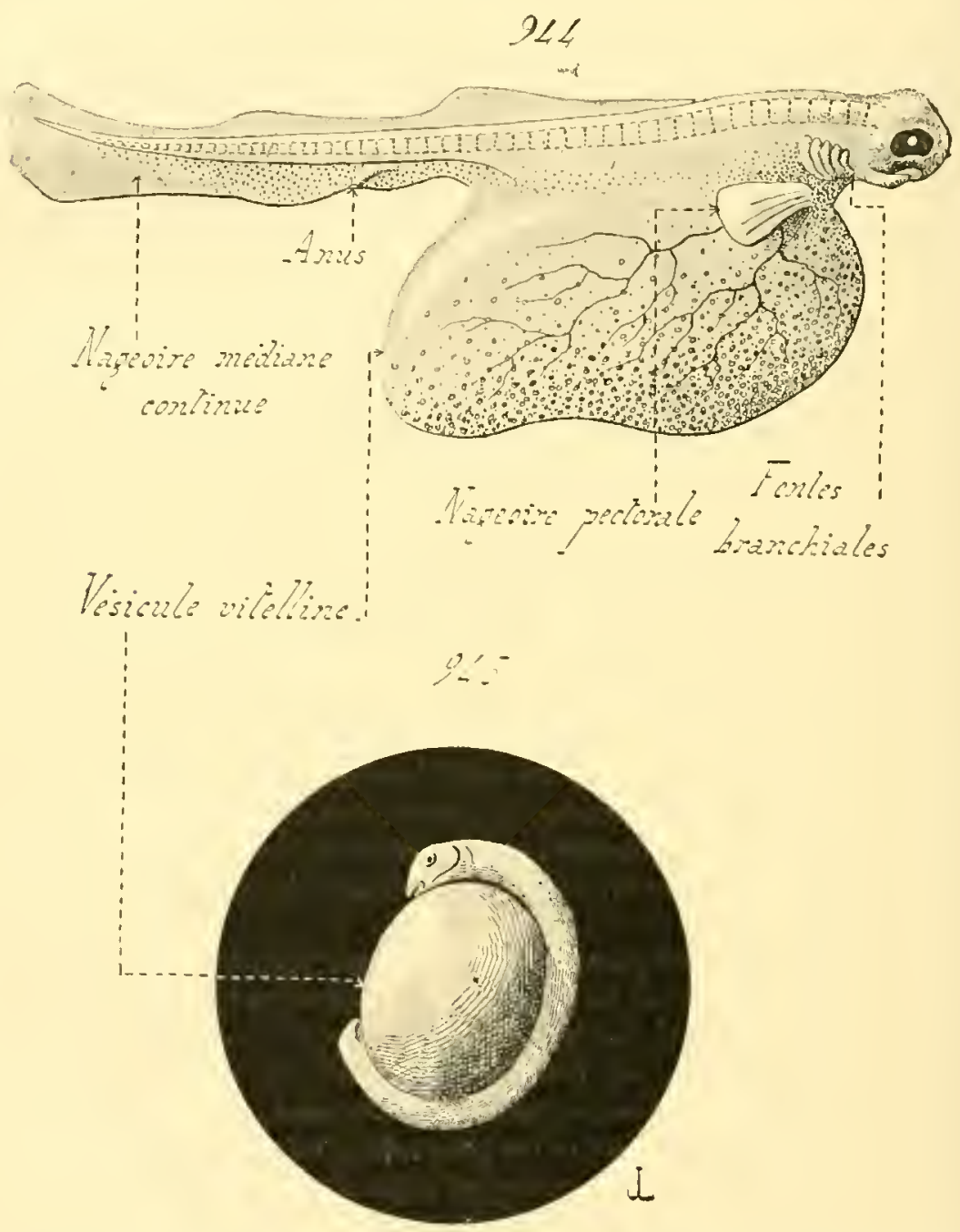

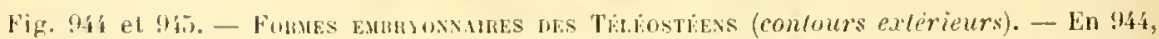
larve de Saumon, venant l'échor; d'apris les recherches faites par \%. Ciepe. - Ln \%4, larve lle llireng, un peu avant son éclosion: d'après les recherches failes par hüpller.

"xemple est ollert par les stromaters, qui, jeunes, possident des rentrales, el, alultes, sont privés de nageoires ile cette sorte, on ne les ont representives que par de petits replis. - Ailleurs, les changements 
atteignent, de préférence, l'allure générale du corps. L'un des exemples les mieux connus est, à cet égard, celui du Sammon. Après la résorption de sa vésicule vitelline, le jeune individu mesure, an moyenne, trois it quatre centimètres de longuenr; sa forme est, ì peu près, celle d'une Truite; son corps est gris, barré de bandes transversales plus loncées. Il grandit sous eet aspeet, durant une année environ, puis, lout en ayant encore, comme les Truiles, le vomer garni de donts, son opercule commence à rappeler eclui des Sammons adultes, el sa conleur se modifie; la région dorsale du corps devient d'un bleu métallique, el lianche la face ventrale. En eet état, les jeunes, qui vivaient dans les cours d'eau, descendent à la mer, et, Jorsqu ils remoutent les rivières, deux ou trois mois apres, lour allure a encore changé; ils offrent les caractères de l'adulte, pas très prononcés encore, et no les acceutuent qu'après nu autre voyge i la mer, suivi d'un retour dans l'eau douce.

Les cliangements, subis par les jennes Téléostéens, sont plus complexus encore, dans le cas oì ils atteignent, à la fois, la forme du corjs et la disposition de plusieurs appendices. Les individus sont alors si différents des adultes, qu'on les avait placés autrefois dans des genres ditférents. Ainsi, le Leptocephahus Morrisi est le jeune du Conger vulgaris; les Ityomorus sont de jeunes Nellustomus. - Parfois, ces dissemblances sont fort grandes. Les petits Dactylopterus (Poissons volants) étaient placés dans le grenre Cephulacanthus; leurs nageoires pectorales sont beaucoup plus courtes que celles de l'adulte, et à peine divisées. Les larves des Histiophorus (Scomberidés) ont nue tète globuleuse, une petile nageoire dorsale, el des aiguillons sur les opercules; tout cn griandissant, leur's màchoires s'amplifient en un long museau, semblable i celui des . Tiphius (Espadons), donl ils sont voisins, leur dorsale augmente ses dimensions, et leur's épines operculaires disparaissent. Par une métamorphose inverse, les Rhynchichthys, qui sout les jennes des Holocentrus ou des Myripristis, sont munis d'un museau en forme de bec, et de nombreux aiguillons placés sur la tèle; ces appendices tombent ensuite, et le museau se raccourcit au point de devenir obtus.

Les métamorphoses les plus grandes, de toules celles subies par les Téléostéens, se rapportent aux déviations organiques des Pleuronectides. Elles ont été ohservées par Steenstrup, et par Agassiz. - Les yeux sont d'abord symétriques, et situés de part ol d'autre de la tète, chez les jeunes, dont le corps mesure deux it trois centimètres de longueur. Puis, l'un d'eux se reporte en haut, et pénètre, ce faisant, dans les téguments, de manicre a parvenir au niveau de l'os frontal. Il s'enfonce alors dans ha hase de la nageoire dorsale, en arrièce du frontal, et sort de l'autre cóté, pour se placer non loin le son congénere. La nageoire dorsale le sépare de la face qu’il rient de quitter; et les deux youx restent voisins désormais. Suivant les genres, l'uil migratenr est, tantôt le droit, tantiot le gauche. - liorbite, privédr son globe ornlaire, se clòt entierenent. Len nerls optiques sont assez longs pour se prèter a ce royage ta cir- 
culation sanguine est fort aclive, durant les pluases de ce trammatisme normal; divers vaisseanx céphaliques sout munis de renflements conlractiles, nommés les cours oculaires. - La canse première de cette migration est, sans doutr, l'adaptation juroure à cos Poissons, qui vivent dans la vase, ronchés sur un des rốs de lem corps. La face couchée est colle privée dyeux; d'abord leintée, dle se dionlore, el devient blanche, par l’atrophie des chéments jigmentés. Sans doute, cette lisparition est due à un réflexr sympathique, causé lui-mème par la perte de l'aril; Pouchet a montré qu'il est possible de décolorer unc Truite sur un des côtés, par la perte de l'ail correspondant.

Dévelopements vurures. - Les changements suhis par les embryons des Télćostrens vivipares sont rucore pru ronnus. Ces ètres éclosent à l'élat parfait. Surement, dos comnexions s'établissent, entre la paroi de

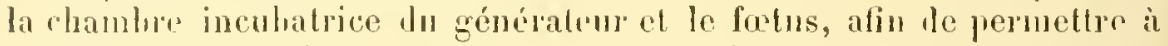
co dernier de respirer el de s"alimenter; mais les procédés suivis suml junorós, saul, dans uno faible mesure, en ce qui concerne les syngnathilís, les Anableps, et les Blenuides du grenre Zoarces. - Chez ces dernier's, lovaire de la fenclle contient une cavité, ou sont placós les embryons, et où parvient égatement un lipuide, composé de lymphe et de sang cxtravasés, à la suite de la rupture cles vaisseaux voisins. Les embryons avalent ce liquile, qui renferme de nombreux globules sanguins et lymphatiques, se nomrissent de lui, et respirent sans doute loxygène qu'il contient, grâce à la riche vascularisation de leur paroi intestinale. Chez les Anableps (fantille des Cyprinodontidés), la vósicule vitelline porte des rillosités vasculaires, qui effectuent les échanges entre le ganératem et le fortus. Chacm des embryous des Syngnalhides est mfermé dans nue loge particuliere, dont les parois possedent de nomlıeux raisseaux sanguns; cenx-ı: sonl, sans mul donle, chargés de lni fournir les matóriaux nécessaires pour entretenir son existence. Ces logetles à embryons se développent daus la cavité incubatrice du générateur mile, qu'elles cloisonnent.

IV. Sélaciens. - Tous les Sélaciens subissent un développement lietal; leurs embryons, munis d'me volumineuse vésicule rilelline, éclosent lorsque leur organisme est acheré, on peu s'en faut. Seulement, l’évolulion rliflère, suivant les lypes, par le licu où elle saccomplit. Plusieurs les représentanls de la rlasse sont oripares, alors que les

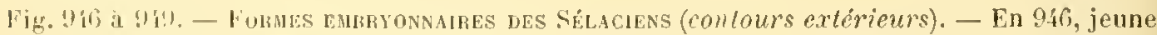
"mbryon de Seyllim, commungat à se dilimiter sur sa visicule vitiline. - En 947, "mbryon jus avaneé le sicyllium, non bin d'ectore, montré en place dans la coute de son ceuf, dunt une partie a éte onverte el rabattu; d'apres Moreau. - En 94 , cmbryon avance d'une Torpedo marmoruta, encore munj de ses branchies transitoiles el de son cordon vitellin (on curdon ombilital); d'apres Morean. - En 949, embryon avancé d'un Mrustelus levis, muni de son corlon et de son placenta, ce dernier etant accolé a la paroi le la cavilè utèrine; d'après J. Müller. 


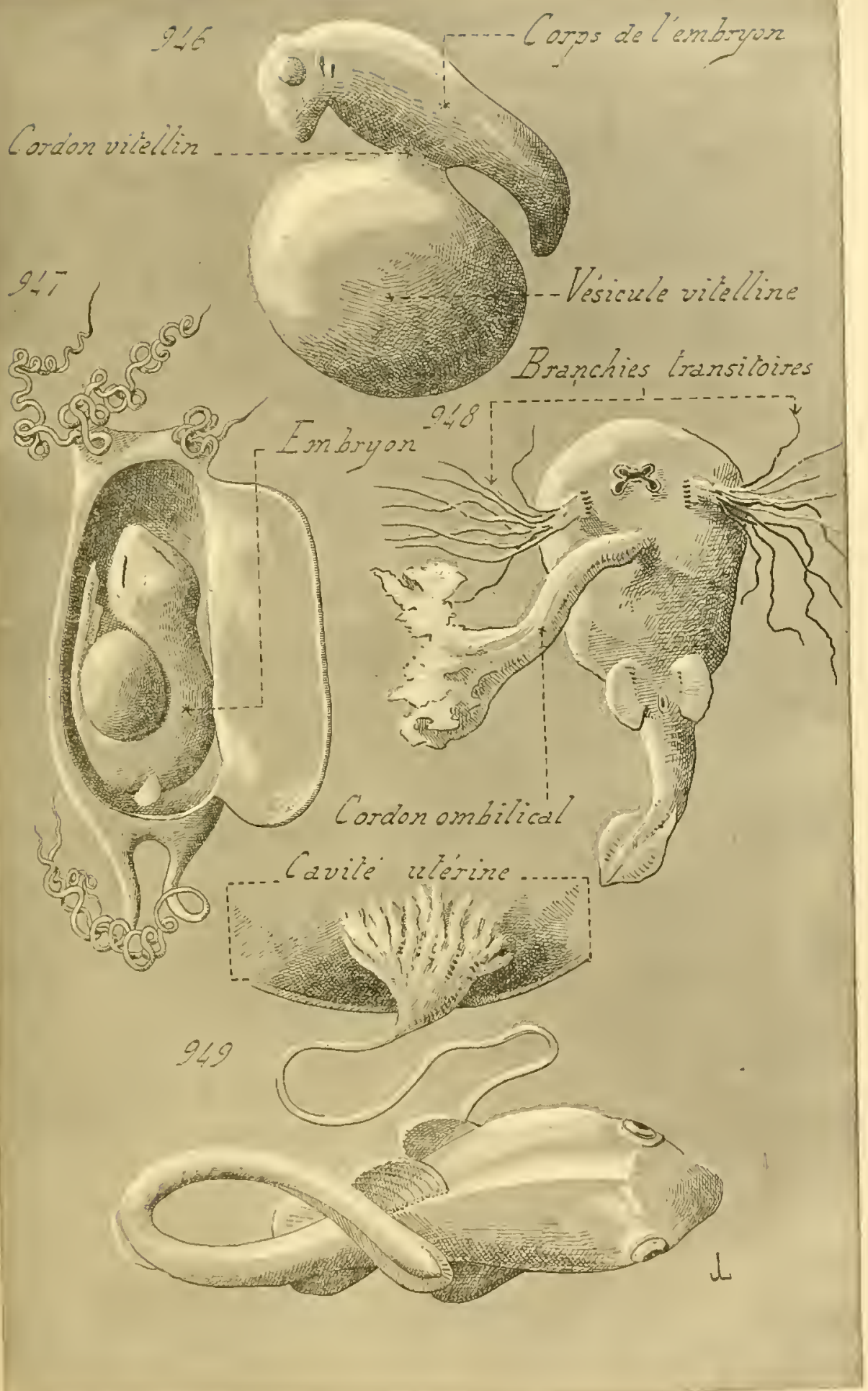


aulres sont vivipares; les genpes, pourrus de l'oriparilé, se bornent anx Scyllium, Pristiurus, Cestracion, parmi les Sipualidés, aux Rioja parmi les Rajidés, el aux llolocéphales (Chimcere, C'allorhynchus). Sauli celle dissemblance, les primripales des parlicularités de l'embryogénie concordent daus les deux cas.

Le deutolécithe ovulaire ronstitue un amas considérable, an-dessus duquel se délimile l'cmbryon. Cet amas rompose une grosse vésicule. vitellime, d'abord attarhée, par une large base, à la face ventrale du corps; la zone d'insertion se rélrécil ensuite, à mesure que le développement progresse, et sallonge en mème lemps, four donner mu cordon d'union, le cordon vitellin, ou cordon ombilical. L'cmbryon se fagonne, aux dépens du blastoderme embryomaire, pendant que le blastodermo para-emembryonnaire s'élend aulour de la vésicule vitelline, el lni l'orme sa fraroi. - Lorsque tous ces plıénomenes, qui se manifestent à la fois. sont acherés, le fotus les Sélaciens possède un corps, aux contours nellement limités. pourn, sur sa lace ventrale, l'muc résicule mulpilive sphérique, suspendue à un cordon. Sauf par sa privalion d'ammios et de vésicule allantoïde, il ressemble, de tonte façon, à nn embryon de Sauropsidé, d'Oiseau ou de Reptile. Cette structure répond à une accenluation, phus marquée, dres phenomenes offerts par les autres lchtlyojsidés; la cause en est due a la présence, dans l'ovule, d'une plus grande ¡uantité de vitellus nutritil.

La moilié postérieure du corps est entouréc, comme sa correspondante des Ganoïdes, el des Téléostécns, par une nageoire continuc, impaire el médiane. Les nageoires défuitives de l'adulte se dégagent, de cet appendire initial, par les mèmes moyens que chez les deux tỵes précédents; la quene conserve la disposilion hétérocerque. - Toutes les fentes viscérales émettent des longs alpendices, qui font saillic au dehors, et méritent, à cause de leur aspect et de leur provenance, le nom de brunchies externes. La première des lentes viscérales (évent) u'cu porte "ju'une rangée; loutes les autres (fentes branchiales), saul' la dernicre, qui en a seulement une, en possèdent deux séries. Ces branchies sont aussi grandes, sinon davanlage, que lenrs similaires des jeunes larves d'Amphiliens; ellos different de ces dernières, pourtant, en re qu'clles dépendent de la région profonde des fentes branchiales, el non de leur partic exlérieure. Aussi, leur surlace est-elle constituée par une assise épithéliale d'origine endodermique, et uon pas ecloderminue. Ces annexes, pichrment vaseularisés, srrvent à la pespiration embryonnaire; ils sont en pluspetite quanlité chez les Rajidés que chez les squalidés; ils manquenl, par balancement organique, aux fulus mmnis de villosités placentaires sur leur vésiculr vilelline. - Les branchies cxternes des Sélaciens sont spéciales anx cmbryous, et tombent quelgue peu avant l'éclosion.

La vésicule vitulline diminne de volume, à mesure que l'érolution s'aceomplit. La résorplion du deutolécille, qu'elle contient, s'ellectue, 
tout d'alord, par la pénétration directe de redernier dans l’introstin. liorifice de communication semble s'olstruer frar la suite; les vaisseanx sanguins, creusés dans la praroi de la résicule, remplissint. des lors, le principal ròle daus ce phénoméne. - Iu déhut, alors qu'une moitié seulement de la vésicule est recomerte par sa paroi, l'mmbryon imot uno artere vitelline, loranche de laorte dorsale; colle-ei se partagren deux rameaux recourbés en crosse. Puis, la jaroi aucmentant sa surface, les deux crosses artérielles s'allongent, tout en converguant l'une vers l'autre, et finissont prar s'unir, en formant un cercle artériè, qui embrasse une calolle, de la visirule vitrllino, placée an-dessous de l’unbryon. Lamean artériel envoie, dans cette calotte, des loraches nomhronses: celles-ci se jeltent dans des ramuscules veinenx, qui se rassemblont en une seule veine vilelline, allant s'onvir dans to conr; cette reine, a son drbul, et a cause de sa posilion. affecte une lorme anmulaire, qui disparait par la suite. Lo corele arlériel s'élaroit sans cesse, en so déplaçant dans la paroi vitelline. el irrignanl mon valutte loujours plus grande de cette derniere; cu difinilive, col continuant lonjours son mouvement initial, il se ferme dans l'hémisphère opyosé à celui ou son ebauche a pris naissance. Il s'est alor's converti en un trone artériel, simple sur toute son étenulue, et pouru le branches nombreuses. La veine vitelline perd cusuite ses relations directes aver le runr; elle soure dans la portion, de la veine sous-intestinale, qui doit devenir la veine porte.

Les embryous, dans le cas des développements ovijares, sont repliés sur eux-mèmes dans la cavité que limitent lenrs coques, et se trourent en contact arec elles. Les évolutions vivipares entrainent diantres rapports, puisque les coques choriomailes sont fort minces, el rapidement résorbées; le fuctus est situé dans la cavité de l'utérus maternel. - Une telle connexité est, chez rertains lypes, la canse te dispositions destinces a mieux permettre les érlunges nutritifs entre la mere el ses petits. La paroi utérine est, chez la plupart les Rajilés vivipares, le siège d'une intense congestion sanguine: elle shypurophie, et proutuit de longs filaments encherètrés, richement vasıularisis, pamilıspmols sont placés les emliryous; la totalité le ces expansions est rejeléc, avec lus pelils, an moment de laparlurition. Divers Syualiles, les Earcharias et le Mustelus levis, montrent le mème phénoncene, mais arec des applications diflérentes. La paroi de la vésicule vitelliue de charue embryon émet des expansions vasculaires, exactrment semblables aux villosités desplacentas cotylédonaires des Mammifères. Ces appendices vitellins pénètrent dans des dépressions correspondantes de la muqueuse utériur, et s"in-

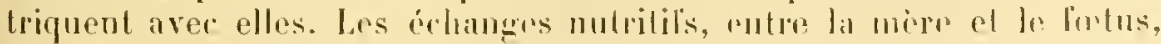

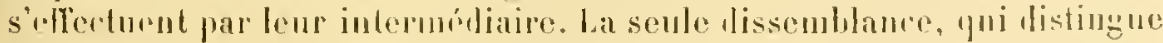

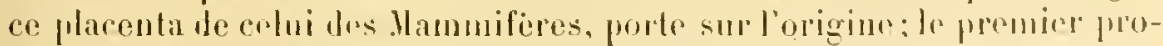
vient de la vésinule vilelline, et le secombl de la vésieule allanböle. 
Quel que soitle mode érolutif, les jeunes, au moment de leur éclosion, ont terminé leur économie, et acquis leur forme définitive. Ils nedifferent des adultes que par leur taille plus restreinte, et par la jossession de l'excélent vitellin, rapidement résorlué ensuite. - Les jennes Rajidés sont les seuls à subir une sorte de métamorphose larvaire. Leur corps est allongá, lorsqu ils naissent, et presque semblable ì cehij d'un squalidé; il s'élargit ensnite, et s'aplatit. Ce changement d'aspect permet de bien concevoir les alfinités naturelles qui unissent, entre enx, deux des trois ordres des Sćlaciens.

\section{\$4. - Généralités sur les annexes embryonnaires des Amniotes.}

1. Gonsidérations générales. - De tous les Vertóbrés inférieurs, les Sélaciens sont ceux qui se rapprochent le plus des Amniotes, en tant ipuallure de leur développenent. Les embryons de ces animaux sont. munis d'une vésicule vilelline, distincto du corps, et reliée à lui par un cordon élroit. - Le blastoderme de leurs ovules se divise en une zone embryonnaire et une zone para-embryonnaire. La première, sitnée sur l'emplacement le la cicatricule initiale, donne seule l'organisme de l'embryon. La seconde compose la proi vitelline; comme, tout en ne prenant aucune part au façonnement de l'économie, clle entre dans Ia constitution du petit ètre, l'expression " para-embryonnaire " est flus exacte que celle d" "extra-embryomaire ", dont les auteurs se servent parfois pour la désigner. La paroi vitelline contient des raisseanx nombreux, unis à ceux de l'embryon, qui puisent, par osmose, les matériaux nutritifs dans la masse deutolécithique de la vésicule, et les transportent dans tous les appareils du corpss.

Une telle division du l, lastoderme, en zone embryonnaire et zone para-embryonnare, existe bien, chez les Amniotes, au débnt de l'évolution; senlement, les phénomènes se compliquent par la production de denx annexrs, l'amnios et la vésicule allantoüde, dont les Sélaciens sont toujours privés. Le premirr de ces appemlices complémentaires est engentré par la zone para-embryonnaire, el le second par l'enluryon. La zone paratembryonnaire, qui embrasse de beaucoup la plus grande surface de l'auf, se divise, tout en s'étendant, en deux parties : l'une proximale, qui entoure la zone émbryonnaire à la façon d'une bande ammlaire, assez étroite; l'autre diskale, qui enchasse lo reste de l'ueuf, et constitue une calotte, un pen plus grande qu'un hémisphère, diamétralement opposée à l'ensemble de la partic proximale et de la zone embryonnaire. Toutes ces dúlimitations sont superticielles, en ce sens 'qu'elles s'effectuent sur un blastoderme qui enveloppe l'a uf entier, ou plutót le volumineux amas mulritif le l'cuf, et recouve sa surface. La partie distalr se borne ì enviromner le deutolécithe: l'expression aire vilelline, souvent employée pour la désigner, est, prar suile, des plus 
justes. La promière, on proximale, est chargée de lonmo maissance a des replis, qui grandisscut, sétendent, el se roumissent au-dissus do lembryon, de manière à cirronscrire une cavité, lans lirpuelle celui-ci est renfermé. Col espace est la cavite amniotizue; l'ousemble des replis comprose l'amnios; aussi, par opprosition a la parlie distale, peut-on donner le nom daire amniotique à la bande proximale.

Les replis amniotiques, et la paroi vitellineréelle, ne sont pas fournis par toute l'épraisseur de l'aire amniotique et le l'ajo vitrlline. Ces deux aires sont constituérs prar le blastoderme para-embryonnairr, composé a son tour des trois feuillets, disposis dans leur ordre normal : l'ectoderme en delırs, le mésoderme au milien, et l'ndoderme en dedans; celui-ci touche directement au vitellus nulritif, on an liquide qui le remplare chez les Mammifères viviprares. - Le colome, qui se creuse dans l'éjithélio-mésoderme de la \%one embryonnaire, śćtenul dans la zone paraembryonnaire, el se percégalement dass le mesoderme de celte dernière. La substance de ceflr zone se partage ainsi in doux lames, l'une externe, l'autre interne, que sépare la cavité culomique extŕrieure ì l'embryon; celle-ci est dite, à cause de sa situation, tantôt la cavité pleuroperritonéale extru-embryonnaire, lantùt, et plus simplement, le calome extra-embryonnaire, on, mienx, le calome externe. la lame internr, seule, continue a invelopjer la vitellus nutritif; la lame externe ast distincted'elle, car le colome externe s'étend entre toutes les lenx, commençant par la région qui entoure directement la zone embryounairr, et pénélrant ensuite, frar un vaai rlivage, dans tont le fenillet moyen du blastoderme para-cmliryonnaire. Cetle cavité s'amplifie, lors des phases ultirieures de l’évolution, rt constitur un raste espace, dans lequel se trouve susprndue la vésicule vitelline, composée jau le deutolécithe qu'entoure la lame interue; elle se sépare, a mème tomps, dı culone vrai de l'eulıron, et devient indépendante.

Les denx lames de laire vitellino (lame externe el lame interne de la partie distale le la zone para-embryommaire) ne subissent point de trop' grands changements. La lame interne se résorlse avo le drutolécithe qu'elle enveloppe; la lame externe contracte des allérences, de nature variable, aver les milienx qui entomrent l'ouf (membrane vitelline, coques, paroi utérine et ses clépendances), el avec la résinule allantoïde, qui pénètre dans le colome exteruc. - les lames do liare amniolique (lame externe et lame iuterne de la parlie proximale de la zone paraembryonnaire) se modifirnt daus des juportions plus consilérables. La lame externe produit les replis amniotiques, et frend, frece fail, un grand arcroissement. La lame interue complete, fon sa part, la paroi de la vésicule vilelline dans la région voisino du lembryon, el s’unit à sa correspondante de la pratic distale. Senlement, elle ofl're, de plus que celle-ci, dans mo période oì le colome externe ne s'esl nncore rrensé que dans une zone restreinte du liastoderme para-rmbryonatie, mue vascularisation abondante, qui lui a fait dommer lo nom d'aire vasenlaire. 

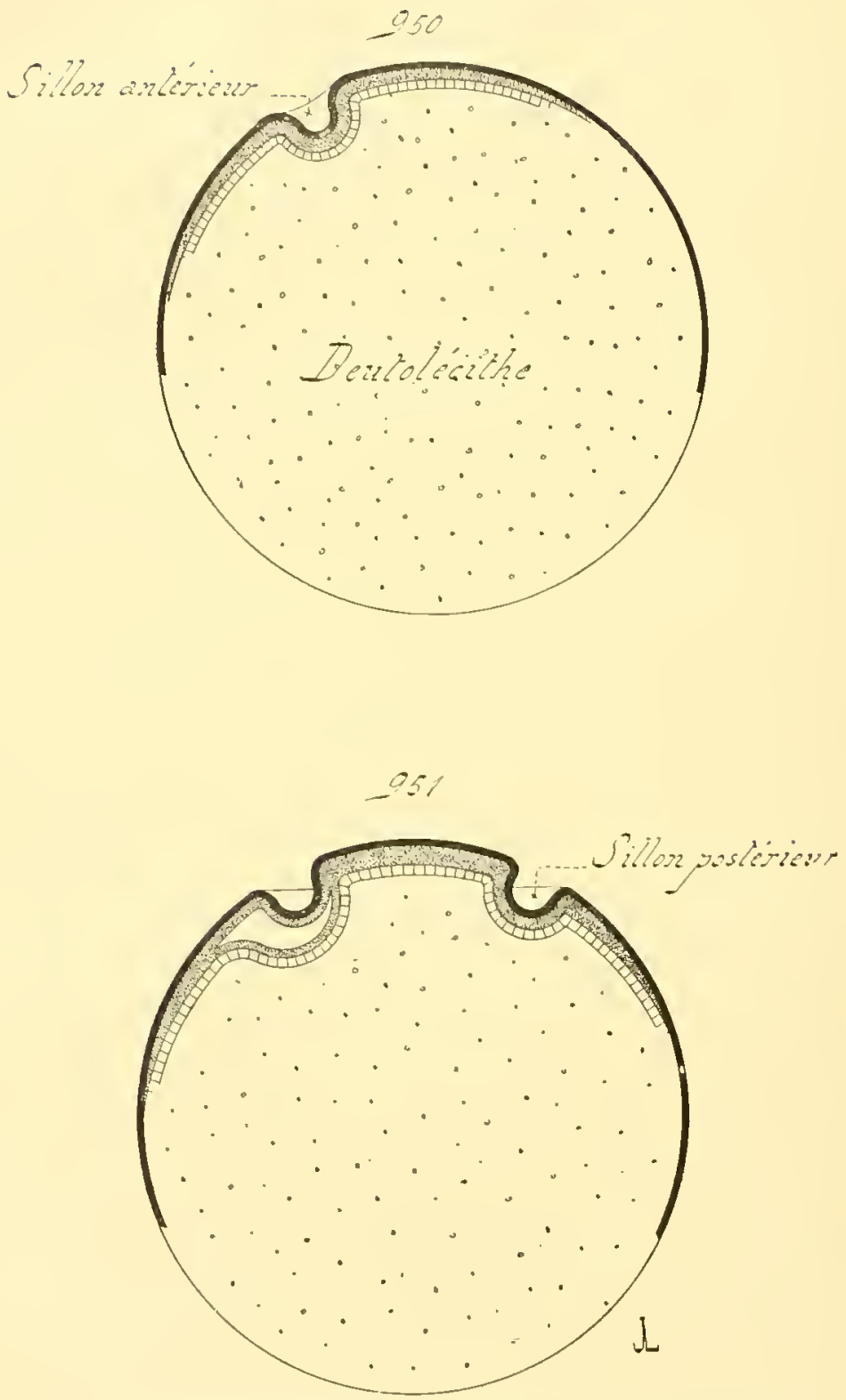

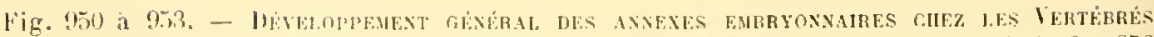
Amvores, el. notammont elıe\% les Samousiles. - Tillean d'ensemble, allant de la fig. 950

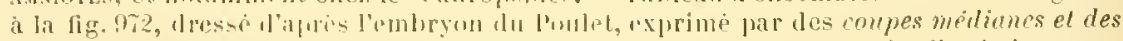

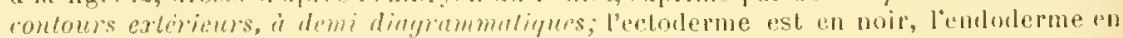

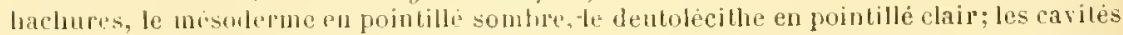
sont en blane.

Lin 950 , coupe mediene, prise au momed ou les trois feullets blastodermiques sunt dèli- 
Plus tard, le colome externe samplifie, les vaisseaux se listribuent it

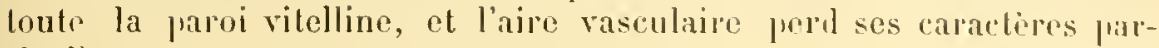
liculiers.

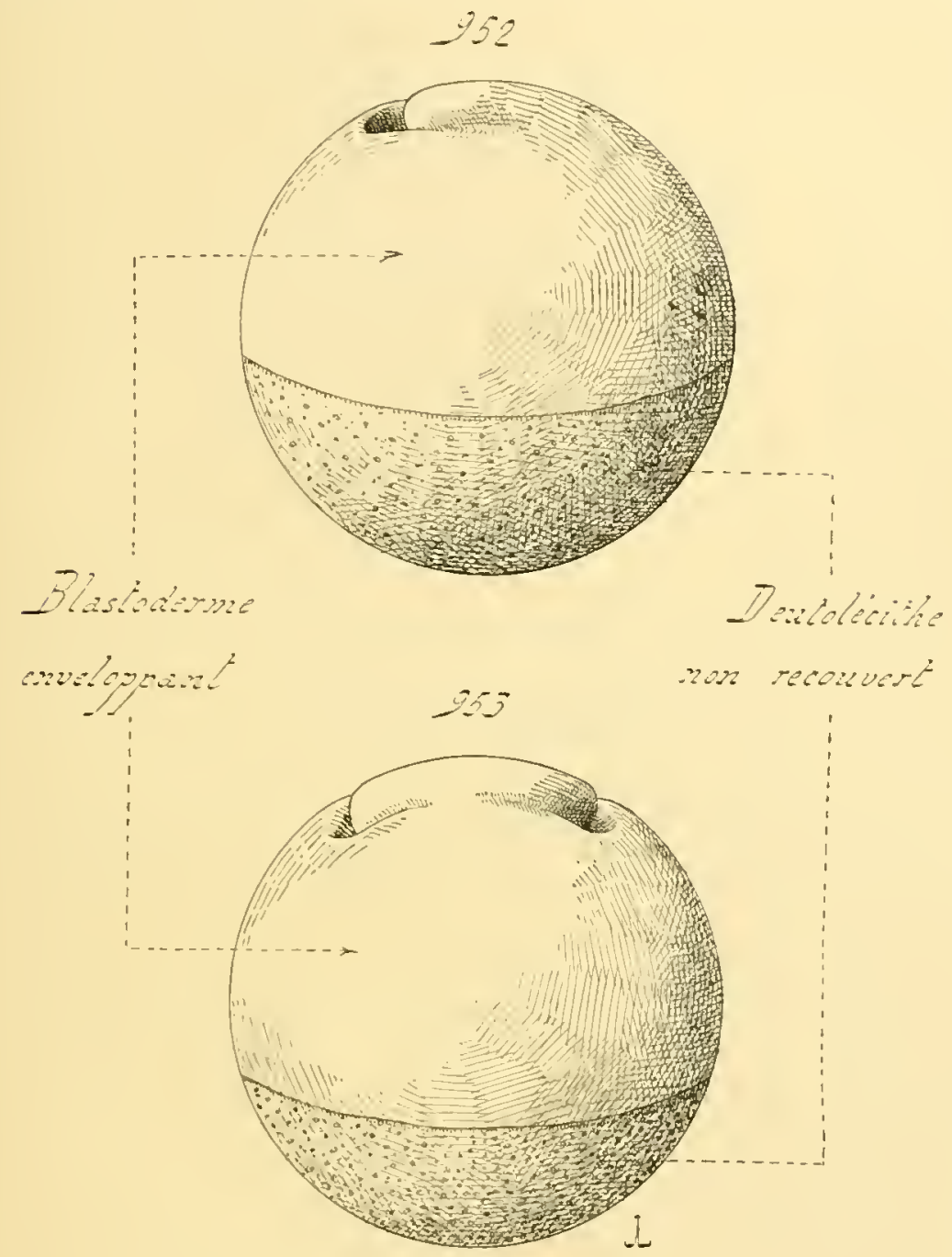

mites, et oi fo hlastoderme lui-mème entoure la moitie supérieur de l'ouas du deuto-

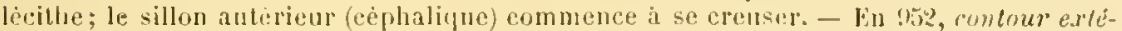
vieur de la méne phase. - En 9.51, coupe médiane d'un itat plus avance; le sillou posterienr (camlal) prend naissance. Ges deux sillons grandissunt pitl lemrs lonts, et vont à la rencontre l'un de l'autre, en produisant les sillons marginaux; ils delimitenl par lis, et cireonserivent, une petite aire blastodermique, qui deviendra sente lormanisme

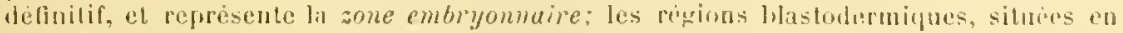
Jehoracles sillons, qui grandissent autong du deutrolicillo pour l'envelopper el enmposer la faroi vitelline, ne prennent aneune part is genese de l'organisme difinitif, el com.

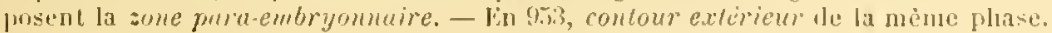


Les faits sont encore rendus plus romplexes jar la présence de la vésicule allantoüle. Cotte dernière est une lépendance de la région postérieure le l’intestin embryonnaire; d'abord semblable à un petit diverticule intestinal, clle ne tarle pas à prendre une rxtension tonjours plus grande, ot à pénétrer dans l enlome externe. Elle s’accroit sans cesse, el finit sourent jar emplir colui-ci, et par s'intercaler entre la lame externe el la lame interne.

Ces organes divers ne se suivent pas dans le temps: ils apparaissunt a de faibles intervalles, et se dérolopent ensuite d'une manière synchrone. Pendant que le blastoderme para-embryonnaire s'étale en surface, et donne l'aire vitelline, le culome externe se perce dans l'aire amniotique déji formée, et l’allantö̈de commence i prendre naissance. Les replis amniotipurs se montrent ensuile, et samplifient, à mesureque le crelone externe, avee l’allantö̈de qu'il contient, sétendent en dehors de l'embryon. - Finalement, reluj-ci posside une disposition complexe, que les Vertébrés inférieurs ne montrent jamais. le foetus des Sélaciens està nu dans ses coques: il se borne à porter une vésicule vitelline. également à nu. Le foctus des Amnioles est rnfermé dans une cavité amniotique, limilée par un amnios; il est pourvu d'une vésicule vitrllino; et l'ensomble de l'embryon, de son amnios, et de son appendice nutritif, se trouve plongé lans une cavité, le colome externe, que limite en dohors la lame exlrrue du blastoderme para-embryounaire. Celle-ci, seule, est en conlact direct avec les milieux extérieurs à l'ovule primordial. Cependant, tous ces annexes sont propres à l'embryou, el ne font point partie de l'organisme léfiuitif; ils so Métrissent quelque peu avant l'éclosion, et leurs demiers vestiges tombent au monent de la mise en liberté.

Tous les Amniotes présentrnt cos phénomènes, cette genèse diapendices compliqués, suivie de leur destruction. Les Mammiferes vivipares montrent, pourtant. quelques altératious dans la marche des phasis du développement; parmi ces changements, les uns tiennent i la production d'un plarenta aux dépens de la vésicule allantö̈le, les aulres à des condensations évolutives. Les résultals sont cependant les mèmes, autant en ce qui touche la structure des aprendices, que lenr disposition mutnelle. Les différences portent sur les seuls procílés employés, et n’alleignent en rien l'homologie fondamentale de Lous les annexes des embryons des Imniotes.

II. Développement de l'amnios. - Ce développement romprend plusieurs phases. Tout l'abord, la zone embryonnaire se délimile au moyen d'un sillon annulaire, et, se ployant sur elle-mème, donne le corps de l'embryon. Pondanl que s'ellectue ce phénoméne, le crulome externe apparait a son lonr; puis les replis amuiotipues prenurnt naissance, s'élemlent, entourent la ravité amuiotique, ot prariennent aiusi à leur période l'état. 


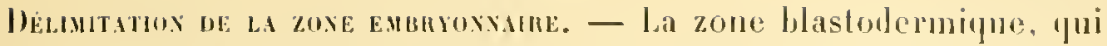
doit constituer le corps de l'embryou, of façonner l'organisme détinitif sans prentre aucune part ì la ggenese des annexes, se délimite du hlastorlerme restant, et composant la rone para-emluyommaire, an moven d"unc rainure cirrulaire. Ce sillon s’approfondit sans cesse, jusqu’à restreindre à un étroit cordon la hande d'union des deux zones, el isole ainsi toute la région destinée à devenir l'embryon hi-même.

Lil première indication decelte rainure se montre en une partie, qui correspond au bord antérieur de la zone embryonnaire; elle s'avance, de lí, sur les cotés de cette dernière, ot atteint ensuite son borl postérienr. Cette ébauche n'est pas tout i lait continue; dans la réalité, quatre sillons, nommés par llis les sillons marginaux, se creusenl d'une manière indépendante; le jremier en date est antérieur, le dernier postérjeur, et les intermédiaires sont latéraux. Mais le phénomène revient i la progression, signalíe tout d'abord, d'une gouttière unique, car ces quatre sillons ne tarlent pas à sunir entre eux. - La rainure. compliete, sapprofondit. La direction snivie par dle, tans ce mouvement, a pour résultat de donner à la zone embryonnaire la forme d'une calotle de faible épaisseur. La bande l'union, entre celte zone et le reste de l'ovule, devient de plus en plus étroite, à mesure que la gouttièro s'enfonce davanlage; elle se ronvertit en un cordon, le cordon vitellin.

La rainure princtre, en son extension, dans le leutolécithe placé sous la zone embryonnare. Elle ne seborme pas i entrer dans le vitellus, mais for'e, en surphrs, atle heruicre à se ployer sur elle-mème, et à prendre l'aspect d'une euvette, lont la concavité est ouverte du côté de ce vitellus. Ce ploirment saccentue lavanlage ot de toutes parts. En avant et en arrière, il a pour etfet d'isoler les leux extrémites du foetus; sur les còtés, il donne i l'ébauche emhryomuaire l'aspect J'une gouttière, dont les borils se rapprochent lim de liautre. le dedaus de cetto goultièe communique avec la vésicule vitelline; leur zone de jonction, d'abord fort large, se rétrécit sans cesse. Lorspue la combure ajproche de son terme, cetto rigion unissante consiste en un rspace tubuleux, étroit, crensi, suivant son axe, dans le rordon vitellin. - La cavité de la grouttièe devient la cavité intestinale de l'embryon; elle est en relation directr, au commencement des phases évolutives, et par l'entremise de ret espace, avec le dentolérithe dont la résicule vitelline est emplie. La totalité de ces diux parties se prisente comme un T majuscule, dans lequel la hranche supéricure, horizontale, correspond a l’ébauche inteslinale, et la branclue inférienre, verticale, an cordon vitellin; la vísicule vitelline est suspendue, comme une grosse boule, a cette derniere. Lal moitié antrienre do la branche horizontale dn 't', tournée vers l'extré-

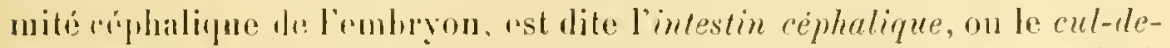

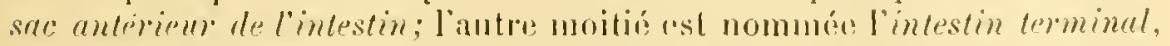
l'intestin postivieur, on lo cul-de-sac posterienr de lintestin. Chacune de ces moitiés débonche dans la luanche verlicale, lans le rordon, par mon 


$$
3
$$


VERTEHHES

$100 \%$

956 Embryose

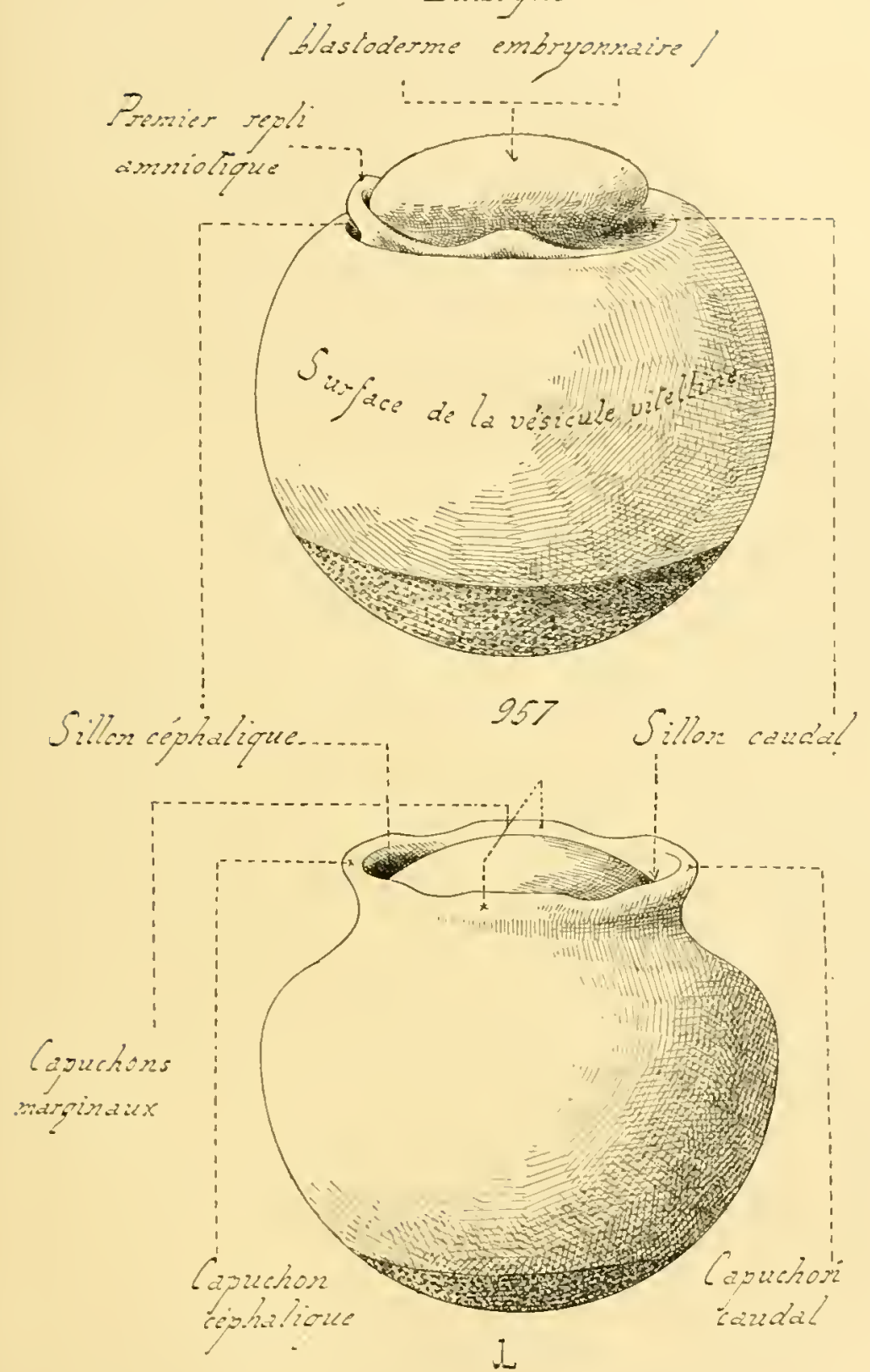

Fn 5it, roupe midiane. Le culome externe, dont la première apparition sest faite lors de? la phase prichitente (fig. ail). commence à somplifier: le repli anniolique antierieur (eapuelion crphaliuge) prend naissance; le blastoderme de la zone pitra-embryonnaire continue a sietendre antour du deutolecithe. - lin 56t; contour extérieur de la nuém. 
oritice spécial : celui de la premiere est lorifice intestinal antérieur: celui le la secondr est l'orifice intestinal postérieur.

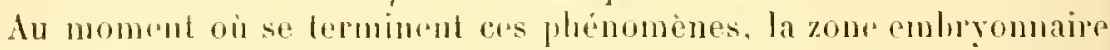

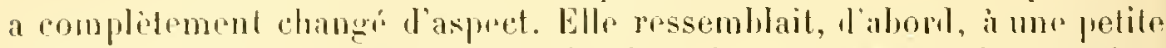
ralolte sphérique, jointe par sos borls a la zonr para-embryounaire, faisant partie de la surface d’une sphere, el placée sur la vésicule vitellinr, tont alf limitr une région. Elte s'est convertir, désormais, en un embryou cylimbripur, aux rontours arrètés, el tout a fait distinct de la vésicule ritelline, a taquello il so rattache soulement par mo fitroit cordon ritellin. Sa ravilé intestinale communique, par l'intermédiaire de ce rlernier, avec la raté, rmplir de deutolícille, de la résicule; cet aliment est ainsi copabl. le pémitrer daus le tube digestif embryonnaire, et de remplir son róle nutritif. Ces connexions cessent bicutôt, par lobturation do l'espace dont le cordon vilellin est creusi: la résorption du deutolécithe est alors ellictué par les vaissanx sanguins, qui parcomrent la prasoi vitrlline.

Les phases de la dilimitation de l'embryon des Ammiotes rappellent lours comespondantes des Sélacions, ot leur ressembleraientractement, si elles existaient siules. Ihais il non est pas ainsi; dis la genese les ébauches le la rainure marginale, le colomo exteme ut l'ammios, faisant lour apparition, complipuent à l'exces les phénomenes. Anssi, birn que la séfaralion de l'imlryon d’arec sa vésicule vitelline s'offectue par los mèmes movens dro les Vurtéloris supéricurs el les Sélaciens, l's faits sont très moditios par la prodnetion des anneses supplémentaires.

Jéveop'enent di colone exterxe, - Le colome extrine commence a apparaitre, soit en mime temps que la rainme marwinale, soil un jeu après elle: ses premiers restiges srereusent sous la ramure elle-mème,

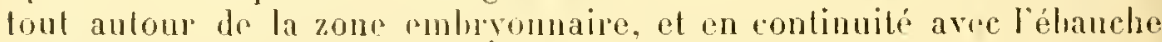
calomique de cette lernière. l'artant dr cette région voising de l'emlryon, elle s'étend dans lis antres parties lu blastoderme para-rmbryonnaire, et le srincle on une lame interne et une lame externe. - Cette division délute, à rause mème de la situation affectée par les rudiments primoriliaux du colome externe, non loin de lembryon. La bande amniotique le la proi vitelline, prochr d. ce dernier, est déjà prartagée en drux lames, alors que l'aire vitelline se frouve encoro ètre simple. Le clivage l'atteint eusuile, pembant que les replis de l'amnios, dérrloppés aux lépens lo celle-la, grantissent antour de l'embryon, et l'enlourent.

phase. - En 955. coupe médiane d'un chat plus avancé. Le colome externe s'est agrandi; le repli amniolique posterienr ("apuchon caulal) et les leplis amniotiques latèrax (capu. chons marginaux) se nonl faronnés a leug lour, el unis au repli antérieur funr former une sorte de cullerelte qui enloure la zone embryonnaire. Le blastoderme de la zone para-emhryonnaire, tans si propresion constante, entoure la majeure part du deulolécilhe. - lin 957 , contous exterieur do la mème phase. 
Le bastodreme para-embryonaire se compose, en allant de dehors en dedans, des trois feuillets superposés : l'ectoderme, le mésodlermo: ef l'endorderme. Le mésorlerme est, à son tour, constitué par hu somatomésenchỵme, ot du splanchuo-mésenchyome, plarés de part el l'aulre d'une assise d'épithélio-mésodlerme. Le calome extrone est creusí ilans cette dernière; aussi lins drux lames sont-elles de ronstilntions dissemhables. - La lame externe comprent, de drhors en tedans, trois conches : l'ectoderme, le somalo-mésonchyme, el une rangée, exterme par rapporl au culome, déléments issus le l'épithélio-mésoderme, soit une somatoplemre. La lame interme offre, ì son tour, de dehors en dedans, trois autres couches: la splanchnoplenre, le splanchno-mísenchyome, et l'endodorme. Le culome exlome, qui sépare l'une do l'autre les deux lames, est limité par la somatopleure en dehors, et par la splanchnoplisure en dedans; il se trouve placé, en égard anx couches qui le circonscrivent, dans une situation exactement semblable à celle du rodomr embryonnaire.

Lectoderme de la lame externe courre la surface le tous ces annexes; il se continue avec celui du cordon vitellin, issn lui-mème de celui qui formait le foml de la rainure marginale, et jar la avec l'ectoderne de lembryon. Une telle liaison existe dans les autres assises, et le cordon vitellin sert ì foutes l’intermédiaire. L'espace, limité par la lame intern', est la cavité mème de la vésicule vitelline, ocrupéc par le deutolécithe, ou par un liquide tenant sa place, et directement unic à l'intestin ir l'embryon, - Aussi, malgré sa complexité, qui tient an clivage produit dans sa paroi par le colome externe, l'ensemble de ces appendices est-il identique, quant au fond, ì l'annexe mutrilif des jeunes lehthyopsidés. Il est une saillie, de forme particulière, et de structure complinuće, de la face ventrale du corps, dans laquelle l'intestin émet un volumineux diverticule, empli ilhabitude par une substance untritive, qui sert it l'alimentation de l'emlryon.

Les assises mésenchymateuses des deux lames conliennent des raisseaux sanguins.Ceux-ci sont, cependant, plus nombreux dans la lame interne, où ils servent à résorler le vitellus nutritif. - Vers le délut du diveloppenent, alors que le culome externe, dans sa progression, a dépassé quelque peul'aire amuiotique, pour s'avancẹ dans l'air vitedline et la eliver, les portions déjil formées de la lame interne oftrent laspect d'une calottr laiblement lombre, placée en derlans du colome externe, étenlue sur une parlie du deutolécilhe, et unie par son centres

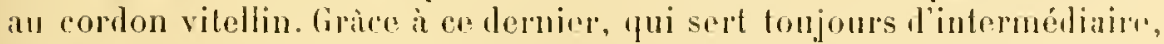
Ir systeme circulatoir de l'embryon s'ahouche aver les valisseaux qui

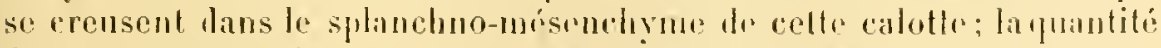

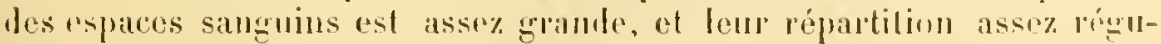
lière, pour mériter it celte dernière le nom d'aire vasculaire, "pur lui domment tous les auleurs. Les trones d'origine de cette vascularisation 

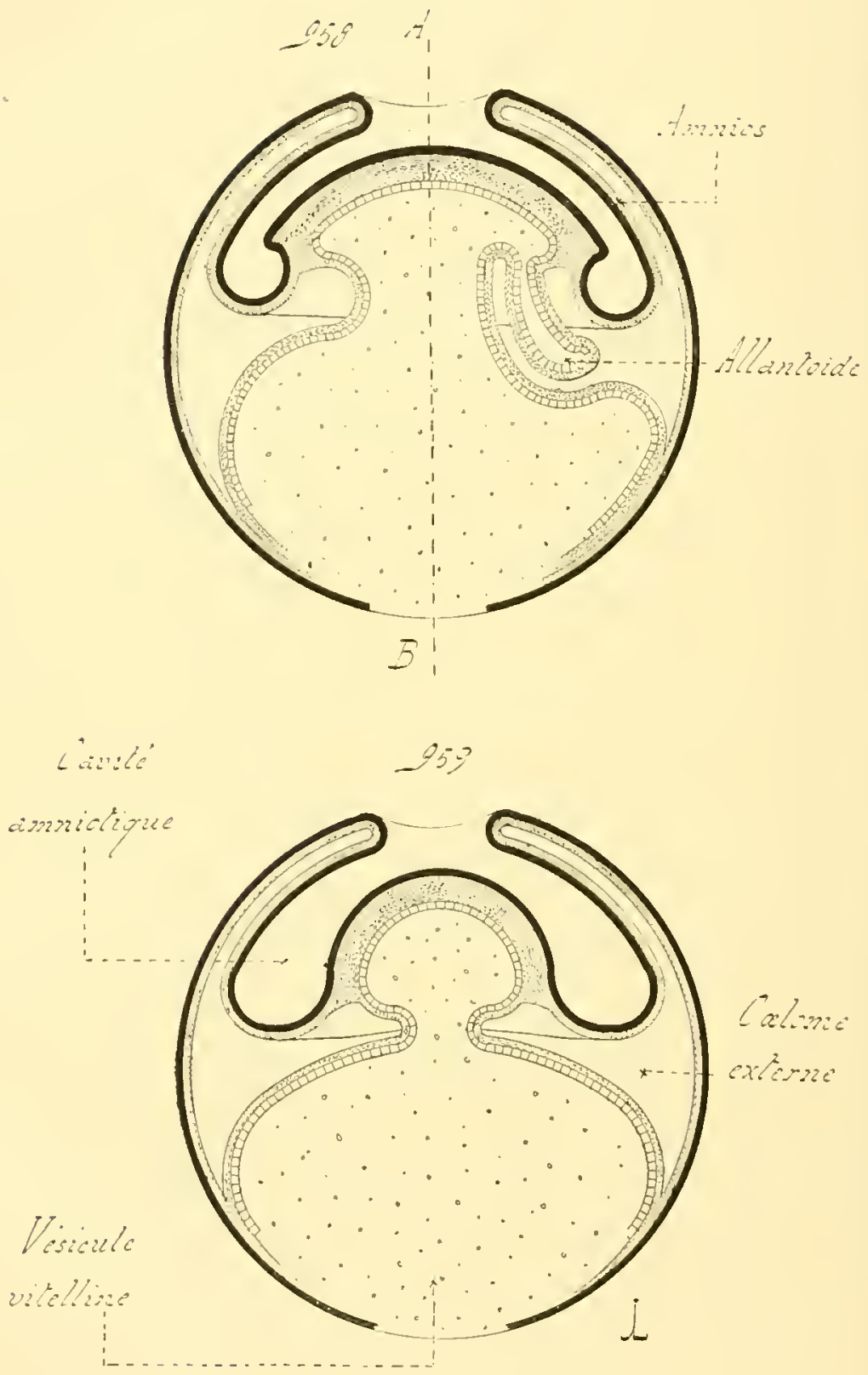

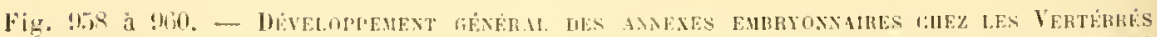
inxotes, et notamment chez les Sauropsides. - Tableau d'ensemble, allant de la lig. ston à la fig. (12. dressi ،'apres l'embryon du l'oulet, cxprimé par des coupes médianes el des contours extèvienrs, à demi dingrimmatiques. L'ectoderme est en noir. l'endoderme en 
sont dits les vaisseaux vitallins, on omphalo-mésentiviques. L'aorte torsale de l'embryon émet deux artires (arteres vitellines, artires omphalo-mésenlériques), l'une droile, l'autre gatuche, qui so distribuent ì l'aire vasculaire. Le sang, apres aroir circulé daus rette dernicre, se rassemble dans deux veines, (veines vilellines, reines omphulo-mesenteriques), l'une droite, l'antre ganche, qui so renlent an sinus veinenx de l'embryon. En outre, le hord mème de l'aire vasculaire, an moven durpel celle-ci s'unit anx portions non enrore clivées de la paroi vitelline, contient un sinus de forme circulaire, car il accompagne le bord el circonserit l'aire

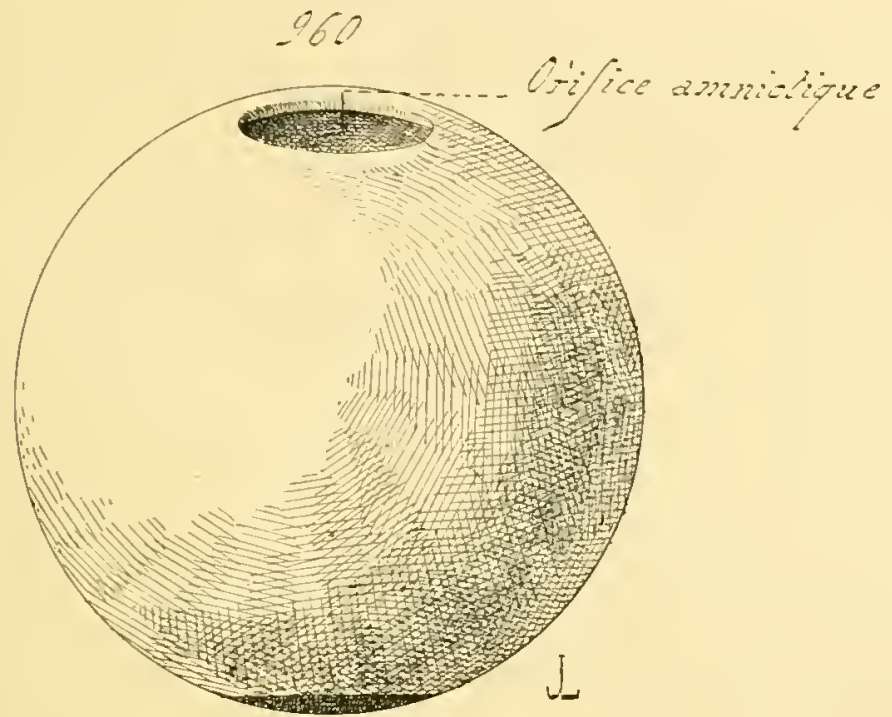

Fig. 060. - La légende accompagne les figures précédentes (058 et 050$)$.

entière: cet espace sanguin, nommé le sinus terminal, est interrompu en une région restreinte, on ses denx houts se replient en derlans pour se rarcorder anx veines vitellines.

Cne telle circulation, fort active, existe ainsi, sauf quelques modificalions spéciales, chez tous les embryons t'Amniotes, pris à une rériode où le colome externe est an délut de son díveloppement.

lachures, le mésoderme en pointillé somhre, le deutoléejlle en pointillè clair; les cavitis sont en blanc.

En 158 , coupe méliane passant par laxe longitudinal de l'embryon; les replis amniotiques, unis en une collerette, gramissent antour de la zone embryonnaire, qui commenee in faronner l'embryon; le rolome externe s'amplifie loujours, et la vesicule allantoide

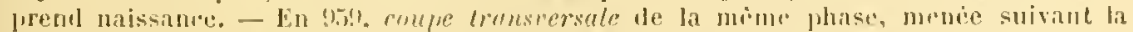

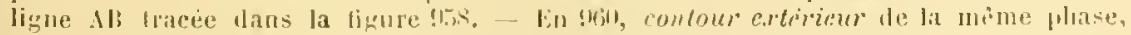

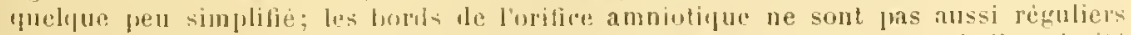
dilns lit nature, et cet orifice lui-mème csl place plus à droite, au-dessus de lextrenite posterieure de lembryon. 
Celte cavité colomique s'étend toujour's d'une manière progressive, el augmente sans cesse la surface de l'aire vasculaire. A mesure que celleci s'amplitie, son sinus lerminal, lonjours silué snr sa limile, se déplace, et séloigne du centre mime de l'aure. Tout en agissant ainsi, il perd son caraclire régulier, el se conlond avec les autres vaisseaux voisins. Cenx-ci modifient également lenrs disposilions fremières, et irriguent III espace plus grand. Finalement, torsque le colome externe a divisé en deux lames toul le blastoderme para-embryonaire, toute la paroi vitelline primitive, la lame interne est complètement vascularisée. l'emlryon ayant alor's alleint me assez grande taille, l's vaisseaux qu elle conlient ont perdu dre leur imporlanre prenièm, par rapport à ceux du corjs. Ils se rassemblent en denx trones principaux, une artère vitelline et une veine vilelline, qui semblent ètre, el sont en réalité, de simples dépendances des vaisseaux mésentériques de l'organisme.

Lo rofome externe n’arrive à sa période d'élal que d'un manière assez lardive, en un moment oì l’amnios est complel, et où la vésicule allantö̈de se trouve déji volumineuse. l'ar sa présence, la paroi vitelline primordiale, le blastoderme para-embryonnaire, d'abord simple, est devenu double, divisé en deux lames concentrípues, qu’il sépare l'une Ie lautre. La lame interne, seule, compose la paroi vitelline déthitive, el conslitue, a vec le deutolécithe qu'elle entoure, la vésicule ritelline vascularisée. La lame externe est siluée en tehors, et séparée d’elle par tonte la largeur du colome externe, qu'orcupe, soil en totalité, soit en parlie, la vésicule allantö̈le. - Ces deux lanes sont, dès lors, entièrement distiucles; plles ne se raccordentl'une à l'autre que far lenrs bases an nivean du corton vitellin, par lenrs premières régions produites. Le calome externe s'obure, en effel, dans l'élendue du cor'lon, afin de s'isoler du cuelome embryonnare, et les lames se sondenll'une a l'autre. Leur épithélio-mésoderme y disparaîl en surphus ; de cette façon, et lor'sque ces phénomènes sont accomplis, le feuiltet moven du cordon se rompose du mésenchyme seul. Ce dernier, vers la ligne d'union du cordon el de la vésicule vitelline, se divise en deux assises, donl l'une se continue avec le splanchno-mésenclıvine de la paroi vilelline (lame interne), el dont lautre agit de mème avec celle partie, de la lame externe, qui a donné lamnios. - La lame externe subil, en ellet, dans l'étendue de l'aire amniotique, des modificalions complexes, dont la fin est la jroduclion d'un amnios.

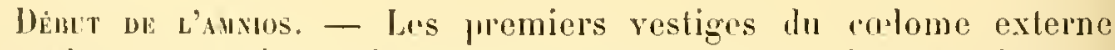
alparaissent au niveau de la rainure marginale, qui sépare la zone cmluryonnaire de la zone para-embryonnaire. Comme ce colome a pour ellet de diviser, par sa présence, le blastoderme para-embryonuare en deux lames, el comme la rainure est un sillon de provenancr superficielle, le lond de ce sillon se troure ronstilué fiar la lame externe. Celle-cipro- 
duil les ébauches amniotiques. Ces dernières sont des bourrelets, dans l'intérieur desquels pénètre le culome externe, qui prenneut naissance dans la rainure mème, alors quelle est preu accentuée encore, un peu en avant du font. Elles dépendent, en somme de la binde proximale, ou de l'aire amnotique, de la zone para-embryonnaire.

Ces bourrelets portent le nom de replis amniotiques. Ils sont au nombre de quatre, comme les élanches de la rainure marginate, et placés de la mène façon. Linn, antérieur, apparait le premier; le second en date est le posterieur; les deux derniers, symétriques, sont lateraux. Ces replis grandissent en s'élevant au-dessus de leur hase; dans leur extension, ils demeurent tonjours creux, et contiennent des expinsions du colome externe. - Etant donnée leur provenance. ils rironscrivent, arec la rainure marginale, la zone appelée à devenir l'embryon. Tout en s'amplifiant, ils so recomrbent au-dessus de cetle zone, it la manière de capuchons, pour la surplomber, el en définilive, jar un accroissement constant, pour l'entourer. Lorsque leur taille est encore minime, leur aspect de capuchon est des plus nets; aussi portent-ils, chacun pour sa parl, les noms de cupuchon antérieur on céphalique, de capuchon postirieur ou caudal, et de capuchons latéraux. An fur et it mesure de leur agrandissement, ils enveloppent une surface toujours plus considérable de l'emliryon, el terminent par le recouvrir à la manière d'un dôme continu. Peudant ce temps, la rainure marginate sapprofondit, entraìnant leurs bases arec elle; the cette sorte, ils s'ílalent sous l'embryon, comme au-dessus de lui, et arrivent juspu'au cordon vitellin.

La pluprart des anteurs décrivent ces phénomènes it la manière d'un affronlement des replis par leurs borls lihres, snivi de laur soudure. Il n'en est pas ainsi dans la réalité. Tout en augmentant leurs timensious. les replis se joignent prar leurs bases, de façon a constituer un bourrefut unique, rirculaire, qui intoure l'embryon comme me collerelte. Celte dernière grandit, jusqu à déprasser le niveau de l'embryon; juis, lorsque celle phase est alteinte, l'extension continue; mais l'ouverture de l'esprace entouré frar la colleretle, et qui contient l'ombryon lui-mème, se rélrécit sans cesse. Une telle restriction devient de plus en plus prononcée, it mesure que le bourrelet s'amplifie; four ternier terme, la colleretle se convertit en mu dòme fermé, qui surplombe le pretit ètre; alle limite, entre elle el lui, me cavité close, la cavité amniolique. - Cet accroissement est inégal. Le bord libre de la rollerette porte des saillies, plus longues les unes que les autres, qui correspondent aux quatre replis primordianx. Liocclusion de l'ouverture circonscrile par ce bord libre, et dite l'orifice amniotique, délute en arant, et finit en arriere, au-dessus de l'extrémité postérieure de l'embryon. En celte région se ferme, d'une manière complete, cet orilice amniolinjue.

Achinanext de hanxus. - A. Les replis amniotipues sont des hourrelets creux, développés sur la lame externe, ot i sesclépens; leur caviti 
rst une expansion du rolome externe. Toul en grandissant, ct s'mussant pour donner la collerelle, lrur cavilé persiste en sa place; aussi les ébanches amniolipues sont-elles conslituées, en ríalité, jar lloux membranes, qu’un espace vile, onvert dans le rolome exlerne, séparel'une dr l"aulre. Celle struclure ne disprarait pas, el se comserve jusqu'au moment où l'amnios est complol; lorsque celle pliase survient, celui-ci se trouve comprosé le lrux membranes concenlriques, l'une interue, l'autre externe, et d'une cavité intercalcie à cus dernières. Ces enveloppes sont fistinctes, désormais, sur loule leur élendue, rt restent complètement isolies. - La membrane interne, qui regardr directement l'embryon, est l'amnios vérilable. La membrane exlerne a reçu divers uoms; le plus employé esl celui de sp̉reuse, lonné par von baïr; les funcipaux des autres sont coux de faux-ammios, on dr membrane sulsonale, surlout usités en ce qui concerne les llammifẻres placentaires. Il serait plus simple de se srrvil des termes exumnios et endammios, déjỉ signalés au sujel des aulres animax (I'lallrelmindlres el Insectes) munis d'enveloppres amniofiques. L'emlamnios est inlerne, placé autom de l'embryon; l'examnjos est la rouchc extérieure, séparéc de la puécédente par la ravilé intercalaił" velle-ci lépend du colome externe, se conlinue avec lui, et peut, en conséquonce, ذlı désignée par la mème expression.

L'examnios et l'enlamnios proviennent également de la lame externe. Ils offrent lone une mème slructure; mais, à rause le leur mode dr dévelopjemeul, leurs assises sont disposées lans un ortre inverse. La lame externe se compose de frois feuillets emboîtés, l'ectoderme, le somato-mésenchyme, et la somalopleure; celle-ci, constituée par une rangée le cellules épithéliales, limite, à son niveau, le culome extrue. - L'examuios conserve la disposition de la lame externe: jl présente de mème, ef de dehors en dedans, l'ecloderme d'abord, puis le somatomésenchyme, enfin la somatopleure. Cet arrangement est cluangé dans l'endamnios (amnios veritable); celui-ci montre, de dehors en dedans, la somaloplenre "n premier lieu, ensuite le somalo-mésenchyme, et enfin l'ectoderme. Ce lernier fenillet est interne dans l'emlamnios, et lourné vers l'embryon: alors qu’il est exlérieur dans l'examnios, et regarde le lehors. Le colome externe, ćlant placé entre les deux enveloppes amnioliøurs, est rijconsirit de lous côtés par la somatopleure, comme dans le reste des appendices.

L'examnios et l'entamnios dillierenl, en sus, par leu's commexions.

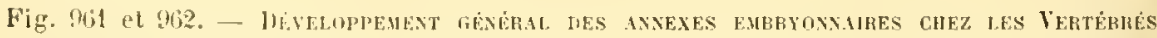
Annotes, el notamment chez les sauropsiles. - l'ableau d'ensemble, allant de la ljg. 9jo

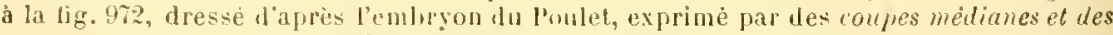
rontours extérieurs, da demi dingrammaligues. liesloderme est en noir, l'endoderme en

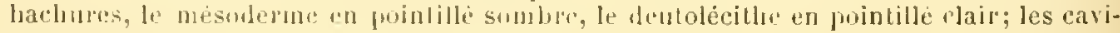
lis sonten blane.

Lin!hil. "oupe midiane jassant par. l'axe longitudinal de l'embryon; l'amnios s'est fermè

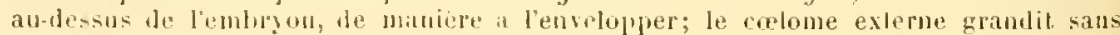
cesse, avec lallantolde qui s"etend dins sa tavite. - En 162, contour extérieur de la 

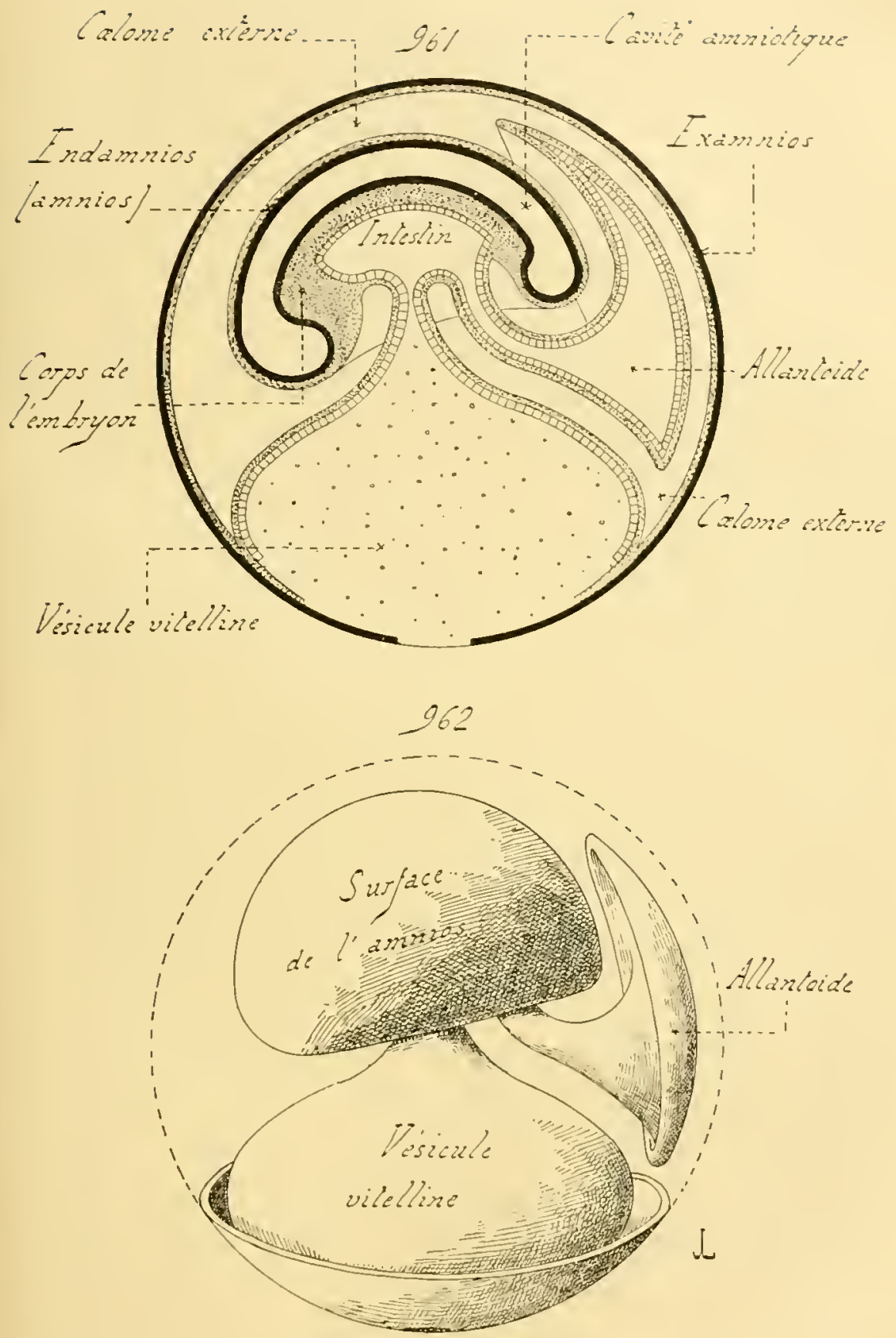

méme pliase. en supposant enleve la majeure part de la lame exterienme fes envelopges embryonatires, alin le montrer les appareils interieurs. 
- L'endamnios demenre attaché à la rainure marginale; an moment où celle-ci est levenue assez profonde pour convertir en un cordon vitellin la rógion mnissant l'embryon à sa résicule nutrilive, l'endamnios, qui a suivi son exlension, s’insère sur le corlon, tans le point mème ò̀ celui-ri se soude a l'embryon. Cetle ligne de routart, siluée sur la face ventrale de ce lemier, portr le nom d'ombilic ammiotiqne, ou rncore celui d'ombilic aludominal; elle est concentrique ì la ligne de conlact du corton vilellin avec le corps, et extérieure par rapport à elle. Celleci est désignée par les termes d'ombilic vitellin, ou d'ombilic intestinal. l'arfois, lans la suile du développenent, l'endamnios ne se borne pas a s'insérer sur la hande de jonction de l'aldomen et du cordon vitellin: il s'étend sur ce dernier, et l'enveloppe à la maniìre d'une gaine. - L'examnios est indépendant de l'endamnios, et entièrement séparé de lui par le corlome externe. Il se relie, par ses hords, ì cetle partie de la lame externe, de beaucoup la plus vaste, qui n'est point intéressée dans la genese des replis amnioliques. Il se continue inlimement avec elle, de faron a former par leur ensemble une seule et même memlirane, plaréc aulour de l'emliryon, it deses autres annexes. Cette membrane est la plus extérieure de toutes les froductions embryonnaires; clle touche directement aux milieux dans lesquels chail plongé l'ovule primordial. A cause de sa rontinuité parfaite, et le sa structure uniforme, les expressions exammios, ou séreuse de von Buër, peurent lui c̀tre appliquées en entier.

Elant données lemr provmance, el leur disposition originelle, les enveloppes de l'amnios circonscrivent deux cavités concentriques, séparées l'me de l'autre par l'endamnios, el ne communiquant pas entre elles. Ia plus extérieure est le rulome externe, intercalé aux deux couches amnioliques. L'interne est la cavité amniotique elle-mème, limitée par l'endamnios. dans laquelle l'embryon est silué. - Cetle carité est restreinte tout d'alord, au moment où l'ammios se complète ct se ferme; elle s'amplifie pal li suite. se remplit d'un liquile, le liquide amniotique, l'eau de l'amnios, et atteint des proprortions considérables. Elle est limitée par l'eetorlerme de loules parts, juisque ce feuillet tapisse, ¿ la fois, la superficie de l'embryon el la face interne de l'endamnios. Le liquide, qu'elle contient, a été surtout examiné, au sujet de sa composilion, chez les Mammiferes placentaires; ces derniers en possedent un plus grand volume que les Amniotes oripares. Il est constilué par de l'oau, tenant des matiores solides en dissolution; la 1naulité de celles-ci, angmentant avec los progrès du développenent, parrient, chez l'llomme, jusqu'à la proportion de $10 \%$. Ces matériaux ronsistrnt, surtout, en chlorures (de sodium et de polassium), en urée, et en lactate de somle. Le liquide amniolique est ainsi cluargé de sulıstances du désassimilation, qui lui arrivent par osmose, et s'aceumulent. 
Par la distension de la cavité amoiotique yn il limitr. l'mmamnios, lamnios véritable, samplitie sans cesse aux déprens du culome externe; celui-ri, d'une manière connexe, se rétrécit dr plus en plus. l'lusieurs des éléments de son somato-mésenehyme se convertissent on filıres musculaires, ot se contractent lentement, a des intervalles prespue reguliers; aussi l'amnios offre-t-il des zones de constriction, qui su deplateent, tantòt dans un sens, tantót dans un autre. Finalement, lorsque le doveloppement apluroche de sa fin. celte membranc commence a s'atrophier; elle se rompt ensuite, au moment de l'éclosion.

B. - Les phénomènes, relatifs ì la genese at à l'achévement dus annexes amniotiques, commencent à les intervalles distincts, quoique petits ; ils s'etfectuent, par la suite, d'une manière prarallele et synchrone. La rainure marginale se montre d'aborl, puis le rulome exterme, rt, en dernier lieu, la collerette amniolique. Mais la premiere de ces cibauches vient à peino de se constituer, fue la seconde apparait, el ensuito la troisième. Toutes trois se complètent. des lors, en mèmr temps, pendant que leblastoderme para-embryomaire, ou seulement son protendoderme lans le cas les Mammiferes vivipar's, amplitie ses dimensions, el progresse a la surface de la région vitelline de l'uruf. En conséquence, il est nécessaire de se représenter, comme s'effectuant à la fois, foutes les phases évolutives précédentes, décrites séparémnnt.

Au moment ou ces phases s'achèrent, la disposition des annexes est derenue fort complexe: l'examnios, situé en dehors, entourc une vaste caviti, le culome externe, dans laquelle se troure plongé l'embryon, muni le sa vésicule vitelline; l'embryon est, en outre, silué dans une" scconde ravité supplémentaire, la cavité amniotique, pleine de liquide, et entourée jar lammios. Cette complexité est rendue plus grande encore jar la présence de la résicule allantoïde, fui naìt rn mème trmps que l'amnios, ou peu aprés lui, el s'ctend dans le celome externe.

III. Développement de la vésicule allantoïde. - La vésicule allantö̈de apjaraît, sanf les cas d'aloriviation montrés par rertains Mammifères à courte gestation, au moment où la collerelte amniotique commence à s'élever pour surplomber l'embryon. Son premier rudiment ust un diverticule, envoyé, par l’intestin postéricur le l'embryon (on le cul-de-sac postérieur le l’intestin), dans lecolome externe, déji asse\% anple. La région dign'slive, ainsi clargée de prodnire l'allantö̈rle, reçoit les canaux excritems des reins (canaux de Iroolf du mésoncphros), et levinula lo cloaque, ou plutèt lo fond du cloapue. - Des son apprition, l'allantö̈le grandil aver rapidilé; elle s'avance dans le culome externe, et s'y amplifie. Son accoossement est parfois lié d’une facon lellement itroite à celui du colome, que ce dernion parail se monsor devant elle, par la pression qu'elle exerce dans son mourement d'exlen- 
1076

CHAMTIE DIX-SIPTIEME
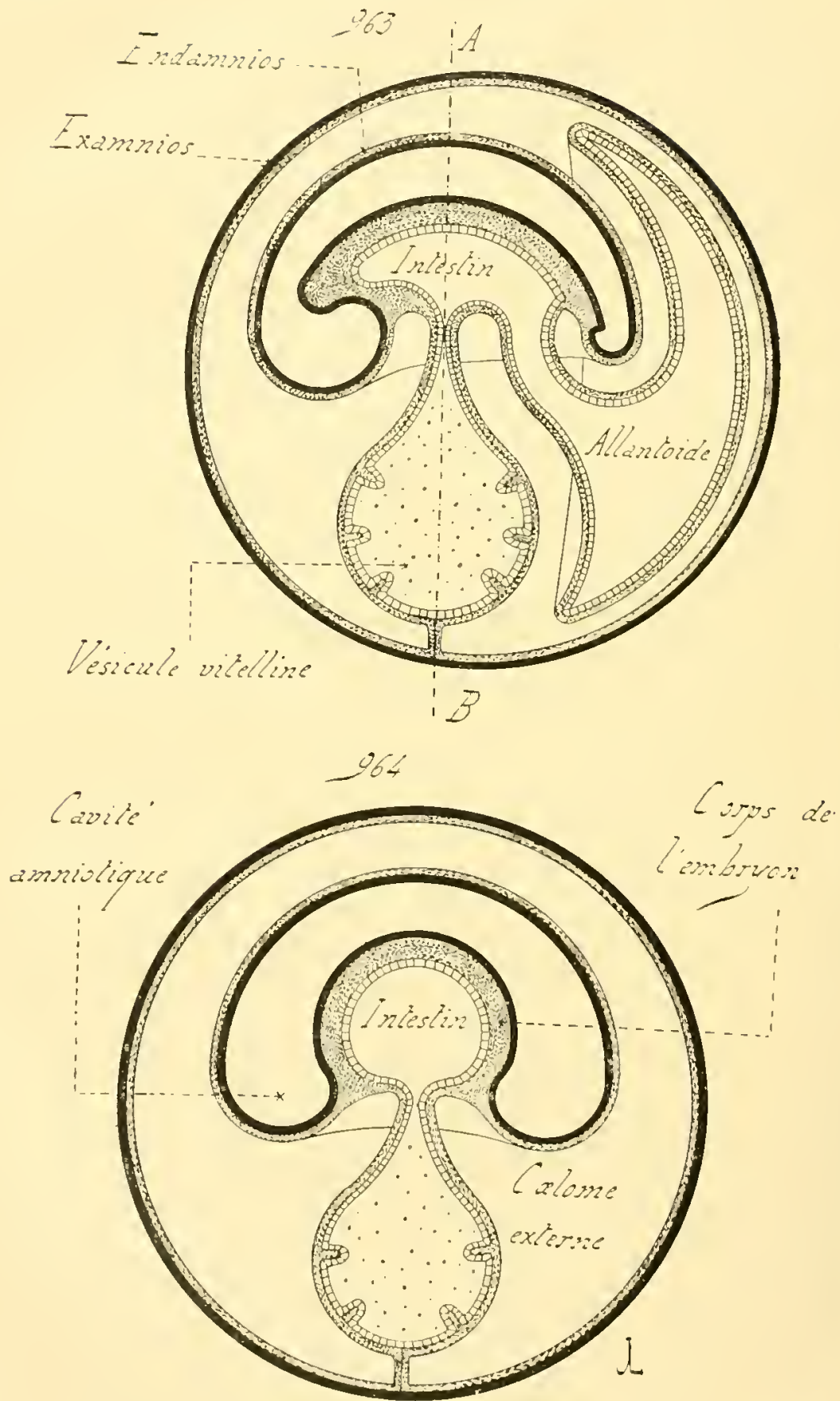

Fig. 9.j3 et nhit. - La légente accompagne la figure suivante (965). 
sion. Ce faisant, elle se divise en deux parts : un pèloncule étroit, l'ouraque, qui s'attache i l'intestin, et constitue la lase dr l'appendien; ot la vésicule elle-même, élargie, placée dans le coelone externe. L'ensemble rajpelle assez bien un champignon, au pied rétréci, et an large chapeau en dòme, moulé dans celte ravité du calome externe, qui entoure l'enbryon avec sa résicule vitelline.

L'ourague est relativement court chez les Amniotes ovipares. - II devient fort long, toul en demenrant stroit, chez les Manmifères pla-

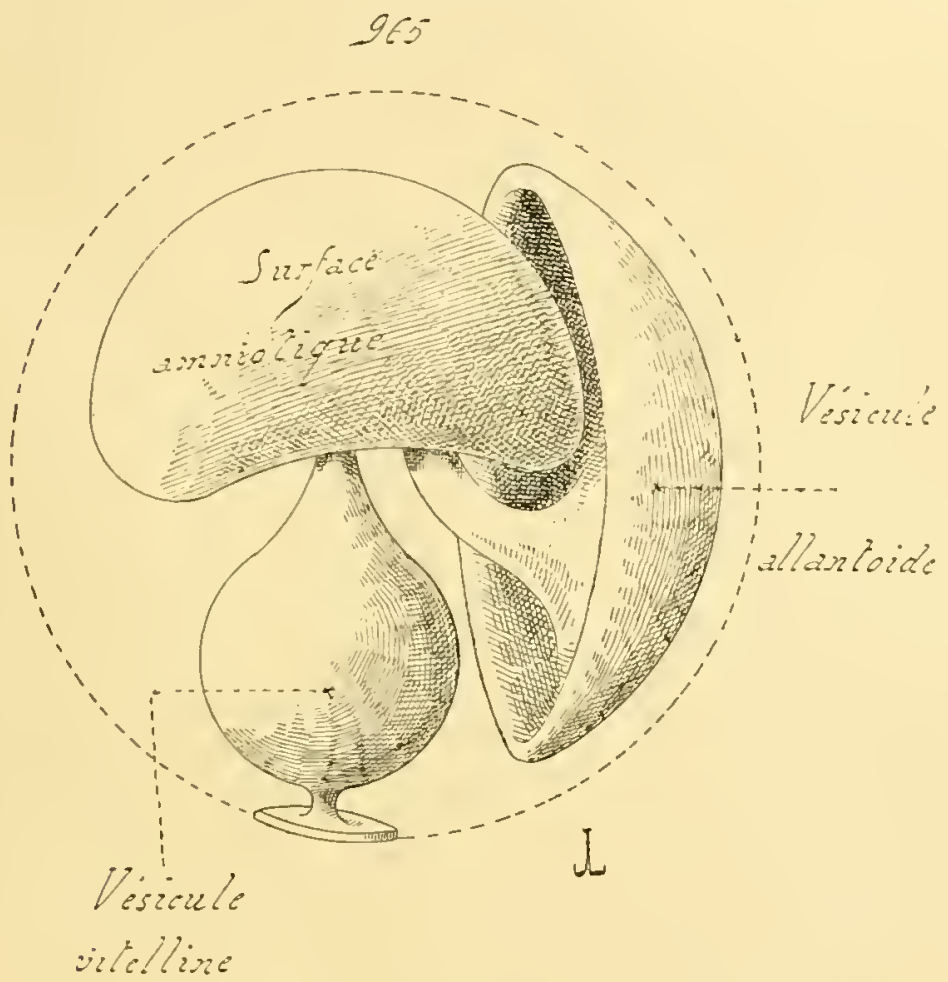

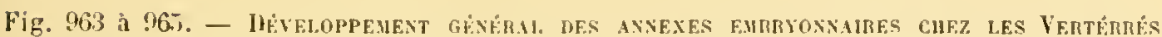

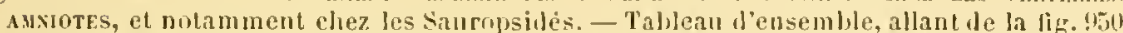
a la fig. 972, lressè l'après l'embryon lu loulel, exprimé jar les coupes médianes et des contours extérieurs, i demi dingrammaliques. l'ectorlerne est en noir, l'endoderme en lachures. le mésolerme en pointillé sombre, le deutolécithe en pointillé clair; Jes cavités sont en lilane.

En 065, coupe médinne passant par l'axe longilulinal de l'ewlryon; le culome externe s'est amplifié au point d'entourer complitement l'amnios et prespue lonte la vesionle vitelline; celle-ci a leja beancoup dininue de taille, et elle eommence à s'isoler lu coti de la cavité intestinale; la vésicule allantoüle frandit, en s'étendant dans le corlome extrone. - En gG', coupe transuersale de la méme phase, menée suivant la ligm Ali de la fig. Ufi, et complétant la fig. (5), pour expliquer le faconnement de l'intestin. - Lin ! 65 , contour extérieur de la méme phase, ensupposant enlevée presune lonte la lame exterienre des enveloppes embryomaires, afin de montrer les ajpajoils intérieurs; celle lame est indiquie frar un pointille. 
rontairos. Il sunit, i son líbut, au cordon vilellin, alors plus gros que

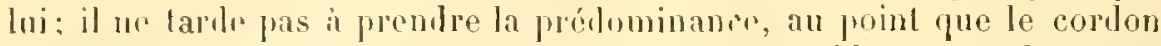
vitellin, of la risicule vitelline elle-mèmr, semblent atre de petits annixes insérés sur lui. Son aspect lui vaut alors le nom de cordon allantö̈dien. l'pxpression ournque étant riservée pour désigner sa lase seule, plonge daus les lissus de l'embryou, ot destiníe í persister sous la forme l'une bande fibreuse, après avoir prouluit la ressic urinaire; le terme "ouraque "sut i indiquer celle bande. - Lorsque sout passées les frrmiores phas's du développenent dos appondices, et loujours daus le cas de la plupart des Mammifíres placentajes, l'amnios s'élale sur le rorton vilellin et le cordon allantöllien, pour les envelopper d'une gaine rommunr. Cot ensemble complexe, qui comprend a la fois ces deux cordons, phus leur envoloppe amniotique, s'attache a la face rentrale de l'abulomen pa l'ombilic, ot tient l'embryon suspemlu dans la ravité amnjolique. le terme de cordon ombilical est alor's méritr par cet appareil, comme l'emploient, du reste, la plupart des auteurs: majs a la condition do ne poinl sen servir, au surplus, pour désigner le seul corlon vitellin primordial, afin de ne pas erere de confusion entre le tout et une dre ses parties.

La vésicule allantö̈le, et son pélloneule, ont même strurture. lls correspondent ì une cragination de l’intestin postérieur, qui souleve, à son niveau, la paroi du corps. Celle-ci se compos", en cetle région, et à cansu dr la jorsenro du corome externo, de trois assises : l'endoderme ru ledans, le splanchno-mésenchyme au milieu, ef la splanchnoplenre en dehors. Cos trois conrhes, seules. entrunt dans la constitution de l'allantoïdr. - A la suitr de la disposition premiere, et dr la direction de laceroissmment, la surlace de la résicule, dirertement en contact avec lo lipuide du colomo externe, est formér par la splanchuoplune. Le splanchno-mósenchymo est situé on dodans do cello-ri; ot, tout à fait vers l'intérieur, limitant la cavité allantoïdienue, lorsqu'olle existe, se frouve lentoderme. Dhabitude, l'indoderme, et surtout la splanchnopleure, sont fort riduits; le phus grand rolume est acquis au méscnchyme, surtoul in ce qui conrerne los Mammiferes plareutaires, ef aux nombroux vaisseanx sanguins crousés dans sa masse.

l'allantoïle, ainsi conslituée, s'éteml dans le colome extrine, et, notamment cho\% les Ammioles ovipares, tinit par l'envahir, pas le remplir en cotirr; ollr ruveloppe, a la fois, lembryon rontoure de son endamnios (amuios véritable), et la vésicule vilelline, tout en demrurant attachér an corpes par un priblonculw elroit. La base de ce dernjer traverse las lissus aldominaux, à la maniere diun tube jorforaul, pour

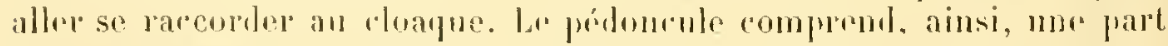

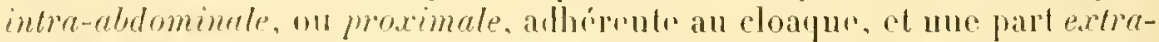
ablominale, ou distule, lión à la vésioule alle-mème. - Au moment de l’éclosion de l'emleryon, lallantölde subit des modilicalions, varialiles sujant les types, it encore incomplitement connues. Ella disparait 
tout entière chez les Sauropsidés, après avoir présenté des pluénomines dr légánérescence, vers la tin des phases évolutivrs. Colle los Mammifires didelplors se rétracte, en diminuant de volmmr, mais conservant ses comexions générales, el rentre completement alans la cavité alulominale du fotus; ello est conservie, el devient la vessie minair de l'animal. Enfin, clez les Mammifères monodolples, sans loute ì raus. de la Lansformalion en un placenta de la plus grande part de la vésicule allantö̈le, celle-ci, avec la zone extra-almominale te son cordon, se détache, au moment de la parturition, du corps de l'euluryon; alle est rejetée, et sa chuto laisse, sur la face rentrale de l'individu, une cicatrice dite lombilic. La part intra-ahdominale demene seule, "t garle ses connexions; sa base reste creuse, el so lonthe, pour se convertir en la vessie urinaire de l'alulte; son sommet se changr en un cordon plein, fibrux, le ligament vesical moyen, qui ratlache à l'omlilic l'extrémilis libre de la ressie. - En somme, l’allantö̈le produit, dans tous les cas, la ressir mrinaire des Mammiferes vivipares, les seuls conmus it cel igard; seulement, collo des Dilelphes est conservéc tont entière pour amener celtr fin, alors que celle drs llonodchlyes n'emploie que sa hase ì cet usage, la plus grandr parlie d’olle-même servant it jroduire le placenta, organe strictement embryonnaire, el rlestiné à c̀lre rejelé.

La vísicule allantoïle noffro pas te mème aspect, chez lous les Amniotes, et ne jone pas le mème rojle. - Colle lles Samopsidés, des Mammiferes ovijares (Monotremes), et des Didelphes, est comparalle a une poche remplie lle liquile, dont les parois, à pen pres lisses et unies, sont richement vascularisées. Celle ahondance de vaisseaux permot à l'apprareil de fonctionner, chcz l's Amniotes ovipares, comme un organe de rospiration embryonnaire. Par un effet le la forme génirale, la partie, lournée vers le dehors, de la paroi allantoüdienne, saccole a l'rammios, el saltache a lui pour former une seulr memliane, le chorion embryomaire, qui sépare la caviti de l'allantö̈le des coques le l'unf. L'air passe au travers de ces dernicres, soit en parcourant les pores des corpurs solides, soit prar osmose on re qui concerno les lipuides, el arrive au nivean de cotle membrane. Le sang alsorlyr de l'oxygene. al se débarrasse de ses produits oxycarlunés. Comme les vaissranx allantö̈licus sont ratlachies à ceux le l'embryon, la cirnulion permet le renouvellement constant du sang, et, par ce moven, la respiration du potit otre, inmolile dans son wuf. - En oulre, lallantoïle sert dr vessio minaire extrieure; le lípuide, lont sil cavilé se trouve amplie, est un. véritable urine embryonmaire. Son pridoneule s'ourro dans le cloapue, oil débouchent également les uretères; l'urine, apres avoir parcouru ces

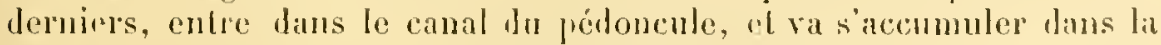
ravité allantoüdienne. I. liquide de cetle dernicro est de couleur jannilre; il tient rn dissolution des corps solides, dont les principanx sonl des

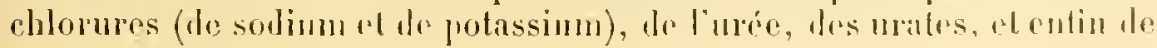




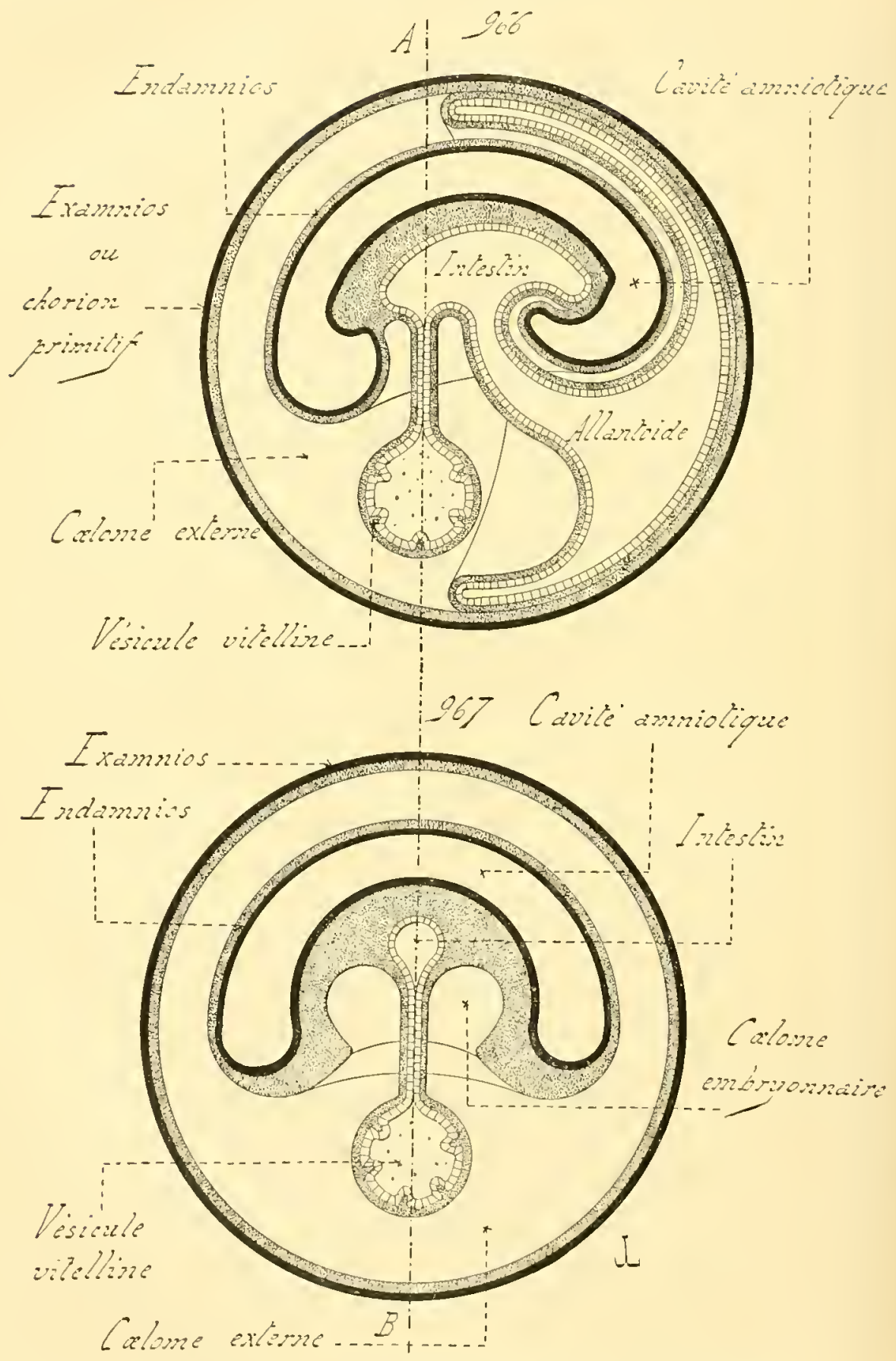

Fig. !bit et 907. - La légend! accompagnc la higure suivante (908). 
Vallantoïne, substance dout la composition se rapproche de colls de l'urée. De mème que pour le liquide amniotique, la quantité de tees matériaux angmente avec les progrès du líveloppement, et atteint उ iो $6 \%$.

L'allantoüde des Mammifères placeutaires subit une évolution dif-

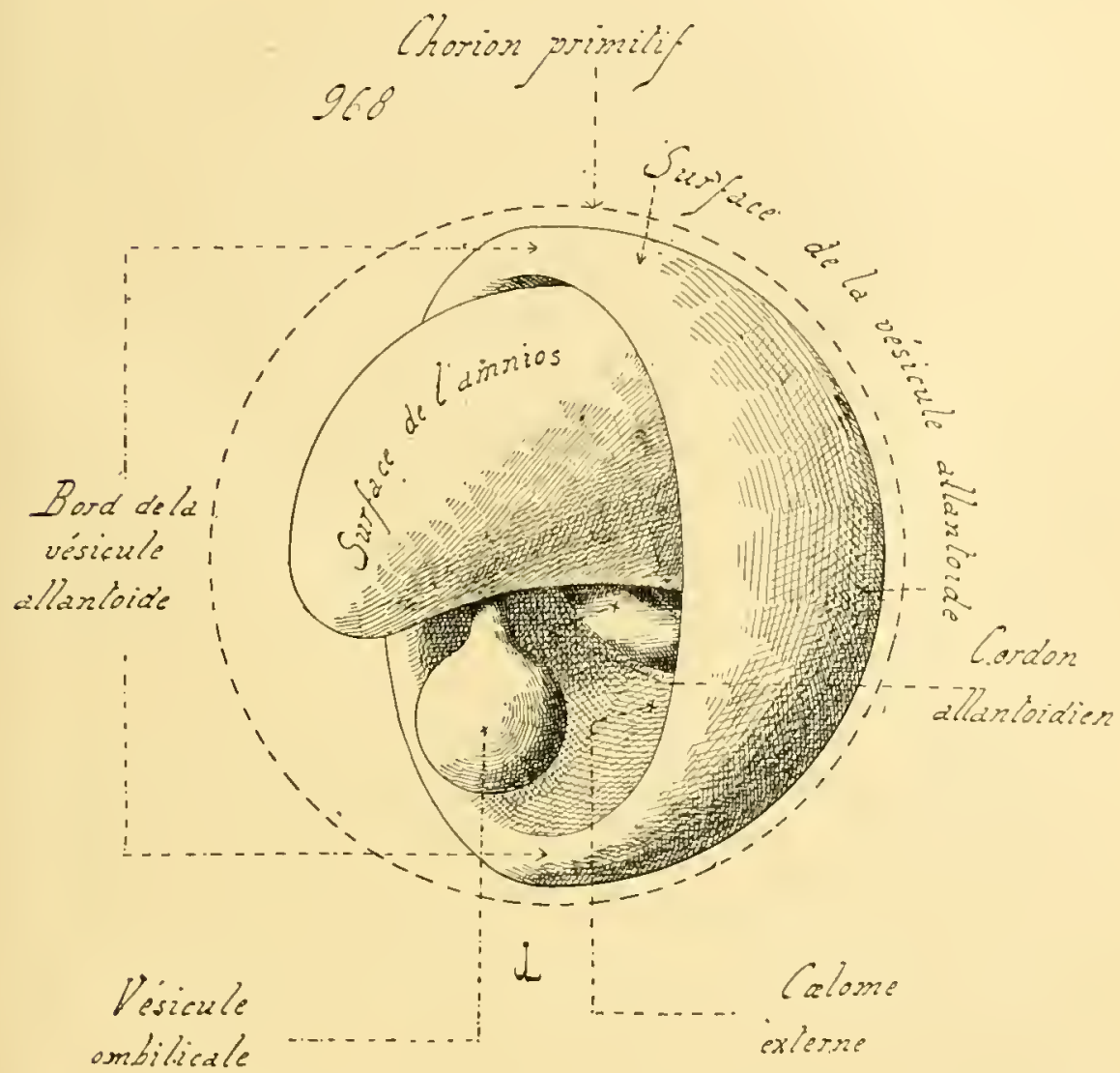

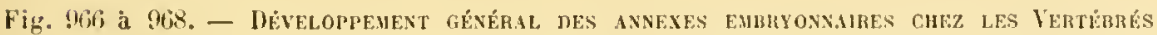
Awiotrs, et notamment ehez les Sauropsides. - T'alıleau d'ensemble, allant de la fig. 9ho ì la fï. 9i2, dressé l'après l'embryon du l'oulet, exprimé par des coupes médianes el des contours exlérieurs, ì demi diagrammatiques, l'ectorlerme est en noir, l'endoderme en hachures, te mesoderme en pointillè sombre, lo deutolecithe en pointillẻ elair; les cavités sont en blanc.

En 960, coupa médiane passant par l'are longitudinal de l'embryon; le colome externe entoure completement l'amnios et la vesicule vitelline; celle-ei, devenue restreinte, cst toujours suspendue par son cordon vitellin (ou mbilical) au corps de l'embryon, mais sa cavité est séparé de celle de l'intestin; la vesioule allantoüde continue à s'itendre. dans la culome externe. - En 967, roupe trunsversule de la meme phase, passant par la

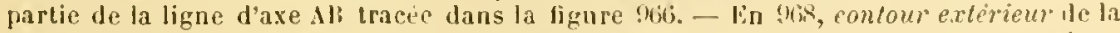
meme pluase, en supposant enlevé la lame extirieure des envelopnes embryonnaires, afil de nontrer les ajpareils intérieurs; cette lame est indicuee par un pointille. 
férente. La porlion dr sa proi, qui se soude a l'examnios prour donner le rhorion emliryonnaire. s'hypertrophie dans des proportions consiléraliles, soit en toitalité, soit on partice et produit le placenta des embryons le ces animanx. Ainsi que l’ont démontré les récentes recherches de M. Duval, l'accroissement placentaire de l'allantoüle est prócób, dans ces mênes régions, far un épajssissement le l'ectodeme de l'examnios, ou du chorion embryomnaire, puisque celui-là est la couche extérieure le celui-ci. Ces zones épaissius constituent la formation désignée par cel auteur, a cause de sa provenance, sous le nom dectoplacenta; elles représentent l’élanche dn placenta total, unissent le cborion ì la paroi utérine, el permottont aux premiers échanges diflusifs de s'eflectuer à leur niveau, en attentant que l'arrivée de la portion allantoüliemne. munje de ses vaisseaux sanguins, dome à ces échanges nne intensití plus grande. - En général, lorsque le placenta est liffus, constitué par les villosités restreintes, ot distinctes, la cavité allantö̈licune persiste, jusque vers la fin de la gestalion; elle se remplit d'urine embryonnare, et fonctionne ì la maniere d'unc vessie. Dans le cas où, par opjosilion, le placenta constitue mn seul corps, Jense et ramassé sur lui-même, la ravité allantoïdienne se clót rapirlement, du moins le plus sonvent. Sa disparition est causcée par l'aceroissement énorme du mésenchyoue do sa paroi, que parcourent les vaisseaux sanguins. L'obturation s'effretue, en dernicr licu, dans le [úloncule; la fermeture de ce dernier s'achève, en movenne, dans le courant du second tiers le la gestation (du quatriome an cinquieme mois), rhez l'llomme.

Dans le luul de suffire à ses diverses fonctions, respiration seule, ou nutrition complete par l'entremise d'un placenta, la paroi de l'allantö̈le contient de mombrenx capillaires sanguins. Ces derniers sont les branches de trones principaus, les vaisseaux allantö̈liens. qui longent le pribloncule, parcourent ainsi le cordon ombilical, et se raccordront au systome circulatoire partirulier de l'embryon. En ce qui tourbe les Mammifères, les termes dr vaissenux ombilicaux, ou de vaisseaux placenlaires, sont souvent employés comme syuonymes du nom précédent; re dernier ast le mejlleur, í ciuse de sa précision, qui empriche toule confusion possible, et devait être seul usité. Les trones vasunlaires, et

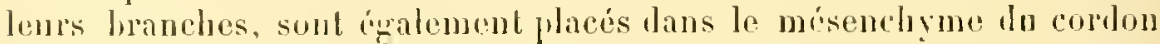
et de la vésicule. - Les artères allantöiliennes sont an momlure de lleux, line droite, l'autre gauche, et demeurent ainsi. Elles proviennent des iliaques frimitives de l'ombryon ; lorsque l’allantö̈le disparaît, les bases de crs artires restent lans le rorps, et constiluent les hypogastriques, w iliaques intrones. - Les veines allantö̈liennes sont également, ì leur début, au nombre de denx; elles se rendent aux canan de Curier, qui lenr serrout d’intermoliaires pour arriver au sinus veineux; bien que l'espace à parcomir soit forl courl, au point quelles s'attarhent à ces cananx, dans la région meme où res derniers sunissent au sinus 
veinenx. I'uis, la veine allantö̈dienne droite ne tarde pas it s'atrophier; ses branches particulières vont s'onvrir dans si correspomblute dr gauche. Eu outre, cefte demicre avait émis, au préalahle, mne branche de communication avec cette partir. de la veine vitellins, nir viennent aboutir les veines sus-lıépatiques; celte lıanche grossit, et acpuicrt lit prépoudérance, tandis que s'alrophie la part mie au canal de Cuvier. Limnique reine allantoülienne a donr perdu ses connexions premières. el s'oure dans la vifelline. Plus tard, au moment de l'éclosion, la cilrculation allantö̈dienne resse, cette veine devient inulile, of se convertit en une bande fibreuss, annexée an foie, le cambl veineux d'A rantius (on d'Aranzi).

Lorsque l'endamnios, en s'accroissant, applique le rordon vitellin contre le cordon allantoülien, ef les enveloppe d'une gaine commune, pour constituer avec eux un seul cordon ombilical, ce dernier contient deux sortes de vaisseaux : les uns vitellins, destinés à la vésicule vitelline; les autres, allantoüliens, yui se rendent à la vésicule allantö̈de. La disposition de ces troncs vasculaires serait, en conséquence, assez. complexe, si, dans ce cas, qui s'applique surtout aux llammifères placentaires, les vaisseaux vitellins ne disparaissaient d'une façon précoce, pour ne laisser sulssister 'jue les vaisseaux allantoïdiens. Coux-ci, au nombre de lrois, deux artères ef une veine, car l'alrophie de la reine droite est hàtive, sont les seuls qui parcourent le cordon ombilical, durant la majeure partie de la gestation.

W. Nature des annexes embryonnaires des Amniotes. La préseme de l'amnios, el celle de l'allantoüde, sont lires à deux niressités physiologiques. La première est celle de la suspension de l'emlryon dans une cavité close, pleine de liquide. La seconde est celle de la respiration el de la nutrition; le petil ètre, enfermé dans sa coque, oul dans l'ulérus malermel, ne peut respirer arec ses proumons, ni s'alimenter arec son tule ligestif; l'allantö̈de supplée, suivant le cas, ì celle insuffisance, ef permet anx deux fonctions le sexercer.

Ces deux annexes, ohrissant, lans leur genese, à deux impulsions différentes, ne sont pas solidaires. Ils coexistent lans te développement embryonnaire de lous les Amuiotes, croluent d'une manière connexe, et affectent, entre enx, Jes relations étroites, mais ils sont indépendants yuant au foul, quant it lours causes productires.

La résirule allautoüde est, (hez les Amuioles les plus simples el les plus voisins des Vertélorés inférieurs, cho\% les Sauropsillís, un oryan

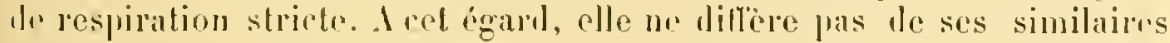
fonctionmels, montrés par lis embryons des tehtlyoprsidés, el notamment par renx des Auphiliens. Son roble se complique frar la production d'un placenta, whez los Mammifires monolelphes, mais w complément ne morlitie pas sa natur essentielle. - Les Ammotes, et les Amplibiens, so rattarlent aux Verlólués munis de magroires, 
1084

CIIAPITRE, DIX-SEPTIEME
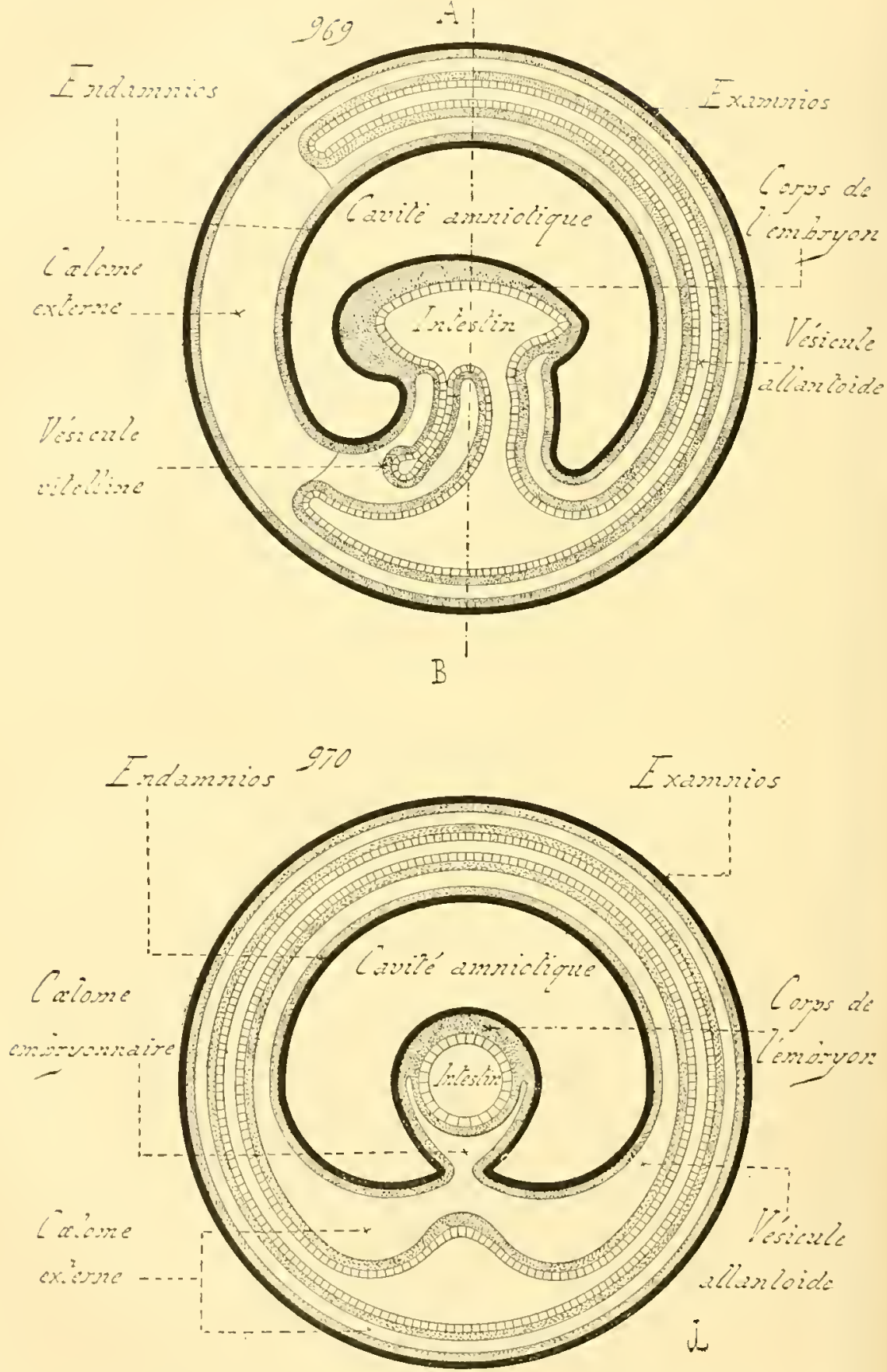

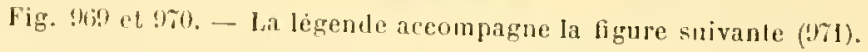


par l'entremise des Slégocéphales lisprarus, si nombrom et si variés durant la période primaire: los Dijneustes et les Mmphiliens actuels sont les derniers vestiges laissés par celte classe, autrefois si importante. Les embryous des Amphihiens offrent une grande divcrsile sous le rapport de leurs appendices respiratoires; les uns possèdent, ¿̀

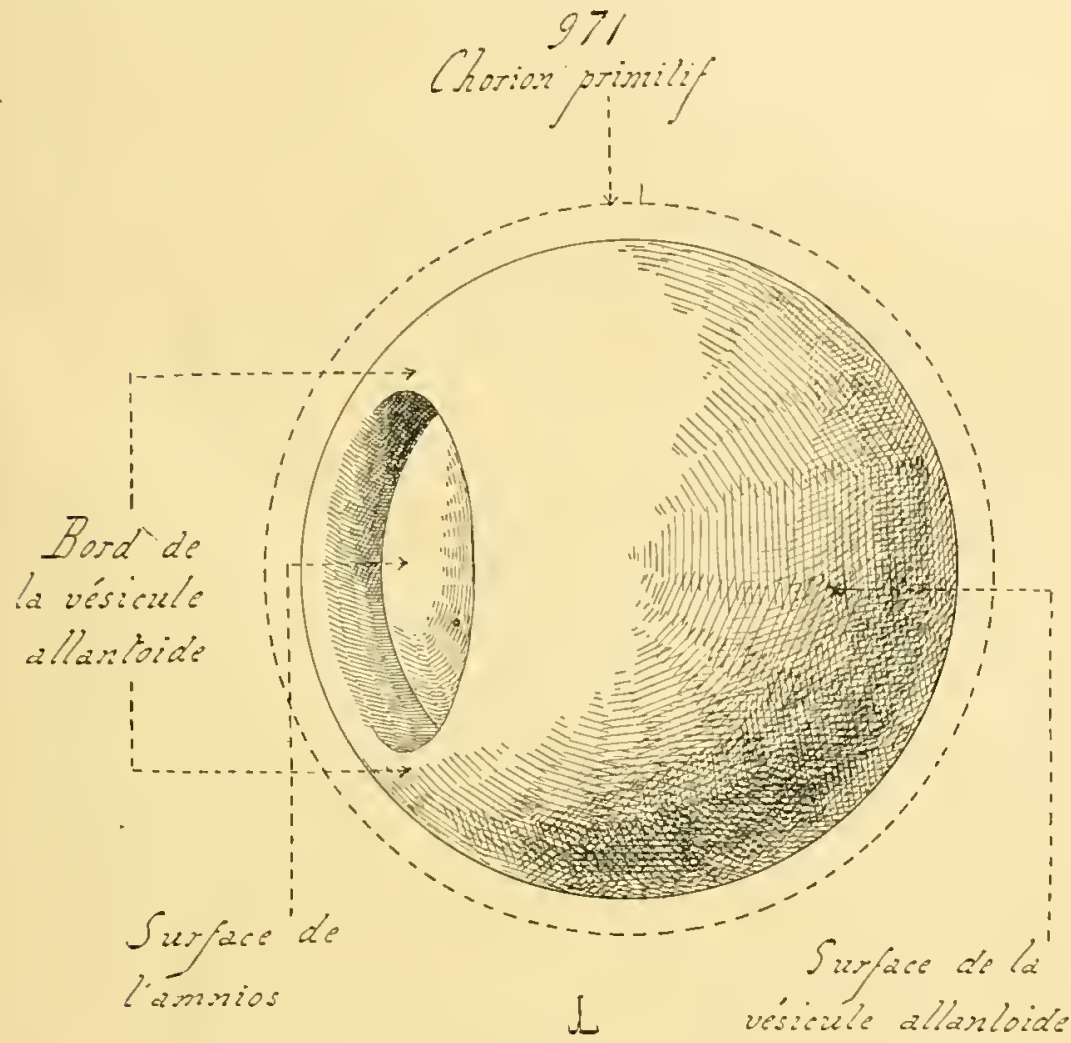

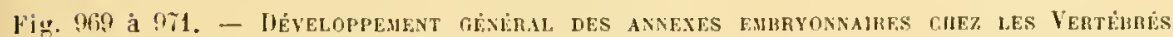

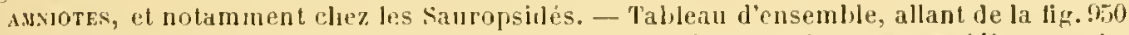

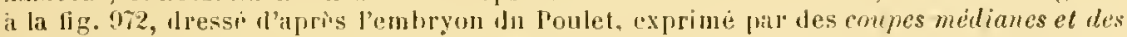
contours extérieurs, i demi dinyrimmatiques. l'ectollerme est en noir, l'endoderme en lıahures, le mèsorlerme en pointillẻ sombre, le deutulccithe en pointillé clair; les cavités sont en blane.

lin 969, coupe médiane passant par l'axe longiludinal de l'emlryon; la vésieule vitelline est devenue fort petite, et la visienle allantoüde oeeupe le culome externe presijue entier; en eette phase, l'évolution embryonnaire approche de sa lin. - lin 970, roupe transversale de la mème phase, passint par laxe Al3 de la lig. Wo. - lin 97, contour extèrieur de la méme phase, en supposant enlevè la lame extérienro des enveloppes embryounaires, afin de montrer les apprarcils intérieurs; cette lame est indiquce par un pointille.

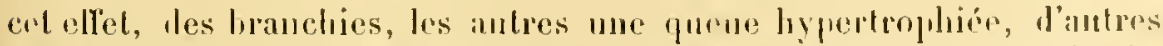
encore des plaquos lógumontaines ventrales. Cutte diversiti existait, selon toutes probabilités, et plus prononcée encore, che\% les stégocí- 
phales d'autrefois. Sans doute, les embryons do certains d'entro enx prorluisaiont, anx lépensdes parois de leur 'loarur, une expansion leur servant d'aprareil respiratoirn; cenx de l'lylodes marlinicensis actuell. amplitient leur yueuc, et "rux de la liuna opisthodon émettent des saillirs troumentaires pépi-cloacales, lans le mème hut. Cel apjendice, dont la notion dancienne présence, toute subjective, parait exacte crerndant, d’aprés les données acquises, a élé l' point de dípart de l'allantoüle des Amniotes.

Cette vésinule rxiste, arue roustancr, chez l's embryous de tous les Amniotes actuels, et constitur leur unique organe dre respration; la liversilé, montrée i cet égarl par les Imphibiens, el, sans doute, par les Stégocéplıales disparus, ne se retrouve pas.

La présence d'une enveloppe amniotique semble lirir, par contre, à une cause toute mécaniqur. - Lembryon, jour se développer d'une façon complète, et ne pas nuire, ce faisant, à lui-même, ni à ce qui l'entoure, doit ètre plongé lans un milien liquide. Ce milien est, en effel. incaprable de froisser les régions en voie d'uxtension; il constitue mo sorte de coussinet protecteur, permettant au petit ètre de faire les quelques mouvements qüil exécute sur place; entin, il facilite les ichanges Jiflusifs. Dans le cas des aenfs pondus dans l'ean, la pénétration constante de celte dernière, à travers la coqur, permet à l'enveloppe immédiate de lembrion de se Jiluer; mais re fait ast impossible pour les ovules déposés sur le sol, rt, en définitive, plongris lans l'air, comme le sont ceux des Sauropsidés. La nécessité l'une cavité pleine de liquide, et contenant l'embrvon, s'impose pontant: aussi, cette cavité se délimito par le plissement, at l'amplifination, des portions apjendiculaires les plus voisines de l'embryon. Ce phénomène aloulit a la production d'un amnios à double membrane. Tres probablement, cet annexe s'est développé, tont l'abord, rhez divers Stégocéphales, Jont la disposition des membres lénote une romplete existence lerrostre, et s'est conservé chez les Sauropsides, comme chez les Mammifieres ovipares. Cos derniers l'ont transmis aux Mammiferes vivipares, fuoique la nécessité do cet organe se fasse sentir, à canse de la viviparité mème, d’une facon moins jressante.

La mème cause amène, du reste, les mèmes effets chez l'autres animanx. Outro les Vertély amniotes, les ètres munis, avec une rertaine constance, denveloppes ammiotiques, sont les l'lathelminthes et les Insectes. - bion que les aufs de plusieurs des premirers (Téniadés) soient terrestres, les l'latodes méritent d'ètre placés ì part; lenr ammios atteint, en effet, tonte son ampleur chez diverses Némertines, alors que plusieurs des autres représcntants de la classe sont privés d"un apprendice similaire : la répartition est loin d’ètre uniforme. En outre, les P'lathelminthes les plus différenciés, ceux dont les adaptations sont les plus complexes, les Trémalodes, et surtout les Cestodes, possident un am- 
nios; mais re dernier, très róluil, tombe dune manière hàlive, dios les premières phasas du dereloppement. En somme, cet apparcil protecteur est loin de posseder, toutes proportions gardies, la valeur fouclionnelle de son analogue des Annioles. - Il nen est pas fout il fait re mème chez les Insectes. L’amnios de ces anjmanx, pouluil dès le commencement des phases emhryonnaires, se dérelopje arverapidité, cl ne se desoreranise quau moment où l'éclosion approche. II ne manque presque jamais, el ne subit des phénomènes de destruction, dı moins en l'état

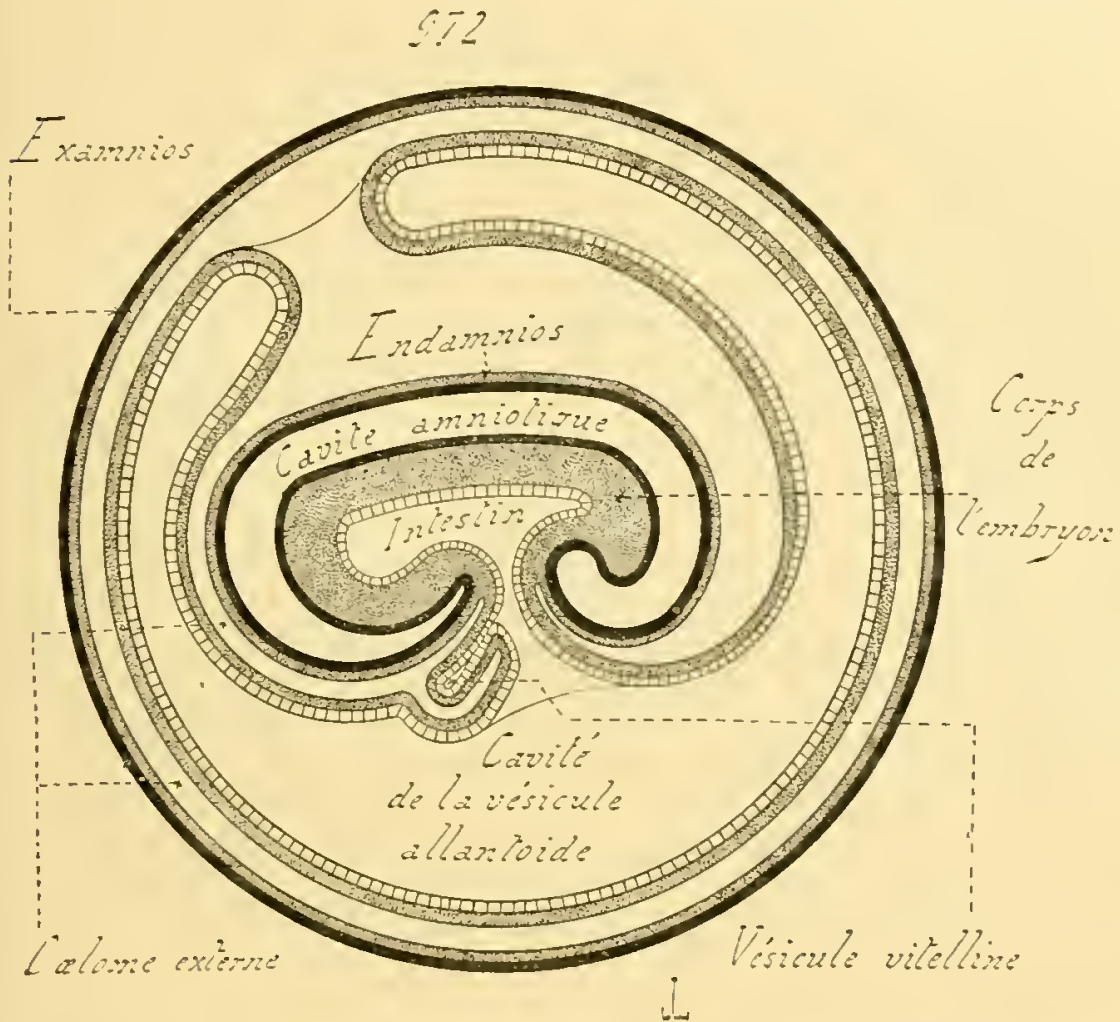

FiL. 9\%. - JRE et notamment cher. les Saurupsidés. - Cette figure termine le tableau d'ensemble, commence par la fig. 950 , dresse d'après l'embryon du Poulet, exprime par des coupes médinnes el par des conlours extérieurs, it demi diayrammntiques. l'ectoderme est en noir, l'endoderme en lathures, le mesorlerme en pointille sombre: les cariles sont en bine. - Celle figure représente une roupe médiane pussnut pur l'are longiludimal de l'embryou, vers la fin du developpement de ce dernier; la vésicule vitelline niest plus yu'un vestige, et la vésieule allantoirle, parvenue au comble de son accroissement. comnence a se fletrir.

Ln ee qui concerne plus specialement les llammifères, les figures 900 is 997 completent les Jonnees fonrnies par le present tableau densemble. guant aux dispositions reelles des annexus embryonnaires des sauropsides, elles sont indiques, d'apries le l'oulet, par les ligures suivantes, numerotees de 1933 a 985. 
présent de nos commaissances, que dans le cas des Insectes aquatiøues, lont les aufs sont pondus daus l'ean. Des vestiges de ret appendice paraissent exister chez les Myriapodes, et mème chez divers Arachnides. Or ces ètres déposent, l'une manière uniforme, et sauf quelques rares exceptions, leurs wn fans le sol, ou sur la terre. La relation de cause i effet semble vraiment identique à sa correspondante les Amniotes; ces ceufs, plongés dans l'air, doivent produire une enveloppe amniotique, destinée a limiter, autour de l'embryon, une cavité remplie de liquide. Les quelques autres animanx, Némaiodes, Annelís, et Gastéropodes pulmonés, dont les aufs no sont point placés dans l'eau, suppléent à cette alsence par le moyen d'un chorion imperméable, ou peu perméable, empèchant de s’évaporer le liquide déposé, an préalable, dans le vitellus par le générateur, et par la rapidilé de l’évolution; en outre, ces oufs sont pondus dans la terre humide, ou dans un milien contenant une dose suffisaute d'humidité.

La nécessilé llune gaine liquide autour de tout organe doné de mouvements est telle, que l'économic en produit, d'une manière constante, pour entourer les appareits moliles el contractiles. Les procédés mis en auvre sont des plus divers; mais le résultat est identique. Les muscles glissent dans des fourreaux conjonctifs, véritables éponges imbibées de lymphe. Les vaisseamx sanguins sont enveloppés d'une gaine lymphatique. Le cuenr est plongé lans une cavité péricardique; les ponmons sont placés dans une cavité plemale. L'intestin de tous les animaux, lès qu'il acquiert une certaine complexité, portant a la fois sur la structure comme sur les fonctions, el nécessitant des contractions péristaltiques, levient imlépenlant de ce qui l'entoure, et se trouve situé dans une cavité péritonéale. - Cette cause générale exerce son effet sur l'organisme embryommaire tout entier, également mobile; elle a pour résultat la genèse d'une cavité amniotique, que limite l'amnios.

La présence de l'amnios, chez les Vertébrés, est donc liéc à une nécessité physiologrique, distincte de celle qui a pour effet la production de l'allantoïde. Ces denx besoins se sont manifestés, crpendant, et d'une manière parallèle, chez les mèmes animanx; ils ont amené le dévelopfrement comnexe les deux appendices correspondants, et ont permis leurs relations mutuelles. - En ce qui touche plutôt l'amnios, la compllexité extrème de lorganisme, beancoup plus grande que chez les Insectes, a élé l'une des causes, sinon l'unique cause, dn creusement dn coelome externe. La résorption de l'ahondant deutolécithe nécessite l'emploi de vaisseaux sanguius; la loi l'économie exergant ici son influence, la fraroi vilelline ne détache qu'une partic d'elle-mêne pour façonner l’amnios, ot maintiont lo vitellus nutritif réuni en un soul amas localisé. La portion délachéc se sépare, par clivage, de celle qui deneure comme faroi vitelline; ce clivage n'est antre que le creusement du corlome externe. Celui-ci s’amplitie par la suite, et s'étend beancoup plus loin 
que la base de l'amnios, L'agrandissument, dans co sens, est dì. sans doule, à la résicule allantoüle; celle-ci péniotre łans lorulome, s’y étale, et $\mathrm{y}$ prend une extension considérahle.

\section{\$. - Formes et annexes embryonnaires des Sauropsidés.}

l. Considérations générales. - L'oviparit’́ est la rógle, ılans lo développenent des Sampopidis. La femelle pond des aufs fécondés, entourés de coques épaissos, dans l’intérienr desquelles se développent les jeunes. Lovule se segmente pendant quil parcont l'oviducle, ot s'entoure, it mesure, de ses diverses coques. L'embryon, parvenu à son étal définitif, brise celles de ces derniores qui restent encore autour le lui, et arrive dans les milieux extérieurs. - Les Sauropsidés vivipares, peu nombreux, appartienuent lous à la rlasse des Reptiles. Les phases de leur évolution ne different point de celles montrées par leurs congénères, car la viviparité de ces ôtres se horne à la conservation, par la femelle, de ses uufs lans son oviducte; an lieu de les pondre, celle-ci les grarde dans ses voies sexuelles, où ils se développent comme s’ils avaicut été rejelés. Chez les Vipères, les mienx connues à cel ŕgard, la femelle expulse ses aufs au moment où les ambryons ont achevé leur organisme; de suite après la ponte, cenx-ci percent lenr corjue, et leviennent libres. Ils ressemblent en tout a leur génératenr, sauf par la laille, encore petite; ils portent, appendus a leur face ventrale, les derniers vestiges de leur vésicule vitelline, ¡ui tombent, détachés par les premiers mouvements de replation.

Lidentité complète des aufs le tous les Saurojssidés porte à croire que les dispositions de forme, affectées par les embryons et par leurs annexes, sont semblables, du moins dans lenrs traits essentiels. I in quelconque d'entre eux peut ètre choisi comme type : les moditications, subjes par lui, sont, à peu de chose pròs, celles de lous les autres. Le Poulet est, sous ce rapport, l’ètre le mienx étudié et le plus conun; son exemple servira de base, toules proportions grarlées dans le lemps el ilans l'espace.

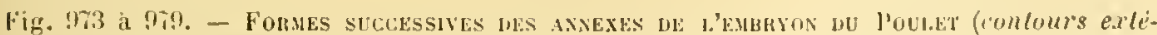
rieurs, daprès Mallias buval: la coque calcaire est supposée ouvelte, el l'albumine enlevee, pour laisser voir l'embryon el ses appendices; la couve calcaire est représentéc dans la fig. $\$ 73$, alors qu'elle est seulement indiquée par son contour dans les autres dessins). - Jn 9i3, ueuf fraicluement pondu, avec sa petite cicatricule reposant sur le

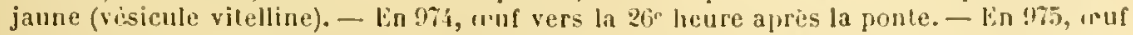
au puatrieme jour; l'emluryon esl vu le faee. - lin $97 \%$, oful an mine jour; l'embryon

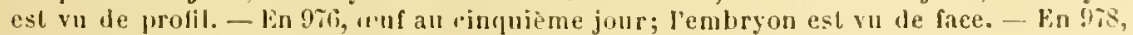
usuf au sixieme jour; l'embryon est vu le face. - En t7?, embryon an septieme jour, vu de coile.

Ces dessins completent les ligures numérotees 807 el 172 à 8\$3. Les dispositions réelles yu’ils expriment sont expliquées dans les figules précédentes (tableau d'ensemble allant

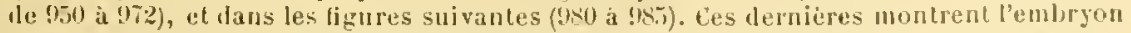
entouré de tontes sos enveloppes, ilors que les premirres s'appliquent seulempnt anx appendices embryonmaires siricts. 


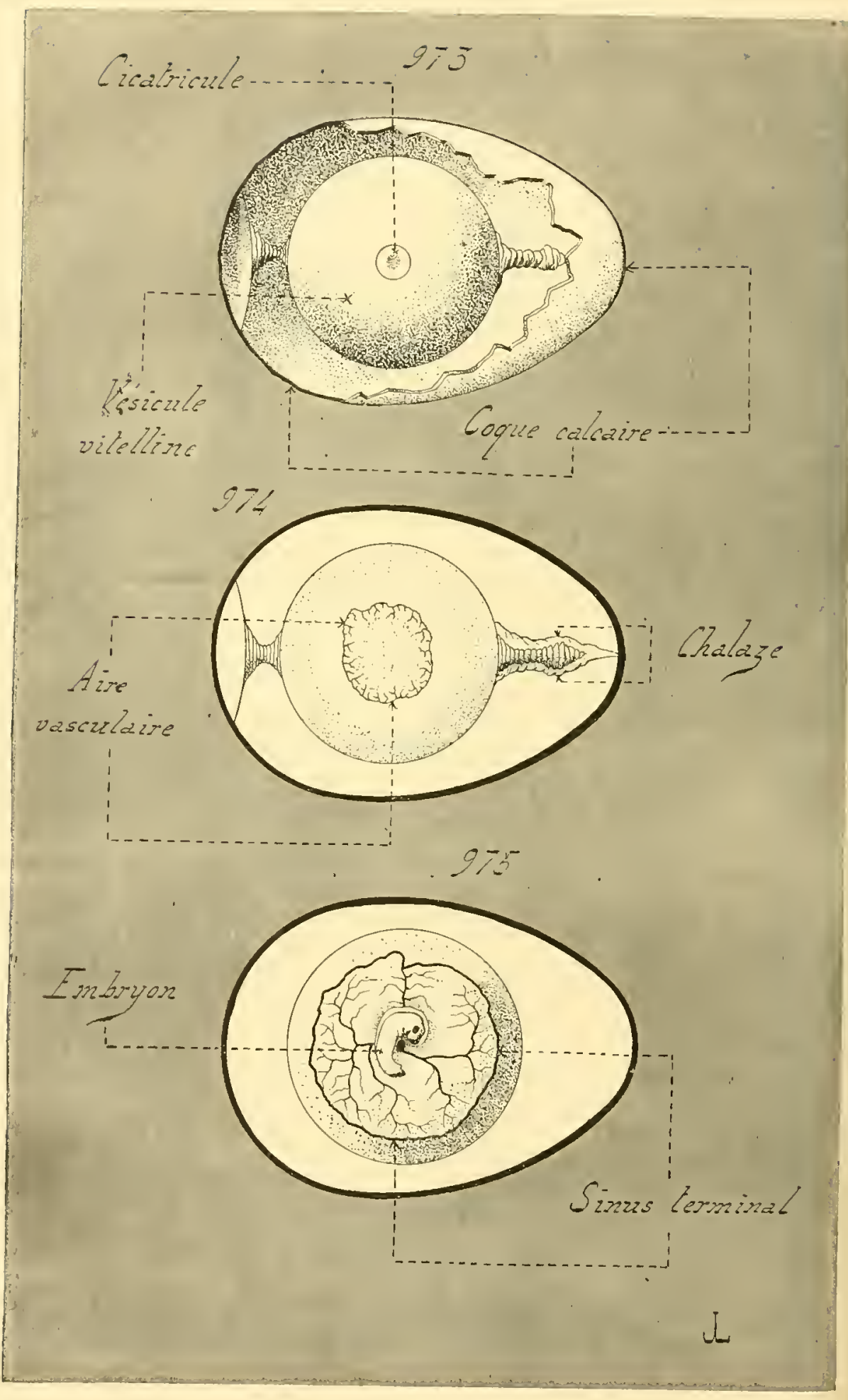




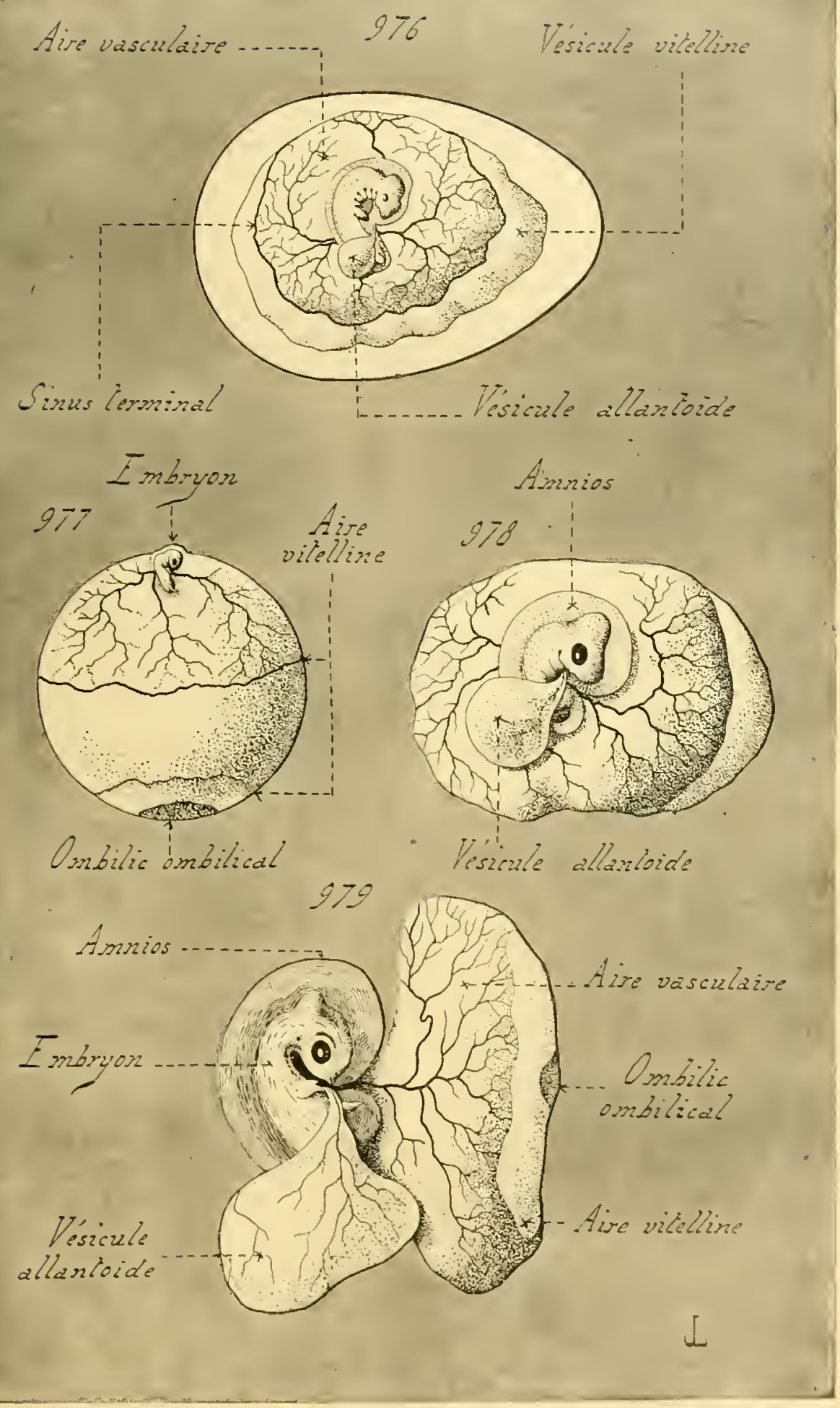




\section{Phases embryonnaires du Poulet, choisi comme type.}

- I'mases avténeumis a l'écusion. - 1. Lat cicatricule se segmente, el donne les premiers rudiments du blastoderme. Celui-ci, comparable a une pelite calotte. s'aceroit par ses hords, el s'amplifie sans cesse, en reconvant à mesure le dentolécilhe de la vésicule vitellinc, el s’insiunant entre ce lernier et la membrane vitelline. La cavilé sons-germinale se creuse an-dussous de sa portion centrale, entre cette derniere el le vitellus. La présence de rel espace a pour effet de diviser le blastoderme en deux parts : l'une centrale, qui se sćpare avec facilité Ju deutolécitle, puisqu'elle est isolée de lui an moven de la cavilé sousgerminale; l'autre atlachée an vilellus nutrilif. La première est nommóe, par les autenrs, l'aire transparente, ou l'aire pellucide, du blastoderme; la seconde est dite l'aire opaque. Ces exprirssions sont dues a l'aspect différent présenté par ces aires, lorsqu'on les enleve le l'auf, pour les examincr dans la lumière réflúchie, par trausparence; la première laisse passer les rayons hmineux, alors qu’il n’en est pas de mème pour la seconde, à larpelle adhèrent des granules vitellins. L'aire pellucide correspond sensiblement à la zone embryonnaire; sa position centrale l'empeche de grandir en surface, puisque le blastoderme s'accroit par ses hords seuls. L'aire oparue, par contre, s'amplifie, à cause de sa situation marginale; elle compose la zone para-embryonuaire. - Toutes ces transformalions s"effectnent durant le prenier jour de la ponte. Le hlastoderme, par son extension, s'est converti en une ralothe, dont la largenr est, à peu près. la moitié de celle d'un hémisphère. Ses parties centrales se sont déji dillérrnciées, ont prorlnit les trois feuillets, el ont engendré la ligne prinitive, avec les ébanches du nenraxe.

Mans le courant du second jour, le bastorlerme progresse d'nne manière sulfisante pour recouvrir, environ, un hémisphère de la vésicule vilelline. L'embryon continue ì se faronner dans l'aire transparente; l'extrémité antérieure de son nenraxe s'élargit el donne les vésicules cérćlrales; les mésosomitrs sont déjà nombreux. L'aire oparjue, c’est-àdire la zone para-emhryonnaire en voie d'exlension, se livise en denx parties : l'aire vasculaire, et l'are vitelline. La première entoure directement le corps le l'embryon; limitée, sur sa pripiphérie, par le sinus terminal, qui marpue sa ligne dinion aree laire vitelline, son nom lui est mérité prar les nomlurenx vaisseaux sanguins dont elle est creusér. La seconde constitue les borls mème, toujours en voie d'extension progressive, du hastoderme para-embryonnaire; ello esl privéc de vaisseaux, mais l'aire vasculaire angmente à ses dépens, par l'irrigation d'un territoire foujour's plus vaste du luastoderme qui la compose. - La rainure marginalo, et les replis amnioliques, foul leur apprarition. Le collome externe se perce sous ces derniers, placés dans rette région, de l'aire vasculaire, qui touche directement a l'imbryon. La bande amniolique, ou proximale, chargée d'engendrer les enveloples de l'ammios, ne correspond donc pas it toute l'aire vasculaire, mais senlement ì une 
partie de rette derniere. L'orule entier, toujunr's rntonré par sa menbrane vitellime, est situé au centre le ses cofues: colles-ci nont meore subi aucune modification.

los régions, déjả ébanchres, augmentent leur masse pendant le troisiome jour. La zon embryonaire commence i s'incurver en gouttière, pou se délimiter J" sa rísicule vilelline. Le curome axterno grandit. et contient déja la résicule allantölle, rucore petilr, qui prend alors maissance. La collerelte ammiotipue s'amplitio, al recouve la majenre partie de l'embryon. Entin, l'aire vilclline, c'est-à-dire relt. bande, du blastoderme para-enlyryomaire, fui s'étemel à la surface du deutolécithe, s'arance dans l’hémisphère opposé a celui qui jorte l'rmbryon sur son sommet. Laire vasculaire, loujours circouscrile far son sinus terminal, s'élargit aux dépens de laire vitolline. - Ces livers phénomènes d’accroissement continuent à s'effectuer durant lo qualrième et le einquieme jour de l’inculation, sans trop morlitier les relations muluelles dis parties léjà produites.

La complexité devient plus grrande vers le sixieme jour. L'embryon, déjà volumineus, a délimité les principales régions de son corps; l'amnios s'est refermé au-dessus de lui, el l'enveloppe complètement; le corron vitellin, étroil, le sépare nelloment de sa vésicule vilelline, encore beaucoup plus grosse que lui. L'air vasculaire, fort large, embrasse presque lout l'hémisphire supérieur de la vésiculo nulritive; son sinus terminal commence it perlre le sa netteté. Le ralome externe, placé en dehors J'elle, a Jone clivé le lilastorlerme para-cubryonnaire sur loule l'étındue de cet hémisphere; la résicule allantoüde, jlus ample, s'avance dans sa cavilé, el proćmine surloul aulour de l"amnios, de facon à former une calotle recouvrant ce dernier. Laire vitelline est parvenue à recourir la presqur totaliti du dentolécithe: mais elle ne se feme pas, et laisse, dans la région diamétralement opposie a l'embryon, un rispace assez. large, oì le dentolécithe reste ì nu. Cet espace est l'ombilic ombilienl de M. Iuval; a son niveau, le vilellus nutritif n'est síparó de la coque la plus interne, soit de la rouche allumineuse, que par la minimo épaisseur de la membrane vitelline. - Lassise d'albumine esl encore entiore; seulement la clumbre a ail, crensíe entre les deux lanes de la membrane coquillio, sest amplitiée, à la suitr dr la prinétration, au travers des pores Jont la coque calcaire est pereée, d'une certaine quantité d'air venant du deliors.

B. - A datre du septieme jour de limenbation, lembryon, loujours entouré de son ammios, s’acroil arer rapidité, el se ilitrórencic i mesure, au détriment de sa résicnle vitelline, qui diminue de laille. Lallantöle agit de mère vis-i-r is de l'allumine; elle s'amplitic dans

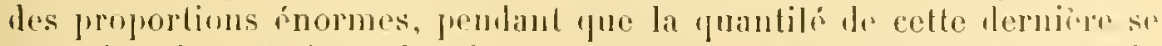
restreint; la fremire alsorlur la seconde. el la fail aimsi servir à la mutrition de l'embryon. - Colte alsorplion est farjlitée par la genóse 


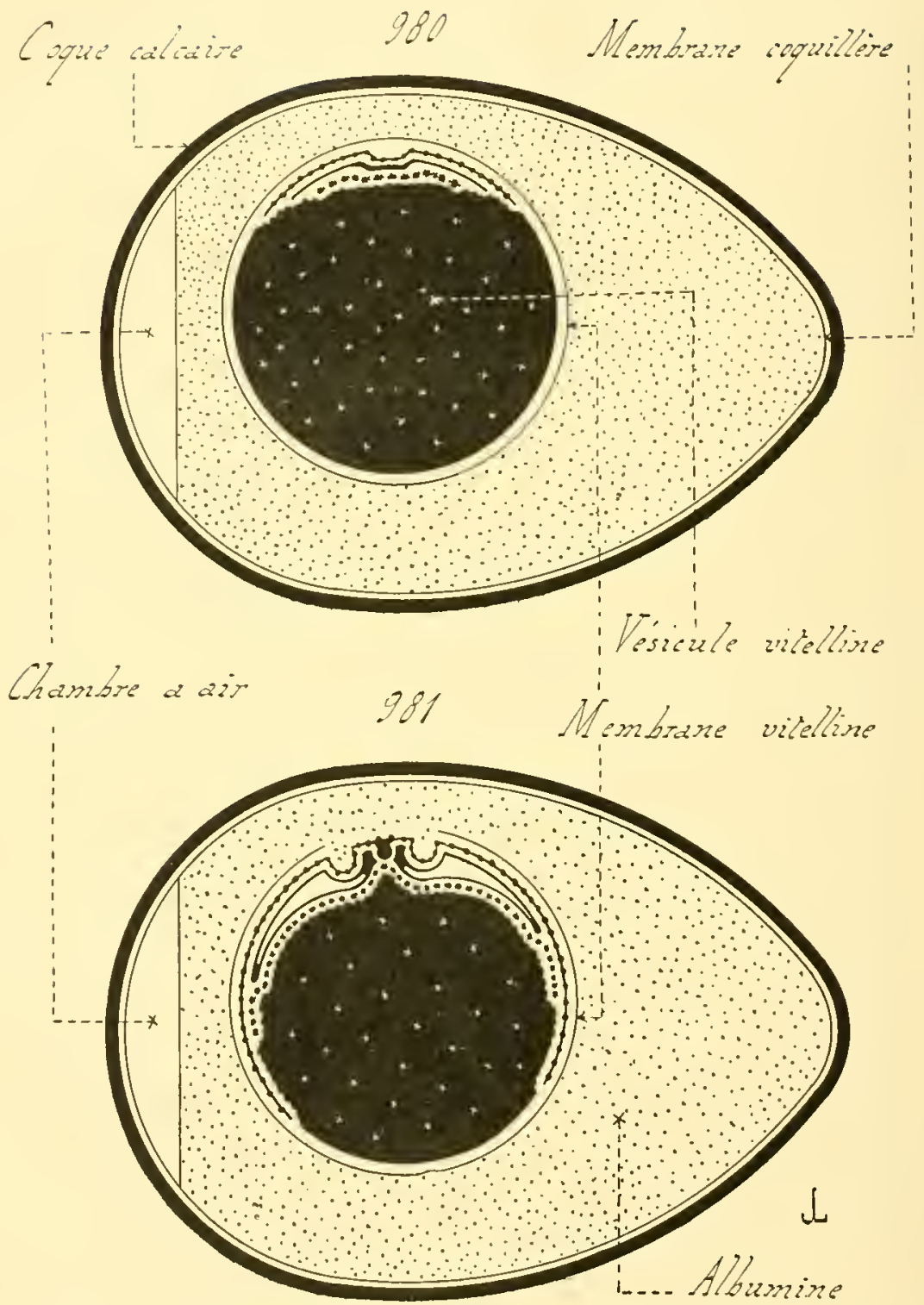

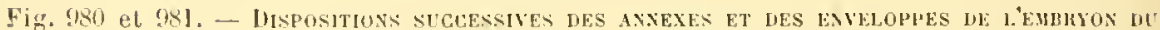
Pount crouges medianes et longitudinales de l'ouf entier, à demi diagrammatigues, conformes aux figures similaires donnees par Mathias buval). L'ectoderme est indiyue par une ligne noueuse, l'prododome pir une ligne de points étoiles; le mé-uderme est en

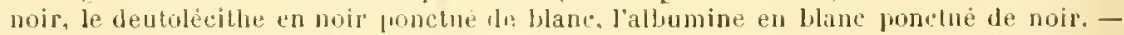

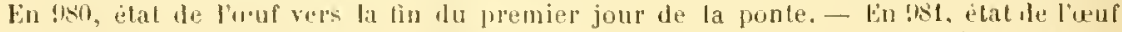
vers le delout du troisiem jour. - his suite de ce developpement est exprimee par les tigures suivantes. nume puties de 989 a 
l'un appareil remarquable, hien ronnu depuis les recherches failes par M. Hural, et nommé, par cel auteur, li sac placentö̈le. Cet organe est un hourrelet rir'ulaire, jroduil par' les boris de l'allantöile en voie l'extension, qui soulève à son njeau l'examujos, ch la fait s'avancer dans la masse albumineuse; la paroi de ce bonrrelet émot des villosités vasculaires, qui pénétrent également daus rette delnirre, et augmentent l'ótendue les surfaces de conlact. Le sar placentö̈de ellectue sa première apparition vers le neuvieme jour du développement; il précise sus rontours, el se lélinite, à mesure que sarroilt l'allantö̈le, lout il est la partie margiuale, ot que diminue l'alhmine, sans cessr absorbice par lui. Il occupe, dans l'ueuf, la région diamétralement opposée à l'enbrvon, et se tronve séparé de lui par loute l'épaisseur de la vésicule vitelline. L’ombilic ombilical, yui se vascularise à son lour vers la fin le l'incubation, car la paroi vitelline linit par le recouvir, sert à allarlur le sac placentö̈le, situé autour do l'amas allumineux, à la vésicule vitelline ello-mème.

La frósence d’un tel appareil dénote la facilité aver laquelle l’allantor̈de acyuiert, a rause de sa vasubrisalion abondante, des fonclions le nutrition prar osmose. Cet organe sert à l'alimintation de l'emhryon, tout comme le placenta des Mammifores monorlelphes; il est engeniré, ile mème, par la vésjcule allantoüle. Senlement, au lieu d'élablir des relations directes ontre le futus el l'un des organes de la mère, il effectue ces rapports entre l'embryon el un proulujt d'origine maternelle, déposé par le générateur aulour le l'ovule qu'il pond. L’bomologie entre ces denx organes, placenta et sac plarentö̈le, considérés en euxmimes, abstraction faite de leurs dispositions dans l'espace, semble che indiscutahle; elle est incomplete pourtant, car le seconu n'est pas précédé, lans son ivolution, et contrairemont i ce quil en est pour le premier, par la genése d'un ectoplacenta, formation spéciale aux Manmiferes, et diveloppée aux dépens de l'ectoderme lu chorion.

Lembryon grandit sans cesse anx léprens de sa résicule vilelline. qui diminue di mesure, el perd sa forme spliéripue, pour prendre des rontours irréguliers; le corlon vilellin, trés étroil, la séprare nettemont Je l'organisme. Les appareils se perfeclioment sans discontinucr, donnant a l'aspect extérieur une lisposition plus précise, el plus frorhe de celle de l'adulte. - Laire vasculairs s'amplitie, an point d'envalir la paroi vilelline entière, alteignant en dernier lien l'ombilic ombilinal; lonte rette paroi se trouve munir de vaisseanx sangnins, de solte pu'il n'existo plus de ditlérence entre une viritable air. vasculare, et une aire vitelline non vaseularisie. Fille buet en surplus, el sur sil fare? internı, des villosités, qui pénètent dans le leututécithe, el amplifient la surface d'ahsurplion. Le curnome externe entome, d'une facon com-

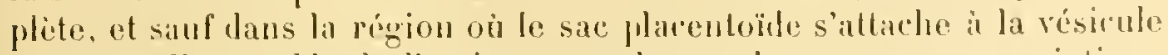
vitelline, l'ensemble tr l'embryon el le ses lenx ambes ammiolique el mutritif. - Lallantoüle empilit tonte la civite du cuelome. Sa paroi 

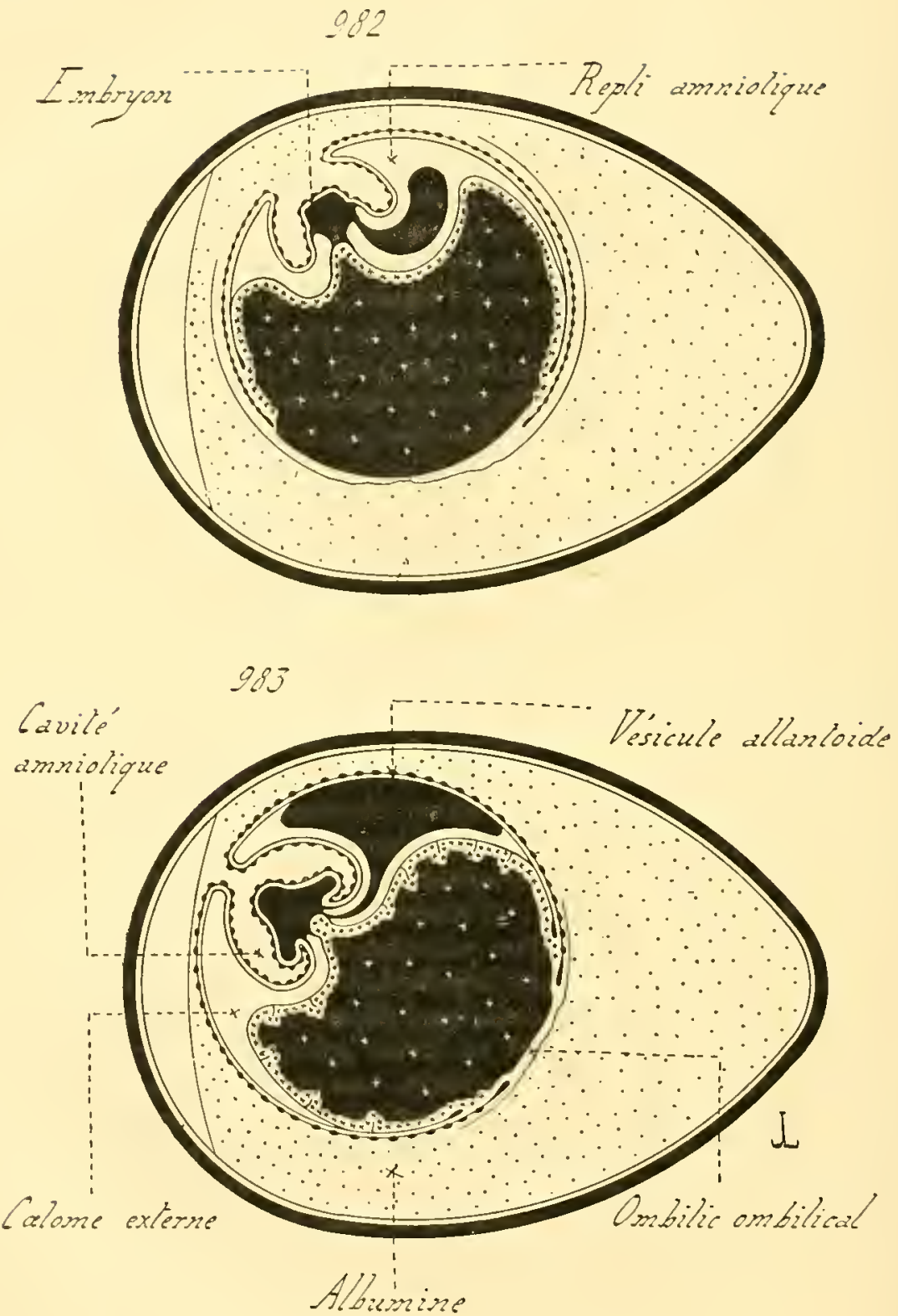

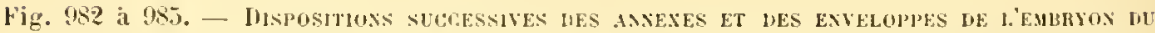
Poulet (coupes médianes et longitudinales le l"wuf entier. il demi diryrammaliques, conformes aux figures similaires lonnès par Hathias loval). L'eclunlerme est indique par une ligne noueuse, l'endodermu par une ligne de points étoilés: le deutolecitue (vésicule

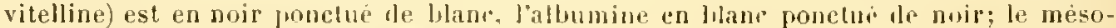
derme et la vesicule ałlantoül, sont en noir.

Ces figures font suite aux precelentes (!K0 et981), - En 982, itat de l'ưf au debut du 
interne sapplique contre lamnios of la visinul. vitelline. Sus bords se rejoignent, de maniere is engloler l'alhumine restinte, et at donner

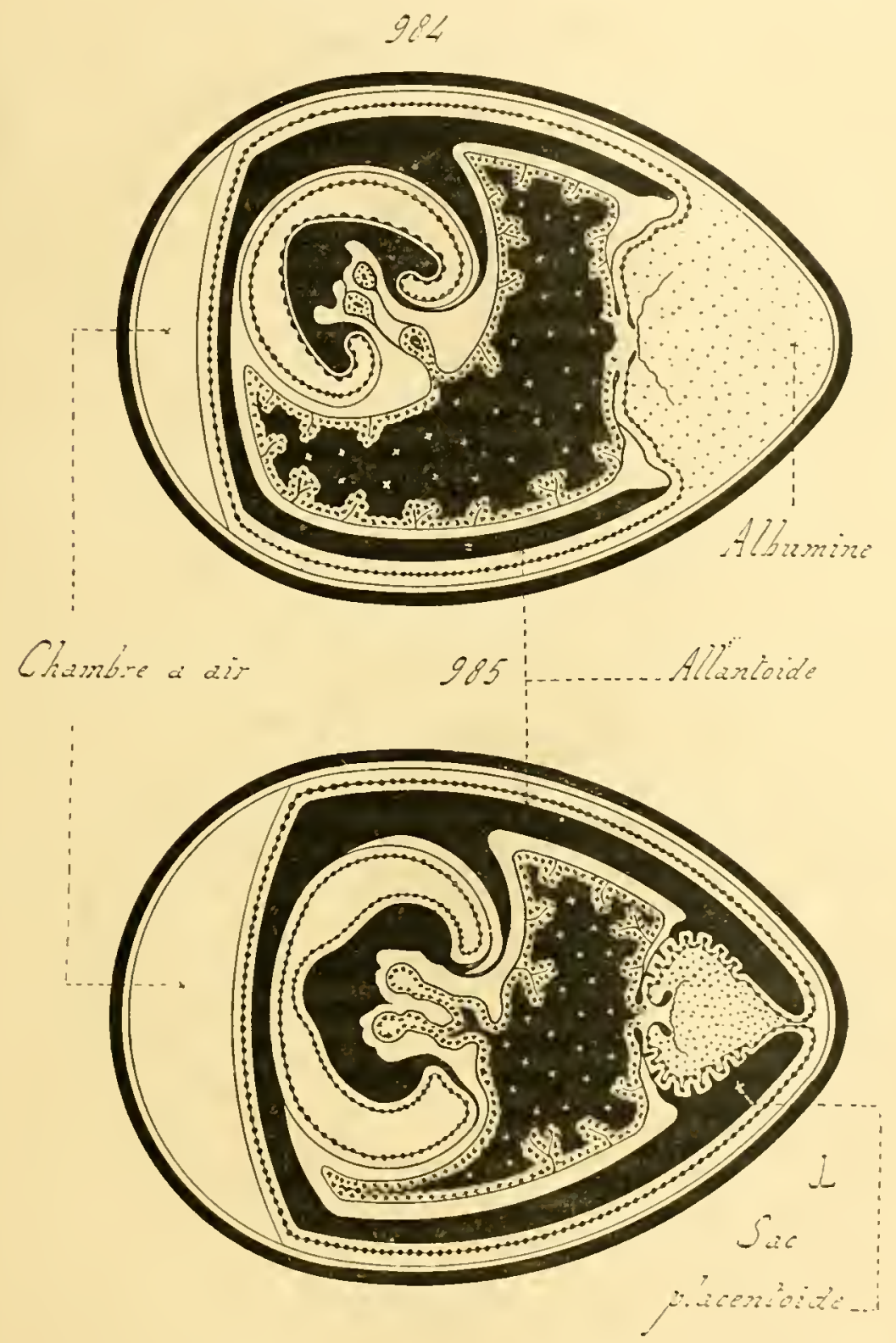

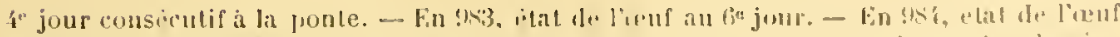

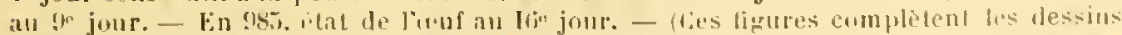

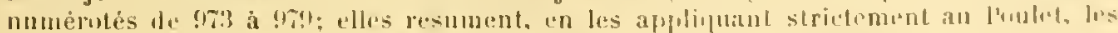

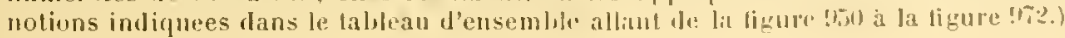


au sac placentönte des conlours arrèlés. Sa paroi extrone s'applique contre l'examnios, el se somde à lui.

Ces phénomònes s'ellectuent, par l'amplification les parties, el lenr ditrérenciation conmexe, lepuis le septieme jour de linnuliation jusquan dix-hublieme, ot an dix-neuvieme. Le moment de l'écosion approche des lors. - la structure de l'unf est bien changie. En dedams de la coque se loove la mombrane coquillere, limilant entre ses deux lames, el vers lo gros bout, me chambre a air fort ample. I la suite de la résorption de l'allumine, prise comme aliment par liembryon, relle membrane entoure lirectement l'examuios soudé il la paroi externe le l'allaulö̈le; il est lone loisible a celte derniere dr puiser, an nivean de la chambre à air. l'oxyóne mócessair à la respiration. La vésicule allantö̈le est elle-mème fort rolumineuse; son aspect est relui d'un' poche fermér. limitant une cavití interne, dont la sulstance so tronverait creusée d'un vaste espace rempli de liquide: elle prorte le sac placentoüde dans sa régrion diamétralement opposée il la chamlıre à air, dans celle qui répond au petit hout de l'ienf. La cavité quelle ciponserit est le colome extrone; celui-ci est virtucl en beanconp te ses frarties, à canse de lapplication étroite de ce qu'il conticut contre ce qui le limite; ses espaces rócls, semblahles a des fentes l’aspect irrégulier, sont remplis de lipuide. Celte cavité renferme l'embryon, alors fort gros, plongé daus sa caviti amniolique entourée par l’ammios, el muni le sa vesicule vilelline, devemue pretile, aux parois plissées, el compalable à un sac aplati contre la face ventrale. Cette vesicule, comme lallantoïle, s'altache à celle-ci par un pérlicule court el étroit.

lembryon posside alors un organisme complet. ou peu s'en fanl. Les annexes, parvenus à lem période d'état, n’oul plus qu’à se détruire. Le pelit ère se léharrasse d'eux, lrist sa coque, el apparaît au dehors.

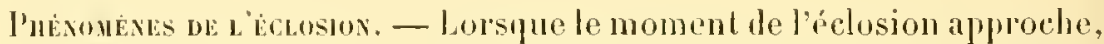
le liquile de l'amnios, el celui dr l'allantö̈ıle, diminnent de puantilé, sans doute far évaprialion au travers de la corpe ralcaire. Jes prois de ces amnexes se plissent, se dessichent quehque pen, et se désorganisent. - Chez la plupart des Oiseaux. la vésicule vilelline se rifracte, tout an restroignant sans cesse sa masse, dans la cavité ablominale de l’embryon. La rélraction opérée, tantôt le coldon s’atrophie le promier, laissant la résicule libre parmi les circourolutions intestinales (Colombins, far exemple); tantot il demeure plus longtemps (I'oulet). Dans les deux cas, il joue lo rôlo d'un conjs dranger, que des vascularisations entoment pour le résortur par phagocytose; ce qui ne larle pas a ètre fait. Il ne parait point en être ainsi cliez les Reptiles; les jumes éclosent, encore munis des dernicrs vestiges de lemr vésicule vitelline, appendus

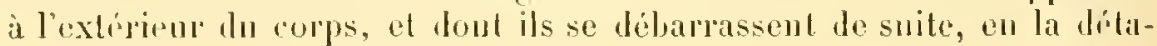


chant, et la laissant tomber; la cicatrice de chutr disparait, et ne laisse aucune trace persistante.

L'embryon est l'agent arlif daus l'éclosion : il hrise lui-nnine si coyue, pour paraitre dans les milieux extérieurs. La plupart rles heptiles possèlent, il ret effet, une dent spéciale, placée sur l’intermaxillaim. qui tombe peu après la mise en liberté de l'individu. Les Oiseaux se servent de leur bec dans le même but; l'extrémité de re dernier est parfois muni d’une sallie, dure el épaisse, qui facilite l'opération, tt disparait ensuitr. - Au moment de l'éclosion, l’allantoüre et l'amuios sont léja lien diminués, et desséchés : la plupart de lenrs vaisseaux ont disparu. Les derniers restes de ces appendives s'atrophicut alor's, ct l'organisme se trouve riduit à lui-mème, par la perte de tous ses annexes. autrefois si rolumineux et si importants.

La plupart des Reptiles, el divers Oiseaux, sunl deja capalıles de so mouvoir, et de salimenter, lès leur mise en liberta; ils ne ditférent das adultes que par leur taille plus restreinte, et par leurs orwanes scxucls encore peu dévelopjés. Un grand nomlıre d'Oiseaux présentent d'autres phénomines; lemr revètement le plumes, tres incomplet, les empèche it la fois de se déplacer, et le se nourrir par eux-mèmes. Plusicurs semaines sont souvent nécessaires pour que les appareils loromotenrs arrivent à l'état parfait; les parents fournissent eux-momes, i leurs descendants, el durant toute cette périorle, les soins et les aliments nécessaires. Les Colombius se servent mème, i cel etfel, d'une sécrétion nulritive, produite par leur jabot, qüils dégurgitent dans le bec de leurs petits.

\section{\$ 6. - Formes et annexes embryonnaires des Mammifères.}

1. Considérations générales. - A. Le développement des Mammifères s'effectue suivant des procédés livers. Parmi ces animaux, les uns sont ovipares, et les autres vivipares; reux-ci comprennent, it lenr tour, des ètres variés, en ce sens que les embryons de plusieurs d'entre eux sont privés d'un placenta, alor's que ceux des autres possèdent tonjours un tel appendice. Les premiers sont les Monotremes, les seronds les Didelphes, et les derniers les Monodelphes. L'alsence d'un placentit -hez les Houtrèmes et les Didelphes leur vaut souvent d'ètre désigués sous le nom commun d'Implacentaires, par opposition au lerme de Placentuires. employé pour qualifier les Honodelphres.

Le défaut dr relations outritives, entre la mère et ses descentants, est complet chez les Monotremes. - Ces rapports rommencent it s'citahlir dans la série des Didelphes, tout en ne s'iccompagnant pint de la présence d'un placenta. Les embrous, munis du leur vésicule vitelline

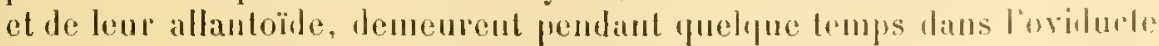
maternel, el adlèerent aux parois de co dernier par colles de leurs ilpren- 
lices. Jes éduanges de nutrition se manifestent par ce moyen; ilscessent bientot, par l'expulsion des jennes, laile avant que lenl organisme soit termine; la gestation oviductaire est courte. Les petits sont recueillis par la mire, et placés llans sa poehe marsupiale, où ils s'achèvent. loxistence de fenx imrubtions successives, dont la première saeeomplit daus les voies sexuelles du générateur femelle, et la seconde dans sa cavité marsupiale, justifie le nom de Didelphes, accorté à res animanx. - Enfin, les relations mutritives de la mére el du foctus atteignent leur comble chez les llonodelphes. Ine seule gestation se présente, effectuée toutr entiòre daus les conluits sexuels, pourvus, à eet effet, l'un utérus, souvent dit la malrice. La vésicule allantoïde donne un placenla, chargé de présider aux échanges de l’alimentation générale. Les descendants ont presque entierement élifio leur structure, au moment oì ils sont rejetés dans les milieux extérieurs.

Les connaissanes, aequises sule développement de cestrois groupes de Mammifires, sont les plus inégales. Elles se borment, en ce qui touche les llonotrèmes, i la constatation de leur oviparité, ot il la présomption de leur jessemblance, sous re rapport, arec les Samropsidés. Elles sont un peu plus grandes an sujet des Dilelphes; elles consistent en quelques données sur la disposition des annexes. Elles ne sont guère completes que pour les llonoldphes. Aussi ces derniers sont-ils presque les seuls visés dans le présent jaragraphe.

13. - Lovule, converti en une culoplanule, saccole ì la paroi de lutirus maternel. Celle-ci s'hypertrophic à son contaet, el, sans doute, des ćchanges nutritifs s'établissent déjà entre elle et l'embron. l’arfois, cette anplitiration a pour etlet l'amener la production le bourrelets, qui s'élargissent en membranes minces. Celles-ci s'étenlent, soit auton" de l'ovule, pour l'envelopper en totalité ou en partie, soit sur la paroi utórine elle-mème. Faconners dès les premières phases le l'évolution. et ne provenant en rien du fictus, puisquelles dépendent de la matrie. elles commencent par posséler une cortaue épaisseur, puis s’amincisseut, el se lessèchent; finalement, elles sont expulsées aree les petils, lors do la parturition. Cette terminaison leur a valu le nom de cadupues. Ces annexes doivent etre pris pour des formations utérines, maternelles, dont la genese a, comme cause, l'hypentrophie des parois de la matuce au contact de lovule, et, comme résultat, laceroissement des surfaces de contact entre ces parois et l'embryon. Une telle ritension est deslinée à permottre l'angmentation des rohanges nutritifs, car, en co moment, le plarenta u'a pas enrore pris naissance.

La coloplanule, tont en grandissant, se divise en ses deux parties, la zone embryonnaje et la zone frara-embryonnaire. La première se dibimite de la secomle, et se siplare d'elle de plus m plus. Colle-ci. l'aloon constiture par une seule assise ectodermique, placée autour de la cavilé para-vilelline, se complique bientót: elle se donble d'une conche 
protendodermique, qui, au moins sur une bande adjarente à l'embryun. sépaissit, puis se prartage en un mésoderme el un endoderne. Dr son coité, la ravité para-vilelline, tout en augumentant ses dimensions dans lous les sens, de façon à rendreplus considéralile la taille de la colophlamule, se remplit d'un liquide épais, semblable il ale lalbumine, el probablemont doué de propriétés nutrilives. Ce lipuide se dépose, sans donte. ¿ la suite des premiers ćchanges diffusifs, élahlis entre l'uterus ot l'embryor.

le exlome externe fait alors son appration selon le mode habiluel. Il s'étend de plus en plus, d'une manière progressive, dans la fraroi romplexe qui limite la cavité para-vilelline, el répond ì la zone paraembryonnaire primitive accrue de la couche protendodermiıue. Il divise cette paroi en une lame externe. cl une lame interne. - La prenione engentre, autour de la zone embryonnaire, les replis amniotiques; ceux-ci s'amplifient, se raccordent par leurs bases, surplomhent l'emlivon, et l'enveloppent de deux membranes. Parmi celles-ci, linterne? estl'enlannios, l'amnios véritable, qui circonscrit, autonr le l'embryn, la carité ammiotique; l'externe est l'examnios, la séreuse le von liäil", yui se contiuue exactement, par ses hords, avec la lame externe dont elle provient. - La première, la lame interne, demenre autour de la eavilé para-vitelline; elle compose, avec elle, la vésicule vitellino des Mammiferes vivipar's, de beanconp plus petite yue son homologue des Mammiferes ovipares el des Sauropisides, cal elle ne contient aucun deutolécithe. Cette vésicule re tarde pas à ètre complètement séjarée de la lame externe. Elle représentr, des lor's, un appentice de taille restreinte, libre dans lr culome externe, et suspendu, par un court cordon vilellin, à la face ventrale de l'embryon. Elle ne s'accroit plus lésormais, alors que tout ce qui l'entoure grandit sans cesse; ses dimensions relatires s'attrinent, jusqu'an moment oì elle n’est plus qu'un élément minime, accolé an cordon allantö̈dien.

La lame externe de la zone para-embryonnaire, des l'instant où sachère l'amnios, constitue, à cause de sa liaison avec l'examnios, nue membrane complète, placée autour du colome externe, el le limilant vers le dehors. Ello est la parlie la phus extérienre de tout l'orgunisme embryonnaire, et se trouve directement en rapport avec la paroi utirine. Elle roprésente une prehe sphériqur, qui contient, dans sa carile, le corps de l'embryon aver ses appendices. Son nnion arer la membranc externe des rrplis amnioliques lui vant d'ètre désignée par les mènes expressions. - Cotte lame est l'me des enveloppes embryonmaires. L'insemble de ces dernicies est qualifie, far los auleurs, du nom de chorion. La mature el la structure de ce chorion raldent, a lis fois. suivant les divers types de Manmiferes, el, pour mu mène forlus, snivant son igge; mais l'examnios, la séreuse de ron baër, constiluc l'une de ses couches les phus importanles, antant sous de rapport de la dispusition que sous celui du ròle joué. 
La résicule allantoïle proud maissance. à mesure jue s'rbanchent el s'étendent lamnios arec le culome cxterue. Elle pénotre dans celfe cavilé, qui samplitic, el s'y agrandil a son tour. Sa prop externe s'applique contre l'rxamnios, el simil il lui, pour constiluer me seule el meme rouchr. - Une pratic de celle derniore, lorsque la soudure est acomplice, prend alor's nu accroissemont énorme, el donne le placentr. La genese de cet ammexe est précédée par celle de l'ectoplacentr, région epaissic le l'ertodrome dr leximnios, quis'arcole a la paroi ulérine. Celle-ci pejul son épilhélium; l'ectoplacenta émet des expansions, qui pénctrent dans son derme, lont les vaisscaux s'lypertrophient, el qui enveloppent ces derniers d'une gaine: le sang maternel, coulenu dans ces espares vasculaires, abandonme aisément, par co movon, aux villosités ectoplacentaires, les substances nutritives yuil renferme. Puis l'allantoïde, arec son méseuchyme richemenl rascularisé, loulle, à son tour. l'ectoplacenta, pour composer avec lui le placenta léfinitif. Celui-ci possede les vaisseaux allanloüdiens: il augmente four nombre, ef les fait pénétrer dans les expansions del'ertoplacenta. Les parois de ces derniers su résorbent, an point de nètre plus que de minces lamelles, introposées aux canaux sanguins de l'utérus et ả ceux le l'annre nutrilif. Les premiers dépendent de l'organisme materuel, el les seronds de l'économie fulale; les érhanges nulpilil's sont désormais, grice à celle disposition fimale, parvenus à leur période l'élat.

Le placenta noftre pas le même aspect chez tous les Mammifires. Sa struclure la plus simple est relle oì il consiste en saillies, éparses sur l'allantoïle, et soulevant l'examnios a leur niveau; on le qualifie, dans ce ras, par l'expression diffus. - Ailleurs. il est un organe umique, tout en présentant des formes variahles. - Une partic le l'allantoüle l'engendre seule; les autres rógions de la vésirules alrophicnl d'labitude, lans for rours du développenent. A la suite de celte diminulion de l'allantoïde, la ravilé amnjotique prent un accroissemont considérable, en diminuant d'autant l'espace occupi par le rolome externe. Elle s'amplifie, refoulant devant elle l'amnios (endamnjos) qui la limite, et l'appliquant, à la fois, sur le rordon allantö̈dien, sur les dernjers restiges de la vésieule vitelline et le son cordon, conlre la face inlerne du placenla, de lallantoüde, el de l'examnios. Les rapports primilifs sont alors changés, par la restriction el la disparilion du colome oxterne; l'examnios, aver les anmexes nutrilifs yưil supporte, élant accolé à l'endamnios, lous deux se lromvent composer une mème membrane: rellr-ci limilr lacavité amniotique, la seule quj exisle alors aulour de l'embryon. Ces changements soml des plus nets dans lo cas de la placentation liscoülalu des l'rimales smperieurs ot te l'llommu.

C. - La sério dr res pluémomènes, qui aboutil, en somme, à la produclion d'un placenla, et a l’établissement, entre la mère el le furlus, d'échanges nutrilits de plus en plus intenses, seffectue d'une manière 

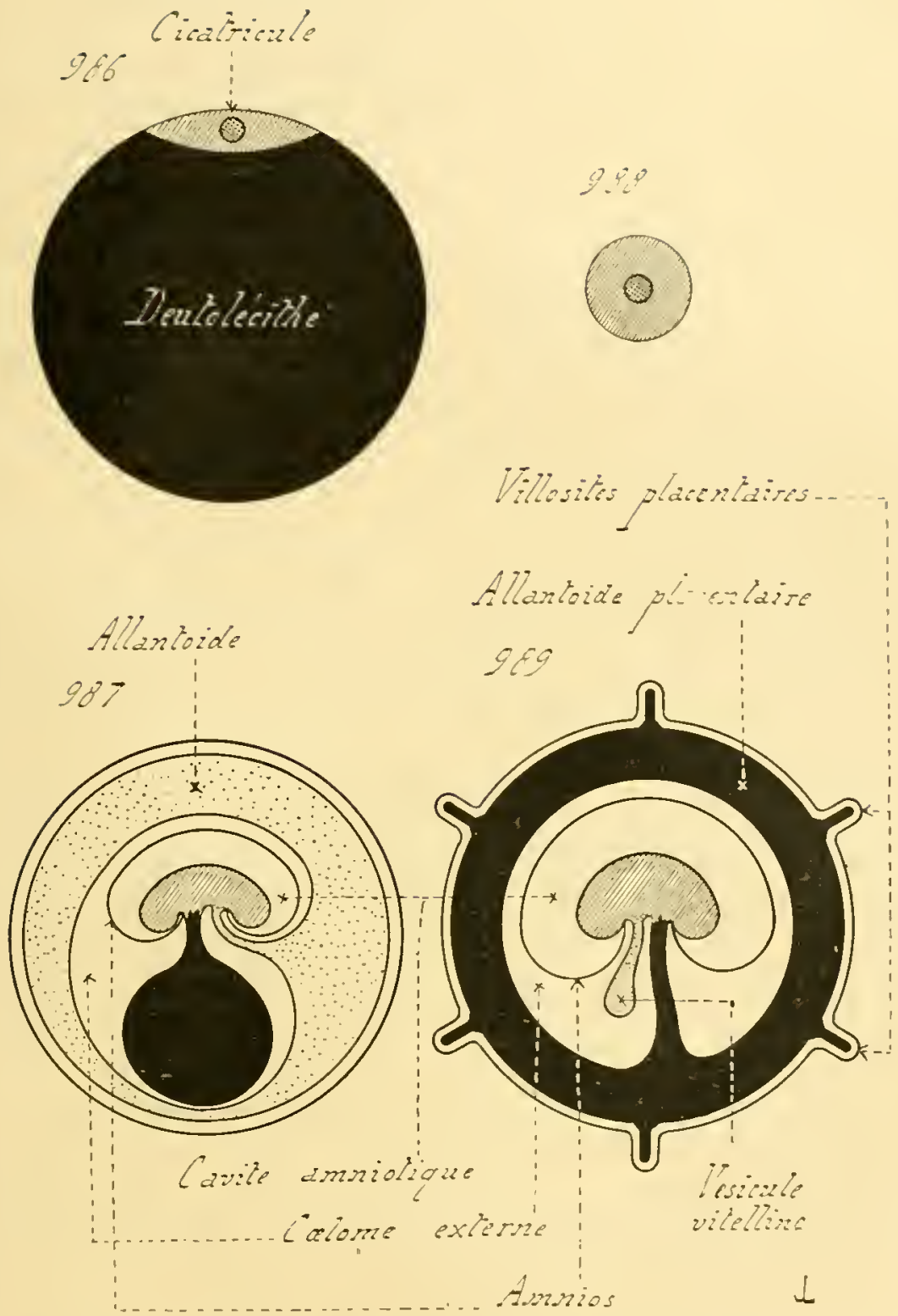
Allantoide pi-cularge 969

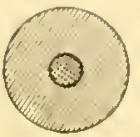


parallèle à l'accroissemul des parties. Afin de so la représenter en son entier, il est néressaire de la comsidérer comme liée à une amplification générale, et progressive. Celte demière cesse pourtant, à les intervalles divers suivant les éléments mise en cause. - Elle s'arrête, en premier licu, pour la vésicule vitelline. Elle continue en ce yui regarde le culome externe, el le placenta, juis s'interrompt lorsque ce lernier organe pravient à sa période d'état. Elle ne demeure avec constance, et jusqu'an boul, que pour l'embryon lui-même. Celui-ci grandit l'une favon rigulière et constante, jusqu'au moment oì, ayant atleint sa taille lélinitive, il est expulsé de l'utérus maternel.

Ces modifications no sont pas, au surplus, exactement semblables chez lous les Hammifires. Elles sont altórées, dans certaius cas, par des déplacements, on mème par des omissions. Ces changements sont connus d'après ceux que possidont les Rongeurs; ils paraissent liés a une grande lurièreté du temus consacré à la gestation, et à la nécessité corrélative d'élificatious rapilles. Ils atteignent surtout les enveloppes embryonnaires, el l'amnios. Les premières se létruisent en majeure parlie, dès les phases initiates, en déterminant le pliénomène connu sous le nom d'inversion des fenillets. Le second se dillérencie sur place, par le creusement de la cavité qüil renferme, sans présenter aucun des états consacrés à la production des replis amniotiques, et à leur extension. Ces changements ollrent l'empreinte d'ume abréviation manifeste.

D. - Ces faits établissent, lans la marche de l'embryogénie, sur re qui touche la forme et la disposition des annexes, une liflérence considérahle entre les llammifèes flacentaires et les Sauropsidés. Sans doute, los llonotrèmes drivent âre rangés à côté de ces deruiers. Quant aux bidelphes, ils établissent une transition entre les deux extrèmes, prar la grambe taille relalive de leur vésicule vitelline, et par leur privation de placenta.

Les Sauropsidés sont ovipares. Leurs aufs, expulsés de suite après la fécondalion, doivent ètre assez gros pour conlenir l'embryon aree tous ses annexes; anssi possedfent-ils mue laille considérable. Ces aufs, limités par une coque inextensible, conservent les mèmes dimensions, depuis le début du développrment jusqu’à sa fin. Le petit útre, enfermé dans celte coque, se noumit aux dépens de sa vésicule vilelline, yui représente la principale masse alimentaire, et respire an moyen de sa vésicule allantö̈le; en conséquence, ces deux appendices sont volumineux, et ne perdent guère le leur importance, surtout en ce qui touche la première, que rers la fin de l'évolulion.

Jes Mammifères placentaires sont vivipares. Leurs unfs, conservés dans l'utérus maternel, et privés le matériaux nutritifs, sont lris petits. Ils subissent une amplification rxtrème, que n'entrave aucune coque extérieure. Le futus, accolé aux prarois ulírines, se nourrit à leurs dépens ; 
tout al'aborl, par la seule diffusion de liquides entre les surfares mises en contact; il produit ensuile un placenta, destiué it rendre cel échange alimentaire plus préxis of plus complet. La vésicule vilolline est petite d'emblée, à cause de la privation de tout deutolícilbe. L'allautöide grandit, afin de donner le placenta: mais sa région placentaire arouiert seule, du moius dans la plupart des cas, me cerlaine prépondérince. linalement, les uniques amexes embryonnaires, vaiment developpes, sont l'ammios el lr placenta.

De telles dillirences sont considriraliles. Leur cause est la substitution de la viviparité à l'oviparité. Les coques externes, la conche albumiurnse manquent de ce fail; lovule, privé de dentolécithe, rst très petit; sa résicule vitelline joue un rôle des plus restreints; el senls, l’amuios, destiné à circouscrire la cavilé amniolique, et le placenla, d'origine allautoinlicnne, acyuicrent de l'imporlance.

II. Caduques. - A. Les carluques sont des zones hypertrophices de la muqueuse utérine. Elles naissent au moment oì l'ovule fícombé arrive dans l'utérus, el s'accoleà une jartie de sa paroi; elles s'amplifieut durant les premieres phases de l'évolution; puis elles s'amincissent, el se rérluisent a de minees lamelles rejetées lors la parturition. L’épaississemenl, destiné à les produire, alteint surtout le derme le la muyueuse avec les glandes qu’il contient; l’épiluélium viluatile s'exfolie el disparail.

Tous les Mammiferes placentaires ne sont pas également pourvus de cadupues. Ces formations appartiennent surtout a ceux dont le placenta est ramassé en un corps compact; elles atteignent um léveloppement extrème chez les Primales supérieurs ot chez l'Homme. - Leur répartition inégale a fait diviser les Honodelphes en dewx séries, dont l'ume' est dite des Adecidués, rt l'autre des Leidués. La première comprend ceux dont les embryons sont pivés de calurgues, el la seconde cenx qui entrent dans le cas coutraire. Celte division n'ost tranchée, el prórise, qu'i la condition wr rogarder seulement les rxlèmes. Hans la réalité, des transitions nombreuses relient les Hammiferes dópourvis de caluques à ceux qui en possèdent. Tous ces animaux peurent dole considérés comme décilus, ear leur muqueuse ntérine słhpertrophir toujours, dans la première périoue de la gestation, el se desquane par places. Seulement, l'amplifiration est minime, et confuse, chez plusienrs d'entre eux; alors quailleurs elle se trouve plus considérable, loul en ayant pour effet de domner des membranes aux limites assez précises.

Les Mammifères munis de cadnques réelles, quoique développérs à des degrés divers, sont les Carnivores, les l'innipioles, les Rongenrs, les Inseclivores, les Chéiroptères, et les Prinates supérieurs; cettra répartition est prise dans l'ensemble. - Chez les antres Hammiféres, la parri utérine s'hypertrophie durant le rut; olle donlole, et triple memo sum épaisseur. Ses grandes s’amplilient; et des éléments embryommires 
nombreux, parmi lesquels sont des cellules de grande laille, apparaissent daus son derme. L’épilhélium se desquame, et lombe. Ces phénomènes

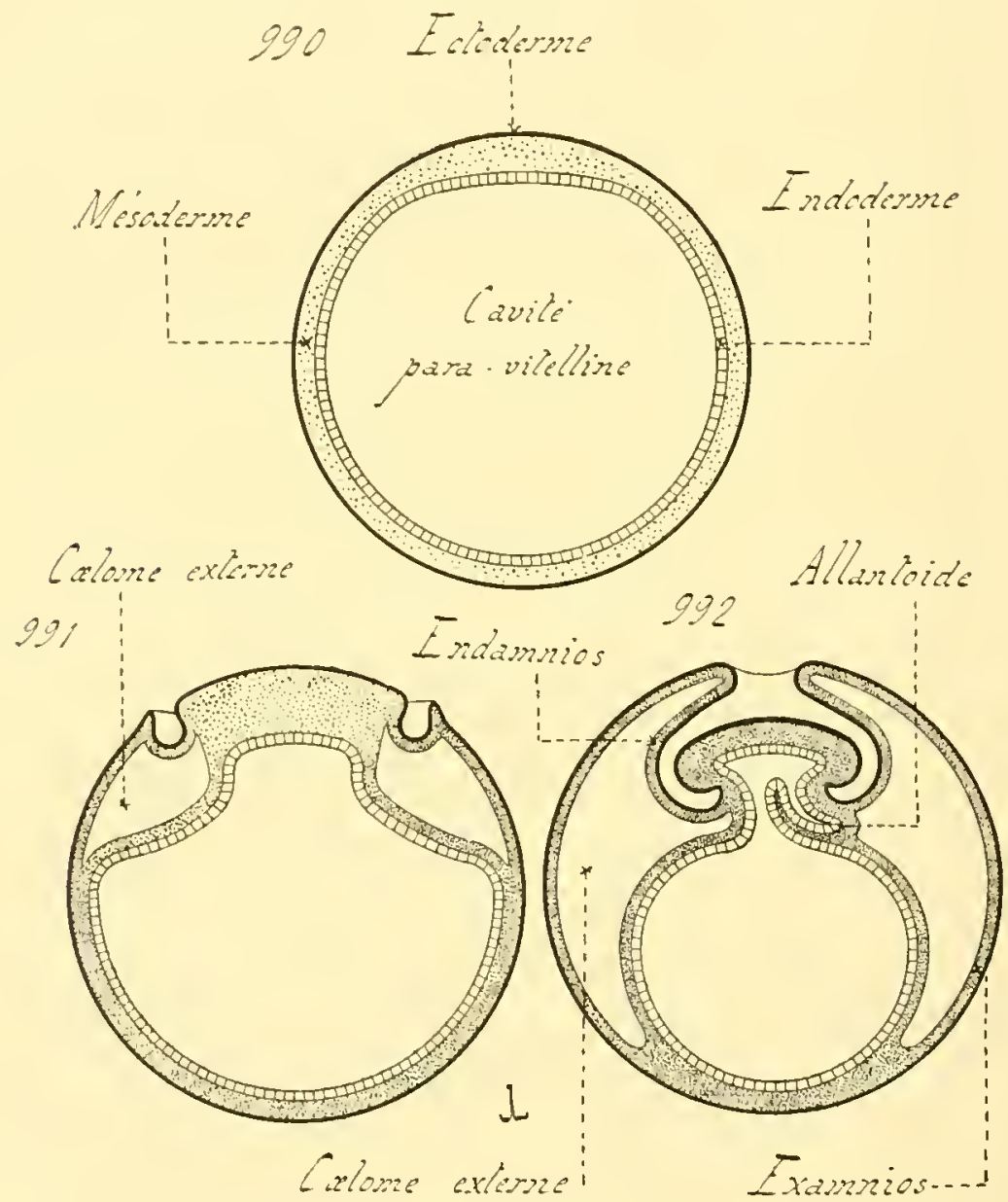

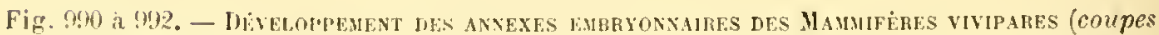
à demi diagnammatiques). Ces figures sont dressees suivant le plan de celles du tableau d'ensemble, allant de la figure 950 a 972 , qu'elles completent en ce qui concesne les llammifères vivipares : l'ectoderme est en noir, l'endoderme en hachures, le mésoderme en pointillé: les carites sont en blane. La suite de ce lèveloprement est donnee par les figures 903 et 994 en ce qui regarde les Mammifères vivipares, et par les figures 905 a $99 \%$ en ce qui tombe plus specialement les Manmiferes monodelphes et placentaires.

En !) pluse de coloplanule, au moment oü les trois feullets se sont lèmites autour de la cavite para-vitelline; dans la réalite, la région inférieure de la figure zone distale du blastoderme para-embryonnaire), ne possède du mésoderme que dans les phases ultérieures, lors du clivage du culome externe. - En 991, phase correspondant à celle de la figure 5 I du tableau gèneral; le ccolome externe et les replis amniotiques font leur apparition. - En 992. Whase correspontant à celle de la figure 9.5 du tableau général; le calome externe et les replis amniotiques s"amplifient. 


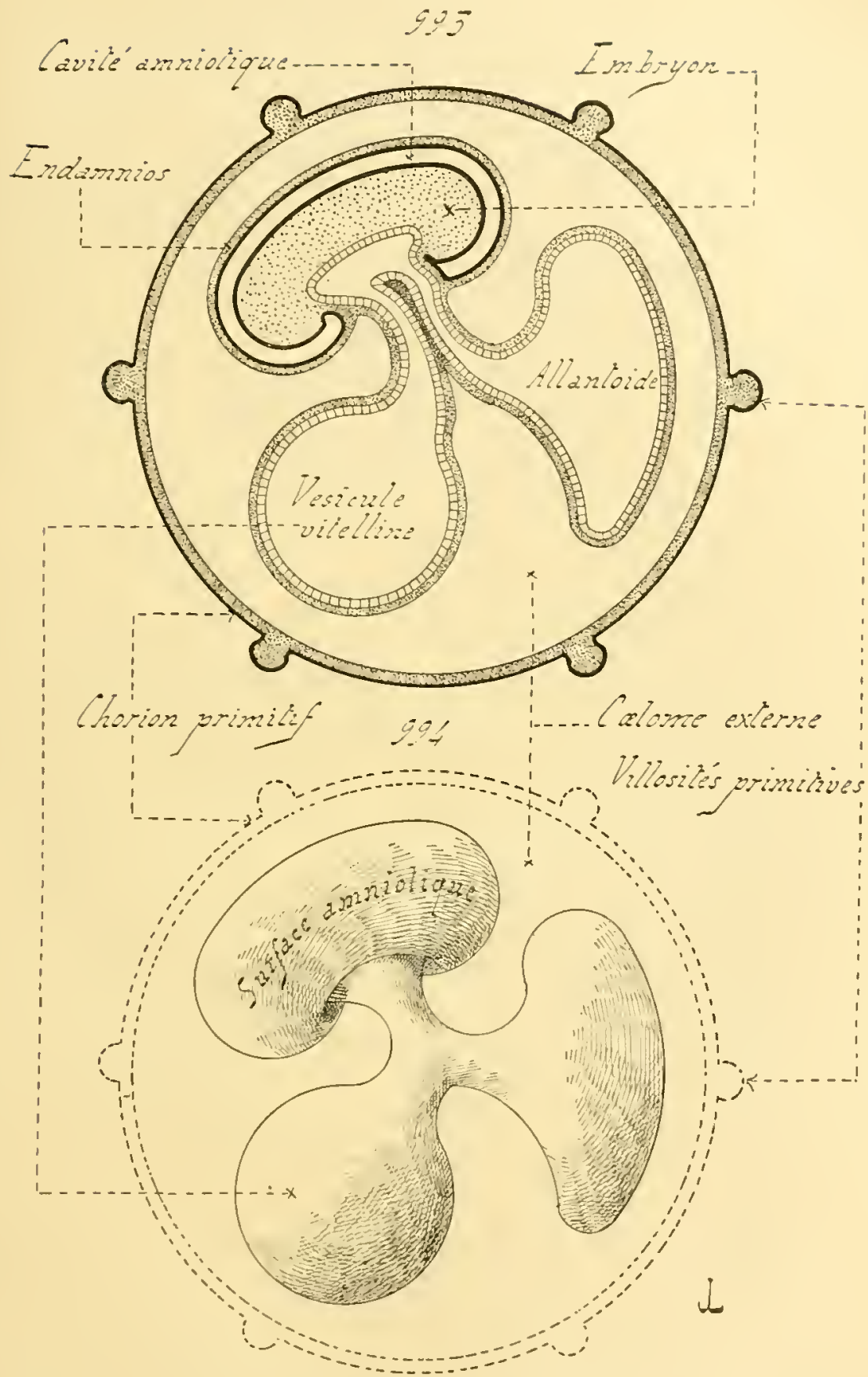

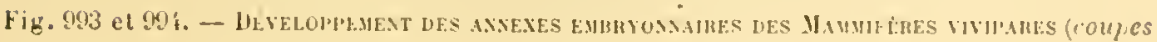


cessent ensuite: mais ils persistrut dans la régiun oủ l'ovule, el plus tard le placenta, s’accolent à la matrice. Ces régions lemeurent ćpaissies; les villosités placentaires pénidrent dans le derme richement vascularisé, et y absorbent les sues nutrilifs apporlés par le sang malrnel.

L'hypertrophie, dans la zone de conlael le l'ombryon et de l'utérus, athin des proportions un peu plus gramles chez les Canivores el les l'imnipieles. La hoursoutlue de la muqueuse est telle, que celle-ci forme une sorte de rupule, enchassant l'ovule fécondé. Celte cupule devient plus profonde chez les liongeurs et les Insectivores; celle des Chéiroptères entoure l'uruf presque toul entier; et enfin, celle des l'rimales supéjieurs l'enveloppe à la façon d'um capsule complete, ancolée au chorion do l'embryon. Cotte membrane, engendrée par la muqueuse utérine. à la snite de son hypertrophie, est lite la caduque réfléchie. - Jusqu'ici, l'ŕpaississıment s’attémue lans les régions de la matrice anxqudles ne siacrolent point lovules; il se conserve seulement dans les zomrs de conlact avec les embryons. Il n'en est pas de mome chez les Primates supérienrs, ou l'lỵertrophie s'étend i la parui ulérine tout entière. Ellr a pour résultat la prisence d'une lame, rejetér au moment de la parturition, au-rlessous dr laquelle la muqueuse se rígémère; cethr lame est nommée la calupue vruie.

l.es anteurs admeldrnt, en outre, la présence d'unc froisième carluque, la sérotine, encore lite inter-utéro-placentaire. Colle-ri serait placro dans la région l'union du placenta avec la matrice; elle aurait pon oljot d'engendrer cetle part de l’annexe placentair' nommér le placentu muternel. - Les remarquables recherches, failes récemment par M. Mural sur les Rongeurs, montrent que le placrnta matrinel nexiste, à vai dire, fas, du moins chez ces derniers animanx; mais la constance des caractères de cet appendice, dans la série entière des Monodelphes, autorise à clendre à lous ce qui est connn chez quelques-uns. La semb partic du placenta, qui soil le provenance maternelle, est le sang que les vaisseanx ulérius fournissent à etorgane: tous les tissus solides dérivent de l'économie embryomaire. Liectoplacenta jénetre dans le derme de la muqueuse utérine, at le dirnit pour englober, et endigner, ses vaisseaux sanguins. Il est donc liun diflicile, dans ce cas, de parter de placenta maternol romme dr cadugue sérotine; le mienx serait de ne plus employer ces deux termes, atin d'éviter des assimilations at des comparaisons inexactes.

\footnotetext{
a demi diagrmmabiques). Ces figures font suite aux précédentes, numérotees de sur a 992, et les mêmes considérations leur sont applicables. - En 993. les replis amuiotiques se sont soulés pour délimiter la taviti amnintique, et le colome externe s'est étendu dans l'auf entier; cette phase corrosponal a celle de la figure "h3 du tableau général. L'examnios (serense de von lair, chorion primitif) emet des expansions superficielles (villosites primitives, villosites non vasculaires), privies de vaisseaux sanguins. lu Gh, comlours extéricurs des annexes embryonnaires, en supposant le chorion pri mitif enlevi.
} 
B. - Le dévelopgrment, et l'évolution, des ralupues ont ité surtont suivis chez l'llomme. Les notions fouruies, à cel égarel. sur les autres Mammitires, et nolammentsur les longerse, línotent me glande constance dans les procédés. Il est done permis dr prembe comme lypes los lomnées acquises sur l'llommr, roll lemant compte. pour les appliqurar iux autres Honodelphes, des qualités littérentes dans le temps et dans l'espace. C'est, en ellel, rhez l'llomme, que les radrumes sont le julus complexes.

la calnune vraie, particulière à l'llomme et aux Primates supérirns's, est nne hypertrophie locale, sur place, de toute la murueuse utirine. Dans son évolution, elle passe par deux phases : line de progression, l'autre de régression. La premiere soutrml du premicr au cinquiène mois de la grossesso: la seconde va de celte demière éfroque jusqu'à la parturition. - La phase de juogression commence à l'arrivée, dams la matrice, de l'ovule fécondé. Lépithélinm viluatile le la muquense utérine s'exfolie, el disparait. Le derme s'épaissit dans dos proportions considórablıs; ses cellules conjonctives se multiplient. Plusieurs d'entre elles s'amplitient à l'exces, el atleignent des dimensions extrèmes; on les nomme les cellules géantes de la caduruo. Les glandes utérines accompaguent cet accroissement, en s'allongeant dans le derme entirr; len' extrémité profonde s’élargit, devient rariqueuse, el se reploie sur ellemème, de façon à occuper un plus grand espace qu’à l’étal normal. Ce phénomène a pour résultat de diviser la caruque en deux assises : l'une adjarente i la musculature de la paroi ulérine, rrensée en tous sens par ses bases glandulaires, est lite la couche spongieuse; l'autre, périphérique, en rapport direct avec la cavité de l'utérus, est nommée, par opposition, la couche compucte, ear ses portions grandulaires sont étroites, à peu près linéares, el le laible volume par suite. Les cellules de ces glandes, cylindriques des l'abord, se ratconrcissent, ot s'aplatissent mome, sauf dans le fond de res dernières. - La caduque vraie mesure environ, au moment où elle atleint toute son amplitule. sept it hnil millimétres d'épaissenr : elle diminue alors, jusqu’i posséder seulement un millimètre, vers le septieme et lo hutieme mois de la gestation. les pores, au moven desquels les glandes s'unraient dans la cavité utérine, se ferment, et disparaissent. Les portions glamblaires de la conche spongiense diminuent, el s'aplatissent, the maniere i posséder l'aspect le cavilés lenticulaires, Lumbs parallibes.

La caluque, ansi diminnée, demenre en plare jusqu'il l'́popue de la parturition. Elle ost alors rojetée, en même temps que l'ombryon, laissant i nu la musculatme nterine, reconverto semlement jar la rógion

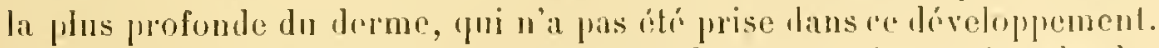

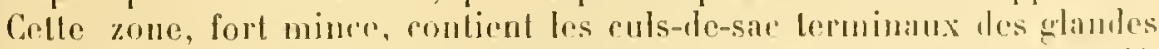

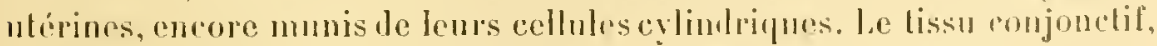
interposé a ces derniers, prolifiere pomr compospre mon nomban dermo. les culs-de-sac sallongent, el constiluent de momrolles grambes lont 
ipithélium sélend antour de leurs orifiees pour donner celui de la mupueuse; celle-ri est, par ce mogen, refaite il nouveau. I'apris Ch. Rohin, la nourclfe muqueuse s'élıache avant la parturition; son épithélinm proviendrait dans ce cas, au moins en partie, lu tissu conjonctif sous-jacent. Linsi que II. Duval l’a témontré, au sujet des Rongeurs, en ce qui concerne la régénération de la paroi après le décollement du placenta, ce fait n’a rien que de normal. puisque l'épithélium et le derme le la muqueuse utérine sont également d’origine mésodermique.

La caduque réflechie, de répartition plus grande que la caluque vraie, est, ì son lébut. un hourrelel annulaire de la muqueuse utérine; celte saillie s'accroil, de façon à entourer l'embryon sur une élendue variable. Aussi, son origine ctant semblable i celle de la caduque vraie, son organisation est-clle identique. Les dithérences principales portent sur les grlandes, qui subissent un élargissement égal dans presque toutes leurs parties, et s'allongent dans le sens de l'accroissement pris par la membrane qui les contiont; elles ont la forme de cavités lenticulaires, fort aplaties. - La caduque réfléchie contient des rellules géantes. Dans le cas des Rongeurs, ainsi que l'ont hémontré les recherches faites par M. Duval, ces éléments proviement dr l’emhryon; ils se détachent de l'ectorlerme du chorion, contribuent à constituer la cadnque, où ils s'accumulent en grand nombre, et s'amplifient dans des proportions énormes. Ils revètent les aspects divers, en se moulant sur ce qui les entoure; leur protoplasme passe il l'état aréolaire; et leurs noyaux s'hypertrophient de leur côté. - Latrophie de cetle caduque est, chez l'llomme, plus précoce que celle de la précédente; elle commence vers le second mois ile la gestation, el débute dans son pôle diamélralement opposé au placenta. Les phases de cette régression ne different pas de relles présentées par la caluque rraie.

Lor'sque Jes deux caduques coexistent, elles ne deviennent pas indépendantes. En continuant toujours a prendre l'llomme pour exemple, la caluque réfléchie, à cause de sa situation comme enveloppe de tout l'organisme embryounaire, qu'elle emboite it la lar:on d'une capsule, est obligée de suivre l'accroissement pris par ce dernier; elle s'élargit a mesure, demeurant toujours en sa place. Elle entoure le futus muni de ses appendices, et se trouve directement flongée dans la carité mème de l'utérus; relle-ci la sépare de la caduque vraie, qui recourre la paroi utérine, partout oì fe placenta ue sattache pas à cette derniere. L'amplifiration est telle, ver's le cinquieme mois le la grossesse, que la cavité de la matrice, aux dépens de qui elle s'effectue, disparait complètement; l'embryon, pourvu de ses annexes, remplit tout l'espace limité prar la paroi utérine. La cadurque réfléchie s'ilccole à la caduque vraie; toutes denx s'unissent en une seule membrane, qui persiste ainsi, sans plus se modifier, justuu à la lin de la grossesse; it ce moment. l'épaissenr totale de lenr ensemble atteint ì peine un millimetre. - Lors de la parturition, cette unique cadnque demiere est entraince arec le placenta. La 
scission entre elle, et les portions persistantes des parois sexuclles, sétablit an nivean mème dı eol; la muquense de re dernich leste en place. (Fig. 1014.)

III. Chorion. - A. Les auteurs désignent par l'expression de chorion embryonnaire, ou filus bricrement de chorion, la membrane qui entonre l'ensemble de l'embryon et les annexes lirertement atlachés à son corps. Comme la disposition de ces annexes varie l'un grompe de Mammifères il l'antre; comme, d'autre part, elle change, pont le mème embryon, dans le cours de sa gestation; il sensuit que ce terme n'a aucune signification exacte, si ce n’est celle llenveloppe extérieure. Il est nécessaire, aftn de préciser, d'emplover des adjectifs, destinés à rnserrer le sens du mot lans des limites déterminées.

Liovule, au moment oi il parvient dansla matrice, est encore revetu de sa zone pellucide. Celle-ci a élé dite, parfois, le chorion primaire on le prochorion. - Lorsque la phase de culoplanule est lépassée, le colome externe fait son apparition, et détermine, par son extension, combince avec celle de l'amnios, le clivage de la zone para-embryonmaire en l'examnios (on la séreuse le von Bä̈r) et la paroi vilelline. L'examnios passe alor's à l'état le chorion, puisqu'il est exlérieur par rapport ì loutes les autres parties issues de l'ovule, et puisqu'il les enveloppe. II mérite le nom de chorion primitif. Sa structure est celle de l'examnios qui le constitue à lui seul; elle compreud un ectoderme extéricur, un somato-mésenchrme sous-jacent, et une somatopleure interne. Parfois, dans le cas oi il existe une caduque rétléchie autour du chorion primitif, ce dernier se souleve prar places, afin d'augmenter les surfaces de conlact, et, par suite, les espaces d'absorption nutritive; il prorluit des expansions, courtes et coniques, nommées les villosités choriales primitives, on encore les villosites non vasculares, à cause de lenr privation de vaisseaux sanguins. Lembrvon humain, vers la seconde et la troisième semaine de son dévelopjement, commence à porter un grand nombre de ces villosités, qui lui tonnent un aspert tomenteux.

Lallantoïde fiit ensuite son apyarition, et jugresse lans le culome externe. Sa paroi extérieure s’aplique contre l'examnios, s’accole à lui, et augmente, par son apjoint, la complexité du chorion. Ce deruier se comprose, à la fois, le l'examnios et de la paroi externe de l'allantoïle, soudés en une seule membrane; afin de le distinguer du précédent, le lerme d'allanto-chorion sert a le désigner. - La présence de l'allantoüle lans le chorion a pour effet de donner à ce dernier des vaisseans sanguins, qui lui manquaient jusqualors; lallantoïde est, en eflet, richement vascularisée. Dans toutes les régrons où parvient celle-ri, oi se forme, en conséquence, un allanto-chorion, ce derniel émet des villosilés, qui contiennent des capillaires sanguins. les appendices sont nommés, afin dr les sépaner des précédents. les villosilrs choriales drimitives, ou les villosités vasculaires; elles en diffípent par le röle que jone 
lallantö̈le dans leur genèse, rt par leur possession de vaisseaux san-

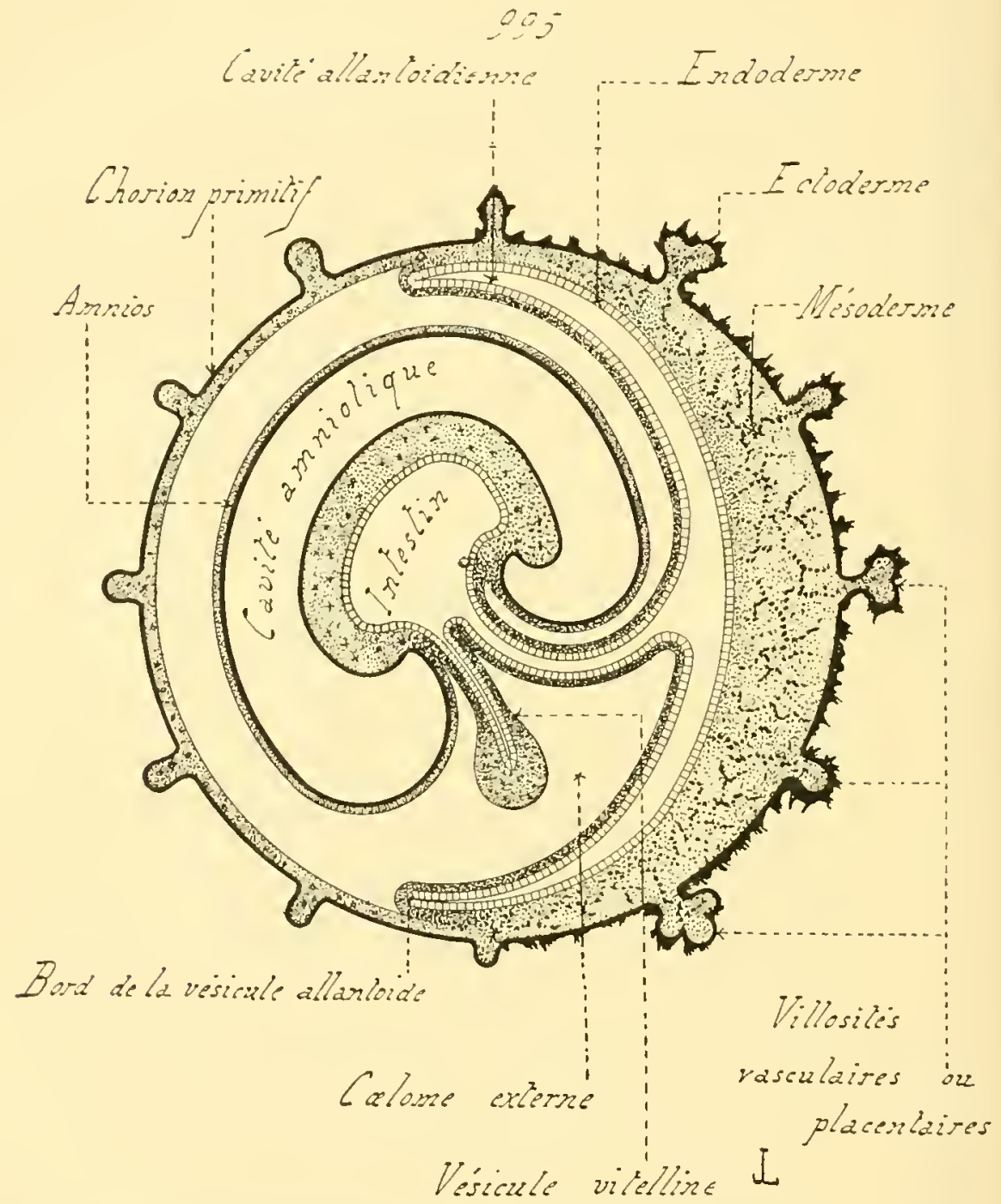

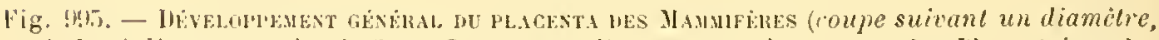
it demi dingrammatique). Cotte figure complète, en ce qui coneerne les P'lacentaires, les dessins preeédents, nmuérotés de 990 à 99 ; ; les feullets embryonnaires sont indiques

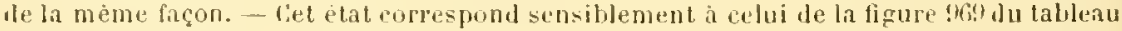
génèral. La vesieule vitelline est devenne fort petitr, alors que ha vésieule allantoide, relice au corps de l'embryon par le cordon allantol̈lien, s'est ampliliee; ee firisant, elle s'tnit a une part du chorion primitif. Les villosites de eette région épaississent leur ectoderme suptrficiel (etoplacenta), puis se laissent penelrer par les vaisseaux allantoidiens; eltes deviennent alors plus rolumineuses (villosilés vasculaires), el donnent le placenta. les vaisseaux allantoïliens sont indịués par des lignes d'un pointille plus gros. 
guins. Cenx-ci sont des branches des vaisseanx allantö̈liens (vaisscanx ombilieaux). Dans le cas oì le rhorion primilif porte des villosités, l'allantoüde, en s’attachant au premier, envoje des rameanx vasculalires dans les secondes; celles-ci sont conservées, passent it l'état de villosité définilives, el angmentent leur's dimensions.

Tous les Ilammifères placentaires sont munis, dans leur léveloppe-

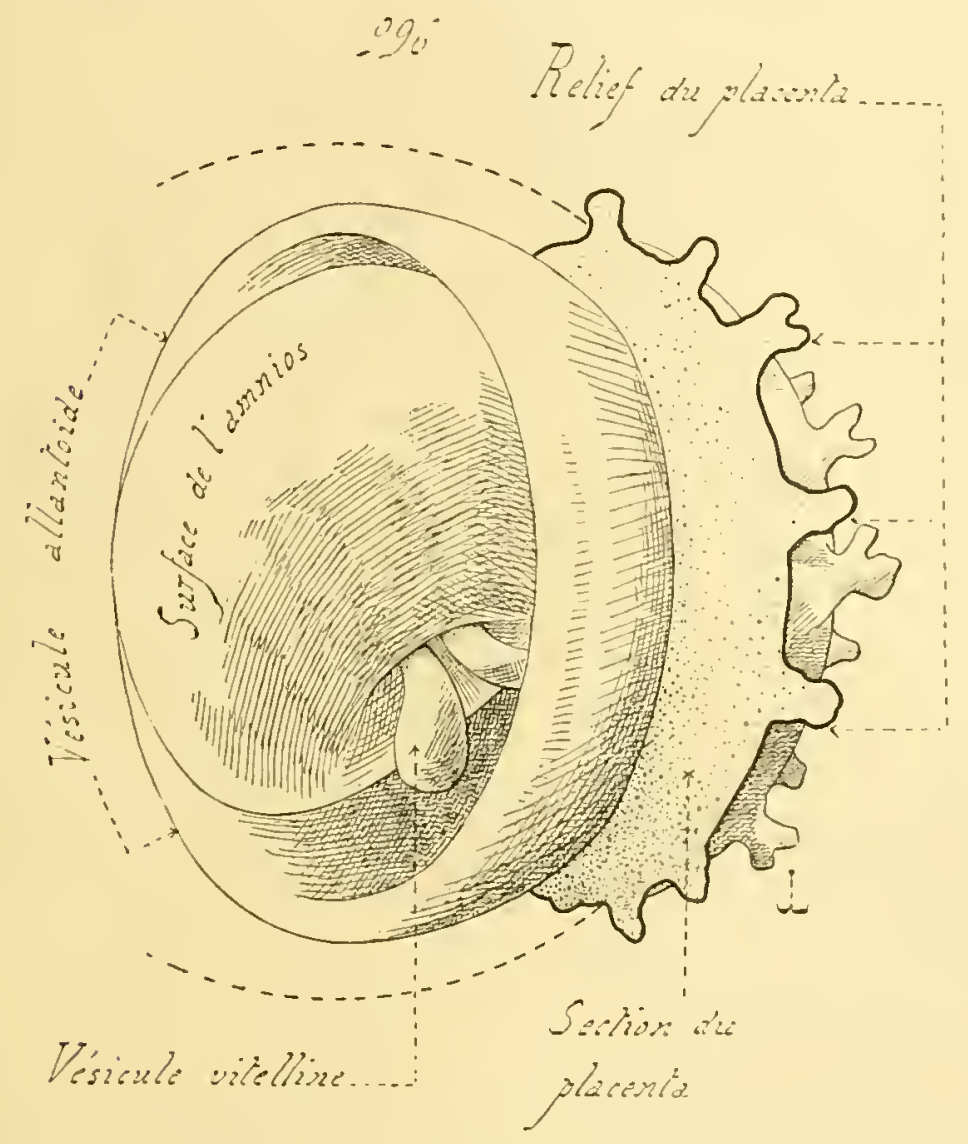

Fig. mi. - Contour extirieur de l'etat precedent, en supposant le choriun primitif enlevi. ainsi yu'une moitic du placenta, afin de laisser voir les appareils internes.

menl, de villosités vasculaires, qui reconvent le chorion partoul vì se

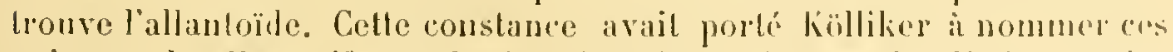

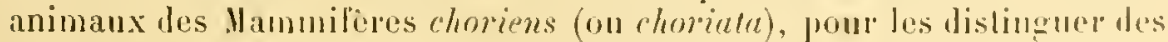
bidelphes et des Jonotremes, dont le chorion demeure lisse (Mammiferes achoriens, on achoria). Cefle dilférence est nne partio de la dissenblance générale élablie entre les Mammifèrs entiomement vivijares. lont les nécessités de nuluition embryomaire sont tres inlonses, el les 
Ilammifères incomplitement vivipares, on les oripares. - Les villosités vasculaires s’atlénuent progressivement, par la suite, dans toutes les zones ou le placenta ne preud pas naissance. Par contre, daus les régions où l'allantoïde engendre l'appareil placentaire, ou l'allanto-chorion se convertit en un placenta, ces villosités angmentent sans cesse de taille et de complexité, et composent elles-mèmes cet appendice nutritif. Dans le cas oir le placenta se trowe diflus, et réparti sur la surface presque entière de l'allanto-chorion, les villosités sont conservées en majenre fart. Mais lorsqu'une bande restreinte de l'allanto-chorion donne seule le placenta, alors ramassé en un corps compact, l'opposition, entre les zones où les villosités s’atténuent, et celles oir elles se développent davantage pour engendrer cet organe, est des plus nettes. La région de diminution devient à peu près lisse; elle porte le nom de chorion lisse (chorion lave): l'autre accentue son asprect initial, et mérite le terme de chorion touffu (chorion frondosum), qui sert à la désigner.

l)ans ce dernier cas, qui correspond à la présence dun placenta dense et compact, les régions allantoüdiennes, non employées dans le façonnement de cet appendice, se rédnisent à une mince lame, placée sous l'examnios et unie à lui; l'allanto-chorion, dans foute sa portion non placentaire, et lisse, constitue par là une membrane peu épaisse. La carité amniotique gramdit alors ì l'excès, repoussant l'endamnios (amnios vrai) devant elle, et l'appliquant contre l'allanto-chorion. Ce ternier acquiert, de ce fait, nne complexité extrème, puisłue l'amnios s'ajoute à lui, et se soude à sa sulıstance. Ce nouvel état, consécutif an précélent, peut étre caractérisé prar le terme d'ammio-chorion, servant i désigner la membrane enveloppante. - L'amnio-chorion mantue à la plupart des Mammiferes placentaires, car l'amnios prend rarement un accroissement tel, yu'il s'accole, en faisant disparaitre lout le colome externe, au chorion existant léjà. Il est, par contre, lien déreloppé chez l'llomme, et, sans doute, chez les Primates supérieurs. Lorsque tous les annexes sont complets, l'amnio-chorion est la senle enveloppe de l'euf; il entoure directement la cavité amniotique, le seul restant le tous les espaces délimités autour de l'embryon. Cette enveloppe est elle-mème donblée en dehors par une lame, résultat de la soulure de la caduque vraie avec la caduque réfléchie. La complexité de la membrane, destince à circonscrire la cavité amniolique, oì se tronve plongé le fotus, est alors des plus grandes. Cette membrane se compose, de dehors en dedans: de la caduque vraie, le la cadnque réfléchie, de l'examnios, le l'allantö̈de non placentaire, enfin de l'endamnios. Malgré son origine multiple, elle constitue un tout simple, qui va en s'amincissant à mesure que le déreloppement progresse; seule, elle sépare l'embryon des milieux environnants, el se creve an moment de la parturition.

B. - Les dispositions prérélentes s'appliquent anx cas oì loutes les parties issues de l'orule sont conservées en leur place. Il n'en est 
pas ainsi chez les Rongeurs, qui présentent uno inversion des fouillets. soit tardive, soit préeoce. Ainsique l'a démontré II. Muval, les emlryous de ces animanx ne possedent point te chorion semblable a celui des aulres Ilammiferes. Les seules lécrions, ponrvues d'une structure romparable, sont celles où se trouve le placenta, petit et liscoüle; partout aillenrs, les enveloppes sont d’une antre nature. Le chorion primitif le ces ètres se détruit en majenre partie, on mème, lans cerlains tas, ne prend pas naissance. Les zones blastorlermipues yui subsistent s'jncurrent autom de lembryon, de manière í reporter lenr endoderme vers le dehors. La membrane extérieure est ainsi tapissée par l'endoderme, et formée par une petite part seulement de la roloplanule; elle rorrespond i nue portion restrejnle lu chorion normal, amplifiée à l'exrès ponr joner son rôle d'enveloppe, et dont les assises sont orientées dans un sens inverse (Voir au chapitre XV1, pagre 991).

Ce fait alıoutit à un résultat des plus remarqualıles. Tous les Mammifères placentaires, sauf eeux en cause, restrejgnent les dimensions de leur résicule vitelline, qui s’atrophie peu à peu. A la suite de la destruction précoce du chorion primitif, ou mème de son défaut l’aparition, une partie de la paroi vitelline persiste chez les longeurs aux feuillets invertis, el donne l'enveloppe exterieure de l'embryon, en se repliant sur elle-mème. Aussi celte derniere est-elle vascularisée, dans loutes les régions oì ne se trouve pas le plarenta, par les vaisseaux vitellins (omphalo-mésentériłues). Les vaisseanx allantöliens (ombilicaux) se rendent au placenta seul, el nöriguent pas la membrane extérieure.

IV. Vésicule vitelline. - Cet appendice se comporte de manières dilléjentes des Diılelphes anx llonodelphes, et, parmi res derniers, de cenx dont la disposition est normale à cenx dont les feuillets sont invertis.

La vésicule vilelline des Didelphes reste volumineuse, pendant toute la durée de la gestation. Richement vascularisée par les vaisseaux vitellins, elle est plongée dans le culone externe, et s'y amplifie, tandis que l'allantoïde de ces animaux demeure petite. lille saccole à l'examnios, et le double, en agissant comme l'allantoïle des Monodelphes visit-vis de la mène mentrane; les régions d'union sont souvent nommées, par les auteurs, le chorion vitellin, ou le vitello-rhorion. La zone de conlact ímet des villosités, yui šatlachent a la paroi de l'utírus maternel, et y puisent des sues nutrilifs. Ces villosilés sout petites et éparses, à la maniere de celles qui composent le placenta dilfus de certains Monodelphes; seulement leur provenance diffire, rar clles dépendent de la résicule vitelline, et non de l'allantoïde. - Celte disposition rorrespond an premier legré de la viviparilé, le la nutrition ntérine, les llannifires. Sonvent, chez les Phuscolarctos par exemple, et i "anse de l'inportance de son ròle, la vesieule vitelline prend un atcroissement énorme: 
pllr grandit dans le culome externe, et entonre fresque toul l'embryon, alor's yue l’allintoinde resle petile.

Chez les Monoulelplues, la vésioule vitelline est l'aluord volumineuse; pris, comme le rile mutrilif est jouc par l'allantö̈de, elle se restreint, el diminne de dimensions. I son dóhul, la coloplanule de ces animanx se compose de la ravilé para-vitelline, que sumonte l'embryon accompagné de ses élıuches ammiotipues, et que limite, partout ailleurs, la zone para-embryonnaire, entore constiluée par l'ectoderme seul. Cette phase est communc anx embryons de tous ces animax; les differences viemnent. suivant que les états ultérieurs comportent la persistance des lenillels dans leur siluation acquise, on lien leur inversion.

Dans le premier cas, l'ectoderme de la zone para-embryonmaire est conservé en sa place; il se double de mésoderme el d'endoderme; le colome externe se reuse, et livise l'ensemble en deux lanes. La lame externe, l'exammios, représente le chorion primilif; la lame inteme conlimue à circonscrire la cavilé para-vitelline, el à composer avec elle la vésicule vitelline. liembryon grandit; son corlome externe samplifie; l'annexe vitellin suil, toul d'abord, cet accroissement, mais lans des jroportions beancoup moindres, el ne tarde jas à s'arrèter lans celte voic. Alors que toules les autres parties de l'embryon angmentent lenr's dimensions, il demeure avé la mème laille, et paraìt, par conséquent, se rapelisser ì mesure. linalement, il nest plus qu'un appendive de minime imporfance, attaché à l'embryon, et privé le lout rôle. -4 son déhul, les vaisseaux vitellins (omphato-mésentériques) se dóveloppent daus sa paroi; ils salroplient, pendant que la vésicule se rélrécil. Le canal de son cordon l'allache se comble. La lace interne de sa paroi se convere, dies l'ahord, de pelites saillies vasculaires, rapjelant relles des Sanropsidés, mais privées de toute fonction, et disparaissant d'une manière hâtive. l'endorlerme, qui la limite en derlans, se desquame; ses rellules tombent dans la cavité de la vésicule, où elles se résolvent en granulations. Cetle derniere, fort restreinle, contient un liquide, tenant en dissolulion iles sels alcalins. - En somme, par tous ses détails, l'évolution de la vísicule vilelline est une régression constante, depnis le moment oir le culome externe la sépare de l'examnios.

Les phénomenes changent dans le cas de l'inversion des fenillets. La zone para-embryonnaire le la erloplannle s'atrophie, soil d'une manire précoce, soil linim maniere lardive. Elle ne persiste que Jans mue région arljacente a l'emhryon, oì elle se complique, et produit le culome exlerne, l'amnios é le placenta. I la suite de cette perte, la cavilé paravilelline lisparail agralement, et d'emblée, puisque la paroi, yui la circonserivait, n'rxiste plus. Alors l'emlıyon, entouré de son amnios, se sćpare de son placenta, ol ne lui reste altaché pue par le corlon allanLölden, et pir une membrane périphérique allant se raceorder aux borils de cet appentice nutrilif. Celle membrane, prouluite peu à peu par l'éloignement progressif de l'embryon el du plaroula, est lí résultal 
de létirement d'une parlie, de la zone para-embryonnaire conservéc, non emplovée dans la genèse de ce dernior, ni dans celle de l'amnios. Celte parlie, tont en grandissant, se relourne sur elle-mẻme, et porte son endoderme vers le dehors. Ainsi étahlie, elle conserve cetle disposilion, et forme l'enveloppe extírienre de l'embryon muni de ses appondices. - Par comparaison arec les autres Ilammifires monodelphes, la vésicule vitelline disparail d'une facon précoce, el rapilement: sauf une partie yni demeure pour façonmer, en se retommanl sur elle-mime, la memlirane deslinée a limiler, el à isoler de la cisvité ulérine, l'espace occupé par le fretus et ses annexes.

V. Gœlome externe. - Le culome externe varie d'aspect, suivant l'extension prise par l'allantoïde, of par l'amnios. Ces denx appendices s'amplifient, en effel, aux dépens de sa cavilé, el la diminuent d'aulant quils sont eux-mèmes plus grands. Les dewx extromes en pareil cas, sont ollerts par les Didelphes d'une part, et les Honodelphes an placenta discoide d'autre part. L'allantoïde el l'amnios des prenier's demeurent rostreints; seule, la vésicule vilelline acquierl une certaine préjromlírance; anssi le colome externe reste assez raste, of forme me large cavité où se trourent plongés tous les annexes. l'ar contre, chez les seconds, el surtout chez l'llomme, l’ammios, distendu par la cavilé amniotinue, acquiert des proportions considéralıles; il s’altache à la région non placentaire de l'allantö̈le, qui saccole elle-mème an chorion primilif, de maniere a entrainer la disparition de tout le culome externe. Celui-ci, d’abord présent, est ainsi comblé par l'aceroissement exagéré de ce qu'il contient, el ne se creuse phus ì noureau.

A cause de sa siluation entre le chorion primitif el l'amnios, les auteurs désignent souvent cet annexe, dans le cas de sa persistance, par le terme de cavité ammio-choriale. Dans ce mème cas, el surtout chez les Ruminauls, des cellules, apparlenant aux parois mésolemirgues qui le limilent, se détachent de ces dernières, el tombent dans le calome externe. Ellos y conslituent nn lissn misenchymatemx embryonnaire, composis de collules étoilées, plongées dans une abondantr substance londanentale : Dastre l'a nommé le lissu inter-ennexiel.

VI. Amnios. - 1. Sauf dans le cas relatif a l'inversion précoce des fenillets hastodermiques, l'amnios des Mimmiferes est engendré suirant les procédés habituels : qualre replis s'élèvent autour de l'embryon, et s'unissent en une collerette, qui, grandissant toujours, et rétrécissant it mesure son orifice, finit par entomer complitenent le petil itre. Ce phénomène existe encore lorspue l’inversion des feuillets est tardive, comme il en est chez le Lapun; les replis amniotipues prennent naissance en dedans des ébaurlues ectoplatentaires, entre ces dernières el lazone embryonnare. - Mais il no se relrouve phs si l'in-

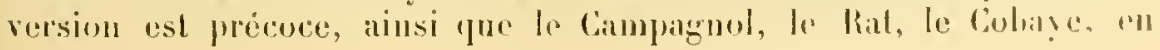


offrent des exemples. Les ruliments de l’amnios et du placenta, déjà fort proches l'nn le l'antre cher le Lapin, ne constituent 'pu'un seul corps, formé par un épaississement local de l'ecloderme de la cœloplanule. Cette zone eclodermique grandil, et, ce faisant, se divise en denx parts : l'une supéricure et externe. l'autre inféricure et interne, aljacente a l'embryon. La première représente l'ectoplacenta, qui se modifie snivant ses tendances spéciales. La seconde est l’amnios. Celle-ri se creuse d'une cavité, soit lorsqu’elle est encore confondue avee la précédente (Campagnol, Rat), soit isolíment (Colaye). En ce moment de son évolution, elle est une vésicule sphérique, crense, à la paroi composée sculement de cellules ectodermiques, qui repose sur l'embryon. Le protendoderme voisin ne tarde pas à lui fournir des éléments mésodermiques, qui complètent l'organisation de celle paroi; de plus, la vésicule entiere se déprime, et s'ćtend antour de l'embryon, de manière à l'envelopper, et à acquérir ainsi sa disposition finale. L'amnios est alors constitué suivant un mode bien différent dn procédé habituel, et qui dérive de lui par une abréviation, dont le Lapin montre les premiers linéaments. Entre temps, l'allantoüle s’était étendue, en contournant l'amnios et s'allachant à sa paroi, pour alter retrouver l'ectoplacenta, et le convertir en un placenta définitif. (Voir an chapitre XV'I, pages 1001 à 1008.)

Te telles connexions, fort dissemhlables des rapjorts hahituels, ont été préciscies dans tons leurs détails, an sujet des Rongeurs, par H. Duval. Sans doute, des relations équivalentes existent chez l'embryon humain. - Les auteurs, et notamment llis, ont signalé la présence, dans ce dernier cas, et tout au délout de la gestation, vers la troisième semaine, d'une expansion qui relie le corps de l'embryon au chorion primitif. Cet appendice, nommé le pédicule abdominal, se compose d'un prolongement de l'amnios, déjà développé i cette époque, anquel s'attache le rudiment de l'allantoïde, entouré par une gaine conjonctive renfermant les vaissenux allantö̈diens. Ce pédoncule manque à tous les Mammifères dont l'amnios se façonne suivant les procédés mormaux, juisque l'allantö̈de s'étend directement saus le calome externe, et ne s'altaclie pas, du moins dès son début, à la paroi amniotique. Par contre, chez les Rongeurs dont l'inversion est précoce, et dont l'amuios se délimite directement contre l'embryon, sans anrune genise de replis, l'allantö̈de adhère à ce durnier pour s'avancer vers l'ectoplacenta. Les relations sont illentiqups i celles montres par fllomme, y compris l'existence d'un prolongement amniolique, qui se manifeste an moment où les deux b́banches, de l'amnios el du placenta, se séparent l'une de l'autre.

Le pélicule abdominal de l'embrron lumain est done une lormation semblable à relle des liongeurs précédents, mais qui ne s'accompagne point l'une inversion des fenillets embryonnaires. Si l'on rapproche de celte particularité le fait relatif à la grenèse rapide de l'amnios, déjá présent, d’après Coste, ver's la fin le la seconde semaine du déve- 
loppement, on en vient à penser que, peutedre, ret appendice prend naissance l’une manière directe, sans ancune genèse préalalıle de replis. Ce n’est là qu'une hypothèse; car les premières phases de l’évolution

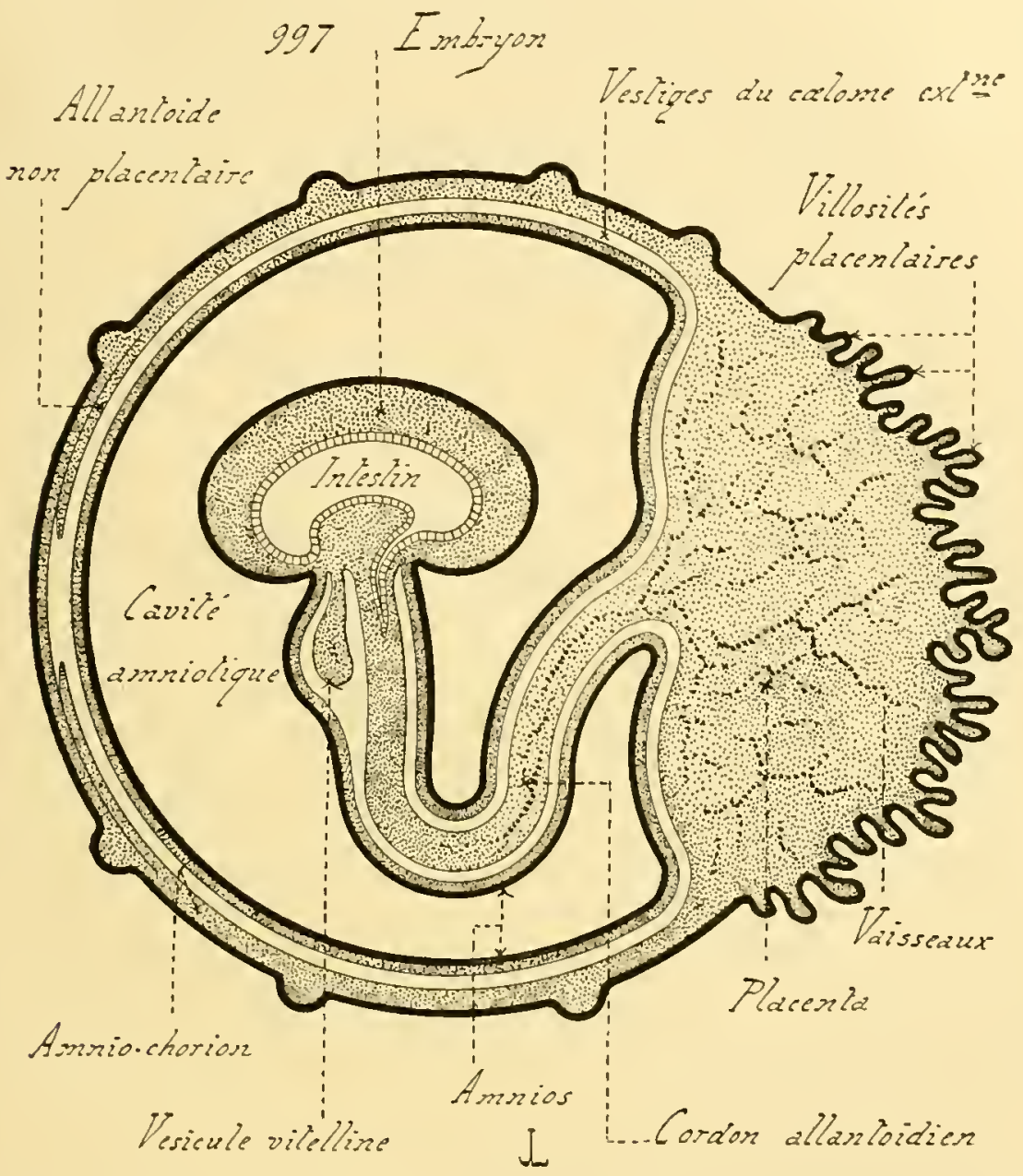

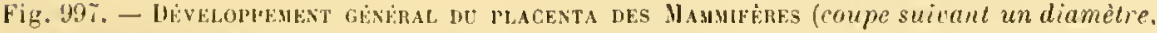
i demi dingrammatique). Cette ligure complète les précélentes, numèrotées 905 et 990 , en ce mèue facon que la figure 995, et que les ligures 990 it 994 : l'ectoderme est en noir, l'untorlerme en hachures, le mésoderme en pointillé; les ravitès sont en blane.

l.e placenta, levenu très epais, s'est ramassi en un lisque. Il n'est fourni que par une portion de l'allantoüle, l'autre portion s'étendant sous le chorion primitif presum entier; de plus, la cavite amniotique s'amplifie à l'exces, appliquant l'amnios contre la fave interne tle l'allantoïle non plicentajre, contre celle du placenta, et contre le cordon allantöidien. Ia vésicule vitelline est fort reiluite; l'ensemble de ses restiges, et du cordon allantödien, engainé par l'amnios, comprose le cordon ombilical, ou cordon placentarre. 
"mbryonnaire de l'llommo sont à preine rommues; les nolions précédentes lom domment pourtant un certain appui.

li. - Lammios, on, ponr employer un terme plus préris, l'endamnios, rest-idline la membrane interne de tout l'appareil amoiotique, ne prend pas un accroissement égal chro lous les Mammiferes placentaires; par suite, ses connexions varient d'un tyje a l'autre. Dans tous les cas, il est me membrane continuc, lestinée i circonscrire, sul toute son étendue, la ravité ammiolique, ou se troure plongé l’enhryon. Ses rapports dépendent de l'extension prise par celte cavité; comme il est entonré lni-mème par le colome exteme, l'amplification de celle-lá s'efforlue au détriment de celui-ci. - Worlinaire, l'agrandissement de l'ammios est assez lestreint, pour laisser sulsister me partie do roelome externe: ce dernier demenre intercalé, sons la forme d'une fente remplie. de liquide, à la paroi amniotigue el an 'horion. Par contre, daus certains cas, el surtoul chez l'llomme, l'accroissement est tel, que l'amnios fail disparaître toutes traces du colome externe, et s'accole an chorion, nom constituer avec hi un amnio-chorion. Les rapports sont alor's bien différents les premicrs, puisfue la paroi amniotinue fait partie du chorion général, et revêt, cu outre, la surface de tous les autres appendices, placenta el rordon ombilical. A la suite de l'atrophic du coslome, la cavité amniolique, fort vasle, est la seule qui persiste autour de l'emliryon.

La paroi ammiolipue est recouverte en dedans, du côté de la cavité fu'elle limile, par un épithélium de provenance ectoderminue; re dernier est simple, el pavimenteux, phus rarement cylindricue. Parfois, il prolifire par places, el produit dres petites saillies, dites les caroncules amniotiques lorsqu'elles sont indivises, el les villosités amniotiques dams lecas on elles sont ramitiées. - Ie liquide ammiotique, l'eau de l'amnios, augmente saus cesso dr quantité prndant les denx jremiers tiers de la gestation, el diminne ensuite, sans doute l'une maniere connexe à l'acroissment du futus. Eu ce qui concerne l'llomme, il mesure mo litre muvim vers le rinquibue et le sixibme mois de la grossesse, et m demi-litre sumlement vers la fin de la gestalion.

V'll. Vésicule allantoïde. - La disposition de la vésicule allantoïde des Mammiferes vivipares dépend de celle du placenta qu'elle fonruit.

Cet appendice est petil, chez les Didelphes. Les relations nutritives, établies entre les embryous de ces animax et l'utérus maternel, sont etfechúes par la vésicule vitelline. La allantoüde n'y prend ancune part; aussi demenre-t-elle restreinte, et séparce du chorion par le colome externe.

Il nin est point ainsi chez les Mnorlelphes. Les conmexions mutrilives sont données par l'allantoïle, qui se soude el s'accole au rhorion, 
sur un espace d'étendue rariahle, mais toujours assez grand, ct forme avec hii un allanto-chorion. Les vaisseaux allantoüliens se ramifient en abondance dans ce dernier, el vascularisent les villosités qu'il possède. Celles-ci, recouvertes par l'ectoderme du chorion, qui prolifere plus ou moins, pénèlrent dans l’épaisseur de la muqueuse utrine, el y puisent les matériaux nécessaires à l'alimentalion de l'embryon. Elles constituent le placenta.

Jans le cas où les villosilés placentaires sont réparties sur un vaste espace, l'allantö̈de offre l'aspect d'une vésicule remplic de liquide. Sa paroi s’épaissit bien, afin de supporter les annexes mulpilifs avre leurs vaisseanx, mais pas an point de faire disparaitre loute ravile inforne. La mème disposition existe lorsque l'allanto-chorion entirr se ronvertit en un placenta simple, comme il en est chez les longeurs : l'allanto-chorion n'est alors qu'une partic assez restreinte du chorion tolal. - Mais il n’en est plus de mème lorsqu'une zone seule de l'allanlo-chorion donne un placenta compacl, ainsi jue lo fait se présente pour l’tlomme. L'allantoïde s'étend contre le chorion primitil, et le donble complètement, de facon à le transformer tout enticr en allanto-chorion. Une région seulement de ce dernier s'lıpertrophie, se vascularise atouramment, et se change en un placenta dense el ramassé; toules les autres porlions allantö̈liennes diminuent, et se restreignent à une lame mince. Ancune cavité n'existe dans ce cas; toule la substance de l'allantoüde est conposée de tissus solides. L'annios, en s'étendant, s'applique contre la portion non placentaire de l'allanto-chorion, et se soude à elle. La lame allantoïdienne, ainsi prise, ef intercaléc à l’amnios el au chorion primilif, a reçu divers noms; elle est la membrane intermédiaive de Bischoff, le magma réticulé de Velpeau, la membrane limite de Jungluluth, la membrane lamineuse de Joulin, etc.

VIII. Cordon ombilical. - Cet appendice se compose du cordon vitellin el du cordon allantoïdien, ou placentaire, soudés l'un à l'aulre, el prarfois revêtus, sur une élendue variable, d'nne gaine donnée par l'amuios. - Au début, le cordon vitellin, volumineux par rapport aux autres annexes, existe seml. Il porte la vesicnle vilelline, suspendue dans le colome externe; il renferme, dans sa paroi, les vaisseamx vilellins, on omphalo-mésentériques. l'uis, l'allantoüde prend naissance, ot s'accroil extromement, ainsi que son pélicule, alors que la risioule vilelline demeure stationnaire, son cordon également, et que leurs vaisseaux s’alroplicnt. le pédoncule de l'allantö̈le grossit saus cesse, el devient tres épais; il se convertit en un cordon, qui contient les vaisseaux allantö̈liens (encore nommés ombilicaux, ou placentaires) daus sa subslance. Lannexe vitellin entier se somle ì lui, et lous deux composent ensemble le corilon ombilical. Seulement, la part de beancoup la plus grande, dans la constifution de celernier, est réservéc an cordon allantöldien. Les vaisseaux vitellins ayant disparu, les seuls rameaux vaseu- 
laires, yui parcourent lappendice ombilical, sont les deux artères el la veine allantoüdiennes, chargées d'irriguer le placenta.

Les choses en restent la chez la phupart des Mammifères placentaires. Elles se compliquent darantage, lorsque l'amnios s'éteul à l'excès pour former un amnio-chorion; il reconve également le cordon ombilical, par le fail mène de son amplification, et l'enveloppe d'une gaine. Chez l'llomme, cette gaine va depuis l'insertion abdominale du cordon jusqua l'insertion placentaire; elle est complete ef continue. Les zonos mésodermiques, appartenant à la paroi de l'amnios el ícelle du cordon, se soudent en un seul corps; elles se convertissent en un mésenchyme a la sulistance fondamentale abondante, du trie des tissus muqueux, of dont l'ensemble a reçu le nom de gélutine de Warhon. A la suite de l'oblitération des canaux qui parcouraient le cordon vitellin et le cordon allantoüdien, el de la destruction de leurs prarois épilhéliales, le cordon ombilical achevé se compose, sculement, de la gaîne amniotique, des vaisseaux allantöldiens, et du mésenchyme. La surface de la gaine est revètue par un épithélium stratitié, de provenance ectodermique, puisqu’il n'est autre que celui de l'ammios.

IX. Placenta. - Le placenta les Mammifères esl foujours, lorsiqu’il existe, de provenance allautoïdienne. II correspond ì une partie de la paroi de l'allantoïle, qui s’accole au chorion primitif, el s’épaissit; cel allanto-chorion émet, soit par toute sa surface, soit par une zone restreinte de cette dernière, des villosités, qui s'attachent à la paroi de l'ulérus maternel. Ces expansions composent le placenta; leur aspect est très diver's; mais elles offrent ce caractère commun de dépendre de l'allantoïde, et d'ètre abondamment irriguées par les raisseaux allantö̈diens. Aussi, ces derniers sont-ils souvent désignés sous le nom de vaisseaux placentaires, dans le eas particulier des Mlammilères pourvus d'un placenta. Cet organe manque aux Honotrèmes et aux Didelphes.

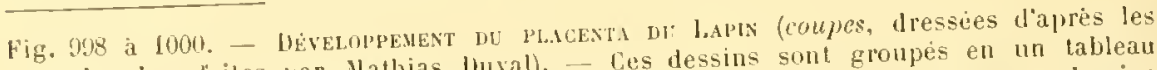
recherches lailes par Mathias Mural). - Ces dessins sont groupes en un tableau d'ensemble, allant de la figure !!38 a la figure 1009. Its correspondent aux dessins diagrammatipues, numerotés de 901 a $\$ 09$; mais ils expriment, en surplus, les disposilions rélles el les connexions avec les tissus maternels. Hans les coupes grossies, les edifieations de provenance ectoplacentaire sont à fond noir, et les lissus maternels à fond blane.

Ln 998, ovule en place slans la cavite uterine, et accole aux deux lobes utèrins (ou cotyledons uterins), dont le derme de la muqueuse est hypertrophie. - Lin 999, compe grossie de l'emhryon el d'une partie de sa région placentaire; eet ctat correspond a celui de la fig. 90 . Leetoderme de la région placentaire s'hypertrophie, el envoie des expansions

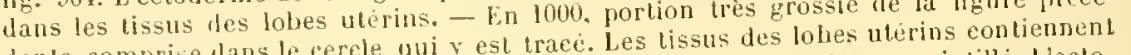
denle, comprise dans le cercle yui y est traedeci sont representées en pointillé. L'ectodes vaisseaux sanguins. el des glandes; celles-ci sont leprese l'ectoplacenta, divise en derme hypertrophie dle la regton placrntaindare. Au-tlessous de lectoplacenta se trouve une covche plasmodiale el tme com somalopleure), puis un vide (le calome externe). puis

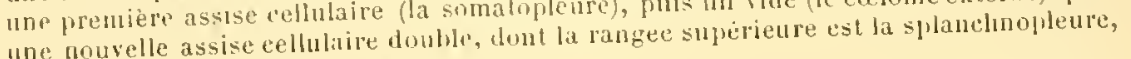
et la rangée inferieure l'endoderme. 


$$
0
$$


On admeltail, jusqu'à ces lernières années, que le placenta se composait de deux parlies : l'une l'origine embryonnaire, l'autre d'origine maternelle; la première était lite le placentr fotal, el la seconde le placenta malernel. Les nolions récemment acquises ont démontré que cet appendice est, tout enlier, produit par l'embryon; l'utérus de la mère se borne a fonrir le sang qui pénètre dans la trame placentaire, el ne donne aucun tissu solide. - Le chorion primitif commence par façonner, dans la région clıargée l'engendrer le placenta, et par un épaissis-

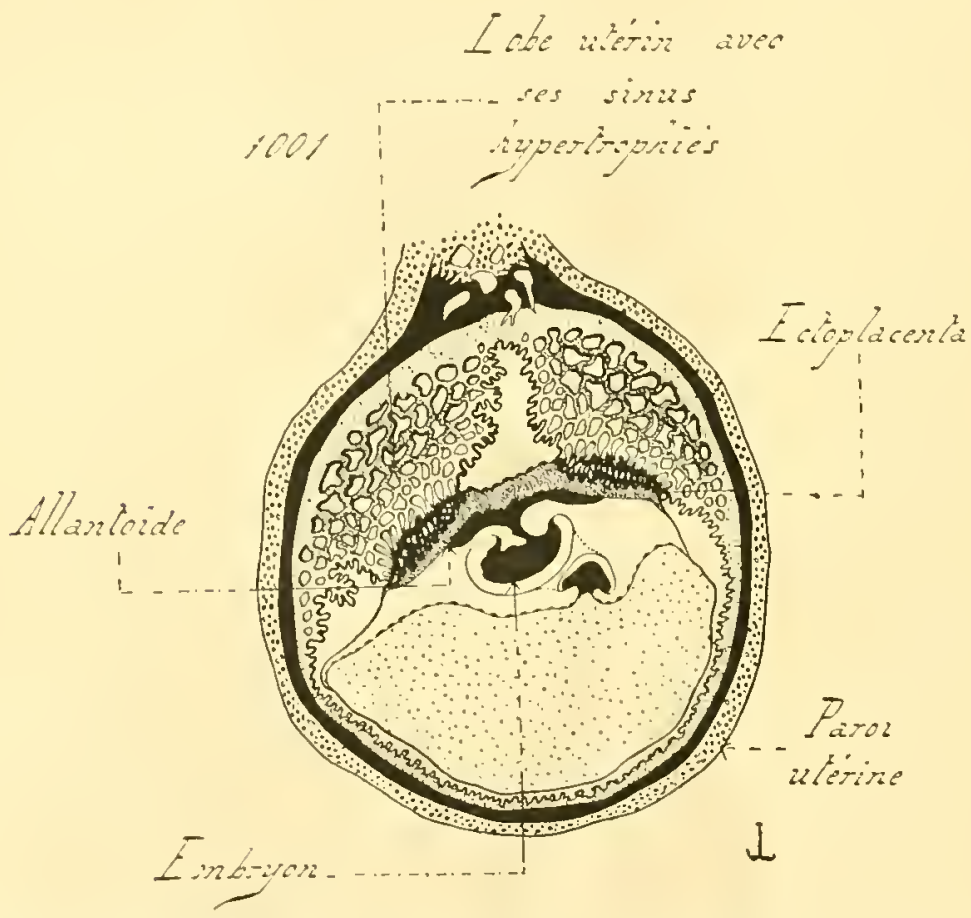

Fig. 1001. - Jiviloppement nu Placenta de Lapis (coupe d'ensemble d'un utérus gravide, d'apris les recherches faites par Mathias Imwal). Cetle figure fait partie du lalleau d'ensemble allant de la lig. 9ns it la fig. long) Jes consideritions, exposées an sujet des lig. 198 a $100 \%$, leur snot applicables. - Cet clat correspond a celui de la figure $900 ;$ la substance de l'ectoplacenia sc suludivise en colonnes, et la vèsicule allantoìde commence à la jénétrer pour la vasculariser.

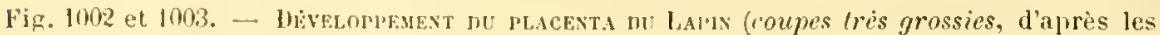
recherclies faites par llathias luval). Ces figures font partie du lableau d'ensemble allant de la fig. 998 à la fig. 1009; les considerations, exprimees au sujet des lig. 908 à 1000 , lenr sont applicables. - Fin 100, portion grossie de l'ectoplacenta tle la figure prècedente (fig. lonil); la substan'e de l'ectoplacenta se livise en colonnes, el cndigue les sinus de la paroi utérine; d'aulre part, elle commence átre pénéluée par la résieule allantoïde, qui lui apporte des raisseaux sanguins (remaniement). - in 1002, portion grossie d'un cctoplacenta un peu plus avanci. l'ar la pinétration loujours plus grande de la vésicule allantoïde, l'ectoplacenta se change en placenta délinitif, et se résuut, par sa subdivision croissante, en un réseau lubuleax. 


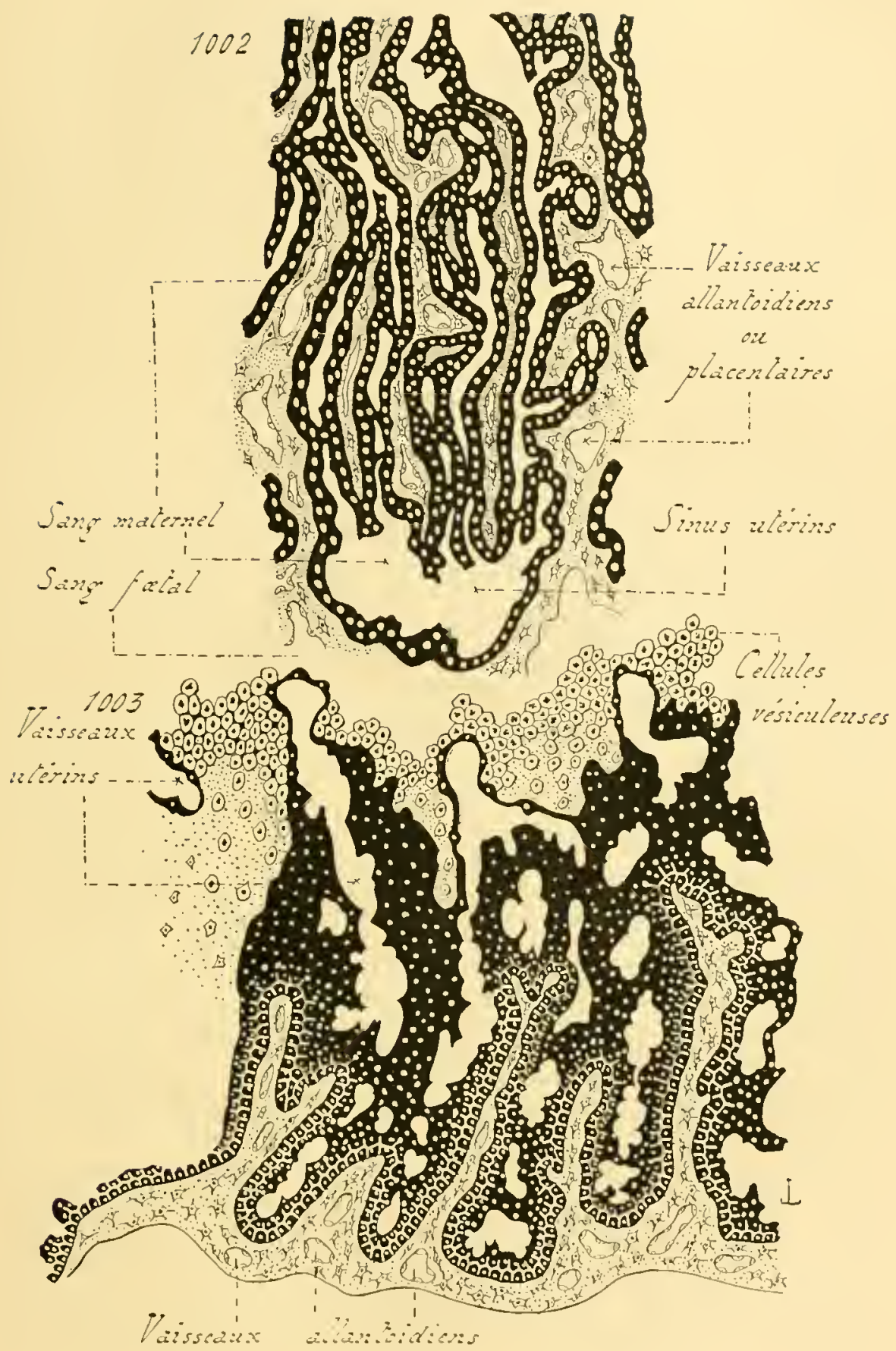


sement de son ectoderme, un rorps nommé l'ectoplacenta. Cette ébauche de la formation placentairr se lie inlimement à la muqueuse ulérine, y pénitre au moyen de ses villosilés, el rffectue les premiers échanges nutritifs entre la mere el le futus. Puis, l'allantoüle s'accole à l'ecloplaceuta, lui procure des vaisseaux sanguins, yui pénètrent dans ses villosilés, le remanie de celte facon, en lui donnant une complexité plus grande, et compose avec lui le plicenta définilif. Cel appareil est. par ce moyen, produil en entier par l'organisme embryonnaire; et, sauf le sang de la paroi ulérine, il ne contient aucune part maternelle. L'erreur, qui avait conduit à almettro l'existence l'un placenta maternel, venait llune olservalion inexacle : on croyail que l'ecloplacenta, à cause de ses connexions étroites, et précoces, avec la muquense de l'utérus, était engendié par elle.

Ces notions nouvelies, sur le dévelopjement du placenta, constituent l'une des plus importantes dérouvertes de l'embryologie moderne, et la plus remarqualole. Dues tout entières à Mathias Duval, elles montrent la constanle uniformitó de la nutrition placenlaire rhez tous les animaux; lorganisme maternel se borne à fommir le sang, ou peu s'en faul, les édifications de tissus solides élant données par l'économie de l'embryou. Les recherches, effectuées par 11 . Duval, ont porté sur les Rongeurs. De récentes études, failes sur l'autres Mammifères, sur des Chéiroptères, des Inseclivores, des Carnivores, par Ed. van Beneden, Huhrecht, Masins, les ont.confirmées.

Développenent de placenta. - Bien que les phases du développement de lappareil placentaire ne soient pas encore connues chez tous les Mammiferes; il est permis le penser qu'elles se corresponient; la constance de la structure, el de la situation générale, de cel organe, aulorisent à le croire. La diversilé porte sur la quantité des phénomènes évolulifs, non sur leur qualilé; l'ectoplacenta est plus ou moins épais, les athérences à la paroi utérine sonl plus ou moins profondes et étroites, mais les faits essenticls sont homologues parlout. - Aussi, est-il ulile, afin tr mieux préciser, de clıoisir un type quelconque, et de l'examiner en détail; sauf quelques variantes, dimportance fort secondaire, cet exemple s'élend aux autres placentas.

Le type, adopté dans la llescription suivante, est le Lapin, auquel II. Duval a cousaré uue ćtule des plus completes. Cet animal olfre une particularilé iutéressante, en ce sens que l'éhauche de son placenta se compose de denx parlies, qui se raccordent par la suite, lout en gardant nue certaine autonomie. Les phases se ressemblent dans les denx zones. - Ces phases se succedent en quatre temps. Tout d'ahord, l'ectoplacenta se faconno, el s’illache i la paroi utépine : ciest la période de formation. Puis, lallantoüle vientajouler son appoint, apporle ses vaisseaux, et eomplique la structure lotale : c'est la période de remaniement. Dans une troisiome piriode, d'achivement, le placenla se complite, 
el arrive à sa structure d'álat. Enfin, an moment de la parturition, de la période de décollement, il se détache de la paroi utérue, qui se restaule, après la chute de l'appendice lié à elle jusque-là.

$1^{\circ}$ P'ériode de formation de l'ectoplacenta. - Pendant le rut, el arant que lovule fécondé ne s'accole i la paroi de la corne utérine, celle-ci subil des modifications préalables, destinées à préparer son allhérence prochaino au placenta. La muqueuse s'épaissit en lleux zones, symétripues par rapport à la région mésométrique. Ces zones constituent deux bourrelets volmmineux, qui s'avancent on une forte saillie dans la cavité de la matrice; ils sont dits les lobes colylédonaires. Le sillon, connexe à la région mésométrique, qui les sépare l'un de l’autre, est le sillon inter-cotylédonaire. Chacn de ces lobes s'adaple a l'me les denx parlies du placenta, et se comporte comme son congénère. Il se compose, comme la muqueuse dont il provient, d'un épitlélium, et d'un derme sous-jacent. Lépithélium se convertit en mn synertium, parsemé de noyaux, aceumnlés de préférence dans sa zone profonde; un tel changement gagne, de proche en proche, les parois des glandes dont les lohes sont creusís. Les capjlaires du derme s'elargissent; le tissu conjonclif euviromant les entoure le cellules, lisposées sur plusiemrs couches, qui perlent leurs expansions ćtojlées, et s'arroudissent.

Lorsque s’achève cette préparation de l'organisme maternel, vers la fin du septieme jour de la gestation, la coloplanule embryonnaire dome naissance à son ectoplacenta. Son ectoderme s’épaissil, par la multiplication abondante le ses cellules, en ses deux régions, accolées aux lobes cotrlédonaires, qui encadrent les bluauches amnjotiques. L'épithélium utérin disparait alors; l'ectoderme de l'embryon tonche directement au lissu conjonctif du derme, et se soude à lui. ll continue ì proliférer, et avance dans ce derme. en sujvant de préférence les parois des cavités glanlulaires, qui lui ouvrent, pour ainsi dire, une roie de pénélration; il enveloppe, de cette façon, les capillaires superficiels de la muqueuse. - Ce fajsant, il se divise en deux conches. L'une, arjacente ì l'emlryon, est composée de cellules aux contonrs distincts; lautre, accolíe à l'utérus maternel, constituéc par un syucytium où ne se reconnail aucune membrane cellulaire, est la partie envahissante. II. Iuval nomme cetle dernière la couche plasmarliale, et couche cellulaire la premiere. Ed. ran Benelen emploie, dans ses études sur les Chéiropteres, et pour dósigner les assises correspondantes, les termes de plasmodiblaste et de cytoblaste. Ces deux landes proliferent sans cesse, en augrmentant la quautité de leurséléments constitulifs : la couche plasmoliale, par la division dirncte de ses noyaux; la conche cellulaire. par une kaygokinise réclle.

la pénétration de la conche plasmodiale s’accentue constamment; cette assise émet des bandes d'avancée, qui commencent par tapisser les parois des cavités glaudulaires, en se sulıstituaul i leur épillólium, et 
fjnissent pas emplir les cavités elles-màmes. Cet mvahissement inígal, plus accentué par places, lome a l'ensemble de cetle comche l'aspect l'me lame, pourvue d'un grand nombre de villosités rameuses, quj entrent toujours plus prolondément dans le derme des lobes colvédonaires. - La conche plasmodiale ajpive ansi an niveau des capillaires superliciels de ces lerniers. Elle rommence par les entourer, puis, l'endothélium rasenlaire disparaissant, clle prend sa phace. Une telle sulıstitulion a pour effet de mettre, dans celle rigion, le sang maternel en contact direct avec l'édification placentajue le l'embryon, sans aucune interposition de tissu d'aulre sorte. Il se produit en ce cas, pour employer l'expression imagée due ì Ml. Iuval, une hemorhagie maternelle, endiguee par le placenta embryomnaire.

L’ectoplacenta est achevé lles lors. L’allantoïde s’álait léveloppée, et agrandie, sul res entrefaites; elle s'athache à ce dernier, lui donne des raisseaux sangnins, lranches de ses propres vaisseaux allantoidjens (ou ombilicaus), le remanje, el foumit, avec lui, le placenta détinitif.

Q. Piriode de remaniement. - A. L'anncxe placentaire, ausi complété far l'appoint que luj fomnit l’allantoïde mumie de ses raisseaux, complique à l'excis sa struclure. Le résultat, aupuel tendent les nouveanx phénomènes évolulifs, est l'amplificalion extrême, au moyen de subdivisions et de ramifications forl nombreuses, les surfaces de contact entre le sang maternel et le placenla. Lorsque ce hut est alleint, ce dernier appareil consiste en un lacis de capillaires, groupés en lobules, ot plongés dans de vastes espaces sanguins de la paroi utériue. l'ou' ce laire, ì mesure que les vaisseaux allantojdiens pénètrent dans l'ectoplacenta pour le rasculariser, celui-ci avance davantage ses villosités dans l’épaissem de l’utérus, el les partage en un réseau de tules, qui se suldivisent eux-mèmes en abondants canalicules, placés côle ì côle.

Les villosités de l'ectoplacenta olfrent l'aspect de colonnes aux conlours sinuenx, encastrées daus la muqueuse ntérine, on elles entourent directement les cavités des capillaires maternels; aussi M. Duval les nomme-t-il les lobes colonnaires. Toutes saltachenl, comme à une base commune, à cette parlie de la paroj embryommaire qui les porte; l'allantoïde, avec son tissu conjonclif semé de vasseanx, s'athehe à cetle partie, et enroie des expansions vasculaires dans tous les lobes. - Les échanges nutrilifs, entre la mère et le foctus, ont des lors changé de

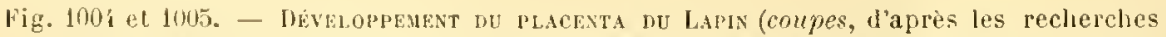
faites par Nathias luval). Ces ligures font partie du tableau d'ensemble, allant de la ligure y9s à la figure l(00! ; les considerations, exprimes au sujel des ligures 998 à 1000 , leur sont applicalıles. - En 100i. poltion d'une coupe d'ensemble de l'utèus gravide; (cet état corlespond á celui de la figure $90 \%$. Le réseau tuhulaire du placenta est aehevé. - En lon, portion grossie de la coupe prededente, montrant, de haut en bas, toutes les combe's qui composent la paroi utèine el le placenta intriqués. les espaces, laissés en lilane daus la ligure entiere, sont les vaisseaux sanguins; il fanl se les representer comme lormant un reseau continu dans tumte l'umasseur de ces tissus. 


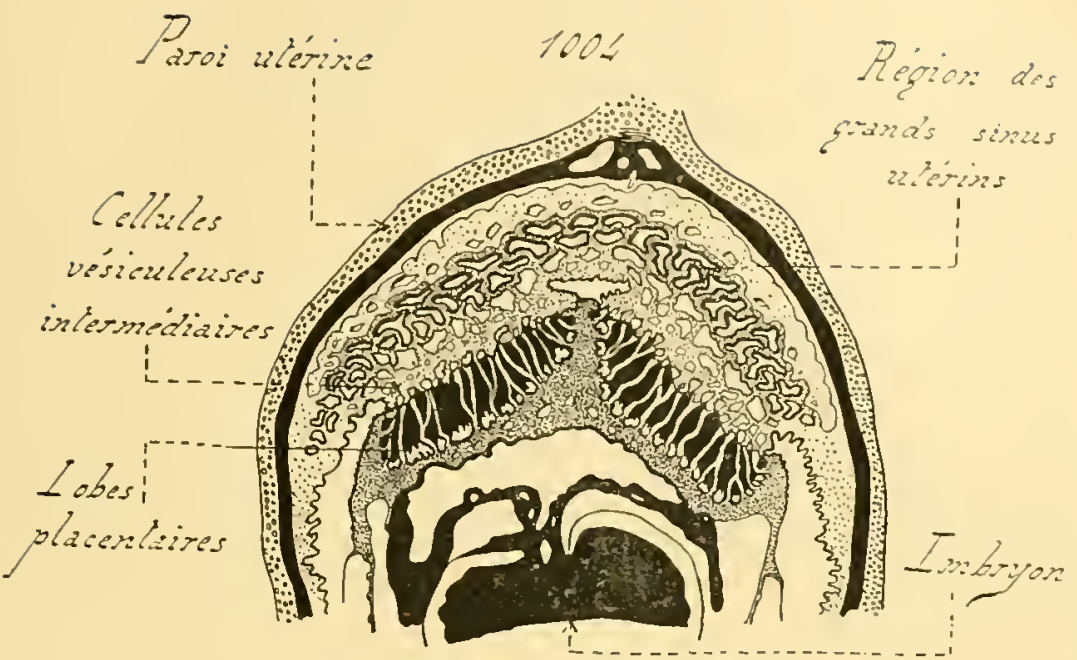

1005
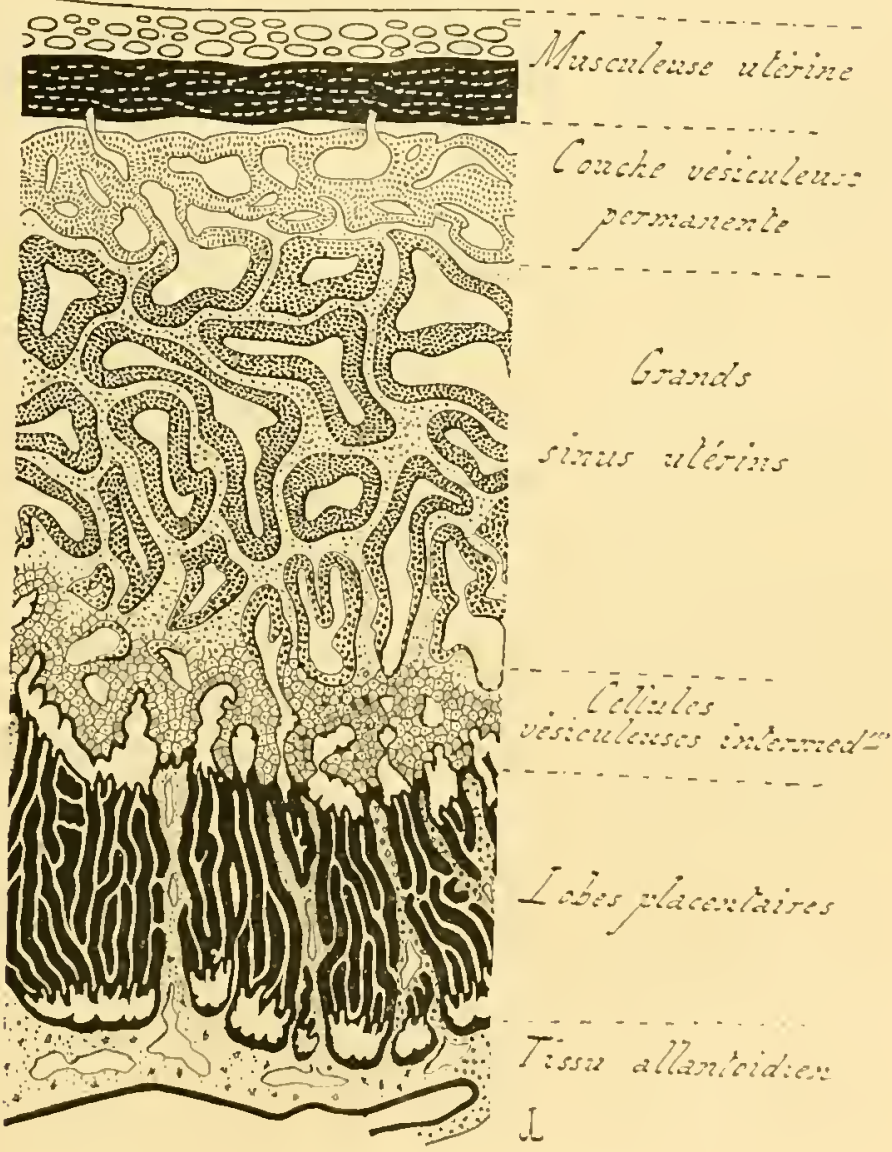
nature. An déhul, avant la renue do lallantoïle, los villositós itaient haignés par le sang maternel, qui leur foumissait les matrianx d'alimentation; mais res derniers étaient obligés de parcomrir, par diflusion de cellule a cellule, toute la masse de l'ectoplacenta pour arriver jusqu'à l'embryon. lors choses changent dès lors. Les lohes colonmaires blant rascularisés, les sulistances nutritives passent dans le sang que contienment ces lobes, d'où les vaisseaux allantoüliens les transportent, avec plus de rapilité et le farilité, dans le corps de l'embryon. I a nutrition rst ainsi julus aisée.

A mosure que les expansious allantö̈diennes pénètrent dans les lobes colonuaires, pour en former laxe, cenx-ci s'avancent toujours plus profondément dans le derme utériu, et englobent un plus grand nombre le ses vaisseaux. Tout en agissant ainsi, chacun d'eux se suldivise en ranalicules allongés, 't anastomosés dans tous les sens an travers des cavités sanguines matruelles; il sp courertil en mn réseau, ou mu complexus, de tubes enchevètrés. Chaque tube contient, en son axe, une assise conjonctive, de provenance allantoüdienne, renfermant des capillairos sanguins; sa surface se compose d'une hande plasmodiale, seméc de novaux, issue de lectoplacenta, ot lirectement laiguée par le sang utórin. Lóphange nutritif s'úblit entre ce lernier, et le sang des capillaires du tube, an travers de la bande superficielle. En comparant celte ivolution a celle d'une glande, la villosité cctoplacentaire, se partageant en tuhes, rappelle un lobe se livisant m lobules. Chacun de ces Iolmles se scinde, à son lour, par mu émiettenent de l'ensemble, toujours destiné a amplifier les surfaces de contact, en un réseau de canalicules.

$\Lambda$ cet effet, la hamle plasmorlialo de chaque tulo angmente, par la livision directe, le nombre de ses novaux, et s’épraissit. L’hypertrophie, inégale, a ponr effet de prorluire les expansions, qui s'avancent entre les tules d'un même lobe, et s’anastomosent en nn réseau. Les capillaires axiaux du tule entront dans ces appendices, et los vascularisent; mais ils y pénètrent seuls, sans itre accompagnis par le tissu conjonttif qui les entoure dans le tube lui-meme. Ces expansions sagencent en une lrame serrée, dont les divers éléments, plongés dans le sang maternel, nont, pour toute proi, yunne mince bande plasmorliale, an travers le laquefle les échanges nutrilifs sont des plus aisés.

la lobe colonnaire acquiert ainsi une disposition complrxe. Dabord simple, il commence par se scinder en lohul's, dout les parois, encore épaisses, comprenment, à la fois, me bande plasmodiale et mne assise conjonrtive. Il continue onsuite ce mourment de division, et partage chacun de ses lobules en un résean dexpansions cylimbriques, de canalicules, dout la paroi, lort mince, se compose senlement diune étroite bande plasmodiale. Ces divers éléments renferment tous des capillaires sanguins, hranches des vaisseaux allantoüliens, et sont ì nu dans le sang de l’utérus maternel. An moven de celte différenciation 
rroissante, les surfaces de coutart eutre les deux organes, celle de l'utérus et relle du plarenla, augmentent ì l'excis leur élendue; ot les parois, qui séparent le sang de l'un de celui de l'aulre, deviennent de plus en plus minces.

B. - Pendant que s'effecluent ces pliénomènes, rolalifs à la diffirenciation sur place, les lobes placentaires, ou plutol leur extrémilé de pénélration, avaucent toujours plus loin dans la muqueuse ulipine, dans la saillie cotylédonaire de cette muqueuse. Anssi celte lernière se modifie-t-elle d'une manière connexe à celle progression constante. Constiluée, à son début, par du tissu conjonclif semé le vaisseaux, res derniers s’amplifient dans des proportions extrèmes, et passent à l'état de sinus, nommés les sinus nérins, ou les lacs sanguins uterrins. Les cellules conjonctives se multiplient, et deviennent gloluleuses; leur nombre augmente, au point de les tasser les unes rontre les autres, par une diminution corrélative de la substance fondamentale; leur protoplasme se remplit d'enclaves liquiles. En cet étal, ol a cause de ce dernier fail, elles sont dites les cellules vésiculeuses. Inis, ì mesure que le placenta s'arance el se complète, ces éléments se détruisent.

Ces changements ne se produiseut pas l'une maniere semblalle dans toute l’épaisseur de la paroi utérine. La musculature demeure indemne. la couche conjonctive, directement placée en derlans des muscles, convertil lien ses éléments en cellules résiculeuses, mais ses vaisseaux restent intacts el petits. C'est à son niveau que se décolle le placenta; aussi, a-t-elle été nommée, par M. Dural, la couche vésiculeuse protectrice, ou la couche vesiculeuse permanente. - En dedans de cette hernière se tronve une région épaisse, dont lous les vaisseaux se convertissent en vastes sinus sanguins. Les rellules vésiculeuses composent, lout d’abord, une épaisse paroi ì res poches sanguines; puis elles se détruisent, lorsque les sommels pénétrants des loles placentaires arrivent à leur niveau. Lassise plasmouliale de ces expansious fait disparaitre ces éléments, et se sulıstitue à eux pour endigner les sinus. Tout en avauçant, ils entraînent égalemeut l'atrophic des autres rellules vésiculeuses, placées entre ces carités vasculaires; mais, daus loute celte région, les lobes placentaires ne se divisent pas en lobules, ni en canalicules. - Enfin, en dedans de la précédente, est située la zone oì le placenta s'est différencié en un lacis complexe de tuhes ef de canalicules.

L'envahissement de la muqueuse utériue, par l'édification placentaire, approche alors de son terme. Les deux saillies, produiles par cefle muqueuse, sont pénétrées par les tissus du placenta, qui se sulstiluent a lenr propre substance, tout en consorvant leurs cavitis sauguines, quils entourent et circonscrivent. Les parties les plus profomles de res lissus se hornent ì produire ce lernier phinomeno, à limiler les vaissfanx maternels, sans modilier lear nature; ils garlent leur struclure plas- 
modiale, et ne la changent pas; lenr rôle nutritif est forcóment minime. Par contre, dans leur's zones hasilaires, vascularisées parl'allantoüle, les tissus placentaires se subdivisent on un résean complexe te tubes et de canalicules, destiné à pernettre des échanges nutritifs des plus intenses entre le sang de la mere el cetui dufoetus.

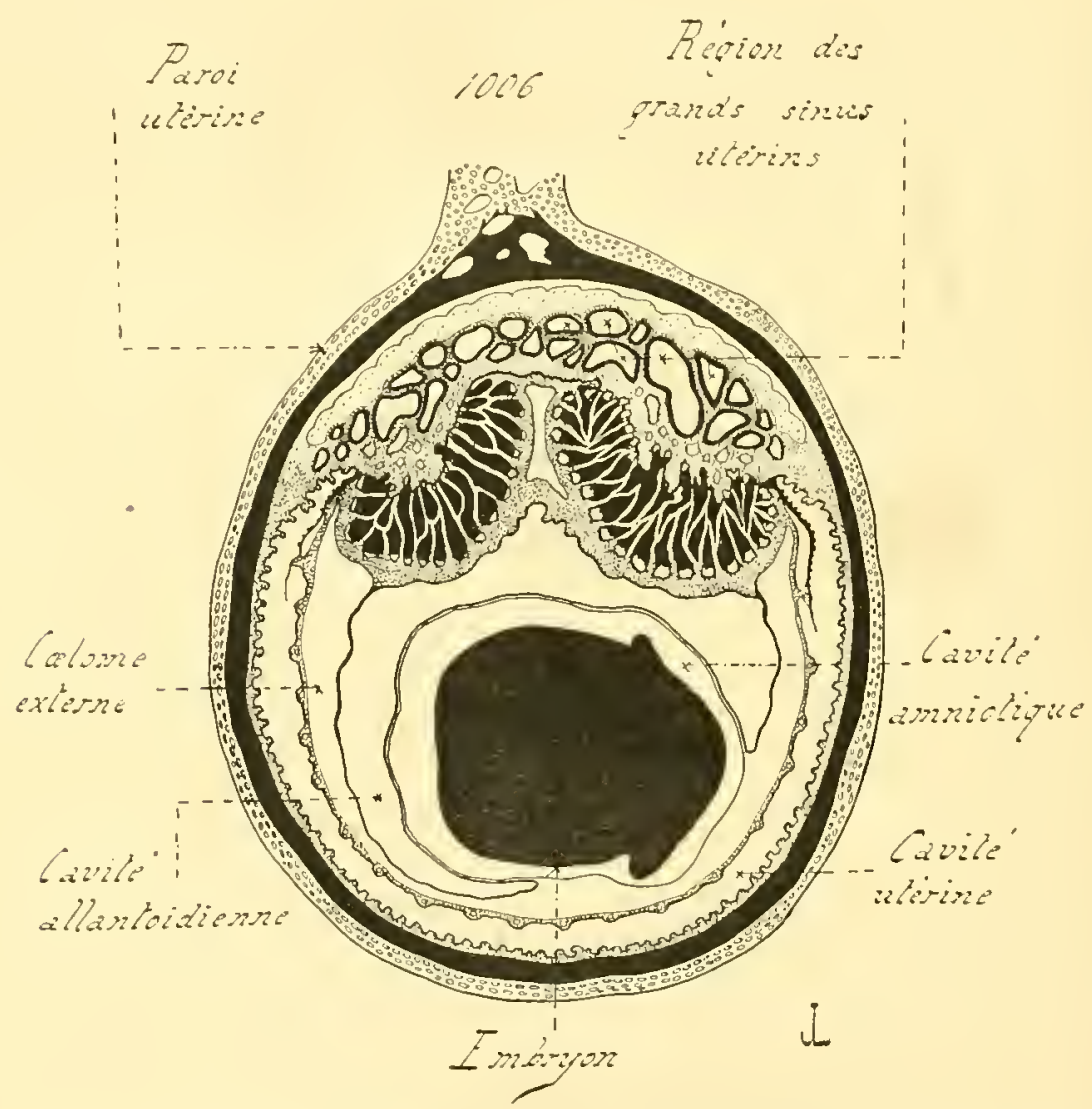

Fig. [1006. - Deveromenest nu plachita du Lapin (coupe d'ensemble d'un utérno gravide, d'apres les recherches faites par llathias buval). - Cetle figure faic partie du tableau d'ensemble, allant de la fig. 9os a la fig. 100\%. L'elat, quelle représente, correspond a celui de la ligure $m 0$; Ie placenta parrient a sa periode d'achevement.

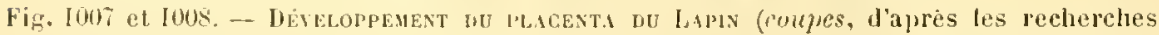
fitites par Mathias Inval). - Ces figures font partie lu tableau d'ensemble allant de la lig. 998 a la fig. $100 \%$ : les considerations, exprimees an sujet des lig. (x, is 1000, leur sont applicaliles.

En l007, portion d'une coupe d'utèrus gravide, vers la fin de la gestation; la comparaison avec la fig. torfj permel d'apprceier les modifications survenues daus la conche protectrice, et dans celle des grands sinus uterins. - En I008, portion grossie d'un placenta et de la couche utérine adjacente, vers la mème epoque: la comparaison avec la fig. I005 permel de bien saisir les détails de ces changements; les espaces laissés en blanc sont les vaisseaux sanguins. 

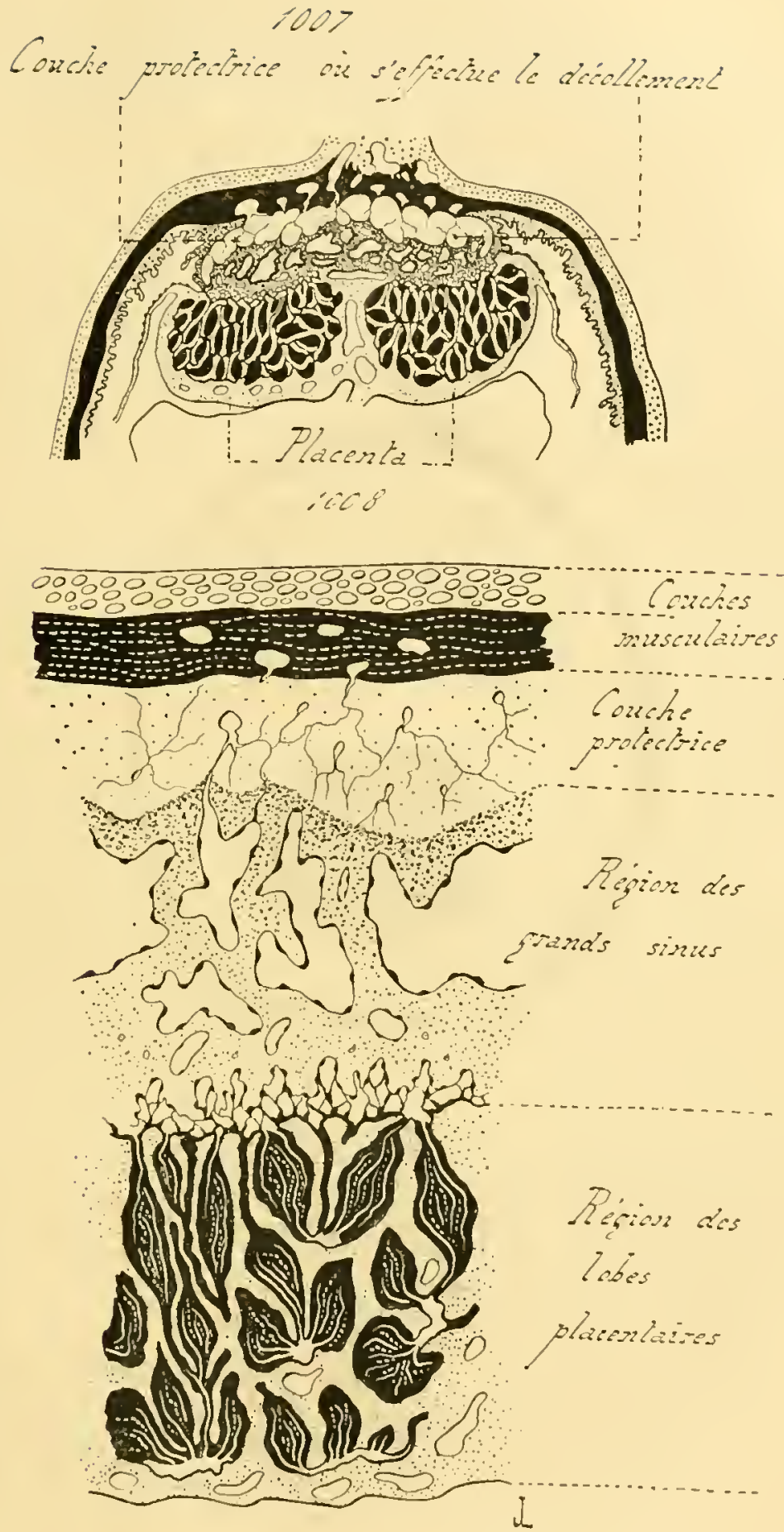
3० Période d'achèvement. - Le placenta a peu à laire, les lors, pour parrenir à sa structure d’état. Les morlifications supplémentaires se produisent, en mìne temps, dans ce qui reste des tissus utérins, et dans les tissus du placenta.

En ce qui concerne la couche vésiculense protectrice de la paroi ulérine, ses éléments acquièrent, avec nettéé, le calactère de cellules vésiculeuses, el ses raisseaux sanguins demenrent petits. Ces derniers relient les ramounx rasculaires, yui traversent la musculature de la malrice, aux gros sinus endigués par le placenta; ainsi que le fait remarquer Ml. Duval, ils composent une sorte de filtre, interposé sur le trajef de la circulation maternelle. Cette disposition est en rapport avec la venue proclıaine du décollement placentaire, gui s'elfeclue au niveau de cetle assise, c’est-à-dire dans la régrion mème où les vaisseaux sanguins, étant les plus petits, l'hémorrhagie résultant de la rupture se trouve plus restreinte. - l'arlont aillenrs, el en dedans de celle couche, les tissus utérins, constitués par les rellules vésiculeuses, se détruisent. Les sinus, crensés en eux, s'élargissent de ce fait, et s'unissent en un petit nombre de grandes poches sanguines. La couche plasmodiale du placenta renplace les tissus utérins disparus, et, tout en ayant un volume moindre, entoure ces poches; par un fait remarqualble, elle se convertil, à mesure, en cellules, qui se lassent autour des sinus, et se disposent en bandes épithéliales stratifiées.

En dedans de celte zone se trouve la région occupée par le placenta différencié et subdivisé. Au début de la période d’achòrement, cet appareil se compose, en somme, d'un réseau tres complexe, formé de fins canalicules. Les moditications qu'il sulil consistent en l'amincissement, puis en la disparilion, de la mince assise plasmodiale de ces derniers. Chaque canalicule est alors réduit à son capillaire sanguin, puisque sa couche superficielle s'est atrophice. Tous ces capillaires sont plongés dans le sang des lacunes utérines, où se fromvaient placés les canalicules eux-mèmes. Lorsque ce phénomène rst terminé, le plarenta consiste en un assemblage de lobes, composés le lobules, et cumposés enx-mèmes de capillaires, directement susjendus dans le sangr maternel. - Le mince endothélium de ces capillaires est alors la seule harriere opposće aux échanges nutritifs; cenx-ci s'eflectuent aisément, par osmose, à travers son épaisseur. Et, afiulle rendre ces échanges plus complets, le sang foctal circule, daus ces capillaires, en sens inverse de la direction suivie, dans les lacunes qui les ontoment, par le sang malernel.

¿' Decollement du placentu. - Lorsque tout ce développement est fermine, les lissus solides de l'ancienne muquense utérine n'existent plus, du moins dans les régions où s'attache le placenta. Seules, ses cavités sunguines deneurent, en samplitiant; of son ancicune sulstance se trouve remplace par les tissus placentaires, qui endignent ces 
espaces. Le placenta s'est sulsstitué à la murueuse, el n'est séparé de la musculature ulérine que par la couche vésiculense potechrice. Ses contours se sont mettement délimilés: sa hase d'insertion sul l'ulérus se rétrécil el se prérise.

Au moment de la parturition, les cellules vésiruleuses de l'assise protechrice se délruisent par places. La sulistance de cette dernièce devient làche, peu cohérente; et, fimalement, les contractions de la musculature utérine la détachent d'une façon complète. Comme le placenta athere à la matrice par l'entremise de cette assise, il se lroure lilre de ce fait, et tombe dans la cavité de l'utérus, d'oci il esl expulsó. - Les vaisseaux de la couche protectrice élant petits, l'hémorrhagie, occasionnée par la rupture, est restreinte; elle se trouve, dans les conditions prósentes, réluite le plus qu il esl jossilule.

Le placenta décollé, la musculature ulérine se présenle presque à nu dans toute la zone de rupture; elle est recouverle par une mince couche conjonctive, dernicr vestige de l'assise protectrice. La cicalrisation se produit fort vile; d’après des expériences faites par Straus et SanchezToledo, des microbes pallogènes, introduits dans la carité utririne de suite après la parturition, ne provoquent aucune inleclion. Ce fait dénote une obturation très rapide des vaisseaux rompus. - La murueuse se régénìre ensuite, de facon í se remetlre dans sa structure normale, el complète. Ce fait s'ellectue suivant deux procédés, selon que la surface mise à nu est petite, ou selon qu'elle occupe une vaste ćlendue.

l.e lapin offre un exemple du premier cas. Lutérus se distend, durant la geslation, par la présence les embryons ef de leurs annexes dans sa cavilé; sa paroi s'amincil en conséquence. Il revient sur lui-mème au moment de la parturition; sa paroi reprend son épaisseur normale. Ce phénomène, lout mécanique, a pour effet de restreindre de beauroup la surface laissée à vif par le décollement. La plaie mesure à peine leux ou trois millimètres de diamètre, alors qu'elle aurait présenlé, dans le mème sens, deux ou trois centimelres, si les choses élaient restées en l'élat. Puis la muqueuse, plissér sur elle-mème autour de l'insertion du placenta, étale ses plis, et recouvre complètement le jetil espace dénudé.

Le Rat et la Souris donnent un exemple lu second procédé. La couche vésiculeuse proleclrice manque à ces animaux; elle est remplacée par une lame, composée de cellules géantes, accoléc à la musculature ulérine, et produile par la régrion plasmodiale du placenla; cetle assise, engendrée par l'embryon, diţère, frar son origine, de sa similare du Lajun, puisque celle-ci est de provenance maleruelle. Le róle joué est le mème; retle lame se détache, et, par l'ellet de son décollement, sépare le placenta de la paroi utérine. - Comme la comehe de séparalion n'apprarticnt pas à cette dernièr , et romme elle est assez ample, la cicatrice haisséc par sa chute est fort étendue. Le retour de l'ulérus à ses dimensions normales nest pas suffisant pour l'amililer; celle combaclion a pour seul etlel de réduire le diamelre des vaisseans sanguins 
mis à mu, et d'arrèter l'hémorragie consécutive à la chute du placenta. La mince bande de tissu conjonctif, demier reste do la muqueuse utérine primilive, interposée i la lame précédente a a la musculature, demeure à vif, privée de tout revioment épithélial. Ce dernier est alors engendré par le tissu conjonetif lui-méne, dont plusienrs éléments se portent ì sa surface, se mulliplient, ol se disposent en une couche épithéliale complele. - Une folle origine parait extraorlinaire, car, dans la règle, les épithóliums ol les assises ronjonctives n’ont que des relations de contigülé, el sont indéprudauts sous tous les autres rapports. Elle n'a, 'n réalite, rien yur the normal, comme le fait olserver

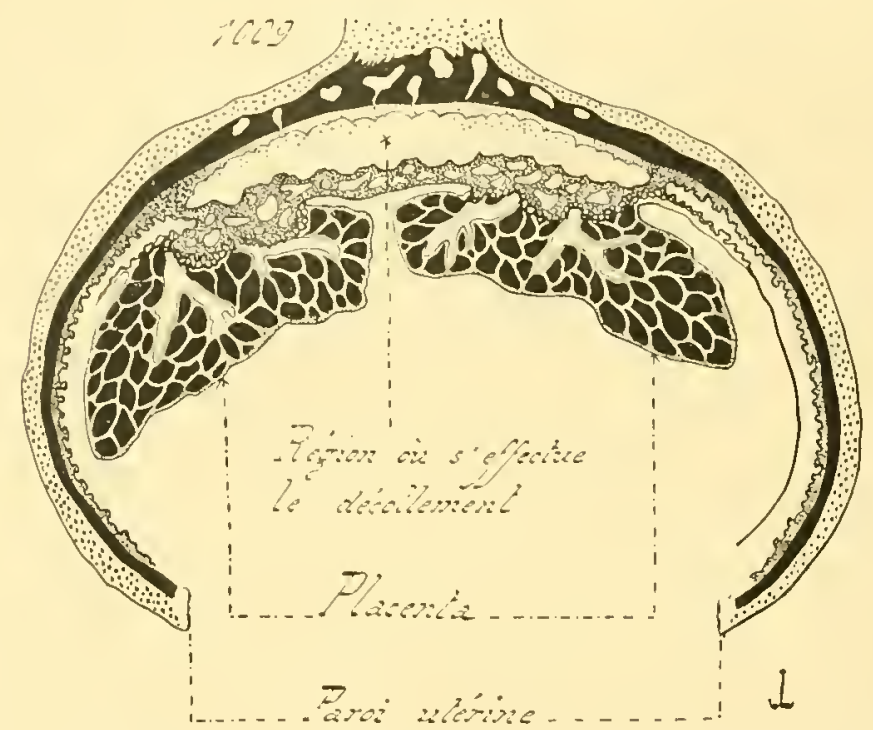

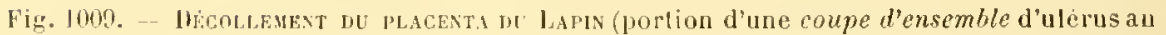
moment de la parturition, d'apres les recherches faites na . Jathias lluval). - Cetle figure termine le tableau d'ensemble, qui commence a la fig. 998. La comparaison avec la lig. 1007 permet de roncevoir le mècanisme de ce décollement.

11. luval; puisque l'épilhólium ulérin est de provenance mésodemique, comme lo lissu ronjonrlif sur lirjuel il repose. Ce plémomìne est idenlique à celui lonné par les apparcils irrigateurs, dont les endothidiums sont fournis, on réparés, par les tissus conjonctifs environnants, car tous out uème origime esscntielle, et appartiennent également au feuillet moyell.

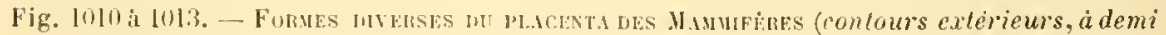
dinyrammaliques, en ce suns yur les dessins representent la surface du chorion, munie du placenta, et que cette surfare est uniformèment ramenéu à relle de la spluére). - En 1010, placenta dilfus. - En 1011, placenta colylèdonaide. - En 1012, placenta zonaire. En 1013, placenta diseoida!. 

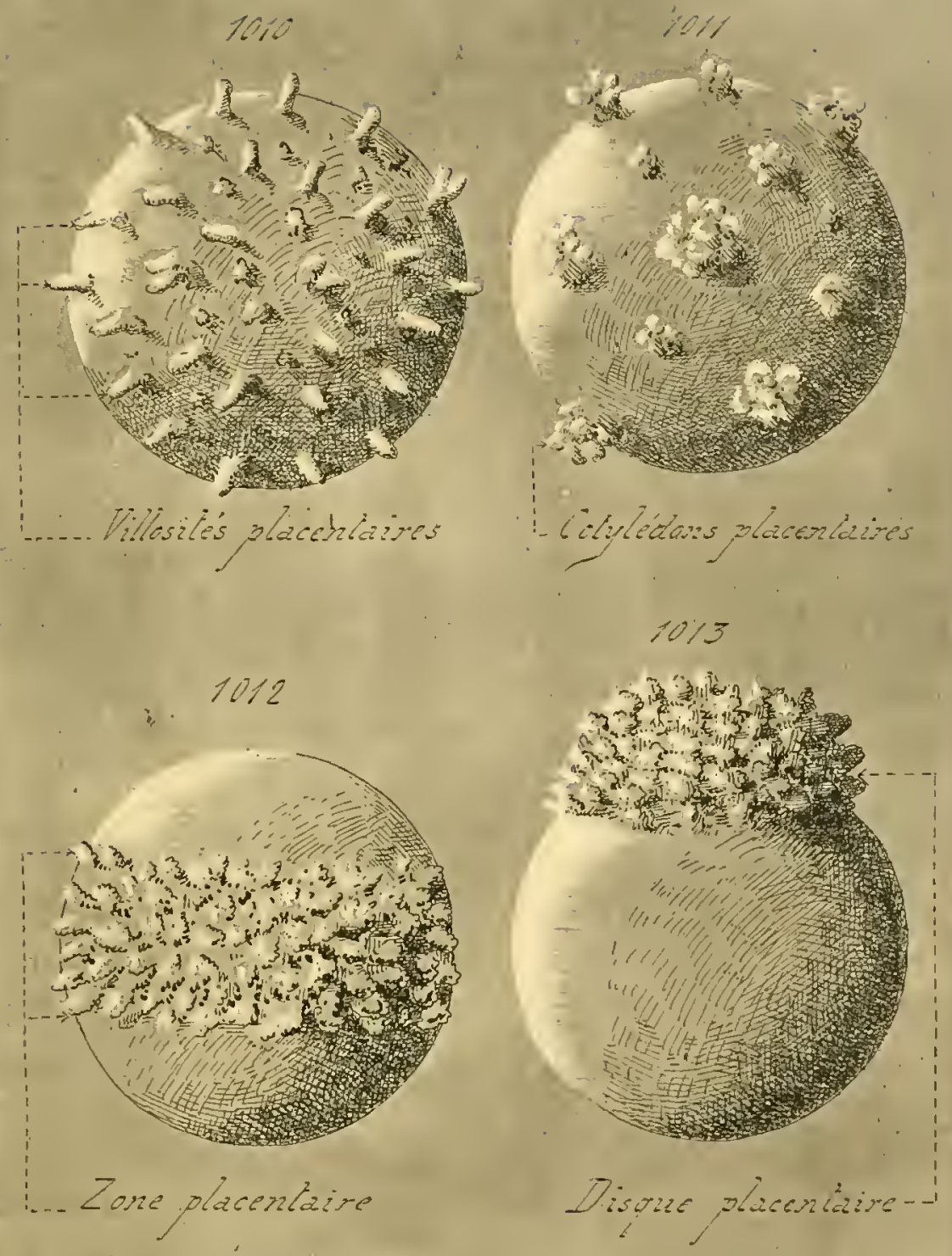
Fonues mucextures. - Les diverses formes do plapoutas, ollertes par los Mammifères, sont bien ronnurs, grice aux recherohes de nombreux

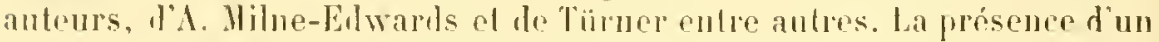
type délerminé de cel appareil est parfois caractólistique l"un ordre; mais le fait n'est pastonjours rai. linsi, les lidenlés présentent. on peu s"en faut, ì cel cogarl, tous les aspects principaux. En ontre, la ressemhance, sous re rapport, nest pas unr raison pour admettre un rapplochement entre les ordres. Les Proboscidiens el les Camivores possèdent les placentas à peu près semblables; de mème les Rongenrs el les lrinates, bien que les allures ginrirales el les commexions de rel appenlice suient fort différumtes.

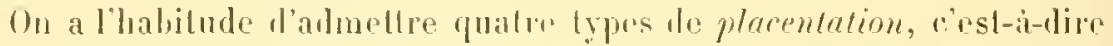
yuatre dispositions distinctes dans la manire d'atre du placenta: la plarentation diffuse, la placentation cotylédonaire. la placentation zonaire, et la placentation discoïlale. En réalité, il en existr ciny. car la dernière se présente suivant deux moles, selon qur l'allantoide entire est emploýn à domer le placenta, ou selon quiune partie seulement de sa surface sert ì cet effet.

La placentation difluse est celle dans laguelle l'allanto-horion porte, sur tonte son étendue, des villosités simples, courtes, pénétrant lans des cavités correspontantes de la fraroi uterine, et sen détachant aisément lors de la parturition. Il sétablit semlemunt des rulabons de contact entre les villosilés vaseulaires du rhorion ol les cavités de la paroi utérine; les rapillaires de cette dernière conservent leurs dimensions normales, el demeurent plongés lans le lerme de la muqueuse, qui n’est pras détruit. Ce type est le plus simple d. lous: il existe chez quelques Edentés (les Pangolius, par cremple), les Cótacés, les Sirénides, les Ongulés impariligités, les l'arilierilés bunorlontes, les Pariligités sćlénodontes appartenant aux familles des Tragnlidés et des Camélidés, et les Lémurions.

La placentation cotyliblomire est un progrès sur la précélente. Les villosilés vasculaires sont plus grandes, et ramenses; elles se grompent en anas volmumeux, nommés les cotylédons. Ces lerniers pénètrent dans les ravités correspondantes de la paroi utérine; celle-ri s'hypertrophic antonr d'enx, pour rembe l'union plus intime, mais elle demeur entière cepremdint, ne subil qu'une desquamation de som épithélium, et conserve presque ả ses vaisseaux leur taille babituelle. La flupart les Pardigités sćlinoduntes appartiemurnt à ce lype. D’après Tïrner, les cilufes et le Cerus mexicums offutuent un passage de la placentation dilluse à la plaerntation cotylédonaire, car ils possedent, ¿ la fois, des courles villosités et des cotylédons.

La plarentation zonaire rappelle la précélente, avee cette différence que les cotylélons, plus nombreux el plus petits, sont répartis sur une lande óquatoriale, et dessiuent une zone aulour du chorion, laissant les denx poiles entierrment lisses. Les rapports aree la mupnense utérine 
sont, à leur tour, plus étroils; les villosilés plarnutaiues pénèlrent lans l'épaisseur du derme superficiel de cetle lernière, el y untoment des capillaires élargis, convertis en sinus. Les Carnirores, les l'inmipèles, les Proloscidiens, les Iyraciens, el quelques kdentés (l'Oryctŕpope, par exemple), sont pourvis de relte sorle de placenta.

La placentation liscoïlale rst l'expression la plus parfaitr. el la plus complexe, deres dispositions nutritives. Le placenta est un corps rpais, arronuli comme un disque, volumineux, el composé par l'assemblage de toutes les villosités vasculaires. Il commence par saccoler a la paroi ulérine; juis, a mesure quil grandil, il pénelre dans la muquense do relte dernière, se suhstitue à ses tissus soliles, el endigue ses vaisseanx sanguins, alors fort élargis: ses villosités deriennent ì lem tour très ramenses. La couche envahissante, qui précede les ćlificalions fonetionnelles du plarenta, el délruit la muquense à mesurr quelle jénidre, est une lame plasmorliale. - Ce ty ye compreml deux formes, qui nont eutre elles aucun rapłrorl, si ce nest par la ressemblance générale les organes achevés : la placentation pan-discoüdale, et la placentation mérodiscoüdale. La premicre est aulonome; l'allanto-chorion, peu élendu, se convertit toul entier en placenta: elle existe chez les Rongeurs, les Chéiroplères, el les lnsectivores. La seconde se rallarhe a la plarenLation diffuse des Lémurieus, par le rassemblement de lontes les villosités lans un espace restreint the l'allanto-chorion; celui-ci esl fort ample, mais il ne porte le placenta que sur une ralotte le sa surface, le resle demeurant lisse, el privé le toule fonction. En outre, les rillosités sont lrès rameuses, el, à rn juger d'ajuè l'aspect final, se comportent avec la muqueuse utériue comme leurs similaires des Rongenrs. Les l'rimates sont les seuls à olfrir ce mode le placentatiou.

\section{Répartition des annexes dans la série des Mammifères.} A. - La disposilion des annries embryonnaires les Ionotremes n'est

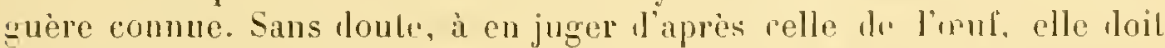
rappeler sa correspondanle des Sanropsidés: la résicule vitelline est gramle, remplie d’un deulolicilhe yui serta la mutrilion llu pelit idre, et yui se résorbe au fur et à mesure du déveloplement de ce dernior. l'arlout ailleurs, éest-à-dire rhez lous les llammifieros vivipares, la résicule ritelline, plus petite relativement, ne contient aucun deutolécillie.

Les Marsupianx ellecluent un passage les Monotrimos anx Mammifỉres placentiors. In mêm que ces derniers, ils sont vivipares, al privés de dentolécithe dans lemrs aul's; mais, comme les premiers, ils ne produisent point de placenta aux dépens le l'allantoüle. Colle vósicule s'arance lans fre corlome externe, oi elle demoure suspendue, se vaseularise vers la fin de la première gostalion, mais ne satlachr poinl

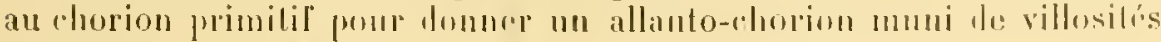

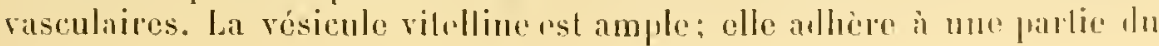


phorion primilit, sims paraila s'y somler inlimemont. el envois des expansions lims quelpurs courtes vilusités qui prement maissance sur

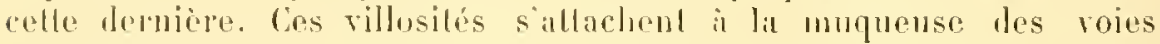
sexuelles de la fomollo: les expansions de provenance vitelline, contenurs dans lour intélicur, sont vascularisćes frar les vaisseaux vilollins (ou omphalo-mésentóriques), el dos ćchanges mulrilifs s'étahlissent à lem niveau. Senlenment, ces commexions sont dr faille durée; l'embryon est prérocement expulsé pour subir sa seconde gostation dans la poche matrmpiale te sa mire, on il se nourit du lail yur lui procurent les lélines.

Les Jonolelphes se délachrnt des liasupiamx jar la persistance de la premicre gestation, pui existe juspu au moment où l'organisme fotal sacheve, et lemmure senle de ce fait. Les relations mulritives effectures dans lutérus sont plus inlenses, jar suile; la résicule vitolline, insulfisante jour les donner, ì cause de sa faihle rascularisation, est supplée far la résinule allanloüle. Colle-ci sacole i me partic du chorion primitil, le comerlil en allanto-rhorion: et celui-ci produil des villosilés placentaires, qui s'altarhent à la paroi utrine. - Des Marsupiaux par-

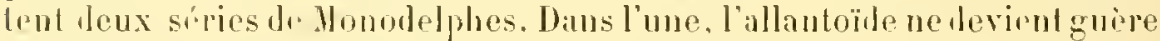

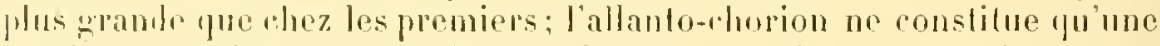
porlion restreinte lu rhorion lotal, rt se moditir lout entier en un

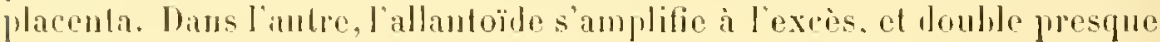
lout le chorion printif, simon en entier; l'allanto-chorion est, en conséquenre, fort éleudu, el plusieurs zones do sa surface, réprarties de manieres divorses, romposunt soules lapprareil parentaire. Ces lewx

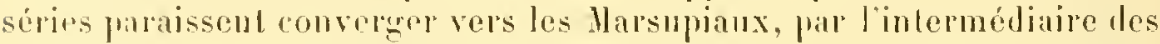
Edentés el les Cótacés, hien que ceux-ci inclinent julutôl vers la seconde. la premiire renfermo las Rongrurs. les Inseclivores, el les Chéiropteres: la sroconde comprend les aulres llammifères placentaires.

IP. - Chez les représentants de la premire série, el sauf le cas phalif a l'inversion des fenillets, la résiculr vilelline est, au débul do la gestalion, grande el ample: elle consorve des dimensions assez forles,

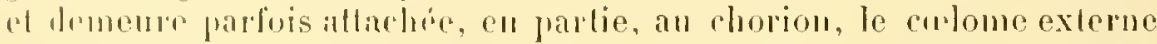

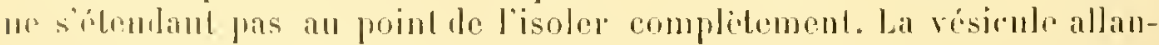
loide va s'atheher is la calolle, du chorion printif, opposio is l'appendice

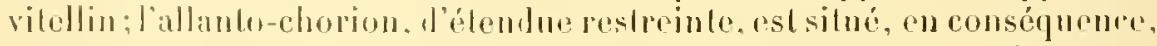

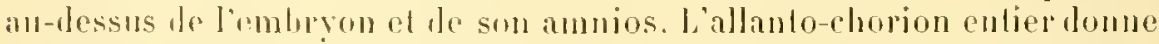

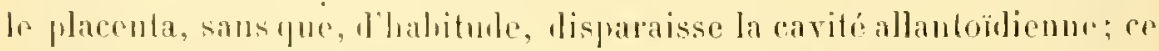

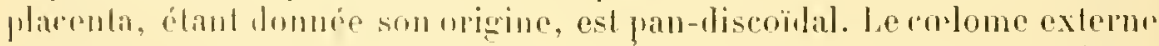

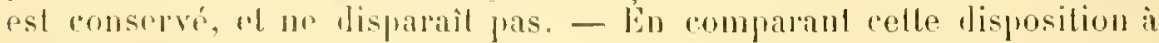

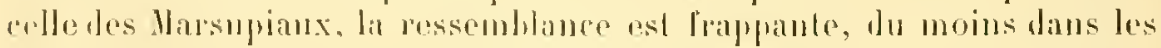

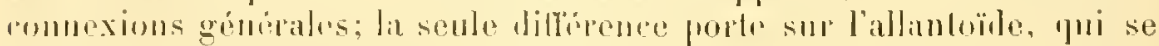

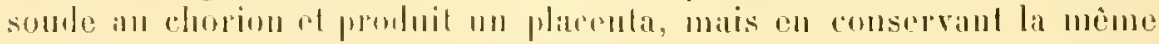

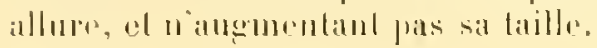




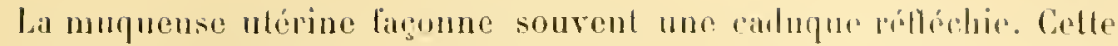
enveloppe s'étemd assez, domdinaire, jour entomer la moilio ou les trois puarts du chopion.

Dans la eas de l’inversion des fenillets, la majeure part du rlurion

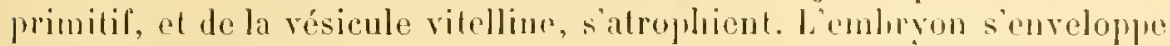
de ce qui hui reste de la paroi de cetle derniere, en relommant fos lenillets sur enx-mèmes, cl les disposant dans m ordre inverse (page 9!)1).

C. - Tous les autres Monodelphes sont remarpuahles par la grande extension que prend leur vésienle allantö̈le. Col appendiec progresse daus le culome, et s'atlache it la majenre partie du chorion promitil, on à ce chorion enticr, pour le convertir en allanto-chorion. Arant que lallantoüle nagisse ainsi. le phorinn primitif porte des villosités non vasculaires, dn moins dans li majorité des cas; l’anure allantoülien, en s’ajoulant ì lui, fouruit des vaisseaux à ces expansions, el les comvertil en villosités vasulaires. Celles-ci se disposent alors de manières diverses, suivant les trpes de placentation. La caviti allantoödienur su rétrécit durant ces phénomenes, et, parfois, lisparail complètement. La vésicule vitelline esl de pelite laille. A cause de l'extrême amplitication acquise par l'allantoüde, le colome externe est dimimó; il s'olume mème en enlier lans le cas oì, comme clıez les Primales, el surtont chez l'llomme, la cavité amniolique prend nu graml accroissement.

Les Edentés sont remarpuables on ce pu'ils possedent la plupart des types de placentations. Ils ollient, i cet égard, les indications des divers états, qui se troment fixés, of comstants, rhez les aulres Placentaires; ce fait est en rapport avec lrurs affinilés naturelles, qui les placent à la base des Inmmifères monodrlphes. - La platentalion des Pangolius est diffuse. Par une diminution de la région fonctionnelle, le placenla des Tamanoirs ollie l'aspect d'mne vastr calolle, ou d'un dome. Par mue diminution semblable, mais "xercée dans un antre sens, relui des Oryctéropes, el celui du Bradypus novem-cinctus, sont zonaires. Enlin, par la restriclion, plus gramlr encore, du placenta en dome, on arrive à la placentation discoïdale des Paressenx el de la plupart des Tatous; celle derniòn concorte avec la presonce l'nne caluque réfléchie.

la plupart des Mammiferes dout la placentation est diffuse, ou colylédonaire, ol motamment les Célacés, les Sirénides, el los (Mngulés, ollipont presque une disposition identique, saul les diversitós introduites par les dillérences de la forme placentairo. Lemrutrus est bicorno, on hipartile; les anmexes embryomaires s'établissent suivant ret aspert, et s'allongent dans les denx parties, l'embryon, entouré de son amnios, demenrant cenlal. Dans le cas, fréquenl, ou la portée se comprose dr plusieurs foelus, les phorions, mis an contarl, se somdent sonvent les mus anx autres. Parfois, les lonx cornes allantö̈liennes, jus longurs que celles da rlorion primitif, loment ces drenières, las lraversent, et font sabllic dans la cavilé nterine; on les nomme les dierdicules de lal- 


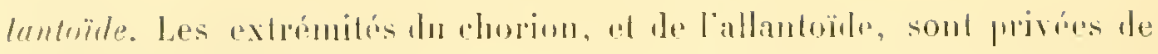
villasilis plarentaires.

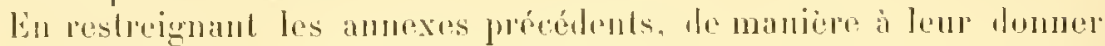

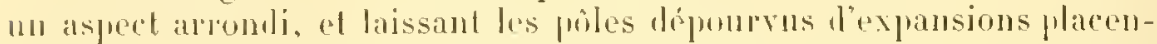
taines, on obtiont la disposition offerte par los Carnivores el les l’inniprifes, dont le placenta est zonairr. Les premières villosités vasculaires se developpent sur un espare lestreind, demaniere a simuler un placenta discoïlal; puis clles augmentent en nomlire, ef occupent nne plus enrande blendue. I son délnut, la zone plarentaire lient la moitié, on

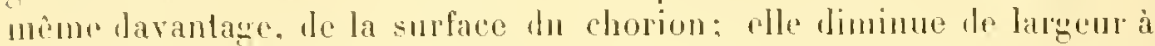
mesme qua la gestation avance, et ne mesure plus, vers le moment de la farturition, yne le liers, on la moitié, de ses limensions premières. Ine eaduque réllichie, lont la présence est connexe a cefle diminution de la région placentaire comme dendue, se dévoloppe aux dípens de la muquense uterine, el enchasso le churiun. Cetle membrane, asser petite dez lo Chien, est plus arande chez le Chat, et plus ample encore, l'apres

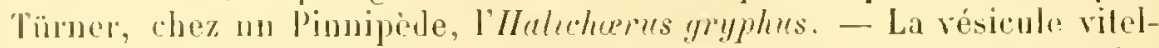
line des Carnivores, hien que séprare du chorion, demenre assez volumineuse pendant lonte la duréc de la gestation.

Les P'rohoscidiens prossident un placenlazonaire: seulemenl. les deux pôles de leur chorion, lisses chez les Canjores, portent une fouffe de villosités. - Les Ilylaciens sont égalument pourvis l'une placentation zonaire, semblable ì celle du Chat; avec celte dillérence que leur visirule vitelline diminne de taille rapidement, et satrophie, d'a prós 'Timmer, d'une manière jrécoce.

l.es Lemuriens sont remarquables en ce yuils othrent, d'une façon fermanente, des dispositions temporaires chez les l'rimates. Leur vésiculo vitellime se pestreint rapidrment et sallophie, pembant que leur chorion primilil émel les villosilés non vasculaires. l'uis la vésieule allantö̈le grandit, el s'éteml an-rlessous de ce chorion entier. pour le convertir en allantu-rhurion; elle envoie des vaisscam daus les villosités précédentes, qui demenrent en leur place, et romposent ainsi un placenla dilfus. Les hosers en restent la; la cavité allantö̈dienne persiste et il un se probut ancume cadurue.

Les l'rimates, et l'llommo, passent par un premier élal, illentiune it colui des Lémuriens, el Jonnent ensuile leur placenta méro-discoüdal. La

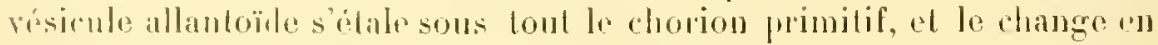
111 alliutu-chorion, muni de villosites rasculairs. Puis, quelpues-mos

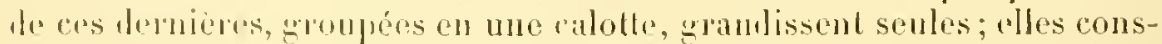
libent le ehorion fontlin (chorion frondosum) des auteurs, et faconnent un placenla massif, el comprat. Les autres villosités s’atlénuent; lespace ocenpe par elles est le chorion lisse (chorion lave), qui est bien nue

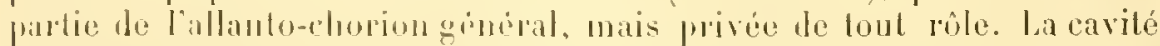
allantoülienne disparail d'une manjèe compliele. En relation avec l'al-

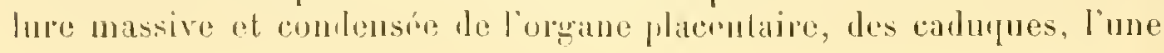




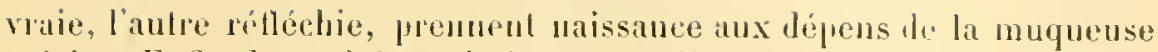
ulérine. Eufiu, la cavilé annioligur s̀umplifie à l'exces, en restreignant

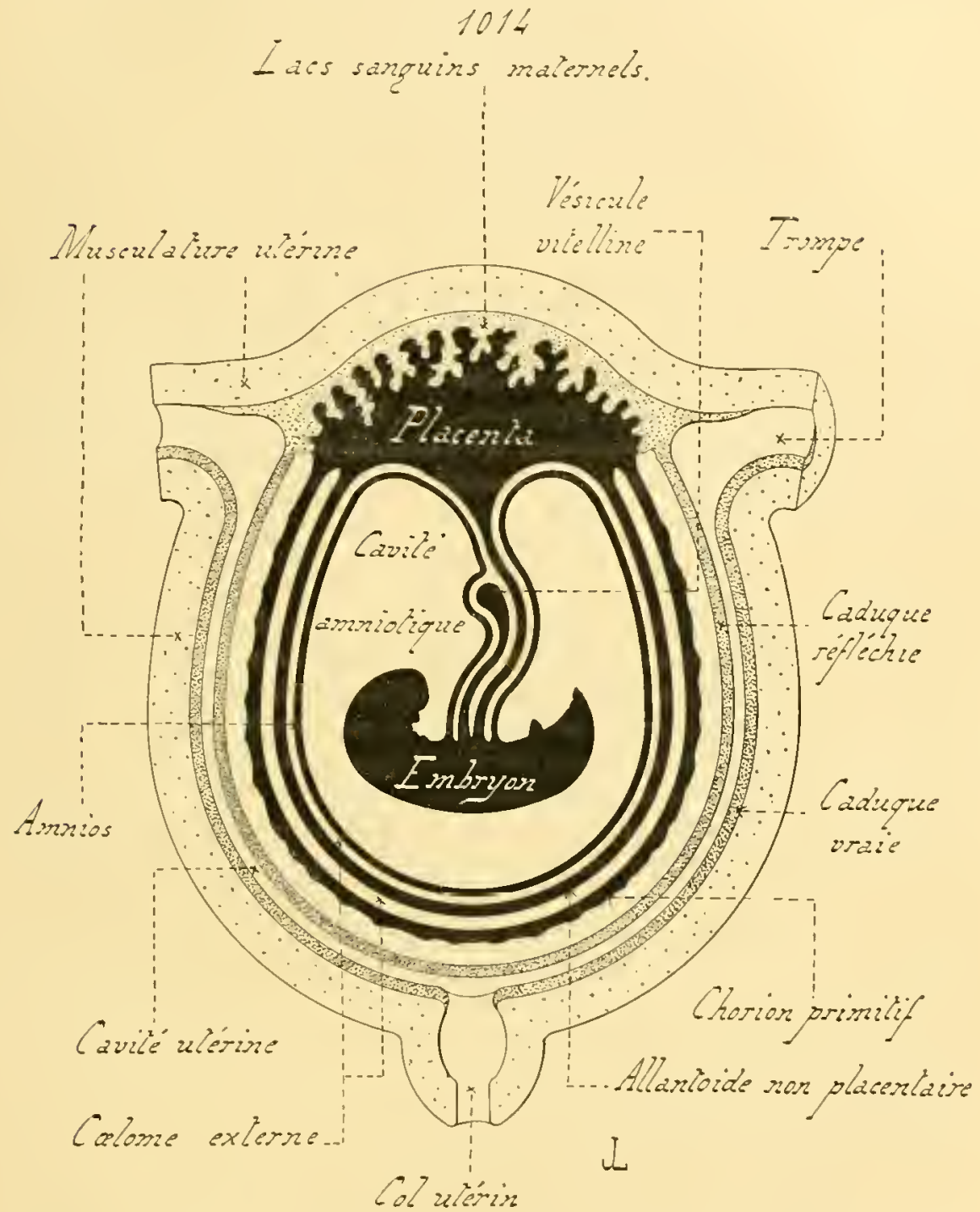

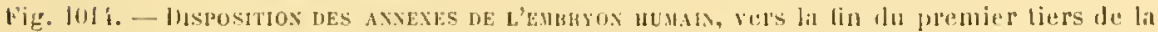
festation, au moment ois tous tes anneses sont emerre presents et distincts (conye l'ensemble de l'ulerus gravide. mediane th longiturlinale, passant par les trompes et par le col). l'embryon, el les appendices jui proviennent de lui, sunt en noir; les licsus maternels en puintille, plus clair puur la faroi uterine, phis sombre funt les annexes

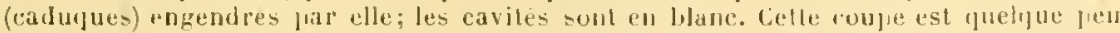
diagramnatique, to ee sens que lis envelojpes embryonnaires sont, dans lia realite, plus mones et plus proches les unes fles autres. 


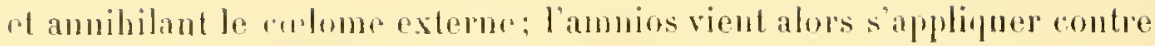
la face interne do lallanto-chorion, el leconvertit en un amnio-elonion. - Les enveloppes embryomnaires, lout en blant plus nombreusesquailleurs, paraissunt avoir uirr strurture plus simple, car elles sont soudées les unes anx antres. Linsi, chez l'llomme, l'embrun, dans la seconde

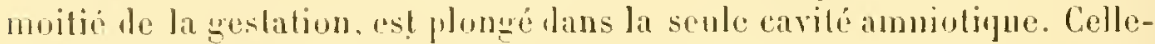
ci est limité par une envoloppe, quj se compose de cing lames, autrelois distinctes. al désormais mues: la calurue vraje, la caduque rélléchie, lechorion primitif, la paroi allantoulienne, el la paroi ammiotique.

En sommr, sous le rapprort de la disposition de lrurs amnexes amlivonnaires, les Jammiferes monodelphes se répartisisent en trois sépies, qui converout rualement vers les lidentés al vers les ldidelphes. La premiorr contient les liongenrs, Jes lnsuctivores, et les Chéirojtẻres; la seconde renferme lous les groupes, sanf les Lémurjens, lont la placentation est dillnse, cotylidonaire, ou zonaire; la troisiome commence anx Limmiens, ot funt anx l'rimates. Ces lrois séries parassent concorder avec colles que fommissent los aflinités naturelles, lécelies jar les jugries récents de l'anatomie compráe el te la paléontologie.

\section{RÉSUME}

S 1. Coxsmenatmoxs gexinalis. - Les embryons des Vertébrés sont plus semblables entre eux que cenx des antres animanx. Leur alluro commune est domnéc par la présence constante d'une notocorde el d'un neuraxe. Lenrs dillérences lienuent, soil a la complexité variable de l'organisme adulte, soit ì la nature du développement, soit à la présence, ou ì l'absence, d'annexes embryonnaires.

I.s développements larvaires appartiennent en propre aux Vertébrés inférienrs, nais n'existent pas chez tous; ils manquent anx Immiotes. Les hares des Vertélurés sont recomaissables a leur structure complexe, et au plan de leur économie; elles portent souvont une pelite vésicule vilelline, qui se résorbe d'une manière précoce. - Jes développements fótanx sont spériaux aux Amniotes, et alusjeurs lertébrés inlérieurs, tels qur les Sélarieus al divers Muphibiens; tantôt ils concordent avec me orifrarité du générateur, tantôl avec une viviparité. Les embryons, soumis il mue telle évolution, possèdent presque toujours une volumineuse vésicule vitelline, constiture par nu amas consilérable de vilellus mutritil: eeuxdes Amniotes portent, en sulplus, une enveloppe protertrice dile l'amnios, el un appendice, la résicule allantö̈le, émané de la région postérirnre de l’intestin. Ces embryous, isolés des milieux extérieurs, se rerourlent plus on moins sur enx-mèmes, dans les cavilés qui Jes abritent; une des formes de celle eourhure est la tlexion cranjenne, par laquello l'extrénité antríneure de la tè se replie vers la line ventrale du r.olpes.

los annexes embryonnaires les Vurébrés ne se bornent pas à la 
vésicule vilelline, la vésicule allautoülle, pt l'aunios; iłs sont en róalité phus nombreux et plus rariés. Ils consistent : soit an anmexes llorigino extra-orulaire, les coques ot l'allumine des oripares, les calupues do rertains Jammiferes vivipares; soil en annexes lorigine ovulaire, la vesicule vilelline; soit en ammexes d'origine embryomnaire, dont les uns, fort divers, servent à la nutrition générale, comme la vésicule allantoïde, et dont les autres, rgalemrnt variós, sont plutòt des appendiers de relation, comme l'ammios. Une des particularités caractíristipues du développement les Vertébris est la production lrópnente diun placenta, aux dépens de quelques-mus de ces anmexes.

S 2. Fonnes enbrovxunes des Achanexs ret des Crolostones. - Les Acranieus subissent un développement larvaje des plus francs. L'emlrron est mis en liherté des le début de la phase gastrulaire, el ne resse de mener une vie libre. - Les Cyclostomes possedent aussi une évolution larvaire, moins complete cependant; l'ovule rontient une certaine quanlilé de deutolécithe, qui retarde liustant de l'éclosion. La duríe de la vie larvaire est fort longue, car l'individu accomplit, sous celte forme, tout son développement nutritif. Puis l'animal passe à l'état adulte, sans amplifier sa taille, mirit rapidement ses éléments sexuels, et menrt peu après la fécondation opércée.

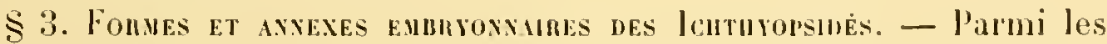
Amphibiens, les uns, plus nombreux, sulissent une évolution larvaire, el les autres un développement fatal. Les larves des premiers sont dites souvent des tètards; les ovules, dont elles proviennent, contiennent peu de lentolécithe. Les tètards, au moment de leur éclosion, sont inunis de branchies extérienres, qui leur servent dappareils respiratoires, el qui se difruisent par la suite, d'une quantité variable selon la structuro de l'organisme adulte; les membres font leur apparition dans le cours de la vie larvaje. - Les Gymmophiones possèdent un léveloppement fortal. Tous les Urodèles, sauf deux espèces de Salamandres, othent, par contre, une évolution larvaire. Il en est de mème pour la majorité des Anoures; les tètards de ces derniers subissent des métamorphoses assez complexes, dout les principales phases porlent sur les luanchies el sur la louche. Dans le cas des développements futanx. le leutolécithe, amassé en yuanlité considérable, constitue une vésicule vitelline; el, de plus, cerlaines des régions dı corps, variables suivant les types, se modifient en vor d'effectuer des échanges nutritifs.

Les fianoïdes présentent une évolution larvaire; seulement l’óclosion est tarlive, car liunt contient une asse\% crande masse de vitellus mutritif, qui alimente l'embryon durant les premières phases de sou évolution. l'embryon libre parvient à l'itat adulte, sans subir de trop grands rlangements; les principales modilications portent sur la risicule vitelline, qui se résorbe, sur la disposition des nageoires, ot sur l'aspeet d'un diśpur alhésif, placé en avaut de la lonche. 
Les unuls des Téliostáms, hien que pelils, contiennent assoz de vitellus mutritif pour que l'emhryon élauche ses principanx appareils aranl foute éclosion; lorsque a phénomene intervient, l'excélent du vilellus rompose une résicule vilulline, altachée, par une large hase, it la fare ventrale du corps. Les mélamorphoses, subies ensule par l'individu, portent sur la résorplion de cette vésicule, sur l'accroissenent du corps, sur le perfectionmement des systemes organiques, et sur la disposilion les nageones. Ces changements sont rendus phis complexes dans le ras de possession, par l'embryou, d'appendicrs supplémentaires, tels que nageoires ou aiguillous, qui salrophient an moment du passage ¿ liblat ahulte; ils sont surlout considérables chez les Pleuronecles, dont les deux venx se placent sur le mème coté de la tèle. Quelques Tríosléens sont viripares; les phases de leur développenent sont encore pu connues.

Tons les Sélaciens prósentent un developlenent lictal. Leurs aufs, volumbueux, contiement une grande ynantite de deutolécithe; relui-ci conslitue un vésicule vitelline, atlachée au corps de l'emhryon par nu longr corlon vitellin, el destince à alimenter l'individu pendant toule son crolution. Lembryon s'chauche au-dessus de sa vésiule vilelline, el ferfectionne son organisme d'une maniere progressive, sans sulir detrop gramls changements; les principanx de ces demicrs portent sur la disposition des nageoires, el sur la genese, surie dr l'atrophie, de longues loumbies exterues. Cortains Sélaciens sont ovipares; la plupart sonl vivipares, l’incuhation ayanl liru dans les voies sexuelles de la nore. Parlois, en ce dernier cas, la vísicule vitelline produit un placenta.

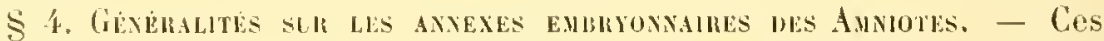
annexes, pni ne manquent jamais, consistent en une résicule vitelline. une vésicule allantö̈le, el un amnios. L’unf les Amnioles est divisé en leux parties: une zone cmbryonare, ef me zone parambiyonnare. La première, a elle seule, donne l'emhron mblier: celui-ci produit, à son tour, el a ses dépens, la vésicule allantölde. La région proximale de la seconde foumit l'amnios, la région distale composanl la vésicule vitelline arec sa paroi.

La zone embryonnaire se délimile de la zone para-embryonnaire au moyen l'un itranglement, qui ra en s'appofondissant: les ébauchos le cette constriction sont les sillons marginanx, La région étranglée devent, en sallongeant, le cordon vitellin. qui unit la vésicule vilelline an corps de lembryon. - Cette eomstrichon se mandeste aux dépens de la binde proximale de la zone para-embryonaire. Ia substance de celle hande se divise en lenx lames, par le cleuscmenl d’une ravilé, dite le carlome "xlerne, an sein de son mésoderme. Celle cavilé setrul dans tonte la bamle proxinale, parvent en sus dans la bande distale, et clive te blastorlemes de la zone para-embryomaire en deux couches distinctes, la lano riterne et la lane interne. La premiere 
limitr, vers le dehors, lensemble de lembryon ot de ses appendies; lit

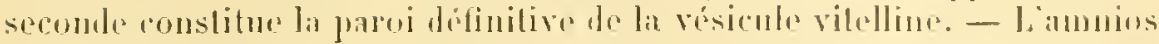
est produit par la portion do lane externe intéressée dans la gentios des sillons marginaux. Celle régrion se soulève en ipatre replis crenx, dont lis cavile communique avec le colome exterme; res replis grandissont, el s'unissent en une collerelle placée anlonr de l'embrym. Cetle dernirre s'amplifie, restreint son orifire, le ferme, el se convertit an une double membrane qui enveloppe l'embryon. La membrane externe est l'examnios, continn avec la lame externe lent elle provient; la membrane interne est l'endamuios, on l'amnios réel, yui circonserit la cavité amniolique, dans layuelle se trouve plongé l'embryon.

Lallantoüde est un diverticule émis par l’intestin postérieur; sa cavité communique aver les nreteres. Ce divertiruld parvient dans le culome exterse, el s'y amplifie, enveloppant, dune part, he corps de l'enbryon avec son amnios el sa résicule vitelline, lapissant, d'autre part, lit lane externe. Cel alpendice fonctionne comme vessie mrinaire, el jone, en outre, un róle important dans la nutrition et la respiration du pretil ètre; á cet effel, sa paroi est richement vascularisée. Iu moment de la parturition, une partie, au moins, de la vésicule allantö̈de esl conservée dans le but de comproser la vessie nrinaire de l'adulte, lorspu'il en existe une.

La présence d'un ammios paraît liée it la nécessité de maintenir l'emluyon plongé dans un milieu liquide. Celle de l'allantorde se raccorde an lesoin d'assures lia nulrition de l'embryon, immoliliss' dans ses envelopres, el incapalule de se déplacrr.

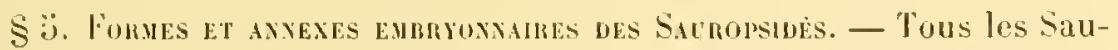
ropsidés sont ovipares; la viviparité de certains l'entre eux se lome it la couservalion des dufs dans les voies sexuelles de la femelle. La constance de structure des ovnles autorise i jenser que les changements, subis par l'imbryon dans ses coques, sont à peu près les mèmes pour tons ces aninans.

A cause de labondance du deutolícillse, la vésicule vitelline est volumineuse: elle perd de sa taille dans le conrs du développensent, i mesure yue grossil l'embryon, alinenté par le vitellus qu'elle contient. La résicule allantuide s'étend dans le colome externe, el l'envalit en entier; sa riche vasenlarisation lui prernel de fonctionner romme appareil respiratoire, el d'alsorber l'air qui pénetre au travers das cófues wrulaires. De filus, elle joue un rôle considérable dans la nutrition de l'embryon; une partie de sil substance se convertil en mu orgiane, le sac placentoüle, destiné à résurber l'alliumine.

Un peu avant l'érlosion, tous les annexes, annios, vésicules vileflim

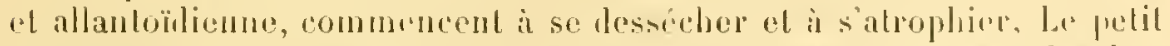
itre brise alors les conges qui l'enveloppent, et a débarrasse des derniers vestiges dre ses apjermlicess 


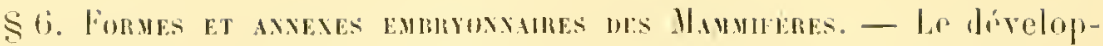

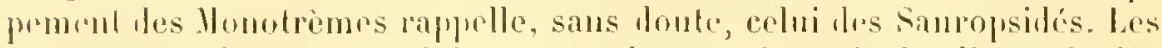

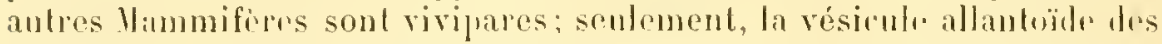
bidelphes lemenre simple, romme son homologue des lieptiles et dres (liseaux, alors que celle des Momodolphes prodnit un placenta, organe le provenance embryomahe, destiná à sumir a la paroi utione de la mèe pour puiser dans ses vaisseaux sanguins les malériaux nutritifs nécessaires a l'alimentation.

larfois, clez cortains Monodelphes, la paroi uterine s'bypophophie dans le cours de la gestation. Ces régions livpertrophicies somb dites les raluques; ellescommement par s'épaissir, four' s'amincir ensuile, s’atrophier en partie, at se trowver rejeties an moment de la parturition. Ces membranes sont an nombre de denx; la calnque vraie, el la caduque rélléchie. La première répond à nur hyjertrophie sur place le touto la muyneuse utérine; la secomle à une hoursoutlure locale, développée au confact de l'emliron, et acerue de maniere a entourer ce dermier, soit en tolalite, soit en partie. La calupue vaic nexiste guire que rlsez les Primatrs supérieurs. La caluque réllóchie rst plus liéquente; les l'rimates la possident, pt mème phusiemrs autres ordres de llammiferes.

Lorsque tous les annexes de l'embryon sont constitués, leur partie extériemre constitue une membrane superficielle, dite le clorion, qui entoure lous lis aubes éléments cmbryomnaires. Le chorion varie de nature suivant hrs ordres ha Mammifies, ot suivant l'ige du foklus. Conslitué, a son déhnt, par la senle lame externe unie i l’examnios, il saugrmente plus tard, au moins sur me zone dr son étendue, de l"allantoïle, yni s’atlache a sa face interne: il so convertit ainsi en un allantochorion. l'artois, chez les l'rimates sujérieurs notamment, l'amnios va se soutler i lui, ef le laansformer en un amnio-chorion. Dans lr vas des Rongenrs aux louillets invertis, le rhorion est lomé par une portion de la zone para-cmbryonmaire primilive, qui samplitic en se retoumant sur elte-mème.

Contrairement à celle des Sauropsidés, la vésirule vitelline les llammilires autres que les Honotromes ne conticut jamais de deutolécithe. Celle des l)idelphrs demeure assez ample, et lonctionne mème comme appareil de nutrition, en italilissant des échanges mutritifs entre sa paroi et cello le l'ovilucte maternel. La vésicule vitulline des Monolelphes no jone aucun rile, et diminue rapidement l'importance, alors que les autres annexes granlissent sans cesse.

le culome externe contiont la vésicule allantö̈le, et l'embryon entoure le son ammios. Il disparait lorsque ce lernice promd un aceroissement considérable. Il persistr dans lr cas contraire, et se remplit parfois l'un tissu conjonclif particulier, le lissu inter-annexiel.

Lamnios est, d'ordinaire, prouluil suivant les procédés habitnels: au

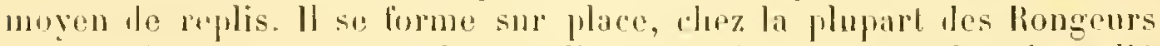
anx froillets invertis, anx dépens l’un épaississementectorlermique, li: 
il l'́bauche du placenta. Ce dernior mode génétipue existe pent-itre chez l'llomme, à en juger d'apris l'aulhérence précoce élablie ontre lamnios el la jeune résieule allantoüde. Lorspue l'amnios s'amplifie an point de faire disparaitre le calome externe, la ravilé anniotique est le senl espace, rempli de liquide, qui soil plarí autour de l'embryon.

Liallantoüde des Didelphes reste pelite. el simple: celle iles llonodelphes donne le placenta. La cavilé demenre dans le cas oì l'appendice placentaire est divisé en un cerlain nombre déléments distincts; elle disparail lorsque cel annexe est ranassé sur lui-mème : du moins dans lil règle.

Le cordon ombilical se compose des deux pódicules soudés de la vésicule vitelline of de la résicule allantö̈de; celui de celle dernière est de beaucoup le plus volumineux. Si l'amnios prend un grand aceroissement, il recouvre ce cordon entier, et l'enveloppe comme d'unc gaine.

Les Mammiferes monorlelphes sont les seuls à posséler un placenta; ce dernier provient de l'allantoüde. Le chorion primitif commence par émeltre des villosités. dont l'evtoderme s’épaissil, et pénètre dans la murueuse utérine: puis la vésicule allantoïle se soude à re chorion, le ronvertit en allanto-rhorion, el envoie des raisseanx sanguins dans les rillosités; des échanges nutritifs s'étahlissent alors. par diflusion. entre le sang entrronnaire tle res derniers et le sang maternel de la paroi ulérine. - La première éhauche de l'organe placentaire est f'ectoplacenta, saillie cetodermique produite par le chorion. L'eetoplacenta saltache ì la muqueuse de l'ulćrns, dont l’épilhélinm disparaît, el envoie des expansions plasmorliales lans le derme de cette muquense; le terme se détruit pendant que les expansions arancent. et ne laisse subsister que ses raisseaux. Ceux-ri samplitient, el sont endigués prar les éléments de l'eetoplacenta. Lallantö̈le s'unit alors an chorion, et remanic l'ectoplacenta en lui fournissant les vaisseaux sanguins; elle le ronvertit en placenta définitif. Les zones profondes de l'ectoplacenta demeurent à part de ce phénomène, et se bornent à circonscrire les raisseaux les plus proches de la musculature utérine; mais non les zones superlicjelles. Colles-ei, pénétrées par les vaisseaux allantoüliens, se résolvent en un lacis de canalirules rasculairrs, contemus dans les espaces sanguins de l'ulérus. Lorsine leplacenta s'achiove, celle division ranaliculitire est poussée à l'extrome, amplifiant de beauroup les surfares de contact; et, de plus, la substance des canalicules s'atroplice, laissant les capillaires allantoüliens suspendus it nu dans les ranaux sanguins de la paroi utérine. Le plarenta est alors arrivé à sa privode d'état. An moment te la parturition, il se décolle, uon loin de la musculalure de l'ntérus: la paroi de ce lernier organe su reconstitue alors,

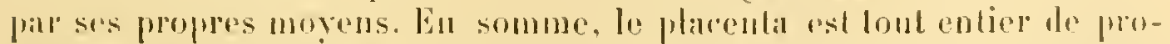

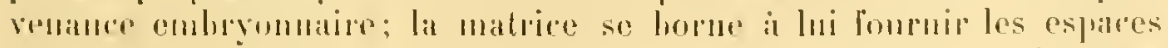

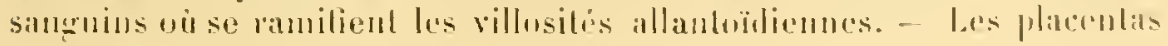


des Honoulelphes ne sont pas semblahles les uns aux autres: ils apparliennent a cinq lypes. Le placenta dillus est constilué par des vilositós courles el éparses : le placenta cotylédonaire, par des villosités ramifiées el réunies en plusieurs groupes, dits cotylídons; le placenta zonaire, par des villosités dispusées sur une hande équatoriale dn chorion: fro plarenta pan-discoïlal, par une masse compracte de villosités oecupant lout l'allanto-chorion: entin. le placenta méro-discoüdal, par un amas dense et serré de villosilés, placées sur une partie soulement de l’allanto-chorion.

Les annexes emlryonnaires des Honotremes sont arrangés, sans doute, romme lenrs similaires des Samropsidés. Cenx des Didelphes comprement un amnios, nne vésiculr vitelline assez volumineuse, et une petite vésicule allantö̈le non placentaire. Couxdes Monodelythes se répartissent, par leur disposition, en deux súvies, également rallachées aux Didelphes. - La première série renferme les Rongenrs, les Inseclivores, el les Chéiroptères; l'allure gínérale est celle des Didehphes, arec cetle diff́rence que l'allantö̈le, demeurant petite, se convertil toute entiere en un placenta pan-discoüdal. - Dans la seconde série, qui conlient tons les antres lloudelphes, la vésicule allantö̈de devient fort grande, et produit un allanto-ehorion très étendu, dont plusieurs régions, variables snivant les types de placentation, portent les villositis jlacentaires. 


\section{TABLES ALPHABETIQUES}

Ces tables sont an nomlire de denx : l'une d'elles contient les noms de genres, l'autre renferme les termes techuigues. Les principaux auteurs sont signalés à leur plice, soil dans le texte, soit dans lexplication les figures; il a été inutile de donner la liste de leur's mémoires, pullirín tout au long dans plusieurs liecueils périodiques et Revues bibliographiques : la Bibliotheca soologicn do Taschenherg. les Jahresherichte ïber die Fortschrille der Anatomie und Physiologie, le Zoologischer Anseiger, le Zoologischer Jahresbericht. etc. - Limpression de ce volume ayant commencé dans le cour's du premier semestre de l'aunée 1893 , les traraux d'embryologic, parus depuis ce moment, nont pu ètre inliqués. Les principaux d'entre eux se rapportent aux Vertébrẻs et anx Arthropodes; ils confirment, par leur ensemble, les notions exprimées dans cet ouvrage. Une exception doit ètre faite en faveur de limportant mémoire, écrit par Kaiser, inséré dans la Bibliotheca zoologica de Chun el Leckiart (1893), et relatif í la structure et au développement des Acanthocéphales. Ce naturaliste étudic ces ètres avec létail. et je regrette d'aroir connu trop tard son renvre, qui m'aurait permis de compléter les données exposées dans les pages 330-333.

L. H.

\section{TABLE ALPHABETTIQUE \\ IES TEIMES TECIINIOLIS}

Abachinale (face), 717.

Abdominal (pedicule), 1118.

Aboral (sac; Echinodermes), 736 .

A canthophore (Inrve), 316.

Aetinale (face), 718 .

setinopolype (ou inthopolype), 187, 2.8.
Actinotroque (larve), ill, i12, ils.

Actinula (larve), 142.

Idhesif (organe; Trochozoaires), 4 h.

. 1 lima (larve). 50).

Allanto-chorion, 1111 .

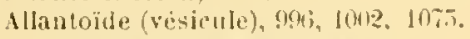

- (diverticule de l'), 11 il.

Allantoïlien (copdon), 107s. 
Mllantoirdiens (raisseanx), Ins?.

Imbulacraire (amean), 640 , bill, fis?.

- (cimal). lise.

- (roselle), (ín, ibl.

Imbulacraires (vaisseaux), lite.

Imetaholaire. 51.

Ammocule (larie), Jo3(1.

Imnio-choriale (1:avile), $111 \%$.

Imnio-chorion, !11 i.

Imnjo-placentaire (caviti). I0nl.

Imnios (. Irthropodes). 486.

- (Eehinodormes), 70.

- (liripates), lilz.

- (Plathelminthes), 298, 304, 30ki.

- (Tinebozoaires), 341.

- (leptebres), 912. $1960,1002,10132.111 \%$

imniotiques (eapuehons), $10 \%$.

imniotipuc (caroneule), 1120.

- (cavile), firl.

- (lipuisle). Jorit.

- (orifice), 1071.

Imnioligues (replis), forl.

Imnioli(jue (villosile), $\$ 118$.

Amoboille (phase), 33.

Ampliblaslula. si;.

Imphidisifue, 11:3.

Amphisrinique (biryeimides). 11.

- (Sporozoaires), $2 \pi$.

Inal (lobe; Euhinodermes), 704.

Anoure (1imbryon; Tuniciers), $81 \%$.

Inthopolype (ou Actinopolype), Is7, 22 .

Irénolokie, 67.

Iscidio a gregee, 830 .

- composée, $8: 30$.

$$
\text { simple, s30 }
$$

- sociale, 8:30.

Ascirlinzoide, wh, sil, sib.

Atrial (Tube, Tuniciers), 801.

Alrum ("Iuniciers), Bol.

Mroyule (larve), 421.

Aulilive (crele, T'unieiers), 7oR.

Iurioularia (larve), $8994,696$.

Ixial (organe), $73 i ;, 7 \% 0$.

Ixiale (cavite) 7it.

\section{B}

lialancier (Vertébrés), I03i.

diamleletles mesordermigues ('trochozisaires), 3i2.

liasale (playun), 731, 7332.

Ciasilaire (memluane), 25s.

- (plaque, lichiuodermes), 732.

- (jlaque, Seyphozoaires), ?(i1.

Bec corné (Virtiliris), 10 iz:

livider (organe 1le). 8 tiz.

Bipinnaria (larve), 71:3.

Blastoryte, !r!!.

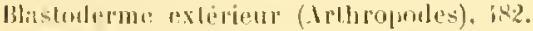
intrine (trtlonpoules), 182.

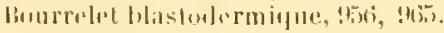

Blastoüdale (urigine), I23.
Blastolécilhinue (band(e), 97'.

Blastopore vilullin, I02?.

Blastostyle, 15!.

Bonche asophagienne (Tuniciers), 801.

Bourgeonnement basilaire ('Iniciers). 833. - iesophagien (Tuniciers). 833.

- pylorijue (l'uniciers), 833.

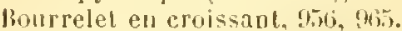

Brachiolaria (1arve), $7 \mathrm{t} 3$.

Branchiale (fente, Vertebres). 1034.

liranchie extroe (Vertilires), lo3i, 1049, 111.0 .0$.

Dranchie interno (Vertebros), 1042, l114?.

- Iracheonne, 520.

Rranchio-intestinale (vesiculo), 778.

liras brachiolaire, 710.

- de la Brachiolaire, 714.

- du Plutens, 702. 724.

Buccal (siphon), 813.

- (vestibule, Vertibris), 1043.

Caducues, $110 \%$.

Carlurue inter-utero-jucentaire, 1108.

- rifléchie, Illo.

- vaie, Ilon.

Calcosepte, $17 \%$.

Calotle (Echinodermes), 730.

- (Plathelminthes), 303.

- ('Trochozoaires), 414.

Calyce (Sesphozonires), $2(0)$.

Calycinale (plaque), 722.

lialycohlaste, 263.

Calyeonula (larve), lí.

Calyptopis (larve), 500.

Canal An sable, 682 .

- veineux d's ranzi. Jos3.

Callıamme, 216.

C:audal (bourgeon), 945.

Camblale (prolulierance), 94.

Cellulaire (couche; placenta), 11:7.

('ellule geante (Caduque), Iton.

Cimentaire (glinde), 49\%.

Cenlrale (ibaucle), 909, 915, 9.s0.

Centro-dorsale (plaque), 67.7, 721, 732, 763.

ciephalin, ?s.

Cepplalique (lole ; Jéripales), 617.

- (playue, Trochozoaires), 422.

Cereaire, $313,314$.

Celcaria setifera, 313.

Cerebral (cul-rle-sac: funiciers), sis.

Crebrale (vésicule; 'Tuniviers). 780, 7!5.

Chaine (Tunjeiers), 8.,0).

chalaze, $0 \% 3$.

Chambre a air, 63.

Chandelier (cellule en), sti9.

flunille, sao.

thitinogene (couche), 30\%.

- (épiltelium), 563. (matri(**3). 56?.

Clistion embryonnaire (Veltebres), 1111. 
Chorion frondosum, $111 \mathrm{f}$.

- lisve, 1114.

- lisse, $111 \mathrm{i}$.

- prinaire. 1111.

- primitif. 1111.

- toultu, 1114.

- vilellin, 11 l.

Chrysalide, ists.

- a cacon, 524.

- enroulie, 524.

- succinte, 524.

- suspendue, 524.

Cicatriculaire (zone), 94 i, 052.

Cicalricule (Arthropodes), 400 )

- (T'rochozoaires), 380.

— Vertélrès), 905, 91:2, 944, 952.

Cidaridienne (phase), 712.

Claviforme (glande), 923 .

Clitellum, 437,

Cloacal (siphon), \$13.

Cloacale (vésicule; 'Tuniciers), 801.

Cloison (Scyphozoaires), 171.

- ('Trochozoaires), 430.

- coronale, 251 .

- primaire. 240.

- secondarre, 246.

Cloisonnaire (canal), 214.

- (cavitè), 214.

Cocon (Arthropodes), $518,529$.

- (Plathelminthes), 302.

Coeliaque (cavitè), $7 \$ 0$.

Colome externe, 992, 996, 1002, 1059, 1066, 1117.

Coelome extra-embryonnaire, 1059.

Coloplanule, 979.

Conenchyme, 26\%, 275.

Conosarcale (origine), 122.

Coenr (Echinodermes), 681.

- (Entéropneustes), 763, 766.

Colonnaire (lobe), 1128.

Columellaire (cavilè; Échinodermes), 730 .

Cône, 561.

Coquillère, (glande), 404.

- (nembrane), 953.

Cordale (goutliere), 898 .

Cordo-mesodermique (vẻsicule), 778.

Cordon visceral (Tuniciers), 814 .

Cornéagene (cellule), 561 .

Carnéule, 50 l.

Corps jaune, 87\%. - (faux), 874.

Cotylèdon placentaire, 1138.

Cotyledonaire (lobe), 1127.

Couronne, 181, 251.

Craniemne (flexion), 1023.

Cryptoniscien (phase de), 499.

Ctenula (larve), 2:22.

Cumulus primitif (Arthropodes), 480.

Cyallıozoüle, 809, 841, 846.

Cycle (Scyphozoaires), 181.

- (cloisons), 254,

- (tentacules), 232.
Cyclopenene (larve), $52 \%$.

cyelops (phase de). 490

Cycloraplic (larve), 5?0).

Cydippide (phase de), 220 .

Cyplionaute (larve), $112, \$ 15$.

Cypris (phase de), 49.

Cyrtopia (larve), 50t.

Cysticercoïde, 318.

Cysticerque, 31 \%. $31 \%, 328$.

Cysticle (Trochozoaires), 4l?, 44.

Cystideen (état), 735.

Cystique (cavité; Plathelminthes), 31 \&.

- (paroi; Sarcodaires), 4.

Cystogine (cellule), 327 .

Cytoblaste, $t 127$.

Cytode (gencrateur), 35.

\section{D}

llélamination, 132.

lleutocérébral (lobe), 552.

lleulocérèron, 546.

Jentonephridie, 433.

Jeutoplasmigène, 28\%.

lentosepte, 180,241 .

Deutospore, 25.

Deutovum, 507.

Dipleurula (larve), (i36).

Disconula (larve), lút.

Disque (Bchinodermes), 688, $717, \pi 34$.

- ('Trochozoaires), 41 亿.

- adhesif (Vertébres), 1041, 1048.

- imaginal, 530.

- iarvaire (Echinodermes), 688.

Distal (ecloderme, endoderme), 195.

Dorsal (canal, Arthropodes), $4(00$

- (pore) 639, 650 .

\section{F}

lau de l'annios, 1074.

Ectodermique (eavilé; Vertébrés), 1001.

Ectoplacenta, 992, 1002, 1126 .

Eleoblaste, 785.

Embryon gemmipare, (Itydrozoaires), 13:3, 14:.

Embryon gemmipare (Tuniciers), sos.

limbryounaire (aire), 987.

- (corps; Sarcodaires), 39.

- (noyau; Acanthocephales), 33:2.

- (tache), 987.

- zone),910, 911,916, 953,979, 1058.

Endamnios (Arthropodes), 486.

- (Plithelminthes), 298, 30\%, $30 \%$.

- (Vertebres), 1072.

Indocole, $17 \%$.

Endoderme primaire (Arthropodes), $5 i 1$.

- secondaire (Arthropodes), 571.

Findogene (embryon; Ciliaires). Gi.

- (vesicule), 323 .

Endoplaste. $\{3$.

lindoplastule, 43. 
linkystement (Sarmblaires), f.

Finteritgue (lube: Artluroporles), 5\%3.

Eutirocule droil (lichinolermes), (i.). - gauche (Echinodermes). $65 \%$

lintiroporien (bourrelet),

Enteroporienne (région), 90.5 .

Entonnoir vibratile (lichnodermes), 742.

Epaulette, 703.

liplippium, $45 \%$.

Fipliyra (larve), 214, 220.

lipicarde, $42.5,83 \%$, 833, 83i.

Lipicarlique (tube), 82., 832.833.

Eipilerminut (lame), !01.

Fipimere, s8\%.

Erichthus (larve), $500,503$.

Eusiphonula (larve), 142.

Fxamnios (1rthropodes), 486 ,

-_ (1'latlelminthes), 298. 304, 306.

- (Vertebrès), 10:2.

lixocrile, $1 \% 6$.

lixogène (vésicule), 323.

lixtra-inurale (cavitè), 261.

\section{F}

Falciforme (corps), 25, 33.

Fausse-palte, 51., 521.

Faux-amnios, 1072.

lenelle aplatie (0rthonectiles), 76.

- cylindrique (Ortloneclides), 76.

Fixateur (stolon: Tuniciers), 807.

Follicule ovarien, siz.

Fossette tixalrice, 730 .

- ventrale.730.

Furcilia (larve), 501.

lialle. $5 \geqslant 1 \%$.

Gamollaste, 3r.

Ganglion du tronc (T'unicit's). slú.

Gangliogene (cellule), 5 i.

Gasterotroyue (larve), 421.

Gastral (uesoderme), $118,950$.

Ciemmule (l'lathelminthes), 310.

- (spongiaires), 111.

- (Truchozoaires), 4̇í.

Géneratenr (liverticule), 57.

Germigène, $28 \%$.

(ierminale (membrane), 321), 322.

(ierminatif (disque), !60.

- (ipithélium), 870 .

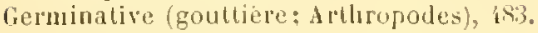

- (muraille), 974.

- (taclie: Liclinodermes), 64?.

Cionade, 125.

Fronoplrore, 12t.

- melusiforme, 12 i.

Conozoürle, 118.

Coutlière primilive, (Arthopodes), $\{8,3$.

firaff (follicule ou vesicule de), siz.

Granule rose, 538 .
Granuleuses (couche de cellules), 773.

(iranuleuse (membrane), $\times 73$.

\section{II}

Ilabitat intermédiaire, 325.

Ilectocotyle, $36^{2}$ \%.

llexacanthe (embryon), $3 \mathbf{H}$.

llexapode (larve; Arachnides), 50\%.

- (larve; Myriapoles), 513.

llistoblaste, j30.

llistolyse, 531.

llntométabolaires, 515.

llole tefinitif, 325.

- intermédiaire, 325.

IIydatide, $31 \%$

IIydatique (membrane), 31!), 322.

II ir rocole, $63 \%, 65 \%$.

llydrophore (anneau), 640. 6til. 68?.

- (canal), 656 .

- (rosette), 645, 661, 682.

- (ube), 639, 681.

Hydropore, $630,656$.

llydrollize, 159.

llydrula (larve), 138.

Ilypermétamorphose, 523.

llypols ranchiale (gouttiere), 818.

lly poderme (Artliropodes), 543.

- (Trochozoaires), 422.

llypoganglionnaire (glande), 815.

11 ypomère, s89.

llypopliysaire (cocum; Tuniciers). 815.

- (glande), 815.

\section{$I$}

Infusoriforme (embryon), 7:.

Infusorigine (corps), 72 .

Initiale du mesenchyme (Echinodermes), 6.51.

- mésodermique (Trochozoaires), 362.

- sexuelle, 397, 437, 601.

Inter-annexiel (tiss 11$), 111 \%$.

Inter-eotyléclonaire (sillon), $112 \%$.

Intermediaire (membrane), 1121 .

Inter-ombilico-placentaire (lame). 909.

Intestin (cul-de-sac antèrieur). 1063.

- (cul-de-sac postèrieur), 1063.

- ceplialique, 1063.

- postanal. 803, 891.

- postèrieur, 1063.

- terminal, 1003.

latestinal antérieur (orifice), 1060.

- postérieur (orifice), 1060.

Intra-murale (cavilé), 201.

\section{IK}

lientrogone (larve), 493, 495.

hispller (risicule de), 940.

liysle (Ciliaires), 63.

- ('lathelmintlies), 328.

- (Salcodaires), 4. 
labre, 5il.

Lageniforme (individu). 3..

lame calcaire. 176. provisoire (Irthropodes), $53 \pi$.

Laminellse (membrane). $\mathbb{I}$ I.

Lamprillon (larve), 1030.

Lamprison (larve), 1030.

Larve de Desor, 29!.

- de Loven, 60.

- de Muller, 30\%.

- primaire (['lathelminllues), 310.

- secondaire ('lathelminthes), 310,31 '.

Laterale (plaque), 880.

Limite (membrane), 1121.

l.oge (Sarcodaires), 9.

- (Scyphozoaires), [7].

- coronale, 251.

- lobaire, 216.

- inarginale, 216 .

\section{IM}

Macrogonidie, $48,64$.

Macrosepte, 245.

Macrospore, 31.

Maerotype, 25?.

Macrozuilie, 48 .

Madreporite, 605 .

Ilagma réticulé, 1121.

Manteau (I'lathelminthes), 305.

Marginale (èbauche), $909,95 \%, 05$. - (membrane), 10,.

Marginal (lobe), 1it.

Marginale (plaque), 722 .

Marginal (sıllon), 10ti3.

Jassue (glande en). 923 .

Medullaire (bande vibralile), $\{20$.

- (bourrelel), 919.

- (canal), 9I9.

- (goutliere; Tuniciers), T96.

- (goutlière; Vertẻbres), 89\%.

- (playue; Trochozoaires), 422.

- (plaque; lertébrés), 897.

- (replis), 919.

Meduse (developpement; Ilydrozoaires), 154.

Iéluse (développement; Scyphozoaires), 214.

Yèlusoüıle (ronopliore), 125.

- (elat), 226.

Mègalope (larve), 50:3, 504.

Membrane propre, 23.5.

Merucytc, (4)

Mertensia (phase), 220.

Mesenchyme primaire, 3132 .

Jésentère (Chutognathes), 6iki.

- Echinodermes), 600.

- (Vertébrés), sxs.

- intermediaire (Fchinodermes), 737.

- Lngitudinal (lichinolermes). 7ir.
Mesenteron Arthropoltes. . $15 \%$.

Mésuecle, lio.

Mésomètre. s80.

.lesosomile, 885.

Mesotroque (larve), $\$ 21$.

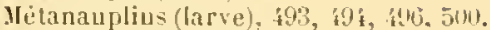

Mélasepte, Isll, 2\&.

- primaire, 181, 250.

- secondaire, 181,250

Métasome (Echinodermes), 68\%.

- ('lathelminthes), 313.

- (Trochozonires), 398, 403.

Mèlasomique (ube), \$12, flf́.

Microgonidie. $\{8,6$ f́.

Mieronoyau, 43.

Ylicronucléus, 43 .

Microseple, 24.

llicrospore, 30.

Ilicrolype, 252.

Microzoidde, 45.

Mitraria (larve), 4IS, 420.

Moelle caudale (Tuniciers), 795.

- somatique (Tuniciers), 795,

Jonogenique (Mèsozoaires), 71.

- (Sporozoaires), 25.

Ilue daccroissement, 523, 54 .

- de developpement, de perfectionnement, ou de transformation, 523, 544.

Iluller (canal de), 868 .

Vuraille, 260.

Musculaire (plaque, Tunieiers), 792.

- (plaque, Vertébrés), \$8\%.

Myẻlencéphale (Tuniciers), s1'.

Myomère, $\$ .99$.

Myolome, 889 .

Mysis (phase de), 501 ,

\section{IV}

Sauplius (larve), 491, 493, 406, 500, 503.

Tematogene, 70 .

- primaire, il.

- secondaire, Tl.

Sephridie definitive, $\mathbf{4 3 3}$.

- primordiale, 433.

Xèphridien (cordon), $\{36$.

Xephroblaste, $395,436$.

Xèphrotome, 889.

Ferveuse (lame), 901.

Seuraxe (Tuniciers), 779, 791.

- (Vertébrès), $896,918$.

Neurale (glande), 815.

Seurenterique (canal; Tuniciers), iso. - (eanal; Vertebrès), $897,919,970$.

Teurollaste, 549.

rid d'ovules, Szl.

Xidamentaire (cordon), 318.

Non embryonnalie (aire). Voir para-eml)ryonnaire.

Notocorde (lintéropneustes), ibit,

- (1uniciers), 7テs, 792.

- (1ertebris), sos. !1:. 
Xotocorile (etui de la), 900).

Nototropue (larve), $\{21$.

Xoyau de reliquat, 33.

jymphe (Crustaces), 494.

- (Insecles), 518.

Treelle (Artlıroporles), 558.

Glontophore (Echinolermes), 721.

Oecie, 412.

1]iil composé. 56 \}.

(Esophagien (orifice; Tuniciers), so\}.

liuf (o)mposé. 302.

- l'èté (Arthropodes), 4.0.

- - (Nèmathelminthes), 340.

- - (Plathelminthes), 200.

- - (Trochozoaires), 369.

d'liver (Irlhropodes). 4., 5R.

- (Xemathelmintles), 340.

- - (Plathelminthes), 289.

- - (Trochozoaires), $36 \%$.

Iinf simple, 293.

Ombilic, 1079 .

- abdominal, 1074.

- amniotique. 1074 .

- intestinal, 1074.

- ombilical, 1093.

- vitellin, 1074.

Ombilical (cordon; Verlébrés), 950, 1056, $107 x, 1121$.

Ombilicale (vesicule; Vertéhrus), 905.

Ombilicanx (vaisseanx), 10,82.

Ommalidie, 558,561.

omplıalo-mésentériques (vaisseaux), 106?.

Opaque (aire), $565,1092$.

uptique (coupe: Arthropodes), 550.

- (plaque), 553.

- (tige), 564.

- (visicule), 55\%.

"plogène (conche), 56 4.

Orale (plaque), 732 .

Mrgane cloisonnè, 740.

- de lojanus, 434.

- dorsal (Arthropodes), 5il.

- - (Eehinodermes), 681.

- - (Trochozoaires), 114, 414.

- larvaire (Echinollermes), 720.

- pyriforme (Trochozoaires), $4 \mathbf{i}$.

-- segmentaire, 436.

- spongieux, 742.

- ventral (Peripates), 621.

Orthoraphe (larve), 520.

11stracode (phase), 494.

Duraque, fort.

Ovoipapule (Tuniciers). 810.

Oroide (glande). GSI.

\section{P}

l'ara-embryonnaire (zone), (1)

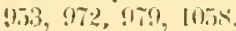

Para-noyan (Mesozoaires), 72.

Para-nuclèus (Giliaires), 13.

- - (Mesnzoaires), 72.

I ara-vilelline (cavile), $916,979$.

I'arenchymulairc (type), 8..

I'ariètal (sac; Fehinodermes), 737.

l'edonculaire (cordon), 731 .

pellucide (aire), 10:2.

- (zone), \$73, 982.

Pentacrinoide (ètat), 739.

l'entactula (larve), 642.

l'entagone gènital, 68 t.

l'éribranchiale (cavilé). 81\%.

Péricoronale (gouttière), 8I\&.

Péricesophagien (sac; Echinodermes), 73\%.

F'ériprocte, 685.

l'ristomal (mésoderme), ?'R, 9,0.

Pèrilonéal (sac; Echinodermes), 736.

lerivilelline (membrane), 381 .

letite boule à noyau, 538.

phinger (tube de), sil.

l'hagocylose enbryonnaire, 538, 706, 804 , 1043.

Pharyngien (diverticule), 766 .

Phase première (Echinodermes), 686.

Phyllosome (larve), 503 .

Phryxoide (phase), 499.

Pied (Trochozoaires), 404.

- (cellule a), 869.

Pierreux (canal), 682.

P'ilidium (larve), 294, $206,298,308$.

l'innule, 740.

L"lacenta (Mammifëres), 1122.

- (I'éripates), 612

- (Tuniciers', 809.

- (Vertèbrés), 096.

- fietal, 112í

- maternel, 1108, 1124.

Placentaire (cordon; Péripates), 612.

- (cordon; Vertébrés), 1121.

l'lacenlaires (vaisseaıx), 108?.

Placentation, 1138.

- colyledonaire, 1133 .

- diffuse, 1138

- discoïdale, 1139.

- mèro-discoirdale, 113?.

- pan-discoïdale, 1139.

- zonaire, 1138.

llacentoïde (sac), 1095.

Plasmodiale (coltche), $112 \%$.

Plasmodiblaste, 1127.

Plastidogene (appareil; Echinodermes), 681.

plérocerijue (embryon), 317, 328.

l'leuro-péritonéale-extra-emtryonnaire (cavite), 10.59.

'luteus (larve), 690, 701, 72'.

l'newmatophore. 116.

Polype, $116,170$.

Polypier, 250.

bolypide, \{t2, fit.

Polytroifue (larve), 421.

I'ost-abdomen (Tunieiers), št1. 
Princritenne (glande), silo.

l'rivertiolie, sis.

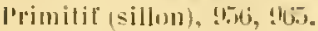

l'rimitive (frouttière; Arthrupodes), Jil

- (gouttière, ligne; Vertébrés), 913,45\%, 965.

(vesicule; 'Tuniıiers). 83 í.

probuscidien (individu), 5s.

['roluscidienne (glande), 766.

l'rocirdiqu" (e'ylindre), 52\%, $\$ 34$.

Prociphalique (lobe; Artliropodes), 5ut; 515.

Prochurion. 1111.

l'roglottis, 321.

l'roligère (cumulus; disque), si3.

- (vésieule), 320, 322.

l'rosome (Eehinodermes), $68 s$.

- (Trochozoaires), 39s, 40:3.

Protenterocile, (j3i, , tis.).

l'rothylrula (larve), 1:0.

l'otocérebral (lohe), inis.

l'rotucerebron, 5 iti.

l'rotohydra, Jik.

Protonephridie, 433.

Protonymonon (larve), 5it.

Prolosepte, 180, 240.

Protospore, 25.

Protovertebre, 865.

Proluzoe (larve), 500, $50: 3$.

l'roximal (Eetoderme, endoilerme), 4ks.

l'seudofilaire, 35 .

P'seurlo-gastrula, sio.

Pseullo-navicelle, 2i.

Psendu-nymphe, .2?

l'seudovaire, 585.

l'sorospermie, :-)

l'upe (Irthropoles), 49, 509, 518.

- (liclinodermes), $19 \%, 734$.

['yriforme (oryane; ]rochozoaires), f4́.

- (phase; llydrozoaires), 1 i0.

\section{R}

Kacines (Crustacis), 495.

liadiale (plaque), 735.

Radiole, tisis.

Raphe carlianue, $\$ 27$.

- postèrienr, 48. ventral, sls.

liauber (couche de), sto.

Rèdir, 311, 312.

liemprit むu germe. !น

liesiduelle (\%on), lom.

litinule,

lietro-plsaryngien (sillon), 818.

lihabulome, 56 l.

lihalulomere, intl.

lilagon, 102 .

Rhombogène, 71.

Rhopalie, 174.

Romale (cellule; Vertehris), sis?.

liusette, 6 :3. liosette (cellule en), on.

liotation (momsement as), ius.

\section{S}

Sae ural (lielinorlermiss), 73\%.

salcusome,

Scarabeoïde (larve), 52,

schizopode (phase de), .ill.

sclérotome, $89 \%$.

Scolex, 314, 317 .

Scorpenoide (phase), l(15)!.

seyphistome, 211$).$

scyphopolype, 15i, 210.

scyphula (larve), $185,20 \%$.

Stecondatre (vésicule), 321, 322.

Segment primordial, 855 .

Sereuse amniotique (Arthropoites), $480^{\circ}$. - de von Baèr, lor:.

Sérotine (caduıpe), 1108.

Sertoli (cellule de), 809.

Sexuelle (indillèrence), vis.

sinus rhomboüdal, tro. terminal, $106 \%$

siphonula (larve), 142.

soie (Trochuzoaires), 424.

Somatique (courbure), 1023.

Sous-ambulacraire (cavité), (\$ง).

sous-germinale (eavilé), yil.

Sous-tentaculaire (cavite), 740 ).

Soutien (cellule de), sis?.

Spermatophore (Trochozoaires), 3tis.

Spermatozoïle vermiforme, 3tis.

Spiracle, 1042.

Spongieux (organe), 736 .

Sporadin, 28.

spore, i, 60 .

sporoeyste, $311,312$.

sporoduete, 30 .

spurophore, 1?i.

Sporosac, $1 \geq 4$.

sporulaire (paroi), i, 60.

Statoblaste, $\{4: 3$.

Stoloniale (cloison; Tuniciers), 832.

Strobilt' (Plathelninthes), 32?.

(Scyphozoaires), 219.

Strobilisation monodiseale, 219.

- polydiscale, 219.

sub-zonale (membrane), lo72.

Suçuir (Crustacès), 495.

Support dorsal (1'uniciers), $\$ 51$.

systime ('tuniciers), s3i.

\section{$T$}

Telubliste, 345.

'Tentaculaim (canal), $68^{\circ} \%$.

- zone, liss.

Terminale (par|ue), 721.

Testa (conche du), 773.

Tétiurd (larve), 10tol.

letranthe cenilryon), :3li. 
lhyroidienne (gouttière; Tunicier's), r.2.3.

l'ornaria (larve), itil.

Transpareute (aire), !1; $4,10 ! 1 \cdot 2$.

Trèna, \$:2?.

Trichorine (cellule), sit.

Trilolite (phase fle), int. ins.

Triongulin (larve), $523,528$.

Tritocerelural (lobe), t.2.

Tritocécilıron, 516 .

Trachophore (larve), :360.

Trompe (glande de la), "60\%.

Tunitue, 8l3. reflechie, re?.

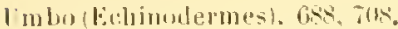

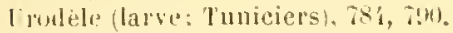

C'rostyle. 1050.

l'terins (lacs sanguins), 1131. (sinus), I131.

llepus (Tuniciers), 811.

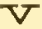

Vasculaire (aire), $175,106 \%, 1012$.

laso-periloneale (resicule), (3in.

lèlım, 408.

Ventouse (l'rochozonires), 4 If.

- Verlebris), J133i, 1041.

Ventrale (goultiere), $\$ 18$

Vermiforme (emliryon), it, 73.

Vésiculaile (cavite: l'lathelminthes), 31 i.

Vésiculaire (phase), $20 \%$.

Vésiculeuse (cellule: plincenta), 1131

- (couche), 1131.

Vestibulaire (orifice), 7ls.

- (visicule), $\% 3 \%$.
Vestibule (Flinolermes), s.

Vibratile (organe), sli.

Villosite (Tuniciers), sit.

- cluriale, IIII.

- non vasculaire, 1111 .

- vasculaire, 1111.

Vitellin (bouchon), 934 .

- (Lourrelet), 97.

- (cordon), 9.41, 97.5, 105i, 1043.

Vilelline (aire), $975,1092$.

- (artère), 1457, 1160\%.

- (cullule; Irthropodes), $170,180,5 \pi 1$.

- (cellule; l'lathelminthes), 289.

- (veine), $105 \%, 100 \%$.

- (vesicule: Arthropodes). 460 et silivantes.

Vildlline (vésicule; Ilydrozoaires), 130.

- (vesicule; 'T rochozoaires), 3\$1, 397.

- vésicule; 'T'uniciers), s19.

vesicule; Vertebres), (05, 912, 944, 47. 959, 1080, 105is, 1037, 104i, 1046. 104!, $10,1,111, \mathrm{x}$.

vilellins (vaisseaux), 1069.

Vitello-chorim (ou omphalo-chorion), 1115.

Vitellogene, 285.

vitellus blanc, $05 ?$.

Voile,

\section{W}

Wirthon (gélittine da), 112?.

linull (canil) de) veri.

\section{Z}

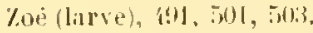

\%onspore, 4. 


\title{
TABLE ILP IIABETIOUE
}

\author{
DES NOMS DE GEXIIES
}

\section{A}

Alraxis, i2t,

Alhthere, fill?

Arilius, rix.

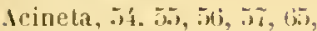

leipenser (Esturgeon, Sterlet), 933, 938, 940,1045.

Actinia. 20\%.

Aelinospharium. 37,38 .

Igalma, 130.

Igalmopsis, 13i. lit, liu.

Airelena, iso, isol.

Aggregata. 23.

Aglaura. 132.

Aiptasia, 2il.

Ileippe, five.

slopliota, 1 亿3.

Mlytes, six.

inblystoma, 800, 103i).

Amphidinium, 17.

Amplisleptus, 6:

Amplilina, 32?.

Amphioxus, kx', !12(1, 102!)

Ampliura, bik, 1j49, 724.

Analileps, Itosi.

Inapta, 618 .

Anchorella. 497.

incliylostomum, 351 .

An fuillula, 3 i2.

Anguis (1)rvet), ris.

Inthopliysa, 13.

Anurella, $80 \%$.

Aphis, 58s.

Ipis (Ilieille), 529.

Aplysilla, 103.

Apolemia, 121 .

Apus, 4.ti, 493, ivi.

Irachnactis, 23?.

Arbacia, 705,700 ;

Arcella, 19, 2 .

Archigetes, $317,322$.

Argiope, 382. 389, il5.

irgonalita, 3 ibi.

irgulus, 49.

Irtemin, fist, ski.
Arvicola (Campagnol), lowl. 1118.

I seandra, si.

Isearis, 3if, 3ist.

iscetta. 8t.

Isellus, 402, quis.

Iseidia, Tyl.

Ascidiella, 7\% . \$27. 829\%

Ispidiotus. $58 \%$

Aspredo, siz.

Istacus (Eerevisse), fis, 462 , iั 3 , 5í.

Isteracanthion, 66ti, i1!!, 721).

Isterias, its.

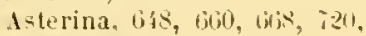
i23, 话.

Aulosphierides, 10.

Aurelia, 19s, $21 \%$

lutolytus, $3(\%), 41$.

\section{B}

lialanoglossus, 7...).

lialantidium, 6 , 47,61 .

laalanus, 493.

liatrachoseps, vib, $103 \%$.

Benedenia, 20.

Beroe, 224, 227.

Bicosceca, 14.

Bilharzia, 288.

Biloculina, :!.

Biorliza, ระ̃.

lioltenia, soí.

bombinator, 10 i2.

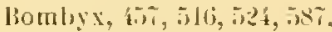

fonellia, 363, 349.

Borlasia, 2尺:.

Bothriocephialus, 306, 32心.

Motryllus, $\times 37,840,812$.

Brachiella, \$! 7 .

bradyus (l'arcsieux), 11 il.

liranchiobdella, 39., 3?k;

liufo, Siji.

Bunoles, 215.

Bursaria, ili.
Ca!lorlynehus, 116.3\%

Camelopardalis(Girafe), l Қ心.

Canis (Chien), 11 亿2.

Careharias. Sit; 10\%:

Gatchesium, i\%, 4 .

Catenula. 314.

Cavia (Cobaye), 11005, 111

Cecidomya, 45i, 521 .

Cecilia, $103 i$.

Ceplualothrix, 295.

Cejon, 498.

Cerambs, $52 \mathrm{k}$.

Ceratium, 17.

Cerromonas, 12.

Cerianthus, ?05, 2:32.

Cervus, 113 .

Cestracion. 10\%

Cestus, 22í.

Cetochilus, 410 (1), $4151,412,473$, 493.

Clialina, 113

Chalinula, $: 1$.

Chermes, 5isis.

Chetopterus, 421.

Chilomonas, l'3.

Chimiera, 14 ist.

Chironomus, $4 \pi, 5 \%$, ,

Cliton, 368, $405,408$.

Chlathrulina, 3ะ.

Chotoraster, 4 íl.

Chutonotus, 3 it).

Chromis, संत.

Chrysiora, 194;, 1!\%.

Chrysomitra, 117.

Cillaris, lit?.

Ciliophrys, is.

Clava. 1?:

Claveliua. $751.8011,81 \mathrm{i}, 525$, $8: 2,839,836$.

tilepsid rina, 30, 31.

lilepsine, 3:4\%.

lilione, h; 113.

lilupea (llaleng), sici, loi,2. Llytia, 121 . 


\section{0}

Coctinlium, 29!1, :33.

Codonimu, 10:2.

Cudosiga, 15.

tusocormus, 83i.

Cuenurus (Cysticerque du 'l'e. nia), 319

Coleps, 5n.

Colpoda, 192.

Conmilula, t53, 6.14, 671, 672. 7.)

Conger, 1053.

lordyluphora, 12í.

Coretlira, 53?.

Corticifera, 25?

Lorymorplia, 125.

Cirangon, 503.

Cribrella, 649, 745

lirislalella, 1 i3.

Sryptophialus, tivi.

lirystalloüles, I:30.

lilenaria. J!!.

Cucullanus, 392.

Cucumaria, 6is. bitis, bin.

culex, 51!, 521.

Cuniculus (lapin), (thit, !) $996,998,1118,1126$.

Cunina, 146.

ryanea, 1!17, 210, 215.

lyclosporit, 29.

lymothor, 466 .

liynips, 529.

Cypris, 402, 40\%.

(ivthre, 494 .

\section{T1}

Dactyletlira, 1038. 104 .

lactylopterus, 1053 .

lhasychone, $4 \mathrm{~s}$.

Jasypus (Talou), 1141.

dendrocolum, 3100.

Jentalina, 9.

Jentalium, 3\%5, 405, 4018.

llicyema, 73.

yidemnum, 827.

llinobryon, 14.

llinopliysis, 17.

liphyes, I l.

lisconalia, 1 ti3.

listomum. 30, $311,313,314$, 326.

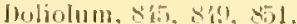

llopocidaris, tio is. 705. 711.

Imatuneulus, 33 .

lytisens, 5is.

\section{F}

liclijuna. sis.

lichinaster, if?

linhinococens (Cysticeryut lu Tenia), 31! 32?.

\section{TUELE ALPHABETIUI E.}

Echinocyamus. 7\%. TH.

Echinorhynchus, $3: 31$.

lehinus, $655,715,706,711$.

Fehiurus, $398,\{\geq 1$.

Eginopsis, 132.

Eimeria. $29,33,31$.

Enchtroides, 30:4, 395, dis.

Epenthesis, J62. Itíf.

Ephumera, 520.

Ephydatia, $43,112$.

Eplyropsis, 10\%.

Pipibulia, 1:35.

Epieanta, 5é.

Epicrium. 930, 1030.

lipistylis, is.

lipizoantlus, 25:.

lisperella, 103.

lislleria, i.4.

Eucharis, 201, 223, 224.

Eulenilrium, 122, 130.

Luglena, $1: 3,3 !\}$.

Eupagurus, 4izi:

lupluansia, 5(0), 5013.

Fupomatus. 3!1), 3!1?.

lintina. 197.

\section{$F$}

Felis (cihat), $114 \%$.

Filaria, $341,352$.

Galaxea, 2ir.

finllus (l'oulet), 9is, 90z, 968, $1089,1064,104)$.

Gamocystis, 30.

Gaslrollasla, 162, 16i.

Gastrophilus, Til.

Geophilus, 5jt.

Flenodinium, 17.

lilobigeriniles, ?.

Gonatinia, $27 \mathrm{I}$

Goniocilaris, (j)9.

Gordides, 353.

Gorgonia, 1 is

Gromia, 6, 7 .

Gyrodactylus, $3309,321.320$. livropeltis, in.

\section{FI}

Ilaimen(Monoxtnia), 306, 25\%. $20 \%$.

Jalicluerus, 1142.

llalisarea, 84, !), 17.

Ildriorystis, 11.

Ildiaslreat $2 \%$.

Jlemiaster, (j4), 701.

Ilosita. 40,

Mloturonereis. $3 t i t$, it?

ll'sanilit, li: llistiuphorus, 10:3.

IIt)loesntrus, tos.s.

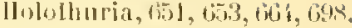

lJumarus, ins, .04.

Ilomo (Ifomme), 817, 570,872 , $1074,110 \%, 111 \mathrm{t}, 111 \%, 111 \mathrm{~s}$ $1121,1142$.

Ilylutebne, ins.

Ilytractinit, 122, 1:24.

Ilydrophile, is!), $4 !(4,517$.

llydrophis, s7s'

llylimes, lon

Ilyoprorus, 11053 .

llyperina, 499.

lly rix (laman), 11 i?.

\section{I}

Holis, isis.

lchthydium, 340 .

lehthyophluirius, 62 , 63.

Inachus, End?

Isopliyllia. 275.

Isuspol'a. 23, 3:\%

Julus, 513.

\section{I}

Kilossia, 2?.

\section{工}

lagena,!)

lecanium,

Lepridosteus, 94. 1045.

Leptasterias, 6i:?.

Leplocephalus, J1153.

leptodiscus, 17.

Lerneopoda, 4! 7 .

Leueoplinys, 4!, 61 .

Libellula, 520.

Limulus, 505.

Lintila, it5.

lineıs, $292,299,300$.

Liriope, 12\%, 14.

lithobius. 513.

Lopalorliynelins 418,420 .

Lophocalyx, 112.

Lucernaire. L!99.

lumbriconereis, $\{21$.

Lyosa, itis

lytister, T4.)

l, ytlit, $5: 21$.

\section{M}

Malaendulella, 30.

Manis (l'angulin), Jlas.

Manlis, isto

Manlispra, .2.

yelore. 5ét. 
Melolontha (lianneton), 51?. $523,528$.

Jenobranchus, sili, I036.

Mesostomum, 28!), 291.

Viaslor, 457, 585, 58\%.

Mierolydra, llít.

Niernstomides, 288, 307, 319 , 320.

Niliola, $3 i$.

Miliolites, 9.

Mitlrodia, 7 个.

Moïna, 460, 462, 173.

Jonobia,

Monocaulus, 12\%.

Ionostomum, 314.

Monoxenia, 206, 25\%, 367 .

Morrhua (Morue), 876.

Mus (Hat, Souris), 1001, 1118 , 1135.

Muscides, 533.

Mustefus, 876, 105\%, 1057.

Mylabris, 524 .

Myrianida, 441.

Myripristis, 1053.

Myrmeleo, 525.

Mysis, 5.20, 563 .

Myxodyctium, 5 .

llyzostomum, 32?.

\section{IV}

Nais, 411

Nanaster, 745 .

Nassa, $37 \%$.

Nebalia, 497.

Yereis, $366,411,412$.

Nerine, 421.

Nettastomus, $10,73$.

Noctiluea, 15, 17, 19.

Nollosaria, \&, 9.

Notodelplis, 878.

Nummulites, 9.

Oniseus, $406,517$.

Ophizeantla, 699.

Uphiactis, 745.

Ophiocnirla, 74.5.

Ophiocoma, 745.

Ophiothela, 745.

Ophiotrix, 693, 723.

Oplyryodendron, 56, 58, 6is.

Orbitolites, 9.

Ornillorhynchus, 878.

Ortlıospora, 2!), 33.

1) ryclerope, 1130,11 il.

Iscarella, 90, 97.

lixyrus, $343,34,350,351$.
E

Palemon, 159, 463.

Palinurus (Lanenuste), 45s, 503.

Paludina, 373.

Halython, 25?.

l'aradoxites, 330.

l'aramacium, 50.

l'atella, 40s.

Pedicellina, 386, 389.

l'elitgia, I!17, 217.

Pelagonemertes, 307.

Pelobates, 86i7.

Pemphigus, 5Rs.

Peneus, 501, 513

l'enuatula, 270.

l'entastomum, 580.

l'eridinium, Ji, 39.

Jeripatus, 610.

l'eristedion, 10is!.

perophora, 8\%9.

lelromyzon Lamproie), ?26, 1029 .

Phascolaretos, 1115.

'hascolosoma, 415.

Phalansterium, 16.

l'hialidium, 126, 16 t.

Plilou romus, $10 \%$.

fluilonexis, 30 ti.

l'horonis, 36i, 384, 358, 402, 10s, 111, 412, 41.;.

phrygane, 5\%.

l'hryxus, 499.

Ihyllophoris. 6i?.

phylloxera, 58?.

l'hysophora, 133, 141.

Pieris, 457, 587.

lipa, 87s, 104 .

Plakina, 83.

Plalygaster, 527, 520.

Heuroncetes, 1053.

l'lumatella, 4 i3.

I'neumodermon, 408.

l'odlocoryne, 15?.

l'odophrya, $58,59$.

Polyasterias, 7 45.

P'olybostricluss, 3tifi, 4i2.

lolytesmus, 513.

Jolygorlius, 39\}, 418, \{?0.

l'olymorphina, ?

Polvpterus, 10 t5.

Polystomum, 326.

Porcellio, 46i, 466, 476, 498, 5:7, 568, 576, 582.

Porospora, 35.

Porlunus, 503.

l'ristiurus, $10 . \overline{0}$.

l'rostonum, 28?, 200).

l'roteus, 10:36.

l'rotodrilus, 391.

'rotospongia, 10 . l'rotula, til.

l'sendis, 10 í.

l'solus, fit?, 699.

l'syche, $4.7,5 \times 7$.

l'teraster, 720,723 .

rulex, 521 .

l'yrosoma, 775, 78?, 809, 8:1, 841 .

\section{R}

Raja, 1056.

Rana (Grenouille), 867, 932, $943,1034,1045$.

Reniera, 103, 112.

Renilla, $2 \% 0$.

Mhabfitis, 3il, 343. 3. t.

Mhaldonema, 341, 3.54.

Hhabloplemra, 3R?, ,18.

Mheuphax, 7.8.

libinoderma, 87.8.

Mhopalona, \&?R.

lihopalura, 75.

linynchichthys, 1053.

Rolalines, ?, 30 .

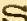

Saccamina, 8

Saconereis, 306, 112.

Sacculina, $403,49 \pi$.

Sagilla, iolin.

salamandra, 878, 1036.

Salmo (Saumon), 1052.

Salpa, 7\%, 789, 804, 811, 84.5, $84 \%$.

salpingeca, li.

sarrophaga, 5ั5.

sarsia, 10?

Schizaster, 706 .

Schizostomum, 291.

Sicolopendra, 53 \%.

Scomber (Maquereau), sri.

Scorpuna, 1051.

Seutigera, ili.

Scyllium, fosi.

Siebastes, 877.

Sipunculus, 389), 390.

sirerlon (Axololl), S66, 1037.

Sirex, 2021.

Sitaris, 524, 528.

Solenobia, 4.5, 587.

Solenophrya, $5 x$.

Spalaugus, 706.

Splumephrya, it.

spio, t?

Spirillina, 3 i.

spirochona, $5 \%$.

Spirostomulu, 46.

spungilles, $93,103,113$.

spumisterias, (ii?.

sipuammulina, ?. 
Sijuilla, .013.

Steenstrupia, 125.

Stentor, 50.

Stephanomia, 133.

stemaspis, 421.

Stomobrachium, 164.

Strongylosoma, $512,513$.

Stylochus, 307.

itylonychia, 49, 50.

Stylops, 525 .

Suberites, 113.

sycandra, 85, , $\$ 6$.

Syllis, itl.

Symporlium, 186, 230, 237.

Synapta, $648,651,605$.

syngnathes, 105 .

\section{I}

Tacardia, 587.

T'amandua (Tamanoir), 1141.

Tanystylum, 5.5.

Tendra, $3 \$ 6$.

Tenia, 316, 318, 310, 325, 328.

Tenthredo, 526, 528 .

T'eras. $5 x$.

Trimella, 121.

'J'esserantla, 191.

Tetlya, 112.

f'elilla, 112.

Tetrapleron ('letraplatia), 233.

'Thaumantias, 164.

'thecidium. 383.

'inea, 515.

'lipula, 535.

Torpedo, 876, 105\%.

'l'raehinus, fonst.

Tremoetopus, 3 tic.

Trichina, $341.343,351$.

Trichorlyychus, 62.

Trigla, 1051.

'riloculines, !.. 36.

'Triton, 932, 912, 1137.

'rochammina, \&.

T'roehosplurera, 399, 404.

Tubularia, 12: $129,141$.

Uroulat, (ins.
V

Vampyrella, 2:3.

Vanessa, 52i.

Vermetus, ios.

Vertebraliua, ?.

Vespertilio (Chauve-Souris, Murin), 872, (184, 986.

Vipera, 878, 11189.

Volucella, 533.

Vorticelles, 47, \& 4 if.

x

Xiplias (Espadon), $10: 33$.

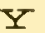

lungia, 307.

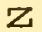

7oanthines, $232,252$.

Zoarees, $105 \mathrm{i}$. 
Librairie C. REINWALD \& C ${ }^{10}, 15$, rue des Saints-Pères, Paris

\author{
DERNIÈRES PUBLICATIONS
}

relatives aux sciences médicales et naturelles

\title{
TRAITÉ \\ $\mathrm{DE}$ \\ PHYSIOLOGIE HUMAINE \\ COMPRENANT
}

l'llistologie el l'Anatomie nicroscopingue el les primcipales applications

\section{MÉDECINE PRATIQUE Par L. LANDOIS}

Professeur de Physiologie et Directeur de I"Institut physiologique de l'Universite de Greifswalu. TraduUt SUR LA SEPTIEME ÉdITION ALLEMANDE

par

\section{G. MOQUIN-TANDON}

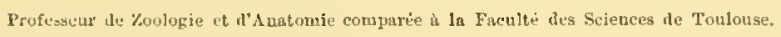

Un volume grand in- $\mathbf{8}^{0}$, orné de $\mathbf{3 5 6}$ figures dans le texte. Cartonné à l'anglaise..... : $\mathbf{B :}$ fr.

\section{TR A IT É \\ D'ANATOMIE HUMAINE \\ sum}

C. GEGENBAUR

PROFESSEU D'AXATOMIF: ET DIRECTEUR DE L'AXSTITUT ANATOMIOUE DE LIEIDELBERG

Traduit sur la troisième érlition allemande

\section{Par Charles JULIN}

Doctenr és seiences naturelles, ehargé des conrs d'Anatomie comparéc et d'Anatomio topographiugu ¿ la Faeulté do Médecino do Liège.

Un volume gr. in-8 orné de 626 figures dans le texte, dont un grand nombre tirées en couleurs.

Cartonné à l'anglaise 


\section{TRAITE D'EMBRYOLOGIE}

OU HISTOIRE IIU IUÉVELOPPEUENT

b

\section{L'IIOIIIE ET DES VERTÉBRES \\ I'A ll}

\section{OSGAR HERTWIG}

Professcur d'anntonite humane nt d'anatome compare; Directeur alu deuxime Institut athatomique de l'Unirenite de Berlin.

Traluit sur la troisiéme édition allemande

Par CHARLES JULIN

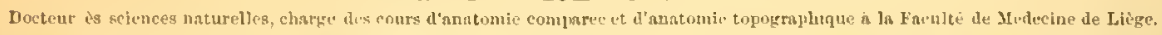

Un volume graud iu-8, orné de 339 figures dans le texte et 2 planches en chromolitbographie. Broché.... 1 \$ fr.; cartonné ì l’anglaise..... 1 (i fr. 50

\section{MANUEL \\ D'ANATOMIE COMPAREE \\ DES \\ VERTÉBRES \\ I'A H}

R. WIEDERSHEIM

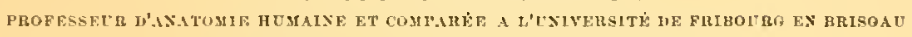

Traduit sur la deurieme édition allemande

Par G. MOQUIN-TANDON

Professeur de Zonlogie et a'Anatonie comprée a la Fuculté des gciences de Toulonse.

Un volume grand in-8, orné de 302 fig. dans le texte. Broché, $1: 2 \mathrm{fr}$; cart. ì l'angl, $1: 3$ fr. $\mathbf{5} 0$

\section{RECHERCHES}

S IT R

LA PRODUCTION ARTIFICIELLE DES

\section{MONSTRUOSITES}

ESSAIS DE TLRATOGENIE EXPERIMFNTALE

Par M. Camille DARESTE

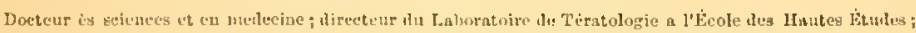

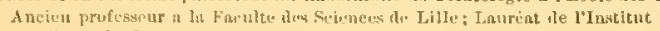

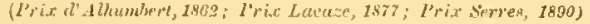

DEUXIEME ÉDITION REVUE ET AUGMENTÉE

Un vol.gr. in-8, orné de 62 fig. intercalées dans le texte et de 16 planches chromolithograpnqques. Cartonné à l'anglaise, $28 \mathrm{fr}$. 


\title{
B I B LIOTH ĖQUE
}

DES

\section{SCIENCES CONTEMPORAINES}

\author{
DES SAVANTS ET DES LTTELATEUIS LES l'LLS USTINITES
}

Lepois le sieele dernier, les sciences ont pris un énergique essor en s"instritnt de la lèeonde muthude de l'observation et rle l'experieuce on s'est mis it recueillir, dans tontes les directions, les faits positifs, a lesconpitrer, it les classer et it en tirer des conséquenees léritines. Les rusultats dej.t obtenus sont merveilleux. Hes problemes qui semblaient levoir a jamais échapper it la connaissance de l'homme ont éte itbordes et en partie résolus. Mais jusqu' ih prisent ces inagutiques acquisitions de la libre recherehe n'ont pas ete inises it la portee des gens du monde; elle: sunt eparses dius une maltitade de recueils, memoires et ouvinges spuciatax, et, eependant, il n'est plus jermis de rester étrangur a ces enquetes de l'esprit stientitique moderoe, de quelque oeil quon les eavisage. De ces rillexious est née la presente entreprise. Chaque traile formera un volume, ivec gravures quad ee sera necessaire, et ile prix modique.

Un plan uniforme, fermemenl mainlenu par un conité de rédaction, présile à la distribution des matières, aux proportions de l'œeuvre el à l'esprit génèral de la collection. Un auleur dont l'curre esl publiee sous ce palronage présente done toutes les garanlies de survir el de conpélence.

Conditions de la souscription. - Cette collection parat par volunes in-12 format anglais; chaque bolume a de 10 in 15 leuiles, ou de 350 a 500 pages a woins. I.es prix varient, suivant la déeessité, de 4 in 5 lrancs.

\section{EN VEITE}

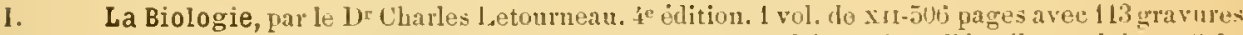
interealées dans le texte........... Broché, 4.50 ; reliè toile anglaise, $5 \mathrm{fr}$.

I1. La Linguistique, par Abel Hovelacinte. f́ élition, revue et augrmentée.

1 vol. de xvi-\{50 pages.......... libehé, 4.50 ; relie tuile anglaiso, $5 \mathrm{fr}$.

11I. L'Anthropologie, par lo Dr Paul Togninard, avee preface du professeur Paul Broca. f́ édition. 1 vol. de xv1-560 pages aree 52 gray....... Broclré, 5 fr.; relie toile anglaise, 575

IV. L'Esthétique, jar Eugrène Véron. 3e édition.

1 vol. de xxvil-496 pages. . . . . . . . . lruché, 4.51 ; relie toile anglaise, $5 \mathrm{fr}$.

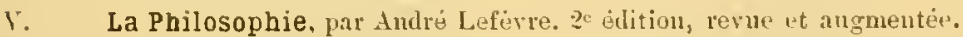

I vol. do $v-63 t$ pages. ............. Broché, $5 \mathrm{fr}$; relié tuile anglaise, 5.75

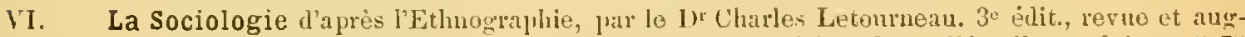
mentée. I rol. do xvı-bُos pages. . . . . . . liruehé, $5 \mathrm{fr}$; relio toile anglaise, 575

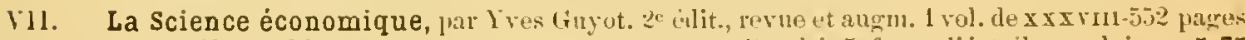

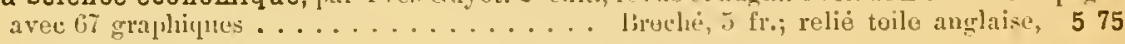

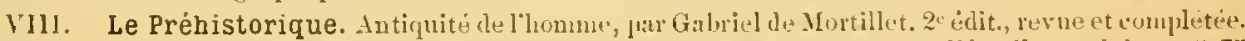

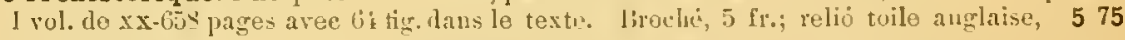

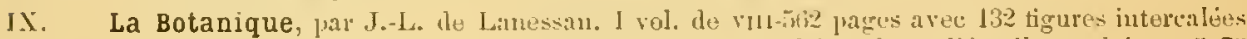
lans lo texte. . . . . . . . . . . . . IBruchú, if fr.; relié toilu anclaise, 575

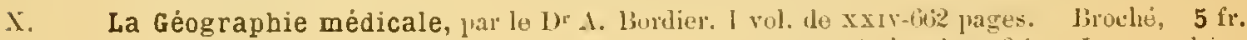
Le cahier de 21 cartes explicatives se rend separement en sus ila prix du volume, 2 flo. - Les exemplairs

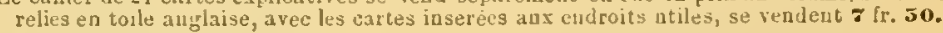

Xl. La Morale, par Èngene Véron.

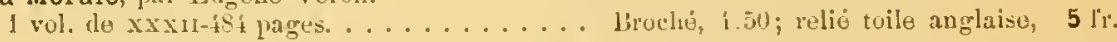

XI1. La Politique expérimentale, par Léon Donuat. 2 élitiun, revue, eurrigúe et augmentéu d'um :lplendice sur les récentes applieations de la Néthodle expérimentale en France. I rol. de xı-5ss pages.............. Broché, 5 fr.; relié toile anglaise, 575

X11I. Les Problèmes de l'Histoire, prar Panl Mongeolle, avec jréface par Yves Guyot.

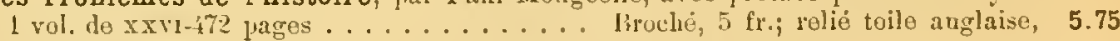

IIV. La Pédagogie. Son évolution et son histoire, par C. Lssaurat.

1 vol. de xu-500 prages. . . . . . . . . . Broché, $5 \mathrm{fr}$.; reliè toile anglaisn, 5.75

XV. L'Agriculture et la Science agronomique, par Albert Latrbalétrier.

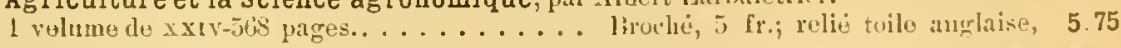

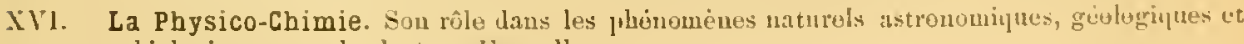
biolugiqnes, par lo docteur Fauvelle.

1 vol. do xxiv-jle pages.

liroché, is fr.; relie tuile anglaise, 575

XVII. La Religion, par André Lefüvre.

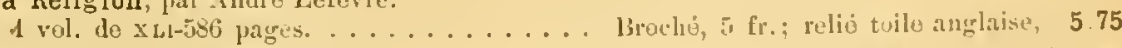

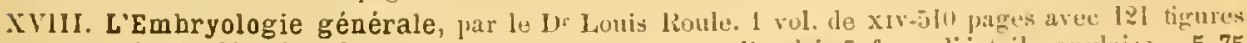
interealées dans lo texto........... 13ruché, 5 fr.; relio toilo anglitise, 5.75 


\section{I. - Sciences nalurelles - Médecine - Anthropologie}

\section{OUVRAGES DE CHARLES DARWIN}

La Descendance de l'Homme et la Sẻlection sexuelle. Traduit d'aprés la secomle cilition anglaise revue et augm. par l'anteur, par Edmond liarbier, preface de Carl Vogt. 3e edit. française (2̌ tirage).

I volume in-so aree gravures sur bois. . . . . . . . . Cartonne i l'anglaise, 12.50

L'Expression des Émotions chez l'Homme et les Animaux. Traluit de l'anglais par les Drs Samnel Pozzi et René lienoît. 2c édition, revne et corrigéc (nonvean tirage).

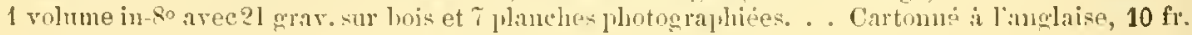

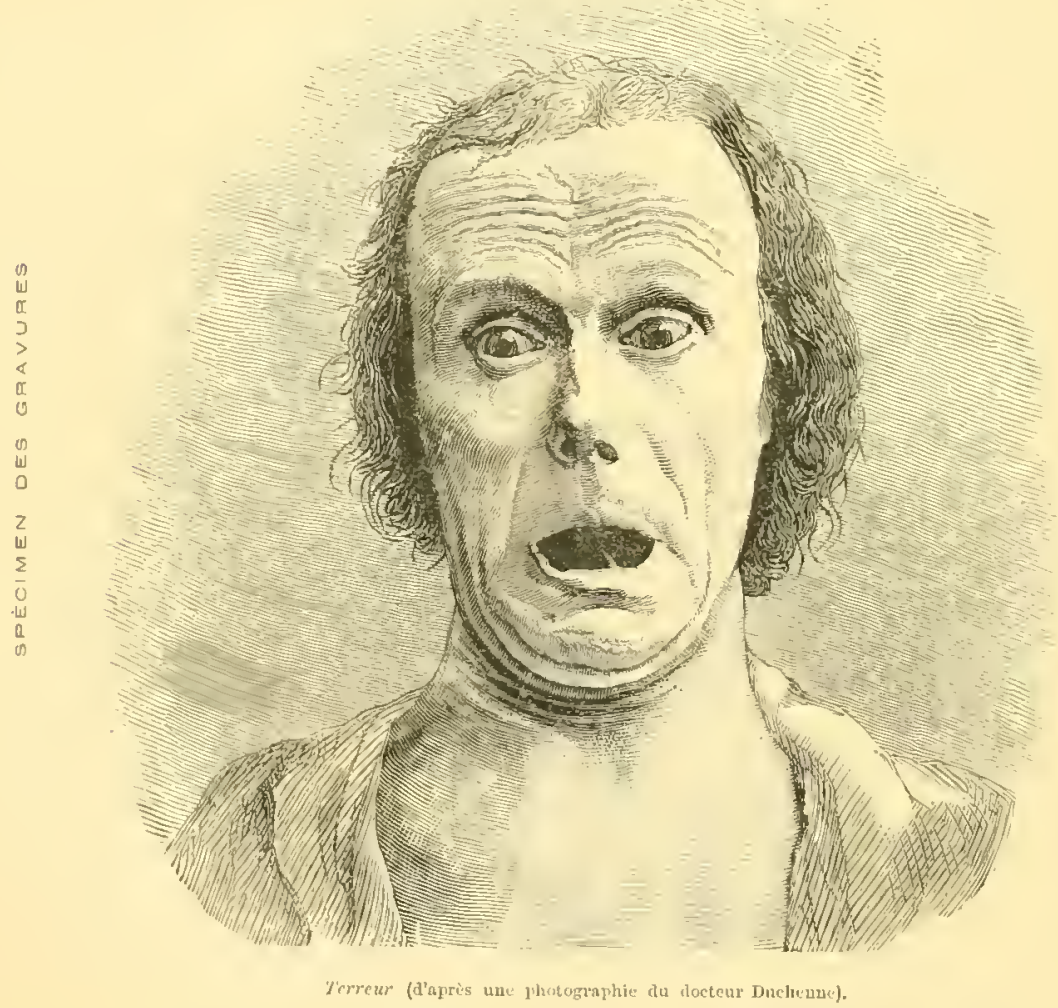

L'Origine des Espèces an moyon de la sélection naturelle, on la Iutte ponr l'existence dans la nature. T'rarluit sur l'édition anglaise léfinitive par Edmond Barbier.

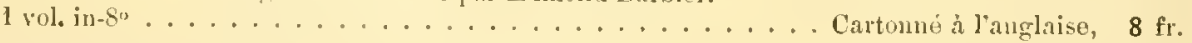

De la Variation des Animaux et des Plantes à l'etat domestique. Traduit sur la seconde edition anglaise par Ed. Barbier, preface lar. Garl Vugt.

2 vol. ill-\$, avec 43 gravures sur bois . . . . . . . . . Cartonné à l'anglaise, 20 l'r.

De la Fécondation des Orcbidées par les Insectes et des bons rèsultats du croisement. Traluit de l'anglais par la. liérolle, zo élition.

1 rol. in-so, avee 34 gravires dans le text . . . . . . . Cartomne à l'anglaise, 8 fr.

Voyage d'un naturaliste autour du monde, fait à bord du narire Beagle, de 1831 a 1836 . Traduit de l'anglais par 1l. Erl. Barbier. 2e étition.

l vol. in-8o avec gravures sur bois . . . . . . . . . Cartonné à l'anglaise, $10 \mathrm{fr}$ 
Les Mouvements et les Habitudes des Plantes grimpantes. Traluit de l'anglais sur la deuxieme édition pan le J) Richard fiordon. 2o idition.

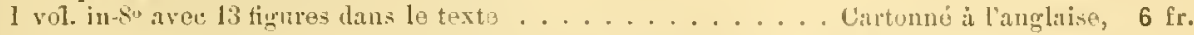

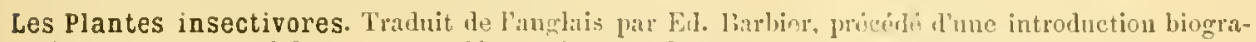
phique et augmente de notes eomplómentaires jue le profusenr Clarles Martins.

1 vol. in-su avee 30 tignres daus le texte . . . . . . . . . Cartunnè à l'anghaise, $10 \mathrm{fr}$.

Des Effets de la Fécondation croisée et directe dans le règne végétal. T'raduit de l'anglais et annoté avee l'autorisation do l'auteur, par lo $\mathrm{J}^{\mathrm{r}}$ Erlonari lleckel.

1 vol. in-go . . . . . . . . . . . . . . . . . .

Des différentes Formes de Fleurs dans les phantes do li mêmo esprece. Traduit de ranghis avee Yautorisation de l'anteur et annoté par lo Dr Edunari lleckel, précéde d'une préface analytique du professent Coutance. I vol. in-8 arec 15 gravures dans lo toxte ... Cartenné à l'anglaise, $8 \mathrm{fr}$.

La Faculté motrice dans les Plantes. Avee lin collahoration do F' Darwin fils. Traduit de l'anglais, annoté et auguenté d'une préface par le Dr Eduard lleckel.

1 vol. in-8o avec gravures . . . . . . . . . . . Cartonné á l'anglaiso, $10 \mathrm{fr}$.

Rôle des Vers de terre dans la formation de la terre végétalo. Traduit de langlais par M. Levếque, préface de M. Edmond Perrier.

1 vol. in- $8^{\prime}$ avec 15 grarures sur bois, intercalées dans lo texte . . Cartonné à l'anglaise, $7 \mathrm{fr}$.

Les Récifs de Corail, leur strueture et leur distrihutiun. Traduit lo l'anglais d'aprés la 2e édition par M. L. Cosserat. I vol. in-so avee 3 planehos hor's texto . . . . . Cartonné à l'anglaise, 8 fr.

\section{LA VIE ET LI CORRESPONDANCE}

\section{DE \\ CHARLES DARWIN}

Avec un chapilre autobiographique

\section{Publiés par son fils M. FRANCIS DARWIN}

Traduit de l'anglais

\section{Par Henry C. de VARIGNY}

Doctcur è sciences

2 vol. in-8", avec portraits, gravure et autographe. Cartonués in l'anglaise....... $20 \mathrm{fr}$.

\section{OUVRAGES DE ERNEST HAECKEL}

PROFESSEOR DE ZOOLOGIE A I'UNIVERSITÉ D'IENA.

Histoire de la Création des Êtres organisés d'après les lois naturelles. Cunfúroneos scientili-

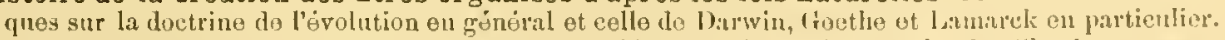

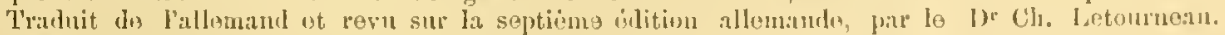

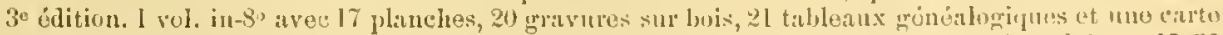

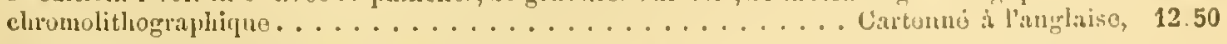

Lettres d'un voyageur dans l'Inde. T'adıit de l'allenand lar lo 1)r Ch. Lotommoan.

1 vol. in- $\delta^{\circ} \ldots \ldots \ldots \ldots \ldots \ldots \ldots \ldots \ldots \ldots \ldots \ldots$ Cartune i l'anghiso, 8 fr. 


\title{
T R A I T É \\ D'ANATOIIIE COIPARÉE \\ PRITIOULE
}

\section{CARL VOGT $_{\text {et ÉmIL }}$ YUNG}

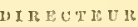

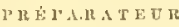

du Lat,oratoire l'Anatomie comparee de Microscopie de l'Unisersite de Genéve.

Tome I. Un vol. gr. in-8, arec 425 figures dans le texte, dont un grand nombre tirées en couleurs.

Cartonné à l'auglaise........................ $28 \mathrm{fr}$.

Le présent ouvrage formera dcux rolumes grand in-So. Le second volume est publié par livraisons de 5 feuilles chu'une, avec des grubures intercalies dans le texte. Les unze premières livraisons du tome $1 I$ sont en vente. - Prix de chaque livraison.................. 2 fr. 50

\section{AVIS TRES IMPORTANT}

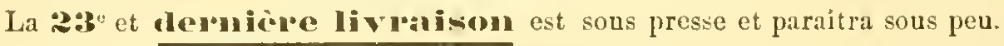

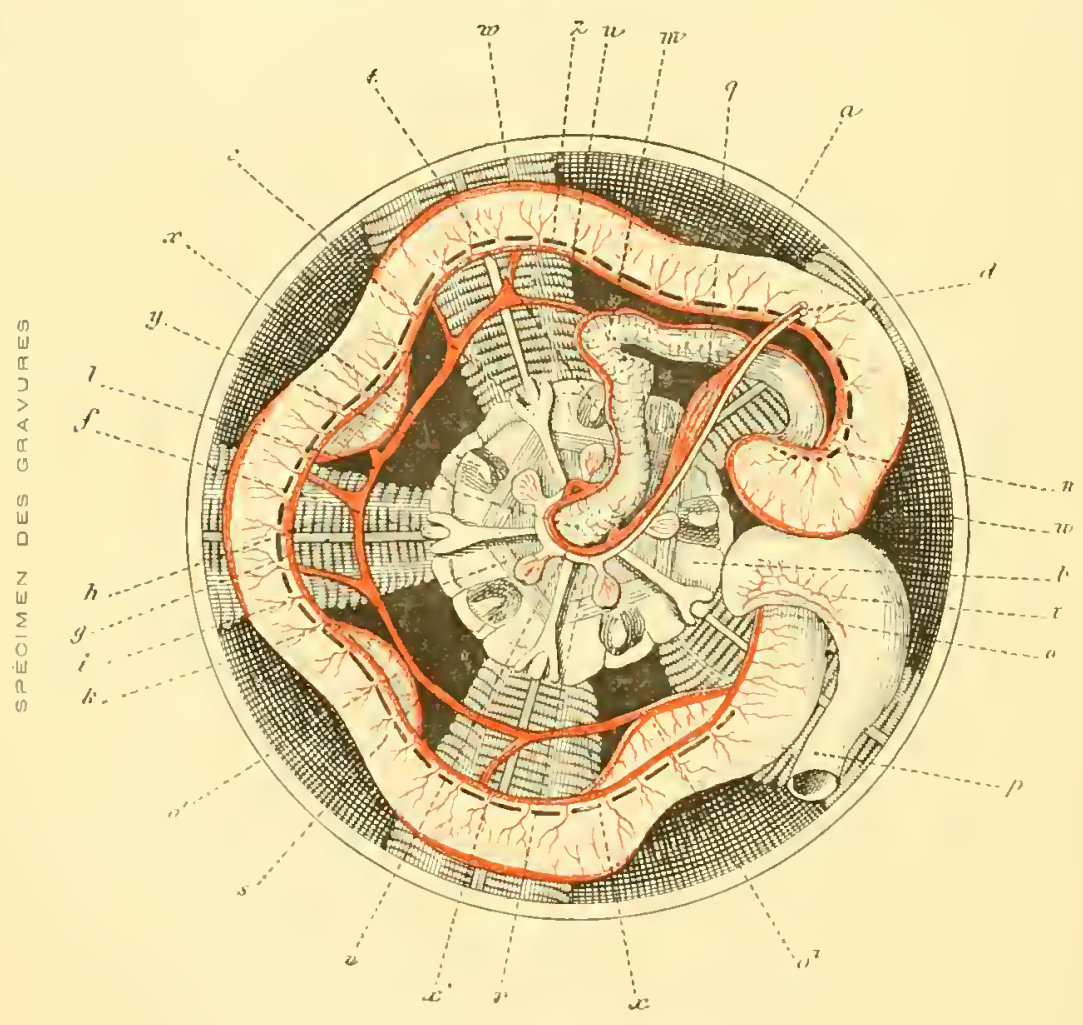

Gruvure lirus du chapitre deg Echimdes.

Le Tratle it Anatomic comjerce pratique, dont nous annongons la publication, est destiné surtout a servir de gnide dans les lavoratoires zoologriques.

Une longue experienee, atquise antant dans divers laboratoires et stations maritine's que dans la direction

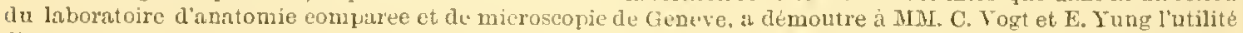

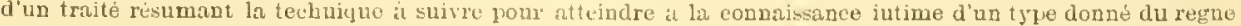
animal.

Le but de ee Traité, qui scra composé d'nue série de monographics anatomiqnes de tyjes résumant l'organisation aumale tout entière, chit de mettre l'etuliant en mesuro de questionner methodiquement in nature pour lui arracher ses suerets. En sortunt des éecles prépiratoires, le jeune hommo doit apprendro il voir, à observer, a frire des expérienees, et e'est ilors qu'il lui faut des jalous, des points de repere pour suivre uno ronte ausai herissée de diffienltes. 


\section{OUVRAGES DE CARL VOGT}

Lettres physiologiques. Premiẻe edition framçaise de l'auteur. I vol. in-So aroc 110 grarures sur

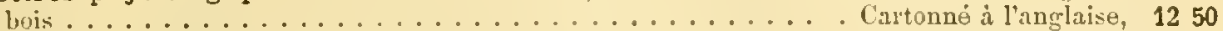

Leçons sur les animaux utiles et nuisibles. les bêtes calomniées et mal jugées. Traduit de l'allemand jar M. G. Bayret, levin par l'anten et aceompagnu do gravures sur bois. $3^{\circ}$ édition. Onvage contonno par la socicité protectrico des animan.

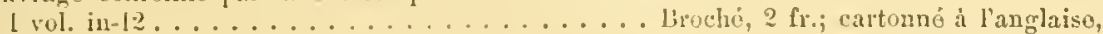

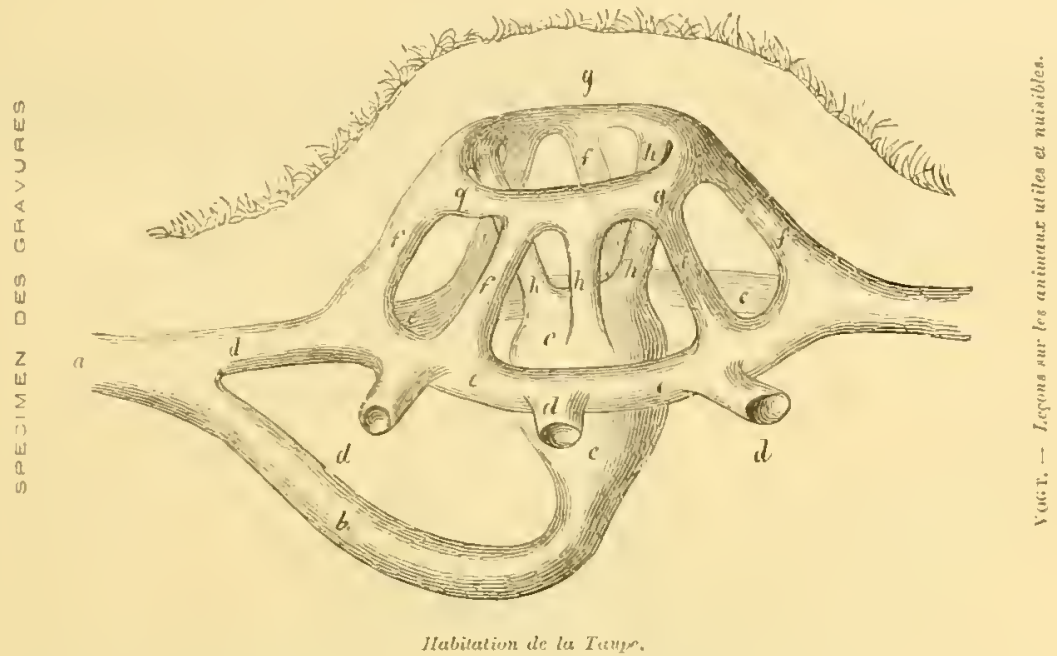

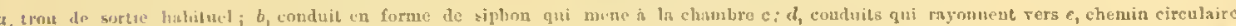

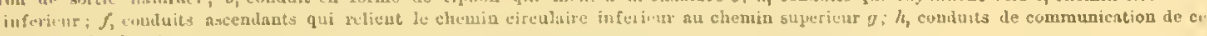
chrtain to hit chatubro c.

Leçons sur l'Homme, sa place dans la creation et dans l'luistuiro do la terre. Traduction françaiso

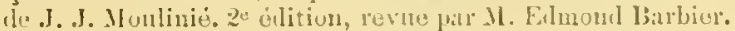

I vul. in-io avoc gravues dan- le texto. . . . . . . . . Cartonné à l'anglaise, 10 fr.

La Provenance des Entozoaires de l'homme et lon divolution. Conférence faite au Congrès international des scionces meilicales a fieneve, lo 15) soptembo 187\%. 1 rol. in-3o arec 61 tigures

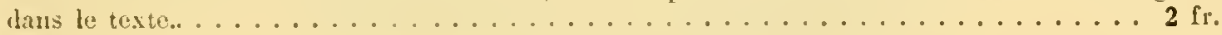

\section{OUVRAGES IEE LOUIS BUCHNER}

L'Homme selon la Science, son passe, son prèsent, son avenir, on J'vit venons-nous? - Qui sommcs-

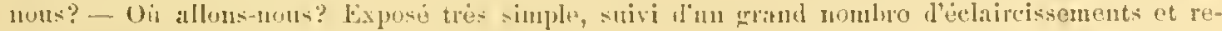

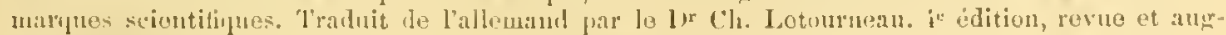

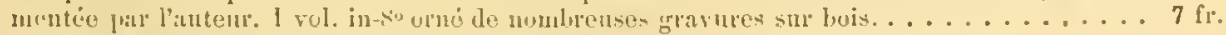

Force et Matiẻre, ou principes de l'urlie naturel do lunivers mis it la prortio do tuls, avee mus

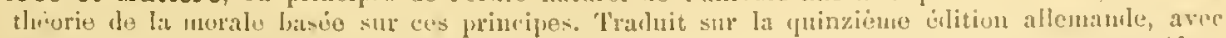

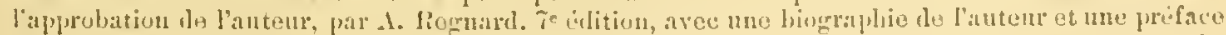
lu traductenr. I vol. in-so avec le portrat do l'antent. . . . . . . . . . . . . . . . . 7 fr. 
Conférences sur la Théorie darwinienne du la trinsmutatiun des especes et lo l'apparition du un mle organique. Application de cotto thorio a l'homm. Sas rapports avee la dowtrine lu progrés

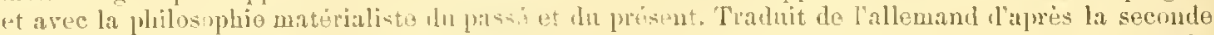

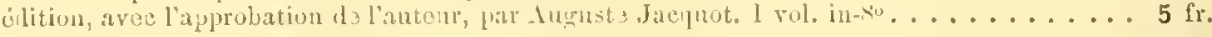

La Vie psychique des bêtes. 'Trulnit đa l'all mand par le D Cl. Lutommean. 1 rol, in-So arec gravures sur bois. Broché, $7 \mathrm{lr}$; reliés toile, tr. dorós. . . . . . . . . . . . . . $9 \mathrm{fr}$

Lumière et Vie. Truis leçons populabes l'histoire naturelle sum lo suleil dams ses rapports avec la vie, sur la circulation des fores cot la tan du nonde, sur la philosophie de la gínération. Traduit de lallemand par le Dr Ch, letuumoan. I vol. in-80. . . . . . . . . . . . . . . . $6 \mathrm{fr}$.

Nature et Science. Étules, critiques ot mémoiros, mis à la portée de tons. Douxiẻme rolume.

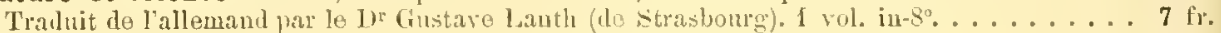

\title{
MEMOIRES D'ANTHROPOLOGIE De PAUL BROCA
}

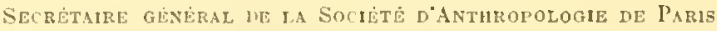 \\ Professeur a la lacultí de Mledecine, Mejbre de q'academie de Medecine
}

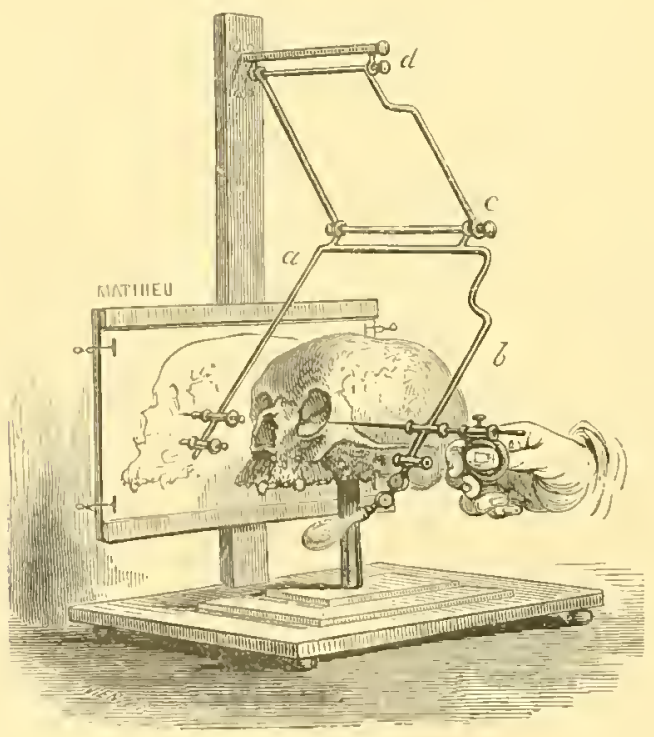

Stercograjile do Troea.

Tomes I, II et III. 3 vul. in-So avec cartes, planches et gravures. . . Cartonnés à l'anglaise, 22.50 I. tome III se vend senl séparúment. . . . . . . . . . . . . . . 7 .

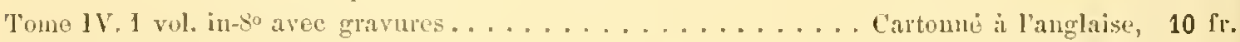

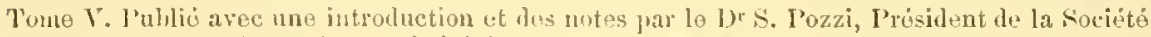

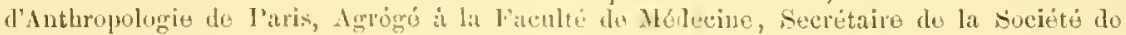
Uhirmroie.

1 rol. in-8o arec gravures. . . . . . . . . . . Cartunnó à l'anglaise, 14 fr.

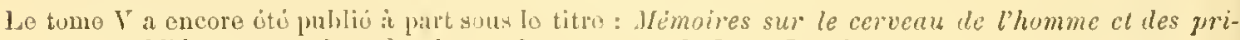
mates, jubliés suec une intruduction et des notes jar le Ior s. P'uzzi.

1 vol. in-8a . . . . . . . . . . . . . . . . . . . . . . Broché, 


\section{TR A I TÉ}

UE

\section{PHYSIOLOGIE HUMAINE}

COMPRENANT

l'llistologic el l'h hatomic unicroscopinue el les prinejejales applicalions

\section{MÉDECINE PRATIQUE \\ Par L. LANDOIS \\ Professeur de Physiologie et Directeur ale l'Institut lhysiologique de l'Universite de Gruifrwah.}

TRAULIT SIR LA SEPTIINAE EDITION ALLEMANDE

par

\section{G. MOQUIN-TANDON}

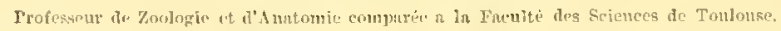

Un volume grand in-8 $8^{\circ}$ orné de 356 figures dans le texte. Cartonné à l'anghise.....

$32 \mathrm{fr}$.

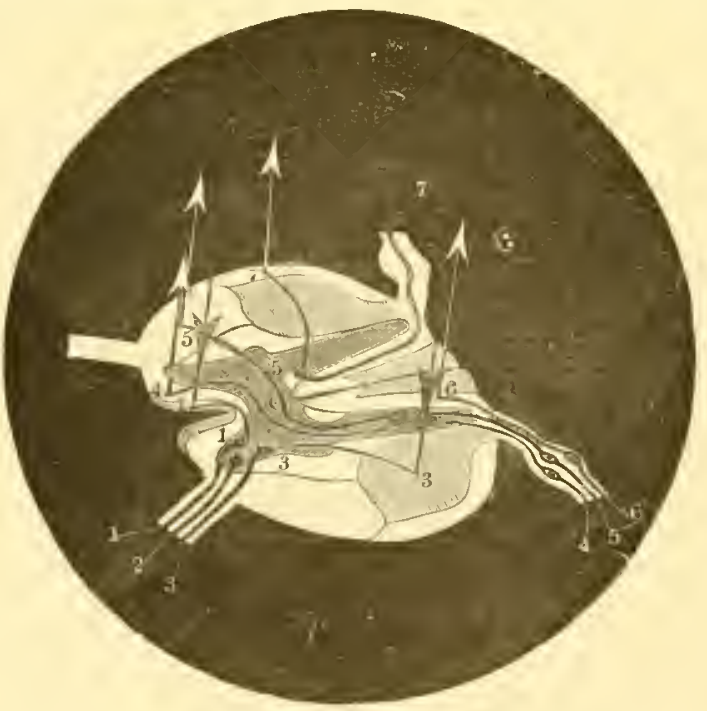

Trajet lies roies motrices ut sensitives dans in mocild.

Lo trajte do Professour Landois, ciont la premiere édition date de 1s8n, cst rapidement derenn elassique en Alleruagno. Le savant Professeur, que ses nombroux traxux sur les différentes hranches do la plysiologie, sa vaste érudition, son cxpérience de l'enseignement avaicnt preparé de longue man à une centre de ce genre, a $\mathrm{ka}$ condenser sons n ne formo clairc et coneise, sans rien omettre d'essentiel, l'enscmble de nos connaissanecs actuolles sur le fonetionnement dn corps humain. Alais ce qui constitue surtont l'originalité de son ouvrage et co qui ña pas pen contribné i en assurer le succés, éest la lareo part qu'il a faite aux applications da nédecine pratique. C'est ainsi que l'étudo des processns normaux est topiours suivic d'un court expose de lears altérations pathologiqnes; do lib sorte le lectenr peut euzbruser d'un conp d'ail les rapports qni lient les uns anx antres et ¿border plus tard avec plas de fruit l'etude de la patlologie. "est également dans lo mémo csirrit que l'auteur décrit avec plus de détails qu"on n'a l"labitudo de le friro dans les traites do physiologio les methodes ct les prouddes qn'il importe au praticien do connaitre, ot q̨u'il met largement à contribution l'histologie et l'anatomio microscopique. 


\title{
TR A ITÉ
}

\section{D'ANATOIIIE IIU IIIINE}

PAR

\author{
C. GEGENBAUR
}

PROFESSEU D'AXATOME FT DIRECTEUR DE l.'ixstitut ANATOMIQUE DE HEIDELBERG

\section{Traduit sur la troisième édition allemande}

\section{Par Charles JULIN}

Doctenr ès sciences naturclles, chargè des conrs d'Anatomie comparéo et d'Anatomio topographiquo a la Frculté de Mrédecino de Liége.

Un rolume gr. in-8 orné de 626 figures dans le texte, dont un grand nombre tirées en couleurs Cartonné à l'anglaise $35 \mathrm{fr}$.

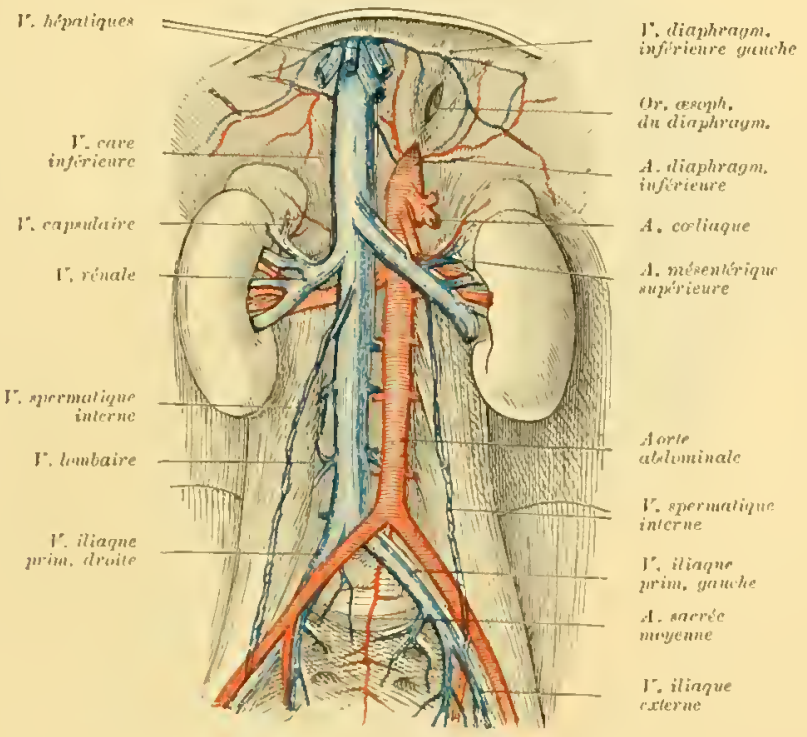

Teine cave inferieure et norte ablominale.

Personne n'étuit micax i méme do publier on Traité d'nnatomie lumaine, au point de voo comparatif et phylogénique, que M. C. Gegenbanr, à qui nous devons de si importants onvrages spéciaus et un Traité d'Anatomic comparce dont la publication a fait epeque dans lia science. Anssi sa nouvelle ouvre a-t-clle cu un sncecés éclatant. C'est de la troisième édition que nons arons entrepris la traduction française que nons livrons au mondo scientiflque et médical. Nous ne dontons nullement qno la publication de cet ouvrago no soit bion accueillic en France, où les scienecs morphologiques et médicalcs ont resa une si grando impulsion dans ces dernieres annécs.

Lo Traité d'Anatomie humaine est divisó ("n huit chapitres, Lo premier est consacré aux notions générales

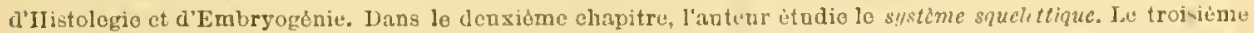

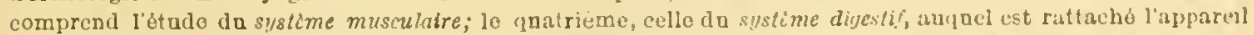
respiratoire. Lo cinquiémo chapitro traite dn sustime vusculaire; lo sixième, du suslime uro-ginilal; lo septiésno, da systime nerceux, et onfin le haitiémo, du systime cutune, comprenant la pestu et ses dérivè, ainsi que les orgines des sens. 


\section{RECIIERCIIIS SUR LA PRODUCTION ARTIFLCIELLE}

\section{MONSTIRUOSITES}

OU

\section{ESSAIS DE TÉRATOGÉNIE EXPÉRIMENTALE}

\section{Par M. Camille DARESTE}

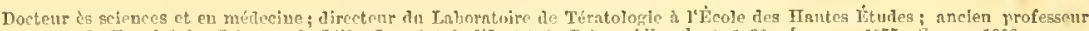
a Ia Freulté des Scjencug de Lille. Laurént de I'Instutut. PrIx : Alhumbert, 1sG2; Lacaze, 1577; Serres, 1890.

\section{DEUXIËME ÉDITION, REVUE ET AUGMENTÉE}

Un rol. gr. ill-80 orné de 62 fir. dans le texte et de 16 planches chromolithographiques. Cartonné à l'anglaise.................. $28 \mathrm{f}$ :

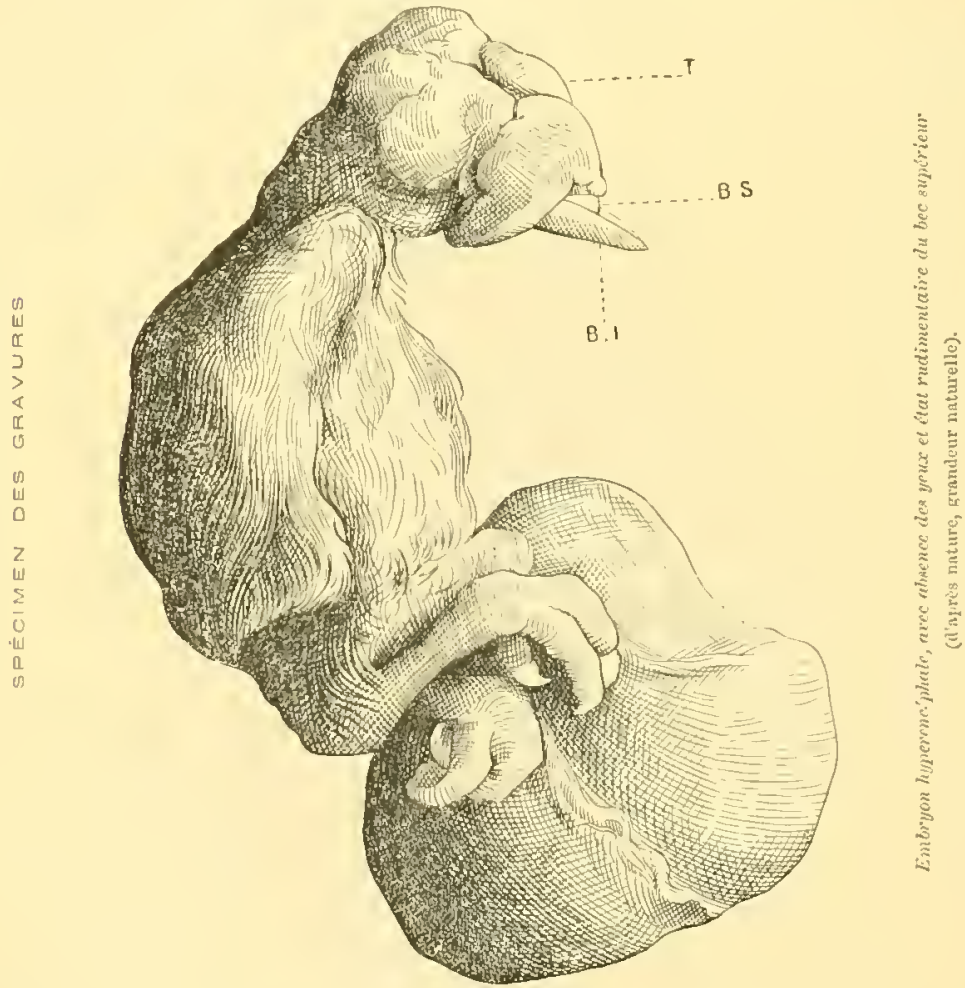

Si le merito d'avoir eréé la tératologie appartient aux deux illustres Geoffroy Sajnt-11 iaire, le Dr Dareste a eclui davoir ourert ane voie nonvelle ef fonle la tiratogénie.

I)ans son premier essai, il s'etait princigalement oceupé de l'évolution normale et monstrueuse, dont il n'avait

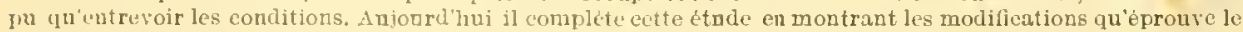
germe jendant l'epogue qui siepre la ponte de la mise et inenbation: il y a sur ee point un chapitre nouveau consuréé a l'influené des conditions lihysiques et surtout des conditions ehimiqnes, telles que eelles de l'air, de l'humidité (moisissures), du retonrncment le l'puf. ete. ete. La deuxiéme partie, qui traite de la tératogénie génerale, c'st pen modifée, sauf les piriugriph's relatils anx exees do déreloppement et aux métaluorphoses.

La troisiéme partie comprentl la teratogúnie spéciale: depuis la premiére édition, l'embryogenie da poulet a étél'ohjut de déconrertes nonvelles importautus dneśs un partie à Mathias-Dural : gráce a ces faits, M. Dareste a pu se montrer plus explieite sar clivers points. "ext lans cette partie de louvrage qu est exposé lin question de la dualité normale ot teritulogique du errur: il est anjourd'hui incontestable qne e'est bien a M. Daresteque l'on cloit ectte dieonverte, qui plus tapd, on 1K\$, a th consacrée par les experienees direetes rle Warynski et Fol : ees physiologistes ont pu maintenir l'éturtement des blustemes eardiaques de mauiére a les eontraindre à se dévelonìur isolément. 


\title{
TRAITÉ D'EMBRYOLOGIE
}

017

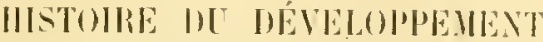

\section{DE L'IIOHIL VIT DES VERTÉBRTS \\ PAIR}

\section{Oscar HERTWIG}

Directenr du II. Institut anatomique de l'Universite de Berlin.

Truduil sur la troisieme edilion allemande

\section{Par Charles J UIIN}

Un volume grand iu-\$ orné de 339 figr. dans le texte et 2 planches en chromolithographie. Broché,

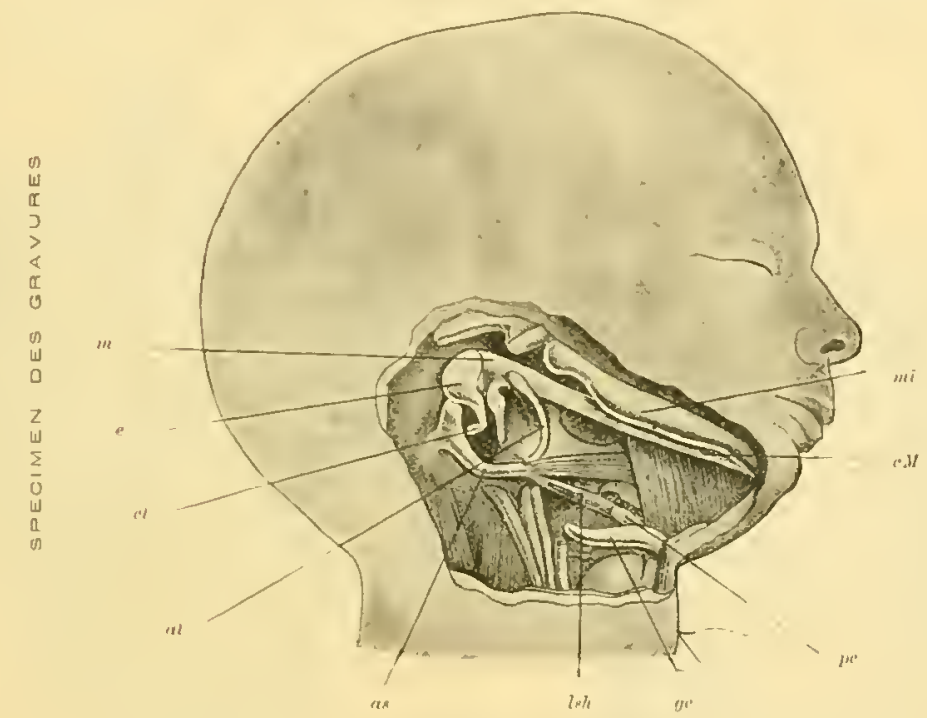

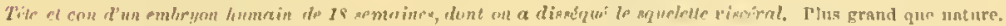
joijures Kölliker.

L'embryologie nous sert maintenant tous les jours pour reconstitner l'histoiro, non senlement desorganismes, mais encore des organes; tons les traites d'auatomio modernes l'ont priso pour base, et pourtant elle apparait eneore hérissế de difficultés à l'étndiant, quj so perd dans la complexité des plis et des fentes branchiales de l'embryon. Nous croyons que rarement nn professenr a pu arriver à la puissance démonstrative, à l'extre̊me elarté qui éclate à chaque page de ce livre d'Ilertwig, quo l'on troave toujonrs trop bref, tant il a su rassembler tontes les matiéres relatives à son sujet et les grouper de telle sorto que, ehaeune s'expliguant par les antres, il ca résultât nn tout dapparence trés simple.

Le tranté de M. llertwig a obtrnu na tel succés en Allemagne qu'en moins do quatro ans il a ou troiséditions.

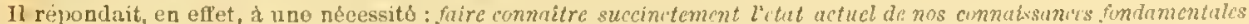

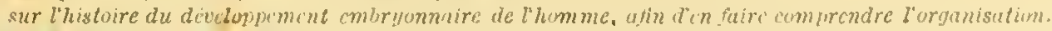

Chacun sait qn'il est inpossible de bien eomprondro l'anatomie humaine sins connaitro dans ses traits csentiels lo developpement de l'embryon humain. Aussi, dans la plupret des Fiacultés do medecino existe-t-il actnellement un enseipnement spécial do l'embryologie.

Cette pensée, qui dejá aviat inspiré M. C. Gegunbaur dans la publication de son Truile al al natumb: lamaine, a determinc $\mathrm{M}$. llertwig à écire le présent onvrage.

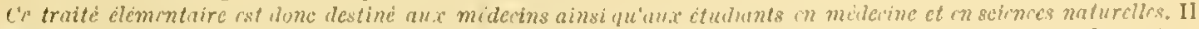

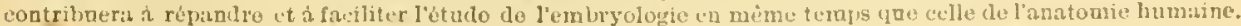

fes nombrenses figures ef planelues chromolithographiés lont il est orné aidcunt lesucoup ì la eampréJeasion des divers prouessne dn dóveloppenent. 


\section{MANUEL D'ANATOMIE COMIAREE}
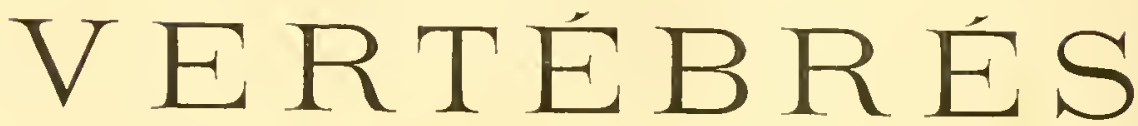

PAR

\section{R. WIEDERSHEIM}

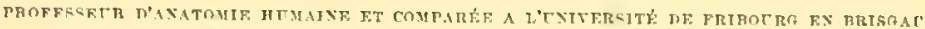

Traduit sur la deuxiome idition allemande

Par G. MOQUIN-TANDON

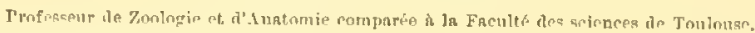

Un rol. grand in-8n orué de 302 figg. dans le texte. ....... Broché, 12 fr.

Cartonné à l'angliaise. . . 13.50

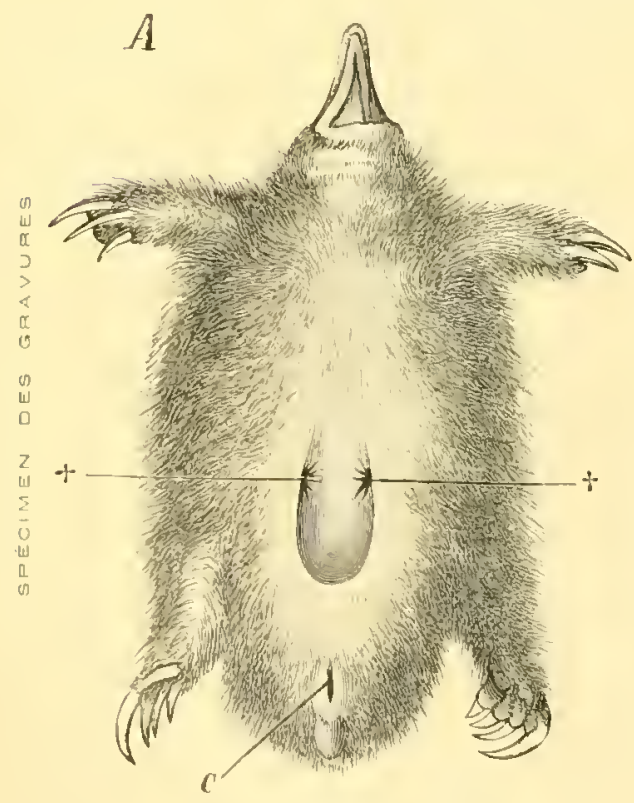

A. Fore infiriowe d"wor frumlln at Echilon hystrix yentume limontastiun.

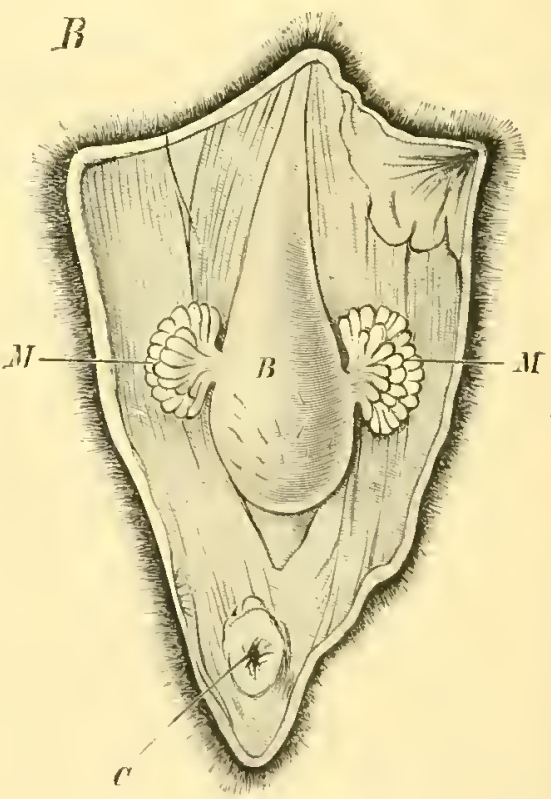

13 Fare dorarle de la prau du veutre nit la mime frmalle.

Résnmé didactique et trés clair, qui apprendra beanconp à cenx qui venlent voir comment progressent les organes en s'elevant des animaux inférieurs aux supérieurs.

Lianteur. bien contu par ses nombreux traranx sur les différents groupes de Vertébrés, s'est proposé de condenser dans un petit nombre do pages nos connaisances les plus précises sur la morphologie de ces animanx. Il ne s'est pas borne purement et simplement a passer en revne et a décrire lea formes si diremes que revètent les organes dans les différents types, mai il a essayé d'expliquer et d'interpréter ces rariations en s'appuyant sur les donnees de l'ombryologio et de la paléontologie.

Ce Manurl, qui représente ainsi sona nne forme succincte nu tablenu d'ensemble des résnltats acquis, sera. nous ez sommes convineds, bien neeneilli de tons cenx qui realent s'initier a l'Anatomie comparée des Vertèbrés, trop négligée de nos joura, et qui no pourraient trouver ailleurs de gaide meilleur et plns sùr. 


\section{BMBRYOLOGIE of TRLITÉ COMIPLET}

\section{DEVELOPPEVENT DE L'IIOVIIE ET DES ANIMAUX SUPERIEURS \\ par Albert KöLliker \\ Professeur d'anatomio à l'Université de Wurzbourg.}

Tralurtion fuite sur la 2" idit. allemande, par Aimé SCHNEIDER, Prof. à la Facultè dis siriences de Poiticrs Retue et mise an courant des derniirs connaissances par lauteur, avec une priface par $\mathbf{H}$. de LACAZE-DUTHIERS Nemtre de l'Institut de France, sons les anspices duquel la trailuction a èté faite.

1 vol. gr. in-8o avec 606 fig. dans le texte. Cartonné toile anglaisc... 30 fr.

\section{ÉLÉMENTS D'EMBRYOLOGIE}

par

M. FOSTER et Francis BALFOUR

Traduit de langlais par le Dr E. ROCHEFORT

1 vol. iu- $8^{\circ}$ arec 71 gravures sur bois. Cartonné it l'anglaise.

$7 \mathrm{fr}$.

\section{MANUEL D'ANATOMIE COMPARÉE par CARL GEGENBAUR \\ Professour à I'Tnirersité al'Hetrlelbrg}

Trantuit en francris sous la direvtion du Professeur CARL VOGT

I vol. gr. in-S arec 319 gravures sur bois intercalées dans le texte.

Brnclié, 18 fr.; cart. à l’anglaise.

$20 \mathrm{fr}$.

\section{F O R M U L A I R E}

\section{PACULTÉ DE MÉDECINE DE VIRNNE}

DONNANT LES PRESCRIPTIONS THERAPETIQUES

UTILISEES PAR TAN IPROFESETRS

Albert, Bamberger, Benedikt, Billroth. C. Braun, Gruber, Kaposi, Meynert, Monti,

Neumann, Schnitzler, Stellwag de Carion, Ultzmann, Widerhofer

Publici par le $\mathbf{D}^{\mathrm{r}}$ Théod. WIETHE, ancien chef de clinique a Vienne.

Traduit sur la se élition allemande par le $\mathbf{D} \mathbf{E}$. VOGT

2e édition, revue, corrigée et augnentéc d'un formulaire destiné á l'art dentaine.

Un fort rol. in-32, cart. toile, tranches rouges, coins arrondis. $4 \mathrm{fr}$. 


\section{MANUEL TECHNIQUE}

\section{DE

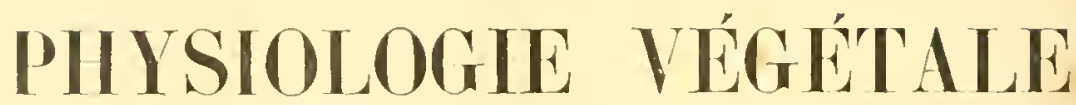

Par le Docteur W. DETMER

Professeur de l'Universite d'Tena.

TRAUUT DE T'ALEEMAN" PAR LE DOCTEIR IIENRI MICIIETLS

Revu et augmenté par l'auteur.

Un volume gr. in-8 a vec 130 figures daus le texte. Broché, 10 fr.; cartonné à Yauglaise, 11 fr. 50

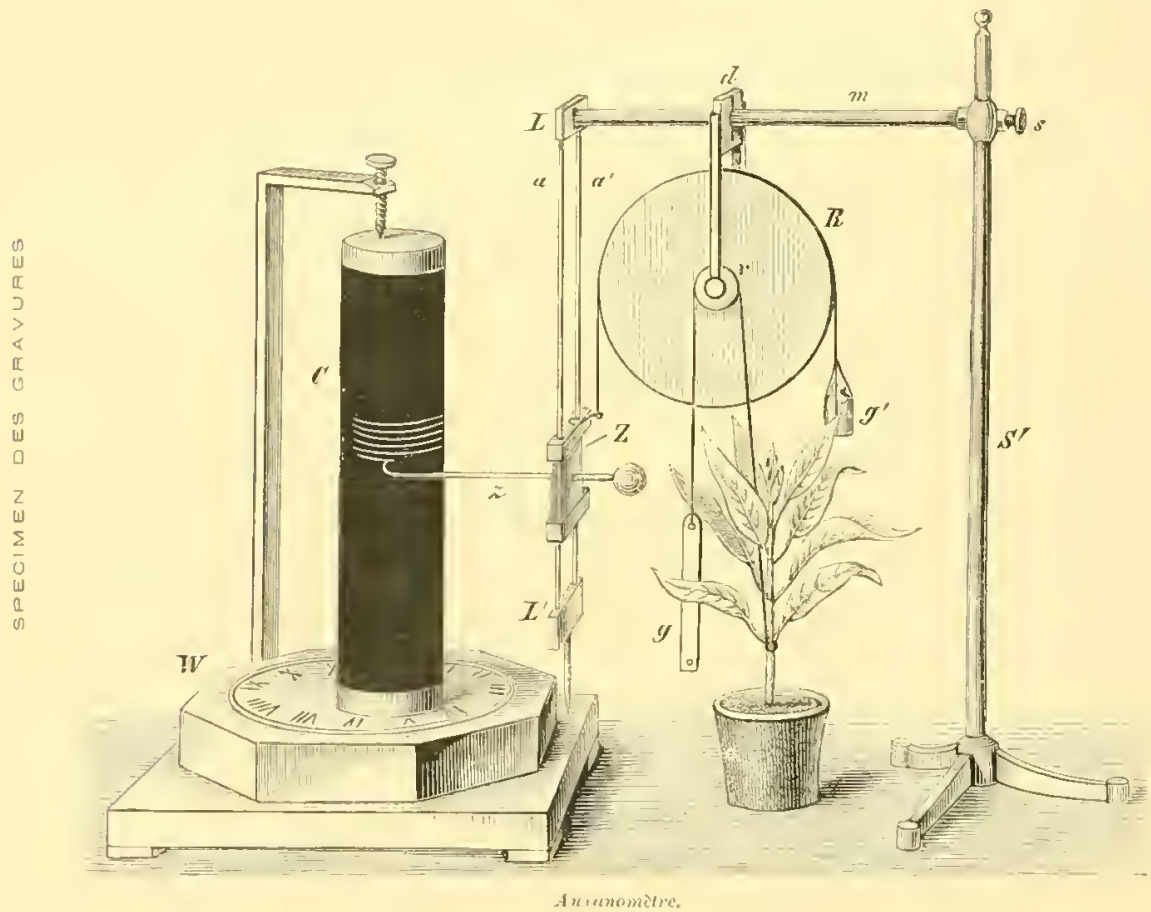

\section{LE LIVRE DE LA NATURE}

$\mathrm{OU}$

LECONS ELENENAIRES

de Physique, d'Astronomie, de Chimie, de Minéralogie, de Gèologie, de Botanique, de Physiologie et de Zoologie Par le Dr Frédéric SCHEDLER

Truduit sur la 1 se idition allemande arec l'anturisation de l'auteur et des iditeurs PAR ADOLPIH SCHFLER w IIENRI WELTER

2 volumes in-8o, avec 1,026 gravures dans le texte, 2 cartos astronomiques et 2 planches coloriées.

Broché. . . . . . . . . . . . . . . . . . . . . . . . $12 \mathrm{fr}$.

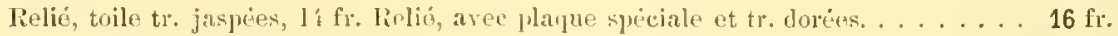

On vend séplarment :

Éléments de Botanique. I vohme in-8n, avec 237 gravires. . . . . . . . . . liroclié 2.50

Éléments de Zoologie, d'Anatomie et de Physiologie. I vol. in-\&" avec 22li grav. Broche 4 li: 


\title{
A R G I I E S
}

DE

\section{Z00LOGIE EXPERIIENTALE}

\author{
ET GÉNÉRALE
}

Histoire natarelle - Horphologie - Histologie - Érolution des animaux

PERLIEFS SOLS LA DLRFCTION DE

\section{HENRI DE LACAZE-DUTHIERS}

Membre de l'Institut de Frnnce (Acadt́mie des sciences),

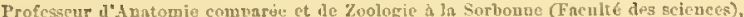

Fondateur et directeur des labuntoires de Zoologie expérimentale de lioscoff eq de la station de Banguls-sur-Mfer (Iaboratoire Amago)

Yrusideat de In Section des Sciences naturellus (Ëcole des Hantes Etudes).

Fondee en 1872, cette importante collection se compose à ce jeur de 20 volnmes lormant 2 séries, plus 2 ralumes supplementaires LE PIEMIER TOLUME DE LA 3e SH́RIE (1893) FST FX COTIKS DE PTBLICATION

I'resque tous les travaux et recherehes faits dans les Laboratoires de Zuolugie exprimentale de Roscoff (Finistere) et de la station naritime de lianvuls-sur-Mer (Trrénces-urientales) sont publiés dans les Arehives de Zoologie, yni comptent au nombre de leurs collahoratenrs des Professeur's de la Sorbonue et du Muséum, des Facultés des siciences le France et de nombrenx savants étrangers.

Les Arohices de Zoologie expérimentale el générule parassent par caliers trimestriels.

Quatre caliers on numéros forment un volume grand in-so, avec plancles noires et coloriées. Prix de l'abonnement. - Paris : $40 \mathrm{fr}$. - Iepartements ot Etranger : $42 \mathrm{fr}$.

Aucun cahier n'est vendu separement.

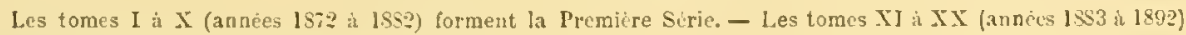
forment la Deuxiène Sèrie.

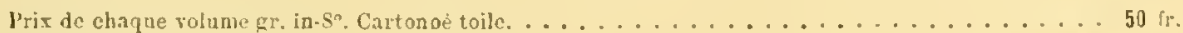

Le tome XXI (annie 1893) est en cours de publication.

Il a paru en oulre de la collection :

Le tume XIII bis (supplementaire a l'anno 185., on tome 111 bis de la deuxime sirie.

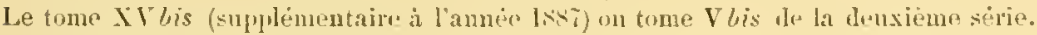

Prix de chaque volume gr. in-\$o Tartonnt toile. . . . . . . . . . . . . . . 50 fr.

\section{ESSA IS}

\section{SUR

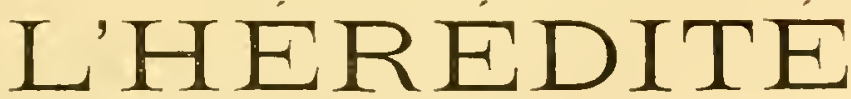

$\mathrm{ET}$

\section{LA SÉLECTION NATURELLE}

\section{par A. WEISMANN}

Irofessenr à l'liniversiti de Fribourg en Irrísgau.

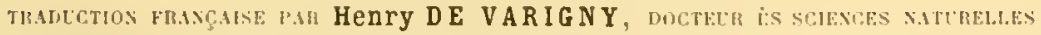

Membre de la Socictio de Biolonit.

Un volume in-8. Cartonné à l'anglaise 
ANAGNOSTAKIS (A.) - Contribulion a lhisloire de la chirurgie. La Méthode antiseptique chez

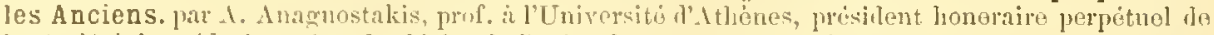

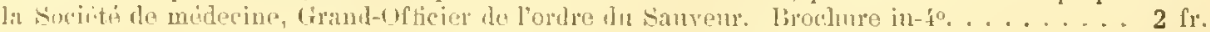

BLANG (1)r II.) - Aide-mémoire de Zoologie, par le Tr Itenri Blanc, professeur le zoologio t.

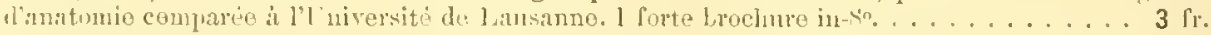

BRUNNER (Dr IJenri). - Guide pour l'analyse chinique qualitative des substances minćrales nt les acides organiques et alealoides les plus importants, prar le Ir Jenri Brumner, professen do chinio a l'Acalémie de Lansame, directem de l'Ecole de pharmacie. 1 rol. gr. in-S".

Cartonné à l’anglaise, $5 \mathrm{fr}$.

CASSELMANN (Dr Arthro). - Guide pour l'analyse de l'urine, des sériments et des concrétions mirnires au point do vuo physiologrique et pathologique, par le Jor Arthur Casselnam. Traduit do l'allimand, avee l'auturisation de l'antenr, par G. F. Stroll. Broclune in-fo, avec 2 planches. 2 fr.

CHEPMELL (le I) E. C.). - Médecine homcopathique à l'usage des fauilles. liégime, lygièno et traiteurnt, par le docten. Chepuell. Traduit ave l'antorisation de l'autem', sur la luitieme et derniere élition anglaise, par Frnest lemoine, doctenr en nélecine do la Faenlté de l'aris. 20 calit.

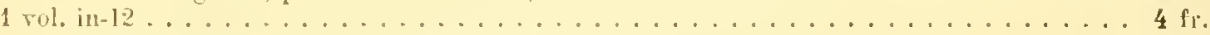

— Traitement homoopathique du choléra. Fxtrait le l'Homanpalhie des Fumilles, du doctenr Chepmell. Traduit sur la terniere élition anglaise, par Ernest lemoine, docten en wérlecine do la Faculte do I'aris. Brochure in-12 . . . . . . . . . . . . . . . . . 25 c.

GOULON (hilimond). - Synthèse du Transformisme. Nescription ólémentaire de l'urolution unirerselle, par liaimond Coulon. 1 volume grand in-ko. . . . . . . . . . . . . . $5 \mathrm{fr}$.

COUTANCE (A.). - La Lutte pour l'existence, pal A. Contance, professem d'histuire natmrello i l'Ecrle d médecine navalo de Brest. 1 rol. in-fo. . . . . . . . . . . . . . . 7.50

GADEAU DE KERVILLE (IIenri), - Causeries sur le Transformisme, par Henri fadean de Keu-

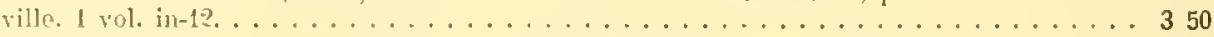

GORUP-BESANEZ (IN E.). - Traité d'analyse zoochimique qualitative et quantitative. Cnide pratique pour les recherches physiologiques et cliniques, par le In E. Gormpliesanez, prof. de "himie a l'Universite d'Erlangen. Traluit sur la troisieme édition allemande et angmenté par le 1) L. Gantier. I rol. grant in-\$o, avec 129 fignres dans lo texte. . . Cartouné id l'anglaise, 12.50

GRABE (C.). - Guide pratique pour l'analyse quantitative, par C. Grielie, professem a l'Uni-

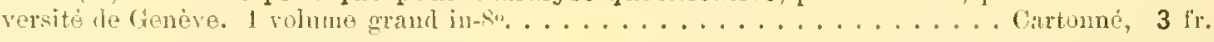

HUXLEY (T. H.). - Leçons de Physiologie élémentaire, par. T. 1I, lIuxley. 'Traluit de l'anglais

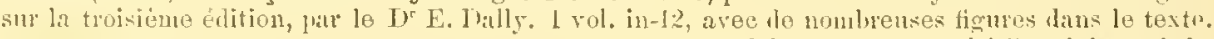
liroché, 350 ; cartonnó à l'anglaise, $4 \mathrm{fr}$.

JORISSENNE ( $\mathrm{D}: \mathrm{G} \cdot$ ). - Nouveau signe de la Grossesse, par le D) G. Jorisanne. Broclume

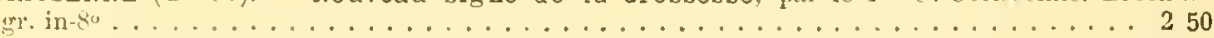

LABARTHE (l’.). - Les Eaux minérales et les Bains de mer de la France. Noureau guile pra-

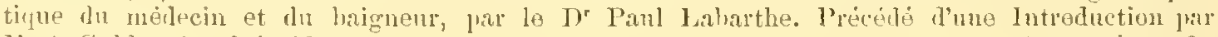

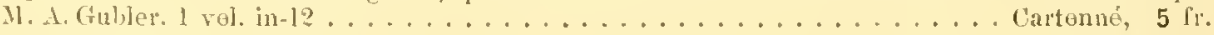

LARBALETRIER (A.). - Le Tabac. Etudes historiques, chimiques, agronomiques, inlustrielles, Iỵgiéniques et fiscales sur lo tabac a fumer, à priser et à mâcher. Manuel pratique ì l'usage lles

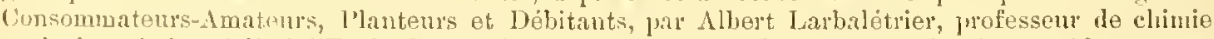

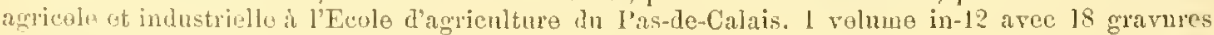

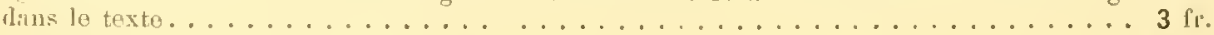

LUBBOCK ( . olu Lulhock. Trad. par Edmond liarbier. 1 vol. in-12 avee 131 gravmes dans le texte.

jiraché, 2 î); cartanué à l'anghaise, plaque spéciale, $3 \mathrm{fr}$.

- De l'Origine et des Métamorphoses des Insectes, par Sir Jolm Lubbock. Trafuit par Jules

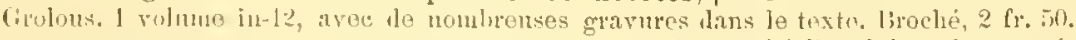

cartonné ì l'anglaise, plache spéciale, $3 \mathrm{lr}$.

MAGNUS (Jugo). - Histoire de l'Évolution du sens des couleurs, par llugro Magmus, profescenr

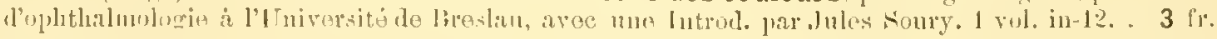

MARGOU (.1.). - De la science en France, 1r.r. . Marcon. 1 vol. in-s". . . . . . . . . . 5 lir.

MARTIN (Hrunst). - Histoire des Monstres, depmis l'autiqnité jusqu'ù nos jours, par le 1) Erums

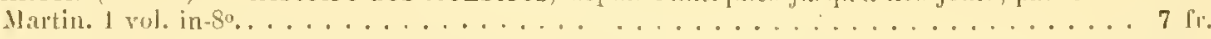

MOHR (Nr.). - Toxicologie chimique. Guilo pratique pour la detemination chimique des poisons,

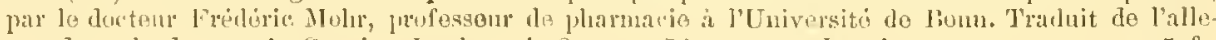
mand par lo doctenr I. Gautior. 1 volune in- $8^{\circ}$, arvec 50 gravures dans le texte... . . . 5 fl. 
REICHARDT (E.). - Guide pour l'analyse de l'Eau, an point de me de l'hygiene et de l'induntrie. Précédé de l'kxamen des prineipess sur lesquels on doit s'appliquer dans l'appriciation de l'eau potahle, par le docteur E. Roicharlt. T'raduit de l'allemand avec l'auturiaation de l'auteur. par G. E. Strohl. 1 rol, in-so, aree 31 tig. dans te texte. . . . . . . . . . . . 4.50

Revue d'Anthropologie. Publice sons la direction do II. Panl liroca, secrétaire géneral de la sincieto d'Anthropologie, directenr du Laboratoire d'Anthropologie de l'Ecolo des Hantes Etudes, professeur

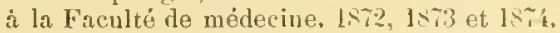

Ire, $2^{e}$ et $3^{\circ}$ années ou volumes $1,11,31$.

Cliague volume, $20 \mathrm{fr}$.

ROMANES (G. J.). - L'Évolution mentale chez les Animaux, jau Garorgo Joln Romanes. Suivi d'un essai postlume sur l'instinct par Clarles Darwin. Traduit de l'anglais par le Dr ] enry C. de Varigny. 1 vol, in-So aree 4 figures dans lo texte et I fruntispice. . Cartomio a l'anglaise, 8 li.

ROSSI (D. C.). - Le Darwinisme et les Générations spontanées. ol liéjonse anx réfutations de

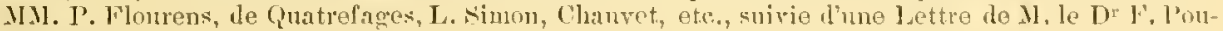

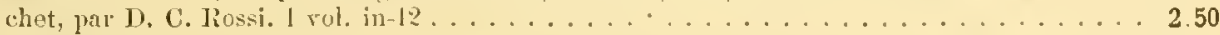

SACHS (1)r J. ron). - Histoire de la Botanique, du xvic sicele it LSfo, par le l) J. ron Sachs, professeur de botanique à l'Lniversité de Würzbuntg, ete. Traluetion françase prar llenry de Varigny,

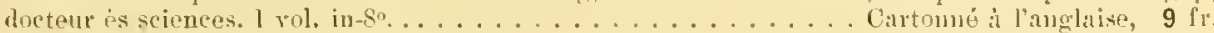

SCHLESINGER (R.). - Examen microscopique et microchimique des fibres textiles, tant natırelles "pue teintes, suvi l'un Essai sur la Caractérisation do la haine régénéréo (shoddy), par lo

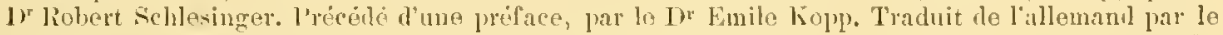
I) L. Gautier. I volume in-so, avec 32 gravures dans le texte. . . . . . . . . . $4 \mathrm{l} r$.

SCHMID et Fr. WOLFRUM. - Instruction sur l'Essai chimique des médicaments, a l'ısage des Médecins, des l'larmaciens, des ] rognistos et des Eleves qui púparent lours derniers examens

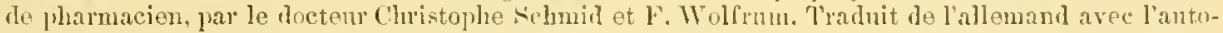
risation des auteurs par lo doctour G. E. Strolıl. I vol, gr. in-R"... . Cartonné ì l'anglaise, 6 fr.

SCHORLEMMER (C.). - Origine et développement de la Chimie organique, par C. Schorlemnuer. Traduit de l'anglais, avee l'autorisation de l'antenr, par Alexandre chanaride. I rol. in-12, avec fignres. . . . . . . . . . . . . Cartonué à l'anglaise, tranches rongess, 350

STAEOELER (f.). - Instruction sur l'Analyse chimique qualitative des substances minérales, par f. Staedeler, rovue par II. Kolbe. Traluit sur la sixieme édition allentaude, par le I $^{\prime}$ L. Gantier, avec une gravure dans lo texte et un tablean colorie d'analyse spectrale. I volume in-12. . . . . . . . . . . . . . . . Cartonne ì l'anghaise, 2.50

WALLACE (1. li.). - La Sélection naturelle. Essais jar Alfred-linssel Wallace. Tradnit dle l'anglais sur la denxieme idition, avec l'antorisation de l'autenr, par Lucien de Cimbolle. 1 volume

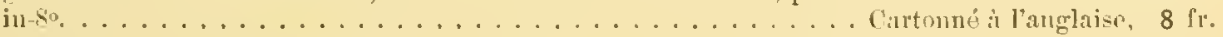

YUNG (Émile). - Hypnotisme et Spiritisme (Les faits positils et les faits jmésmús). Confërences

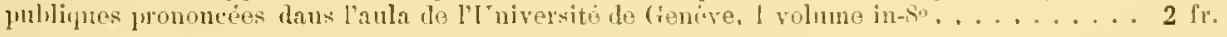

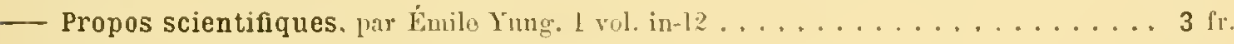

Tableaux synoptiques de la classification des Animaux, dressés par Ėulo Yung, pro-

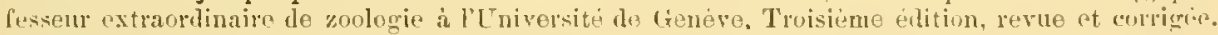

Broclute intsin.

\title{
LA TERRE
}

\section{EVOLUTION DE LA VIE A SA SURFACE}

\author{
SON PASEE, SON PRÉEET, SON AYENJl:
}

P.IR

\section{Emmanuel VAUCHEZ}

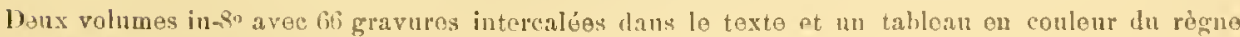
végétal et du rigne animal. 


\section{I. - Philosophic \\ L'ÉVOLUTION RELIGIEUSE}

DANS LES

\section{DIVERSES RAGES HUMAINES}

PAR

\section{Ch. LETOURNEAU}

Secrétaire général de la Société d'Anthropologie, Professeur A l'Éeolo d'Antliropologie.

Un volume in -8 ................ $10 \mathrm{fr}$.

ASSIER (Adolphe (1'). - Essai de Philosophie naturelle. Te Ciel, la T'erre, l'Homme, par Adulphe d'Issier.

Premiere ratie : le riel. I vol. in-1?.................. 250

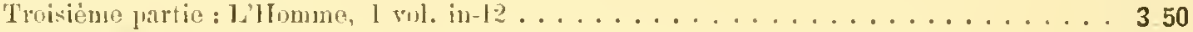

BÉRAUD (T. H.). - Étude sur l'Idée de Dieu dans le spiritualisme moderne, par P. M. Béraul. 1 vol. int-12. . . . . . . . . . . . . . . . . . . . . . . . $4 \mathrm{fr}$.

BORDIER (Ir A.). - La Vie des sociétés, par lo J)r l. liordier, professenr à l'École d'Anthopologie de Paris. $!$ volume in $8^{\circ} \ldots \ldots \ldots \ldots \ldots \ldots \ldots \ldots \ldots \ldots \ldots \ldots \ldots \ldots . \ldots \ldots$ fr.

BRESSON (Léopolii). - Idées modernes. Cosmologie, Sociologie, par Lóopold liresson. I vohume

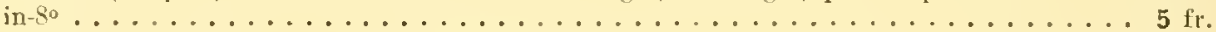

— Eludes de sociologie. Les trois évolutions, intellectuelle, socinle, unrale, par Léopold liresson. 1 volumo in-8. . . . . . . . . . . . . . . . . . . . . . . . $6 \mathrm{fr}$.

BURnouf (Émile). - La vie et la Pensée. líments réels do Philosophie, par Émile Burnouf, dirertem honoraire de l'Ecole d'dthénes. I rul. in-fo aree gravires dans le texte . . . . . $7 \mathrm{fr}$.

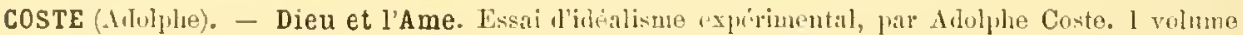
in-12. . . . . . . . . . . . . . . . . . . . . . . 250

DIDEROT. - Euvres choisies. Edition du ventenaire (30 juillet 1\&8\}), publice par les soius dz

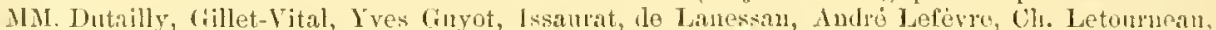

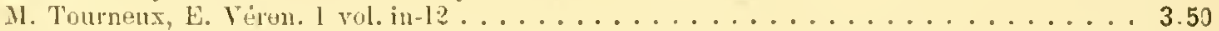

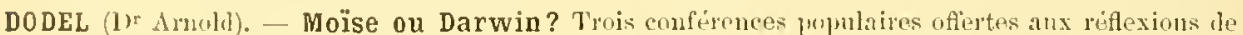
tous cenx qui cherchent la virite, par lo Jr Aruoli Dodel, professeur titulaire le hotanique a l'Uni-

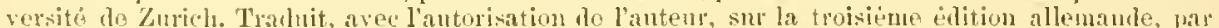

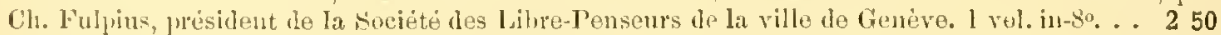

GENER (Pompero). - Contribution it l'étude de l'évolution des idées. La Mort et le Diable. Ilistoire

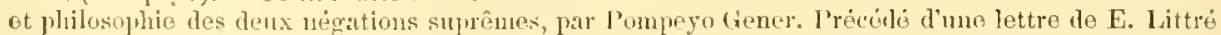

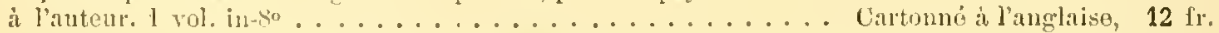

GIRARD DE RIALLE. - La Mythologie comparée. ToMf preMIfr : Theorie du fétichisme. - Solcier's et sorcellerie. - Le fétichisme chez les Cal'res, che\% les anciens Chinois, chez les punples

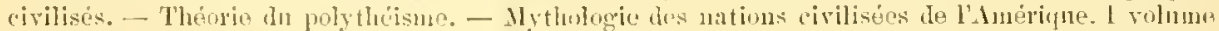

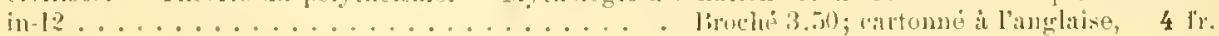

GUBERNATIS (Mngrolo dNo - La Mythologie des Plantes, ou les Légendes du règne végétal.

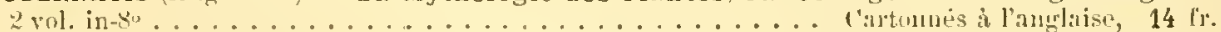

ISNARD (e docten Félix). - Spiritualisme et Matérialisme, par le dectenr Fílix Ismart. I rol.

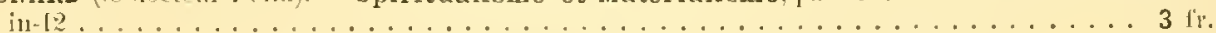

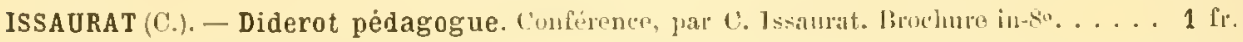

LANGE (F. A.). - Histoire du Matérialisme et critigno dr son intrortance a notre ciprpue,

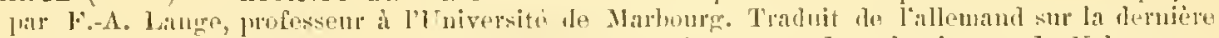
Gulion, avec l'autorisation de l'auteus, far b. l'ounerol, aree une lutrolnetion par 1). Nolen.

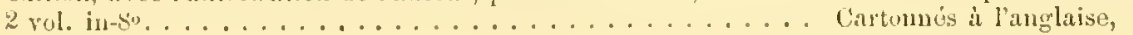


LETOURNEAU (Ch.). - Physiologie des Passions, par Ch. Letourneau. 2e edit., revie et anonentede. 1 vol, in-l?.

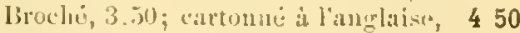

Science et Matérialisme, par Ch. letourneau. 1 vol. in-12

lirohè, i. jil; cartonné à l'anglaise, 5.25

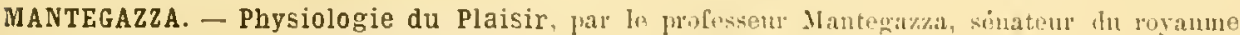

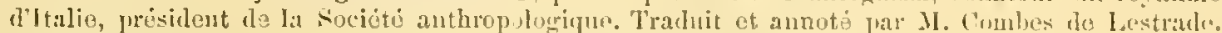
I vol. in-So.

MAUDSLEY (Ienry). - Physiologie de l'esprit, par IIeny Maulshey. Thaluit rle l'anclais pal

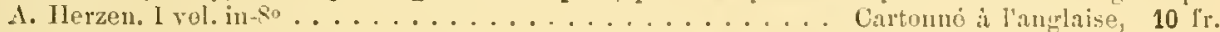

MICHEL (Louis). - Libre arbitre et liberté, par Louis Michol. I volume in-12.

MULLER (l. Max). - origine et développement de la Religion, étudiós à la lunièro dos religions de l'Inde. Leçons faites a Wostninster Abbey, par $\mathbf{F}$. Max Mullor. Traduites do l'anglais pa

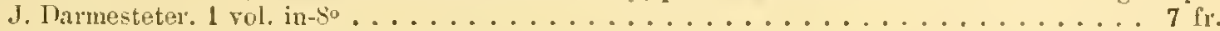

PICHARD (Prosper). - Doctrine du réel. Catéchisme à l'usago des geus qui ne se payent pas rlo mots. Précédé d'une préface par E. Littro. Fouvello élition. I rol. in-1?. . . . . . . . . 2 fr.

POL DE SAINT-LÉONARD. - Les Fils de Dieu et les Célestes intermédiaires. I volume

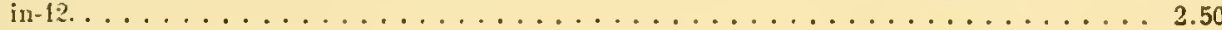

POMPERY (E. de). - La morale naturelle et la religion de l'humanité, jar Edouatel de Ponpery. 1 vol. in-12 élégaument lur. avec couverture siuili-japon. . . . . . . . . . . . . 3.50

- Quintessences féminines, par E. do I'vnpery. l vol. in-12. . . . . . . . . . . . 3.50

- Simple métaphysique, par Elouad de Poupery. 1 broch. iu-8o, avec supplémont. . . 1 tir.

— Les Thèlèmites de Rabelais et les Harmoniens de Fournier, par E. de l'oupery. 1 bro-

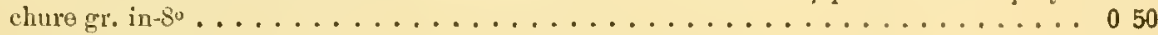

La Vie de Voltaire. L'llomme et son oenre, par E. de Pompery. 1 rol. in-12 . . . . 2 fl'.

ROLLAND (Camille). - Esprit et Matière, ou Yotions populaires de Plilosophie scientifique, suivies do l'Arbre généalogique complet de l'homme, d'après les données de IIaeckel, par Camille líolland, ingénieur. 1 rol. in-12 avec deux planches. . . . . . . . . . . . Cartonné à l'anglaise, 2.50

RUELLE (Ch.). - De la vérité dans l'Histoire du christianisme. Lettres d"un laìiuo sur Jésus, pal Ch. Ruelle, auteur de la ścience populaire de Claudius. - La thólogio ot la science. MI. Renan et les thóologiens, - La résurrection de Júsus d'après les textes. - Lecturo de l'ency-

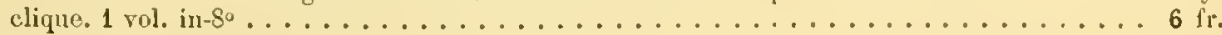

SETCHÉNOFF (Ivan). - Études psychologiques. 'Traduit du russe par Victor Durély. Avec uno

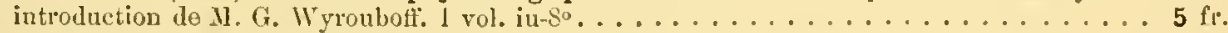

SOURY (Jules). - Études historiques sur les religions, les arts, la civilisation de l'Asio antérienre et de la Grèce, par Jules soury. I vol. in-\$o. . . . . . . . . . . . . . . . . 7.50

SPINOZA (B. de). - Lettres de B. despinoza inedites en français. 'luadnites et aunotóos par J.-G. P'rat.

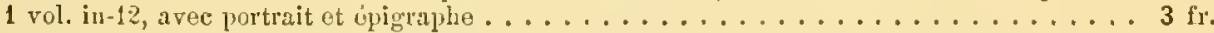

STRAUSS (David-Frédérie). - L'Ancienne et la Nouvelle foi. Confession par David-Frédẻric Strauss. Traduit de lalleurand sur la se édition par Lonis Narval, et angmenté d'uno l'réfaco par E. Littrü.

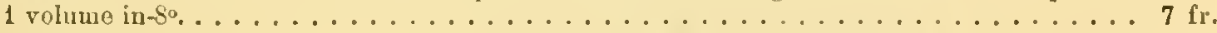

Voltaire. Six confórencos de David-Iródóric Stranss. Traduit do l’allenand sur la troisiómo édition par Louis Narval, précédo d'une Lettre-Prélaco du traducteur ì. N. Littró. 1 vol.

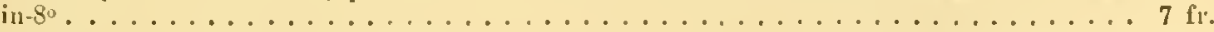

TYLOR (M. Fdward B.). - La Civilisation primitive, par Il. Edward B. Tylor. 'Tomo 1. Tradirit de l'anglais sur la deuxiene edition par Ilmo Paulino Brunet. - Touo 1I. Tradnit de l'anglais suj

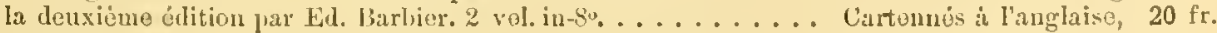

VIARD0T (Lonis). - Libre examen. Aprolorie d'un incrédulo, par Lonis Viarlot. $0^{0}$ udition tris augr-

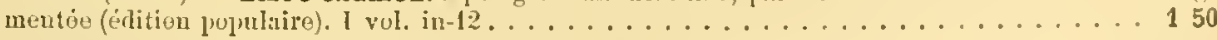

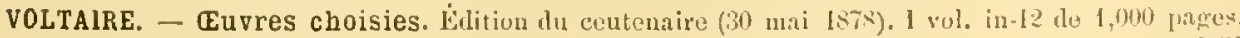
avec portrait do Voltaire, . . . . . . . . . . . . . . . . . . . . 250 
III. - Archéologie - Prélistorique

\section{TIRYNTHE}

\section{LE PALAIS PRÉHISTORIQUE}

DES ROIS DE TIRYNTHE

\section{RÉSULTAT DES DERNIERES FOUILLES \\ Par Henri SGHLIEMANN}

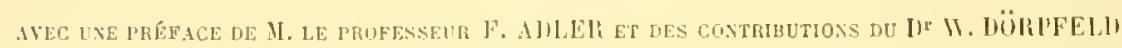

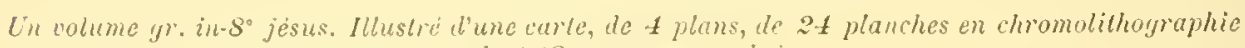
et le $1 \mathrm{~s} \&$ gravures sur luis.

Caltonnage anglais non jogné, arec titre en noir..................... 32 fr.

Retie en demi-maroginin, plaques speciales ur et noll, dore sur tranches.......... 40 fr.

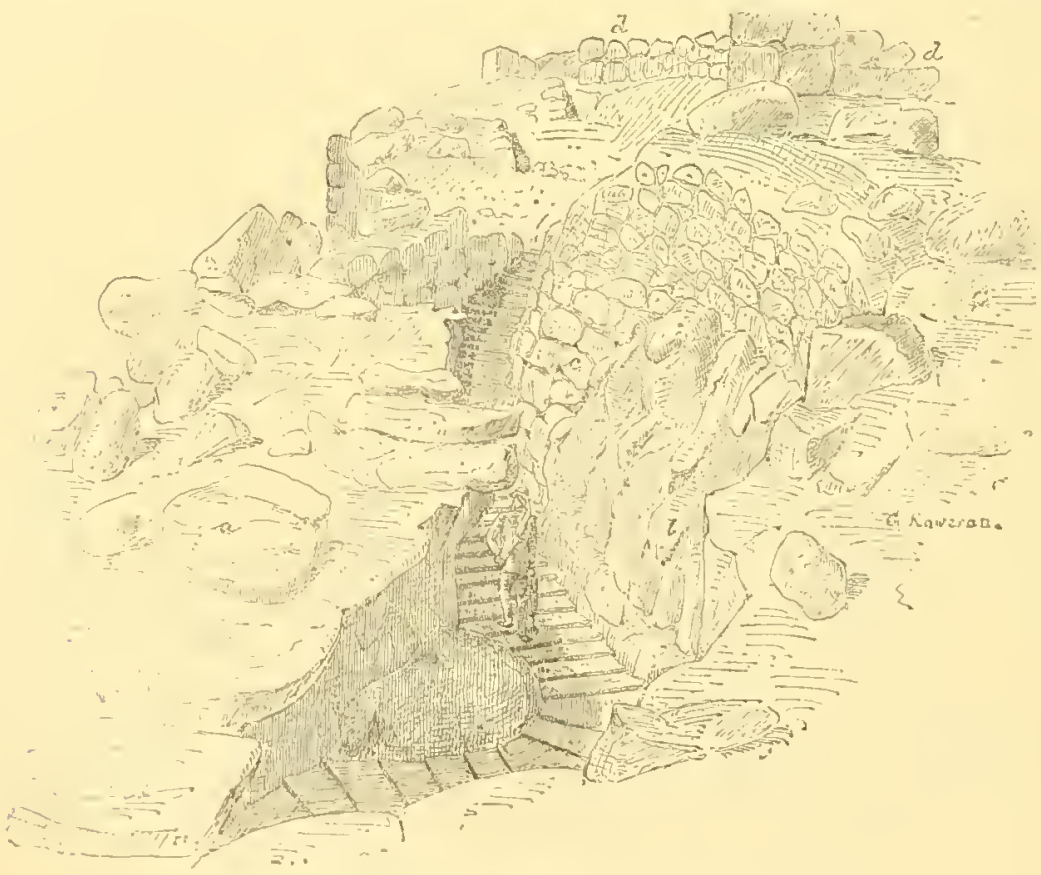

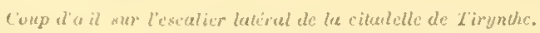

CHANTRE (Ernst). - Recherches anthropologiques dans le Caucase, par Eruest Chantre. sons-

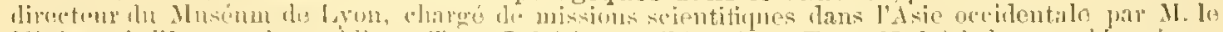

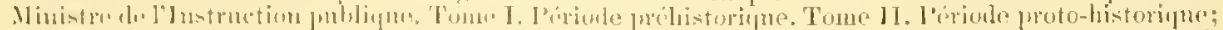

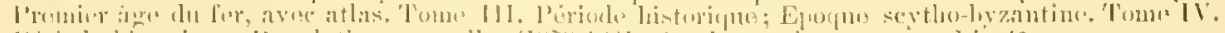

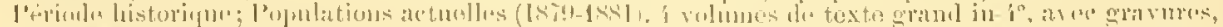

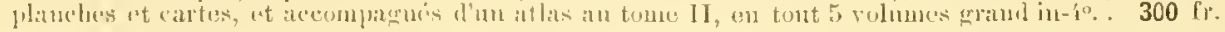

DESOR (li.) "t l'. le LORIOL. - Echinologie helvétique. Description des Oursins fossiles de

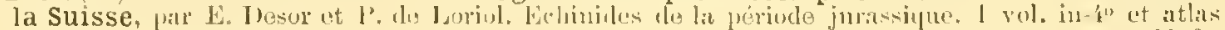

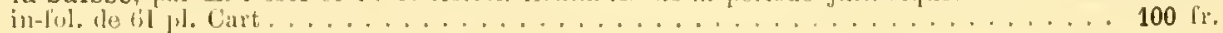

lionvritge a été public en li livraisons. 
HABERT (Théophile). - La Poterie antique parlante. Monographio contenant plus de 1,800 noms et marcques de potiers gallo-ramains, 37 jlanches intóessant l'Anbe, la Côte-d'Or, la Marne, lit Haute-llarne et l'Yomne, par Théophile Habert, archóolorne.

1 rol. de texte et $11 n$ album te 37 planches in-io.

$45 \mathrm{rr}$.

LEPIC (le vicomte). - Grottes de Savigny, commune de l.2 Iiolle, canton d'Albens (Saruic), y:u

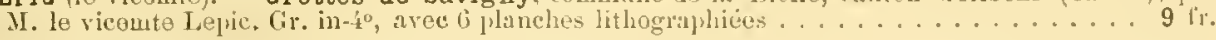

LEPIC (le ricente) et Jules do LUBAC. - Stations préhistoriques de la vallée du Rhỏne, en

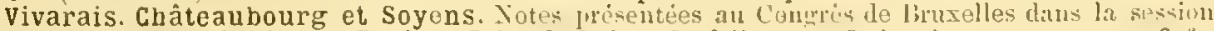

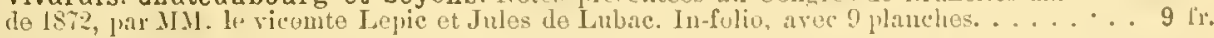

Matériaux pour l'histoire primitive et naturelle de l'Homme. lievue mensuelle illustrér, fon-

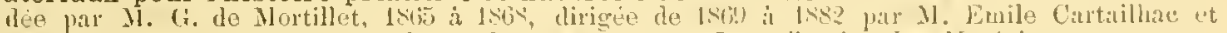
E. Clantre. Format in-80, avec de nombenses gravures. La collection oles . latériaux so eompusis

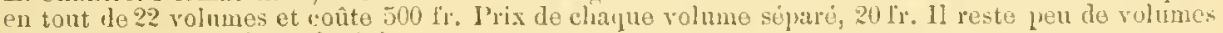
sejpares, la plupart étant épuises.

MORTILLET (Gabriel (le). - Le Signe de la croix avant le christianisme, par Galriel do Mortillet. I vol. in-So, avec 117 gravures sur bois . . . . . . . . . . . . . . . . . . 6 li.

MORTILLET (Gabriel et Adrien de). Musée prénistorique, par Galriel et Adrien do Jortillot. Album lo 100 planches contenant 800 dessins classós muthodiquement. I vol. in-10..... 35 li.

NILSSON (Sven). - Les Habitants primitifs de Ia Scandinavie. Essai d'ethuographio comparie,

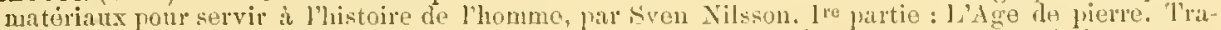
duit du suedois sur lo manuscrit de la troisieme edition proquée par l'auteur. I vol. in-so, aver: 16 planches. . . . . . . . . . . . . . . . C.artonné à l'anglaise, 12 l'ı.

RHOMAIDĖS (C.). - Les Musées d'Athènes, gr. in-10 avec texto grece, allemand, français et anglais. (Atliènes).

Cet ourrage parait par livraisons avec texte et planches. Les 2 promiires sont en vente. Chaque livraison, $7 \mathrm{fr} .50$

SALMON (Philipne). - Dictionnaire paléoethnologique du déprartement le l'Auhe, jrar l'Jiliprn Salmon, nembre de la Commission des monmments mégalithifues do France et d'Mgérie, memlin

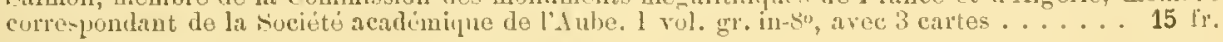

— Les Races humaines préhistoriques, jar Thilippe silmon. Hrochure gr. in-So . . . 250

VANDEN-BERGHE (Maximilien). - Elules anthropoloriques. L'homme avant l'histoire, notions

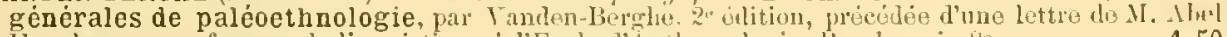

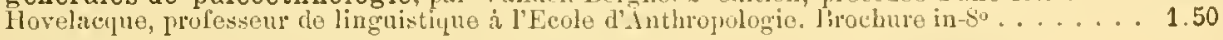

\section{IV. - Hisloire - Géographie - Politique}

BORDIER ( $\mathrm{Dr}^{\circ}$ A.). - La Colonisation scientifique et les colonies françaises, pir le l) 1 . lió-

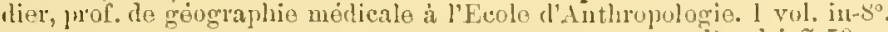

Broclec, 7.50; cartonné à l'angrlitses, 8.50

BULWER (Gir Ir.). - Essai sur Talleyrand, far sir IInri Lytton Bulwer, ancien ambassalen. 'Traduit de l'anglais, avee l'autorisation de l'anteur, par cieorges I'errut. I vol. in-3o.....5 l'n.

CHAMPION (Elme). - Esprit de la Révolution française, pal Ełne Champion. 1 vol. in-12. 3.50

DELTUF (1'aul). - Essai sur les Euvres et la Doctrine de Machiavel, arre la traductiun litti-

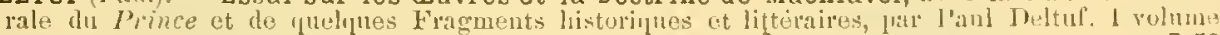

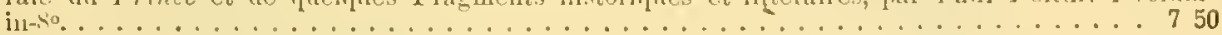

DEVAUX (l'aul). - Études politiques sur l'Histoire ancienne et moderne et sur l'influence tos

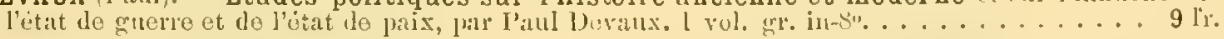

ENGELMANN (R.). - L'CEuvre d'Homère illustrie jor l'art des aucirns. Tratuit dus l'allemalul.

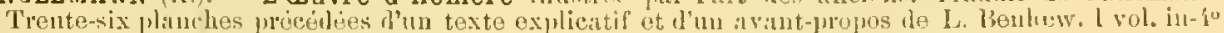

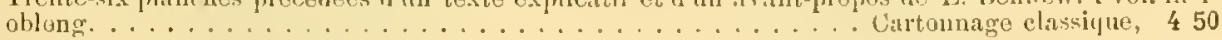

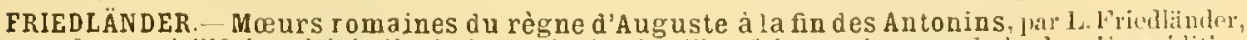

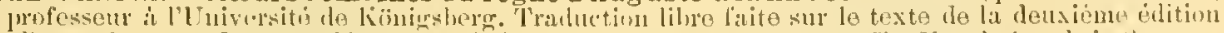
allemande, avec des consilemations généralos et dus remaryues, jar Ch. Vougel. i vol. in-so.

lirochís, $2 s \mathrm{fr}$. lieliés en demi-miarouin, $35 \mathrm{f}$.

GUYOT (Yves).-Lettres sur la politique coloniale. I vol. in-12, avec I curteot 2 graphines. 4 fr.

LÉFEVRE (Anlrü). - L'Homme à travers les âges. Essais do ("ritịne historịne. 1 vol. in-12.

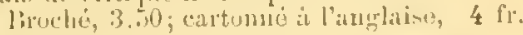

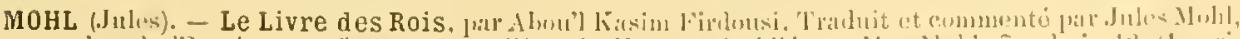

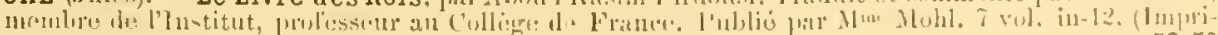

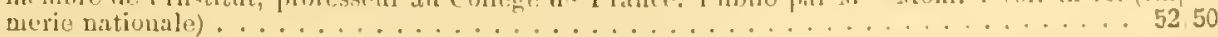

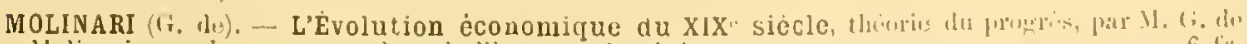

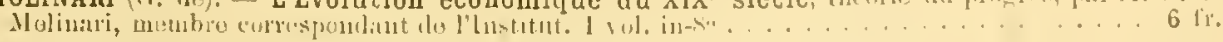

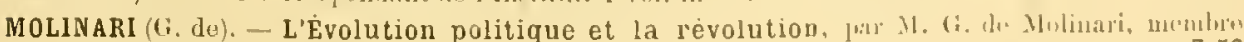
correspondant de l'I Institut. I vol. H11-8̌. 
MOLINARI. - Au Canada et aux Montagnes Rocheuses, en limasie, en Corio et it l'Exposition uni-

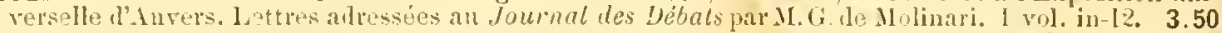

MOREAU DE JONNES (1.), - Etat économique et social de la France depuis Henri IV jusqu'à Louis XIV (1539-1715, jar A. Dorean d Jonnes, membre de l'Institnt. I vol, in-s" . . . . $7 \mathrm{fr}$. POPPER. - Terre de feu. Conférence lonne it l'Institut géographigne argentin, lo 5 mars 1 ks'

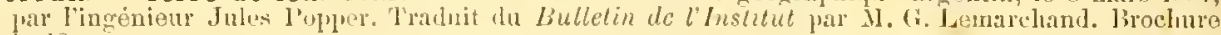

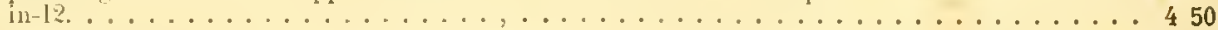

ROBIQUET (l'aul). - Histoire municipale de Paris depuis les origines jusqu'à l'avenement de

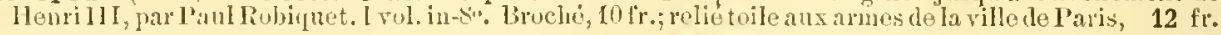

TISCHENDORF (Constantin). - Terre sainte, par Constantin Tischendorf, arec los souvenirs du pelerinage do $\mathrm{s}$. 1. I. le grand-duc Constantin. 1 vol. in-so avec 3 gravures. . . . . . . 5 fr.

VOGEL (Charles). - Le Monde terrestre an point actnel de la cirilisation. Nouvean rócil de Géographie comparée descriptive et commerciale avee 111 Introdnction, l'imlication des sources ef cartes, et $u$ répertoire alphabitique, par Charles Togel.

L'ourrage complet forme 3 volumes, divisés en 5 parties, gr. in-So:

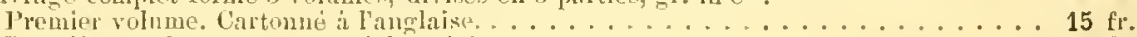

Denxième volume. Cartonné ì l'anglaiso . . . . . . . . . . . . $18 \mathrm{fr}$.

Premiere partie du truisiene volume. Cartonnè a langlaike........... 9 fr.

Denxième - $\quad-\quad-\ldots \ldots \ldots \ldots 12 \mathrm{fr}$.

Troisieme $-\quad-\quad-\ldots \ldots \ldots \ldots \ldots \ldots 12 \mathrm{fr}$.

Lourrage complet en 3 rolumes, divikes en 5 parties, Cartonne a l'anglaise. . . . . . . 66 fr. Felio en demi-marupuin, tr. jeigue, $72 \mathrm{fr}$.

Il a ité fait un tirage spéciul de la 1 rw partie du tome III de cet ouvrage, sous le titre:

\section{L'EUROPE ORIENTALE DEPUIS LE TRAITÉ DE BERLIN}

Cetto partie contient la linssie, la l'ologne ot la lrinlande, la lioumanie, la Serbio et lo IIonténégro,

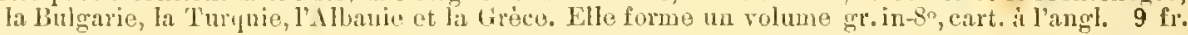

VOGEL (Cliarles). - Le Portugal et ses colonies. Tablean politique et commercial do la monarehie portugaise dius son état actuel, avec des alluexes et des notes sulplémentaires, par Cliarlos

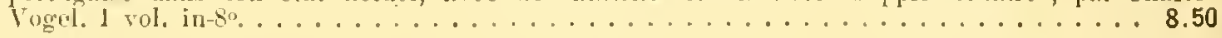

\section{LETTRES SUR LE CONGO}

\section{RECIT D'UN VOYAGE SCIENTIFIQUE}

EYTRE LEMBOUGUULE HU RLEVE ET LE COXHLUET WU KASSÄ̈

\section{Par Édouard DUPONT}

Directenr du Iusée royal d'histoire natarelle de Bruxelles.
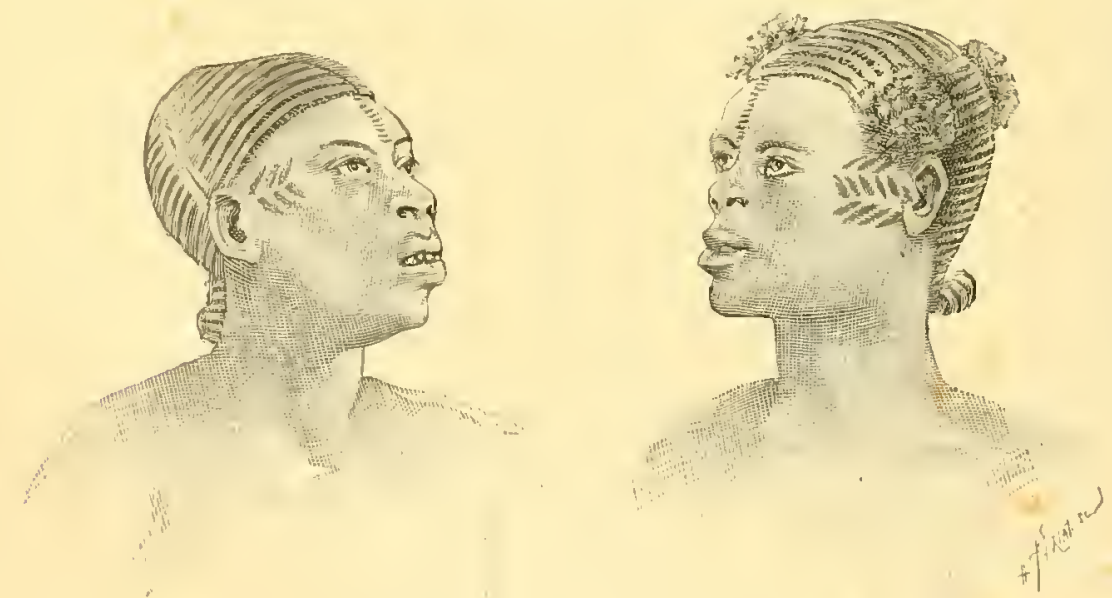

Un volume grand in-9", illustro de 12 gravures sur bois et de 11 cartes et platuches hors texte. Brochú. .... $15 \mathrm{fr}$. Cartonnó toilo anglaise. . . . $16 \mathrm{fr}$. 


\title{
V. - Linguistique - Littérature - Livres ctassiques
}

AHN (F. II.). - Syllabaire allemand. Premières leçons de langue allenande, avoc: mu nouvaiu

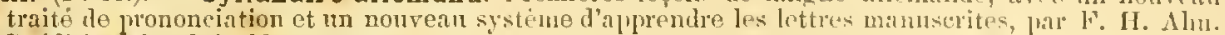

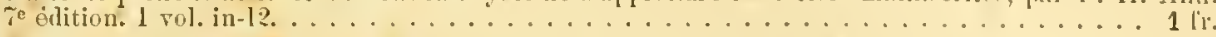

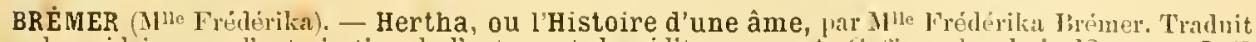
In suèlois arec l'autorisation lo l'anteur et des éditeurs, par' 1. Cictiroy. 1 rol. in-12... 350

BRET-HARTE. - Scènes de la vie californienne et Esipisses de morms transatlintiques, par Bret-

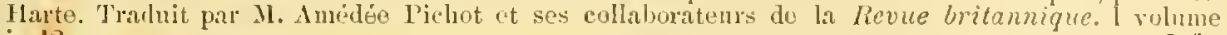

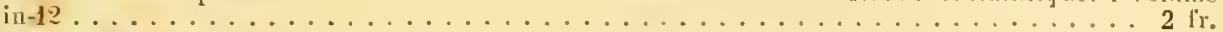

BROUGHTON (Mixs). - Comme une fleur, autobiographie. Traduit do l'anglais par Argusto do Viguerie. $2 *$ élition, revo. 1 vol, in-12, imprimé arec encadrement en conlenr.

Relió toile, tr. dor. et plaque spéciale, $5 \mathrm{fr}$.

BRUNHS (C.). - Nouveau Manuel de logarithmes a sept dócimales, pour les nomlures et les fonctions trigonométrifues, rédigé par U. Brunlı, doctenr en philosophie, dirocten de l'ohservatoire et prol'essenr a'astronomio ì Leipzig. I vol. gr. in-So, édit. stéréotype. (Lei jzig, I:. Tanchnitz.) $5 \mathrm{fl}$.

Choix de Nouvelles russes, de lemontoft, de Ponclikine, Ton Wiespn, etc. Traduit du russe par II. J. N. C'hopin, antent' inno Histoire de Kussie, do l'llistoire des révolutions des peuples du

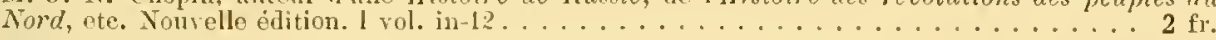

DELTUF (Panl). - Les Tragédies du foyer, par F'an] [beltuf, I rol. in-12 . . . . . . . . 2 l'r.

FAURJEL (C.). - Histoire de la Poésie provençale. Coms fait a la Juculté des lettres de Paris, par M. .. Fantiel, menbre de l'Institut. 3 volumes in-tio . . . . . . . . . . . . 24 fr.

GoLOVINE (M. Iran). - Mémoires d'un Prêtre russe, on la Russie religiense, lar M. Iran Golo-

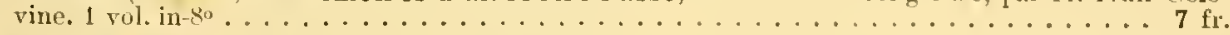

HEYSE (Parl). - La Rabbiata et d'autres Nouvelles, par l'aul Heyse. T'raluit de l'allemand par

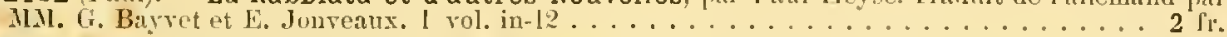

HOVELACQUE (A.) et Julien VINSON. - Études de Linguistique et al'Ethnographie, I rolıme in-12. Iroche, $4 \mathrm{fr}$; cartome il l'anglaise, $5 \mathrm{fl}$

Impressions de voyage d'un Russe en Europe. 1 rol. in-12 . . . . . . . . . . . . 250

MAIGNE (Jules). - Traité de Prononciation française et Manuel do lecture it haute roix. Guile théoriple et pratique des Français et des étrangers, l'ar M. Jnles Maigne. I rol. in-12.

Cartomó à l'auglaise, $3 \mathrm{fr}$.

MANTEGAZZA ( $\left.\mathrm{I}^{\prime}.\right)$. - Une Journée à Madère, pax l'. Mantegaza. Tradıit de l'italien avee l'auto-

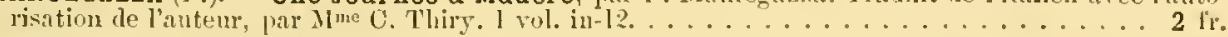

MARSH (Mls.s.). - Emilia Wyndham, jar l'antenr he "Two old men's tales; Mount sorel ", etı. (Mrs. Marsh.) Traduit librenent de l'anglais. 2 vol. in-12 réunis en un seul . . . . . . . . 5 fr.

MARY LAFON. - Histoire littéraire du Midi de la France, lia Mary Laliun. 1 rol. in- 1 * 7.50

MонL (.Jules). - Vingt-sept ans d'histoire des études orientales. liapports faits a la societé

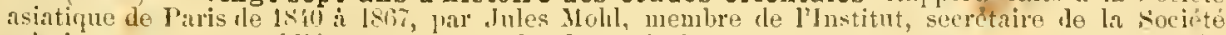

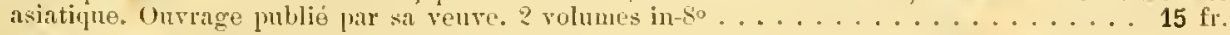

MÜLLER (Utto). - Charlotte Ackermann. Sourenirs du thêtre do llambourcr an wrue siécle, par Ot to Miiller. "Traduit par J.-J. l'orchat. I rol. in-8o . . . . . . . . . . . . . 2 fr.

OLIVIER (Lóon A.). * Grammaire élémentaire du grec moderne. (Athènes.) l vol. in-\$o. . 5 fl.

SANDER (E. 1I.).- Promenade de Paris au Rigi, racontéo (en allenand) pour servir t'introduetion a la lecture des anteurs allemands, 1:ar E. H1. Sander. 2o édition revie et corvigée. 1 vól. in-18.

Cartonnage classịue, 75 cent.

WITT (Mmes de). - La Vie des deux côtés de l'Atlantique, antrefois et anjonrd'lui. Traduit de

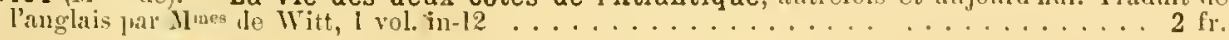

\section{VI. - Bibliographie - Divers}

\section{BULLETIN MEASLEL DE LA LIBRAIRIE FRANGAISE}

\author{
Publié par G. REINWALD et Gie
}

1893. - 35̃e année. Format iu-8 -8 parges par mois.

Prix de labomement: Paris et la France, 2 fi. 50. Fitrunger, $3 \mathrm{fr}$.

Ce lulletin parait an conmencenent de claquo mois et lonne los titros et los prix des priucipales nouvolles publications de France, ainsi que de celles en lajnuo frangaiso ódities en lbelgique, en Suisse, en Allemarne, etc., etc. 
BERLEPSCH. - Nouveau Guide en Suisse, par Berlejrch. 20 idition, illustrée. 1 vol. in-12, avec 23 cartes ot plans, 10 panoramas des Alpes et 38 gravires sul aeier d'aprés des plotographies.

Cartomné à l'anglaise, $5 \mathrm{fr}$.

Instructions aux capitaines de la marine marchande naviguant sur les côtes du layaume-1 Jui,

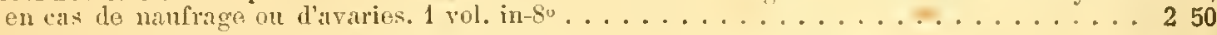

LIEBIG (J. de). - Sur un nouvel Aliment pour nourrissons (la Bonillie de Liebigr), avec Instruc-

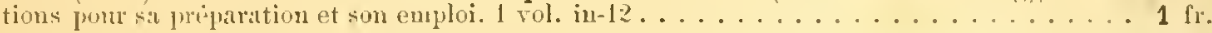

MOLTKE (Jo). - Campagnes des Russes dans la Turquie d'Europe en IS2S et I829. Tradnit Ie l'allenaud dı colomel baron de Moltke, par $A$. Temmler, professeur à l'Feole inpiriale l'iatat-major. 2 vol. in-8o

J.es cartes accompaguant cet ouvrage sont épuisees.

RAMÉE (1)anicl). - Dictionnaire général des termes d'Architecture, "n français, allenand, anglais et italien, par liniel lamee, arehitecte. 1 vohme in-\$. . . . . . . . . . . $8 \mathrm{f}_{1}$.

__ Histoire générale de l'Architecture, par llaniel lamée, architecte. 2 vol. gr. in- $\mathcal{S}^{\circ}$ avec 523 grurures sur bois . . . . . . . . . . . . . . . . . . . Brochér, $30 \mathrm{fr}$

STCHERBATOW (Généal prince). - Le feld-marèchal prince Paskevitsch, sa, vio politiquo et

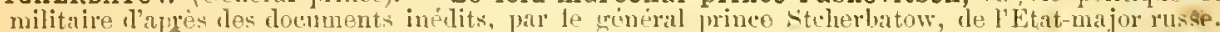

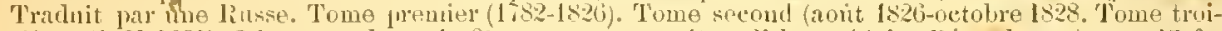

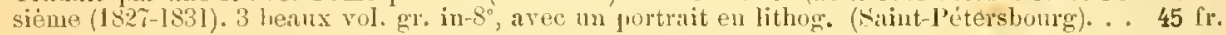

TÉLIAKOFFSKY (A.). - Manuel de Fortification permanente, pilr A. Téliakotlsky, colonel vlu génie. 'Traduit du russe par Gomean. 1 vol. gr. in-8o, avee un atlas in-4o do io planches. . . 20 fl. WELTER (Henri). - Essai sur l'histoire du café, lar Henri Welter. 1 vol. in-12. . . . . 350

\section{VII. - Diclionnaires}

\section{DICTIONNAIRE UNITERSEL DE LA LANGUE FRANGAISE}

Rédicred d'après les travaux et les mémoires des mentres des cing classes de l'Institut, enrichi d'exemples em. pruntis aux ecrivains, aux pluilologues et aux savants les plus celebres, depuis le seizi me siecle jusqu'a nos jours,

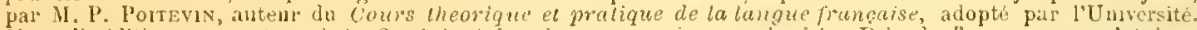
Nouvelle édition, revue et corrigèe, 2 vol. in-t, iuprimes sur papier graud raisin. Prix de l'ouviage conplet, bro-

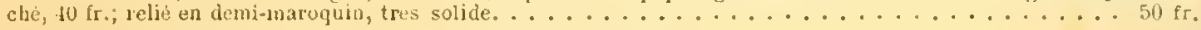

Dictionnaire technologique dans les langues française, anglaise et allemande, renfernant lo: termes techniques usités daus les arts et métiers et lans l'indnstrio en géneral, rèdigo par M. A. Tolhansen, levu par M. L. Tolhausen.

Ire fratie : Français-allemand-anglalis. 1 vol. in-1?, avec un nouvan guan supl. $12 \mathrm{fr}$.

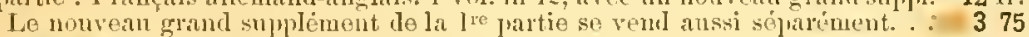

$1 l^{\mathrm{c}}$ partie. Anglais-allenand-français. l vol. in-12............. 1125

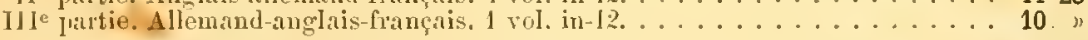

Dictionary of the English and French Languages with the Aceentuation and al litteral l'romuciation, by 11 . James and 1. Moté. 1 volume in-12. . . . . . . . . . . . . . . 7 tí..

Dictionary of the English and Italian Languages with the Italian 1'ronunciativu, by Wr. Jaues

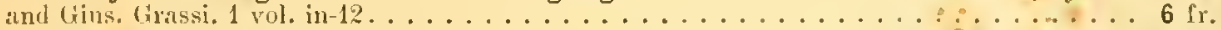

Dictionary of the English and German Languages loy W. James, thoroughly revised and partly

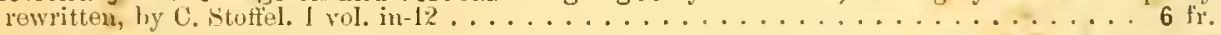

Dictionnaire anglais-allemand et allemand-anglais, par 1 essely. 1 vol, in-16. Cartouné à l'anglaise, $3 \mathrm{fr}$.

Dictionnaire anglais-espagnol et espagnol-anglais, par Wessely 'ot Gironès. 1 vol. in-16. Cartomné à I'anglaise, $3 \mathrm{fr}$.

Dictionnaire anglais-français et français-anglais, pa Wessely. 1 vol. in-16.

Cartumé à l'anglaise, $2 \mathrm{fr}$.

Dictionnaire anglais-italien et italien-anglais, par Wessely. 1 volume in-16. Cartonué à l'anğlaise, $3 \mathrm{fl}$.

Dictionnaire espagnol-français et français espagnol, pall Louis 'T'ollausen, 1 irol in-16. Cartonné

Dictionnaire français-allemand et allemand-français, jar 1 tessely. 1 vol. in-10.

Cartomange classique, $1 \mathrm{fr}$; cartomné à l'anglaise, $2 \mathrm{fr}$.

Dictionnaire italien-allemand et allemand-italien, jar locella. I volume in-16.

liroché, 2 fr.; cartonné ì l'anglaise, 3 lir.

Dictionnaire latin-anglais et anglais-latin. 1 vol. in-16. Cartonnè ì l'anglaise, $3 \mathrm{fr}$. 
• 



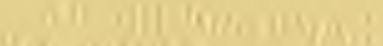

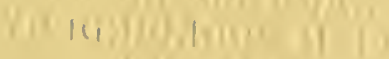
$(1 / 1111$ 


,
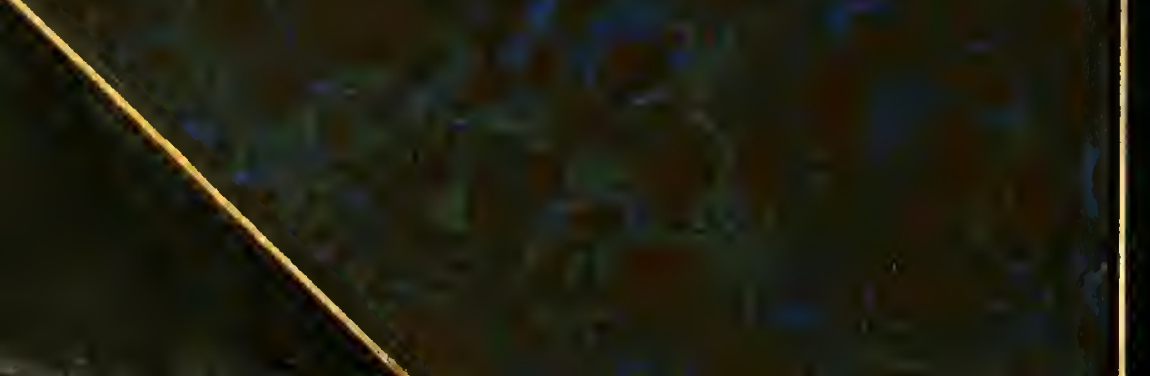